\title{
Financial Statistics of Major U.S. Publicly Owned Electric Utilities 1995
}

July 1997

Energy Information Administration

Office of Coal, Nuclear, Electric and Altemate Fuels

U.S. Department of Energy

Washington, DC 20585

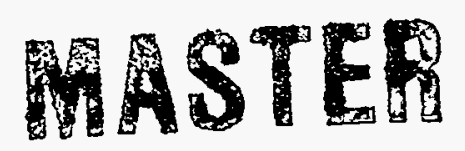




\section{Contacts}

The Financial Statistics of Major US. Publicly Owned Electric Utilities is prepared annually by the Coal and Electric Data and Renewables Division; Office of Coal, Nuclear, Electric and Alternate Fuels (CNEAF); Energy Information Administration (EIA); U.S. Department of Energy (DOE).

General information regarding the contents of this publication may be directed to:

National Energy Information Center (202/586-8800)

Internet E-Mail: INFOCTR@EIA.DOE.GOV

General information about the data appearing in this publication may be directed to:

Howard L. Walton

Director, Coal and Electric Data and Renewables Division

(202/426-1223) or Fax (202/426-1308)

Internet E-Mail: IIWALTON@EIA.DOE.GOV
Questions and comments may be directed to:

Roger L. Sacquety

Project Manager

(202/426-1160) or Fax (202/426-1308)

Internet E-Mail: RSACQUET@EIA.DOE.GOV

Spccific information about the data contained in the FORM EIA -412 may be directed to:

Charlene Harris-Russell

Survey Statistician

(202/426-1163) or Fax (202/426-1308)

Internet E-Mail: CHARRISR@EIA.DOE.GOV

Historial data may be obtained from:

Charlene Harris-Russell

Survey Statistician

(202/426-1163) or Fax (202/426-1308)

Internet E-Mail: CHARRISR@EIA.DOE.GOV

\section{Quality}

You are entitled to quality products and quality service. We ask your help in ensuring that this report meets the highest standards for quality. If you have any comments or suggestions about this publication, please contact Roger L. Sacquety on (202) 426-1160 or FAX (202) 426-1308.

For general inquiries about energy data, please contact the National Energy Information Center on (202) 586-8800. Internet users may contact them at this address: INFOCTR@EIA.DOE.GOV 


\section{DISCLAMMIER}

Portions of this document may be illegible in electronic image products. Images are produced from the best available original document. 


\section{Tables}

Page

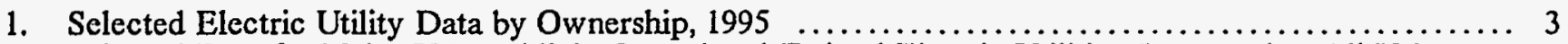

2. Selected Data for Major U.S. Publicly Owned and Federal Electric Utilities Compared to All U.S. Publicly Owned and Federal Electric Utilities, $1995 \ldots \ldots \ldots \ldots \ldots \ldots \ldots \ldots \ldots \ldots \ldots \ldots \ldots \ldots$

3. Ten Largest U.S. Publicly Owned Generator Electric Utilitics Ranked by Megawatthour Sales to Ultimate Consumers, 1995

4. Ten Largest U.S. Publicly Owned Generator Electric Utilities Ranked by Megawatthour Sales for Resale, 1995

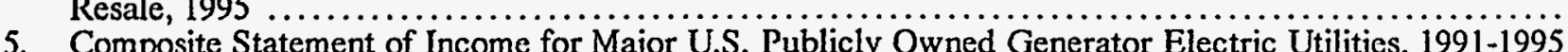

6. Composite Balance Sheet for Major U.S. Publicly Owned Generator Electric Utilities at End of Period, $1991-1995$

7. Composite Financial Indicators for Major U.S. Publicly Owned Generator Electric Utilities, 1991-1995

8. Electric Operation and Maintenance Expenses for Major U.S. Publicly Owned Generator Electric Utilities, $1991-1995$........................................................... 15

9. Electric Utility Plant for Major U.S. Publicly Owned Generator Electric Utilities at End of Period, 1991-1995

10. Number of Consumers, Sales, and Operating Revenue for Major U.S. Publicly Owned Generator

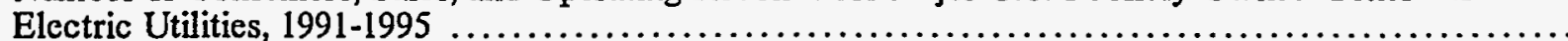

11. Electric Energy Account for Major U.S. Publicly Owned Generator Electric Utilities, $1991-1995 \ldots \ldots$

12. Ten Largest U.S. Publicly Owned Nongenerator Electric Utilities Ranked by Megawatthour Sales to

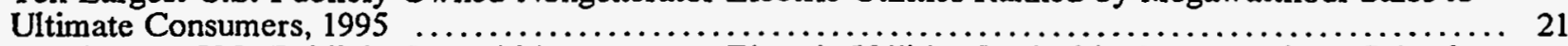

13. Ten Largest U.S. Publicly Owned Nongenerator Electric Utilities Ranked by Megawatthour Sales for Resale, 1995

14. Composite Statement of Income for Major U.S. Publicly Owned Nongenerator Electric Utilities, 1991-1995

15. Composite Balance Sheet for Major U.S. Publicly Owned Nongenerator Electric Utilities at End of

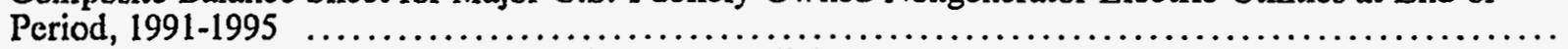

16. Composite Financial Indicators for Major U.S. Publicly Owned Nongenerator Electric Utilities, 1991-1995

17. Electric Operation and Maintenance Expenses for Major U.S. Publicly Owned Nongenerator Electric Utilities, $1991-1995$.............................................................

18. Electric Utility Plant for Major U.S. Publicly Owned Nongenerator Electric Utilities at End of Period, 1991-1995

19. Number of Consumers, Sales, and Operating Revenue for Major U.S. Publicly Owned Nongenerator Electric Utilities, 1991-1995

20.

21. Statement of Income by Major U.S. Publicly Owned Electric Utility Within State, $1995 \ldots \ldots \ldots \ldots \ldots$

22. Balance Sheet by Major U.S. Publicly Owned Electric Utility Within State at End of Period, 1995 ...

23. Electric Operation and Maintenance Expenses by Major U.S. Publicly Owned Electric Utility Within State, 1995

24. Electric Utility Plant by Major U.S. Publicly Owned Electric Utility Within State at End of Period, 1995

25. Number of Consumers, Sales, and Operating Revenue by Major U.S. Publicly Owned Electric Utility

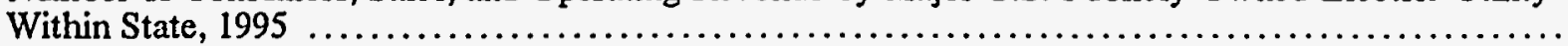

26. Electric Energy Account by Major U.S. Publicly Owned Electric Utility Within State, 1995 .........

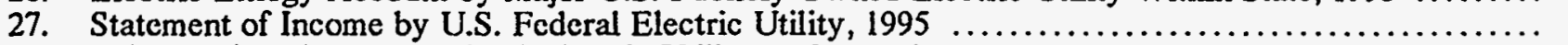

28. Balance Sheet by U.S. Federal Electric Utility on September $30,1995 \ldots \ldots \ldots \ldots \ldots \ldots \ldots \ldots \ldots \ldots \ldots \ldots \ldots$.

29. Electric Operation and Maintenance Expenses by U.S. Federal Electric Utility, $1995 \ldots \ldots \ldots \ldots \ldots$

30. Electric Utility Plant by U.S. Federal Electric Utility on September $30,1995 \ldots \ldots \ldots \ldots \ldots \ldots \ldots$

31. Number of Consumers, Sales, and Operating Revenue by U.S. Federal Electric Utility, 1995 .........

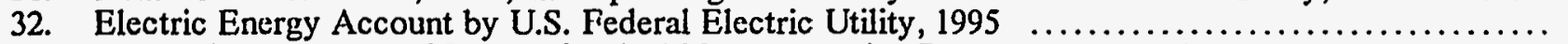

A1. Composite Statement of Income for the U.S. Cooperative Borrowers, $1991-1995 \ldots \ldots \ldots \ldots \ldots \ldots \ldots \ldots$

A2. Composite Balance Sheet for the U.S. Cooperative Borrowers on December 31, 1991 1995 ..........

A3. Electric Operation and Maintenance Expenses for the U.S. Cooperative Borrowers, 1991-1995 ......
A4. Number of Consumers, Sales, and Operating Revenue for the U.S. Cooperative Distributor Borrowers, 1991-1995 
B1. Major U.S. Publicly Owned Electric Utilitics Added to and Deleted from the Form EIA-412,

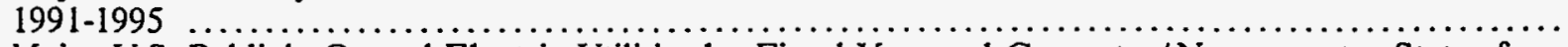

B2. Major U.S. Publicly Owned Electric Utilitics by Fiscal Year and Generator/Nongenerator Status from

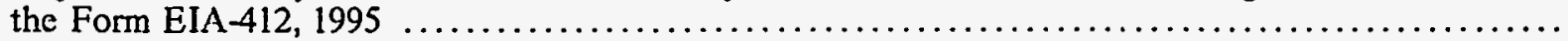

B3. Major U.S. Publicly Owned Electric Utilities by State and Generator/Nongenerator Status, 1995 ....

B4. Major U.S. Publicly Owned Electric Utilities That Submitted the Form EIA-412, $1995 \ldots \ldots \ldots \ldots$

C1. Ten Largest U.S. Publicly Owned Generator Electric Utilities Ranked by Megawatthour Sales to Ultimate Consumers with Financial Year Ending on June $30,1995 \ldots \ldots \ldots \ldots \ldots \ldots \ldots \ldots \ldots \ldots$

C2. Ten Largest U.S. Publicly Owned Generator Electric Utilities Ranked by Megawatthour Sales for

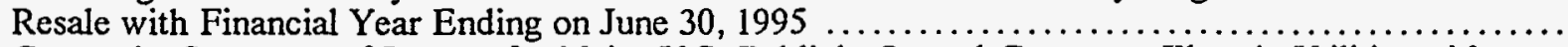

C3. Composite Statement of Income for Major U.S. Publicly Owned Generator Electric Utilities with

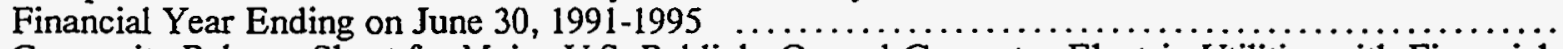

C4. Composite Balance Sheet for Major U.S. Publicly Owned Generator Electric Utilities with Financial

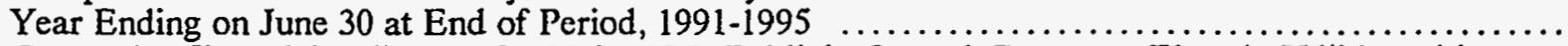

C5. Composite Financial Indicators for Major U.S. Publicly Owned Generator Electric Utilities with

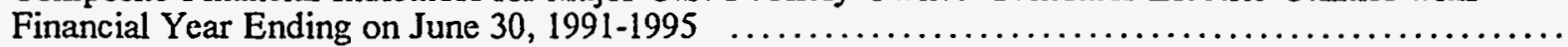

C6. Electric Operation and Maintenance Expenses for Major U.S. Publicly Owned Generator Electric

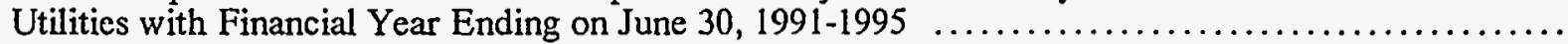

C7. Electric Utility Plant for Major U.S. Publicly Owned Generator Electric Utilities with Financial Year

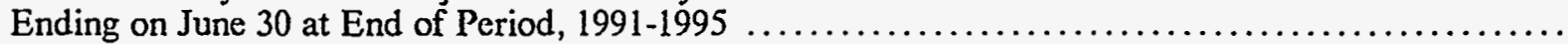

C8. Number of Consumers, Sales, and Operating Revenue for Major U.S. Publicly Owned Generator

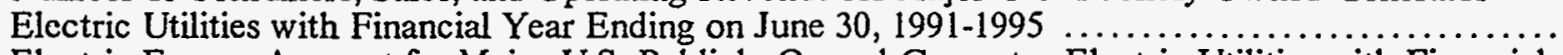

C9. Electric Energy Account for Major U.S. Publicly Owned Generator Electric Utilities with Financial

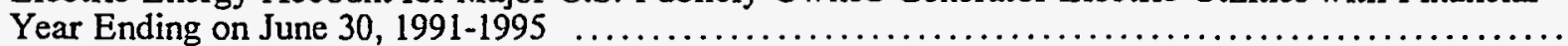

C10. Ten Largest U.S. Publicly Owned Generator Electric Utilities Ranked by Megawatthour Sales to

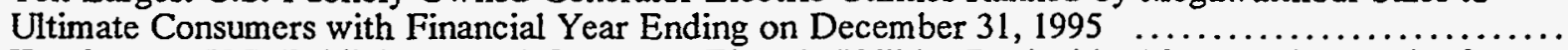

C11. Ten Largest U.S. Publicly Owned Generator Electric Utilities Ranked by Megawatthour Sales for

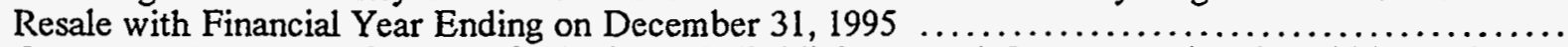

C12. Composite Statement of Income for Major U.S. Publicly Owned Generator Electric Utilities with

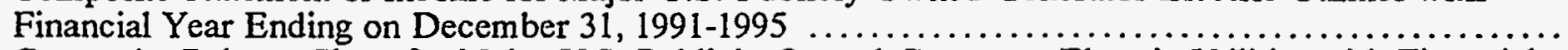

C13. Composite Balance Sheet for Major U.S. Publicly Owned Generator Electric Utilities with Financial Year Ending on December 31 at End of Period, 1991-1995

C14. Composite Financial Indicators for Major U.S. Publicly Owned Generator Electric Utilities with

C15. Electric Operation and Maintenance Expenses for Major U.S. Publicly Owned Generator Electric

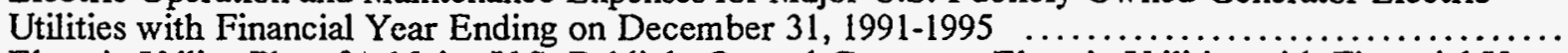

C16. Electric Utility Plant for Major U.S. Publicly Owned Generator Electric Utilities with Financial Year Ending on December 31 at End of Period, 1991-1995

Number of Consumers, Sales, and Operating Revenue for Major U.S. Publicly Owned Generator

C17. Number of Consumers, Sales, and Operating Revenue for Major U.S. Publ

Year Ending on December 31, 1991-1995

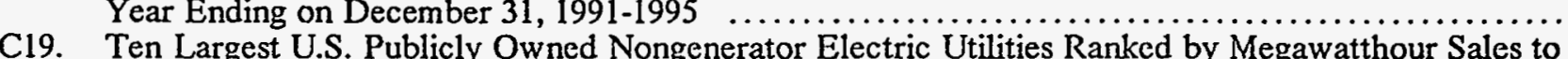

Ultimate Con. Prers with Financial Year Ending

C20. U.S. Publicly Owned Nongenerator Electric Utilities Ranked by Megawatthour Sales for Resale with Financial Year Ending on June 30, 1995

C21. Composite Statement of Income for Major U.S. Publicly Owned Nongenerator Electric Utilities with Financial Year Ending on June 30, 1991-1995

C22. Composite Balance Sheet for Major U.S. Publicly Owned Nongenerator Electric Utilities with Financial Year Ending on June 30 at End of Period, 1991-1995

Composite Financial Indicators for Major U.S. Publicly Owned Nongenerator Elcctric Utilities with

Financial Year Ending on June 30, 1991-1995

Electric Opcration and Maintenance Expenses for Major U.S. Publicly Owned Nongenerator Electric

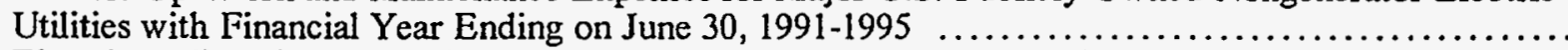

C25. Electric Utility Plant for Major U.S. Publicly Owned Nongenerator Electric Utilities with Financial Year Ending on June 30 at End of Period, 1991-1995

C26. Number of Consumers, Sales, and Operating Revenue for Major U.S. Publicly Owned Nongenerator Electric Utilities with Financial Year Ending on June 30, 1991-1995 ............................

C27. Electric Energy Account for Major U.S. Publicly Owned Nongenerator Electric Utilities with Financial Year Ending on June 30, 1991-1995

Ten Largest U.S. Publicly Owned Nongenerator Electric Utilities Ranked by Megawatthour Sales to Ultimate Consumers with Financial Year Ending on December 31, 1995 ......................

C29. Ten Largest U.S. Publicly Owned Nongenerator Electric Utilities Ranked by Megawatthour Sales for Resale with Financial Year Ending on December 31, 1995

C30. Composite Statement of Income for Major U.S. Publicly Owned Nongenerator Electric Utilities with Financial Year Ending on December 31, 1991-1995 
C31. Composite Balance Sheet for Major U.S. Publicly Owned Nongenerator Electric Utilities with Financial Year Ending on December 31 at End of Period, 1991-1995

C32. Composite Financial Indicators for Major U.S. Publicly Owned Nongenerator Electric Utilities with

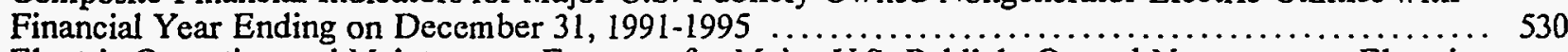

C33. Electric Operation and Maintenance Expenses for Major U.S. Publicly Owned Nongenerator Electric Utilities with Financial Year Ending on December 31, 1991-1995

C34. Electric Utility Plant for Major U.S. Publicly Owned Nongenerator Electric Utilities with Financial Year Ending on December 31 at End of Period, 1991-1995

C35. Number of Consumers, Sales, and Operating Revenue for Major U..... Publicly Owned Nongenerator

Electric Utilities with Financial Year Ending on December 31, 1991-1995

C36. Electric Energy Account for Major U.S. Publicly Owned Nongenerator Electric Utilities with Financial Year Ending on December 31, 1991-1995

C37. Twenty Largest U.S. Publicly Owned Electric Utilities Ranked by Megawatthour Sales to Uitimate Consumers for All Respondents, 1995

C38. Twenty Largest U.S. Publicly Owned Electric Utilities Ranked by Megawatthour Sales for Resale for All Respondents, 1995

C39. Twenty Largest U.S. Publicly Owned Electric Utilities Ranked by Electric Utility Revenues for All

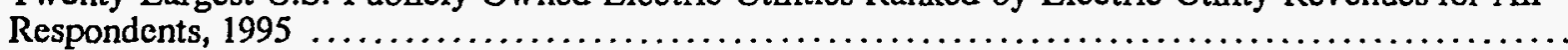

C40. Twenty Largest U.S. Publicly Owned Electric Utilities Ranked by Purchase Power Expenses for Ail Respondents, 1995 .......................................................

C41. Twenty Largest U.S. Publicly Owned Electric Utilities Ranked by Electric Utility Plant for Ali

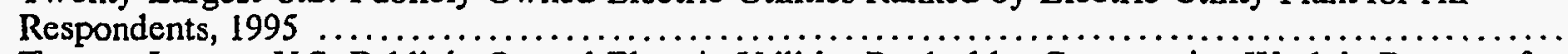

C42. Twenty Largest U.S. Publicly Owned Electric Utilities Ranked by Construction Work in Progress for All Respondents, 1995

C43. Composite Statement of Income for Major U.S. Publicly Owned Electric Utilities for All Respondents, $1991-1995$

C44. Composite Balance Sheet for Major U.S. Publicly Owned Electric Utilities for All Respondents at

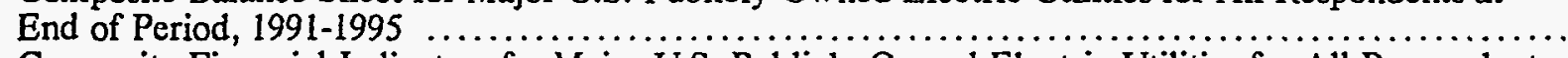

C45. Composite Financial Indicators for Major U.S. Publicly Owned Electric Utilities for All Respondents,

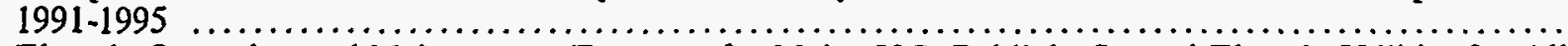

C46. Electric Operation and Maintenance Expenses for Major U.S. Publicly Owned Electric Utilities for All Respondents, 1991-1995

C47. Electric Utility Plant for Major U.S. Publicly Owned Electric Utilities for Ail Respondents at End of Period, 1991-1995

C48. Number of Consumers, Sales, and Operating Revenue for Major U.S. Publicly Owned Electric Utilities for All Respondents, 1991-1995

C49. Electric Energy Account for Major U.S. Publicly Owned Electric Utilities for All Respondents, 1991-1995

C50. Comparison of the Electric Energy Account for Major U.S. Publicly Owned Electric Utilities for Ail

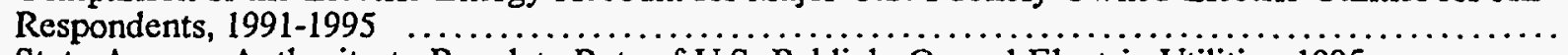

D1. State Agency Authority to Regulate Rate of U.S. Publicly Owned Electric Utilities, $1995 \ldots \ldots \ldots . . . .$.

\section{Illustrations}

1. Total Electric Utility Plant per Dollar of Revenue, $1991-1995$........................... 7

2. Long-Term Debt, Construction Work In Process, and Nuclear Fuel for TVA, $1991-1995 \ldots \ldots \ldots \ldots \ldots 463$

3. The Department of Energy's Five Power Marketing Administrations Service Areas, 1995 .......... 465

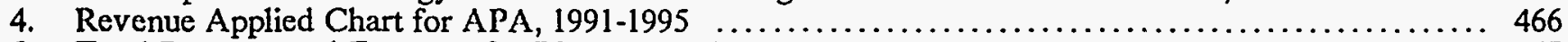

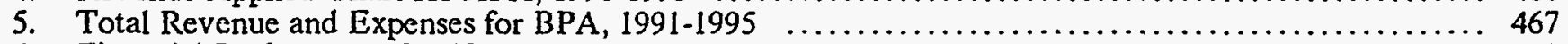

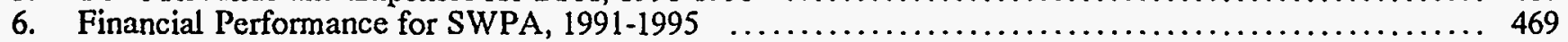

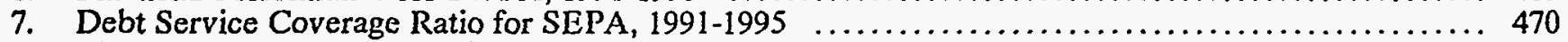

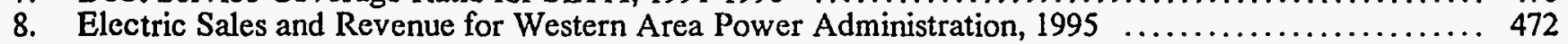

B1. Principal Business Office of the Major U.S. Publicly Owned Electric Utilities, $1995 \ldots \ldots \ldots \ldots \ldots . . .499$ 


\section{Introduction}

\section{About This Publication}

The 1995 Edition of The Financial Statistics of Major U.S. Publicly Owned Electric Utilities publication presents 5 years (1991 through 1995) of summary financial data and current year detailed financial data on the major publicly owned electric utilities. The objective of the publication is to provide Federal and State governments, industry, and the general public with current and historical data that can be used for policymaking and decisionmaking purposes related to publicly owned electric utility issues.

Generator (Tables 3 through 11) and nongenerator (Tables 12 through 20) summaries are presented in this publication. Five years of summary financial data are provided (Tables 5 through 11 and 14 through 20). Summaries of generators for fiscal years ending June 30 and December 31, nongenerators for fiscal years ending June 30 and December 31 , and summaries of all respondents are provided in Appendix C.

The composite tables present aggregates of income statement and balance sheet data, as well as financial indicators. Composite tables also display electric operation and maintenance expenses, electric utility plant, number of consumers, sales of electricity, and operating revenue, and electric energy account data.

The primary source of publicly owned financial data is the Form EIA-412, "Annual Report of Public Electric Utilitics." Public electric utilitics file this survey on a fiscal year, rather than a calendar year basis, in conformance with their recordkeeping practices. The EIA undertook a review of the form EIA-412 submissions to determine if alternative classifications of publicly owned clectric utilities would permit the inclusion of all respondents. The review indicated that financial indicators differ most according to whether or not a publicly owned elcctric utility generates electricity. Therefore, the main body of the report provides summary information in generator/nongenerator classifications.

\section{History}

As the result of the Federal Power Act of 1935, the Federal Power Commission (FPC), which was the predecessor to the Federal Energy Regulatory Commission (FERC), began collccting financial statistics for investor-owned electric utilities in 1938. In 1946, the FPC started collecting financial statistics on publicly owned electric utilitics. The Energy Information Administration (EIA) upon its establishment in October 1977 took over the responsibility of gathering and publishing the financial statistics from the FERC. In 1982, the EIA combined the contents of two publications containing financial statistics of investorowned (private) and publicly owned electric utilities into a single volume, the Financial Statistics of Selected Electric Utilities. In 1991, the publication titles were changed to the Financial Statistics of Major InvestorOwned Electric Utilities and the Financial Statistics of Major Publicly Owned Electric Utilities. In 1992, the publication titles were further changed to the Financial Statistics of Major U.S. Investor-Owned Electric Utilities and the Financial Statistics of Major U.S. Publicly Owned Electric Utilities.

Currently, the Financial Statistics of Major US. Publicly Owned Electric Utilities publication is prepared by the Electric Operating and Financial Data Branch; Coal and Electric Data and Renewables Division; Office of Coal, Nuclear, Electric and Alternate Fuels; EIA; U.S. Department of Energy. The format was designed to be used by a variety of private, electric power industry, and government users. The publication contents and format have evolved over the years to better serve the needs and requirements of the targeted audience.

\section{About The Industry}

The U.S. electric power industry is a combination of electric utilities (investor-owned, publicly owned, cooperatives, and Federal) and nonutility power producers. Investor-owned electric utilities account for over three-fourths of the sales of electricity and revenue in the industry. Historically, the investorowned electric utilities served the large consolidated markets and operated in all States except Nebraska. Hawaii is the only State in which all electricity is supplied by investor-owned electric utilities.

Publicly owned electric utilities are nonprofit operations that have been established to serve their communities and nearby consumers at cost. The publicly owned electric utilities in this publication include municipals, public power districts, State authorities, irrigation districts, and other State organizations. Publicly owned electric utilities are exempt from taxes and can obtain new financing at lower rates than investor-owned electric utilities.

The publicly owned electric utilities are divided into generators and nongenerators (In contrast, virtually all investor-owned electric utilities own and operate generating capacity). Generators are those clectric utilities that own/operate generating capacity to supply some or all of their consumer needs. However, some 
generators supplement their demand by purchasing power. The nongenerators do not produce electric power for end use and rely exclusively on purchasing power. Their primary function is to transmit and distribute electricity to their consumers. The nongenerators comprise over half of the total number of major publicly owned electric utilities.

Cooperative electric utilities are owned by their members and are established to provide electricity to those members. The Rural Electrification Administration (prior to the Rural Utilities Service), U.S. Department of Agriculture, was established under the Rural Electrification Act of 1936 with the purpose to extend electric service to small rural communities (usually under 1,500 consumers) and farms where it was more expensive to provide service. The National Rural Utilities Cooperative Finance Corporation, the Federal Financing Bank, and the Bank for Cooperatives are the most important sources of debt financing for Cooperatives. Cooperative borrowers (855 of 931 in 1995 total cooperatives) currently operate in 46 States. Financial data for the cooperative borrowers are found in the Statistical Report, Rural Electric Borrowers published by the Rural Utilities Service of the U.S. Department of Agriculture. Summary tables for the cooperative borrowers are provided in Appendix A.

Federal electric utilities are also presented in this publication and include the five Federal power marketing administrations, the Tennessee Valley Authority, the U.S. Army Corps of Engineers, and the U.S. Bureau of Indian Affairs. The five Federal power marketing administrations are the Alaska Power Administration, the Bonneville Power Administration, the Southeastern Power Administration, the Southwestern Power Administration, and the Western Area Power Administration. Electric power produced by Federal electric utilities is generated primarily by water resources. This power, which is not produced for profit, is primarily wholesaled to other electric utilities rather than being distributed to ultimate consumers. As required by law, publicly owned and conperative electric utilities are given preference in the purchase of this less expensive power produced by the Federal electric utilities.

\section{Data Users}

The Financial Statistics of Major U.S. Publicly Owned Electric Utilities publication provides information about the financial results from operations of publicly owned electric utilities for use by government, industry, electric utilities, financial organizations and educational institutions in energy planning. In the private sector, the readers of this publication are researchers and analysts associated with the financial markets, the policymaking and decisionmaking members of electric utility companies, and economic development organizations. Other organizations that may be interested in the data presented in this publication include manufacturers of electric power equipment and marketing organizations. In the public sector, the readers of this publication include analysts, researchers, statisticians, and other professionals engaged in regulatory, policy, and program activities. These individuals are generally associated with the Congress, other legislative bodies, State public service commissions, universities, and national strategic planning organizations.

\section{Sources and Coverage}

Publicly owned electric utilities are required to submit the Form EIA-412 when the generation, transmission, or distribution of electricity, for the two previous years, results in one of the following :

- 120,000 megawatthours of sales to ultimate consumers.

- 120,000 megawatthours of sales for resale.

These criteria are based on data reported on the Form EIA-861, "Annual Electric Utility Report." This survey is submitted by all electric utilities in the United States, its territories, and Puerto Rico. Appendix B contains a list of the major publicly owned electric utilities that submitted form EIA 412 data for 1995 .

Many of the publicly owned electric utilities are selfregulated while some fall under the jurisdiction of State public service commissions as shown in Appendix D. Because of the absence of required reporting to a specific regulatory body, the accounting practices and policies of publicly owned electric utilities vary considerably. Many use the FERC Uniform System of Accounts or variations of this and other accounting systems. The composite statistics provided in this publication must be viewed with an appropriate degree of caution.

The Form EIA-412 is used to collect detailed annual accounting, financial, and other operating characteristics of publicly owned electric utilities for publication in EIA reports. In 1995, 512 major publicly owned electric utilities submitted data to the EIA. Although calendar year reporting of data is preferred, electric utilities are given the option of reporting data on a fiscal year basis. This option is permitted in order to minimize respondent burden in preparing the data. When reporting by fiscal year, electric utilities must rcport operational data for a 12-month period and show consistency in fiscal periods and accounting practices.

\section{Industry Profile}

Selected electric utility data for 1995 are compiled from the Form EIA-861 for the total universe of electric utilities. In 1995, there were 3,199 investorowned, publicly owned, Federal, and cooperative electric utilities (Table 1).

Key facts concerning sales and revenues in 1995 are as follows :

- The 244 investor-owned electric utilities $(7.6$ percent of all electric utilitics) accounted for 78.9 
percent of all revenues from sales of elcetricity to ultimate consumers and 41.1 percent of all revenues from salcs for resale.

- The 2,014 publicly owned electric utilities $(62.9$ percent of all electric utilities) accounted for 12.5 percent of all revenues from sales to ultimate consumers and 18.5 percent of all revenues from sales for resale.

- The 931 cooperative electric utilities (29.1 percent of all electric utilities) accounted for 8.0 percent. of all revenues from sales to ultimate consumers and 23.8 percent of all revenues from sales for resale.
- The 10 Federal electric utilitics accounted for 0.6 percent of all revenues from sales to ultimate consumers and 16.5 percent of all revenues from sales for resale.

- The average ultimate consumers revenue per kilowatthour ranged from 2.7 to 7.1 cents depending on the type of electric utility. The overall average was 6.9 cents.

- The average sales for resale revenue per kilowatthour ranged from 3.3 to 3.9 cents, depending on the type of electric utility. The overall average was 3.5 cents.

Table 1. Selected Electric Utility Data by Ownership, 1995

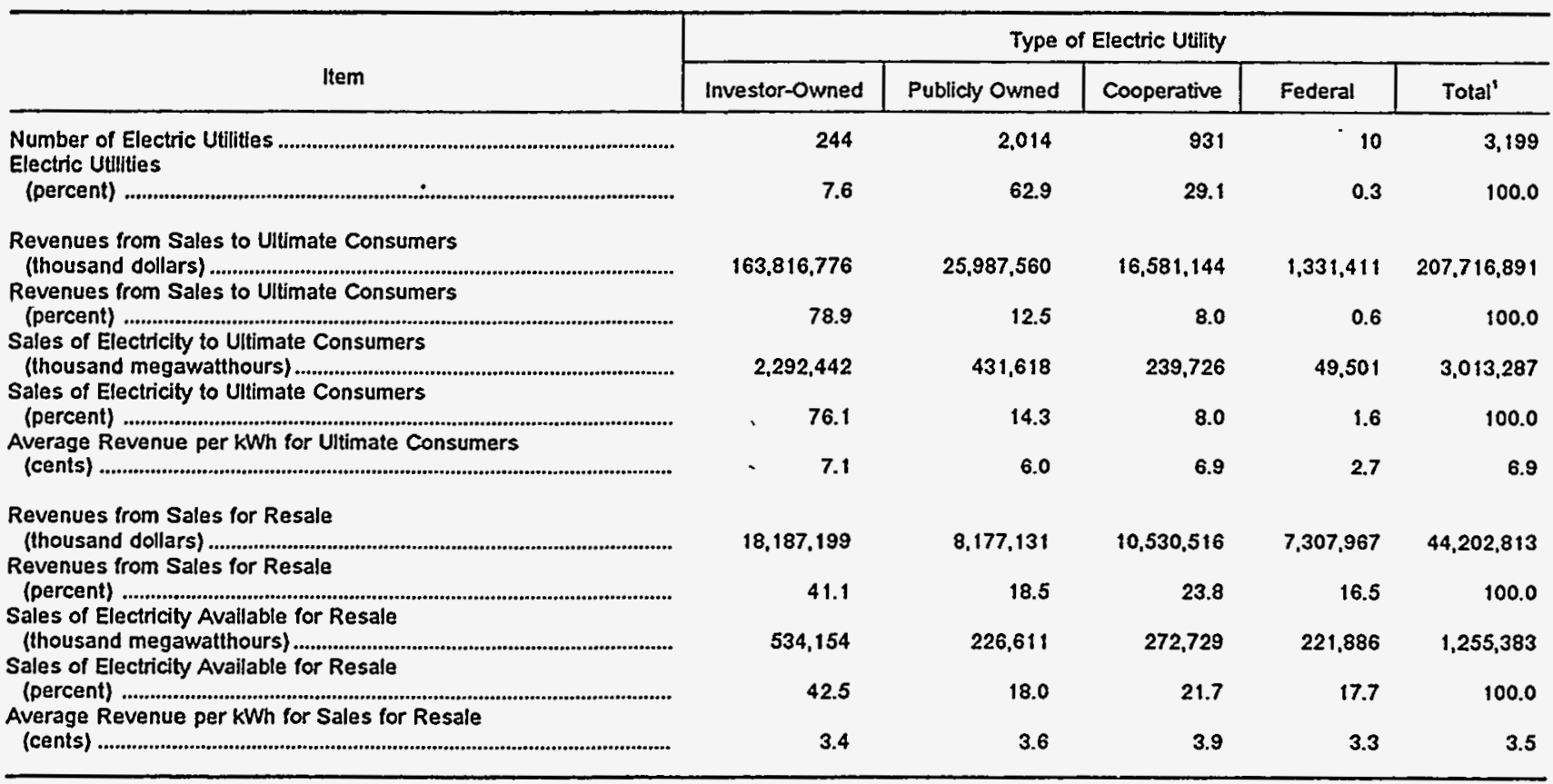

- Includes only those electric utilities in the United States and the District of Columbia. Note: Totals may not equal sum of components because of independent rounding.

Source: Energy Information Administration, Form EIA-861, "Annual Electric Utility Report." Data are based on calendar year submissions. 
This publication will concentrate on selected operational data for 512 of the 2,014 publicly owned electric utilities and for 8 of the 10 Federal electric utilities in the United States. Table 2 compares these utilities with the total values reported by all publicly owned and Federal electric utilities on the Form EIA-861.

In 1995, the 512 major publicly owned electric utilities in this publication accounted for 87.8 percent of the revenues from sales to ultimate consumers and 99.0 percent of the revenucs from sales for resale of all publicly owned electric utilities (Table 2). The 8 Federal electric utilitics in this publication cover the entire Federal segment.

This publication contains summary and detailed data for 512 major publicly owed electric utilitics (tables 3 through 26). Also, included are summary and detailed data for the 8 federal electric utilities (tables 27 through 32).

Appendix A tables contain 5 years of summary statistics on U.S. rural electric cooperative borrowers (Tables A1 through A4).

Appendix B contains a list of the major U.S publicly owned electric utility respondents. The major U.S. publicly owned electric utilitics added and deleted for 1991 through 1995 are listed (table B1). The number of generator/nongenerator respondents for June 30 , for December 31, and for the "other" fiscal years are provided ('Table B2). The total number of respondents by State and generating status of the respondents are also provided (Table B3). The name, State, financial reporting date, and generating status of the respondents are also provided (Table B4).

Appendix $\mathrm{C}$ contains summary statistics for generating and nongencrating major U.S. publicly owned electric utilities for the fiscal year periods ending June 30 and December 31, as well as for all respondents (Tables $\mathrm{Cl}$ through $\mathrm{C} 50$ ).

Appendix $D$ contains a list of the State agencies which have regulatory oversight of publicly owned electric utilities.

Appendix E contains all Technical Notes for the publication. The key sections are Sources of Data, Quality of Data, Formulas and Calculations, and General Information.

The Glossary defines common terms used in the publication.

Table 2. Selected Data for Major U.S. Publicly Owned and Federal Electric Utilities Compared to All U.S. Publicly Owned and Federal Electric Utilities, 1995

\begin{tabular}{|c|c|c|}
\hline Item & Publicly Owned & Federal' \\
\hline $\begin{array}{l}\text { Number of Electric Utilities in This Report . } \\
\text { Share of Electric Utilities Within Ownership Class }\end{array}$ & 512 & 8 \\
\hline $\begin{array}{l}\text { (percent) } \\
\text { Revenues from Sales to Ultimate Consumers }\end{array}$ & 25.4 & 80.0 \\
\hline $\begin{array}{l}\text { (thousand dollars) ................................................ } \\
\text { Share of Revenues from Sales to Ulimate Consums }\end{array}$ & $22,817,360$ & $1,305,424$ \\
\hline $\begin{array}{l}\text { (percent) } \\
\text { Sales of Electricity to Uitimate Consumers }\end{array}$ & 87.8 & 98.1 \\
\hline $\begin{array}{l}\text { (thousand megawatthours) } \\
\text { Share of Sales of Electricity to Uitimate Consumers }\end{array}$ & 382,705 & 49,161 \\
\hline $\begin{array}{l}\text { Share of Sales of Electricity to Ultimate Consumers } \\
\text { (percent) }\end{array}$ & 88.7 & 99.3 \\
\hline $\begin{array}{l}\text { Revenues from Sales for Resale } \\
\text { (thousand dollars) }\end{array}$ & $8,094,766$ & $7,307,247$ \\
\hline $\begin{array}{l}\text { Share of Revenues from Sales for Resale } \\
\text { (percent) ... } \\
\text { Sales of Electricity Available for Resale }\end{array}$ & 99.0 & 100.0 \\
\hline $\begin{array}{l}\text { (thousand megawatthours) } \\
\text { Shave of Sales of Electricity Available for Resale }\end{array}$ & 224,360 & 221,832 \\
\hline 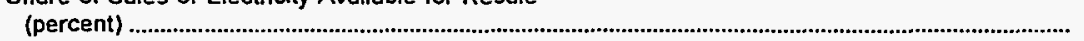 & 99.0 & 100.0 \\
\hline
\end{tabular}

' The Department of Interior-U.S. Bureau of Reclamation and the Department of State-International Water and Boundary Commission do not file the Form ElA-412; however, their energy is marketed and reported by the Bonneville Power Administration, the Southeastern Power Administration, the Southwestern Power Administration, and the Western Area Power Administration. Source: Energy Information Administration, Form ElA-861. "Annual Electric Utility Report." Data are based on calendar year submissions. 
Summary Statistics of Major U.S. Publicly Owned Electric Utilities 


\section{Factors Affecting Major U.S. Publicly Owned Electric Utilities During 1995}

\section{Overview}

Summary financial statistics are provided for major U.S. publicly owned electric utilities. These statistics include data for 512 electric utilities for 1995; 503 electric utilities for 1994; 495 electric utilities for 1993; 483 electric utilities for 1992; and 470 electric utilities for 1991. Over the five years summarized in this report, a net of 42 publicly owned electric utilities have been added as Form EIA-412 respondents. Currently, these additional respondents represent 8.2 percent of the 1995 total respondents base, but have a small impact on overall reported publicly owned electric utility investments.

Economic Context. The first half of 1995 was represented by a slowing of economic growth, but by the third quarter the economy had turned around. Rising interest rates during 1995 and the economic crisis in Mexico had an effect on slowing growth in the economy. This resulted in an increase in inventory and decreasing manufacturing output. Later in the year, these inventories were reduced and manufacturing resumed towards its previous levels.

Short term interest rates, which had risen in 1994 and early 1995 , helped to keep in check inflationary pressures. The Consumer Price Index (CPI) increased by 2.5 percent during the year and was 0.2 percentage points down from the 1994 increase. This was partly the result of lower energy prices and a decline in the rise in food prices. For the past four years inflation has been lower than 3.0 percent per year, the lowest consecutive rates since the early 1960's. Because of the slowing of growth, interest rates fell steadily and thus had the effect of helping to reverse the decline in the economy. The second-half recovery was greater than had been expected. The unemployment rate after falling in 1994, was able to remain unchanged in 1995.

Weather. Megawatthour sales of electricily are always affected by variations in weather from year to year as well as within the same year. The commonly used index of energy consumption is based on degree-days. Heating degree-days indicate how many degrees the mean temperature fell below 65 degrees, whereas cooling degree-days indicate how many degrces the mean temperature rose above 65 degrees for the day. Concerning heating demand in 1995, weather was milder overall for the first quarter, but the fourth quarter was much colder than in 1994. The U.S. average for heating degree-days in 1995 was 17.4 percent higher than 1994. The exception was in the states that compose the Mountain and Pacific Census Divisions where the change was 7.0 and 21.3 percent lower. Cooling degree-days were affected by July and August heat haves, thereby causing the number to be 4.6 percent higher than in 1994. The impact of weather variations on electric utility sales is mostly upon the residential sector.

\section{Generator Electric Utilities versus Nongenerator Electric Utilities}

The next. section of the publication discusses generator and nongenerator electric utilities separately. The two groups are distinct because of operational differences resulting in significantly different financial profiles. For example, significant plant production expenses would not exist for nongenerator electric utilities because existing production plant expenses are mainly maintenance costs for standby plants. It should be noted that both generator and nongenerator electric utilities report according to varying fiscal years that are determined by their political localities.

Because nongenerator electric utilities purchase all their power needs, they have lcss plant investment than generator electric utilities do per dollar of revenue generated. In 1995, generator electric utilities showed $\$ 3.82$ of electric utility plant per dollar of electric utility operating revenue, compared with $\$ 1.13$ for nongenerator electric utilities.

Operation and maintenance (O\&M) expenses represent very different costs between the two groups of electric utilities. Purchase power expenses, which comprise the majority of nongenerators' O\&M expenses, contain all the associated costs for the generating plants from which the power was purchased, including depreciation. This causes nongenerators' O\&M expenses to appear higher than generators' O\&M expenses on a mills per kilowatthour basis. In 1995, nongenerators' O\&M expenses were 88.0 percent of revenues and depreciation was only 3.7 percent. For generators, depreciation of plant is shown directly, since all or some of their generating needs are met by their own plants. Generators' O\&M expenses represented only 64.9 percent of revenues, but depreciation was 11.9 percent of revenues.

Financing is also different for the two groups. Generator electric utilities, with their larger plant investments per dollar of revenue, have more debt per dollar of revenuc than nongenerator electric utilities. The large amount of debt creates greater interest expense. Interest expense represented 17.9 percent of revenues in 1995 for the generators versus just 1.5 percent of revenues for the nongenerators (Tables 7 and 16). 
Figure 1. Total Electric Utility Plant per Dollar of Revenue, 1991-1995

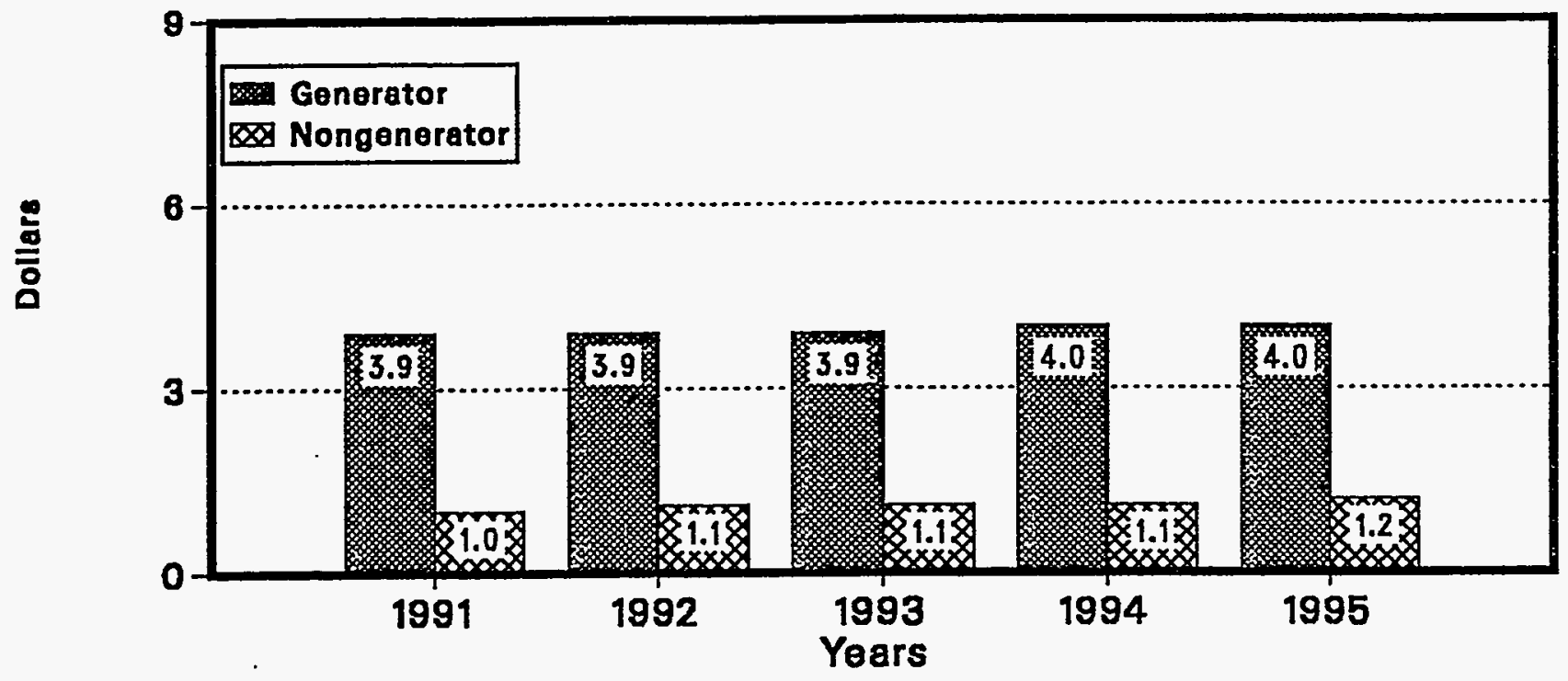

Nota: Summary date aro provided in Tobles 7 and 18.

Sourco: Energy Information Administration. Form EiA-412. 'Annual Report of Public Electric Utilities." 


\section{Financial Performance for Generator Electric Utilities}

Financial statistical summaries are provided for major publicly owned generator electric utilities which include 226 electric utilities for 1995; 227 electric utilities for 1994; 226 electric utilities for 1993; 225 electric utilities for 1992; and 218 electric utilities for 1991. New respondents and electric utilities no longer reporting from the previous years are listed in Appendix B.

\section{Highlights of Generator Financial Performance}

Increased sales and decreased revenues combined with modest growth in operating expenses to yield a 2.5-percent decrease in electric operating income. After accounting for changes in other income and deductions, net income grew 32.8 percent over the prior year (note that 1993 was an off-year for this segment with net income down 30.5 percent below 1992 levels). Key indicators of the generator electric utilities financial performance were:

- Electric revenues were down 1.3 percent on the basis of a 0.9 percent decrease in retail sales and a 2.1-percent decrease in sales for resale.

- Electric operation and maintenance expenses were up 0.4 percent, but on a per kilowatthour sold basis decreased to 31.0 mills.

- Interest expense continued its downward trend in 1995, dropping for the fourth year.

- Assets decreased a modest $\$ 0.5$ billion in 1995 , after increasing the four previous years.

- Investments in distribution plant continued to increase the most in electric plant, up $\$ 0.8$ billion.

\section{Income Statement}

The Composite Statement of Income for major publicly owned generator electric utilities for the years 1991 to 1995 is presented in Table 5. Net income of $\$ 1.2$ billion for generator electric utilities was up a substantial 32.8 percent from the previous year.

Revenues. Generator electric utilities revenues were $\$ 23.5$ billion a 0.9 -percent increase from the previous year. In 1995, there was greater wholesale than retail growth; however, revenues declined from both wholesale and retail consumers.

Electric Utility Operating Expenses. Total electric utility operating expenses of $\$ 19.0$ billion were up 1.6 percent over the previous year, and the largest increase in expenses was in depreciation expenses, up $\$ 0.2$ billion to $\$ 2.8$ billion in 1995 . Depreciation expenses accounted for 15.0 percent of the total electric operating expenses. The sccond largest contrib- utor to increased expenses was operating expenses, which account for 72.0 percent of total electric utility operating expenses (up slightly, 0.5 percent over the previous year). Expenses associated with tax and tax equivalents, amoritization, property losses, and regulatory studics also inceased slightly in 1995 contributing to the increase in total electric utility operating expenses. Only maintenance expenses decreased $(0.6$ percent) from the previous year.

Production Expenses. Production expenses were $\$ 11.4$ billion in 1995, down 0.8 percent over the prior year (Table 8). Production expenses represented 75.1 percent of total operations and maintenance expenses and declined on a mills per kilowatthour basis 0.6 percent (26.1 mills per kilowatthours sold in 1995).

At $\$ 5.6$ billion in 1995 , purchased power represents the largest production expense. Historically, despite self generation, generating publicly owned electric utilities have spent less than 50 percent of total production expenses on purchased power. Purchased power expenses were down 0.2 percent over the previous year.

In 1995, steam generating expenses were the second largest production expense, $\$ 3.9$ billion, representing 33.9 percent of total expenses. Steam production expenses were down 4.0 percent from the prior year. Nuclear power production expenses of $\$ 1.3$ billion were also down, off 1.2 percent from the prior year's value, and represented 11.2 percent of total production expenses in 1995.

Hydraulic, other power generation, and other production expenses accounted for the remaining $\$ 0.6$ billion of total power production expenses. Combined these production expenses accounted for only 5.7 percent of the total production expenses.

Fuel expenses in 1995 were $\$ 2.5$ billion, down 26.6 percent from the previous year, and represented 21.7 percent of total production expenses. This was down from 29.4 percent of total production expenses in 1994 and yielded to increased purchased power and other production expenses.

Transmission and Distribution Expenses. After increasing 2.4 percent in 1994, transmission and distribution expenses were up a modest 2.2 percent in 1995. Transmission expenses of $\$ 0.7$ billion were up 4.2 percent over the prior year, while distribution expenses of $\$ 0.8$ billion were up 0.5 percent. On a mills per kilowatthour sold basis, both transmission and distribution expenses remained unchanged at 1.6 and 1.9 , respectively.

Electric Utility Income. Operating revenues increased $\$ 0.2$ billion, while expenses increased $\$ 0.3$ billion and provided a decrease of $\$ 0.3$ billion in electric utility operating income. An increase in other electric income of $\$ 0.1$ billion accompanied by a slight incrcase in other electric deductions, offset the slight decrease in electric utility income $(0.5$ percent from the prior year). 
Interest Expense. Interest expense was $\$ 4.2$ billion in 1995, down 3.0 percent from $\$ 4.3$ billion in 1994. Debt outstanding as reported on the balance sheet decreased $\$ 1.8$ billion compared with the $\$ 0.6$ billion increase between 1993 and 1994.

Net Income. The positive effect of the reduction in interest expense mentioned above was directly offset by an increase in other income deductions which yielded a modest $\$ 0.2$ billion decrease to $\$ 0.9$ billion for income before extraordinary items.

\section{Balance Sheet}

The Composite Balance Sheet for publicly owned generator electric utilities revealed a 0.4 -percent decrease in assets for the year (Table 6).

Assets and Other Debits. Decreases in total assets were slightly off from prior years values by $\$ 0.5$ billion. This 1995 decrease in assets contrasts with the $\$ 1.9$ biliion added in 1994. Net electric utility plant (including net nuclear fuel) represents 55.8 percent of the assets. Total other property and investments accounted for 18.5 percent of the total assets or $\$ 21$ billion. Other changes in assets include:

- Construction work in progress (CWIP) decreased slightly in 1995, down 0.4 percent over the $\$ 4.2$ billion figure for 1994 .

- Changes in miscellaneous current and accrued assets dominated the decrease in total current and accrued assets. Miscellaneous accounts represented $\$ 0.5$ billion of the $\$ 0.7$ billion decrease in current and accrued assets.

Electric Utility Plant. Electric utility plant in service increased 1.6 percent to $\$ 85.2$ billion in 1995 (Table 9). Net utility plant increased to $\$ 87.0$ billion (Table 6). Notable changes in electric utility plant account included:

- Increases in total production plant represented 15.9 percent of the change in total electric plant in service, up $\$ 0.2$ billion. While steam production plant remains the largest component of production plant at $\$ 24.5$ billion, and provided the greatest increase in 1995 , up $\$ 0.3$ billion over the prior year. Other production plant only accounted for $\$ 2.5$ billion out of the total production plant of $\$ 53.5$ billion at the end of 1995 . While essentially unchanged from the prior year, nuclear plant investments of $\$ 18.7$ billion accounted for 21.9 percent of the total elcctric plant in service. (Publicly owned generator electric utilities have significant nuclear plant investment exposure.) Production plant accounts for 62.8 percent of the total clectric plant in service.

- Increases in distribution plant was significant, accounting for $\$ 1.0$ billion or 31.9 percent of the increase in total assets. By the end of 1995, distribution plant accounted for 18.9 percent of total electric plant in service.
- Transmission plant changed little during 1995, increasing a modest $\$ 0.2$ billion and represented 11.1 percent of total electric plant in service.

- General plant showed a modest decrease from the previous year $\$ 5.5$ billión in 1995 , which was 27.9 percent of the total increase in electric plant in service. However, general plant remained at 6.6 percent of total electric plant in service.

Liabilitics and Other Credits. Increases in proprietary capital dominated the changes on the liabilities side of the balance sheet, accounting for 51.2 percent of the $\$ 1.9$ billion decrease. Increases in retained earnings added $\$ 0.6$ billion of the $\$ 1.0$ billion of additional proprietary capital at year's end. Proprietary capital increased from 24.5 percent in 1994 to 25.4 percent in 1995 of total capitalization (proprietary capital plus long-term debt). Other significant changes in liability and other credit accounts included:

- Long-term debt decreased $\$ 1.8$ billion, or 2.4 percent to $\$ 75.0$ billion in 1995. Advances from municipalities and other decreased $\$ 0.5$ billion, but was offset by a $\$ 0.3$ billion increase in the deduction from the unamortized discount on long. term debt. Decreases in long-term debt accounted for 27.7 percent of the decrease in total liabilities and other credits.

- Notes payable accounted for most ( $\$ 0.1$ billion) of the nearly $\$ 0.2$ billion in total current and accrued liabilities.

- Increases in total deferred credits of over $\$ 0.2$ billion for 1995 were up 6.1 percent from the previous year.

\section{Consumers, Sales, and Revenue}

The information in this section is based on the data reported on the Form EIA-861.

Sales Growth. Sales to ultimate consumers of the major publicly owned generator electric utilities grew 1.2 percent in 1995 , a modest improvement over the 2.8-percent increase in sales between 1993 and 1994 (Table 10). The commercial sales more than offset the 7.1-percent decrease in sales to industrial or large consumers. Industrial sales represented 30.0 percent of total sales to ultimate consumers n 1995 , down from 32.4 percent in 1994. Of the 2.9 million megawatthours increase in sales to ultimate consumers, the 6.5 million megawatthours increase by the commercial consumers more than offset the 5.2 million megawatthour decrease in industrial sales.

Residential sales were up a modest 2.0 percent in 1995 versus the 2.7-percent increase in sales experienced in 1994. Residential sales represented 32.1 percent of total sales to ultimate consumers for 1995 .

Average Revenue (Revenues Divided by Sales). Average revenues from sales to ultimate consumers remained essentially unchanged between 1994 and 1995 , decreasing modestly 2.1 percent to 61.2 mills per kilowatthour. Residential and commercial consumers 
both provided decreases in average revenues of 1.1 percent, while industrial consumers provided decreases of 7.1 percent. The average revenue provided by residential consumers in 1995 was 69.8 mills per kilowatthour versus 70.7 mills per kilowatthour in 1994. The average revenue provided by industrial consumers in 1995 was 44.8 mills per kilowatthour versus 48.0 mills per kilowatthour in 1994. The average revenue provided by commercial consumers in 1995 was 66.4 mills per kilowatthour verses 67.1 mills per kilowatthour in 1994.

Average revenue per consumer per month from the commercial and residential consumers, in 1995, increased 7.3 and 1.9 percent, respectively. The average revenue monthly provided by commercial consumers was $\$ 404.76$ per month up from 1994 when the average was $\$ 375.25$ per month. The average revenue monthly provided by residential consumers was $\$ 58.81$ in 1995 compared with $\$ 57.51$ in 1994 .

In 1995, average revenue provided by industrial consumers decreased $\$ 498.89$ to $\$ 5,205.27$. Average industrial revenue decreased 8.7 percent from the 1994 average of $\$ 5,704.16$.

Sales for Resale. Sales for resale were up 5.3 percent in 1995 , reaching 47.0 percent of total electricity sales. The share of total electricity sales provided by sales for resale increased marginally in 1995 (up 1.0 percent from the 46.0-percent level in 1994). The share of revenues represented by sales for resale was 34.4 percent in 1995 compared to 34.7 percent in 1994 (a modest decrease of 0.9 percent to $\$ 7.7$ billion). Average revenues from sales for resale decreased 7.5 percent to 36.1 mills per kilowatthour, up from 38.8 mills per kilowatthour in 1994.

\section{Generation and Purchased Power.}

In 1995, total net energy generated and received increased 2.5 percent, which corresponded closely with the increase in sales volume (Table 11). Net generation as a percent of the total net energy required increased moderately in 1995 , to 66.6 percent. The corresponding figures for 1994 and 1993 were 65.8 percent and 66.9 percent, respectively.

Net hydroelectric generation (conventional hydroelectric generation and net hydro-pumped storage) increased 24.3 percent from the prior year, increasing its proportion of total purchased power and net generation (i.e., total supply) to 17.7 percent. Steam generation decreased 6.9 percent in 1995 , accounting for 36.0 percent of the total supply. Nuclear generation increased 15.7 percent. Nuclear generation accounted for 13.0 percent of total supply in 1995, up from 11.6 percent in 1994.

Purchased power continues to play an ever increasing role in the supply mix of publicly owned generator electric utilities. In 1995, purchased power represented 30.1 percent of the supply mix and purchases from electric utilities dominated the power purchases, accounting for 95.6 percent of power purchases. However, purchases from nonutilities are increasing at a phenomenal rate up 400 percent from 1994.

In 1995 , steam power production expenses were 22.8 mills per kilowatthour generated, up 2.6 percent from 22.2 mills per kilowatthour in 1994. Despite the 16.8-percent decline from the prior year, nuclear power production expenses were 20.8 mills per kilowatthour generated. 
Table 3. Ten Largest U.S. Publicly Owned Generator Electric Utilities Ranked by Megawatthour Sales to Ultimate Consumers, 1995

\begin{tabular}{|c|c|c|c|}
\hline Publicly Owned Electric Utilities & State & Amount & Percent \\
\hline 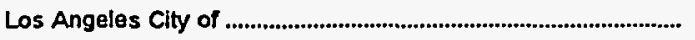 & California & $20,513,243$ & 8.56 \\
\hline 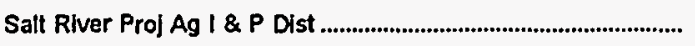 & Arizona & $16,667,262$ & 6.96 \\
\hline 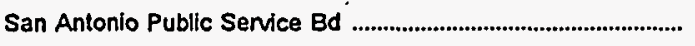 & Texas & $13,646,836$ & 5.70 \\
\hline Power Authority of State of NY & New York & $13,043,997$ & 5.45 \\
\hline Jacksonville Electric Auth & Florida & $9,268,850$ & 3.87 \\
\hline 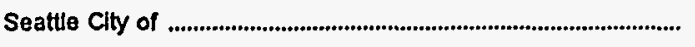 & Washington & $8,788,829$ & 3.67 \\
\hline 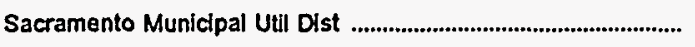 & California & $8,458,888$ & 3.53 \\
\hline South Carolina Pub Serv Auth & South Carolina & 7.739117 & 3.23 \\
\hline Austin City of & Texas & $7,585,563$ & 3.17 \\
\hline 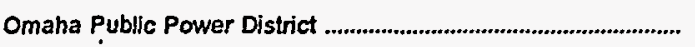 & Nebraska & $7,456,745$ & 3.11 \\
\hline Subtotal & & $113,169,330$ & 47.24 \\
\hline
\end{tabular}

Note: Percentage calculations are based on total generator electric utilities.

Source: Energy Information Administration, Form EIA-412, "Annual Report of Public Electric Utilities." Individual electric utilities report fiscal year data. Appendix B shows the fiscal year for each electric utility.

Table 4. Ten Largest U.S. Publicly Owned Generator Electric Utilities Ranked by Megawatthour Sales for Resale, 1995

\begin{tabular}{|c|c|c|c|}
\hline Publicly Owned Electric Utilities & State & Amount & Percent \\
\hline Power Authority of State of NY & New York & $27,446,460$ & 12.96 \\
\hline Intermountain Power Agency & Utah & $10,648,021$ & 5.03 \\
\hline 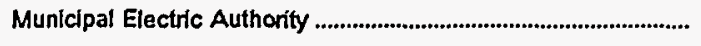 & Georgia & $10,449,304$ & 4.93 \\
\hline 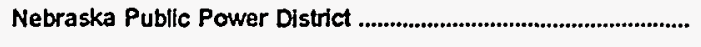 & Nebraska & $9,660,396$ & 4.56 \\
\hline 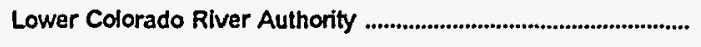 & Texas & $9,386,632$ & 4.43 \\
\hline PUD No 1 of Chelan County & Washington & $8,319,784$ & 3.93 \\
\hline South Carolina Pub Serv Auth & South Carolina & $8,283,056$ & 3.91 \\
\hline 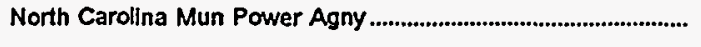 & North Carolina & $7,003,590$ & 3.31 \\
\hline Washington Pub Pur Supply Sys & Washington & $6,998,827$ & 3.30 \\
\hline 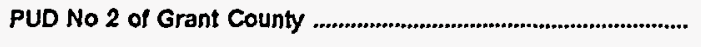 & Washington & $6,855,085$ & 3.24 \\
\hline 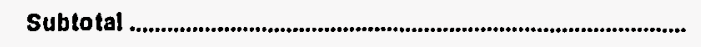 & & $105,051,155$ & 49.59 \\
\hline
\end{tabular}

Note: Percentage calculations are based on total generator electric utilities.

Source: Energy Information Administration, Form ElA-412, "Annual Report of Public Electric Utilities." Individual electric utilities report fiscal year data. Appendix $B$ shows the fiscal year for each electric utility. 
Table 5. Composite Statement of Income for Major U.S. Publicly Owned Generator Electric Utilities, 1991-1995

(Thousand Dollars)

\begin{tabular}{|c|c|c|c|c|c|}
\hline Item & 1995 & 1994 & 1993 & 1992 & 1991 \\
\hline 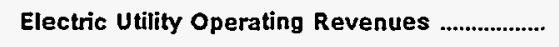 & $23,472,888$ & $23,266,686$ & $22,521,847$ & $21,686,349$ & $21,082,870$ \\
\hline 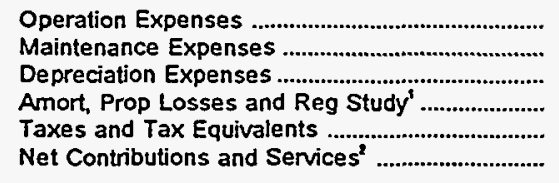 & $\begin{array}{r}13,652,884 \\
1,575,208 \\
2,802,473 \\
131,121 \\
797,189 \\
-\end{array}$ & $\begin{array}{r}13,577,615 \\
1,584,444 \\
2,591,423 \\
129,137 \\
766,068 \\
-\end{array}$ & $\begin{array}{r}13,241,567 \\
1,565,293 \\
2,441,927 \\
154,172 \\
759,205 \\
-\end{array}$ & $\begin{array}{r}12,527,435 \\
1,564,792 \\
2,285,807 \\
131,472 \\
681,140 \\
-\end{array}$ & $\begin{array}{r}12,155,075 \\
1,446,295 \\
2,300,532 \\
5 \\
595,719 \\
389,300\end{array}$ \\
\hline $\begin{array}{l}\text { Total Electric Utility Operating } \\
\text { Expenses }\end{array}$ & $18,958,876$ & $18,648,687$ & $18,162,164$ & $\{7,190,647$ & $16,886,921$ \\
\hline $\begin{array}{l}\text { Net Electric Utility Operating Income } \\
\text { Income from Electric Plant Leased }\end{array}$ & $4,514,013$ & $4,617,999$ & $4,359,683$ & $4,495,703$ & $4,195,949$ \\
\hline 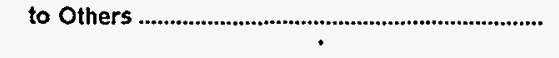 & 16,365 & 30,242 & 23,576 & 15.129 & 5,842 \\
\hline Electric Utility Operating Income ..................... & $4,530,377$ & $4,648,240$ & $4,383,258$ & $4,510,832$ & $4,201,891$ \\
\hline 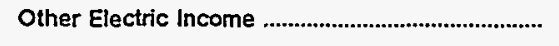 & $1,371,621$ & $1,237,067$ & $1,455,984$ & $1,839,484$ & $1,890,138$ \\
\hline $\begin{array}{l}\text { Other Electric Deductions } \\
\text { Allowance for Other Funds Used }\end{array}$ & 198,944 & 136,309 & 262,574 & 225,472 & 123,345 \\
\hline 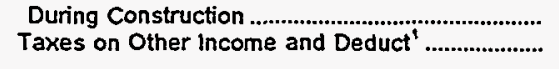 & $\begin{array}{r}9,145 \\
23,870\end{array}$ & $\begin{array}{r}7,872 \\
39,890\end{array}$ & $\begin{array}{l}28,476 \\
25,751\end{array}$ & $\begin{array}{l}24,183 \\
24,380\end{array}$ & $\begin{array}{r}71,025 \\
-\end{array}$ \\
\hline 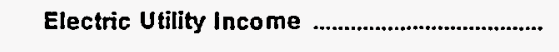 & $5,688,329$ & $5,716,920$ & $5,579,392$ & $6,124,646$ & $6,039,710$ \\
\hline 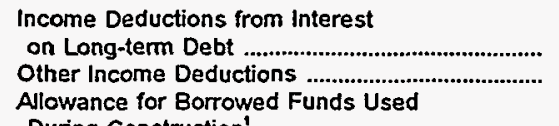 & $\begin{array}{r}4,206,294 \\
570,311\end{array}$ & $\begin{array}{r}4,332,296 \\
387,497\end{array}$ & $\begin{array}{r}4,433,067 \\
291,966\end{array}$ & $\begin{array}{r}4,757,583 \\
313,884\end{array}$ & $\begin{array}{r}4,775.003 \\
430.796\end{array}$ \\
\hline 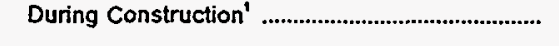 & $-48,543$ & $-38,652$ & -43.010 & $-45,719$ & - \\
\hline 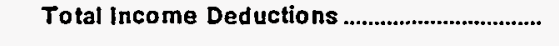 & $4,728,063$ & $4,681,141$ & $4,682,023$ & $5,025,758$ & $5,205,799$ \\
\hline 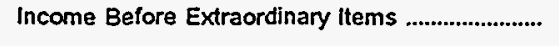 & 960,266 & $1,035,779$ & 897,369 & $1,098,889$ & 833,911 \\
\hline 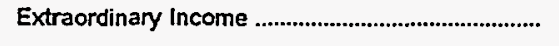 & 307,740 & 77,340 & 69.757 & 111,239 & 99,430 \\
\hline 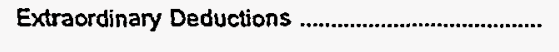 & 56,822 & 201,551 & 283,984 & 226.514 & 164.974 \\
\hline Net Income & $1,211,184$ & 911,568 & 683,142 & 983,613 & 768,367 \\
\hline \multicolumn{6}{|c|}{$\begin{array}{l}\text { Data reporting initiated in } 1992 \text {. } \\
\text { Data reporting discontinued in } 1992 . \\
\text { - Data not available. } \\
\text { Note: Totals may not equal sum of components because of independent rounding. Detailed data are provided in Table } 21 \text {. The num- } \\
\text { ber of publicly owned generating electric itilities for end of period is } 226 \text { for } 1995,227 \text { for } 1994,226 \text { for 1993, 225 for 1992, and } 218 \text { for } \\
1991 \text {. The City of Gaffney (SC), City of .jsceola (AR), and City of Redding (CA) were nongenerators for 1991 through 1993, but became } \\
\text { generators in } 1994 \text {. The City of Kennett (MO) and the City of Morgan City (LA) were generators } 1991 \text { through 1993, but became non- } \\
\text { generators in 1994. Emerald Peoples Utility District (OR), City of Bryan (OH), and Northern Wasco County PUD (OR) were nongenerators for } \\
\text { 1991, but became generators in } 1992 \text {. } \\
\text { Source: Energy Information Administration, Form EIA-412, "Annual Report of Public Electric Utilities." Individual electric utilities report } \\
\text { fiscal year data. Appendix B shows the fiscal year for each electric uttlity. }\end{array}$} \\
\hline
\end{tabular}


Table 6. Composite Balance Sheet for Major U.S. Publicly Owned Generator Electric Utilities at End of Period, 1991-1995

(Thousand Dollars)

\begin{tabular}{|c|c|c|c|c|c|}
\hline Item & 1995 & 1994 & 1993 & 1992 & 1991 \\
\hline \multicolumn{6}{|l|}{ Electric Utility Plant } \\
\hline 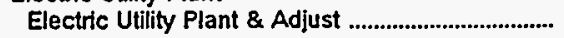 & $86,958,613$ & $85,250,576$ & $81,995,168$ & $79,555,377$ & $81,535,543$ \\
\hline 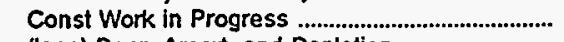 & $4,212,261$ & $4,229,508$ & $3,777,408$ & $3,532,582$ & - \\
\hline 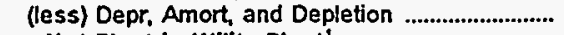 & $28,600,640$ & $26,779,491$ & & & $20,798,127$ \\
\hline Nel Electric Utility Plant ${ }^{1}$..................................... & $\begin{array}{r}62,570,234 \\
2,600,445\end{array}$ & $\begin{array}{r}62,700,593 \\
2,564,002\end{array}$ & $\begin{array}{r}61,547,988 \\
2,580,570\end{array}$ & $\begin{array}{r}60,786,867 \\
2,271,919\end{array}$ & - \\
\hline $\begin{array}{l}\text { (less) Amort of Nucl Fuel' } \\
\text { Net Elec Plant Incl Nucl Fuel }\end{array}$ & $\begin{array}{r}1,758.071 \\
63,412,608\end{array}$ & $\begin{array}{r}1,688,491 \\
63,576,104\end{array}$ & $\begin{array}{r}1,650,975 \\
62,477,584\end{array}$ & $\begin{array}{r}1,348,032 \\
61,710,753\end{array}$ & $60,737,41 \overline{6}$ \\
\hline \multicolumn{6}{|l|}{ Other Property \& Investments } \\
\hline Nonutility Property & $6,478,362$ & $6,011,888$ & $5,453,823$ & $5,000,781$ & $4,701,488$ \\
\hline (less) Accum Provisions for Depr \& Amort .......... & $1,910.192$ & $1,903,408$ & $1,763,781$ & $1,646,040$ & $1.530,242$ \\
\hline 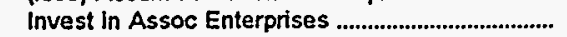 & 36,316 & 259.765 & 351,033 & 238,493 & 77,443 \\
\hline 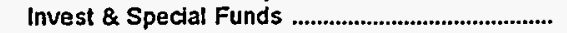 & $16,392,429$ & $16,605,752$ & $16,446,328$ & $14,618,703$ & $14,083,892$ \\
\hline Total Other Property \& Investments .............. & $20,996,914$ & $20,973,996$ & $20,487,402$ & $18,228,937$ & $17,332,581$ \\
\hline \multicolumn{6}{|l|}{ Current and Accrued Assets } \\
\hline $\begin{array}{l}\text { Cash, Working Funds \& Investments } \\
\text { Notes \& Other Receivables }\end{array}$ & $\begin{array}{r}8.811 .457 \\
809,388\end{array}$ & $\begin{array}{r}9,571,515 \\
693,020\end{array}$ & $\begin{array}{r}9,563,657 \\
725,707\end{array}$ & $\begin{array}{r}9,378,734 \\
736,137\end{array}$ & $\begin{array}{l}9,325,031 \\
2,321,436\end{array}$ \\
\hline Customer Accts Receivable' & $1,952,922$ & $2,001,427$ & $1,999,590$ & $1,763,091$ & - \\
\hline (less) Accum Prov for Uncollected Accts ............. & 72,376 & 66,493 & 106,485 & 99,830 & 93,358 \\
\hline 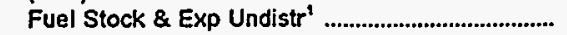 & 539.131 & 542,697 & 496.149 & 544,131 & - \\
\hline 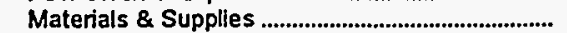 & $1,081,332$ & $1,130,673$ & $1,107,019$ & $1,163,156$ & $1,629,673$ \\
\hline 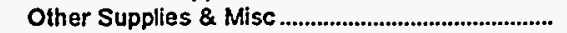 & 45,965 & - & - & - & - \\
\hline 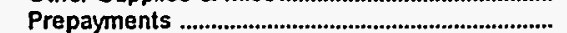 & 223,028 & 253,603 & 241,763 & 249,621 & 273,137 \\
\hline Accrued Utility Revenues' ...................................... & 398,826 & 313,896 & 303,140 & 258,068 & - \\
\hline $\begin{array}{l}\text { Miscelianeous Current \& Accrued Assets ............. } \\
\text { Total Current \& Accrued Assets .................. }\end{array}$ & $\begin{array}{r}1,296,771 \\
15,086,442\end{array}$ & $\begin{array}{r}1,341,955 \\
15,782,291\end{array}$ & $\begin{array}{r}1,026,573 \\
15,357,112\end{array}$ & $\begin{array}{r}997,599 \\
14,990,707\end{array}$ & $\begin{array}{r}628,771 \\
14,084,691\end{array}$ \\
\hline \multicolumn{6}{|l|}{ Deferred Debits } \\
\hline 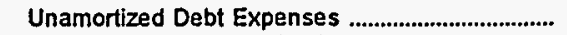 & $2,582,636$ & $2,784,363$ & $2,427,106$ & $2,200,298$ & $1,838,193$ \\
\hline Extraordinary Losses, Study Cost ............................ & $1,633,362$ & 517,236 & 911,714 & 465,291 & 34,360 \\
\hline Misc Debt, R \& D Exp. Unamrt Losses ................. & $10,026,679$ & $10,612,155$ & $10,648,504$ & $9,351,452$ & $9,017,609$ \\
\hline $\begin{array}{l}\text { Total Deferred Debits } \\
\text { Total Assets \& Other Debits }\end{array}$ & $113,738,640$ & $114,246,146$ & $112,309,422$ & $\begin{array}{r}12,017,041 \\
106,947,439\end{array}$ & $\begin{array}{r}10,890,161 \\
103,044,849\end{array}$ \\
\hline \multicolumn{6}{|l|}{ Proprietary Capital } \\
\hline 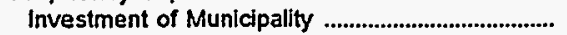 & $1,878,305$ & $1,553,731$ & $1,565,518$ & 1.601 .685 & $1,677,807$ \\
\hline 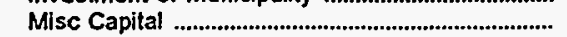 & 261,665 & 270,335 & 205,855 & 92,311 & $-14,474$ \\
\hline Retalned Earnings & $23,307,191$ & $22,694,785$ & 21.756 .224 & $21,129,231$ & $20,558,709$ \\
\hline $\begin{array}{l}\text { Total Proprietary Capital .......................................... } \\
\text { Long-term Debt }\end{array}$ & $25,447,162$ & $24,518,851$ & $23,527,598$ & $22,823,226$ & $22,222,042$ \\
\hline \multicolumn{4}{|l|}{ Long-term Debt } & & \\
\hline 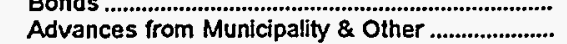 & $\begin{array}{r}13,320,390 \\
4,426,379\end{array}$ & $4,934,423$ & R $3,747,518$ & $\begin{array}{r}2,57,020 \\
2,531,683\end{array}$ & $\begin{array}{r}68,241,190 \\
3,198,284\end{array}$ \\
\hline Unamort Prem on Long-term Debt ......................... & 348,015 & 56,467 & 96,902 & 60,388 & 13.414 \\
\hline (less) Unamort Discount on Long-term Debt ....... & $3,112,633$ & $3,373,060$ & $2,830,002$ & $2,960,305$ & $2,581,371$ \\
\hline 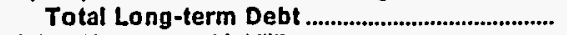 & $74,982,156$ & $76,815,309$ & $76,168,783$ & $72,004,391$ & $68,871,516$ \\
\hline \multicolumn{6}{|l|}{ Other Noncument Liabilities } \\
\hline 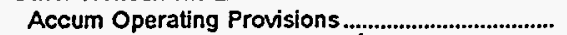 & 556,419 & 596,899 & 475,624 & 694,074 & 622,507 \\
\hline 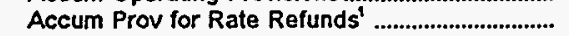 & 157,935 & 104,507 & 115,164 & 4,277 & - \\
\hline Total Other Noncurrent Ljabilities ................. & 714,354 & 701,406 & 590,789 & 698,351 & 622,507 \\
\hline \multicolumn{6}{|l|}{ Current and Accrued Uabilities } \\
\hline Notes Payable & $1,348,606$ & $1,249,705$ & $1.310,284$ & $1,117,110$ & $1,164,516$ \\
\hline 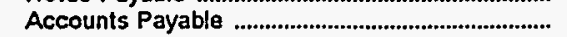 & $2,142,509$ & $2,151,413$ & $2,056,839$ & $2,019.801$ & $1,845,315$ \\
\hline 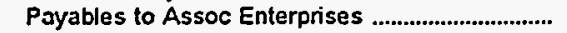 & 351,767 & 312,779 & 304.054 & 284,324 & 240,228 \\
\hline Customer Deposits & 320,250 & 311,864 & 284,735 & 297,901 & 268,456 \\
\hline Taxes Accrued & 215,340 & 219,358 & 202,354 & 191,865 & 258,660 \\
\hline Interest Accrued & $1,536,951$ & $1,506,666$ & $1,472,136$ & $1,464,605$ & $1,509,266$ \\
\hline Misc Current \& Accrued Labilities ........................... & $3,169,439$ & $3,161,371$ & $2,963,651$ & $2,705,171$ & $2,558,230$ \\
\hline $\begin{array}{l}\text { Total Current \& Accrued Liabilities ................ } \\
\text { Deferred Credits }\end{array}$ & $9,084,862$ & $8,913,155$ & $8,594,053$ & $8,080,777$ & $7,844,671$ \\
\hline \multirow{5}{*}{ 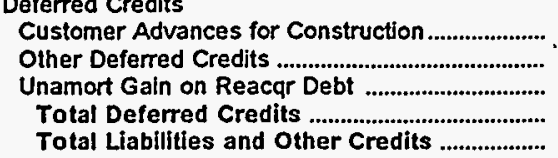 } & 199,920 & 171,987 & 170,922 & 168,889 & 141,050 \\
\hline & $3,272,692$ & $2,891,952$ & $2,947,484$ & $2,787,138$ & $2,775,909$ \\
\hline & 37,494 & 233,486 & 309,794 & 384,667 & 567,153 \\
\hline & $3,510,106$ & $3,297,425$ & $3,428,200$ & $3,340,694$ & $3,484,113$ \\
\hline & $113,738,640$ & $114,246,146$ & $112,309,422$ & $106,947,439$ & $103,044,849$ \\
\hline
\end{tabular}

Data reporting initiated in 1992.

$R=$ Revised Data.

Note: Totals may not equal sum of components because of independent rounding. Detailed data are provided in Table 21 . The number of publicly owned generating electric utilities for end of period is 226 for 1995, 227 for 1994, 226 for 1993,225 for 1992 , and 218 for 1991. The City of Gaffney (SC), City of Osceola (AR), and City of Redding (CA) were nongenerators for 1991 through 1993. but became generators In 1994. The City of Kennett (MO) and the City of Morgan City (LA) were generators 1991 through 1993, but became nongenerators in 1994. Emerald Peoples Utility District (OR). City of Bryan (OH), and Northern Wasco County PUD (OR) were nongenerators for 1991 , but became generators in 1992.

Source: Energy Information Administration, Form EIA-412, "Annual Report of Public Electric Utilities." Individual electric utilities report fiscal year data. Appendix $B$ shows the fiscal year for each electric utility. 
Table 7. Composite Financial Indicators for Major U.S. Publicly Owned Generator Electric Utilities, 1991-1995

\begin{tabular}{|c|c|c|c|c|c|}
\hline Item & 1995 & 1994 & 1993 & 1992 & 1991 \\
\hline Total Electric Utility Plant per Dollar of Revenue & 4.0 & 4.0 & 3.9 & 3.9 & 3.9 \\
\hline Current Assets to Current Liabilities .......................... & 1.7 & 1.8 & 1.8 & 1.9 & 1.8 \\
\hline $\begin{array}{l}\text { Total Electric Utility Plant as a Percent of Total } \\
\text { Assets }\end{array}$ & 82.4 & 80.6 & 78.7 & 79.8 & 79.1 \\
\hline $\begin{array}{l}\text { Net Electric Utility Plant as a Percent of Total } \\
\text { Assets }\end{array}$ & 55.8 & 55.6 & 55.6 & 57.7 & 58.9 \\
\hline Debt as a Percent of Total Liabilities ........................ & 73.9 & 75.0 & 75.5 & 74.9 & 74.4 \\
\hline $\begin{array}{l}\text { Depreciation, Amortization and Depletion } \\
\text { as a Percent of Total Electric Utility Plant .......... }\end{array}$ & 32.4 & 30.9 & 29.3 & 27.7 & 25.5 \\
\hline $\begin{array}{l}\text { Electric Operation and Maintenance Expenses } \\
\text { as a Percent of } \\
\text { Electric Utility Operating Revenues ............................ }\end{array}$ & 64.9 & 65.2 & 65.7 & 65.0 & 64.5 \\
\hline $\begin{array}{l}\text { Electric Depreciation and Amortization } \\
\text { as a Percent of } \\
\text { Electric Utility Operating Revenues ....................... }\end{array}$ & 11.9 & 11.1 & 10.8 & 10.5 & 10.9 \\
\hline $\begin{array}{l}\text { Taxes and Tax Equivalents } \\
\text { as a Percent of } \\
\text { Electric Utility Operating Revenues ....................... }\end{array}$ & 3.4 & 3.3 & 3.4 & 3.1 & 2.8 \\
\hline $\begin{array}{l}\text { Interest on Long-term Debt } \\
\text { as a Percent of } \\
\text { Electric Utility Operating Revenues ...................... }\end{array}$ & 17.9 & 18.6 & 19.7 & 21.9 & 22.6 \\
\hline $\begin{array}{l}\text { Net Income as a Percent of Electric } \\
\text { Utility Operating Revenues }\end{array}$ & 5.2 & 3.9 & 3.0 & 4.5 & 3.6 \\
\hline Purchased Power Cents Per Kilowatthour ............ & 3.6 & 3.6 & 3.6 & 3.7 & 3.8 \\
\hline 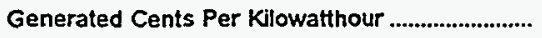 & 1.8 & 1.9 & 1.9 & 1.9 & 1.8 \\
\hline $\begin{array}{l}\text { Total Power Supply Per } \\
\text { Kllowatthour Sold }\end{array}$ & 2.5 & 2.6 & -2.6 & 2.6 & 2.6 \\
\hline
\end{tabular}

Note: Totals may not equal sum of components because of independent rounding. Detailed data are provided in Table 21. The number of pubticly owned generating electric utilities for end of period is 226 for 1995, 227 for 1994, 226 for 1993,225 for 1992 , and 218 for 1991. The City of Gaffney (SC), City of Osceola (AR), and City of Redding (CA) were nongenerators for 1991 through 1993, but became generators in 1994. The City of Kennett (MO) and the City of Morgan City (LA) were generators 1991 through 1993, but became nongenerators in 1994. Emerald Peoples Utility District (OR), City of Bryan (OH), and Northern Wasco County PUD (OR) were nongenerators for 1991. but became generators in 1992.

Source: Energy information Administration, Form ElA-4 12. "Annual Report of Public Electric Utilities." Individual electric utilities report fiscal year data. Appendix $B$ shows the fiscal year for each electric utility. 
Table 8. Electric Operation and Maintenance Expenses for Major U.S. Publicly Owned Generator Electric Utilities, 1991-1995

(Thousand Dollars)

\begin{tabular}{|c|c|c|c|c|c|}
\hline Item & 1995 & 1994 & 1993 & 1992 & 1991 \\
\hline \multicolumn{6}{|l|}{ Production Expenses } \\
\hline 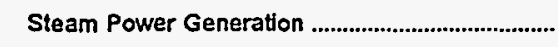 & $3,883,864$ & $4,037,562$ & $4,104,660$ & $3,761,983$ & $3,688,328$ \\
\hline 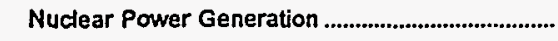 & $1,276,994$ & $1,291,932$ & $1,304,604$ & $1,318,443$ & $1,217,567$ \\
\hline 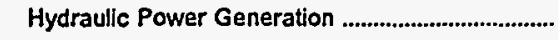 & 260,833 & 243,794 & 241,456 & 244,143 & 225,691 \\
\hline 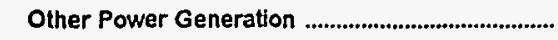 & 213.297 & 177.422 & 178,489 & 175,250 & 167,133 \\
\hline 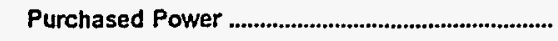 & $5,630,686$ & 5.639 .389 & $5,350,345$ & $5,225,943$ & $5,059,469$ \\
\hline 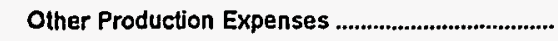 & 175,466 & 140.427 & 127,581 & 72,589 & 88,298 \\
\hline 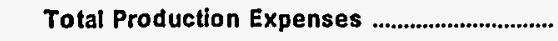 & $11,441,140$ & $11,530,527$ & $11,307,136$ & $10,798,351$ & $10,446,486$ \\
\hline 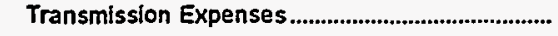 & 741,704 & 710,745 & 687,949 & 634,583 & 608,062 \\
\hline 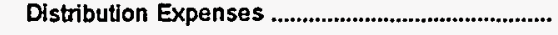 & 831,151 & 826,853 & 812,479 & 767,396 & 700,869 \\
\hline 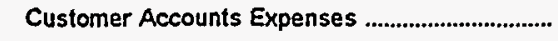 & 323,122 & 316,794 & 314,992 & 299,209 & 290.006 \\
\hline Customer Service and Information Expenses ..... & 102,061 & 104.101 & 94,089 & 82,731 & 73.913 \\
\hline 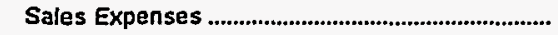 & 19,617 & 22,436 & 17.210 & 17.545 & 18.077 \\
\hline Administrative and General Expenses .................. & $1,769,298$ & $1,652,093$ & $1,573,005$ & $1,492,411$ & $1,463,958$ \\
\hline $\begin{array}{l}\text { Total Electric Operation } \\
\text { and Maintenance Expenses }\end{array}$ & $15,228,092$ & $15,163,549$ & $14,806,860$ & $14,092,227$ & $13,601,370$ \\
\hline \multicolumn{6}{|l|}{ Fuel Expenses in Operation } \\
\hline 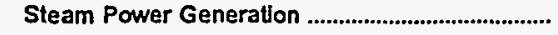 & $2,163,202$ & $2,970,626$ & $3,036,075$ & $2,733,568$ & $2,634,840$ \\
\hline 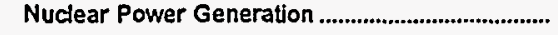 & 221,948 & 313,803 & 299.445 & 303,042 & 345,206 \\
\hline 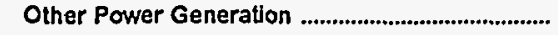 & 100,619 & 101,290 & 102,401 & $\mathbf{8 2 , 8 2 3}$ & 92,111 \\
\hline \multicolumn{6}{|l|}{ Number of Elec Dept Employees } \\
\hline Regular Full-time' & 56,051 & 59,073 & 58,603 & 60.435 & - \\
\hline 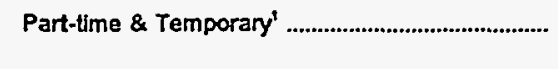 & $\begin{array}{r}2,150 \\
58,201\end{array}$ & $\begin{array}{r}2,567 \\
61,640\end{array}$ & $\begin{array}{r}2,610 \\
61,213\end{array}$ & $\begin{array}{r}2,812 \\
63,247\end{array}$ & - \\
\hline
\end{tabular}

1 Data reporting initiated in 1992.

Note: Totals may not equal sum of components because of independent rounding. Detailed data are provided in Table 21 . The number of publicly owned generating electric utilities for end of period is 226 for 1995, 227 for 1994,226 for 1993,225 for 1992 , and 218 for 1991. The City of Gaffney (SC). City of Osceola (AR), and City of Redding (CA) were nongenerators for 1991 through 1993. but became generators in 1994. The City of Kennett (MO) and the City of Morgan City (LA) were generators 1991 through 1993, but became nongenerators in 1994. Emerald Peoples Utility District (OR), City of Bryan (OH), and Northern Wasco County PUD (OR) were nongenerators for 1991. but became generators in 1992.

Source: Energy Information Administration, Form EIA-412, "Annual Report of Public Electric Utilities." Individual electric utijities repont fiscal year data. Appendix B shows the fiscal year for each electric utility. 
Table 9. Electric Utility Plant for Major U.S. Publicly Owned Generator

Electric Utilities at End of Period, 1991-1995

(Thousand Dollars)

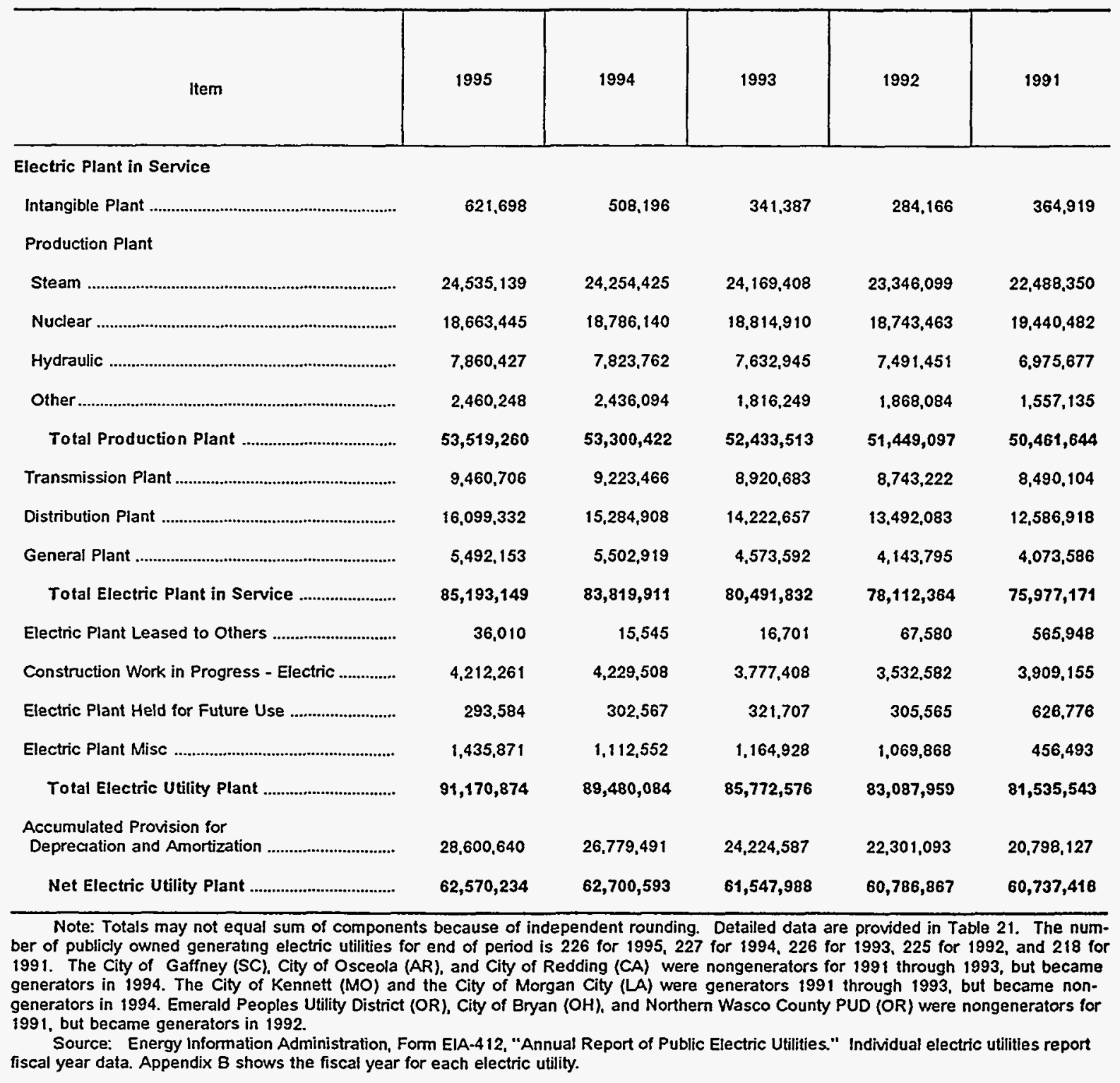


Table 10. Number of Consumers, Sales, and Operating Revenue for Major U.S. Publicly Owned Generator Electric Utilities, 1991-1995

\begin{tabular}{|c|c|c|c|c|c|}
\hline Item & 1995 & 1994 & 1993 & 1992 & 1991 \\
\hline \multicolumn{6}{|l|}{ Number of Consumers } \\
\hline 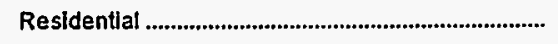 & $7,658,248$ & $7,614,061$ & $7,489,340$ & $7,399,653$ & $7,320,039$ \\
\hline Commercial or Small & $1,000,320$ & 992,375 & 985,258 & 977,783 & 894,604 \\
\hline 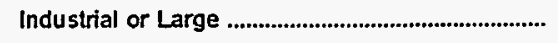 & 51,768 & 54,196 & 51,989 & 50.465 & 45,202 \\
\hline Other & 104,078 & 99,554 & 92,891 & 158,098 & 162,871 \\
\hline Total Ultimate Consumers ................................. & $8,814,414$ & $8,760,186$ & $8,619,478$ & $8,585,999$ & $8,422,716$ \\
\hline \multicolumn{6}{|l|}{ Sales for the Year (megawatthours) } \\
\hline 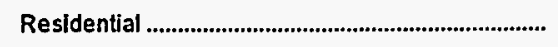 & $77,446,630$ & $75,909,946$ & $74,252,932$ & $71,313,263$ & $71,667,965$ \\
\hline 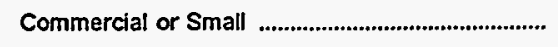 & $73,082,039$ & $66,553,738$ & $68,401,493$ & $66,801,045$ & $65,283,723$ \\
\hline 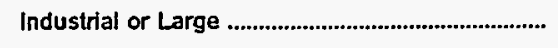 & $72,156,095$ & $77,301,989$ & 71.517 .638 & $70,698,216$ & $68,550,382$ \\
\hline Other & $18,697,163$ & $18,727,718$ & $17.804,844$ & $17,977,295$ & $17.643,031$ \\
\hline Total Sales to Uitimate Consumers ................ & $241,381,927$ & $238,493,391$ & $231,976,907$ & $226,789,819$ & $223,145,101$ \\
\hline 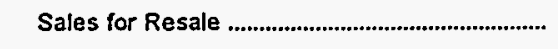 & $214,229,768$ & $203,426,731$ & $198,650,136$ & $184,259,846$ & $183,508,522$ \\
\hline 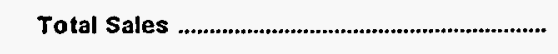 & $455,611,695$ & $441,920,122$ & $430,627,043$ & $411,049,665$ & $406,653,623$ \\
\hline \multicolumn{6}{|l|}{$\begin{array}{l}\text { Operating Revenues for the Year } \\
\text { (thousand dollars) }\end{array}$} \\
\hline 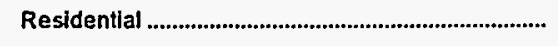 & $5,404,877$ & $5,363,914$ & $5,168,480$ & $4,885,087$ & $4,759,672$ \\
\hline Commercial or Small & $4,855,259$ & $4,468,693$ & $4,658,839$ & $4,434,108$ & $4,244,293$ \\
\hline Industrial or Large & $3,233,599$ & $3,709,714$ & $3,365,369$ & $3,243,937$ & $3,117,161$ \\
\hline Other & $1,274,338$ & $1,352,861$ & $1,279,902$ & $1,242,026$ & $1,105,045$ \\
\hline $\begin{array}{l}\text { Total Revenues from Sales to } \\
\text { Ultimate Consumers }\end{array}$ & $14,768,073$ & $14,895,182$ & $14,472,590$ & $13,805,158$ & $13,226,171$ \\
\hline Sales for Resale & $7,737,830$ & $7.902,934$ & $7,592,335$ & 7.246 .170 & $6.995,157$ \\
\hline $\begin{array}{l}\text { Total Revenues From Sales of } \\
\text { Electricity }\end{array}$ & $22,505,903$ & $22,798,116$ & $22,064,925$ & $21,051,328$ & $20,221,328$ \\
\hline
\end{tabular}

Note: Totals may not equal sum of components because of independent rounding. Detailed data are provided in Table 21 . The number of publicly owned generating electric utilities for end of period is 226 for 1995, 227 for 1994, 226 for 1993,225 for 1992 , and 218 for 1991. The City of Gaffney (SC). City of Osceola (AR), and City of Redding (CA) were nongenerators for 1991 through 1993, but became generators in 1994. The City of Kennett (MO) and the City of Morgan City (LA) were generators 1991 through 1993, but became nongenerators in 1994. Emerald Peoples Utility District (OR), City of Bryan (OH), and Northern Wasco County PUD (OR) were nongenerators for 1991, but became generators in 1992. sions.

Source: Energy Information Administration, Form EIA-861, "Annual Electric Utility Report" Data are based on calendar year submis- 
Table 11. Electric Energy Account for Major U.S. Publicly Owned Generator Electric Utilities, 1991-1995

(Megawatthours)

\begin{tabular}{|c|c|c|c|c|c|}
\hline Item & 1995 & 1994 & 1993 & 1992 & 1991 \\
\hline \multicolumn{6}{|l|}{ Sources of Energy } \\
\hline 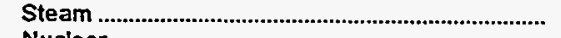 & $170,232,784$ & $181,935,951$ & $179,616,592$ & $169,087,041$ & $164.401,739$ \\
\hline Nuclear & $61,425,458$ & $53,082,028$ & $48,580,405$ & $52,565,245$ & $57,756,871$ \\
\hline 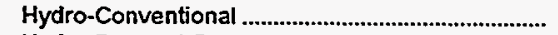 & $78,246,578$ & $64,584,646$ & $71,114,954$ & $65,807,396$ & $73,348,633$ \\
\hline Hydro-Pumped Storage & $5,488,354$ & $4,161,991$ & $4,423,179$ & $4,722,771$ & $3,789,638$ \\
\hline Other & $3,741,342$ & $3,288,915$ & $3,053,440$ & $2,940,656$ & $3,137,344$ \\
\hline $\begin{array}{l}\text { (Less) Energy for Pumping } \\
\text { Total Net Generation }\end{array}$ & $\begin{array}{r}4,025,506 \\
315,109,010\end{array}$ & $\begin{array}{r}4,609,045 \\
302,444,488\end{array}$ & $\begin{array}{r}4,354,233 \\
302,434,335\end{array}$ & $\begin{array}{r}4,255,476 \\
290,867,622\end{array}$ & $\begin{array}{r}3,904,547 \\
298,529,666\end{array}$ \\
\hline 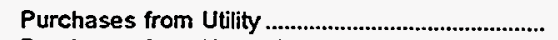 & $145,038,513$ & $155,682,364$ & $148,390,636$ & $140,184,294$ & $135,721,748$ \\
\hline 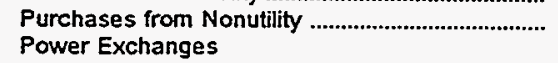 & $6,655,007$ & $1,330,033$ & $1,353,022$ & 887,430 & $1,023,894$ \\
\hline 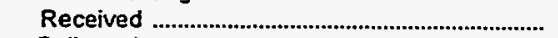 & $27,607,895$ & $18,536,937$ & $21,148,873$ & $18,630,155$ & $19,499,318$ \\
\hline 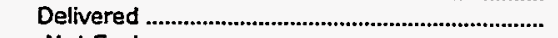 & $21,664,702$ & $16,749,120$ & $21,036,289$ & $18,482,571$ & $22,632,364$ \\
\hline Net Exchanges & $5,943,182$ & $1,787,820$ & 112,592 & 147.591 & $-3,133,045$ \\
\hline \multicolumn{6}{|l|}{ Transmission for Others (Wheeling) } \\
\hline 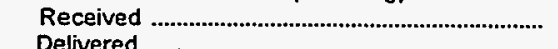 & $25,415,896$ & $29,584,752$ & $26,921,886$ & $22,140,593$ & $27,653,990$ \\
\hline Delivered ................................................... & $25,209,468$ & $29,288,330$ & $26,654,703$ & $21,936,332$ & $27,447,579$ \\
\hline 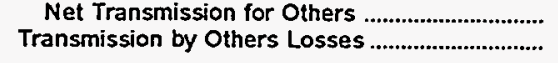 & $\begin{array}{r}206,428 \\
-124,194\end{array}$ & $\begin{array}{r}296,423 \\
-355,513\end{array}$ & $\begin{array}{r}267,183 \\
-282,349\end{array}$ & $\begin{array}{r}204,261 \\
-242,982\end{array}$ & $\begin{array}{r}206,410 \\
-162,245\end{array}$ \\
\hline \multicolumn{6}{|l|}{ Total Net Energy Generated and } \\
\hline Received & $472,827,955$ & $461,185,617$ & $452,275,424$ & $432,048,203$ & $432,186,432$ \\
\hline \multicolumn{6}{|l|}{ Disposition of Energy } \\
\hline Sales to Ultimate Consumers & $239,543,049$ & $237,232,643$ & $232,596,331$ & $225,275,670$ & $222,657,472$ \\
\hline 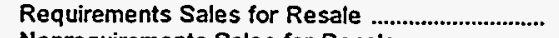 & $157,420,636$ & $158,681,120$ & $154,746,622$ & $145,946,599$ & $154,882,433$ \\
\hline $\begin{array}{l}\text { Nonrequirements Sales for Resale .............................. } \\
\text { Fumished Without Charoe }\end{array}$ & $54,417,784$ & $42,193,324$ & $41,023,702$ & $36,390,513$ & $30,076,686$ \\
\hline $\begin{array}{l}\text { Furnished Without Charge } \\
\text { Used by Utility (excluding station use) }\end{array}$ & $2,788,094$ & $1,697,254$ & $1.727,438$ & $1,632,802$ & $1,639,051$ \\
\hline 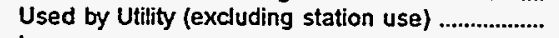 & $4,116,098$ & $5,222,487$ & $5,071,240$ & $6,633,786$ & $7,627,773$ \\
\hline Losses & $14,542,300$ & $16,158,776$ & $17,110,110$ & $16,168,831$ & $15,302,995$ \\
\hline Total Disposition & $472,827,955$ & $461,185,617$ & $452,275,424$ & $432,048,203$ & $432,186,432$ \\
\hline
\end{tabular}

Note: Totals may not equal sum of components because of independent rounding. Detailed data are provided in Table 21 . The number of publicly owned generating electric utilities for end of period is 226 for 1995, 227 for 1994, 226 for 1993,225 for 1992 , and 218 for 1991. The City of Gaffney (SC). City of Osceola (AR), and City of Redding (CA) were nongenerators for 1991 through 1993, but became generators in 1994. The City of Kennett (MO) and the City of Morgan City (LA) were generators 1991 through 1993, but became nongenerators in 1994. Emerald Peoples Utility District (OR). City of Bryan (OH), and Northern Wasco County PUD (OR) were nongenerators for 1991, but became generators in 1992. Double counting occurs in components of both sources and disposition of energy and thus neither provides a true total. Purchases from utilities, net exchanges, and net wheeling (except for imports) are included in net generation. Sales for resale is included in sales to ultimate consumers.

Source: Energy Information Administration, Fom ElA-412, "Annual Report of Public Electric Utilities." Individual electric utilities report fiscal year data. Appendix B shows the fiscal year for each electric utility. 


\section{Financial Performance for Nongenerator Electric Utilities}

Financial statistical summaries are provided for major publicly owned nongenerator electric utilities which include 286 electric utilities for 1995; 276 electric utilities for 1994; 269 clectric utilities for 1993; 258 electric utilities for 1992 and 252 electric utilities for 1991. New respondents and electric utilities no longer reporting from the previous years are listed in Appendix B.

\section{Highlights of Nongenerator Financial Performance}

Despite total electric utility operating costs increasing faster than revenue, the publicly owned nongenerator electric utilities net income was up 15.6 percent. Key factors in the financial performance of the nongenerator electric utilities were:

- Revenues were up 5.5 percent with total electric operating expenses up 5.4 percent.

- Purchased power costs per kilowatthour sold increased 2.8 percent and represented 75.4 percent of the total costs to consumers (up from 77.2 percent in 1994).

- Debt outstanding and interest expenses increased $\$ 0.7$ billion and $\$ 0.1$ billion or 26.4 percent and 16.9 percent, respectively.

\section{Income Statement}

The Composite Statement of Income for major publicly owned nongenerator electric utilities for the years 1991 to 1995 is presented (Table 14). Net income of $\$ 0.4$ billion for nongenerator electric utilities was up 15.6 percent over the prior year. Income before extraordinary items jumped 16.2 percent to $\$ 0.4$ billion in 1995 .

Revenues. Nongenerator electric utilities revenues showed an increase of 5.5 percent to $\$ 8.4$ billion in 1995. Increased sales were a major contributing factor to increased revenues. Revenues from sales to ultimate consumers increased by $\$ 0.4$ billion in 1995 .

Elcetric Utility Operating Expenses. Total electric utility operating expenses of $\$ 8.0$ billion were up 5.4 percent over the previous year. The largest dollar increase was in operation expenses (up 4.6 percent or $\$ 0.3$ billion in 1995). Operation expenses accounted for 90.0 percent of total electric utility expenses. The second largest contributor was depreciation expense, which accounted for 3.9 percent of total electric utility operating expense and was up 15.3 percent over the prior year. Maintenance expenses accounted for 3.1 percent of the total and were up 6.7 percent over the previous ycar. Tax and tax equivalents were up 21.2 percent in 1995. These tax expenses accounted for 3.1 percent of total electric utility operating expenses in 1995.

Production Expenses. Production expenses were up 3.8 percent over the prior year, accounting for $\$ 6.4$ billion of expenses (Table 17). Purchased power expenses represented virtually all of production expenses, which averaged 44.3 mills per kilowatthour sold (Table 19), up 2.8 percent from the prior year.

Transmission and Distribution Expenses. Transmission expenses accounted for only 0.3 mills per kilowatthour sold, up 5.4 percent in 1995. however, on a total dollar basis, transmission expenses were up 5.6 percent, (accounting for $\$ 0.2$ billion). Distribution expenses accounted for 3.1 mills per kilowatthour sold or $\$ 0.4$ billion dollars of operation and maintenance expense and were up 7.1 percent in dollar terms and 6.9 percent in terms of mills per kilowatthour sold in 1995.

Electric Utility Income. With revenues increasing slight more than total electric operating expenses, net electric utility operating income was up 6.5 percent to $\$ 0.5$ billion in 1995. Electric utility income jumped 13.7 percent to $\$ 0.6$ billion in 1995 , up from $\$ 0.5$ billion in 1994 .

Interest Expense. Nongenerator electric utilities Increased their debt by $\$ 0.7$ billion for the year ending 1995, with interest expenses up 16.9 percent, which amounted to $\$ 0.1$ billion in 1995 .

Net Income. Slightly higher percent increase in revenues versus electric utility operating expenses and 20.8 percent increase in other electric income produced an increase of 15.6 percent in net income. Net income of $\$ 0.4$ billion in 1995 was up for the fifth year in a row.

\section{Balance Sheet}

The Composite Balance Sheet for publicly owned nongenerator electric utilities had a large increase of 15.0 percent in 1995 (Table 15).

Assets and Other Debits. Increases in electric utility plant contributed a significant gain on the asset side of the balance sheet in 1995, increasing 12.3 percent on a gross basis and 8.9 percent on a net basis. Total assets and other debits amounted to $\$ 11.8$ billion in 1995, up from $\$ 10.3$ billion in 1994 .

Electric Utility Plant. Electric utility plant in service increased 12.4 percent to $\$ 9.5$ billion in 1995 (table 18). distribution plant increased 7.1 percent from $\$ 6.3$ billion in 1994 to $\$ 6.8$ billion in 1995. Distribution plant rcpresented 71.4 percent of total utility electric plant in service for the nongenerator electric utilities. Other changes in asset and debt accounts include:

- Net electric plant including nuclear fuel represented $\$ 6.3$ billion or 52.9 percent of total in 1995 , down from 53.4 percent in 1994. 
- Total other property and investments increased slightly from 18.5 percent to 18.6 percent of total, ending the year at $\$ 2.2$ billion.

- Total current and accrued assets of $\$ 2.9$ billion also increased slightly from 24.3 percent of total in 1994 to 24.4 percent in 1995.

Liabilities and Other Credits. The most significant increase in liabilities and other credits was a 26.4-percent increase in total long-term debt and a 10.5-percent increase in total proprietary capital. The total proprietary capital account represents the equity that the nongencrator electric utilitics have in electric operations. In 1995, the equity fraction of total capitalization (assumed here to be defined as the sum of total proprietary capital and total long-term debt) decreased to 66.8 percent, compared with 69.8 percent in 1994. This ratio represents one of the most distinguishing differences between the generator and nongenerator electric utilities. For the generator elcctric utilities, this equity ratio was 25.3 percent in 1995 . Other changes in liabilities and other credits included:

- Long-term debt at year-end increased from $\$ 2.7$ billion in 1994 to $\$ 3.4$ billion in 1995 .

- Total proprietary capital increased $\$ 0.7$ billion to $\$ 6.9$ billion in 1995.

- Total capitalization represented 87.7 percent of total liabilities and other credits in 1995, the same as it represented in 1994.

- Current and accrued liabilities at 10.4 percent of total represented the only other significant element of total liabilities and other credits.

\section{Consumers, Sales, and Revenue}

The information in this section is based upon the Form EIA-861.

Sales Growth. Sales to ultimate consumers of the publicly owned nongenerator electric utilities grew 4.7 percent in 1995, a decrease from the 5.6 percent sales growth between 1993 and 1994 (table 19). Commercial sales increased at a 5.3-percent rate. Residental sales remained the same, while industrial sales expanded the most, increasing at a 9.2-percent rate.

The variance in growth rates across the sectors slightly shifted the relative sector mix of sales to uitimate consumers and proved to be another area where nongenerator electric utilities varied significantly from generator electric utilities. The commercial share of total sales to ultimate consumers of nongenerator electric utilities accounted for only 17.2 percent. In the case of generator electric utilitics, commercial sales accounted for 30.3 percent of total sales (a figure parallel with that of the investor-owned segment of the elcctric power industry).

Average Revenue (Revenues Divided by Sales). While average revenue from industrial and residential consumers increased 1.2 and 0.8 percent, respectfully, in 1995 , commcrcial produced less average revenue in 1995 than they produced in 1994, a difference of 0.5 percent. Residential consumers paid on average 62.3 mills per kilowatthour for electricity in 1995, while commercial consumers paid 65.0 mills per kilowatthour and industrial consumers paid 48.8 mills per kilowatthour.

Consumption per consumer in the residential sector was down 4.8 percent. Commercial consumption per consumer was up 1.7 percent and industrial consumption per consumer was up 3.5 percent in 1995. The average monthly bill paid by residential, commercial and industrial consumers amounted to $\$ 64.88, \$ 235.73$, and $\$ 4,697.54$, respectively. The residential monthly bill decreased 4.0 percent, while the commercial and industrial monthly bills increased 1.2 percent and 4.6 percent, respectively.

Resale sales jumped 23.5 percent from 1994 to 1995. Sales for resale accounted for 6.5 percent of the total nongenerator electric utility sales of electricity in 1995. Without any generating resources of their own, sales for resale in the nongenerator segment are not very significant to the overall sales and revenues of these entities. In 1995, sales for resale revenues accounted for $\$ 0.3$ billion dollars or 4.2 percent of total revenues from the sale of electricity.

Total revenues were up 6.0 percent for the year (table 19). Increased sales volume resulted in increased revenues in 1995. Average revenues were 55.6 mills per kilowatthour sold in 1995 versus 55.4 mills per kilowatthour sold in 1994.

\section{Purchased Power}

In 1995, purchased power from electric utilities and nonutilities essentially remained the same at 149.7 million megawatthours. Purchased power accounted for 44.3 mills per kilowatthour sold of the total average revenue of 58.8 mills per kilowatthour, or 75.4 percent of the costs to the consumer. 
Table 12. Ten Largest U.S. Publicly Owned Nongenerator Electric Utilities Ranked by Megawatthour Sales to Ultimate Consumers, 1995

\begin{tabular}{|c|c|c|c|}
\hline Publicly Owned Electric Utilities & State & Amount & Percent \\
\hline Memphis City of & Tennessee & $12,030,683$ & 8.92 \\
\hline 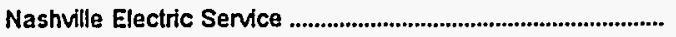 & Tennessee & $10,521,870$ & 7.80 \\
\hline 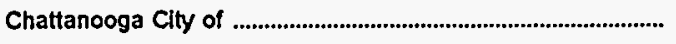 & Tennessee & $5,350,719$ & 3.97 \\
\hline 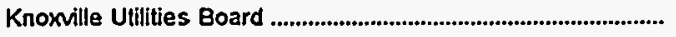 & Tennessee & $4,703,769$ & 3.49 \\
\hline Huntsville City of & Alabama & $3,690,259$ & 2.74 \\
\hline PUD No 1 of Clark County & Washington & $3,662,771$ & 2.72 \\
\hline Johnson City Clty of & Tennessee & $1,545,804$ & 1.15 \\
\hline 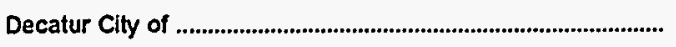 & Alabama & $1,418,883$ & 1.05 \\
\hline PUD No 1 of Benton County & Washington & $1,372,157$ & 1.02 \\
\hline 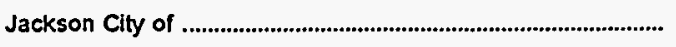 & Tennessee & $1,277,865$ & .95 \\
\hline Subtotal & & $45,574,780$ & 33.79 \\
\hline
\end{tabular}

Note: Percentage calculations are based on total nongenerator electric utilities.

Source: Energy Information Administration, Form EIA-412, "Annual Report of Public Electric Utilities." Individual electric utilities report fiscal year data. Appendix $\mathbf{B}$ shows the fiscal year for each electric utility.

Table 13. Ten Largest U.S. Publicly Owned Nongenerator Electric Utilities Ranked by Megawatthour Sales for Resale, 1995

\begin{tabular}{|c|c|c|c|}
\hline Publicly Owned Electric Utilities & State & Amount & Percent \\
\hline 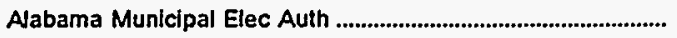 & Alabama & $2,530,960$ & 31.01 \\
\hline 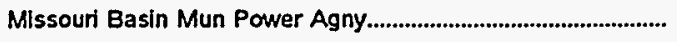 & South Dakota & $1,853,342$ & 22.71 \\
\hline 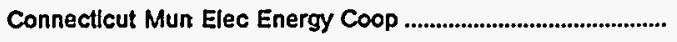 & Connecticut & $1,654,907$ & 20.28 \\
\hline Avizona Power Authority & Avizona & $1,016,063$ & 12.45 \\
\hline 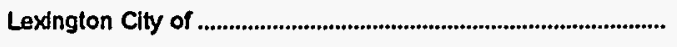 & North Carolina & 454,622 & 5.57 \\
\hline 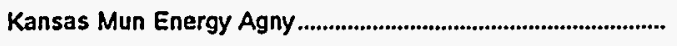 & Kansas & 304,342 & 3.73 \\
\hline 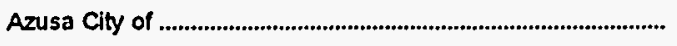 & California & 150,751 & 1.85 \\
\hline 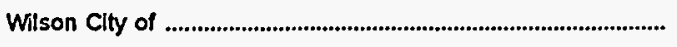 & North Carolina & 62,618 & .77 \\
\hline 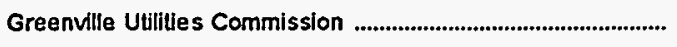 & North Carolina & 29,000 & .36 \\
\hline 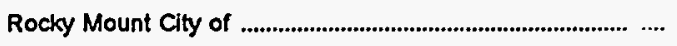 & North Carolina & 17,733 & .22 \\
\hline 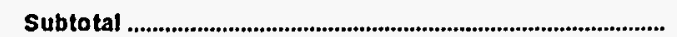 & & $8,074,338$ & 98.94 \\
\hline
\end{tabular}

Note: Percentage calculations are based on total nongenerator electric utilities.

Source: Energy Information Administration, Form EIA-412, "Annual Report of Public Electric Utilities." Individual electric utilities report fiscal year data. Appendix $B$ shows the fiscal year for each electric utility. 
Table 14. Composite Statement of Income for Major U.S. Publicly Owned Nongenerator Electric Utilities, 1991-1995

(Thousand Dollars)

\begin{tabular}{|c|c|c|c|c|c|}
\hline Item & 1995 & 1994 & 1993 & 1992 & 1991 \\
\hline Electric Utility Operating Revenues ..................... & $8,435,445$ & $7,995,632$ & $7,523,453$ & $7,247,407$ & $7,119,875$ \\
\hline 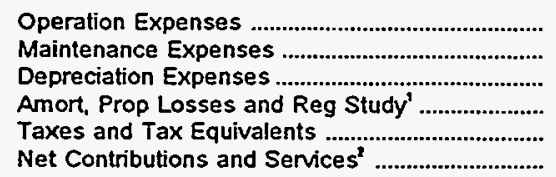 & $\begin{array}{r}7,172,858 \\
249,580 \\
309,892 \\
2,832 \\
243,648 \\
-\end{array}$ & $\begin{array}{r}6,857,970 \\
233,967 \\
268,790 \\
4,980 \\
201,038 \\
-\end{array}$ & $\begin{array}{r}6,424,798 \\
207,046 \\
252,850 \\
3,887 \\
174,681 \\
-\end{array}$ & $\begin{array}{r}6,244,831 \\
192,635 \\
248,040 \\
3,039 \\
154,994 \\
-\end{array}$ & $\begin{array}{r}6,119,385 \\
186,267 \\
246,594 \\
138,491 \\
168,882\end{array}$ \\
\hline $\begin{array}{l}\text { Total Electric Utility Operating } \\
\text { Expenses }\end{array}$ & $7,978,811$ & $7,566,745$ & $7,063,260$ & $6,843,539$ & $6,859,619$ \\
\hline 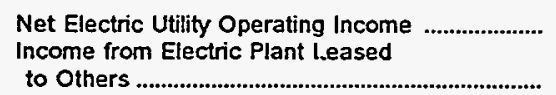 & 456,634 & 428,887 & 460.193 & 403,868 & $\begin{array}{r}260,255 \\
3.264\end{array}$ \\
\hline Electric Utility Operating Income ..................... & 460,979 & 431,071 & 462,598 & 405,642 & 263,520 \\
\hline Other Electric Income & 215,559 & 178.515 & 172,569 & 172.938 & 147,117 \\
\hline $\begin{array}{l}\text { Other Electric Deductions } \\
\text { Allowance for Other Funds Used }\end{array}$ & 73,718 & 79,813 & 74,084 & 98,838 & 13,949 \\
\hline $\begin{array}{l}\text { During Construction } \\
\text { Taxes on Other Income and Deduct' }\end{array}$ & $\begin{array}{r}41 \\
4,013\end{array}$ & $\begin{array}{r}51 \\
3,274\end{array}$ & $\begin{array}{r}106 \\
2,174\end{array}$ & $\begin{array}{r}39 \\
1,427\end{array}$ & $\begin{array}{r}1,608 \\
-\end{array}$ \\
\hline Electric Utility Income & 598,847 & 526,551 & 559,015 & 478,354 & 398,294 \\
\hline 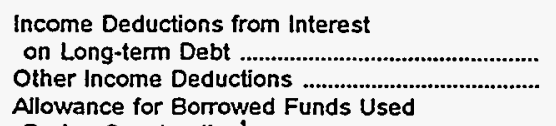 & $\begin{array}{r}127,013 \\
41,571\end{array}$ & $\begin{array}{r}108,647 \\
47,961\end{array}$ & $\begin{array}{r}114,527 \\
58,534\end{array}$ & $\begin{array}{r}109,378 \\
31,560\end{array}$ & $\begin{array}{r}112,031 \\
27,775\end{array}$ \\
\hline 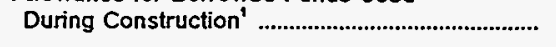 & 48 & -175 & -270 & -78 & - \\
\hline Total Income Deductions & 168,632 & 156,433 & 172,792 & 140,861 & 139,806 \\
\hline 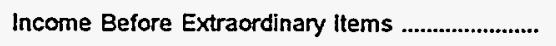 & 430,215 & 370,118 & 386,223 & 337,493 & 258,488 \\
\hline Extraordinary income & 15,359 & 36,207 & 17,981 & 35,508 & 24,074 \\
\hline Extraordinary Deductions & 22,018 & 40,028 & 43,581 & 37.664 & 33,326 \\
\hline Net Income & 423,556 & 366,297 & 360,624 & 335,338 & 249,236 \\
\hline \multicolumn{6}{|c|}{$\begin{array}{l}\text { Data reporting initiated in } 1992 \text {. } \\
\text { Data reporting discontinued in } 1992 \text {. } \\
\text { - Data not available. } \\
\text { Note: Totals may not equal sum, of components because of independent rounding. Detailed data are provided in Table 21. The num- } \\
\text { ber of publicly owned nongenerating electric utilities for end of peniod is } 286 \text { for } 1995,276 \text { for } 1994,269 \text { for } 1993,258 \text { for } 1992 \text {, and } 252 \\
\text { for } 1991 \text {. The City of Gaffney (SC). City of Osceola (AR), and City of Redding (CA) were nongenerators for 1991 through 1993, but be- } \\
\text { came generators in 1994. The City of Kennett (MO) and City of Morgan City (LA) were generators for 1991 through 1993, but became non- } \\
\text { generators in 1994. Emerald Peoples Utility District (OR), City of Bryan (OH), and Northern Wasco County PUD (OR) were nongenerators } \\
\text { for 1991, but became generators in 1992. } \\
\text { Source: Energy Information Administration, Form ElA-412, "Annual Report of Public Electric Utilities." Individual electric utilities report } \\
\text { fiscal year data. Appendix } B \text { shows the fiscal year for each electric utility. }\end{array}$} \\
\hline
\end{tabular}


Table 15. Composite Balance Sheet for Major U.S. Publicly Owned Nongenerator Electric Utilities at End of Period, 1991-1995

(Thousand Dollars)

\begin{tabular}{|c|c|c|c|c|c|}
\hline Item & 1995 & 1994 & 1993 & 1992 & 1991 \\
\hline \multicolumn{6}{|l|}{ Electric Utility Plant } \\
\hline $\begin{array}{l}\text { Electric Utility Plant \& Adjust } \\
\text { Const Work in Progress }\end{array}$ & $\begin{array}{r}9,555,886 \\
380,178\end{array}$ & $\begin{array}{r}8,506,732 \\
253,118\end{array}$ & $\begin{array}{r}8,055,891 \\
261,205\end{array}$ & $\begin{array}{r}7.474,793 \\
258,244\end{array}$ & $7,318,688$ \\
\hline 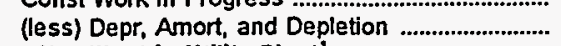 & $3,663,906$ & $3,263,791$ & $3,048,867$ & $2,852,034$ & $2,656,267$ \\
\hline Net Electric Utility Plant' .......................................... & $6,272,158$ & $5,496,059$ & $5,268,229$ & $4,881,003$ & \\
\hline 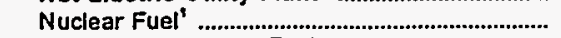 & 787 & - & - & - & - \\
\hline 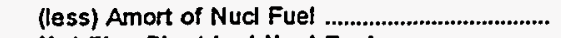 & 5,607 & - & - & - & - \\
\hline Net Elec. Plant Incl Nucl Fuel ................................... & $6,272,158$ & $5,496,059$ & $5,268,229$ & $4,881,003$ & - \\
\hline \multicolumn{6}{|l|}{ Other Property \& Investments } \\
\hline 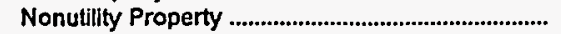 & $1,590,847$ & $1,529.415$ & $1,503.937$ & $1,407,105$ & $1,368,349$ \\
\hline (less) Accum Provisions for Depr \& Amort ........... & 420,053 & 378,494 & 374,268 & 331,064 & 310,379 \\
\hline 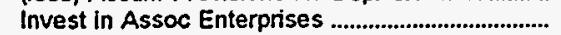 & 71,685 & 22,531 & 20,759 & 16,768 & 10,274 \\
\hline 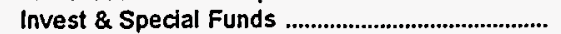 & 954,420 & 730.742 & 761,295 & 797,642 & 781.364 \\
\hline Total Other Property \& investments .............. & $2,196,898$ & $1,904,194$ & $1,911,724$ & $1,890,451$ & $1,849,607$ \\
\hline \multicolumn{6}{|l|}{ Current and Accrued Assets } \\
\hline Cash, Working Funds \& Investments ...................... & $1,551,504$ & $1,292,506$ & $1,327,201$ & $1,142.447$ & $1,103,512$ \\
\hline Notes \& Other Receivables & 439,357 & 406,300 & 377,135 & $\begin{array}{r}311,782 \\
377995\end{array}$ & 743,971 \\
\hline Customer Accts Receivable ${ }^{1}$ & $\begin{array}{r}443,603 \\
20,751\end{array}$ & $\begin{array}{r}382,764 \\
19,943\end{array}$ & $\begin{array}{r}374,415 \\
19,173\end{array}$ & $\begin{array}{r}377,995 \\
21,554\end{array}$ & 20.887 \\
\hline $\begin{array}{l}\text { (less) Accum Prov for Uncollected Accts ............. } \\
\text { Fuel Stock \& Exp Undistr' ........................................ }\end{array}$ & 1.075 & 2,433 & 264 & 1,180 & 20.001 \\
\hline Materials \& Supplies & 181,792 & 176,286 & 176,825 & 168.474 & 167,291 \\
\hline 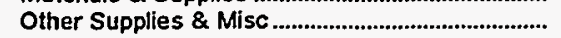 & 10,875 & & & & \\
\hline 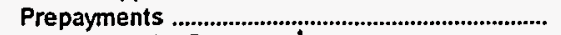 & 137,368 & 141.586 & 151,504 & 155.980 & 104,547 \\
\hline 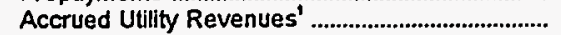 & 42,019 & 33.663 & 31,701 & 29.411 & - \\
\hline Miscellaneous Current \& Accrued Assets ............. & 97,246 & 82,222 & 75,888 & 61,368 & 63,698 \\
\hline 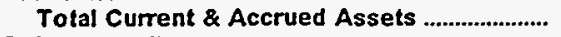 & $2,884,088$ & $2,497,816$ & $2,495,760$ & $2,227,084$ & $2,162,131$ \\
\hline \multicolumn{6}{|l|}{ Deferred Debits } \\
\hline 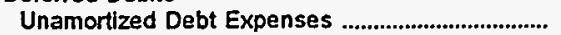 & 143,630 & 105,075 & 109,026 & 91.016 & 70,967 \\
\hline 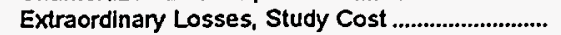 & 8,795 & 5,159 & 6,718 & 4,360 & - \\
\hline Misc Debt, R \& D Exp, Unamit Losses ............... & 340.267 & 290,212 & 308.163 & 290,887 & 253.473 \\
\hline Total Deferred Debits .............................................. & 492,691 & 400,447 & 423,907 & 386,263 & 324,440 \\
\hline Total Assets \& Other Debits ................................. & $11,841,016$ & $10,298,517$ & $10,099,620$ & $9,384,801$ & $8,998,600$ \\
\hline \multicolumn{6}{|l|}{ 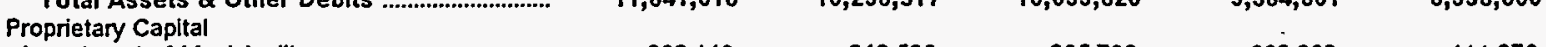 } \\
\hline 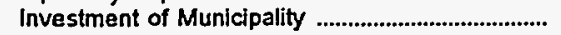 & 368,140 & 343,536 & 325.706 & 263,868 & 411,372 \\
\hline 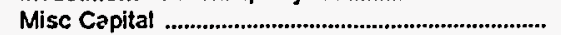 & $\mathbf{5 7 4 , 6 5 5}$ & 501,696 & 450.733 & 429,805 & 466,780 \\
\hline 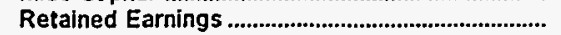 & $5,996,173$ & $5,436,414$ & $5,206,936$ & $4,828,568$ & $4,366,799$ \\
\hline Total Proprietary Capital ....................................... & $6,938,969$ & $6,281,647$ & $5,983,376$ & $5,522,242$ & $5,244,951$ \\
\hline \multicolumn{6}{|l|}{ Long-term Debt } \\
\hline 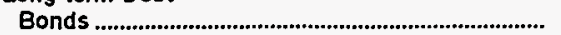 & $2,936,125$ & $2,282,753$ & $2,470,313$ & $2,277,558$ & $2,174,746$ \\
\hline 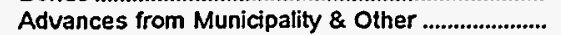 & 519,261 & 444,506 & 442,009 & 440,938 & 383,340 \\
\hline Unamort Prem on Long-term Debt .............................. & -75 & 4,485 & 543 & 9,962 & 2,437 \\
\hline (less) Unamort Discount on Long-term Debt ....... & 13,555 & 8,237 & 14,048 & 14,736 & 18,088 \\
\hline 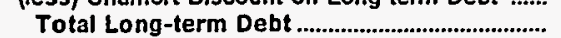 & $3,441,757$ & $2,723,507$ & $2,898,817$ & $2,713,721$ & $2,542,435$ \\
\hline \multicolumn{6}{|l|}{ Other Noncurrent Labilities } \\
\hline Accum Operating Provisions............................... & 12,931 & 11,380 & 10,525 & 10,078 & 55,488 \\
\hline Accum Prov for Rate Refunds' ...................................... & 3,248 & & 224 & 206 & \\
\hline Total Other Noncurrent Liabilities ................... & 16,179 & 11,414 & 10,749 & 10,284 & 55,488 \\
\hline \multicolumn{6}{|l|}{ Current and Accrued Labilities } \\
\hline Notes Payable ................................................................ & 123,320 & 65,262 & 54,495 & 50,560 & 69,765 \\
\hline 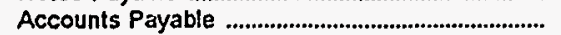 & 720,456 & 687,920 & 667,104 & 607,825 & 592,275 \\
\hline Payables to Assoc Enterprises ..................................... & 22,983 & 12,918 & 10,391 & 16,355 & 29,295 \\
\hline 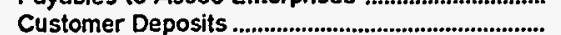 & 147.202 & 144,062 & 137,456 & 125.964 & 116,132 \\
\hline 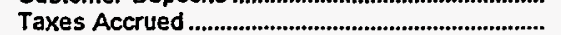 & 26,820 & 26,922 & 23,935 & 21,355 & 36,991 \\
\hline Interest Accrued ..................................................... & 43.419 & 38.475 & 36.594 & 59,637 & 40,611 \\
\hline Misc Current \& Accrued Liabilities ........................... & 148,423 & 123,382 & 109,891 & 102,169 & 84,054 \\
\hline Total Current \& Accrued Liabilities .................. & $1,232,623$ & $1,098,941$ & $1,039,867$ & 982,587 & 968,924 \\
\hline \multicolumn{6}{|l|}{ Deferred Credits } \\
\hline Customer Advances for Construction ........................... & 60,127 & 59.491 & 57,474 & 48,058 & 48,299 \\
\hline 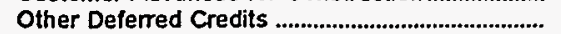 & 133,773 & 118,618 & 107,830 & 101,658 & 136,614 \\
\hline 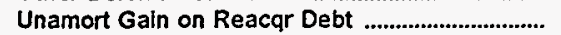 & 17.587 & 4,900 & 1,508 & 4,973 & 1,890 \\
\hline 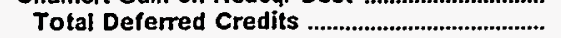 & 211,487 & 183,009 & 166,812 & 154,689 & 186,803 \\
\hline Total Liabilities and Other Credits .................... & $11,841,016$ & $10,298,517$ & $10,099,620$ & $9,384,801$ & $8,998,600$ \\
\hline
\end{tabular}

Data reporting iniliated in 1992.

Note: Totals may not equal sum of components because of independent rounding. Detailed data are provided in Table 21 . The number of publicly owned nongenerating electric utilities for end of period is 286 for 1995,276 for 1994,269 for 1993,258 for 1992 , and 252 for 1991. The City of Gaffney (SC). City of Osceola (AR), and City of Redding (CA) were nongenerators for 199t through 1993, but became generators in 1994. The City of Kennett (MO) and City of Morgan City (LA) were generators for 1991 through 1993, but became nongenerators in 1994. Emerald Peoples Utility District (OR). City of Bryan (OH), and Northern Wasco County PUD (OR) were nongenerators for 1991, but became generators in 1992.

Source: Energy Information Administration, Form EIA-412, "Annual Report of Public Electric Public Electric Utilities." Individual electric utilities report fiscal year data. Appendix B shows the fiscal year for each electric utility. 
Table 16. Composite Financial Indicators for Major U.S. Publicly Owned

Nongenerator Electric Utilities, 1991-1995

\begin{tabular}{|c|c|c|c|c|c|}
\hline Item & 1995 & 1994 & 1993 & 1992 & 1991 \\
\hline Total Electric Utility Plant per Dollar of Revenue & 1.2 & 1.1 & 1.1 & 1.1 & 1.0 \\
\hline 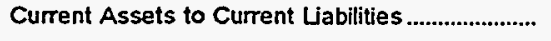 & 2.3 & 2.3 & 2.4 & 2.3 & 2.2 \\
\hline $\begin{array}{l}\text { Total Electric Utility Plant as a Percent of Total } \\
\text { Assets }\end{array}$ & 839 & 851 & 824 & 894 & $81 ?$ \\
\hline Net Electric Utility Plant as a Percent of Total & & & & & \\
\hline Assets & 52.9 & 53.4 & 52.2 & 52.0 & 51.8 \\
\hline Debt as a Percent of Total Liabilities ........................ & 39.5 & 37.1 & 39.0 & 39.4 & 39.0 \\
\hline $\begin{array}{l}\text { Depreciation, Amortization and Depletion } \\
\text { as a Percent of Total Electric Utility Plant .......... }\end{array}$ & 36.9 & 37.3 & 36.7 & 36.9 & 36.3 \\
\hline $\begin{array}{l}\text { Electric Operation and Maintenance Expenses } \\
\text { as a Percent of } \\
\text { Electric Utility Operating Revenues ............................ }\end{array}$ & 88.0 & 88.7 & 88.1 & 88.8 & 88.6 \\
\hline $\begin{array}{l}\text { Electric Depreciation and Amortization } \\
\text { as a Percent of } \\
\text { Electric Utility Operating Revenues ....................... }\end{array}$ & 3.7 & 3.4 & 3.4 & 3.4 & 3.5 \\
\hline $\begin{array}{l}\text { Taxes and Tax Equivalents } \\
\text { as a Percent of } \\
\text { Electric Utility Operating Revenues ....................... }\end{array}$ & 2.9 & 2.5 & 2.3 & 2.1 & 1.9 \\
\hline $\begin{array}{l}\text { Interest on Long-term Debt } \\
\text { as a Percent of } \\
\text { Electric Utility Operating Revenues ......................... }\end{array}$ & 1.5 & 1.4 & 1.5 & 1.5 & 1.6 \\
\hline 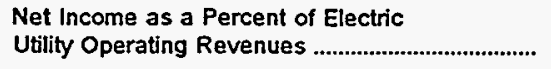 & 5.0 & 4.6 & 4.8 & - 4.6 & 3.5 \\
\hline Purchased Power Cents Per Kilowatthour............ & 4.3 & 4.1 & 4.1 & 4.1 & 4.1 \\
\hline
\end{tabular}


Table 17. Electric Operation and Maintenance Expenses for Major U.S. Publicly Owned Nongenerator Electric Utilities, 1991-1995 (Thousand Dollars)

\begin{tabular}{|c|c|c|c|c|c|}
\hline Item & 1995 & 1994 & 1993 & 1992 & 1991 \\
\hline \multicolumn{6}{|l|}{ Production Expenses } \\
\hline Steam Power Generation ............................................. & 10,931 & 284 & 362 & 416 & 544 \\
\hline Nuclear Power Generation .......................................... & - & - & - & - & - \\
\hline 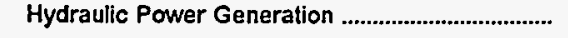 & 87 & 23 & 92 & 15 & 7 \\
\hline Other Power Generation & 17,575 & 1,500 & 1.249 & 622 & 97 \\
\hline 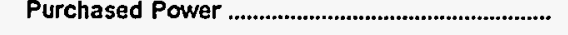 & $6,357,328$ & 6.169 .491 & $5,746,737$ & $5,608,871$ & $5,51 t, 698$ \\
\hline 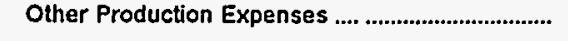 & 36,043 & 14,405 & 13,283 & 7,993 & 14,274 \\
\hline Total Production Expenses ...................................... & $6,421,965$ & $6,185,703$ & $5,761,722$ & $5,617,918$ & $5,526,621$ \\
\hline 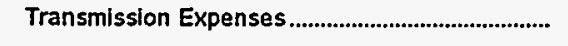 & 46,769 & 44,274 & 41,796 & 43,128 & 37,107 \\
\hline 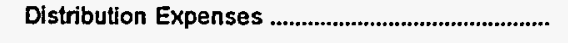 & 442,727 & 413,250 & 386,932 & 357.995 & 326,810 \\
\hline 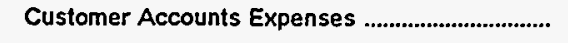 & 125,143 & 119,019 & 117,353 & 109,196 & 103,456 \\
\hline Customer Service and Information Expenses ..... & 17.934 & 16,941 & 17,166 & 15.629 & 15,743 \\
\hline 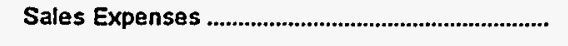 & 9,535 & 9,845 & 8,704 & 11.646 & 11,587 \\
\hline Administrative and General Expenses .................... & 358,367 & 302,904 & 298.151 & 281,954 & 284,327 \\
\hline $\begin{array}{l}\text { Total Electric Operation } \\
\text { and Maintenance Expenses .................................. }\end{array}$ & $7,422,439$ & $7,091,937$ & $6,631,823$ & $6,437,466$ & $6,305,652$ \\
\hline \multicolumn{6}{|l|}{ Fuel Expenses in Operation } \\
\hline Steam Power Generation ............................................... & 124 & - & 2 & 13 & 2 \\
\hline Nuclear Power Generation ............................................. & - & - & - & - & - \\
\hline 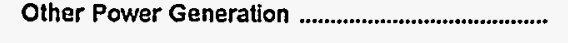 & 122 & 13 & 13 & 5 & 2 \\
\hline \multicolumn{6}{|l|}{ Number of Elec Dept Employees } \\
\hline Regular Full-time' & 14.637 & 14,850 & 14,712 & 14,458 & - \\
\hline Part-time \& Temporary' & $\begin{array}{r}334 \\
14,971\end{array}$ & $\begin{array}{r}367 \\
15,217\end{array}$ & $\begin{array}{r}1.031 \\
15,743\end{array}$ & $\begin{array}{r}1,054 \\
15,512\end{array}$ & $\overline{-}$ \\
\hline \multicolumn{6}{|c|}{ 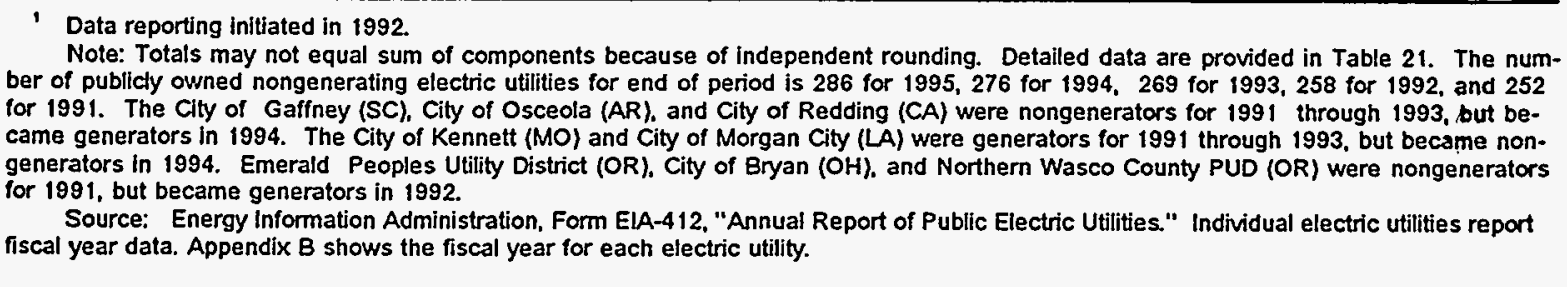 } \\
\hline
\end{tabular}


Table 18. Electric Utility Plant for Major U.S. Publicly Owned Nongenerator

Electric Utilities at End of Period, 1991-1995

(Thousand Dollars)

\begin{tabular}{|c|c|c|c|c|c|}
\hline Item & 1995 & 1994 & 1993 & 1992 & 1991 \\
\hline \multicolumn{6}{|l|}{ Electric Plant in Service } \\
\hline Intangible Plant & 20,387 & 18,825 & 10,565 & 10,549 & 8,292 \\
\hline \multicolumn{6}{|l|}{ Production Plant } \\
\hline Steam & 134,701 & 79,781 & 69,761 & 69,727 & 68,062 \\
\hline Nuclear & - & - & - & - & - \\
\hline Hydraulic & 264,238 & 15,345 & 15,334 & 15,334 & 15,334 \\
\hline Other & 80,662 & 35,502 & 27,082 & 18,984 & 19,164 \\
\hline Total Production Plant ....................................... & 479,601 & 130,628 & 112,177 & 104,045 & 102,560 \\
\hline Transmission Plant & 860,091 & 697,132 & 628,184 & 602,713 & 589,808 \\
\hline Distribution Plant & $6,760,020$ & $6,313,989$ & $5,923,094$ & $5,354,892$ & $5,192,372$ \\
\hline General Plant & $1,349,688$ & $1,265,635$ & $1,286,857$ & $1,312,183$ & $1,147,474$ \\
\hline Total Electric Plant in Service ...................... & $9,469,786$ & $8,426,208$ & $7,960,877$ & $7,384,383$ & $7,040,506$ \\
\hline 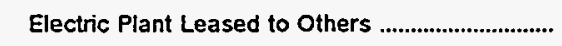 & 19,625 & 745 & 704 & 615 & 662 \\
\hline Construction Work in Progress - Electric .................. & 380,178 & 253.118 & 261,205 & 258,244 & 210,030 \\
\hline 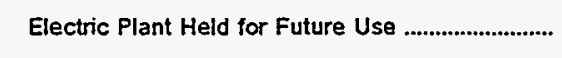 & 12,511 & 11,069 & 16,268 & 16,074 & 13,860 \\
\hline Electric Plant Misc & 53.963 & 68,710 & 78,042 & 73,722 & 53,630 \\
\hline 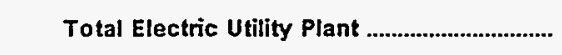 & $9,936,064$ & $8,759,850$ & $8,317,096$ & $7,733,037$ & $7,318,688$ \\
\hline 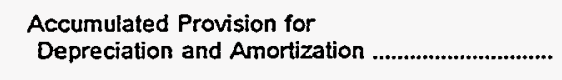 & $3,663,906$ & $3,263,791$ & $3,048,867$ & $2,852,034$ & $2,656,267$ \\
\hline 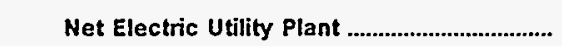 & $6,272,158$ & $5,496,059$ & $5,268,229$ & $4,881,003$ & $4,662,421$ \\
\hline
\end{tabular}

Note: Totals may not equal sum of components because of independent rounding. Detailed data are provided in Table 21. The number of publicly owned nongenerating electric utilities for end of period is 286 for 1995, 276 for 1994, 269 for 1993, 258 for 1992, and 252 for 1991. The City of Gaffiney (SC). City of Osceola (AR), and City of Redding (CA) were nongenerators for 1991 through 1993, but became generators in 1994. The City of Kennett (MO) and City of Morgan City (LA) were generators for 1991 through 1993, but became nongenerators in 1994. Emerald Peoples Utility Oistrict (OR), City of Bryan (OH), and Northern Wasco County PUD (OR) were nonge;erators for 1991, but became generators in 1992.

Source: Energy Information Administration, Form EIA-4 12, "Annual Report of Public Electric Utilities." Individual electric utilities report fiscal year data. Appendix B shows the fiscal year for each electric utility. 
Table 19. Number of Consumers, Sales, and Operating Revenue for Major U.S. Publicly Owned Nongenerator Electric Utilities, 1991-1995

\begin{tabular}{|c|c|c|c|c|c|}
\hline Item & 1995 & 1994 & 1993 & 1992 & 1991 \\
\hline \multicolumn{6}{|l|}{ Number of Consumers } \\
\hline Residentia! & $4,096,214$ & $3,914,442$ & $3,830,086$ & $3,705,525$ & $3,624,017$ \\
\hline Commercial or Small & 560.844 & 541,723 & 517,443 & 499.250 & 503,917 \\
\hline Industrial or Large & 54,800 & 51,956 & 48,652 & 45,537 & 30,629 \\
\hline Other & 74,342 & 64,542 & 68,043 & 87,037 & 103,377 \\
\hline 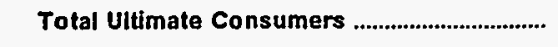 & $4,786,200$ & $4,572,663$ & $4,464,224$ & $4,337,349$ & $4,261,940$ \\
\hline \multicolumn{6}{|l|}{ Sales for the Year (megawatthours) } \\
\hline 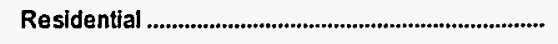 & $51,170,366$ & $51,347,293$ & $48,808,834$ & $46,306,852$ & $46,808,977$ \\
\hline Commercial or Small & $24,403,691$ & $23,173,716$ & $22,130,179$ & $21,815,955$ & $26,987,619$ \\
\hline 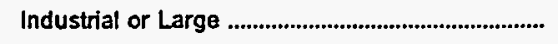 & $63,291,857$ & $57,975,900$ & $54,452,381$ & $51,453,636$ & $44,693,894$ \\
\hline Other & $2,784.978$ & $2,754,024$ & $2,669,498$ & $2,936.880$ & 3.146 .985 \\
\hline Total Sales to Ultimate Consumers ................ & $141,650,892$ & $135,250,933$ & $128,060,892$ & $122,513,323$ & $121,637,475$ \\
\hline Sales for Resale & $9,839,847$ & $7,968,820$ & $7,428,071$ & $7,506,885$ & $7,288,781$ \\
\hline 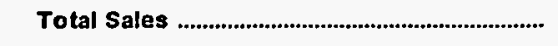 & $151,490,739$ & $143,219,753$ & $135,488,963$ & $430,020,208$ & $128,926,256$ \\
\hline \multicolumn{6}{|l|}{$\begin{array}{l}\text { Operating Revenues for the Year } \\
\text { (thousand dollars) }\end{array}$} \\
\hline 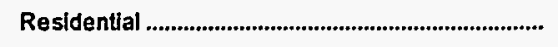 & $3,189,139$ & $3,174,212$ & $2,956,759$ & $2,785,966$ & $2,752,710$ \\
\hline 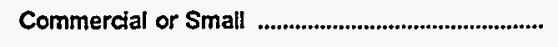 & $1,586,513$ & $1,514,358$ & $1,448,407$ & $1,412,309$ & $1,680,252$ \\
\hline 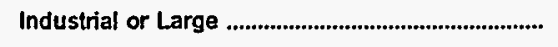 & $3,089,101$ & $2,801,005$ & $2,675,253$ & $2,553,929$ & $2,188,095$ \\
\hline 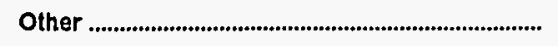 & 203,652 & 186,033 & 182,112 & 189,783 & 198,756 \\
\hline $\begin{array}{l}\text { Total Revenues from Sales to } \\
\text { Ultimate Consumers }\end{array}$ & $8,068,405$ & $7,675,608$ & $7,262,531$ & $6,941,987$ & $6,819,813$ \\
\hline 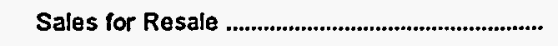 & 349,658 & 263,032 & 246,614 & 232,879 & 226,388 \\
\hline $\begin{array}{l}\text { Total Revenues From Sales of } \\
\text { Electricity }\end{array}$ & $8,418,063$ & $7,938,640$ & $7,509,145$ & $7,174,866$ & $7,046,201$ \\
\hline
\end{tabular}

Note: Totals may not equal sum of components because of independent rounding. Detailed data are provided in Table 21 . The number of publicty owned nongenerating electric utilities for end of period is 286 for 1995, 276 for 1994, 269 for 1993,258 for 1992 , and 252 for 1901. The City of Gaffney (SC). City of Osceola (AR), and City of Redding (CA) were nongenerators for 1991 through 1993, but became generators in 1994. The City of Kennett (MO) and City of Morgan City (LA) were generators for 1991 through 1993, but became nongenerators in 1994. Emerald Peoples Utility District (OR), City of Bryan (OH), and Northern Wasco County PUD (OR) were nongenerators for 1991, but became generators in 1992. slons.

Source: Energy Information Administration, Form ElA-861, "Annual Electric Utility Report" Data are based on calendar year submis- 
Table 20. Electric Energy Account for Major U.S. Publicly Owned Nongenerator Electric Utilities, 1991-1995

(Megawatthours)

\begin{tabular}{|c|c|c|c|c|c|}
\hline Item & 1995 & 1994 & 1993 & 1992 & 1991 \\
\hline \multicolumn{6}{|l|}{ Sources of Energy } \\
\hline Steam & - & - & - & - & - \\
\hline Nuclear & - & - & - & - & - \\
\hline 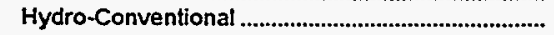 & - & - & - & - & - \\
\hline Hydro-Pumped Storage & - & - & - & - & - \\
\hline Other & - & - & - & - & - \\
\hline 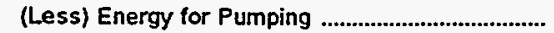 & - & - & - & - & - \\
\hline 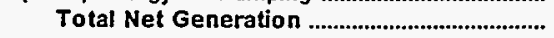 & - & - & - & - & - \\
\hline 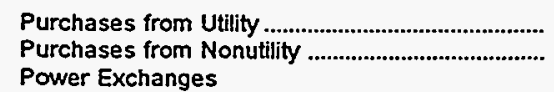 & $\begin{array}{r}147,375,343 \\
1,420,021\end{array}$ & $\begin{array}{r}149,325,324 \\
310,443\end{array}$ & $\begin{array}{r}141,301,052 \\
190,793\end{array}$ & $\begin{array}{r}136,137,665 \\
197,947\end{array}$ & $\begin{array}{r}133,942,064 \\
356,845\end{array}$ \\
\hline 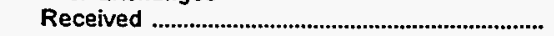 & 924,369 & 505,977 & 328,487 & 363,092 & 289,014 \\
\hline Delivered & 308,786 & 163,845 & 127,897 & 158,997 & 202,905 \\
\hline Net Exchanges .................................................... & 615,583 & 342,132 & 200,591 & 204,095 & 86,109 \\
\hline \multicolumn{6}{|l|}{ Transmission for Others (Wheeling) } \\
\hline Received & 586.304 & 501,119 & 311,854 & 1,986 & 7,164 \\
\hline 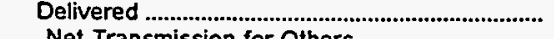 & 245.722 & 499,627 & 307,924 & 1,986 & 7,164 \\
\hline Net Transmission for Others & 340,582 & 1,492 & 3,930 & - & - \\
\hline 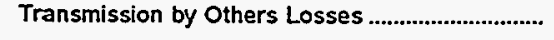 & $-36,862$ & $-2,416$ & $-3,930$ & -220 & $-7,488$ \\
\hline \multicolumn{6}{|l|}{ Total Net Energy Generated and } \\
\hline \multicolumn{6}{|l|}{ Disposition of Energy } \\
\hline $\begin{array}{l}\text { Sales to Ultimate Consumers } \\
\text { Requirements Sales for Resale }\end{array}$ & $\begin{array}{r}135,277,956 \\
7,405,476\end{array}$ & $\begin{array}{r}135,074,037 \\
7,136,752\end{array}$ & $\begin{array}{r}127,375,590 \\
6,414,892\end{array}$ & $\begin{array}{r}122,526,111 \\
6,153,006\end{array}$ & $\begin{array}{r}120,874,508 \\
6,411,988\end{array}$ \\
\hline Nonrequirements Sales for Resale ........................ & 756,760 & 857.994 & 918,823 & $1,427,509$ & $1,010.926$ \\
\hline 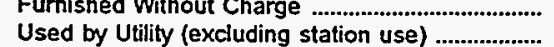 & 239,108 & 299,317 & 281,140 & 218,278 & 242,338 \\
\hline Losses & $5.717,325$ & $\begin{array}{r}279,718 \\
6,389,169\end{array}$ & $\begin{array}{r}262,001 \\
6,439,913\end{array}$ & $\begin{array}{r}243.524 \\
5070.991\end{array}$ & 237,494 \\
\hline Total Disposition & $149,714,667$ & $149,976,976$ & $141,692,435$ & $136,539,486$ & $134,377,529$ \\
\hline
\end{tabular}

- Data not available.

Note: Totals may not equal sum of components because of independent rounding. Detailed data are provided in Table 21 . The number of publicly owned nongenerating electric utilities for end of period is 286 for 1995,276 for 1994,269 for 1993,258 for 1992 , and 252 for 1991. The City of Gaffney (SC), City of Osceola (AR), and City of Redding (CA) were nongenerators for 1991 through 1993, but became generators in 1994. The City of Kennett (MO) and City of Morgan City (LA) were generators for 1991 through 1993, but becarrie nongenerators in 1994. Emerald Peoples Utility District (OR). City of Bryan (OH), and Northern Wasco County PUD (OR) were nongenerators for 1991, but became generators in 1992. Double counting occurs in components of both sources and disposition of energy and thus neither provides a true total. Purchases from utilities, net exchanges, and net wheeling (except for imports) are included in net generation. Sales for resale is included in sales to ultimate consumers.

Source: Energy Information Administration, Form ElA-412, "Annual Report of Public Electric Utilities." Individual electric utilities report fiscal year data. Appendix B shows the fiscal year for each electric utility. 
Detailed Statistics of Major U.S. Publicly Owned Electric Utilities 
Table 21. Statement of Income by Major U.S. Publicly Owned Electric Utility Within State, 1995

(Thousand Dollars)

\begin{tabular}{|c|c|c|c|c|c|c|}
\hline Item & $\begin{array}{l}\text { Alabama } \\
\text { Alabama } \\
\text { Municipal } \\
\text { Elec Auth } \\
\text { September } 30\end{array}$ & $\begin{array}{l}\text { Alabama } \\
\text { Albertville } \\
\text { Municipal } \\
\text { Utils Bd } \\
\text { June } 30\end{array}$ & $\begin{array}{c}\text { Alabama } \\
\text { Andalusia } \\
\text { City of } \\
\text { September } 30\end{array}$ & $\begin{array}{l}\text { Alabama } \\
\text { Athens } \\
\text { City of } \\
\text { December } 31\end{array}$ & $\begin{array}{l}\text { Alabama } \\
\text { Bessemer } \\
\text { City of } \\
\text { June } 30\end{array}$ & $\begin{array}{l}\text { Alabama } \\
\text { Cullman } \\
\text { Power Board } \\
\text { June } 30\end{array}$ \\
\hline Electric Utility Operating Revenues ............. & 92,914 & 20,523 & 14,510 & 38,070 & 17,922 & 16,853 \\
\hline 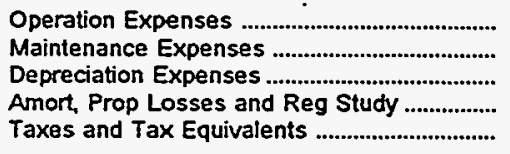 & $\begin{array}{r}72,206 \\
0 \\
264 \\
0 \\
1,030\end{array}$ & $\begin{array}{r}18,983 \\
574 \\
492 \\
0 \\
439\end{array}$ & $\begin{array}{r}12,489 \\
83 \\
314 \\
0 \\
0\end{array}$ & $\begin{array}{r}33,528 \\
1,039 \\
990 \\
6 \\
960\end{array}$ & $\begin{array}{r}15,475 \\
987 \\
814 \\
0 \\
815\end{array}$ & $\begin{array}{r}15.655 \\
292 \\
419 \\
0 \\
315\end{array}$ \\
\hline $\begin{array}{l}\text { Total Electric Utility Operating } \\
\text { Expenses }\end{array}$ & 73,500 & 20,489 & 12,887 & 36,522 & 18,091 & 16,681 \\
\hline $\begin{array}{l}\text { Net Electric Utility Operating Income } \\
\text { Income from Electric Plant Leased } \\
\text { to Others }\end{array}$ & 19.414 & $\begin{array}{r}33 \\
0\end{array}$ & $\begin{array}{r}1,623 \\
0\end{array}$ & $\begin{array}{r}1,547 \\
0\end{array}$ & $\begin{array}{r}-169 \\
0\end{array}$ & $\begin{array}{r}172 \\
0\end{array}$ \\
\hline Electric Utility Operating Income .............. & 49,414 & 33 & 1,623 & 1,547 & -169 & 172 \\
\hline 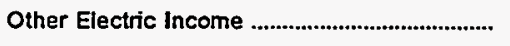 & 4,224 & 290 & 85 & 880 & 157 & 181 \\
\hline $\begin{array}{l}\text { Other Electric Deductions .................................... } \\
\text { Allowance for Other Funds Used }\end{array}$ & 12,728 & 0 & 1.164 & 0 & 12 & 2 \\
\hline 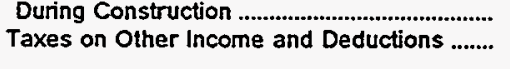 & $\begin{array}{l}0 \\
0\end{array}$ & $\begin{array}{l}0 \\
0\end{array}$ & $\begin{array}{l}0 \\
0\end{array}$ & $\begin{array}{l}0 \\
0\end{array}$ & $\begin{array}{l}0 \\
0\end{array}$ & $\begin{array}{l}0 \\
0\end{array}$ \\
\hline 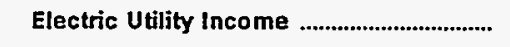 & 10,909 & 323 & 544 & 2,427 & -24 & 351 \\
\hline 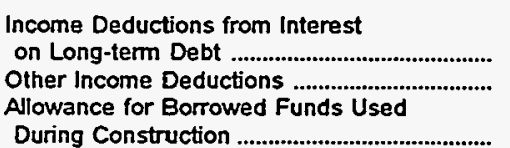 & $\begin{array}{r}10,657 \\
0\end{array}$ & $\begin{array}{l}0 \\
0\end{array}$ & $\begin{array}{l}0 \\
0\end{array}$ & $\begin{array}{r}1,292 \\
13\end{array}$ & $\begin{array}{r}147 \\
2\end{array}$ & $\begin{array}{r}174 \\
9\end{array}$ \\
\hline 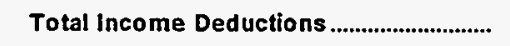 & 10,657 & $\mathbf{0}$ & 0 & 1,305 & 149 & 183 \\
\hline Income Before Extraordinary Items ................... & 252 & 323 & 544 & 1,122 & -173 & 167 \\
\hline Extraordinary Income & 0 & 0 & 0 & 134 & 176 & 0 \\
\hline 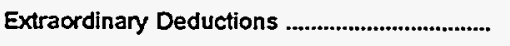 & 0 & 0 & 0 & 67 & 88 & 0 \\
\hline Net Income & 252 & 323 & 544 & 1,189 & -85 & 167 \\
\hline
\end{tabular}

Nole: Totals may not equal sum of components because of independent rounding.

Source: Energy Information Administration, Form ElA-412, "Annual Report of Public Electric Utilities." 
Table 21. Statement of Income by Major U.S. Publicly Owned Electric Utility Within State, 1995 (Continued)

(Thousand Dollars)

\begin{tabular}{|c|c|c|c|c|c|c|}
\hline Item & $\begin{array}{l}\text { Alabama } \\
\text { Decatur } \\
\text { City of } \\
\text { June } 30\end{array}$ & $\begin{array}{l}\text { Alabama } \\
\text { Dothan } \\
\text { City of } \\
\text { September } 30\end{array}$ & $\begin{array}{c}\text { Alabama } \\
\text { Florence } \\
\text { City of } \\
\text { June } 30\end{array}$ & $\begin{array}{c}\text { Aabama } \\
\text { Foley } \\
\text { City of } \\
\text { (Riviera Utils) } \\
\text { December } 31\end{array}$ & $\begin{array}{c}\text { Alabama } \\
\text { Fort Payne } \\
\text { Improvement } \\
\text { Auth } \\
\text { June } 30\end{array}$ & $\begin{array}{l}\text { Alabama } \\
\text { Guntersville } \\
\text { Electric } \\
\text { Board } \\
\text { June } 30\end{array}$ \\
\hline Electric Utility Operating Revenues ............ & 59,513 & 53,769 & 61,081 & 36,124 & 17,613 & 12,043 \\
\hline 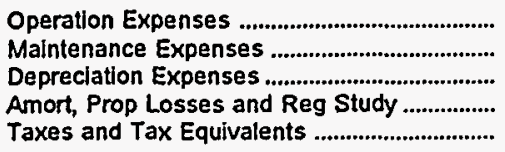 & $\begin{array}{r}56,388 \\
681 \\
1,319 \\
33 \\
1,038\end{array}$ & $\begin{array}{r}39,517 \\
495 \\
2,104 \\
0 \\
0\end{array}$ & $\begin{array}{r}53,100 \\
2,019 \\
2,422 \\
12 \\
2,148\end{array}$ & $\begin{array}{r}26,710 \\
727 \\
2,247 \\
0 \\
3,163\end{array}$ & $\begin{array}{r}15,758 \\
420 \\
384 \\
6 \\
319\end{array}$ & $\begin{array}{r}10.846 \\
288 \\
290 \\
0 \\
241\end{array}$ \\
\hline $\begin{array}{l}\text { Total Electric Utility Operating } \\
\text { Expenses }\end{array}$ & 59,460 & 42,116 & 59,702 & 32,847 & 16,886 & 11,664 \\
\hline $\begin{array}{l}\text { Net Electric Utility Operating Income } \\
\text { Income from Electric Plant Leased } \\
\text { to Others..... }\end{array}$ & 53 & 11,654 & 1,380 & 3.277 & 727 & 379 \\
\hline Electric Utility Operating Income ............ & 53 & 11,654 & 1,380 & 3,277 & 727 & 379 \\
\hline Other Electric Income & 673 & 0 & 844 & 827 & 359 & 199 \\
\hline $\begin{array}{l}\text { Other Electric Deductions ................................ } \\
\text { Allowance for Other Funds Used }\end{array}$ & 0 & 0 & 0 & 0 & 0 & 1 \\
\hline 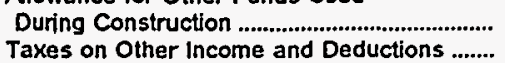 & $\begin{array}{l}0 \\
0\end{array}$ & $\begin{array}{l}0 \\
0\end{array}$ & $\begin{array}{l}0 \\
0\end{array}$ & $\begin{array}{l}0 \\
0\end{array}$ & $\begin{array}{l}0 \\
0\end{array}$ & $\begin{array}{l}0 \\
0\end{array}$ \\
\hline 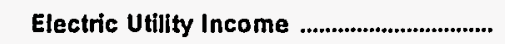 & 725 & 11,654 & 2,223 & 4,104 & 1,085 & 578 \\
\hline $\begin{array}{l}\text { Income Deductions from Interest } \\
\text { on Long-tem Debt ............................................ } \\
\text { Other Income Deductions ............................ } \\
\text { Allowance for Borrowed Funds Used }\end{array}$ & $\begin{array}{l}0 \\
0\end{array}$ & $\begin{array}{l}0 \\
0\end{array}$ & $\begin{array}{r}0 \\
16\end{array}$ & $\begin{array}{r}775 \\
20\end{array}$ & $\begin{array}{r}268 \\
45\end{array}$ & $\begin{array}{r}23 \\
1\end{array}$ \\
\hline 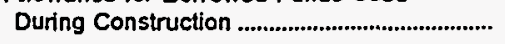 & 0 & 0 & $\mathbf{0}$ & 0 & 0 & $\mathbf{0}$ \\
\hline Total Income Deductions .............................. & 0 & 0 & 16 & 795 & 314 & 24 \\
\hline Income Before Extraordinary Items ................. & 725 & 11,654 & 2,207 & 3,310 & 772 & 554 \\
\hline Extraordinary Income & 0 & 0 & 0 & 0 & 0 & 0 \\
\hline 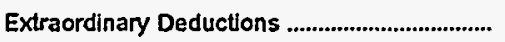 & 0 & 0 & 123 & 0 & 0 & 0 \\
\hline 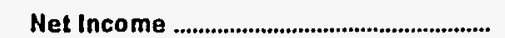 & 725 & 11,654 & 2,084 & 3,310 & 772 & 554 \\
\hline
\end{tabular}

Note: Totals may not equal sum of components because of independent rounding.

Source: Energy Information Administration. Form EIA-4 12, "Annual Report of Public Electric Utilities." 
Table 21. Statement of Income by Major U.S. Publicly Owned Electric Utility Within State, 1995 (Continued)

(Thousand Dollars)

\begin{tabular}{|c|c|c|c|c|c|c|}
\hline Item & $\begin{array}{l}\text { Alabama } \\
\text { Hartselle } \\
\text { City of } \\
\text { June } 30\end{array}$ & $\begin{array}{l}\text { Aabama } \\
\text { Huntsville } \\
\text { City of } \\
\text { September } 30\end{array}$ & $\begin{array}{l}\text { Alabama } \\
\text { Muscle } \\
\text { Shoals } \\
\text { City of } \\
\text { June } 30\end{array}$ & $\begin{array}{c}\text { Alabama } \\
\text { Opelika } \\
\text { City of } \\
\text { September } 30\end{array}$ & $\begin{array}{c}\text { Alabama } \\
\text { Scottsboro } \\
\text { City of } \\
\text { June } 30\end{array}$ & $\begin{array}{l}\text { Alabama } \\
\text { Sheffield } \\
\text { Utilities } \\
\text { June } 30\end{array}$ \\
\hline Electric Utility Operating Revenues ............ & 7,221 & 191,813 & 11,523 & 16,323 & 17,474 & 24,265 \\
\hline 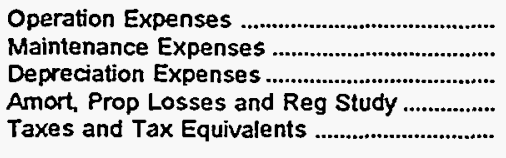 & $\begin{array}{r}6,671 \\
262 \\
184 \\
0 \\
82\end{array}$ & $\begin{array}{r}175,845 \\
3,512 \\
5,198 \\
0 \\
5,392\end{array}$ & $\begin{array}{r}10,005 \\
383 \\
428 \\
0 \\
417\end{array}$ & $\begin{array}{r}12,899 \\
513 \\
638 \\
0 \\
0\end{array}$ & $\begin{array}{r}15,714 \\
795 \\
486 \\
0 \\
341\end{array}$ & $\begin{array}{r}21.257 \\
1,132 \\
1,061 \\
21 \\
707\end{array}$ \\
\hline $\begin{array}{c}\text { Total Electric Utility Operating } \\
\text { Expenses }\end{array}$ & 7,199 & 189,948 & 11,233 & 14,050 & 17,336 & 24,178 \\
\hline $\begin{array}{l}\text { Net Electric Utility Operating Income } \\
\text { Income from Electric Plant Leased } \\
\text { to Others }\end{array}$ & $\begin{array}{r}22 \\
0\end{array}$ & $\begin{array}{r}1,865 \\
0\end{array}$ & 289 & $\begin{array}{r}2,274 \\
0\end{array}$ & $\begin{array}{r}138 \\
0\end{array}$ & 87 \\
\hline Electric Utility Operating Income ............. & 22 & 1,865 & 289 & 2,274 & 138 & 87 \\
\hline Other Electric Income & 134 & 5,902 & 176 & 364 & 260 & 726 \\
\hline $\begin{array}{l}\text { Other Electric Deductions ........................... } \\
\text { Allowance for Other Funds Used }\end{array}$ & 0 & o & 0 & 151 & 0 & 17 \\
\hline 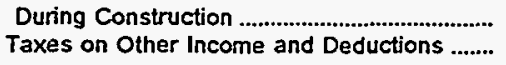 & $\begin{array}{l}0 \\
0\end{array}$ & $\begin{array}{l}0 \\
0\end{array}$ & $\begin{array}{l}0 \\
0\end{array}$ & $\begin{array}{l}0 \\
0\end{array}$ & $\begin{array}{l}0 \\
0\end{array}$ & $\begin{array}{l}\mathbf{0} \\
\mathbf{0}\end{array}$ \\
\hline 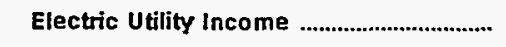 & 155 & 7,767 & 465 & 2,487 & 398 & 798 \\
\hline 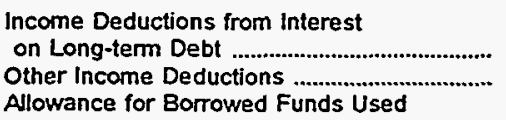 & $\begin{array}{r}20 \\
1\end{array}$ & $\begin{array}{l}384 \\
561\end{array}$ & $\begin{array}{r}56 \\
3\end{array}$ & $\begin{array}{r}211 \\
1.196\end{array}$ & $\begin{array}{r}185 \\
28\end{array}$ & $\begin{array}{r}101 \\
3\end{array}$ \\
\hline 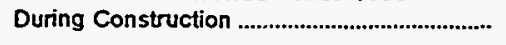 & 0 & 0 & 0 & 0 & 75 & 0 \\
\hline 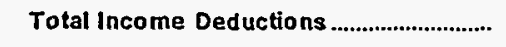 & 21 & 945 & 59 & 1,407 & 288 & 105 \\
\hline Income Before Extraordinary ltems ...................... & 134 & 6,822 & 406 & 1,079 & 110 & 691 \\
\hline 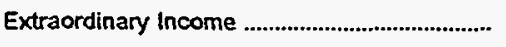 & 0 & 0 & 0 & 0 & 0 & 0 \\
\hline 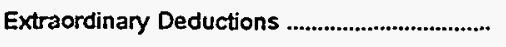 & 0 & 0 & 0 & 0 & 64 & 0 \\
\hline Net Income & 134 & 6,822 & 406 & 1,079 & 46 & 691 \\
\hline
\end{tabular}

Note: Totals may not equal sum of components because of independent rounding.

Source: Eneroy Information Administration, Form ElA-4 12, "Annual Report of Public Electric Utilities." 
Table 21. Statement of Income by Major U.S. Publicly Owned Electric Utility Within State, 1995 (Continued)

(Thousand Dollars)

\begin{tabular}{|c|c|c|c|c|c|c|}
\hline Item & $\begin{array}{c}\text { Alabama } \\
\text { Sylacauga } \\
\text { Utilities } \\
\text { Board }\end{array}$ & $\begin{array}{c}\text { Alabama } \\
\text { Troy } \\
\text { City of } \\
\text { September } 30\end{array}$ & $\begin{array}{c}\text { Alabama } \\
\text { Tuskegee } \\
\text { City of } \\
\text { September } 30\end{array}$ & $\begin{array}{l}\text { Alaska } \\
\text { Alaska } \\
\text { Energy } \\
\text { Authority } \\
\text { June } 30\end{array}$ & $\begin{array}{c}\text { Alaska } \\
\text { Anchorage } \\
\text { City of } \\
\text { December } 31\end{array}$ & $\begin{array}{l}\text { Alaska } \\
\text { Fairbanks } \\
\text { City of } \\
\text { December } 31\end{array}$ \\
\hline Electric Utility Operating Revenues ............ & 12,173 & 13,442 & 9,193 & 23,847 & 70,983 & 16,193 \\
\hline 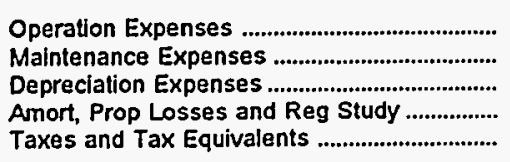 & $\begin{array}{r}7,735 \\
410 \\
487 \\
0 \\
1,370\end{array}$ & $\begin{array}{r}9.476 \\
303 \\
281 \\
0 \\
2,744\end{array}$ & $\begin{array}{r}7.770 \\
0 \\
270 \\
0 \\
0\end{array}$ & $\begin{array}{r}3,755 \\
1,349 \\
23,066 \\
0 \\
0\end{array}$ & $\begin{array}{r}37,498 \\
3,708 \\
10,160 \\
515 \\
1,999\end{array}$ & $\begin{array}{r}11.492 \\
388 \\
1.754 \\
0 \\
940\end{array}$ \\
\hline $\begin{array}{c}\text { Total Electric Utility Operating } \\
\text { Expenses }\end{array}$ & 10,001 & 12,804 & 8,040 & 28,170 & 53,879 & 14,574 \\
\hline $\begin{array}{l}\text { Net Electric Utility Operating Income } \\
\text { Income from Electric Plant Leased } \\
\text { to Others }\end{array}$ & $\begin{array}{r}2,171 \\
0\end{array}$ & 639 & 1,153 & $\begin{array}{r}-4,323 \\
0\end{array}$ & 17,103 & $\begin{array}{r}1,619 \\
0\end{array}$ \\
\hline Electric Utility Operating Income .............. & 2,171 & 639 & 1,153 & $-4,323$ & 17,103 & 1,619 \\
\hline Other Electric Income & 0 & 414 & 273 & 2,899 & 2.833 & 0 \\
\hline $\begin{array}{l}\text { Other Electric Deductions } \\
\text { Allowance for Other Funds Used } \\
\text { During Construction ............................................... } \\
\text { Taxes on Other Income and Deductions ....... }\end{array}$ & $\begin{array}{l}0 \\
0\end{array}$ & $\begin{array}{l}0 \\
0\end{array}$ & $\begin{array}{l}0 \\
0\end{array}$ & $\stackrel{0}{0}$ & $\begin{array}{l}0 \\
0\end{array}$ & $\begin{array}{r}20 \\
0\end{array}$ \\
\hline Electric Utility Income & 2,174 & 1,053 & 881 & $-1,424$ & 49,936 & 1,640 \\
\hline 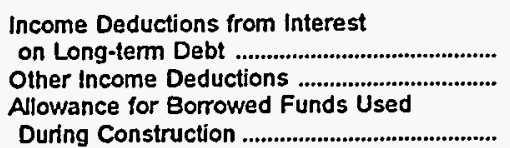 & $\begin{array}{r}138 \\
0 \\
0\end{array}$ & $\begin{array}{r}379 \\
28\end{array}$ & $\begin{array}{l}0 \\
0\end{array}$ & $\begin{array}{r}17.783 \\
0\end{array}$ & $\begin{array}{r}11,658 \\
3,110\end{array}$ & $\begin{array}{r}1,105 \\
-247\end{array}$ \\
\hline 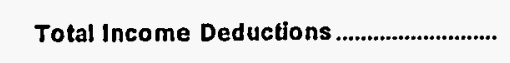 & 138 & 406 & 0 & 17,783 & 14,072 & 858 \\
\hline Income Before Extraordinary Items ...................... & 2,033 & 647 & 881 & $-19,207$ & 5,865 & 782 \\
\hline 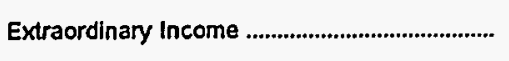 & 0 & 0 & 0 & 0 & 0 & 0 \\
\hline 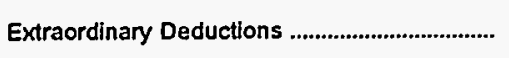 & 0 & 0 & 0 & 0 & 0 & 0 \\
\hline Net Income & 2,033 & 647 & 881 & $-19,207$ & 5,865 & 782 \\
\hline
\end{tabular}

Note: Totals may not equal sum of components because of independent rounding.

Source: Energy Information Administration, Form ElA-412, "Annual Report of Public Slectric Utilities." 
Table 21. Statement of Income by Major U.S. Publicly Owned Electric Utility Within State, 1995 (Continued)

(Thousand Dollars)

\begin{tabular}{|c|c|c|c|c|c|c|}
\hline Item & $\begin{array}{c}\text { Alaska } \\
\text { Ketchikan } \\
\text { City of } \\
\text { December } 31\end{array}$ & $\begin{array}{l}\text { Arizona } \\
\text { Arizona } \\
\text { Power } \\
\text { Authority } \\
\text { June } 30\end{array}$ & $\begin{array}{c}\text { Arizona } \\
\text { Electrical } \\
\text { Dist } \\
\text { No2 } \\
\text { Pinal Cnty } \\
\text { December } 31\end{array}$ & $\begin{array}{l}\text { Arizona } \\
\text { Mesa } \\
\text { City of } \\
\text { June } 30\end{array}$ & $\begin{array}{l}\text { Arizona } \\
\text { Navajo } \\
\text { Tribal } \\
\text { Utility } \\
\text { Auth } \\
\text { December } 31\end{array}$ & $\begin{array}{l}\text { Arizona } \\
\text { Salt River } \\
\text { Prol Ag } \\
\text { I \& P Dist } \\
\text { April } 30\end{array}$ \\
\hline Electric Utility Operating Revenues ............. & 12,885 & 19,200 & 8,294 & 23,159 & 36,761 & $1,443,555$ \\
\hline 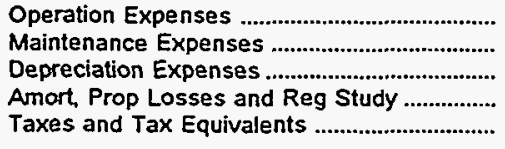 & $\begin{array}{r}8,742 \\
915 \\
1,587 \\
0 \\
324\end{array}$ & $\begin{array}{r}19,271 \\
0 \\
79 \\
0 \\
0\end{array}$ & $\begin{array}{r}7,068 \\
219 \\
732 \\
0 \\
0\end{array}$ & $\begin{array}{r}15,985 \\
2,238 \\
1,519 \\
-2,864 \\
0\end{array}$ & $\begin{array}{r}28,297 \\
1,416 \\
4,571 \\
0 \\
0\end{array}$ & $\begin{array}{r}644,887 \\
86,808 \\
185,358 \\
11,072 \\
188,476\end{array}$ \\
\hline $\begin{array}{l}\text { Total Electric Utility Operating } \\
\text { Expenses }\end{array}$ & 11,568 & 19,350 & 8,019 & 16,877 & 34,284 & $1,116,601$ \\
\hline $\begin{array}{l}\text { Net Electric Utility Operating Income } \\
\text { Income from Electric Plant Leased } \\
\text { to Others }\end{array}$ & 1,317 & -150 & 274 & 6,282 & 2,478 & 326,954 \\
\hline Electric Utility Operating Income .............. & 1,317 & -150 & 274 & 6,282 & 2,478 . & 327,148 \\
\hline Other Electric income & 604 & 4,463 & 89 & 335 & 425 & 33,415 \\
\hline $\begin{array}{l}\text { Other Electric Deductions } \\
\text { Allowance for Other Funds Used }\end{array}$ & 0 & 0 & 0 & o & 457 & 5,474 \\
\hline $\begin{array}{l}\text { During Construction } \\
\text { Taxes on Other Income and Deductions ....................... }\end{array}$ & $\begin{array}{l}0 \\
0\end{array}$ & $\begin{array}{l}0 \\
0\end{array}$ & $\begin{array}{l}0 \\
0\end{array}$ & $\begin{array}{l}0 \\
0\end{array}$ & $\begin{array}{l}0 \\
0\end{array}$ & $\begin{array}{l}0 \\
0\end{array}$ \\
\hline Electric Utility Income & 1,921 & 4,313 & 364 & 6,617 & 2,446 & 355,089 \\
\hline 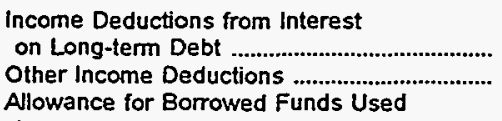 & $\begin{array}{r}500 \\
19\end{array}$ & $\begin{array}{r}4,239 \\
61\end{array}$ & $\begin{array}{l}0 \\
0\end{array}$ & $\begin{array}{r}93 \\
0\end{array}$ & $\begin{array}{r}1,077 \\
0\end{array}$ & $\begin{array}{r}205,564 \\
77,567\end{array}$ \\
\hline 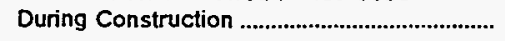 & 0 & 0 & 0 & 0 & -110 & $-7,019$ \\
\hline 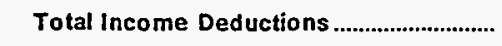 & 518 & 4,300 & $\mathbf{0}$ & 93 & 967 & 216,112 \\
\hline Income Before Extraordinary Items ...................... & 1,403 & 13 & 364 & 6,524 & 1,479 & 138,877 \\
\hline Extraordinary Income & 106 & 0 & 746 & 0 & 0 & 0 \\
\hline Extraordinary Deductions ......................................... & 0 & 0 & 0 & 0 & 0 & 0 \\
\hline Net Income & 1,509 & 13 & 1,110 & 6,524 & 1,479 & 138,977 \\
\hline
\end{tabular}

Source: Energy Information Administration, Form EIA-412, "Annual Report of Public Electric Utilities." 
Table 21. Statement of Income by Major U.S. Publicly Owned Electric Utility Within State, 1995 (Continued)

(Thousand Dollars)

\begin{tabular}{|c|c|c|c|c|c|c|}
\hline Item & $\begin{array}{l}\text { Arizona } \\
\text { Tohono } \\
\text { OOdham } \\
\text { Utility Auth } \\
\text { December } 31\end{array}$ & $\begin{array}{l}\text { Arkansas } \\
\text { Benton } \\
\text { City of } \\
\text { December } 31\end{array}$ & $\begin{array}{l}\text { Arkansas } \\
\text { Bentonville } \\
\text { City of } \\
\text { December } 31\end{array}$ & $\begin{array}{c}\text { Arkansas } \\
\text { Clarksville } \\
\text { Light } \\
\& \\
\text { Water Co } \\
\text { September } 30\end{array}$ & $\begin{array}{l}\text { Arkansas } \\
\text { Conway } \\
\text { Corp } \\
\text { December } 31\end{array}$ & $\begin{array}{c}\text { Arkansas } \\
\text { Hope } \\
\text { City of } \\
\text { December } 31\end{array}$ \\
\hline Electric Utility Operating Revenues ............ & 6,147 & 15,858 & 10,304 & 9,338 & 29,633 & 11,051 \\
\hline 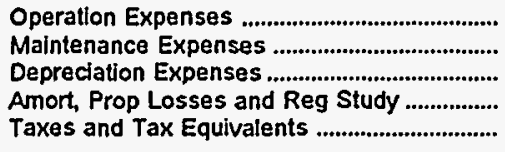 & $\begin{array}{r}5,347 \\
91 \\
302 \\
0 \\
0\end{array}$ & $\begin{array}{r}10,463 \\
202 \\
311 \\
100 \\
660\end{array}$ & $\begin{array}{r}8.151 \\
99 \\
275 \\
0 \\
675\end{array}$ & $\begin{array}{r}5,815 \\
262 \\
518 \\
0 \\
0\end{array}$ & $\begin{array}{r}20,311 \\
1,397 \\
2,540 \\
0 \\
565\end{array}$ & $\begin{array}{r}8,302 \\
674 \\
587 \\
0 \\
0\end{array}$ \\
\hline $\begin{array}{l}\text { Total Electric Utility Operating } \\
\text { Expenses }\end{array}$ & 5,741 & 11,737 & 9,200 & 6,595 & 24,812 & 9,564 \\
\hline 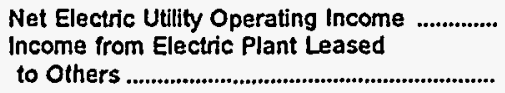 & 406 & 4.121 & 1,105 & 2,743 & $\begin{array}{r}4,821 \\
0\end{array}$ & $\begin{array}{r}1,488 \\
0\end{array}$ \\
\hline Electric Utility Operating Income .............. & 406 & 4,121 & 1,105 & 2,743 & 4,821 & 1,488 \\
\hline Other Electric Income & 45 & 428 & 8 & 148 & 1,190 & 0 \\
\hline $\begin{array}{l}\text { Other Electric Deductions ................................. } \\
\text { Allowance for Other Funds Used }\end{array}$ & 0 & 0 & 0 & 0 & 827 & 0 \\
\hline Taxes on Other Income and Deductions ........ & 0 & 0 & $\begin{array}{l}0 \\
0\end{array}$ & 0 & 0 & 0 \\
\hline 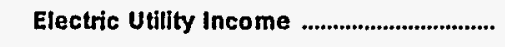 & 451 & 4,549 & 1,113 & 2,891 & 5,184 & 1,488 \\
\hline 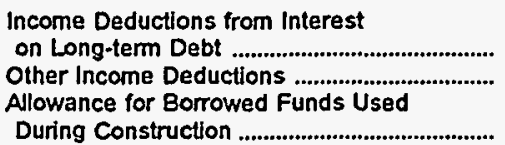 & $\begin{array}{r}234 \\
13\end{array}$ & $\begin{array}{l}0 \\
0\end{array}$ & $\begin{array}{r}110 \\
0\end{array}$ & $\begin{array}{r}32 \\
898\end{array}$ & $\begin{array}{r}1.430 \\
37\end{array}$ & $\begin{array}{r}0 \\
523\end{array}$ \\
\hline Total Income Deductions ............................. & 247 & 0 & 110 & 931 & 1,466 & 523 \\
\hline Income Before Extraordinary Items ................... & 204 & 4,549 & 1,003 & 1,961 & 3,718 & 965 \\
\hline 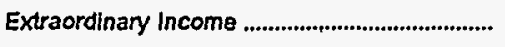 & 0 & 0 & 0 & 0 & 0 & 0 \\
\hline Extraordinary Deductions .................................... & 0 & 0 & 0 & 0 & 0 & 0 \\
\hline Net Income & 204 & 4,549 & 1,003 & 1,961 & 3,718 & 965 \\
\hline
\end{tabular}

Note: Totals may not equal sum of components because of independent roundıng.

Sourcs: Energy Information Adminstration, Form ELA-412, "Annual Report of Public Electric Utilities." 
Table 21. Statement of Income by Major U.S. Publicly Owned Electric Utility Within State, 1995 (Continued)

(Thousand Dollars)

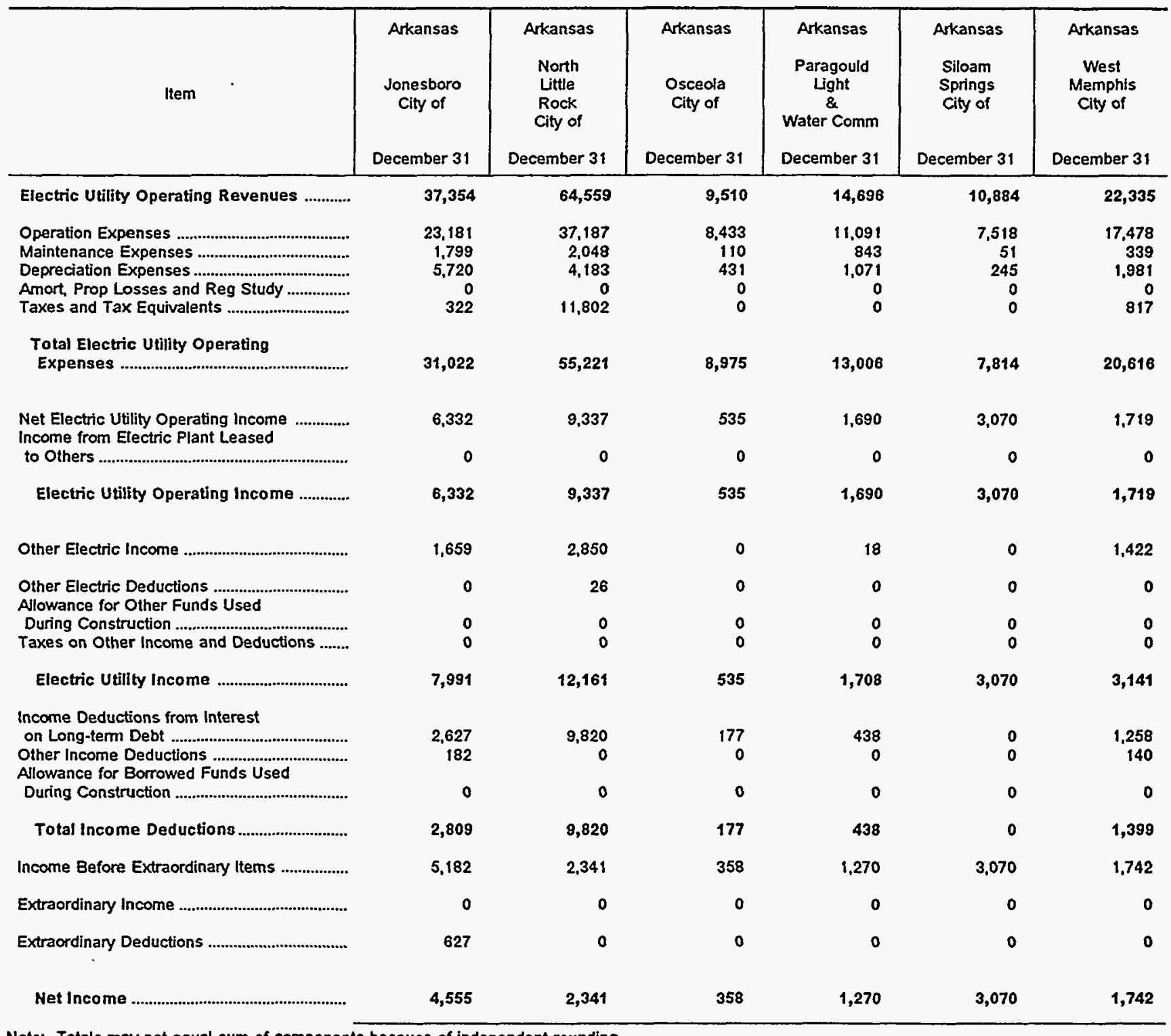

Note: Totals may not equal sum of components because of independent rounding.

Source: Energy Information Administration, Form EIA-412, "Annuai Report of Public Electric Utilities." 
Table 21. Statement of Income by Major U.S. Publicly Owned Electric Utility Within State, 1995 (Continued) (Thousand Dollars)

\begin{tabular}{|c|c|c|c|c|c|c|}
\hline Item & $\begin{array}{l}\text { California } \\
\text { Alameda } \\
\text { City of } \\
\text { June } 30\end{array}$ & $\begin{array}{l}\text { California } \\
\text { Anaheim } \\
\text { City of } \\
\text { June } 30\end{array}$ & $\begin{array}{l}\text { California } \\
\text { Azusa } \\
\text { City of } \\
\text { June } 30\end{array}$ & $\begin{array}{l}\text { California } \\
\text { Burbank } \\
\text { City of } \\
\text { June } 30\end{array}$ & $\begin{array}{l}\text { California } \\
\text { California } \\
\text { Dept } \\
\text { Wtr } \\
\text { Resources } \\
\text { June } 30\end{array}$ & $\begin{array}{l}\text { California } \\
\text { Colton } \\
\text { City of } \\
\text { June } 30\end{array}$ \\
\hline Electric Utility Operating Revenues ........... & 46,935 & 240,175 & 22,329 & 93,766 & 150,179 & 24,240 \\
\hline 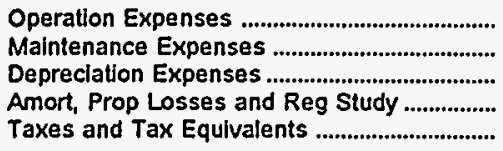 & $\begin{array}{r}38,488 \\
369 \\
1,966 \\
0 \\
341\end{array}$ & $\begin{array}{r}171,404 \\
11,924 \\
15,547 \\
36 \\
0\end{array}$ & $\begin{array}{r}17,534 \\
1,556 \\
83 \\
0 \\
1,830\end{array}$ & $\begin{array}{r}71,905 \\
8,545 \\
4,876 \\
0 \\
5,629\end{array}$ & $\begin{array}{r}49,775 \\
0 \\
43,266 \\
0 \\
1,630\end{array}$ & $\begin{array}{r}20,814 \\
85 \\
531 \\
0 \\
488\end{array}$ \\
\hline 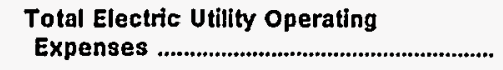 & 41,164 & 198,911 & 21,003 & 90,955 & 94,671 & 21,919 \\
\hline 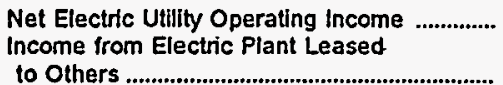 & 5,771 & 41,264 & 1,327 & $\begin{array}{r}2,811 \\
0\end{array}$ & $\begin{array}{r}55,508 \\
0\end{array}$ & $\begin{array}{r}2,321 \\
0\end{array}$ \\
\hline Electric Utility Operating Income ............. & 5,771 & 41,264 & 1,327 & 2,811 & 55,508 & 2,321 \\
\hline Other Electric Income & 942 & 7,357 & 1,055 & 1,451 & 4,933 & 118 \\
\hline $\begin{array}{l}\text { Other Electric Deductions ................................ } \\
\text { Allowance for Other Funds Used }\end{array}$ & 0 & 0 & 998 & 0 & 0 & 0 \\
\hline $\begin{array}{l}\text { During Construction ...................................... } \\
\text { Taxes on Other Income and Deductions ....... }\end{array}$ & $\begin{array}{l}\mathbf{0} \\
\mathbf{0}\end{array}$ & $\begin{array}{l}0 \\
0\end{array}$ & $\begin{array}{l}0 \\
0\end{array}$ & $\begin{array}{l}0 \\
0\end{array}$ & $\begin{array}{l}0 \\
0\end{array}$ & $\begin{array}{l}0 \\
0\end{array}$ \\
\hline Electric Utility income & 6,713 & 48,621 & 1,383 & 4,262 & 60,441 & 2,439 \\
\hline 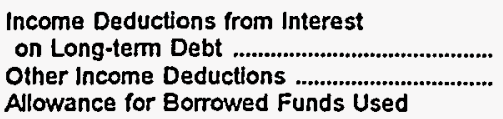 & $\begin{array}{r}554 \\
10\end{array}$ & $\begin{array}{r}22,618 \\
0\end{array}$ & $\begin{array}{l}0 \\
0\end{array}$ & $\begin{array}{r}1,991 \\
0\end{array}$ & $\begin{array}{r}53,792 \\
0\end{array}$ & $\begin{array}{l}38 \\
87\end{array}$ \\
\hline During Construction & 0 & 0 & 0 & $\mathbf{0}$ & 0 & 0 \\
\hline Total Income Deductions ................................ & 563 & 22,618 & 0 & 1,991 & 53,792 & 125 \\
\hline 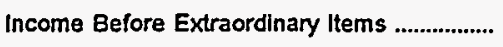 & 6,150 & 26,003 & 1,383 & 2,271 & 6,649 & 2,314 \\
\hline Extraordinary Income & 0 & 0 & 0 & 0 & 7.325 & 0 \\
\hline 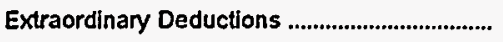 & 0 & 0 & 0 & 0 & 1,884 & 0 \\
\hline Net Income & 6,150 & 26,003 & 1,383 & 2,271 & 12,090 & 2,314 \\
\hline
\end{tabular}

Note: Totals may not equal sum of components because of independent rounding.

Source: Energy Information Administration, Form ElA-412, "Annual Report of Public Electric Utilities." 
Table 21. Statement of Income by Major U.S. Publicly Owned Electric Utility Within State, 1995 (Continued)

(Thousand Dollars)

\begin{tabular}{|c|c|c|c|c|c|c|}
\hline Item & $\begin{array}{c}\text { California } \\
\text { East Bay } \\
\text { Municipal } \\
\text { Util } \\
\text { Dist } \\
\text { December } 31\end{array}$ & $\begin{array}{c}\text { California } \\
\text { Glendale } \\
\text { City of } \\
\text { June } 30\end{array}$ & $\begin{array}{c}\text { California } \\
\text { Imperial } \\
\text { Imigation } \\
\text { District } \\
\text { December } 31\end{array}$ & $\begin{array}{c}\text { California } \\
\text { Kings River } \\
\text { Conservation } \\
\text { Dist } \\
\text { June } 30\end{array}$ & $\begin{array}{l}\text { California } \\
\text { Lassen } \\
\text { Municipa! } \\
\text { Utility Dist } \\
\text { June } 30\end{array}$ & $\begin{array}{l}\text { California } \\
\text { Lodi } \\
\text { City of } \\
\text { June } 30\end{array}$ \\
\hline Electric Utility Operating Revenues ........... & 0 & 96,192 & 192,067 & 11,738 & 14,510 & 34,048 \\
\hline 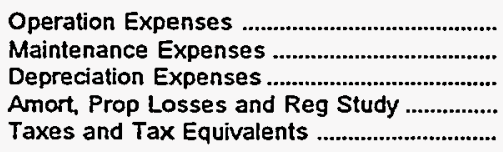 & $\begin{array}{l}0 \\
0 \\
0 \\
0 \\
0\end{array}$ & $\begin{array}{r}67,861 \\
6,010 \\
8,750 \\
0 \\
0\end{array}$ & $\begin{array}{r}129,136 \\
14,739 \\
20,263 \\
0 \\
1,477\end{array}$ & $\begin{array}{r}4,141 \\
550 \\
1,519 \\
132 \\
0\end{array}$ & $\begin{array}{r}8,416 \\
397 \\
768 \\
0 \\
0\end{array}$ & $\begin{array}{r}25,887 \\
1,766 \\
501 \\
0 \\
1,002\end{array}$ \\
\hline $\begin{array}{l}\text { Total Electric Utility Operating } \\
\text { Expenses }\end{array}$ & 0 & 82,621 & 165,615 & 6,342 & 9,581 & 29,156 \\
\hline $\begin{array}{l}\text { Net Electric Utility Operating Income } \\
\text { Income from Electric Plant Leased } \\
\text { to Others }\end{array}$ & 0 & 13.571 & 26,453 & 5,395 & $\begin{array}{r}4,929 \\
0\end{array}$ & 4,892 \\
\hline Electric Utility Operating Income .............. & 0 & 13,571 & 26,453 & 5,395 & 4,929 & 4,892 \\
\hline Other Electric Income & 0 & 4,981 & 5,198 & 390 & 594 & 1,285 \\
\hline $\begin{array}{l}\text { Other Electric Deductions .......................... } \\
\text { Allowance for Other Funds Used }\end{array}$ & 0 & 10,746 & 9 & 0 & 0 & 4,046 \\
\hline 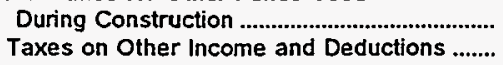 & $\begin{array}{l}0 \\
0\end{array}$ & $\begin{array}{l}0 \\
0\end{array}$ & $\begin{array}{l}0 \\
0\end{array}$ & $\begin{array}{l}0 \\
0\end{array}$ & $\begin{array}{l}0 \\
0\end{array}$ & $\begin{array}{l}0 \\
0\end{array}$ \\
\hline 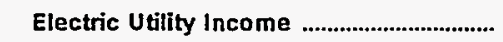 & $\mathbf{0}$ & 7,806 & 31,641 & 5,785 & 5,522 & 2,130 \\
\hline 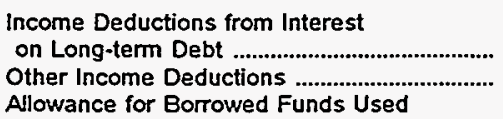 & $\begin{array}{l}0 \\
0\end{array}$ & $\begin{array}{r}985 \\
7\end{array}$ & $\begin{array}{r}10,539 \\
0\end{array}$ & $\begin{array}{l}4,126 \\
1,714\end{array}$ & $\begin{array}{r}1,933 \\
0\end{array}$ & $\begin{array}{l}0 \\
0\end{array}$ \\
\hline 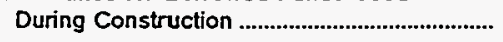 & 0 & 0 & 0 & 0 & 0 & $\mathbf{0}$ \\
\hline 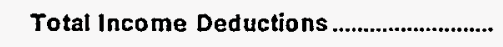 & 0 & 992 & 10,539 & 5,840 & 1,933 & $\mathbf{0}$ \\
\hline Income Before Extraordinary Items ................. & 0 & 6,814 & 21,102 & -55 & 3,589 & 2,130 \\
\hline Extraordinary Income & 0 & 5,886 & 0 & 0 & 0 & 0 \\
\hline 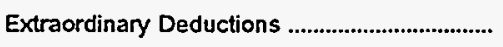 & 0 & 0 & 0 & 0 & 0 & 0 \\
\hline 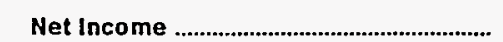 & 0 & 12,700 & 21,102 & -55 & 3,589 & 2,130 \\
\hline
\end{tabular}

Note: Totals may not equal sum of components because of independent rounding.

Source: Energy Information Administration, Form ElA-4 12, "Annual Report of Public Electric Utilities." 
Table 21. Statement of Income by Major U.S. Publicly Owned Electric Utility Within State, 1995 (Continued)

(Thousand Dollars)

\begin{tabular}{|c|c|c|c|c|c|c|}
\hline Item & $\begin{array}{l}\text { California } \\
\text { Los Angeles } \\
\text { City of } \\
\text { June } 30\end{array}$ & $\begin{array}{c}\text { California } \\
\text { Merced } \\
\text { Irrigation } \\
\text { District } \\
\text { December } 31\end{array}$ & $\begin{array}{l}\text { California } \\
\text { Metropolitan } \\
\text { Water } \\
\text { District } \\
\text { June } 30\end{array}$ & $\begin{array}{l}\text { California } \\
\text { Modesto } \\
\text { Irrigation } \\
\text { District } \\
\text { December } 31\end{array}$ & $\begin{array}{c}\text { California } \\
\text { MSR } \\
\text { Public } \\
\text { Power } \\
\text { Agency } \\
\text { December } 31\end{array}$ & $\begin{array}{l}\text { California } \\
\text { Northern } \\
\text { Califcrnia } \\
\text { Power Agny } \\
\text { June } 30\end{array}$ \\
\hline Electric Utlity Operating Revenues ............. & $1,972,786$ & 6,306 & 9,649 & 130,272 & 90,338 & 188,103 \\
\hline 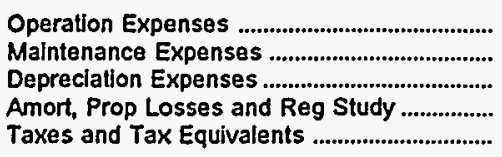 & $\begin{array}{r}1,358,489 \\
138,144 \\
203,758 \\
0 \\
18,287\end{array}$ & $\begin{array}{r}822 \\
1,942 \\
673 \\
0 \\
829\end{array}$ & $\begin{array}{r}1,511 \\
0 \\
2,503 \\
0 \\
0\end{array}$ & $\begin{array}{r}106,932 \\
7,190 \\
9,879 \\
0 \\
0\end{array}$ & $\begin{array}{r}48,219 \\
3,960 \\
8,381 \\
0 \\
851\end{array}$ & $\begin{array}{r}97,658 \\
4,123 \\
31,037 \\
0 \\
0\end{array}$ \\
\hline $\begin{array}{l}\text { Total Electric Utility Operating } \\
\text { Expenses }\end{array}$ & $1,718,678$ & 4,265 & 4,014 & 124,001 & 61,410 & 132,818 \\
\hline $\begin{array}{l}\text { Net Electric Utilty Operating Income ............... } \\
\text { Income from Electric Plant Leased } \\
\text { to Others ........................................................... }\end{array}$ & 254,108 & 2,041 & 5,635 & 6,272 & 28,929 & 55,285 \\
\hline Electric Utility Operating Income .............. & 254,108 & 2,041 & 5,635 & 6,272 & 28,929 & 55,285 \\
\hline 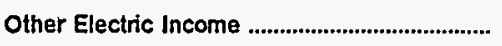 & 21,816 & 0 & 0 & 14,063 & 11.791 & 45.409 \\
\hline $\begin{array}{l}\text { Other Electric Deductions ................................. } \\
\text { Allowance for Other Funds Used }\end{array}$ & 0 & 0 & 0 & 88,154 & 0 & 0 \\
\hline 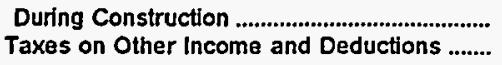 & $\begin{array}{l}0 \\
0\end{array}$ & $\begin{array}{l}0 \\
0\end{array}$ & $\begin{array}{l}0 \\
0\end{array}$ & $\begin{array}{l}0 \\
0\end{array}$ & $\begin{array}{l}0 \\
0\end{array}$ & $\begin{array}{l}\mathbf{0} \\
\mathbf{0}\end{array}$ \\
\hline 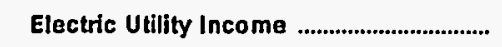 & 275,924 & 2,041 & 5,635 & $-67,819$ & 40,719 & 100,694 \\
\hline 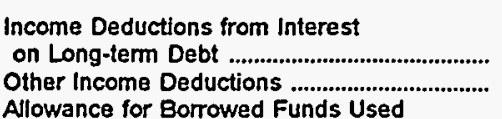 & $\begin{array}{r}186,226 \\
33,564\end{array}$ & $\begin{array}{r}806 \\
0\end{array}$ & $\begin{array}{l}0 \\
0\end{array}$ & $\begin{array}{r}16,578 \\
932\end{array}$ & $\begin{array}{r}34,259 \\
830\end{array}$ & $\begin{array}{r}110,593 \\
6,759\end{array}$ \\
\hline 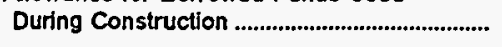 & $-3,783$ & 0 & 0 & 0 & 0 & 0 \\
\hline Total Income Deductions ............................. & 216,006 & 806 & $\mathbf{0}$ & 17,510 & 35,089 & 117,352 \\
\hline Income Before Extraordinary Items ................. & 59,918 & 1,235 & 5,635 & $-85,329$ & 5,630 & $-16,658$ \\
\hline Extraordinary Income & 0 & 0 & 0 & 0 & 0 & 0 \\
\hline 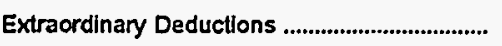 & 0 & 0 & 0 & $\mathbf{0}$ & 0 & 0 \\
\hline 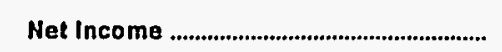 & 59,918 & 1,235 & 5,635 & $-85,329$ & 5,630 & $-16,658$ \\
\hline
\end{tabular}

Note: Totals may not equal sum of components because of independent rounding.

Source: Energy Information Administration, Form ElA-412, "Annual Report of Public Electric Utilities." 
Table 21. Statement of Income by Major U.S. Publicly Owned Electric Utility Within State, 1995 (Continued)

(Thousand Dollars)

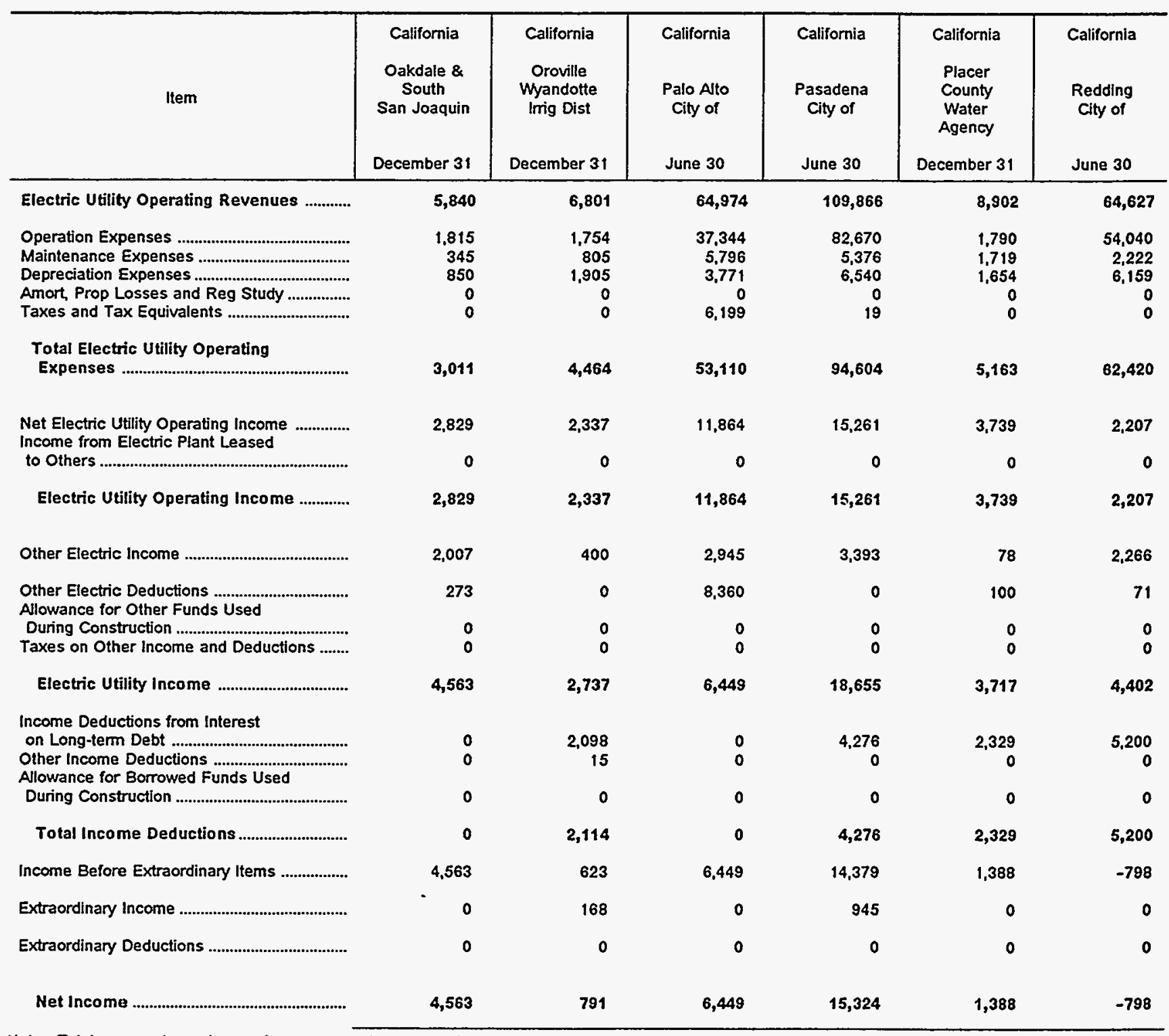

Note: Totals may not equal sum of components because of independent rounding.

Source: Energy Information Administration. Form EIA-412, "Annual Report of Public Electric Utilities." 
Table 21. Statement of Income by Major U.S. Publicly Owned Electric Utility Within State, 1995 (Continued)

(Thousand Dollars)

\begin{tabular}{|c|c|c|c|c|c|c|}
\hline Item & $\begin{array}{l}\text { California } \\
\text { Riverside } \\
\text { City of } \\
\text { June } 30\end{array}$ & $\begin{array}{l}\text { California } \\
\text { Roseville } \\
\text { City of } \\
\text { June } 30\end{array}$ & $\begin{array}{l}\text { California } \\
\text { Sacramento } \\
\text { Municipal } \\
\text { Util Dist } \\
\text { December } 31\end{array}$ & $\begin{array}{c}\text { California } \\
\text { San Francisco } \\
\text { City } \\
\& \\
\text { County of } \\
\text { June } 30\end{array}$ & $\begin{array}{l}\text { California } \\
\text { Santa } \\
\text { Clara } \\
\text { City of } \\
\text { June } 30\end{array}$ & $\begin{array}{l}\text { California } \\
\text { Southern } \\
\text { California } \\
\text { P P } \\
\text { A } \\
\text { June } 30\end{array}$ \\
\hline Electric Utility Operating Revenues ............ & 155,898 & 47,465 & 613,896 & 74,429 & 157,990 & 274,853 \\
\hline 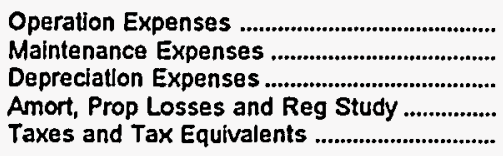 & $\begin{array}{r}125,455 \\
6,188 \\
11,733 \\
0 \\
0\end{array}$ & $\begin{array}{r}30,511 \\
6,854 \\
2,423 \\
0 \\
2,017\end{array}$ & $\begin{array}{r}401,176 \\
27,344 \\
54,356 \\
64,066 \\
146\end{array}$ & $\begin{array}{r}39,270 \\
5,266 \\
8,988 \\
0 \\
994\end{array}$ & $\begin{array}{r}139,438 \\
7,612 \\
8,449 \\
0 \\
8,360\end{array}$ & $\begin{array}{r}69,664 \\
17,579 \\
64,489 \\
0 \\
11,613\end{array}$ \\
\hline 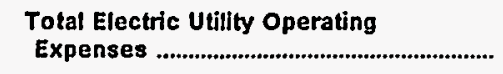 & 143,376 & 41,804 & 547,088 & 54,517 & 163,859 & 163,345 \\
\hline 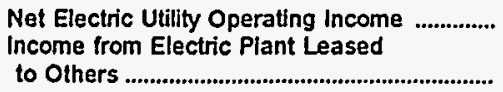 & 12,522 & 5,660 & $\begin{array}{r}66,808 \\
0\end{array}$ & 19.912 & $-5,869$ & 111,508 \\
\hline Electric Utility Operating Income ............. & 12,522 & 5,660 & 66,808 & 19,912 & $-5,869$ & 111,508 \\
\hline 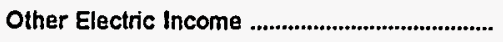 & 6,970 & 1,148 & 45,479 & 17,858 & 15,388 & 23,884 \\
\hline $\begin{array}{l}\text { Other Electric Deductions } \\
\text { Alowance for Other Funds Used }\end{array}$ & 16,311 & 0 & 6,538 & 0 & 3,304 & 0 \\
\hline $\begin{array}{l}\text { During Construction .............................................. } \\
\text { Taxes on Other Income and Deductions .... }\end{array}$ & $\begin{array}{l}0 \\
0\end{array}$ & $\begin{array}{l}0 \\
0\end{array}$ & $\begin{array}{r}473 \\
0\end{array}$ & $\begin{array}{l}0 \\
0\end{array}$ & $\begin{array}{l}0 \\
0\end{array}$ & $\begin{array}{l}0 \\
0\end{array}$ \\
\hline 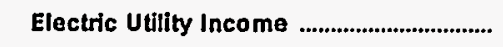 & 3,181 & 6,808 & 106,222 & 37,769 & 6,215 & 135,391 \\
\hline $\begin{array}{l}\text { Income Deductions from Interest } \\
\text { on Long-term Debt ........................................ } \\
\text { Other Income Deductions ............................ } \\
\text { Allowance for Borrowed Funds Used }\end{array}$ & $\begin{array}{r}11,057 \\
30\end{array}$ & $\begin{array}{r}481 \\
0\end{array}$ & $\begin{array}{r}124,488 \\
20,337\end{array}$ & $\begin{array}{l}1 \\
0\end{array}$ & $\begin{array}{r}13.629 \\
30\end{array}$ & $\begin{array}{r}174,140 \\
0\end{array}$ \\
\hline 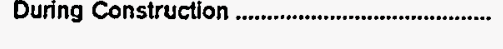 & 0 & 0 & -4.114 & 0 & 0 & 0 \\
\hline 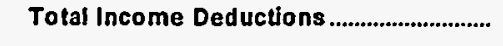 & 11,087 & 481 & 140,714 & 1 & 13,659 & 174,140 \\
\hline Income Before Extraordinary Items .................. & $-7,906$ & 6,327 & $-34,489$ & 37,768 & $-7,444$ & $-38,748$ \\
\hline 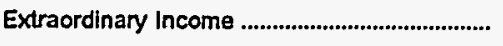 & $\mathbf{0}$ & 0 & 0 & 1,621 & 0 & 0 \\
\hline 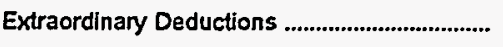 & 0 & 0 & 0 & 33,820 & 0 & 0 \\
\hline Net Income & $-7,908$ & 6,327 & $-34,489$ & 5,569 & $-7,444$ & $-38,748$ \\
\hline
\end{tabular}

Note: Totals may not equal sum of components because of independent rounding.

Source: Energy Information Administration, Form EIA-412, "Annual Report of Public Electric Utilities." 
Table 21. Statement of Income by Major U.S. Publicly Owned Electric Utility Within State, 1995 (Continued)

(Thousand Dollars)

\begin{tabular}{|c|c|c|c|c|c|c|}
\hline Item & $\begin{array}{c}\text { California } \\
\text { Turock } \\
\text { Irrigation } \\
\text { District } \\
\text { December } 31\end{array}$ & $\begin{array}{l}\text { California } \\
\text { Vernon } \\
\text { City of } \\
\text { June } 30\end{array}$ & $\begin{array}{l}\text { California } \\
\text { Yuba } \\
\text { County } \\
\text { Water } \\
\text { Agency } \\
\text { June } 30\end{array}$ & $\begin{array}{c}\text { Colorado } \\
\text { Arkansas } \\
\text { River } \\
\text { Power } \\
\text { Authority } \\
\text { December } 31\end{array}$ & $\begin{array}{c}\text { Colorado } \\
\text { Colorado } \\
\text { Springs } \\
\text { City of } \\
\text { December } 31\end{array}$ & $\begin{array}{l}\text { Colorado } \\
\text { Fort Collins } \\
\text { City of } \\
\text { December } 31\end{array}$ \\
\hline Electric Utility Operating Revenues ............ & 101,267 & 52,829 & 11,865 & 10,252 & 170,609 & 49,031 \\
\hline 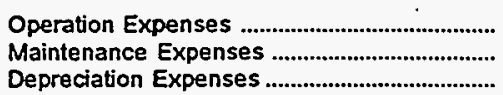 & $\begin{array}{r}67,274 \\
4,690 \\
7,900\end{array}$ & $\begin{array}{r}37,957 \\
2,823 \\
3,205\end{array}$ & $\begin{array}{r}2,680 \\
685 \\
2,604\end{array}$ & $\begin{array}{r}10,140 \\
0 \\
0\end{array}$ & $\begin{array}{l}94,104 \\
16,804 \\
27,414\end{array}$ & $\begin{array}{r}42,309 \\
710 \\
3,860\end{array}$ \\
\hline 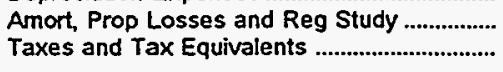 & $\begin{array}{l}0 \\
0\end{array}$ & $\begin{array}{r}0 \\
1,524\end{array}$ & $\begin{array}{r}112 \\
0\end{array}$ & $\begin{array}{l}0 \\
0\end{array}$ & $\begin{array}{r}0 \\
11,212\end{array}$ & $\begin{array}{r}0 \\
2,775\end{array}$ \\
\hline $\begin{array}{c}\text { Total Electric Utility Operating } \\
\text { Expenses }\end{array}$ & 79,863 & 45,510 & 6,080 & 10,140 & 149,534 & 49,655 \\
\hline $\begin{array}{l}\text { Net Electric Utility Operating Income } \\
\text { Income from Electric Plant Leased } \\
\text { to Others }\end{array}$ & 21,403 & 7,319 & 5,784 & 112 & 21,075 & $\begin{array}{r}-624 \\
0\end{array}$ \\
\hline Electric Utility Operating Income ............. & 21,403 & 7,319 & 5,784 & 112 & 21,075 & -624 \\
\hline Other Electric Income & 224 & 10,063 & 953 & 608 & 9,150 & 2,492 \\
\hline $\begin{array}{l}\text { Other Electric Deductions } \\
\text { Allowance for Other Funds Used }\end{array}$ & 0 & 252 & 0 & 0 & 0 & $\mathbf{0}$ \\
\hline $\begin{array}{l}\text { During Construction .................................. } \\
\text { Taxes on Other Income and Deductions ...... }\end{array}$ & $\begin{array}{l}0 \\
0\end{array}$ & 0 & $\begin{array}{l}0 \\
0\end{array}$ & $\begin{array}{l}0 \\
0\end{array}$ & $\begin{array}{r}251 \\
0\end{array}$ & $\begin{array}{l}0 \\
0\end{array}$ \\
\hline 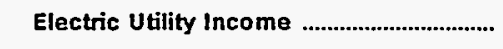 & 21,627 & 17,129 & 6,737 & 720 & 30,477 & 1,868 \\
\hline 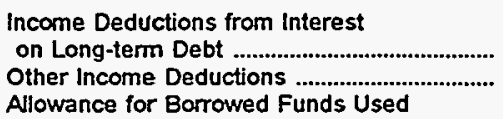 & $\begin{array}{r}9,291 \\
0\end{array}$ & $\begin{array}{r}0 \\
8,804\end{array}$ & $\begin{array}{r}4,253 \\
12\end{array}$ & $\begin{array}{l}0 \\
0\end{array}$ & $\begin{array}{r}27,044 \\
419\end{array}$ & $\begin{array}{l}0 \\
0\end{array}$ \\
\hline 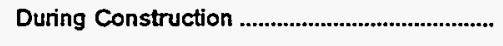 & 0 & 0 & 0 & 0 & -458 & $\mathbf{0}$ \\
\hline 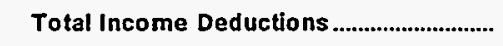 & 9,291 & 8,804 & 4,265 & $\mathbf{0}$ & 27,004 & $\mathbf{0}$ \\
\hline Income Before Extraordinary Items ................... & 12,336 & 8.325 & 2,472 & 720 & 3,472 & 1,868 \\
\hline Extraordinary Income & 0 & 0 & 0 & 0 & 0 & $\mathbf{0}$ \\
\hline 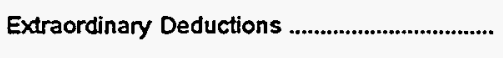 & 0 & 0 & 0 & 0 & 613 & 0 \\
\hline Net Income & 12,336 & 8,325 & 2,472 & 720 & 2,859 & 1,868 \\
\hline
\end{tabular}

Note: Totals may not equal sum of components because of independent rounding.

Source: Energy Information Administration, Form EIA-412, "Annual Report of Public Slectric Utilities." 
Table 21. Statement of Income by Major U.S. Publicly Owned Electric Utility Within State, 1995 (Continued)

(Thousand Dollars)

\begin{tabular}{|c|c|c|c|c|c|c|}
\hline Item & $\begin{array}{c}\text { Colorado } \\
\text { Fort Morgan } \\
\text { City of } \\
\text { December } 31\end{array}$ & $\begin{array}{c}\text { Colorado } \\
\text { Longmont } \\
\text { City of } \\
\text { December } 31\end{array}$ & $\begin{array}{l}\text { Colorado } \\
\text { Loveland } \\
\text { City of } \\
\text { December } 31\end{array}$ & $\begin{array}{c}\text { Colorado } \\
\text { Platte River } \\
\text { Power } \\
\text { Authority } \\
\text { December } 31\end{array}$ & $\begin{array}{l}\text { Connecticut } \\
\text { Connecticut } \\
\text { Mun } \\
\text { Elec } \\
\text { Engy Coop } \\
\text { December } 31\end{array}$ & $\begin{array}{l}\text { Connecticut } \\
\text { Groton } \\
\text { City of } \\
\text { June } 30\end{array}$ \\
\hline Electric Utilty Operating Revenues ............. & 7,058 & 24,684 & 22,785 & 136,212 & 84,678 & 44,424 \\
\hline 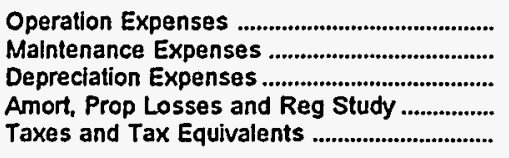 & $\begin{array}{r}5,072 \\
305 \\
333 \\
0 \\
917\end{array}$ & $\begin{array}{r}21,802 \\
737 \\
1,158 \\
0 \\
1,472\end{array}$ & $\begin{array}{r}16,182 \\
866 \\
1,487 \\
0 \\
1,376\end{array}$ & $\begin{array}{r}61,089 \\
9,812 \\
21,985 \\
7,894 \\
0\end{array}$ & $\begin{array}{r}77,485 \\
0 \\
1,806 \\
0 \\
0\end{array}$ & $\begin{array}{r}38,661 \\
419 \\
1,292 \\
0 \\
1.868\end{array}$ \\
\hline $\begin{array}{l}\text { Total Electric Utility Operating } \\
\text { Expenses ......................................................... }\end{array}$ & 6,627 & 25,169 & 19,911 & 100,781 & 79,291 & 42,240 \\
\hline $\begin{array}{l}\text { Net Electric Utility Operating Income } \\
\text { Income from Electric Plant Leased } \\
\text { to Others }\end{array}$ & 431 & $\begin{array}{r}-485 \\
0\end{array}$ & $\begin{array}{r}2,874 \\
0\end{array}$ & $\begin{array}{r}35.431 \\
0\end{array}$ & $\begin{array}{r}5,387 \\
0\end{array}$ & $\begin{array}{r}2,183 \\
0\end{array}$ \\
\hline Electric Utility Operating Income .............. & 431 & -485 & 2,874 & 35,431 & 5,387 & 2,183 \\
\hline 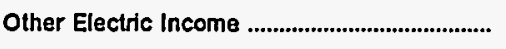 & 159 & 511 & 1,280 & 13.885 & 4,725 & 589 \\
\hline Other Electric Deductions .................................... & 0 & 31 & 1,086 & 0 & 5,629 & 195 \\
\hline $\begin{array}{l}\text { During Construction .................................... } \\
\text { Taxes on Other Income and Deductions ....... }\end{array}$ & $\begin{array}{l}0 \\
0\end{array}$ & $\begin{array}{l}0 \\
0\end{array}$ & $\begin{array}{l}0 \\
0\end{array}$ & $\begin{array}{l}0 \\
0\end{array}$ & $\begin{array}{l}0 \\
0\end{array}$ & $\begin{array}{l}0 \\
0\end{array}$ \\
\hline 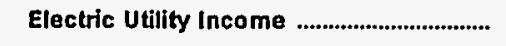 & 590 & -5 & 3,068 & 49,316 & 4,483 & 2,577 \\
\hline 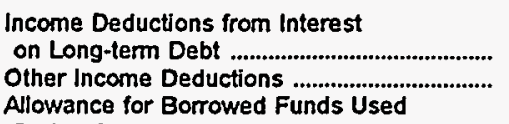 & $\begin{array}{l}0 \\
0\end{array}$ & $\begin{array}{l}0 \\
0\end{array}$ & $\begin{array}{r}504 \\
0\end{array}$ & $\begin{array}{r}32,095 \\
5,227\end{array}$ & $\begin{array}{l}0 \\
0\end{array}$ & $\begin{array}{r}432 \\
1,200\end{array}$ \\
\hline 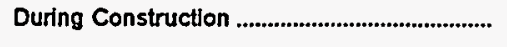 & 0 & 0 & 0 & 0 & 0 & -21 \\
\hline Total Income Deductions ............................... & 0 & 0 & 504 & 37,322 & 0 & 1,611 \\
\hline Income Before Extraordinary Items .................. & 590 & -5 & 2,564 & 11,995 & 4,483 & 966 \\
\hline 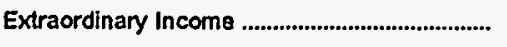 & 0 & 0 & 0 & 0 & 0 & 0 \\
\hline 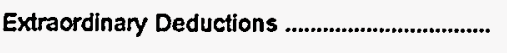 & 0 & 0 & 0 & 0 & 0 & 0 \\
\hline 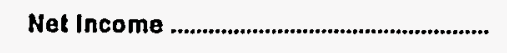 & 590 & -5 & 2,564 & 11,995 & 4,483 & 966 \\
\hline
\end{tabular}

Note: Totals may not equal sum of components because of independent rounding

Source: Energy Information Administration, Form EIA-412, "Annual Report of Public Electric Utilities." 
Table 21. Statement of Income by Major U.S. Publicly Owned Electric Utility Within State, 1995 (Continued)

(Thousand Dollars)

\begin{tabular}{|c|c|c|c|c|c|c|}
\hline Item & $\begin{array}{l}\text { Connecticut } \\
\text { Nonwich } \\
\text { City of } \\
\text { June } 30\end{array}$ & $\begin{array}{l}\text { Connecticut } \\
\text { Wallingford } \\
\text { Town of } \\
\text { June } 30\end{array}$ & $\begin{array}{l}\text { Delaware } \\
\text { Dover } \\
\text { City of } \\
\text { June } 30\end{array}$ & $\begin{array}{l}\text { Delaware } \\
\text { Milford } \\
\text { City of } \\
\text { September } 30\end{array}$ & $\begin{array}{c}\text { Delaware } \\
\text { Newark } \\
\text { City of } \\
\text { December } 31\end{array}$ & $\begin{array}{l}\text { Florida } \\
\text { Bartow } \\
\text { City of } \\
\text { September } 30\end{array}$ \\
\hline Electric Utility Operating Revenues ............ & 27,415 & 40,320 & 41,079 & 11,533 & 21,280 & 22,371 \\
\hline 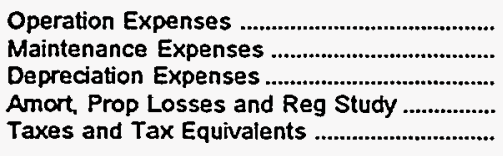 & $\begin{array}{r}24,206 \\
878 \\
1,105 \\
0 \\
1,401\end{array}$ & $\begin{array}{r}34,775 \\
1,969 \\
1,418 \\
0 \\
1,728\end{array}$ & $\begin{array}{r}29,482 \\
0 \\
2,994 \\
0 \\
954\end{array}$ & $\begin{array}{r}7,623 \\
935 \\
289 \\
0 \\
0\end{array}$ & $\begin{array}{r}14,908 \\
266 \\
485 \\
0 \\
0\end{array}$ & $\begin{array}{r}16,290 \\
0 \\
381 \\
0 \\
0\end{array}$ \\
\hline $\begin{array}{l}\text { Total Electric Utility Operating } \\
\text { Expenses }\end{array}$ & 27,590 & 39,889 & 33,430 & 8,848 & 15,659 & 16,670 \\
\hline 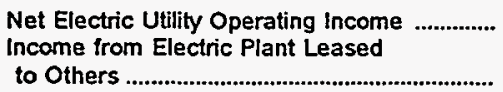 & $\begin{array}{r}-175 \\
641\end{array}$ & 431 & 7,650 & 2,685 & 5,621 & $\begin{array}{r}5.700 \\
0\end{array}$ \\
\hline Electric Utility Operating Income ............. & 466 & 431 & 7,650 & 2,685 & 5,621 & 5,700 \\
\hline 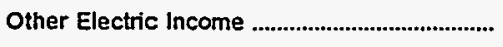 & 136 & 855 & 1,529 & 765 & 0 & 230 \\
\hline $\begin{array}{l}\text { Other Electric Deductions ............................... } \\
\text { Allowance for Other Funds Used } \\
\text { During Construction ..................................... } \\
\text { Taxes on Other Income and Deductions ...... }\end{array}$ & $\begin{array}{l}0 \\
0\end{array}$ & 501 & $\begin{array}{l}0 \\
0\end{array}$ & $\begin{array}{l}0 \\
0\end{array}$ & $\begin{array}{l}0 \\
0\end{array}$ & $\begin{array}{l}0 \\
0\end{array}$ \\
\hline Electric Utility Income ................................... & 603 & 786 & 9,179 & 3,379 & 5,621 & 5,931 \\
\hline 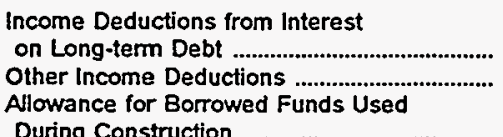 & $\begin{array}{r}402 \\
5\end{array}$ & $\begin{array}{l}0 \\
0\end{array}$ & $\begin{array}{r}1,974 \\
0 \\
71\end{array}$ & 2,386 & $\begin{array}{l}0 \\
0\end{array}$ & $\begin{array}{l}0 \\
0\end{array}$ \\
\hline Total Income Deductions ................................. & 407 & $\mathbf{0}$ & 2,045 & 2,386 & 0 & 0 \\
\hline Income Before Extraordinary Items .................. & 196 & 786 & 7.134 & 993 & 5,621 & 5,931 \\
\hline 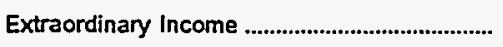 & 0 & 0 & 0 & 0 & 0 & 0 \\
\hline 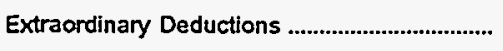 & 0 & 0 & 3.673 & 0 & 0 & 5,810 \\
\hline Net Income & 196 & 786 & 3,461 & 993 & 5,621 & 120 \\
\hline
\end{tabular}

Note: Totals may not equal sum of components because of independent rounding.

Sourcs: Energy Information Admisistration, Form ElA-412, "Annual Report of Public Electric Utilities." 
Table 21. Statement of Income by Major U.S. Publicly Owned Electric Utility Within State, 1995 (Continued) (Thousand Dollars)

\begin{tabular}{|c|c|c|c|c|c|c|}
\hline Item & $\begin{array}{c}\text { Florida } \\
\text { Florida } \\
\text { Municipa! } \\
\text { Power Agency } \\
\text { September } 30\end{array}$ & $\begin{array}{c}\text { Florida } \\
\text { Fort Pierce } \\
\text { Utilities } \\
\text { Auth } \\
\text { September } 30\end{array}$ & $\begin{array}{c}\text { Florida } \\
\text { Gainesville } \\
\text { Regional } \\
\text { Utitities } \\
\text { September } 30\end{array}$ & $\begin{array}{c}\text { Florida } \\
\text { Homestead } \\
\text { City of } \\
\text { September } 30\end{array}$ & $\begin{array}{c}\text { Florida } \\
\text { Jacksonville } \\
\text { Beach } \\
\text { City of } \\
\text { September } 30\end{array}$ & $\begin{array}{c}\text { Florida } \\
\text { Jacksonville } \\
\text { Electric } \\
\text { Auth } \\
\text { September } 30\end{array}$ \\
\hline Electric Utility Operating Revenues ........... & 182,940 & 40,117 & 119,757 & 22,473 & 45,660 & 739,386 \\
\hline 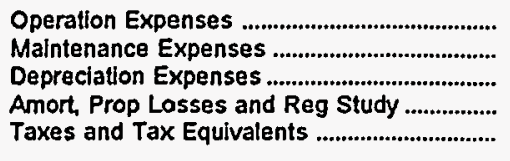 & $\begin{array}{r}115,360 \\
4,267 \\
11,535 \\
0 \\
0\end{array}$ & $\begin{array}{r}26,754 \\
2,454 \\
4,286 \\
0 \\
940\end{array}$ & $\begin{array}{r}59,851 \\
9,203 \\
18,594 \\
0 \\
13,463\end{array}$ & $\begin{array}{r}19,273 \\
3,984 \\
2,002 \\
0 \\
1,409\end{array}$ & $\begin{array}{r}36,997 \\
381 \\
2,238 \\
0 \\
379\end{array}$ & $\begin{array}{r}375,680 \\
47,676 \\
114,906 \\
0 \\
15,547\end{array}$ \\
\hline $\begin{array}{l}\text { Total Electric Utility Operating } \\
\text { Expenses }\end{array}$ & 131,162 & 34,434 & 101,111 & 26,668 & 39,996 & 553,809 \\
\hline 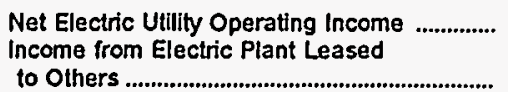 & $\begin{array}{r}51.778 \\
0\end{array}$ & $\begin{array}{r}5,683 \\
0\end{array}$ & 18,646 & $\begin{array}{r}-4,195 \\
0\end{array}$ & 5,665 & 185,577 \\
\hline Electric Utility Operating Income ............. & 51,778 & 5,683 & 18,646 & $-4,195$ & 5,665 & 185,577 \\
\hline Other Electric Income & 10,819 & 1,405 & 6,350 & 3,167 & 1,351 & 48,555 \\
\hline $\begin{array}{l}\text { Other Electric Deductions ................................. } \\
\text { Allowance for Other Funds Used }\end{array}$ & 0 & 0 & 0 & 0 & 3.712 & 0 \\
\hline $\begin{array}{l}\text { During Construction ...................................... } \\
\text { Taxes on Other Income and Deductions ....... }\end{array}$ & $\begin{array}{l}\mathbf{0} \\
\mathbf{0}\end{array}$ & $\begin{array}{l}0 \\
0\end{array}$ & $\begin{array}{l}0 \\
0\end{array}$ & $\begin{array}{l}0 \\
0\end{array}$ & $\begin{array}{l}0 \\
0\end{array}$ & $\begin{array}{l}0 \\
0\end{array}$ \\
\hline 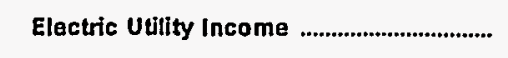 & 62,597 & 7,088 & 24,997 & $-1,028$ & 3,304 & 234,132 \\
\hline 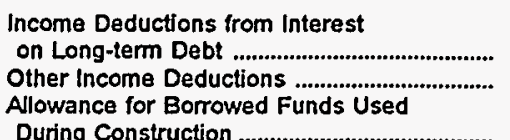 & $\begin{array}{l}36,400 \\
26,197\end{array}$ & $\begin{array}{l}3,138 \\
3,035\end{array}$ & $\begin{array}{r}17,076 \\
0\end{array}$ & $\begin{array}{r}433 \\
0\end{array}$ & $\begin{array}{r}4,227 \\
0\end{array}$ & $\begin{array}{r}165.118 \\
-1,616\end{array}$ \\
\hline 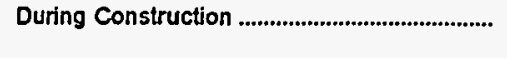 & 0 & 0 & 0 & 0 & 0 & $-2,790$ \\
\hline Total Income Deductions .................................. & 62,597 & 6,173 & 17,076 & 433 & 4,227 & 160,712 \\
\hline Income Before Extraordinary Items .................. & 0 & 915 & 7,921 & $-1,461$ & -924 & 73,420 \\
\hline 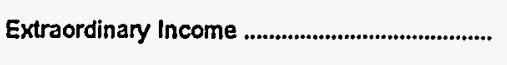 & 0 & 0 & 0 & 0 & 0 & 0 \\
\hline 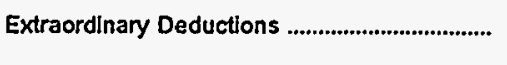 & 0 & 0 & 0 & 0 & 0 & 0 \\
\hline Net Income & $\mathbf{0}$ & 915 & 7,921 & $-1,461$ & -924 & 73,420 \\
\hline
\end{tabular}

Source: Energy Information Administration, Form ElA-412, "Annual Report of Public Electric Utitities." 
Table 21. Statement of Income by Major U.S. Publicly Owned Electric Utility Within State, 1995 (Continued)

(Thousand Dollars)

\begin{tabular}{|c|c|c|c|c|c|c|}
\hline Item & $\begin{array}{l}\text { Florida } \\
\text { Key West } \\
\text { City of } \\
\text { September } 30\end{array}$ & $\begin{array}{c}\text { Florida } \\
\text { Kissimmee } \\
\text { Utility } \\
\text { Authority } \\
\text { September } 30\end{array}$ & $\begin{array}{l}\text { Florida } \\
\text { Lake Worth } \\
\text { City of } \\
\text { September } 30\end{array}$ & $\begin{array}{l}\text { Forida } \\
\text { Lakeland } \\
\text { City of } \\
\text { September } 30\end{array}$ & $\begin{array}{l}\text { Florida } \\
\text { Leesburg } \\
\text { City of } \\
\text { September } 30\end{array}$ & $\begin{array}{c}\text { Florida } \\
\text { New Smyrna } \\
\text { Beach } \\
\text { Utils Comm } \\
\text { September } 30\end{array}$ \\
\hline Electric Utility Operating Revenues ............. & 52,303 & 66,848 & 33,020 & 170,018 & 30,785 & 25,612 \\
\hline 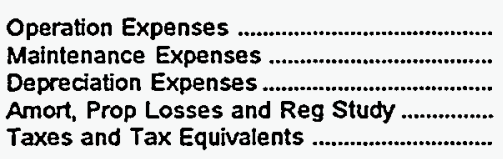 & $\begin{array}{r}32,845 \\
3,179 \\
4,934 \\
0 \\
1,323\end{array}$ & $\begin{array}{r}40,471 \\
3,437 \\
8,683 \\
-3,484 \\
10\end{array}$ & $\begin{array}{r}22,154 \\
1,314 \\
2,633 \\
0 \\
4,403\end{array}$ & $\begin{array}{r}82,450 \\
15,420 \\
18,854 \\
0 \\
0\end{array}$ & $\begin{array}{r}20,152 \\
1,454 \\
1,683 \\
140 \\
737\end{array}$ & $\begin{array}{r}18,777 \\
820 \\
1,886 \\
203 \\
1,500\end{array}$ \\
\hline $\begin{array}{l}\text { Total Electric Utility Operating } \\
\text { Expenses }\end{array}$ & 42,281 & 49,118 & 30,504 & 116,723 & 24,165 & 23,186 \\
\hline 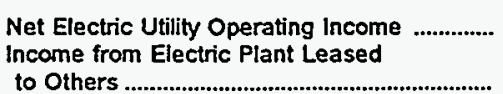 & 10,022 & 17,729 & 2,515 & 53,295 & 6.619 & 2,427 \\
\hline Electric Utility Operating Income ............ & 10,022 & 17,729 & 2,515 & 53,295 & 6,619 & 2,427 \\
\hline 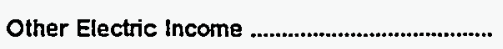 & 1,631 & 5,422 & 1,766 & 23,023 & 1,211 & 686 \\
\hline $\begin{array}{l}\text { Other Electric Deductions .................................. } \\
\text { Allowance for Other Funds Used }\end{array}$ & 0 & 6,095 & 0 & 10,895 & 3,565 & 43 \\
\hline $\begin{array}{l}\text { During Construction .............................. } \\
\text { Taxes on Other Income and Deductions ....... }\end{array}$ & $\begin{array}{l}0 \\
0\end{array}$ & $\begin{array}{l}0 \\
0\end{array}$ & $\begin{array}{l}0 \\
0\end{array}$ & $\begin{array}{l}0 \\
0\end{array}$ & $\begin{array}{l}0 \\
0\end{array}$ & $\begin{array}{l}0 \\
0\end{array}$ \\
\hline 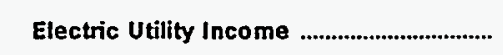 & 11,653 & 17,057 & 4,282 & 65,423 & 4,265 & 3,070 \\
\hline 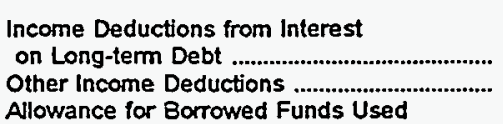 & $\begin{array}{r}8,341 \\
0\end{array}$ & $\begin{array}{l}6,061 \\
1,420\end{array}$ & $\begin{array}{r}2,169 \\
0\end{array}$ & $\begin{array}{r}23,829 \\
1,600\end{array}$ & $\begin{array}{r}1,066 \\
0\end{array}$ & $\begin{array}{r}1,790 \\
116\end{array}$ \\
\hline 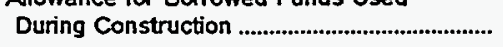 & 0 & 0 & 0 & 0 & 0 & 0 \\
\hline Total Income Deductions .............................. & 8,341 & 7,481 & 2,169 & 25,429 & 1,066 & 1,906 \\
\hline Income Before Extraordinary Items .................. & 3,313 & 9,576 & 2,113 & 39,994 & 3,199 & 1,164 \\
\hline 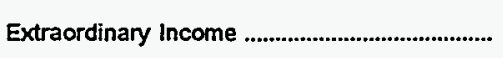 & 0 & 0 & 0 & 0 & 0 & $\mathbf{0}$ \\
\hline 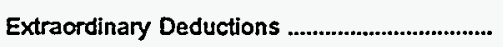 & 0 & 0 & 0 & 0 & 0 & 0 \\
\hline 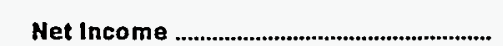 & 3,313 & 9,576 & 2,113 & 39,994 & 3,199 & 1,164 \\
\hline
\end{tabular}

Note: Totals may not equal sum of components because of independent rounding

Source: Energy Information Administration, Form EIA-412, "Annual Report of Public Electric Utilities." 
Table 21. Statement of Income by Major U.S. Publicly Owned Electric Utility Within State, 1995 (Continued)

(Thousand Dollars)

\begin{tabular}{|c|c|c|c|c|c|c|}
\hline Item & $\begin{array}{l}\text { Florida } \\
\text { Ocala } \\
\text { City of } \\
\text { September } 30\end{array}$ & $\begin{array}{l}\text { Forida } \\
\text { Orlando } \\
\text { Utilities } \\
\text { Comm } \\
\text { September } 30\end{array}$ & $\begin{array}{l}\text { Florida } \\
\text { Quincy } \\
\text { City of } \\
\text { September } 30\end{array}$ & $\begin{array}{c}\text { Florida } \\
\text { Reedy Creek } \\
\text { Improvement } \\
\text { Dist }\end{array}$ & $\begin{array}{l}\text { Florida } \\
\text { St Cloud } \\
\text { City of } \\
\text { September } 30\end{array}$ & $\begin{array}{c}\text { Florida } \\
\text { Tallahassee } \\
\text { City of }\end{array}$ \\
\hline Electric Utility Operating Revenues ............. & 79,323 & 317,225 & 9,791 & 60,154 & 25,846 & 184,419 \\
\hline 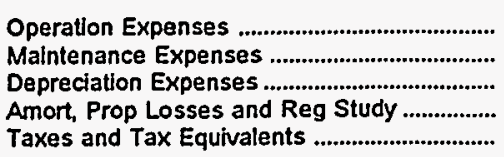 & $\begin{array}{r}53,320 \\
2,153 \\
3,126 \\
499 \\
2,023\end{array}$ & $\begin{array}{r}147,085 \\
23,204 \\
38,974 \\
135 \\
17,782\end{array}$ & $\begin{array}{r}6,576 \\
477 \\
204 \\
0 \\
148\end{array}$ & $\begin{array}{r}44,479 \\
4,785 \\
4,898 \\
0 \\
2,020\end{array}$ & $\begin{array}{r}16,929 \\
427 \\
3,108 \\
0 \\
578\end{array}$ & $\begin{array}{r}119,803 \\
10,303 \\
14,236 \\
167 \\
0\end{array}$ \\
\hline $\begin{array}{c}\text { Total Electric Utility Operating } \\
\text { Expenses }\end{array}$ & 61,121 & 227,181 & 7,405 & 56,182 & 21,042 & 144,509 \\
\hline 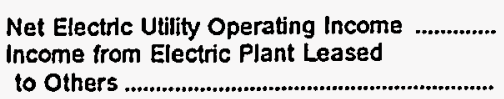 & 18,202 & 90,043 & 2,386 & 3.972 & $\begin{array}{r}4,803 \\
0\end{array}$ & $\begin{array}{r}39,910 \\
0\end{array}$ \\
\hline Electric Utility Operating Income ............ & 18,202 & 90,043 & 2,386 & 3,972 & 4,803 & 39,910 \\
\hline 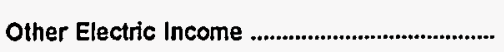 & 1,417 & 25,508 & 191 & 0 & 404 & 7,708 \\
\hline $\begin{array}{l}\text { Other Electric Deductions ................................ } \\
\text { Allowance for Other Funds Used } \\
\text { During Construction ...................................... } \\
\text { Taxes on Other Income and Deductions ........ }\end{array}$ & 592 & $\begin{array}{l}0 \\
0\end{array}$ & $\begin{array}{l}0 \\
0\end{array}$ & 329 & $\begin{array}{l}0 \\
0\end{array}$ & 498 \\
\hline Electric Utility Income & 19,026 & 115,552 & 2,569 & 3,642 & 5,208 & 47,120 \\
\hline 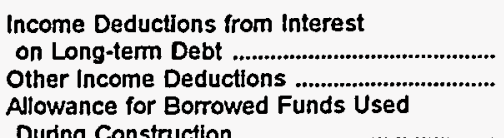 & $\begin{array}{r}953 \\
0\end{array}$ & $\begin{array}{l}71,686 \\
10,361\end{array}$ & $\begin{array}{l}0 \\
0\end{array}$ & $\begin{array}{r}7.073 \\
143\end{array}$ & $\begin{array}{r}1,651 \\
0\end{array}$ & $\begin{array}{r}6,528 \\
38,950 \\
-3,232\end{array}$ \\
\hline 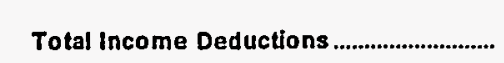 & 953 & 82,047 & 0 & 7,216 & 1,651 & 42,246 \\
\hline Income Before Extraordinary items ................... & 18,074 & 33,504 & 2,569 & $-3,573$ & 3,556 & 4,874 \\
\hline 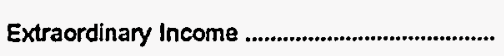 & 0 & 0 & 0 & 0 & 0 & 0 \\
\hline Extraordinary Deductlons & 0 & 0 & 0 & 0 & 0 & 0 \\
\hline 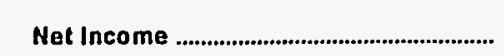 & 18,074 & 33,504 & 2,569 & $-3,573$ & 3,556 & 4,874 \\
\hline
\end{tabular}

Note: Totals may not equal sum of components because of independent rounding.

Source: Energy Information Administration. Form EIA-412, "Annual Report of Public Electric Utilities." 
Table 21. Statement of Income by Major U.S. Publicly Owned Electric Utility Within State, 1995 (Continued)

(Thousand Dollars)

\begin{tabular}{|c|c|c|c|c|c|c|}
\hline Item & $\begin{array}{c}\text { Florida } \\
\text { Vero } \\
\text { Beach } \\
\text { City of } \\
\text { September } 30\end{array}$ & $\begin{array}{l}\text { Georgia } \\
\text { Albany Water } \\
\text { Gas \& Light } \\
\text { Comm } \\
\text { June } 30\end{array}$ & $\begin{array}{l}\text { Georgia } \\
\text { Calhoun } \\
\text { City of } \\
\text { June } 30\end{array}$ & $\begin{array}{l}\text { Georgia } \\
\text { Cartersville } \\
\text { City of } \\
\text { June } 30\end{array}$ & $\begin{array}{l}\text { Georgia } \\
\text { College } \\
\text { Park City of } \\
\text { June } 30\end{array}$ & $\begin{array}{l}\text { Georgia } \\
\text { Covington } \\
\text { City of } \\
\text { December } 31\end{array}$ \\
\hline Electric Utility Operating Revenues ............ & 47,027 & 54,768 & 19,980 & 25,897 & 17,717 & 16,179 \\
\hline 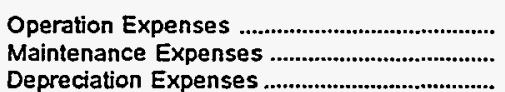 & $\begin{array}{r}29,600 \\
3,161 \\
4,466\end{array}$ & $\begin{array}{r}48,975 \\
1,801 \\
1,256\end{array}$ & $\begin{array}{r}16,989 \\
179 \\
305\end{array}$ & $\begin{array}{r}22,777 \\
96 \\
364\end{array}$ & $\begin{array}{r}15,186 \\
202 \\
284\end{array}$ & $\begin{array}{r}12,388 \\
186 \\
209\end{array}$ \\
\hline 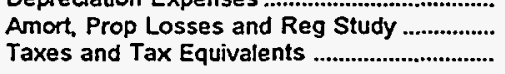 & $\begin{array}{r}0 \\
83\end{array}$ & $\begin{array}{r}1,200 \\
0\end{array}$ & $\begin{array}{l}0 \\
0\end{array}$ & $\begin{array}{r}304 \\
0 \\
0\end{array}$ & $\begin{array}{r}204 \\
0 \\
0\end{array}$ & $\begin{array}{r}400 \\
0 \\
691\end{array}$ \\
\hline $\begin{array}{l}\text { Total Electric Utility Operating } \\
\text { Expenses }\end{array}$ & 37,310 & 52,033 & 17,473 & 23,237 & 15,671 & 13,474 \\
\hline $\begin{array}{l}\text { Net Electric Utility Operating Income } \\
\text { income from Electric Plant Leased }\end{array}$ & 9,718 & 2,734 & 2,507 & 2,659 & 2,046 & 2,705 \\
\hline 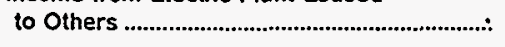 & 0 & $\mathbf{0}$ & 0 & 0 & 0 & $\mathbf{0}$ \\
\hline Electric Utility Operating Income ............... & 9,718 & 2,734 & 2,507 & 2,659 & 2,046 & 2,705 \\
\hline 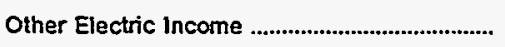 & 1,327 & 902 & 0 & 207 & 379 & 350 \\
\hline $\begin{array}{l}\text { Other Electric Deductions ...................................... } \\
\text { Allowance for Other Funds Used }\end{array}$ & 0 & 0 & 0 & 2,738 & 460 & $\mathbf{0}$ \\
\hline 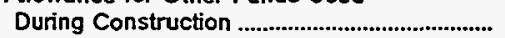 & 0 & 0 & 0 & 0 & 0 & 0 \\
\hline Taxes on Other income and Deductions ........ & 0 & 0 & 0 & 0 & 0 & 0 \\
\hline Electric Utility Income & 11,045 & 3,637 & 2,507 & 129 & 1,964 & 3,055 \\
\hline 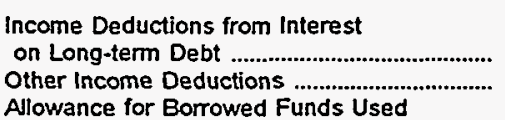 & $\begin{array}{l}5,011 \\
2,957\end{array}$ & $\begin{array}{r}0 \\
25\end{array}$ & $\begin{array}{r}0 \\
3,451\end{array}$ & $\begin{array}{l}1 \\
0\end{array}$ & $\begin{array}{l}0 \\
0\end{array}$ & $\begin{array}{r}15 \\
0\end{array}$ \\
\hline 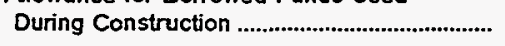 & 0 & 0 & 0 & 0 & 0 & 0 \\
\hline 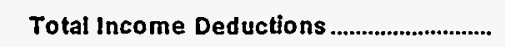 & 7,968 & 25 & 3,451 & 1 & $\mathbf{0}$ & 15 \\
\hline Income Before Extraordinary ltems .................. & 3,077 & 3,612 & -944 & 127 & 1,964 & 3,040 \\
\hline 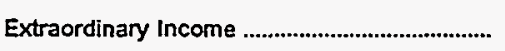 & 0 & 0 & 8,587 & 0 & 0 & 0 \\
\hline 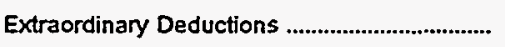 & 0 & 0 & 5,937 & 0 & 0 & 0 \\
\hline Net Income & 3,077 & 3,612 & 1,706 & 127 & 1,964 & 3,040 \\
\hline
\end{tabular}

Note: Totals may not equal sum of components because of independent rounding.

Source: Energy Information Administration, Form ELA-412, "Annual Report of Public Electric Utilities." 
Table 21. Statement of Income by Major U.S. Publicly Owned Electric Utility Within State, 1995 (Continued)

(Thousand Dollars)

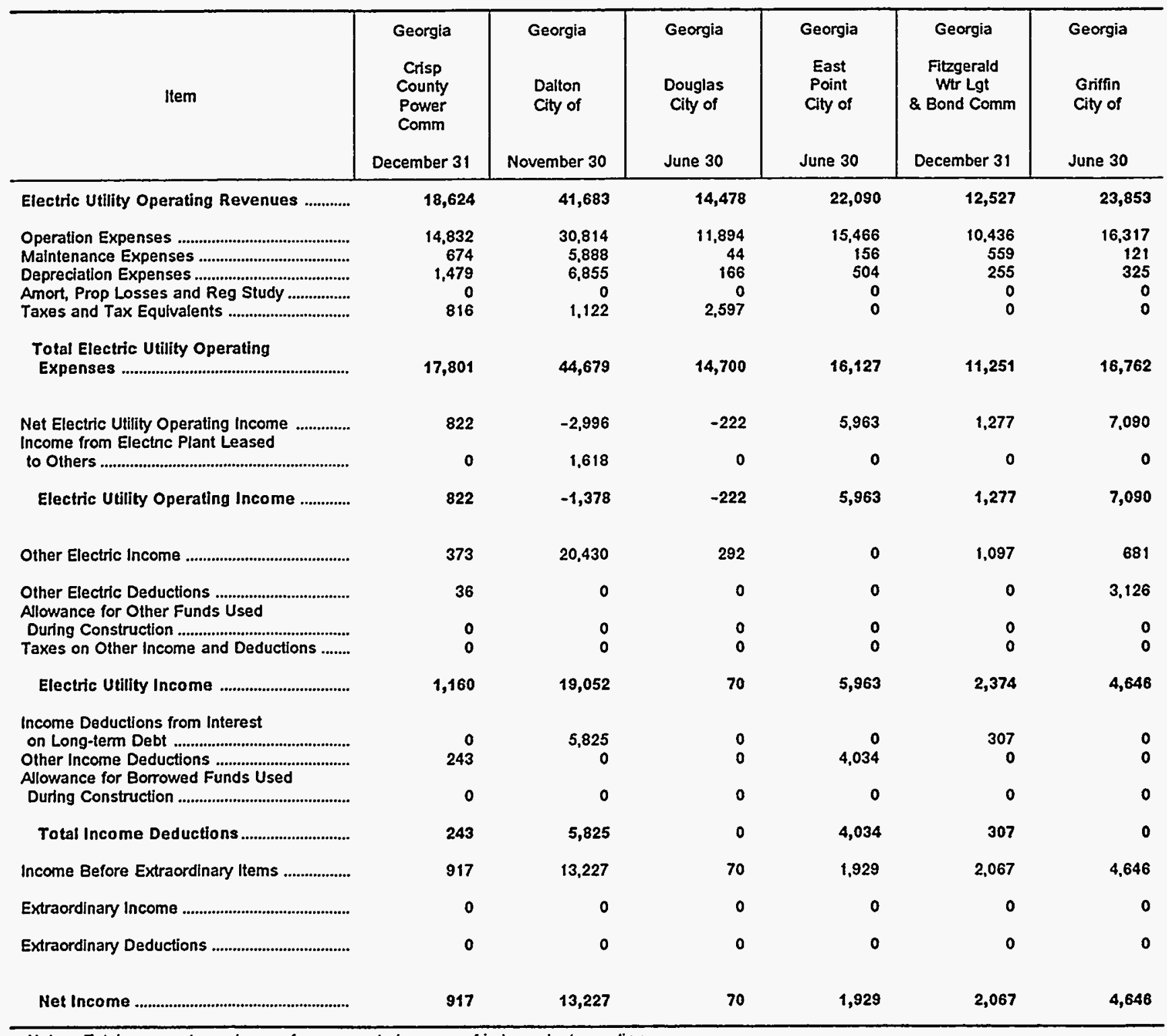

Note: Totals may not equal sum of components because of independent rounding.

Source: Energy Information Administration, Form ElA-412, "Annual Report of Public Electric Utilities." 
Table 21. Statement of Income by Major U.S. Publicly Owned Electric Utility Within State, 1995 (Continued)

(Thousand Dollars)

\begin{tabular}{|c|c|c|c|c|c|c|}
\hline Item & $\begin{array}{l}\text { Georgia } \\
\text { La Grange } \\
\text { City of } \\
\text { June } 30\end{array}$ & $\begin{array}{l}\text { Georgia } \\
\begin{array}{l}\text { Lawrenceville } \\
\text { City of }\end{array} \\
\text { August } 30\end{array}$ & $\begin{array}{l}\text { Georgia } \\
\text { Marietta } \\
\text { City of } \\
\text { June } 30\end{array}$ & $\begin{array}{c}\text { Georgia } \\
\text { Moultrie } \\
\text { City of } \\
\text { September } 30\end{array}$ & $\begin{array}{l}\text { Georgia } \\
\text { Municipal } \\
\text { Electric } \\
\text { Authority } \\
\text { December } 31\end{array}$ & $\begin{array}{c}\text { Georgia } \\
\text { Thomasville } \\
\text { City of } \\
\text { December } 31\end{array}$ \\
\hline Electric Utility Operating Revenues ............. & 27,060 & 15,580 & 69,333 & 12,398 & 500,592 & 28,660 \\
\hline 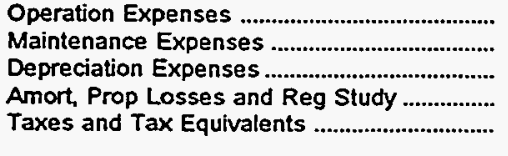 & $\begin{array}{r}22,760 \\
12 \\
2,070 \\
0 \\
0\end{array}$ & $\begin{array}{r}14,380 \\
16 \\
416 \\
0 \\
0\end{array}$ & $\begin{array}{r}54,822 \\
0 \\
1,588 \\
0 \\
0\end{array}$ & $\begin{array}{r}10,688 \\
0 \\
237 \\
0 \\
0\end{array}$ & $\begin{array}{r}169,571 \\
38,389 \\
95,924 \\
26,927 \\
2,918\end{array}$ & $\begin{array}{r}23,750 \\
687 \\
951 \\
0 \\
1,193\end{array}$ \\
\hline $\begin{array}{l}\text { Total Electric Utility Operating } \\
\text { Expenses ........................................................ }\end{array}$ & 24,842 & 14,811 & 56,410 & 10,925 & 333,729 & 26,582 \\
\hline 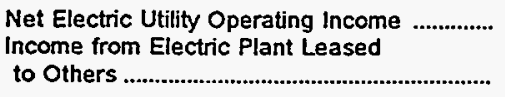 & 2,218 & 768 & 12,923 & 1,474 & 166,863 & 2,078 \\
\hline Electric Utility Operating Income ............. & 2,218 & 768 & 12,923 & 1,474 & 166,863 & 2,078 \\
\hline 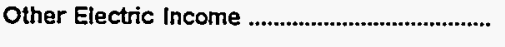 & 0 & 0 & o & 29 & 39,585 & 133 \\
\hline $\begin{array}{l}\text { Other Electric Deductions ......................................... } \\
\text { Allowance for Other Funds Used }\end{array}$ & 0 & 0 & 0 & 0 & 1 & 44 \\
\hline $\begin{array}{l}\text { During Construction } \\
\text { Taxes on Other Income and Deductions }\end{array}$ & $\begin{array}{l}0 \\
0\end{array}$ & $\begin{array}{r}0 \\
768\end{array}$ & $\begin{array}{l}0 \\
0\end{array}$ & $\begin{array}{l}0 \\
0\end{array}$ & $\begin{array}{r}0 \\
543\end{array}$ & $\begin{array}{l}0 \\
0\end{array}$ \\
\hline Electric Utility Income & 2,218 & $\mathbf{0}$ & 12,923 & 1,503 & 205,904 & 2,168 \\
\hline 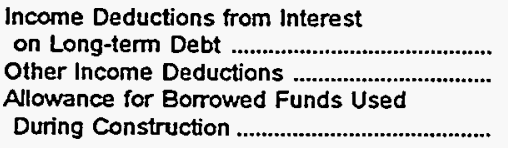 & $\begin{array}{l}0 \\
0\end{array}$ & $\begin{array}{l}0 \\
0\end{array}$ & $\begin{array}{l}0 \\
0\end{array}$ & $\begin{array}{r}0 \\
1,629\end{array}$ & $\begin{array}{l}235,335 \\
-35,036\end{array}$ & $\begin{array}{r}0 \\
27\end{array}$ \\
\hline Total Income Deductions & 0 & 0 & 0 & 1,629 & 200,753 & 27 \\
\hline Income Before Extraordinary items ...................... & 2,218 & 0 & 12,923 & -126 & 5,151 & 2,141 \\
\hline Extraordinary Income & 0 & 0 & 0 & 0 & 0 & 0 \\
\hline 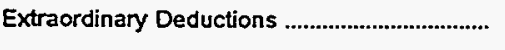 & 0 & 0 & 0 & 0 & 0 & 0 \\
\hline Net Income ........................................................ & 2,218 & 0 & 12,923 & -126 & 5,151 & 2,141 \\
\hline
\end{tabular}

Note: Totals may not equal sum of components because of independent rounding.

Source: Eneroy Information Administration, Form EIA-412, "Annual Report of Public Electric Utilities." 
Table 21. Statement of Income by Major U.S. Publicly Owned Electric Utility Within State, 1995 (Continued)

(Thousand Dollars)

\begin{tabular}{|c|c|c|c|c|c|c|}
\hline Item & $\begin{array}{l}\text { Idaho } \\
\text { Idaho } \\
\text { Falls } \\
\text { City of } \\
\text { September } 30\end{array}$ & $\begin{array}{l}\text { llinois } \\
\text { Batavia } \\
\text { City of } \\
\text { December } 31\end{array}$ & $\begin{array}{l}\text { Illinois } \\
\text { Geneva } \\
\text { City of } \\
\text { April } 30\end{array}$ & $\begin{array}{c}\text { Illinois } \\
\text { Illinois } \\
\text { Municipal } \\
\text { Elec Agency } \\
\text { April } 30\end{array}$ & $\begin{array}{c}\text { Illinois } \\
\text { Naperville } \\
\text { City of } \\
\text { April } 30\end{array}$ & $\begin{array}{l}\text { Illinots } \\
\text { Rochelle } \\
\text { Municipal } \\
\text { Uthities } \\
\text { Apnl } 30\end{array}$ \\
\hline Electric Utility Operating Revenues ............ & 35,341 & 14,753 & 11,502 & 67,859 & 50,129 & 13,041 \\
\hline 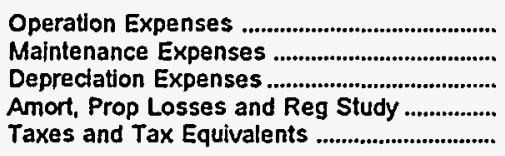 & $\begin{array}{r}20,082 \\
2,465 \\
3,589 \\
485 \\
2,314\end{array}$ & $\begin{array}{r}12,041 \\
154 \\
671 \\
0 \\
641\end{array}$ & $\begin{array}{r}9,759 \\
0 \\
896 \\
0 \\
467\end{array}$ & $\begin{array}{r}56,267 \\
616 \\
3,111 \\
0 \\
0\end{array}$ & $\begin{array}{r}47,596 \\
906 \\
3,821 \\
0 \\
0\end{array}$ & $\begin{array}{r}8,801 \\
865 \\
1,182 \\
0 \\
116\end{array}$ \\
\hline 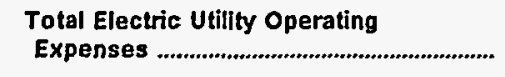 & 28,935 & 13,507 & 11,122 & 59,994 & 52,323 & 10,964 \\
\hline $\begin{array}{l}\text { Net Electric Utility Operating Income } \\
\text { Income from Electric Plant Leased } \\
\text { to Others }\end{array}$ & 6,406 & 1.246 & 380 & 7,865 & $\begin{array}{r}-2,194 \\
0\end{array}$ & $\begin{array}{r}2,076 \\
0\end{array}$ \\
\hline Electric Utility Operating Income ............. & 6,406 & 1,246 & 380 & 7,865 & $-2,194$ & 2,076 \\
\hline 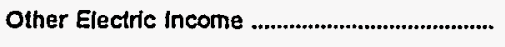 & 2,955 & 757 & 411 & 1,636 & 2,162 & 232 \\
\hline $\begin{array}{l}\text { Other Electric Deductions ................................. } \\
\text { Allowance for Other Funds Used }\end{array}$ & 893 & 0 & 0 & 0 & 0 & 0 \\
\hline Taxes on Other Income and Deductions ......... & 0 & 0 & 0 & 0 & 0 & 0 \\
\hline 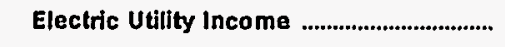 & 8,468 & 2,003 & 791 & 9,501 & -32 & 2,308 \\
\hline 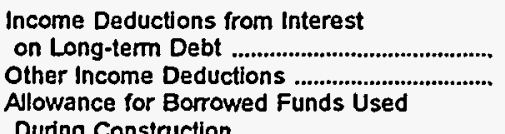 & $\begin{array}{r}6,800 \\
0\end{array}$ & $\begin{array}{l}0 \\
0\end{array}$ & $\begin{array}{r}0 \\
67\end{array}$ & $\begin{array}{r}7.217 \\
627\end{array}$ & $\begin{array}{r}1.041 \\
0\end{array}$ & $\begin{array}{r}554 \\
33\end{array}$ \\
\hline During Construction ............................................... & $\mathbf{0}$ & 0 & 0 & 0 & 0 & 0 \\
\hline Total Income Deductions ............................. & 6,800 & 0 & 67 & 7,844 & 1,041 & 587 \\
\hline Income Before Extraordinary ltems ................. & 1,668 & 2,003 & 723 & $t, 657$ & $-1,074$ & 1,721 \\
\hline 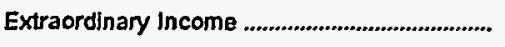 & 0 & 0 & 0 & 290 & 0 & 0 \\
\hline 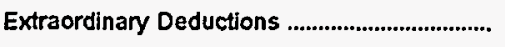 & 0 & 299 & 0 & 0 & 0 & 0 \\
\hline Net Income & 1,668 & 1,703 & 723 & 1,946 & $-1,074$ & 1,721 \\
\hline
\end{tabular}

Note: Tatals may not equal sum of components because of independent rounding.

Source: Energy Information Administration, Form EIA-412, "Annual Report of Public Electric Utilities." 
Table 21. Statement of Income by Major U.S. Publicly Owned Electric Utility Within State, 1995 (Continued)

(Thousand Dollars)

\begin{tabular}{|c|c|c|c|c|c|c|}
\hline Item & $\begin{array}{l}\text { Illinois } \\
\text { Springfield } \\
\text { City of } \\
\text { February } 28\end{array}$ & $\begin{array}{l}\text { Illinois } \\
\text { St Charles } \\
\text { City of } \\
\text { April } 30\end{array}$ & $\begin{array}{l}\text { Indiana } \\
\text { Anderson } \\
\text { City of } \\
\text { December } 31\end{array}$ & $\begin{array}{l}\text { Indiana } \\
\text { Auburn } \\
\text { City of } \\
\text { December } 31\end{array}$ & $\begin{array}{l}\text { Indiana } \\
\text { Bluffton } \\
\text { City of } \\
\text { December } 31\end{array}$ & $\begin{array}{c}\text { Indiana } \\
\text { Crawtordsville } \\
\text { Elec } \\
\text { Lgt\&Pwr co } \\
\text { December } 31\end{array}$ \\
\hline Electric Utility Operating Revenues ............ & 97,092 & 28,370 & 38,890 & 17,966 & 8,633 & 21,324 \\
\hline 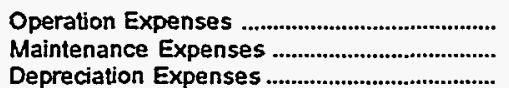 & $\begin{array}{l}50,704 \\
13,263 \\
13,222\end{array}$ & $\begin{array}{r}17,013 \\
5,201 \\
1,010\end{array}$ & $\begin{array}{r}33,352 \\
1,111 \\
1,734\end{array}$ & $\begin{array}{r}16,364 \\
158 \\
424\end{array}$ & $\begin{array}{r}7.957 \\
346 \\
288\end{array}$ & $\begin{array}{r}17,154 \\
1,187 \\
1,113\end{array}$ \\
\hline 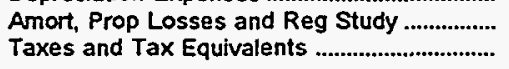 & $\begin{array}{r}87 \\
4,102\end{array}$ & 0 & $\begin{array}{r}0 \\
1,040\end{array}$ & $\begin{array}{r}0 \\
212\end{array}$ & $\begin{array}{r}0 \\
157\end{array}$ & $\begin{array}{r}75 \\
504\end{array}$ \\
\hline $\begin{array}{l}\text { Total Electric Utility Operating } \\
\text { Expenses }\end{array}$ & 81,378 & 23,224 & 37,238 & 17,157 & 8,748 & 20,034 \\
\hline $\begin{array}{l}\text { Net Electric Utility Operating Income .............. } \\
\text { Income from Electric Plant Leased }\end{array}$ & 15,714 & 5,146 & 1,653 & 809 & -115 & 1,290 \\
\hline to Others & 0 & 0 & 0 & 0 & 0 & $\mathbf{0}$ \\
\hline Electric Utility Operating Income .............. & 15,714 & 5,146 & 1,653 & 809 & -115 & 1,290 \\
\hline Other Electric Income & 2,324 & 0 & 123 & 404 & 216 & 343 \\
\hline $\begin{array}{l}\text { Other Electric Deductions .............................. } \\
\text { Allowance for Other Funds Used }\end{array}$ & 0 & $\mathbf{0}$ & 0 & 0 & 28 & 106 \\
\hline 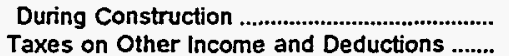 & $\begin{array}{l}0 \\
0\end{array}$ & $\begin{array}{l}0 \\
0\end{array}$ & $\begin{array}{l}0 \\
0\end{array}$ & $\begin{array}{l}\mathbf{0} \\
\mathbf{0}\end{array}$ & $\begin{array}{l}0 \\
0\end{array}$ & $\begin{array}{l}0 \\
0\end{array}$ \\
\hline Electric Utility Income & 18,038 & 5,146 & 1,776 & 1,213 & 73 & 1,528 \\
\hline $\begin{array}{l}\text { Income Deductions from Interest } \\
\text { on Long-tem Debt .......................................... } \\
\text { Other Income Deductions ......................... } \\
\text { Alowance for Borrowed Funds Used }\end{array}$ & $\begin{array}{r}6,132 \\
237\end{array}$ & $\begin{array}{l}0 \\
0\end{array}$ & $\begin{array}{r}38 \\
8\end{array}$ & $\begin{array}{r}37 \\
0\end{array}$ & $\begin{array}{l}0 \\
0\end{array}$ & $\begin{array}{l}419 \\
144\end{array}$ \\
\hline During Construction & 0 & 0 & 0 & 0 & 0 & 0 \\
\hline Total Income Deductions ................................ & 6,369 & 0 & 45 & 37 & $\mathbf{0}$ & 564 \\
\hline Income Before Extraordinary Items .................... & 11,668 & 5,146 & 1,730 & 1,176 & 73 & 964 \\
\hline Extraordinary Income & 1,031 & 0 & 0 & 0 & 0 & 0 \\
\hline 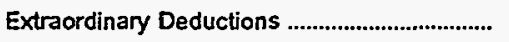 & 0 & 0 & 0 & 0 & 0 & 0 \\
\hline 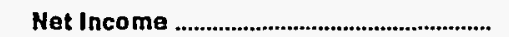 & 12,700 & 5,146 & 1,730 & 1,176 & 73 & 964 \\
\hline
\end{tabular}

Note: Totals may not equal sum of components because of independent rounding.

Source: Energy Information Administration, Form EIA-412, "Annual Report of Public Electric Utilities." 
Table 21. Statement of Income by Major U.S. Publicly Owned Electric Utility Within State, 1995 (Continued)

(Thousand Dollars)

\begin{tabular}{|c|c|c|c|c|c|c|}
\hline Item & $\begin{array}{l}\text { Indiana } \\
\text { Frankfort } \\
\text { City of } \\
\text { December } 31\end{array}$ & $\begin{array}{l}\text { Indiana } \\
\text { Greenfield } \\
\text { City of } \\
\text { December } 31\end{array}$ & $\begin{array}{c}\text { Indiana } \\
\text { Indiana } \\
\text { Municipal } \\
\text { Power Agency } \\
\text { December } 31\end{array}$ & $\begin{array}{l}\text { Indiana } \\
\text { Jasper } \\
\text { City of } \\
\text { December } 31\end{array}$ & $\begin{array}{l}\text { Indiana } \\
\text { Lebanon } \\
\text { City of } \\
\text { December } 31\end{array}$ & $\begin{array}{l}\text { Indiana } \\
\text { Logansport } \\
\text { City of } \\
\text { December } 31\end{array}$ \\
\hline Electric Utility Operating Revenues ............ & 15,638 & 9,321 & 156,933 & 15,205 & 7,956 & 18,043 \\
\hline 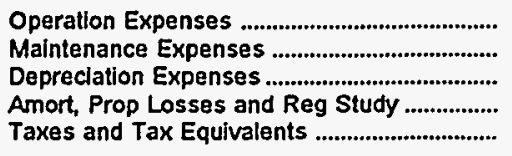 & $\begin{array}{r}13,626 \\
168 \\
587 \\
0 \\
252\end{array}$ & $\begin{array}{r}7,701 \\
678 \\
270 \\
0 \\
0\end{array}$ & $\begin{array}{r}120,587 \\
3,718 \\
9,434 \\
4 \\
1,474\end{array}$ & $\begin{array}{r}13,146 \\
480 \\
562 \\
0 \\
281\end{array}$ & $\begin{array}{r}6,765 \\
311 \\
343 \\
0 \\
162\end{array}$ & $\begin{array}{r}12,845 \\
2,169 \\
1,561 \\
0 \\
384\end{array}$ \\
\hline $\begin{array}{l}\text { Total Electric Utility Operating } \\
\text { Expenses }\end{array}$ & 14,633 & 8,649 & 135,216 & 14,470 & 7,582 & 16,959 \\
\hline 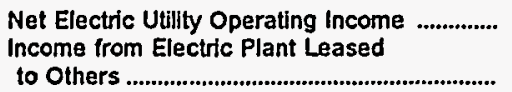 & 1,005 & 672 & 21,717 & 735 & 374 & $\begin{array}{r}1,084 \\
0\end{array}$ \\
\hline Electric Utility Operating Income ............. & 1,005 & 672 & 21,717 & 735 & 374 & 1,084 \\
\hline Other Electric Income & 254 & 106 & 9,508 & 242 & 153 & 684 \\
\hline $\begin{array}{l}\text { Other Electric Deductions ................................ } \\
\text { Allowance for Other Funds Used } \\
\text { During Construction ........................................ } \\
\text { Taxes on Other Income and Deductions ........ }\end{array}$ & $\begin{array}{l}0 \\
0\end{array}$ & $\begin{array}{l}0 \\
0\end{array}$ & $\begin{array}{l}0 \\
0\end{array}$ & $\begin{array}{l}0 \\
0\end{array}$ & $\begin{array}{l}0 \\
0\end{array}$ & $\begin{array}{l}0 \\
0\end{array}$ \\
\hline Electric Utility Income & 1,258 & 777 & 31,219 & 977 & 527 & 1,768 \\
\hline 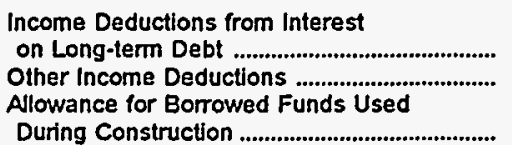 & $\begin{array}{l}0 \\
0\end{array}$ & $\begin{array}{r}118 \\
0\end{array}$ & $\begin{array}{r}23,132 \\
4,392 \\
-179\end{array}$ & $\begin{array}{r}469 \\
31\end{array}$ & $\begin{array}{l}0 \\
0\end{array}$ & $\begin{array}{r}0 \\
844\end{array}$ \\
\hline 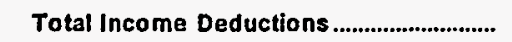 & $\mathbf{0}$ & 118 & 27,345 & 499 & 0 & 844 \\
\hline Income Before Extraordinary Items ................. & 1,258 & 658 & 3,874 & 478 & 527 & 924 \\
\hline Extraordinary Income & 0 & 0 & 3,571 & 0 & 0 & 0 \\
\hline 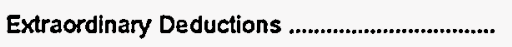 & $\mathbf{0}$ & 0 & 0 & 1,186 & 0 & 0 \\
\hline 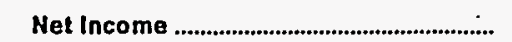 & 1,258 & 659 & 7,445 & -708 & 527 & 924 \\
\hline
\end{tabular}

Note: Totals may not equal sum of components because of independent rounding.

Source: Energy Information Aummistration, Form ElA-412, "Annual Report of Public Electric Utilities." 
Table 21. Statement of Income by Major U.S. Publicly Owned Electric Utility Within State, 1995 (Continued) (Thousand Dollars)

\begin{tabular}{|c|c|c|c|c|c|c|}
\hline Item & $\begin{array}{c}\text { Indiana } \\
\text { Mishawaka } \\
\text { City of } \\
\text { December } 31\end{array}$ & $\begin{array}{c}\text { Indiana } \\
\text { Peru } \\
\text { City of } \\
\text { December } 31\end{array}$ & $\begin{array}{l}\text { Indiana } \\
\text { Richmond } \\
\text { City of } \\
\text { December } 31\end{array}$ & $\begin{array}{c}\text { Indiana } \\
\text { Scottsburg } \\
\text { City of } \\
\text { December } 31\end{array}$ & $\begin{array}{c}\text { Indiana } \\
\text { Washington } \\
\text { City of } \\
\text { December } 31\end{array}$ & $\begin{array}{l}\text { lowa } \\
\text { Ames } \\
\text { City of } \\
\text { June } 30\end{array}$ \\
\hline Electric Utility Operating Revenues .............. & 29,687 & 10,370 & 44,042 & 8,320 & 7,975 & 21,694 \\
\hline 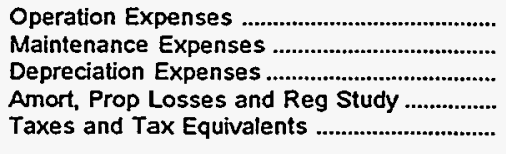 & $\begin{array}{r}24,800 \\
662 \\
1,285 \\
0 \\
488\end{array}$ & $\begin{array}{r}7,730 \\
431 \\
950 \\
0 \\
391\end{array}$ & $\begin{array}{r}32,872 \\
3,048 \\
3,109 \\
0 \\
2,900\end{array}$ & $\begin{array}{r}7.280 \\
0 \\
153 \\
0 \\
92\end{array}$ & $\begin{array}{r}7,351 \\
243 \\
280 \\
0 \\
202\end{array}$ & $\begin{array}{r}14,837 \\
0 \\
3,501 \\
0 \\
811\end{array}$ \\
\hline 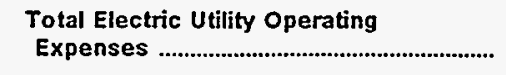 & 27,235 & 9,502 & 41,929 & 7,526 & 8,075 & 19,150 \\
\hline $\begin{array}{l}\text { Net Electric Utility Operating Income } \\
\text { Income from Electric Plant Leased } \\
\text { to Others }\end{array}$ & 2,451 & 868 & 2,113 & 794 & $\begin{array}{r}-100 \\
0\end{array}$ & 2,545 \\
\hline Electric Utility Operating Income .................. & 2,451 & 868 & 2,113 & 794 & -100 & 2,545 \\
\hline Other Electric Income & 354 & 205 & 1,208 & 0 & 30 & 1,105 \\
\hline $\begin{array}{l}\text { Other Electric Deductions ............................... } \\
\text { Allowance for Other Funds Used } \\
\text { During Construction ........................................ } \\
\text { Taxes on Other Income and Deductions ....... }\end{array}$ & $\begin{array}{l}0 \\
0\end{array}$ & $\begin{array}{r}0 \\
220\end{array}$ & $\begin{array}{l}0 \\
0\end{array}$ & $\begin{array}{l}0 \\
0\end{array}$ & $\begin{array}{r}0 \\
55\end{array}$ & $\begin{array}{l}0 \\
0\end{array}$ \\
\hline 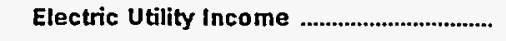 & 2,805 & 853 & 3,238 & 794 & -126 & 3,650 \\
\hline 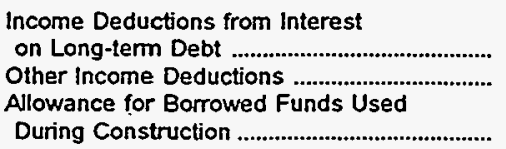 & $\begin{array}{l}17 \\
50\end{array}$ & $\begin{array}{r}107 \\
6\end{array}$ & $\begin{array}{l}0 \\
0\end{array}$ & $\begin{array}{l}0 \\
0\end{array}$ & 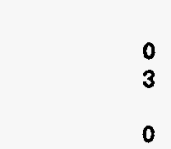 & $\begin{array}{r}1,444 \\
0\end{array}$ \\
\hline 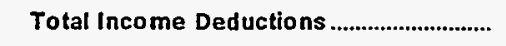 & 66 & 112 & 0 & $\mathbf{0}$ & 3 & 1,444 \\
\hline Income Before Extraordinary Items ....................... & 2,739 & 741 & 3,238 & 794 & -128 & 2,206 \\
\hline Extraordinary Income & 0 & 0 & 0 & 0 & $\mathbf{0}$ & 0 \\
\hline 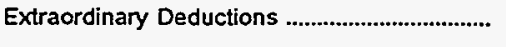 & 0 & 0 & 0 & 0 & 0 & 1 \\
\hline 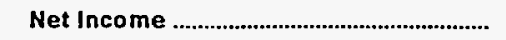 & 2,739 & 741 & 3,238 & 794 & -128 & 2,205 \\
\hline
\end{tabular}

Note: Totals may not equal sum of components because of independent rounding.

Source: Energy Information Administration, Form EIA-412, "Annual Report of Public Electric Utilizes." 
Table 21. Statement of Income by Major U.S. Publicly Owned Electric Utility Within State, 1995 (Continued)

(Thousand Dollars)

\begin{tabular}{|c|c|c|c|c|c|c|}
\hline Item & $\begin{array}{c}\text { lowa } \\
\text { Cedar } \\
\text { Falls } \\
\text { City of } \\
\text { December } 31\end{array}$ & $\begin{array}{l}\text { lowa } \\
\text { Muscatine } \\
\text { City of } \\
\text { December } 31\end{array}$ & $\begin{array}{c}\text { lowa } \\
\text { Pella } \\
\text { City of } \\
\text { December } 31\end{array}$ & $\begin{array}{c}\text { Kansas } \\
\text { Chanute } \\
\text { City of } \\
\text { December } 31\end{array}$ & $\begin{array}{c}\text { Kansas } \\
\text { Coffeyville } \\
\text { City of }\end{array}$ & $\begin{array}{c}\text { Kansas } \\
\text { Garden } \\
\text { City City of } \\
\text { December } 31\end{array}$ \\
\hline Electric Utility Operating Revenues ............ & 14,314 & 46,203 & 9,793 & 9,087 & 11,496 & 12,160 \\
\hline 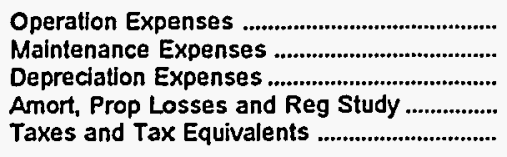 & $\begin{array}{r}8,239 \\
1,591 \\
2,286 \\
73 \\
549\end{array}$ & $\begin{array}{r}27.207 \\
5,548 \\
8,523 \\
0 \\
99\end{array}$ & $\begin{array}{r}10,228 \\
726 \\
0 \\
0 \\
0\end{array}$ & $\begin{array}{r}5.009 \\
851 \\
561 \\
0 \\
700\end{array}$ & $\begin{array}{r}7.701 \\
663 \\
1.511 \\
0 \\
550\end{array}$ & $\begin{array}{r}12,348 \\
0 \\
340 \\
0 \\
0\end{array}$ \\
\hline 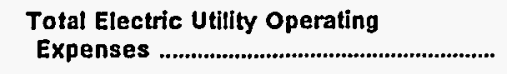 & 12,739 & 41,377 & 10,954 & 7,121 & 10,425 & 12,688 \\
\hline 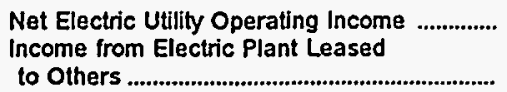 & 1,575 & 4,826 & $\begin{array}{r}-1,161 \\
0\end{array}$ & 1,965 & 1,070 & $\begin{array}{r}-529 \\
0\end{array}$ \\
\hline Electric Utillty Operating Income ............. & 1,575 & 4,826 & $-1,161$ & 1,965 & 1,070 & -529 \\
\hline Other Electric Income & 959 & 11,733 & 746 & 180 & 177 & 55 \\
\hline Other Electric Deductions ................................... & 16 & 0 & 0 & 0 & 386 & 0 \\
\hline 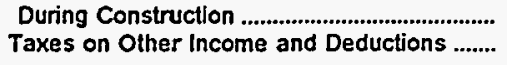 & $\begin{array}{r}41 \\
0\end{array}$ & $\begin{array}{l}0 \\
0\end{array}$ & $\begin{array}{l}0 \\
0\end{array}$ & $\begin{array}{l}0 \\
0\end{array}$ & $\begin{array}{l}0 \\
0\end{array}$ & $\begin{array}{l}0 \\
0\end{array}$ \\
\hline 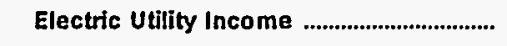 & 2,559 & 16,559 & -415 & 2,145 & 861 & -474 \\
\hline 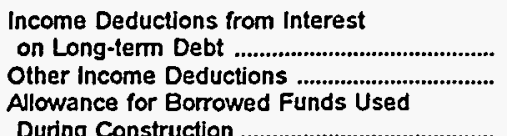 & $\begin{array}{l}0 \\
4\end{array}$ & $\begin{array}{r}12,449 \\
0\end{array}$ & $\begin{array}{r}308 \\
0\end{array}$ & $\begin{array}{r}1,065 \\
0\end{array}$ & $\begin{array}{l}0 \\
0\end{array}$ & $\begin{array}{r}0 \\
497\end{array}$ \\
\hline 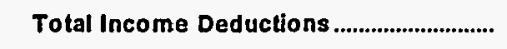 & 4 & 12,449 & 308 & 1,065 & $\mathbf{0}$ & 497 \\
\hline Income Before Extraordinary Items ...................... & 2,556 & 4,110 & -723 & 1,080 & 861 & -971 \\
\hline Extraordinary Income .............................................. & 186 & 0 & 0 & 0 & 41 & $\mathbf{0}$ \\
\hline 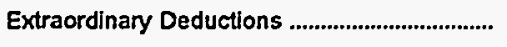 & 0 & 0 & 0 & 0 & 0 & 0 \\
\hline Net Income & 2,742 & 4,110 & -723 & 1,080 & 901 & -971 \\
\hline
\end{tabular}

Note: Totals may not equal sum of components because of independent rounding.

Source: Energy Information Administration, Form ElA-412, "Annual Report of Public Electric Utilities." 
Table 21. Statement of Income by Major U.S. Publicly Owned Electric Utility Within State, 1995 (Continued)

(Thousand Dollars)

\begin{tabular}{|c|c|c|c|c|c|c|}
\hline Item & $\begin{array}{c}\text { Kansas } \\
\text { Kansas } \\
\text { City City of } \\
\text { December } 31\end{array}$ & $\begin{array}{c}\text { Kansas } \\
\text { Kansas } \\
\text { Municipal } \\
\text { Energy } \\
\text { Agency } \\
\text { December } 31\end{array}$ & $\begin{array}{l}\text { Kansas } \\
\text { McPherson } \\
\text { City of } \\
\text { December } 31\end{array}$ & $\begin{array}{l}\text { Kansas } \\
\text { Winfield } \\
\text { City of } \\
\text { December } 31\end{array}$ & $\begin{array}{c}\text { Kentucky } \\
\text { Bardstown } \\
\text { City of } \\
\text { December } 31\end{array}$ & $\begin{array}{l}\text { Kentucky } \\
\text { Bowling } \\
\text { Green } \\
\text { City of } \\
\text { June } 30\end{array}$ \\
\hline Electric Utility Operating Revenues ............ & 123,915 & 8,798 & 20,906 & 12,744 & 6,766 & 39,609 \\
\hline 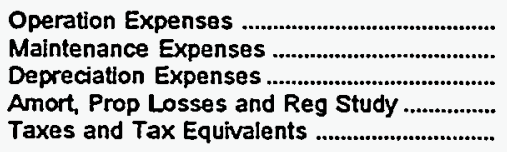 & $\begin{array}{r}79,127 \\
19,455 \\
18,661 \\
966 \\
2,370\end{array}$ & $\begin{array}{r}10,179 \\
1 \\
73 \\
192 \\
32\end{array}$ & $\begin{array}{r}16,336 \\
1,357 \\
1,779 \\
0 \\
810\end{array}$ & $\begin{array}{r}9,779 \\
0 \\
890 \\
0 \\
0\end{array}$ & $\begin{array}{r}5.157 \\
297 \\
123 \\
0 \\
0\end{array}$ & $\begin{array}{r}33,934 \\
1,257 \\
1,492 \\
0 \\
1,591\end{array}$ \\
\hline $\begin{array}{l}\text { Total Electric Utility Operating } \\
\text { Expenses }\end{array}$ & 120,578 & 10,477 & 20,283 & 10,668 & 5,576 & 38,274 \\
\hline 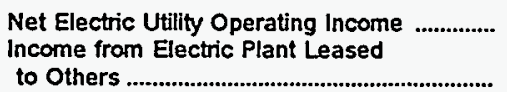 & $\begin{array}{r}3.336 \\
0\end{array}$ & $\begin{array}{r}-1,679 \\
2,119\end{array}$ & $\begin{array}{r}623 \\
0\end{array}$ & $\begin{array}{r}2,075 \\
0\end{array}$ & $\begin{array}{r}1,190 \\
0\end{array}$ & $\begin{array}{r}1,335 \\
0\end{array}$ \\
\hline Electric Utility Operating Income ............. & 3,336 & 440 & 623 & 2,075 & 1,190 & 1,335 \\
\hline 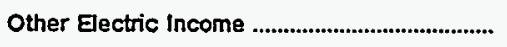 & 2,654 & 392 & 1,823 & 156 & 244 & 844 \\
\hline $\begin{array}{l}\text { Other Electric Deductions ................................. } \\
\text { Allowance for Other Funds Used }\end{array}$ & 0 & 104 & 0 & 0 & 949 & 0 \\
\hline 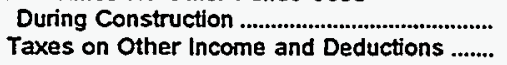 & $\begin{array}{l}0 \\
0\end{array}$ & $\begin{array}{l}0 \\
0\end{array}$ & $\begin{array}{l}0 \\
0\end{array}$ & $\begin{array}{r}0 \\
882\end{array}$ & $\begin{array}{l}0 \\
0\end{array}$ & $\begin{array}{l}0 \\
0\end{array}$ \\
\hline Electric Utility income .................................. & 5,990 & 728 & 2,446 & 1,349 & 485 & 2,179 \\
\hline 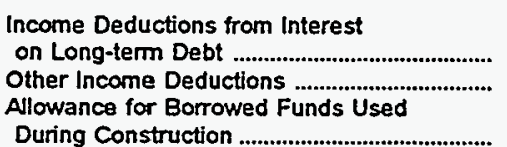 & $\begin{array}{r}12,932 \\
0\end{array}$ & $\begin{array}{r}698 \\
0\end{array}$ & $\begin{array}{r}1,108 \\
0\end{array}$ & $\begin{array}{r}306 \\
0 \\
0\end{array}$ & $\begin{array}{l}0 \\
0 \\
0\end{array}$ & $\begin{array}{r}497 \\
116 \\
0\end{array}$ \\
\hline Total Income Deductions ............................. & 12,932 & 698 & 1,108 & 306 & $\mathbf{0}$ & 612 \\
\hline Income Before Extraordinary ltems ................... & $-6,942$ & 30 & 1,338 & 1,043 & 485 & 1,566 \\
\hline 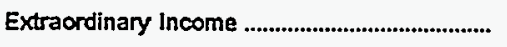 & 0 & 0 & 0 & 0 & 0 & 0 \\
\hline 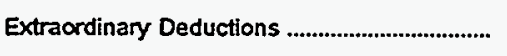 & 0 & 0 & 0 & 0 & 0 & 0 \\
\hline Net Income & $-6,942$ & 30 & 1,338 & 1,043 & 485 & 1,566 \\
\hline
\end{tabular}

Note: Totals may not equal sum of components because of independent rounding.

Source: Energy Information Administration, Form ElA-412, "Annual Report of Public Electric Utilities." 
Table 21. Statement of Income by Major U.S. Publicly Owned Electric Utility Within State, 1995 (Continued)

(Thousand Dollars)

\begin{tabular}{|c|c|c|c|c|c|c|}
\hline Item & $\begin{array}{c}\text { Kentucky } \\
\text { Frankfort } \\
\text { City of } \\
\text { June } 30\end{array}$ & $\begin{array}{l}\text { Kentucky } \\
\text { Franklin } \\
\text { City of } \\
\text { June } 30\end{array}$ & $\begin{array}{l}\text { Kentucky } \\
\text { Glasgow } \\
\text { City of } \\
\text { June } 30\end{array}$ & $\begin{array}{l}\text { Kentucky } \\
\text { Henderson } \\
\text { City } \\
\text { Utility Comm } \\
\text { May } 31\end{array}$ & $\begin{array}{l}\text { Kentucky } \\
\text { Hopkinsville } \\
\text { City of } \\
\text { June } 30\end{array}$ & $\begin{array}{l}\text { Kentucky } \\
\text { Madisonville } \\
\text { Municipal } \\
\text { Utuls } \\
\text { June } 30\end{array}$ \\
\hline Electric Utility Operating Revenues ............ & 24,520 & 9,224 & 16,257 & 25,009 & 20,618 & 12,318 \\
\hline 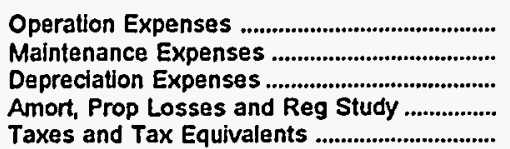 & $\begin{array}{r}21,908 \\
1,092 \\
812 \\
0 \\
80\end{array}$ & $\begin{array}{r}8,365 \\
214 \\
169 \\
0 \\
344\end{array}$ & $\begin{array}{r}14,832 \\
300 \\
614 \\
9 \\
401\end{array}$ & $\begin{array}{r}14,235 \\
5,283 \\
4,598 \\
0 \\
0\end{array}$ & $\begin{array}{r}19,062 \\
657 \\
491 \\
0 \\
738\end{array}$ & $\begin{array}{r}9,055 \\
954 \\
264 \\
0 \\
0\end{array}$ \\
\hline 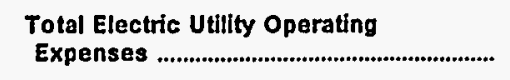 & 23,989 & 9,091 & 16,155 & 24,116 & 20,948 & 10,273 \\
\hline 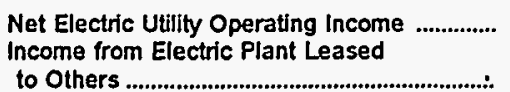 & 531 & 133 & 102 & 893 & -330 & 2,046 \\
\hline Electric Utility Operating Income ............. & 531 & 133 & 102 & 893 & -330 & 2,046 \\
\hline 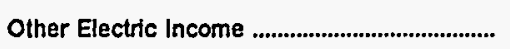 & 8,016 & 128 & 442 & 1,789 & 592 & 35 \\
\hline 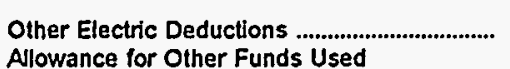 & 6,571 & 0 & 5 & 0 & 0 & 0 \\
\hline $\begin{array}{l}\text { During Construction ... } \\
\text { Taxes on Other Income and Deductions ......... }\end{array}$ & $\begin{array}{r}0 \\
76\end{array}$ & $\begin{array}{l}0 \\
0\end{array}$ & $\begin{array}{l}0 \\
0\end{array}$ & $\begin{array}{l}0 \\
0\end{array}$ & $\begin{array}{l}0 \\
0\end{array}$ & $\begin{array}{l}0 \\
0\end{array}$ \\
\hline 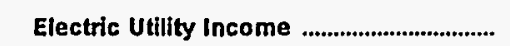 & 1,900 & 261 & 539 & 2,682 & 262 & 2,080 \\
\hline 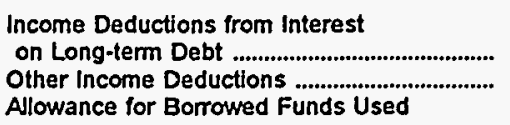 & $\begin{array}{r}240 \\
0\end{array}$ & $\begin{array}{l}0 \\
9\end{array}$ & $\begin{array}{r}287 \\
30\end{array}$ & $\begin{array}{r}770 \\
0\end{array}$ & $\begin{array}{r}122 \\
17\end{array}$ & $\begin{array}{r}0 \\
3,071\end{array}$ \\
\hline 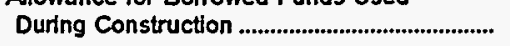 & 0 & 0 & 0 & 0 & 0 & $\mathbf{0}$ \\
\hline 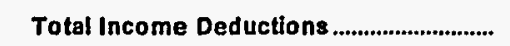 & 240 & 9 & 317 & 770 & 139 & 3,071 \\
\hline 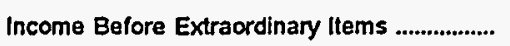 & 1,660 & 252 & 222 & 1.912 & 123 & -890 \\
\hline Extraordinary Income & 0 & 0 & 0 & 0 & 0 & 0 \\
\hline 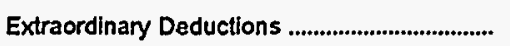 & $\mathbf{0}$ & 0 & 0 & 0 & 0 & $\mathbf{0}$ \\
\hline Net Income & 1,660 & 252 & 222 & 1,912 & 123 & -990 \\
\hline
\end{tabular}

Note: Totals may not equal sum of components because of independent rounding.

Source: Energy Information Administration, Form ELA-4 12, "Annual Report of Public Electric Utilities." 
Table 21. Statement of Income by Major U.S. Publicly Owned Electric Utility Within State, 1995 (Continued)

(Thousand Dollars)

\begin{tabular}{|c|c|c|c|c|c|c|}
\hline Item & $\begin{array}{l}\text { Kentucky } \\
\text { Mayfield } \\
\text { City of } \\
\text { June } 30\end{array}$ & $\begin{array}{l}\text { Kentucky } \\
\text { Murray } \\
\text { City of } \\
\text { June } 30\end{array}$ & $\begin{array}{c}\text { Kentucky } \\
\text { Owensboro } \\
\text { City of } \\
\text { May } 31\end{array}$ & $\begin{array}{l}\text { Kentucky } \\
\text { Paducah } \\
\text { City of } \\
\text { June } 30\end{array}$ & $\begin{array}{l}\text { Louisiana } \\
\text { Alexandria } \\
\text { City of } \\
\text { April } 30\end{array}$ & $\begin{array}{l}\text { Louisiana } \\
\text { Lafayette } \\
\text { City of } \\
\text { October } 31\end{array}$ \\
\hline Electric Utility Operating Revenues ............ & 8,980 & 12,590 & 52,331 & 31,890 & 41,249 & 110,676 \\
\hline 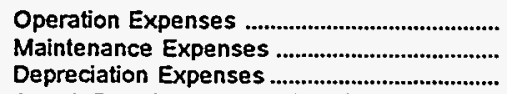 & $\begin{array}{r}7.740 \\
453 \\
160\end{array}$ & $\begin{array}{r}11,557 \\
398 \\
306\end{array}$ & $\begin{array}{r}32,551 \\
5,164 \\
5,057\end{array}$ & $\begin{array}{r}28,050 \\
863 \\
1,550\end{array}$ & $\begin{array}{r}26,699 \\
863 \\
1,804\end{array}$ & $\begin{array}{r}73,373 \\
2,485 \\
5,122\end{array}$ \\
\hline 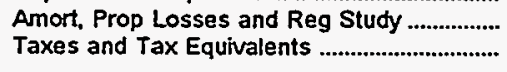 & $\begin{array}{r}0 \\
375\end{array}$ & $\begin{array}{r}0 \\
496\end{array}$ & $\begin{array}{r}0 \\
3,507\end{array}$ & $\begin{array}{r}0 \\
1,431\end{array}$ & 2,130 & $\begin{array}{l}1,591 \\
8,148\end{array}$ \\
\hline $\begin{array}{l}\text { Total Electric Utility Operating } \\
\text { Expenses }\end{array}$ & 8,728 & 12,758 & 46,279 & 31,894 & 31,496 & 90,719 \\
\hline $\begin{array}{l}\text { Net Electric Utility Operating Income } \\
\text { Income from Electric Plant Lea..... }\end{array}$ & 252 & -168 & 6,052 & -4 & 9.753 & 19.957 \\
\hline 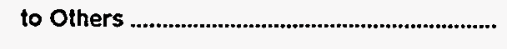 & 0 & 0 & 0 & $\mathbf{0}$ & 0 & 0 \\
\hline Electric Utility Operating Income ............. & 252 & -168 & 6,052 & -4 & 9,753 & 19,957 \\
\hline 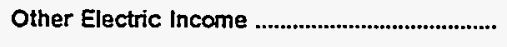 & 71 & 126 & 7.492 & 632 & 2,157 & 3,707 \\
\hline Other Electric Deductions & 0 & 0 & 0 & 95 & 1,792 & 2,370 \\
\hline 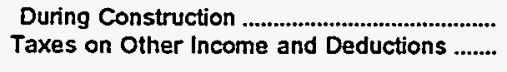 & $\begin{array}{l}0 \\
0\end{array}$ & $\begin{array}{l}0 \\
0\end{array}$ & $\begin{array}{l}0 \\
0\end{array}$ & $\begin{array}{l}0 \\
0\end{array}$ & $\begin{array}{r}0 \\
748\end{array}$ & $\begin{array}{l}0 \\
0\end{array}$ \\
\hline 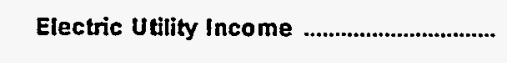 & 323 & -42 & 13,544 & 534 & 9,369 & 29,294 \\
\hline $\begin{array}{l}\text { Income Deductions from Interest } \\
\text { on Long-term Debt ............................................ } \\
\text { Other Income Deductions ............................... } \\
\text { Allowance for Borrowed Funds Used }\end{array}$ & $\begin{array}{l}0 \\
8\end{array}$ & $\begin{array}{r}0 \\
10\end{array}$ & $\begin{array}{r}17,614 \\
0\end{array}$ & $\begin{array}{r}267 \\
28\end{array}$ & $\begin{array}{l}3,098 \\
3,353\end{array}$ & $\begin{array}{r}1,733 \\
0\end{array}$ \\
\hline 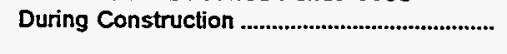 & 0 & 0 & -7.518 & 0 & 0 & 0 \\
\hline 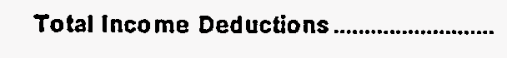 & 8 & 10 & 10,096 & 295 & 6,451 & 1,733 \\
\hline Income Before Extraordinary Items .................. & 315 & -52 & 3.448 & 238 & 2,918 & 19,561 \\
\hline Extraordinary Income & 0 & 0 & 0 & 0 & 2,243 & 0 \\
\hline 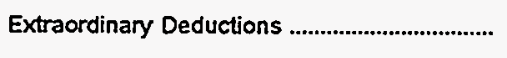 & $\mathbf{0}$ & 0 & 0 & 0 & 0 & 0 \\
\hline 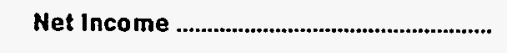 & 315 & -52 & 3,448 & 238 & 5,161 & 19,561 \\
\hline
\end{tabular}

Note: Totals may not equal sum of components because of independent rounding.

Source: Energy Information Administration. Form ElA-412, "Annual Report of Public Electric Utilities." 
Table 21. Statement of Income by Major U.S. Publicly Owned Electric Utility Within State, 1995 (Continued)

(Thousand Dollars)

\begin{tabular}{|c|c|c|c|c|c|c|}
\hline Item & $\begin{array}{l}\text { Louisiana } \\
\text { Latayette } \\
\text { Public } \\
\text { Power Auth } \\
\text { October } 31\end{array}$ & $\begin{array}{l}\text { Louisiana } \\
\text { Louisiana } \\
\text { Energy } \\
\& \\
\text { Power Auth } \\
\text { December } 31\end{array}$ & $\begin{array}{c}\text { Louisiana } \\
\text { Morgan } \\
\text { City City of } \\
\text { December } 31\end{array}$ & $\begin{array}{l}\text { Louisiana } \\
\begin{array}{c}\text { Natchitoches } \\
\text { City of }\end{array} \\
\text { May } 31\end{array}$ & $\begin{array}{l}\text { Louisiana } \\
\text { Ruston } \\
\text { City of } \\
\text { September } 30\end{array}$ & $\begin{array}{c}\text { Louisiana } \\
\text { Terrebonne } \\
\text { Parish } \\
\text { Consol Govt } \\
\text { December } 31\end{array}$ \\
\hline Electric Utility Operating Revenues ............ & 42,013 & 54,006 & 10,790 & 21,857 & 11,522 & 18,075 \\
\hline 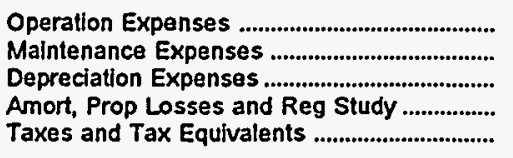 & $\begin{array}{r}25,484 \\
2,253 \\
4,318 \\
0 \\
0\end{array}$ & $\begin{array}{r}42,422 \\
1,306 \\
2,442 \\
1,753 \\
0\end{array}$ & $\begin{array}{r}8,081 \\
295 \\
844 \\
0 \\
0\end{array}$ & $\begin{array}{r}14,854 \\
691 \\
3,205 \\
0 \\
0\end{array}$ & $\begin{array}{r}8,687 \\
1,072 \\
0 \\
0 \\
0\end{array}$ & $\begin{array}{r}11,123 \\
1,319 \\
1,584 \\
0 \\
747\end{array}$ \\
\hline $\begin{array}{c}\text { Total Electric Utility Operating } \\
\text { Expenses }\end{array}$ & 32,054 & 47,923 & 9,221 & 18,750 & 9,759 & 14,773 \\
\hline 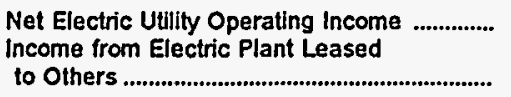 & $\begin{array}{r}9.959 \\
0\end{array}$ & $\begin{array}{r}6,084 \\
0\end{array}$ & $\begin{array}{r}1,569 \\
0\end{array}$ & $\begin{array}{r}3,107 \\
0\end{array}$ & $\begin{array}{r}1,762 \\
0\end{array}$ & $\begin{array}{r}3,302 \\
0\end{array}$ \\
\hline Electric Utility Operating Income ............. & 9,959 & 6,084 & 1,569 & 3,107 & 1,762 & 3,302 \\
\hline 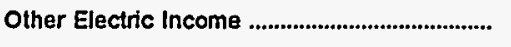 & 1,436 & 1,922 & 35 & 1,811 & 228 & 824 \\
\hline $\begin{array}{l}\text { Other Electric Deductions } \\
\text { Allowance for Other Funds Used } \\
\text { During Construction }\end{array}$ & 0 & 0 & 0 & 0 & 0 & 576 \\
\hline Taxes on Other Income and Deductions ....... & 0 & 0 & 0 & 0 & $\begin{array}{l}0 \\
0\end{array}$ & $\begin{array}{l}0 \\
0\end{array}$ \\
\hline 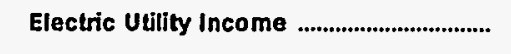 & 11,395 & 8,006 & 1,604 & 4,918 & 1,990 & 3,550 \\
\hline 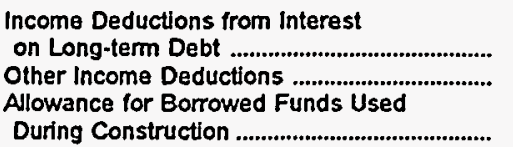 & $\begin{array}{l}9,051 \\
1,276\end{array}$ & $\begin{array}{r}7,927 \\
0\end{array}$ & $\begin{array}{r}325 \\
0\end{array}$ & $\begin{array}{l}0 \\
0\end{array}$ & $\begin{array}{r}158 \\
1,473\end{array}$ & $\begin{array}{l}0 \\
0\end{array}$ \\
\hline 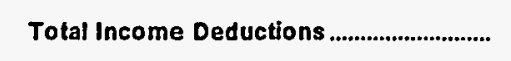 & 10,327 & 7,927 & 325 & 0 & 1,631 & 0 \\
\hline Income Before Extraordinary Items .................. & 1,068 & 79 & 1,280 & 4,918 & 359 & 3,550 \\
\hline 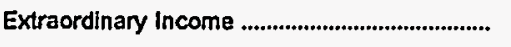 & 0 & 0 & 0 & 0 & 0 & 0 \\
\hline 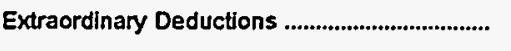 & 0 & 0 & 0 & 0 & 0 & 0 \\
\hline 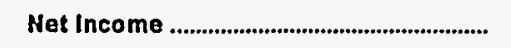 & 1,068 & 79 & 1,280 & 4,918 & 359 & 3,550 \\
\hline
\end{tabular}

Note: Totals may not equal sum of components because of independent rounding.

Source: Energy Information Administration, Form EIA-412, "Annual Report of Public Electric Utilities." 
Table 21. Statement of Income by Major U.S. Publicly Owned Electric Utility Within State, 1995 (Continued)

(Thousand Dollars)

\begin{tabular}{|c|c|c|c|c|c|c|}
\hline Item & $\begin{array}{l}\text { Maryland } \\
\text { Easton } \\
\text { Utilities } \\
\text { Comm } \\
\text { June } 30\end{array}$ & $\begin{array}{l}\text { Maryland } \\
\text { Hagerstown } \\
\text { City of } \\
\text { June } 30\end{array}$ & $\begin{array}{l}\text { Massachusetts } \\
\text { Braintree } \\
\text { Town of } \\
\text { December } 3 t\end{array}$ & $\begin{array}{c}\text { Massachusetts } \\
\text { Chicopee } \\
\text { City of } \\
\text { December } 31\end{array}$ & $\begin{array}{l}\text { Massachusetts } \\
\text { Concord } \\
\text { Town of } \\
\text { December } 31\end{array}$ & $\begin{array}{c}\text { Massachusetts } \\
\text { Danvers } \\
\text { Town of } \\
\text { December } 31\end{array}$ \\
\hline Electric Utility Operating Revenues ............ & 14,029 & 16,949 & 31,373 & 30,452 & 12,726 & 28,871 \\
\hline 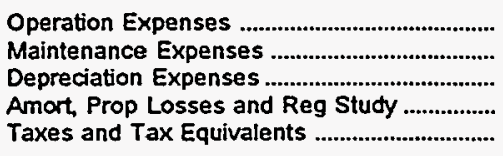 & $\begin{array}{r}9,267 \\
690 \\
1,352 \\
0 \\
450\end{array}$ & $\begin{array}{r}14.121 \\
250 \\
730 \\
464 \\
308\end{array}$ & $\begin{array}{r}24,803 \\
2,697 \\
1,980 \\
0 \\
0\end{array}$ & $\begin{array}{r}23,450 \\
1,883 \\
2,423 \\
0 \\
849\end{array}$ & $\begin{array}{r}9,802 \\
219 \\
850 \\
0 \\
0\end{array}$ & $\begin{array}{r}27,546 \\
514 \\
704 \\
0 \\
0\end{array}$ \\
\hline $\begin{array}{l}\text { Total Electric Utility Operating } \\
\text { Expenses }\end{array}$ & 11,759 & 15,872 & 29,481 & 28,604 & 10,872 & 28,763 \\
\hline 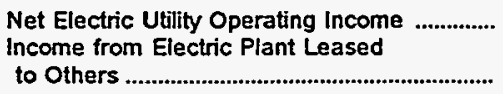 & 2,271 & 1,076 & $\begin{array}{r}1,892 \\
0\end{array}$ & $\begin{array}{r}1,848 \\
0\end{array}$ & $\begin{array}{r}1,855 \\
0\end{array}$ & $\begin{array}{r}108 \\
0\end{array}$ \\
\hline Electric Utility Operating Income .............. & 2,271 & 1,076 & 1,892 & 1,848 & 1,855 & 108 \\
\hline 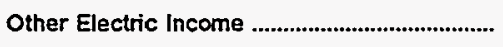 & 181 & 235 & 386 & 583 & 644 & 977 \\
\hline $\begin{array}{l}\text { Other Electric Deductions ................................ } \\
\text { Allowance for Other Funds Used } \\
\text { During Construction ...................................... } \\
\text { Taxes on Other Income and Deductions ........ }\end{array}$ & $\begin{array}{l}0 \\
0\end{array}$ & $\begin{array}{l}0 \\
0\end{array}$ & $\begin{array}{l}0 \\
0\end{array}$ & $\begin{array}{l}0 \\
0\end{array}$ & $\begin{array}{l}0 \\
0\end{array}$ & $\begin{array}{r}0 \\
0 \\
596\end{array}$ \\
\hline 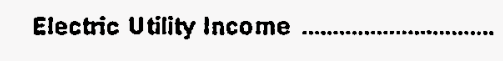 & 2,452 & 1,311 & 2,278 & 2,385 & 2,499 & 489 \\
\hline 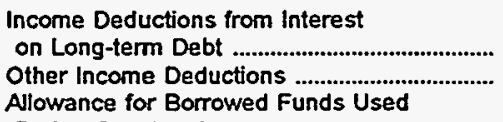 & $\begin{array}{l}583 \\
105\end{array}$ & $\begin{array}{r}59 \\
0\end{array}$ & $\begin{array}{r}0 \\
13\end{array}$ & $\begin{array}{l}455 \\
344\end{array}$ & $\begin{array}{r}439 \\
11\end{array}$ & $\begin{array}{l}\mathbf{0} \\
\mathbf{0}\end{array}$ \\
\hline 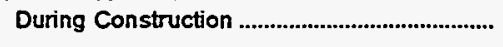 & 0 & 0 & 0 & 0 & 0 & 0 \\
\hline 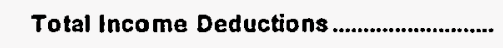 & 688 & 59 & 13 & 799 & 450 & 0 \\
\hline Income Before Extraordinary Items .................... & 1,764 & 1,252 & 2,265 & 1,586 & 2,049 & 489 \\
\hline 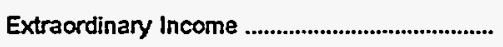 & 0 & 0 & 0 & 0 & 0 & 0 \\
\hline 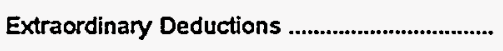 & 0 & 0 & 0 & 0 & 0 & 0 \\
\hline Net Income & 1,764 & 1,252 & 2,265 & 1,586 & 2,049 & 489 \\
\hline
\end{tabular}

Note: Totals may not equal sum of components because of independent rounding.

Source: Energy Information Administration, Form ELA-412, "Annual Report of Public Electric Utilities." 
Table 21. Statement of Income by Major U.S. Publicly Owned Electric Utility Within State, 1995 (Continued)

(Thousand Dollars)

\begin{tabular}{|c|c|c|c|c|c|c|}
\hline Item & $\begin{array}{l}\text { Massachusetts } \\
\text { Hingham } \\
\text { Clty of } \\
\text { December } 31\end{array}$ & $\begin{array}{c}\text { Massachusetts } \\
\text { Holyoke } \\
\text { City of } \\
\text { December } 31\end{array}$ & $\begin{array}{l}\text { Massachusetts } \\
\text { Hudson } \\
\text { Town of } \\
\text { December } 31\end{array}$ & $\begin{array}{l}\text { Massachusetts } \\
\text { Littleton } \\
\text { Town of } \\
\text { December } 31\end{array}$ & $\begin{array}{l}\text { Massachusetts } \\
\text { Mansfield } \\
\text { Town of } \\
\text { December } 31\end{array}$ & $\begin{array}{l}\text { Massachusetts } \\
\text { Massachusetts } \\
\text { Mun } \\
\text { Whis } \\
\text { Elec Co } \\
\text { December } 31\end{array}$ \\
\hline Electric Utility Operating Revenues ............ & 13,471 & 26,389 & 27,299 & 14,615 & 18,764 & 212,172 \\
\hline 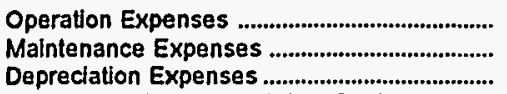 & $\begin{array}{r}11,349 \\
455 \\
654\end{array}$ & $\begin{array}{r}22,031 \\
1,362 \\
1,452\end{array}$ & $\begin{array}{r}26,186 \\
620 \\
569\end{array}$ & $\begin{array}{r}12,774 \\
400 \\
421\end{array}$ & $\begin{array}{r}15,554 \\
366 \\
250\end{array}$ & $\begin{array}{r}90,969 \\
9,458 \\
45,755\end{array}$ \\
\hline $\begin{array}{l}\text { Amort, Prop Losses and Reg Study .................. } \\
\text { Taxes and Tax Equivalents ................................ }\end{array}$ & $\begin{array}{l}\mathbf{0} \\
\mathbf{0}\end{array}$ & $\begin{array}{l}0 \\
0\end{array}$ & $\begin{array}{r}0 \\
234\end{array}$ & $\begin{array}{r}0 \\
11\end{array}$ & $\begin{array}{r}0 \\
165\end{array}$ & $\begin{array}{r}0 \\
7.447\end{array}$ \\
\hline $\begin{array}{c}\text { Total Electric Utility Operating } \\
\text { Expenses }\end{array}$ & 12,458 & 24,845 & 27,609 & 13,606 & 16,336 & 153,629 \\
\hline $\begin{array}{l}\text { Net Electric Utility Operating Income } \\
\text { Income from Electric Plant Lea...... }\end{array}$ & 1,013 & 1,544 & -310 & 1,009 & 2,428 & 58,543 \\
\hline to Others & 0 & 0 & $\mathbf{0}$ & $\mathbf{0}$ & 0 & 0 \\
\hline Electric Utility Operating Income ............. & 1,013 & 1,544 & -310 & 1,009 & 2,428 & 58,543 \\
\hline Other Electric Income & 201 & 303 & 739 & 606 & 162 & 13,780 \\
\hline $\begin{array}{l}\text { Other Electric Deductions } \\
\text { Allowance for Other Funds Used }\end{array}$ & 0 & 0 & 363 & 0 & 0 & 0 \\
\hline 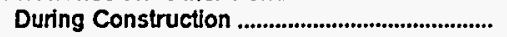 & 0 & 0 & 0 & 0 & 0 & 104 \\
\hline Taxes on Other Income and Deductions ........ & 0 & 0 & 0 & 0 & 0 & 0 \\
\hline 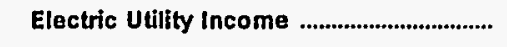 & 1,213 & 1,847 & 66 & 1,615 & 2,590 & 72,428 \\
\hline $\begin{array}{l}\text { Income Deductions from Interest } \\
\text { on Long-term Debt .............................................. } \\
\text { Other Income Deductions .............................. } \\
\text { Allowance for Borrowed Funds Used }\end{array}$ & $\begin{array}{r}231 \\
24\end{array}$ & $\begin{array}{r}251 \\
82\end{array}$ & $\begin{array}{l}0 \\
1\end{array}$ & $\begin{array}{l}2 \\
0\end{array}$ & $\begin{array}{r}0 \\
14\end{array}$ & $\begin{array}{r}73,637 \\
3,135\end{array}$ \\
\hline 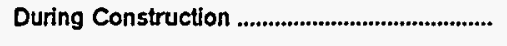 & 0 & 0 & 0 & 3 & 0 & 0 \\
\hline 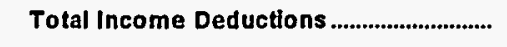 & 255 & 333 & 1 & 5 & 14 & 76,772 \\
\hline Income Before Extraordinary Items .................. & 959 & 1,514 & 65 & 1,610 & 2,576 & $-4,344$ \\
\hline 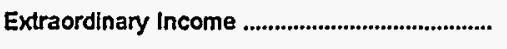 & 0 & 0 & 0 & 0 & 0 & 4,344 \\
\hline 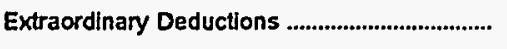 & 0 & 0 & 0 & 0 & 0 & 0 \\
\hline 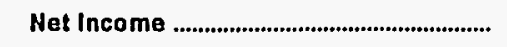 & 959 & 1,514 & 65 & 4,610 & 2,576 & 0 \\
\hline
\end{tabular}

Note: Totals may not equal sum of components because of independent rounding.

Source: Energy Information Administration, Form EIA-412, "Annual Report of Public Electric Utilities." 
Table 21. Statement of Income by Major U.S. Publicly Owned Electric Utility Within State, 1995 (Continued) (Thousand Dollars)

\begin{tabular}{|c|c|c|c|c|c|c|}
\hline Item & $\begin{array}{l}\text { Massachusetts } \\
\text { Middleborough } \\
\text { Town of } \\
\text { December } 31\end{array}$ & $\begin{array}{c}\text { Massachusetts } \\
\text { North } \\
\text { Attleborough } \\
\text { Town of } \\
\text { December } 31\end{array}$ & $\begin{array}{l}\text { Massachusetts } \\
\text { Nonwood } \\
\text { City of } \\
\text { June } 30\end{array}$ & $\begin{array}{l}\text { Massachusetts } \\
\text { Peabody } \\
\text { City of } \\
\text { December } 31\end{array}$ & $\begin{array}{l}\text { Massachusetts } \\
\text { Reading } \\
\text { Town of } \\
\text { December } 31\end{array}$ & $\begin{array}{c}\text { Massachusetts } \\
\text { Shrewsbury } \\
\text { Town of } \\
\text { December } 31\end{array}$ \\
\hline Electric Utility Operating Revenues ............ & 17,325 & 18,410 & 27,748 & 36,927 & 51,612 & 20,423 \\
\hline 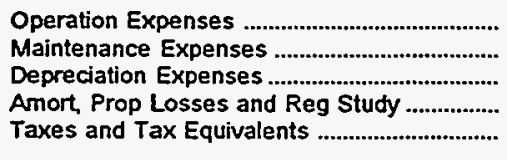 & $\begin{array}{r}15,539 \\
804 \\
767 \\
0 \\
270\end{array}$ & $\begin{array}{r}15,056 \\
619 \\
989 \\
0 \\
39\end{array}$ & $\begin{array}{r}24,092 \\
698 \\
1,081 \\
0 \\
0\end{array}$ & $\begin{array}{r}31,491 \\
601 \\
1,756 \\
10 \\
0\end{array}$ & $\begin{array}{r}44,589 \\
994 \\
2,032 \\
0 \\
568\end{array}$ & $\begin{array}{r}18,031 \\
682 \\
724 \\
0 \\
0\end{array}$ \\
\hline $\begin{array}{l}\text { Total Electric Utility Operating } \\
\text { Expenses }\end{array}$ & 17,380 & 16,704 & 25,871 & 33,859 & 48,182 & 19,436 \\
\hline $\begin{array}{l}\text { Net Electric Utility Operating Income } \\
\text { Income from Electric Plant Leased } \\
\text { to Others }\end{array}$ & $\begin{array}{r}-54 \\
0\end{array}$ & $\begin{array}{r}1,706 \\
0\end{array}$ & $\begin{array}{r}1,877 \\
0\end{array}$ & $\begin{array}{r}3,068 \\
0\end{array}$ & $\begin{array}{r}3,430 \\
0\end{array}$ & $\begin{array}{r}987 \\
0\end{array}$ \\
\hline Electric Utility Operating Income ............. & -54 & 1,706 & 1,877 & 3,068 & 3,430 & 987 \\
\hline Other Electric Income & $\$ 71$ & 651 & 16 & 630 & 840 & 155 \\
\hline $\begin{array}{l}\text { Other Electric Deductions ............................... } \\
\text { Allowance for Other Funds Used }\end{array}$ & 0 & 0 & 0 & 0 & 0 & 0 \\
\hline 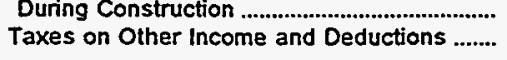 & $\begin{array}{l}0 \\
0\end{array}$ & $\begin{array}{l}0 \\
0\end{array}$ & $\begin{array}{l}0 \\
0\end{array}$ & $\begin{array}{l}0 \\
0\end{array}$ & $\begin{array}{l}0 \\
0\end{array}$ & $\begin{array}{l}0 \\
\mathbf{0}\end{array}$ \\
\hline 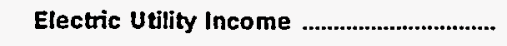 & 117 & 2,357 & 1,892 & 3,698 & 4,271 & 1,142 \\
\hline 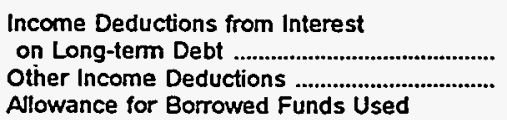 & $\begin{array}{r}0 \\
61\end{array}$ & $\begin{array}{r}178 \\
17\end{array}$ & $\begin{array}{r}0 \\
88\end{array}$ & $\begin{array}{r}1,155 \\
19\end{array}$ & $\begin{array}{r}290 \\
42\end{array}$ & $\begin{array}{r}7 \\
19\end{array}$ \\
\hline During Construction & 0 & 0 & 0 & 0 & 0 & 0 \\
\hline 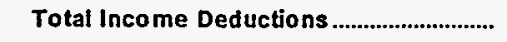 & 61 & 195 & 88 & 1,174 & 331 & 26 \\
\hline Income Before Extraordinary Items .................. & 56 & 2,163 & 1,804 & 2.524 & 3,939 & 1,115 \\
\hline 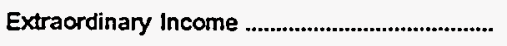 & 0 & 0 & 0 & 0 & 0 & 0 \\
\hline 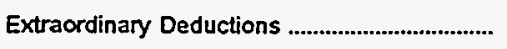 & 0 & 0 & 0 & 0 & 0 & 0 \\
\hline Net Income & 56 & 2,163 & 1,804 & 2,524 & 3,939 & 1,115 \\
\hline
\end{tabular}

Note: Totals may not equal sum of components because of independent rounding.

Sourse: Energy Information Adrinistration, Form EIA-412, "Annual Report of Public Electric Utilities." 
Table 21. Statement of Income by Major U.S. Publicly Owned Electric Utility Within State, 1995 (Continued)

(Thousand Dollars)

\begin{tabular}{|c|c|c|c|c|c|c|}
\hline Item & $\begin{array}{l}\text { Massachusetts } \\
\text { Taunton } \\
\text { City of } \\
\text { December } 31\end{array}$ & $\begin{array}{l}\text { Massachusetts } \\
\text { Wakefield } \\
\text { Town of } \\
\text { December } 31\end{array}$ & $\begin{array}{l}\text { Massachusetts } \\
\text { Wellesley } \\
\text { Town of } \\
\text { December } 31\end{array}$ & $\begin{array}{l}\text { Massachusetts } \\
\text { Westfield } \\
\text { City of } \\
\text { December } 31\end{array}$ & $\begin{array}{l}\text { Michigan } \\
\text { Bay } \\
\text { City City of } \\
\text { June } 30\end{array}$ & $\begin{array}{l}\text { Michigan } \\
\text { Coldwater } \\
\text { Board } \\
\text { of } \\
\text { Public Util } \\
\text { June } 30\end{array}$ \\
\hline Electric Utility Operating Revenues ............. & 42,770 & 15,554 & 16,246 & 30,129 & 16,516 & 11,655 \\
\hline 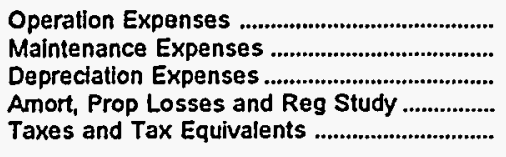 & $\begin{array}{r}28,475 \\
4,259 \\
4,027 \\
0 \\
0\end{array}$ & $\begin{array}{r}14,041 \\
447 \\
703 \\
0 \\
581\end{array}$ & $\begin{array}{r}12,419 \\
911 \\
780 \\
0 \\
0\end{array}$ & $\begin{array}{r}25,840 \\
1,147 \\
2,072 \\
0 \\
250\end{array}$ & $\begin{array}{r}13,117 \\
792 \\
0 \\
0 \\
359\end{array}$ & $\begin{array}{r}9,818 \\
221 \\
420 \\
0 \\
677\end{array}$ \\
\hline 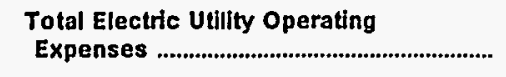 & 36,761 & 15,772 & 14,110 & 29,309 & 14,268 & 11,136 \\
\hline 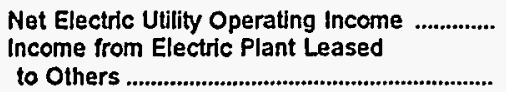 & 6,009 & $\begin{array}{r}-218 \\
0\end{array}$ & 2,136 & 821 & 2,249 & 520 \\
\hline Electric Utility Operating Income ................ & 6,009 & -218 & 2,136 & 821 & 2,249 & 520 \\
\hline Other Electric Income & 430 & 96 & 64 & 380 & 0 & 325 \\
\hline $\begin{array}{l}\text { Other Electric Deductions ................................ } \\
\text { Allowance for Other Funds Used }\end{array}$ & 0 & 0 & 0 & 0 & 0 & o \\
\hline $\begin{array}{l}\text { During Construction ............................. } \\
\text { Taxes on Other Income and Deductions ....... }\end{array}$ & $\begin{array}{r}0 \\
2,360\end{array}$ & $\begin{array}{l}0 \\
0\end{array}$ & $\begin{array}{l}0 \\
0\end{array}$ & $\begin{array}{l}0 \\
0\end{array}$ & $\begin{array}{l}0 \\
0\end{array}$ & $\begin{array}{l}0 \\
0\end{array}$ \\
\hline Electric Utility Income & 4,078 & -122 & 2,199 & 1,200 & 2,249 & 845 \\
\hline 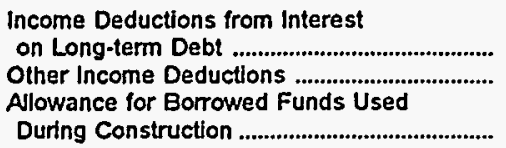 & $\begin{array}{r}1,239 \\
18\end{array}$ & $\begin{array}{r}0 \\
19\end{array}$ & $\begin{array}{l}26 \\
32\end{array}$ & $\begin{array}{r}280 \\
53\end{array}$ & $\begin{array}{l}0 \\
0\end{array}$ & $\begin{array}{r}43 \\
0\end{array}$ \\
\hline 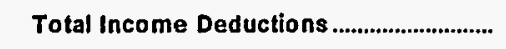 & 1,256 & 19 & 58 & 333 & 0 & 43 \\
\hline Income Before Extraordinary Items ................... & 2,822 & -141 & 2,141 & 868 & 2,249 & 802 \\
\hline Extraordinary Income & $\mathbf{0}$ & 0 & 0 & 0 & 0 & $\mathbf{0}$ \\
\hline 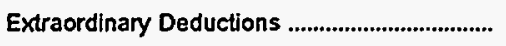 & 0 & 0 & 0 & 0 & 0 & 0 \\
\hline 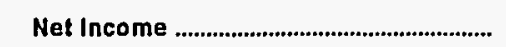 & 2,822 & -141 & 2,141 & 868 & 2,249 & 802 \\
\hline
\end{tabular}

Note: Totals may not equal sum of components because of independent rounding.

Source: Energy Information Administration, Form ElA.412, "Annual Report of Public Electric Utijities." 
Table 21. Statement of Income by Major U.S. Publicly Owned Electric Utility Within State, 1995 (Continued)

(Thousand Dollars)

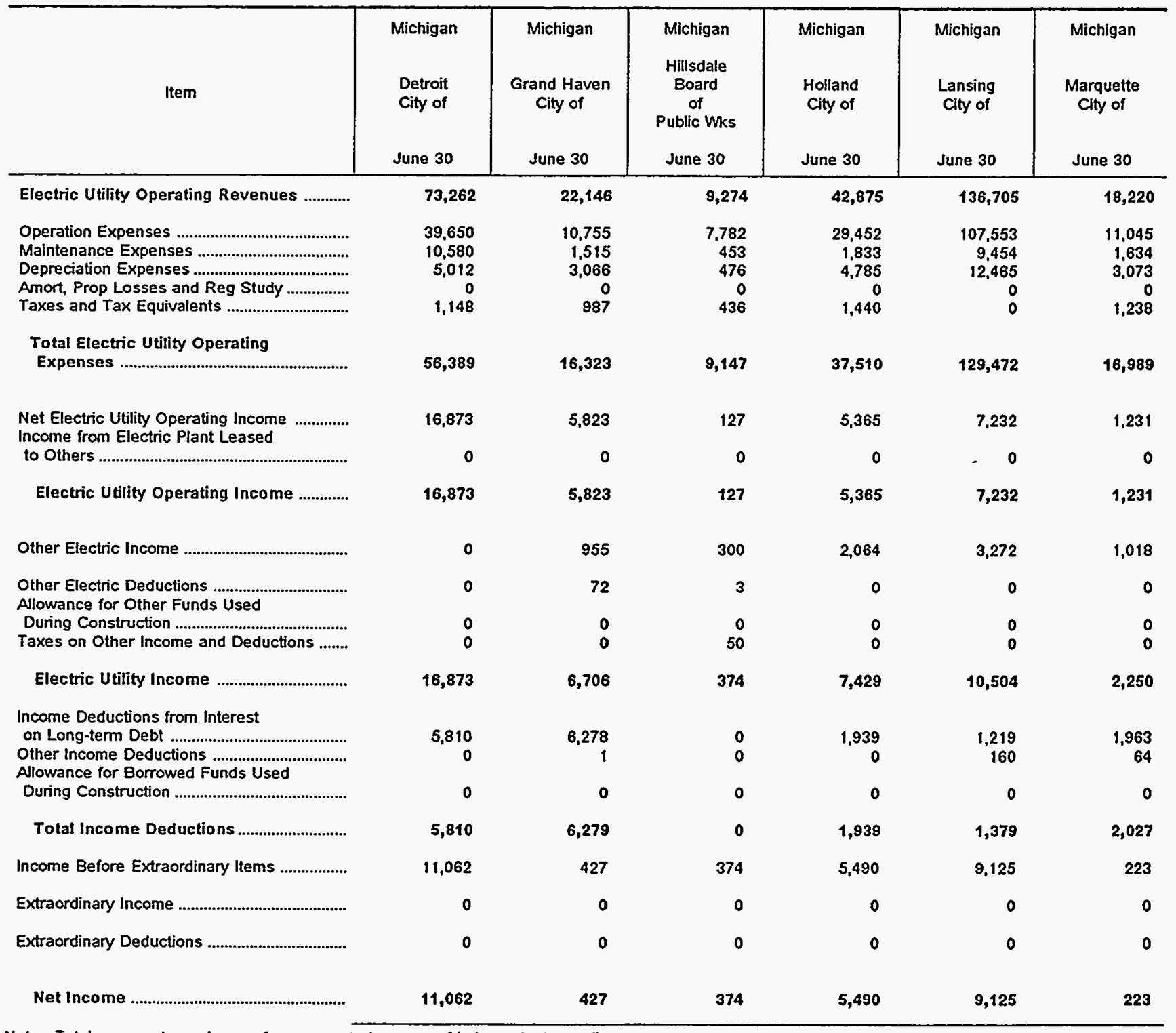

Note: Totals may not equal sum of components because of independent rounding.

Source: Energy information Administration, Form ElA-4 12, "Annual Report of Public Electric Utilities." 
Table 21. Statement of Income by Major U.S. Publicly Owned Electric Utility Within State, 1995 (Continued)

(Thousand Dollars)

\begin{tabular}{|c|c|c|c|c|c|c|}
\hline Item & $\begin{array}{l}\text { Michigan } \\
\text { Michigan } \\
\text { Public } \\
\text { Power Agency } \\
\\
\text { December } 31\end{array}$ & $\begin{array}{l}\text { Michigan } \\
\text { Michigan } \\
\text { South } \\
\text { Central } \\
\text { Pur Agy } \\
\text { June } 30\end{array}$ & $\begin{array}{c}\text { Michigan } \\
\text { Sturgis } \\
\text { City of } \\
\text { September } 30\end{array}$ & $\begin{array}{l}\text { Michigan } \\
\text { Traverse } \\
\text { City City of } \\
\text { June } 30\end{array}$ & $\begin{array}{l}\text { Michigan } \\
\text { Wyandotte } \\
\text { Municipal } \\
\text { Serv Comm } \\
\text { September } 30\end{array}$ & $\begin{array}{l}\text { Michigan } \\
\text { Zeeland } \\
\text { City of } \\
\text { June } 30\end{array}$ \\
\hline Electric Utility Operating Revenues ............ & 101,163 & 24,835 & 13,950 & 14,221 & 20,069 & 9,426 \\
\hline 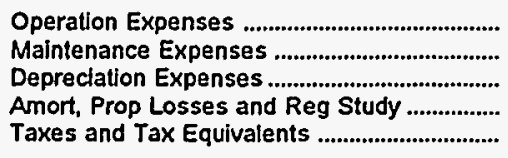 & $\begin{array}{r}61,805 \\
3,137 \\
18,399 \\
1,355 \\
746\end{array}$ & $\begin{array}{r}15,128 \\
1,001 \\
2,963 \\
0 \\
40\end{array}$ & $\begin{array}{r}10,035 \\
265 \\
1,180 \\
0 \\
914\end{array}$ & $\begin{array}{r}9,609 \\
1.540 \\
866 \\
34 \\
755\end{array}$ & $\begin{array}{r}14,388 \\
967 \\
3,228 \\
0 \\
487\end{array}$ & $\begin{array}{r}6,936 \\
356 \\
608 \\
0 \\
0\end{array}$ \\
\hline $\begin{array}{c}\text { Total Electric Utillty Operating } \\
\text { Expenses }\end{array}$ & 85,442 & 19,132 & 12,393 & 12,803 & 19,069 & 7,900 \\
\hline 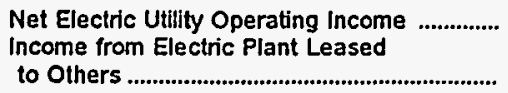 & 15,721 & 5,703 & $\begin{array}{r}1,557 \\
0\end{array}$ & $\begin{array}{r}1.418 \\
0\end{array}$ & 1,000 & 1,526 \\
\hline Electric Utility Operating Income .............. & 15,721 & 5,703 & 1,557 & 1,418 & 1,000 & 1,526 \\
\hline Other Electric Income .............................................. & 6,742 & 1.745 & 796 & 491 & 791 & 311 \\
\hline $\begin{array}{l}\text { Other Electric Deductions ................................ } \\
\text { Allowance for Other Funds Used }\end{array}$ & 0 & 0 & 0 & 0 & 0 & 0 \\
\hline $\begin{array}{l}\text { During Construction ....................................... } \\
\text { Taxes on Other Income and Deductions ....... }\end{array}$ & $\begin{array}{l}0 \\
0\end{array}$ & $\begin{array}{l}0 \\
0\end{array}$ & $\begin{array}{l}0 \\
0\end{array}$ & $\begin{array}{l}\mathbf{0} \\
\mathbf{0}\end{array}$ & $\begin{array}{r}643 \\
0\end{array}$ & $\begin{array}{l}0 \\
0\end{array}$ \\
\hline 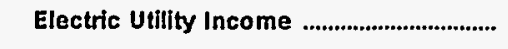 & 22,463 & 7,448 & 2,353 & 1,909 & 2,434 & 1,837 \\
\hline 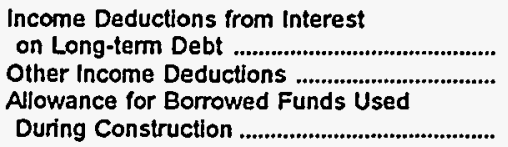 & $\begin{array}{r}23,661 \\
-1,199 \\
0\end{array}$ & $\begin{array}{r}5,728 \\
543\end{array}$ & $\begin{array}{r}185 \\
0\end{array}$ & $\begin{array}{l}0 \\
4\end{array}$ & $\begin{array}{r}3.699 \\
102\end{array}$ & $\begin{array}{l}153 \\
161\end{array}$ \\
\hline 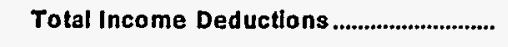 & 22,462 & 6,272 & 185 & 4 & 3,801 & 314 \\
\hline Income Before Extraordinary Items .................... & 1 & 1,177 & 2,168 & 1.905 & $-1,367$ & 1.524 \\
\hline Extraordinary Income & 0 & 0 & 0 & 0 & 0 & 0 \\
\hline 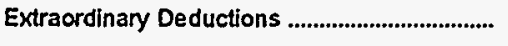 & 0 & 0 & 1,083 & 0 & 0 & 0 \\
\hline Net Income & 1 & 1,177 & 1,085 & 1,905 & $-1,367$ & 1,524 \\
\hline
\end{tabular}

Note: Totals may not equal sum of components because of independent rounding.

Source: Energy Information Administration, Form ElA-412, "Annua! Report of Public Electric Utilities." 
Table 21. Statement of Income by Major U.S. Publicly Owned Electric Utility Within State, 1995 (Continued)

(Thousand Dollars)

\begin{tabular}{|c|c|c|c|c|c|c|}
\hline Item & $\begin{array}{l}\text { Minnesota } \\
\text { Alexandria } \\
\text { City of } \\
\text { December } 31\end{array}$ & 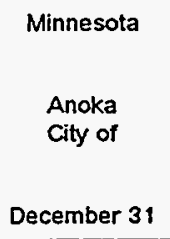 & $\begin{array}{l}\text { Minnesota } \\
\text { Austin } \\
\text { City of } \\
\text { December } 31\end{array}$ & $\begin{array}{c}\text { Minnesota } \\
\text { Brainerd } \\
\text { Public } \\
\text { Utilities } \\
\text { December } 31\end{array}$ & $\begin{array}{l}\text { Minnesota } \\
\text { Chaska } \\
\text { City of } \\
\text { December } 31\end{array}$ & $\begin{array}{l}\text { Minnesota } \\
\text { Fairmont } \\
\text { Public } \\
\text { Utilities } \\
\text { Comm } \\
\text { December } 31\end{array}$ \\
\hline Electric Utility Operating Revenues ............. & 9,152 & 13,147 & 17,447 & 7,456 & 9,879 & 8,992 \\
\hline 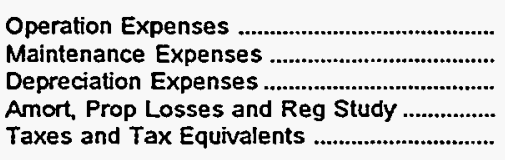 & $\begin{array}{r}7.596 \\
357 \\
475 \\
0 \\
458\end{array}$ & $\begin{array}{r}10.248 \\
172 \\
518 \\
0 \\
965\end{array}$ & $\begin{array}{r}19,160 \\
1,109 \\
712 \\
0 \\
3\end{array}$ & $\begin{array}{r}6.755 \\
85 \\
420 \\
0 \\
0\end{array}$ & $\begin{array}{r}7.702 \\
0 \\
381 \\
0 \\
0\end{array}$ & $\begin{array}{r}9,932 \\
905 \\
504 \\
0 \\
0\end{array}$ \\
\hline $\begin{array}{l}\text { Total Electric Utility Operating } \\
\text { Expenses }\end{array}$ & 8,886 & 11,903 & 20,984 & 7,261 & 8,063 & 11,341 \\
\hline $\begin{array}{l}\text { Net Electric Utility Operating Income } \\
\text { Income from Electric Plant Leased } \\
\text { to Others }\end{array}$ & 265 & 1,243 & $-3,537$ & 196 & 1.816 & $-2,349$ \\
\hline Electric Utility Operating Income .............. & 265 & 1,243 & 976 & 196 & 1,816 & $-2,349$ \\
\hline Other Electric Income & 371 & 111 & 453 & 288 & 309 & 2,218 \\
\hline $\begin{array}{l}\text { Other Electric Deductions } \\
\text { Allowance for Other Funds Used }\end{array}$ & 0 & 0 & 4 & 0 & 0 & $\mathbf{0}$ \\
\hline 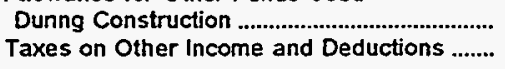 & $\begin{array}{l}0 \\
0\end{array}$ & $\begin{array}{l}0 \\
0\end{array}$ & $\begin{array}{r}0 \\
976\end{array}$ & $\begin{array}{l}0 \\
0\end{array}$ & $\begin{array}{r}0 \\
1,166\end{array}$ & $\begin{array}{l}\mathbf{0} \\
\mathbf{0}\end{array}$ \\
\hline Electric Utility Income & 636 & 1,355 & 448 & 484 & 959 & -131 \\
\hline 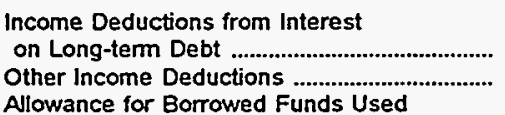 & $\begin{array}{l}0 \\
4\end{array}$ & $\begin{array}{l}0 \\
0\end{array}$ & $\begin{array}{l}0 \\
0\end{array}$ & $\begin{array}{l}0 \\
0\end{array}$ & $\begin{array}{r}95 \\
0\end{array}$ & $\begin{array}{l}158 \\
141\end{array}$ \\
\hline 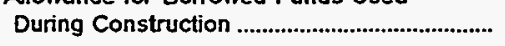 & 0 & 0 & 0 & 0 & 0 & 0 \\
\hline 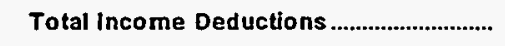 & 4 & 0 & 0 & 0 & 95 & 298 \\
\hline Income Before Extraordinary Items ...................... & 632 & 1,355 & 448 & 484 & 863 & -430 \\
\hline Extraordinary Income & 0 & 0 & 0 & 0 & 0 & 0 \\
\hline 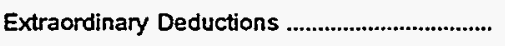 & 0 & 0 & 0 & 0 & 0 & 0 \\
\hline 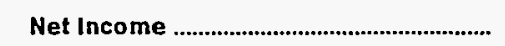 & 632 & 1,355 & 448 & 484 & 863 & -430 \\
\hline
\end{tabular}

Note: Totals may not equal sum of components because of independent rounding.

Source: Energy Information Administration, Form EIA-4 12, "Annual Report of Public Electric Utilities." 
Table 21. Statement of Income by Major U.S. Publicly Owned Electric Utility Within State, 1995 (Continued)

(Thousand Dollars)

\begin{tabular}{|c|c|c|c|c|c|c|}
\hline Item & $\begin{array}{l}\text { Minnesota } \\
\text { Hutchinson } \\
\text { Utilities } \\
\text { Comm } \\
\text { December } 31\end{array}$ & $\begin{array}{c}\text { Minnesota } \\
\text { Marshall } \\
\text { City of } \\
\text { December } 31\end{array}$ & $\begin{array}{c}\text { Minnesota } \\
\text { Moorhead } \\
\text { City of } \\
\text { December } 31\end{array}$ & $\begin{array}{l}\text { Minnesota } \\
\text { New Ulm } \\
\text { Public } \\
\text { Utilities } \\
\text { Comm } \\
\text { December } 31\end{array}$ & $\begin{array}{l}\text { Minnesota } \\
\text { Northern } \\
\text { Municipal } \\
\text { Power Agny } \\
\\
\text { December } 31\end{array}$ & $\begin{array}{c}\text { Minnesota } \\
\text { Owatonna } \\
\text { City of } \\
\text { December } 31\end{array}$ \\
\hline Electric Utility Operating Revenues ............ & 11,211 & 13,038 & 14,353 & 9,268 & 38,039 & 18,826 \\
\hline 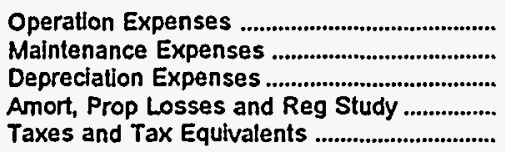 & $\begin{array}{r}9,146 \\
431 \\
1,344 \\
0 \\
0\end{array}$ & $\begin{array}{r}12,119 \\
353 \\
882 \\
0 \\
530\end{array}$ & $\begin{array}{r}10,593 \\
533 \\
813 \\
30 \\
3,019\end{array}$ & $\begin{array}{r}7,710 \\
628 \\
0 \\
0 \\
466\end{array}$ & $\begin{array}{r}10,372 \\
2,384 \\
7,420 \\
0 \\
0\end{array}$ & $\begin{array}{r}16,096 \\
1,330 \\
958 \\
0 \\
0\end{array}$ \\
\hline 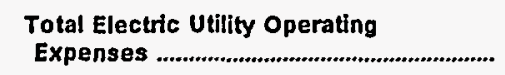 & 10,921 & 13,884 & 14,988 & 8,804 & 20,176 & 18,385 \\
\hline $\begin{array}{l}\text { Net Electric Utility Operating Income } \\
\text { Income from Electric Plant Leased..... }\end{array}$ & 289 & -846 & -635 & 464 & 17,862 & 441 \\
\hline to Others & 0 & 301 & 103 & 0 & 0 & 0 \\
\hline Electric Utility Operating Income .............. & 289 & -545 & -532 & 464 & 17,862 & 441 \\
\hline Other Electric Income & 194 & 1,011 & 369 & 444 & 2,788 & 453 \\
\hline $\begin{array}{l}\text { Other Electric Deductions ........................... } \\
\text { Allowance for Other Funds Used }\end{array}$ & 0 & 0 & 0 & 5 & 0 & 553 \\
\hline 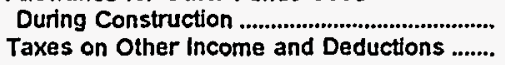 & $\begin{array}{l}0 \\
0\end{array}$ & $\begin{array}{r}14 \\
0\end{array}$ & $\begin{array}{l}0 \\
0\end{array}$ & $\begin{array}{l}0 \\
0\end{array}$ & $\begin{array}{l}0 \\
0\end{array}$ & $\begin{array}{l}0 \\
0\end{array}$ \\
\hline Electric Utility Income & 484 & 481 & -163 & 903 & 20,651 & 340 \\
\hline 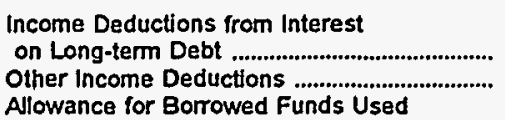 & $\begin{array}{r}653 \\
17\end{array}$ & $\begin{array}{l}0 \\
0\end{array}$ & $\begin{array}{r}233 \\
0\end{array}$ & $\begin{array}{r}185 \\
0\end{array}$ & $\begin{array}{r}20,651 \\
0\end{array}$ & $\begin{array}{r}372 \\
0\end{array}$ \\
\hline 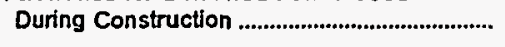 & 0 & 0 & 0 & 0 & 0 & 0 \\
\hline Total Income Deductions ................................ & 670 & $\mathbf{0}$ & 233 & 185 & 20,651 & 372 \\
\hline Income Before Extraordinary ltems .................. & -186 & 481 & -395 & 718 & 0 & -32 \\
\hline 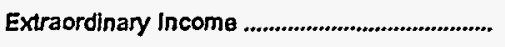 & 0 & 0 & 0 & 0 & 0 & 0 \\
\hline Extraordinary Deductions ....................................... & 0 & 0 & 0 & 0 & 0 & 0 \\
\hline 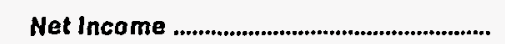 & -186 & 481 & -395 & 718 & 0 & -32 \\
\hline
\end{tabular}

Note: Totals may not equal sum of components because of independent rounding.

Source: Energy Information Administration. Form EIA-412, "Annual Report of Public Electric Utilities." 
Table 21. Statement of Income by Major U.S. Publicly Owned Electric Utility Within State, 1995 (Continued)

(Thousand Dollars)

\begin{tabular}{|c|c|c|c|c|c|c|}
\hline Item & $\begin{array}{c}\text { Minnesota } \\
\text { Rochester } \\
\text { Public } \\
\text { Utilities } \\
\text { December } 31\end{array}$ & $\begin{array}{c}\text { Minnesota } \\
\text { Shakopee } \\
\text { Public } \\
\text { Utilities } \\
\text { Comm } \\
\text { December } 31\end{array}$ & $\begin{array}{l}\text { Minnesota } \\
\text { Southern } \\
\text { Minnesota } \\
\text { Mun P } \\
\text { Agny } \\
\text { December } 31\end{array}$ & $\begin{array}{c}\text { Minnesota } \\
\text { Western } \\
\text { Minnesota } \\
\text { Mun } \\
\text { Pwr Agny } \\
\text { December } 31\end{array}$ & $\begin{array}{c}\text { Minnesota } \\
\text { Willmar } \\
\text { Municipal } \\
\text { Utils Comm } \\
\text { December } 31\end{array}$ & $\begin{array}{l}\text { Minnesota } \\
\text { Worthington } \\
\text { City of } \\
\text { December } 31\end{array}$ \\
\hline Electric Utility Operating Revenues ............. & 75,804 & 8,722 & 106,396 & 59,899 & 12,514 & 8,079 \\
\hline 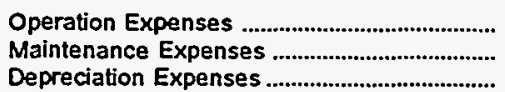 & $\begin{array}{r}59,175 \\
2,838 \\
2,300\end{array}$ & $\begin{array}{r}6.917 \\
426 \\
194\end{array}$ & $\begin{array}{r}51,624 \\
4,115 \\
4,897\end{array}$ & $\begin{array}{r}58,542 \\
0 \\
77\end{array}$ & $\begin{array}{r}8,172 \\
540 \\
932\end{array}$ & $\begin{array}{r}6,592 \\
185 \\
385\end{array}$ \\
\hline 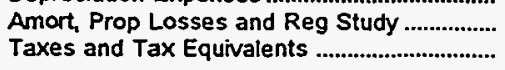 & $\begin{array}{r}38 \\
5,652\end{array}$ & $\begin{array}{r}66 \\
558\end{array}$ & $\begin{array}{r}0 \\
7,955\end{array}$ & $\begin{array}{r}0 \\
24\end{array}$ & $\begin{array}{r}0 \\
1,037\end{array}$ & $\begin{array}{l}0 \\
0\end{array}$ \\
\hline $\begin{array}{l}\text { Total Electric Utility Operating } \\
\text { Expenses }\end{array}$ & 70,004 & 8,161 & 68,590 & 58,643 & 10,681 & 7,162 \\
\hline $\begin{array}{l}\text { Net Electric Utility Operating Income } \\
\text { Income from Electric Plant Leased..... } \\
\text { to Others }\end{array}$ & 5.800 & 561 & 37,806 & $\begin{array}{r}1,255 \\
0\end{array}$ & $\begin{array}{r}1.833 \\
0\end{array}$ & $\begin{array}{r}917 \\
0\end{array}$ \\
\hline Electric Utility Operating Income .............. & 5,800 & 561 & 37,806 & 1,255 & 1,833 & 917 \\
\hline 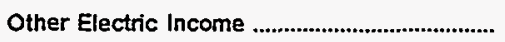 & 699 & 305 & 8,971 & 1,099 & 1,098 & 309 \\
\hline $\begin{array}{l}\text { Other Electric Deductions .................................. } \\
\text { Allowance for Other Funds Used }\end{array}$ & 147 & 0 & 0 & 0 & 0 & 1 \\
\hline $\begin{array}{l}\text { During Construction ......................................... } \\
\text { Taxes on Other Income and Deductions ......... }\end{array}$ & $\begin{array}{l}0 \\
0\end{array}$ & $\begin{array}{l}0 \\
0\end{array}$ & $\begin{array}{l}0 \\
0\end{array}$ & $\begin{array}{l}0 \\
0\end{array}$ & $\begin{array}{l}0 \\
0\end{array}$ & $\begin{array}{l}0 \\
0\end{array}$ \\
\hline Electric Utility Income & 6,352 & 865 & 46,777 & 2,354 & 2,931 & 1,225 \\
\hline 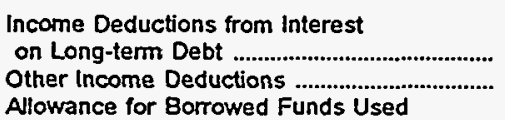 & $\begin{array}{r}0 \\
126\end{array}$ & $\begin{array}{r}197 \\
0\end{array}$ & $\begin{array}{r}37,846 \\
4,548\end{array}$ & $\begin{array}{l}0 \\
0\end{array}$ & $\begin{array}{r}674 \\
51\end{array}$ & $\begin{array}{l}0 \\
0\end{array}$ \\
\hline 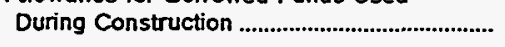 & 0 & 0 & -173 & 0 & 0 & 0 \\
\hline 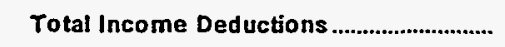 & 126 & 197 & 42,220 & 0 & 724 & 0 \\
\hline Income Before Extraordinary Items .................. & 6,226 & 668 & 4,556 & 2,354 & 2,207 & 1,225 \\
\hline 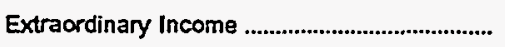 & 0 & 0 & 0 & 0 & 0 & 0 \\
\hline 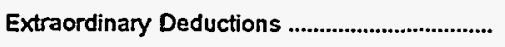 & 0 & 0 & 0 & 0 & 0 & $\mathbf{0}$ \\
\hline 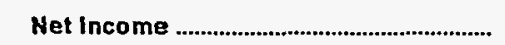 & 6,226 & 668 & 4,556 & 2,354 & 2,207 & 1,225 \\
\hline
\end{tabular}

Note: Totals may not equal sum of components because of independent rounding.

Source: Energy Information Administration, Form ElA-412, "Annual Report of Public Electric Utilities." 
Table 21. Statement of Income by Major U.S. Publicly Owned Electric Utility Within State, 1995 (Continued)

(Thousand Dollars)

\begin{tabular}{|c|c|c|c|c|c|c|}
\hline Item & $\begin{array}{l}\text { Mississippi } \\
\text { Aberdeen } \\
\text { City of } \\
\text { June } 30\end{array}$ & $\begin{array}{c}\text { Mississippi } \\
\text { Clarksdale } \\
\text { City of } \\
\text { September } 30\end{array}$ & $\begin{array}{l}\text { Mississippi } \\
\text { Columbus } \\
\text { City of } \\
\text { June } 30\end{array}$ & $\begin{array}{l}\text { Mississippi } \\
\text { Greenwood } \\
\text { Utilitfes } \\
\text { Comm } \\
\text { September } 30\end{array}$ & $\begin{array}{l}\text { Mississippi } \\
\text { Holly } \\
\text { Springs } \\
\text { City of } \\
\text { June } 30\end{array}$ & $\begin{array}{l}\text { Mississippl } \\
\text { Louisville } \\
\text { Electric } \\
\text { System } \\
\text { June } 30\end{array}$ \\
\hline Electric Utility Operating Revenues ............. & 8,392 & 12,651 & 22,850 & 15,931 & 12,664 & 8,586 \\
\hline 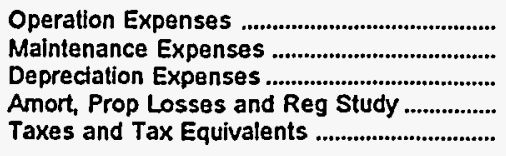 & $\begin{array}{r}7,946 \\
122 \\
142 \\
0 \\
278\end{array}$ & $\begin{array}{r}9,201 \\
337 \\
891 \\
0 \\
0\end{array}$ & $\begin{array}{r}21.526 \\
626 \\
550 \\
0 \\
1,274\end{array}$ & $\begin{array}{r}12,058 \\
752 \\
751 \\
0 \\
0\end{array}$ & $\begin{array}{r}10,519 \\
555 \\
440 \\
0 \\
657\end{array}$ & $\begin{array}{r}7,754 \\
142 \\
284 \\
0 \\
216\end{array}$ \\
\hline 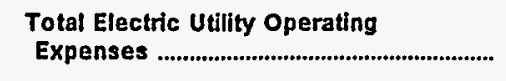 & 8,487 & 10,429 & 23,976 & 13,561 & 12,171 & 8,396 \\
\hline $\begin{array}{l}\text { Net Electric Utility Operating Income .............. } \\
\text { Income from Electric Plant Leased }\end{array}$ & -96 & 2,222 & $-1,126$ & 2,370 & 493 & 189 \\
\hline Electric Utility Operating Income ............. & -96 & 2,222 & $-1,126$ & 2,370 & 493 & 189 \\
\hline 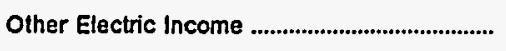 & 101 & 383 & 388 & 847 & 95 & 130 \\
\hline $\begin{array}{l}\text { Other Electric Deductions ............................. } \\
\text { Allowance for Other Funds Used } \\
\text { During Construction ...................................... } \\
\text { Taxes on Other Income and Deductions ....... }\end{array}$ & $\begin{array}{l}0 \\
0\end{array}$ & $\begin{array}{l}0 \\
0\end{array}$ & $\begin{array}{l}\mathbf{0} \\
\mathbf{0}\end{array}$ & $\begin{array}{r}1,396 \\
0 \\
0\end{array}$ & $\begin{array}{l}4 \\
0 \\
0\end{array}$ & $\begin{array}{l}0 \\
0\end{array}$ \\
\hline Electric Utility Income & -4 & 2,538 & -743 & 1,821 & 584 & 315 \\
\hline $\begin{array}{l}\text { Income Deductions from Interest } \\
\text { on Long-term Debt ............................................ } \\
\text { Other Income Deductions ................................ } \\
\text { Allowance for Borrowed Funds Used }\end{array}$ & $\begin{array}{l}0 \\
0\end{array}$ & $\begin{array}{r}132 \\
6\end{array}$ & $\begin{array}{r}0 \\
15\end{array}$ & $\begin{array}{l}8 \\
0\end{array}$ & $\begin{array}{l}5 \\
0\end{array}$ & $\begin{array}{l}0 \\
0\end{array}$ \\
\hline Total Income Deductions .............................. & 0 & 138 & 15 & 8 & $\mathbf{5}$ & 0 \\
\hline Income Before Extraordinary Items ................... & -4 & 2,399 & -758 & 1,812 & 579 & 315 \\
\hline 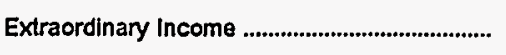 & 0 & 312 & 0 & 0 & 0 & 0 \\
\hline Extraordlnary Deductions .................................... & 0 & 32 & 0 & 0 & 0 & 0 \\
\hline 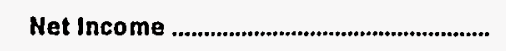 & -4 & 2,679 & -758 & 1,812 & 579 & 315 \\
\hline
\end{tabular}

Note: Totals may not equal sum of components because of independent rounding.

Source: Energy Information Administration. Form EIA-412, "Annual Report of Public Electric Utilities." 
Table 21. Statement of Income by Major U.S. Publicly Owned Electric Utility Within State, 1995 (Continued) (Thousand Dollars)

\begin{tabular}{|c|c|c|c|c|c|c|}
\hline Item & $\begin{array}{l}\text { Mississippi } \\
\text { Municipal } \\
\text { Energy } \\
\text { Agency } \\
\text { of MS } \\
\text { September } 30\end{array}$ & $\begin{array}{l}\text { Mississippi } \\
\text { New Albany } \\
\text { City of } \\
\text { June } 30\end{array}$ & $\begin{array}{l}\text { Mississippi } \\
\text { Oxford } \\
\text { City of } \\
\text { June } 30\end{array}$ & $\begin{array}{l}\text { Mississippi } \\
\text { Starkville } \\
\text { City of } \\
\text { June } 30\end{array}$ & $\begin{array}{l}\text { Mississippi } \\
\text { Tupelo } \\
\text { City of } \\
\text { June } 30\end{array}$ & $\begin{array}{l}\text { Mississippi } \\
\text { West } \\
\text { Point } \\
\text { City of } \\
\text { June } 30\end{array}$ \\
\hline Electric Utility Operating Revenues .............. & 30,014 & 13,453 & 8,522 & 17,733 & 33,405 & 9,934 \\
\hline 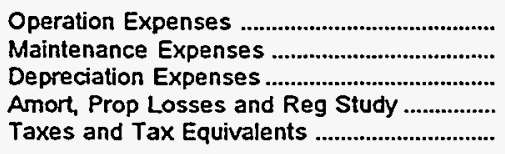 & $\begin{array}{r}29,968 \\
0 \\
325 \\
0 \\
0\end{array}$ & $\begin{array}{r}11,918 \\
474 \\
345 \\
0 \\
491\end{array}$ & $\begin{array}{r}7,685 \\
181 \\
175 \\
0 \\
524\end{array}$ & $\begin{array}{r}15,706 \\
275 \\
375 \\
11 \\
808\end{array}$ & $\begin{array}{r}30,412 \\
528 \\
751 \\
0 \\
2,020\end{array}$ & $\begin{array}{r}8,772 \\
327 \\
215 \\
0 \\
513\end{array}$ \\
\hline $\begin{array}{l}\text { Total Electric Utility Operating } \\
\text { Expenses }\end{array}$ & 30,293 & 13,229 & 8,564 & 17,175 & 33,710 & 9,828 \\
\hline 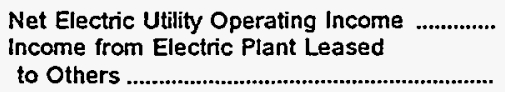 & $\begin{array}{r}-278 \\
0\end{array}$ & 224 & -42 & 558 & -305 & 106 \\
\hline Electric Utility Operating Income ............... & -278 & 224 & -42 & 558 & -305 & 106 \\
\hline Other Electric Income & 382 & 303 & 132 & 442 & 494 & 58 \\
\hline 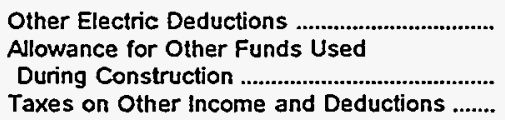 & $\begin{array}{l}0 \\
0\end{array}$ & $\begin{array}{l}0 \\
0\end{array}$ & $\begin{array}{l}0 \\
0\end{array}$ & $\begin{array}{l}0 \\
0\end{array}$ & $\begin{array}{l}0 \\
0\end{array}$ & $\begin{array}{l}0 \\
0\end{array}$ \\
\hline 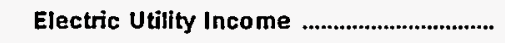 & 103 & 525 & 51 & 986 & 190 & 164 \\
\hline 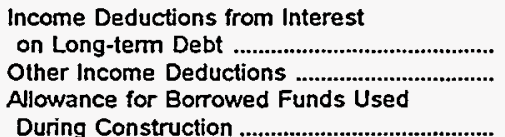 & $\begin{array}{l}0 \\
0\end{array}$ & $\begin{array}{l}5 \\
4\end{array}$ & $\begin{array}{r}0 \\
17\end{array}$ & $\begin{array}{r}295 \\
42\end{array}$ & $\begin{array}{l}0 \\
0\end{array}$ & $\begin{array}{r}10 \\
2\end{array}$ \\
\hline Total Income Deductions .................................. & $\mathbf{0}$ & 9 & 17 & 348 & 0 & 12 \\
\hline Income Before Extraordinary Items ................... & 103 & 516 & 34 & 638 & 190 & 152 \\
\hline Extraordinary Income & 0 & 0 & 0 & 0 & 0 & 0 \\
\hline 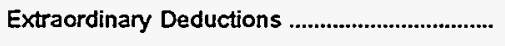 & 0 & 0 & 45 & 0 & 0 & 0 \\
\hline 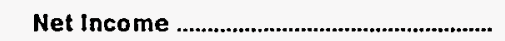 & 103 & 516 & -10 & 638 & 190 & 152 \\
\hline
\end{tabular}

Note: Totals may not equal sum of components because of independent rounding.

Source: Energy Information Administration. Form EIA-412, "Annual Report of Public Electric Utilities." 
Table 21. Statement of Income by Major U.S. Publicly Owned Electric Utility Within State, 1995 (Continued) (Thousand Dollars)

\begin{tabular}{|c|c|c|c|c|c|c|}
\hline Item & $\begin{array}{l}\text { Missouri } \\
\text { Carthage } \\
\text { City of } \\
\text { June } 30\end{array}$ & $\begin{array}{l}\text { Missouri } \\
\text { Columbia } \\
\text { City of } \\
\text { September } 30\end{array}$ & $\begin{array}{l}\text { Missouri } \\
\text { Hannibal } \\
\text { City of } \\
\text { June } 30\end{array}$ & $\begin{array}{c}\text { Missouri } \\
\text { Independence } \\
\text { City of } \\
\text { June } 30\end{array}$ & $\begin{array}{l}\text { Missouri } \\
\text { Kennett } \\
\text { City of } \\
\text { June } 30\end{array}$ & $\begin{array}{l}\text { Missouri } \\
\text { Kirkwood } \\
\text { City of } \\
\text { March } 31\end{array}$ \\
\hline Electric Utility Operating Revenues ............ & 9,653 & 50,832 & 10,730 & 56,094 & 4,767 & 11,753 \\
\hline 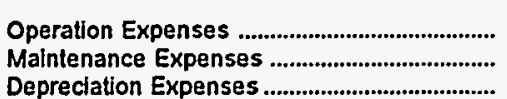 & $\begin{array}{r}8,286 \\
358 \\
524\end{array}$ & $\begin{array}{r}36,245 \\
2,763 \\
3,470\end{array}$ & $\begin{array}{r}8,852 \\
567 \\
373\end{array}$ & $\begin{array}{r}35,117 \\
5,674 \\
5,412\end{array}$ & $\begin{array}{r}4,339 \\
251 \\
526\end{array}$ & $\begin{array}{r}8,462 \\
724 \\
178\end{array}$ \\
\hline 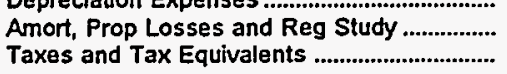 & $\begin{array}{r}3 \\
0\end{array}$ & $\begin{array}{r}0 \\
4,269\end{array}$ & $\begin{array}{r}0 \\
439\end{array}$ & 6,163 & $\begin{array}{l}0 \\
0\end{array}$ & $\begin{array}{l}0 \\
0\end{array}$ \\
\hline $\begin{array}{l}\text { Total Electric Utility Operating } \\
\text { Expenses ........................................................ }\end{array}$ & 9,169 & 46,749 & 10,231 & 52,365 & 5,116 & 9,363 \\
\hline $\begin{array}{l}\text { Net Electric Utility Operating Income } \\
\text { Income from Electric Plant Leased... }\end{array}$ & 484 & 4,084 & 500 & 3,728 & -349 & 2,390 \\
\hline 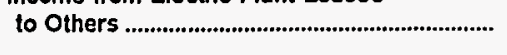 & 0 & 0 & 0 & 0 & 238 & 0 \\
\hline Electric Utility Operating Income .............. & 484 & 4,084 & 500 & 3,728 & -111 & 2,390 \\
\hline 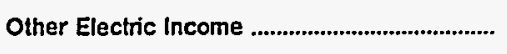 & 326 & 3,272 & 369 & 2,656 & 0 & 277 \\
\hline $\begin{array}{l}\text { Other Electric Deductions ................................ } \\
\text { Allowance for Other Funds Used }\end{array}$ & 140 & 222 & 0 & 0 & 79 & $\mathbf{0}$ \\
\hline 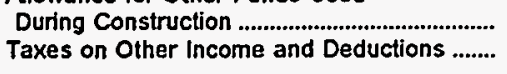 & $\begin{array}{l}0 \\
0\end{array}$ & $\begin{array}{l}0 \\
0\end{array}$ & $\begin{array}{l}0 \\
0\end{array}$ & $\begin{array}{l}0 \\
0\end{array}$ & $\begin{array}{l}0 \\
0\end{array}$ & $\begin{array}{l}0 \\
0\end{array}$ \\
\hline 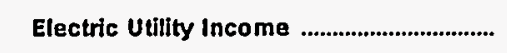 & 670 & 7,134 & 868 & 6,385 & -190 & 2,667 \\
\hline 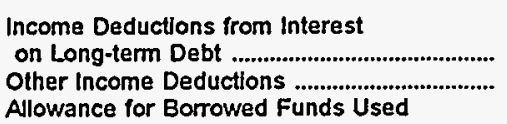 & $\begin{array}{l}0 \\
0\end{array}$ & $\begin{array}{r}2,634 \\
819\end{array}$ & $\begin{array}{l}0 \\
0\end{array}$ & $\begin{array}{r}2.336 \\
85\end{array}$ & $\begin{array}{l}0 \\
0\end{array}$ & $\begin{array}{r}23 \\
0\end{array}$ \\
\hline During Construction .............................................. & 0 & 0 & 0 & 0 & 0 & 0 \\
\hline Total Income Deductions .............................. & 0 & 3,453 & 0 & 2,421 & 0 & 23 \\
\hline Income Before Extraordinary Items ................. & 670 & 3,681 & 868 & 3,963 & -190 & 2,644 \\
\hline 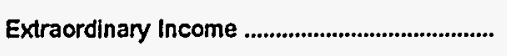 & 0 & 0 & 0 & 0 & 0 & 0 \\
\hline Extraordinary Deductions .................................... & 0 & 0 & 0 & 0 & 0 & 0 \\
\hline Net Income & 670 & 3,681 & 868 & 3,963 & -190 & 2,644 \\
\hline
\end{tabular}

Note: Tota!s may not equal sum of components because of incenendent rounding.

Source: Energy information Adm!nistration, Form E1A-412, "Annual Report of Public Electric Utilities." 
Table 21. Statement of Income by Major U.S. Publicly Owned Electric Utility Within State, 1995 (Continued)

(Thousand Dollars)

\begin{tabular}{|c|c|c|c|c|c|c|}
\hline Item & $\begin{array}{l}\text { Missouri } \\
\text { Lebanon } \\
\text { City of } \\
\text { October } 31\end{array}$ & $\begin{array}{c}\text { Missour } \\
\text { Marshall } \\
\text { City of } \\
\text { September } 30\end{array}$ & $\begin{array}{l}\text { Missouri } \\
\text { Monett } \\
\text { City of } \\
\text { March } 31\end{array}$ & $\begin{array}{c}\text { Missouri } \\
\text { Poplar } \\
\text { Bluff } \\
\text { City of } \\
\text { December } 31\end{array}$ & $\begin{array}{c}\text { Missoun } \\
\text { Rolla } \\
\text { City of } \\
\text { September } 30\end{array}$ & $\begin{array}{l}\text { Missouri } \\
\text { Sikeston } \\
\text { City of } \\
\text { May } 31\end{array}$ \\
\hline Electric Utility Operating Revenues ............ & 11,440 & 9,825 & 8,571 & 11,280 & 11,763 & 52,806 \\
\hline 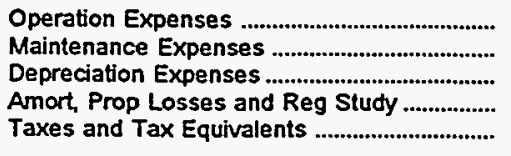 & $\begin{array}{r}9,238 \\
0 \\
0 \\
0 \\
0\end{array}$ & $\begin{array}{r}4,693 \\
1,357 \\
1,475 \\
0 \\
0\end{array}$ & $\begin{array}{r}6,254 \\
36 \\
226 \\
0 \\
0\end{array}$ & $\begin{array}{r}8,435 \\
703 \\
780 \\
0 \\
0\end{array}$ & $\begin{array}{r}9.295 \\
374 \\
442 \\
0 \\
1,358\end{array}$ & $\begin{array}{r}30,949 \\
5,903 \\
3,052 \\
0 \\
0\end{array}$ \\
\hline $\begin{array}{l}\text { Total Electric Utility Operating } \\
\text { Expenses }\end{array}$ & 9,238 & 7,526 & 6,516 & 9,918 & 11,470 & 39,903 \\
\hline $\begin{array}{l}\text { Net Electric Utility Operating Income } \\
\text { Income from Electric Plant Leased } \\
\text { to Others }\end{array}$ & $\begin{array}{r}2,202 \\
0\end{array}$ & $\begin{array}{r}2,300 \\
0\end{array}$ & $\begin{array}{r}2,054 \\
0\end{array}$ & $\begin{array}{r}1,362 \\
0\end{array}$ & $\begin{array}{r}293 \\
0\end{array}$ & $\begin{array}{r}12,903 \\
0\end{array}$ \\
\hline Electric Utility Operating Income ............. & 2,202 & 2,300 & 2,054 & 1,362 & 293 & 12,903 \\
\hline 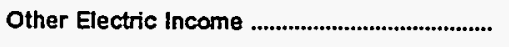 & 2,246 & 445 & 7 & 882 & 352 & 2,430 \\
\hline Other Electric Deductions ................................. & 946 & 897 & 0 & 0 & 1 & 0 \\
\hline 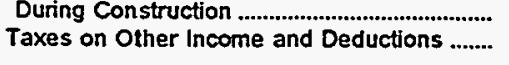 & $\begin{array}{l}0 \\
0\end{array}$ & $\begin{array}{l}0 \\
0\end{array}$ & $\begin{array}{l}0 \\
0\end{array}$ & $\begin{array}{l}0 \\
0\end{array}$ & $\begin{array}{l}0 \\
0\end{array}$ & $\begin{array}{l}\mathbf{0} \\
\mathbf{0}\end{array}$ \\
\hline Electric Utility Income .................................. & 3,503 & 1,848 & 2,062 & 2,244 & 644 & 15,333 \\
\hline 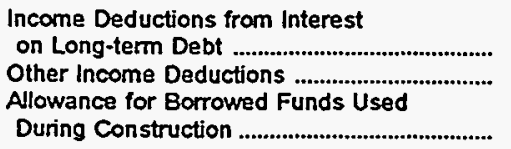 & $\begin{array}{l}249 \\
210\end{array}$ & $\begin{array}{l}92 \\
30\end{array}$ & $\begin{array}{r}0 \\
505\end{array}$ & $\begin{array}{l}0 \\
0\end{array}$ & $\begin{array}{r}0 \\
-117 \\
0\end{array}$ & $\begin{array}{r}13,538 \\
279\end{array}$ \\
\hline Total Income Deductions .............................. & 459 & 122 & 505 & $\mathbf{0}$ & -117 & 13,817 \\
\hline Income Betore Extraordinary Items ................. & 3,044 & 1,726 & 1,557 & 2,244 & 761 & 1.516 \\
\hline 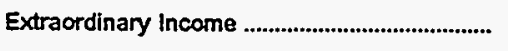 & -300 & 0 & 0 & 0 & 0 & 0 \\
\hline Extraordinary Deductions ......................................... & 0 & 0 & 0 & 0 & 0 & 0 \\
\hline 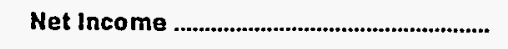 & 2,744 & 1,726 & 1,557 & 2,244 & 761 & 1,516 \\
\hline
\end{tabular}

Note: Totals may not equal sum of components because of independent rounding.

Source: Energy Information Administration, Form ElA-412, "Annual Report of Public Electric Utilities." 
Table 21. Statement of Income by Major U.S. Publicly Owned Electric Utility Within State, 1995 (Continued)

(Thousand Dollars)

\begin{tabular}{|c|c|c|c|c|c|c|}
\hline Item & $\begin{array}{l}\text { Missouri } \\
\text { Springfield } \\
\text { City of } \\
\text { September } 30\end{array}$ & $\begin{array}{c}\text { Missouri } \\
\text { West } \\
\text { Plains } \\
\text { City of } \\
\text { December } 31\end{array}$ & $\begin{array}{l}\text { Nebraska } \\
\text { Beatrice } \\
\text { City of } \\
\text { July } 31\end{array}$ & $\begin{array}{c}\text { Nebraska } \\
\text { Central } \\
\text { Nebraska } \\
\text { Pub } \\
\text { P\&l Dist } \\
\text { December } 31\end{array}$ & $\begin{array}{l}\text { Nebraska } \\
\text { Cornhusker } \\
\text { Public } \\
\text { Power Dist } \\
\text { December } 31\end{array}$ & $\begin{array}{c}\text { Nebraska } \\
\text { Dawson } \\
\text { County } \\
\text { Public } \\
\text { Pur Dist } \\
\text { December } 31\end{array}$ \\
\hline Electric Utility Operating Revenues ............. & 111,536 & 10,259 & 7,335 & 9,832 & 11,837 & 17,475 \\
\hline 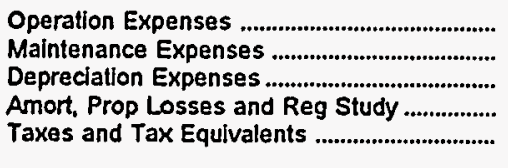 & $\begin{array}{r}63,454 \\
16,694 \\
13,913 \\
0 \\
3,342\end{array}$ & $\begin{array}{r}9,320 \\
180 \\
581 \\
0 \\
0\end{array}$ & $\begin{array}{r}5,958 \\
284 \\
489 \\
0 \\
0\end{array}$ & $\begin{array}{r}2,806 \\
1,559 \\
2,364 \\
0 \\
8\end{array}$ & $\begin{array}{r}9,226 \\
632 \\
1,017 \\
0 \\
0\end{array}$ & $\begin{array}{r}13.266 \\
505 \\
1.257 \\
0 \\
175\end{array}$ \\
\hline 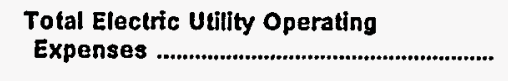 & 97,403 & 10,081 & 6,732 & 6,737 & 10,875 & 15,202 \\
\hline 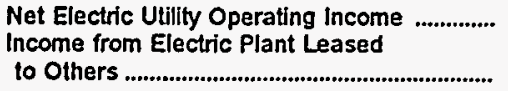 & $\begin{array}{r}14,133 \\
5,344\end{array}$ & $\begin{array}{r}178 \\
0\end{array}$ & 603 & $\begin{array}{r}3,095 \\
45\end{array}$ & 962 & 2,272 \\
\hline Electric Utility Operating Income .............. & 19,477 & 178 & 603 & 3,141 & 962 & 2,272 \\
\hline Other Electric Income .............................................. & 16,636 & 0 & 93 & 637 & 272 & 1.499 \\
\hline $\begin{array}{l}\text { Other Electric Deductions } \\
\text { Allowance for Other Funds Used }\end{array}$ & $\mathbf{0}$ & 0 & 303 & 0 & 0 & 0 \\
\hline $\begin{array}{l}\text { During Construction .................................... } \\
\text { Taxes on Other Income and Deductions ....... }\end{array}$ & $\begin{array}{r}65 \\
0\end{array}$ & $\begin{array}{l}0 \\
0\end{array}$ & $\begin{array}{l}0 \\
0\end{array}$ & $\begin{array}{l}0 \\
0\end{array}$ & $\begin{array}{l}0 \\
0\end{array}$ & $\begin{array}{l}0 \\
0\end{array}$ \\
\hline 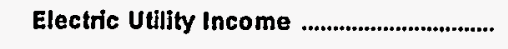 & 36,178 & 178 & 393 & 3,778 & 1,233 & 3,771 \\
\hline $\begin{array}{l}\text { Income Deductions from Interest } \\
\text { on Long-term Debt ......................................... } \\
\text { Other Income Deductions ........................... } \\
\text { Allowance for Borowed Funds Used }\end{array}$ & $\begin{array}{r}9,117 \\
807\end{array}$ & $\stackrel{0}{0}$ & $\begin{array}{l}0 \\
0\end{array}$ & $\begin{array}{r}10 \\
171\end{array}$ & $\begin{array}{r}576 \\
-158\end{array}$ & $\begin{array}{r}432 \\
24\end{array}$ \\
\hline 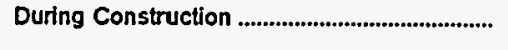 & -426 & 0 & 0 & 0 & 0 & 0 \\
\hline 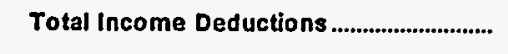 & 9,498 & 0 & 0 & 181 & 418 & 456 \\
\hline Income Before Extraordinary Items .................. & 26,680 & 178 & 393 & 3,597 & 815 & 3,315 \\
\hline Extraordinary Income & 0 & 0 & 0 & 18,290 & 0 & 0 \\
\hline 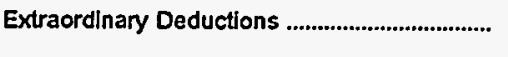 & 0 & 0 & 0 & 0 & 0 & 882 \\
\hline 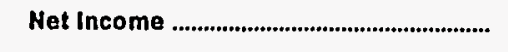 & 26,680 & 178 & 393 & 21,887 & 815 & 2,433 \\
\hline
\end{tabular}

Note: Totals may not equal sum of components because of Independent rounding.

Source: Energy Information Administration. Form ElA-412, "Annual Report of Public Electric Utitities." 
Table 21. Statement of Income by Major U.S. Publicly Owned Electric Utility Within State, 1995 (Continued)

(Thousand Dollars)

\begin{tabular}{|c|c|c|c|c|c|c|}
\hline Item & $\begin{array}{l}\text { Nebraska } \\
\text { Fremont } \\
\text { City of } \\
\text { July } 31\end{array}$ & $\begin{array}{c}\text { Nebraska } \\
\text { Grand Island } \\
\text { City of } \\
\text { July } 31\end{array}$ & $\begin{array}{c}\text { Nebraska } \\
\text { Hastings } \\
\text { City of } \\
\text { December } 31\end{array}$ & $\begin{array}{c}\text { Nebraska } \\
\text { Lincoln } \\
\text { Electric } \\
\text { System } \\
\text { December } 31\end{array}$ & $\begin{array}{c}\text { Nebraska } \\
\text { Loup } \\
\text { River } \\
\text { Public } \\
\text { Power Dist } \\
\text { Oecember } 31\end{array}$ & $\begin{array}{l}\text { Nebraska } \\
\text { Municipal } \\
\text { Energy } \\
\text { Agency } \\
\text { of NE } \\
\text { March } 31\end{array}$ \\
\hline Electric Utility Operating Revenues ............ & 14,184 & 24,850 & 15,293 & 132,009 & 44,674 & 32,583 \\
\hline 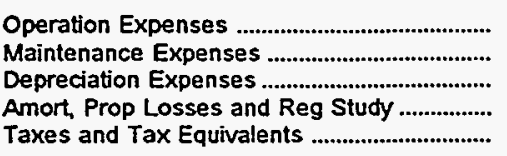 & $\begin{array}{r}9,153 \\
1,857 \\
2,366 \\
0 \\
1,367\end{array}$ & $\begin{array}{r}10,984 \\
1,635 \\
5,075 \\
109 \\
613\end{array}$ & $\begin{array}{r}8,632 \\
1,184 \\
2,679 \\
0 \\
601\end{array}$ & $\begin{array}{r}84,714 \\
7,178 \\
12,624 \\
647 \\
5,716\end{array}$ & $\begin{array}{r}37,716 \\
1,680 \\
1,453 \\
11 \\
2,348\end{array}$ & $\begin{array}{r}28,244 \\
0 \\
1,214 \\
0 \\
0\end{array}$ \\
\hline $\begin{array}{l}\text { Total Electric Utility Operating } \\
\text { Expenses }\end{array}$ & 14,743 & 18,416 & 13,096 & 110,879 & 43,210 & 29,458 \\
\hline 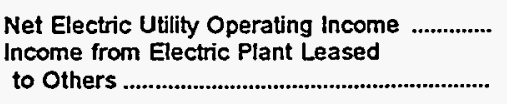 & $\begin{array}{r}-559 \\
0\end{array}$ & 6,434 & 2,198 & 21,130 & 1,464 & $\begin{array}{r}3,125 \\
0\end{array}$ \\
\hline Electric Utifity Operating Income ............. & -559 & 6,434 & 2,198 & 21,130 & 1,464 & 3,125 \\
\hline 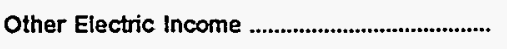 & 2,045 & 1,201 & 2,922 & 2,856 & 1,070 & 912 \\
\hline $\begin{array}{l}\text { Other Electric Deductions ............................. } \\
\text { Allowance for Other Funds Used }\end{array}$ & 53 & 35 & 0 & 0 & 12 & 0 \\
\hline $\begin{array}{l}\text { During Construction ....................................... } \\
\text { Taxes on Other Income and Deductions ........ }\end{array}$ & $\begin{array}{l}0 \\
0\end{array}$ & $\begin{array}{l}0 \\
0\end{array}$ & $\begin{array}{l}0 \\
0\end{array}$ & $\begin{array}{l}0 \\
0\end{array}$ & $\begin{array}{l}0 \\
0\end{array}$ & $\begin{array}{l}0 \\
0\end{array}$ \\
\hline Electric Utility Income .................................... & 1,432 & 7,601 & 5,120 & 23,987 & 2,522 & 4,037 \\
\hline $\begin{array}{l}\text { Income Deductions from Interest } \\
\text { on Long-term Debt ............................................ } \\
\text { Other Income Deductions ............................. } \\
\text { Allowance for Borrowed Funds Used } \\
\text { During Construction ........................................ }\end{array}$ & $\begin{array}{r}841 \\
0\end{array}$ & $\begin{array}{r}2,204 \\
99\end{array}$ & $\begin{array}{r}3,543 \\
0\end{array}$ & $\begin{array}{r}14,735 \\
2,079 \\
-162\end{array}$ & $\begin{array}{l}0 \\
0\end{array}$ & $\begin{array}{r}2,785 \\
0 \\
0\end{array}$ \\
\hline 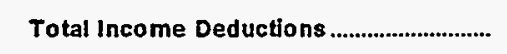 & 841 & 2,304 & 3,543 & 16,652 & 0 & 2,785 \\
\hline Income Before Extraordinary Items .................. & 592 & 5,297 & 1,577 & 7,334 & 2,522 & 1,252 \\
\hline 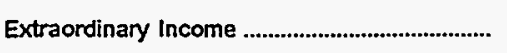 & 0 & 0 & 0 & 0 & 0 & $\mathbf{0}$ \\
\hline 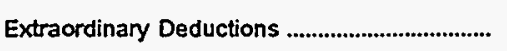 & 0 & 0 & 0 & 0 & 0 & 0 \\
\hline Net Income & 592 & 5,297 & 1,577 & 7,334 & 2,522 & 1,252 \\
\hline
\end{tabular}

Note: Totals may not equal sum of components because of incependent rounding

Source: Energy Information Administration, Form ElA-412, "Annual Report of Public Electric Utilities." 
Table 21. Statement of Income by Major U.S. Publicly Owned Electric Utility Within State, 1995 (Continued)

(Thousand Dollars)

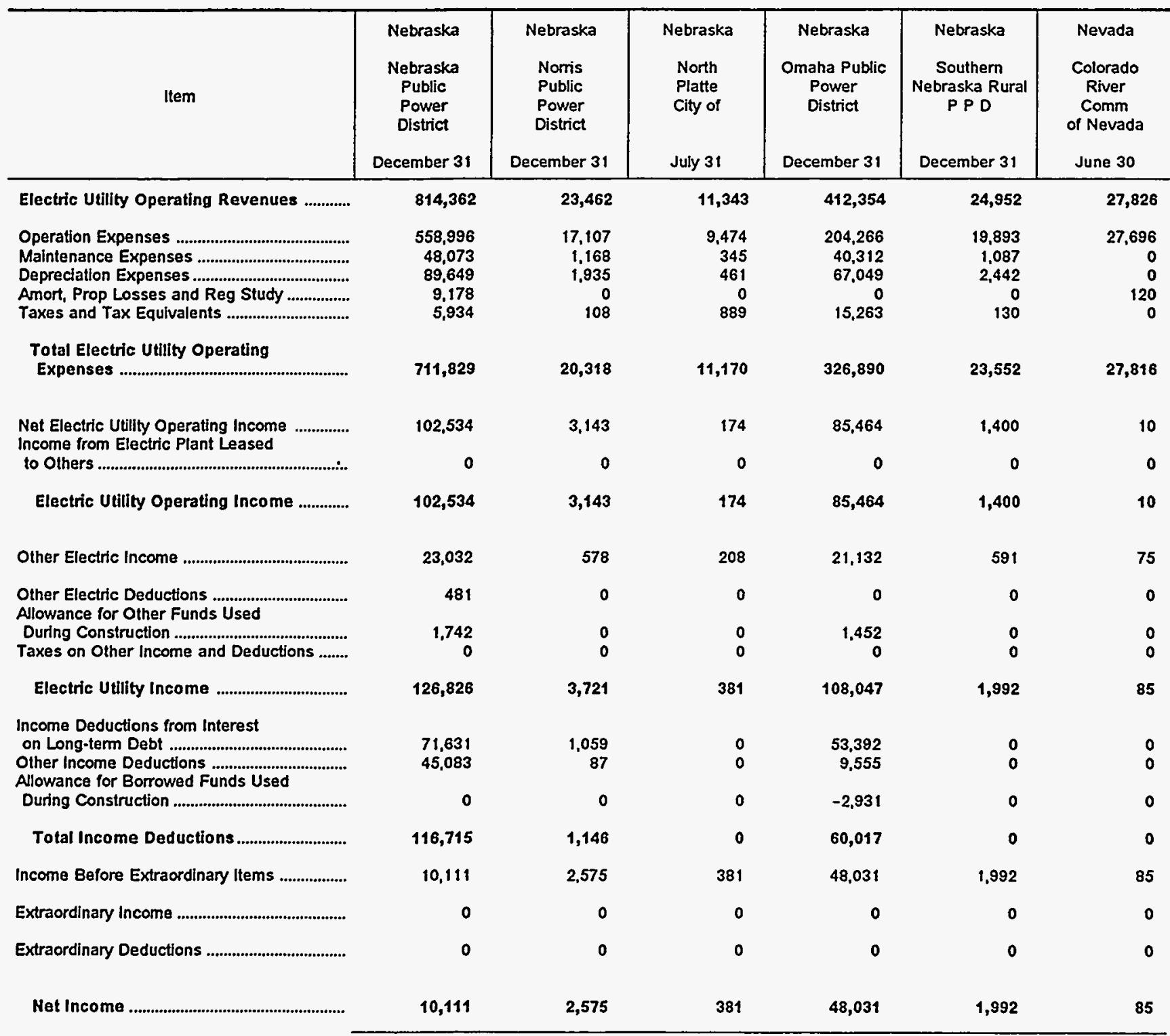

Note: Totals may not equal sum of components because of independent rounding.

Source: Energy Information Administration, Form EIA-412, "Annual Report of Public Electric Utilities." 
Table 21. Statement of Income by Major U.S. Publicly Owned Electric Utility Within State, 1995 (Continued) (Thousand Dollars)

\begin{tabular}{|c|c|c|c|c|c|c|}
\hline Item & $\begin{array}{c}\text { Nevada } \\
\text { Overton } \\
\text { Power } \\
\text { District } \\
\text { No } 5 \\
\text { December } 31\end{array}$ & $\begin{array}{c}\text { New Jersey } \\
\text { Madison } \\
\text { Borough } \\
\text { December } 31\end{array}$ & $\begin{array}{l}\text { New Jersey } \\
\text { Vineland } \\
\text { City of } \\
\text { June } 30\end{array}$ & $\begin{array}{l}\text { New Mexico } \\
\text { Farmington } \\
\text { City of } \\
\text { June } 30\end{array}$ & $\begin{array}{l}\text { New Mexico } \\
\text { Gallup } \\
\text { City of } \\
\text { June } 30\end{array}$ & $\begin{array}{l}\text { New Mexico } \\
\text { Los Aamos } \\
\text { County } \\
\text { June } 30\end{array}$ \\
\hline Electric Utility Operating Revenues ............. & 12,390 & 11,756 & 39,000 & 45,016 & 13,857 & 29,783 \\
\hline 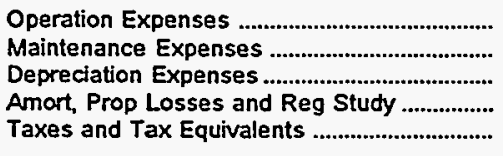 & $\begin{array}{r}6,159 \\
322 \\
900 \\
0 \\
20\end{array}$ & $\begin{array}{r}7.380 \\
0 \\
0 \\
0 \\
0\end{array}$ & $\begin{array}{r}31,494 \\
2,115 \\
2,016 \\
0 \\
579\end{array}$ & $\begin{array}{r}17,558 \\
2,744 \\
5,108 \\
0 \\
3,067\end{array}$ & $\begin{array}{r}11,369 \\
173 \\
472 \\
0 \\
675\end{array}$ & $\begin{array}{r}17,227 \\
1,282 \\
2,365 \\
0 \\
645\end{array}$ \\
\hline $\begin{array}{l}\text { Total Electric Utility Operating } \\
\text { Expenses }\end{array}$ & 7,402 & 7,380 & 36,204 & 28,477 & 12,688 & 21,519 \\
\hline 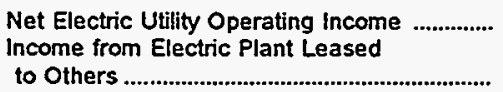 & 4,987 & 4,375 & 2,795 & 16.539 & 1,169 & $\begin{array}{r}8,264 \\
0\end{array}$ \\
\hline Electric Utility Operating Income ............. & 4,987 & 4,375 & 2,795 & 16,539 & 1,169 & 8,264 \\
\hline Other Electric Income & 190 & 614 & 1,437 & 1,985 & 47 & 1.516 \\
\hline $\begin{array}{l}\text { Other Electric Deductions } \\
\text { Allowance for Other Funds Used }\end{array}$ & 645 & 0 & 0 & 0 & 549 & 247 \\
\hline 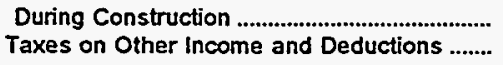 & $\begin{array}{l}0 \\
0\end{array}$ & $\begin{array}{l}0 \\
0\end{array}$ & $\begin{array}{l}0 \\
0\end{array}$ & $\begin{array}{l}0 \\
0\end{array}$ & $\begin{array}{l}0 \\
0\end{array}$ & $\begin{array}{l}0 \\
0\end{array}$ \\
\hline Electric Utility Income & 4,533 & 4,990 & 4,232 & 18,524 & 666 & 9,534 \\
\hline 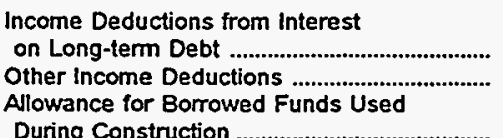 & $\begin{array}{l}0 \\
0\end{array}$ & $\begin{array}{l}0 \\
0\end{array}$ & $\begin{array}{l}235 \\
111\end{array}$ & $\begin{array}{r}10,073 \\
541\end{array}$ & $\begin{array}{l}0 \\
0\end{array}$ & $\begin{array}{l}6,389 \\
1,707\end{array}$ \\
\hline 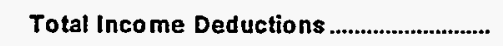 & $\mathbf{0}$ & 0 & 346 & 10,614 & $\mathbf{0}$ & 8,095 \\
\hline 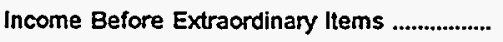 & 4,533 & 4,990 & 3,887 & 7,911 & 666 & 1,438 \\
\hline Extraordinary Income & 0 & 0 & 0 & 0 & 0 & $\mathbf{0}$ \\
\hline Extraordinary Deductions & 0 & 0 & 0 & 0 & 0 & 212 \\
\hline 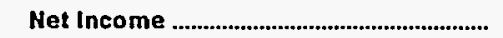 & 4,533 & 4,990 & 3,887 & 7,911 & 666 & 1,226 \\
\hline
\end{tabular}

Note: Totals may not equal sum of components because of independent rounding.

Source: Energy Information Administration. Form ElA-412, "Annual Report of Public Electric Utilities." 
Table 21. Statement of Income by Major U.S. Publicly Owned Electric Utility Within State, 1995 (Continued)

(Thousand Dollars)

\begin{tabular}{|c|c|c|c|c|c|c|}
\hline Item & $\begin{array}{c}\text { New York } \\
\text { Fairport } \\
\text { Village of } \\
\text { May } 31\end{array}$ & $\begin{array}{c}\text { New York } \\
\text { Freeport } \\
\text { Village of } \\
\text { Inc }\end{array}$ & $\begin{array}{l}\text { New York } \\
\text { Jamestown } \\
\text { City of } \\
\text { December } 31\end{array}$ & $\begin{array}{l}\text { New York } \\
\text { Lake Placid } \\
\text { Village Inc } \\
\text { July } 31\end{array}$ & $\begin{array}{l}\text { New York } \\
\text { Massena } \\
\text { Town of } \\
\text { December } 31\end{array}$ & $\begin{array}{l}\text { New York } \\
\text { Plattsburgh } \\
\text { City of }\end{array}$ \\
\hline Electric Utility Operating Revenues ............. & 11,442 & 14,911 & 23,060 & 3,875 & 6,272 & 11,059 \\
\hline 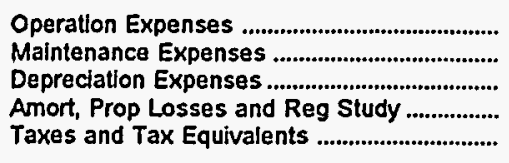 & $\begin{array}{r}8,874 \\
272 \\
666 \\
0 \\
582\end{array}$ & $\begin{array}{r}10,796 \\
1,088 \\
988 \\
0 \\
1,607\end{array}$ & $\begin{array}{r}13,673 \\
1,508 \\
2,328 \\
0 \\
2,175\end{array}$ & $\begin{array}{r}3,299 \\
29 \\
285 \\
0 \\
53\end{array}$ & $\begin{array}{r}3,370 \\
179 \\
432 \\
287 \\
0\end{array}$ & $\begin{array}{r}8,203 \\
407 \\
911 \\
0 \\
27\end{array}$ \\
\hline 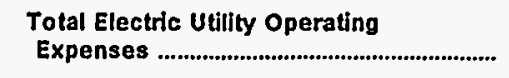 & 10,395 & 14,479 & 19,684 & 3,667 & 4,269 & 9,548 \\
\hline 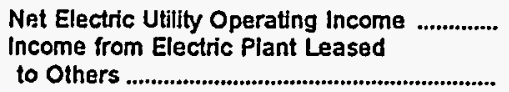 & $\begin{array}{r}1,047 \\
16\end{array}$ & $\begin{array}{r}433 \\
20\end{array}$ & 3,376 & 208 & $\begin{array}{r}2,003 \\
0\end{array}$ & $\begin{array}{r}1,511 \\
0\end{array}$ \\
\hline Electric Utility Operating Income ............. & 1,063 & 453 & 3,376 & 208 & 2,003 & 1,511 \\
\hline Other Electric Income & 119 & 284 & 74 & 16 & 140 & 77 \\
\hline Other Electric Deductions .................................... & 5 & 0 & 5 & 0 & 0 & 0 \\
\hline 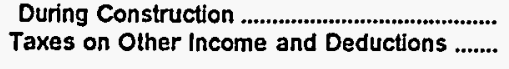 & $\begin{array}{l}0 \\
0\end{array}$ & $\begin{array}{l}0 \\
0\end{array}$ & $\begin{array}{l}0 \\
0\end{array}$ & $\begin{array}{l}0 \\
0\end{array}$ & $\begin{array}{r}0 \\
295\end{array}$ & $\begin{array}{l}0 \\
0\end{array}$ \\
\hline 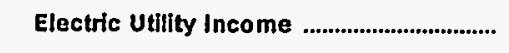 & 1,178 & 736 & 3,445 & 224 & 1,847 & 1,588 \\
\hline 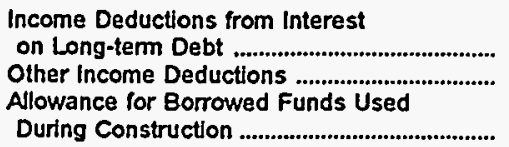 & $\begin{array}{r}68 \\
3 \\
0\end{array}$ & $\begin{array}{r}63 \\
40 \\
0\end{array}$ & $\begin{array}{r}1,040 \\
0\end{array}$ & $\begin{array}{r}168 \\
50 \\
0\end{array}$ & $\begin{array}{r}523 \\
4 \\
0\end{array}$ & $\begin{array}{r}309 \\
9 \\
0\end{array}$ \\
\hline 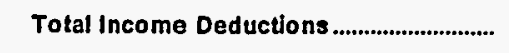 & 71 & 102 & 1,040 & 218 & 528 & 318 \\
\hline Income Before Extraordinary Items ................. & 1,107 & 634 & 2,406 & 6 & 1,319 & 1,270 \\
\hline 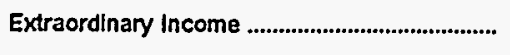 & 0 & 0 & 0 & 0 & 0 & $\mathbf{0}$ \\
\hline 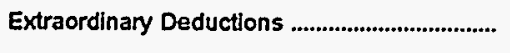 & 0 & 0 & 0 & 0 & 0 & 0 \\
\hline 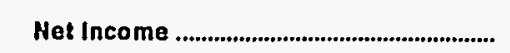 & 1,107 & 634 & 2,406 & 6 & 1,319 & 1,270 \\
\hline
\end{tabular}

Source: Energy Information Administration, Form EIA-412, "Annual Report of Public Electric Utilities." 
Table 21. Statement of Income by Major U.S. Publicly Owned Electric Utility Within State, 1995 (Continued) (Thousand Dollars)

\begin{tabular}{|c|c|c|c|c|c|c|}
\hline Item & $\begin{array}{c}\text { New York } \\
\text { Power } \\
\text { Authority } \\
\text { of State of NY } \\
\text { December } 31\end{array}$ & $\begin{array}{c}\text { New York } \\
\text { Rockville } \\
\text { Centre } \\
\text { Village of } \\
\text { May } 31\end{array}$ & $\begin{array}{c}\text { New York } \\
\text { Solvay } \\
\text { Village of } \\
\text { May } 31\end{array}$ & $\begin{array}{l}\text { North Carolina } \\
\text { Albemarle } \\
\text { City of } \\
\text { June } 30\end{array}$ & $\begin{array}{l}\text { North Carolina } \\
\text { Concord } \\
\text { City of } \\
\text { June } 30\end{array}$ & $\begin{array}{l}\text { North Carolina } \\
\text { Elizabeth } \\
\text { City City of } \\
\text { June } 30\end{array}$ \\
\hline Electric Utility Operating Revenues ............ & $1,412,691$ & 11,902 & 4,870 & 18,476 & 29,387 & 21,825 \\
\hline 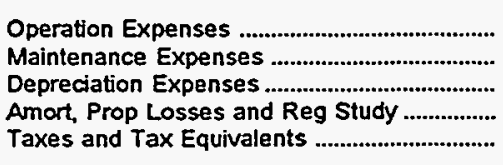 & $\begin{array}{r}1,006,936 \\
139,258 \\
209,475 \\
0 \\
0\end{array}$ & $\begin{array}{r}8,296 \\
0 \\
904 \\
0 \\
1,358\end{array}$ & $\begin{array}{r}4,052 \\
159 \\
286 \\
0 \\
115\end{array}$ & $\begin{array}{r}17,489 \\
0 \\
684 \\
0 \\
0\end{array}$ & $\begin{array}{r}19,215 \\
2,940 \\
1,035 \\
0 \\
0\end{array}$ & $\begin{array}{r}18,701 \\
476 \\
946 \\
0 \\
495\end{array}$ \\
\hline $\begin{array}{l}\text { Total Electric Utility Operating } \\
\text { Expenses }\end{array}$ & $1,355,669$ & 10,559 & 4,612 & 18,174 & 23,190 & 21,619 \\
\hline 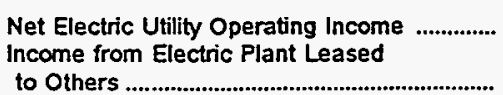 & $\begin{array}{r}57,022 \\
1,652\end{array}$ & 1,344 & 258 & 302 & 6,197 & $\begin{array}{r}206 \\
0\end{array}$ \\
\hline Electric Utility Operating Income ............. & 58,674 & 1,344 & 258 & 302 & 6,197 & 206 \\
\hline 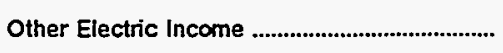 & 94,260 & 153 & 16 & 142 & 492 & 198 \\
\hline $\begin{array}{l}\text { Other Electric Deductions ............................... } \\
\text { Allowance for Other Funds Used } \\
\text { During Construction ....................................... } \\
\text { Taxes on Other Income and Deductions ........ }\end{array}$ & $\begin{array}{l}0 \\
0\end{array}$ & $\begin{array}{l}0 \\
0\end{array}$ & $\begin{array}{l}0 \\
0\end{array}$ & $\begin{array}{r}1,074 \\
0 \\
0\end{array}$ & $\begin{array}{l}0 \\
0\end{array}$ & 418 \\
\hline 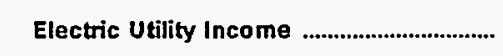 & 152,934 & 1,497 & 274 & -630 & 6,671 & -13 \\
\hline 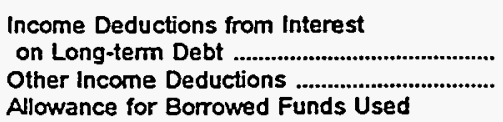 & $\begin{array}{r}188,560 \\
7,275\end{array}$ & $\begin{array}{r}780 \\
56\end{array}$ & $\begin{array}{r}137 \\
1\end{array}$ & $\begin{array}{l}0 \\
0\end{array}$ & $\begin{array}{r}276 \\
4,076\end{array}$ & $\begin{array}{l}\mathbf{0} \\
\mathbf{0}\end{array}$ \\
\hline 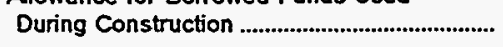 & 0 & -49 & 0 & 0 & 0 & $\mathbf{0}$ \\
\hline 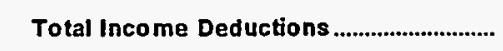 & 195,835 & 786 & 137 & 0 & 4,352 & 0 \\
\hline Income Before Extraordinary Items .................... & $-42,901$ & 710 & 136 & -630 & 2,319 & -13 \\
\hline 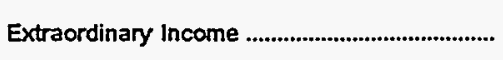 & 7,605 & 0 & 0 & 0 & 0 & 0 \\
\hline 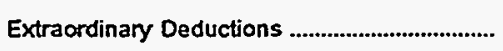 & 13,158 & 0 & 0 & 0 & 0 & $\mathbf{0}$ \\
\hline Net Income & $-48,454$ & 710 & 136 & -630 & 2,349 & -13 \\
\hline
\end{tabular}

Note: Totals may not equal sum of components because of independent rounding.

Source: Energy Information Administration, Form ElA-412, "Annual Report of Public Electric Utilities." 
Table 21. Statement of Income by Major U.S. Publicly Owned Electric Utility Within State, 1995 (Continued) (Thousand Dollars)

\begin{tabular}{|c|c|c|c|c|c|c|}
\hline Item & $\begin{array}{l}\text { North Carolina } \\
\text { Fayetteville } \\
\text { Public } \\
\text { Works Comm } \\
\text { June } 30\end{array}$ & $\begin{array}{l}\text { North Carolina } \\
\text { Forest City } \\
\text { Town of } \\
\text { June } 30\end{array}$ & $\begin{array}{l}\text { North Carolina } \\
\text { Gastonia } \\
\text { City of } \\
\text { June } 30\end{array}$ & $\begin{array}{l}\text { North Carolina } \\
\text { Greenville } \\
\text { Utilities } \\
\text { Comm } \\
\text { June } 30\end{array}$ & $\begin{array}{l}\text { North Carolina } \\
\text { High } \\
\text { Point } \\
\text { Town } \\
\text { of } \\
\text { June } 30\end{array}$ & $\begin{array}{l}\text { North Carolina } \\
\text { Kinston } \\
\text { City of } \\
\text { June } 30\end{array}$ \\
\hline Electric Utility Operating Revenues ............ & 118,521 & 8,404 & 43,378 & 96,822 & 65,104 & 36,052 \\
\hline 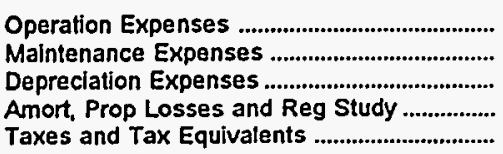 & $\begin{array}{r}74,298 \\
2,977 \\
8,687 \\
424 \\
19,969\end{array}$ & $\begin{array}{r}6,636 \\
24 \\
118 \\
0 \\
0\end{array}$ & $\begin{array}{r}33,291 \\
1,222 \\
1,410 \\
0 \\
0\end{array}$ & $\begin{array}{r}87,426 \\
2,362 \\
3,871 \\
0 \\
2,803\end{array}$ & $\begin{array}{r}50,721 \\
4,499 \\
1,728 \\
0 \\
0\end{array}$ & $\begin{array}{r}34,098 \\
0 \\
693 \\
2 \\
0\end{array}$ \\
\hline 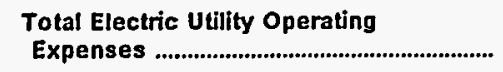 & 106,355 & 6,778 & 35,922 & 96,461 & 56,948 & 34,793 \\
\hline 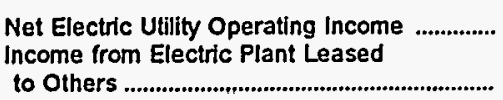 & 12,167 & 1,627 & 7,456 & 361 & $\begin{array}{r}8,156 \\
0\end{array}$ & $\begin{array}{r}1,258 \\
0\end{array}$ \\
\hline Electric Utility Operating Income ............. & 12,167 & 1,627 & 7,456 & 361 & 8,156 & 1,258 \\
\hline Other Electric Income & 1,913 & 312 & 250 & 984 & 765 & 722 \\
\hline $\begin{array}{l}\text { Other Electric Deductions .................................... } \\
\text { Allowance for Other Funds Used }\end{array}$ & 0 & 0 & 0 & 0 & 3,100 & 0 \\
\hline $\begin{array}{l}\text { During Construction ......................................... } \\
\text { Taxes on Other Income and Deductions ....... }\end{array}$ & $\begin{array}{l}0 \\
0\end{array}$ & $\begin{array}{l}0 \\
0\end{array}$ & $\begin{array}{l}0 \\
0\end{array}$ & $\begin{array}{l}0 \\
0\end{array}$ & $\begin{array}{l}0 \\
0\end{array}$ & $\begin{array}{l}0 \\
0\end{array}$ \\
\hline Electric Utility Income & 14,080 & 1,939 & 7,706 & 1,345 & 5,820 & 1,980 \\
\hline 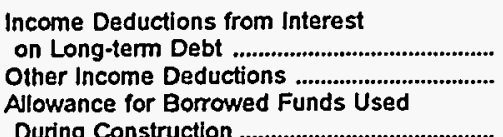 & $\begin{array}{r}3,231 \\
54\end{array}$ & $\begin{array}{l}0 \\
0\end{array}$ & $\begin{array}{r}0 \\
748\end{array}$ & $\begin{array}{r}286 \\
0 \\
0\end{array}$ & $\begin{array}{r}18 \\
0 \\
0\end{array}$ & $\begin{array}{r}244 \\
0 \\
0\end{array}$ \\
\hline Total Income Deductions ............................ & 3,285 & 0 & 748 & 286 & 18 & 244 \\
\hline Income Before Extraordinary Items ................. & 10,794 & 1.939 & 6,958 & 1,059 & 5,802 & 1,736 \\
\hline Extraordinary Income & 0 & 0 & 0 & 0 & 0 & $\mathbf{0}$ \\
\hline 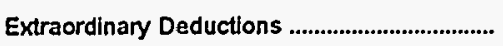 & 0 & 0 & 0 & o & 0 & 0 \\
\hline 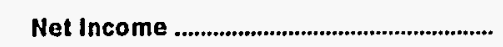 & 10,794 & 1,939 & 6,958 & 1,059 & 5,802 & 1,736 \\
\hline
\end{tabular}

Note: Totals may not equal sum of components because of independent rounding.

Source: Energy Information Administration, Form ElA-412, "Annual Report of Public Electric Utilities." 
Table 21. Statement of Income by Major U.S. Publicly Owned Electric Utility Within State, 1995 (Continued)

(Thousand Dollars)

\begin{tabular}{|c|c|c|c|c|c|c|}
\hline Item & $\begin{array}{c}\text { North Carolina } \\
\text { Laurinburg } \\
\text { City of }\end{array}$ & $\begin{array}{l}\text { North Caroina } \\
\text { Lexington } \\
\text { City of } \\
\text { June } 30\end{array}$ & $\begin{array}{c}\text { North Carolina } \\
\text { Lumberton } \\
\text { City of } \\
\text { June } 30\end{array}$ & $\begin{array}{l}\text { North Carolina } \\
\text { Monroe } \\
\text { City of } \\
\text { June } 30\end{array}$ & $\begin{array}{c}\text { North Carolina } \\
\text { Morganton } \\
\text { City of } \\
\text { June } 30\end{array}$ & $\begin{array}{l}\text { North Carolina } \\
\text { Murphy } \\
\text { Clty of } \\
\text { June } 30\end{array}$ \\
\hline Electric Utility Operating Revenues ............ & 0 & 35,879 & 21,846 & 27,951 & 19,541 & 6,714 \\
\hline 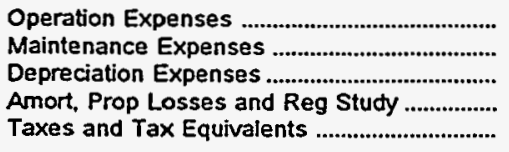 & $\begin{array}{l}0 \\
0 \\
0 \\
0 \\
0\end{array}$ & $\begin{array}{r}29,747 \\
186 \\
767 \\
0 \\
773\end{array}$ & $\begin{array}{r}20,908 \\
83 \\
491 \\
0 \\
0\end{array}$ & $\begin{array}{r}23,192 \\
0 \\
893 \\
0 \\
639\end{array}$ & $\begin{array}{r}16,522 \\
0 \\
450 \\
0 \\
0\end{array}$ & $\begin{array}{r}6,101 \\
162 \\
234 \\
0 \\
59\end{array}$ \\
\hline $\begin{array}{c}\text { Total Electric Utility Operating } \\
\text { Expenses }\end{array}$ & 0 & 31,474 & 21,482 & 24,724 & 16,972 & 6,556 \\
\hline 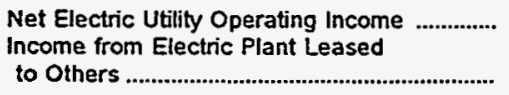 & 0 & $\begin{array}{r}4,405 \\
0\end{array}$ & 365 & 3,227 & 2,569 & 159 \\
\hline Electric Utility Operating Income .............. & $\mathbf{0}$ & 4,405 & 365 & 3,227 & 2,569 & 159 \\
\hline Other Electric Income & 0 & 96 & 817 & 930 & 388 & 217 \\
\hline 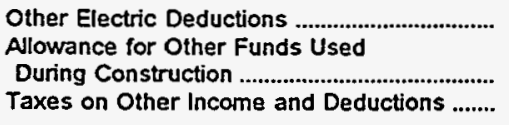 & $\begin{array}{l}0 \\
0\end{array}$ & 4,260 & 1,700 & $\begin{array}{l}0 \\
0\end{array}$ & $\begin{array}{l}0 \\
0\end{array}$ & $\begin{array}{l}0 \\
0\end{array}$ \\
\hline Electric Utility Income & 0 & 241 & -519 & 4,157 & 2,956 & 365 \\
\hline 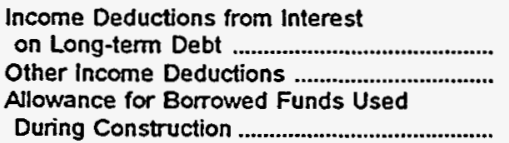 & $\begin{array}{l}0 \\
0\end{array}$ & $\begin{array}{r}41 \\
0\end{array}$ & $\begin{array}{r}1 \\
139\end{array}$ & $\begin{array}{r}4 \\
917\end{array}$ & $\begin{array}{r}0 \\
187\end{array}$ & $\begin{array}{l}\mathbf{0} \\
\mathbf{0}\end{array}$ \\
\hline 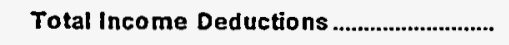 & 0 & $\mathbf{4 1}$ & 140 & 921 & 187 & 0 \\
\hline Income Before Extraordinary Items ...................... & 0 & 200 & -659 & 3,236 & 2,769 & 365 \\
\hline Extraordinary Income & 0 & 0 & 0 & 0 & 0 & 0 \\
\hline 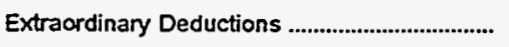 & 0 & 0 & 0 & 0 & 0 & 0 \\
\hline Net Income & $\mathbf{0}$ & 200 & -659 & 3,236 & 2,769 & 365 \\
\hline
\end{tabular}

Note: Totals may not equal sum of components because of inderendent rounaing.

Sou:se: Energy Information Ad!n:nistration, Form ElA-412. "Annual Report of Public Electric Utitities." 
Table 21. Statement of Income by Major U.S. Publicly Owned Electric Utility Within State, 1995 (Continued)

(Thousand Dollars)

\begin{tabular}{|c|c|c|c|c|c|c|}
\hline Item & $\begin{array}{l}\text { North Carolina } \\
\text { New Bern } \\
\text { City of } \\
\text { June } 30\end{array}$ & $\begin{array}{c}\text { North Carolina } \\
\text { New River } \\
\text { Light } \\
\& \\
\text { Power Co } \\
\text { December } 31\end{array}$ & $\begin{array}{c}\text { North Carollna } \\
\text { North } \\
\text { Carolina } \\
\text { Eastern M P A } \\
\text { December } 31\end{array}$ & $\begin{array}{c}\text { North Carolina } \\
\text { North } \\
\text { Carolina } \\
\text { Mun } \\
\text { Power Agny } \\
\text { December } 31\end{array}$ & $\begin{array}{l}\text { North Carolina } \\
\text { Rocky Mount } \\
\text { City of } \\
\text { June } 30\end{array}$ & $\begin{array}{l}\text { North Carolina } \\
\text { Shelby } \\
\text { City of } \\
\text { June } 30\end{array}$ \\
\hline Electric Utility Operating Revenues ............ & 34,422 & 12,324 & 462,664 & 413,852 & 61,184 & 12,464 \\
\hline 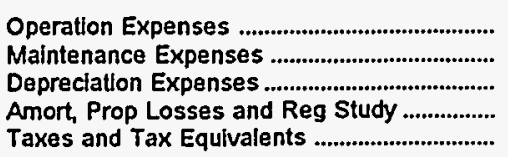 & $\begin{array}{r}32,036 \\
0 \\
915 \\
0 \\
0\end{array}$ & $\begin{array}{r}10,243 \\
0 \\
341 \\
0 \\
396\end{array}$ & $\begin{array}{r}230,553 \\
14,954 \\
49,642 \\
0 \\
17,925\end{array}$ & $\begin{array}{r}200,643 \\
43,942 \\
46,221 \\
0 \\
21,956\end{array}$ & $\begin{array}{r}55,847 \\
0 \\
1,212 \\
0 \\
0\end{array}$ & $\begin{array}{r}9.841 \\
335 \\
255 \\
0 \\
0\end{array}$ \\
\hline 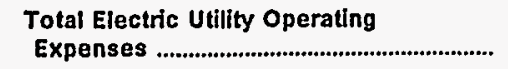 & 32,951 & 10,980 & 313,074 & 312,762 & 57,059 & 10,431 \\
\hline 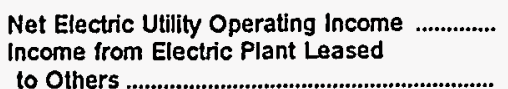 & $\begin{array}{r}1,472 \\
0\end{array}$ & 1,343 & 149,590 & 101,090 & 4.126 & $\begin{array}{r}2,032 \\
0\end{array}$ \\
\hline Electric Utility Operating Income ............... & 1,472 & 1,343 & 149,590 & 101,090 & 4,126 & 2,032 \\
\hline 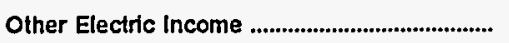 & 260 & 153 & 102,228 & 65,728 & 76 & 163 \\
\hline $\begin{array}{l}\text { Other Electric Deductions .................................. } \\
\text { Allowance for Other Funds Used }\end{array}$ & 0 & 0 & 0 & 0 & 0 & 0 \\
\hline 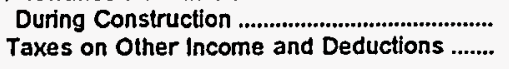 & $\begin{array}{l}0 \\
0\end{array}$ & $\begin{array}{l}0 \\
0\end{array}$ & $\begin{array}{l}0 \\
0\end{array}$ & $\begin{array}{l}0 \\
0\end{array}$ & $\begin{array}{l}0 \\
0\end{array}$ & $\begin{array}{l}0 \\
0\end{array}$ \\
\hline 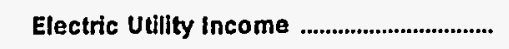 & 1,732 & 1,496 & 251,818 & 166,818 & 4,202 & 2,198 \\
\hline 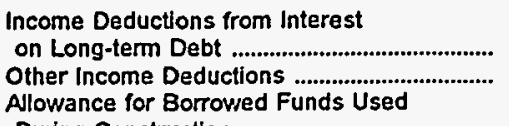 & $\begin{array}{r}53 \\
0\end{array}$ & $\begin{array}{l}0 \\
0\end{array}$ & $\begin{array}{r}219,127 \\
34,227\end{array}$ & $\begin{array}{r}139,084 \\
27,734\end{array}$ & $\begin{array}{r}82 \\
3.739\end{array}$ & $\begin{array}{r}89 \\
2\end{array}$ \\
\hline 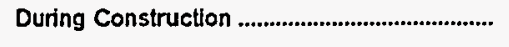 & 0 & 0 & $-1,536$ & 0 & 0 & 0 \\
\hline 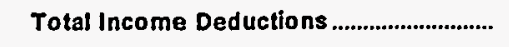 & 53 & 0 & 251,818 & 166,818 & 3,821 & 91 \\
\hline Income Before Extraordinary Items .................... & 1,679 & 1,496 & 0 & 0 & 380 & 2,104 \\
\hline Extraordinary Income & 0 & 0 & 0 & 0 & $\mathbf{0}$ & 0 \\
\hline 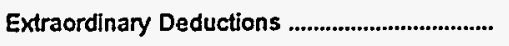 & 0 & 0 & 0 & 0 & 0 & 0 \\
\hline 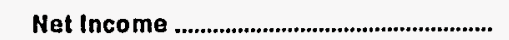 & 1,679 & 1,496 & $\mathbf{0}$ & $\mathbf{0}$ & 380 & 2,104 \\
\hline
\end{tabular}

Note: Totals may not equal sum of components because of independent rounding.

Source: Energy Information Administration, Form Eln-412, "Annual Report of Public Electric Utihties." 
Table 21. Statement of Income by Major U.S. Publicly Owned Electric Utility Within State, 1995 (Continued)

(Thousand Dollars)

\begin{tabular}{|c|c|c|c|c|c|c|}
\hline Item & $\begin{array}{l}\text { North Carolina } \\
\text { Statesville } \\
\text { City of } \\
\text { June } 30\end{array}$ & $\begin{array}{l}\text { North Carolina } \\
\text { Tarboro } \\
\text { Town of } \\
\text { June } 30\end{array}$ & $\begin{array}{l}\text { North Carolina } \\
\text { Washington } \\
\text { City of } \\
\text { June } 30\end{array}$ & $\begin{array}{l}\text { North Carolina } \\
\text { Wilson } \\
\text { City of } \\
\text { June } 30\end{array}$ & $\begin{array}{c}\text { Ohio } \\
\text { American } \\
\text { Mun } \\
\text { Power } \\
\text { Ohio Inc } \\
\text { December } 31\end{array}$ & $\begin{array}{c}\text { Ohio } \\
\text { Bowling } \\
\text { Green } \\
\text { City of } \\
\text { December } 31\end{array}$ \\
\hline Electric Utility Operating Revenues ............. & 25,901 & 21,046 & 21,605 & 83,402 & 161,933 & 17,560 \\
\hline 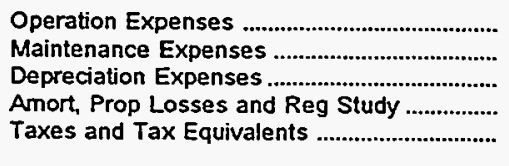 & $\begin{array}{r}23,458 \\
0 \\
562 \\
0 \\
0\end{array}$ & $\begin{array}{r}19,170 \\
0 \\
591 \\
0 \\
0\end{array}$ & $\begin{array}{r}19,598 \\
1,031 \\
1,033 \\
0 \\
0\end{array}$ & $\begin{array}{r}76,312 \\
534 \\
1,733 \\
0 \\
0\end{array}$ & $\begin{array}{r}135,854 \\
7.850 \\
3.490 \\
548 \\
8,255\end{array}$ & $\begin{array}{r}16,021 \\
876 \\
515 \\
0 \\
1\end{array}$ \\
\hline $\begin{array}{l}\text { Total Electric Utility Operating } \\
\text { Expenses . }\end{array}$ & 24,020 & 19,761 & 21,662 & 78,579 & 155,997 & 17,413 \\
\hline 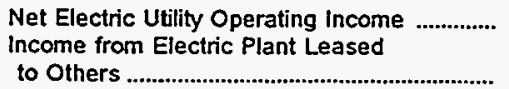 & $\begin{array}{r}1,882 \\
0\end{array}$ & 1,285 & $\begin{array}{r}-57 \\
0\end{array}$ & 4,823 & 5,936 & 147 \\
\hline Electric Utility Operating Income ............... & 1,882 & 1,285 & -57 & 4,823 & 5,936 & 147 \\
\hline Other Electric Income & 365 & 436 & 773 & 1,620 & 1,237 & 636 \\
\hline $\begin{array}{l}\text { Other Electric Deductions } \\
\text { Allowance for Other Funds Used }\end{array}$ & 93 & 389 & 0 & 152 & 0 & 0 \\
\hline 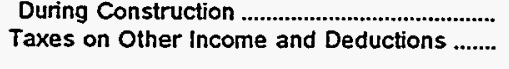 & $\begin{array}{l}0 \\
0\end{array}$ & $\begin{array}{r}0 \\
86\end{array}$ & $\begin{array}{l}0 \\
0\end{array}$ & $\begin{array}{l}0 \\
0\end{array}$ & $\begin{array}{l}0 \\
0\end{array}$ & $\begin{array}{l}0 \\
0\end{array}$ \\
\hline 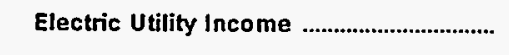 & 2,154 & 1,246 & 716 & 6,292 & 7,174 & 783 \\
\hline 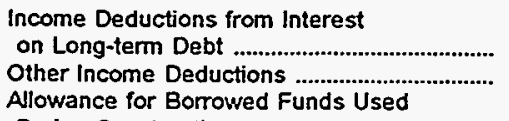 & $\begin{array}{r}637 \\
0\end{array}$ & $\begin{array}{l}0 \\
0\end{array}$ & $\begin{array}{r}285 \\
0\end{array}$ & $\begin{array}{r}44 \\
0\end{array}$ & $\begin{array}{r}6,920 \\
0\end{array}$ & $\begin{array}{l}8 \\
0\end{array}$ \\
\hline 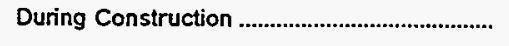 & 0 & 0 & 0 & 0 & 0 & 0 \\
\hline 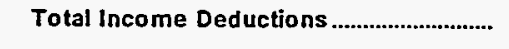 & 637 & 0 & 285 & 44 & 6,920 & 8 \\
\hline Income Before Extraordinary Items ...................... & 1,517 & 1,246 & 431 & 6,248 & 254 & 775 \\
\hline Extraordinary Income & 0 & 0 & 0 & 0 & 0 & $\mathbf{0}$ \\
\hline 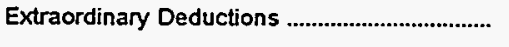 & 0 & 0 & 0 & 0 & 0 & 0 \\
\hline 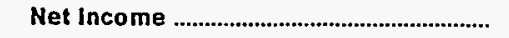 & 1,517 & 1,246 & 431 & 6,248 & 254 & 775 \\
\hline
\end{tabular}

Note: Totals may not equal sum of components because of independent rounding

Source: Energy Information Administration. Form EIA-412, "Annual Report of Public Electric Utilities." 
Table 21. Statement of Income by Major U.S. Publicly Owned Electric Utility Within State, 1995 (Continued)

(Thousand Dollars)

\begin{tabular}{|c|c|c|c|c|c|c|}
\hline Item & $\begin{array}{c}\text { Ohio } \\
\text { Bryan } \\
\text { City of } \\
\text { December } 31\end{array}$ & $\begin{array}{c}\text { Ohio } \\
\text { Celina } \\
\text { City of } \\
\text { December } 31\end{array}$ & $\begin{array}{c}\text { Ohio } \\
\text { Cleveland } \\
\text { City of } \\
\text { December } 31\end{array}$ & $\begin{array}{c}\text { Ohio } \\
\text { Clyde } \\
\text { City of } \\
\text { December } 31\end{array}$ & $\begin{array}{c}\text { Ohio } \\
\text { Columbus } \\
\text { City of } \\
\text { December } 31\end{array}$ & $\begin{array}{l}\text { Ohio } \\
\text { Cuyahoga } \\
\text { Falls } \\
\text { City of } \\
\text { December } 31\end{array}$ \\
\hline Electric Utility Operating Revenues ............. & 10,887 & 7,254 & 90,724 & 6,654 & 40,420 & 20,207 \\
\hline 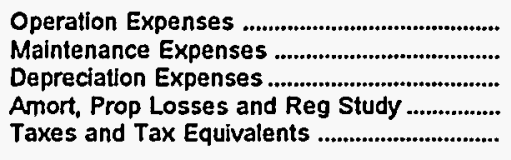 & $\begin{array}{r}10,494 \\
462 \\
273 \\
0 \\
0\end{array}$ & $\begin{array}{r}5,945 \\
497 \\
0 \\
0 \\
0\end{array}$ & $\begin{array}{r}54,778 \\
16,537 \\
5,885 \\
0 \\
0\end{array}$ & $\begin{array}{r}5,016 \\
0 \\
0 \\
0 \\
0\end{array}$ & $\begin{array}{r}24,676 \\
7,714 \\
2,636 \\
0 \\
0\end{array}$ & $\begin{array}{r}18,617 \\
0 \\
736 \\
0 \\
0\end{array}$ \\
\hline 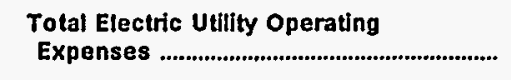 & 11,229 & 6,442 & 77,201 & 5,016 & 35,026 & 19,352 \\
\hline 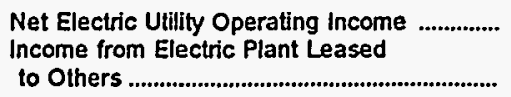 & $\begin{array}{r}-342 \\
0\end{array}$ & 812 & 13,523 & 1,638 & 5,394 & 855 \\
\hline Electric Utility Operating Income .............. & -342 & 812 & 13,523 & 1,638 & 5,394 & 855 \\
\hline Other Electric Income & 221 & 83 & 1,349 & 7 & 1,265 & 2 \\
\hline Other Electric Deductions & 0 & 0 & 13 & 74 & 0 & 0 \\
\hline 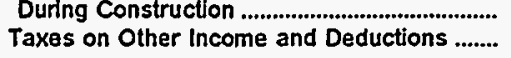 & $\begin{array}{l}0 \\
0\end{array}$ & $\begin{array}{l}0 \\
0\end{array}$ & $\begin{array}{l}0 \\
0\end{array}$ & $\begin{array}{l}0 \\
0\end{array}$ & $\begin{array}{l}0 \\
0\end{array}$ & $\begin{array}{l}0 \\
0\end{array}$ \\
\hline Electric Utility Income & -121 & 896 & 14,859 & 1,572 & 6,659 & 857 \\
\hline 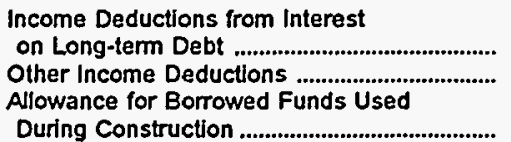 & $\begin{array}{r}34 \\
0\end{array}$ & $\begin{array}{r}0 \\
2,166\end{array}$ & $\begin{array}{r}10,126 \\
0\end{array}$ & $\begin{array}{r}775 \\
0\end{array}$ & $\begin{array}{r}3,717 \\
0\end{array}$ & $\begin{array}{r}246 \\
0\end{array}$ \\
\hline 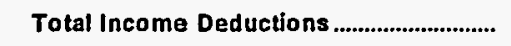 & 34 & 2,166 & 10,126 & 775 & 3,717 & 246 \\
\hline Income Before Extraordinary Items ................... & -155 & $-1,270$ & 4,733 & 797 & 2.942 & 610 \\
\hline Extraordinary Income & 0 & 0 & 0 & 0 & 0 & 0 \\
\hline 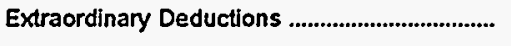 & 0 & 0 & 0 & 0 & 0 & 0 \\
\hline Net Income ................................................................. & -155 & $-1,270$ & 4,733 & 797 & 2,942 & 610 \\
\hline
\end{tabular}

Source: Energy Information Administration, Form ElA-412, "Annual Report of Public Electric Utilities." 
Table 21. Statement of Income by Major U.S. Publicly Owned Electric Utility Within State, 1995 (Continued)

(Thousand Dollars)

\begin{tabular}{|c|c|c|c|c|c|c|}
\hline Item & $\begin{array}{c}\text { Ohio } \\
\text { Dover } \\
\text { City of } \\
\text { December } 31\end{array}$ & $\begin{array}{c}\text { Ohio } \\
\text { Hamilton } \\
\text { City of } \\
\text { December } 31\end{array}$ & $\begin{array}{c}\text { Ohio } \\
\text { Napoleon } \\
\text { City of } \\
\text { December } 31\end{array}$ & $\begin{array}{c}\text { Ohio } \\
\text { Niles } \\
\text { City of } \\
\text { December } 31\end{array}$ & $\begin{array}{c}\text { Ohio } \\
\text { Orville } \\
\text { City of } \\
\text { December } 31\end{array}$ & $\begin{array}{c}\text { Ohio } \\
\text { Painesville } \\
\text { City of } \\
\text { December } 31\end{array}$ \\
\hline Electric Utility Operating Revenues ............ & 15,251 & 44,879 & 9,328 & 17,227 & 16,107 & 14,463 \\
\hline 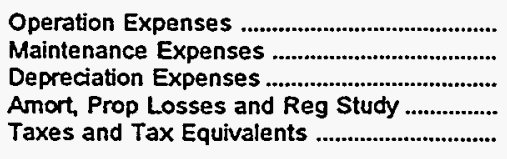 & $\begin{array}{r}7,125 \\
0 \\
2,639 \\
0 \\
0\end{array}$ & $\begin{array}{r}24,103 \\
3,587 \\
6,709 \\
0 \\
0\end{array}$ & $\begin{array}{r}9,513 \\
0 \\
0 \\
0 \\
0\end{array}$ & $\begin{array}{r}17,150 \\
0 \\
0 \\
0 \\
0\end{array}$ & $\begin{array}{r}10,104 \\
2,147 \\
1,498 \\
0 \\
65\end{array}$ & $\begin{array}{r}12,316 \\
0 \\
1,161 \\
0 \\
0\end{array}$ \\
\hline $\begin{array}{l}\text { Total Electric Utility Operating } \\
\text { Expenses }\end{array}$ & 9,764 & 34,399 & 9,513 & 17,150 & 13,814 & 13,477 \\
\hline $\begin{array}{l}\text { Net Electric Utility Operating Income } \\
\text { Income from Electric Plant Leased } \\
\text { to Others }\end{array}$ & 5,487 & 10.479 & $\begin{array}{r}-185 \\
532\end{array}$ & 77 & 2,293 & 986 \\
\hline Electric Utility Operating Income ............. & 5,487 & 10,479 & 347 & 77 & 2,293 & 986 \\
\hline 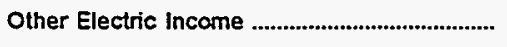 & 19 & 2,711 & 0 & 52 & 576 & 678 \\
\hline $\begin{array}{l}\text { Other Electric Deductions ................................ } \\
\text { Allowance for Other Funds Used }\end{array}$ & 0 & 0 & 0 & 0 & 1,542 & 0 \\
\hline $\begin{array}{l}\text { During Construction ................................ } \\
\text { Taxes on Other Income and Deductions ...... }\end{array}$ & $\begin{array}{l}0 \\
0\end{array}$ & $\begin{array}{l}0 \\
0\end{array}$ & $\begin{array}{l}0 \\
0\end{array}$ & $\begin{array}{l}0 \\
0\end{array}$ & $\begin{array}{l}0 \\
0\end{array}$ & $\begin{array}{l}0 \\
0\end{array}$ \\
\hline Electric Utility Income ................................. & 5,505 & 13,190 & 347 & 129 & 1,326 & 1,664 \\
\hline 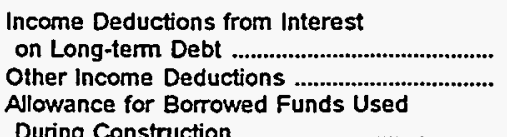 & $\begin{array}{r}383 \\
0\end{array}$ & $\begin{array}{r}12,599 \\
0\end{array}$ & $\begin{array}{l}0 \\
0\end{array}$ & $\begin{array}{l}0 \\
0\end{array}$ & $\begin{array}{l}0 \\
0\end{array}$ & $\begin{array}{r}369 \\
19\end{array}$ \\
\hline During Construction & 383 & $\begin{array}{r}0 \\
12,599\end{array}$ & 0 & $\begin{array}{l}0 \\
0\end{array}$ & $\begin{array}{l}0 \\
0\end{array}$ & $\begin{array}{r}0 \\
389\end{array}$ \\
\hline 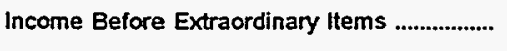 & 5,122 & 592 & 347 & 129 & 1,326 & 1,275 \\
\hline Extraordinary Income & 0 & 0 & 0 & 0 & 0 & 5 \\
\hline 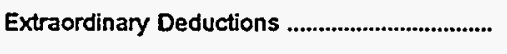 & 0 & 0 & 0 & 0 & 0 & 19 \\
\hline Net Income & 5,122 & 592 & 347 & 129 & 1,326 & 1,261 \\
\hline
\end{tabular}

Note: Totals may not equal sum of components because of independent rounding.

Source: Energy Information Administration, Form ElA-412, "Annual Report of Public Electric Utilities." 
Table 21. Statement of Income by Major U.S. Publicly Owned Electric Utility Within State, 1995 (Continued)

(Thousand Dollars)

\begin{tabular}{|c|c|c|c|c|c|c|}
\hline Item & $\begin{array}{c}\text { Ohio } \\
\text { Piqua } \\
\text { City of } \\
\text { December } 31\end{array}$ & $\begin{array}{c}\text { Ohio } \\
\text { St Marys } \\
\text { City of } \\
\text { December } 31\end{array}$ & $\begin{array}{c}\text { Ohio } \\
\text { Wadsworth } \\
\text { City of }\end{array}$ & $\begin{array}{c}\text { Ohio } \\
\text { Wapakoneta } \\
\text { City of }\end{array}$ & $\begin{array}{c}\text { Ohio } \\
\text { Westerville } \\
\text { City of } \\
\text { December } 31\end{array}$ & $\begin{array}{l}\text { Oklahoma } \\
\text { Altus } \\
\text { City of } \\
\text { June } 30\end{array}$ \\
\hline Electric Utility Operating Revenues ............. & 15,623 & 7,754 & 12,730 & 6,988 & 19,010 & 10,318 \\
\hline 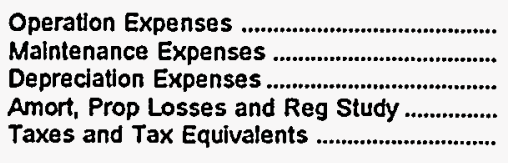 & $\begin{array}{r}11,059 \\
1,269 \\
1,029 \\
0 \\
0\end{array}$ & $\begin{array}{r}6,491 \\
1,199 \\
284 \\
0 \\
0\end{array}$ & $\begin{array}{r}12,291 \\
0 \\
416 \\
0 \\
0\end{array}$ & $\begin{array}{r}6,310 \\
386 \\
0 \\
0 \\
0\end{array}$ & $\begin{array}{r}12,171 \\
3,249 \\
850 \\
0 \\
0\end{array}$ & $\begin{array}{r}8,249 \\
54 \\
443 \\
0 \\
0\end{array}$ \\
\hline 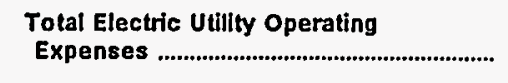 & 13,357 & 7,974 & 12,707 & 6,696 & 16,271 & 8,745 \\
\hline 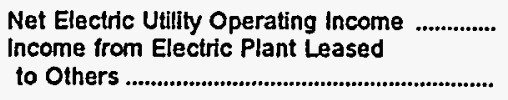 & $\begin{array}{r}2,266 \\
0\end{array}$ & $\begin{array}{r}-223 \\
15\end{array}$ & 24 & 292 & $\begin{array}{r}2,739 \\
0\end{array}$ & $\begin{array}{r}1,572 \\
0\end{array}$ \\
\hline Electric Utility Operating Income .............. & 2,266 & -208 & 24 & 292 & 2,739 & 1,572 \\
\hline 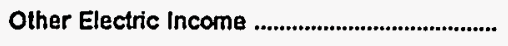 & 228 & 266 & 276 & 0 & 0 & 294 \\
\hline $\begin{array}{l}\text { Other Electric Deductions ............................... } \\
\text { Allowance for Other Funds Used } \\
\text { During Construction ........................................ } \\
\text { Taxes on Other Income and Deductions ....... }\end{array}$ & 211 & $\begin{array}{l}0 \\
0\end{array}$ & $\begin{array}{l}0 \\
0\end{array}$ & $\begin{array}{l}0 \\
0\end{array}$ & $\begin{array}{l}0 \\
0\end{array}$ & $\begin{array}{l}0 \\
0\end{array}$ \\
\hline Electric Utility Income & 2,283 & 58 & 275 & 292 & 2,735 & 1,866 \\
\hline 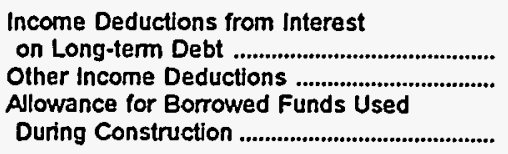 & $\begin{array}{r}504 \\
0\end{array}$ & $\begin{array}{r}356 \\
0\end{array}$ & $\stackrel{0}{0}$ & 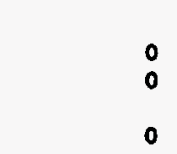 & $\begin{array}{l}0 \\
0\end{array}$ & $\begin{array}{l}\mathbf{0} \\
\mathbf{0}\end{array}$ \\
\hline 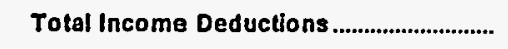 & 504 & 356 & 0 & 0 & 0 & $\mathbf{0}$ \\
\hline Income Before Extraordinary Items ...................... & 1,779 & -298 & 275 & 292 & 2,735 & 1,866 \\
\hline Extraordinary Income & 0 & 0 & 0 & 0 & 0 & $\mathbf{0}$ \\
\hline 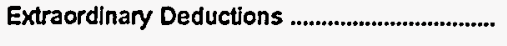 & 0 & 0 & 0 & 0 & 0 & 318 \\
\hline 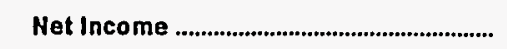 & 1,779 & -298 & 275 & 292 & 2,735 & 1,548 \\
\hline
\end{tabular}

Note: Totals may not equal sum of components because of independent rounding.

Source: Energy Information Administration. Form EIA-412, "Annual Report of Public Electric Utilities." 
Table 21. Statement of Income by Major U.S. Publicly Owned Electric Utility Within State, 1995 (Continued)

(Thousand Dollars)

\begin{tabular}{|c|c|c|c|c|c|c|}
\hline Item & $\begin{array}{l}\text { Oklahoma } \\
\text { Claremore } \\
\text { City of } \\
\text { June } 30\end{array}$ & $\begin{array}{l}\text { Oklahoma } \\
\text { Duncan } \\
\text { City of } \\
\text { June } 30\end{array}$ & $\begin{array}{l}\text { Oklahoma } \\
\text { Edmond } \\
\text { City of } \\
\text { June } 30\end{array}$ & $\begin{array}{c}\text { Oklahoma } \\
\text { Grand River } \\
\text { Dam } \\
\text { Authority } \\
\text { December } 31\end{array}$ & $\begin{array}{l}\text { OkJahoma } \\
\text { Miami } \\
\text { City of } \\
\text { June } 30\end{array}$ & $\begin{array}{c}\text { Oklahoma } \\
\text { Oklahoma } \\
\text { Municipal } \\
\text { Power Auth } \\
\text { December } 31\end{array}$ \\
\hline Electric Utility Operating Revenues ............ & 12,975 & 8,287 & 28,393 & 165,312 & 7,344 & 68,565 \\
\hline 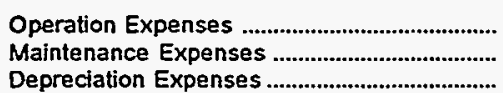 & $\begin{array}{r}7,760 \\
1,091 \\
0\end{array}$ & $\begin{array}{r}6,046 \\
20 \\
695\end{array}$ & $\begin{array}{r}23,789 \\
115 \\
1,441\end{array}$ & $\begin{array}{l}72,279 \\
11,558 \\
26,085\end{array}$ & $\begin{array}{r}5,233 \\
456 \\
142\end{array}$ & $\begin{array}{r}46,935 \\
1,869 \\
5,449\end{array}$ \\
\hline 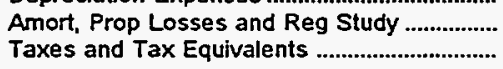 & 0 & $\begin{array}{l}\mathbf{0} \\
\mathbf{0}\end{array}$ & $\begin{array}{r}0 \\
3,441\end{array}$ & $\begin{array}{l}0 \\
0\end{array}$ & $\begin{array}{r}0 \\
1,023\end{array}$ & $\begin{array}{r}0 \\
1,208\end{array}$ \\
\hline $\begin{array}{l}\text { Total Electric Utility Operating } \\
\text { Expenses }\end{array}$ & 8,852 & 6,762 & 28,785 & 109,922 & 6,855 & 55,461 \\
\hline $\begin{array}{l}\text { Net Electric Utility Operating Income } \\
\text { Income from Electric Plant Leased }\end{array}$ & 4,123 & 1.526 & -393 & 55,390 & 489 & 13.104 \\
\hline 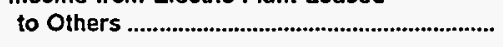 & 0 & 0 & 0 & 0 & 0 & $\mathbf{0}$ \\
\hline Electric Utility Operating Income .............. & 4,123 & 1,526 & -393 & 55,390 & 489 & 13,104 \\
\hline Other Electric Income & 0 & 365 & 410 & 16,175 & 244 & 4,338 \\
\hline $\begin{array}{l}\text { Other Electric Deductions ............................. } \\
\text { Allowance for Other Funds Used }\end{array}$ & 0 & 0 & 0 & 0 & 0 & 0 \\
\hline 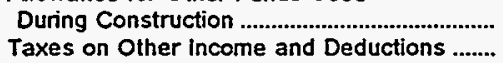 & $\begin{array}{l}0 \\
0\end{array}$ & $\begin{array}{l}0 \\
0\end{array}$ & $\begin{array}{l}0 \\
0\end{array}$ & $\begin{array}{l}0 \\
0\end{array}$ & $\begin{array}{l}0 \\
0\end{array}$ & $\begin{array}{l}0 \\
0\end{array}$ \\
\hline 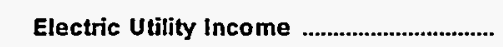 & 4,123 & 1,891 & 17 & 71,565 & 734 & 17,442 \\
\hline 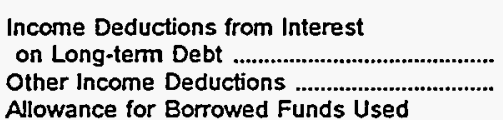 & $\begin{array}{l}0 \\
0\end{array}$ & $\begin{array}{r}0 \\
3,151\end{array}$ & $\begin{array}{r}160 \\
0\end{array}$ & $\begin{array}{l}59,898 \\
14,415\end{array}$ & $\begin{array}{l}0 \\
0\end{array}$ & $\begin{array}{r}21.619 \\
595\end{array}$ \\
\hline 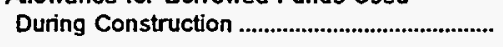 & 0 & 0 & 0 & 0 & 0 & 0 \\
\hline 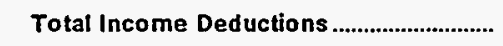 & 0 & 3,151 & 160 & 74,313 & $\mathbf{0}$ & 22,214 \\
\hline Income Before Extraordinary Items .................. & 4,123 & $-1,260$ & -142 & $-2,748$ & 734 & $-4,772$ \\
\hline 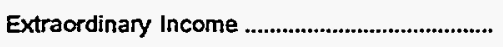 & 0 & 3 & 0 & 3,471 & 0 & 5,653 \\
\hline 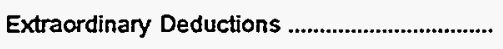 & 0 & 0 & 0 & 0 & 0 & 0 \\
\hline Net Income & 4,123 & $-1,257$ & -142 & 722 & 734 & 881 \\
\hline
\end{tabular}

Note: Totals may not equal sum of components because of independent rounding.

Source: Energy information Administration. Form EIA-412, "Annual Report of Public Electric Utilities." 
Table 21. Statement of Income by Major U.S. Publicly Owned Electric Utility Within State, 1995 (Continued)

(Thousand Dollars)

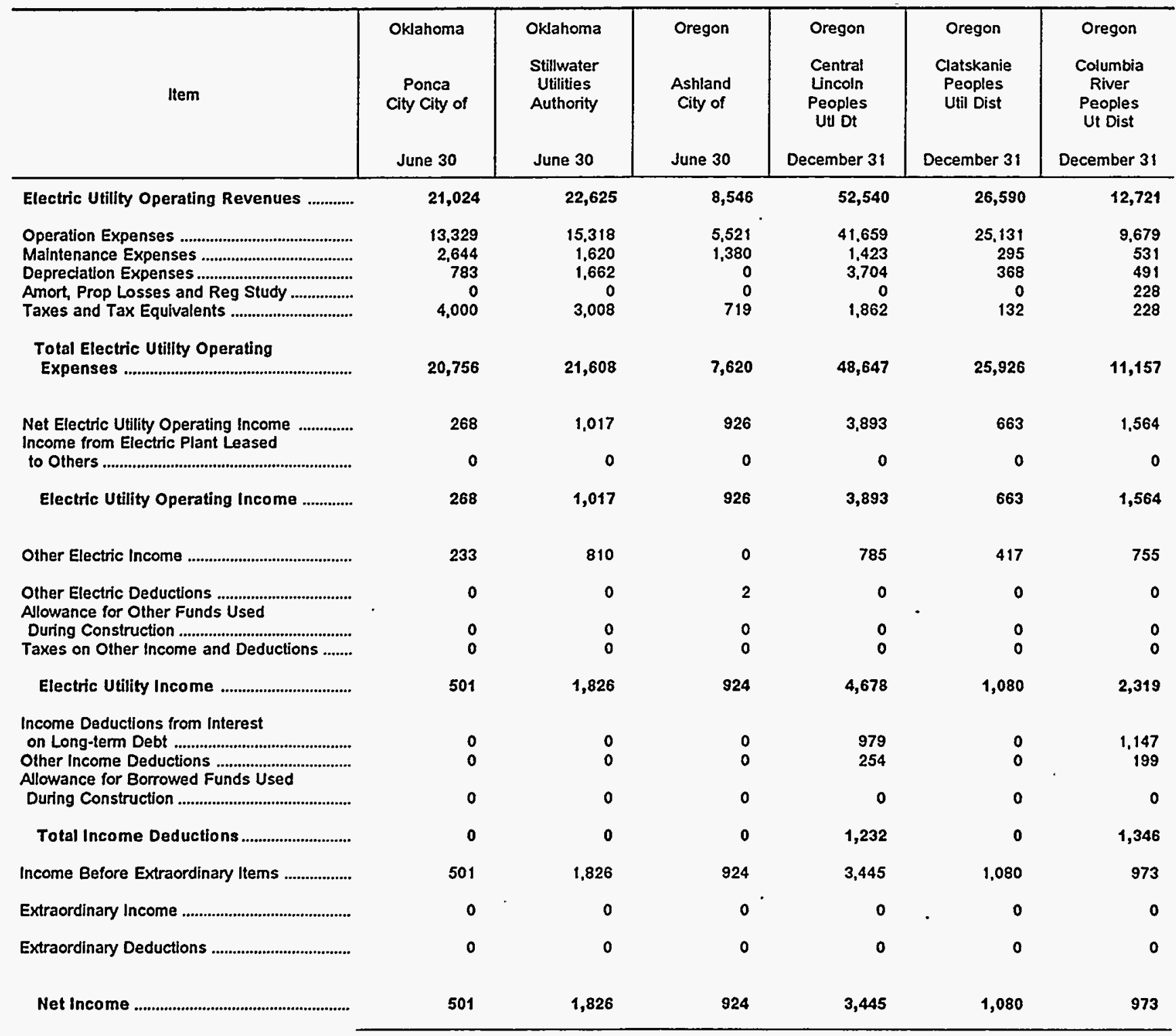

Note: Totals may not equal sum of components because of independent rounding.

Source: Energy Information Administration, Form EIA-412, "Annual Report of Public Electric Utilities." 
Table 21. Statement of Income by Major U.S. Publicly Owned Electric Utility Within State, 1995 (Continued)

(Thousand Dollars)

\begin{tabular}{|c|c|c|c|c|c|c|}
\hline Item & $\begin{array}{c}\text { Oregon } \\
\text { Emerald } \\
\text { Peoples } \\
\text { Utility Dist } \\
\text { December } 31\end{array}$ & $\begin{array}{l}\text { Oregon } \\
\text { Eugene } \\
\text { City of } \\
\text { December } 31\end{array}$ & $\begin{array}{c}\text { Oregon } \\
\text { Forest Grove } \\
\text { City of } \\
\text { June } 30\end{array}$ & $\begin{array}{l}\text { Oregon } \\
\begin{array}{c}\text { McMinnville } \\
\text { City of }\end{array} \\
\text { June } 30\end{array}$ & $\begin{array}{c}\text { Oregon } \\
\text { Northern } \\
\text { Wasco } \\
\text { County PUD } \\
\text { December } 31\end{array}$ & $\begin{array}{c}\text { Oregon } \\
\text { Springfield } \\
\text { City of } \\
\text { December } 31\end{array}$ \\
\hline Electric Utility Operating Revenues ............ & 21,736 & 103,967 & 8,233 & 22,475 & 12,954 & 32,865 \\
\hline 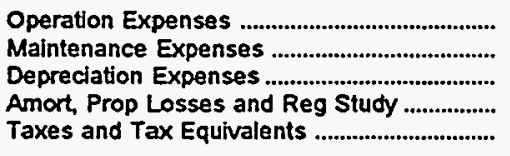 & $\begin{array}{r}13,062 \\
980 \\
2,195 \\
666 \\
387\end{array}$ & $\begin{array}{r}70,143 \\
4,048 \\
10,624 \\
0 \\
7,155\end{array}$ & $\begin{array}{r}6,431 \\
270 \\
419 \\
0 \\
474\end{array}$ & $\begin{array}{r}20,342 \\
0 \\
750 \\
0 \\
1,104\end{array}$ & $\begin{array}{r}9,038 \\
572 \\
1,087 \\
0 \\
489\end{array}$ & $\begin{array}{r}26,268 \\
890 \\
1,208 \\
166 \\
1,461\end{array}$ \\
\hline $\begin{array}{l}\text { Total Electric Utility Operating } \\
\text { Expenses }\end{array}$ & 17,290 & 91,970 & 7,594 & 22,195 & 14,186 & 29,991 \\
\hline 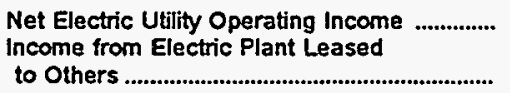 & $\begin{array}{r}4.446 \\
29\end{array}$ & $\begin{array}{r}11,897 \\
0\end{array}$ & $\begin{array}{r}639 \\
0\end{array}$ & $\begin{array}{r}280 \\
0\end{array}$ & $\begin{array}{r}1.769 \\
0\end{array}$ & $\begin{array}{r}2,874 \\
0\end{array}$ \\
\hline Electric Utility Operating Income .............. & 4,475 & 11,997 & 639 & 280 & 1,769 & 2,874 \\
\hline Other Electric Income & 1.009 & 2,030 & 55 & 636 & 3.219 & 461 \\
\hline $\begin{array}{l}\text { Other Electric Deductions } \\
\text { Allowance for Other Funds Used }\end{array}$ & 0 & 1.661 & 0 & $\mathbf{0}$ & 0 & 0 \\
\hline $\begin{array}{l}\text { During Construction .................................... } \\
\text { Taxes on Other Income and Deductions ....... }\end{array}$ & $\begin{array}{l}0 \\
0\end{array}$ & $\begin{array}{r}95 \\
0\end{array}$ & $\begin{array}{l}0 \\
0\end{array}$ & $\begin{array}{l}0 \\
0\end{array}$ & $\begin{array}{l}0 \\
0\end{array}$ & $\begin{array}{l}9 \\
0\end{array}$ \\
\hline Electric Utility Income .................................... & 5,484 & 12,461 & 694 & 816 & 4,988 & 3,343 \\
\hline 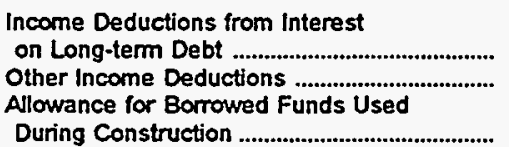 & $\begin{array}{r}4.065 \\
779\end{array}$ & $\begin{array}{r}5,142 \\
0 \\
-73\end{array}$ & $\begin{array}{r}0 \\
63 \\
0\end{array}$ & $\begin{array}{r}0 \\
134 \\
0\end{array}$ & $\begin{array}{r}1,471 \\
101 \\
0\end{array}$ & $\begin{array}{r}170 \\
24\end{array}$ \\
\hline Total Income Deductions ............................ & 4,844 & 5,070 & 63 & 134 & 1,572 & 194 \\
\hline Income Before Extraordinary Items ................... & 640 & 7,391 & 631 & 782 & 3,416 & 3,149 \\
\hline 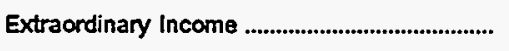 & $\mathbf{0}$ & 0 & 0 & 0 & 0 & 0 \\
\hline Extraordinary Deductions ......................................... & $\mathbf{0}$ & 0 & $\mathbf{0}$ & 0 & 0 & 0 \\
\hline Net Income & 640 & 7,391 & 631 & 782 & 3,416 & 3,149 \\
\hline
\end{tabular}

Note: Totals may not equal sum of components because of independent rounding.

Source: Energy Information Administration, Form EIA-412, "Annual Report of Public Electric Utilities." 
Table 21. Statement of Income by Major U.S. Publicly Owned Electric Utility Within State, 1995 (Continued)

(Thousand Dollars)

\begin{tabular}{|c|c|c|c|c|c|c|}
\hline Item & $\begin{array}{l}\text { Oregon } \\
\text { Tillamook } \\
\text { Peoples } \\
\text { Utility Dist } \\
\text { December } 31\end{array}$ & $\begin{array}{l}\text { Pennsylvania } \\
\text { Chambersburg } \\
\text { Borough of } \\
\text { December } 31\end{array}$ & $\begin{array}{c}\text { Pennsylvania } \\
\text { Ephrata } \\
\text { Borough of } \\
\text { December } 31\end{array}$ & $\begin{array}{l}\text { Pennsylvania } \\
\text { Lansdale } \\
\text { Borough of } \\
\text { December } 31\end{array}$ & $\begin{array}{l}\text { South Carolina } \\
\text { Camden } \\
\text { City of } \\
\text { June } 30\end{array}$ & $\begin{array}{c}\text { South Carolina } \\
\text { Easley } \\
\text { Combined } \\
\text { Utility } \\
\text { System } \\
\text { March } 31\end{array}$ \\
\hline Electric Utility Operating Revenues ............. & 17,675 & 14,611 & 8,911 & 11,080 & 10,194 & 14,438 \\
\hline 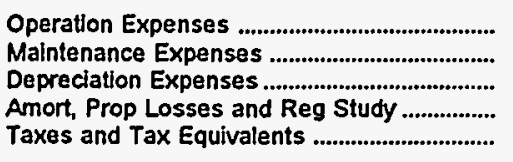 & $\begin{array}{r}14,104 \\
1,250 \\
1,213 \\
41 \\
572\end{array}$ & $\begin{array}{r}11,891 \\
296 \\
761 \\
0 \\
550\end{array}$ & $\begin{array}{r}6,316 \\
2,413 \\
0 \\
0 \\
0\end{array}$ & $\begin{array}{r}7,881 \\
0 \\
378 \\
0 \\
0\end{array}$ & $\begin{array}{r}8,657 \\
0 \\
312 \\
0 \\
0\end{array}$ & $\begin{array}{r}11,810 \\
614 \\
541 \\
0 \\
0\end{array}$ \\
\hline 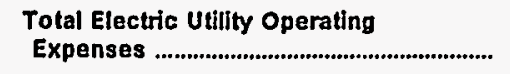 & 17,180 & 13,498 & 8,729 & 8,259 & 8,969 & 12,965 \\
\hline 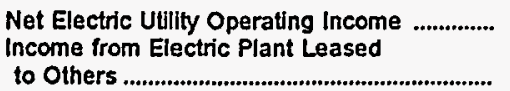 & 495 & 1,113 & 181 & $\begin{array}{r}2,821 \\
0\end{array}$ & $\begin{array}{r}1.225 \\
0\end{array}$ & $\begin{array}{r}1.472 \\
0\end{array}$ \\
\hline Electric Utility Operating Income .............. & 495 & 1,113 & 181 & 2,821 & 1,225 & 1,472 \\
\hline 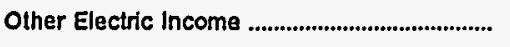 & 597 & 385 & $\mathbf{0}$ & 1,480 & 1,282 & 263 \\
\hline $\begin{array}{l}\text { Other Electric Deductions ............................. } \\
\text { Allowance for Other Funds Used }\end{array}$ & $\mathbf{0}$ & 100 & 0 & 0 & 0 & 162 \\
\hline 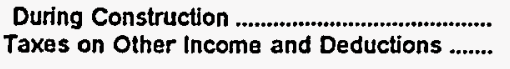 & $\begin{array}{l}0 \\
0\end{array}$ & $\begin{array}{l}0 \\
0\end{array}$ & $\begin{array}{l}0 \\
0\end{array}$ & $\begin{array}{l}0 \\
0\end{array}$ & $\begin{array}{l}0 \\
0\end{array}$ & $\begin{array}{l}0 \\
0\end{array}$ \\
\hline 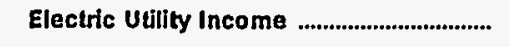 & 1,091 & 1,398 & 181 & 4,301 & 2,507 & 1,573 \\
\hline 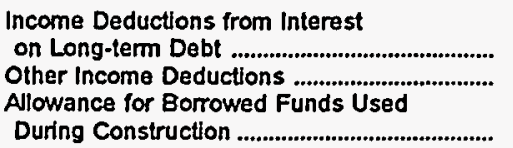 & $\begin{array}{r}686 \\
11\end{array}$ & $\begin{array}{l}0 \\
0\end{array}$ & $\begin{array}{l}0 \\
0\end{array}$ & $\begin{array}{r}451 \\
26\end{array}$ & $\begin{array}{r}246 \\
0\end{array}$ & $\begin{array}{l}221 \\
861\end{array}$ \\
\hline 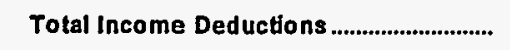 & 657 & $\mathbf{0}$ & 0 & 476 & 246 & 1,082 \\
\hline Income Before Extraordinary Items .................... & 434 & 1,398 & 181 & 3,824 & 2,262 & 492 \\
\hline 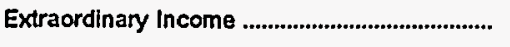 & 0 & 0 & 0 & 0 & 928 & 0 \\
\hline 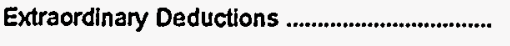 & 0 & 0 & 0 & 0 & 3,217 & 0 \\
\hline 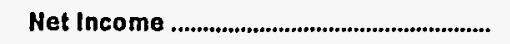 & 434 & 1,398 & 181 & 3,824 & -28 & 492 \\
\hline
\end{tabular}

Note: Totals may not equal sum of components because of independent rounding

Scurce: Energy Information Administration, Form ElA-412, "Annual Report of Public Electric Utilities." 
Table 21. Statement of Income by Major U.S. Publicly Owned Electric Utility Within State, 1995 (Continued) (Thousand Dollars)

\begin{tabular}{|c|c|c|c|c|c|c|}
\hline Item & $\begin{array}{l}\text { South Carolina } \\
\text { Gaffney } \\
\text { City of } \\
\text { March } 31\end{array}$ & $\begin{array}{l}\text { South Carolina } \\
\text { Greenwood } \\
\text { Commissioners } \\
\text { Pub Wk } \\
\text { December } 31\end{array}$ & $\begin{array}{c}\text { South Carolina } \\
\text { Greer } \\
\text { Comm } \\
\text { of } \\
\text { Public Works } \\
\text { December } 31\end{array}$ & $\begin{array}{l}\text { South Carolina } \\
\text { Newberry } \\
\text { City of } \\
\text { June } 30\end{array}$ & $\begin{array}{l}\text { South Carolina } \\
\text { Orangeburg } \\
\text { City of } \\
\text { September } 30\end{array}$ & $\begin{array}{c}\text { South Carolina } \\
\text { Piedmont } \\
\text { Municipal } \\
\text { Power Agny } \\
\text { December } 31\end{array}$ \\
\hline Electric Utility Operating Revenues ............ & 12,775 & 14,104 & 11,572 & 9,991 & 40,384 & 149,133 \\
\hline 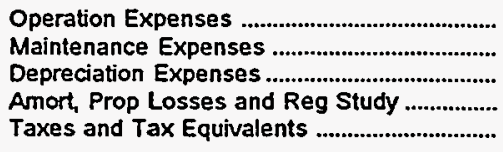 & $\begin{array}{r}9,473 \\
139 \\
929 \\
0 \\
0\end{array}$ & $\begin{array}{r}12,573 \\
0 \\
468 \\
0 \\
0\end{array}$ & $\begin{array}{r}10,165 \\
0 \\
564 \\
0 \\
0\end{array}$ & $\begin{array}{r}8,641 \\
0 \\
267 \\
0 \\
0\end{array}$ & $\begin{array}{r}33,269 \\
0 \\
1,530 \\
0 \\
0\end{array}$ & $\begin{array}{r}74,297 \\
12,308 \\
21.204 \\
0 \\
4,402\end{array}$ \\
\hline $\begin{array}{l}\text { Total Electric Utility Operating } \\
\text { Expenses }\end{array}$ & 10,541 & 13,042 & 10,729 & 8,908 & 34,800 & 112,211 \\
\hline $\begin{array}{l}\text { Net Electric Utility Operating Income } \\
\text { Income from Electric Plant Leased } \\
\text { to Others }\end{array}$ & $\begin{array}{r}2,234 \\
0\end{array}$ & $\begin{array}{r}1,062 \\
0\end{array}$ & $\begin{array}{r}843 \\
0\end{array}$ & $\begin{array}{r}1,083 \\
0\end{array}$ & $\begin{array}{r}5.584 \\
0\end{array}$ & $\begin{array}{r}36,922 \\
0\end{array}$ \\
\hline Electric Utility Operating Income ............. & 2,234 & 4,062 & 843 & 1,083 & 5,584 & 36,922 \\
\hline Other Electric Income & 216 & 309 & 1,827 & 296 & 505 & 36,587 \\
\hline $\begin{array}{l}\text { Other Electric Deductions } \\
\text { Allowance for Other Funds Used }\end{array}$ & 175 & -530 & 0 & 103 & 0 & $-32,889$ \\
\hline $\begin{array}{l}\text { During Construction ................................. } \\
\text { Taxes on Other Income and Deductions ...... }\end{array}$ & $\begin{array}{l}0 \\
0\end{array}$ & $\begin{array}{l}0 \\
0\end{array}$ & $\begin{array}{l}0 \\
0\end{array}$ & $\begin{array}{l}0 \\
0\end{array}$ & $\begin{array}{l}0 \\
0\end{array}$ & $\begin{array}{l}0 \\
0\end{array}$ \\
\hline 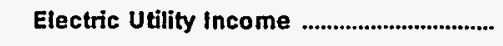 & 2,275 & 1,901 & 2,670 & 1,277 & 6,089 & 106,398 \\
\hline $\begin{array}{l}\text { Income Deductions from Interest } \\
\text { on Long-term Debt .......................................... } \\
\text { Other Income Deductions ............................ } \\
\text { Allowance for Borrowed Funds Used }\end{array}$ & $\begin{array}{l}0 \\
0\end{array}$ & $\begin{array}{l}0 \\
0\end{array}$ & $\begin{array}{r}334 \\
1,396\end{array}$ & $\begin{array}{r}85 \\
0\end{array}$ & $\begin{array}{r}166 \\
0\end{array}$ & $\begin{array}{l}86,624 \\
18,550\end{array}$ \\
\hline 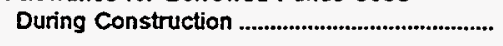 & 0 & 0 & 0 & 0 & 0 & 0 \\
\hline Total Income Deductions ............................. & $\mathbf{0}$ & 0 & 1,731 & 85 & 166 & 105,174 \\
\hline Income Before Extraordinary Items ..................... & 2,275 & 1,901 & 939 & 1,191 & 5,923 & 1,224 \\
\hline 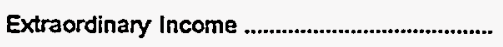 & 0 & 0 & 0 & 0 & 0 & $\mathbf{0}$ \\
\hline 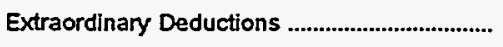 & 0 & 0 & 0 & 0 & 0 & 0 \\
\hline Net Income & 2,275 & 1,901 & 939 & 1,191 & 5,923 & 1,224 \\
\hline
\end{tabular}

Note: Totals may not equal sum of components because of independent rounding.

Source: Energy Information Administration, Form EIA-412, "Annual Report of Public Electric Utilities." 
Table 21. Statement of Income by Major U.S. Publicly Owned Electric Utility Within State, 1995 (Continued)

(Thousand Dollars)

\begin{tabular}{|c|c|c|c|c|c|c|}
\hline Item & $\begin{array}{l}\text { South Carolina } \\
\text { Rock Hill } \\
\text { City of } \\
\text { December } 31\end{array}$ & $\begin{array}{l}\text { South Carolina } \\
\text { Seneca } \\
\text { City of } \\
\text { June } 30\end{array}$ & $\begin{array}{l}\text { South Carolina } \\
\text { South } \\
\text { Carolina } \\
\text { Pub } \\
\text { Serv Auth } \\
\text { December } 31\end{array}$ & $\begin{array}{l}\text { South Dakota } \\
\text { Brookings } \\
\text { City of }\end{array}$ & $\begin{array}{l}\text { South Dakota } \\
\text { Heartland } \\
\text { Consumers } \\
\text { Power Dist } \\
\text { December } 31\end{array}$ & $\begin{array}{l}\text { South Dakota } \\
\text { Missouri } \\
\text { Basin } \\
\text { Mun } \\
\text { Power Agny } \\
\text { December } 31\end{array}$ \\
\hline Electric Utility Operating Revenues ............ & 42,203 & 8,756 & 640,361 & 8,662 & 12,439 & 59,899 \\
\hline 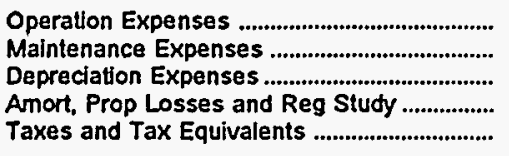 & $\begin{array}{r}29,116 \\
3,235 \\
1,013 \\
0 \\
7,591\end{array}$ & $\begin{array}{r}6,148 \\
122 \\
1,233 \\
0 \\
0\end{array}$ & $\begin{array}{r}328,545 \\
50,516 \\
90,692 \\
0 \\
1,917\end{array}$ & $\begin{array}{r}6,207 \\
793 \\
599 \\
2 \\
529\end{array}$ & $\begin{array}{r}8,139 \\
0 \\
1,158 \\
108 \\
371\end{array}$ & $\begin{array}{r}58,542 \\
0 \\
77 \\
0 \\
24\end{array}$ \\
\hline $\begin{array}{l}\text { Total Electric Utility Operating } \\
\text { Expenses }\end{array}$ & 40,956 & 7,503 & 471,670 & 8,130 & 9,776 & 58,643 \\
\hline 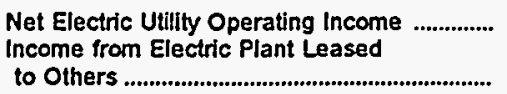 & 1,246 & 1.253 & 168,691 & 532 & 2,663 & 1,255 \\
\hline Electric Utility Operating Income .............. & 1,246 & 1,253 & 168,691 & 532 & 2,663 & 1,255 \\
\hline Other Electric Income & 1,264 & 0 & 20,663 & 152 & 995 & 1,099 \\
\hline $\begin{array}{l}\text { Other Electric Deductions .................................. } \\
\text { Allowance for Other Funds Used }\end{array}$ & 24 & 0 & 0 & 0 & 0 & 0 \\
\hline 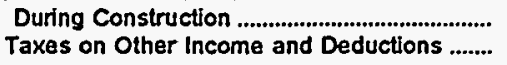 & $\begin{array}{l}0 \\
0\end{array}$ & $\begin{array}{l}0 \\
0\end{array}$ & $\begin{array}{l}0 \\
0\end{array}$ & $\begin{array}{l}0 \\
0\end{array}$ & $\begin{array}{l}0 \\
0\end{array}$ & $\begin{array}{l}0 \\
0\end{array}$ \\
\hline 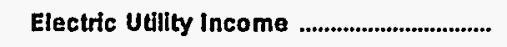 & 2,487 & 1,253 & 189,354 & 685 & 3,658 & 2,354 \\
\hline 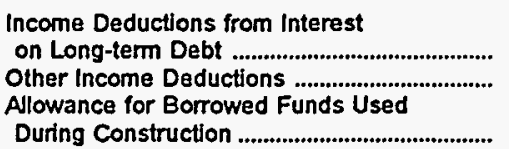 & $\begin{array}{r}568 \\
1,599\end{array}$ & $\begin{array}{l}0 \\
0\end{array}$ & $\begin{array}{r}123,865 \\
15,186\end{array}$ & $\begin{array}{l}0 \\
0\end{array}$ & $\begin{array}{r}3.843 \\
-216\end{array}$ & $\begin{array}{l}0 \\
0\end{array}$ \\
\hline Total Income Deductions ................................. & 2,167 & 0 & 139,051 & 0 & 3,627 & 0 \\
\hline Income Before Extraordinary Items .................. & 320 & 1,253 & 50,303 & 685 & 31 & 2,354 \\
\hline 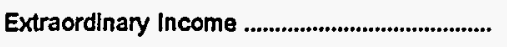 & 0 & 0 & 0 & 0 & 0 & 0 \\
\hline 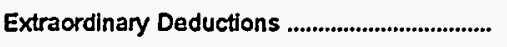 & 0 & 0 & 0 & 0 & 0 & 0 \\
\hline Net Income & 320 & 1,253 & 50,303 & 685 & 31 & 2,354 \\
\hline
\end{tabular}

Note: Totals may not equal sum of components because of independent rounding.

Source: Energy Information Administration. Form EIA-412, "Annual Report of Public Electric Utilities." 
Table 21. Statement of Income by Major U.S. Publicly Owned Electric Utility Within State, 1995 (Continued)

(Thousand Dollars)

\begin{tabular}{|c|c|c|c|c|c|c|}
\hline Item & $\begin{array}{c}\text { South Dakota } \\
\text { Pierre } \\
\text { City of } \\
\text { December } 31\end{array}$ & $\begin{array}{l}\text { South Dakota } \\
\text { Watertown } \\
\text { Municipal } \\
\text { Utilities } \\
\text { December } 31\end{array}$ & $\begin{array}{c}\text { Tennessee } \\
\text { Alcoa } \\
\text { Utilities } \\
\text { June } 30\end{array}$ & $\begin{array}{l}\text { Tennessee } \\
\text { Athens } \\
\text { Utility } \\
\text { Board } \\
\text { June } 30\end{array}$ & $\begin{array}{l}\text { Tennessee } \\
\text { Benton } \\
\text { County } \\
\text { June } 30\end{array}$ & $\begin{array}{l}\text { Tennessee } \\
\text { Bolivar } \\
\text { City of } \\
\text { June } \mathbf{3 0}\end{array}$ \\
\hline Electric Utility Operating Revenues ............ & 7,253 & 9,365 & 24,659 & 25,630 & 12,162 & 12,665 \\
\hline 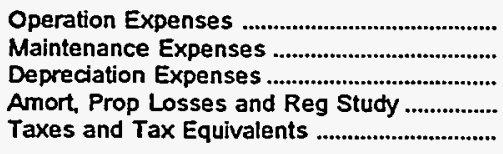 & $\begin{array}{r}5,219 \\
164 \\
0 \\
0 \\
2,115\end{array}$ & $\begin{array}{r}7,985 \\
637 \\
864 \\
0 \\
0\end{array}$ & $\begin{array}{r}22,102 \\
1,002 \\
676 \\
0 \\
541\end{array}$ & $\begin{array}{r}23,456 \\
870 \\
594 \\
2 \\
485\end{array}$ & $\begin{array}{r}10,523 \\
753 \\
484 \\
0 \\
355\end{array}$ & $\begin{array}{r}11,215 \\
531 \\
527 \\
0 \\
307\end{array}$ \\
\hline $\begin{array}{l}\text { Total Electric Utility Operating } \\
\text { Expenses }\end{array}$ & 7,499 & 9,486 & 24,321 & 25,407 & 12,116 & 12,579 \\
\hline 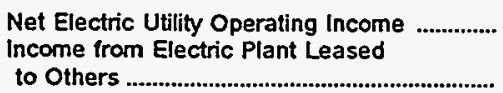 & $\begin{array}{r}-245 \\
0\end{array}$ & $\begin{array}{r}-121 \\
0\end{array}$ & 338 & 223 & 46 & 85 \\
\hline Electric Utility Operating Income ............. & -245 & -121 & 338 & 223 & 46 & 85 \\
\hline Other Electric Income ............................................. & -26 & 307 & 575 & 286 & 267 & 166 \\
\hline Other Electric Deductions .............................. & 0 & 548 & 0 & 31 & 0 & 0 \\
\hline 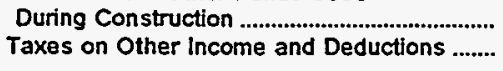 & $\begin{array}{l}0 \\
0\end{array}$ & $\begin{array}{l}0 \\
0\end{array}$ & $\begin{array}{l}0 \\
0\end{array}$ & $\begin{array}{l}0 \\
0\end{array}$ & $\begin{array}{l}0 \\
0\end{array}$ & $\begin{array}{l}0 \\
0\end{array}$ \\
\hline 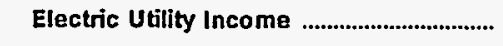 & -272 & -362 & 913 & 477 & 313 & 251 \\
\hline 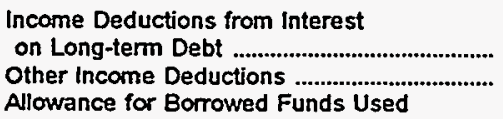 & $\begin{array}{l}0 \\
0\end{array}$ & $\begin{array}{l}0 \\
0\end{array}$ & $\begin{array}{r}156 \\
6\end{array}$ & $\begin{array}{l}0 \\
0\end{array}$ & $\begin{array}{r}32 \\
1\end{array}$ & $\begin{array}{r}145 \\
2\end{array}$ \\
\hline 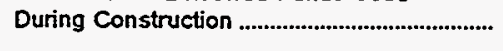 & 0 & 0 & 0 & 0 & 0 & 0 \\
\hline Total Income Deductions ............................. & $\mathbf{0}$ & 0 & 162 & 0 & 33 & 147 \\
\hline Income Before Extraordinary Items .................. & -272 & -362 & 751 & 477 & 280 & 105 \\
\hline 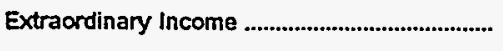 & 0 & 0 & 0 & 0 & 0 & $\mathbf{0}$ \\
\hline 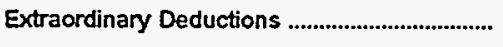 & 0 & 0 & 50 & 0 & 0 & $\mathbf{0}$ \\
\hline Net Income & -272 & -362 & 702 & 477 & 280 & 105 \\
\hline
\end{tabular}

Note: Totals may not equal sum of components because of independent rounding.

Source: Energy Information Administration, Form EIA-412, "Annual Report of Public Electric Utilities." 
Table 21. Statement of Income by Major U.S; Publicly Owned Electric Utility Within State, 1995 (Continued)

(Thousand Dollars)

\begin{tabular}{|c|c|c|c|c|c|c|}
\hline Item & $\begin{array}{l}\text { Tennessee } \\
\text { Bristol } \\
\text { City of } \\
\text { June } 30\end{array}$ & $\begin{array}{l}\text { Tennessee } \\
\text { Brownsville } \\
\text { City of } \\
\text { June } 30\end{array}$ & $\begin{array}{l}\text { Tennessee } \\
\text { Carroll } \\
\text { County } \\
\text { June } 30\end{array}$ & $\begin{array}{c}\text { Tennessee } \\
\begin{array}{c}\text { Chattanooga } \\
\text { City of }\end{array} \\
\text { June } 30\end{array}$ & $\begin{array}{l}\text { Tennessee } \\
\text { Clarksville } \\
\text { City of } \\
\text { June } 30\end{array}$ & $\begin{array}{l}\text { Tennessee } \\
\text { Cleveland } \\
\text { City of } \\
\text { June } 30\end{array}$ \\
\hline Electric Utility Operating Revenues ............ & 40,358 & 9,776 & 21,287 & 282,660 & 49,254 & 46,599 \\
\hline 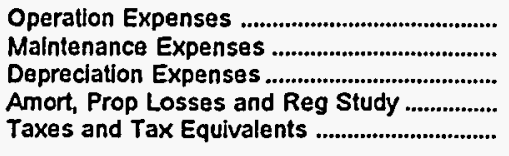 & $\begin{array}{r}36,481 \\
1,870 \\
1,188 \\
0 \\
995\end{array}$ & $\begin{array}{r}9,027 \\
107 \\
201 \\
37 \\
173\end{array}$ & $\begin{array}{r}19,157 \\
229 \\
635 \\
-24 \\
413\end{array}$ & $\begin{array}{r}255,300 \\
9,946 \\
8,453 \\
0 \\
7,447\end{array}$ & $\begin{array}{r}43,539 \\
1,554 \\
1,161 \\
1,745 \\
927\end{array}$ & $\begin{array}{r}41,583 \\
1,262 \\
1,430 \\
177 \\
1,021\end{array}$ \\
\hline 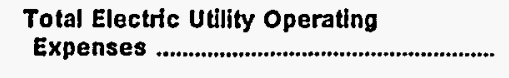 & 40,534 & 9,545 & 20,410 & 281,146 & 48,927 & 45,473 \\
\hline 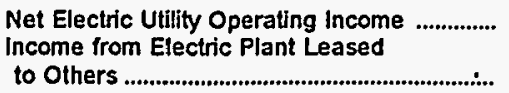 & $\begin{array}{r}-175 \\
0\end{array}$ & $\begin{array}{r}231 \\
0\end{array}$ & $\begin{array}{r}878 \\
0\end{array}$ & $\begin{array}{r}1,513 \\
0\end{array}$ & 328 & 1.126 \\
\hline Electric Utility Operating Income ............. & -175 & 231 & 878 & $\cdot 1,513$ & 328 & 1,126 \\
\hline Other Electric Income & 1,881 & 159 & 307 & 3,957 & 1,363 & 579 \\
\hline $\begin{array}{l}\text { Other Electric Deductions ............................. } \\
\text { Allowance for Other Funds Used } \\
\text { During Construction }\end{array}$ & 0 & 0 & 0 & 0 & 2 & 0 \\
\hline $\begin{array}{l}\text { During Construction ........................................ } \\
\text { Taxes on Olher Income and Deductions ....... }\end{array}$ & $\begin{array}{l}0 \\
0\end{array}$ & $\begin{array}{l}0 \\
0\end{array}$ & $\begin{array}{l}0 \\
0\end{array}$ & $\begin{array}{l}0 \\
0\end{array}$ & $\begin{array}{l}0 \\
0\end{array}$ & $\begin{array}{l}0 \\
0\end{array}$ \\
\hline 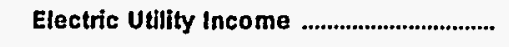 & 1,786 & 390 & 1,185 & 5,471 & 1,688 & 1,706 \\
\hline 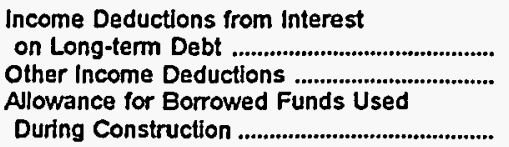 & $\begin{array}{r}0 \\
18 \\
0\end{array}$ & $\begin{array}{r}33 \\
1 \\
0\end{array}$ & $\begin{array}{r}40 \\
3 \\
0\end{array}$ & $\begin{array}{r}0 \\
273 \\
0\end{array}$ & $\begin{array}{r}454 \\
54\end{array}$ & $\begin{array}{r}0 \\
49\end{array}$ \\
\hline Total Income Deductions ............................ & 18 & 33 & 44 & 273 & 508 & 49 \\
\hline Income Before Extraordinary Items ................. & 1,768 & 357 & 1,141 & 5,198 & 1.180 & 1,657 \\
\hline Extraordinary Income ............................................. & 0 & 0 & 0 & 0 & 0 & 0 \\
\hline 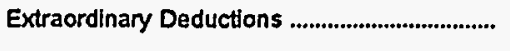 & 0 & 0 & 0 & 0 & 0 & 0 \\
\hline Net Income & 1,768 & 357 & 1,141 & 5,198 & 1,180 & 1,657 \\
\hline
\end{tabular}

Note: Totals may not equal sum of components because of independent rounding.

Source: Energy Information Administration, Form ElA-412, "Annual Report of Public Electric Utilities." 
Table 21. Statement of Income by Major U.S. Publicly Owned Electric Utility Within State, 1995 (Continued)

(Thousand Dollars)

\begin{tabular}{|c|c|c|c|c|c|c|}
\hline Item & $\begin{array}{l}\text { Tennessee } \\
\text { Clinton } \\
\text { City of } \\
\text { June } 30\end{array}$ & $\begin{array}{c}\text { Tennessee } \\
\text { Columbia } \\
\text { City of } \\
\text { June } 30\end{array}$ & $\begin{array}{l}\text { Tennessee } \\
\text { Cookeville } \\
\text { City of } \\
\text { June } 30\end{array}$ & $\begin{array}{l}\text { Tennessee } \\
\begin{array}{c}\text { Covington } \\
\text { City of }\end{array} \\
\text { June } 30\end{array}$ & $\begin{array}{l}\text { Tennessee } \\
\text { Dayton } \\
\text { City of } \\
\text { June } 30\end{array}$ & $\begin{array}{l}\text { Tennessee } \\
\text { Dickson } \\
\text { City of } \\
\text { June } 30\end{array}$ \\
\hline Electric Utility Operating Revenues ............. & 34,945 & 27,149 & 25,813 & 11,458 & 10,807 & 33,887 \\
\hline 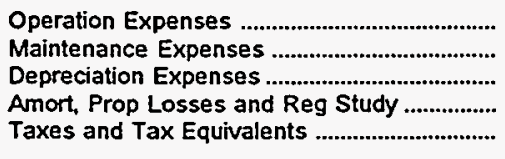 & $\begin{array}{r}30,943 \\
1,251 \\
1.265 \\
0 \\
950\end{array}$ & $\begin{array}{r}24,595 \\
952 \\
1,008 \\
0 \\
580\end{array}$ & $\begin{array}{r}23.469 \\
746 \\
621 \\
90 \\
458\end{array}$ & $\begin{array}{r}10,303 \\
236 \\
220 \\
175 \\
228\end{array}$ & $\begin{array}{r}9,547 \\
293 \\
269 \\
0 \\
234\end{array}$ & $\begin{array}{r}29,805 \\
2,191 \\
1,185 \\
0 \\
575\end{array}$ \\
\hline $\begin{array}{l}\text { Total Electric Utility Operating } \\
\text { Expenses ......................................................... }\end{array}$ & 34,410 & 27,134 & 25,384 & 11,163 & 10,344 & 33,756 \\
\hline 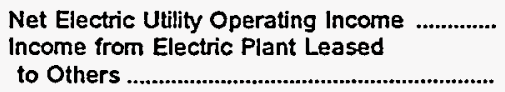 & 535 & 15 & $\begin{array}{r}429 \\
0\end{array}$ & 295 & 463 & 131 \\
\hline Electric Utility Operating Income ............... & 535 & 15 & 429 & 295 & 463 & 131 \\
\hline Other Electric Income & 572 & 388 & 302 & 453 & 132 & 645 \\
\hline $\begin{array}{l}\text { Other Electric Deductions } \\
\text { Allowance for Other Funds Used } \\
\text { During Construction ......................................... } \\
\text { Taxes on Other Income and Deductions ....... }\end{array}$ & $\begin{array}{l}0 \\
0\end{array}$ & $\begin{array}{l}0 \\
0\end{array}$ & $\stackrel{0}{0}$ & $\begin{array}{l}0 \\
0\end{array}$ & $\stackrel{0}{0}$ & $\begin{array}{l}0 \\
0\end{array}$ \\
\hline 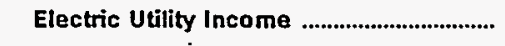 & 1,101 & 403 & 732 & 743 & 595 & 776 \\
\hline $\begin{array}{l}\text { Income Deductions from Interest } \\
\text { on Long-term Debt .......................................... } \\
\text { other Income Deductions....................... } \\
\text { Allowance for Borrowed Funds Used }\end{array}$ & $\begin{array}{r}82 \\
1\end{array}$ & $\begin{array}{r}128 \\
29\end{array}$ & $\begin{array}{l}64 \\
21\end{array}$ & $\begin{array}{r}38 \\
2\end{array}$ & $\begin{array}{l}0 \\
0\end{array}$ & $\begin{array}{r}797 \\
6\end{array}$ \\
\hline 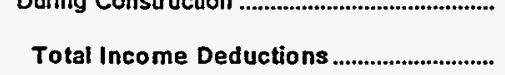 & 83 & 156 & 85 & 40 & 0 & 887 \\
\hline Income Before Extraordinary Items ...................... & 1,018 & 246 & 647 & 703 & 595 & -111 \\
\hline Extraordinary Income & 0 & 0 & 0 & 0 & 0 & 0 \\
\hline 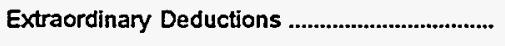 & 0 & 0 & 78 & 0 & 0 & 0 \\
\hline 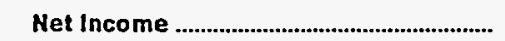 & 1,018 & 246 & 569 & 703 & 595 & -111 \\
\hline
\end{tabular}

Note: Totals may not equal sum of components because of independent rounding.

Source: Energy Information Administration. Form ElA-412, "Annual Report of Public Electric Utilities." 
Table 21. Statement of Income by Major U.S. Publicly Owned Electric Utility Within State, 1995 (Continued) (Thousand Dollars)

\begin{tabular}{|c|c|c|c|c|c|c|}
\hline Item & $\begin{array}{c}\text { Tennessee } \\
\text { Dyersburg } \\
\text { City of } \\
\text { June } 30\end{array}$ & $\begin{array}{c}\text { Tennessee } \\
\text { Elizabethton } \\
\text { City of } \\
\text { June } 30\end{array}$ & $\begin{array}{c}\text { Tennessee } \\
\text { Enwin } \\
\text { Town of } \\
\text { June } 30\end{array}$ & $\begin{array}{l}\text { Tennessee } \\
\text { Etswah } \\
\text { City of } \\
\text { June } 30\end{array}$ & $\begin{array}{c}\text { Tennessee } \\
\text { Fayetteville } \\
\text { City of } \\
\text { June } 30\end{array}$ & $\begin{array}{l}\text { Tennessee } \\
\text { Gallatin } \\
\text { City of } \\
\text { June } 30\end{array}$ \\
\hline Electric Utllity Operating Revenues ............ & 29,177 & 27,765 & 10,564 & 7,028 & 21,997 & 22,646 \\
\hline 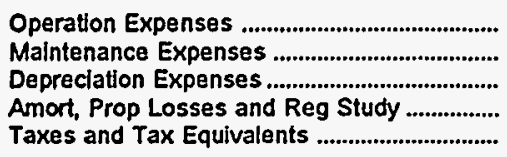 & $\begin{array}{r}25.436 \\
805 \\
977 \\
0 \\
637\end{array}$ & $\begin{array}{r}24,418 \\
711 \\
871 \\
0 \\
800\end{array}$ & $\begin{array}{r}9,599 \\
299 \\
266 \\
0 \\
216\end{array}$ & $\begin{array}{r}6,357 \\
310 \\
204 \\
0 \\
145\end{array}$ & $\begin{array}{r}18,956 \\
520 \\
915 \\
0 \\
657\end{array}$ & $\begin{array}{r}21,245 \\
418 \\
433 \\
37 \\
302\end{array}$ \\
\hline 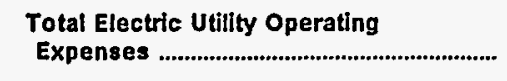 & 27,855 & 26,801 & 10,380 & 7,016 & 21,048 & 22,435 \\
\hline 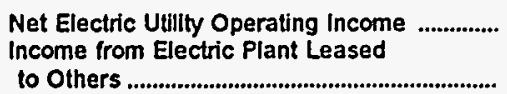 & 1,322 & 964 & 184 & 12 & 949 & 211 \\
\hline Electric Utility Operating Income .............. & 1,322 & 964 & 184 & 12 & 949 & 211 \\
\hline Other Electric Income & 716 & 301 & 191 & 117 & 627 & 500 \\
\hline $\begin{array}{l}\text { Other Electric Deductions } \\
\text { Alowance for Other Funds Used }\end{array}$ & 6 & 0 & 0 & 2 & 10 & 8 \\
\hline $\begin{array}{l}\text { During Construction ...................................... } \\
\text { Taxes on Other Income and Deductions ....... }\end{array}$ & $\begin{array}{l}0 \\
0\end{array}$ & $\begin{array}{l}0 \\
0\end{array}$ & $\begin{array}{l}0 \\
0\end{array}$ & $\begin{array}{l}0 \\
0\end{array}$ & $\begin{array}{l}0 \\
0\end{array}$ & $\begin{array}{l}0 \\
0\end{array}$ \\
\hline 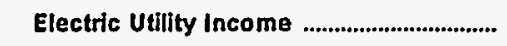 & 2,032 & 1,265 & 375 & 127 & 1,567 & 703 \\
\hline 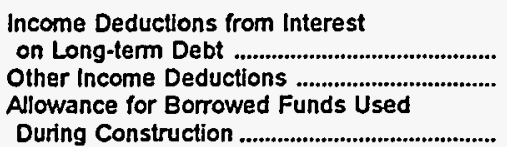 & $\begin{array}{r}412 \\
37\end{array}$ & $\begin{array}{l}43 \\
24\end{array}$ & $\begin{array}{l}0 \\
6 \\
0\end{array}$ & $\begin{array}{r}3 \\
26\end{array}$ & $\begin{array}{r}526 \\
23\end{array}$ & $\begin{array}{l}0 \\
6\end{array}$ \\
\hline 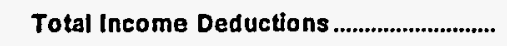 & 448 & 67 & 6 & 29 & 549 & 6 \\
\hline Income Before Extraordinary Items ................. & 1.583 & 1,198 & 369 & 98 & 1.018 & 697 \\
\hline 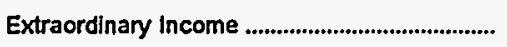 & 0 & 0 & 0 & 0 & 0 & 0 \\
\hline Extraordinary Deductions ..................................... & 0 & 0 & 0 & 0 & 0 & 0 \\
\hline Net Income & 1,583 & 1,198 & 369 & 98 & 1,018 & 697 \\
\hline
\end{tabular}

Note: Totals may not equal sum of components because of independent rounding.

Source: Energy Information Administration, Form EIA-412. "Annual Report of Public Electric Utilities." 
Table 21. Statement of Income by Major U.S. Publicly Owned Electric Utility Within State, 1995 (Continued)

(Thousand Dollars)

\begin{tabular}{|c|c|c|c|c|c|c|}
\hline Item & $\begin{array}{l}\text { Tennessee } \\
\text { Greeneville } \\
\text { City of } \\
\text { June } 30\end{array}$ & $\begin{array}{l}\text { Tennessee } \\
\begin{array}{c}\text { Harriman } \\
\text { City of }\end{array} \\
\text { June } 30\end{array}$ & $\begin{array}{l}\text { Tennessee } \\
\text { Humboldt } \\
\text { City of } \\
\text { June } 30\end{array}$ & $\begin{array}{l}\text { Tennessee } \\
\text { Jackson } \\
\text { City of } \\
\text { June } 30\end{array}$ & $\begin{array}{l}\text { Tennessee } \\
\text { Johnson } \\
\text { City City of } \\
\text { June } 30\end{array}$ & $\begin{array}{l}\text { Tennessee } \\
\text { Knoxvilte } \\
\text { Utilities } \\
\text { Board } \\
\text { June } 30\end{array}$ \\
\hline Electric Utility Operating Revenues .............. & 44,782 & 15,027 & 11,696 & 66,356 & 83,080 & 259,908 \\
\hline 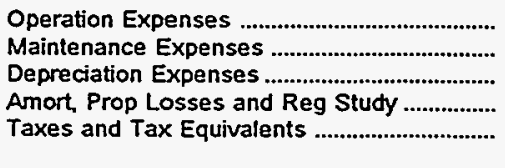 & $\begin{array}{r}41,655 \\
1,527 \\
1,495 \\
0 \\
801\end{array}$ & $\begin{array}{r}12,460 \\
755 \\
719 \\
0 \\
258\end{array}$ & $\begin{array}{r}11.187 \\
203 \\
236 \\
61 \\
201\end{array}$ & $\begin{array}{r}58,362 \\
1,316 \\
2,219 \\
65 \\
1,493\end{array}$ & $\begin{array}{r}75,722 \\
2,954 \\
2,059 \\
0 \\
1,652\end{array}$ & $\begin{array}{r}231,612 \\
8,785 \\
9,239 \\
0 \\
6,905\end{array}$ \\
\hline 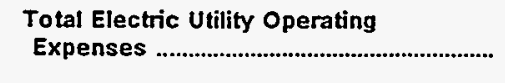 & 45,478 & 14,192 & 11,889 & 63,456 & 82,387 & 256,541 \\
\hline $\begin{array}{l}\text { Net Electric Utility Operating Income } \\
\text { Income from Electric Plant Leased } \\
\text { to Others }\end{array}$ & -696 & 835 & -192 & 2,900 & $\begin{array}{r}693 \\
0\end{array}$ & $\begin{array}{r}3,367 \\
0\end{array}$ \\
\hline Electric Utility Operating Income ............... & -696 & 835 & -192 & 2,900 & 693 & 3,367 \\
\hline 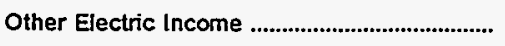 & 1,367 & 388 & 294 & 1,200 & 1,208 & $\mathbf{5 . 4 4 1}$ \\
\hline $\begin{array}{l}\text { Other Electric Deductions ........................................ } \\
\text { Allowance for Other Funds Used }\end{array}$ & 24 & 6 & 0 & 1 & 0 & 0 \\
\hline 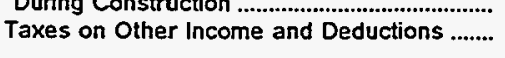 & 0 & $\begin{array}{l}0 \\
0\end{array}$ & $\begin{array}{l}0 \\
0\end{array}$ & $\begin{array}{l}0 \\
0\end{array}$ & $\begin{array}{l}0 \\
0\end{array}$ & $\begin{array}{l}0 \\
0\end{array}$ \\
\hline 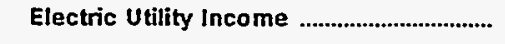 & 646 & 1,217 & 401 & 4,099 & 1,901 & 8,808 \\
\hline 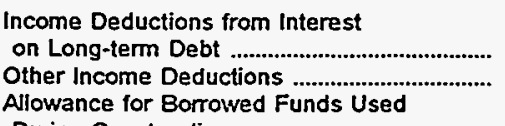 & $\begin{array}{l}0 \\
0\end{array}$ & $\begin{array}{r}28 \\
1\end{array}$ & $\begin{array}{r}11 \\
0\end{array}$ & $\begin{array}{r}743 \\
29\end{array}$ & $\begin{array}{r}0 \\
36\end{array}$ & $\begin{array}{r}1,787 \\
254\end{array}$ \\
\hline 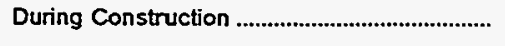 & 0 & 22 & 0 & 0 & 0 & 0 \\
\hline 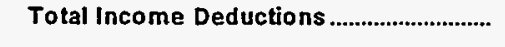 & 0 & 50 & 11 & 772 & 36 & 2,021 \\
\hline Income Before Extraordinary Items ...................... & 646 & 1,167 & 90 & 3,328 & 1,866 & 6,787 \\
\hline Extraordinary Income & 0 & 0 & 0 & 0 & 916 & 0 \\
\hline 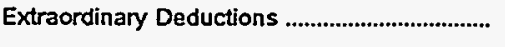 & 290 & 0 & 0 & 0 & 0 & 0 \\
\hline 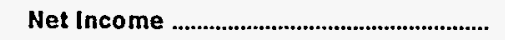 & 356 & 1,167 & 90 & 3,328 & 2,782 & 6,787 \\
\hline
\end{tabular}

Note: Totals may not equal sum of components because of independent rounding.

Source: Energy Information Administration, Form ElA-412, "Annual Report of Public Electric Utilities." 
Table 21. Statement of Income by Major U.S. Publicly Owned Electric Utility Within State, 1995 (Continued)

(Thousand Dollars)

\begin{tabular}{|c|c|c|c|c|c|c|}
\hline Item & $\begin{array}{c}\text { Tennessee } \\
\text { Lawrenceburg } \\
\text { City of } \\
\text { June } 30\end{array}$ & $\begin{array}{l}\text { Tennessee } \\
\text { LaFollette } \\
\text { City of } \\
\text { June } 30\end{array}$ & $\begin{array}{l}\text { Tennessee } \\
\text { Lebanon } \\
\text { City of } \\
\text { June } 30\end{array}$ & $\begin{array}{c}\text { Tennessee } \\
\text { Lenoir } \\
\text { City City of } \\
\text { June } 30\end{array}$ & $\begin{array}{l}\text { Tennessee } \\
\text { Lewisburg } \\
\text { City of } \\
\text { June } 30\end{array}$ & $\begin{array}{l}\text { Tennessee } \\
\text { Lexington } \\
\text { City of } \\
\text { June } 30\end{array}$ \\
\hline Electric Utility Operating Revenues ............ & 24,560 & 20,305 & 18,880 & 60,275 & 14,684 & 23,126 \\
\hline 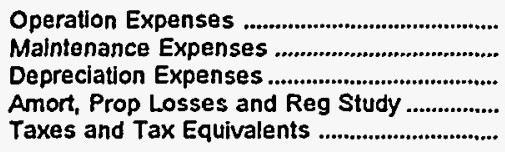 & $\begin{array}{r}22,306 \\
738 \\
751 \\
0 \\
538\end{array}$ & $\begin{array}{r}18,061 \\
744 \\
833 \\
0 \\
482\end{array}$ & $\begin{array}{r}17,594 \\
282 \\
389 \\
17 \\
339\end{array}$ & $\begin{array}{r}52,334 \\
1,953 \\
1,930 \\
0 \\
1,440\end{array}$ & $\begin{array}{r}13.384 \\
196 \\
346 \\
41 \\
309\end{array}$ & $\begin{array}{r}20,687 \\
778 \\
754 \\
0 \\
501\end{array}$ \\
\hline $\begin{array}{l}\text { Total Electric Utility Operating } \\
\text { Expenses }\end{array}$ & 24,333 & 20,119 & 18,620 & 57,657 & 14,276 & 22,720 \\
\hline 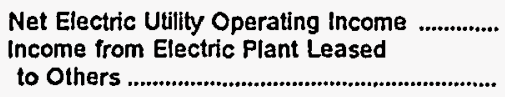 & 227 & 185 & 260 & $\begin{array}{r}2,618 \\
0\end{array}$ & 408 & 406 \\
\hline Electric Utilty Operating Income ............. & 227 & 185 & 260 & 2,618 & 408 & 406 \\
\hline 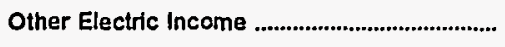 & 342 & 409 & 165 & 1,144 & 144 & 445 \\
\hline $\begin{array}{l}\text { Other Electric Deductions } \\
\text { Allowance for Other Funds Used }\end{array}$ & 10 & 20 & 135 & 1 & 2 & 0 \\
\hline $\begin{array}{l}\text { During Construction ....................................... } \\
\text { Taxes on Other Income and Deductions ....... }\end{array}$ & $\begin{array}{l}0 \\
0\end{array}$ & $\begin{array}{l}0 \\
0\end{array}$ & $\begin{array}{l}0 \\
0\end{array}$ & $\begin{array}{l}0 \\
0\end{array}$ & $\begin{array}{l}0 \\
0\end{array}$ & $\begin{array}{l}0 \\
0\end{array}$ \\
\hline Electric Utility Income .............................. & 560 & $\mathbf{5 7 5}$ & 291 & 3,761 & $\mathbf{5 5 0}$ & 851 \\
\hline 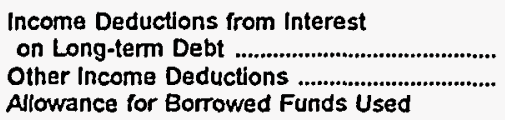 & $\begin{array}{l}1 \\
0\end{array}$ & $\begin{array}{r}218 \\
22\end{array}$ & $\begin{array}{l}0 \\
0\end{array}$ & $\begin{array}{r}1,271 \\
54\end{array}$ & $\begin{array}{r}30 \\
3\end{array}$ & $\begin{array}{l}0 \\
0\end{array}$ \\
\hline 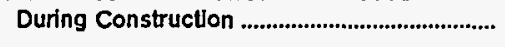 & 0 & 0 & 0 & 0 & 0 & 0 \\
\hline Total Income Deductions ............................. & 1 & 240 & 0 & 1,326 & 33 & 0 \\
\hline Income Before Extraordinary Items .................. & 558 & 335 & 291 & 2.435 & 518 & 851 \\
\hline 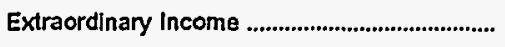 & 0 & 0 & 0 & 0 & 0 & 0 \\
\hline 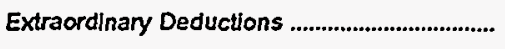 & 0 & 0 & 0 & $\mathbf{0}$ & 0 & 0 \\
\hline Net Income & 558 & 335 & 291 & 2,435 & 518 & 851 \\
\hline
\end{tabular}

Note: Totals may not equal sum of components because of independent rounding.

Source: Energy Information Administration, Form EIA-412, "Annual Report of Public Electric Utilities." 
Table 21. Statement of Income by Major U.S. Publicly Owned Electric Utility Within State, 1995 (Continued)

(Thousand Dollars)

\begin{tabular}{|c|c|c|c|c|c|c|}
\hline Item & $\begin{array}{l}\text { Tennessee } \\
\text { Loudon } \\
\text { Utilities } \\
\text { Board } \\
\text { June } 30\end{array}$ & $\begin{array}{l}\text { Tennessee } \\
\text { Maryille } \\
\text { Utilities } \\
\text { June } 30\end{array}$ & $\begin{array}{l}\text { Tennessee } \\
\text { McMinnville } \\
\text { Electric } \\
\text { System } \\
\text { June } 30\end{array}$ & $\begin{array}{l}\text { Tennessee } \\
\text { Memphis } \\
\text { City of } \\
\text { June } 30\end{array}$ & $\begin{array}{l}\text { Tennessee } \\
\text { Milan } \\
\text { City of } \\
\text { June } 30\end{array}$ & $\begin{array}{l}\text { Tennessee } \\
\begin{array}{c}\text { Monistown } \\
\text { City of }\end{array} \\
\text { June } 30\end{array}$ \\
\hline Electric Utility Operating Revenues .............. & 14,975 & 27,350 & 12,343 & 675,956 & 12,072 & 34,930 \\
\hline 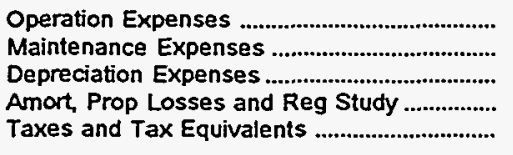 & $\begin{array}{r}13,226 \\
285 \\
415 \\
0 \\
347\end{array}$ & $\begin{array}{r}25,018 \\
794 \\
991 \\
4 \\
621\end{array}$ & $\begin{array}{r}11,287 \\
329 \\
449 \\
45 \\
289\end{array}$ & $\begin{array}{r}581.977 \\
27.055 \\
20.151 \\
0 \\
21,066\end{array}$ & $\begin{array}{r}11,212 \\
456 \\
325 \\
0 \\
217\end{array}$ & $\begin{array}{r}31,648 \\
889 \\
840 \\
299 \\
645\end{array}$ \\
\hline $\begin{array}{l}\text { Total Electric Utility Operating } \\
\text { Expenses }\end{array}$ & 14,273 & 27,428 & 12,399 & 650,250 & 12,209 & 34,320 \\
\hline 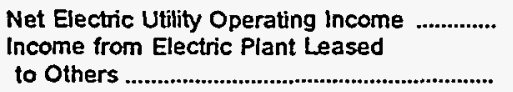 & $\begin{array}{r}702 \\
0\end{array}$ & $\begin{array}{r}-78 \\
0\end{array}$ & -56 & $\begin{array}{r}25,706 \\
0\end{array}$ & $\begin{array}{r}-138 \\
0\end{array}$ & 610 \\
\hline Electric Utility Operating Income ............... & 702 & -78 & -56 & 25,706 & -138 & 610 \\
\hline Other Electric Income & 599 & 425 & 254 & 30,659 & 214 & 554 \\
\hline $\begin{array}{l}\text { Other Electric Deductions } \\
\text { Allowance for Other Funds Used }\end{array}$ & 61 & 0 & 8 & 421 & 9 & 4 \\
\hline $\begin{array}{l}\text { During Construction } \\
\text { Taxes on Other Income and Deductions ......... }\end{array}$ & $\begin{array}{l}0 \\
0\end{array}$ & $\begin{array}{l}0 \\
0\end{array}$ & $\begin{array}{l}0 \\
0\end{array}$ & $\begin{array}{l}0 \\
0\end{array}$ & $\begin{array}{l}0 \\
0\end{array}$ & $\begin{array}{l}0 \\
0\end{array}$ \\
\hline Electric Utility Income & 1,240 & 347 & 190 & 55,944 & 67 & 1,160 \\
\hline 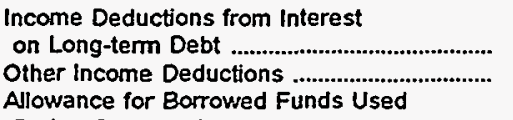 & $\begin{array}{r}428 \\
54\end{array}$ & $\begin{array}{r}86 \\
7\end{array}$ & $\begin{array}{r}0 \\
20\end{array}$ & $\begin{array}{r}11,144 \\
584\end{array}$ & $\begin{array}{l}0 \\
0\end{array}$ & $\begin{array}{r}2 \\
40\end{array}$ \\
\hline 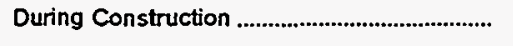 & 27 & 0 & 0 & 0 & 0 & 0 \\
\hline 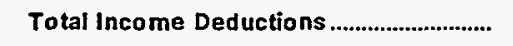 & 509 & 93 & 20 & 11,728 & 0 & 42 \\
\hline 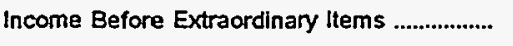 & 730 & 254 & 170 & 44,216 & 67 & 1,118 \\
\hline 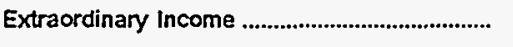 & 1,006 & 0 & 0 & 0 & 0 & 0 \\
\hline 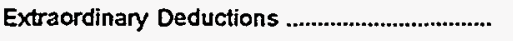 & 503 & 0 & 0 & 0 & 0 & $\mathbf{0}$ \\
\hline 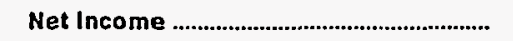 & 1,233 & 254 & 170 & 44,216 & 67 & 1,118 \\
\hline
\end{tabular}

Note: Totals may not equal sum of components because of independent rounding.

Source: Energy information Administration. Form ElA-412, "Annual Report of Public Electric Utilities." 
Table 21. Statement of Income by Major U.S. Publicly Owned Electric Utility Within State, 1995 (Continued)

(Thousand Dollars)

\begin{tabular}{|c|c|c|c|c|c|c|}
\hline Item & $\begin{array}{l}\text { Tennessee } \\
\begin{array}{c}\text { Murfreesboro } \\
\text { City of }\end{array} \\
\text { June } 30\end{array}$ & $\begin{array}{c}\text { Tennessee } \\
\text { Nashville } \\
\text { Electric } \\
\text { Senvice } \\
\text { June } 30\end{array}$ & $\begin{array}{l}\text { Tennessee } \\
\text { Newport } \\
\text { City of } \\
\text { June } 30\end{array}$ & $\begin{array}{l}\text { Tennessee } \\
\text { Oak Ridge } \\
\text { City of } \\
\text { June } 30\end{array}$ & $\begin{array}{c}\text { Tennessee } \\
\text { Paris } \\
\text { City of } \\
\text { June } 30\end{array}$ & $\begin{array}{l}\text { Tennessee } \\
\text { Pulaskj } \\
\text { City of } \\
\text { June } 30\end{array}$ \\
\hline Electric Utility Operating Revenues ............ & 47,343 & 566,281 & 4,367 & 25,373 & 23,224 & 22,335 \\
\hline 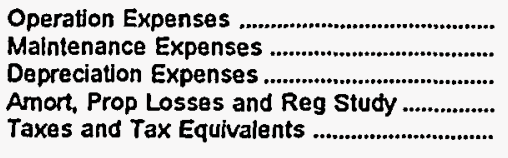 & $\begin{array}{r}42,718 \\
601 \\
1,222 \\
156 \\
1,206\end{array}$ & $\begin{array}{r}510,985 \\
18,194 \\
19,115 \\
0 \\
12,700\end{array}$ & $\begin{array}{r}3,916 \\
105 \\
101 \\
6 \\
83\end{array}$ & $\begin{array}{r}22,212 \\
937 \\
790 \\
11 \\
665\end{array}$ & $\begin{array}{r}20,714 \\
809 \\
886 \\
0 \\
486\end{array}$ & $\begin{array}{r}19,658 \\
796 \\
810 \\
0 \\
593\end{array}$ \\
\hline $\begin{array}{l}\text { Total Electric Utility Operating } \\
\text { Expenses }\end{array}$ & 45,904 & 560,993 & 4,211 & 24,615 & 22,895 & 21,856 \\
\hline $\begin{array}{l}\text { Net Electric Utility Operating Income } \\
\text { Income from Electric Plant Leased } \\
\text { to Others }\end{array}$ & $\begin{array}{r}1.439 \\
0\end{array}$ & 5,288 & 155 & 758 & 329 & 479 \\
\hline Electric Utility Operating Income ............. & 1,439 & 5,288 & 155 & 758 & 329 & 479 \\
\hline Other Electric Income & 915 & 10,992 & 269 & 328 & 430 & 254 \\
\hline $\begin{array}{l}\text { Other Electric Deductions .............................. } \\
\text { Allowance for Other Funds Used } \\
\text { During Construction ........................................ } \\
\text { Taxes on Other Income and Deductions ....... }\end{array}$ & $\begin{array}{l}0 \\
0\end{array}$ & $\begin{array}{l}0 \\
0\end{array}$ & $\begin{array}{l}0 \\
0\end{array}$ & $\begin{array}{l}0 \\
0 \\
0\end{array}$ & $\begin{array}{l}0 \\
0\end{array}$ & $\begin{array}{l}0 \\
0\end{array}$ \\
\hline 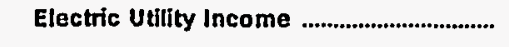 & 2,350 & 16,279 & 425 & 1,086 & 757 & 720 \\
\hline 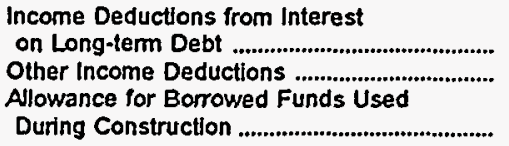 & $\begin{array}{r}243 \\
43\end{array}$ & $\begin{array}{r}10,960 \\
699\end{array}$ & $\begin{array}{r}77 \\
1\end{array}$ & $\begin{array}{r}305 \\
6\end{array}$ & $\begin{array}{r}144 \\
3\end{array}$ & $\begin{array}{r}216 \\
2\end{array}$ \\
\hline Total Income Deductions .............................. & 286 & 11,659 & 77 & 311 & 147 & 218 \\
\hline Income Belore Extraordinary Items ................... & 2,064 & 4,620 & 347 & 774 & 610 & 503 \\
\hline 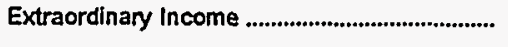 & 0 & 0 & 0 & 0 & 0 & 0 \\
\hline Extraordinary Deductions ......................................... & $\mathbf{0}$ & 0 & 0 & 0 & 0 & 0 \\
\hline Net Income & 2,064 & 4,620 & 347 & 774 & 610 & 503 \\
\hline
\end{tabular}

Note: Totals may not equal sum of components because of independent rounding.

Source: Energy Information Administration, Form EIA-412, "Annual Report of Public Electric Utilities." 
Table 21. Statement of Income by Major U.S. Publicly Owned Electric Utility Within State, 1995 (Continued)

(Thousand Dollars)

\begin{tabular}{|c|c|c|c|c|c|c|}
\hline item & $\begin{array}{l}\text { Tennessee } \\
\text { Ripley } \\
\text { City of } \\
\text { June } 30\end{array}$ & $\begin{array}{l}\text { Tennessee } \\
\text { Rockwood } \\
\text { City of } \\
\text { June } 30\end{array}$ & $\begin{array}{c}\text { Tennessee } \\
\text { Sevier } \\
\text { County } \\
\text { Electric } \\
\text { System } \\
\text { June } 30\end{array}$ & $\begin{array}{l}\text { Tennessee } \\
\text { Shelbyville } \\
\text { City of } \\
\text { June } 30\end{array}$ & $\begin{array}{l}\text { Tennessee } \\
\text { Springfield } \\
\text { City of } \\
\text { June } 30\end{array}$ & $\begin{array}{l}\text { Tennessee } \\
\text { Sweetwater } \\
\text { City of } \\
\text { June } 30\end{array}$ \\
\hline Electric Utility Operating Revenues ............ & 12,764 & 15,489 & $\mathbf{5 2 , 4 7 3}$ & 17,411 & 11,960 & 10,492 \\
\hline 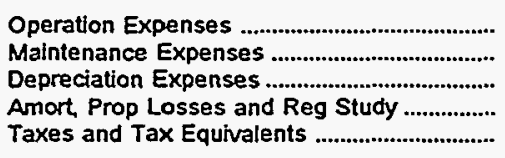 & $\begin{array}{r}12,242 \\
163 \\
214 \\
35 \\
208\end{array}$ & $\begin{array}{r}13,701 \\
671 \\
481 \\
20 \\
454\end{array}$ & $\begin{array}{r}45,595 \\
1,321 \\
2,072 \\
41 \\
942\end{array}$ & $\begin{array}{r}16,409 \\
315 \\
359 \\
36 \\
401\end{array}$ & $\begin{array}{r}10,099 \\
180 \\
412 \\
104 \\
254\end{array}$ & $\begin{array}{r}9,092 \\
406 \\
415 \\
0 \\
231\end{array}$ \\
\hline 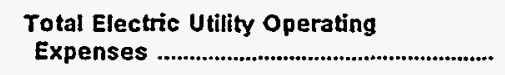 & 12,862 & 15,327 & 49,970 & 17,520 & 11,048 & 10,145 \\
\hline $\begin{array}{l}\text { Net Electric Utility Operating Income } \\
\text { Income from Electric Plant Leased } \\
\text { to Others }\end{array}$ & -98 & 163 & 2,503 & $\begin{array}{r}-110 \\
0\end{array}$ & 912 & 347 \\
\hline Electric Utility Operating Income .............. & -98 & 163 & 2,503 & -110 & 912 & 347 \\
\hline Other Electric Income & 351 & 301 & 898 & 257 & 223 & 265 \\
\hline $\begin{array}{l}\text { Other Electric Deductions } \\
\text { Allowance for Other Funds Used } \\
\text { During Construction.............. }\end{array}$ & 0 & 3 & 0 & 2 & 0 & 0 \\
\hline $\begin{array}{l}\text { During Construction } \\
\text { Taxes on Other Income and Deductions......... }\end{array}$ & $\begin{array}{l}0 \\
0\end{array}$ & $\begin{array}{l}0 \\
0\end{array}$ & $\begin{array}{l}0 \\
0\end{array}$ & $\begin{array}{l}0 \\
0\end{array}$ & $\begin{array}{l}0 \\
0\end{array}$ & $\begin{array}{l}0 \\
0\end{array}$ \\
\hline 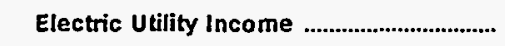 & 254 & 461 & 3,401 & 145 & 1,135 & 612 \\
\hline 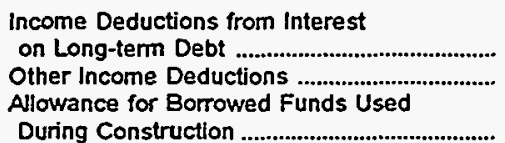 & $\begin{array}{l}0 \\
0\end{array}$ & $\begin{array}{r}36 \\
0\end{array}$ & $\begin{array}{l}102 \\
108\end{array}$ & $\begin{array}{r}0 \\
17\end{array}$ & $\begin{array}{r}58 \\
5\end{array}$ & $\begin{array}{l}0 \\
4\end{array}$ \\
\hline 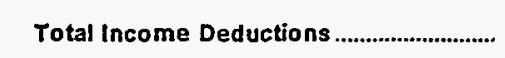 & 0 & 36 & 209 & 17 & 63 & 4 \\
\hline Income Before Extraordinary Items .................. & 254 & 425 & 3,191 & 128 & 1,072 & 608 \\
\hline 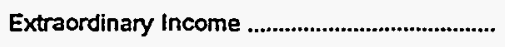 & 0 & 0 & 0 & 0 & 0 & 0 \\
\hline 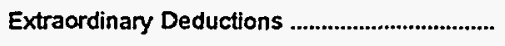 & 0 & 0 & 0 & 0 & 0 & 0 \\
\hline 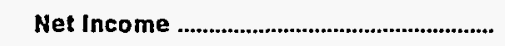 & 254 & 425 & 3,191 & 128 & 1,072 & 608 \\
\hline
\end{tabular}

Note: Totals may not equal sum of components because of independent rounding.

Source: Energy Information Admínistration, Form EIA-412, "Annual Report of Public Electric Utinities." 
Table 21. Statement of Income by Major U.S. Publicly Owned Electric Utility Within State, 1995 (Continued) (Thousand Dollars)

\begin{tabular}{|c|c|c|c|c|c|c|}
\hline Item & $\begin{array}{l}\text { Tennessee } \\
\text { Tullahoma } \\
\text { Board } \\
\text { of } \\
\text { Pub Utils } \\
\text { June } 30\end{array}$ & $\begin{array}{l}\text { Tennessee } \\
\text { Union } \\
\text { City City of } \\
\text { June } 30\end{array}$ & $\begin{array}{l}\text { Tennessee } \\
\text { Weakley } \\
\text { County } \\
\text { Mun } \\
\text { Elec Sys } \\
\text { June } 30\end{array}$ & $\begin{array}{l}\text { Tennessee } \\
\text { Winchester } \\
\text { City of } \\
\text { June } 30\end{array}$ & $\begin{array}{l}\text { Texas } \\
\text { Austin } \\
\text { City of }\end{array}$ & $\begin{array}{c}\text { Texas } \\
\text { Brenham } \\
\text { City of } \\
\text { September } 30\end{array}$ \\
\hline Electric Utility Operating Revenues ............ & 14,475 & 15,254 & 25,572 & 7,895 & 522,751 & 13,035 \\
\hline 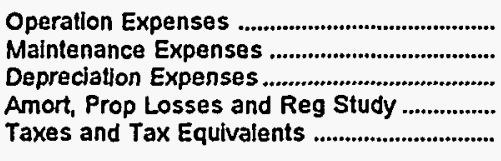 & $\begin{array}{r}13.110 \\
657 \\
487 \\
12 \\
321\end{array}$ & $\begin{array}{r}14,704 \\
264 \\
362 \\
6 \\
269\end{array}$ & $\begin{array}{r}23,007 \\
567 \\
914 \\
0 \\
542\end{array}$ & $\begin{array}{r}7.009 \\
218 \\
261 \\
3 \\
166\end{array}$ & $\begin{array}{r}233,556 \\
40,019 \\
66,288 \\
0 \\
0\end{array}$ & $\begin{array}{r}11,208 \\
768 \\
224 \\
0 \\
642\end{array}$ \\
\hline 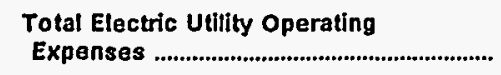 & 14,586 & 15,606 & 25,030 & 7,656 & 339,863 & 12,842 \\
\hline 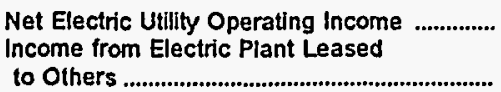 & $\begin{array}{r}-111 \\
0\end{array}$ & -353 & 542 & 239 & $\begin{array}{r}182,888 \\
0\end{array}$ & 193 \\
\hline Electric Utility Operating Income .................. & -111 & -353 & 542 & 239 & 182,888 & 193 \\
\hline Other Electric Income & 301 & 323 & 470 & 106 & 18,421 & 19 \\
\hline $\begin{array}{l}\text { Other Electric Deductions } \\
\text { Allowance for Other Funds Used............................. }\end{array}$ & 7 & 3 & 0 & 5 & 1,067 & 0 \\
\hline 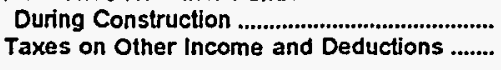 & $\begin{array}{l}0 \\
0\end{array}$ & $\begin{array}{l}0 \\
0\end{array}$ & $\begin{array}{l}0 \\
0\end{array}$ & $\begin{array}{l}0 \\
0\end{array}$ & $\begin{array}{l}0 \\
0\end{array}$ & $\begin{array}{l}0 \\
0\end{array}$ \\
\hline Electric Utility Income & 183 & -32 & 1,012 & 341 & 200,242 & 212 \\
\hline 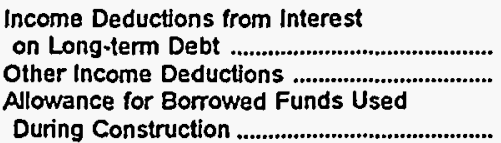 & $\begin{array}{r}104 \\
2\end{array}$ & $\begin{array}{l}0 \\
0\end{array}$ & $\begin{array}{r}0 \\
14\end{array}$ & $\begin{array}{l}0 \\
4\end{array}$ & $\begin{array}{r}133,489 \\
24,316\end{array}$ & $\begin{array}{r}35 \\
8\end{array}$ \\
\hline 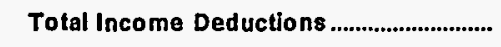 & 107 & 0 & 14 & 4 & 157,805 & 41 \\
\hline Income Before Extraordinary Items .................. & 76 & -32 & 998 & 337 & 42,437 & 171 \\
\hline Extraordinary Income & 0 & 0 & 0 & 0 & 0 & 0 \\
\hline 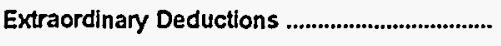 & 0 & 0 & 0 & 0 & $\mathbf{0}$ & 0 \\
\hline 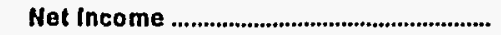 & 76 & -32 & 898 & 337 & 42,437 & 171 \\
\hline
\end{tabular}

Note: Totals may not equal sum of components because of injependent rounding.

Source: Energy Information Administration, Form EIA-412, "Annual Report of Public Electric Utilities." 
Table 21. Statement of Income by Major U.S. Publicly Owned Electric Utility Within State, 1995 (Continued)

(Thousand Dollars)

\begin{tabular}{|c|c|c|c|c|c|c|}
\hline Item & $\begin{array}{c}\text { Texas } \\
\text { Brownsville } \\
\text { Public } \\
\text { Utils Board } \\
\text { September } 30\end{array}$ & $\begin{array}{c}\text { Texas } \\
\text { Bryan } \\
\text { City of } \\
\text { September } 30\end{array}$ & $\begin{array}{c}\text { Texas } \\
\text { College } \\
\text { Station } \\
\text { City of } \\
\text { September } 30\end{array}$ & $\begin{array}{l}\text { Texas } \\
\text { Denton } \\
\text { City of } \\
\text { September } 30\end{array}$ & $\begin{array}{c}\text { Texas } \\
\text { Floresville } \\
\text { City of } \\
\text { December } 31\end{array}$ & $\begin{array}{l}\text { Texas } \\
\text { Garland } \\
\text { City of } \\
\text { September } 30\end{array}$ \\
\hline Electric Utility Operating Revenues ............. & 45,534 & 83,504 & 35,065 & 63,053 & 10,526 & 136,142 \\
\hline 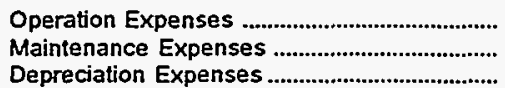 & $\begin{array}{r}27,315 \\
2,160 \\
3,716\end{array}$ & $\begin{array}{r}65,140 \\
1,606 \\
4,549\end{array}$ & $\begin{array}{r}27,895 \\
812 \\
815\end{array}$ & $\begin{array}{r}48,582 \\
2,050 \\
3,226\end{array}$ & $\begin{array}{r}8,671 \\
295 \\
653\end{array}$ & $\begin{array}{r}107,481 \\
8,632 \\
7,086\end{array}$ \\
\hline 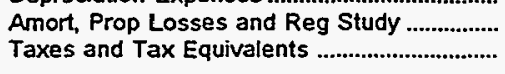 & $\begin{array}{r}0 \\
433\end{array}$ & $\begin{array}{r}0 \\
3,516\end{array}$ & $\begin{array}{r}0 \\
3,702\end{array}$ & 2,944 & 0 & $\begin{array}{r}0 \\
7,290\end{array}$ \\
\hline $\begin{array}{c}\text { Total Electric Utility Operating } \\
\text { Expenses }\end{array}$ & 33,624 & 74,810 & 33,225 & 56,801 & 9,619 & 130,488 \\
\hline $\begin{array}{l}\text { Net Electric Utility Operating Income } \\
\text { Income from Electric Plant Leased } \\
\text { to Others }\end{array}$ & 11,911 & 8,694 & 1,840 & 6,252 & 907 & 5,654 \\
\hline Electric Utility Operating Income ............. & 11,911 & 8,694 & 1,840 & 6,252 & 907 & 5,654 \\
\hline Other Electric Income & 22,486 & 1,130 & 1,140 & 1,881 & 475 & 1,406 \\
\hline $\begin{array}{l}\text { Other Electric Deductions } \\
\text { Alowance for Other Funds Used }\end{array}$ & 1.134 & 0 & 0 & 1,000 & 0 & 0 \\
\hline $\begin{array}{l}\text { During Construction .......................................... } \\
\text { Taxes on Other Income and Deductions ..... }\end{array}$ & $\begin{array}{l}0 \\
0\end{array}$ & $\begin{array}{l}0 \\
0\end{array}$ & $\begin{array}{l}0 \\
0\end{array}$ & $\begin{array}{l}0 \\
0\end{array}$ & $\begin{array}{l}0 \\
0\end{array}$ & $\begin{array}{l}0 \\
0\end{array}$ \\
\hline 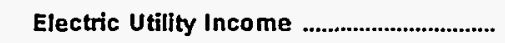 & 33,263 & 9,824 & 2,979 & 7,132 & 1,382 & 7,059 \\
\hline 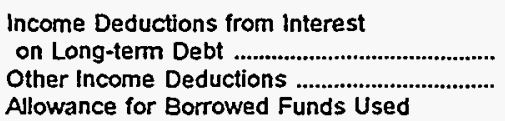 & $\begin{array}{r}5,983 \\
20,780\end{array}$ & $\begin{array}{r}1.415 \\
108\end{array}$ & $\begin{array}{r}793 \\
7\end{array}$ & $\begin{array}{r}1.302 \\
82\end{array}$ & $\begin{array}{r}280 \\
0\end{array}$ & $\begin{array}{r}790 \\
10,556\end{array}$ \\
\hline 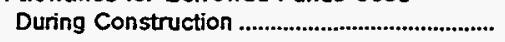 & 0 & 0 & 0 & 0 & 0 & 0 \\
\hline 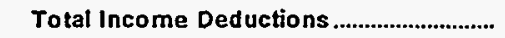 & 26,764 & 1,524 & 800 & 1,384 & 280 & 11,346 \\
\hline Income Before Extraordinary Items .................... & 6,499 & 8,300 & 2,179 & 5,749 & 1,103 & $-4,287$ \\
\hline Extraordinary Income & 0 & 0 & 0 & 0 & 0 & $\mathbf{0}$ \\
\hline 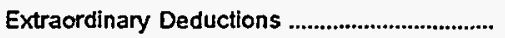 & 0 & 143 & 0 & 0 & 0 & 0 \\
\hline 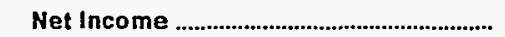 & 6,499 & 8,157 & 2,179 & 5,749 & 1,103 & $-4,287$ \\
\hline
\end{tabular}

Note: Totals may not equal sum of components because of independent rounding.

Source: Energy Information Administration, Form EIA-412, "Annual Report of Public Electric Utilities." 
Table 21. Statement of Income by Major U.S. Publicly Owned Electric Utility Within State, 1995 (Continued)

(Thousand Dollars)

\begin{tabular}{|c|c|c|c|c|c|c|}
\hline Item & $\begin{array}{c}\text { Texas } \\
\text { Georgetown } \\
\text { City of }\end{array}$ & $\begin{array}{c}\text { Texas } \\
\text { Greenville } \\
\text { Electric } \\
\text { Util Sys } \\
\text { September } 30\end{array}$ & $\begin{array}{c}\text { Texas } \\
\text { Jasper } \\
\text { City of } \\
\text { September } 30\end{array}$ & $\begin{array}{c}\text { Texas } \\
\text { Kerville } \\
\text { Public } \\
\text { Utility } \\
\text { Board } \\
\text { September } 30\end{array}$ & $\begin{array}{l}\text { Texas } \\
\text { Lower } \\
\text { Colorado } \\
\text { River } \\
\text { Authority } \\
\text { June } 30\end{array}$ & $\begin{array}{l}\text { Texas } \\
\text { Lubbock } \\
\text { City of } \\
\text { September } 30\end{array}$ \\
\hline Electric Utility Operating Revenues ............ & 12,865 & 28,600 & 11,925 & 22,690 & 374,513 & 53,880 \\
\hline 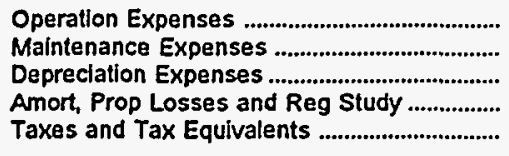 & $\begin{array}{r}9,629 \\
197 \\
313 \\
0 \\
262\end{array}$ & $\begin{array}{r}22,772 \\
1,808 \\
1,808 \\
0 \\
1,170\end{array}$ & $\begin{array}{r}11,116 \\
163 \\
185 \\
0 \\
0\end{array}$ & $\begin{array}{r}17,979 \\
788 \\
994 \\
170 \\
15\end{array}$ & $\begin{array}{r}199,374 \\
24,536 \\
41,715 \\
0 \\
0\end{array}$ & $\begin{array}{r}39,024 \\
849 \\
4,165 \\
0 \\
6,540\end{array}$ \\
\hline 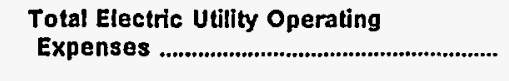 & 10,402 & 27,558 & 11,463 & 19,946 & 265,624 & 50,579 \\
\hline 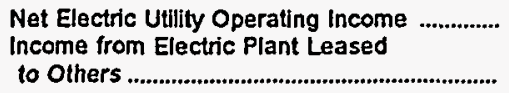 & 2,464 & 1,042 & 461 & 2,745 & 108,889 & 3,301 \\
\hline Electric Utility Operating Income ............. & 2,464 & 1,042 & 461 & 2,745 & 108,889 & 3,301 \\
\hline Other Electric Income & 129 & 737 & 138 & 628 & 42,456 & 3,393 \\
\hline $\begin{array}{l}\text { Other Electric Deductions .................................. } \\
\text { Allowance for Other Funds Used }\end{array}$ & 0 & 0 & -15 & 0 & 47,433 & 0 \\
\hline 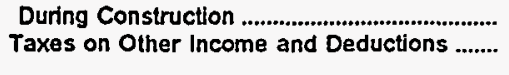 & $\begin{array}{l}0 \\
0\end{array}$ & $\begin{array}{l}0 \\
0\end{array}$ & $\begin{array}{l}0 \\
0\end{array}$ & $\begin{array}{r}32 \\
0\end{array}$ & $\begin{array}{l}0 \\
0\end{array}$ & $\begin{array}{l}0 \\
0\end{array}$ \\
\hline 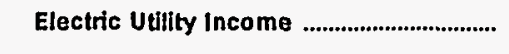 & 2,593 & 1,779 & 614 & 3,405 & 103,911 & 6,694 \\
\hline $\begin{array}{l}\text { Income Deductions from Interest } \\
\text { on Long-tem Debt ................................................ } \\
\text { Other Income Deductions ............................. } \\
\text { Allowance for Borrowed Funds Used } \\
\text { During Construction ............................................ }\end{array}$ & $\begin{array}{r}23 \\
2,635 \\
0\end{array}$ & $\begin{array}{r}842 \\
415 \\
0\end{array}$ & $\begin{array}{l}2 \\
0 \\
0\end{array}$ & $\begin{array}{r}1,964 \\
0 \\
0\end{array}$ & $\begin{array}{r}72,717 \\
-330 \\
0\end{array}$ & $\begin{array}{r}1,717 \\
0\end{array}$ \\
\hline Total Income Deductions .............................. & 2,657 & 1,258 & 2 & 1,964 & 72,387 & 1,717 \\
\hline Income Before Extraordinary Items ................... & -64 & 521 & 612 & 1,440 & 31.524 & 4,977 \\
\hline 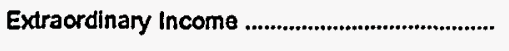 & 0 & 0 & $\mathbf{0}$ & 0 & 0 & 0 \\
\hline 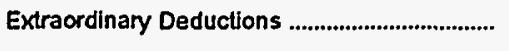 & 0 & 0 & 151 & 0 & 0 & 0 \\
\hline Net Income & -64 & 521 & 461 & 1,440 & 31,524 & 4,977 \\
\hline
\end{tabular}

Note: Totals may not equal sum of components because of independent rounding.

Source: Energy Information Administration. Form ElA-412, "Annual Report of Public Electric Utilities." 
Table 21. Statement of Income by Major U.S. Publicly Owned Electric Utility Within State, 1995 (Continued)

(Thousand Dollars)

\begin{tabular}{|c|c|c|c|c|c|c|}
\hline Item & $\begin{array}{c}\text { Texas } \\
\text { New Braunfels } \\
\text { City of } \\
\text { July } 31\end{array}$ & $\begin{array}{c}\text { Texas } \\
\text { Sam Rayburn } \\
\text { Municipal } \\
\text { Pwr } \\
\text { Agny } \\
\text { September } 30\end{array}$ & $\begin{array}{c}\text { Texas } \\
\text { San Antonio } \\
\text { Public } \\
\text { Senvice Bd } \\
\text { January } 31\end{array}$ & $\begin{array}{c}\text { Texas } \\
\text { San Marcos } \\
\text { City of }\end{array}$ & $\begin{array}{l}\text { Texas } \\
\text { Seguin } \\
\text { City of } \\
\text { September } 30\end{array}$ & $\begin{array}{c}\text { Texas } \\
\text { Texas } \\
\text { Municipal } \\
\text { Power Agency } \\
\text { September } 30\end{array}$ \\
\hline Electric Utility Operating Revenues ............. & 38,925 & $\mathbf{3 3 , 4 7 0}$ & 775,987 & 20,701 & 13,104 & 174,208 \\
\hline 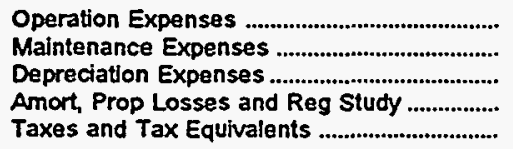 & $\begin{array}{r}32,457 \\
826 \\
1,765 \\
0 \\
1,252\end{array}$ & $\begin{array}{r}14,465 \\
2,737 \\
4,622 \\
0 \\
0\end{array}$ & $\begin{array}{r}289,527 \\
68,701 \\
141,507 \\
0 \\
95,109\end{array}$ & $\begin{array}{r}16,760 \\
653 \\
561 \\
0 \\
1,617\end{array}$ & $\begin{array}{r}9,378 \\
174 \\
197 \\
-\quad 0 \\
0\end{array}$ & $\begin{array}{r}72,838 \\
9,042 \\
19,758 \\
0 \\
0\end{array}$ \\
\hline $\begin{array}{l}\text { Total Electric Utility Operating } \\
\text { Expenses }\end{array}$ & 36,300 & 21,824 & 594,844 & 19,592 & 9,749 & 101,638 \\
\hline $\begin{array}{l}\text { Net Electric Utility Operating Income } \\
\text { Income from Electric Plant Leased } \\
\text { to Others }\end{array}$ & $\begin{array}{l}2,626 \\
1,030\end{array}$ & 11,647 & 181,143 & 1,109 & 3,355 & 72,570 \\
\hline Electric Utility Operating Income .............. & 3,656 & 11,647 & 182,813 & 1,109 & 3,355 & 72,570 \\
\hline 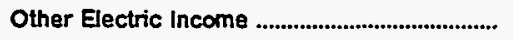 & 682 & 10.987 & 29,908 & 884 & 152 & 12.394 \\
\hline $\begin{array}{l}\text { Other Electric Deductions } \\
\text { Allowance for Other Funds Used.................... }\end{array}$ & 0 & 0 & 1.340 & 0 & 0 & 0 \\
\hline 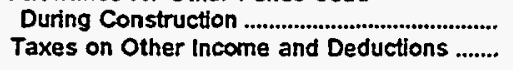 & $\begin{array}{l}0 \\
0\end{array}$ & $\begin{array}{r}240 \\
0\end{array}$ & $\begin{array}{r}0 \\
17,990\end{array}$ & $\begin{array}{l}0 \\
0\end{array}$ & $\begin{array}{l}0 \\
0\end{array}$ & $\begin{array}{l}0 \\
0\end{array}$ \\
\hline Electric Utility Income & 4,337 & 22,874 & 193,391 & 1,993 & 3,507 & 84,984 \\
\hline $\begin{array}{l}\text { Income Deductions from Interest } \\
\text { on Long-term Debt ....................................... } \\
\text { Other Income Deductions ............................. } \\
\text { Allowance for Borrowed Funds Used }\end{array}$ & $\begin{array}{r}386 \\
0\end{array}$ & $\begin{array}{r}15,034 \\
5,012\end{array}$ & $\begin{array}{r}145,811 \\
36,907\end{array}$ & $\begin{array}{r}907 \\
1\end{array}$ & $\begin{array}{l}0 \\
0\end{array}$ & $\begin{array}{r}2,248 \\
91,071\end{array}$ \\
\hline During Construction & 0 & 0 & $-2,818$ & 0 & 0 & 0 \\
\hline 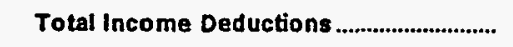 & 386 & 20,046 & 179,900 & 908 & 0 & 93,319 \\
\hline Income Before Extraordinary Items ................... & 3,951 & 2,828 & 13,491 & 1,085 & 3.507 & $-8,355$ \\
\hline 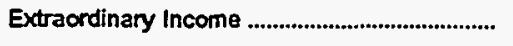 & 0 & 0 & 0 & 0 & $\mathbf{0}$ & 233,840 \\
\hline 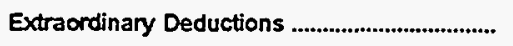 & 0 & 0 & 0 & 0 & 0 & 0 \\
\hline Het Income ............................................................. & 3,951 & 2,828 & 13,491 & 1,085 & 3,507 & 225,585 \\
\hline
\end{tabular}

Note: Totals may not equal sum of components because of independent rounding.

Source: Energy Information Administration. Form ElA-412, "Annual Report of Public Electric Utilities." 
Table 21. Statement of Income by Major U.S. Publicly Owned Electric Utility Within State, 1995 (Continued)

(Thousand Dollars)

\begin{tabular}{|c|c|c|c|c|c|c|}
\hline Hem & $\begin{array}{c}\text { Texas } \\
\text { Toledo Bend } \\
\text { Project } \\
\text { Joint } \\
\text { Oper } \\
\text { August } 30\end{array}$ & $\begin{array}{c}\text { Texas } \\
\text { Weatherford } \\
\text { Mun } \\
\text { Utility } \\
\text { System } \\
\text { September } 30\end{array}$ & $\begin{array}{l}\text { Utah } \\
\text { Bountiful } \\
\text { City City of } \\
\text { June } 30\end{array}$ & $\begin{array}{l}\text { Intermountain } \\
\text { Power Agency } \\
\text { June } 30\end{array}$ & $\begin{array}{l}\text { Utah } \\
\text { Logan } \\
\text { City of } \\
\text { June } 30\end{array}$ & $\begin{array}{l}\text { Utah } \\
\text { Murray } \\
\text { City of } \\
\text { June } 30\end{array}$ \\
\hline Electric Utility Operating Revenues ............ & 12,875 & 14,951 & 13,066 & 642,846 & 17,339 & 19,082 \\
\hline 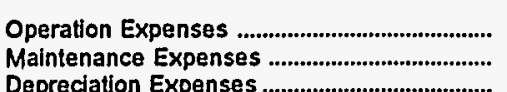 & $\begin{array}{r}100 \\
8,622 \\
727\end{array}$ & $\begin{array}{r}8,188 \\
856 \\
512\end{array}$ & $\begin{array}{l}6,835 \\
1,603 \\
1,215\end{array}$ & $\begin{array}{r}202,821 \\
26,511 \\
95,267\end{array}$ & $\begin{array}{r}11,386 \\
318 \\
983\end{array}$ & $\begin{array}{r}12,758 \\
801 \\
1,659\end{array}$ \\
\hline 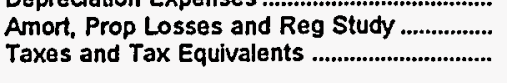 & 0 & $\begin{array}{r}0 \\
735\end{array}$ & 1,963 & $\begin{array}{r}0 \\
30.205\end{array}$ & $\begin{array}{r}0 \\
151\end{array}$ & $\begin{array}{r}0 \\
1,666\end{array}$ \\
\hline 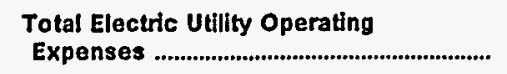 & 9,449 & 10,292 & 11,616 & 354,804 & 12,838 & 16,883 \\
\hline $\begin{array}{l}\text { Net Electric Utility Operating Income ............... } \\
\text { Income from Electric Plant Leased }\end{array}$ & 3,426 & 4,659 & 1,450 & 288,042 & 4,501 & 2,199 \\
\hline 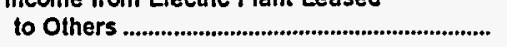 & $\mathbf{0}$ & 0 & 0 & 0 & 0 & 0 \\
\hline Electric Utility Operating Income .............. & 3,426 & 4,659 & 1,450 & 288,042 & 4,501 & 2,199 \\
\hline 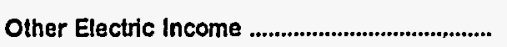 & 0 & 443 & 38 & 63,029 & 392 & $\mathbf{0}$ \\
\hline $\begin{array}{l}\text { Other Electric Deductions ................................... } \\
\text { Allowance for Other Funds Used }\end{array}$ & 0 & 0 & 0 & 0 & 0 & 0 \\
\hline $\begin{array}{l}\text { During Construction ........................................ } \\
\text { Taxes on Other Income and Deductions ....... }\end{array}$ & $\begin{array}{l}0 \\
0\end{array}$ & $\begin{array}{l}0 \\
0\end{array}$ & $\begin{array}{l}\mathbf{0} \\
\mathbf{0}\end{array}$ & $\begin{array}{l}0 \\
0\end{array}$ & $\begin{array}{l}0 \\
0\end{array}$ & $\begin{array}{l}0 \\
0\end{array}$ \\
\hline Electric Utillty Income & 3,426 & 5,102 & 1,488 & 351,071 & 4,893 & 2,199 \\
\hline $\begin{array}{l}\text { Income Deductions from Interest } \\
\text { on Long-term Debt ........................................ } \\
\text { Other Income Deductions ................................... } \\
\text { Allowance for Borrowed Funds Used }\end{array}$ & $\begin{array}{r}8,033 \\
0\end{array}$ & $\begin{array}{r}234 \\
0\end{array}$ & $\begin{array}{l}0 \\
0\end{array}$ & $\begin{array}{l}366,275 \\
-15,204\end{array}$ & $\begin{array}{r}592 \\
0\end{array}$ & $\begin{array}{l}0 \\
0\end{array}$ \\
\hline 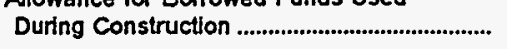 & $\mathbf{0}$ & 0 & 0 & 0 & 0 & 0 \\
\hline 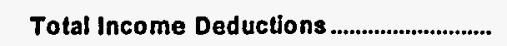 & 8,033 & 234 & 0 & 351,071 & 592 & $\mathbf{0}$ \\
\hline Income Before Extraordinary Items .................. & $-4,607$ & 4,868 & 1,488 & 0 & 4,301 & 2,199 \\
\hline 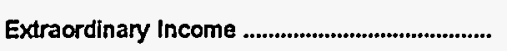 & $\mathbf{0}$ & 0 & 0 & $\mathbf{0}$ & 0 & 0 \\
\hline 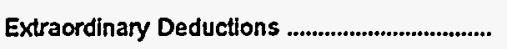 & $\mathbf{0}$ & 0 & 0 & $\mathbf{0}$ & 0 & $\mathbf{0}$ \\
\hline 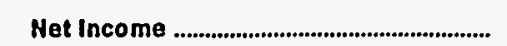 & $-4,607$ & 4,868 & 1,488 & 0 & 4,301 & 2,199 \\
\hline
\end{tabular}

Note: Totals may not equal sum of components because of independent rounding.

Source: Energy Information Administration, Form ElA-4 12, "Annual Report of Public Electric Utillites." 
Table 21. Statement of Income by Major U.S. Publicly Owned Electric Utility Within State, 1995 (Continued)

(Thousand Dollars)

\begin{tabular}{|c|c|c|c|c|c|c|}
\hline Item & $\begin{array}{c}\text { Utah } \\
\text { Provo } \\
\text { City Corp } \\
\text { June } 30\end{array}$ & $\begin{array}{c}\text { Utah } \\
\text { St George } \\
\text { City of } \\
\text { June } 30\end{array}$ & $\begin{array}{c}\text { Utah } \\
\text { Utah } \\
\text { Associated } \\
\text { Mun } \\
\text { Power Sys } \\
\text { March } 31\end{array}$ & $\begin{array}{c}\text { Utah } \\
\text { Utah } \\
\text { Municipal } \\
\text { Power Agency } \\
\text { June } 30\end{array}$ & $\begin{array}{l}\text { Vermont } \\
\text { Burlington } \\
\text { City of } \\
\text { June } 30\end{array}$ & $\begin{array}{c}\text { Vermont } \\
\text { Vemont } \\
\text { Public } \\
\text { Pvr } \\
\text { Supply Auth } \\
\text { December } 31\end{array}$ \\
\hline Electric Utility Operating Revenues ............ & 36,348 & 21,630 & 46,284 & 31,943 & 39,519 & 8,749 \\
\hline 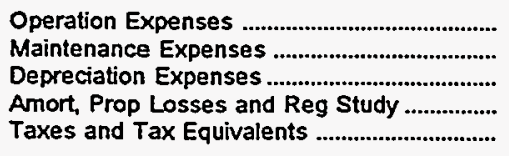 & $\begin{array}{r}25,390 \\
0 \\
3,578 \\
0 \\
0\end{array}$ & $\begin{array}{r}17.177 \\
0 \\
1,235 \\
0 \\
1,563\end{array}$ & $\begin{array}{r}31,413 \\
1,422 \\
3,922 \\
0 \\
994\end{array}$ & $\begin{array}{r}20,398 \\
7,621 \\
939 \\
0 \\
143\end{array}$ & $\begin{array}{r}24,216 \\
1,573 \\
978 \\
2,729 \\
1,182\end{array}$ & $\begin{array}{r}5,595 \\
336 \\
827 \\
0 \\
212\end{array}$ \\
\hline $\begin{array}{l}\text { Total Electric Utility Operating } \\
\text { Expenses }\end{array}$ & 28,968 & 19,975 & 37,750 & 29,101 & 30,677 & 6,971 \\
\hline 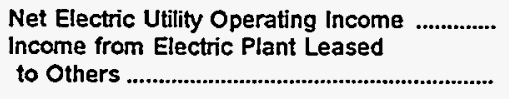 & $\begin{array}{r}7.380 \\
0\end{array}$ & 1.655 & 8,534 & $\begin{array}{r}2,842 \\
0\end{array}$ & $\begin{array}{r}8,841 \\
0\end{array}$ & $\begin{array}{r}1,778 \\
0\end{array}$ \\
\hline Electric Utility Operating Income ............. & 7,380 & 1,655 & 8,534 & 2,842 & 8,841 & 1,778 \\
\hline 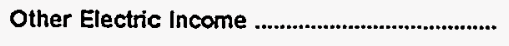 & 442 & 730 & 3,197 & 999 & 1,763 & 336 \\
\hline Other Electric Deductions ................................. & 0 & 0 & 0 & 0 & 242 & 0 \\
\hline $\begin{array}{l}\text { During Construction ....................................................... } \\
\text { Taxes on Other Income and Deductions .... }\end{array}$ & $\begin{array}{l}0 \\
0\end{array}$ & $\begin{array}{l}0 \\
0\end{array}$ & $\begin{array}{l}0 \\
0\end{array}$ & $\begin{array}{l}0 \\
0\end{array}$ & $\begin{array}{l}0 \\
0\end{array}$ & $\begin{array}{l}\mathbf{0} \\
\mathbf{0}\end{array}$ \\
\hline Electric Utility Income ................................. & 7,822 & 2,385 & 11,731 & 3,841 & 10,363 & 2,114 \\
\hline 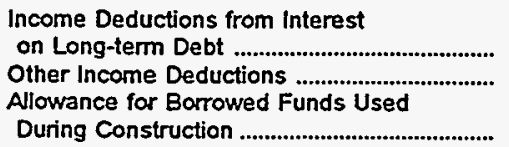 & $\begin{array}{r}3,496 \\
100\end{array}$ & $\begin{array}{l}0 \\
0\end{array}$ & $\begin{array}{r}8,417 \\
0\end{array}$ & $\begin{array}{r}3,087 \\
143\end{array}$ & $\begin{array}{r}6,806 \\
115\end{array}$ & $\begin{array}{r}2,018 \\
683\end{array}$ \\
\hline 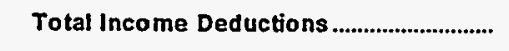 & 3,596 & 0 & 8,417 & 3,230 & 6,921 & 2,700 \\
\hline Income Before Extraordinary Items .................. & 4,226 & 2,385 & 3,314 & 611 & 3,442 & -586 \\
\hline 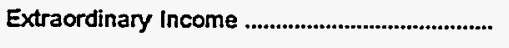 & 0 & 0 & 0 & 370 & 0 & 0 \\
\hline 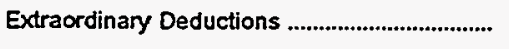 & 4,090 & 0 & 0 & 370 & 0 & 0 \\
\hline Net Income & 136 & 2,385 & 3,314 & 611 & 3,442 & -586 \\
\hline
\end{tabular}

Note: Totals may not equal sum of components because of independent rounding.

Source: Energy Information Administration. Form ElA-412, "Annual Report of Public Electric Utilities." 
Table 21. Statement of Income by Major U.S. Publicly Owned Electric Utility Within State, 1995 (Continued)

(Thousand Dollars)

\begin{tabular}{|c|c|c|c|c|c|c|}
\hline Item & $\begin{array}{l}\text { Virginia } \\
\text { Bedford } \\
\text { City of } \\
\text { June } 30\end{array}$ & $\begin{array}{l}\text { Virginla } \\
\text { Bristol } \\
\text { Utilities } \\
\text { Board } \\
\\
\text { June } 30\end{array}$ & $\begin{array}{l}\text { Virginia } \\
\text { Danville } \\
\text { City of } \\
\text { June } 30\end{array}$ & $\begin{array}{c}\text { Virginia } \\
\begin{array}{c}\text { Harrisonburg } \\
\text { City of }\end{array} \\
\text { June } 30\end{array}$ & $\begin{array}{l}\text { Virginia } \\
\text { Manassas } \\
\text { City of } \\
\text { June } 30\end{array}$ & $\begin{array}{l}\text { Virginia } \\
\text { Martinsville } \\
\text { City of } \\
\text { June } 30\end{array}$ \\
\hline Electric Utility Operating Revenues ............ & 11,420 & 24,917 & 42,984 & 32,496 & 16,930 & 10,750 \\
\hline 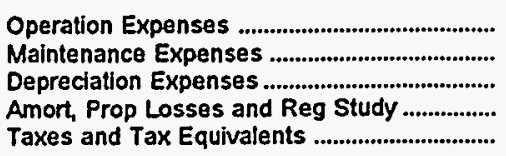 & $\begin{array}{r}8,442 \\
343 \\
523 \\
0 \\
0\end{array}$ & $\begin{array}{r}23,337 \\
806 \\
730 \\
0 \\
506\end{array}$ & $\begin{array}{r}30,762 \\
1,365 \\
1,531 \\
0 \\
0\end{array}$ & $\begin{array}{r}25,140 \\
507 \\
1,482 \\
184 \\
189\end{array}$ & $\begin{array}{r}14,018 \\
650 \\
1,355 \\
0 \\
456\end{array}$ & $\begin{array}{r}6,807 \\
431 \\
835 \\
0 \\
88\end{array}$ \\
\hline 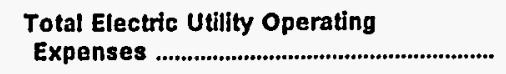 & 9,308 & 25,379 & 33,659 & 27,501 & 16,479 & 8,161 \\
\hline $\begin{array}{l}\text { Not Electric Utility Operating Income } \\
\text { Income from Electric Plant Leased.... }\end{array}$ & 2,111 & -462 & 9,325 & 4,995 & 450 & 2,589 \\
\hline 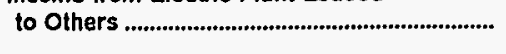 & 0 & 0 & 85 & 0 & 0 & 0 \\
\hline Etectric Utility Operating Income ............. & 2,111 & -462 & 9,410 & 4,995 & 450 & 2,589 \\
\hline Other Electric Income ........................................... & 498 & 707 & 668 & 256 & 1,159 & 0 \\
\hline $\begin{array}{l}\text { Other Electric Deductions } \\
\text { Allowance for Other Funds Used }\end{array}$ & 0 & 0 & 0 & 0 & -72 & 1.736 \\
\hline $\begin{array}{l}\text { During Construction ....................................... } \\
\text { Taxes on Other Income and Deductions ....... }\end{array}$ & $\begin{array}{l}0 \\
0\end{array}$ & $\begin{array}{l}0 \\
0\end{array}$ & $\begin{array}{l}0 \\
0\end{array}$ & $\begin{array}{l}0 \\
0\end{array}$ & $\begin{array}{l}0 \\
0\end{array}$ & $\begin{array}{l}0 \\
0\end{array}$ \\
\hline 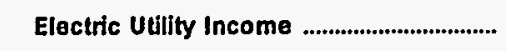 & 2,609 & 245 & 10,077 & 5,251 & 1,681 & 854 \\
\hline $\begin{array}{l}\text { Income Deductions from Interest } \\
\text { on Long-term Debt ............................................. } \\
\text { Other Income Deductions ............................... } \\
\text { Allowance for Borrowed Funds Used }\end{array}$ & $\begin{array}{r}860 \\
1,221\end{array}$ & $\begin{array}{r}0 \\
17\end{array}$ & $\begin{array}{r}413 \\
0\end{array}$ & $\begin{array}{r}191 \\
0\end{array}$ & $\begin{array}{r}1.537 \\
-633\end{array}$ & $\begin{array}{l}0 \\
0\end{array}$ \\
\hline 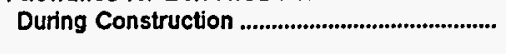 & 0 & 0 & 0 & 0 & 0 & 0 \\
\hline Total Income Deductions ............................. & 2,081 & 17 & 413 & 191 & 904 & 0 \\
\hline Income Before Extraordlnary Items .................. & 528 & 228 & 9,665 & 5,060 & 777 & 854 \\
\hline Extraordinary Income & 0 & 0 & 0 & 0 & 0 & 0 \\
\hline Extraordinary Deductions ................................... & 0 & 0 & 0 & 0 & 0 & 0 \\
\hline Net Income & $\mathbf{5 2 8}$ & 228 & 9,665 & 5,060 & 777 & 854 \\
\hline
\end{tabular}

Note: Totals may not equal sum of components because of independent rounding.

Source: Energy Information Ad-ministration. Form ElA-412, "Annual Report of Public Electric Utilities." 
Table 21. Statement of Income by Major U.S. Publicly Owned Electric Utility Within State, 1995 (Continued) (Thousand Dollars)

\begin{tabular}{|c|c|c|c|c|c|c|}
\hline ltem & $\begin{array}{l}\text { Virginia } \\
\text { Radford } \\
\text { City of } \\
\text { June } 30\end{array}$ & $\begin{array}{l}\text { Virginia } \\
\text { Salem } \\
\text { City of } \\
\text { June } 30\end{array}$ & $\begin{array}{l}\text { Virginia } \\
\text { Virginia } \\
\text { Tech } \\
\text { Electric } \\
\text { Senvice } \\
\text { June } 30\end{array}$ & $\begin{array}{c}\text { Washington } \\
\text { Centralia } \\
\text { City of } \\
\text { December } 31\end{array}$ & $\begin{array}{l}\text { Washington } \\
\text { Ellensburg } \\
\text { City of } \\
\text { December } 31\end{array}$ & $\begin{array}{c}\text { Washington } \\
\text { Port Angeles } \\
\text { City of } \\
\text { December } 31\end{array}$ \\
\hline Electric Utility Operating Revenues ............. & 16,024 & 16,623 & 11,809 & 9,282 & 7,704 & 23,005 \\
\hline 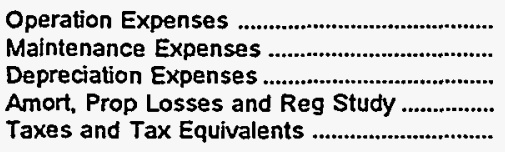 & $\begin{array}{r}12.584 \\
350 \\
803 \\
0 \\
137\end{array}$ & $\begin{array}{r}13,798 \\
191 \\
761 \\
0 \\
1,000\end{array}$ & $\begin{array}{r}9,960 \\
684 \\
0 \\
0 \\
250\end{array}$ & $\begin{array}{r}6,987 \\
441 \\
521 \\
3 \\
829\end{array}$ & $\begin{array}{r}5,946 \\
289 \\
423 \\
0 \\
803\end{array}$ & $\begin{array}{r}18,408 \\
1,865 \\
581 \\
0 \\
2,226\end{array}$ \\
\hline $\begin{array}{l}\text { Total Electric Utility Operating } \\
\text { Expenses }\end{array}$ & 13,873 & 15,750 & 10,894 & 8,781 & 7,461 & 23,080 \\
\hline $\begin{array}{l}\text { Net Electric Utility Operating Income } \\
\text { Income from Electric Plant Leased } \\
\text { to Others }\end{array}$ & 2,152 & 873 & 915 & 501 & 243 & -75 \\
\hline Electric Utility Operating Income .............. & 2,152 & 873 & 915 & 501 & 243 & -75 \\
\hline Other Electric Income & 403 & 268 & 120 & 476 & 301 & 332 \\
\hline $\begin{array}{l}\text { Other Electric Deductions } \\
\text { Allowance for Other Funds Used }\end{array}$ & 1.422 & 0 & 0 & 0 & 47 & 0 \\
\hline $\begin{array}{l}\text { During Construction } \\
\text { Taxes on Other Income and Deductions }\end{array}$ & $\begin{array}{l}0 \\
0\end{array}$ & $\begin{array}{l}0 \\
0\end{array}$ & $\begin{array}{l}0 \\
0\end{array}$ & $\begin{array}{l}0 \\
0\end{array}$ & $\begin{array}{l}0 \\
0\end{array}$ & $\begin{array}{l}0 \\
0\end{array}$ \\
\hline 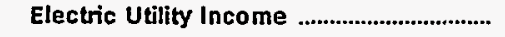 & 1,132 & 1,141 & 1,034 & 977 & 497 & 256 \\
\hline 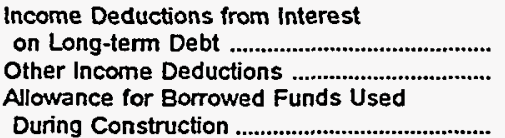 & $\begin{array}{r}216 \\
0\end{array}$ & $\begin{array}{r}606 \\
1,583\end{array}$ & $\begin{array}{l}176 \\
105\end{array}$ & $\begin{array}{r}159 \\
38\end{array}$ & $\begin{array}{r}31 \\
0\end{array}$ & $\begin{array}{r}261 \\
65 \\
0\end{array}$ \\
\hline Total Income Deductions ............................... & 216 & 2,189 & 281 & 197 & 31 & 325 \\
\hline Income Before Extraordinary Items ................... & 916 & $-1,048$ & 753 & 780 & 465 & -69 \\
\hline 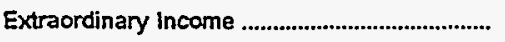 & 0 & 0 & 0 & 0 & 0 & 0 \\
\hline 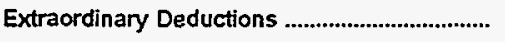 & 0 & 0 & 0 & 0 & 0 & 0 \\
\hline Net Income & 916 & $-1,048$ & 753 & 780 & 465 & -69 \\
\hline
\end{tabular}

Note: Totals may not equal sum of components because of independent rounding.

Source: Energy information Administration, Form ElA-412, "Annual Report of Public Electric Utiities." 
Table 21. Statement of Income by Major U.S. Publicly Owned Electric Utility Within State, 1995 (Continued)

(Thousand Dollars)

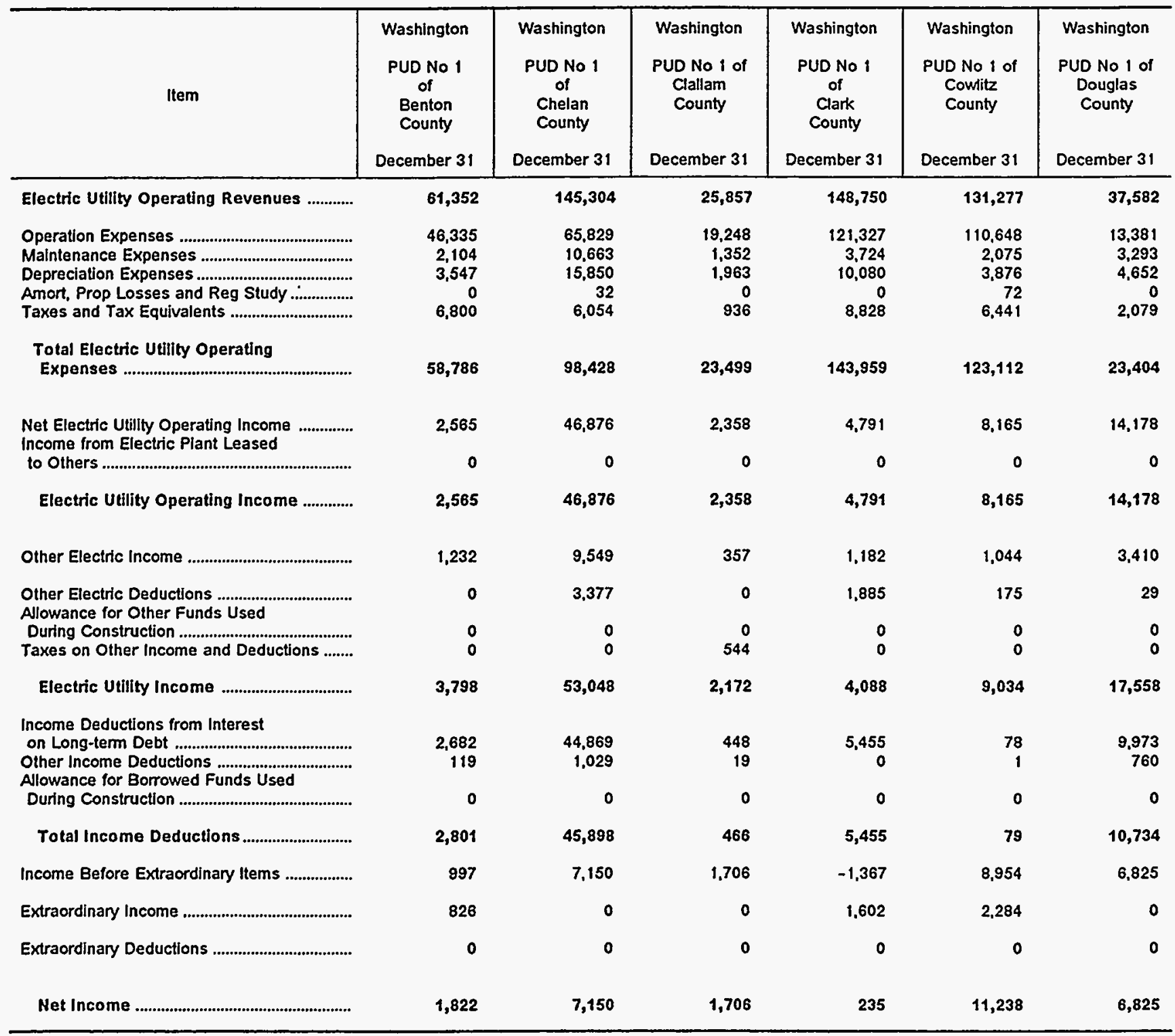

Note; Totals may not equal sum of components because of independent rounding.

Source: Energy Information Administration. Form E1A-412, "Annual Report of Public Electric Utilities." 
Table 21. Statement of Income by Major U.S. Publicly Owned Electric Utility Within State, 1995 (Continued) (Thousand Dollars)

\begin{tabular}{|c|c|c|c|c|c|c|}
\hline Hem & $\begin{array}{l}\text { Washington } \\
\text { PUD No } 1 \text { of } \\
\text { Franklin } \\
\text { County } \\
\text { December } 31\end{array}$ & $\begin{array}{c}\text { Washington } \\
\text { PUD No } 1 \\
\text { of } \\
\text { Grays } \\
\text { Harbor Cnty } \\
\text { December } 31\end{array}$ & $\begin{array}{l}\text { Washington } \\
\text { PUD No } 1 \text { of } \\
\text { Klickitat } \\
\text { County } \\
\text { December } 31\end{array}$ & $\begin{array}{c}\text { Washington } \\
\text { PUD No } 1 \\
\text { of } \\
\text { Lewis } \\
\text { County } \\
\text { December } 31\end{array}$ & $\begin{array}{l}\text { Washington } \\
\text { PUD No } 1 \text { of } \\
\text { Okanogan } \\
\text { County }\end{array}$ & $\begin{array}{l}\text { Washington } \\
\text { PUD No } 1 \text { of } \\
\text { Pend Oreille } \\
\text { Cnty } \\
\text { December } 31\end{array}$ \\
\hline Electric Utility Operating Revenues ............ & 28,267 & 50,726 & 12,938 & 31,435 & 16,826 & 21,613 \\
\hline 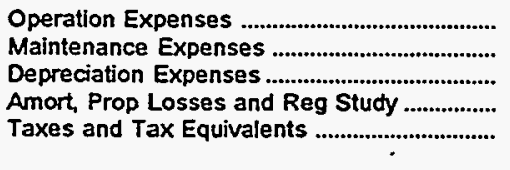 & $\begin{array}{r}21,550 \\
685 \\
1,251 \\
141 \\
1,920\end{array}$ & $\begin{array}{r}37,145 \\
4,947 \\
3,351 \\
0 \\
2,892\end{array}$ & $\begin{array}{r}9,701 \\
577 \\
1,041 \\
0 \\
828\end{array}$ & $\begin{array}{r}22,536 \\
1,520 \\
1,713 \\
0 \\
1,975\end{array}$ & $\begin{array}{r}13,965 \\
697 \\
1,721 \\
28 \\
1,726\end{array}$ & $\begin{array}{r}14,926 \\
1,236 \\
1,136 \\
0 \\
1,348\end{array}$ \\
\hline $\begin{array}{c}\text { Total Electric Utility Operating } \\
\text { Expenses }\end{array}$ & 25,548 & 48,336 & 12,147 & 27,745 & 18,138 & 18,646 \\
\hline 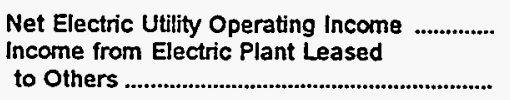 & 2,720 & $\begin{array}{r}2,390 \\
0\end{array}$ & $\begin{array}{r}790 \\
0\end{array}$ & $\begin{array}{r}3,691 \\
0\end{array}$ & $\begin{array}{r}-1,312 \\
0\end{array}$ & $\begin{array}{r}2,966 \\
0\end{array}$ \\
\hline Electric Utility Operating Income ............. & 2,720 & 2,390 & 790 & 3,691 & $-1,312$ & 2,986 \\
\hline 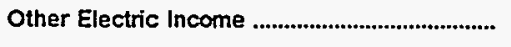 & 695 & 2,497 & 318 & 1,070 & 821 & 640 \\
\hline $\begin{array}{l}\text { Other Electric Deductions } \\
\text { Allowance for Other Funds Used }\end{array}$ & 36 & 0 & 0 & 0 & 42 & 0 \\
\hline $\begin{array}{l}\text { During Construction ..................................... } \\
\text { Taxes on Other Income and Deductions ....... }\end{array}$ & $\begin{array}{l}0 \\
0\end{array}$ & $\begin{array}{l}2 \\
0\end{array}$ & $\begin{array}{l}0 \\
0\end{array}$ & $\begin{array}{l}0 \\
0\end{array}$ & $\begin{array}{l}0 \\
0\end{array}$ & $\begin{array}{l}0 \\
0\end{array}$ \\
\hline Electric Utility Income ................................... & 3,379 & 4,890 & 1,108 & 4,761 & -533 & 3,606 \\
\hline 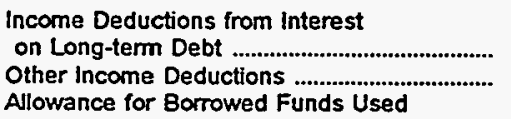 & $\begin{array}{r}1,675 \\
0\end{array}$ & $\begin{array}{r}35 \\
2,676\end{array}$ & $\begin{array}{r}499 \\
48\end{array}$ & $\begin{array}{l}0 \\
0\end{array}$ & $\begin{array}{l}3 \\
0\end{array}$ & $\begin{array}{l}233 \\
118\end{array}$ \\
\hline 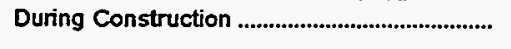 & 0 & 0 & 0 & 0 & 0 & 0 \\
\hline 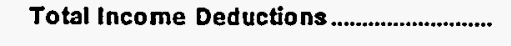 & 1,675 & 2,710 & 547 & $\mathbf{0}$ & 3 & 351 \\
\hline Income Before Extraordinary Items ................. & 1,703 & 2,179 & 561 & 4,761 & -536 & 3,255 \\
\hline 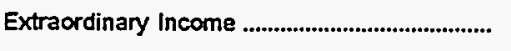 & 6 & 717 & 160 & 328 & 111 & 0 \\
\hline 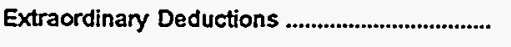 & $\mathbf{0}$ & 0 & 0 & 0 & 0 & 0 \\
\hline Net Income & 1,709 & 2,896 & 721 & 5,090 & -425 & 3,255 \\
\hline
\end{tabular}

Note: Totals may not equal sum of components because of independent rounding.

Source: Energy Information Administration, Form ElA-412, "Annual Report of Public Electric Utilities." 
Table 21. Statement of Income by Major U.S. Publicly Owned Electric Utility Within State, 1995 (Continued)

(Thousand Dollars)

\begin{tabular}{|c|c|c|c|c|c|c|}
\hline Item & $\begin{array}{l}\text { Washington } \\
\text { PUD No } 1 \text { of } \\
\text { Snohomish } \\
\text { County } \\
\text { December } 31\end{array}$ & $\begin{array}{l}\text { Washington } \\
\text { PUD No } 1 \text { of } \\
\text { Whatcom } \\
\text { County } \\
\text { December } 31\end{array}$ & $\begin{array}{c}\text { Washington } \\
\text { PUD No } 2 \\
\text { of } \\
\text { Grant } \\
\text { County } \\
\text { December } 31\end{array}$ & $\begin{array}{l}\text { Washington } \\
\text { PUD No } 2 \text { of } \\
\text { Pacific } \\
\text { County } \\
\text { December } 31\end{array}$ & $\begin{array}{c}\text { Washington } \\
\text { PUD No } 3 \\
\text { of } \\
\text { Mason } \\
\text { County } \\
\text { December } 31\end{array}$ & $\begin{array}{l}\text { Washington } \\
\text { Richland } \\
\text { City of } \\
\text { December } 31\end{array}$ \\
\hline Electric Utility Operating Revenues ............. & 309,784 & 4,253 & 96,728 & 14,078 & 26,100 & 26,910 \\
\hline 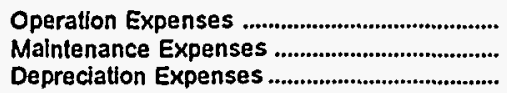 & $\begin{array}{r}217,118 \\
17,336 \\
23,346\end{array}$ & $\begin{array}{r}4,360 \\
53 \\
84\end{array}$ & $\begin{array}{l}39,461 \\
17,156 \\
14,971\end{array}$ & $\begin{array}{r}10,026 \\
777 \\
1,111\end{array}$ & $\begin{array}{r}19,090 \\
2,274 \\
2,370\end{array}$ & $\begin{array}{r}21,946 \\
649 \\
1,141\end{array}$ \\
\hline 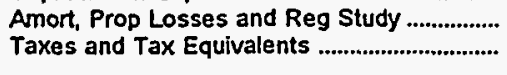 & $\begin{array}{r}0 \\
13,763\end{array}$ & $\begin{array}{r}0 \\
257\end{array}$ & $\begin{array}{r}0 \\
5,976\end{array}$ & $\begin{array}{r}0 \\
628\end{array}$ & 951 & $\begin{array}{r}0 \\
2,858\end{array}$ \\
\hline $\begin{array}{l}\text { Total Electric Utility Operating } \\
\text { Expenses }\end{array}$ & 274,563 & 4,753 & 77,564 & 12,542 & 24,684 & 26,594 \\
\hline $\begin{array}{l}\text { Net Electric Utility Operating Income } \\
\text { Income from Electric Plant Leased }\end{array}$ & 38,221 & -501 & 19,164 & 1,536 & 1,416 & 316 \\
\hline 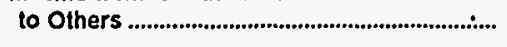 & 0 & 0 & 0 & 0 & 0 & $\mathbf{0}$ \\
\hline Electric Utility Operating Income ............. & 38,221 & -501 & 19,164 & 1,536 & 1,416 & 316 \\
\hline Other Electric Income & 14,776 & 110 & 9,029 & 1,133 & 726 & 657 \\
\hline $\begin{array}{l}\text { Other Electric Deductions ................................ } \\
\text { Allowance for Other Funds Used }\end{array}$ & 0 & 0 & 0 & 710 & 12 & 0 \\
\hline 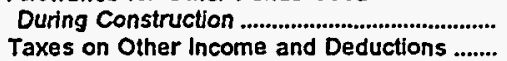 & $\begin{array}{r}4,002 \\
0\end{array}$ & $\begin{array}{l}0 \\
0\end{array}$ & $\begin{array}{l}0 \\
0\end{array}$ & $\begin{array}{r}0 \\
297\end{array}$ & $\begin{array}{r}0 \\
79\end{array}$ & $\begin{array}{l}0 \\
0\end{array}$ \\
\hline Electric Utitty Income .................................... & 56,999 & -391 & 28,193 & 1,663 & 2,051 & 973 \\
\hline 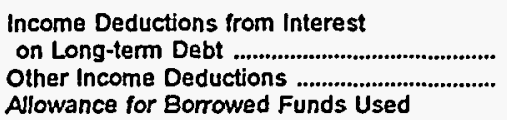 & $\begin{array}{r}38,060 \\
6,230\end{array}$ & $\begin{array}{l}0 \\
0\end{array}$ & $\begin{array}{r}21,156 \\
832\end{array}$ & $\begin{array}{r}331 \\
0\end{array}$ & $\begin{array}{r}996 \\
35\end{array}$ & $\begin{array}{l}900 \\
523\end{array}$ \\
\hline 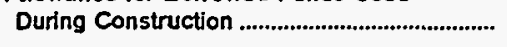 & 0 & 0 & 0 & 0 & 0 & 0 \\
\hline 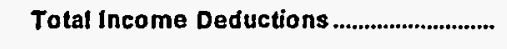 & 44,290 & 0 & 21,988 & 331 & 1,031 & 1,423 \\
\hline Income Before Extraordinary Items ...................... & 12,709 & -391 & 6,206 & 1,331 & 1,021 & -450 \\
\hline Extraordinary Income & 0 & 0 & 3,377 & 138 & 158 & 0 \\
\hline Extraordinary Deductions ....................................... & 0 & 0 & 0 & 0 & 0 & 0 \\
\hline Net Income & 12,709 & -391 & 9,582 & 1,469 & 1,178 & -450 \\
\hline
\end{tabular}

Note: Totals may not equal sum of components because of independent rounding.

Source: Energy Information Administration, Form EIA-412, "Annual Report of Public Electric Utilities." 
Table 21. Statement of Income by Major U.S. Publicly Owned Electric Utility Within State, 1995 (Continued)

(Thousand Dollars)

\begin{tabular}{|c|c|c|c|c|c|c|}
\hline Item & $\begin{array}{l}\text { Washington } \\
\text { Seattle } \\
\text { City of } \\
\text { December } 31\end{array}$ & $\begin{array}{l}\text { Washington } \\
\text { Tacoma } \\
\text { City of } \\
\text { December } 31\end{array}$ & $\begin{array}{c}\text { Washington } \\
\text { Vera } \\
\text { Imigation } \\
\text { District \#15 } \\
\text { December } 31\end{array}$ & $\begin{array}{l}\text { Washington } \\
\text { Washington } \\
\text { Pub } \\
\text { Pwr } \\
\text { Supply Sys } \\
\text { June } 30\end{array}$ & $\begin{array}{l}\text { Wisconsin } \\
\text { Badger Power } \\
\text { Marketing } \\
\text { Auth } \\
\text { December } 31\end{array}$ & $\begin{array}{l}\text { Wisconsin } \\
\text { Jefferson } \\
\text { City of } \\
\text { December } 31\end{array}$ \\
\hline Electric Utility Operating Revenues .............. & 329,808 & 209,618 & 7,444 & 464,591 & 11,163 & 6,790 \\
\hline 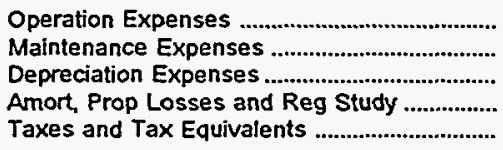 & $\begin{array}{r}193,483 \\
20,954 \\
39,607 \\
0 \\
37,786\end{array}$ & $\begin{array}{r}101,239 \\
18,054 \\
18,870 \\
225 \\
22,701\end{array}$ & $\begin{array}{r}6.131 \\
317 \\
489 \\
0 \\
288\end{array}$ & $\begin{array}{r}154,330 \\
46,552 \\
112,198 \\
549 \\
2,759\end{array}$ & $\begin{array}{r}10,286 \\
8 \\
157 \\
36 \\
122\end{array}$ & $\begin{array}{r}5,514 \\
89 \\
290 \\
0 \\
209\end{array}$ \\
\hline $\begin{array}{l}\text { Total Electric Utility Operating } \\
\text { Expenses }\end{array}$ & 291,831 & 161,089 & 7,224 & 316,387 & 10,609 & 6,102 \\
\hline 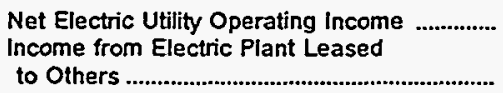 & $\begin{array}{r}37,978 \\
0\end{array}$ & 48,529 & 219 & 148,203 & 553 & 687 \\
\hline Electric Utility Operating Income .............. & 37,978 & 48,529 & 219 & 148,203 & 560 & 687 \\
\hline Other Electric Income & 9,244 & 5,565 & 209 & 20.034 & 101 & 167 \\
\hline $\begin{array}{l}\text { Other Electric Deductions } \\
\text { Allowance for Other Funds Used }\end{array}$ & 232 & 2,669 & 21 & 2,721 & 0 & 0 \\
\hline 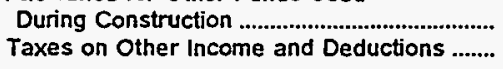 & $\begin{array}{l}0 \\
0\end{array}$ & $\begin{array}{l}0 \\
0\end{array}$ & $\begin{array}{l}0 \\
0\end{array}$ & $\begin{array}{l}0 \\
0\end{array}$ & $\begin{array}{l}0 \\
0\end{array}$ & $\begin{array}{l}0 \\
0\end{array}$ \\
\hline 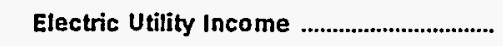 & 46,989 & 51,426 & 406 & 165,516 & 662 & 854 \\
\hline 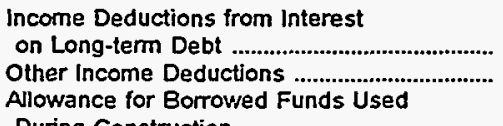 & $\begin{array}{l}40,989 \\
15,814\end{array}$ & $\begin{array}{r}26,547 \\
2,129\end{array}$ & $\begin{array}{r}136 \\
0\end{array}$ & $\begin{array}{r}160,240 \\
5,276\end{array}$ & $\begin{array}{l}319 \\
118\end{array}$ & $\begin{array}{r}287 \\
17\end{array}$ \\
\hline 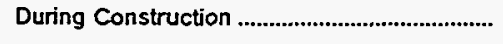 & $-5,713$ & $-5,397$ & 0 & 0 & 0 & 0 \\
\hline 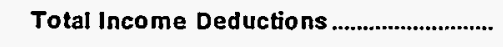 & 51,091 & 23,278 & 136 & 165,516 & 437 & 304 \\
\hline Income Before Extraordinary ltems ................... & $-4,102$ & 28,148 & 271 & 0 & 225 & 550 \\
\hline 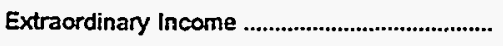 & 0 & 3,633 & 0 & 0 & 0 & 0 \\
\hline 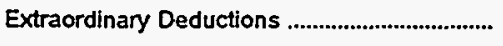 & 0 & 0 & 0 & 0 & 0 & 0 \\
\hline 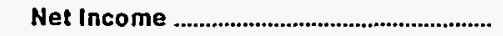 & $-4,102$ & 31,781 & 271 & 0 & 225 & 550 \\
\hline
\end{tabular}

Note: Totals may not equal sum of components because of independent rounding.

Source: Energy Information Administration, Form EIA-412, "Annual Report of Public Electric Utilities." 
Table 21. Statement of Income by Major U.S. Publicly Owned Electric Utility Within State, 1995 (Continued)

(Thousand Dollars)

\begin{tabular}{|c|c|c|c|c|c|c|}
\hline Item & $\begin{array}{l}\text { Wisconsin } \\
\text { Kaukauna } \\
\text { City of } \\
\text { December } 31\end{array}$ & $\begin{array}{l}\text { Wisconsin } \\
\text { Manitowoc } \\
\text { Public } \\
\text { Utilities } \\
\text { December } 31\end{array}$ & $\begin{array}{c}\text { Wisconsin } \\
\begin{array}{c}\text { Marshfield } \\
\text { City of }\end{array} \\
\text { December } 31\end{array}$ & $\begin{array}{c}\text { Wisconsin } \\
\text { Menasha } \\
\text { City of } \\
\text { December } 31\end{array}$ & $\begin{array}{c}\text { Wisconsin } \\
\text { New London } \\
\text { Electric\&Water } \\
\text { Util } \\
\text { December } 31\end{array}$ & $\begin{array}{l}\text { Wisconsin } \\
\begin{array}{c}\text { Oconomowoc } \\
\text { City of }\end{array} \\
\text { December } 31\end{array}$ \\
\hline Electric Utility Operating Revenues ............ & 25,229 & 24,230 & 14,272 & 23,102 & 7,779 & 8,967 \\
\hline 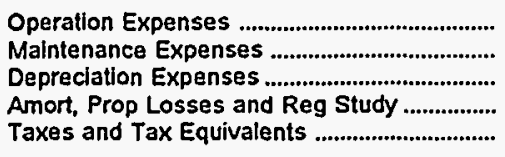 & $\begin{array}{r}20,347 \\
721 \\
1,183 \\
0 \\
1,044\end{array}$ & $\begin{array}{r}16,384 \\
1,140 \\
2,111 \\
0 \\
1,594\end{array}$ & $\begin{array}{r}10.690 \\
365 \\
849 \\
5 \\
566\end{array}$ & $\begin{array}{r}20,260 \\
410 \\
761 \\
5 \\
714\end{array}$ & $\begin{array}{r}6,740 \\
0 \\
241 \\
0 \\
291\end{array}$ & $\begin{array}{r}7.184 \\
214 \\
511 \\
32 \\
420\end{array}$ \\
\hline 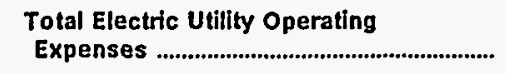 & 23,295 & 21,230 & 12,475 & 22,150 & 7,273 & 8,361 \\
\hline 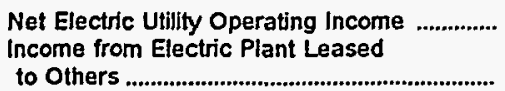 & 1,934 & 3,000 & 1,797 & 952 & 506 & 606 \\
\hline Electric Utility Operating Income ............. & 1,934 & 3,000 & 1,797 & 952 & 506 & 606 \\
\hline Other Electric Income ............................................... & 150 & 687 & 213 & 213 & 104 & 207 \\
\hline $\begin{array}{l}\text { Other Electric Deductions ................................ } \\
\text { Allowance for Other Funds Used } \\
\text { During Construction ......................................... } \\
\text { Taxes on Other Income and Deductions ....... }\end{array}$ & $\begin{array}{r}0 \\
150\end{array}$ & $\begin{array}{l}0 \\
0\end{array}$ & 218 & $\begin{array}{l}0 \\
0\end{array}$ & $\begin{array}{l}0 \\
0 \\
0\end{array}$ & $\begin{array}{l}0 \\
0\end{array}$ \\
\hline 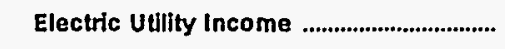 & 1,934 & 3,687 & 1,791 & 1,165 & 610 & 814 \\
\hline 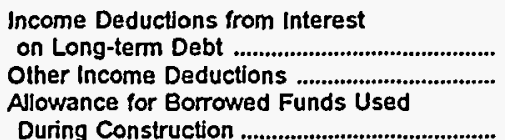 & $\begin{array}{l}\mathbf{0} \\
\mathbf{0}\end{array}$ & $\begin{array}{r}1,376 \\
173\end{array}$ & $\begin{array}{r}448 \\
35\end{array}$ & $\begin{array}{r}477 \\
22\end{array}$ & $\begin{array}{l}0 \\
0\end{array}$ & $\begin{array}{r}113 \\
0\end{array}$ \\
\hline Total Income Deductions ............................. & 0 & 1,549 & 483 & 500 & 0 & 113 \\
\hline Income Before Extraordinary Items .................. & 1,934 & 2,138 & 1,308 & 665 & 610 & 700 \\
\hline 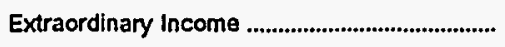 & 0 & 0 & 0 & 0 & 0 & 0 \\
\hline Extraordinary Deductions ....................................... & 0 & 0 & 0 & $\mathbf{0}$ & 0 & 0 \\
\hline 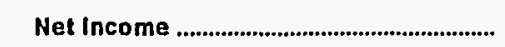 & 1,934 & 2,138 & 1,308 & 665 & 610 & 700 \\
\hline
\end{tabular}

Note: Totals may not equal sum of components because of independent rounding

Source: Energy Intormation Administration, Form ELA-412, "Annual Report of Public Electric Utilities." 
Table 21. Statement of Income by Major U.S. Publicly Owned Electric Utility Within State, 1995 (Continued)

(Thousand Dollars)

\begin{tabular}{|c|c|c|c|c|c|c|}
\hline Item & $\begin{array}{l}\text { Wisconsin } \\
\text { Plymouth } \\
\text { City of } \\
\text { December } 31\end{array}$ & $\begin{array}{l}\text { Wisconsin } \\
\text { Reedsburg } \\
\text { Utility Comm } \\
\text { December } 31\end{array}$ & $\begin{array}{c}\text { Wisconsin } \\
\text { Shawano } \\
\text { Municipal } \\
\text { Utilities } \\
\text { December } 31\end{array}$ & $\begin{array}{c}\text { Wisconsin } \\
\text { Sheboygan } \\
\text { Falls } \\
\text { City of } \\
\text { December } 31\end{array}$ & $\begin{array}{c}\text { Wisconsin } \\
\text { Sturgeon } \\
\text { Bay City of } \\
\text { December } 31\end{array}$ & $\begin{array}{l}\text { Wisconsin } \\
\text { Sun Prairie } \\
\text { Water \& Light } \\
\text { Comm } \\
\text { December } 31\end{array}$ \\
\hline Electric Utility Operating Revenues .............. & 7,797 & 7,779 & 9,578 & 7,601 & 7,522 & 7,925 \\
\hline 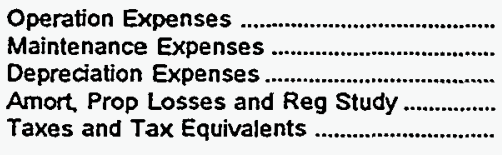 & $\begin{array}{r}6.259 \\
151 \\
458 \\
0 \\
285\end{array}$ & $\begin{array}{r}6.808 \\
101 \\
318 \\
0 \\
255\end{array}$ & $\begin{array}{r}8,171 \\
119 \\
338 \\
0 \\
313\end{array}$ & $\begin{array}{r}6,653 \\
0 \\
265 \\
0 \\
175\end{array}$ & $\begin{array}{r}5,578 \\
237 \\
575 \\
0 \\
414\end{array}$ & $\begin{array}{r}6.700 \\
148 \\
475 \\
0 \\
308\end{array}$ \\
\hline $\begin{array}{l}\text { Total Electric Utility Operating } \\
\text { Expenses }\end{array}$ & 7,154 & 7,482 & 8,942 & 7,093 & 6,804 & 7,631 \\
\hline 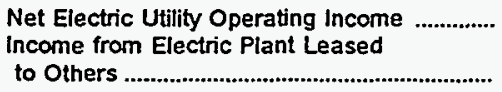 & 643 & 296 & 635 & 508 & 718 & 294 \\
\hline Electric Utility Operating Income .............. & 643 & 302 & 871 & 508 & 718 & 591 \\
\hline Other Electric Income & 53 & 59 & 184 & 0 & 177 & 90 \\
\hline $\begin{array}{l}\text { Other Electric Deductions } \\
\text { Allowance for Other Funds Used } \\
\text { During Construction .............................................. } \\
\text { Taxes on Other Income and Deductions ....... }\end{array}$ & $\begin{array}{l}0 \\
0\end{array}$ & 183 & $\begin{array}{l}0 \\
0\end{array}$ & $\begin{array}{l}0 \\
0\end{array}$ & $\begin{array}{l}0 \\
0\end{array}$ & $\begin{array}{l}0 \\
0\end{array}$ \\
\hline Electric Utility Income & 683 & 177 & 1,019 & 508 & 847 & 681 \\
\hline 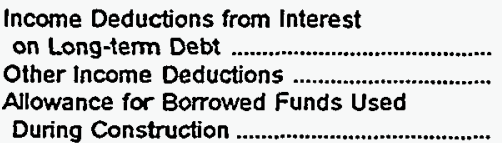 & $\begin{array}{l}17 \\
27\end{array}$ & $\begin{array}{l}0 \\
0\end{array}$ & $\begin{array}{r}152 \\
10\end{array}$ & $\begin{array}{l}0 \\
0\end{array}$ & $\begin{array}{r}399 \\
97\end{array}$ & $\begin{array}{l}0 \\
0\end{array}$ \\
\hline 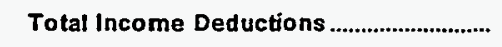 & 44 & 0 & 162 & 0 & 496 & 0 \\
\hline Income Before Extraordinary ltems ................... & 639 & 177 & 857 & 508 & 350 & 681 \\
\hline Extraordinary Income & 0 & 0 & $163^{\circ}$ & 0 & 0 & 0 \\
\hline 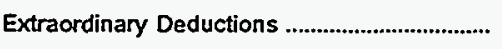 & 0 & 0 & 6 & 0 & 0 & 0 \\
\hline Net Income & 639 & 177 & 1,015 & 508 & 350 & 681 \\
\hline
\end{tabular}

Note: Totals may not equal sum of components because of independent rounding.

Source: Energy Information Administration, Form ElA-412, "Annual Report of Public Electric Utilities." 
Table 21. Statement of Income by Major U.S. Publicly Owned Electric Utility Within State, 1995 (Continued)

(Thousand Dollars)

\begin{tabular}{|c|c|c|c|c|}
\hline Item & $\begin{array}{l}\text { Wisconsin } \\
\text { Wisconsin } \\
\text { Publlc } \\
\text { Power } \\
\text { Ine Sys } \\
\text { December } 31\end{array}$ & $\begin{array}{l}\text { Wisconsin } \\
\text { Wisconsin } \\
\text { Rapids WW } \\
\& L \\
\text { Comm } \\
\text { December } 31\end{array}$ & $\begin{array}{l}\text { Wyoming } \\
\text { Gillette } \\
\text { City of } \\
\text { June } 30\end{array}$ & $\begin{array}{l}\text { Wyoming } \\
\text { Wyoming } \\
\text { Municipal } \\
\text { Power Agency } \\
\text { December } 31\end{array}$ \\
\hline Electric Utility Operating Revenues ............ & 116,165 & 10,177 & 11,115 & 5,683 \\
\hline 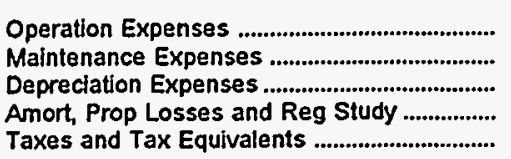 & $\begin{array}{r}100,471 \\
1,519 \\
3,082 \\
935 \\
2,617\end{array}$ & $\begin{array}{r}7.611 \\
456 \\
665 \\
0 \\
509\end{array}$ & $\begin{array}{r}9,956 \\
0 \\
425 \\
103 \\
68\end{array}$ & $\begin{array}{r}3.434 \\
345 \\
687 \\
0 \\
104\end{array}$ \\
\hline 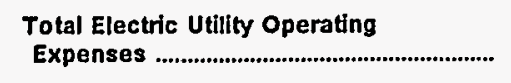 & 108,623 & 9,241 & 10,553 & 4,570 \\
\hline 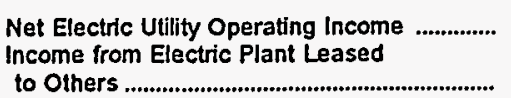 & $\begin{array}{r}7,542 \\
0\end{array}$ & 936 & 562 & $\begin{array}{r}1,113 \\
0\end{array}$ \\
\hline Electric Utility Operating Income .............. & 7,542 & 936 & 562 & 1,113 \\
\hline 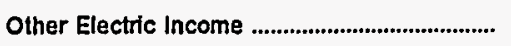 & 6,735 & 253 & 0 & 539 \\
\hline $\begin{array}{l}\text { Other Electric Deductions .............................. } \\
\text { Allowance for Other Funds Used } \\
\text { During Construction ....................................... } \\
\text { Taxes on Other Income and Deductions ....... }\end{array}$ & $\begin{array}{l}0 \\
0\end{array}$ & $\begin{array}{l}0 \\
0\end{array}$ & $\begin{array}{l}0 \\
0\end{array}$ & $\begin{array}{l}0 \\
0\end{array}$ \\
\hline 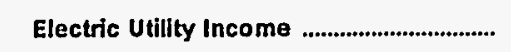 & 14,276 & 1,124 & 562 & 1,652 \\
\hline 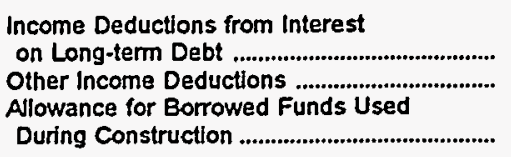 & $\begin{array}{l}9,109 \\
3,425\end{array}$ & $\begin{array}{l}0 \\
2\end{array}$ & $\begin{array}{l}0 \\
0\end{array}$ & $\begin{array}{r}1,101 \\
71\end{array}$ \\
\hline 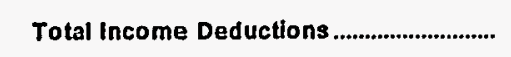 & 12,534 & 2 & 0 & 1,172 \\
\hline Income Before Extraordinary Items ................... & 1,742 & 1,122 & 562 & 480 \\
\hline 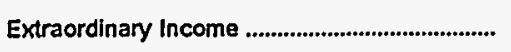 & 0 & 0 & 0 & 0 \\
\hline 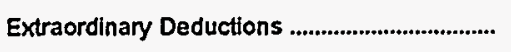 & 0 & 0 & 0 & 0 \\
\hline 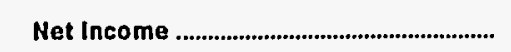 & 1,742 & 1,122 & 562 & 480 \\
\hline
\end{tabular}

Note: Totals may not equal sum of components because of independent rounding.

Source: Energy Information Administration, Form ElA-412, "Annual Report of Public Electric Utilities." 
Table 22. Balance Sheet by Major U.S. Publicly Owned Electric Utility Within State at End of Period, 1994

(Thousand Dollars)

\begin{tabular}{|c|c|c|c|c|c|c|}
\hline Item & $\begin{array}{l}\text { Alabama } \\
\text { Alabama } \\
\text { Municipal } \\
\text { Elec Auth } \\
\text { September } 30\end{array}$ & $\begin{array}{l}\text { Alabama } \\
\text { Albertville } \\
\text { Municipal } \\
\text { Utils Bd } \\
\text { June } 30\end{array}$ & $\begin{array}{c}\text { Alabama } \\
\text { Andalusia } \\
\text { City of } \\
\text { September } 30\end{array}$ & $\begin{array}{l}\text { Alabama } \\
\text { Athens } \\
\text { City of } \\
\text { December } 31\end{array}$ & $\begin{array}{l}\text { Alabama } \\
\text { Bessemer } \\
\text { City of } \\
\text { June } 30\end{array}$ & $\begin{array}{c}\text { Alabama } \\
\text { Cullman } \\
\text { Power Board } \\
\text { June } 30\end{array}$ \\
\hline \multicolumn{7}{|l|}{ Electric Utility Plant } \\
\hline 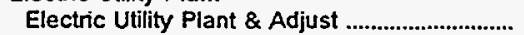 & 0 & 13,809 & 3,710 & 43,070 & 20,742 & 13,721 \\
\hline 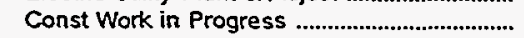 & 0 & 43 & 0 & 146 & 761 & 109 \\
\hline (less) Depr, Amort, and Depletion ......................... & 0 & 5,192 & 1,304 & 15,233 & 10,043 & 5,737 \\
\hline Net Electric Utility Plant ..................................... & 0 & 8,660 & 2,406 & 27,983 & 11,460 & 8,093 \\
\hline Nuclear Fuel ........................................................ & 0 & 0 & 0 & 0 & 0 & 0 \\
\hline (less) Amort of Nucl Fuel ................................. & 0 & 0 & 0 & 0 & 0 & o \\
\hline 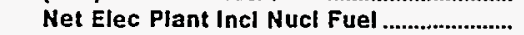 & 0 & 8,660 & 2,406 & 27,983 & 11,460 & 8,093 \\
\hline \multicolumn{7}{|l|}{ Other Property \& Investments } \\
\hline Nonutility Property ................................................... & 3,302 & 0 & 12,161 & 0 & 0 & $\mathbf{0}$ \\
\hline (less) Accum Provisions for Depr \& Amort.... & 561 & 0 & 2,332 & 0 & 0 & $\mathbf{0}$ \\
\hline 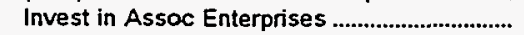 & 0 & 0 & 2,817 & 0 & 0 & 0 \\
\hline 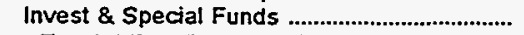 & 25,422 & 16 & 335 & 2,258 & 34 & 405 \\
\hline Total Other Property \& Investments ....... & 28,163 & 16 & 12,980 & 2,258 & 34 & 405 \\
\hline \multicolumn{7}{|l|}{ Current and Accrued Assets } \\
\hline Cash, Working Funds \& Investments ............... & 7.169 & 2,977 & 842 & 2,535 & $\$, 100$ & 975 \\
\hline 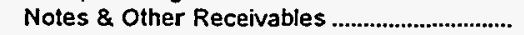 & & 1,840 & 11 & 3,535 & 4,476 & 2,057 \\
\hline Customer Accts Receivable ..................................... & 8,871 & 0 & 1,236 & 0 & 0 & 0 \\
\hline (less) Accum Prov for Uncollected Accts ...... & & 0 & 0 & 0 & 0 & $\mathbf{0}$ \\
\hline 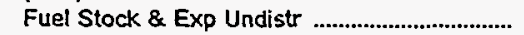 & 0 & 0 & 0 & 0 & 0 & 0 \\
\hline Materials \& Supplies ................................................. & 478 & 164 & 195 & 403 & 279 & 402 \\
\hline 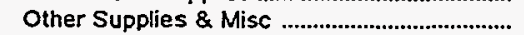 & 0 & 0 & 0 & 0 & 0 & 0 \\
\hline Prepayments ................................................................. & 84,456 & 20 & 42 & 273 & 434 & 16 \\
\hline Accrued Utility Revenues ......................................... & 0 & 0 & 0 & 0 & 0 & 0 \\
\hline Miscellaneous Current \& Accrued Assets ..... & 0 & 31 & 0 & 54 & 26 & 30 \\
\hline Total Current \& Accrued Assets ............... & 100,973 & 5,031 & 2,325 & 6,800 & 6,315 & 3,480 \\
\hline \multicolumn{7}{|l|}{ Deferred Debits } \\
\hline Unamortized Debt Expenses .................................... & 11,493 & 0 & 63 & 282 & 11 & 110 \\
\hline 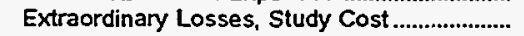 & & 0 & 0 & 0 & 0 & 0 \\
\hline Misc Debt, R \& D Exp, Unamrt Losses .......... & 44,302 & 1,089 & 0 & 454 & 2,057 & 799 \\
\hline Total Deferred Debits .......................................... & 55,795 & 1,089 & 63 & 735 & 2,068 & 909 \\
\hline 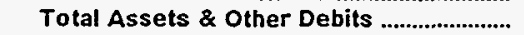 & 184,932 & 14,796 & 17,774 & 37,776 & 19,877 & 12,888 \\
\hline \multicolumn{7}{|l|}{ Proprietary Capital } \\
\hline 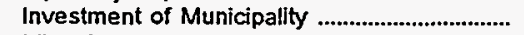 & 0 & 0 & 5,430 & 0 & 0 & 0 \\
\hline 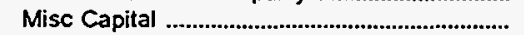 & 0 & 0 & 49 & 0 & 0 & 0 \\
\hline 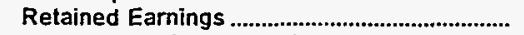 & 784 & 10,667 & 6,670 & 20,697 & 10,053 & 6,704 \\
\hline \multirow{2}{*}{\multicolumn{7}{|c|}{ Long-term Debt }} \\
\hline & & & & & & \\
\hline 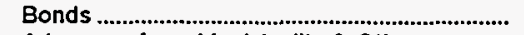 & 176,610 & 0 & 4,097 & 11,450 & 2,100 & 3,010 \\
\hline Advances from Municipality \& Other ............... & 0 & 1,082 & 0 & 479 & 1,996 & 756 \\
\hline Unamort Prem on Long-term Debt .................... & 0 & 0 & 0 & 0 & -18 & 0 \\
\hline (less) Unamort Discount on Long-term Debt & 1,238 & 0 & 0 & 0 & 0 & 0 \\
\hline 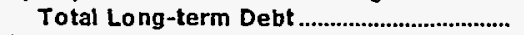 & 175,372 & 1,082 & 4,097 & 11,929 & 4,078 & 3,766 \\
\hline \multicolumn{7}{|l|}{ Other Noncurrent Labilities } \\
\hline 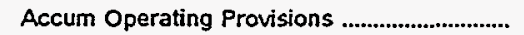 & 0 & 0 & 0 & 0 & 0 & 0 \\
\hline 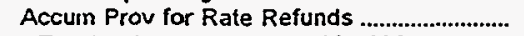 & 0 & 0 & 0 & 0 & 0 & 0 \\
\hline Total Other Noncurrent ! iahilities ............ & 0 & 0 & 0 & 0 & 0 & 0 \\
\hline \multicolumn{7}{|l|}{ Current and Accrued Liabilities } \\
\hline Notes Payable & 0 & 0 & 0 & 66 & 12 & o \\
\hline 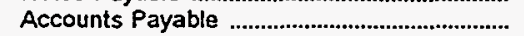 & 7,906 & 2,020 & 1,057 & 3,543 & 4,365 & 1,683 \\
\hline Payables to Assoc Enterprises ............................. & 0 & 0 & 0 & 0 & 0 & 0 \\
\hline 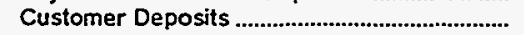 & 0 & 526 & 332 & 1,199 & 1,089 & 414 \\
\hline Taxes Accrued .............................................................. & 0 & 0 & 75 & 0 & 7 & 23 \\
\hline Interest Accrued ............................................................... & 819 & 0 & 65 & 0 & 0 & 57 \\
\hline Misc Current \& Accrued Liabilities..................... & 51 & 500 & 0 & 338 & 273 & 171 \\
\hline Total Current \& Accrued Liabilities .......... & 8,776 & 3,046 & 1,529 & 5,145 & 5,747 & 2,348 \\
\hline \multicolumn{7}{|l|}{ Deferred Credits } \\
\hline Customer Advances for Construction .............. & 0 & $\mathbf{0}$ & 0 & 0 & 0 & 0 \\
\hline Other Deferred Credits .......................................... & 0 & 0 & 0 & 5 & 0 & 69 \\
\hline Unamort Gain on Reacqr Debt ............................... & 0 & 0 & 0 & 0 & 0 & 0 \\
\hline Total Deferred Credits ....................................... & 0 & 0 & 0 & 5 & 0 & 69 \\
\hline Total Liabilities and Other Credits ............. & 184,932 & 14,796 & 17,774 & 37,776 & 19,877 & 12,888 \\
\hline
\end{tabular}

Note: Totals may not equal sum of components because of independent rounding.

Source: Energy Information Administration, Form EIA-412, "Annual Report of Public Electric Utilities." 
Table 22. Balance Sheet by Major U.S. Publicly Owned Electric Utility Within State at End of Period, 1994 (Continued) (Thousand Dollars)

\begin{tabular}{|c|c|c|c|c|c|c|}
\hline Item & $\begin{array}{l}\text { Alabama } \\
\text { Decatur } \\
\text { City of } \\
\text { June } 30\end{array}$ & $\begin{array}{l}\text { Alabama } \\
\text { Dothan } \\
\text { City of } \\
\text { September } 30\end{array}$ & $\begin{array}{l}\text { Alabama } \\
\text { Florence } \\
\text { City of } \\
\text { June } 30\end{array}$ & $\begin{array}{c}\text { Alabama } \\
\text { Foley } \\
\text { City of } \\
\text { (Riviera Utils) } \\
\text { December } 31\end{array}$ & $\begin{array}{c}\text { Alabama } \\
\text { Fort Payne } \\
\text { Improvement } \\
\text { Auth } \\
\text { June } 30\end{array}$ & $\begin{array}{l}\text { Alabama } \\
\text { Guntersville } \\
\text { Electric } \\
\text { Board } \\
\text { June } 30\end{array}$ \\
\hline \multicolumn{7}{|l|}{ Electric Utility Plant } \\
\hline 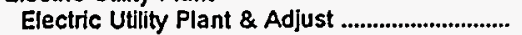 & 41,651 & 59,026 & 78,442 & 61,160 & 13,260 & $\mathbf{9 , 9 3 1}$ \\
\hline 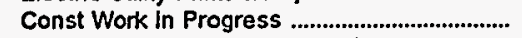 & 662 & & 1,024 & 607 & 909 & 192 \\
\hline 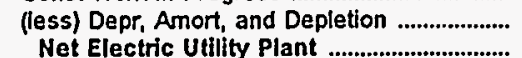 & $\begin{array}{l}18,756 \\
23,557\end{array}$ & $\begin{array}{l}23,228 \\
35,798\end{array}$ & $\begin{array}{l}33,503 \\
45,963\end{array}$ & $\begin{array}{l}20,916 \\
40,851\end{array}$ & $\begin{array}{l}5,211 \\
8,957\end{array}$ & $\begin{array}{l}4.104 \\
6,019\end{array}$ \\
\hline 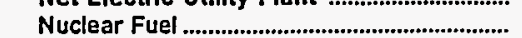 & & 0 & 0 & 0 & 0 & 0 \\
\hline 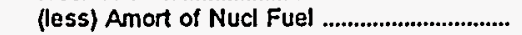 & & 0 & 0 & 0 & 0 & 0 \\
\hline 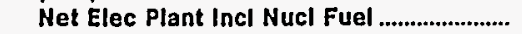 & 23,557 & 35,798 & 45,963 & 40,851 & 8,957 & 6,019 \\
\hline \multicolumn{7}{|l|}{ Other Property \& Investments } \\
\hline 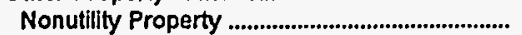 & 3 & 0 & 0 & 0 & 0 & 0 \\
\hline (less) Accum Provisions for Depr \& Amort.... & $\mathbf{0}$ & 0 & 0 & 0 & 0 & 0 \\
\hline 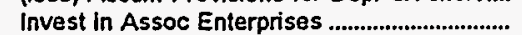 & 0 & 0 & 0 & 0 & 0 & 0 \\
\hline 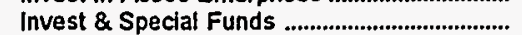 & 0 & 0 & 919 & 9,624 & 328 & 21 \\
\hline Total Other Property \& Investments ........ & 3 & 0 & 919 & 9,624 & 328 & 21 \\
\hline \multicolumn{7}{|l|}{ Current and Accrued Assets } \\
\hline 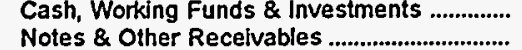 & 6,367 & $\begin{array}{r}10.047 \\
110\end{array}$ & $\begin{array}{l}1,882 \\
7,645\end{array}$ & $\begin{array}{l}6,1 / 7 \\
1,565\end{array}$ & $\begin{array}{l}2,217 \\
1,639\end{array}$ & $\begin{array}{r}1,381 \\
951\end{array}$ \\
\hline 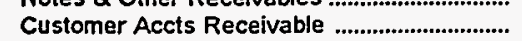 & 0 & 3,627 & 0 & 4,059 & 1.000 & 0 \\
\hline (less) Accum Prov for Uncollected Accts ...... & 0 & 0 & 0 & 53 & 0 & 0 \\
\hline Fuel Stock \& Exp Undistr ................................... & 0 & 0 & 0 & 0 & 0 & 0 \\
\hline 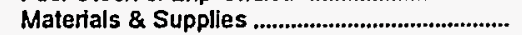 & 552 & 0 & 1,430 & 905 & 179 & 97 \\
\hline Other Supplies \& Misc ............................................... & 0 & 239 & 0 & 0 & 0 & 0 \\
\hline 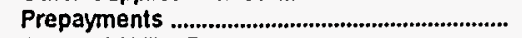 & 26 & 0 & 45 & 1.442 & 41 & 43 \\
\hline Accrued Utility Revenues ...................................... & 0 & 0 & 0 & 0 & 0 & 0 \\
\hline MIscellaneous Current \& Accrued Assets ..... & 0 & 8 & 126 & 101 & 53 & 36 \\
\hline Total Current \& Accrued Assets ................... & 12,317 & 14,530 & 11,127 & 14,197 & 4,128 & 2,509 \\
\hline \multicolumn{7}{|l|}{ Deferred Debits } \\
\hline Unamortized Debt Expenses .................................... & 0 & $\mathbf{0}$ & 0 & 159 & 132 & 16 \\
\hline Extraordinary Losses, Study Cost ............................. & 0 & 0 & 0 & 0 & 0 & 0 \\
\hline Misc Debt, $R$ \& $D$ Exp, Unamrt Losses .......... & 1,785 & 0 & 2,494 & 0 & 1.835 & 636 \\
\hline Total Deferred Debits ..................................... & 1,785 & & 2,494 & 159 & 1,966 & 651 \\
\hline Total Assets \& Other Debits ........................... & 37,662 & 50,329 & 60,503 & 64,831 & 15,380 & 9,200 \\
\hline \multicolumn{7}{|l|}{ Proprietary Capital } \\
\hline 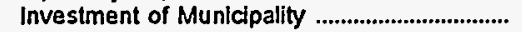 & 0 & 0 & 0 & 0 & 0 & 0 \\
\hline 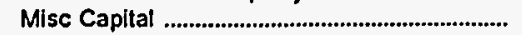 & 0 & 0 & 0 & $-1,087$ & 0 & 0 \\
\hline 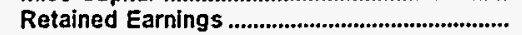 & 32,102 & 43,209 & 46,843 & 50,249 & 7.663 & 6.879 \\
\hline Total Proprietary Capital ................................... & 32,102 & 43,209 & 46,843 & 49,162 & 7,663 & 6,879 \\
\hline \multicolumn{7}{|l|}{ Long-term Debt } \\
\hline 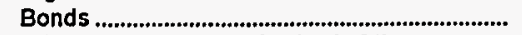 & 0 & 0 & 220 & 9,648 & 4.707 & 355 \\
\hline Advances from Municipality \& Other ............... & 233 & 0 & 2,505 & 0 & 591 & 650 \\
\hline Unamort Prem on Long-term Debt ..................... & 0 & 0 & 0 & 0 & 0 & 0 \\
\hline (less) Unamort Discount on Long-term Debt & 0 & 0 & 0 & 0 & 0 & 0 \\
\hline 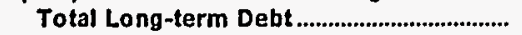 & 233 & 0 & 2,725 & 9,648 & 5,298 & 1,005 \\
\hline \multicolumn{7}{|l|}{ Other Noncurrent Liabilities } \\
\hline 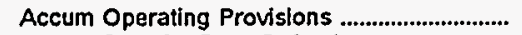 & 0 & 0 & 0 & 234 & 0 & 0 \\
\hline 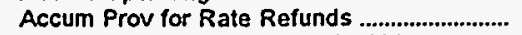 & 0 & 0 & 0 & 0 & 0 & 0 \\
\hline $\begin{array}{l}\text { Total Other Noncurrent Liabilities ............. } \\
\text { Current and Accrued Liabilities }\end{array}$ & 0 & 0 & 0 & 234 & 0 & 0 \\
\hline \multicolumn{7}{|l|}{ Current and Accrued Liabilities } \\
\hline 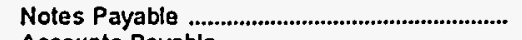 & $\begin{array}{r}0 \\
0\end{array}$ & 0 & 0 & & 45 & 0 \\
\hline 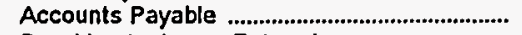 & 4,978 & 3,725 & 6,395 & 2,876 & 1,675 & 920 \\
\hline 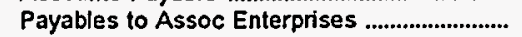 & 0 & 0 & 0 & 0 & 0 & 0 \\
\hline 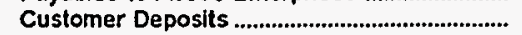 & 0 & 2,944 & 3,413 & 1,639 & 490 & 318 \\
\hline Taxes Accrued ................................................................ & 0 & 2 & 0 & 530 & 0 & 0 \\
\hline 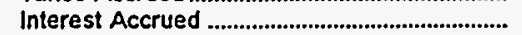 & 0 & 0 & 0 & 528 & 0 & $\mathbf{5}$ \\
\hline Misc Current \& Accrued Liabilities..................... & 349 & 448 & 1,127 & 12 & 207 & 73 \\
\hline Total Current \& Accrued Liabilities .......... & 5,327 & 7,119 & 10,935 & 5,584 & 2,417 & 1,316 \\
\hline \multicolumn{7}{|l|}{ Deferred Credits } \\
\hline Customer Advances for Construction ............... & 0 & 0 & 0 & 0 & 0 & 0 \\
\hline 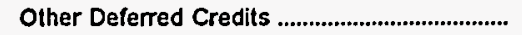 & 0 & 0 & 0 & 202 & 2 & 0 \\
\hline 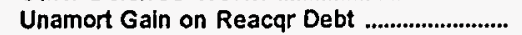 & 0 & 0 & 0 & $\mathbf{0}$ & 0 & 0 \\
\hline 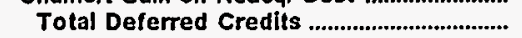 & & & & 202 & & \\
\hline Total Liabilities and Other Credits ............ & 37,662 & 50,329 & 60,503 & 64,831 & 15,380 & 9,200 \\
\hline
\end{tabular}

Note: Totals may not equal sum of components because of independent rounding.

Source: Energy Information Administration, Form EIA-412, "Annual Report of Public Electric Utilities." 
Table 22. Balance Sheet by Major U.S. Publicly Owned Electric Utility Within State at End of Period, 1994 (Continued)

(Thousand Dollars)

\begin{tabular}{|c|c|c|c|c|c|c|}
\hline Item & $\begin{array}{l}\text { Alabama } \\
\begin{array}{l}\text { Hartselle } \\
\text { City of }\end{array} \\
\text { June } 30\end{array}$ & $\begin{array}{l}\text { Alabama } \\
\text { Huntsville } \\
\text { City of } \\
\text { September } 30\end{array}$ & $\begin{array}{l}\text { Alabama } \\
\text { Muscle } \\
\text { Shoals } \\
\text { City of } \\
\text { June } 30\end{array}$ & $\begin{array}{l}\text { Alabama } \\
\text { Opelika } \\
\text { City of } \\
\text { September } 30\end{array}$ & $\begin{array}{l}\text { Alabama } \\
\text { Scottsboro } \\
\text { City of } \\
\text { June } 30\end{array}$ & $\begin{array}{l}\text { Alabama } \\
\text { Sheffield } \\
\text { Utilities } \\
\text { June } 30\end{array}$ \\
\hline \multicolumn{7}{|l|}{ Electric Utility Plant } \\
\hline Electric Utility Plant \& Adjust .................................... & 5,420 & 167,579 & 15,145 & 19,636 & 15,520 & 34,840 \\
\hline 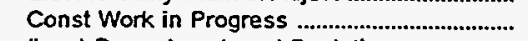 & 84 & 8,120 & 194 & 752 & 295 & 1,278 \\
\hline (less) Depr, Amort, and Depletion ...................... & 2,433 & 67,318 & 4,930 & 11,086 & 5,933 & 15,660 \\
\hline 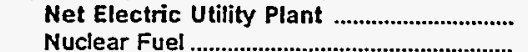 & $\begin{array}{r}3,071 \\
0\end{array}$ & $\begin{array}{r}108,380 \\
0\end{array}$ & $\begin{array}{r}10,409 \\
0\end{array}$ & 9,302 & 9,882 & 20,558 \\
\hline 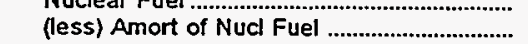 & 0 & 0 & 0 & 0 & $\begin{array}{l}0 \\
0\end{array}$ & $\begin{array}{l}\mathbf{0} \\
\mathbf{0}\end{array}$ \\
\hline 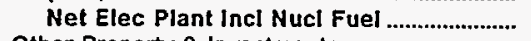 & 3,071 & 108,380 & 10,409 & 9,302 & 9,882 & 20,558 \\
\hline \multicolumn{7}{|l|}{ Other Property \& Investments } \\
\hline Nonutility Property ................................................. & 0 & 0 & 0 & 0 & 0 & 158 \\
\hline (less) Accum Provisions for Depr \& Amort.... & 0 & 0 & 0 & 0 & 0 & 0 \\
\hline 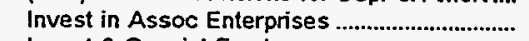 & 0 & 0 & 0 & 78 & 0 & 0 \\
\hline 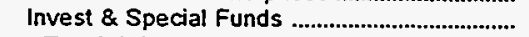 & 5 & 32,908 & 149 & 857 & 506 & 2,512 \\
\hline $\begin{array}{l}\text { Total Other Property \& Investments ....... } \\
\text { Current and Accrued Assets }\end{array}$ & 5 & 32,908 & 149 & 935 & 506 & 2,670 \\
\hline 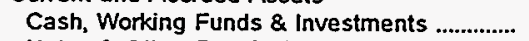 & 808 & 23,671 & 471 & 6,534 & 422 & 627. \\
\hline 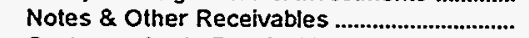 & 960 & 8,856 & 1,482 & 44 & 1.680 & 2,810 \\
\hline 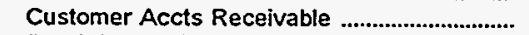 & 0 & 0 & 0 & 1,434 & 0 & 0 \\
\hline (less) Accum Prov for Uncollected Accts ....... & 0 & 0 & 0 & 0 & 0 & 0 \\
\hline 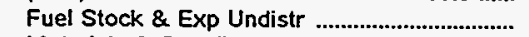 & 0 & 0 & 0 & 0 & 0 & 0 \\
\hline Materials \& Supplies ...................................................... & 118 & 4,081 & 204 & 331 & 149 & 890 \\
\hline 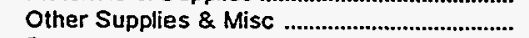 & 0 & 0 & 0 & 0 & 0 & 0 \\
\hline Prepayments ………………………………………......... & 8 & 44 & 103 & 11 & 20 & 186 \\
\hline 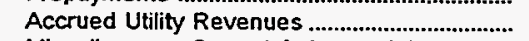 & 0 & 0 & 0 & 0 & 0 & 0 \\
\hline Miscellaneous Current \& Accrued Assets ..... & 20 & 802 & 29 & 30 & 54 & 92 \\
\hline $\begin{array}{l}\text { Total Current \& Accrued Assets ...................... } \\
\text { Deferred Debits }\end{array}$ & 1,913 & 37,454 & 2,288 & 8,384 & 2,325 & 4,603 \\
\hline Unamortized Debt Expenses ............................... & 10 & 355 & 27 & 74 & 27 & 13 \\
\hline 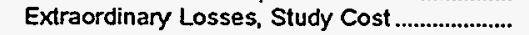 & 0 & 0 & 0 & 0 & 0 & 0 \\
\hline Misc Debt, R \& D Exp, Unamit Losses .......... & 438 & 1,523 & 743 & 0 & 1,617 & 1,895 \\
\hline Total Deferred Debits ........................................ & 448 & 1,877 & 771 & 74 & 1,644 & 1,907 \\
\hline Total Assets \& Other Debits ............................ & 5,438 & 180,619 & 13,617 & 18,696 & 14,357 & 29,739 \\
\hline \multicolumn{7}{|l|}{ Proprietary Capital } \\
\hline 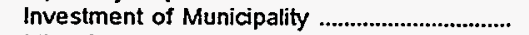 & 0 & o & 0 & 0 & 0 & 0 \\
\hline Misc Capital .................................................................. & 0 & 0 & 0 & 0 & 0 & 0 \\
\hline Retained Earnings .......................................................... & 3,863 & 132,866 & 10,182 & 12,060 & 6,952 & 22,557 \\
\hline \multicolumn{6}{|l|}{ Long-term Debt } & 22,557 \\
\hline Bonds & 491 & 15,000 & 820 & 2,843 & 3,387 & 1,375 \\
\hline 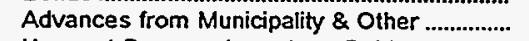 & 334 & 154 & 735 & 1,017 & 1,465 & 1,884 \\
\hline Unamort Prem on Long-term Debt ........................ & 0 & 0 & 0 & 0 & -35 & 0 \\
\hline (less) Unamort Discount on Long-tem Debt & 0 & 0 & 0 & 0 & 0 & 0 \\
\hline $\begin{array}{l}\text { Total Long-term Debt....................................... } \\
\text { Other Noncuurent Liabilities }\end{array}$ & 826 & 15,154 & 1,555 & 3,860 & 4,817 & 3,259 \\
\hline $\begin{array}{l}\text { Other Noncurrent Liabilities } \\
\text { Accum Operating Provisions .............................. }\end{array}$ & $\mathbf{0}$ & \multicolumn{5}{|c|}{ Other Noncurrent Liabilities } \\
\hline 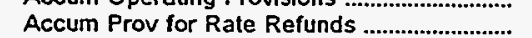 & 0 & $\begin{array}{l}0 \\
0\end{array}$ & $\begin{array}{l}0 \\
0\end{array}$ & $\begin{array}{l}0 \\
0\end{array}$ & $\begin{array}{l}0 \\
0\end{array}$ & $\begin{array}{l}0 \\
0\end{array}$ \\
\hline 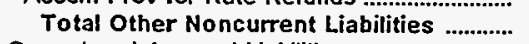 & 0 & 0 & 0 & 0 & 0 & 0 \\
\hline \multicolumn{7}{|l|}{ Current and Accrued Liabilities } \\
\hline 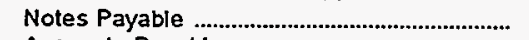 & 0 & 0 & 0 & 495 & 46 & 0 \\
\hline 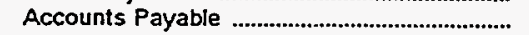 & 636 & 18,663 & 1,353 & 1,546 & 1,928 & 2,746 \\
\hline Payables to Assoc Enterprises ................................. & 0 & 0 & 0 & 0 & 0 & 0 \\
\hline Customer Deposits .................................................... & 0 & 11,222 & 442 & 597 & 427 & 671 \\
\hline Taxes Accrued .............................................................. & 0 & 0 & 0 & 0 & 22 & 6 \\
\hline 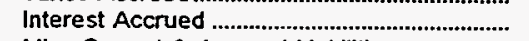 & 0 & 67 & 14 & 15 & 28 & 15 \\
\hline Misc Current \& Accrued Liabilities ........................... & 114 & 1,730 & 71 & 122 & 135 & 485 \\
\hline $\begin{array}{l}\text { Total Current \& Accrued Liabilities ....................... } \\
\text { Deferred Credits }\end{array}$ & 749 & 31,682 & 1,880 & 2,776 & 2,587 & 3,923 \\
\hline Customer Advances for Construction ............... & 0 & 0 & 0 & $\mathbf{0}$ & 0 & 0 \\
\hline 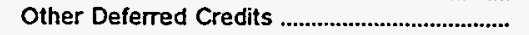 & 0 & 917 & 0 & 0 & 0 & 0 \\
\hline Unamort Gain on Reacqr Debt .............................. & 0 & 0 & 0 & 0 & 0 & 0 \\
\hline 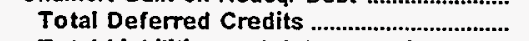 & & 917 & 0 & $\mathbf{0}$ & $\mathbf{0}$ & 0 \\
\hline Total Liabilities and Other Credits ............ & 5,438 & 180,619 & 13,617 & 18,696 & 14,357 & 29,739 \\
\hline
\end{tabular}

Note: Totals may not equal sum of components because of independent rounding.

Source: Energy Information Administration, Form EIA-412, "Annual Report of Public Electric Utilities." 
Table 22. Balance Sheet by Major U.S. Publicly Owned Electric Utility Within State at End of Period, 1994 (Continued)

(Thousand Dollars)

\begin{tabular}{|c|c|c|c|c|c|c|}
\hline Item & $\begin{array}{c}\text { Alabama } \\
\text { Sylacauga } \\
\text { Utilities } \\
\text { Board } \\
\text { September } 30\end{array}$ & $\begin{array}{c}\text { Alabama } \\
\text { Troy } \\
\text { City of } \\
\text { September } 30\end{array}$ & $\begin{array}{l}\text { Alabama } \\
\text { Tuskegee } \\
\text { City of } \\
\text { September } 30\end{array}$ & $\begin{array}{l}\text { Alaska } \\
\text { Alaska } \\
\text { Energy } \\
\text { Authority } \\
\text { June } 30\end{array}$ & $\begin{array}{c}\text { Alaska } \\
\text { Anchorage } \\
\text { City of } \\
\text { December } 31\end{array}$ & $\begin{array}{l}\text { Alaska } \\
\text { Fairbanks } \\
\text { City of } \\
\text { December } 31\end{array}$ \\
\hline \multicolumn{7}{|l|}{ Electric Utility Plant } \\
\hline 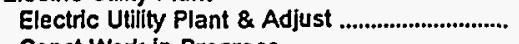 & 10,701 & 10,037 & 7,138 & 932,696 & 273,996 & 49.661 \\
\hline Const Work in Progress & & 0 & 0 & 0 & 6,308 & 694 \\
\hline $\begin{array}{l}\text { (less) Depr, Amort, and Depletion } \\
\text { Net Electric Utility Plant }\end{array}$ & $\begin{array}{l}6,409 \\
4,292\end{array}$ & $\begin{array}{l}5,898 \\
4,139\end{array}$ & $\begin{array}{l}3,693 \\
3,445\end{array}$ & $\begin{array}{l}195,021 \\
737,675\end{array}$ & $\begin{array}{l}125,107 \\
155,197\end{array}$ & $\begin{array}{l}30,821 \\
19,534\end{array}$ \\
\hline Nuclear Fuel ........................................................... & 0 & 0 & 0 & 0 & 0 & 0 \\
\hline 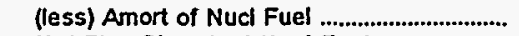 & 0 & o & 0 & 0 & 0 & 0 \\
\hline Net Elec Plant Inct Nucl Fuel .......................... & 4,292 & 4,139 & 3,445 & 737,675 & 155,197 & 19,534 \\
\hline \multicolumn{7}{|l|}{ Other Property \& Investments } \\
\hline Nonutility Property ...................................................... & 0 & 0 & 0 & 0 & 0 & 135,458 \\
\hline (less) Accum Provisions for Depr \& Amort.... & 0 & 0 & 0 & 0 & 0 & \\
\hline 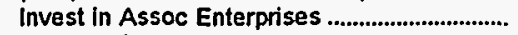 & 0 & 0 & 0 & 0 & 0 & 0 \\
\hline 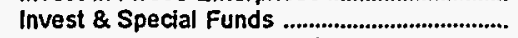 & 5,350 & 5,193 & 0 & 0 & 26,573 & 0 \\
\hline Total Other Property \& Investments ........ & 5,350 & 5,193 & $\mathbf{0}$ & 0 & 26,573 & 135,458 \\
\hline \multicolumn{7}{|l|}{ Current and Accrued Assets } \\
\hline Cash, Working Funds \& Investments .............. & 284 & 971 & 1,134 & 47.181 & 13,304 & 11,932 \\
\hline 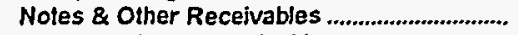 & 0 & 0 & 235 & 0 & 0 & 134 \\
\hline 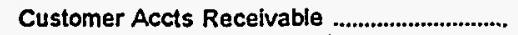 & 1,574 & 2,134 & 3,322 & 7,242 & 5,680 & 4.759 \\
\hline (less) Accum Prov for Uncollected Accts ...... & 0 & 0 & 0 & 0 & 212 & 309 \\
\hline 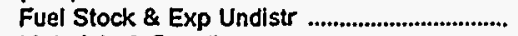 & 0 & 0 & 0 & 0 & 615 & 0 \\
\hline 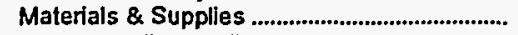 & 328 & 238 & 50 & 0 & 2,957 & 3,291 \\
\hline Other Supplies \& Misc .................................................. & 0 & 0 & 0 & 0 & 0 & 0 \\
\hline 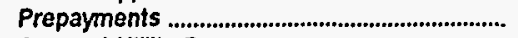 & 0 & 11 & 0 & 0 & 1,369 & 170 \\
\hline Accrued Utility Revenues ........................................... & 0 & 0 & 0 & 0 & 0 & 3,186 \\
\hline Miscellaneous Current \& Accrued Assets ..... & 21 & 0 & 0 & 1,139 & 433 & 0 \\
\hline Total Current \& Accrued Assets ................... & 2,207 & 3,355 & 4,741 & 55,562 & 24,145 & 23,163 \\
\hline \multicolumn{7}{|l|}{ Deferred Debits } \\
\hline 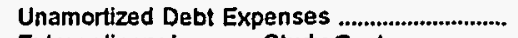 & 132 & 0 & 168 & 0 & 2,099 & 0 \\
\hline Extraordinary Losses, Study Cost....................... & 0 & 0 & 0 & 0 & 0 & 0 \\
\hline Mlsc Debt, R \& D Exp, Unamrt Losses .......... & 0 & 0 & 0 & 0 & 29,208 & 0 \\
\hline Total Deferred Debits ......................................... & 132 & & 168 & 0 & 31,306 & $\mathbf{0}$ \\
\hline 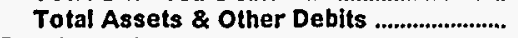 & 11,980 & 12,687 & 8,354 & 793,237 & 237,221 & 178,155 \\
\hline \multirow{2}{*}{\multicolumn{7}{|c|}{ Proprietary Capital }} \\
\hline & 625 & 0 & 4,515 & 619.801 & 0 & 8.785 \\
\hline 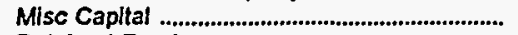 & o & 0 & D & 0 & 0 & 61,538 \\
\hline 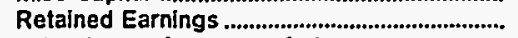 & 8,083 & 720 & 2,233 & $-182,815$ & 54,750 & 34,002 \\
\hline Total Proprietary Capital ..................................... & 8,708 & 720 & 6,748 & 436,986 & 54,750 & 104,325 \\
\hline \multicolumn{7}{|l|}{ Long-term Debt } \\
\hline Advances from Municipality \& Other ............. & $\begin{array}{r}2,390 \\
0\end{array}$ & 0 & 0 & 184,793 & 116,970 & $\begin{array}{r}47.487 \\
0\end{array}$ \\
\hline Unamort Prem on Long-term Debt ..................... & 0 & o & 0 & 0 & 4,013 & 0 \\
\hline (less) Unamort Discount on Long-term Debt & & 200 & 0 & 16.232 & 7,618 & 0 \\
\hline 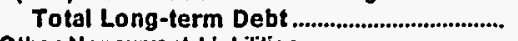 & 2,395 & 11,605 & 552 & 339,672 & 173,365 & 47,487 \\
\hline \multicolumn{7}{|l|}{ Other Noncurrent Labilities } \\
\hline 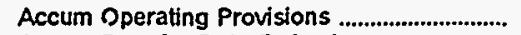 & c & 0 & 0 & 0 & 767 & 12,105 \\
\hline Accum Prov for Rate Refunds .......................... & 0 & 0 & 0 & 0 & 0 & 0 \\
\hline Total Other Noncurrent Liabillties ............. & 0 & o & 0 & 0 & 767 & 12,105 \\
\hline \multicolumn{7}{|l|}{ Current and Accrued Liabilities } \\
\hline Notes Payable ........................................................... & 328 & 0 & 0 & 2.820 & 0 & 815 \\
\hline 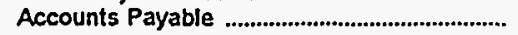 & 349 & 859 & 767 & 1,236 & 3,890 & 2,912 \\
\hline 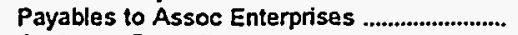 & 0 & 0 & 0 & 0 & 0 & 0 \\
\hline 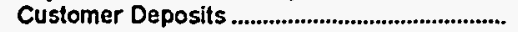 & 150 & 254 & 288 & 0 & 1,012 & 847 \\
\hline Taxes Accrued & 0 & 8 & 0 & 0 & 0 & 0 \\
\hline 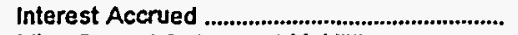 & 49 & 161 & 0 & 11,681 & 957 & 1,745 \\
\hline Misc Current \& Accrued Liabilities.................... & 0 & 118 & 0 & 842 & 1.757 & 7,919 \\
\hline Total Current \& Accrued Liabilities ........... & 877 & 1,400 & 1,055 & 16,579 & 7,615 & 14,238 \\
\hline \multicolumn{7}{|l|}{ Deferred Credits } \\
\hline Customer Advances for Construction .............. & 0 & 0 & 0 & 0 & 151 & 0 \\
\hline 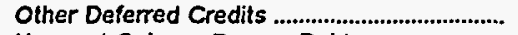 & 0 & 0 & 0 & 0 & 573 & 0 \\
\hline Unamort Galn on Reacqr Debt ........................... & 0 & $-1,038$ & 0 & 0 & 0 & 0 \\
\hline Total Deferred Credits ......................................... & 0 & $-1,038$ & $\mathbf{0}$ & 0 & 724 & 0 \\
\hline Total Liabilities and Other Credits ............ & 11,980 & 12,687 & 8,354 & 793,237 & 237,221 & 178,155 \\
\hline
\end{tabular}

Note: Totals may not equal sum of components because of independent rounding.

Source: Energy information Administration, Form EIA-412, "Annual Report of Public Electric Utilities." 
Table 22. Balance Sheet by Major U.S. Publicly Owned Electric Utility Within State at End of Period, 1994 (Continued)

(Thousand Dollars)

\begin{tabular}{|c|c|c|c|c|c|c|}
\hline Item & $\begin{array}{c}\text { Alaska } \\
\text { Ketchikan } \\
\text { City of } \\
\text { December } 31\end{array}$ & $\begin{array}{l}\text { Avizona } \\
\text { Arizona } \\
\text { Power } \\
\text { Authority } \\
\text { June } 30\end{array}$ & $\begin{array}{c}\text { Avizona } \\
\text { Electrical } \\
\text { Dist } \\
\text { No2 } \\
\text { Pinal Cnty } \\
\text { December } 31\end{array}$ & $\begin{array}{l}\text { Mesa } \\
\text { City of } \\
\text { June } 30\end{array}$ & $\begin{array}{l}\text { Arizona } \\
\text { Navajo } \\
\text { Tribal } \\
\text { Utility } \\
\text { Auth } \\
\text { December } 31\end{array}$ & $\begin{array}{l}\text { Arizona } \\
\text { Salt River } \\
\text { Proj Ag } \\
\text { I \& P Dist } \\
\text { April } 30\end{array}$ \\
\hline \multicolumn{7}{|l|}{ Electric Utility Plant } \\
\hline 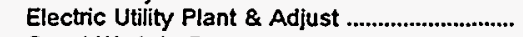 & 49,126 & 1,174 & 17,083 & 55,074 & 118,192 & $5,768,002$ \\
\hline Const Work in Progress & 6,270 & 0 & 0 & 4,395 & 10,242 & 253,640 \\
\hline $\begin{array}{l}\text { (less) Depr, Amort, and Depletion ......................... } \\
\text { Net Electric Utility Plant ............................... }\end{array}$ & $\begin{array}{l}22,623 \\
32,774\end{array}$ & $\begin{array}{l}786 \\
388\end{array}$ & $\begin{array}{l}7,301 \\
9,782\end{array}$ & $\begin{array}{l}14,143 \\
45,326\end{array}$ & $\begin{array}{l}47.744 \\
80,689\end{array}$ & $\begin{array}{l}1,878,626 \\
4,143,016\end{array}$ \\
\hline Nuclear Fuel & 0 & 0 & 0 & 0 & 0 & 231,068 \\
\hline 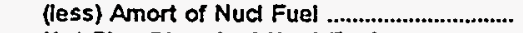 & 0 & 0 & 0 & 0 & 0 & 184,649 \\
\hline $\begin{array}{l}\text { Net Elec Plant Incl Nucl Fuel ............................ } \\
\text { Other Property \& investments }\end{array}$ & 32,774 & 388 & 9,782 & 45,326 & 80,689 & $4,189,435$ \\
\hline Nonutility Property & 0 & $\mathbf{0}$ & $\mathbf{0}$ & 691,884 & 879 & 68,428 \\
\hline (less) Accum Provisions for Depr \& Amort.... & 0 & 0 & 0 & 132,974 & 446 & 1,364 \\
\hline 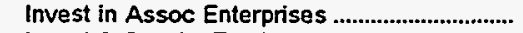 & 0 & 0 & 292 & 0 & 2,164 & 9,678 \\
\hline 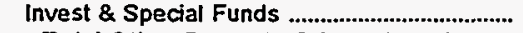 & 8,625 & 3.720 & 50 & 0 & 0 & 321,537 \\
\hline $\begin{array}{l}\text { Total Other Property \& Investments ....... } \\
\text { Current and Accrued Assets }\end{array}$ & 8,625 & 3,720 & 342 & 558,910 & 2,597 & 398,279 \\
\hline $\begin{array}{l}\text { Current and Accrued Assets } \\
\text { Cash, Working Funds \& investments ............. }\end{array}$ & 8,248 & \multicolumn{5}{|c|}{ Current and Accrued Assets } \\
\hline 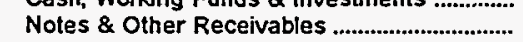 & $\begin{array}{l}0,248 \\
4,096\end{array}$ & $\begin{array}{r}24,139 \\
0\end{array}$ & $\begin{array}{r}11,066 \\
0\end{array}$ & $\begin{array}{l}32,310 \\
28,316\end{array}$ & $\begin{array}{r}2,929 \\
530\end{array}$ & $\begin{array}{r}344,369 \\
14,519\end{array}$ \\
\hline 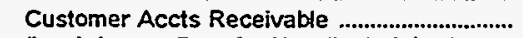 & 624 & 2,154 & 821 & 0 & 4,038 & 62,214 \\
\hline (less) Accum Prov for Uncollected Accts ...... & 150 & 0 & 0 & 653 & 457 & 1.061 \\
\hline 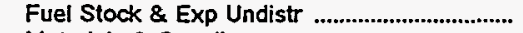 & 0 & 0 & 0 & 0 & 3 & 40,579 \\
\hline 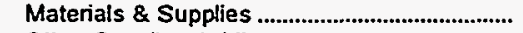 & 1,387 & 0 & $\checkmark / 0$ & 0 & 1,835 & 79.427 \\
\hline 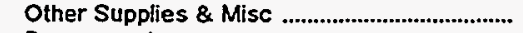 & 0 & 0 & 0 & 0 & 103 & 0 \\
\hline Prepayments & 242 & 1.712 & 6.224 & 124 & 67 & 2,422 \\
\hline 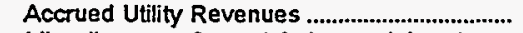 & $\mathbf{0}$ & 0 & 0 & 0 & 989 & 22,843 \\
\hline Miscellaneous Current \& Accrued Assets ..... & $\mathbf{0}$ & 253 & 0 & 0 & 0 & 8,521 \\
\hline $\begin{array}{l}\text { Total Current \& Accrued Assets ................ } \\
\text { Deferred Debits }\end{array}$ & 14,448 & 28,258 & 48,781 & 60,097 & 10,036 & 573,933 \\
\hline 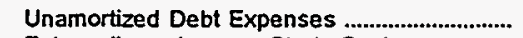 & 860 & 53,863 & 0 & 292 & 0 & 5,336 \\
\hline Extraordinary Losses, Study Cost .......................... & 0 & 0 & 0 & 0 & 2,939 & 323,059 \\
\hline Misc Debt, R \& D Exp, Unamrt Losses .......... & 0 & 0 & 0 & 10,522 & 0 & 0 \\
\hline 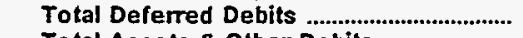 & 860 & 53,863 & 0 & 10,814 & 2,939 & 328,395 \\
\hline \multicolumn{5}{|l|}{ Proprietary Capital } & 96,262 & $5,490,042$ \\
\hline 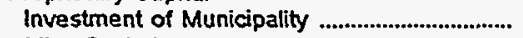 & $\mathbf{0}$ & 0 & 0 & 57,708 & $\mathbf{0}$ & 0 \\
\hline 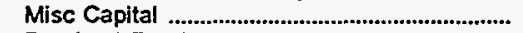 & 0 & 9 & 0 & 278,186 & 39,088 & 0 \\
\hline Retained Earnings & 27,646 & 5,628 & 28,160 & 85,075 & 20,793 & $1,329,715$ \\
\hline $\begin{array}{l}\text { Total Proprietary Capital ..................................... } \\
\text { Long-term Debt }\end{array}$ & Long-term Debt & 5,637 & 28,160 & 420,969 & 59,881 & $1,329,715$ \\
\hline Bonds & 26,545 & 80,295 & 0 & 183,448 & 0 & $3,329,276$ \\
\hline Advances from Municipality \& Other ................ & 0 & 0 & 0 & 824 & 22,544 & 375,000 \\
\hline Unamort Prem on Long-term Debt ................... & 0 & 0 & 4 & 84 & 0 & 0 \\
\hline (less) Unamort Discount on Long-term Debt & 0 & 2,097 & 0 & 0 & 0 & 111,204 \\
\hline $\begin{array}{l}\text { Total Long-term Debt } \\
\text { Other Noncurent Labilities }\end{array}$ & 26,545 & 78,198 & 4 & 184,355 & 22,544 & $3,593,072$ \\
\hline \multicolumn{7}{|l|}{ Other Noncurrent Labilities } \\
\hline 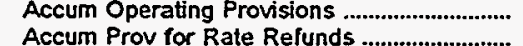 & 0 & 0 & 0 & 0 & 0 & 86,417 \\
\hline 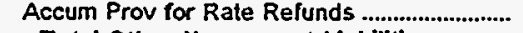 & 0 & 0 & 0 & 0 & $\mathbf{0}$ & 0 \\
\hline \multicolumn{6}{|l|}{ Current and Accrued Liabilities } & 86,417 \\
\hline 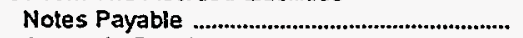 & 0 & 0 & 0 & 51,548 & 3,362 & $\mathbf{0}$ \\
\hline Accounts Payable & 2,165 & 1,322 & 469 & 2,610 & 2,437 & 115,966 \\
\hline 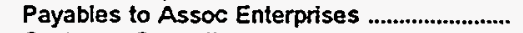 & 0 & 0 & 0 & 1,607 & 0 & 0 \\
\hline Customer Deposits & 314 & 0 & 231 & 4,642 & 64 & 42,553 \\
\hline Taxes Accrued & 0 & 0 & 0 & 0 & 0 & 77.149 \\
\hline Interest Accrued & 36 & 1,034 & 40 & 5,893 & 0 & 64,336 \\
\hline Misc Current \& Accrued Liabilities.................. & 0 & 38 & 0 & 3,524 & 2,883 & 138,748 \\
\hline $\begin{array}{l}\text { Total Current \& Accrued Liabilities ........... } \\
\text { Deferred Credits }\end{array}$ & \multicolumn{4}{|c|}{ Deferred Credits } & 8,746 & 438,753 \\
\hline Customer Advances for Construction .............. & 0 & 0 & 0 & 0 & 689 & 6,511 \\
\hline 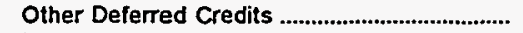 & 0 & 0 & 0 & 0 & 4.403 & 35,575 \\
\hline 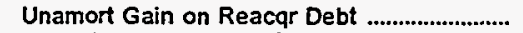 & $\mathbf{0}$ & 0 & 0 & 0 & 0 & 0 \\
\hline Total Deferred Credits ...................................... & 0 & $\mathbf{0}$ & $\mathbf{0}$ & 0 & 5,091 & 42,086 \\
\hline Total Liabilities and Other Credits ............. & 56,706 & 86,229 & 28,904 & 675,148 & 96,262 & $5,490,042$ \\
\hline
\end{tabular}

Note: Totals may not equal sum of components because of independent rounding.

Source: Energy Information Administration, Form EIA-412, "Annual Report of Public Electric Utilities." 
Table 22. Balance Sheet by Major U.S. Publicly Owned Electric Utility Within State at End of Period, 1994 (Continued)

(Thousand Dollars)

\begin{tabular}{|c|c|c|c|c|c|c|}
\hline Item & $\begin{array}{l}\text { Avizona } \\
\text { Tohono } \\
\text { OOdham } \\
\text { Utility Auth } \\
\text { December } 31\end{array}$ & $\begin{array}{l}\text { Arkansas } \\
\text { Benton } \\
\text { City of } \\
\text { December } 31\end{array}$ & $\begin{array}{c}\text { Bentonville } \\
\text { City of }\end{array}$ & $\begin{array}{l}\text { Arkansas } \\
\text { Clarksville } \\
\text { Light } \\
\text { \& } \\
\text { Water Co } \\
\text { September } 30\end{array}$ & $\begin{array}{l}\text { Arkansas } \\
\text { Conway } \\
\text { Corp }\end{array}$ & $\begin{array}{c}\text { Arkansas } \\
\text { Hope } \\
\text { City of } \\
\text { December } 31\end{array}$ \\
\hline \multicolumn{7}{|l|}{ Electric Utillty Plant } \\
\hline 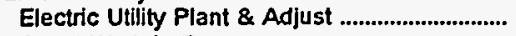 & 10,913 & 8,342 & 46,536 & 13.235 & 69,877 & 16,234 \\
\hline Const Work in Progress & 70 & 0 & 1,589 & 0 & 283 & 0 \\
\hline 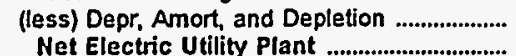 & $\begin{array}{l}3,069 \\
7,815\end{array}$ & $\begin{array}{l}5,766 \\
2,575\end{array}$ & $\begin{array}{l}11,173 \\
36,952\end{array}$ & $\begin{array}{l}4,012 \\
9,223\end{array}$ & $\begin{array}{l}27,743 \\
42,417\end{array}$ & $\begin{array}{r}5,406 \\
10,828\end{array}$ \\
\hline 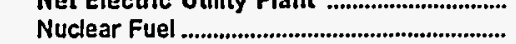 & $\begin{array}{r}1,80 \\
0\end{array}$ & 0 & 0 & 0 & 0 & 0 \\
\hline (less) Amort of Nucl Fuel ........................... & 0 & 0 & 0 & 0 & 0 & 0 \\
\hline Net Elec Plant Incl Nucl Fuel ........................ & 7,915 & 2,575 & 36,952 & 9,223 & 42,417 & 10,828 \\
\hline \multicolumn{7}{|l|}{ Other Property \& Investments } \\
\hline Nonutillty Property & 0 & $\mathbf{0}$ & 0 & 29,738 & 407 & 607 \\
\hline (less) Accum Provisions for Depr \& Amort.... & 0 & 0 & 0 & 5,466 & 0 & 0 \\
\hline 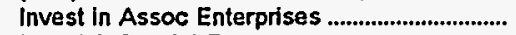 & 177 & 0 & 0 & 11 & 2,368 & 0 \\
\hline Imvest \& Special Funds ....................................... & 89 & 2,765 & 5.493 & 4,052 & 18,369 & 1,023 \\
\hline Total Other Property \& Investments ....... & 266 & 2,765 & 5,493 & 28,336 & 21,144 & 1,630 \\
\hline \multicolumn{7}{|l|}{ Current and Accrued Assets } \\
\hline Cash, Working Funds \& Investments .............. & 324 & 891 & 2,287 & 3,448 & 774 & 3,705 \\
\hline 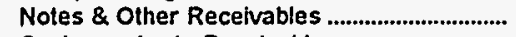 & 139 & 0 & 486 & 85 & 1,262 & 105 \\
\hline 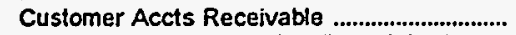 & 741 & 1,865 & 1,309 & 1,366 & 2,413 & 703 \\
\hline (less) Accum Prov for Uncollected Accts ....... & 0 & 0 & 0 & 44 & 111 & 29 \\
\hline 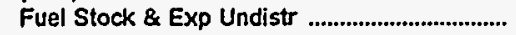 & 0 & 0 & $\mathbf{0}$ & 0 & 1,098 & 8 \\
\hline 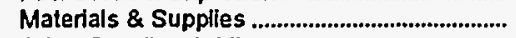 & 247 & 201 & 735 & 693 & 414 & 186 \\
\hline 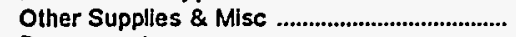 & 0 & 0 & 0 & 0 & 1,165 & 0 \\
\hline 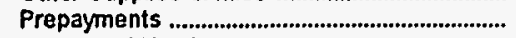 & 33 & 0 & 0 & 90 & 9 & 37 \\
\hline 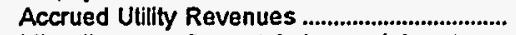 & 0 & 0 & 1,083 & 499 & 0 & 558 \\
\hline Miscellaneous Current \& Accrued Assets ..... & 1 & 0 & 0 & 0 & 766 & 10 \\
\hline Total Current \& Accrued Assets .............. & 1,486 & 2,957 & 5,901 & 6,137 & 7,789 & 5,283 \\
\hline \multicolumn{7}{|l|}{ Deferred Debits } \\
\hline 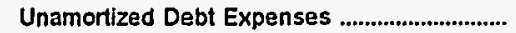 & 0 & 0 & 616 & 86 & 87 & 0 \\
\hline Extraordinary Losses, Study Cost..................... & 0 & 0 & 0 & 0 & 0 & 0 \\
\hline Misc Debt, R \& D Exp, Unamrt Losses ......... & 48 & 0 & 0 & 0 & 533 & $\mathbf{0}$ \\
\hline 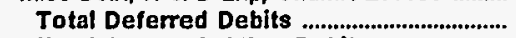 & 48 & 0 & 616 & 86 & 619 & 0 \\
\hline Total Assets \& Other Debits ........................ & 9,714 & 8,297 & 48,961 & 43,782 & 71,969 & 17,741 \\
\hline \multicolumn{7}{|l|}{ Proprietary Capital } \\
\hline Investment of Municipality ................................. & $\mathbf{0}$ & $\mathbf{0}$ & 7,302 & 0 & 179 & 0 \\
\hline 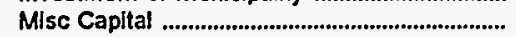 & 0 & 0 & 0 & 11,678 & 2,184 & 0 \\
\hline 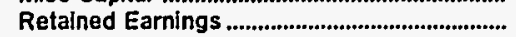 & 4,340 & 7,179 & 18,695 & 20,019 & 41,006 & 10,702 \\
\hline Total Proprietary Capital ................................ & 4,340 & 7,179 & 25,998 & 31,697 & 43,369 & 10,702 \\
\hline \multicolumn{7}{|l|}{ Long-term Debt } \\
\hline Bonds & 0 & 0 & 9,255 & 9.890 & 24,605 & 5,150 \\
\hline Advances from Municipality \& Other ................ & 4,791 & 0 & 12,000 & 0 & 0 & 0 \\
\hline 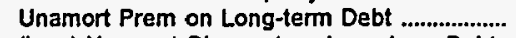 & 0 & 0 & 0 & 0 & 0 & $\mathbf{0}$ \\
\hline (less) Unamort Discount on Long-tem Debt & 0 & 0 & 0 & 180 & 331 & 0 \\
\hline Total Long-term Debt & 4,791 & 0 & 21,255 & 9,710 & 24,274 & 5,150 \\
\hline \multicolumn{7}{|l|}{ Other Noncurrent Llabilities } \\
\hline 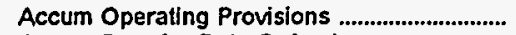 & 0 & 0 & 0 & 0 & 0 & 203 \\
\hline Accum Prov for Rate Refunds ............................ & 0 & 0 & 0 & 0 & $\mathbf{0}$ & 0 \\
\hline Total Other NoncurTent Liabilities ............. & $\mathbf{0}$ & $\mathbf{0}$ & $\mathbf{0}$ & 0 & 0 & 203 \\
\hline \multicolumn{7}{|l|}{ Current and Accrued Liabilities } \\
\hline Notes Payable & 0 & 0 & 0 & 0 & 0 & 214 \\
\hline Accounts Payable & 418 & 697 & 986 & 1.376 & 2,820 & 766 \\
\hline Payables to Assoc Enterprises ......................... & 0 & 0 & 24 & 0 & 0 & 0 \\
\hline 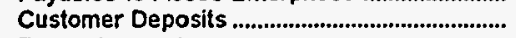 & 4 & 402 & 376 & 263 & 516 & 426 \\
\hline 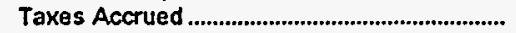 & 0 & 17 & 108 & 0 & 0 & 0 \\
\hline Interest Accrued & 0 & 0 & 54 & 109 & 538 & 208 \\
\hline Misc Current \& Accrued Liabilities.................... & 161 & 1 & 161 & 627 & 0 & 72 \\
\hline Total Current \& Accrued Liabilities .......... & 584 & 1,118 & 1,709 & 2,375 & 3,874 & 1,686 \\
\hline \multicolumn{7}{|l|}{ Deferred Credits } \\
\hline Customer Advances for Construction ............. & 0 & 0 & 0 & 0 & $\mathbf{0}$ & 0 \\
\hline 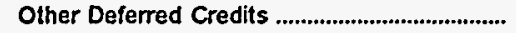 & 0 & 0 & 0 & 0 & 453 & 0 \\
\hline Unamort Gain on Reacqr Debt ........................... & 0 & 0 & 0 & 0 & $\mathbf{0}$ & 0 \\
\hline 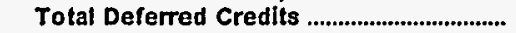 & 0 & 0 & 0 & 0 & 453 & $\mathbf{0}$ \\
\hline Total Llabilities and Other Credits ............ & 9,714 & 8,297 & 48,961 & 43,782 & 71,969 & 17,741 \\
\hline
\end{tabular}

Note: Totals may not equal sum of components because of independent rounding.

Source: Energy Information Administration, Form ElA-412, "Annual Report of Public Electric Utilities." 
Table 22. Balance Sheet by Major U.S. Publicly Owned Electric Utility Within State at End of Period, 1994 (Continued)

(Thousand Dollars)

\begin{tabular}{|c|c|c|c|c|c|c|}
\hline Item & $\begin{array}{l}\text { Arkansas } \\
\text { Jonesboro } \\
\text { City of } \\
\text { December } 31\end{array}$ & $\begin{array}{l}\text { Arkansas } \\
\text { North } \\
\text { Little } \\
\text { Rock } \\
\text { City of } \\
\text { December } 31\end{array}$ & $\begin{array}{l}\text { Arkansas } \\
\text { Osceola } \\
\text { City of } \\
\text { December } 31\end{array}$ & $\begin{array}{c}\text { Arkansas } \\
\text { Paragould } \\
\text { Light } \\
\text { \& } \\
\text { Water Comm } \\
\text { December } 31\end{array}$ & $\begin{array}{l}\text { Arkansas } \\
\text { Siloam } \\
\text { Springs } \\
\text { City of } \\
\text { December } 31\end{array}$ & $\begin{array}{l}\text { Arkansas } \\
\text { West } \\
\text { Memphis } \\
\text { City of } \\
\text { December } 31\end{array}$ \\
\hline \multicolumn{7}{|l|}{ Electric Utility Plant } \\
\hline Electric Utility Plant \& Adjust ................................ & 143,710 & 155,303 & 20,829 & 29.706 & 5.075 & 30,071 \\
\hline 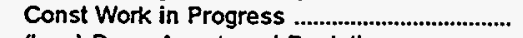 & 1,162 & 909 & & 0 & 196 & 0 \\
\hline $\begin{array}{l}\text { (less) Depr, Amort, and Depletion } \\
\text { Net Electric Utility PJant }\end{array}$ & $\begin{array}{l}70,707 \\
\mathbf{7 4 , 1 6 5}\end{array}$ & $\begin{array}{r}38,753 \\
117,458\end{array}$ & $\begin{array}{r}9,132 \\
11,697\end{array}$ & $\begin{array}{l}11,468 \\
18,238\end{array}$ & $\begin{array}{r}485 \\
4.786\end{array}$ & $\begin{array}{l}14,387 \\
15,684\end{array}$ \\
\hline 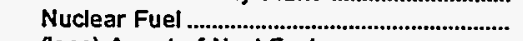 & 0 & 0 & 0 & 0 & 0 & $\begin{array}{r}10,004 \\
0\end{array}$ \\
\hline (less) Amort of Nucl Fuel ........................... & & 0 & 0 & 0 & 0 & 0 \\
\hline 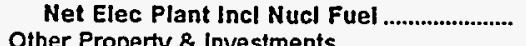 & 74,165 & 117,458 & 11,697 & 18,238 & 4,786 & 15,684 \\
\hline \multicolumn{7}{|l|}{ Other Property \& investments } \\
\hline (less) Accum Provisions for Depr \& Amort.... & $\begin{array}{r}368 \\
0\end{array}$ & $\begin{array}{l}0 \\
0\end{array}$ & $\begin{array}{l}0 \\
0\end{array}$ & $\begin{array}{l}0 \\
0\end{array}$ & 0 & $\begin{array}{l}30,083 \\
19,077\end{array}$ \\
\hline 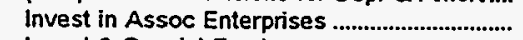 & 16,639 & 0 & 0 & 0 & 0 & $\begin{array}{r}19,0 / 7 \\
0\end{array}$ \\
\hline 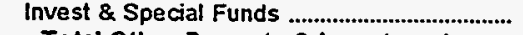 & 4,546 & 36,733 & 1,986 & 4,105 & 0 & 0 \\
\hline $\begin{array}{l}\text { Total Other Property \& Investments ....... } \\
\text { Current and Accrued Assets }\end{array}$ & 21,553 & 36,733 & 1,986 & 4,105 & 0 & 11,006 \\
\hline Cash, Working Funds \& Investments ............... & 20,184 & 11,853 & 212 & 475 & 2,536 & 25,004 \\
\hline Notes \& Other Recervables ................................... & & 90 & 827 & 79 & 525 & 1,590 \\
\hline Customer Accts Receivable ........................... & 3,704 & 3,516 & 795 & 1,149 & 15 & 1,984 \\
\hline (less) Accum Prov for Uncollected Accts ...... & 125 & 218 & 35 & 0 & 0 & 150 \\
\hline 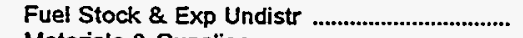 & 2,871 & 0 & 77 & 0 & 0 & 574 \\
\hline Materials \& Supplies .................................................. & 1,638 & 792 & 386 & 577 & 224 & o \\
\hline 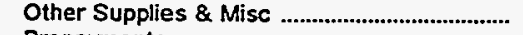 & 14 & 0 & 0 & 0 & 0 & 596 \\
\hline 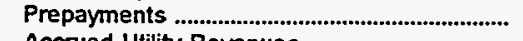 & 481 & 56 & 26 & 20 & 44 & 79 \\
\hline Accrued Utility Revenues & 713 & 2,353 & 72 & 0 & 0 & 691 \\
\hline Miscellaneous Current \& Accrued Assets ..... & 311 & & 0 & 0 & 0 & \\
\hline $\begin{array}{l}\text { Total Current \& Accrued Assets ................ } \\
\text { Deferred Debits }\end{array}$ & 29,792 & 18,442 & 2,361 & 2,300 & 3,345 & 30,369 \\
\hline 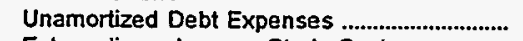 & 585 & 2,778 & 64 & 1,602 & 62 & 639 \\
\hline 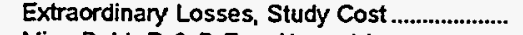 & 0 & & 0 & 0 & 0 & 0 \\
\hline Misc Debt, R \& D Exp, Unamrt Losses .......... & 0 & 0 & 0 & 0 & 0 & 1 \\
\hline Total Deferred Debits ....................................... & 585 & 2,778 & 64 & 1,602 & 62 & 639 \\
\hline $\begin{array}{l}\text { Total Assets \& Other Debits ........................ } \\
\text { Proprietary Capital }\end{array}$ & 126,095 & 175,411 & 16,108 & 26,244 & 8,192 & 57,698 \\
\hline $\begin{array}{l}\text { Propnetary Capital } \\
\text { Investment of Municipality ...................................... }\end{array}$ & 0 & 18,022 & 1,308 & 0 & 0 & 2,746 \\
\hline Misc Capital & 219 & 0 & 0 & 0 & 0 & 0 \\
\hline Retained Earnings & 70,989 & 0 & 11,412 & 26,609 & 3,654 & 33,769 \\
\hline $\begin{array}{l}\text { Total Proprietary Capital ................................... } \\
\text { Long-term Debt }\end{array}$ & 71,208 & 18,022 & 12,720 & 26,609 & 3,654 & 36,515 \\
\hline 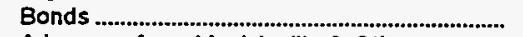 & 42,725 & 148,365 & 2,805 & 8,950 & 3,626 & 19,045 \\
\hline Advances from Municipality \& Other ................ & 1,797 & 0 & 143 & 0 & 0 & 0 \\
\hline Unamort Prem on Long-term Debt .................. & 0 & 0 & 0 & 0 & 0 & 0 \\
\hline (less) Unamort Discount on Long-term Debt & 710 & 0 & 0 & 0 & 0 & 833 \\
\hline Total Long-term Debt ........................................ & 43,812 & 148,365 & 2,948 & 8,950 & 3,626 & 18,212 \\
\hline \multicolumn{7}{|l|}{ Other Noncurrent Labilities } \\
\hline 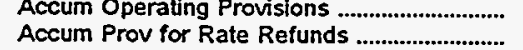 & $\begin{array}{r}346 \\
0\end{array}$ & $\begin{array}{l}0 \\
0\end{array}$ & $\begin{array}{l}0 \\
0\end{array}$ & 0 & 0 & $\begin{array}{l}0 \\
0\end{array}$ \\
\hline Total Other Noncurrent Liabilities ............. & 346 & 0 & $\begin{array}{l}0 \\
0\end{array}$ & $\begin{array}{l}0 \\
0\end{array}$ & 0 & $\begin{array}{l}0 \\
0\end{array}$ \\
\hline \multicolumn{7}{|l|}{ Current and Accrued Liabilities } \\
\hline 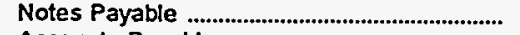 & 3,292 & 0 & 0 & 0 & 609 & 226 \\
\hline 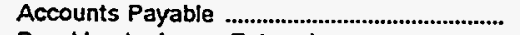 & 6,367 & 3,477 & 230 & 1,275 & 0 & 468 \\
\hline Payables to Assoc Enterprises ............................... & 0 & 0 & 1 & 0 & 0 & 0 \\
\hline Customer Deposits & 474 & 0 & 164 & 216 & 172 & 693 \\
\hline Taxes Accrued & 106 & 0 & 23 & 0 & 0 & 0 \\
\hline Interest Accrued & 204 & 4,805 & 21 & 147 & 0 & 629 \\
\hline Misc Current \& Accrued Liabilities .................... & 286 & 742 & 0 & 22 & 131 & 955 \\
\hline $\begin{array}{l}\text { Total Current \& Accrued Liabilities ........... } \\
\text { Deferred Credits }\end{array}$ & 10,730 & 9,025 & 439 & 1,660 & 912 & 2,971 \\
\hline Customer Advances for Construction .............. & 0 & $\mathbf{0}$ & 0 & 0 & 0 & 0 \\
\hline Other Deferred Credits ............................................. & 0 & 0 & 0 & $-10,975$ & 0 & 0 \\
\hline Unamort Gain on Reacqr Debt ............................... & 0 & 0 & 0 & 0 & 0 & 0 \\
\hline 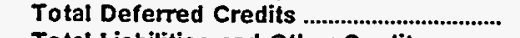 & 0 & 0 & 0 & $-10,975$ & 0 & \\
\hline Total Liabilities and Other Credits ............ & 126,095 & $175,41,1$ & 16,108 & 26,244 & 8,192 & 57,698 \\
\hline
\end{tabular}

Note: Totals may not equal sum of components because of independent rounding.

Source: Energy Information Administration, Form EIA-412, "Annual Report of Public Electric Utilities." 
Table 22. Balance Sheet by Major U.S. Publicly Owned Electric Utility Within State at End of Period, 1994 (Continued)

(Thousand Dollars)

\begin{tabular}{|c|c|c|c|c|c|c|}
\hline Item & $\begin{array}{l}\text { California } \\
\text { Alameda } \\
\text { City of } \\
\text { June } 30\end{array}$ & $\begin{array}{l}\text { California } \\
\text { Anaheim } \\
\text { City of } \\
\text { June } 30\end{array}$ & $\begin{array}{l}\text { California } \\
\text { Azusa } \\
\text { City of } \\
\text { June } 30\end{array}$ & $\begin{array}{l}\text { California } \\
\text { Burbank } \\
\text { City of } \\
\text { June } 30\end{array}$ & $\begin{array}{l}\text { California } \\
\text { California } \\
\text { Dept } \\
\text { Wtr } \\
\text { Resources } \\
\text { June } 30\end{array}$ & $\begin{array}{l}\text { Colton } \\
\text { City of } \\
\text { June } 30\end{array}$ \\
\hline \multicolumn{7}{|l|}{ Electric Utility Plant } \\
\hline 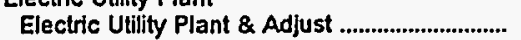 & 49,854 & 518,936 & $16,889$. & 172,384 & 860,497 & 13.913 \\
\hline Const Work in Progress & & 20,927 & 0 & 24,609 & 0 & 1,616 \\
\hline $\begin{array}{l}\text { (less) Depr, Amort, and Depletion } \\
\text { Net Electric Utility Plant }\end{array}$ & $\begin{array}{l}15,128 \\
34,726\end{array}$ & $\begin{array}{l}135,213 \\
404,650\end{array}$ & $\begin{array}{r}4,907 \\
11,982\end{array}$ & $\begin{array}{r}101,116 \\
95,877\end{array}$ & $\begin{array}{l}303,578 \\
556,919\end{array}$ & $\begin{array}{l}6,082 \\
9,447\end{array}$ \\
\hline 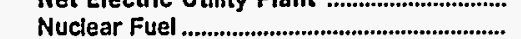 & 0 & 43,646 & 0 & 0 & 0 & 0 \\
\hline 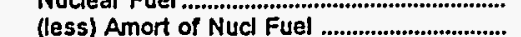 & 0 & 38.758 & 0 & 0 & 0 & 0 \\
\hline Net Elec Plant Incl Nuci Fuel ...................... & 34,726 & 409,538 & 11,982 & 95,877 & 556,919 & 9,447 \\
\hline \multicolumn{7}{|l|}{ Other Property \& Investments } \\
\hline 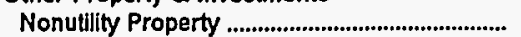 & 0 & 0 & 0 & 0 & 0 & $\mathbf{0}$ \\
\hline (less) Accum Provisions for Depr \& Amort.... & 0 & 0 & 0 & 0 & 0 & 0 \\
\hline Invest in Assoc Enterprises ............................. & 0 & 0 & 8,997 & 0 & 0 & 0 \\
\hline 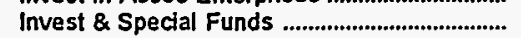 & 20.757 & 0 & 0 & 0 & 44,970 & 0 \\
\hline Total Other Property \& Investments ........ & 20,757 & 0 & 8,997 & 0 & 44,970 & $\mathbf{0}$ \\
\hline \multicolumn{7}{|l|}{ Current and Accrued Assets } \\
\hline Cash, Working Funds \& Investments ............. & 12,374 & 205,540 & 12,870 & 12,734 & 152,106 & 0 \\
\hline 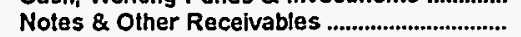 & 0 & 4,602 & 4,044 & 1,096 & 11,297 & 8,674 \\
\hline 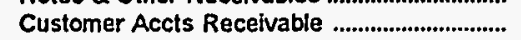 & 3,761 & 21,864 & 2,391 & 14,438 & 0 & 3,533 \\
\hline (less) Accum Prov for Uncollected Accts ...... & 4 & 0 & 0 & 0 & 0 & 0 \\
\hline 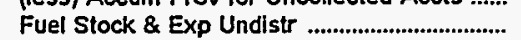 & 0 & 0 & 0 & 0 & 0 & 0 \\
\hline Materials \& Supplies ........................................... & 1,311 & 4,816 & 379 & 3,166 & 9,248 & 0 \\
\hline Other Supplies \& Misc & 0 & 0 & 0 & 1,972 & 0 & 1,559 \\
\hline 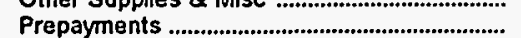 & 44 & 2,013 & 0 & 0 & 0 & 0 \\
\hline Accrued Utility Revenues & 0 & 0 & 0 & 0 & 0 & 0 \\
\hline Miscellaneous Current \& Accrued Assets ..... & 432 & 3,372 & 0 & 0 & o & 573 \\
\hline Total Current \& Accrued Assets ............... & 17,917 & 242,207 & 19,684 & 33,406 & 172,651 & 14,339 \\
\hline \multicolumn{7}{|l|}{ Deferred Debits } \\
\hline 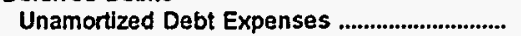 & 90 & 24,045 & 0 & 666 & $\mathbf{0}$ & 0 \\
\hline 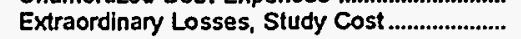 & 0 & 0 & 0 & 0 & 0 & 0 \\
\hline Misc Debt, R \& D Exp, Unamrt Losses .......... & $-2,974$ & 694 & 0 & 0 & 272,582 & 0 \\
\hline 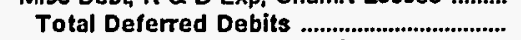 & $-2,884$ & 24,739 & 0 & 666 & 272,582 & 0 \\
\hline Total Assets \& Other Debits ......................... & 70,516 & 676,484 & 40,664 & 129,949 & $1,047,122$ & 23,785 \\
\hline \multicolumn{7}{|l|}{ Proprietary Capital } \\
\hline 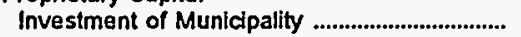 & 0 & 14,629 & $64 t$ & 0 & 36.749 & 0 \\
\hline 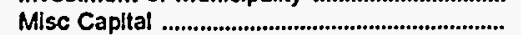 & 14,192 & 0 & 0 & 6,287 & 0 & 0 \\
\hline 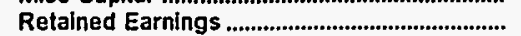 & 43,611 & 155,724 & 37,156 & 71,373 & $-15,297$ & 21,494 \\
\hline Total Proprietary Capital ................................. & 57,803 & 170,353 & 37,798 & 77,660 & 21,452 & 21,494 \\
\hline \multicolumn{7}{|l|}{ Long-term Debt } \\
\hline Bonds & 0 & 320,857 & 0 & 41,923 & 787,474 & 560 \\
\hline Advances from Municipality \& Other .................. & 8,125 & 13,937 & 185 & 0 & 0 & 0 \\
\hline Unamort Prem on Long-term Debt ................... & 0 & 0 & 0 & 0 & 0 & 0 \\
\hline (less) Unamort Discount on Long-term Debt & & 8,068 & 0 & 0 & 18,166 & 0 \\
\hline 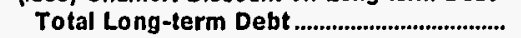 & 8,125 & 326,726 & 185 & 41,923 & 769,308 & 560 \\
\hline \multicolumn{7}{|l|}{ Other Noncurrent Ljabilities } \\
\hline Accum Operating Provislons ............................... & 0 & 0 & 0 & 0 & 10,352 & $\mathbf{0}$ \\
\hline 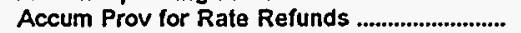 & 0 & 55,786 & 0 & 0 & 0 & 0 \\
\hline Total Other Noncurrent Ljabilities ............ & 0 & 55,786 & 0 & 0 & 10,352 & 0 \\
\hline \multicolumn{7}{|l|}{ Current and Accrued Uabilities } \\
\hline 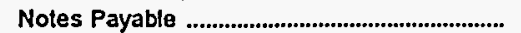 & 0 & 25,250 & 0 & 0 & 6,625 & \\
\hline 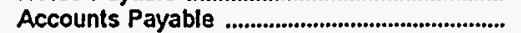 & 1,041 & 9,958 & 1,268 & 5,564 & 11,117 & 751 \\
\hline Payables to Assoc Enterprises .......................... & 17 & 0 & 0 & 3,347 & 0 & 0 \\
\hline 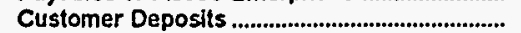 & 215 & 5,322 & 1,413 & 561 & 0 & 720 \\
\hline 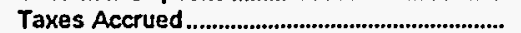 & 0 & 0 & 0 & 0 & 0 & 0 \\
\hline Interest Accrued & 44 & 5,091 & 0 & 198 & 6,901 & 0 \\
\hline Misc Current \& Accrued Labilities.................... & 2,021 & 25,128 & 0 & 0 & 20.166 & 261 \\
\hline $\begin{array}{l}\text { Total Current \& Accrued Liabilities .......... } \\
\text { Deferred Credits }\end{array}$ & \multicolumn{5}{|c|}{ Deferred Credits } & 1,732 \\
\hline Customer Advances for Construction ............. & 0 & 32,744 & 0 & 0 & 0 & 0 \\
\hline Other Deferred Credits .......................................... & 1,250 & 20,126 & 0 & 696 & 201,201 & 0 \\
\hline Unamort Gain on Reacqr Debt ........................... & 0 & 0 & 0 & 0 & 0 & 0 \\
\hline Total Deferred Credits .................................... & 1,250 & 52,870 & $\mathbf{0}$ & 696 & 201,201 & $\mathbf{0}$ \\
\hline Total Llabilities and Other Credits ............ & 70,516 & 676,484 & 40,664 & 129,949 & $1,047,122$ & 23,785 \\
\hline
\end{tabular}

Note: Totals may not equal sum of components because of independent rounding.

Source; Energy Information Administration, Form EIA-412, "Annual Report of Public Electric Utilities." 
Table 22. Balance Sheet by Major U.S. Publicly Owned Electric Utility Within State at End of Period, 1994 (Continued)

(Thousand Dollars)

\begin{tabular}{|c|c|c|c|c|c|c|}
\hline Item & $\begin{array}{c}\text { California } \\
\text { East Bay } \\
\text { Municipal } \\
\text { Util } \\
\text { Dist } \\
\text { December } 31\end{array}$ & $\begin{array}{l}\text { California } \\
\text { Glendale } \\
\text { City of } \\
\text { June } 30\end{array}$ & $\begin{array}{c}\text { California } \\
\text { Imperial } \\
\text { Irrigation } \\
\text { District }\end{array}$ & $\begin{array}{c}\text { California } \\
\text { Kings River } \\
\begin{array}{c}\text { Conservation } \\
\text { Dist }\end{array} \\
\text { June } 30\end{array}$ & $\begin{array}{l}\text { California } \\
\text { Lassen } \\
\text { Municipal } \\
\text { Utility Dist } \\
\text { June } 30\end{array}$ & $\begin{array}{l}\text { California } \\
\text { Lodi } \\
\text { City of } \\
\text { June } 30\end{array}$ \\
\hline \multicolumn{7}{|l|}{ Electric Utility Plant } \\
\hline 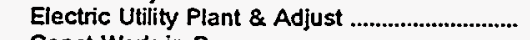 & 0 & 249,461 & 711,678 & 65,495 & 24,031 & 15,091 \\
\hline Const Work in Progress & 0 & 5,314 & 1,896 & 0 & 0 & 242 \\
\hline (less) Depr, Amort, and Depletion ..................... & 0 & 119,160 & 213,127 & 16,846 & 4,958 & 3.856 \\
\hline Net Electric Utility Plant ................................. & 0 & 135,615 & 500,447 & 48,648 & 19,073 & 11,476 \\
\hline 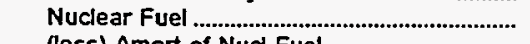 & 0 & 0 & 0 & 0 & 0 & 0 \\
\hline 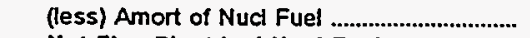 & 0 & 0 & 0 & 0 & 0 & 0 \\
\hline & 0 & 135,615 & 500,447 & 48,648 & 19,073 & 11,476 \\
\hline \multicolumn{7}{|l|}{ Other Property \& Investments } \\
\hline $\begin{array}{l}\text { Nonutility Property ................ } \\
\text { (less) Accum Provisions for Depr \& Amort }\end{array}$ & 0 & 0 & 0 & $\mathbf{0}$ & 0 & 0 \\
\hline $\begin{array}{l}\text { (less) Accum Provisions for Depr \& Amort.... } \\
\text { Invest in Assoc Enterprises }\end{array}$ & $\begin{array}{l}0 \\
0\end{array}$ & 0 & 0 & 0 & 0 & 0 \\
\hline $\begin{array}{l}\text { Invest in Assoc Enterprises } \\
\text { Invest \& Special Funds }\end{array}$ & $\begin{array}{l}0 \\
0\end{array}$ & 0 & $\begin{array}{r}0 \\
107\end{array}$ & 0 & 0 & 0 \\
\hline Total Other Property \& Investments ........ & $\begin{array}{l}0 \\
0\end{array}$ & $\begin{array}{l}0 \\
0\end{array}$ & 107,747 & 8,940 & 0 & 0 \\
\hline \multicolumn{7}{|l|}{ Current and Accrued Assets } \\
\hline Cash, Working Funds \& Investments ................. & 0 & 35.946 & 74 & 0 & 7,036 & 7,583 \\
\hline Notes \& Other Receivables ................................ & 0 & 14,456 & 0 & 0 & 88 & 109 \\
\hline 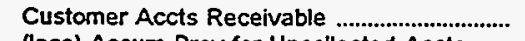 & 0 & 0 & 19,585 & 0 & 2.033 & 2,383 \\
\hline (less) Accum Prov for Uncollected Accts ...... & 0 & 288 & 3,574 & 0 & 369 & 119 \\
\hline 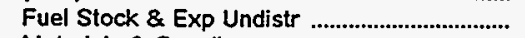 & 0 & 113 & 3,124 & 0 & 0 & 0 \\
\hline Materials \& Supplies ......................................................... & 0 & 4,946 & 10,603 & 49 & 857 & 717 \\
\hline Other Supplies \& Misc ............................................. & 0 & 0 & 0 & $\mathbf{0}$ & 0 & o \\
\hline Prepayments ............................................................. & 0 & 766 & 2,733 & 22 & 148 & 0 \\
\hline Accrued Utility Revenues ..................................... & $\mathbf{0}$ & 0 & 0 & 0 & 0 & 0 \\
\hline Miscellaneous Current \& Accrued Assets ..... & 0 & 0 & 0 & 0 & 0 & 0 \\
\hline $\begin{array}{l}\text { Total Current \& Accrued Assets ................ } \\
\text { Deferred Debits }\end{array}$ & 0 & 55,939 & 32,545 & 71 & 9,792 & 10,672 \\
\hline 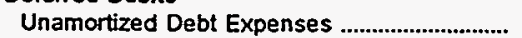 & $\mathbf{0}$ & \\
\hline Extraordinary Losses, Study Cost ....................... & 0 & $\begin{array}{l}0 \\
0\end{array}$ & $\begin{array}{l}0 \\
0\end{array}$ & $\begin{array}{r}631 \\
0\end{array}$ & $\begin{array}{l}0 \\
0\end{array}$ & $\begin{array}{l}0 \\
0\end{array}$ \\
\hline Misc Debt, R \& D Exp, Unamrt Losses .......... & 0 & 0 & 0 & 12,760 & 0 & 0 \\
\hline Total Deferred Debits ......................................... & 0 & o & 0 & 13,392 & 0 & 0 \\
\hline 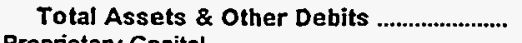 & 0 & 191,554 & 640,740 & 71,051 & 28,865 & 22,148 \\
\hline \multicolumn{7}{|l|}{ Proprietary Capital } \\
\hline 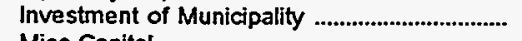 & 0 & 0 & 0 & 0 & 0 & 0 \\
\hline Misc Capital & 0 & 23,272 & 0 & 272 & 969 & 0 \\
\hline Retained Earnings ......................................................... & 0 & 149,131 & 424,564 & 0 & 4.839 & 20,992 \\
\hline $\begin{array}{l}\text { Total Proprietary Capital ................................ } \\
\text { Long-term Debt }\end{array}$ & 0 & 172,403 & 424,564 & 272 & 5,808 & 20,992 \\
\hline 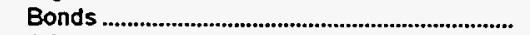 & 0 & 9,057 & 0 & 66,139 & 21,510 & $\mathbf{0}$ \\
\hline Advances from Municipality \& Other ................ & 0 & 0 & 156,476 & 0 & 0 & 0 \\
\hline Unamort Prem on Long-term Debt ................. & 0 & 0 & 1,470 & 0 & 0 & 0 \\
\hline (less) Unamort Discount on Long-term Debt & 0 & 0 & 296 & 0 & 0 & 0 \\
\hline 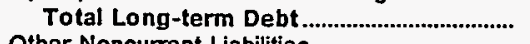 & 0 & 9,057 & 157,650 & 66,139 & 21,510 & $\mathbf{0}$ \\
\hline \multicolumn{7}{|l|}{ Other Noncurrent Liabilities } \\
\hline & 0 & 0 & 0 & 0 & 0 & $\mathbf{0}$ \\
\hline Accum Prov for Rate Refunds ........................... & 0 & 0 & 0 & 0 & 0 & 0 \\
\hline & 0 & 0 & 0 & 0 & 0 & 0 \\
\hline 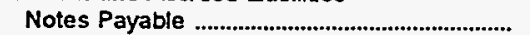 & 0 & 3,180 & 0 & 0 & 0 & 0 \\
\hline Accounts Payable ................................................. & 0 & 4.489 & 11,647 & 2,592 & 575 & 1,007 \\
\hline 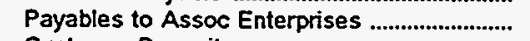 & 0 & 0 & 0 & 0 & 0 & 0 \\
\hline 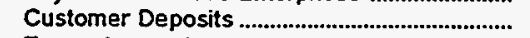 & 0 & 894 & 1,539 & 0 & 124 & 149 \\
\hline Taxes Accrued & 0 & 4 & 0 & 0 & 0 & 0 \\
\hline Interest Accrued & 0 & 51 & 1,866 & 2,048 & 311 & 0 \\
\hline 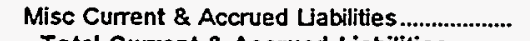 & 0 & 995 & 39,369 & 0 & 457 & 0 \\
\hline $\begin{array}{l}\text { Total Current \& Accrued Liabilities ........... } \\
\text { Deferred Credits }\end{array}$ & 0 & 9,613 & 54,422 & 4,640 & 1,467 & 1,156 \\
\hline Customer Advances for Construction .............. & 0 & 481 & 9 & 0 & 80 & 0 \\
\hline Other Deferred Credits ............................................. & 0 & 0 & 4,095 & 0 & 0 & 0 \\
\hline Unamort Gain on Reacqr Debt ............................ & 0 & 0 & 0 & 0 & 0 & 0 \\
\hline 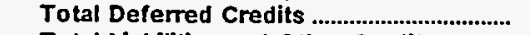 & $\mathbf{0}$ & 481 & 4,104 & 0 & 80 & 0 \\
\hline Total Liabilities and Other Credits ............ & 0 & 191,554 & 640,740 & 71,051 & 28,865 & 22,148 \\
\hline
\end{tabular}

Note: Totals may not equal sum of components because of independent rounding.

Source: Energy Information Administration. Form ElA-412, "Annual Report of Public Electric Utlities." 
Table 22. Balance Sheet by Major U.S. Publicly Owned Electric Utility Within State at End of Period, 1994 (Continued)

(Thousand Dollars)

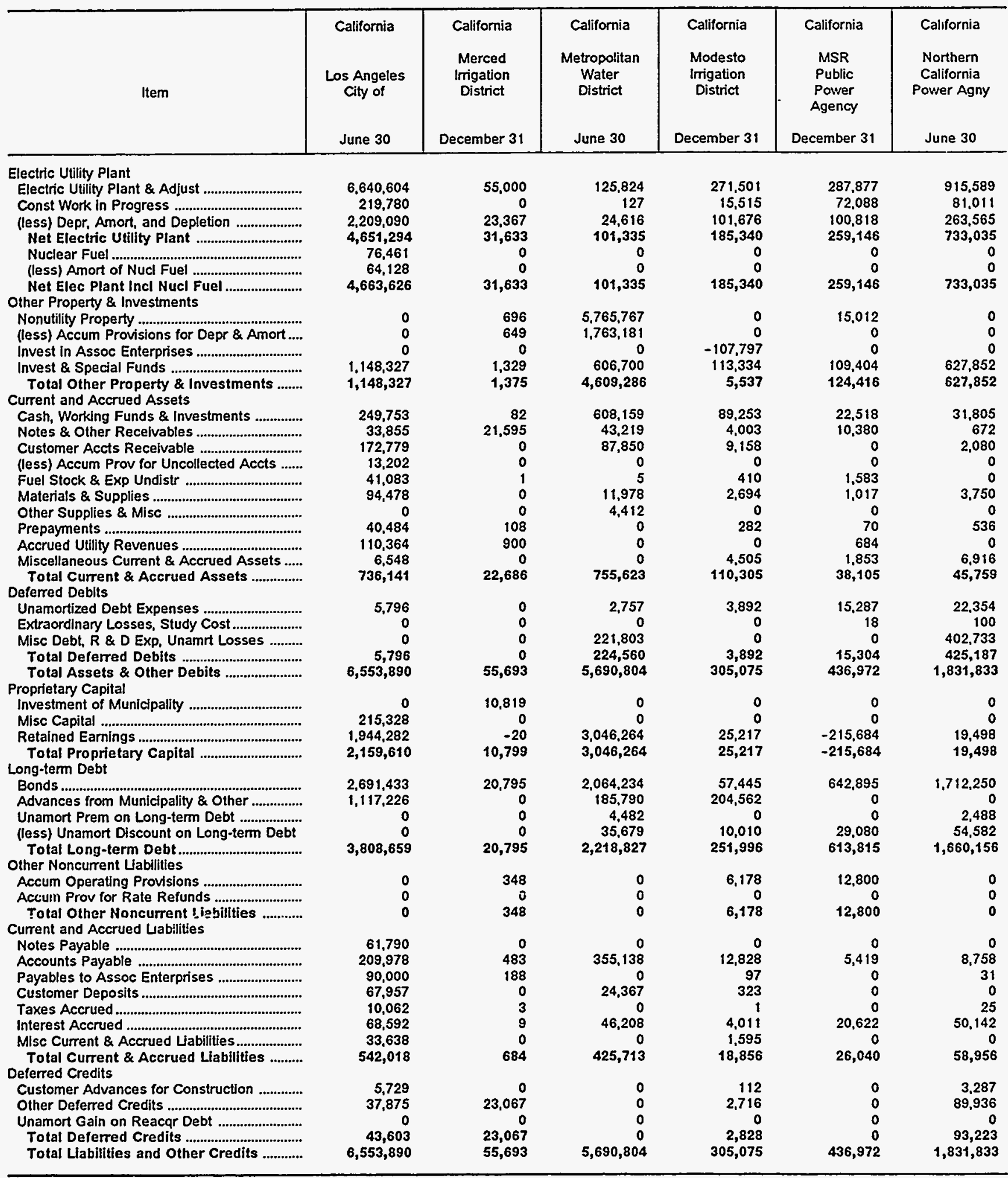

Note: Totals may not equal sum of components because of independent rounding.

Source: Energy Information Administration, Form EIA-4 12, "Annual Report of Public Electric Utilities." 
Table 22. Balance Sheet by Major U.S. Publicly Owned Electric Utility Within State at End of Period, 1995 (Thousand Dollars)

\begin{tabular}{|c|c|c|c|c|c|c|}
\hline Item & $\begin{array}{c}\text { California } \\
\text { Oakdale \& } \\
\text { South } \\
\text { San Joaquin } \\
\text { December } 31\end{array}$ & $\begin{array}{c}\text { California } \\
\text { Oroville } \\
\text { Wyandotte } \\
\text { Irrig Dist } \\
\text { December } 31\end{array}$ & $\begin{array}{l}\text { California } \\
\text { Palo Alto } \\
\text { City of } \\
\text { June } 30\end{array}$ & $\begin{array}{l}\text { California } \\
\text { Pasadena } \\
\text { City of } \\
\text { June } 30\end{array}$ & $\begin{array}{c}\text { California } \\
\text { Placer } \\
\text { County } \\
\text { Water } \\
\text { Agency } \\
\text { December } 31\end{array}$ & $\begin{array}{l}\text { California } \\
\text { Redding } \\
\text { City of } \\
\text { June } 30\end{array}$ \\
\hline \multicolumn{7}{|l|}{ Electric Utility Plant } \\
\hline Electric Utility Plant \& Adjust ............................... & 60,714 & 85,430 & 127,378 & 249,431 & 117,210 & 140,060 \\
\hline Const Work in Progress & 391 & 832 & 4,262 & 16,332 & 692 & 55.187 \\
\hline (less) Depr. Amort, and Depletion ..................... & 24,386 & 40,460 & $\begin{array}{l}48,301 \\
83,339\end{array}$ & 120,881 & 44,184 & 49,237 \\
\hline & 36,720 & $\begin{array}{r}45,802 \\
0\end{array}$ & 83,339 & 144,883 & 73,718 & 446,011 \\
\hline $\begin{array}{l}\text { Nuclear Fuel } \\
\text { (less) Amort of Nucl Fuel }\end{array}$ & $\begin{array}{l}0 \\
0\end{array}$ & $\begin{array}{l}0 \\
0\end{array}$ & $\begin{array}{l}0 \\
0\end{array}$ & 0 & 0 & $\mathbf{0}$ \\
\hline $\begin{array}{l}\text { (less) Amort of Nucl Fuel } \\
\text { Net Elec Plant Incl Nucl Fuel.................... }\end{array}$ & & $\begin{aligned} 0 \\
0\end{aligned}$ & 0 & 0 & 0 & 0 \\
\hline \multirow{2}{*}{\multicolumn{5}{|c|}{ Other Property \& Investments }} & 73,718 & 146,011 \\
\hline 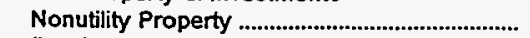 & 0 & 0 & & & & \\
\hline (less) Accum Provisions for Depr \& Amort.... & 0 & 0 & 0 & 0 & 0 & 679 \\
\hline 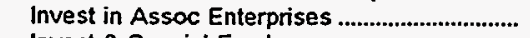 & 0 & 0 & 0 & 0 & 0 & 21 \\
\hline Invest \& Special Funds ........................................... & 0 & 0 & 0 & 0 & 1,144 & 0 \\
\hline $\begin{array}{l}\text { Total Other Property \& Investments ....... } \\
\text { Current and Accrued Assets }\end{array}$ & $\mathbf{0}$ & 0 & 0 & 0 & 1,144 & 2,812 \\
\hline Cash, Working Funds \& Investments .............. & 20,782 & 5,146 & 55.156 & 50,668 & 360 & 46,519 \\
\hline Notes \& Other Receivables .................................. & 1,048 & 366 & 7,211 & 430 & 71 & 6.733 \\
\hline Customer Accts Receivable ................................... & 0 & 0 & 0 & 13,096 & 0 & $\mathbf{3 , 3 2 0}$ \\
\hline (less) Accum Prov for Uncollected Accts ...... & 0 & 0 & 104 & 420 & 0 & 81 \\
\hline Fuel Stock \& Exp Undistr ...................................... & 0 & 0 & 0 & 3,018 & 0 & 0 \\
\hline Materials \& Supplies .................................................. & 0 & 0 & 0 & 4,444 & 0 & 4,474 \\
\hline 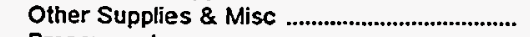 & 0 & 0 & 0 & 0 & 0 & 0 \\
\hline 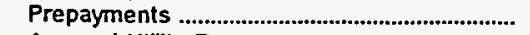 & 305 & 61 & 0 & 6,300 & 335 & 0 \\
\hline Accrued Utility Revenues & 0 & 0 & 0 & 0 & 0 & 2,182 \\
\hline Miscellaneous Current \& Accrued Assets ..... & 236 & 0 & 0 & 0 & 14 & 0 \\
\hline $\begin{array}{l}\text { Total Current \& Accrued Assets ................. } \\
\text { Deferred Debits }\end{array}$ & 22,371 & 5,573 & 62,263 & 77,536 & 780 & 63,148 \\
\hline 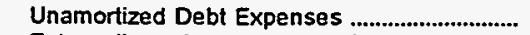 & 0 & 0 & 0 & 0 & 0 & 2,425 \\
\hline Extraordinary Losses, Study Cost.................... & 0 & 0 & 0 & 0 & 0 & 0 \\
\hline Misc Debt, $R$ \& D Exp, Unamrt Losses .......... & 0 & 0 & 0 & 0 & 0 & 0 \\
\hline 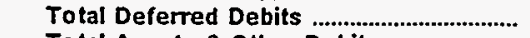 & 0 & 0 & o & 0 & 0 & 2,425 \\
\hline Total Assets \& Other Debits & 59,090 & 51,375 & 145,602 & 222,419 & 75,641 & 214,396 \\
\hline \multicolumn{7}{|l|}{ Proprietary Capital } \\
\hline Investment of Municipality ....................................... & 0 & 0 & 0 & 0 & 0 & 0 \\
\hline Misc Capital & 0 & 0 & 17.138 & 0 & 0 & 25,357 \\
\hline 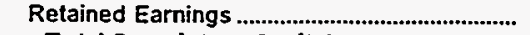 & 57,382 & 4,789 & 124,367 & 134,936 & 12,278 & 32,265 \\
\hline $\begin{array}{l}\text { Total Proprietary Capital .................................. } \\
\text { Long-term Debt }\end{array}$ & 57,382 & 4,789 & 141,505 & 134,936 & 12,278 & 57,621 \\
\hline Bonds & 0 & 42,335 & 0 & 74,355 & 59,640 & 145,608 \\
\hline Advances from Municipality \& Other ............... & 0 & 0 & 0 & 0 & 426 & 798 \\
\hline Unamort Prem on Long-term Debt ....................... & 802 & 2,833 & 0 & 0 & 207 & 0 \\
\hline (less) Unamort Discount on Long-term Debt & 0 & 1,330 & 0 & 0 & 0 & 477 \\
\hline Total Long-term Debt................................ & 802 & 43,837 & $\mathbf{0}$ & 74,355 & 60,273 & 145,930 \\
\hline \multicolumn{7}{|l|}{ Other Noncurrent Liabilities } \\
\hline 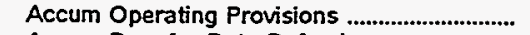 & 0 & 0 & 791 & 0 & 161 & 0 \\
\hline Accum Prov for Rate Refunds .......................... & 0 & 0 & 0 & 0 & 0 & 0 \\
\hline \multirow{2}{*}{\multicolumn{7}{|c|}{ Current and Accrued Liabilities }} \\
\hline & & & & & & \\
\hline 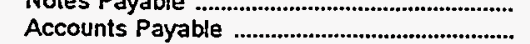 & 304 & $\begin{aligned} 0 \\
116\end{aligned}$ & 2,806 & 2.567 & $\begin{array}{r}1.410 \\
106\end{array}$ & $\begin{array}{r}0 \\
5999\end{array}$ \\
\hline 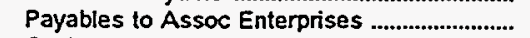 & 0 & 0 & 0 & 2,0 & $\begin{array}{r}106 \\
38\end{array}$ & $\begin{array}{r}5,999 \\
0\end{array}$ \\
\hline 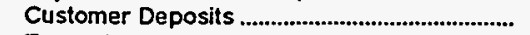 & 0 & 0 & 370 & 2,151 & 0 & 0 \\
\hline 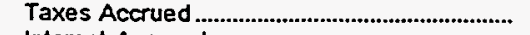 & 0 & 0 & 0 & 0 & 0 & 0 \\
\hline Interest Accrued & 0 & 1.025 & 0 & 1,792 & 1,127 & 1,192 \\
\hline 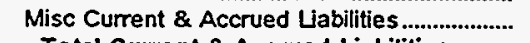 & 602 & 1,607 & 130 & 6,617 & 248 & 3,649 \\
\hline & 10,841 \\
\hline Customer Advances for Construction ............. & 0 & 0 & 0 & 0 & 0 & 4 \\
\hline 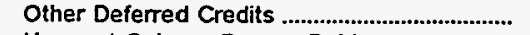 & 0 & 0 & 0 & 0 & $\mathbf{0}$ & 0 \\
\hline 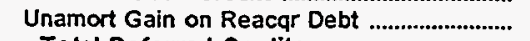 & 0 & 0 & 0 & 0 & 0 & $\mathbf{0}$ \\
\hline Total Deferred Credits ......................................... & 0 & o & 0 & 0 & 0 & \\
\hline Total Liabilities and Other Credits ............ & 59,090 & 51,375 & 145,602 & 222,419 & 75,641 & 214,396 \\
\hline
\end{tabular}

Note: Totals may not equal sum of components because of independent rounding.

Source: Energy Information Administration, Form EIA-412, "Annual Report of Public Electric Utilities." 
Table 22. Balance Sheet by Major U.S. Publicly Owned Electric Utility Within State at End of Period, 1995

(Thousand Dollars)

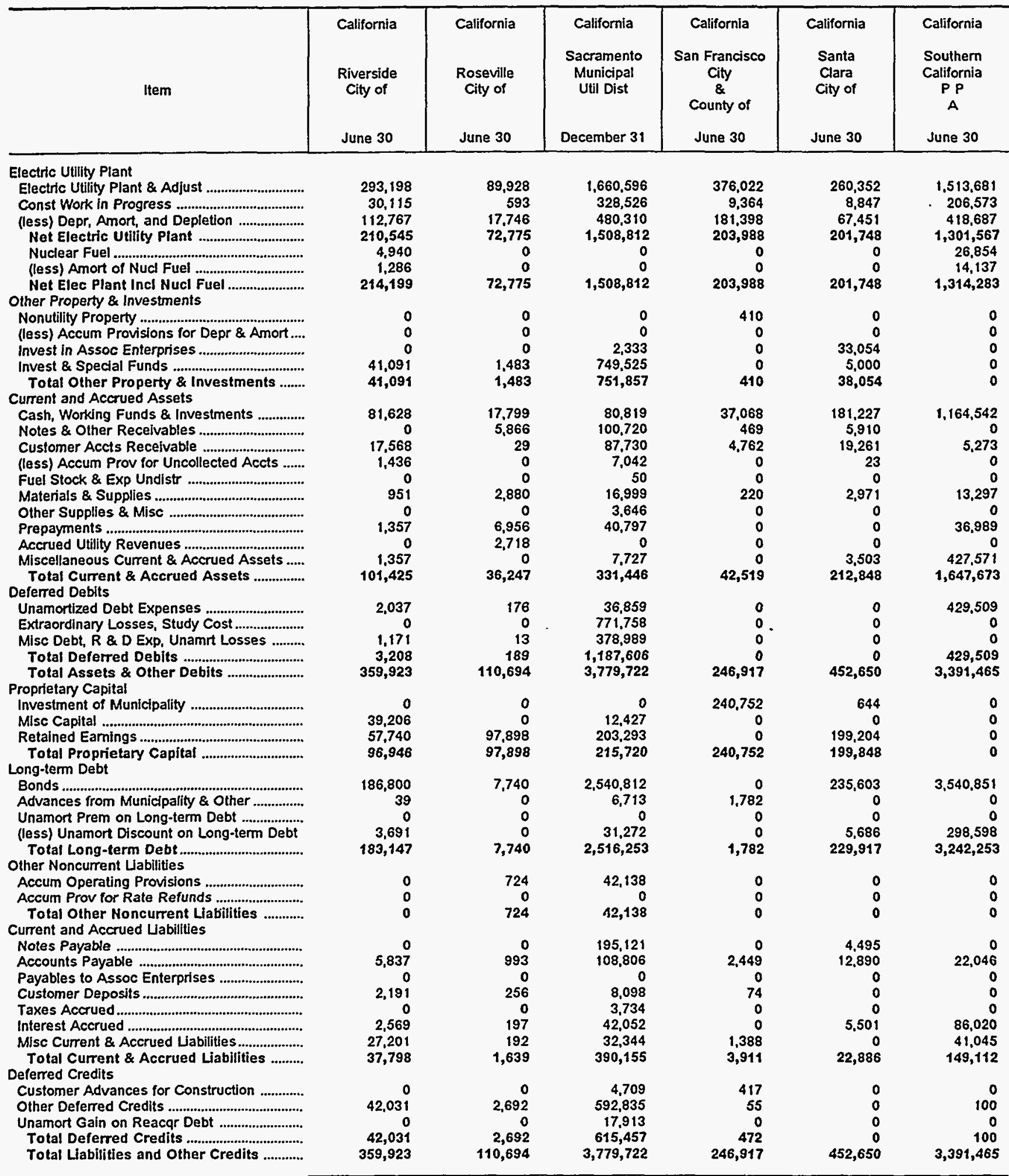

Note: Totals may not equal sum of components because of independent rounding.

Source: Energy Information Administration, Form ElA-412. "Annual Report of Public Electric Utilities." 
Table 22. Balance Sheet by Major U.S. Publicly Owned Electric Utility Within State at End of Period, 1995

(Thousand Dollars)

\begin{tabular}{|c|c|c|c|c|c|c|}
\hline Item & $\begin{array}{l}\text { California } \\
\text { Turlock } \\
\text { Imigation } \\
\text { District } \\
\text { December } 31\end{array}$ & $\begin{array}{l}\text { California } \\
\text { Vernon } \\
\text { City of } \\
\text { June } 30\end{array}$ & $\begin{array}{l}\text { California } \\
\text { Yuba } \\
\text { County } \\
\text { Water } \\
\text { Agency } \\
\text { June } 30\end{array}$ & $\begin{array}{c}\text { Colorado } \\
\text { Arkansas } \\
\text { River } \\
\text { Power } \\
\text { Authority } \\
\text { December } 31\end{array}$ & $\begin{array}{l}\text { Colorado } \\
\text { Colorado } \\
\text { Springs } \\
\text { City of } \\
\text { December } 31\end{array}$ & $\begin{array}{l}\text { Colorado } \\
\text { Fort Collins } \\
\text { City of } \\
\text { December } 31\end{array}$ \\
\hline \multicolumn{7}{|l|}{ Electric Utility Plant } \\
\hline Electric Utility Plant \& Adjust ................................. & 245,536 & 73,712 & 199,373 & 2,710 & 750,576 & 93,568 \\
\hline Const Work in Progress ...................................... & 75,716 & 19.104 & & & 65,889 & 4,833 \\
\hline 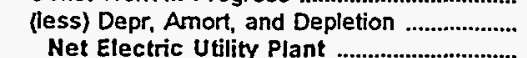 & $\begin{array}{r}78,190 \\
243,062\end{array}$ & $\begin{array}{l}29,547 \\
63,268\end{array}$ & $\begin{array}{r}57,483 \\
141,891\end{array}$ & $\begin{array}{r}836 \\
4.584\end{array}$ & $\begin{array}{l}242,879 \\
573,586\end{array}$ & $\begin{array}{l}41,791 \\
58,609\end{array}$ \\
\hline 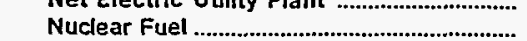 & $\begin{array}{r}243,002 \\
0\end{array}$ & $\begin{array}{r}0 ., 208 \\
0\end{array}$ & $\begin{array}{r}141,881 \\
0\end{array}$ & $\begin{array}{r}4,584 \\
0\end{array}$ & 0 & $\begin{array}{r}36,609 \\
0\end{array}$ \\
\hline (less) Amort of Nud Fuel .................................... & 0 & 0 & 0 & 0 & 0 & \\
\hline $\begin{array}{l}\text { Net Elec Plant Incl Nucl Fuel ......................... } \\
\text { Other Property \& Investments }\end{array}$ & 243,062 & 63,268 & 141,891 & 4,584 & 573,586 & 56,609 \\
\hline Nonutility Property & 33,899 & 482 & 527 & 593 & 0 & 270 \\
\hline (less) Accum Provisions for Depr \& Amort .... & 8.680 & 0 & 112 & 272 & 0 & \\
\hline 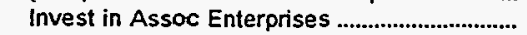 & & 0 & 0 & 0 & 298 & 0 \\
\hline Invest \& Special Funds ................................................ & 50,485 & 49,230 & 44,687 & 3,838 & 36,356 & 0 \\
\hline $\begin{array}{l}\text { Total Other Property \& Investments........ } \\
\text { Current and Accrued Assets }\end{array}$ & 75,705 & 49,712 & 45,102 & 4,158 & 36,654 & 270 \\
\hline Cash, Working Funds \& Investments .................. & 32,778 & 60,176 & 260 & 7,734 & 35,285 & 18,040 \\
\hline Notes \& Other Receivables ................................. & 1,041 & 3,922 & 1,204 & & 1,369 & \\
\hline 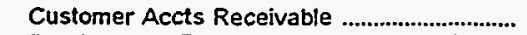 & 8,816 & 2,039 & 0 & 1,717 & 19,447 & 6,901 \\
\hline (less) Accum Prov for Uncollected Accts ...... & 420 & 0 & 0 & 0 & 908 & 150 \\
\hline Fuel Stock \& Exp Undistr ....................................... & 0 & 0 & 0 & 0 & 0 & \\
\hline 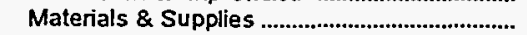 & 1,945 & 77 & 0 & 65 & 12,214 & 2,394 \\
\hline Other Supplies \& Misc .......................................... & & 0 & 0 & 39 & 0 & 0 \\
\hline 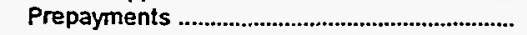 & 2,224 & 4,516 & 111 & 0 & 560 & o \\
\hline 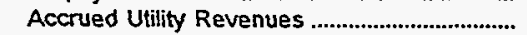 & 0 & 3,295 & 0 & 0 & 0 & 0 \\
\hline Miscellaneous Current \& Accrued Assets ...... & 280 & 1,152 & 0 & 0 & 704 & \\
\hline Total Current \& Accrued Assets .................... & 46,664 & 75,176 & 1,575 & 9,556 & 68,672 & 27,185 \\
\hline Unamortized Debt Expenses ................................ & 2,517 & 0 & 1,454 & 359 & 6,276 & 0 \\
\hline Extraordinary Losses, Study Cost .................... & 0 & 0 & 0 & 0 & 0 & 0 \\
\hline Misc Debt, $R$ \& D Exp, Unamrt Losses .......... & 0 & 0 & 0 & 0 & 907 & 0 \\
\hline 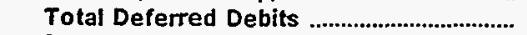 & 2,517 & 0 & 1,454 & 179 & 7,184 & \\
\hline 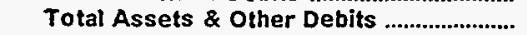 & 367,948 & 188,156 & 190,022 & 9,329 & 686,095 & 84,064 \\
\hline \multicolumn{7}{|l|}{ Proprietary Capital } \\
\hline 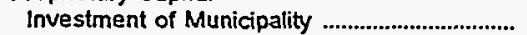 & 0 & 0 & 0 & 0 & 0 & 27,360 \\
\hline 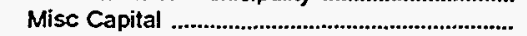 & 419 & 0 & 0 & 0 & 455 & 0 \\
\hline Retained Earnings ..................................................... & 133,744 & 178,168 & 64,032 & 5,547 & 223,838 & 52,607 \\
\hline 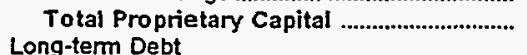 & 134,163 & 178,168 & 64,032 & 5,547 & 224,293 & 79,967 \\
\hline \multicolumn{7}{|l|}{$\begin{array}{l}\text { Long-term Debt } \\
\text { Bonds }\end{array}$} \\
\hline Advances from Municipality \& Other ................. & $\begin{array}{r}81,905 \\
126,996\end{array}$ & $\begin{array}{r}0 \\
3,364\end{array}$ & $\begin{array}{r}100,366 \\
1,815\end{array}$ & $\begin{array}{r}2,810 \\
0\end{array}$ & $\begin{array}{r}241,362 \\
3,543\end{array}$ & $\begin{array}{l}0 \\
0\end{array}$ \\
\hline Unamort Prem on Long-term Debt .................... & & 0 & 0 & 0 & 0 & 0 \\
\hline (less) Unamort Discount on Long-term Debt & 3,951 & 0 & 0 & 81 & 0 & 0 \\
\hline Total Long-term Debt ...................................... & 204,949 & 3,364 & 102,181 & 2,729 & 244,905 & o \\
\hline \multicolumn{7}{|l|}{ Other Noncurrent Liabilities } \\
\hline Accum Operating Provisions ................................ & 0 & 0 & 0 & 0 & 1,963 & 0 \\
\hline Accum Prov for Rate Refunds .............................. & 0 & 0 & 0 & 0 & 14 & 0 \\
\hline \multicolumn{6}{|l|}{ Current and Accrued Liabilities } & 0 \\
\hline 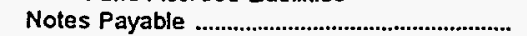 & 0 & 0 & 0 & 0 & 0 & 0 \\
\hline Accounts Payable ................................................. & 11,954 & 5,065 & 3,188 & 994 & 18,210 & 3,446 \\
\hline Payables to Assoc Enterprises ......................... & 0 & 448 & 0 & 0 & 0 & 0 \\
\hline Customer Deposits & 587 & 196 & 0 & 0 & 375 & 0 \\
\hline 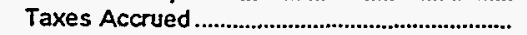 & 0 & 570 & 0 & 0 & 0 & 0 \\
\hline 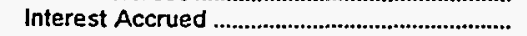 & 4,109 & 242 & 2,961 & 33 & 1,914 & 0 \\
\hline Misc Current \& Accrued Liablities..................... & 4,715 & 104 & & 27 & 9,608 & 652 \\
\hline Total Current \& Accrued Liabilities .......... & 21,366 & 6,624 & 6,149 & 1,053 & 30,108 & 4,098 \\
\hline \multicolumn{7}{|l|}{ Deferred Credits } \\
\hline Customer Advances for Construction .............. & 445 & 0 & $\begin{aligned} 0 \\
17560\end{aligned}$ & 0 & 2,620 & 0 \\
\hline 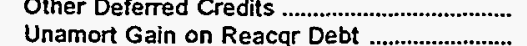 & $\begin{array}{r}7,024 \\
0\end{array}$ & $\begin{array}{l}0 \\
0\end{array}$ & $\begin{array}{r}17,660 \\
0\end{array}$ & $\begin{array}{l}0 \\
0\end{array}$ & $\begin{array}{r}932 \\
181,261\end{array}$ & $\begin{array}{l}0 \\
0\end{array}$ \\
\hline 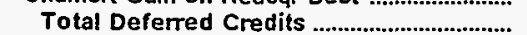 & 7,469 & 0 & $\$ 7,660$ & 0 & 184,812 & 0 \\
\hline Total Liabilities and other Credits ............. & 367,948 & 188,156 & 190,022 & 9,329 & 686,095 & 84,064 \\
\hline
\end{tabular}

Note: Totals may not equal sum of components because of independent rounding.

Source: Energy Information Administration, Form EIA-412, "Annual Report of Public Electric Utitities." 
Table 22. Balance Sheet by Major U.S. Publicly Owned Electric Utility Within State at End of Period, 1995

(Thousand Dollars)

\begin{tabular}{|c|c|c|c|c|c|c|}
\hline Item & $\begin{array}{l}\text { Colorado } \\
\text { Fort Morgan } \\
\text { City of } \\
\text { December } 31\end{array}$ & $\begin{array}{l}\text { Colorado } \\
\text { Longmont } \\
\text { City of }\end{array}$ & $\begin{array}{l}\text { Colorado } \\
\text { Loveland } \\
\text { City of }\end{array}$ & $\begin{array}{c}\text { Colorado } \\
\text { Platte River } \\
\text { Power } \\
\text { Authority } \\
\text { December } 31\end{array}$ & $\begin{array}{l}\text { Connecticut } \\
\text { Connecticut } \\
\text { Mun } \\
\text { Elec } \\
\text { Engy Coop } \\
\text { December } 31\end{array}$ & $\begin{array}{l}\text { Groton } \\
\text { City of } \\
\text { June } 30\end{array}$ \\
\hline \multicolumn{7}{|l|}{ Electric Utility Plant } \\
\hline 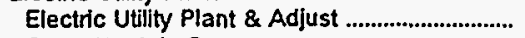 & 12,113 & 41,859 & 47,689 & 768,339 & 53,862 & 31,251 \\
\hline 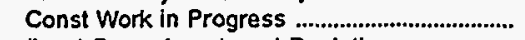 & 27 & 0 & 853 & 4,898 & 2 & 832 \\
\hline 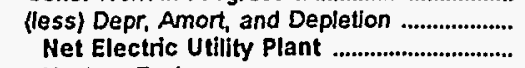 & $\begin{array}{l}3,887 \\
8,254\end{array}$ & $\begin{array}{l}16,906 \\
24,953\end{array}$ & $\begin{array}{l}12,430 \\
36,113\end{array}$ & $\begin{array}{l}270,267 \\
502,971\end{array}$ & $\begin{array}{l}16,070 \\
37,794\end{array}$ & $\begin{array}{l}16,797 \\
15,286\end{array}$ \\
\hline Nuclear Fuel & 0 & 0 & 0 & 0 & 787 & 0 \\
\hline 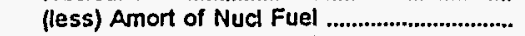 & 0 & 0 & 0 & 0 & 0 & 0 \\
\hline Net Elec Plant Incl Nucl Fuel ............................ & 8,254 & 24,953 & 36,113 & 502,971 & 38,581 & 15,286 \\
\hline \multicolumn{7}{|l|}{ Other Property \& Investments } \\
\hline Nonutility Property & $\mathbf{0}$ & 0 & 0 & 0 & 0 & 0 \\
\hline (less) Accum Provisions for Depr \& Amort.... & 0 & 0 & 0 & 0 & 0 & 0 \\
\hline 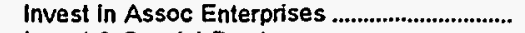 & 0 & 0 & 540 & 0 & 916 & 0 \\
\hline 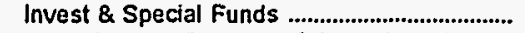 & 0 & 0 & 4,063 & 207,800 & 23,286 & 0 \\
\hline Total Other Property \& Investments ....... & $\mathbf{0}$ & 0 & 4,602 & 207,800 & 24,202 & $\mathbf{0}$ \\
\hline Current and Accrued Assets & & & & - & & \\
\hline Cash, Working Funds \& Investments ............... & 277 & 6,529 & 6,485 & 27,120 & 7,078 & 7,177 \\
\hline 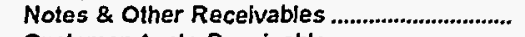 & 0 & 8 & 0 & 1 & 24,205 & 0 \\
\hline 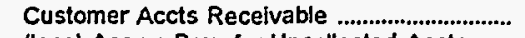 & 626 & 3,303 & 1,550 & 11,685 & 13,058 & 4,171 \\
\hline (less) Accum Prov for Uncollected Accts ...... & 5 & 91 & 17 & 0 & 0 & 237 \\
\hline 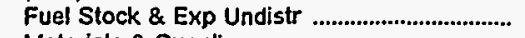 & 0 & 0 & 0 & 3,069 & 0 & 0 \\
\hline 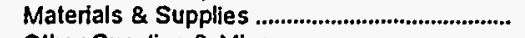 & 390 & 0 & 036 & 8,100 & 0 & 503 \\
\hline 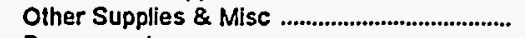 & 0 & 0 & $\mathbf{0}$ & 427 & 0 & 0 \\
\hline Prepayments & 0 & 0 & 16 & 0 & 0 & 0 \\
\hline 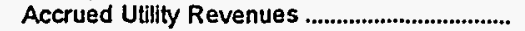 & $\mathbf{0}$ & 0 & 0 & 0 & 0 & 1,043 \\
\hline Miscellaneous Current \& Accrued Assets ..... & 0 & 65 & 213 & 5,381 & 3,164 & 538 \\
\hline \multicolumn{6}{|l|}{ Deferred Debits } & 13,195 \\
\hline 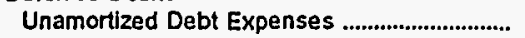 & 0 & $\mathbf{0}$ & 0 & 5,397 & 31,028 & 0 \\
\hline Extraordinary Losses, Study Cost ..................... & 0 & 0 & 0 & 596 & 0 & 0 \\
\hline Misc Debt, $R$ \& D Exp, Unamrt Losses ......... & $\mathbf{0}$ & 0 & 0 & 60,442 & 52,447 & 287 \\
\hline 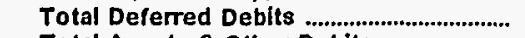 & 0 & 0 & 0 & 66,435 & 83,475 & 287 \\
\hline \multicolumn{6}{|l|}{ Proprietary Capital } & 28,768 \\
\hline 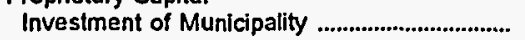 & 0 & 11,334 & 0 & 0 & 0 & 0 \\
\hline Misc Capital & 0 & 0 & 0 & 356 & 5,688 & 0 \\
\hline 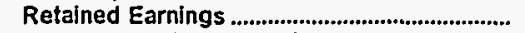 & 8,941 & 20,799 & 43,808 & 223,061 & 0 & 11.518 \\
\hline $\begin{array}{l}\text { Total Proprietary Capital ................................... } \\
\text { Long-term Debt }\end{array}$ & & 11,518 \\
\hline 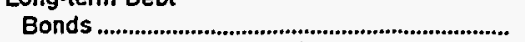 & 0 & 0 & 0 & 563.460 & 146,379 & 5,994 \\
\hline Advances from Municipality \& Other ............... & 0 & 40 & 551 & 40,527 & 0 & 0 \\
\hline 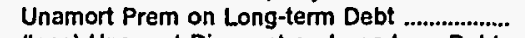 & 0 & 0 & 0 & 0 & 0 & 0 \\
\hline (less) Unamort Discount on Long-term Debt & 0 & 0 & 0 & 10,540 & 0 & 0 \\
\hline \multicolumn{6}{|l|}{ Other Noncurrent Uabilities } & 5,994 \\
\hline Accum Operating Provisions ................................. & 0 & 0 & 0 & 6,565 & $\mathbf{0}$ & 0 \\
\hline Accum Prov for Rate Refunds .......................... & $\mathbf{0}$ & 0 & 0 & 0 & 0 & 0 \\
\hline \multicolumn{6}{|l|}{ Current and Accrued Liabilities } & 0 \\
\hline Notes Payable & $\mathbf{0}$ & 0 & 133 & 0 & 4,625 & 575 \\
\hline 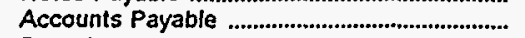 & $\mathbf{0}$ & 1.584 & 1,632 & 5.584 & 13,209 & 5.794 \\
\hline 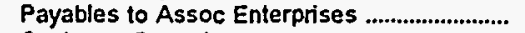 & 0 & 0 & 0 & 0 & 3,481 & 0 \\
\hline 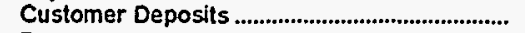 & 87 & 514 & 269 & 0 & 0 & 1,968 \\
\hline Taxes Accrued & 0 & 68 & 0 & 0 & 0 & 403 \\
\hline Interest Accrued & $\mathbf{0}$ & 0 & 0 & 2,884 & 0 & 43 \\
\hline Misc Current \& Accrued Liabilities .................... & 2 & 428 & 214 & 867 & 0 & 2,473 \\
\hline \multicolumn{6}{|l|}{ Deferred Credits } & 11,256 \\
\hline Customer Advances for Construction ................ & 511 & 0 & 485 & 223 & $\mathbf{0}$ & 0 \\
\hline 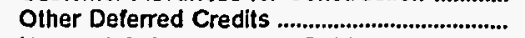 & 0 & 0 & 2,708 & 0 & 20,379 & 0 \\
\hline 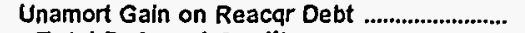 & 0 & 0 & 0 & 0 & 0 & 0 \\
\hline 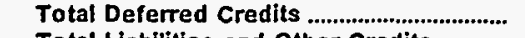 & 511 & 0 & 3,193 & 223 & 20,379 & 0 \\
\hline Total Liabilities and Other Credits ............. & 9,541 & 34,768 & 49,800 & 832,988 & 193,761 & 28,768 \\
\hline
\end{tabular}

Note: Totals may not equal sum of components because of independent rounding.

Source: Energy Information Administration, Form ElA-412, "Annual Report of Public Electric Utilities." 
Table 22. Balance Sheet by Major U.S. Publicly Owned Electric Utility Within State at End of Period, 1995

(Thousand Dollars)

\begin{tabular}{|c|c|c|c|c|c|c|}
\hline Item & $\begin{array}{l}\text { Connecticut } \\
\text { Norwich } \\
\text { City of } \\
\text { June } 30\end{array}$ & $\begin{array}{l}\text { Connecticut } \\
\text { Wallingford } \\
\text { Town of } \\
\text { June } 30\end{array}$ & $\begin{array}{l}\text { Delaware } \\
\text { Dover } \\
\text { City of } \\
\text { June } 30\end{array}$ & $\begin{array}{l}\text { Delaware } \\
\text { Milford } \\
\text { City of } \\
\text { September } 30\end{array}$ & $\begin{array}{l}\text { Delaware } \\
\text { Newark } \\
\text { City of } \\
\text { December } 31\end{array}$ & $\begin{array}{l}\text { Bartow } \\
\text { City of }\end{array}$ \\
\hline \multicolumn{7}{|l|}{ Electric Utility Plant } \\
\hline 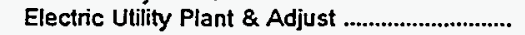 & 27,712 & 50,648 & 101,607 & 7,265 & 0 & 12,377 \\
\hline 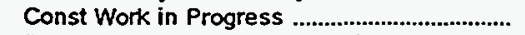 & 7,442 & & 4 & 0 & 0 & 103 \\
\hline (less) Depr, Amort, and Depletion .................... & 17,858 & 26,869 & 35,924 & 4,457 & 0 & 0 \\
\hline Net Electric Utility Plant ....................................... & 17,295 & 23,779 & 65,688 & 2,807 & 0 & 12,480 \\
\hline $\begin{array}{l}\text { Nuclear Fuel . } \\
\text { (less) Amort of Nucl Fuel }\end{array}$ & 0 & 0 & 0 & 0 & 0 & 0 \\
\hline 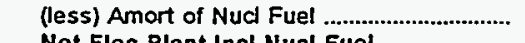 & 0 & 0 & 0 & $\mathbf{0}$ & 0 & 5,607 \\
\hline $\begin{array}{l}\text { Net Elec Plant Incl Nucl Fuel ............................ } \\
\text { Other Property \& Investments }\end{array}$ & 17,295 & 23,779 & 65,688 & 2,807 & 0 & 6,873 \\
\hline & 0 & 0 & 0 & 0 & 0 & 0 \\
\hline (less) Accum Provisions for Depr \& Amort.... & 0 & 0 & 0 & 0 & 0 & 0 \\
\hline 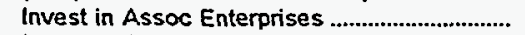 & 0 & 0 & 0 & 0 & 0 & 2,281 \\
\hline 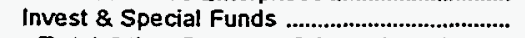 & 402 & 0 & 16,598 & 0 & 0 & 4,804 \\
\hline $\begin{array}{l}\text { Total Other Property \& Investments ........ } \\
\text { Current and Accrued Assets }\end{array}$ & 402 & 0 & 16,598 & 0 & 0 & 7,084 \\
\hline Cash. Working Funds \& Investments ............... & 3,480 & 6,909 & 2,171 & 4,469 & 0 & 29 \\
\hline 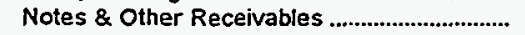 & 3,045 & 0 & 1,172 & 990 & 0 & 0 \\
\hline 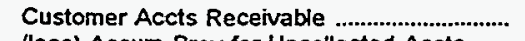 & 2,889 & 4,371 & 3,002 & 1,309 & 0 & 2,737 \\
\hline (less) Accum Prov for Uncollected Accts ...... & 1,124 & 201 & 30 & 0 & 0 & 200 \\
\hline 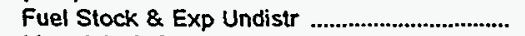 & 0 & 47 & 308 & o & 0 & 907 \\
\hline Materials \& Supplies ................................................ & 315 & 893 & 1,872 & 908 & 0 & 0 \\
\hline Other Supplies \& Misc ................................................ & 0 & 0 & 0 & 0 & 0 & 0 \\
\hline 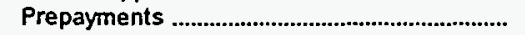 & 73 & 4 & 0 & 2 & $\mathbf{0}$ & 0 \\
\hline Accrued Utility Revenues .......................................... & 0 & 0 & 0 & 0 & 0 & 0 \\
\hline Miscellaneous Current \& Accrued Assets ..... & 426 & 85 & 0 & 0 & 0 & 0 \\
\hline $\begin{array}{l}\text { Total Current \& Accrued Assets ................ } \\
\text { Deferred Debits }\end{array}$ & 9,104 & 12,108 & 8,495 & 7,677 & 0 & 3,472 \\
\hline Unamortized Debt Expenses .................................. & 0 & 0 & 0 & 0 & 0 & 0 \\
\hline 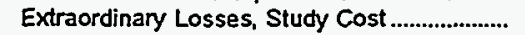 & 0 & 0 & 0 & 0 & 0 & 0 \\
\hline Misc Debt, R \& D Exp, Unamrt Losses ......... & 0 & 0 & 0 & 0 & 0 & 0 \\
\hline Total Deferred Debits ....................................... & 0 & 0 & 0 & $\mathbf{0}$ & 0 & 0 \\
\hline 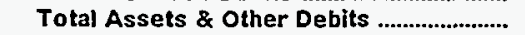 & 26,802 & 35,888 & 90,781 & 10,484 & 0 & 17,430 \\
\hline \multicolumn{7}{|l|}{ Proprietary Capital } \\
\hline 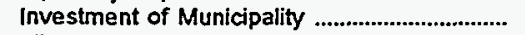 & 0 & 0 & 0 & 0 & 0 & 27 \\
\hline 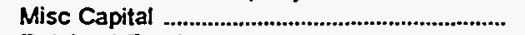 & 0 & 0 & 0 & 0 & 0 & 0 \\
\hline 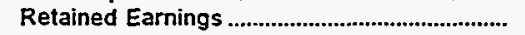 & 14,802 & 29,629 & 49,525 & 9,488 & 0 & 13,105 \\
\hline 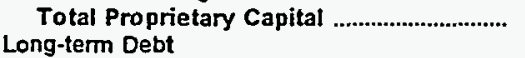 & 14,802 & 29,629 & 49,525 & 9,488 & 0 & 13,132 \\
\hline 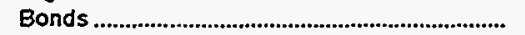 & 303 & 420 & 30,684 & 0 & 0 & 0 \\
\hline Advances from Municipality \& Other ................ & 6,036 & 0 & 0 & 0 & 0 & 0 \\
\hline Unamort Prem on Long-term Debt .................... & 0 & 0 & 0 & 0 & 0 & 0 \\
\hline (less) Unamort Discount on Long-term Debt & 0 & 0 & & 0 & 0 & 0 \\
\hline 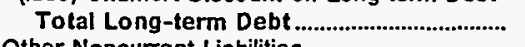 & 6,340 & 420 & 30,684 & 0 & 0 & 0 \\
\hline \multicolumn{7}{|l|}{ Other Noncurrent Liabilities } \\
\hline 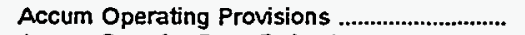 & 160 & 0 & 6,942 & $\mathbf{0}$ & 0 & 0 \\
\hline Accum Prov for Rate Refunds ................................ & 0 & 0 & 0 & 0 & 0 & 0 \\
\hline $\begin{array}{l}\text { Total Other Noncurrent Liabilities ............. } \\
\text { Current and Accrued Liabilities }\end{array}$ & & 0 & 0 & 0 \\
\hline Notes Payable & 0 & $\mathbf{0}$ & 0 & 0 & 0 & 0 \\
\hline 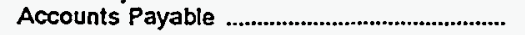 & 3,703 & 3,040 & 1.753 & 761 & 0 & 2,974 \\
\hline 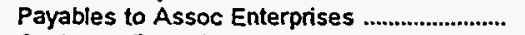 & 0 & 0 & 0 & 1 & 0 & 400 \\
\hline 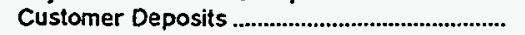 & 234 & 1,231 & 614 & 154 & 0 & 664 \\
\hline Taxes Accrued ............................................................ & 295 & 409 & 0 & 0 & 0 & 122 \\
\hline 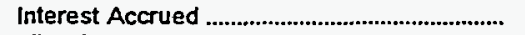 & 0 & 210 & 987 & 0 & 0 & 0 \\
\hline Misc Current \& Accrued Liabilities.......................... & 20 & 731 & 276 & 38 & 0 & 138 \\
\hline $\begin{array}{l}\text { Total Current \& Accrued Liabilities .......... } \\
\text { Deferred Credits }\end{array}$ & 4,252 & 5,621 & 3,630 & 955 & 0 & 4,298 \\
\hline Customer Advances for Construction ................. & 1,247 & 67 & 0 & 0 & 0 & $\mathbf{0}$ \\
\hline 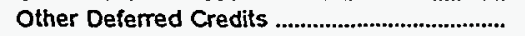 & 0 & 150 & 0 & 42 & 0 & $\mathbf{0}$ \\
\hline 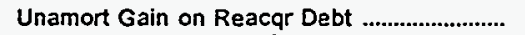 & 0 & 0 & 0 & 0 & $\mathbf{0}$ & 0 \\
\hline Total Deferred Credits .................................... & 1,247 & 217 & 0 & 42 & 0 & 0 \\
\hline Total Liabilities and Other Credits ............ & 26,802 & 35,888 & 90,781 & 10,484 & 0 & 17,430 \\
\hline
\end{tabular}

Note: Totals may not equal sum of components because of independent rounding.

Source: Energy Information Administration, Form EIA-412, "Annual Report of Public Electric Utilities." 
Table 22. Balance Sheet by Major U.S. Publicly Owned Electric Utility Within State at End of Period, 1995

(Thousand Doliars)

\begin{tabular}{|c|c|c|c|c|c|c|}
\hline Item & $\begin{array}{c}\text { Florida } \\
\text { Florida } \\
\text { Muricipal } \\
\text { Power Agency } \\
\text { September } 30\end{array}$ & $\begin{array}{c}\text { Florida } \\
\text { Fort Pierce } \\
\text { Utlities } \\
\text { Auth } \\
\text { September } 30\end{array}$ & $\begin{array}{c}\text { Florida } \\
\text { Gainesville } \\
\text { Regional } \\
\text { Utilities } \\
\text { September } 30\end{array}$ & $\begin{array}{l}\text { Florida } \\
\begin{array}{c}\text { Homestead } \\
\text { City of }\end{array} \\
\text { September } 30\end{array}$ & $\begin{array}{c}\text { Florida } \\
\text { Jacksonville } \\
\text { Beach } \\
\text { City of } \\
\text { September } 30\end{array}$ & $\begin{array}{c}\text { Flonda } \\
\text { Jacksonville } \\
\text { Electric } \\
\text { Auth } \\
\text { September } 30\end{array}$ \\
\hline \multicolumn{7}{|l|}{ Electric Utility Plant } \\
\hline 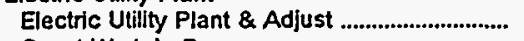 & 381,237 & 113,282 & 432,806 & 46,371 & 80,527 & $3,018,402$ \\
\hline 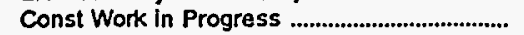 & 39.786 & 1,774 & 41.382 & & 1.997 & 24,432 \\
\hline (less) Depr, Amort, and Depletion .................... & 101,746 & 49,488 & 152,867 & 21,273 & 24,142 & $\begin{array}{r}765,464 \\
2,277,371\end{array}$ \\
\hline Net Electric Utility Plant .................................... & 319,277 & 65,567 & $\begin{array}{r}321,321 \\
5,391\end{array}$ & $\begin{array}{r}25,098 \\
0\end{array}$ & 58,382 & $\begin{array}{r}2,277,371 \\
0\end{array}$ \\
\hline 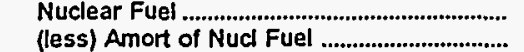 & $\begin{array}{r}11,135 \\
0\end{array}$ & & 4,795 & 0 & $\begin{array}{l}0 \\
0\end{array}$ & $\begin{array}{l}0 \\
0\end{array}$ \\
\hline Net Elec Plant Incl Nucl Fuel ......................... & 330,412 & 65,567 & 321,917 & 25,098 & 58,382 & $2,277,371$ \\
\hline \multicolumn{7}{|l|}{ Other Property \& Investments } \\
\hline 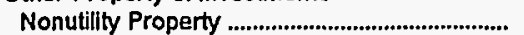 & 0 & 0 & 0 & 0 & $\mathbf{0}$ & \\
\hline (less) Accum Provisions for Depr \& Amort.... & 0 & 0 & 0 & 0 & 0 & 0 \\
\hline 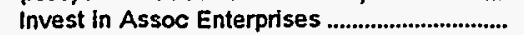 & 0 & 0 & 0 & $\mathbf{0}$ & 0 & 0 \\
\hline Invest \& Special Funds ............................................ & 98,214 & 15,465 & 0 & 0 & 18,768 & 595,037 \\
\hline Total Other Property \& Investments ........ & 98,214 & 15,465 & 0 & 0 & 18,768 & 595,037 \\
\hline $\begin{array}{l}\text { Current and Accrued Assets } \\
\text { Cash, Working Funds \& Investments .............. }\end{array}$ & 55,113 & 13,540 & 98,365 & 7,039 & 6,727 & 141,614 \\
\hline 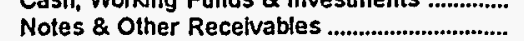 & 723 & 446 & 3,863 & 12,031 & 0 & 7,778 \\
\hline 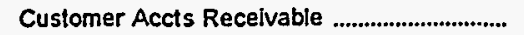 & 15,634 & 3,541 & 9,566 & 3.150 & 6,440 & 90,328 \\
\hline (less) Accum Prov for Uncollected Accts ....... & 0 & 32 & 910 & 832 & 0 & 1,712 \\
\hline Fuel Stock \& Exp Undistr ........................................ & 571 & 0 & 5,295 & 84 & 0 & 39,071 \\
\hline 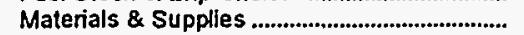 & 0 & 2,379 & 4,744 & 3,234 & 0 & 42,799 \\
\hline 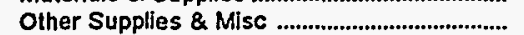 & 0 & 1,378 & 121 & 0 & 1,218 & 0 \\
\hline Prepayments ............, & 1,964 & 93 & 0 & 2 & 0 & 39 \\
\hline 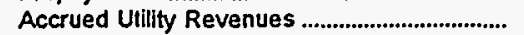 & 0 & 1,709 & 7,521 & 1,284 & 0 & \\
\hline Miscellaneous Current \& Accrued Assets ..... & 0 & 165 & 373 & 34 & 0 & 7,894 \\
\hline Total Current \& Accrued Assets ................ & 74,005 & 23,218 & 128,939 & 26,027 & 14,385 & 327,810 \\
\hline \multicolumn{7}{|l|}{ Deferred Debits } \\
\hline 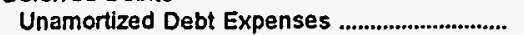 & 9,260 & 909 & 2,629 & 0 & 872 & 29,406 \\
\hline 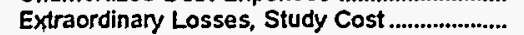 & & 350 & & 0 & 0 & 7,571 \\
\hline Misc Debt, R \& D Exp, Unamrt Losses .......... & 223,346 & 797 & 38,401 & 0 & 0 & 368,769 \\
\hline Total Deferred Debits ......................................... & 232,606 & 2,055 & 41,029 & 0 & 872 & 405,746 \\
\hline 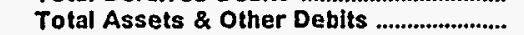 & 735,237 & 106,306 & 491,885 & 51,125 & 92,406 & $3,605,965$ \\
\hline \multicolumn{7}{|l|}{ Proprietary Capital } \\
\hline 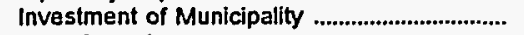 & 0 & 0 & 0 & 3.951 & 0 & 0 \\
\hline 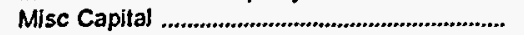 & 0 & 0 & 0 & 0 & 8,143 & 0 \\
\hline 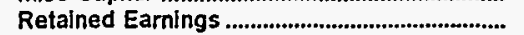 & 0 & 39.185 & 177,406 & 31,430 & 9,897 & 540,911 \\
\hline Total Proprietary Capital ..................................... & 0 & 39,185 & 177,406 & 35,381 & 18,040 & 540,911 \\
\hline \multicolumn{7}{|l|}{ Long-term Debt } \\
\hline 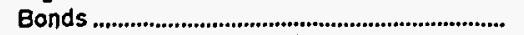 & 660.235 & 52,630 & 221,522 & 0 & 61.061 & $2,769,308$ \\
\hline Advances from Municipality \& Other ............... & 26,574 & 0 & 48,409 & 6,402 & 0 & 7,341 \\
\hline 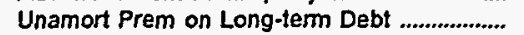 & 0 & 0 & 0 & 0 & 0 & \\
\hline (less) Unamort Discount on Long-term Debt & 7.297 & 0 & 4,234 & 0 & 0 & 46,076 \\
\hline 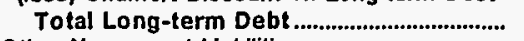 & 679,512 & 52,630 & 265,697 & 6,402 & 61,061 & $2,730,573$ \\
\hline \multicolumn{7}{|l|}{ Other Noncurrent Liabilities } \\
\hline 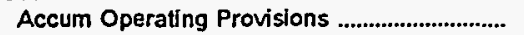 & 0 & 1,896 & 0 & 0 & 587 & 169,549 \\
\hline 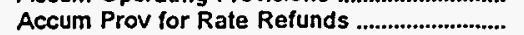 & 0 & & 0 & 0 & 0 & \\
\hline Total Other Noncurrent Liabilities ............. & 0 & 1,896 & 0 & o & 587 & 169,549 \\
\hline \multicolumn{7}{|l|}{ Current and Accrued Liabilities } \\
\hline 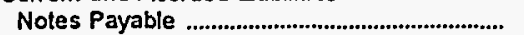 & 11.225 & 1.437 & 0 & 0 & 1.113 & \\
\hline 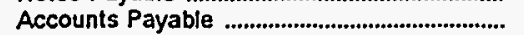 & 22,172 & 5,592 & 5,629 & 1.734 & 3,311 & 38,682 \\
\hline Payables to Assoc Enterprises ................................ & 0 & & & 4,508 & & 4,048 \\
\hline 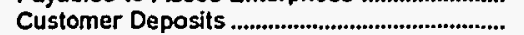 & 0 & 2,563 & 5,104 & 1,569 & 2,060 & 15.610 \\
\hline 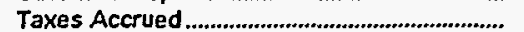 & 0 & 1,502 & 265 & 0 & 0 & 3.233 \\
\hline 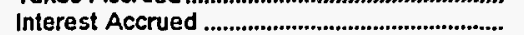 & 17,741 & $i, 502$ & 7,082 & 1,253 & 1.921 & 60,564 \\
\hline Misc Current \& Accrued Ljabilities .......................... & 2,238 & & 23,877 & 277 & 4,313 & 20,861 \\
\hline Total Current \& Accrued Liabilities ........... & 53,376 & 12,595 & 41,956 & 9,342 & 12,718 & 142,998 \\
\hline \multicolumn{7}{|l|}{ Deferred Credits } \\
\hline Customer Advances for Construction .............. & 0 & $\mathbf{0}$ & & 0 & 0 & \\
\hline 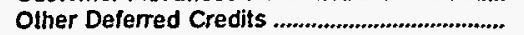 & 2,349 & 0 & 6,826 & 0 & 0 & 21,934 \\
\hline Unamort Gain on Reacqr Debt ............................ & & 0 & & 0 & 0 & \\
\hline 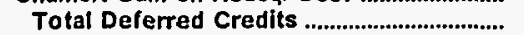 & 2,349 & o & 6,826 & 0 & 0 & 21,934 \\
\hline Total Liabilities and Other Credits ............. & 735,237 & 106,306 & 491,885 & 51,125 & 92,406 & $3,605,965$ \\
\hline
\end{tabular}

Note: Totals may not equal sum of components because of independent rounding.

Source: Energy Information Administration, Form EJA-412, "Annual Report of Public Electric Utilities." 
Table 22. Balance Sheet by Major U.S. Publicly Owned Electric Utility Within State at End of Period, 1995

(Thousand Dollars)

\begin{tabular}{|c|c|c|c|c|c|c|}
\hline Item & $\begin{array}{c}\text { Florida } \\
\text { Key West } \\
\text { City of } \\
\text { September } 30\end{array}$ & $\begin{array}{c}\text { Florida } \\
\text { Kissimmee } \\
\text { Utılity } \\
\text { Authority } \\
\text { September } 30\end{array}$ & $\begin{array}{l}\text { Lake Worth } \\
\text { City of }\end{array}$ & $\begin{array}{c}\text { Lakeland } \\
\text { City of } \\
\text { September } 30\end{array}$ & $\begin{array}{c}\text { Florida } \\
\text { Leesburg } \\
\text { City of } \\
\text { September } 30\end{array}$ & $\begin{array}{c}\text { Florida } \\
\text { New Smyrna } \\
\text { Beach } \\
\text { Utils Comm } \\
\text { September } 30\end{array}$ \\
\hline \multicolumn{7}{|l|}{ Electric Utility Piant } \\
\hline Electric Utility Plant \& Adjust ............................. & 170,837 & 208,209 & 80,511 . & 568,504 & 47,345 & 58,134 \\
\hline Const Work in Progress & 3,469 & 22,485 & 619 & 25,257 & 2,131 & 975 \\
\hline $\begin{array}{l}\text { (less) Depr, Amort, and Depletion } \\
\text { Net Electric Utility Plant }\end{array}$ & $\begin{array}{r}67,509 \\
106,797\end{array}$ & $\begin{array}{r}65,069 \\
165,626\end{array}$ & $\begin{array}{l}41,707 \\
39,424\end{array}$ & $\begin{array}{l}189,897 \\
403,864\end{array}$ & $\begin{array}{l}17,332 \\
32,143\end{array}$ & $\begin{array}{l}22,630 \\
38,479\end{array}$ \\
\hline 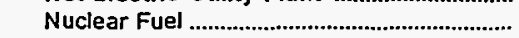 & 0 & 2,572 & 0 & 0 & 707 & 1.959 \\
\hline (less) Amort of Nucl Fuel ........................... & 0 & 2,288 & 0 & 0 & 382 & 1,960 \\
\hline 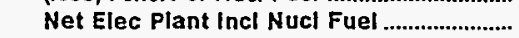 & 106,797 & 165,910 & 39,424 & 403,864 & 32,468 & 36,479 \\
\hline \multicolumn{7}{|l|}{ Other Property \& Investments } \\
\hline 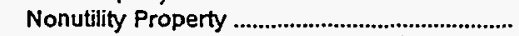 & 0 & 0 & 0 & 65,776 & 0 & 62,312 \\
\hline (less) Accum Provisions for Depr \& Amort.... & 0 & 0 & 0 & 18,042 & 0 & 16,287 \\
\hline 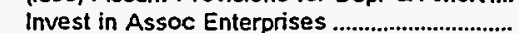 & 0 & 0 & 0 & 0 & 0 & 0 \\
\hline 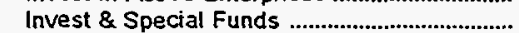 & 19,655 & 125,541 & 14,358 & 147,457 & 14,600 & 16,365 \\
\hline Total Other Property \& Investments ....... & 19,655 & 125,541 & 14,358 & 195,192 & 14,600 & 62,389 \\
\hline \multicolumn{7}{|l|}{ Current and Accrued Assets } \\
\hline Cash, Working Funds \& Investments ............. & 4,086 & 12,574 & 5,237 & 20,263 & 6,676 & 1,251 \\
\hline 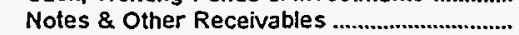 & 405 & 361 & 618 & 635 & 2,105 & 349 \\
\hline 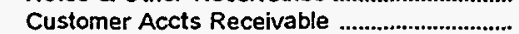 & 4,720 & 8,084 & 2,721 & 15,584 & 2,339 & 1,467 \\
\hline (less) Accum Prov for Uncollected Accts ..... & 123 & 178 & 0 & 569 & 458 & 57 \\
\hline Fuel Stock \& Exp Undistr .............................. & 1,218 & 344 & 0 & 6,143 & 0 & 0 \\
\hline 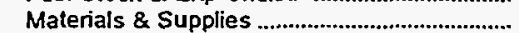 & 2,385 & 4,752 & 0 & 17,782 & 1,232 & 1,585 \\
\hline 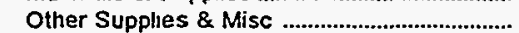 & 0 & 0 & 1,774 & 0 & 0 & 33 \\
\hline 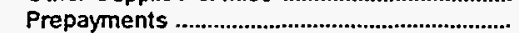 & 753 & 35 & 65 & 828 & 0 & 139 \\
\hline 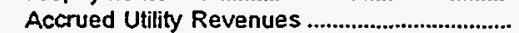 & 0 & 0 & 0 & 2,284 & 0 & 2,779 \\
\hline Miscellaneous Current \& Accrued Assets ..... & 0 & 54 & 0 & 1,144 & 0 & 0 \\
\hline Total Current \& Accrued Assets ................... & 13,444 & 26,026 & 10,415 & 64,094 & 11,894 & 7,555 \\
\hline \multicolumn{7}{|l|}{ Deferred Debits } \\
\hline 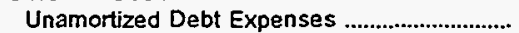 & 3,235 & 2,655 & 600 & 2,770 & 121 & 643 \\
\hline Extraordinary Losses, Study Cost ..................... & 0 & 0 & 0 & 0 & 0 & 0 \\
\hline Misc Debt, $R$ \& D Exp, Unamrt Losses ......... & 0 & 54,637 & 0 & 0 & 0 & 0 \\
\hline 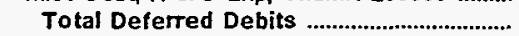 & 3,235 & 57,292 & 600 & 2,770 & 121 & 643 \\
\hline 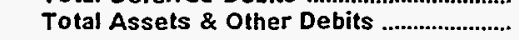 & 143,131 & 374,768 & 64,797 & 665,920 & 59,083 & 107,066 \\
\hline \multicolumn{7}{|l|}{ Proprietary Capital } \\
\hline 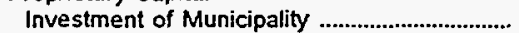 & 0 & 0 & 0 & 0 & 0 & 31,205 \\
\hline 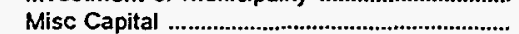 & 0 & 0 & 0 & 0 & 0 & o \\
\hline Retained Earnings ................................................ & 18,039 & 111,682 & 24,180 & 226,432 & 36,222 & 5,459 \\
\hline 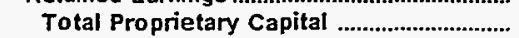 & 18,039 & 111,682 & 24,180 & 226,432 & 36,222 & 36,664 \\
\hline \multicolumn{7}{|l|}{ Long-term Debt } \\
\hline 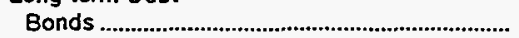 & 116,149 & 239,545 & $35,590^{\circ}$ & 393,726 & 13,748 & 64,010 \\
\hline Advances from Municipality \& Other .............. & 0 & 0 & 0 & 34,793 & 1,745 & 0 \\
\hline Unamort Prem on Long-term Debt ................... & 0 & 0 & 0 & 0 & 0 & 0 \\
\hline (less) Unamort Discount on Long-term Debt & 0 & 4,933 & 0 & 23,171 & 101 & 1,434 \\
\hline Total Long-term Debt & 116,149 & 234,612 & 35,590 & 405,348 & 15,392 & 62,576 \\
\hline \multicolumn{7}{|l|}{ Other Noncurrent Labilities } \\
\hline 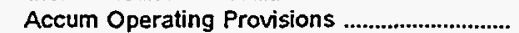 & 0 & 128 & 0 & 0 & 0 & 1,787 \\
\hline Accum Prov for Rate Refunds ......................... & 0 & 0 & 0 & 0 & 0 & 0 \\
\hline Total Other Noncurrent Liabilities ............. & $\mathbf{0}$ & 128 & 0 & 0 & $\mathbf{0}$ & 1,787 \\
\hline \multicolumn{7}{|l|}{ Current and Accrued Liabilities } \\
\hline 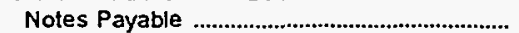 & 0 & 0 & 0 & 0 & o & $\mathbf{0}$ \\
\hline 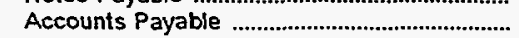 & 2,929 & 5,059 & 1,616 & 7,694 & 1.552 & 1,545 \\
\hline 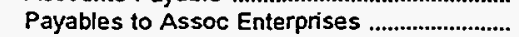 & 449 & 1,079 & 745 & 0 & 0 & 511 \\
\hline 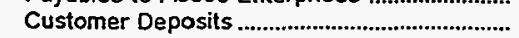 & 3,725 & 2,889 & 0 & 9,658 & 1.296 & 1,009 \\
\hline 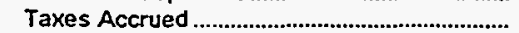 & 148 & 229 & 153 & 816 & 0 & 0 \\
\hline Interest Accrued & 827 & 6,814 & 0 & 12,465 & 458 & $1,9+1$ \\
\hline 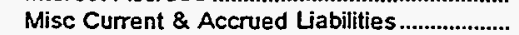 & 755 & 11,278 & 2,512 & 1,756 & 1,286 & 1,027 \\
\hline Tolal Current \& Accrued Liabilities .......... & 8,833 & 27,348 & 5,026 & 32,389 & 4,592 & 6,002 \\
\hline \multicolumn{7}{|l|}{ Deferred Credits } \\
\hline Customer Advances for Construction ............. & 0 & 997 & 0 & 0 & 82 & $\mathbf{0}$ \\
\hline 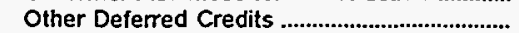 & 110 & 0 & 0 & 1,750 & 2,795 & 37 \\
\hline 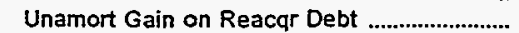 & 0 & 0 & 0 & 0 & 0 & 0 \\
\hline 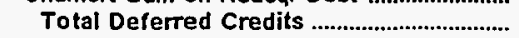 & 110 & 997 & $\mathbf{0}$ & 1,750 & 2,877 & 37 \\
\hline Total Liabilities and Other Credits ............ & 143,131 & 374,768 & 64,797 & 665,920 & 59,083 & 107,066 \\
\hline
\end{tabular}

Note: Totals may not equal sum of components because of independent rounding.

Source: Energy Information Administration, Form EIA-412. "Annual Report of Public Electric Utilities." 
Table 22. Balance Sheet by Major U.S. Publicly Owned Electric Utility Within State at End of Period, 1995

(Thousand Dollars)

\begin{tabular}{|c|c|c|c|c|c|c|}
\hline Item & $\begin{array}{c}\text { Florida } \\
\text { Ocala } \\
\text { City of } \\
\text { September } 30\end{array}$ & $\begin{array}{l}\text { Florida } \\
\text { Orlando } \\
\text { Utilities } \\
\text { Comm } \\
\text { September } 30\end{array}$ & $\begin{array}{c}\text { Florida } \\
\text { Quincy } \\
\text { City of } \\
\text { September } 30\end{array}$ & $\begin{array}{c}\text { Florida } \\
\text { Reedy Creek } \\
\text { Improvement } \\
\text { Dist }\end{array}$ & $\begin{array}{l}\text { Florida } \\
\text { St Cloud } \\
\text { City of } \\
\text { September } 30\end{array}$ & $\begin{array}{c}\text { Florida } \\
\begin{array}{c}\text { Tallahassee } \\
\text { City of }\end{array} \\
\text { September } 30\end{array}$ \\
\hline \multicolumn{7}{|l|}{ Electric Utility Plant } \\
\hline Electric Utility Plant \& Adjust ................................ & 89,526 & $1,320,031$ & 6,769 & 128,306 & 72.720 & 406,289 \\
\hline 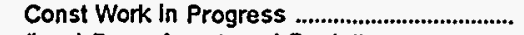 & 15,644 & 286.167 & & 8,088 & 390 & 36.876 \\
\hline $\begin{array}{l}\text { (less) Depr, Amort, and Depletion } \\
\text { Net Electric Utility Plant }\end{array}$ & $\begin{array}{l}32,858 \\
72,312\end{array}$ & $\begin{array}{r}383,572 \\
1,222,626\end{array}$ & $\begin{array}{l}3,069 \\
3,700\end{array}$ & $\begin{array}{r}23,628 \\
112,766\end{array}$ & $\begin{array}{l}23,913 \\
49,197\end{array}$ & $\begin{array}{l}171,548 \\
271,617\end{array}$ \\
\hline 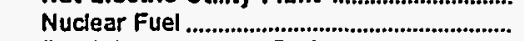 & 2,616 & 22,053 & 0 & 0 & 0 & 0 \\
\hline 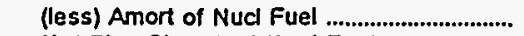 & 2.114 & 20.701 & 0 & 0 & 0 & 0 \\
\hline Net Elec Plant Incl Nucl Fuel .............................. & 72,815 & $1,223,978$ & 3,700 & 112,768 & 49,197 & 271,617 \\
\hline \multicolumn{7}{|l|}{ Other Property \& Investments } \\
\hline Nonutility Property & 0 & 400 & 0 & 0 & 0 & 7,568 \\
\hline (less) Accum Provisions for Depr \& Amort.... & 0 & & 0 & 0 & 0 & 4,552 \\
\hline invest in Assoc Enterprises ....................................... & 673 & 0 & $\mathbf{0}$ & 0 & 0 & 0 \\
\hline 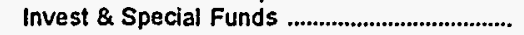 & 29,650 & 330,907 & 1,003 & 0 & 0 & 103,643 \\
\hline Total Other Property \& Investments ....... & 30,322 & 331,300 & 1,003 & 0 & 0 & 106,659 \\
\hline \multicolumn{7}{|l|}{ Current and Accrued Assets } \\
\hline Cash. Working Funds \& Investments .............. & 2 & 106,240 & 253 & 34,444 & 3,784 & 10,297 \\
\hline 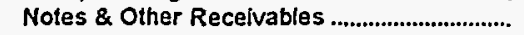 & 1,092 & 908 & 24 & 544 & 23 & 661 \\
\hline Customer Accts Receivable ................................ & 7,040 & 32,692 & 880 & 1,147 & 1,648 & 16,123 \\
\hline (iess) Accum Prov for Uncollected Accts ...... & 295 & 862 & 244 & 0 & 150 & 982 \\
\hline 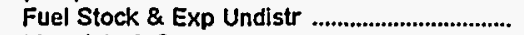 & & 7,866 & 0 & 66 & 0 & 1,578 \\
\hline 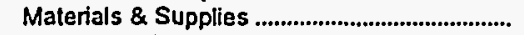 & 2,072 & 25,346 & 104 & 1,220 & 1,840 & 0 \\
\hline 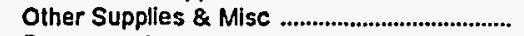 & 0 & 626 & 0 & 0 & 0 & 0 \\
\hline 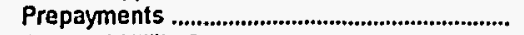 & 331 & 1,000 & 15 & 124 & 36 & 0 \\
\hline 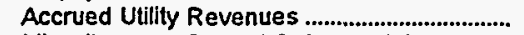 & 4,599 & 14,158 & 0 & 2,951 & 1,812 & 0 \\
\hline Miscellaneous Current \& Accrued Assets ..... & 203 & 7,672 & 0 & & & 0 \\
\hline Total Current \& Accrued Assets ............... & 15,045 & 195,646 & 1,032 & 40,494 & 8,993 & 27,677 \\
\hline \multicolumn{7}{|l|}{ Deferred Debits } \\
\hline Unamortized Debt Expenses ................................ & 211 & 2,941 & 0 & 2,340 & 466 & 359 \\
\hline Extraordinary Losses, Study Cost...................... & 0 & & 0 & 0 & 0 & 0 \\
\hline Misc Debt, R \& D Exp, Unamrt Losses .......... & 0 & 25,846 & 0 & 0 & 3,831 & 0 \\
\hline Total Deferred Debits .......................................... & 211 & 28,787 & & 2,340 & 4,298 & 359 \\
\hline Total Assets \& Other Debits .............................. & 118,394 & $1,779,711$ & 5,735 & 155,600 & 62,487 & 406,312 \\
\hline \multicolumn{7}{|l|}{ Proprietary Capital } \\
\hline 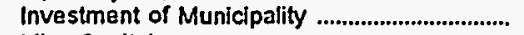 & 0 & 0 & 0 & 0 & 0 & $\mathbf{0}$ \\
\hline Mlsc Capital .................................................................... & 0 & 0 & 200 & 0 & 4,170 & 0 \\
\hline 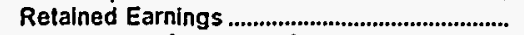 & 76,168 & 324,340 & 4,112 & 2,258 & 31,070 & 268,919 \\
\hline \multirow{2}{*}{\multicolumn{7}{|c|}{ Long-term Debt }} \\
\hline & & & & & & \\
\hline 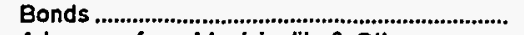 & 24,557 & $1,393,036$ & 85 & 141,840 & 24,400 & 110,819 \\
\hline Advances from Municipality \& Other ............... & 0 & 0 & 0 & 0 & 0 & 0 \\
\hline Unamort Prem on Long-term Debt ................... & 0 & 0 & 0 & 0 & 0 & 0 \\
\hline (less) Unamort Discount on Long-term Debt & & 143,253 & 0 & 8,995 & 298 & 1,122 \\
\hline Total Long-term Debt ........................................... & 24,557 & $1,249,782$ & 85 & 132,844 & 24,102 & 109,697 \\
\hline \multicolumn{7}{|l|}{ Other Noncurrent Ljabilities } \\
\hline Accum Operating Provislons ................................... & 1.436 & 0 & 0 & 0 & 0 & 0 \\
\hline 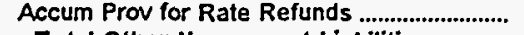 & & 0 & 0 & 0 & 0 & 0 \\
\hline Total Other Noncurrent Liabilities ............. & 1,436 & 0 & 0 & 0 & 0 & $\mathbf{0}$ \\
\hline \multicolumn{7}{|l|}{ Current and Accrued Labilities } \\
\hline $\begin{array}{l}\text { Notes Payable } \\
\text { Accounts Payable }\end{array}$ & 4,836 & $\begin{array}{l}18,412 \\
37,103\end{array}$ & $\begin{array}{r}0 \\
868\end{array}$ & $\begin{array}{r}0 \\
10,881\end{array}$ & $\begin{array}{r}700 \\
1,351\end{array}$ & $\begin{array}{r}20,084 \\
0\end{array}$ \\
\hline 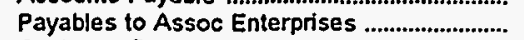 & 917 & 1,710 & 0 & 0 & 0 & 7,236 \\
\hline 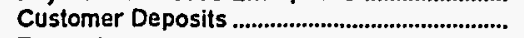 & 3.253 & 13,257 & 356 & 0 & 463 & 0 \\
\hline Taxes Accrued …....................................................... & 388 & & 0 & 693 & 0 & 0 \\
\hline 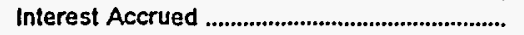 & 749 & 34,824 & 1 & 4,683 & 257 & 0 \\
\hline Misc Current \& Accrued Ljabilities...................... & 336 & 6.497 & 112 & & 373 & 0 \\
\hline Total Current \& Accrued Llabilities .......... & 10,480 & 111,803 & 1,337 & 16,257 & 3,145 & 27,320 \\
\hline \multicolumn{7}{|l|}{ Deferred Credits } \\
\hline Customer Advances for Construction .............. & 4.454 & 27,350 & 0 & 0 & $\mathbf{0}$ & 0 \\
\hline 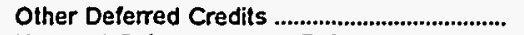 & 1.299 & 66,435 & 0 & 4,241 & 0 & 376 \\
\hline Unamort Gain on Reacqr Debt ............................ & & & 0 & 0 & 0 & 0 \\
\hline Total Deferred Credits ........................................ & 5,753 & 93,785 & 0 & 4,241 & 0 & 376 \\
\hline Total Llabilities and Other Credits ............. & 118,394 & $1,779,711$ & 5,735 & 155,600 & 62,487 & 406,312 \\
\hline
\end{tabular}

Note: Totals may not equal sum of components because of independent rounding.

Source: Energy Information Administration, Form ElA-4 12, "Annual Report of Public Electric Utilities." 
Table 22. Balance Sheet by Major U.S. Publicly Owned Electric Utility Within State at End of Period, 1995 (Thousand Dollars)

\begin{tabular}{|c|c|c|c|c|c|c|}
\hline Item & $\begin{array}{c}\text { Florida } \\
\text { Vero } \\
\text { Beach } \\
\text { City of } \\
\text { September } 30\end{array}$ & $\begin{array}{l}\text { Georgia } \\
\text { Albany Water } \\
\text { Gas \& Light } \\
\text { Comm } \\
\text { June } 30\end{array}$ & $\begin{array}{l}\text { Georgia } \\
\text { Calhoun } \\
\text { City of } \\
\text { June } 30\end{array}$ & $\begin{array}{c}\text { Cartersville } \\
\text { City of } \\
\text { June } 30\end{array}$ & $\begin{array}{c}\text { Georgia } \\
\text { College } \\
\text { Park City of } \\
\text { June } 30\end{array}$ & $\begin{array}{l}\text { Georgia } \\
\text { Covington } \\
\text { City of } \\
\text { December } 31\end{array}$ \\
\hline \multicolumn{7}{|l|}{ Electric Utility Plant } \\
\hline 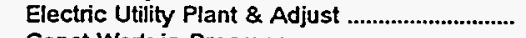 & 154,142 & 30,149 & 66,495 & 11,654 & 9,169 & 6,793 \\
\hline Const Work in Progress & 817 & 0 & 2,198 & 0 & 0 & 0 \\
\hline 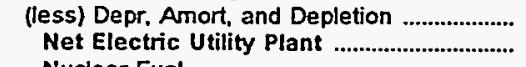 & $\begin{array}{r}48,158 \\
106,801\end{array}$ & $\begin{array}{r}20,359 \\
9,791\end{array}$ & $\begin{array}{l}16,358 \\
52,335\end{array}$ & $\begin{array}{l}3,238 \\
8,416\end{array}$ & $\begin{array}{l}3,923 \\
5,246\end{array}$ & $\begin{array}{l}3,556 \\
3,237\end{array}$ \\
\hline 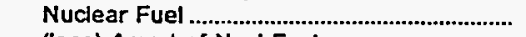 & 0 & 0 & 0 & 0 & 0 & 0 \\
\hline 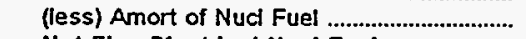 & $\mathbf{0}$ & 0 & 0 & 0 & 0 & $\mathbf{0}$ \\
\hline $\begin{array}{l}\text { Net Elec Plant Incl Nucl Fuel .......................... } \\
\text { Other Property \& Investments }\end{array}$ & 106,801 & 9,791 & 52,335 & 8,416 & 5,246 & 3,237 \\
\hline 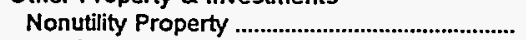 & 0 & 44,636 & 0 & 0 & 0 & 0 \\
\hline (less) Accum Provisions for Depr \& Amort .... & 0 & 26,525 & 0 & 0 & 0 & $\mathbf{0}$ \\
\hline 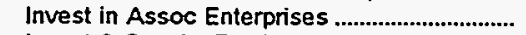 & 0 & 0 & 0 & 0 & 0 & 0 \\
\hline 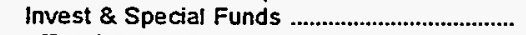 & 12,798 & 12,503 & 0 & 0 & 0 & 0 \\
\hline $\begin{array}{l}\text { Total Other Property \& Investments ....... } \\
\text { Current and Accrued Assets }\end{array}$ & 12,798 & 30,614 & 0 & 0 & 0 & 0 \\
\hline Cash, Working Funds \& Investments .............. & 10.521 & 2,328 & 6,920 & 2,774 & 6,381 & 63 \\
\hline 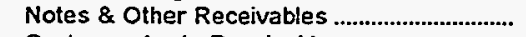 & 126 & 1,115 & 0 & 0 & 319 & 0 \\
\hline Customer Accts Receivable & 6,563 & 10,960 & 2,865 & 3,739 & 2,703 & 1.521 \\
\hline (less) Accum Prov for Uncollected Accts ...... & 863 & 280 & 0 & 339 & 258 & 9 \\
\hline 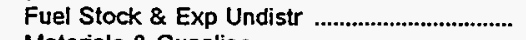 & 1,397 & 0 & 0 & 0 & 0 & 1 \\
\hline Materials \& Supplies & 2,948 & 3,241 & 1,263 & 863 & 0 & 266 \\
\hline 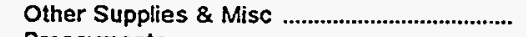 & 5 & 0 & 0 & 0 & 0 & $\mathbf{0}$ \\
\hline 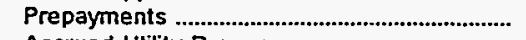 & 5 & 321 & 78 & 0 & 50 & 17 \\
\hline Accrued Utility Revenues & 0 & 0 & 0 & 0 & 0 & 170 \\
\hline Miscellaneous Current \& Accrued Assets ..... & 168 & 0 & 41 & 0 & 0 & 0 \\
\hline $\begin{array}{l}\text { Total Current \& Accrued Assets .............. } \\
\text { Deferred Debits }\end{array}$ & 20,870 & 17,686 & 11,168 & 7,037 & 9,194 & 2,030 \\
\hline 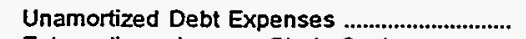 & 1,061 & 0 & 600 & 0 & 0 & 0 \\
\hline 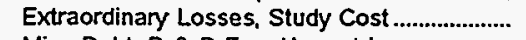 & 0 & 0 & 0 & 0 & 0 & 0 \\
\hline Misc Debt, $\dot{R}$ \& D Exp. Unamit Losses ......... & 0 & 937 & 0 & 0 & 0 & $\mathbf{0}$ \\
\hline 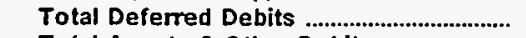 & 1,061 & 937 & 600 & $\mathbf{0}$ & $\mathbf{0}$ & 0 \\
\hline $\begin{array}{l}\text { Total Assets \& Other Debits ............................ } \\
\text { Proprietary Capital }\end{array}$ & 141,530 & 59,027 & 64,103 & 15,453 & 14,440 & 5,267 \\
\hline \multicolumn{6}{|l|}{ Proprietary Capital } & \\
\hline 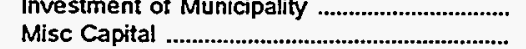 & $\begin{array}{r}16,983 \\
0\end{array}$ & 325 & $\begin{array}{r}0 \\
0\end{array}$ & $\begin{array}{l}0 \\
0\end{array}$ & $\begin{array}{r}1,285 \\
0\end{array}$ & 16 \\
\hline 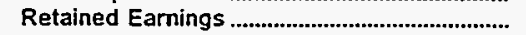 & $\begin{array}{r}0 \\
30,913\end{array}$ & 48,607 & 34,416 & $\begin{array}{r}0 \\
12,351\end{array}$ & $\begin{array}{r}0 \\
11,240\end{array}$ & $\begin{array}{r}0 \\
3,897\end{array}$ \\
\hline $\begin{array}{l}\text { Total Proprietary Capital .................................. } \\
\text { Long-term Debt }\end{array}$ & 47,896 & 48,932 & 40,145 & 12,351 & 12,526 & $\begin{array}{l}3,897 \\
3,912\end{array}$ \\
\hline 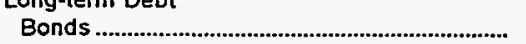 & 87,740 & 585 & 6,245 & 0 & \multicolumn{2}{|c|}{ Long-term Debt } \\
\hline Advances from Municipality \& Other ................ & 343 & 0 & 13,304 & 0 & $\begin{array}{r}0 \\
17\end{array}$ & 240 \\
\hline Unamort Prem on Long-term Debt ................... & 0 & 0 & 0 & 0 & $\begin{array}{r}17 \\
0\end{array}$ & $\begin{array}{l}0 \\
0\end{array}$ \\
\hline (less) Unamort Discount on Long-term Debt & 1,779 & 0 & 0 & 0 & 0 & $\begin{array}{l}0 \\
0\end{array}$ \\
\hline 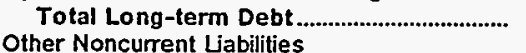 & 86,304 & 585 & 19,549 & o & 17 & 240 \\
\hline \multicolumn{7}{|l|}{ Other Noncurrent Liabilities } \\
\hline $\begin{array}{l}\text { Accum Operating Provisions } \\
\text { Accum Prov for Rate Refunds }\end{array}$ & 0 & 0 & 0 & 0 & 0 & $\mathbf{0}$ \\
\hline Accum Prov for Rate Refunds ........................ & 0 & $\hat{0}$ & 0 & 0 & 0 & 0 \\
\hline & 0 & $\mathbf{0}$ & 0 & $\mathbf{0}$ & $\mathbf{0}$ & $\mathbf{0}$ \\
\hline \multicolumn{7}{|l|}{ Current and Accrued Labilities } \\
\hline & 1,316 & 173 & 992 & 0 & 0 & $\mathbf{0}$ \\
\hline $\begin{array}{l}\text { Accounts Payable } \\
\text { Payables to Assoc Enterprises }\end{array}$ & 2,304 & 4,662 & 2,179 & 2,178 & 1,389 & 712 \\
\hline & 0 & 1,950 & 76 & 0 & 112 & 0 \\
\hline 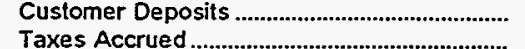 & 1,648 & 270 & 964 & 466 & 0 & 340 \\
\hline & 0 & 0 & 9 & 0 & 0 & 0 \\
\hline interest Accrued & 1,572 & 0 & 103 & 0 & 0 & 1 \\
\hline Misc Current \& Accrued Liabilities........................ & 490 & 1,519 & 87 & 357 & 398 & 42 \\
\hline $\begin{array}{l}\text { Total Current \& Accrued Liabilities .......... } \\
\text { Deferred Credits }\end{array}$ & 7,330 & 8,574 & 4,410 & 3,001 & 1,898 & 1,096 \\
\hline Customer Advances for Construction ............. & 0 & 0 & 0 & 100 & 0 & 18 \\
\hline 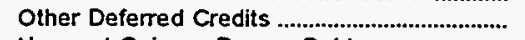 & 0 & 937 & 0 & 0 & 0 & 0 \\
\hline 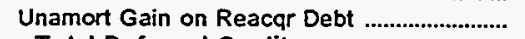 & $\mathbf{0}$ & 0 & 0 & 0 & 0 & 0 \\
\hline Total Deferred Credits & 0 & 937 & 0 & 100 & 0 & 18 \\
\hline Total Liabilities and Other Credits ............ & 141,530 & 59,027 & 64,103 & 15,453 & 14,440 & 5,267 \\
\hline
\end{tabular}

Note: Totals may not equal sum of components because of independent rounding.

Source: Energy Information Administration, Form EIA-412, "Annual Report of Public Electric Utilities." 
Table 22. Balance Sheet by Major U.S. Publicly Owned Electric Utility Within State at End of Period, 1995

(Thousand Dollars)

\begin{tabular}{|c|c|c|c|c|c|c|}
\hline Item & $\begin{array}{c}\text { Georgia } \\
\text { Crisp } \\
\text { County } \\
\text { Power } \\
\text { Comm } \\
\text { December } 31\end{array}$ & $\begin{array}{c}\text { Georgia } \\
\begin{array}{l}\text { Dalton } \\
\text { City of }\end{array} \\
\text { November } 30\end{array}$ & $\begin{array}{l}\text { Georgia } \\
\text { Douglas } \\
\text { City of } \\
\text { June } 30\end{array}$ & $\begin{array}{l}\text { Georgia } \\
\text { East } \\
\text { Point } \\
\text { City of } \\
\text { June } 30\end{array}$ & $\begin{array}{c}\text { Georgia } \\
\text { Fitzgerald } \\
\text { Wtr Lgt } \\
\text { \& Bond Comm } \\
\text { December } 31\end{array}$ & $\begin{array}{l}\text { Georgia } \\
\text { Grifin } \\
\text { City of } \\
\text { June } 30\end{array}$ \\
\hline \multicolumn{7}{|l|}{ Electric Utillty Plant } \\
\hline 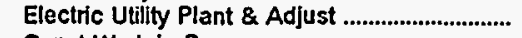 & 41.435 & 207,118 & 4,274 & 7,746 & 7,109 & 11,791 \\
\hline Const Work in Progress & 975 & 1,446 & & & 0 & 0 \\
\hline 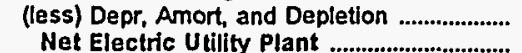 & $\begin{array}{l}24,772 \\
17,638\end{array}$ & $\begin{array}{r}71,052 \\
137,512\end{array}$ & $\begin{array}{l}2,382 \\
1,892\end{array}$ & $\begin{array}{l}4,067 \\
3,679\end{array}$ & $\begin{array}{l}3,248 \\
3,862\end{array}$ & $\begin{array}{r}325 \\
11,466\end{array}$ \\
\hline 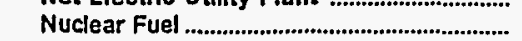 & & 11,979 & 0 & & & \\
\hline 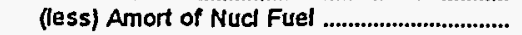 & 0 & 7.167 & 0 & 0 & o & 0 \\
\hline Net Elec Plant Incl Nucl Fuel ........................... & 17,638 & 142,324 & 1,892 & 3,679 & 3,862 & 11,466 \\
\hline \multicolumn{7}{|l|}{ Other Property \& Investments } \\
\hline 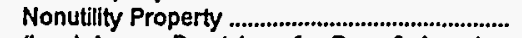 & 0 & 2,974 & 664 & 0 & 18.283 & 33,877 \\
\hline (less) Accum Provisions for Depr \& Amort.... & 0 & 403 & 431 & 0 & 5,135 & 9,233 \\
\hline 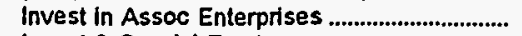 & 0 & 10,678 & 0 & o & 0 & 0 \\
\hline 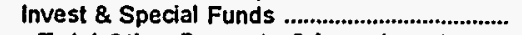 & 999 & 235,909 & 0 & 0 & 1,766 & 0 \\
\hline Total Other Property \& Investments ........ & 999 & 249,158 & 233 & 0 & 14,914 & 24,644 \\
\hline \multicolumn{7}{|l|}{ Current and Accrued Assets } \\
\hline Cash, Working Funds \& Investments ............... & 1,516 & 3,261 & 1,339 & 0 & 1,529 & 1,031 \\
\hline 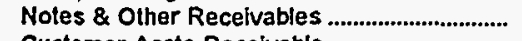 & 1,059 & 19 & 87 & 1.167 & 12 & 4,240 \\
\hline Customer Accts Receivable ............................. & 1,520 & 2,518 & 1,690 & 3,930 & 379 & 0 \\
\hline (less) Accum Prov for Uncollected Accts ....... & 48 & 70 & 70 & 169 & 133 & 0 \\
\hline 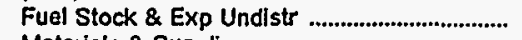 & 169 & 1.772 & 0 & 0 & 1 & 0 \\
\hline 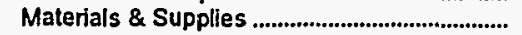 & 416 & 4,524 & 579 & 974 & 618 & 760 \\
\hline 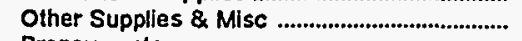 & 137 & 59 & 0 & 0 & 0 & 0 \\
\hline 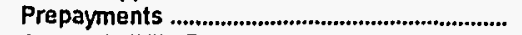 & 96 & 1,294 & 0 & 343 & 0 & 83 \\
\hline 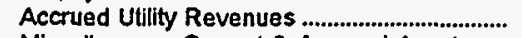 & 0 & 0 & 0 & 816 & 0 & 0 \\
\hline Miscellaneous Current \& Accrued Assets ...... & 0 & 0 & 0 & 0 & 0 & 0 \\
\hline Total Current \& Accrued Assets .................... & 4,864 & 13,377 & 3,625 & 7,051 & 2,407 & 6,114 \\
\hline \multicolumn{7}{|l|}{ Deferred Debits } \\
\hline 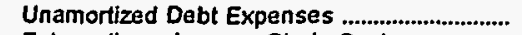 & 0 & 743 & 0 & 0 & 635 & 0 \\
\hline Extraordinary Losses, Study Cost...................... & 0 & 0 & 0 & 0 & 0 & 0 \\
\hline Misc Debt, R \& D Exp, Unamrt Losses .......... & 0 & 953 & 0 & 0 & 0 & 0 \\
\hline Total Deferred Debits ........................................ & & 1,696 & & & 635 & \\
\hline $\begin{array}{l}\text { Total Assets \& Other Debits ........................... } \\
\text { Proprietary Capital }\end{array}$ & 23,501 & 406,555 & & 42,223 \\
\hline 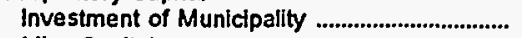 & 0 & 0 & 280 & 0 & 0 & 0 \\
\hline 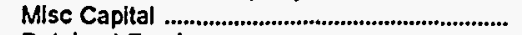 & 0 & 0 & 1,292 & 0 & 0 & 0 \\
\hline 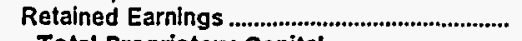 & 21.700 & 294.866 & 3,812 & 7.050 & 15,014 & 27,696 \\
\hline $\begin{array}{l}\text { Total Proprietary Capital ........................................ } \\
\text { Long-term Debt }\end{array}$ & 21,700 & 294,866 & 5,384 & 7,050 & 15,014 & 27,696 \\
\hline 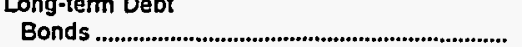 & 0 & 85,320 & $\mathbf{0}$ & 0 & 4,035 & 12,847 \\
\hline Advances from Municipality \& Other ................ & 0 & & 0 & 0 & 0 & 0 \\
\hline Unamort Prem on Long-term Debt .................... & 0 & -126 & 0 & $\mathbf{0}$ & 1,963 & 0 \\
\hline (less) Unamort Discount on Long-term Debt & 0 & & 0 & 0 & 697 & 0 \\
\hline $\begin{array}{l}\text { Total Long-term Debt } \\
\text { Other Noncument Uabilities }\end{array}$ & 0 & 85,194 & 0 & 0 & 5,302 & 12,847 \\
\hline 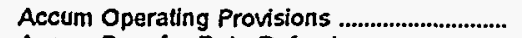 & 0 & 925 & 0 & 0 & 0 & 0 \\
\hline Accum Prov for Rate Refunds ........................... & 0 & 0 & 0 & 0 & 0 & 0 \\
\hline Total Other Noncurrent Liabilities ............ & $\mathbf{0}$ & 925 & 0 & o & 0 & 0 \\
\hline \multicolumn{7}{|l|}{ Current and Accrued Labillties } \\
\hline $\begin{array}{l}\text { Notes Payable } \\
\text { Accounts Payable }\end{array}$ & $\begin{array}{r}0 \\
1059\end{array}$ & $\begin{array}{r}0 \\
3,655\end{array}$ & $\begin{array}{l}0 \\
0\end{array}$ & $\begin{array}{r}0 \\
2456\end{array}$ & $\begin{array}{r}0 \\
119\end{array}$ & $\begin{array}{r}0 \\
150\end{array}$ \\
\hline & $\begin{aligned} 1,008 \\
0\end{aligned}$ & $\begin{array}{r}3,653 \\
0\end{array}$ & 0 & $\begin{array}{r}2,456 \\
0\end{array}$ & $\begin{array}{r}1,119 \\
0\end{array}$ & $\begin{array}{r}150 \\
0\end{array}$ \\
\hline 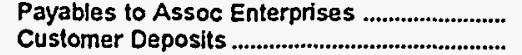 & 377 & 785 & 294 & 447 & 241 & 970 \\
\hline 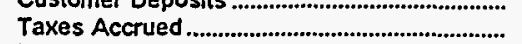 & 123 & 0 & 0 & 0 & 0 & 0 \\
\hline 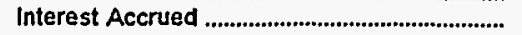 & 0 & 2,383 & 0 & 316 & 47 & 0 \\
\hline Misc Current \& Accrued Liabilities.................... & 242 & 4,375 & 72 & 470 & 91 & 560 \\
\hline Total Current \& Accrued Liabilities ........... & 1,801 & 11,198 & 366 & 3,690 & 1,498 & 1,680 \\
\hline \multicolumn{7}{|l|}{ Deferred Credits } \\
\hline Customer Advances for Construction .............. & 0 & 2,246 & 0 & 0 & 0 & 0 \\
\hline 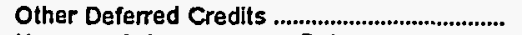 & 0 & 12,126 & 0 & 0 & 4 & 0 \\
\hline 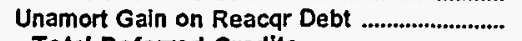 & 0 & 0 & 0 & 0 & 0 & 0 \\
\hline 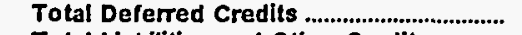 & $\mathbf{0}$ & 14,372 & 0 & o & 4 & 0 \\
\hline Total Liabilities and Other Credits ............ & 23,501 & 406,555 & 5,750 & 10,740 & 21,817 & 42,223 \\
\hline
\end{tabular}

Note: Totals may not equal sum of components because of independent rounding.

Source: Energy Information Administration. Form EIA-412, "Annual Report of Public Electric Utilities." 
Table 22. Balance Sheet by Major U.S. Publicly Owned Electric Utility Within State at End of Period, 1995

(Thousand Dollars)

\begin{tabular}{|c|c|c|c|c|c|c|}
\hline Item & $\begin{array}{l}\text { Georgia } \\
\text { La Grange } \\
\text { City of } \\
\text { June } 30\end{array}$ & $\begin{array}{l}\text { Georgia } \\
\text { Lawrenceville } \\
\text { City of } \\
\text { August } 30\end{array}$ & $\begin{array}{l}\text { Georgia } \\
\text { Marietta } \\
\text { City of } \\
\text { June } 30\end{array}$ & $\begin{array}{c}\text { Georgia } \\
\text { Moultrie } \\
\text { City of } \\
\text { September } 30\end{array}$ & $\begin{array}{l}\text { Georgia } \\
\text { Municipal } \\
\text { Electric } \\
\text { Authority } \\
\text { December } 31\end{array}$ & $\begin{array}{c}\text { Georgia } \\
\text { Thomasville } \\
\text { City of } \\
\text { December } 31\end{array}$ \\
\hline \multicolumn{7}{|l|}{ Electric Utility Piant } \\
\hline Electric Utility Plant \& Adjust .............................. & 8,442 & 13,293 & 42,644 & 6,615 & $3,059,779$ & 16,411 \\
\hline 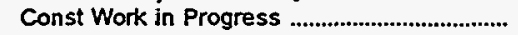 & & & & & 20,165 & 690 \\
\hline 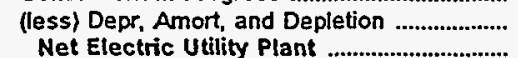 & $\begin{array}{l}2,284 \\
6,157\end{array}$ & $\begin{array}{l}3,795 \\
9,498\end{array}$ & $\begin{array}{l}18,212 \\
24,432\end{array}$ & $\begin{array}{l}3,937 \\
2,678\end{array}$ & $\begin{array}{r}937,049 \\
2,142,895\end{array}$ & $\begin{array}{r}5,745 \\
11,358\end{array}$ \\
\hline 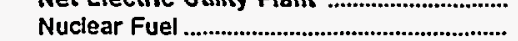 & 0 & 0 & $\begin{array}{rll}2 \pi,+0< \\
0\end{array}$ & $\begin{aligned} 2,060 \\
0\end{aligned}$ & $\begin{array}{r}2,14<, 030 \\
389,601\end{array}$ & 0 \\
\hline 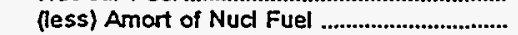 & 0 & 0 & 0 & 0 & 339,509 & 0 \\
\hline Net Elec Plant Incl Nucl Fuel ............................. & 6,157 & 9,498 & 24,432 & 2,678 & $2,192,987$ & 11,356 \\
\hline \multicolumn{7}{|l|}{ Other Property \& Investments } \\
\hline Nonutlity Property ........................................................ & 0 & 0 & 48,554 & 775 & 0 & $\mathbf{0}$ \\
\hline (less) Accum Provisions for Depr \& Amort.... & $\mathbf{0}$ & 0 & 20,736 & 541 & 0 & $\mathbf{0}$ \\
\hline 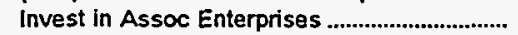 & 0 & 0 & 0 & 0 & $\mathbf{0}$ & 0 \\
\hline Invest \& Special Funds ................................................. & 0 & 0 & 0 & 0 & $1,343,546$ & 0 \\
\hline $\begin{array}{l}\text { Total Other Property \& Investments ....... } \\
\text { Current and Accrued Assets }\end{array}$ & 0 & 0 & 27,818 & 234 & $1,343,546$ & 0 \\
\hline Cash, Working Funds \& Investments .............. & \multicolumn{2}{|c|}{ Current and Accrued Assets } & 31,154 & 723 & & 778 \\
\hline 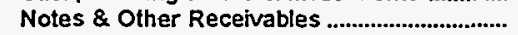 & 0 & $0^{\circ}$ & 241 & 3 & 23,936 & 503 \\
\hline 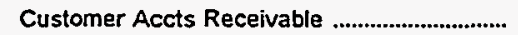 & 0 & 2,595 & 12,970 & 1,441 & 36,362 & 2,158 \\
\hline (less) Accum Prov for Uncollected Accts ....... & 0 & 254 & 811 & 387 & 0 & 76 \\
\hline 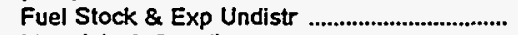 & 0 & 0 & 0 & 0 & 12,102 & 0 \\
\hline 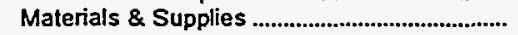 & 0 & $\mathbf{0}$ & 2,205 & 473 & 39.751 & 695 \\
\hline 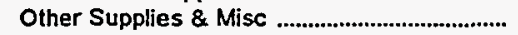 & o & 0 & 0 & 0 & 500 & 0 \\
\hline 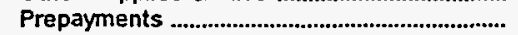 & 0 & 0 & 45 & 21 & 2,190 & 3 \\
\hline 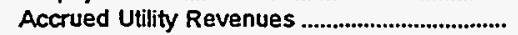 & 0 & 0 & 0 & 0 & 0 & 1.780 \\
\hline Miscellaneous Current \& Accrued Assets ..... & 0 & 0 & 0 & 0 & 0 & 8 \\
\hline Total Current \& Accrued Assets ................... & 0 & 2,869 & 45,802 & 2,274 & 266,207 & 5,848 \\
\hline \multicolumn{7}{|l|}{ Deferred Debits } \\
\hline 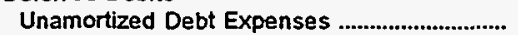 & 0 & 0 & 123 & 0 & 322,166 & $\mathbf{0}$ \\
\hline 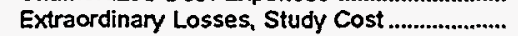 & 0 & 0 & 0 & 0 & 0 & 0 \\
\hline Misc Debt, $R$ \& D Exp, Unamrt Losses .......... & 0 & 0 & 4,125 & 0 & 685,847 & $\mathbf{0}$ \\
\hline Total Deferred Debits ....................................... & o & 0 & 4,248 & & $1,008,013$ & $\mathbf{0}$ \\
\hline Total Assets \& Other Debits ....................... & 6,157 & 12,367 & 102,301 & 5,186 & $4,810,753$ & 17,204 \\
\hline \multicolumn{7}{|l|}{ Proprietary Capital } \\
\hline 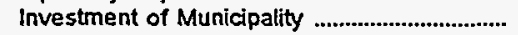 & 0 & 0 & 1.206 & 12 & 0 & 0 \\
\hline 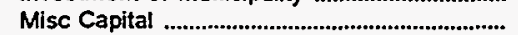 & 0 & 0 & 49 & 0 & 0 & 242 \\
\hline Retained Earnings ............................................................... & 6,157 & 10,802 & 82,074 & 4,482 & 0 & 13,007 \\
\hline Total Proprietary Capital ....................................... & 6,157 & 10,802 & 83,329 & 4,494 & 0 & 13,250 \\
\hline \multicolumn{7}{|l|}{ Long-term Debt } \\
\hline 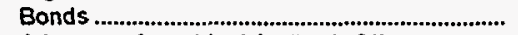 & 0 & 0 & 6,940 & 0 & $3,803,640$ & $\mathbf{0}$ \\
\hline Advances from Municipality \& Other ................ & 0 & $\mathbf{0}$ & 8 & 0 & 541,728 & $\mathbf{0}$ \\
\hline Unamort Prem on Long-term Debt ..................... & 0 & 0 & 0 & 0 & 28,679 & 0 \\
\hline (less) Unamort Discount on Long-term Debt & 0 & 0 & 0 & 0 & 67,332 & 0 \\
\hline 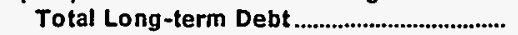 & 0 & $\mathbf{0}$ & 6,948 & 0 & $4,306,715$ & o \\
\hline \multicolumn{7}{|l|}{ Other Noncurrent Labilities } \\
\hline 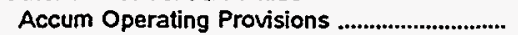 & 0 & 0 & 0 & 0 & 7,954 & 0 \\
\hline 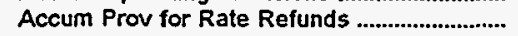 & 0 & 0 & 0 & 0 & 0 & o \\
\hline Total Other Noncurrent Liabilities ............. & 0 & 0 & 0 & 0 & 7,954 & o \\
\hline \multicolumn{7}{|l|}{ Current and Accrued Liabilities } \\
\hline 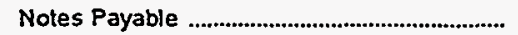 & 0 & 0 & 925 & 0 & 10,200 & 1,111 \\
\hline Accounts Payable …………................................. & 0 & 1,565 & 5,661 & 685 & 40.161 & 1,959 \\
\hline 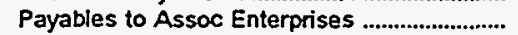 & 0 & 0 & & 0 & 0 & 42 \\
\hline 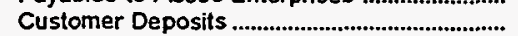 & 0 & 0 & 2,296 & 0 & 0 & 636 \\
\hline 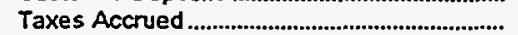 & 0 & 0 & 361 & 0 & 10 & 86 \\
\hline 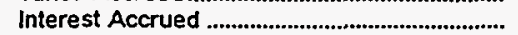 & 0 & 0 & 88 & 0 & 102,009 & o \\
\hline Misc Current \& Accrued Liabilities..................... & 0 & 0 & 2,693 & 0 & 905 & 120 \\
\hline Total Current \& Accrued Liabilities ........... & 0 & 1,565 & 12,024 & 685 & 153,285 & 3,954 \\
\hline \multicolumn{7}{|l|}{ Deferred Credits } \\
\hline Customer Advances for Construction .............. & 0 & o & $\mathbf{0}$ & 0 & 0 & 0 \\
\hline Other Deferred Credits ....................................... & 0 & 0 & 0 & 7 & 342,799 & 0 \\
\hline Unamort Gain on Reacqr Debt ......................... & 0 & 0 & 0 & 0 & 0 & 0 \\
\hline Total Deferred Credits ......................................... & 0 & 0 & 0 & 7 & 342,799 & 0 \\
\hline Total Liabitities and Other Credits ............ & 6,157 & 12,367 & 102,301 & 5,186 & $4,810,753$ & 17,204 \\
\hline
\end{tabular}

Note: Totals may not equal sum of components because of independent rounding

Source: Energy Information Administration, Form EIA-412, "Annual Report of Public Electric Utilities." 
Table 22. Balance Sheet by Major U.S. Publicly Owned Electric Utility Within State at End of Period, 1995 (Thousand Dollars)

\begin{tabular}{|c|c|c|c|c|c|c|}
\hline Item & $\begin{array}{c}\text { Idaho } \\
\text { Idaho } \\
\text { Falls } \\
\text { City of } \\
\text { September } 30\end{array}$ & $\begin{array}{l}\text { Batavia } \\
\text { City of }\end{array}$ & $\begin{array}{l}\text { Geneva } \\
\text { City of }\end{array}$ & $\begin{array}{c}\text { Illinois } \\
\text { Illinois } \\
\text { Municipal } \\
\text { Elec Agency }\end{array}$ & $\begin{array}{l}\text { Napenille } \\
\text { City of } \\
\text { April } 30\end{array}$ & $\begin{array}{l}\text { Illinois } \\
\text { Rochelle } \\
\text { Municipal } \\
\text { Utilities } \\
\text { Apnl } 30\end{array}$ \\
\hline \multicolumn{7}{|l|}{ Electric Utitity Plant } \\
\hline 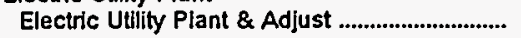 & 131,031 & 17,582 & 22,728 & 96,893 & 116,221 & 30,423 \\
\hline 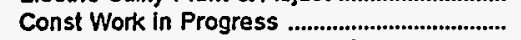 & 687 & 0 & 50 & 597 & 12,143 & 158 \\
\hline 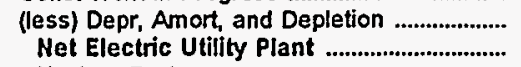 & $\begin{array}{l}37,952 \\
93,766\end{array}$ & $\begin{array}{l}7,677 \\
9,905\end{array}$ & $\begin{array}{r}9,963 \\
12,815\end{array}$ & $\begin{array}{l}12,564 \\
84,926\end{array}$ & $\begin{array}{r}26,173 \\
102,191\end{array}$ & $\begin{array}{l}16,853 \\
13,729\end{array}$ \\
\hline 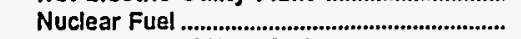 & 0 & 0 & 0 & 0 & 0 & 0 \\
\hline 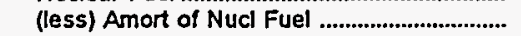 & 0 & 0 & 0 & 0 & 0 & 0 \\
\hline Net Elec Plant Incl Nucl Fuel ...................... & 93,766 & 9,905 & 12,815 & 84,926 & 102,191 & 13,729 \\
\hline \multicolumn{7}{|l|}{ Other Property \& Investments } \\
\hline Nonutility Property & 0 & 0 & 0 & 0 & 0 & 0 \\
\hline (less) Accum Provisions for Depr \& Amort.... & 0 & 0 & 0 & 0 & 0 & 0 \\
\hline Invest in Assoc Enterprises ................................ & 0 & 0 & 0 & 0 & 0 & 0 \\
\hline 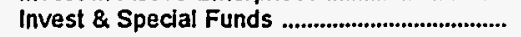 & 10,763 & 0 & 2,570 & 0 & 8,810 & 2,851 \\
\hline Total Other Property \& Investments ........ & 10,763 & 0 & 2,570 & $\mathbf{0}$ & 8,810 & 2,851 \\
\hline \multicolumn{7}{|l|}{ Current and Accrued Assets } \\
\hline Cash, Working Funds \& Investments ............. & 4,158 & 5,731 & 2,622 & 30,530 & 30,610 & 1,764 \\
\hline Notes \& Other Receivables ............................... & 479 & 792 & 1,246 & 0 & 0 & 815 \\
\hline 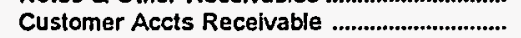 & 2,558 & 1,560 & 25 & 4,109 & 5,325 & 1,128 \\
\hline (less) Accum Prov for Uncollected Accts ...... & 397 & 0 & 0 & 0 & 202 & 117 \\
\hline Fuel Stock \& Exp Undistr .................................. & 0 & 0 & 0 & 0 & 0 & 254 \\
\hline 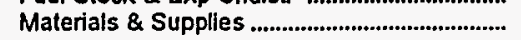 & 1,954 & 1,120 & 426 & 0 & 5,256 & 520 \\
\hline 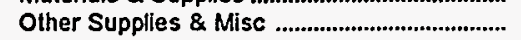 & 0 & 0 & 22 & 0 & 0 & 0 \\
\hline 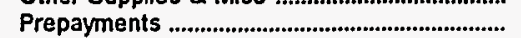 & 0 & 1 & 0 & 33 & 102 & 51 \\
\hline 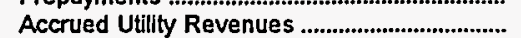 & 0 & 0 & 0 & 0 & 218 & 209 \\
\hline Miscellaneous Current \& Accrued Assets ..... & 328 & 0 & 0 & 0 & 869 & 60 \\
\hline Total Current \& Accrued Assets ................... & 9,079 & 9,205 & 4,342 & 34,672 & 42,179 & 4,683 \\
\hline \multicolumn{7}{|l|}{ Deferred Debits } \\
\hline Unamortized Debt Expenses ................................. & 1,382 & 0 & 74 & 3.031 & 0 & 73 \\
\hline 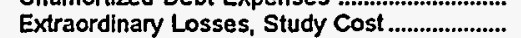 & 1,807 & 0 & 0 & 0 & 0 & 0 \\
\hline Misc Debt, R \& D Exp, Unamrt Losses .......... & 2,415 & 0 & 0 & 3.174 & 0 & 401 \\
\hline 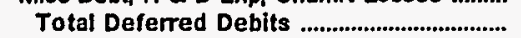 & 5,603 & 0 & 74 & 6,205 & 0 & 473 \\
\hline 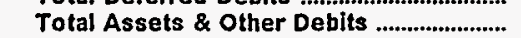 & 119,212 & 19,110 & 19,802 & 125,804 & 153,180 & 21,736 \\
\hline \multicolumn{7}{|l|}{ Proprletary Capital } \\
\hline 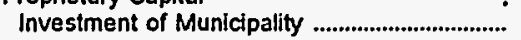 & $\mathbf{0}$ & 0 & 0 & 0 & 25,220 & 0 \\
\hline 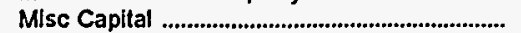 & 0 & 0 & 1,181 & 0 & 0 & 0 \\
\hline 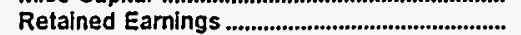 & 32,238 & 17,123 & 14,189 & 6,909 & 105,046 & 11,880 \\
\hline Total Proprietary Capital ................................ & 32,238 & 17,123 & 15,370 & 6,909 & 130,266 & $\$ 1,880$ \\
\hline \multicolumn{7}{|l|}{ Long-term Debt } \\
\hline 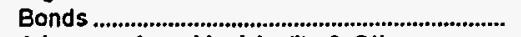 & 56,073 & 0 & 0 & 118,990 & 14,885 & 7,586 \\
\hline Advances from Municipality \& Other ............... & 0 & 0 & 0 & 0 & 637 & 0 \\
\hline Unamort Prem on Long-term Debt ................... & 21,088 & 0 & 0 & 0 & 0 & 0 \\
\hline (less) Unamort Discount on Long-term Debt & 0 & 0 & 0 & 6,143 & 0 & 0 \\
\hline 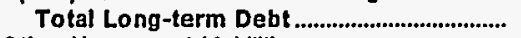 & 77,161 & 0 & 0 & 112,847 & 15,522 & 7,586 \\
\hline \multicolumn{7}{|l|}{ Other Noncurrent Uabilities } \\
\hline 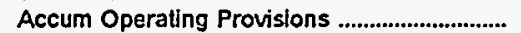 & 0 & 0 & 2,155 & 0 & 0 & 0 \\
\hline Accum Prov for Rate Refunds .......................... & 0 & 0 & 652 & 0 & 0 & 0 \\
\hline Total Other Noncurrent Llabilities ............ & 0 & 0 & 2,807 & $\mathbf{0}$ & 0 & $\mathbf{0}$ \\
\hline \multicolumn{7}{|l|}{ Current and Accrued Labilities } \\
\hline Notes Payable & 0 & 0 & 24 & 0 & 0 & 415 \\
\hline 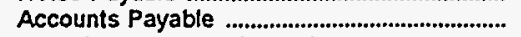 & 1,413 & 1.874 & 1,325 & 4,169 & 2,323 & 1.000 \\
\hline Payables to Assoc Enterprises ......................... & 379 & 0 & 276 & 0 & 1,748 & 0 \\
\hline 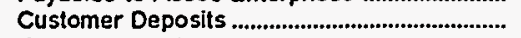 & 2 & 94 & 0 & $\mathbf{0}$ & 0 & 0 \\
\hline 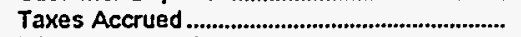 & 0 & 0 & 0 & 0 & 0 & 39 \\
\hline Interest Accrued & 686 & 0 & 0 & 1,738 & 0 & 277 \\
\hline Misc Current \& Accrued Liabilities.................... & 7,333 & 19 & 0 & 81 & 3,321 & 226 \\
\hline Total Current \& Accrued Liabilities .......... & 9,813 & 1,987 & 1,625 & 5,988 & 7,392 & 1,957 \\
\hline \multicolumn{7}{|l|}{ Deferred Credits } \\
\hline Customer Advances for Construction ............. & 0 & 0 & 0 & 0 & 0 & 54 \\
\hline Other Deferred Credits ........................................... & 0 & 0 & 0 & 60 & 0 & 258 \\
\hline Unamort Gain on Reacqr Debt ......................... & 0 & 0 & 0 & 0 & 0 & 0 \\
\hline 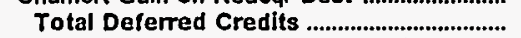 & 0 & $\mathbf{0}$ & 0 & 60 & 0 & 312 \\
\hline Total Llabilities and Other Credits ............ & 119,212 & 19,110 & 19,802 & 125,804 & 153,180 & 21,736 \\
\hline
\end{tabular}

Note: Totals may not equal sum of components because of independent rounding

Source: Energy Information Administration, Form ElA-4 12, "Annual Report of Public Electric Utilities." 
Table 22. Balance Sheet by Major U.S. Publicly Owned Electric Utility Within State at End of Period, 1995

(Thousand Dollars)

\begin{tabular}{|c|c|c|c|c|c|c|}
\hline Item & $\begin{array}{l}\text { Illinois } \\
\begin{array}{l}\text { Springfield } \\
\text { City of }\end{array} \\
\text { February } 28\end{array}$ & $\begin{array}{l}\text { Illinois } \\
\text { St Charies } \\
\text { City of } \\
\text { April } 30\end{array}$ & $\begin{array}{l}\text { Indiana } \\
\text { Anderson } \\
\text { City of } \\
\text { December } 31\end{array}$ & $\begin{array}{l}\text { Indiana } \\
\text { Auburn } \\
\text { City of } \\
\text { December } 31\end{array}$ & $\begin{array}{l}\text { Indiana } \\
\text { Bluffton } \\
\text { City of } \\
\text { December } 31\end{array}$ & $\begin{array}{c}\text { Indiana } \\
\text { Crawfordsville } \\
\text { Elec } \\
\text { Lgt\&Pwr Co } \\
\text { December } 31\end{array}$ \\
\hline \multicolumn{7}{|l|}{ Electric Utility Plant } \\
\hline 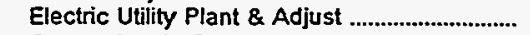 & 369,105 & 30,674 & 55,715 & 15,449 & 8,907 & 32,345 \\
\hline Const Work in Progress & 17,708 & & 749 & 1,283 & 0 & 183 \\
\hline (less) Depr, Amort, and Depletion ..................... & 185,720 & 8,975 & 23,714 & 5,471 & 4,690 & 17,397 \\
\hline Net Electric Utility Plant ....................................... & 201,093 & 21,698 & 32,750 & 11,261 & 4,217 & 15,131 \\
\hline 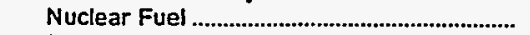 & 0 & 0 & 0 & 0 & 0 & 0 \\
\hline 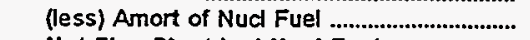 & 0 & 0 & 0 & 0 & 0 & 0 \\
\hline $\begin{array}{l}\text { Net Elec Ptant Incl Nucl Fuel ............................. } \\
\text { Other Propert } 8 \text { Investments }\end{array}$ & 201,093 & 21,698 & 32,750 & 11,261 & 4,217 & 15,131 \\
\hline 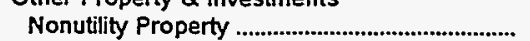 & 4,987 & \\
\hline (less) Accum Provisions for Depr \& Amort.... & & 0 & 0 & 0 & 0 & 0 \\
\hline Invest in Assoc Enterprises ...................................... & 0 & 0 & 0 & 0 & 0 & 0 \\
\hline 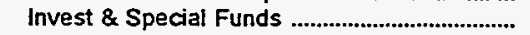 & 72,123 & 0 & 0 & 3,704 & 1.023 & 0 \\
\hline $\begin{array}{l}\text { Total Other Property \& Investments ....... } \\
\text { Current and Accrued Assets }\end{array}$ & \multicolumn{5}{|c|}{ Current and Accrued Assets } & \\
\hline Cash, Working Funds \& Investments ............... & 9,488 & 13,397 & 5.602 & 7,514 & 939 & 6,707 \\
\hline Notes \& Other Receivables ................................. & 975 & 643 & 312 & 259 & 10 & 0 \\
\hline Customer Acets Receivable ................................... & 6,165 & 1,694 & 2,032 & 192 & 516 & 683 \\
\hline (less) Accum Prov for Uncollected Accts ...... & -485 & 4 & 511 & 0 & 41 & 0 \\
\hline Fuel Stock \& Exp Undistr ......................................... & 2,204 & 0 & 0 & 0 & 0 & 80 \\
\hline 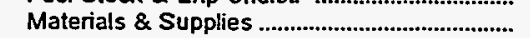 & 6,337 & 40 & 598 & 0 & 656 & 653 \\
\hline 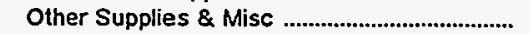 & 95 & 0 & 8 & 523 & 0 & 1 \\
\hline 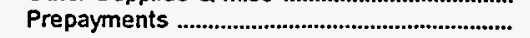 & 1,250 & 72 & 0 & 45 & 14 & 138 \\
\hline 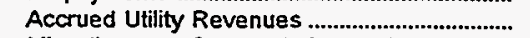 & 3,871 & 112 & 0 & 0 & 0 & 0 \\
\hline Miscellaneous Current \& Accrued Assets ..... & & 38 & 0 & 0 & 0 & 37 \\
\hline $\begin{array}{l}\text { Total Current \& Accrued Assets .................... } \\
\text { Deferred Debits }\end{array}$ & 30,902 & 15,993 & 8,440 & 8,533 & 2,094 & 8,299 \\
\hline 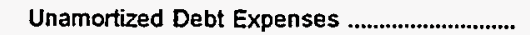 & 228 & 0 & 125 & 0 & 66 & 154 \\
\hline Extraordinary Losses, Study Cost ....................... & 0 & 0 & 0 & 0 & 0 & 0 \\
\hline Misc Debt, R \& D Exp, Unamrt Losses ........... & 0 & 0 & 523 & 0 & 0 & 569 \\
\hline Total Deferred Debits ........................................... & 228 & 0 & 648 & & 66 & 723 \\
\hline $\begin{array}{l}\text { Total Assets \& Other Debits ............................ } \\
\text { Proprietary Capital }\end{array}$ & 309,332 & 37,691 & 41,839 & 23,498 & 7,400 & 24,153 \\
\hline \multicolumn{7}{|l|}{ Proprietary Capital } \\
\hline 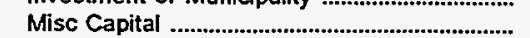 & 11,055 & 0 & 0 & 0 & 0 & $\begin{array}{l}0 \\
0\end{array}$ \\
\hline Retained Earnings ................................................ & 153,529 & 36,029 & 28,810 & 21,563 & 6,400 & 15,313 \\
\hline 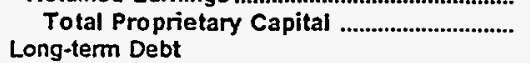 & 164,584 & 36,029 & 28,810 & 21,563 & 6,400 & 15,313 \\
\hline Bonds & 115,745 & 0 & 4,265 & 470 & 0 & 6,665 \\
\hline Advances from Municipality \& Other ................ & 0 & 0 & 0 & 0 & 0 & 0 \\
\hline Unamort Prem on Long-term Debt .................... & 0 & 0 & 0 & 0 & 0 & 0 \\
\hline (less) Unamort Discount on Long-term Debt & 960 & 0 & 0 & 0 & 0 & 0 \\
\hline 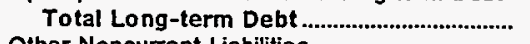 & 114,785 & 0 & 4,265 & 470 & $\mathbf{0}$ & 6,665 \\
\hline \multicolumn{7}{|l|}{ Other Noncurtent Liabilities } \\
\hline 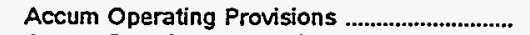 & 0 & 0 & 56 & 0 & 0 & 0 \\
\hline 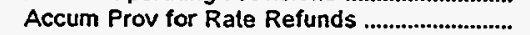 & 0 & 0 & 0 & 0 & 0 & 0 \\
\hline & 0 & $\mathbf{0}$ & 56 & 0 & 0 & 0 \\
\hline 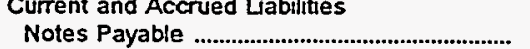 & 6,320 & $\mathbf{0}$ & 0 & 2 & 0 & 0 \\
\hline 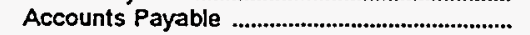 & 8,620 & 1,109 & 4,687 & 1,405 & 618 & 1,931 \\
\hline 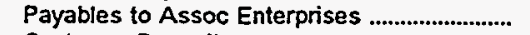 & 0 & 343 & 0 & 0 & 0 & 0 \\
\hline 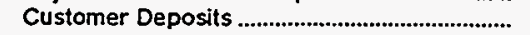 & 702 & 185 & 334 & 17 & 106 & 87 \\
\hline 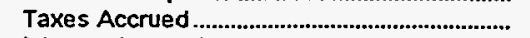 & 4 & 0 & 119 & 27 & 2 & 2 \\
\hline 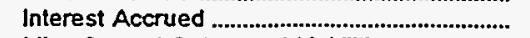 & 4,324 & 0 & 1 & 14 & 0 & 0 \\
\hline 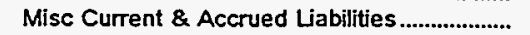 & 0 & 0 & 0 & 0 & 0 & 155 \\
\hline $\begin{array}{l}\text { Total Current \& Accrued Liabilities ............ } \\
\text { Deferred Credits }\end{array}$ & & 1,638 & 5,141 & 1,466 & 726 & 2,175 \\
\hline Customer Advances for Construction ............. & 956 & D & 3,567 & 0 & 196 & 0 \\
\hline 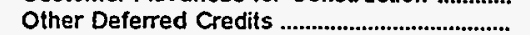 & 0 & 25 & 0 & 0 & 78 & 0 \\
\hline 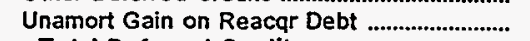 & 9,039 & 0 & & 0 & 0 & 0 \\
\hline Total Deferred Credits ....................................... & 9,995 & 25 & 3,567 & o & 274 & 0 \\
\hline Total Liabilities and Other Credits ............ & 309,332 & 37,691 & 41,839 & 23,498 & 7,400 & 24,153 \\
\hline
\end{tabular}

Note: Totals may not equal sum of components because of independent rounding.

Source: Energy Information Administration, Form EIA-412, "Annual Report of Public Electric Utilities." 
Table 22. Balance Sheet by Major U.S. Publicly Owned Electric Utility Within State at End of Period, 1995

(Thousand Dollars)

\begin{tabular}{|c|c|c|c|c|c|c|}
\hline Item & $\begin{array}{c}\text { Indiana } \\
\text { Frankfort } \\
\text { City of } \\
\text { December } 31\end{array}$ & $\begin{array}{c}\text { Indiana } \\
\text { Greenfield } \\
\text { City of } \\
\text { December } 31\end{array}$ & $\begin{array}{c}\text { Indiana } \\
\text { Indiana } \\
\text { Municipal } \\
\text { Power Agency } \\
\text { December } 31\end{array}$ & $\begin{array}{l}\text { Indiana } \\
\text { Jasper } \\
\text { City of } \\
\text { December } 31\end{array}$ & $\begin{array}{l}\text { Indiana } \\
\text { Lebanon } \\
\text { City of } \\
\text { December } 31\end{array}$ & $\begin{array}{l}\text { Indiana } \\
\text { Logansport } \\
\text { City of } \\
\text { December } 31\end{array}$ \\
\hline \multicolumn{7}{|l|}{ Electric Utillty Plant } \\
\hline Electric Utility Plant \& Adjust ................................ & 18,919 & 8,740 & 313,528 & 21,727 & 9,380 & 60,112 \\
\hline Const Work in Progress ...................................... & 800 & 0 & 2,886 & 301 & 0 & 114 \\
\hline $\begin{array}{l}\text { (less) Depr, Amort, and Depletion .................... } \\
\text { Net Electric Utility Plant }\end{array}$ & $\begin{array}{r}7,193 \\
12,526\end{array}$ & $\begin{array}{l}2,456 \\
6,283\end{array}$ & $\begin{array}{r}74,048 \\
242,365\end{array}$ & $\begin{array}{r}7,535 \\
14,494\end{array}$ & $\begin{array}{r}4,864 \\
4,516\end{array}$ & $\begin{array}{l}28,687 \\
31,539\end{array}$ \\
\hline 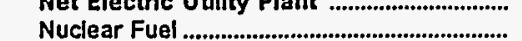 & $\begin{array}{r}12,3<0 \\
0\end{array}$ & $\begin{array}{r}0,200 \\
0\end{array}$ & $\begin{array}{r}242,500 \\
0\end{array}$ & $\begin{array}{r}14,474 \\
0\end{array}$ & 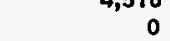 & 0 \\
\hline (less) Amort of Nud Fuel ..................................... & 0 & 0 & 0 & 0 & 0 & 0 \\
\hline Net Elec Plant Incl Nucl Fuel ............................. & 12,526 & 6,283 & 242,365 & 14,494 & 4,516 & 31,539 \\
\hline \multicolumn{7}{|l|}{ Other Property \& Investments } \\
\hline 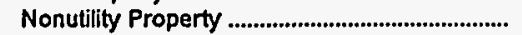 & 0 & 0 & 0 & 0 & 0 & 0 \\
\hline (less) Accum Provisions for Depr \& Amort... & 0 & 0 & 0 & 0 & 0 & 0 \\
\hline Invest in Assoc Enterprises ....................................... & 0 & 0 & 0 & 0 & 0 & 0 \\
\hline 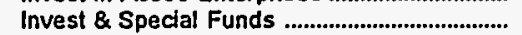 & 0 & 1,229 & 0 & 2.009 & 0 & 7,803 \\
\hline $\begin{array}{l}\text { Total Other Property \& Investments ....... } \\
\text { Current and Accrued Assets }\end{array}$ & 0 & 1,229 & 0 & 2,009 & 0 & 7,803 \\
\hline Cash, Working Funds \& Investments ................... & 8,321 & 2,067 & 102,714 & 1,356 & 3,581 & 310 \\
\hline 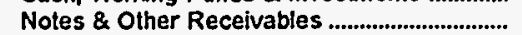 & 221 & 493 & 3,097 & 0 & 0 & 90 \\
\hline Customer Accts Recelvable ........................................ & 1,041 & 522 & 20,546 & 1,258 & 657 & 1,656 \\
\hline (less) Accum Prov for Uncollected Accts ....... & 0 & 0 & 0 & 35 & 72 & 2 \\
\hline 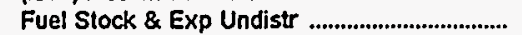 & 0 & 0 & 3,900 & 31 & 0 & 0 \\
\hline 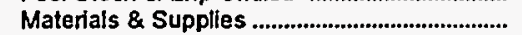 & 552 & 571 & 1,381 & 1,677 & 272 & 81 \\
\hline 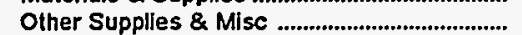 & 0 & 0 & 16 & 0 & 0 & 1,917 \\
\hline 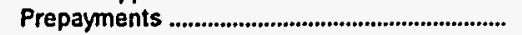 & 37 & 0 & 3,359 & 78 & 0 & 381 \\
\hline 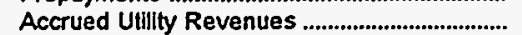 & 0 & 0 & 0 & 0 & 0 & 19 \\
\hline Miscellaneous Current \& Accrued Assets ..... & & 0 & 1,567 & 0 & 26 & \\
\hline Total Current \& Accrued Assets .................. & 10,176 & 3,653 & 136,579 & 4,366 & 4,464 & 4,453 \\
\hline \multicolumn{7}{|l|}{ Deferred Debits } \\
\hline 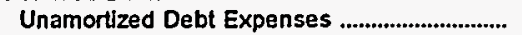 & 0 & 41 & 5.403 & 100 & 0 & 0 \\
\hline 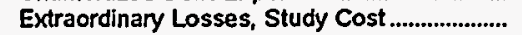 & 0 & 0 & 55,552 & -2 & 0 & 0 \\
\hline Misc Debt, R \& D Exp, Unamrt Losses .......... & 0 & 0 & 942 & 5 & 0 & 0 \\
\hline 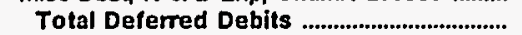 & & 41 & 61,897 & 103 & o & \\
\hline Total Assets \& Other Debits ............................. & 22,702 & 11,207 & 440,842 & 20,972 & 8,980 & 43,795 \\
\hline \multicolumn{7}{|l|}{ Proprietary Capita! } \\
\hline 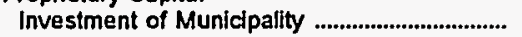 & 0 & 0 & 0 & 0 & 0 & 0 \\
\hline 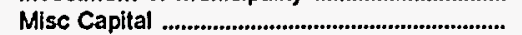 & 0 & 0 & 0 & 149 & 0 & 0 \\
\hline 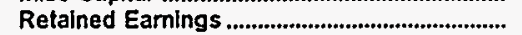 & 18,428 & 7,591 & 50,184 & 11,250 & 7,870 & 26,886 \\
\hline Total Proprietary Capital ....................................... & 18,428 & 7,591 & 50,184 & 11,399 & 7,870 & 26,886 \\
\hline \multicolumn{7}{|l|}{ Long-term Debt } \\
\hline 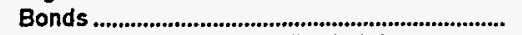 & 0 & 1,515 & 401,535 & 7,620 & 0 & 13,325 \\
\hline Advances from Municipality \& Other ................ & 0 & 0 & 0 & 0 & 0 & 0 \\
\hline Unamort Prem on Long-term Debt .................... & 0 & 0 & $-39,145$ & 0 & 0 & $\mathbf{0}$ \\
\hline (less) Unamort Discount on Long-term Debt & 0 & 0 & 13,246 & 0 & 0 & 0 \\
\hline Total Long-term Debt .......................................... & 0 & 1,515 & 349,144 & 7,620 & 0 & 13,325 \\
\hline \multicolumn{7}{|l|}{ Other Noncurrent Uablitites } \\
\hline Accum Operating Provisions ................................... & 0 & 0 & 0 & 0 & 250 & 159 \\
\hline 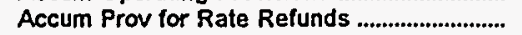 & 0 & 0 & 0 & 0 & 0 & 0 \\
\hline Total Other Honcurrent Liabilities ............ & o & 0 & 0 & 0 & 250 & 159 \\
\hline \multicolumn{7}{|l|}{ Current and Accrued Labilitles } \\
\hline 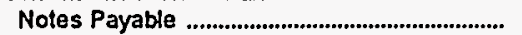 & 0 & 0 & 10,000 & 0 & 0 & 0 \\
\hline Accounts Payable ................................................. & 1,001 & 1.124 & 12,232 & 970 & 464 & 843 \\
\hline Payables to Assoc Enterprises ........................ & 0 & 0 & 0 & 0 & 0 & o \\
\hline 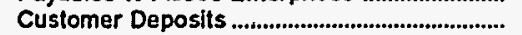 & 244 & 100 & 0 & 190 & 83 & 81 \\
\hline 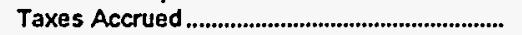 & 25 & 18 & 1,200 & 0 & 47 & 0 \\
\hline 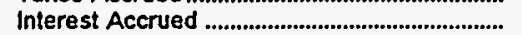 & 0 & 0 & 11.566 & 0 & 0 & 422 \\
\hline Misc Current \& Accrued Liabilities.......................... & 131 & 19 & 1,264 & -2 & 157 & 2,078 \\
\hline Total Current \& Accrued Liabilities ........... & 1,401 & 1,261 & 36,262 & 1,158 & 751 & 3,425 \\
\hline \multicolumn{7}{|l|}{ Deferred Credits } \\
\hline Customer Advances for Construction .............. & 0 & 840 & 0 & 0 & 109 & 0 \\
\hline Other Deferred Credits ............................................... & 2,873 & 0 & 5,252 & 794 & 0 & 0 \\
\hline Unamort Gain on Reacqr Debt ................................ & 0 & 0 & 0 & 0 & 0 & 0 \\
\hline 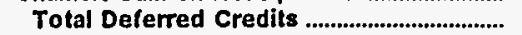 & 2,873 & 840 & 5,252 & 794 & 109 & \\
\hline Total Liabilities and Other Credits ............ & 22,702 & 11,207 & 440,842 & 20,972 & 8,980 & 43,795 \\
\hline
\end{tabular}

Note: Totals may not equal sum of components because of independent rounding.

Source: Energy Information Administration, Form ElA-412, "Annual Report of Public Electric Utilities." 
Table 22. Balance Sheet by Major U.S. Publicly Owned Electric Utility Within State at End of Period, 1995

(Thousand Dollars)

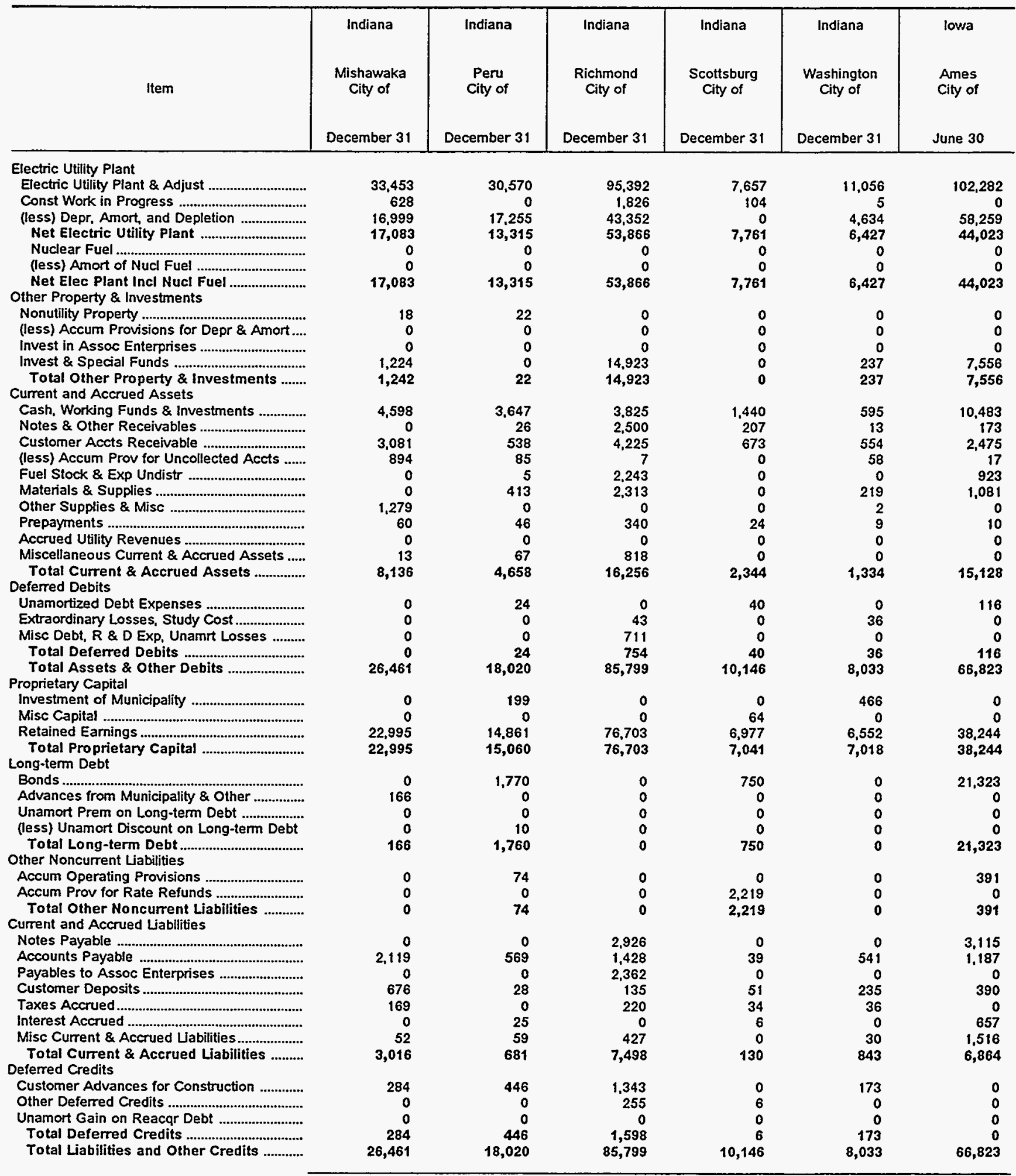

Note: Totals may not equal sum of components because of independent rounding.

Source: Energy Information Administration, Form EIA-412, "Annual Report of Public Electric Utilities." 
Table 22. Balance Sheet by Major U.S. Publicly Owned Electric Utility Within State at End of Period, 1995

(Thousand Dollars)

\begin{tabular}{|c|c|c|c|c|c|c|}
\hline Item & $\begin{array}{c}\text { lowa } \\
\text { Cedar } \\
\text { Falls } \\
\text { City of } \\
\text { December } 31\end{array}$ & $\begin{array}{c}\text { lowa } \\
\text { Muscatine } \\
\text { City of } \\
\text { December } 31\end{array}$ & $\begin{array}{l}\text { lowa } \\
\text { Pella } \\
\text { City of } \\
\text { December } 31\end{array}$ & $\begin{array}{c}\text { Kansas } \\
\text { Chanute } \\
\text { City of } \\
\text { December } 31\end{array}$ & $\begin{array}{l}\text { Kansas } \\
\text { Coffeyville } \\
\text { City of } \\
\text { December } 31\end{array}$ & $\begin{array}{c}\text { Kansas } \\
\text { Garden } \\
\text { City City of } \\
\text { December } 31\end{array}$ \\
\hline \multicolumn{7}{|l|}{ Electric Utility Plant } \\
\hline Electric Utility Plant \& Adjust ................................ & 71,317 & 294,372 & 0 & 28,717 & 37,783 & 15,862 \\
\hline 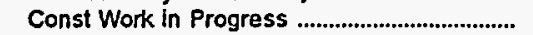 & 686 & 914 & 0 & 0 & 0 & 0 \\
\hline (less) Depr, Amort, and Depletion ...................... & $\begin{array}{l}37,783 \\
34.219\end{array}$ & $\begin{array}{l}129.259 \\
166.027\end{array}$ & $\stackrel{0}{0}$ & $\begin{array}{l}11.042 \\
17,675\end{array}$ & 24,997 & 8.993 \\
\hline 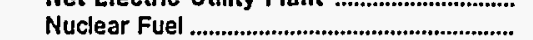 & & 0 & 0 & 0 & 2,10 & 0,000 \\
\hline 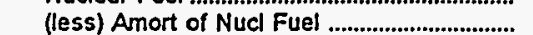 & 0 & 0 & 0 & 0 & 0 & 0 \\
\hline \multicolumn{7}{|l|}{ Other Property \& Investments } \\
\hline Nonutility Property ................................................ & 0 & 0 & 0 & 0 & 0 & 585 \\
\hline (iess) Accum Provisions for Depr \& Amort.... & 0 & o & 0 & 0 & 0 & 484 \\
\hline 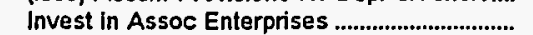 & 0 & 0 & 0 & 0 & 0 & 32 \\
\hline 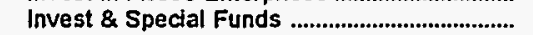 & 4,644 & 123,400 & 0 & 0 & 247 & 232 \\
\hline \multicolumn{7}{|l|}{ Current and Accrued Assets } \\
\hline 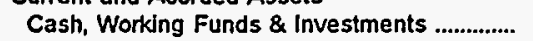 & 10,355 & 7,723 & 10,847 & 1.753 & 8,250 & 1,419 \\
\hline Notes \& Other Receivables ....................................... & & 13 & 0 & 0 & 0 & 45 \\
\hline 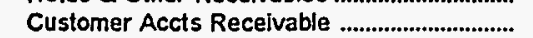 & 1,407 & 4,455 & 825 & 264 & 785 & 548 \\
\hline (less) Accum Prov for Uncollected Accts ...... & & 20 & 0 & 0 & 0 & 0 \\
\hline Fuel Stock \& Exp Undistr .................................... & 1,281 & 3,839 & 156 & 12 & 475 & 0 \\
\hline 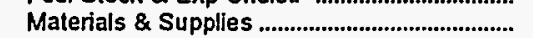 & 351 & 4,088 & 270 & 538 & 613 & 0 \\
\hline Other Supplies \& Misc ............................................. & 0 & 0 & 0 & 0 & 0 & 0 \\
\hline Prepayments ............................................................. & 97 & 617 & 0 & 0 & 0 & 0 \\
\hline 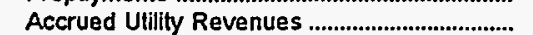 & 360 & 0 & 0 & 0 & 0 & 0 \\
\hline Miscellaneous Current \& Accrued Assets ..... & 171 & 1,890 & 183 & 0 & 0 & 0 \\
\hline Total Current \& Accrued Assets ....................... & 14,014 & 22,605 & 12,283 & 2,568 & 10,122 & 2,011 \\
\hline 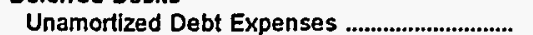 & 0 & 2,599 & 24 & 0 & 0 & 0 \\
\hline Extraordinary Losses, Study Cost ....................... & 0 & 9,590 & 0 & 0 & 0 & 0 \\
\hline Misc Debt, R \& D Exp, Unamrt Losses .......... & 2,047 & 3,047 & 0 & 0 & 0 & 0 \\
\hline Total Deferred Debits ..................................... & 2,047 & 15,236 & & 0 & 0 & $\mathbf{0}$ \\
\hline 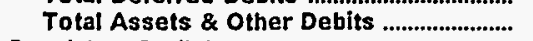 & 54,925 & 327,268 & 12,306 & 20,243 & 23,156 & 9,246 \\
\hline \multirow{2}{*}{\multicolumn{7}{|c|}{$\begin{array}{l}\text { Proprietary Capital } \\
\text { Investment of }\end{array}$}} \\
\hline & 0 & 0 & 0 & 0 & 9.159 & 0 \\
\hline 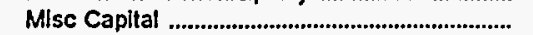 & 0 & 0 & 0 & 0 & 0 & 0 \\
\hline 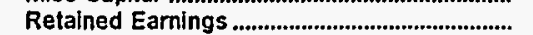 & 50,760 & 133,373 & 6.430 & 4,623 & 9.425 & 8,179 \\
\hline 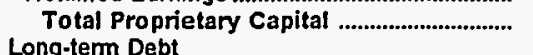 & 50,760 & 133,373 & 6,430 & 4,623 & 18,584 & 8,179 \\
\hline \multicolumn{7}{|l|}{ Long-tem Debt } \\
\hline 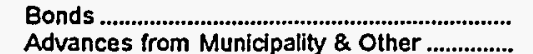 & 0 & 182,655 & 4,800 & 15,620 & 0 & 0 \\
\hline Advances from Municipality \& Other ............... & $\mathbf{0}$ & & 0 & 0 & 0 & 57 \\
\hline Unamort Prem on Long-term Debt .................... & 0 & 0 & 0 & 0 & 0 & 0 \\
\hline (less) Unamort Discount on Long-term Debt & 0 & 9.787 & 78 & 0 & 0 & 0 \\
\hline 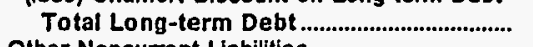 & 0 & 172,868 & 4,722 & 15,620 & $\mathbf{0}$ & 57 \\
\hline \multicolumn{7}{|l|}{ Other Noncurrent Labilities } \\
\hline 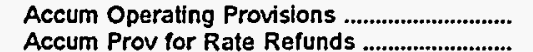 & $\begin{array}{l}0 \\
0\end{array}$ & & 0 & 0 & 1,088 & 0 \\
\hline 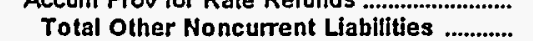 & $\begin{array}{l}0 \\
0\end{array}$ & $\begin{array}{l}0 \\
0\end{array}$ & $\begin{array}{l}0 \\
0\end{array}$ & $\begin{array}{l}0 \\
0\end{array}$ & $\begin{array}{r}0 \\
1,088\end{array}$ & $\begin{array}{l}0 \\
0\end{array}$ \\
\hline \multicolumn{7}{|l|}{ Current and Accrued Liabilities } \\
\hline 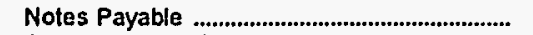 & 0 & 0 & 325 & 0 & 0 & 28 \\
\hline Accounts Payable ........................................................... & 1,282 & 1,074 & 719 & 0 & 2,452 & 904 \\
\hline 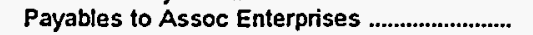 & 25 & 0 & 0 & 0 & 0 & 0 \\
\hline 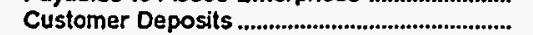 & 76 & 129 & 2 & 0 & 247 & 76 \\
\hline 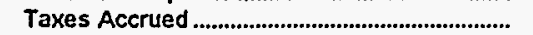 & 360 & 170 & 0 & 0 & 0 & 0 \\
\hline 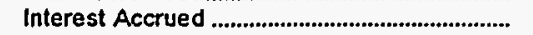 & 14 & 5,642 & 24 & 0 & 0 & 1 \\
\hline Misc Current \& Accrued Labilities...................... & 361 & 1,374 & 84 & 0 & 0 & 1 \\
\hline $\begin{array}{l}\text { Total Current \& Accrued Liabilities ........... } \\
\text { Defered Credits }\end{array}$ & 2,117 & 8,390 & 1,154 & 0 & 2,699 & 1,010 \\
\hline Customer Advances for Construction .............. & 0 & & $\mathbf{0}$ & 0 & 0 & 0 \\
\hline 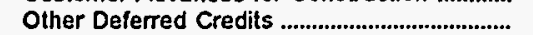 & 2.047 & 12,637 & 0 & 0 & 785 & 0 \\
\hline 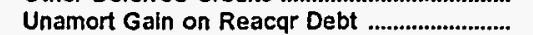 & & & 0 & 0 & 0 & 0 \\
\hline Total Deferred Credits ........................................... & 2,047 & 12,637 & & & 785 & $\mathbf{0}$ \\
\hline Total Liabilities and Other Credits ............ & 54,925 & 327,268 & 12,306 & 20,243 & 23,156 & 9,246 \\
\hline
\end{tabular}

Note: Totals may not equal sum of components because of independent rounding.

Source: Energy Information Administration. Form ElA-412, "Annual Report of Public Electric Utilities." 
Table 22. Balance Sheet by Major U.S. Publicly Owned Electric Utility Within State at End of Period, 1995

(Thousand Dollars)

\begin{tabular}{|c|c|c|c|c|c|c|}
\hline Item & $\begin{array}{c}\text { Kansas } \\
\text { Kansas } \\
\text { City City of } \\
\text { December } 31\end{array}$ & $\begin{array}{l}\text { Kansas } \\
\text { Kansas } \\
\text { Municipal } \\
\text { Energy } \\
\text { Agency } \\
\text { December } 31\end{array}$ & $\begin{array}{c}\text { Kansas } \\
\text { McPherson } \\
\text { City of } \\
\text { December } 31\end{array}$ & $\begin{array}{l}\text { Kansas } \\
\text { Winfield } \\
\text { City of } \\
\text { December } 31\end{array}$ & $\begin{array}{l}\text { Kentucky } \\
\text { Bardstown } \\
\text { City of } \\
\text { December } 31\end{array}$ & $\begin{array}{l}\text { Kentucky } \\
\text { Bowling } \\
\text { Green } \\
\text { City of } \\
\text { June } 30\end{array}$ \\
\hline \multicolumn{7}{|l|}{ Electric Utility Plant } \\
\hline 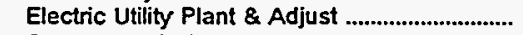 & 602,456 & 1,519 & 50,314 & 33,207 & 4,245 & 41,202 \\
\hline Const Work in Progress & 42,363 & & 1,806 & & & 1,863 \\
\hline (less) Depr, Amort, and Depletion ..................... & 256,367 & 605 & 28,529 & 15,965 & 900 & 13,665 \\
\hline Net Electric Utility Plant .................................. & 388,453 & 914 & 23,591 & 17,242 & 3,346 & 29,400 \\
\hline 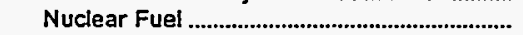 & 0 & 0 & 0 & 0 & 0 & 0 \\
\hline 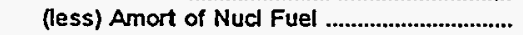 & 0 & 0 & 0 & 0 & 0 & 0 \\
\hline $\begin{array}{l}\text { Net Elec Plant Incl Nucl Fuel ......................... } \\
\text { Other Property \& Investments }\end{array}$ & 388,453 & 914 & 23,591 & 17,242 & 3,346 & 29,400 \\
\hline 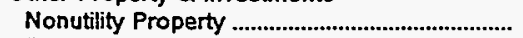 & 0 & 0 & 407 & 0 & 320 & o \\
\hline (less) Accum Provisions for Depr \& Amort.... & 0 & 0 & 0 & 0 & 237 & 0 \\
\hline 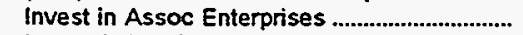 & 0 & 0 & 0 & 0 & 0 & o \\
\hline 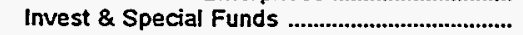 & 14,096 & 6.514 & 44,407 & 878 & 0 & 3,622 \\
\hline $\begin{array}{l}\text { Total Other Property \& Investments ........ } \\
\text { Current and Accrued Assets }\end{array}$ & 14,096 & 6,514 & 44,814 & 878 & 83 & 3,622 \\
\hline Cash. Working Funds \& Investments ................ & 28,773 & 972 & 5,183 & 2,124 & 3,209 & 2,052 \\
\hline 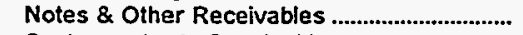 & 5,307 & 1,263 & & 1,450 & 0 & 2,829 \\
\hline 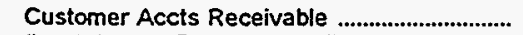 & 15,135 & 0 & 2,214 & 85 & 583 & 0 \\
\hline (less) Accum Prov for Uncollected Accts ....... & 2,033 & 0 & 0 & 0 & 0 & o \\
\hline 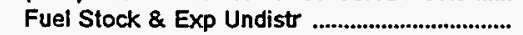 & 12,730 & 0 & 18 & 28 & 0 & 0 \\
\hline Materials \& Supplies .................................................... & 14,933 & 0 & 952 & 0 & 603 & 702 \\
\hline 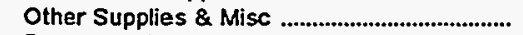 & 0 & 0 & 0 & 0 & 0 & 0 \\
\hline 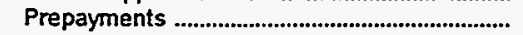 & 1,347 & 375 & 21 & 0 & 0 & 177 \\
\hline Accrued Utility Revenues .......................................... & 5,854 & 0 & 0 & 0 & 0 & 0 \\
\hline Miscellaneous Current \& Accrued Assets ..... & & 0 & 427 & 0 & 50 & 38 \\
\hline $\begin{array}{l}\text { Total Current \& Accrued Assets ................ } \\
\text { Deferred Debits }\end{array}$ & 82,046 & 2,610 & 8,815 & 3,687 & 4,445 & 5,797 \\
\hline 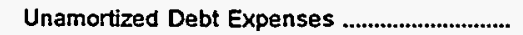 & 4,985 & 511 & 450 & 0 & 0 & 46 \\
\hline Extraordinary Losses, Study Cost ..................... & & & 0 & 0 & 0 & 0 \\
\hline Misc Debt, $R \&$ D Exp, Unamrt Losses .......... & 1.155 & 5,328 & 0 & 0 & 0 & 962 \\
\hline $\begin{array}{l}\text { Total Deferred Debits .... } \\
\text { Total Assets \& Other Debits }\end{array}$ & $\begin{array}{r}6,140 \\
490,735\end{array}$ & $\begin{array}{r}5,839 \\
15,877\end{array}$ & $\begin{array}{r}450 \\
77.670\end{array}$ & $\begin{array}{r}0 \\
21,808\end{array}$ & $\begin{array}{r}0 \\
7,874\end{array}$ & $\begin{array}{r}1,008 \\
39,828\end{array}$ \\
\hline \multicolumn{7}{|l|}{ 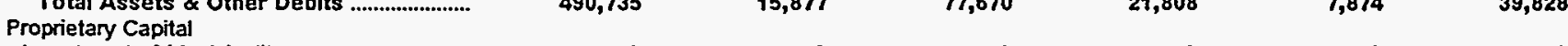 } \\
\hline 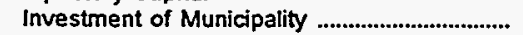 & 0 & 0 & 0 & 0 & 0 & 0 \\
\hline Misc Capital & 1.711 & 0 & 0 & 0 & 0 & o \\
\hline 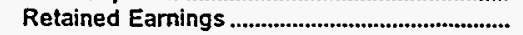 & 276,607 & 2,262 & 31,330 & 16,374 & 7,032 & 23,972 \\
\hline \multicolumn{6}{|l|}{ Long-term Debt } & 23,972 \\
\hline 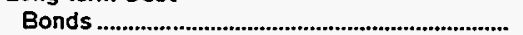 & 181,564 & 11,880 & 44,196 & 4,495 & 0 & 9,410 \\
\hline Advances from Municipality \& Other ................ & 0 & 0 & 0 & 0 & 0 & 894 \\
\hline Unamort Prem on Long-term Debt ........................ & 0 & 0 & 0 & 0 & 0 & -140 \\
\hline (less) Unamort Discount on Long-term Debt & 0 & 149 & 0 & 0 & 0 & 0 \\
\hline 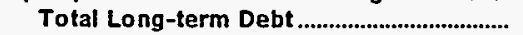 & 181,564 & 11,731 & 44,196 & 4,495 & 0 & 10,164 \\
\hline \multicolumn{7}{|l|}{ Other Noncurrent Liabilities } \\
\hline Accum Operating Provisions ................................. & 2,472 & 0 & 0 & 0 & 0 & 0 \\
\hline 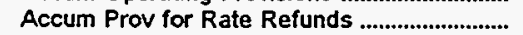 & 0 & 0 & 0 & 0 & 0 & 0 \\
\hline $\begin{array}{l}\text { Total Other Noncurrent Liabilities ............ } \\
\text { Current and Accrued Liabilities }\end{array}$ & 2,472 & 0 & 0 & 0 & 0 & 0 \\
\hline Notes Payable & 0 & 0 & 0 & 175 & 0 & 578 \\
\hline 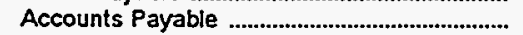 & 22,613 & 1,233 & 1,368 & 640 & 678 & 2,128 \\
\hline 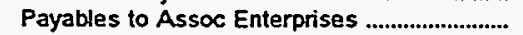 & 0 & 0 & 0 & 0 & 0 & 0 \\
\hline 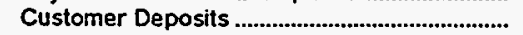 & 1,872 & 0 & 126 & 0 & 120 & 2,416 \\
\hline 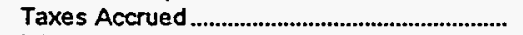 & 274 & 0 & 0 & 0 & 0 & 153 \\
\hline 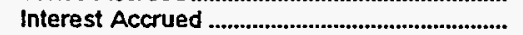 & 3,621 & 62 & 187 & 93 & 0 & 0 \\
\hline Misc Current \& Accrued Liabilities .......................... & 0 & 72 & 463 & 112 & 43 & 354 \\
\hline $\begin{array}{l}\text { Total Current \& Accrued Liabilities ........... } \\
\text { Deferred Credits }\end{array}$ & 28,380 & 1,367 & 2,144 & 1,020 & 842 & 5,629 \\
\hline Customer Advances for Construction ............... & 0 & 0 & 0 & 0 & 0 & 63 \\
\hline 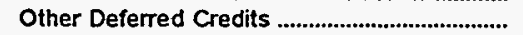 & 0 & 517 & 0 & -81 & 0 & 0 \\
\hline 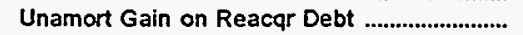 & 0 & 0 & 0 & 0 & o & o \\
\hline Total Deferred Credits ........................................ & $\mathbf{0}$ & 517 & 0 & -81 & 0 & 63 \\
\hline Total Liabilities and Other Credits ............. & 490,735 & 15,877 & 77,670 & 21,808 & 7,874 & 39,828 \\
\hline
\end{tabular}

Note: Totals may not equal sum of components because of independent rounding.

Source: Energy Information Administration, Form ElA-412, "Annual Report of Public Electric Utilities." 
Table 22. Balance Sheet by Major U.S. Publicly Owned Electric Utility Within State at End of Period, 1995

(Thousand Dollars)

\begin{tabular}{|c|c|c|c|c|c|c|}
\hline Item & $\begin{array}{l}\text { Kentucky } \\
\text { Frankfort } \\
\text { City of } \\
\text { June } 30\end{array}$ & $\begin{array}{l}\text { Kentucky } \\
\text { Franklin } \\
\text { City of } \\
\text { June } 30\end{array}$ & $\begin{array}{l}\text { Kentucky } \\
\text { Glasgow } \\
\text { City of } \\
\text { June } 30\end{array}$ & $\begin{array}{l}\text { Kentucky } \\
\text { Henderson } \\
\text { City } \\
\text { Utility Comm } \\
\text { May } 31\end{array}$ & $\begin{array}{l}\text { Kentucky } \\
\text { Hopkinsville } \\
\text { City of } \\
\text { June } 30\end{array}$ & $\begin{array}{l}\text { Kentucky } \\
\text { Madisonville } \\
\text { Municipal } \\
\text { Utils } \\
\text { June 30 }\end{array}$ \\
\hline \multicolumn{7}{|l|}{ Electric Utility Plant } \\
\hline 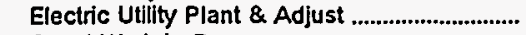 & 23,654 & 6.088 & 16,024 & 103,066 & 15,837 & 4,667 \\
\hline 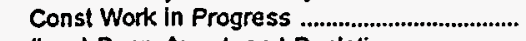 & & 157 & 110 & 41,395 & 112 & \\
\hline 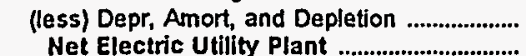 & 12,912 & 1,908 & $\begin{array}{r}5.862 \\
10.272\end{array}$ & 66,731 & $\begin{array}{l}7.092 \\
8.857\end{array}$ & $\begin{array}{r}0 \\
4,667\end{array}$ \\
\hline 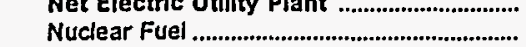 & $\begin{array}{r}10,742 \\
0\end{array}$ & $\begin{array}{l}4,301 \\
0\end{array}$ & $\begin{array}{r}10,212 \\
0\end{array}$ & $\pi, 109$ & $\begin{array}{r}8,851 \\
0\end{array}$ & $\begin{array}{r}4,601 \\
0\end{array}$ \\
\hline 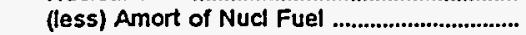 & 0 & 0 & 0 & 0 & 0 & \\
\hline $\begin{array}{l}\text { Net Elec Plant Incl Nucl Fuel .......................... } \\
\text { Other Property \& Investments }\end{array}$ & 10,742 & 4,337 & 10,272 & 77,729 & 8,857 & 4,667 \\
\hline 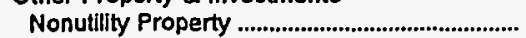 & 28,635 & 0 & 0 & 0 & 187 & \\
\hline (less) Accum Provisions for Depr \& Amort.... & 10,547 & 0 & 0 & 0 & 0 & \\
\hline 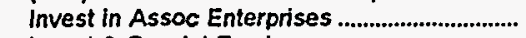 & & 0 & 0 & 0 & 0 & 0 \\
\hline 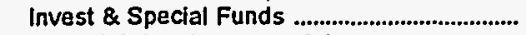 & 5,564 & 465 & 2,181 & 27,895 & 2,664 & 0 \\
\hline $\begin{array}{l}\text { Total Other Property \& Investments....... } \\
\text { Current and Accrued Assets }\end{array}$ & 23,652 & 465 & 2,181 & 27,995 & 2,851 & 0 \\
\hline Cash, Working Funds \& Investments .............. & 2,403 & 1.085 & 350 & 4,064 & 1,873 & 508 \\
\hline Notes \& Other Receivables ...................................... & 3.970 & 637 & 1,126 & 39 & 1,726 & \\
\hline Customer Accts Receivable & 0 & 0 & 0 & 211 & 0 & 1,422 \\
\hline (less) Accum Prov for Uncollected Accts ...... & 3 & 0 & 0 & 3 & 0 & \\
\hline 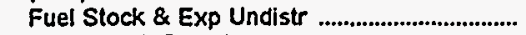 & 0 & 0 & 0 & 777 & 0 & \\
\hline Materials \& Supplies ................................................ & 2,390 & 117 & 276 & 769 & 235 & 468 \\
\hline 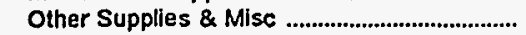 & 0 & 0 & 0 & 1,810 & 0 & 0 \\
\hline 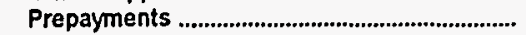 & 144 & 41 & 130 & 310 & 162 & 24 \\
\hline 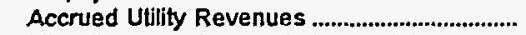 & 0 & 0 & 0 & 802 & 0 & 0 \\
\hline Miscellaneous Current \& Accrued Assets ..... & $i$ & 10 & 9 & & 104 & 464 \\
\hline $\begin{array}{l}\text { Total Current \& Accrued Assets .................. } \\
\text { Deferred Debits }\end{array}$ & 8,905 & 1,890 & 1,891 & 8,780 & 4,099 & 2,893 \\
\hline 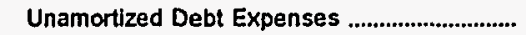 & 0 & 0 & 68 & 462 & 14 & 0 \\
\hline Extraordinary Losses, Study Cost...................... & 0 & 0 & 5 & 0 & 0 & 0 \\
\hline Misc Debt, R \& D Exp, Unamrt Losses ......... & 0 & 121 & 84 & 0 & 208 & 0 \\
\hline Total Deferred Debits ...................................... & & 121 & 157 & 462 & 222 & \\
\hline Total Assets \& Other Debits .......................... & 43,298 & 6,813 & 14,501 & 114,966 & 16,029 & 7,560 \\
\hline \multicolumn{7}{|l|}{ Proprietary Capital } \\
\hline 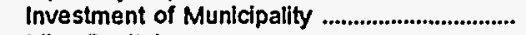 & 0 & 0 & 0 & 0 & 0 & 0 \\
\hline 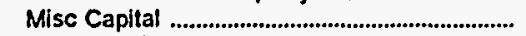 & 0 & 0 & 0 & 30,100 & 0 & 129 \\
\hline 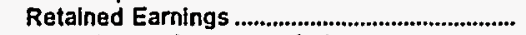 & 34,263 & 5,631 & 7.475 & 0 & 11,785 & 4,540 \\
\hline Total Proprietary Capital ................................... & 34,263 & 5,631 & 7,475 & 30,100 & 11,785 & 4,670 \\
\hline 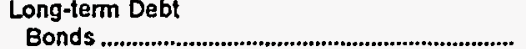 & 3,959 & 0 & 4.788 & 33,230 & 1.775 & 0 \\
\hline 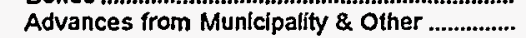 & 0 & 113 & 77 & 0 & 214 & 62 \\
\hline Unamort Prem on Long-term Debt ................... & 0 & 0 & -85 & 0 & -15 & 0 \\
\hline (less) Unamort Discount on Long-term Debt & & 0 & 0 & 0 & 0 & 0 \\
\hline $\begin{array}{l}\text { Total Long-term Debt } \\
\text { Other Noncurrent Liabilities }\end{array}$ & 3,959 & 113 & 4,780 & 33,230 & 1,974 & 62 \\
\hline 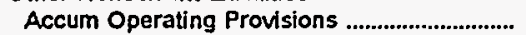 & 0 & 0 & 0 & 0 & 0 & 0 \\
\hline Accum Prov for Rate Refunds ............................. & 0 & 0 & 0 & 0 & 0 & 0 \\
\hline $\begin{array}{l}\text { Total Other Noncurrent ! !ebilities ............. } \\
\text { Current and Accrued Labilities }\end{array}$ & o & o & 0 & 0 & 0 & o \\
\hline 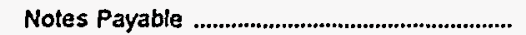 & 0 & 0 & 274 & 3,765 & 0 & \\
\hline 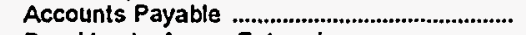 & 3,277 & 758 & 1.402 & 5,537 & 1,667 & 2,535 \\
\hline 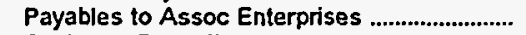 & 0 & 0 & 33 & 0 & 0 & 0 \\
\hline 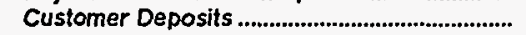 & 606 & 222 & 315 & 331 & 366 & 216 \\
\hline 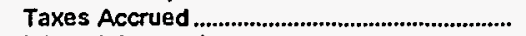 & 225 & 22 & 73 & 0 & 107 & 0 \\
\hline 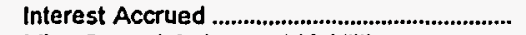 & 202 & 0 & 5 & 527 & 42 & 76 \\
\hline Misc Current \& Accrued Labilities........................ & 447 & & 103 & 36,711 & 53 & 0 \\
\hline Total Current \& Accrued Liabilities .......... & 4,758 & 1,009 & 2,204 & 46,871 & 2,235 & 2,828 \\
\hline \multicolumn{7}{|l|}{ Deferred Credits } \\
\hline Customer Advances for Construction .............. & 0 & 0 & 0 & 0 & 0 & 0 \\
\hline 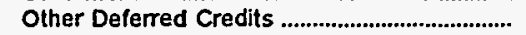 & 318 & 61 & 42 & 4,765 & 35 & 0 \\
\hline Unamort Gain on Reacqr Debt ............................... & 0 & 0 & 0 & 0 & 0 & 0 \\
\hline Total Deferred Credits ........................................ & 318 & 61 & 42 & 4,765 & & \\
\hline Total Liabilitles and Other Credits ............... & 43,298 & 6,813 & 14,501 & 114,966 & 16,029 & 7,560 \\
\hline
\end{tabular}

Note: Totals may not equal sum of components because of independent rounding.

Source: Energy Information Administration, Form EIA-412, "Annual Report of Public Electric Utilities." 
Table 22. Balance Sheet by Major U.S. Publicly Owned Electric Utility Within State at End of Period, 1995 (Thousand Dollars)

\begin{tabular}{|c|c|c|c|c|c|c|}
\hline Item & $\begin{array}{l}\text { Kentucky } \\
\text { Mayfield } \\
\text { City of } \\
\text { June } 30\end{array}$ & $\begin{array}{l}\text { Kentucky } \\
\text { Murray } \\
\text { City of } \\
\text { June } 30\end{array}$ & $\begin{array}{c}\text { Owensboro } \\
\text { City of } \\
\text { May } 31\end{array}$ & $\begin{array}{l}\text { Paducah } \\
\text { City of } \\
\text { June } 30\end{array}$ & $\begin{array}{l}\text { Alexandria } \\
\text { City of } \\
\text { April } 30\end{array}$ & $\begin{array}{c}\text { Lafayette } \\
\text { City of }\end{array}$ \\
\hline \multicolumn{7}{|l|}{ Electric Utility Plant } \\
\hline Electric Utility Plant \& Adjust ............................. & 6,097 & 8,721 & 135.991 & 46,514 & 146,297 & 230,913 \\
\hline 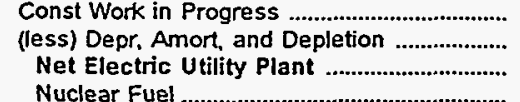 & $\begin{array}{r}65 \\
2,645 \\
3,517 \\
0\end{array}$ & $\begin{array}{r}21 \\
4,254 \\
4,488 \\
0\end{array}$ & $\begin{array}{r}145,609 \\
76,581 \\
205,019 \\
0\end{array}$ & $\begin{array}{r}750 \\
14,568 \\
32,695 \\
0\end{array}$ & $\begin{array}{r}517 \\
64,774 \\
82,039 \\
0\end{array}$ & $\begin{array}{r}207 \\
97,699 \\
133,421 \\
0\end{array}$ \\
\hline $\begin{array}{l}\text { Nuclear Fuel } \\
\text { (less) Amort of Nucl Fuel }\end{array}$ & $\begin{array}{l}0 \\
0\end{array}$ & $\begin{array}{l}\mathbf{0} \\
0\end{array}$ & $\begin{array}{l}0 \\
0\end{array}$ & $\begin{array}{l}\mathbf{0} \\
\mathbf{0}\end{array}$ & $\begin{array}{l}0 \\
0\end{array}$ & $\begin{array}{l}0 \\
0\end{array}$ \\
\hline $\begin{array}{l}\text { Net Elec Plant Incl Nucl Fuel ........................... } \\
\text { Other Property \& Investments }\end{array}$ & 3,517 & 4,488 & 205,019 & 32,695 & 82,039 & 133,421 \\
\hline Nonutility Property & 0 & 0 & 0 & 0 & 2,739 & 0 \\
\hline (less) Accum Provisions for Depr \& Amort.... & 0 & 0 & 0 & $\mathbf{0}$ & 0 & 0 \\
\hline 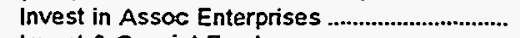 & 0 & 0 & 0 & $\mathbf{0}$ & 0 & $\mathbf{0}$ \\
\hline Invest \& Special Funds & 4 & 695 & 111,613 & 1,436 & 38,548 & 90,126 \\
\hline $\begin{array}{l}\text { Total Other Property \& Investments ....... } \\
\text { Cumrent and Accrued Assets }\end{array}$ & 4 & 695 & 111,613 & 1,436 & 41,287 & 90,126 \\
\hline $\begin{array}{l}\text { Cash, Working Funds \& Investments ............. } \\
\text { Notes \& Other Receivables }\end{array}$ & $\begin{array}{r}81 \\
1,366\end{array}$ & $\begin{array}{r}713 \\
1.202\end{array}$ & $\begin{array}{r}13,169 \\
195\end{array}$ & 2,731 & 8,922 & 3,583 \\
\hline 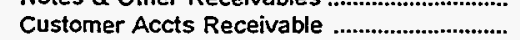 & $\begin{array}{r}1,000 \\
0\end{array}$ & $\begin{array}{r}1,202 \\
0\end{array}$ & 2,189 & $\begin{array}{r}2,002 \\
0\end{array}$ & $\begin{array}{r}6,439 \\
0\end{array}$ & $\begin{array}{r}2,759 \\
13,647\end{array}$ \\
\hline (less) Accum Prov for Uncollected Accts ...... & 0 & 0 & 509 & 0 & 587 & 381 \\
\hline 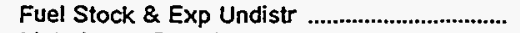 & 0 & 0 & 0 & 0 & 0 & 1.440 \\
\hline 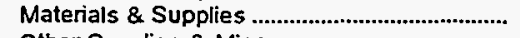 & 101 & 207 & 1,044 & 811 & 1,986 & 1,437 \\
\hline Other Supplies \& Misc & 0 & 0 & 0 & $\mathbf{0}$ & 0 & 0 \\
\hline 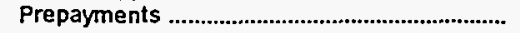 & 11 & 2 & 12 & 31 & 0 & 9 \\
\hline 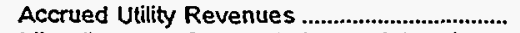 & 0 & 0 & 0 & 0 & 2,319 & 0 \\
\hline Miscellaneous Current \& Accrued Assets ..... & 6 & 20 & 0 & 127 & 0 & 742 \\
\hline $\begin{array}{l}\text { Total Current \& Accrued Assets ................. } \\
\text { Deferred Debits }\end{array}$ & 1,565 & 2,144 & 16,099 & 5,703 & 19,080 & 23,236 \\
\hline 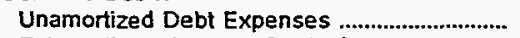 & 0 & 0 & 1,547 & 81 & 0 & 608 \\
\hline Extraordinary Losses, Study Cost ......................... & 0 & 0 & 660 & 0 & 0 & 15 \\
\hline Misc Debt, R \& D Exp, Unamrt Losses .......... & 2 & 47 & 0 & 446 & 0 & 2,866 \\
\hline $\begin{array}{l}\text { Total Deferred Debits .................................................... } \\
\text { Total Assets \& Other Debits }\end{array}$ & $\begin{array}{r}2 \\
5,088\end{array}$ & $\begin{array}{r}47 \\
7,374\end{array}$ & $\begin{array}{r}2,207 \\
334,938\end{array}$ & $\begin{array}{r}527 \\
40,361\end{array}$ & $\begin{array}{r}0 \\
142,406\end{array}$ & $\begin{array}{r}3,489 \\
250,273\end{array}$ \\
\hline Proprietary Capital & & & & & & \\
\hline 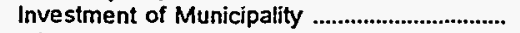 & 0 & 0 & 1,773 & 0 & 37,228 & 5,318 \\
\hline Misc Capital & 0 & 0 & 0 & 0 & 0 & $\mathbf{0}$ \\
\hline 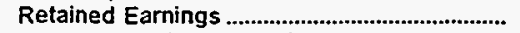 & 3.921 & 5,850 & 61,750 & 32,066 & 41,194 & 147,068 \\
\hline $\begin{array}{l}\text { Total Proprietary Capital } \\
\text { Long-term Debt }\end{array}$ & 3,921 & 5,850 & 63,522 & 32,066 & 78,422 & 152,385 \\
\hline 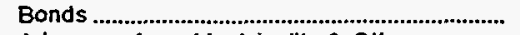 & 0 & 0 & 256.996 & 4,180 & 55,735 & 53,905 \\
\hline Advances from Municipality \& Other ............... & 2 & 0 & 6,148 & 400 & 108 & 0 \\
\hline Unamort Prem on Long-term Debt ................... & 0 & 0 & 0 & -69 & 0 & 0 \\
\hline (less) Unamort Discount on Long-term Debt & 0 & 0 & 2,751 & 0 & 0 & 0 \\
\hline Total Long-term Debt & 2 & $\mathbf{0}$ & 260,393 & 4,511 & 55,843 & 53,905 \\
\hline Other Noncurrent Liabilities & & & & & & \\
\hline 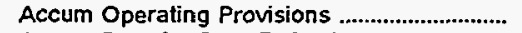 & 0 & 0 & 0 & 0 & 0 & 0 \\
\hline Accum Prov for Rate Refunds ........................... & 0 & $\mathbf{0}$ & 0 & 0 & 0 & 0 \\
\hline $\begin{array}{l}\text { Total Other Noncurrent Liabilities } \\
\text { Current and Accrued Liabilities }\end{array}$ & $\mathbf{0}$ & $\mathbf{0}$ & $\mathbf{0}$ & $\mathbf{0}$ & 0 & 0 \\
\hline Notes Payable & 0 & 0 & 0 & 0 & 149 & 0 \\
\hline Accounts Payable & 816 & 1,010 & 5,316 & 2,551 & 1,241 & 5,840 \\
\hline 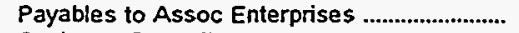 & 0 & 0 & 0 & 0 & 487 & 0 \\
\hline 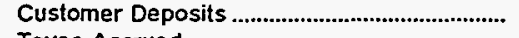 & 205 & 411 & 0 & 529 & 2,818 & 3,893 \\
\hline Taxes Accrued & 62 & 69 & 0 & 160 & 0 & 0 \\
\hline Interest Accrued & 0 & 0 & 3,201 & 131 & 1,549 & 2,161 \\
\hline 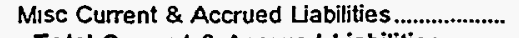 & 81 & 33 & 1,216 & 241 & 1,898 & 196 \\
\hline $\begin{array}{l}\text { Total Current \& Accrued Liabilities .......... } \\
\text { Deferred Credits }\end{array}$ & 1,164 & 1,524 & 9,733 & 3,612 & 8,141 & 12,089 \\
\hline Customer Advances for Construction .............. & 0 & $\mathbf{0}$ & 0 & 0 & 0 & 31,893 \\
\hline 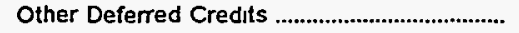 & 0 & 0 & 1.289 & 172 & 0 & 0 \\
\hline Unamort Gain on Reacqr Debt .......................... & 0 & 0 & 0 & 0 & 0 & 0 \\
\hline 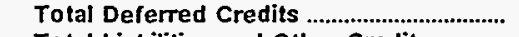 & & 0 & 1,289 & 172 & $\mathbf{0}$ & 31,893 \\
\hline Total Liabilities and Other Credits ............ & 5,088 & 7,374 & 334,938 & 40,361 & 142,406 & 250,273 \\
\hline
\end{tabular}

Note: Totals may not equal sum of components because of independent rounding.

Source: Energy Information Administration, Form EIA-412, "Annual Report of Public Electric Utilities." 
Table 22. Balance Sheet by Major U.S. Publicly Owned Electric Utility Within State at End of Period, 1995

(Thousand Dollars)

\begin{tabular}{|c|c|c|c|c|c|c|}
\hline Item & $\begin{array}{l}\text { Louisiana } \\
\text { Lafayette } \\
\text { Public } \\
\text { Power Auth } \\
\text { October } 31\end{array}$ & $\begin{array}{l}\text { Louisiana } \\
\text { Louisiana } \\
\text { Energy } \\
\& \\
\text { Power Auth } \\
\text { December } 31\end{array}$ & $\begin{array}{l}\text { Louisiana } \\
\text { Morgan } \\
\text { City City of } \\
\text { December } 31\end{array}$ & $\begin{array}{c}\text { Natchitoches } \\
\text { City of } \\
\text { May } 31\end{array}$ & $\begin{array}{c}\begin{array}{c}\text { Ruston } \\
\text { City of }\end{array} \\
\text { September } 30\end{array}$ & $\begin{array}{c}\text { Louisiana } \\
\text { Terrebonne } \\
\text { Parish } \\
\text { Consol Govt } \\
\\
\text { December } 31\end{array}$ \\
\hline \multicolumn{7}{|l|}{ Electric Utility Plant } \\
\hline 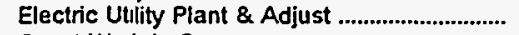 & 150,485 & 87,290 & 28,755 & 9,952 & 30,932 & 53,170 \\
\hline Const Work in Progress ..................................... & 2,594 & 785 & 4 & 55,964 & 0 & 3,608 \\
\hline $\begin{array}{l}\text { (less) Depr, Amort, and Deptetion } \\
\text { Net Electric Utility Plant }\end{array}$ & $\begin{array}{l}62,936 \\
90,143\end{array}$ & $\begin{array}{l}22,556 \\
65,519\end{array}$ & $\begin{array}{r}19,692 \\
9,067\end{array}$ & $\begin{array}{l}17,566 \\
48,350\end{array}$ & $\begin{array}{l}19,665 \\
11,267\end{array}$ & $\begin{array}{l}36,422 \\
20,356\end{array}$ \\
\hline Nuclear Fuel & 0 & 0 & 0 & 0 & 0 & 0 \\
\hline 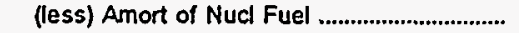 & 0 & 0 & 0 & 0 & 0 & 0 \\
\hline $\begin{array}{l}\text { Net Elec Plant Incl Nucl Fuel } \\
\text { Other Property \& Investments }\end{array}$ & 90,143 & 65,519 & 9,067 & 48,350 & 11,267 & 20,356 \\
\hline Nonutility Property & 0 & 1,388 & 0 & 0 & 0 & 14,363 \\
\hline (less) Accum Provisions for Depr \& Amort .... & $\mathbf{0}$ & 123 & 0 & 0 & $\mathbf{0}$ & 6,217 \\
\hline 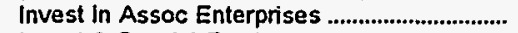 & 0 & 0 & 0 & 0 & 0 & 0 \\
\hline 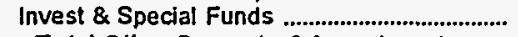 & 18,069 & 17,823 & 0 & 0 & 3,730 & 9,288 \\
\hline $\begin{array}{l}\text { Total Other Property \& Investments ....... } \\
\text { Current and Accrued Assets }\end{array}$ & 18,069 & 19,088 & $\mathbf{0}$ & 0 & 3,730 & 17,434 \\
\hline Cash, Working Funds \& Investments .............. & 23,222 & 12,560 & 4,801 & 475 & 1,081 & 10,492 \\
\hline Notes \& Other Receivables ............................... & 12 & 113 & 79 & 242 & 600 & 248 \\
\hline 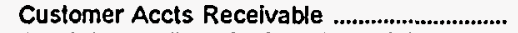 & 183 & 2,796 & 1,078 & 3,053 & 733 & 1,044 \\
\hline (less) Accum Prov for Uncollected Accts ...... & 0 & 0 & 0 & 0 & 0 & 0 \\
\hline 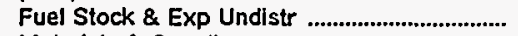 & 7,653 & 3,318 & 0 & 0 & 0 & 0 \\
\hline 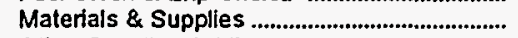 & 1,643 & 0 & 170 & 635 & 0 & 0 \\
\hline 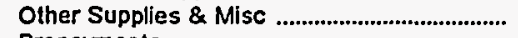 & 0 & 0 & 0 & 0 & 416 & 47 \\
\hline 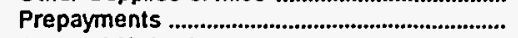 & 6 & 115 & 228 & 0 & 36 & 0 \\
\hline Accrued Utility Revenues .................................. & 0 & 0 & 695 & 0 & 812 & 1,818 \\
\hline Miscellaneous Current \& Accrued Assets ..... & 0 & 0 & 580 & 0 & 0 & 6,357 \\
\hline Total Current \& Accrued Assets .............. & 32,718 & 18,903 & 7,632 & 4,405 & 3,679 & 20,006 \\
\hline \multicolumn{7}{|l|}{ Deterred Debits } \\
\hline Unamortized Debt Expenses ................................ & 309 & 32,309 & 134 & 0 & 0 & 0 \\
\hline Extraordinary Losses, Study Cost .................... & 23,674 & 0 & 0 & 0 & 0 & 0 \\
\hline Misc Debt, R \& D Exp, Unamrt Losses .......... & 18,260 & 771 & 0 & 0 & 0 & 0 \\
\hline Total Deferred Debits & 42,242 & 33,080 & 134 & $\mathbf{0}$ & 0 & 0 \\
\hline 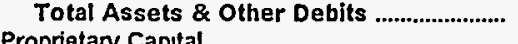 & 183,171 & 136,590 & 16,833 & 52,755 & 18,677 & 57,796 \\
\hline \multicolumn{7}{|l|}{ Proprietary Capital } \\
\hline 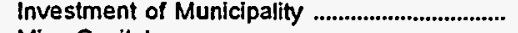 & $\mathbf{0}$ & 0 & 4,333 & 551 & $\mathbf{0}$ & 6,993 \\
\hline 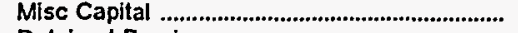 & 0 & 0 & 0 & 29,775 & 0 & 0 \\
\hline Retained Earnings ..................................................... & 6,890 & 9,430 & 3,091 & 5,178 & 13,084 & 29,053 \\
\hline $\begin{array}{l}\text { Total Proprietary Capital } \\
\text { Long-term Debt }\end{array}$ & 6,890 & 9,430 & 7,424 & 35,504 & 13,084 & 36,046 \\
\hline Bonds & 169,895 & 120,920 & 5,664 & 15,128 & 1,835 & 16.465 \\
\hline Advances from Municipality \& Other ................ & 0 & 0 & 1,238 & 0 & 211 & 0 \\
\hline Unamort Prem on Long-term Debt ................... & $\mathbf{0}$ & 0 & 0 & 0 & 0 & 0 \\
\hline (less) Unamort Discount on Long-term Debt & 2,479 & 5,364 & 0 & 0 & 0 & 0 \\
\hline Total Long-term Debt ........................................ & 167,416 & 115,556 & 6,902 & 15,128 & 2,046 & 16,465 \\
\hline \multicolumn{7}{|l|}{ Other Noncurrent Liabilities } \\
\hline 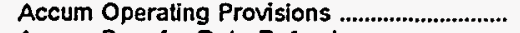 & $\mathbf{0}$ & 0 & 0 & 0 & 0 & 0 \\
\hline Accum Prov for Rate Refunds .......................... & $\mathbf{0}$ & 0 & 0 & 0 & 0 & 0 \\
\hline $\begin{array}{l}\text { Total Other Noncurrent Liabilities ............ } \\
\text { Current and Accrued Uabilities }\end{array}$ & $\mathbf{0}$ & $\mathbf{0}$ & $\mathbf{0}$ & $\mathbf{0}$ & $\mathbf{0}$ & 0 \\
\hline 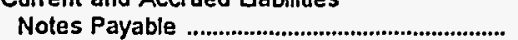 & \multicolumn{6}{|c|}{ Current and Accrued Labilities } \\
\hline 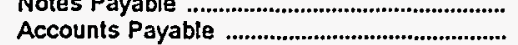 & 3.549 & 3755 & 888 & 0 & 1.140 & 690 \\
\hline Payables to Assoc Enterprises & $\begin{array}{r}3.549 \\
532\end{array}$ & $\begin{array}{r}3.150 \\
0\end{array}$ & $\begin{array}{r}54 \\
0\end{array}$ & 1,434 & 755 & 1,806 \\
\hline 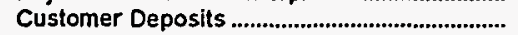 & 0 & 0 & 736 & $\begin{array}{r}0 \\
578\end{array}$ & $\begin{array}{l}652 \\
574\end{array}$ & $\begin{array}{r}0 \\
892\end{array}$ \\
\hline Taxes Accrued & 0 & $\mathbf{0}$ & 0 & 91 & $\begin{array}{r}3 / 4 \\
0\end{array}$ & $\begin{array}{r}802 \\
0\end{array}$ \\
\hline 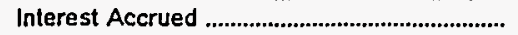 & 4,784 & 3,925 & 187 & 0 & 204 & 0 \\
\hline Misc Current \& Accrued Liabilities..................... & 0 & 3,924 & 643 & 20 & 221 & 1,896 \\
\hline $\begin{array}{l}\text { Total Current \& Accrued Liabilities .......... } \\
\text { Deferred Credits }\end{array}$ & 8,865 & 11,604 & 2,507 & 2,123 & 3,547 & 5,285 \\
\hline Customer Advances for Construction ............. & 0 & 0 & 0 & 0 & 0 & 0 \\
\hline 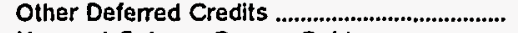 & 0 & 0 & 0 & 0 & 0 & $\mathbf{0}$ \\
\hline Unamort Gain on Reacqr Debt ............................ & 0 & 0 & 0 & 0 & 0 & 0 \\
\hline Total Deferred Credits & $\mathbf{0}$ & $\mathbf{0}$ & 0 & 0 & $\mathbf{0}$ & $\mathbf{0}$ \\
\hline Total Llabilities and Other Credits ............ & 183,171 & 136,590 & 16,833 & 52,755 & 18,677 & 57,796 \\
\hline
\end{tabular}

Note: Totals may not equal sum of components because of independent rounding

Source: Energy Information Administration, Form EIA-412, "Annual Report of Public Electric Utilities." 
Table 22. Balance Sheet by Major U.S. Publicly Owned Electric Utility Within State at End of Period, 1995

(Thousand Dollars)

\begin{tabular}{|c|c|c|c|c|c|c|}
\hline Item & $\begin{array}{l}\text { Maryland } \\
\text { Easton } \\
\text { Utilities } \\
\text { Comm } \\
\text { June } 30\end{array}$ & $\begin{array}{l}\text { Maryland } \\
\text { Hagerstown } \\
\text { City of } \\
\text { June } 30\end{array}$ & $\begin{array}{l}\text { Massachusetts } \\
\text { Braintree } \\
\text { Town of } \\
\text { December } 31\end{array}$ & $\begin{array}{l}\text { Massachusetts } \\
\text { Chicopee } \\
\text { City of } \\
\text { December } 31\end{array}$ & $\begin{array}{l}\text { Massachusetts } \\
\text { Concord } \\
\text { Town of } \\
\text { December } 31\end{array}$ & $\begin{array}{c}\text { Massachusetts } \\
\text { Danvers } \\
\text { Town of } \\
\text { December } 31\end{array}$ \\
\hline \multicolumn{7}{|l|}{ Electric Utility Plant } \\
\hline 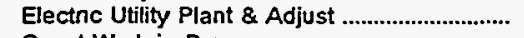 & 42,240 & 25,141 & 67,249 & 68,808 & 30,957 & 24,848 \\
\hline Const Work in Progress & 1,477 & 1,269 & 0 & 412 & 31 & 0 \\
\hline 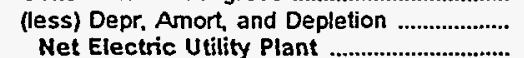 & $\begin{array}{l}18,335 \\
25,382\end{array}$ & $\begin{array}{l}10,956 \\
15,454\end{array}$ & $\begin{array}{l}32,989 \\
34,260\end{array}$ & $\begin{array}{l}27,326 \\
41,893\end{array}$ & $\begin{array}{r}8,683 \\
22,305\end{array}$ & $\begin{array}{l}11,556 \\
13,292\end{array}$ \\
\hline 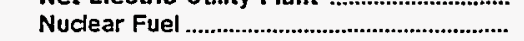 & & 0 & 0 & 4,556 & $2<, 00$ & 0 \\
\hline 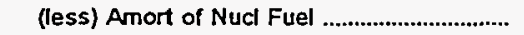 & 0 & 0 & 0 & 3,845 & 0 & 0 \\
\hline \multicolumn{7}{|l|}{ Other Property \& Investments } \\
\hline Nonutility Property .......................................... & 454 & 0 & 0 & 0 & 0 & 0 \\
\hline (less) Accum Provisions for Depr \& Amort.... & 78 & 0 & 0 & 0 & 0 & 0 \\
\hline 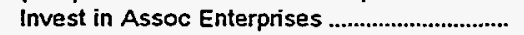 & 0 & 0 & 0 & 0 & 0 & $23 i$ \\
\hline Invest \& Special Funds ............................................... & 0 & 0 & 6,169 & 7,305 & 4,447 & 35 \\
\hline $\begin{array}{l}\text { Total Other Property \& Investments ....... } \\
\text { Current and Accrued Assets }\end{array}$ & 376 & 0 & 6,169 & 7,305 & 4,447 & 266 \\
\hline Cash, Working Funds \& Investments ................. & 2,496 & 4,708 & 3,532 & 2,535 & 4,681 & 4,418 \\
\hline Notes \& Other Receivables ...................................... & 82 & 265 & 52 & 683 & 63 & 362 \\
\hline 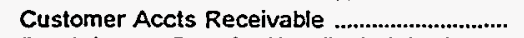 & 1,345 & 2,496 & 2,353 & 2,687 & 2,253 & 3,575 \\
\hline (less) Accum Prov for Uncollected Accts ....... & 0 & 749 & 130 & 125 & 30 & 0 \\
\hline 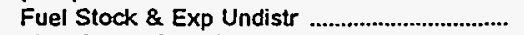 & 451 & 0 & 1 & 27 & 0 & 0 \\
\hline Materials \& Supplies ............................................. & 759 & 0 & 270 & 2,194 & 549 & 0 \\
\hline Other Supplies \& Misc ............................................. & 0 & 287 & 0 & 0 & 0 & 902 \\
\hline 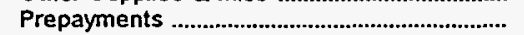 & 29 & 9 & 13 & 797 & 58 & 318 \\
\hline 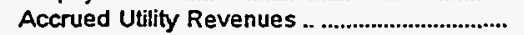 & 1.059 & 0 & 568 & 0 & 545 & 6,437 \\
\hline Miscellaneous Current \& Accrued Assets ..... & & 0 & 16 & 29 & 0 & 419 \\
\hline $\begin{array}{l}\text { Total Current \& Accrued Assets ................. } \\
\text { Deferred Debits }\end{array}$ & 6,220 & 7,016 & 6,675 & 8,828 & 8,120 & 16,430 \\
\hline 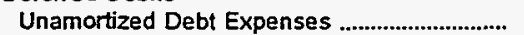 & 116 & 0 & 0 & 0 & 55 & 7 \\
\hline 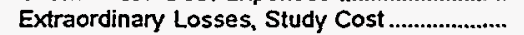 & 0 & 0 & 106 & 1 & 0 & 0 \\
\hline Misc Debt, $R$ \& D Exp, Unamrt Losses .......... & 46 & 0 & 436 & 1,466 & 0 & 0 \\
\hline Total Deferred Debits ....................................... & 162 & 0 & 542 & 1,467 & 55 & 7 \\
\hline $\begin{array}{l}\text { Total Assets \& Other Debits ............................ } \\
\text { Proprietary Capital }\end{array}$ & 32,141 & 22,470 & 47,647 & 60,203 & 34,926 & 29,995 \\
\hline \multicolumn{7}{|l|}{ Proprietary Capital } \\
\hline 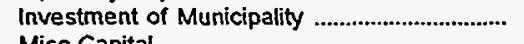 & 13,307 & 0 & 44,244 & 51,085 & 3,941 & 0 \\
\hline 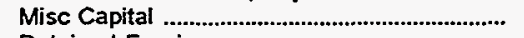 & & 585 & 0 & 0 & 0 & 0 \\
\hline Retained Earnings ....................................................... & 6,807 & 18,234 & 0 & 0 & 19,919 & 28,087 \\
\hline $\begin{array}{l}\text { Total Proprietary Capital ........................................... } \\
\text { Long-term Debt }\end{array}$ & 20,115 & 18,819 & 44,244 & 51,085 & 23,859 & 28,087 \\
\hline Bonds & 9.279 & 738 & 0 & 0 & 8,313 & 200 \\
\hline Advances from Municipality \& Other ............... & 412 & 0 & 0 & 25 & 0 & 0 \\
\hline Unamort Prem on Long-term Debt ................... & 0 & 0 & 0 & 0 & 0 & 0 \\
\hline (less) Unamort Discount on Long-term Debt & 0 & 0 & 0 & 0 & 0 & 0 \\
\hline 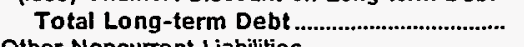 & 9,691 & 738 & 0 & 25 & 8,313 & 200 \\
\hline \multicolumn{7}{|l|}{ Other Noncurrent Liabilities } \\
\hline Accum Operating Provisions ................................ & 0 & 0 & 0 & 0 & 98 & 0 \\
\hline 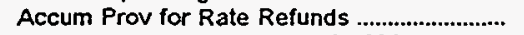 & 0 & 0 & 0 & 0 & 378 & 0 \\
\hline $\begin{array}{l}\text { Total Other Noncurrent Liabilities ............ } \\
\text { Current and Accrued Liabilities }\end{array}$ & $\mathbf{0}$ & 0 & 0 & 0 & 474 & 0 \\
\hline 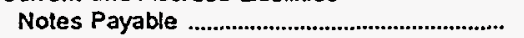 & 70 & 82 & 0 & 0 & 0 & 100 \\
\hline 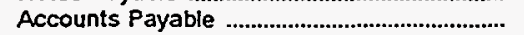 & 612 & 1,481 & 3,022 & 2,435 & 1,513 & 974 \\
\hline Payables to Assoc Enterprises .............................. & 0 & 0 & 0 & 0 & 0 & 0 \\
\hline 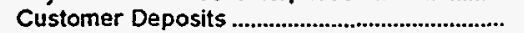 & 174 & 561 & 175 & 823 & 123 & 430 \\
\hline 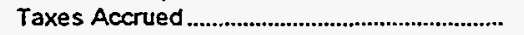 & 0 & 37 & 0 & 248 & 12 & 125 \\
\hline 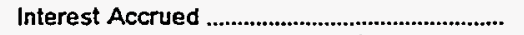 & 135 & 42 & 0 & 144 & 161 & 0 \\
\hline Misc Current \& Accrued Liabilities............................. & 1,171 & 709 & 0 & 938 & 2 & 79 \\
\hline $\begin{array}{l}\text { Total Current \& Accrued Liabilities ........... } \\
\text { Deferred Credits }\end{array}$ & 2,162 & 2,912 & 3,197 & 4,588 & 1,811 & 1,708 \\
\hline Customer Advances for Construction .............. & 173 & 0 & 0 & 2,039 & 109 & 0 \\
\hline Other Deferred Credits .............................................. & 0 & 0 & 206 & 2,466 & 359 & 0 \\
\hline Unamort Gain on Reacqr Debt ............................ & 0 & 0 & 0 & 0 & 0 & 0 \\
\hline Total Deferred Credits ...................................... & 173 & 0 & 206 & 4,505 & 468 & 0 \\
\hline Total Liabilities and Other Credits ............. & 32,141 & 22,470 & 47,647 & 60,203 & 34,926 & 29,895 \\
\hline
\end{tabular}

Note: Totals may not equal sum of components because of independent rounding

Source: Energy Information Administration, Form ElA-412, "Annual Report of Public Electric Utilities." 
Table 22. Balance Sheet by Major U.S. Publicly Owned Electric Utility Within State at End of Period, 1995

(Thousand Dollars)

\begin{tabular}{|c|c|c|c|c|c|c|}
\hline Item & $\begin{array}{l}\text { Massachusetts } \\
\text { Hingham } \\
\text { City of } \\
\text { December } 31\end{array}$ & $\begin{array}{c}\text { Massachusetts } \\
\begin{array}{c}\text { Holyoke } \\
\text { City of }\end{array} \\
\text { December } 31\end{array}$ & $\begin{array}{l}\text { Massachusetts } \\
\text { Hudson } \\
\text { Town of } \\
\text { December } 31\end{array}$ & $\begin{array}{l}\text { Massachusetts } \\
\text { Littleton } \\
\text { Town of } \\
\text { December } 31\end{array}$ & $\begin{array}{l}\text { Massachusetts } \\
\text { Mansfield } \\
\text { Town of } \\
\text { December } 31\end{array}$ & $\begin{array}{c}\text { Massachusetts } \\
\text { Massachusetts } \\
\text { Mun } \\
\text { Whis } \\
\text { Elec Co } \\
\text { December } 31\end{array}$ \\
\hline \multicolumn{7}{|l|}{ Electric Utility Plant } \\
\hline 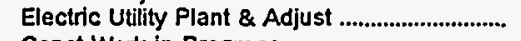 & 22,462 & 54,272 & 18,989 & 16,015 & 10,409 & $1,233,477$ \\
\hline 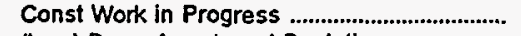 & & 1,441 & & 181 & 0 & 1,331 \\
\hline 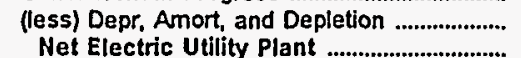 & $\begin{array}{r}6,767 \\
15,685\end{array}$ & $\begin{array}{l}32,225 \\
23,488\end{array}$ & $\begin{array}{r}13,119 \\
5,870\end{array}$ & $\begin{array}{l}6,521 \\
9,676\end{array}$ & $\begin{array}{l}6,254 \\
4.156\end{array}$ & $\begin{array}{l}327,459 \\
907,349\end{array}$ \\
\hline Nuclear Fuel ............................................................ & 0 & 0 & 235 & 0 & 0 & 78,557 \\
\hline 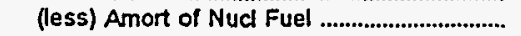 & 0 & 0 & 177 & 0 & 0 & 64,743 \\
\hline 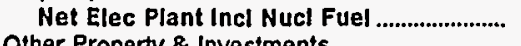 & 15,695 & 23,488 & 5,928 & 9,676 & 4,156 & 921,163 \\
\hline \multicolumn{7}{|l|}{ Other Property \& Investments } \\
\hline & 0 & 20,887 & 0 & 0 & 0 & 0 \\
\hline (less) Accum Provisions for Depr \& Amort.... & $\begin{array}{l}0 \\
0\end{array}$ & 11,491 & 0 & 0 & 0 & 0 \\
\hline & 0 & 0 & 146 & 0 & 0 & 0 \\
\hline 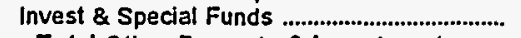 & 1,654 & 1,907 & 12,631 & 8,361 & 1,678 & 0 \\
\hline \multicolumn{6}{|l|}{ Current and Accrued Assets } & 0 \\
\hline Cash, Worklng Funds \& Investments ................. & 1,279 & 7,605 & 2,799 & 60 & 4,555 & 203,355 \\
\hline 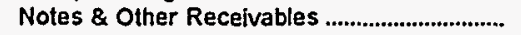 & 1,274 & 723 & 225 & 278 & 52 & 7,577 \\
\hline Customer Accts Receivable ...................................... & 0 & 6,700 & 2,731 & 1,327 & 1,703 & 2,544 \\
\hline (less) Accum Prov for Uncollected Accts ...... & $\mathbf{0}$ & 500 & 0 & 20 & 0 & 0 \\
\hline Fuel Stock \& Exp Undistr ......................................... & 0 & 905 & 222 & 473 & 0 & 2,880 \\
\hline 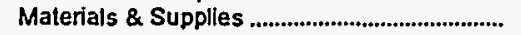 & 231 & 1,227 & 816 & 0 & 524 & 10,935 \\
\hline 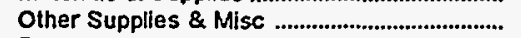 & 0 & 0 & 0 & 0 & 0 & 0 \\
\hline 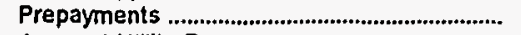 & 609 & 1,125 & 591 & 2,154 & 2,926 & 6.018 \\
\hline 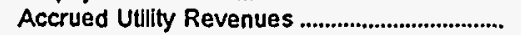 & 0 & 0 & 147 & 0 & 0 & 5,561 \\
\hline Miscellaneous Current \& Accrued Assets..... & 0 & 526 & 0 & 0 & 0 & 1 \\
\hline Total Current \& Accrued Assets .................... & 3,392 & 18,310 & 7,532 & 4,272 & 9,761 & 238,872 \\
\hline \multicolumn{7}{|l|}{ Deferred Debits } \\
\hline 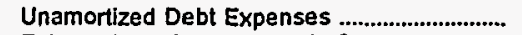 & 64 & 182 & 0 & 0 & 0 & 32,739 \\
\hline Extraordinary Losses, Study Cost...................... & 0 & 0 & 0 & 0 & 0 & 1,281 \\
\hline Misc Debt, R \& D Exp, Unamrt Losses .......... & 0 & 1,385 & 0 & 0 & 3 & 224,143 \\
\hline Total Deferred Debits ......................................... & & 1,566 & & o & 3 & 258,163 \\
\hline Total Assets \& Other Debits .......................... & 20,808 & 54,667 & 26,238 & 22,308 & 15,597 & $1,418,198$ \\
\hline \multicolumn{7}{|l|}{ Proprietary Capital } \\
\hline 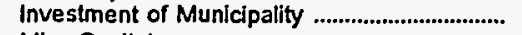 & o & 0 & 20 & 20,314 & 0 & 0 \\
\hline 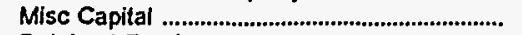 & 0 & 0 & 0 & 0 & 13 & 0 \\
\hline Retained Earnings ......................................................... & 14,240 & 41,898 & 24,054 & 0 & 14,269 & 0 \\
\hline Total Proprietary Capital .................................... & 14,240 & 41,898 & 24,074 & 20,314 & 14,281 & 0 \\
\hline \multicolumn{7}{|l|}{ Long-term Debt } \\
\hline 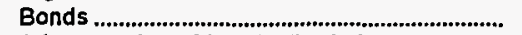 & 3,235 & 4,005 & 0 & 0 & 0 & $1,303,465$ \\
\hline Advances from Municipality \& Other ................ & 0 & 0 & 0 & 0 & 0 & 0 \\
\hline Unamort Prem on Long-term Debt ...................... & 0 & 0 & 0 & 0 & 0 & 0 \\
\hline (less) Unamort Discount on Long-term Debt & 0 & 0 & 0 & 0 & 0 & 0 \\
\hline \multicolumn{6}{|l|}{ Other Noncurrent Labilities } & $1,303,465$ \\
\hline 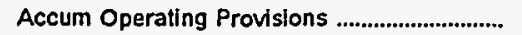 & 0 & 0 & 605 & 0 & 60 & 2,179 \\
\hline Accum Prov for Rate Refunds .......................... & 0 & 0 & 0 & 1.045 & 0 & 0 \\
\hline Total Other Noncurrent Liabilities ............. & 0 & 0 & 605 & 1,045 & 60 & 2,179 \\
\hline \multicolumn{7}{|l|}{ Current and Accrued Liabilities } \\
\hline Accounts Payable ............................................................... & 1,286 & 6,826 & 1,133 & 871 & 727 & 33,395 \\
\hline 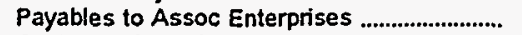 & 432 & & 0 & 0 & 302 & 0 \\
\hline 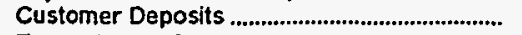 & 325 & 1,034 & 405 & 38 & 190 & 0 \\
\hline 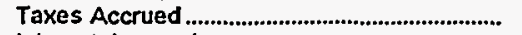 & -1 & 0 & 15 & 0 & 37 & 92 \\
\hline 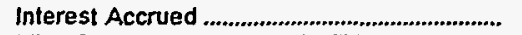 & 68 & 42 & 0 & 0 & 0 & 329 \\
\hline 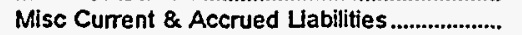 & 114 & & 0 & 40 & 0 & 48,618 \\
\hline Total Current \& Accrued Liabilities .......... & \multicolumn{4}{|c|}{ Deferred Credits } & & 82,434 \\
\hline $\begin{array}{l}\text { Deferred Credits } \\
\text { Customer Advances for Construction .............. }\end{array}$ & 537 & 0 & 0 & 0 & 0 & 5 \\
\hline 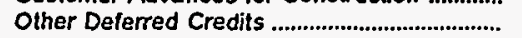 & 570 & 861 & 5 & 0 & 0 & 30.115 \\
\hline 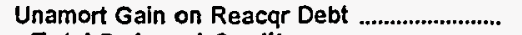 & & 0 & 0 & 0 & 0 & 0 \\
\hline 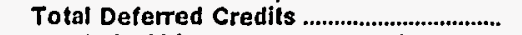 & 1,107 & 861 & 5 & 0 & 0 & 30,120 \\
\hline Total Liabilities and Other Credits ............. & 20,806 & 54,667 & 26,238 & 22,308 & 15,597 & $1,418,198$ \\
\hline
\end{tabular}

Note: Totals may not equal sum of components because of independent rounding.

Source: Energy Information Administration, Form ElA-412, "Annual Report of Public Electric Utilities." 
Table 22. Balance Sheet by Major U.S. Publicly Owned Electric Utility Within State at End of Period, 1995

(Thousand Dollars)

\begin{tabular}{|c|c|c|c|c|c|c|}
\hline Item & $\begin{array}{l}\text { Massachusetts } \\
\text { Middleborough } \\
\text { Town of } \\
\text { December } 31\end{array}$ & $\begin{array}{l}\text { Massachusetts } \\
\text { North } \\
\text { Attleborough } \\
\text { Town of } \\
\text { December } 31\end{array}$ & $\begin{array}{l}\text { Massachusetts } \\
\text { Nonwood } \\
\text { City of } \\
\text { June } 30\end{array}$ & $\begin{array}{l}\text { Massachusetts } \\
\text { Peabody } \\
\text { City of } \\
\text { December } 31\end{array}$ & $\begin{array}{l}\text { Massachusetts } \\
\text { Reading } \\
\text { Town of } \\
\text { December } 31\end{array}$ & $\begin{array}{l}\text { Massachusetts } \\
\text { Shrewsbury } \\
\text { Town of } \\
\text { December } 31\end{array}$ \\
\hline \multicolumn{7}{|l|}{ Electric Utility Plant } \\
\hline 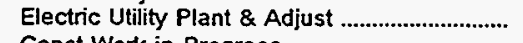 & 16,076 & 20,785 & 23,141 & 63,960 & 50,990 & 25,881 \\
\hline Const Work in Progress & & 1,796 & & & 0 & 0 \\
\hline (less) Depr, Amort, and Depletion ..................... & 7,309 & 7,202 & 15,943 & 25,292 & 22.141 & 12.186 \\
\hline $\begin{array}{l}\text { Net Electric Utility Plant } \\
\text { Nuclear Fuel }\end{array}$ & $\begin{array}{r}8,767 \\
0\end{array}$ & $\begin{array}{r}15,378 \\
0\end{array}$ & $\begin{array}{r}7,198 \\
0\end{array}$ & 38,668 & 28,849 & 13,695 \\
\hline (less) Amort of Nud Fuel .............................. & & 0 & 0 & $\begin{array}{l}0 \\
0\end{array}$ & $\begin{array}{l}0 \\
0\end{array}$ & 0 \\
\hline Net Elec Plant Incl Nucl Fuel ......................... & 8,767 & 15,378 & 7,198 & 38,668 & 28,849 & 13,695 \\
\hline \multicolumn{7}{|l|}{ Other Property \& Investments } \\
\hline Nonutility Property ................. & 0 & 0 & 0 & 0 & 0 & 0 \\
\hline (less) Accum Provisions for Depr \& Amort.... & 0 & 0 & 0 & 0 & 0 & 0 \\
\hline & 104 & 90 & 0 & 0 & 449 & 156 \\
\hline 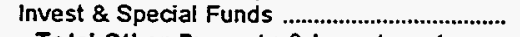 & 1,485 & 3,005 & 3,009 & 9,323 & 4,115 & 4,371 \\
\hline $\begin{array}{l}\text { Total Other Property \& Investments ....... } \\
\text { Current and Accrued Assets }\end{array}$ & 1,589 & 3,095 & & 4,527 \\
\hline Cash, Working Funds \& Investments .............. & 2,052 & 6.752 & 193 & 6,205 & 14,616 & 4,370 \\
\hline 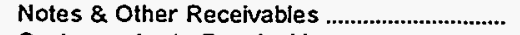 & 137 & 24 & 0 & 126 & 336 & 49 \\
\hline Customer Accts Receivable & 3,242 & 1,534 & 1,283 & 3,949 & 3,199 & 1,440 \\
\hline (less) Accum Prov for Uncollected Accts ....... & 400 & 474 & 605 & 100 & 300 & 0 \\
\hline 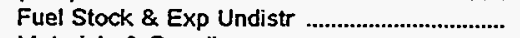 & 0 & 10 & 0 & 95 & 0 & 0 \\
\hline Materials \& Supplies ............................................... & 733 & 841 & 0 & 945 & 655 & 171 \\
\hline 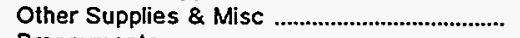 & 0 & 0 & 0 & 0 & 69 & 0 \\
\hline 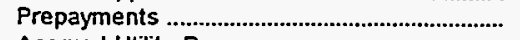 & 1,871 & $17 i$ & 0 & 948 & 1,158 & 1,361 \\
\hline Accrued Utility Revenues ...................................... & 0 & 0 & 0 & 0 & 0 & 0 \\
\hline Miscellaneous Current \& Accrued Assets ..... & 0 & 0 & 0 & 0 & 0 & 0 \\
\hline $\begin{array}{l}\text { Total Current \& Accrued Assets .................. } \\
\text { Deferred Debits }\end{array}$ & 7,635 & 8,857 & 871 & 12,169 & 19,733 & 7,390 \\
\hline Unamortized Debt Expenses ..................................... & 0 & 273 & 0 & 176 & 24 & 0 \\
\hline Extraordinary Losses, Study Cost ..................... & 0 & 0 & 0 & 0 & 0 & 0 \\
\hline Misc Debt, R \& D Exp, Unamrt Losses .......... & 8 & 0 & 0 & 0 & 0 & 1 \\
\hline Total Deferred Debits ......................................... & 8 & 273 & 0 & 176 & 24 & 1 \\
\hline 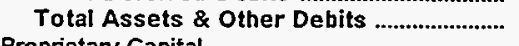 & 17,999 & 27,603 & 11,078 & 60,335 & 53,171 & 25,612 \\
\hline \multicolumn{7}{|l|}{ Proprietary Capital } \\
\hline & 11,052 & 0 & 8,367 & 5.560 & 35,848 & 0 \\
\hline 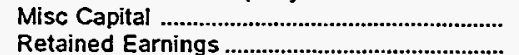 & 3,131 & 674 & 0 & 0 & 0 & 0 \\
\hline & & 20.486 & 241 & 24.627 & 0 & 23,363 \\
\hline \multicolumn{6}{|l|}{ Long-term Debt } & \\
\hline 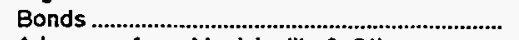 & 970 & 3,119 & 0 & 18,575 & 6,365 & 50 \\
\hline Advances from Municipality \& Other ................. & 0 & 0 & 0 & 0 & 0 & 25 \\
\hline Unamort Prem on Long-term Debt ....................... & 0 & 0 & 0 & 0 & 0 & 0 \\
\hline (less) Unamort Discount on Long-term Debt & 0 & 0 & 0 & 0 & 0 & 0 \\
\hline Other Noncurrent Liabilities & 970 & 3,119 & 0 & 18,575 & 6,365 & 75 \\
\hline 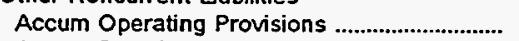 & 0 & 0 & 0 & 7,863 & 0 & 0 \\
\hline 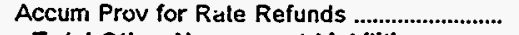 & 0 & $\mathbf{0}$ & 0 & 0 & 0 & 0 \\
\hline & \multicolumn{3}{|c|}{ Current and Accrued Liabilities } & 7,863 & 0 & 0 \\
\hline Notes Payable & 0 & 0 & 0 & 0 & 0 & 0 \\
\hline Accounts Payable ................................................ & 1,081 & 1,804 & 1,693 & 1,641 & 4,253 & 1,598 \\
\hline Payables to Assoc Enterprises .......................... & 0 & 0 & 0 & 21 & 0 & 0 \\
\hline 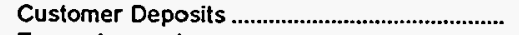 & 10 & 274 & 518 & 1,652 & 700 & 437 \\
\hline 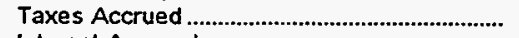 & 22 & 2 & 107 & 0 & 0 & 13 \\
\hline Interest Accrued & 26 & 14 & 0 & 395 & 84 & 1 \\
\hline 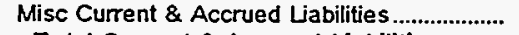 & 225 & 1.231 & 17 & 0 & 1,044 & 0 \\
\hline $\begin{array}{l}\text { Total Current \& Accrued Liabilities ........... } \\
\text { Deferred Credits }\end{array}$ & 1,363 & 3,324 & 2,335 & 3,710 & 6,081 & 2,051 \\
\hline Customer Advances for Construction .............. & 0 & 0 & 135 & 0 & 3,527 & 0 \\
\hline 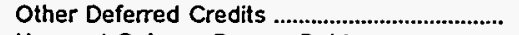 & 1,482 & 0 & 0 & 0 & 1,350 & 123 \\
\hline Unamort Gain on Reacqr Debt ......................... & 0 & 0 & 0 & 0 & 0 & 0 \\
\hline Total Deferred Credits ..................................... & 1,482 & & 135 & 0 & 4,876 & 123 \\
\hline Total Liabilities and Other Credits ............ & 17,999 & 27,603 & 11,078 & 60,335 & 53,171 & 25,612 \\
\hline
\end{tabular}

Note: Totals may not equal sum of components because of independent rounding.

Source: Energy Information Administration, Form EIA-412, "Annual Report of Public Electric Utilities." 
Table 22. Balance Sheet by Major U.S. Publicly Owned Electric Utility Within State at End of Period, 1995

(Thousand Dollars)

\begin{tabular}{|c|c|c|c|c|c|c|}
\hline Item & $\begin{array}{l}\text { Massachusetts } \\
\text { Taunton } \\
\text { City of } \\
\text { December } 31\end{array}$ & $\begin{array}{l}\text { Massachusetts } \\
\text { Wakefield } \\
\text { Town of } \\
\text { December } 31\end{array}$ & $\begin{array}{l}\text { Massachusetts } \\
\text { Wellesley } \\
\text { Town of } \\
\text { December } 31\end{array}$ & $\begin{array}{l}\text { Massachusetts } \\
\text { Westfield } \\
\text { City of } \\
\text { December } 31\end{array}$ & $\begin{array}{l}\text { Michigan } \\
\text { Bay } \\
\text { City City of } \\
\text { June } 30\end{array}$ & $\begin{array}{l}\text { Michigan } \\
\text { Coldwater } \\
\text { Board } \\
\text { of } \\
\text { Public Util } \\
\text { June } 30\end{array}$ \\
\hline \multicolumn{7}{|l|}{ Electric Utility Plant } \\
\hline 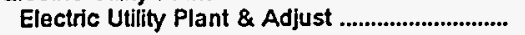 & 107,009 & 14,546 & 29.209 & 25,640 & 45,910 & 15,468 \\
\hline 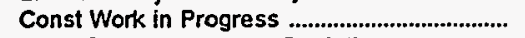 & 2,446 & 0 & 671 & 1,070 & 0 & 0 \\
\hline 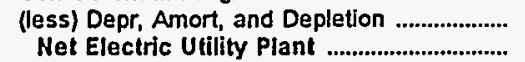 & $\begin{array}{l}60,723 \\
48,733\end{array}$ & $\begin{array}{r}11,945 \\
2,601\end{array}$ & $\begin{array}{l}12,982 \\
16,898\end{array}$ & $\begin{array}{l}10,795 \\
15,915\end{array}$ & $\begin{array}{l}15,357 \\
30,553\end{array}$ & $\begin{array}{l}8,643 \\
6,825\end{array}$ \\
\hline 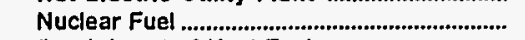 & 304 & 0 & 0 & 0 & 0 & 0 \\
\hline 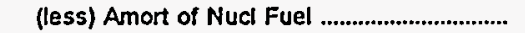 & 222 & 0 & 0 & 0 & 0 & $\mathbf{0}$ \\
\hline Net Elec Plant Incl Nucl Fuel .......................... & 48,814 & 2,601 & 16,898 & 15,915 & 30,553 & 6,825 \\
\hline \multicolumn{7}{|l|}{ Other Property \& Investments } \\
\hline Nonutility Property & 0 & 0 & 0 & 0 & 0 & 0 \\
\hline (less) Accum Provisions for Depr \& Amort .... & 0 & 0 & 0 & 0 & 0 & 0 \\
\hline 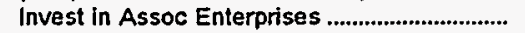 & 0 & 0 & 0 & 9,553 & 0 & 0 \\
\hline 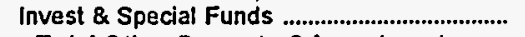 & 11,475 & 623 & 1,871 & 1,371 & 7,140 & 2,924 \\
\hline $\begin{array}{l}\text { Total Other Property \& Investments ....... } \\
\text { Cument and Accrued Assets }\end{array}$ & 11,475 & 623 & 1,871 & 10,924 & 7,140 & 2,924 \\
\hline Cash, Working Funds \& Investments .............. & 2,623 & 2,711 & 2,939 & 7,609 & 11,589 & 43 \\
\hline 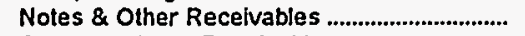 & 331 & 2,315 & 0 & 107 & 633 & 1,732 \\
\hline Customer Accts Receivable ................................ & 3.831 & 184 & 1,665 & 5,527 & 1,340 & 1,309 \\
\hline (less) Accum Prov for Uncollected Accts ...... & 0 & 145 & 45 & 1,172 & 37 & 0 \\
\hline Fuel Stock \& Exp Undistr ............................... & 592 & 0 & 0 & 0 & 0 & $\mathbf{0}$ \\
\hline 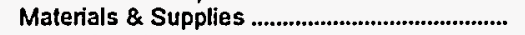 & 940 & 444 & 551 & 1.177 & 1,972 & 387 \\
\hline 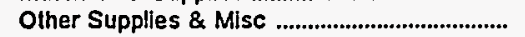 & 0 & 0 & 0 & 0 & 0 & 0 \\
\hline 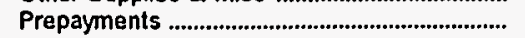 & 921 & 618 & -77 & 1,151 & 0 & 18 \\
\hline Accrued Utility Revenues .................................... & 0 & 0 & 0 & 0 & 0 & 0 \\
\hline Miscellaneous Current \& Accrued Assets ..... & 558 & 0 & 52 & 0 & 0 & 0 \\
\hline Total Current \& Accrued Assets .............. & 9,796 & 6,128 & 5,085 & 14,399 & 15,496 & 3,488 \\
\hline \multicolumn{7}{|l|}{ Deferred Debits } \\
\hline Unamortized Debt Expenses ................................ & 0 & 0 & 0 & 22 & 910 & 0 \\
\hline Extraordinary Losses, Study Cost ...................... & 0 & 0 & 0 & 0 & 0 & 0 \\
\hline Misc Debt, R \& D Exp, Unamrt Losses .......... & 190 & 7 & 0 & 153 & 2,315 & 0 \\
\hline Total Deferred Debits ...................................... & 190 & 7 & 0 & 175 & 3,226 & 0 \\
\hline Total Assets \& Other Debits ........................ & 70,275 & 9,358 & 23,854 & 41,414 & 56,416 & 13,238 \\
\hline \multicolumn{7}{|l|}{ Proprietary Capital } \\
\hline 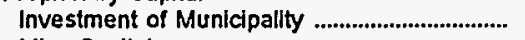 & 46,472 & 0 & 1,917 & 24,261 & 0 & 10,080 \\
\hline 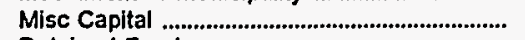 & 0 & 0 & 0 & 0 & 0 & 0 \\
\hline 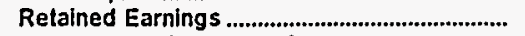 & 0 & 5,811 & 19,051 & 0 & 30,076 & 0 \\
\hline Total Proprietary Capital ................................... & 46,472 & 5,811 & 20,968 & 24,261 & 30,076 & 10,080 \\
\hline \multicolumn{7}{|l|}{ Long-term Debt } \\
\hline 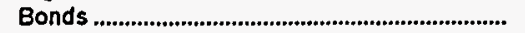 & 15,440 & 0 & 300 & 8,120 & 23,945 & 437 \\
\hline Advances from Municipality \& Other ................ & 0 & 0 & 0 & 0 & 88 & 710 \\
\hline Unamort Prem on Long-term Debt .................. & 0 & 0 & 0 & 0 & 0 & 0 \\
\hline (less) Unamort Discount on Long-term Debt & 0 & 0 & 0 & 0 & 0 & 0 \\
\hline 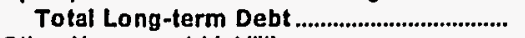 & 15,440 & 0 & 300 & 8,120 & 24,033 & 1,147 \\
\hline \multicolumn{7}{|l|}{ Other Noncurrent LJabilities } \\
\hline 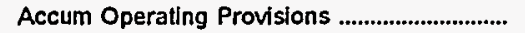 & $\mathbf{0}$ & 0 & 0 & $\mathbf{0}$ & 0 & 0 \\
\hline Accum Prov for Rate Refunds ......................... & 0 & 0 & 0 & 0 & 0 & 0 \\
\hline Total Other Noncurrent Ljabiltities ............ & 0 & 0 & $\mathbf{0}$ & $\mathbf{0}$ & 0 & 0 \\
\hline \multicolumn{7}{|l|}{ Current and Accrued Labilities } \\
\hline 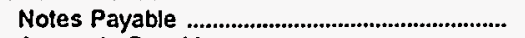 & 0 & 0 & 0 & 0 & 1,240 & 0 \\
\hline 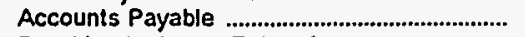 & 3,273 & 1,642 & 1,926 & 3.580 & 165 & 971 \\
\hline Payables to Assoc Enterprises ............................ & 0 & 0 & 0 & 250 & 610 & 162 \\
\hline Customer Deposits & 420 & 630 & 420 & 136 & 68 & 73 \\
\hline 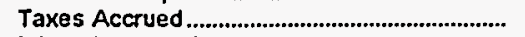 & 0 & $\mathbf{0}$ & 0 & -24 & $\mathbf{0}$ & 0 \\
\hline Interest Accrued & 528 & 0 & 0 & 102 & 0 & 24 \\
\hline Misc Current \& Accrued Labilities .................... & 292 & 1,275 & 170 & 3,381 & 178 & 781 \\
\hline Total Current \& Accrued Liabilities .......... & 4,513 & 3,547 & 2,516 & 7,425 & 2,261 & 2,011 \\
\hline \multicolumn{7}{|l|}{ Deferred Credits } \\
\hline Customer Advances for Construction .............. & 0 & 0 & 70 & 0 & 46 & 0 \\
\hline 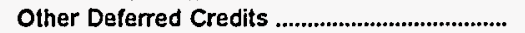 & 3,850 & 0 & 0 & 1,608 & 0 & 0 \\
\hline Unamort Gain on Reacqr Debt ......................... & 0 & 0 & 0 & 0 & 0 & 0 \\
\hline Total Deferred Credits & 3,850 & 0 & 70 & 1,608 & 48 & 0 \\
\hline Total Liabilities and Other Credits ............ & 70,275 & 9,358 & 23,854 & 41,414 & 56,416 & 13,238 \\
\hline
\end{tabular}

Note: Totals may not equal sum of components because of independent rounding.

Source: Energy Information Administration. Form EIA-412, "Annual Report of Public Electric Utilities." 
Table 22. Balance Sheet by Major U.S. Publicly Owned Electric Utility Within State at End of Period, 1995 (Thousand Dollars)

\begin{tabular}{|c|c|c|c|c|c|c|}
\hline Item & $\begin{array}{l}\text { Michigan } \\
\text { Detroit } \\
\text { City of } \\
\text { June } 30\end{array}$ & $\begin{array}{l}\text { Michigan } \\
\text { Grand Haven } \\
\text { City of } \\
\text { June } 30\end{array}$ & $\begin{array}{l}\text { Michigan } \\
\text { Hillsdale } \\
\text { Board } \\
\text { of } \\
\text { Public Wks } \\
\text { June } 30\end{array}$ & $\begin{array}{l}\text { Michigan } \\
\text { Holland } \\
\text { City of } \\
\text { June } 30\end{array}$ & $\begin{array}{l}\text { Michigan } \\
\text { Lansing } \\
\text { City of } \\
\text { June } 30\end{array}$ & $\begin{array}{c}\text { Michigan } \\
\begin{array}{c}\text { Marquette } \\
\text { City of }\end{array} \\
\text { June } 30\end{array}$ \\
\hline \multicolumn{7}{|l|}{ Electric Utility Plant } \\
\hline 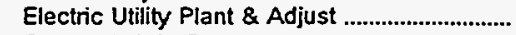 & 283,942 & 104,374 & 10.950 & 98,464 & 396,396 & 98,312 \\
\hline 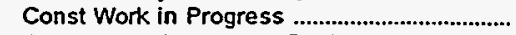 & 15,826 & 1.421 & 563 & 3,716 & 19,324 & 17 \\
\hline (less) Depr, Amort, and Depletion .................... & 125,966 & 46,380 & 7,694 & 46,125 & 232,166 & 45,126 \\
\hline Net Electric Utility Plant .................................... & 173,801 & 59,414 & 3,818 & 56,055 & 183,553 & 53,204 \\
\hline 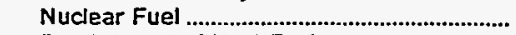 & 0 & 0 & 0 & 0 & 0 & 0 \\
\hline 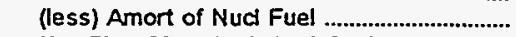 & 0 & 0 & 0 & 0 & 0 & 0 \\
\hline $\begin{array}{l}\text { Net Elec Plant Incl Nucl Fuel .......................... } \\
\text { Other Property \& Investments }\end{array}$ & 173,801 & 59,414 & 3,818 & 56,055 & 183,553 & 53,204 \\
\hline 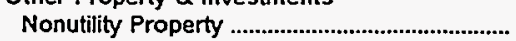 & 0 & 0 & 0 & 0 & 0 & $\mathbf{0}$ \\
\hline (less) Accum Provisions for Depr \& Amort.... & 0 & 0 & 0 & 0 & 0 & $\mathbf{0}$ \\
\hline 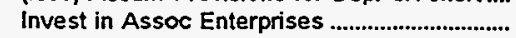 & 0 & 0 & 1,193 & 0 & 0 & 0 \\
\hline 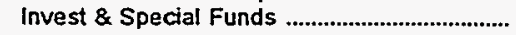 & 0 & 0 & 3,389 & 0 & 21,649 & 14,815 \\
\hline $\begin{array}{l}\text { Total Other Property \& Investments } \\
\text { Current and Accrued Assets }\end{array}$ & 0 & 0 & 4,582 & 0 & 21,649 & 14,815 \\
\hline Cash, Working Funds \& Investments ................... & 81,054 & 20,444 & 1,406 & 40,742 & 49,441 & 5,275 \\
\hline Notes \& Other Receivables ................................ & 7,851 & 351 & 85 & 949 & 0 & 0 \\
\hline Customer Accts Receivable ................................ & 20,949 & 1,508 & 968 & 2,019 & 10,566 & 1,150 \\
\hline (less) Accum Prov for Uncollected Accts ....... & 2,395 & 0 & 0 & 10 & 525 & 154 \\
\hline 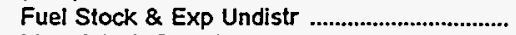 & 2,352 & 2,506 & 0 & 4.689 & 7,394 & 1,004 \\
\hline 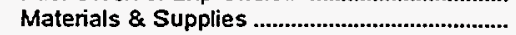 & 8,434 & 0 & 808 & 2,107 & 3,777 & 378 \\
\hline 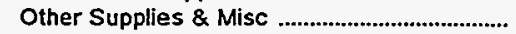 & 0 & 0 & 0 & 0 & 0 & 0 \\
\hline 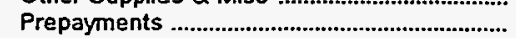 & 0 & 56 & 11 & 2 & 297 & 49 \\
\hline 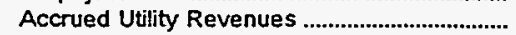 & 0 & 0 & 0 & 2,032 & 0 & 0 \\
\hline Miscellaneous Current \& Accrued Assets ..... & 0 & 47 & 141 & 0 & 2,187 & 5 \\
\hline $\begin{array}{l}\text { Total Current \& Accrued Assets .................... } \\
\text { Deferred Debits }\end{array}$ & 118,245 & 24,912 & 3,419 & 52,532 & 73,136 & 7,708 \\
\hline Unamortized Debt Expenses ..................................... & 0 & 13,482 & 0 & 0 & 0 & 402 \\
\hline Extraordinary Losses, Study Cost ...................... & 0 & 0 & 0 & 0 & 0 & 0 \\
\hline Misc Debt, $R$ \& D Exp, Unamrt Losses .......... & 1,668 & 0 & 0 & 0 & 3,602 & 0 \\
\hline Total Deferred Debits ......................................... & 1,668 & 13,482 & 0 & $\mathbf{0}$ & 3,602 & 402 \\
\hline 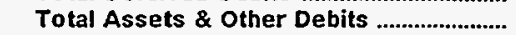 & 293,715 & 97,809 & 11,819 & 108,587 & 281,941 & 76,129 \\
\hline \multicolumn{7}{|l|}{ Proprietary Capital } \\
\hline 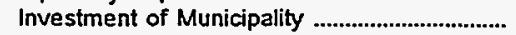 & 260,019 & 0 & 0 & 0 & 0 & 0 \\
\hline 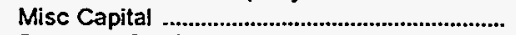 & $-215,892$ & 0 & 0 & 0 & $-37,998$ & 0 \\
\hline Retained Earnings ............................................................. & 168,108 & 910 & 10,797 & 70,850 & 261,497 & 30,836 \\
\hline \multicolumn{7}{|l|}{ Long-term Debt } \\
\hline 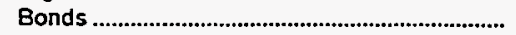 & 69,950 & 94,190 & 0 & 32,915 & 21,830 & 39,485 \\
\hline Advances from Municipality \& Other ................ & 0 & 0 & 0 & 0 & 2,064 & 0 \\
\hline Unamort Prem on Long-term Debt .......................... & 0 & 0 & 0 & 0 & 0 & 0 \\
\hline (less) Unamort Discount on Long-term Debt & 0 & 3,186 & 0 & 1.591 & 0 & 453 \\
\hline 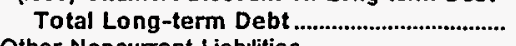 & 69,950 & 91,004 & 0 & 31,324 & 23,894 & 39,032 \\
\hline \multicolumn{7}{|l|}{ Other Noncurrent Liabulities } \\
\hline 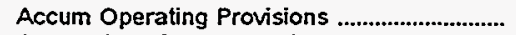 & 0 & 0 & 0 & 0 & 22,976 & 751 \\
\hline Accum Prov for Rate Refunds .............................. & 0 & 0 & 0 & 0 & 0 & 0 \\
\hline $\begin{array}{l}\text { Total Other Noncurrent Liapilities ............. } \\
\text { Current and Accrued Liabilities }\end{array}$ & $\mathbf{0}$ & 0 & 0 & 0 & 22,976 & 751 \\
\hline 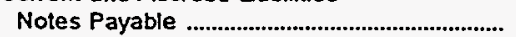 & 0 & 0 & 993 & 0 & 0 & 2,020 \\
\hline Accounts Payable ................................................ & 6,167 & 1,224 & 0 & 4,809 & 7,471 & 784 \\
\hline 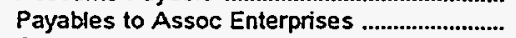 & 0 & 0 & 0 & 0 & 0 & 0 \\
\hline 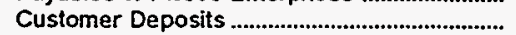 & 420 & 171 & 17 & 426 & 715 & 1,001 \\
\hline 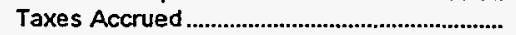 & 0 & 74 & 0 & -28 & 0 & 143 \\
\hline Interest Accrued ................................................................. & 0 & 2,531 & 0 & 890 & 606 & 990 \\
\hline Misc Current \& Accrued Liabilities ...................... & 4,943 & 1,895 & 11 & 315 & 2,566 & 0 \\
\hline $\begin{array}{l}\text { Total Current \& Accrued Liabilities ........... } \\
\text { Deferred Credits }\end{array}$ & 11,530 & 5,895 & 1,022 & 6,413 & 11,358 & 4,938 \\
\hline Customer Advances for Construction ................ & 0 & 0 & 0 & 0 & 214 & 573 \\
\hline Other Deferred Credits ........................................... & 0 & 0 & 0 & 0 & 0 & 0 \\
\hline Unamort Gain on Reacqr Debt .......................... & 0 & 0 & 0 & 0 & 0 & 0 \\
\hline Total Deferred Credits .................................... & 0 & 0 & 0 & 0 & 214 & 573 \\
\hline Total Liabilities and Other Credits ............. & 293,715 & 97,809 & 11,819 & 108,587 & 281,941 & 76,129 \\
\hline
\end{tabular}

Note: Totals may not equal sum of components because of independent rounding.

Source: Energy Information Administration, Form EIA-4 12, "Annual Report of Public Electric Utilities." 
Table 22. Balance Sheet by Major U.S. Publicly Owned Electric Utility Within State at End of Period, 1995 (Thousand Dollars)

\begin{tabular}{|c|c|c|c|c|c|c|}
\hline Item & $\begin{array}{c}\text { Michigan } \\
\text { Michigan } \\
\text { Public } \\
\text { Power Agency } \\
\\
\text { December } 31\end{array}$ & $\begin{array}{l}\text { Michigan } \\
\text { Michigan } \\
\text { South } \\
\text { Central } \\
\text { Pur Agy } \\
\text { June } 30\end{array}$ & $\begin{array}{c}\begin{array}{c}\text { Sturgis } \\
\text { City of }\end{array} \\
\text { September } 30\end{array}$ & $\begin{array}{l}\text { Traverse } \\
\text { City City of }\end{array}$ & $\begin{array}{l}\text { Michigan } \\
\text { Wyandotte } \\
\text { Municipal } \\
\text { Serv Comm } \\
\text { September } 30\end{array}$ & $\begin{array}{l}\text { Zeeland } \\
\text { City of } \\
\text { June } 30\end{array}$ \\
\hline \multicolumn{7}{|l|}{ Electric Utility Plant } \\
\hline 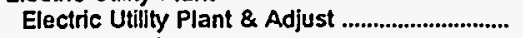 & 469,662 & 74.713 & 31.021 & 32,330 & 107,860 & 23,512 \\
\hline 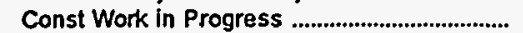 & 0 & 906 & 0 & 753 & -19 & 1,516 \\
\hline 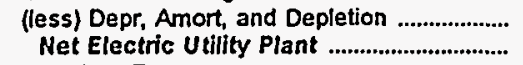 & $\begin{array}{l}151,020 \\
318,642\end{array}$ & $\begin{array}{l}28,611 \\
47,008\end{array}$ & $\begin{array}{l}15,863 \\
15,158\end{array}$ & $\begin{array}{l}13,345 \\
19,738\end{array}$ & $\begin{array}{l}38,200 \\
69,641\end{array}$ & $\begin{array}{r}8,512 \\
16,515\end{array}$ \\
\hline 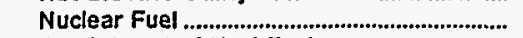 & 0 & 0 & 0 & 0 & 0 & 0 \\
\hline 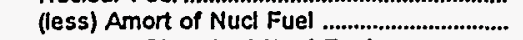 & 0 & 0 & 0 & 0 & 0 & 0 \\
\hline $\begin{array}{l}\text { Net Elec Plant Incl Nucl Fuel ...................... } \\
\text { Other Property \& Investments }\end{array}$ & 318,642 & 47,008 & 15,158 & 19,738 & 69,641 & 16,515 \\
\hline \multicolumn{7}{|l|}{ Other Property \& Investments } \\
\hline (less) Accum Provisions for Depr \& Amort.... & 70 & 0 & 0 & 0 & $\begin{array}{l}0 \\
0\end{array}$ & $\begin{array}{l}0 \\
0\end{array}$ \\
\hline 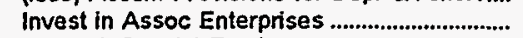 & 0 & 0 & 0 & 0 & 0 & 0 \\
\hline 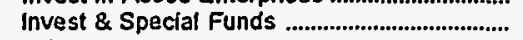 & 115,737 & 25,180 & 7,908 & 651 & $\mathbf{0}$ & 6,659 \\
\hline $\begin{array}{l}\text { Total Other Property \& Investments ....... } \\
\text { Current and Accrued Assets }\end{array}$ & 116,337 & 25,180 & 7,908 & 651 & 0 & 6,659 \\
\hline Cash, Working Funds \& Investments .............. & 16,512 & 70 & 460 & 6,194 & 3,285 & 855 \\
\hline Notes \& Other Receivables ................................. & & 96 & 225 & 85 & 10,660 & 10 \\
\hline 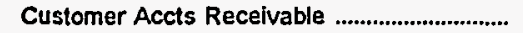 & 9,592 & 2,692 & 1,826 & 1,372 & 1,182 & 1,072 \\
\hline (less) Accum Prov for Uncollected Accts ...... & & 0 & 0 & 136 & 47 & 0 \\
\hline 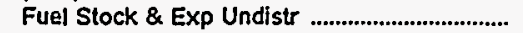 & 10,397 & 1,417 & 0 & 0 & 355 & 0 \\
\hline 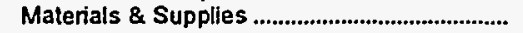 & 2,847 & 17 & 359 & 632 & 1,001 & 247 \\
\hline Other Supplies \& Misc ....................................... & 0 & 99 & 0 & 704 & 121 & 0 \\
\hline 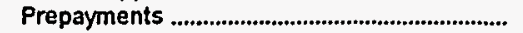 & 0 & 22 & $\mathbf{0}$ & 123 & 0 & 0 \\
\hline Accrued Utility Revenues ...................................... & 0 & 0 & 0 & 0 & 2,135 & 0 \\
\hline Miscellaneous Current \& Accrued Assets ..... & 52 & 569 & 1,469 & 5 & 94 & 0 \\
\hline $\begin{array}{l}\text { Total Current \& Accrued Assets ............... } \\
\text { Deferred Debits }\end{array}$ & 39,399 & 4,983 & 4,338 & 8,978 & 18,786 & 2,185 \\
\hline Unamortized Debt Expenses ................................ & 3,834 & 2,363 & $\mathbf{0}$ & 374 & 0 & 0 \\
\hline Extraordinary Losses, Study Cost ...................... & 0 & 110 & 0 & 0 & 0 & 0 \\
\hline Misc Debt, $R$ \& D Exp. Unamrt Losses ......... & 0 & 27,206 & 0 & 0 & 0 & 0 \\
\hline 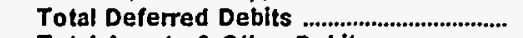 & 3,834 & 29,679 & 0 & 374 & 0 & 0 \\
\hline Total Assets \& Other Debits ........................... & 478,213 & 106,850 & 27,404 & 29,742 & 88,427 & 25,360 \\
\hline \multicolumn{7}{|l|}{ Proprietary Capital } \\
\hline 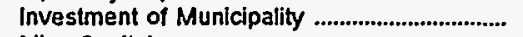 & 531 & 0 & 0 & 56 & 0 & $\mathbf{0}$ \\
\hline 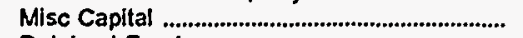 & 0 & 0 & 0 & 0 & 0 & 529 \\
\hline 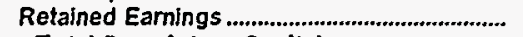 & 259 & 4,677 & 20,212 & 25,636 & 27,606 & 14,915 \\
\hline $\begin{array}{l}\text { Total Proprietary Capital ................................. } \\
\text { Long-tem Debt }\end{array}$ & 790 & 4,677 & 20,212 & 25,692 & 27,606 & 15,445 \\
\hline Bonds & 419,499 & 101,605 & 3.225 & 2,540 & 56,930 & 8,590 \\
\hline Advances from Municipality \& Other................ & 0 & 0 & 0 & 0 & 0 & 0 \\
\hline Unamort Prem on Long-term Debt ................... & 0 & 0 & 0 & 0 & 0 & 0 \\
\hline (less) Unamort Discount on Long-term Debt & 0 & 2,808 & 0 & 0 & 0 & 0 \\
\hline $\begin{array}{l}\text { Total Long-term Debt......................................... } \\
\text { Other Noncurrent Liabillties }\end{array}$ & 419,499 & 98,797 & 3,225 & 2,540 & 56,930 & 8,590 \\
\hline Accum Operating Provisions ............................ & 0 & 0 & 1,239 & 328 & 25 & 0 \\
\hline Accum Prov for Rate Refunds ........................ & 0 & 0 & 0 & 0 & 0 & 0 \\
\hline \multicolumn{6}{|l|}{ Current and Accrued Liabilities } & $\mathbf{0}$ \\
\hline 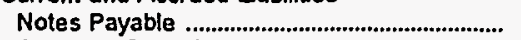 & 8,412 & 0 & 0 & 195 & 3,662 & 0 \\
\hline Accounts Payable & 2,976 & 2,058 & 2,425 & 763 & 0 & 1,177 \\
\hline Payables to Assoc Enterprises ......................... & 0 & 0 & 0 & 0 & 0 & 0 \\
\hline 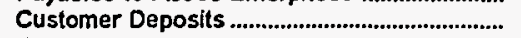 & 0 & 0 & 3 & 75 & 204 & 0 \\
\hline 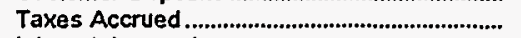 & 0 & 29 & 0 & 0 & 0 & 0 \\
\hline 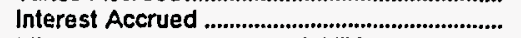 & 11,783 & 964 & 0 & 64 & 0 & 115 \\
\hline Misc Current \& Accrued Labilities..................... & 710 & 325 & 0 & 85 & 0 & 33 \\
\hline $\begin{array}{l}\text { Total Current \& Accrued Liabilities .......... } \\
\text { Deferred Credits }\end{array}$ & 23,880 & 3,376 & 2,428 & 1,182 & 3,866 & 1,325 \\
\hline Customer Advances for Construction ............. & $\mathbf{0}$ & 0 & 300 & 0 & 0 & 0 \\
\hline 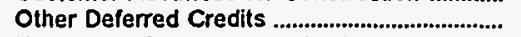 & 34,044 & 0 & 0 & 0 & 0 & 0 \\
\hline 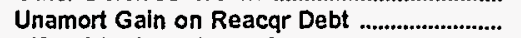 & 0 & 0 & 0 & 0 & 0 & 0 \\
\hline 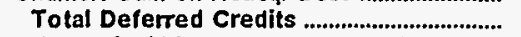 & 34,044 & $\mathbf{0}$ & 300 & $\mathbf{0}$ & o & 0 \\
\hline Total Liabilities and Other Credits ............ & 478,213 & 106,850 & 27,404 & 29,742 & 88,427 & 25,360 \\
\hline
\end{tabular}

Note: Totals may not equal sum of components because of independent rounding.

Source: Energy Information Administration, Form ElA-412, "Annual Report of Public Electric Utilities." 
Table 22. Balance Sheet by Major U.S. Publicly Owned Electric Utility Within State at End of Period, 1995

(Thousand Doliars)

\begin{tabular}{|c|c|c|c|c|c|c|}
\hline Item & $\begin{array}{l}\text { Minnesota } \\
\text { Alexandria } \\
\text { City of } \\
\text { December } 31\end{array}$ & $\begin{array}{c}\text { Minnesota } \\
\text { Anoka } \\
\text { City of } \\
\text { December } 31\end{array}$ & $\begin{array}{l}\text { Minnesota } \\
\text { Austin } \\
\text { City of } \\
\text { December } 31\end{array}$ & $\begin{array}{c}\text { Minnesota } \\
\text { Brainerd } \\
\text { Public } \\
\text { Utilities } \\
\text { December } 31\end{array}$ & $\begin{array}{c}\text { Minnesota } \\
\text { Chaska } \\
\text { City of } \\
\text { December } 31\end{array}$ & $\begin{array}{l}\text { Minnesota } \\
\text { Fainmont } \\
\text { Public } \\
\text { Utilities } \\
\text { Comm } \\
\text { December } 31\end{array}$ \\
\hline \multicolumn{7}{|l|}{ Electric Utility Plant } \\
\hline 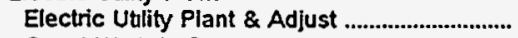 & 15,725 & 15,016 & 34,552 & 7,461 & 9,340 & 19.179 \\
\hline Const Work in Progress & 336 & 0 & 15 & 76 & 0 & 0 \\
\hline 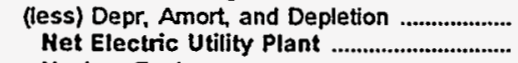 & $\begin{array}{l}9,135 \\
6,926\end{array}$ & $\begin{array}{l}6,935 \\
8,080\end{array}$ & $\begin{array}{l}21,318 \\
13,248\end{array}$ & $\begin{array}{l}3,465 \\
4,072\end{array}$ & $\begin{array}{l}3,939 \\
5,401\end{array}$ & $\begin{array}{r}11,828 \\
7,351\end{array}$ \\
\hline Nuclear Fuel & 0 & 0 & 0 & 0 & 0 & 0 \\
\hline 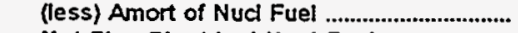 & 0 & 0 & 0 & 0 & 0 & 0 \\
\hline $\begin{array}{l}\text { Net Elec Plant Incl Nucl Fuel ......................... } \\
\text { Other Property \& Investments }\end{array}$ & Other Property \& Investments & 8,080 & 13,248 & 4,072 & 5,401 & 7,351 \\
\hline 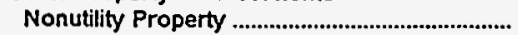 & 5,387 & 0 & 15,285 & 1,555 & 0 & $\mathbf{0}$ \\
\hline (less) Accum Provisions for Depr \& Amort .... & 2,095 & 0 & 6,880 & 745 & 0 & 0 \\
\hline 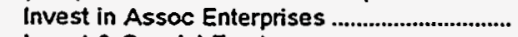 & 0 & 0 & $\mathbf{0}$ & 0 & 0 & 0 \\
\hline 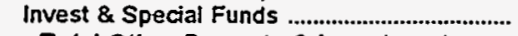 & 6,234 & 0 & 9,939 & 4,893 & 0 & 0 \\
\hline $\begin{array}{l}\text { Total Other Property \& Investments ....... } \\
\text { Current and Accrued Assets }\end{array}$ & 9,526 & $\mathbf{0}$ & 18,344 & 5,704 & $\mathbf{0}$ & 0 \\
\hline $\begin{array}{l}\text { Cash, Working Funds \& Investments } \\
\text { Notes \& Other Receivables }\end{array}$ & $\begin{array}{l}77 \\
77\end{array}$ & $\begin{array}{r}5.438 \\
0\end{array}$ & $\begin{array}{r}7.371 \\
79\end{array}$ & $\begin{array}{r}16 \\
150\end{array}$ & $\begin{array}{r}4,589 \\
624\end{array}$ & $\begin{array}{r}401 \\
5,260\end{array}$ \\
\hline 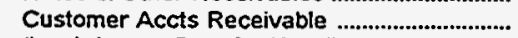 & 382 & 1,640 & 2,748 & 630 & 937 & 2,341 \\
\hline (less) Accum Prov for Uncollected Accts ...... & 10 & 0 & 60 & 0 & 8 & 32 \\
\hline 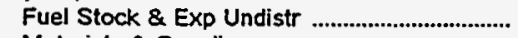 & 6 & 0 & 1 & 0 & 0 & 29 \\
\hline 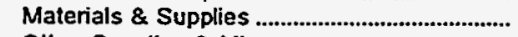 & 20 & 382 & :,v64 & 672 & 670 & 264 \\
\hline 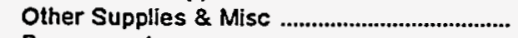 & 523 & 0 & 30 & 0 & 0 & 0 \\
\hline Prepayments & 111 & 0 & 640 & 32 & 0 & 0 \\
\hline 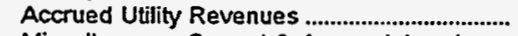 & 0 & 0 & 0 & 0 & 398 & 0 \\
\hline Miscellaneous Current \& Accrued Assets ..... & 0 & 76 & 283 & 0 & 0 & 0 \\
\hline $\begin{array}{l}\text { Total Current \& Accrued Assets ............... } \\
\text { Deferred Debits }\end{array}$ & 1,186 & 7,536 & 12,156 & 1,500 & 7,211 & 8,263 \\
\hline 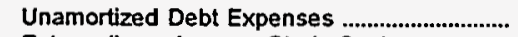 & 0 & 0 & 581 & 0 & 1,978 & 0 \\
\hline Extraordinary Losses, Study Cost ...................... & 0 & 0 & 0 & 0 & 0 & 0 \\
\hline Misc Debt, R \& D Exp, Unamrt Losses .......... & 698 & 0 & 0 & 0 & 0 & $\mathbf{0}$ \\
\hline Total Deferred Debits ..................................... & 698 & 0 & 581 & 0 & 1,978 & 0 \\
\hline \multicolumn{6}{|l|}{ Proprietary Capital } & 15,615 \\
\hline 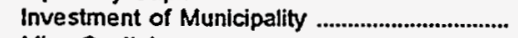 & 0 & 0 & 0 & 853 & 0 & 320 \\
\hline 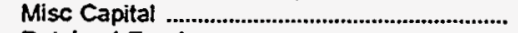 & 2,228 & 0 & 0 & 18 & 1,366 & 0 \\
\hline 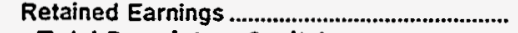 & 13,766 & 13,487 & 33,563 & 8.866 & 9.618 & 14,515 \\
\hline \multicolumn{5}{|l|}{ Long-term Debt } & 10,985 & 14,835 \\
\hline Bonds & 0 & 0 & 0 & 0 & 830 & $\mathbf{0}$ \\
\hline Advances from Municipality \& Other ............... & 0 & 0 & 0 & 0 & 1,987 & $\mathbf{0}$ \\
\hline Unamort Prem on Long-term Debt ................... & 0 & 0 & 0 & 0 & 0 & 0 \\
\hline (less) Unamort Discount on Long-term Debt & 0 & 0 & 0 & 0 & 0 & $\mathbf{0}$ \\
\hline 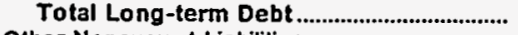 & 0 & 0 & 0 & $\mathbf{0}$ & 2,817 & 0 \\
\hline \multicolumn{7}{|l|}{ Other Noncurrent Liabilities } \\
\hline 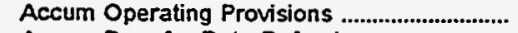 & 0 & $\mathbf{0}$ & 4,580 & 193 & $\mathbf{0}$ & 0 \\
\hline 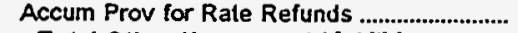 & $\mathbf{0}$ & 0 & 0 & 0 & 0 & 0 \\
\hline $\begin{array}{l}\text { Total Other Noncurrent Liabilities ............ } \\
\text { Current and Accrued Labilities }\end{array}$ & Current and Accrued Liabilities & $\mathbf{0}$ & 4,580 & 193 & $\mathbf{0}$ & $\mathbf{0}$ \\
\hline 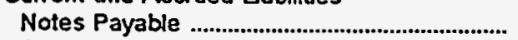 & 0 & 0 & 0 & 0 & 0 & 0 \\
\hline 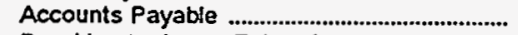 & 673 & 810 & 2,155 & 550 & 726 & 741 \\
\hline 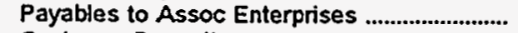 & 422 & 0 & 0 & 660 & 0 & 11 \\
\hline 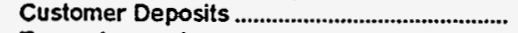 & 64 & 1.096 & 119 & 93 & 61 & 28 \\
\hline Taxes Accrued & 0 & 0 & 146 & 29 & 0 & 0 \\
\hline Interest Accrued & 0 & 56 & 4 & 0 & 0 & 0 \\
\hline Misc Current \& Accrued Liabilities ................... & 485 & 167 & 588 & 13 & $\mathbf{0}$ & 0 \\
\hline $\begin{array}{l}\text { Total Current \& Accrued Liabilities .......... } \\
\text { Deferred Credits }\end{array}$ & 1,644 & 2,129 & 3,012 & 1,346 & 788 & 780 \\
\hline Customer Advances for Construction ............. & 0 & 0 & 0 & 0 & 0 & 0 \\
\hline 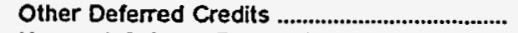 & 698 & 0 & 3,173 & 0 & 0 & 0 \\
\hline Unamort Gain on Reacqr Debt & 0 & 0 & 0 & 0 & 0 & 0 \\
\hline Total Deferred Credits .................................. & 698 & 0 & 3,173 & 0 & 0 & 0 \\
\hline Total Liabilities and Other Credits ............ & 18,395 & 15,616 & 44,328 & 11,276 & 14,590 & 15,615 \\
\hline
\end{tabular}

Note: Totals may not equal sum of components because of independent rounding.

Source: Energy Information Administration, Form ElA-412, "Annual Report of Public Electric Utilities." 
Table 22. Balance Sheet by Major U.S. Publicly Owned Electric Utility Within State at End of Period, 1995

(Thousand Dollars)

\begin{tabular}{|c|c|c|c|c|c|c|}
\hline Item & $\begin{array}{l}\text { Minnesota } \\
\text { Hutchinson } \\
\text { Utilities } \\
\text { Comm } \\
\text { December } 31\end{array}$ & $\begin{array}{c}\text { Minnesota } \\
\begin{array}{c}\text { Marshall } \\
\text { City of }\end{array} \\
\text { December } 31\end{array}$ & $\begin{array}{l}\text { Minne sota } \\
\text { Moorhead } \\
\text { City of } \\
\text { December } 31\end{array}$ & $\begin{array}{l}\text { Minnesota } \\
\text { New Ulm } \\
\text { Public } \\
\text { Utilities } \\
\text { Comm } \\
\text { December 31 }\end{array}$ & $\begin{array}{l}\text { Minnesota } \\
\text { Northern } \\
\text { Municipal } \\
\text { Power Agny } \\
\text { December } 31\end{array}$ & $\begin{array}{l}\text { Minnesota } \\
\text { Owatonna } \\
\text { City of } \\
\text { December } 31\end{array}$ \\
\hline \multicolumn{7}{|l|}{ Electric Utility Plant } \\
\hline 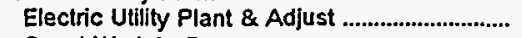 & 49,639 & 22,631 & 31,206 & 26,765 & 322,216 & 28,123 \\
\hline 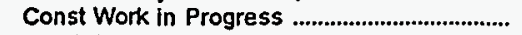 & & 262 & 335 & 45 & & 144 \\
\hline 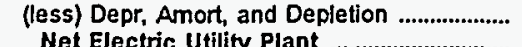 & $\begin{array}{l}15,946 \\
33,694\end{array}$ & $\begin{array}{r}7,489 \\
15,404\end{array}$ & $\begin{array}{l}15,986 \\
15,556\end{array}$ & 14,616 & $\begin{array}{r}25,650 \\
29656\end{array}$ & 14,142 \\
\hline 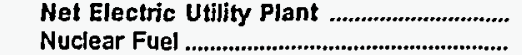 & $\begin{array}{r}33,694 \\
0\end{array}$ & $\begin{array}{r}15,404 \\
0\end{array}$ & $\begin{array}{r}15,556 \\
0\end{array}$ & $\begin{array}{r}12,194 \\
0\end{array}$ & $\begin{array}{r}296,566 \\
0\end{array}$ & $\begin{array}{r}14,125 \\
0\end{array}$ \\
\hline 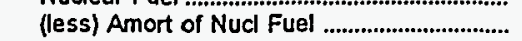 & 0 & 0 & 0 & 0 & 0 & 0 \\
\hline & 33,694 & 15,404 & 15,556 & 12,194 & 296,566 & 14,125 \\
\hline \multicolumn{7}{|l|}{ Other Property \& Investments } \\
\hline (less) Accum Provisions for Depr \& Amort.... & 0 & 0 & 0 & 0 & 0 & 0 \\
\hline 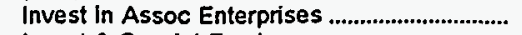 & 0 & 2.029 & 0 & 0 & 0 & 0 \\
\hline 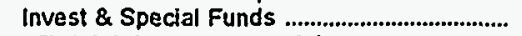 & 1,428 & 1,469 & 6,317 & 1,900 & 57,395 & 916 \\
\hline $\begin{array}{l}\text { Total Other Property \& Investments ....... } \\
\text { Current and Accrued Assets }\end{array}$ & 1,428 & 3,498 & 6,317 & 1,900 & 57,395 & 916 \\
\hline \multicolumn{6}{|l|}{$\begin{array}{l}\text { Curtent and Accrued Assets } \\
\text { Cash. Working Funds \& Investments ............... }\end{array}$} & 6,663 \\
\hline 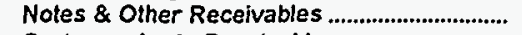 & & 0 & 60 & 292 & 1,323 & 79 \\
\hline 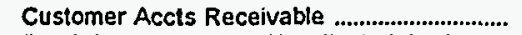 & 1,232 & 1,522 & 943 & -9 & 0 & 1,285 \\
\hline (less) Accum Prov for Uncollected Accts ...... & 24 & 0 & 0 & 0 & 0 & 53 \\
\hline 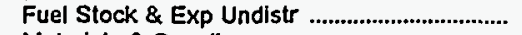 & 0 & 0 & 0 & 139 & 0 & \\
\hline 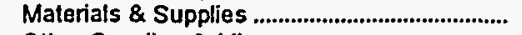 & 598 & 0 & 303 & 1,015 & 0 & 453 \\
\hline 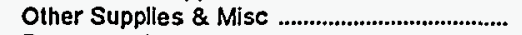 & 0 & $54 !$ & 0 & 0 & 0 & 0 \\
\hline 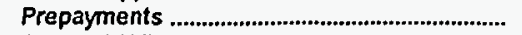 & o & 45 & 8 & 6 & 0 & 47 \\
\hline 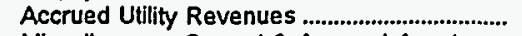 & 0 & 0 & 0 & 707 & 0 & 453 \\
\hline Miscellaneous Current \& Accrued Assets ..... & 25 & 0 & & 249 & 0 & 1,279 \\
\hline $\begin{array}{l}\text { Total Current \& Accrued Assets ................. } \\
\text { Deferred Debits }\end{array}$ & 2,907 & 10,868 & 1,456 & 7,346 & 1,457 & 10,206 \\
\hline Unamortized Debt Expenses ................................ & 167 & 241 & 0 & 0 & 0 & 601 \\
\hline Extraordinary Losses, Study Cost ...................... & 0 & 123 & 0 & 0 & 0 & 0 \\
\hline Misc Debt, R \& D Exp, Unamrt Losses .......... & 0 & -88 & 0 & o & 0 & 260 \\
\hline 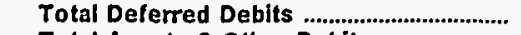 & 167 & 275 & 0 & 0 & 0 & 861 \\
\hline Total Assets \& Other Debits ............................ & 38,196 & 30,045 & 23,329 & 21,440 & 355,418 & 26,108 \\
\hline \multicolumn{7}{|l|}{ Proprietary Capital } \\
\hline 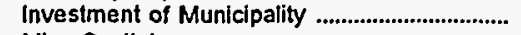 & 17,991 & 0 & 0 & 0 & 0 & 0 \\
\hline 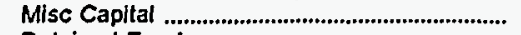 & & 0 & 0 & 0 & 0 & 0 \\
\hline 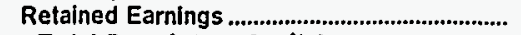 & 4,722 & 19,073 & 16,989 & 17.475 & 0 & 16,495 \\
\hline $\begin{array}{l}\text { Total Proprietary Capital .................................. } \\
\text { Long-term Debt }\end{array}$ & 22,712 & 19,073 & 16,989 & 17,475 & 0 & 16,495 \\
\hline 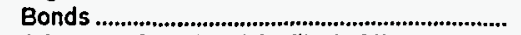 & 13,300 & 9,029 & 3,018 & 3,085 & 344,960 & 6,778 \\
\hline Advances from Municipality $\&$ Other ................ & & & & 0 & 0 & \\
\hline Unamort Prem on Long-term Debt ....................... & 0 & 0 & 0 & 0 & 0 & \\
\hline (less) Unamort Discount on Long-term Debt & 0 & 0 & & 32 & 0 & 135 \\
\hline 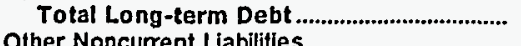 & 13,300 & 9,029 & 3,018 & 3,053 & 344,960 & 6,643 \\
\hline \multicolumn{7}{|l|}{ Other Noncurrent Liabilities } \\
\hline 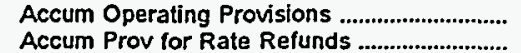 & $\begin{array}{l}0 \\
0\end{array}$ & $\begin{array}{l}0 \\
0\end{array}$ & $\begin{array}{l}0 \\
0\end{array}$ & $\begin{array}{l}0 \\
0\end{array}$ & $\begin{array}{l}0 \\
0\end{array}$ & $\begin{array}{r}489 \\
0\end{array}$ \\
\hline Total Other Noncurrent Liabilities ............ & 0 & 0 & 0 & 0 & 0 & 489 \\
\hline \multicolumn{7}{|l|}{ Current and Accrued Labilities } \\
\hline 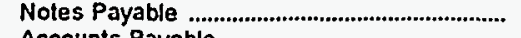 & $.1,050$ & 254 & 1,694 & 175 & 0 & \\
\hline 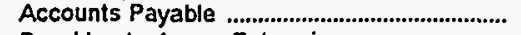 & 804 & 1,371 & 1,016 & 547 & 133 & 1,276 \\
\hline Payables to Ássoc Enterprises ............................... & 0 & 0 & 304 & 0 & 0 & 83 \\
\hline 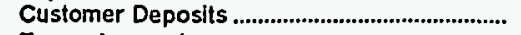 & 51 & 43 & 111 & 0 & 0 & 17 \\
\hline 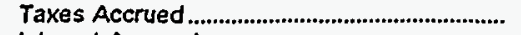 & 0 & 0 & 43 & 0 & 0 & \\
\hline Interest Accrued & 56 & 212 & 35 & 9 & 10,325 & 186 \\
\hline Misc Current \& Accrued Liabilities.................... & 223 & 63 & 118 & 181 & 0 & 741 \\
\hline Total Current \& Accrued Liabilities ........... & 2,184 & 1,944 & 3,321 & 912 & 10,458 & 2,304 \\
\hline \multicolumn{7}{|l|}{ Deferred Credits } \\
\hline Customer Advances for Construction .............. & 0 & 0 & 0 & 0 & 0 & \\
\hline 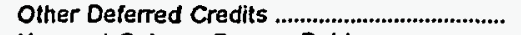 & $\mathbf{0}$ & 0 & 0 & 0 & 0 & 178 \\
\hline Unamort Gain on Reacar Debt ............................. & 0 & 0 & 0 & 0 & 0 & 0 \\
\hline 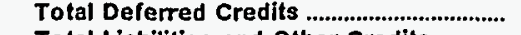 & & & 0 & 0 & 0 & 178 \\
\hline Total Liabilities and Other Credits ............ & 38,196 & 30,045 & 23,329 & 21,440 & 355,418 & 26,108 \\
\hline
\end{tabular}

Note: Totals may not equal sum of components because of independent rounding.

Source: Energy information Administration, Form ElA-412, "Annual Report of Public Electric Utilities." 
Table 22. Balance Sheet by Major U.S. Publicly Owned Electric Utility Within State at End of Period, 1995 (Thousand Dollars)

\begin{tabular}{|c|c|c|c|c|c|c|}
\hline Item & $\begin{array}{c}\text { Minnesota } \\
\text { Rochester } \\
\text { Public } \\
\text { Utilities } \\
\text { December } 31\end{array}$ & $\begin{array}{l}\text { Minnesota } \\
\text { Shakopee } \\
\text { Public } \\
\text { Utilities } \\
\text { Comm } \\
\text { December } 31\end{array}$ & $\begin{array}{l}\text { Minnesota } \\
\text { Southern } \\
\text { Minnesota } \\
\text { Mun P } \\
\text { Agny } \\
\text { December } 31\end{array}$ & $\begin{array}{c}\text { Minnesota } \\
\text { Western } \\
\text { Minnesota } \\
\text { Mun } \\
\text { Pur Agny } \\
\text { December } 31\end{array}$ & $\begin{array}{c}\text { Minnesota } \\
\text { Willmar } \\
\text { Municipal } \\
\text { Utils Comm } \\
\text { December } 31\end{array}$ & $\begin{array}{l}\text { Worthington } \\
\text { City of }\end{array}$ \\
\hline \multicolumn{7}{|l|}{ Electric Utility Plant } \\
\hline 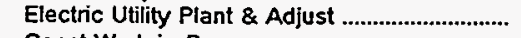 & 109,590 & 6,812 & 523.831 & 2,737 & 30,021 & 12,931 \\
\hline 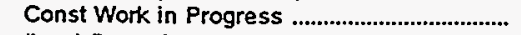 & 3,710 & 1,298 & 11,331 & 0 & 166 & 0 \\
\hline $\begin{array}{l}\text { (less) Depr, Amort, and Depletion ................... } \\
\text { Net Electric Utility Plant ............................... }\end{array}$ & $\begin{array}{l}54.746 \\
58,555\end{array}$ & $\begin{array}{l}2,467 \\
5,643\end{array}$ & $\begin{array}{l}130,412 \\
404,750\end{array}$ & $\begin{array}{r}776 \\
1,961\end{array}$ & $\begin{array}{l}16,767 \\
13,420\end{array}$ & $\begin{array}{l}5,392 \\
7,538\end{array}$ \\
\hline 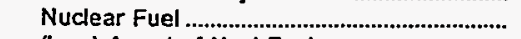 & 0 & 0 & 0 & 0 & 0 & 0 \\
\hline 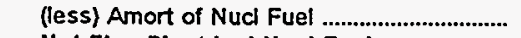 & 0 & 0 & 0 & 0 & 0 & 0 \\
\hline $\begin{array}{l}\text { Net Elec Plant Incl Nucl Fuel ........................... } \\
\text { Other Property \& Investments }\end{array}$ & 58,555 & 5,643 & 404,750 & 1,961 & 13,420 & 7,538 \\
\hline 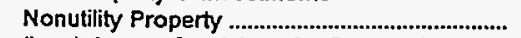 & 336 & 0 & 43 & 0 & 12,305 & 0 \\
\hline (less) Accum Provisions for Depr \& Amort .... & 166 & 0 & 0 & 0 & 3,859 & 0 \\
\hline 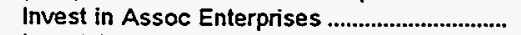 & 0 & 0 & 0 & 0 & 0 & 0 \\
\hline Invest \& Special Funds & 134 & 2,987 & 61,826 & 9,862 & 7,764 & 0 \\
\hline \multicolumn{7}{|l|}{ Current and Accrued Assets } \\
\hline Cash, Working Funds \& Investments ................ & 12,300 & 2,482 & 106,116 & 6,483 & 5,156 & 4,074 \\
\hline 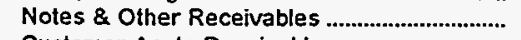 & 1,418 & 113 & 0 & 0 & 0 & 1,074 \\
\hline 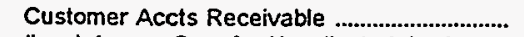 & 3.871 & 888 & 9,721 & 7,787 & 1,610 & 4 \\
\hline (less) Accum Prov for Uncollected Accts ...... & 30 & 0 & 0 & 0 & 0 & 0 \\
\hline 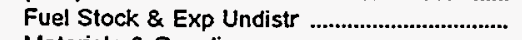 & 820 & 0 & 5.260 & 51 & 135 & 0 \\
\hline 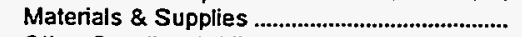 & 2,052 & 0 & 2,682 & 0 & 344 & 76 \\
\hline 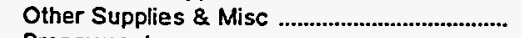 & 0 & 280 & 0 & 0 & 0 & 0 \\
\hline 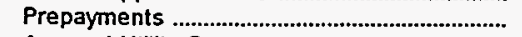 & 233 & 19 & 4,488 & 1.600 & 135 & 14 \\
\hline 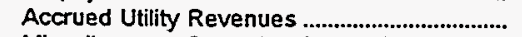 & 3.284 & 0 & 0 & 0 & 0 & 0 \\
\hline Miscellaneous Current \& Accrued Assets ..... & 202 & 30 & 9,553 & 291 & 0 & 0 \\
\hline $\begin{array}{l}\text { Total Current \& Accrued Assets ............... } \\
\text { Deferred Debits }\end{array}$ & 24,151 & 3,811 & 137,821 & 16,213 & 7,380 & 5,241 \\
\hline Unamortized Debt Expenses ................................ & 0 & 81 & 167,215 & 0 & 302 & $\mathbf{0}$ \\
\hline 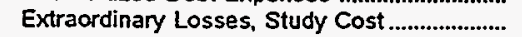 & 0 & 0 & 158 & $\mathbf{0}$ & $\begin{array}{r}0 \\
0\end{array}$ & 0 \\
\hline Misc Debt, R \& D Exp, Unamrt Losses .......... & 319 & 0 & 111,375 & 5 & 0 & 0 \\
\hline 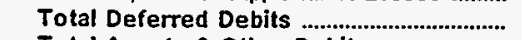 & 319 & 81 & 278,748 & 5 & 302 & 0 \\
\hline Total Assets \& Other Debits .......................... & 83,327 & 12,523 & 883,189 & 28,040 & 37,313 & 12,780 \\
\hline \multicolumn{7}{|l|}{ Proprietary Capital } \\
\hline 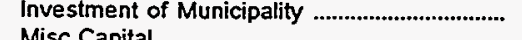 & 0 & 0 & 0 & 0 & $\mathbf{0}$ & 0 \\
\hline 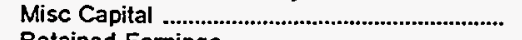 & 0 & 0 & 0 & 0 & 0 & 0 \\
\hline 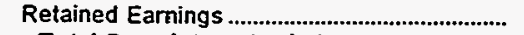 & 69,070 & 8,047 & 23.704 & 22,406 & 23,718 & 12,097 \\
\hline 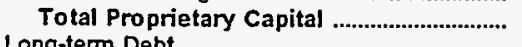 & 69,070 & 8,047 & 23,704 & 22,406 & 23,718 & 12,097 \\
\hline \multicolumn{6}{|l|}{ Long-term Debt } & \\
\hline 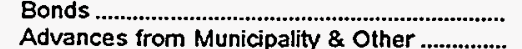 & $\begin{array}{r}0 \\
1,400\end{array}$ & $\begin{array}{r}2,490 \\
603\end{array}$ & $\begin{array}{r}1,211,795 \\
0\end{array}$ & $\begin{array}{l}0 \\
0\end{array}$ & 10,034 & 0 \\
\hline & $\begin{array}{r}1,400 \\
0\end{array}$ & $\begin{array}{r}603 \\
0\end{array}$ & $\begin{array}{l}0 \\
0\end{array}$ & 0 & 0 & 0 \\
\hline $\begin{array}{l}\text { Unamort Prem on Long-tem Debt ................ } \\
\text { (less) Unamort Discount on Long-tem Debt }\end{array}$ & 0 & $\begin{array}{l}0 \\
0\end{array}$ & $\begin{array}{r}0 \\
466,408\end{array}$ & 0 & 0 & 0 \\
\hline & 0 & 0 & 466,408 & 0 & 0 & 0 \\
\hline 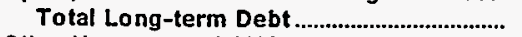 & 1,400 & 3,093 & 745,387 & $\mathbf{0}$ & 10,034 & $\mathbf{0}$ \\
\hline \multicolumn{7}{|l|}{ Other Noncurrent Labilities } \\
\hline 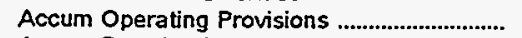 & 3,867 & 0 & 0 & 0 & 0 & 0 \\
\hline Accum Prov for Rate Refunds .......................... & 0 & $\mathbf{0}$ & 0 & 0 & 0 & 0 \\
\hline Total Other Noncurrent Liabilities ............. & 3,867 & 0 & $\mathbf{0}$ & $\mathbf{0}$ & 0 & 0 \\
\hline \multicolumn{7}{|l|}{ Current and Accrued Liabilities } \\
\hline Notes Payable & 0 & 0 & 24,000 & 0 & 1,537 & 0 \\
\hline Accounts Payable & 4,814 & 913 & 5,906 & 1,736 & 568 & 582 \\
\hline 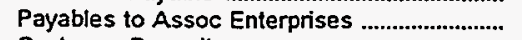 & 572 & 292 & 945 & 3,872 & 124 & 26 \\
\hline 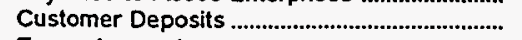 & 570 & 122 & 0 & 0 & 118 & 66 \\
\hline Taxes Accrued & 425 & 0 & 8,132 & 24 & 51 & 0 \\
\hline Interest Accrued & 0 & 56 & 18,508 & 0 & 293 & 0 \\
\hline Misc Current \& Accrued Liabilities.................... & 1,347 & $\mathbf{0}$ & 21,350 & 2 & 870 & 9 \\
\hline $\begin{array}{l}\text { Total Current \& Accrued Liabilities .......... } \\
\text { Deferred Credits }\end{array}$ & 7,728 & 1,382 & 78,841 & 5,634 & 3,560 & 683 \\
\hline Customer Advances for Construction ............. & 0 & $\mathbf{0}$ & 0 & 0 & 0 & 0 \\
\hline 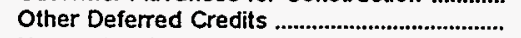 & 1,263 & 0 & 35,258 & 0 & 0 & 0 \\
\hline 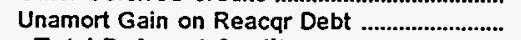 & 0 & 0 & 0 & 0 & 0 & 0 \\
\hline 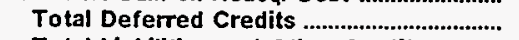 & 1,263 & 0 & 35,258 & 0 & 0 & $\mathbf{0}$ \\
\hline Total Liabilities and Other Credits ............. & 83,327 & 12,523 & 883,189 & 28,040 & 37,343 & 12,780 \\
\hline
\end{tabular}

Note: Totals may not equal sum of components because of independent rounding.

Source: Energy Information Administration, Form EIA-412, "Annual Report of Public Electric Utilities." 
Table 22. Balance Sheet by Major U.S. Publicly Owned Electric Utility Within State at End of Period, 1995

(Thousand Dollars)

\begin{tabular}{|c|c|c|c|c|c|c|}
\hline Item & $\begin{array}{l}\text { Mississippi } \\
\text { Aberdeen } \\
\text { City of } \\
\text { June } 30\end{array}$ & $\begin{array}{l}\text { Mississippi } \\
\text { Clarksdale } \\
\text { City of } \\
\text { September } 30\end{array}$ & $\begin{array}{l}\text { Mississippi } \\
\text { Columbus } \\
\text { City of } \\
\text { June } 30\end{array}$ & $\begin{array}{l}\text { Mississippi } \\
\text { Greenwood } \\
\text { Utilties } \\
\text { Comm } \\
\text { September } 30\end{array}$ & $\begin{array}{l}\text { Mississippi } \\
\text { Holly } \\
\text { Springs } \\
\text { City of } \\
\text { June } 30\end{array}$ & $\begin{array}{l}\text { Mississippi } \\
\text { Louisville } \\
\text { Electric } \\
\text { System } \\
\text { June } 30\end{array}$ \\
\hline \multicolumn{7}{|l|}{ Electric Utility Plant } \\
\hline Electric Utility Plant \& Adjust ............................. & 4,663 & 27,295 & 16,843 & 26,992 & 14,165 & 9,047 \\
\hline 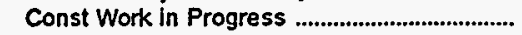 & 12 & 280 & 50 & 4,298 & 126 & 155 \\
\hline (less) Depr, Amort, and Depletion .......................... & 2,241 & 19,414 & 9,148 & 16,194 & 5,459 & 3,071 \\
\hline Net Electric Utility Plant ................................... & $\mathbf{2 , 4 3 4}$ & 8,161 & 7,745 & 15,097 & 8,832 & 6,130 \\
\hline Nuclear Fuel ...................................................... & 0 & 0 & 0 & 0 & 0 & 0 \\
\hline (less) Amort of Nud Fuel .............................. & 0 & 0 & 0 & 0 & 0 & 0 \\
\hline Net Elec Plant Incl Nucl Fuel ............................. & 2,434 & 8,161 & 7,745 & 15,097 & 8,832 & 6,130 \\
\hline \multicolumn{7}{|l|}{ Other Property \& Investments } \\
\hline 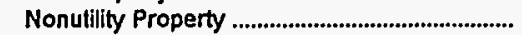 & 0 & 0 & 0 & 0 & $\mathbf{0}$ & 0 \\
\hline (less) Accum Provisions for Depr \& Amort .... & 0 & 0 & 0 & 0 & 0 & 0 \\
\hline 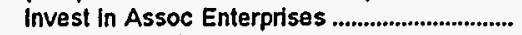 & 0 & 0 & 0 & 0 & 16 & 0 \\
\hline 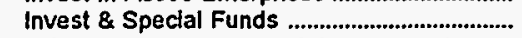 & 7 & 3,998 & 0 & 10,009 & 1,548 & 8 \\
\hline $\begin{array}{l}\text { Total Other Property \& Investments ....... } \\
\text { Current and Accrued Assets }\end{array}$ & 7 & 3,998 & 0 & 10,009 & 1,564 & 8 \\
\hline Current and Accrued Assets & 60 & 1.716 & 3,818 & 4,435 & 864 & 1.279 \\
\hline 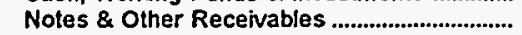 & 1,133 & 1,978 & 1.966 & 334 & 314 & 1,523 \\
\hline Customer Accts Receivable ................................... & 0 & 1,226 & 0 & 1.519 & 912 & 0 \\
\hline (less) Accum Prov for Uncollected Accts ....... & 0 & 0 & 0 & 49 & -2 & 0 \\
\hline 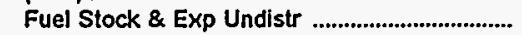 & 0 & 161 & 0 & 728 & 0 & 0 \\
\hline 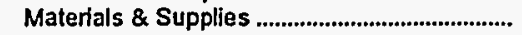 & 120 & 159 & 463 & 322 & 298 & 119 \\
\hline 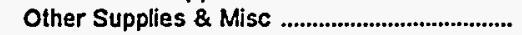 & 0 & 0 & 0 & 0 & 0 & 0 \\
\hline Prepayments .......................................................................... & 11 & 197 & 25 & 106 & 14 & 3 \\
\hline 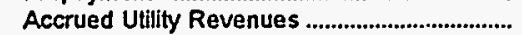 & 0 & 481 & 0 & 598 & 0 & 0 \\
\hline Miscellaneous Current \& Accrued Assets ..... & 26 & 4,036 & 56 & 0 & 54 & 37 \\
\hline Total Current \& Accrued Assets ............... & 1,349 & 9,955 & 6,328 & 7,993 & 2,458 & 2,961 \\
\hline \multicolumn{7}{|l|}{ Deferred Debits } \\
\hline 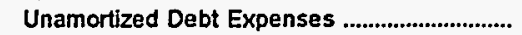 & 0 & 0 & 0 & 0 & 0 & 0 \\
\hline Extraordinary Losses, Study Cost ...................... & 0 & 0 & 0 & 0 & 0 & 0 \\
\hline Misc Debt, $R$ \& D Exp, Unamst Losses .......... & 540 & 0 & 11 & 0 & 16 & 71 \\
\hline Total Deferred Debits ....................................... & 540 & & & 0 & 16 & 71 \\
\hline 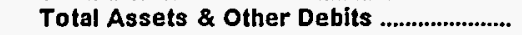 & 4,330 & 22,114 & 14,084 & 33,099 & 12,871 & 9,171 \\
\hline \multicolumn{7}{|l|}{ Proprietary Capital } \\
\hline 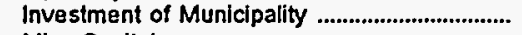 & 0 & 2,059 & 0 & 0 & 0 & o \\
\hline 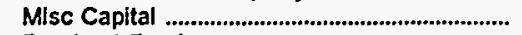 & 0 & 167 & 0 & 0 & 0 & 0 \\
\hline 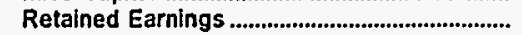 & 2,728 & 15,837 & 10,323 & 30,842 & 11,156 & 8,005 \\
\hline Total Proprietary Capital ........................................ & 2,728 & 18,063 & 10,323 & 30,842 & 11,156 & 8,005 \\
\hline \multicolumn{7}{|l|}{ Long-term Debt } \\
\hline 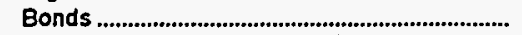 & 0 & 1,830 & 0 & 80 & 0 & o \\
\hline Advances from Municipality \& Other ................. & 562 & 72 & 14 & 12 & 14 & 8 \\
\hline Unamort Prem on Long-term Debt ....................... & 0 & 0 & 0 & 0 & 0 & 0 \\
\hline (less) Unamort Discount on Long-term Debt & 0 & 0 & 0 & 0 & 0 & 0 \\
\hline 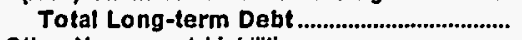 & 562 & 1,902 & 14 & 92 & 14 & 8 \\
\hline \multicolumn{7}{|l|}{ Other Noncurrent Labilities } \\
\hline 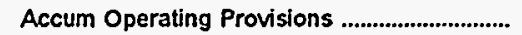 & 0 & 0 & 0 & 0 & 0 & 0 \\
\hline Accurn Prov for Rale Refunds ............................... & a & 0 & 0 & 0 & 0 & 0 \\
\hline Total Other Noncurrent Liabilities .............. & 0 & 0 & 0 & 0 & o & 0 \\
\hline \multicolumn{7}{|l|}{ Current and Accrued Labilities } \\
\hline 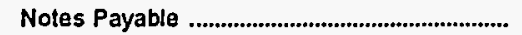 & 0 & 115 & 0 & 0 & 0 & 0 \\
\hline 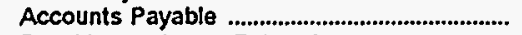 & 812 & 1,143 & 2,681 & 1,286 & 1,118 & 870 \\
\hline Payables to Assoc Enterprises ........................... & 0 & 0 & 0 & 121 & 0 & 0 \\
\hline 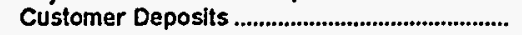 & 192 & 550 & 989 & 497 & 508 & 207 \\
\hline Taxes Accrued ................................................................. & 1 & 42 & 0 & 92 & 46 & 18 \\
\hline 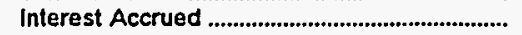 & 0 & 2 & 0 & 0 & 0 & 0 \\
\hline Misc Current \& Accrued Uabilities....................... & 36 & 295 & 72 & 75 & 20 & 63 \\
\hline Total Current \& Accrued Liabilities ........... & 1,041 & 2,149 & 3,742 & 2,071 & 1,692 & 1,159 \\
\hline \multicolumn{7}{|l|}{ Deferred Credits } \\
\hline Customer Advances for Construction .............. & 0 & 0 & 0 & 72 & 0 & 0 \\
\hline Other Deferred Credits .................................................. & 0 & 0 & 5 & 23 & $\boldsymbol{9}$ & 0 \\
\hline 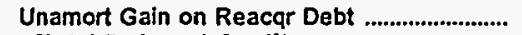 & 0 & 0 & 0 & 0 & 0 & 0 \\
\hline Total Deferred Credits ........................................ & 0 & 0 & 5 & 94 & 9 & 0 \\
\hline Total Liabilities and Other Credits ............. & 4,330 & 22,114 & 14,084 & 33,099 & 12,871 & 9,171 \\
\hline
\end{tabular}

Note: Totals may not equal sum of components because of independent rounding.

Source: Energy Information Administration, Form EIA-412, "Annual Report of Public Electric Utilities." 
Table 22. Balance Sheet by Major U.S. Publicly Owned Electric Utility Within State at End of Period, 1995 (Thousand Dollars)

\begin{tabular}{|c|c|c|c|c|c|c|}
\hline Item & $\begin{array}{l}\text { Mississippi } \\
\text { Municipal } \\
\text { Energy } \\
\text { Agency } \\
\text { of MS } \\
\text { September } 30\end{array}$ & $\begin{array}{l}\text { Mississippi } \\
\text { New Albany } \\
\text { City of } \\
\text { June } 30\end{array}$ & $\begin{array}{l}\text { Mississippi } \\
\text { Oxford } \\
\text { City of } \\
\text { June } 30\end{array}$ & $\begin{array}{l}\text { Mississippi } \\
\text { Starkville } \\
\text { City of } \\
\text { June } 30\end{array}$ & $\begin{array}{l}\text { Mississippi } \\
\text { Tupelo } \\
\text { City of } \\
\text { June } 30\end{array}$ & $\begin{array}{c}\text { Mississippi } \\
\text { West } \\
\text { Point } \\
\text { City of } \\
\\
\text { June } 30\end{array}$ \\
\hline \multicolumn{7}{|l|}{ Electric Utility Plant } \\
\hline 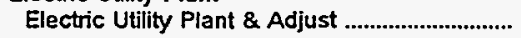 & 771 & 12,304 & 6.168 & 12,906 & 24,764 & 7,132 \\
\hline Const Work in Progress & 8,713 & 527 & 2,201 & 3,271 & 81 & 275 \\
\hline $\begin{array}{l}\text { (less) Depr, Amort, and Depletion } \\
\text { Net Electric Utility Plant }\end{array}$ & $\begin{array}{r}216 \\
9,268\end{array}$ & $\begin{array}{l}4,483 \\
8,348\end{array}$ & $\begin{array}{l}2,339 \\
6,030\end{array}$ & $\begin{array}{r}4,353 \\
11,823\end{array}$ & $\begin{array}{r}7,988 \\
16,857\end{array}$ & $\begin{array}{l}2,681 \\
4,726\end{array}$ \\
\hline 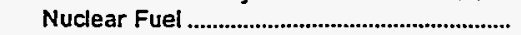 & 0 & 0 & 0 & 0 & 0 & 0 \\
\hline 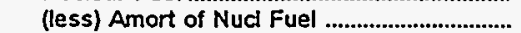 & 0 & 0 & 0 & 0 & 0 & 0 \\
\hline Net Elec Plant Incl Nucl Fuel .......................... & 9,268 & 8,348 & 6,030 & 11,823 & 16,857 & 4,726 \\
\hline \multicolumn{7}{|l|}{ Other Property \& Investments } \\
\hline 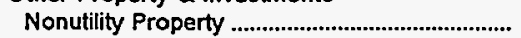 & 0 & 0 & 0 & 0 & 0 & 0 \\
\hline (less) Accum Provisions for Depr \& Amort .... & 0 & 0 & 0 & 0 & 0 & 0 \\
\hline 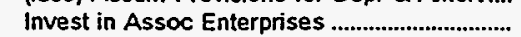 & 0 & 0 & 0 & 0 & 0 & 0 \\
\hline 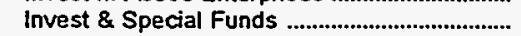 & 4,477 & 138 & 11 & 2,058 & 23 & 93 \\
\hline Total Other Property \& Investments ....... & 4,477 & 138 & 11 & 2,058 & 23 & 93 \\
\hline \multicolumn{7}{|l|}{ Current and Accrued Assets } \\
\hline 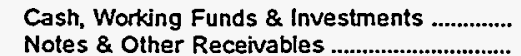 & $\begin{array}{r}1,702 \\
18\end{array}$ & $\begin{array}{l}1,988 \\
2,157\end{array}$ & $\begin{array}{r}440 \\
1,613\end{array}$ & $\begin{array}{l}3,402 \\
1,668\end{array}$ & $\begin{array}{l}4,128 \\
4,045\end{array}$ & $\begin{array}{r}250 \\
1,192\end{array}$ \\
\hline 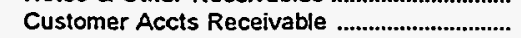 & 2,982 & 0 & 0 & 0 & 0 & 0 \\
\hline (less) Accum Prov for Uncollected Accts ...... & 0 & 0 & 0 & 0 & 0 & 0 \\
\hline 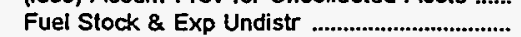 & 0 & 0 & 0 & 0 & 0 & 0 \\
\hline 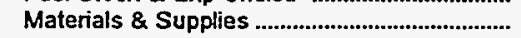 & 0 & 296 & 168 & 263 & 351 & 187 \\
\hline 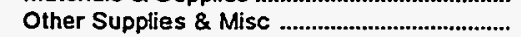 & 0 & 0 & 0 & 0 & 0 & 0 \\
\hline 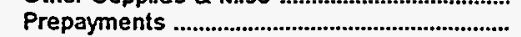 & 10 & 18 & 22 & 36 & 35 & 24 \\
\hline Accrued Utility Revenues & 0 & 0 & 0 & 0 & 0 & 0 \\
\hline Miscellaneous Current \& Accrued Assets ..... & 66 & 57 & 12 & 41 & 30 & 2 \\
\hline $\begin{array}{l}\text { Total Current \& Accrued Assets ............... } \\
\text { Deferred Debits }\end{array}$ & 4,778 & 4,516 & 2,254 & 5,411 & 8,589 & 1,654 \\
\hline 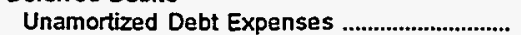 & 0 & 0 & 0 & 87 & 0 & 3 \\
\hline 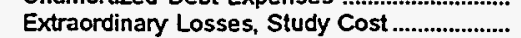 & 0 & 0 & 2 & 1,158 & 0 & $\ddot{0}$ \\
\hline 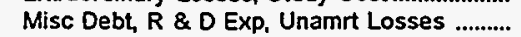 & 0 & 85 & 122 & 6 & 296 & 41 \\
\hline Total Deferred Debits & $\mathbf{0}$ & 85 & 124 & 1,252 & 296 & 43 \\
\hline 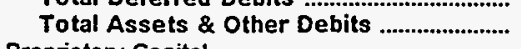 & 18,523 & 13,086 & 8,419 & 20,543 & 25,765 & 6,517 \\
\hline \multicolumn{7}{|l|}{ Proprietary Capital } \\
\hline 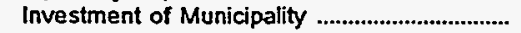 & 0 & 0 & 0 & 0 & 0 & 0 \\
\hline Misc Capital & 0 & 0 & 0 & 0 & 0 & 0 \\
\hline 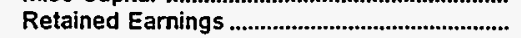 & 8,381 & 11,352 & 5,747 & 9,027 & 20,525 & 4,884 \\
\hline \multicolumn{7}{|l|}{ Long-term Debt } \\
\hline Bonds & 4,555 & 66 & 0 & 5,525 & 0 & 180 \\
\hline Advances from Municipality \& Other ............... & 0 & 47 & 92 & 6 & 322 & 22 \\
\hline 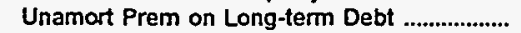 & 0 & 0 & 0 & 0 & 0 & 0 \\
\hline (less) Unamort Discount on Long-term Debt & 0 & 0 & 0 & 0 & 0 & 0 \\
\hline Total Long-term Debt & 4,555 & 113 & 92 & 5,531 & 322 & 202 \\
\hline \multicolumn{7}{|l|}{ Other Noncurrent Liabilities } \\
\hline Accum Operating Provisions .............................. & 66 & 0 & 0 & 0 & 0 & 0 \\
\hline 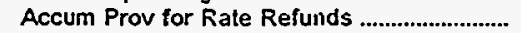 & 0 & 0 & 0 & 0 & 0 & 0 \\
\hline Total Other Noncurrent Liabilities ............. & 66 & 0 & 0 & $\mathbf{0}$ & 0 & 0 \\
\hline \multicolumn{7}{|l|}{ Current and Accrued Labilities } \\
\hline 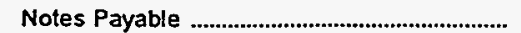 & 1,070 & 0 & 0 & 178 & 0 & \\
\hline 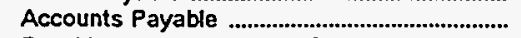 & 4,295 & 931 & 1,625 & 4,482 & 3,840 & 1.112 \\
\hline Payables to Assoc Enterprises ............................ & 0 & 0 & 0 & 0 & 0 & 0 \\
\hline 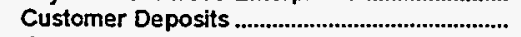 & 0 & 587 & 709 & 1,058 & 891 & 282 \\
\hline 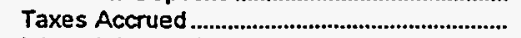 & 0 & 0 & 85 & 3 & 0 & 0 \\
\hline Interest Accrued & 156 & 5 & 0 & 22 & 0 & 15 \\
\hline Misc Current \& Accrued Liabilities................... & 0 & 102 & 156 & 200 & 187 & 23 \\
\hline Total Current \& Accrued Liabilities .......... & 5,521 & 1,625 & 2,574 & 5,943 & 4,918 & 1,431 \\
\hline \multicolumn{7}{|l|}{ Deferred Credits } \\
\hline Customer Advances for Construction ............. & 0 & 0 & 0 & 0 & 0 & 0 \\
\hline 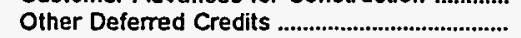 & 0 & -4 & 6 & 43 & 0 & 0 \\
\hline 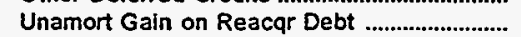 & 0 & 0 & 0 & 0 & 0 & 0 \\
\hline 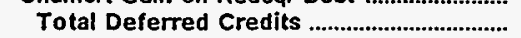 & $\mathbf{0}$ & -4 & 6 & 43 & $\mathbf{0}$ & o \\
\hline Total Liabilities and Other Credits ............ & 18,523 & 13,086 & 8,419 & 20,543 & 25,765 & 6,517 \\
\hline
\end{tabular}

Note: Totals may not equal sum of components because of independent rounding.

Source: Energy Information Administration, Form ElA-412, "Annual Report of Public Electric Utilities." 
Table 22. Balance Sheet by Major U.S. Publicly Owned Electric Utility Within State at End of Period, 1995 (Thousand Dollars)

\begin{tabular}{|c|c|c|c|c|c|c|}
\hline Item & $\begin{array}{l}\text { Missouri } \\
\text { Carthage } \\
\text { City of } \\
\text { June } 30\end{array}$ & $\begin{array}{l}\text { Missouri } \\
\text { Columbia } \\
\text { City of } \\
\text { September } 30\end{array}$ & $\begin{array}{l}\text { Missouri } \\
\text { Hannibal } \\
\text { City of } \\
\text { June } 30\end{array}$ & $\begin{array}{c}\text { Independence } \\
\text { City of } \\
\text { June } 30\end{array}$ & $\begin{array}{l}\text { Missouri } \\
\text { Kennett } \\
\text { City of } \\
\text { June } 30\end{array}$ & $\begin{array}{l}\text { Missouri } \\
\text { Kirkwood } \\
\text { City of } \\
\text { March } 31\end{array}$ \\
\hline \multicolumn{7}{|l|}{ Electric Utility Plant } \\
\hline Electric Utility Plant \& Adjust ................................ & 21,289 & 80,582 & 10,823 & 161,339 & 14,358 & 4,659 \\
\hline 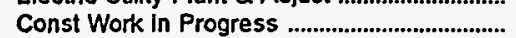 & 16 & 5,566 & 89 & 26,327 & 0 & 554 \\
\hline $\begin{array}{l}\text { (less) Depr, Amort, and Depletion } \\
\text { Net Electric Utility Plant }\end{array}$ & $\begin{array}{r}14,415 \\
6,891\end{array}$ & $\begin{array}{l}34,863 \\
51,284\end{array}$ & $\begin{array}{l}7,402 \\
3,510\end{array}$ & $\begin{array}{l}93,120 \\
94,546\end{array}$ & $\begin{array}{r}11,343 \\
3,015\end{array}$ & $\begin{array}{l}2,753 \\
2,460\end{array}$ \\
\hline Nuclear Fuel & 0 & 0 & 0 & $\begin{array}{r}0,4,2+0 \\
0\end{array}$ & 0 & 0 \\
\hline (less) Amort of Nucl Fuel ........................ & 0 & 0 & 0 & 0 & 0 & 0 \\
\hline 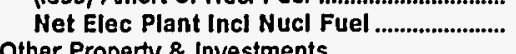 & 6,891 & 51,284 & $\mathbf{3 , 5 1 0}$ & 94,546 & 3,015 & 2,460 \\
\hline \multicolumn{7}{|l|}{ Other Property \& Investments } \\
\hline Nonutility Property & 0 & 44,135 & 0 & 0 & 0 & 0 \\
\hline (less) Accum Provisions for Depr \& Amort.... & 0 & 10,936 & 0 & 0 & 0 & 0 \\
\hline 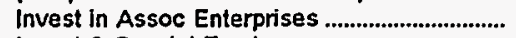 & 0 & 0 & 1,095 & 0 & 0 & 0 \\
\hline 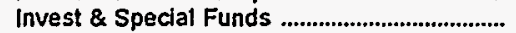 & 104 & 21,412 & 6,642 & 16,854 & 0 & 0 \\
\hline \multicolumn{7}{|l|}{ Current and Accrued Assets } \\
\hline Cash, Working Funds \& Investments .............. & 3,048 & 9.548 & 3,010 & 16,714 & 2,439 & 6,853 \\
\hline Notes \& Other Receivables .............................. & 14 & 311 & 100 & 284 & 0 & 0 \\
\hline 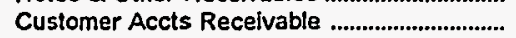 & 625 & 6,074 & 886 & 3,333 & 129 & 981 \\
\hline (less) Accum Prov for Uncollected Accts ...... & 20 & 71 & 20 & 188 & 0 & 0 \\
\hline 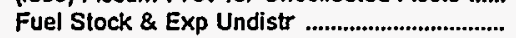 & 0 & 360 & 0 & 3,598 & 97 & 0 \\
\hline 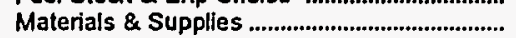 & 357 & 2,777 & 245 & 3,956 & 0 & 101 \\
\hline 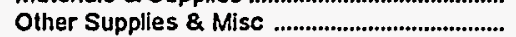 & 0 & 465 & 0 & 0 & 0 & 0 \\
\hline 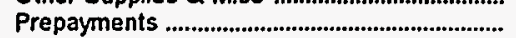 & 63 & 47 & 61 & 29 & 331 & 3 \\
\hline 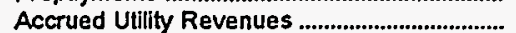 & 0 & 2,274 & 0 & 3,715 & 0 & 0 \\
\hline Miscellaneous Current \& Accrued Assets ..... & 21 & 1,259 & 0 & 447 & 0 & 0 \\
\hline Total Current \& Accrued Assets ............... & 4,108 & 23,044 & 4,282 & 31,888 & 2,996 & 7,939 \\
\hline \multicolumn{7}{|l|}{ Deferred Debits } \\
\hline Unamortized Debt Expenses ............................ & $\mathbf{t 1 2}$ & 377 & 0 & 2,867 & 0 & 0 \\
\hline 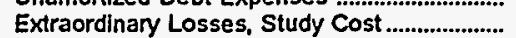 & 0 & 0 & 0 & 0 & 0 & 0 \\
\hline Misc Debt, R \& D Exp, Unamrt Losses ......... & 0 & 0 & 0 & 2,085 & 0 & 0 \\
\hline 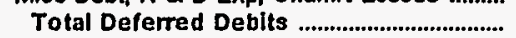 & 112 & 377 & $\mathbf{0}$ & 4,952 & 0 & 0 \\
\hline 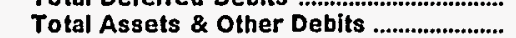 & 11,216 & 129,317 & 15,528 & 148,240 & 6,011 & 10,399 \\
\hline \multicolumn{7}{|l|}{ Proprietary Capital } \\
\hline 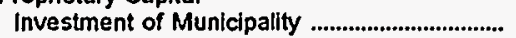 & 0 & 1,255 & 0 & 0 & 191 & 0 \\
\hline Misc Capital & 236 & 0 & 0 & 0 & 12 & 268 \\
\hline 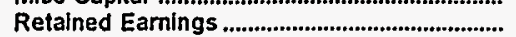 & 6,895 & 67,645 & 14,072 & 105,874 & 5,130 & 8,073 \\
\hline $\begin{array}{l}\text { Total Proprietary Capital } \\
\text { Leng................................... }\end{array}$ & 7,131 & 68,900 & 14,072 & 105,874 & 5,333 & 8,341 \\
\hline Bonds & 0 & 50,085 & \multicolumn{4}{|c|}{ Long-term Debt } \\
\hline Advances from Municipality \& Other ............... & 2,668 & $\begin{array}{r}00,000 \\
0\end{array}$ & 0 & $\begin{array}{r}34,185 \\
0\end{array}$ & $\begin{array}{l}0 \\
0\end{array}$ & 1,227 \\
\hline Unamort Prem on Long-term Debt ................. & 0 & 0 & 0 & 0 & 0 & 0 \\
\hline (less) Unamort Dlscount on Long-term Debt & $\mathbf{0}$ & 391 & 0 & 0 & 0 & 0 \\
\hline 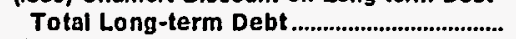 & 2,668 & 49,694 & 0 & 34,185 & 0 & 1,227 \\
\hline \multicolumn{7}{|l|}{ Other Noncurrent Uabillties } \\
\hline Accum Operating Provisions ................................ & 0 & 0 & 302 & 1,774 & 0 & 26 \\
\hline 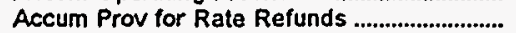 & 0 & 0 & 0 & 0 & 0 & 0 \\
\hline Total Other Noncurrent Liabilities ............ & 0 & 0 & 302 & 1,774 & 0 & 26 \\
\hline \multicolumn{7}{|l|}{ Current and Accrued Uabilities } \\
\hline 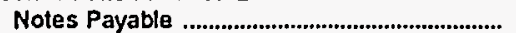 & 0 & 0 & 0 & 0 & 0 & o \\
\hline 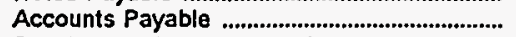 & 699 & 3.270 & 1,017 & 3,340 & 294 & 468 \\
\hline Payables to Assoc Enterprises .......................... & 0 & 0 & 0 & 0 & 0 & 8 \\
\hline Customer Deposits ............................................... & 98 & 1,709 & 134 & 820 & 278 & 84 \\
\hline 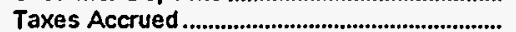 & 0 & 555 & 0 & 0 & 0 & 0 \\
\hline 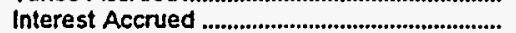 & 619 & 1,108 & 0 & 190 & 0 & 16 \\
\hline Misc Current \& Accrued Liabilities................... & 0 & 4,081 & 3 & 950 & 106 & 186 \\
\hline Total Current \& Accrued Liabilities .......... & 1,417 & 10,723 & 1,154 & 5,299 & 678 & 761 \\
\hline \multicolumn{7}{|l|}{ Deferred Credits } \\
\hline Customer Advances for Construction ............. & 0 & 0 & 0 & 1,108 & $\mathbf{0}$ & 0 \\
\hline 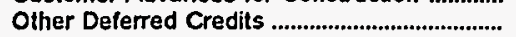 & 0 & 0 & 0 & 0 & 0 & 44 \\
\hline 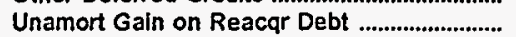 & 0 & 0 & 0 & 0 & 0 & 0 \\
\hline 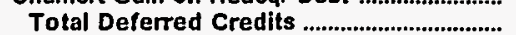 & 0 & 0 & 0 & 1,108 & $\mathbf{0}$ & 44 \\
\hline Total Llabilities and Other Credits ............ & 11,216 & 129,317 & 15,528 & 148,240 & 6,011 & 10,399 \\
\hline
\end{tabular}

Note: Totals may not equal sum of components because of independent rounding.

Source: Energy Information Administration. Form ElA-412, "Annual Report of Public Electric Utilities." 
Table 22. Balance Sheet by Major U.S. Publicly Owned Electric Utility Within State at End of Period, 1995 (Thousand Dollars)

\begin{tabular}{|c|c|c|c|c|c|c|}
\hline Item & $\begin{array}{l}\text { Missouri } \\
\text { Lebanon } \\
\text { City of } \\
\text { October } 31\end{array}$ & $\begin{array}{l}\text { Missouri } \\
\text { Marshalf } \\
\text { City of } \\
\text { September } 30\end{array}$ & $\begin{array}{l}\text { Missouri } \\
\text { Monett } \\
\text { City of } \\
\text { March } 31\end{array}$ & $\begin{array}{c}\text { Missouri } \\
\text { Poplar } \\
\text { Bluff } \\
\text { City of } \\
\text { December } 31\end{array}$ & $\begin{array}{c}\text { Missouri } \\
\text { Rolla } \\
\text { City of } \\
\text { September } 30\end{array}$ & $\begin{array}{l}\text { Sikeston } \\
\text { City of } \\
\text { May } 31\end{array}$ \\
\hline \multicolumn{7}{|l|}{ Electric Utility Plant } \\
\hline Electric Utility Plant \& Adjust ............................. & $\mathbf{0}$ & 40,385 & 4,972 & 23,290 & 10,075 & 222,080 \\
\hline Const Work in Progress & 0 & 235 & 0 & 0 & 33 & 925 \\
\hline $\begin{array}{l}\text { (less) Depr, Amort, and Depletion } \\
\text { Net Electric Utility Plant }\end{array}$ & $\begin{array}{l}0 \\
0\end{array}$ & $\begin{array}{l}18,733 \\
\mathbf{2 1 , 8 8 7}\end{array}$ & $\begin{array}{l}3,319 \\
1,653\end{array}$ & $\begin{array}{r}9,578 \\
13,712\end{array}$ & $\begin{array}{l}6,608 \\
3,500\end{array}$ & $\begin{array}{r}69,272 \\
153,733\end{array}$ \\
\hline 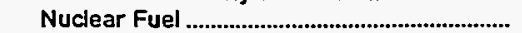 & 0 & 0 & 0 & 0 & 0 & 0 \\
\hline 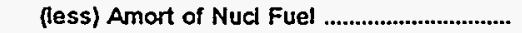 & 0 & 0 & 0 & $\mathbf{0}$ & 0 & 0 \\
\hline Net Elec Plant Incl Nuci Fuel ........................ & $\mathbf{0}$ & 21,887 & 1,653 & 13,712 & 3,500 & 153,733 \\
\hline \multicolumn{7}{|l|}{ Other Property \& Investments } \\
\hline Nonutility Property & 0 & 0 & 0 & 0 & 6,105 & $\mathbf{0}$ \\
\hline (less) Accum Provisions for Depr \& Amort.... & 0 & 0 & 0 & 0 & 3,150 & 0 \\
\hline 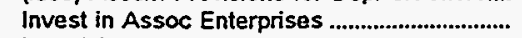 & 0 & 0 & 0 & 0 & 0 & 0 \\
\hline 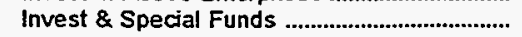 & 0 & 0 & 0 & 12,230 & 4,684 & 33,586 \\
\hline Total Other Property \& investments ....... & $\mathbf{0}$ & 0 & 0 & 12,230 & 7,638 & 33,586 \\
\hline \multicolumn{7}{|l|}{ Current and Accrued Assets } \\
\hline Cash, Working Funds \& Investments ............. & $\mathbf{0}$ & 7,452 & 17.459 & 1,251 & 830 & 10,725 \\
\hline 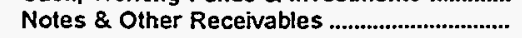 & 0 & 156 & 567 & 15 & 0 & 170 \\
\hline Customer Accts Receivable ............................... & 0 & 994 & 0 & 680 & 902 & 7,063 \\
\hline (less) Accum Prov for Uncollected Accts ...... & 0 & 0 & 0 & 129 & 15 & 121 \\
\hline 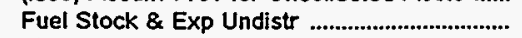 & 0 & 32 & 0 & 63 & 0 & 11,819 \\
\hline 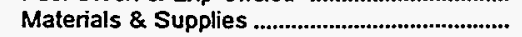 & 0 & 787 & 0 & 0 & 388 & 2,086 \\
\hline 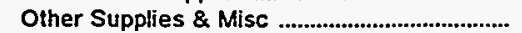 & 0 & 0 & 0 & 517 & 0 & 0 \\
\hline 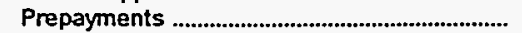 & 0 & 110 & 0 & 42 & 23 & 264 \\
\hline 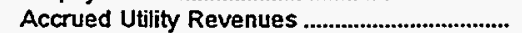 & 0 & 210 & 0 & 824 & 0 & 0 \\
\hline Miscellaneous Current \& Accrued Assets ..... & $\mathbf{0}$ & 94 & 0 & 3,259 & 88 & 685 \\
\hline Total Current \& Accrued Assets ............... & $\mathbf{0}$ & 9,835 & 18,026 & 6,521 & 2,216 & 32,691 \\
\hline \multicolumn{7}{|l|}{ Deferred Debits } \\
\hline 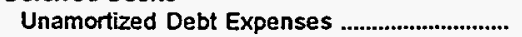 & 0 & 0 & 0 & 0 & 0 & 16,011 \\
\hline 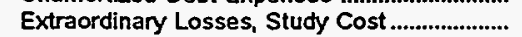 & 0 & 0 & 0 & 0 & 0 & 0 \\
\hline Misc Debt, R \& D Exp, Unamrt Losses .......... & 0 & 0 & 0 & 0 & 0 & 173 \\
\hline 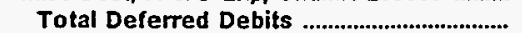 & $\mathbf{0}$ & $\mathbf{0}$ & $\mathbf{0}$ & $\mathbf{0}$ & $\mathbf{0}$ & 16,184 \\
\hline 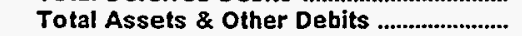 & 0 & 31,722 & 19,680 & 32,463 & 13,355 & 236,195 \\
\hline \multicolumn{7}{|l|}{ Proprietary Capital } \\
\hline 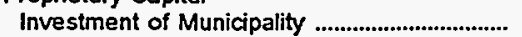 & $\mathbf{0}$ & 180 & 0 & 0 & 64 & $\mathbf{0}$ \\
\hline 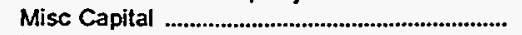 & 0 & $\mathbf{0}$ & 0 & 0 & 0 & 0 \\
\hline 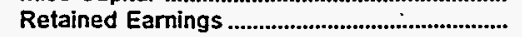 & 0 & 28,254 & 19,060 & 31,283 & 11,866 & -266 \\
\hline Total Proprietary Capital .................................. & 0 & 28,434 & 19,060 & 31,283 & 11,929 & -266 \\
\hline \multicolumn{7}{|l|}{ Long-term Debt } \\
\hline Bonds & 0 & 1,450 & 0 & 0 & 0 & 222,435 \\
\hline Advances from Municipality \& Other ................ & 0 & 0 & 0 & 0 & 0 & 0 \\
\hline 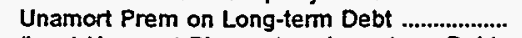 & 0 & 0 & 0 & 0 & 0 & 0 \\
\hline (less) Unamort Discount on Long-term Debt & 0 & $\mathbf{0}$ & 0 & 0 & 0 & 4,343 \\
\hline Total Long-term Debt & 0 & 1,450 & 0 & $\mathbf{0}$ & 0 & 218,092 \\
\hline \multicolumn{7}{|l|}{ Other Noncurrent Liabilities } \\
\hline 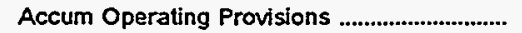 & 0 & 0 & 0 & 0 & 0 & 0 \\
\hline 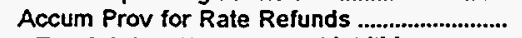 & 0 & 0 & 0 & 0 & 0 & $\mathbf{0}$ \\
\hline Total Other Noncurrent Ljabilities ............ & $\mathbf{0}$ & $\mathbf{0}$ & 0 & $\mathbf{0}$ & $\mathbf{0}$ & 0 \\
\hline \multicolumn{7}{|l|}{ Current and Accrued Liabilities } \\
\hline 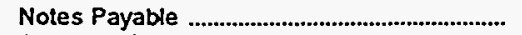 & 0 & 0 & 0 & 0 & 0 & $\mathbf{0}$ \\
\hline Accounts Payable & 0 & 1,072 & 473 & 674 & 805 & 1,260 \\
\hline 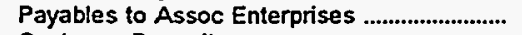 & 0 & 0 & 0 & 0 & 200 & 0 \\
\hline Customer Deposits & 0 & 177 & 147 & 167 & 309 & 321 \\
\hline Taxes Accrued & 0 & 239 & 0 & 30 & 0 & 16 \\
\hline Interest Accrued & 0 & 22 & $\mathbf{0}$ & 0 & 0 & 6,769 \\
\hline Misc Current \& Accrued Labilities..................... & 0 & 328 & 0 & 200 & 111 & 749 \\
\hline Total Current \& Accrued Liabilities .......... & $\mathbf{0}$ & 1,838 & 620 & 1,072 & 1,425 & 9,116 \\
\hline \multicolumn{7}{|l|}{ Deferred Credits } \\
\hline Customer Advances for Construction .............. & 0 & 0 & 0 & 109 & 0 & $\mathbf{0}$ \\
\hline 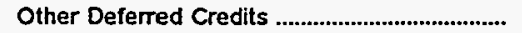 & 0 & 0 & 0 & 0 & 0 & 9,253 \\
\hline 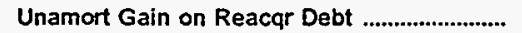 & 0 & 0 & 0 & 0 & 0 & 0 \\
\hline 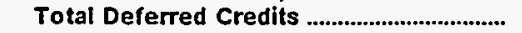 & $\mathbf{0}$ & 0 & 0 & 109 & 0 & 9,253 \\
\hline Total Liabilities and Other Credits ............ & $\mathbf{0}$ & 31,722 & 19,680 & 32,463 & 13,355 & 236,195 \\
\hline
\end{tabular}

Note: Totals may not equal sum of components because of independent rounding.

Source: Energy Information Administration, Form ElA-412, "Annual Report of Public Electric Utilities." 
Table 22. Balance Sheet by Major U.S. Publicly Owned Electric Utility Within State at End of Period, 1995

(Thousand Doliars)

\begin{tabular}{|c|c|c|c|c|c|c|}
\hline Item & $\begin{array}{l}\text { Missouri } \\
\text { Springfield } \\
\text { City of } \\
\text { September } 30\end{array}$ & $\begin{array}{l}\text { Missouri } \\
\text { West } \\
\text { Plains } \\
\text { City of } \\
\text { December } 31\end{array}$ & $\begin{array}{c}\text { Beatrice } \\
\text { City of }\end{array}$ & $\begin{array}{c}\text { Nebraska } \\
\text { Central } \\
\text { Nebraska } \\
\text { Pub } \\
\text { P\&l Dist } \\
\text { December 31 }\end{array}$ & $\begin{array}{c}\text { Nebraska } \\
\text { Cornhusker } \\
\text { Public } \\
\text { Power Dist } \\
\text { December } 31\end{array}$ & $\begin{array}{c}\text { Nebraska } \\
\text { Dawson } \\
\text { County } \\
\text { Public } \\
\text { Pwr Dist } \\
\text { December } 31\end{array}$ \\
\hline \multicolumn{7}{|l|}{ Electric Utility Plant } \\
\hline 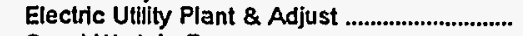 & 426,810 & 5.425 & 13,059 & 118,815 & 34,088 & 48,106 \\
\hline Const Work in Progress & 13,512 & 0 & 1,182 & 120 & 125 & 2,521 \\
\hline (less) Depr, Amort, and Depletion ..................... & $\begin{array}{l}134,805 \\
305,517\end{array}$ & & $\begin{array}{l}7,589 \\
6,652\end{array}$ & $\begin{array}{l}39,937 \\
78,997\end{array}$ & 10,902 & 20,641 \\
\hline 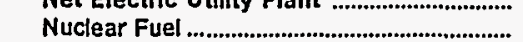 & 0 & 0 & 0 & 0 & 0 & $\begin{array}{r}29,300 \\
0\end{array}$ \\
\hline 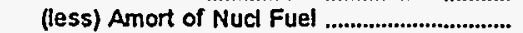 & 0 & 0 & 0 & 0 & 0 & 0 \\
\hline $\begin{array}{l}\text { Net Elec Plant Incl Nucl Fuel ........................... } \\
\text { Other Property \& Investments }\end{array}$ & 305,517 & 5,425 & 6,652 & 78,997 & 23,311 & 29,986 \\
\hline 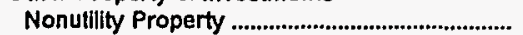 & 0 & 15,440 & 0 & 68 & 0 & 19 \\
\hline (less) Accum Provisions for Depr \& Amort .... & 0 & 6,562 & 0 & 0 & 0 & 2 \\
\hline Invest In Assoc Enterprises ................................ & $\mathbf{0}$ & 39 & 0 & 0 & 774 & 43 \\
\hline 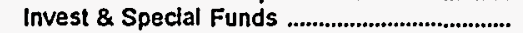 & 125,313 & 597 & 0 & 10,804 & 1,617 & 1.165 \\
\hline Total Other Property \& Investments ....... & 125,313 & 9,514 & 0 & 10,871 & 2,391 & 1,225 \\
\hline \multicolumn{7}{|l|}{ Cument and Accrued Assets } \\
\hline 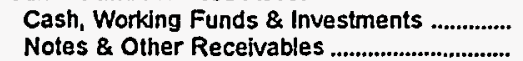 & $\begin{array}{r}10,353 \\
766\end{array}$ & $\begin{array}{r}680 \\
50\end{array}$ & $\begin{array}{r}919 \\
0\end{array}$ & $\begin{array}{l}4,470 \\
5,800\end{array}$ & $\begin{array}{r}1,887 \\
23\end{array}$ & $\begin{array}{r}13,798 \\
1,740\end{array}$ \\
\hline Customer Accts Receivable .............................. & 12,748 & 933 & 618 & 0 & 1,763 & 1,903 \\
\hline (less) Accum Prov for Uncollected Accts ...... & 100 & 0 & 81 & 4 & 20 & 84 \\
\hline 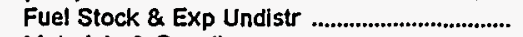 & 8,165 & 0 & 0 & 0 & 3 & 0 \\
\hline 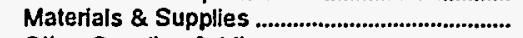 & 10.690 & 775 & 0 & 561 & 486 & 998 \\
\hline 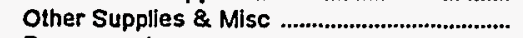 & $\mathbf{0}$ & 0 & 306 & 0 & 0 & 156 \\
\hline 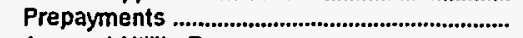 & 329 & 17 & 12 & 97 & 34 & 103 \\
\hline Accrued Utility Revenues ................................... & 0 & 0 & 320 & 0 & 0 & $\mathbf{0}$ \\
\hline Miscellaneous Current \& Accrued Assets ..... & 0 & 0 & 12 & 3,246 & 25 & 84 \\
\hline $\begin{array}{l}\text { Total Current \& Accrued Assets ............... } \\
\text { Deferred Debits }\end{array}$ & 42,953 & 2,455 & 2,107 & 14,170 & 4,203 & 18,698 \\
\hline 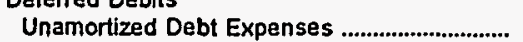 & 333 & 0 & 0 & $\mathbf{0}$ & 353 & 16 \\
\hline Extraordinary Losses, Study Cost ......................... & 0 & 0 & 0 & 36 & 0 & 0 \\
\hline Misc Debt, R \& D Exp, Unamrt Losses ......... & 11,572 & 0 & 0 & 16 & 525 & 211 \\
\hline Total Deferred Debits & 11,905 & $\mathbf{0}$ & 0 & 53 & 878 & 226 \\
\hline Total Assets \& Other Debits ......................... & 485,688 & 17,394 & 8,759 & 104,092 & 30,783 & 50,136 \\
\hline \multicolumn{7}{|l|}{ Proprietary Capital } \\
\hline Investment of Municipality & 0 & 5,605 & 180 & $\mathbf{0}$ & 0 & 0 \\
\hline 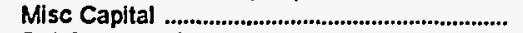 & 0 & 1,502 & 375 & 0 & 0 & 0 \\
\hline 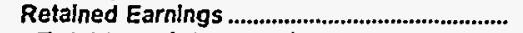 & 344,449 & 8,151 & 7,142 & 49,057 & 15,993 & 35.954 \\
\hline \multicolumn{7}{|l|}{ Long-term Debt } \\
\hline 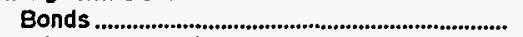 & 90,295 & 625 & 0 & $\mathbf{0}$ & 10,515 & 0 \\
\hline Advances from Municipality \& Other ................ & 15,722 & 408 & 0 & 0 & 0 & 11.100 \\
\hline Unamort Prem an Long-term Debt .................. & 0 & 0 & 0 & 0 & 0 & 0 \\
\hline (less) Unamort Discount on Long-term Debt & 1,006 & 0 & 0 & 0 & 0 & 0 \\
\hline Total Long-term Debt & 105,010 & 1,033 & 0 & $\mathbf{0}$ & 10,515 & 11,100 \\
\hline \multicolumn{7}{|l|}{ Other Noncurrent Labilities } \\
\hline 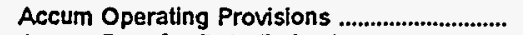 & 8,831 & 0 & 0 & 1,122 & 0 & 973 \\
\hline Accum Prov for Rate Refunds .......................... & $\mathbf{0}$ & 0 & 0 & 0 & 0 & 0 \\
\hline $\begin{array}{l}\text { Total Other Noncurrent Liabilities ............ } \\
\text { Current and Accrued Labilities }\end{array}$ & 8,831 & $\mathbf{0}$ & $\mathbf{0}$ & 1,122 & $\mathbf{0}$ & 973 \\
\hline 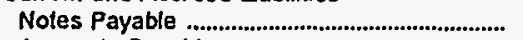 & 0 & 72 & 0 & 0 & 0 & 0 \\
\hline 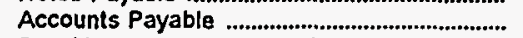 & 7,654 & 713 & 748 & 903 & 742 & 986 \\
\hline 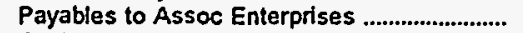 & 1,126 & 0 & 159 & 0 & 0 & 0 \\
\hline 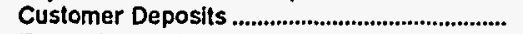 & 872 & 298 & 74 & 1 & 71 & 171 \\
\hline Taxes Accrued & 0 & 0 & 61 & 8 & 34 & 90 \\
\hline Interest Accrued & 1,411 & 0 & 0 & 0 & 194 & 15 \\
\hline Misc Current \& Accrued Labilities.................... & 6,571 & 19 & 19 & 402 & 166 & 727 \\
\hline \multicolumn{6}{|l|}{ Deferred Credits } & 1,988 \\
\hline Customer Advances for Construction .............. & 1 & 0 & 0 & 0 & 0 & 0 \\
\hline 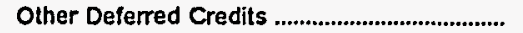 & 9,764 & 0 & 0 & 52,599 & 124 & 121 \\
\hline Unamort Gain on Reacqr Debt .......................... & 0 & 0 & 0 & 0 & 2,945 & 0 \\
\hline 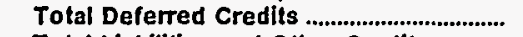 & 9,765 & $\mathbf{0}$ & 0 & 52,599 & 3,068 & 121 \\
\hline Total Llabilities and Other Credits ............. & 485,688 & 17,394 & 8,759 & 104,092 & 30,783 & 50,136 \\
\hline
\end{tabular}

Note: Totals may not equal sum of components because of independent rounding.

Source: Energy Information Administration, Form EIA-412, "Annual Report of Public Electric Utilities." 
Table 22. Balance Sheet by Major U.S. Publicly Owned Electric Utility Within State at End of Period, 1995 (Thousand Dollars)

\begin{tabular}{|c|c|c|c|c|c|c|}
\hline Item & $\begin{array}{l}\text { Nebraska } \\
\text { Fremont } \\
\text { City of } \\
\text { July } 31\end{array}$ & $\begin{array}{c}\text { Nebraska } \\
\begin{array}{c}\text { Grand Island } \\
\text { City of }\end{array} \\
\text { July } 31\end{array}$ & $\begin{array}{c}\text { Nebraska } \\
\text { Hastings } \\
\text { City of } \\
\text { December } 31\end{array}$ & $\begin{array}{c}\text { Nebraska } \\
\text { Lincoln } \\
\text { Electric } \\
\text { System } \\
\text { December } 31\end{array}$ & $\begin{array}{c}\text { Nebraska } \\
\text { Loup } \\
\text { River } \\
\text { Public } \\
\text { Power Dist } \\
\text { December } 31\end{array}$ & $\begin{array}{l}\text { Nebraska } \\
\text { Municipal } \\
\text { Energy } \\
\text { Agency } \\
\text { of NE } \\
\text { March } 31\end{array}$ \\
\hline \multicolumn{7}{|l|}{ Electric Utility Plant } \\
\hline Electric Utility Plant \& Adjust ................................ & 67,044 & 166,560 & 107,369 & 451,221 & 57,804 & 33.449 \\
\hline Const Work in Progress & 1,494 & 1.211 & 433 & 45,560 & 3,815 & 0 \\
\hline 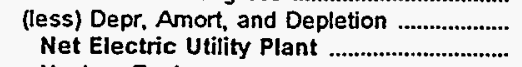 & $\begin{array}{l}49,538 \\
19,000\end{array}$ & $\begin{array}{l}72,059 \\
95,712\end{array}$ & $\begin{array}{l}39,730 \\
68,072\end{array}$ & $\begin{array}{l}150,576 \\
346,206\end{array}$ & $\begin{array}{l}25,725 \\
35,894\end{array}$ & $\begin{array}{r}2,523 \\
30,926\end{array}$ \\
\hline 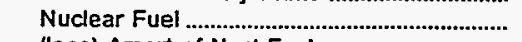 & 0 & 0 & 0 & 0 & 0 & 0 \\
\hline 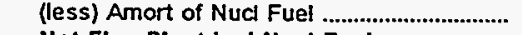 & 0 & 0 & 0 & 0 & 0 & 0 \\
\hline $\begin{array}{l}\text { Net Elec Plant Inct Nucl Fuel } \\
\text { Other........................ }\end{array}$ & 19,000 & 95,712 & 68,072 & 346,206 & 35,894 & 30,926 \\
\hline Nonutility Property & 0 & 416 & 0 & 0 & 496 & 3,344 \\
\hline (less) Accum Provisions for Depr \& Amort.... & 0 & 0 & 0 & 0 & 0 & 821 \\
\hline 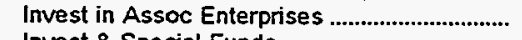 & 0 & 0 & 0 & 0 & $\mathbf{0}$ & 0 \\
\hline 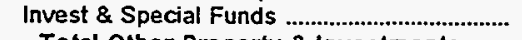 & 23,167 & 9,784 & 10,903 & 14,791 & 11,163 & 8,100 \\
\hline \multicolumn{7}{|l|}{ Current and Accrued Assets } \\
\hline Cash, Working Funds \& Investments .............. & 8 & 13,660 & 7,485 & 37,904 & 6,168 & 272 \\
\hline Notes \& Other Receivables ................................. & 196 & 1,328 & 0 & 3,866 & 19 & 0 \\
\hline Customer Accts Receivable & 542 & 1,959 & 1,603 & 4,834 & 3,240 & 4,462 \\
\hline (less) Accum Prov for Uncollected Accts ...... & 54 & 110 & 0 & 225 & 4 & 0 \\
\hline 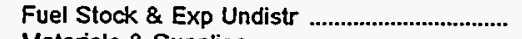 & 546 & 1,411 & 1,030 & 1,993 & $\mathbf{0}$ & 0 \\
\hline 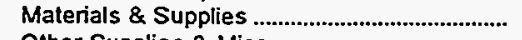 & 0 & 2,899 & 0 & 5,814 & 1.116 & 0 \\
\hline 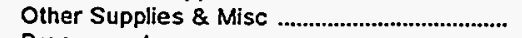 & 1,861 & 0 & 751 & 12 & 30 & 0 \\
\hline Prepayments & 173 & 333 & 14 & 225 & 178 & 168 \\
\hline 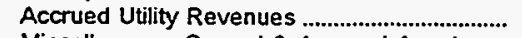 & 1,829 & 0 & 0 & 6,307 & 0 & 0 \\
\hline Miscellaneous Current \& Accrued Assets ..... & 689 & 0 & 220 & 1,356 & 204 & 3,004 \\
\hline $\begin{array}{l}\text { Total Current \& Accrued Assets ................ } \\
\text { Deferred Debits }\end{array}$ & 5,791 & 21,480 & 11,104 & 62,087 & 10,951 & 7,906 \\
\hline 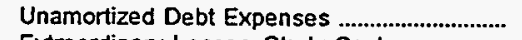 & 121 & 369 & 0 & 37,246 & 0 & 3,655 \\
\hline 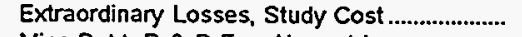 & 0 & 0 & 0 & 972 & 51 & 0 \\
\hline Misc Debt, R \& D Exp, Unamrt Losses .......... & -7 & 1,946 & 11 & 10,932 & 657 & 10,596 \\
\hline 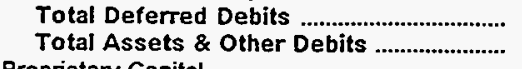 & $\begin{array}{r}114 \\
48,071\end{array}$ & $\begin{array}{r}2,315 \\
129,706\end{array}$ & $\begin{array}{r}11 \\
90,089\end{array}$ & $\begin{array}{r}49,150 \\
472,235\end{array}$ & $\begin{array}{r}708 \\
59,212\end{array}$ & $\begin{array}{l}14,251 \\
63,706\end{array}$ \\
\hline \multicolumn{7}{|l|}{ Proprietary Capital } \\
\hline Investment of Municipality & 0 & 0 & 0 & 0 & 0 & $\mathbf{0}$ \\
\hline 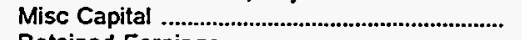 & 0 & 0 & 0 & 0 & 0 & 0 \\
\hline 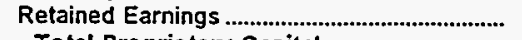 & 36,215 & 90,136 & 25,985 & 129,195 & 53,444 & 3,076 \\
\hline $\begin{array}{l}\text { Total Proprietary Capital .................................. } \\
\text { Long-term Debt }\end{array}$ & 36,215 & 90,136 & 25,985 & 129,195 & 53,444 & 3,076 \\
\hline 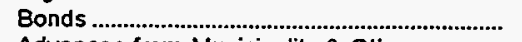 & 8,400 & 36,205 & 62.700 & 271,380 & 0 & 48,855 \\
\hline Advances from Municipality \& Other ................ & 0 & 768 & 0 & 27.075 & 0 & 0 \\
\hline Unamort Prem on Long-term Debt ................... & 0 & 0 & 0 & 0 & 0 & 0 \\
\hline (less) Unamort Discount on Long-term Debt & 0 & 0 & 1,507 & 0 & $\mathbf{0}$ & 0 \\
\hline $\begin{array}{l}\text { Total Long-term Debt .............................................. } \\
\text { Other Noncurrent Liabilities }\end{array}$ & 8,400 & 36,973 & 61,193 & 298,455 & $\mathbf{0}$ & 48,855 \\
\hline Accum Operating Provisions ............................. & 0 & 0 & 0 & 0 & 0 & 4,969 \\
\hline 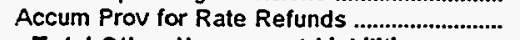 & 0 & 0 & 0 & 0 & $\mathbf{0}$ & 0 \\
\hline $\begin{array}{l}\text { Total Other Noncurrent Liabilities ............ } \\
\text { Current and Accrued Liabilities }\end{array}$ & 0 & $\mathbf{0}$ & 0 & 0 & $\mathbf{0}$ & 4,969 \\
\hline 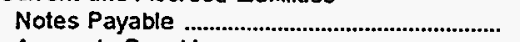 & 0 & 0 & 0 & 8,130 & 0 & 2,000 \\
\hline Accounts Payable & 284 & 457 & 184 & 13,846 & 3,052 & 3,372 \\
\hline 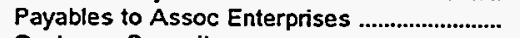 & 0 & 0 & 414 & 0 & 0 & $\mathbf{0}$ \\
\hline Customer Deposits & 59 & 95 & 50 & 12 & 153 & 0 \\
\hline Taxes Accrued & 75 & 788 & 0 & 5,990 & 1.747 & 1,367 \\
\hline Interest Accrued & 64 & 896 & 1,740 & 4,738 & 16 & 67 \\
\hline Misc Current \& Accrued Liabilities....................... & 380 & 361 & 0 & 8,109 & 269 & 0 \\
\hline $\begin{array}{l}\text { Total Current \& Accrued Liabilities .......... } \\
\text { Jeferred Credits }\end{array}$ & 861 & 2,597 & 2,388 & 40,826 & 5,238 & 6,806 \\
\hline Customer Advances for Construction .............. & 0 & 0 & 0 & 0 & 0 & 0 \\
\hline 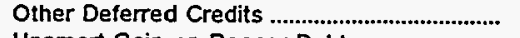 & 153 & $\mathbf{0}$ & 524 & 3,759 & 530 & 0 \\
\hline 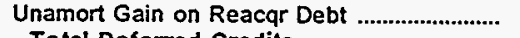 & 2,442 & $\mathbf{0}$ & 0 & 0 & 0 & 0 \\
\hline 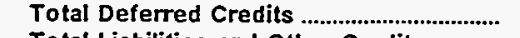 & 2,595 & 0 & 524 & 3,759 & $\mathbf{5 3 0}$ & 0 \\
\hline Total Liabilities and Other Credits ............ & 48,071 & 129,706 & 90,089 & 472,235 & 59,212 & 63,706 \\
\hline
\end{tabular}

Note: Totals may not equal sum of components because of independent rounding.

Source: Energy Information Administration, Form EIA-412, "Annual Report of Public Electric Utilities." 
Table 22. Balance Sheet by Major U.S. Publicly Owned Electric Utility Within State at End of Period, 1995 (Thousand Dollars)

\begin{tabular}{|c|c|c|c|c|c|c|}
\hline Item & $\begin{array}{c}\text { Nebraska } \\
\text { Nebraska } \\
\text { Public } \\
\text { Power } \\
\text { District } \\
\text { December } 31\end{array}$ & $\begin{array}{c}\text { Nebraska } \\
\text { Norris } \\
\text { Public } \\
\text { Power } \\
\text { District } \\
\text { December } 31\end{array}$ & $\begin{array}{l}\text { Nebraska } \\
\text { North } \\
\text { Platte } \\
\text { City of } \\
\text { July } 31\end{array}$ & $\begin{array}{c}\text { Nebraska } \\
\text { Omaha Public } \\
\text { Power } \\
\text { District } \\
\text { December } 31\end{array}$ & $\begin{array}{c}\text { Nebraska } \\
\text { Southern } \\
\text { Nebraska Rural } \\
\text { P P D } \\
\text { December } 31\end{array}$ & $\begin{array}{c}\text { Nevada } \\
\text { Colorado } \\
\text { River } \\
\text { Comm } \\
\text { of Nevada } \\
\text { June } 30\end{array}$ \\
\hline \multicolumn{7}{|l|}{ Electric Utility Plant } \\
\hline Electric Utility Plant \& Adjust ............................ & $1,849,446$ & 62,783 & 13,744 & $2,059,371$ & 75,583 & 0 \\
\hline Const Work in Progress & 255,741 & 472 & 783 & 109,036 & 413 & 0 \\
\hline $\begin{array}{l}\text { (less) Depr, Amort, and Depletion .................... } \\
\text { Net Electric Utility Plant ................................. }\end{array}$ & $\begin{array}{r}865,968 \\
1,239,219\end{array}$ & $\begin{array}{l}20,075 \\
43,180\end{array}$ & $\begin{array}{l}8,572 \\
5,955\end{array}$ & $\begin{array}{r}774,687 \\
1,393,721\end{array}$ & $\begin{array}{l}34,285 \\
41,711\end{array}$ & 0 \\
\hline 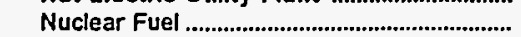 & 430,082 & 0 & 0 & 135,985 & 0 & 0 \\
\hline 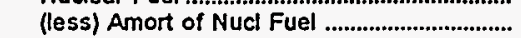 & 328,673 & 0 & 0 & 68,763 & 0 & 0 \\
\hline $\begin{array}{l}\text { Net Elec Plant Incl Nucl Fuel .......................... } \\
\text { Other Property \& Investments }\end{array}$ & $1,340,628$ & 43,180 & 5,955 & $1,460,944$ & 41,711 & $\mathbf{0}$ \\
\hline 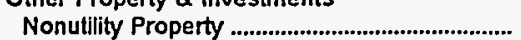 & 0 & 0 & 0 & 0 & 0 & 276,954 \\
\hline (less) Accum Provisions for Depr \& Amort .... & 0 & 0 & 0 & 0 & 0 & 83,919 \\
\hline 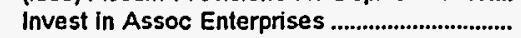 & 0 & 0 & 0 & 0 & 1.577 & 0 \\
\hline 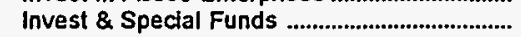 & 178,969 & 3,700 & 0 & 386,183 & 0 & 185,083 \\
\hline $\begin{array}{l}\text { Total Other Property \& Investments ....... } \\
\text { Current and Accrued Assets }\end{array}$ & 178,969 & 3,700 & 0 & 386,183 & 1,577 & 378,118 \\
\hline Cash, Working Funds \& Investments .............. & 331,218 & 6,689 & 3,366 & 41,899 & 12,983 & 7,156 \\
\hline Notes \& Other Receivables ............................... & 32,748 & 27 & 0 & 52,948 & 0 & 3,178 \\
\hline Customer Accts Receivable .................................. & 34,965 & 2,088 & 710 & 28,383 & 1.927 & 7.142 \\
\hline (less) Accum Prov for Uncollected Accts ....... & 154 & 44 & 29 & 1,103 & 55 & 0 \\
\hline 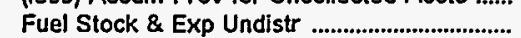 & 8.191 & 0 & 0 & 9,664 & 0 & 0 \\
\hline Materials \& Supplies & 8,654 & 1,232 & 546 & 36,388 & 1,703 & 0 \\
\hline 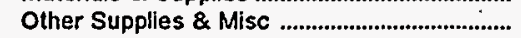 & 1,750 & 0 & 0 & 346 & 0 & 66 \\
\hline 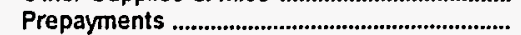 & 0 & 114 & 9 & $3,75 i$ & 76 & 7.058 \\
\hline Accrued Utility Revenues .................................. & 72,356 & 997 & 0 & 16,512 & 0 & 0 \\
\hline Miscellaneous Current \& Accrued Assets ..... & 6,044 & 0 & 78 & 7,096 & 96 & 0 \\
\hline $\begin{array}{l}\text { Total Current \& Accrued Assets ............... } \\
\text { Deferred Debits }\end{array}$ & 495,772 & 11,103 & 4,682 & 195,883 & 16,731 & 24,600 \\
\hline Unamortized Debt Expenses ............................. & 2,802 & 784 & 0 & 1.936 & 0 & 8,559 \\
\hline Extraordinary Losses, Study Cost ...................... &.$\quad 284$ & 0 & 0 & 0 & 0 & 0 \\
\hline Misc Debt, R \& D Exp, Unamrt Losses ......... & 86,706 & 234 & 0 & 96,445 & 230 & 49.042 \\
\hline 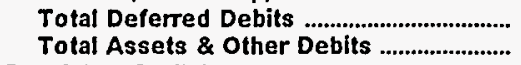 & $\begin{array}{r}89,792 \\
2,105,162\end{array}$ & $\begin{array}{r}1,018 \\
59,001\end{array}$ & $\begin{array}{r}0 \\
10,637\end{array}$ & $\begin{array}{r}98,381 \\
2,141,390\end{array}$ & $\begin{array}{r}230 \\
60,249\end{array}$ & $\begin{array}{r}57,602 \\
460,320\end{array}$ \\
\hline \multicolumn{7}{|l|}{ Proprietary Capital } \\
\hline 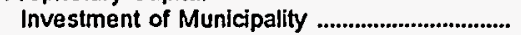 & 0 & 0 & 0 & 0 & 0 & 1,526 \\
\hline 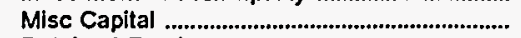 & 0 & $\mathbf{0}$ & 0 & 0 & 0 & 0 \\
\hline 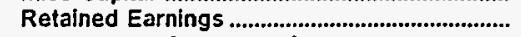 & 240,748 & 34,311 & 9,207 & 811,298 & 56.315 & $-50,399$ \\
\hline \multicolumn{7}{|l|}{ Long-term Debt } \\
\hline 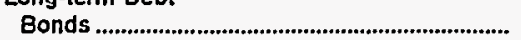 & $1,412,685$ & 19,745 & 0 & 918,290 & $\mathbf{0}$ & 302,968 \\
\hline Advances from Municipality \& Other ............... & 1.711 & 0 & 0 & 83,968 & $\mathbf{0}$ & 179,046 \\
\hline Unamort Prem on Long-term Debt .................. & 0 & 0 & 0 & 0 & 0 & 0 \\
\hline (less) Unamort Discount on Long-term Debt & 4,075 & 0 & 0 & 10,409 & 0 & 0 \\
\hline & $1,410,321$ & 19,745 & $\mathbf{0}$ & 991,849 & 0 & 482,014 \\
\hline $\begin{array}{l}\text { Other Noncurrent Uabilities } \\
\text { Accum Operating Provisions }\end{array}$ & 0 & 0 & 0 & 4.631 & 0 & Other Noncurrent Labilities \\
\hline 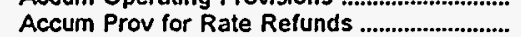 & 0 & 0 & 0 & $\begin{array}{r}4,001 \\
0\end{array}$ & 0 & 0 \\
\hline \multicolumn{7}{|l|}{ Current and Accrued Liabilities } \\
\hline 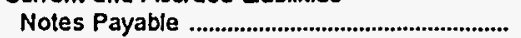 & 94,693 & 0 & 0 & 29,194 & 0 & 0 \\
\hline 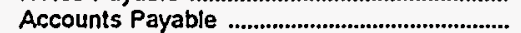 & 49,613 & 4,000 & 1,312 & 30.229 & 2,812 & 5,687 \\
\hline Payables to Assoc Enterprises ......................... & 5,013 & 0 & 0 & 0 & 0 & 0 \\
\hline 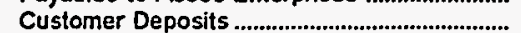 & 1,219 & 50 & 118 & 5,758 & 49 & 0 \\
\hline 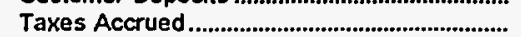 & 6,503 & 158 & 0 & 14,328 & 0 & 0 \\
\hline Interest Accrued & 144 & 207 & 0 & 23,540 & 0 & 7.042 \\
\hline Misc Current \& Accrued Labilities..................... & 273,387 & 530 & 0 & 34,760 & 1,073 & 9,574 \\
\hline $\begin{array}{l}\text { Total Current \& Accrued Liabilities .......... } \\
\text { Deferred Credits }\end{array}$ & 430,571 & 4,945 & 1,430 & 137,809 & 3,933 & 22,302 \\
\hline Customer Advances for Construction ............. & $\mathbf{0}$ & 0 & 0 & 372 & 0 & 0 \\
\hline 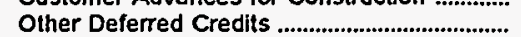 & 23,522 & 0 & 0 & 195,430 & 0 & 4,876 \\
\hline Unamort Gain on Reacqr Debt ......................... & 0 & 0 & 0 & 0 & 0 & 0 \\
\hline 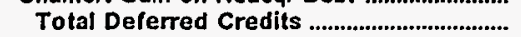 & 23,522 & 0 & 0 & 195,803 & $\mathbf{0}$ & 4,876 \\
\hline Total Llabilities and Other Credits ............ & $2,105,162$ & 59,001 & 10,637 & $2,141,390$ & 60,249 & 460,320 \\
\hline
\end{tabular}

Note: Totals may not equal sum of components because of independent rounding.

Source: Energy Information Administration, Form EIA-412, "Annual Report of Public Electric Utilities." 
Table 22. Balance Sheet by Major U.S. Publicly Owned Electric Utility Within State at End of Period, 1995

(Thousand Dollars)

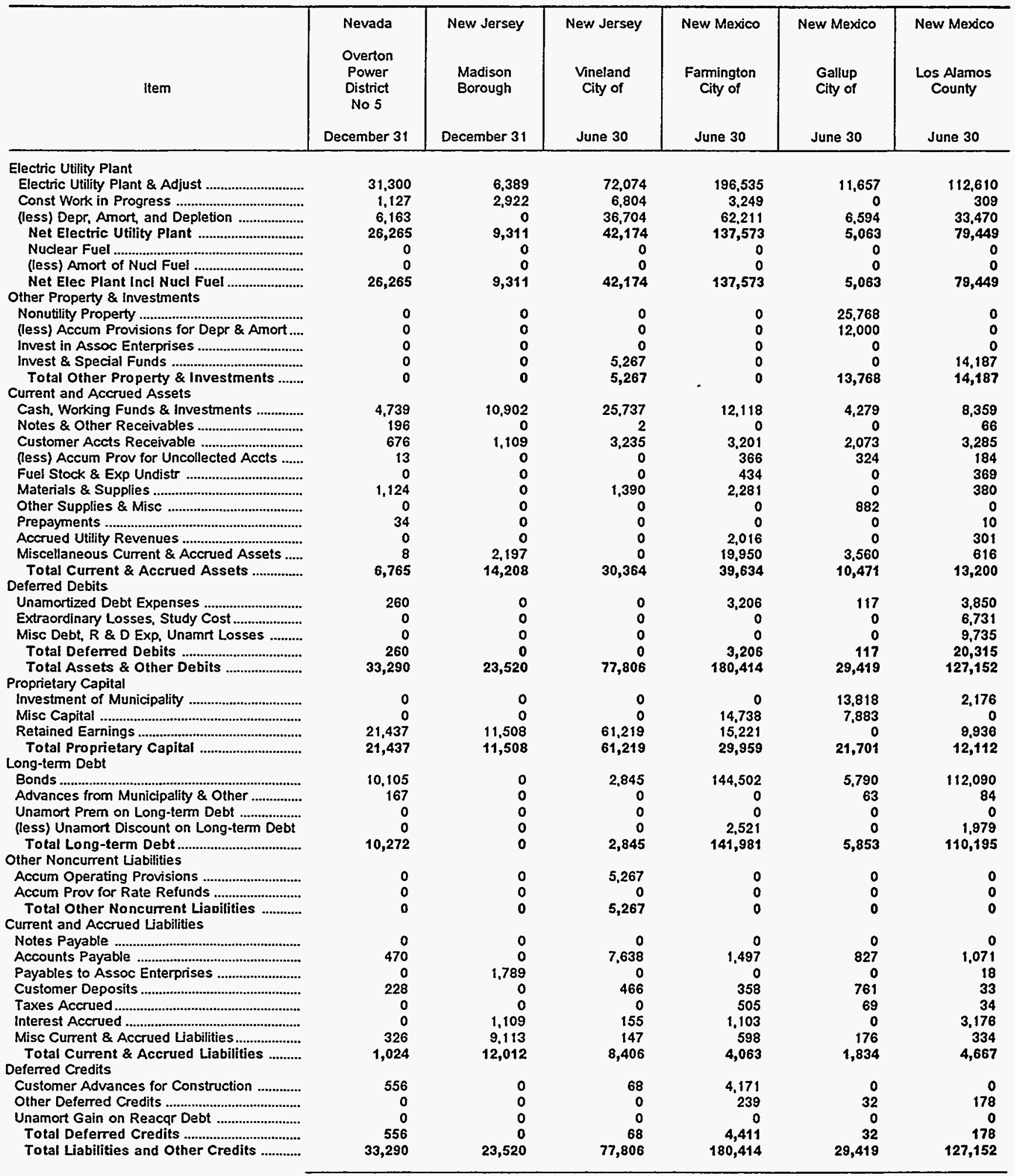

Note: Totals may not equal sum of components because of independent rounding.

Source: Energy Information Administration, Form EIA-412, "Annual Report of Public Electric Utilities." 
Table 22. Balance Sheet by Major U.S. Publicly Owned Electric Utility Within State at End of Period, 1995 (Thousand Dollars)

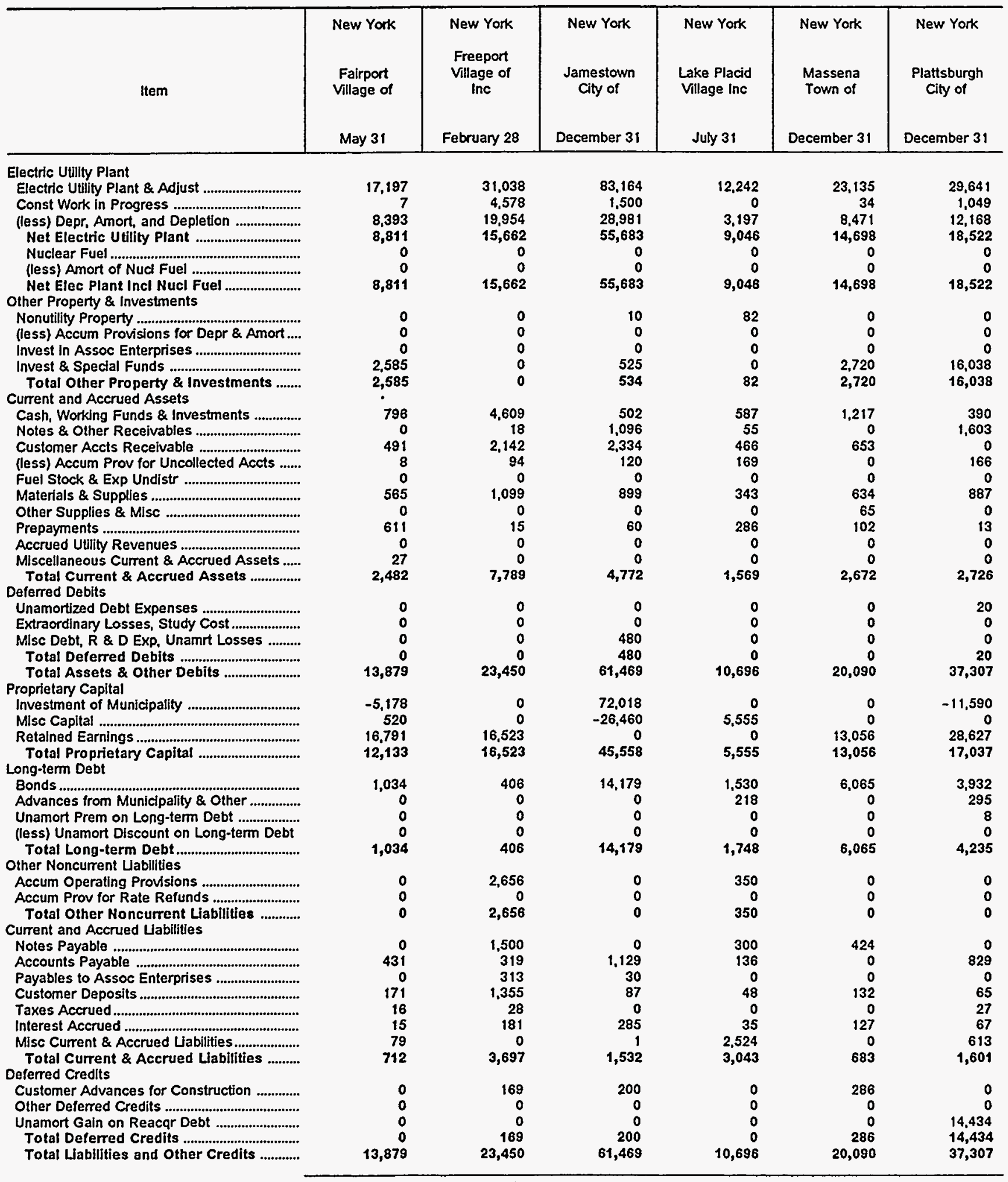

Note: Totals may not equal sum of components because of independent rounding.

Source: Energy Information Administration, Form ElA-412, "Annual Report of Public Electric Utitities." 
Table 22. Balance Sheet by Major U.S. Publicly Owned Electric Utility Within State at End of Period, 1995 (Thousand Dollars)

\begin{tabular}{|c|c|c|c|c|c|c|}
\hline Item & $\begin{array}{c}\text { New York } \\
\text { Power } \\
\text { Authority } \\
\text { of State of NY } \\
\text { December } 31\end{array}$ & $\begin{array}{l}\text { New York } \\
\text { Rockville } \\
\text { Centre } \\
\text { Village of } \\
\text { May } 31\end{array}$ & $\begin{array}{l}\text { New York } \\
\text { Solvay } \\
\text { Village of } \\
\text { May } 31\end{array}$ & $\begin{array}{l}\text { North Carolina } \\
\text { Albemarle } \\
\text { City of } \\
\text { June } 30\end{array}$ & $\begin{array}{l}\text { North Carolina } \\
\text { Concord } \\
\text { City of } \\
\text { June } 30\end{array}$ & $\begin{array}{l}\text { North Carolina } \\
\text { Elizabeth } \\
\text { City City of } \\
\text { June } 30\end{array}$ \\
\hline \multicolumn{7}{|l|}{ Electric Utility Plant } \\
\hline Electric Utility Plant \& Adjust .............................. & $5,088,363$ & 29,200 & 10,576 & 18,813 & 38,889 & 24,939 \\
\hline Const Work in Progress & 203,691 & 7,781 & 69 & 0 & 0 & 0 \\
\hline 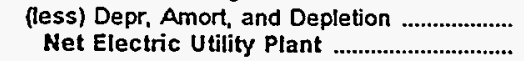 & $\begin{array}{l}1,866,964 \\
3,425,090\end{array}$ & $\begin{array}{l}14,426 \\
22,554\end{array}$ & $\begin{array}{l}4,300 \\
6,344\end{array}$ & $\begin{array}{r}10,963 \\
7,850\end{array}$ & $\begin{array}{l}20,324 \\
18,565\end{array}$ & $\begin{array}{r}8,909 \\
16,030\end{array}$ \\
\hline Nuclear Fuel & 353,593 & 0 & 0 & 0 & 0 & 0 \\
\hline 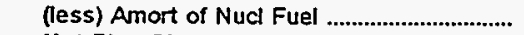 & 200,454 & 0 & 0 & 0 & 0 & 0 \\
\hline $\begin{array}{l}\text { Net Elec Plant Incl Nucl Fuel ........................... } \\
\text { Other Property \& Investments }\end{array}$ & $3,578,229$ & 22,554 & 6,344 & 7,850 & $.18,565$ & 16,030 \\
\hline \multicolumn{7}{|l|}{ Other Property \& Investments } \\
\hline (less) Accum Provisions for Depr \& Amort .... & $\begin{array}{l}0 \\
0\end{array}$ & 0 & 0 & 0 & 0 & 0 \\
\hline & 0 & 0 & 0 & 0 & 0 & 0 \\
\hline 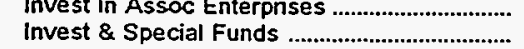 & 0 & 0 & 0 & 0 & $\mathbf{0}$ & 250 \\
\hline & 409,338 & 143 & 0 & 0 & 0 & 0 \\
\hline \multicolumn{7}{|l|}{ Current and Accrued Assets } \\
\hline Cash, Working Funds \& Investments ............. & 894,692 & 703 & 223 & 2,550 & 8,728 & 3,885 \\
\hline 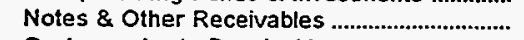 & 9,779 & 72 & 0 & 0 & 203 & 1,000 \\
\hline 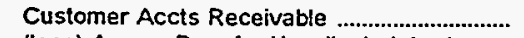 & 138,087 & $1,04 \overline{1}$ & 1,173 & 1,964 & 3,517 & 2,364 \\
\hline (less) Accum Prov for Uncollected Accts ...... & 0 & 189 & 721 & 0 & 0 & 104 \\
\hline 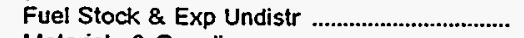 & 8,164 & 0 & 0 & 0 & 0 & 0 \\
\hline 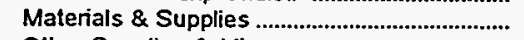 & 71,494 & 492 & 315 & 1,180 & 2,106 & 1,270 \\
\hline 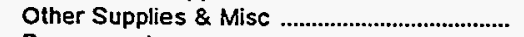 & 0 & 992 & 0 & 0 & 0 & 0 \\
\hline 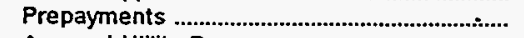 & 6,074 & 128 & 0 & 3 & 0 & 0 \\
\hline 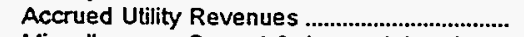 & 0 & 735 & 0 & 0 & 0 & 0 \\
\hline Miscellaneous Current \& Accrued Assets ..... & 16,688 & 2,009 & 136 & 0 & 0 & 2 \\
\hline $\begin{array}{l}\text { Total Current \& Accrued Assets ............... } \\
\text { Deferred Debits }\end{array}$ & $1,144,978$ & 5,984 & 1,127 & 5,697 & 14,554 & 8,417 \\
\hline 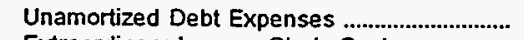 & 22,623 & 145 & 0 & 0 & 348 & 0 \\
\hline 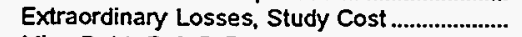 & 0 & 0 & 0 & 0 & 0 & $\mathbf{0}$ \\
\hline Misc Debt, R \& D Exp, Unamrt Losses .......... & 227,965 & 0 & 31 & 0 & 0 & 0 \\
\hline 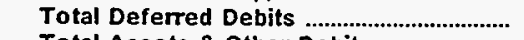 & 250,588 & 146 & 31 & 0 & 348 & $\mathbf{0}$ \\
\hline $\begin{array}{l}\text { Total Assets \& Other Debits ............................. } \\
\text { Proprietary Capital }\end{array}$ & $5,383,133$ & 28,827 & 7,502 & 13,547 & 33,468 & 24,697 \\
\hline Investment of Municipality ................................. & 0 & $-6,801$ & 0 & 5,315 & 0 & 158 \\
\hline Misc Capital & 0 & 0 & 0 & 0 & 0 & 0 \\
\hline 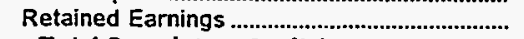 & $1,395,487$ & 18,817 & 4,523 & 6,544 & 18,690 & 22,579 \\
\hline $\begin{array}{l}\text { Total Proprietary Capital .................................. } \\
\text { Long-term Debt }\end{array}$ & $1,395,487$ & 12,016 & 4,523 & 11,859 & 18,690 & 22,738 \\
\hline Bonds & $2,800,185$ & 13,562 & 1,393 & 0 & 11,513 & $\mathbf{0}$ \\
\hline Advances from Municipality \& Other .................... & 200,000 & 0 & 0 & 0 & 7 & 0 \\
\hline Unamort Prem on Long-term Debt ................... & 0 & 0 & 25 & 0 & 0 & 0 \\
\hline (less) Unamort Discount on Long-term Debt & 57,598 & 0 & 0 & 0 & 0 & $\mathbf{0}$ \\
\hline 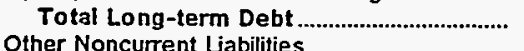 & $2,942,587$ & 13,562 & 1,418 & $\mathbf{0}$ & 11,520 & $\mathbf{0}$ \\
\hline \multicolumn{7}{|l|}{ Other Noncurrent Liabilities } \\
\hline 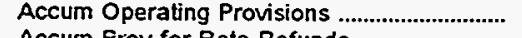 & 4,390 & $\begin{array}{r}1,416 \\
0\end{array}$ & 0 & 0 & $\mathbf{0}$ & 0 \\
\hline Accum Frov for Rate Refunds & 0 & 0 & 0 & 0 & 0 & $\mathbf{0}$ \\
\hline $\begin{array}{l}\text { Tntal Other Noncurrent Liabilities ............ } \\
\text { Surrent and Accrued Liablities }\end{array}$ & 4,390 & 1,416 & o & o & $\mathbf{0}$ & 0 \\
\hline 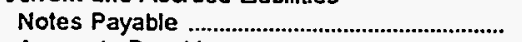 & 178,971 & 0 & 125 & 0 & 0 & 0 \\
\hline Accounts Payable & 13,290 & 905 & 290 & 1,513 & 2,592 & 1,626 \\
\hline 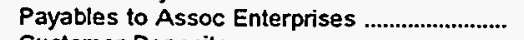 & 0 & 0 & 23 & 0 & 0 & 0 \\
\hline 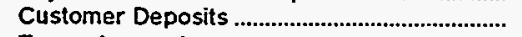 & 0 & 404 & 42 & 144 & 502 & 250 \\
\hline Taxes Accrued & 0 & 0 & 13 & 0 & 0 & 0 \\
\hline Interest Accrued & 3,191 & 263 & 40 & 0 & 53 & 0 \\
\hline Misc Current \& Accrued Labilities..................... & 157,136 & 261 & 253 & 31 & 110 & 84 \\
\hline $\begin{array}{l}\text { Total Current \& Accrued Liabilities .......... } \\
\text { Deferred Credits }\end{array}$ & 352,588 & 1,833 & 786 & 1,688 & 3,257 & 1,959 \\
\hline Customer Advances for Construction ............. & 0 & 0 & 775 & 0 & 0 & 0 \\
\hline 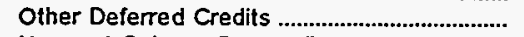 & 688,081 & 0 & 0 & 0 & 0 & 0 \\
\hline 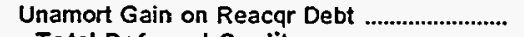 & 0 & 0 & 0 & 0 & 0 & 0 \\
\hline Total Deferred Credits ................................. & 688,081 & 0 & 775 & 0 & 0 & $\mathbf{0}$ \\
\hline Total Liabilities and Other Credits ............... & $5,383,133$ & 28,827 & 7,502 & 13,547 & 33,468 & 24,697 \\
\hline
\end{tabular}

Note: Totals may not equal sum of components because of independent rounding.

Source: Energy Information Administration, Form EIA-412. "Annual Report of Public Electric Utilities." 
Table 22. Balance Sheet by Major U.S. Publicly Owned Electric Utility Within State at End of Period, 1995

(Thousand Dollars)

\begin{tabular}{|c|c|c|c|c|c|c|}
\hline Item & $\begin{array}{l}\text { North Carolina } \\
\text { Fayetteville } \\
\text { Public } \\
\text { Works Comm } \\
\text { June } 30\end{array}$ & $\begin{array}{l}\text { North Carolina } \\
\text { Forest City } \\
\text { Town of } \\
\text { June } 30\end{array}$ & $\begin{array}{l}\text { North Carolina } \\
\text { Gastonia } \\
\text { City of } \\
\text { June } 30\end{array}$ & $\begin{array}{l}\text { North Carolina } \\
\text { Greenville } \\
\text { Utilities } \\
\text { Comm } \\
\text { June } 30\end{array}$ & $\begin{array}{c}\text { North Carolina } \\
\text { High } \\
\text { Point } \\
\text { Town } \\
\text { of } \\
\text { June } 30\end{array}$ & $\begin{array}{l}\text { North Carolina } \\
\text { Kinston } \\
\text { City of } \\
\text { June } 30\end{array}$ \\
\hline \multicolumn{7}{|l|}{ Electric Utillty Plant } \\
\hline 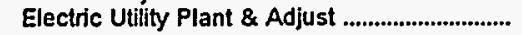 & 227,877 & 5,324 & 42,987 & 92,286 & 62,214 & 20,237 \\
\hline 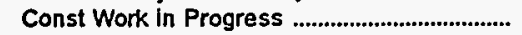 & 13,467 & & & 3,183 & 0 & 855 \\
\hline (less) Depr, Amort, and Depletion ....................... & 73,572 & 2,614 & 22,290 & 47,214 & 25,347 & 8.535 \\
\hline 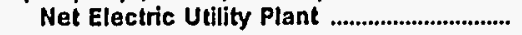 & 167,772 & 2,710 & 20,697 & 48,254 & 36,868 & 12,557 \\
\hline Nuclear Fuel ...................................................... & 0 & 0 & 0 & 0 & 0 & 0 \\
\hline (less) Amort of Nucl Fuel ............................. & 0 & 0 & 0 & 0 & 0 & 0 \\
\hline Net Elec Plant Incl Nucl Fuel ....................... & 167,772 & 2,710 & 20,697 & 48,254 & 36,868 & 12,557 \\
\hline \multicolumn{7}{|l|}{ Other Property \& Investments } \\
\hline 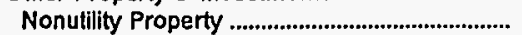 & 0 & 0 & 0 & 0 & 0 & 0 \\
\hline (less) Accum Provisions for Depr \& Amort.... & 0 & 0 & 0 & 0 & 0 & o \\
\hline 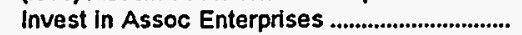 & 0 & 0 & 0 & 0 & 0 & 0 \\
\hline Invest \& Special Funds ............................................ & 8,047 & 1.871 & 0 & 0 & 0 & 0 \\
\hline Total Other Property \& Investments ........ & 8,047 & 1,871 & 0 & 0 & 0 & 0 \\
\hline \multicolumn{7}{|l|}{ Current and Accrued Assets } \\
\hline Cash, Working Funds \& Investments .............. & 29,161 & 3,987 & 4,935 & 16,954 & 18,730 & 5,582 \\
\hline Notes \& Other Receivables .................................. & 737 & 0 & 0 & 48 & 0 & 647 \\
\hline Customer Accts Recelvable ..................................... & 8,640 & 1,128 & 4,304 & 10,898 & 3,256 & 4,214 \\
\hline (less) Accum Prov for Uncollected Accts ...... & 40 & 0 & 1,278 & 0 & 0 & 274 \\
\hline 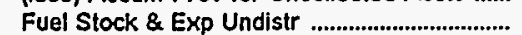 & 1,473 & 0 & 0 & 0 & 0 & 0 \\
\hline 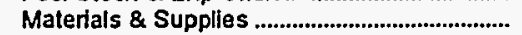 & 7,082 & 0 & 412 & 2.224 & 0 & 1.062 \\
\hline 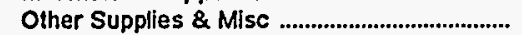 & 1,694 & 0 & 0 & 0 & 0 & 0 \\
\hline 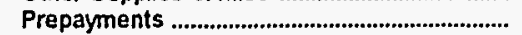 & 53 & 0 & 0 & 8 & 0 & 0 \\
\hline 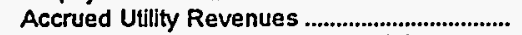 & 5,281 & 0 & 0 & 0 & 309 & 0 \\
\hline Miscellaneous Current \& Accrued Assets ..... & 267 & & 2.058 & 299 & 0 & 0 \\
\hline Total Current \& Accrued Assets ................ & 54,349 & 5,115 & 10,431 & 30,431 & 22,296 & 11,231 \\
\hline \multicolumn{7}{|l|}{ Deferred Debits } \\
\hline 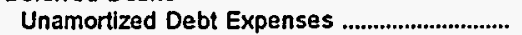 & 2,688 & 0 & 0 & 0 & 0 & 15 \\
\hline Extraordinary Losses, Study Cost...................... & & 0 & 0 & 0 & 0 & 0 \\
\hline Misc Debt, R \& D Exp, Unamrt Losses .......... & 0 & 0 & 0 & 0 & 0 & 0 \\
\hline Total Deferred Debits ........................................... & 2,688 & & 0 & 0 & & \\
\hline Total Assets \& Other Debils ......................... & 232,855 & 9,695 & 31,129 & 78,686 & 59,164 & 23,803 \\
\hline \multicolumn{7}{|l|}{ Proprietary Capital } \\
\hline 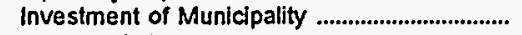 & 0 & 2,308 & 4,084 & 0 & 0 & 0 \\
\hline 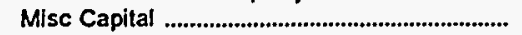 & 0 & 0 & 0 & 0 & 158 & 0 \\
\hline Retalned Earnings .................................................... & 148,418 & 6,603 & 23,372 & 60,246 & 53.701 & 15,694 \\
\hline Total Proprietary Capital ...................................... & 148,418 & 8,911 & 27,456 & 60,246 & 53,859 & 15,694 \\
\hline \multicolumn{7}{|l|}{ Long-term Debt } \\
\hline 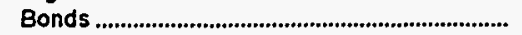 & 71,133 & 0 & 0 & 6,121 & 0 & 2,196 \\
\hline Advances from Municipality \& Other................ & 0 & 0 & 0 & 0 & 0 & 1,887 \\
\hline Unamort Prem on Long-term Debt ...................... & 0 & 0 & 0 & 0 & 150 & 0 \\
\hline (less) Unamort Discount on Long-term Debt & 0 & 0 & 0 & 0 & 0 & 0 \\
\hline 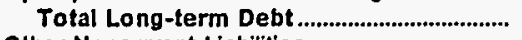 & 71,133 & 0 & 0 & 6,121 & 150 & 4,083 \\
\hline \multicolumn{7}{|l|}{ Other Noncurrent Labilities } \\
\hline 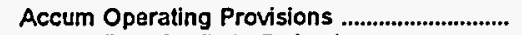 & 0 & 0 & 0 & $\mathbf{0}$ & 0 & 0 \\
\hline 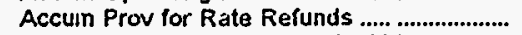 & 0 & 0 & 0 & o & 0 & 0 \\
\hline 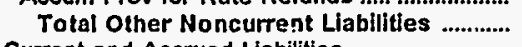 & 0 & 0 & $\mathbf{0}$ & 0 & o & o \\
\hline \multicolumn{7}{|l|}{ Current and Accrued Uabilities } \\
\hline 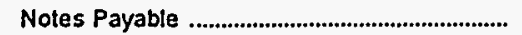 & 0 & 0 & 0 & 0 & 0 & 0 \\
\hline 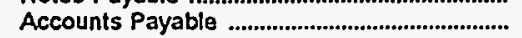 & 8,623 & 554 & 3,366 & 9,882 & 4,602 & 3.420 \\
\hline Payables to Assoc Enterprises ................................. & & $\mathbf{0}$ & 0 & 0 & 0 & 0 \\
\hline 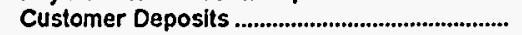 & 1,359 & 219 & 192 & 655 & 361 & 509 \\
\hline Taxes Accrued ................................................................ & 39 & 0 & 0 & 0 & 0 & 0 \\
\hline Interest Accrued ............................................................... & 1,174 & 0 & 0 & 127 & 2 & 0 \\
\hline Misc Current \& Accrued Uabilities.......................... & 2,109 & 10 & 115 & 1,478 & 189 & 98 \\
\hline Total Current \& Accrued Liabilities ........... & 13,304 & 784 & 3,673 & 12,142 & 5,154 & 4,027 \\
\hline \multicolumn{7}{|l|}{ Deferred Credits } \\
\hline Customer Advances for Construction .............. & 0 & 0 & 0 & 177 & 0 & 0 \\
\hline Other Deferred Credits ........................................... & 0 & 0 & 0 & 0 & 0 & 0 \\
\hline Unamort Gain on Reacgr Debt .............................. & 0 & 0 & 0 & 0 & 0 & 0 \\
\hline Total Deferred Credits .................................. & 0 & 0 & 0 & 177 & 0 & o \\
\hline Total Liabilities and Other Credits ............. & 232,855 & 9,695 & 31,129 & 78,686 & 59,164 & 23,803 \\
\hline
\end{tabular}

Note: Totals may not equal sum of components because of independent rounding.

Source: Energy Information Administration, Form EIA-412, "Annual Report of Public Electric Utilities." 
Table 22. Balance Sheet by Major U.S. Publicly Owned Electric Utility Within State at End of Period, 1995 (Thousand Dollars)

\begin{tabular}{|c|c|c|c|c|c|c|}
\hline Item & $\begin{array}{l}\text { North Carolina } \\
\text { Laurinburg } \\
\text { City of }\end{array}$ & $\begin{array}{l}\text { North Carolina } \\
\text { Lexington } \\
\text { City of } \\
\text { June } 30\end{array}$ & $\begin{array}{l}\text { North Carolina } \\
\text { Lumberton } \\
\text { City of } \\
\text { June } 30\end{array}$ & $\begin{array}{l}\text { Monroe } \\
\text { City of } \\
\text { June } 30\end{array}$ & $\begin{array}{l}\text { Morganton } \\
\text { City of } \\
\text { June } 30\end{array}$ & $\begin{array}{l}\text { Murphy } \\
\text { City of } \\
\text { June } 30\end{array}$ \\
\hline \multicolumn{7}{|l|}{ Electric Utility Plant } \\
\hline Electric Utility Plant \& Adjust ................................ & 0 & 30,169 & 12,058 & 25,375 & 13,051 & 7,952 \\
\hline Const Work in Progress & 0 & 1,046 & 97 & 5,239 & 8 & 189 \\
\hline 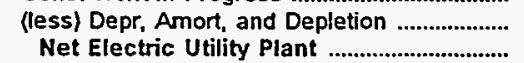 & $\begin{array}{l}0 \\
0\end{array}$ & $\begin{array}{l}10,326 \\
20,890\end{array}$ & $\begin{array}{l}6,661 \\
5,495\end{array}$ & $\begin{array}{r}8,141 \\
22,473\end{array}$ & $\begin{array}{l}5,439 \\
7,619\end{array}$ & $\begin{array}{l}2,481 \\
5,660\end{array}$ \\
\hline Nuclear Fuel & 0 & 0 & 0 & 0 & 0 & 0 \\
\hline 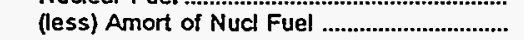 & 0 & 0 & 0 & 0 & 0 & 0 \\
\hline 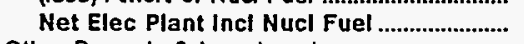 & 0 & 20,890 & 5,495 & 22,473 & 7,619 & 5,660 \\
\hline \multicolumn{7}{|l|}{ Other Property \& Investments } \\
\hline Nonutility Property & 0 & 0 & 0 & 0 & 0 & 0 \\
\hline (less) Accum Provisions for Depr \& Amort .... & 0 & $\mathbf{0}$ & 0 & 0 & 0 & 0 \\
\hline 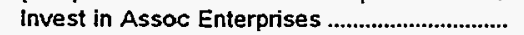 & 0 & 0 & 0 & 0 & 0 & 0 \\
\hline Invest \& Special Funds & 0 & 0 & 0 & 4,059 & 0 & 2,147 \\
\hline Total Other Property \& Investments ....... & 0 & $\mathbf{0}$ & 0 & 4,059 & 0 & 2,147 \\
\hline \multicolumn{7}{|l|}{ Current and Accrued Assets } \\
\hline Cash, Working Funds \& Investments ............... & 0 & 870 & 1,587 & 17.904 & 8,781 & 522 \\
\hline 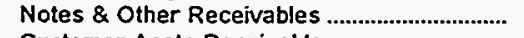 & 0 & 3,126 & 442 & 0 & 600 & 543 \\
\hline Customer Accts Receivable ................................ & 0 & 0 & 1.488 & 2,032 & 1.867 & 0 \\
\hline (less) Accum Prov for Uncollected Accts ...... & 0 & $\mathbf{0}$ & 0 & 0 & 0 & 0 \\
\hline 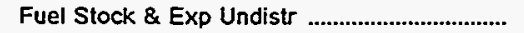 & 0 & 0 & 0 & 0 & 0 & 0 \\
\hline 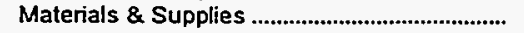 & 0 & 420 & 404 & 1,397 & 0 & 173 \\
\hline 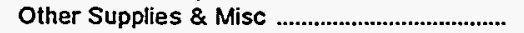 & 0 & 0 & 0 & 0 & 0 & 0 \\
\hline 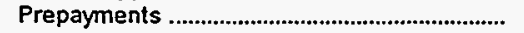 & 0 & 728 & 0 & 0 & 0 & 135 \\
\hline Accrued Utility Revenues & 0 & 569 & 0 & 0 & 0 & 0 \\
\hline Miscellaneous Current \& Accrued Assets ..... & 0 & 512 & 0 & 0 & 100 & 0 \\
\hline $\begin{array}{l}\text { Total Current \& Accrued Assets ................. } \\
\text { Deferred Debits }\end{array}$ & 0 & 6,226 & 3,921 & 21,333 & 11,348 & 1,373 \\
\hline 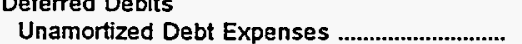 & 0 & 0 & \\
\hline 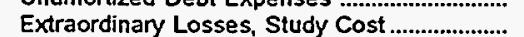 & 0 & 0 & $\begin{array}{l}0 \\
0\end{array}$ & $\begin{array}{l}0 \\
0\end{array}$ & $\begin{array}{l}0 \\
0\end{array}$ & $\begin{array}{l}0 \\
0\end{array}$ \\
\hline Misc Debt, R \& D Exp, Unamrt Losses ......... & 0 & 0 & 0 & 177 & 0 & 75 \\
\hline Total Deferred Debits & 0 & 0 & 0 & 177 & 0 & 75 \\
\hline $\begin{array}{l}\text { Total Assets \& Other Debits .......................... } \\
\text { Proprietary Capital }\end{array}$ & Proprietary Capital & 27,116 & 9,416 & 48,042 & 18,968 & 9,255 \\
\hline 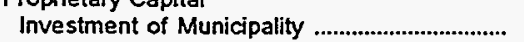 & 0 & 4,090 & 957 & 0 & 3,172 & 0 \\
\hline Misc Capital & 0 & 0 & 0 & 997 & 0 & 0 \\
\hline 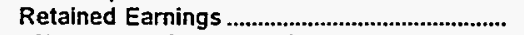 & 0 & 10,562 & 5,936 & 39,506 & 14.107 & 8,468 \\
\hline $\begin{array}{l}\text { Total Proprietary Capital ................................... } \\
\text { Long-tem Debt }\end{array}$ & 0 & 14,652 & 6,893 & 40,503 & 17,278 & 8,468 \\
\hline 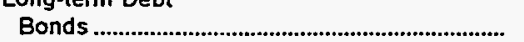 & 0 & 90 & 0 & 0 & 0 & 0 \\
\hline Advances from Municipality \& Other ............... & 0 & 8,157 & 0 & 0 & 0 & 62 \\
\hline Unamort Prem on Long-term Debt ................... & 0 & 0 & 0 & 0 & 0 & 0 \\
\hline (less) Unamort Discount on Long-term Debt & 0 & 0 & 0 & 0 & $\mathbf{0}$ & 0 \\
\hline 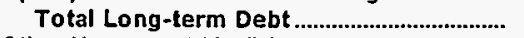 & 0 & 8,247 & $\mathbf{0}$ & 0 & $\mathbf{0}$ & 62 \\
\hline \multicolumn{7}{|l|}{ Other Noncurrent Liabilties } \\
\hline 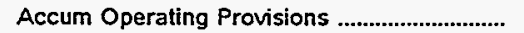 & 0 & 0 & 0 & 0 & 0 & $\mathbf{0}$ \\
\hline Accum Prov for Rate Refunds ......................... & 0 & 0 & 0 & 0 & 0 & 0 \\
\hline \multicolumn{6}{|l|}{ Current and Accrued Labilities } & 0 \\
\hline 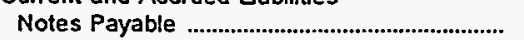 & 0 & 868 & 61 & 4,934 & 0 & 0 \\
\hline 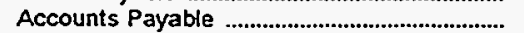 & 0 & 2,730 & 1,947 & 2,156 & 1,430 & 442 \\
\hline 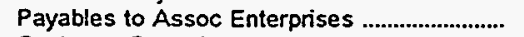 & 0 & 0 & 0 & 0 & 0 & 0 \\
\hline 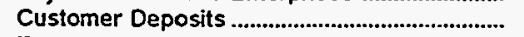 & 0 & 569 & 514 & 417 & 221 & 228 \\
\hline Taxes Accrued & 0 & 0 & 0 & 0 & 0 & 0 \\
\hline 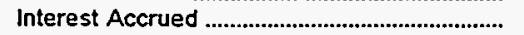 & 0 & 0 & 0 & 0 & 0 & 0 \\
\hline Misc Current \& Accrued Liabilities.................... & 0 & 49 & 0 & 32 & 38 & 54 \\
\hline $\begin{array}{l}\text { Total Current \& Accrued Liabilities .......... } \\
\text { Deferred Credits }\end{array}$ & 0 & 4,216 & 2,523 & 7,538 & 1,689 & 724 \\
\hline Customer Advances for Construction ............. & 0 & $\mathbf{0}$ & 0 & 0 & 0 & $\mathbf{0}$ \\
\hline 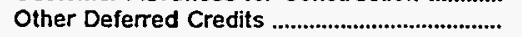 & 0 & 0 & 0 & 0 & 0 & 0 \\
\hline 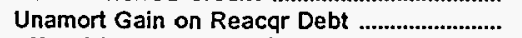 & 0 & 0 & 0 & 0 & 0 & 0 \\
\hline 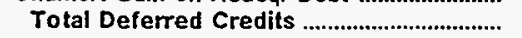 & 0 & 0 & 0 & 0 & 0 & o \\
\hline Total Liabilities and Other Credits ............. & $\mathbf{0}$ & 27,116 & 9,416 & 48,042 & 18,968 & 9,255 \\
\hline
\end{tabular}

Note: Totals may not equal sum of components because of independent rounding.

Source: Energy Information Administration, Form EIA-412, "Annual Report of Public Electric Utilities." 
Table 22. Balance Sheet by Major U.S. Publicly Owned Electric Utility Within State at End of Period, 1995

(Thousand Dollars)

\begin{tabular}{|c|c|c|c|c|c|c|}
\hline Item & $\begin{array}{l}\text { North Carolina } \\
\text { New Bern } \\
\text { City of } \\
\text { June } 30\end{array}$ & $\begin{array}{c}\text { North Carolina } \\
\text { New River } \\
\text { Light } \\
\& \\
\text { Power Co } \\
\text { December } 31\end{array}$ & $\begin{array}{c}\text { North Carolina } \\
\text { North } \\
\text { Carolina } \\
\text { Eastern M P A } \\
\text { December } 31\end{array}$ & $\begin{array}{c}\text { North Carolina } \\
\text { North } \\
\text { Carolina } \\
\text { Mun } \\
\text { Power Agny } \\
\text { December } 31\end{array}$ & $\begin{array}{l}\text { North Carolina } \\
\text { Rocky Mount } \\
\text { City of } \\
\text { June } 30\end{array}$ & $\begin{array}{l}\text { North Carolina } \\
\text { Shelby } \\
\text { City of } \\
\text { June } 30\end{array}$ \\
\hline \multicolumn{7}{|l|}{ Electric Utillty Plant } \\
\hline 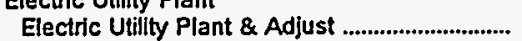 & 24,024 & 12,281 & $1,435,731$ & $1,405,440$ & 38,736 & 8,925 \\
\hline Const Work in Progress & 258 & & 14,617 & 34,602 & & 0 \\
\hline 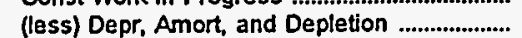 & 10,594 & 3,205 & 445,793 & 372,622 & 15,258 & 4,872 \\
\hline Net Electric Utility Plant ................................ & 13,687 & 9,162 & $1,004,555$ & $1,067,420$ & 23,479 & 4,053 \\
\hline Nuclear Fuel .............................................. & & 0 & 68,367 & 101,567 & 0 & 0 \\
\hline (less) Amort of Nued Fuel ................................. & & 0 & 38,581 & 53,256 & 0 & 0 \\
\hline 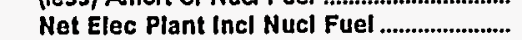 & 13,687 & 9,162 & $1,034,341$ & $1,115,731$ & 23,479 & 4,053 \\
\hline \multicolumn{7}{|l|}{ Other Property \& Investments } \\
\hline 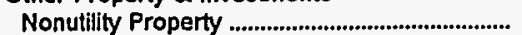 & 0 & 0 & 2,373 & 3,167 & 0 & 0 \\
\hline (less) Accum Provislons for Depr \& Amort.... & 0 & 0 & 468 & 1,255 & 0 & 0 \\
\hline 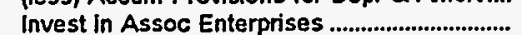 & 0 & 5,735 & 0 & 0 & 0 & 0 \\
\hline 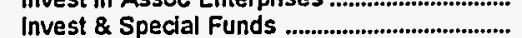 & 0 & 1,700 & 574,082 & 358,505 & 0 & 338 \\
\hline Total Other Property \& Investments ....... & 0 & 7,435 & 575,987 & 360,417 & $\mathbf{0}$ & 338 \\
\hline \multicolumn{7}{|l|}{ Current and Accrued Assets } \\
\hline Cash, Working Funds \& Investments ................ & 4,433 & 158 & 196,552 & 20,322 & 843 & 2,930 \\
\hline 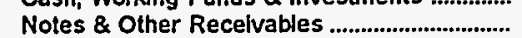 & & 1.192 & 0 & 441 & 47 & 18 \\
\hline Customer Accts Receivable ................................... & 3,795 & 28 & 35,165 & 18,302 & 6,238 & 608 \\
\hline (less) Accum Prov for Uncollected Accts ...... & & 29 & & & 0 & 0 \\
\hline 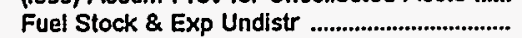 & 0 & 0 & 1,403 & 0 & 0 & 0 \\
\hline Materials \& Supplies ............................................. & 1,191 & 285 & 8,283 & 15,490 & 721 & 594 \\
\hline Other Supplies \& Misc ....................................... & 0 & 0 & 0 & 0 & 0 & 0 \\
\hline 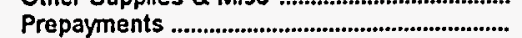 & 0 & 17 & 940 & 148 & 0 & 0 \\
\hline Accrued Utility Revenues ..................................... & 0 & 0 & 0 & 0 & 0 & 0 \\
\hline Miscellaneous Current \& Accrued Assets .... & 0 & 2 & 0 & 583,583 & 0 & 0 \\
\hline Total Current \& Accrued Assets ..................... & 9,419 & 1,653 & 242,343 & 638,286 & 7,848 & 4,150 \\
\hline \multicolumn{7}{|l|}{ Deferred Debits } \\
\hline 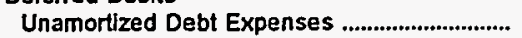 & 0 & 0 & 40,119 & 33,032 & o & 51 \\
\hline Extraordinary Losses, Study Cost ..................... & 0 & 0 & & 348,818 & 0 & 0 \\
\hline Misc Debt, R \& D Exp, Unamrt Losses ........... & 0 & 0 & $1,750,851$ & 0 & 0 & 0 \\
\hline Total Deferred Debits ............................................. & & & $1,790,970$ & 381,850 & 0 & 51 \\
\hline 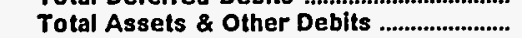 & 23,107 & 18,249 & $3,643,641$ & $2,496,284$ & 31,327 & 8,592 \\
\hline \multicolumn{7}{|l|}{ Proprietary Capital } \\
\hline 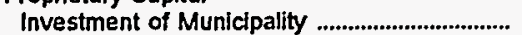 & 4.452 & 0 & 0 & 0 & 0 & $\mathbf{0}$ \\
\hline 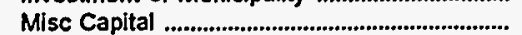 & & 0 & 0 & o & 1,139 & 88 \\
\hline Retalned Earnings ....................................... & 13,935 & 16,574 & 26,000 & 7,400 & 23,420 & 4,684 \\
\hline Total Proprietary Capital ............................. & 18,387 & 16,574 & 26,000 & 7,400 & 24,559 & 4,772 \\
\hline \multicolumn{7}{|l|}{ Long-term Debt } \\
\hline 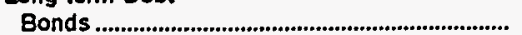 & 0 & 0 & $3,452,680$ & $2,313,582$ & 709 & 2,515 \\
\hline Advances from Municipality \& Other ............... & 942 & 0 & 34.610 & 251,876 & 132 & 0 \\
\hline Unamort Prem on Long-term Debt .................... & 0 & 320 & 17,928 & 11,019 & 0 & 0 \\
\hline (less) Unamort Discount on Long-tem Debt & 0 & 0 & 145.928 & 171,884 & 0 & 0 \\
\hline Total Long-term Debt. ....................................... & 942 & 320 & $3,359,290$ & $2,404,593$ & 842 & 2,515 \\
\hline \multicolumn{7}{|l|}{ Other Noncurrent Ljabilities } \\
\hline Accum Operating Provisions ................................. & 0 & 0 & 0 & 0 & 0 & 0 \\
\hline Accum Prov for Rate Refunds ........................... & 0 & 0 & 0 & 0 & 0 & 0 \\
\hline Total Other Noncurrent Liabilities ............. & 0 & o & 0 & 0 & 0 & 0 \\
\hline \multicolumn{7}{|l|}{ Current and Accrued Labilities } \\
\hline 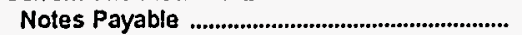 & 411 & 130 & 138,131 & 0 & 0 & 73 \\
\hline 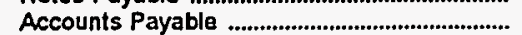 & 2,573 & 989 & 7.485 & 6.161 & 5,004 & 905 \\
\hline Payables to Assoc Enterprises ........................... & 0 & 0 & 0 & 0 & 0 & 0 \\
\hline 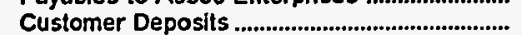 & 725 & 217 & 0 & 0 & 668 & 280 \\
\hline 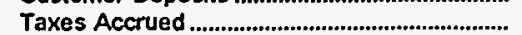 & 0 & 0 & 6.679 & 13,680 & 0 & 0 \\
\hline 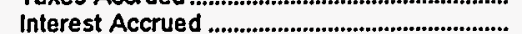 & 0 & 15 & 106,056 & 62,973 & 82 & 16 \\
\hline Mlsc Current \& Accrued Uabilities................... & 70 & 4 & 0 & 0 & 172 & 30 \\
\hline Total Current \& Accrued Liabilities ........... & 3,778 & 1,355 & 258,351 & 82,814 & 5,926 & 1,304 \\
\hline \multicolumn{7}{|l|}{ Deferred Credits } \\
\hline Customer Advances for Construction .............. & 0 & 0 & 0 & 0 & 0 & 0 \\
\hline Other Deferred Credits ...................................... & 0 & 0 & 0 & 1,477 & 0 & 0 \\
\hline Unamort Gain on Reacqr Debt .......................... & 0 & 0 & 0 & 0 & 0 & 0 \\
\hline Total Deferred Credits .................................. & & 0 & 0 & 1,477 & 0 & $\mathbf{0}$ \\
\hline Total Liabillties and Other Credits ............ & 23,107 & 18,249 & $3,643,641$ & $2,496,284$ & 31,327 & 8,592 \\
\hline
\end{tabular}

Note: Totals may not equal sum of components because of independent rounding

Source: Energy Information Administration, Form ELA-412, "Annual Report of Public Electric Utitities." 
Table 22. Balance Sheet by Major U.S. Publicly Owned Electric Utility Within State at End of Period, 1995 (Thousand Dollars)

\begin{tabular}{|c|c|c|c|c|c|c|}
\hline Item & $\begin{array}{l}\text { North Carolina } \\
\text { Statesville } \\
\text { City of } \\
\text { June } 30\end{array}$ & $\begin{array}{l}\text { North Carolina } \\
\text { Tarboro } \\
\text { Town of } \\
\text { June } 30\end{array}$ & $\begin{array}{l}\text { North Carolina } \\
\begin{array}{c}\text { Washington } \\
\text { City of }\end{array} \\
\text { June } 30\end{array}$ & $\begin{array}{l}\text { North Carolina } \\
\text { Wilson } \\
\text { City of } \\
\text { June } 30\end{array}$ & $\begin{array}{c}\text { Ohio } \\
\text { American } \\
\text { Mun } \\
\text { Power } \\
\text { Ohio Inc } \\
\text { December } 31\end{array}$ & $\begin{array}{l}\text { Ohlo } \\
\text { Bowing } \\
\text { Green } \\
\text { City of } \\
\text { December } 31\end{array}$ \\
\hline \multicolumn{7}{|l|}{ Electric Utility Plant } \\
\hline 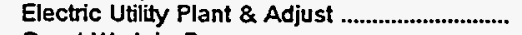 & 16,473 & 19,235 & 28,610 & 53,253 & 69,558 & 18,353 \\
\hline Const Work in Progress & 814 & & 130 & 1,122 & 84 & 171 \\
\hline (less) Depr, Amort, and Depletion ....................... & 6,958 & 6,578 & 10,831 & 27,894 & 22,871 & 9,223 \\
\hline Net Electric Utility Plant ..................................... & 10,329 & 12,656 & 17,908 & 26,480 & 46,771 & 9,302 \\
\hline 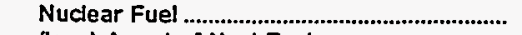 & 0 & 0 & 0 & 0 & 0 & 0 \\
\hline 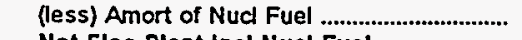 & 0 & 0 & 0 & 0 & 0 & 0 \\
\hline $\begin{array}{l}\text { Net Elec Plant Incl Nucl Fuel .......................... } \\
\text { Other Property \& Investments }\end{array}$ & 10,329 & 12,656 & 17,908 & 26,480 & 46,771 & 9,302 \\
\hline 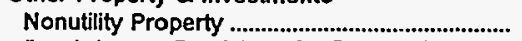 & 1,002 & 0 & 0 & 0 & 2,007 & 0 \\
\hline (less) Accum Provisions for Depr \& Amort.... & 562 & 0 & 1,875 & 0 & 920 & 0 \\
\hline 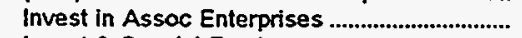 & 0 & 0 & 0 & 0 & 0 & 0 \\
\hline 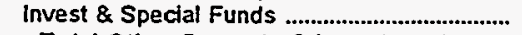 & 0 & 0 & 0 & 0 & 12,881 & 5,794 \\
\hline $\begin{array}{l}\text { Total Other Property \& Investments ....... } \\
\text { Current and Accrued Assets }\end{array}$ & 440 & 0 & $-1,875$ & 0 & 13,968 & 5,794 \\
\hline Cash. Working Funds \& Investments ................. & 7,103 & 7,548 & 7.747 & 25,130 & 8,576 & 978 \\
\hline Notes \& Other Receivables ...................................... & 48 & 2,044 & & 1,486 & 201 & 0 \\
\hline 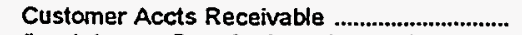 & 3,277 & 0 & 2,149 & 2,506 & 14.621 & 889 \\
\hline (less) Accum Prov for Uncollected Accts ....... & 289 & -31 & 0 & 170 & 0 & 0 \\
\hline 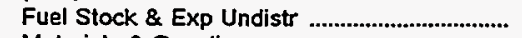 & 0 & 0 & 0 & 0 & 210 & 0 \\
\hline 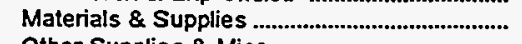 & 1,154 & 609 & 0 & 1,233 & 5,716 & 1,101 \\
\hline 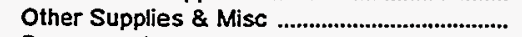 & 0 & 0 & 573 & 0 & 0 & 0 \\
\hline 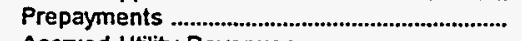 & 16 & 0 & 0 & 43 & 303 & 15 \\
\hline 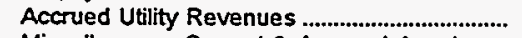 & 0 & 0 & 0 & 5,718 & 0 & 852 \\
\hline Miscellaneous Current \& Accrued Assets ..... & 0 & 0 & 0 & & 3,985 & 0 \\
\hline Total Current \& Accrued Assets ................. & 11,309 & 10,231 & 10,470 & 35,945 & 33,612 & 3,833 \\
\hline \multicolumn{7}{|l|}{ Deferred Debits } \\
\hline Unamortized Debt Expenses .............................. & 0 & 0 & 0 & 0 & 0 & $\mathbf{0}$ \\
\hline 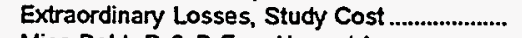 & 0 & 0 & 0 & 0 & 0 & o \\
\hline Misc Debt, R \& D Exp, Unamrt Losses .......... & $\mathbf{0}$ & 0 & 0 & 0 & 0 & 0 \\
\hline Total Deferred Debits ....................................... & 0 & 0 & 0 & o & 0 & 0 \\
\hline Total Assets \& Other Debits ............................ & 22,078 & 22,888 & 26,503 & 62,425 & 94,351 & 18,928 \\
\hline \multicolumn{7}{|l|}{ Proprietary Capital } \\
\hline 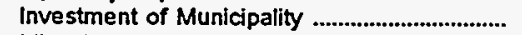 & 34 & 906 & 159 & 80 & 566 & 11,895 \\
\hline 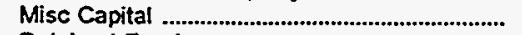 & 158 & 0 & 167 & 10 & 0 & 0 \\
\hline Retained Earnings & 19,466 & 19,726 & 18,683 & 51,368 & 4,208 & 775 \\
\hline 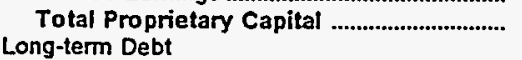 & 19,658 & 20,631 & 19,009 & 51,459 & 4,773 & 12,670 \\
\hline 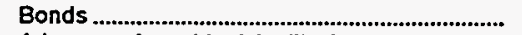 & 180 & 0 & 2,703 & 50 & 61,464 & $\mathbf{0}$ \\
\hline Advances from Municipality \& Other ............... & 0 & 0 & 1,990 & 0 & 0 & 0 \\
\hline Unamort Prem on Long-term Debt ...................... & 0 & 0 & 0 & 0 & 0 & 0 \\
\hline (less) Unamort Discount on Long-term Debt & 0 & 0 & 0 & 0 & 0 & 0 \\
\hline Total Long-term Debt ............................................. & 180 & 0 & 4,693 & 50 & 61,464 & o \\
\hline $\begin{array}{l}\text { Other Noncurrent Uabilities } \\
\text { Accum Operating Provisions ............................... }\end{array}$ & \multicolumn{6}{|c|}{ Other Noncurrent Uabilities } \\
\hline 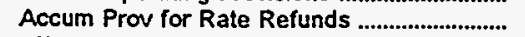 & $\begin{array}{r}68 \\
0\end{array}$ & $\begin{array}{l}0 \\
0\end{array}$ & $\begin{array}{l}0 \\
0\end{array}$ & $\begin{array}{l}0 \\
0\end{array}$ & 0 & $\begin{array}{l}0 \\
0\end{array}$ \\
\hline $\begin{array}{l}\text { Total Other Noncurrent Liabilities ............. } \\
\text { Current and Accrued Liabilities }\end{array}$ & 68 & 0 & 0 & 0 & 0 & 0 \\
\hline 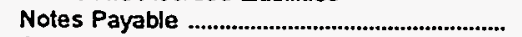 & 0 & 0 & 548 & 2,869 & 0 & 4.355 \\
\hline 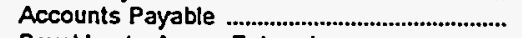 & 2,067 & 1,941 & 1,648 & 6,478 & 11,883 & 1,298 \\
\hline 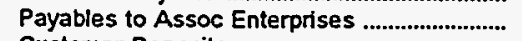 & 0 & 0 & 0 & 0 & 182 & 0 \\
\hline 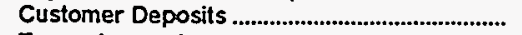 & 104 & 270 & 180 & 675 & 0 & 0 \\
\hline 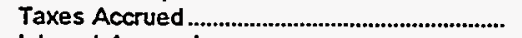 & 0 & 0 & 0 & 0 & 5,650 & 0 \\
\hline Interest Accrued & 1 & 0 & 425 & 0 & 1.734 & 11 \\
\hline Misc Current \& Accrued Liabilities...................... & 0 & 46 & 0 & 894 & 3,776 & 326 \\
\hline $\begin{array}{l}\text { Total Current \& Accrued Liabilities ........... } \\
\text { Deferred Credits }\end{array}$ & 2,172 & 2,256 & 2,801 & 10,916 & 23,225 & 5,990 \\
\hline Customer Advances for Construction ................ & 0 & 0 & 0 & 0 & 0 & 269 \\
\hline Other Deferred Credits .......................................... & 0 & 0 & 0 & 0 & 4,889 & 0 \\
\hline 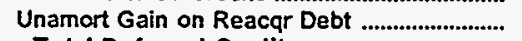 & 0 & 0 & 0 & 0 & 0 & o \\
\hline Total Deferred Credits .................................... & 0 & & 0 & & 4,889 & 269 \\
\hline Total Liabilities and Other Credits ............ & 22,078 & 22,888 & 26,503 & 62,425 & 94,351 & 18,928 \\
\hline
\end{tabular}

Note: Totals may not equal sum of components because of independent rounding.

Source: Energy Information Administration, Form ElA-4 12, "Annual Report of Public Electric Utilities." 
Table 22. Balance Sheet by Major U.S. Publicly Owned Electric Utility Within State at End of Period, 1995

(Thousand Dollars)

\begin{tabular}{|c|c|c|c|c|c|c|}
\hline Item & $\begin{array}{l}\text { Ohio } \\
\text { Bryan } \\
\text { City of } \\
\text { December } 31\end{array}$ & $\begin{array}{l}\text { Ohio } \\
\text { Celina } \\
\text { City of }\end{array}$ & $\begin{array}{c}\text { Cleveland } \\
\text { City of }\end{array}$ & $\begin{array}{c}\text { Ohio } \\
\text { Clyde } \\
\text { City of } \\
\text { December } 31\end{array}$ & $\begin{array}{c}\text { Ohio } \\
\text { Columbus } \\
\text { City of } \\
\text { December } 31\end{array}$ & $\begin{array}{c}\text { Ohio } \\
\text { Cuyahoga } \\
\text { Falls } \\
\text { City of } \\
\text { December } 31\end{array}$ \\
\hline \multicolumn{7}{|l|}{ Electric Utility Plant } \\
\hline Electric Utility Plant \& Adjust ................................ & 14,843 & 20,443 & 233,102 & 11 & 85,997 & 21,705 \\
\hline Const Work in Progress & 0 & 0 & 76,304 & 0 & 0 & 0 \\
\hline (less) Depr, Amort, and Depletion ................................ & 11,494 & $\begin{aligned} 0 \\
20\end{aligned}$ & 101,002 & 0 & 34,753 & 11,624 \\
\hline $\begin{array}{l}\text { Net Electric Utility Plant } \\
\text { Nuclear Fuel }\end{array}$ & $\begin{array}{r}3,349 \\
0\end{array}$ & $\begin{array}{r}20,443 \\
0\end{array}$ & $\begin{array}{r}208,404 \\
0\end{array}$ & $\begin{array}{r}11 \\
0\end{array}$ & $\begin{array}{r}51,244 \\
0\end{array}$ & $\begin{array}{r}10,082 \\
0\end{array}$ \\
\hline 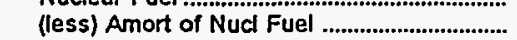 & 0 & 0 & 0 & 0 & 0 & 0 \\
\hline Net Elec Plant Incl Nucl Fuel ............................ & 3,349 & 20,443 & 208,404 & 11 & 51,244 & 10,082 \\
\hline \multicolumn{7}{|l|}{ Other Property \& Investments } \\
\hline 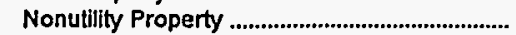 & 0 & 0 & 0 & 0 & 0 & 0 \\
\hline (less) Accum Provisions for Depr \& Amort .... & 0 & 0 & 0 & 0 & 0 & 0 \\
\hline 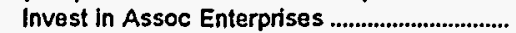 & 0 & 0 & 0 & 0 & 8,550 & 0 \\
\hline 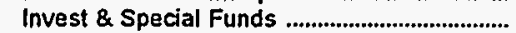 & 0 & 0 & 96,583 & 1 & 6,596 & 0 \\
\hline \multirow{2}{*}{\multicolumn{7}{|c|}{ Current and Accrued Assets }} \\
\hline Cash, Working Funds \& Investments .............. & 2,711 & 336 & 9,581 & & & \\
\hline 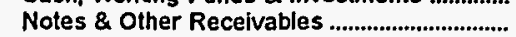 & 28 & 0 & $\begin{array}{r}1.00 \\
0\end{array}$ & 0 & 558 & 888 \\
\hline 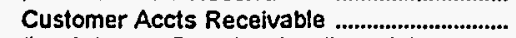 & 1,155 & 341 & 11,341 & 1 & 5,252 & 2,779 \\
\hline (less) Accum Prov for Uncollected Accts ...... & 0 & 290 & 359 & 0 & 0 & 0 \\
\hline 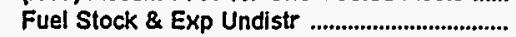 & 0 & 0 & 0 & 0 & 0 & 0 \\
\hline Materials \& Supplies ....................................... & 368 & 908 & 7,741 & 0 & 1,412 & 2,431 \\
\hline 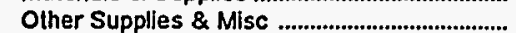 & 0 & 2 & 55 & 0 & 0 & 0 \\
\hline 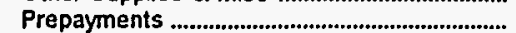 & 30 & 11 & 1,196 & 0 & 0 & 38 \\
\hline Accrued Utility Revenues ................................. & 0 & 654 & 130 & 0 & 0 & 0 \\
\hline Miscellaneous Current \& Accrued Assets ..... & 0 & 0 & 0 & 0 & 5 & 0 \\
\hline Total Current \& Accrued Assets ............... & 4,292 & 1,961 & 29,685 & 3 & 10,198 & 14,251 \\
\hline \multicolumn{7}{|l|}{ Deferred Debits } \\
\hline Unamortized Debt Expenses .............................. & 0 & 0 & 3,259 & 1 & 0 & 0 \\
\hline 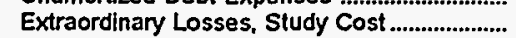 & 0 & 0 & 0 & 0 & 0 & 0 \\
\hline Misc Debt, R \& D Exp, Unamrt Losses .......... & 0 & 0 & 0 & 0 & 0 & 0 \\
\hline Total Deferred Debits ................................. & o & $\mathbf{0}$ & 3,259 & 1 & $\mathbf{0}$ & $\mathbf{0}$ \\
\hline Total Assets \& Other Debits & 7,641 & 22,404 & 337,933 & 16 & 76,588 & 24,332 \\
\hline \multicolumn{7}{|l|}{ Proprietary Capital } \\
\hline 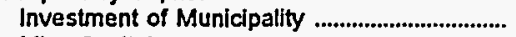 & 0 & 21,353 & 12,183 & 0 & 17,172 & 0 \\
\hline 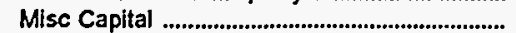 & 0 & 0 & 0 & 0 & 0 & 0 \\
\hline 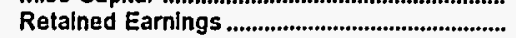 & 6,729 & 536 & 64,391 & 4 & -27.572 & 17,907 \\
\hline $\begin{array}{l}\text { Total Proprietary Capital } \\
\text { Long-term Debt }\end{array}$ & 6,729 & 21,888 & 76,575 & 4 & $-10,400$ & 17,907 \\
\hline 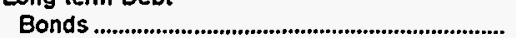 & 0 & 0 & 245,286 & 11 & 81,454 & 3.660 \\
\hline Advances from Municipality \& Other .............. & 0 & 0 & $\begin{array}{r}2+200 \\
0\end{array}$ & 0 & 0 & 0 \\
\hline 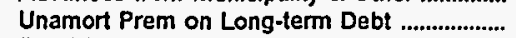 & 0 & 0 & 0 & 0 & 0 & 0 \\
\hline (less) Unamort Discount on Long-term Debt & 0 & 0 & 0 & 0 & 0 & 0 \\
\hline 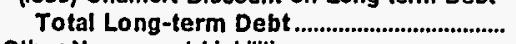 & $\mathbf{0}$ & 0 & 245,286 & 11 & 81,454 & 3,660 \\
\hline \multicolumn{7}{|l|}{ Other Noncurrent Liabilitles } \\
\hline 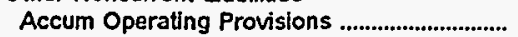 & $\mathbf{0}$ & 59 & 2,211 & 0 & 0 & 0 \\
\hline 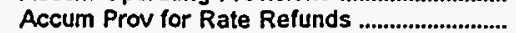 & 0 & 0 & 0 & 0 & 0 & 0 \\
\hline $\begin{array}{l}\text { Total Other Noncurrent Liabilities } \\
\text { Current and Accrued Liabilities... }\end{array}$ & \multicolumn{2}{|c|}{ Current and Accrued Liabilities } & 2,211 & 0 & 0 & 0 \\
\hline 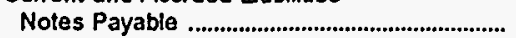 & 0 & 0 & 0 & 0 & 327 & 0 \\
\hline 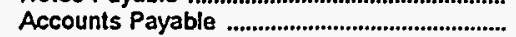 & 836 & 344 & 5,652 & 0 & 2,173 & 1,554 \\
\hline Payables to Assoc Enterprises ......................... & 0 & 0 & 0 & 0 & 175 & 64 \\
\hline 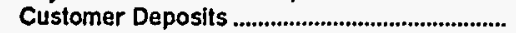 & 0 & 112 & 0 & 0 & 499 & 182 \\
\hline 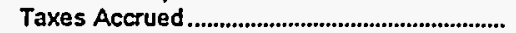 & 0 & 0 & 0 & 0 & 0 & 0 \\
\hline Interest Accrued & 0 & 0 & 1,955 & 0 & 559 & 18 \\
\hline 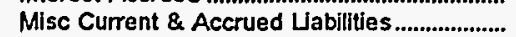 & 77 & o & 6,254 & 0 & 1.165 & 947 \\
\hline $\begin{array}{l}\text { Total Current \& Accrued Liabilities .......... } \\
\text { Deferred Credits }\end{array}$ & 913 & 456 & 13,860 & 1 & 4,898 & 2,766 \\
\hline Customer Advances for Construction ............. & 0 & 0 & 0 & 0 & 0 & 0 \\
\hline 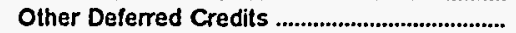 & 0 & 0 & 0 & 0 & 636 & 0 \\
\hline 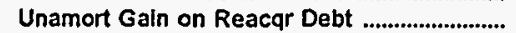 & 0 & 0 & 0 & 0 & 0 & 0 \\
\hline 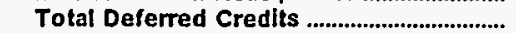 & 0 & 0 & $\mathbf{0}$ & 0 & 636 & $\mathbf{0}$ \\
\hline Total Liabllities and Other Credits ............. & 7,641 & 22,404 & 337,933 & 16 & 76,588 & 24,332 \\
\hline
\end{tabular}

Note: Totals may not equal sum of components because of independent rounding.

Source: Energy Information Administration, Form ElA-412, "Annual Report of Public Electric Utilities." 
Table 22. Balance Sheet by Major U.S. Publicly Owned Electric Utility Within State at End of Period, 1995

(Thousand Dollars)

\begin{tabular}{|c|c|c|c|c|c|c|}
\hline Item & $\begin{array}{c}\text { Ohio } \\
\text { Dover } \\
\text { City of } \\
\text { December } 31\end{array}$ & $\begin{array}{c}\text { Ohio } \\
\begin{array}{c}\text { Hamilton } \\
\text { City of }\end{array} \\
\text { December } 31\end{array}$ & $\begin{array}{c}\text { Ohio } \\
\text { Napoleon } \\
\text { City of } \\
\text { December } 31\end{array}$ & $\begin{array}{c}\text { Ohio } \\
\text { Niles } \\
\text { City of } \\
\text { December } 31\end{array}$ & $\begin{array}{l}\text { Ohio } \\
\text { Orville } \\
\text { City of } \\
\text { December } 31\end{array}$ & $\begin{array}{c}\text { Ohio } \\
\text { Painesville } \\
\text { City of }\end{array}$ \\
\hline \multicolumn{7}{|l|}{ Electric Utility Plant } \\
\hline Electric Utility Plant \& Adjust .................................. & 9,945 & 248,130 & 2,412 & 12,013 & 53,470 & 38,706 \\
\hline Const Work in Progress & & 4,398 & & & 460 & \\
\hline 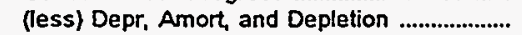 & & 85,776 & & 7,001 & 28,496 & 23,796 \\
\hline Net Electric Utility Plant ....................................... & 9,945 & 166,753 & 2,412 & 5,012 & 25,434 & 14,910 \\
\hline 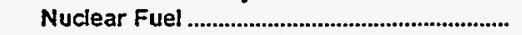 & 0 & 0 & 0 & 0 & 0 & 0 \\
\hline 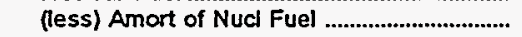 & & 0 & 0 & 0 & 0 & 0 \\
\hline Net Elec Plant Incl Nucl Fuel ........................ & $\mathbf{9 , 9 4 5}$ & 166,753 & 2,412 & 5,012 & 25,434 & 14,910 \\
\hline \multicolumn{7}{|l|}{ Other Property \& Investments } \\
\hline 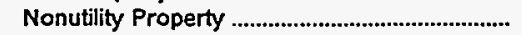 & 0 & $\mathbf{0}$ & 0 & 0 & 0 & 0 \\
\hline (less) Accum Provisions for Depr \& Amort.... & 0 & 0 & 0 & 0 & 0 & 0 \\
\hline 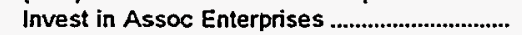 & o & 0 & 0 & 0 & 0 & $\mathbf{0}$ \\
\hline 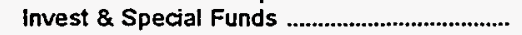 & 0 & 27,691 & 0 & 0 & 0 & 8,422 \\
\hline $\begin{array}{l}\text { Total Other Property \& Investments ....... } \\
\text { Current and Accrued Assets }\end{array}$ & 0 & 27,691 & 0 & 0 & 0 & 8,422 \\
\hline Cash, Working Funds \& Investments ............... & 1 & 5,170 & $\mathbf{0}$ & 5.909 & 8,160 & 670 \\
\hline Notes \& Other Receivables .................................... & 147 & 7.045 & 0 & 0 & 79 & 0 \\
\hline 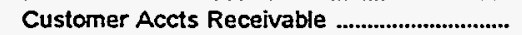 & 1,647 & 0 & 0 & 1.516 & 2,086 & 1,846 \\
\hline (less) Accum Prov for Uncollected Accts ...... & 0 & 0 & 0 & 0 & 117 & 0 \\
\hline Fuel Stock \& Exp Undistr ......................................... & 0 & 0 & 0 & 0 & 0 & 0 \\
\hline 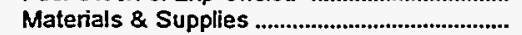 & 687 & 1.756 & 0 & 0 & 2,095 & 728 \\
\hline Other Supplies \& Misc ............................................ & 264 & 0 & 0 & 0 & 0 & 0 \\
\hline Prepayments ..................................................................... & 97 & 268 & 0 & 0 & 22 & 18 \\
\hline Accrued Utility Revenues ........................................... & 1,784 & 0 & o & 0 & 0 & 0 \\
\hline Miscellaneous Current \& Accrued Assets ..... & 8.139 & 5.641 & 0 & 0 & 126 & 0 \\
\hline $\begin{array}{l}\text { Total Current \& Accrued Assets ................ } \\
\text { Deferred Debits }\end{array}$ & 12,766 & 19,880 & 0 & 7,425 & 12,450 & 3,262 \\
\hline 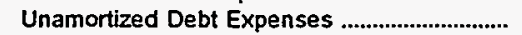 & 0 & 2,595 & 0 & 0 & 464 & 0 \\
\hline Extraordinary Losses, Study Cost ...................... & 0 & 0 & 0 & 0 & 0 & 0 \\
\hline Misc Debt, R \& D Exp, Unamrt Losses .......... & 0 & 0 & 0 & 0 & 0 & 0 \\
\hline Total Deferred Debits ............................................ & & 2,595 & 0 & 0 & 464 & \\
\hline Total Assets \& Other Debits ........................... & 22,712 & 216,918 & 2,412 & 12,437 & 38,348 & 26,594 \\
\hline \multicolumn{7}{|l|}{ Proprietary Capital } \\
\hline 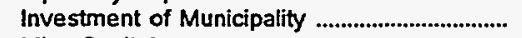 & 135 & 0 & 0 & 0 & 0 & 42 \\
\hline Misc Capital ................................................................ & 0 & 1,056 & 0 & 0 & $\mathbf{0}$ & 0 \\
\hline 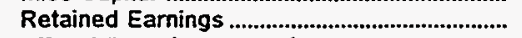 & 9,798 & $-5,007$ & 2,412 & 9,797 & 19,129 & 18,241 \\
\hline $\begin{array}{l}\text { Total Proprietary Capital ....................................... } \\
\text { Long-term Debt }\end{array}$ & 9,933 & $-3,951$ & 2,412 & 9,797 & 19,129 & 18,283 \\
\hline 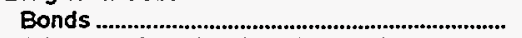 & 10,865 & 206,041 & 0 & 0 & 17,365 & 6,105 \\
\hline Advances from Municipality \& Other ................ & 347 & 0 & 0 & 0 & 0 & 0 \\
\hline Unamort Prem on Long-term Debt ....................... & 0 & 0 & 0 & 0 & 0 & 0 \\
\hline (less) Unamort Discount on Long-term Debt & 0 & 0 & 0 & 0 & 0 & 0 \\
\hline Total Long-term Debt & 11,212 & 206,041 & 0 & 0 & 17,365 & 6,105 \\
\hline \multicolumn{7}{|l|}{ Other Noncurrent Liabilities } \\
\hline Accum Operating Provisions .................................. & 0 & 1,144 & 0 & 0 & 0 & 226 \\
\hline 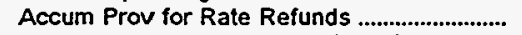 & 0 & 0 & 0 & 0 & 0 & 0 \\
\hline $\begin{array}{l}\text { Total Other Noncurrent Liabilities ............ } \\
\text { Current and Accrued Liabilities }\end{array}$ & 0 & 1,144 & 0 & 0 & 0 & 228 \\
\hline 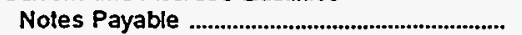 & 0 & 3,930 & $\mathbf{0}$ & 0 & 560 & \\
\hline Accounts Payable ....................................................... & 693 & 6,217 & 0 & 0 & 460 & 1,723 \\
\hline Payables to Assoc Enterprises .............................. & 101 & 0 & 0 & 0 & 0 & 0 \\
\hline 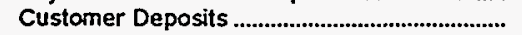 & 62 & 391 & 0 & 0 & 0 & 256 \\
\hline 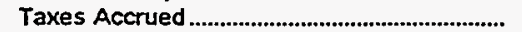 & 0 & 0 & 0 & 0 & 0 & 0 \\
\hline 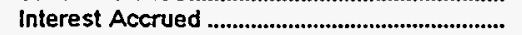 & 58 & 2.711 & 0 & 0 & 124 & 0 \\
\hline Misc Current \& Accrued Liabilities ...................... & 652 & 435 & 0 & 2,640 & 710 & \\
\hline $\begin{array}{l}\text { Total Current \& Accrued Liabilities ........... } \\
\text { Deferred Credits }\end{array}$ & 1,566 & 13,683 & 0 & 2,640 & 1,854 & 1,980 \\
\hline Customer Advances for Construction .............. & 0 & 0 & 0 & $\mathbf{0}$ & 0 & 0 \\
\hline Other Deferred Credits ............................................ & 0 & 0 & 0 & 0 & 0 & 0 \\
\hline Unamort Gain on Reacqr Debt ........................... & 0 & 0 & 0 & 0 & 0 & 0 \\
\hline 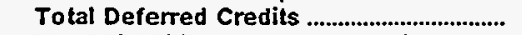 & & & 0 & $\mathbf{0}$ & & \\
\hline Total Liabilities and Other Credits ............ & 22,712 & 216,918 & 2,412 & 12,437 & 38,348 & 26,594 \\
\hline
\end{tabular}

Note: Totals may not equal sum of components because of independent rounding.

Source: Energy Information Administration, Form ElA-412, "Annual Report of Public Electric Utilities." 
Table 22. Balance Sheet by Major U.S. Publicly Owned Electric Utility Within State at End of Period, 1995

(Thousand Dollars)

\begin{tabular}{|c|c|c|c|c|c|c|}
\hline Item & $\begin{array}{c}\text { Ohio } \\
\text { Piqua } \\
\text { City of } \\
\text { December } 31\end{array}$ & $\begin{array}{c}\text { Ohio } \\
\text { St Marys } \\
\text { City of } \\
\text { December } 31\end{array}$ & $\begin{array}{c}\text { Ohio } \\
\text { Wadsworth } \\
\text { City of }\end{array}$ & $\begin{array}{c}\text { Ohio } \\
\text { Wapakoneta } \\
\text { City of }\end{array}$ & $\begin{array}{c}\text { Ohio } \\
\text { Westerville } \\
\text { City of } \\
\text { December } 31\end{array}$ & $\begin{array}{l}\text { OkJahoma } \\
\text { Altus } \\
\text { City of } \\
\text { June } 30\end{array}$ \\
\hline \multicolumn{7}{|l|}{ Electric Utility Plant } \\
\hline 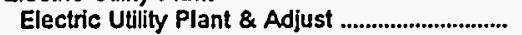 & 45,602 & 16,120 & 12,226 & $\mathbf{0}$ & 23.770 & 7,973 \\
\hline 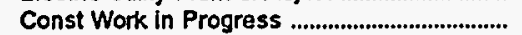 & 610 & 2 & 0 & 0 & 1.041 & 0 \\
\hline (less) Depr, Amort, and Depletion ...................... & 21,329 & $\begin{array}{r}10,742 \\
5,380\end{array}$ & $\begin{array}{l}4,603 \\
7,623\end{array}$ & $\begin{array}{l}0 \\
0\end{array}$ & $\begin{array}{l}10.064 \\
14.746\end{array}$ & $\begin{array}{l}5,812 \\
2,161\end{array}$ \\
\hline 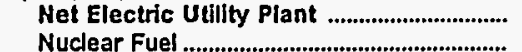 & $\begin{array}{r}24,883 \\
0\end{array}$ & $\begin{array}{r}3,380 \\
0\end{array}$ & $\begin{array}{r}1,623 \\
0\end{array}$ & 0 & $\begin{array}{r}74,140 \\
0\end{array}$ & $\begin{array}{r}2,361 \\
0\end{array}$ \\
\hline (less) Amort of Nud Fuel ............................... & 0 & 0 & 0 & 0 & 0 & 0 \\
\hline Net Elec Plant Incl Nucl Fuel ........................... & 24,883 & 5,380 & 7,623 & 0 & 14,746 & 2,161 \\
\hline \multirow{2}{*}{\multicolumn{7}{|c|}{ Other Property \& Investments }} \\
\hline Nonutility Property ....................................................... & & & & & & \\
\hline (less) Accum Provisions for Depr \& Amort.... & $\mathbf{0}$ & 0 & 0 & $\mathbf{0}$ & 0 & 0 \\
\hline 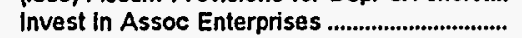 & $\mathbf{0}$ & 0 & 0 & o & 0 & 0 \\
\hline 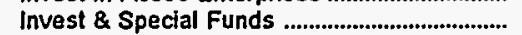 & 1,121 & 3,204 & 0 & $\mathbf{0}$ & 0 & 0 \\
\hline Total Other Property \& Investments ........ & 1,121 & 3,204 & 0 & 0 & 0 & 0 \\
\hline \multicolumn{7}{|l|}{ Current and Accrued Assets } \\
\hline Cash, Working Funds \& Investments ............... & 2,428 & 1,682 & 1,481 & 2,573 & 31,363 & 7,614 \\
\hline Notes \& Other Receivables ...................................... & 35 & 0 & 0 & 0 & 0 & 0 \\
\hline Customer Accts Receivable ................................. & 1,119 & 615 & 1,760 & o & 2,856 & 1,255 \\
\hline \{less\} Accum Prov for Uncollected Accts ...... & 89 & 0 & 0 & 0 & 71 & 310 \\
\hline Fuel Stock \& Exp Undistr .......................................... & 157 & 0 & 0 & $\mathbf{0}$ & 0 & 0 \\
\hline 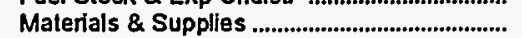 & 462 & 273 & 740 & 0 & 1,037 & 615 \\
\hline 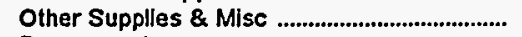 & 0 & 0 & 0 & $\mathbf{0}$ & 0 & 0 \\
\hline 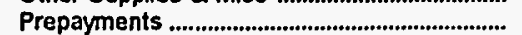 & 177 & 55 & 14 & 0 & 0 & $\mathbf{0}$ \\
\hline 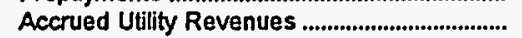 & 641 & 56 & 0 & 0 & 0 & $\mathbf{0}$ \\
\hline Miscellaneous Current \& Accrued Assets ..... & 96 & & 2,754 & 0 & 14 & 109 \\
\hline Total Current \& Accrued Assets .................... & 5,027 & 2,684 & 6,751 & 2,573 & 35,198 & 9,283 \\
\hline \multicolumn{7}{|l|}{ Deferred Debits } \\
\hline 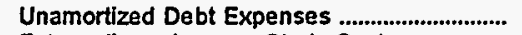 & 0 & 176 & 0 & o & 0 & 0 \\
\hline 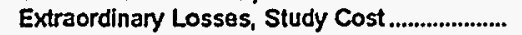 & $\mathbf{0}$ & 0 & 0 & 0 & 0 & 0 \\
\hline Misc Debt, R \& D Exp, Unamrt Losses .......... & 0 & 0 & 0 & 0 & 0 & 0 \\
\hline Total Deferred Debits ........................................ & & 176 & 0 & 0 & 0 & 0 \\
\hline 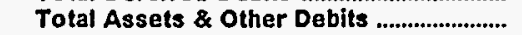 & 31,030 & 11,445 & 14,374 & 2,573 & 49,945 & 11,444 \\
\hline \multicolumn{7}{|l|}{ Proprietary Capital } \\
\hline 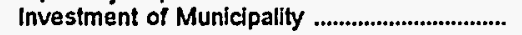 & 0 & 0 & 0 & 1,066 & 0 & 3,184 \\
\hline Misc Capital ..................................................................... & $\mathbf{0}$ & 47 & 40 & 0 & 272 & 0 \\
\hline 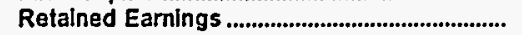 & 21,181 & 5,553 & 11.580 & 1,507 & 47,676 & 6,689 \\
\hline Total Proprietary Capital ....................................... & 21,181 & 5,600 & $\$ 1,620$ & 2,573 & 47,949 & 9,872 \\
\hline \multicolumn{7}{|l|}{ Long-term Debt } \\
\hline 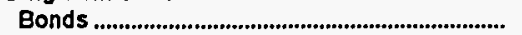 & 8,116 & 4,980 & 0 & 0 & 0 & 0 \\
\hline Advances from Municipality \& Other ..................... & 0 & 116 & 0 & 0 & 0 & 0 \\
\hline Unamort Prem on Long-term Debt ...................... & 0 & 0 & 0 & 0 & $\mathbf{0}$ & 0 \\
\hline (less) Unamort Discount on Long-term Debt & & & 0 & 0 & 0 & 0 \\
\hline 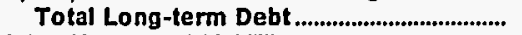 & 8,116 & 5,096 & o & o & 0 & o \\
\hline \multicolumn{7}{|l|}{ Other Noncurrent Lablities } \\
\hline 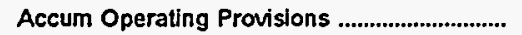 & 485 & 0 & 0 & 0 & 347 & 0 \\
\hline Accum Prov for Rate Refunds .......................... & & 0 & 0 & 0 & 0 & 0 \\
\hline Total Other Noncurrent Liabilities ............ & 485 & 0 & 0 & 0 & 347 & 0 \\
\hline \multicolumn{7}{|l|}{ Current and Accrued Uabilities } \\
\hline 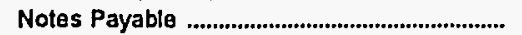 & 0 & 0 & 0 & 0 & 0 & 0 \\
\hline 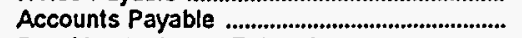 & 861 & 376 & 811 & 0 & 1,395 & 1,572 \\
\hline Payables to Assoc Enterprises ............................ & 0 & 0 & 0 & 0 & 0 & 0 \\
\hline 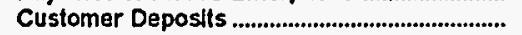 & 0 & 229 & 0 & 0 & 37 & 0 \\
\hline 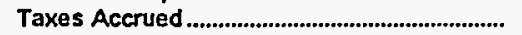 & $\mathbf{0}$ & 0 & 0 & 0 & 0 & 0 \\
\hline Interest Accrued ................................................ & 0 & 27 & 14 & 0 & 0 & 0 \\
\hline Misc Current \& Accrued Labilities...................... & 387 & 116 & 1,929 & 0 & 217 & 0 \\
\hline \multirow{2}{*}{\multicolumn{7}{|c|}{ Deferred Credits }} \\
\hline & & & & & & \\
\hline Customer Advances for Construction .............. & 0 & 0 & 0 & 0 & 0 & 0 \\
\hline Other Deferred Credits ................................................. & 0 & $\mathbf{0}$ & 0 & 0 & 0 & 0 \\
\hline Unamort Gain on Reacqr Debt .......................... & 0 & 0 & 0 & 0 & 0 & 0 \\
\hline Total Deferred Credits ......................................... & o & 0 & o & 0 & 0 & o \\
\hline Total Liabilities and Other Credits ............. & 31,030 & 11,445 & 14,374 & 2,573 & 49,945 & 11,444 \\
\hline
\end{tabular}

Note: Totals may not equal sum of components because of independent rounding.

Source: Energy Information Administration, Form EIA-412, "Annual Report of Public Electric Utilities." 
Table 22. Balance Sheet by Major U.S. Publicly Owned Electric Utility Within State at End of Period, 1995

(Thousand Dollars)

\begin{tabular}{|c|c|c|c|c|c|c|}
\hline Item & $\begin{array}{l}\text { Claremore } \\
\text { City of } \\
\text { June } 30\end{array}$ & $\begin{array}{l}\text { Oklahoma } \\
\text { Duncan } \\
\text { City of } \\
\text { June } 30\end{array}$ & $\begin{array}{l}\text { Oklahoma } \\
\text { Edmond } \\
\text { City of } \\
\text { June } 30\end{array}$ & $\begin{array}{c}\text { OkJahoma } \\
\text { Grand River } \\
\text { Dam } \\
\text { Authority } \\
\text { December } 31\end{array}$ & $\begin{array}{l}\text { Oklahoma } \\
\text { Miami } \\
\text { City of } \\
\text { June } 30\end{array}$ & $\begin{array}{c}\text { Oklahoma } \\
\text { Oklahoma } \\
\text { Municipal } \\
\text { Power Auth } \\
\text { December } 31\end{array}$ \\
\hline \multicolumn{7}{|l|}{ Electric Utility Plant } \\
\hline 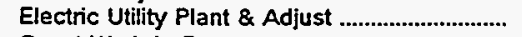 & 0 & 20,095 & 40,598 & 877.680 & 3,026 & 196,775 \\
\hline Const Work in Progress & 0 & 73 & 1 & 13,342 & 0 & 351 \\
\hline $\begin{array}{l}\text { (less) Depr, Amort, and Depletion } \\
\text { Net Electric Utility Plant }\end{array}$ & $\begin{array}{l}0 \\
0\end{array}$ & $\begin{array}{r}10,786 \\
9,383\end{array}$ & $\begin{array}{l}18,026 \\
22,573\end{array}$ & $\begin{array}{l}325,421 \\
565,602\end{array}$ & $\begin{array}{r}2,262 \\
764\end{array}$ & $\begin{array}{r}37,896 \\
159,230\end{array}$ \\
\hline 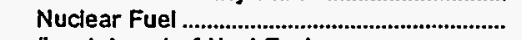 & 0 & 0 & 0 & 0 & 0 & 0 \\
\hline 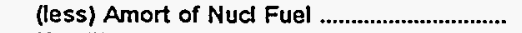 & 0 & 0 & 0 & 0 & 0 & 0 \\
\hline \multicolumn{7}{|l|}{ Other Property \& Investments } \\
\hline Nonutility Property & 0 & 0 & 0 & 33 & 11,901 & $\mathbf{0}$ \\
\hline (less) Accum Provisions for Depr \& Amort.... & 0 & 0 & 0 & 0 & 4,819 & $\mathbf{0}$ \\
\hline 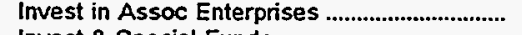 & 0 & 0 & 0 & 0 & 0 & 0 \\
\hline Invest \& Special Funds ...................................... & 0 & 0 & 0 & 125,828 & 0 & 68,669 \\
\hline \multicolumn{7}{|l|}{ Current and Accrued Assets } \\
\hline Cash, Working Funds \& Investments .............. & 608 & 3,926 & 7,642 & 129,026 & 7,414 & 28,803 \\
\hline 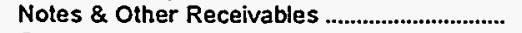 & 0 & 0 & 1 & 2,786 & 61 & 5,550 \\
\hline Customer Accts Receivable & 1,431 & 1,115 & 3,441 & 13,064 & 733 & 0 \\
\hline (less) Accum Prov for Uncollected Accts ....... & 334 & 31 & 46 & 63 & 194 & 0 \\
\hline Fuel Stock \& Exp Undistr & 0 & 0 & 0 & 6,476 & 0 & 0 \\
\hline 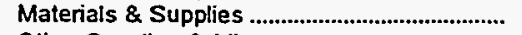 & 0 & 0 & 0 & 18,149 & 724 & 0 \\
\hline 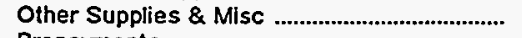 & 0 & 0 & 0 & 2 & 0 & 0 \\
\hline 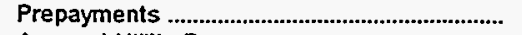 & 0 & 0 & 0 & 744 & 0 & 0 \\
\hline 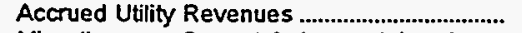 & 0 & 0 & 0 & 0 & 0 & 0 \\
\hline Miscellaneous Current \& Accrued Assets ..... & 0 & 12 & 45 & 2,201 & 0 & 2,964 \\
\hline $\begin{array}{l}\text { Total Current \& Accrued Assets ............... } \\
\text { Deferred Debits }\end{array}$ & 1,705 & 5,021 & 11,084 & 172,386 & 8,738 & $\mathbf{3 7 , 3 1 7}$ \\
\hline 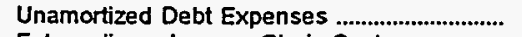 & 0 & 0 & 18 & 9,499 & 0 & 98,299 \\
\hline 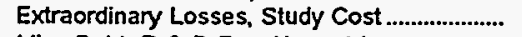 & 0 & 0 & 0 & 180 & 0 & 0 \\
\hline Misc Debt, R \& D Exp, Unamrt Losses .......... & 0 & 0 & 0 & 245,228 & 0 & 51,345 \\
\hline 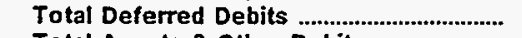 & 0 & 0 & 18 & 254,908 & 0 & 149,644 \\
\hline $\begin{array}{l}\text { Total Assets \& Other Debits } \\
\text { Proprietary Capital }\end{array}$ & 1,705 & 14,404 & 33,676 & $1,118,757$ & 16,584 & 414,860 \\
\hline 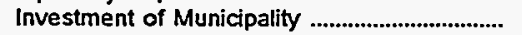 & 0 & 13,400 & 0 & 0 & 0 & 0 \\
\hline 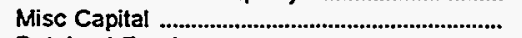 & 0 & 2 & 0 & 0 & 0 & 0 \\
\hline 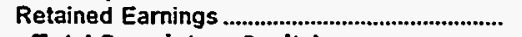 & 941 & 0 & 25,650 & 31,246 & 15,537 & 11,954 \\
\hline $\begin{array}{l}\text { Total Proprietary Capital } \\
\text { Long-term Debt }\end{array}$ & 941 & 13,402 & 25,650 & 31,246 & 15,537 & 11,954 \\
\hline 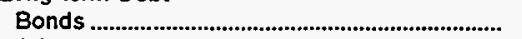 & 0 & 0 & 2,818 & $1,071,165$ & 0 & 390,430 \\
\hline Advances from Municipality \& Other ................ & 0 & 0 & 0 & 1,566 & 0 & 0 \\
\hline 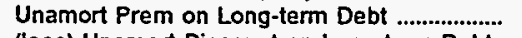 & 0 & 0 & 0 & 0 & 0 & 0 \\
\hline (less) Unamort Discount on Long-term Debt & 0 & 0 & 0 & 24,361 & 0 & 15,150 \\
\hline Total Long-term Debt & 0 & 0 & 2,818 & $1,048,370$ & $\mathbf{0}$ & 375,280 \\
\hline \multicolumn{7}{|l|}{ Other Noncurrent Liabilities } \\
\hline 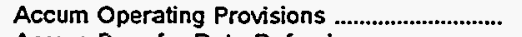 & 0 & 0 & 98 & 0 & 0 & 0 \\
\hline Accum Prov for Rate Refunds .................... & 0 & 0 & 0 & 0 & 0 & 0 \\
\hline $\begin{array}{l}\text { Total Other Noncurrent Liabilities } \\
\text { Current and Accrued Liabilities }\end{array}$ & $\mathbf{0}$ & 0 & 98 & 0 & 0 & 0 \\
\hline 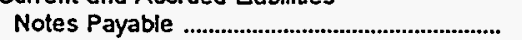 & & & & \multicolumn{3}{|c|}{ Current and Accrued Liabilities } \\
\hline 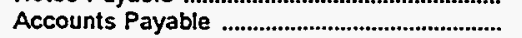 & 764 & 78 & 2,477 & 6,709 & $\begin{array}{r}0 \\
758\end{array}$ & 0 \\
\hline 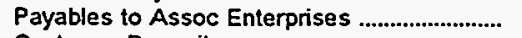 & 0 & 578 & 0 & 0 & 0 & 4,304 \\
\hline 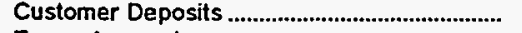 & 0 & 347 & 2,493 & 0 & 289 & 0 \\
\hline Taxes Accrued & 0 & 0 & 0 & 0 & 0 & 0 \\
\hline Interest Accrued & 0 & 0 & 66 & 4,920 & 0 & 10,810 \\
\hline Misc Current \& Accrued Liabilities ..................... & 0 & 0 & 3 & 5,858 & 0 & 4,245 \\
\hline $\begin{array}{l}\text { Total Current \& Accrued Liabilities .......... } \\
\text { Deferred Credits }\end{array}$ & 764 & 1,002 & 5,038 & 17,488 & 1,047 & 19,358 \\
\hline Customer Advances for Construction .............. & 0 & 0 & 0 & 0 & 0 & 7,900 \\
\hline Other Deferred Credits ........................................ & 0 & 0 & 71 & 21,653 & 0 & 367 \\
\hline Unamort Gain on Reacqr Debt ........................... & 0 & 0 & 0 & 0 & 0 & 0 \\
\hline Total Deferred Credits ..................................... & 0 & 0 & 71 & 21,653 & $\mathbf{0}$ & 8,267 \\
\hline Total Liabilities and Other Credits ............. & 1,705 & 14,404 & 33,676 & $1,118,757$ & 16,584 & 414,860 \\
\hline
\end{tabular}

Note: Totals may not equal sum of components because of independent rounding.

Source: Energy Information Administration, Form ElA-412. "Annual Report of Pubtic Electric Utilities." 
Table 22. Balance Sheet by Major U.S. Publicly Owned Electric Utility Within State at End of Period, 1995 (Thousand Dollars)

\begin{tabular}{|c|c|c|c|c|c|c|}
\hline Item & $\begin{array}{l}\text { Oklahoma } \\
\text { Ponca } \\
\text { Clty City of } \\
\text { June } 30\end{array}$ & $\begin{array}{l}\text { Oklahoma } \\
\text { Stillwater } \\
\text { Utilities } \\
\text { Authority } \\
\text { June } 30\end{array}$ & $\begin{array}{l}\text { Oregon } \\
\text { Ashland } \\
\text { City of } \\
\text { June } 30\end{array}$ & $\begin{array}{l}\text { Oregon } \\
\text { Central } \\
\text { Lincoln } \\
\text { Peoples } \\
\text { UtI Dt } \\
\text { December } 31\end{array}$ & $\begin{array}{c}\text { Oregon } \\
\text { Clatskanie } \\
\text { Peoples } \\
\text { Util Dist } \\
\text { December } 31\end{array}$ & $\begin{array}{l}\text { Oregon } \\
\text { Columbia } \\
\text { River } \\
\text { Peoples } \\
\text { Ut Dist } \\
\text { December } 31\end{array}$ \\
\hline \multicolumn{7}{|l|}{ Electric Utility Plant } \\
\hline 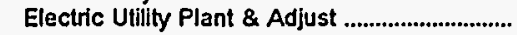 & 35,818 & 40,444 & 12,523 & 85,937 & 7,175 & 24,601 \\
\hline 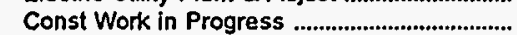 & & 97 & 0 & 13,971 & 468 & 75 \\
\hline (less) Depr, Amort, and Depletion ..................... & 16,389 & 15,533 & 0 & 38,628 & 3,833 & 4,932 \\
\hline Nel Electric Utility Plant ................................. & 19,429 & 25,009 & 12,523 & 61,280 & 3,810 & 19,744 \\
\hline 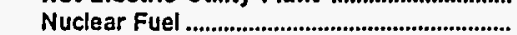 & 0 & 0 & 0 & 0 & 0 & 0 \\
\hline (less) Amort of Nucl Fuel .............................. & 0 & 0 & 0 & 0 & 0 & 0 \\
\hline Net Elec Plant Incl Nucl Fuel ......................... & 19,429 & 25,009 & 12,523 & 61,280 & 3,810 & 19,744 \\
\hline \multicolumn{7}{|l|}{ Other Property \& Investments } \\
\hline 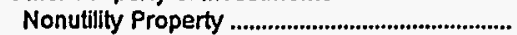 & 0 & 0 & 0 & 0 & 0 & 1 \\
\hline (less) Accum Provisions for Depr \& Amort.... & 0 & 0 & 0 & 0 & 0 & 0 \\
\hline 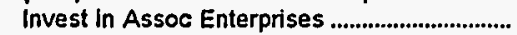 & 0 & 0 & 0 & 0 & 0 & 0 \\
\hline Invest \& Special Funds ........................................ & 3,835 & 0 & 0 & 9,158 & 241 & 3,371 \\
\hline & 3,835 & \multicolumn{2}{|c|}{ Current and Accrued Assets } & 9,158 & 241 & 3,371 \\
\hline Cash, Working Funds \& Investments .............. & 6 & 15,116 & 798 & 2,470 & 4,730 & 1,190 \\
\hline 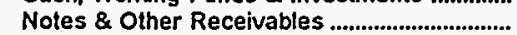 & 13 & 26 & 149 & $\mathbf{3 , 7 1 6}$ & 0 & 60 \\
\hline Customer Accts Receivable .................................... & 1,622 & 3,374 & 478 & 177 & 2,591 & 1,409 \\
\hline (less) Accum Prov for Uncollected Accts ....... & c & 19 & 0 & 204 & 9 & 37 \\
\hline Fuel Stock \& Exp Undistr ....................................... & 0 & 0 & 0 & & 0 & 0 \\
\hline 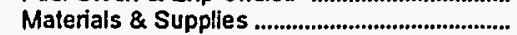 & 0 & 540 & 498 & 2,143 & 185 & 371 \\
\hline Other Supplles \& Misc ......................................... & 0 & 0 & 0 & 344 & 0 & 0 \\
\hline 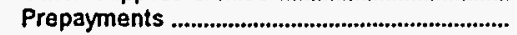 & 0 & 0 & 0 & 1,240 & 65 & 85 \\
\hline 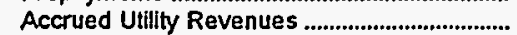 & 0 & 0 & 0 & 0 & 0 & 0 \\
\hline Miscellaneous Current \& Accrued Assets ..... & & & & 99 & 17 & 19 \\
\hline Total Current \& Accrued Assets ................ & 4,641 & 19,036 & 1,923 & 9,984 & 7,579 & 3,097 \\
\hline \multicolumn{7}{|l|}{ Deferred Debits } \\
\hline 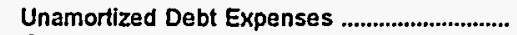 & 0 & 0 & 499 & 355 & 0 & 2,587 \\
\hline 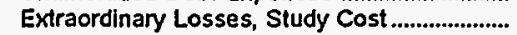 & 0 & 0 & 0 & 0 & 0 & 0 \\
\hline Misc Debt, $R$ \& D Exp, Unamrt Losses .......... & 0 & 0 & 0 & 6,113 & 0 & 0 \\
\hline Total Deferred Debits ..................................... & & 0 & 499 & 6,468 & o & 2,587 \\
\hline Total Assets \& Other Debits ........................... & 24,906 & 44,045 & 14,945 & 86,890 & 11,630 & 28,799 \\
\hline \multicolumn{7}{|l|}{ Proprietary Capital } \\
\hline 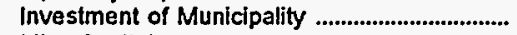 & 0 & 11,817 & 2,267 & 0 & 0 & 0 \\
\hline 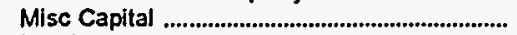 & 0 & 0 & 1.204 & 0 & 0 & 9,729 \\
\hline 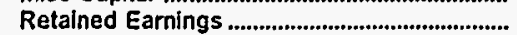 & 20,439 & 30,463 & 10,256 & 56,991 & 8,699 & 0 \\
\hline 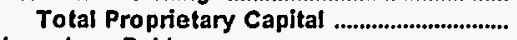 & 20,439 & 42,279 & 13,727 & 56,991 & 8,699 & 9,729 \\
\hline \multicolumn{7}{|l|}{ Long-lerm Debt } \\
\hline 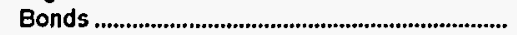 & 2,970 & 0 & 499 & 19.615 & 0 & 16,070 \\
\hline Advances from Municipality \& Other ................ & 0 & 0 & 0 & 0 & 0 & 0 \\
\hline Unamort Prem on Long-term Debt .................... & 0 & 0 & 0 & 0 & 0 & o \\
\hline (less) Unamort Discount on Long-term Debt & 0 & 0 & 0 & 0 & 0 & 0 \\
\hline 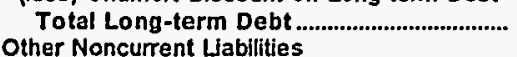 & 2,970 & 0 & 499 & 19,615 & 0 & 16,070 \\
\hline 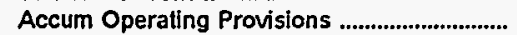 & 0 & 0 & 0 & 2,062 & 39 & 0 \\
\hline Accum Prov for Rate Refunds .............................. & 0 & 0 & 0 & & 0 & 0 \\
\hline 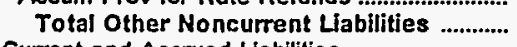 & o & 0 & 0 & 2,062 & 39 & o \\
\hline \multicolumn{7}{|l|}{ Current and Accrued Liabilities } \\
\hline 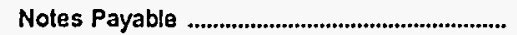 & 0 & 0 & 0 & 0 & 2,386 & 0 \\
\hline 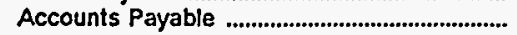 & 559 & 1,566 & 518 & 4,394 & 0 & 1,292 \\
\hline Payables to Assoc Enterprises .......................... & 0 & 20 & 0 & 0 & 23 & 0 \\
\hline 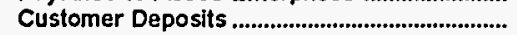 & 762 & 0 & 96 & 206 & 0 & 51 \\
\hline 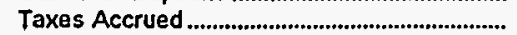 & 0 & 0 & 0 & 0 & 0 & 78 \\
\hline Interest Accrued ...................................................... & 103 & 0 & 0 & 11 & 1 & 189 \\
\hline Misc Current \& Accrued Luabilities.......................... & 73 & 180 & 62 & 0 & 0 & 257 \\
\hline Total Current \& Accrued Liabilities .......... & 1,497 & 1,766 & 677 & 4,612 & 2,410 & 1,868 \\
\hline \multicolumn{7}{|l|}{ Deferred Credits } \\
\hline Customer Advances for Construction .............. & $\mathbf{0}$ & 0 & 10 & 1 & 464 & 307 \\
\hline Other Deferred Credits ........................................... & 0 & 0 & 32 & 3,609 & 18 & 825 \\
\hline Unamort Gain on Reacqr Debt ............................. & 0 & 0 & 0 & 0 & 0 & 0 \\
\hline Total Deferred Credits ........................................ & & & 42 & 3,610 & 482 & 1,132 \\
\hline Total Liabilities and Other Credits ............. & 24,906 & 44,045 & 14,945 & 86,890 & 11,630 & 28,799 \\
\hline
\end{tabular}

Note: Totals may not equal sum of components because of independent rounding.

Source: Energy Information Administration, Form ElA-412, "Annual Report of Public Electric Utilities." 
Table 22. Balance Sheet by Major U.S. Publicly Owned Electric Utility Within State at End of Period, 1995

(Thousand Dollars)

\begin{tabular}{|c|c|c|c|c|c|c|}
\hline Item & $\begin{array}{c}\text { Oregon } \\
\text { Emerald } \\
\text { Peoples } \\
\text { Utility Dist } \\
\text { December } 31\end{array}$ & $\begin{array}{c}\begin{array}{c}\text { Eugene } \\
\text { City of }\end{array} \\
\text { December } 31\end{array}$ & $\begin{array}{c}\text { Oregon } \\
\text { Forest Grove } \\
\text { City of } \\
\text { June } 30\end{array}$ & $\begin{array}{c}\text { McMinnville } \\
\text { City of } \\
\text { June } 30\end{array}$ & $\begin{array}{c}\text { Oregon } \\
\text { Northern } \\
\text { Wasco } \\
\text { County PUD } \\
\text { December } 31\end{array}$ & $\begin{array}{c}\text { Oregon } \\
\begin{array}{c}\text { Springfield } \\
\text { City of }\end{array} \\
\text { December } 31\end{array}$ \\
\hline \multicolumn{7}{|l|}{ Electric Utility Plant } \\
\hline 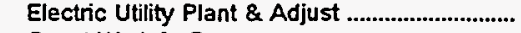 & 75,101 & 306,170 & 11,847 & 22,488 & 34,819 & 46,350 \\
\hline 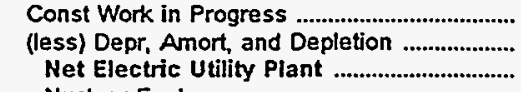 & $\begin{array}{r}943 \\
29,713 \\
46,331\end{array}$ & $\begin{array}{r}6,668 \\
134,105 \\
178,733\end{array}$ & $\begin{array}{r}110 \\
4,025 \\
7,932\end{array}$ & $\begin{array}{r}160 \\
6,163 \\
16,484\end{array}$ & $\begin{array}{r}1,861 \\
10,659 \\
26,021\end{array}$ & $\begin{array}{r}2,032 \\
15,201 \\
33,181\end{array}$ \\
\hline Nuclear Fuel & 0 & 0 & 0 & 0 & 0 & 0 \\
\hline 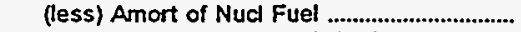 & 0 & 0 & 0 & 0 & 0 & 0 \\
\hline $\begin{array}{l}\text { Net Elec Plant Incl Nucl Fuel ............................. } \\
\text { Other Property \& Investments }\end{array}$ & \\
\hline Nonutility Property & $\mathbf{0}$ & 0 & 0 & 0 & 0 & 0 \\
\hline (less) Accum Provisions for Depr \& Amort.... & 0 & $\mathbf{0}$ & 0 & 0 & 0 & 0 \\
\hline 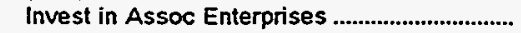 & 0 & 0 & 0 & 0 & $\mathbf{0}$ & 0 \\
\hline $\begin{array}{l}\text { Invest \& Special Funds ........................... } \\
\text { Total Other Property \& Investments ...... } \\
\text { Current and Accrued Assets }\end{array}$ & $\begin{array}{l}8,879 \\
8,879\end{array}$ & $\begin{array}{l}4,441 \\
4,441\end{array}$ & $\begin{array}{l}0 \\
0\end{array}$ & $\begin{array}{l}0 \\
0\end{array}$ & $\begin{array}{l}32,984 \\
32,984\end{array}$ & $\begin{array}{l}3,237 \\
3,237\end{array}$ \\
\hline Cash, Working Funds \& Investments .............. & 3,742 & 25,278 & 1.428 & 4,314 & 5,372 & 6,346 \\
\hline 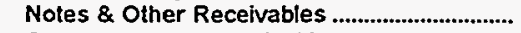 & 2,826 & $\mathbf{0}$ & 34 & 257 & 347 & 410 \\
\hline Customer Accts Receivable & 1,476 & 14,638 & 459 & 1,495 & 853 & 3,636 \\
\hline (less) Accum Prov for Uncollected Accts ...... & 43 & 209 & 82 & 14 & 90 & 71 \\
\hline 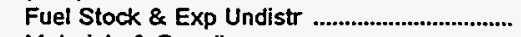 & 0 & 0 & $\mathbf{0}$ & 0 & 0 & 0 \\
\hline 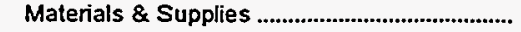 & 0 & 2,211 & 0 & 225 & 495 & 1,331 \\
\hline 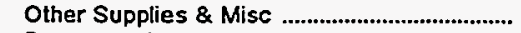 & 408 & 0 & 234 & 0 & 0 & 0 \\
\hline 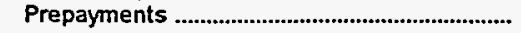 & 204 & $\mathbf{5 3 4}$ & 0 & 0 & 127 & 29 \\
\hline 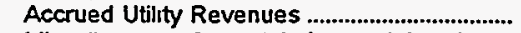 & 1,160 & 7,081 & 0 & 0 & 0 & $\mathbf{0}$ \\
\hline Miscellaneous Current \& Accrued Assets ..... & 0 & 9,441 & 98 & 0 & 0 & 35 \\
\hline $\begin{array}{l}\text { Total Current \& Accrued Assets ................ } \\
\text { Deferred Debits }\end{array}$ & 9,773 & 58,975 & 2,171 & 6,276 & 7,104 & 11,716 \\
\hline Unamortized Debt Expenses ................................ & 1,107 & 420 & 0 & 0 & 696 & 67 \\
\hline 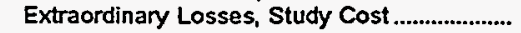 & 9,102 & 1,894 & 0 & 0 & 185 & 0 \\
\hline Misc Debt, $R$ \& D Exp, Unamrt Losses ......... & 0 & 26,987 & 0 & 651 & 13,460 & 1,154 \\
\hline Total Deferred Debits ...................... & 10,209 & $\begin{array}{r}29,301 \\
271,450\end{array}$ & $\begin{array}{r}0 \\
10.102\end{array}$ & $\begin{array}{r}651 \\
23.411\end{array}$ & 14,341 & $\begin{array}{r}1,221 \\
-9,354\end{array}$ \\
\hline \multicolumn{7}{|l|}{ Proprietary Capital } \\
\hline Investment of Municipality & 0 & 0 & 9,042 & 440 & 76 & 0 \\
\hline 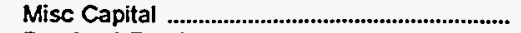 & 0 & 0 & 0 & 3,128 & 64 & 3,193 \\
\hline 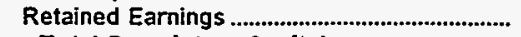 & 1,978 & 134.830 & 631 & 17,432 & 12,792 & 36,034 \\
\hline $\begin{array}{l}\text { Total Proprietary Capital .................................. } \\
\text { Long-term Debt }\end{array}$ & 1,978 & 134,830 & 9,673 & 20,999 & 12,932 & 39,226 \\
\hline 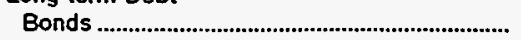 & 64,005 & 94,428 & 0 & 0 & 61,994 & 3,095 \\
\hline Advances from Municipality \& Other ............... & 3,313 & 0 & 0 & 665 & 0 & 0 \\
\hline 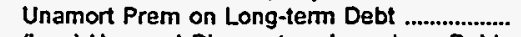 & 0 & 0 & 0 & 0 & 0 & 0 \\
\hline (less) Unamort Discount on Long-term Debt & 632 & 2,750 & 0 & 0 & 0 & 0 \\
\hline 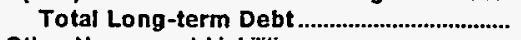 & 66,686 & 91,678 & $\mathbf{0}$ & 665 & 61,994 & 3,095 \\
\hline \multicolumn{7}{|l|}{ Other Noncurrent Labilities } \\
\hline 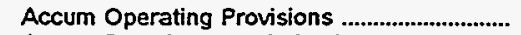 & 0 & 0 & 0 & 0 & 0 & 0 \\
\hline 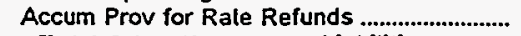 & 0 & 0 & 0 & 0 & 0 & 0 \\
\hline $\begin{array}{l}\text { Total Other Noncurrent Liabilities ............ } \\
\text { Current and Accrued Uabilities }\end{array}$ & 0 & 0 & 0 & $\mathbf{0}$ & $\mathbf{0}$ & $\mathbf{0}$ \\
\hline \multicolumn{7}{|l|}{ Current and Accrued Uabilities } \\
\hline 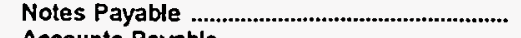 & 0 & 0 & 81 & 0 & 0 & 4.467 \\
\hline Accounts Payable & 2,068 & 31,964 & 0 & 1,571 & 3,590 & 0 \\
\hline 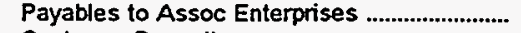 & 0 & 0 & 0 & 0 & 0 & $\mathbf{0}$ \\
\hline 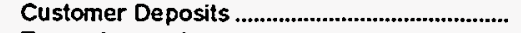 & 15 & 210 & 0 & 8 & 70 & 562 \\
\hline Taxes Accrued & 4 & 864 & 0 & 0 & 49 & 16 \\
\hline Interest Accrued & 688 & 4.020 & 0 & 0 & 790 & 85 \\
\hline Misc Current \& Accrued Liabilities ..................... & 2,981 & 5,275 & 0 & 168 & 265 & 657 \\
\hline $\begin{array}{l}\text { Total Current \& Accrued Liabilities .......... } \\
\text { Deferred Credits }\end{array}$ & 5,755 & 42,333 & 81 & 1,747 & 4,763 & 5,787 \\
\hline Customer Advances for Construction .............. & 0 & 278 & 305 & 0 & 17 & 38 \\
\hline 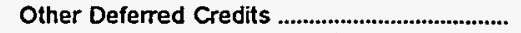 & 772 & 855 & 43 & 0 & 744 & 1,208 \\
\hline 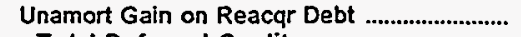 & 0 & 1,476 & 0 & 0 & 0 & 0 \\
\hline Total Deferred Credits & 772 & 2,610 & 348 & 0 & 760 & 1,246 \\
\hline Total Liabilities and Other Credits ............. & 75,192 & 271,450 & 10,102 & 23,411 & 80,449 & 49,354 \\
\hline
\end{tabular}

Note: Totals may not equal sum of components because of independent rounding.

Source: Energy Information Administration, Form EIA-412, "Annual Report of Public Electric Utilities." 
Table 22. Balance Sheet by Major U.S. Publicly Owned Electric Utility Within State at End of Period, 1995

(Thousand Dollars)

\begin{tabular}{|c|c|c|c|c|c|c|}
\hline Item & $\begin{array}{l}\text { Oregon } \\
\text { Tillamook } \\
\text { Peoples } \\
\text { Utility Dist } \\
\text { December } 31\end{array}$ & $\begin{array}{c}\text { Pennsylvania } \\
\text { Chambersburg } \\
\text { Borough of } \\
\text { December } 31\end{array}$ & $\begin{array}{c}\text { Pennsyivania } \\
\text { Ephrata } \\
\text { Borough of } \\
\text { December } 31\end{array}$ & $\begin{array}{c}\text { Pennsyivania } \\
\text { Lansdale } \\
\text { Borough of } \\
\text { December } 31\end{array}$ & $\begin{array}{l}\text { Camden } \\
\text { City of } \\
\text { June } 30\end{array}$ & $\begin{array}{l}\text { South Carolina } \\
\text { Easley } \\
\text { Combined } \\
\text { Utility } \\
\text { System } \\
\text { March } 31\end{array}$ \\
\hline \multicolumn{7}{|l|}{ Electric Utility Plant } \\
\hline Electric Utility Plant \& Adjust .................................. & 37,938 & 27,559 & 0 & 10,088 & 11,373 & 19,236 \\
\hline 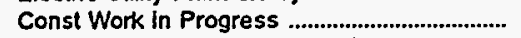 & 1,206 & 454 & 0 & 0 & 0 & 0 \\
\hline $\begin{array}{l}\text { (less) Depr, Amort, and Depletion } \\
\text { Het Electric Utillty Plant }\end{array}$ & $\begin{array}{l}10,556 \\
28,587\end{array}$ & $\begin{array}{l}14,877 \\
13,136\end{array}$ & $\begin{array}{l}0 \\
0\end{array}$ & $\begin{array}{l}4,461 \\
5,627\end{array}$ & $\begin{array}{l}8,956 \\
2,417\end{array}$ & $\begin{array}{r}6,339 \\
12,897\end{array}$ \\
\hline 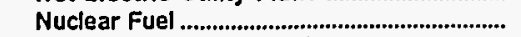 & 0 & 0 & 0 & 0 & 0 & 0 \\
\hline (less) Amort of Nucl Fuel ............................... & 0 & 0 & 0 & 0 & 0 & 0 \\
\hline 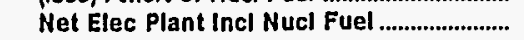 & 28,587 & 13,136 & 0 & 5,627 & 2,417 & 12,897 \\
\hline \multicolumn{7}{|l|}{ Other Property \& Investments } \\
\hline 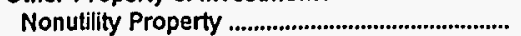 & 0 & 0 & 0 & 0 & 13,468 & 33,870 \\
\hline (less) Accum Provisions for Depr \& Amort.... & 0 & 0 & 0 & $\mathbf{0}$ & 2,850 & 12,234 \\
\hline Invest in Assoc Enterprises .............................. & 13 & 0 & 0 & 0 & 0 & 0 \\
\hline 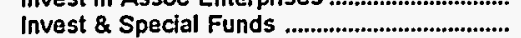 & 4,600 & 1,189 & 0 & 0 & 1,203 & 3,752 \\
\hline $\begin{array}{l}\text { Total Other Property \& Investments ....... } \\
\text { Current and Accrued Assets }\end{array}$ & 4,613 & 1,189 & 0 & 0 & 11,821 & 25,388 \\
\hline Cash, Working Funds \& Investments .............. & 5,039 & 2,825 & 0 & 17,018 & 2,323 & 651 \\
\hline 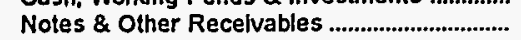 & 575 & 0 & 0 & 284 & 0 & 233 \\
\hline Customer Accts Receivable ............................. & 1,324 & 1.072 & 0 & 1,167 & 855 & 1,847 \\
\hline (less) Accum Prov for Uncollected Accts ...... & 92 & 1 & 0 & 60 & 0 & 0 \\
\hline Fuel Stock \& Exp Undistr .................................. & 0 & 39 & 0 & 0 & 0 & 0 \\
\hline 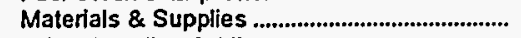 & 544 & 0 & 0 & 0 & 425 & 544 \\
\hline Other Supplies \& Misc ........................................... & 80 & 0 & 0 & 332 & 0 & 0 \\
\hline 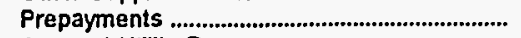 & 163 & 7 & 0 & 0 & 41 & 0 \\
\hline Accrued Utility Revenues ...................................... & 0 & 880 & 0 & 0 & 0 & 0 \\
\hline Mlscellaneous Current \& Accrued Assets ..... & 66 & 48 & 0 & 0 & 0 & 0 \\
\hline $\begin{array}{l}\text { Total Current \& Accrued Assets .............. } \\
\text { Deferred Debits }\end{array}$ & 7,700 & 4,869 & 0 & 18,742 & 3,644 & 3,275 \\
\hline 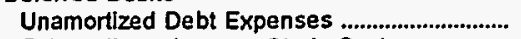 & 182 & 0 & 0 & 141 & 0 & 20 \\
\hline Extraordinary Losses, Study Cost ..................... & 81 & 0 & 0 & 0 & $\mathbf{0}$ & 0 \\
\hline Misc Debt, R \& D Exp, Unamrt Losses ......... & 1,217 & 0 & 0 & 0 & $\mathbf{0}$ & 0 \\
\hline Total Deferred Debits ................................... & 1,480 & 0 & 0 & 141 & 0 & 20 \\
\hline Total Assets \& Other Debits ....................... & 42,380 & 19,194 & $\mathbf{0}$ & 24,510 & 17,881 & 41,581 \\
\hline \multicolumn{7}{|l|}{ Proprietary Capital } \\
\hline 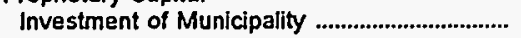 & 0 & 764 & 0 & 1,580 & 0 & 229 \\
\hline 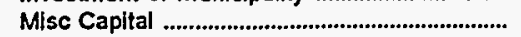 & 0 & 0 & 0 & 14,609 & 0 & 13,427 \\
\hline 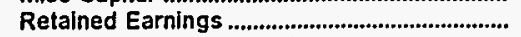 & 23,008 & 17.016 & 0 & 0 & 13,211 & 18,426 \\
\hline $\begin{array}{l}\text { Total Proprietary Capital ............................... } \\
\text { Long-term Debt }\end{array}$ & 23,008 & 17,780 & $\mathbf{0}$ & 16,189 & 13,211 & 32,082 \\
\hline 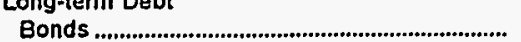 & 14,574 & 0 & 0 & 7,415 & 3,065 & 4,490 \\
\hline Advances from Municipality \& Other ............... & 0 & 0 & 0 & 0 & 0 & 10 \\
\hline Unamort Prem on Long-term Debt ................... & 0 & 0 & 0 & $\mathbf{0}$ & 0 & $\mathbf{0}$ \\
\hline (less) Unamort Discount on Long-term Debt & 0 & 0 & 0 & 0 & $\mathbf{0}$ & 0 \\
\hline 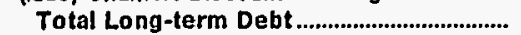 & 14,574 & 0 & 0 & 7,415 & 3,065 & 4,500 \\
\hline \multicolumn{7}{|l|}{ Other Noncurrent Uabilities } \\
\hline 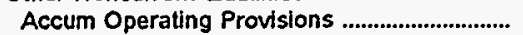 & 0 & 0 & 0 & $\mathbf{0}$ & 41 & $\mathbf{0}$ \\
\hline Accum Prov for Rate Refunds .......................... & 0 & 0 & 0 & 0 & 0 & 0 \\
\hline Total Other Noncurrent Liabilities ............ & 0 & 0 & 0 & 0 & 41 & 0 \\
\hline \multicolumn{7}{|l|}{ Current and Accrued Liabilities } \\
\hline 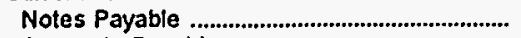 & 0 & 0 & $\mathbf{0}$ & 0 & 0 & 656 \\
\hline 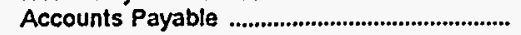 & 3,100 & 968 & 0 & 537 & 911 & 306 \\
\hline Payables to Assoc Enterprises ........................... & 0 & 0 & 0 & 0 & 0 & 0 \\
\hline Customer Deposits & 65 & 0 & 0 & 272 & 290 & 419 \\
\hline 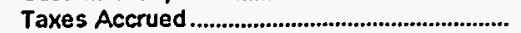 & 0 & 0 & 0 & 0 & 0 & 0 \\
\hline Interest Accrued & 340 & 0 & 0 & 36 & 70 & 72 \\
\hline Misc Cument \& Accrued Uabilities.................... & 423 & 123 & 0 & 60 & 293 & 1,194 \\
\hline $\begin{array}{l}\text { Total Current \& Accrued Liabilities .......... } \\
\text { Deferred Credits }\end{array}$ & 3,927 & 1,091 & $\mathbf{0}$ & 906 & 1,565 & 2,646 \\
\hline Customer Advances for Construction ............. & 0 & 323 & 0 & 0 & $\mathbf{0}$ & 238 \\
\hline 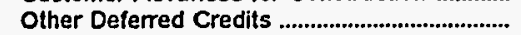 & 871 & 0 & 0 & 0 & 0 & 2,114 \\
\hline Unamort Gain on Reacqr Debt ........................... & 0 & 0 & 0 & 0 & 0 & 0 \\
\hline 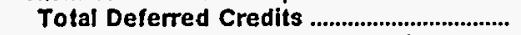 & 871 & 323 & 0 & $\mathbf{0}$ & 0 & 2,353 \\
\hline Total Liabilities and Other Credits ............ & 42,380 & 19,194 & 0 & 24,510 & 17,881 & 41,581 \\
\hline
\end{tabular}

Note: Totals may not equal sum of components because of independent rounding.

Source: Energy Information Administration, Form ElA-412, "Annual Report of Public Electric Utilities." 
Table 22. Balance Sheet by Major U.S. Publicly Owned Electric Utility Within State at End of Period, 1995

(Thousand Dollars)

\begin{tabular}{|c|c|c|c|c|c|c|}
\hline Item & $\begin{array}{l}\text { South Carolina } \\
\text { Gaffney } \\
\text { City of } \\
\text { March } 31\end{array}$ & $\begin{array}{l}\text { South Carolina } \\
\text { Greenwood } \\
\text { Commissioners } \\
\text { Pub Wk } \\
\text { December } 31\end{array}$ & $\begin{array}{c}\text { South Carolina } \\
\text { Greer } \\
\text { Comm } \\
\text { of } \\
\text { Public Works } \\
\text { December } 31\end{array}$ & $\begin{array}{l}\text { South Carolina } \\
\text { Newbery } \\
\text { City of } \\
\text { June } 30\end{array}$ & $\begin{array}{l}\text { South Carolina } \\
\text { Orangeburg } \\
\text { City of } \\
\text { September } 30\end{array}$ & $\begin{array}{c}\text { South Carolina } \\
\text { Piedmont } \\
\text { Municipal } \\
\text { Power Agny } \\
\text { December } 31\end{array}$ \\
\hline \multicolumn{7}{|l|}{ Electric Utility Plant } \\
\hline 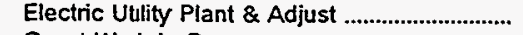 & 2,165 & 9,864 & 95,212 & 8,095 & 56.667 & 542,765 \\
\hline Const Work in Progress & 0 & & 3,747 & 0 & 72 & 11,105 \\
\hline (less) Depr, Amort, and Depletion .................... & 912 & 4,157 & 23,391 & 4,589 & 13,979 & 168,649 \\
\hline 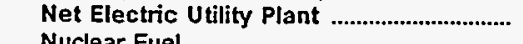 & 1,253 & 5,707 & 75,568 & 3,506 & 42,760 & 385,221 \\
\hline 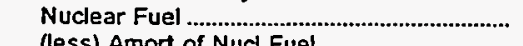 & 0 & 0 & 0 & 0 & 0 & 32,351 \\
\hline 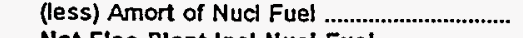 & 0 & 0 & 0 & 0 & 0 & 20,392 \\
\hline \multirow{2}{*}{\multicolumn{6}{|c|}{ Other Property \& Investments }} & 397,180 \\
\hline & & & & & 4,795 & \\
\hline (less) Accum Provisions for Depr \& Amort.... & 5,850 & 14,615 & $\begin{array}{l}0 \\
0\end{array}$ & 10,302 & 2,231 & $\begin{array}{l}0 \\
0\end{array}$ \\
\hline 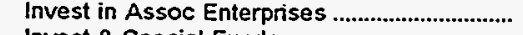 & 0 & & 0 & 0 & 0 & 0 \\
\hline 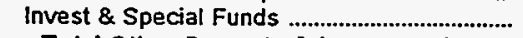 & & 7,801 & 1,236 & 6,161 & 13,172 & 187,321 \\
\hline \multicolumn{7}{|l|}{ Current and Accrued Assets } \\
\hline 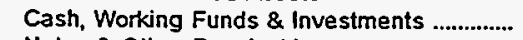 & 5,102 & 6,482 & 1,855 & 2,247 & 1,605 & 326,110 \\
\hline 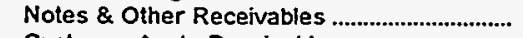 & & & 567 & 4 & 66 & 2,688 \\
\hline Customer Accts Receivable .............................. & 887 & 5,109 & 3,436 & 1,094 & 2,051 & 9,509 \\
\hline (less) Accum Prov for Uncollected Accts ....... & 59 & 0 & 0 & 40 & 46 & 0 \\
\hline 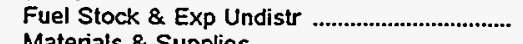 & 0 & 0 & 10 & 0 & 76 & 0 \\
\hline Materials \& Supplies .................................................... & 418 & 1,373 & 761 & 596 & 2,678 & 5,157 \\
\hline 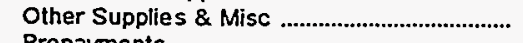 & 67 & 0 & 0 & 0 & 0 & 0 \\
\hline Prepayments & 0 & 85 & 0 & 0 & 87 & 0 \\
\hline Accrued Utility Revenues ..................................... & 833 & 0 & 0 & 0 & 1 & 0 \\
\hline Miscellaneaus Current \& Accrued Assets ..... & 0 & 1 & $\mathbf{0}$ & 287 & 57,386 & 0 \\
\hline $\begin{array}{l}\text { Total Current \& Accrued Assets ................ } \\
\text { Deferred Debits }\end{array}$ & 7,248 & 13,050 & 6,629 & 4,188 & 63,903 & 343,464 \\
\hline Unamortized Debt Expenses ................................ & 0 & 498 & 37 & 0 & 0 & 20,129 \\
\hline Extraordinary Losses, Study Cost..................... & 0 & 0 & 0 & 0 & 0 & 0 \\
\hline Misc Debt, R \& D Exp, Unamrt Losses .......... & 0 & 1,123 & 0 & 0 & 0 & 439,139 \\
\hline Total Deferred Debits .......................................... & 0 & 1,621 & 37 & 0 & 0 & 459,268 \\
\hline $\begin{array}{l}\text { Total Assets \& Other Debits } \\
\text { Proprieta.................... }\end{array}$ & 18,840 & 79,386 & 83,470 & 28,239 & 122,399 & $1,387,233$ \\
\hline 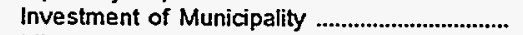 & 0 & 0 & 0 & 0 & 0 & 0 \\
\hline 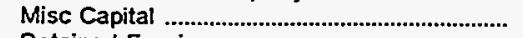 & 0 & 6,358 & 17,591 & 449 & 0 & 0 \\
\hline Retained Earnings .............................................. & 15,371 & 45,585 & 50,890 & 16,227 & $\$ 12,226$ & 10,575 \\
\hline $\begin{array}{l}\text { Total Proprietary Capital ........................................ } \\
\text { Long-term Debt }\end{array}$ & 15,371 & 51,943 & 68,481 & 16,676 & 112,226 & 10,575 \\
\hline Bonds & 2,317 & 21,020 & 11,031 & 9,905 & 3.650 & $1,364,241$ \\
\hline Advances from Municipality \& Other ................ & 0 & 0 & 0 & 440 & 0 & 0 \\
\hline Unamort Prem on Long-term Debt .................... & 0 & 0 & 0 & 0 & 0 & 0 \\
\hline (less) Unamort Discount on Long-term Debt & & & 0 & 0 & 0 & 64,555 \\
\hline \multicolumn{7}{|l|}{ Other Noncurrent Liabilities } \\
\hline 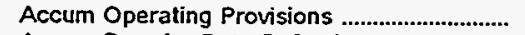 & 0 & 1,483 & 0 & 0 & 180 & 16,037 \\
\hline 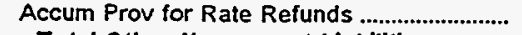 & 0 & & 0 & 0 & 629 & 0 \\
\hline \multicolumn{7}{|l|}{ Current and Accrued Liabilities } \\
\hline 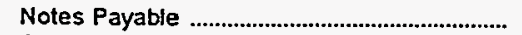 & 0 & 1,180 & 0 & 1,049 & 0 & 0 \\
\hline 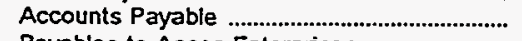 & 126 & 3,479 & 3,279 & 0 & 4,143 & 704 \\
\hline 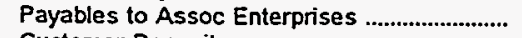 & 0 & 0 & 0 & 0 & 726 & 0 \\
\hline 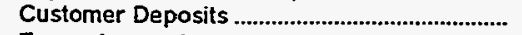 & 313 & 111 & 346 & 0 & 0 & 0 \\
\hline Taxes Accrued & 61 & 0 & 0 & 0 & 0 & 4,368 \\
\hline Interest Accrued ............................................ & 0 & 95 & 0 & 99 & 0 & 55,863 \\
\hline 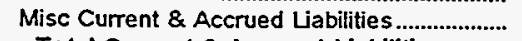 & 652 & 76 & 333 & 70 & 845 & \\
\hline \multicolumn{7}{|l|}{ Deferred Credits } \\
\hline Customer Advances for Construction .............. & 0 & 0 & 0 & 0 & 0 & 0 \\
\hline Other Deferred Credits ......................................... & 0 & 0 & 0 & 0 & 0 & 0 \\
\hline Unamort Gain on Reacgr Debt ............................ & 0 & 0 & 0 & 0 & 0 & 0 \\
\hline Total Deferred Credits ....................................... & 0 & & $\mathbf{0}$ & $\mathbf{0}$ & 0 & 0 \\
\hline Total Liabilities and Other Credits ............ & 18,840 & 79,386 & 83,470 & 28,239 & 122,399 & $1,387,233$ \\
\hline
\end{tabular}

Note: Totals may not equal sum of components because of independent rounding.

Source: Energy Information Administration, Form EIA-412, "Annual Report of Public Electric Utilities." 
Table 22. Balance Sheet by Major U.S. Publicly Owned Electric Utility Within State at End of Period, 1995

(Thousand Dollars)

\begin{tabular}{|c|c|c|c|c|c|c|}
\hline Item & $\begin{array}{c}\text { South Carolina } \\
\text { Rock Hill } \\
\text { City of } \\
\text { December } 31\end{array}$ & $\begin{array}{l}\text { South Carolina } \\
\text { Seneca } \\
\text { City of } \\
\text { June } 30\end{array}$ & $\begin{array}{l}\text { South Carolina } \\
\text { South } \\
\text { Carolina } \\
\text { Pub } \\
\text { Serv Auth } \\
\text { December } 31\end{array}$ & $\begin{array}{l}\text { South Dakota } \\
\text { Brookings } \\
\text { City of } \\
\text { December } 31\end{array}$ & $\begin{array}{l}\text { South Dakota } \\
\text { Heartland } \\
\text { Consumers } \\
\text { Power Dist } \\
\text { December } 31\end{array}$ & $\begin{array}{c}\text { South Dakota } \\
\text { Missour } \\
\text { Basin } \\
\text { Mun } \\
\text { Power Agny } \\
\text { December } 31\end{array}$ \\
\hline \multicolumn{7}{|l|}{ Electric Utility Plant } \\
\hline Electric Utility Plant \& Adjust ............................ & 33,593 & 29,084 & $3,181,541$ & 19,921 & 57,627 & 2,737 \\
\hline 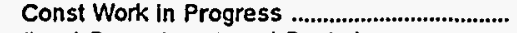 & 1,442 & & 71.661 & 66 & 203 & 0 \\
\hline 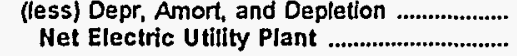 & $\begin{array}{l}12,957 \\
22,078\end{array}$ & $\begin{array}{l}11,696 \\
17,388\end{array}$ & $\begin{array}{r}974,077 \\
2,279,125\end{array}$ & $\begin{array}{r}6,159 \\
13,828\end{array}$ & $\begin{array}{r}9,221 \\
48,608\end{array}$ & $\begin{array}{r}776 \\
1,961\end{array}$ \\
\hline Nuclear Fuel & 0 & 0 & 46,994 & 0 & 0 & 0 \\
\hline (less) Amort of Nucl Fuel ................................ & 0 & 0 & 30,060 & $\mathbf{0}$ & 0 & 0 \\
\hline 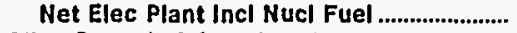 & 22,078 & 17,388 & $2,296,059$ & 13,828 & 48,608 & 1,961 \\
\hline \multicolumn{7}{|l|}{ Other Property \& Investments } \\
\hline Nonutility Property & 115,590 & 0 & 1,938 & 0 & 0 & 0 \\
\hline (less) Accum Provislons for Depr \& Amort.... & 26,038 & 0 & 217 & $\mathbf{0}$ & 0 & 0 \\
\hline 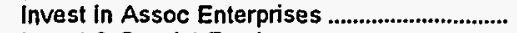 & 0 & 0 & 0 & 0 & 0 & 0 \\
\hline 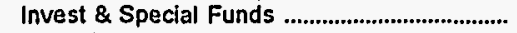 & 0 & $\mathbf{0}$ & 271,550 & $\mathbf{0}$ & 9,429 & 9,862 \\
\hline Total Other Property \& Investments ....... & 89,553 & 0 & 273,271 & 0 & 9,429 & 9,862 \\
\hline \multicolumn{7}{|l|}{ Current and Accrued Assets } \\
\hline Cash, Working Funds \& Investments ............... & 13,527 & 6.094 & 201,869 & 2,176 & 4,870 & 6,483 \\
\hline Notes \& Other Receivables ................................ & 2,844 & 0 & 0 & 0 & 161 & 0 \\
\hline 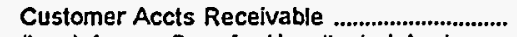 & 7,431 & 1,164 & 64.895 & 1,219 & 1,000 & 7,787 \\
\hline (less) Accum Prov for Uncollected Accts ....... & 0 & 0 & 712 & 8 & 0 & 0 \\
\hline 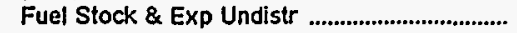 & 0 & 0 & 43,088 & 0 & 0 & 51 \\
\hline 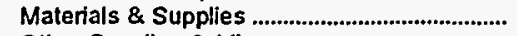 & 1,344 & 0 & 32,722 & 239 & 2,265 & 0 \\
\hline 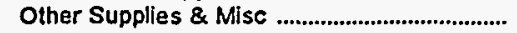 & 0 & 0 & 0 & 0 & 0 & $\mathbf{0}$ \\
\hline 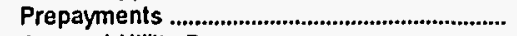 & 0 & .0 & 1,096 & 44 & 18 & 1,600 \\
\hline 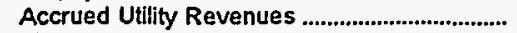 & 0 & 0 & 0 & 0 & 180 & 0 \\
\hline Miscellaneous Current \& Accrued Assets ..... & 0 & 361 & 2,756 & 80 & 120 & 291 \\
\hline Total Current \& Accrued Assets ............... & 25,246 & 7,619 & 345,714 & 3,750 & 8,614 & 16,213 \\
\hline \multicolumn{7}{|l|}{ Deferred Debits } \\
\hline 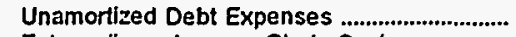 & 5,025 & 0 & 25,393 & 0 & 3,816 & 0 \\
\hline Extraordinary Losses, Study Cost ..................... & 0 & 0 & 0 & $\mathbf{0}$ & 0 & 0 \\
\hline Misc Debt, R \& D Exp, Unamrt Losses ......... & 0 & 0 & 786,045 & 0 & 1,336 & 5 \\
\hline 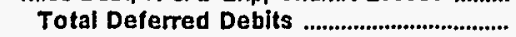 & 5,025 & 0 & 811,438 & 0 & 5,152 & 5 \\
\hline 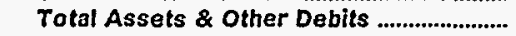 & 141,902 & 25,007 & $3,726,482$ & 17,578 & 71,804 & 28,040 \\
\hline \multicolumn{7}{|l|}{ Proprietary Capital } \\
\hline 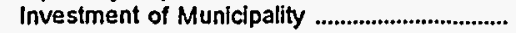 & $\mathbf{0}$ & 4,199 & 34,438 & 0 & 0 & 0 \\
\hline 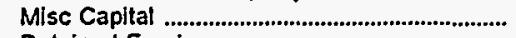 & 43,540 & 0 & -0 & 0 & 0 & 0 \\
\hline 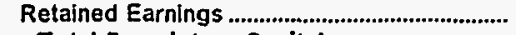 & 25,844 & 19,012 & 700.595 & 16,630 & 2,035 & 22,406 \\
\hline Total Proprietary Capital ................................. & 69,384 & 23,210 & 735,033 & 16,630 & 2,035 & 22,406 \\
\hline \multicolumn{7}{|l|}{ Long-term Debt } \\
\hline Bonds & 0 & 0 & $2,411,400$ & 0 & 62,695 & $\mathbf{0}$ \\
\hline Advances from Municipality \& Other ................. & 65,590 & 0 & 46.130 & 0 & 0 & 0 \\
\hline Unamort Prem on Long-term Debt .................... & $\mathbf{0}$ & 0 & 0 & 0 & 0 & 0 \\
\hline (less) Unamort Discount on Long-term Debt & 0 & 0 & 55,343 & 0 & 0 & 0 \\
\hline Total Long-term Debt & 65,590 & $\mathbf{0}$ & $2,402,187$ & 0 & 62,695 & 0 \\
\hline \multicolumn{7}{|l|}{ Other Noncurrent Liabilities } \\
\hline Accum Operating Provisions ................................. & 0 & 0 & 0 & $\mathbf{0}$ & 0 & 0 \\
\hline Accum Prov for Rate Refunds ............................ & 0 & $\mathbf{0}$ & 0 & 0 & 0 & 0 \\
\hline Total Other Noncurrent Liabilities .......... & $\mathbf{0}$ & $\mathbf{0}$ & $\mathbf{0}$ & $\mathbf{0}$ & $\mathbf{0}$ & $\mathbf{0}$ \\
\hline \multicolumn{7}{|l|}{ Current and Accrued Labilities } \\
\hline 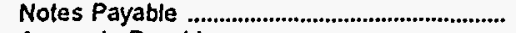 & 0 & 0 & 389,562 & 0 & 0 & 0 \\
\hline Accounts Payable & 3,631 & 728 & 39,313 & 826 & 593 & 1,736 \\
\hline Payables to Assoc Enterprises ............................ & 0 & 0 & 0 & 0 & 0 & 3.872 \\
\hline 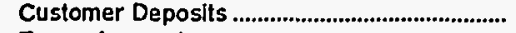 & 1,409 & 426 & 5,670 & $\mathbf{0}$ & $\mathbf{0}$ & 0 \\
\hline Taxes Accived & 0 & 0 & 2,142 & 90 & 162 & 24 \\
\hline Interest Accrued & 0 & 0 & 66.410 & 0 & 1.921 & 0 \\
\hline Misc Current \& Accrued Liabilities.................... & 1,099 & 642 & 83,044 & 32 & 1,578 & 2 \\
\hline $\begin{array}{l}\text { Total Current \& Accrued Liabilities .......... } \\
\text { Deferred Credits }\end{array}$ & 6,139 & 1,796 & 586,141 & 948 & 4,254 & 5,634 \\
\hline Customer Advances for Construction ............. & 0 & 0 & 0 & 0 & 0 & 0 \\
\hline Other Deferred Credits ........................................... & 790 & 0 & 2,954 & 0 & 560 & 0 \\
\hline Unamort Gain on Reacqr Debt ............................ & 0 & 0 & 167 & 0 & 2,260 & 0 \\
\hline 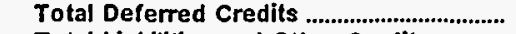 & 790 & 0 & 3,121 & $\mathbf{0}$ & 2,820 & $\mathbf{0}$ \\
\hline Total Liabilities and Other Credits ............ & 141,902 & 25,007 & $3,726,482$ & 17,578 & 71,804 & 28,040 \\
\hline
\end{tabular}

Note: Totals may not equal sum of components because of independent rounding.

Source: Energy Information Administration, Form ElA-412, "Annual Report of Public Electric Utilities." 
Table 22. Balance Sheet by Major U.S. Publicly Owned Electric Utility Within State at End of Period, 1995

(Thousand Dollars)

\begin{tabular}{|c|c|c|c|c|c|c|}
\hline Item & $\begin{array}{c}\text { South Dakota } \\
\text { Pierre } \\
\text { City of } \\
\text { December } 31\end{array}$ & $\begin{array}{c}\text { South Dakota } \\
\text { Watertown } \\
\text { Municipal } \\
\text { Utilities } \\
\text { December } 31\end{array}$ & $\begin{array}{l}\text { Tennessee } \\
\text { Alcoa } \\
\text { Utilities } \\
\text { June } 30\end{array}$ & $\begin{array}{l}\text { Tennessee } \\
\text { Athens } \\
\text { Utility } \\
\text { Board } \\
\text { June } 30\end{array}$ & $\begin{array}{l}\text { Tennessee } \\
\text { Benton } \\
\text { County } \\
\text { June } 30\end{array}$ & $\begin{array}{l}\text { Tennessee } \\
\begin{array}{l}\text { Bolivar } \\
\text { City of }\end{array} \\
\text { June } 30\end{array}$ \\
\hline \multicolumn{7}{|l|}{ Electric Utility Plant } \\
\hline 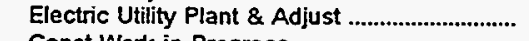 & 8,271 & 17,967 & 19,593 & 19,299 & 15,181 & 15,812 \\
\hline Const Work in Progress & & 199 & 1,955 & 755 & 34 & 702 \\
\hline $\begin{array}{l}\text { (less) Depr, Amort, and Depletion } \\
\text { Net Electric Utility Plant }\end{array}$ & $\begin{array}{l}3,114 \\
5,158\end{array}$ & $\begin{array}{r}11,868 \\
6,297\end{array}$ & $\begin{array}{r}7,054 \\
14,494\end{array}$ & $\begin{array}{r}7,022 \\
13,032\end{array}$ & $\begin{array}{l}5,992 \\
9,223\end{array}$ & $\begin{array}{r}5,613 \\
10,901\end{array}$ \\
\hline 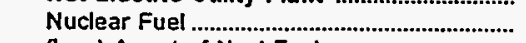 & 0 & 0 & 0 & 0 & 0 & 0 \\
\hline 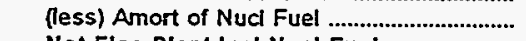 & 0 & 0 & 0 & 0 & 0 & 0 \\
\hline $\begin{array}{l}\text { Net Elec Plant Incl Nucl Fuel ............................ } \\
\text { Other Property \& Investments }\end{array}$ & 5,158 & 6,297 & 14,494 & 13,032 & 9,223 & 10,901 \\
\hline 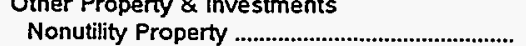 & 0 & 0 & 0 & 0 & 0 & 0 \\
\hline (less) Accum Provisions for Depr \& Amort.... & 0 & 0 & 0 & 0 & 0 & 0 \\
\hline 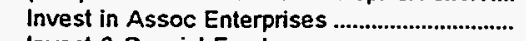 & 0 & 0 & 0 & 0 & 0 & 0 \\
\hline Invest \& Special Funds .......................................... & 528 & 0 & 1,706 & 0 & 1,061 & 140 \\
\hline \multicolumn{2}{|l|}{ Current and Accrued Assets } & 0 & 1,706 & o & 1,061 & 140 \\
\hline Cash, Working Funds \& Investments ............... & 1,406 & 2,422 & 4.273 & 310 & 62 & 834 \\
\hline Notes \& Other Receivables ........................................ & 0 & & 1,660 & 1,747 & 1,030 & 1,557 \\
\hline Customer Accts Receivable .................................. & 624 & 1,283 & 0 & 0 & 0 & 0 \\
\hline (less) Accum Prov for Uncollected Accts ....... & 57 & 8 & 0 & 0 & 0 & 0 \\
\hline Fuel Stock \& Exp Undistr ....................................... & 0 & 0 & 0 & 0 & 0 & 0 \\
\hline 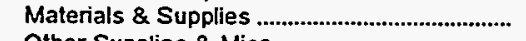 & 600 & 354 & 336 & 177 & 152 & 316 \\
\hline 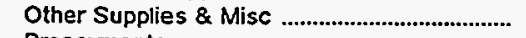 & 0 & 0 & 0 & 0 & 0 & 0 \\
\hline Prepayments .................................................................... & 1,478 & $\mathbf{0}$ & 3 & 8 & 83 & 5 \\
\hline 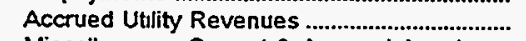 & 1 & 0 & 0 & 0 & 0 & 0 \\
\hline Miscellaneous Current \& Accrued Assets..... & 0 & 10 & 137 & 63 & 12 & 17 \\
\hline $\begin{array}{l}\text { Total Current \& Accrued Assets ..................... } \\
\text { Deferred Debits }\end{array}$ & 4,052 & 4,061 & 6,409 & 2,305 & 1,339 & 2,729 \\
\hline 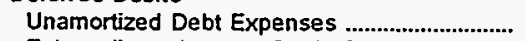 & 0 & 0 & 31 & 0 & 2 & 53 \\
\hline Extraordinary Losses, Study Cost..................... & 0 & 0 & 0 & o & 0 & 0 \\
\hline Misc Debt, R \& D Exp, Unamrt Losses .......... & 0 & 0 & 1.208 & 793 & 286 & 1,183 \\
\hline Total Deferred Debits ..................................... & 0 & 0 & 1,239 & 793 & 288 & 1,236 \\
\hline Total Assets \& Other Debits .......................... & 9,737 & 10,358 & 23,848 & 16,130 & 11,911 & 15,008 \\
\hline $\begin{array}{l}\text { Propretary Capital } \\
\text { Investment of Municipality ................................... }\end{array}$ & 62 & 0 & 0 & \\
\hline Misc Capital ............................................................. & 0 & 165 & 0 & 0 & 0 & 0 \\
\hline Retained Earnings & 8,621 & 8,277 & 13,331 & 14,231 & 9.134 & 8,212 \\
\hline Total Proprietary Capital ................................. & 8,683 & 8,442 & 13,331 & 14,231 & 9,134 & 8,212 \\
\hline \multicolumn{7}{|l|}{ Long-term Debt } \\
\hline $\begin{array}{l}\text { Bonds ................................................... } \\
\text { Advances from Municipality \& Other }\end{array}$ & 0 & $\mathbf{0}$ & 3,317 & 0 & 465 & 1,180 \\
\hline Advances from Municipality \& Other .................. & 0 & 0 & 1,035 & 803 & 291 & 2,791 \\
\hline Unamort Prem on Long-term Debt ................... & 0 & 0 & -24 & 0 & 0 & 0 \\
\hline (less) Unamort Discount on Long-term Debt & 0 & 0 & 0 & 0 & 0 & 0 \\
\hline $\begin{array}{l}\text { Total Long-term Debt ........................................... } \\
\text { Other Noncurrent Liabilities }\end{array}$ & 0 & 0 & 4,327 & 803 & 756 & 3,971 \\
\hline \multicolumn{7}{|l|}{ Other Noncurrent Liabilities } \\
\hline $\begin{array}{l}\text { Accum Operating Provisions ........................................ } \\
\text { Accum Prov for Rate Refunds }\end{array}$ & $\begin{array}{r}76 \\
0\end{array}$ & $\begin{array}{l}0 \\
0\end{array}$ & 0 & 0 & 0 & 0 \\
\hline Accum Prov for Rate Refunds ........................ & 0 & 0 & 0 & 0 & 0 & 0 \\
\hline \multicolumn{7}{|l|}{ Current and Accrued Liabilities } \\
\hline 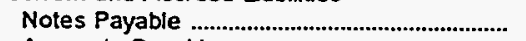 & 0 & 0 & 0 & 0 & 0 & 0 \\
\hline 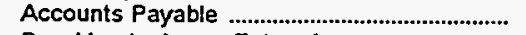 & 705 & 1,061 & 3,628 & 860 & 948 & 2,069 \\
\hline Payables to Assoc Enterprises ............................ & 0 & 17 & 0 & 0 & 0 & 0 \\
\hline 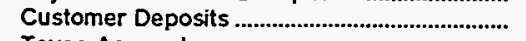 & 237 & 167 & 1,649 & 0 & 415 & 470 \\
\hline Taxes Accrued & 29 & 69 & 0 & 0 & 0 & 0 \\
\hline Interest Accrued .............................................................. & 0 & 0 & 49 & 0 & 9 & 8 \\
\hline 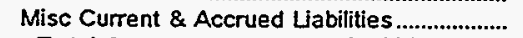 & 7 & 603 & 463 & 230 & 649 & 276 \\
\hline \multicolumn{7}{|l|}{ Deferred Credits } \\
\hline Customer Advances for Construction .................. & 0 & 0 & 400 & 0 & 0 & 0 \\
\hline Other Deferred Credits & 0 & 0 & 0 & 5 & -1 & 0 \\
\hline Unamort Gain on Reacqr Debt .............................. & 0 & 0 & 0 & 0 & 0 & 0 \\
\hline Total Deferred Credits .......................................... & $\mathbf{0}$ & 0 & 400 & 5 & -1 & 0 \\
\hline Total Liabilities and Other Credits .............. & 9,737 & 10,358 & 23,848 & 16,130 & 11,911 & 15,006 \\
\hline
\end{tabular}

Note: Totals may not equal sum of components because of independent rounding.

Source: Energy Information Administration. Form EIA-412, "Annual Report of Public Electric Utilities." 
Table 22. Balance Sheet by Major U.S. Publicly Owned Electric Utility Within State at End of Period, 1995

(Thousand Dollars)

\begin{tabular}{|c|c|c|c|c|c|c|}
\hline Item & $\begin{array}{l}\text { Tennessee } \\
\text { Bristol } \\
\text { City of } \\
\text { June } 30\end{array}$ & $\begin{array}{l}\text { Tennessee } \\
\text { Brownsville } \\
\text { City of } \\
\text { June } 30\end{array}$ & $\begin{array}{l}\text { Tennessee } \\
\text { Carroll } \\
\text { County } \\
\text { June } 30\end{array}$ & $\begin{array}{l}\text { Tennessee } \\
\begin{array}{c}\text { Chattanooga } \\
\text { City of }\end{array} \\
\text { June } 30\end{array}$ & $\begin{array}{l}\text { Tennessee } \\
\text { Clarksville } \\
\text { City of } \\
\text { June } 30\end{array}$ & $\begin{array}{l}\text { Tennessee } \\
\text { Cleveland } \\
\text { City of } \\
\text { June } 30\end{array}$ \\
\hline \multicolumn{7}{|l|}{ Electric Utility Plant } \\
\hline 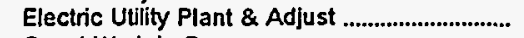 & 43,986 & 7,116 & 20,928 & 265,356 & 49,939 & 51,888 \\
\hline Const Work in Progress & 3.543 & 828 & 127 & 7,291 & 467 & 1,062 \\
\hline 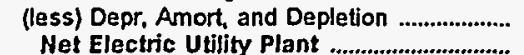 & $\begin{array}{l}23,228 \\
24,301\end{array}$ & $\begin{array}{l}2,588 \\
5,356\end{array}$ & $\begin{array}{r}8,540 \\
12,515\end{array}$ & $\begin{array}{l}105,811 \\
166,836\end{array}$ & $\begin{array}{l}12,628 \\
37,778\end{array}$ & $\begin{array}{l}17,647 \\
35,303\end{array}$ \\
\hline 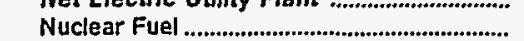 & & 0 & 0 & $\begin{array}{r}100,000 \\
0\end{array}$ & $\begin{aligned} 3, \pi / 8 \\
0\end{aligned}$ & 0 \\
\hline 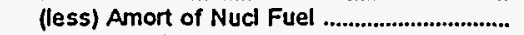 & 0 & 0 & 0 & 0 & 0 & 0 \\
\hline $\begin{array}{l}\text { Net Elec Plant Inct Nucl Fuel ........................... } \\
\text { Other Property \& Investments }\end{array}$ & 24,301 & 5,356 & 12,515 & 166,836 & 37,778 & 35,303 \\
\hline 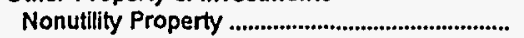 & 190 & 0 & 0 & 0 & 535 & 0 \\
\hline (less) Accum Provisions for Depr \& Amort.... & 0 & 0 & 0 & 0 & 0 & 0 \\
\hline 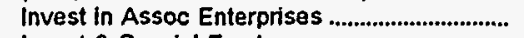 & 0 & 0 & 0 & 0 & 0 & 0 \\
\hline 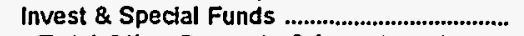 & 10,200 & 668 & 1,328 & 8,083 & 6.607 & 38 \\
\hline $\begin{array}{l}\text { Total other Property \& Investments ........ } \\
\text { Current and Accrued Assets }\end{array}$ & 10,390 & 668 & 1,328 & 8,083 & 7,142 & 38 \\
\hline 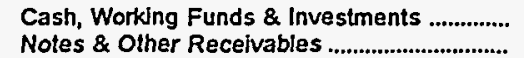 & $\begin{array}{l}2,197 \\
2,333\end{array}$ & $\begin{array}{r}186 \\
1,021\end{array}$ & $\begin{array}{r}885 \\
1,941\end{array}$ & $\begin{array}{l}18,876 \\
14,120\end{array}$ & $\begin{array}{l}1,245 \\
3,639\end{array}$ & $\begin{array}{l}2,891 \\
4,479\end{array}$ \\
\hline 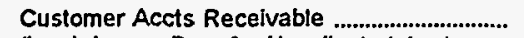 & 0 & 0 & 0 & 0 & 0 & 0 \\
\hline (less) Accum Prov for Uncollected Accts ...... & 0 & 0 & 0 & 0 & 0 & 0 \\
\hline 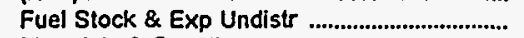 & 0 & 0 & 0 & 0 & 0 & 0 \\
\hline 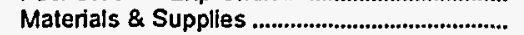 & 562 & 174 & 413 & 3,861 & 566 & 791 \\
\hline 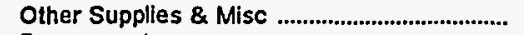 & 0 & 0 & 0 & 0 & 0 & 0 \\
\hline 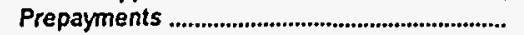 & 128 & 49 & 94 & 857 & 0 & 7 \\
\hline 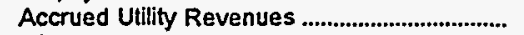 & 0 & 0 & 0 & 0 & 0 & 0 \\
\hline Miscellaneous Current \& Accrued Assets ..... & 61 & 8 & 49 & 15,834 & 94 & 57 \\
\hline $\begin{array}{l}\text { Total Current \& Accrued Assets ................. } \\
\text { Deferred Debits }\end{array}$ & 5,280 & 1,438 & 3,382 & 53,548 & 5,544 & 8,224 \\
\hline 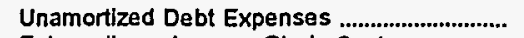 & 0 & 3 & 14 & 0 & 124 & 0 \\
\hline 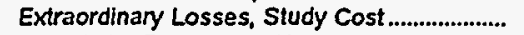 & 0 & 0 & 0 & 0 & 0 & 0 \\
\hline Misc Debt, R \& D Exp, Unamit Losses .......... & 5,351 & 21 & 84 & 12,262 & 5,407 & 2,397 \\
\hline Total Deferred Debits .................................... & 5,351 & 24 & 98 & 12,262 & 5,530 & 2,397 \\
\hline $\begin{array}{l}\text { Total Assets \& Other Debits ............................ } \\
\text { Proprietary Capital }\end{array}$ & 45,322 & 7,486 & 17,322 & 240,728 & 55,994 & 45,963 \\
\hline \multicolumn{7}{|l|}{ Proprietary Capital } \\
\hline 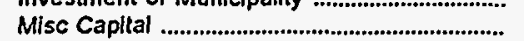 & 0 & 0 & 0 & 0 & 0 & 0 \\
\hline 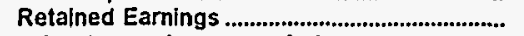 & 41,715 & 5,643 & 13,401 & 177,334 & 28,576 & 35,915 \\
\hline 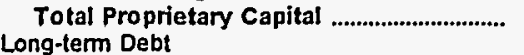 & \multirow{2}{*}{\multicolumn{4}{|c|}{ Long-term Debt }} & 28,576 & 35,915 \\
\hline 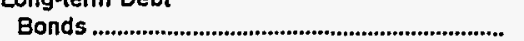 & 0 & & & 11,139 & 9,525 & \\
\hline Advances from Municipality \& Other .......................... & 0 & 1 & 75 & 14,115 & 4,225 & 2,156 \\
\hline Unamort Prem on Long-term Debt ................... & 0 & 0 & -10 & 0 & -107 & 0 \\
\hline (less) Unamort Discount on Long-term Debt & 0 & 0 & 0 & 0 & 0 & 0 \\
\hline 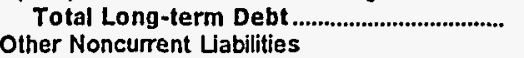 & $\mathbf{0}$ & 466 & 905 & 25,253 & 13,643 & 2,156 \\
\hline Accum Operating Provisions ................................ & 0 & $\mathbf{0}$ & 0 & 0 & 0 & 0 \\
\hline 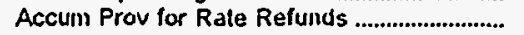 & 0 & 0 & 0 & 0 & 0 & 0 \\
\hline \multicolumn{5}{|l|}{ Current and Accrued Liabilities } & & 0 \\
\hline 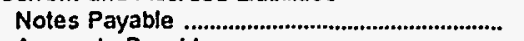 & 0 & 0 & 0 & 1,298 & 0 & 0 \\
\hline 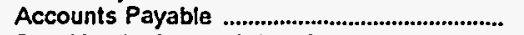 & 2,047 & 1,097 & 1,704 & 20,943 & 3,963 & 4,675 \\
\hline Payables to Assoc Enterprises .......................... & 0 & 0 & 0 & 0 & 0 & 0 \\
\hline 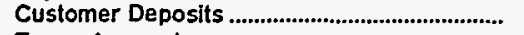 & 638 & 188 & 449 & 5,634 & 1,616 & 1,025 \\
\hline 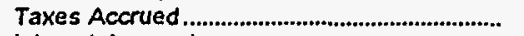 & 221 & 0 & 324 & 6,165 & 0 & 0 \\
\hline Interest Accrued .................................................................... & 0 & 2 & 0 & 0 & $15 i$ & 0 \\
\hline Misc Current \& Accrued Labilities..................... & 673 & 2 & 515 & 1,753 & 1,165 & 369 \\
\hline $\begin{array}{l}\text { Total Current \& Accrued Liabilities ........... } \\
\text { Deferred Credits }\end{array}$ & 3,578 & 1,289 & 2,992 & 35,793 & 6,895 & 6,069 \\
\hline Customer Advances for Construction .............. & 0 & 0 & 5 & 0 & 0 & 0 \\
\hline 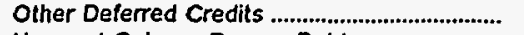 & 29 & 87 & 18 & 2,348 & 6,880 & 1.822 \\
\hline 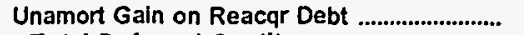 & 0 & 0 & 0 & 0 & 0 & 0 \\
\hline 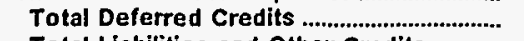 & 29 & 87 & 23 & 2,348 & 6,880 & 1,822 \\
\hline Total Liabilities and Other Credits ............ & 45,322 & 7,486 & 17,322 & 240,728 & 55,994 & 45,963 \\
\hline
\end{tabular}

Note: Totals may not equal sum of components because of independent rounding.

Source: Energy Information Administration, Form EIA-412, "Annual Report of Public Electric Utilities." 
Table 22. Balance Sheet by Major U.S. Publicly Owned Electric Utility Within State at End of Period, 1995

(Thousand Dollars)

\begin{tabular}{|c|c|c|c|c|c|c|}
\hline Item & $\begin{array}{l}\text { Tennessee } \\
\text { Clinton } \\
\text { City of } \\
\text { June } 30\end{array}$ & $\begin{array}{l}\text { Tennessee } \\
\text { Columbia } \\
\text { City of } \\
\text { June } 30\end{array}$ & $\begin{array}{c}\text { Tennessee } \\
\text { Cookeville } \\
\text { City of } \\
\text { June } 30\end{array}$ & $\begin{array}{l}\text { Tennessee } \\
\text { Covington } \\
\text { City of } \\
\text { June } 30\end{array}$ & $\begin{array}{l}\text { Tennessee } \\
\text { Dayton } \\
\text { City of } \\
\text { June } 30\end{array}$ & $\begin{array}{l}\text { Dickson } \\
\text { City of } \\
\text { June } 30\end{array}$ \\
\hline \multicolumn{7}{|l|}{ Electric Utility Plant } \\
\hline 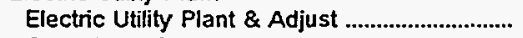 & 39,439 & 29,722 & 20,093 & 7.937 & 11.466 & 41,525 \\
\hline Const Work in Progress & 701 & 296 & 190 & 49 & 197 & 4,193 \\
\hline 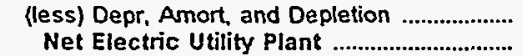 & $\begin{array}{l}13,702 \\
26,439\end{array}$ & $\begin{array}{l}10,425 \\
19,593\end{array}$ & $\begin{array}{r}5,275 \\
15,009\end{array}$ & $\begin{array}{l}2,436 \\
5,551\end{array}$ & $\begin{array}{l}3,753 \\
7,910\end{array}$ & $\begin{array}{l}13,836 \\
31,882\end{array}$ \\
\hline 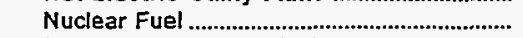 & 0 & 0 & 0 & 0 & 0 & 0 \\
\hline 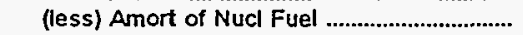 & 0 & 0 & 0 & 0 & 0 & 0 \\
\hline 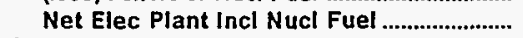 & 26,439 & 19,593 & 15,009 & 5,551 & 7,910 & 31,882 \\
\hline \multicolumn{7}{|l|}{ Other Property \& Investments } \\
\hline 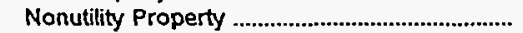 & 0 & 0 & 0 & 0 & 0 & 0 \\
\hline (less) Accum Provisions for Depr \& Amort.... & 0 & 0 & 0 & 0 & 0 & 0 \\
\hline 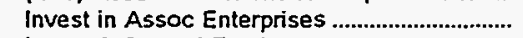 & 0 & 0 & 0 & 0 & 0 & 0 \\
\hline 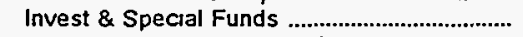 & 665 & 1.879 & 121 & 803 & 0 & 2,917 \\
\hline \multicolumn{7}{|l|}{ Current and Accrued Assets } \\
\hline 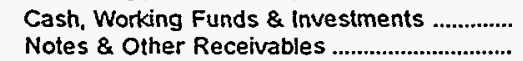 & $\begin{array}{l}1,438 \\
3,690\end{array}$ & $\begin{array}{r}460 \\
1,427\end{array}$ & $\begin{array}{r}757 \\
1,860\end{array}$ & $\begin{array}{l}5,281 \\
1,091\end{array}$ & $\begin{array}{r}1,246 \\
989\end{array}$ & $\begin{array}{l}1,751 \\
2,582\end{array}$ \\
\hline 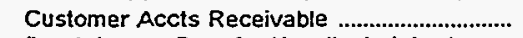 & 0 & 0 & 0 & 0 & 0 & 0 \\
\hline (less) Accum Prov for Uncollected Accts ...... & 0 & 0 & 0 & 0 & 0 & 0 \\
\hline 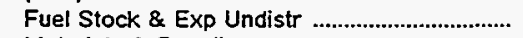 & 0 & 0 & 0 & 0 & 0 & 0 \\
\hline 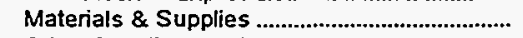 & 669 & 586 & 644 & 115 & 123 & 755 \\
\hline 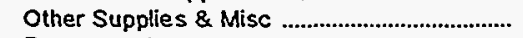 & 0 & 0 & 0 & 0 & 0 & 0 \\
\hline 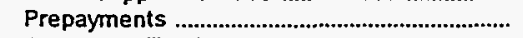 & 257 & 28 & 7 & 324 & 6 & 0 \\
\hline 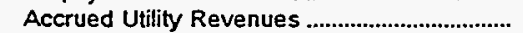 & 0 & 0 & 0 & 0 & 0 & 0 \\
\hline Miscellaneous Current \& Accrued Assets ..... & 116 & 50 & 34 & 19 & 70 & 154 \\
\hline $\begin{array}{l}\text { Total Current \& Accrued Assets .............. } \\
\text { Deferred Debits }\end{array}$ & 6,171 & 2,551 & 3,302 & 6,830 & 2,434 & 5,242 \\
\hline 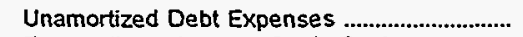 & 0 & 51 & 7 & 10 & 0 & 81 \\
\hline Extraordinary Losses, Study Cost ...................... & 0 & 0 & 0 & 0 & 0 & 0 \\
\hline Misc Debt, R \& D Exp, Unamrt Losses ......... & 3,165 & 1,200 & 334 & 336 & 234 & 499 \\
\hline 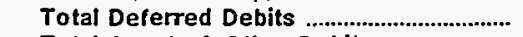 & 3,165 & 1,251 & 340 & 347 & 234 & 580 \\
\hline $\begin{array}{l}\text { Total Assets \& Other Debits ......................... } \\
\text { Proprietany Capital }\end{array}$ & 36,439 & 25,274 & 18,773 & 13,530 & 10,578 & 40,621 \\
\hline 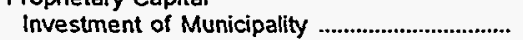 & 0 & 0 & 0 & 0 & 0 & 0 \\
\hline 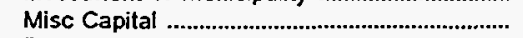 & 0 & 0 & 0 & 0 & 0 & 0 \\
\hline 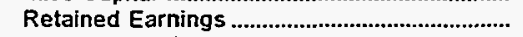 & 26,736 & 18,448 & 14,534 & 10,616 & 9,061 & 17,184 \\
\hline 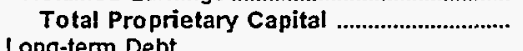 & 26,736 & 18,448 & 14,534 & 10,616 & Long-term Debt & 17,184 \\
\hline 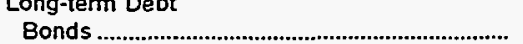 & 1,845 & 2,985 & 1,005 & 550 & 0 & 7,657 \\
\hline 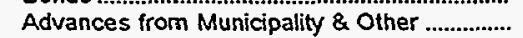 & 3,173 & 1,095 & 344 & 140 & 229 & 11,571 \\
\hline Unamort Prem on Long-term Debt ................... & 0 & -39 & 0 & -6 & 0 & -14 \\
\hline (less) Unamort Discount on Long-term Debt & 0 & 0 & 0 & 0 & 0 & 0 \\
\hline 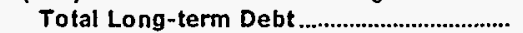 & 5,018 & 4,041 & 1,349 & 684 & 229 & 19,214 \\
\hline \multicolumn{7}{|l|}{ Other Noncument Liabilities } \\
\hline Accum Operating Provisions ............................... & 0 & 0 & 0 & 0 & 0 & 0 \\
\hline 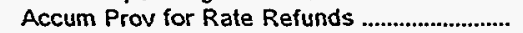 & 0 & 0 & 0 & 0 & 0 & 0 \\
\hline Total Other Noncurrent Liabilities ............ & 0 & $\mathbf{0}$ & $\mathbf{0}$ & 0 & 0 & 0 \\
\hline \multicolumn{7}{|l|}{ Current and Acorued Liabilities } \\
\hline 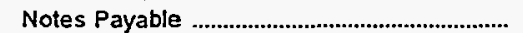 & 0 & 0 & 0 & 0 & 0 & 144 \\
\hline Accounts Payable & 2,868 & 1,054 & 2,139 & 980 & 1,095 & 2,641 \\
\hline Payables to Assoc Enterprises ............................ & 0 & 0 & 0 & 0 & 0 & 0 \\
\hline Customer Deposits & 941 & 996 & 451 & 271 & 153 & 1,260 \\
\hline Taxes Accrued & 0 & 0 & 0 & 0 & 0 & 0 \\
\hline Interest Accrued & 30 & 46 & 17 & 9 & 0 & 120 \\
\hline 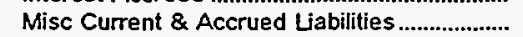 & 827 & 689 & 64 & 37 & 40 & 56 \\
\hline $\begin{array}{l}\text { Total Current \& Accrued Liabilities .......... } \\
\text { Deferred Credits }\end{array}$ & 4,667 & 2,786 & 2,671 & 1,297 & 1,288 & 4,223 \\
\hline Customer Advances for Construction ............. & 0 & 0 & 0 & 0 & 0 & 0 \\
\hline 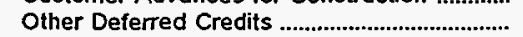 & 17 & 0 & 217 & 933 & 0 & 0 \\
\hline Unamort Gain on Reacar Debt & 0 & 0 & 0 & 0 & 0 & 0 \\
\hline 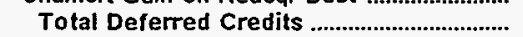 & 17 & $\mathbf{0}$ & 217 & 933 & 0 & 0 \\
\hline Total Liabilities and Other Credits ............ & 36,439 & 25,274 & 18,773 & 13,530 & 10,578 & 40,621 \\
\hline
\end{tabular}

Note: Totals may not equal sum of components because of independent rounding.

Source: Energy Information Administration, Form EIA-412, "Annual Report of Public Electric Utilities." 
Table 22. Balance Sheet by Major U.S. Publicly Owned Electric Utility Within State at End of Period, 1995

(Thousand Dollars)

\begin{tabular}{|c|c|c|c|c|c|c|}
\hline Item & $\begin{array}{l}\text { Tennessee } \\
\text { Dyersburg } \\
\text { City of } \\
\text { June } 30\end{array}$ & $\begin{array}{l}\text { Tennessee } \\
\text { Elizabethton } \\
\text { City of } \\
\text { June } 30\end{array}$ & $\begin{array}{l}\text { Tennessee } \\
\text { Enwin } \\
\text { Town of } \\
\text { June } 30\end{array}$ & $\begin{array}{l}\text { Tennessee } \\
\text { Etowah } \\
\text { City of } \\
\text { June } 30\end{array}$ & $\begin{array}{l}\text { Tennessee } \\
\text { Fayetteville } \\
\text { City of } \\
\text { June } 30\end{array}$ & $\begin{array}{l}\text { Tennessee } \\
\text { Gallatin } \\
\text { City of } \\
\text { June } 30\end{array}$ \\
\hline \multicolumn{7}{|l|}{ Electric Utility Plant } \\
\hline 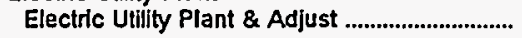 & 27,947 & 30,948 & 9,020 & 6,134 & 29,653 & 11,999 \\
\hline 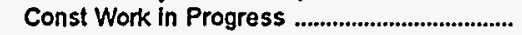 & 1,163 & 381 & 507 & 46 & 1,355 & 42 \\
\hline (less) Depr, Amort, and Depletion ..................... & 8.724 & 11,819 & 3.714 & 2,550 & 10,030 & 5,804 \\
\hline 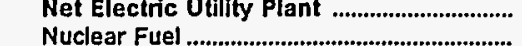 & $\begin{array}{r}20,386 \\
0\end{array}$ & $\begin{array}{r}19,509 \\
0\end{array}$ & $\begin{array}{r}5,813 \\
0\end{array}$ & $\begin{array}{r}3,630 \\
0\end{array}$ & $\begin{array}{r}20,978 \\
0\end{array}$ & $\begin{array}{r}6,237 \\
0\end{array}$ \\
\hline (less) Amort of Nucl Fuel ................................. & & & 0 & 0 & 0 & 0 \\
\hline Net Elec Plant Incl Nucl Fuel ......................... & 20,386 & 19,509 & 5,813 & 3,630 & 20,978 & 6,237 \\
\hline \multicolumn{7}{|l|}{ Other Property \& Investments } \\
\hline (less) Accum Provisions for Depr \& Amort.... & 0 & 0 & 0 & 0 & $\begin{array}{l}0 \\
0\end{array}$ & 0 \\
\hline 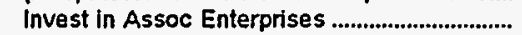 & 0 & 0 & 0 & 0 & 0 & 0 \\
\hline 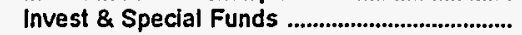 & 3,189 & 775 & 14 & 583 & 5.173 & 2,576 \\
\hline $\begin{array}{l}\text { Total Other Property \& Investments ........ } \\
\text { Curent and Acrued Assets }\end{array}$ & 3,189 & 775 & 14 & 583 & 5,173 & 2,576 \\
\hline Cash, Working Funds \& Investments .............. & 1,317 & 1,017 & 1,074 & 21 & 49 & 3,667 \\
\hline 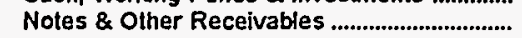 & 2,272 & 1,514 & 947 & 781 & 1,348 & 1,499 \\
\hline 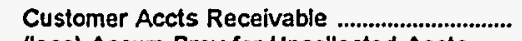 & 0 & 0 & 0 & 0 & 0 & 0 \\
\hline (less) Accum Prov for Uncollected Accts ...... & 0 & 0 & 0 & $\mathbf{0}$ & 0 & 0 \\
\hline 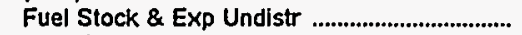 & 0 & $\mathbf{0}$ & 0 & 0 & 0 & 0 \\
\hline 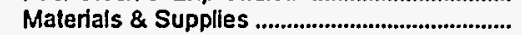 & 753 & 537 & 202 & 131 & 524 & 271 \\
\hline 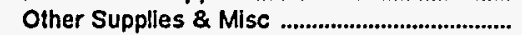 & 0 & 0 & 0 & 0 & 0 & 0 \\
\hline 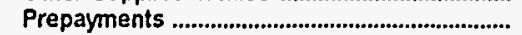 & 54 & 0 & 0 & 13 & 33 & 131 \\
\hline 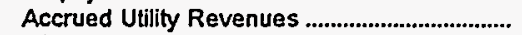 & 0 & 0 & 0 & 0 & 0 & 0 \\
\hline Miscellaneous Current \& Accrued Assets ..... & 76 & 85 & 317 & 15 & 65 & 25 \\
\hline Total Current \& Accrued Assets ................. & 4,472 & 3,154 & 2,540 & 961 & 2,020 & 5,594 \\
\hline \multicolumn{7}{|l|}{ Deferred Debits } \\
\hline Unamortized Debt Expenses .................................. & 92 & 0 & 0 & 0 & 114 & 0 \\
\hline Extraordinary Losses, Study Cost ...................... & 0 & 0 & 0 & 0 & 26 & 0 \\
\hline Misc Debt, R \& D Exp, Unamrt Losses .......... & 1,034 & 3,129 & 758 & 540 & 630 & 367 \\
\hline Total Deferred Debits ........................................... & 1,126 & 3,129 & 758 & 540 & 769 & 367 \\
\hline 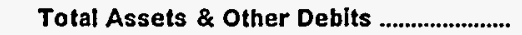 & 29,173 & 26,567 & 9,125 & 5,714 & 28,940 & 14,773 \\
\hline \multirow{2}{*}{\multicolumn{7}{|c|}{$\begin{array}{l}\text { Proprietary Capital } \\
\text { Investment of Municipality }\end{array}$}} \\
\hline & 0 & 0 & 0 & 0 & 0 & $\mathbf{0}$ \\
\hline 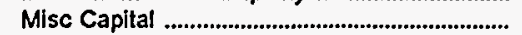 & 0 & 0 & 0 & 0 & 0 & 0 \\
\hline 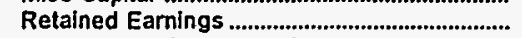 & 16,911 & 18,937 & 6,747 & 3,309 & 14,824 & 11,937 \\
\hline 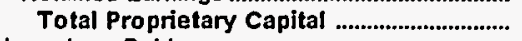 & 16,911 & 18,937 & 6,747 & 3,309 & 14,824 & 11,937 \\
\hline \multicolumn{7}{|l|}{ Long-term Debt } \\
\hline 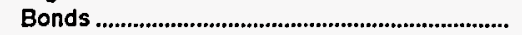 & 8,135 & 855 & 0 & 152 & 8,985 & 0 \\
\hline Advances from Municipality \& Other ................ & 889 & 3,190 & 661 & 397 & 2.224 & 353 \\
\hline Unamort Prem on Long-term Debt ..................... & -91 & 0 & 0 & 468 & -59 & 0 \\
\hline (less) Unamort Discount on Long-term Debt & & 0 & 0 & 0 & 0 & 0 \\
\hline $\begin{array}{l}\text { Total Long-term Debt.................................................... } \\
\text { Other Noncurrent Uabilities }\end{array}$ & 8,933 & 4,045 & 661 & 1,016 & 11,150 & 353 \\
\hline 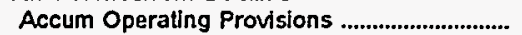 & $\mathbf{0}$ & 0 & 0 & 0 & 0 & 0 \\
\hline Accum Prov for Rate Refunds ......................... & 0 & 0 & 0 & 0 & 0 & 0 \\
\hline $\begin{array}{l}\text { Total Other Noncurrent Liabilities ............. } \\
\text { Current and Accrued Labilities }\end{array}$ & 0 & 0 & 0 & 0 & 0 & 0 \\
\hline 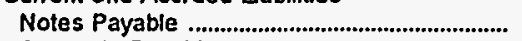 & 0 & & 0 & 0 & 106 & 0 \\
\hline Accounts Payable ....................................................... & 2,434 & 1.774 & 1,481 & 947 & 1,312 & 1.847 \\
\hline 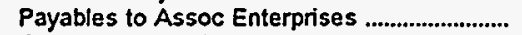 & 0 & 0 & 0 & 0 & 0 & 0 \\
\hline 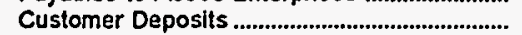 & 423 & 897 & 169 & 73 & 599 & 415 \\
\hline 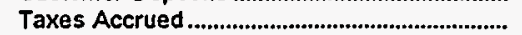 & 2 & 0 & 0 & 0 & 0 & 0 \\
\hline 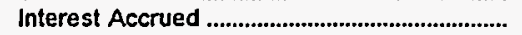 & 161 & 3 & 0 & 6 & 29 & 0 \\
\hline 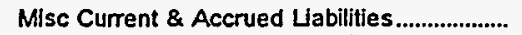 & 151 & 911 & 61 & 213 & 913 & 155 \\
\hline Total Current \& Accrued Liabilities .......... & 3,172 & 3,585 & 1,710 & 1,239 & 2,959 & 2,417 \\
\hline \multicolumn{7}{|l|}{ Deferred Credits } \\
\hline Customer Advances for Construction ............. & 0 & 0 & 7 & 0 & 0 & 0 \\
\hline 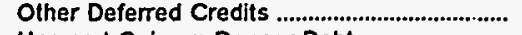 & 158 & 0 & 0 & 150 & 8 & 66 \\
\hline Unamort Gain on Reacqr Debt .......................... & 0 & 0 & 0 & 0 & 0 & 0 \\
\hline Total Deferred Credits ............................................ & 158 & & & 150 & 8 & 68 \\
\hline Total Liabilities and Other Credits ............ & 29,173 & 26,567 & 9,125 & 5,714 & 28,940 & 14,773 \\
\hline
\end{tabular}

Note: Totals may not equal sum of components because of independent rounding.

Source: Energy Information Administration, Form ELA-412, "Annual Report of Public Electric Utilities." 
Table 22. Balance Sheet by Major U.S. Publicly Owned Electric Utility Within State at End of Period, 1995 (Thousand Dollars)

\begin{tabular}{|c|c|c|c|c|c|c|}
\hline Item & $\begin{array}{l}\text { Tennessee } \\
\text { Greeneville } \\
\text { City of } \\
\text { June } 30\end{array}$ & $\begin{array}{c}\text { Tennessee } \\
\begin{array}{c}\text { Hamiman } \\
\text { City of }\end{array} \\
\text { June } 30\end{array}$ & $\begin{array}{l}\text { Tennessee } \\
\text { Humboldt } \\
\text { City of } \\
\text { June } 30\end{array}$ & $\begin{array}{l}\text { Tennessee } \\
\text { Jackson } \\
\text { City of } \\
\text { June } 30\end{array}$ & $\begin{array}{l}\text { Tennessee } \\
\text { Johnson } \\
\text { City City of } \\
\text { June } 30\end{array}$ & $\begin{array}{c}\text { Tennessee } \\
\text { Knoxville } \\
\text { Utilities } \\
\text { Board } \\
\text { June } 30\end{array}$ \\
\hline \multicolumn{7}{|l|}{ Electric Utility Plant } \\
\hline Electric Utility Plant \& Adjust ............................... & 45,412 & 20,286 & 7.764 & 60,975 & 70,865 & 291,839 \\
\hline Const Work in Progress & 322 & 258 & 245 & 1,117 & 3.470 & 16,839 \\
\hline 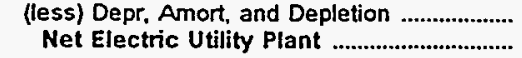 & $\begin{array}{l}17,196 \\
28,538\end{array}$ & $\begin{array}{r}8,646 \\
11,899\end{array}$ & $\begin{array}{l}2,801 \\
5,208\end{array}$ & $\begin{array}{l}23,862 \\
38,230\end{array}$ & $\begin{array}{l}27,282 \\
47,053\end{array}$ & $\begin{array}{l}143,314 \\
165,364\end{array}$ \\
\hline Nuclear Fuel ..................................................... & & 0 & 0 & 0 & 0 & 0 \\
\hline 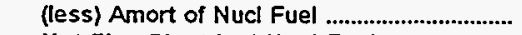 & 0 & 0 & 0 & 0 & 0 & 0 \\
\hline Net Elec Plant Incl Nucl Fuel .......................... & 28,538 & 11,899 & 5,208 & 38,230 & 47,053 & 165,364 \\
\hline \multicolumn{7}{|l|}{ Other Property \& Investments } \\
\hline & 0 & 0 & 0 & 0 & 0 & 0 \\
\hline $\begin{array}{l}\text { (less) Accum Provisions for Depr \& Amort.... } \\
\text { Invest in Assoc Enterprises .............................. }\end{array}$ & 0 & 0 & 0 & 0 & 0 & o \\
\hline 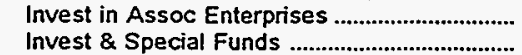 & 7560 & 0 & 0 & 0 & 0 & 0 \\
\hline 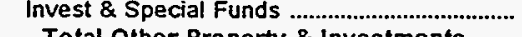 & 7,560 & 188 & 358 & 7,857 & 3,708 & 22,722 \\
\hline $\begin{array}{l}\text { Total Other Property \& Investments ....... } \\
\text { Current and Accrued Assets }\end{array}$ & 7,560 & 188 & 358 & 7,857 & 3,708 & 22,722 \\
\hline Cash, Working Funds \& Investments ............. & 4.243 & 2,715 & 1.544 & 3,346 & 585 & 15,803 \\
\hline Notes \& Other Receivables ................................... & 2,896 & 1,017 & 1,528 & 5,795 & 5,596 & 16,855 \\
\hline 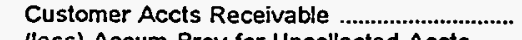 & 0 & 0 & 0 & 0 & 0 & 0 \\
\hline (less) Accum Prov for Uncollected Accts ...... & 0 & 0 & 0 & 0 & 0 & 0 \\
\hline Fuel Stock \& Exp Undistr ....................................... & 0 & 0 & 0 & 0 & 0 & 0 \\
\hline 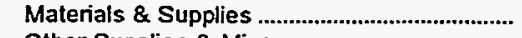 & 1,126 & 164 & 301 & 586 & 1,022 & 3,311 \\
\hline 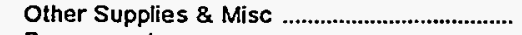 & 0 & 0 & 0 & 0 & 0 & 0 \\
\hline 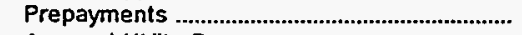 & 87 & 8 & 30 & 0 & 0 & 441 \\
\hline Accrued Utlity Revenues & 0 & 0 & 0 & 0 & 0 & 0 \\
\hline Miscellaneous Current \& Accrued Assets ..... & 149 & 948 & 8 & 76 & 247 & 93 \\
\hline Total Current \& Accrued Assets ................ & 8,500 & 4,852 & 3,410 & 9,802 & 7,450 & 36,503 \\
\hline \multicolumn{7}{|l|}{ Deferred Debits } \\
\hline & 0 & 2 & 0 & 58 & 0 & 185 \\
\hline 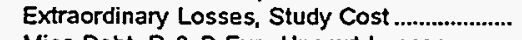 & 0 & 0 & 0 & 0 & 0 & 0 \\
\hline Misc Debt, R \& D Exp. Unamrt Losses .......... & 6,715 & 1,102 & 509 & 2,487 & 7,738 & 11,737 \\
\hline Total Deferred Debits ........................................... & 6,715 & 1,104 & 509 & 2,544 & 7,738 & 11,922 \\
\hline 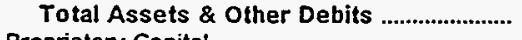 & 51,313 & 18,043 & 9,485 & 58,434 & 65,949 & 236,511 \\
\hline \multicolumn{7}{|l|}{ Proprietary Capital } \\
\hline 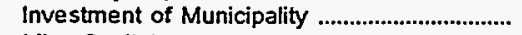 & 0 & 0 & 0 & 0 & 0 & 0 \\
\hline Misc Capital & 0 & 0 & 0 & 0 & 0 & $\mathbf{0}$ \\
\hline Retained Earnings ......................................................... & 43,557 & 13,787 & 7,083 & 34.088 & 49,097 & 124.038 \\
\hline $\begin{array}{l}\text { Total Proprietary Capital ......................................... } \\
\text { Long-tem Debt }\end{array}$ & 43,557 & 13,787 & 7,083 & 34,088 & 49,097 & 124,036 \\
\hline $\begin{array}{l}\text { Long-tem Debt } \\
\text { Bonds ............................................................................. }\end{array}$ & \multicolumn{4}{|c|}{ Long-tem Debt } & 0 & 51,250 \\
\hline 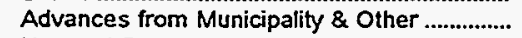 & 6,676 & 159 & 455 & 672 & 7.740 & 10,273 \\
\hline Unamort Prem on Long-term Debt .................... & 0 & 0 & 0 & $-9 i$ & 0 & -554 \\
\hline (less) Unamort Discount on Long-term Debt & 0 & 0 & 0 & & 0 & 0 \\
\hline Total Long-term Debt & 6,676 & 866 & 630 & 17,034 & 7,740 & 60,969 \\
\hline \multicolumn{7}{|l|}{ Other Noncurrent Liabillties } \\
\hline 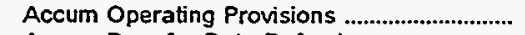 & 0 & 0 & 0 & 0 & 0 & $\mathbf{0}$ \\
\hline 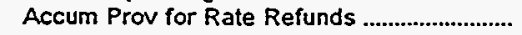 & 0 & 0 & 0 & 0 & 0 & 0 \\
\hline Total Other Noncurrent Liabilities ............ & 0 & 0 & 0 & 0 & 0 & 0 \\
\hline \multicolumn{7}{|l|}{ Current and Accrued Liabilities } \\
\hline 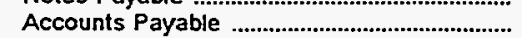 & 337 & 1,912 & 1,454 & 4,619 & 6,471 & 19.196 \\
\hline Payables to Ássoc Enterprises ............................ & 0 & 0 & 0 & 0 & 0 & 0 \\
\hline 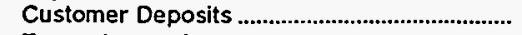 & 164 & 404 & 80 & 0 & 871 & 7,261 \\
\hline 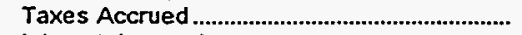 & 0 & 0 & 0 & 0 & 0 & 0 \\
\hline Interest Accrued & 0 & 0 & 0 & 401 & 0 & 0 \\
\hline 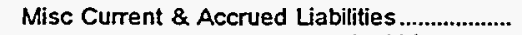 & 552 & 137 & 38 & 640 & 1,754 & 7,379 \\
\hline $\begin{array}{l}\text { Total Current \& Accrued Liabilities .......... } \\
\text { Deferred Credits }\end{array}$ & 1,054 & 2,458 & 1,572 & 5,660 & 9,096 & 34,824 \\
\hline Customer Advances for Construction ................. & 0 & 0 & 0 & 0 & 16 & 2,239 \\
\hline Other Deferred Credits .......................................... & 26 & 933 & 200 & 1,651 & 0 & 14,443 \\
\hline Unamort Gain on Reacqr Debt ............................... & 0 & 0 & 0 & 0 & 0 & \\
\hline 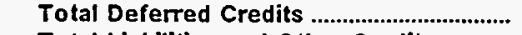 & 26 & 933 & 200 & 1,651 & 16 & 16,682 \\
\hline Total Liabilities and Other Credits ............ & 51,313 & 18,043 & 9,485 & 58,434 & 65,949 & 236,511 \\
\hline
\end{tabular}

Note: Totals may not equal sum of components because of independent rounding.

Source: Energy Information Administration, Form EIA-412, "Annual Report of Public Electric Utilities." 
Table 22. Balance Sheet by Major U.S. Publicly Owned Electric Utility Within State at End of Period, 1995

(Thousand Dollars)

\begin{tabular}{|c|c|c|c|c|c|c|}
\hline Item & $\begin{array}{l}\text { Tennessee } \\
\begin{array}{c}\text { Lawrenceburg } \\
\text { City of }\end{array} \\
\text { June } 30\end{array}$ & $\begin{array}{l}\text { Tennessee } \\
\begin{array}{l}\text { LaFollette } \\
\text { City of }\end{array} \\
\text { June } 30\end{array}$ & $\begin{array}{l}\text { Tennessee } \\
\text { Lebanon } \\
\text { City of } \\
\text { June } 30\end{array}$ & $\begin{array}{l}\text { Tennessee } \\
\text { Lenoir } \\
\text { City City of } \\
\text { June } 30\end{array}$ & $\begin{array}{l}\text { Tennessee } \\
\text { Lewisburg } \\
\text { City of } \\
\text { June } 30\end{array}$ & $\begin{array}{l}\text { Tennessee } \\
\text { Lexington } \\
\text { City of } \\
\text { June } 30\end{array}$ \\
\hline \multicolumn{7}{|l|}{ Electric Utility Plant } \\
\hline Electric Utility Plant \& Adjust ................................ & 25,244 & 28.407 & 13,617 & 67,997 & 11,155 & 23,688 \\
\hline Const Work in Progress ........................................... & 298 & 618 & 236 & 374 & 49 & 347 \\
\hline 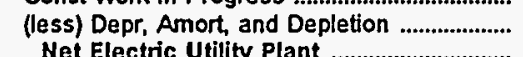 & 10,098 & $\begin{array}{r}10,168 \\
18,857\end{array}$ & $\begin{array}{l}4,652 \\
9,201\end{array}$ & $\begin{array}{l}16,222 \\
52,150\end{array}$ & $\begin{array}{l}3,660 \\
7,545\end{array}$ & $\begin{array}{r}8,622 \\
15,414\end{array}$ \\
\hline 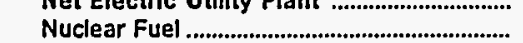 & & 0 & 0 & 0 & 0 & 0 \\
\hline (less) Amort of Nucl Fuel ............................. & 0 & 0 & 0 & 0 & 0 & 0 \\
\hline Net Elec Plant Inct Nucl Fuel ............................. & 15,443 & 18,857 & 9,201 & 52,150 & 7,545 & 15,414 \\
\hline \multicolumn{7}{|l|}{ Other Property \& Investments } \\
\hline 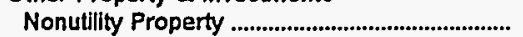 & 568 & 0 & 0 & 0 & 0 & 0 \\
\hline (less) Accum Provisions for Depr \& Amort.... & 0 & 0 & 0 & 0 & 0 & 0 \\
\hline Invest in Assoc Enterprises .............................. & 0 & 0 & 0 & 0 & 0 & 0 \\
\hline 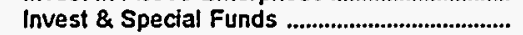 & 257 & 6,497 & 0 & 3,070 & 154 & 2,682 \\
\hline $\begin{array}{l}\text { Total Other Property \& Investments ....... } \\
\text { Current and Accrued Assets }\end{array}$ & 825 & 6,497 & 0 & 3,070 & 154 & 2,682 \\
\hline Cash, Working Funds \& Investments .............. & 1,307 & 1,988 & 1,527 & 155 & 2.559 & 960 \\
\hline Notes \& Other Receivables ..................................... & 2,027 & 1,933 & 1,388 & 4,399 & 812 & 1,618 \\
\hline 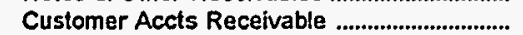 & 0 & 0 & 0 & 0 & 0 & 0 \\
\hline (less) Accum Prov for Uncollected Accts ...... & 0 & 0 & 0 & 0 & 0 & 0 \\
\hline 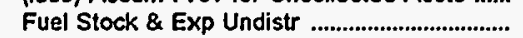 & 0 & 0 & 0 & 0 & 0 & 0 \\
\hline Materials \& Supplies ................................................. & 253 & 513 & 278 & 880 & 223 & 414 \\
\hline Other Supplies \& Misc ............................................. & 0 & 0 & 0 & 0 & 0 & 0 \\
\hline Prepayments ............................................................. & 36 & 0 & 5 & 130 & 1 & 45 \\
\hline 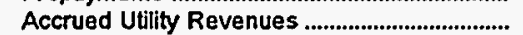 & 0 & 0 & 0 & 0 & 0 & 0 \\
\hline Miscellaneous Current \& Accrued Assets ..... & 855 & 1,102 & 15 & 1.974 & 11 & 91 \\
\hline $\begin{array}{l}\text { Total Current \& Accrued Assets ................... } \\
\text { Deferted Deblts }\end{array}$ & 4,478 & 5,536 & 3,213 & 7,539 & 3,607 & 3,126 \\
\hline Unamortized Debt Expenses .................................. & 0 & 215 & 0 & 374 & 0 & 0 \\
\hline 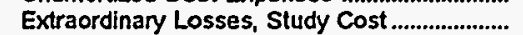 & 37 & 0 & 0 & 0 & 0 & 0 \\
\hline Misc Debt, R \& D Exp, Unamrt Losses .......... & 1,999 & 1,127 & 411 & 2,399 & 287 & 820 \\
\hline 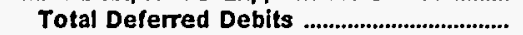 & 2,035 & 1,341 & 411 & 2,773 & 287 & 820 \\
\hline Total Assets \& Other Debits ............................. & 22,782 & 32,232 & 12,825 & 65,532 & 11,593 & 22,043 \\
\hline \multicolumn{7}{|l|}{ Proprietary Capital } \\
\hline 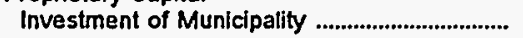 & 0 & 0 & 0 & 0 & 0 & $\mathbf{0}$ \\
\hline 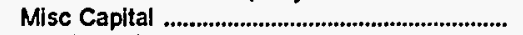 & 0 & 0 & 0 & 0 & 0 & 0 \\
\hline 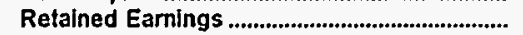 & 16,717 & 16,007 & 9,434 & 32,923 & 9,094 & 18,253 \\
\hline Total Proprietary Capital ...................................... & 16,717 & 16,007 & 9,434 & 32,923 & 9,094 & 18,253 \\
\hline \multicolumn{7}{|l|}{ Long-term Debt } \\
\hline 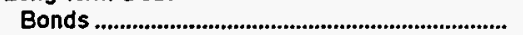 & 0 & 7,940 & 0 & 21,185 & 570 & 0 \\
\hline Advances from Municipality \& Other ................. & 2,051 & 4,108 & 405 & 2,238 & 177 & 823 \\
\hline Unamort Prem on Long-term Debt ................... & 0 & -25 & 0 & 0 & 0 & 0 \\
\hline (less) Unamort Discount on Long-term Debt & & & 0 & 0 & 0 & 0 \\
\hline 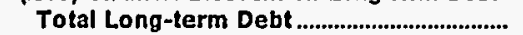 & 2,051 & 12,023 & 405 & 23,423 & 748 & 823 \\
\hline \multicolumn{7}{|l|}{ Other Noncurrent Labilities } \\
\hline 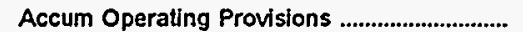 & 0 & 0 & 0 & 0 & 0 & 0 \\
\hline Accum Prov for Rate Refunds ............................... & 0 & 0 & 0 & 0 & 0 & 0 \\
\hline Total Other Noncurrent Liabilities ............. & 0 & o & 0 & 0 & 0 & 0 \\
\hline \multicolumn{7}{|l|}{ Current and Accrued Liablities } \\
\hline 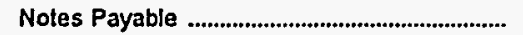 & 0 & 71 & 0 & 0 & 0 & 0 \\
\hline Accounts Payable ....................................................... & 3,452 & 3,220 & 2,384 & 5,300 & 1,180 & 1,848 \\
\hline Payables to Assoc Enterprises .............................. & & 0 & 0 & 0 & 0 & 0 \\
\hline Customer Deposits ......................................................... & 290 & 664 & 520 & 1,975 & 221 & 138 \\
\hline Taxes Accrued ................................................... & 0 & 0 & 47 & 0 & 0 & 0 \\
\hline 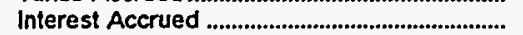 & 0 & 26 & 0 & 101 & 0 & 0 \\
\hline Misc Current \& Accrued Liabilities...................... & 225 & 221 & 32 & 1,099 & 70 & 980 \\
\hline Total Current \& Accrued Llabilities ........... & 3,966 & 4,201 & 2,984 & 8,475 & 1,471 & 2,967 \\
\hline $\begin{array}{l}\text { Deferred Credits } \\
\text { Customer Advances for Construction ............. }\end{array}$ & 40 & 0 & 0 & 648 & 0 & $\mathbf{0}$ \\
\hline 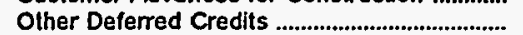 & 8 & 0 & 2 & 63 & 281 & 0 \\
\hline Unamort Gain on Reacqr Debt ............................. & 0 & 0 & $\overline{0}$ & 0 & 0 & 0 \\
\hline Total Deferred Credits ................................... & 48 & 0 & 2 & 711 & 281 & 0 \\
\hline Total Llabilities and Other Credits ............ & 22,782 & 32,232 & 12,825 & 65,532 & 11,593 & 22,043 \\
\hline
\end{tabular}

Note: Tolals may not equal sum of components because of independent rounding

Source: Energy Information Administration, Form ElA-412, "Annual Report of Public Electric Utilities." 
Table 22. Balance Sheet by Major U.S. Publicly Owned Electric Utility Within State at End of Period, 1995

(Thousand Dollars)

\begin{tabular}{|c|c|c|c|c|c|c|}
\hline Item & $\begin{array}{l}\text { Tennessee } \\
\text { Loudon } \\
\text { Utilities } \\
\text { Board } \\
\text { June } 30\end{array}$ & $\begin{array}{l}\text { Tennessee } \\
\text { Maryille } \\
\text { Utilities } \\
\text { June } 30\end{array}$ & $\begin{array}{l}\text { Tennessee } \\
\text { McMinnville } \\
\text { Electric } \\
\text { System } \\
\text { June } 30\end{array}$ & $\begin{array}{l}\text { Tennessee } \\
\text { Memphis } \\
\text { City of } \\
\text { June } 30\end{array}$ & $\begin{array}{l}\text { Tennessee } \\
\text { Milan } \\
\text { City of } \\
\text { June } 30\end{array}$ & $\begin{array}{l}\text { Tennessee } \\
\text { Morristown } \\
\text { City of } \\
\text { June } 30\end{array}$ \\
\hline \multicolumn{7}{|l|}{ Electric Utility Plant } \\
\hline 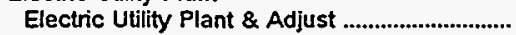 & 19,750 & 26,330 & 12,879 & 763,133 & 11,310 & 30,437 \\
\hline 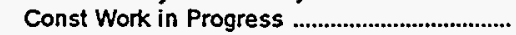 & 2,115 & 1,313 & 38 & 32,813 & 474 & 906 \\
\hline (less) Depr, Amort, and Depletion ..................... & $\begin{array}{r}4,318 \\
17.547\end{array}$ & $\begin{array}{r}8,627 \\
19.016\end{array}$ & $\begin{array}{l}5,435 \\
7,483\end{array}$ & $\begin{array}{l}264,723 \\
531.224\end{array}$ & $\begin{array}{l}5,243 \\
6,541\end{array}$ & $\begin{array}{l}10,648 \\
200695\end{array}$ \\
\hline Nuclear Fuel ....................................................... & & & 0 & 0 & 0 & 0 \\
\hline 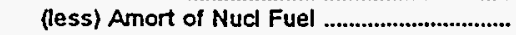 & 0 & 0 & 0 & 0 & 0 & 0 \\
\hline $\begin{array}{l}\text { Net Elec Plant Incl Nucl Fuel ....................... } \\
\text { Other Property \& Investments }\end{array}$ & 17,547 & 19,016 & 7,483 & 531,224 & 6,541 & 20,695 \\
\hline 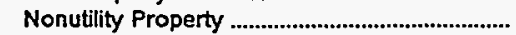 & 0 & 93 & 0 & 0 & 0 & 0 \\
\hline (less) Accum Provisions for Depr \& Amort.... & 0 & 0 & 0 & 0 & 0 & 0 \\
\hline 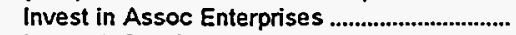 & 0 & 0 & 0 & 0 & 0 & 0 \\
\hline Invest \& Special Funds ............................................ & 1,159 & 583 & 400 & 51,004 & 0 & 14 \\
\hline $\begin{array}{l}\text { Total Other Property \& Investments ....... } \\
\text { Current and Accrued Assets }\end{array}$ & \multicolumn{6}{|c|}{ Current and Accrued Assets } \\
\hline Cash, Working Funds \& Investments .............. & 203 & 444 & 860 & 44,338 & 317 & 5,168 \\
\hline Notes \& Other Receivables ........................................ & 1,969 & 1,814 & 564 & 54,583 & 1,192 & 3,213 \\
\hline Customer Accts Receivable .................................. & 0 & 0 & 0 & 0 & 0 & 0 \\
\hline (less) Accum Prov for Uncollected Accts ....... & 0 & 0 & 0 & 0 & 0 & 0 \\
\hline Fuel Stock \& Exp Undistr ..................................... & 0 & 0 & 0 & 0 & 0 & 0 \\
\hline 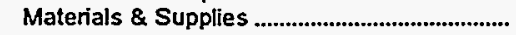 & 325 & 472 & 134 & 10,183 & 181 & 637 \\
\hline 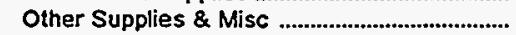 & 0 & 0 & 0 & 0 & 0 & 0 \\
\hline 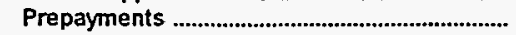 & 7 & 20 & 15 & 0 & 53 & 0 \\
\hline 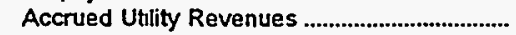 & 0 & 0 & 0 & 0 & 0 & $\mathbf{0}$ \\
\hline Miscellaneous Current \& Accrued Assets..... & 19 & 75 & 21 & 5,427 & 23 & 747 \\
\hline Total Current \& Accrued Assets ................ & 2,522 & 2,826 & 1,595 & 114,532 & 1,766 & 9,766 \\
\hline \multicolumn{7}{|l|}{ Deferred Debits } \\
\hline Unamortized Debt Expenses ................................... & 49 & 30 & 0 & 2,984 & 0 & $\mathbf{0}$ \\
\hline Extraordinary Losses, Study Cost...................... & 0 & 0 & 0 & 0 & 0 & 0 \\
\hline Misc Debt, $R$ \& D Exp. Unamrt Losses .......... & 1,154 & 673 & 593 & 15,281 & 868 & 1,785 \\
\hline Total Deferred Debits & 1,203 & 703 & 593 & 18,265 & 868 & 1,785 \\
\hline 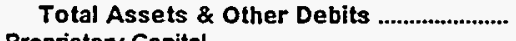 & 22,432 & 23,220 & 10,070 & 715,025 & 9,175 & 32,260 \\
\hline \multirow{2}{*}{\multicolumn{7}{|c|}{$\begin{array}{l}\text { Proprietary Capital } \\
\text { Investment of Municipality }\end{array}$}} \\
\hline & 0 & 0 & 0 & 0 & 0 & 0 \\
\hline 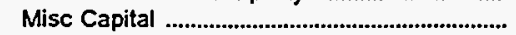 & 0 & 0 & 0 & 0 & 0 & 0 \\
\hline Retained Earnings .............................................................. & 9,280 & 16,297 & 8.497 & 394.244 & 6,820 & 23,611 \\
\hline Total Proprietary Capital ................................ & 9,280 & 16,297 & 8,497 & 394,244 & 6,820 & 23,611 \\
\hline \multicolumn{4}{|l|}{ Long-term Debt } & & & \\
\hline Advances from Municipality \& Other ................ & 2 & 527 & 574 & 3,350 & 863 & 1,821 \\
\hline Unamort Prem on Long-term Debt .................... & -64 & -13 & 0 & 0 & 0 & 0 \\
\hline (less) Unamort Discount on Long-term Debt & & & 0 & 0 & 0 & 0 \\
\hline $\begin{array}{l}\text { Total Long-term Debt ............................................ } \\
\text { Other Noncurrent Labilities }\end{array}$ & 8,989 & 3,244 & 574 & 235,805 & 863 & 1,827 \\
\hline 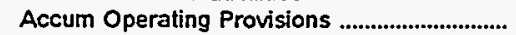 & 0 & 0 & 0 & 0 & 0 & 0 \\
\hline 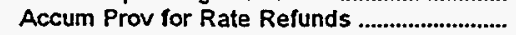 & 0 & 0 & 0 & 0 & 0 & 0 \\
\hline $\begin{array}{l}\text { Total Other Noncurrent Liabilities ............ } \\
\text { Current and Accrued Labilities }\end{array}$ & 0 & 0 & 0 & 0 & 0 & 0 \\
\hline 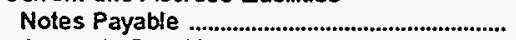 & 0 & 0 & 0 & 0 & 0 & $\mathbf{0}$ \\
\hline 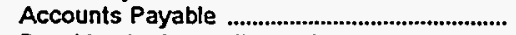 & 3,865 & 3,007 & 41 & 57,298 & 1,213 & 3,190 \\
\hline 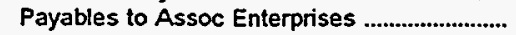 & 0 & 0 & 0 & 0 & 0 & 0 \\
\hline 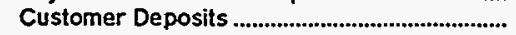 & 4 & 303 & 503 & 0 & 172 & 1,259 \\
\hline 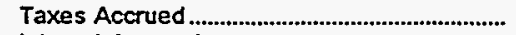 & 0 & 0 & 0 & 2.160 & 0 & 0 \\
\hline 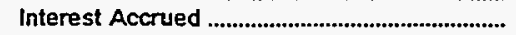 & 22 & 18 & 0 & 0 & 0 & 0 \\
\hline Misc Current \& Accrued Liabilities..................... & 246 & 351 & 221 & 5,025 & 98 & 963 \\
\hline $\begin{array}{l}\text { Total Current \& Accrued Liabilities .......... } \\
\text { Deferred Credits }\end{array}$ & 4,137 & 3,680 & 765 & 64,483 & 1,484 & 5,411 \\
\hline Customer Advances for Construction .............. & 27 & 0 & 0 & 1,724 & 8 & 0 \\
\hline 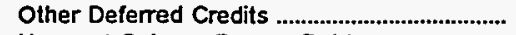 & 0 & 0 & 233 & 18,769 & 0 & 1.410 \\
\hline 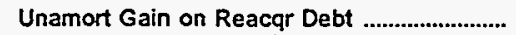 & 0 & 0 & 0 & 0 & 0 & \\
\hline Total Deferred Credits ....................................... & & 0 & 233 & 20,493 & & 1,410 \\
\hline Total Liabilities and Other Credits ............ & 22,432 & 23,220 & 10,070 & 715,025 & 9,175 & 32,260 \\
\hline
\end{tabular}

Note: Totals may not equal sum of components because of independent rounding.

Source: Energy Information Administration, Form ElA-412, "Annual Report of Public Electric Utilities." 
Table 22. Balance Sheet by Major U.S. Publicly Owned Electric Utility Within State at End of Period, 1995 (Thousand Dollars)

\begin{tabular}{|c|c|c|c|c|c|c|}
\hline Item & $\begin{array}{c}\text { Tennessee } \\
\text { Murfreesboro } \\
\text { City of } \\
\text { June } 30\end{array}$ & $\begin{array}{l}\text { Tennessee } \\
\text { Nashville } \\
\text { Electric } \\
\text { Service } \\
\text { June } \mathbf{3 0}\end{array}$ & $\begin{array}{l}\text { Tennessee } \\
\text { Newport } \\
\text { City of } \\
\text { June } 30\end{array}$ & $\begin{array}{l}\text { Tennessee } \\
\text { Oak Ridge } \\
\text { City of } \\
\text { June } 30\end{array}$ & $\begin{array}{l}\text { Tennessee } \\
\text { Paris } \\
\text { City of } \\
\text { June } 30\end{array}$ & $\begin{array}{l}\text { Pulaskj } \\
\text { City of } \\
\text { June } 30\end{array}$ \\
\hline \multicolumn{7}{|l|}{ Electric Utility Plant } \\
\hline Electric Utility Plant \& Adjust ............................. & 39,345 & 566,447 & 3,381 & 27,486 & 27,944 & 25,823 \\
\hline Const Work in Progress & 1,591 & 24,658 & 560 & 6,975 & 497 & 1,263 \\
\hline $\begin{array}{l}\text { (less) Depr, Amort, and Depletion .................... } \\
\text { Net Electric Utility Plant .............................. }\end{array}$ & $\begin{array}{l}11,709 \\
29,228\end{array}$ & $\begin{array}{l}215,150 \\
375,955\end{array}$ & $\begin{array}{l}1,067 \\
2,875\end{array}$ & $\begin{array}{l}10,507 \\
23,954\end{array}$ & $\begin{array}{l}12,474 \\
15,968\end{array}$ & $\begin{array}{r}9,697 \\
17,389\end{array}$ \\
\hline 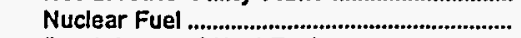 & 0 & 0 & 0 & 0 & 0 & 0 \\
\hline 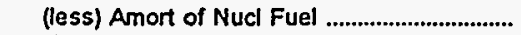 & 0 & 0 & 0 & 0 & 0 & 0 \\
\hline Net Elec Plant Incl Nucl Fuel ......................... & 29,228 & 375,955 & 2,875 & 23,954 & 15,968 & 17,389 \\
\hline \multicolumn{7}{|l|}{ Other Property \& Investments } \\
\hline 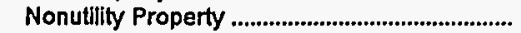 & 0 & 0 & 0 & 0 & 0 & 0 \\
\hline (less) Accum Provisions for Depr \& Amort.... & 0 & 0 & 0 & 0 & 0 & 0 \\
\hline 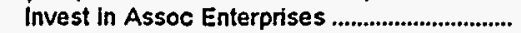 & 0 & 0 & 0 & 0 & 0 & 0 \\
\hline 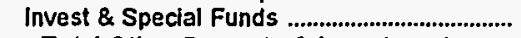 & 6,467 & 51,928 & 365 & 523 & 1,649 & 894 \\
\hline $\begin{array}{l}\text { Total Other Property \& Investments ....... } \\
\text { Current and Accrued Assets }\end{array}$ & 6,467 & 51,928 & 365 & 523 & 1,649 & 894 \\
\hline Cash. Working Funds \& Investments .............. & 3,228 & 43,235 & 539 & 1,947 & 1,009 & 320 \\
\hline Notes \& Other Receivables ............................. & 2,412 & 36,641 & 463 & 2,307 & 1,077 & 1,523 \\
\hline 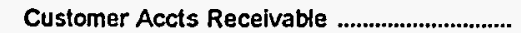 & 0 & 0 & 0 & 0 & 0 & 0 \\
\hline (less) Accum Prov for Uncollected Accts ...... & 0 & 0 & 0 & 0 & 0 & 0 \\
\hline 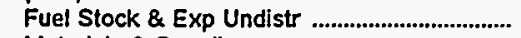 & 0 & 0 & 0 & 0 & 0 & 0 \\
\hline 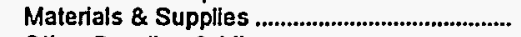 & 743 & 7,711 & 81 & 410 & 337 & 167 \\
\hline 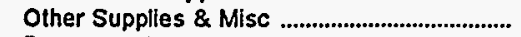 & 0 & 0 & 0 & 0 & 0 & 0 \\
\hline 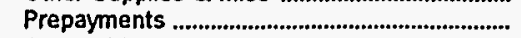 & 30 & 330 & 6 & 0 & 7 & 78 \\
\hline Accrued Utility Revenues ................................... & 0 & 0 & 0 & 0 & 0 & 0 \\
\hline Mlscellaneous Current \& Accrued Assets ..... & 73 & 24,329 & 10 & 29 & 57 & 1,179 \\
\hline $\begin{array}{l}\text { Total Current \& Accrued Assets ............... } \\
\text { Deferred Debits }\end{array}$ & 6,486 & 112,245 & 1,100 & 4,693 & 2,488 & 3,267 \\
\hline Unamortized Debt Expenses ................................ & 51 & 1,436 & 0 & 43 & 39 & 17 \\
\hline Extraordinary Losses, Study Cost ..................... & 0 & 0 & 0 & 0 & 0 & 0 \\
\hline Misc Debt, R \& D Exp, Unamrt Losses ......... & 1,865 & 22,064 & 203 & 2,198 & 1,991 & 913 \\
\hline 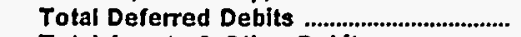 & 1,916 & 23,500 & 203 & 2,241 & 2,030 & 930 \\
\hline $\begin{array}{l}\text { Total Assets \& Other Debits ............................ } \\
\text { Proprietan Capital }\end{array}$ & 44,098 & 563,629 & 4,543 & 31,411 & 22,135 & 22,479 \\
\hline \multicolumn{7}{|l|}{ Proprietary Capital } \\
\hline & $\begin{array}{l}0 \\
0\end{array}$ & $\begin{array}{l}0 \\
0\end{array}$ & 0 & 0 & 0 & 0 \\
\hline $\begin{array}{l}\text { Misc Capital } \\
\text { Retained Earnings }\end{array}$ & $\begin{array}{r}0 \\
32,176\end{array}$ & $\begin{array}{r}0 \\
262779\end{array}$ & 0 & 0 & 0 & 0 \\
\hline & 32,176 & 262,779 & 2,765 & 12,817 & 15,408 & 15,574 \\
\hline $\begin{array}{l}\text { Total Proprietary Capital .................................... } \\
\text { Long-term Debt }\end{array}$ & 32,176 & 262,779 & 2,765 & 12,817 & 15,408 & 15,574 \\
\hline 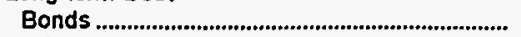 & 6,930 & 194,745 & 900 & 5,945 & 2,295 & 3,388 \\
\hline Advances from Municipality \& Other ............... & 1,520 & 16,668 & 194 & 8,232 & 1,934 & 925 \\
\hline Unamort Prem on Long-term Debt .................. & -34 & $-2,638$ & 0 & -70 & 0 & 0 \\
\hline (less) Unamort Discount on Long-term Debt & 0 & 0 & 0 & 0 & 0 & 0 \\
\hline Total Long-term Debt & 8,446 & 208,775 & 1,094 & 14,107 & 4,229 & 4,312 \\
\hline \multicolumn{7}{|l|}{ Other Noncurrent Labilities } \\
\hline 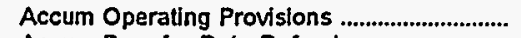 & 0 & 0 & 0 & 0 & 0 & 0 \\
\hline Accum Prov for Rate Refunds ........................... & 0 & 0 & 0 & 0 & 0 & 0 \\
\hline \multicolumn{6}{|l|}{ Current and Accrued Labilities } & 0 \\
\hline 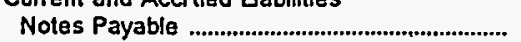 & 62 & 1,950 & 0 & 0 & 0 & 15 \\
\hline Accounts Payable & 692 & 72,029 & 574 & 3,698 & 1,742 & 2,191 \\
\hline Payables to Assoc Enterprises ............................ & 0 & 0 & 0 & 0 & 0 & 0 \\
\hline 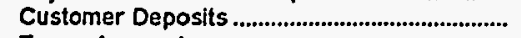 & 1,373 & 7,189 & 68 & 413 & 477 & 291 \\
\hline Taxes Accrued & 0 & 0 & 0 & 0 & 0 & 41 \\
\hline 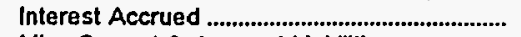 & $\mathbf{0}$ & 0 & 25 & 101 & 11 & 0 \\
\hline Misc Current \& Accrued Luabilities.................... & 575 & 2,210 & 9 & 230 & 172 & 47 \\
\hline $\begin{array}{l}\text { Total Current \& Accrued Llabilities .......... } \\
\text { Deferred Credits }\end{array}$ & 2,703 & 83,378 & 675 & 4,441 & 2,401 & 2,585 \\
\hline Customer Advances for Construction ............ & 0 & 522 & 0 & 0 & 0 & $\mathbf{0}$ \\
\hline 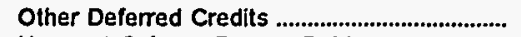 & 802 & 8,176 & 9 & 45 & 96 & 8 \\
\hline Unamort Galn on Reacqr Debt ........................ & 0 & 0 & 0 & 0 & 0 & 0 \\
\hline 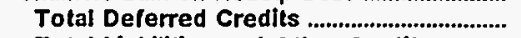 & 802 & 8,697 & 9 & 45 & 96 & 8 \\
\hline Total Llabilities and Other Credits ............ & 44,098 & 563,629 & 4,543 & 31,411 & 22,135 & 22,479 \\
\hline
\end{tabular}

Note: Tolals may not equal sum of components because of independent rounding.

Source: Energy Information Administration, Form ElA-4 12, "Annual Report of Public Electric Utilities." 
Table 22. Balance Sheet by Major U.S. Publicly Owned Electric Utility Within State at End of Period, 1995 (Thousand Dollars)

\begin{tabular}{|c|c|c|c|c|c|c|}
\hline Item & $\begin{array}{l}\text { Tennessee } \\
\text { Ripley } \\
\text { City of } \\
\text { June } 30\end{array}$ & $\begin{array}{l}\text { Tennessee } \\
\text { Rockwood } \\
\text { City of } \\
\text { June } 30\end{array}$ & $\begin{array}{l}\text { Tennessee } \\
\text { Sevier } \\
\text { County } \\
\text { Electric } \\
\text { System } \\
\text { June } 30\end{array}$ & $\begin{array}{c}\text { Tennessee } \\
\text { Shelbyville } \\
\text { City of } \\
\text { June } 30\end{array}$ & $\begin{array}{c}\text { Springfield } \\
\text { City of }\end{array}$ & $\begin{array}{c}\text { Tennessee } \\
\text { Sweetwater } \\
\text { City of } \\
\text { June } 30\end{array}$ \\
\hline \multicolumn{7}{|l|}{ Electric Utility Plant } \\
\hline Electric Utility Plant \& Adjust ............................... & 9,137 & 18,099 & 69,471 & 12,213 & 11,837 & 12.449 \\
\hline Const Work in Progress & 111 & 1,525 & 631 & 321 & 548 & 40 \\
\hline 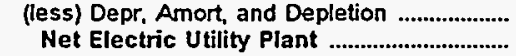 & $\begin{array}{l}2,669 \\
6,579\end{array}$ & $\begin{array}{r}5,987 \\
13,637\end{array}$ & $\begin{array}{l}19,270 \\
50,833\end{array}$ & $\begin{array}{l}5,096 \\
7,438\end{array}$ & $\begin{array}{l}4,425 \\
7,959\end{array}$ & $\begin{array}{l}4,025 \\
8,465\end{array}$ \\
\hline 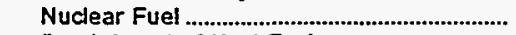 & 0 & 0 & 0 & 0 & 0 & 0 \\
\hline 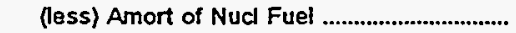 & 0 & 0 & 0 & 0 & 0 & 0 \\
\hline $\begin{array}{l}\text { Net Elec Plant Incl Nucl Fuel ......................... } \\
\text { Other Property \& Investments }\end{array}$ & 6,579 & 13,637 & 50,833 & 7,438 & 7,959 & 8,465 \\
\hline Nonutility Property & $\mathbf{0}$ & $\mathbf{0}$ & 0 & 0 & 0 & 0 \\
\hline (less) Accum Provisions for Depr \& Amort.... & 0 & 0 & 0 & 0 & 0 & 0 \\
\hline 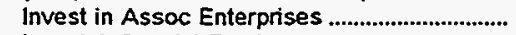 & $\mathbf{0}$ & 0 & 0 & 0 & 0 & 0 \\
\hline 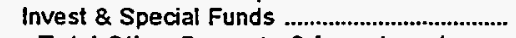 & 4,668 & 10 & 1,534 & 12 & 1,851 & 569 \\
\hline $\begin{array}{l}\text { Total Other Property \& Investments ....... } \\
\text { Current and Accrued Assets }\end{array}$ & \multicolumn{5}{|c|}{ Current and Accrued Assets } & 569 \\
\hline $\begin{array}{l}\text { Cash, Working Funds \& lnvestments } \\
\text { Notes \& Other Receivables }\end{array}$ & $\begin{array}{r}560 \\
1,138\end{array}$ & $\begin{array}{r}1,042 \\
738\end{array}$ & $\begin{array}{l}3,401 \\
2,737\end{array}$ & $\begin{array}{l}3,468 \\
2,011\end{array}$ & $\begin{array}{l}557 \\
831\end{array}$ & $\begin{array}{l}502 \\
244\end{array}$ \\
\hline 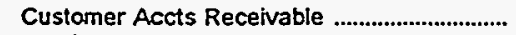 & 0 & 0 & 0 & 0 & 0 & 0 \\
\hline (less) Accum Prov for Uncollected Accts ...... & 0 & 0 & 0 & 0 & 0 & 0 \\
\hline Fuel Stock \& Exp Undistr & 0 & 0 & 0 & 0 & 0 & 0 \\
\hline 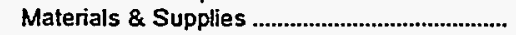 & 218 & 225 & 808 & 148 & 161 & 262 \\
\hline Other Supplies \& Misc & 0 & 0 & 0 & 0 & 0 & 0 \\
\hline 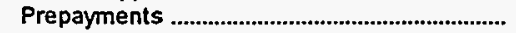 & 71 & 0 & 0 & 57 & 211 & 59 \\
\hline 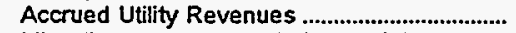 & 0 & 0 & 0 & 0 & 0 & 0 \\
\hline Miscellaneous Current \& Accrued Assets ..... & 23 & 735 & 2,269 & 78 & 10 & 30 \\
\hline $\begin{array}{l}\text { Total Current \& Accrued Assets ................ } \\
\text { Deferred Debits }\end{array}$ & 2,012 & 2,739 & 9,214 & 5,763 & 1,770 & 1,096 \\
\hline 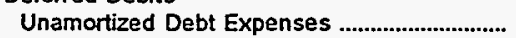 & 0 & 0 & 0 & 0 & 14 & 0 \\
\hline 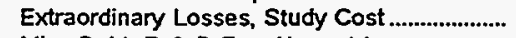 & 0 & 0 & 0 & 0 & 0 & 0 \\
\hline Misc Debt, R \& D Exp, Unamrt Losses ......... & 1,029 & 0 & 1,885 & 626 & 385 & 929 \\
\hline 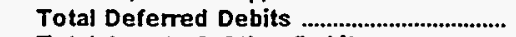 & 1,029 & 0 & 1,885 & 626 & 399 & 929 \\
\hline Total Assets \& Other Debits ............................ & 14,288 & 16,385 & 63,466 & 13,840 & 11,979 & 11,059 \\
\hline \multicolumn{7}{|l|}{ Proprietary Capital } \\
\hline 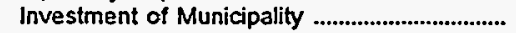 & 0 & 0 & 0 & $\mathbf{0}$ & 0 & $\mathbf{0}$ \\
\hline 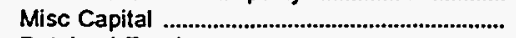 & 0 & 0 & 0 & 0 & 0 & $\mathbf{0}$ \\
\hline 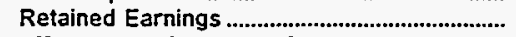 & 10,605 & 12,605 & 49,777 & 10,612 & 7,611 & 10,467 \\
\hline Total Proprietary Capital ............................... & 10,605 & 12,605 & 49,777 & 10,612 & 7,611 & 10,467 \\
\hline \multicolumn{7}{|l|}{ Long-term Debt } \\
\hline 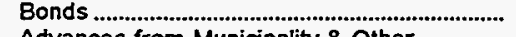 & 0 & 975 & 2,845 & 0 & 910 & 0 \\
\hline Advances from Municipality \& Other ............... & 1,025 & 0 & 1,785 & 608 & 405 & 0 \\
\hline Unamort Prem on Long-term Debt ................... & 0 & 0 & 0 & 0 & 0 & $\mathbf{0}$ \\
\hline (less) Unamort Discount on Long-term Debt & 0 & 0 & 0 & 0 & 0 & 0 \\
\hline 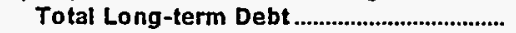 & 1,025 & 975 & 4,630 & 608 & 1,315 & $\mathbf{0}$ \\
\hline \multicolumn{7}{|l|}{ Other Noncurrent Labilities } \\
\hline 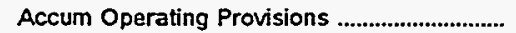 & 0 & 0 & 0 & 0 & 0 & 0 \\
\hline Accum Prov for Rate Refunds ......................... & 0 & 0 & 0 & 0 & 0 & 0 \\
\hline Total Other Noncurrent Liabilities ............ & 0 & 0 & 0 & $\mathbf{0}$ & 0 & 0 \\
\hline \multicolumn{7}{|l|}{ Current and Accrued Labilines } \\
\hline Notes Payable & 0 & 0 & 0 & 0 & 4 & 0 \\
\hline Accounts Payable & 1,237 & 2,114 & 3,916 & 1,862 & 2,282 & 281 \\
\hline 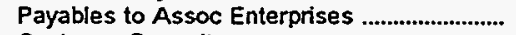 & $\mathbf{0}$ & 0 & 0 & 0 & 0 & 0 \\
\hline 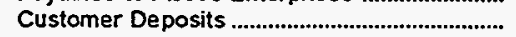 & 406 & 417 & 4,042 & 479 & 45 & 160 \\
\hline Taxes Accrued & 0 & 0 & 0 & 0 & $\mathbf{0}$ & 0 \\
\hline Interest Accrued & 0 & 11 & 51 & 0 & 0 & 0 \\
\hline Misc Current \& Accrued Labilities.................... & 175 & 224 & 1,008 & 72 & 46 & 152 \\
\hline $\begin{array}{l}\text { Total Cument \& Accrued Liabilities ......... } \\
\text { Deferred Credits }\end{array}$ & 1,818 & 2,765 & 9,016 & 2,413 & 2,376 & 593 \\
\hline \multicolumn{7}{|l|}{ Deferred Credits } \\
\hline 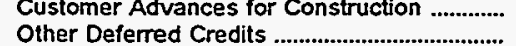 & $\begin{array}{r}0 \\
840\end{array}$ & $\begin{aligned} 0 \\
40\end{aligned}$ & 0 & $\begin{aligned} 0 \\
207\end{aligned}$ & $\begin{array}{r}0 \\
670\end{array}$ & 0 \\
\hline 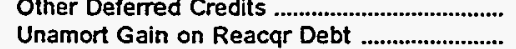 & $\begin{array}{r}840 \\
0\end{array}$ & $\begin{array}{r}40 \\
0\end{array}$ & $\begin{array}{r}42 \\
0\end{array}$ & $\begin{array}{r}207 \\
0\end{array}$ & $\begin{array}{r}676 \\
0\end{array}$ & 0 \\
\hline 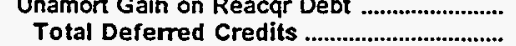 & 840 & 40 & 42 & $\begin{array}{r}0 \\
207\end{array}$ & $\begin{array}{r}0 \\
676\end{array}$ & $\begin{array}{l}0 \\
0\end{array}$ \\
\hline Total Liabilities and Other Credits ............ & 14,288 & 16,385 & 63,466 & 13,840 & 11,979 & 11,059 \\
\hline
\end{tabular}

Note: Totals may not equal sum of components because of independent rounding.

Source: Energy Information Administration, Form ElA-412, "Annual Report of Public Electric Utilities." 
Table 22. Balance Sheet by Major U.S. Publicly Owned Electric Utility Within State at End of Period, 1995 (Thousand Dollars)

\begin{tabular}{|c|c|c|c|c|c|c|}
\hline Item & $\begin{array}{l}\text { Tennessee } \\
\text { Tullahoma } \\
\text { Board } \\
\text { of } \\
\text { Pub Utils } \\
\text { June } 30\end{array}$ & $\begin{array}{l}\text { Tennessee } \\
\text { Union } \\
\text { City City of } \\
\text { June } 30\end{array}$ & $\begin{array}{l}\text { Tennessee } \\
\text { Weakley } \\
\text { County } \\
\text { Mun } \\
\text { Elec Sys } \\
\text { June } 30\end{array}$ & $\begin{array}{l}\text { Tennessee } \\
\text { Winchester } \\
\text { City of } \\
\text { June } 30\end{array}$ & $\begin{array}{c}\text { Austin } \\
\text { City of } \\
\text { September } 30\end{array}$ & $\begin{array}{c}\text { Texas } \\
\text { Brenham } \\
\text { City of } \\
\text { September } 30\end{array}$ \\
\hline \multicolumn{7}{|l|}{ Electric Utility Plant } \\
\hline 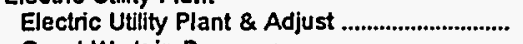 & 13,813 & 10,060 & 29,030 & 7,985 & $2,305,448$ & 9,063 \\
\hline 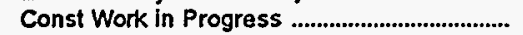 & 111 & 263 & 1,624 & 504 & 70,005 & \\
\hline 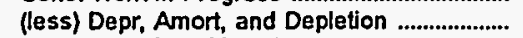 & 6,019 & 3,912 & 13,680 & 3,362 & 680.744 & $\mathbf{3 . 4 4 4}$ \\
\hline 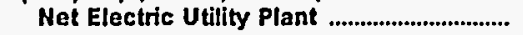 & 7,905 & 6,411 & 16,973 & 5,127 & $1,694,709$ & 5,619 \\
\hline Nuclear Fuel ............................................................. & 0 & 0 & 0 & 0 & 96.158 & 0 \\
\hline 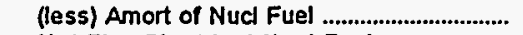 & & 0 & 0 & 0 & 59,541 & 0 \\
\hline Net Elec Plant Incl Nucl Fuel ............................ & 7,905 & 6,411 & 16,973 & 5,127 & $1,731,325$ & 5,619 \\
\hline \multicolumn{7}{|l|}{ Other Property \& Investments } \\
\hline Nonutlity Property & 0 & 37 & 0 & 0 & 0 & $\mathbf{0}$ \\
\hline (less) Accum Provisions for Depr \& Amort.... & 0 & 0 & 0 & 0 & 0 & 0 \\
\hline 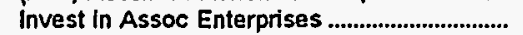 & 0 & 0 & 0 & 0 & 0 & 0 \\
\hline Invest \& Special Funds ................................................. & 266 & 233 & 1,790 & 12 & 264,298 & 2,824 \\
\hline Total Other Property \& Investments ........ & 266 & 270 & 1,790 & 12 & 264,298 & 2,824 \\
\hline \multicolumn{7}{|l|}{ Current and Accrued Assets } \\
\hline Cash, Working Funds \& Investments ............... & 2,566 & 3,174 & 706 & 988 & 55,794 & 1,307 \\
\hline Notes \& Other Receivables .................................... & 1,016 & 1,142 & 1.745 & 676 & 613 & 0 \\
\hline 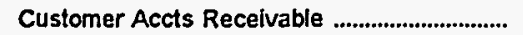 & 0 & 0 & 0 & 0 & 59,999 & 1,170 \\
\hline (less) Accum Prov for Uncollected Accts ....... & 0 & 0 & 0 & 0 & 3,579 & 34 \\
\hline 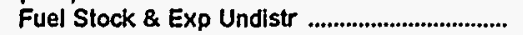 & 0 & 0 & 0 & 0 & 19,025 & 0 \\
\hline Materials \& Supplies ................................................. & 414 & 142 & 430 & 91 & 31,117 & 84 \\
\hline Other Supplles \& Misc .............................................. & 0 & 0 & 0 & 0 & 0 & 0 \\
\hline 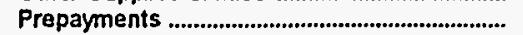 & 45 & 8 & 54 & 16 & 865 & 0 \\
\hline 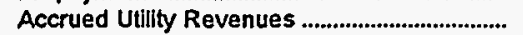 & 0 & 0 & 0 & 0 & 0 & 0 \\
\hline Miscellaneous Current \& Accrued Assets ..... & 24 & 91 & 74 & 14 & 0 & 0 \\
\hline Total Current \& Accrued Assets ................ & 4,066 & 4,558 & 3,009 & 1,785 & 163,833 & 2,528 \\
\hline \multicolumn{7}{|l|}{ Deferred Debils } \\
\hline 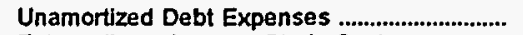 & 11 & 0 & 0 & 0 & 8,356 & 6 \\
\hline Extraordinary Losses, Study Cost ....................... & 0 & 4 & 0 & 0 & 0 & 0 \\
\hline Misc Debt, R \& D Exp, Unamtt Losses ........... & 545 & 142 & 2,070 & 150 & 309,662 & 0 \\
\hline 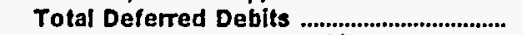 & 556 & 146 & 2,070 & 150 & 318,018 & 6 \\
\hline 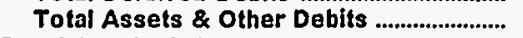 & 12,793 & 11,385 & 23,842 & 7,074 & $2,477,474$ & 10,977 \\
\hline \multicolumn{7}{|l|}{ Proprietary Capital } \\
\hline 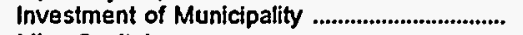 & $\mathbf{0}$ & 0 & 0 & 0 & 576 & $\mathbf{0}$ \\
\hline 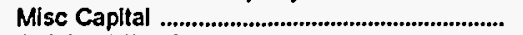 & 0 & 0 & 0 & 0 & 56.939 & 0 \\
\hline 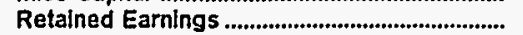 & 8,177 & 9,746 & 18,845 & 5,962 & 462,356 & 8,423 \\
\hline Total Proprietary Capital ....................................... & 8,177 & 9,746 & 18,845 & 5,962 & 519,871 & 8,423 \\
\hline \multicolumn{7}{|l|}{ Long-term Debt } \\
\hline 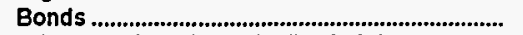 & 1,575 & 0 & 0 & 0 & $1,773,736$ & 485 \\
\hline Advances from Munlcipallity \& Other .................. & 537 & 134 & 2,101 & 160 & 42.781 & 0 \\
\hline Unamort Prem on Long-term Debt .................... & -7 & 0 & 0 & 0 & 14,835 & 0 \\
\hline (less) Unamort Discount on Long-term Debt & 0 & 0 & 0 & 0 & 54,346 & 0 \\
\hline 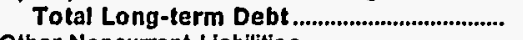 & 2,105 & 134 & 2,101 & 160 & $1,777,005$ & 485 \\
\hline \multicolumn{7}{|l|}{ Other Noncurrent Uabilities } \\
\hline 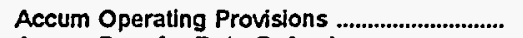 & 0 & 0 & 0 & 0 & 24,898 & $\mathbf{0}$ \\
\hline 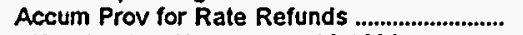 & 0 & 0 & 0 & 0 & 0 & 0 \\
\hline Total Other Noncurrent Liabilities .............. & 0 & 0 & 0 & 0 & 24,898 & 0 \\
\hline \multicolumn{7}{|l|}{ Current and Accrued Labilities } \\
\hline 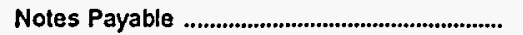 & 26 & 0 & 0 & 0 & 0 & $\mathbf{0}$ \\
\hline 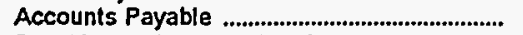 & 1,575 & 1,245 & 1,959 & 639 & 21,995 & 1,187 \\
\hline 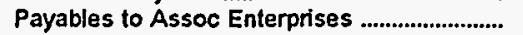 & 0 & 0 & 0 & 0 & 0 & 0 \\
\hline 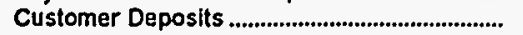 & 638 & 88 & 480 & 244 & 4.198 & 841 \\
\hline 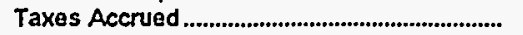 & 0 & 0 & 0 & 0 & 1,103 & 0 \\
\hline 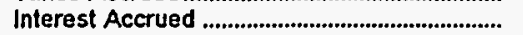 & 0 & 0 & 0 & 0 & 98,681 & 7 \\
\hline Mlsc Current \& Accrued Labilities..................... & 142 & 145 & 453 & 68 & 10,478 & 34 \\
\hline \multirow{2}{*}{\multicolumn{7}{|c|}{ Defered Credits }} \\
\hline & & & & & & \\
\hline Customer Advances for Construction .............. & $\begin{array}{r}0 \\
131\end{array}$ & $\begin{array}{r}0 \\
26\end{array}$ & 0 & 0 & $\begin{array}{r}0 \\
19244\end{array}$ & 0 \\
\hline & $\begin{array}{r}131 \\
0\end{array}$ & $\begin{array}{r}26 \\
0\end{array}$ & $\begin{array}{l}4 \\
0\end{array}$ & $\begin{array}{l}0 \\
0\end{array}$ & $\begin{array}{r}19,244 \\
0\end{array}$ & $\begin{array}{l}0 \\
0\end{array}$ \\
\hline 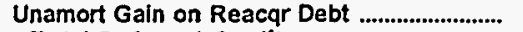 & 0 & 0 & 0 & 0 & 0 & $\mathbf{0}$ \\
\hline Total Deferred Credits ......................................... & 131 & 26 & 4 & 0 & 19,244 & 0 \\
\hline Total Llabilities and Other Credits ............ & 12,793 & 11,385 & 23,842 & 7,074 & $2,477,474$ & 10,977 \\
\hline
\end{tabular}

Note: Totals may not equal sum of components because of independent rounding.

Source: Energy Information Administration, form EIA-412, "Annual Report of Public Electric Utilities." 
Table 22. Balance Sheet by Major U.S. Publicly Owned Electric Utility Within State at End of Period, 1995

(Thousand Dollars)

\begin{tabular}{|c|c|c|c|c|c|c|}
\hline Item & $\begin{array}{c}\text { Texas } \\
\text { Brownsville } \\
\text { Public } \\
\text { Utils Board } \\
\\
\text { September } 30\end{array}$ & $\begin{array}{l}\text { Texas } \\
\text { Bryan } \\
\text { City of }\end{array}$ & $\begin{array}{l}\text { Texas } \\
\text { College } \\
\text { Station } \\
\text { City of }\end{array}$ & $\begin{array}{l}\text { Denton } \\
\text { City of }\end{array}$ & $\begin{array}{c}\begin{array}{c}\text { Floresulle } \\
\text { City of }\end{array} \\
\text { December } 31\end{array}$ & $\begin{array}{l}\text { Garland } \\
\text { City of }\end{array}$ \\
\hline \multicolumn{7}{|l|}{ Electric Utility Plant } \\
\hline 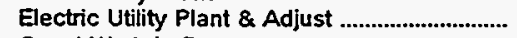 & 271,143 & 133,103 & 28,986 & 99,701 & 26,151 & 212,607 \\
\hline Const Work in Progress & 52,968 & 4,207 & 6,172 & 1,110 & 0 & 4,782 \\
\hline $\begin{array}{l}\text { (less) Depr, Amort, and Depletion } \\
\text { Net Electric Utility Plant }\end{array}$ & $\begin{array}{r}86,524 \\
237,588\end{array}$ & $\begin{array}{l}57,210 \\
80,100\end{array}$ & $\begin{array}{r}9,737 \\
25,421\end{array}$ & $\begin{array}{l}59,562 \\
41,249\end{array}$ & $\begin{array}{l}10,386 \\
15,765\end{array}$ & $\begin{array}{r}97,920 \\
119,469\end{array}$ \\
\hline Nuclear Fuel & 0 & 0 & 0 & 0 & 0 & 0 \\
\hline 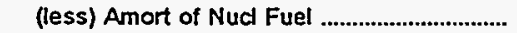 & 0 & 0 & 0 & 0 & 0 & $\mathbf{0}$ \\
\hline $\begin{array}{l}\text { Net Elec Plant Incl Nucl Fuel ........................ } \\
\text { Other Property \& Investments }\end{array}$ & 237,588 & 80,100 & 25,421 & 41,249 & 15,765 & 119,469 \\
\hline Nonutility Property ................................................ & 0 & 0 & 209 & 0 & 0 & 0 \\
\hline (less) Accum Provisions for Depr \& Amort .... & 0 & 0 & 106 & 0 & 0 & 0 \\
\hline 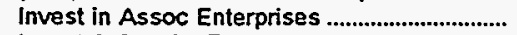 & 0 & 803 & 0 & 5,882 & 0 & 0 \\
\hline Invest \& Special Funds & 28,264 & 17,002 & 0 & 0 & 1,392 & 6,928 \\
\hline \multicolumn{7}{|l|}{ Current and Accrued Assets } \\
\hline 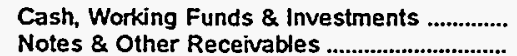 & $\begin{array}{r}15.577 \\
379\end{array}$ & $\begin{array}{l}7,857 \\
4,400\end{array}$ & $\begin{array}{r}16.163 \\
1,827\end{array}$ & $\begin{array}{r}42,535 \\
1,363\end{array}$ & $\begin{array}{r}1,804 \\
41\end{array}$ & $\begin{array}{r}23,728 \\
5,524\end{array}$ \\
\hline 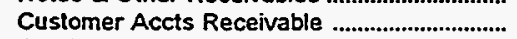 & $\mathbf{5 , 6 3 7}$ & 7,763 & 4,027 & 12.984 & 786 & 20,106 \\
\hline (less) Accum Prov for Uncollected Accts ...... & 134 & 152 & 785 & 6,400 & 15 & \\
\hline 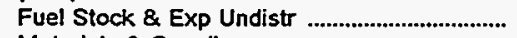 & 1,861 & 0 & 0 & 1,283 & 0 & 3,046 \\
\hline Materials \& Supplies & 1,597 & 2,746 & 825 & 0 & 378 & 852 \\
\hline 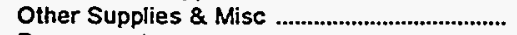 & 0 & 185 & 1 & 0 & 0 & 0 \\
\hline 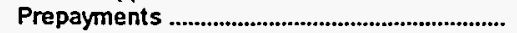 & 59 & 0 & 1,272 & 0 & 86 & 0 \\
\hline 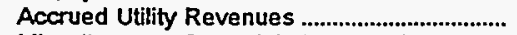 & 594 & 529 & 992 & 3,197 & 0 & 0 \\
\hline Miscellaneous Current \& Accrued Assets ..... & 637 & 0 & 0 & 956 & 8 & 221 \\
\hline $\begin{array}{l}\text { Total Current \& Accrued Assets ................ } \\
\text { Deferred Debits }\end{array}$ & 26,207 & 23,328 & 24,322 & 55,918 & 3,088 & 53,477 \\
\hline 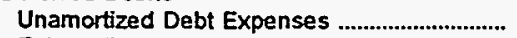 & 5,999 & 97 & 131 & 279 & 0 & 0 \\
\hline Extraordinary Losses, Study Cost ..................... & 0 & 0 & 0 & 0 & 0 & 0 \\
\hline Misc Debt, R \& D Exp, Unamrt Losses .......... & 2,731 & 0 & 0 & 0 & 0 & 38 \\
\hline 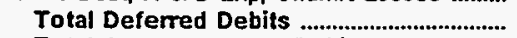 & 8,730 & 97 & 131 & 279 & 0 & 38 \\
\hline \multicolumn{6}{|l|}{ Proprietary Capital } & 179,912 \\
\hline 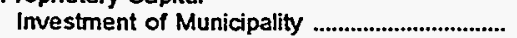 & 43,242 & 0 & 3.486 & 0 & 0 & 0 \\
\hline 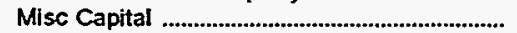 & 0 & $\mathbf{0}$ & 0 & 516 & 0 & 0 \\
\hline 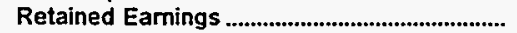 & 60,263 & 94,259 & 26.729 & 75,598 & 15,401 & 161,642 \\
\hline $\begin{array}{l}\text { Total Proprietary Capital ................................... } \\
\text { Long-term Debt }\end{array}$ & 103,505 & 94,259 & 30,216 & 76,114 & 15,401 & 161,642 \\
\hline 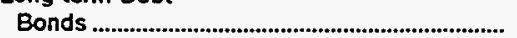 & 163,846 & 21,245 & 14,099 & 0 & 3,550 & 12,298 \\
\hline Advances from Municipality \& Other ............... & 23,595 & 0 & 52 & 22,182 & 0 & 0 \\
\hline Unamort Prem on Long-term Debt ................... & 0 & 0 & 2 & 0 & 0 & 0 \\
\hline (less) Unamort Discount on Long-term Debt & 3,263 & 0 & 0 & 134 & 48 & 0 \\
\hline Total Long-term Debt & 184,178 & 21,245 & 14,153 & 22,048 & 3,502 & 12,298 \\
\hline \multicolumn{7}{|l|}{ Other Noncurrent Labilities } \\
\hline 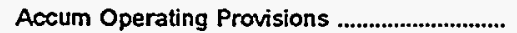 & 0 & $\mathbf{0}$ & 0 & 0 & 0 & 0 \\
\hline 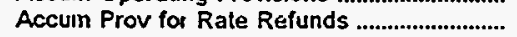 & 0 & 0 & 0 & 0 & 0 & 0 \\
\hline Total Other Noncurrent Liabilities ............ & $\mathbf{0}$ & 0 & $\mathbf{0}$ & $\mathbf{0}$ & 0 & $\mathbf{0}$ \\
\hline \multicolumn{7}{|l|}{ Current and Accrued Labilities } \\
\hline 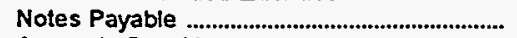 & 1 & 2,906 & 0 & 0 & 272 & 0 \\
\hline Accounts Payable & 4,662 & 191 & 3,137 & 3,140 & 572 & 4,817 \\
\hline 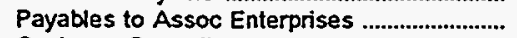 & 0 & 0 & 0 & 0 & 0 & 18 \\
\hline 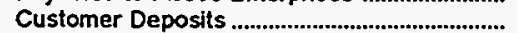 & 1,584 & 1,245 & 1,738 & 1,103 & 228 & 0 \\
\hline Taxes Accrued & 31 & 0 & 0 & 0 & 11 & 0 \\
\hline 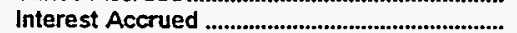 & 951 & 380 & 168 & 416 & 134 & 84 \\
\hline Misc Current \& Accrued Labilities..................... & 5,527 & 1,020 & 538 & 507 & 85 & 910 \\
\hline $\begin{array}{l}\text { Total Current \& Accrued Liabilities .......... } \\
\text { Deferred Credits }\end{array}$ & 12,756 & 5,742 & 5,581 & 5,166 & 1,303 & 5,928 \\
\hline Customer Advances for Construction ............. & 11 & 0 & 24 & 0 & 40 & 0 \\
\hline 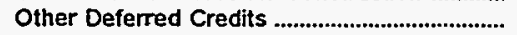 & 338 & 83 & 3 & 0 & 0 & 44 \\
\hline Unamort Gain on Reacqr Debt ........................... & 0 & 0 & 0 & 0 & 0 & 0 \\
\hline 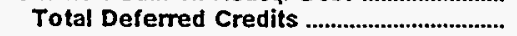 & 349 & 83 & 27 & 0 & 40 & 44 \\
\hline Total Liabilities and Other Credits ............ & 300,789 & 121,329 & 49,976 & 103,328 & 20,245 & 179,912 \\
\hline
\end{tabular}

Note: Totals may not equal sum of components because of independent rounding.

Source: Energy Information Administration, Form ElA-412, "Annual Report of Public Electric Utilities." 
Table 22. Balance Sheet by Major U.S. Publicly Owned Electric Utility Within State at End of Period, 1995

(Thousand Dollars)

\begin{tabular}{|c|c|c|c|c|c|c|}
\hline Item & $\begin{array}{c}\text { Texas } \\
\text { Georgetown } \\
\text { City of }\end{array}$ & $\begin{array}{c}\text { Texas } \\
\text { Greenville } \\
\text { Electric } \\
\text { Util Sys } \\
\text { September } 30\end{array}$ & $\begin{array}{c}\text { Texas } \\
\text { Jasper } \\
\text { City of } \\
\text { September } 30\end{array}$ & $\begin{array}{c}\text { Texas } \\
\text { Kemille } \\
\text { Public } \\
\text { Utility } \\
\text { Board } \\
\text { September } 30\end{array}$ & $\begin{array}{l}\text { Texas } \\
\text { Lower } \\
\text { Colorado } \\
\text { River } \\
\text { Authority } \\
\text { June } 30\end{array}$ & $\begin{array}{l}\text { Texas } \\
\text { Lubbock } \\
\text { City of } \\
\text { September } 30\end{array}$ \\
\hline \multicolumn{7}{|l|}{ Electric Utility Plant } \\
\hline 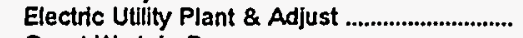 & 5,617 & 53,012 & 0 & 30,110 & $1,486,602$ & 134,109 \\
\hline 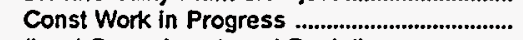 & 594 & 0 & 0 & 408 & 83,427 & 9,367 \\
\hline 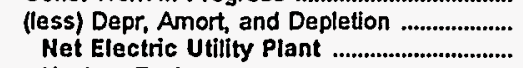 & $\begin{array}{l}2,558 \\
3,654\end{array}$ & $\begin{array}{l}31,103 \\
21,908\end{array}$ & $\begin{array}{l}0 \\
0\end{array}$ & $\begin{array}{r}9,606 \\
20,912\end{array}$ & $\begin{array}{r}460,715 \\
1,109,313\end{array}$ & $\begin{array}{l}51,930 \\
91,546\end{array}$ \\
\hline 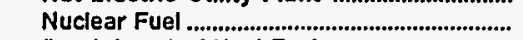 & 0 & 0 & 0 & 0 & 0 & 0 \\
\hline 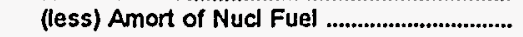 & 0 & 0 & 0 & 0 & 0 & 0 \\
\hline Net Elec Plant Incl Nucl Fuel ........................ & 3,654 & 21,908 & 0 & 20,912 & $1,109,313$ & 91,546 \\
\hline \multicolumn{7}{|l|}{ Other Property \& Investments } \\
\hline Nonutility Property & 780 & 0 & 8,457 & 0 & 10,223 & 0 \\
\hline (less) Accum Provisions for Depr \& Amort .... & 107 & 0 & 4,165 & 0 & 1,576 & 0 \\
\hline 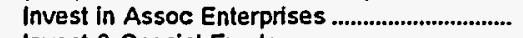 & $\mathbf{0}$ & 0 & 0 & 0 & 0 & 0 \\
\hline 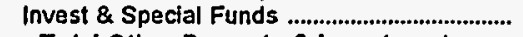 & 0 & 8,892 & 0 & 6,812 & 192,941 & 0 \\
\hline \multirow{2}{*}{\multicolumn{7}{|c|}{ Current and Accrued Assets }} \\
\hline Cash, Working Funds \& Investments .............. & 3,895 & 2,970 & 1,307 & 4,003 & & \\
\hline 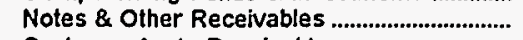 & 1,482 & 0 & 0 & 43 & $\begin{array}{r}21,026 \\
4,837\end{array}$ & $\begin{array}{l}8,617 \\
4,675\end{array}$ \\
\hline 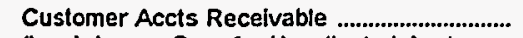 & 2,077 & 4,246 & 1,942 & 1.247 & 37,320 & 0 \\
\hline (less) Accum Prov for Uncollected Accts ...... & 59 & 310 & 0 & 109 & 562 & 0 \\
\hline Fuel Stock \& Exp Undistr & 0 & 181 & 0 & 0 & 40,256 & 0 \\
\hline 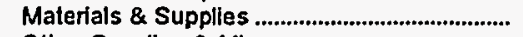 & 0 & 1,009 & 258 & 690 & 22,530 & 0 \\
\hline 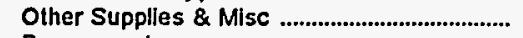 & 0 & 0 & 0 & 0 & 0 & 0 \\
\hline 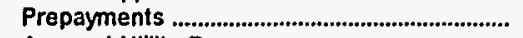 & 0 & 0 & 195 & 1,684 & 5,102 & 0 \\
\hline 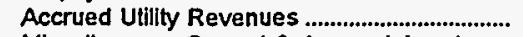 & 0 & 0 & 89 & 0 & 7,318 & 0 \\
\hline Miscellaneous Current \& Accrued Assets ..... & $\mathbf{0}$ & 0 & 0 & -116 & 1,712 & 183 \\
\hline $\begin{array}{l}\text { Total Current \& Accrued Assets ............... } \\
\text { Deferred Debits }\end{array}$ & 7,395 & 8,097 & 3,790 & 7,443 & 139,540 & 13,575 \\
\hline 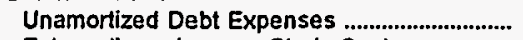 & 62 & 418 & 0 & 618 & 16,474 & 0 \\
\hline Extraordinary Losses, Study Cost ...................... & 0 & 0 & 0 & 114 & 0 & 0 \\
\hline Misc Debt, R \& D Exp, Unamrt Losses ......... & 0 & 0 & 0 & 0 & 224,803 & 28,664 \\
\hline 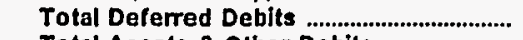 & 62 & 418 & $\mathbf{0}$ & 733 & 241,277 & 28,664 \\
\hline 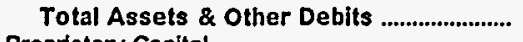 & 11,784 & 39,316 & 8,082 & 35,900 & $1,691,718$ & 133,785 \\
\hline \multicolumn{7}{|l|}{ Proprietary Capital } \\
\hline 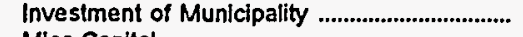 & 3.699 & 200 & 0 & 0 & 0 & 8,119 \\
\hline 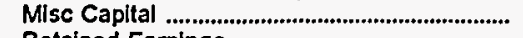 & 0 & 0 & 0 & 0 & 11,347 & 0 \\
\hline 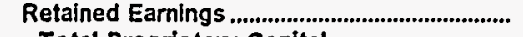 & 3,611 & 19,137 & 4.082 & 3,639 & 425,088 & 92,125 \\
\hline $\begin{array}{l}\text { Total Proprietary Capital ................................. } \\
\text { Long-term Debt }\end{array}$ & 7,311 & 19,337 & 4,082 & 3,639 & 436,435 & 100,243 \\
\hline 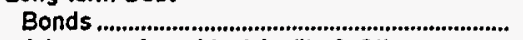 & 2,482 & 15,107 & 4,000 & 30,235 & $1,451,933$ & 25,006 \\
\hline Advances from Municipality \& Other ................ & 9 & 0 & 0 & 0 & 3,779 & 1,328 \\
\hline 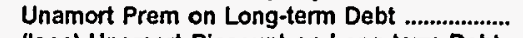 & $\mathbf{0}$ & $\mathbf{0}$ & $\mathbf{0}$ & 0 & 0 & 0 \\
\hline (less) Unamort Discount on Long-term Debt & 0 & 0 & 0 & 1,133 & 116,645 & 0 \\
\hline Total Long-term Debt & 2,491 & 15,107 & 4,000 & 29,102 & $1,339,066$ & 26,334 \\
\hline \multicolumn{7}{|l|}{ Other Noncurrent Uabilities } \\
\hline Accum Operating Provisions ............................. & 0 & 0 & 0 & 0 & 0 & 0 \\
\hline Accum Prov for Rate Refunds & 0 & 0 & 0 & 0 & 0 & 0 \\
\hline \multicolumn{6}{|l|}{ Current and Accrued Labilities } & 0 \\
\hline 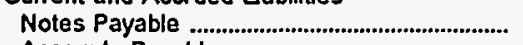 & 0 & 1,590 & $\mathbf{0}$ & 0 & 0 & 0 \\
\hline Accounts Payable & 1,477 & 1,667 & 0 & 2,072 & 18.507 & 6,451 \\
\hline Payables to Assoc Enterprises ........................... & 0 & 0 & 0 & 0 & 0 & 0 \\
\hline 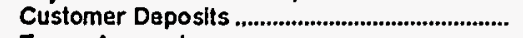 & 403 & 532 & 0 & 270 & 6 & 28 \\
\hline 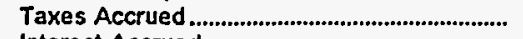 & 0 & $\mathbf{0}$ & 0 & 0 & 206 & 99 \\
\hline 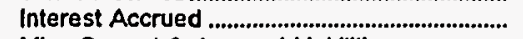 & 33 & 100 & 0 & 816 & 33,518 & 630 \\
\hline Misc Current \& Accrued Labilitles..................... & 69 & 370 & 0 & 0 & 15,777 & 0 \\
\hline $\begin{array}{l}\text { Total Current \& Accrued Liabilities .......... } \\
\text { Deferred Credits }\end{array}$ & 1,982 & 4,259 & 0 & 3,159 & 68,014 & 7,208 \\
\hline \multicolumn{7}{|l|}{ Deferred Credits } \\
\hline Customer Advances for Construction .............. & 0 & 613 & 0 & 0 & 409 & 0 \\
\hline & 0 & 0 & 0 & 0 & 25,598 & 0 \\
\hline 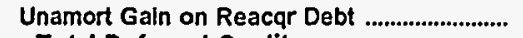 & 0 & $\mathbf{0}$ & 0 & 0 & $-177,804$ & 0 \\
\hline 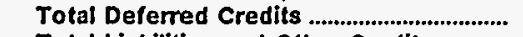 & 0 & 613 & 0 & $\mathbf{0}$ & $-151,797$ & 0 \\
\hline Total Llabilities and Other Credits ............ & 11,784 & 39,316 & 8,082 & 35,900 & $1,691,718$ & 133,785 \\
\hline
\end{tabular}

Note: Totals may not equal sum of components because of independent rounding.

Source: Energy Intormation Administration, Form EIA-412, "Annual Report of Public Electric Utilities." 
Table 22. Balance Sheet by Major U.S. Publicly Owned Electric Utility Within State at End of Period, 1995

(Thousand Dollars)

\begin{tabular}{|c|c|c|c|c|c|c|}
\hline Item & $\begin{array}{c}\text { Texas } \\
\text { New Braunfels } \\
\text { City of } \\
\text { July } 31\end{array}$ & $\begin{array}{c}\text { Texas } \\
\text { Sam Raybum } \\
\text { Municipal } \\
\text { Pwr } \\
\text { Agny } \\
\text { September } 30\end{array}$ & $\begin{array}{c}\text { Texas } \\
\text { San Antonio } \\
\text { Public } \\
\text { Service Bd } \\
\\
\text { January } 31\end{array}$ & $\begin{array}{c}\text { San Marcos } \\
\text { City of }\end{array}$ & $\begin{array}{c}\text { Seguin } \\
\text { City of } \\
\text { September } 30\end{array}$ & $\begin{array}{c}\text { Texas } \\
\text { Texas } \\
\text { Municipal } \\
\text { Power Agency }\end{array}$ \\
\hline \multicolumn{7}{|l|}{ Electric Utility Plant } \\
\hline Electric Utility Plant \& Adjust .............................. & 56,690 & 143,077 & $4,577,103$ & 17,100 & 6,610 & 787,599 \\
\hline 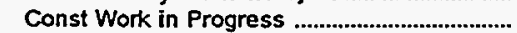 & 103 & 4,634 & 162,313 & 2,137 & 0 & 32,317 \\
\hline 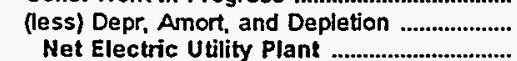 & $\begin{array}{l}22,383 \\
34,410\end{array}$ & $\begin{array}{l}49,007 \\
98,704\end{array}$ & $\begin{array}{r}946,069 \\
3,793,347\end{array}$ & $\begin{array}{r}6,583 \\
12,654\end{array}$ & $\begin{array}{l}4,027 \\
2,583\end{array}$ & $\begin{array}{l}324,778 \\
495,138\end{array}$ \\
\hline Nuclear Fuel & 0 & 0 & 176,527 & 0 & 0 & 0 \\
\hline 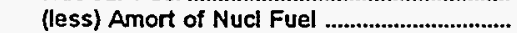 & 0 & 0 & 116,298 & $\mathbf{0}$ & 0 & $\mathbf{0}$ \\
\hline 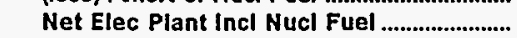 & 34,410 & 98,704 & $3,853,576$ & 12,654 & 2,583 & 495,138 \\
\hline \multicolumn{7}{|l|}{ Other Property \& Investments } \\
\hline 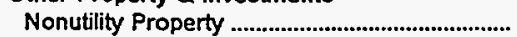 & 67,090 & 0 & 0 & $\mathbf{0}$ & 0 & 0 \\
\hline (less) Accum Provisions for Depr \& Amort .... & 22,728 & 0 & 0 & $\mathbf{0}$ & 0 & 0 \\
\hline 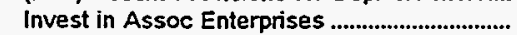 & 0 & 0 & 0 & 0 & 0 & 0 \\
\hline 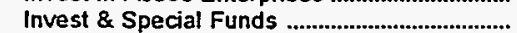 & 8,113 & 48,332 & 378,685 & $\mathbf{0}$ & 1,633 & 164,510 \\
\hline Total Other Property \& Investments ....... & 52,476 & 48,332 & 378,685 & $\mathbf{0}$ & 1,633 & 164,510 \\
\hline \multicolumn{7}{|l|}{ Current and Accrued Assets } \\
\hline Cash, Working Funds \& Investments ............. & 7,152 & 15,885 & 158,356 & 14,137 & 1,403 & 55,297 \\
\hline 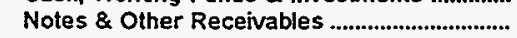 & 1,605 & 1,182 & 11,134 & 631 & 22 & 10,596 \\
\hline 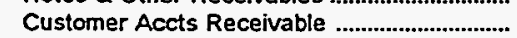 & 3,793 & 2,183 & 56,860 & 4,010 & 1,287 & 0 \\
\hline (less) Accum Prov for Uncollected Accts ...... & 0 & & 2,431 & 1,040 & 0 & 0 \\
\hline 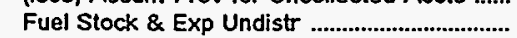 & 0 & 1,521 & 27,772 & 0 & 0 & 832 \\
\hline 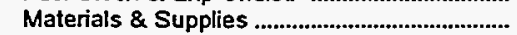 & 890 & 905 & 56,049 & 386 & 698 & 4,385 \\
\hline 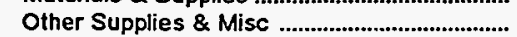 & 0 & 0 & 1,290 & 92 & 0 & 0 \\
\hline Prepayments & 101 & 114 & 3,152 & 30 & 0 & 0 \\
\hline 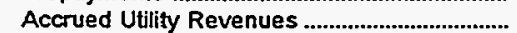 & 0 & 0 & 0 & 0 & 552 & 0 \\
\hline Miscellaneous Current \& Accrued Assets ..... & 0 & 72 & 4,847 & 51 & 0 & 2,532 \\
\hline 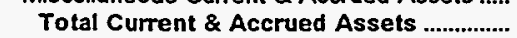 & 13,540 & 21,861 & 317,030 & 18,297 & 3,962 & 73,642 \\
\hline \multicolumn{7}{|l|}{ Deferred Debits } \\
\hline Unamortized Debt Expenses ............................. & 0 & 3,541 & 5,853 & 282 & 28 & 18,564 \\
\hline 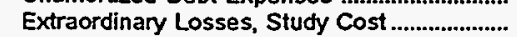 & 0 & 0 & 0 & 0 & 0 & 970 \\
\hline Misc Debt, R \& D Exp, Unamrt Losses .......... & 0 & 111,667 & 21,820 & 0 & 0 & 788,880 \\
\hline 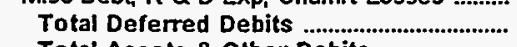 & 0 & 115,208 & 27,673 & 282 & 28 & 808,414 \\
\hline 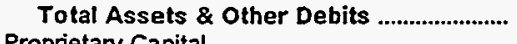 & 100,427 & 284,105 & $4,576,964$ & 31,233 & 8,206 & $1,541,704$ \\
\hline \multicolumn{7}{|l|}{ Proprietary Capital } \\
\hline Investment of Municipality & 2,426 & 0 & 0 & 0 & 0 & 0 \\
\hline 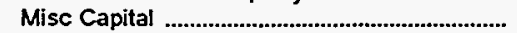 & 0 & 0 & 0 & 788 & 3,121 & 0 \\
\hline 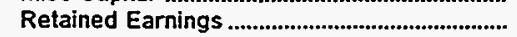 & 41,455 & 42,235 & $1,761,330$ & 10,019 & 3,844 & 38,631 \\
\hline $\begin{array}{l}\text { Total Proprietary Capital .................................. } \\
\text { Long-term Debt }\end{array}$ & \multicolumn{6}{|c|}{ Long-term Debt } \\
\hline 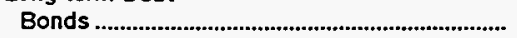 & 25,365 & 233,611 & $2,787,915$ & 16,125 & 0 & $1,128,782$ \\
\hline Advances from Municipality \& Other .............. & 14.409 & 0 & 0 & 0 & 0 & 288,162 \\
\hline Unamort Prem on Long-term Debt ................... & 0 & 0 & 277,800 & 0 & 0 & 0 \\
\hline (less) Unamort Discount on Long-term Debt & 107 & 0 & 510,923 & 293 & 0 & 22,534 \\
\hline 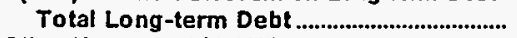 & 39,667 & 233,611 & $2,554,792$ & 15,832 & 0 & $1,394,410$ \\
\hline \multicolumn{7}{|l|}{ Other Noncurrent Liabilities } \\
\hline 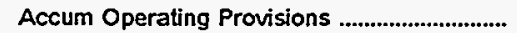 & 0 & 0 & 36,727 & 73 & 0 & 0 \\
\hline 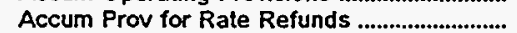 & 0 & 0 & 0 & 0 & 0 & 0 \\
\hline Total Other Noncurrent Liabilities ............ & 0 & 0 & 36,727 & 73 & $\mathbf{0}$ & 0 \\
\hline \multicolumn{7}{|l|}{ Current and Accrued Liabilities } \\
\hline Notes Payable & 1,622 & 0 & 0 & 410 & 0 & 36,000 \\
\hline Accounts Payable & 4,230 & 743 & 67,058 & 1,802 & 935 & 48,215 \\
\hline Payables to Assoc Enterprises ......................... & 0 & 0 & 106,000 & 805 & 0 & 2,865 \\
\hline 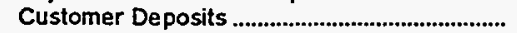 & 557 & 0 & 25,776 & 1,021 & 217 & 0 \\
\hline 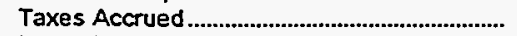 & 0 & 0 & 962 & 59 & 0 & 0 \\
\hline 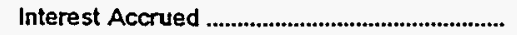 & 163 & 7,517 & 2,814 & 0 & 0 & $\mathbf{0}$ \\
\hline Misc Current \& Accrued Liabilities..................... & 1,225 & 0 & 664 & 424 & 89 & 21,583 \\
\hline $\begin{array}{l}\text { Total Current \& Accrued Liabilities .......... } \\
\text { Deferred Credits }\end{array}$ & 7,796 & 8,260 & 203,274 & 4,521 & 1,241 & 108,663 \\
\hline Customer Advances for Construction ............. & 9.083 & $\mathbf{0}$ & 11,669 & 0 & 0 & 0 \\
\hline 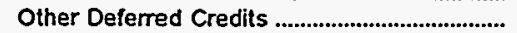 & 0 & $\mathbf{0}$ & 9,172 & 0 & 0 & $\mathbf{0}$ \\
\hline 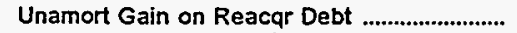 & 0 & 0 & 0 & 0 & 0 & $\mathbf{0}$ \\
\hline 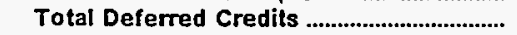 & 9,083 & 0 & 20,841 & $\mathbf{0}$ & $\mathbf{0}$ & $\mathbf{0}$ \\
\hline Total Liabilities and Other Credits ................... & 100,427 & 284,105 & $4,576,964$ & 31,233 & 8,206 & $1,541,704$ \\
\hline
\end{tabular}

Note: Totals may not equal sum of components because of independent rounding

Source: Energy Information Administration, Form ELA-412, "Annual Report of Public Electric Utilties." 
Table 22. Balance Sheet by Major U.S. Publicly Owned Electric Utility Within State at End of Period, 1995

(Thousand Dollars)

\begin{tabular}{|c|c|c|c|c|c|c|}
\hline Item & $\begin{array}{l}\text { Texas } \\
\text { Toledo Bend } \\
\text { Project } \\
\text { Joint } \\
\text { Oper } \\
\text { August } 30\end{array}$ & $\begin{array}{c}\text { Texas } \\
\text { Weatherford } \\
\text { Mun } \\
\text { Utility } \\
\text { System } \\
\text { September } 30\end{array}$ & $\begin{array}{c}\text { Utah } \\
\text { Bountiful } \\
\text { City City of } \\
\text { June } 30\end{array}$ & $\begin{array}{c}\text { Utah } \\
\text { Intermountain } \\
\text { Power Agency } \\
\text { June } 30\end{array}$ & $\begin{array}{l}\text { Logan } \\
\text { City of } \\
\text { June } 30\end{array}$ & $\begin{array}{l}\text { Murray } \\
\text { City of } \\
\text { June } 30\end{array}$ \\
\hline \multicolumn{7}{|l|}{ Electric Utility Plant } \\
\hline 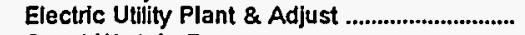 & 72,653 & 12,669 & 35,250 & $2,768,307$ & 28,754 & 42,827 \\
\hline 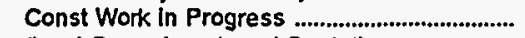 & & 399 & 672 & 0 & 0 & 151 \\
\hline (less) Depr. Amort, and Depletion .................... & & 7.510 & 13,342 & 621,175 & 10.408 & 22,509 \\
\hline 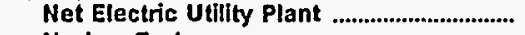 & 72,653 & 5,558 & 22,581 & $2,147,132$ & 18,346 & 20,470 \\
\hline Nuclear Fuel ............................................................... & & 0 & & 0 & 0 & 0 \\
\hline 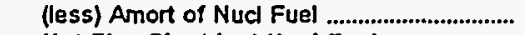 & 0 & 0 & 0 & 0 & 0 & 0 \\
\hline Net Elec Plant Incl Nucl Fuel ............................ & 72,653 & 5,558 & 22,581 & $2,147,132$ & 18,346 & 20,470 \\
\hline \multicolumn{7}{|l|}{ Other Property \& Investments } \\
\hline 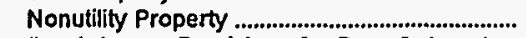 & 0 & 45,454 & 0 & 28.176 & 334 & 0 \\
\hline (less) Accum Provisions for Depr \& Amort.... & 0 & 6,982 & 0 & & 145 & 0 \\
\hline 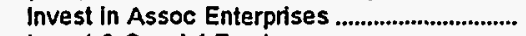 & 0 & 0 & 9,752 & 0 & 0 & 7 \\
\hline 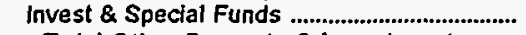 & 0 & 8,864 & & $2,701,913$ & 0 & 32 \\
\hline Total Other Property \& Investments ....... & $\mathbf{0}$ & 47,336 & 9,752 & $2,730,089$ & 189 & 39 \\
\hline \multicolumn{7}{|l|}{ Current and Accrued Assets } \\
\hline Cash, Working Funds \& Investments .................. & 211 & 8,037 & 6,344 & 65,253 & 6,145 & 18.488 \\
\hline 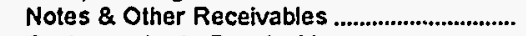 & 0 & 306 & 67 & 19,500 & 45 & 0 \\
\hline 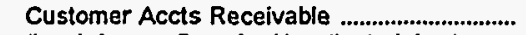 & 0 & 1.721 & 1,440 & 0 & 1,966 & 2,132 \\
\hline (less) Accum Prov for Uncollected Accts ...... & 0 & 111 & 14 & 0 & 53 & 118 \\
\hline 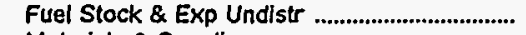 & 0 & 0 & 0 & 56,375 & 0 & $\mathbf{0}$ \\
\hline Materials \& Supplies ................................................ & 0 & 1,256 & $i, 256$ & 13,133 & 868 & 908 \\
\hline 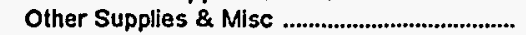 & 0 & 0 & 0 & 0 & 0 & 0 \\
\hline 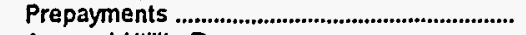 & $\mathbf{0}$ & 0 & 0 & 0 & 0 & 3,416 \\
\hline 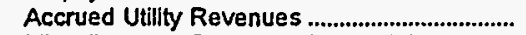 & 0 & 633 & 0 & 0 & 0 & 0 \\
\hline Miscellaneous Current \& Accrued Assets ..... & 4 & 150 & 0 & 2,220 & 0 & 161 \\
\hline Total Current \& Accrued Assets ................. & 215 & 11,991 & 9,093 & 156,481 & 8,971 & 24,986 \\
\hline \multicolumn{7}{|l|}{ Deferred Debils } \\
\hline Unamortized Debt Expenses ..................................... & 0 & 474 & 0 & 875,404 & 130 & 130 \\
\hline Extraordlnary Losses, Study Cost ..................... & 0 & 0 & 0 & 0 & 0 & 0 \\
\hline Mlsc Debt, R \& D Exp, Unamrt Losses ......... & 0 & 0 & 0 & $1,056,208$ & 0 & 0 \\
\hline Total Deferred Debits ......................................... & & 474 & 0 & $1,931,612$ & 130 & 130 \\
\hline Total Assets \& Other Debits ........................... & 72,868 & 65,359 & 41,425 & $6,965,314$ & 27,636 & 45,625 \\
\hline \multicolumn{7}{|l|}{ Proprietary Capita! } \\
\hline 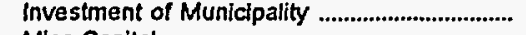 & 72,653 & 7,564 & 0 & o & 0 & 77 \\
\hline 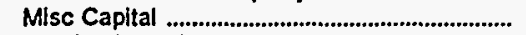 & 0 & & 531 & 0 & 874 & 88 \\
\hline 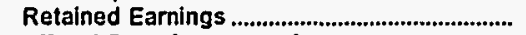 & 202 & 34,220 & 33,992 & 0 & 16,782 & 37,207 \\
\hline Total Proprietary Capital .................................... & 72,855 & 41,785 & 34,523 & 0 & 17,657 & 37,372 \\
\hline \multicolumn{6}{|l|}{ Long-term Debt } & 6,300 \\
\hline Advances from Municipality $\&$ Other ............. & 0 & 0 & 5,431 & 19,550 & 87 & 0,000 \\
\hline Unamort Prem on Long-term Debt .................... & 0 & 0 & 0 & 0 & 0 & 0 \\
\hline (less) Unamort Discount on Long-term Debt & 0 & 230 & 0 & 212,204 & 0 & o \\
\hline 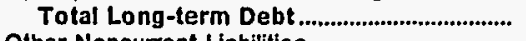 & 0 & 20,710 & 5,431 & $5,092,065$ & 7,652 & 6,300 \\
\hline \multicolumn{7}{|l|}{ Other Noncurrent Labilities } \\
\hline 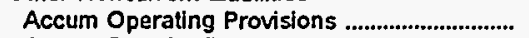 & 0 & 0 & 0 & o & 0 & 0 \\
\hline 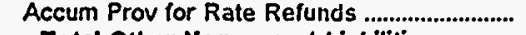 & 0 & 0 & $\mathbf{0}$ & 0 & 0 & 0 \\
\hline Total Other Noncurrent Liabllities ............. & 0 & 0 & 0 & 0 & 0 & 0 \\
\hline \multicolumn{7}{|l|}{ Cument and Accrued Liabilities } \\
\hline 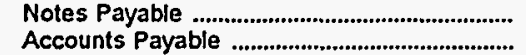 & $\begin{array}{r}0 \\
13\end{array}$ & 1,438 & $\begin{array}{r}0 \\
1,225\end{array}$ & $\begin{array}{r}0 \\
37,514\end{array}$ & $\begin{array}{r}10 \\
1.298\end{array}$ & $9 \begin{array}{r}0 \\
940\end{array}$ \\
\hline Payables to Assoc Enterprises ........................ & 0 & 0 & 0 & 0 & 0 & 137 \\
\hline 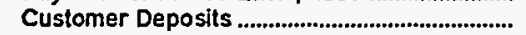 & 0 & 57 & 247 & 0 & 600 & 515 \\
\hline 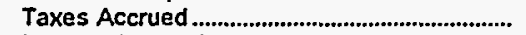 & 0 & 149 & 0 & 0 & 0 & 0 \\
\hline 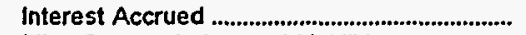 & 0 & 108 & 0 & 155,494 & 261 & 36 \\
\hline Misc Current \& Accrued Liabilities.................... & 0 & 701 & 0 & $1,680,241$ & 158 & 325 \\
\hline $\begin{array}{l}\text { Total Current \& Accrued Liabilities ........... } \\
\text { Deferred Credits }\end{array}$ & 13 & 2,452 & 1,472 & $1,873,249$ & 2,327 & 1,953 \\
\hline Customer Advances for Construction .............. & 0 & 0 & 0 & 0 & 0 & 0 \\
\hline 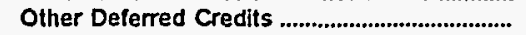 & 0 & 413 & 0 & 0 & 0 & 0 \\
\hline Unamort Gain on Reacqr Debt .......................... & 0 & 0 & 0 & 0 & 0 & 0 \\
\hline Total Deferred Credits ......................................... & & 413 & 0 & 0 & $\mathbf{0}$ & 0 \\
\hline Total Liabilities and other Credits ............ & 72,868 & 65,359 & 41,425 & $6,965,314$ & 27,636 & 45,625 \\
\hline
\end{tabular}

Note: Totals may not equal sum of components because of independent rounding.

Source: Energy Information Administration, Form ElA-412. "Annual Report of Public Electric Utilities." 
Table 22. Balance Sheet by Major U.S. Publicly Owned Electric Utility Within State at End of Period, 1995 (Thousand Dollars)

\begin{tabular}{|c|c|c|c|c|c|c|}
\hline Item & $\begin{array}{c}\text { Utah } \\
\text { Provo } \\
\text { City Corp } \\
\text { June } 30\end{array}$ & $\begin{array}{c}\text { Utah } \\
\text { St George } \\
\text { City of } \\
\text { June } 30\end{array}$ & $\begin{array}{c}\text { Utah } \\
\text { Utah } \\
\text { Associated } \\
\text { Mun } \\
\text { Power Sys } \\
\text { March 31 }\end{array}$ & $\begin{array}{c}\text { Utah } \\
\text { Utah } \\
\text { Municipal } \\
\text { Power Agency } \\
\text { June } 30\end{array}$ & $\begin{array}{l}\text { Vermont } \\
\begin{array}{l}\text { Burlington } \\
\text { City of }\end{array} \\
\text { June } 30\end{array}$ & $\begin{array}{l}\text { Vermont } \\
\text { Vemont } \\
\text { Public } \\
\text { Pwr } \\
\text { Supply Auth } \\
\text { December } 31\end{array}$ \\
\hline \multicolumn{7}{|l|}{ Electric Utility Plant } \\
\hline 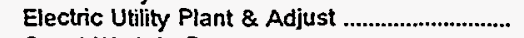 & 90,918 & 33,297 & 127,491 & 35,593 & 76,053 & 20,837 \\
\hline Const Work in Progress & & & 1,765 & 648 & 29 & \\
\hline 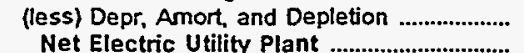 & $\begin{array}{l}41,870 \\
49,048\end{array}$ & $\begin{array}{l}10,531 \\
22,767\end{array}$ & $\begin{array}{r}23,936 \\
105,320\end{array}$ & $\begin{array}{r}8,198 \\
28,042\end{array}$ & $\begin{array}{l}28,816 \\
47,267\end{array}$ & $\begin{array}{r}9,372 \\
11,465\end{array}$ \\
\hline 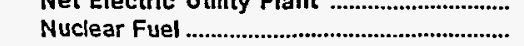 & $\begin{array}{r}49,046 \\
0\end{array}$ & $\begin{array}{r}2<, 10 \\
0\end{array}$ & $\begin{array}{r}100,320 \\
0\end{array}$ & $\begin{array}{r}28,042 \\
0\end{array}$ & $\begin{array}{r}4 r, 268 \\
0\end{array}$ & $\begin{array}{r}71,465 \\
0\end{array}$ \\
\hline 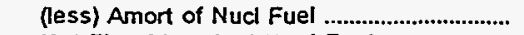 & 0 & 0 & 0 & 0 & 0 & 0 \\
\hline Net Elec Plant Incl Nucl Fuel .......................... & 49,048 & 22,767 & 105,320 & 28,042 & 47,267 & 11,465 \\
\hline \multicolumn{7}{|l|}{ Other Property \& Investments } \\
\hline Nonutility Property & 1,800 & 0 & 0 & 0 & 776 & o \\
\hline (less) Accum Provisions for Depr \& Amort.... & 0 & $\mathbf{0}$ & 0 & 0 & 0 & 0 \\
\hline 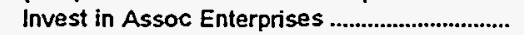 & 0 & 0 & 0 & 0 & 2.235 & 0 \\
\hline 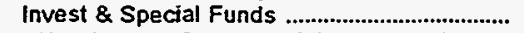 & 0 & 0 & 0 & 14,605 & 4,989 & 6,898 \\
\hline & 1,800 & 0 & $\mathbf{0}$ & 14,605 & 8,000 & 6,898 \\
\hline \multicolumn{7}{|l|}{ Current and Accrued Assets } \\
\hline 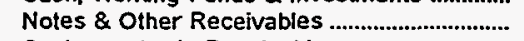 & 143 & 1,632 & 0 & 2,886 & 1,679 & 1.109 \\
\hline 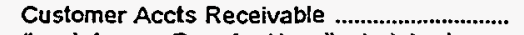 & 4,549 & 2,596 & 10,464 & 2,671 & 3.711 & 0 \\
\hline (less) Accum Prov for Uncollected Accts ....... & 0 & 349 & 0 & 0 & 149 & 0 \\
\hline 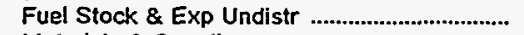 & 0 & 0 & 0 & 2,251 & 238 & 243 \\
\hline Materials \& Supplies ................................................. & 978 & 2,249 & 0 & 273 & 1.469 & 0 \\
\hline 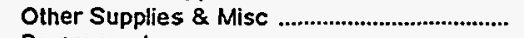 & 0 & 0 & 1,509 & 0 & 140 & 0 \\
\hline 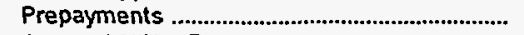 & 0 & 0 & 0 & 181 & 1,580 & 0 \\
\hline 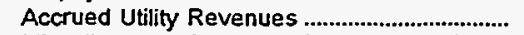 & 0 & 0 & 132 & 0 & 367 & 0 \\
\hline Miscellaneous Current \& Accrued Assets ..... & 0 & 3,478 & 0 & 0 & 0 & 0 \\
\hline Total Current \& Accrued Assets ................ & 12,970 & 16,583 & 36,659 & 10,137 & 27,063 & 1,606 \\
\hline \multicolumn{7}{|l|}{ Deferred Debits } \\
\hline 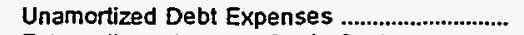 & 0 & 0 & 6.164 & 987 & 2,955 & 1,204 \\
\hline Extraordinary Losses, Study Cost ...................... & 0 & 0 & 40,713 & 5.609 & 10 & 0 \\
\hline Misc Debt, R \& D Exp, Unamit Losses .......... & 0 & 0 & 0 & 0 & 50,371 & 10,919 \\
\hline Total Deferred Debits ......................................... & & 0 & 46,877 & 6,598 & 53,336 & 12,123 \\
\hline \multirow{2}{*}{\multicolumn{7}{|c|}{ Proprietary Capital }} \\
\hline & & & & & & \\
\hline 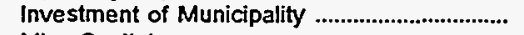 & 0 & 0 & 127 & 3 & 0 & 0 \\
\hline 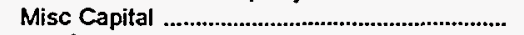 & 0 & 1,523 & 0 & 0 & 0 & 0 \\
\hline Retained Earnings …………................................................ & 4,437 & 35.017 & 0 & 0 & 27,299 & $-2,646$ \\
\hline Total Proprietary Capital ................................... & 4,437 & 36,540 & 127 & 3 & 27,299 & $-2,646$ \\
\hline \multicolumn{7}{|l|}{ Long-term Debt } \\
\hline 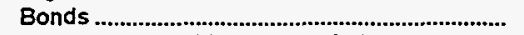 & 55,804 & 0 & 154,770 & 55,768 & 100,861 & 32,890 \\
\hline Advances from Municipality $\&$ Other ............... & & 0 & 0 & 0 & 12 & 1,354 \\
\hline Unamort Prem on Long-term Debt ....................... & $-1,090$ & 0 & 0 & 0 & 1 & $-3,267$ \\
\hline (less) Unamort Discount on Long-term Debt & & 0 & 0 & 0 & 639 & \\
\hline $\begin{array}{l}\text { Total Long-term Debt ............................................. } \\
\text { Other Noncurrent Liabilities }\end{array}$ & 54,714 & 0 & 154,770 & 55,768 & 100,235 & 30,978 \\
\hline Accum Operating Provisions ................................... & 0 & 0 & 0 & 0 & 429 & 0 \\
\hline Accum Prov for Rate Refunds ........................... & 0 & 0 & 0 & 0 & 0 & 0 \\
\hline Total Other Noncurrent Liabilities ............ & 0 & 0 & 0 & 0 & 429 & o \\
\hline \multicolumn{7}{|l|}{ Current and Accrued Liabilities } \\
\hline 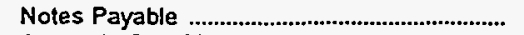 & 0 & 0 & 0 & 0 & 608 & 0 \\
\hline Accounts Payable ...................................................... & 2,402 & 2,276 & 1,973 & 1,787 & 1,759 & 684 \\
\hline 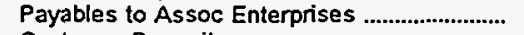 & & 0 & 0 & 0 & 192 & 0 \\
\hline Customer Deposits .................................................... & 1,197 & 534 & 0 & 0 & 8 & $\mathbf{0}$ \\
\hline 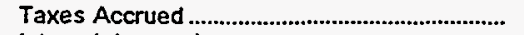 & 144 & 0 & 545 & 0 & 130 & 0 \\
\hline Interest Accrued ................................................................. & 430 & 0 & 2,062 & 1,538 & 3,257 & 1,009 \\
\hline Mise Current \& Accrued Libilities.................... & 494 & 0 & 10,093 & 285 & 519 & 2,068 \\
\hline Total Current \& Accrued Liabilities ........... & 4,667 & 2,810 & 14,673 & 3,610 & 6,475 & 3,760 \\
\hline \multicolumn{7}{|l|}{ Deferred Credits } \\
\hline Customer Advances for Construction .............. & 0 & 0 & 19,285 & 0 & 45 & 0 \\
\hline 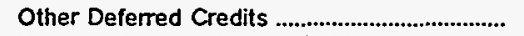 & 0 & 0 & 0 & 0 & 1.182 & $\mathbf{0}$ \\
\hline Unamort Gain on Reacqr Debt .......................... & 0 & 0 & 0 & 0 & 0 & $\mathbf{0}$ \\
\hline Total Deferred Credits .......................................... & 0 & 0 & 49,285 & 0 & 1,227 & \\
\hline Total Liabilities and Other Credits ............ & 63,818 & 39,350 & 188,856 & 59,381 & 135,666 & 32,092 \\
\hline
\end{tabular}

Note: Totals may not equal sum of components because of independent rounding.

Source: Energy Information Administration, Form EIA-412, "Annual Report of Public Electric Utilities." 
Table 22. Balance Sheet by Major U.S. Publicly Owned Electric Utility Within State at End of Period, 1995

(Thousand Dollars)

\begin{tabular}{|c|c|c|c|c|c|c|}
\hline Item & $\begin{array}{l}\text { Virginia } \\
\text { Bedford } \\
\text { City of } \\
\text { June } 30\end{array}$ & $\begin{array}{l}\text { Virginia } \\
\text { Bristol } \\
\text { Utilities } \\
\text { Board } \\
\text { June } 30\end{array}$ & $\begin{array}{l}\text { Virginia } \\
\begin{array}{l}\text { Danville } \\
\text { City of }\end{array} \\
\text { June } 30\end{array}$ & $\begin{array}{c}\text { Virginia } \\
\begin{array}{c}\text { Harisonburg } \\
\text { City of }\end{array} \\
\text { June } 30\end{array}$ & $\begin{array}{l}\text { Virginia } \\
\begin{array}{c}\text { Manassas } \\
\text { City of }\end{array} \\
\text { June } 30\end{array}$ & $\begin{array}{l}\text { Virginia } \\
\begin{array}{c}\text { Martinsville } \\
\text { City of }\end{array} \\
\text { June } 30\end{array}$ \\
\hline \multicolumn{7}{|l|}{ Electric Utility Plant } \\
\hline 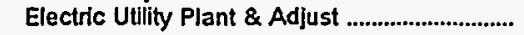 & 17,890 & 23,709 & 58,636 & 45,357 & 40,003 & 17,873 \\
\hline 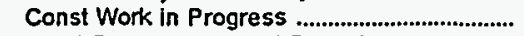 & & 1,152 & 6,463 & 1,510 & 348 & \\
\hline (less) Depr, Amort, and Depletion .................... & 6,003 & 11,101 & 25,289 & 16,160 & 13,810 & 7.630 \\
\hline 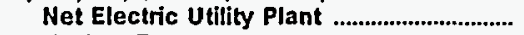 & 11,886 & 13,760 & 39,810 & 30,707 & 26,541 & 10,243 \\
\hline 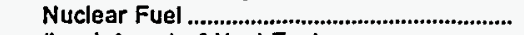 & & 0 & 0 & 0 & 0 & 0 \\
\hline 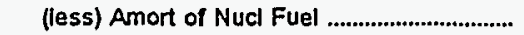 & 0 & 0 & 0 & 0 & 0 & 0 \\
\hline Net Elec Plant Incl Nucl Fuel ......................... & 11,886 & 13,760 & 39,810 & 30,707 & 26,541 & 10,243 \\
\hline \multicolumn{7}{|l|}{ Other Property \& Investments } \\
\hline 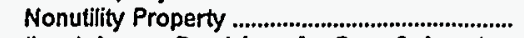 & 0 & 56 & 0 & 0 & 0 & 0 \\
\hline (less) Accum Provislons for Depr \& Amort .... & 0 & 0 & 0 & 0 & $\mathbf{0}$ & 0 \\
\hline 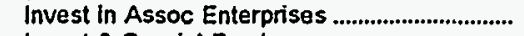 & 0 & 0 & 0 & 0 & 0 & $\mathbf{0}$ \\
\hline 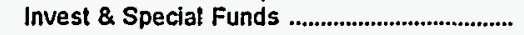 & 0 & 661 & 0 & 1 & 0 & 0 \\
\hline \multicolumn{6}{|l|}{ Current and Accrued Assets } & 0 \\
\hline Cash, Working Funds \& Investments .............. & 4,681 & 3,495 & 8,481 & 4,934 & 1,674 & 1,974 \\
\hline 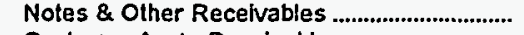 & & 723 & 303 & 328 & 345 & 0 \\
\hline 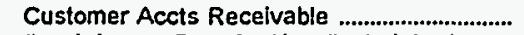 & 1,385 & 0 & 4,492 & 2,312 & 1,825 & 1,439 \\
\hline (less) Accum Prov for Uncollected Accts ...... & 0 & 0 & 0 & 0 & 9 & 60 \\
\hline 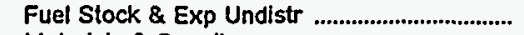 & 0 & 0 & 0 & 0 & 0 & 0 \\
\hline Materials \& Supplies .................................................. & 0 & 471 & 764 & 1,264 & 0 & 0 \\
\hline 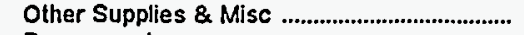 & 0 & 0 & 0 & 0 & 0 & 0 \\
\hline 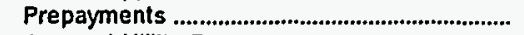 & 0 & 0 & 0 & 15 & 0 & 237 \\
\hline 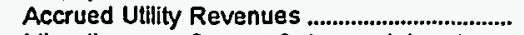 & 0 & 0 & 0 & 499 & 0 & 0 \\
\hline Miscellaneous Current \& Accrued Assets ..... & 104 & 1,303 & 0 & 18 & 0 & \\
\hline $\begin{array}{l}\text { Total Current \& Accrued Assets ................. } \\
\text { Deferred Debits }\end{array}$ & 6,169 & 5,991 & 14,040 & 9,371 & 3,834 & 3,590 \\
\hline Unamortized Debt Expenses ................................. & \\
\hline 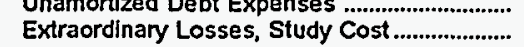 & $\begin{array}{r}2,354 \\
0\end{array}$ & $\begin{array}{l}0 \\
0\end{array}$ & $\begin{array}{l}0 \\
0\end{array}$ & $\begin{array}{r}12 \\
0\end{array}$ & $\begin{array}{l}0 \\
0\end{array}$ & $\begin{array}{l}0 \\
0\end{array}$ \\
\hline Misc Debt, R \& D Exp, Unamrt Losses ......... & & 1,764 & 0 & 0 & 0 & 0 \\
\hline 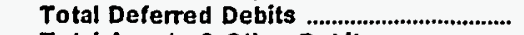 & 2,354 & 1,764 & & 12 & & \\
\hline Total Assets \& Other Debits ............................. & 20,409 & 22,231 & 53,850 & 40,091 & 30,375 & 13,833 \\
\hline \multicolumn{7}{|l|}{ Proprietary Capital } \\
\hline 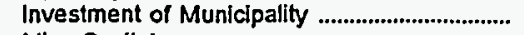 & 4,265 & $\mathbf{0}$ & 36,764 & 1.199 & 656 & 0 \\
\hline 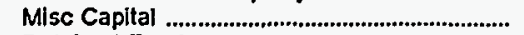 & & 0 & 0 & 0 & 0 & 0 \\
\hline 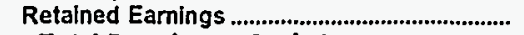 & $-1,292$ & 19,623 & 3,538 & 33.591 & 18,047 & 13,351 \\
\hline Total Proprietary Capital ................................ & 2,973 & 19,623 & 40,302 & 34,790 & 18,704 & 13,351 \\
\hline \multicolumn{7}{|l|}{ Long-term Debt } \\
\hline 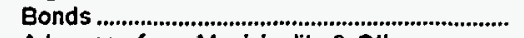 & 16,250 & 0 & 8,685 & 0 & 7,845 & $\mathbf{0}$ \\
\hline Advances from Munlcipality \& Other ................ & & 0 & 162 & 0 & 872 & 0 \\
\hline Unamort Prem on Long-term Debt ....................... & 0 & 0 & 0 & 2,200 & 0 & $\mathbf{0}$ \\
\hline (less) Unamort Discount on Long-term Debt & 0 & 0 & 0 & 0 & 0 & 0 \\
\hline 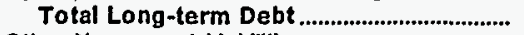 & 16,250 & 0 & 8,847 & 2,200 & 8,717 & $\mathbf{0}$ \\
\hline \multicolumn{7}{|l|}{ Other Noncurrent Labilities } \\
\hline 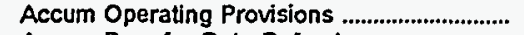 & 0 & 0 & 0 & 0 & 0 & $\mathbf{0}$ \\
\hline 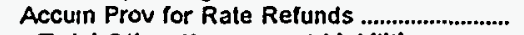 & 0 & 0 & 0 & 0 & 0 & $\mathbf{0}$ \\
\hline $\begin{array}{l}\text { Total Other Noncurrent Llabilities ............ } \\
\text { Current and Accrued Liabilities }\end{array}$ & 0 & 0 & 0 & 0 & 0 & 0 \\
\hline 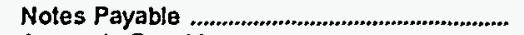 & 0 & 0 & 0 & 269 & 234 & 0 \\
\hline 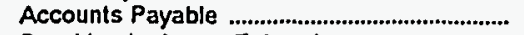 & 617 & 1,913 & 2,721 & 2,294 & 1,178 & 20 \\
\hline 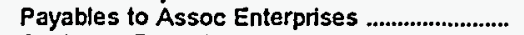 & $\mathbf{0}$ & 0 & 0 & 0 & 0 & 0 \\
\hline 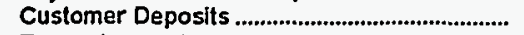 & 104 & 425 & 1,171 & 310 & 546 & 237 \\
\hline 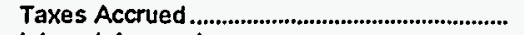 & 0 & 16 & 0 & 0 & 0 & 0 \\
\hline Interest Accrued .............................................................. & 116 & 0 & 149 & 21 & 162 & 0 \\
\hline Misc Current \& Accrued Labillties.................... & 349 & 255 & 652 & 199 & 835 & 225 \\
\hline \multirow{2}{*}{\multicolumn{7}{|c|}{ Deferred Credits }} \\
\hline & & & & & & \\
\hline Customer Advances for Construction .............. & $\mathbf{0}$ & 0 & 0 & 0 & 0 & 0 \\
\hline Other Deferred Credits ................................................ & 0 & 0 & 7 & 6 & 0 & 0 \\
\hline Unamort Gain on Reacqr Debt ........................... & $\mathbf{0}$ & 0 & 0 & 0 & $\mathbf{0}$ & $\mathbf{0}$ \\
\hline Total Deferred Credits ..................................... & & & & & & \\
\hline Total Liabilities and Other Credits ............ & 20,409 & 22,231 & 53,850 & 40,091 & 30,375 & 13,833 \\
\hline
\end{tabular}

Note: Totals may not equal sum of components because of independent rounding.

Source: Energy Information Administration, Form E1A-412, "Annual Report of Public Electric Utilities." 
Table 22. Balance Sheet by Major U.S. Publicly Owned Electric Utility Within State at End of Period, 1995

(Thousand Dollars)

\begin{tabular}{|c|c|c|c|c|c|c|}
\hline Item & $\begin{array}{l}\text { Virginia } \\
\text { Radford } \\
\text { City of } \\
\text { June } 30\end{array}$ & $\begin{array}{l}\text { Virginia } \\
\text { Salem } \\
\text { City of } \\
\text { June } 30\end{array}$ & $\begin{array}{c}\text { Virginia } \\
\text { Virginia } \\
\text { Tech } \\
\text { Electric } \\
\text { Service } \\
\text { June } 30\end{array}$ & $\begin{array}{l}\text { Washington } \\
\text { Centralia } \\
\text { City of } \\
\text { December } 31\end{array}$ & $\begin{array}{l}\text { Washington } \\
\text { Ellensburg } \\
\text { City of } \\
\text { December } 31\end{array}$ & $\begin{array}{l}\text { Washington } \\
\text { Port Angeles } \\
\text { City of } \\
\text { December } 31\end{array}$ \\
\hline \multicolumn{7}{|l|}{ Electric Utility Plant } \\
\hline 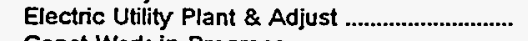 & 14,318 & 21,020 & 0 & 20.156 & 13,916 & 20,171 \\
\hline 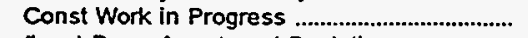 & & & 0 & 0 & & 2,115 \\
\hline (less) Depr, Amort, and Depletion ....................... & 8.674 & 10,898 & 0 & 8,581 & 6,248 & 7,446 \\
\hline $\begin{array}{l}\text { Net Electric Utility Plant ................................. } \\
\text { Nuclear Fuel . }\end{array}$ & $\begin{array}{r}5,643 \\
0\end{array}$ & 10,122 & 0 & 11,575 & 7,668 & 14,840 \\
\hline 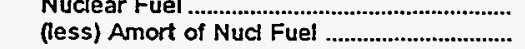 & $\begin{array}{l}0 \\
0\end{array}$ & 0 & $\begin{array}{l}0 \\
0\end{array}$ & $\begin{array}{l}0 \\
0\end{array}$ & $\begin{array}{l}0 \\
0\end{array}$ & $\begin{array}{l}0 \\
0\end{array}$ \\
\hline $\begin{array}{l}\text { Net Elec Plant Incl Nucl Fuel ............................. } \\
\text { Other Property \& Investments }\end{array}$ & 5,643 & 10,122 & 0 & 11,575 & 7,668 & 14,840 \\
\hline 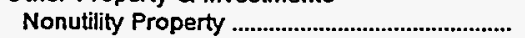 & 0 & 0 & 0 & 69 & 314 & 0 \\
\hline (less) Accum Provisions for Depr \& Amort.... & 0 & 0 & 0 & 0 & 115 & 0 \\
\hline 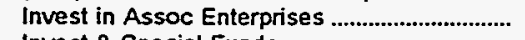 & 0 & 0 & 0 & 0 & 0 & 0 \\
\hline 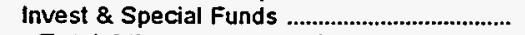 & 0 & 1,112 & 0 & 875 & 0 & 0 \\
\hline $\begin{array}{l}\text { Total Other Property \& Investments ....... } \\
\text { Current and Accrued Assets }\end{array}$ & 0 & 1,112 & 0 & 944 & 198 & 0 \\
\hline \multicolumn{6}{|l|}{ Cash, Working Funds \& Investments .................. } & 5.086 \\
\hline 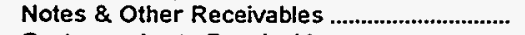 & 4,301 & 144 & 1,337 & 23 & 0 & 668 \\
\hline Customer Accts Receivable ...................................... & 1,416 & 769 & 408 & 906 & 750 & 2,943 \\
\hline (less) Accum Prov for Uncollected Accts ....... & 74 & 47 & 0 & 10 & 9 & 0 \\
\hline 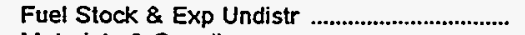 & 0 & 0 & 0 & 0 & 0 & 0 \\
\hline 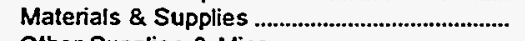 & 214 & 559 & 355 & 211 & 392 & 911 \\
\hline Other Supplies \& Misc ................................................ & 0 & 0 & 0 & 0 & 0 & 0 \\
\hline 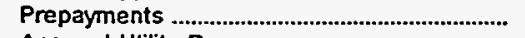 & 0 & 0 & 1 & 0 & 0 & 0 \\
\hline 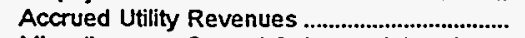 & 0 & 1,232 & 0 & 179 & 0 & 0 \\
\hline Miscellaneous Current \& Accrued Assets ..... & 0 & & 0 & 7 & 0 & 0 \\
\hline $\begin{array}{l}\text { Total Current \& Accrued Assets .................. } \\
\text { Deferred Debits }\end{array}$ & 10,154 & 4,295 & 3,734 & 1,168 & 1,920 & 9,607 \\
\hline 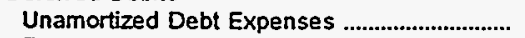 & 0 & 0 & 2,470 & 0 & 0 & 54 \\
\hline Extraordinary Losses, Study Cost ........................... & 0 & 0 & 0 & 0 & 0 & 0 \\
\hline Misc Debt, R \& D Exp, Unamrt Losses .......... & 0 & 0 & 0 & 0 & 0 & 0 \\
\hline Total Deferred Debits ...................................... & 0 & 0 & 2,470 & 0 & 0 & 54 \\
\hline 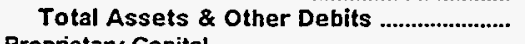 & 15,298 & 15,529 & 6,204 & 13,686 & 9,786 & 24,501 \\
\hline \multicolumn{7}{|l|}{ Proprietary Capital } \\
\hline 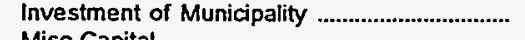 & 0 & o & $\mathbf{0}$ & 552 & 0 & 987 \\
\hline Misc Capital ........................................................... & 0 & 0 & 0 & 0 & 0 & 0 \\
\hline 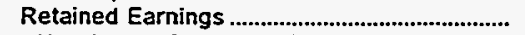 & 11,234 & 5,469 & 2,909 & 9,062 & 8,953 & 12,855 \\
\hline 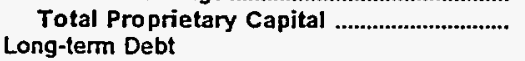 & 11,234 & 5,469 & 2,909 & 9,614 & 8,953 & 13,841 \\
\hline 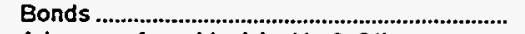 & 3,300 & 8,420 & 2,470 & 675 & 0 & 5,475 \\
\hline Advances from Municipality \& Other ................ & 0 & 31 & 0 & 0 & 110 & 0 \\
\hline Unamort Prem on Long-term Debt ...................... & 0 & 0 & 0 & 0 & 0 & 0 \\
\hline (less) Unamort Discount on Long-term Debt & 0 & 59 & 0 & 13 & 0 & 0 \\
\hline $\begin{array}{l}\text { Total Long-term Debt................................... } \\
\text { Other Noncurrent Ljabilities }\end{array}$ & 3,300 & 8,392 & 2,470 & 662 & 110 & 5,475 \\
\hline Accum Operating Provisions ................................... & $\mathbf{0}$ & 0 & 0 & 335 & 0 & 136 \\
\hline Accum Prov for Rate Refunds ............................ & $\mathbf{0}$ & 0 & 0 & 0 & 0 & 0 \\
\hline \multicolumn{7}{|l|}{ Curren! and Accrued Labilities } \\
\hline 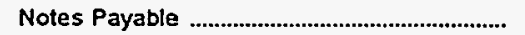 & 1,025 & $\mathbf{0}$ & 0 & 2.044 & 0 & 0 \\
\hline Accounts Payable .................................................... & 0 & 1,182 & 633 & 665 & 631 & 2,125 \\
\hline 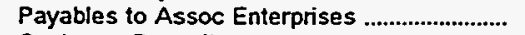 & 0 & 0 & 0 & 0 & 0 & 57 \\
\hline Customer Deposits ...................................................... & 126 & 249 & 0 & 312 & 0 & 48 \\
\hline Taxes Accrued ............................................................ & 0 & 0 & 0 & 0 & 0 & 89 \\
\hline Interest Accrued ................................................... & 0 & 94 & 14 & 4 & 0 & 195 \\
\hline 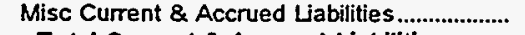 & 112 & 142 & 178 & 0 & 91 & 312 \\
\hline $\begin{array}{l}\text { Total Current \& Accrued Liabilities ........... } \\
\text { Deferred Credits }\end{array}$ & 1,263 & 1,668 & 825 & 3,025 & 723 & 2,827 \\
\hline Customer Advances for Construction .............. & 0 & 0 & 0 & 41 & 0 & 2,222 \\
\hline Other Deferred Credits ........................................ & 0 & 0 & 0 & 8 & 0 & 0 \\
\hline Unamort Gain on Reacqr Debt ........................... & 0 & 0 & 0 & 0 & 0 & 0 \\
\hline Total Deferred Credits ..................................... & 0 & o & & & & 2,222 \\
\hline Total Liabilities and Other Credits ............ & 15,798 & 15,529 & 6,204 & 13,686 & 9,786 & 24,501 \\
\hline
\end{tabular}

Note: Totals may not equal sum of components because of independent rounding.

Source: Energy information Administration. Form ElA-412, "Annual Report of Public Electric Utilities." 
Table 22. Balance Sheet by Major U.S. Publicly Owned Electric Utility Within State at End of Period, 1995 (Thousand Dollars)

\begin{tabular}{|c|c|c|c|c|c|c|}
\hline Item & $\begin{array}{c}\text { Washington } \\
\text { PUD No } 1 \\
\text { of } \\
\text { Benton } \\
\text { County } \\
\text { December } 31\end{array}$ & $\begin{array}{c}\text { Washington } \\
\text { PuD No } 1 \\
\text { of } \\
\text { Chelan } \\
\text { County } \\
\text { December } 31\end{array}$ & $\begin{array}{l}\text { Washington } \\
\text { PUD No } 1 \text { of } \\
\text { Clallam } \\
\text { County }\end{array}$ & $\begin{array}{c}\text { Washington } \\
\text { PUD No } 1 \\
\text { of } \\
\text { Clark } \\
\text { County } \\
\text { December } 31\end{array}$ & $\begin{array}{l}\text { Washington } \\
\text { PUD No } 1 \text { of } \\
\text { Cowlitz } \\
\text { County } \\
\text { December } 31\end{array}$ & $\begin{array}{l}\text { Washington } \\
\text { PUD No } 1 \text { of } \\
\text { Douglas } \\
\text { County } \\
\text { December } 31\end{array}$ \\
\hline \multicolumn{7}{|l|}{ Electric Utility Plant } \\
\hline 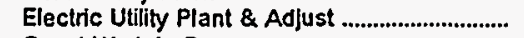 & 96,200 & 927,049 & 64,862 & 256,956 & 121,731 & 287,294 \\
\hline Const Work in Progress & 3,280 & 24,309 & 1.791 & 3,437 & 454 & 1,474 \\
\hline 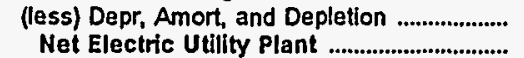 & $\begin{array}{l}39,022 \\
60,458\end{array}$ & $\begin{array}{l}189,648 \\
761,710\end{array}$ & $\begin{array}{l}34,507 \\
32,146\end{array}$ & $\begin{array}{r}99,016 \\
161,377\end{array}$ & $\begin{array}{l}54,413 \\
67,773\end{array}$ & $\begin{array}{r}54,921 \\
233,848\end{array}$ \\
\hline 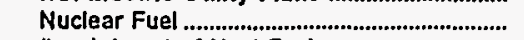 & 0 & 0 & 0 & 0 & 0 & 0 \\
\hline 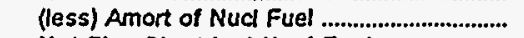 & $\mathbf{0}$ & 0 & 0 & $\mathbf{0}$ & 0 & 0 \\
\hline Net Elec Plant Incl Nucl Fuel ........................ & 60,458 & 761,710 & 32,146 & 161,377 & 67,773 & 233,848 \\
\hline \multicolumn{7}{|l|}{ Other Property \& Investments } \\
\hline 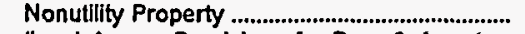 & 0 & 0 & 0 & 116 & 1 & 0 \\
\hline (less) Accum Provisions for Depr \& Amort .... & $\mathbf{0}$ & 0 & 0 & 8 & 0 & 0 \\
\hline 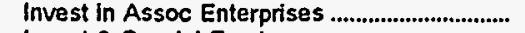 & $\mathbf{0}$ & 6,867 & 0 & 0 & 1,174 & $\mathbf{0}$ \\
\hline 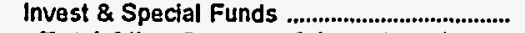 & 21,072 & 114,205 & 3,960 & 7,986 & 1.892 & 28,828 \\
\hline $\begin{array}{l}\text { Total Other Property \& Investments ....... } \\
\text { Current and Accrued Assets }\end{array}$ & 21,072 & 121,072 & 3,960 & 8,093 & 3,067 & 28,828 \\
\hline Cash, Working Funds \& Investments .............. & 7,730 & 38,896 & 4,070 & 26,652 & 16,651 & 19.423 \\
\hline 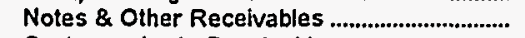 & 304 & 7.598 & 398 & 879 & 2,070 & 1,754 \\
\hline 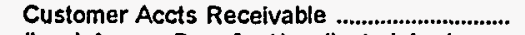 & 4,753 & 8.055 & 1,768 & 24,182 & 9,244 & 883 \\
\hline (less) Accum Prov for Uncollected Accts ...... & 12 & 30 & 35 & 1,553 & 102 & 30 \\
\hline 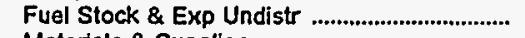 & 0 & 0 & 0 & 0 & 0 & 0 \\
\hline 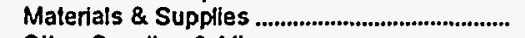 & 1,590 & 5,150 & 1.182 & 2.018 & 2,239 & 1,583 \\
\hline 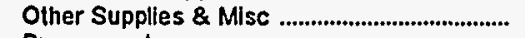 & 130 & 158 & 156 & 416 & 19 & 25 \\
\hline 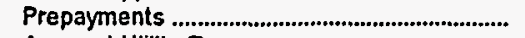 & 76 & 615 & 209 & 249 & 501 & 659 \\
\hline 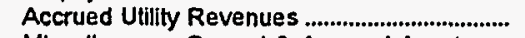 & 0 & 0 & 0 & 5.989 & 0 & 0 \\
\hline Miscellaneous Current \& Accrued Assets ..... & 584 & 1,287 & 47 & 0 & 128 & 1,244 \\
\hline $\begin{array}{l}\text { Total Current \& Accrued Assets ............... } \\
\text { Deferred Debits }\end{array}$ & 15,154 & 61,729 & 7,794 & 58,832 & 30,750 & 25,541 \\
\hline 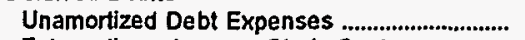 & 1,128 & 16,068 & 171 & 2,977 & 1 & 2,477 \\
\hline Extraordinary Losses, Study Cost ...................... & 9 & 1,783 & 0 & 0 & 0 & 297 \\
\hline Misc Debt, R \& D Exp, Unamrt Losses .......... & 13 & 34,200 & 0 & 2,177 & 49 & 29.888 \\
\hline 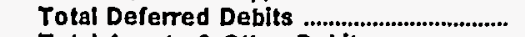 & 1,150 & 52,051 & 171 & 5,154 & 51 & 32,663 \\
\hline 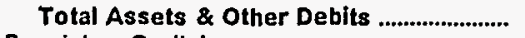 & 97,834 & 996,562 & 44,072 & 233,456 & 101,640 & 320,879 \\
\hline \multicolumn{7}{|l|}{ Proprietary Capital } \\
\hline 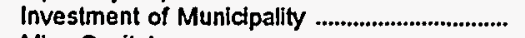 & 0 & 21,821 & 0 & 0 & 0 & 0 \\
\hline 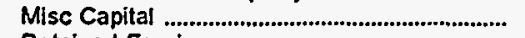 & 0 & 0 & 0 & 19.871 & 0 & 0 \\
\hline 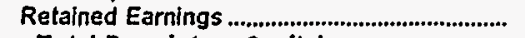 & 35,091 & 228,512 & 29,033 & 74,532 & 71,323 & 105,103 \\
\hline $\begin{array}{l}\text { Total Proprietary Capital ................................ } \\
\text { Long-term Debt }\end{array}$ & 35,091 & 250,333 & 29,033 & 94,403 & 71,323 & 105,103 \\
\hline 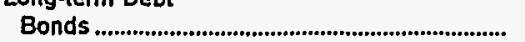 & 46,035 & 462,406 & 7,042 & 95,545 & 1,765 & 200,975 \\
\hline Advances from Municipality \& Other ............... & 1,689 & 209,927 & 42 & 2,586 & 0 & 0 \\
\hline Unamort Prem on Long-term Debt .................... & 0 & 0 & 0 & 0 & 0 & 0 \\
\hline (less) Unamort Discount on Long-term Debt & 349 & 4,826 & 0 & 3 & 1 & 0 \\
\hline 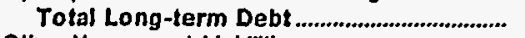 & 47,375 & 667,507 & 7,083 & 98,128 & 1,764 & 200,975 \\
\hline \multicolumn{7}{|l|}{ Other Noncurrent Lablities } \\
\hline Accum Operating Provisions ................................ & 0 & $\mathbf{0}$ & 0 & 0 & 1,733 & 0 \\
\hline 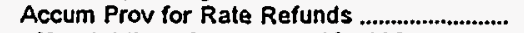 & 0 & 0 & 0 & 0 & 1,344 & 0 \\
\hline Total Other Noncurrent Llabilities ............ & 0 & 0 & 0 & 0 & 3,077 & 0 \\
\hline \multicolumn{7}{|l|}{ Current and Accrued Labilities } \\
\hline 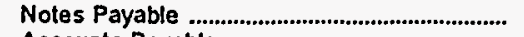 & 515 & 0 & 0 & 6,512 & 0 & 1.375 \\
\hline Accounts Payable & 4,248 & 32,041 & 4,508 & 17,976 & 9,785 & 1,832 \\
\hline Payables to Assoc Enterprises .......................... & 0 & 10,954 & $\mathbf{0}$ & $\mathbf{0}$ & 73 & 0 \\
\hline 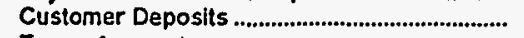 & 622 & 197 & 265 & 1 & 313 & 144 \\
\hline 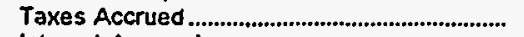 & 1,710 & 2,761 & 713 & 3,621 & 2,344 & 1,099 \\
\hline 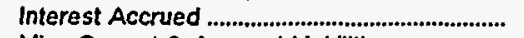 & 503 & 2,467 & 167 & 2,150 & 22 & 3,438 \\
\hline Misc Current \& Accrued Liabilitles..................... & 1,231 & 19,693 & 412 & 10,503 & 519 & 2,060 \\
\hline $\begin{array}{l}\text { Total Current \& Accrued Labilities .......... } \\
\text { Deferred Credits }\end{array}$ & 8,828 & 68,113 & 6,065 & 40,763 & 13,057 & 9,949 \\
\hline Customer Advances for Construction ............. & 6,509 & $\mathbf{0}$ & 243 & 0 & 12,395 & 10 \\
\hline 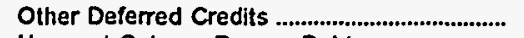 & 30 & 10,609 & 1,648 & 162 & 25 & 4,167 \\
\hline Unamort Gain on Reacqr Debt ........................... & 0 & 0 & 0 & 0 & 0 & 676 \\
\hline Total Deferred Credits ...................................... & 6,540 & 10,609 & 1,891 & 162 & 12,420 & 4,853 \\
\hline Total Llabilities and Other Credits ........... & 97,834 & 996,562 & 44,072 & 233,456 & 101,640 & 320,879 \\
\hline
\end{tabular}

Note: Totals may not equal sum of components because of independent rounding

Source: Energy information Administration. Form ElA-412, "Annual Report of Public Electric Utilities." 
Table 22. Balance Sheet by Major U.S. Publicly Owned Electric Utility Within State at End of Period, 1995

(Thousand Dollars)

\begin{tabular}{|c|c|c|c|c|c|c|}
\hline Item & $\begin{array}{l}\text { Washington } \\
\text { PUD No } 1 \text { of } \\
\text { Franklin } \\
\text { County } \\
\text { December } 31\end{array}$ & $\begin{array}{c}\text { Washington } \\
\text { PUD No } 1 \\
\text { of } \\
\text { Grays } \\
\text { Harbor Cnty } \\
\text { December } 31\end{array}$ & $\begin{array}{l}\text { Washington } \\
\text { PUD No } 1 \text { of } \\
\text { Klickitat } \\
\text { County } \\
\text { December } 31\end{array}$ & $\begin{array}{c}\text { Washington } \\
\text { PUD No } 1 \\
\text { of } \\
\text { Lewis } \\
\text { County } \\
\text { December } 31\end{array}$ & $\begin{array}{l}\text { Washington } \\
\text { PUD No } 1 \text { of } \\
\text { Okanogan } \\
\text { County }\end{array}$ & $\begin{array}{l}\text { Washington } \\
\text { PUD No } 1 \text { of } \\
\text { Pend Oreille } \\
\text { Cnty } \\
\text { December } 31\end{array}$ \\
\hline \multicolumn{7}{|l|}{ Electric Utility Plant } \\
\hline 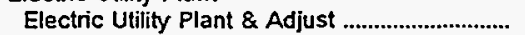 & 46,565 & 109,440 & 41,491 & 59,803 & 53.592 & 47,704 \\
\hline 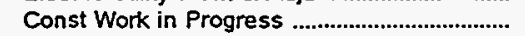 & 3,368 & 3,904 & 3,186 & 14,023 & 2,349 & 2,796 \\
\hline (less) Depr, Amort, and Depletion .................... & 17.694 & 42,369 & 14,303 & 16,426 & 27,458 & 16,878 \\
\hline Net Electric Utility Plant ............................. & 32,239 & 70,974 & 30,375 & 57,399 & 28,483 & 33,622 \\
\hline 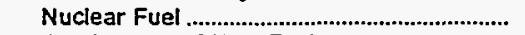 & 0 & 0 & 0 & 0 & 0 & 0 \\
\hline 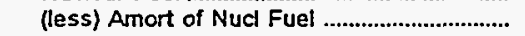 & 0 & 0 & 0 & 0 & 0 & 0 \\
\hline Net Elec Plant Incl Nucl Fuel ............................. & 32,239 & 70,974 & 30,375 & 57,399 & 28,483 & 33,622 \\
\hline \multicolumn{7}{|l|}{ Other Property \& Investments } \\
\hline Nonutility Property & 0 & 121 & 0 & 0 & 0 & 36 \\
\hline (less) Accum Provisions for Depr \& Amort.... & 0 & 0 & 0 & 0 & 0 & 0 \\
\hline 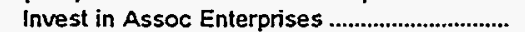 & 0 & 0 & 0 & 0 & 0 & 0 \\
\hline 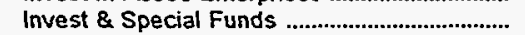 & 4,219 & 2,848 & 3,118 & 6.617 & 4,322 & 2,090 \\
\hline Total Other Property \& Investments ........ & 4,219 & 2,969 & 3,118 & 6,617 & 4,322 & 2,126 \\
\hline Cash, Working Funds \& Investments .............. & 8,281 & 15,427 & 14,784 & 11,079 & 11,834 & 8,298 \\
\hline Notes \& Other Receivables ................................... & 7 & 1,068 & 0 & 0 & 620 & 834 \\
\hline 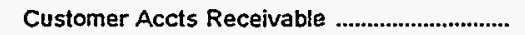 & 3,556 & 4.494 & 1,206 & 2,608 & 918 & 241 \\
\hline (less) Accum Prov for Uncollected Accts ...... & 6 & 101 & 27 & 214 & 14 & 7 \\
\hline 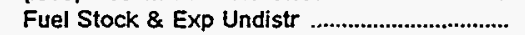 & 0 & 1,653 & 0 & 0 & 0 & 0 \\
\hline Materials \& Supplies ................................................. & 1,168 & 2,705 & 722 & 1,764 & 1,477 & $5 \bar{u}$ \\
\hline 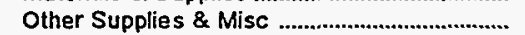 & 0 & 0 & 0 & 225 & -31 & 0 \\
\hline Prepayments ...................................................... & 45 & 88 & 12 & 9 & 36 & 94 \\
\hline 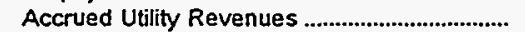 & 0 & 0 & 350 & 1,784 & 0 & 0 \\
\hline Miscellaneous Current \& Accrued Assets ..... & 626 & 14 & 0 & 0 & 0 & 120 \\
\hline Total Current \& Accrued Assets .................... & 13,676 & 25,348 & 17,046 & 17,255 & 14,841 & 10,177 \\
\hline \multicolumn{7}{|l|}{ Deferred Debits } \\
\hline 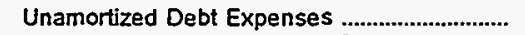 & 379 & 345 & 682 & 0 & 0 & 40 \\
\hline Extraordinary Losses, Study Cost ...................... & 136 & 58 & 2,102 & 0 & 86 & 952 \\
\hline Misc Debt, R \& D Exp, Unamrt Losses ........... & 12 & 39 & -1 & 0 & 164 & 4,456 \\
\hline Total Deferred Debits ....................................... & 527 & 441 & 2,783 & 0 & 250 & 5,448 \\
\hline 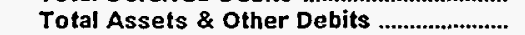 & 50,661 & 99,732 & 53,323 & 81,270 & 47,897 & 51,373 \\
\hline \multicolumn{7}{|l|}{ Proprietary Capital } \\
\hline 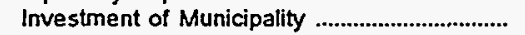 & 1,148 & 0 & 5,413 & 0 & 0 & $\mathbf{0}$ \\
\hline Misc Capital ........................................................... & & 0 & & 1,310 & 0 & 0 \\
\hline 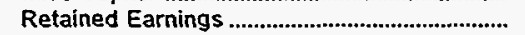 & 15,305 & 71,286 & 15,758 & 73,581 & 42,636 & 40,099 \\
\hline \multicolumn{7}{|l|}{ Long-term Debt } \\
\hline Bonds & 25,860 & 10,815 & 17,705 & 0 & 0 & 1,720 \\
\hline Advances from Municipality \& Other ................. & & 1,250 & 10,907 & 617 & 819 & 4,166 \\
\hline Unamort Prem on Long-term Debt ................... & 0 & 0 & 0 & 0 & 0 & 0 \\
\hline (less) Unamort Discount on Long-term Debt & 567 & & 0 & 0 & 0 & 0 \\
\hline 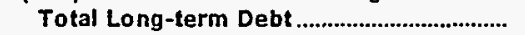 & 25,293 & 12,065 & 28,612 & 617 & 819 & 5,886 \\
\hline \multicolumn{7}{|l|}{ Other Noncurrent Liabilities } \\
\hline Accum Operating Provisions ................................... & 857 & 0 & 0 & 0 & 0 & 0 \\
\hline 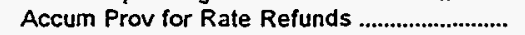 & 0 & 0 & 0 & 0 & 0 & 0 \\
\hline Total Other Noncurrent Liabilities .............. & 857 & 0 & $\mathbf{0}$ & 0 & 0 & 0 \\
\hline \multicolumn{7}{|l|}{ Current and Accived Labilities } \\
\hline 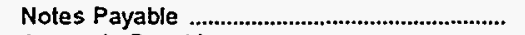 & 2,084 & 2,505 & 0 & 0 & 33 & 453 \\
\hline Accounts Payable ............................................................ & 130 & 5,943 & 2,253 & 254 & 3,174 & 2,389 \\
\hline 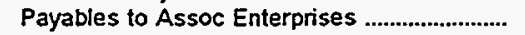 & 0 & 0 & 0 & 418 & 0 & 0 \\
\hline 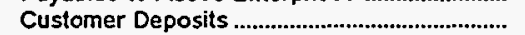 & 330 & 653 & 159 & 378 & 199 & 94 \\
\hline Taxes Accrued .................................................................. & 841 & 1,497 & 362 & 788 & 469 & 642 \\
\hline 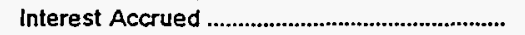 & 526 & 398 & 157 & 0 & 0 & 8 \\
\hline Misc Current \& Accrued Liabilities.................... & 4,007 & 2,651 & 357 & 3,120 & 568 & 564 \\
\hline $\begin{array}{l}\text { Total Current \& Accrued Liabilities .......... } \\
\text {. }\end{array}$ & 7,919 & 13,648 & 3,288 & 4,957 & 4,442 & 4,152 \\
\hline \multicolumn{7}{|l|}{ Deferred Credits } \\
\hline Customer Advances for Construction ................. & 0 & 31 & 14 & 0 & 0 & 86 \\
\hline 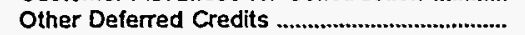 & 140 & 2,702 & 237 & 805 & -1 & 1,151 \\
\hline Unamort Gain on Reacqr Debt ............................. & 0 & & 0 & 0 & 0 & \\
\hline Total Deferred Credits ......................................... & 140 & 2,734 & 251 & 805 & -1 & 1,237 \\
\hline Total Liabilities and Other Credits ............ & 50,661 & 99,732 & 53,323 & 81,270 & 47,897 & 51,373 \\
\hline
\end{tabular}

Note: Totals may not equal sum of components because of independent rounding.

Source: Energy Information Administration, Form EIA-412, "Annual Report of Public Electric Utilities." 
Table 22. Balance Sheet by Major U.S. Publicly Owned Electric Utility Within State at End of Period, 1995

(Thousand Dollars)

\begin{tabular}{|c|c|c|c|c|c|c|}
\hline Item & $\begin{array}{l}\text { Washington } \\
\text { PUD No } 1 \text { of } \\
\text { Snohomish } \\
\text { County } \\
\text { December } 31\end{array}$ & $\begin{array}{l}\text { Washington } \\
\text { PUD No } 1 \text { of } \\
\text { Whatcom } \\
\text { County } \\
\text { December } 31\end{array}$ & $\begin{array}{c}\text { Washington } \\
\text { PUD No } 2 \\
\text { of } \\
\text { Grant } \\
\text { County } \\
\text { December } 31\end{array}$ & $\begin{array}{l}\text { Washington } \\
\text { PUD No } 2 \text { of } \\
\text { Pacific } \\
\text { County } \\
\text { December } 31\end{array}$ & $\begin{array}{c}\text { Washington } \\
\text { PUD No } 3 \\
\text { of } \\
\text { Mason } \\
\text { County } \\
\text { December } 31\end{array}$ & $\begin{array}{c}\text { Washington } \\
\text { Richland } \\
\text { City of } \\
\text { December } 31\end{array}$ \\
\hline \multicolumn{7}{|l|}{ Electric Utility Plant } \\
\hline 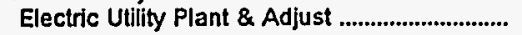 & 808,638 & 2.648 & 646,348 & 28,699 & 73,886 & 48,229 \\
\hline 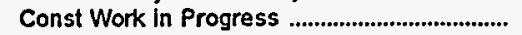 & 176.181 & 9 & 60,833 & 8,182 & 2.729 & 3,664 \\
\hline (less) Depr, Amort, and Depletion ..................... & 214,647 & 649 & 234,510 & 16,095 & 19,497 & 17,946 \\
\hline Net Electric Utility Plant .................................. & 770,172 & 2,008 & 472,672 & 20,786 & 57,118 & 33,948 \\
\hline Nuclear Fuel .................................................................... & & 0 & 0 & 0 & 0 & 0 \\
\hline (less) Amort of Nucl Fuel ................................ & 0 & 0 & 0 & 0 & 0 & 0 \\
\hline Net Elec Plant Incl Nucl Fuel ........................ & 770,172 & 2,008 & 472,672 & 20,786 & 57,118 & 33,948 \\
\hline \multicolumn{7}{|l|}{ Other Property \& Investments } \\
\hline 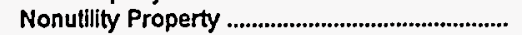 & 0 & 0 & 0 & 0 & 0 & 0 \\
\hline (less) Accum Provisions for Depr \& Amort.... & 0 & 0 & 0 & 0 & 0 & 0 \\
\hline Invest in Assoc Enterprises ............................... & 62,698 & 0 & 0 & 0 & 0 & 0 \\
\hline 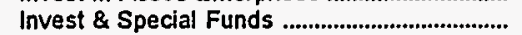 & 203,381 & 1,732 & 91,529 & 5,121 & 4,137 & 1,692 \\
\hline $\begin{array}{l}\text { Total Other Property \& Investments ....... } \\
\text { Current and Accrued Assets }\end{array}$ & 266,079 & 1,732 & 91,529 & 5,121 & 4,137 & 1,692 \\
\hline 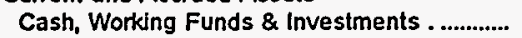 & 29,669 & 0 & 164.133 & 1.753 & 9,154 & 1,194 \\
\hline 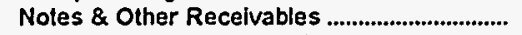 & 10,240 & 39 & 47,883 & 162 & 199 & 1,205 \\
\hline 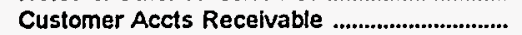 & 42,649 & 444 & 7,579 & 1.063 & 3,214 & 3,946 \\
\hline (less) Accum Prov for Uncollected Accts ...... & 1,435 & 0 & 292 & 34 & 65 & 143 \\
\hline Fuel Stock \& Exp Undistr ................................. & 4,506 & 0 & 0 & 0 & 0 & 0 \\
\hline Materials \& Supplies .............................................. & 5,894 & $\mathbf{0}$ & 4,289 & 2,111 & 2,033 & 1,201 \\
\hline 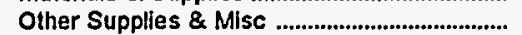 & 0 & 0 & 1,767 & 58 & 41 & 0 \\
\hline Prepayments .............................................................. & 241 & 2 & 0 & 0 & 20 & 0 \\
\hline 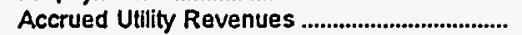 & 0 & 0 & 0 & 3 & 0 & 0 \\
\hline Miscellaneous Current \& Accrued Assets ..... & 2,080 & 325 & 2,033 & & & 19 \\
\hline Total Current \& Accrued Assets ................... & 93,845 & 810 & 227,392 & 5,116 & 14,609 & 7,421 \\
\hline \multicolumn{7}{|l|}{ Deferred Debits } \\
\hline 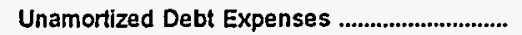 & 7,971 & 0 & 3,933 & 159 & 283 & 0 \\
\hline 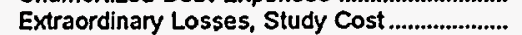 & & 0 & 306 & 0 & 266 & 0 \\
\hline Misc Debt, R \& D Exp, Unamrt Losses ........... & 225,570 & 0 & 4,206 & 111 & 0 & 499 \\
\hline 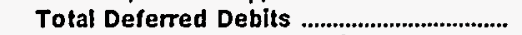 & 233,541 & $\mathbf{0}$ & 8,445 & 270 & 549 & 499 \\
\hline 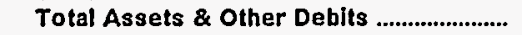 & $1,363,636$ & 4,550 & 800,038 & 31,293 & 76,413 & 43,559 \\
\hline \multicolumn{7}{|l|}{ Proprietary Capital } \\
\hline 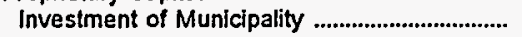 & 0 & 0 & 0 & 0 & 0 & 0 \\
\hline 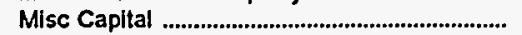 & & 1,547 & 0 & 3,586 & 0 & 0 \\
\hline 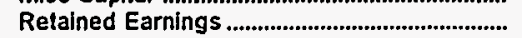 & 222,303 & 2,475 & 273,330 & 18,436 & 42,879 & 11,409 \\
\hline Total Proprietary Capital ...................................... & 222,303 & 4,022 & 273,330 & 22,022 & 42,879 & 11,409 \\
\hline \multicolumn{7}{|l|}{ Long-term Debt } \\
\hline 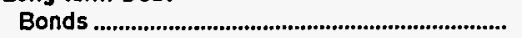 & 725.112 & 0 & 376,379 & 4,995 & 15,965 & 16,000 \\
\hline Advances from Municipality \& Other ................ & 17,332 & 0 & 3,200 & 481 & 0 & 0 \\
\hline Unamort Prem on Long-term Debt .................... & 546 & 0 & 169 & 0 & 0 & 0 \\
\hline (less) Unamort Discount on Long-term Debt & 13,992 & 0 & 11,352 & & 0 & 615 \\
\hline 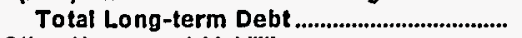 & 728,998 & o & 368,396 & 5,476 & 15,965 & 15,385 \\
\hline \multicolumn{7}{|l|}{ Other Noncurrent Liablities } \\
\hline 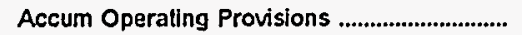 & 2,300 & 0 & 0 & 0 & $\mathbf{0}$ & 0 \\
\hline Accum Prov for Rate Refunds ............................ & & 0 & 0 & 0 & 0 & 0 \\
\hline Total Other Noncurrent Liabilities ............ & 2,300 & 0 & 0 & $\mathbf{0}$ & 0 & 0 \\
\hline \multicolumn{7}{|l|}{ Current and Accrued Luabilities } \\
\hline 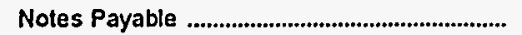 & 13,929 & 0 & 944 & 28 & 436 & 0 \\
\hline Accounts Payable ................................................. & 44,268 & 420 & 15,608 & 2,350 & 3,009 & 3.304 \\
\hline Payables to Assoc Enterprises ................................. & & 0 & 45,976 & 0 & 0 & 0 \\
\hline 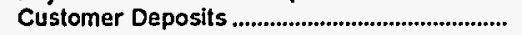 & 597 & 0 & 816 & 319 & 227 & 0 \\
\hline Taxes Accrued .......................................................... & 7,253 & 108 & 3,307 & 345 & 691 & 0 \\
\hline 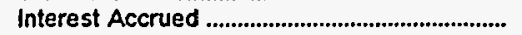 & 23,801 & 0 & 10,134 & 49 & 485 & 147 \\
\hline Misc Current \& Accrued Liabilities...................... & 10,548 & 0 & 80,515 & 218 & 944 & \\
\hline Total Current \& Accrued Liabilities ........... & 400,396 & 527 & 157,301 & 3,308 & 5,792 & 3,451 \\
\hline \multicolumn{7}{|l|}{ Deferred Credits } \\
\hline Customer Advances for Construction ............. & & $\mathbf{0}$ & 413 & 487 & 831 & 13,315 \\
\hline Other Deferred Credits .................................................. & 309,638 & 0 & 598 & -1 & 10,945 & 0 \\
\hline Unamort Gain on Reacqr Debt .............................. & 0 & 0 & 0 & 0 & 0 & \\
\hline Total Deferred Credits ....................................... & 309,638 & 0 & 1,011 & 487 & 11,777 & 13,315 \\
\hline Total Liabilities and Other Credits ............ & $1,363,636$ & 4,550 & 800,038 & 34,293 & 76,413 & 43,559 \\
\hline
\end{tabular}

Note: Totals may not equal sum of components because of independent rounding.

Source: Energy Information Administration, Form EIA-412, "Annual Report of Public Electric Utilities." 
Table 22. Balance Sheet by Major U.S. Publicly Owned Electric Utility Within State at End of Period, 1995

(Thousand Dollars)

\begin{tabular}{|c|c|c|c|c|c|c|}
\hline Item & $\begin{array}{c}\text { Washington } \\
\text { Seattle } \\
\text { City of } \\
\text { December } 31\end{array}$ & $\begin{array}{l}\text { Washington } \\
\text { Tacoma } \\
\text { City of } \\
\text { December } 31\end{array}$ & $\begin{array}{c}\text { Washington } \\
\text { Vera } \\
\text { Irrigation } \\
\text { District \#15 } \\
\text { December } 31\end{array}$ & $\begin{array}{c}\text { Washington } \\
\text { Washington } \\
\text { Pub } \\
\text { Pwr } \\
\text { Supply Sys } \\
\text { June } 30\end{array}$ & $\begin{array}{l}\text { Wisconsin } \\
\text { 8adger Power } \\
\begin{array}{c}\text { Marketing } \\
\text { Auth }\end{array} \\
\text { December } 31\end{array}$ & $\begin{array}{c}\text { Wisconsin } \\
\text { Jefferson } \\
\text { City of } \\
\text { December } 31\end{array}$ \\
\hline \multicolumn{7}{|l|}{ Electric Utility Plant } \\
\hline 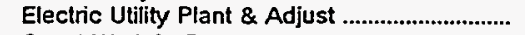 & $1,382,194$ & 717,092 & 14,221 & $3,396,453$ & 5,934 & 8,234 \\
\hline Const Work in Progress & 54,932 & 23,397 & 429 & 63,656 & 10 & 199 \\
\hline 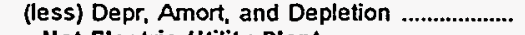 & 579,253 & 260,267 & 4.848 & $1,124,050$ & 1,444 & 2,409 \\
\hline Net Electric Utility Plant ................................. & 857,874 & 480,222 & $\mathbf{9 , 8 0 2}$ & $2,336,060$ & 4,500 & 6,024 \\
\hline 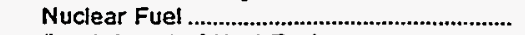 & 0 & 0 & 0 & 244,189 & 0 & 0 \\
\hline 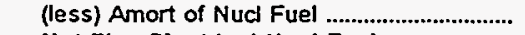 & o & 0 & 0 & 91,192 & 0 & 0 \\
\hline Net Elec Plant Incl Nucl Fuel .......................... & 857,874 & 480,222 & 9,802 & $2,489,058$ & 4,500 & 6,024 \\
\hline \multicolumn{7}{|l|}{ Other Property \& Investments } \\
\hline 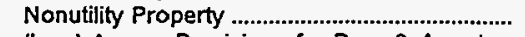 & 6,017 & 175 & 0 & 0 & 0 & 0 \\
\hline (less) Accum Provisions for Depr \& Amort.... & 2,331 & 8 & 0 & 0 & 0 & 0 \\
\hline Invest in Assoc Enterprises ................................... & 248 & 0 & 0 & 0 & 0 & 0 \\
\hline 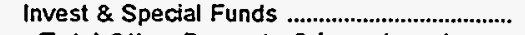 & 147,079 & 59.154 & 391 & 214,116 & 1.802 & 0 \\
\hline $\begin{array}{l}\text { Total Other Property \& Investments ........ } \\
\text { Current and Accrued Assets }\end{array}$ & 151,014 & 59,321 & 391 & 214,116 & 1,802 & $\mathbf{0}$ \\
\hline Cash, Working Funds \& Investments .............. & 34,117 & 101,512 & 1,072 & 52,237 & 4 & 3,205 \\
\hline 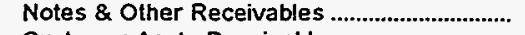 & 13,349 & 10,253 & 398 & 74,550 & 947 & 20 \\
\hline Customer Accts Receivable ............................... & 28,747 & 15,473 & 579 & 0 & 0 & 591 \\
\hline (less) Accum Prov for Uncollected Accts ...... & 2,182 & 359 & 0 & 155 & $\mathbf{0}$ & o \\
\hline 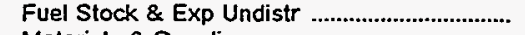 & 3,889 & 3.299 & 0 & 0 & 0 & 0 \\
\hline Materials \& Supplies & 20,355 & 4,419 & 269 & 50,381 & 0 & 186 \\
\hline Other Supplies \& Misc ............................................. & 175 & 0 & 0 & 8,552 & 0 & 0 \\
\hline 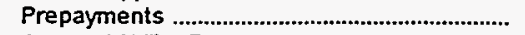 & 673 & 458 & 58 & 874 & 16 & 12 \\
\hline 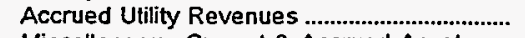 & 29,867 & 13,591 & 0 & 0 & 0 & 0 \\
\hline Miscellaneous Current \& Accrued Assets ..... & 4,090 & 1,666 & 0 & $\mathbf{0}$ & 15 & 15 \\
\hline $\begin{array}{l}\text { Total Current \& Accrued Assets ................ } \\
\text { Deferred Debits }\end{array}$ & 133,078 & 150,312 & 2,374 & 186,439 & 982 & 4,029 \\
\hline Unamortized Debt Expenses .............................. & 1,658 & 4,766 & 97 & 17,543 & 213 & 755 \\
\hline Extraordinary Losses, Study Cost ........................ & & & 0 & 17,361 & 704 & 0 \\
\hline Misc Debt, R \& D Exp, Unamrt Losses ......... & 108,403 & 10.144 & 0 & 3,593 & 0 & 0 \\
\hline 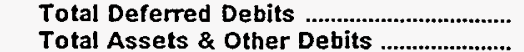 & $\begin{array}{r}110,061 \\
1,252,026\end{array}$ & $\begin{array}{r}14,910 \\
704,765\end{array}$ & $\begin{array}{r}97 \\
12,665\end{array}$ & $\begin{array}{r}38,496 \\
2,928,109\end{array}$ & $\begin{array}{r}917 \\
8,201\end{array}$ & $\begin{array}{r}755 \\
10,808\end{array}$ \\
\hline \multicolumn{7}{|l|}{ Proprietary Capital } \\
\hline 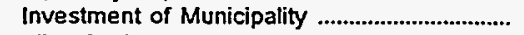 & 0 & 0 & 0 & 0 & 0 & 159 \\
\hline 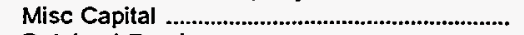 & 0 & 0 & 0 & o & 0 & 257 \\
\hline 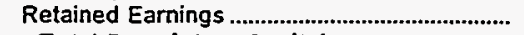 & 263,528 & 250,567 & 8.519 & 0 & 850 & 4.073 \\
\hline Total Proprietary Capital ................................. & 263,528 & 250,567 & 8,519 & 0 & 850 & 4,489 \\
\hline \multicolumn{7}{|l|}{ Long-term Debt } \\
\hline 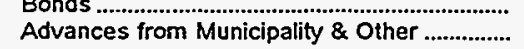 & $\begin{array}{r}833,495 \\
0\end{array}$ & $\begin{array}{r}420,144 \\
0\end{array}$ & $\begin{array}{r}2,674 \\
0\end{array}$ & $\begin{array}{r}2,697,701 \\
0\end{array}$ & $\begin{array}{r}6,430 \\
0\end{array}$ & $\begin{array}{l}0 \\
0\end{array}$ \\
\hline Unamort Prem on Long-term Debt .................... & & 173 & 0 & 2,020 & 0 & 0 \\
\hline (less) Unamort Discount on Long-term Debt & 10,344 & 9,569 & 0 & 105,847 & 0 & 0 \\
\hline 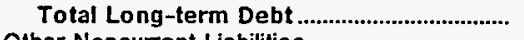 & 823,151 & 410,748 & 2,674 & $2,593,874$ & 6,430 & 0 \\
\hline \multicolumn{7}{|l|}{ Other Noncurrent Liabilities } \\
\hline 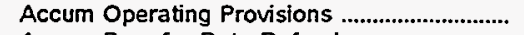 & 4,421 & 0 & 0 & 5,862 & 0 & 0 \\
\hline Accum Prov for Rate Refunds ............................ & 99,116 & 0 & 0 & & 0 & 0 \\
\hline $\begin{array}{l}\text { Total Other Noncurrent Liabilities ............. } \\
\text { Current and Accrued Liabilities }\end{array}$ & 103,537 & 0 & $\mathbf{0}$ & 5,862 & 0 & $\mathbf{0}$ \\
\hline 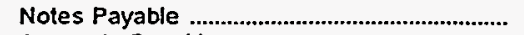 & 0 & 0 & 0 & 0 & 0 & 5,465 \\
\hline 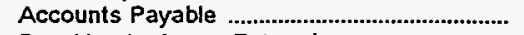 & 28,469 & 13,882 & 768 & 66,165 & 822 & 517 \\
\hline 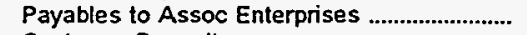 & 4,756 & 516 & 455 & 41,580 & 0 & 164 \\
\hline 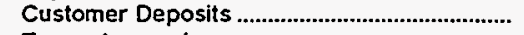 & 64 & 1.493 & -1 & 0 & 0 & 1 \\
\hline 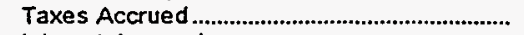 & 6,631 & 3,289 & 0 & 1,123 & 0 & 0 \\
\hline 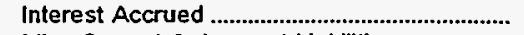 & 12,348 & 10,783 & 104 & 95 & 77 & 142 \\
\hline Misc Current \& Accrued Liabilities..................... & 8,736 & 11,249 & 146 & 29.673 & 0 & 31 \\
\hline $\begin{array}{l}\text { Total Current \& Accrued Liabilities .......... } \\
\text { Deferred Credits }\end{array}$ & 61,003 & 41,214 & 1,471 & 138,636 & 900 & 6,319 \\
\hline Customer Advances for Construction ............. & 0 & 1,118 & 0 & 0 & 2 & 0 \\
\hline Other Deferred Credits & 808 & 1,119 & 0 & 189,674 & 19 & $\mathbf{0}$ \\
\hline Unamort Gain on Reacqr Debt ......................... & 0 & 0 & 0 & 64 & 0 & 0 \\
\hline Total Deferred Credits ............................ & $\begin{array}{r}808 \\
\end{array}$ & $\begin{array}{r}2,237 \\
705\end{array}$ & $\begin{aligned} 0 \\
0\end{aligned}$ & 189,737 & 22 & \\
\hline Total Liabilities and Other Credits ............ & $1,252,026$ & 704,765 & 12,665 & $2,928,109$ & 8,201 & 10,808 \\
\hline
\end{tabular}

Note: Totals may not equal sum of components because of independent rounding.

Source: Energy Information Administration, Form ElA-412, "Annual Report of Public Electric Utilities." 
Table 22. Balance Sheet by Major U.S. Publicly Owned Electric Utility Within State at End of Period, 1995

(Thousand Dollars)

\begin{tabular}{|c|c|c|c|c|c|c|}
\hline Item & $\begin{array}{l}\text { Wisconsin } \\
\text { Kaukauna } \\
\text { City of } \\
\text { December } 31\end{array}$ & $\begin{array}{c}\text { Wisconsin } \\
\text { Manitowoc } \\
\text { Public } \\
\text { Utilities } \\
\text { December } 31\end{array}$ & $\begin{array}{c}\text { Marshifield } \\
\text { City of } \\
\text { December } 31\end{array}$ & $\begin{array}{c}\text { Menasha } \\
\text { City of } \\
\text { December } 31\end{array}$ & $\begin{array}{c}\text { Wisconsin } \\
\text { New London } \\
\text { Electric\&Water } \\
\text { Util } \\
\text { December } 31\end{array}$ & $\begin{array}{c}\text { Oconomowoc } \\
\text { City of }\end{array}$ \\
\hline \multicolumn{7}{|l|}{ Electric Utility Plant } \\
\hline 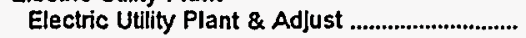 & 42,149 & 66,363 & 30,154 & 24,462 & 8,484 & 16,750 \\
\hline Const Work in Progress & 322 & 1,134 & 296 & 79 & 2 & 11 \\
\hline $\begin{array}{l}\text { (Jess) Depr, Amort, and Depletion } \\
\text { Net Electric Utility Plant }\end{array}$ & $\begin{array}{l}16,977 \\
25,494\end{array}$ & $\begin{array}{l}22,344 \\
45,153\end{array}$ & $\begin{array}{r}7,271 \\
23,179\end{array}$ & $\begin{array}{l}12,356 \\
12,185\end{array}$ & $\begin{array}{l}2,503 \\
5,984\end{array}$ & $\begin{array}{r}5,991 \\
10,770\end{array}$ \\
\hline 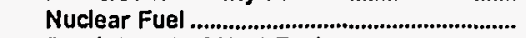 & 0 & 0 & 0 & 0 & 0 & 0 \\
\hline 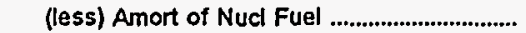 & 0 & 0 & 0 & 0 & 0 & 0 \\
\hline Net Elec Plant Incl Nucl Fuel ...................... & 25,494 & 45,153 & 23,179 & 12,185 & 5,984 & 10,770 \\
\hline \multicolumn{7}{|l|}{ Other Property \& investments } \\
\hline 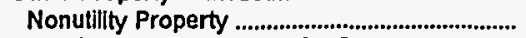 & 657 & 173 & 7,067 & 258 & 6,964 & 0 \\
\hline (less) Accum Provisions for Depr \& Amort.... & 202 & 4 & 6.135 & 0 & 1.149 & 0 \\
\hline 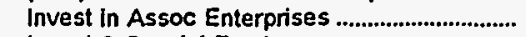 & 0 & 0 & 0 & 0 & 0 & 0 \\
\hline 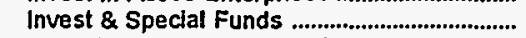 & 4.556 & 4,845 & 1,566 & 3,174 & 2,378 & 679 \\
\hline Total Other Property \& Investments ....... & 5,011 & 5,014 & 2,498 & 3,432 & 8,193 & 679 \\
\hline \multicolumn{7}{|l|}{ Current and Accrued Assets } \\
\hline Cash, Working Funds \& Investments .............. & 957 & 8,011 & 2,842 & 31 & -60 & 2,668 \\
\hline 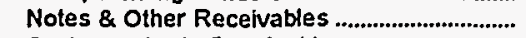 & 668 & 249 & 48 & 2 & 121 & 673 \\
\hline 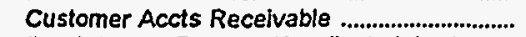 & 2,496 & 1,485 & 1,194 & 2,087 & 968 & 813 \\
\hline (less) Accum Prov for Uncollected Accts ...... & 30 & 0 & 0 & 3 & 0 & 0 \\
\hline 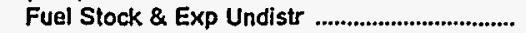 & 0 & 0 & 90 & 0 & 0 & 0 \\
\hline 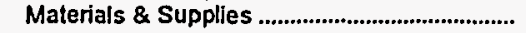 & 671 & 642 & 295 & 207 & 242 & 309 \\
\hline Other Supplies \& Misc & 0 & 0 & 0 & 0 & 0 & 0 \\
\hline 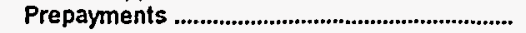 & 537 & 49 & 14 & 36 & 36 & 12 \\
\hline 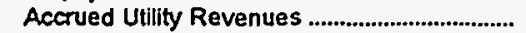 & 0 & 0 & 0 & 42 & 200 & 0 \\
\hline Miscellaneous Current \& Accrued Assets ..... & 0 & 109 & 31 & o & 23 & $\mathbf{0}$ \\
\hline $\begin{array}{l}\text { Total Current \& Accrued Assets ............... } \\
\text { Deferred Debits }\end{array}$ & 5,299 & 10,546 & 4,514 & 2,401 & 1,530 & 4,476 \\
\hline 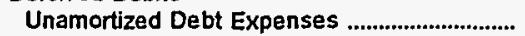 & 309 & 1,081 & 179 & 154 & 180 & 33 \\
\hline Extraordinary Losses, Study Cost..................... & 0 & 239 & 0 & 599 & 0 & 0 \\
\hline Mlsc Debt, R \& D Exp. Unamrt Losses ......... & 894 & 13 & 25 & 0 & 1,113 & 235 \\
\hline 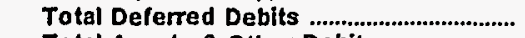 & 1,203 & 1,334 & 204 & 753 & 1,293 & 268 \\
\hline \multicolumn{6}{|l|}{ Proprietary Capital } & 16,193 \\
\hline 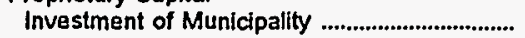 & 0 & 0 & 0 & 435 & 186 & 297 \\
\hline 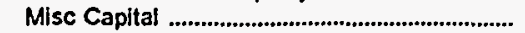 & 0 & 0 & 0 & 7,326 & 1,991 & 2,409 \\
\hline 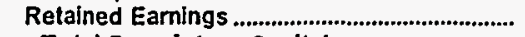 & 15,568 & 31,650 & 18,700 & 657 & 5,208 & 10,737 \\
\hline $\begin{array}{l}\text { Total Proprietary Capital ............................... } \\
\text { Long-term Debt }\end{array}$ & 15,568 & 31,650 & 18,700 & 8,418 & 7,384 & 13,443 \\
\hline 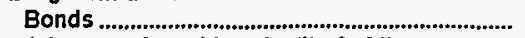 & 16,250 & 23,314 & 8,375 & 6,415 & 7,580 & 1,706 \\
\hline Advances from Municipality \& Other ................ & 0 & 4 & 0 & 625 & 95 & 0 \\
\hline Unamort Prem on Long-term Debt ..................... & 0 & 0 & 0 & 0 & 0 & 0 \\
\hline (less) Unamort Discount on Long-term Debt & 0 & 0 & 0 & 0 & 0 & 0 \\
\hline 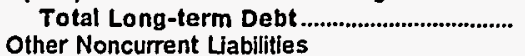 & 16,250 & 23,319 & 8,375 & 7,040 & 7,675 & 1,706 \\
\hline Accum Operating Provisions ............................. & 0 & 947 & 0 & 0 & 175 & 0 \\
\hline Accum Prov for Rate Refunds ........................... & 0 & 0 & 0 & 0 & 0 & 0 \\
\hline $\begin{array}{l}\text { Total Other Noncurrent Liabilities ............ } \\
\text { Current and Accrued Uabilities }\end{array}$ & $\mathbf{0}$ & 947 & 0 & 0 & 175 & 0 \\
\hline 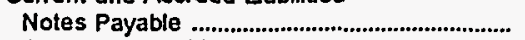 & 0 & 1,542 & 0 & 0 & 0 & o \\
\hline 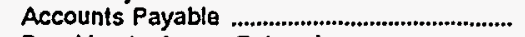 & 1,700 & 1,288 & 937 & 1,486 & 506 & 642 \\
\hline Payables to Assoc Enterprises ......................... & 0 & 0 & 180 & 0 & 181 & 0 \\
\hline Customer Deposits & 3 & 68 & 66 & 0 & 22 & 37 \\
\hline 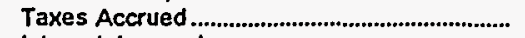 & 685 & 1,367 & 420 & 569 & 679 & 345 \\
\hline Interest Accrued & 46 & 504 & 51 & 147 & 55 & 19 \\
\hline Misc Current \& Accrued Labilities.................... & 0 & 76 & 341 & 0 & 24 & 0 \\
\hline $\begin{array}{l}\text { Total Current \& Accrued Llabilities .......... } \\
\text { Deferred Credits }\end{array}$ & 2,434 & 4,844 & 1,995 & 2,202 & 1,467 & 1,043 \\
\hline Customer Advances for Construction ............. & 2,655 & 1,274 & 1,325 & 391 & 5 & 0 \\
\hline 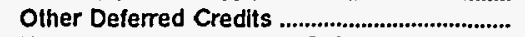 & 100 & 12 & 0 & 720 & 292 & 0 \\
\hline Unamort Galn on Reacqr Debt ......................... & 0 & 0 & 0 & 0 & 0 & 0 \\
\hline 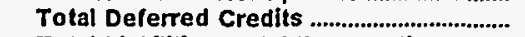 & 2,755 & 1,286 & 1,325 & 1,111 & 297 & o \\
\hline Total Liabilities and Other Credits ............ & 37,007 & 62,047 & 30,395 & 18,771 & 16,999 & 16,193 \\
\hline
\end{tabular}

Note: Totals may not equal sum of components because of independent rounding.

Source: Energy Information Administration, Form EIA-412, "Annual Report of Public Electric Utilities." 
Table 22. Balance Sheet by Major U.S. Publicly Owned Electric Utility Within State at End of Period, 1995

(Thousand Dollars)

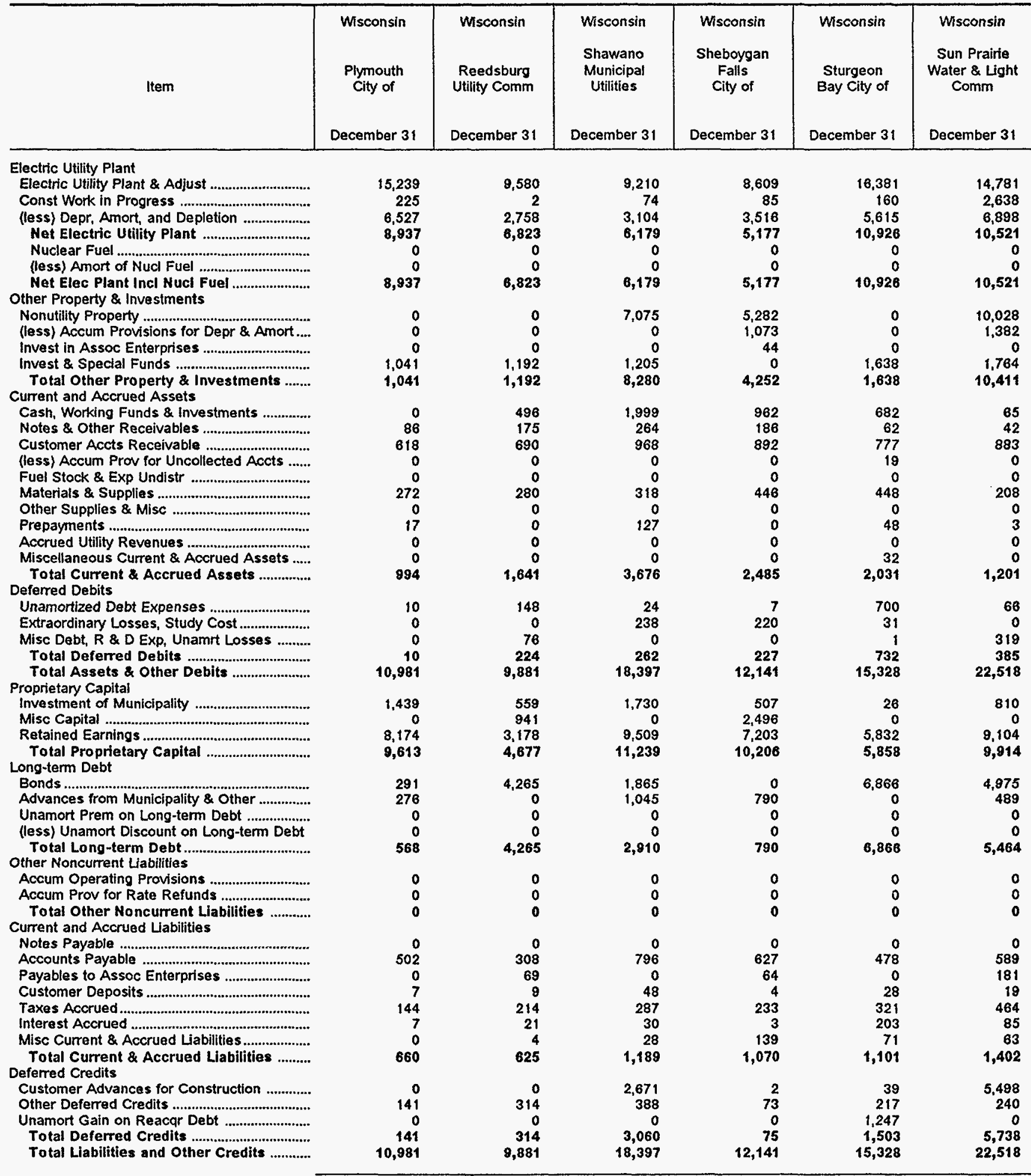

Note: Totals may not equal sum of components because of independent rounding.

Source: Energy Information Administration, Form ElA-412, "Annual Report of Public Electric Utilities." 
Table 22. Balance Sheet by Major U.S. Publicly Owned Electric Utility Within State at End of Period, 1995

(Thousand Dollars)

\begin{tabular}{|c|c|c|c|c|}
\hline ltem & $\begin{array}{l}\text { Wisconsin } \\
\text { Wisconsin } \\
\text { Public } \\
\text { Power } \\
\text { Inc Sys } \\
\text { December } 31\end{array}$ & $\begin{array}{l}\text { Wisconsin } \\
\text { Wisconsin } \\
\text { Rapids W W } \\
\& \text { L } \\
\text { Comm } \\
\text { December } 31\end{array}$ & $\begin{array}{l}\text { Gillette } \\
\text { City of } \\
\text { June } 30\end{array}$ & $\begin{array}{l}\text { Wyoming } \\
\text { Wyoming } \\
\text { Municipal } \\
\text { Power Agency } \\
\text { December } 31\end{array}$ \\
\hline \multicolumn{5}{|l|}{ Electric Utility Plant } \\
\hline 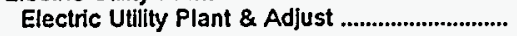 & 141,854 & 18,692 & 19,619 & 22,534 \\
\hline 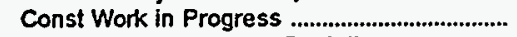 & 570 & 61 & 0 & \\
\hline $\begin{array}{l}\text { (less) Depr, Amort, and Depletion } \\
\text { Net Electric Utility Plant }\end{array}$ & $\begin{array}{r}37,271 \\
105,154\end{array}$ & $\begin{array}{r}5,845 \\
12,908\end{array}$ & $\begin{array}{l}9,714 \\
9,905\end{array}$ & $\begin{array}{r}7,999 \\
14,536\end{array}$ \\
\hline 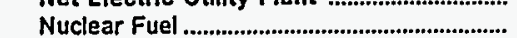 & 0 & 0 & 0 & 0 \\
\hline (less) Amort of Nucl Fuel ............................. & 0 & 0 & 0 & 0 \\
\hline 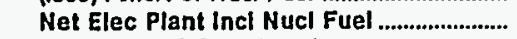 & 105,154 & 12,908 & 9,905 & 14,536 \\
\hline \multicolumn{5}{|l|}{ Other Property \& Investments } \\
\hline 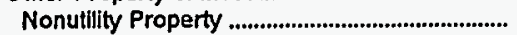 & $\mathbf{0}$ & 0 & $\mathbf{0}$ & 0 \\
\hline (less) Accum Provislons for Depr \& Amort.... & 0 & 0 & 0 & 0 \\
\hline 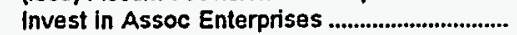 & $\mathbf{0}$ & 0 & 0 & 0 \\
\hline 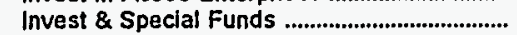 & 31,741 & 1,837 & 206 & 5,756 \\
\hline Total Other Property \& Investments ....... & 31,741 & 1,837 & 206 & 5,756 \\
\hline \multicolumn{5}{|l|}{ Current and Accrued Assets } \\
\hline Cash, Working Funds \& Investments .............. & 12,618 & 1,075 & 498 & 3,656 \\
\hline Notes \& Other Receivables ................................. & 253 & 266 & 8 & 45 \\
\hline 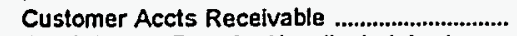 & 9,023 & 472 & 925 & 369 \\
\hline (less) Accum Prov for Uncollected Accts ....... & 0 & 0 & 81 & 0 \\
\hline 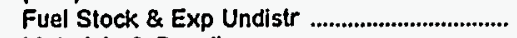 & 1.092 & 0 & 0 & 179 \\
\hline 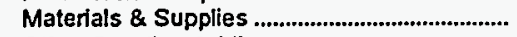 & 1,354 & 349 & 0 & 802 \\
\hline 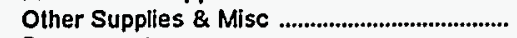 & 0 & 0 & 0 & 0 \\
\hline 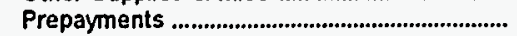 & 105 & 48 & 0 & 10 \\
\hline 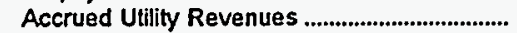 & 0 & 0 & 0 & 550 \\
\hline Miscellaneous Current \& Accrued Assets ..... & 354 & 12 & 0 & 125 \\
\hline Total Current \& Accrued Assets ............... & 24,800 & 2,222 & 1,351 & 5,736 \\
\hline \multicolumn{5}{|l|}{ Deferred Debits } \\
\hline 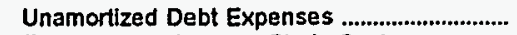 & 2,833 & 3 & 0 & 1,177 \\
\hline Extraordinary Losses, Study Cost......................... & 0 & 0 & 0 & 241 \\
\hline Misc Debt, R \& D Exp, Unamrt Losses ......... & 30,020 & 44 & 0 & 360 \\
\hline 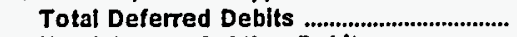 & 32,853 & 47 & 0 & 1,778 \\
\hline Total Assets \& Other Debits ........................ & 194,548 & 17,013 & 11,462 & 27,806 \\
\hline \multicolumn{5}{|l|}{ Propretary Capital } \\
\hline 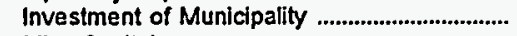 & $\mathbf{0}$ & 675 & 0 & 0 \\
\hline 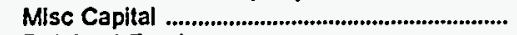 & $\mathbf{0}$ & $\mathbf{0}$ & 0 & 0 \\
\hline 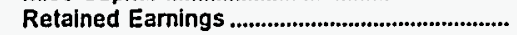 & 11,260 & 11,419 & 10,345 & 7,818 \\
\hline Total Proprietary Capital ................................... & 11,260 & 12,094 & 10,345 & 7,818 \\
\hline \multicolumn{5}{|l|}{ Long-term Debt } \\
\hline 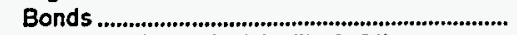 & 162,495 & 0 & 0 & 18,230 \\
\hline Advances from Municipality \& Other ................ & 0 & 526 & 0 & 0 \\
\hline Unamort Prem on Long-term Debt ................. & 0 & 0 & 0 & 0 \\
\hline (less) Unamort Discount on Long-tem Debt & 3,350 & 0 & 0 & 0 \\
\hline 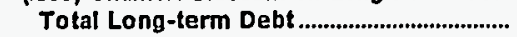 & 159,145 & 526 & $\mathbf{0}$ & 18,230 \\
\hline \multicolumn{5}{|l|}{ Other Noncurrent Labilities } \\
\hline Accum Operating Provislons ............................ & 3,777 & 0 & 0 & 0 \\
\hline Accum Prov for Rate Refunds ......................... & 0 & 0 & 0 & 0 \\
\hline Total Other Noncurrent Liabilities ........... & 3,777 & $\mathbf{0}$ & $\mathbf{0}$ & $\mathbf{0}$ \\
\hline \multicolumn{5}{|l|}{ Current and Accrued Liabilities } \\
\hline 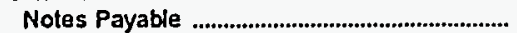 & 0 & 0 & 0 & 0 \\
\hline 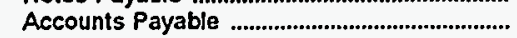 & 9,658 & 396 & 0 & 423 \\
\hline 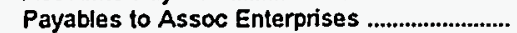 & 0 & 92 & 755 & 0 \\
\hline 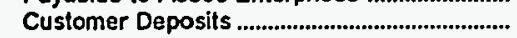 & 0 & 17 & 204 & 0 \\
\hline 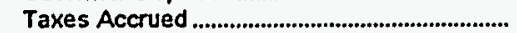 & 1,700 & 365 & 0 & 0 \\
\hline 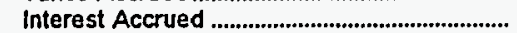 & 3,519 & 7 & 0 & 551 \\
\hline Mlsc Current \& Accrued Labilities.................... & 3,556 & 317 & 159 & 784 \\
\hline Total Current \& Accrued Llabilities .......... & 18,434 & 1,194 & 1,117 & 1,758 \\
\hline \multicolumn{5}{|l|}{ Deferred Credits } \\
\hline Customer Advances for Construction .............. & 0 & 18 & 0 & 0 \\
\hline 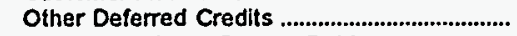 & 1,933 & 3,181 & 0 & 0 \\
\hline Unamort Gain on Reacqr Debt ........................... & 0 & 0 & 0 & 0 \\
\hline 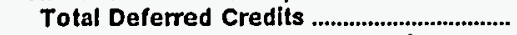 & 1,933 & 3,199 & $\mathbf{0}$ & $\mathbf{0}$ \\
\hline Total Liabifities and Other Credits ............ & 194,548 & 17,013 & 11,462 & 27,806 \\
\hline
\end{tabular}

Note: Totals may not equal sum of components because of independent rounding.

Source: Energy Information Administration, Form EIA-412, "Annual Report of Public Electric Utilities." 
Table 23. Electric Operation and Maintenance Expenses by Major U.S. Publicly Owned Electric Utility Within State, 1995 (Thousand Dollars)

\begin{tabular}{|c|c|c|c|c|c|c|}
\hline Item & $\begin{array}{l}\text { Alabama } \\
\text { Alabama } \\
\text { Municipal } \\
\text { Elec Auth } \\
\text { September } 30\end{array}$ & $\begin{array}{l}\text { Alabama } \\
\text { Albertville } \\
\text { Municipal } \\
\text { Utils Bd } \\
\text { June } 30\end{array}$ & $\begin{array}{l}\text { Alabama } \\
\text { Andalusia } \\
\text { City of } \\
\text { September } 30\end{array}$ & $\begin{array}{l}\text { Alabama } \\
\text { Athens } \\
\text { City of } \\
\text { December } 31\end{array}$ & $\begin{array}{l}\text { Alabama } \\
\text { Bessemer } \\
\text { City of } \\
\text { June } 30\end{array}$ & $\begin{array}{c}\text { Alabama } \\
\text { Cullman } \\
\text { Power Board } \\
\text { June } 30\end{array}$ \\
\hline \multicolumn{7}{|l|}{ Production Expenses } \\
\hline 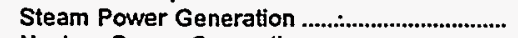 & 0 & 0 & 0 & $\mathbf{0}$ & 0 & 0 \\
\hline Nuclear Power Generation ........................................ & 0 & 0 & 0 & 0 & 0 & 0 \\
\hline 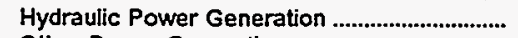 & 0 & 0 & 0 & 0 & 0 & 0 \\
\hline 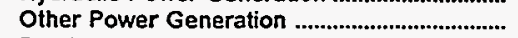 & 0 & $\mathbf{0}$ & 0 & $\mathbf{0}$ & 0 & 0 \\
\hline 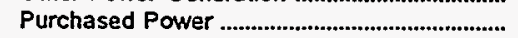 & 68,980 & 17,856 & 11,832 & 31,359 & 13,968 & 14,424 \\
\hline Other Production Expenses ..................................... & 0 & 0 & 0 & 0 & 0 & 0 \\
\hline Total Production Expenses ............................ & 68,980 & 17,856 & 11,832 & 31,359 & 13,968 & 14,424 \\
\hline Transmission Expenses....................................... & 2,116 & 0 & 0 & 265 & 0 & 0 \\
\hline Distribution Expenses & 0 & 910 & 83 & 1,550 & 1,295 & 547 \\
\hline $\begin{array}{l}\text { Customer Accounts Expenses ............................. } \\
\text { Customer Senvice and Information }\end{array}$ & 0 & 309 & 562 & 592 & 317 & 401 \\
\hline 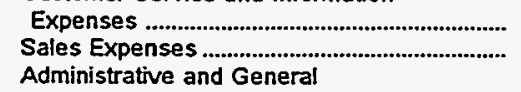 & $\begin{array}{l}0 \\
0\end{array}$ & $\begin{array}{l}33 \\
25\end{array}$ & $\begin{array}{l}0 \\
0\end{array}$ & $\begin{array}{l}24 \\
27\end{array}$ & $\begin{array}{r}16 \\
0\end{array}$ & $\begin{array}{l}36 \\
21\end{array}$ \\
\hline Expenses & 1,110 & 424 & 95 & 750 & 867 & 518 \\
\hline 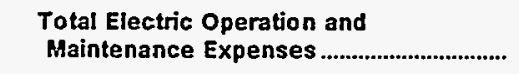 & 72,206 & 19,558 & 12,572 & 34,567 & 16,462 & 15,947 \\
\hline \multicolumn{7}{|l|}{ Fuel Expenses in Operation } \\
\hline Steam Power Generation ................................... & 0 & 0 & 0 & 0 & 0 & 0 \\
\hline Nuclear Power Generation ................................ & 0 & 0 & 0 & 0 & 0 & 0 \\
\hline Other Power Generation ................................... & 0 & 0 & 0 & 0 & 0 & 0 \\
\hline & & & & & & \\
\hline \multicolumn{7}{|l|}{ Number of Elec Dept Employees } \\
\hline 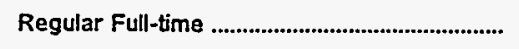 & 5 & 31 & 0 & 67 & 32 & 22 \\
\hline 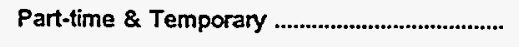 & 0 & 0 & 0 & 0 & 0 & 0 \\
\hline 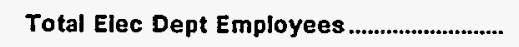 & 5 & 31 & 0 & 67 & 32 & 22 \\
\hline
\end{tabular}

Note: Totals may not equal sum of components because of independent rounding.

Source: Energy Information Administration, Form EIA-412, "Annual Report of Public Electric Utilities." 
Table 23. Electric Operation and Maintenance Expenses by Major U.S. Publicly Owned Electric Utility Within State, 1995 (Continued) (Thousand Dollars)

\begin{tabular}{|c|c|c|c|c|c|c|}
\hline Ilem & $\begin{array}{l}\text { Alabama } \\
\text { Decatur } \\
\text { City of } \\
\text { June } 30\end{array}$ & $\begin{array}{l}\text { Alabama } \\
\text { Dothan } \\
\text { City of } \\
\text { September } 30\end{array}$ & $\begin{array}{l}\text { Alabama } \\
\text { Florence } \\
\text { City of } \\
\text { June } 30\end{array}$ & $\begin{array}{c}\text { Alabama } \\
\text { Foley } \\
\text { City of } \\
\text { (Riviera Utils) } \\
\text { December } 31\end{array}$ & $\begin{array}{l}\text { Alabama } \\
\text { Fort Payne } \\
\text { Improvement } \\
\text { Auth } \\
\text { June } 30\end{array}$ & $\begin{array}{l}\text { Alabama } \\
\text { Guntersville } \\
\text { Electric } \\
\text { Board } \\
\text { June } 30\end{array}$ \\
\hline 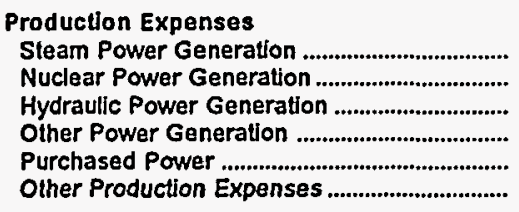 & $\begin{array}{r}0 \\
0 \\
0 \\
0 \\
54,262 \\
0\end{array}$ & $\begin{array}{r}0 \\
0 \\
0 \\
0 \\
37,864 \\
0\end{array}$ & $\begin{array}{r}0 \\
0 \\
0 \\
0 \\
48,127 \\
0\end{array}$ & $\begin{array}{r}0 \\
0 \\
0 \\
0 \\
23,801 \\
0\end{array}$ & $\begin{array}{r}0 \\
0 \\
0 \\
0 \\
14.796 \\
0\end{array}$ & $\begin{array}{r}0 \\
0 \\
0 \\
0 \\
10,073 \\
0\end{array}$ \\
\hline Total Production Expenses .............................. & 54,262 & 37,864 & 48,127 & 23,801 & 14,798 & 10,073 \\
\hline $\begin{array}{l}\text { Transmission Expenses ......................................... } \\
\text { Dlstribution Expenses ..................................... } \\
\text { Customer Accounts Expenses ........................ } \\
\text { Customer Service and Information }\end{array}$ & $\begin{array}{r}0 \\
1,509 \\
469\end{array}$ & $\begin{array}{r}0 \\
1,275 \\
0\end{array}$ & $\begin{array}{r}489 \\
3,167 \\
907\end{array}$ & $\begin{array}{r}217 \\
1,314 \\
488\end{array}$ & $\begin{array}{r}0 \\
796 \\
220\end{array}$ & $\begin{array}{r}0 \\
508 \\
218\end{array}$ \\
\hline 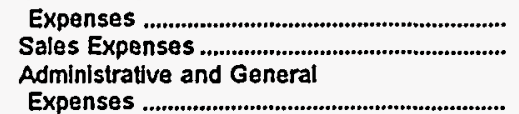 & $\begin{array}{r}52 \\
24 \\
752\end{array}$ & $\begin{array}{l}0 \\
0\end{array}$ & $\begin{array}{r}103 \\
50\end{array}$ & $\begin{array}{l}22 \\
49\end{array}$ & $\begin{array}{r}18 \\
15 \\
332\end{array}$ & $\begin{array}{l}10 \\
23\end{array}$ \\
\hline $\begin{array}{l}\text { Total Electric Operation and } \\
\text { Maintenance Expenses.................................. }\end{array}$ & 57,069 & 40,012 & 55,119 & 27,437 & 16,177 & 11,134 \\
\hline \multicolumn{7}{|l|}{ Fuel Expenses in Operation } \\
\hline 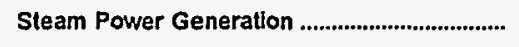 & 0 & 0 & 0 & $\mathbf{0}$ & 0 & 0 \\
\hline 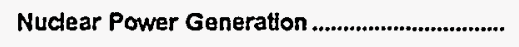 & 0 & 0 & 0 & 0 & 0 & 0 \\
\hline 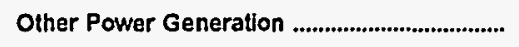 & 0 & 0 & 0 & 0 & 0 & 0 \\
\hline \multicolumn{7}{|l|}{ Number of Elec Dept Employees } \\
\hline Regular Full-time & 60 & 94 & 158 & 121 & 23 & 23 \\
\hline 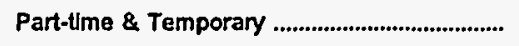 & 0 & 2 & 0 & 0 & 0 & 0 \\
\hline 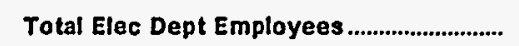 & 60 & 96 & 158 & 121 & 23 & 23 \\
\hline
\end{tabular}

Note: Totals may not equal sum of components because of independent rounding.

Source: Energy Information Administration, Form EIA-4 12, "Annual Report of Public Electric Utilities." 
Table 23. Electric Operation and Maintenance Expenses by Major U.S. Publicly Owned Electric Utility Within State, 1995 (Continued) (Thousand Dollars)

\begin{tabular}{|c|c|c|c|c|c|c|}
\hline Hem & $\begin{array}{l}\text { Alabama } \\
\text { Hartselle } \\
\text { City of } \\
\text { June } 30\end{array}$ & $\begin{array}{c}\text { Alabama } \\
\begin{array}{c}\text { Huntsville } \\
\text { City of }\end{array} \\
\text { September } 30\end{array}$ & $\begin{array}{l}\text { Alabama } \\
\text { Muscle } \\
\text { Shoals } \\
\text { City of } \\
\text { June } 30\end{array}$ & $\begin{array}{l}\text { Alabama } \\
\text { Opelika } \\
\text { City of } \\
\text { September } 30\end{array}$ & $\begin{array}{l}\text { Alabama } \\
\text { Scottsboro } \\
\text { City of } \\
\text { June } 30\end{array}$ & $\begin{array}{l}\text { Alabama } \\
\text { Sheffield } \\
\text { Utilities } \\
\text { June } 30\end{array}$ \\
\hline \multicolumn{7}{|l|}{ Production Expenses } \\
\hline 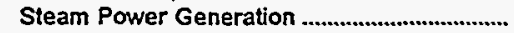 & 0 & 0 & 0 & 0 & 0 & $\mathbf{0}$ \\
\hline 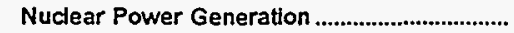 & 0 & 0 & 0 & 0 & $\mathbf{0}$ & 0 \\
\hline Hydraulic Power Generation ............................... & 0 & 0 & 0 & 0 & 0 & 0 \\
\hline 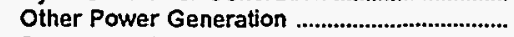 & 0 & 0 & 0 & 0 & 0 & 0 \\
\hline 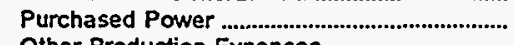 & 6,169 & 168,959 & 9,246 & 11,974 & 14,536 & 18,671 \\
\hline 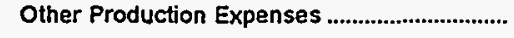 & 0 & 0 & 0 & 0 & 0 & 0 \\
\hline Total Production Expenses ............................ & 6,169 & 168,959 & 9,246 & 11,974 & 14,536 & 18,671 \\
\hline $\begin{array}{l}\text { Transmission Expenses } \\
\text { Distribution Expenses }\end{array}$ & $\begin{array}{r}0 \\
368\end{array}$ & $\begin{array}{r}78 \\
5,558\end{array}$ & $\begin{array}{r}0 \\
620\end{array}$ & $\begin{array}{r}0 \\
701\end{array}$ & $\begin{array}{r}0 \\
1.155\end{array}$ & $\begin{array}{r}21 \\
1,919\end{array}$ \\
\hline $\begin{array}{l}\text { Customer Accounts Expenses } \\
\text { Customer Service and Information }\end{array}$ & 125 & 1,899 & 143 & 0 & $\begin{array}{r}1,150 \\
355\end{array}$ & 568 \\
\hline Expenses & 6 & 221 & 40 & 0 & 27 & 21 \\
\hline 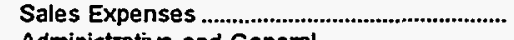 & 10 & 114 & 0 & 0 & 11 & 44 \\
\hline Administrative and General & & & & & & \\
\hline 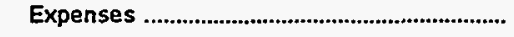 & 254 & 2,528 & 339 & 736 & 426 & 1,143 \\
\hline $\begin{array}{l}\text { Total Electric Operation and } \\
\text { Maintenance Expenses ................................. }\end{array}$ & 6,933 & 179,358 & 10,388 & 13,411 & 16,509 & 22,389 \\
\hline \multicolumn{7}{|l|}{ Fuel Expenses in Operation } \\
\hline 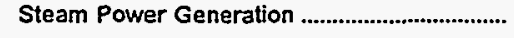 & 0 & 0 & 0 & 0 & 0 & 0 \\
\hline 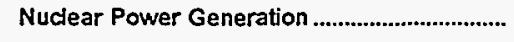 & 0 & 0 & 0 & 0 & 0 & $\mathbf{0}$ \\
\hline Other Power Generation & 0 & 0 & 0 & 0 & 0 & 0 \\
\hline \multicolumn{7}{|l|}{ Number of Elec Dept Employees } \\
\hline Regular Full-time & 0 & 249 & 22 & 32 & 31 & 63 \\
\hline 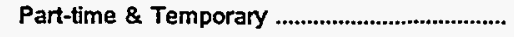 & 0 & 0 & 0 & 0 & 0 & 0 \\
\hline 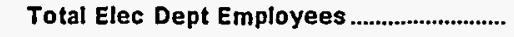 & $\mathbf{0}$ & 249 & 22 & 32 & 31 & 63 \\
\hline
\end{tabular}

Note: Tolals may not equal sum of components because of independent rounding.

Source: Energy Information Administration, Form ElA-412. "Annual Report of Public Electric Utilities." 
Table 23. Electric'Operation and Maintenance Expenses by Major U.S. Publicly Owned Electric Utility Within State, 1995 (Continued) (Thousand Dollars)

\begin{tabular}{|c|c|c|c|c|c|c|}
\hline Item & $\begin{array}{c}\text { Alabama } \\
\text { Sylacauga } \\
\text { Utilities } \\
\text { Board } \\
\text { September } 30\end{array}$ & $\begin{array}{c}\text { Alabama } \\
\text { Troy } \\
\text { City of } \\
\text { September } 30\end{array}$ & $\begin{array}{l}\text { Alabama } \\
\text { Tuskegee } \\
\text { City of } \\
\text { September } 30\end{array}$ & $\begin{array}{l}\text { Alaska } \\
\text { Alaska } \\
\text { Energy } \\
\text { Authority } \\
\text { June } 30\end{array}$ & $\begin{array}{c}\text { Alaska } \\
\text { Anchorage } \\
\text { City of } \\
\text { December } 31\end{array}$ & $\begin{array}{l}\text { Alaska } \\
\text { Fairbanks } \\
\text { City of } \\
\text { December } 31\end{array}$ \\
\hline 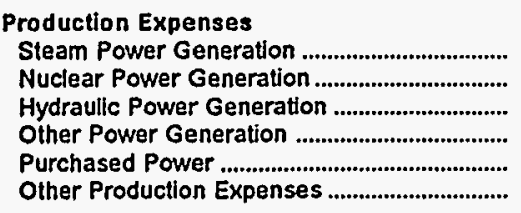 & $\begin{array}{r}0 \\
0 \\
0 \\
0 \\
6,368 \\
0\end{array}$ & $\begin{array}{r}0 \\
0 \\
0 \\
0 \\
8.220 \\
0\end{array}$ & $\begin{array}{r}0 \\
0 \\
0 \\
0 \\
6.079 \\
0\end{array}$ & $\begin{array}{r}0 \\
0 \\
1,465 \\
29 \\
0 \\
509\end{array}$ & $\begin{array}{r}1,869 \\
0 \\
0 \\
20,868 \\
5,090 \\
879\end{array}$ & $\begin{array}{r}8,674 \\
0 \\
0 \\
0 \\
1,313 \\
0\end{array}$ \\
\hline Total Production Expenses .......................... & 6,368 & 8,220 & 6,079 & 2,003 & 28,705 & 9,987 \\
\hline 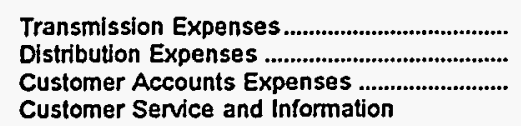 & $\begin{array}{r}0 \\
932 \\
140\end{array}$ & $\begin{array}{r}0 \\
463 \\
0\end{array}$ & $\begin{array}{l}0 \\
0 \\
0\end{array}$ & $\begin{array}{r}1,142 \\
0 \\
0\end{array}$ & $\begin{array}{r}549 \\
5,608 \\
2,781\end{array}$ & $\begin{array}{r}0 \\
975 \\
0\end{array}$ \\
\hline 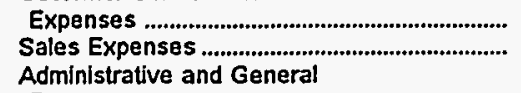 & $\begin{array}{r}19 \\
0\end{array}$ & $\begin{array}{r}495 \\
0\end{array}$ & $\begin{array}{l}0 \\
0\end{array}$ & $\begin{array}{l}0 \\
0\end{array}$ & $\begin{array}{r}136 \\
0\end{array}$ & $\begin{array}{l}0 \\
0\end{array}$ \\
\hline 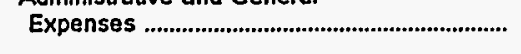 & 685 & 601 & 1,691 & 1,959 & 3,426 & 918 \\
\hline 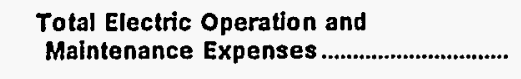 & 8,145 & 9,779 & 7,770 & 5,104 & 41,206 & 11,880 \\
\hline \multicolumn{7}{|l|}{ Fuel Expenses in Operation } \\
\hline Steam Power Generation ..................................... & 0 & 0 & 0 & 0 & 0 & 0 \\
\hline Nuclear Power Generation ................................... & 0 & 0 & 0 & 0 & 0 & 0 \\
\hline 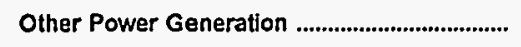 & 0 & 0 & 0 & 0 & 17,263 & 0 \\
\hline \multicolumn{7}{|l|}{ Number of Elec Dept Employees } \\
\hline 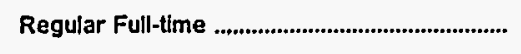 & 25 & 0 & 25 & 4 & 208 & 41 \\
\hline Part-time \& Temporary ..................................... & 1 & 0 & 0 & 1 & 17 & 3 \\
\hline Totat Elec Dept Employees .............................. & 26 & $\mathbf{0}$ & 25 & 5 & 225 & 44 \\
\hline
\end{tabular}

Note: Totals may not equal sum of components because of independent rounding.

Source: Energy Information Administration, Form EIA-412, "Annual Report of Public Electric Utilities." 
Table 23. Electric Operation and Maintenance Expenses by Major U.S. Publicly Owned Electric Utility Within State, 1995 (Continued) (Thousand Dollars)

\begin{tabular}{|c|c|c|c|c|c|c|}
\hline Item & $\begin{array}{l}\text { Alaska } \\
\text { Ketchikan } \\
\text { City of } \\
\text { December } 31\end{array}$ & $\begin{array}{l}\text { Arizona } \\
\text { Arizona } \\
\text { Power } \\
\text { Authority } \\
\text { June } 30\end{array}$ & $\begin{array}{c}\text { Arizona } \\
\text { Electrical } \\
\text { Dist } \\
\text { No2 } \\
\text { Pinal Cnty } \\
\text { December } 31\end{array}$ & $\begin{array}{l}\text { Arizona } \\
\text { Mesa } \\
\text { City of } \\
\text { June } 30\end{array}$ & $\begin{array}{l}\text { Arizona } \\
\text { Navajo } \\
\text { Tribal } \\
\text { Utility } \\
\text { Auth } \\
\text { December } 31\end{array}$ & $\begin{array}{l}\text { Arizona } \\
\text { Salt River } \\
\text { Proj Ag } \\
\text { I \& P Dist } \\
\text { April } 30\end{array}$ \\
\hline \multicolumn{7}{|l|}{ Production Expenses } \\
\hline Steam Power Generation ........................................ & 0 & 0 & 0 & 0 & 0 & 274,751 \\
\hline 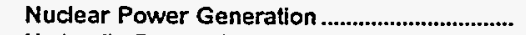 & 0 & 0 & 0 & 0 & 0 & 83,352 \\
\hline Hydraulic Power Generation ................................. & 776 & 0 & 0 & 0 & 0 & 10,780 \\
\hline 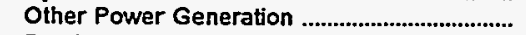 & 2,548 & 0 & 0 & 0 & 0 & 11,539 \\
\hline 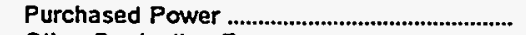 & 3.825 & 15,065 & 5,945 & 13,939 & 20,193 & 151,701 \\
\hline 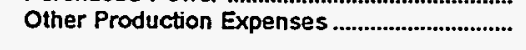 & & 0 & 0 & 0 & 0 & 3,230 \\
\hline 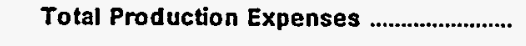 & 7,150 & 15,065 & 5,945 & 13,939 & 20,193 & 535,352 \\
\hline 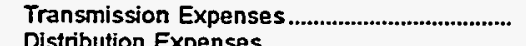 & $\begin{array}{r}19 \\
1905\end{array}$ & 3,280 & 0 & 0 & 341 & 12,600 \\
\hline 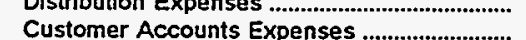 & $\begin{array}{r}1,025 \\
0\end{array}$ & $\stackrel{0}{0}$ & 669 & 2,678 & 3,308 & 40,573 \\
\hline Customer Service and Information & & 0 & 191 & 0 & 1,641 & 22,533 \\
\hline 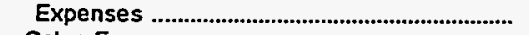 & 170 & 0 & 0 & 455 & 3 & 7,285 \\
\hline 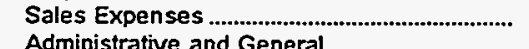 & 0 & 0 & 0 & 75 & 90 & 3,390 \\
\hline 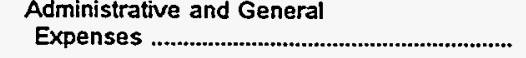 & 1,294 & 926 & 482 & 1,074 & 4,137 & 109,962 \\
\hline Total Electric Operation and & & & & & & \\
\hline 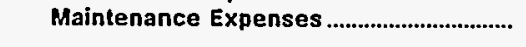 & 9,657 & 19,271 & 7,288 & 18,222 & 29,713 & 731,695 \\
\hline \multicolumn{7}{|l|}{ Fuel Expenses in Operation } \\
\hline 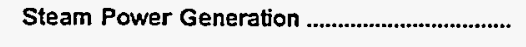 & 0 & 0 & 0 & 0 & 0 & 211,147 \\
\hline 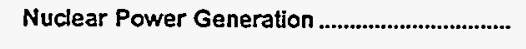 & 0 & 0 & 0 & 0 & 0 & 24,857 \\
\hline 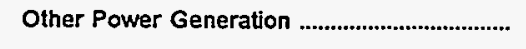 & 0 & 0 & 0 & 0 & 0 & 6,745 \\
\hline \multicolumn{7}{|l|}{ Number of Elec Dept Employees } \\
\hline 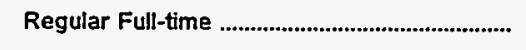 & 42 & 0 & 20 & 55 & 98 & 3,781 \\
\hline 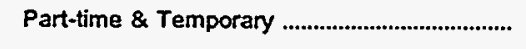 & 2 & 0 & 0 & 1 & 0 & 140 \\
\hline Total Elec Dept Employees .............................. & 44 & 0 & 20 & 56 & 98 & 3,921 \\
\hline
\end{tabular}

Note: Totals may not equal sum of components because of independent rounding

Source: Energy Information Administration, Form ElA-412, "Annual Report of Public Electric Utilities." 
Table 23. Electric Operation and Maintenance Expenses by Major U.S. Publicly Owned Electric Utility Within State, 1995 (Continued)

(Thousand Dollars)

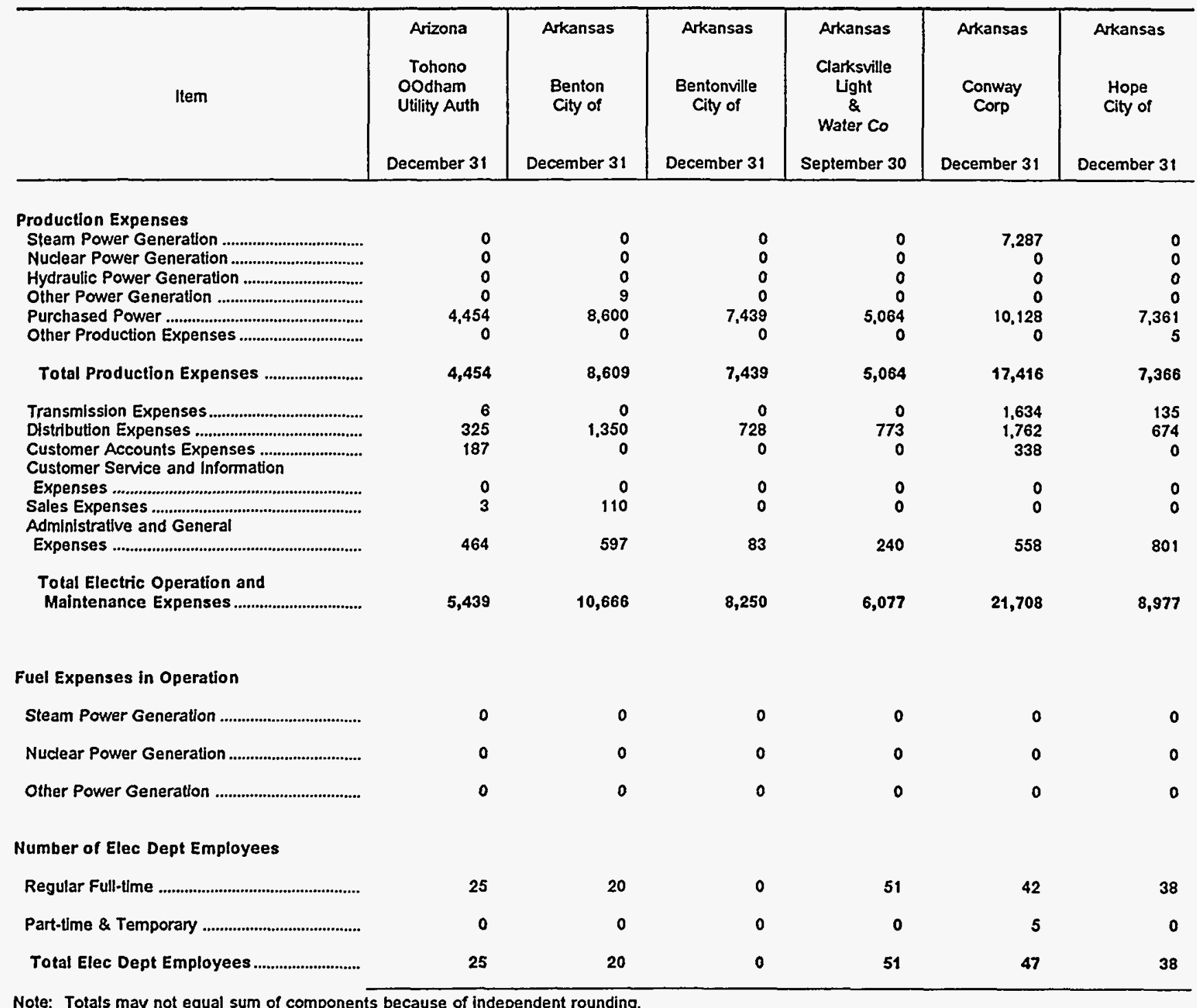

Note: Totals may not equal sum of components because of independent rounding.

Source: Energy Information Administration, Form ElA-412, "Annual Report of Public Electric Utilities." 
Table 23. Electric Operation and Maintenance Expenses by Major U.S. Publicly Owned Electric Utility Within State, 1995 (Continued)

(Thousand Dollars)

\begin{tabular}{|c|c|c|c|c|c|c|}
\hline Item & $\begin{array}{l}\text { Arkansas } \\
\text { Jonesboro } \\
\text { City of } \\
\text { December } 31\end{array}$ & $\begin{array}{l}\text { Arkansas } \\
\text { North } \\
\text { Little } \\
\text { Rock } \\
\text { City of } \\
\text { December } 31\end{array}$ & $\begin{array}{l}\text { Arkansas } \\
\text { Osceola } \\
\text { City of } \\
\text { December } 31\end{array}$ & $\begin{array}{l}\text { Arkansas } \\
\text { Paragould } \\
\text { Light } \\
\&\end{array}$ & $\begin{array}{l}\text { Arkansas } \\
\text { Siloam } \\
\text { Springs } \\
\text { City of } \\
\text { December } 31\end{array}$ & $\begin{array}{c}\text { Arkansas } \\
\text { West } \\
\text { Memphis } \\
\text { City of }\end{array}$ \\
\hline
\end{tabular}

Production Expenses

Steam Power Generation

Never Power Generation

Hydraulic Power Generation

Other Power Generation

Purchased Power ...

Total Production Expenses

Transmission Expenses.

Distribution Expenses

Customer Accounts Expenses ..........................

Customer Service and Information

Expenses.

Sales Expenses

Administrative and General

Expenses

Total Electric Operation and

Maintenance Expenses.

Fuel Expenses in Operation

Steam Power Generation

3,972

Nuclear Power Generation

Other Power Generation

Number of Elec Dept Employees

Regular Full-time

101

Part-time \& Temporary

Total Elec Dept Employees

9.047
0
0
0
11.284
0

$$
\begin{array}{r}
0 \\
0 \\
0 \\
579 \\
31,777 \\
0
\end{array}
$$

0
0
0
0
5.841
129

32,356

2.168

1,209

20

1,209

0

1,261

24,980

39,235

5,969

0

610

0

0

1,964

8,544

0
0
0
0
6,389
0

457

0
0
0
40
9.498
0

6,389

0
1,108
0

0
1,667

280

0

449

11,934

00

0

0

\begin{abstract}
97
\end{abstract}
38

0

38

97

33

33

21

16

0

16

Note: Totals may not equal sum of components because of independent rounding.

Source: Energy Information Administration, Form ElA-412, "Annual Report of Public Electric Utilities." 
Table 23. Electric Operation and Maintenance Expenses by Major U.S. Publicly Owned Electric Utility Within State, 1995 (Continued)

(Thousand Dollars)

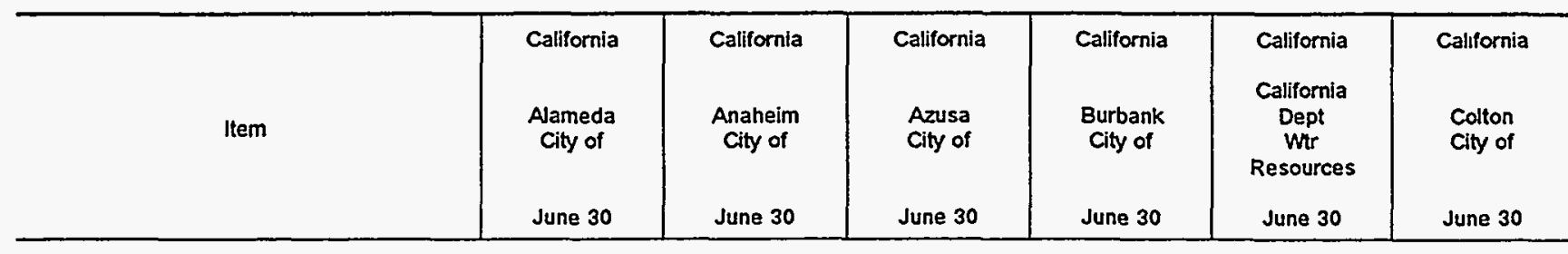

Production Expenses

Steam Power Generation.

Nuclear Power Generation

Hydraulle Power Ger

Other Power Generation .

Purchased Power

Production Expenses

Total Production Expenses ..........................

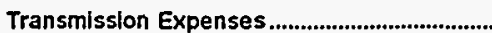

Distribution Expenses ..............................................

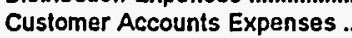

Customer Senvice and Information

Expenses

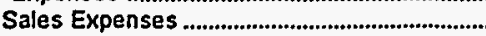

Administrative and General

Expenses

31.749
376

32,125

\section{1,267}

1,267
1,082

223

223
25

4,087

Total Electric Operation and

Maintenance Expenses

Fuel Expenses in Operation

Steam Power Generation

Nuclear Power Generation

Other Power Generation

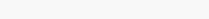

Number of Elec Dept Employees

Regular Fuil-time .............................................

Part-time \& Temporary .

88

252

4

92

47

299

183,328 $\mathbf{0}$

0
Total Elec Dept Employees ............................

14.918
0
0
0
43,598
0

58,516

6,621

6,973

2,268

$$
\begin{aligned}
& \mathbf{0} \\
& \mathbf{0}
\end{aligned}
$$

6,072

80,450

19,090

1,079
0
11,269
37,427
0
0

49,775

o

0
0

0

0

$\mathbf{0}$

49,775

is because of independent rounding

Note: Totals may not equal sum of components

Source: Energy Information Administration, Form ElA-412, "Annual Report of Public Electric Utilities." 
Table 23. Electric Operation and Maintenance Expenses by Major U.S. Publicly Owned Electric Utility Within State, 1995 (Continued)

(Thousand Dollars)

\begin{tabular}{|c|c|c|c|c|c|c|}
\hline Item & $\begin{array}{c}\text { California } \\
\text { East Bay } \\
\text { Municipal } \\
\text { Util } \\
\text { Dist } \\
\text { December } 31\end{array}$ & $\begin{array}{l}\text { California } \\
\text { Glendale } \\
\text { City of } \\
\text { June } 30\end{array}$ & $\begin{array}{c}\text { California } \\
\text { Imperial } \\
\text { Imigation } \\
\text { District } \\
\text { December } 31\end{array}$ & $\begin{array}{c}\text { California } \\
\text { Kings River } \\
\text { Conservation } \\
\text { Dist } \\
\text { June } 30\end{array}$ & $\begin{array}{l}\text { California } \\
\text { Lassen } \\
\text { Municipal } \\
\text { Utility Dist } \\
\text { June } 30\end{array}$ & $\begin{array}{l}\text { California } \\
\text { Lodi } \\
\text { City of } \\
\text { June } 30\end{array}$ \\
\hline \multicolumn{7}{|l|}{ Production Expenses } \\
\hline 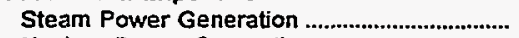 & 0 & 10,355 & 16,204 & 0 & 0 & $\mathbf{0}$ \\
\hline Nuclear Power Generation ................................... & 0 & 0 & 0 & 0 & 0 & 0 \\
\hline 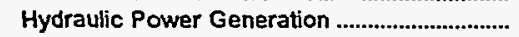 & 0 & 0 & 5,727 & 4.691 & 0 & 0 \\
\hline 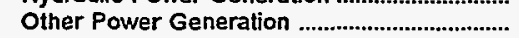 & 0 & 1,290 & 641 & 0 & 0 & 0 \\
\hline Purchased Power & 0 & 37,860 & 87,584 & 0 & 6.340 & 22,383 \\
\hline Other Production Expenses ................................... & 0 & 5,755 & 835 & 0 & 0 & 1,150 \\
\hline Total Production Expenses ........................ & 0 & 55,260 & 110,991 & 4,691 & 6,340 & 23,533 \\
\hline 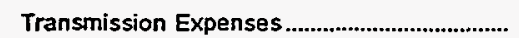 & 0 & 1,284 & 3,362 & 0 & 8 & $\mathbf{0}$ \\
\hline 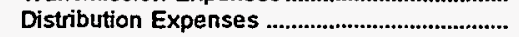 & 0 & 5,475 & 10,548 & 0 & 709 & 1,766 \\
\hline $\begin{array}{l}\text { Customer Accounts Expenses ........................ } \\
\text { Customer Service and Information }\end{array}$ & 0 & 3,021 & 4,095 & 0 & 255 & 743 \\
\hline 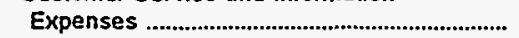 & 0 & 0 & 0 & $\mathbf{0}$ & 139 & $\mathbf{0}$ \\
\hline Sales Expenses & 0 & 0 & 0 & 0 & 0 & 0 \\
\hline \multicolumn{7}{|l|}{ Administrative and General } \\
\hline Expenses & 0 & 8,831 & 14,878 & 0 & 1,362 & 1.611 \\
\hline $\begin{array}{l}\text { Total Electric Operation and } \\
\text { Maintenance Expenses................................. }\end{array}$ & 0 & 73,871 & 143,875 & 4,691 & 8,813 & 27,654 \\
\hline \multicolumn{7}{|l|}{ Fuel Expenses in Operation } \\
\hline 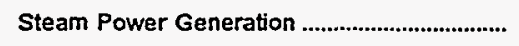 & 0 & 0 & 9,824 & 0 & 0 & 0 \\
\hline Nuclear Power Generation ................................... & 0 & 0 & 0 & 0 & 0 & 0 \\
\hline 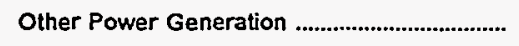 & 0 & 0 & 53 & 0 & 0 & $\mathbf{0}$ \\
\hline \multicolumn{7}{|l|}{ Number of Elec Dept Employees } \\
\hline Regular Full-time & 0 & 0 & 0 & 0 & 17 & 38 \\
\hline 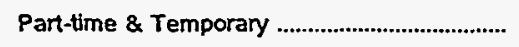 & 0 & 0 & 0 & 0 & 0 & 0 \\
\hline 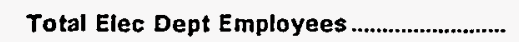 & 0 & 0 & 0 & 0 & 17 & 38 \\
\hline
\end{tabular}

Note: Totals may not equal sum of components because of independent rounding.

Source: Energy Information Administration, Form EIA-412, "Annual Report of Public Electric Utilities." 
Table 23. Electric Operation and Maintenance Expenses by Major U.S. Publicly Owned Electric Utility Within State, 1995 (Continued) (Thousand Dollars)

\begin{tabular}{|c|c|c|c|c|c|c|}
\hline Item & $\begin{array}{l}\text { California } \\
\begin{array}{l}\text { Los Angeles } \\
\text { City of }\end{array} \\
\text { June } 30\end{array}$ & $\begin{array}{c}\text { California } \\
\text { Merced } \\
\text { Imigation } \\
\text { District } \\
\text { December } 31\end{array}$ & $\begin{array}{l}\text { California } \\
\text { Metropolitan } \\
\text { Water } \\
\text { District } \\
\text { June } 30\end{array}$ & $\begin{array}{l}\text { California } \\
\text { Modesto } \\
\text { Irrigation } \\
\text { District } \\
\text { December } 31\end{array}$ & $\begin{array}{c}\text { California } \\
\text { MSR } \\
\text { Public } \\
\text { Power } \\
\text { Agency } \\
\text { December } 31\end{array}$ & $\begin{array}{l}\text { California } \\
\text { Northern } \\
\text { California } \\
\text { Power Agny } \\
\text { June } 30\end{array}$ \\
\hline \multicolumn{7}{|l|}{ Production Expenses } \\
\hline $\begin{array}{l}\text { Steam Power Generation } \\
\text { Nuclear Power Generation }\end{array}$ & $\begin{array}{r}306,331 \\
25,989\end{array}$ & $\begin{array}{l}0 \\
0\end{array}$ & $\begin{array}{l}0 \\
0\end{array}$ & $\begin{array}{l}0 \\
0\end{array}$ & $\begin{array}{r}22,719 \\
0\end{array}$ & $\begin{array}{r}49,789 \\
0\end{array}$ \\
\hline Hydraulic Power Generation .............................. & 18,037 & $\begin{array}{r}2,429 \\
0\end{array}$ & $\begin{array}{r}1,511 \\
0\end{array}$ & $\begin{array}{r}680 \\
5667\end{array}$ & $\begin{array}{l}0 \\
0\end{array}$ & 2,734 \\
\hline 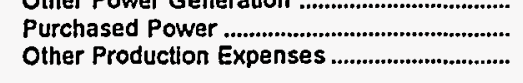 & $\begin{array}{r}659,612 \\
0\end{array}$ & $\begin{array}{l}0 \\
0\end{array}$ & $\begin{array}{l}0 \\
0\end{array}$ & $\begin{array}{r}87,315 \\
1,713\end{array}$ & $\begin{array}{r}24,724 \\
66\end{array}$ & $\begin{array}{r}26,607 \\
5,419\end{array}$ \\
\hline 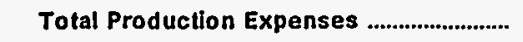 & $1,010,146$ & 2,429 & 1,511 & 95,376 & 47,510 & 85,707 \\
\hline 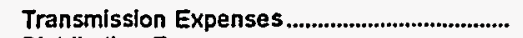 & 35,620 & 0 & 0 & 367 & 2,665 & 12.403 \\
\hline 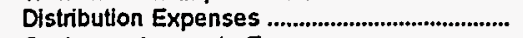 & 127,611 & 0 & 0 & 5,627 & 0 & 0 \\
\hline $\begin{array}{l}\text { Customer Accounts Expenses .............................. } \\
\text { Customer Service and Information }\end{array}$ & 58,971 & 0 & 0 & 3,764 & 0 & 0 \\
\hline 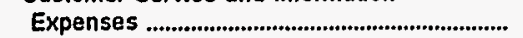 & 23,061 & 0 & 0 & 486 & 0 & 0 \\
\hline $\begin{array}{l}\text { Sales Expenses ......................................................... } \\
\text { Administrative and General }\end{array}$ & 0 & 0 & 0 & 0 & 0 & 0 \\
\hline 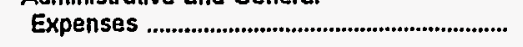 & 241,225 & 334 & 0 & 8,502 & 2,004 & 3,671 \\
\hline $\begin{array}{l}\text { Total Electric Operation and } \\
\text { Maintenance Expenses .............................. }\end{array}$ & $1,496,634$ & 2,764 & 1,511 & 114,122 & 52,179 & 101,781 \\
\hline \multicolumn{7}{|l|}{ Fuel Expenses in Operation } \\
\hline Steam Power Generation ..................................... & 229,950 & 0 & 0 & 0 & 0 & 0 \\
\hline Nuctear Power Generation .................................. & 9,047 & 0 & 0 & 0 & 0 & 0 \\
\hline 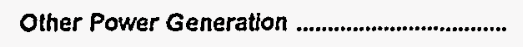 & 7 & 0 & 0 & 3,186 & 0 & 0 \\
\hline \multicolumn{7}{|l|}{ Number of Elec Dept Employees } \\
\hline Regular Fult-time ..................................................... & 7.507 & 11 & 57 & 279 & 177 & 174 \\
\hline 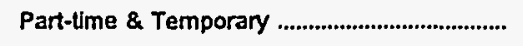 & 411 & 0 & 0 & 11 & 0 & 3 \\
\hline Total Elec Dept Employees ............................. & 7,918 & 11 & 57 & 290 & 177 & 177 \\
\hline
\end{tabular}

Source: Energy Information Administration, Form ElA-412. "Annual Report of Public Electric Utilities." 
Table 23. Electric Operation and Maintenance Expenses by Major U.S. Publicly Owned Electric Utility Within State, 1995 (Continued) (Thousand Dollars)

\begin{tabular}{|c|c|c|c|c|c|c|}
\hline Item & $\begin{array}{c}\text { Calıfornia } \\
\text { Oakdale \& } \\
\text { South } \\
\text { San Joaquin } \\
\text { December } 31\end{array}$ & $\begin{array}{c}\text { California } \\
\text { Oroville } \\
\text { Wyandotte } \\
\text { Imig Dist } \\
\text { December } 31\end{array}$ & $\begin{array}{l}\text { California } \\
\text { Palo Alto } \\
\text { City of } \\
\text { June } 30\end{array}$ & $\begin{array}{l}\text { California } \\
\text { Pasadena } \\
\text { City of } \\
\text { June } 30\end{array}$ & $\begin{array}{c}\text { California } \\
\text { Placer } \\
\text { County } \\
\text { Water } \\
\text { Agency } \\
\text { December } 31\end{array}$ & $\begin{array}{l}\text { California } \\
\text { Redding } \\
\text { City of } \\
\text { June } 30\end{array}$ \\
\hline \multicolumn{7}{|l|}{ Production Expenses } \\
\hline 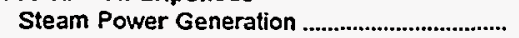 & 0 & 0 & 0 & 13,909 & 0 & 4,361 \\
\hline 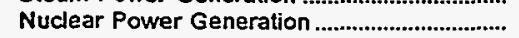 & 0 & 0 & 0 & 0 & 0 & 0 \\
\hline 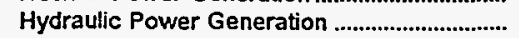 & 863 & 2,559 & 0 & 71 & 2,413 & 11 \\
\hline 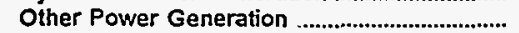 & 0 & 0 & 0 & 74 & 0 & 15 \\
\hline 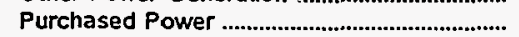 & 0 & 0 & 30,242 & 57,866 & 0 & 35,127 \\
\hline Other Production Expenses ..................................... & 0 & 0 & 0 & 716 & 8 & 0 \\
\hline Total Production Expenses .......................... & 863 & 2,559 & 30,242 & 72,637 & 2,421 & 39,514 \\
\hline 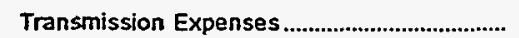 & 0 & 0 & 0 & 1,093 & 118 & 0 \\
\hline 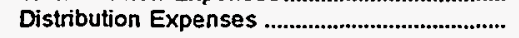 & 0 & 0 & 9,203 & 4,815 & 0 & 4,151 \\
\hline $\begin{array}{l}\text { Customer Accounts Expenses ............................ } \\
\text { Customer Service and Information }\end{array}$ & 0 & 0 & 0 & 1,158 & 0 & 1.132 \\
\hline 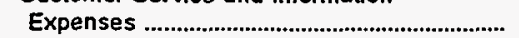 & 0 & 0 & 0 & 0 & $\mathbf{0}$ & 0 \\
\hline $\begin{array}{l}\text { Sales Expenses ......................... } \\
\text { Administrative and General }\end{array}$ & 0 & 0 & 0 & 164 & 0 & 0 \\
\hline 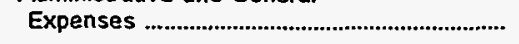 & 1,297 & 0 & 3,695 & 8,179 & 970 & 11,465 \\
\hline 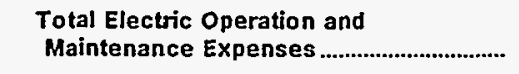 & 2,161 & 2,559 & 43,140 & 88,045 & 3,509 & 56,261 \\
\hline \multicolumn{7}{|l|}{ Fuel Expenses in Operation } \\
\hline 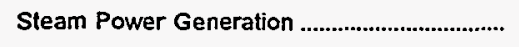 & 0 & 0 & 0 & 9,054 & 0 & 1,927 \\
\hline Nuclear Power Generation .................................... & 0 & 0 & 0 & 0 & 0 & 0 \\
\hline Other Power Generation ...................................... & 0 & 0 & 0 & 0 & 0 & $\mathbf{0}$ \\
\hline \multicolumn{7}{|l|}{ Number of Elec Dept Employees } \\
\hline 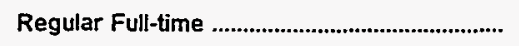 & 21 & 0 & 104 & 229 & 16 & 100 \\
\hline 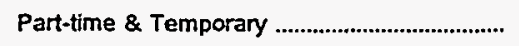 & 0 & 0 & 0 & 4 & 3 & 6 \\
\hline 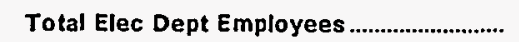 & 21 & $\mathbf{0}$ & 104 & 233 & 19 & 108 \\
\hline
\end{tabular}

Note: Totals may not equal sum of components because of independent rounding.

Source: Energy Information Administration, Form EIA-412, "Annual Report of Public Electric Utilities." 
Table 23. Electric Operation and Maintenance Expenses by Major U.S. Publicly Owned Electric Utility Within State, 1995 (Continued)

(Thousand Dollars)

\begin{tabular}{|c|c|c|c|c|c|c|}
\hline Item & $\begin{array}{l}\text { California } \\
\text { Rlverside } \\
\text { City of } \\
\text { June } 30\end{array}$ & $\begin{array}{l}\text { California } \\
\text { Roseville } \\
\text { City of } \\
\text { June } 30\end{array}$ & $\begin{array}{l}\text { California } \\
\text { Sacramento } \\
\text { Municipal } \\
\text { Util Dist } \\
\text { December } 31\end{array}$ & $\begin{array}{l}\text { California } \\
\text { San Francisco } \\
\text { City } \\
\& \\
\text { County of } \\
\text { June } 30\end{array}$ & $\begin{array}{l}\text { California } \\
\text { Santa } \\
\text { Clara } \\
\text { City of } \\
\text { June } 30\end{array}$ & $\begin{array}{l}\text { California } \\
\text { Southern } \\
\text { California } \\
\text { P P } \\
\text { A } \\
\text { June } 30\end{array}$ \\
\hline 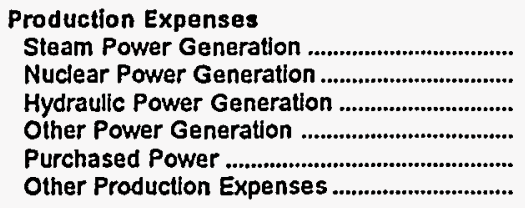 & $\begin{array}{r}0 \\
10,345 \\
0 \\
0 \\
81,984 \\
631\end{array}$ & $\begin{array}{r}0 \\
0 \\
0 \\
0 \\
26,056 \\
2,019\end{array}$ & $\begin{array}{r}15,428 \\
0 \\
9,004 \\
2,721 \\
230,517 \\
49,869\end{array}$ & $\begin{array}{r}0 \\
0 \\
4,816 \\
0 \\
25,066 \\
0\end{array}$ & $\begin{array}{r}0 \\
0 \\
55 \\
7,419 \\
113,183 \\
522\end{array}$ & $\begin{array}{r}34,834 \\
24,660 \\
0 \\
0 \\
2,097 \\
262\end{array}$ \\
\hline Total Production Expenses ........................... & 92,960 & 28,075 & 307,538 & 29,882 & 121,178 & 61,853 \\
\hline 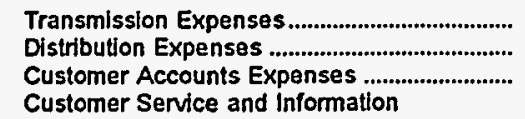 & $\begin{array}{r}15,475 \\
6,527 \\
4,326\end{array}$ & $\begin{array}{r}0 \\
6,854 \\
1,077\end{array}$ & $\begin{array}{l}22,354 \\
27,523 \\
22,734\end{array}$ & $\begin{array}{r}2,503 \\
0 \\
0\end{array}$ & $\begin{array}{r}36 \\
3.228 \\
9\end{array}$ & $\begin{array}{r}16,519 \\
0 \\
0\end{array}$ \\
\hline 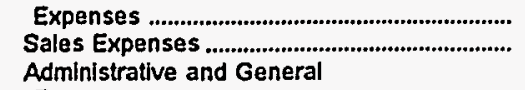 & $\begin{array}{r}1,528 \\
13\end{array}$ & $\begin{array}{l}0 \\
0\end{array}$ & $\begin{array}{r}11.308 \\
948\end{array}$ & $\begin{array}{l}0 \\
0\end{array}$ & $\begin{array}{r}0 \\
55\end{array}$ & $\begin{array}{l}0 \\
0\end{array}$ \\
\hline 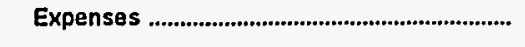 & 10,813 & 1,359 & 36,116 & 12,151 & 22,544 & 8.870 \\
\hline 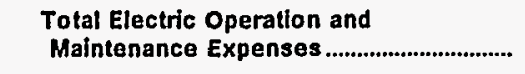 & 131,643 & 37,365 & 428,520 & 44,536 & 147,050 & 87,243 \\
\hline \multicolumn{7}{|l|}{ Fuel Expenses in Operation } \\
\hline 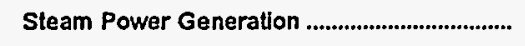 & $\mathbf{0}$ & 0 & 11,893 & 0 & 0 & 0 \\
\hline 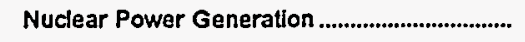 & .0 & 0 & 0 & 0 & 0 & 0 \\
\hline Other Power Generatlon ....................................... & 0 & 0 & 958 & 0 & 0 & 0 \\
\hline \multicolumn{7}{|l|}{ Number of Elec Dept Employees } \\
\hline Regular Full-time & 268 & 65 & 2,252 & 33 & 105 & 16 \\
\hline Part-1Ime \& Temporary ......................................... & 12 & 13 & 88 & 0 & 6 & 0 \\
\hline Total Elec Dept Employees .......................... & 280 & 78 & 2,340 & 33 & 111 & 16 \\
\hline
\end{tabular}

Note: Totals may not equal sum of components because of independent rounding.

Source: Energy Information Administration, Form ElA-412, "Annual Report of Public Electric Utilities." 
Table 23. Electric Operation and Maintenance Expenses by Major U.S. Publicly Owned Electric Utility Within State, 1995 (Continued) (Thousand Dollars)

\begin{tabular}{|c|c|c|c|c|c|c|}
\hline Item & $\begin{array}{c}\text { California } \\
\text { Turlock } \\
\text { Irrigation } \\
\text { District } \\
\text { December } 31\end{array}$ & $\begin{array}{l}\text { California } \\
\text { Vernon } \\
\text { City of } \\
\text { June } 30\end{array}$ & $\begin{array}{l}\text { California } \\
\text { Yuba } \\
\text { County } \\
\text { Water } \\
\text { Agency } \\
\text { June } 30\end{array}$ & $\begin{array}{c}\text { Colorado } \\
\text { Arkansas } \\
\text { River } \\
\text { Power } \\
\text { Authority } \\
\text { December } 31\end{array}$ & $\begin{array}{l}\text { Colorado } \\
\text { Colorado } \\
\text { Springs } \\
\text { City of } \\
\text { December } 31\end{array}$ & $\begin{array}{l}\text { Colorado } \\
\text { Fort Collins } \\
\text { City of }\end{array}$ \\
\hline \multicolumn{7}{|l|}{ Production Expenses } \\
\hline 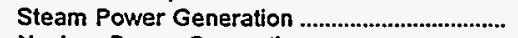 & 0 & 0 & 0 & 0 & 62,210 & 0 \\
\hline Nuclear Power Generation .................................. & 0 & 0 & 0 & 0 & 0 & 0 \\
\hline 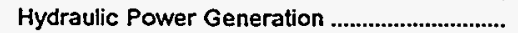 & 3,119 & 0 & 2,025 & 0 & 226 & 0 \\
\hline 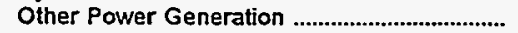 & 1.430 & 1,968 & 0 & 0 & 0 & 0 \\
\hline 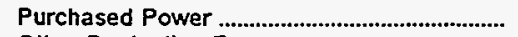 & 50,520 & 29,858 & 0 & 8,493 & 13,556 & 34,388 \\
\hline 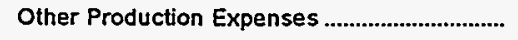 & 287 & 0 & 0 & 0 & 0 & 0 \\
\hline Total Production Expenses ......................... & 55,355 & 31,826 & 2,025 & 8,493 & 75,991 & 34,388 \\
\hline Transmission Expenses & 332 & 2,358 & 0 & 854 & 2,120 & 0 \\
\hline 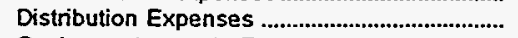 & 6,838 & 3,718 & 0 & 0 & 13,729 & 4,141 \\
\hline $\begin{array}{l}\text { Customer Accounts Expenses } \\
\text { Customer Service and information }\end{array}$ & 0 & 0 & 0 & 113 & 5,457 & 1,497 \\
\hline Expenses & 0 & 340 & 0 & 0 & 465 & 459 \\
\hline 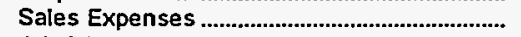 & 0 & 0 & 0 & 0 & 0 & 0 \\
\hline \multicolumn{7}{|l|}{ Administrative and General } \\
\hline Expenses & 9,438 & 2,538 & 1,340 & 680 & 13,146 & 2,534 \\
\hline 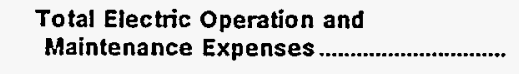 & 71,964 & 40,781 & 3,365 & 10,140 & 110,908 & 43,019 \\
\hline \multicolumn{7}{|l|}{ Fuel Expenses in Operation } \\
\hline 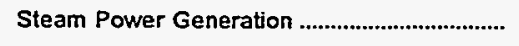 & 0 & 0 & 0 & 0 & 0 & 0 \\
\hline Nucdear Power Generation .................................. & 0 & 0 & 0 & 0 & 0 & $\mathbf{0}$ \\
\hline Other Power Generation .................................... & 0 & 0 & 0 & 0 & $\mathbf{0}$ & 0 \\
\hline \multicolumn{7}{|l|}{ Number of Elec Dept Employees } \\
\hline 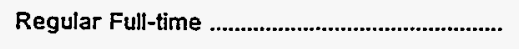 & 379 & 0 & 16 & 5 & 520 & 117 \\
\hline 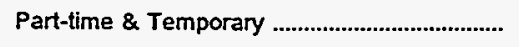 & 4 & 0 & 2 & 0 & 26 & 20 \\
\hline Total Elec Dept Employees ............................ & 383 & $\mathbf{0}$ & 18 & 5 & 546 & 137 \\
\hline
\end{tabular}

Note: Totals may not equal sum of components because of independent rounding.

Source: Energy Information Administration, Form EIA-412, "Annual Report of Public Electric Utilities." 
Table 23. Electric Operation and Maintenance Expenses by Major U.S. Publicly Owned Electric Utility Within State, 1995 (Continued) (Thousand Dollars)

\begin{tabular}{|c|c|c|c|c|c|c|}
\hline \multirow{3}{*}{ Item } & Colorado & Colorado & Colorado & Colorado & Connecticut & Connecticut \\
\hline & $\begin{array}{c}\text { Fort Morgan } \\
\text { City of }\end{array}$ & $\begin{array}{l}\text { Longmont } \\
\text { City of }\end{array}$ & $\begin{array}{l}\text { Loveland } \\
\text { City of }\end{array}$ & $\begin{array}{c}\text { Platte River } \\
\text { Power } \\
\text { Authority }\end{array}$ & $\begin{array}{c}\text { Connecticut } \\
\text { Mun } \\
\text { Elec } \\
\text { Engy Coop }\end{array}$ & $\begin{array}{l}\text { Groton } \\
\text { City of }\end{array}$ \\
\hline & December $3 \mathbf{t}$ & December 31 & December 31 & December 31 & December 31 & June 30 \\
\hline
\end{tabular}

Production Expenses

Steam Power Generation

Nuclear Power Generation

Hydraulle Power Gene

Other Power Generation

Other Production Expenses

Total Production Expenses

Transmission Expenses

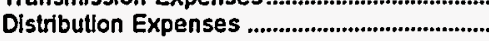

Customer Accounts Expenses ..........................

Customer Service and Information

Expenses ..............................................................

Sales Expenses ......................................................

Administrative and General

Expenses

Total Electric Operation and

Maintenance Expenses

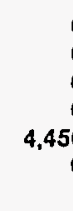

4,456

0
431

431
93

0

397

5,377

0
0
0
0
17.779
289

18,068

0

1,986
0

1,284

1,201

22,539

17,048

1,507

714

162

194
47,136
0
0
0
14,175
748

62,059

2,395

94

6.448

70,901

77,485

Fuel Expenses in Operation

Steam Power Generation ..................................

Nuclear Power Generation

Other Power Generation

Number of Elec Dept Employees

Regular Full-time

13

Part-time \& Temporary

Total Elec Dept Employees

13
0

0

0

0
0

0

0

0

55

189

5

54

55
4

59

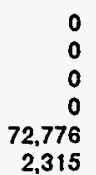

75,091

154

1,207

308

7
6

2,326

2,394

0

Note: Totals may not equal sum of components because of independent rounding.

Source: Energy Information Administration, Form ElA-412, "Annual Report of Public Electric Utilities." 
Table 23. Electric Operation and Maintenance Expenses by Major U.S. Publicly Owned Electric Utility Within State, 1995 (Continued) (Thousand Dollars)

\begin{tabular}{|c|c|c|c|c|c|c|}
\hline Item & $\begin{array}{l}\text { Connecticut } \\
\begin{array}{c}\text { Nonwich } \\
\text { City of }\end{array} \\
\text { June } 30\end{array}$ & $\begin{array}{l}\text { Connecticut } \\
\text { Wallingford } \\
\text { Town of } \\
\text { June } 30\end{array}$ & $\begin{array}{l}\text { Delaware } \\
\text { Dover } \\
\text { City of } \\
\text { June } 30\end{array}$ & $\begin{array}{c}\text { Delaware } \\
\text { Milford } \\
\text { City of } \\
\text { September } 30\end{array}$ & $\begin{array}{c}\text { Delaware } \\
\begin{array}{c}\text { Newark } \\
\text { City of }\end{array} \\
\text { December } 31\end{array}$ & $\begin{array}{c}\text { Florida } \\
\text { Bartow } \\
\text { City of } \\
\text { September } 30\end{array}$ \\
\hline \multicolumn{7}{|l|}{ Production Expenses } \\
\hline 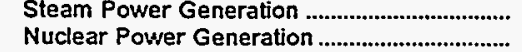 & $\begin{array}{l}0 \\
0\end{array}$ & $\begin{array}{r}679 \\
0\end{array}$ & $\begin{array}{r}8,729 \\
0\end{array}$ & $\begin{array}{l}0 \\
0\end{array}$ & $\begin{array}{l}0 \\
0\end{array}$ & $\begin{array}{l}0 \\
0\end{array}$ \\
\hline 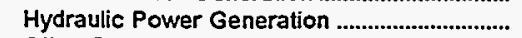 & 307 & 0 & 0 & 0 & 0 & 0 \\
\hline Other Power Generation ...................................... & 63 & 0 & 0 & 0 & 0 & 0 \\
\hline 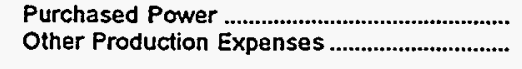 & $\begin{array}{r}17,665 \\
0\end{array}$ & $\begin{array}{r}29,452 \\
0\end{array}$ & $\begin{array}{r}13,832 \\
0\end{array}$ & $\begin{array}{r}6,365 \\
0\end{array}$ & $\begin{array}{r}13,892 \\
0\end{array}$ & $\begin{array}{r}12,187 \\
0\end{array}$ \\
\hline 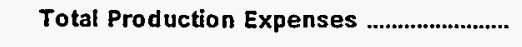 & 18,034 & 30,131 & 22,561 & 6,365 & 13,892 & 12,187 \\
\hline 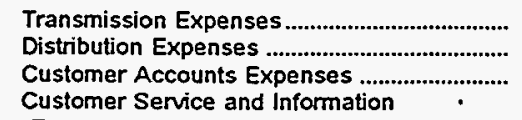 & $\begin{array}{l}230 \\
856 \\
958\end{array}$ & $\begin{array}{r}7 \\
2,190 \\
850\end{array}$ & $\begin{array}{r}3,574 \\
0 \\
0\end{array}$ & $\begin{array}{r}0 \\
2,145 \\
0\end{array}$ & $\begin{array}{r}0 \\
1,282 \\
0\end{array}$ & $\begin{array}{r}0 \\
383 \\
116\end{array}$ \\
\hline 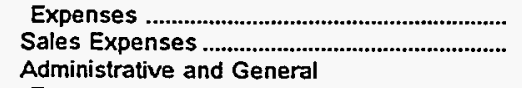 & $\begin{array}{l}0 \\
0\end{array}$ & $\begin{array}{r}65 \\
0\end{array}$ & $\begin{array}{l}0 \\
0\end{array}$ & $\begin{array}{l}0 \\
0\end{array}$ & $\begin{array}{l}0 \\
0\end{array}$ & $\begin{array}{l}0 \\
0\end{array}$ \\
\hline 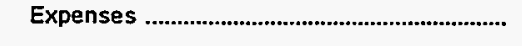 & 5,005 & 3,501 & 3,347 & 49 & 0 & 3,603 \\
\hline $\begin{array}{l}\text { Total Electric Operation and } \\
\text { Maintenance Expenses ............................... }\end{array}$ & 25,084 & 36,743 & 29,482 & 8,558 & 15,174 & 16,290 \\
\hline \multicolumn{7}{|l|}{ Fuel Expenses in Operation } \\
\hline 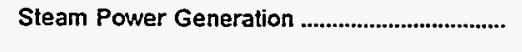 & 0 & 34 & 4.829 & 0 & 0 & 0 \\
\hline 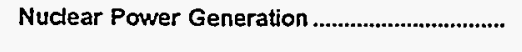 & 0 & 0 & 0 & 0 & 0 & 0 \\
\hline Other Power Generation ............................................ & 0 & 0 & 0 & 0 & 0 & 0 \\
\hline \multicolumn{7}{|l|}{ Number of Elec Dept Employees } \\
\hline 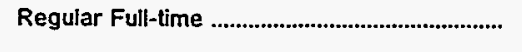 & 55 & 75 & 98 & 11 & 21 & 25 \\
\hline 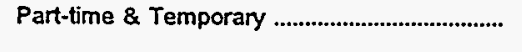 & 0 & 1 & 1 & 0 & 0 & 0 \\
\hline Total Elec Dept Employees ................................. & 55 & 76 & 99 & 11 & 21 & 25 \\
\hline
\end{tabular}

Note: Totals may not equal sum of components because of independent rounding.

Source: Energy Information Administration, Form EIA-412, "Annual Report of Public Electric Utiities." 
Table 23. Electric Operation and Maintenance Expenses by Major U.S. Publicly Owned Electric Utility Within State, 1995 (Continued)

(Thousand Dollars)

\begin{tabular}{|c|c|c|c|c|c|c|}
\hline Item & $\begin{array}{c}\text { Florida } \\
\text { Florida } \\
\text { Municipa! } \\
\text { Power Agency } \\
\text { September } 30\end{array}$ & $\begin{array}{l}\text { Florida } \\
\text { Fort Pierce } \\
\text { Utilities } \\
\text { Auth } \\
\text { September } 30\end{array}$ & $\begin{array}{c}\text { Florida } \\
\text { Gainesville } \\
\text { Regional } \\
\text { Utilities } \\
\text { September } 30\end{array}$ & $\begin{array}{c}\text { Fiorida } \\
\text { Homestead } \\
\text { City of } \\
\text { September } 30\end{array}$ & $\begin{array}{c}\text { Florida } \\
\text { Jacksonville } \\
\text { Beach } \\
\text { City of } \\
\text { September } 30\end{array}$ & $\begin{array}{c}\text { Florida } \\
\text { Jacksonville } \\
\text { Electric } \\
\text { Auth } \\
\text { September } 30\end{array}$ \\
\hline \multicolumn{7}{|l|}{ Production Expenses } \\
\hline 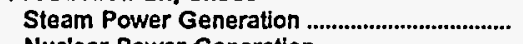 & 17,886 & 10,925 & 46,489 & 0 & 0 & 265,206 \\
\hline Nuclear Power Generation .......................................... & 9,781 & & 1,345 & 0 & 0 & 0 \\
\hline 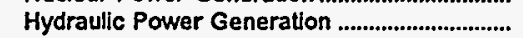 & 0 & 0 & 0 & 0 & 0 & 0 \\
\hline Other Power Generation ......................................... & 4,528 & 27 & 495 & 3,663 & 0 & 1,102 \\
\hline 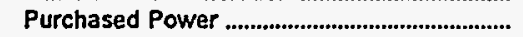 & 66,861 & 12,797 & 1,638 & 10,798 & 31,094 & 75,408 \\
\hline 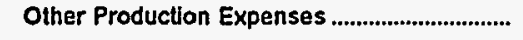 & 489 & 0 & 415 & 714 & 0 & \\
\hline Total Production Expenses ............................. & 99,545 & 23,749 & 50,382 & 15,175 & 31,094 & 341,716 \\
\hline 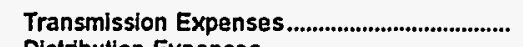 & 12,766 & 520 & 655 & 4 & 21 & 8,161 \\
\hline 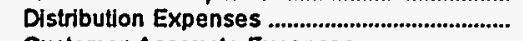 & & 1,525 & 5,413 & 2,775 & 1.652 & 21,388 \\
\hline $\begin{array}{l}\text { Customer Accounts Expenses ......................... } \\
\text { Customer Senvice and Information }\end{array}$ & 0 & 465 & 2,335 & 1,917 & -28 & 10,412 \\
\hline 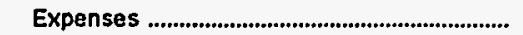 & 0 & 0 & 41 & 0 & 0 & 831 \\
\hline 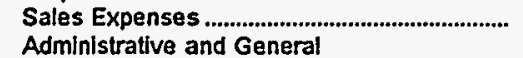 & 0 & 0 & 355 & 0 & 0 & 0 \\
\hline 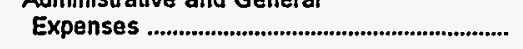 & 7,316 & 2.949 & 9,873 & 3,386 & 4,640 & 40,850 \\
\hline $\begin{array}{l}\text { Total Electric Operation and } \\
\text { Maintenance Expenses ................................... }\end{array}$ & 119,627 & 29,209 & 69,053 & 23,257 & 37,378 & 423,356 \\
\hline \multicolumn{7}{|l|}{ Fuel Expenses in Operation } \\
\hline 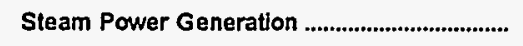 & 13,618 & 7,877 & 35,942 & 0 & 0 & 196.239 \\
\hline 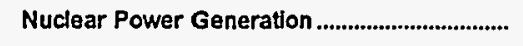 & 3,168 & 0 & 444 & 0 & 0 & 0 \\
\hline 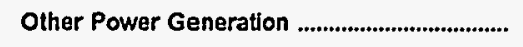 & 3.481 & 11 & 380 & 1,200 & 0 & 689 \\
\hline \multicolumn{7}{|l|}{ Number of Elec Dept Employees } \\
\hline 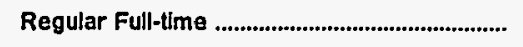 & 0 & 81 & 436 & 98 & 74 & 1,728 \\
\hline Part-time \& Temporary & $\mathbf{0}$ & 0 & 15 & 0 & 1 & 103 \\
\hline 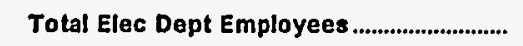 & 0 & 81 & 451 & 98 & 75 & 1,831 \\
\hline
\end{tabular}

Note: Totals may not equal sum of components because of independent rounding.

Source: Energy Information Administration, Form EIA-412, "Annual Report of Public Electric Utilities." 
Table 23. Electric Operation and Maintenance Expenses by Major U.S. Publicly Owned Electric Utility Within State, 1995 (Continued) (Thousand Dollars)

\begin{tabular}{|c|c|c|c|c|c|c|}
\hline Item & $\begin{array}{l}\text { Florida } \\
\text { Key West } \\
\text { City of } \\
\text { September } 30\end{array}$ & $\begin{array}{l}\text { Florida } \\
\text { Kissimmee } \\
\text { Utility } \\
\text { Authority } \\
\text { September } 30\end{array}$ & $\begin{array}{l}\text { Florida } \\
\text { Lake Worth } \\
\text { City of } \\
\text { September } 30\end{array}$ & $\begin{array}{c}\text { Florida } \\
\text { Lakeland } \\
\text { City of } \\
\text { September } 30\end{array}$ & $\begin{array}{l}\text { Florida } \\
\text { Leesburg } \\
\text { City of } \\
\text { September } 30\end{array}$ & $\begin{array}{c}\text { Florida } \\
\text { New Smyrna } \\
\text { Beach } \\
\text { Utils Comm } \\
\text { September } 30\end{array}$ \\
\hline  & $\begin{array}{r}2,144 \\
0 \\
0 \\
1,547 \\
22,686 \\
165\end{array}$ & $\begin{array}{r}8,055 \\
1,087 \\
0 \\
6,952 \\
18,776 \\
0\end{array}$ & $\begin{array}{r}9,154 \\
0 \\
0 \\
0 \\
11,890 \\
192\end{array}$ & $\begin{array}{r}50,524 \\
0 \\
0 \\
12,495 \\
5,545 \\
0\end{array}$ & $\begin{array}{r}0 \\
1,151 \\
0 \\
0 \\
16,847 \\
0\end{array}$ & $\begin{array}{r}0 \\
889 \\
0 \\
423 \\
13,160 \\
356\end{array}$ \\
\hline 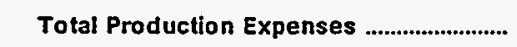 & 26,542 & 34,870 & 21,236 & 68,564 & 17,998 & 14,829 \\
\hline 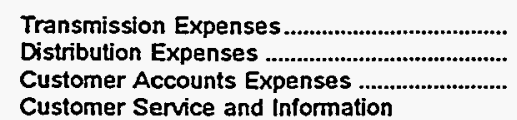 & $\begin{array}{r}260 \\
2,052 \\
902\end{array}$ & $\begin{array}{r}390 \\
2,515 \\
1,885\end{array}$ & $\begin{array}{r}618 \\
928 \\
0\end{array}$ & $\begin{array}{l}1,340 \\
7,772 \\
2,797\end{array}$ & $\begin{array}{r}0 \\
2,178 \\
847\end{array}$ & $\begin{array}{r}311 \\
1,459 \\
499\end{array}$ \\
\hline 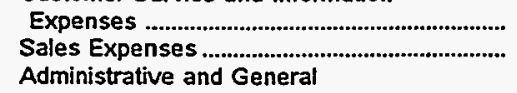 & $\begin{array}{l}0 \\
0\end{array}$ & $\begin{array}{r}765 \\
0\end{array}$ & $\begin{array}{l}0 \\
0\end{array}$ & $\begin{array}{r}694 \\
0\end{array}$ & $\begin{array}{l}0 \\
0\end{array}$ & $\begin{array}{l}0 \\
0\end{array}$ \\
\hline 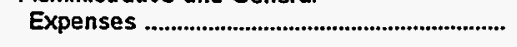 & 6,268 & 3,484 & 687 & 16,703 & 583 & 2,499 \\
\hline 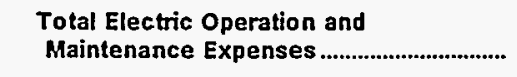 & 36,025 & 43,908 & 23,468 & 97,870 & 21,605 & 19,597 \\
\hline \multicolumn{7}{|l|}{ Fuel Expenses in Operation } \\
\hline 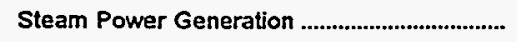 & 435 & 6.550 & 0 & 36,274 & 0 & 0 \\
\hline 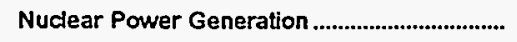 & 0 & 321 & 0 & 0 & 0 & 141 \\
\hline Other Power Generation ..................................... & o & 3,607 & 0 & 10,446 & 0 & 178 \\
\hline \multicolumn{7}{|l|}{ Number of Elec Dept Employees } \\
\hline 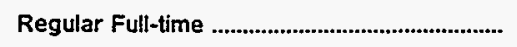 & 167 & 251 & 139 & 751 & 49 & 88 \\
\hline Part-time \& Temporary ........................................ & 1 & 0 & 4 & 42 & 0 & 0 \\
\hline Total Elec Dept Employees ............................. & 168 & 251 & 143 & 793 & 49 & 88 \\
\hline
\end{tabular}

Note: Totals may not equal sum of components because of independent rounding.

Source: Energy Information Administration, Form ElA-412, "Annual Report of Public Electric Utilities." 
Table 23. Electric Operation and Maintenance Expenses by Major U.S. Publicly Owned Electric Utility Within State, 1995 (Continued)

(Thousand Dollars)

\begin{tabular}{|c|c|c|c|c|c|c|}
\hline Item & $\begin{array}{c}\text { Florida } \\
\text { Ocala } \\
\text { City of } \\
\text { September } 30\end{array}$ & $\begin{array}{l}\text { Florida } \\
\text { Orfando } \\
\text { Utilities } \\
\text { Comm } \\
\text { September } 30\end{array}$ & $\begin{array}{l}\text { Florida } \\
\text { Quincy } \\
\text { City of } \\
\text { September } 30\end{array}$ & $\begin{array}{l}\quad \text { Florida } \\
\text { Reedy Creek } \\
\text { Improvement } \\
\text { Dist } \\
\text { September } 30\end{array}$ & $\begin{array}{l}\text { Florida } \\
\text { St Cloud } \\
\text { City of } \\
\text { September } 30\end{array}$ & $\begin{array}{c}\text { Florida } \\
\text { Tallahassee } \\
\text { City of } \\
\text { September } 30\end{array}$ \\
\hline 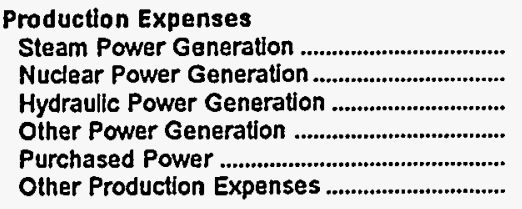 & $\begin{array}{r}0 \\
1,804 \\
0 \\
0 \\
46,081 \\
0\end{array}$ & $\begin{array}{r}118,583 \\
9,687 \\
0 \\
3,120 \\
3,088 \\
397\end{array}$ & $\begin{array}{r}0 \\
0 \\
0 \\
0 \\
6,071 \\
0\end{array}$ & $\begin{array}{r}1,027 \\
0 \\
0 \\
6,579 \\
30,730 \\
452\end{array}$ & $\begin{array}{r}0 \\
0 \\
0 \\
1,470 \\
12,158 \\
0\end{array}$ & $\begin{array}{r}63,438 \\
1,630 \\
0 \\
0 \\
34,838 \\
454\end{array}$ \\
\hline Total Production Expenses .......................... & 47,885 & 134,875 & 6,071 & 38,788 & 13,628 & 100,360 \\
\hline 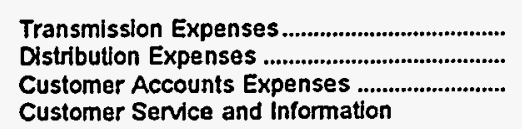 & $\begin{array}{r}0 \\
4,761 \\
578\end{array}$ & $\begin{array}{l}5,435 \\
5,302 \\
5,913\end{array}$ & $\begin{array}{r}0 \\
477 \\
229\end{array}$ & $\begin{array}{r}0 \\
9,270 \\
0\end{array}$ & $\begin{array}{r}162 \\
2,650 \\
0\end{array}$ & $\begin{array}{r}848 \\
7,026 \\
8,688\end{array}$ \\
\hline 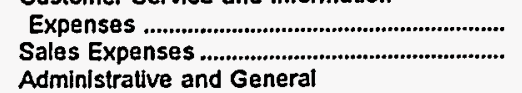 & $\begin{array}{l}228 \\
184\end{array}$ & $\begin{array}{r}983 \\
34\end{array}$ & $\begin{array}{l}0 \\
0\end{array}$ & $\begin{array}{l}0 \\
0\end{array}$ & $\begin{array}{r}1,159 \\
0\end{array}$ & $\begin{array}{l}0 \\
0\end{array}$ \\
\hline 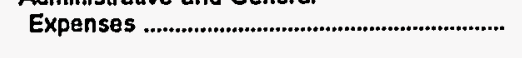 & 1,836 & 17,747 & 277 & 1,206 & -244 & 13,184 \\
\hline $\begin{array}{l}\text { Total Electric Operation and } \\
\text { Maintenance Expenses ..................................... }\end{array}$ & 55,473 & 170,289 & 7,054 & 49,265 & 17,356 & 130,106 \\
\hline \multicolumn{7}{|l|}{ Fuel Expenses in Operation } \\
\hline 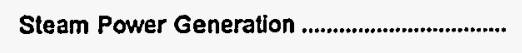 & $\mathbf{0}$ & 96,946 & 0 & 696 & 0 & 50,588 \\
\hline Nuclear Power Generation .................................... & 0 & 2,682 & 0 & 0 & 0 & 0 \\
\hline Other Power Generation ...................................... & 0 & 2,030 & 0 & 3,921 & 69 & 0 \\
\hline \multicolumn{7}{|l|}{ Number of Elec Dept Employees } \\
\hline 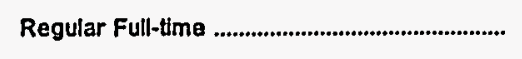 & 144 & 476 & 10 & 73 & 83 & 382 \\
\hline 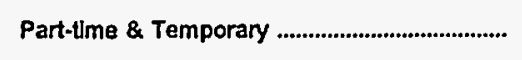 & 1 & 0 & 0 & 0 & 4 & 18 \\
\hline 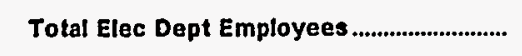 & 145 & 476 & 10 & 73 & 87 & 401 \\
\hline
\end{tabular}

Note: Totals may not equal sum of components because of independent rounding.

Source: Energy information Administration, Form EIA-412. "Annual Report of Public Electric Utilities." 
Table 23. Electric Operation and Maintenance Expenses by Major U.S. Publicly Owned Electric Utility Within State, 1995 (Continued)

(Thousand Dollars)

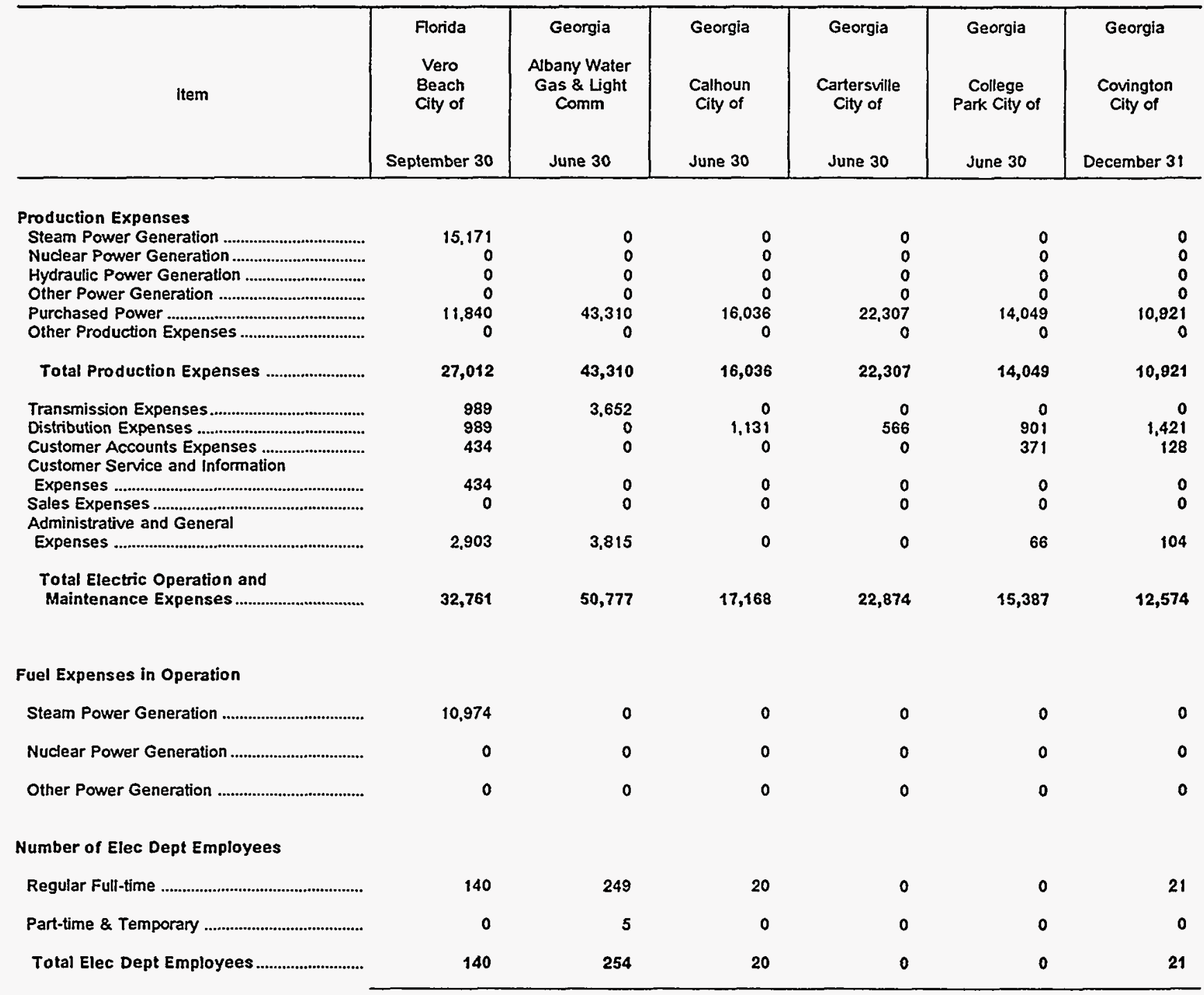

Note: Totals may not equal sum of components because of independent rounding.

Source: Energy Information Administration, Form EIA-412, "Annual Report of Public Electric Utilities." 
Table 23. Electric Operation and Maintenance Expenses by Major U.S. Publicly Owned Electric Utility Within State, 1995 (Continued) (Thousand Dollars)

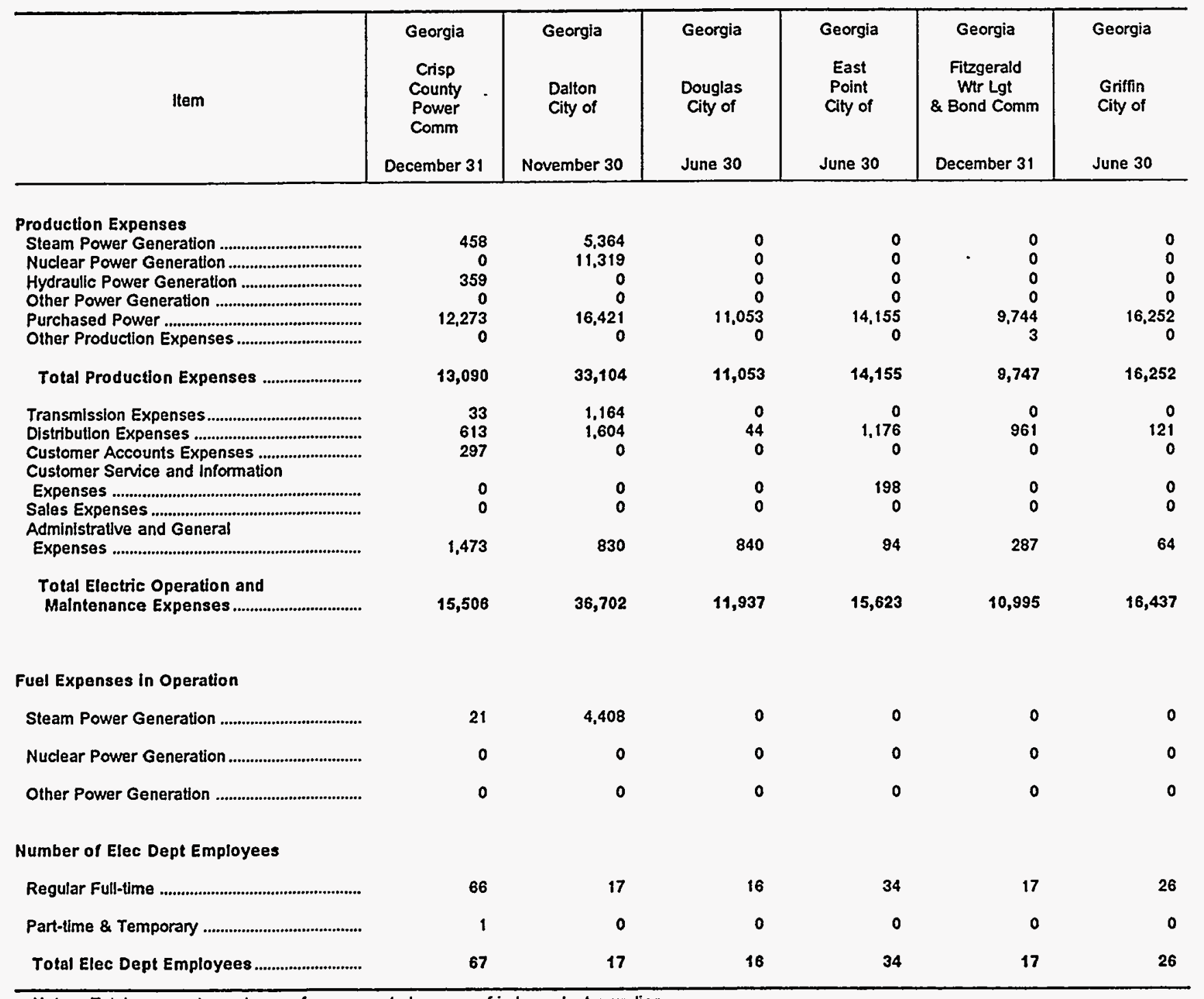

Note: Totals may not equal sum of components because of independent rounding.

Source: Energy Information Administration, Form ElA-412, "Annual Report of Public Electric Utilities." 
Table 23. Electric Operation and Maintenance Expenses by Major U.S. Publicly Owned Electric Utility Within State, 1995 (Continued) (Thousand Dollars)



Note: Totals may not equal sum of components because of independent rounding.

Source: Energy Information Administration, Form ELA-412, "Annual Report of Public Electric Utilities." 
Table 23. Electric Operation and Maintenance Expenses by Major U.S. Publicly Owned Electric Utility Within State, 1995 (Continued)

(Thousand Dollars)

\begin{tabular}{|c|c|c|c|c|c|c|}
\hline Item & $\begin{array}{l}\text { Idaho } \\
\text { Idaho } \\
\text { Falls } \\
\text { City of } \\
\text { September } 30\end{array}$ & $\begin{array}{l}\text { Illinois } \\
\text { Batavia } \\
\text { City of } \\
\text { December } 31\end{array}$ & $\begin{array}{l}\text { Hlinois } \\
\text { Geneva } \\
\text { City of } \\
\text { Apnl } 30\end{array}$ & $\begin{array}{l}\text { Ulinois } \\
\text { Ullinois } \\
\text { Municipa! } \\
\text { Elec Agency } \\
\text { April } 30\end{array}$ & $\begin{array}{l}\text { Illinois } \\
\begin{array}{c}\text { Napenille } \\
\text { City of }\end{array} \\
\text { April } 30\end{array}$ & $\begin{array}{l}\text { Mllinois } \\
\text { Rochelle } \\
\text { Municipal } \\
\text { Utilities } \\
\text { April } 30\end{array}$ \\
\hline \multicolumn{7}{|l|}{ Production Expenses } \\
\hline Steam Power Generation .................................... & 0 & 0 & 0 & 6,534 & 0 & 3,040 \\
\hline Nuclear Power Generation ................................. & 0 & 0 & 0 & 0 & $\mathbf{0}$ & 0 \\
\hline Hydraulic Power Generation .............................. & 1,084 & 0 & 0 & 0 & $\mathbf{0}$ & 0 \\
\hline 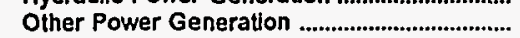 & 0 & 0 & 0 & 0 & 0 & 660 \\
\hline 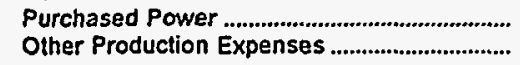 & $\begin{array}{r}16,434 \\
0\end{array}$ & $\begin{array}{r}10.598 \\
0\end{array}$ & $\begin{array}{r}8,442 \\
0\end{array}$ & $\begin{array}{r}35,103 \\
8,025\end{array}$ & $\begin{array}{r}38,914 \\
0\end{array}$ & $\begin{array}{r}3,989 \\
0\end{array}$ \\
\hline Total Production Expenses ........................... & 17,517 & 10,598 & 8,442 & 49,663 & 38,914 & 7,688 \\
\hline 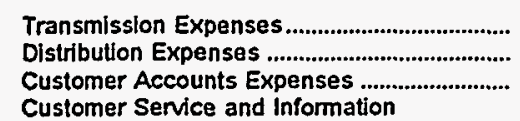 & $\begin{array}{r}96 \\
2,111 \\
916\end{array}$ & $\begin{array}{r}0 \\
915 \\
506\end{array}$ & $\begin{array}{r}0 \\
687 \\
24\end{array}$ & $\begin{array}{r}5,505 \\
0 \\
0\end{array}$ & $\begin{array}{r}0 \\
5,483 \\
399\end{array}$ & $\begin{array}{r}1 \\
598 \\
128\end{array}$ \\
\hline 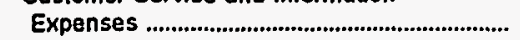 & 10 & 0 & 0 & 0 & 685 & 0 \\
\hline 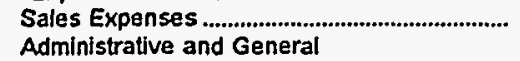 & 0 & 0 & 0 & 0 & 0 & 0 \\
\hline 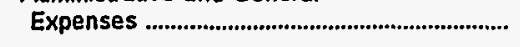 & 1,897 & 175 & 606 & 1,715 & 3,021 & 1,251 \\
\hline $\begin{array}{l}\text { Total Electric Operation and } \\
\text { Maintenance Expenses ................................ }\end{array}$ & 22,547 & 12,194 & 9,759 & 56,883 & 48,502 & 9,667 \\
\hline \multicolumn{7}{|l|}{ Fuel Expenses in Operation } \\
\hline Steam Power Generation ..................................... & 0 & 0 & 0 & 0 & 0 & 2,223 \\
\hline 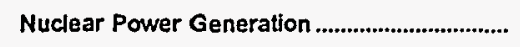 & 0 & 0 & 0 & 0 & 0 & 0 \\
\hline 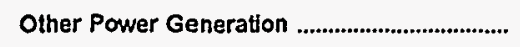 & $\mathbf{0}$ & 0 & 0 & 0 & 0 & 132 \\
\hline \multicolumn{7}{|l|}{ Number of Elec Dept Employees } \\
\hline Regular Full-time ................................................ & 56 & 21 & 0 & 14 & 101 & 44 \\
\hline 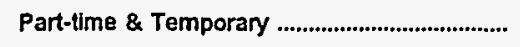 & 3 & 1 & 0 & 0 & 0 & 1 \\
\hline Total Elec Dept Employees ............................ & 59 & 22 & 0 & 14 & 101 & 45 \\
\hline
\end{tabular}

Note: Totals may not equal sum of components because of independent rounding.

Source: Energy Information Administration, Form ElA-412, "Annual Report of Public Electric Utilities." 
Table 23. Electric Operation and Maintenance Expenses by Major U.S. Publicly Owned Electric Utility Within State, 1995 (Continued)

(Thousand Dollars)

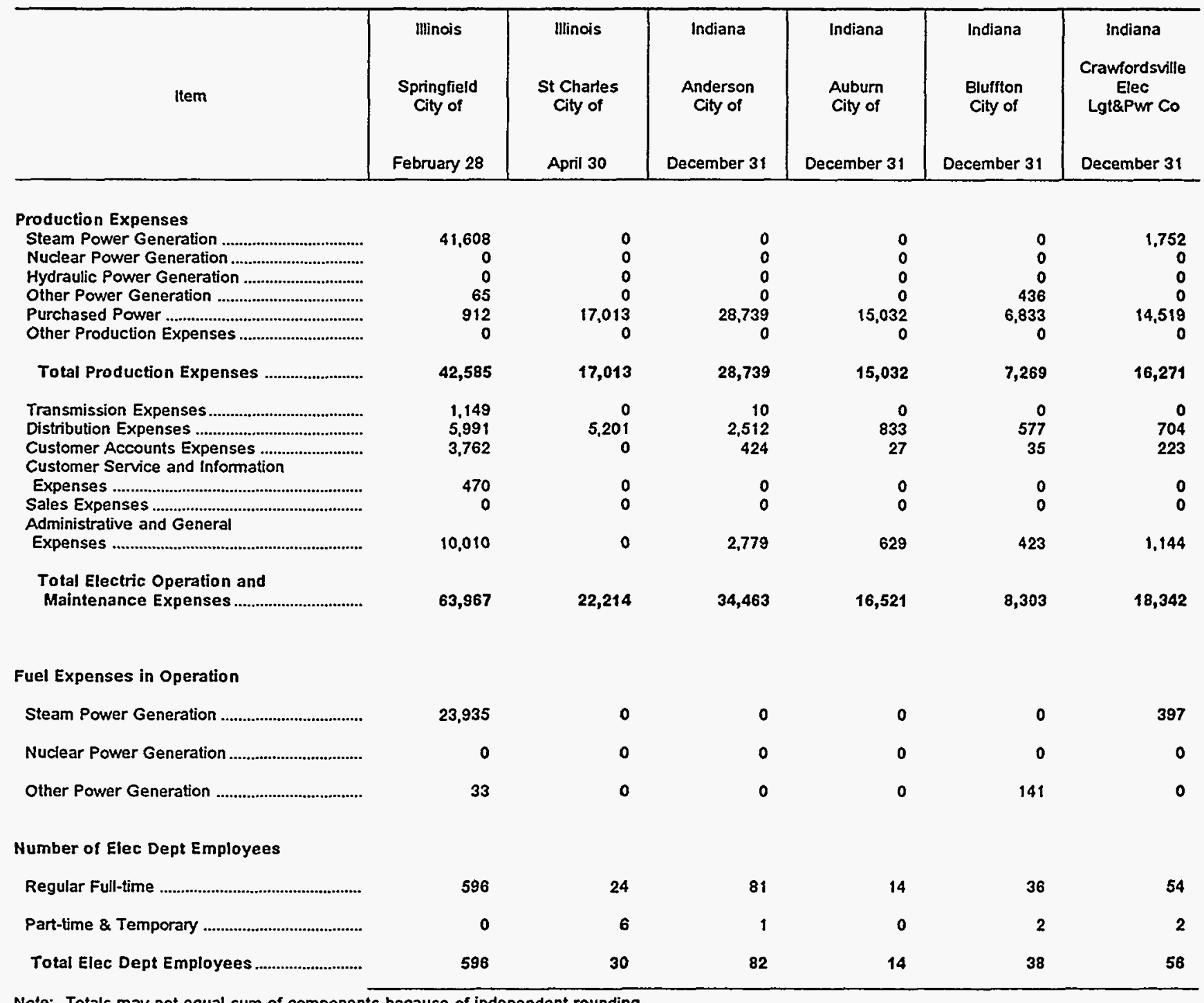

Note: Totals may not equal sum of components because of independent rounding

Source: Energy Information Administration. Form ELA-412, "Annual Report of Public Electric Utilities." 
Table 23. Electric Operation and Maintenance Expenses by Major U.S. Publicly Owned Electric Utility Within State, 1995 (Continued)

(Thousand Dollars)

\begin{tabular}{|c|c|c|c|c|c|c|}
\hline item & $\begin{array}{l}\text { Indiana } \\
\text { Frankfort } \\
\text { City of } \\
\text { December } 31\end{array}$ & $\begin{array}{l}\text { Indiana } \\
\text { Greentield } \\
\text { City of } \\
\text { December } 31\end{array}$ & $\begin{array}{c}\text { Indiana } \\
\text { Indiana } \\
\text { Municipal } \\
\text { Power Agency } \\
\text { December } 31\end{array}$ & $\begin{array}{l}\text { Indiana } \\
\text { Jasper } \\
\text { City of } \\
\text { December } 31\end{array}$ & $\begin{array}{l}\text { Indiana } \\
\text { Lebanon } \\
\text { City of } \\
\text { December } \mathbf{3 1}\end{array}$ & $\begin{array}{l}\text { Indiana } \\
\text { Logansport } \\
\text { City of } \\
\text { December } 31\end{array}$ \\
\hline 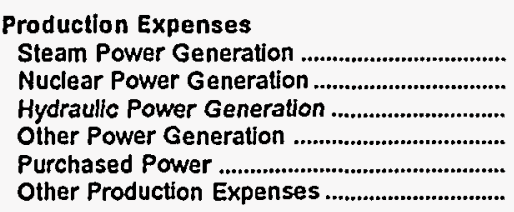 & $\begin{array}{r}0 \\
0 \\
0 \\
0 \\
12,220 \\
0\end{array}$ & $\begin{array}{r}0 \\
0 \\
0 \\
0 \\
7.194 \\
0\end{array}$ & $\begin{array}{r}27,576 \\
0 \\
0 \\
1,065 \\
85,255 \\
391\end{array}$ & $\begin{array}{r}2,166 \\
0 \\
0 \\
0 \\
9,863 \\
0\end{array}$ & $\begin{array}{r}0 \\
0 \\
0 \\
0 \\
5,905 \\
0\end{array}$ & $\begin{array}{r}6,847 \\
0 \\
0 \\
73 \\
5,379 \\
0\end{array}$ \\
\hline 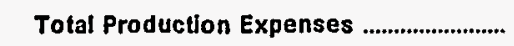 & 12,220 & 7,194 & 114,287 & 12,029 & 5,905 & 12,299 \\
\hline 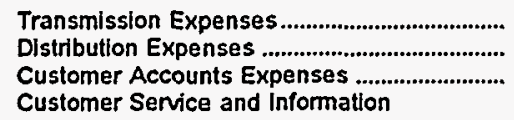 & $\begin{array}{r}0 \\
532 \\
207\end{array}$ & $\begin{array}{r}0 \\
678 \\
109\end{array}$ & $\begin{array}{r}6,645 \\
940 \\
0\end{array}$ & $\begin{array}{r}1 \\
682 \\
60\end{array}$ & $\begin{array}{r}7 \\
382 \\
146\end{array}$ & $\begin{array}{r}0 \\
1,459 \\
121\end{array}$ \\
\hline 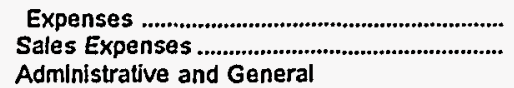 & $\begin{array}{l}0 \\
0\end{array}$ & $\begin{array}{l}0 \\
0\end{array}$ & $\begin{array}{r}35 \\
0\end{array}$ & $\begin{array}{l}0 \\
0\end{array}$ & $\begin{array}{l}0 \\
0\end{array}$ & $\begin{array}{r}25 \\
0\end{array}$ \\
\hline 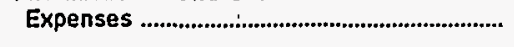 & 835 & 399 & 2,397 & 855 & 636 & 1,109 \\
\hline 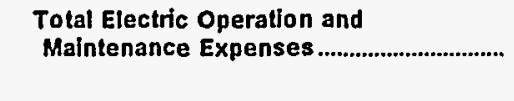 & 13,795 & 8,379 & 124,305 & 13,627 & 7,076 & 15,014 \\
\hline \multicolumn{7}{|l|}{ Fuel Expenses in Operation } \\
\hline Steam Power Generation .................................... & 0 & 0 & 18,285 & 1,103 & 0 & $\mathbf{0}$ \\
\hline Nuclear Power Generation .................................. & 0 & 0 & 0 & 0 & 0 & 0 \\
\hline Other Power Generation .................................... & 0 & 0 & 681 & 0 & 0 & 0 \\
\hline \multicolumn{7}{|l|}{ Number of Elec Dept Employees } \\
\hline Regular Full-time & 26 & 29 & 23 & 46 & 18 & 69 \\
\hline 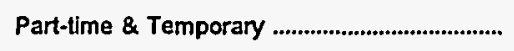 & 0 & 6 & 0 & 0 & 0 & \\
\hline Total Elec Dept Employees ............................... & 26 & 35 & 23 & 46 & 18 & 70 \\
\hline
\end{tabular}

Note: Totals may not equal sum of components because of independent rounding.

Source: Energy Information Administration, Form ELA-412, "Annual Report of Public Electric Utilities." 
Table 23. Electric Operation and Maintenance Expenses by Major U.S. Publicly Owned Electric Utility Within State, 1995 (Continued) (Thousand Dollars)

\begin{tabular}{|c|c|c|c|c|c|c|}
\hline Item & $\begin{array}{l}\text { Indiana } \\
\text { Mishawaka } \\
\text { City of } \\
\text { December } 31\end{array}$ & $\begin{array}{c}\text { Indiana } \\
\text { Peru } \\
\text { City of } \\
\text { December } 31\end{array}$ & $\begin{array}{l}\text { Indiana } \\
\text { Richmond } \\
\text { City of } \\
\text { December } 31\end{array}$ & $\begin{array}{c}\text { Indiana } \\
\text { Scottsburg } \\
\text { City of } \\
\text { December } 31\end{array}$ & $\begin{array}{c}\text { Indiana } \\
\text { Washington } \\
\text { City of } \\
\text { December } 31\end{array}$ & $\begin{array}{l}\text { lowa } \\
\text { Ames } \\
\text { City of } \\
\text { June } 30\end{array}$ \\
\hline \multicolumn{7}{|l|}{ Production Expenses } \\
\hline 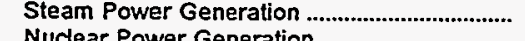 & 0 & 677 & 13,318 & 0 & 0 & 8,677 \\
\hline & 0 & 0 & 0 & 0 & 0 & \\
\hline 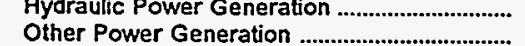 & $\begin{array}{l}0 \\
0\end{array}$ & $\begin{array}{l}0 \\
0\end{array}$ & $\begin{array}{l}0 \\
0\end{array}$ & $\begin{array}{l}0 \\
0\end{array}$ & 0 & 0 \\
\hline & 21,538 & $\begin{array}{r}0 \\
5,602\end{array}$ & 15,323 & 6,390 & 0 & 0 \\
\hline 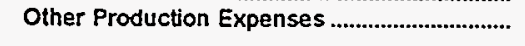 & 0 & $\begin{array}{r}3,602 \\
0\end{array}$ & 0 & 0 & $\begin{array}{r}6,541 \\
0\end{array}$ & $\begin{array}{r}2,051 \\
364\end{array}$ \\
\hline 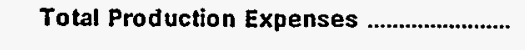 & 21,538 & 6,279 & 28,642 & 6,390 & 6,541 & 11,092 \\
\hline $\begin{array}{l}\text { Transmission Expenses } \\
\text { Distribution Expenses }\end{array}$ & $\begin{array}{r}0 \\
2,374\end{array}$ & $\begin{array}{r}22 \\
629\end{array}$ & $\begin{array}{r}37 \\
2,483\end{array}$ & $\begin{array}{l}354 \\
148\end{array}$ & $\begin{array}{r}0 \\
649\end{array}$ & $\begin{array}{r}0 \\
2.847\end{array}$ \\
\hline $\begin{array}{l}\text { Customer Accounts Expenses ........................... } \\
\text { Customer Service and Information }\end{array}$ & 665 & 165 & 569 & 70 & 178 & 0 \\
\hline Expenses ........................................................ & 0 & 0 & 133 & 0 & 0 & 381 \\
\hline $\begin{array}{l}\text { Sales Expenses ............................................... } \\
\text { Administrative and General }\end{array}$ & 0 & 0 & 0 & 0 & 0 & 0 \\
\hline 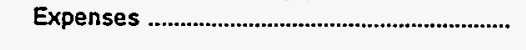 & 885 & 1,065 & 4,057 & 318 & 226 & 517 \\
\hline $\begin{array}{l}\text { Total Electric Operation and } \\
\text { Maintenance Expenses }\end{array}$ & 25,462 & 8,161 & 35,920 & 7,280 & 7,594 & 14,837 \\
\hline \multicolumn{7}{|l|}{ Fuel Expenses in Operation } \\
\hline 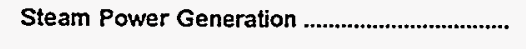 & 0 & 225 & 0 & 0 & 0 & 5,376 \\
\hline Nuclear Power Generation ................................... & 0 & 0 & 0 & 0 & 0 & 0 \\
\hline 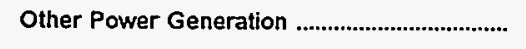 & 0 & 0 & 0 & 0 & 0 & 0 \\
\hline \multicolumn{7}{|l|}{ Number of Elec Dept Employees } \\
\hline Regular Full-time ..................................................... & 66 & 42 & 161 & 7 & 29 & 83 \\
\hline 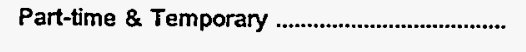 & 12 & 10 & 23 & 0 & 0 & 1 \\
\hline Total Elec Dept Employees ................................ & 78 & 52 & 184 & 7 & 29 & 84 \\
\hline
\end{tabular}

Note: Totals may not equal sum of components because of independent rounding.

Source: Energy Information Administration, Form EIA-412, "Annual Report of Public Electric Utilities." 
Table 23. Electric Operation and Maintenance Expenses by Major U.S. Publicly Owned Electric Utility Within State, 1995 (Continued)

(Thousand Dollars)

\begin{tabular}{|c|c|c|c|c|c|c|}
\hline Item & $\begin{array}{l}\text { lowa } \\
\text { Cedar } \\
\text { Falls } \\
\text { City of } \\
\text { December } 31\end{array}$ & $\begin{array}{c}\text { lowa } \\
\text { Muscatine } \\
\text { City of } \\
\text { December } 31\end{array}$ & $\begin{array}{c}\text { lowa } \\
\text { Pella } \\
\text { City of } \\
\text { December } 31\end{array}$ & $\begin{array}{c}\text { Kansas } \\
\text { Chanute } \\
\text { City of } \\
\text { December } 31\end{array}$ & $\begin{array}{c}\text { Kansas } \\
\text { Coffeyville } \\
\text { City of } \\
\text { December } 31\end{array}$ & $\begin{array}{l}\text { Kansas } \\
\text { Garden } \\
\text { City City of } \\
\text { December } 31\end{array}$ \\
\hline \multicolumn{7}{|l|}{ Production Expenses } \\
\hline 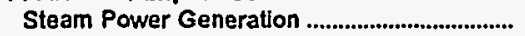 & 4,833 & 23,802 & 3,843 & 0 & 4,386 & $\mathbf{0}$ \\
\hline 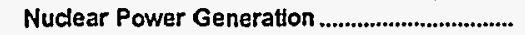 & & & & 0 & & 0 \\
\hline Hydraulic Power Generation ...................................... & $\mathbf{0}$ & 0 & 0 & 0 & 0 & 0 \\
\hline 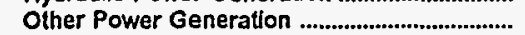 & 124 & 0 & 0 & 698 & 0 & 0 \\
\hline Purchased Power ................................................................. & 1,133 & 386 & 2,120 & 3,577 & 2,347 & 9.082 \\
\hline 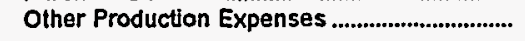 & 82 & 1,042 & 2,246 & 292 & 0 & 1,330 \\
\hline Total Production Expenses ............................... & 6,172 & 25,231 & 8,209 & 4,567 & 6,733 & 10,412 \\
\hline 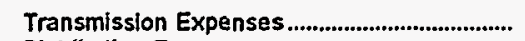 & 464 & 320 & 0 & 36 & 0 & 0 \\
\hline 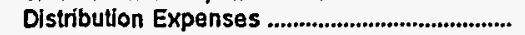 & 1,127 & 1.562 & 1,073 & 683 & 934 & 612 \\
\hline 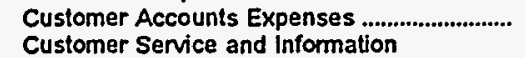 & 338 & 285 & 0 & 200 & 0 & 0 \\
\hline 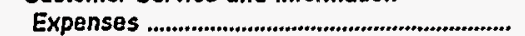 & 153 & 110 & 0 & 176 & 195 & 2 \\
\hline 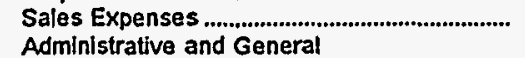 & 0 & 0 & 0 & 0 & 0 & 572 \\
\hline 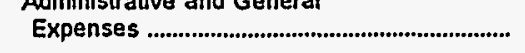 & 1,575 & 5,248 & 1.671 & 197 & 502 & 751 \\
\hline Total Electric Operation and & & & & & & \\
\hline 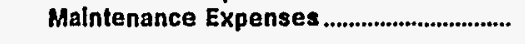 & 9,830 & 32,755 & 10,954 & 5,860 & 8,364 & 12,348 \\
\hline \multicolumn{7}{|l|}{ Fuel Expenses in Operation } \\
\hline 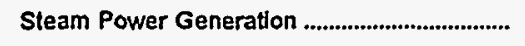 & 2,964 & 15,269 & 2,662 & 0 & 2,092 & 0 \\
\hline Nuclear Power Generation .................................. & 0 & 0 & 0 & 0 & 0 & 0 \\
\hline 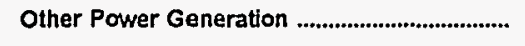 & 49 & 0 & 0 & 196 & 0 & 0 \\
\hline \multicolumn{7}{|l|}{ Number of Elec Dept Employees } \\
\hline 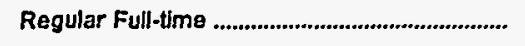 & 88 & 243 & 29 & 25 & 40 & 16 \\
\hline 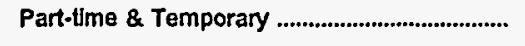 & 5 & 3 & 0 & 0 & 6 & 0 \\
\hline 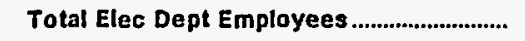 & 93 & 246 & 29 & 25 & 48 & 16 \\
\hline
\end{tabular}

Note: Totals may not equal sum of components because of independent rounding.

Source: Energy Information Administration, Form ELA-412, "Annual Report of Public Electric Utilities." 
Table 23. Electric Operation and Maintenance Expenses by Major U.S. Publicly Owned Electric Utility Within State, 1995 (Continued)

(Thousand Dollars)

\begin{tabular}{|c|c|c|c|c|c|c|}
\hline Item & $\begin{array}{c}\text { Kansas } \\
\text { Kansas } \\
\text { City City of } \\
\text { December } 31\end{array}$ & $\begin{array}{c}\text { Kansas } \\
\text { Kansas } \\
\text { Municipal } \\
\text { Energy } \\
\text { Agency } \\
\text { December } 31\end{array}$ & $\begin{array}{c}\text { Kansas } \\
\begin{array}{c}\text { McPherson } \\
\text { City of }\end{array} \\
\text { December } 31\end{array}$ & $\begin{array}{l}\text { Kansas } \\
\text { Winfield } \\
\text { City of } \\
\text { December } 31\end{array}$ & $\begin{array}{l}\text { Kentucky } \\
\text { Bardstown } \\
\text { City of } \\
\text { December } 31\end{array}$ & $\begin{array}{l}\text { Kentucky } \\
\text { Bowling } \\
\text { Green } \\
\text { City of } \\
\text { June } 30\end{array}$ \\
\hline
\end{tabular}

Production Expenses

Steam Power Generation.

Nuclear Power Generation

Hydraulic Power Generation ..............................

Other Power Generation

Other Production Expenses ...............................

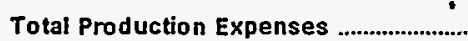

Transmission Expenses

Distribution Expenses

Customer Accounts Expenses ..........................

Customer Service and information

Expenses...

Sales Expenses

Administrative and General

Expenses

$\begin{array}{rr}62,934 & \\ 0 & \\ 0 & \\ 0 & \\ 5,113 & 8,7\end{array}$
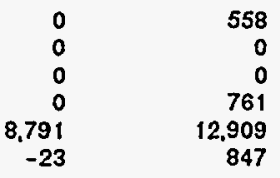

0
0
0
0
6,034
1,688

$\begin{array}{rr}0 & 0 \\ 0 & 0 \\ 0 & 0 \\ 0 & 0 \\ 4,646 & 30,952 \\ 0 & 0\end{array}$

68,798

8,768

15,075

7,722

4,646

30,952

522

10,629

3,608

157

49

1,695

0
749

0
297

0
297
8

0

$0 \quad 128$

207

490

0
0

3

167

15,025

1,254

740

0

67

Total Electric Operation and

Maintenance Expenses

98,582

10,180

17,693

1,100

1,154

Fuel Expenses in Operation

Steam Power Generation

Nuclear Power Generation

Other Power Generation
0

0

0

648

0

648
0

0

0

9

1

10
169

0

381

61

1

62

Note: Totals may not equal sum of components because of independent rounding.

Source: Energy Information Administration, Form ElA-412, "Annual Report of Public Electric Utilities." 
Table 23. Electric Operation and Maintenance Expenses by Major U.S. Publicly Owned Electric Utility Within State, 1995 (Continued)

(Thousand Dollars)

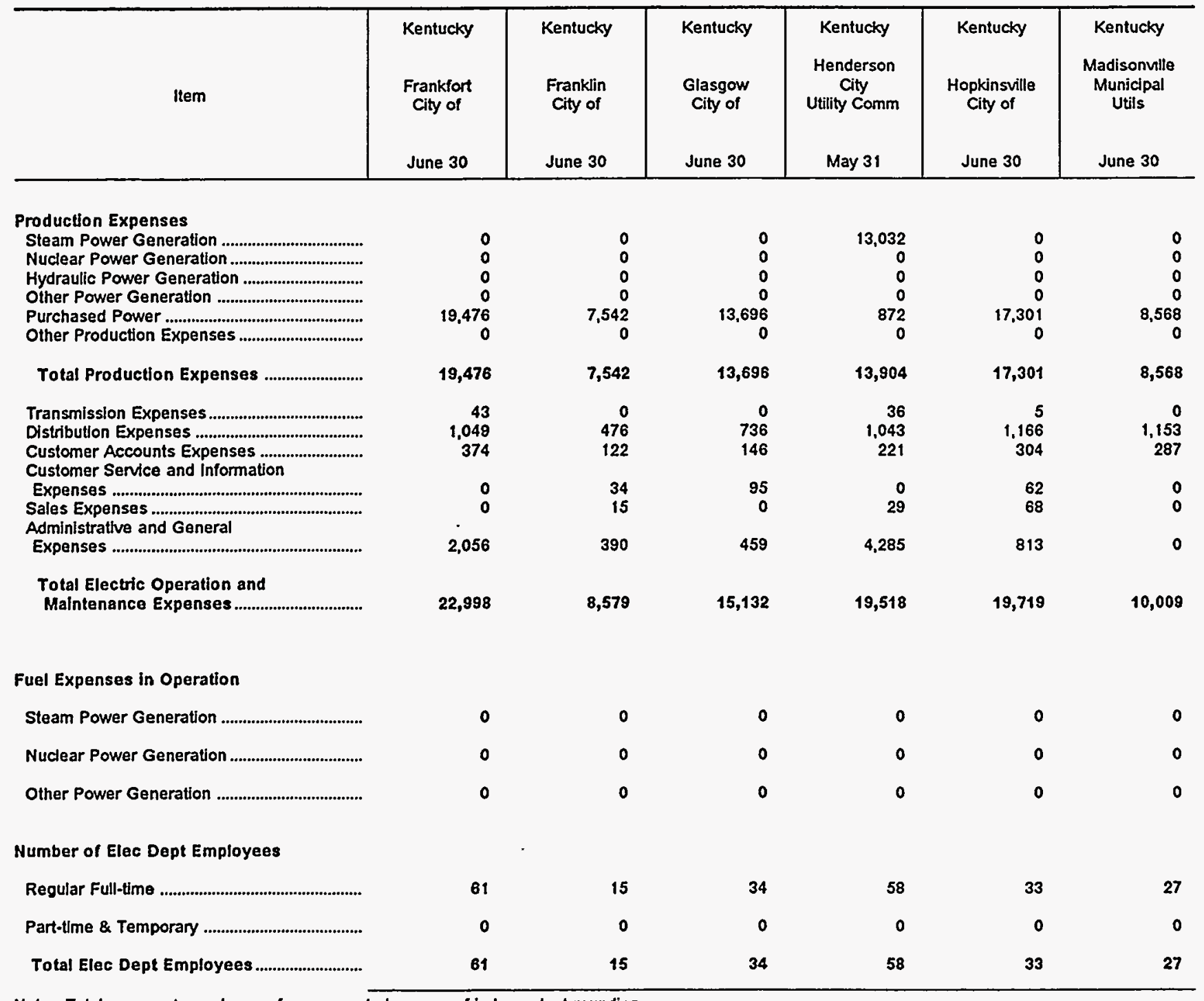

Note: Totals may not equal sum of components because of independent rounding.

Source: Energy Information Administration, Form EIA-4 12, "Annual Report of Public Electric Utilities." 
Table 23. Electric Operation and Maintenance Expenses by Major U.S. Publicly Owned Electric Utility Within State, 1995 (Continued)

(Thousand Dollars)

\begin{tabular}{|c|c|c|c|c|c|c|}
\hline \multirow{3}{*}{ Item } & Kentucky & Kentucky & Kentucky & Kentucky & Louisiana & Louisiana \\
\hline & $\begin{array}{l}\text { Mayfield } \\
\text { City of }\end{array}$ & $\begin{array}{l}\text { Murray } \\
\text { City of }\end{array}$ & $\begin{array}{l}\text { Owensboro } \\
\text { City of }\end{array}$ & $\begin{array}{l}\text { Paducah } \\
\text { City of }\end{array}$ & $\begin{array}{l}\text { Alexandria } \\
\text { City of }\end{array}$ & $\begin{array}{l}\text { Lafayette } \\
\text { City of }\end{array}$ \\
\hline & June 30 & June 30 & May 31 & June 30 & April 30 & October 31 \\
\hline
\end{tabular}

Production Expenses

Steam Powar Generation

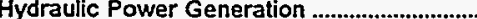

Other Power Generation

Purchased Power ...................................................

Other Production Expenses

Total Production Expenses

Transmission Expenses.

Distribution Expenses

Customer Accounts Expenses

Customer Service and Information

Expenses

Sales Expenses

Administrative and General

Expenses

Total Electric Operation and

Maintenance Expenses

$\begin{array}{rr}0 & \\ 0 & \\ 0 & \\ 0 & \\ 6,881 & \\ 0 & 10,658 \\ & \\ 6,881 & 10,658 \\ 0 & \\ 638 & 67 \\ 178 & 167 \\ 51 & \\ 8 & 13 \\ 438 & \\ 8,193 & 433\end{array}$

Nuclear Power Generation .......................................
29,751

751
0
0
0
342

342
0

30,093

300

2.836

683

0
0

3,803

37,715
0
0
0
0

24,345

0

24,345

48

1,792

753

88
227

1,660

28,913
1,020
0
0
0
14,358
8,216

23,594

2528

2,528

0

1,439

27,562

Fuel Expenses in Operation

Steam Power Generation

0

Nuclear Power Generation

0

Other Power Generation

0

0

o

0

10,671

$\mathbf{0}$

0

o

Number of Elec Dept Employees

Regular Full-time

27

20

183

71

$\cdot 23$

172

Part-time \& Temporary

0

0

5

0

0

5

Total Elec Dept Employees

27

20

188

71

23

177

Note: Totals may not equal sum of components because of independent rounding.

Source: Energy Information Administration, Form EIA-412, "Annual Report of Public Electric Utilities." 
Table 23. Electric Operation and Maintenance Expenses by Major U.S. Publicly Owned Electric Utility Within State, 1995 (Continued) (Thousand Dollars)

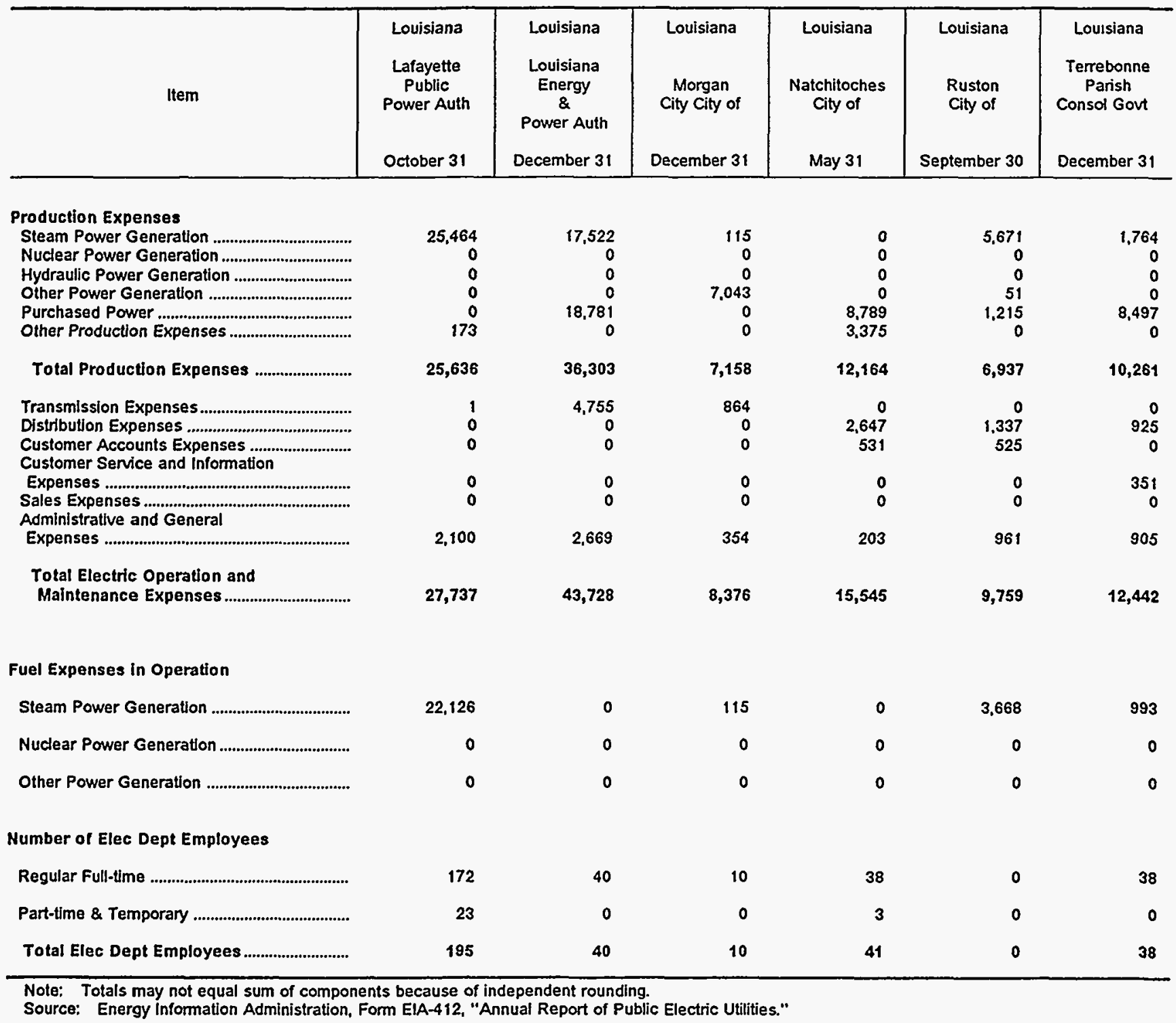


Table 23. Electric Operation and Maintenance Expenses by Major U.S. Publicly Owned Electric Utility Within State, 1995 (Continued)

(Thousand Dollars)

\begin{tabular}{|c|c|c|c|c|c|c|}
\hline Item & $\begin{array}{l}\text { Maryland } \\
\text { Easton } \\
\text { Utilities } \\
\text { Comm } \\
\text { June } 30\end{array}$ & $\begin{array}{l}\text { Maryland } \\
\text { Hagerstown } \\
\text { City of } \\
\text { June } 30\end{array}$ & $\begin{array}{l}\text { Massachusetts } \\
\text { Braintree } \\
\text { Town of } \\
\text { December } 31\end{array}$ & $\begin{array}{l}\text { Massachusetts } \\
\text { Chicopee } \\
\text { City of } \\
\text { December } 31\end{array}$ & $\begin{array}{l}\text { Massachusetts } \\
\text { Concord } \\
\text { Town of } \\
\text { December } 31\end{array}$ & $\begin{array}{c}\text { Massachusetts } \\
\text { Danvers } \\
\text { Town of } \\
\text { December } 31\end{array}$ \\
\hline \multicolumn{7}{|l|}{ Production Expenses } \\
\hline 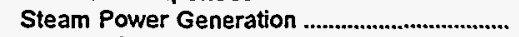 & 0 & 0 & 5,237 & 0 & 0 & 0 \\
\hline 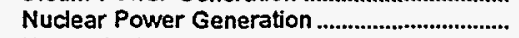 & 0 & 0 & 0 & 2,463 & 0 & 0 \\
\hline 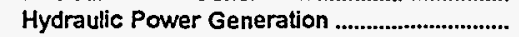 & 0 & 0 & 0 & 0 & 0 & 0 \\
\hline 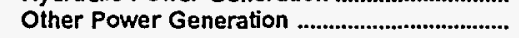 & 2,054 & 0 & 22 & 87 & 0 & 0 \\
\hline Purchased Power & 5,736 & 12,011 & 16,541 & 15,460 & 8,127 & 24,440 \\
\hline 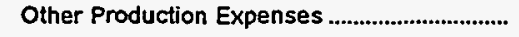 & 185 & 0 & 215 & 319 & 117 & 0 \\
\hline 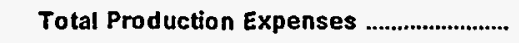 & 7,975 & 12,011 & 22,015 & 18,329 & 8,245 & 24,440 \\
\hline 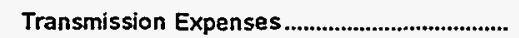 & 29 & 0 & 59 & 78 & 80 & 0 \\
\hline Distribution Expenses ......................................... & 669 & 787 & 1,834 & 2,540 & 289 & 1,299 \\
\hline $\begin{array}{l}\text { Customer Accounts Expenses ............................ } \\
\text { Customer Service and Information }\end{array}$ & 186 & 447 & 659 & 720 & 199 & 619 \\
\hline 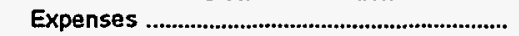 & 2 & 27 & 0 & 321 & 27 & 0 \\
\hline 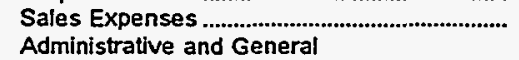 & 0 & 0 & 188 & 0 & 27 & 0 \\
\hline 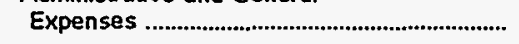 & 1,097 & 1,100 & 2,744 & 3,345 & 1.156 & 1.701 \\
\hline 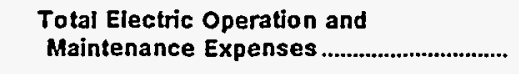 & 9,957 & 14,371 & 27,500 & 25,333 & 10,022 & 28,059 \\
\hline \multicolumn{7}{|l|}{ Fuel Expenses in Operation } \\
\hline Steam Power Generation ...................................... & 0 & 0 & 2,726 & 0 & 0 & 0 \\
\hline Nuclear Power Generation ................................ & 0 & 0 & 0 & 0 & 0 & 0 \\
\hline 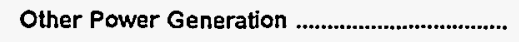 & 1,095 & 0 & 13 & 0 & 0 & $\mathbf{0}$ \\
\hline \multicolumn{7}{|l|}{ Number of Elec Dept Employees } \\
\hline 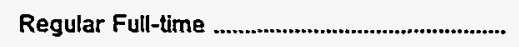 & 59 & 36 & 80 & 73 & 24 & 40 \\
\hline 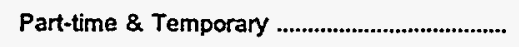 & 0 & 1 & 1 & 2 & 4 & 2 \\
\hline 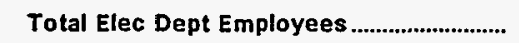 & 59 & 37 & 81 & 75 & 28 & 42 \\
\hline
\end{tabular}

Note: Totals may not equal sum of components because of independent rounding.

Source: Energy Information Administration. Form ELA-412, "Annual Report of Public Electric Utilities." 
Table 23. Electric Operation and Maintenance Expenses by Major U.S. Publicly Owned Electric Utility Within State, 1995 (Continued) (Thousand Dollars)

\begin{tabular}{|c|c|c|c|c|c|c|}
\hline Item & $\begin{array}{l}\text { Massachusetts } \\
\text { Hingham } \\
\text { City of }\end{array}$ & $\begin{array}{l}\text { Massachusetts } \\
\text { Holyoke } \\
\text { City of } \\
\text { December } 31\end{array}$ & $\begin{array}{c}\text { Massachusetts } \\
\text { Hudson } \\
\text { Town of } \\
\text { December } 31\end{array}$ & $\begin{array}{c}\text { Massachusetts } \\
\text { Littleton } \\
\text { Town of } \\
\text { December } 31\end{array}$ & $\begin{array}{l}\text { Massachusetts } \\
\text { Mansfield } \\
\text { Town of } \\
\text { December } 31\end{array}$ & $\begin{array}{l}\text { Massachusetts } \\
\text { Massachusetts } \\
\text { Mun } \\
\text { Whls } \\
\text { Elec Co } \\
\text { December } 31\end{array}$ \\
\hline \\
\hline 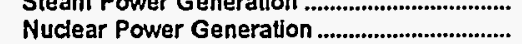 & 0 & $\begin{array}{r}918 \\
0\end{array}$ & 118 & 0 & 0 & 26,349 \\
\hline 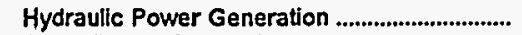 & $\mathbf{0}$ & 121 & 0 & 0 & 0 & 0 \\
\hline 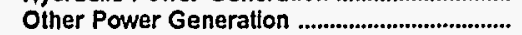 & 0 & 0 & 639 & 0 & 0 & 18,557 \\
\hline 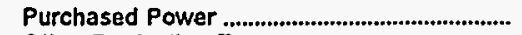 & 9,553 & 17,073 & 22,592 & 10,090 & 13,357 & 38,064 \\
\hline & 77 & 95 & 47 & 99 & 0 & 10 \\
\hline 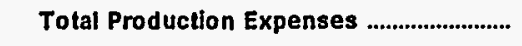 & 9,629 & 18,207 & 23,395 & 10,313 & 13,357 & 83,843 \\
\hline Transmission Expenses ............................................ & 462 & $\begin{array}{r}703 \\
1,733\end{array}$ & $\begin{array}{l}958 \\
418\end{array}$ & $\begin{array}{l}505 \\
747\end{array}$ & $\begin{array}{l}785 \\
704\end{array}$ & 2,834 \\
\hline 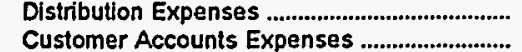 & $\begin{array}{l}754 \\
297\end{array}$ & $\begin{array}{r}1,733 \\
739\end{array}$ & $\begin{array}{l}418 \\
287\end{array}$ & $\begin{array}{l}747 \\
255\end{array}$ & $\begin{array}{l}704 \\
247\end{array}$ & $\begin{array}{l}0 \\
0\end{array}$ \\
\hline Customer Service and Information & & & & & & 6 \\
\hline 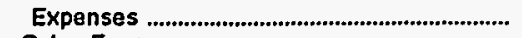 & 0 & 0 & 0 & 0 & 0 & 0 \\
\hline Sales Expenses ....................................... & 0 & 14 & 8 & 75 & 0 & 0 \\
\hline 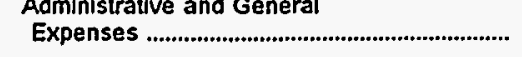 & 662 & 1.997 & 1.739 & 1,279 & 828 & 13,750 \\
\hline $\begin{array}{l}\text { Total Electric Operation and } \\
\text { Maintenance Expenses ................................... }\end{array}$ & 11,804 & 23,393 & 26,807 & 13,174 & 15,921 & 100,426 \\
\hline \multicolumn{7}{|l|}{ Fue! Expenses in Operation } \\
\hline Steam Power Generation ......................................... & 0 & 0 & 0 & 93 & 0 & 617 \\
\hline Nuclear Power Generation ...................................... & 0 & 0 & 36 & 0 & 0 & 8,971 \\
\hline 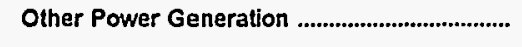 & 0 & 0 & 147 & 0 & 0 & 14,541 \\
\hline \multicolumn{7}{|l|}{ Number of Elec Dept Employees } \\
\hline 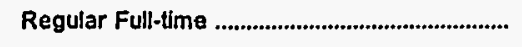 & 23 & 75 & 33 & 30 & 19 & 118 \\
\hline 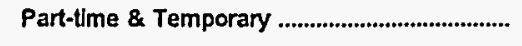 & 2 & 2 & 0 & 1 & 1 & 6 \\
\hline Total Elec Dept Employees .............................. & 25 & 77 & 33 & 31 & 20 & 124 \\
\hline
\end{tabular}

Note: Totals may not equal sum of components because of independent rounding.

Source: Energy Information Administration. Form ElA-412, "Annual Report of Public Electric Utilities." 
Table 23. Electric Operation and Maintenance Expenses by Major U.S. Publicly Owned Electric Utility Within State, 1995 (Continued) (Thousand Dollars)

\begin{tabular}{|c|c|c|c|c|c|c|}
\hline Item & $\begin{array}{l}\text { Massachusetts } \\
\text { Middleborough } \\
\text { Town of }\end{array}$ & $\begin{array}{c}\text { Massachusetts } \\
\text { North } \\
\text { Attleborough } \\
\text { Town of }\end{array}$ & $\begin{array}{l}\text { Massachusetts } \\
\text { Norwood } \\
\text { City of }\end{array}$ & $\begin{array}{l}\text { Massachusetts } \\
\text { Peabody } \\
\text { City of }\end{array}$ & $\begin{array}{l}\text { Massachusetts } \\
\text { Reading } \\
\text { Town of }\end{array}$ & $\begin{array}{c}\text { Massachusetts } \\
\text { Shrewsbury } \\
\text { Town of }\end{array}$ \\
\hline & December 31 & December 31 & June 30 & December 31 & December 31 & December 31 \\
\hline
\end{tabular}

Production Expenses

Steam Power Generation

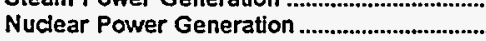

Hydraulic Power Generation .............................

Other Power Generation

Purchased Power .................................................

Other Production Expenses

Total Production Expenses

Transmission Expenses.

Distribution Expenses ...

Customer Accounts Expenses ..........................

Customer Service and information

Expenses.

Sales Expenses

Administrative and General

Expenses

Total Electric Operation and

Maintenance Expenses.

Fuel Expenses in Operation

Steam Power Generation

Nuclear Power Generation

Other Power Generation

Number of Elec Dept Employees

Regular Full-time

Part-time \& Temporary

0
0
0
0

12,823
0

12,823

739

1,241
649

0

26

865

243
0
0
0
11,555
189

0
0
0
0
21,287
0

11,987

21,287

887

826

0
1,166

552

547

0
336

0

1,330

1,454

16,343

15,675

24,790

0
0
0
581

25,891

0

26,472

222

1,431

581

0

3,384

3.384

32,092

0

0

37,851

37,851

1
2828

1,693

0

340

2,870

45,583
37

0

0

0

0

0

0

0

26

5

31

$39 \quad 31$

0

0

0

50

0

so
90

Total Elec Dept Employees

38

76

90

37

Source: Energy Information Administration, Form EIA-412, "Annual Report of Public Electric Utilities." 
Table 23. Electric Operation and Maintenance Expenses by Major U.S. Publicly Owned Electric Utility Within State, 1995 (Continued) (Thousand Dollars)

\begin{tabular}{|c|c|c|c|c|c|c|}
\hline Item & $\begin{array}{l}\text { Massachusetts } \\
\text { Taunton } \\
\text { City of } \\
\text { December } 31\end{array}$ & $\begin{array}{l}\text { Massachusetts } \\
\text { Wakefield } \\
\text { Town of } \\
\text { December } 31\end{array}$ & $\begin{array}{c}\text { Massachusetts } \\
\text { Wellesley } \\
\text { Town of } \\
\text { December } 31\end{array}$ & $\begin{array}{l}\text { Massachusetts } \\
\text { Westfield } \\
\text { City of } \\
\text { December } 31\end{array}$ & $\begin{array}{c}\text { Michigan } \\
\text { Bay } \\
\text { City City of } \\
\text { June } 30\end{array}$ & $\begin{array}{l}\text { Michigan } \\
\text { Coldwater } \\
\text { Board } \\
\text { of } \\
\text { Public Util } \\
\text { June } 30\end{array}$ \\
\hline 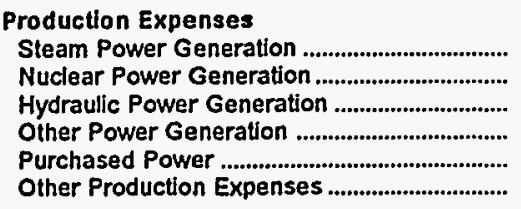 & $\begin{array}{r}7.994 \\
225 \\
0 \\
0 \\
15,243 \\
188\end{array}$ & $\begin{array}{r}0 \\
0 \\
0 \\
0 \\
11,895 \\
0\end{array}$ & $\begin{array}{r}0 \\
0 \\
0 \\
0 \\
10,512 \\
0\end{array}$ & $\begin{array}{r}0 \\
0 \\
0 \\
0 \\
20,830 \\
243\end{array}$ & $\begin{array}{r}0 \\
0 \\
0 \\
0 \\
9,800 \\
0\end{array}$ & $\begin{array}{r}76 \\
0 \\
0 \\
219 \\
8,557 \\
0\end{array}$ \\
\hline Total Production Expenses .......................... & 23,651 & 11,895 & 10,512 & 21,073 & 9,800 & 8,852 \\
\hline 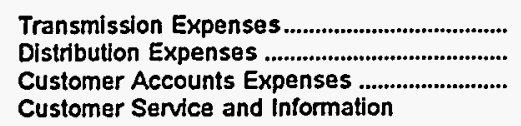 & $\begin{array}{r}287 \\
2,585 \\
1,355\end{array}$ & $\begin{array}{r}0 \\
1.167 \\
356\end{array}$ & $\begin{array}{r}348 \\
1,462 \\
293\end{array}$ & $\begin{array}{r}1,436 \\
2,396 \\
83\end{array}$ & $\begin{array}{r}0 \\
2,322 \\
0\end{array}$ & $\begin{array}{r}0 \\
437 \\
90\end{array}$ \\
\hline $\begin{array}{l}\text { Expenses } \\
\text { Sales Expenses } \\
\text { Administrative and General }\end{array}$ & $\begin{array}{r}0 \\
18\end{array}$ & $\begin{array}{r}0 \\
20\end{array}$ & $\begin{array}{r}0 \\
22\end{array}$ & $\begin{array}{l}0 \\
0\end{array}$ & $\begin{array}{l}0 \\
0\end{array}$ & $\begin{array}{l}0 \\
0\end{array}$ \\
\hline 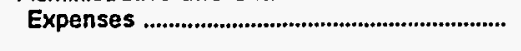 & 4,838 & 1,049 & 693 & 1,999 & 1,786 & 660 \\
\hline $\begin{array}{l}\text { Total Electric Operation and } \\
\text { Maintenance Expenses ................................ }\end{array}$ & 32,734 & 14,488 & 13,330 & 26,987 & 13,908 & 10,039 \\
\hline \multicolumn{7}{|l|}{ Fuel Expenses in Operation } \\
\hline Steam Power Generation ..................................... & 3,149 & 0 & 0 & 0 & 0 & 0 \\
\hline Nuclear Power Generation ..................................... & 34 & 0 & 0 & 0 & 0 & 0 \\
\hline Other Power Generation ...................................... & 0 & 0 & 0 & 0 & 0 & 102 \\
\hline \multicolumn{7}{|l|}{ Number of Elec Dept Employees } \\
\hline 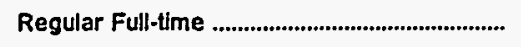 & 161 & 31 & 41 & 60 & 45 & 17 \\
\hline 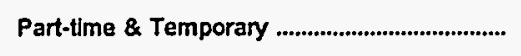 & $\mathbf{0}$ & 1 & 0 & 0 & 0 & 0 \\
\hline 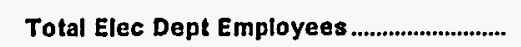 & 161 & 32 & 41 & 60 & 45 & 17 \\
\hline
\end{tabular}

Note: Totals may not equal sum of components because of independent rounding.

Source: Energy Information Administration, Form ElA-412, "Annual Report of Public Electric Utilities." 
Table 23. Electric Operation and Maintenance Expenses by Major U.S. Publicly Owned Electric Utility Within State, 1995 (Continued) (Thousand Dollars)

\begin{tabular}{|c|c|c|c|c|c|c|}
\hline Item & $\begin{array}{l}\text { Michigan } \\
\text { Detroit } \\
\text { City of } \\
\text { June } 30\end{array}$ & $\begin{array}{c}\text { Michigan } \\
\begin{array}{c}\text { Grand Haven } \\
\text { City of }\end{array} \\
\text { June } 30\end{array}$ & $\begin{array}{l}\text { Michigan } \\
\text { Hillsdale } \\
\text { Board } \\
\text { of } \\
\text { Public Wks } \\
\text { June } 30\end{array}$ & $\begin{array}{l}\text { Michigan } \\
\text { Holland } \\
\text { City of } \\
\text { June } 30\end{array}$ & $\begin{array}{l}\text { Michigan } \\
\text { Lansing } \\
\text { City of } \\
\text { June } 30\end{array}$ & $\begin{array}{l}\text { Michigan } \\
\text { Marquette } \\
\text { City of } \\
\text { June } 30\end{array}$ \\
\hline \multicolumn{7}{|l|}{ Production Expenses } \\
\hline $\begin{array}{l}\text { Steam Power Generation } \\
\text { Nuclear Power Generation }\end{array}$ & 17.197 & 8,859 & 0 & 9,600 & 43,896 & 8,492 \\
\hline Hydraulic Power Generation & $\begin{array}{l}0 \\
0\end{array}$ & 0 & 0 & 0 & 0 & 0 \\
\hline 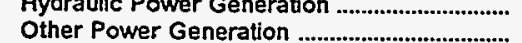 & 0 & 0 & 0 & 0 & 17 & 469 \\
\hline 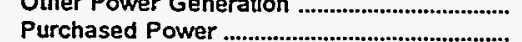 & 0 & 142 & 565 & 179 & 0 & 45 \\
\hline 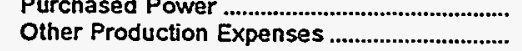 & $\begin{array}{r}11,551 \\
0\end{array}$ & $\begin{array}{r}1.045 \\
127\end{array}$ & $\begin{array}{r}6,585 \\
0\end{array}$ & $\begin{array}{r}17,572 \\
0\end{array}$ & $\begin{array}{r}40,932 \\
0\end{array}$ & $\begin{array}{r}363 \\
0\end{array}$ \\
\hline Total Production Expenses ........................... & 28,748 & 10,173 & 7,150 & 27,351 & 84,845 & 9,370 \\
\hline $\begin{array}{l}\text { Transmission Expenses } \\
\text { Distribution Expenses }\end{array}$ & 1,012 & 0 & 134 & 0 & 1,180 & 1 \\
\hline 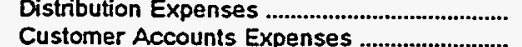 & 9,259 & 629 & 418 & 1,646 & 4,995 & 709 \\
\hline $\begin{array}{l}\text { Customer Accounts Expenses .......................... } \\
\text { Customer Service and Information }\end{array}$ & 0 & 293 & 0 & 273 & 2,551 & 352 \\
\hline 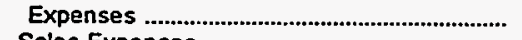 & $\mathbf{0}$ & 0 & 0 & 166 & 0 & 25 \\
\hline $\begin{array}{l}\text { Sales Expenses } \\
\text { Administrative and General }\end{array}$ & $\mathbf{0}$ & 8 & 0 & 68 & 301 & 25 \\
\hline 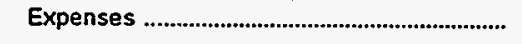 & 11,211 & 1,167 & 533 & 1,783 & 23,136 & 2,197 \\
\hline 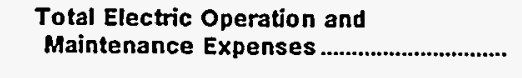 & 50,229 & 12,269 & 8,235 & 31,285 & 117,007 & 12,679 \\
\hline \multicolumn{7}{|l|}{ Fuel Expenses in Operation } \\
\hline 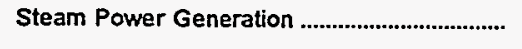 & 0 & 6,508 & 0 & 6,911 & 31,583 & 6.481 \\
\hline Nuclear Power Generation .................................. & 0 & 0 & 0 & 0 & 0 & 0 \\
\hline 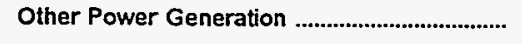 & 0 & 23 & 124 & 147 & 0 & 20 \\
\hline \multicolumn{7}{|l|}{ Number of Elec Dept Employees } \\
\hline 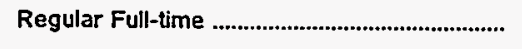 & $\mathbf{0}$ & 34 & 29 & 70 & 631 & 80 \\
\hline 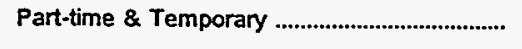 & 0 & 0 & 0 & 1 & 2 & 1 \\
\hline 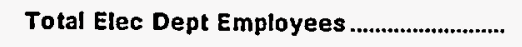 & $\mathbf{0}$ & 34 & 29 & 71 & 633 & 81 \\
\hline
\end{tabular}

Note: Totals may not equal sum of components because of independent rounding.

Source: Energy Information Administration, Form ElA-412, "Annual Report of Public Electric Utilities." 
Table 23. Electric Operation and Maintenance Expenses by Major U.S. Publicly Owned Electric Utility Within State, 1995 (Continued) (Thousand Dollars)

\begin{tabular}{|c|c|c|c|c|c|c|}
\hline Item & $\begin{array}{l}\text { Michigan } \\
\text { Michigan } \\
\text { Public } \\
\text { Power Agency } \\
\text { December } 31\end{array}$ & $\begin{array}{l}\text { Michigan } \\
\text { Michigan } \\
\text { South } \\
\text { Central } \\
\text { Pur Agy } \\
\text { June } 30\end{array}$ & $\begin{array}{c}\text { Michigan } \\
\text { Sturgis } \\
\text { City of } \\
\text { September } 30\end{array}$ & $\begin{array}{l}\text { Michigan } \\
\text { Traverse } \\
\text { City City of } \\
\text { June } 30\end{array}$ & $\begin{array}{l}\text { Michigan } \\
\text { Myandotte } \\
\text { Municipal } \\
\text { Serv Comm } \\
\text { September } 30\end{array}$ & $\begin{array}{l}\text { Michigan } \\
\text { Zeeland } \\
\text { City of } \\
\text { June } 30\end{array}$ \\
\hline 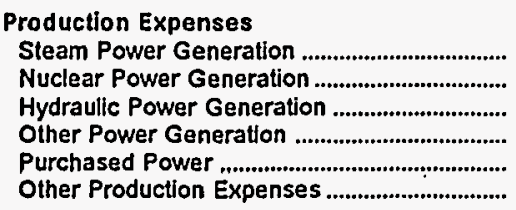 & $\begin{array}{r}37,984 \\
0 \\
0 \\
0 \\
24,949 \\
0\end{array}$ & $\begin{array}{r}7.754 \\
0 \\
0 \\
51 \\
6.643 \\
0\end{array}$ & $\begin{array}{r}0 \\
0 \\
50 \\
763 \\
7.551 \\
0\end{array}$ & $\begin{array}{r}1,432 \\
0 \\
6 \\
0 \\
7,036 \\
0\end{array}$ & $\begin{array}{r}11,442 \\
0 \\
0 \\
0 \\
0 \\
0\end{array}$ & $\begin{array}{r}0 \\
0 \\
0 \\
1,296 \\
4,739 \\
0\end{array}$ \\
\hline Total Production Expenses ........................... & 62,933 & 14,447 & 8,363 & 8,474 & 11,442 & 6,035 \\
\hline 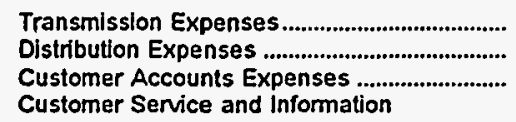 & $\begin{array}{r}2,009 \\
0 \\
0\end{array}$ & $\begin{array}{r}165 \\
0 \\
0\end{array}$ & $\begin{array}{r}22 \\
600 \\
212\end{array}$ & $\begin{array}{r}0 \\
1,262 \\
120\end{array}$ & $\begin{array}{l}747 \\
233 \\
112\end{array}$ & $\begin{array}{r}427 \\
230 \\
79\end{array}$ \\
\hline 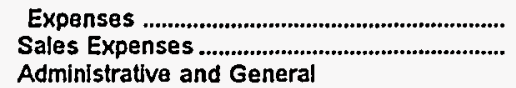 & $\begin{array}{l}\mathbf{0} \\
\mathbf{0}\end{array}$ & $\begin{array}{l}0 \\
0\end{array}$ & $\begin{array}{l}0 \\
0\end{array}$ & $\begin{array}{r}298 \\
62\end{array}$ & $\begin{array}{r}244 \\
93\end{array}$ & $\begin{array}{l}0 \\
0\end{array}$ \\
\hline 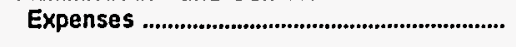 & $\mathbf{0}$ & 1,517 & 1.103 & 931 & 2,484 & 522 \\
\hline $\begin{array}{l}\text { Total Electric Operation and } \\
\text { Maintenance Expenses ................................ }\end{array}$ & 64,942 & 16,129 & 10,300 & 11,148 & 15,355 & 7,293 \\
\hline$\cdot$ & & & & & & \\
\hline \multicolumn{7}{|l|}{ Fuel Expenses in Operation } \\
\hline 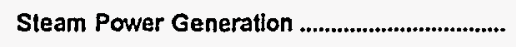 & 0 & 4,754 & 0 & 131 & 0 & 0 \\
\hline Nuclear Power Generation ................................... & 0 & 0 & 0 & 0 & 0 & 0 \\
\hline Other Power Generation ...................................... & 0 & 0 & 353 & 0 & 0 & 770 \\
\hline \multicolumn{7}{|l|}{ Number of Elec Dept Employees } \\
\hline 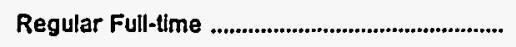 & 8 & 51 & 29 & 47 & 76 & 18 \\
\hline Part-time \& Tentporary ........................................ & 0 & 1 & 0 & 0 & 0 & 3 \\
\hline 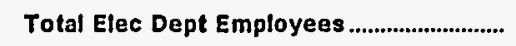 & 8 & 52 & 29 & 47 & 76 & 21 \\
\hline
\end{tabular}

Note: Totals may not equal sum of components because of independent rounding.

Source: Energy Information Administration. Form EIA-412, "Annual Report of Public Electric Utilities." 
Table 23. Electric Operation and Maintenance Expenses by Major U.S. Publicly Owned Electric Utility Within State, 1995 (Continued)

(Thousand Dollars)

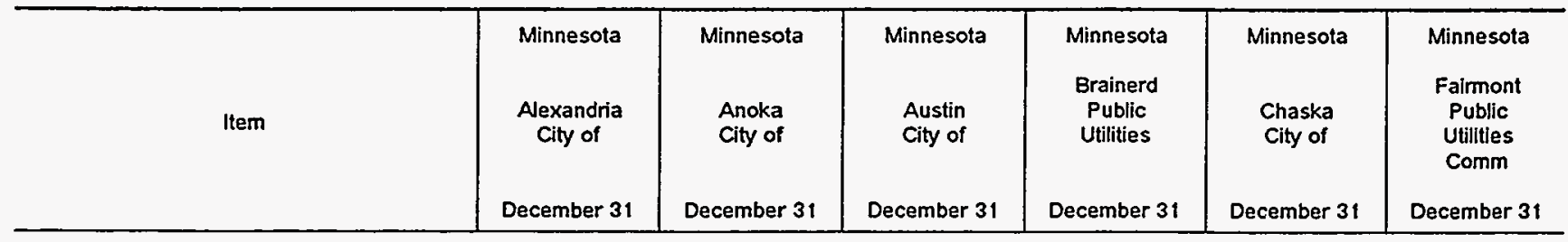

Production Expenses

Steam Power Generation .

Nuclear Power Generation ...................................

Hydraulic Power Generation

Other Power Generation

Other Production Expenses ...............................

Total Production Expenses

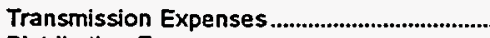

Distribution Expenses.

Customer Accounts Expenses

Customer Service and Information

Expenses

Administrative and General

Expenses

Total Electric Operation and

Maintenance Expenses

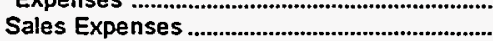

5.476

0
0
0
62
5.476
7

5,545

1,090

545

249

9
0

516

7,954
4,196

0
0
0
0

9.033

0

9,033

0
610

610
332

0
0

445

10,421

20,269
0
0
0
0
5.433

141

5,574

0
659

0

0
0

608

6,840

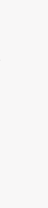

0
0
0
0
6,873
0

1,323

0

0

7,940

0

9,264

10

531

0
0

1,032

10,837

Fuel Expenses in Operation

Steam Power Generation ..................................

Nuclear Power Generation .

0

0

Other Power Generation

Number of Elec Dept Employees

Regular Full-time

25

19

0

Part-time \& Temporary

Total Elec Dept Employees ..

25

6

25

0

0

53

0

0

0

o

Note: Totals may not equal sum of components because of independent rounding.

Source: Energy Information Administration, Form EIA-412, "Annual Report of Public Electric Utilities." 
Table 23. Electric Operation and Maintenance Expenses by Major U.S. Publicly Owned Electric Utility Within State, 1995 (Continued)

(Thousand Dollars)

\begin{tabular}{|c|c|c|c|c|c|c|}
\hline Item & $\begin{array}{l}\text { Minnesota } \\
\text { Hutchinson } \\
\text { Utilities } \\
\text { Comm } \\
\text { December } 31\end{array}$ & $\begin{array}{c}\text { Minnesota } \\
\text { Marshall } \\
\text { City of } \\
\text { December } 31\end{array}$ & $\begin{array}{c}\text { Minnesota } \\
\text { Moorhead } \\
\text { City of } \\
\text { December } 31\end{array}$ & $\begin{array}{l}\text { Minnesota } \\
\text { New Ulm } \\
\text { Public } \\
\text { Utilities } \\
\text { Comm } \\
\text { December } 31\end{array}$ & $\begin{array}{c}\text { Minnesota } \\
\text { Northern } \\
\text { Municipal } \\
\text { Power Agny } \\
\text { December } 31\end{array}$ & $\begin{array}{c}\text { Minnesota } \\
\text { Owatonna } \\
\text { City of } \\
\text { December } 31\end{array}$ \\
\hline 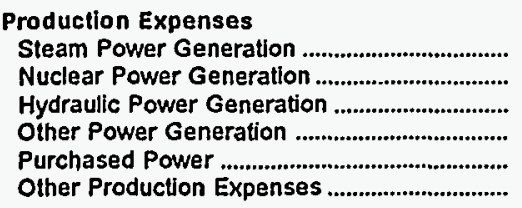 & $\begin{array}{r}0 \\
0 \\
0 \\
4,318 \\
3,631 \\
0\end{array}$ & $\begin{array}{r}0 \\
0 \\
0 \\
353 \\
9.524 \\
0\end{array}$ & $\begin{array}{r}0 \\
0 \\
0 \\
123 \\
8,553 \\
0\end{array}$ & $\begin{array}{r}2,517 \\
0 \\
0 \\
0 \\
3,298 \\
781\end{array}$ & $\begin{array}{r}11,905 \\
0 \\
0 \\
0 \\
0 \\
0\end{array}$ & $\begin{array}{r}0 \\
0 \\
0 \\
1,168 \\
14,273 \\
0\end{array}$ \\
\hline Total Production Expenses ......................... & 7,949 & 9,878 & 8,676 & 6,597 & 11,905 & 15,439 \\
\hline 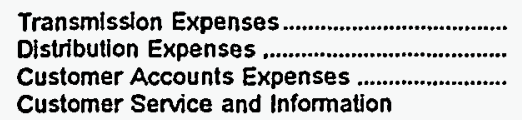 & $\begin{array}{r}13 \\
389 \\
105\end{array}$ & $\begin{array}{r}863 \\
891 \\
0\end{array}$ & $\begin{array}{r}0 \\
930 \\
347\end{array}$ & $\begin{array}{r}22 \\
431 \\
83\end{array}$ & $\begin{array}{r}743 \\
0 \\
0\end{array}$ & $\begin{array}{r}0 \\
1,076 \\
332\end{array}$ \\
\hline 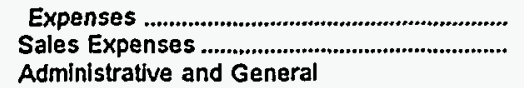 & $\begin{array}{r}18 \\
0\end{array}$ & $\begin{array}{r}21 \\
0\end{array}$ & $\begin{array}{r}309 \\
0\end{array}$ & $\begin{array}{l}0 \\
0\end{array}$ & $\begin{array}{l}0 \\
0\end{array}$ & $\begin{array}{r}55 \\
0\end{array}$ \\
\hline 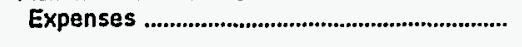 & 1,102 & 819 & 864 & 1,206 & 109 & 525 \\
\hline 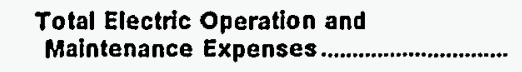 & 9,577 & 12,472 & 11,126 & 8,339 & 12,756 & 17,426 \\
\hline \multicolumn{7}{|l|}{ Fuel Expenses in Operation } \\
\hline Steam Power Generation ................................... & 0 & $\mathbf{0}$ & 0 & 0 & 7,880 & 0 \\
\hline Nuclear Power Generation ................................ & 0 & 0 & 0 & 0 & 0 & 0 \\
\hline 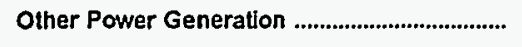 & 2,976 & 0 & 0 & 0 & 0 & 0 \\
\hline \multicolumn{7}{|l|}{ Number of Elec Dept Employees } \\
\hline Regular Full-time & 52 & 10 & 20 & 22 & 0 & 39 \\
\hline 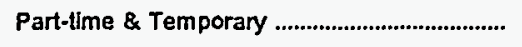 & 0 & 0 & 6 & 0 & 0 & 0 \\
\hline Total Elec Dept Employees ............................ & 52 & 10 & 26 & 22 & 0 & 39 \\
\hline
\end{tabular}

Note: Totals may not equal sum of components because of independent rounding.

Source: Energy Information Administration, Form EIA-4 12, "Annual Report of Public Electric Utilities." 
Table 23. Electric Operation and Maintenance Expenses by Major U.S. Publicly Owned Electric Utility Within State, 1995 (Continued) (Thousand Dollars)

\begin{tabular}{|c|c|c|c|c|c|c|}
\hline Item & $\begin{array}{c}\text { Minnesota } \\
\text { Rochester } \\
\text { Public } \\
\text { Utilities } \\
\text { December } 31\end{array}$ & $\begin{array}{c}\text { Minnesota } \\
\text { Shakopee } \\
\text { Public } \\
\text { Utilities } \\
\text { Comm } \\
\text { December } 31\end{array}$ & $\begin{array}{l}\text { Minnesota } \\
\text { Southem } \\
\text { Minnesota } \\
\text { Mun P } \\
\text { Agny } \\
\text { December } 31\end{array}$ & $\begin{array}{c}\text { Minnesota } \\
\text { Western } \\
\text { Minnesota } \\
\text { Mun } \\
\text { Pwr Agny } \\
\text { December } 31\end{array}$ & $\begin{array}{c}\text { Minnesota } \\
\text { Willmar } \\
\text { Municipal } \\
\text { Utils Comm } \\
\text { December } 31\end{array}$ & $\begin{array}{c}\text { Minnesota } \\
\begin{array}{c}\text { Worthington } \\
\text { City of }\end{array} \\
\text { December } 31\end{array}$ \\
\hline \multicolumn{7}{|l|}{ Production Expenses } \\
\hline 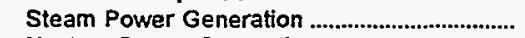 & 7,505 & 0 & 33,424 & 0 & 1.926 & 0 \\
\hline 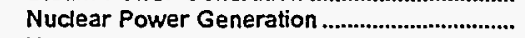 & 0 & 0 & 0 & 0 & 0 & 0 \\
\hline 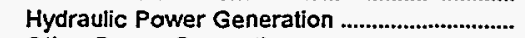 & 176 & 0 & 0 & 0 & 0 & 0 \\
\hline 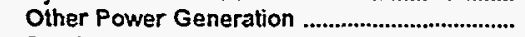 & 181 & 0 & 0 & 0 & 0 & 0 \\
\hline 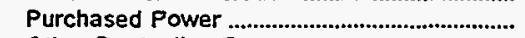 & 47,520 & 6,359 & 15,652 & 44,941 & 4,812 & 4.975 \\
\hline 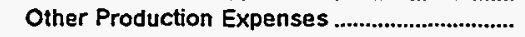 & 294 & 0 & 817 & 68 & 0 & 0 \\
\hline 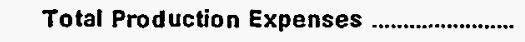 & 55,676 & 6,359 & 49,893 & 45,009 & 6,738 & 4,975 \\
\hline 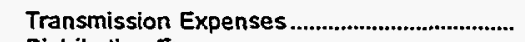 & 259 & 0 & 676 & 11,078 & 18 & 946 \\
\hline 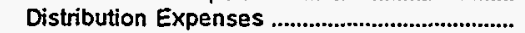 & 1,972 & 559 & 0 & 0 & 630 & 369 \\
\hline $\begin{array}{l}\text { Customer Accounts Expenses } \\
\text { Customer Senvice and Information }\end{array}$ & 1,039 & 134 & 0 & 2 & 185 & 124 \\
\hline 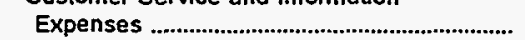 & 124 & 0 & 0 & 0 & 0 & 53 \\
\hline 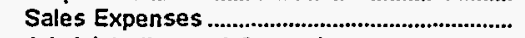 & 41 & 0 & 0 & 0 & 0 & 0 \\
\hline \multicolumn{7}{|l|}{ Administrative and General } \\
\hline 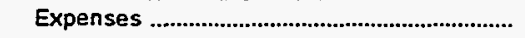 & 2,903 & 292 & 5,170 & 2,452 & 1,140 & 310 \\
\hline 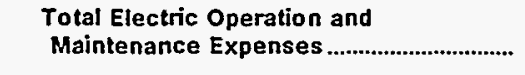 & 62,014 & 7,343 & 55,739 & 58,542 & 8,712 & 6,777 \\
\hline \multicolumn{7}{|l|}{ Fuel Expenses in Operation } \\
\hline 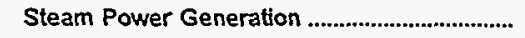 & 4,366 & 0 & 22,629 & 0 & 1,226 & 0 \\
\hline 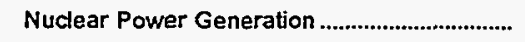 & 0 & 0 & 0 & 0 & 0 & $\mathbf{0}$ \\
\hline 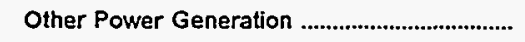 & 123 & 0 & 0 & 0 & 0 & $\mathbf{0}$ \\
\hline \multicolumn{7}{|l|}{ Number of Elec Dept Employees } \\
\hline Regular Full-time & 156 & 16 & 37 & 24 & 45 & 10 \\
\hline Part-time \& Temporary ......................................... & 0 & 7 & 0 & 2 & 0 & 0 \\
\hline Total Elec Dept Employees .............................. & 156 & 23 & 37 & 26 & 45 & 10 \\
\hline
\end{tabular}

Note: Totals may not equal sum of components because of independent rounding.

Source: Energy Information Administration, Form EIA-412, "Annual Report of Public Electric Utilities." 
Table 23. Electric Operation and Maintenance Expenses by Major U.S. Publicly Owned Electric Utility Within State, 1995 (Continued)

(Thousand Dollars)

\begin{tabular}{c|c|c|c|c|c|c}
\hline & Mississippi & Mississippi & Mississippi & Mississippi & Mississippi & Mississippi \\
Item & Aberdeen & Clarksdale & Columbus & $\begin{array}{c}\text { Greenwood } \\
\text { Utllities } \\
\text { City of }\end{array}$ & $\begin{array}{c}\text { Holly } \\
\text { Springs } \\
\text { City of }\end{array}$ & $\begin{array}{c}\text { Louisville } \\
\text { Electric } \\
\text { System }\end{array}$ \\
& June 30 & September 30 & June 30 & September 30 & June 30 & June 30 \\
\hline
\end{tabular}

Production Expenses

Steam Power Generation

Nuclear Power Generation

Hydraulic Power Generation ...............................

Other Power Generation

Purchased Power

Other Production Expenses

Total Production Expenses

0
0
0
0
7,379
0

Transmission Expenses.

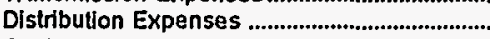

Customer Accounts Expenses ...........................

Customer Senice and information

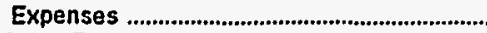

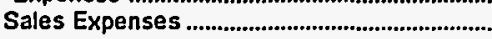

Administrative and General

Expenses

Total Electric Operation and

Malntenance Expenses.

7,379

0

253

110

39

39
18

268

8,068

9,538

1,985
0
0
0
6,161
16

8,162

0

394
201

201

0
0

781

0
0
0
0
20,337
0

1,842

1,842

0
9,060

9.060
0

20,337

10,902

0
864

864
219

4

4

112

616

22,152

12,810

7,896

Fuel Expenses in Operation

Steam Power Generation

Nuclear Power Generation

Other Power Generation

o

0

0

1,402

0

37

0

37
0

14

0
0
0

0

0

0

0

Number of Elec Dept Employees

Part-time \& Temporary

Total Elec Dept Employees

Note: Totals may not equal sum of components because of independent rounding.

Source: Energy Information Administration, Form ElA-412, "Annual Report of Public Electric Utilities." 
Table 23. Electric Operation and Maintenance Expenses by Major U.S. Publicly Owned Electric Utility Within State, 1995 (Continued)

(Thousand Dollars)

\begin{tabular}{|c|c|c|c|c|c|c|}
\hline Item & $\begin{array}{l}\text { Mississıppi } \\
\text { Municipal } \\
\text { Energy } \\
\text { Agency } \\
\text { of MS } \\
\text { September } 30\end{array}$ & $\begin{array}{l}\text { Mississippi } \\
\text { New Albany } \\
\text { City of } \\
\text { June } 30\end{array}$ & $\begin{array}{l}\text { Mississippi } \\
\text { Oxford } \\
\text { City of } \\
\text { June } 30\end{array}$ & $\begin{array}{l}\text { Mississippi } \\
\text { Starkville } \\
\text { City of } \\
\text { June } 30\end{array}$ & $\begin{array}{l}\text { Mississippi } \\
\text { Tupelo } \\
\text { City of } \\
\text { June } 30\end{array}$ & $\begin{array}{l}\text { Mississippi } \\
\text { West } \\
\text { Point } \\
\text { City of } \\
\text { June } 30\end{array}$ \\
\hline 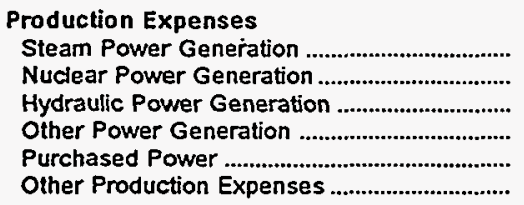 & $\begin{array}{r}0 \\
0 \\
0 \\
0 \\
26,660 \\
0\end{array}$ & $\begin{array}{r}0 \\
0 \\
0 \\
0 \\
11,016 \\
0\end{array}$ & $\begin{array}{r}0 \\
0 \\
0 \\
0 \\
7,110 \\
0\end{array}$ & $\begin{array}{r}0 \\
0 \\
0 \\
0 \\
14,850 \\
0\end{array}$ & $\begin{array}{r}0 \\
0 \\
0 \\
0 \\
28,984 \\
0\end{array}$ & $\begin{array}{r}0 \\
0 \\
0 \\
0 \\
8,352 \\
0\end{array}$ \\
\hline Total Production Expenses .......................... & 26,660 & 11,016 & 7,110 & 14,850 & 28,984 & 8,352 \\
\hline 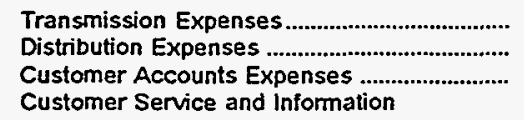 & $\begin{array}{r}2,748 \\
0 \\
0\end{array}$ & $\begin{array}{r}0 \\
857 \\
212\end{array}$ & $\begin{array}{r}0 \\
332 \\
134\end{array}$ & $\begin{array}{r}1 \\
568 \\
195\end{array}$ & $\begin{array}{r}0 \\
1,043 \\
312\end{array}$ & $\begin{array}{r}0 \\
457 \\
87\end{array}$ \\
\hline 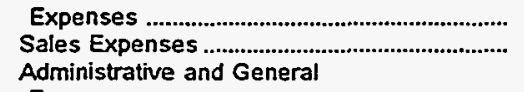 & $\begin{array}{l}0 \\
0\end{array}$ & $\begin{array}{r}4 \\
12\end{array}$ & $\begin{array}{l}22 \\
37\end{array}$ & $\begin{array}{l}18 \\
12\end{array}$ & $\begin{array}{l}75 \\
57\end{array}$ & $\begin{array}{l}11 \\
17\end{array}$ \\
\hline 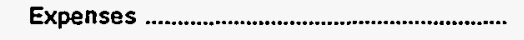 & 560 & 292 & 231 & 337 & 469 & 176 \\
\hline $\begin{array}{l}\text { Total Electric Operation and } \\
\text { Maintenance Expenses }\end{array}$ & 29,968 & 12,392 & 7,866 & 15,981 & 30,940 & 9,100 \\
\hline \multicolumn{7}{|l|}{ Fuel Expenses in Operation } \\
\hline 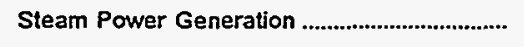 & 0 & 0 & 0 & 0 & 0 & 0 \\
\hline 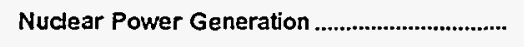 & 0 & 0 & 0 & 0 & 0 & o \\
\hline 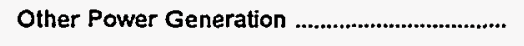 & 0 & 0 & 0 & 0 & 0 & 0 \\
\hline \multicolumn{7}{|l|}{ Number of Elec Dept Employees } \\
\hline 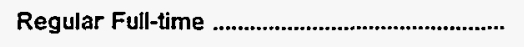 & 4 & 33 & 22 & 34 & 58 & 12 \\
\hline 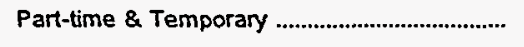 & 0 & o & 0 & 0 & 0 & 0 \\
\hline Total Elec Dept Employees ................................. & 4 & 33 & 22 & 34 & 58 & 12 \\
\hline
\end{tabular}

Note: Totals may not equal sum of components because of independent rounding.

Source: Energy Information Administration, Form ElA-412, "Annual Report of Public Electric Utilities." 
Table 23. Electric Operation and Maintenance Expenses by Major U.S. Publicly Owned Electric Utility Within State, 1995 (Continued)

(Thousand Dollars)

\begin{tabular}{|c|c|c|c|c|c|c|}
\hline Item & $\begin{array}{l}\text { Missouri } \\
\text { Carthage } \\
\text { City of } \\
\text { June } 30\end{array}$ & $\begin{array}{l}\text { Missoun } \\
\text { Columbia } \\
\text { City of } \\
\text { September } 30\end{array}$ & $\begin{array}{l}\text { Missouri } \\
\text { Hanniba! } \\
\text { City of } \\
\text { June } 30\end{array}$ & $\begin{array}{l}\text { Missouri } \\
\text { Independence } \\
\text { City of } \\
\text { June } 30\end{array}$ & $\begin{array}{l}\text { Missouri } \\
\text { Kennett } \\
\text { City of } \\
\text { June } 30\end{array}$ & $\begin{array}{l}\text { Missouri } \\
\text { Kirkwood } \\
\text { City of } \\
\text { Mareh } 31\end{array}$ \\
\hline 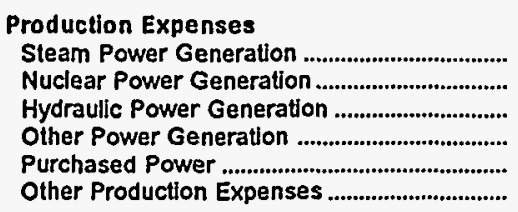 & $\begin{array}{r}0 \\
0 \\
0 \\
416 \\
6,575 \\
73\end{array}$ & $\begin{array}{r}4,671 \\
0 \\
0 \\
0 \\
26,968 \\
16\end{array}$ & $\begin{array}{r}0 \\
0 \\
0 \\
0 \\
7.863 \\
0\end{array}$ & $\begin{array}{r}5,765 \\
0 \\
0 \\
344 \\
20.570 \\
563\end{array}$ & $\begin{array}{r}0 \\
0 \\
0 \\
486 \\
2,971 \\
0\end{array}$ & $\begin{array}{r}0 \\
0 \\
0 \\
0 \\
7,515 \\
0\end{array}$ \\
\hline Total Production Expenses ............................. & 7,064 & 31,655 & 7,863 & 27,242 & 3,457 & 7,515 \\
\hline 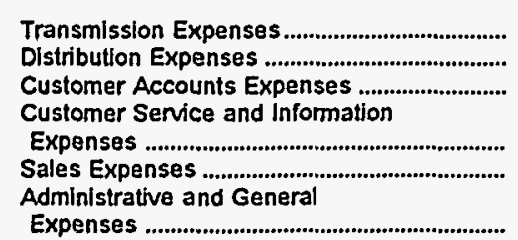 & $\begin{array}{r}0 \\
356 \\
143 \\
2 \\
0\end{array}$ & $\begin{array}{r}0 \\
3,828 \\
1,368 \\
0 \\
0\end{array}$ & $\begin{array}{r}0 \\
567 \\
105 \\
23 \\
79\end{array}$ & $\begin{array}{r}2,206 \\
5,411 \\
1,825 \\
207 \\
0\end{array}$ & $\begin{array}{r}0 \\
671 \\
0\end{array}$ & $\begin{array}{r}0 \\
898 \\
185\end{array}$ \\
\hline $\begin{array}{l}\text { Total Electric Operation and } \\
\text { Malntenance Expenses ................................... }\end{array}$ & 8,645 & 39,009 & 9,419 & 40,791 & 4,590 & 9,186 \\
\hline \multicolumn{7}{|l|}{ Fuel Expenses in Operation } \\
\hline Steam Power Generation ....................................... & 0 & 0 & 0 & 1,605 & 0 & 0 \\
\hline Nuclear Power Generation .................................... & 0 & 0 & 0 & 0 & 0 & 0 \\
\hline 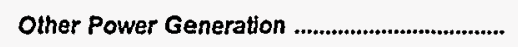 & 0 & 0 & 0 & 218 & 0 & o \\
\hline \multicolumn{7}{|l|}{ Number of Elec Dept Employees } \\
\hline 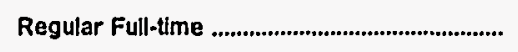 & 36 & 197 & 34 & 208 & 42 & 19 \\
\hline 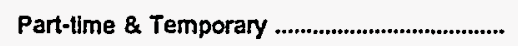 & 0 & 18 & 0 & 0 & 0 & 0 \\
\hline 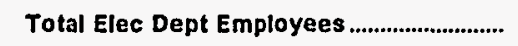 & 36 & 215 & 34 & 208 & 42 & 19 \\
\hline
\end{tabular}

Note: Totals may not equal sum of components because of independent rounding

Sourca: Energy Information Administration, Form ElA-412, "Annual Report of Public Electric Utilities." 
Table 23. Electric Operation and Maintenance Expenses by Major U.S. Publicly Owned Electric Utility Within State, 1995 (Continued)

(Thousand Dollars)

\begin{tabular}{c|c|c|c|c|c|c}
\hline & Missouri & Missouri & Missouri & Missouri & Missouri \\
Item & $\begin{array}{c}\text { Lebanon } \\
\text { City of }\end{array}$ & $\begin{array}{c}\text { Marshall } \\
\text { City of } \\
\text { Bluff } \\
\text { City of }\end{array}$ & $\begin{array}{c}\text { Monett } \\
\text { City of }\end{array}$ & $\begin{array}{c}\text { Rolla } \\
\text { City of }\end{array}$ & $\begin{array}{c}\text { Sikeston } \\
\text { City of }\end{array}$ \\
\hline
\end{tabular}

Production Expenses

Steam Power Generation

Nuclear Power Generation ....................................

Hydraulic Power Generation

Other Power Generation

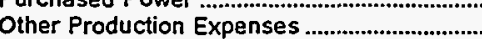

Total Production Expenses

Transmission Expenses

Customer Accounts Expenses ...........................

Customer Service and Information

Expenses

Sales Expenses

Administrative and General

Expenses

Total Electric Operation and

Maintenance Expenses

Fuel Expenses in Operation

Steam Power Generation

Nuclear Power Generation.

Other Power Generation

Number of Elec Dept Employees

Regular Full-time

Part-time \& Temporary

Total Elec Dept Employees
Distribution Expenses

0
0
0
0
7.476
0

2,960
0
0
0
1,783
0

0
0
0
0
5,490
0

$$
7,476
$$

4,743

5,490

0
1,462
0

15
474

377

0

0
0

300

9,238

6,050
0
0
0
0
8,776
0

28,998

0

0

3,227

6,457

131

6,648

8,776

32,223

0
950

0
374

154

1.092

294

0

3,242

1,540

36,851

9,138

9,670

Note: Totals may not equal sum of components because of independent rounding.

Source: Energy Information Administration, Form EIA-412, "Annual Report of Public Electric Utilities." 
Table 23. Electric Operation and Maintenance Expenses by Major U.S. Publicly Owned Electric Utility Within State, 1995 (Continued) (Thousand Dollars)

\begin{tabular}{|c|c|c|c|c|c|c|}
\hline Item & $\begin{array}{c}\text { Missouri } \\
\text { Springfield } \\
\text { City of }\end{array}$ & $\begin{array}{l}\text { Missouri } \\
\text { West } \\
\text { Plains } \\
\text { City of } \\
\text { December } 31\end{array}$ & $\begin{array}{l}\text { Nebraska } \\
\text { Beatrice } \\
\text { City of } \\
\text { July } 31\end{array}$ & $\begin{array}{c}\text { Nebraska } \\
\text { Central } \\
\text { Nebraska } \\
\text { Pub } \\
\text { P\&l Dist } \\
\text { December } 31\end{array}$ & $\begin{array}{c}\text { Nebraska } \\
\text { Cornhusker } \\
\text { Public } \\
\text { Power Dist } \\
\\
\text { December } 31\end{array}$ & $\begin{array}{c}\text { Nebraska } \\
\text { Dawson } \\
\text { County } \\
\text { Public } \\
\text { Pwr Dist } \\
\text { December } 31\end{array}$ \\
\hline
\end{tabular}

Production Expenses

Steam Power Generation .

Nuclear Power Generation.

Hydraulic Power Generation

Other Power Generation

Purchased Por

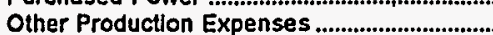

Total Production Expenses

Transmission Expenses.

Distribution Expenses

Customer Accounts Expenses .........................

Customer Service and Information

Expenses

Sales Expenses

Administrative and General

Expenses

Total Electric Operation and

Maintenance Expenses
45,384

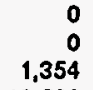

13,526
0

60,264

324
8682

1,767

3

0

9,108

80,148

0
0
0
0
5,759
0

5,759

345
3,396

0

$\therefore$

o

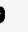

0
0
0
0
5,202
0

5,202

278

6,242

0
0
2,445
0
0
0

2,445

0
568

78

115
0

78

1,900

4,365 $\begin{array}{rr}0 & 0 \\ 0 & 0 \\ 0 & 0 \\ 0 & 0 \\ 7,728 & 10,492 \\ 0 & 0\end{array}$

$7,728 \quad 10,492$

$98 \quad 26$

$242 \quad 397$

10268

1,38

13,771
Fuel Expenses in Operation
Steam Power Generation

29,706

0

Nuclear Power Generation .................................

Other Power Generation

, 153
149

3

152 o

$\mathbf{0}$

0

18

0

18
6

67
70

2.

72
0

0

0
Note: Totals may not equal sum of components because of independent rounding.

Source: Energy Information Administration, Form EIA-412, "Annual Report of Public Electric Utilities." 
Table 23. Electric Operation and Maintenance Expenses by Major U.S. Publicly Owned Electric Utility Within State, 1995 (Continued)

(Thousand Dollars)

\begin{tabular}{|c|c|c|c|c|c|c|}
\hline Item & $\begin{array}{l}\text { Nebraska } \\
\begin{array}{l}\text { Fremont } \\
\text { City of }\end{array} \\
\text { July } 31\end{array}$ & $\begin{array}{l}\text { Nebraska } \\
\text { Grand Island } \\
\text { City of } \\
\text { July } 31\end{array}$ & $\begin{array}{c}\text { Nebraska } \\
\text { Hastings } \\
\text { City of }\end{array}$ & $\begin{array}{l}\text { Nebraska } \\
\text { Lincoln } \\
\text { Electric } \\
\text { System } \\
\text { December } 31\end{array}$ & $\begin{array}{c}\text { Nebraska } \\
\text { Loup } \\
\text { River } \\
\text { Public } \\
\text { Power Dist } \\
\text { December } 31\end{array}$ & $\begin{array}{l}\text { Nebraska } \\
\text { Municipal } \\
\text { Energy } \\
\text { Agency } \\
\text { of NE } \\
\text { March } 31\end{array}$ \\
\hline \multicolumn{7}{|l|}{ Production Expenses } \\
\hline 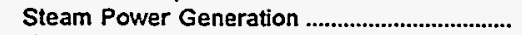 & 7,261 & 7,566 & 6,214 & 12,398 & 0 & 2,026 \\
\hline Nuclear Power Generation ......................................... & 0 & 0 & 0 & 0 & 0 & 0 \\
\hline 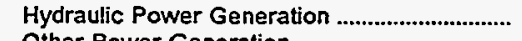 & 0 & 0 & 0 & 0 & 1,502 & 0 \\
\hline 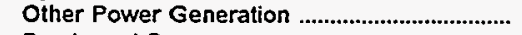 & 0 & 0 & 83 & 1,123 & 4 & 0 \\
\hline $\begin{array}{l}\text { Purchased Power } \\
\text { Other Production Expenses }\end{array}$ & 506 & 723 & 1,149 & $\begin{array}{r}59,205 \\
1,225\end{array}$ & 33,765 & 19,456 \\
\hline & 3 & 0 & 0 & 1,235 & 0 & 0 \\
\hline Total Production Expenses ............................ & 7,769 & 8,289 & 7,447 & 73,961 & 35,272 & 21,482 \\
\hline 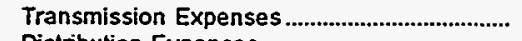 & 0 & 153 & 117 & 1,932 & 366 & 4,041 \\
\hline Distribution Expenses & 1,191 & 950 & 399 & 6,319 & 896 & 0 \\
\hline $\begin{array}{l}\text { Customer Accounts Expenses ........................... } \\
\text { Customer Service and Information }\end{array}$ & 214 & 713 & 287 & 2,159 & 514 & 0 \\
\hline Expenses …....................................................... & 0 & 0 & 43 & 1,734 & 90 & $\mathbf{0}$ \\
\hline $\begin{array}{l}\text { Sales Expenses ............................................. } \\
\text { Administrative and General }\end{array}$ & 0 & 0 & 0 & 0 & 34 & 0 \\
\hline 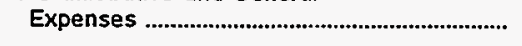 & 1,836 & 2,513 & 1,524 & 5,787 & 2,225 & 2,722 \\
\hline $\begin{array}{l}\text { Total Electric Operation and } \\
\text { Maintenance Expenses }\end{array}$ & 11,010 & 12,619 & 9,816 & 94,892 & 39,397 & 28,244 \\
\hline \multicolumn{7}{|l|}{ Fuel Expenses in Operation } \\
\hline 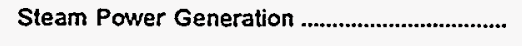 & 3,654 & 4.735 & 3,935 & 6.371 & 0 & 933 \\
\hline Nuclear Power Generation ...................................... & 0 & 0 & 0 & 0 & 0 & 0 \\
\hline 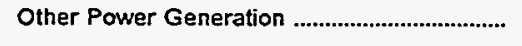 & 0 & 0 & 59 & 395 & 0 & 0 \\
\hline \multicolumn{7}{|l|}{ Number of Elec Dept Employees } \\
\hline 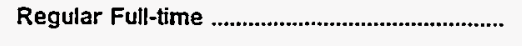 & 114 & 104 & 95 & 391 & 108 & 38 \\
\hline 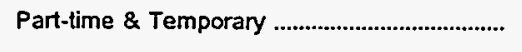 & 10 & 0 & 0 & 16 & 18 & 2 \\
\hline Total Elec Dept Employees .................................. & 124 & 104 & 95 & 407 & 126 & 40 \\
\hline
\end{tabular}

Note: Totals may not equal sum of components because of independent rounding.

Source: Energy Information Administration, Form ElA-4 12, "Annual Report of Public Electric Utilities." 
Table 23. Electric Operation and Maintenance Expenses by Major U.S. Publicly Owned Electric Utility Within State, 1995 (Continued) (Thousand Dollars)

\begin{tabular}{|c|c|c|c|c|c|c|}
\hline item & $\begin{array}{c}\text { Nebraska } \\
\text { Nebraska } \\
\text { Public } \\
\text { Power } \\
\text { District } \\
\text { December } 31\end{array}$ & $\begin{array}{c}\text { Nebraska } \\
\text { Noris } \\
\text { Public } \\
\text { Power } \\
\text { District } \\
\text { December } 31\end{array}$ & $\begin{array}{l}\text { Nebraska } \\
\text { North } \\
\text { Platte } \\
\text { City of } \\
\text { July } 31\end{array}$ & $\begin{array}{c}\text { Nebraska } \\
\text { Omaha Public } \\
\text { Power } \\
\text { District } \\
\text { December } 31\end{array}$ & $\begin{array}{c}\text { Nebraska } \\
\text { Southern } \\
\text { Nebraska Rural } \\
\text { P P D } \\
\text { December } 31\end{array}$ & $\begin{array}{l}\text { Nevada } \\
\text { Colorado } \\
\text { River } \\
\text { Comm } \\
\text { of Nevada } \\
\text { June } 30\end{array}$ \\
\hline \multicolumn{7}{|l|}{ Production Expenses } \\
\hline Steam Power Generation ...................................... & 111.407 & 0 & 0 & 75,768 & 0 & 0 \\
\hline Nuclear Power Generation .................................. & 115,618 & 0 & 0 & 106,074 & 0 & 0 \\
\hline Hydraulic Power Generation .............................. & 2,662 & 0 & 0 & 0 & 0 & 0 \\
\hline Other Power Generation ....................................... & 1.955 & 0 & 0 & 921 & 0 & 0 \\
\hline 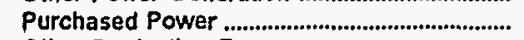 & 301,460 & 14,647 & 8,339 & $-10,594$ & 17,157 & 24,567 \\
\hline 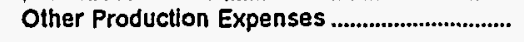 & 1,487 & 0 & 0 & 6,715 & 0 & 0 \\
\hline Total Production Expenses ............................ & 534,590 & 14,647 & 8,339 & 178,883 & 17,157 & 24,567 \\
\hline 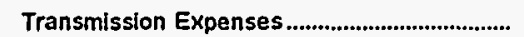 & 15,075 & 66 & 29 & 4.675 & 92 & 0 \\
\hline 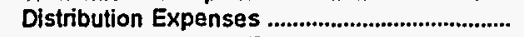 & 13,225 & 1.922 & 623 & 28,794 & 1,086 & 0 \\
\hline $\begin{array}{l}\text { Customer Accounts Expenses ............................. } \\
\text { Customer Service and Information }\end{array}$ & 5,915 & 415 & 326 & 11,081 & 416 & 0 \\
\hline 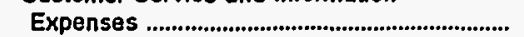 & 2,528 & 247 & 74 & 3,951 & 105 & 0 \\
\hline 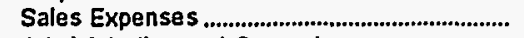 & 4,987 & 0 & 0 & 135 & 6 & 0 \\
\hline Administrative and General & & & & & & \\
\hline 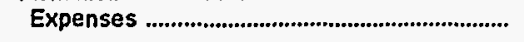 & 30,749 & 979 & 428 & 17,060 & 2,118 & 3,128 \\
\hline $\begin{array}{l}\text { Total Electric Operation and } \\
\text { Maintenance Expenses ................................ }\end{array}$ & 607,068 & 18,275 & 9,819 & 244,579 & 20,980 & 27,696 \\
\hline \multicolumn{7}{|l|}{ Fuel Expenses in Operation } \\
\hline Steam Power Generation ................................... & 82,908 & 0 & 0 & 44,954 & 0 & 0 \\
\hline Nuclear Power Generation ................................. & 22,158 & 0 & 0 & 32,157 & 0 & 0 \\
\hline Other Power Generation ..................................... & 653 & 0 & 0 & 606 & 0 & $\mathbf{0}$ \\
\hline \multicolumn{7}{|l|}{ Number of Elec Dept Employees } \\
\hline 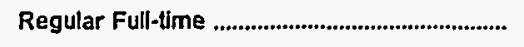 & 2,212 & 72 & 34 & 2.297 & 77 & 8 \\
\hline Part-time \& Temporary ........................................ & 102 & 1 & 0 & 64 & 0 & 11 \\
\hline 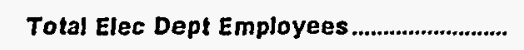 & 2,314 & 73 & 34 & 2,361 & 77 & 19 \\
\hline
\end{tabular}

Note: Totals may not equal sum of components because of independent rounding.

Source: Energy Information Administration, Form ElA-412, "Annual Report of Public Electric Utilities." 
Table 23. Electric Operation and Maintenance Expenses by Major U.S. Publicly Owned Electric Utility Within State, 1995 (Continued)

(Thousand Dollars)

\begin{tabular}{|c|c|c|c|c|c|c|}
\hline item & $\begin{array}{c}\text { Nevada } \\
\text { Overton } \\
\text { Power } \\
\text { District } \\
\text { No } 5 \\
\text { December } 31\end{array}$ & $\begin{array}{l}\text { New Jersey } \\
\text { Madison } \\
\text { Borough } \\
\text { December } 31\end{array}$ & $\begin{array}{l}\text { New Jersey } \\
\text { Vineland } \\
\text { City of } \\
\text { June } 30\end{array}$ & $\begin{array}{l}\text { New Mexico } \\
\text { Farmington } \\
\text { City of } \\
\text { June } 30\end{array}$ & $\begin{array}{l}\text { New Mexico } \\
\text { Gallup } \\
\text { City of } \\
\text { June } 30\end{array}$ & $\begin{array}{l}\text { New Mexico } \\
\text { Los Alamos } \\
\text { County } \\
\text { June } 30\end{array}$ \\
\hline \multicolumn{7}{|l|}{ Production Expenses } \\
\hline 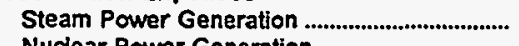 & 0 & 0 & 6,547 & 8,096 & 0 & 5,540 \\
\hline 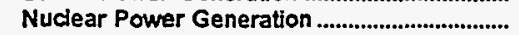 & 0 & 0 & & 0 & 0 & 0 \\
\hline Hydraulic Power Generation ................................. & 0 & $\mathbf{0}$ & 0 & 514 & 0 & 467 \\
\hline Other Power Generation ......................................... & 0 & 0 & 245 & 2,753 & 0 & 0 \\
\hline 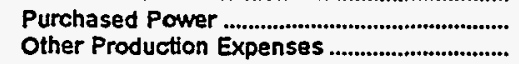 & $\begin{array}{r}4,099 \\
0\end{array}$ & $\begin{array}{r}6.551 \\
0\end{array}$ & $\begin{array}{r}20,254 \\
96\end{array}$ & $\begin{array}{r}2,872 \\
251\end{array}$ & $\begin{array}{r}8,653 \\
0\end{array}$ & $\begin{array}{r}7.735 \\
550\end{array}$ \\
\hline Total Production Expenses ............................ & 4,089 & 6,551 & 27,142 & 14,486 & 8,653 & 14,291 \\
\hline 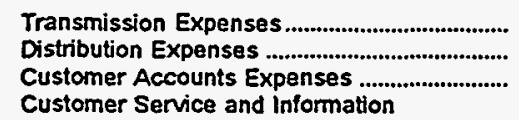 & $\begin{array}{r}17 \\
962 \\
192\end{array}$ & $\begin{array}{l}0 \\
0 \\
0\end{array}$ & $\begin{array}{r}2 \\
2,252 \\
796\end{array}$ & $\begin{array}{r}424 \\
2,163 \\
1,049\end{array}$ & $\begin{array}{r}0 \\
173 \\
0\end{array}$ & $\begin{array}{r}1,847 \\
1,361 \\
541\end{array}$ \\
\hline 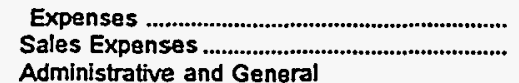 & $\begin{array}{r}22 \\
0\end{array}$ & $\begin{array}{l}0 \\
0\end{array}$ & $\begin{array}{l}0 \\
\theta\end{array}$ & $\begin{array}{r}31 \\
2\end{array}$ & $\begin{array}{r}235 \\
0\end{array}$ & $\begin{array}{l}0 \\
0\end{array}$ \\
\hline 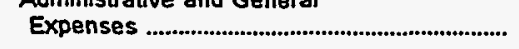 & 1.190 & 828 & 3,408 & 2,146 & 2,480 & 468 \\
\hline $\begin{array}{l}\text { Total Electric Operation and } \\
\text { Maintenance Expenses ................................ }\end{array}$ & 6,481 & 7,380 & 33,609 & 20,302 & 11,542 & 18,509 \\
\hline \multicolumn{7}{|l|}{ Fuel Expenses in Operation } \\
\hline 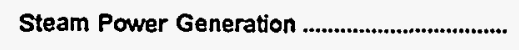 & 0 & 0 & 2,062 & 5,728 & 0 & 0 \\
\hline Nuclear Power Generation ..................................... & 0 & 0 & 0 & 0 & 0 & 0 \\
\hline 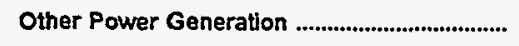 & 0 & $\mathbf{0}$ & 138 & 2,677 & 0 & 0 \\
\hline \multicolumn{7}{|l|}{ Number of Elec Dept Employees } \\
\hline 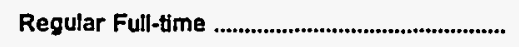 & 38 & 0 & 165 & 94 & 21 & 15 \\
\hline 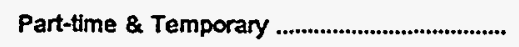 & 0 & 0 & 4 & 2 & 0 & 0 \\
\hline 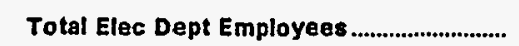 & 38 & $\mathbf{0}$ & 169 & 96 & 21 & 15 \\
\hline
\end{tabular}

Note: Totals may not equal sum of components because of independent rounding.

Source: Energy Information Administration, Form ElA-412, "Annual Report of Public Electric Utilities." 
Table 23. Electric Operation and Maintenance Expenses by Major U.S. Publicly Owned Electric Utility Within State, 1995 (Continued) (Thousand Dollars)

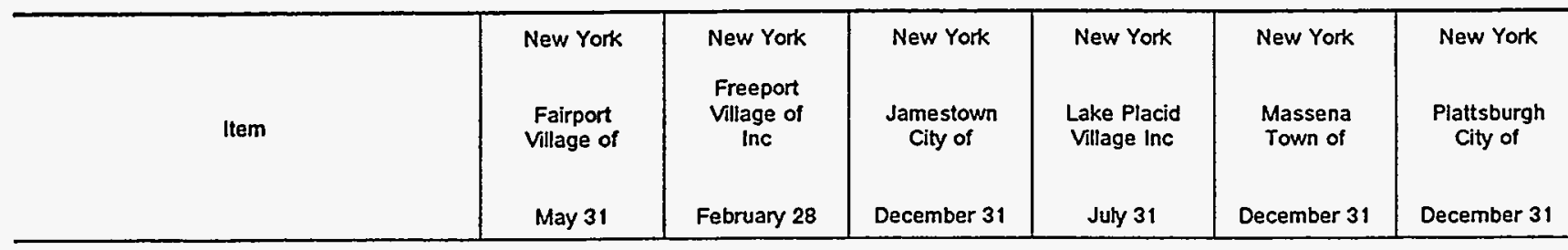

\section{Production Expenses}

Steam Power Generation

Nuclear Power Generation

Hydraulic Power Generation

Other Power Generation

Total Production Expenses

Transmission Expenses.

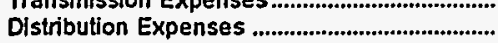

Customer Accounts Expenses .........................

Customer Service and Information

Expenses

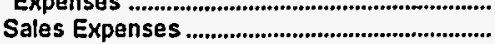

Administrative and General

Expenses

Total Electric Operation and

Maintenance Expenses

0
0
0
0
6.598
0

6,598

31

1,335

323

0
0

859

9,146
0
0
0
3,009
5,200
0

8,209

29

520

599

0
17

17

2,510

11,884

15,181

11,446

1,149
537

0

$-49$

1,974

0
0
0
0
2,249
0

0
0
0
0
2,147
0

2,249

2,147

\section{8}

506

195

3

368

3,329

3,549

8,610

Fuel Expenses in Operation

Steam Power Generation

Nuclear Power Generation

0

0

0

34

6

40

0
0

3,380
0
0

0

0

o

\section{486}

195

0

0

695

$-38$

717

Other Power Generation

Number of Elec Dept Employees

Regular Futl-time

Part-time \& Temporary

Total Elec Dept Employees .............................

Note: Totals may not equal sum of components because of independent rounding.

Source: Energy Information Administration, Form ElA-412, "Annual Report of Public Electric Utilities." 
Table 23. Electric Operation and Maintenance Expenses by Major U.S. Publicly Owned Electric Utility Within State, 1995 (Continued) (Thousand Dollars)

\begin{tabular}{|c|c|c|c|c|c|c|}
\hline Item & $\begin{array}{c}\text { New York } \\
\text { Power } \\
\text { Authority } \\
\text { of State of NY } \\
\text { December } 31\end{array}$ & $\begin{array}{l}\text { New York } \\
\text { Rockville } \\
\text { Centre } \\
\text { Village of } \\
\text { May } 31\end{array}$ & $\begin{array}{c}\text { New York } \\
\text { Solvay } \\
\text { Village of } \\
\text { May } 31\end{array}$ & $\begin{array}{l}\text { North Carolina } \\
\text { Albemarte } \\
\text { City of } \\
\text { June } 30\end{array}$ & $\begin{array}{l}\text { North Carolina } \\
\text { Concord } \\
\text { City of } \\
\text { June } 30\end{array}$ & $\begin{array}{l}\text { North Carolina } \\
\text { Elizabeth } \\
\text { City City of } \\
\text { June } 30\end{array}$ \\
\hline \multicolumn{7}{|l|}{ Production Expenses } \\
\hline Steam Power Generation & 126,742 & 0 & 0 & $\mathbf{0}$ & 0 & 0 \\
\hline 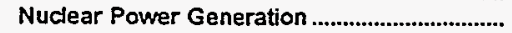 & 233,239 & 0 & 0 & 0 & 0 & 0 \\
\hline Hydraulic Power Generation ................................. & 56,005 & 0 & 0 & 0 & 0 & 0 \\
\hline 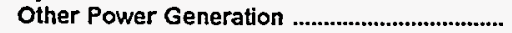 & 0 & 1,933 & 0 & 0 & 0 & 0 \\
\hline 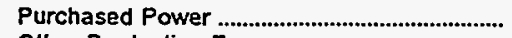 & 190,905 & 3,730 & 2,936 & 15,482 & 17,766 & 17,675 \\
\hline 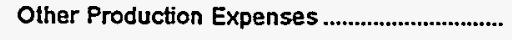 & 0 & 0 & 0 & 0 & 0 & 0 \\
\hline Total Production Expenses .............................. & 606,891 & 5,663 & 2,936 & 15,482 & 17,767 & 17,675 \\
\hline 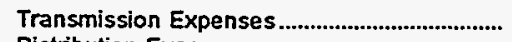 & 314,740 & 87 & 0 & 0 & 0 & 0 \\
\hline 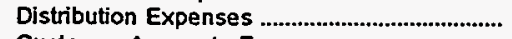 & 0 & 807 & 653 & 1,474 & 2,940 & 2,236 \\
\hline $\begin{array}{l}\text { Customer Accounts Expenses ........................... } \\
\text { Customer Service and Information }\end{array}$ & 0 & 314 & 197 & 0 & 0 & . \\
\hline 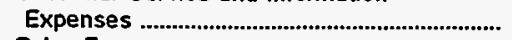 & 0 & 0 & 0 & 0 & 0 & 225 \\
\hline Sales Expenses & 0 & 0 & 1 & 0 & 0 & 0 \\
\hline 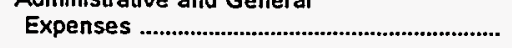 & 224,563 & 1,425 & 423 & 533 & 1.448 & 43 \\
\hline 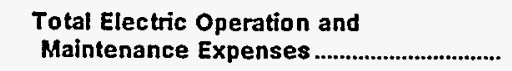 & $1,146,194$ & 8,296 & 4,211 & 17,489 & 22,155 & 20,177 \\
\hline
\end{tabular}

Fuel Expenses in Operation

Steam Power Generation

Nuclear Power Generation

0
0
0

0

0

0

0

$\begin{array}{ll}0 & 0 \\ 0 & 0 \\ 0 & 0\end{array}$

Number of Elec Dept Employees

Regular Full-time

3,387
113
3,500

43

22

22

55

16

Part-time \& Temporary .

44

1

Total Elec Dept Employees

3,500

24

23

55

16

Note: Totals may not equal sum of components because of independent rounding.

Source: Energy Information Administration. Form ElA-412, "Annual Report of Public Electric Utilities." 
Table 23. Electric Operation and Maintenance Expenses by Major U.S. Publicly Owned Electric Utility Within State, 1995 (Continued) (Thousand Dollars)

\begin{tabular}{|c|c|c|c|c|c|c|}
\hline Item & $\begin{array}{l}\text { North Carolina } \\
\text { Fayetteville } \\
\text { Public } \\
\text { Works Comm } \\
\text { June } 30\end{array}$ & $\begin{array}{l}\text { North Carolina } \\
\text { Forest City } \\
\text { Town of } \\
\text { June } 30\end{array}$ & $\begin{array}{l}\text { North Carolina } \\
\text { Gastonia } \\
\text { City of } \\
\text { June } 30\end{array}$ & $\begin{array}{c}\text { North Carolina } \\
\text { Greenville } \\
\text { Utilities } \\
\text { Comm } \\
\text { June } 30\end{array}$ & $\begin{array}{c}\text { North Carolina } \\
\text { High } \\
\text { Point } \\
\text { Town } \\
\text { of } \\
\text { June } 30\end{array}$ & $\begin{array}{l}\text { North Carolina } \\
\text { Kinston } \\
\text { City of } \\
\text { June } 30\end{array}$ \\
\hline
\end{tabular}

Production Expenses

Steam Power Generation

Nuclear Power Generation

Hydraulic Power Gener

Other Power Generation

Purchased Power

Other Production Expenses

Total Production Expenses

Transmission Expenses

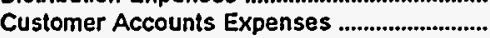

Customer Service and Information

Expenses ...........

Sales Expenses ...................................................

Administrative and General

Expenses

Total Electric Operation and

Maintenance Expenses.

Fuel Expenses in Operation

Steam Power Generatlon

Nuclear Power Generation.

Other Power Generation

(5n)

Number of Elec Dept Employees

Regular Full-time .............................................

Part-time \& Temporary

Total Elec Dept Employees

251
0
0
653
65,100
2

66,005

190

4,447

1,114

644
0

4.876

77,275

6,660

0
0
0
0
31,419
0

0
0
0
0

81,473

0

31,419

81,473

176

2,959
692

509

123

3,855

89,788

34,512

$\begin{array}{rr}0 & 0 \\ 0 & 0 \\ 0 & 0 \\ 0 & 0 \\ 47.799 & 31.350 \\ 597 & 0\end{array}$

48,395

31,350

4,091

823

767

0
1,267

267
0

692

0

452

1.481

5,220

34,098

Note: Totals may not equal sum of components because of independent rounding.

Source: Energy Information Administration, Form ElA-412, "Annual Report of Public Electric Utilities." 
Table 23. Electric Operation and Maintenance Expenses by Major U.S. Publicly Owned Electric Utility Within State, 1995 (Continued) (Thousand Dollars)

\begin{tabular}{|c|c|c|c|c|c|c|}
\hline \multirow{3}{*}{ Htem } & North Carolina & North Carolina & North Carolina & North Carolina & North Carolina & North Carolina \\
\hline & $\begin{array}{l}\text { Laurinburg } \\
\text { City of }\end{array}$ & $\begin{array}{l}\text { Lexington } \\
\text { City of }\end{array}$ & $\begin{array}{l}\text { Lumberton } \\
\text { City of }\end{array}$ & $\begin{array}{l}\text { Monroe } \\
\text { City of }\end{array}$ & $\begin{array}{c}\text { Morganton } \\
\text { City of }\end{array}$ & $\begin{array}{l}\text { Murphy } \\
\text { City of }\end{array}$ \\
\hline & December 31 & June 30 & June 30 & June 30 & June 30 & June 30 \\
\hline
\end{tabular}

Production Expenses

Steam Power Generation

Nuclear Power Generation .....................................

Hydraulic Power Generation

Other Power Generation

Purchased Power

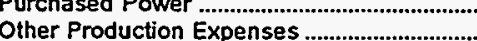

Total Production Expenses

Transmission Expenses

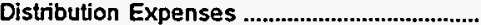

Customer Accounts Expenses ............................

Customer Service and Information

Expenses

Sales Expenses

Administrative and General

Expenses

$\begin{array}{ll}0 & \\ 0 & \\ 0 & \\ 0 & \\ 0 & \\ 0 & \\ 0 & 26,535 \\ 0 & \\ 0 & \\ 0 & \\ 0 & \\ 0 & \\ 0 & \\ & \end{array}$

Total Electric Operation and

Maintenance Expenses

$\mathbf{0}$

29,933

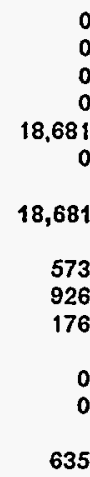

20,990
0
0
0
0
21,327
0

21,327

0

1,385
349

0

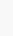

128

23,192

$\begin{array}{rr}0 & 0 \\ 0 & 0 \\ 0 & 0 \\ 0 & 0 \\ 14,963 & 5,315 \\ 0 & 0\end{array}$

14,963

5,315

0

72

9

23

487

1,559

16,522

6,263

Fuel Expenses in Operation

Steam Power Generation

Nuclear Power Generation

Other Power Generation

Number of Elec Dept Employees

Regular Full-time

Part-time \& Temporary

Total Elec Dept Employees
0

0

$\begin{array}{ll}0 & 0 \\ 0 & 0 \\ 0 & 0\end{array}$

0

0

0
35

2

37
0

o

0

36

0

36
20

0

20
0

0

0

Note: Totals may not equal sum of components because of independent rounding.

Source: Energy Information Administration, Form EIA-412, "Annual Report of Public Electric Utilities." 
Table 23. Electric Operation and Maintenance Expenses by Major U.S. Publicly Owned Electric Utility Within State, 1995 (Continued)

(Thousand Dollars)

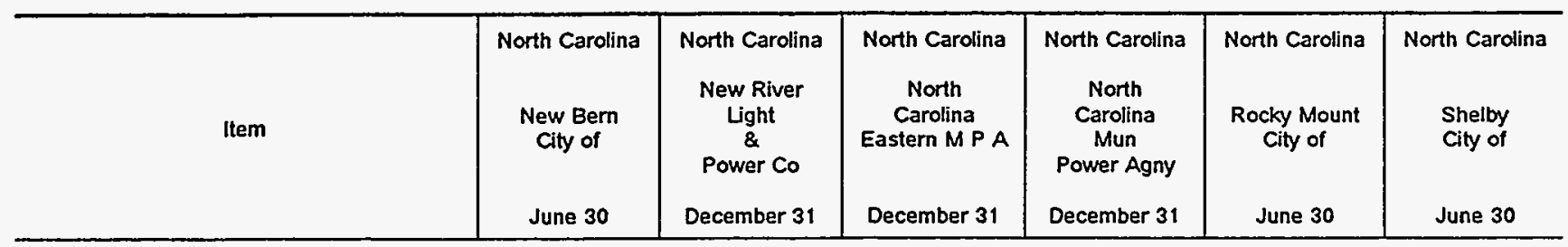

Production Expenses

Steam Power Generation

Nuclear Power Generation

Hydraullc Power Generation ....2.

Other Power Generation

Purchased Power ..................................................

Other Production Expenses

0
0
0
0
26,930
1,100

Total Production Expenses ........................

Transmission Expenses.

Distribution

Customer Accounts Expenses ...........................

Customer Service and Information

Expenses

Sales Expenses ...................................................

Administrative and General

Expenses

28,031

0
1,088

1,088
119

0

2,797

Total Electric Operation and

Maintenance Expenses

$\begin{array}{rr}0 & 24,265 \\ 0 & 55,570 \\ 0 & 0 \\ 0 & 0 \\ 9,086 & 115,694 \\ 0 & 3,204\end{array}$

9,086

0

509

336

23

290

10,243

24,265
55,570

5,570

3,204

198,733

15,120

2,580

0

0

29,074

245,507

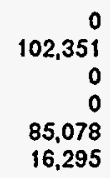

203,724

9.687

1,021

0

0

30,153

244,585

10,176

Fuel Expenses in Operation

Steam Power Generation .

Nuclear Power Generation

0

0

0

22,000

15,422

0

0

0

0

Other Power Generation

Number of Elec Dept Employees

Regular Full-time

Part-time \& Temporary

66

0

Total Elec Dept Employees

68
27

1

28

0
0
0
0
51,380
0

51,380

0
3,878
0

0

589

404

Note: Totals may not equal sum of components because of independent rounding.

Source: Energy Information Administration, Form ElA-412, "Annual Report of Public Electric Utilities." 
Table 23. Electric Operation and Maintenance Expenses by Major U.S. Publicly Owned Electric Utility Within State, 1995 (Continued) (Thousand Dollars)

\begin{tabular}{|c|c|c|c|c|c|c|}
\hline Item & $\begin{array}{c}\text { North Carolina } \\
\text { Statesville } \\
\text { City of } \\
\text { June } 30\end{array}$ & $\begin{array}{c}\text { North Carolina } \\
\text { Tarboro } \\
\text { Town of } \\
\text { June } 30\end{array}$ & $\begin{array}{c}\text { North Carolina } \\
\text { Washington } \\
\text { City of } \\
\text { June } 30\end{array}$ & $\begin{array}{l}\text { North Carolina } \\
\text { Wilson } \\
\text { City of } \\
\text { June } 30\end{array}$ & $\begin{array}{c}\text { Ohio } \\
\text { American } \\
\text { Mun } \\
\text { Power } \\
\text { Ohio Inc } \\
\text { December 31 }\end{array}$ & $\begin{array}{c}\text { Ohio } \\
\text { Bowling } \\
\text { Green } \\
\text { City of } \\
\text { December } 31\end{array}$ \\
\hline \multicolumn{7}{|l|}{ Production Expenses } \\
\hline 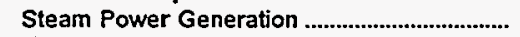 & 0 & 0 & 0 & 0 & 20,963 & $\mathbf{0}$ \\
\hline 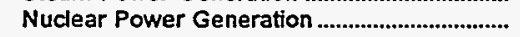 & 0 & 0 & 0 & 0 & 0 & 0 \\
\hline 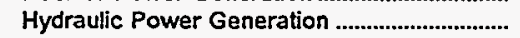 & 0 & 0 & 0 & 0 & 0 & 0 \\
\hline 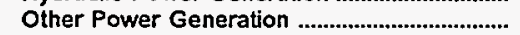 & 0 & 0 & 0 & 0 & 0 & 0 \\
\hline Purchased Power & 21,444 & 17,984 & 16,487 & 69,707 & 116,591 & 14,290 \\
\hline Other Production Expenses .................................... & 0 & 0 & 0 & 0 & 0 & 0 \\
\hline 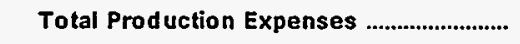 & 21,444 & 17,984 & 16,487 & 69,707 & 137,554 & 14,290 \\
\hline 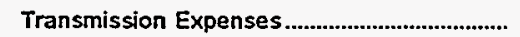 & $\mathbf{0}$ & 0 & 0 & 0 & 0 & 139 \\
\hline 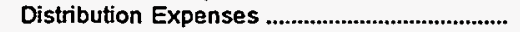 & 0 & 0 & 1,243 & 2,318 & 155 & 1,290 \\
\hline $\begin{array}{l}\text { Customer Accounts Expenses } \\
\text { Customer Service and Information }\end{array}$ & 0 & 0 & 381 & 2,424 & 0 & 392 \\
\hline Expenses & 0 & $\mathbf{0}$ & 158 & 0 & 0 & $\mathbf{0}$ \\
\hline 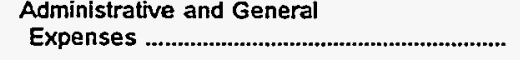 & 2,014 & 1,185 & 2,360 & 2,392 & 5.994 & 720 \\
\hline $\begin{array}{l}\text { Total Electric Operation and } \\
\text { Maintenance Expenses }\end{array}$ & 23,458 & 19,170 & 20,629 & 76,846 & 143,704 & 16,897 \\
\hline \multicolumn{7}{|l|}{ Fuel Expenses in Operation } \\
\hline Steam Power Generation .................................. & 0 & 0 & 0 & 0 & 9,495 & 0 \\
\hline 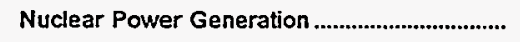 & 0 & 0 & 0 & 0 & 0 & 0 \\
\hline 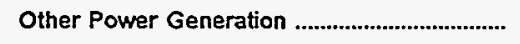 & 0 & 0 & 0 & 0 & 0 & 0 \\
\hline \multicolumn{7}{|l|}{ Number of Elec Dept Employees } \\
\hline Regular Full-time & 24 & 21 & 43 & 71 & 119 & 32 \\
\hline 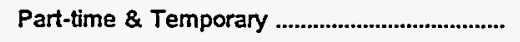 & 0 & 0 & 1 & 0 & 0 & 0 \\
\hline 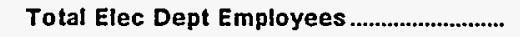 & 24 & 21 & 44 & 71 & 119 & 32 \\
\hline
\end{tabular}

Note: Totals may not equal sum of components because of independent rounding.

Source: Energy Information Administration, Form ElA-412, "Annual Report of Public Electric Utilities." 
Table 23. Electric Operation and Maintenance Expenses by Major U.S. Publicly Owned Electric Utility Within State, 1995 (Continued)

(Thousand Dollars)

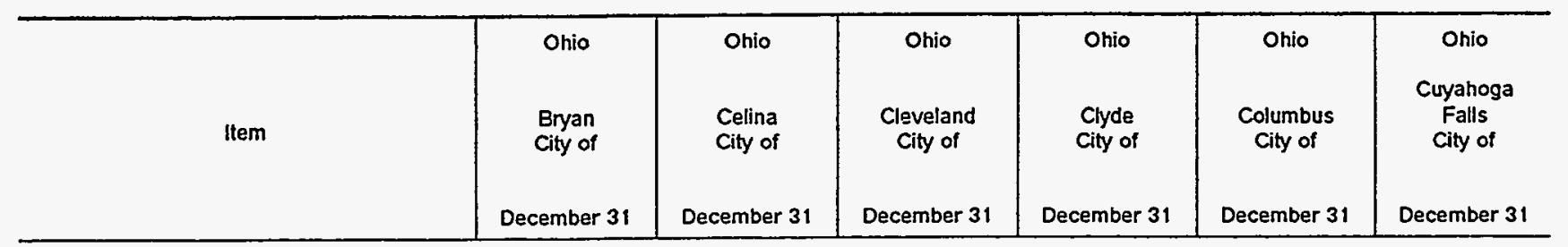

Production Expenses

Steam Power Generation ...

Nuclear Power Generation

Hydraulic Power Generation

Other Power Generation

Purchased Power

Other Production Expenses

Total Production Expenses

Transmission Expenses.

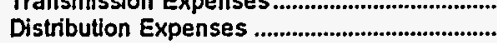

Customer Accounts Expenses ........................

Customer Service and Information

Expenses...

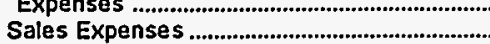

Administrative and General

Expenses

Total Electric Operation and

Maintenance Expenses

Fuel Expenses in Operation

Steam Power Generation ..................................

Nuclear Power Generation .

Other Power Generation

Number of Elec Dept Employees

Regular Full-time

Part-time \& Temporary

Total Elec Dept Employees

0
0
0
262
6,183
0

6,446

0

891
0

0

0
0

3,620

10,957

6,442
275
0
0
1,690
42,965
0

44,929

890

17,365

1,506

464

276

5,886

71,316
0
0
0
0
4,278
0

4,278

0
597

597
69

(0)

0
0

72

5,016

0
0
128
0
20,283
0

0
0
0
0
14.137
0

14,137

0

117

699

0
0

3.664

3,000

18,617

Note: Totals may not equal sum of components because of independent rounding.

Source: Energy Information Administration, Form ElA-4 12, "Annual Report of Public Electric Utilities." 
Table 23. Electric Operation and Maintenance Expenses by Major U.S. Publicly Owned Electric Utility Within State, 1995 (Continued)

(Thousand Dollars)

\begin{tabular}{|c|c|c|c|c|c|c|}
\hline Item & $\begin{array}{l}\text { Ohio } \\
\text { Dover } \\
\text { City of } \\
\text { December } 31\end{array}$ & $\begin{array}{c}\text { Ohio } \\
\begin{array}{c}\text { Hamilton } \\
\text { City of }\end{array} \\
\text { December } 31\end{array}$ & $\begin{array}{c}\text { Ohio } \\
\begin{array}{c}\text { Napoleon } \\
\text { City of }\end{array} \\
\text { December } 31\end{array}$ & $\begin{array}{c}\text { Ohio } \\
\text { Niles } \\
\text { City of } \\
\text { December } 31\end{array}$ & $\begin{array}{l}\text { Ohio } \\
\text { Orvulle } \\
\text { City of } \\
\text { December } 31\end{array}$ & $\begin{array}{c}\text { Ohio } \\
\text { Painesville } \\
\text { City of }\end{array}$ \\
\hline \multicolumn{7}{|l|}{ Production Expenses } \\
\hline 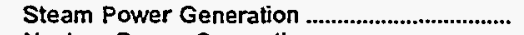 & 0 & 8,557 & 0 & 0 & 7,533 & 3,643 \\
\hline Nuclear Power Generation ......................................... & o & & 0 & 0 & 0 & \\
\hline Hydraulic Power Generation ................................. & 0 & 1,303 & 0 & 0 & 0 & 0 \\
\hline Other Power Generation ............................................ & 0 & 1,363 & 0 & 0 & 0 & 0 \\
\hline Purchased Power & 4,263 & 7,888 & 6,790 & 13,646 & 1,561 & 1.597 \\
\hline 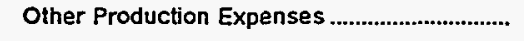 & 1,355 & & 0 & 0 & 0 & 7,076 \\
\hline Total Production Expenses ............................... & 5,618 & 19,112 & 6,790 & 13,646 & 9,094 & 12,316 \\
\hline 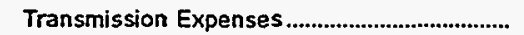 & 0 & 726 & 0 & 0 & 0 & o \\
\hline Distribution Expenses ................................................. & 1,373 & 1,423 & 0 & 0 & 966 & 0 \\
\hline $\begin{array}{l}\text { Customer Accounts Expenses } \\
\text { Customer Senvice and Information }\end{array}$ & 0 & 998 & 0 & 0 & 0 & 0 \\
\hline 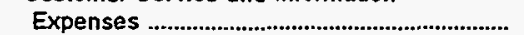 & 0 & 0 & 0 & 0 & 0 & 0 \\
\hline Sales Expenses ............................................... & 0 & 63 & 0 & 0 & 0 & 0 \\
\hline 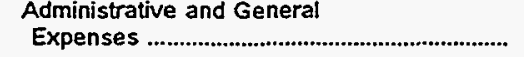 & 134 & 5.369 & 2,722 & 3,504 & 2,191 & 0 \\
\hline 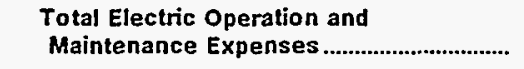 & 7,125 & 27,690 & 9,513 & 17,150 & 12,251 & 12,316 \\
\hline \multicolumn{7}{|l|}{ Fuel Expenses in Operation } \\
\hline 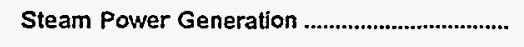 & 0 & 3,410 & 0 & 0 & 0 & 3,643 \\
\hline 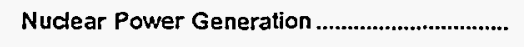 & 0 & 0 & 0 & 0 & 0 & 0 \\
\hline Other Power Generation & 0 & 1,328 & 0 & 0 & 0 & 0 \\
\hline \multicolumn{7}{|l|}{ Number of Elec Dept Employees } \\
\hline Regular Full-time & 36 & 109 & 18 & 0 & 88 & 63 \\
\hline Part-time \& Temporary & 0 & 2 & 0 & 0 & 3 & 0 \\
\hline 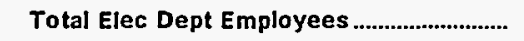 & 36 & 111 & 18 & 0 & 91 & 63 \\
\hline
\end{tabular}

Note: Totals may not equal sum of components because of independent rounding.

Source: Energy information Administration, Form EIA-412, "Annual Report of Public Electric Utilities." 
Table 23. Electric Operation and Maintenance Expenses by Major U.S. Publicly Owned Electric Utility Within State, 1995 (Continued) (Thousand Dollars)

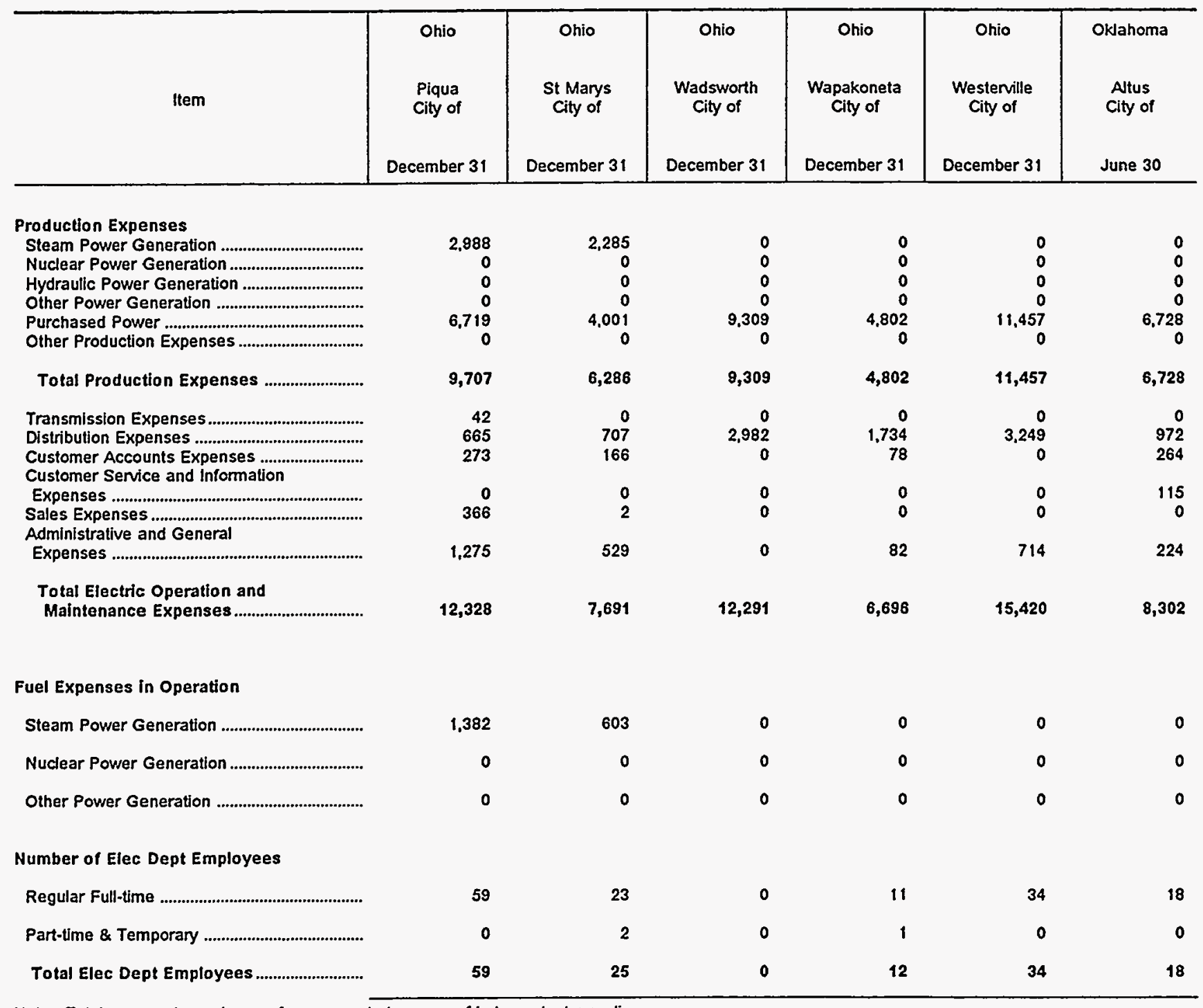

Note: Totals may not equal sum of components because of independent rounding.

Source: Energy Information Administration. Form ElA-412, "Annual Report of Public Electric Utilities." 
Table 23. Electric Operation and Maintenance Expenses by Major U.S. Publicly Owned Electric Utility Within State, 1995 (Continued)

(Thousand Dollars)

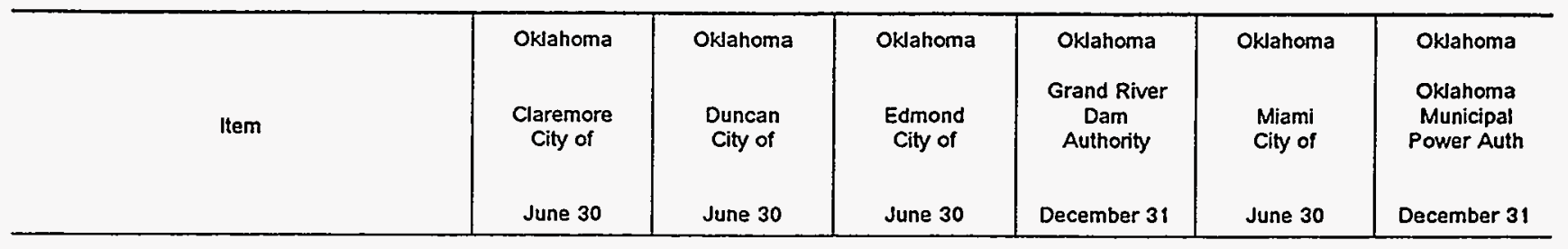

Production Expenses

Steam Power Generation

Nuclear Power Generation

Hydraulic Power Generation

Other Power Generation .

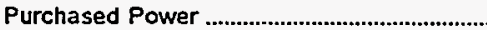

Other Production Expenses ...............................

Total Production Expenses

Transmission Expenses

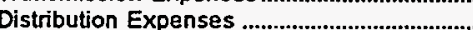

Customer Accounts Expenses

Customer Service and Information

Expenses.

Sales Expenses

Administrative and General

Expenses

Total Electric Operation and

Maintenance Expenses

Fuel Expenses in Operation

Steam Power Generation

Nuclear Power Generation

Other Power Generation

Number of Elec Dept Employees

Regular Full-time

Part-time \& Temporary .

33

0

Total Elec Dept Employees

0
0
0
0
7,416
0

0
0
0
0
4,646
0

0
0
0
0
20,665
0

4,646

20,665

0
1,091

0
1,421

344

0

0

0

8,852

6,067
58,554

3,467

3.467
0

6,087

68,108

5,614

181

90

9,844

83,837
0
0
0
0
4,919

4,919
0

4,919

0
456

456

42

219

219

5,690

12,383

0

353

23,443

37,407

8,840

0

0
0

2,557

48,804

Note: Totals may not equal sum of components because of independent rounding.

Source: Energy Information Administration, Form ElA-4 12, "Annual Report of Public Electric Utilities." 
Table 23. Electric Operation and Maintenance Expenses by Major U.S. Publicly Owned Electric Utility Within State, 1995 (Continued) (Thousand Dollars)

\begin{tabular}{|c|c|c|c|c|c|c|}
\hline Item & $\begin{array}{l}\text { OkJahoma } \\
\text { Ponca } \\
\text { City City of } \\
\text { June } 30\end{array}$ & $\begin{array}{l}\text { Okfahoma } \\
\text { Stillwater } \\
\text { Utilities } \\
\text { Authority } \\
\text { June } 30\end{array}$ & $\begin{array}{l}\text { Oregon } \\
\text { Ashland } \\
\text { City of } \\
\text { June } 30\end{array}$ & $\begin{array}{c}\text { Oregon } \\
\text { Central } \\
\text { Lincoln } \\
\text { Peoples } \\
\text { Ut Dt } \\
\text { December } 31\end{array}$ & $\begin{array}{l}\text { Oregon } \\
\text { Clatskanie } \\
\text { Peoples } \\
\text { Util Dist } \\
\text { December } 31\end{array}$ & $\begin{array}{l}\text { Oregon } \\
\text { Columbla } \\
\text { River } \\
\text { Peoples } \\
\text { Ut Dist } \\
\text { December } 31\end{array}$ \\
\hline
\end{tabular}

Production Expenses

Steam Power Generation ..

Nuclear Power Generation .........

Hydraulic Power Generation

Other Power Generation

Purchased Power

810
0
0
595
11,444
0

2,322
0
0
0
10,933
0

0
0
0
0
4.815
0

0
0
0
0
35,887
0

0
0
0
0
23,795
0

0
0
0
0
7,303
0

Total Production Expenses ........................

12,849

13,255

4,815

35,887

23,795

7,303

Transmission Expenses

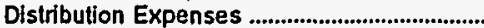

Customer Accounts Expenses ...........................

Customer Senvice and Information

Expenses...

Sales Expense

Administrative and General

Expenses.

0
2,546
0
118
0

470

0
2086

0
2.885

2,885
1,202

0

361
66

0
1,021

1,021

317

352

174

460

406
77

198

270

Total Electric Operation and

Malntenance Expenses.

15,973

680

2.755

1,124

1,006

Fuel Expenses in Operation

Steam Power Generation

10,209

0

0

0

16,938

6,901

43,082

25,426

1,994

0

0

0

0

0

0

0

Other Power Generation

Number of Elec Dept Employees

Regular Full-time

Part-time \& Temporary

52

62

8

Total Elec Dept Employees

53

70

0

Note: Totals may not equal sum of components because of independent rounding

Source: Energy Information Administration, Form ElA-412, "Annual Report of Public Electric Utilities." 
Table 23. Electric Operation and Maintenance Expenses by Major U.S. Publicly Owned Electric Utility Within State, 1995 (Continued) (Thousand Dollars)

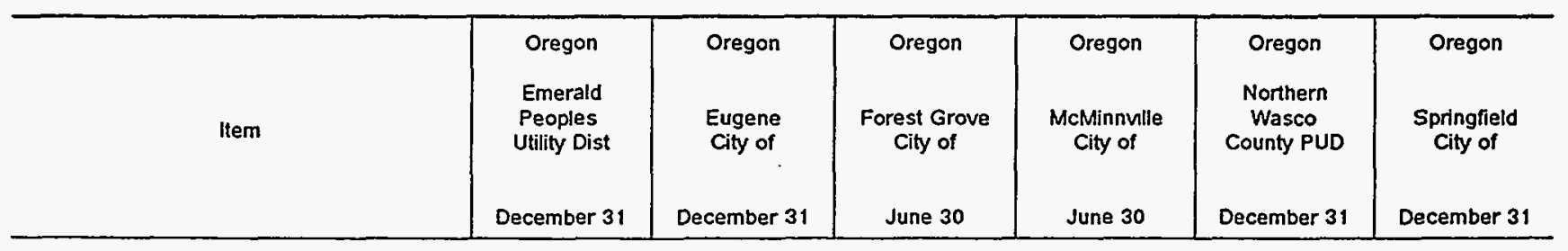

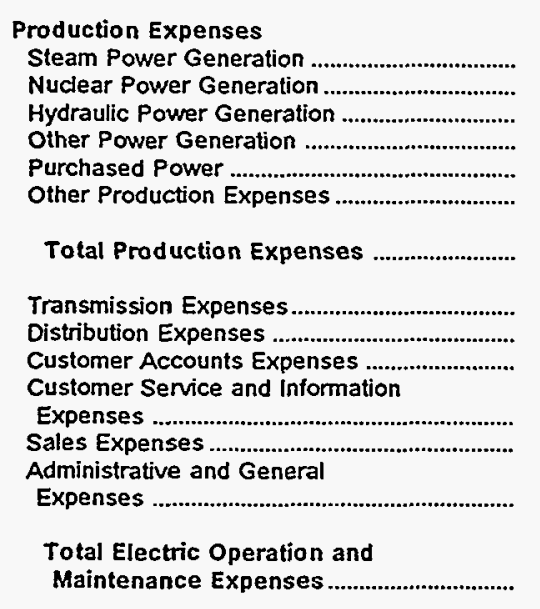

Fuel Expenses in Operation

Steam Power Generation

Nuclear Power Generation

Other Power Generation

Number of Elec Dept Employees

Regular Full-time

Part-time \& Temporary

Total Elec Dept Employees

0
0
0
213
10,331
0

1,490
0
2,882
2,122
40,597
1,830

10,544

48,921

0
1,503

2,657

3,275

80
0

1,195

14,042

74,191

0
0
0
0
5,217
0

0
0
0
0
18,419
0

5,217

0
416

416
62

620
0

12,547

6,704

0
981
187

756

20,342

0
0
241
0
7,496
0

0
0
0
0
23,058
0

23,058

7,737

0
1.550

1.550
909

1.197
0

443

9,610

27,158

Note: Totals may not equal sum of components because of independent rounding.
Source: Energy Information Administration, Form ElA-412, "Annual Report of Public Electric Utilities." 
Table 23. Electric Operation and Maintenance Expenses by Major U.S. Publicly Owned Electric Utility Within State, 1995 (Continued)

(Thousand Dollars)

\begin{tabular}{|c|c|c|c|c|c|c|}
\hline llem & $\begin{array}{l}\text { Oregon } \\
\text { Tillamook } \\
\text { Peoples } \\
\text { Utility Dist } \\
\text { December } 31\end{array}$ & $\begin{array}{c}\text { Pennsytvania } \\
\text { Chambersburg } \\
\text { Borough of } \\
\text { December } 31\end{array}$ & $\begin{array}{c}\text { Pennsylvania } \\
\text { Ephrata } \\
\text { Borough of } \\
\text { December } 31\end{array}$ & $\begin{array}{c}\text { Pennsyivania } \\
\text { Lansdale } \\
\text { Borough of } \\
\text { December } 31\end{array}$ & $\begin{array}{l}\text { South Carolina } \\
\text { Camden } \\
\text { City of } \\
\text { June } 30\end{array}$ & $\begin{array}{c}\text { South Carolina } \\
\text { Easley } \\
\text { Combined } \\
\text { Utility } \\
\text { System } \\
\text { March } 31\end{array}$ \\
\hline 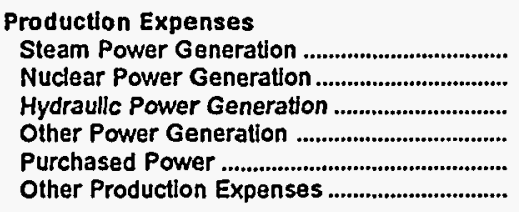 & $\begin{array}{r}0 \\
0 \\
0 \\
0 \\
10,114 \\
0\end{array}$ & $\begin{array}{r}11 \\
0 \\
0 \\
150 \\
10,468 \\
372\end{array}$ & $\begin{array}{r}0 \\
0 \\
0 \\
0 \\
5,333 \\
0\end{array}$ & $\begin{array}{r}0 \\
0 \\
0 \\
0 \\
5,878 \\
0\end{array}$ & $\begin{array}{r}0 \\
0 \\
0 \\
0 \\
7,725 \\
0\end{array}$ & $\begin{array}{r}0 \\
0 \\
0 \\
0 \\
10,980 \\
0\end{array}$ \\
\hline Total Production Expenses .......................... & 10,114 & 11,002 & 5,333 & 5,878 & 7,725 & 10,980 \\
\hline 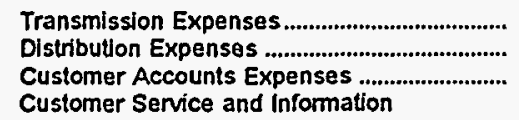 & $\begin{array}{r}0 \\
2,232 \\
520\end{array}$ & $\begin{array}{r}27 \\
466 \\
207\end{array}$ & $\begin{array}{r}0 \\
2,413 \\
0\end{array}$ & $\begin{array}{r}13 \\
721 \\
245\end{array}$ & $\begin{array}{r}0 \\
642 \\
0\end{array}$ & $\begin{array}{r}0 \\
741 \\
59\end{array}$ \\
\hline $\begin{array}{l}\text { Expenses } \\
\text { Sales Expenses } \\
\text { Administrative and General }\end{array}$ & $\begin{array}{r}329 \\
54\end{array}$ & $\begin{array}{l}0 \\
0\end{array}$ & $\begin{array}{l}0 \\
0\end{array}$ & $\begin{array}{l}0 \\
0\end{array}$ & $\begin{array}{l}0 \\
0\end{array}$ & $\begin{array}{l}0 \\
8\end{array}$ \\
\hline 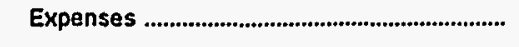 & 2,105 & 484 & 983 & 1.024 & 289 & 637 \\
\hline 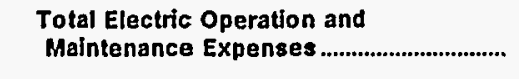 & 15,354 & 12,187 & 8,729 & 7,881 & 8,657 & 12,425 \\
\hline \multicolumn{7}{|l|}{ Fuel Expenses in Operation } \\
\hline 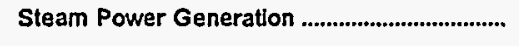 & 0 & 0 & 0 & 0 & 0 & 0 \\
\hline Nuclear Power Generation ................................... & 0 & 0 & 0 & 0 & 0 & 0 \\
\hline 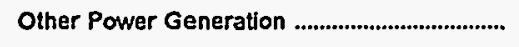 & 0 & 0 & 0 & 0 & 0 & 0 \\
\hline \multicolumn{7}{|l|}{ Number of Elec Dept Employees } \\
\hline Regular Full-time & 70 & 28 & 8 & 19 & 12 & 20 \\
\hline 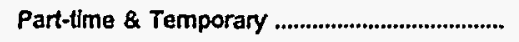 & 11 & 0 & 0 & 1 & 4 & 0 \\
\hline Total Elec Dept Employees ............................. & 81 & 28 & 8 & 20 & 16 & 20 \\
\hline
\end{tabular}

Source: Energy Information Administration, Form ElA-412, "Annual Report of Public Electric Utilities." 
Table 23. Electric Operation and Maintenance Expenses by Major U.S. Publicly Owned Electric Utility Within State, 1995 (Continued) (Thousand Dollars)

\begin{tabular}{|c|c|c|c|c|c|c|}
\hline Item & $\begin{array}{l}\text { South Carolina } \\
\text { Gaffney } \\
\text { City of } \\
\text { March } 31\end{array}$ & $\begin{array}{l}\text { South Carolina } \\
\text { Greenwood } \\
\text { Commissioners } \\
\text { Pub Wk } \\
\text { December } 31\end{array}$ & $\begin{array}{c}\text { South Carolina } \\
\text { Greer } \\
\text { Comm } \\
\text { of } \\
\text { Public Works } \\
\text { December } 31\end{array}$ & $\begin{array}{l}\text { South Carolina } \\
\text { Newberry } \\
\text { City of } \\
\text { June } 30\end{array}$ & $\begin{array}{l}\text { South Carolina } \\
\text { Orangeburg } \\
\text { City of }\end{array}$ & $\begin{array}{l}\text { South Carolina } \\
\text { Pledmont } \\
\text { Munlcipal } \\
\text { Power Agny } \\
\text { December } 31\end{array}$ \\
\hline
\end{tabular}

Production Expenses

Steam Power Generation

Nuclear Power Generation

Hydraulic Power Generation

Other Power Generation ................................

Purchased Power ...................................................

Other Production Expenses .

Total Production Expenses

Transmission Expenses.

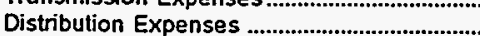

Customer Accounts Expenses

Customer Service and Information

Expenses

Sales Expenses

Administrative and General

Expenses

$\begin{array}{rr}0 & \\ 0 & \\ 0 & \\ 17 & \\ 7,470 & \\ 0 & 10,7 \\ 7,488 & 10,78 \\ 0 & \\ 1,008 & \\ 0 & \\ 0 & \\ 0 & \\ 1,116 & \end{array}$

$\begin{array}{rr}0 & \\ 0 & \\ 0 & \\ 0 & \\ 0 & \\ 0,784 & 9,33 \\ 0,784 & \end{array}$

$\begin{array}{rrr}0 & 0 & \\ 0 & 0 & \\ 0 & 0 & \\ 0 & 0 & 1,68 \\ 9,333 & 7,813 & 28,66 \\ 0 & 0 & \end{array}$

0
0
0
1,684
28,661
0

32.0

0

36,553

, 333

7,813

30,346

68,823

$\begin{array}{rl}0 & 451\end{array}$

451
0

39

234

0

0

2,259

3,562

1,752

132

0
0

0

0

83

0

147

200

0
0

Total Electric Operation and

Maintenance Expenses.

Fuel Expenses in Operation

Steam Power Generation ..

0

0

Nuclear Power Generation

Other Power Generation

Number of Elec Dept Employees

Regular Full-time

Part-time \& Temporary

16

3

Total Elec Dept Employees

o

0
0
0

0
0
0

0
0
616

Note: Totals may not equal sum of components because of independent rounding.

Source: Energy Information Administration, Form EIA-412, "Annual Report of Public Electric Utilities." 
Table 23. Electric Operation and Maintenance Expenses by Major U.S. Publicly Owned Electric Utility Within State, 1995 (Continued)

(Thousand Dollars)

\begin{tabular}{|c|c|c|c|c|c|c|}
\hline Item & $\begin{array}{l}\text { South Carolina } \\
\begin{array}{c}\text { Rock Hill } \\
\text { City of }\end{array} \\
\text { December } 31\end{array}$ & $\begin{array}{l}\text { South Carolina } \\
\text { Seneca } \\
\text { City of } \\
\text { June } 30\end{array}$ & $\begin{array}{c}\text { South Carolina } \\
\text { South } \\
\text { Carolina } \\
\text { Pub } \\
\text { Serv Auth } \\
\text { December } 31\end{array}$ & $\begin{array}{l}\text { South Dakota } \\
\text { Brookings } \\
\text { City of } \\
\text { December } 31\end{array}$ & $\begin{array}{l}\text { South Dakota } \\
\text { Heartland } \\
\text { Consumers } \\
\text { Power Dist } \\
\text { December } 31\end{array}$ & $\begin{array}{l}\text { South Dakota } \\
\text { Missour } \\
\text { Basin } \\
\text { Mun } \\
\text { Power Agny } \\
\text { December } 31\end{array}$ \\
\hline \multicolumn{7}{|l|}{ Production Expenses } \\
\hline 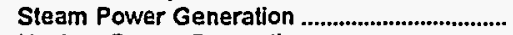 & 0 & 0 & 221,629 & 0 & 3,338 & 0 \\
\hline Nuclear Power Generation ..................................... & 0 & 0 & 39,118 & 0 & 0 & 0 \\
\hline Hydraulic Power Generation ................................... & 0 & 0 & 4,717 & 0 & 0 & $\mathbf{0}$ \\
\hline 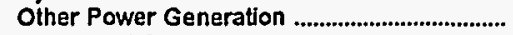 & 0 & 0 & 1,419 & o & 0 & 0 \\
\hline 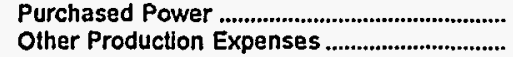 & $\begin{array}{r}28,571 \\
0\end{array}$ & $\begin{array}{r}6,148 \\
0\end{array}$ & $\begin{array}{r}30,593 \\
734\end{array}$ & $\begin{array}{r}5,366 \\
29\end{array}$ & $\begin{array}{r}2,450 \\
43\end{array}$ & $\begin{array}{r}44,941 \\
68\end{array}$ \\
\hline Total Production Expenses ............................. & 28,571 & 6,148 & 298,210 & 5,395 & 5,831 & 45,009 \\
\hline 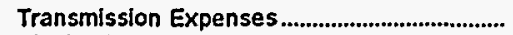 & 0 & 0 & 10,816 & 69 & 1,355 & 11,078 \\
\hline 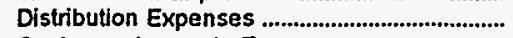 & 3,235 & 122 & 6,270 & 907 & 0 & 0 \\
\hline $\begin{array}{l}\text { Customer Accounts Expenses .............................. } \\
\text { Customer Senice and Information }\end{array}$ & 0 & 0 & 2,245 & 142 & 0 & 2 \\
\hline 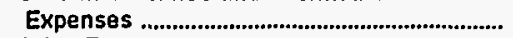 & 0 & 0 & 1.037 & 0 & 0 & 0 \\
\hline $\begin{array}{l}\text { Sales Expenses ................................................... } \\
\text { Administrative and General }\end{array}$ & 0 & 0 & 1.465 & 0 & 0 & 0 \\
\hline 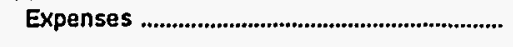 & 546 & 0 & 59,018 & 486 & 953 & 2.452 \\
\hline 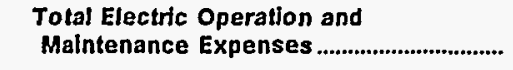 & 32,352 & 6,270 & 379,061 & 7,000 & 8,139 & 58,542 \\
\hline \multicolumn{7}{|l|}{ Fuel Expenses In Operation } \\
\hline 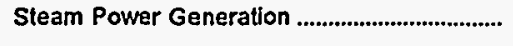 & 0 & 0 & 179.118 & 0 & 1.853 & 0 \\
\hline 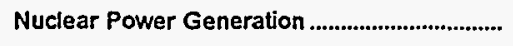 & 0 & 0 & 12,307 & 0 & 0 & 0 \\
\hline 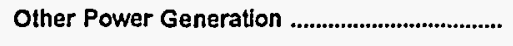 & 0 & 0 & 520 & $\mathbf{0}$ & 0 & 0 \\
\hline \multicolumn{7}{|l|}{ Number of Elec Dept Employees } \\
\hline Regular Full-time ................................................... & 29 & 0 & 1,826 & 24 & 7 & 24 \\
\hline Part-time \& Temporary ............................................... & 0 & 0 & 18 & 3 & 1 & 2 \\
\hline Total Elec Dept Employees ................................ & 29 & 0 & 1,844 & 27 & 8 & 26 \\
\hline
\end{tabular}

Source: Energy Information Administration, Form EIA-412, "Annual Report of Public Electric Utilities." 
Table 23. Electric Operation and Maintenance Expenses by Major U.S. Publicly Owned Electric Utllity Within State, 1995 (Continued)

(Thousand Dollars)

\begin{tabular}{|c|c|c|c|c|c|c|}
\hline Item & $\begin{array}{l}\text { South Dakota } \\
\text { Pierre } \\
\text { City of }\end{array}$ & $\begin{array}{c}\text { South Dakota } \\
\text { Watertown } \\
\text { Municipal } \\
\text { Utilities }\end{array}$ & $\begin{array}{c}\text { Tennessee } \\
\text { Alcoa } \\
\text { Utilities }\end{array}$ & $\begin{array}{l}\text { Tennessee } \\
\text { Athens } \\
\text { Utility } \\
\text { Board }\end{array}$ & $\begin{array}{l}\text { Tennessee } \\
\text { Benton } \\
\text { County }\end{array}$ & $\begin{array}{l}\text { Tennessee } \\
\text { Bolivar } \\
\text { City of }\end{array}$ \\
\hline & December 31 & December 31 & June 30 & June 30 & June 30 & June 30 \\
\hline
\end{tabular}

Production Expenses

Steam Power Generation

Nuclear Power Generation.

Hydraulic Power Generation

Other Power Generation

Purchased Power

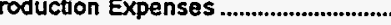

Total Production Expenses

Transmission Expenses

Distribution Expenses

Customer Accounts Expenses

Customer Senvice and Information

Expenses.

Sales Expenses

Administrative and General

Expenses

Total Electric Operation and

Maintenance Expenses

Fuel Expenses in Operation

Steam Power Generation

Nuclear Power Generation.

Other Power Generation

4.436

4,436
0

4,436

0
948

948
0

0$$
0
$$

5,384
0
0
0
0
$+9,684$
0

19,684

231

1,426

599

0
34

1.130

23,104

0
0
0
0
21,517
0

21,517

96
1607

1,607
336

0

39

732

24,326

Number of Elec Dept Employees

Regular Full-time

Part-time \& Temporary

0

0

0

o

0

0

0

0

0

0

0

0

o

0

Total Elec Dept Employees

0

9
61

4

65
47

0

47
45

0

45
43

34

$\mathbf{0}$

34

Note: Totals may not equal sum of components because of independent rounding.

Source: Energy Information Administration, Form ElA-412, "Annual Report of Public Electric Utilities." 
Table 23. Electric Operation and Maintenance Expenses by Major U.S. Publicly Owned Electric Utility Within State, 1995 (Continued) (Thousand Dollars)

\begin{tabular}{|c|c|c|c|c|c|c|}
\hline Item & $\begin{array}{l}\text { Tennessee } \\
\text { Bristol } \\
\text { City of } \\
\text { June } 30\end{array}$ & $\begin{array}{c}\text { Tennessee } \\
\text { Brownsville } \\
\text { City of } \\
\text { June } 30\end{array}$ & $\begin{array}{l}\text { Tennessee } \\
\text { Carroll } \\
\text { County } \\
\text { June } 30\end{array}$ & $\begin{array}{c}\text { Tennessee } \\
\begin{array}{c}\text { Chattanooga } \\
\text { City of }\end{array} \\
\text { June } 30\end{array}$ & $\begin{array}{c}\text { Tennessee } \\
\text { Clarksville } \\
\text { City of } \\
\text { June } 30\end{array}$ & $\begin{array}{l}\text { Tennessee } \\
\text { Cleveland } \\
\text { City of } \\
\text { June } 30\end{array}$ \\
\hline 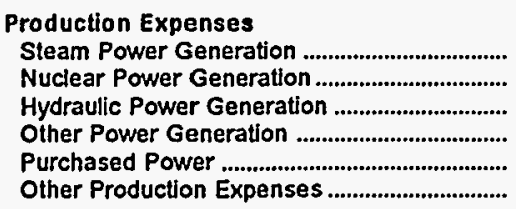 & $\begin{array}{r}0 \\
0 \\
0 \\
0 \\
34.494 \\
0\end{array}$ & $\begin{array}{r}0 \\
0 \\
0 \\
0 \\
8,354 \\
0\end{array}$ & $\begin{array}{r}0 \\
0 \\
0 \\
0 \\
17,482 \\
0\end{array}$ & $\begin{array}{r}0 \\
0 \\
0 \\
0 \\
231,098 \\
0\end{array}$ & $\begin{array}{r}0 \\
0 \\
0 \\
0 \\
39,868 \\
0\end{array}$ & $\begin{array}{r}0 \\
0 \\
0 \\
0 \\
38,610 \\
0\end{array}$ \\
\hline Total Production Expenses .......................... & 34,494 & 8,354 & 17,482 & 231,098 & 39,868 & 38,610 \\
\hline 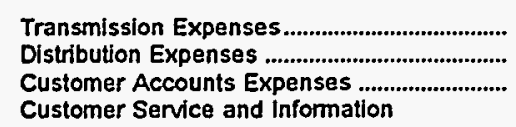 & $\begin{array}{r}209 \\
2,235 \\
502\end{array}$ & $\begin{array}{r}0 \\
398 \\
129\end{array}$ & $\begin{array}{r}2 \\
818 \\
539\end{array}$ & $\begin{array}{r}1,246 \\
16,327 \\
5.704\end{array}$ & $\begin{array}{r}150 \\
2,532 \\
928\end{array}$ & $\begin{array}{r}37 \\
2.048 \\
624\end{array}$ \\
\hline 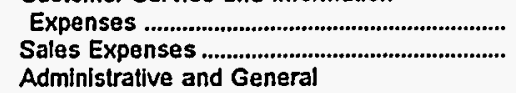 & $\begin{array}{r}80 \\
130\end{array}$ & $\begin{array}{l}8 \\
8\end{array}$ & $\begin{array}{l}18 \\
14\end{array}$ & $\begin{array}{r}0 \\
1,682\end{array}$ & $\begin{array}{r}195 \\
50\end{array}$ & $\begin{array}{r}71 \\
126\end{array}$ \\
\hline 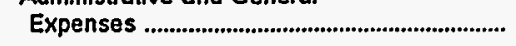 & 702 & 237 & 512 & 9,190 & 1,369 & 1,329 \\
\hline $\begin{array}{l}\text { Total Electric Operation and } \\
\text { Maintenance Expenses ............................. }\end{array}$ & 38,351 & 9,134 & 19,386 & 265,246 & 45,093 & 42,845 \\
\hline \multicolumn{7}{|l|}{ Fuel Expenses in Operation } \\
\hline Steam Power Generation ................................. & 0 & 0 & 0 & 0 & 0 & 0 \\
\hline Nuclear Power Generation ............................... & 0 & 0 & 0 & 0 & 0 & 0 \\
\hline Other Power Generation ...................................... & 0 & 0 & 0 & 0 & 0 & 0 \\
\hline \multicolumn{7}{|l|}{ Number of Elec Dept Employees } \\
\hline 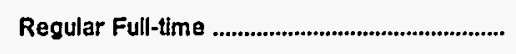 & 67 & 16 & 47 & 493 & 87 & 70 \\
\hline 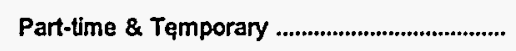 & 0 & 0 & 0 & 0 & 0 & 0 \\
\hline Total Elec Dept Employees ............................... & 67 & 16 & 47 & 493 & 87 & 70 \\
\hline
\end{tabular}

Note: Totals may not equal sum of components because of independent rounding.

Source: Energy Information Administration. Form EIA-412, "Annual Report of Public Electric Utilities." 
Table 23. Electric Operation and Maintenance Expenses by Major U.S. Publicly

Owned Electric Utility Within State, 1995 (Continued)

(Thousand Dollars)

\begin{tabular}{c|c|c|c|c|c|c}
\hline & Tennessee & Tennessee & Tennessee & Tennessee & Tennessee & Tennessee \\
Item & $\begin{array}{l}\text { Cinton } \\
\text { City of }\end{array}$ & $\begin{array}{c}\text { Columbia } \\
\text { City of }\end{array}$ & $\begin{array}{c}\text { Cookeville } \\
\text { City of }\end{array}$ & $\begin{array}{c}\text { Covington } \\
\text { City of }\end{array}$ & $\begin{array}{c}\text { Dayton } \\
\text { City of }\end{array}$ & $\begin{array}{c}\text { Dickson } \\
\text { City of }\end{array}$ \\
June 30 & June 30 & June 30 & June 30 & June 30 & June 30 \\
\hline
\end{tabular}

Production Expenses

Steam Power Generation

Nuclear Power Generation

Hydraulic Power Generation

Other Power Generation

Purchased Power

Other Production Expenses .................................

Total Production Expenses

Transmission Expenses

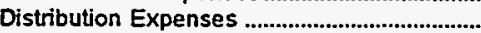

Customer Accounts Expenses .........................

Customer Service and Information

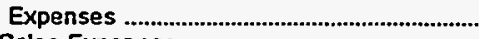

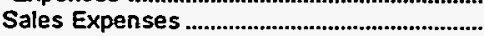

Administrative and General

Expenses .

Total Electric Operation and

Maintenance Expenses

Fuel Expenses in Operation

Steam Power Generation ..

Nuclear Power Generation

Other Power Generation

Number of Elec Dept Employees

Regular Full-time

Part-time \& Temporary

Total Elec Dept Employees

22,934

28,152

22,934

125

1.998

823

14

35

1,049

32,195

25,546
22,110

22,110

0
1,665

332

24

26

565

24,215

300

$\begin{array}{rr}0 & 0 \\ 0 & 0 \\ 0 & 0 \\ 0 & 0 \\ 8,941 & 27,652 \\ 0 & 0\end{array}$

8,941

27,652

9,661

0
434

434
227

0
2.821

795

429

0

32
30

10

30

667

304

208

667

10,539

9,840

31,996

Note: Totals may not equal sum of components because of independent rounding.

Source: Energy Information Administration, Form ElA-412, "Annual Report of Public Electric Utilities." 
Table 23. Electric Operation and Maintenance Expenses by Major U.S. Publicly Owned Electric Utility Within State, 1995 (Continued)

(Thousand Dollars)

\begin{tabular}{|c|c|c|c|c|c|c|}
\hline Item & $\begin{array}{l}\text { Tennessee } \\
\text { Dyersburg } \\
\text { City of } \\
\text { June } 30\end{array}$ & $\begin{array}{l}\text { Tennessee } \\
\text { Elizabethton } \\
\text { City of } \\
\text { June } 30\end{array}$ & $\begin{array}{l}\text { Tennessee } \\
\text { Envin } \\
\text { Town of } \\
\text { June } 30\end{array}$ & $\begin{array}{l}\text { Tennessee } \\
\text { Etowah } \\
\text { City of } \\
\text { June } 30\end{array}$ & $\begin{array}{l}\text { Tennessee } \\
\text { Fayetteville } \\
\text { City of } \\
\text { June } 30\end{array}$ & $\begin{array}{l}\text { Tennessee } \\
\text { Gallatin } \\
\text { City of } \\
\text { June } 30\end{array}$ \\
\hline \multicolumn{7}{|l|}{ Production Expenses } \\
\hline 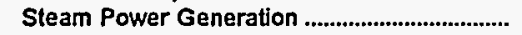 & 0 & 0 & 0 & 0 & 0 & \\
\hline Nuclear Power Generation ....................................... & 0 & 0 & 0 & 0 & 0 & 0 \\
\hline 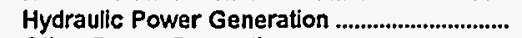 & 0 & $\mathbf{0}$ & 0 & 0 & 0 & 0 \\
\hline Other Power Generation ..................................... & 0 & 0 & 0 & 0 & 0 & \\
\hline 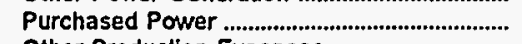 & 23,670 & 22,248 & 8,859 & 5,863 & 16,952 & 20,196 \\
\hline 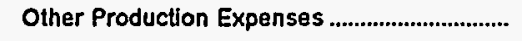 & 0 & 0 & 0 & 0 & 0 & \\
\hline Total Production Expenses ........................... & 23,670 & 22,248 & 8,859 & 5,863 & 16,952 & 20,196 \\
\hline 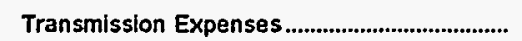 & 8 & 23 & 0 & 1 & 0 & \\
\hline Distribution Expenses ............................................ & 1,316 & 1,215 & 539 & 444 & 1,104 & 763 \\
\hline $\begin{array}{l}\text { Customer Accounts Expenses .............................. } \\
\text { Customer Senvice and Information }\end{array}$ & 380 & 574 & 204 & 134 & 408 & 292 \\
\hline 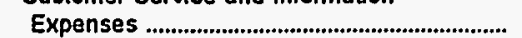 & 35 & 0 & 21 & 7 & 96 & \\
\hline $\begin{array}{l}\text { Sales Expenses ...................................... } \\
\text { Administrative and }\end{array}$ & 42 & 132 & 0 & 6 & 20 & 15 \\
\hline 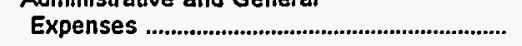 & 790 & 937 & 275 & 212 & 897 & 392 \\
\hline $\begin{array}{l}\text { Total Electric Operation and } \\
\text { Maintenance Expenses................................. }\end{array}$ & 26,241 & 25,129 & 9,898 & 6,667 & 19,477 & 21,664 \\
\hline
\end{tabular}

Fuel Expenses in Operation

Steam Power Generation ................................

Nuclear Power Generation.

Other Power Generation

Regular Full-time

Part-time \& Temporary

Total Elec Dept Employees
Number of Elec Dept Employees
0

0

0

51

o

51
0

o

0

57

o

57
0

0

0
0

0

0

\section{0}

0

0
0

0

0

Note: Totals may not equal sum of components because of independent rounding.

Source: Energy Information Administration, Form EIA-412, "Annual Report of Public Electric Utilities."

\begin{tabular}{rrrr}
20 & 15 & 67 & 29 \\
0 & 0 & 0 & 0 \\
20 & 15 & 67 & 29 \\
\hline
\end{tabular}

0
0
0
0
6
0
6
1
2
6
5
0
0
0
0
0
0
0


Table 23. Electric Operation and Maintenance Expenses by Major U.S. Publicly Owned Electric Utility Within State, 1995 (Continued) (Thousand Dollars)

\begin{tabular}{|c|c|c|c|c|c|c|}
\hline Item & $\begin{array}{c}\text { Tennessee } \\
\text { Greeneville } \\
\text { City of } \\
\text { June } 30\end{array}$ & $\begin{array}{l}\text { Tennessee } \\
\text { Harriman } \\
\text { City of } \\
\text { June } 30\end{array}$ & $\begin{array}{l}\text { Tennessee } \\
\text { Humboldt } \\
\text { City of } \\
\text { June } 30\end{array}$ & $\begin{array}{l}\text { Tennessee } \\
\text { Jackson } \\
\text { City of } \\
\text { June } 30\end{array}$ & $\begin{array}{l}\text { Tennessee } \\
\text { Johnson } \\
\text { City City of } \\
\text { June } 30\end{array}$ & $\begin{array}{l}\text { Tennessee } \\
\text { Knoxville } \\
\text { Utilities } \\
\text { Board } \\
\text { June } 30\end{array}$ \\
\hline \multicolumn{7}{|l|}{ Production Expenses } \\
\hline 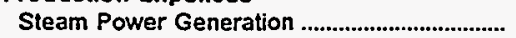 & 0 & 0 & 0 & 0 & 0 & 0 \\
\hline Nuclear Power Generation .................................. & 0 & 0 & 0 & 0 & 0 & 0 \\
\hline Hydraulic Power Generation ............................. & 0 & 0 & 0 & 0 & 0 & 0 \\
\hline 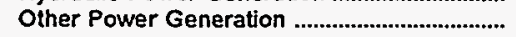 & 0 & 0 & 0 & 0 & 0 & 0 \\
\hline 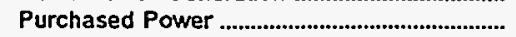 & 38,147 & 11,046 & 10,529 & 54.127 & 70,853 & 209,313 \\
\hline 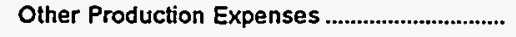 & 0 & 0 & 0 & 0 & 0 & 0 \\
\hline Total Production Expenses .............................. & 38,147 & 11,046 & 10,529 & 54,127 & 70,853 & 209,313 \\
\hline Transmission Expenses................................................... & 90 & 0 & 11 & 169 & 326 & 0 \\
\hline 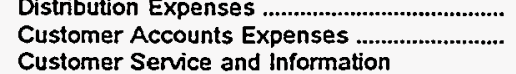 & $\begin{array}{r}2,911 \\
785\end{array}$ & $\begin{array}{l}962 \\
398\end{array}$ & $\begin{array}{r}462 \\
81\end{array}$ & $\begin{array}{r}2,567 \\
864\end{array}$ & $\begin{array}{l}4,407 \\
1,776\end{array}$ & $\begin{array}{r}14,750 \\
5,873\end{array}$ \\
\hline 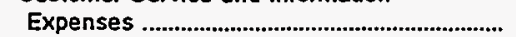 & 63 & 20 & 14 & 146 & 60 & 665 \\
\hline $\begin{array}{l}\text { Sales Expenses } \\
\text { Administrative and General }\end{array}$ & 104 & 0 & 11 & 26 & 148 & 0 \\
\hline 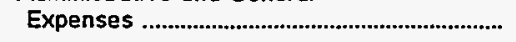 & 1,083 & 788 & 282 & 1,779 & 1,105 & 9,797 \\
\hline Total Electric Operation and & & & & & & \\
\hline 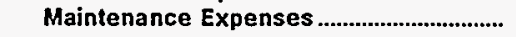 & 43,182 & 13,215 & 11,391 & 59,678 & 78,675 & 240,397 \\
\hline
\end{tabular}

Fuel Expenses in Operation

Steam Power Generation .

Nuclear Power Generation.

o

0

Other Power Generation

Number of Elec Dept Employees

Regular Full-time

Part-time \& Temporary

77

0

77

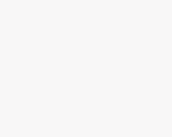

0
0
0

0

0
0
0

0

0

0

41

15

0

41

15

120

562

0

0

0

0

120

562

Note: Totals may not equal sum of components because of independent rounding

Source: Energy Information Administration, Form ElA-412, "Annual Report of Public Electric Utilities." 
Table 23. Electric Operation and Maintenance Expenses by Major U.S. Publicly Owned Electric Utility Within State, 1995 (Continued)

(Thousand Dollars)

\begin{tabular}{|c|c|c|c|c|c|c|}
\hline Item & $\begin{array}{c}\text { Tennessee } \\
\text { Lawrenceburg } \\
\text { City of } \\
\text { June } 30\end{array}$ & $\begin{array}{l}\text { Tennessee } \\
\text { LaFoliette } \\
\text { City of } \\
\text { June } 30\end{array}$ & $\begin{array}{l}\text { Tennessee } \\
\text { Lebanon } \\
\text { City of } \\
\text { June } 30\end{array}$ & $\begin{array}{l}\text { Tennessee } \\
\text { Lenoir } \\
\text { City City of } \\
\text { June } 30\end{array}$ & $\begin{array}{l}\text { Tennessee } \\
\text { Lewisburg } \\
\text { City of } \\
\text { June } 30\end{array}$ & $\begin{array}{l}\text { Tennessee } \\
\text { Lexington } \\
\text { City of } \\
\text { June } 30\end{array}$ \\
\hline 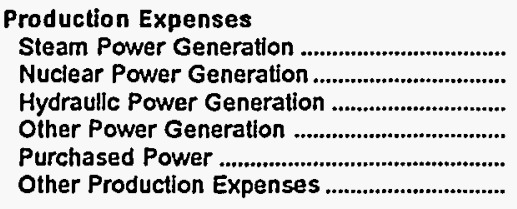 & $\begin{array}{r}0 \\
0 \\
0 \\
0 \\
20,240 \\
0\end{array}$ & $\begin{array}{r}0 \\
0 \\
0 \\
0 \\
16,011 \\
0\end{array}$ & $\begin{array}{r}0 \\
0 \\
0 \\
0 \\
16,347 \\
0\end{array}$ & $\begin{array}{r}0 \\
0 \\
0 \\
0 \\
47,690 \\
0\end{array}$ & $\begin{array}{r}0 \\
0 \\
0 \\
0 \\
12,399 \\
0\end{array}$ & $\begin{array}{r}0 \\
0 \\
0 \\
0 \\
18,218 \\
0\end{array}$ \\
\hline Total Production Expenses .......................... & 20,240 & 16,011 & 16,347 & 47,690 & 12,399 & 18,218 \\
\hline 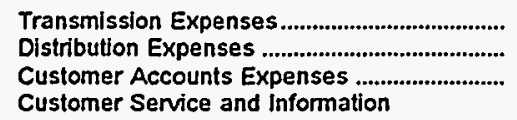 & $\begin{array}{r}33 \\
1,151 \\
517\end{array}$ & $\begin{array}{r}2 \\
1,479 \\
414\end{array}$ & $\begin{array}{r}0 \\
698 \\
237\end{array}$ & $\begin{array}{r}0 \\
3,407 \\
1.487\end{array}$ & $\begin{array}{r}0 \\
533 \\
140\end{array}$ & $\begin{array}{r}0 \\
1,582 \\
423\end{array}$ \\
\hline 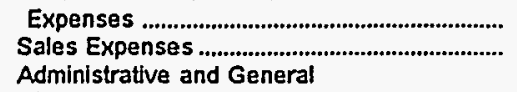 & $\begin{array}{l}57 \\
13\end{array}$ & $\begin{array}{l}15 \\
28\end{array}$ & $\begin{array}{r}14 \\
0\end{array}$ & $\begin{array}{r}0 \\
30\end{array}$ & $\begin{array}{r}25 \\
1\end{array}$ & $\begin{array}{l}32 \\
35\end{array}$ \\
\hline 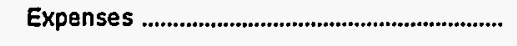 & 1.034 & 854 & 579 & 1,672 & 483 & 1.176 \\
\hline $\begin{array}{l}\text { Total Electric Operation and } \\
\text { Maintenance Expenses............................... }\end{array}$ & 23,044 & 18,805 & 17,875 & 54,286 & 13,580 & 21,465 \\
\hline \multicolumn{7}{|l|}{ Fuel Expenses in Operation } \\
\hline Steam Power Generation .................................. & 0 & 0 & 0 & 0 & 0 & 0 \\
\hline Nuclear Power Generation ................................... & 0 & 0 & 0 & 0 & 0 & 0 \\
\hline 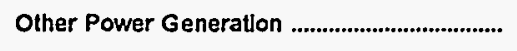 & 0 & 0 & 0 & 0 & 0 & 0 \\
\hline \multicolumn{7}{|l|}{ Number of Elec Dept Employees } \\
\hline 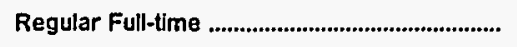 & 63 & 57 & 50 & 119 & 27 & 71 \\
\hline 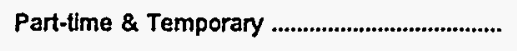 & 0 & 0 & 0 & 0 & 0 & 0 \\
\hline 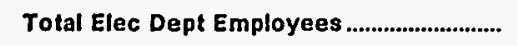 & 63 & 57 & 50 & 119 & 27 & 71 \\
\hline
\end{tabular}

Note: Totals may not equal sum of components because of independent rounding.

Source: Energy Information Administration, Form EIA-412, "Annual Report of Public Electric Utilities." 
Table 23. Electric Operation and Maintenance Expenses by Major U.S. Publicly Owned Electric Utility Within State, 1995 (Continued)

(Thousand Dollars)

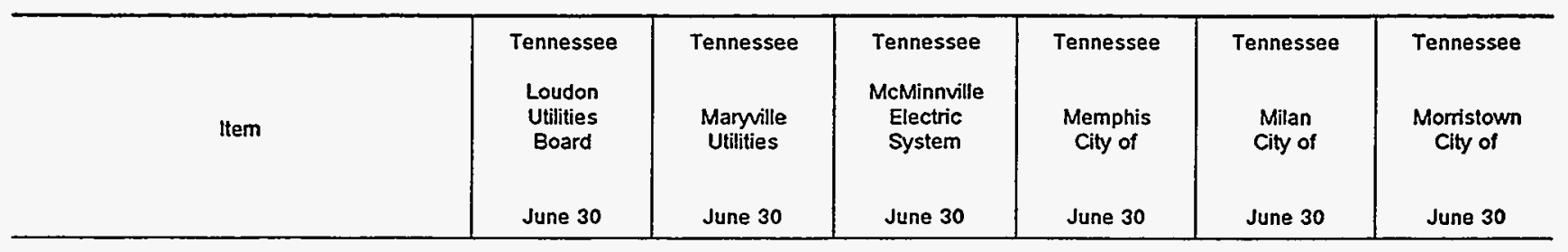

Production Expenses

Steam Power Generation

Nuciear Power Generation.

Hydraulic Power Generation

Other Power Generation

Purchased Power .....................................................

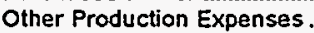

0
0
0
0
12,395
0

0
0
0
0
23,211
0

0
0
0
0
10,208
0

0
0
0
0
515,555
0

0
0
0
0

10,387

$12,395 \quad 23,211$

10,208

515,555

10,387

Transmission Expenses.

0

58

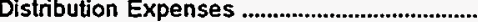

Customer Accounts Expenses .........................

Customer Senvice and Information

Expenses.

Sales Expenses

Administrative and General

Expenses

121

1,240

0
569

4,085

45,044

9,511

$\begin{array}{rr}0 & 1 \\ -79 & 27\end{array}$

196

57
31

459

858

555

912

33,169

11,616

609,032

Total Electric Operation and

Maintenance Expenses.

13,511

25,812

609,032

11,668

29,596

7
1,616

0$$
906
$$

Fuel Expenses in Operation

Steam Power Generation .

0
0
0

0
0
0

0
0
0

0
0
0

$\begin{array}{ll}0 & 0 \\ 0 & 0 \\ 0 & 0\end{array}$

Number of Elec Dept Employees

Regular Full-time ..

$\begin{array}{ll}19 & 39 \\ 0 & 0\end{array}$

\begin{tabular}{rrrr}
31 & 1,508 & 26 & 85 \\
0 & 0 & 0 & 0 \\
31 & 1,508 & 26 & 85 \\
\hline
\end{tabular}

Total Elec Dept Employees.

19

39

Note: Totals may not equal sum of components because of independent rounding.

Source: Energy Information Administration, Form EIA-412, "Annual Report of Public Electric Utilities." 
Table 23. Electric Operation and Maintenance Expenses by Major U.S. Publicly Owned Electric Utility Within State, 1995 (Continued) (Thousand Dollars)

\begin{tabular}{|c|c|c|c|c|c|c|}
\hline Item & $\begin{array}{l}\text { Tennessee } \\
\text { Murfreesboro } \\
\text { City of } \\
\text { June } 30\end{array}$ & $\begin{array}{l}\text { Tennessee } \\
\text { Nashville } \\
\text { Electric } \\
\text { Service } \\
\text { June } 30\end{array}$ & $\begin{array}{l}\text { Tennessee } \\
\text { Newport } \\
\text { City of } \\
\text { June } 30\end{array}$ & $\begin{array}{l}\text { Tennessee } \\
\text { Oak Ridge } \\
\text { City of } \\
\text { June } 30\end{array}$ & $\begin{array}{l}\text { Tennessee } \\
\text { Paris } \\
\text { City of } \\
\text { June } 30\end{array}$ & $\begin{array}{l}\text { Tennessee } \\
\text { Pulaskj } \\
\text { City of } \\
\text { June } 30\end{array}$ \\
\hline \multicolumn{7}{|l|}{ Production Expenses } \\
\hline 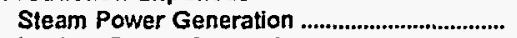 & 0 & 0 & 0 & 0 & 0 & 0 \\
\hline Nuclear Power Generation .................................. & 0 & 0 & 0 & 0 & 0 & 0 \\
\hline Hydraulic Power Generation .............................. & 0 & 0 & 0 & 0 & 0 & 0 \\
\hline 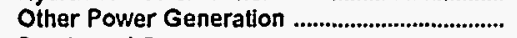 & 0 & 0 & 0 & 0 & 0 & 0 \\
\hline 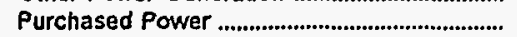 & 40,423 & 466,754 & 3,717 & 20,731 & 19,376 & 18,142 \\
\hline 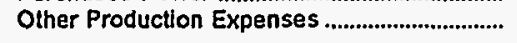 & 0 & 0 & 0 & 0 & 0 & 0 \\
\hline Total Production Expenses ........................... & 40,423 & 466,754 & 3,717 & 20,731 & 19,376 & 18,142 \\
\hline $\begin{array}{l}\text { Distribution Expenses ...................................................... } \\
\text { Customer Accounts Expenses }\end{array}$ & 1.217 & 25,754 & $\begin{array}{r}187 \\
33\end{array}$ & 1,248 & 1.094 & 1,282 \\
\hline $\begin{array}{l}\text { Customer Accounts Expenses .......................... } \\
\text { Customer Service and Information }\end{array}$ & 635 & 14,611 & 33 & 427 & 405 & 275 \\
\hline 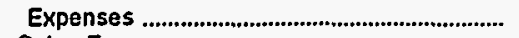 & 54 & 1,153 & 1 & 6 & 47 & 65 \\
\hline Sales Expenses & 25 & -6 & 0 & 75 & 24 & 23 \\
\hline Administrative and General & & & & & & \\
\hline 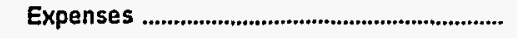 & 965 & 20,913 & 84 & 625 & 536 & 668 \\
\hline 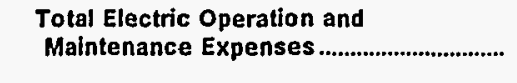 & 43,319 & 529,178 & 4,021 & 23,149 & 21,523 & 20,453 \\
\hline \multicolumn{7}{|l|}{ Fuel Expenses in Operation } \\
\hline 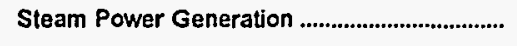 & 0 & 0 & 0 & 0 & 0 & 0 \\
\hline Nuclear Power Generation .................................. & 0 & 0 & 0 & $\mathbf{0}$ & 0 & 0 \\
\hline 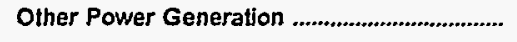 & 0 & 0 & 0 & 0 & 0 & 0 \\
\hline \multicolumn{7}{|l|}{ Number of Elec Dept Employees } \\
\hline Regular Full-time & 66 & 994 & 9 & 0 & 50 & 54 \\
\hline 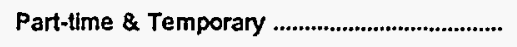 & 0 & 0 & 0 & 0 & 0 & 0 \\
\hline 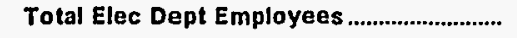 & 66 & 994 & 9 & 0 & 50 & 54 \\
\hline
\end{tabular}

Note: Totals may not equal sum of components because of independent rounding.

Source: Energy Information Administration. Form ElA-412, "Annual Report of Public Electric Utilities." 
Table 23. Electric Operation and Maintenance Expenses by Major U.S. Publicly

Owned Electric Utility Within State, 1995 (Continued)

(Thousand Dollars)

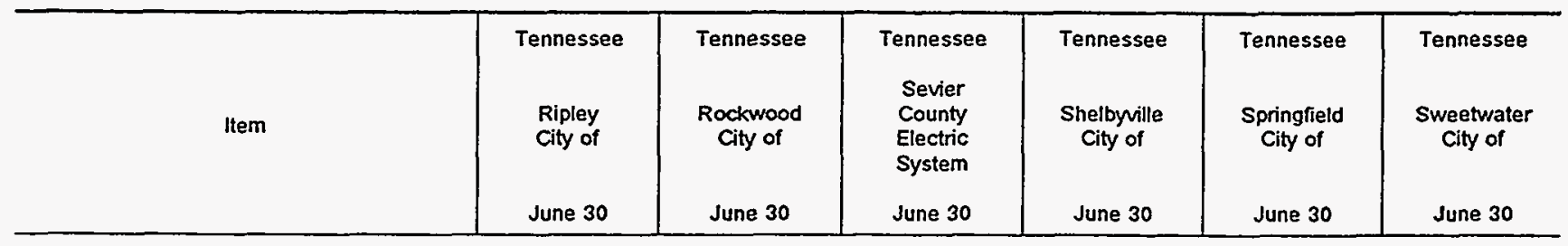

Production Expenses

Steam Power Generation

Nuclear Power Generation

Hydraulic Power Generation

Other Power Generation

Purchased Power

Other Production

(n)

Total Production Expenses

Transmission Expenses.

Customer Accounts Expenses .................

Customer Service and Information

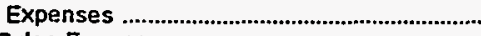

Sales Expenses.

Administrative and General

Expenses

Total Electric Operation and

Maintenance Expenses

Fuel Expenses in Operation

Steam Power Generation

Nuclear Power Generation

Other Power Generation

Number of Elec Dept Employees

Regular Full-time

Part-time \& Temporary

Total Elec Dept Employees

0
0
0
0
12,370
0

11,082

39

443

171

4

48

620

12,405

0

0

082

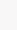

12,370

0

946

385

2

6

662

14,372

14,3
June 30

0
0
0
0
41,972
0

41,972

138
2.316

1,130

43

81

1.237

46,916

16,724

0
0
0
0
15.292
0

15,292

0
699

232

17
0

483

$\begin{array}{rr}0 & 0 \\ 0 & 0 \\ 0 & 0 \\ 0 & 0 \\ 9,184 & 8,450 \\ 0 & 0\end{array}$

9,184

8,450

0

456

298

18
8

14

0
540
154

154

7
2

346

0,279

9,498

Note: Totals may not equal sum of components because of independent rounding.

Source: Energy Information Administration, Form EIA-412, "Annual Report of Public Electric Utilities." 
Table 23. Electric Operation and Maintenance Expenses by Major U.S. Publicly Owned Electric Utility Within State, 1995 (Continued) (Thousand Dollars)

\begin{tabular}{|c|c|c|c|c|c|c|}
\hline Item & $\begin{array}{l}\text { Tennessee } \\
\text { Tullahoma } \\
\text { Board } \\
\text { of } \\
\text { Pub Utils } \\
\text { June } 30\end{array}$ & $\begin{array}{l}\text { Tennessee } \\
\text { Union } \\
\text { City City of } \\
\text { June } 30\end{array}$ & $\begin{array}{l}\text { Tennessee } \\
\text { Weakley } \\
\text { County } \\
\text { Mun } \\
\text { Elec Sys } \\
\text { June } 30\end{array}$ & $\begin{array}{l}\text { Tennessee } \\
\text { Winchester } \\
\text { City of } \\
\text { June } 30\end{array}$ & $\begin{array}{c}\text { Texas } \\
\text { Austin } \\
\text { City of } \\
\text { September } 30\end{array}$ & $\begin{array}{c}\text { Texas } \\
\text { Brenham } \\
\text { City of } \\
\text { September } 30\end{array}$ \\
\hline \multicolumn{7}{|l|}{ Production Expenses } \\
\hline 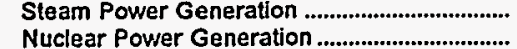 & $\begin{array}{l}0 \\
0\end{array}$ & $\begin{array}{l}0 \\
0\end{array}$ & $\begin{array}{l}0 \\
0\end{array}$ & $\begin{array}{l}0 \\
0\end{array}$ & $\begin{array}{r}113,936 \\
52,931\end{array}$ & $\begin{array}{l}0 \\
0\end{array}$ \\
\hline 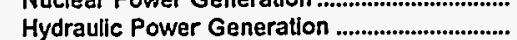 & 0 & 0 & 0 & 0 & 0 & 0 \\
\hline Other Power Generation ........................................... & $\mathbf{0}$ & 0 & 0 & 0 & 0 & 0 \\
\hline 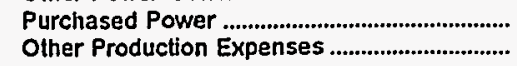 & $\begin{array}{r}12,185 \\
0\end{array}$ & $\begin{array}{r}13,766 \\
0\end{array}$ & $\begin{array}{r}21,125 \\
0\end{array}$ & $\begin{array}{r}6.678 \\
0\end{array}$ & $\begin{array}{l}2,460 \\
4,896\end{array}$ & $\begin{array}{r}10.720 \\
0\end{array}$ \\
\hline Total Production Expenses ........................... & 12,185 & 13,766 & 21,125 & 6,678 & 174,223 & 10,720 \\
\hline $\begin{array}{l}\text { Transmission Expenses } \\
\text { Distribution Expenses }\end{array}$ & $\begin{array}{r}0 \\
898\end{array}$ & $\begin{array}{r}68 \\
445\end{array}$ & $\begin{array}{r}24 \\
1,106\end{array}$ & $\begin{array}{r}0 \\
318\end{array}$ & $\begin{array}{r}2,170 \\
24,548\end{array}$ & $\begin{array}{r}0 \\
768\end{array}$ \\
\hline $\begin{array}{l}\text { Customer Accounts Expenses ................................. } \\
\text { Customer Senice and Information }\end{array}$ & 253 & 189 & 483 & 85 & 13,887 & 0 \\
\hline 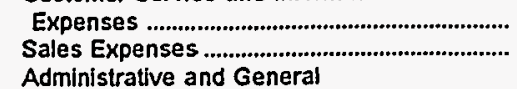 & $\begin{array}{l}19 \\
36\end{array}$ & $\begin{array}{l}25 \\
28\end{array}$ & $\begin{array}{l}39 \\
88\end{array}$ & $\begin{array}{l}8 \\
0\end{array}$ & $\begin{array}{r}16.019 \\
0\end{array}$ & $\begin{array}{l}0 \\
0\end{array}$ \\
\hline 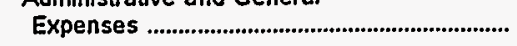 & 375 & 448 & 710 & 137 & 42,728 & 489 \\
\hline $\begin{array}{l}\text { Total Electric Operation and } \\
\text { Maintenance Expenses .................................. }\end{array}$ & 13,766 & 14,968 & 23,575 & 7,226 & 273,575 & 11,976 \\
\hline \multicolumn{7}{|l|}{ Fuel Expenses in Operation } \\
\hline Steam Power Generation ........................................ & $\mathbf{0}$ & 0 & 0 & 0 & 82,960 & 0 \\
\hline Nuclear Power Generation .................................... & 0 & 0 & 0 & 0 & 16.747 & 0 \\
\hline 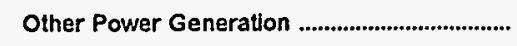 & 0 & 0 & 0 & 0 & 0 & 0 \\
\hline \multicolumn{7}{|l|}{ Number of Elec Dept Employees } \\
\hline 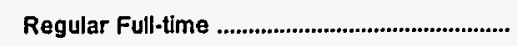 & 30 & 18 & 66 & 14 & 1,218 & 9 \\
\hline 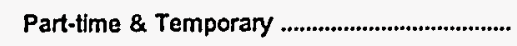 & $\mathbf{0}$ & 0 & 0 & 0 & 112 & 0 \\
\hline Total Elec Dept Employees .................................. & 30 & 18 & 66 & 14 & 1,330 & 9 \\
\hline
\end{tabular}

Note: Totals may not equal sum of components because of independent rounding.

Source: Energy Information Administration, Form ElA-412, "Annual Report of Public Electric Utilities." 
Table 23. Electric Operation and Maintenance Expenses by Major U.S. Publicly Owned Electric Utility Within State, 1995 (Continued)

(Thousand Dollars)

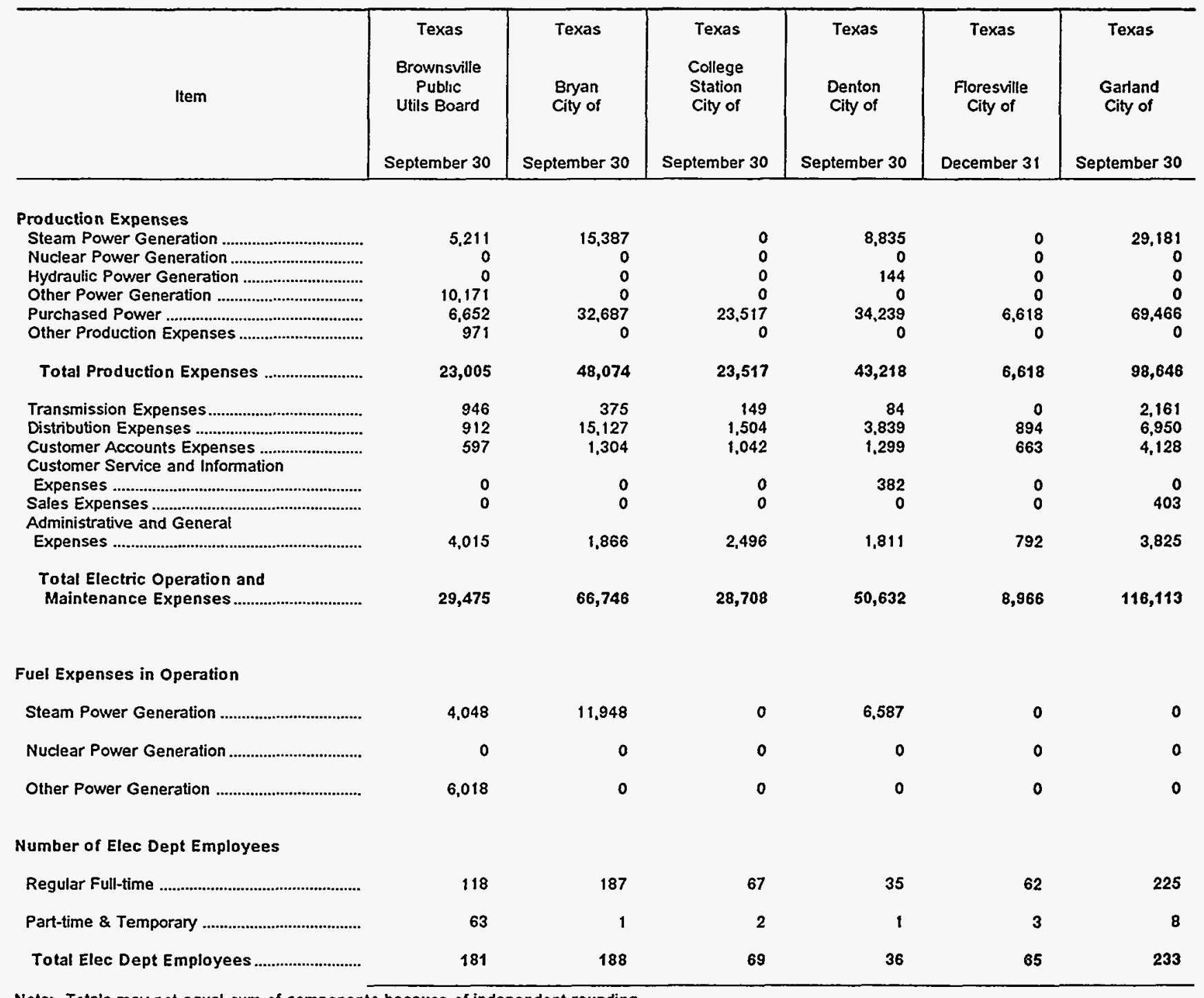

Note: Totals may not equal sum of components because of independent rounding.

Source: Energy Information Administration, Form EIA-412, "Annual Report of Public Electric Utilities." 
Table 23. Electric Operation and Maintenance Expenses by Major U.S. Publicly Owned Electric Utility Within State, 1995 (Continued)

(Thousand Dollars)

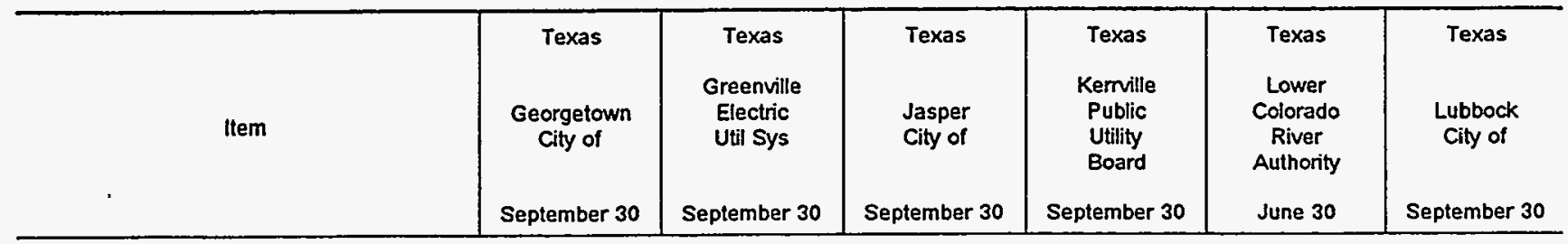

\section{Production Expenses}

Steam Power Generation

Nuclear Power Generation

Hydraullic Power Generation .

Oiher Power Generation

Purchased Power ...................................................

Other Production Expenses..........................

Total Production Expenses

Transmission Expenses.

Customer Accounts Expenses .........................

Customer Service and Information

Expenses .

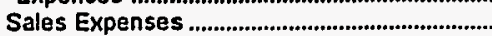

Administrative and General

Expenses

0

$0 \quad 3,770$

00

8,215

Total Electric Operation and

Maintenance Expenses

Fuel Expenses in Operation

Steam Power Generation

Nuclear Power Generation

Other Power Generation

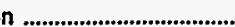

Number of Elec Dept Employees

Regular Full-time ...............................................

Part-time \& Temporary

Total Elec Depl Employees
Distribution Expenses
0
8,215

$$
\begin{array}{r}
187 \\
16,380 \\
0
\end{array}
$$

$$
20,338
$$

0
97
0

0
0

1,414

0
1,880

1,880
0
0

0

0

0
0
0
0
10,245
679

10,924

0
163

163
0

192
0

0

9,826

11,279

1.590
0
1

0

0

0

23

11

73

0

11

0
0
0
0
15,703
0
15,703

169,896

0
3,537

3,537
0

3,352

3,169

179,954

23,661

495

1,385

18,416

18,235

0

0

12,604

30,839

0
1.352

431

0
3.690

3,639

0
1,175

530

1,193

18,768

223,910

39,873

Note: Totals may not equal sum of components because of independent rounding.

Source: Energy Information Administration, Form EIA-412, "Annual Report of Public Electric Utilities." 
Table 23. Electric Operation and Maintenance Expenses by Major U.S. Publicly Owned Electric Utility Within State, 1995 (Continued)

(Thousand Dollars)

\begin{tabular}{|c|c|c|c|c|c|c|}
\hline Item & $\begin{array}{c}\text { Texas } \\
\text { New Braunfels } \\
\text { City of } \\
\text { July } 31\end{array}$ & $\begin{array}{c}\text { Texas } \\
\text { Sam Rayburn } \\
\text { Municipal } \\
\text { Pwr } \\
\text { Agny } \\
\text { September } 30\end{array}$ & $\begin{array}{c}\text { Texas } \\
\text { San Antonio } \\
\text { Public } \\
\text { Senvice Bd } \\
\text { January } 31\end{array}$ & $\begin{array}{c}\text { Texas } \\
\text { San Marcos } \\
\text { City of } \\
\text { September } 30\end{array}$ & $\begin{array}{c}\text { Texas } \\
\text { Seguin } \\
\text { City of } \\
\text { September } 30\end{array}$ & $\begin{array}{c}\text { Texas } \\
\text { Texas } \\
\text { Municipal } \\
\text { Power Agency } \\
\text { September } 30\end{array}$ \\
\hline \multicolumn{7}{|l|}{ Production Expenses } \\
\hline 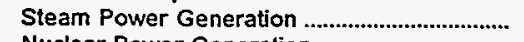 & 0 & 13,411 & 155,512 & 0 & 0 & 67,315 \\
\hline 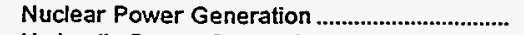 & 0 & 0 & 84,700 & 0 & 0 & 0 \\
\hline Hydraulic Power Generation ................................ & 13 & 0 & 0 & 0 & $\mathbf{0}$ & $\mathbf{0}$ \\
\hline 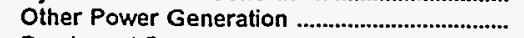 & 0 & 0 & 0 & 0 & 0 & 0 \\
\hline 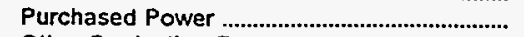 & 30,468 & 2,679 & 4,667 & 14,217 & 8,728 & 0 \\
\hline 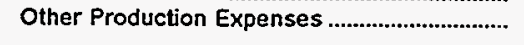 & 0 & 0 & 69 & 0 & 0 & 0 \\
\hline 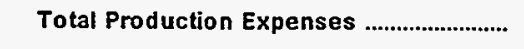 & 30,481 & 16,090 & 244,948 & 14,217 & 8,728 & 67,315 \\
\hline $\begin{array}{l}\text { Transmission Expenses } \\
\text { Distribution Expenses }\end{array}$ & 125 & 0 & 3.718 & 0 & 0 & 3,256 \\
\hline 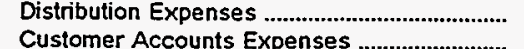 & 1,349 & 0 & 30.864 & 1,008 & 824 & 0 \\
\hline $\begin{array}{l}\text { Customer Accounts Expenses } \\
\text { Customer Senvice and Information }\end{array}$ & 464 & 0 & 8,144 & 943 & 0 & 0 \\
\hline 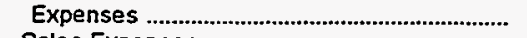 & 0 & 0 & 2,450 & 66 & 0 & 0 \\
\hline $\begin{array}{l}\text { Sales Expenses } \\
\text { Administrative and General }\end{array}$ & 0 & 0 & 0 & 0 & 0 & 0 \\
\hline 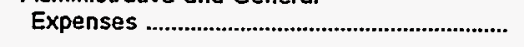 & 864 & 1,112 & 68,105 & 1,179 & 0 & 11,309 \\
\hline 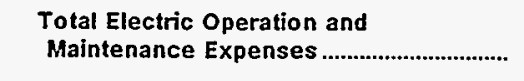 & 33,283 & 17,202 & 358,228 & 17,413 & 8,551 & 81,880 \\
\hline \multicolumn{7}{|l|}{ Fuel Expenses in Operation } \\
\hline 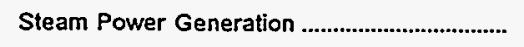 & 0 & 10.539 & 0 & 0 & 0 & 51,697 \\
\hline 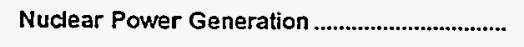 & 0 & 0 & 0 & 0 & $\mathbf{0}$ & 0 \\
\hline 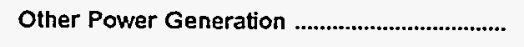 & 0 & 0 & 0 & 0 & 0 & 0 \\
\hline \multicolumn{7}{|l|}{ Number of Elec Dept Employees } \\
\hline 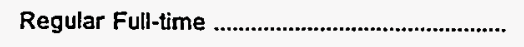 & 69 & 3 & 2,714 & 46 & 20 & 227 \\
\hline 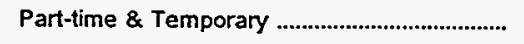 & 0 & 0 & 0 & 3 & 0 & $\mathbf{0}$ \\
\hline 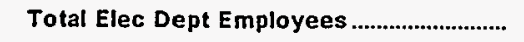 & 69 & 3 & 2,714 & 49 & 20 & 227 \\
\hline
\end{tabular}

Note: Totals may not equal sum of components because of independent rounding

Source: Energy Information Administration, Form E1A-412. "Annual Report of Public Electric Utilities." 
Table 23. Electric Operation and Maintenance Expenses by Major U.S. Publicly Owned Electric Utility Within State, 1995 (Continued)

(Thousand Dollars)

\begin{tabular}{|c|c|c|c|c|c|c|}
\hline Item & $\begin{array}{l}\text { Texas } \\
\text { Toledo Bend } \\
\text { Project } \\
\text { Joint } \\
\text { Oper } \\
\text { August } 30\end{array}$ & $\begin{array}{c}\text { Texas } \\
\text { Weatherford } \\
\text { Mun } \\
\text { Utility } \\
\text { System } \\
\text { September } 30\end{array}$ & $\begin{array}{c}\text { Utah } \\
\text { Bountiful } \\
\text { City City of } \\
\text { June } 30\end{array}$ & $\begin{array}{l}\text { Intermountain } \\
\text { Power Agency } \\
\text { June } 30\end{array}$ & $\begin{array}{l}\text { Utah } \\
\text { Logan } \\
\text { City of } \\
\text { June } 30\end{array}$ & $\begin{array}{l}\text { Utah } \\
\text { Murray } \\
\text { City of } \\
\text { June } 30\end{array}$ \\
\hline 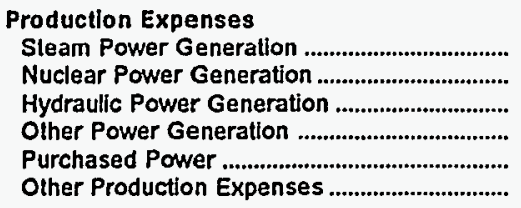 & $\begin{array}{r}0 \\
0 \\
8,722 \\
0 \\
0 \\
0\end{array}$ & $\begin{array}{r}0 \\
0 \\
0 \\
126 \\
6,813 \\
0\end{array}$ & $\begin{array}{r}0 \\
0 \\
152 \\
703 \\
5,326 \\
31\end{array}$ & $\begin{array}{r}203,510 \\
0 \\
0 \\
0 \\
0 \\
0\end{array}$ & $\begin{array}{r}0 \\
0 \\
124 \\
370 \\
9,167 \\
0\end{array}$ & $\begin{array}{r}0 \\
0 \\
129 \\
99 \\
9.734 \\
0\end{array}$ \\
\hline Total Production Expenses ............................. & 8,722 & 6,939 & 6,211 & 203,510 & 9,661 & 9,962 \\
\hline 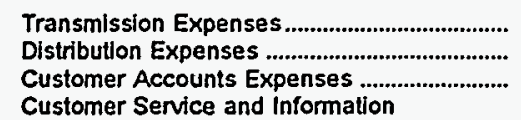 & $\begin{array}{l}0 \\
0 \\
0\end{array}$ & $\begin{array}{r}0 \\
856 \\
222\end{array}$ & $\begin{array}{r}0 \\
937 \\
72\end{array}$ & $\begin{array}{r}9,279 \\
0 \\
0\end{array}$ & $\begin{array}{r}135 \\
746 \\
0\end{array}$ & $\begin{array}{r}87 \\
1.420 \\
401\end{array}$ \\
\hline 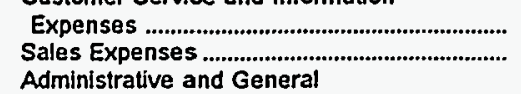 & $\begin{array}{l}0 \\
0\end{array}$ & $\begin{array}{l}0 \\
0\end{array}$ & $\begin{array}{l}0 \\
0\end{array}$ & $\begin{array}{l}0 \\
0\end{array}$ & $\begin{array}{r}0 \\
178\end{array}$ & $\begin{array}{r}199 \\
0\end{array}$ \\
\hline 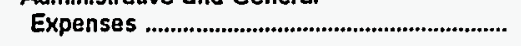 & 0 & 1,027 & 1,218 & 16.543 & 985 & 1,491 \\
\hline $\begin{array}{l}\text { Total Electric Operation and } \\
\text { Maintenance Expenses .................................... }\end{array}$ & 8,722 & 9,044 & 8,438 & 229,332 & 11,704 & 13,559 \\
\hline \multicolumn{7}{|l|}{ Fuel Expenses in Operation } \\
\hline 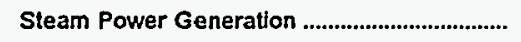 & 0 & 0 & 0 & 165,519 & 0 & $\mathbf{0}$ \\
\hline 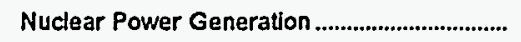 & 0 & 0 & 0 & 0 & 0 & 0 \\
\hline 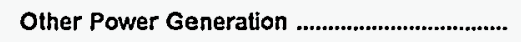 & 0 & 0 & 131 & 0 & 6 & 17 \\
\hline \multicolumn{7}{|l|}{ Number of Elec Dept Employees } \\
\hline Regular Full-time & 0 & 37 & 34 & 0 & 30 & 51 \\
\hline 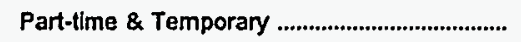 & 0 & 3 & 12 & 0 & 12 & 0 \\
\hline Total Elec Dept Employees ........................... & 0 & 40 & 46 & 0 & 42 & 51 \\
\hline
\end{tabular}

Note: Totals may not equal sum of components because of independent rounding.

Source: Energy Information Administration, Form ElA-412, "Annual Report of Public Electric Utilities." 
Table 23. Electric Operation and Maintenance Expenses by Major U.S. Publicly Owned Electric Utility Within State, 1995 (Continued)

(Thousand Dollars)

\begin{tabular}{|c|c|c|c|c|c|c|}
\hline Item & $\begin{array}{l}\text { Utah } \\
\text { Provo } \\
\text { City Corp } \\
\text { June } 30\end{array}$ & $\begin{array}{l}\text { Utah } \\
\text { St George } \\
\text { City of } \\
\text { June } 30\end{array}$ & $\begin{array}{c}\text { Utah } \\
\text { Utah } \\
\text { Associated } \\
\text { Mun } \\
\text { Power Sys } \\
\text { March } 31\end{array}$ & $\begin{array}{c}\text { Utah } \\
\text { Utah } \\
\text { Municipal } \\
\text { Power Agency } \\
\text { June } 30\end{array}$ & $\begin{array}{l}\text { Vermont } \\
\text { Burlington } \\
\text { City of } \\
\text { June } 30\end{array}$ & $\begin{array}{l}\text { Vermont } \\
\text { Vermont } \\
\text { Public } \\
\text { Pwr } \\
\text { Supply Auth } \\
\text { December } 31\end{array}$ \\
\hline \multicolumn{7}{|l|}{ Production Expenses } \\
\hline Steam Power Generation ................................... & 0 & 0 & 11,589 & 7,621 & 3,375 & 1,730 \\
\hline 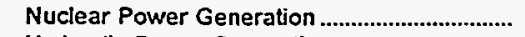 & 0 & 0 & 0 & 0 & 0 & 0 \\
\hline Hydraulic Power Generation ............................... & 0 & 0 & 0 & 0 & 0 & 0 \\
\hline 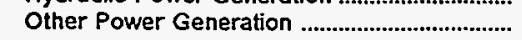 & 0 & 369 & 0 & 9,523 & 159 & 0 \\
\hline 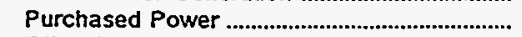 & 23,364 & 14,515 & 12,317 & 8,967 & 14,223 & 3.244 \\
\hline 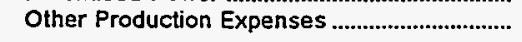 & $-3,307$ & 0 & 13 & 205 & 745 & 3 \\
\hline Total Production Expenses .............................. & 20,057 & 14,884 & 23,919 & 26,316 & 18,502 & 4,977 \\
\hline 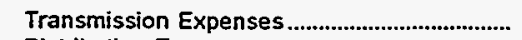 & 261 & 0 & 5,031 & 1,278 & 504 & 261 \\
\hline 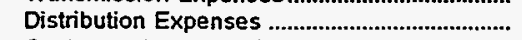 & 2,661 & 0 & 0 & 0 & 2,056 & 0 \\
\hline $\begin{array}{l}\text { Customer Accounts Expenses .......................... } \\
\text { Customer Service and Information }\end{array}$ & 1,165 & 0 & 0 & 0 & 1,331 & 0 \\
\hline Expenses & 143 & 0 & 0 & 0 & 376 & 0 \\
\hline $\begin{array}{l}\text { Sales Expenses .............................................. } \\
\text { Administrative and General }\end{array}$ & 0 & 0 & 0 & 0 & 0 & $\mathbf{0}$ \\
\hline 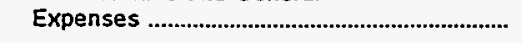 & 1.103 & 2,293 & 3,885 & 426 & 3,019 & 694 \\
\hline 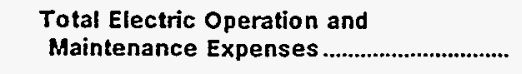 & 25,390 & 17,177 & 32,835 & 28,019 & 25,789 & 5,931 \\
\hline \multicolumn{7}{|l|}{ Fuel Expenses in Operation } \\
\hline Steam Power Generation ..................................... & 0 & 0 & 0 & 0 & 2,368 & 1,037 \\
\hline Nuclear Power Generation .................................. & 0 & 0 & 0 & 0 & 0 & 0 \\
\hline 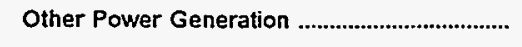 & 0 & 9 & 0 & 4,724 & 80 & 0 \\
\hline \multicolumn{7}{|l|}{ Number of Elec Dept Employees } \\
\hline 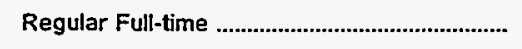 & 89 & 37 & 0 & 28 & 158 & 10 \\
\hline 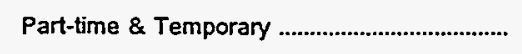 & 5 & 5 & 0 & 0 & 4 & 0 \\
\hline 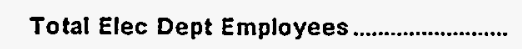 & 94 & 42 & 0 & 28 & 162 & 10 \\
\hline
\end{tabular}

Note: Totals may not equal sum of components because of independent rounding.

Source: Energy Information Administration, Form EIA-412, "Annual Report of Public Electric Utilities." 
Table 23. Electric Operation and Maintenance Expenses by Major U.S. Publicly Owned Electric Utility Within State, 1995 (Continued)

(Thousand Dollars)

\begin{tabular}{|c|c|c|c|c|c|c|}
\hline Item & $\begin{array}{l}\text { Virginia } \\
\text { Bedford } \\
\text { City of } \\
\text { June } 30\end{array}$ & $\begin{array}{l}\text { Virginia } \\
\text { Bristol } \\
\text { Utilities } \\
\text { Board } \\
\text { June } 30\end{array}$ & $\begin{array}{l}\text { Virginia } \\
\text { Danville } \\
\text { City of } \\
\text { June } 30\end{array}$ & $\begin{array}{l}\text { Virginia } \\
\begin{array}{l}\text { Harrisonburg } \\
\text { City of }\end{array} \\
\text { June } 30\end{array}$ & $\begin{array}{l}\text { Virginia } \\
\text { Manassas } \\
\text { City of } \\
\text { June } 30\end{array}$ & $\begin{array}{l}\text { Virginia } \\
\begin{array}{l}\text { Martinsville } \\
\text { City of }\end{array} \\
\text { June } 30\end{array}$ \\
\hline 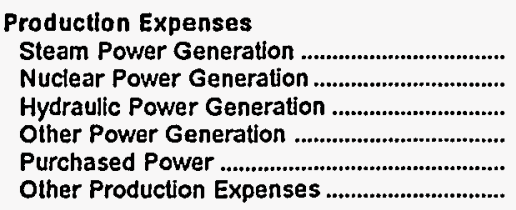 & $\begin{array}{r}0 \\
0 \\
250 \\
0 \\
7,061 \\
122\end{array}$ & $\begin{array}{r}0 \\
0 \\
0 \\
0 \\
21.014 \\
0\end{array}$ & $\begin{array}{r}0 \\
0 \\
605 \\
0 \\
27,794 \\
183\end{array}$ & $\begin{array}{r}0 \\
0 \\
0 \\
0 \\
23,377 \\
0\end{array}$ & $\begin{array}{r}0 \\
0 \\
28 \\
681 \\
10,927 \\
0\end{array}$ & $\begin{array}{r}0 \\
0 \\
286 \\
0 \\
5,918 \\
0\end{array}$ \\
\hline Total Production Expenses ............................ & 7,433 & 21,014 & 28,582 & 23,377 & 11,637 & 6,204 \\
\hline $\begin{array}{l}\text { Transmission Expenses........................................ } \\
\text { Distribution Expenses ................................. } \\
\text { Customer Accounts Expenses ..................... } \\
\text { Customer Service and Information }\end{array}$ & $\begin{array}{l}159 \\
527 \\
119\end{array}$ & $\begin{array}{r}0 \\
1.430 \\
305\end{array}$ & $\begin{array}{r}326 \\
1,561 \\
1,085\end{array}$ & $\begin{array}{r}13 \\
1,063 \\
466\end{array}$ & $\begin{array}{r}0 \\
948 \\
408\end{array}$ & $\begin{array}{r}0 \\
644 \\
125\end{array}$ \\
\hline 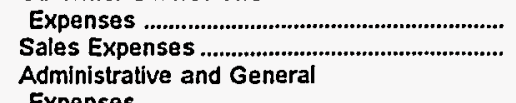 & $\begin{array}{l}0 \\
0\end{array}$ & $\begin{array}{r}23 \\
567\end{array}$ & $\begin{array}{l}0 \\
0\end{array}$ & $\begin{array}{r}4 \\
13\end{array}$ & $\begin{array}{r}136 \\
0\end{array}$ & $\begin{array}{l}0 \\
0\end{array}$ \\
\hline 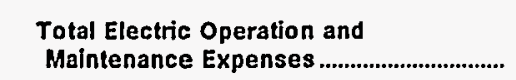 & 8,785 & 24,143 & 32,128 & 25,647 & 14,669 & 7,238 \\
\hline \multicolumn{7}{|l|}{ Fuel Expenses in Operation } \\
\hline 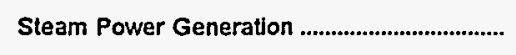 & 0 & 0 & 0 & 0 & 0 & 0 \\
\hline Nuciear Power Generation ...................................... & 0 & 0 & 0 & 0 & 0 & 0 \\
\hline 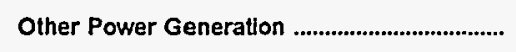 & 0 & 0 & 0 & 0 & 0 & 0 \\
\hline \multicolumn{7}{|l|}{ Number of Elec Dept Employees } \\
\hline 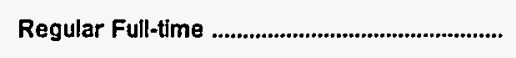 & 18 & 49 & 78 & 46 & 48 & 19 \\
\hline 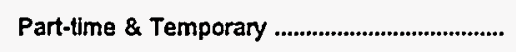 & 0 & 0 & 0 & 3 & $0^{\prime}$ & 1 \\
\hline Total Elec Dept Employees ................................ & 18 & 49 & 78 & 49 & 48 & 20 \\
\hline
\end{tabular}

Note: Totals may not equal sum of components because of independent rounding.

Source: Energy Information Administration, Form ElA-412, "Annual Report of Public Electric Utilities." 
Table 23. Electric Operation and Maintenance Expenses by Major U.S. Publicly Owned Electric Utility Within State, 1995 (Continued) (Thousand Dollars)

\begin{tabular}{|c|c|c|c|c|c|c|}
\hline Item & $\begin{array}{l}\text { Virginia } \\
\text { Radford } \\
\text { City of } \\
\text { June } 30\end{array}$ & $\begin{array}{l}\text { Virginia } \\
\text { Salem } \\
\text { City of } \\
\text { June } 30\end{array}$ & $\begin{array}{l}\text { Virginia } \\
\text { Virginia } \\
\text { Tech } \\
\text { Electric } \\
\text { Service } \\
\text { June } 30\end{array}$ & $\begin{array}{c}\text { Washington } \\
\text { Centralia } \\
\text { City of } \\
\text { December } 31\end{array}$ & $\begin{array}{l}\text { Washington } \\
\text { Ellensburg } \\
\text { City of }\end{array}$ & $\begin{array}{l}\text { Washington } \\
\text { Port Angeles } \\
\text { City of } \\
\text { December } 31\end{array}$ \\
\hline
\end{tabular}

Production Expenses

Steam Power Generation

Nuclear Power Generation

Hydraulic Power Generation

Other Power Generation

Purchased Power

Other Production Expenses ...............................

Total Production Expenses

Transmission Expenses.

Distribution Expenses

Customer Accounts Expenses

Customer Service and Information

Expenses.

Sales Expenses

Administrative and General

Expenses

Total Electric Operation and

Maintenance Expenses

$\begin{array}{rr}0 & \\ 0 & \\ 11 & \\ 0 & \\ 11,998 & 11,959 \\ 13 & \\ 12,023 & 11,959 \\ 0 & \\ 352 & 1,28 \\ 0 & \\ 130 & \\ 0 & 21 \\ 428 & 527\end{array}$

12,933

13,989

100
0
0
0
7,256
0

7,356

0
2,405

2,405

173

0

711

10,644

0
0
566
0
4,737
0

5,303

118

981

531

0
0

495

7,428

Fuel Expenses in Operation

Steam Power Generation

Nuclear Power Generation ...............................

Other Power Generation

0

0

0

23

Regular Full-time

Part-time \& Temporary

Total Elec Dept Employees
0

23
0

0

0

30

6

36
0

0

0

26

13

39 $\begin{array}{rr}0 & 0 \\ 0 & 0 \\ 0 & 52 \\ 0 & 0 \\ 4,986 & 17,420 \\ 0 & 0\end{array}$

4,986

17,473

0
367

229

0

1,855

256

112

577

582

20,273

Note: Totals may not equal sum of components because of independent rounding.

Source: Energy Information Administration, Form ElA-412, "Annual Report of Public Electric Utilities." 
Table 23. Electric Operation and Maintenance Expenses by Major U.S. Publicly Owned Electric Utility Within State, 1995 (Continued)

(Thousand Dollars)

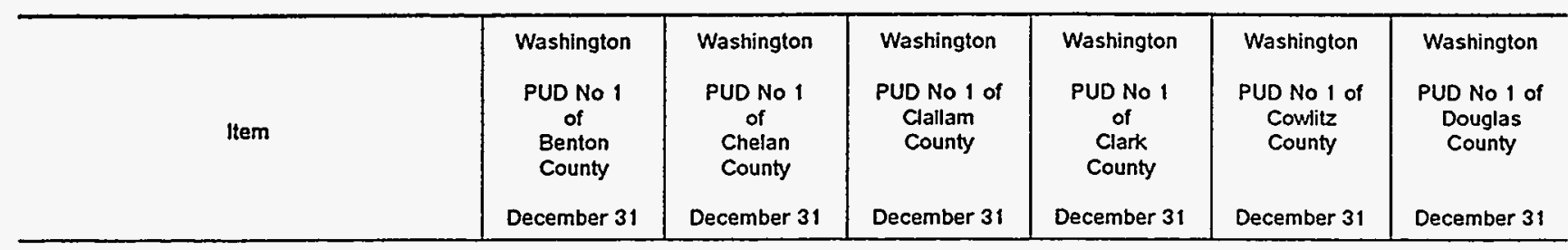

Production Expenses

Steam Power Generation .

Nuclear Power Generation

Hydraulic Power Gene

Other Power Generation ...

Total Production Expenses

Transmission Expenses.

Distribution Expenses ............................................

Customer Accounts Expenses ..........................

Customer Service and Information

Expenses .............................................................

Sales Expenses ..................................................

Administrative and General

Expenses

Total Electric Operation and

Maintenance Expenses..

Fuel Expenses in Operation

Nuclear Power Generation

Other Power Generation

Number of Elec Dept Employees

Regular Full-time

133

Part-ijme \& Temporary

Total Elec Dept Employees

0
0
0
0
14,513
0

0
0
0
0
103,613
565

14,513

104,178

145

2,179

1,075

27

8,177

5,810

101
0

322
0

3,745

0

16,176

2,587

48,439

76,492

20,600

238

25,050

$\begin{array}{rr}0 & 0 \\ 0 & 0 \\ 238 & 6,571 \\ 0 & 0 \\ 103,832 & 1,309 \\ 61 & 264\end{array}$

104,130

8,144

536

3,193

1,657

959

1,885

454

431

72

2,776

5,160

112,722

16,674

Note: Totals may not equal sum of components because of independent rounding

Source: Energy Information Administration, Form ELA-412, "Annual Report of Public Electric Utilities." 
Table 23. Electric Operation and Maintenance Expenses by Major U.S. Publicly Owned Electric Utility Within State, 1995 (Continued)

(Thousand Dollars)

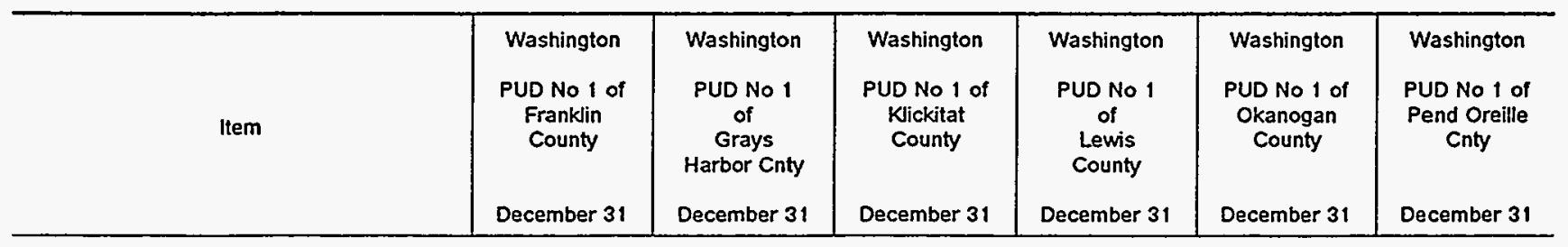

\section{Production Expenses}

Steam Power Generation

Nuclear Power Generation

Hydraulic Power Generation

Other Power Generation

Purchased Power ......................................

Other Production Expenses ...................................

Total Production Expenses

Transmission Expenses

Distribution Expenses

Customer Accounts Expenses .........................

Customer Service and Information

Expenses ..............................................................

Administrative and Genera!

Expenses

Total Electric Operation and

Maintenance Expenses.

Fuel Expenses in Operation

Steam Power Generation ..

Nuclear Power Generation

Other Power Generation

Number of Elec Dept Employees

Regular Full-time

Part-time \& Temporary

Total Elec Dept Employees

0
0
0
0
18,433
0

4,971
0
2
0
23,561
250

18,433

28,784

0
1,297

594
5606

553

1,875

1,875

-18
0

1,755
0

1,970

3.478

22,235

42,093

0
0
0
0
7.871
0
7,871

31
1,001
398
102
0
875
10,278

0
0
16
0

19,152

0

19,168

353
2177

1,237

0
3

1,118

24,056

0
0
19
0
11.135
43

11,197

40
1,528

1,528
488

-3
0

1,411

1,411

14,662
0
0
1,564
0
9,453
1,359

12,376

41
1,319

393

0
9

2,024

16,162

Note: Totals may not equal sum of components because of independent rounding.

Source: Energy Information Administration, Form EIA-412, "Annual Report of Public Electric Utilities." 
Table 23. Electric Operation and Maintenance Expenses by Major U.S. Publicly Owned Electric Utility Within State, 1995 (Continued)

(Thousand Dollars)

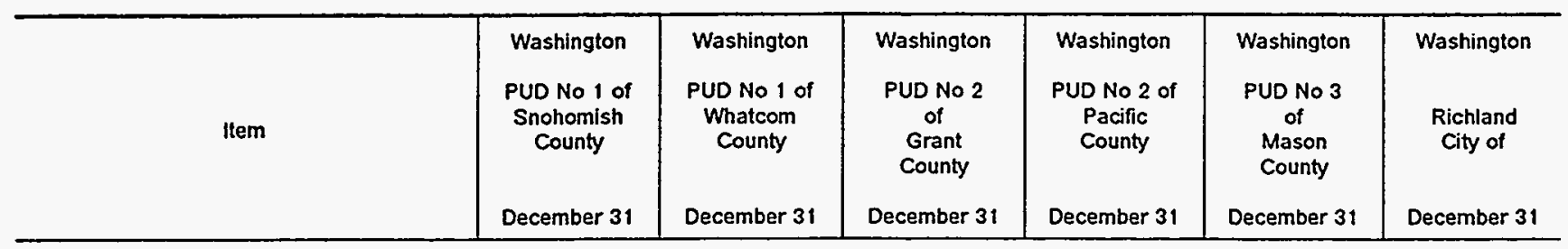

Production Expenses

Steam Power Generation

Nuclear Power Generation

Hydraulic Power Generat

Other Power Generation

Other Production Expenses

Total Production Expenses ........................

Transmission Expenses.

Distribution Exper

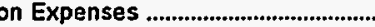

Customer Accounts Expenses ..........................

Customer Senvice and Information

Expenses.

Sales Expenses .......................................................

Administrative and General

Expenses

Total Electric Operation and

Maintenance Expenses.

Fuel Expenses in Operation

Steam Power Generation

Nuclear Power Generation

Other Power Generation

Number of Elec Dept Employees

Regular Full-time

Part-time \& Temporary

Total Elec Dept Employees

$$
\begin{array}{r}
8,249 \\
0 \\
724 \\
0 \\
168,049 \\
67
\end{array}
$$

177,089

4,223

27,838

8,647

696

15,962

$\begin{array}{rr}0 & 0 \\ 0 & 0 \\ 0 & 22,621 \\ 0 & 0 \\ 4,172 & 15,213 \\ 0 & 0\end{array}$

0
0
0
0
8,331
0

0
0
0
0
14,579
0

8,331

14,579

2
1,047

454

0
3,521

1,078

568

13

866

9,434

234,454

4,413

56,617

10,803

Note: Totals may not equal sum of components because of independent rounding

Source: Energy Information Administration, Form EIA-412, "Annual Report of Public Electric Utilities." 
Table 23. Electric Operation and Maintenance Expenses by Major U.S. Publicly Owned Electric Utility Within State, 1995 (Continued)

(Thousand Dollars)

\begin{tabular}{|c|c|c|c|c|c|c|}
\hline Item & $\begin{array}{c}\text { Washington } \\
\text { Seattle } \\
\text { City of } \\
\text { December } 31\end{array}$ & $\begin{array}{c}\text { Washington } \\
\text { Tacoma } \\
\text { City of } \\
\text { December } 31\end{array}$ & $\begin{array}{c}\text { Washington } \\
\text { Vera } \\
\text { Irrigation } \\
\text { District \#15 } \\
\text { December } 31\end{array}$ & $\begin{array}{l}\text { Washington } \\
\text { Washington } \\
\text { Pub } \\
\text { Pwr } \\
\text { Supply Sys } \\
\text { June } 30\end{array}$ & $\begin{array}{l}\text { Wisconsin } \\
\text { Badger Power } \\
\text { Marketing } \\
\text { Auth }\end{array}$ & $\begin{array}{c}\text { Wisconsin } \\
\text { Jefferson } \\
\text { City of } \\
\text { December } 31\end{array}$ \\
\hline \multicolumn{7}{|l|}{ Production Expenses } \\
\hline Steam Power Generation ...................................... & 9,915 & 17,962 & 0 & 0 & 0 & 0 \\
\hline 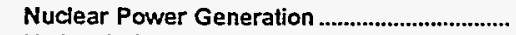 & & & 0 & 139,932 & 0 & 0 \\
\hline Hydraulic Power Generation .................................... & 15,796 & 8.403 & 0 & 990 & 0 & 0 \\
\hline 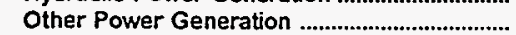 & & 0 & 0 & 0 & 0 & 0 \\
\hline 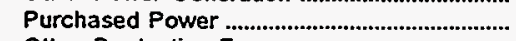 & 79,465 & 49,108 & 5.186 & 0 & 10.025 & 5,087 \\
\hline 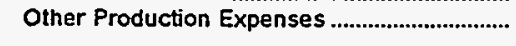 & 2,608 & 744 & 0 & 0 & 0 & 0 \\
\hline 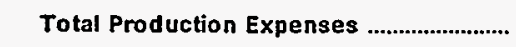 & 107,784 & 76,217 & 5,186 & 140,922 & 10,025 & 5,087 \\
\hline Transmission Expenses & 17,586 & 3,631 & 0 & 299 & 39 & 0 \\
\hline Distribution Expenses .............................................. & 33,104 & 13,190 & 505 & 0 & 0 & 270 \\
\hline $\begin{array}{l}\text { Customer Accounts Expenses } \\
\text { Customer Senvice and Information }\end{array}$ & 15,828 & 3,749 & 0 & 0 & 0 & 53 \\
\hline 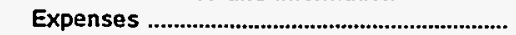 & 6,931 & 2,405 & 372 & 0 & 0 & 0 \\
\hline 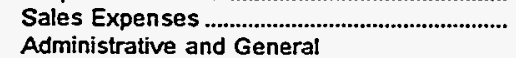 & 0 & 83 & 50 & 0 & 0 & 18 \\
\hline 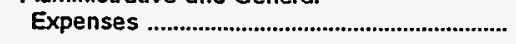 & 33,205 & 20,019 & 335 & 59,662 & 230 & 175 \\
\hline Total Electric Operation and & & & & & & \\
\hline 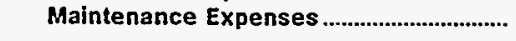 & 214,438 & 119,293 & 6,448 & 200,882 & 10,294 & 5,603 \\
\hline \multicolumn{7}{|l|}{ Fuel Expenses in Operation } \\
\hline 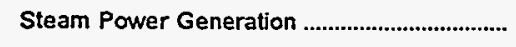 & 0 & 10,473 & 0 & 0 & 0 & 0 \\
\hline Nuclear Power Generation ........................................ & 0 & 0 & 0 & 30,757 & 0 & 0 \\
\hline 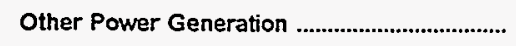 & 0 & 0 & 0 & 0 & 0 & 0 \\
\hline \multicolumn{7}{|l|}{ Number of Elec Dept Employees } \\
\hline 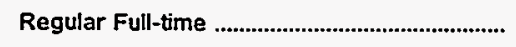 & 1,706 & 707 & 29 & 1,292 & 0 & 7 \\
\hline 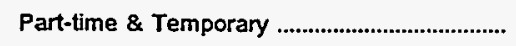 & 115 & 60 & 0 & 37 & 0 & 0 \\
\hline 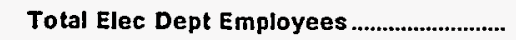 & 1,821 & 767 & 29 & 1,329 & 0 & 7 \\
\hline
\end{tabular}

Note: Totals may not equal sum of components because of independent rounding.

Source: Energy Information Administration, Form ElA-4 12, "Annual Report of Public Electric Utilities." 
Table 23. Electric Operation and Maintenance Expenses by Major U.S. Publicly

Owned Electric Utility Within State, 1995 (Continued)

(Thousand Dollars)

\begin{tabular}{c|c|c|c|c|c|c}
\hline & Wisconsin & Wisconsin & Wisconsin & Wisconsin & Wisconsin & Wisconsin \\
Item & $\begin{array}{c}\text { Manitowoc } \\
\text { Cublic } \\
\text { City of } \\
\text { Utilities }\end{array}$ & $\begin{array}{c}\text { Marshfield } \\
\text { City of }\end{array}$ & $\begin{array}{c}\text { Menasha } \\
\text { City of }\end{array}$ & $\begin{array}{c}\text { New London } \\
\text { Electric\&Water } \\
\text { Util }\end{array}$ & $\begin{array}{c}\text { Oconomowoc } \\
\text { City of }\end{array}$ \\
December 31 & December 31 & December 31 & December 31 & December 31 & December 31 \\
\hline
\end{tabular}

Production Expenses

Steam Power Generation.

Nuclear Power Generation

Hydraulic Power Gen

Other Power Generation .

Purchased Power

Production Expenses

Total Production Expenses ........................

Transmission Expenses

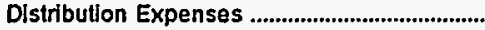

Customer Accounts Expenses ..........................

Customer Service and Information

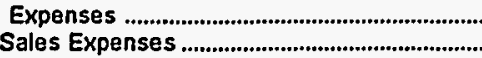

Sales Expenses ..................................................

Expenses

Total Electric Operation and

Maintenance Expenses..

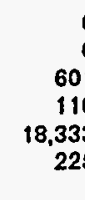

19,269

37

692

182

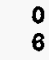

883

21,068

8,259
0
0
149
6,421
1

14,830

43

653

336

0

230

1,430

17,524

11,055
706
0
0
0
18,334
0

19,040

8
470

470
159

0

200

791

20,670 $\begin{array}{rr}0 & 0 \\ 0 & 0 \\ 0 & 0 \\ 0 & 0 \\ 6.188 & 6.429 \\ 0 & 0\end{array}$

6,188

6,429

0

338

122

0

423

181

6,740

7,398

Fuel Expenses in Operation

Steam Power Generation

Nuclear Power Generation

Other Power Generation

Number of Elec Dept Employees

Regular Full-time

Part-time \& Temporary

Total Elec Dept Employees
0

o

4

$\begin{array}{rrr}5.321 & 0 \\ 0 & 0 \\ 104 & -2\end{array}$

43

3

46

9

o

0

0

0

Note: Totals may not equal sum of components because of independent rounding

Source: Energy Information Administration, Form E1A-4 12, "Annual Report of Public Electric Utilities." 
Table 23. Electric Operation and Maintenance Expenses by Major U.S. Publicly Owned Electric Utility Within State, 1995 (Continued)

(Thousand Dollars)

\begin{tabular}{|c|c|c|c|c|c|c|}
\hline Item & $\begin{array}{l}\text { Wisconsin } \\
\text { Plymouth } \\
\text { City of } \\
\text { December } 31\end{array}$ & $\begin{array}{c}\text { Wisconsin } \\
\text { Reedsburg } \\
\text { Utility Comm } \\
\text { December } 31\end{array}$ & $\begin{array}{c}\text { Wisconsin } \\
\text { Shawano } \\
\text { Municipal } \\
\text { Utilities } \\
\text { December } 31\end{array}$ & $\begin{array}{c}\text { Wisconsin } \\
\text { Sheboygan } \\
\text { Falls } \\
\text { City of } \\
\text { December } 31\end{array}$ & $\begin{array}{l}\text { Wisconsin } \\
\text { Sturgeon } \\
\text { Bay City of } \\
\text { December } 31\end{array}$ & $\begin{array}{l}\text { Wisconsin } \\
\text { Sun Prairie } \\
\text { Water \& Light } \\
\text { Comm } \\
\text { December } 31\end{array}$ \\
\hline \multicolumn{7}{|l|}{ Production Expenses } \\
\hline 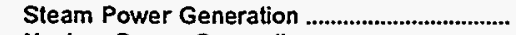 & 0 & 0 & 0 & 0 & 0 & 0 \\
\hline Nuclear Power Generation .................................... & 0 & 0 & 0 & 0 & 0 & 0 \\
\hline 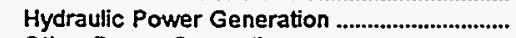 & 0 & 0 & 0 & 0 & 0 & 0 \\
\hline 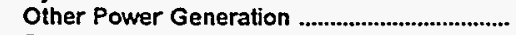 & 0 & 0 & 0 & 0 & 0 & 0 \\
\hline 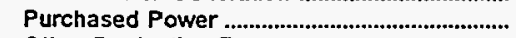 & 5,620 & 6,314 & 7,741 & 6,261 & 4,969 & 6,196 \\
\hline Other Production Expenses ..................................... & 0 & 0 & 0 & 0 & 0 & 0 \\
\hline Total Production Expenses ............................... & 5,620 & 6,314 & 7,741 & 6,261 & 4,969 & 6,196 \\
\hline 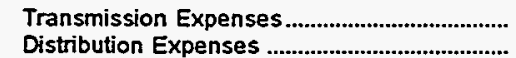 & 0 & 8 & $\begin{array}{r}2 \\
178\end{array}$ & 0 & 8 & 0 \\
\hline $\begin{array}{l}\text { Customer Accounts Expenses ..................................................... } \\
\text { Customer Service and Information }\end{array}$ & 90 & 56 & 73 & 47 & 151 & 87 \\
\hline $\begin{array}{l}\text { Customer Service and Information } \\
\text { Expenses }\end{array}$ & 0 & 0 & 0 & 0 & 0 & 0 \\
\hline 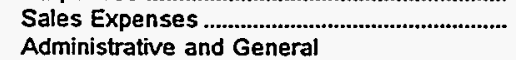 & 9 & 97 & 0 & 0 & 76 & 96 \\
\hline 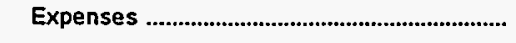 & 280 & 209 & 296 & 119 & 259 & 199 \\
\hline $\begin{array}{l}\text { Total Electric Operation and } \\
\text { Maintenance Expenses }\end{array}$ & 6,410 & 6,909 & 8,290 & 6,653 & 5,815 & 6,848 \\
\hline \multicolumn{7}{|l|}{ Fuel Expenses in Operation } \\
\hline 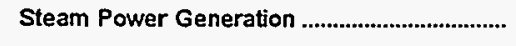 & 0 & 0 & 0 & 0 & 0 & 0 \\
\hline Nudear Power Generation ......................................... & 0 & 0 & 0 & 0 & 0 & 0 \\
\hline Other Power Generation .......................................... & 0 & 0 & 0 & 0 & 0 & 0 \\
\hline \multicolumn{7}{|l|}{ Number of Elec Dept Employees } \\
\hline 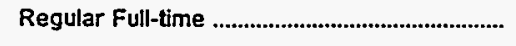 & 18 & 12 & 12 & 9 & 15 & 23 \\
\hline 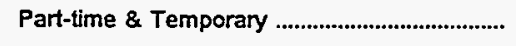 & 0 & 0 & 0 & 0 & 0 & 0 \\
\hline Total Elec Dept Employees ................................. & 18 & 12 & 12 & $\mathbf{9}$ & 15 & 23 \\
\hline
\end{tabular}

Note: Totals may not equal sum of components because of independent rounding.

Source: Energy Information Administration, Form EIA-412, "Annual Report of Public Electric Utilities." 
Table 23. Electric Operation and Maintenance Expenses by Major U.S. Publicly Owned Electric Utility Within State, 1995 (Continued)

(Thousand Dollars)

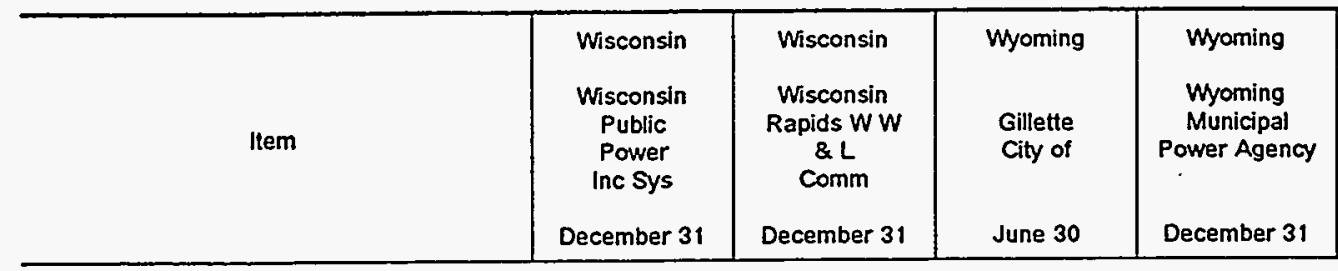

Production Expenses

Steam Power Generation

Nuclear Power Generation ...................................

Hydraullc Power Generation

Other Power Generation

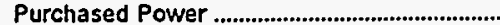

Other Production Expenses ..............................

Total Production Expenses

11,532
0
0
1,008
78,289
3

0
0
0
0
6,613
0

$\begin{array}{rr}0 & 1,648 \\ 0 & 0 \\ 0 & 0 \\ 0 & 0 \\ 8,320 & 1,593 \\ 0 & 0\end{array}$

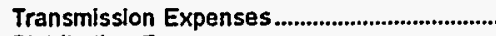

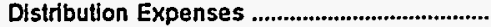

Customer Accounts Expenses

Customer Senvice and Information

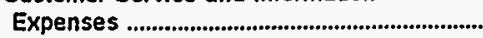

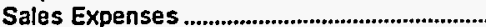

Administrative and General

Expenses

90,831

6,613

8,320

3,242

6,542

0
0

0

$59 \quad 68$

246

30

0

0
0

132

70
0

4,617

3

0

0

Total Electric Operation and

Maintenance Expenses .................................

101,990

536

890

399

8,067

9,956

3,779

Fuel Expenses in Operation

Steam Power Generation ..................................

8,922

Nuclear Power Generation

o

647

0

0

0

0

0

0

0

Other Power Generation

Number of Elec Dept Employees

Regular Full-time

4

$\begin{array}{rrr}29 & 13 & 5 \\ 2 & 2 & 0 \\ 31 & 15 & 5\end{array}$

Total Elec Dept Employees

2

43

31

15

Note: Totals may not equal sum of components because of independent rounding

Source: Energy Information Administration, Form EIA-412, "Annual Report of Public Electric Utilities." 
Table 24. Electric Utility Plant by Major U.S. Publicly Owned Electric Utility Within State at End of Period, 1995 (Thousand Dollars)

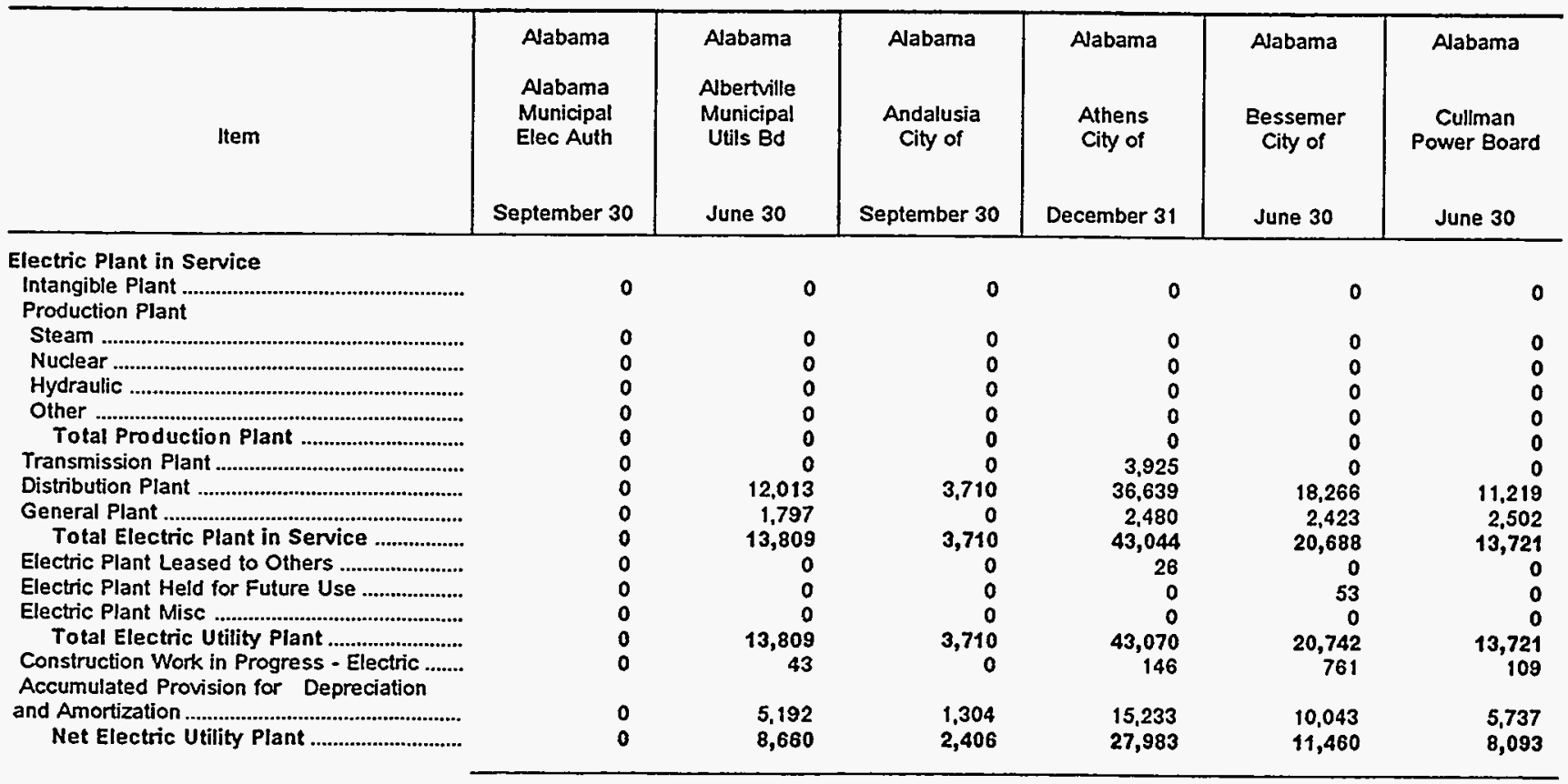

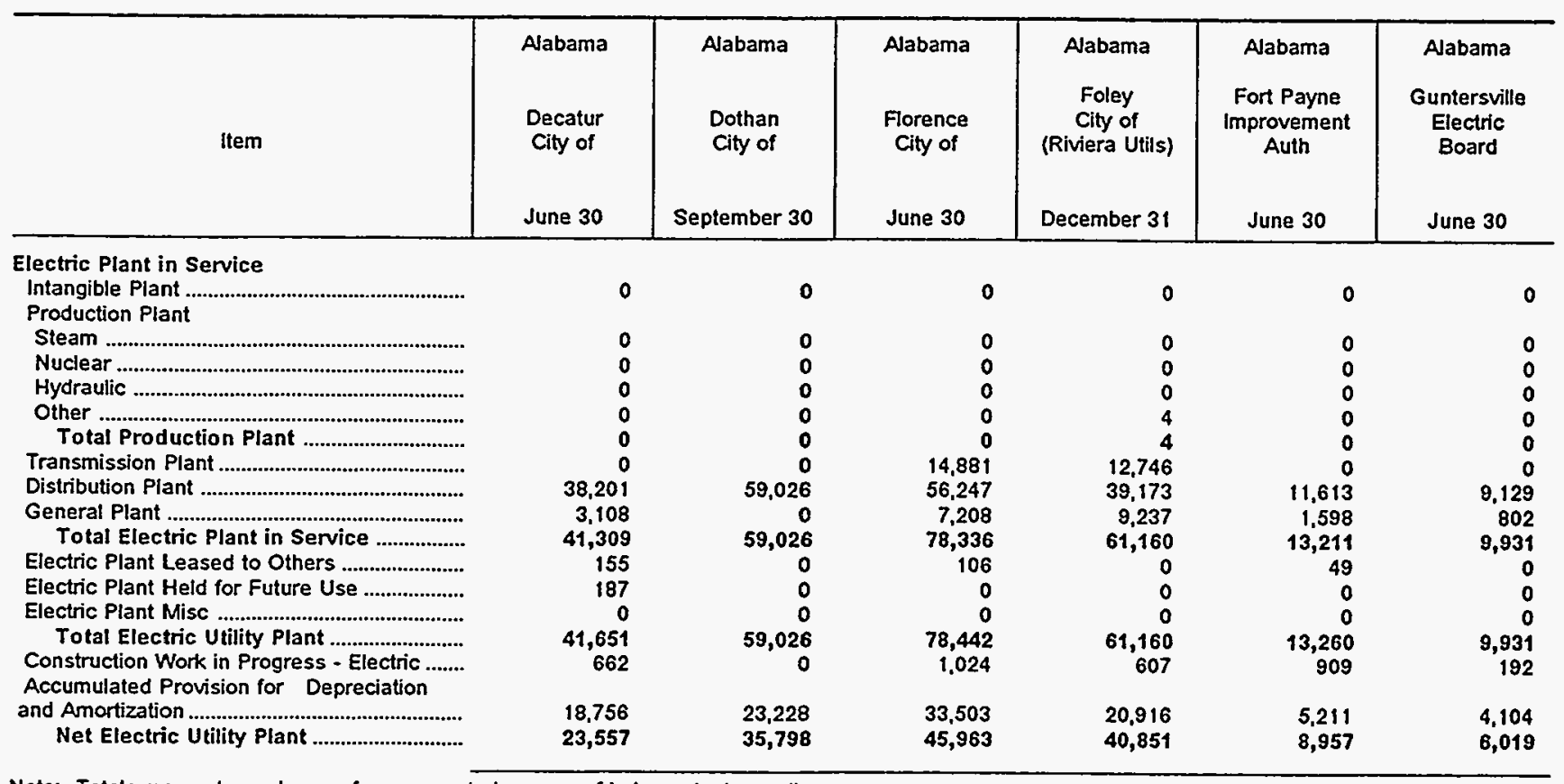

Note: Totals may not equal sum of components because of independent rounding.

Source: Energy Information Administration, Form ElA-412, "Annual Report of Public Electric Utilities." 
Table 24. Electric Utility Plant by Major U.S. Publicly Owned Electric Utility Within State at End of Period, 1995 (Continued)

(Thousand Dollars)

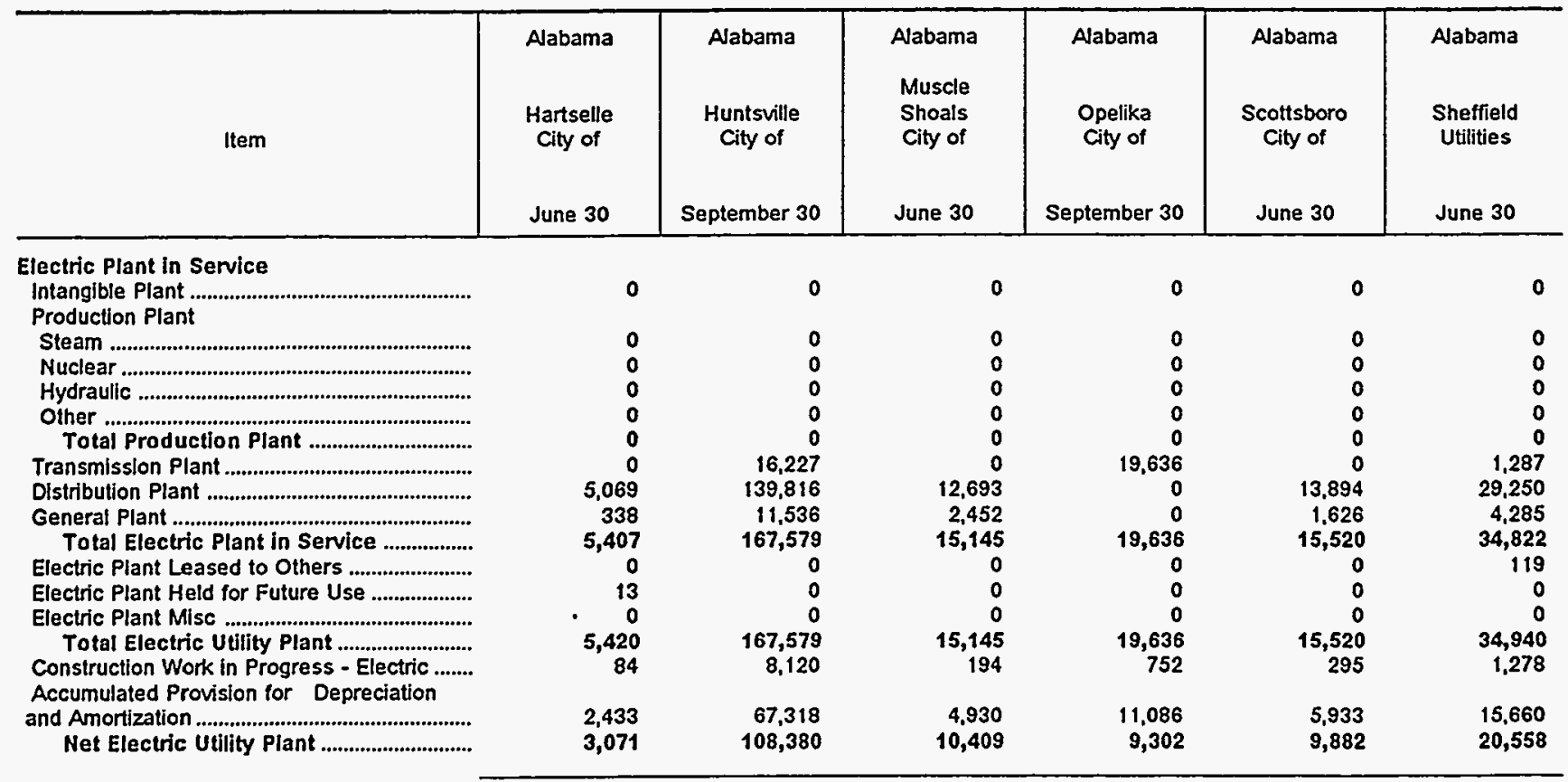

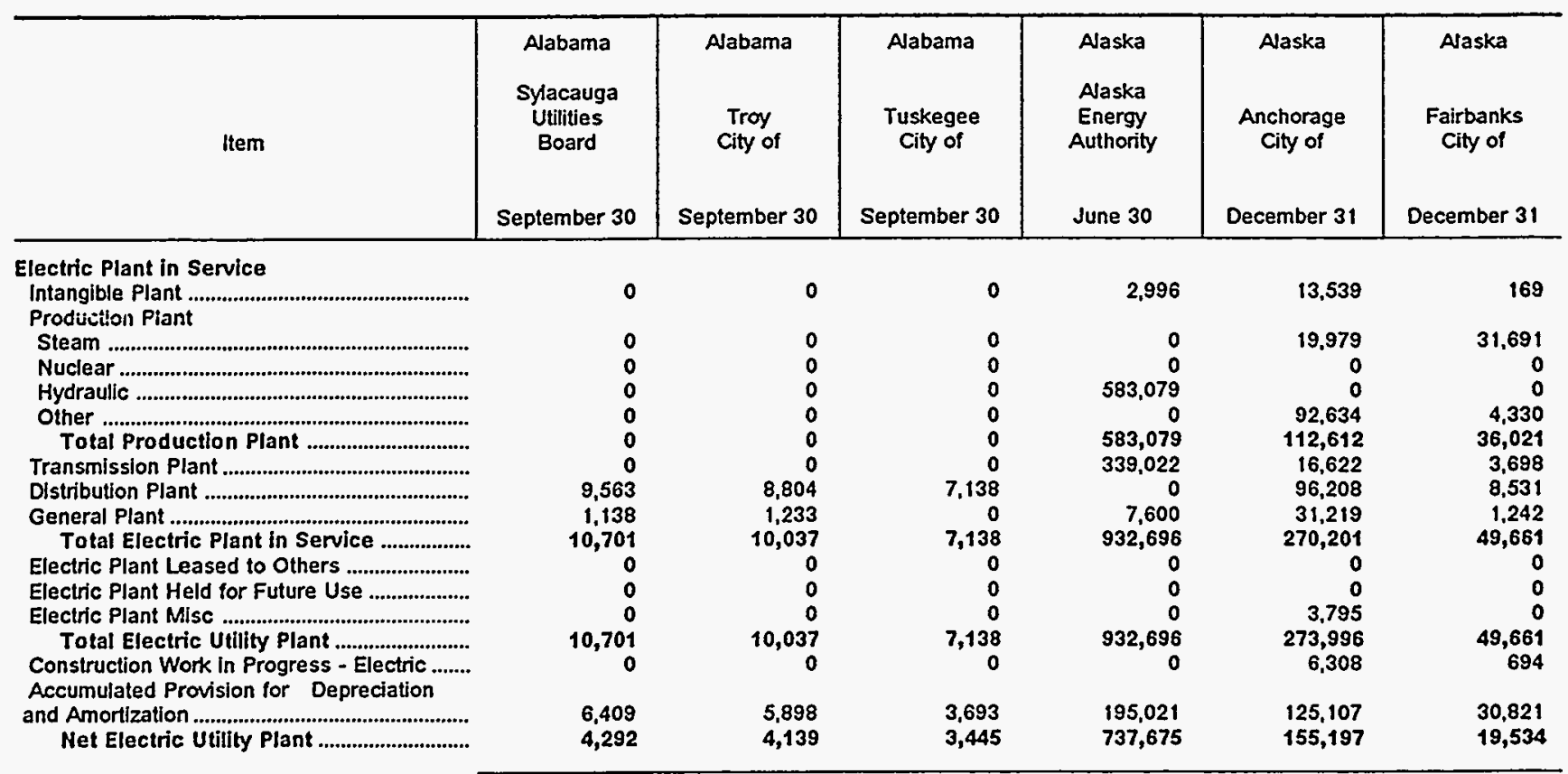

Note: Totals may not equal sum of components because of independent rounding.

Source: Energy Information Administration, Form EIA-412, "Annual Report of Public Electric Utilities." 
Table 24. Electric Utility Plant by Major U.S. Publicly Owned Electric Utility Within State at End of Period, 1995 (Continued)

(Thousand Dollars)

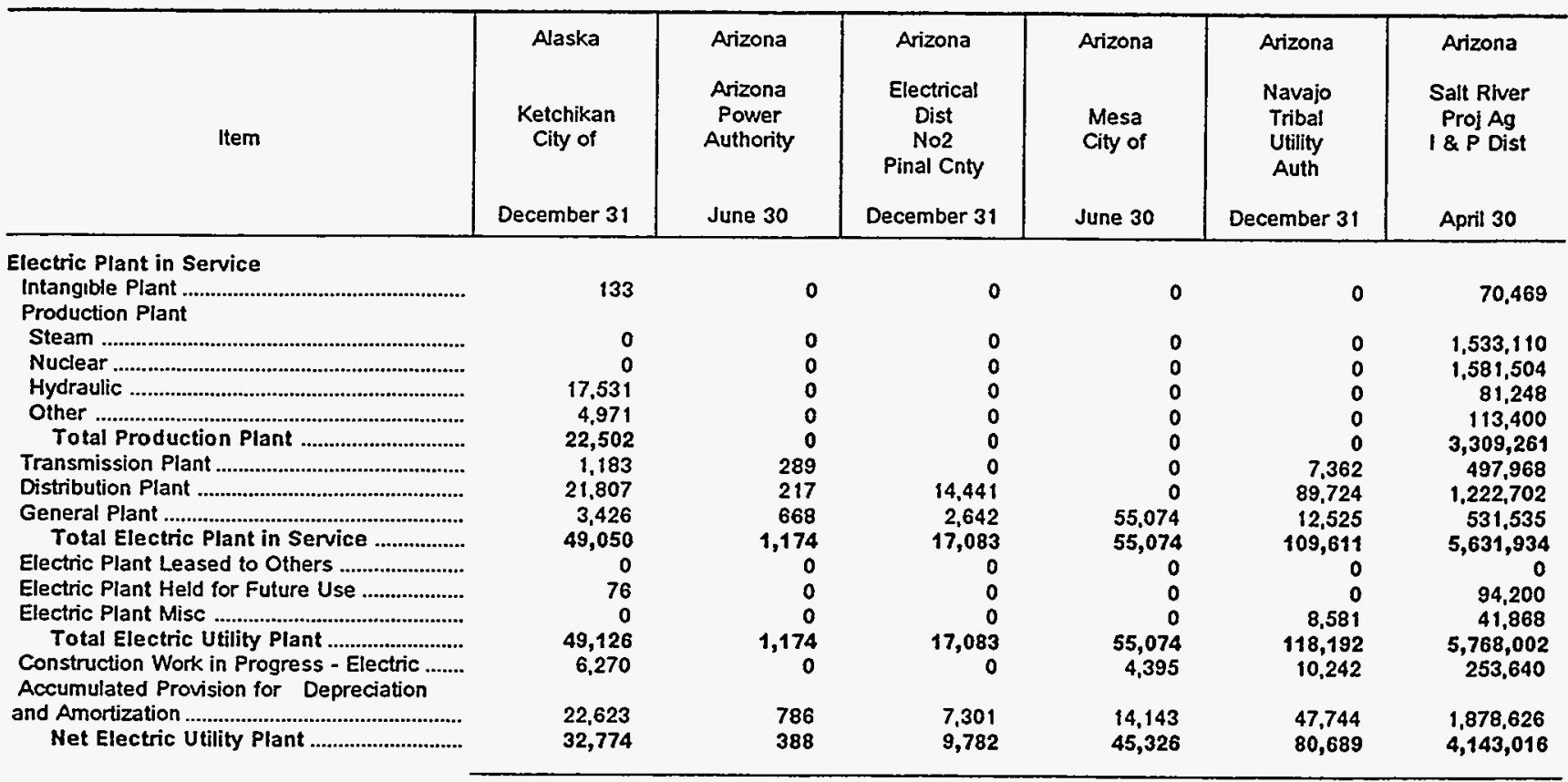

\begin{tabular}{|c|c|c|c|c|c|c|}
\hline Item & $\begin{array}{l}\text { Arizona } \\
\text { Tohono } \\
\text { OOdham } \\
\text { Utility Auth } \\
\text { December } 31\end{array}$ & $\begin{array}{l}\text { Arkansas } \\
\text { Benton } \\
\text { City of } \\
\text { December } 31\end{array}$ & $\begin{array}{l}\text { Arkansas } \\
\text { Bentonville } \\
\text { City of }\end{array}$ & $\begin{array}{l}\text { Arkansas } \\
\text { Clarksville } \\
\text { Uight } \\
\& \\
\text { Water Co } \\
\text { September } 30\end{array}$ & $\begin{array}{c}\text { Arkansas } \\
\text { Conway } \\
\text { Corp } \\
\text { December } 31\end{array}$ & $\begin{array}{c}\text { Arkansas } \\
\text { Hope } \\
\text { City of } \\
\text { December } 31\end{array}$ \\
\hline \multicolumn{7}{|l|}{ Electric Plant in Service } \\
\hline $\begin{array}{l}\text { Intangible Plant } \\
\text { Production Plant }\end{array}$ & 0 & 0 & 102 & 0 & 0 & $\mathbf{0}$ \\
\hline Steam & 0 & 0 & 0 & 0 & 39,283 & 0 \\
\hline 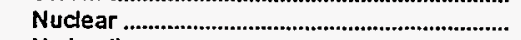 & 0 & 0 & 0 & 0 & 0 & 0 \\
\hline 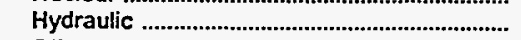 & 0 & 0 & 0 & 0 & 0 & 0 \\
\hline Other & 0 & 1,691 & 0 & 0 & 0 & 7,341 \\
\hline 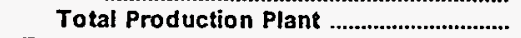 & 0 & 1,691 & 0 & 0 & 39,283 & 7,341 \\
\hline 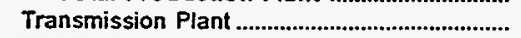 & 1,885 & 0 & 0 & 3,388 & 0 & 0 \\
\hline 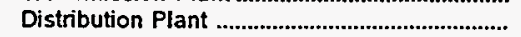 & 7,946 & 6,651 & 0 & 8,910 & 24,931 & 7,921 \\
\hline $\begin{array}{l}\text { General Plant } \\
\text { Total Electric Plant in Service }\end{array}$ & $\begin{array}{r}1,083 \\
10,913\end{array}$ & $\begin{array}{r}0 \\
8,342\end{array}$ & $\begin{array}{l}46,434 \\
46,536\end{array}$ & $\begin{array}{r}937 \\
13,235\end{array}$ & $\begin{array}{r}5,663 \\
69,877\end{array}$ & $\begin{array}{r}925 \\
16,188\end{array}$ \\
\hline 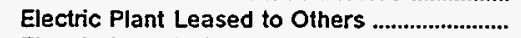 & 0 & 0 & 0 & 0 & 0 & 0 \\
\hline Electric Plant Held for Future Use .................... & 0 & 0 & 0 & 0 & 0 & 0 \\
\hline 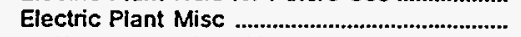 & 0 & 0 & 0 & 0 & 0 & 46 \\
\hline 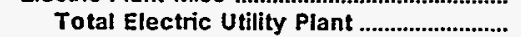 & 10,913 & 8,342 & 46,536 & 13,235 & 69,877 & 16,234 \\
\hline $\begin{array}{l}\text { Construction Work in Progress - Electric ........ } \\
\text { Accumulated Provsion for Depreciation }\end{array}$ & 70 & 0 & 1,589 & 0 & 283 & $\begin{array}{r}10,204 \\
0\end{array}$ \\
\hline 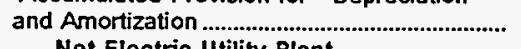 & 3,069 & 5.766 & 11,173 & 4.012 & 27,743 & 5,406 \\
\hline Net Electric Utility Plant .................................. & 7,915 & 2,575 & 36,952 & 9,223 & 42,417 & 10,828 \\
\hline
\end{tabular}

Source: Energy Information Administration, Form EIA-412, "Annual Report of Public Electric Utilities." 
Table 24. Electric Utility Plant by Major U.S. Publicly Owned Electric Utility Within State at End of Period, 1995 (Continued)

(Thousand Dollars)

\begin{tabular}{|c|c|c|c|c|c|c|}
\hline Item & $\begin{array}{c}\text { Arkansas } \\
\text { Jonesboro } \\
\text { City of } \\
\text { December } 31\end{array}$ & $\begin{array}{c}\text { Arkansas } \\
\text { North } \\
\text { Little } \\
\text { Rock } \\
\text { City of } \\
\text { December } 31\end{array}$ & $\begin{array}{c}\text { Arkansas } \\
\text { Osceola } \\
\text { City of } \\
\text { December } 31\end{array}$ & $\begin{array}{l}\text { Arkansas } \\
\text { Paragould } \\
\text { Light } \\
\& \\
\text { Water Comm } \\
\text { December } 31\end{array}$ & $\begin{array}{c}\text { Arkansas } \\
\text { Siloam } \\
\text { Springs } \\
\text { City of } \\
\text { December } 31\end{array}$ & $\begin{array}{l}\text { Arkansas } \\
\text { West } \\
\text { Memphis } \\
\text { City of } \\
\text { December } 31\end{array}$ \\
\hline \multicolumn{7}{|l|}{ Electric Plant in Service } \\
\hline $\begin{array}{l}\text { Production Plant } \\
\text { Steam }\end{array}$ & & 0 & 0 & 0 & 0 & 18.780 \\
\hline Steam & $\begin{array}{r}16,689 \\
0\end{array}$ & 0 & 0 & 0 & $\begin{array}{l}0 \\
0\end{array}$ & $\begin{array}{r}18,780 \\
0\end{array}$ \\
\hline 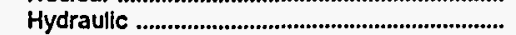 & $\mathbf{0}$ & 111.798 & 0 & 0 & 0 & 0 \\
\hline Other & $\mathbf{0}$ & 0 & 0 & 0 & 0 & 0 \\
\hline Total Production Plant & 76,689 & 111,798 & $\mathbf{0}$ & $\mathbf{0}$ & $\mathbf{0}$ & 18,780 \\
\hline 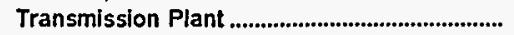 & 511 & 0 & 0 & 0 & 0 & 0 \\
\hline 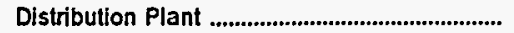 & 48,614 & 36,987 & 12,193 & 28,975 & 0 & 0 \\
\hline 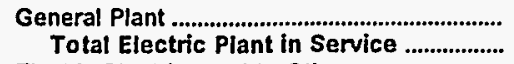 & $\begin{array}{r}9,768 \\
143,710\end{array}$ & $\begin{array}{r}6,519 \\
155,303\end{array}$ & $\begin{array}{r}8,635 \\
20,829\end{array}$ & $\begin{array}{r}0 \\
29,706\end{array}$ & $\begin{array}{l}5,075 \\
5,075\end{array}$ & $\begin{array}{r}0 \\
30,071\end{array}$ \\
\hline Electric Plant Leased to Others ...................... & 0 & 0 & 0 & 0 & 0 & 0 \\
\hline Electric Plant Held for Future Use .................... & $\mathbf{0}$ & 0 & 0 & 0 & 0 & 0 \\
\hline 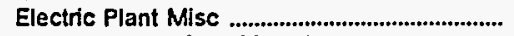 & 0 & 0 & 0 & 0 & 0 & 0 \\
\hline 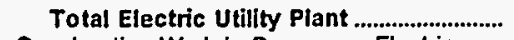 & 143,710 & 155,303 & 20,829 & 29,706 & 5,075 & 30,071 \\
\hline $\begin{array}{l}\text { Construction Work in Progress - Electric ....... } \\
\text { Accumulated Provision for Depreciation }\end{array}$ & 1,162 & 909 & 0 & 0 & 196 & 0 \\
\hline 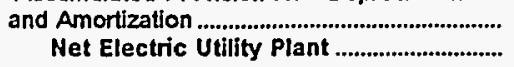 & $\begin{array}{l}70,707 \\
74,165\end{array}$ & $\begin{array}{r}38,753 \\
117,458\end{array}$ & $\begin{array}{r}9,132 \\
11,697\end{array}$ & $\begin{array}{l}11,468 \\
18,238\end{array}$ & $\begin{array}{r}485 \\
4,786\end{array}$ & $\begin{array}{l}14,387 \\
15,684\end{array}$ \\
\hline
\end{tabular}



Note: Totals may not equal sum of components because of independent rounding.

Source: Energy Information Administration, Form EIA-412, "Annual Report of Public Electric Utilities." 
Table 24. Electric Utility Plant by Major U.S. Publicly Owned Electric Utility Within State at End of Period, 1995 (Continued)

(Thousand Dollars)

\begin{tabular}{|c|c|c|c|c|c|c|}
\hline Item & $\begin{array}{c}\text { California } \\
\text { East Bay } \\
\text { Municipal } \\
\text { Utıl } \\
\text { Dist } \\
\text { December } 31\end{array}$ & $\begin{array}{l}\text { California } \\
\text { Glendale } \\
\text { City of } \\
\text { June } 30\end{array}$ & $\begin{array}{c}\text { California } \\
\text { Imperial } \\
\text { Imigation } \\
\text { District } \\
\text { December } 31\end{array}$ & $\begin{array}{c}\text { California } \\
\text { Kings River } \\
\begin{array}{c}\text { Conservation } \\
\text { Dist }\end{array} \\
\text { June } 30\end{array}$ & $\begin{array}{l}\text { California } \\
\text { Lassen } \\
\text { Municipal } \\
\text { Utility Dist } \\
\text { June } 30\end{array}$ & $\begin{array}{l}\text { California } \\
\text { Lodi } \\
\text { City of } \\
\text { June } 30\end{array}$ \\
\hline \multicolumn{7}{|l|}{ Electric Plant in Service } \\
\hline $\begin{array}{l}\text { Intangible Plant } \\
\text { Production Plant }\end{array}$ & 0 & 0 & 769 & 0 & 0 & 0 \\
\hline Steam & 0 & 49,566 & 114,665 & 0 & 0 & 0 \\
\hline Nuclear & 0 & 0 & 0 & 0 & 0 & 0 \\
\hline 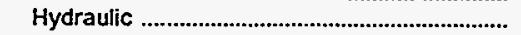 & 0 & 0 & 52,169 & 65,495 & 0 & 0 \\
\hline Other & 0 & 0 & 24,553 & 0 & 0 & 0 \\
\hline 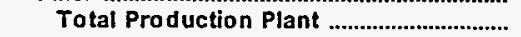 & $\mathbf{0}$ & 49,566 & 191,386 & 65,495 & 0 & 0 \\
\hline 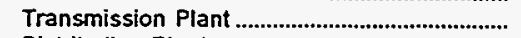 & 0 & 49,364 & 216,219 & 0 & 5,123 & 0 \\
\hline 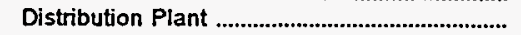 & 0 & 113,506 & 250.759 & 0 & 16,904 & 15,091 \\
\hline General Plant & 0 & 37,025 & 51,868 & 0 & 2,004 & 0 \\
\hline 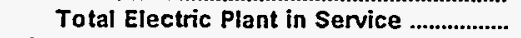 & 0 & 249,461 & 711,000 & 65,495 & 24,031 & 15,091 \\
\hline 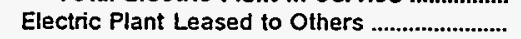 & 0 & 0 & 0 & 0 & 0 & 0 \\
\hline 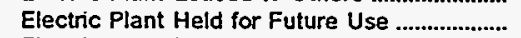 & 0 & 0 & 677 & 0 & 0 & 0 \\
\hline Electric Plant Misc & 0 & 0 & 0 & 0 & 0 & 0 \\
\hline Total Electric Utility Plant & 0 & 249,461 & 711,678 & 65,495 & 24,031 & 15,091 \\
\hline $\begin{array}{l}\text { Construction Work in Progress - Electric ........ } \\
\text { Accumulated Provision for Depreciation }\end{array}$ & 0 & 5,314 & 1,896 & 0 & 0 & 242 \\
\hline 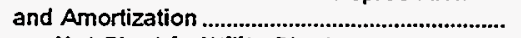 & 0 & 119.160 & 213,127 & 16,846 & 4,958 & 3.856 \\
\hline 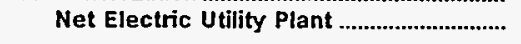 & $\mathbf{0}$ & 135,615 & 500,447 & 48,648 & 19,073 & 11,476 \\
\hline
\end{tabular}

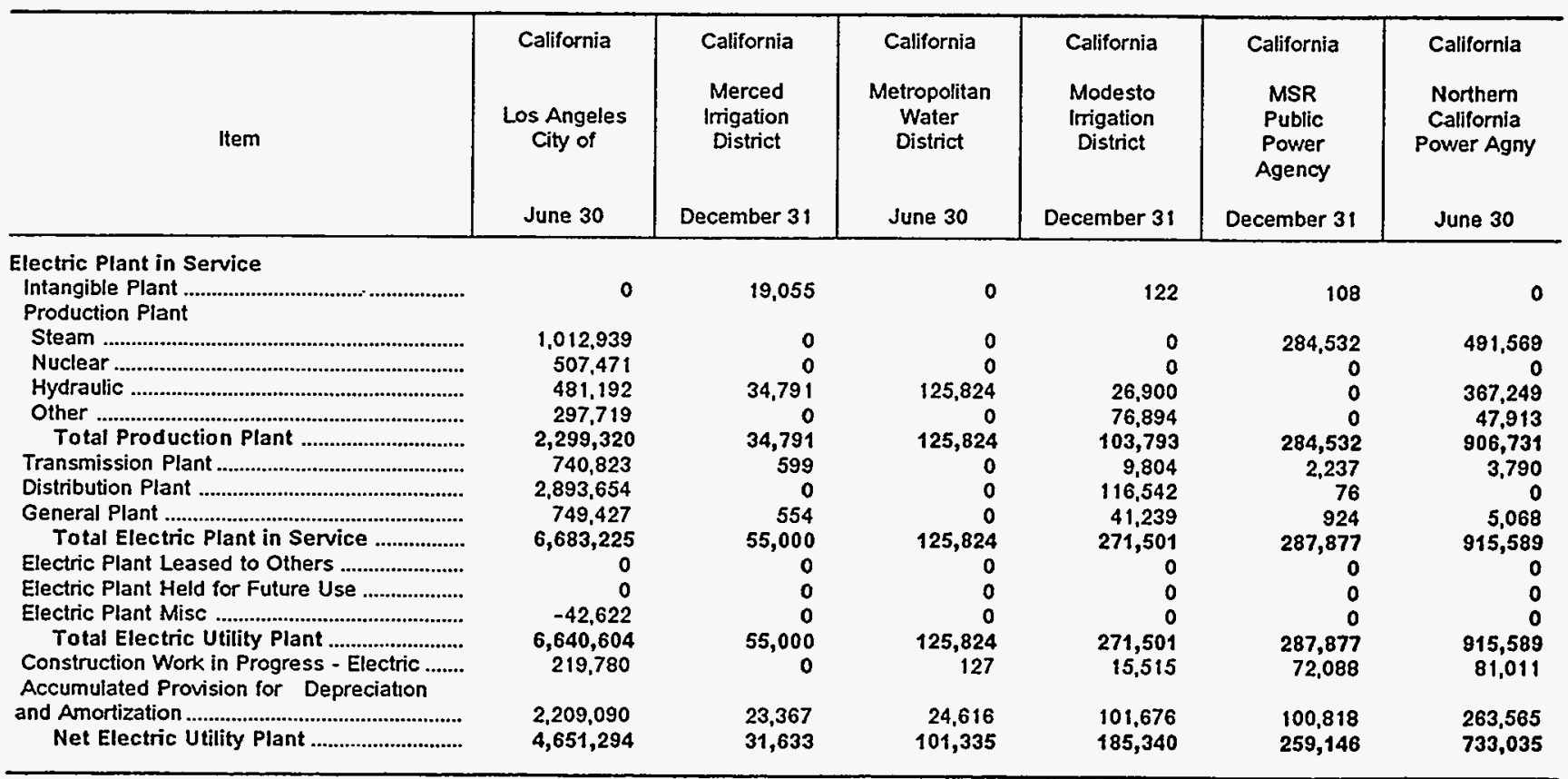

Nole: Totals may not equal sum of components because of independent rounding.

Source: Energy Information Administration, Form EIA-412, "Annual Report of Public Electric Utilities." 
Table 24. Electric Utility Plant by Major U.S. Publicly Owned Electric Utility Within State at End of Period, 1995 (Thousand Dollars)

\begin{tabular}{|c|c|c|c|c|c|c|}
\hline Item & $\begin{array}{c}\text { California } \\
\text { Oakdale \& } \\
\text { South } \\
\text { San Joaquin } \\
\text { December } 31\end{array}$ & $\begin{array}{c}\text { California } \\
\text { Oroville } \\
\text { Wyandotte } \\
\text { Inig Dist } \\
\text { December } 31\end{array}$ & $\begin{array}{l}\text { California } \\
\text { Palo Alto } \\
\text { City of } \\
\text { June } 30\end{array}$ & $\begin{array}{l}\text { California } \\
\text { Pasadena } \\
\text { City of } \\
\text { June } 30\end{array}$ & $\begin{array}{c}\text { California } \\
\text { Placer } \\
\text { County } \\
\text { Water } \\
\text { Agency } \\
\text { December } 31\end{array}$ & $\begin{array}{l}\text { California } \\
\text { Redding } \\
\text { City of } \\
\text { June } 30\end{array}$ \\
\hline 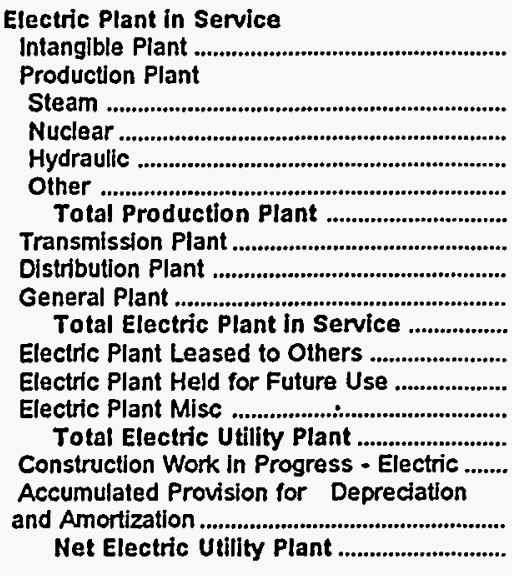 & $\begin{array}{r}0 \\
0 \\
58,729 \\
0 \\
58,729 \\
0 \\
0 \\
1,986 \\
60,714 \\
0 \\
0 \\
0 \\
60,714 \\
391 \\
24,386 \\
36,720\end{array}$ & $\begin{array}{r}0 \\
0 \\
0 \\
0 \\
0 \\
1,136 \\
79,938 \\
4,356 \\
85,430 \\
0 \\
0 \\
0 \\
85,430 \\
832 \\
40,460 \\
45,802\end{array}$ & $\begin{array}{r}0 \\
0 \\
0 \\
0 \\
0 \\
0 \\
0 \\
127,378 \\
0 \\
127,378 \\
0 \\
0 \\
0 \\
127,378 \\
4,262 \\
48,301 \\
83,339\end{array}$ & $\begin{array}{r}0 \\
46,322 \\
0 \\
5,694 \\
6,971 \\
58,988 \\
41,659 \\
141,419 \\
7,366 \\
249,431 \\
0 \\
0 \\
0 \\
0 \\
249,431 \\
16,332 \\
\\
120,881 \\
144,883\end{array}$ & $\begin{array}{r}0 \\
0 \\
110,691 \\
8 \\
110,700 \\
439 \\
0 \\
5,928 \\
117,210 \\
0 \\
0 \\
0 \\
117,210 \\
692 \\
\\
44,184 \\
73,718\end{array}$ & $\begin{array}{r}14,054 \\
0 \\
0 \\
0 \\
14,054 \\
0 \\
0 \\
123,869 \\
137,922 \\
0 \\
2,138 \\
0 \\
140,060 \\
55,187\end{array}$ \\
\hline
\end{tabular}

\begin{tabular}{|c|c|c|c|c|c|c|}
\hline Item & $\begin{array}{l}\text { California } \\
\text { Riverside } \\
\text { City of } \\
\text { June } 30\end{array}$ & $\begin{array}{l}\text { California } \\
\text { Roseville } \\
\text { City of } \\
\text { June } 30\end{array}$ & $\begin{array}{c}\text { Califomia } \\
\text { Sacramento } \\
\text { Municipal } \\
\text { Util Dist } \\
\text { December } 31\end{array}$ & $\begin{array}{l}\text { California } \\
\text { San Francisco } \\
\text { City } \\
\& \\
\text { County of } \\
\text { June } 30\end{array}$ & $\begin{array}{l}\text { California } \\
\text { Santa } \\
\text { Clara } \\
\text { City of } \\
\text { June } 30\end{array}$ & $\begin{array}{c}\text { California } \\
\text { Southern } \\
\text { California } \\
\text { P P } \\
\text { A } \\
\text { June } 30\end{array}$ \\
\hline 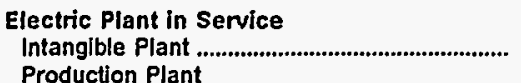 & 0 & $\mathbf{0}$ & 147 & 7,658 & 0 & 8.091 \\
\hline 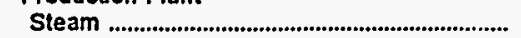 & $\mathbf{0}$ & $\mathbf{0}$ & 92,230 & 0 & 0 & 183,309 \\
\hline 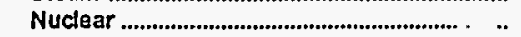 & 122,866 & 0 & 0 & $\mathbf{0}$ & 0 & 603,678 \\
\hline 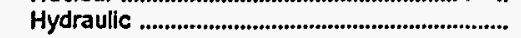 & 0 & 0 & 236,309 & 94,699 & 136,573 & 0 \\
\hline 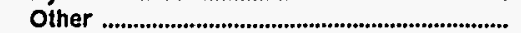 & 0 & 0 & 175,427 & 0 & 19,737 & 0 \\
\hline 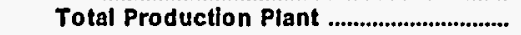 & 122,866 & $\mathbf{0}$ & 503,965 & 94,699 & 156,310 & 786,987 \\
\hline 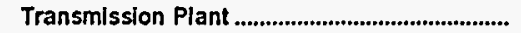 & 14.469 & 0 & 147,320 & 13,679 & 0 & 689,447 \\
\hline 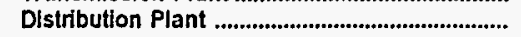 & 145,781 & 89,006 & 714.414 & 5,612 & 0 & 0 \\
\hline 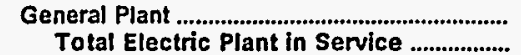 & $\begin{array}{r}10,082 \\
293,198\end{array}$ & $\begin{array}{r}922 \\
89,928\end{array}$ & $\begin{array}{r}269,613 \\
1,635,460\end{array}$ & $\begin{array}{r}2,472 \\
124,121\end{array}$ & $\begin{array}{l}104,042 \\
260,352\end{array}$ & $\begin{array}{r}29,156 \\
1,513,681\end{array}$ \\
\hline 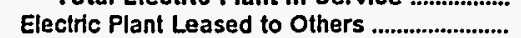 & 0 & 0 & 0 & 0 & 0 & 0 \\
\hline Electric Plant Held for Future Use .................... & 0 & 0 & 111 & 0 & 0 & 0 \\
\hline 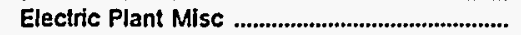 & 0 & 0 & 25,025 & 251.901 & 0 & 0 \\
\hline $\begin{array}{l}\text { Total Electric Utility Plant ........................ } \\
\text { Construction Work in Progress - Electric ....... } \\
\text { Accumulated Provision for Depreciation }\end{array}$ & $\begin{array}{r}293,198 \\
30,115\end{array}$ & $\begin{array}{r}89,928 \\
593\end{array}$ & $\begin{array}{r}1,660,596 \\
328,526\end{array}$ & $\begin{array}{r}376,022 \\
9,364\end{array}$ & $\begin{array}{r}260,352 \\
8,847\end{array}$ & $\begin{array}{r}1,513,681 \\
206,573\end{array}$ \\
\hline 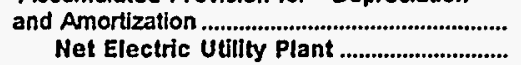 & $\begin{array}{l}112,767 \\
210,545\end{array}$ & $\begin{array}{l}17,746 \\
72,775\end{array}$ & $\begin{array}{r}480,310 \\
1,508,812\end{array}$ & $\begin{array}{l}181,398 \\
203,988\end{array}$ & $\begin{array}{r}67,451 \\
201,748\end{array}$ & $\begin{array}{r}418,687 \\
1,301,567\end{array}$ \\
\hline
\end{tabular}

Note: Totals may not equal sum of components because of independent rounding.

Source: Energy Information Administration, Form EIA-412, "Annual Report of Public Electric Utilities." 
Table 24. Electric Utility Plant by Major U.S. Publicly Owned Electric Utility Within State at End of Period, 1995 (Continued)

(Thousand Dollars)

\begin{tabular}{|c|c|c|c|c|c|c|}
\hline Item & $\begin{array}{c}\text { California } \\
\text { Turlack } \\
\text { Irrigatıon } \\
\text { District } \\
\text { December } 31\end{array}$ & $\begin{array}{l}\text { California } \\
\text { Vernon } \\
\text { City of } \\
\text { June } 30\end{array}$ & $\begin{array}{l}\text { California } \\
\text { Yuba } \\
\text { County } \\
\text { Water } \\
\text { Agency } \\
\text { June } 30\end{array}$ & $\begin{array}{l}\text { Colorado } \\
\text { Arkansas } \\
\text { River } \\
\text { Power } \\
\text { Authority } \\
\text { December } 31\end{array}$ & $\begin{array}{l}\text { Colorado } \\
\text { Colorado } \\
\text { Springs } \\
\text { City of } \\
\text { December } 31\end{array}$ & $\begin{array}{l}\text { Colorado } \\
\text { Fort Collins } \\
\text { City of } \\
\text { December } 31\end{array}$ \\
\hline 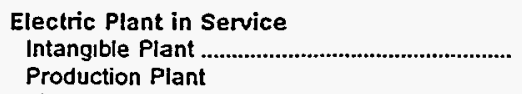 & 0 & 0 & 500 & 0 & 0 & 10 \\
\hline Steam & 0 & 0 & 0 & 0 & 253,834 & 0 \\
\hline 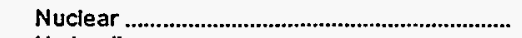 & 0 & 0 & 0 & 0 & 0 & 0 \\
\hline Hydraulic & 80,412 & 0 & 189,945 & 0 & 2,585 & 0 \\
\hline Other & 0 & 4,384 & 0 & 0 & 0 & 0 \\
\hline Total Production Plant ...................................... & 80,412 & 4,384 & 189,945 & 0 & 256,419 & 0 \\
\hline Transmission Plant ................................................ & 19,264 & 47,399 & 1.356 & 2,710 & 60,802 & 1.471 \\
\hline 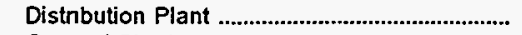 & 90,008 & 19,852 & 0 & 0 & 376,244 & 75,726 \\
\hline General Plant ........................................................... & 36.290 & 2,077 & 3.088 & 0 & 41,067 & 16,360 \\
\hline Total Electric Plant in Service .................. & 225,974 & 73,712 & 194,888 & 2,710 & 734,532 & 93,568 \\
\hline Electric Plant Leased to Others ......................... & 19,562 & 0 & 0 & 0 & 16,044 & 0 \\
\hline Electric Plant Held for Future Use ......................... & 0 & 0 & 0 & 0 & 0 & 0 \\
\hline 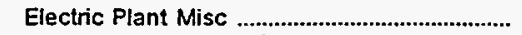 & 0 & 0 & 4,485 & 0 & 0 & 0 \\
\hline 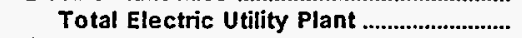 & 245,536 & 73,712 & 199,373 & 2,710 & 750,576 & 93,568 \\
\hline $\begin{array}{l}\text { Construction Work in Progress - Electric ........ } \\
\text { Accumulated Provision for Depreciation }\end{array}$ & 75.716 & 19,104 & & & 65,889 & 4,833 \\
\hline and Amortization & 78,190 & 29,547 & 57,483 & 836 & 242.879 & 41.791 \\
\hline Net Electric Utitity Plant ................................. & 243,062 & 63,268 & 141,891 & 4,584 & 573,586 & 56,609 \\
\hline
\end{tabular}

\begin{tabular}{|c|c|c|c|c|c|c|}
\hline Item & $\begin{array}{l}\text { Colorado } \\
\text { Fort Morgan } \\
\text { City of } \\
\text { December } 31\end{array}$ & $\begin{array}{l}\text { Colorado } \\
\text { Longmont } \\
\text { City of } \\
\text { December } 31\end{array}$ & $\begin{array}{l}\text { Colorado } \\
\text { Loveland } \\
\text { City of } \\
\text { December } 31\end{array}$ & $\begin{array}{c}\text { Colorado } \\
\text { Platte River } \\
\text { Power } \\
\text { Authority } \\
\text { December } 31\end{array}$ & $\begin{array}{c}\text { Connecticut } \\
\text { Connecticut } \\
\text { Mun } \\
\text { Elec } \\
\text { Engy Coop } \\
\text { December } 31\end{array}$ & $\begin{array}{l}\text { Connecticut } \\
\text { Groton } \\
\text { City of } \\
\text { June } 30\end{array}$ \\
\hline $\begin{array}{l}\text { Electric Plant in Service } \\
\text { Intangible Plant ........................................... } \\
\text { Production Plant }\end{array}$ & 0 & 0 & 0 & 0 & 942 & 0 \\
\hline Steam & 0 & 0 & 0 & 636,146 & 0 & 0 \\
\hline Nuclear & 0 & 0 & 0 & 0 & 0 & 0 \\
\hline 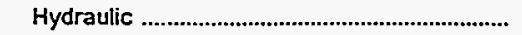 & 0 & 380 & 1,505 & 0 & 0 & 0 \\
\hline Other & 0 & 3,358 & 0 & 0 & 0 & 0 \\
\hline 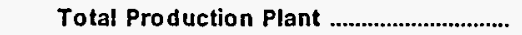 & 0 & 3,738 & 1,505 & 636,146 & 0 & 0 \\
\hline Transmission Plant .................................................. & 0 & 0 & 3,933 & 105,059 & 0 & 7,359 \\
\hline Distribution Plant ....................................................... & 11,068 & 37,670 & 36,734 & 0 & 0 & 15,827 \\
\hline General Plant & 1,045 & 450 & 5,517 & 12,955 & 52,920 & 3,099 \\
\hline Total Electric Plant in Service .................. & 12,113 & 41,859 & 47,689 & 754,160 & 53,862 & 26,285 \\
\hline Electric Plant Leased to Others ................................. & 0 & 0 & 0 & 0 & 0 & 0 \\
\hline Electne Plant Held for Future Use .................... & 0 & 0 & 0 & 0 & 0 & 0 \\
\hline 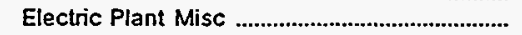 & 0 & 0 & 0 & 14,179 & 0 & 4.966 \\
\hline 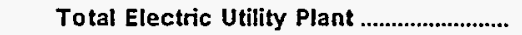 & 12,113 & 41,859 & 47,689 & 768,339 & 53,862 & 31,251 \\
\hline $\begin{array}{l}\text { Construction Work in Progress - Electric ........ } \\
\text { Accumulated Provision for Depreciation }\end{array}$ & 27 & 0 & 853 & 4,898 & 2 & 832 \\
\hline and Amortization & 3,887 & 16,906 & 12,430 & 270,267 & 16,070 & 16,797 \\
\hline Net Electric Utility Plant ................................... & 8,254 & 24,953 & 36,113 & 502,971 & 37,794 & 15,286 \\
\hline
\end{tabular}

Note: Totals may not equal sum of components because of independent rounding.

Source: Energy Information Administration, Form EIA-412, "Annual Report of Public Electric Utilities." 
Table 24. Electric Utility Plant by Major U.S. Publicly Owned Electric Utility Within State at End of Period, 1995 (Continued)

(Thousand Dollars)

\begin{tabular}{|c|c|c|c|c|c|c|}
\hline Item & $\begin{array}{l}\text { Connecticut } \\
\text { Nonvich } \\
\text { City of } \\
\text { June } 30\end{array}$ & $\begin{array}{l}\text { Connecticut } \\
\text { Wallingford } \\
\text { Town of } \\
\text { June } 30\end{array}$ & $\begin{array}{l}\text { Delaware } \\
\text { Dover } \\
\text { City of } \\
\text { June } 30\end{array}$ & $\begin{array}{l}\text { Delaware } \\
\text { Milford } \\
\text { City of } \\
\text { Seplember } 30\end{array}$ & $\begin{array}{c}\text { Delaware } \\
\text { Newark } \\
\text { City of } \\
\text { December } 31\end{array}$ & $\begin{array}{c}\text { Florida } \\
\text { Bartow } \\
\text { City of } \\
\text { September } 30\end{array}$ \\
\hline 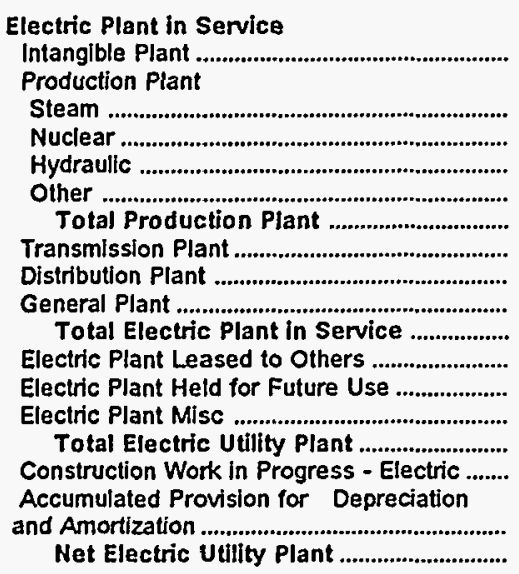 & $\begin{array}{r}0 \\
0 \\
0 \\
0 \\
2,912 \\
2,377 \\
5,289 \\
2,705 \\
15,687 \\
4,031 \\
27,712 \\
0 \\
0 \\
0 \\
27,712 \\
7,442\end{array}$ & $\begin{array}{r}0 \\
6,719 \\
0 \\
0 \\
0 \\
6,719 \\
1,282 \\
37,995 \\
4,652 \\
50,648 \\
0 \\
0 \\
0 \\
50,648 \\
0\end{array}$ & $\begin{array}{r}0 \\
62,404 \\
0 \\
0 \\
0 \\
62,404 \\
16,779 \\
20,838 \\
1,586 \\
101,607 \\
0 \\
0 \\
0 \\
101,607 \\
4\end{array}$ & $\begin{array}{r}0 \\
0 \\
0 \\
0 \\
0 \\
0 \\
7,265 \\
0 \\
7,265 \\
0 \\
0 \\
0 \\
7,265 \\
0\end{array}$ & $\begin{array}{l}0 \\
0 \\
0 \\
0 \\
0 \\
0 \\
0 \\
0 \\
0 \\
0 \\
0 \\
0 \\
0 \\
0\end{array}$ & $\begin{array}{r}0 \\
0 \\
0 \\
0 \\
0 \\
0 \\
12,377 \\
0 \\
12,377 \\
0 \\
0 \\
0 \\
12,377 \\
103\end{array}$ \\
\hline
\end{tabular}

\begin{tabular}{|c|c|c|c|c|c|c|}
\hline Item & $\begin{array}{c}\text { Florida } \\
\text { Florida } \\
\text { Municipal } \\
\text { Power Agency } \\
\text { September } 30\end{array}$ & $\begin{array}{c}\text { Florida } \\
\text { Fort Pierce } \\
\text { Utilities } \\
\text { Auth } \\
\text { September } 30\end{array}$ & $\begin{array}{c}\text { Flonida } \\
\text { Gainesville } \\
\text { Regional } \\
\text { Utilities } \\
\text { September } 30\end{array}$ & $\begin{array}{c}\text { Florida } \\
\text { Homestead } \\
\text { City of } \\
\text { September } 30\end{array}$ & $\begin{array}{c}\text { Florida } \\
\text { Jacksonville } \\
\text { Beach } \\
\text { City of } \\
\text { September } 30\end{array}$ & $\begin{array}{l}\text { Florida } \\
\text { Jacksonville } \\
\text { Electric } \\
\text { Auth } \\
\text { September } 30\end{array}$ \\
\hline \multicolumn{7}{|l|}{ Electric Plant in Service } \\
\hline $\begin{array}{l}\text { Intangible Plant } \\
\text { Production Plant }\end{array}$ & 598 & 0 & 0 & 0 & 0 & 612 \\
\hline Steam & 317,077 & 38,927 & 250,000 & 0 & $\mathbf{0}$ & $1,900,788$ \\
\hline 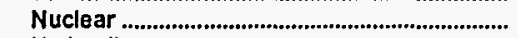 & 0 & 0 & 0 & 0 & 0 & 0 \\
\hline 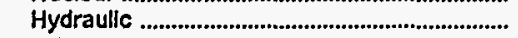 & 0 & 0 & 0 & 0 & 0 & $\mathbf{0}$ \\
\hline 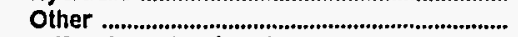 & 63,535 & 781 & 0 & 0 & 0 & 48,338 \\
\hline Total Production Plant ............................. & 380,612 & 39,709 & 250,000 & 0 & 0 & $1,949,126$ \\
\hline 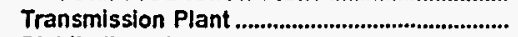 & 0 & 15,180 & 149,316 & 0 & 0 & 275,834 \\
\hline 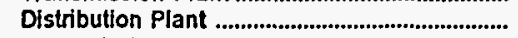 & 0 & 48,640 & 0 & 0 & 80,527 & 642,832 \\
\hline $\begin{array}{l}\text { General Plant } \\
\text { Total Electric Plant ín Service }\end{array}$ & $\begin{array}{r}27 \\
381,237\end{array}$ & $\begin{array}{r}9,752 \\
113,282\end{array}$ & $\begin{array}{r}33,490 \\
432,806\end{array}$ & $\begin{array}{l}46,371 \\
46,371\end{array}$ & $\begin{array}{r}0 \\
80,527\end{array}$ & $\begin{array}{r}113,823 \\
2,982,227\end{array}$ \\
\hline Electric Plant Leased to Others ........................... & 0 & 0 & 0 & 0 & 0 & 0 \\
\hline 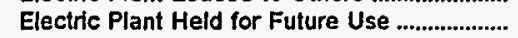 & 0 & 0 & 0 & 0 & 0 & 1,048 \\
\hline 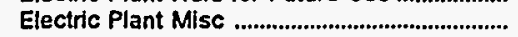 & 0 & 0 & 0 & 0 & 0 & 35,127 \\
\hline 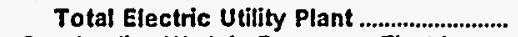 & 381,237 & 113,282 & 432,806 & 46,371 & 80,527 & $3,018,402$ \\
\hline $\begin{array}{l}\text { Construcllon Work in Progress - Electric ....... } \\
\text { Accumulated Provision for Depreciation }\end{array}$ & 39,786 & 1,774 & 41,382 & 0 & 1,997 & 24,432 \\
\hline 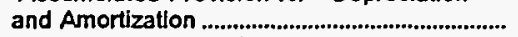 & 101,746 & 49,488 & 152,867 & 21,273 & 24,142 & 765,464 \\
\hline Net Electric Utility Plant .................................. & 319,277 & 65,567 & 321,321 & 25,098 & 58,382 & $2,277,371$ \\
\hline
\end{tabular}

Note: Totals may not equal sum of components because of independent rounding.

Source: Energy Information Administration, Form ElA-412, "Annual Report of Public Electric Utilities." 
Table 24. Electric Utility Plant by Major U.S. Publicly Owned Electric Utility Within State at End of Period, 1995 (Continued) (Thousand Dollars)

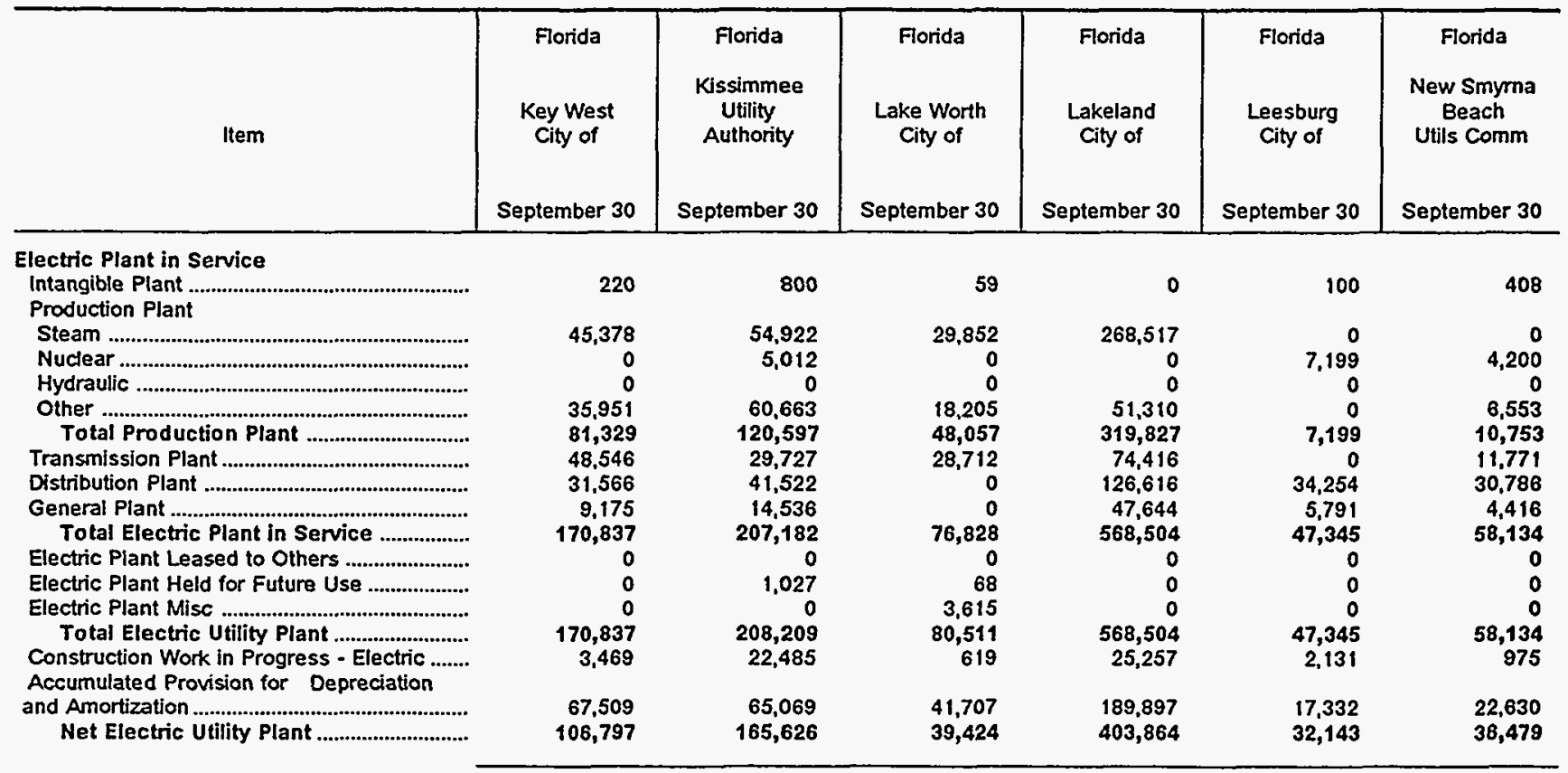

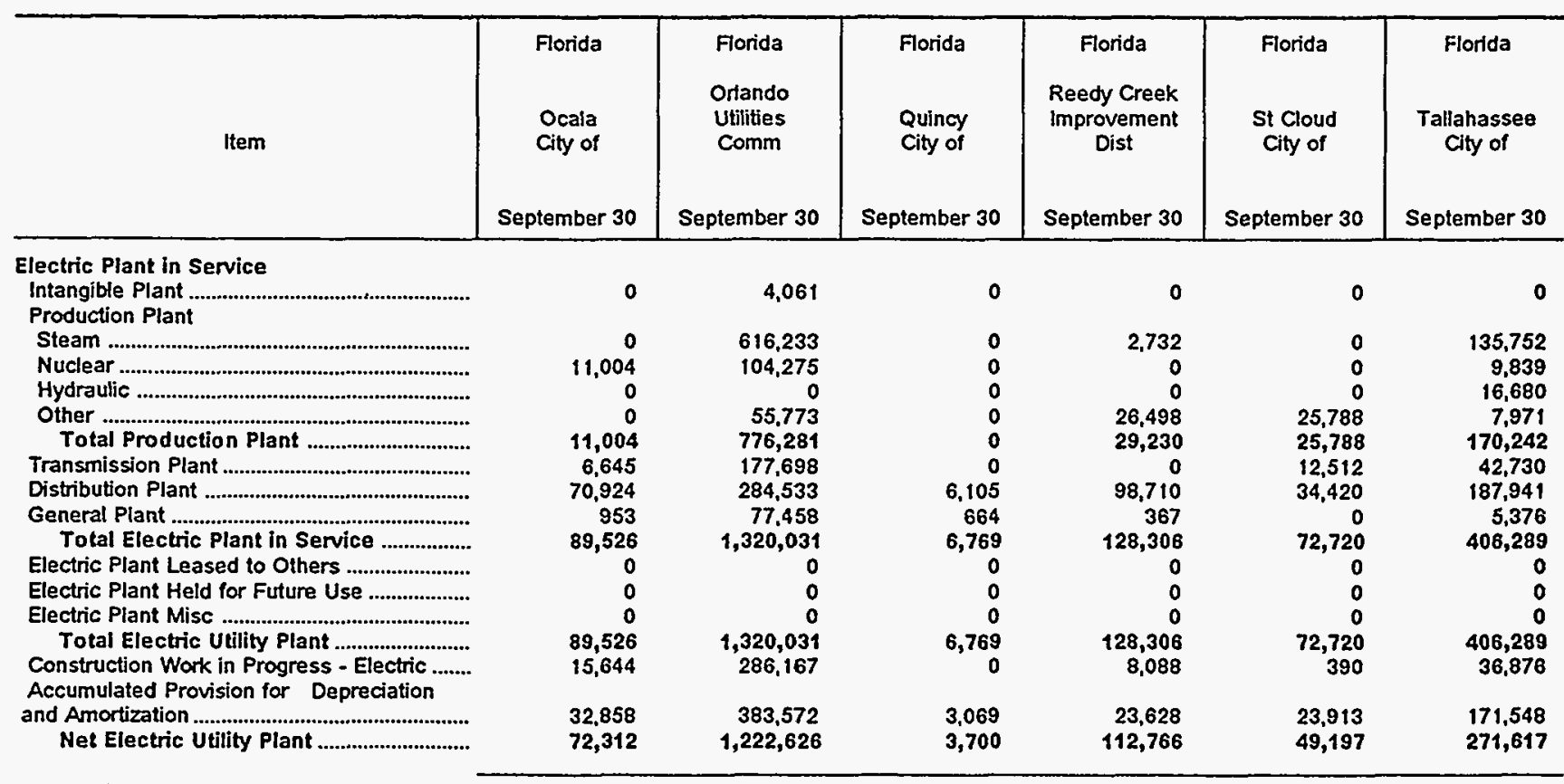

Note: Totals may not equal sum of components because of independent rounding.

Source: Energy information Administration, Form EIA-412, "Annual Report of Public Electric Utilities." 
Table 24. Electric Utility Plant by Major U.S. Publicly Owned Electric Utility Within State at End of Period, 1995 (Continued)

(Thousand Dollars)

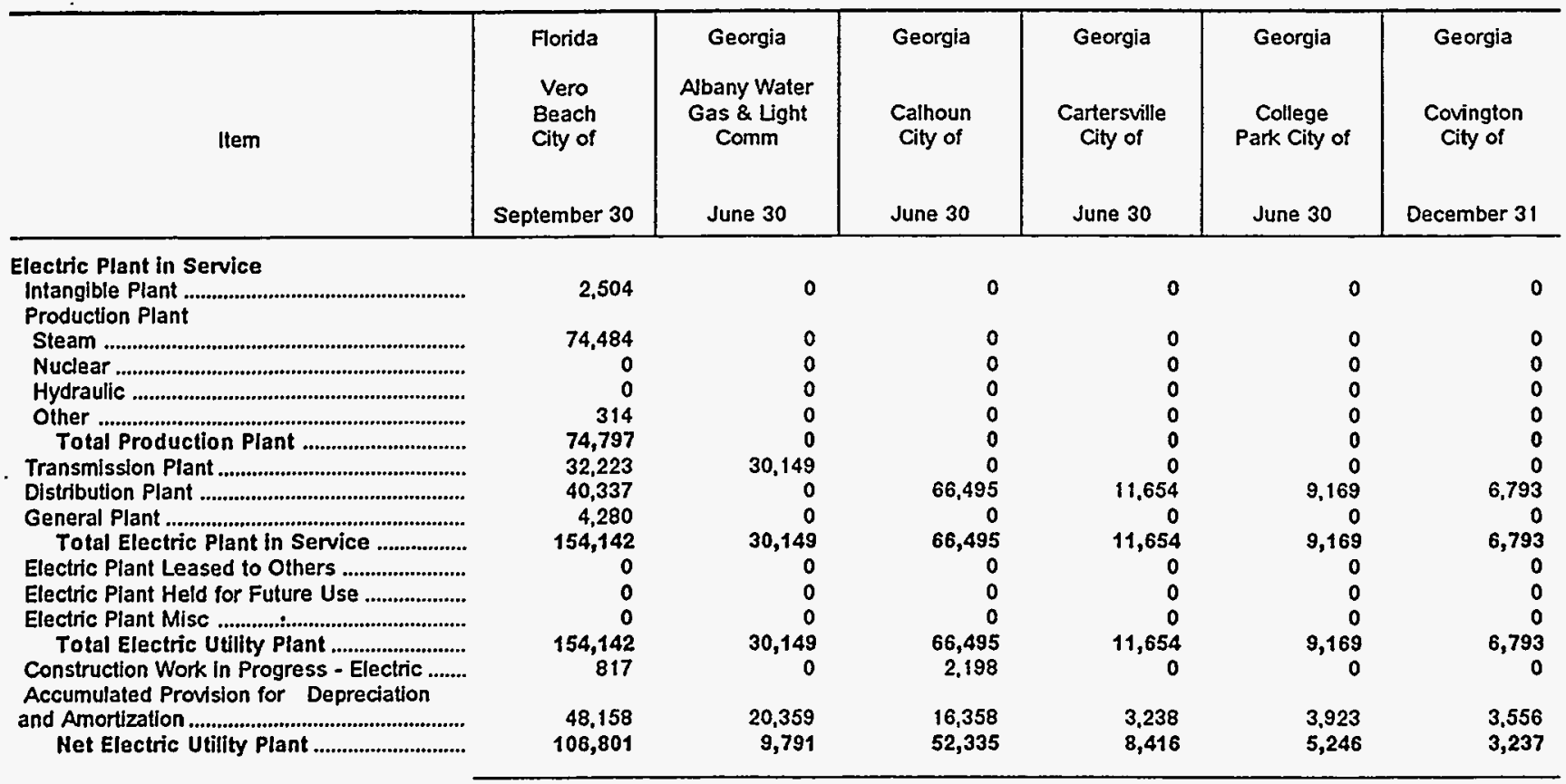

\begin{tabular}{|c|c|c|c|c|c|c|}
\hline Item & $\begin{array}{l}\text { Georgia } \\
\text { Crisp } \\
\text { County } \\
\text { Power } \\
\text { Comm } \\
\text { December } 31\end{array}$ & $\begin{array}{l}\text { Georgia } \\
\text { Dalton } \\
\text { City of } \\
\text { November } 30\end{array}$ & $\begin{array}{l}\text { Georgia } \\
\text { Douglas } \\
\text { City of } \\
\text { June } 30\end{array}$ & $\begin{array}{c}\text { Georgia } \\
\text { East } \\
\text { Point } \\
\text { City of } \\
\text { June } 30\end{array}$ & $\begin{array}{c}\text { Georgia } \\
\text { Fitzgerald } \\
\text { Wtr Lgt } \\
\text { \& Bond Comm } \\
\text { December } 31\end{array}$ & $\begin{array}{l}\text { Georgia } \\
\text { Griffin } \\
\text { City of } \\
\text { June } 30\end{array}$ \\
\hline \multicolumn{7}{|l|}{ Electric Plant In Service } \\
\hline 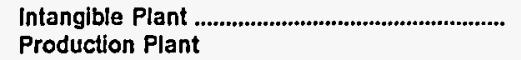 & 106 & 0 & 0 & 0 & 0 & 0 \\
\hline Steam & 5,123 & 22,433 & 0 & 0 & 0 & 0 \\
\hline 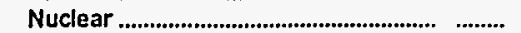 & 0 & 131,676 & 0 & 0 & 0 & 0 \\
\hline 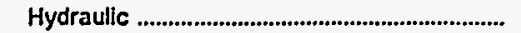 & 5,953 & 0 & 0 & 0 & 0 & 0 \\
\hline Other & 0 & 0 & 0 & 0 & 0 & 0 \\
\hline Total Production Plant ............................... & 11,076 & 154,109 & 0 & 0 & 0 & $\mathbf{0}$ \\
\hline 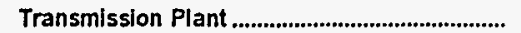 & 2,052 & 32,177 & 0 & 0 & 2.206 & 0 \\
\hline 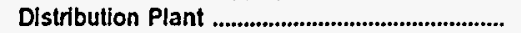 & 24,066 & 19,248 & 4,274 & 1.504 & 3,101 & 0 \\
\hline 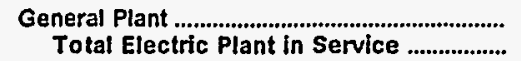 & $\begin{array}{r}4,136 \\
41,435\end{array}$ & $\begin{array}{r}1,584 \\
207,118\end{array}$ & $\begin{array}{r}0 \\
4,274\end{array}$ & $\begin{array}{l}6,242 \\
7,746\end{array}$ & $\begin{array}{l}1.803 \\
7,109\end{array}$ & $\begin{array}{r}11,791 \\
11,791\end{array}$ \\
\hline Electric Plant Leased to Others ............................ & 0 & 0 & 0 & 0 & 0 & 0 \\
\hline Electric Plant Held for Future Use ...................... & 0 & 0 & 0 & 0 & 0 & 0 \\
\hline 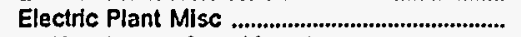 & 0 & 0 & 0 & 0 & 0 & 0 \\
\hline 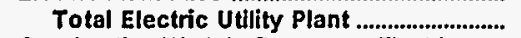 & 41,435 & 207,118 & 4,274 & 7,746 & 7,109 & 11,791 \\
\hline $\begin{array}{l}\text { Construction Work in Progress - Electric ....... } \\
\text { Accumulated Provision for Depreciation }\end{array}$ & 975 & 1,446 & 0 & 0 & 0 & 0 \\
\hline and Amortization & 24,772 & 71,052 & 2,382 & 4,067 & 3,248 & 325 \\
\hline 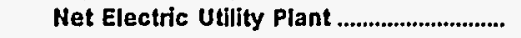 & 17,638 & 137,512 & 1,892 & 3,679 & 3,862 & 11,466 \\
\hline
\end{tabular}

Note: Totals may not equal sum of components because of independent rounding.

Source: Energy Information Administration, Form EIA-412, "Annual Report of Public Electric Utilities." 
Table 24. Electric Utility Plant by Major U.S. Publicly Owned Electric Utility Within State at End of Period, 1995

(Thousand Dollars)

\begin{tabular}{|c|c|c|c|c|c|c|}
\hline Item & $\begin{array}{l}\text { Georgia } \\
\text { La Grange } \\
\text { City of } \\
\text { June } 30\end{array}$ & $\begin{array}{l}\text { Georgia } \\
\text { Lawrenceville } \\
\text { City of } \\
\text { August } 30\end{array}$ & $\begin{array}{l}\text { Georgia } \\
\text { Marietta } \\
\text { City of } \\
\text { June } 30\end{array}$ & $\begin{array}{l}\text { Georgia } \\
\text { Moultrie } \\
\text { City of } \\
\text { September } 30\end{array}$ & $\begin{array}{l}\text { Georgia } \\
\text { Municipal } \\
\text { Electric } \\
\text { Authority } \\
\text { December } 31\end{array}$ & $\begin{array}{c}\text { Georgia } \\
\begin{array}{c}\text { Thomasvitle } \\
\text { City of }\end{array} \\
\text { December } 31\end{array}$ \\
\hline 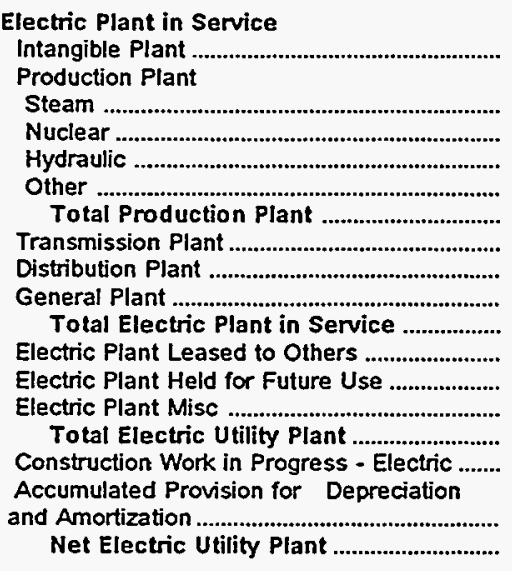 & $\begin{array}{r}0 \\
0 \\
0 \\
0 \\
0 \\
0 \\
0 \\
0 \\
0 \\
8,442 \\
8,442 \\
0 \\
0 \\
0 \\
8,442 \\
0\end{array}$ & $\begin{array}{r}0 \\
0 \\
0 \\
0 \\
0 \\
0 \\
0 \\
0 \\
13,293 \\
0 \\
13,293 \\
0 \\
0 \\
0 \\
13,293 \\
0\end{array}$ & $\begin{array}{r}0 \\
0 \\
0 \\
0 \\
0 \\
0 \\
0 \\
0 \\
42,644 \\
0 \\
42,644 \\
0 \\
0 \\
0 \\
42,644 \\
0\end{array}$ & $\begin{array}{r}0 \\
0 \\
0 \\
0 \\
0 \\
0 \\
0 \\
0 \\
6,615 \\
0 \\
6,615 \\
0 \\
0 \\
0 \\
6,615 \\
0 \\
\\
3,937 \\
2,678\end{array}$ & $\begin{array}{r}230 \\
\\
427,776 \\
2,191,720 \\
0 \\
2,139 \\
2,621,635 \\
212,264 \\
105,457 \\
11,299 \\
2,950,885 \\
0 \\
482 \\
108,412 \\
3,059,779 \\
20,165\end{array}$ & $\begin{array}{r}0 \\
0 \\
0 \\
0 \\
0 \\
0 \\
14,159 \\
2,253 \\
16,411 \\
0 \\
0 \\
0 \\
16,411 \\
690\end{array}$ \\
\hline
\end{tabular}

\begin{tabular}{|c|c|c|c|c|c|c|}
\hline Item & $\begin{array}{l}\text { Idaho } \\
\text { Idaho } \\
\text { Falls } \\
\text { City of } \\
\text { September } 30\end{array}$ & $\begin{array}{l}\text { Illinois } \\
\text { Batavia } \\
\text { City of } \\
\text { December } 31\end{array}$ & $\begin{array}{l}\text { Illinois } \\
\text { Geneva } \\
\text { City of } \\
\text { April } 30\end{array}$ & $\begin{array}{c}\text { Illinois } \\
\text { Mlinois } \\
\text { Municipal } \\
\text { Elec Agency } \\
\text { April } 30\end{array}$ & $\begin{array}{c}\text { Illinois } \\
\begin{array}{c}\text { Napenille } \\
\text { City of }\end{array} \\
\text { April } 30\end{array}$ & $\begin{array}{l}\text { Illinois } \\
\text { Rochelle } \\
\text { Municipal } \\
\text { Utilities } \\
\text { April } 30\end{array}$ \\
\hline \multicolumn{7}{|l|}{ Electric Plant in Service } \\
\hline 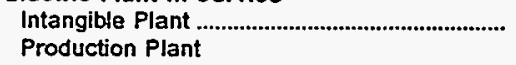 & 2,036 & 0 & 0 & 0 & 0 & 0 \\
\hline Steam & 0 & 0 & 0 & 94,369 & 0 & 11,147 \\
\hline Nuclear & $\mathbf{0}$ & 0 & 0 & 0 & 0 & 0 \\
\hline 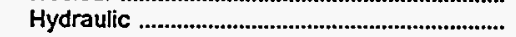 & 92,870 & 0 & 0 & 0 & 0 & 0 \\
\hline Other & 0 & 0 & 0 & $\mathbf{0}$ & 0 & 5762 \\
\hline Total Production Plant & 92,870 & 0 & 0 & 94,369 & $\mathbf{0}$ & 16,909 \\
\hline 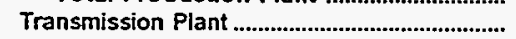 & 6,742 & 0 & 0 & 0 & 5,936 & 0 \\
\hline 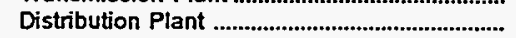 & 25,253 & 14,823 & 20,055 & 0 & 99,748 & 11.798 \\
\hline 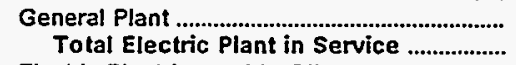 & $\begin{array}{r}4,131 \\
131,031\end{array}$ & $\begin{array}{r}2,759 \\
17,582\end{array}$ & $\begin{array}{r}2,672 \\
22,728\end{array}$ & $\begin{array}{r}2,525 \\
96,893\end{array}$ & $\begin{array}{r}10,537 \\
116,221\end{array}$ & $\begin{array}{r}1,717 \\
30,423\end{array}$ \\
\hline 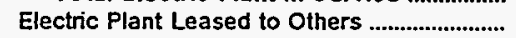 & 0 & 0 & 0 & 0 & 0 & 0 \\
\hline Electric Plant Held for Future Use .................... & 0 & 0 & 0 & 0 & 0 & 0 \\
\hline 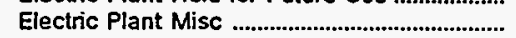 & $\mathbf{0}$ & 0 & 0 & 0 & 0 & 0 \\
\hline $\begin{array}{l}\text { Total Electric Utility Plant ......................... } \\
\text { Construction Work in Progress - Electric ....... } \\
\text { Accumulated Provision for Depreciation }\end{array}$ & $\begin{array}{r}131,031 \\
687\end{array}$ & $\begin{array}{r}17,582 \\
0\end{array}$ & $\begin{array}{r}22,728 \\
50\end{array}$ & $\begin{array}{r}96,893 \\
597\end{array}$ & $\begin{array}{r}116,221 \\
12,143\end{array}$ & $\begin{array}{r}30,423 \\
158\end{array}$ \\
\hline and Amortization & $\begin{array}{l}37,952 \\
93,766\end{array}$ & $\begin{array}{l}7,677 \\
9,905\end{array}$ & $\begin{array}{r}9,963 \\
12,815\end{array}$ & $\begin{array}{l}12,564 \\
84,926\end{array}$ & $\begin{array}{r}26,173 \\
102,191\end{array}$ & $\begin{array}{l}16,853 \\
13,729\end{array}$ \\
\hline
\end{tabular}

Note: Totals may not equal sum of components because of independent rounding.

Source: Energy Information Administration, Form ElA-4 12, "Annual Report of Public Electric Utilities." 
Table 24. Electric Utility Plant by Major U.S. Publicly Owned Electric Utility Within State at End of Period, 1995 (Continued)

(Thousand Dollars)

\begin{tabular}{|c|c|c|c|c|c|c|}
\hline Item & $\begin{array}{l}\text { Illinois } \\
\text { Springfield } \\
\text { City of } \\
\text { February } 28\end{array}$ & $\begin{array}{l}\text { Illinois } \\
\text { St Charles } \\
\text { City of } \\
\text { Aprit } 30\end{array}$ & $\begin{array}{c}\text { Indiana } \\
\text { Anderson } \\
\text { City of } \\
\text { December } 31\end{array}$ & $\begin{array}{l}\text { Indiana } \\
\text { Auburn } \\
\text { City of } \\
\text { December } 31\end{array}$ & $\begin{array}{l}\text { Indiana } \\
\text { Bluffton } \\
\text { City of } \\
\text { December } 31\end{array}$ & $\begin{array}{c}\text { Indiana } \\
\text { Crawfordsville } \\
\text { Elec } \\
\text { Lgt\&Pwr Co } \\
\text { December } 31\end{array}$ \\
\hline \multicolumn{7}{|l|}{ Electrfc Plant In Service } \\
\hline $\begin{array}{l}\text { Intangible Plant } \\
\text { Production Plant }\end{array}$ & 0 & 0 & $\mathbf{0}$ & 0 & 0 & 184 \\
\hline Steam & 178,785 & 0 & 0 & 0 & 0 & 12.889 \\
\hline 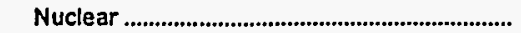 & 0 & 0 & 0 & 0 & 0 & 0 \\
\hline 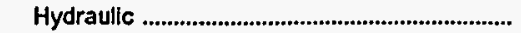 & 0 & 0 & 0 & 0 & 0 & 0 \\
\hline Other & 6,508 & 0 & 0 & 75 & 1,238 & 0 \\
\hline 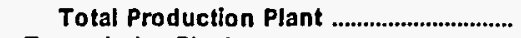 & 185,293 & 0 & o & 75 & 1,238 & 12,889 \\
\hline Transmission Plant & 36,491 & 0 & 1,178 & 275 & 268 & 1.243 \\
\hline 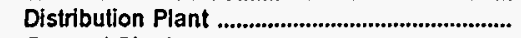 & 118.228 & 30.607 & 46.992 & 12.740 & 6.381 & 14,396 \\
\hline 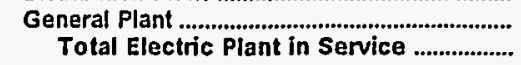 & $\begin{array}{r}22,189 \\
362,201\end{array}$ & $\begin{array}{r}67 \\
30,674\end{array}$ & $\begin{array}{r}7,544 \\
55,715\end{array}$ & $\begin{array}{r}2,360 \\
15,449\end{array}$ & $\begin{array}{l}1,020 \\
8,907\end{array}$ & $\begin{array}{r}3,393 \\
32,105\end{array}$ \\
\hline 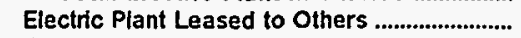 & 0 & 0 & 0 & 0 & 0 & 0 \\
\hline Electric Plant Held for Future Use .................... & 4,987 & 0 & 0 & 0 & 0 & 51 \\
\hline 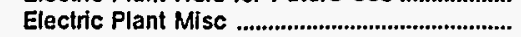 & 1,917 & 0 & 0 & 0 & 0 & 189 \\
\hline Total Electric Utitity Plant ............................ & 369,105 & 30,674 & 55,715 & 15,449 & 8,907 & 32,345 \\
\hline $\begin{array}{l}\text { Construction Work in Progress - Electric ....... } \\
\text { Accumulated Provision for Depreciation }\end{array}$ & 17.708 & 0 & 749 & 1,283 & 0 & 183 \\
\hline 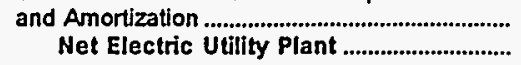 & $\begin{array}{l}185,720 \\
201,093\end{array}$ & $\begin{array}{r}8,975 \\
21,698\end{array}$ & $\begin{array}{l}23,714 \\
32,750\end{array}$ & $\begin{array}{r}5,471 \\
11,261\end{array}$ & $\begin{array}{l}4,690 \\
4,217\end{array}$ & $\begin{array}{l}17,397 \\
15,131\end{array}$ \\
\hline
\end{tabular}

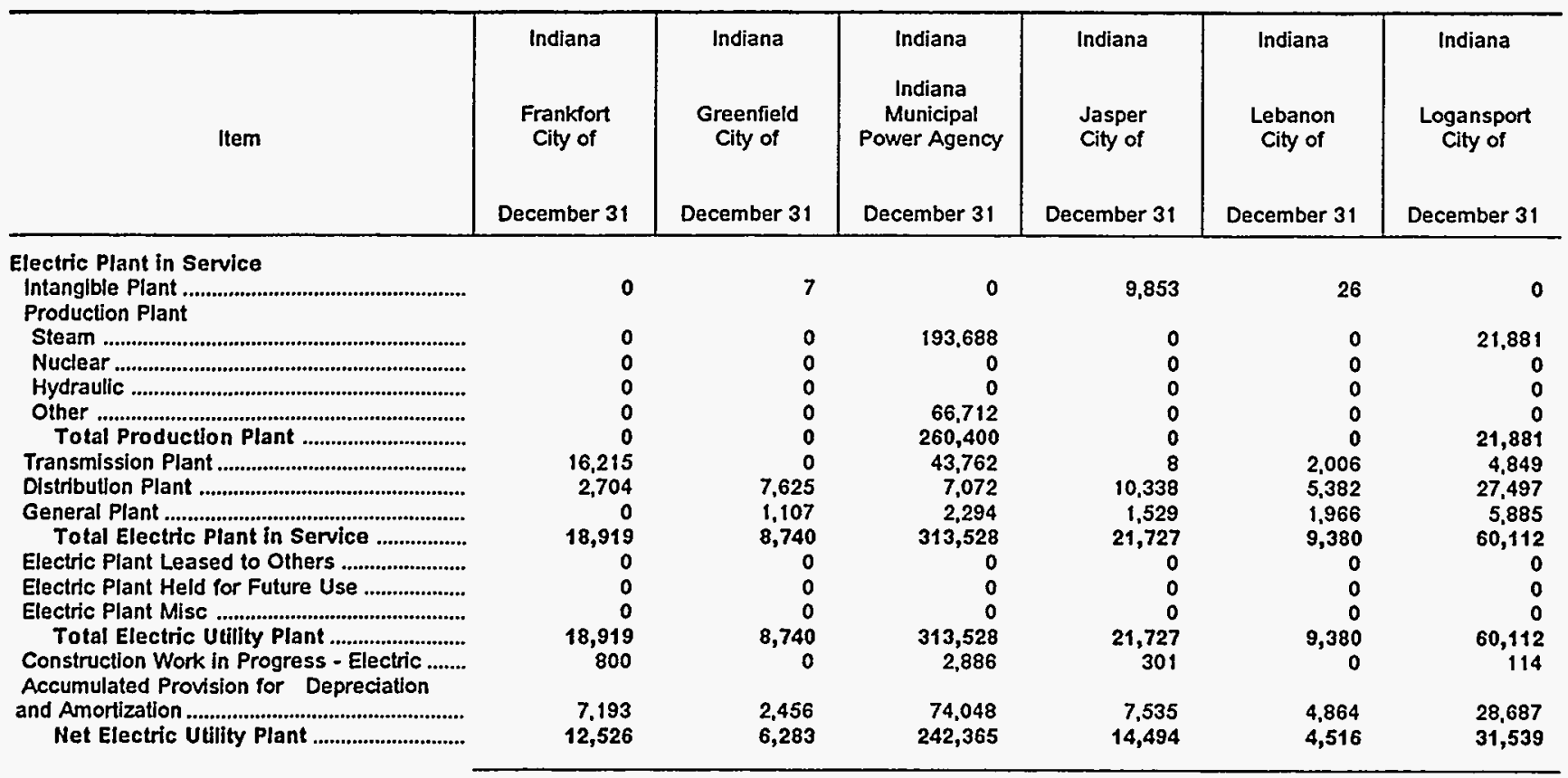

Note: Totals may not equal sum of components because of independent rounding.

Source: Energy Information Administration, Form ElA-412, "Annual Report of Public Electric Utilities." 
Table 24. Electric Utility Plant by Major U.S. Publicly Owned Electric Utility Within State at End of Period, 1995 (Continued)

(Thousand Dollars)

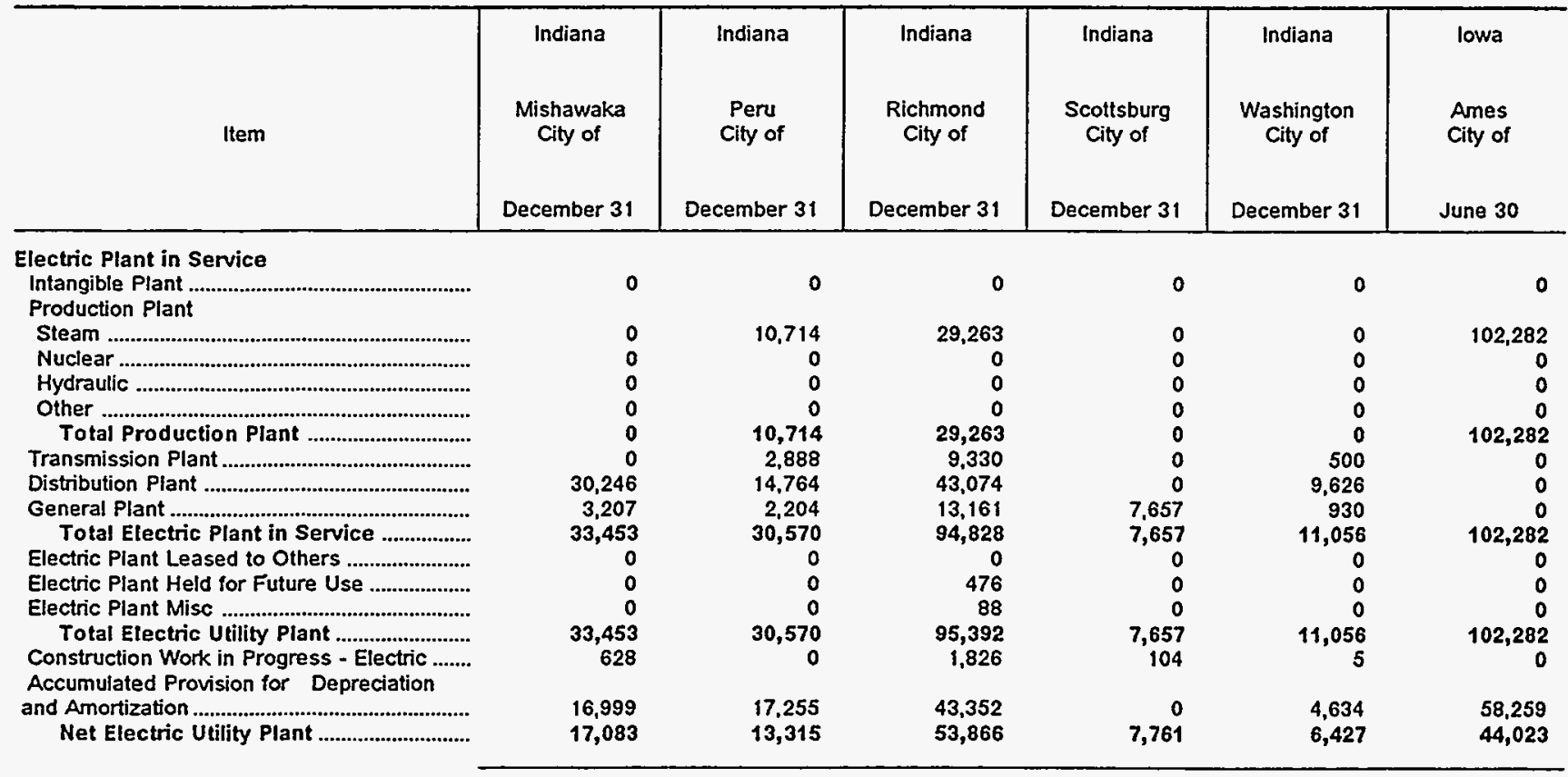

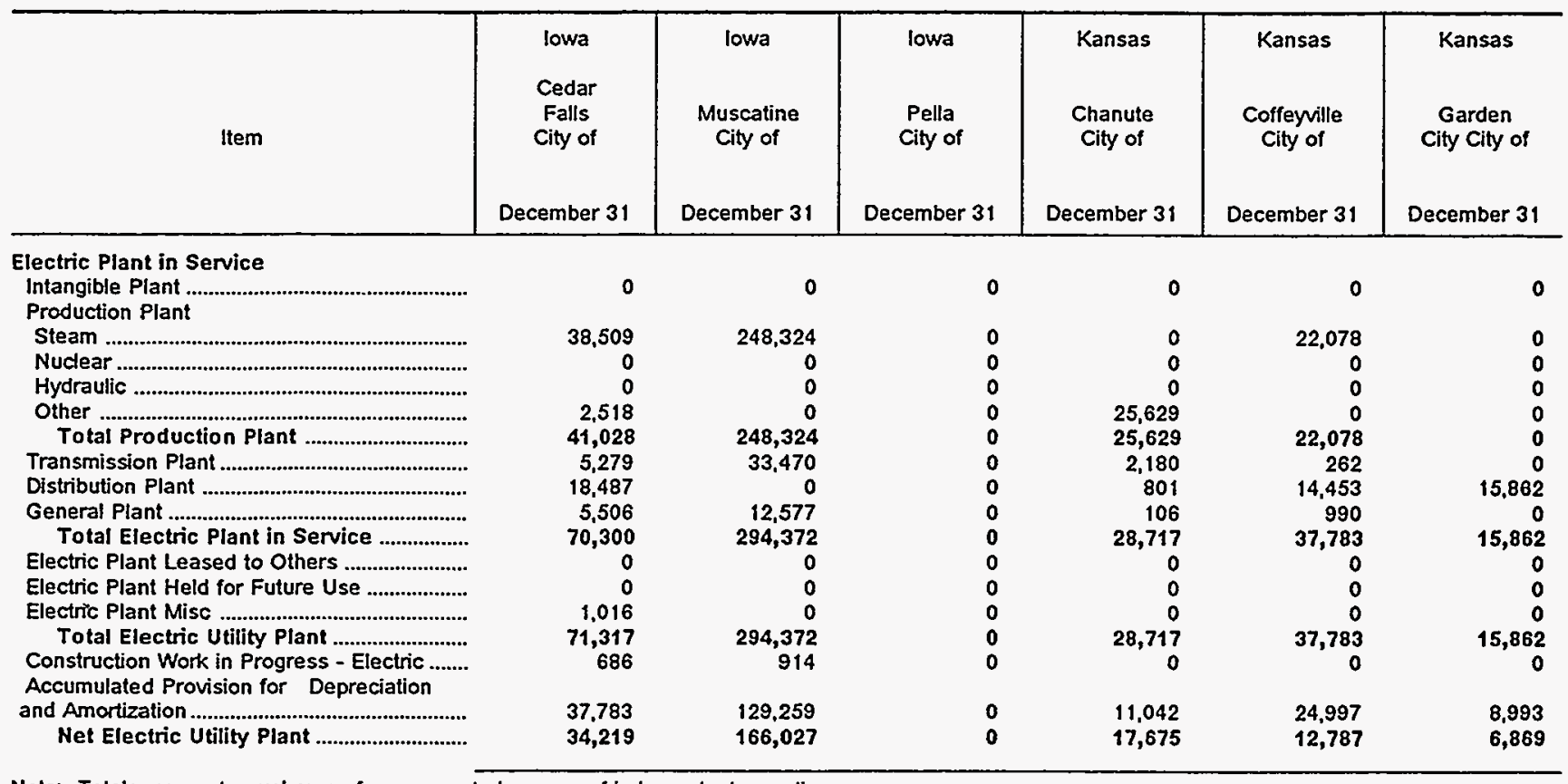

Note: Totals may not equal sum of components because of independent rounding.

Source: Energy Information Administration, Form EIA-412, "Annual Report of Public Electric Utilities." 
Table 24. Electric Utility Plant by Major U.S. Publicly Owned Electric Utility Within State at End of Period, 1995 (Continued)

(Thousand Dollars)

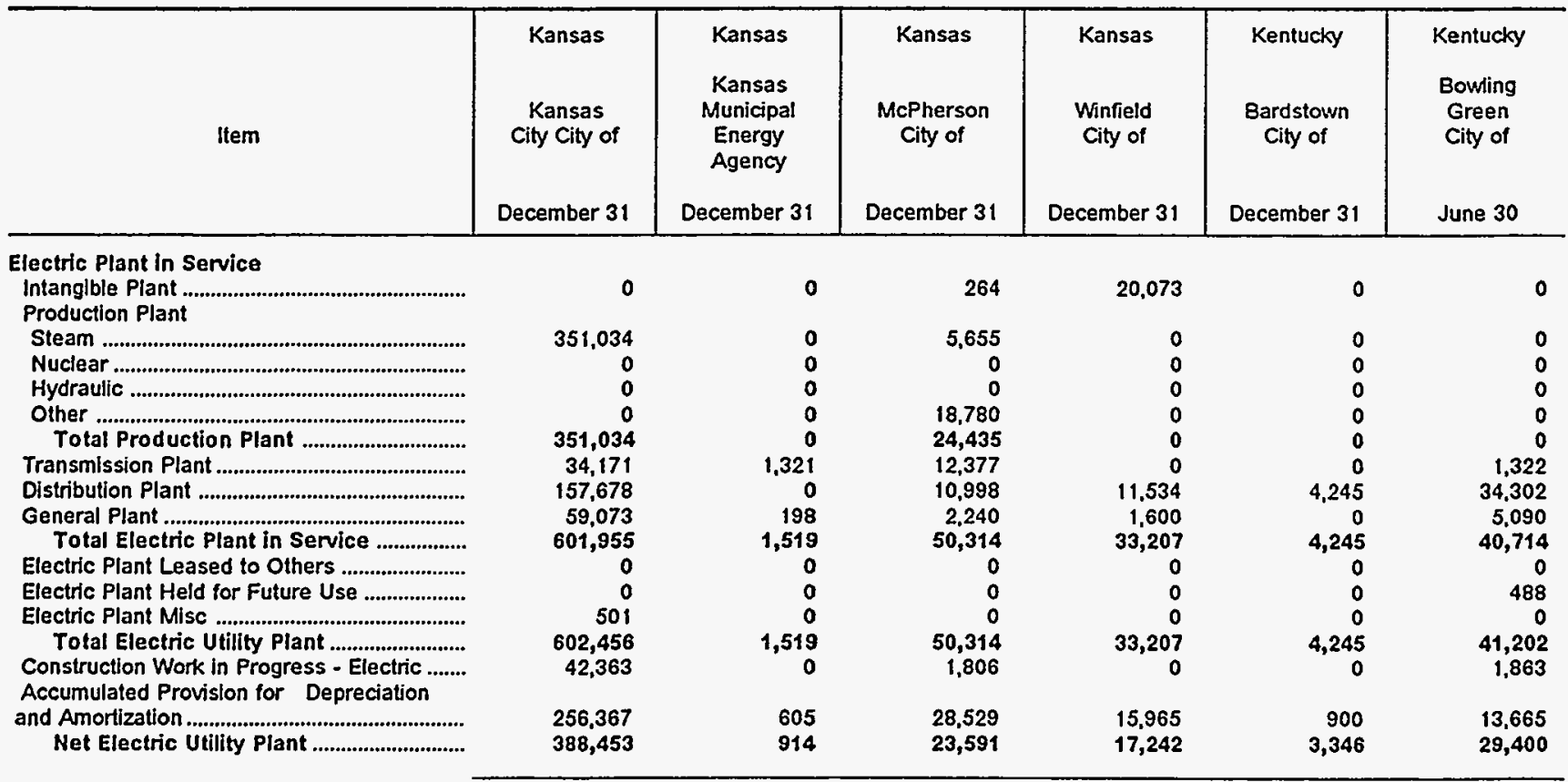

\begin{tabular}{|c|c|c|c|c|c|c|}
\hline Item & $\begin{array}{l}\text { Kentucky } \\
\text { Frankfort } \\
\text { City of } \\
\text { June } 30\end{array}$ & $\begin{array}{l}\text { Kentucky } \\
\text { Franklin } \\
\text { City of } \\
\text { June } 30\end{array}$ & $\begin{array}{l}\text { Kentucky } \\
\text { Glasgow } \\
\text { City of } \\
\text { June } 30\end{array}$ & $\begin{array}{l}\text { Kenfucky } \\
\text { Henderson } \\
\text { City } \\
\text { Utility Comm } \\
\text { May } 31\end{array}$ & $\begin{array}{l}\text { Kentucky } \\
\text { Hopkinsville } \\
\text { City of } \\
\text { June } 30\end{array}$ & $\begin{array}{l}\text { Kentucky } \\
\text { Madisonville } \\
\text { Municipal } \\
\text { Utils }\end{array}$ \\
\hline \multicolumn{7}{|l|}{ Electric Plant in Service } \\
\hline $\begin{array}{l}\text { Intangible Plant } \\
\text { Productlon Plant }\end{array}$ & $\mathbf{0}$ & $\mathbf{0}$ & 0 & 0 & 0 & 0 \\
\hline Steam & 0 & 0 & 0 & 82,235 & 0 & 0 \\
\hline 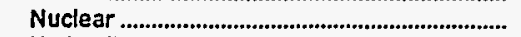 & 0 & 0 & 0 & 0 & 0 & 0 \\
\hline 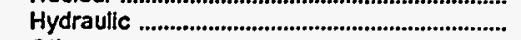 & 0 & 0 & 0 & 0 & 0 & 0 \\
\hline Other & 0 & 0 & 0 & 413 & 0 & 0 \\
\hline Total Production Plant & $\mathbf{0}$ & 0 & $\mathbf{0}$ & 82,648 & 0 & 0 \\
\hline 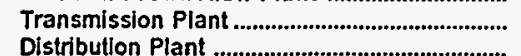 & $\begin{array}{r}7,998 \\
15,656\end{array}$ & $\begin{array}{r}0 \\
5.044\end{array}$ & $\begin{array}{r}956 \\
10.802\end{array}$ & $\begin{array}{r}5,997 \\
11712\end{array}$ & $\begin{array}{r}479 \\
11430\end{array}$ & $\begin{array}{r}0 \\
4.667\end{array}$ \\
\hline $\begin{array}{l}\text { General Plant } \\
\text { Total Electric Plant in Service }\end{array}$ & $\begin{array}{r}0 \\
23,654\end{array}$ & $\begin{array}{l}1,044 \\
6,088\end{array}$ & $\begin{array}{r}4,213 \\
15,972\end{array}$ & $\begin{array}{r}2,708 \\
103,066\end{array}$ & $\begin{array}{r}3,928 \\
15,837\end{array}$ & $\begin{array}{r}0 \\
4.00 \\
4.667\end{array}$ \\
\hline 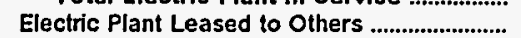 & 0 & 0 & 53 & $\begin{array}{r}10,000 \\
0\end{array}$ & $\begin{array}{r}0,007 \\
0\end{array}$ & 4,00 \\
\hline Electric Plant Held for Future Use .................... & 0 & 0 & 0 & 0 & 0 & 0 \\
\hline 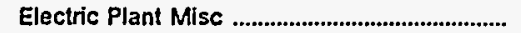 & 0 & 0 & 0 & 0 & 0 & 0 \\
\hline Total Electric Utility Plant .............................. & 23,654 & 6,088 & 16,024 & 103,066 & 15,837 & 4,667 \\
\hline $\begin{array}{l}\text { Construction Work in Progress - Electric ........ } \\
\text { Accumulated Provision for Depreciation }\end{array}$ & 0 & 157 & 110 & 41,395 & 112 & 0 \\
\hline $\begin{array}{l}\text { and Amortization } \\
\text { Net Electric Utility Plant }\end{array}$ & $\begin{array}{l}12,912 \\
10,742\end{array}$ & $\begin{array}{l}1.908 \\
4,337\end{array}$ & $\begin{array}{r}5,862 \\
10,272\end{array}$ & $\begin{array}{l}66,731 \\
77,729\end{array}$ & $\begin{array}{l}7.092 \\
8,857\end{array}$ & $\begin{array}{r}0 \\
4,667\end{array}$ \\
\hline
\end{tabular}

Note: Totals may not equal sum of components because of independent rounding.

Source: Energy Information Administration. Form EIA-412, "Annual Report of Public Electric Utilities." 
Table 24. Electric Utility Plant by Major U.S. Publicly Owned Electric Utility Within State at End of Period, 1995 (Continued)

(Thousand Dollars)

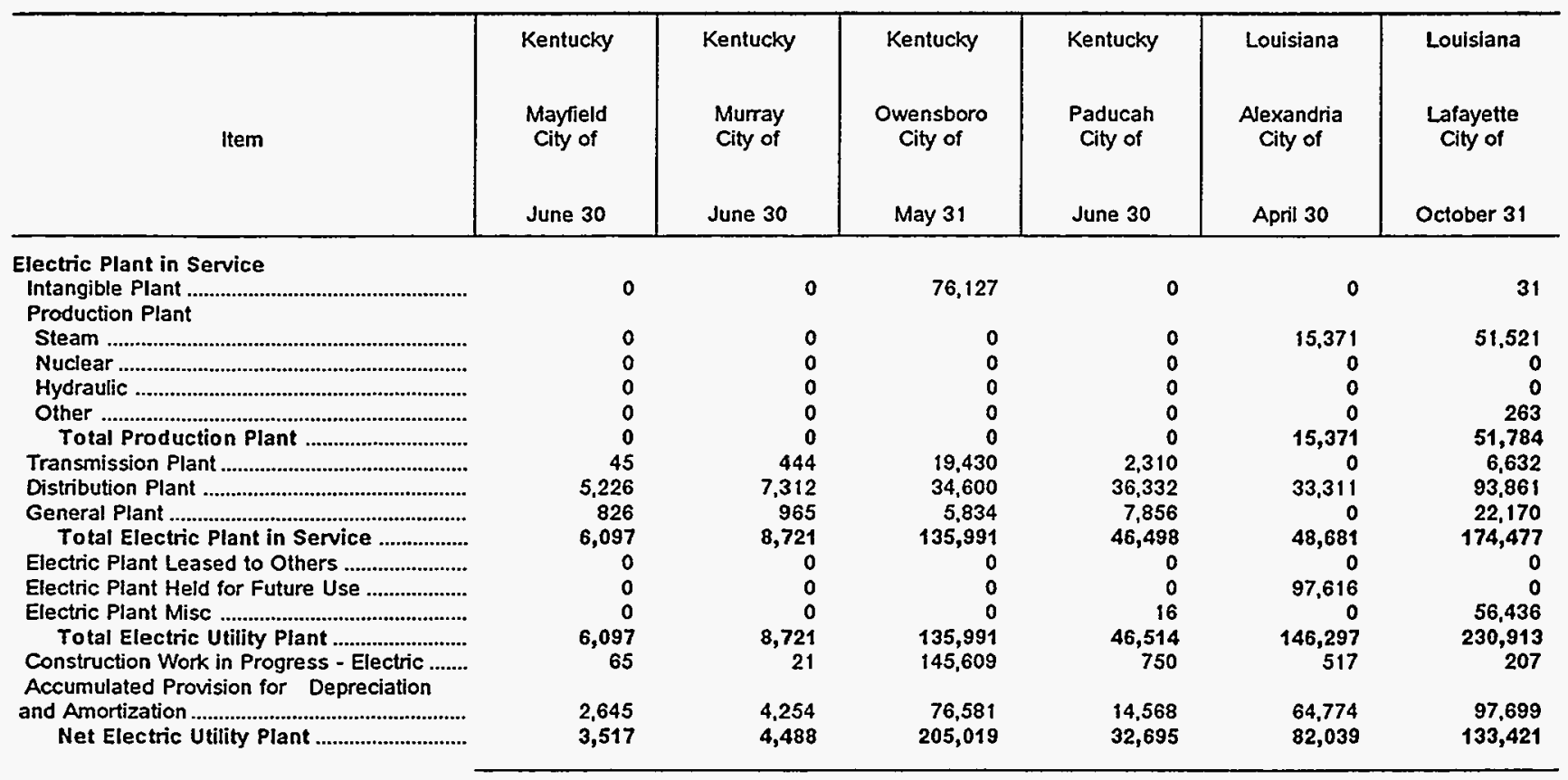

\begin{tabular}{|c|c|c|c|c|c|c|}
\hline Item & $\begin{array}{l}\text { Louisiana } \\
\text { Lafayette } \\
\text { Public } \\
\text { Power Auth } \\
\text { October } 31\end{array}$ & $\begin{array}{l}\text { Louisiana } \\
\text { Louisiana } \\
\text { Energy } \\
\text { \& } \\
\text { Power Auth } \\
\text { December } 31\end{array}$ & $\begin{array}{l}\text { Louisiana } \\
\text { Morgan } \\
\text { City City of } \\
\text { December } 31\end{array}$ & $\begin{array}{c}\text { Louisiana } \\
\begin{array}{c}\text { Natchitoches } \\
\text { City of }\end{array} \\
\text { May } 31\end{array}$ & $\begin{array}{l}\text { Louisiana } \\
\text { Ruston } \\
\text { City of } \\
\text { September } 30\end{array}$ & $\begin{array}{c}\text { Louisiana } \\
\text { Terrebonne } \\
\text { Parish } \\
\text { Consol Govt } \\
\\
\text { December } 31\end{array}$ \\
\hline \multicolumn{7}{|l|}{ Electric Plant in Service } \\
\hline 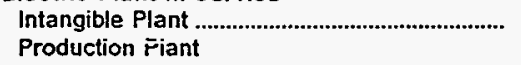 & 0 & 8,575 & 11 & 0 & 0 & 0 \\
\hline Steam & 126,666 & 57,883 & 18,909 & 0 & 13,037 & 28,305 \\
\hline 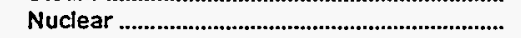 & 0 & 0 & 0 & 0 & 0 & 0 \\
\hline 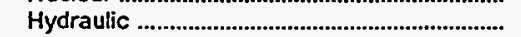 & 0 & 0 & 0 & 0 & 0 & 0 \\
\hline Other & 0 & 0 & 0 & 0 & 3,190 & 0 \\
\hline Total Production Plant & 126,666 & 57,883 & 18,909 & 0 & 16,227 & 28,305 \\
\hline 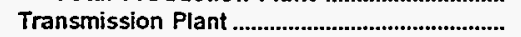 & 0 & 410 & 8,681 & 0 & 0 & 0 \\
\hline 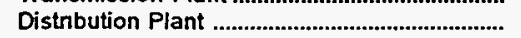 & 0 & 16 & 0 & 0 & 14.155 & 24,865 \\
\hline $\begin{array}{l}\text { General Plant } \\
\text { Total Electric Plant in Service }\end{array}$ & $\begin{array}{r}23,820 \\
150,485\end{array}$ & $\begin{array}{r}4,684 \\
71.568\end{array}$ & $\begin{array}{r}0 \\
27.602\end{array}$ & $\begin{array}{l}9.952 \\
9.952\end{array}$ & $\begin{array}{r}549 \\
3032\end{array}$ & $\begin{array}{r}0 \\
53170\end{array}$ \\
\hline 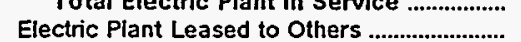 & $\begin{array}{r}150,485 \\
0\end{array}$ & $\begin{array}{r}1,508 \\
0\end{array}$ & $\begin{array}{r}2 \pi, 602 \\
0\end{array}$ & $\begin{array}{r}9,952 \\
0\end{array}$ & $\begin{array}{r}30,932 \\
0\end{array}$ & $\begin{aligned} 53,170 \\
0\end{aligned}$ \\
\hline 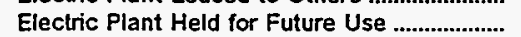 & 0 & 0 & 0 & 0 & 0 & 0 \\
\hline 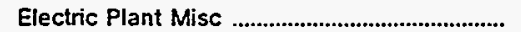 & 0 & 15,722 & 1,153 & 0 & 0 & $\mathbf{0}$ \\
\hline Total Electric Utility Plant & 150,485 & 87,290 & 28,755 & 9,952 & 30,932 & 53,170 \\
\hline $\begin{array}{l}\text { Construction Work in Progress - Electric ........ } \\
\text { Accumulated Provision for Depreciation }\end{array}$ & 2,594 & 785 & 4 & 55,964 & 0 & 3,608 \\
\hline 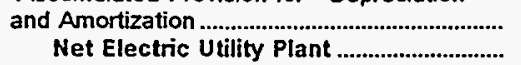 & $\begin{array}{l}62,936 \\
90,143\end{array}$ & $\begin{array}{l}22,556 \\
65,519\end{array}$ & $\begin{array}{r}19,692 \\
9,067\end{array}$ & $\begin{array}{l}17,566 \\
48,350\end{array}$ & $\begin{array}{l}19,665 \\
11,267\end{array}$ & $\begin{array}{l}36,422 \\
20,356\end{array}$ \\
\hline
\end{tabular}

Note: Totals may not equal sum of components because of independent rounding

Source: Energy Information Administration, Form EIA-412, "Annual Report of Public Electric Utilities." 
Table 24. Electric Utility Plant by Major U.S. Publicly Owned Electric Utility Within State at End of Period, 1995

(Thousand Dollars)

\begin{tabular}{|c|c|c|c|c|c|c|}
\hline Item & $\begin{array}{l}\text { Maryland } \\
\text { Easton } \\
\text { Utilities } \\
\text { Comm } \\
\text { June } 30\end{array}$ & $\begin{array}{l}\text { Maryland } \\
\text { Hagerstown } \\
\text { City of } \\
\text { June } 30\end{array}$ & $\begin{array}{l}\text { Massachusetts } \\
\text { Braintree } \\
\text { Town of } \\
\text { December } 31\end{array}$ & $\begin{array}{l}\text { Massachusetts } \\
\text { Chicopee } \\
\text { City of } \\
\text { December } 31\end{array}$ & $\begin{array}{l}\text { Massachusetts } \\
\text { Concord } \\
\text { Town of } \\
\text { December } 31\end{array}$ & $\begin{array}{l}\text { Massachusetts } \\
\text { Danvers } \\
\text { Town of } \\
\text { December } 31\end{array}$ \\
\hline \multicolumn{7}{|l|}{ Electric Plant in Service } \\
\hline $\begin{array}{l}\text { Intangible Plant } \\
\text { Production Plant }\end{array}$ & $\mathbf{0}$ & 0 & 0 & 0 & 2,086 & 0 \\
\hline Steam & 0 & 0 & 26,948 & 0 & 0 & 0 \\
\hline 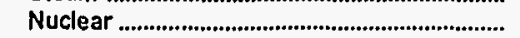 & 0 & 0 & 0 & 38,510 & 0 & 0 \\
\hline 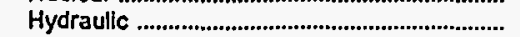 & 0 & 0 & 0 & 0 & 0 & 0 \\
\hline Other & 21,667 & $\mathbf{0}$ & 755 & 1.729 & 0 & 0 \\
\hline Total Production Plant & 21,667 & $\mathbf{0}$ & 27,703 & 40,238 & 0 & 0 \\
\hline 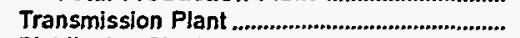 & 0 & 0 & 13,407 & 204 & 13,273 & 0 \\
\hline 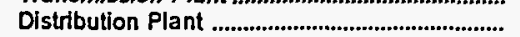 & 18,006 & 23,582 & 21,955 & 21.855 & 13,039 & 21,348 \\
\hline 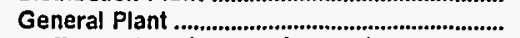 & 2,567 & 1,559 & 4,184 & 5,672 & 2,559 & 3.500 \\
\hline Total Electric Plant in Service .................. & 42,240 & 25,141 & 67,249 & 67,969 & 30,957 & 24,848 \\
\hline Electric Plant Leased to Others ............................ & 0 & 0 & 0 & 0 & 0 & 0 \\
\hline Electric Plant Held for Future Use ................... & 0 & 0 & 0 & 0 & 0 & 0 \\
\hline 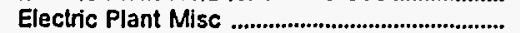 & 0 & 0 & 0 & 839 & 0 & 0 \\
\hline 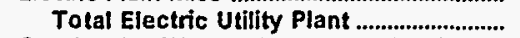 & 42,240 & 25,141 & 67,249 & 68,808 & 30,957 & 24,848 \\
\hline $\begin{array}{l}\text { Construction Work in Progress - Electric ........ } \\
\text { Accumulated Provision for Depreciation }\end{array}$ & 1,477 & 1,269 & 0 & 412 & 31 & 0 \\
\hline 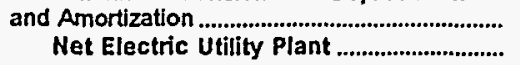 & $\begin{array}{l}18,335 \\
25,382\end{array}$ & $\begin{array}{l}10,956 \\
15,454\end{array}$ & $\begin{array}{l}32,989 \\
34,260\end{array}$ & $\begin{array}{l}27,326 \\
41,893\end{array}$ & $\begin{array}{r}8,683 \\
22,305\end{array}$ & $\begin{array}{l}11,556 \\
13,292\end{array}$ \\
\hline
\end{tabular}

\begin{tabular}{|c|c|c|c|c|c|c|}
\hline Item & $\begin{array}{l}\text { Massachusetts } \\
\text { Hingham } \\
\text { City of } \\
\text { December } 31\end{array}$ & $\begin{array}{l}\text { Massachusetts } \\
\text { Holyoke } \\
\text { City of } \\
\text { December } 31\end{array}$ & $\begin{array}{c}\text { Massachusetts } \\
\text { Hudson } \\
\text { Town of } \\
\text { December } 31\end{array}$ & $\begin{array}{l}\text { Massachusetts } \\
\text { Littleton } \\
\text { Town of } \\
\text { December } 31\end{array}$ & $\begin{array}{l}\text { Massachusetts } \\
\text { Mansfield } \\
\text { Town of } \\
\text { December } 31\end{array}$ & $\begin{array}{c}\text { Massachusetts } \\
\text { Massachusetts } \\
\text { Mun } \\
\text { Whls } \\
\text { Elec Co } \\
\text { December } 31\end{array}$ \\
\hline 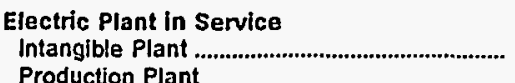 & 0 & 0 & 4 & 0 & 0 & 1,168 \\
\hline 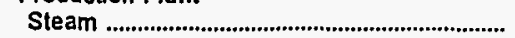 & 0 & 17,569 & 0 & 346 & 0 & 7,293 \\
\hline 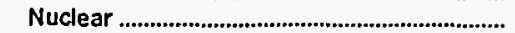 & 0 & 0 & 2,707 & 0 & 0 & 992,001 \\
\hline 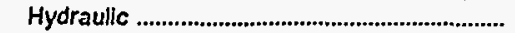 & 0 & 2,252 & 0 & 0 & 0 & 0 \\
\hline Other & 0 & 2,011 & 4,176 & 0 & 0 & 184,682 \\
\hline 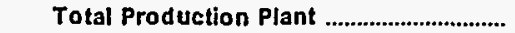 & 0 & 21,832 & 6,883 & 346 & 0 & $1,183,977$ \\
\hline 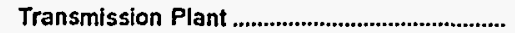 & 1,438 & 6,185 & 1,644 & 15 & 0 & 30,694 \\
\hline 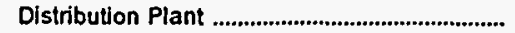 & 19,164 & 23,919 & 8,671 & 11,258 & 9,219 & 0 \\
\hline 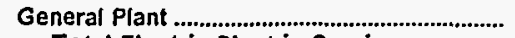 & 1,860 & 2,336 & 1,787 & 4,396 & 1,190 & 17.638 \\
\hline Total Electric Plant in Service .................... & 22,462 & 54,272 & 18,989 & 16,015 & 10,409 & $1,233,477$ \\
\hline 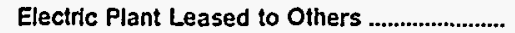 & 0 & 0 & 0 & 0 & 0 & 0 \\
\hline Electric Plant Held for Future Use .................... & 0 & $\mathbf{0}$ & 0 & 0 & 0 & 0 \\
\hline 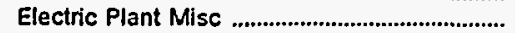 & 0 & 0 & 0 & 0 & 0 & 0 \\
\hline Total Electric Utility Plant .......................... & 22,462 & 54,272 & 18,989 & 16,015 & 10,409 & $1,233,477$ \\
\hline $\begin{array}{l}\text { Construction Work in Progress - Electric ....... } \\
\text { Accumulated Provision for Depreciation }\end{array}$ & 0 & 1,441 & 0 & 181 & 0 & 1,331 \\
\hline $\begin{array}{l}\text { and Amortization } \\
\text { Net Electric Utility Plant }\end{array}$ & $\begin{array}{r}6,767 \\
15,695\end{array}$ & $\begin{array}{l}32,225 \\
23,488\end{array}$ & $\begin{array}{r}13,119 \\
5,870\end{array}$ & $\begin{array}{l}6,521 \\
9,676\end{array}$ & $\begin{array}{l}6,254 \\
4,156\end{array}$ & $\begin{array}{l}327,459 \\
907,349\end{array}$ \\
\hline
\end{tabular}

Note: Totals may not equal sum of components because of independent rounding.

Source: Energy information Administration, Form ElA-4 12, "Annual Report of Public Electric Utitities." 
Table 24. Electric Utility Plant by Major U.S. Publicly Owned Electric Utility Within State at End of Period, 1995 (Continued) (Thousand Dollars)

\begin{tabular}{|c|c|c|c|c|c|c|}
\hline Item & $\begin{array}{l}\text { Massachusetts } \\
\text { Middleborough } \\
\text { Town of } \\
\text { December } 31\end{array}$ & $\begin{array}{l}\text { Massachusetts } \\
\text { North } \\
\text { Attleborough } \\
\text { Town of } \\
\text { December } 31\end{array}$ & $\begin{array}{l}\text { Massachusetts } \\
\text { Norwood } \\
\text { City of } \\
\text { June } 30\end{array}$ & $\begin{array}{l}\text { Massachusetts } \\
\text { Peabody } \\
\text { City of } \\
\text { December } 31\end{array}$ & $\begin{array}{l}\text { Massachusetts } \\
\text { Reading } \\
\text { Town of } \\
\text { December } 31\end{array}$ & $\begin{array}{l}\text { Massachusetts } \\
\text { Shrewsbury } \\
\text { Town of } \\
\text { December } 31\end{array}$ \\
\hline \multicolumn{7}{|l|}{ Electric Plant in Service } \\
\hline $\begin{array}{l}\text { Intangible Plant .......................................................... } \\
\text { Production Plant }\end{array}$ & 0 & 0 & 0 & 0 & 0 & 0 \\
\hline Steam & 0 & 785 & 0 & 0 & 0 & 0 \\
\hline 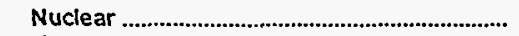 & 0 & 0 & 0 & 0 & 0 & 0 \\
\hline 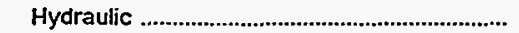 & 0 & 0 & 0 & 0 & 0 & 0 \\
\hline Other & 0 & 0 & 0 & 22,108 & $\mathbf{0}$ & 3,064 \\
\hline Total Production Plant & $\mathbf{0}$ & 785 & 0 & 22,108 & 0 & 3,064 \\
\hline 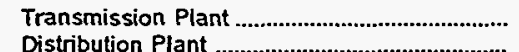 & 2,793 & 1,774 & 1,011 & 7.412 & 2,258 & 2,250 \\
\hline 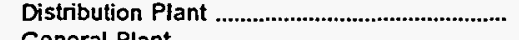 & 10,700 & 13,527 & 20,135 & 25,144 & 36,977 & 16,585 \\
\hline $\begin{array}{l}\text { General Plant } \\
\text { Total EJectric Plant in Service }\end{array}$ & $\begin{array}{r}2,583 \\
16,076\end{array}$ & $\begin{array}{r}4,699 \\
20,785\end{array}$ & $\begin{array}{r}1,995 \\
23,141\end{array}$ & $\begin{array}{r}9,296 \\
63,960\end{array}$ & $\begin{array}{l}11,755 \\
50,990\end{array}$ & $\begin{array}{r}3,982 \\
25,881\end{array}$ \\
\hline Electric Plant Leased to Others .......................... & 0 & 0 & 0 & 0 & 0 & 0 \\
\hline Electric Plant Held for Future Use ....................... & 0 & 0 & 0 & 0 & 0 & 0 \\
\hline 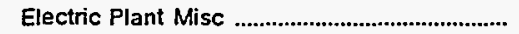 & 0 & 0 & 0 & 0 & 0 & 0 \\
\hline 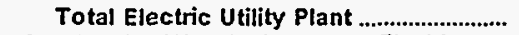 & 16,076 & 20,785 & 23,141 & 63,960 & 50,990 & 25,881 \\
\hline $\begin{array}{l}\text { Construction Work in Progress - Electric ....... } \\
\text { Accumulated Provision for Depreciation }\end{array}$ & 0 & 1,796 & 0 & 0 & 0 & 0 \\
\hline $\begin{array}{l}\text { and Amortization } \\
\text { Net Electric Utility Plant }\end{array}$ & $\begin{array}{l}7,309 \\
8,767\end{array}$ & $\begin{array}{r}7,202 \\
15,378\end{array}$ & $\begin{array}{r}15,943 \\
\mathbf{7 , 1 9 8}\end{array}$ & $\begin{array}{l}25,292 \\
38,668\end{array}$ & $\begin{array}{l}22,141 \\
28,849\end{array}$ & $\begin{array}{l}12,186 \\
13,695\end{array}$ \\
\hline
\end{tabular}

\begin{tabular}{|c|c|c|c|c|c|c|}
\hline Item & $\begin{array}{l}\text { Massachusetts } \\
\text { Taunton } \\
\text { City of } \\
\text { December } 31\end{array}$ & $\begin{array}{l}\text { Massachusetts } \\
\text { Wakefield } \\
\text { Town of } \\
\text { December } 31\end{array}$ & $\begin{array}{c}\text { Massachusetts } \\
\text { Wellesley } \\
\text { Town of } \\
\text { December } 31\end{array}$ & $\begin{array}{l}\text { Massachusetts } \\
\text { Westfield } \\
\text { City of } \\
\text { December } 31\end{array}$ & $\begin{array}{c}\text { Michigan } \\
\text { Bay } \\
\text { City City of } \\
\text { June } 30\end{array}$ & $\begin{array}{l}\text { Michigan } \\
\text { Coldwater } \\
\text { Board } \\
\text { of } \\
\text { Public Util } \\
\text { June } 30\end{array}$ \\
\hline \multicolumn{7}{|l|}{ Electric Plant in Service } \\
\hline $\begin{array}{l}\text { Intangible Plant } \\
\text { Production Plant }\end{array}$ & 0 & 0 & 0 & 0 & 0 & $\mathbf{0}$ \\
\hline Steam & 56,206 & 0 & 0 & 0 & o & 7,129 \\
\hline 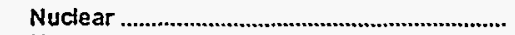 & 3,988 & 0 & 0 & 0 & 0 & 0 \\
\hline 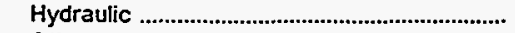 & 0 & $\mathbf{0}$ & 0 & 0 & 0 & $\mathbf{0}$ \\
\hline Other & 1,112 & 0 & 0 & 0 & 7,914 & $\mathbf{0}$ \\
\hline Total Production Plant .................................. & 61,306 & 0 & $\mathbf{0}$ & $\mathbf{0}$ & 7,914 & 7,129 \\
\hline 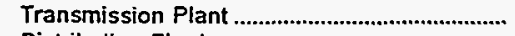 & 7.076 & 0 & 6,534 & 0 & 0 & 0 \\
\hline 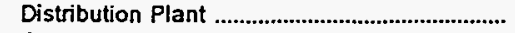 & 32,317 & 13,952 & 20,927 & 19,379 & 37,143 & 5,772 \\
\hline $\begin{array}{l}\text { General Plant } \\
\text { Total Electric Plant in Service }\end{array}$ & $\begin{array}{r}6,310 \\
107,009\end{array}$ & $\begin{array}{r}594 \\
14,546\end{array}$ & $\begin{array}{r}1,747 \\
29,209\end{array}$ & $\begin{array}{r}6,261 \\
25,640\end{array}$ & $\begin{array}{r}853 \\
45,910\end{array}$ & $\begin{array}{r}2,566 \\
15,468\end{array}$ \\
\hline 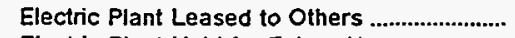 & 0 & 0 & 0 & 0 & 0 & 0 \\
\hline Electric Plant Held for Future Use ................... & 0 & $\mathbf{0}$ & 0 & 0 & $\mathbf{0}$ & $\mathbf{0}$ \\
\hline 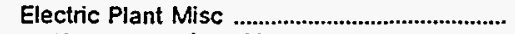 & 0 & 0 & 0 & 0 & 0 & 0 \\
\hline Total Electric Utility Plant ............................ & 107,009 & 14,546 & 29,209 & 25,640 & 45,910 & 15,468 \\
\hline $\begin{array}{l}\text { Construction Work in Progress - Electric ........ } \\
\text { Accumulated Provision for Depreciation }\end{array}$ & 2,446 & 0 & 671 & 1.070 & 0 & $\mathbf{0}$ \\
\hline and Amortization & 60,723 & 11,945 & 12,982 & 10,795 & 15,357 & 8,643 \\
\hline Net Electric Utility Plant ............................... & 48,733 & 2,601 & 16,898 & 15,915 & 30,553 & 6,825 \\
\hline
\end{tabular}

Note: Totals may not equal sum of components because of independent rounding.

Source: Energy Information Administration, Form ElA-412, "Annual Report of Public Electric Utilities." 
Table 24. Electric Utility Plant by Major U.S. Publicly Owned Electric Utility Within State at End of Period, 1995 (Continued)

(Thousand Dollars)

\begin{tabular}{|c|c|c|c|c|c|c|}
\hline Item & $\begin{array}{l}\text { Michigan } \\
\text { Detroit } \\
\text { City of } \\
\text { June } 30\end{array}$ & $\begin{array}{c}\text { Michigan } \\
\begin{array}{c}\text { Grand Haven } \\
\text { City of }\end{array} \\
\text { June } 30\end{array}$ & $\begin{array}{c}\text { Michigan } \\
\text { Hillsdale } \\
\text { Board } \\
\text { of } \\
\text { Public Wks } \\
\text { June } 30\end{array}$ & $\begin{array}{l}\text { Michigan } \\
\text { Holland } \\
\text { City of } \\
\text { June } 30\end{array}$ & $\begin{array}{l}\text { Michigan } \\
\text { Lansing } \\
\text { City of } \\
\text { June } 30\end{array}$ & $\begin{array}{l}\text { Michigan } \\
\text { Marquette } \\
\text { City of } \\
\text { June } 30\end{array}$ \\
\hline \multicolumn{7}{|l|}{ Electric Plant in Service } \\
\hline $\begin{array}{l}\text { Intangible Plant ............................................................... } \\
\text { Production Plant }\end{array}$ & 0 & 0 & 0 & 0 & 718 & 0 \\
\hline 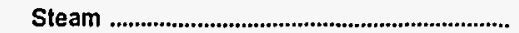 & 94,743 & 81,698 & 0 & 33,261 & 189,598 & 66,086 \\
\hline Nuclear & 0 & 0 & 0 & 0 & 0 & 0 \\
\hline 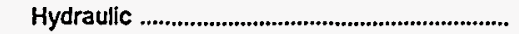 & 0 & 0 & 0 & 0 & 5,550 & 5,164 \\
\hline Other & 2,508 & 4,434 & 5,419 & 33,239 & 0 & 4,378 \\
\hline Total Production Plant ................................ & 97,252 & 86,132 & 5,419 & 66,500 & 195,148 & 75,628 \\
\hline 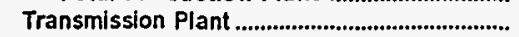 & 23,449 & 0 & 25 & 0 & 38,029 & 1,324 \\
\hline 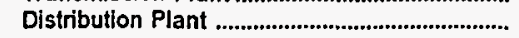 & 151,151 & 16,817 & 4,550 & 27,709 & 131,927 & 17,378 \\
\hline 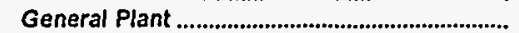 & 12,091 & 1,425 & 939 & 4,255 & 30,574 & 3,983 \\
\hline Total Electric Plant in Service ..................... & 283,942 & 104,374 & 10,932 & 98,464 & 396,396 & 98,312 \\
\hline 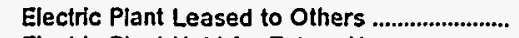 & 0 & 0 & 0 & 0 & 0 & 0 \\
\hline Electric Plant Held for Future Use ..................... & 0 & 0 & 17 & 0 & 0 & 0 \\
\hline 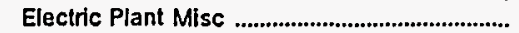 & 0 & 0 & 0 & 0 & 0 & 0 \\
\hline 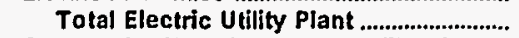 & 283,942 & 104,374 & 10,950 & 98,464 & 396,396 & 98,312 \\
\hline $\begin{array}{l}\text { Construction Work in Progress - Electric ....... } \\
\text { Accumulated Provision for Depreciation }\end{array}$ & 15,826 & 1,421 & 563 & 3,716 & 19,324 & 17 \\
\hline and Amortization & $\begin{array}{l}125,966 \\
173,801\end{array}$ & $\begin{array}{l}46,380 \\
59,414\end{array}$ & $\begin{array}{l}7,694 \\
3,818\end{array}$ & $\begin{array}{l}46,125 \\
56,055\end{array}$ & $\begin{array}{l}232,166 \\
183,553\end{array}$ & $\begin{array}{l}45,126 \\
53,204\end{array}$ \\
\hline
\end{tabular}

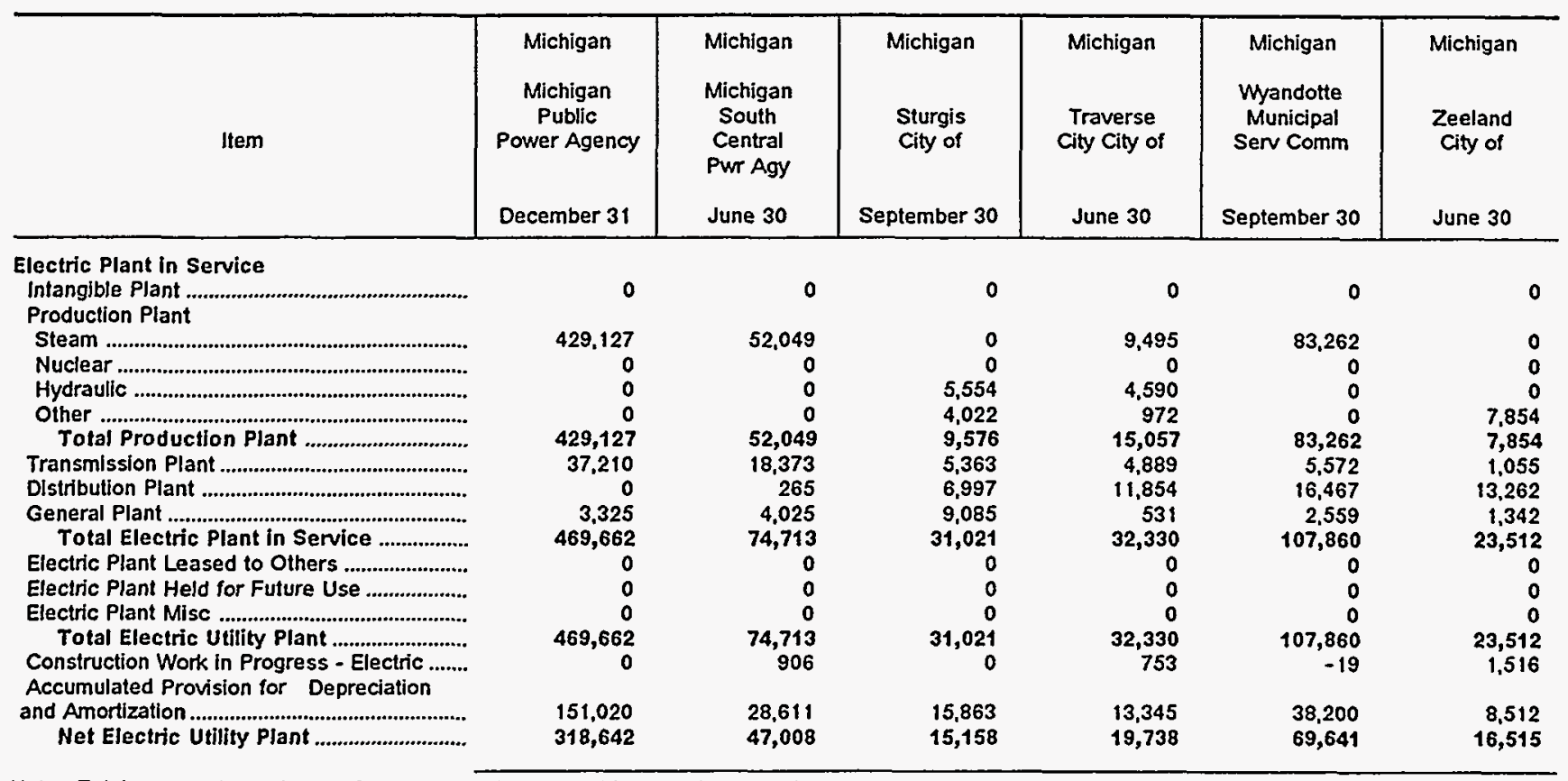

Note: Totals may not equal sum of components because of independent rounding

Source: Energy Information Administration, Fom Ela-412, "Annual Report of Public Electric Utilities." 
Table 24. Electric Utility Plant by Major U.S. Publicly Owned Electric Utility Within State at End of Period, 1995 (Continued) (Thousand Dollars)

\begin{tabular}{|c|c|c|c|c|c|c|}
\hline Item & $\begin{array}{l}\text { Minnesota } \\
\text { Alexandria } \\
\text { City of } \\
\text { December } 31\end{array}$ & $\begin{array}{l}\text { Minnesota } \\
\text { Anoka } \\
\text { City of } \\
\text { December } 31\end{array}$ & $\begin{array}{l}\text { Minnesota } \\
\text { Austin } \\
\text { City of } \\
\text { December } 31\end{array}$ & $\begin{array}{l}\text { Minnesota } \\
\text { Brainerd } \\
\text { Public } \\
\text { Utilities } \\
\text { December } 31\end{array}$ & $\begin{array}{l}\text { Minnesota } \\
\text { Chaska } \\
\text { City of } \\
\text { December } 31\end{array}$ & $\begin{array}{l}\text { Minnesota } \\
\text { Fairmont } \\
\text { Public } \\
\text { Utilities } \\
\text { Comm } \\
\text { December } 31\end{array}$ \\
\hline $\begin{array}{l}\text { Electric Plant in Service } \\
\text { Intangible Plant ............................................ } \\
\text { Production Plant }\end{array}$ & 0 & 0 & 0 & 0 & 0 & 390 \\
\hline Steam & 494 & 0 & 16,057 & 0 & 0 & 5,085 \\
\hline 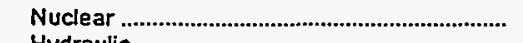 & 0 & 0 & 0 & 0 & 0 & 0 \\
\hline 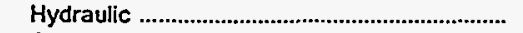 & 0 & 0 & 0 & 0 & 0 & 0 \\
\hline Other & 2,072 & 0 & 0 & 0 & 0 & 2,398 \\
\hline Total Production Plant ..................................... & 2,566 & $\mathbf{0}$ & 16,057 & $\mathbf{0}$ & 0 & 7,483 \\
\hline Transmission Plant & 901 & 106 & 894 & 0 & 0 & 2,756 \\
\hline 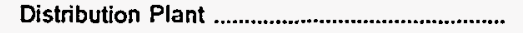 & 10,352 & 13,591 & 15,371 & 7,461 & 8,531 & 5,477 \\
\hline $\begin{array}{l}\text { General Plant } \\
\text { Total Electric Plant in Service }\end{array}$ & $\begin{array}{r}1,905 \\
15,725\end{array}$ & $\begin{array}{r}1,319 \\
15,016\end{array}$ & $\begin{array}{r}2,230 \\
34,552\end{array}$ & $\begin{array}{r}0 \\
7,461\end{array}$ & $\begin{array}{r}809 \\
9,340\end{array}$ & $\begin{array}{r}3,073 \\
19,179\end{array}$ \\
\hline 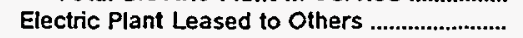 & 0 & 0 & 0 & 0 & 0 & 0 \\
\hline Electric Plant Held for Future Use ...................... & 0 & 0 & 0 & 0 & 0 & 0 \\
\hline 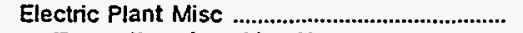 & 0 & 0 & 0 & 0 & 0 & 0 \\
\hline 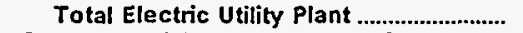 & 15,725 & 15,016 & 34,552 & 7,461 & 9,340 & 19,179 \\
\hline $\begin{array}{l}\text { Construction Work in Progress - Electric ....... } \\
\text { Accumulated Provision for Depreciation }\end{array}$ & 336 & 0 & 15 & 76 & 0 & 0 \\
\hline $\begin{array}{l}\text { and Amortization } \\
\text { Net Electric Utility Plant }\end{array}$ & $\begin{array}{l}9,135 \\
6,926\end{array}$ & $\begin{array}{l}6,935 \\
8,080\end{array}$ & $\begin{array}{l}21,318 \\
13,248\end{array}$ & $\begin{array}{l}3,465 \\
4,072\end{array}$ & $\begin{array}{l}3,939 \\
5,401\end{array}$ & $\begin{array}{r}11,828 \\
7,351\end{array}$ \\
\hline
\end{tabular}

\begin{tabular}{|c|c|c|c|c|c|c|}
\hline Item & $\begin{array}{l}\text { Minnesota } \\
\text { Hutchinson } \\
\text { Utilities } \\
\text { Comm } \\
\text { December } 31\end{array}$ & $\begin{array}{l}\text { Minnesota } \\
\text { Marshall } \\
\text { City of } \\
\text { December } 31\end{array}$ & $\begin{array}{l}\text { Minnesota } \\
\text { Moorhead } \\
\text { City of } \\
\text { December } 31\end{array}$ & $\begin{array}{l}\text { Minnesota } \\
\text { New Ulm } \\
\text { Public } \\
\text { Utilities } \\
\text { Comm } \\
\text { December } 31\end{array}$ & $\begin{array}{l}\text { Minnesota } \\
\text { Northern } \\
\text { Municipal } \\
\text { Power Agny } \\
\text { December } 31\end{array}$ & $\begin{array}{c}\text { Minnesola } \\
\text { Owatonna } \\
\text { City of } \\
\text { December } 31\end{array}$ \\
\hline \multicolumn{5}{|l|}{ Electric Plant in Service } & 0 & 0 \\
\hline $\begin{array}{l}\text { Production Fiant } \\
\text { Steam }\end{array}$ & 0 & 0 & 3.060 & 12549 & 291.955 & 6.743 \\
\hline 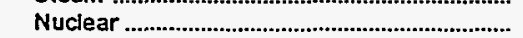 & 0 & 0 & 0 & 0 & 0 & 0 \\
\hline 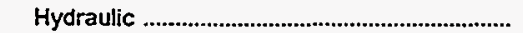 & 0 & 0 & 0 & 0 & 0 & $\mathbf{0}$ \\
\hline Other & 33,483 & 1,912 & 0 & 0 & 0 & 1,936 \\
\hline 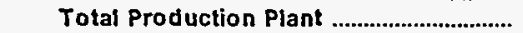 & 33,483 & 1,912 & 3,060 & 12,549 & 291,955 & 8,679 \\
\hline 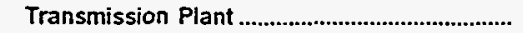 & 5,967 & 3,051 & 3,437 & 4,904 & 30,261 & 2,532 \\
\hline 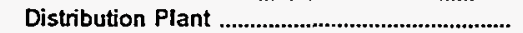 & 8,640 & 14,641 & 13,979 & 9,312 & 0 & 13,160 \\
\hline General Plant & 1,549 & 3,027 & 1,341 & 0 & 0 & 3,751 \\
\hline Total Electric Plant in Service ................. & 49,639 & 22,631 & 22,073 & 26,765 & 322,216 & 28,123 \\
\hline 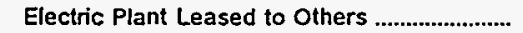 & 0 & 0 & 0 & 0 & 0 & 0 \\
\hline Electric Plant Held for Future Use .................... & 0 & 0 & 9,134 & 0 & 0 & 0 \\
\hline 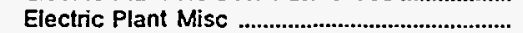 & 0 & 0 & 0 & 0 & 0 & 0 \\
\hline 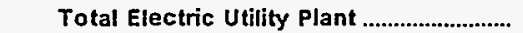 & 49,639 & 22,631 & 31,206 & 26,765 & 322,216 & 28,123 \\
\hline $\begin{array}{l}\text { Construction Work in Progress - Electric ....... } \\
\text { Accumulated Provision for Depreciation }\end{array}$ & 0 & 262 & 335 & 45 & 0 & 144 \\
\hline 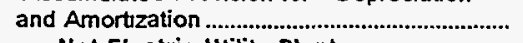 & 15,946 & 7,489 & 15,986 & 14,616 & 25,650 & 14,142 \\
\hline 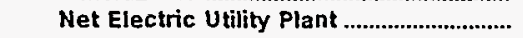 & 33,694 & 15,404 & 15,556 & 12,194 & 296,566 & 14,125 \\
\hline
\end{tabular}

Note: Totals may not equal sum of components because of independent rounding.

Source: Energy Information Administration, Form EIA-4 12, "Annual Report of Public Electric Utilities." 
Table 24. Electric Utility Plant by Major U.S. Publicly Owned Electric Utility Within State at End of Period, 1995 (Continued)

(Thousand Dollars)

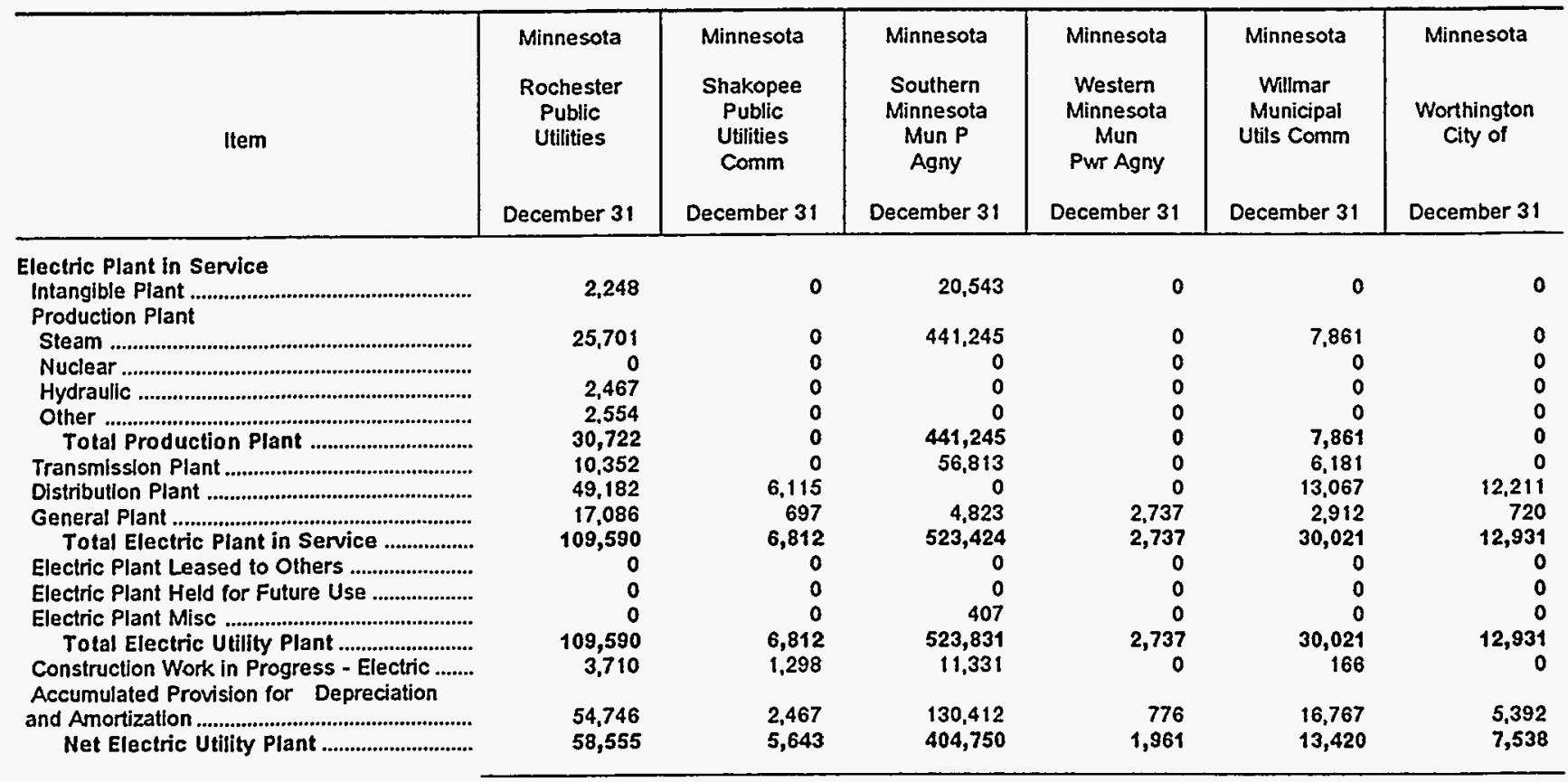

\begin{tabular}{|c|c|c|c|c|c|c|}
\hline Item & $\begin{array}{l}\text { Mississippi } \\
\text { Aberdeen } \\
\text { City of } \\
\text { June } \mathbf{3 0}\end{array}$ & $\begin{array}{l}\text { Mississippi } \\
\text { Clarksdale } \\
\text { City of } \\
\text { September } 30\end{array}$ & $\begin{array}{l}\text { Mississippi } \\
\text { Columbus } \\
\text { City of } \\
\text { June } 30\end{array}$ & $\begin{array}{l}\text { Mississippi } \\
\text { Greenwood } \\
\text { Utilities } \\
\text { Comm } \\
\text { September } 30\end{array}$ & $\begin{array}{l}\text { Mississippi } \\
\text { Holly } \\
\text { Springs } \\
\text { City of } \\
\text { June } 30\end{array}$ & $\begin{array}{l}\text { Mississippi } \\
\text { Louisville } \\
\text { Electric } \\
\text { System } \\
\text { June } 30\end{array}$ \\
\hline 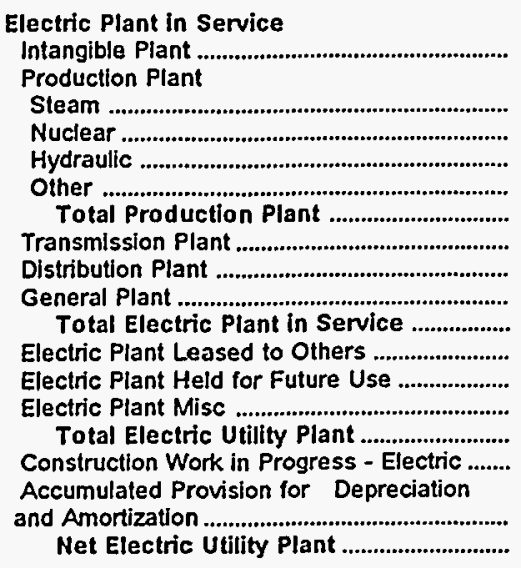 & $\begin{array}{r}0 \\
0 \\
0 \\
0 \\
0 \\
0 \\
3,729 \\
934 \\
4,663 \\
0 \\
0 \\
0 \\
4,663 \\
12 \\
\\
2,241 \\
2,434\end{array}$ & $\begin{array}{r}0 \\
15,199 \\
0 \\
0 \\
0 \\
15,199 \\
3,702 \\
7,134 \\
1,260 \\
27,295 \\
0 \\
0 \\
0 \\
27,295 \\
280\end{array}$ & $\begin{array}{r}0 \\
0 \\
0 \\
0 \\
0 \\
0 \\
10 \\
14,744 \\
2,088 \\
16,843 \\
0 \\
0 \\
0 \\
16,843 \\
50\end{array}$ & $\begin{array}{r}13,784 \\
0 \\
0 \\
1,163 \\
14,946 \\
731 \\
8,899 \\
2,416 \\
26,992 \\
0 \\
0 \\
0 \\
26,992 \\
4,298 \\
16,194 \\
15,097\end{array}$ & $\begin{array}{r}0 \\
0 \\
0 \\
0 \\
0 \\
0 \\
11,910 \\
2,254 \\
14,165 \\
0 \\
0 \\
0 \\
14,165 \\
126 \\
\\
5,459 \\
8,832\end{array}$ & $\begin{array}{r}0 \\
0 \\
0 \\
0 \\
0 \\
202 \\
7,654 \\
1,191 \\
9,047 \\
0 \\
0 \\
0 \\
9,047 \\
155\end{array}$ \\
\hline
\end{tabular}

Note: Totais may not equal sum of components because of independent rounding.

Source: Energy Information Administration, Form EIA-412. "Annual Report of Public Electric Utilities." 
Table 24. Electric Utility Plant by Major U.S. Publicly Owned Electric Utility Within State at End of Period, 1995

(Thousand Dollars)

\begin{tabular}{|c|c|c|c|c|c|c|}
\hline Item & $\begin{array}{l}\text { Mississippi } \\
\text { Municipal } \\
\text { Energy } \\
\text { Agency } \\
\text { of MS } \\
\text { September } 30\end{array}$ & $\begin{array}{l}\text { Mississippi } \\
\text { New Albany } \\
\text { City of } \\
\text { June } 30\end{array}$ & $\begin{array}{l}\text { Mississippi } \\
\text { Oxford } \\
\text { City of } \\
\text { June } 30\end{array}$ & $\begin{array}{c}\text { Starkville } \\
\text { City of } \\
\text { June } 30\end{array}$ & $\begin{array}{l}\text { Mississippi } \\
\text { Tupelo } \\
\text { City of } \\
\text { June } 30\end{array}$ & $\begin{array}{l}\text { Mississippi } \\
\text { West } \\
\text { Point } \\
\text { City of } \\
\text { June } 30\end{array}$ \\
\hline \multicolumn{7}{|l|}{ Electric Plant in Service } \\
\hline $\begin{array}{l}\text { Intangible Plant } \\
\text { Production Plant }\end{array}$ & 196 & 0 & 0 & 0 & 0 & 0 \\
\hline Steam & 0 & 0 & 0 & 0 & 0 & 0 \\
\hline Nuclear & 0 & 0 & 0 & 0 & 0 & 0 \\
\hline Hydraulic & 0 & 0 & 0 & 0 & 0 & 0 \\
\hline Other & 297 & 0 & 0 & 0 & 0 & 0 \\
\hline 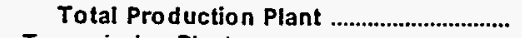 & 297 & o & 0 & 0 & 0 & 0 \\
\hline 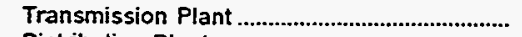 & 0 & 0 & 0 & 303 & 876 & 76 \\
\hline 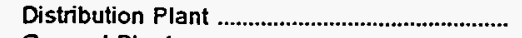 & 0 & 11,041 & 5,200 & 10,529 & 21,777 & 6,168 \\
\hline General Plant & 278 & 1,263 & 967 & 2,054 & 2.110 & 888 \\
\hline Total Electric Plant in Service ..................... & 771 & 12,304 & 6,168 & 12,885 & 24,764 & 7,132 \\
\hline 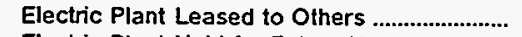 & 0 & 0 & 0 & 0 & 0 & 0 \\
\hline Electric Plant Held for Future Use .................... & 0 & 0 & 0 & 20 & 0 & 0 \\
\hline 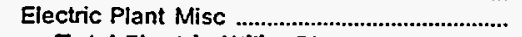 & 0 & 0 & 0 & 0 & 0 & 0 \\
\hline Total Electric Utility Plant & 771 & 12,304 & 6,168 & 12,906 & 24,764 & 7,132 \\
\hline $\begin{array}{l}\text { Construction Work in Progress - Electric ........ } \\
\text { Accumulated Provision for Depreciation }\end{array}$ & 8,713 & 527 & 2,201 & 3,271 & 81 & 275 \\
\hline and Amortization & 216 & 4,483 & 2,339 & 4,353 & 7,988 & 2,681 \\
\hline 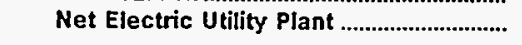 & 9,268 & 8,348 & 6,030 & 11,823 & 16,857 & 4,726 \\
\hline
\end{tabular}

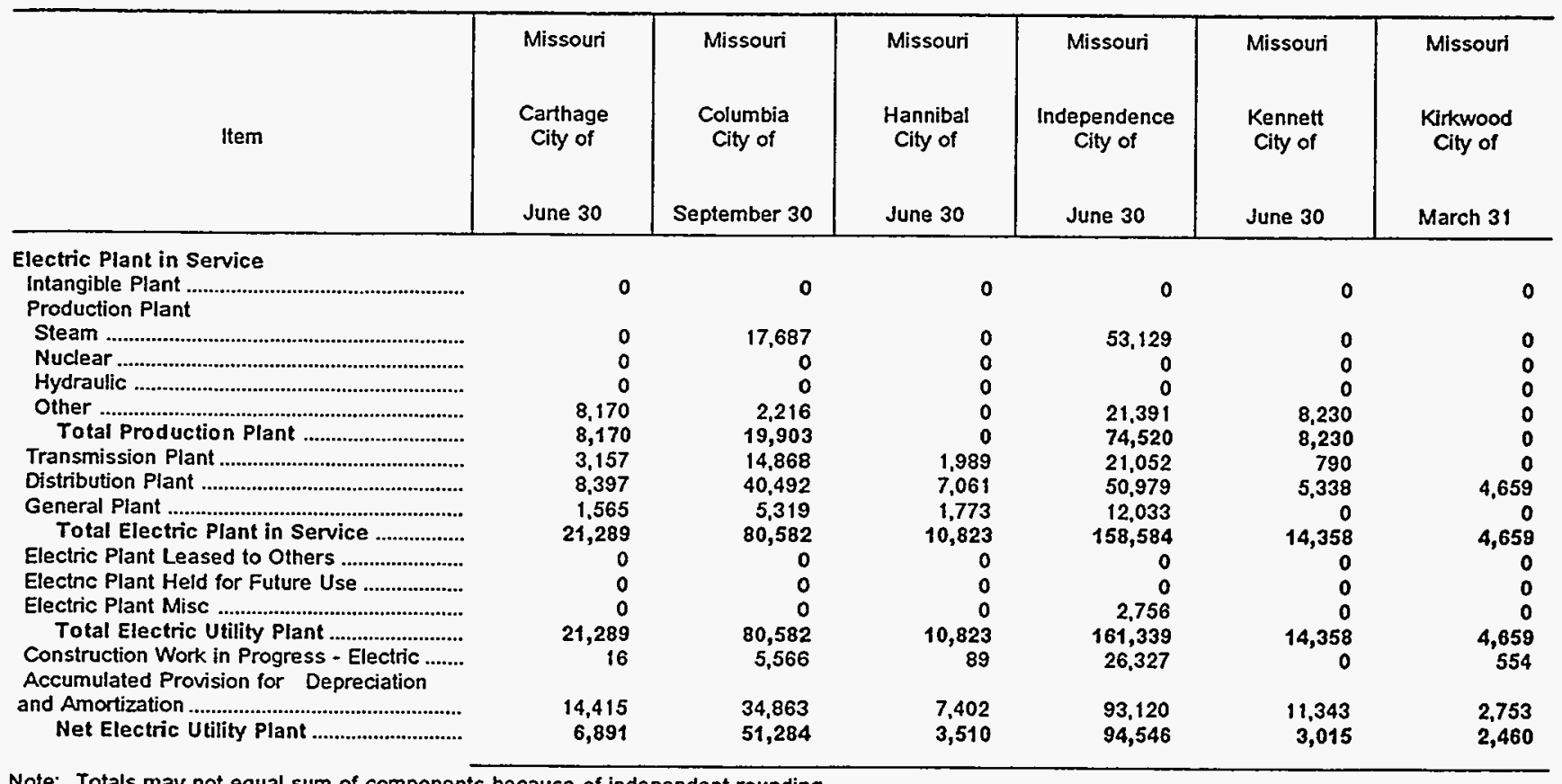

Note: Totals may not equal sum of components because of independent rounding.

Source: Energy Information Administration, Form EIA-412, "Annual Report of Public Electric Utilities." 
Table 24. Electric Utility Plant by Major U.S. Publicly Owned Electric Utility Within State at End of Period, 1995 (Continued)

(Thousand Dollars)

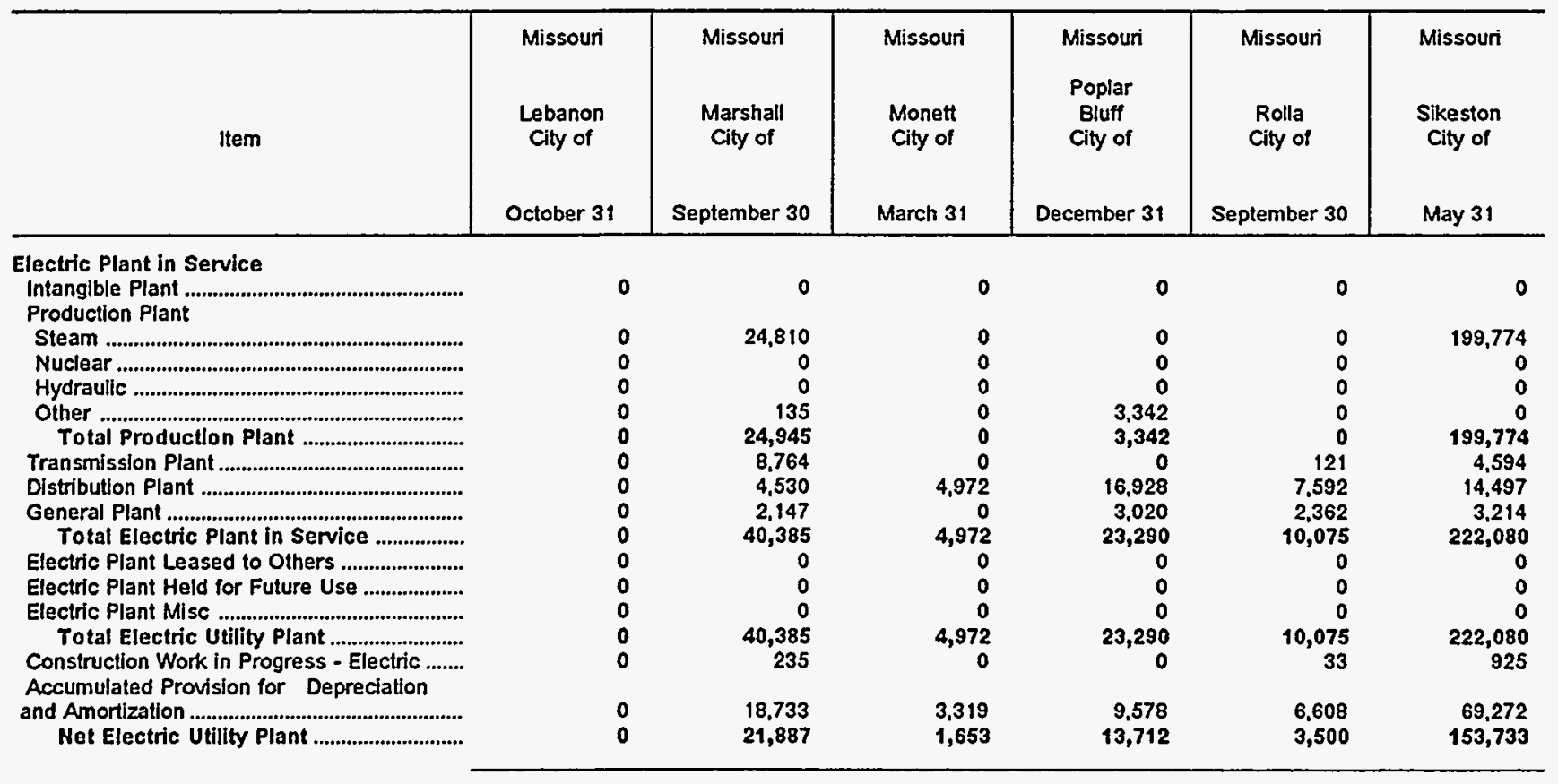

\begin{tabular}{|c|c|c|c|c|c|c|}
\hline Item & $\begin{array}{l}\text { Missouri } \\
\begin{array}{c}\text { Springfield } \\
\text { City of }\end{array} \\
\text { September } 30\end{array}$ & $\begin{array}{l}\text { Missouri } \\
\text { West } \\
\text { Plains } \\
\text { City of } \\
\text { December } 31\end{array}$ & $\begin{array}{l}\text { Nebraska } \\
\text { Beatrice } \\
\text { City of } \\
\text { July } 31\end{array}$ & $\begin{array}{c}\text { Nebraska } \\
\text { Central } \\
\text { Nebraska } \\
\text { Pub } \\
\text { P\&l Dist } \\
\text { December } 31\end{array}$ & $\begin{array}{c}\text { Nebraska } \\
\text { Cornhusker } \\
\text { Public } \\
\text { Power Dist } \\
\\
\text { December } 31\end{array}$ & $\begin{array}{c}\text { Nebraska } \\
\text { Dawson } \\
\text { County } \\
\text { Public } \\
\text { Pwr Dist } \\
\text { December } 31\end{array}$ \\
\hline \multicolumn{7}{|l|}{ Electric Plant in Service } \\
\hline 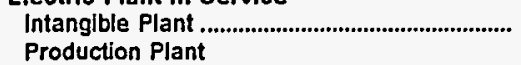 & 0 & 0 & 13,059 & 16,196 & 1 & 3 \\
\hline Steam & 175,208 & 0 & 0 & $\mathbf{0}$ & $\mathbf{0}$ & 0 \\
\hline Nuclear & 0 & 0 & 0 & $\mathbf{0}$ & 0 & $\mathbf{0}$ \\
\hline 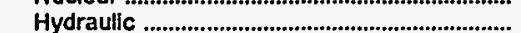 & 0 & 0 & 0 & 96,446 & 0 & 0 \\
\hline Other & 51,604 & 0 & 0 & 0 & 0 & 0 \\
\hline Total Production Plant & 226,812 & $\mathbf{0}$ & 0 & 96,446 & 0 & $\mathbf{0}$ \\
\hline 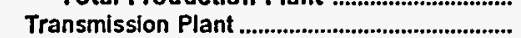 & 49,784 & 0 & 0 & 1,873 & 3,180 & 5,007 \\
\hline Dlstribution Plant & 140,907 & 5,425 & 0 & 0 & 27,370 & 38,316 \\
\hline $\begin{array}{l}\text { General Plant } \\
\text { Total Electric Plant in Service }\end{array}$ & $\begin{array}{r}9,307 \\
426,810\end{array}$ & $\begin{array}{r}0 \\
5,425\end{array}$ & $\begin{array}{r}0 \\
13,059\end{array}$ & $\begin{array}{r}4,300 \\
118,815\end{array}$ & $\begin{array}{r}3,537 \\
34,088\end{array}$ & $\begin{array}{r}4,776 \\
48,102\end{array}$ \\
\hline Electric Plant Leased to Others ....................... & 0 & 0 & 0 & 0 & 0 & 4 \\
\hline Electric Plant Held for Future Use ................... & 0 & 0 & 0 & 0 & 0 & 1 \\
\hline 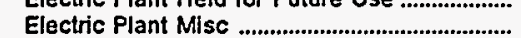 & 0 & 0 & 0 & 0 & 0 & 0 \\
\hline 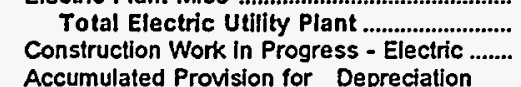 & $\begin{array}{r}426,810 \\
13,512\end{array}$ & $\begin{array}{r}5,425 \\
0\end{array}$ & $\begin{array}{r}13,059 \\
1,182\end{array}$ & $\begin{array}{r}118,815 \\
120\end{array}$ & $\begin{array}{r}34,088 \\
125\end{array}$ & $\begin{array}{r}48,106 \\
2,521\end{array}$ \\
\hline 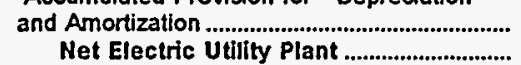 & $\begin{array}{l}134,805 \\
305,517\end{array}$ & $\begin{array}{r}0 \\
5,425\end{array}$ & $\begin{array}{l}7,589 \\
6,652\end{array}$ & $\begin{array}{l}39,937 \\
78,997\end{array}$ & $\begin{array}{l}10,902 \\
23,311\end{array}$ & $\begin{array}{l}20,641 \\
29,986\end{array}$ \\
\hline
\end{tabular}

Note: Totals may not equal sum of components because of independent rounding.

Source: Energy Information Administration, Form EIA-412، "Annual Report of Public Electric Utilities." 
Table 24. Electric Utility Plant by Major U.S. Publicly Owned Electric Utility Within State at End of Period, 1995 (Continued)

(Thousand Dollars)

\begin{tabular}{|c|c|c|c|c|c|c|}
\hline Item & $\begin{array}{l}\text { Nebraska } \\
\text { Fremont } \\
\text { City of } \\
\text { July } 31\end{array}$ & $\begin{array}{c}\text { Nebraska } \\
\text { Grand Island } \\
\text { City of } \\
\text { July } 31\end{array}$ & $\begin{array}{c}\text { Nebraska } \\
\text { Hastings } \\
\text { City of } \\
\text { December } 31\end{array}$ & $\begin{array}{c}\text { Nebraska } \\
\text { Lincoln } \\
\text { Electric } \\
\text { System } \\
\text { December } 31\end{array}$ & $\begin{array}{c}\text { Nebraska } \\
\text { Loup } \\
\text { River } \\
\text { Public } \\
\text { Power Dist } \\
\text { December } 31\end{array}$ & $\begin{array}{c}\text { Nebraska } \\
\text { Municipal } \\
\text { Energy } \\
\text { Agency } \\
\text { of NE } \\
\text { March } 31\end{array}$ \\
\hline $\begin{array}{l}\text { Electric Plant in Service } \\
\text { Intangible Plant } \\
\text { Production Plant }\end{array}$ & 0 & 3,116 & 0 & 10,188 & 0 & 28,305 \\
\hline Steam & 49,714 & 119,205 & 75,835 & 139,403 & 0 & 0 \\
\hline Nuclear & 0 & 0 & 0 & 0 & 0 & 0 \\
\hline 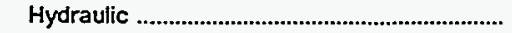 & 0 & 0 & 0 & 0 & 10,471 & 0 \\
\hline Other & 0 & 0 & 2,628 & 13,068 & 0 & 0 \\
\hline Total Production Plant ............................... & 49,714 & 119,205 & 78,463 & 152,471 & 10,471 & $\mathbf{0}$ \\
\hline Transmission Plant & 289 & 10,746 & 9,668 & 86,346 & 14,894 & 0 \\
\hline Distribution Plant & 12,979 & 28,437 & 16,885 & 168,721 & 23,590 & 0 \\
\hline General Plant & 4,062 & 2,889 & 2,352 & 28,666 & 8,442 & 0 \\
\hline Total Electric Plant in Service ..................... & 67,044 & 164,393 & 107,369 & 446,392 & 57,397 & 28,305 \\
\hline Electric Plant Leased to Others ........................... & 0 & 0 & 0 & 0 & 0 & 0 \\
\hline Electric Plant Held for Future Use ................... & 0 & 0 & 0 & 0 & 0 & 0 \\
\hline 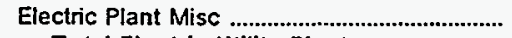 & 0 & 2,167 & 0 & 4,829 & 407 & 5,143 \\
\hline Total Electric Utility Plant & 67,044 & 166,560 & 107,369 & 451,221 & 57,804 & 33,449 \\
\hline $\begin{array}{l}\text { Construction Work in Progress - Electric ........ } \\
\text { Accumulated Provision for Depreciation }\end{array}$ & 1,494 & 1,211 & 433 & 45,560 & 3,815 & 0 \\
\hline 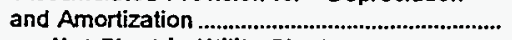 & 49,538 & 72,059 & 39,730 & 150,576 & 25.725 & 2,523 \\
\hline 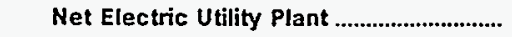 & 19,000 & 95,712 & 68,072 & 346,206 & 35,894 & 30,926 \\
\hline
\end{tabular}

\begin{tabular}{|c|c|c|c|c|c|c|}
\hline Item & $\begin{array}{c}\text { Nebraska } \\
\text { Nebraska } \\
\text { Public } \\
\text { Power } \\
\text { District } \\
\text { December } 31\end{array}$ & $\begin{array}{c}\text { Nebraska } \\
\text { Norris } \\
\text { Public } \\
\text { Power } \\
\text { District } \\
\text { December } 31\end{array}$ & $\begin{array}{l}\text { Nebraska } \\
\text { North } \\
\text { Platte } \\
\text { City of } \\
\\
\text { July } 31\end{array}$ & $\begin{array}{c}\text { Nebraska } \\
\text { Omaha Public } \\
\text { Power } \\
\text { District } \\
\text { December } 31\end{array}$ & $\begin{array}{c}\text { Nebraska } \\
\text { Southern } \\
\text { Nebraska Rural } \\
\text { P P D } \\
\text { December } 31\end{array}$ & $\begin{array}{l}\text { Nevada } \\
\text { Colorado } \\
\text { River } \\
\text { Comm } \\
\text { of Nevada } \\
\text { June } 30\end{array}$ \\
\hline \multicolumn{7}{|l|}{ Electric Plant in Service } \\
\hline $\begin{array}{l}\text { Intangible Plant ................................................. } \\
\text { Production Plant }\end{array}$ & 3,374 & 2 & 0 & 0 & 0 & 0 \\
\hline Steam & 763,521 & 0 & 0 & 650,732 & 0 & 0 \\
\hline Nuclear & 353,692 & 0 & 0 & 422,448 & 0 & 0 \\
\hline 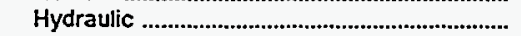 & 22,065 & 0 & 0 & 0 & 0 & 0 \\
\hline Other & 15.962 & 0 & 0 & 21,324 & 0 & 0 \\
\hline 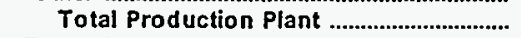 & $1,155,241$ & $\mathbf{0}$ & 0 & $1,094,504$ & $\mathbf{0}$ & 0 \\
\hline 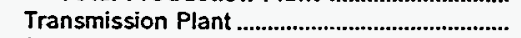 & 455,448 & 7,737 & 592 & 165,342 & 3,440 & 0 \\
\hline 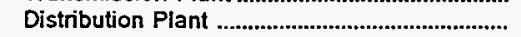 & 117,219 & 47,048 & 10,262 & 614,668 & 65,658 & 0 \\
\hline 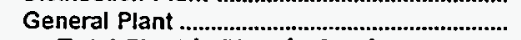 & 118,164 & 7,537 & 2,890 & 176,859 & 6,485 & 0 \\
\hline Total Electric Plant in Service ................... & $1,849,446$ & 62,324 & 13,744 & $2,051,374$ & 75,583 & 0 \\
\hline 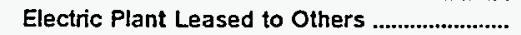 & 0 & 0 & 0 & 0 & 0 & 0 \\
\hline Electric Plant Held for Future Use ................... & 0 & 0 & 0 & 0 & 0 & 0 \\
\hline 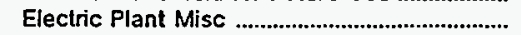 & 0 & 459 & 0 & 7.998 & 0 & 0 \\
\hline 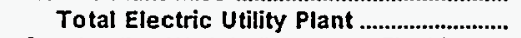 & $1,849,446$ & 62,783 & 13,744 & $2,059,371$ & 75,583 & $\mathbf{0}$ \\
\hline $\begin{array}{l}\text { Construction Work in Progress - Electric ....... } \\
\text { Accumulated Provision for Depreciation }\end{array}$ & 255,741 & 472 & 783 & 109,036 & 413 & 0 \\
\hline 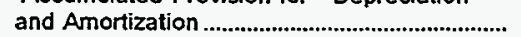 & 865,968 & 20,075 & 8.572 & 774,687 & 34,285 & 0 \\
\hline Net Electric Utility Plant ................................ & $1,239,219$ & 43,180 & 5,955 & $1,393,721$ & 41,711 & 0 \\
\hline
\end{tabular}

Note: Totals may not equal sum of components because of independent rounding.

Source: Energy Information Administration, Form EIA-412, "Annual Report of Public Electric Utilities." 
Table 24. Electric Utility Plant by Major U.S. Publicly Owned Electric Utility Within State at End of Period, 1995 (Continued)

(Thousand Dollars)

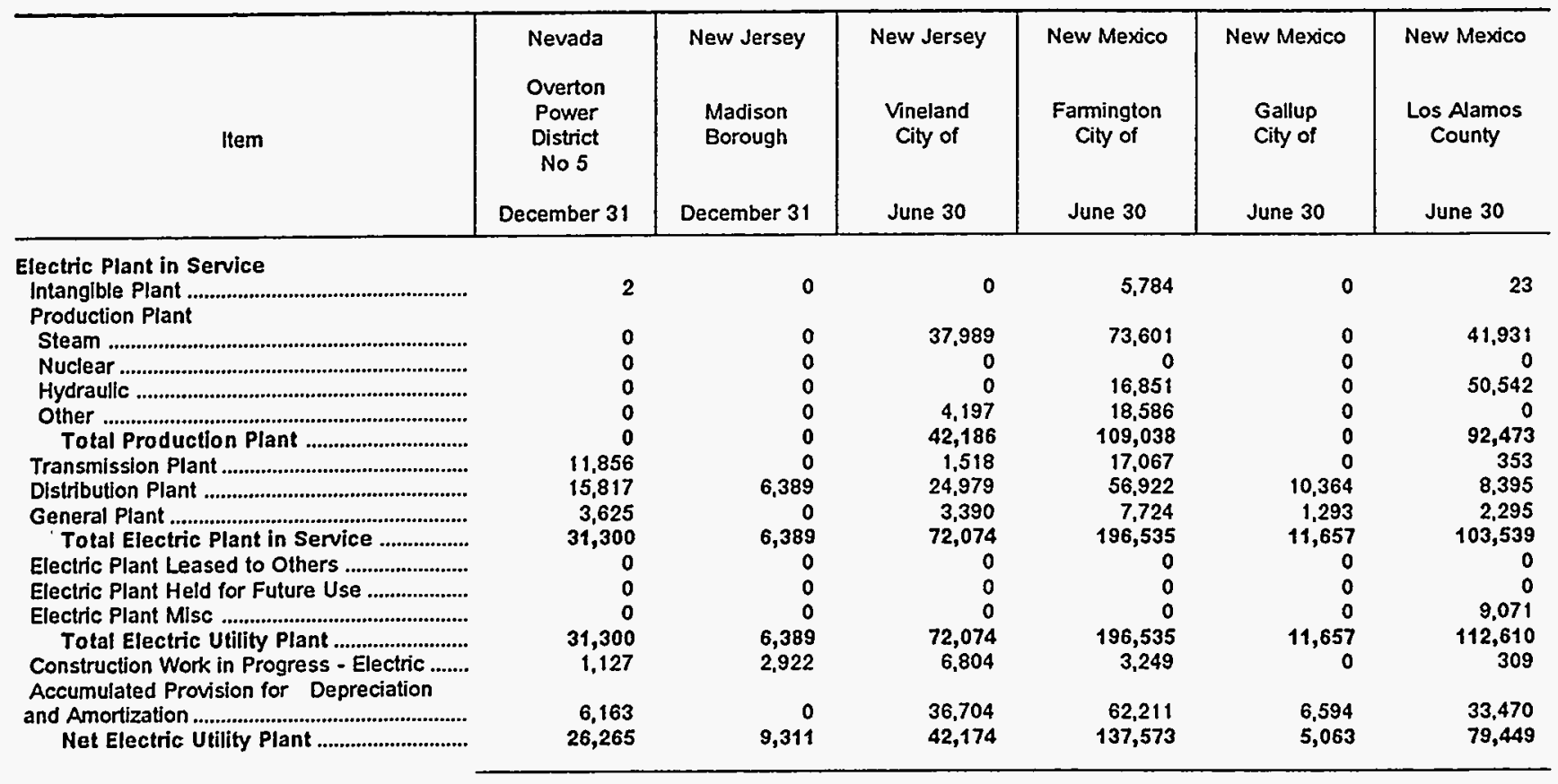

\begin{tabular}{|c|c|c|c|c|c|c|}
\hline Item & $\begin{array}{l}\text { New York } \\
\text { Fairport } \\
\text { Village of } \\
\text { May } 31\end{array}$ & $\begin{array}{c}\text { New York } \\
\text { Freeport } \\
\text { Village of } \\
\text { Inc }\end{array}$ & $\begin{array}{c}\text { New York } \\
\text { Jamestown } \\
\text { City of } \\
\text { December } 31\end{array}$ & $\begin{array}{l}\text { New York } \\
\text { Lake Placid } \\
\text { Village inc } \\
\text { July } 31\end{array}$ & $\begin{array}{c}\text { New York } \\
\text { Massena } \\
\text { Town of } \\
\text { December } 31\end{array}$ & $\begin{array}{l}\text { New York } \\
\text { Plattsburgh } \\
\text { City of } \\
\text { December } 31\end{array}$ \\
\hline 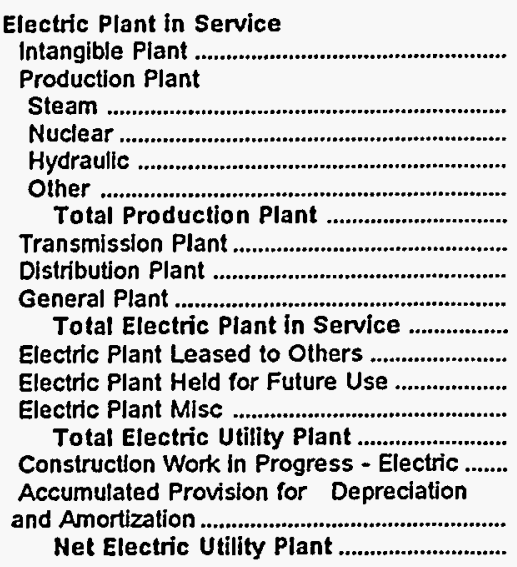 & $\begin{array}{r}0 \\
0 \\
0 \\
0 \\
0 \\
3,915 \\
11,785 \\
1,496 \\
17,197 \\
0 \\
0 \\
0 \\
17,197 \\
7\end{array}$ & $\begin{array}{r}0 \\
0 \\
0 \\
0 \\
14,262 \\
14,262 \\
1,763 \\
13,119 \\
1,880 \\
31,025 \\
0 \\
13 \\
0 \\
31,038 \\
4,578\end{array}$ & $\begin{array}{r}48,050 \\
0 \\
0 \\
0 \\
48,050 \\
7,804 \\
22,937 \\
4,373 \\
83,164 \\
0 \\
0 \\
0 \\
83,164 \\
1,500\end{array}$ & $\begin{array}{r}1 \\
0 \\
0 \\
0 \\
0 \\
0 \\
0 \\
11,467 \\
775 \\
12,242 \\
0 \\
0 \\
0 \\
12,242 \\
0\end{array}$ & $\begin{array}{r}0 \\
0 \\
0 \\
0 \\
0 \\
4,785 \\
10,171 \\
1,568 \\
18,687 \\
0 \\
0 \\
4,448 \\
23,135 \\
34 \\
8,471 \\
14,698\end{array}$ & $\begin{array}{r}0 \\
0 \\
0 \\
0 \\
0 \\
7,959 \\
17,488 \\
4,189 \\
29,641 \\
0 \\
0 \\
0 \\
29,641 \\
1,049 \\
\\
12,168 \\
18,522\end{array}$ \\
\hline
\end{tabular}

Note: Totals may not equal sum of components because of independent rounding.

Source: Energy Information Administration, Form ElA-412, "Annual Report of Public Electric Utilities." 
Table 24. Electric Utility Plant by Major U.S. Publicly Owned Electric Utility Within State at End of Period, 1995 (Continued)

(Thousand Dollars)

\begin{tabular}{|c|c|c|c|c|c|c|}
\hline Item & $\begin{array}{c}\text { New York } \\
\text { Power } \\
\text { Authority } \\
\text { of State of NY } \\
\text { December } 31\end{array}$ & $\begin{array}{l}\text { New York } \\
\text { Rockville } \\
\text { Centre } \\
\text { Village of } \\
\text { May } 31\end{array}$ & $\begin{array}{c}\text { New York } \\
\text { Solvay } \\
\text { Village of } \\
\text { May } 31\end{array}$ & $\begin{array}{l}\text { North Carolina } \\
\text { Albemare } \\
\text { City of } \\
\text { June } 30\end{array}$ & $\begin{array}{l}\text { North Carolina } \\
\text { Concord } \\
\text { City of } \\
\text { June } 30\end{array}$ & $\begin{array}{l}\text { North Carolina } \\
\text { Elizabeth } \\
\text { City City of } \\
\text { June } 30\end{array}$ \\
\hline 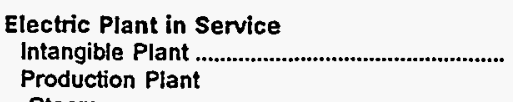 & 0 & 0 & 0 & 0 & 0 & 0 \\
\hline Steam & 437,474 & 0 & 0 & 0 & 0 & 0 \\
\hline 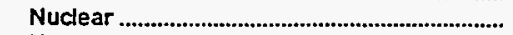 & $1,517,966$ & 0 & 0 & 0 & 0 & 0 \\
\hline 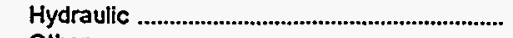 & $1,409,054$ & 0 & 0 & 0 & 0 & 0 \\
\hline Other & 0 & 8,917 & 0 & 0 & 0 & 0 \\
\hline Total Production Plant ................................. & $3,364,494$ & 8,917 & 0 & 0 & 0 & 0 \\
\hline Transmission Plant & $1,479,698$ & 5.464 & 0 & 0 & 0 & 0 \\
\hline 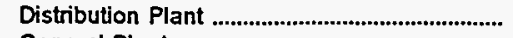 & 0 & 13,683 & 10,576 & 17,862 & 0 & 19,561 \\
\hline 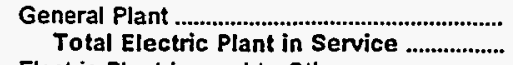 & $\begin{array}{r}244,171 \\
5,088,363\end{array}$ & $\begin{array}{r}1,135 \\
29,200\end{array}$ & $\begin{array}{r}0 \\
10,576\end{array}$ & $\begin{array}{r}951 \\
18,813\end{array}$ & $\begin{array}{l}38,889 \\
38,889\end{array}$ & $\begin{array}{r}5,378 \\
24,939\end{array}$ \\
\hline 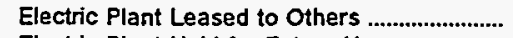 & 0 & 0 & 0 & 0 & 0 & 0 \\
\hline Electric Plant Held for Future Use ................... & 0 & 0 & 0 & 0 & 0 & 0 \\
\hline Electric Plant Misc & 0 & 0 & 0 & 0 & 0 & 0 \\
\hline $\begin{array}{l}\text { Total Electric Utility Plant } \\
\text { Construction Work in Progress - Electric ............................. } \\
\text { Accumulated Provision for Depreciation }\end{array}$ & $\begin{array}{c}5,088,363 \\
203,691\end{array}$ & $\begin{array}{r}29,200 \\
7,781\end{array}$ & $\begin{array}{r}10,576 \\
69\end{array}$ & $\begin{array}{r}18,813 \\
0\end{array}$ & $\begin{array}{r}38,889 \\
0\end{array}$ & $\begin{array}{r}24,939 \\
0\end{array}$ \\
\hline $\begin{array}{l}\text { and Amortization } \\
\text { Net Electric Utility Plant }\end{array}$ & $\begin{array}{l}1,866,964 \\
3,425,090\end{array}$ & $\begin{array}{l}14,426 \\
22,554\end{array}$ & $\begin{array}{l}4,300 \\
6,344\end{array}$ & $\begin{array}{r}10,963 \\
7,850\end{array}$ & $\begin{array}{l}20,324 \\
18,565\end{array}$ & $\begin{array}{r}8,909 \\
16,030\end{array}$ \\
\hline
\end{tabular}

\begin{tabular}{|c|c|c|c|c|c|c|}
\hline Item & $\begin{array}{c}\text { North Carolina } \\
\text { Fayetteville } \\
\text { Public } \\
\text { Works Comm } \\
\text { June } 30\end{array}$ & $\begin{array}{l}\text { North Carolina } \\
\text { Forest City } \\
\text { Town of } \\
\text { June } 30\end{array}$ & $\begin{array}{c}\text { North Carolina } \\
\text { Gastonia } \\
\text { City of } \\
\text { June } 30\end{array}$ & $\begin{array}{c}\text { North Carolina } \\
\text { Greenville } \\
\text { Utilities } \\
\text { Comm } \\
\text { June } 30\end{array}$ & $\begin{array}{c}\text { North Carolina } \\
\text { High } \\
\text { Point } \\
\text { Town } \\
\text { of } \\
\text { June } 30\end{array}$ & $\begin{array}{l}\text { North Carolina } \\
\text { Kinston } \\
\text { City of } \\
\text { June } 30\end{array}$ \\
\hline \multicolumn{7}{|l|}{ Electric Plant in Service } \\
\hline $\begin{array}{l}\text { Intangible Plant } \\
\text { Production Plant }\end{array}$ & 1,371 & 0 & 0 & 0 & 0 & $\mathbf{0}$ \\
\hline Steam & 58,882 & 0 & $\mathbf{0}$ & 0 & 0 & 0 \\
\hline 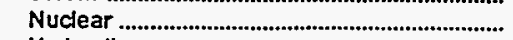 & 0 & 0 & 0 & 0 & 0 & 0 \\
\hline 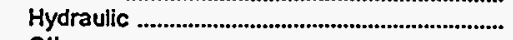 & 0 & 0 & 0 & 0 & 0 & 0 \\
\hline Other & 39,797 & 0 & 0 & 0 & 0 & 0 \\
\hline 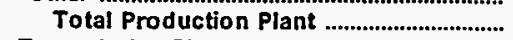 & 98,678 & 0 & $\mathbf{0}$ & 0 & 0 & 0 \\
\hline 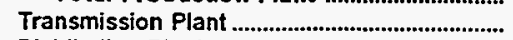 & 23,394 & 0 & 42,987 & 0 & 0 & o \\
\hline 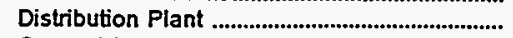 & 89.300 & 5,008 & 0 & 81,506 & 0 & 14,596 \\
\hline General Plant & 15,133 & 316 & 0 & 10,779 & 62,214 & 5,641 \\
\hline Total Electric Plant in Service ..................... & 227,877 & 5,324 & 42,987 & 92,286 & 62,214 & 20,237 \\
\hline Electric Plant Leased to Others ........................ & 0 & 0 & 0 & 0 & 0 & 0 \\
\hline Electric Plant Held for Future Use ..................... & 0 & 0 & 0 & 0 & 0 & 0 \\
\hline 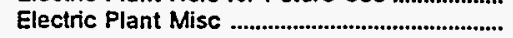 & 0 & 0 & 0 & 0 & 0 & 0 \\
\hline Total Electric Utility Plant & 227,877 & 5,324 & 42,987 & 92,286 & 62,214 & 20,237 \\
\hline $\begin{array}{l}\text { Construction Work in Progress - Electric ........ } \\
\text { Accumulated Provision for Depreciation }\end{array}$ & 13,467 & 0 & 0 & 3,183 & 0 & 855 \\
\hline and Amortization & 73,572 & 2,614 & 22,290 & 47.214 & 25,347 & 8,535 \\
\hline Net Electric Utility Plant & 167,772 & 2,710 & 20,697 & 48,254 & 36,868 & 12,557 \\
\hline
\end{tabular}

Source: Energy Information Administration, Form EIA-412, "Annual Report of Public Electric Utilities." 
Table 24. Electric Utility Plant by Major U.S. Publicly Owned Electric Utility Within State at End of Period, 1995

(Thousand Dollars)

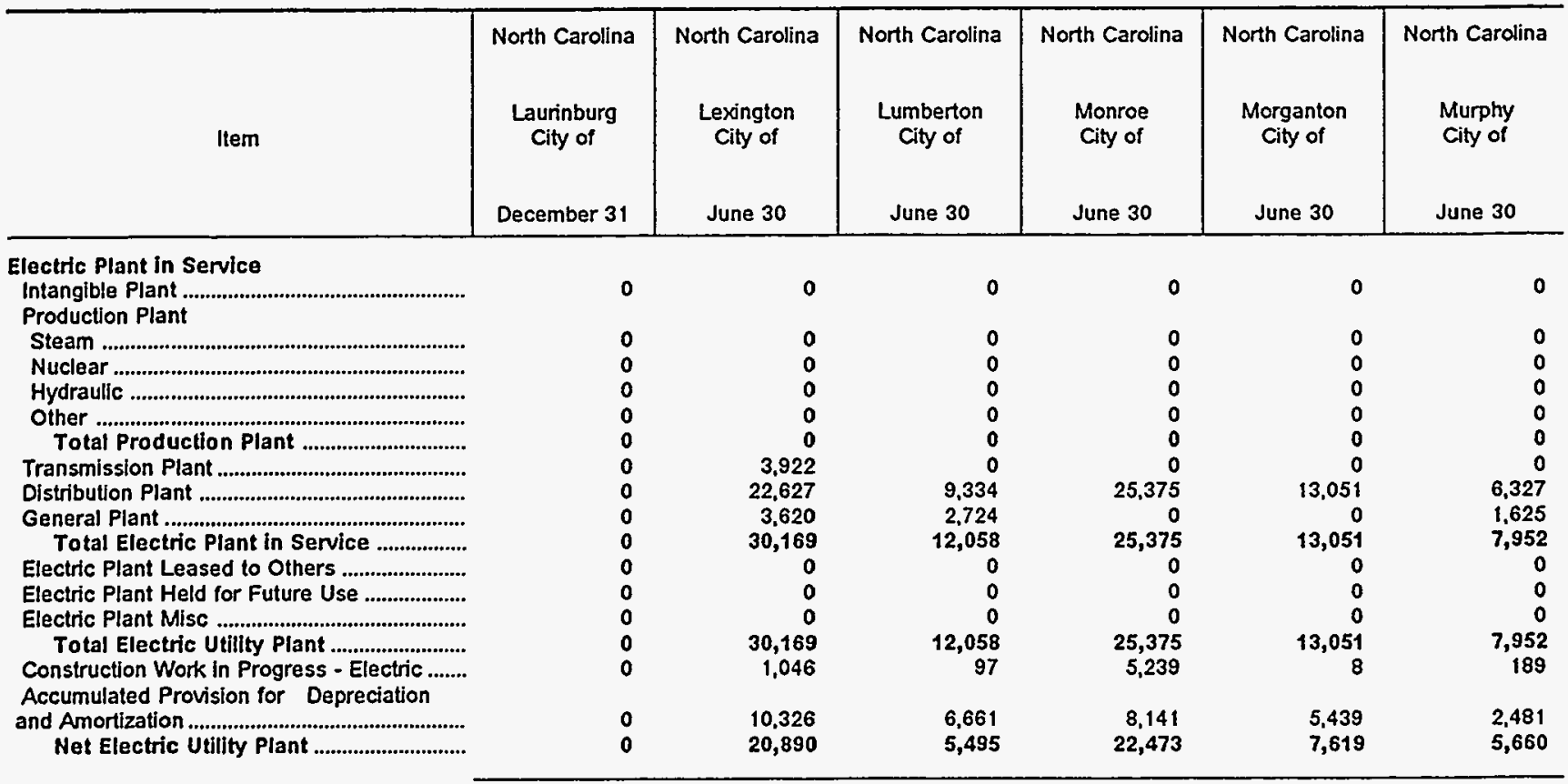

\begin{tabular}{|c|c|c|c|c|c|c|}
\hline Item & $\begin{array}{l}\text { North Carolina } \\
\text { New Bern } \\
\text { City of } \\
\text { June } 30\end{array}$ & $\begin{array}{l}\text { North Carolina } \\
\text { New River } \\
\text { Light } \\
\text { \& } \\
\text { Power Co } \\
\text { December } 31\end{array}$ & $\begin{array}{c}\text { North Carolina } \\
\text { North } \\
\text { Carolina } \\
\text { Eastern M P A } \\
\text { December } 31\end{array}$ & $\begin{array}{c}\text { North Carolina } \\
\text { North } \\
\text { Carolina } \\
\text { Mun } \\
\text { Power Agny } \\
\text { December } 31\end{array}$ & $\begin{array}{l}\text { North Carolina } \\
\text { Rocky Mount } \\
\text { City of } \\
\text { June } 30\end{array}$ & $\begin{array}{l}\text { North Carolina } \\
\text { Shelby } \\
\text { City of } \\
\text { June } 30\end{array}$ \\
\hline \multicolumn{7}{|l|}{ Electric Plant In Service } \\
\hline 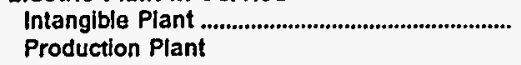 & 0 & 0 & 0 & 0 & 0 & 0 \\
\hline 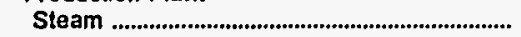 & 0 & 0 & 130,183 & 0 & 0 & 0 \\
\hline 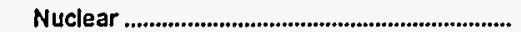 & 0 & 0 & $1,171,355$ & $1,394,481$ & 0 & 0 \\
\hline 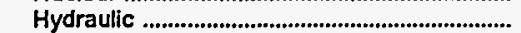 & 0 & 0 & 0 & 0 & 0 & 0 \\
\hline Other & 0 & 0 & 0 & 0 & 0 & 0 \\
\hline Total Production Plant & 0 & $\mathbf{0}$ & $1,301,538$ & $1,394,481$ & $\mathbf{0}$ & 0 \\
\hline 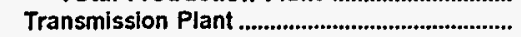 & 0 & 0 & 0 & 10,959 & 0 & 0 \\
\hline 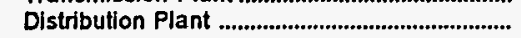 & 0 & 9,995 & 0 & 0 & 38,736 & 8,925 \\
\hline 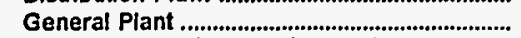 & 24,024 & 2,286 & 134,193 & 0 & 0 & 0 \\
\hline Total Electric Plant in Service & 24,024 & 12,281 & $1,435,731$ & $1,405,440$ & 38,736 & 8,925 \\
\hline Electric Plant Leased to Others ........................ & 0 & 0 & 0 & 0 & 0 & 0 \\
\hline Electric Plant Held for Future Use ................... & 0 & 0 & 0 & 0 & 0 & 0 \\
\hline 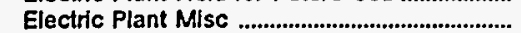 & 0 & 0 & 0 & 0 & 0 & 0 \\
\hline Total Electric Utility Plant ............................ & 24,024 & 12,281 & $1,435,731$ & $1,405,440$ & 38,736 & 8,925 \\
\hline $\begin{array}{l}\text { Construction Work in Progress - Electric ....... } \\
\text { Accumulated Provision for Depreciation }\end{array}$ & 258 & 86 & 14.617 & 34,602 & 0 & 0 \\
\hline 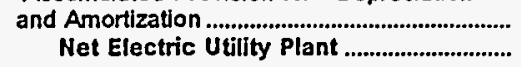 & $\begin{array}{l}10,594 \\
13,687\end{array}$ & $\begin{array}{l}3,205 \\
9,162\end{array}$ & $\begin{array}{r}445,793 \\
1,004,555\end{array}$ & $\begin{array}{r}372,622 \\
1,067,420\end{array}$ & $\begin{array}{l}15,258 \\
23,479\end{array}$ & $\begin{array}{l}4,872 \\
4,053\end{array}$ \\
\hline
\end{tabular}

Note: Totals may not equal sum of components because of independent rounding.

Source: Energy Information Administration, Form EIA-412, "Annual Report of Public Electric Utilities." 
Table 24. Electric Utility Plant by Major U.S. Publicly Owned Electric Utility Within State at End of Period, 1995 (Continued)

(Thousand Dollars)

\begin{tabular}{|c|c|c|c|c|c|c|}
\hline Item & $\begin{array}{c}\text { North Carolina } \\
\text { Statesville } \\
\text { City of } \\
\text { June } 30\end{array}$ & $\begin{array}{c}\text { North Carolina } \\
\text { Tarboro } \\
\text { Town of } \\
\text { June } 30\end{array}$ & $\begin{array}{c}\text { North Carolina } \\
\begin{array}{c}\text { Washington } \\
\text { City of }\end{array} \\
\text { June } 30\end{array}$ & $\begin{array}{l}\text { North Carolina } \\
\text { Wilson } \\
\text { City of } \\
\text { June } 30\end{array}$ & $\begin{array}{c}\text { Ohio } \\
\text { American } \\
\text { Mun } \\
\text { Power } \\
\text { Ohio Inc } \\
\text { December } 31\end{array}$ & $\begin{array}{c}\text { Ohio } \\
\text { Bowling } \\
\text { Green } \\
\text { City of } \\
\text { December } 31\end{array}$ \\
\hline \multicolumn{7}{|l|}{ Electric Plant in Service } \\
\hline $\begin{array}{l}\text { Intangible Plant } \\
\text { Production Plant }\end{array}$ & 0 & 0 & 0 & 0 & 7,718 & 0 \\
\hline Steam & 0 & 0 & 0 & 0 & 60,358 & 0 \\
\hline Nuclear & 0 & 0 & 0 & 0 & 0 & 0 \\
\hline 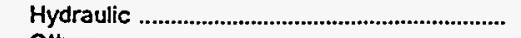 & 0 & 0 & 0 & 0 & 0 & 0 \\
\hline Other & 0 & 0 & 0 & 0 & 0 & 0 \\
\hline 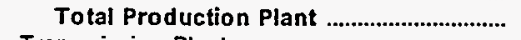 & 0 & 0 & 0 & 0 & 60,358 & 0 \\
\hline Transmission Plant & $\mathbf{0}$ & 0 & 23,796 & 0 & 670 & 588 \\
\hline 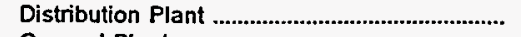 & 16,473 & 19,235 & 0 & 47,600 & 0 & 13,818 \\
\hline 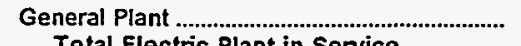 & $\begin{array}{r}0 \\
0\end{array}$ & 0 & 4,814 & 5,653 & 812 & 3,946 \\
\hline Total Electric Plant in Service ................... & 16,473 & 19,235 & 28,610 & 53,253 & 69,558 & 18,353 \\
\hline Electric Plant Leased to Others ........................... & 0 & 0 & 0 & 0 & 0 & 0 \\
\hline Electric Plant Held for Future Use ....................... & 0 & 0 & 0 & 0 & 0 & $\mathbf{0}$ \\
\hline 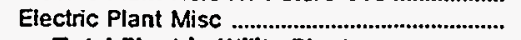 & 0 & 0 & 0 & 0 & 0 & 0 \\
\hline Total Electric Utility Plant & 16,473 & 19,235 & 28,610 & 53,253 & 69,558 & 18,353 \\
\hline $\begin{array}{l}\text { Construction Work in Progress - Electric ........ } \\
\text { Accumulated Provision for Depreciation }\end{array}$ & 814 & 0 & 130 & 1.122 & 84 & 171 \\
\hline $\begin{array}{l}\text { and Amortization } \\
\text { Net Electric Utility Plant }\end{array}$ & $\begin{array}{r}6,958 \\
10,329\end{array}$ & $\begin{array}{r}6,578 \\
12,656\end{array}$ & $\begin{array}{l}10,831 \\
17,908\end{array}$ & $\begin{array}{l}27,894 \\
26,480\end{array}$ & $\begin{array}{l}22,871 \\
46,771\end{array}$ & $\begin{array}{l}9,223 \\
9,302\end{array}$ \\
\hline
\end{tabular}

\begin{tabular}{|c|c|c|c|c|c|c|}
\hline Item & $\begin{array}{c}\text { Ohio } \\
\text { Bryan } \\
\text { City of } \\
\text { December } 31\end{array}$ & $\begin{array}{c}\text { Ohio } \\
\text { Celina } \\
\text { City of } \\
\text { December } 31\end{array}$ & $\begin{array}{c}\text { Ohio } \\
\text { Cleveland } \\
\text { City of } \\
\text { December } 31\end{array}$ & $\begin{array}{c}\text { Ohio } \\
\text { Clyde } \\
\text { City of } \\
\text { December } 31\end{array}$ & $\begin{array}{c}\text { Ohio } \\
\text { Columbus } \\
\text { City of } \\
\text { December } 31\end{array}$ & $\begin{array}{c}\text { Ohio } \\
\text { Cuyahoga } \\
\text { Falls } \\
\text { City of } \\
\text { December } 31\end{array}$ \\
\hline $\begin{array}{l}\text { Electric Plant in Service } \\
\text { Intangible Plant .................................................... } \\
\text { Production Plaint }\end{array}$ & 0 & 0 & 0 & 0 & 0 & 0 \\
\hline 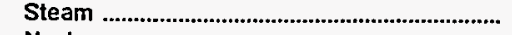 & 0 & 5,898 & 37,037 & 0 & 3.569 & 0 \\
\hline 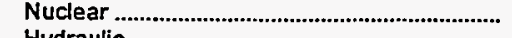 & 0 & 0 & 0 & 0 & 0 & 0 \\
\hline 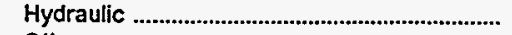 & 0 & 0 & 0 & 0 & 0 & 0 \\
\hline Other & 0 & 0 & 6,528 & 0 & 0 & 0 \\
\hline Total Production Plant & $\mathbf{0}$ & 5,898 & 43,565 & 0 & 3,569 & 0 \\
\hline 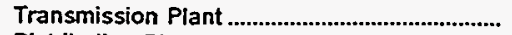 & 0 & 0 & 76,704 & 0 & 45,403 & 711 \\
\hline 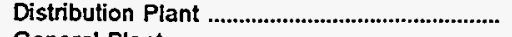 & 0 & 13,970 & 97,275 & 11 & 9,602 & 18,805 \\
\hline 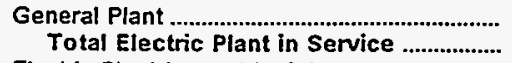 & $\begin{array}{l}14,843 \\
14,843\end{array}$ & $\begin{array}{r}575 \\
20,443\end{array}$ & $\begin{array}{r}15,558 \\
233,102\end{array}$ & $\begin{array}{r}0 \\
11\end{array}$ & $\begin{array}{l}27,422 \\
85,997\end{array}$ & $\begin{array}{r}2,189 \\
21,705\end{array}$ \\
\hline 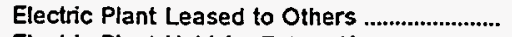 & 0 & 0 & 0 & 0 & 0 & 0 \\
\hline Electric Plant Held for Future Use ....................... & 0 & 0 & 0 & 0 & 0 & 0 \\
\hline Electric Plant Misc & 0 & 0 & 0 & 0 & o & 0 \\
\hline Total Electric Utility Plant & 14,843 & 20,443 & 233,102 & 11 & 85,997 & 21,705 \\
\hline $\begin{array}{l}\text { Construction Work in Progress - Electric ....... } \\
\text { Accumulated Provision for Depreciation }\end{array}$ & 0 & 0 & 76,304 & 0 & 0 & 0 \\
\hline 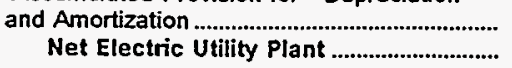 & $\begin{array}{r}11,494 \\
3,349\end{array}$ & $\begin{array}{r}0 \\
20,443\end{array}$ & $\begin{array}{l}101,002 \\
208,404\end{array}$ & $\begin{aligned} 0 \\
11\end{aligned}$ & $\begin{array}{l}34,753 \\
51,244\end{array}$ & $\begin{array}{r}11,624 \\
10,082\end{array}$ \\
\hline
\end{tabular}

Note: Totals may not equal sum of components because of independent rounding.

Source: Energy information Administration, Form EIA-412, "Annual Report of Public Electric Utilities." 
Table 24. Electric Utility Plant by Major U.S. Publicly Owned Electric Utility Within State at End of Period, 1995 (Continued)

(Thousand Dollars)

\begin{tabular}{|c|c|c|c|c|c|c|}
\hline Item & $\begin{array}{c}\text { Ohio } \\
\text { Dover } \\
\text { City of } \\
\text { December } 31\end{array}$ & $\begin{array}{c}\text { Ohio } \\
\begin{array}{c}\text { Hamilton } \\
\text { City of }\end{array} \\
\text { December } 31\end{array}$ & $\begin{array}{c}\text { Ohio } \\
\text { Napoleon } \\
\text { City of } \\
\text { December } 31\end{array}$ & $\begin{array}{c}\text { Ohio } \\
\text { Niles } \\
\text { City of } \\
\text { December } 31\end{array}$ & $\begin{array}{l}\text { Ohio } \\
\text { Orville } \\
\text { City of } \\
\text { December } 31\end{array}$ & $\begin{array}{c}\text { Ohio } \\
\text { Painesville } \\
\text { City of } \\
\text { December } 31\end{array}$ \\
\hline $\begin{array}{l}\text { Electric Plant in Service } \\
\text { Intangible Plant } \\
\text { Production Plant }\end{array}$ & 0 & 0 & 0 & 0 & 40,303 & 0 \\
\hline Steam & 0 & 42,142 & 0 & 0 & 0 & 29,064 \\
\hline Nuclear & 0 & 0 & 0 & 0 & 0 & 0 \\
\hline 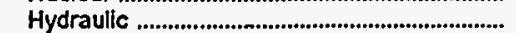 & 0 & 141,367 & 0 & 0 & 0 & 0 \\
\hline Other & 0 & 6.294 & 0 & 0 & 0 & 0 \\
\hline Total Production Plant & 0 & 189,803 & 0 & 0 & 0 & 29,064 \\
\hline 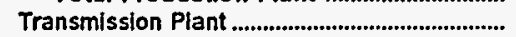 & 0 & 27.621 & 0 & 0 & 0 & 0 \\
\hline 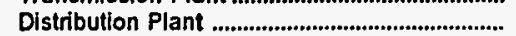 & 0 & 23,171 & 2,412 & 0 & 10,453 & 9,642 \\
\hline 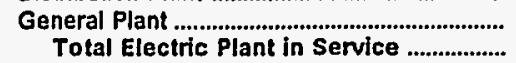 & $\begin{array}{l}9,945 \\
9,945\end{array}$ & $\begin{array}{r}7,535 \\
248,130\end{array}$ & $\begin{array}{r}0 \\
2,412\end{array}$ & $\begin{array}{l}12,013 \\
12,013\end{array}$ & $\begin{array}{r}2,715 \\
53,470\end{array}$ & $\begin{array}{r}0 \\
38,706\end{array}$ \\
\hline 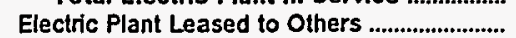 & 0 & 0 & 0 & 0 & 0 & 0 \\
\hline 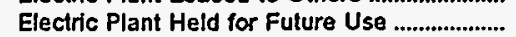 & 0 & 0 & 0 & 0 & 0 & 0 \\
\hline 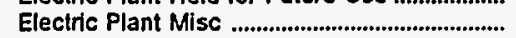 & 0 & 0 & 0 & 0 & 0 & 0 \\
\hline 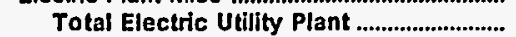 & 9,945 & 248,130 & 2,412 & 12,013 & 53,470 & 38,706 \\
\hline $\begin{array}{l}\text { Construction Work in Progress - Electric ........ } \\
\text { Accumulated Provision for Depreciation }\end{array}$ & 0 & 4,398 & 0 & 0 & 460 & 0 \\
\hline 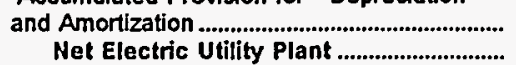 & $\begin{array}{r}0 \\
9,945\end{array}$ & $\begin{array}{r}85,776 \\
166,753\end{array}$ & $\begin{array}{r}0 \\
2,412\end{array}$ & $\begin{array}{l}7,001 \\
5,012\end{array}$ & $\begin{array}{l}28,496 \\
25,434\end{array}$ & $\begin{array}{l}23,796 \\
14,910\end{array}$ \\
\hline
\end{tabular}

\begin{tabular}{|c|c|c|c|c|c|c|}
\hline Item & $\begin{array}{c}\text { Ohio } \\
\text { Piqua } \\
\text { City of } \\
\text { December } 31\end{array}$ & $\begin{array}{c}\text { Ohio } \\
\text { St Marys } \\
\text { City of } \\
\text { December } 31\end{array}$ & $\begin{array}{c}\text { Ohio } \\
\text { Wadsworth } \\
\text { City of } \\
\text { December } 31\end{array}$ & $\begin{array}{c}\text { Ohio } \\
\text { Wapakoneta } \\
\text { City of } \\
\text { December } 31\end{array}$ & $\begin{array}{c}\text { Ohio } \\
\text { Westenille } \\
\text { City of } \\
\text { December } 31\end{array}$ & $\begin{array}{l}\text { Oklahoma } \\
\text { Altus } \\
\text { City of } \\
\text { June } 30\end{array}$ \\
\hline 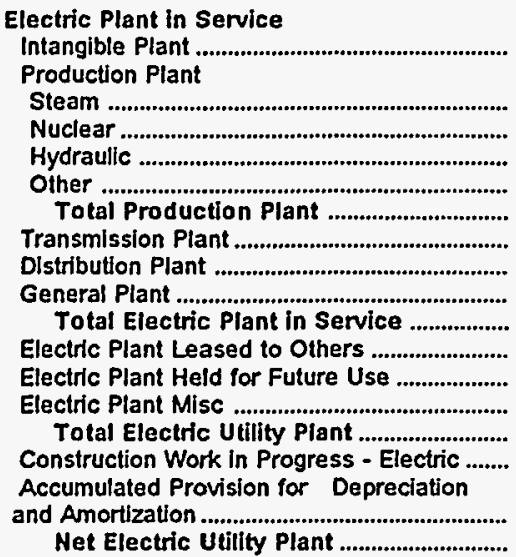 & $\begin{array}{r}770 \\
20,229 \\
0 \\
0 \\
131 \\
20,360 \\
2,560 \\
19,427 \\
2,484 \\
45,602 \\
0 \\
0 \\
0 \\
45,602 \\
610 \\
\\
21,329 \\
24,883\end{array}$ & $\begin{array}{r}0 \\
0 \\
0 \\
0 \\
0 \\
0 \\
0 \\
0 \\
16,120 \\
16,120 \\
0 \\
0 \\
0 \\
16,120 \\
2\end{array}$ & $\begin{array}{r}0 \\
0 \\
0 \\
0 \\
0 \\
0 \\
0 \\
0 \\
11,876 \\
350 \\
12,226 \\
0 \\
0 \\
0 \\
12,226 \\
0\end{array}$ & $\begin{array}{l}0 \\
0 \\
0 \\
0 \\
0 \\
0 \\
0 \\
0 \\
0 \\
0 \\
0 \\
0 \\
0 \\
0\end{array}$ & $\begin{array}{r}0 \\
0 \\
0 \\
0 \\
0 \\
0 \\
1,497 \\
18,179 \\
4,093 \\
23,770 \\
0 \\
0 \\
0 \\
23,770 \\
1,041 \\
10,064 \\
14,746\end{array}$ & $\begin{array}{r}0 \\
0 \\
0 \\
0 \\
0 \\
7,973 \\
0 \\
0 \\
7,973 \\
0 \\
0 \\
0 \\
7,973 \\
0 \\
5,812 \\
2,161\end{array}$ \\
\hline
\end{tabular}

Note: Totals may not equal sum of components because of independent rounding.

Source: Energy Information Administration, Form EIA-4 12, "Annua! Report of Public Electric Utilities." 
Table 24. Electric Utility Plant by Major U.S. Publicly Owned Electric Utility Within State at End of Period, 1995 (Continued)

(Thousand Dollars)

\begin{tabular}{|c|c|c|c|c|c|c|}
\hline Item & $\begin{array}{l}\text { Oklahoma } \\
\text { Claremore } \\
\text { City of } \\
\text { June } 30\end{array}$ & $\begin{array}{l}\text { Oklahoma } \\
\text { Duncan } \\
\text { City of } \\
\text { June } 30\end{array}$ & $\begin{array}{l}\text { Oklahoma } \\
\text { Edmond } \\
\text { City of } \\
\text { June } 30\end{array}$ & $\begin{array}{c}\text { Oklahoma } \\
\text { Grand River } \\
\text { Dam } \\
\text { Authority } \\
\text { December } 31\end{array}$ & $\begin{array}{l}\text { Oklahoma } \\
\text { Miami } \\
\text { City of } \\
\text { June } 30\end{array}$ & $\begin{array}{c}\text { OkJahoma } \\
\text { OkJahoma } \\
\text { Municipal } \\
\text { Power Auth } \\
\text { December } 31\end{array}$ \\
\hline \multicolumn{7}{|l|}{ Electric Plant in Service } \\
\hline 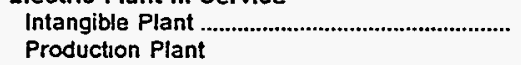 & 0 & 0 & 0 & 0 & 0 & 0 \\
\hline Steam & 0 & 0 & 0 & 622,607 & 0 & 114,404 \\
\hline 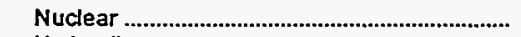 & 0 & 0 & 0 & 0 & 0 & 0 \\
\hline 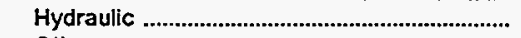 & 0 & 0 & 0 & 71,513 & 0 & 35,682 \\
\hline Other & 0 & 0 & 0 & 0 & 0 & 35,942 \\
\hline 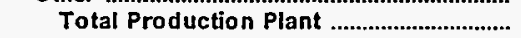 & 0 & $\mathbf{0}$ & 0 & 694,120 & 0 & 186,028 \\
\hline 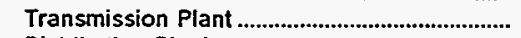 & 0 & 0 & 0 & 115,518 & 0 & 3,950 \\
\hline 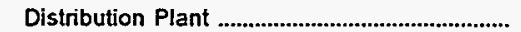 & 0 & 20,095 & 40,598 & 0 & 1,530 & 1,220 \\
\hline General Plant & 0 & 0 & 0 & 24,851 & 1,496 & 2,511 \\
\hline 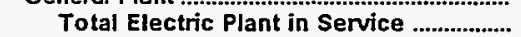 & 0 & 20,095 & 40,598 & 834,489 & 3,026 & 193,709 \\
\hline 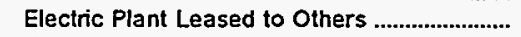 & 0 & 0 & 0 & 0 & 0 & 0 \\
\hline Electric Plant Held for Future Use ..................... & 0 & 0 & 0 & 14 & 0 & 3,066 \\
\hline 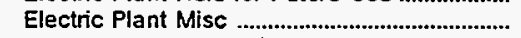 & 0 & 0 & 0 & 43,177 & 0 & 0 \\
\hline Total Electric Utility Plant & 0 & 20,095 & 40,598 & 877,680 & 3,026 & 186,775 \\
\hline $\begin{array}{l}\text { Construction Work in Progress - Electric ....... } \\
\text { Accumulated Provision for Depreciation }\end{array}$ & 0 & 73 & 1 & 13,342 & 0 & 351 \\
\hline and Amortization & 0 & 10,786 & 18,026 & 325,421 & 2,262 & 37,896 \\
\hline 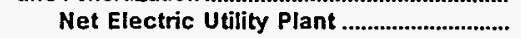 & $\mathbf{0}$ & 9,383 & 22,573 & 565,602 & 764 & 159,230 \\
\hline
\end{tabular}

\begin{tabular}{|c|c|c|c|c|c|c|}
\hline Item & $\begin{array}{l}\text { Oklahoma } \\
\text { Ponca } \\
\text { City City of } \\
\text { June } 30\end{array}$ & $\begin{array}{l}\text { Oklahoma } \\
\text { Stillwater } \\
\text { Utilities } \\
\text { Authority } \\
\text { June } 30\end{array}$ & $\begin{array}{l}\text { Oregon } \\
\text { Ashland } \\
\text { City of } \\
\text { June } 30\end{array}$ & $\begin{array}{c}\text { Oregon } \\
\text { Central } \\
\text { Lincoln } \\
\text { Peoples } \\
\text { UtI Dt } \\
\text { December } 31\end{array}$ & $\begin{array}{c}\text { Oregon } \\
\text { Clatskanie } \\
\text { Peoples } \\
\text { Util Dist } \\
\text { December } 31\end{array}$ & $\begin{array}{c}\text { Oregon } \\
\text { Columbia } \\
\text { River } \\
\text { Peoples } \\
\text { Ut Dist } \\
\text { December } 31\end{array}$ \\
\hline \multicolumn{7}{|l|}{ Electric Plant in Service } \\
\hline $\begin{array}{l}\text { Intangible Plant } \\
\text { Production Plant }\end{array}$ & 0 & 0 & 0 & 148 & 7 & 0 \\
\hline 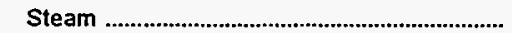 & 16,538 & 15,198 & 0 & 0 & 0 & $\mathbf{0}$ \\
\hline 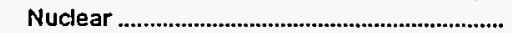 & 0 & 0 & 0 & 0 & 0 & 0 \\
\hline 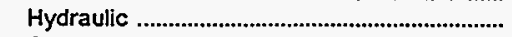 & 0 & 0 & 940 & 0 & 0 & 0 \\
\hline Other & 6.270 & $\mathbf{0}$ & 0 & 0 & 0 & 0 \\
\hline 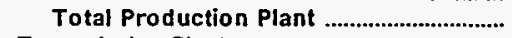 & 22,808 & 15,198 & 940 & 0 & 0 & 0 \\
\hline 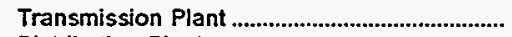 & 1,888 & 957 & 0 & 65,325 & 0 & 812 \\
\hline 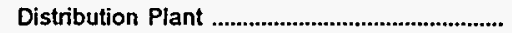 & 10,772 & 20,571 & 11,583 & 0 & 5,303 & 11,793 \\
\hline 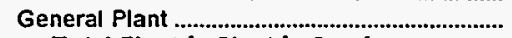 & 350 & 3,718 & 0 & 20,464 & 1,865 & 4,122 \\
\hline Total Electric Plant in Service ...................... & 35,818 & 40,444 & 12,523 & 85,937 & 7,175 & 16,727 \\
\hline 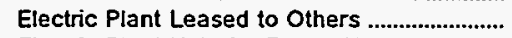 & 0 & 0 & 0 & 0 & 0 & 0 \\
\hline Electric Plant Held for Future Use .................... & 0 & 0 & 0 & 0 & 0 & 0 \\
\hline 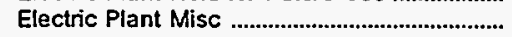 & 0 & 0 & 0 & 0 & 0 & 7,874 \\
\hline Total Electric Utility Plant ............................ & 35,818 & 40,444 & 12,523 & 85,937 & 7,175 & 24,601 \\
\hline $\begin{array}{l}\text { Construction Work in Progress - Electric ........ } \\
\text { Accumulated Provision for Depreciation }\end{array}$ & 0 & 97 & 0 & 13,971 & 468 & 75 \\
\hline 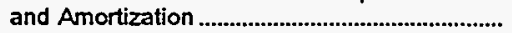 & 16,389 & 15,533 & 0 & 38,628 & 3,833 & 4,932 \\
\hline Net Electric Utility Plant .................................. & 19,429 & 25,009 & 12,523 & 61,280 & 3,810 & 19,744 \\
\hline
\end{tabular}

Note: Totals may not equal sum of components because of independent rounding.

Source: Energy Information Administration, Form E!A-412, "Annual Report of Public Electric Utilities." 
Table 24. Electric Utility Plant by Major U.S. Publicly Owned Electric Utility Within State at End of Period, 1995 (Continued)

(Thousand Dollars)

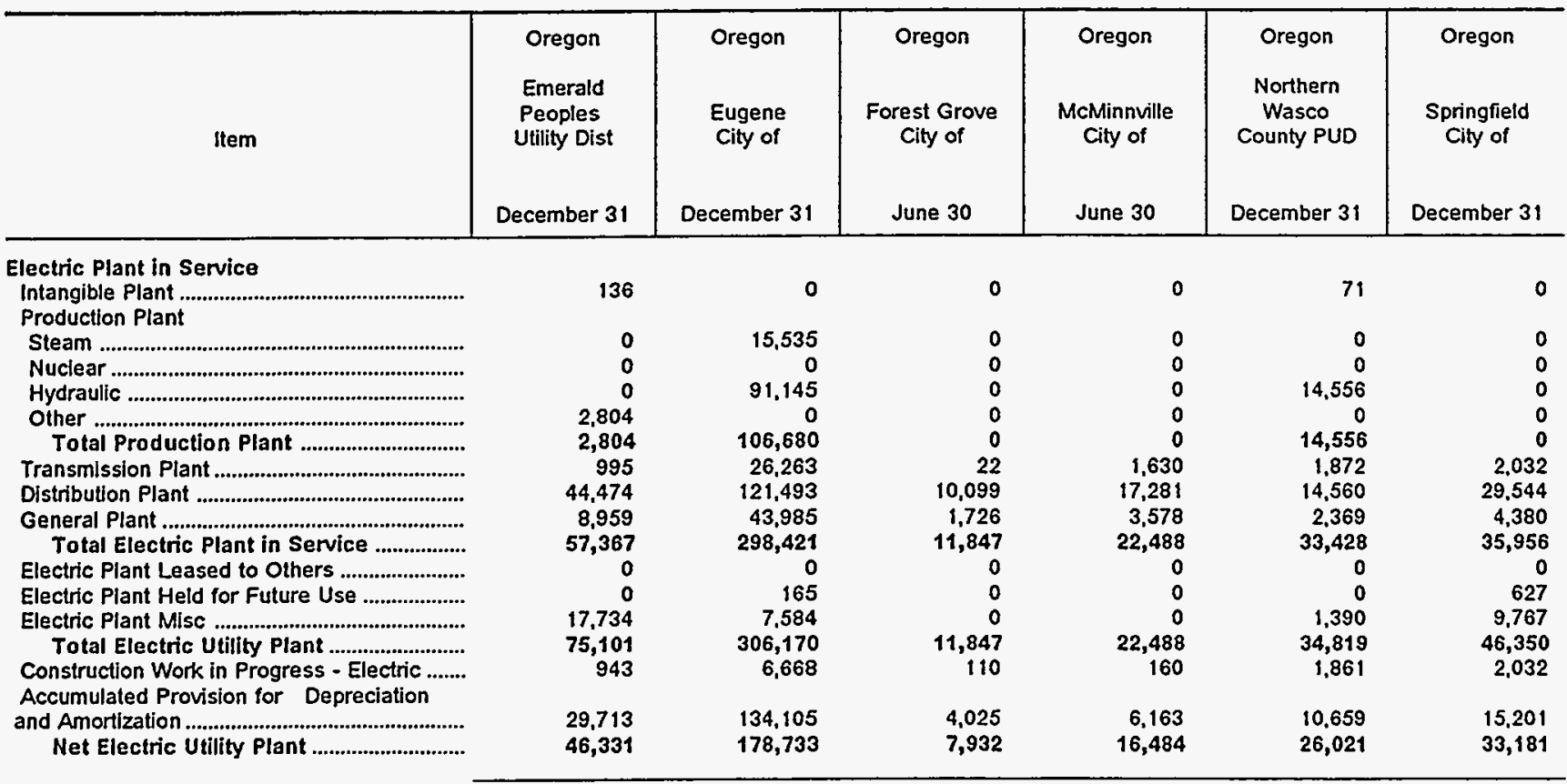

\begin{tabular}{|c|c|c|c|c|c|c|}
\hline Item & $\begin{array}{c}\text { Oregon } \\
\text { Tillamook } \\
\text { Peoples } \\
\text { Utility Dist } \\
\text { December } 31\end{array}$ & $\begin{array}{c}\text { Pennsylvania } \\
\text { Chambersburg } \\
\text { Borough of } \\
\text { December } 31\end{array}$ & $\begin{array}{l}\text { Pennsylvania } \\
\text { Ephrata } \\
\text { Borough of } \\
\text { December } 31\end{array}$ & $\begin{array}{l}\text { Pennsylvania } \\
\text { Lansdale } \\
\text { Borough of } \\
\text { December } 31\end{array}$ & $\begin{array}{l}\text { South Carolina } \\
\text { Camden } \\
\text { City of } \\
\text { June } 30\end{array}$ & $\begin{array}{c}\text { South Carolina } \\
\text { Easley } \\
\text { Combined } \\
\text { Utility } \\
\text { System } \\
\text { March } 31\end{array}$ \\
\hline \multicolumn{7}{|l|}{ Electric Plant in Service } \\
\hline $\begin{array}{l}\text { Intangible Plant } \\
\text { Production Plant }\end{array}$ & 1 & 5 & 0 & 0 & 0 & 0 \\
\hline Steam & 0 & 4,666 & 0 & 0 & 0 & 0 \\
\hline 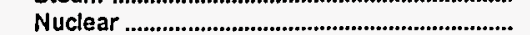 & 0 & 0 & 0 & 0 & 0 & 0 \\
\hline 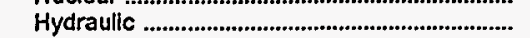 & 0 & 0 & 0 & 0 & 0 & 0 \\
\hline Other & 0 & 1,396 & 0 & 0 & 0 & 0 \\
\hline Total Production Plant & 0 & 6,062 & $\mathbf{0}$ & $\mathbf{0}$ & 0 & 0 \\
\hline 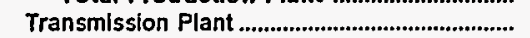 & 1,117 & 4,121 & 0 & 2,890 & 0 & 0 \\
\hline 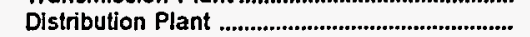 & 28,766 & 16,448 & 0 & 5,900 & 0 & 19,236 \\
\hline 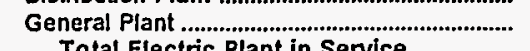 & 6,451 & $\begin{array}{r}924 \\
27559\end{array}$ & 0 & $\begin{array}{r}1,298 \\
10,088\end{array}$ & 11,373 & $\begin{array}{r}0 \\
19.236\end{array}$ \\
\hline 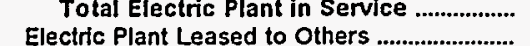 & $\begin{array}{r}36,334 \\
0\end{array}$ & $\begin{array}{r}27,559 \\
0\end{array}$ & $\begin{array}{l}0 \\
0\end{array}$ & $\begin{array}{r}10,088 \\
0\end{array}$ & $\begin{array}{r}11,3 / 3 \\
0\end{array}$ & $\begin{array}{r}10,200 \\
0\end{array}$ \\
\hline 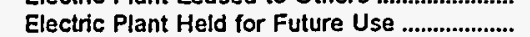 & 0 & 0 & 0 & 0 & 0 & 0 \\
\hline 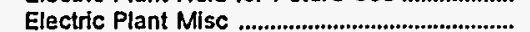 & 1,603 & 0 & 0 & 0 & 0 & 0 \\
\hline Total Electric Utility Plant & 37,938 & 27,559 & $\mathbf{0}$ & 10,088 & 11,373 & 19,236 \\
\hline $\begin{array}{l}\text { Construction Work in Progress - Electric ....... } \\
\text { Accumulated Provision for Depreciation }\end{array}$ & 1,206 & 454 & 0 & 0 & 0 & 0 \\
\hline 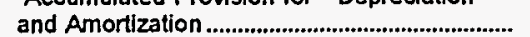 & 10,556 & 14,877 & 0 & 4,461 & 8.956 & 6,339 \\
\hline 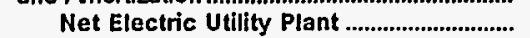 & 28,587 & 13,136 & $\mathbf{0}$ & 5,627 & 2,417 & 12,897 \\
\hline
\end{tabular}

Note: Totals may not equal sum of components because of independent rounding

Source: Energy Information Administration, Form EIA-412, "Annual Report of Public Electric Utilities." 
Table 24. Electric Utility Plant by Major U.S. Publicly Owned Electric Utility Within State at End of Period, 1995 (Thousand Dollars)

\begin{tabular}{|c|c|c|c|c|c|c|}
\hline Item & $\begin{array}{c}\text { South Carolina } \\
\text { Gaffney } \\
\text { City of } \\
\text { March } 31\end{array}$ & $\begin{array}{l}\text { South Carolina } \\
\text { Greenwood } \\
\text { Commissioners } \\
\text { Pub Wk } \\
\text { December } 31\end{array}$ & $\begin{array}{c}\text { South Carolina } \\
\text { Greer } \\
\text { Comm } \\
\text { of } \\
\text { Public Works } \\
\text { December } 31\end{array}$ & $\begin{array}{l}\text { South Carolina } \\
\text { Newberry } \\
\text { City of } \\
\text { June } 30\end{array}$ & $\begin{array}{l}\text { South Carolina } \\
\text { Orangeburg } \\
\text { City of }\end{array}$ & $\begin{array}{c}\text { South Carolina } \\
\text { Pledmont } \\
\text { Municipal } \\
\text { Power Agny } \\
\\
\text { December } 31\end{array}$ \\
\hline \multicolumn{7}{|l|}{ Electric Plant in Service } \\
\hline $\begin{array}{l}\text { Intangible Plant } \\
\text { Production Plant }\end{array}$ & 0 & 0 & $\mathbf{0}$ & 0 & 0 & 0 \\
\hline Steam & $\mathbf{0}$ & 0 & 0 & 0 & $\mathbf{0}$ & 0 \\
\hline 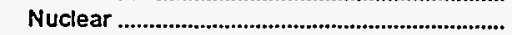 & 0 & 0 & 0 & 0 & 0 & 541,147 \\
\hline 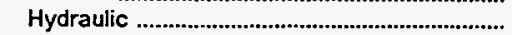 & 0 & 0 & 0 & 0 & 0 & 0 \\
\hline Other & 516 & 0 & 0 & 0 & 11,536 & $\mathbf{0}$ \\
\hline 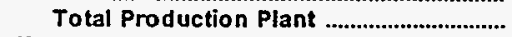 & 516 & 0 & $\mathbf{0}$ & 0 & 11,536 & 541,147 \\
\hline 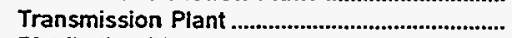 & 0 & 0 & 13,157 & 0 & 45,131 & 0 \\
\hline 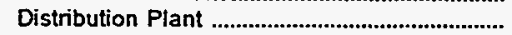 & 1,649 & 9,864 & 0 & 0 & 0 & 360 \\
\hline General Plant & 0 & 0 & 82,055 & 8,095 & 0 & 1,258 \\
\hline 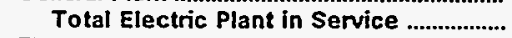 & 2,165 & 9,864 & 95,212 & 8,095 & 56,667 & 542,765 \\
\hline 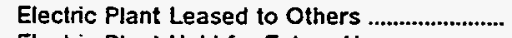 & 0 & 0 & 0 & 0 & 0 & 0 \\
\hline Electric Plant Held for Future Use ..................... & 0 & 0 & 0 & 0 & 0 & 0 \\
\hline 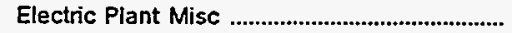 & 0 & 0 & 0 & 0 & 0 & 0 \\
\hline Total Electric Utility Plant ............................. & 2,165 & 9,864 & 95,212 & 8,095 & 56,667 & 542,765 \\
\hline $\begin{array}{l}\text { Construction Work in Progress - Electric ....... } \\
\text { Accumulated Provision for Depreciation }\end{array}$ & 0 & 0 & 3,747 & 0 & 72 & 11,105 \\
\hline $\begin{array}{l}\text { and Amortization } \\
\text { Net Electric Utility Plant }\end{array}$ & $\begin{array}{r}912 \\
1,253\end{array}$ & $\begin{array}{r}4,157 \\
\sqrt{5,707}\end{array}$ & $\begin{array}{l}23,391 \\
75,568\end{array}$ & $\begin{array}{l}4,589 \\
3,506\end{array}$ & $\begin{array}{l}13,979 \\
42,760\end{array}$ & $\begin{array}{l}168,649 \\
385,221\end{array}$ \\
\hline
\end{tabular}

\begin{tabular}{|c|c|c|c|c|c|c|}
\hline Item & $\begin{array}{l}\text { South Carolina } \\
\text { Rock Hill } \\
\text { City of } \\
\text { December } 31\end{array}$ & $\begin{array}{l}\text { South Carolina } \\
\text { Seneca } \\
\text { City of } \\
\text { June } 30\end{array}$ & $\begin{array}{c}\text { South Carolina } \\
\text { South } \\
\text { Carolina } \\
\text { Pub } \\
\text { Serv Auth } \\
\text { December } 31\end{array}$ & $\begin{array}{c}\text { South Dakota } \\
\text { Brookings } \\
\text { City of }\end{array}$ & $\begin{array}{l}\text { South Dakota } \\
\text { Heartland } \\
\text { Consumers } \\
\text { Power Dist } \\
\text { December } 31\end{array}$ & $\begin{array}{l}\text { South Dakota } \\
\text { Missour } \\
\text { Basin } \\
\text { Mun } \\
\text { Power Agny } \\
\text { December } 31\end{array}$ \\
\hline \multicolumn{7}{|l|}{ Electric Plant in Service } \\
\hline $\begin{array}{l}\text { Intangible Plant } \\
\text { Production Plant }\end{array}$ & 0 & 0 & 9,806 & 0 & 0 & 0 \\
\hline Steam & 0 & 0 & 980,436 & 0 & 48,440 & $\mathbf{0}$ \\
\hline Nuclear & 0 & 0 & 449,181 & 0 & 0 & 0 \\
\hline 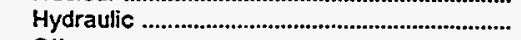 & 0 & 0 & 70,767 & 0 & 0 & 0 \\
\hline Other & 0 & 0 & 25.137 & 0 & 0 & 0 \\
\hline Total Production Plant ................................... & 0 & 0 & $1,525,521$ & 0 & 48,440 & 0 \\
\hline 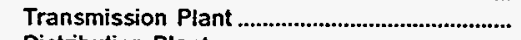 & 0 & 0 & 509,766 & 3,835 & 8,401 & 0 \\
\hline Distribution Plant & 33,593 & 29,084 & 264,978 & 12,192 & 0 & 0 \\
\hline General Plant & 0 & 0 & 142,842 & 3,894 & 786 & 2,737 \\
\hline 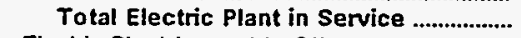 & 33,593 & 29,084 & $2,452,913$ & 19,921 & 57,627 & 2,737 \\
\hline Electric Plant Leased to Others ........................... & 0 & 0 & 0 & 0 & 0 & $\mathbf{0}$ \\
\hline Electric Plant Held for Future Use .................... & 0 & 0 & 12,351 & 0 & 0 & 0 \\
\hline Electric Plant Misc & 0 & 0 & 716,277 & 0 & 0 & 0 \\
\hline Total Electric Utility Plant & 33,593 & 29,084 & $3,181,541$ & 19,921 & 57,627 & 2,737 \\
\hline $\begin{array}{l}\text { Construction Work in Progress - Electric ....... } \\
\text { Accumulated Provision for Depreciation }\end{array}$ & 1,442 & 0 & 71,661 & 66 & 203 & 0 \\
\hline 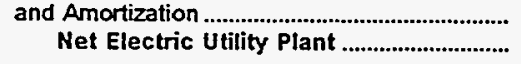 & $\begin{array}{l}12,957 \\
22,078\end{array}$ & $\begin{array}{l}11,696 \\
17,388\end{array}$ & $\begin{array}{r}974,077 \\
2,279,125\end{array}$ & $\begin{array}{r}6,159 \\
13,828\end{array}$ & $\begin{array}{r}9,221 \\
48,608\end{array}$ & $\begin{array}{r}776 \\
1,961\end{array}$ \\
\hline
\end{tabular}

Source: Energy Information Administration, Form ElA-412, "Annual Report of Public Electric Utilities." 
Table 24. Electric Utility Plant by Major U.S. Publicly Owned Electric Utility Within State at End of Period, 1995 (Continued)

(Thousand Dollars)

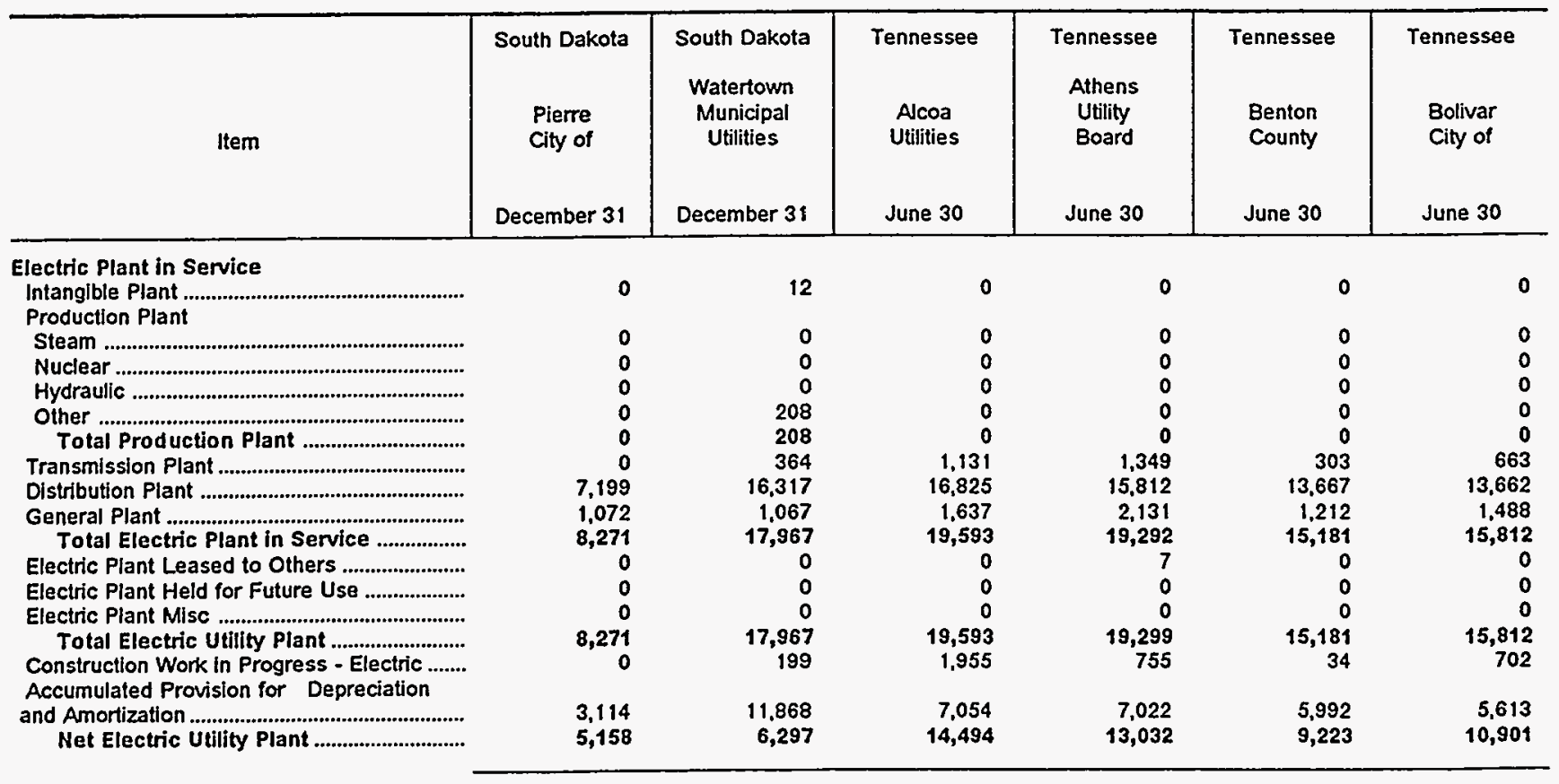

\begin{tabular}{|c|c|c|c|c|c|c|}
\hline Item & $\begin{array}{l}\text { Tennessee } \\
\text { Bristol } \\
\text { City of } \\
\text { June } 30\end{array}$ & $\begin{array}{l}\text { Tennessee } \\
\text { Brownsville } \\
\text { City of } \\
\text { June } 30\end{array}$ & $\begin{array}{l}\text { Tennessee } \\
\text { Carroll } \\
\text { County } \\
\text { June } 30\end{array}$ & $\begin{array}{c}\text { Tennessee } \\
\begin{array}{c}\text { Chattanooga } \\
\text { City of }\end{array} \\
\text { June } 30\end{array}$ & $\begin{array}{l}\text { Tennessee } \\
\text { Clarksville } \\
\text { City of } \\
\text { June } 30\end{array}$ & $\begin{array}{l}\text { Tennessee } \\
\text { Cleveland } \\
\text { City of } \\
\text { June } 30\end{array}$ \\
\hline 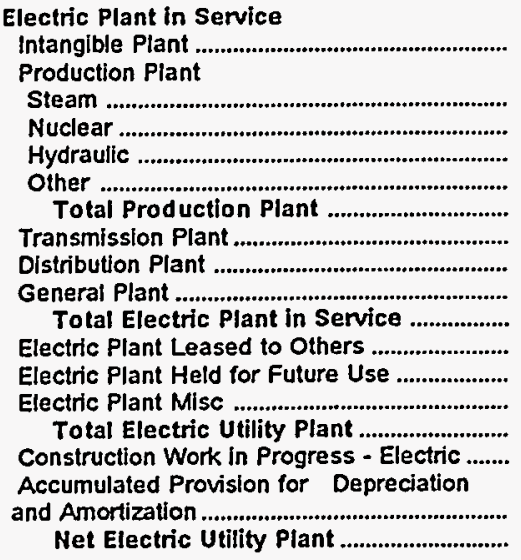 & $\begin{array}{r}0 \\
0 \\
0 \\
0 \\
0 \\
11,821 \\
29,211 \\
2,954 \\
43,986 \\
0 \\
0 \\
0 \\
43,986 \\
3,543\end{array}$ & $\begin{array}{r}0 \\
0 \\
0 \\
0 \\
0 \\
0 \\
0 \\
290 \\
5,045 \\
1.463 \\
6,798 \\
110 \\
208 \\
0 \\
0 \\
7,116 \\
828\end{array}$ & $\begin{array}{r}0 \\
0 \\
0 \\
0 \\
0 \\
678 \\
18,659 \\
1,591 \\
20,928 \\
0 \\
0 \\
0 \\
20,928 \\
127\end{array}$ & $\begin{array}{r}0 \\
0 \\
0 \\
0 \\
0 \\
31,305 \\
203,299 \\
30,752 \\
265,356 \\
0 \\
0 \\
0 \\
265,356 \\
7,291\end{array}$ & $\begin{array}{r}0 \\
0 \\
0 \\
0 \\
0 \\
2,050 \\
34,433 \\
4,898 \\
41,382 \\
8,557 \\
0 \\
0 \\
49,939 \\
467\end{array}$ & $\begin{array}{r}0 \\
0 \\
0 \\
0 \\
0 \\
4,298 \\
40,577 \\
4,422 \\
49,297 \\
2,591 \\
0 \\
0 \\
51,888 \\
1,062\end{array}$ \\
\hline
\end{tabular}

Note: Totals may not equal sum of components because of independent rounding.

Source: Energy Information Administration. Form EIA-412, "Annual Report of Public Electric Utilities." 
Table 24. Electric Utility Plant by Major U.S. Publicly Owned Electric Utility Within State at End of Period, 1995 (Continued)

(Thousand Dollars)

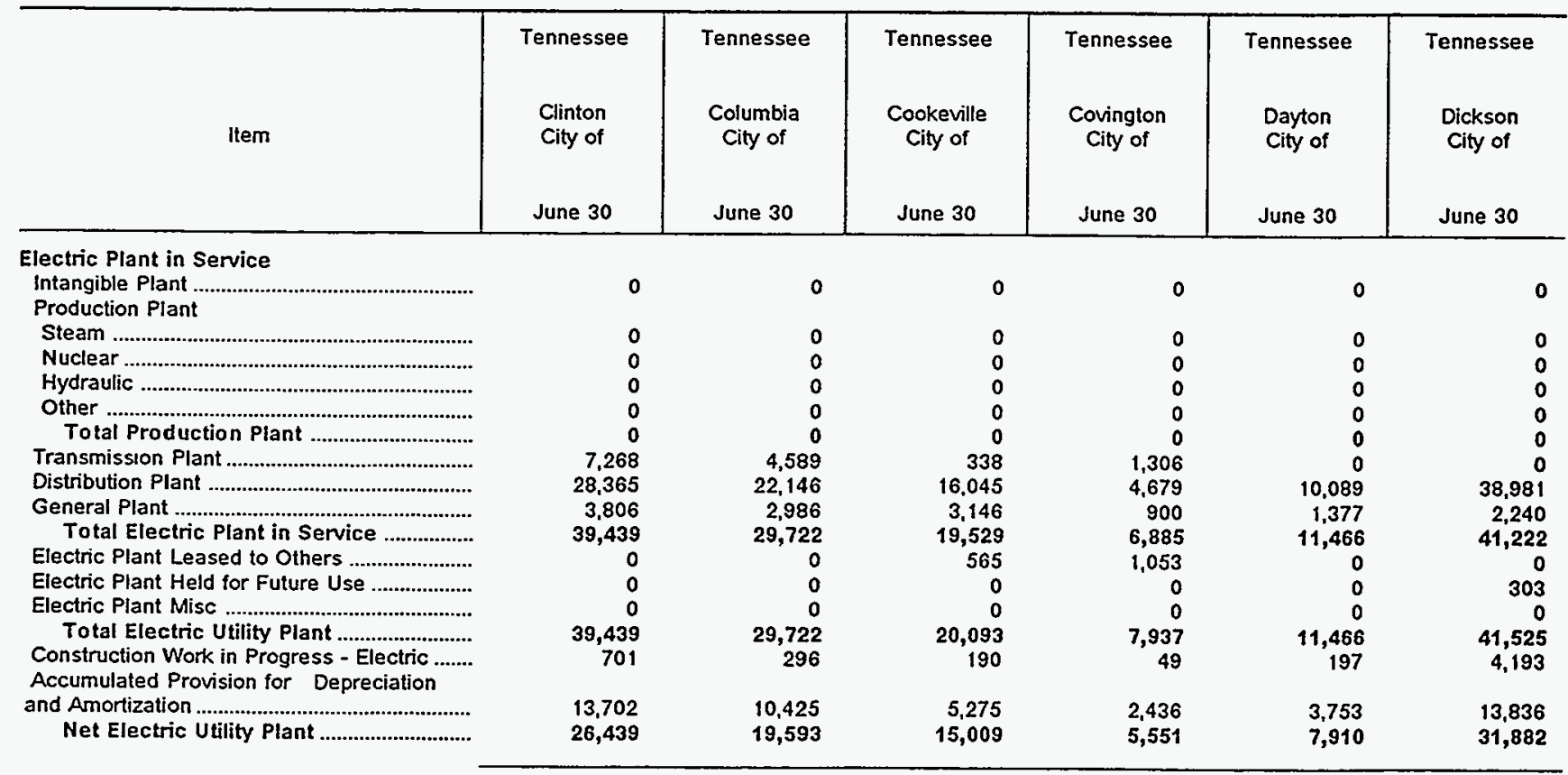

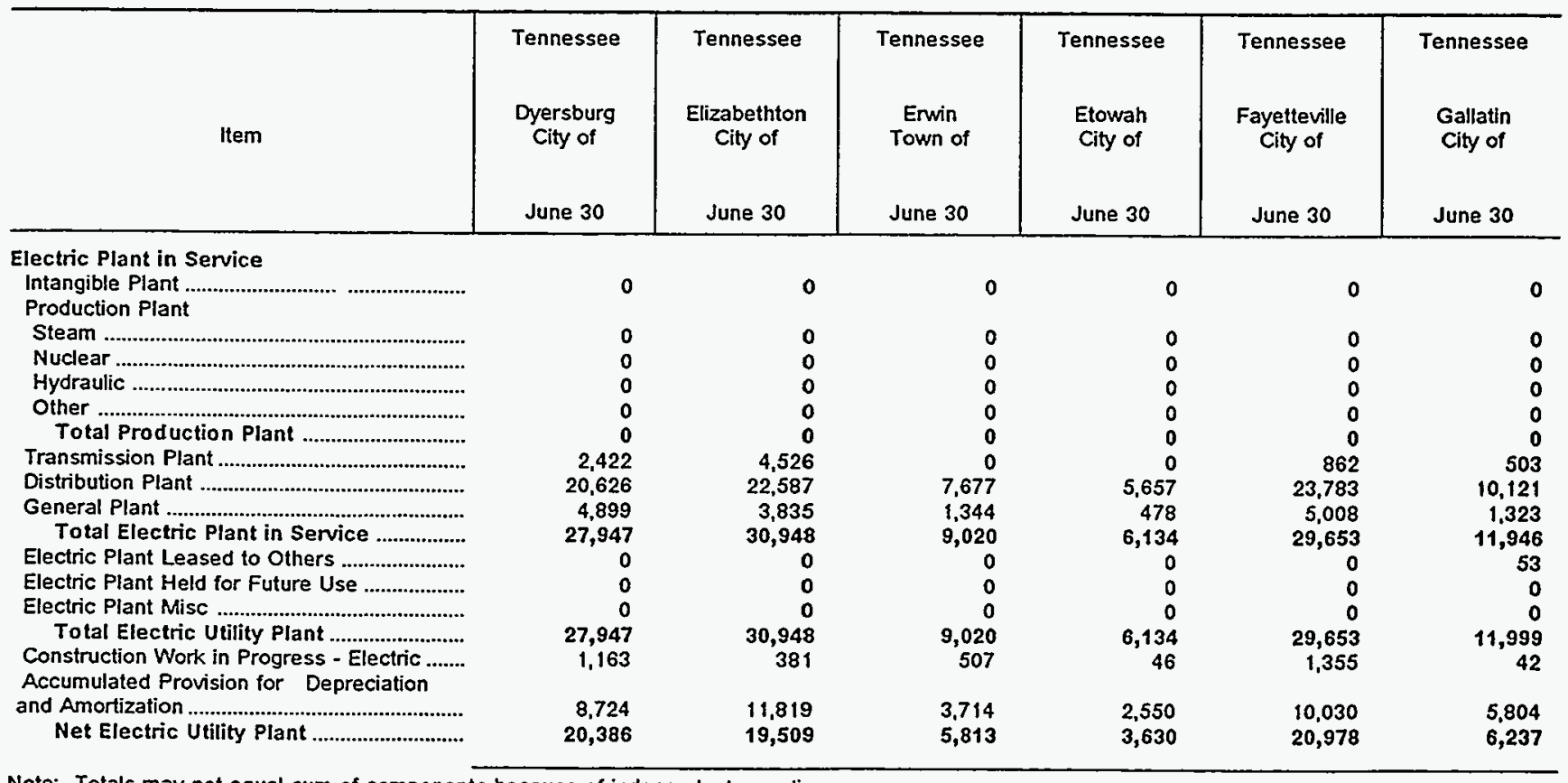

Note: Totals may not equal sum of components because of independent rounding.

Source: Energy Information Administration, Form EIA-412, "Annual Report of Public Electric Utilities." 
Table 24. Electric Utility Plant by Major U.S. Publicly Owned Electric Utility Within State at End of Period, 1995 (Continued)

(Thousand Dollars)

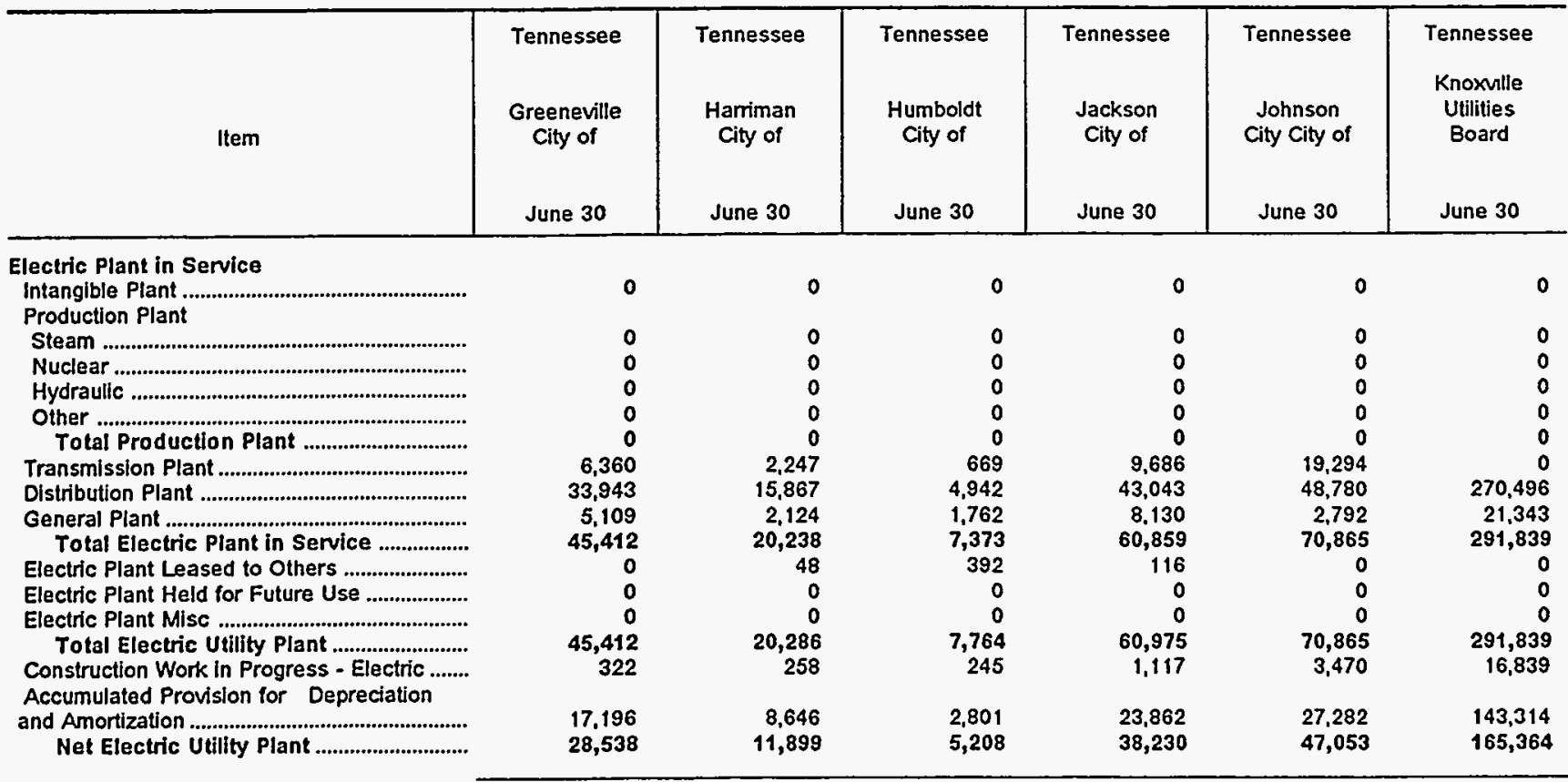

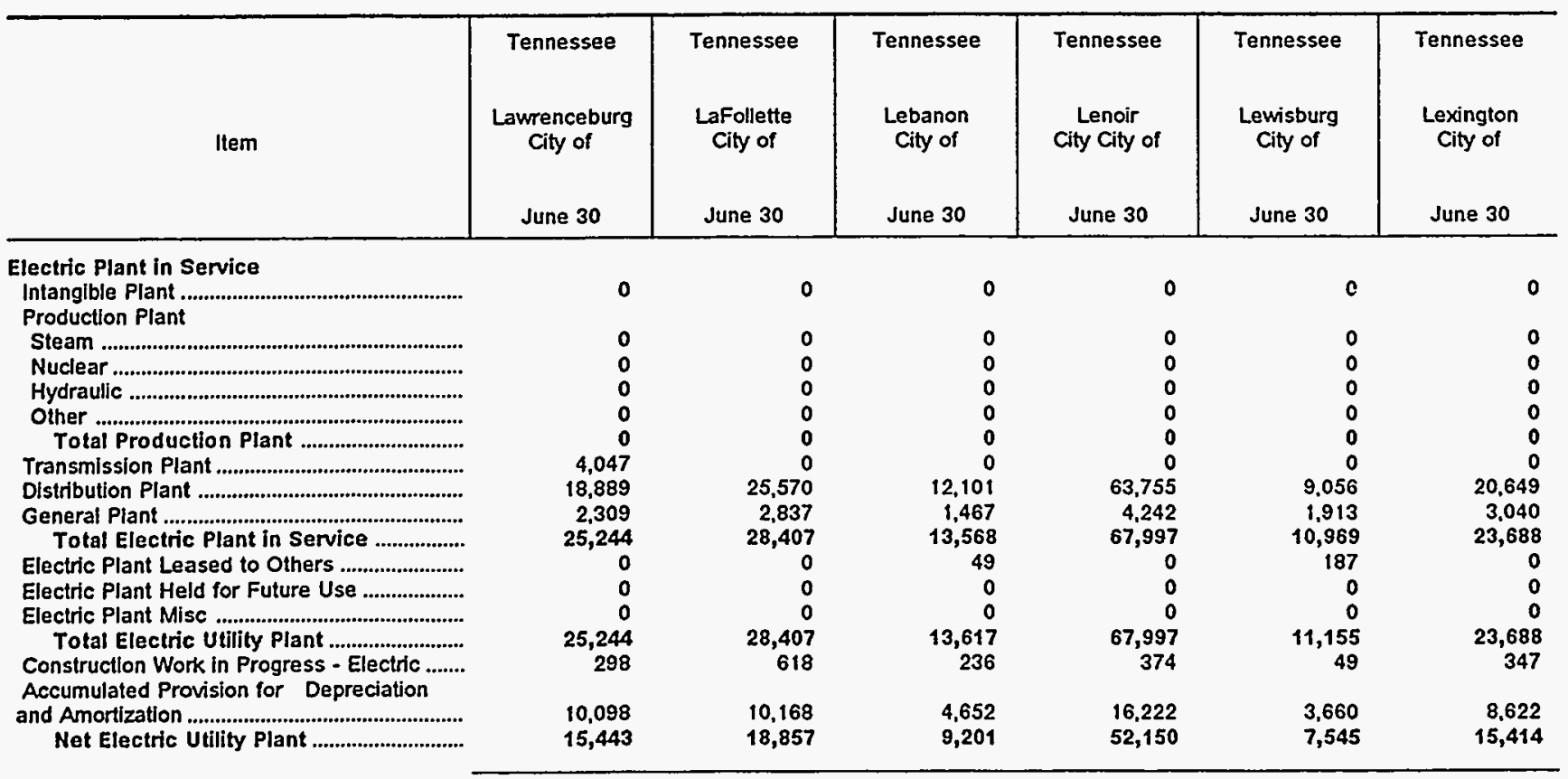

Note: Totals may not equal sum of components because of independent rounding.

Source: Energy Information Administration, Form EIA-412, "Annual Report of Public Electric Utilities." 
Table 24. Electric Utility Plant by Major U.S. Publicly Owned Electric Utility Within State at End of Period, 1995 (Continued) (Thousand Dollars)

\begin{tabular}{|c|c|c|c|c|c|c|}
\hline Item & $\begin{array}{l}\text { Tennessee } \\
\text { Loudon } \\
\text { Utilities } \\
\text { Board } \\
\text { June } 30\end{array}$ & $\begin{array}{l}\text { Tennessee } \\
\text { Maryville } \\
\text { Utilities } \\
\text { June } 30\end{array}$ & $\begin{array}{l}\text { Tennessee } \\
\text { McMinnville } \\
\text { Electric } \\
\text { System } \\
\text { June } 30\end{array}$ & $\begin{array}{l}\text { Tennessee } \\
\text { Memphis } \\
\text { City of } \\
\text { June } 30\end{array}$ & $\begin{array}{l}\text { Tennessee } \\
\text { Milan } \\
\text { City of } \\
\text { June } 30\end{array}$ & $\begin{array}{l}\text { Tennessee } \\
\text { Mornstown } \\
\text { City of } \\
\text { June } 30\end{array}$ \\
\hline \multicolumn{7}{|l|}{ Electric Plant in Service } \\
\hline $\begin{array}{l}\text { Intangible Plant } \\
\text { Production Plant }\end{array}$ & 0 & 0 & 0 & 0 & 0 & 0 \\
\hline Steam & 0 & 0 & 0 & 0 & 0 & 0 \\
\hline 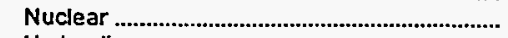 & 0 & 0 & 0 & 0 & 0 & 0 \\
\hline 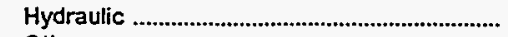 & 0 & 0 & 0 & 0 & 0 & 0 \\
\hline Other & 0 & 0 & 0 & 0 & 0 & 0 \\
\hline 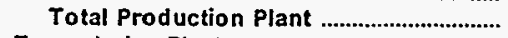 & $\mathbf{0}$ & 0 & 0 & 0 & $\mathbf{0}$ & 0 \\
\hline 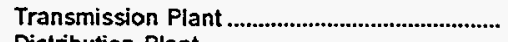 & 5,560 & 2,301 & 0 & 142,125 & 2,159 & 4,673 \\
\hline 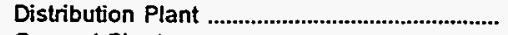 & 13,500 & 19,314 & 10,888 & 567,408 & 8,092 & 18,843 \\
\hline & $\begin{array}{r}690 \\
490\end{array}$ & 4,701 & 1,691 & 53,600 & 1,049 & 5,073 \\
\hline $\begin{array}{l}\text { Total Electric Plant in Service } \\
\text { Electric Plant Leased to Others }\end{array}$ & 19,750 & 26,316 & 12,579 & 763,133 & 11,300 & 28,589 \\
\hline & $\begin{array}{l}0 \\
0\end{array}$ & 14 & 301 & 0 & 0 & 1,827 \\
\hline Electric Plant Misc & 0 & 0 & 0 & 0 & 10 & 0 \\
\hline Total Electric Utility Plant & & 0 & $\begin{array}{r}0 \\
070\end{array}$ & 0 & 0 & 21 \\
\hline $\begin{array}{l}\text { Total Electric Utility Plant ........................ } \\
\text { Construction Work in Progress - Electric ....... } \\
\text { Accumulated Provision for Depreciation }\end{array}$ & $\begin{array}{r}19,750 \\
2,115\end{array}$ & $\begin{array}{r}26,330 \\
1,313\end{array}$ & $\begin{array}{r}12,879 \\
38\end{array}$ & $\begin{array}{r}763,133 \\
32,813\end{array}$ & $\begin{array}{r}11,310 \\
474\end{array}$ & $\begin{array}{r}30,437 \\
906\end{array}$ \\
\hline $\begin{array}{l}\text { and Amortization } \\
\text { Net Electric Utility Plant }\end{array}$ & $\begin{array}{r}4,318 \\
17,547\end{array}$ & $\begin{array}{r}8,627 \\
19,016\end{array}$ & $\begin{array}{l}5,435 \\
7,483\end{array}$ & $\begin{array}{l}264,723 \\
\mathbf{5 3 1}, 224\end{array}$ & $\begin{array}{l}5,243 \\
6,541\end{array}$ & $\begin{array}{l}10,648 \\
20,695\end{array}$ \\
\hline
\end{tabular}

\begin{tabular}{|c|c|c|c|c|c|c|}
\hline Item & $\begin{array}{l}\text { Tennessee } \\
\begin{array}{c}\text { Murfreesboro } \\
\text { City of }\end{array} \\
\text { June } 30\end{array}$ & $\begin{array}{l}\text { Tennessee } \\
\text { Nashville } \\
\text { Electric } \\
\text { Senvice } \\
\text { June } 30\end{array}$ & $\begin{array}{l}\text { Tennessee } \\
\text { Newport } \\
\text { City of } \\
\text { June } 30\end{array}$ & $\begin{array}{l}\text { Tennessee } \\
\text { Oak Ridge } \\
\text { City of } \\
\text { June } 30\end{array}$ & $\begin{array}{l}\text { Tennessee } \\
\text { Paris } \\
\text { City of } \\
\text { June } 30\end{array}$ & $\begin{array}{l}\text { Tennessee } \\
\text { Pulaskj } \\
\text { City of } \\
\text { June } 30\end{array}$ \\
\hline \multicolumn{7}{|l|}{ Electric Plant in Service } \\
\hline $\begin{array}{l}\text { Intangible Plant } \\
\text { Production Plant }\end{array}$ & 0 & 0 & 0 & 0 & 0 & 0 \\
\hline Steam & 0 & 0 & 0 & 0 & 0 & $\mathbf{0}$ \\
\hline 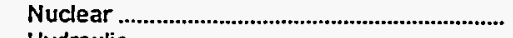 & 0 & 0 & 0 & 0 & 0 & $\mathbf{0}$ \\
\hline 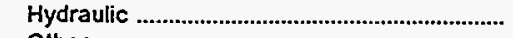 & 0 & 0 & 0 & 0 & 0 & 0 \\
\hline Other & 0 & 0 & 0 & 0 & 0 & 0 \\
\hline 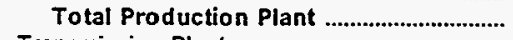 & $\mathbf{0}$ & 0 & 0 & 0 & $\mathbf{0}$ & $\mathbf{0}$ \\
\hline 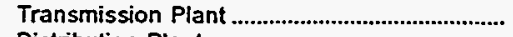 & 0 & 0 & 319 & 1,419 & 1.910 & 0 \\
\hline 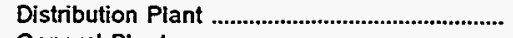 & 34,215 & 510,002 & 2.485 & 24,709 & 24,218 & 22,741 \\
\hline 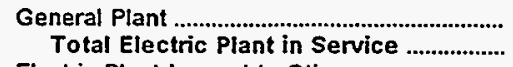 & $\begin{array}{r}4,517 \\
38,733\end{array}$ & $\begin{array}{r}56,446 \\
566,447\end{array}$ & $\begin{array}{r}556 \\
3,360\end{array}$ & $\begin{array}{r}1,259 \\
27,386\end{array}$ & $\begin{array}{r}1,816 \\
27,944\end{array}$ & $\begin{array}{r}3,081 \\
25,823\end{array}$ \\
\hline 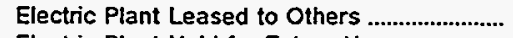 & 0 & 0 & 21 & 100 & 0 & 0 \\
\hline Electric Plant Held for Future Use ...................... & 613 & 0 & 0 & 0 & 0 & 0 \\
\hline Electric Plant Misc & 0 & 0 & 0 & 0 & 0 & 0 \\
\hline $\begin{array}{l}\text { Total Electric Utility Plant ........................ } \\
\text { Construction Work in Progress - Electric ....... } \\
\text { Accumulated Provision for Depreciation }\end{array}$ & $\begin{array}{r}39,345 \\
1,591\end{array}$ & $\begin{array}{r}566,447 \\
24,658\end{array}$ & $\begin{array}{r}3,381 \\
560\end{array}$ & $\begin{array}{r}27,486 \\
6,975\end{array}$ & $\begin{array}{r}27,944 \\
497\end{array}$ & $\begin{array}{r}25,823 \\
1,263\end{array}$ \\
\hline $\begin{array}{l}\text { and Amortization } \\
\text { Net Electric Utility Plant }\end{array}$ & $\begin{array}{l}11,709 \\
29,228\end{array}$ & $\begin{array}{l}215,150 \\
375,955\end{array}$ & $\begin{array}{l}1,067 \\
2,875\end{array}$ & $\begin{array}{l}10,507 \\
23,954\end{array}$ & $\begin{array}{l}12,474 \\
15,968\end{array}$ & $\begin{array}{r}9,697 \\
17,389\end{array}$ \\
\hline
\end{tabular}

Note: Totals may not equal sum of components because of independent rounding.

Source: Energy Information Administration. Form EIA-412, "Annual Report of Public Electric Utilities." 
Table 24. Electric Utility Plant by Major U.S. Publicly Owned Electric Utility Within State at End of Period, 1995

(Thousand Dollars)

\begin{tabular}{|c|c|c|c|c|c|c|}
\hline Item & $\begin{array}{l}\text { Tennessee } \\
\text { Ripley } \\
\text { City of } \\
\text { June } 30\end{array}$ & $\begin{array}{l}\text { Tennessee } \\
\text { Rockwood } \\
\text { City of } \\
\text { June } 30\end{array}$ & $\begin{array}{c}\text { Tennessee } \\
\text { Sevier } \\
\text { County } \\
\text { Electric } \\
\text { System } \\
\text { June } 30\end{array}$ & $\begin{array}{c}\text { Tennessee } \\
\text { Shelbyville } \\
\text { City of } \\
\text { June } 30\end{array}$ & $\begin{array}{c}\text { Tennessee } \\
\begin{array}{c}\text { Springfield } \\
\text { City of }\end{array} \\
\text { June } 30\end{array}$ & $\begin{array}{l}\text { Tennessee } \\
\text { Sweetwater } \\
\text { City of } \\
\text { June } 30\end{array}$ \\
\hline 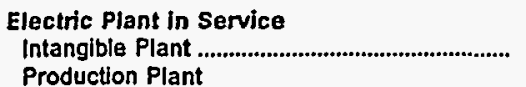 & 0 & 0 & $\mathbf{0}$ & 0 & 0 & 0 \\
\hline Steam & $\mathbf{0}$ & $\mathbf{0}$ & 0 & 0 & 0 & $\mathbf{0}$ \\
\hline Nuclear ......................................................................... & 0 & 0 & 0 & 0 & 0 & 0 \\
\hline 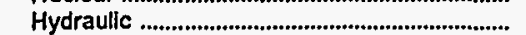 & 0 & 0 & 0 & 0 & 0 & 0 \\
\hline Other & 0 & 0 & 0 & 0 & 0 & 0 \\
\hline Total Production Plant .................................... & 0 & $\mathbf{0}$ & 0 & 0 & 0 & 0 \\
\hline Transmission Plant ................................................... & 592 & 0 & 13,337 & 0 & 0 & 0 \\
\hline 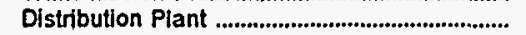 & 5.683 & 16,729 & 49,688 & 10,411 & 9,470 & 11,275 \\
\hline 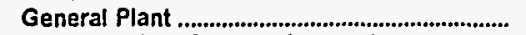 & 1,648 & 1,160 & 5,691 & 1,566 & 1,422 & 1,174 \\
\hline Total Electric Plant in Service ....................... & 7,923 & 17,889 & 68,716 & 11,978 & 10,893 & 12,449 \\
\hline Electric Plant Leased to Others ............................ & 0 & 210 & 755 & 235 & 944 & 0 \\
\hline Electric Plant Held for Future Use ..................... & 0 & 0 & 0 & 0 & 0 & 0 \\
\hline 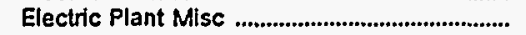 & 1,214 & 0 & 0 & 0 & 0 & 0 \\
\hline Total Electric Utility Plant ................................... & 9,137 & 18,099 & 69,471 & 12,213 & 11,837 & 12,449 \\
\hline $\begin{array}{l}\text { Construction Work in Progress - Electric ....... } \\
\text { Accumulated Provision for Depreciation }\end{array}$ & 111 & 1.525 & 631 & 321 & 548 & 40 \\
\hline and Amortization & 2,669 & 5,987 & 19,270 & 5,096 & 4,425 & 4.025 \\
\hline Net Electric Utility Plant ................................... & 6,579 & 13,637 & 50,833 & 7,438 & 7,959 & 8,465 \\
\hline
\end{tabular}

\begin{tabular}{|c|c|c|c|c|c|c|}
\hline Item & $\begin{array}{l}\text { Tennessee } \\
\text { Tullahoma } \\
\text { Board } \\
\text { of } \\
\text { Pub Utils } \\
\text { June } 30\end{array}$ & $\begin{array}{l}\text { Tennessee } \\
\text { Union } \\
\text { City City of } \\
\text { June } 30\end{array}$ & $\begin{array}{c}\text { Tennessee } \\
\text { Weakley } \\
\text { County } \\
\text { Mun } \\
\text { Elec Sys } \\
\text { June } 30\end{array}$ & $\begin{array}{l}\text { Tennessee } \\
\text { Winchester } \\
\text { City of } \\
\text { June } 30\end{array}$ & $\begin{array}{l}\text { Texas } \\
\text { Austin } \\
\text { City of } \\
\text { September } 30\end{array}$ & $\begin{array}{c}\text { Texas } \\
\begin{array}{c}\text { Brenham } \\
\text { City of }\end{array} \\
\text { September } 30\end{array}$ \\
\hline $\begin{array}{l}\text { Electric Plant in Service } \\
\text { Intangible Plant ................................................... } \\
\text { Production Plant }\end{array}$ & 0 & 0 & 0 & $\mathbf{0}$ & 0 & 0 \\
\hline Steam & 0 & 0 & 0 & 0 & 464,511 & 0 \\
\hline 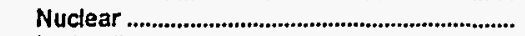 & 0 & 0 & 0 & 0 & 920,975 & 0 \\
\hline 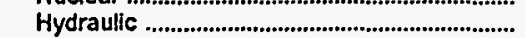 & 0 & 0 & 0 & 0 & 0 & 0 \\
\hline Other & 0 & 0 & 0 & 0 & 4,507 & 0 \\
\hline Total Production Plant ................................ & 0 & 0 & 0 & 0 & $1,389,993$ & \\
\hline Transmission Plant ............................................. & 0 & 1.281 & 2,895 & 0 & 158,243 & 0 \\
\hline 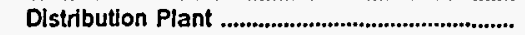 & 11,366 & 7,161 & 23.313 & 6.966 & 632,544 & 9,063 \\
\hline 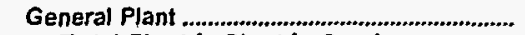 & 2,192 & 1,514 & 2,822 & 1.019 & 92,755 & \\
\hline Total Electric Plant in Service ........................... & 13,557 & 9,956 & 29,030 & 7,985 & $2,273,534$ & 9,063 \\
\hline Electric Plant Leased to Others ......................... & 255 & 0 & 0 & 0 & 0 & 0 \\
\hline Electric Plant Held for Future Use .......................... & 0 & 104 & 0 & 0 & 31,914 & \\
\hline 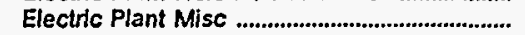 & & 0 & 0 & 0 & 0 & \\
\hline Total Electric Utility Plant ........................... & 13,813 & 10,060 & 29,030 & 7,985 & $2,305,448$ & 9,063 \\
\hline $\begin{array}{l}\text { Construction Work in Progress - Electric ........ } \\
\text { Accumulated Provision for Depreciation }\end{array}$ & 111 & 263 & 1,624 & 504 & 70,005 & \\
\hline 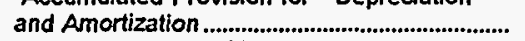 & 6,019 & 3,912 & 13,680 & 3,362 & 680,744 & 3,444 \\
\hline Net Electric Utility Plant ..................................... & 7,905 & 6,411 & 16,973 & 5,127 & $1,694,709$ & 5,619 \\
\hline
\end{tabular}

Note: Totals may not equal sum of components because of independent rounding.

Source: Energy Information Administration, Form ElA-412, "Annual Report of Public Electric Utilities." 
Table 24. Electric Utility Plant by Major U.S. Publicly Owned Electric Utility Within State at End of Period, 1995 (Continued) (Thousand Dollars)

\begin{tabular}{|c|c|c|c|c|c|c|}
\hline Item & $\begin{array}{c}\text { Texas } \\
\text { Brownsville } \\
\text { Public } \\
\text { Utils Board } \\
\text { September } 30\end{array}$ & $\begin{array}{c}\text { Texas } \\
\text { Bryan } \\
\text { City of } \\
\text { September } 30\end{array}$ & $\begin{array}{l}\text { Texas } \\
\text { College } \\
\text { Station } \\
\text { City of } \\
\text { September } 30\end{array}$ & $\begin{array}{l}\text { Texas } \\
\text { Denton } \\
\text { City of } \\
\text { September } 30\end{array}$ & $\begin{array}{c}\text { Texas } \\
\text { Floresville } \\
\text { City of } \\
\text { December } 31\end{array}$ & $\begin{array}{c}\text { Texas } \\
\text { Gartand } \\
\text { City of } \\
\text { September } 30\end{array}$ \\
\hline 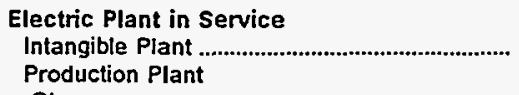 & 19,689 & 0 & 0 & 0 & 0 & 0 \\
\hline Steam & 0 & 54,253 & 0 & 30,861 & 0 & 77,053 \\
\hline 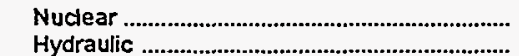 & $\begin{array}{l}0 \\
0\end{array}$ & $\begin{array}{l}0 \\
0\end{array}$ & $\begin{array}{l}0 \\
0\end{array}$ & $\begin{array}{r}0 \\
8.734\end{array}$ & $\begin{array}{l}0 \\
0\end{array}$ & $\begin{array}{l}0 \\
0\end{array}$ \\
\hline 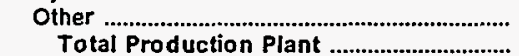 & $\begin{array}{l}268 \\
268\end{array}$ & $\begin{array}{r}226 \\
54,479\end{array}$ & $\begin{array}{l}0 \\
0\end{array}$ & $\begin{array}{r}751 \\
40,346\end{array}$ & $\begin{array}{l}0 \\
0\end{array}$ & $\begin{array}{r}0 \\
77,053\end{array}$ \\
\hline 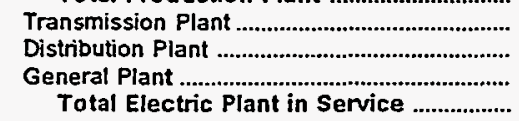 & $\begin{array}{r}65,934 \\
50,675 \\
134,577 \\
271,143\end{array}$ & $\begin{array}{r}19,533 \\
55,411 \\
3,680 \\
133,103\end{array}$ & $\begin{array}{r}9,136 \\
15,991 \\
3,859 \\
28,986\end{array}$ & $\begin{array}{r}6,022 \\
48,625 \\
4,709 \\
99,701\end{array}$ & $\begin{array}{r}1,497 \\
21,765 \\
2,889 \\
26,151\end{array}$ & $\begin{array}{r}19,730 \\
94,113 \\
21,710 \\
212,607\end{array}$ \\
\hline Electric Plant Leased to Others .......................... & 0 & 0 & 0 & 0 & 0 & 0 \\
\hline Electric Plant Held for Future Use ...................... & 0 & 0 & 0 & 0 & 0 & $\mathbf{0}$ \\
\hline 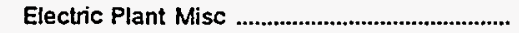 & 0 & 0 & 0 & 0 & 0 & $\mathbf{0}$ \\
\hline $\begin{array}{l}\text { Total Electric Utility Plant } \\
\text { Construction Work in Progress - Electric ....................... } \\
\text { Accumulated Provision for Depreciation }\end{array}$ & $\begin{array}{r}271,143 \\
52,968\end{array}$ & $\begin{array}{r}133,103 \\
4,207\end{array}$ & $\begin{array}{r}28,986 \\
6,172\end{array}$ & $\begin{array}{r}99,701 \\
1,110\end{array}$ & $\begin{array}{r}26,151 \\
0\end{array}$ & $\begin{array}{r}212,607 \\
4,782\end{array}$ \\
\hline and Amortization & $\begin{array}{r}86,524 \\
237,588\end{array}$ & $\begin{array}{l}57,210 \\
80,100\end{array}$ & $\begin{array}{r}9,737 \\
25,421\end{array}$ & $\begin{array}{l}59,562 \\
41,249\end{array}$ & $\begin{array}{l}10,386 \\
15,765\end{array}$ & $\begin{array}{r}97,920 \\
119,469\end{array}$ \\
\hline
\end{tabular}

\begin{tabular}{|c|c|c|c|c|c|c|}
\hline Item & $\begin{array}{c}\text { Texas } \\
\text { Georgetown } \\
\text { City of }\end{array}$ & $\begin{array}{c}\text { Texas } \\
\text { Greenville } \\
\text { Electric } \\
\text { Util Sys } \\
\text { September 30 }\end{array}$ & $\begin{array}{l}\text { Texas } \\
\text { Jasper } \\
\text { City of } \\
\text { September } 30\end{array}$ & $\begin{array}{c}\text { Texas } \\
\text { Kernille } \\
\text { Public } \\
\text { Utility } \\
\text { Board } \\
\text { September } 30\end{array}$ & $\begin{array}{l}\text { Texas } \\
\text { Lower } \\
\text { Colorado } \\
\text { River } \\
\text { Authority } \\
\text { June } 30\end{array}$ & $\begin{array}{c}\text { Texas } \\
\text { Lubbock } \\
\text { City of } \\
\text { September } 30\end{array}$ \\
\hline \multicolumn{7}{|l|}{ Electric Plant in Service } \\
\hline 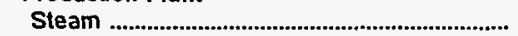 & 0 & 18,573 & 0 & 0 & 891,153 & 0 \\
\hline 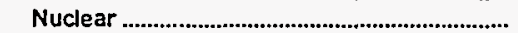 & 0 & 0 & 0 & 0 & 0 & 0 \\
\hline 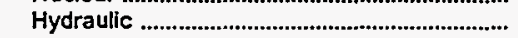 & 0 & 0 & 0 & 0 & 84,253 & 0 \\
\hline Other & 0 & 4,973 & 0 & 0 & 0 & 0 \\
\hline Total Production Plant & 0 & 23,546 & $\mathbf{0}$ & 0 & 975,406 & $\mathbf{0}$ \\
\hline 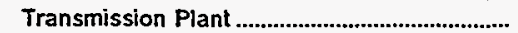 & 0 & 1,660 & 0 & 0 & 276,167 & 0 \\
\hline 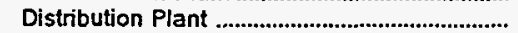 & 0 & 22,940 & 0 & 25,357 & 4,481 & 0 \\
\hline General Plant & 5,617 & $\begin{array}{r}4,865 \\
53,012\end{array}$ & 0 & $\begin{array}{r}5,163 \\
3 n, 720\end{array}$ & 150,302 & 133,955 \\
\hline $\begin{array}{l}\text { Total Electric Plant in Service } \\
\text { Electric Plant Leased to Others }\end{array}$ & $\begin{array}{r}5,617 \\
0\end{array}$ & $\begin{array}{r}53,012 \\
0\end{array}$ & $\begin{array}{l}0 \\
0\end{array}$ & $\begin{array}{r}30,720 \\
0\end{array}$ & $\begin{array}{r}1,406,723 \\
1\end{array}$ & $\begin{array}{r}133,955 \\
0\end{array}$ \\
\hline Electric Plant Held for Future Use .................. & 0 & 0 & 0 & 0 & 0 & $\mathbf{0}$ \\
\hline 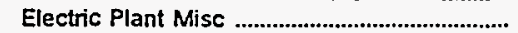 & 0 & 0 & 0 & -610 & 79.878 & 154 \\
\hline 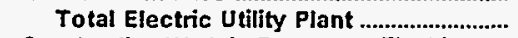 & 5,617 & 53,012 & 0 & 30,110 & $1,486,602$ & 134,109 \\
\hline $\begin{array}{l}\text { Construction Work in Progress - Electric ....... } \\
\text { Accumulated Provision for Depreciation }\end{array}$ & 594 & 0 & 0 & 408 & 83,427 & 9,367 \\
\hline and Amortization & 2,558 & 31,103 & 0 & 9,606 & 460,715 & 51,930 \\
\hline Net Electric Utility Plant ............................... & 3,654 & 21,908 & 0 & 20,912 & $1,109,313$ & 91,546 \\
\hline
\end{tabular}

Note: Totals may not equal sum of components because of independent rounding.

Source: Energy Information Administration, Form ElA-412, "Annual Report of Public Electric Utilities." 
Table 24. Electric Utility Plant by Major U.S. Publicly Owned Electric Utility Within State at End of Period, 1995 (Continued)

(Thousand Dollars)

\begin{tabular}{|c|c|c|c|c|c|c|}
\hline Item & $\begin{array}{c}\text { Texas } \\
\text { New Braunfels } \\
\text { City of } \\
\text { July } 3 \mathfrak{1}\end{array}$ & $\begin{array}{c}\text { Texas } \\
\text { Sam Rayburn } \\
\text { Municipal } \\
\text { Pwr } \\
\text { Agny } \\
\text { September } 30\end{array}$ & $\begin{array}{c}\text { Texas } \\
\text { San Antonio } \\
\text { Public } \\
\text { Senvice Bd } \\
\text { January } 31\end{array}$ & $\begin{array}{c}\text { Texas } \\
\text { San Marcos } \\
\text { City of } \\
\text { September } 30\end{array}$ & $\begin{array}{c}\text { Texas } \\
\text { Seguin } \\
\text { City of } \\
\text { September } 30\end{array}$ & $\begin{array}{c}\text { Texas } \\
\text { Texas } \\
\text { Municipal } \\
\text { Power Agency } \\
\text { September } 30\end{array}$ \\
\hline 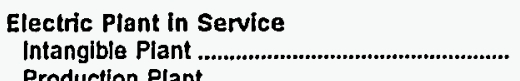 & 0 & \multicolumn{5}{|c|}{ Electric Plant in Service } \\
\hline Steam & $\mathbf{0}$ & 133,573 & $1,149,240$ & 0 & 0 & 628,124 \\
\hline Nuclear & 0 & 0 & $2.161,716$ & 0 & 0 & 0 \\
\hline 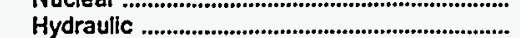 & 14,757 & 0 & 0 & 0 & 522 & 0 \\
\hline Other & 0 & 0 & 0 & 0 & 0 & $\mathbf{0}$ \\
\hline Total Production Plant & 14,757 & 133,573 & $3,310,956$ & 0 & 522 & 628,124 \\
\hline 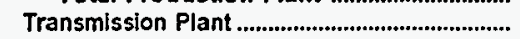 & 10.061 & 0 & 232,699 & 0 & 883 & 138,778 \\
\hline 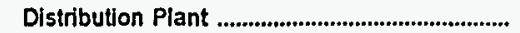 & 25,641 & 9,168 & 822,218 & 10,658 & 4,191 & 0 \\
\hline General Plant ........................................................ & $\begin{array}{r}6,231 \\
56,690\end{array}$ & $\begin{array}{r}0 \\
143,077\end{array}$ & $\begin{array}{r}180,850 \\
4,546,723\end{array}$ & $\begin{array}{r}2,576 \\
13,234\end{array}$ & $\begin{array}{l}1,014 \\
6,610\end{array}$ & $\begin{array}{r}10,242 \\
777,144\end{array}$ \\
\hline 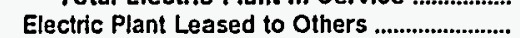 & 0 & 0 & 0 & 0 & 0 & 403 \\
\hline Electric Plant Held for Future Use ..................... & 0 & 0 & 30,380 & 0 & 0 & 9,515 \\
\hline 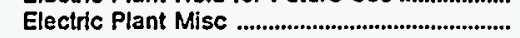 & 0 & 0 & 0 & 3,867 & 0 & 537 \\
\hline 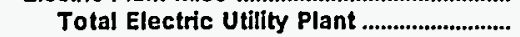 & 56,690 & 143,077 & $4,577,103$ & 17,100 & 6,610 & 787,599 \\
\hline $\begin{array}{l}\text { Construction Work in Progress - Electric ........ } \\
\text { Accumulated Provision for Depreciation }\end{array}$ & 103 & 4,634 & 162,313 & 2,137 & 0 & 32,317 \\
\hline $\begin{array}{l}\text { and Amortization } \\
\text { Net Electric Utility Plant }\end{array}$ & $\begin{array}{l}22,383 \\
34,410\end{array}$ & $\begin{array}{l}49,007 \\
98,704\end{array}$ & $\begin{array}{r}946,069 \\
3,793,347\end{array}$ & $\begin{array}{r}6,583 \\
12,654\end{array}$ & $\begin{array}{l}4,027 \\
2,583\end{array}$ & $\begin{array}{l}324,778 \\
495,138\end{array}$ \\
\hline
\end{tabular}

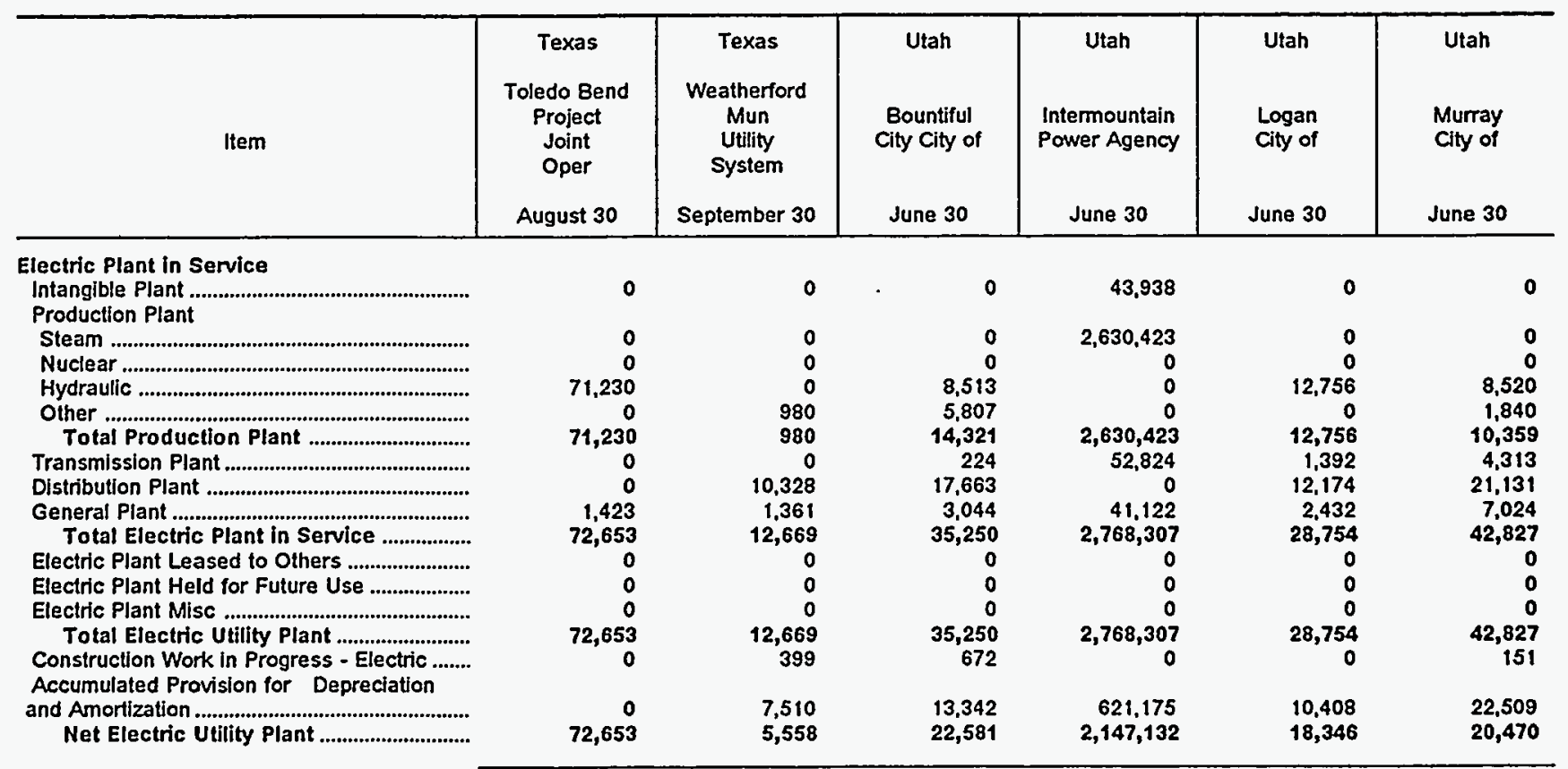

Note: Totals may not equal sum of components because of independent rounding.

Source: Energy Information Administration, Form ElA-412, "Annual Report of Public Electric Utilities." 
Table 24. Electric Utility Plant by Major U.S. Publicly Owned Electric Utility Within State at End of Period, 1995 (Continued)

(Thousand Dollars)

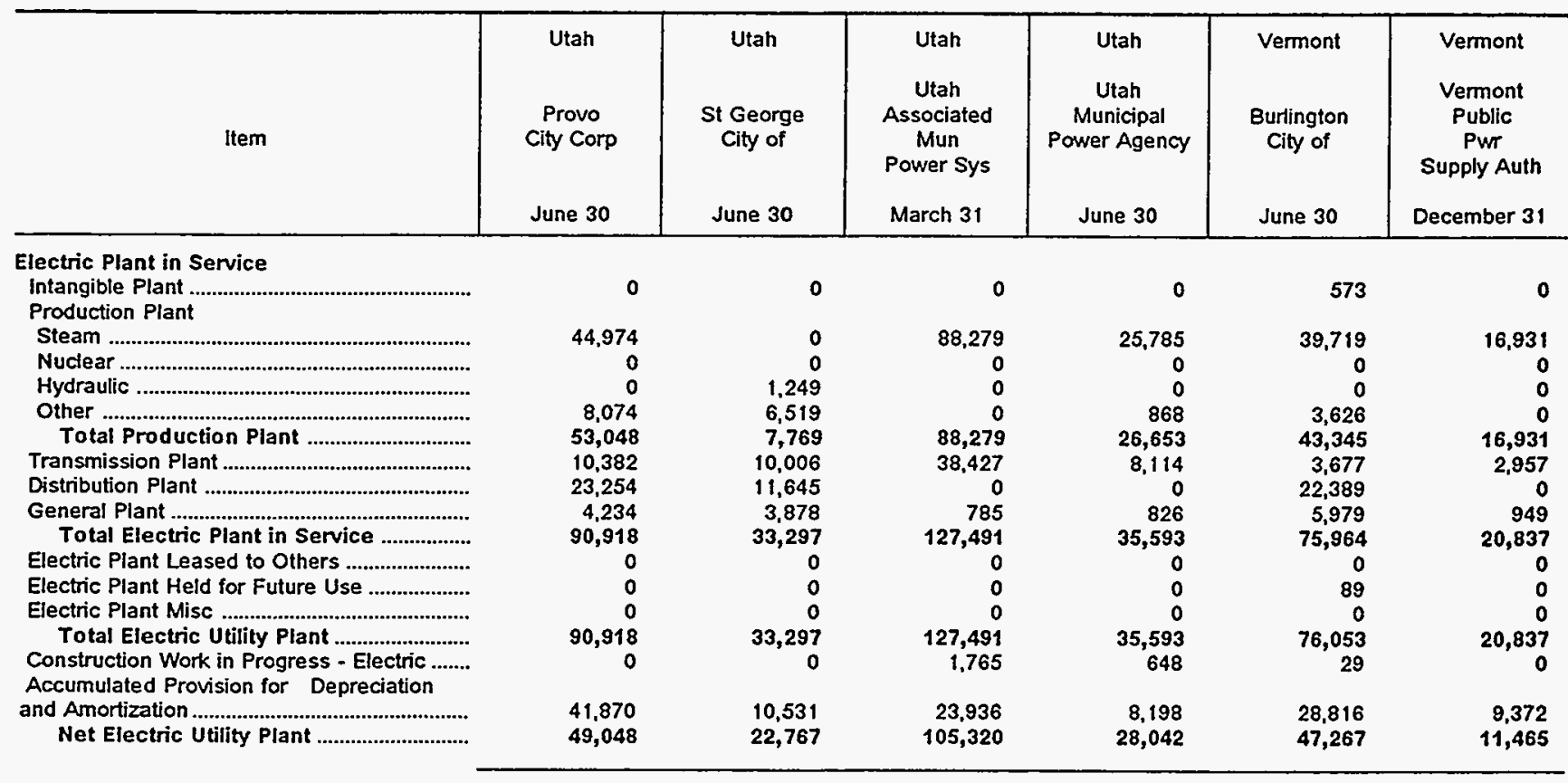

\begin{tabular}{|c|c|c|c|c|c|c|}
\hline Item & $\begin{array}{l}\text { Virginia } \\
\text { Bedford } \\
\text { City of } \\
\text { June } 30\end{array}$ & $\begin{array}{l}\text { Virginia } \\
\text { Bristol } \\
\text { Utilities } \\
\text { Board } \\
\text { June } 30\end{array}$ & $\begin{array}{l}\text { Virginia } \\
\text { Danville } \\
\text { City of } \\
\text { June } 30\end{array}$ & $\begin{array}{c}\text { Virginia } \\
\begin{array}{c}\text { Harrisonburg } \\
\text { City of }\end{array} \\
\text { June } 30\end{array}$ & $\begin{array}{l}\text { Virginia } \\
\begin{array}{c}\text { Manassas } \\
\text { City of }\end{array} \\
\text { June } 30\end{array}$ & $\begin{array}{l}\text { Virginia } \\
\text { Martinsulle } \\
\text { City of } \\
\text { June } 30\end{array}$ \\
\hline \multicolumn{7}{|l|}{ Electric Plant in Service } \\
\hline 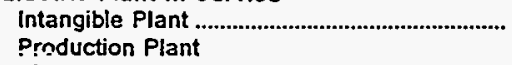 & 184 & 0 & 908 & 0 & 0 & 0 \\
\hline Steam & 0 & 0 & 0 & 286 & 0 & 0 \\
\hline 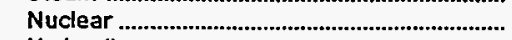 & 0 & 0 & 0 & 0 & $\mathbf{0}$ & 0 \\
\hline 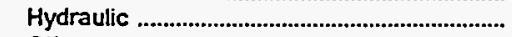 & 11,122 & 0 & 3,480 & 0 & 0 & 270 \\
\hline Other & 0 & 0 & 0 & 3,308 & 0 & 0 \\
\hline 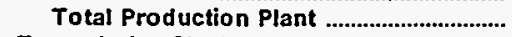 & 11,122 & 0 & 3,480 & 3,594 & 0 & 270 \\
\hline 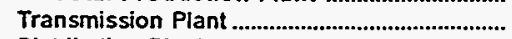 & 2,196 & 0 & 2,103 & 5,168 & 15 & 0 \\
\hline 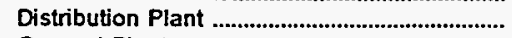 & 3,569 & 20,250 & 49,307 & 29,111 & 39,988 & 16,260 \\
\hline $\begin{array}{l}\text { General Plant } \\
\text { Total Electric Plant in Service }\end{array}$ & $\begin{array}{r}819 \\
17,890\end{array}$ & $\begin{array}{r}3,459 \\
23,709\end{array}$ & $\begin{array}{r}2,838 \\
58,636\end{array}$ & $\begin{array}{r}3,688 \\
41,562\end{array}$ & $\begin{array}{r}0 \\
40,003\end{array}$ & $\begin{array}{r}1,344 \\
17,873\end{array}$ \\
\hline 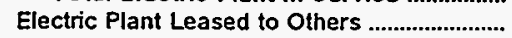 & 0 & 0 & 0 & 0 & $\begin{array}{r}40,000 \\
0\end{array}$ & 0 \\
\hline Electric Plant Held for Future Use ....................... & 0 & 0 & 0 & 0 & 0 & 0 \\
\hline Electric Plant Misc & 0 & 0 & 0 & 3,795 & 0 & o \\
\hline 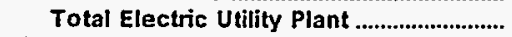 & 17,890 & 23,709 & 58,636 & 45,357 & 40,003 & 17,873 \\
\hline $\begin{array}{l}\text { Construction Work in Progress - Electric ....... } \\
\text { Accumulated Provision for Depreciation }\end{array}$ & 0 & 1,152 & 6,463 & 1,510 & 348 & 0 \\
\hline 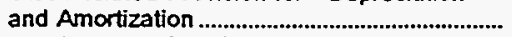 & 6,003 & 11,101 & 25,289 & 16,160 & 13,810 & 7,630 \\
\hline 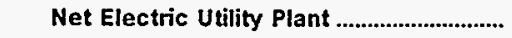 & 11,886 & 13,760 & 39,810 & 30,707 & 26,541 & 10,243 \\
\hline
\end{tabular}

Note: Totals may not equal sum of components because of independent rounding.

Source: Energy Information Administration, Form EIA-412, "Annual Report of Public Electric Utilities." 
Table 24. Electric Utility Plant by Major U.S. Publicly Owned Electric Utility Within State at End of Period, 1995 (Continued)

(Thousand Dollars)

\begin{tabular}{|c|c|c|c|c|c|c|}
\hline Item & $\begin{array}{l}\text { Virginia } \\
\text { Radford } \\
\text { City of } \\
\text { June } 30\end{array}$ & $\begin{array}{l}\text { Virginia } \\
\text { Salem } \\
\text { City of } \\
\text { June } 30\end{array}$ & $\begin{array}{l}\text { Virginia } \\
\text { Virginia } \\
\text { Tech } \\
\text { Electric } \\
\text { Service } \\
\text { June } 30\end{array}$ & $\begin{array}{c}\text { Washington } \\
\text { Centralia } \\
\text { City of } \\
\text { December } 31\end{array}$ & $\begin{array}{l}\text { Washington } \\
\text { Ellensburg } \\
\text { City of } \\
\text { December } 31\end{array}$ & $\begin{array}{l}\text { Washington } \\
\text { Port Angeles } \\
\text { City of } \\
\text { December } 31\end{array}$ \\
\hline 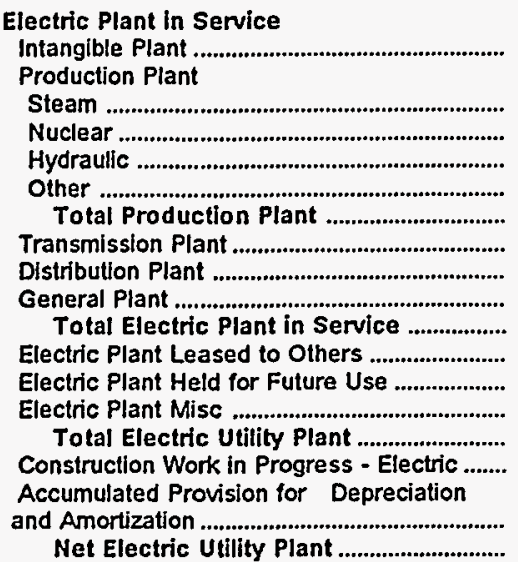 & $\begin{array}{r}0 \\
0 \\
0 \\
0 \\
455 \\
0 \\
455 \\
3,835 \\
10,028 \\
0 \\
14,318 \\
0 \\
0 \\
0 \\
14,318 \\
0\end{array}$ & $\begin{array}{r}0 \\
0 \\
0 \\
0 \\
0 \\
0 \\
0 \\
0 \\
21,020 \\
21,020 \\
0 \\
0 \\
0 \\
21,020 \\
0\end{array}$ & $\begin{array}{l}0 \\
0 \\
0 \\
0 \\
0 \\
0 \\
0 \\
0 \\
0 \\
0 \\
0 \\
0 \\
0 \\
0\end{array}$ & $\begin{array}{r}3,078 \\
0 \\
0 \\
0 \\
6,860 \\
0 \\
6,860 \\
931 \\
7,574 \\
1,712 \\
20,156 \\
0 \\
0 \\
0 \\
20,156 \\
0\end{array}$ & $\begin{array}{r}0 \\
0 \\
0 \\
0 \\
0 \\
0 \\
13,326 \\
453 \\
13,779 \\
0 \\
0 \\
137 \\
13,916 \\
0\end{array}$ & $\begin{array}{r}0 \\
0 \\
1,650 \\
0 \\
1,650 \\
631 \\
17,308 \\
581 \\
20,171 \\
0 \\
0 \\
0 \\
20,171 \\
2,115\end{array}$ \\
\hline
\end{tabular}

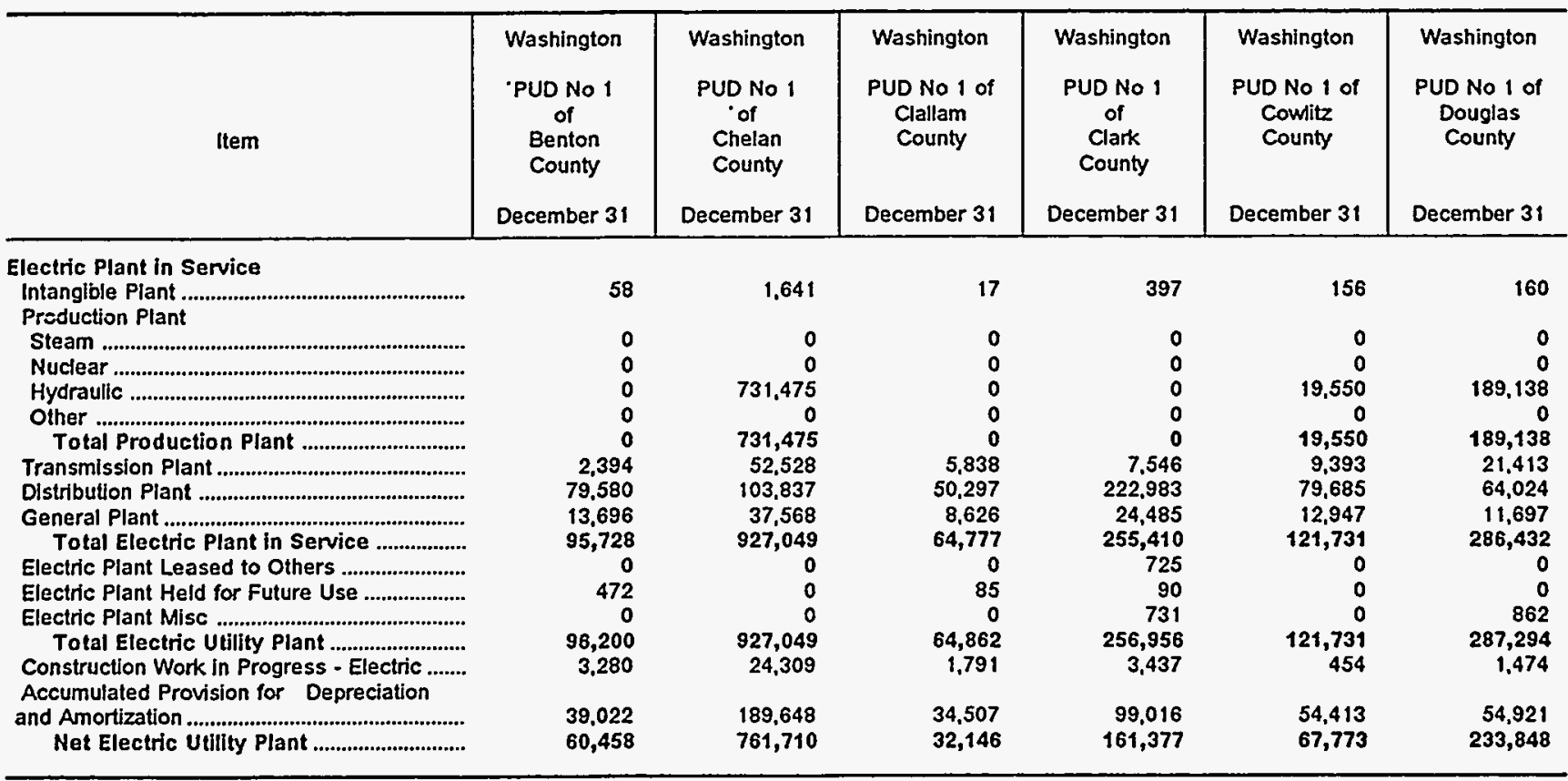

Note: Totals may not equal sum of components because of independent rounding.

Source: Energy Information Administration, Form ElA-412, "Annual Report of Public Electric Utilities." 
Table 24. Electric Utility Plant by Major U.S. Publicly Owned Electric Utility Within State at End of Period, 1995

(Thousand Dollars)

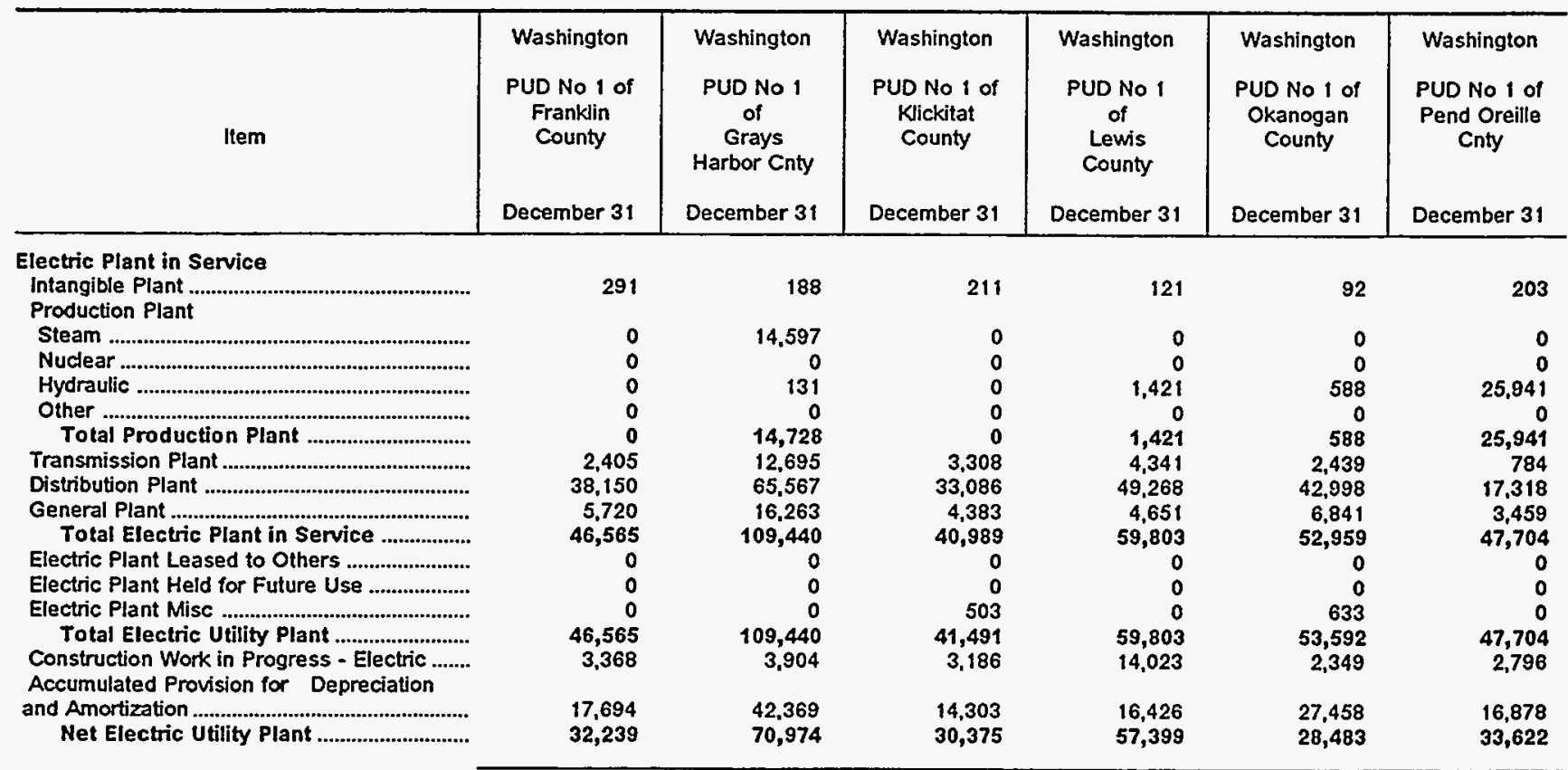

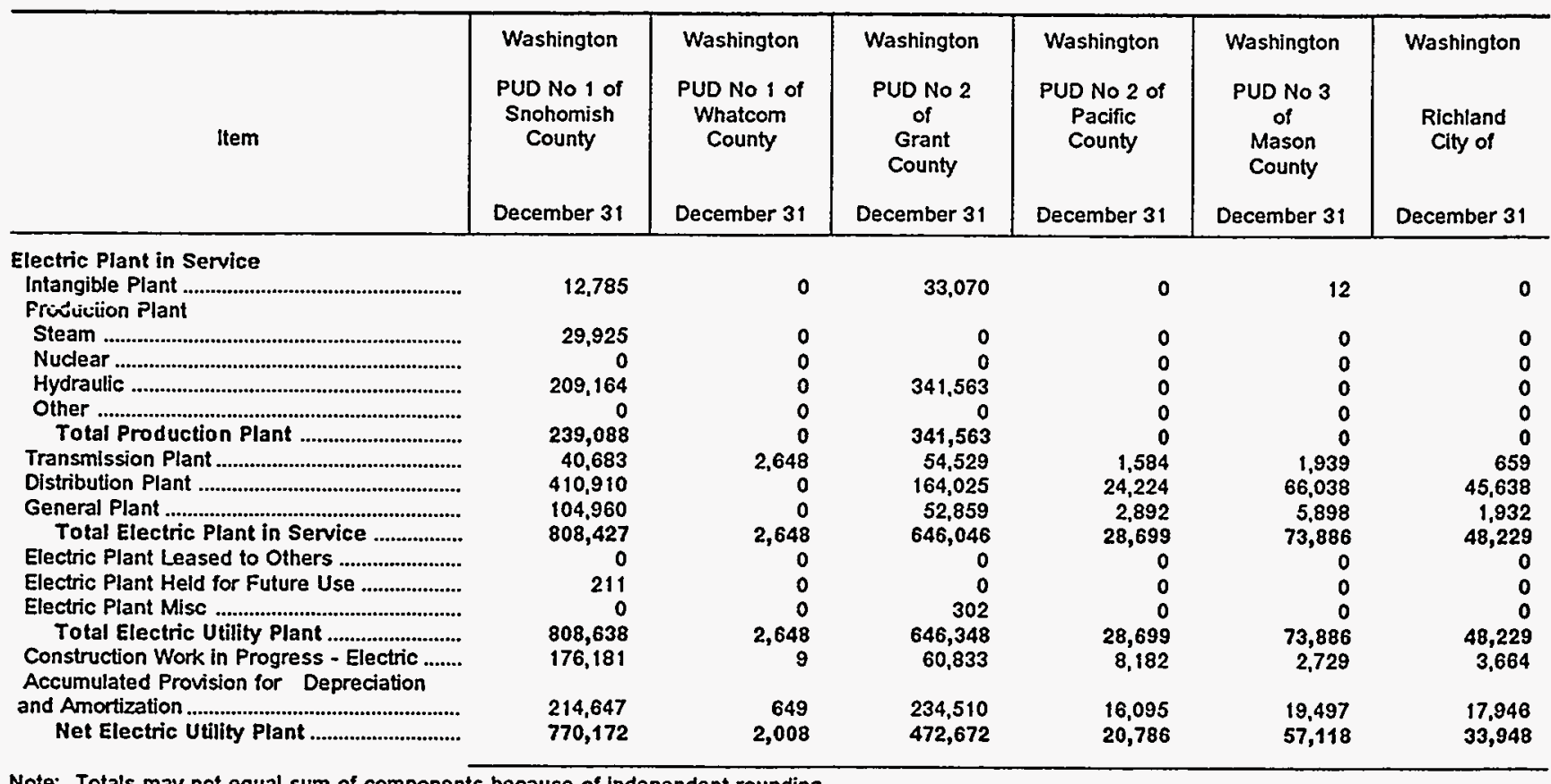

Note: Totals may not equal sum of components because of independent rounding.

Source: Energy Information Administration, Form EIA-412, "Annual Report of Public Electric Utilities." 
Table 24. Electric Utility Plant by Major U.S. Publicly Owned Electric Utility Within State at End of Period, 1995 (Continued)

(Thousand Dollars)

\begin{tabular}{|c|c|c|c|c|c|c|}
\hline Item & $\begin{array}{c}\text { Washington } \\
\text { Seattle } \\
\text { City of } \\
\text { December } 31\end{array}$ & $\begin{array}{c}\text { Washington } \\
\text { Tacoma } \\
\text { City of } \\
\text { December } 31\end{array}$ & $\begin{array}{c}\text { Washington } \\
\text { Vera } \\
\text { Imigation } \\
\text { District \#15 } \\
\text { December } 31\end{array}$ & $\begin{array}{l}\text { Washington } \\
\text { Washington } \\
\text { Pub } \\
\text { Pwr } \\
\text { Supply Sys } \\
\text { June } 30\end{array}$ & $\begin{array}{l}\text { Wisconsin } \\
\text { Badger Power } \\
\text { Marketing } \\
\text { Auth } \\
\text { December } 31\end{array}$ & $\begin{array}{l}\text { Wisconsin } \\
\text { Jefferson } \\
\text { City of } \\
\text { December } 31\end{array}$ \\
\hline 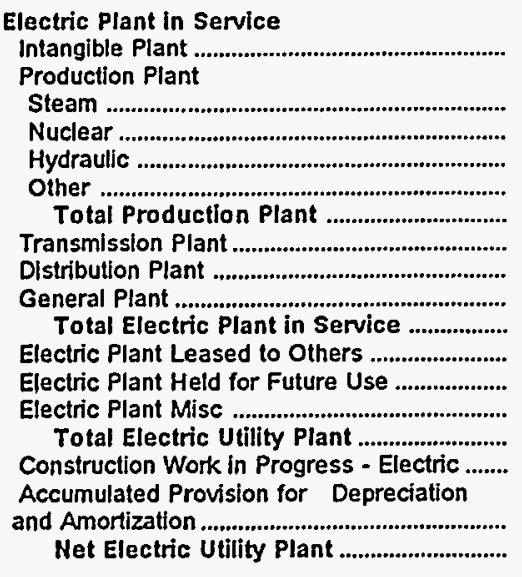 & $\begin{array}{r}27,039 \\
0 \\
450,597 \\
0 \\
477,636 \\
87,337 \\
617,107 \\
163,303 \\
1,379,695 \\
0 \\
2,499 \\
0 \\
1,382,194 \\
54,932 \\
\\
579,253 \\
857,874\end{array}$ & $\begin{array}{r}86,167 \\
0 \\
302,254 \\
0 \\
388,421 \\
77,288 \\
196,674 \\
40,132 \\
716,094 \\
0 \\
275 \\
723 \\
717,092 \\
23,397\end{array}$ & $\begin{array}{r}0 \\
0 \\
0 \\
0 \\
0 \\
0 \\
11,376 \\
2,844 \\
14,221 \\
0 \\
0 \\
0 \\
14,221 \\
429\end{array}$ & $\begin{array}{r}0 \\
3,220,153 \\
12,083 \\
0 \\
3,232,236 \\
5,202 \\
0 \\
159,015 \\
3,396,453 \\
0 \\
0 \\
0 \\
3,396,453 \\
63,656\end{array}$ & $\begin{array}{r}0 \\
0 \\
0 \\
0 \\
0 \\
5,221 \\
0 \\
133 \\
5,365 \\
0 \\
0 \\
569 \\
5,934 \\
10\end{array}$ & $\begin{array}{r}0 \\
0 \\
0 \\
0 \\
0 \\
0 \\
7,533 \\
701 \\
8,234 \\
0 \\
0 \\
0 \\
8,234 \\
199\end{array}$ \\
\hline
\end{tabular}

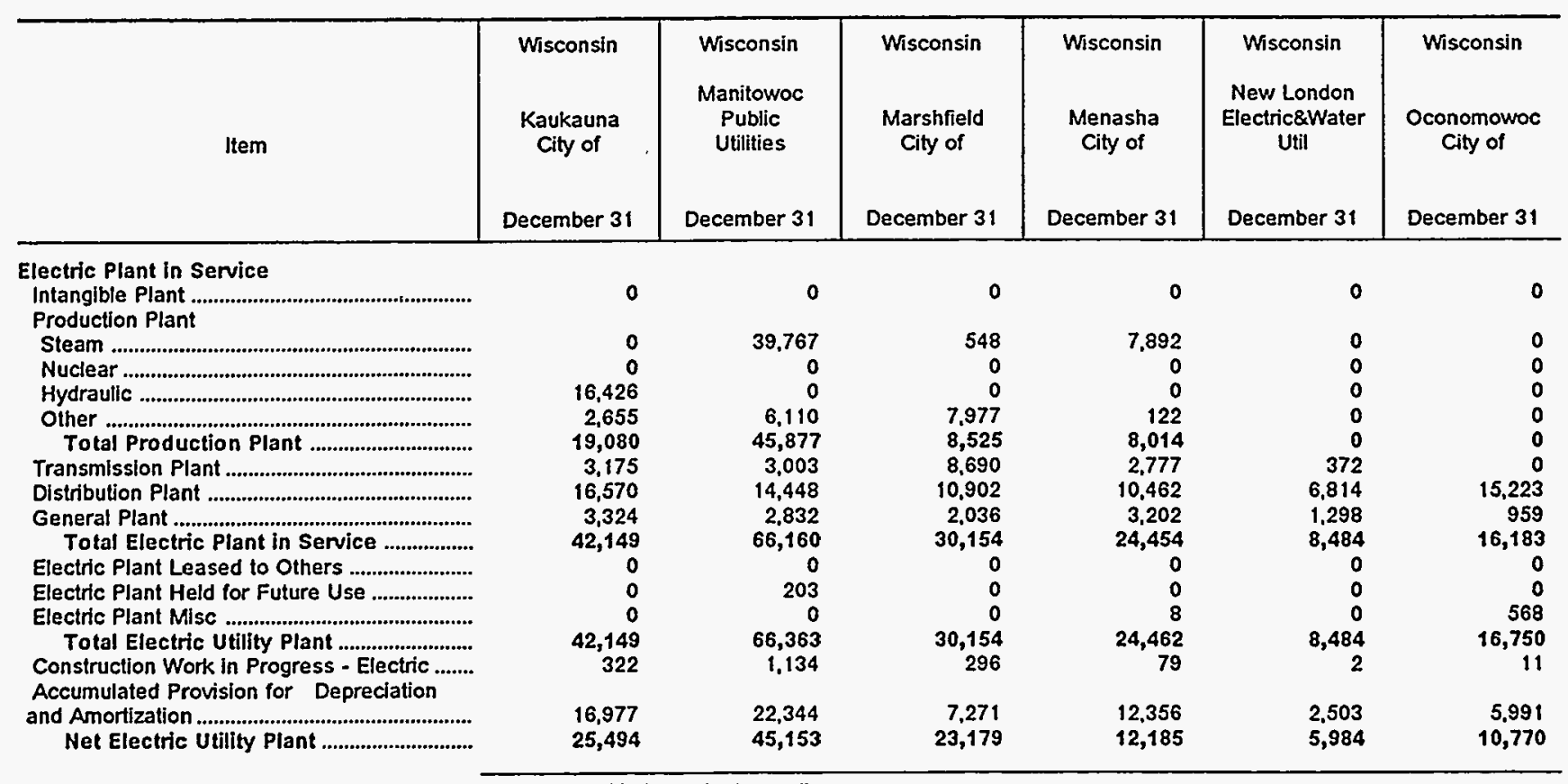

Note: Totals may not equal sum of components because of independent rounding.

Source: Energy Information Administration, Form ElA-412, "Annual Report of Public Electric Utilities." 
Table 24. Electric Utility Plant by Major U.S. Publicly Owned Electric Utility Within State at End of Period, 1995 (Continued)

(Thousand Dollars)

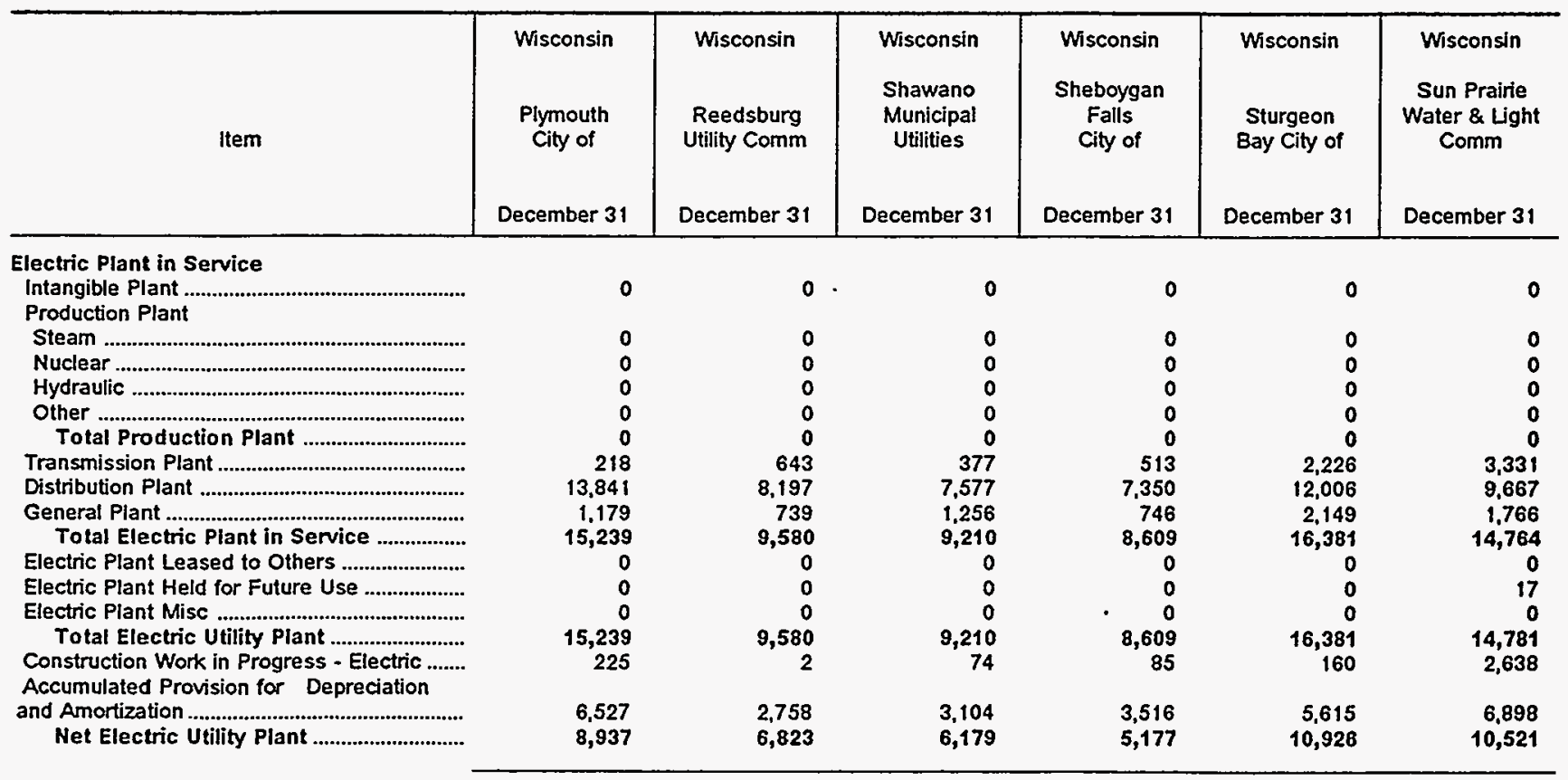

\begin{tabular}{|c|c|c|c|c|}
\hline Item & $\begin{array}{c}\text { Wisconsin } \\
\text { Wisconsin } \\
\text { Public } \\
\text { Power } \\
\text { Inc Sys } \\
\text { December } 31\end{array}$ & $\begin{array}{c}\text { Wisconsin } \\
\text { Wisconsin } \\
\text { Rapids W W } \\
\& L \\
\text { Comm } \\
\text { December } 31\end{array}$ & $\begin{array}{l}\text { Wyoming } \\
\text { Gillette } \\
\text { City of } \\
\text { June } 30\end{array}$ & $\begin{array}{l}\text { Wyoming } \\
\text { Wyoming } \\
\text { Municipal } \\
\text { Power Agency } \\
\text { December } 31\end{array}$ \\
\hline 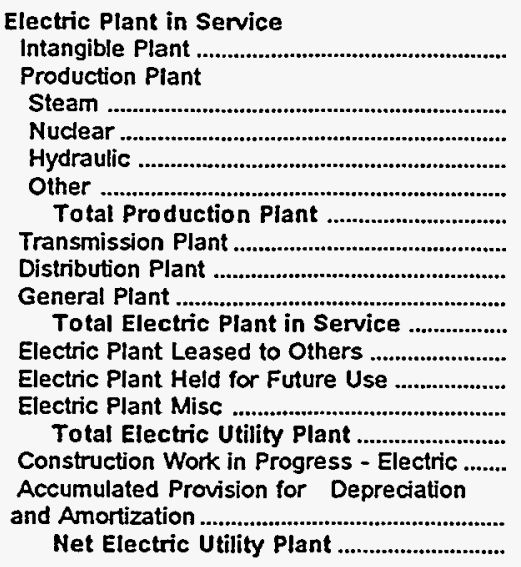 & $\begin{array}{r}15,985 \\
\\
74,626 \\
0 \\
0 \\
29,231 \\
103,857 \\
1,034 \\
205 \\
5,181 \\
126,262 \\
0 \\
0 \\
15,592 \\
141,854 \\
570 \\
\\
37,271 \\
105,154\end{array}$ & $\begin{array}{r}0 \\
0 \\
0 \\
0 \\
0 \\
0 \\
0 \\
0 \\
17,043 \\
1,648 \\
18,691 \\
0 \\
1 \\
0 \\
18,692 \\
61\end{array}$ & $\begin{array}{r}0 \\
0 \\
0 \\
0 \\
0 \\
0 \\
0 \\
1,155 \\
18,141 \\
323 \\
19,619 \\
0 \\
0 \\
0 \\
19,619 \\
0\end{array}$ & $\begin{array}{r}908 \\
15,538 \\
0 \\
0 \\
0 \\
15,538 \\
5,230 \\
0 \\
856 \\
22,532 \\
0 \\
0 \\
2 \\
22,534 \\
1 \\
7,999 \\
14,536\end{array}$ \\
\hline
\end{tabular}

Note: Totals may not equal sum of components because of independent rounding.

Source: Energy Information Administration, Form ELA-412, "Annual Report of Public Electric Utilities." 
Table 25. Number of Consumers, Sales, and Operating Revenue by Major U.S. Publicly Owned Electric Utility Within State, 1995

\begin{tabular}{|c|c|c|c|c|c|c|}
\hline Item & $\begin{array}{l}\text { Alabama } \\
\text { Alabama } \\
\text { Municipal } \\
\text { Elec Auth } \\
\text { September } 30\end{array}$ & $\begin{array}{l}\text { Alabama } \\
\text { Albertville } \\
\text { Municipal } \\
\text { Utils Bd } \\
\text { June } 30\end{array}$ & $\begin{array}{l}\text { Alabama } \\
\text { Andalusia } \\
\text { City of } \\
\text { September } 30\end{array}$ & $\begin{array}{c}\text { Alabama } \\
\text { Athens } \\
\text { City of } \\
\text { December } 31\end{array}$ & $\begin{array}{l}\text { Alabama } \\
\text { Bessemer } \\
\text { City of } \\
\text { June } 30\end{array}$ & $\begin{array}{c}\text { Alabama } \\
\text { Cullman } \\
\text { Power Board } \\
\text { June } 30\end{array}$ \\
\hline \multicolumn{7}{|l|}{ Number of Consumers } \\
\hline 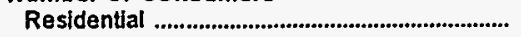 & $\mathbf{0}$ & 6,912 & 3.728 & 24,726 & 10,875 & 6,059 \\
\hline Commercial or Small & $\mathbf{0}$ & 1,450 & 707 & 3,861 & 1,316 & 1.449 \\
\hline 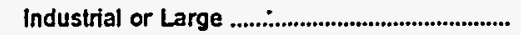 & $\mathbf{0}$ & 163 & 50 & 337 & 236 & 211 \\
\hline Other & 0 & 6 & 4 & 108 & 21 & 38 \\
\hline $\begin{array}{l}\text { Total Ultimate Consumers } \\
\text { Sales for the Year (megawatthours) }\end{array}$ & $\mathbf{0}$ & 8,531 & 4,489 & 29,032 & 12,448 & 7,757 \\
\hline 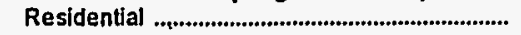 & $\mathbf{0}$ & 97,576 & 43,795 & 388,001 & 117,124 & 83,780 \\
\hline 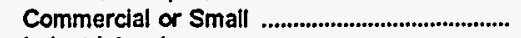 & $\mathbf{0}$ & 22,919 & 21,668 & 52,027 & 30,326 & 29,525 \\
\hline Industrial or Large & $\mathbf{0}$ & 336,726 & 259,686 & 207.508 & 157,940 & 189,513 \\
\hline $\begin{array}{l}\text { Other } \\
\text { Total to Ultimate Consumers }\end{array}$ & $\begin{array}{l}\mathbf{0} \\
\mathbf{0}\end{array}$ & $\begin{array}{r}3,983 \\
461,204\end{array}$ & $\begin{array}{r}1,415 \\
326,564\end{array}$ & $\begin{array}{r}8,682 \\
656,218\end{array}$ & $\begin{array}{r}6,360 \\
311,750\end{array}$ & $\begin{array}{r}6,139 \\
308,957\end{array}$ \\
\hline 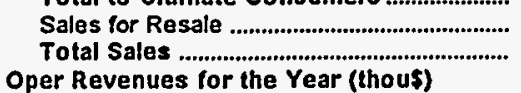 & $\begin{array}{l}2,530,961 \\
2,530,961\end{array}$ & 461,204 & $\begin{array}{r}0 \\
326,564\end{array}$ & $\begin{array}{r}0 \\
656,218\end{array}$ & $\begin{array}{r}0 \\
311,750\end{array}$ & $\begin{array}{r}0 \\
308,957\end{array}$ \\
\hline 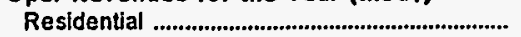 & 0 & 5,454 & 3,049 & 22,390 & 7,362 & 4,814 \\
\hline 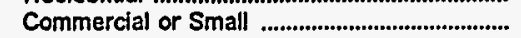 & 0 & 1,454 & 1,994 & 3,512 & 2,019 & 1,886 \\
\hline 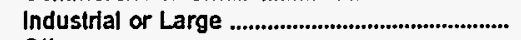 & 0 & 13,223 & 9,548 & 11,078 & 7,752 & 9.726 \\
\hline Other & 0 & 303 & 102 & 790 & 525 & 355 \\
\hline Total to Ultimate Consumers ............................ & 0 & 20,434 & 14,693 & 37,770 & 17,658 & 16,781 \\
\hline Sales for Resale & 92,914 & 0 & 0 & 0 & 0 & 0 \\
\hline Total Revenues From Sales of Elec......... & 92,914 & 20,434 & 14,693 & 37,770 & 17,658 & 16,781 \\
\hline
\end{tabular}

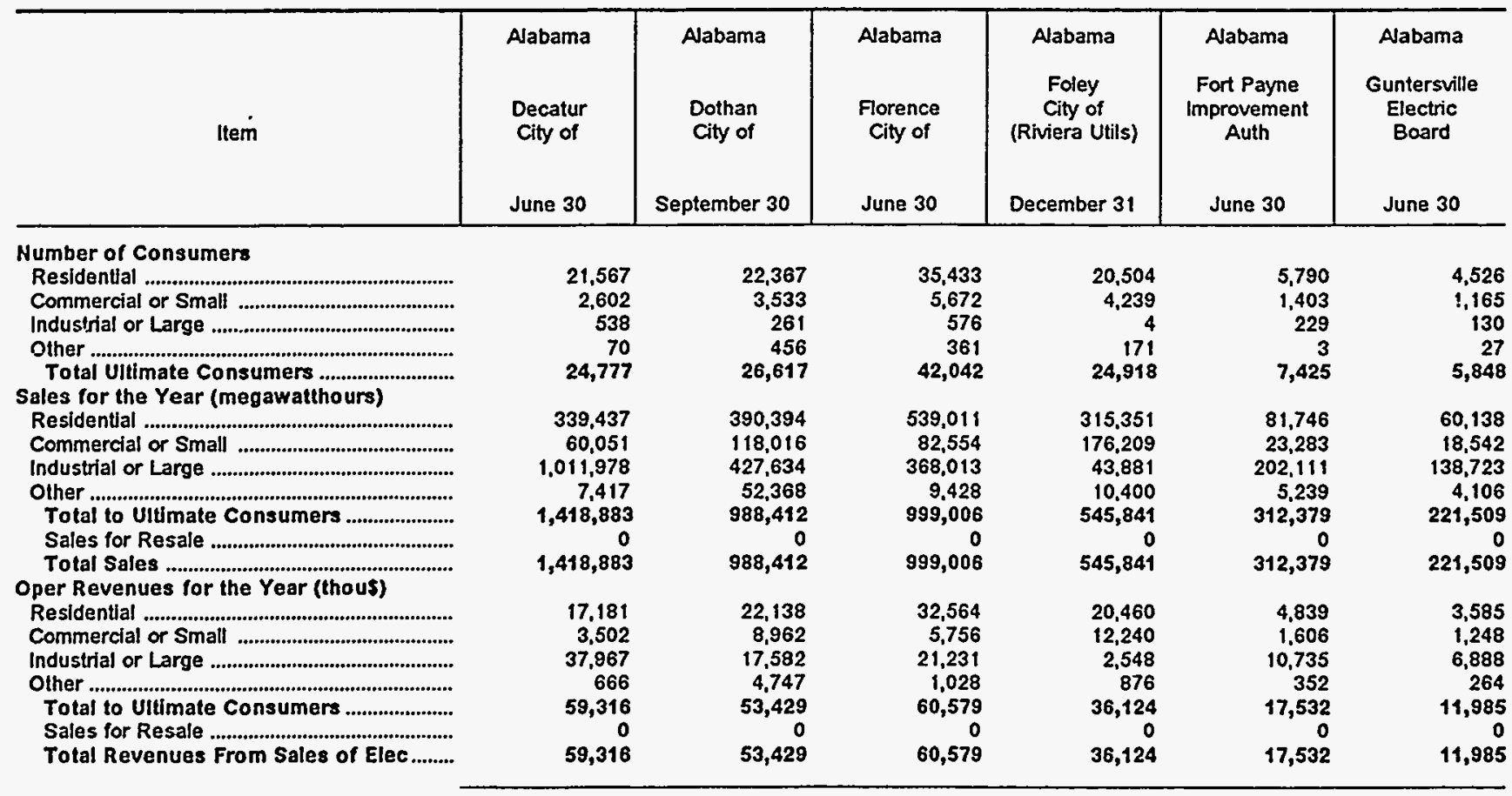

Note: Totals may not equal sum of components because of independent rounding.

Source: Energy Information Administration, Form EIA-861, "Annual Electric Utility Report." Data are submitted on a calendar year. 
Table 25. Number of Consumers, Sales, and Operating Revenue by Major U.S. Publicly Owned Electric Utility Within State, 1995 (Continued)

\begin{tabular}{|c|c|c|c|c|c|c|}
\hline Item & $\begin{array}{l}\text { Alabama } \\
\text { Hartselle } \\
\text { City of } \\
\text { June } 30\end{array}$ & $\begin{array}{c}\text { Alabama } \\
\text { Huntsville } \\
\text { City of } \\
\text { September } 30\end{array}$ & $\begin{array}{l}\text { Alabama } \\
\text { Muscle } \\
\text { Shoals } \\
\text { City of } \\
\text { June } 30\end{array}$ & $\begin{array}{l}\text { Alabama } \\
\text { Opelika } \\
\text { City of } \\
\text { September } 30\end{array}$ & $\begin{array}{l}\text { Alabama } \\
\text { Scottsboro } \\
\text { City of } \\
\text { June } 30\end{array}$ & $\begin{array}{l}\text { Alabama } \\
\text { Sheffield } \\
\text { Utilities } \\
\text { June } 30\end{array}$ \\
\hline \multicolumn{7}{|l|}{ Number of Consumers } \\
\hline 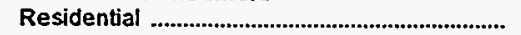 & 3,633 & 104,621 & 4,609 & 8,730 & 6,108 & 14,650 \\
\hline 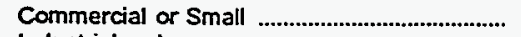 & 826 & 12,972 & 1,006 & 1.274 & 1,276 & 2,358 \\
\hline 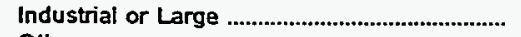 & 84 & 2.136 & 167 & 6 & 167 & 240 \\
\hline $\begin{array}{l}\text { Other } \\
\text { Total Ultimate Consumers } \\
\text { Sales for the Year (megawatthours) }\end{array}$ & $\begin{array}{r}22 \\
4,565\end{array}$ & $\begin{array}{r}76 \\
119,805\end{array}$ & $\begin{array}{r}37 \\
5,819\end{array}$ & $\begin{array}{r}68 \\
10,078\end{array}$ & $\begin{array}{r}5 \\
7,556\end{array}$ & $\begin{array}{r}222 \\
17,470\end{array}$ \\
\hline 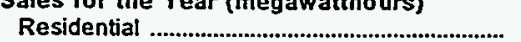 & & 1652931 & & & & \\
\hline $\begin{array}{l}\text { Commercial or Small } \\
\text { Industrial or Large }\end{array}$ & $\begin{array}{l}54,200 \\
13,366 \\
55,999\end{array}$ & $\begin{array}{r}246,697 \\
1765,790\end{array}$ & $\begin{array}{r}70,845 \\
22,173 \\
100,233\end{array}$ & $\begin{array}{l}102,000 \\
124,000\end{array}$ & $\begin{array}{r}88,659 \\
21,220\end{array}$ & $\begin{array}{r}210,138 \\
35,625\end{array}$ \\
\hline $\begin{array}{l}\text { Other } \\
\text { Total to UItimate Consumers }\end{array}$ & $\begin{array}{r}55,999 \\
2,184 \\
125,807\end{array}$ & $\begin{array}{r}1,765,790 \\
24,841 \\
3,690,259\end{array}$ & $\begin{array}{r}100,233 \\
3,676 \\
196,927\end{array}$ & $\begin{array}{r}90,000 \\
6,000 \\
322,000\end{array}$ & $\begin{array}{r}235,762 \\
4,124 \\
349,765\end{array}$ & $\begin{array}{r}140,695 \\
5,345 \\
391,803\end{array}$ \\
\hline 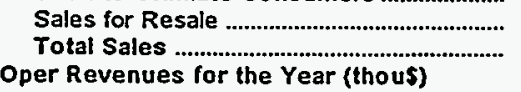 & $\begin{array}{r}0 \\
125,807\end{array}$ & $\begin{array}{r}0 \\
3,690,259\end{array}$ & $\begin{array}{r}0 \\
196,927\end{array}$ & $\begin{array}{r}0 \\
322,000\end{array}$ & $\begin{array}{r}0 \\
349,765\end{array}$ & $\begin{array}{r}0 \\
391,803\end{array}$ \\
\hline 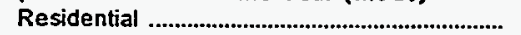 & 3,031 & 89,155 & 4,181 & 6.270 & 5,230 & 13,034 \\
\hline 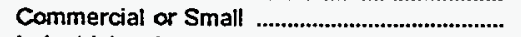 & 868 & 14,713 & 1,477 & 7,500 & 1,435 & 2,546 \\
\hline Industrial or Large & 3,108 & 84,205 & 5,474 & 4,395 & 10,409 & 8,002 \\
\hline Other & 174 & 2,257 & 318 & 426 & 326 & 442 \\
\hline Total to UItimate Consumers ...................... & 7,181 & 190,330 & 11,450 & 18,591 & 17,400 & 24,024 \\
\hline Sales for Resale & & 0 & 0 & 0 & 0 & \\
\hline Total Revenues From Sales of Elec......... & 7,181 & 190,330 & 11,450 & 18,591 & 17,400 & 24,024 \\
\hline
\end{tabular}

\begin{tabular}{|c|c|c|c|c|c|c|}
\hline Item & $\begin{array}{c}\text { Alabama } \\
\text { Sylacauga } \\
\text { Utilities } \\
\text { Board } \\
\text { September } 30\end{array}$ & $\begin{array}{c}\text { Alabama } \\
\text { Troy } \\
\text { City of } \\
\text { September } 30\end{array}$ & $\begin{array}{l}\text { Alabama } \\
\text { Tuskegee } \\
\text { City of } \\
\text { September } 30\end{array}$ & $\begin{array}{l}\text { Alaska } \\
\text { Alaska } \\
\text { Energy } \\
\text { Authority } \\
\text { June } 30\end{array}$ & $\begin{array}{c}\text { Alaska } \\
\text { Anchorage } \\
\text { City of } \\
\text { December } 31\end{array}$ & $\begin{array}{c}\text { Alaska } \\
\text { Fairbanks } \\
\text { Clty of } \\
\text { December } 31\end{array}$ \\
\hline \multicolumn{7}{|l|}{ Number of Consumers } \\
\hline 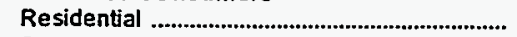 & 5,296 & 5.223 & 6,631 & 0 & 23,711 & 4,554 \\
\hline 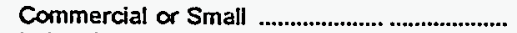 & 813 & 1,020 & 564 & 0 & 5.714 & 1,576 \\
\hline Industrial or Large & 12 & 103 & 79 & 0 & 0 & 0 \\
\hline Other & 1 & 56 & 0 & 0 & 292 & 1 \\
\hline \multicolumn{5}{|l|}{ Sales for the Year (megawatthours) } & 29,717 & 6,131 \\
\hline Residential & 62,611 & 76,541 & 55,900 & 0 & 147,408 & 28,186 \\
\hline 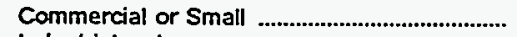 & 47,253 & 21,126 & 14,334 & 0 & 664,331 & 119,032 \\
\hline Industrial or Large & 64,936 & 132,762 & 73,101 & 0 & 0 & 0 \\
\hline $\begin{array}{l}\text { Other } \\
\text { Total to Ultimate Consumers }\end{array}$ & $\begin{array}{r}3,346 \\
178,146\end{array}$ & $\begin{array}{r}1,487 \\
231,916\end{array}$ & $\begin{array}{r}0 \\
143,335\end{array}$ & $\begin{array}{l}0 \\
0\end{array}$ & $\begin{array}{r}19,029 \\
830,768\end{array}$ & $\begin{array}{r}2,382 \\
149,600\end{array}$ \\
\hline Sales for Resale & & & 0 & 696,604 & 50,079 & $\begin{array}{r}340,000 \\
0\end{array}$ \\
\hline Total Sales & 178,146 & 231,916 & 143,335 & 696,604 & 880,847 & 149,600 \\
\hline \multicolumn{7}{|l|}{ Oper Revenues for the Year (thou\$) } \\
\hline Residential & 4,306 & 4,357 & 4,221 & 0 & 14,509 & 2,839 \\
\hline 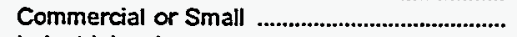 & 3,848 & 1,419 & 1,055 & 0 & 52,614 & 13,092 \\
\hline 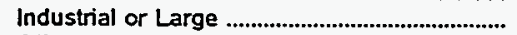 & 3,665 & 7,779 & 3,517 & 0 & 0 & 0 \\
\hline Other & 214 & 87 & 0 & 0 & 1,709 & 262 \\
\hline 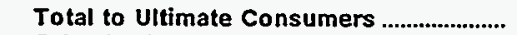 & 12,033 & 13,642 & 8,793 & 0 & 68,832 & 16,193 \\
\hline 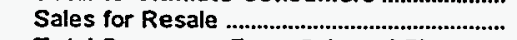 & 0 & 0 & & 22,585 & 1,252 & \\
\hline Total Revenues From Sales of Elec ......... & 12,033 & 13,642 & 8,793 & 22,585 & 70,084 & 16,193 \\
\hline
\end{tabular}

Note: Totals may not equal sum of components because of independent rounding.

Source: Energy Information Administration. Form ELA-861, "Annual Electric Utility Report." Data are submitted on a calendar year. 
Table 25. Number of Consumers, Sales, and Operating Revenue by Major U.S. Publicly Owned Electric Utility Within State, 1995 (Continued)

\begin{tabular}{|c|c|c|c|c|c|c|}
\hline Item & $\begin{array}{c}\text { Alaska } \\
\text { Ketchikan } \\
\text { City of } \\
\text { December } 31\end{array}$ & $\begin{array}{l}\text { Avizona } \\
\text { Arizona } \\
\text { Power } \\
\text { Authority } \\
\\
\text { June } 30\end{array}$ & $\begin{array}{c}\text { Arizona } \\
\text { Electrical } \\
\text { Dist } \\
\text { No2 } \\
\text { Pinal Cnty } \\
\text { December } 31\end{array}$ & $\begin{array}{l}\text { Mesa } \\
\text { City of } \\
\text { June } 30\end{array}$ & $\begin{array}{l}\text { Arizona } \\
\text { Navajo } \\
\text { Tribal } \\
\text { Utility } \\
\text { Auth } \\
\text { December } 31\end{array}$ & $\begin{array}{l}\text { Arizona } \\
\text { Salt River } \\
\text { Proj } \mathrm{Ag} \\
\text { I \& P Dist } \\
\text { April } 30\end{array}$ \\
\hline \multicolumn{7}{|l|}{ Number of Consumers } \\
\hline 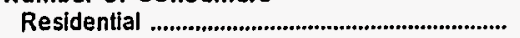 & 5,922 & 0 & 2,234 & 12,938 & 24,701 & 549,041 \\
\hline 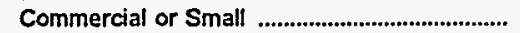 & 977 & 0 & 279 & 2,221 & 2,930 & 46,751 \\
\hline 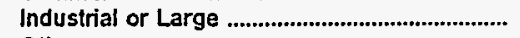 & 12 & 0 & 20 & 0 & 4 & 41 \\
\hline $\begin{array}{l}\text { Other } \\
\text { Total Ultimate Consumers ........................ } \\
\text { Sales for the Year (megawatthours) }\end{array}$ & $\begin{array}{r}2 \\
6,913\end{array}$ & $\begin{array}{l}0 \\
0\end{array}$ & $\begin{array}{r}439 \\
2,972\end{array}$ & $\begin{array}{r}139 \\
15,298\end{array}$ & $\begin{array}{l}10,064 \\
37,699\end{array}$ & $\begin{array}{r}9,194 \\
605,027\end{array}$ \\
\hline 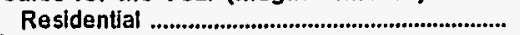 & 57,527 & 0 & 25,190 & 128,710 & 106,776 & $7,209,279$ \\
\hline $\begin{array}{l}\text { Commercial or Small } \\
\text { Inidustrial or Large }\end{array}$ & $\begin{array}{l}61,752 \\
24,373\end{array}$ & $\begin{array}{l}0 \\
0\end{array}$ & $\begin{array}{l}10,950 \\
36,970\end{array}$ & $\begin{array}{r}162,688 \\
0\end{array}$ & $\begin{array}{l}152,403 \\
248,158\end{array}$ & $\begin{array}{l}5,945,843 \\
3,491,023\end{array}$ \\
\hline 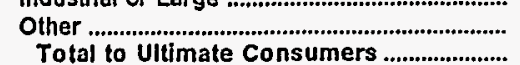 & $\begin{array}{r}7.291 \\
150,943\end{array}$ & $\begin{array}{l}0 \\
0\end{array}$ & $\begin{array}{r}84,280 \\
157,390\end{array}$ & $\begin{array}{r}35,220 \\
326,618\end{array}$ & $\begin{array}{r}19,705 \\
527,042\end{array}$ & $\begin{array}{r}614,126 \\
17,260,271\end{array}$ \\
\hline 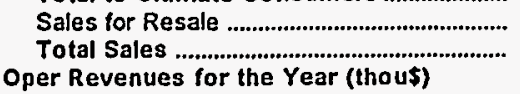 & $\begin{array}{r}0 \\
150,943\end{array}$ & $\begin{array}{l}891,063 \\
891,063\end{array}$ & $\begin{array}{r}0 \\
157,390\end{array}$ & $\begin{array}{r}81 \\
326,699\end{array}$ & $\begin{array}{r}0 \\
527,042\end{array}$ & $\begin{array}{r}4,691,797 \\
21,952,068\end{array}$ \\
\hline Residential & $\begin{array}{l}5,330 \\
5,287\end{array}$ & $\begin{array}{l}0 \\
0\end{array}$ & $\begin{array}{l}2,162 \\
1,033\end{array}$ & $\begin{array}{l}11,602 \\
13,099\end{array}$ & $\begin{array}{r}8,045 \\
11,915\end{array}$ & $\begin{array}{l}600,859 \\
409,277\end{array}$ \\
\hline Industrial or Large & 1,847 & 0 & 2,407 & 0 & 14.707 & 154,056 \\
\hline Other & 151 & 0 & 2,620 & 1,967 & 1,886 & 45,257 \\
\hline Total to Ultimate Consumers .......................... & 12,615 & $\mathbf{0}$ & 8,222 & 26,668 & 36,553 & $1,209,449$ \\
\hline $\begin{array}{l}\text { Sales for Resale .................................................. } \\
\text { Total Revenues From Sales of Elec }\end{array}$ & $\begin{array}{r}0 \\
12,615\end{array}$ & $\begin{array}{l}20,643 \\
20,643\end{array}$ & $\begin{array}{r}0 \\
8,222\end{array}$ & $\begin{array}{r}1 \\
26,669\end{array}$ & $\begin{array}{r}0 \\
36,553\end{array}$ & $\begin{array}{r}111,196 \\
1,320,645\end{array}$ \\
\hline
\end{tabular}

\begin{tabular}{|c|c|c|c|c|c|c|}
\hline Item & $\begin{array}{l}\text { Arizona } \\
\text { Tohono } \\
\text { OOdham } \\
\text { Utility Auth } \\
\text { December } 31\end{array}$ & $\begin{array}{l}\text { Arkansas } \\
\text { Benton } \\
\text { City of } \\
\text { December } 31\end{array}$ & $\begin{array}{c}\text { Arkansas } \\
\begin{array}{c}\text { Bentonville } \\
\text { City of }\end{array} \\
\text { December } 31\end{array}$ & $\begin{array}{c}\text { Arkansas } \\
\text { Clarksville } \\
\text { Light } \\
\& \\
\text { Water Co } \\
\text { September } 30\end{array}$ & $\begin{array}{l}\text { Arkansas } \\
\text { Conway } \\
\text { Corp }\end{array}$ & $\begin{array}{c}\text { Arkansas } \\
\text { Hope } \\
\text { City of } \\
\text { December } 31\end{array}$ \\
\hline \multicolumn{7}{|l|}{ Number of Consumers } \\
\hline Residential & 2,487 & 8,037 & 6,028 & 2,906 & 13,633 & 5,728 \\
\hline 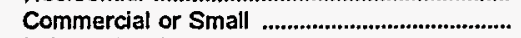 & 398 & 1,097 & 769 & 523 & 1,742 & 1,033 \\
\hline 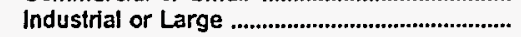 & 1 & 19 & $173^{\circ}$ & 66 & 70 & 1 \\
\hline 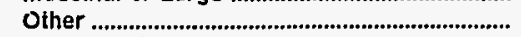 & 20 & 0 & 0 & 0 & 3 & 1,769 \\
\hline $\begin{array}{l}\text { Total Ultimate Consumers ............................ } \\
\text { Sales for the Year (megawatthours) }\end{array}$ & 2,906 & 9,153 & 6,970 & 3,495 & 15,448 & 8,531 \\
\hline 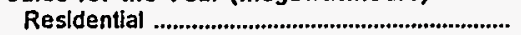 & 15,831 & 78,165 & 57,088 & 30,693 & 153,248 & 55,693 \\
\hline $\begin{array}{l}\text { Commercial or Small } \\
\text { Industrial or Large }\end{array}$ & $\begin{array}{l}17,882 \\
54,337\end{array}$ & $\begin{array}{l}55,647 \\
37,299\end{array}$ & $\begin{array}{r}15,950 \\
169,370\end{array}$ & $\begin{array}{r}14,042 \\
152,721\end{array}$ & $\begin{array}{r}77,561 \\
325,136\end{array}$ & $\begin{array}{r}105,113 \\
34,228\end{array}$ \\
\hline Other & $\begin{array}{r}4,126 \\
92,176\end{array}$ & $\begin{array}{r}0 \\
171.111\end{array}$ & $\begin{array}{r}0 \\
242.408\end{array}$ & $\begin{array}{r}0 \\
197.456\end{array}$ & $\begin{array}{r}9.129 \\
565.074\end{array}$ & $\begin{array}{r}2,207 \\
197,241\end{array}$ \\
\hline 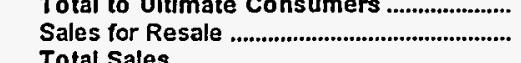 & $\begin{array}{r}92,176 \\
0 \\
92,176\end{array}$ & $\begin{array}{r}171,111 \\
0 \\
171,111\end{array}$ & $\begin{array}{r}242,408 \\
0 \\
242,408\end{array}$ & $\begin{array}{r}191,400 \\
0 \\
197,456\end{array}$ & $\begin{array}{r}565,074 \\
0 \\
565,074\end{array}$ & $\begin{array}{r}197,241 \\
0 \\
197,241\end{array}$ \\
\hline \multicolumn{7}{|l|}{ Oper Revenues for the Year (thous) } \\
\hline 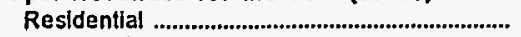 & 1,393 & $\cdot 8,369$ & 3,922 & 1,479 & 9,136 & 3,450 \\
\hline Commercial or Small ........................................... & 1,445 & 5,102 & 805 & 1,076 & 5,012 & 5.826 \\
\hline Industrial or Large & 2,844 & 2,387 & 5,254 & 6,596 & 14,784 & 1,296 \\
\hline Other & 362 & 0 & 0 & 0 & 563 & 479 \\
\hline 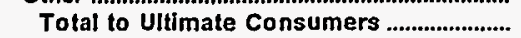 & 6,044 & 15,858 & 9,981 & 9,151 & 29,495 & 11,051 \\
\hline 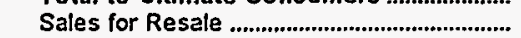 & & 0 & & 0 & 0 & \\
\hline Total Revenues From Sales of Elec........ & 6,044 & 15,858 & 9,981 & 9,151 & 29,495 & 11,051 \\
\hline
\end{tabular}

Note: Totals may not equal sum of components because of independent rounding.

Source: Energy Information Administration, Form ElA-861, "Annual Electric Utility Report." Data are submitted on a calendar year. 
Table 25. Number of Consumers, Sales, and Operating Revenue by Major U.S. Publicly Owned Electric Utility Within State, 1995 (Continued)

\begin{tabular}{|c|c|c|c|c|c|c|}
\hline Item & $\begin{array}{c}\text { Arkansas } \\
\text { Jonesboro } \\
\text { City of } \\
\text { December } 31\end{array}$ & $\begin{array}{c}\text { Arkansas } \\
\text { North } \\
\text { Little } \\
\text { Rock } \\
\text { City of } \\
\text { December } 31\end{array}$ & $\begin{array}{c}\text { Arkansas } \\
\text { Osceola } \\
\text { City of } \\
\text { December } 31\end{array}$ & $\begin{array}{c}\text { Arkansas } \\
\text { Paragould } \\
\text { Light } \\
\text { \& } \\
\text { Water Comm } \\
\text { December } 31\end{array}$ & $\begin{array}{c}\text { Arkansas } \\
\text { Siloam } \\
\text { Springs } \\
\text { City of } \\
\text { December } 31\end{array}$ & $\begin{array}{c}\text { Arkansas } \\
\text { West } \\
\text { Memphis } \\
\text { City of } \\
\text { December } 31\end{array}$ \\
\hline \multicolumn{7}{|l|}{ Number of Consumers } \\
\hline 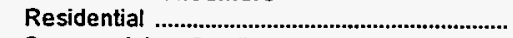 & 21,144 & 31,446 & 3,153 & 8,565 & 3,924 & 10,000 \\
\hline Commercial or Small & 3,533 & 4,071 & 494 & 1,375 & 603 & 1,305 \\
\hline Industrial or Large & 165 & 174 & 23 & 47 & 80 & $\begin{array}{r}1.000 \\
0\end{array}$ \\
\hline Other & $\begin{array}{r}1 \\
24,843\end{array}$ & $\begin{array}{r}36 \\
35,727\end{array}$ & $\begin{array}{r}0 \\
3,670\end{array}$ & $\begin{array}{r}2,355 \\
12,342\end{array}$ & $\begin{array}{r}0 \\
4,607\end{array}$ & $\begin{array}{r}48 \\
11,353\end{array}$ \\
\hline \multicolumn{7}{|l|}{ Sales for the Year (megawatthours) } \\
\hline Residential & 273,756 & 333,742 & 41,618 & 129,558 & 40,819 & 132,853 \\
\hline 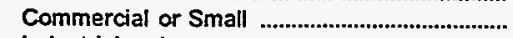 & 114,068 & 176,743 & 17,747 & 51,887 & 12,348 & 183,087 \\
\hline Industrial or Large & 450,931 & 326,415 & 124,631 & 192,753 & 139,418 & 0 \\
\hline 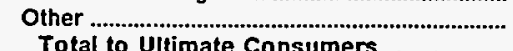 & 15,425 & 14,587 & 0 & 4,196 & $\begin{aligned} 0 \\
0\end{aligned}$ & 4,530 \\
\hline Sales for Resale & $\begin{array}{r}854,180 \\
77,792\end{array}$ & 851,487 & $\begin{array}{r}183,996 \\
0\end{array}$ & 378,394 & 192,585 & 320,470 \\
\hline \multicolumn{3}{|l|}{ Oper Revenues for the Year (thou\$) } & 183,996 & $\begin{array}{r}67,969 \\
446,363\end{array}$ & $\begin{array}{r}0 \\
192,585\end{array}$ & $\begin{array}{r}0 \\
320,470\end{array}$ \\
\hline Residential ................ & 13,314 & 29,101 & 2.151 & 5.109 & 2789 & \\
\hline 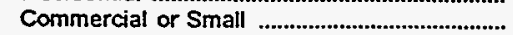 & 6,340 & 13,743 & 917 & 2,130 & 1,012 & 11,312 \\
\hline 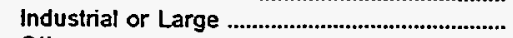 & 15,641 & 20,852 & 6,442 & 5,394 & 4,294 & 0 \\
\hline Other & 412 & 828 & 0 & 772 & $\begin{array}{r}4,204 \\
0\end{array}$ & 295 \\
\hline Total to Ultimate Consumers ........................ & 35,707 & 64,524 & 9,510 & 13,405 & 8,095 & 19,523 \\
\hline Sales for Resale & 1,647 & 0 & 0 & 1,060 & 0 & \\
\hline Total Revenues From Sales of Elec......... & 37,354 & 64,524 & 9,510 & 14,465 & 8,095 & 19,523 \\
\hline
\end{tabular}

\begin{tabular}{|c|c|c|c|c|c|c|}
\hline Item & $\begin{array}{l}\text { California } \\
\text { Alameda } \\
\text { City of } \\
\text { June } 30\end{array}$ & $\begin{array}{l}\text { California } \\
\text { Anaheim } \\
\text { City of } \\
\text { June } 30\end{array}$ & $\begin{array}{l}\text { California } \\
\text { Azusa } \\
\text { City of } \\
\text { June } 30\end{array}$ & $\begin{array}{l}\text { California } \\
\text { Burbank } \\
\text { City of } \\
\text { June } 30\end{array}$ & $\begin{array}{l}\text { California } \\
\text { California } \\
\text { Dept } \\
\text { Wtr } \\
\text { Resources } \\
\text { June } 30\end{array}$ & $\begin{array}{l}\text { California } \\
\text { Colton } \\
\text { City of } \\
\text { June } 30\end{array}$ \\
\hline \multicolumn{7}{|l|}{ Number of Consumers } \\
\hline 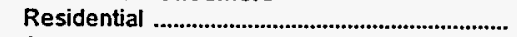 & 28,021 & 88.295 & 12,816 & 43,900 & 0 & 14,697 \\
\hline 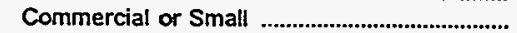 & 3,153 & 14,761 & 1,328 & 6,248 & 0 & 1,629 \\
\hline Industrial or Large & 3 & 573 & 32 & 201 & 0 & 25 \\
\hline Other & 268 & 670 & 174 & 49 & 0 & 129 \\
\hline $\begin{array}{l}\text { Total UItimate Consumers } \\
\text { Sales for the Year (megawatthours) }\end{array}$ & 31,445 & 104,299 & 14,350 & 50,398 & 0 & 16,480 \\
\hline 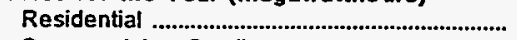 & 128,245 & 517,714 & 63,854 & 232,666 & 0 & 80,234 \\
\hline Commercial or Small & 169,638 & 515,930 & 65,594 & 232,328 & 0 & 74,354 \\
\hline Industrial or Large & 150,256 & $1,117.666$ & 66,403 & 452,660 & 0 & 49,210 \\
\hline 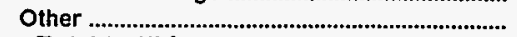 & 13,559 & 93,747 & 6,020 & 32,890 & 0 & 9,243 \\
\hline Total to Ultimate Consumers ........................ & 461,698 & $2,245,057$ & 201,871 & 950,544 & 0 & 213,041 \\
\hline 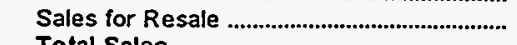 & 0 & 249,528 & 150,751 & 3,644 & $5,307,033$ & 0 \\
\hline \multicolumn{7}{|l|}{ Oper Revenues for the Year (thous) } \\
\hline 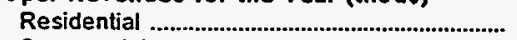 & 14.118 & 50,268 & 5,661 & 23,467 & 0 & 6,688 \\
\hline Commercial or Small & 17,165 & 55,318 & 6,378 & 23,537 & 0 & 7,348 \\
\hline Industrial or Large & 12,544 & 100,050 & 5,753 & 41,330 & 0 & 4,056 \\
\hline Other & 1,430 & 8,137 & 499 & 3,112 & 0 & 856 \\
\hline 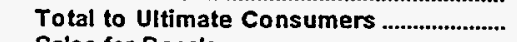 & 45,257 & 213,773 & 18,291 & 91,446 & 0 & 18,948 \\
\hline Sales for Resale & & 3,911 & 3,995 & 50 & 150,179 & \\
\hline Total Revenues From Sales of Elec......... & 45,257 & 217,684 & 22,286 & 91,496 & 150,179 & 18,948 \\
\hline
\end{tabular}

Note: Totals may not equal sum of components because of independent rounding.

Source: Energy Information Administration. Form EIA-861. "Annual Electric Utility Report" Data are submitted on a calendar year. 
Table 25. Number of Consumers, Sales, and Operating Revenue by Major U.S. Publicly Owned Electric Utility Within State, 1995 (Continued)

\begin{tabular}{|c|c|c|c|c|c|c|}
\hline Item & $\begin{array}{c}\text { California } \\
\text { East Bay } \\
\text { Municipal } \\
\text { Util } \\
\text { Dist } \\
\text { December } 31\end{array}$ & $\begin{array}{l}\text { California } \\
\text { Giendale } \\
\text { City of } \\
\text { June } 30\end{array}$ & $\begin{array}{c}\text { California } \\
\text { Imperial } \\
\text { Irrigation } \\
\text { District } \\
\text { December } 31\end{array}$ & $\begin{array}{c}\text { California } \\
\text { Kings River } \\
\text { Conservation } \\
\text { Dist } \\
\text { June } 30\end{array}$ & $\begin{array}{l}\text { California } \\
\text { Lassen } \\
\text { Municipal } \\
\text { Utility Dist } \\
\text { June } 30\end{array}$ & $\begin{array}{l}\text { California } \\
\text { Lodi } \\
\text { City of } \\
\text { June } 30\end{array}$ \\
\hline \multicolumn{7}{|l|}{ Number of Consumers } \\
\hline 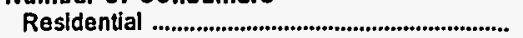 & 0 & 70,191 & 70,631 & 0 & 8.354 & 19,079 \\
\hline Commercial or Small ........................................... & 0 & 12,097 & 12,729 & 0 & 1,224 & 2,990 \\
\hline 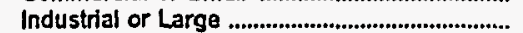 & 0 & 204 & 0 & 0 & 3 & 25 \\
\hline Other & 0 & 4 & 1,509 & 0 & 89 & 258 \\
\hline $\begin{array}{l}\text { Total Uttimate Consumers ................................. } \\
\text { Sales for the Year (megawatthours) }\end{array}$ & 0 & 82,496 & 84,869 & 0 & 9,670 & 22,352 \\
\hline 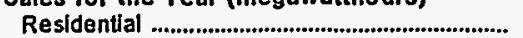 & 0 & 344,040 & 867,229 & 0 & 65,954 & 124,411 \\
\hline 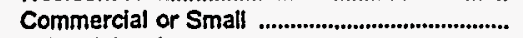 & 0 & 316,194 & $1,369,597$ & 0 & 39,754 & 126,556 \\
\hline 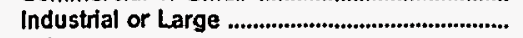 & 0 & 352,099 & 0 & 0 & 17,249 & 86,687 \\
\hline Other & 0 & 9,093 & 64,287 & 0 & 3,276 & 10.556 \\
\hline Total to Ultimate Consumers ........................ & 0 & $1,021,426$ & $2,301,113$ & 0 & 126,233 & 348,210 \\
\hline 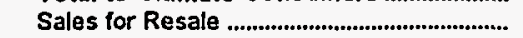 & 204,967 & 4,804 & 341,712 & 445,104 & 0 & \\
\hline Total Sales & 204,967 & $1,026,230$ & $2,642,825$ & 445,104 & 126,233 & 348,210 \\
\hline \multicolumn{7}{|l|}{ Oper Revenues for the Year (thou\$) } \\
\hline 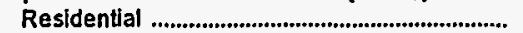 & $\mathbf{0}$ & 33,847 & 68,637 & 0 & 6,303 & 13,339 \\
\hline 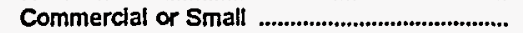 & 0 & 32,262 & 104,541 & 0 & 4,492 & 13,016 \\
\hline 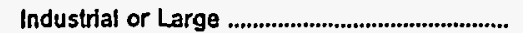 & 0 & 29,237 & 0 & 0 & 2,030 & 6,657 \\
\hline Other & 0 & 930 & 5,096 & 0 & 622 & 1,116 \\
\hline 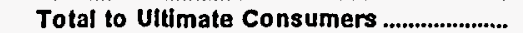 & $\mathbf{0}$ & 96,276 & 178,274 & o & 13,447 & 34,128 \\
\hline 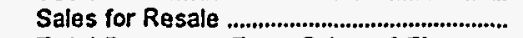 & 2,836 & 61 & 8,587 & 3,383 & 0 & \\
\hline Total Revenues From Sales of Elec......... & 2,836 & 96,337 & 186,861 & 3,383 & 13,447 & 34,128 \\
\hline
\end{tabular}

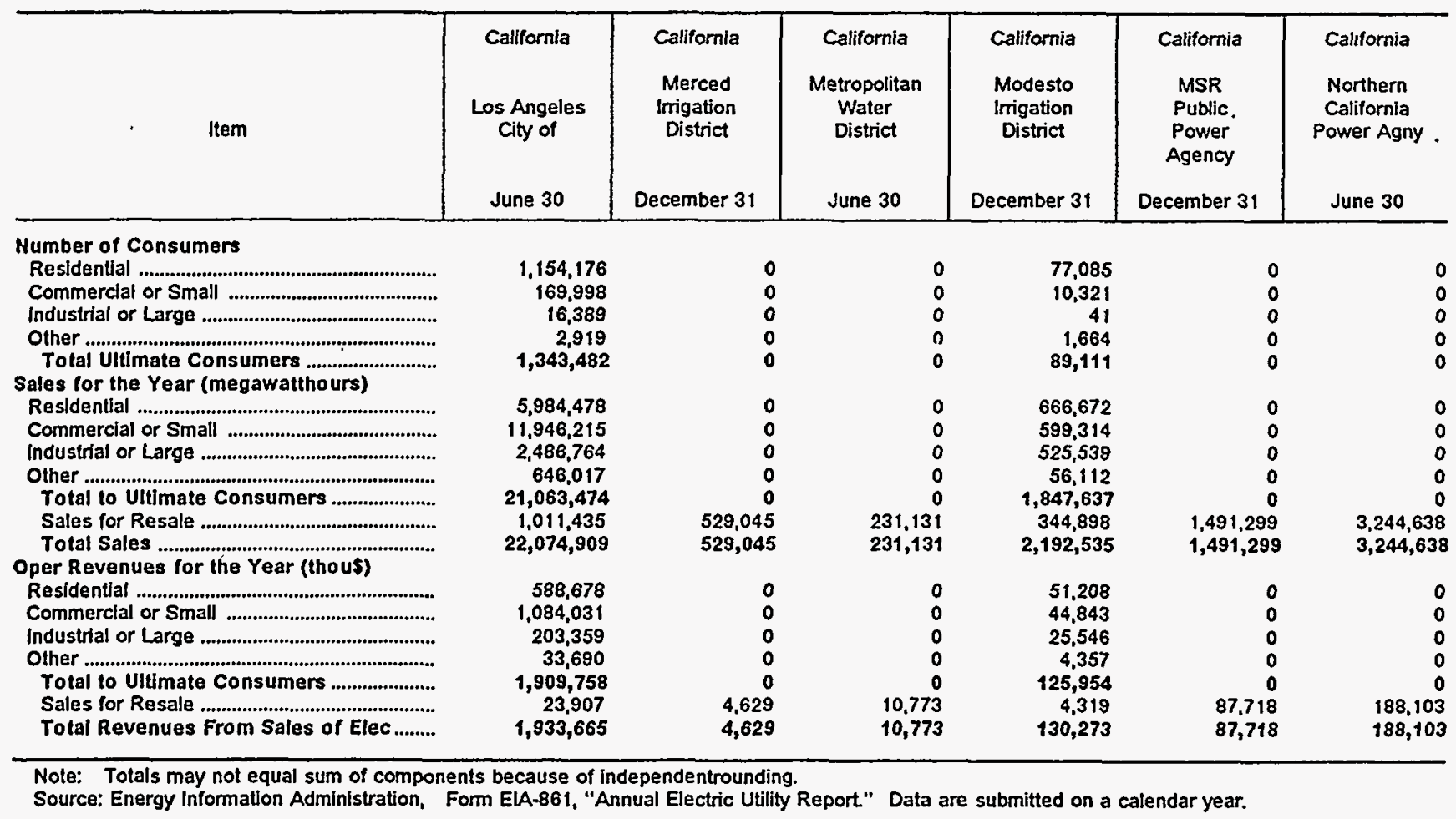


Table 25. Number of Consumers, Sales, and Operating Revenue by Major U.S. Publicly Owned Electric Utility Within State, 1995 (Continued)

\begin{tabular}{|c|c|c|c|c|c|c|}
\hline Item & $\begin{array}{c}\text { California } \\
\text { Oakdale \& } \\
\text { South } \\
\text { San Joaquin } \\
\text { December } 31\end{array}$ & $\begin{array}{c}\text { California } \\
\text { Oroville } \\
\text { Wyandotte } \\
\text { Imig Dist } \\
\text { December } 31\end{array}$ & $\begin{array}{l}\text { Palo Alto } \\
\text { City of } \\
\text { June } 30\end{array}$ & $\begin{array}{l}\text { Pasadena } \\
\text { City of } \\
\text { June } 30\end{array}$ & $\begin{array}{l}\text { California } \\
\text { Placer } \\
\text { County } \\
\text { Water } \\
\text { Agency } \\
\text { December } 31\end{array}$ & $\begin{array}{l}\text { California } \\
\text { Redding } \\
\text { City of } \\
\text { June } 30\end{array}$ \\
\hline \multicolumn{7}{|l|}{ Number of Consumers } \\
\hline 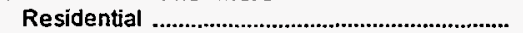 & 0 & 0 & 24,681 & 49,245 & 0 & 30,643 \\
\hline 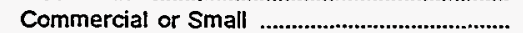 & 0 & 0 & 2,390 & 7,459 & 0 & 4,975 \\
\hline 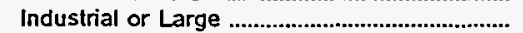 & 0 & 0 & 192 & 929 & 0 & 550 \\
\hline Other & 0 & 0 & 198 & 174 & 0 & 532 \\
\hline 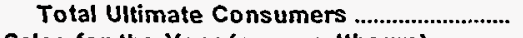 & $\mathbf{0}$ & $\mathbf{0}$ & 27,461 & 57,807 & $\mathbf{0}$ & 36,700 \\
\hline \multicolumn{7}{|l|}{ Sales for the Year (megawatthours) } \\
\hline Residential & 0 & $\mathbf{0}$ & 159,344 & 282,130 & 0 & 314,033 \\
\hline 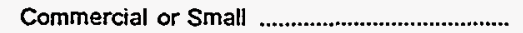 & 0 & 0 & 363,211 & 140.309 & 0 & 306,632 \\
\hline Industrial or Large & 0 & 0 & 458,183 & 657,362 & 0 & 28,065 \\
\hline Other & 0 & 0 & 70,895 & 69,948 & 0 & 31.495 \\
\hline Total to UItimate Consumers ......................... & 0 & $\mathbf{0}$ & $1,051,633$ & $1,149,749$ & 0 & 680,225 \\
\hline 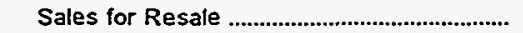 & 553,361 & 738,204 & 0 & 28.722 & $1,601,135$ & 335,954 \\
\hline Total Sales & 553,361 & 738,204 & $1,051,633$ & $1,178,471$ & $1,601,135$ & $1,016,179$ \\
\hline \multicolumn{7}{|l|}{ Oper Revenues for the Year (thous) } \\
\hline 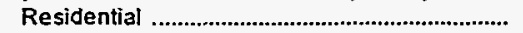 & 0 & 0 & 8,844 & 26,297 & 0 & 22,509 \\
\hline 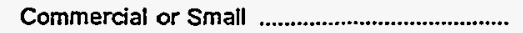 & 0 & 0 & 23,910 & 13,770 & 0 & 23.191 \\
\hline 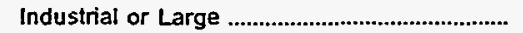 & 0 & 0 & 26,500 & 59,529 & 0 & 2,197 \\
\hline Other & 0 & $\mathbf{0}$ & 4,031 & 7,450 & 0 & 3,183 \\
\hline Total to UItimate Consumers ..................... & 0 & 0 & 63,285 & 107,046 & 0 & 51,080 \\
\hline Sales for Resale & 5,840 & 6.801 & 0 & 695 & 8,902 & 13,712 \\
\hline Total Revenues From Sales of Elec........ & 5,840 & 6,801 & 63,285 & 107,741 & 8,902 & 64,792 \\
\hline
\end{tabular}

\begin{tabular}{|c|c|c|c|c|c|c|}
\hline Item & $\begin{array}{l}\text { California } \\
\text { Riverside } \\
\text { City of } \\
\text { June } 30\end{array}$ & $\begin{array}{l}\text { California } \\
\text { Roseville } \\
\text { City of } \\
\text { June } 30\end{array}$ & $\begin{array}{l}\text { California } \\
\text { Sacramento } \\
\text { Municipal } \\
\text { Util Dist } \\
\text { December } 31\end{array}$ & $\begin{array}{c}\text { California } \\
\text { San Francisco } \\
\text { City } \\
\& \\
\text { County of } \\
\text { June } 30\end{array}$ & $\begin{array}{l}\text { California } \\
\text { Santa } \\
\text { Clara } \\
\text { City of } \\
\\
\text { June } 30\end{array}$ & $\begin{array}{l}\text { California } \\
\text { Southern } \\
\text { California } \\
\text { P P } \\
\text { A } \\
\text { June } 30\end{array}$ \\
\hline \multicolumn{7}{|l|}{ Number of Consumers } \\
\hline Residential & 79,620 & 24,613 & 424,107 & 0 & 38,490 & 0 \\
\hline 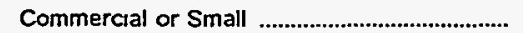 & 8,344 & 3,300 & 44,619 & 6 & 5.208 & 0 \\
\hline Industrial or Large & 200 & 31 & 7,628 & 0 & 1,623 & 0 \\
\hline 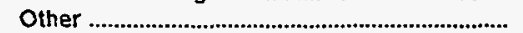 & 122 & 122 & 1,765 & 2 & 397 & 0 \\
\hline Total Uitimate Consumers & 88,286 & 28,066 & 478,119 & 8 & 45,718 & 0 \\
\hline \multicolumn{7}{|l|}{ Sales for the Year (megawatthours) } \\
\hline 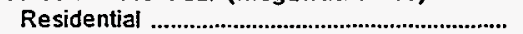 & 551,596 & 196,171 & $3,567,584$ & 0 & 201,432 & 0 \\
\hline Commercial or Small & 398,639 & 185,847 & 723,432 & 446 & 85,339 & 0 \\
\hline Industrial or Large & 567,308 & 211.438 & $4,095,305$ & 0 & $1,891.775$ & 0 \\
\hline Other & 44,545 & 32,723 & 72,567 & 605,122 & 17,474 & 0 \\
\hline 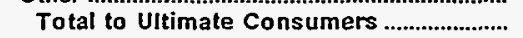 & $1,562,088$ & 626,179 & $8,458,888$ & 605,568 & $2,196,020$ & 0 \\
\hline Sales for Resale & 18,925 & 0 & 116,497 & $1,556,909$ & 112,185 & $3,352,867$ \\
\hline Total Sales & $1,581,013$ & 626,179 & $8,575,385$ & $2,162,477$ & $2,308,205$ & $3,352,867$ \\
\hline \multicolumn{7}{|l|}{ Oper Revenues for the Year (thous) } \\
\hline 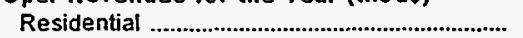 & 59,308 & 15,525 & 290,896 & 0 & 14,289 & 0 \\
\hline Commercial or Small & 42,739 & 13,839 & 59,750 & 20 & 8,985 & 0 \\
\hline Industrial or Large & 51,302 & 13,658 & 291,965 & 0 & 142,653 & 0 \\
\hline Other & 4,804 & 2,656 & 4,640 & 34,015 & 1,330 & 0 \\
\hline Total to UItimate Consumers ........................ & 158,153 & 45,678 & 647,251 & 34,035 & 167,257 & 0 \\
\hline Sales for Resale & 359 & 0 & 992 & 40,833 & 2,099 & 183,603 \\
\hline Total Revenues From Sales of Elec........ & 158,512 & 45,678 & 648,243 & 74,868 & 169,356 & 183,603 \\
\hline
\end{tabular}

Note: Totals may not equal sum of components because of independent rounding.

Source: Energy Information Administration, Form EIA-861, "Annual Electric Utility Report." Data are submitted on a calendar year. 
Table 25. Number of Consumers, Sales, and Operating Revenue by Major U.S. Publicly Owned Electric Utility Within State, 1995 (Continued)

\begin{tabular}{|c|c|c|c|c|c|c|}
\hline Hem & $\begin{array}{c}\text { California } \\
\text { Turlock } \\
\text { Imigation } \\
\text { District } \\
\text { December } 31\end{array}$ & $\begin{array}{l}\text { California } \\
\text { Vernon } \\
\text { City of } \\
\text { June } 30\end{array}$ & $\begin{array}{l}\text { California } \\
\text { Yuba } \\
\text { County } \\
\text { Water } \\
\text { Agency } \\
\text { June } 30\end{array}$ & $\begin{array}{c}\text { Colorado } \\
\text { Arkansas } \\
\text { River } \\
\text { Power } \\
\text { Authority } \\
\text { December } 31\end{array}$ & $\begin{array}{l}\text { Colorado } \\
\text { Colorado } \\
\text { Springs } \\
\text { City of } \\
\text { December } 31\end{array}$ & $\begin{array}{c}\text { Colorado } \\
\text { Fort Collins } \\
\text { City of } \\
\text { December } 31\end{array}$ \\
\hline \multicolumn{7}{|l|}{ Number of Consumers } \\
\hline 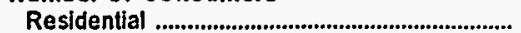 & 52,216 & 28 & 0 & 0 & 137,319 & 37.219 \\
\hline Commercial or Small & 5,858 & 1,057 & 0 & 0 & 17,929 & 5,510 \\
\hline 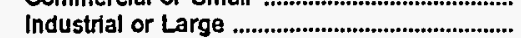 & 1,283 & 853 & 0 & 0 & 346 & 11 \\
\hline 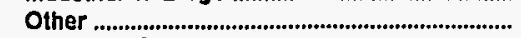 & 4,379 & 102 & 0 & 0 & 929 & 1 \\
\hline \multicolumn{7}{|l|}{ Sales for the Year (megawatthours) } \\
\hline 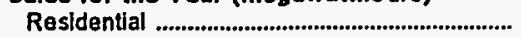 & 468,244 & 137 & 0 & 0 & $1,007,395$ & 310,772 \\
\hline $\begin{array}{l}\text { Commercial or Small } \\
\text { Industrial or Large }\end{array}$ & $\begin{array}{l}104,940 \\
516,792\end{array}$ & $\begin{array}{l}232,418 \\
800,490\end{array}$ & $\begin{array}{l}0 \\
0\end{array}$ & $\begin{array}{l}0 \\
0\end{array}$ & $\begin{array}{r}828,944 \\
1,340,530\end{array}$ & $\begin{array}{l}343,068 \\
294,739\end{array}$ \\
\hline Other & $\begin{array}{r}131,634 \\
1,221,610\end{array}$ & $\begin{array}{r}9,666 \\
1,042,711\end{array}$ & $\begin{array}{l}0 \\
0\end{array}$ & $\begin{array}{l}0 \\
0\end{array}$ & $\begin{array}{r}90,163 \\
3,267,032\end{array}$ & $\begin{array}{r}2,118 \\
950,697\end{array}$ \\
\hline 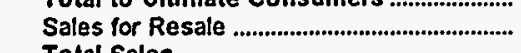 & 308,409 & 0 & $2,155,670$ & 282,401 & 142,668 & 0 \\
\hline \multicolumn{7}{|l|}{ Oper Revenues for the Year (thous) } \\
\hline 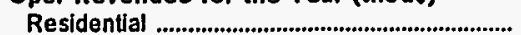 & 41,535 & 3 & 0 & 0 & 59,734 & 17.695 \\
\hline Commercial or Small & 11,054 & 13,034 & 0 & 0 & 43,580 & 18,930 \\
\hline Industrial or Large & 36,472 & 36,020 & 0 & 0 & 53,932 & 12,315 \\
\hline Other & 9,048 & 812 & 0 & 0 & 6,408 & 91 \\
\hline 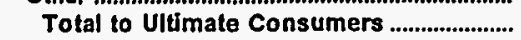 & 98,109 & 49,869 & 0 & 0 & 163,654 & 49,031 \\
\hline 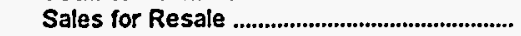 & 3,848 & & 11,857 & 9,912 & 4,765 & \\
\hline Total Revenues From Sales of Elec........ & 101,957 & 49,869 & 11,857 & 9,912 & 168,419 & 49,031 \\
\hline
\end{tabular}

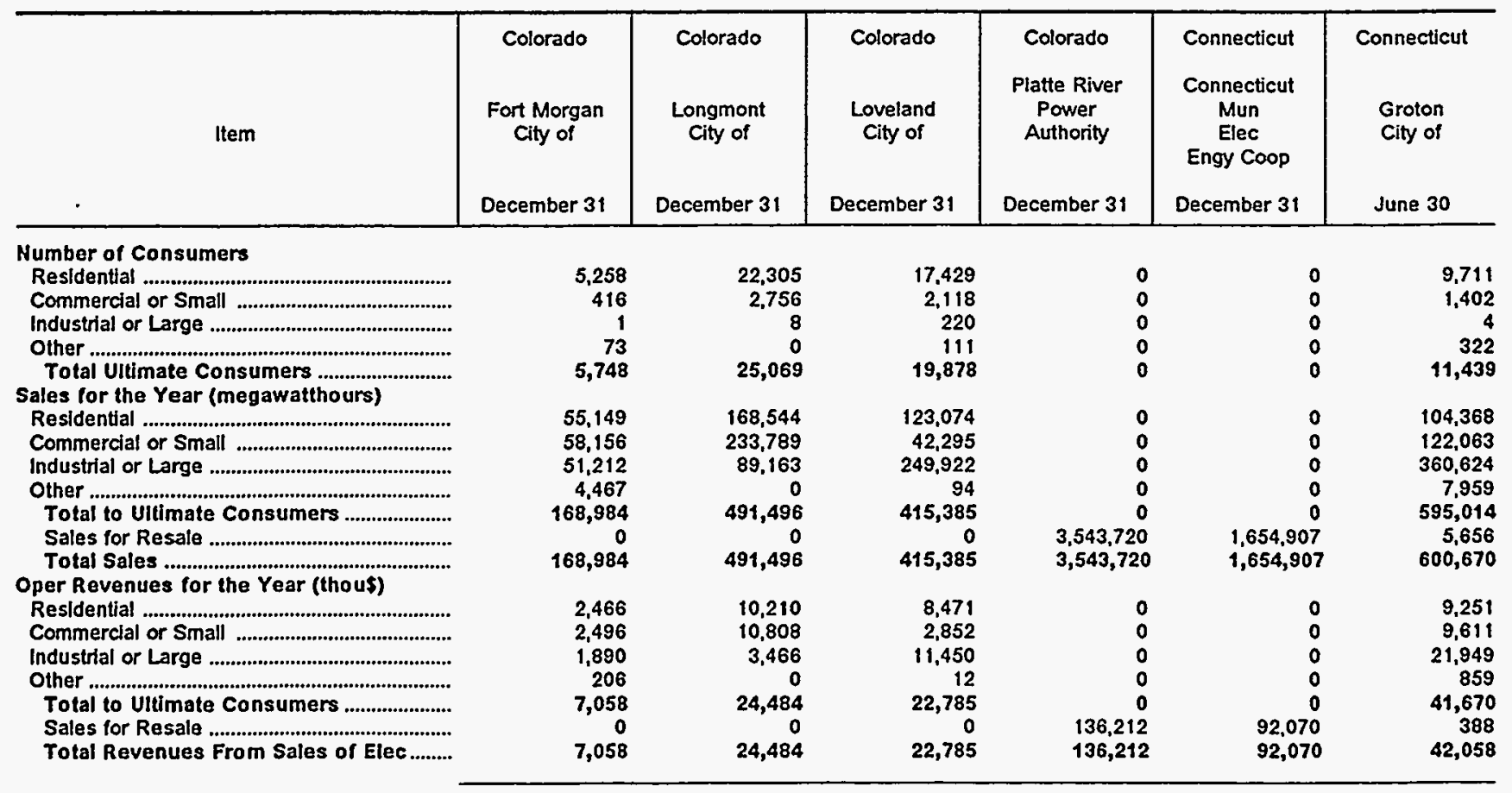

Note: Totals may not equal sum of components because of independent rounding.

Source: Energy Information Administration, Form EIA-861, "Annual Electric Utility Report" Data are submitted on a calendar year. 
Table 25. Number of Consumers, Sales, and Operating Revenue by Major U.S. Publicly Owned Electric Utility Within State, 1995 (Continued)

\begin{tabular}{|c|c|c|c|c|c|c|}
\hline Item & $\begin{array}{l}\text { Connecticut } \\
\text { Norwich } \\
\text { City of } \\
\text { June } 30\end{array}$ & $\begin{array}{l}\text { Connecticut } \\
\text { Wallingford } \\
\text { Town of } \\
\text { June } 30\end{array}$ & $\begin{array}{l}\text { Delaware } \\
\text { Dover } \\
\text { City of } \\
\text { June } 30\end{array}$ & $\begin{array}{l}\text { Delaware } \\
\text { Milford } \\
\text { City of } \\
\text { September } 30\end{array}$ & $\begin{array}{c}\text { Delaware } \\
\text { Newark } \\
\text { City of } \\
\text { December } 31\end{array}$ & $\begin{array}{l}\text { Florida } \\
\text { Bartow } \\
\text { City of } \\
\text { September } 30\end{array}$ \\
\hline \multicolumn{7}{|l|}{ Number of Consumers } \\
\hline 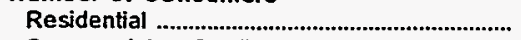 & 16,179 & 18,897 & 16,239 & 3,898 & 8,582 & 8,537 \\
\hline $\begin{array}{l}\text { Commercial or Small } \\
\text { Industrial or Large }\end{array}$ & $\begin{array}{r}1,855 \\
29\end{array}$ & $\begin{array}{r}2,773 \\
29\end{array}$ & $\begin{array}{r}2,518 \\
30\end{array}$ & $\begin{array}{r}686 \\
25\end{array}$ & $\begin{array}{r}1,042 \\
31\end{array}$ & $\begin{array}{r}1,193 \\
297\end{array}$ \\
\hline Other & 191 & 169 & 3 & 183 & 0 & \\
\hline $\begin{array}{l}\text { Total Ultimate Consumers } \\
\text { Sales for the Year (megawatthours) }\end{array}$ & 18,254 & 21,868 & 18,790 & 4,792 & 9,655 & 10,027 \\
\hline 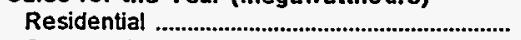 & 103,239 & 169,864 & 152,587 & 40,033 & 73,760 & $\uparrow 18,232$ \\
\hline 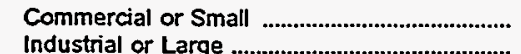 & $\begin{array}{l}89,155 \\
75,825\end{array}$ & $\begin{array}{l}159,374 \\
218,519\end{array}$ & 174,698 & 32,238 & 53,256 & 21.874 \\
\hline Other & 21,350 & 19,944 & $\begin{array}{r}226,323 \\
10,018\end{array}$ & $\begin{array}{r}80,213 \\
2,665\end{array}$ & $\begin{array}{r}164,442 \\
0\end{array}$ & $\begin{array}{r}120,130 \\
0\end{array}$ \\
\hline 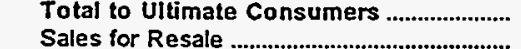 & $\begin{array}{r}289,569 \\
0\end{array}$ & $\begin{array}{r}567,701 \\
0\end{array}$ & 563,628 & 155,149 & 291,458 & 260,236 \\
\hline $\begin{array}{l}\text { Sales for Resale } \\
\text { Total Sales } \\
\text { Oper Revenues for the Year (thous) }\end{array}$ & $\begin{array}{r}0 \\
289,569\end{array}$ & $\begin{array}{r}0 \\
567,701\end{array}$ & $\begin{array}{r}31,418 \\
595,046\end{array}$ & $\begin{array}{r}0 \\
155,149\end{array}$ & $\begin{array}{r}0 \\
291,458\end{array}$ & $\begin{array}{r}0 \\
260,236\end{array}$ \\
\hline 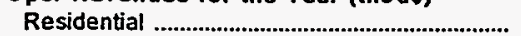 & 10,966 & 13,089 & 13,835 & 3,978 & 6,068 & 9.552 \\
\hline 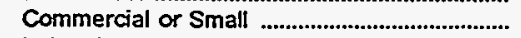 & 8,423 & 12,464 & 14,777 & 2,796 & 4,893 & 2,213 \\
\hline 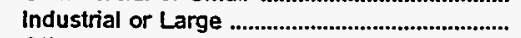 & 5,885 & 12,242 & 13,119 & 4,962 & 10,319 & 10,020 \\
\hline Other & 1,970 & 1.653 & 938 & 236 & 0 & 0 \\
\hline 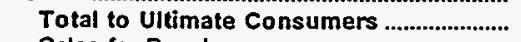 & 27,244 & 39,448 & 42,669 & 11,972 & 21,280 & 21,785 \\
\hline 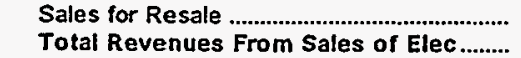 & $\begin{array}{r}0 \\
27,244\end{array}$ & $\begin{array}{r}0 \\
39,448\end{array}$ & $\begin{array}{r}436 \\
43,105\end{array}$ & $\begin{array}{r}0 \\
11,972\end{array}$ & $\begin{array}{r}0 \\
21,280\end{array}$ & $\begin{array}{r}0 \\
21,785\end{array}$ \\
\hline
\end{tabular}

\begin{tabular}{|c|c|c|c|c|c|c|}
\hline Item & $\begin{array}{c}\text { Florida } \\
\text { Florida } \\
\text { Municipal } \\
\text { Power Agency } \\
\text { September } 30\end{array}$ & $\begin{array}{l}\text { Florida } \\
\text { Font Pierce } \\
\text { Utilities } \\
\text { Auth } \\
\text { September } 30\end{array}$ & $\begin{array}{c}\text { Florida } \\
\text { Gainesville } \\
\text { Regional } \\
\text { Utilities } \\
\text { September } 30\end{array}$ & $\begin{array}{c}\text { Florida } \\
\begin{array}{c}\text { Homestead } \\
\text { City of }\end{array} \\
\text { September } 30\end{array}$ & $\begin{array}{c}\text { Florida } \\
\text { Jacksonville } \\
\text { Beach } \\
\text { City of } \\
\text { September } 30\end{array}$ & $\begin{array}{l}\text { Florida } \\
\text { Jacksonville } \\
\text { Electric } \\
\text { Auth } \\
\text { September } 30\end{array}$ \\
\hline \multicolumn{7}{|l|}{ Number of Consumers } \\
\hline Residential & 0 & 19,957 & 62,130 & 11,176 & 22,393 & 288,924 \\
\hline 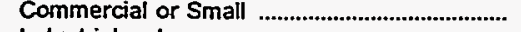 & 0 & 4,004 & 7,305 & 1,436 & 3,813 & 32,603 \\
\hline Industrial or Large & $\mathbf{0}$ & 0 & 13 & 282 & 0 & 197 \\
\hline 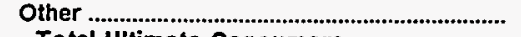 & 0 & 2 & 2,249 & 54 & 525 & 2,548 \\
\hline \multicolumn{7}{|l|}{ Sales for the Year (megawatthours) } \\
\hline Residential & 0 & 216,504 & 703,871 & 128,218 & 356,573 & $4,191,927$ \\
\hline 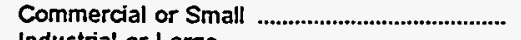 & 0 & 295.922 & 590,006 & 31,084 & 200,426 & $3,165,180$ \\
\hline Industrial or Large & 0 & 0 & 136,775 & 83,538 & 0 & $2,023,639$ \\
\hline Other & 0 & 9,305 & 18,467 & 11,040 & 4,616 & 68,924 \\
\hline Total to Ultimate Consumers ......................... & 0 & 521,731 & $1,449,119$ & 253,880 & 561,615 & $9,449,670$ \\
\hline $\begin{array}{l}\text { Sales for Resale } \\
\text { Total Sales }\end{array}$ & $\begin{array}{l}3,399,162 \\
3,399,162\end{array}$ & $\begin{array}{r}18,966 \\
540,697\end{array}$ & $\begin{array}{r}426,137 \\
1,875,256\end{array}$ & $\begin{array}{r}2,947 \\
256,827\end{array}$ & $\begin{array}{r}0 \\
561.615\end{array}$ & $\begin{array}{r}619,746 \\
10,069,416\end{array}$ \\
\hline \multicolumn{7}{|l|}{ Oper Revenues for the Year (thou\$) } \\
\hline 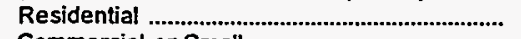 & 0 & 17,165 & 51,958 & 11,314 & 28,190 & 290,329 \\
\hline Commercial or Small & 0 & 21,959 & 41,105 & 2,928 & 18,002 & 175,820 \\
\hline Industrial or Large & 0 & 0 & 7,316 & 7,127 & 0 & 113,976 \\
\hline Other & 0 & 793 & 2,461 & 943 & 495 & 6,714 \\
\hline 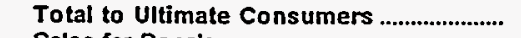 & 0 & 39,917 & 102,840 & 22,312 & 46,687 & 586,939 \\
\hline Sales for Resale & 182,037 & 612 & 14,511 & 291 & 0 & 27,606 \\
\hline Total Revenues From Sales of Elec......... & 182,037 & 40,529 & 117,351 & 22,603 & 46,687 & 614,545 \\
\hline
\end{tabular}

Note: Totals may not equal sum of components because of independent rounding.

Source: Energy Information Administration. Form EIA-861. "Annual Electric Utility Report" Data are submitted on a calendar year. 
Table 25. Number of Consumers, Sales, and Operating Revenue by Major U.S. Publicly Owned Electric Utility Within State, 1995 (Continued)

\begin{tabular}{|c|c|c|c|c|c|c|}
\hline Item & $\begin{array}{c}\text { Florida } \\
\text { Key West } \\
\text { City of } \\
\text { September } 30\end{array}$ & $\begin{array}{c}\text { Florida } \\
\text { Kissimmee } \\
\text { Utility } \\
\text { Authority } \\
\text { September } 30\end{array}$ & $\begin{array}{l}\text { Florida } \\
\text { Lake Worth } \\
\text { City of } \\
\text { September } 30\end{array}$ & $\begin{array}{c}\text { Lakeland } \\
\text { City of } \\
\text { September } 30\end{array}$ & $\begin{array}{c}\text { Forida } \\
\text { Leesburg } \\
\text { City of } \\
\text { September } 30\end{array}$ & $\begin{array}{c}\text { Florida } \\
\text { New Smyrna } \\
\text { Beach } \\
\text { Utils Comm } \\
\text { September } 30\end{array}$ \\
\hline \multicolumn{7}{|l|}{ Number of Consumers } \\
\hline 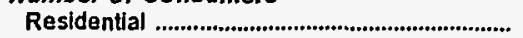 & 21,317 & 32,677 & 20,758 & 82,616 & 14,542 & 17,734 \\
\hline 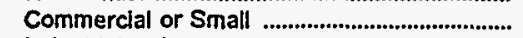 & 2,395 & 7,852 & 3,010 & 9,999 & 2,635 & 1,691 \\
\hline 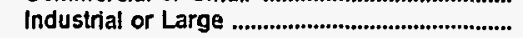 & 620 & 28 & 0 & 51 & 0 & 0 \\
\hline Other & 2 & $\mathbf{0}$ & 857 & 9.317 & 1 & 742 \\
\hline $\begin{array}{l}\text { Total Ultimate Consumers .......................... } \\
\text { Sales for the Year (megawathours) }\end{array}$ & 24,334 & 40,557 & 24,625 & 101,983 & 17,178 & 20,167 \\
\hline 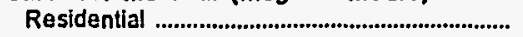 & 251.200 & 428,572 & 202,872 & $1,169,096$ & 178,284 & 193,714 \\
\hline Commercial or Small & 52,800 & 346,913 & 146,309 & 594,521 & 212,069 & 102,737 \\
\hline 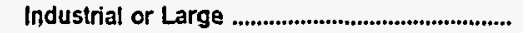 & 193,500 & 80,252 & 0 & 427,049 & 0 & 0 \\
\hline Other & $\begin{array}{r}85,900 \\
583,400\end{array}$ & $\begin{array}{r}0 \\
855,737\end{array}$ & $\begin{array}{r}4,431 \\
353,612\end{array}$ & $\begin{array}{r}86,630 \\
2,277,296\end{array}$ & $\begin{array}{r}160 \\
390,513\end{array}$ & $\begin{array}{r}2,861 \\
299,312\end{array}$ \\
\hline 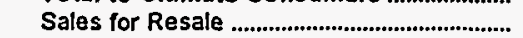 & & 1,248 & 271 & 81,601 & 0 & 0 \\
\hline \multicolumn{7}{|l|}{ Oper Revenues for the Year (thou\$) } \\
\hline 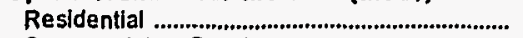 & 16,824 & 33,608 & 17.679 & 88.133 & 14,086 & 15,656 \\
\hline 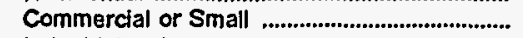 & 4,751 & 25,390 & 13,219 & 42,893 & 16,507 & 8.864 \\
\hline 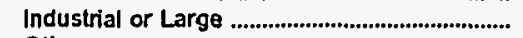 & 14,085 & 4,723 & 0 & 23,004 & 0 & 0 \\
\hline Other & 5,699 & 0 & 631 & 7,504 & 200 & 357 \\
\hline Total to Ultimate Consumers ........................ & 41,359 & 63,721 & 31,529 & 161,534 & 30,793 & 24,877 \\
\hline Sales for Resale & 0 & 31 & 1,046 & 1,538 & 0 & \\
\hline Total Revenues From Sales of Elec........ & 41,359 & 63,752 & 32,575 & 163,072 & 30,793 & 24,877 \\
\hline
\end{tabular}

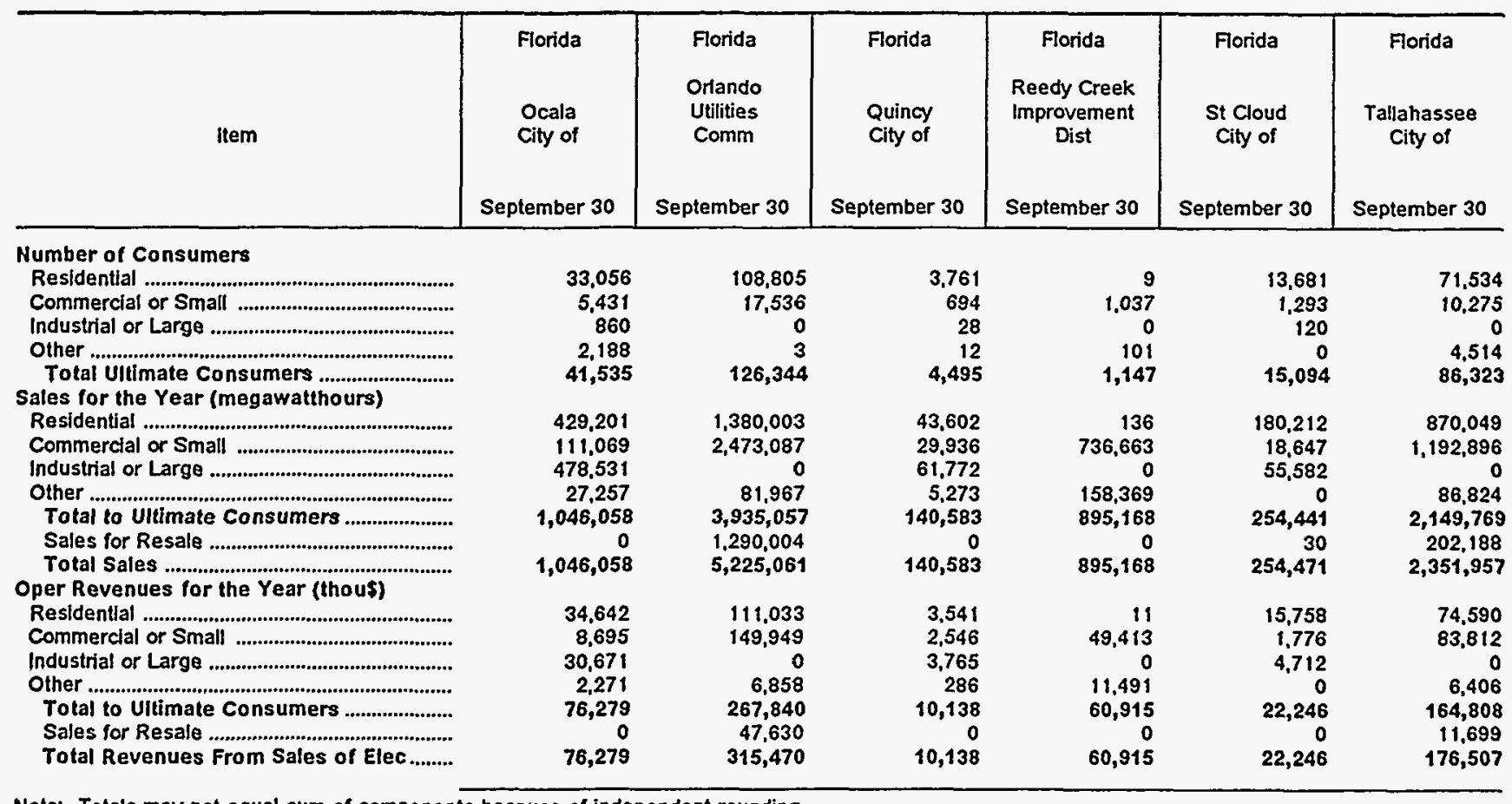

Note: Totals may not equal sum of components because of independent rounding.

Source: Energy Information Administration, Form ElA-861, "Annual Electric Utility Report" Data are submitted on a calendar year. 
Table 25. Number of Consumers, Sales, and Operating Revenue by Major U.S. Publicly Owned Electric Utility Within State, 1995 (Continued)

\begin{tabular}{|c|c|c|c|c|c|c|}
\hline Item & $\begin{array}{c}\text { Florida } \\
\text { Vero } \\
\text { Beach } \\
\text { City of } \\
\text { September } 30\end{array}$ & $\begin{array}{l}\text { Georgia } \\
\text { Albany Water } \\
\text { Gas \& Light } \\
\text { Comm } \\
\text { June } 30\end{array}$ & $\begin{array}{l}\text { Georgia } \\
\text { Calhoun } \\
\text { City of } \\
\text { June } 30\end{array}$ & $\begin{array}{c}\text { Cartersville } \\
\text { City of } \\
\text { June } 30\end{array}$ & $\begin{array}{c}\text { Georgia } \\
\text { College } \\
\text { Park City of } \\
\text { June } 30\end{array}$ & $\begin{array}{l}\text { Georgia } \\
\text { Covington } \\
\text { City of } \\
\text { December } 31\end{array}$ \\
\hline \multicolumn{7}{|l|}{ Number of Consumers } \\
\hline 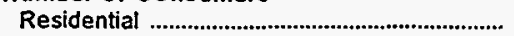 & 22,409 & 30,000 & 2,921 & 4,378 & 9,048 & 6,488 \\
\hline 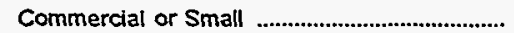 & 4,163 & 4,700 & 802 & 1,052 & 782 & 1,162 \\
\hline Industrial or Large & 1 & 40 & 50 & 29 & 0 & 7 \\
\hline Other & 275 & 3,605 & 0 & 54 & 0 & \\
\hline \multicolumn{7}{|l|}{ Sales for the Year (megawatthours) } \\
\hline 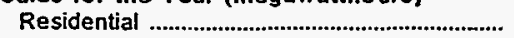 & 297,736 & 355,495 & 26,159 & 45,150 & 88,473 & 73,405 \\
\hline 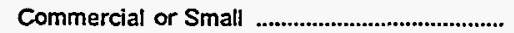 & 241,604 & 469,011 & 74,211 & 78,104 & 162,739 & 81,031 \\
\hline industrial or Large & 11,939 & 10.821 & 230,264 & 325,724 & 0 & 57,437 \\
\hline Other & 2,431 & 18,338 & 0 & 19,972 & 0 & 0 \\
\hline 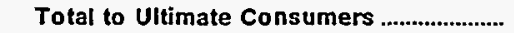 & 553,710 & 853,665 & 330,634 & 468,950 & 251,212 & 211,873 \\
\hline 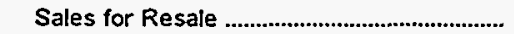 & 103,701 & 0 & 0 & 0 & $\mathbf{0}$ & 0 \\
\hline Total Sales & 657,411 & 853,665 & 330,634 & 468,950 & 251,212 & 211,873 \\
\hline \multicolumn{7}{|l|}{ Oper Revenues for the Year (thous) } \\
\hline Residential & 25,484 & 25.392 & 1,927 & 3,187 & 6.755 & 6,350 \\
\hline 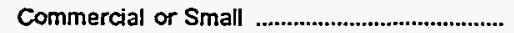 & 18,639 & 27,237 & 5,452 & 6,164 & 10,518 & 7,169 \\
\hline industrial or Large & 897 & 641 & 12,366 & 15,238 & 0 & 2,310 \\
\hline Other & 259 & 1.515 & 0 & 1,342 & 0 & 0 \\
\hline 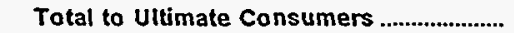 & 45,279 & 54,785 & 19,745 & 25,931 & 17,273 & 15,829 \\
\hline Sales for Resale ................................................. & 1,832 & & 0 & 0 & 0 & \\
\hline Total Revenues From Sales of Elec......... & 47,111 & 54,785 & 19,745 & 25,931 & 17,273 & 15,829 \\
\hline
\end{tabular}

\begin{tabular}{|c|c|c|c|c|c|c|}
\hline Item & $\begin{array}{c}\text { Georgia } \\
\text { Crisp } \\
\text { County } \\
\text { Power } \\
\text { Comm } \\
\text { December } 31\end{array}$ & $\begin{array}{l}\text { Georgia } \\
\text { Dalton } \\
\text { City of } \\
\text { November } 30\end{array}$ & $\begin{array}{l}\text { Georgia } \\
\text { Douglas } \\
\text { City of } \\
\text { June } 30\end{array}$ & $\begin{array}{l}\text { Georgia } \\
\text { East } \\
\text { Point } \\
\text { City of } \\
\text { June } 30\end{array}$ & $\begin{array}{c}\text { Georgia } \\
\text { Fitzgerald } \\
\text { Wtr Lgt } \\
\text { \& Bond Comm } \\
\text { December } 31\end{array}$ & $\begin{array}{l}\text { Georgla } \\
\text { Grifin } \\
\text { City of } \\
\text { June } 30\end{array}$ \\
\hline \multicolumn{7}{|l|}{ Number of Consumers } \\
\hline 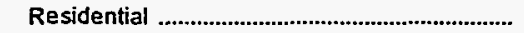 & 8,522 & 9,276 & 3,822 & 15,889 & 5,136 & 12,124 \\
\hline Cornmercial or Small & 1,907 & 2,674 & 1,143 & 1,051 & 652 & 1,862 \\
\hline Industrial or Large & 71 & 89 & 11 & 58 & 39 & 11 \\
\hline Other & 118 & 582 & 2 & 2 & 0 & 79 \\
\hline $\begin{array}{l}\text { Total Uitimate Consumers ................................ } \\
\text { Sales for the Year (megawatthours) }\end{array}$ & Sales for the Year (megawatthours) & 12,621 & 4,978 & 17,000 & 5,827 & 14,076 \\
\hline Residential & 129,891 & 141,377 & 49,492 & 133,595 & 72,107 & 103,976 \\
\hline Commercial or Small & 83,797 & 360,127 & 37,115 & 119,715 & 36,097 & 128,185 \\
\hline 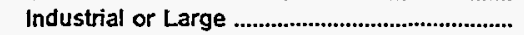 & 113,914 & 696,250 & 127,930 & 79,810 & 78,944 & 44,600 \\
\hline Other & 21,442 & 1,461 & 4,888 & 13,880 & 0 & 11.732 \\
\hline Total to Ultimate Consumers ......................... & 349,044 & $1,199,215$ & 219,425 & 347,000 & 187,148 & 288,493 \\
\hline Sales for Resale & 0 & 38.260 & 0 & 0 & 0 & \\
\hline Total Sales & 349,044 & $1,237,475$ & 219,425 & 347,000 & 187,148 & 288,493 \\
\hline \multicolumn{7}{|l|}{ Oper Revenues for the Year (thou\$) } \\
\hline Residential & 7,219 & 4,175 & 3.757 & 10,022 & 5,125 & 6.690 \\
\hline 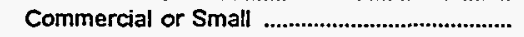 & 5,194 & 15,324 & 2,643 & 6.754 & 2,909 & 8,550 \\
\hline 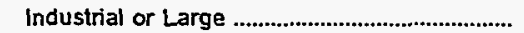 & 4,972 & 21,137 & 7,793 & 4,358 & 4,347 & 1,697 \\
\hline Other & 1,239 & 219 & 285 & 654 & 0 & 522 \\
\hline 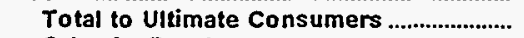 & 18,624 & 40,855 & 14,478 & 21,788 & 12,381 & 17,458 \\
\hline Sales for Resale & 0 & 602 & 0 & 0 & 0 & \\
\hline Total Revenues From Sales of Elec ......... & 18,624 & 41,457 & 14,478 & 21,788 & 12,381 & 17,458 \\
\hline
\end{tabular}

Note: Totals may not equal sum of components because of independentrounding.

Source: Energy Information Administration, Form ElA-861, "Annual Electric Utility Report." Data are submitted on a calendar year. 
Table 25. Number of Consumers, Sales, and Operating Revenue by Major U.S. Publicly Owned Electric Utility Within State, 1995 (Continued)

\begin{tabular}{|c|c|c|c|c|c|c|}
\hline Item & $\begin{array}{l}\text { Georgia } \\
\text { La Grange } \\
\text { City of } \\
\text { June } 30\end{array}$ & $\begin{array}{c}\text { Georgia } \\
\text { Lawrenceville } \\
\text { City of } \\
\text { August } 30\end{array}$ & $\begin{array}{l}\text { Georgia } \\
\text { Marietta } \\
\text { City of } \\
\text { June } 30\end{array}$ & $\begin{array}{c}\text { Georgia } \\
\text { Moultrie } \\
\text { City of } \\
\text { September } 30\end{array}$ & $\begin{array}{l}\text { Georgia } \\
\text { Municipal } \\
\text { Electric } \\
\text { Authority } \\
\text { December } 31\end{array}$ & $\begin{array}{c}\text { Georgia } \\
\text { Thomasville } \\
\text { City of } \\
\text { December } 31\end{array}$ \\
\hline \multicolumn{7}{|l|}{ Number of Consumers } \\
\hline 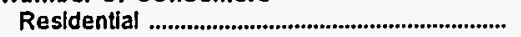 & 10,114 & 6,807 & 32,584 & 5,793 & 0 & 11,113 \\
\hline Commercial or Small & 1,640 & 1,114 & 5,224 & 928 & 0 & 2,127 \\
\hline 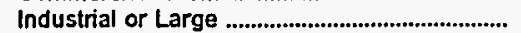 & 0 & 0 & 0 & 110 & 0 & 0 \\
\hline $\begin{array}{l}\text { Other } \\
\text { Total Ultimate Consumers .......................... }\end{array}$ & $\begin{array}{r}0 \\
11,754\end{array}$ & $\begin{array}{r}0 \\
7,921\end{array}$ & $\begin{array}{r}4,022 \\
41,830\end{array}$ & $\begin{array}{r}5 \\
6,836\end{array}$ & $\begin{array}{l}0 \\
0\end{array}$ & $\begin{array}{r}3,140 \\
16,380\end{array}$ \\
\hline 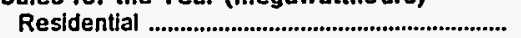 & 102,362 & 76.846 & 316.073 & 70,161 & 0 & 160.733 \\
\hline 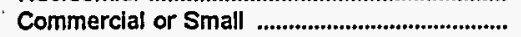 & 355,925 & 136,352 & 549,931 & 25,555 & 0 & $260,31 t$ \\
\hline 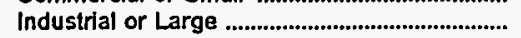 & 0 & 0 & 0 & 57,334 & 0 & 0 \\
\hline Other & $\mathbf{0}$ & 0 & 15,138 & 75 & 0 & 4,411 \\
\hline Total to Ultimate Consumers ....................... & 458,287 & 213,198 & 881,142 & 153,125 & 0 & 425,455 \\
\hline $\begin{array}{l}\text { Sales for Resale } \\
\text { Total Sales }\end{array}$ & $\begin{array}{r}0 \\
458,287\end{array}$ & $\begin{array}{r}0 \\
213,198\end{array}$ & $\begin{array}{r}0 \\
881,142\end{array}$ & $\begin{array}{r}0 \\
153,125\end{array}$ & $\begin{array}{l}10,449,304 \\
10,449,304\end{array}$ & $\begin{array}{r}0 \\
425,455\end{array}$ \\
\hline \multicolumn{7}{|l|}{ Oper Revenues for the Year (thous) } \\
\hline $\begin{array}{l}\text { Residential } \\
\text { Commercial or Small }\end{array}$ & $\begin{array}{r}7,126 \\
20,772\end{array}$ & $\begin{array}{l}5,755 \\
9,646\end{array}$ & $\begin{array}{l}28,698 \\
44,978\end{array}$ & $\begin{array}{l}5,266 \\
2,508\end{array}$ & $\begin{array}{l}0 \\
0\end{array}$ & $\begin{array}{l}11,057 \\
16,479\end{array}$ \\
\hline Industrial or Large & 0 & 0 & 0 & 4,263 & 0 & 0 \\
\hline Other & 0 & 0 & 1,856 & 7 & 0 & 529 \\
\hline Total to Ultimate Consumers & 27,898 & 15,401 & 75,532 & 12,044 & 0 & 28,065 \\
\hline 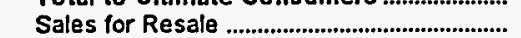 & 0 & 0 & 0 & 0 & 499,377 & \\
\hline Total Revenues From Sales of Elec........ & 27,898 & 15,401 & 75,532 & 12,044 & 499,377 & 28,085 \\
\hline
\end{tabular}

\begin{tabular}{|c|c|c|c|c|c|c|}
\hline Item & $\begin{array}{l}\text { Idaho } \\
\text { Idaho } \\
\text { Falls } \\
\text { City of } \\
\text { September } 30\end{array}$ & $\begin{array}{l}\text { Illinois } \\
\text { Batavia } \\
\text { City of } \\
\text { December } 31\end{array}$ & $\begin{array}{l}\text { Geneva } \\
\text { City of } \\
\text { April } 30\end{array}$ & $\begin{array}{c}\text { Illinois } \\
\text { Illinols } \\
\text { Municipal } \\
\text { Elec Agency } \\
\text { April } 30\end{array}$ & $\begin{array}{c}\text { Naperville } \\
\text { City of } \\
\text { April } 30\end{array}$ & $\begin{array}{l}\text { Illinois } \\
\text { Rochelle } \\
\text { Municipal } \\
\text { Utilities } \\
\text { April } 30\end{array}$ \\
\hline \multicolumn{7}{|l|}{ Number of Consumers } \\
\hline 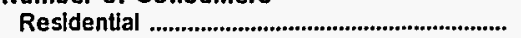 & 18,696 & 7.593 & 6.005 & 0 & 35,804 & 5,342 \\
\hline 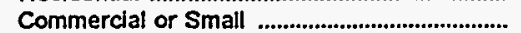 & 2,697 & 524 & 1,117 & 0 & 2,531 & 796 \\
\hline 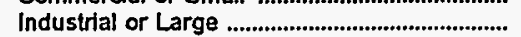 & 7 & 325 & 31 & 0 & 18 & 20 \\
\hline $\begin{array}{l}\text { Other } \\
\text { Total Uitimate Consumers }\end{array}$ & $\begin{array}{r}15 \\
21,415\end{array}$ & $\begin{array}{r}0 \\
8,442\end{array}$ & $\begin{array}{r}2 \\
7,155\end{array}$ & $\begin{array}{l}0 \\
0\end{array}$ & $\begin{array}{r}269 \\
38,622\end{array}$ & $\begin{array}{r}4 \\
6,162\end{array}$ \\
\hline \multicolumn{7}{|l|}{ Sales for the Year (megawatthours) } \\
\hline 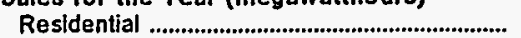 & 274,961 & 65,253 & 47,903 & 0 & 335,334 & 43.021 \\
\hline $\begin{array}{l}\text { Commercial or Small } \\
\text { Industral or Large }\end{array}$ & $\begin{array}{r}231,568 \\
50,748\end{array}$ & $\begin{array}{r}8,068 \\
170,056\end{array}$ & $\begin{array}{l}53,888 \\
80,227\end{array}$ & $\begin{array}{l}0 \\
0\end{array}$ & $\begin{array}{r}294,062 \\
40,535\end{array}$ & $\begin{array}{l}31,657 \\
92,007\end{array}$ \\
\hline $\begin{array}{l}\text { Other } \\
\text { Total to Uitimate Consumers }\end{array}$ & $\begin{array}{r}39,024 \\
596,301\end{array}$ & $\begin{array}{r}0 \\
243,377\end{array}$ & $\begin{array}{r}6,487 \\
188,505\end{array}$ & $\begin{array}{l}0 \\
0\end{array}$ & $\begin{array}{r}67.067 \\
736,998\end{array}$ & $\begin{array}{r}1,677 \\
168,362\end{array}$ \\
\hline 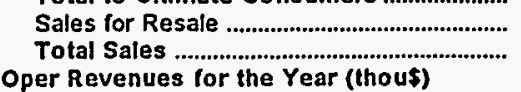 & $\begin{array}{r}0 \\
596,301\end{array}$ & $\begin{array}{r}0 \\
243,377\end{array}$ & $\begin{array}{r}0 \\
188,505\end{array}$ & $\begin{array}{l}1,544,616 \\
1,544,616\end{array}$ & $\begin{array}{r}0 \\
736,998\end{array}$ & $\begin{array}{r}0 \\
168,362\end{array}$ \\
\hline 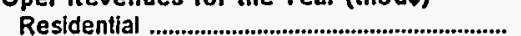 & 12,439 & 4,412 & 3,289 & 0 & 24,673 & 3,651 \\
\hline Commercial or Small & 11,930 & 558 & 3,383 & 0 & 17.807 & 2,700 \\
\hline Industrial or Large & 1,924 & 9,091 & 3,927 & 0 & 2,921 & 5,401 \\
\hline Other & 1,593 & 0 & 310 & 0 & 4,354 & 193 \\
\hline Total to Ultimate Consumers ......................... & 27,886 & 14,061 & 10,909 & $\mathbf{0}$ & 49,755 & 11,945 \\
\hline Sales for Resale ........................................... & 6,968 & & $\begin{array}{r}0 \\
10909\end{array}$ & 70,684 & $\begin{array}{r}0 \\
49755\end{array}$ & $\begin{array}{r}0 \\
11.945\end{array}$ \\
\hline Total Revenues From Sales of Elec......... & 34,854 & 14,061 & 10,909 & 70,684 & 49,755 & 11,945 \\
\hline
\end{tabular}

Note: Tolals may not equal sum of components because of independent rounding.

Source: Energy Information Administration, Form EIA-861, "Annual Electric Utility Report" Data are submitted on a calendar year. 
Table 25. Number of Consumers, Sales, and Operating Revenue by Major U.S. Publicly Owned Electric Utility Within State, 1995 (Continued)

\begin{tabular}{|c|c|c|c|c|c|c|}
\hline Item & $\begin{array}{l}\text { Springfield } \\
\text { City of } \\
\text { February } 28\end{array}$ & $\begin{array}{l}\text { St Charles } \\
\text { City of } \\
\text { April } 30\end{array}$ & $\begin{array}{l}\text { Indiana } \\
\text { Anderson } \\
\text { City of } \\
\text { December } 31\end{array}$ & $\begin{array}{l}\text { Indiana } \\
\text { Auburn } \\
\text { City of } \\
\text { December } 31\end{array}$ & $\begin{array}{l}\text { Indiana } \\
\text { Bluffton } \\
\text { City of } \\
\text { December } 31\end{array}$ & $\begin{array}{c}\text { Indiana } \\
\begin{array}{c}\text { Crawfordsvile } \\
\text { Elec }\end{array} \\
\text { Lgt\&Pwr Co } \\
\text { December } 31\end{array}$ \\
\hline \multicolumn{7}{|l|}{ Number of Consumers } \\
\hline Residential & 55,241 & 9,679 & 30,938 & 4,638 & 4,304 & 7,498 \\
\hline Commercial or Small & 6,431 & 1,464 & 3,495 & 686 & 578 & 1,202 \\
\hline 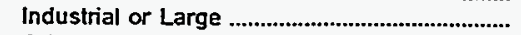 & 1 & 0 & 37 & 79 & 31 & 111 \\
\hline Other & $\begin{array}{r}2,728 \\
64,401\end{array}$ & $\begin{array}{r}68 \\
11,211\end{array}$ & $\begin{array}{r}2 \\
34,472\end{array}$ & $\begin{array}{r}3 \\
5,406\end{array}$ & $\begin{array}{r}71 \\
4,984\end{array}$ & $\begin{array}{r}45 \\
8,856\end{array}$ \\
\hline \multicolumn{7}{|l|}{ Sales for the Year (megawatthours) } \\
\hline Residential & 577,073 & 75,164 & 294,603 & 44.713 & 40,600 & 71,265 \\
\hline Commercial or Small & 966,937 & 289,636 & 286,062 & 18,366 & 25,949 & 29,899 \\
\hline 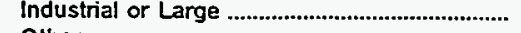 & 21,600 & 0 & 75,898 & 338,538 & 103,902 & 277,242 \\
\hline Other & 6.177 & 9,049 & 4,991 & 1,243 & 4,551 & 3,278 \\
\hline Total to Ultimate Consumers ........................ & $1,571,787$ & 373,849 & 661,554 & 402,860 & 175,002 & 381,684 \\
\hline 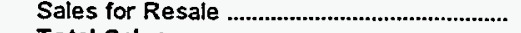 & 151,334 & 0 & 0 & 0 & 0 & 11,336 \\
\hline \multicolumn{5}{|l|}{ Oper Revenues for the Year (thou\$) } & 175,002 & 393,020 \\
\hline Residential & 31,070 & 6,440 & 18,590 & 2,085 & 2,240 & 4,691 \\
\hline 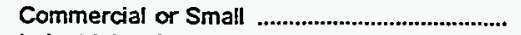 & 59,580 & 19.632 & 16,050 & 1,168 & 1,558 & 1,901 \\
\hline Industrial or Large & 999 & 0 & 3,485 & 14,884 & 4,570 & 12,199 \\
\hline Other & 377 & 634 & 319 & 105 & 265 & 265 \\
\hline 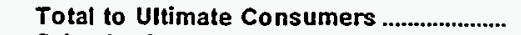 & 92,026 & 26,706 & 38,444 & 18,242 & 8,633 & 19,056 \\
\hline Sales for Resale & 4,029 & 0 & 0 & 0 & 0 & 2,181 \\
\hline Total Revenues From Sales of Elec......... & 96,055 & 26,706 & 38,444 & 18,242 & 8,633 & 21,237 \\
\hline
\end{tabular}

\begin{tabular}{|c|c|c|c|c|c|c|}
\hline Item & $\begin{array}{l}\text { Indiana } \\
\text { Frankfort } \\
\text { City of } \\
\text { December } 31\end{array}$ & $\begin{array}{c}\text { Indiana } \\
\text { Greenfield } \\
\text { City of } \\
\text { December } 31\end{array}$ & $\begin{array}{c}\text { Indiana } \\
\text { Indiana } \\
\text { Municipal } \\
\text { Power Agency } \\
\text { December } 31\end{array}$ & $\begin{array}{l}\text { Indiana } \\
\text { Jasper } \\
\text { City of } \\
\text { December } 31\end{array}$ & $\begin{array}{l}\text { Indiana } \\
\text { Lebanon } \\
\text { City of } \\
\text { December } 31\end{array}$ & $\begin{array}{c}\text { Indiana } \\
\text { Logansport } \\
\text { City of } \\
\text { December } 31\end{array}$ \\
\hline \multicolumn{7}{|l|}{ Number of Consumers } \\
\hline 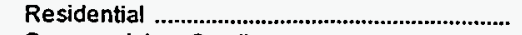 & 7,585 & 5,262 & 0 & 4,868 & 5,447 & 10,378 \\
\hline Commercial or Small & 1,072 & 635 & 0 & 822 & 740 & 2,052 \\
\hline 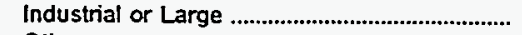 & 97 & 27 & 0 & 124 & 180 & 66 \\
\hline Other & 2 & 62 & 0 & 3 & 11 & 5 \\
\hline \multicolumn{7}{|l|}{ Sales for the Year (megawatthours) } \\
\hline Residential & 67,527 & 46,429 & 0 & 60,613 & 54,670 & 90,207 \\
\hline Commercial or Small & 23,471 & 41,266 & 0 & 37,844 & 18,310 & 70,584 \\
\hline Industrial or Large & 225,842 & 88,304 & 0 & 170,006 & 62,555 & 140,460 \\
\hline Other & 2,620 & 4,034 & 0 & 6,727 & 3.706 & 8,705 \\
\hline 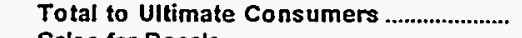 & 319,460 & 180,033 & 0 & 275,190 & 139,241 & 309,956 \\
\hline 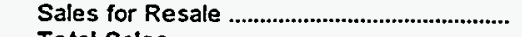 & 0 & 0 & $4,072,696$ & 0 & 0 & 0 \\
\hline \multicolumn{7}{|l|}{ Oper Revenues for the Year (thous) } \\
\hline 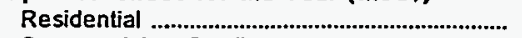 & 4,177 & 2,780 & 0 & 3,646 & 3,341 & 5,830 \\
\hline 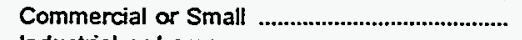 & 1,496 & 2,208 & $\mathbf{0}$ & 2,387 & 1,082 & 4,570 \\
\hline Industrial or Large & 9,409 & 4,002 & 0 & 8,691 & 3,289 & 7,202 \\
\hline Other & 221 & 229 & 0 & 411 & 189 & 441 \\
\hline Total to Ultimate Consumers ....................... & 15,303 & 9,219 & 0 & 15,135 & 7,901 & 18,043 \\
\hline Sales for Resale & 0 & 0 & 156,933 & 0 & 0 & 0 \\
\hline Total Revenues From Sales of Elec......... & 15,303 & 9,219 & 156,933 & 15,135 & 7,901 & 18,043 \\
\hline
\end{tabular}

Note: Totals may not equal sum of components because of independent rounding.

Source: Energy Information Administration, Form EIA-861, "Annual Electric Utility Report." Data are submitted on a calendar year. 
Table 25. Number of Consumers, Sales, and Operating Revenue by Major U.S. Publicly Owned Electric Utility Within State, 1995 (Continued)

\begin{tabular}{|c|c|c|c|c|c|c|}
\hline Item & $\begin{array}{c}\text { Indiana } \\
\text { Mishawaka } \\
\text { City of } \\
\text { December } 31\end{array}$ & $\begin{array}{c}\text { Indiana } \\
\text { Peru } \\
\text { City of } \\
\text { December } 31\end{array}$ & $\begin{array}{l}\text { Indiana } \\
\text { Richmond } \\
\text { City of } \\
\text { December } 31\end{array}$ & $\begin{array}{l}\text { Indiana } \\
\text { Scottsburg } \\
\text { City of }\end{array}$ & $\begin{array}{c}\text { Indiana } \\
\text { Washington } \\
\text { City of } \\
\text { December } 31\end{array}$ & $\begin{array}{l}\text { lowa } \\
\text { Ames } \\
\text { City of } \\
\text { June } 30\end{array}$ \\
\hline \multicolumn{7}{|l|}{ Number of Consumers } \\
\hline 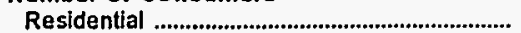 & 20,197 & 9.281 & 18,417 & 2,474 & 6.082 & 15,681 \\
\hline Commercial or Small & 2,843 & 323 & 2,465 & 556 & 870 & 1,796 \\
\hline 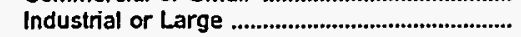 & 0 & 809 & 221 & 74 & 2 & 251 \\
\hline Other & 168 & 123 & 72 & 0 & 43 & 164 \\
\hline $\begin{array}{l}\text { Total Ultimate Consumers .............................. } \\
\text { Sales for the Year (megawatthours) }\end{array}$ & \multicolumn{2}{|c|}{ Sales for the Year (megawatthours) } & 21,175 & 3,104 & 6,997 & 17,892 \\
\hline 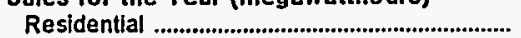 & 155,710 & 84,289 & 186,570 & 28,887 & 62,535 & 112,093 \\
\hline $\begin{array}{l}\text { Commercial or Small } \\
\text { Industrial or Large }\end{array}$ & $\begin{array}{r}308,851 \\
0\end{array}$ & $\begin{array}{r}7,803 \\
95,240\end{array}$ & $\begin{array}{l}113,542 \\
529,673\end{array}$ & $\begin{array}{r}16.992 \\
124,045\end{array}$ & $\begin{array}{l}57,350 \\
21,862\end{array}$ & $\begin{array}{r}43,892 \\
150,633\end{array}$ \\
\hline Other & $\begin{array}{r}21,890 \\
-151\end{array}$ & $\begin{array}{r}9,309 \\
196,644\end{array}$ & 10,693 & $\begin{array}{r}0 \\
169\end{array}$ & $\begin{array}{r}8,400 \\
450,147\end{array}$ & $\begin{array}{r}79,174 \\
385,792\end{array}$ \\
\hline $\begin{array}{l}\text { Total to Ultimate Consumers } \\
\text { Sales for Resale }\end{array}$ & $\begin{array}{r}486,451 \\
0\end{array}$ & $\begin{array}{r}196,641 \\
0\end{array}$ & $\begin{array}{r}840,478 \\
0\end{array}$ & $\begin{array}{r}168,324 \\
0\end{array}$ & $\begin{array}{r}150,147 \\
0\end{array}$ & $\begin{array}{r}385,792 \\
92\end{array}$ \\
\hline $\begin{array}{l}\text { Total Sales ........................................................ } \\
\text { Oper Revenues for the Year (thou\$) }\end{array}$ & 486,451 & 196,641 & 840,478 & 169,924 & 150,147 & 385,884 \\
\hline 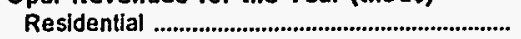 & 10,155 & 4,901 & 11,234 & 1,645 & 3.631 & 8,284 \\
\hline 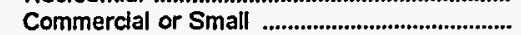 & 17,503 & 425 & 7,192 & 970 & 2,978 & 2.936 \\
\hline 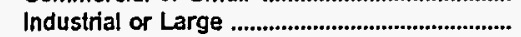 & 0 & 4,531 & 24,236 & 5,820 & 836 & 7.874 \\
\hline Other & 1,556 & 444 & 986 & 0 & 442 & 2,999 \\
\hline 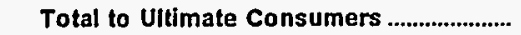 & 29,214 & 10,301 & 43,648 & 8,435 & 7,887 & 22,093 \\
\hline 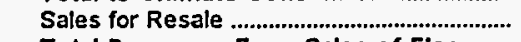 & 0 & $\begin{array}{r}0 \\
\tan 301\end{array}$ & $\begin{array}{r}0 \\
0\end{array}$ & 0 & $\begin{array}{r}0 \\
7897\end{array}$ & \\
\hline Total Revenues From Sales of Elec ......... & 29,214 & 10,301 & 43,648 & 8,435 & 7,887 & 22,097 \\
\hline
\end{tabular}

\begin{tabular}{|c|c|c|c|c|c|c|}
\hline Item & $\begin{array}{c}\text { lowa } \\
\text { Cedar } \\
\text { Falls } \\
\text { City of } \\
\text { December } 31\end{array}$ & $\begin{array}{c}\text { lowa } \\
\text { Muscatine } \\
\text { City of } \\
\text { December } 31\end{array}$ & $\begin{array}{c}\text { lowa } \\
\text { Pella } \\
\text { City of } \\
\text { December } 31\end{array}$ & $\begin{array}{l}\text { Kansas } \\
\text { Chanute } \\
\text { City of } \\
\text { December } 31\end{array}$ & $\begin{array}{c}\text { Kansas } \\
\text { Coffeyulle } \\
\text { City of } \\
\text { December } 31\end{array}$ & $\begin{array}{c}\text { Kansas } \\
\text { Garden } \\
\text { City City of } \\
\text { December } 31\end{array}$ \\
\hline \multicolumn{7}{|l|}{ Number of Consumers } \\
\hline 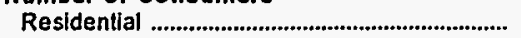 & 13,150 & 9,014 & 3.643 & 4,603 & 6,935 & 8,857 \\
\hline Commercial or Smali & 1,673 & 1,456 & 474 & 848 & 964 & 570 \\
\hline 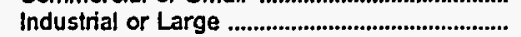 & 47 & 11 & 34 & 89 & 0 & 0 \\
\hline Other . Tot Uitimate Consumers ........................ & $\begin{array}{r}248 \\
15,118\end{array}$ & $\begin{array}{r}34 \\
10,515\end{array}$ & $\begin{array}{r}60 \\
4,211\end{array}$ & $\begin{array}{r}2 \\
5,542\end{array}$ & $\begin{array}{r}0 \\
7,899\end{array}$ & $\begin{array}{r}0 \\
9,427\end{array}$ \\
\hline 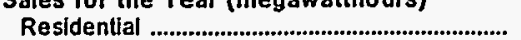 & 131,197 & 91,746 & 32,049 & 40,281 & 53,238 & 62,800 \\
\hline $\begin{array}{l}\text { Commercial or Small } \\
\text { Industrial or Large }\end{array}$ & $\begin{array}{l}90,987 \\
50,487\end{array}$ & $\begin{array}{l}144,225 \\
565.213\end{array}$ & $\begin{array}{l}19,562 \\
89,014\end{array}$ & $\begin{array}{l}35,024 \\
85,387\end{array}$ & $\begin{array}{r}123,209 \\
0\end{array}$ & $\begin{array}{r}93,916 \\
0\end{array}$ \\
\hline Other ..................................................... & $\begin{array}{r}57.654 \\
330.325\end{array}$ & $\begin{array}{r}18,128 \\
819,312\end{array}$ & $\begin{array}{r}5,026 \\
145,651\end{array}$ & $\begin{array}{r}1,248 \\
161,940\end{array}$ & $\begin{array}{r}0 \\
176,447\end{array}$ & $\begin{array}{r}0 \\
156.716\end{array}$ \\
\hline 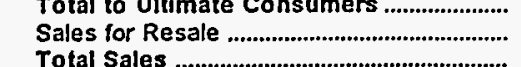 & $\begin{array}{r}730,325 \\
7,669 \\
337,994\end{array}$ & $\begin{array}{r}819,312 \\
491,514 \\
1,310,826\end{array}$ & $\begin{array}{r}145,651 \\
0 \\
145,651\end{array}$ & $\begin{array}{r}101,940 \\
0 \\
161,940\end{array}$ & $\begin{array}{r}170,448 \\
0 \\
176,447\end{array}$ & $\begin{array}{r}0 \\
156,716\end{array}$ \\
\hline Oper Revenues for the Year (thou\$) & & & & & & \\
\hline 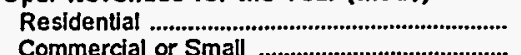 & $\begin{array}{l}6,340 \\
3,979\end{array}$ & $\begin{array}{l}5,947 \\
8,009\end{array}$ & $\begin{array}{l}2,790 \\
1,842\end{array}$ & $\begin{array}{l}2,762 \\
2,236\end{array}$ & $\begin{array}{l}3,839 \\
7,611\end{array}$ & $\begin{array}{l}5,181 \\
7,266\end{array}$ \\
\hline Industrlal or Large & 1,983 & 22,117 & 4,756 & 3,906 & 0 & 0 \\
\hline Other & 1,867 & 722 & 405 & 69 & 0 & 0 \\
\hline 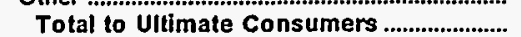 & 14,169 & 36,795 & 9,793 & 8,973 & 11,450 & 12,447 \\
\hline Sales for Resale .......................................... & $\begin{array}{r}145 \\
14.314\end{array}$ & $\begin{array}{r}8,411 \\
45,206\end{array}$ & $\begin{array}{r}0 \\
9,793\end{array}$ & $\begin{array}{r}0 \\
8,973\end{array}$ & $\begin{array}{r}0 \\
11,450\end{array}$ & $\begin{array}{r}0 \\
12,447\end{array}$ \\
\hline
\end{tabular}

Note: Totals may not equal sum of components because of independent rounding.

Source: Energy Information Administration, Form EIA-861, "Annual Electric Utility Report" Data are submitted on a calendar year. 
Table 25. Number of Consumers, Sales, and Operating Revenue by Major U.S. Publicly Owned Electric Utility Within State, 1995 (Continued)

\begin{tabular}{|c|c|c|c|c|c|c|}
\hline Item & $\begin{array}{c}\text { Kansas } \\
\text { Kansas } \\
\text { City City of } \\
\text { December } 31\end{array}$ & $\begin{array}{c}\text { Kansas } \\
\text { Kansas } \\
\text { Municipal } \\
\text { Energy } \\
\text { Agency } \\
\text { December } 31\end{array}$ & $\begin{array}{c}\text { McPherson } \\
\text { City of } \\
\text { December } 31\end{array}$ & $\begin{array}{l}\text { Kansas } \\
\text { Winfield } \\
\text { City of } \\
\text { December } 31\end{array}$ & $\begin{array}{c}\text { Kentucky } \\
\text { Bardstown } \\
\text { City of } \\
\text { December } 31\end{array}$ & $\begin{array}{l}\text { Kentucky } \\
\text { Bowling } \\
\text { Green } \\
\text { City of } \\
\text { June } 30\end{array}$ \\
\hline \multicolumn{7}{|l|}{ Number of Consumers } \\
\hline 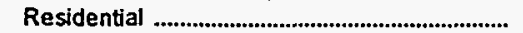 & 58,688 & 0 & 6,617 & 5.646 & 2,661 & 18,408 \\
\hline Commercial or Small & 6,726 & 0 & 1,026 & 1,233 & 788 & 2,925 \\
\hline 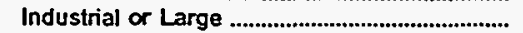 & 121 & 0 & 10 & 100 & 10 & 516 \\
\hline Other & 272 & 0 & 1 & 73 & 349 & 139 \\
\hline Total Ultimate Consumers & 65,807 & 0 & 7,654 & 7,052 & 3,808 & 21,986 \\
\hline \multicolumn{7}{|l|}{ Sales for the Year (megawatthours) } \\
\hline 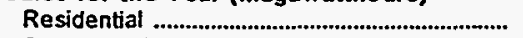 & 505,071 & 0 & 69.129 & 51,923 & 35.236 & 185,710 \\
\hline 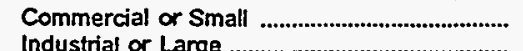 & 766,786 & 0 & 91,663 & $\begin{array}{r}18,634 \\
154,504\end{array}$ & $\begin{array}{l}49,349 \\
63,655\end{array}$ & $\begin{array}{r}64,434 \\
422,089\end{array}$ \\
\hline Other & $\begin{array}{r}742,405 \\
56,595\end{array}$ & 0 & $\begin{array}{r}352,990 \\
4,205\end{array}$ & $\begin{array}{r}154,504 \\
6,197\end{array}$ & $\begin{array}{r}63,655 \\
314\end{array}$ & $\begin{array}{r}422,089 \\
8,191\end{array}$ \\
\hline 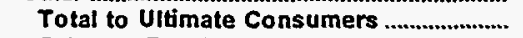 & $2,070,857$ & 0 & 517,987 & 231,258 & 148,554 & 680,424 \\
\hline 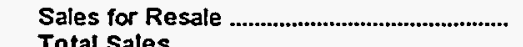 & 404,348 & 304,342 & $\begin{array}{r}39,083 \\
557,070\end{array}$ & 4,886 & $\begin{array}{r}0 \\
148\end{array}$ & $\begin{array}{r}0 \\
680 \\
099\end{array}$ \\
\hline \multicolumn{6}{|l|}{ Oper Revenues for the Year (thous) } & 680,424 \\
\hline 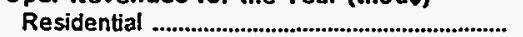 & 32,647 & 0 & 3,256 & 3,695 & 1.784 & 11,778 \\
\hline 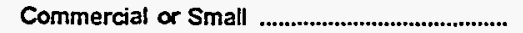 & 44,305 & 0 & 4,142 & 1,292 & 2,426 & 4.413 \\
\hline 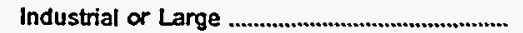 & 29,660 & 0 & 10,236 & 6,842 & 2,577 & 22,569 \\
\hline Other & 2,943 & 0 & 155 & 393 & 33 & 632 \\
\hline 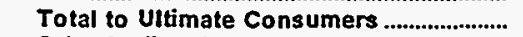 & 109,555 & 0 & 17,789 & 12,222 & 6,820 & 39,392 \\
\hline 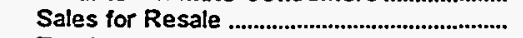 & 12,513 & 8,798 & 3,116 & 212 & & \\
\hline Total Revenues From Sales of Elec........ & 122,068 & 8,798 & 20,905 & 12,434 & 6,820 & 39,392 \\
\hline
\end{tabular}

\begin{tabular}{|c|c|c|c|c|c|c|}
\hline Item & $\begin{array}{l}\text { Kentucky } \\
\text { Frankfort } \\
\text { City of } \\
\text { June } 30\end{array}$ & $\begin{array}{l}\text { Kentucky } \\
\text { Franklin } \\
\text { City of } \\
\text { June } 30\end{array}$ & $\begin{array}{l}\text { Kentucky } \\
\text { Glasgow } \\
\text { City of } \\
\text { June } 30\end{array}$ & $\begin{array}{c}\text { Kentucky } \\
\text { Henderson } \\
\text { City } \\
\text { Utility Comm } \\
\text { May } 31\end{array}$ & $\begin{array}{l}\text { Kentucky } \\
\text { Hopkinsville } \\
\text { City of } \\
\text { June } 30\end{array}$ & $\begin{array}{l}\text { Kentucky } \\
\text { Madisonville } \\
\text { Municipal } \\
\text { Utils } \\
\text { June } 30\end{array}$ \\
\hline \multicolumn{7}{|l|}{ Number of Consumers } \\
\hline Residential .......................... & 15,082 & 3,680 & 4,938 & 9,469 & 11,461 & 7,074 \\
\hline Commercial or Smatt ................................................. & 2,371 & 612 & 1,177 & 3,070 & 1,674 & 1,313 \\
\hline 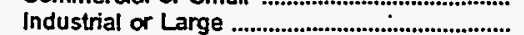 & 281 & 69 & 166 & 13 & 254 & \\
\hline Other & 510 & 27 & 49 & 139 & 19 & 0 \\
\hline Total Uitimate Consumers & 18,244 & 4,388 & 6,330 & 12,691 & 13,408 & 8,387 \\
\hline \multicolumn{7}{|l|}{ Sales for the Year (megawatthours) } \\
\hline 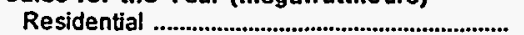 & 182,563 & 42,303 & 54,307 & 115,891 & 129,271 & 71,543 \\
\hline 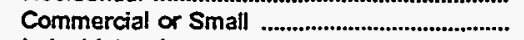 & 61,964 & 10,677 & 20,315 & 176,339 & 35,136 & 201,201 \\
\hline 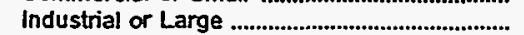 & 365,120 & 137,249 & 237,741 & 136,040 & 239,217 & 0 \\
\hline Other & 30.083 & 1,890 & 3.128 & 5,879 & 5,882 & \\
\hline Total to Ultimate Consumers ........................... & 639,730 & 192,719 & 315,491 & 434,149 & 409,506 & 272,744 \\
\hline 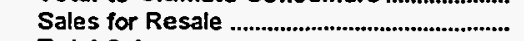 & & & & $1,376,805$ & & \\
\hline \multicolumn{7}{|l|}{ Oper Revenues for the Year (thou\$) } \\
\hline 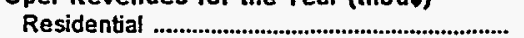 & 7,883 & 2,506 & 3,277 & 4,386 & 7,380 & 3,835 \\
\hline 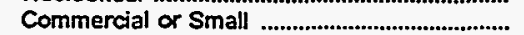 & 2,846 & 702 & 1,399 & 6,019 & 2,251 & 8,162 \\
\hline 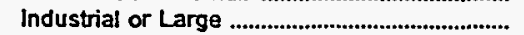 & 13,182 & 5,840 & 11,272 & 3,942 & 10,420 & 0 \\
\hline Other & 1,307 & 135 & 266 & 208 & 459 & 0 \\
\hline Total to Ultimate Consumers ......................... & 25,218 & 9,183 & 16,214 & 14,555 & 20,510 & 11,997 \\
\hline 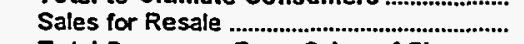 & & & & 11,064 & & \\
\hline Total Revenues From Sales of Elec......... & 25,218 & 9,183 & 16,214 & 25,619 & 20,510 & 11,897 \\
\hline
\end{tabular}

Note: Totals may not equal sum of components because of independent rounding.

Source: Energy Information Administration, Form ELA-861, "Annual Electric Utility Report." Data are submitted on a calendar year. 
Table 25. Number of Consumers, Sales, and Operating Revenue by Major U.S. Publicly Owned Electric Utility Within State, 1995 (Continued)

\begin{tabular}{|c|c|c|c|c|c|c|}
\hline Item & $\begin{array}{l}\text { Kentucky } \\
\text { Mayrield } \\
\text { City of } \\
\text { June } 30\end{array}$ & $\begin{array}{l}\text { Kentucky } \\
\text { Murray } \\
\text { City of } \\
\text { June } 30\end{array}$ & $\begin{array}{c}\text { Kentucky } \\
\text { Owensboro } \\
\text { City of } \\
\text { May } 31\end{array}$ & $\begin{array}{l}\text { Kentucky } \\
\text { Paducah } \\
\text { City of } \\
\text { June } 30\end{array}$ & $\begin{array}{l}\text { Louisiana } \\
\text { Alexandria } \\
\text { City of } \\
\text { April } 30\end{array}$ & $\begin{array}{l}\text { Louisiana } \\
\text { Lafayette } \\
\text { City of } \\
\text { October } 31\end{array}$ \\
\hline \multicolumn{7}{|l|}{ Number of Consumers } \\
\hline 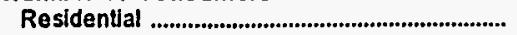 & 4,926 & 5,383 & 21,600 & 18,486 & 21.789 & 42,989 \\
\hline 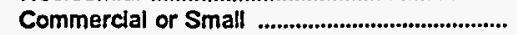 & 763 & 949 & 2,647 & 2,803 & 3,189 & 6,199 \\
\hline 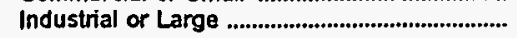 & 117 & 136 & 1,953 & 482 & 0 & 0 \\
\hline Other & 47 & 12 & 3 & 358 & 27 & 2,224 \\
\hline $\begin{array}{l}\text { Total Ultimate Consumers .............................. } \\
\text { Sales for the Year (megawatthours) }\end{array}$ & 5,853 & 6,480 & 26,203 & 22,129 & 25,005 & 51,412 \\
\hline 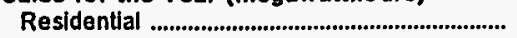 & 52,361 & 69,516 & 211.705 & 206.299 & 261,512 & 648,969 \\
\hline 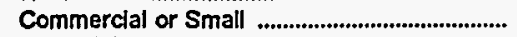 & 14,251 & 20,650 & 40,824 & 52,794 & 346,365 & 772,663 \\
\hline 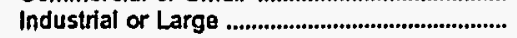 & 74,073 & 133,482 & 462,929 & 251,701 & 0 & 0 \\
\hline Other & 2,339 & 2,331 & 50,425 & 8,941 & 2,576 & 83,418 \\
\hline 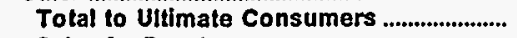 & 143,024 & 225,979 & 765,883 & 519,735 & 610,453 & $1,505,050$ \\
\hline 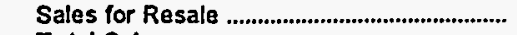 & & & $1,395,807$ & 0 & 0 & 437,891 \\
\hline \multicolumn{4}{|l|}{ Oper Revenues for the Year (thous) } & 519,735 & 610,453 & $1,942,941$ \\
\hline 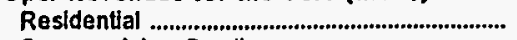 & 3,350 & 4,033 & 10,336 & 12,834 & 18,213 & 42,054 \\
\hline Commercial or Small ............................................ & 993 & 1.311 & 2,038 & 3,695 & 21,582 & 47,353 \\
\hline 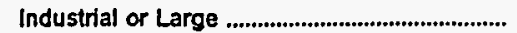 & 4,436 & 7,033 & 15,037 & 14,375 & $\mathbf{0}$ & 0 \\
\hline 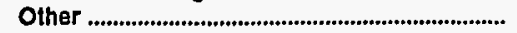 & 151 & 173 & 1,268 & 801 & 165 & 4,680 \\
\hline Total to Ultimate Consumers ..................... & 8,930 & 12,550 & 28,679 & 31,705 & 39,960 & 94,087 \\
\hline 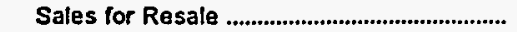 & & 0 & 23.557 & 0 & 0 & 15,264 \\
\hline Total Revenues From Sales of Elec......... & 8,930 & 12,550 & 52,236 & 31,705 & 39,960 & 109,351 \\
\hline
\end{tabular}

\begin{tabular}{|c|c|c|c|c|c|c|}
\hline Item & $\begin{array}{l}\text { Louisiana } \\
\text { Lafayette } \\
\text { Public } \\
\text { Power Auth } \\
\text { October } 31\end{array}$ & $\begin{array}{l}\text { Louisiana } \\
\text { Louisiana } \\
\text { Energy } \\
\& \\
\text { Power Auth } \\
\text { December } 31\end{array}$ & $\begin{array}{l}\text { Louisiana } \\
\text { Morgan } \\
\text { City City of } \\
\text { December } 31\end{array}$ & $\begin{array}{l}\text { Louisiana } \\
\text { Natchitoches } \\
\text { City of } \\
\text { May } 31\end{array}$ & $\begin{array}{l}\text { Louisiana } \\
\begin{array}{c}\text { Ruston } \\
\text { City of }\end{array} \\
\text { September } 30\end{array}$ & $\begin{array}{c}\text { Louisiana } \\
\text { Terrebonne } \\
\text { Parish } \\
\text { Consol Govt } \\
\text { December } 31\end{array}$ \\
\hline \multicolumn{7}{|l|}{ Number of Consumers } \\
\hline 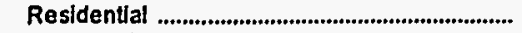 & 0 & o & 4,940 & 6,405 & 7,247 & 7,961 \\
\hline Commerclal or Small & 0 & $\mathbf{0}$ & 1.329 & 899 & 1,066 & 1,395 \\
\hline 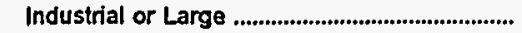 & 0 & 0 & 0 & 10 & 63 & 0 \\
\hline Other & 0 & 0 & 0 & 1 & 4 & 0 \\
\hline $\begin{array}{l}\text { Total Ultimate Consumers .............................. } \\
\text { Sales for the Year (megawatthours) }\end{array}$ & 0 & 0 & 6,269 & 7,315 & 8,380 & 9,356 \\
\hline 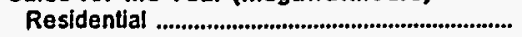 & 0 & 0 & 72,179 & 66,607 & 78,244 & 123,006 \\
\hline Commercial or Small & 0 & 0 & 95,679 & 54,728 & 53,142 & 114,566 \\
\hline Industrial or Large & 0 & 0 & 0 & 79,526 & 51,019 & 0 \\
\hline Other & 0 & 0 & 0 & $\mathbf{5 , 7 8 6}$ & 45,929 & $\mathbf{0}$ \\
\hline Total to Ultimate Consumers ......................... & 0 & 0 & 167,858 & 206,647 & 228,334 & 237,572 \\
\hline $\begin{array}{l}\text { Sales for Resale } \\
\text { Total Sales }\end{array}$ & $\begin{array}{l}1,037,217 \\
1,037,217\end{array}$ & $\begin{array}{l}1,325,775 \\
1,325,775\end{array}$ & $\begin{array}{r}0 \\
167,858\end{array}$ & $\begin{array}{r}0 \\
206,647\end{array}$ & $\begin{array}{r}0 \\
228,334\end{array}$ & $\begin{array}{r}37,006 \\
274,578\end{array}$ \\
\hline \multicolumn{7}{|l|}{ Oper Revenues for the Year (thous) } \\
\hline 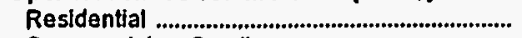 & 0 & 0 & 4,991 & 4,353 & 4,444 & 8,751 \\
\hline 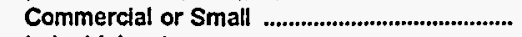 & 0 & 0 & 5,413 & 3,933 & 3,526 & 7,861 \\
\hline 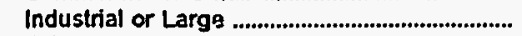 & 0 & 0 & 0 & 4,350 & 2,385 & 0 \\
\hline Other & 0 & 0 & 0 & 407 & 1,679 & 0 \\
\hline Total to Ultimate Consumers ......................... & $\mathbf{0}$ & 0 & 10,404 & 13,043 & 12,034 & 16,612 \\
\hline $\begin{array}{l}\text { Sales for Resale ............................................ } \\
\text { Total Revenues From Sales of Elec ........ }\end{array}$ & $\begin{array}{l}40,812 \\
40,812\end{array}$ & $\begin{array}{l}53,653 \\
53,653\end{array}$ & $\begin{array}{r}0 \\
10,404\end{array}$ & $\begin{array}{r}0 \\
13,043\end{array}$ & $\begin{array}{r}0 \\
12,034\end{array}$ & $\begin{array}{r}554 \\
17,166\end{array}$ \\
\hline
\end{tabular}

Note: Totals may not equal sum of components because of independentrounding.

Source: Energy Information Administration, Form ElA-861, "Annual Electric Utility Report" Data are submitted on a calendar year. 
Table 25. Number of Consumers, Sales, and Operating Revenue by Major U.S. Publicly Owned Electric Utility Within State, 1995 (Continued)

\begin{tabular}{|c|c|c|c|c|c|c|}
\hline Item & $\begin{array}{l}\text { Maryland } \\
\text { Easton } \\
\text { Utilities } \\
\text { Comm } \\
\text { June } 30\end{array}$ & $\begin{array}{l}\text { Maryland } \\
\text { Hagerstown } \\
\text { City of } \\
\text { June } 30\end{array}$ & $\begin{array}{l}\text { Massachusetts } \\
\text { Braintree } \\
\text { Town of } \\
\text { December } 31\end{array}$ & $\begin{array}{l}\text { Massachusetts } \\
\text { Chicopee } \\
\text { City of } \\
\text { December } 3 \mathfrak{t}\end{array}$ & $\begin{array}{l}\text { Massachusetts } \\
\text { Concord } \\
\text { Town of } \\
\text { December } 31\end{array}$ & $\begin{array}{l}\text { Massachusetts } \\
\text { Danvers } \\
\text { Town of } \\
\text { December } 31\end{array}$ \\
\hline \multicolumn{7}{|l|}{ Number of Consumers } \\
\hline 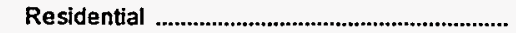 & 6,165 & 15,302 & 11,669 & 24,586 & 6,046 & 9,618 \\
\hline Commercial or Small & 1,636 & 1,986 & 1,861 & 2,164 & 1,092 & 1,316 \\
\hline 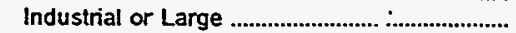 & 0 & 132 & 11 & 26 & 18 & 289 \\
\hline Other & 113 & 64 & 305 & 245 & 56 & 259 \\
\hline $\begin{array}{l}\text { Total Ultimate Consumers } \\
\text { Sales for the Year (megawatthours) }\end{array}$ & 7,914 & 17,484 & 13,846 & 27,021 & 7,212 & 11,482 \\
\hline Residential & 76.590 & 117,430 & 91,617 & 158,182 & 55,361 & 77,393 \\
\hline Commercial or Small & 139,955 & 58,029 & 199,101 & 105,094 & 39,254 & 26,550 \\
\hline Industrial or Large & 0 & 121.194 & 47,800 & 68,595 & 53,944 & 196,991 \\
\hline Other & 10,421 & 8,471 & 14,238 & 44,861 & 7.591 & 11.695 \\
\hline 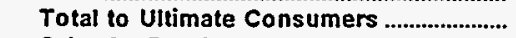 & 226,966 & 305,124 & 352,756 & 376,732 & 156,150 & 312,629 \\
\hline $\begin{array}{l}\text { Sales for Resale } \\
\text { Total Sales }\end{array}$ & $\begin{array}{r}0 \\
226,966\end{array}$ & $\begin{array}{r}0 \\
305,124\end{array}$ & $\begin{array}{r}58,476 \\
411,232\end{array}$ & $\begin{array}{r}8,824 \\
385,556\end{array}$ & $\begin{array}{r}0 \\
156.150\end{array}$ & $\begin{array}{r}7,618 \\
320.247\end{array}$ \\
\hline \multicolumn{7}{|l|}{ Oper Revenues for the Year (thous) } \\
\hline $\begin{array}{l}\text { Residential } \\
\text { Commercial or Small }\end{array}$ & $\begin{array}{l}4,979 \\
8,748\end{array}$ & $\begin{array}{l}7,162 \\
3,459\end{array}$ & $\begin{array}{r}7,360 \\
16,598\end{array}$ & $\begin{array}{r}12,399 \\
9,083\end{array}$ & $\begin{array}{l}4,636 \\
4,251\end{array}$ & $\begin{array}{l}7,885 \\
2,985\end{array}$ \\
\hline Industrial or Large & 0 & 5,583 & 3,455 & 5,176 & 3,423 & 17,710 \\
\hline Other & 714 & 533 & 1,161 & 3,442 & 352 & 1,078 \\
\hline 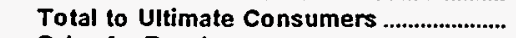 & 14,441 & 16,737 & 28,574 & 30,100 & 12,662 & 29,658 \\
\hline Sales for Resale & & & 2,688 & 228 & 0 & 305 \\
\hline Total Revenues From Sales of Elec......... & 14,441 & 16,737 & 31,262 & 30,328 & 12,662 & 29,963 \\
\hline
\end{tabular}

\begin{tabular}{|c|c|c|c|c|c|c|}
\hline Item & $\begin{array}{l}\text { Massachusetts } \\
\text { Hingham } \\
\text { City of } \\
\text { December } 31\end{array}$ & $\begin{array}{l}\text { Massachusetts } \\
\text { Holyoke } \\
\text { City of } \\
\text { December } 31\end{array}$ & $\begin{array}{c}\text { Massachusetts } \\
\text { Hudson } \\
\text { Town of } \\
\text { December } 31\end{array}$ & $\begin{array}{l}\text { Massachusetts } \\
\text { Littleton } \\
\text { Town of } \\
\text { December } 31\end{array}$ & $\begin{array}{l}\text { Massachusetts } \\
\text { Mansfield } \\
\text { Town of } \\
\text { December } 31\end{array}$ & $\begin{array}{c}\text { Massachusetts } \\
\text { Massachusetts } \\
\text { Mun } \\
\text { Whis } \\
\text { Elec Co } \\
\text { December } 31\end{array}$ \\
\hline \multicolumn{7}{|l|}{ Number of Consumers } \\
\hline Residential & 7,812 & 15,224 & 8,986 & 4,899 & 7,436 & 0 \\
\hline Commercial or Small & 862 & 2,115 & 1,003 & 416 & 487 & 0 \\
\hline 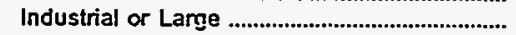 & 45 & 73 & 164 & 66 & 223 & $\mathbf{0}$ \\
\hline Other & 54 & 538 & 265 & $5 i$ & 103 & 0 \\
\hline $\begin{array}{l}\text { Total Ultimate Consumers } \\
\text { Sales for the Year (megawatho........................ }\end{array}$ & 8,773 & 17,950 & 10,418 & 5,432 & 8,249 & 0 \\
\hline Residential & 65,814 & 92,298 & 70,358 & 45,641 & 54.111 & 0 \\
\hline $\begin{array}{l}\text { Commercial or Small } \\
\text { Industrial or Large }\end{array}$ & $\begin{array}{l}23,023 \\
49,029\end{array}$ & $\begin{array}{r}129,845 \\
20,257\end{array}$ & $\begin{array}{r}12,508 \\
222,451\end{array}$ & $\begin{array}{r}8,850 \\
102,229\end{array}$ & $\begin{array}{r}5,857 \\
110,282\end{array}$ & $\begin{array}{l}0 \\
0\end{array}$ \\
\hline Other & 5,704 & 22,917 & $\begin{array}{r}222,401 \\
13,714\end{array}$ & $\begin{array}{r}102,229 \\
5,320\end{array}$ & $\begin{array}{r}110,282 \\
6,873\end{array}$ & $\begin{array}{l}0 \\
0\end{array}$ \\
\hline Total to Ultimate Consumers ......................... & 143,570 & 265,317 & 319,031 & 162,040 & 177,103 & $\mathbf{0}$ \\
\hline $\begin{array}{l}\text { Sales for Resale } \\
\text { Total Sales }\end{array}$ & $\begin{array}{r}394 \\
143,964\end{array}$ & $\begin{array}{r}3,352 \\
268,669\end{array}$ & $\begin{array}{r}708 \\
319,739\end{array}$ & $\begin{array}{r}999 \\
163,039\end{array}$ & $\begin{array}{r}3,414 \\
180,517\end{array}$ & $\begin{array}{l}2,913,554 \\
2,913,554\end{array}$ \\
\hline \multicolumn{7}{|l|}{ Oper Revenues for the Year (thou\$) } \\
\hline Residential & 5,714 & 9,236 & 6,602 & 3,684 & 5,721 & 0 \\
\hline 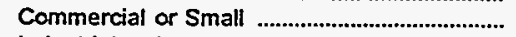 & 2.690 & 13,310 & 1,492 & 837 & 770 & 0 \\
\hline Industrial or Large & 4,137 & 1,463 & 17,235 & 9,530 & 11,094 & 0 \\
\hline Other & 604 & 2,265 & 1,910 & 458 & 840 & 0 \\
\hline Total to Ultimate Consumers ....................... & 13,145 & 26,274 & 27,239 & 14,509 & 18,425 & 0 \\
\hline Sales for Resale & 51 & 115 & 22 & 42 & 158 & 212,172 \\
\hline Total Revenues From Sales of Elec........ & 13,196 & 26,389 & 27,261 & 14,551 & 18,583 & 212,172 \\
\hline
\end{tabular}

Note: Totals may not equal sum of components because of independent rounding.

Source: Energy Information Administration, Form ElA-861, "Annual Electric Utility Report." Data are submitted on a calendar year. 
Table 25. Number of Consumers, Sales, and Operating Revenue by Major U.S. Publicly Owned Electric Utility Within State, 1995 (Continued)

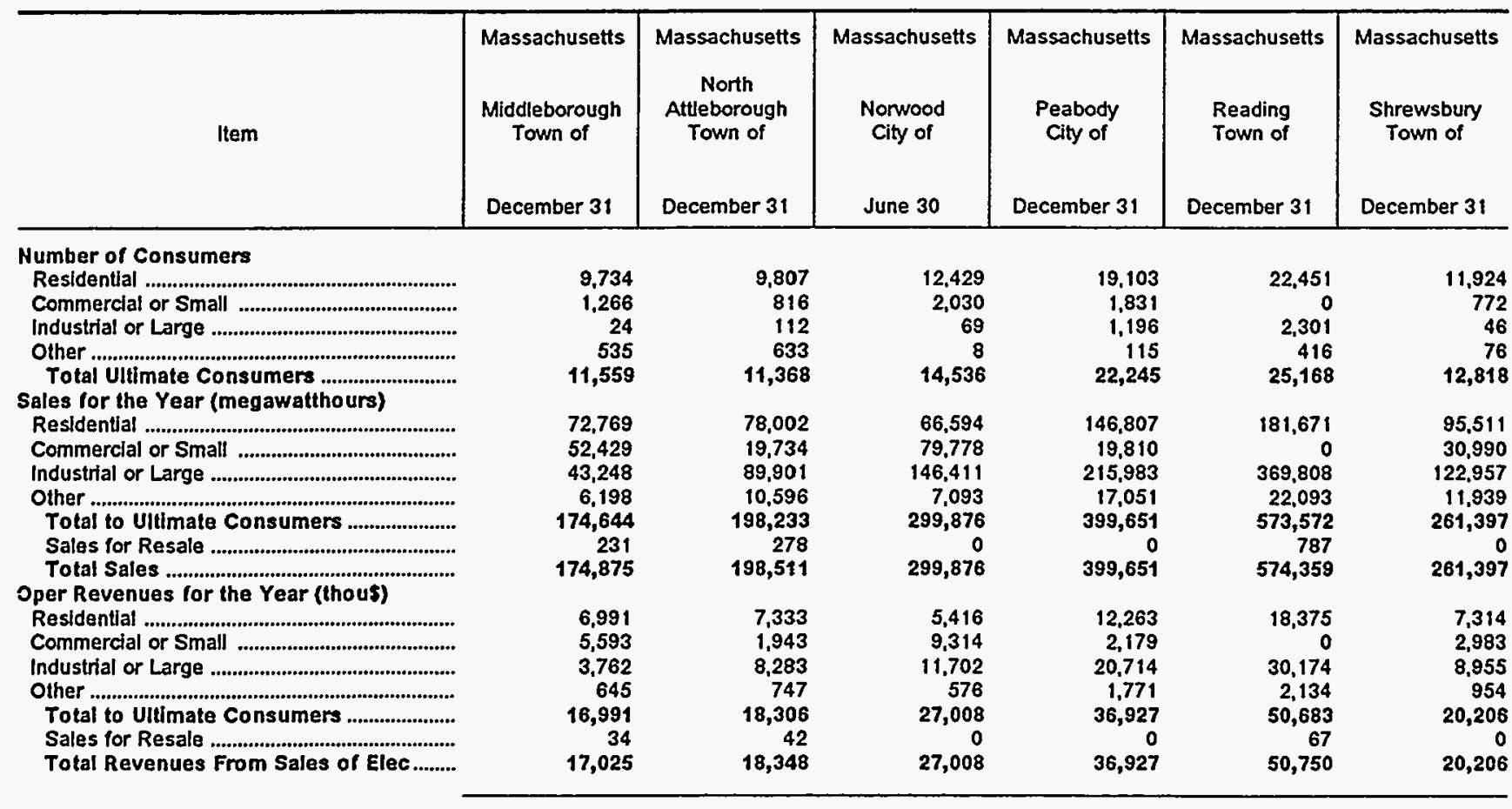

\begin{tabular}{|c|c|c|c|c|c|c|}
\hline Item & $\begin{array}{l}\text { Massachusetts } \\
\text { Taunton } \\
\text { City of } \\
\text { December } 31\end{array}$ & $\begin{array}{l}\text { Massachusetts } \\
\text { Wakefield } \\
\text { Town of } \\
\text { December } 31\end{array}$ & $\begin{array}{l}\text { Massachusetts } \\
\text { Wellesley } \\
\text { Town of } \\
\text { December } 31\end{array}$ & $\begin{array}{c}\text { Massachusetts } \\
\text { Westfield } \\
\text { City of } \\
\text { December } 31\end{array}$ & $\begin{array}{l}\text { Michigan } \\
\text { Bay } \\
\text { City City of } \\
\text { June } 30\end{array}$ & $\begin{array}{l}\text { Michigan } \\
\text { Coldwater } \\
\text { Board } \\
\text { of } \\
\text { Public Util } \\
\text { June } 30\end{array}$ \\
\hline \multicolumn{7}{|l|}{ Number of Consumers } \\
\hline Residential & 26,999 & 9,473 & 8,555 & 14,392 & 17,396 & 4.918 \\
\hline 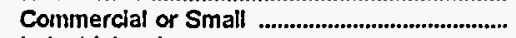 & 4,378 & 1,332 & 981 & 1,594 & 2,388 & 809 \\
\hline Industrial or Large & 74 & 169 & 0 & 135 & 55 & 165 \\
\hline $\begin{array}{l}\text { Other } \\
\text { Total Uitimate Consumers } \\
\text { Sales for the Year (megawatthours) }\end{array}$ & $\begin{array}{r}137 \\
31,588\end{array}$ & $\begin{array}{r}2 \\
10,976\end{array}$ & $\begin{array}{r}75 \\
9,611\end{array}$ & $\begin{array}{r}2 \\
16,123\end{array}$ & $\begin{array}{r}117 \\
19,956\end{array}$ & $\begin{array}{r}152 \\
6,044\end{array}$ \\
\hline 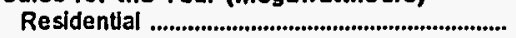 & 194,059 & 61,709 & 74,975 & 103,620 & 106,063 & 31,127 \\
\hline 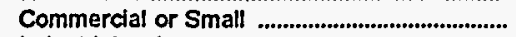 & 155,080 & 22,143 & 100,763 & 84,638 & 97,839 & 18,496 \\
\hline 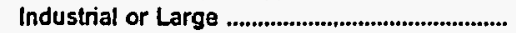 & 136,400 & 65,706 & 0 & 62,206 & 51,379 & 118,417 \\
\hline $\begin{array}{l}\text { Other } \\
\text { Total to Ultimate Consumers }\end{array}$ & $\begin{array}{r}21,782 \\
507,321\end{array}$ & $\begin{array}{r}7,310 \\
156,868\end{array}$ & $\begin{array}{r}9,020 \\
184,758\end{array}$ & $\begin{array}{r}14,544 \\
265,008\end{array}$ & $\begin{array}{r}27,167 \\
282,448\end{array}$ & $\begin{array}{r}383 \\
168,423\end{array}$ \\
\hline Sales for Resale & 41,371 & $\begin{array}{r}100,000 \\
0\end{array}$ & $\begin{array}{r}104,100 \\
0\end{array}$ & $\begin{array}{r}205,008 \\
15,351\end{array}$ & $\begin{array}{r}282,448 \\
0\end{array}$ & $\begin{array}{r}108,423 \\
0\end{array}$ \\
\hline $\begin{array}{l}\text { Total Sales ............................................... } \\
\text { Oper Revenues for the Year (thous) }\end{array}$ & 548,692 & 156,868 & 184,758 & 280,359 & 282,448 & 168,423 \\
\hline 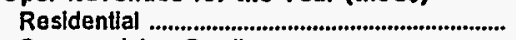 & 15,171 & 5,940 & 6,522 & 10.421 & 7.094 & 2,816 \\
\hline 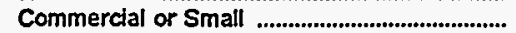 & 13,469 & 2,397 & 8,951 & 10,066 & 7,162 & 1,923 \\
\hline 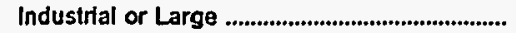 & 9,009 & 6,652 & 0 & 6,552 & 2,576 & 7,303 \\
\hline Other & 1,806 & 565 & 787 & 1,836 & 1,940 & 40 \\
\hline Total to Ultimate Consumers ........................... & 39,455 & 15,554 & 16,260 & 28,875 & 18,772 & 12,082 \\
\hline 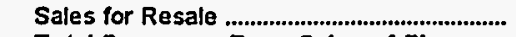 & 3,027 & & 0 & 1,254 & 0 & \\
\hline Total Revenues From Sales of Elec......... & 42,482 & 15,554 & 16,260 & 30,129 & 18,772 & 12,082 \\
\hline
\end{tabular}

Note: Tolals may not equal sum of components because of independent rounding.

Source: Energy Information Administration, Form EIA-861. "Annual Electric Utility Report." Data are submitted on a calendar year. 
Table 25. Number of Consumers, Sales, and Operating Revenue by Major U.S. Publicly Owned Electric Utility Within State, 1995 (Continued)

\begin{tabular}{|c|c|c|c|c|c|c|}
\hline Item & $\begin{array}{l}\text { Michigan } \\
\text { Detroit } \\
\text { City of } \\
\text { June } 30\end{array}$ & $\begin{array}{l}\text { Michigan } \\
\text { Grand Haven } \\
\text { City of } \\
\text { June } 30\end{array}$ & $\begin{array}{l}\text { Michigan } \\
\text { Hillsdale } \\
\text { Board } \\
\text { of } \\
\text { Public Wks } \\
\text { June } 30\end{array}$ & $\begin{array}{l}\text { Michigan } \\
\text { Holland } \\
\text { City of } \\
\text { June } 30\end{array}$ & $\begin{array}{l}\text { Michigan } \\
\text { Lansing } \\
\text { City of } \\
\text { June } 30\end{array}$ & $\begin{array}{l}\text { Michigan } \\
\text { Marquette } \\
\text { City of } \\
\text { June } 30\end{array}$ \\
\hline \multicolumn{7}{|l|}{ Number of Consumers } \\
\hline 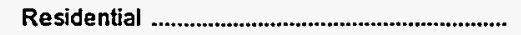 & 0 & 10,039 & 4,632 & 17,722 & 79,147 & 12,656 \\
\hline 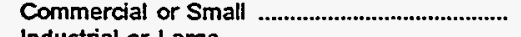 & 1,476 & $t, 108$ & 807 & 3,191 & 12,365 & 8,468 \\
\hline 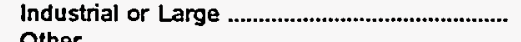 & 8 & 216 & 19 & 100 & 301 & $\begin{array}{r}0 \\
0\end{array}$ \\
\hline Other & $\begin{array}{r}0 \\
1,484\end{array}$ & $\begin{array}{r}241 \\
11,604\end{array}$ & $\begin{array}{r}9 \\
5,467\end{array}$ & $\begin{array}{r}26 \\
21,039\end{array}$ & $\begin{array}{r}2 \\
91,815\end{array}$ & $\begin{array}{r}488 \\
14,613\end{array}$ \\
\hline $\begin{array}{l}\text { Sales for the Year (megawatthours) } \\
\text { Residential }\end{array}$ & 0 & 64.997 & 30,792 & & & 94020 \\
\hline Commercial or Small & 496,050 & 25,868 & 40,414 & $\begin{array}{r}129,363 \\
86,760\end{array}$ & 517,565 & $\begin{array}{r}81,420 \\
113,992\end{array}$ \\
\hline Industrial or Large & 7,769 & 187,356 & 63,949 & 575,130 & $\begin{array}{l}994,023 \\
730,509\end{array}$ & $\begin{array}{r}113,983 \\
0\end{array}$ \\
\hline Other & 0 & 4,665 & 497 & 2,896 & 36,602 & 44,823 \\
\hline 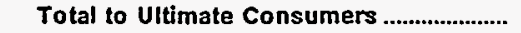 & 503,819 & 282,886 & 135,652 & 794,349 & $2,278,699$ & 240,226 \\
\hline $\begin{array}{l}\text { Sales for Resale } \\
\text { Total Sales }\end{array}$ & $\begin{array}{r}0 \\
503,819\end{array}$ & $\begin{array}{l}101,586 \\
384,472\end{array}$ & $\begin{array}{r}0 \\
135,652\end{array}$ & $\begin{array}{r}145 \\
794,494\end{array}$ & $\begin{array}{r}321,939 \\
2,600,638\end{array}$ & $\begin{array}{r}13,603 \\
253,829\end{array}$ \\
\hline \multicolumn{7}{|l|}{ Oper Revenues for the Year (thou\$) } \\
\hline Residential & 0 & 5,096 & 2,269 & 8,233 & 30,944 & 6,380 \\
\hline 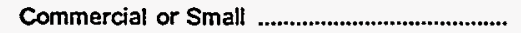 & 44,180 & 2,372 & 2,938 & 6,492 & 54,827 & 7,473 \\
\hline 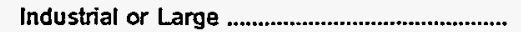 & 2,760 & 11,289 & 3,765 & 29,681 & 34,847 & o \\
\hline Other & 0 & 495 & 29 & 363 & 4,527 & 3,038 \\
\hline 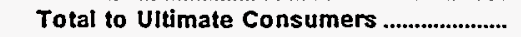 & 46,940 & 19,252 & 9,001 & 44,769 & 125,145 & 16,891 \\
\hline 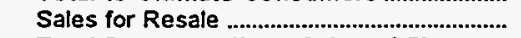 & 0 & 2,537 & & 8 & 9.336 & 751 \\
\hline Total Revenues From Sales of Elec........ & 46,940 & 21,789 & 9,001 & 44,777 & 134,481 & 17,642 \\
\hline
\end{tabular}

\begin{tabular}{|c|c|c|c|c|c|c|}
\hline Item & $\begin{array}{c}\text { Michigan } \\
\text { Michigan } \\
\text { Public } \\
\text { Power Agency } \\
\text { December } 31\end{array}$ & $\begin{array}{l}\text { Michigan } \\
\text { Michigan } \\
\text { South } \\
\text { Central } \\
\text { Pwr Agy } \\
\text { June } 30\end{array}$ & $\begin{array}{c}\text { Sturgis } \\
\text { City of } \\
\text { September } 30\end{array}$ & $\begin{array}{l}\text { Traverse } \\
\text { City City of } \\
\text { June } 30\end{array}$ & $\begin{array}{l}\text { Michigan } \\
\text { Wyandotte } \\
\text { Municipal } \\
\text { Serv Comm } \\
\text { September } 30\end{array}$ & $\begin{array}{l}\text { Michigan } \\
\text { Zeeland } \\
\text { Clty of } \\
\text { June } 30\end{array}$ \\
\hline \multicolumn{7}{|l|}{ Number of Consumers } \\
\hline 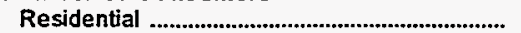 & 0 & 0 & 5,640 & 7,120 & 12,320 & 3,033 \\
\hline Commercial or Smalt & 0 & 0 & 821 & 2,047 & 1,181 & 309 \\
\hline 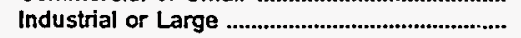 & 0 & 0 & 77 & 23 & 135 & 145 \\
\hline 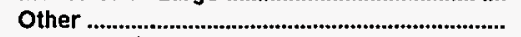 & 0 & 0 & 0 & 1 & 1 & 23 \\
\hline 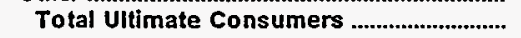 & 0 & 0 & 6,538 & 9,191 & 13,637 & 3,510 \\
\hline \multicolumn{7}{|l|}{ Sales tor the Year (megawatthours) } \\
\hline Residential & 0 & 0 & 44,822 & 38,380 & 71,678 & 21,396 \\
\hline Commercial or Sma!! & 0 & 0 & 55,187 & 108,270 & 21,432 & 17,808 \\
\hline industrial or Large & 0 & 0 & 117,002 & 73,684 & 147,561 & 160,270 \\
\hline 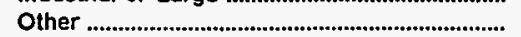 & 0 & 0 & 0 & 853 & 4,127 & 551 \\
\hline 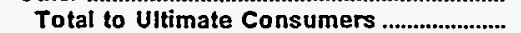 & $\mathbf{0}$ & $\mathbf{0}$ & 217,011 & 221,187 & 244,798 & 200,025 \\
\hline Sales for Resale & $2,810,959$ & 479,175 & 0 & 0 & $\begin{array}{r}0 \\
0\end{array}$ & 0 \\
\hline \multicolumn{6}{|l|}{ Oper Revenues for the Year (thous) } & 200,025 \\
\hline 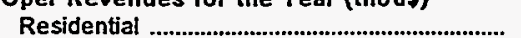 & 0 & 0 & 2,883 & 2,586 & 6,548 & 1.334 \\
\hline Commercial or Small & 0 & 0 & 4,151 & 7,760 & 2,257 & 1,254 \\
\hline 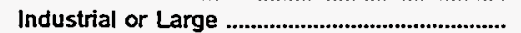 & 0 & 0 & 6.659 & 3,715 & 10,776 & 8,206 \\
\hline Other & 0 & 0 & 0 & 145 & 487 & 52 \\
\hline 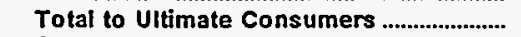 & 0 & $\mathbf{0}$ & 13,693 & 14,206 & 20,068 & 10,846 \\
\hline Sales for Resale & 100,557 & 24,685 & 0 & 0 & 0 & \\
\hline Total Revenues From Sales of Elec......... & 100,557 & 24,685 & 13,693 & 14,206 & 20,068 & 10,846 \\
\hline
\end{tabular}

Note: Totals may not equal sum of components because of independent rounding.

Source: Energy Information Administration, Form EIA-861, "Annual Electric Utitity Report" Data are submitted on a calendar year. 
Table 25. Number of Consumers, Sales, and Operating Revenue by Major U.S. Publicly Owned Electric Utility Within State, 1995 (Continued)

\begin{tabular}{|c|c|c|c|c|c|c|}
\hline Item & $\begin{array}{l}\text { Minnesota } \\
\text { Alexandria } \\
\text { City of } \\
\text { December } 31\end{array}$ & $\begin{array}{c}\text { Minnesota } \\
\text { Anoka } \\
\text { City of } \\
\text { December } 31\end{array}$ & $\begin{array}{c}\text { Minnesota } \\
\text { Austin } \\
\text { City of } \\
\text { December } 31\end{array}$ & $\begin{array}{c}\text { Minnesota } \\
\text { Brainerd } \\
\text { Public } \\
\text { Utilities } \\
\text { Decernber } 39\end{array}$ & $\begin{array}{c}\text { Minnesota } \\
\text { Chaska } \\
\text { City of } \\
\text { December } 31\end{array}$ & $\begin{array}{l}\text { Minnesota } \\
\text { Fairmont } \\
\text { Public } \\
\text { Utilities } \\
\text { Comm } \\
\text { December } 31\end{array}$ \\
\hline \multicolumn{7}{|l|}{ Number of Consumers } \\
\hline 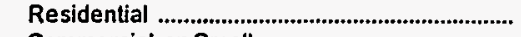 & 6,124 & 9,590 & 9,900 & 5,874 & 4,799 & 5,083 \\
\hline Commercial or Small & 1,201 & 1,073 & 1,117 & 1,157 & 280 & 767 \\
\hline Industrial or Large & 47 & 13 & 1 & 22 & 212 & 16 \\
\hline $\begin{array}{l}\text { Total Uilimate Consumers } \\
\text { Sales for the Year (megawatthours) }\end{array}$ & $\begin{array}{r}109 \\
7,481\end{array}$ & $\begin{array}{r}0 \\
10,676\end{array}$ & $\begin{array}{r}358 \\
11,376\end{array}$ & $\begin{array}{r}58 \\
7,111\end{array}$ & $\begin{array}{r}63 \\
5,354\end{array}$ & $\begin{array}{r}8 \\
5,874\end{array}$ \\
\hline 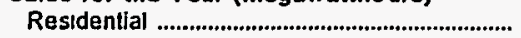 & 54,863 & 67,223 & 70.109 & 40,085 & 39,321 & 38,505 \\
\hline Commercial or Small & 48,185 & 63,575 & 103,310 & 58,431 & 3,684 & 39,278 \\
\hline 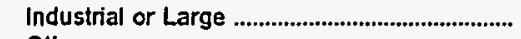 & 82,978 & 96,195 & 81,632 & 38,908 & 129,878 & 60,952 \\
\hline Other & 2,728 & 0 & 4,203 & 5,063 & 5,918 & 5,359 \\
\hline Total to Ultimate Consumers ........................ & 188,754 & 226,993 & 259,254 & 142,487 & 178,801 & 144,094 \\
\hline Sales for Resale & 0 & 0 & 81,540 & 0 & 0 & 1,664 \\
\hline $\begin{array}{l}\text { Total Sales ............................................................ } \\
\text { Oper Revenues for the Year (thous) }\end{array}$ & 188,754 & 226,993 & 340,794 & 142,487 & 178,801 & 145,758 \\
\hline 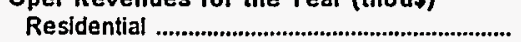 & \multicolumn{6}{|c|}{ Oper Revenues for the Year (thou\$) } \\
\hline 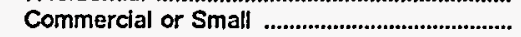 & 2,359 & 3,868 & 7,169 & $\begin{array}{l}2,249 \\
3,088\end{array}$ & $\begin{array}{r}2,603 \\
261\end{array}$ & $\begin{array}{l}2,915 \\
2,722\end{array}$ \\
\hline 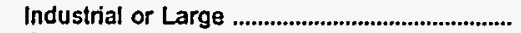 & 3,794 & 4,307 & 4,093 & 1,852 & 6.594 & 3.116 \\
\hline Other & 105 & 0 & 389 & 267 & 247 & 239 \\
\hline Total to Ultimate Consumers ........................ & 8,950 & 12,963 & 17,373 & 7,456 & 9,705 & 8,992 \\
\hline Sales for Resale & & 0 & 0 & 0 & 0 & \\
\hline Total Revenues From Sales of Elec......... & 8,950 & 12,963 & 17,373 & 7,456 & 9,705 & 8,992 \\
\hline
\end{tabular}

\begin{tabular}{|c|c|c|c|c|c|c|}
\hline Item & $\begin{array}{l}\text { Minnesota } \\
\text { Hutchinson } \\
\text { Utilities } \\
\text { Comm } \\
\text { December } 31\end{array}$ & $\begin{array}{c}\text { Minnesota } \\
\text { Marshatl } \\
\text { City of } \\
\text { December } 31\end{array}$ & $\begin{array}{c}\text { Moorhead } \\
\text { City of } \\
\text { December } 31\end{array}$ & $\begin{array}{l}\text { Minnesota } \\
\text { New Ulm } \\
\text { Public } \\
\text { Utilities } \\
\text { Comm } \\
\text { December } 31\end{array}$ & $\begin{array}{c}\text { Minnesota } \\
\text { Northern } \\
\text { Municipal } \\
\text { Power Agny } \\
\text { December } 31\end{array}$ & $\begin{array}{c}\text { Minnesota } \\
\text { Owatonna } \\
\text { City of } \\
\text { December } 31\end{array}$ \\
\hline \multicolumn{7}{|l|}{ Number of Consumers } \\
\hline 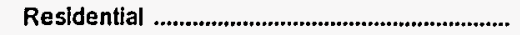 & 4,961 & 5,072 & 11,454 & 5,695 & 0 & 8.185 \\
\hline Commercial or Small & 755 & 785 & 1,538 & 852 & 0 & 703 \\
\hline Industrial or Large & 2 & 87 & 175 & $\mathbf{5}$ & 0 & 72 \\
\hline Other & 1 & 1 & 3 & 2 & 0 & 23 \\
\hline $\begin{array}{l}\text { Total Ultimate Consumers } \\
\text { Sales for the Year (megawatthours) }\end{array}$ & \multicolumn{4}{|c|}{ Sales for the Year (megawatthours) } & 0 & 8,983 \\
\hline 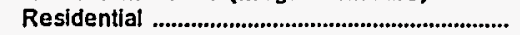 & 41,348 & 50,336 & 131,906 & 42,291 & 0 & 60,135 \\
\hline 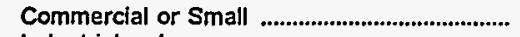 & 70,530 & 28,347 & 30.209 & 55.608 & 0 & 30.734 \\
\hline 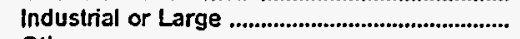 & 164,342 & 281,322 & 178,686 & 68,041 & 0 & 178,326 \\
\hline Other & 1,133 & 837 & 8,393 & 9,719 & 0 & $\begin{array}{r}3,989 \\
73,94\end{array}$ \\
\hline Total to Ultimate Consumers ...................... & 277,353 & 360,842 & 349,194 & 175,659 & 0 & 273,184 \\
\hline Sales for Resale & $\begin{array}{r}2,174 \\
270,527\end{array}$ & $\begin{array}{r}0 \\
0\end{array}$ & 0 & & 858.178 & $\begin{array}{r}0 \\
072184\end{array}$ \\
\hline \multicolumn{7}{|l|}{ Oper Revenues for the Year (thou\$) } \\
\hline 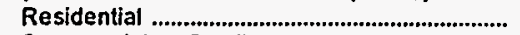 & 2,061 & 2,267 & 5,642 & 2,829 & 0 & 5,031 \\
\hline Commercial or Small & 3,365 & 1,296 & 1,551 & 2,594 & 0 & 2,220 \\
\hline Industrial or Large & 5,650 & 9,324 & 6.678 & 2,961 & $\mathbf{0}$ & 8,685 \\
\hline Other & 47 & 151 & 370 & 809 & 0 & 178 \\
\hline 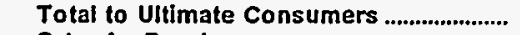 & 11,123 & 13,038 & 14,241 & 9,193 & $\mathbf{0}$ & 16,114 \\
\hline 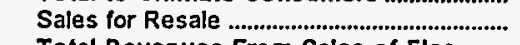 & 41 & 0 & 0 & & 38,039 & \\
\hline Total Revenues From Sales of Elec......... & 11,164 & 13,038 & 14,241 & 9,193 & 38,039 & 16,114 \\
\hline
\end{tabular}

Note: Totals may not equal sum of components because of independent rounding.

Source: Energy Information Administration. Form E!A-861, "Annual Electric Utility Report." Data are submitted on a calendar year. 
Table 25. Number of Consumers, Sales, and Operating Revenue by Major U.S. Publicly Owned Electric Utility Within State, 1995 (Continued)

\begin{tabular}{|c|c|c|c|c|c|c|}
\hline Item & $\begin{array}{c}\text { Minnesota } \\
\text { Rochester } \\
\text { Public } \\
\text { Utilities } \\
\text { December } 31\end{array}$ & $\begin{array}{l}\text { Minnesota } \\
\text { Shakopee } \\
\text { Public } \\
\text { Utilities } \\
\text { Comm } \\
\text { December } 31\end{array}$ & $\begin{array}{l}\text { Minnesota } \\
\text { Southern } \\
\text { Minnesota } \\
\text { Mun P } \\
\text { Agny } \\
\text { December 31 }\end{array}$ & $\begin{array}{c}\text { Minnesota } \\
\text { Western } \\
\text { Minnesota } \\
\text { Mun } \\
\text { Pwr Agny } \\
\text { December } 31\end{array}$ & $\begin{array}{c}\text { Minnesota } \\
\text { Willmar } \\
\text { Municipal } \\
\text { Utils Comm } \\
\text { December } 31\end{array}$ & $\begin{array}{l}\text { Minnesota } \\
\begin{array}{c}\text { Worthington } \\
\text { City of }\end{array} \\
\text { December } 31\end{array}$ \\
\hline \multicolumn{7}{|l|}{ Number of Consumers } \\
\hline 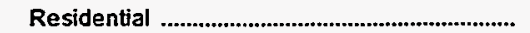 & 31,288 & 5,802 & 0 & 0 & 7,165 & 4,352 \\
\hline Commercial or Small & 3,330 & 724 & 0 & 0 & 1,054 & 671 \\
\hline 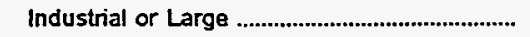 & 19 & 0 & 0 & 0 & 0 & 5 \\
\hline Other & 4 & 1 & 0 & 0 & 0 & 64 \\
\hline \multicolumn{7}{|l|}{ Sales for the Year (megawatthours) } \\
\hline 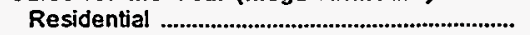 & 233,991 & 48,389 & 0 & 0 & 57.477 & 31,231 \\
\hline Commercial or Small & 319,855 & 102,220 & 0 & 0 & 162,258 & 52,788 \\
\hline 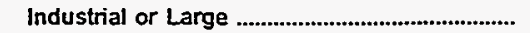 & 353,242 & 0 & 0 & 0 & 0 & 56.442 \\
\hline Other & 13,656 & 1,568 & 0 & 0 & $\mathbf{0}$ & 2,919 \\
\hline 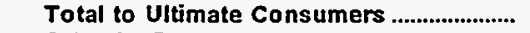 & 920,744 & 152,177 & 0 & $\mathbf{0}$ & 219,735 & 143,380 \\
\hline Sales for Resale & 187,433 & 0 & $2,476,924$ & $1,647,783$ & 0 & 3,345 \\
\hline 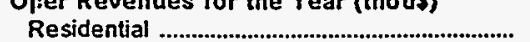 & 19.779 & & 0 & \multicolumn{3}{|c|}{ Oper Revenues for the Year (thou\$) } \\
\hline Commercial or Small & 24,395 & 5,305 & 0 & 0 & $\begin{array}{l}3,600 \\
8,913\end{array}$ & $\begin{array}{l}1,861 \\
3,133\end{array}$ \\
\hline 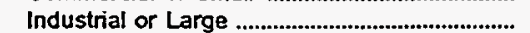 & 22,029 & 0 & 0 & 0 & 0 & 2,761 \\
\hline Other & 1,400 & 43 & 0 & 0 & 0 & 221 \\
\hline 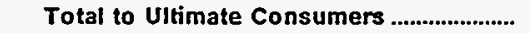 & 67,603 & 8,686 & $\mathbf{0}$ & 0 & 12,513 & 7,976 \\
\hline Sales for Resale & 7,429 & & 106,396 & 41,485 & & 142 \\
\hline Total Revenues From Sales of Elec......... & 75,032 & 8,686 & 106,396 & 41,485 & 12,513 & 8,118 \\
\hline
\end{tabular}

\begin{tabular}{|c|c|c|c|c|c|c|}
\hline Item & $\begin{array}{l}\text { Mississippi } \\
\text { Aberdeen } \\
\text { City of } \\
\text { June } 30\end{array}$ & $\begin{array}{l}\text { Mississippi } \\
\text { Clarksdale } \\
\text { City of } \\
\text { September } 30\end{array}$ & $\begin{array}{l}\text { Mississippi } \\
\text { Columbus } \\
\text { City of } \\
\text { June } 30\end{array}$ & $\begin{array}{l}\text { Mississippi } \\
\text { Greenwood } \\
\text { Utilities } \\
\text { Comm } \\
\text { September } 30\end{array}$ & $\begin{array}{l}\text { Mississippi } \\
\text { Holly } \\
\text { Springs. } \\
\text { City of } \\
\text { June } 30\end{array}$ & $\begin{array}{l}\text { Mississippi } \\
\text { Louisville } \\
\text { Electric } \\
\text { System } \\
\text { June } 30\end{array}$ \\
\hline \multicolumn{7}{|l|}{ Number of Consumers } \\
\hline 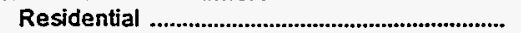 & 2,941 & 6,231 & 9,194 & 8,630 & 8,017 & 2,781 \\
\hline Commercial or Small & 561 & 1,570 & 2,094 & 1,363 & 1,579 & 698 \\
\hline industrial or Large & 77 & 21 & 313 & 4 & 104 & 80 \\
\hline Other & 24 & 84 & 20 & 144 & 16 & 22 \\
\hline $\begin{array}{l}\text { Total Ultimate Consumers ........................... } \\
\text { Sales for the Year (megawatthours) }\end{array}$ & 3,603 & 7,906 & 11,621 & 10,141 & 9,716 & 3,581 \\
\hline Residential & 36,818 & 75.878 & 113,990 & 98,804 & 108,064 & 30,378 \\
\hline $\begin{array}{l}\text { Commercial or Small } \\
\text { Industrial } \propto \text { L Large }\end{array}$ & $\begin{array}{r}9,419 \\
123,303\end{array}$ & $\begin{array}{l}62,337 \\
33,653\end{array}$ & $\begin{array}{r}41,636 \\
293,426\end{array}$ & $\begin{array}{r}123,452 \\
49,430\end{array}$ & $\begin{array}{l}19,240 \\
69,264\end{array}$ & $\begin{array}{r}10,813 \\
115,386\end{array}$ \\
\hline $\begin{array}{l}\text { Other } \\
\text { Total to Ultimate Consumers }\end{array}$ & $\begin{array}{r}2,955 \\
172,495\end{array}$ & $\begin{array}{r}7,888 \\
179,756\end{array}$ & $\begin{array}{r}4,755 \\
453,807\end{array}$ & $\begin{array}{r}11,860 \\
283,546\end{array}$ & $\begin{array}{r}5,087 \\
201,655\end{array}$ & $\begin{array}{r}2,259 \\
158,836\end{array}$ \\
\hline Sales for Resale & 0 & 54,666 & 0 & 0 & 0 & 0 \\
\hline \multicolumn{7}{|l|}{ Oper Revenues for the Year (thous) } \\
\hline 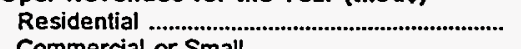 & 2,102 & 4,667 & 6,223 & 5,313 & 6,487 & $\begin{array}{r}1.844 \\
737\end{array}$ \\
\hline $\begin{array}{l}\text { Commercial or Small } \\
\text { Industrial or Large }\end{array}$ & $\begin{array}{r}599 \\
5,417\end{array}$ & $\begin{array}{l}3,719 \\
1,597\end{array}$ & $\begin{array}{r}2,553 \\
13,523\end{array}$ & $\begin{array}{l}6,995 \\
2,321\end{array}$ & $\begin{array}{l}1,364 \\
3,928\end{array}$ & $\begin{array}{r}737 \\
5,788\end{array}$ \\
\hline Other & 228 & 511 & 414 & 815 & 464 & 184 \\
\hline 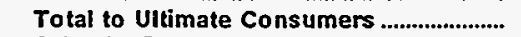 & 8,346 & 10,494 & 22,713 & 15,444 & 12,243 & 8,553 \\
\hline Sales for Resale ................................................ & $\begin{array}{r}0 \\
8,346\end{array}$ & $\begin{array}{r}1,937 \\
12,431\end{array}$ & $\begin{array}{r}0 \\
22,713\end{array}$ & $\begin{array}{r}0 \\
15,444\end{array}$ & $\begin{array}{r}0 \\
12,243\end{array}$ & $\begin{array}{r}0 \\
8,553\end{array}$ \\
\hline
\end{tabular}

Source: Energy Information Administration, Form EIA-861, "Annual Electric Utility Report." Data are submitted on a calendar year. 
Table 25. Number of Consumers, Sales, and Operating Revenue by Major U.S. Publicly Owned Electric Utility Within State, 1995 (Continued)

\begin{tabular}{|c|c|c|c|c|c|c|}
\hline Item & $\begin{array}{l}\text { Mississippi } \\
\text { Municipal } \\
\text { Energy } \\
\text { Agency } \\
\text { of MS } \\
\text { September } 30\end{array}$ & $\begin{array}{l}\text { Mississippi } \\
\text { New Albany } \\
\text { City of } \\
\text { June } 30\end{array}$ & $\begin{array}{l}\text { Mississippi } \\
\text { Oxford } \\
\text { City of } \\
\text { June } 30\end{array}$ & $\begin{array}{l}\text { Mississippi } \\
\text { Starkville } \\
\text { City of } \\
\text { June } 30\end{array}$ & $\begin{array}{l}\text { Mississippi } \\
\text { Tupelo } \\
\text { City of } \\
\text { June } 30\end{array}$ & $\begin{array}{l}\text { Mississippi } \\
\text { West } \\
\text { Point } \\
\text { City of } \\
\text { June } 30\end{array}$ \\
\hline \multicolumn{7}{|l|}{ Number of Consumers } \\
\hline 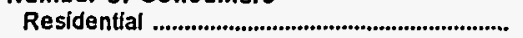 & 0 & 7.492 & 4,974 & 8,021 & 11,048 & 3,404 \\
\hline 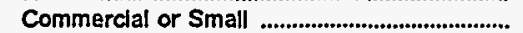 & $\mathbf{0}$ & 1,522 & 807 & 1,075 & 3,231 & 557 \\
\hline 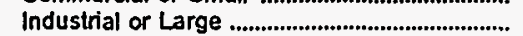 & 0 & 131 & 129 & 171 & 493 & 89 \\
\hline Other & $\mathbf{0}$ & 28 & 24 & 47 & 13 & 8 \\
\hline $\begin{array}{l}\text { Total Uitimate Consumers } \\
\text { Sales for the Year (merawatthours) }\end{array}$ & 0 & 9,173 & 5,934 & 9,314 & 14,785 & 4,058 \\
\hline 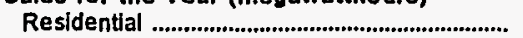 & 0 & 96,768 & 59,574 & 87,062 & 148,072 & 34,895 \\
\hline & 0 & 19,996 & 21,160 & 20,069 & 68,437 & 9,902 \\
\hline $\begin{array}{l}\text { Industrial or Large } \\
\text { Other }\end{array}$ & $\begin{array}{l}0 \\
0\end{array}$ & $\begin{array}{r}104,535 \\
4,073\end{array}$ & $\begin{array}{r}68,049 \\
3,137\end{array}$ & $\begin{array}{r}215,485 \\
3,045\end{array}$ & $\begin{array}{r}409,963 \\
10,276\end{array}$ & $\begin{array}{r}137,211 \\
3,391\end{array}$ \\
\hline Total to Ultimate Consumers ......................... & o & 225,372 & 151,920 & 325,661 & 636,748 & 185,399 \\
\hline 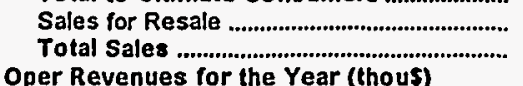 & $\begin{array}{l}863,897 \\
863,897\end{array}$ & $\begin{array}{r}0 \\
225,372\end{array}$ & $\begin{array}{r}0 \\
151,920\end{array}$ & $\begin{array}{r}0 \\
325,661\end{array}$ & $\begin{array}{r}0 \\
636,748\end{array}$ & $\begin{array}{r}0 \\
185,399\end{array}$ \\
\hline $\begin{array}{l}\text { Oper Revenues for the Year (thous) } \\
\text { Residential }\end{array}$ & 0 & 5,778 & 3.397 & 5.370 & \multicolumn{2}{|c|}{ Oper Revenues for the Year (thou\$) } \\
\hline Commercial or Small & 0 & 1,381 & 1,299 & 1,349 & $\begin{array}{l}8,083 \\
4,263\end{array}$ & $\begin{array}{r}2.159 \\
732\end{array}$ \\
\hline Industrial or Large & 0 & 5.919 & 3,489 & 10,683 & 20,249 & 6,749 \\
\hline Other & 0 & 295 & 261 & 245 & 712 & 249 \\
\hline Total to Uitimate Consumers ..................... & $\mathbf{0}$ & 13,373 & 8,446 & 17,647 & 33,307 & 9,889 \\
\hline Sales for Resale & 29,408 & 0 & 0 & 0 & 0 & \\
\hline Total Revenues From Sales of Elec......... & 29,408 & 13,373 & 8,446 & 17,647 & 33,307 & 9,889 \\
\hline
\end{tabular}

\begin{tabular}{|c|c|c|c|c|c|c|}
\hline ifem & $\begin{array}{l}\text { Missour } \\
\text { Carthage } \\
\text { City of } \\
\text { June } 30\end{array}$ & $\begin{array}{l}\text { Missour } \\
\text { Columbia } \\
\text { City of } \\
\text { September } 30\end{array}$ & $\begin{array}{l}\text { Missouri } \\
\text { Hannibal } \\
\text { City of } \\
\text { June } 30\end{array}$ & $\begin{array}{c}\text { Missouri } \\
\text { Independence } \\
\text { City of } \\
\text { June } 30\end{array}$ & $\begin{array}{l}\text { Missouri } \\
\text { Kennett } \\
\text { City of } \\
\text { June } 30\end{array}$ & $\begin{array}{l}\text { Missouri } \\
\text { Kirkwood } \\
\text { City of } \\
\text { March } 31\end{array}$ \\
\hline \multicolumn{7}{|l|}{ Number of Consumers } \\
\hline 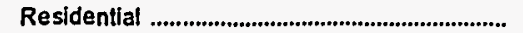 & 5,580 & 26,798 & 7,252 & 45,599 & 4,769 & 8,303 \\
\hline Commercial or Small & 926 & 4,308 & 1,002 & 4,454 & 886 & 965 \\
\hline 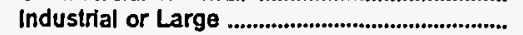 & 20 & 14 & 117 & 10 & 130 & 47 \\
\hline $\begin{array}{l}\text { Other } \\
\text { Total Ultimate Consumers } \\
\text { Sales for the Year (megawatthours) }\end{array}$ & 6,528 & 31,121 & $\begin{array}{r}19 \\
8,390\end{array}$ & $\begin{array}{r}54 \\
50,117\end{array}$ & $\begin{array}{r}0 \\
5,785\end{array}$ & $\begin{array}{r}181 \\
9,496\end{array}$ \\
\hline 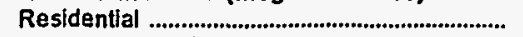 & 47,114 & 265,903 & 63,451 & 404,797 & 59,765 & 82,329 \\
\hline $\begin{array}{l}\text { Commercial or Small } \\
\text { Industrial or Large }\end{array}$ & $\begin{array}{l}41,020 \\
96,821\end{array}$ & $\begin{array}{l}359,560 \\
172,265\end{array}$ & $\begin{array}{l}22,352 \\
99,007\end{array}$ & $\begin{array}{r}383,133 \\
47,862\end{array}$ & $\begin{array}{l}14,913 \\
69,553\end{array}$ & $\begin{array}{l}30,422 \\
65,893\end{array}$ \\
\hline $\begin{array}{l}\text { Other } \\
\text { Total to Ultimate Consumers }\end{array}$ & $\begin{array}{r}10,046 \\
195.001\end{array}$ & $\begin{array}{r}6,113 \\
803,841\end{array}$ & $\begin{array}{r}7.460 \\
192.270\end{array}$ & 9.048 & 0 & 322 \\
\hline 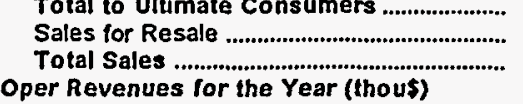 & $\begin{array}{r}195,001 \\
0 \\
195,001\end{array}$ & $\begin{array}{r}803,841 \\
985 \\
804,826\end{array}$ & $\begin{array}{r}192,270 \\
0 \\
192,270\end{array}$ & $\begin{array}{r}844,840 \\
16,769 \\
861,609\end{array}$ & $\begin{array}{r}144,231 \\
0 \\
144,231\end{array}$ & $\begin{array}{r}178,966 \\
0 \\
178,966\end{array}$ \\
\hline 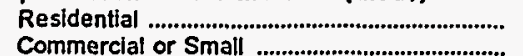 & $\begin{array}{l}2,954 \\
2,275\end{array}$ & $\begin{array}{l}18,493 \\
22,665\end{array}$ & $\begin{array}{l}3,991 \\
1,378\end{array}$ & $\begin{array}{l}30,175 \\
23,543\end{array}$ & $\begin{array}{r}2.107 \\
652\end{array}$ & $\begin{array}{l}6,474 \\
2,223\end{array}$ \\
\hline Industrial or Large & 4,048 & 8,930 & 5,085 & 2,045 & 2,008 & 3,419 \\
\hline Other & 368 & 554 & 276 & 648 & 0 & 61 \\
\hline Total to Ultimate Consumers ...................... & 9,645 & 50,642 & 10,730 & 56,411 & 4,767 & 12,177 \\
\hline $\begin{array}{l}\text { Sales for Resale ................................................ } \\
\text { Total Revenues From Sales of Elec ........ }\end{array}$ & $\begin{array}{r}0 \\
9,645\end{array}$ & $\begin{array}{r}27 \\
50,669\end{array}$ & $\begin{array}{r}0 \\
10,730\end{array}$ & $\begin{array}{r}1,413 \\
57,824\end{array}$ & $\begin{array}{r}0 \\
4,767\end{array}$ & $\begin{array}{r}0 \\
12,177\end{array}$ \\
\hline
\end{tabular}

Note: Totals may not equal sum of components because of independent rounding.

Source: Energy Information Administration, Form EIA-861. "Annual Electric Utility Report" Data are submitted on a calendar year. 
Table 25. Number of Consumers, Sales, and Operating Revenue by Major U.S. Publicly Owned Electric Utility Within State, 1995 (Continued)

\begin{tabular}{|c|c|c|c|c|c|c|}
\hline Item & $\begin{array}{l}\text { Missouri } \\
\text { Lebanon } \\
\text { City of } \\
\text { October } 31\end{array}$ & $\begin{array}{l}\text { Missouri } \\
\text { Marshall } \\
\text { City of } \\
\text { September } 30\end{array}$ & $\begin{array}{l}\text { Missoun } \\
\text { Monett } \\
\text { City of } \\
\text { March } 31\end{array}$ & $\begin{array}{l}\text { Missouri } \\
\text { Poplar } \\
\text { Bluff } \\
\text { City of } \\
\text { December } 31\end{array}$ & $\begin{array}{l}\text { Missouri } \\
\text { Rolla } \\
\text { City of } \\
\text { September } 30\end{array}$ & $\begin{array}{l}\text { Missouri } \\
\text { Sikeston } \\
\text { City of } \\
\text { May } 31\end{array}$ \\
\hline \multicolumn{7}{|l|}{ Number of Consumers } \\
\hline 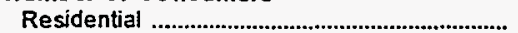 & 3,862 & 4,802 & 3,061 & 7,544 & 5,670 & 7,142 \\
\hline Commercial or Small & 967 & 852 & 579 & 1,415 & 1,200 & 1,516 \\
\hline Industrial or Large & 48 & 4 & 17 & 19 & 129 & 18 \\
\hline Other & 0 & 1 & 2 & 1 & 0 & 0 \\
\hline Total Ultimate Consumers & 4,877 & 5,659 & 3,659 & 8,979 & 6,999 & 8,676 \\
\hline \multicolumn{7}{|l|}{ Sales for the Year (megawatthours) } \\
\hline 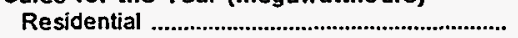 & 46,393 & 41.718 & 28,456 & 100,103 & 70,950 & 94,773 \\
\hline 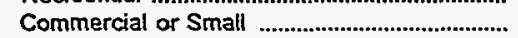 & 36,250 & 65,605 & 29,332 & 114,121 & 32,347 & 98,084 \\
\hline 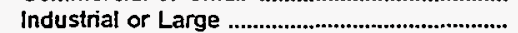 & 65,246 & 50,166 & 98,379 & 53,002 & 114,931 & 53,776 \\
\hline Other & 0 & 1,519 & 3,879 & 303 & 0 & 1,208 \\
\hline 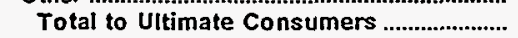 & 147,889 & 159,008 & 160,046 & 267,529 & 218,228 & 247,841 \\
\hline Sales for Resale & 0 & 0 & 0 & 0 & 0 & $1,331,619$ \\
\hline Total Sales & 147,889 & 159,008 & 160,046 & 267,529 & 218,228 & $1,579,460$ \\
\hline \multicolumn{7}{|l|}{ Oper Revenues for the Year (thou\$) } \\
\hline 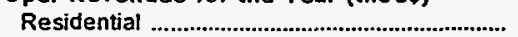 & 2,888 & 3,077 & 1,666 & 4,191 & 3,893 & 4,767 \\
\hline Commercial or Small & 2,489 & 4,257 & 1,529 & 5,140 & 1.722 & 4,859 \\
\hline Industrial or Large & 4,338 & 2,710 & 5,197 & 1,936 & 5,966 & 2,012 \\
\hline Other & 0 & 111 & 165 & 12 & 0 & 101 \\
\hline Total to Ultimate Consumers ....................... & 9,715 & 10,155 & 8,557 & 11,279 & 11,581 & 11,739 \\
\hline Sales for Resale & & & & 0 & 0 & 41,126 \\
\hline Total Revenues From Sales of Elec ......... & 9,715 & 10,155 & 8,557 & 11,279 & 11,581 & 52,865 \\
\hline
\end{tabular}

\begin{tabular}{|c|c|c|c|c|c|c|}
\hline item & $\begin{array}{l}\text { Missouri } \\
\text { Springfield } \\
\text { City of } \\
\text { September } 30\end{array}$ & $\begin{array}{c}\text { Missouri } \\
\text { West } \\
\text { Plains } \\
\text { City of } \\
\text { December } 31\end{array}$ & $\begin{array}{l}\text { Beatrice } \\
\text { City of } \\
\text { July } 31\end{array}$ & $\begin{array}{c}\text { Nebraska } \\
\text { Central } \\
\text { Nebraska } \\
\text { Pub } \\
\text { P\&l Dist } \\
\text { December } 31\end{array}$ & $\begin{array}{c}\text { Nebraska } \\
\text { Cornhusker } \\
\text { Public } \\
\text { Power Dist } \\
\text { December } 31\end{array}$ & $\begin{array}{c}\text { Nebraska } \\
\text { Dawson } \\
\text { County } \\
\text { Public } \\
\text { Pwr Dist } \\
\text { December } 31\end{array}$ \\
\hline \multicolumn{7}{|l|}{ Number of Consumers } \\
\hline 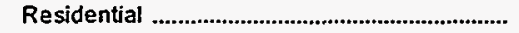 & 71,975 & 5,069 & 5,625 & 0 & 5,140 & $\$ 1,442$ \\
\hline $\begin{array}{l}\text { Commercial or Small } \\
\text { Industrial or Large }\end{array}$ & $\begin{array}{r}11,305 \\
164\end{array}$ & $\begin{array}{l}643 \\
824\end{array}$ & $\begin{array}{l}775 \\
130\end{array}$ & $\begin{array}{l}0 \\
0\end{array}$ & $\begin{array}{r}220 \\
7\end{array}$ & $\begin{array}{r}750 \\
3\end{array}$ \\
\hline $\begin{array}{l}\text { Other } \\
\text { Total Uitimate Consumers ....................................... } \\
\text { Sales for the Year (megawatthours) }\end{array}$ & $\begin{array}{r}0 \\
83,444\end{array}$ & $\begin{array}{r}0 \\
6,536\end{array}$ & $\begin{array}{r}357 \\
6,887\end{array}$ & $\begin{array}{l}0 \\
0\end{array}$ & $\begin{array}{l}2,469 \\
7,836\end{array}$ & $\begin{array}{r}4,143 \\
16,338\end{array}$ \\
\hline Residential & 718,220 & 62,729 & 52,101 & 0 & 112,260 & 153,910 \\
\hline $\begin{array}{l}\text { Commercial or Small } \\
\text { Industrial or Large }\end{array}$ & $\begin{array}{r}1,142,557 \\
406,754\end{array}$ & $\begin{array}{l}16,890 \\
60,390\end{array}$ & $\begin{array}{l}16,582 \\
62,458\end{array}$ & $\begin{array}{l}0 \\
0\end{array}$ & $\begin{array}{l}22,615 \\
43,883\end{array}$ & $\begin{array}{r}36,504 \\
8,759\end{array}$ \\
\hline Other & 0 & 0 & 616 & 0 & 31,391 & 68,592 \\
\hline 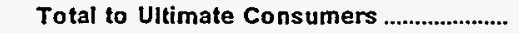 & $2,267,531$ & 140,009 & 131,757 & $\mathbf{0}$ & 210,149 & 267,765 \\
\hline $\begin{array}{l}\text { Sales for Resale } \\
\text { Total Sales }\end{array}$ & $\begin{array}{r}190,712 \\
2,458,243\end{array}$ & $\begin{array}{r}0 \\
140,009\end{array}$ & $\begin{array}{r}0 \\
131,757\end{array}$ & $\begin{array}{l}378,922 \\
378,922\end{array}$ & $\begin{array}{r}2,601 \\
212,750\end{array}$ & $\begin{array}{r}5,511 \\
273,276\end{array}$ \\
\hline \multicolumn{7}{|l|}{ Oper Revenues for the Year (thous) } \\
\hline Residential & 39,613 & 2,955 & 3,188 & 0 & 6,460 & 8,808 \\
\hline 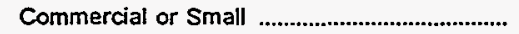 & 52,067 & 1,345 & 982 & 0 & 1,190 & 2,131 \\
\hline Industrial or Large & 15,021 & 4,667 & 2,939 & 0 & 1,743 & 381 \\
\hline Other & 0 & 0 & 45 & 0 & 2,344 & 5,918 \\
\hline 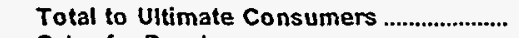 & 106,701 & 8,967 & 7,154 & 0 & 11,737 & 17,238 \\
\hline 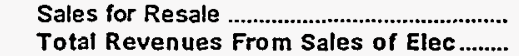 & $\begin{array}{r}5,217 \\
111,918\end{array}$ & $\begin{array}{r}0 \\
8,967\end{array}$ & $\begin{array}{r}0 \\
7,154\end{array}$ & $\begin{array}{l}9,607 \\
9,607\end{array}$ & $\begin{array}{r}37 \\
11,774\end{array}$ & $\begin{array}{r}237 \\
17,475\end{array}$ \\
\hline
\end{tabular}

Note: Totals may not equal sum of components because of independent rounding.

Source: Energy Information Administration, Form ElA-861, "Annual Electric Utility Report" Data are submitted on a calendar year. 
Table 25. Number of Consumers, Sales, and Operating Revenue by Major U.S. Publicly Owned Electric Utility Within State, 1995 (Continued)

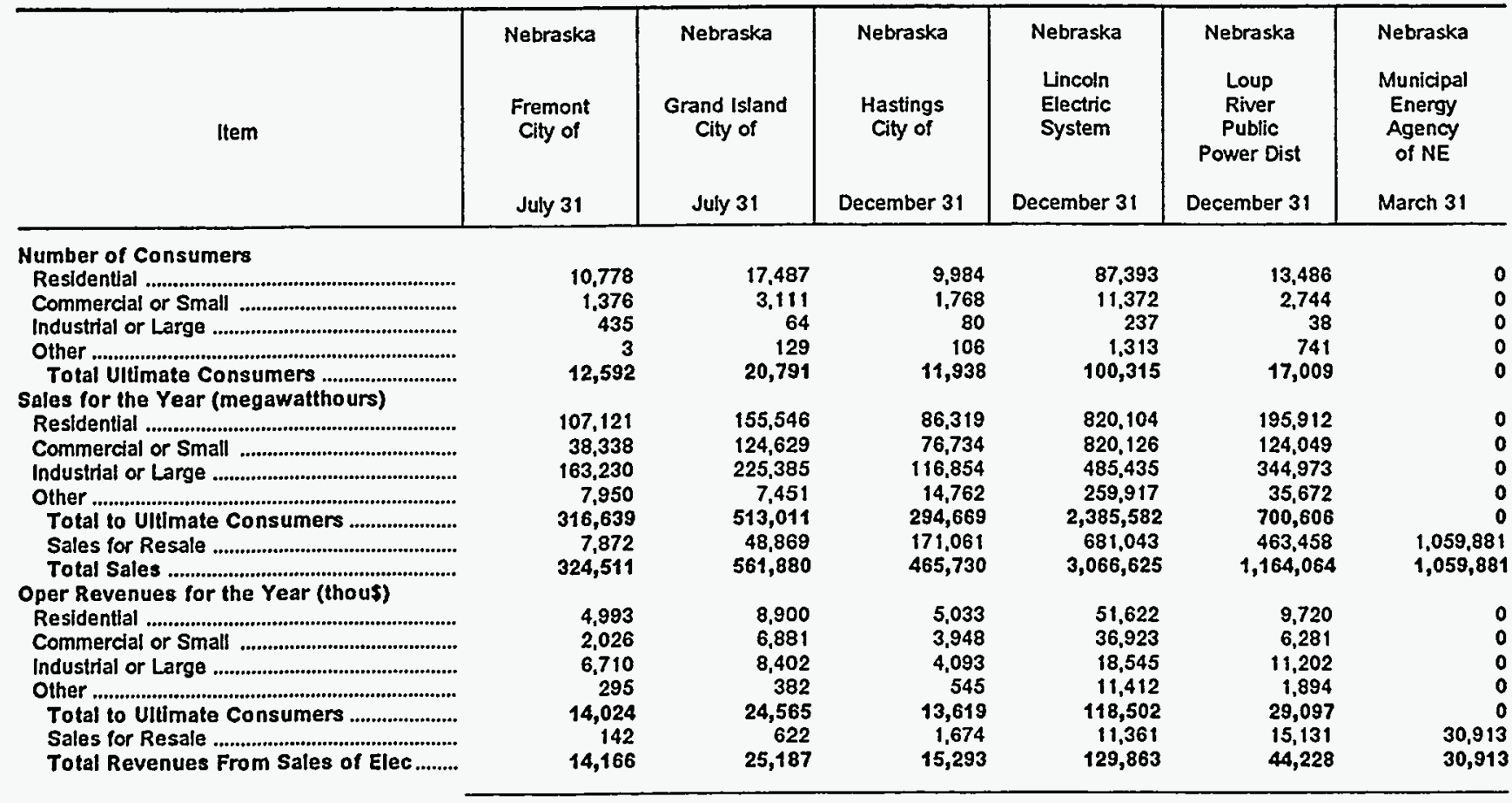

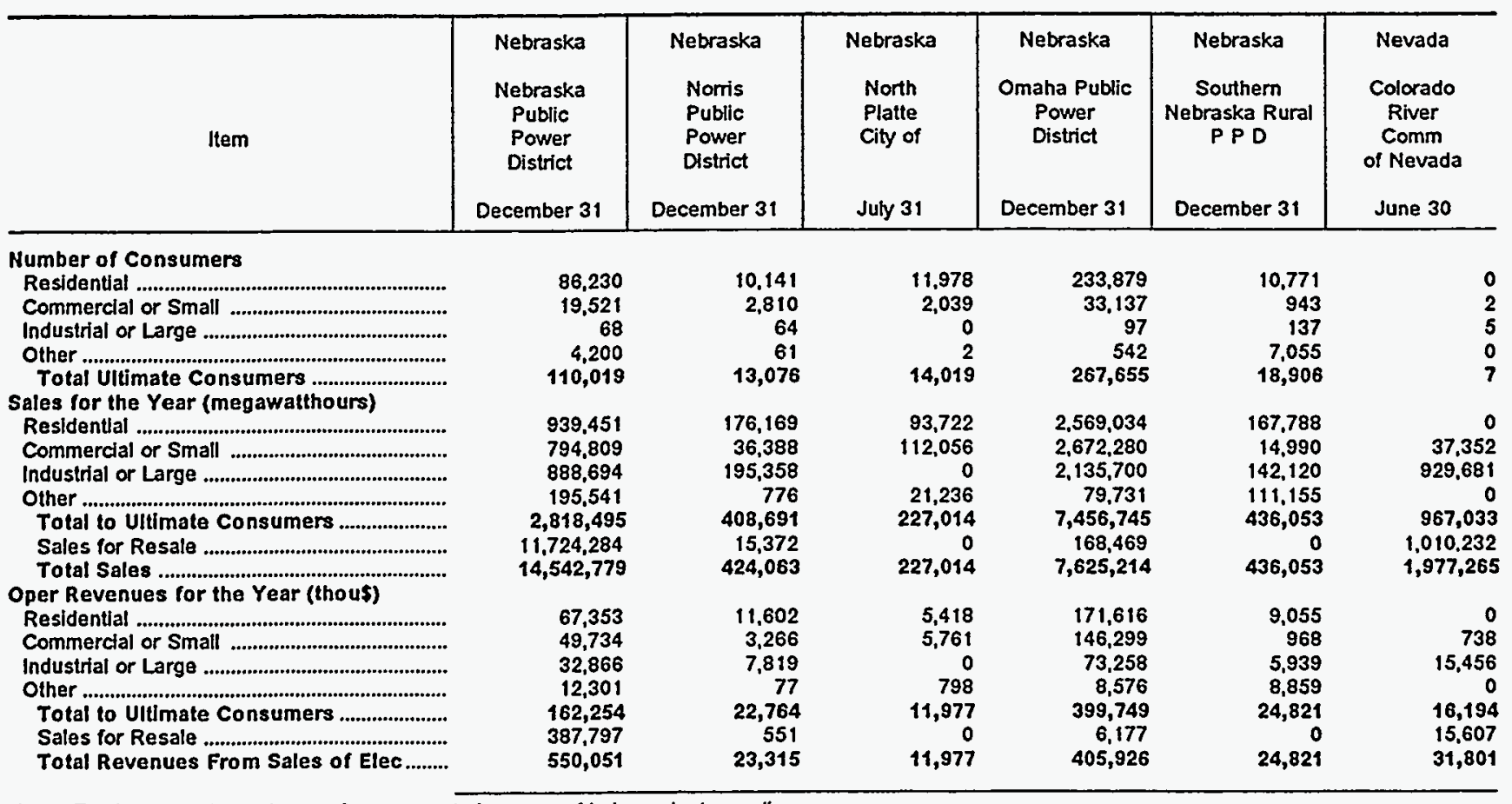

Nole: Totals may not equal sum of components because of independent rounding.

Source: Energy Information Administration, Form EIA-861, "Annual Electric Utility Report." Data are submitted on a calendar year. 
Table 25. Number of Consumers, Sales, and Operating Revenue by Major U.S. Publicly Owned Electric Utility Within State, 1995 (Continued)

\begin{tabular}{|c|c|c|c|c|c|c|}
\hline Item & $\begin{array}{c}\text { Nevada } \\
\text { Overton } \\
\text { Power } \\
\text { District } \\
\text { No } 5 \\
\text { December } 31\end{array}$ & $\begin{array}{c}\text { New Jersey } \\
\text { Madison } \\
\text { Borough } \\
\text { December } 31\end{array}$ & $\begin{array}{l}\text { New Jersey } \\
\text { Vineland } \\
\text { City of } \\
\text { June } 30\end{array}$ & $\begin{array}{l}\text { New Mexico } \\
\text { Farmington } \\
\text { City of } \\
\text { June } 30\end{array}$ & $\begin{array}{l}\text { New Mexico } \\
\text { Gallup } \\
\text { City of } \\
\text { June } 30\end{array}$ & $\begin{array}{l}\text { New Mexico } \\
\text { Los Alamos } \\
\text { County } \\
\text { June } 30\end{array}$ \\
\hline \multicolumn{7}{|l|}{ Number of Consumers } \\
\hline Residential & 4,537 & 5,502 & 15,156 & 25,124 & 7,581 & 7,348 \\
\hline 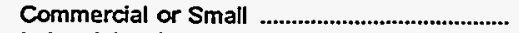 & 722 & 727 & 2,375 & 5,470 & 1,557 & 618 \\
\hline Industrial or Large & 0 & 0 & 77 & 3 & 0 & 0 \\
\hline 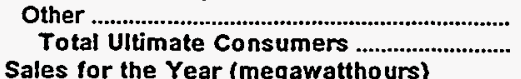 & $\begin{array}{r}173 \\
5,432\end{array}$ & $\begin{array}{r}1 \\
6,230\end{array}$ & $\begin{array}{r}3 \\
17,611\end{array}$ & $\begin{array}{r}2,045 \\
32,642\end{array}$ & $\begin{array}{r}161 \\
9,299\end{array}$ & $\begin{array}{r}4 \\
7,970\end{array}$ \\
\hline 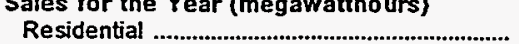 & 72,432 & 41,281 & 120,699 & 161.706 & 40765 & 45865 \\
\hline Commercial or Small & 120,824 & 89,180 & 93,149 & 271,978 & $\begin{array}{r}40,160 \\
110,805\end{array}$ & $\begin{array}{l}95,865 \\
32,850\end{array}$ \\
\hline 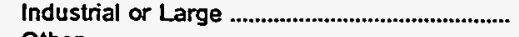 & 0 & $\mathbf{0}$ & 202,676 & 144,282 & 0 & 0 \\
\hline Other Total to Ultimate Consumers .................. & $\begin{array}{r}3,317 \\
196,573\end{array}$ & $\begin{array}{r}1,065 \\
131,526\end{array}$ & $\begin{array}{r}2,240 \\
418,764\end{array}$ & $\begin{array}{r}8,074 \\
586,040\end{array}$ & $\begin{array}{r}22,624 \\
174,194\end{array}$ & $\begin{array}{l}384,493 \\
463,208\end{array}$ \\
\hline $\begin{array}{l}\text { Sales for Resale } \\
\text { Total Sales .......................................................................... } \\
\text { Oper Revenues for the Year (thou }\end{array}$ & $\begin{array}{r}11,923 \\
208,496\end{array}$ & $\begin{array}{r}0 \\
131,526\end{array}$ & 418,764 & $\begin{array}{r}20,656 \\
606,696\end{array}$ & $\begin{array}{r}0 \\
174,194\end{array}$ & $\begin{array}{r}14,017 \\
477,225\end{array}$ \\
\hline 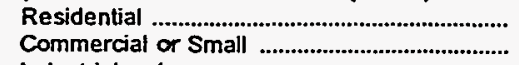 & $\begin{array}{l}3,010 \\
6,083\end{array}$ & $\begin{array}{l}3,853 \\
7,401\end{array}$ & $\begin{array}{r}12,588 \\
9,677\end{array}$ & $\begin{array}{l}13,354 \\
21,348\end{array}$ & $\begin{array}{l}3,237 \\
8,671\end{array}$ & $\begin{array}{l}4,533 \\
3,153\end{array}$ \\
\hline 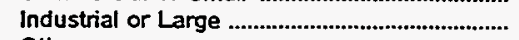 & 0 & 0 & 15,809 & 7,056 & 0 & 0 \\
\hline Other & 192 & 132 & 406 & 1,407 & 1,652 & 19,914 \\
\hline Total to Ultimate Consumers ...................... & $\begin{array}{r}9,285 \\
385 \\
9,670\end{array}$ & $\begin{array}{r}11,386 \\
0\end{array}$ & $\begin{array}{r}38,480 \\
0\end{array}$ & $\begin{array}{r}43,165 \\
1,056\end{array}$ & $\begin{array}{r}13,560 \\
0\end{array}$ & $\begin{array}{r}27,600 \\
221\end{array}$ \\
\hline Total Revenues From Sales of Elec......... & 9,670 & 11,386 & 38,480 & 44,221 & 13,560 & 27,821 \\
\hline
\end{tabular}

\begin{tabular}{|c|c|c|c|c|c|c|}
\hline Item & $\begin{array}{c}\text { New York } \\
\text { Fairport } \\
\text { Village of } \\
\text { May } 31\end{array}$ & $\begin{array}{c}\text { New York } \\
\text { Freeport } \\
\text { Village of } \\
\text { inc } \\
\text { February } 28\end{array}$ & $\begin{array}{c}\text { New York } \\
\text { Jamestown } \\
\text { City of } \\
\text { December } 31\end{array}$ & $\begin{array}{c}\text { New York } \\
\text { Lake Placid } \\
\text { Village Inc } \\
\text { July } 31\end{array}$ & $\begin{array}{c}\text { Massena } \\
\text { Town of } \\
\text { December } 31\end{array}$ & $\begin{array}{c}\text { New York } \\
\text { Plattsburgh } \\
\text { City of }\end{array}$ \\
\hline \multicolumn{7}{|l|}{ Number of Consumers } \\
\hline 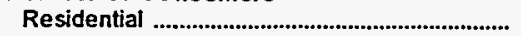 & 13,357 & 13,033 & 17,007 & 3,650 & 7.920 & 7,559 \\
\hline 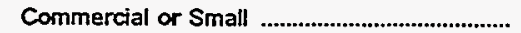 & 1,196 & 1,767 & 2,541 & 754 & 803 & 1,293 \\
\hline Industrial or Large & 7 & 0 & 124 & 0 & 170 & 6 \\
\hline Other & 51 & 124 & 214 & 208 & 257 & 202 \\
\hline $\begin{array}{l}\text { Total Ultimate Consumers } \\
\text { Sales for the Year............................ }\end{array}$ & 14,621 & 14,924 & 19,886 & 4,612 & 9,150 & 8,060 \\
\hline 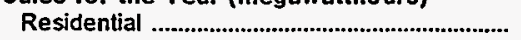 & 200,021 & 104,961 & 138,543 & 55,692 & 79,074 & 148,959 \\
\hline Commercial or Small & 104,062 & 128,339 & 135.991 & 46,251 & 12,708 & 122,653 \\
\hline Industrial or Large & 34,191 & 0 & 170,934 & 0 & 60,010 & 232,763 \\
\hline 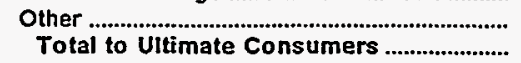 & $\begin{array}{r}2,830 \\
341,104\end{array}$ & $\begin{array}{r}15,238 \\
248,538\end{array}$ & $\begin{array}{r}34,798 \\
480,266\end{array}$ & $\begin{array}{r}24,891 \\
126,834\end{array}$ & $\begin{array}{r}4,325 \\
156,117\end{array}$ & $\begin{array}{r}4,991 \\
509,366\end{array}$ \\
\hline Sales for Resale & 0 & 0 & 78.386 & 0 & 0 & \\
\hline \multicolumn{7}{|l|}{ Oper Revenues for the Year (thou\$) } \\
\hline 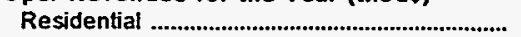 & 6,572 & 6,555 & 6,367 & 1,865 & 3,264 & 3,997 \\
\hline 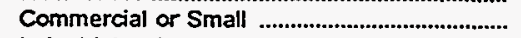 & 3,868 & 7,220 & 6,549 . & 1,424 & 608 & 3,039 \\
\hline Industrial or Large & 787 & 0 & 6,913 & 0 & 2,013 & 3,659 \\
\hline Other & 215 & 1,089 & 1,597 & 706 & 300 & 312 \\
\hline 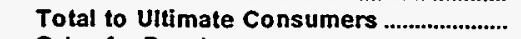 & 11,442 & 14,864 & 21,426 & 3,995 & 6,185 & 11,007 \\
\hline 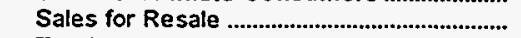 & & 0 & 1,358 & & & \\
\hline Total Revenues From Sales of Elec......... & 11,442 & 14,864 & 22,784 & 3,995 & 6,485 & 11,007 \\
\hline
\end{tabular}

Note: Totals may not equal sum of components because of independent rounding.

Source: Energy Information Administration. Form ElA-861, "Annual Electric Utility Report" Data are submitted on a calendar year. 
Table 25. Number of Consumers, Sales, and Operating Revenue by Major U.S.

Publicly Owned Electric Utility Within State, 1995 (Continued)

\begin{tabular}{|c|c|c|c|c|c|c|}
\hline Item & $\begin{array}{c}\text { New York } \\
\text { Power } \\
\text { Authority } \\
\text { of State of NY } \\
\text { December } 31\end{array}$ & $\begin{array}{l}\text { New York } \\
\text { Rockville } \\
\text { Centre } \\
\text { Village of } \\
\text { May } 31\end{array}$ & $\begin{array}{l}\text { New York } \\
\text { Solvay } \\
\text { Village of } \\
\text { May } 31\end{array}$ & $\begin{array}{l}\text { North Carolina } \\
\text { Abemarie } \\
\text { City of } \\
\text { June } 30\end{array}$ & $\begin{array}{l}\text { North Carolina } \\
\text { Concord } \\
\text { City of } \\
\text { June } 30\end{array}$ & $\begin{array}{l}\text { North Carolina } \\
\text { Elizabeth } \\
\text { City City of } \\
\text { June } 30\end{array}$ \\
\hline \multicolumn{7}{|l|}{ Number of Consumers } \\
\hline 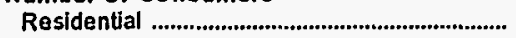 & 0 & 8,892 & 4,516 & 9,010 & 15,572 & 8,590 \\
\hline 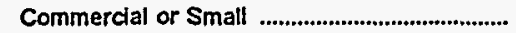 & 4 & 1,208 & 374 & 1,805 & 2,172 & 1.416 \\
\hline Industrial or Large & 25 & 0 & 16 & 23 & 0 & 0 \\
\hline Other & 110 & 46 & 2 & 1 & 1 & 65 \\
\hline $\begin{array}{l}\text { Total Ultimate Consumers } \\
\text { Sales for the Year (megawa....................... }\end{array}$ & 139 & 10,146 & 4,908 & 10,839 & 17,745 & 10,071 \\
\hline 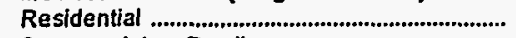 & 0 & 75,110 & 51,778 & 107,399 & 181,965 & 109,513 \\
\hline Commercial or Small & 99,213 & 90,368 & 27.882 & 86,465 & 228,291 & 124,410 \\
\hline 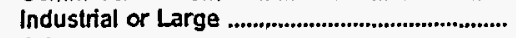 & $4,250,641$ & 0 & 143,381 & 54,578 & 0 & 0 \\
\hline $\begin{array}{l}\text { Other } \\
\text { Total to Uiltimate Consumers }\end{array}$ & $\begin{array}{r}8,694,143 \\
13,043,997\end{array}$ & $\begin{array}{r}5,500 \\
170,978\end{array}$ & $\begin{array}{r}2,189 \\
225,230\end{array}$ & $\begin{array}{r}8,392 \\
256,834\end{array}$ & $\begin{array}{r}1,006 \\
411,262\end{array}$ & $\begin{array}{r}8,953 \\
242,876\end{array}$ \\
\hline $\begin{array}{l}\text { Sales for Resale } \\
\text { Total Sales }\end{array}$ & $\begin{array}{l}27,446,460 \\
40,490,457\end{array}$ & $\begin{array}{r}0 \\
170,978\end{array}$ & $\begin{array}{r}0 \\
225,230\end{array}$ & $\begin{array}{r}0 \\
256.834\end{array}$ & $\begin{array}{r}0 \\
411,262\end{array}$ & 249.876 \\
\hline \multicolumn{7}{|l|}{ Oper Revenues for the Year (thou\$) } \\
\hline Residential & 0 & 5,256 & 1,603 & 9,066 & 14,055 & 11,088 \\
\hline 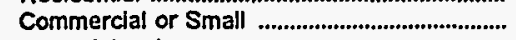 & 5,981 & 6,110 & 746 & 6,744 & 14,089 & 10,547 \\
\hline 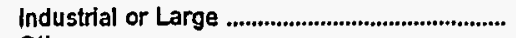 & 89,318 & 0 & 2.642 & 3,107 & 0 & 0 \\
\hline 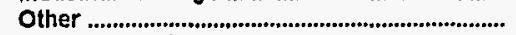 & 706,713 & 372 & 144 & 533 & 65 & 661 \\
\hline Total to Ultimate Consumers ........................ & 802,012 & 11,738 & 5,135 & 19,450 & 28,209 & 22,296 \\
\hline Sales for Resale & 552,507 & 0 & & 0 & 0 & \\
\hline Total Revenues From Sales of Elec......... & $1,354,519$ & 11,738 & 5,135 & 19,450 & 28,209 & 22,296 \\
\hline
\end{tabular}

\begin{tabular}{|c|c|c|c|c|c|c|}
\hline Item & $\begin{array}{c}\text { North Carolina } \\
\text { Fayetteville } \\
\text { Public } \\
\text { Works Comm } \\
\text { June } 30\end{array}$ & $\begin{array}{l}\text { North Carolina } \\
\text { Forest City } \\
\text { Town of } \\
\text { June } 30\end{array}$ & $\begin{array}{c}\text { North Carolina } \\
\text { Gastonia } \\
\text { City of } \\
\text { June } 30\end{array}$ & $\begin{array}{c}\text { North Carolina } \\
\text { Greenville } \\
\text { Utilities } \\
\text { Comm } \\
\text { June } 30\end{array}$ & $\begin{array}{c}\text { North Carolina } \\
\text { High } \\
\text { Point } \\
\text { Town } \\
\text { of } \\
\text { June } 30\end{array}$ & $\begin{array}{l}\text { North Carolina } \\
\text { Kinston } \\
\text { City of } \\
\text { June } 30\end{array}$ \\
\hline \multicolumn{7}{|l|}{ Number of Consumers } \\
\hline 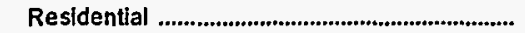 & 57,740 & 3,766 & 20,809 & 37.710 & 26.263 & 10,868 \\
\hline 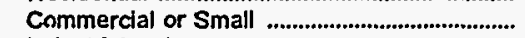 & 6,364 & 890 & 2,885 & 4,927 & 4,265 & 1,888 \\
\hline Industrial or Large & 21 & 0 & 73 & 21 & 326 & 9 \\
\hline $\begin{array}{l}\text { Other } \\
\text { Total Uttimate Consumers ................................. } \\
\text { Sales for the Year (megawatthours) }\end{array}$ & $\begin{array}{r}4,032 \\
68,1,57\end{array}$ & $\begin{array}{r}0 \\
4,656\end{array}$ & $\begin{array}{r}252 \\
24,019\end{array}$ & $\begin{array}{r}12 \\
42,670\end{array}$ & $\begin{array}{r}2 \\
30,856\end{array}$ & $\begin{array}{r}1,610 \\
14,375\end{array}$ \\
\hline 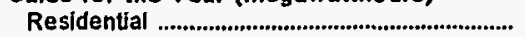 & 768,202 & 48,734 & 217,677 & 438,900 & 274,646 & 135,614 \\
\hline 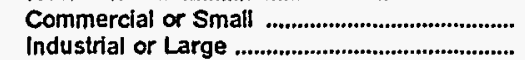 & $\begin{array}{l}5,13,693 \\
450,592\end{array}$ & $\begin{array}{r}99,399 \\
0\end{array}$ & $\begin{array}{l}268,100 \\
109,060\end{array}$ & $\begin{array}{l}311,900 \\
374,600\end{array}$ & $\begin{array}{l}375,860 \\
118,332\end{array}$ & $\begin{array}{l}172,438 \\
128,797\end{array}$ \\
\hline Other & $\begin{array}{r}27,658 \\
1,760,145\end{array}$ & $\begin{array}{r}0 \\
148,133\end{array}$ & $\begin{array}{r}30,507 \\
625,344\end{array}$ & $\begin{array}{r}37,300 \\
1,162,700\end{array}$ & $\begin{array}{r}15,227 \\
784,065\end{array}$ & $\begin{array}{r}8,729 \\
445,578\end{array}$ \\
\hline 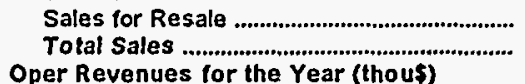 & $\begin{array}{r}94,255 \\
1,854,400\end{array}$ & $\begin{array}{r}0 \\
148,133\end{array}$ & 625,344 & $\begin{array}{r}23,784 \\
1,186,484\end{array}$ & $\begin{array}{r}0 \\
784,065\end{array}$ & 445,578 \\
\hline 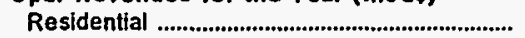 & 57,358 & 3,111 & 19,381 & 40,719 & 25.487 & 13,401 \\
\hline Commercial or Small ............................................... & 34,553 & 5,293 & 21,317 & 26,477 & 26,870 & 14,437 \\
\hline 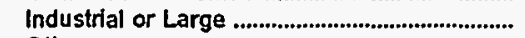 & 22,440 & 0 & 6,902 & 23,690 & 8,231 & 8,042 \\
\hline Other & 2,656 & 0 & 2,102 & 6.785 & 4,516 & 933 \\
\hline Total to Ultimate Consumers .......................... & 117,007 & 8,404 & 49,702 & 97,671 & 65,104 & 36,813 \\
\hline 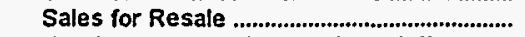 & & 0 & 0 & 1,903 & & \\
\hline Total Revenues From Sales of Elec......... & 117,007 & 8,404 & 49,702 & 99,574 & 65,104 & 36,813 \\
\hline
\end{tabular}

Note: Totals may not equal sum of components because of independentrounding.

Source: Energy Information Administration, Form ElA-861, "Annual Electric Utility Report" Data are submitted on a calendar year. 
Table 25. Number of Consumers, Sales, and Operating Revenue by Major U.S. Publicly Owned Electric Utility Within State, 1995 (Continued)

\begin{tabular}{|c|c|c|c|c|c|c|}
\hline Item & $\begin{array}{l}\text { North Carolina } \\
\text { Laurinburg } \\
\text { City of } \\
\text { December } 31\end{array}$ & $\begin{array}{l}\text { North Carolina } \\
\text { Lexington } \\
\text { City of } \\
\text { June } 30\end{array}$ & $\begin{array}{l}\text { North Carolina } \\
\text { Lumberton } \\
\text { City of } \\
\text { June } 30\end{array}$ & $\begin{array}{l}\text { North Carolina } \\
\text { Monroe } \\
\text { City of } \\
\text { June } 30\end{array}$ & $\begin{array}{l}\text { North Carolina } \\
\begin{array}{c}\text { Morganton } \\
\text { City of }\end{array} \\
\text { June } 30\end{array}$ & $\begin{array}{l}\text { Murphy } \\
\text { City of } \\
\text { June } 30\end{array}$ \\
\hline \multicolumn{7}{|l|}{ Number of Consumers } \\
\hline Residential & 4,678 & 14,635 & 6,949 & 6,256 & 6,122 & 2.461 \\
\hline Commercial or Small & 774 & 2,200 & 1,994 & 1,108 & 1,175 & 1,016 \\
\hline 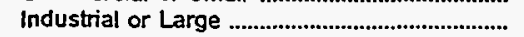 & 0 & 58 & 0 & 481 & 55 & 78 \\
\hline Other & 805 & 183 & 1 & 1,125 & 72 & 4 \\
\hline Total Ultimate Consumers ............................. & 6,257 & 17,076 & 8,944 & 8,970 & 7,424 & 3,559 \\
\hline \multicolumn{7}{|l|}{ Sales for the Year (megawatthours) } \\
\hline Commercial or Small & 67,050 & $\begin{array}{l}180,442 \\
134,567\end{array}$ & 167,012 & 21,933 & 50,451 & $\begin{array}{l}29,070 \\
14,444\end{array}$ \\
\hline 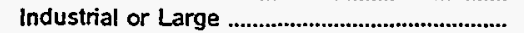 & 0 & 109,721 & 0 & 344,566 & 156,656 & 77,940 \\
\hline $\begin{array}{l}\text { Other } \\
\text { Total to Uitimate Consumers }\end{array}$ & $\begin{array}{r}6,257 \\
125,924\end{array}$ & $\begin{array}{r}5,639 \\
436,369\end{array}$ & $\begin{array}{r}2,251 \\
253,048\end{array}$ & $\begin{array}{r}2,228 \\
444,635\end{array}$ & $\begin{array}{r}18,888 \\
290,670\end{array}$ & $\begin{array}{r}1,244 \\
123,198\end{array}$ \\
\hline 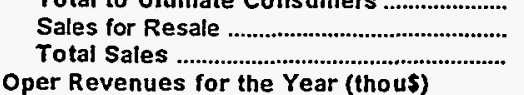 & $\begin{array}{r}125,324 \\
0 \\
125,924\end{array}$ & $\begin{array}{r}436,309 \\
0 \\
436,369\end{array}$ & $\begin{array}{r}253,048 \\
0 \\
253,048\end{array}$ & $\begin{array}{r}444,635 \\
0 \\
444,635\end{array}$ & $\begin{array}{r}290,670 \\
0 \\
290,670\end{array}$ & $\begin{array}{r}123,198 \\
0 \\
123,198\end{array}$ \\
\hline $\begin{array}{l}\text { Residential } \\
\text { Commercial or Small }\end{array}$ & $\begin{array}{l}5,292 \\
5,872\end{array}$ & $\begin{array}{l}16,547 \\
10.628\end{array}$ & $\begin{array}{r}7,685 \\
14,167\end{array}$ & $\begin{array}{l}6,595 \\
2,169\end{array}$ & $\begin{array}{l}5,595 \\
4,308\end{array}$ & $\begin{array}{l}1,817 \\
1,083\end{array}$ \\
\hline Industrial or Large & 0 & 6,414 & 0 & 20,534 & 9,230 & 3,677 \\
\hline Other & 598 & 380 & 312 & 257 & 1,144 & 113 \\
\hline Total to Ultimate Consumers ........................ & 11,762 & 33,969 & 22,164 & 29,555 & 20,277 & 6,690 \\
\hline Sales for Resale & & & $\begin{array}{r}0 \\
29\end{array}$ & & & \\
\hline Total Revenues From Sales of Elec......... & 11,762 & 33,969 & 22,164 & 29,555 & 20,277 & 6,690 \\
\hline
\end{tabular}

\begin{tabular}{|c|c|c|c|c|c|c|}
\hline Item & $\begin{array}{l}\text { North Carolina } \\
\text { New Bern } \\
\text { City of } \\
\text { June } 30\end{array}$ & $\begin{array}{l}\text { North Carolina } \\
\text { New River } \\
\text { Light } \\
\& \\
\text { Power Co } \\
\text { December } 31\end{array}$ & $\begin{array}{l}\text { North Carolina } \\
\text { North } \\
\text { Carolina } \\
\text { Eastern M P A } \\
\text { December } 31\end{array}$ & $\begin{array}{l}\text { North Carolina } \\
\text { North } \\
\text { Carolina } \\
\text { Mun } \\
\text { Power Agny } \\
\text { December } 31\end{array}$ & $\begin{array}{l}\text { North Carolina } \\
\text { Rocky Mount } \\
\text { City of } \\
\text { June } 30\end{array}$ & $\begin{array}{l}\text { North Carolina } \\
\text { Shelby } \\
\text { City of } \\
\text { June } 30\end{array}$ \\
\hline \multicolumn{7}{|l|}{ Number of Consumers } \\
\hline Residential ........................... & 12,885 & 5,067 & 0 & $\mathbf{0}$ & 23.100 & 6,390 \\
\hline Commercial or Small .................................................. & 2,155 & 1.334 & 0 & 0 & 3,487 & 1.274 \\
\hline 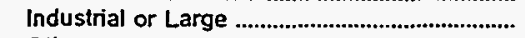 & & 3 & 0 & 0 & 9 & 11 \\
\hline Other & 4 & 242 & 0 & 0 & 115 & \\
\hline 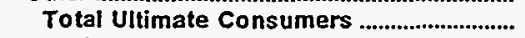 & 15,052 & 6,646 & 0 & 0 & 26,711 & 7,676 \\
\hline \multicolumn{7}{|l|}{ Sales for the Year (megawatthours) } \\
\hline 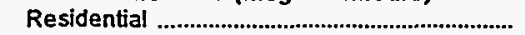 & 177,228 & 42,998 & 0 & 0 & 268,704 & 66,860 \\
\hline 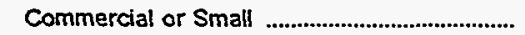 & 132,450 & 78,180 & 0 & 0 & 302,204 & 92,140 \\
\hline Industrial or Large ............................................... & 60,351 & 8,362 & 0 & 0 & 143,721 & 3,715 \\
\hline Other & 3,847 & 43,358 & 0 & 0 & 10,399 & 1.186 \\
\hline Total to Ultimate Consumers ........................ & 373,876 & 172,898 & 0 & $\mathbf{0}$ & 725,028 & 183,901 \\
\hline Sales for Resale ....................................................... & & & $6,532,836$ & $7,003,590$ & 17,733 & \\
\hline \multicolumn{7}{|l|}{ Oper Revenues for the Year (thous) } \\
\hline 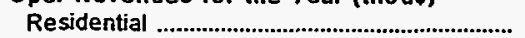 & 17,479 & 3,438 & 0 & 0 & 24,777 & 5,733 \\
\hline Commercial or Small ............................................ & 12,182 & 5,254 & 0 & 0 & 23,664 & 6,463 \\
\hline 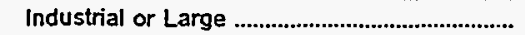 & 4,258 & 528 & 0 & 0 & 7,514 & 273 \\
\hline Other & 414 & 3,073 & 0 & $\mathbf{0}$ & 1,142 & \\
\hline Total to Ultimate Consumers ........................ & 34,333 & 12,293 & 0 & 0 & 57,097 & 12,552 \\
\hline Sales for Resale & & & 462,664 & 413,852 & 1,188 & \\
\hline Total Revenues From Sales of Elec......... & 34,333 & 12,293 & 462,664 & 413,852 & 58,285 & 12,552 \\
\hline
\end{tabular}

Note: Totals may not equal sum of components because of independent rounding.

Source: Energy Information Administration, Form ElA-861, "Annual Electric Utility Report" Data are submitted on a calendar year. 
Table 25. Number of Consumers, Sales, and Operating Revenue by Major U.S. Publicly Owned Electric Utility Within State, 1995 (Continued)

\begin{tabular}{|c|c|c|c|c|c|c|}
\hline Item & $\begin{array}{c}\text { North Carolina } \\
\begin{array}{c}\text { Statesville } \\
\text { City of }\end{array} \\
\text { June } 30\end{array}$ & $\begin{array}{c}\text { North Carolina } \\
\text { Tarboro } \\
\text { Town of } \\
\text { June } 30\end{array}$ & $\begin{array}{l}\text { North Carolina } \\
\text { Washington } \\
\text { City of } \\
\text { June } 30\end{array}$ & $\begin{array}{l}\text { North Carolina } \\
\text { Wilson } \\
\text { City of } \\
\text { June } 30\end{array}$ & $\begin{array}{c}\text { Ohio } \\
\text { American } \\
\text { Mun } \\
\text { Power } \\
\text { Ohio Inc } \\
\text { December } 31\end{array}$ & $\begin{array}{l}\text { Ohio } \\
\text { Bowling } \\
\text { Green } \\
\text { City of } \\
\text { December } 31\end{array}$ \\
\hline \multicolumn{7}{|l|}{ Number of Consumers } \\
\hline 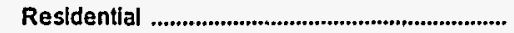 & 9,844 & 5.002 & 9,430 & 28,411 & 0 & 9.739 \\
\hline Commercial or Small & 1,997 & 689 & 1,783 & 3,673 & 0 & 1,388 \\
\hline 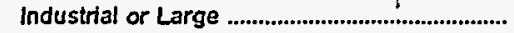 & 33 & 34 & 35 & 12 & 1 & 69 \\
\hline Other & 97 & 2 & 1 & 0 & 0 & 23 \\
\hline \multicolumn{7}{|l|}{ Sales for the Year (megawatthours) } \\
\hline 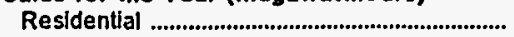 & 85,443 & 53,926 & 105,398 & 324,096 & 0 & 72,255 \\
\hline 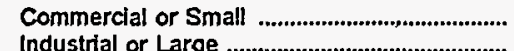 & $\begin{array}{l}167,074 \\
108,184\end{array}$ & $\begin{array}{r}37,899 \\
150,798\end{array}$ & $\begin{array}{l}54,820 \\
75,754\end{array}$ & $\begin{array}{l}270,369 \\
386,661\end{array}$ & $\begin{array}{r}0 \\
788.595\end{array}$ & $\begin{array}{r}46,157 \\
+85,950\end{array}$ \\
\hline Other & 18,439 & 6,856 & 3,030 & $\begin{array}{r}300,001 \\
0\end{array}$ & $\begin{array}{r}186,595 \\
0\end{array}$ & $\begin{array}{r}185,900 \\
2,955\end{array}$ \\
\hline 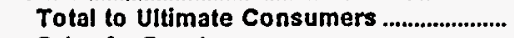 & 379,140 & 249,479 & 239,002 & 981,126 & 788,595 & 307,317 \\
\hline 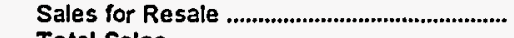 & 0 & 0 & 0 & 63,010 & $4,680,758$ & 2,854 \\
\hline \multicolumn{7}{|l|}{ Oper Revenues for the Year (thous) } \\
\hline 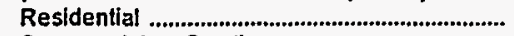 & 6,424 & 6,007 & 11,063 & 31,036 & 0 & 4,788 \\
\hline Commercial or Small & 11,291 & 3,674 & 5,411 & 23,588 & 0 & 2,613 \\
\hline 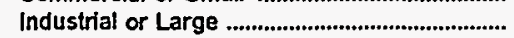 & 6,022 & 11,141 & 5,771 & 25,441 & 13,444 & 9,879 \\
\hline 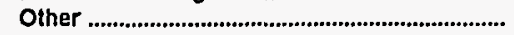 & 1,136 & 671 & 354 & 0 & 0 & 128 \\
\hline Total to Ultimate Consumers .................... & 24,873 & 21,493 & 22,599 & 80,065 & 13,444 & 17,408 \\
\hline Sales for Resale & & 0 & & 5,129 & 147,252 & 152 \\
\hline Total Revenues From Sales of Elec......... & 24,873 & 21,493 & 22,599 & 85,194 & 160,696 & 17,560 \\
\hline
\end{tabular}

\begin{tabular}{|c|c|c|c|c|c|c|}
\hline Item & $\begin{array}{c}\text { Ohio } \\
\text { Bryan } \\
\text { City of } \\
\text { December } 31\end{array}$ & $\begin{array}{l}\text { Ohio } \\
\text { Celina } \\
\text { City of } \\
\text { December } 31\end{array}$ & $\begin{array}{c}\text { Ohio } \\
\text { Cleveland } \\
\text { City of } \\
\text { December } 31\end{array}$ & $\begin{array}{c}\text { Ohio } \\
\text { Clyde } \\
\text { City of } \\
\text { December } 31\end{array}$ & $\begin{array}{c}\text { Ohio } \\
\text { Columbus } \\
\text { City of }\end{array}$ & $\begin{array}{c}\text { Ohio } \\
\text { Cuyahoga } \\
\text { Falls } \\
\text { City of } \\
\text { December } 31\end{array}$ \\
\hline \multicolumn{7}{|l|}{ Number of Consumers } \\
\hline 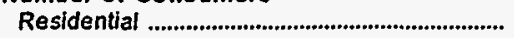 & 4,498 & 6.048 & 61,681 & 1,949 & 8,109 & 19,797 \\
\hline Commercial or Small & 537 & 769 & 6,928 & 245 & 2,476 & 1,404 \\
\hline 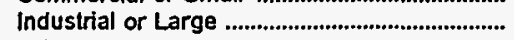 & 124 & 15 & 18 & 6 & 365 & 145 \\
\hline 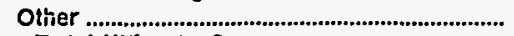 & 0 & 1 & 6 & 0 & 290 & 229 \\
\hline $\begin{array}{l}\text { Total Ultimate Consumers } \\
\text { Sales for the Year (megawatthours) }\end{array}$ & \multicolumn{3}{|c|}{ Sales for the Year (megawatthours) } & 2,200 & 11,240 & 21,575 \\
\hline 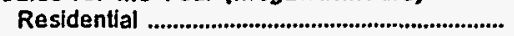 & 43,324 & 61,696 & 339,179 & 15,784 & 49,574 & 134,581 \\
\hline Commercial or Small & 14,064 & 35,069 & 386,509 & 10,981 & 74,143 & 40,353 \\
\hline 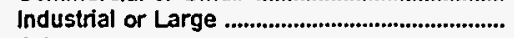 & 163,449 & 47,597 & 364,707 & 107,286 & 480,659 & 128.675 \\
\hline Other & 0 & 1,242 & 57,716 & 0 & 27,985 & 9,151 \\
\hline 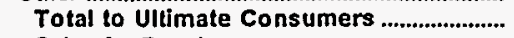 & 220,837 & 145,604 & $1,148,111$ & 134,051 & 632,361 & 312,760 \\
\hline 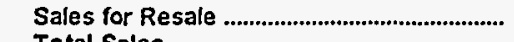 & 40 & $\begin{array}{r}0 \\
0\end{array}$ & $\begin{array}{r}0 \\
0\end{array}$ & 0 & 275 & 0 \\
\hline \multicolumn{7}{|l|}{ Oper Revenues for the Year (thou\$) } \\
\hline 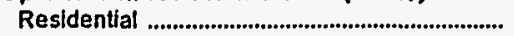 & 2,291 & 3,165 & 30,489 & 1,345 & 3,877 & 9,413 \\
\hline 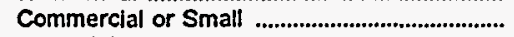 & 935 & 1,912 & 32,332 & 1.070 & 6,072 & 3,022 \\
\hline Industrial or Large & 7,654 & 2,064 & 21.557 & 4,165 & 25,689 & 7,197 \\
\hline Other & 0 & 53 & 6,346 & 0 & 2,312 & 552 \\
\hline 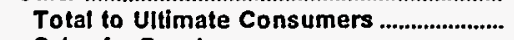 & 10,880 & 7,194 & 90,724 & 6,580 & 37,950 & 20,184 \\
\hline 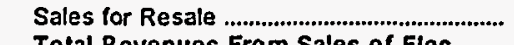 & & & & & & \\
\hline Total Revenues From Sales of Elec......... & 10,884 & 7,194 & 90,724 & 6,580 & 37,974 & 20,184 \\
\hline
\end{tabular}

Note: Totals may not equal sum of components because of independent rounding.

Source: Energy Information Administration, Form ElA-861, "Annual Electric Utility Report." Data are submitted on a calendar year. 
Table 25. Number of Consumers, Sales, and Operating Revenue by Major U.S. Publicly Owned Electric Utility Within State, 1995 (Continued)

\begin{tabular}{|c|c|c|c|c|c|c|}
\hline Item & $\begin{array}{c}\text { Ohio } \\
\text { Dover } \\
\text { City of } \\
\text { December } 31\end{array}$ & $\begin{array}{c}\text { Ohio } \\
\text { Hamilton } \\
\text { City of } \\
\text { December } 31\end{array}$ & $\begin{array}{c}\text { Ohio } \\
\begin{array}{c}\text { Napoleon } \\
\text { City of }\end{array} \\
\text { December } 31\end{array}$ & $\begin{array}{c}\text { Ohio } \\
\text { Niles } \\
\text { City of } \\
\text { December } 31\end{array}$ & $\begin{array}{c}\text { Ohio } \\
\text { Omville } \\
\text { City of } \\
\text { December } 31\end{array}$ & $\begin{array}{c}\text { Ohio } \\
\text { Painesville } \\
\text { City of }\end{array}$ \\
\hline \multicolumn{7}{|l|}{ Number of Consumers } \\
\hline Residential & 5,294 & 23,989 & 4,817 & 10,452 & 5,357 & 8,511 \\
\hline Commercial or Small & 767 & 2,779 & 574 & 1,037 & 625 & 1,689 \\
\hline Industrial or Large & 87 & 51 & 57 & 91 & 10 & 1 \\
\hline Other & 15 & 0 & 287 & 486 & 23 & 0 \\
\hline $\begin{array}{l}\text { Total Ultimate Consumers } \\
\text { Sales for the Year (megawatthours) }\end{array}$ & 6,163 & 28,819 & 5,735 & 12,066 & 6,015 & 10,201 \\
\hline Residential & 47,354 & 217,188 & 43,389 & 79,548 & 61,199 & 61,510 \\
\hline Commercial or Small & 22,689 & 183,300 & 20,330 & 86,437 & 55,303 & 102,071 \\
\hline Industrial or Large & 109,424 & 176,754 & 84,624 & 90,249 & 135,344 & 31,555 \\
\hline Other & 1,318 & 0 & 2,685 & 1,155 & 10,158 & 0 \\
\hline Total to Ultimate Consumers ......................... & 180,785 & 577,242 & 151,028 & 257,389 & 262,004 & 195,136 \\
\hline 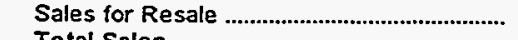 & 0 & 146.692 & 0 & 0 & 41,730 & 0 \\
\hline \multicolumn{6}{|l|}{ Oper Revenues for the Year (thou\$) } & 195,136 \\
\hline 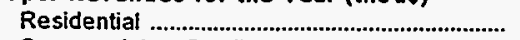 & 3,115 & 16,679 & 2,754 & 6,336 & 3,806 & 5,164 \\
\hline 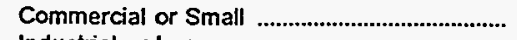 & 1,683 & 15,184 & 1,267 & 5,763 & 3,528 & 7,570 \\
\hline Industrial or Large & 5,541 & 9,007 & 4,797 & 4,985 & 6,869 & 1,410 \\
\hline Other & 491 & 0 & 30 & 124 & 560 & 0 \\
\hline Total to Ultimate Consumers ......................... & 10,830 & 40,870 & 8,848 & 17,208 & 14,763 & 14,144 \\
\hline Sales for Resale & 0 & 3.174 & 0 & 0 & 1,078 & 0 \\
\hline Total Revenues From Sales of Elec......... & 10,830 & 44,044 & 8,848 & 17,208 & 15,841 & 14,144 \\
\hline
\end{tabular}

\begin{tabular}{|c|c|c|c|c|c|c|}
\hline Item & $\begin{array}{c}\text { Ohio } \\
\text { Piqua } \\
\text { City of } \\
\text { December } 31\end{array}$ & $\begin{array}{c}\text { Ohio } \\
\text { St Marys } \\
\text { City of } \\
\text { December } 31\end{array}$ & $\begin{array}{c}\text { Ohio } \\
\text { Wadsworth } \\
\text { City of } \\
\text { December } 31\end{array}$ & $\begin{array}{c}\text { Onio } \\
\text { Wapakoneta } \\
\text { City of }\end{array}$ & $\begin{array}{c}\text { Ohio } \\
\text { Westerville } \\
\text { City of } \\
\text { December } 31\end{array}$ & $\begin{array}{l}\text { Oklahoma } \\
\text { Altus } \\
\text { City of } \\
\text { June } 30\end{array}$ \\
\hline \multicolumn{7}{|l|}{ Number of Consumers } \\
\hline 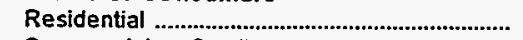 & 8,647 & 3,398 & 8,417 & 4,220 & 11,655 & 7,902 \\
\hline Commercial or Small & 1,043 & 491 & 1,068 & 547 & 1,391 & 1.116 \\
\hline Industrial or Large & 19 & 5 & 129 & 11 & 13 & 95 \\
\hline Other & 0 & 14 & 1 & 0 & 1 & 1 \\
\hline $\begin{array}{l}\text { Total Ultimate Consumers } \\
\text { Sales for the Year (megawatthours) }\end{array}$ & 9,709 & 3,908 & 9,615 & 4,778 & 13,060 & 9,114 \\
\hline 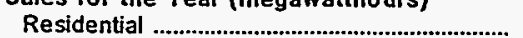 & 74,929 & 30,750 & 74,797 & 43,277 & 159.558 & 71824 \\
\hline Commercial or Small & 96,261 & 44,698 & 51,575 & 57,886 & 139,490 & 30,856 \\
\hline Industrial or Large & 93,542 & 84,519 & 83,790 & 46,873 & 52,838 & 49,891 \\
\hline Other Total to Ultimate Consumers & $\begin{array}{r}1,210 \\
265,942\end{array}$ & $\begin{array}{r}1,729 \\
161,696\end{array}$ & $\begin{array}{r}2,713 \\
212,875\end{array}$ & $\begin{array}{r}0 \\
148,036\end{array}$ & $\begin{array}{r}270 \\
352,156\end{array}$ & $\begin{array}{r}976 \\
153,547\end{array}$ \\
\hline $\begin{array}{l}\text { Sales for Resale } \\
\text { Total Sales .................................................. } \\
\text { Oper Revenues for the Year (thous) }\end{array}$ & $\begin{array}{r}129 \\
266,071\end{array}$ & $\begin{array}{r}8,493 \\
170,189\end{array}$ & 212,875 & $\begin{array}{r}0 \\
148,036\end{array}$ & $\begin{array}{r}0 \\
352,156\end{array}$ & $\begin{array}{r}0 \\
153,547\end{array}$ \\
\hline \multicolumn{7}{|l|}{ Oper Revenues for the Year (thou\$) } \\
\hline Commercial or Small & $\begin{array}{l}4,808 \\
5,828\end{array}$ & $\begin{array}{l}1,865 \\
2,255\end{array}$ & $\begin{array}{l}5,412 \\
3,123\end{array}$ & $\begin{array}{l}2,174 \\
2,927\end{array}$ & $\begin{array}{l}9,175 \\
7,427\end{array}$ & $\begin{array}{l}5,278 \\
2,488\end{array}$ \\
\hline Industrial or Large & 4,835 & 3,241 & 4,092 & 1,887 & 2,152 & 2,491 \\
\hline Other & 14 & 54 & 103 & 0 & 27 & 61 \\
\hline 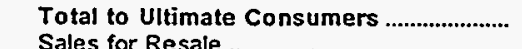 & 15,535 & 7,415 & 12,730 & 6,988 & 18,781 & 10,318 \\
\hline 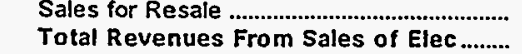 & $\begin{array}{r}15 \\
15,550\end{array}$ & $\begin{array}{r}234 \\
7,649\end{array}$ & $\begin{array}{r}0 \\
12,730\end{array}$ & $\begin{array}{r}0 \\
6,988\end{array}$ & $\begin{array}{r}0 \\
18,781\end{array}$ & $\begin{array}{r}0 \\
10,318\end{array}$ \\
\hline
\end{tabular}

Note: Totals may not equal sum of components because of independent rounding.

Source: Energy Information Administration, Form ElA-861, "Annual Electric Utility Report." Data are submitted on a calendar year. 
Table 25. Number of Consumers, Sales, and Operating Revenue by Major U.S. Publicly Owned Electric Utility Within State, 1995 (Continued)

\begin{tabular}{|c|c|c|c|c|c|c|}
\hline Item & $\begin{array}{l}\text { Oklahoma } \\
\text { Claremore } \\
\text { City of } \\
\text { June } 30\end{array}$ & $\begin{array}{l}\text { Oklahoma } \\
\text { Duncan } \\
\text { City of } \\
\text { June } 30\end{array}$ & $\begin{array}{l}\text { Oklahoma } \\
\text { Edmond } \\
\text { City of } \\
\text { June } 30\end{array}$ & $\begin{array}{c}\text { Okahoma } \\
\text { Grand River } \\
\text { Dam } \\
\text { Authority } \\
\text { December } 31\end{array}$ & $\begin{array}{l}\text { Oklahoma } \\
\text { Miami } \\
\text { City of } \\
\text { June } 30\end{array}$ & $\begin{array}{c}\text { OkJahoma } \\
\text { OkJahoma } \\
\text { Municipal } \\
\text { Power Auth } \\
\text { December } 31\end{array}$ \\
\hline \multicolumn{7}{|l|}{ Number of Consumers } \\
\hline 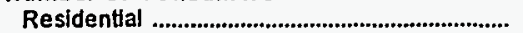 & 7,582 & 6,949 & 22,582 & 0 & 5.729 & 0 \\
\hline 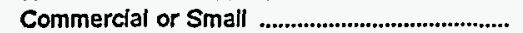 & 1,046 & 1,073 & 2,203 & 49 & 812 & 0 \\
\hline Industrial or Large & 102 & 86 & 149 & 17 & 161 & 0 \\
\hline 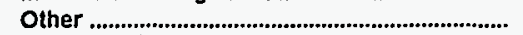 & 0 & 1 & 2,553 & 0 & 2 & 0 \\
\hline $\begin{array}{l}\text { Total UItimate Consumers } \\
\text { Sales for the Year (megawatthours) }\end{array}$ & 8,730 & 8,109 & 27,487 & 66 & 6,704 & 0 \\
\hline 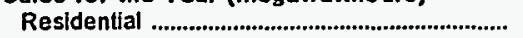 & 80,888 & 70,097 & 279,884 & 0 & 51,973 & 0 \\
\hline $\begin{array}{l}\text { Commercial or Small } \\
\text { Industrial or Large }\end{array}$ & $\begin{array}{r}20,661 \\
104,087\end{array}$ & $\begin{array}{l}30,422 \\
42,581\end{array}$ & $\begin{array}{l}94,650 \\
88,888\end{array}$ & $\begin{array}{r}20,165 \\
625,972\end{array}$ & $\begin{array}{l}13,000 \\
70,969\end{array}$ & $\begin{array}{l}0 \\
0\end{array}$ \\
\hline 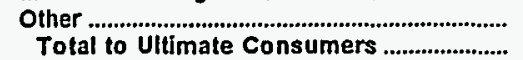 & $\begin{array}{r}0 \\
205,636\end{array}$ & $\begin{array}{r}864 \\
143,964\end{array}$ & $\begin{array}{r}20,316 \\
483,738\end{array}$ & $\begin{array}{r}0 \\
646,137\end{array}$ & $\begin{array}{r}8,977 \\
144,919\end{array}$ & $\begin{array}{l}0 \\
0\end{array}$ \\
\hline 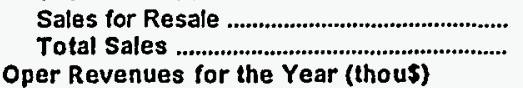 & $\begin{array}{r}0 \\
205,636\end{array}$ & $\begin{array}{r}0 \\
143,964\end{array}$ & $\begin{array}{r}0 \\
483,738\end{array}$ & $\begin{array}{l}4,626,042 \\
5,272,179\end{array}$ & $\begin{array}{r}0 \\
144,919\end{array}$ & $\begin{array}{l}1,581,032 \\
1,581,032\end{array}$ \\
\hline $\begin{array}{l}\text { Residential } \\
\text { Commercial or Small }\end{array}$ & $\begin{array}{l}5,988 \\
1,634\end{array}$ & $\begin{array}{l}4,287 \\
1,755\end{array}$ & $\begin{array}{r}17,727 \\
5,802\end{array}$ & $\begin{array}{r}0 \\
831\end{array}$ & $\begin{array}{r}3,082 \\
709\end{array}$ & $\begin{array}{l}0 \\
0\end{array}$ \\
\hline 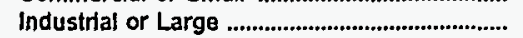 & 5,416 & 2,024 & 4,863 & 19,360 & 3,483 & 0 \\
\hline Other & 0 & 31 & 1,155 & 0 & 447 & 0 \\
\hline 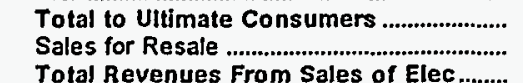 & $\begin{array}{r}13,038 \\
0 \\
13,038\end{array}$ & $\begin{array}{r}8,097 \\
0 \\
8,097\end{array}$ & $\begin{array}{r}29,547 \\
0 \\
29,547\end{array}$ & $\begin{array}{r}20,191 \\
144,263 \\
164,454\end{array}$ & $\begin{array}{r}7,721 \\
0 \\
7,724\end{array}$ & $\begin{array}{r}0 \\
68,565 \\
68,565\end{array}$ \\
\hline
\end{tabular}

\begin{tabular}{|c|c|c|c|c|c|c|}
\hline ftem & $\begin{array}{c}\text { Oklahoma } \\
\text { Ponca } \\
\text { City City of } \\
\text { June } 30\end{array}$ & $\begin{array}{l}\text { OkJahoma } \\
\text { Stillwater } \\
\text { Utilities } \\
\text { Authority } \\
\text { June } 30\end{array}$ & $\begin{array}{l}\text { Oregon } \\
\text { Ashland } \\
\text { City of } \\
\text { June } 30\end{array}$ & $\begin{array}{c}\text { Oregon } \\
\text { Central } \\
\text { Lncoln } \\
\text { Peoples } \\
\text { Utl Dt } \\
\text { December } 31\end{array}$ & $\begin{array}{c}\text { Oregon } \\
\text { Clatskanie } \\
\text { Peoples } \\
\text { Util Dist } \\
\text { December } 31\end{array}$ & $\begin{array}{c}\text { Oregon } \\
\text { Columbia } \\
\text { River } \\
\text { Peoples } \\
\text { Ut Dist } \\
\text { December } 31\end{array}$ \\
\hline \multicolumn{7}{|l|}{ Number of Consumers } \\
\hline 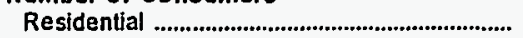 & 13,699 & 13,992 & 7,544 & 27,174 & 2,910 & 7,031 \\
\hline Commercial or Small & 1,690 & 1,440 & 1.045 & 4,363 & 388 & 627 \\
\hline 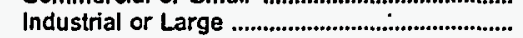 & 21 & 6 & 0 & 114 & 2 & 8 \\
\hline 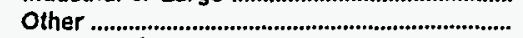 & 103 & 0 & 0 & 25 & $\mathbf{i}$ & 491 \\
\hline $\begin{array}{l}\text { Total Ultimate Consumers } \\
\text { Sales for the Year (megawatthours) }\end{array}$ & 15,513 & 15,438 & 8,589 & 31,676 & 3,301 & 8,157 \\
\hline 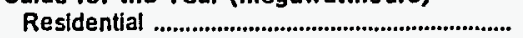 & 126,206 & 138,618 & 81,312 & 361,682 & 51,297 & $10 t, 624$ \\
\hline 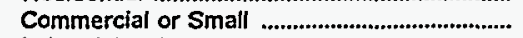 & 115.111 & 118,844 & 79,464 & 195,004 & 24,905 & 23,102 \\
\hline Industrial or Large & 31,770 & 144,323 & 0 & 705,047 & 810,780 & 144,685 \\
\hline Other & 16.154 & 0 & 0 & 3,554 & 177 & 1,142 \\
\hline Total to Uitimate Consumers ........................ & 289,241 & 401,785 & 160,776 & $1,265,287$ & 887,159 & 270,553 \\
\hline 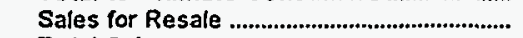 & 0 & 0 & 0 & 0 & 0 & \\
\hline $\begin{array}{l}\text { Total Sales ............................................ } \\
\text { Oper Revenues for the Year (thous) }\end{array}$ & 289,241 & 401,785 & 160,776 & $1,265,287$ & 887,159 & 270,553 \\
\hline 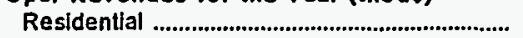 & 11,103 & 9,601 & 3,871 & 19,320 & 1,989 & 5.120 \\
\hline 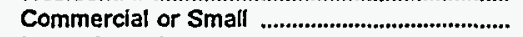 & 7,349 & 7,260 & 3,978 & 9,355 & 1,195 & 1,360 \\
\hline 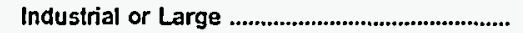 & 1,710 & 6,220 & 0 & 22,838 & 23,403 & 6,125 \\
\hline Other & 981 & 0 & 0 & 630 & $\begin{array}{r}20,400 \\
3\end{array}$ & 116 \\
\hline Total to Ultimate Consumers ....................... & 21,143 & 23,081 & 7,849 & 52,143 & 26,590 & 12,721 \\
\hline 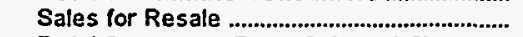 & 0 & 0 & 0 & 0 & 0 & \\
\hline Total Revenues From Sales of Elec........ & 21,143 & 23,081 & 7,849 & 52,143 & 26,590 & 12,721 \\
\hline
\end{tabular}

Note: Totals may not equal sum of components because of independent rounding.

Source: Energy Information Administration, Form ElA-861, "Annual Electric Utility Report." Data are submitted on a calendar year. 
Table 25. Number of Consumers, Sales, and Operating Revenue by Major U.S. Publicly Owned Electric Utility Within State, 1995 (Continued)

\begin{tabular}{|c|c|c|c|c|c|c|}
\hline Item & $\begin{array}{l}\text { Oregon } \\
\text { Emerald } \\
\text { Peoples } \\
\text { Utility Dist } \\
\text { December } 31\end{array}$ & $\begin{array}{l}\text { Oregon } \\
\text { Eugene } \\
\text { City of } \\
\text { December } 31\end{array}$ & $\begin{array}{c}\text { Forest Grove } \\
\text { City of } \\
\text { June } 30\end{array}$ & $\begin{array}{l}\text { Oregon } \\
\text { McMinnville } \\
\text { City of } \\
\text { June } 30\end{array}$ & $\begin{array}{l}\text { Oregon } \\
\text { Northern } \\
\text { Wasco } \\
\text { Colinty PUD } \\
\text { December } 31\end{array}$ & $\begin{array}{c}\text { Oregon } \\
\text { Springfield } \\
\text { City of } \\
\text { December } 31\end{array}$ \\
\hline \multicolumn{7}{|l|}{ Number of Consumers } \\
\hline Residential & 13,729 & 62,784 & 6,075 & 9,558 & 7,413 & 23,130 \\
\hline 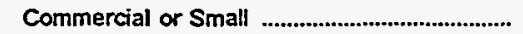 & 1,470 & 7,837 & 738 & 2,544 & 1,174 & 1,900 \\
\hline Industrial or Large & 8 & 1 & 90 & 2 & 160 & 137 \\
\hline Other & 675 & 12 & 365 & 1 & 37 & 239 \\
\hline \multicolumn{7}{|l|}{ Sales for the Year (megawatthours) } \\
\hline 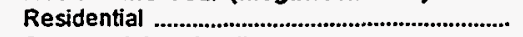 & 211,448 & 931,199 & 93,437 & 166,873 & 115.260 & 339,776 \\
\hline $\begin{array}{l}\text { Commercial or Small } \\
\text { Industrial or Large }\end{array}$ & $\begin{array}{l}77.154 \\
81.776\end{array}$ & $\begin{array}{l}964,869 \\
414,084\end{array}$ & $\begin{array}{l}47,464 \\
70,446\end{array}$ & $\begin{array}{l}147,462 \\
347,604\end{array}$ & $\begin{array}{r}25,892 \\
110,486\end{array}$ & $\begin{array}{l}145,810 \\
333,171\end{array}$ \\
\hline $\begin{array}{l}\text { Other } \\
\text { Total to Ultimate Consumers }\end{array}$ & $\begin{array}{r}9,337 \\
379,715\end{array}$ & $\begin{array}{r}21,553 \\
2,331,705\end{array}$ & $\begin{array}{r}1,623 \\
212,970\end{array}$ & $\begin{array}{r}1,370 \\
663,309\end{array}$ & $\begin{array}{r}1,590 \\
253,228\end{array}$ & $\begin{array}{r}26,818 \\
845,575\end{array}$ \\
\hline $\begin{array}{l}\text { Sales for Resale } \\
\text { Total Sales }\end{array}$ & $\begin{array}{r}0 \\
379,715\end{array}$ & $\begin{array}{r}140,177 \\
2,471,882\end{array}$ & 212,970 & $\begin{array}{r}0 \\
663,309\end{array}$ & $\begin{array}{r}39,945 \\
293,173\end{array}$ & 845,575 \\
\hline \multicolumn{7}{|l|}{ Oper Revenues for the Year (thous) } \\
\hline 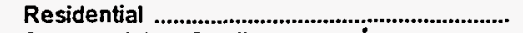 & 12,200 & 40,964 & 3,898 & 5.675 & 5,357 & 15,229 \\
\hline 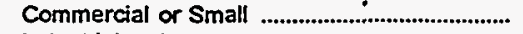 & 4,946 & 37,911 & 1,752 & 6,114 & 1,317 & 5,821 \\
\hline Industria! or Large & 4,165 & 12,993 & 2.281 & 10,639 & 4,137 & 10,388 \\
\hline Other & 425 & 784 & 102 & 47 & 249 & 1.173 \\
\hline Total to Ultimate Consumers ...................... & 21,736 & 92,652 & 8,033 & 22,475 & 11,060 & 32,611 \\
\hline Sales for Resale .................................... & & $\begin{array}{r}7,834 \\
100,486\end{array}$ & & & 1,819 & \\
\hline Total Revenues from Sales of telec........ & 21,736 & 100,486 & 8,033 & 22,475 & 12,879 & 32,611 \\
\hline
\end{tabular}

\begin{tabular}{|c|c|c|c|c|c|c|}
\hline Item & $\begin{array}{c}\text { Oregon } \\
\text { Tillamook } \\
\text { Peoples } \\
\text { Utility Dist } \\
\text { December } 31\end{array}$ & $\begin{array}{c}\text { Pennsylvania } \\
\text { Chambersburg } \\
\text { Borough of } \\
\text { December } 31\end{array}$ & $\begin{array}{l}\text { Pennsylvania } \\
\text { Ephrata } \\
\text { Borough of } \\
\text { December } 31\end{array}$ & $\begin{array}{c}\text { Pennsylvania } \\
\text { Lansdale } \\
\text { Borough of } \\
\text { December } 31\end{array}$ & $\begin{array}{l}\text { South Carolina } \\
\text { Camden } \\
\text { City of } \\
\text { June } 30\end{array}$ & $\begin{array}{c}\text { South Carolina } \\
\text { Easley } \\
\text { Combined } \\
\text { Utility } \\
\text { System } \\
\text { March } 31\end{array}$ \\
\hline \multicolumn{7}{|l|}{ Number of Consumers } \\
\hline 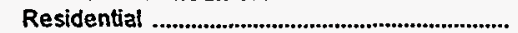 & 14,470 & 8,544 & 5,485 & 6,508 & 8,143 & 9,142 \\
\hline 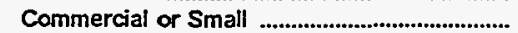 & 1,773 & 1,577 & 755 & 1,281 & 1,157 & 1,334 \\
\hline 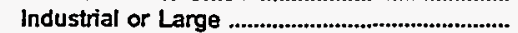 & 3 & 17 & 17 & 30 & 0 & 0 \\
\hline Other & 61 & 67 & 0 & 1 & 0 & o \\
\hline $\begin{array}{l}\text { Total Ultimate Consumers ........................... } \\
\text { Sales for the Year (megawatthours) }\end{array}$ & 16,307 & 10,205 & 6,257 & 7,820 & 9,300 & 10,478 \\
\hline Residential & 185,166 & 67.079 & 58,197 & 38,091 & 90,161 & 118,032 \\
\hline 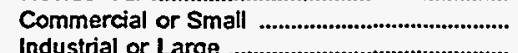 & $\begin{array}{r}105,903 \\
67765\end{array}$ & $\begin{array}{l}82,464 \\
94,820\end{array}$ & 50,905 & 35,207 & 60.739 & 82,726 \\
\hline Other & 3,747 & 5,638 & 0 & 2,160 & 0 & $\mathbf{0}$ \\
\hline Total to Uitimate Consumers & 362,581 & 250,001 & 125,607 & 140,459 & 150,900 & 200,758 \\
\hline 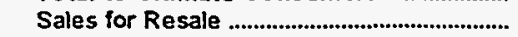 & 0 & 0 & 0 & 0 & 0 & 0 \\
\hline \multicolumn{6}{|l|}{ Oper Revenues for the Year (thou\$) } & 200,758 \\
\hline 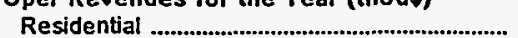 & 10,322 & 4,510 & 4,157 & 3,352 & 7,600 & 9,178 \\
\hline 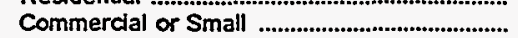 & 4,837 & 5,151 & 3,546 & 3,334 & 5.400 & 5,621 \\
\hline Industrial or Large & 2,084 & 4,523 & 968 & 4,310 & 0 & 0 \\
\hline Other & 254 & 427 & 0 & 84 & 0 & 0 \\
\hline 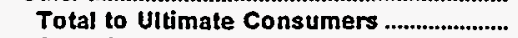 & 17,497 & 14,611 & 8,671 & 11,080 & 13,000 & 14,799 \\
\hline $\begin{array}{l}\text { Sales for Resale } \\
\text { Total Revenues From Sales of Elec......... }\end{array}$ & $\begin{array}{r}0 \\
17,497\end{array}$ & $\begin{array}{r}0 \\
14,611\end{array}$ & $\begin{array}{r}0 \\
8,674\end{array}$ & $\begin{array}{r}0 \\
11,080\end{array}$ & $\begin{array}{r}0 \\
13,000\end{array}$ & $\begin{array}{r}0 \\
14,799\end{array}$ \\
\hline
\end{tabular}

Note: Totals may not equal sum of components because of independentrounding

Source: Energy Information Administration, Form ElA-861. "Annual Electric Utility Report." Data are submitted on a calendar year. 
Table 25. Number of Consumers, Sales, and Operating Revenue by Major U.S. Publicly Owned Electric Utility Within State, 1995 (Continued)

\begin{tabular}{|c|c|c|c|c|c|c|}
\hline Item & $\begin{array}{l}\text { South Carolina } \\
\text { Gaffney } \\
\text { City of } \\
\text { March } 31\end{array}$ & $\begin{array}{l}\text { South Carolina } \\
\text { Greenwood } \\
\text { Commissioners } \\
\text { Pub Wk } \\
\text { December } 31\end{array}$ & $\begin{array}{c}\text { South Carolina } \\
\text { Greer } \\
\text { Comm } \\
\text { of } \\
\text { Public Works } \\
\text { December } 31\end{array}$ & $\begin{array}{l}\text { South Carolina } \\
\text { Newberry } \\
\text { City of } \\
\text { June } 30\end{array}$ & $\begin{array}{l}\text { South Carolina } \\
\text { Orangeburg } \\
\text { City of } \\
\text { September } 30\end{array}$ & $\begin{array}{l}\text { South Carolina } \\
\text { Piedmont } \\
\text { Municipal } \\
\text { Power Agny } \\
\text { December } 31\end{array}$ \\
\hline \multicolumn{7}{|l|}{ Number of Consumers } \\
\hline 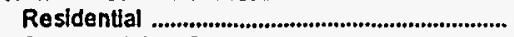 & 6,129 & 10,202 & 7.261 & 3,886 & 18,777 & 0 \\
\hline 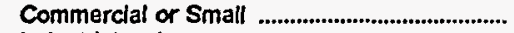 & 870 & 8,620 & 1,197 & 779 & 2,862 & 0 \\
\hline 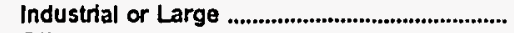 & 22 & 229 & 0 & 12 & 111 & 0 \\
\hline Other & 2,387 & 3 & 1 & $\mathbf{0}$ & 1 & 0 \\
\hline $\begin{array}{l}\text { Total UItimate Consumers ............................. } \\
\text { Sales for the Year (megawathours) }\end{array}$ & 9,408 & 12,054 & 8,459 & 4,677 & 21,751 & 0 \\
\hline 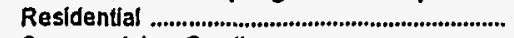 & 64,161 & 100,177 & 90,100 & 41,660 & 253,833 & 0 \\
\hline $\begin{array}{l}\text { Commerclal or Small } \\
\text { Industrial or Large }\end{array}$ & $\begin{array}{l}65,118 \\
34,654\end{array}$ & $\begin{array}{r}24,858 \\
112,37 t\end{array}$ & $\begin{array}{r}73,044 \\
0\end{array}$ & $\begin{array}{l}50,903 \\
46,453\end{array}$ & $\begin{array}{l}127,635 \\
358,619\end{array}$ & $\begin{array}{l}0 \\
0\end{array}$ \\
\hline $\begin{array}{l}\text { Other } \\
\text { Total to Uttimate Consumers }\end{array}$ & $\begin{array}{r}1,985 \\
165,918\end{array}$ & $\begin{array}{r}3,454 \\
240,860\end{array}$ & $\begin{array}{r}1,488 \\
164,632\end{array}$ & $\begin{array}{r}0 \\
139,016\end{array}$ & $\begin{array}{r}1,809 \\
741,896\end{array}$ & 0 \\
\hline $\begin{array}{l}\text { Sales for Resale } \\
\text { Total Sales } \\
\text { Oper Revenues for the Year (thous\}) }\end{array}$ & $\begin{array}{r}0 \\
165,918\end{array}$ & $\begin{array}{r}0 \\
240,860\end{array}$ & $\begin{array}{r}0 \\
164,632\end{array}$ & $\begin{array}{r}0 \\
139,016\end{array}$ & $\begin{array}{r}0 \\
741,896\end{array}$ & $\begin{array}{l}2,570,736 \\
2,570,736\end{array}$ \\
\hline 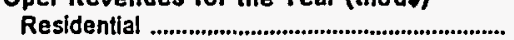 & 4,972 & 6,113 & 6,808 & 3,618 & 15.291 & 0 \\
\hline 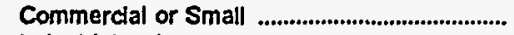 & 5,037 & 1,735 & 4,664 & 3,755 & 8,186 & 0 \\
\hline 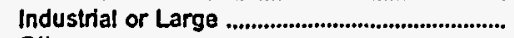 & 2,122 & 5,916 & 0 & 2,286 & 16,523 & 0 \\
\hline Other & 236 & 206 & 100 & 0 & 150 & 0 \\
\hline Total to Ultimate Consumers .......................... & 12,367 & 13,970 & 11,572 & 9,659 & 40,150 & $\mathbf{0}$ \\
\hline 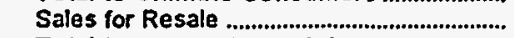 & 0 & 0 & 0 & 0 & 0 & 149,133 \\
\hline Total Revenues From Sales of Elec......... & 12,367 & 13,970 & 11,572 & 9,659 & 40,150 & 149,133 \\
\hline
\end{tabular}

\begin{tabular}{|c|c|c|c|c|c|c|}
\hline - Item & $\begin{array}{l}\text { South Carolina } \\
\text { Rock Hill } \\
\text { City of } \\
\text { December } 31\end{array}$ & $\begin{array}{l}\text { South Carolina } \\
\text { Seneca } \\
\text { City of } \\
\text { June } 30\end{array}$ & $\begin{array}{c}\text { South Carolina } \\
\text { South } \\
\text { Carolina } \\
\text { Pub } \\
\text { Serv Auth } \\
\text { December } 31\end{array}$ & $\begin{array}{l}\text { South Dakota } \\
\text { Brookings } \\
\text { City of } \\
\text { December } 31\end{array}$ & $\begin{array}{l}\text { South Dakota } \\
\text { Heartland } \\
\text { Consumers } \\
\text { Power Dist } \\
\\
\text { December } 31\end{array}$ & $\begin{array}{l}\text { South Dakota } \\
\text { Missouri } \\
\text { Basin } \\
\text { Mun } \\
\text { Power Agny } \\
\text { December } 31\end{array}$ \\
\hline \multicolumn{7}{|l|}{ Number of Consumers } \\
\hline Residential ............................................................. & 19,255 & 4,441 & 85,188 & 6,283 & 0 & 0 \\
\hline 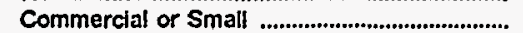 & 2,674 & 837 & 16,596 & 925 & 0 & 0 \\
\hline Industrial or Large & 8 & 3 & 31 & 34 & 0 & 0 \\
\hline Other & 0 & 1 & 441 & 89 & C & 0 \\
\hline $\begin{array}{l}\text { Total UItimate Consumers ........................... } \\
\text { Sales for the Year (megawatthours) }\end{array}$ & 21,937 & 5,282 & 102,256 & 7,331 & 0 & 0 \\
\hline 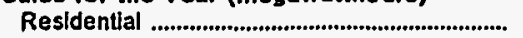 & 218,417 & 50,028 & $1,104,053$ & 65,468 & 0 & 0 \\
\hline 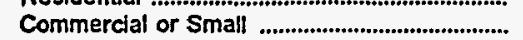 & 270,880 & 46,316 & $1,273,769$ & 38,833 & 0 & 0 \\
\hline Industrial or Large & 37,799 & 35,008 & $5,310,516$ & 75,392 & 0 & 0 \\
\hline Other & 0 & 1.505 & 50,779 & 13,132 & 0 & 0 \\
\hline Total to Uitimate Consumers ........................ & 527,096 & 132,857 & $7,739,117$ & 192,825 & o & 0 \\
\hline 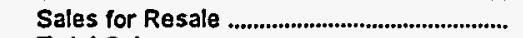 & 0 & 0 & $8,283,056$ & & 412,036 & $1,853,342$ \\
\hline 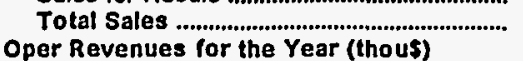 & 527,096 & 132,857 & $16,022,173$ & 192,825 & $\mathbf{4 1 2 , 0 3 6}$ & $1,853,342$ \\
\hline 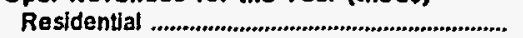 & 18,364 & 3,467 & 71,131 & 2,629 & 0 & 0 \\
\hline Commercial or Small & 21,395 & 3,734 & 70.629 & 1,866 & 0 & 0 \\
\hline 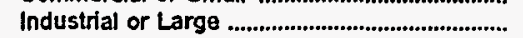 & 2,444 & 1,652 & 168,050 & 3.121 & 0 & 0 \\
\hline Other & 0 & 113 & 2,685 & 685 & 0 & 0 \\
\hline 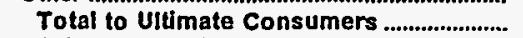 & 42,203 & 8,966 & 312,495 & 8,301 & o & o \\
\hline 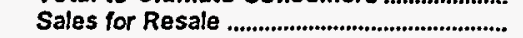 & 0 & 0 & 322,424 & & 11,699 & 59,899 \\
\hline Total Revenues From Sales of Elec........ & 42,203 & 8,966 & 634,919 & 8,301 & 11,699 & 59,899 \\
\hline
\end{tabular}

Note: Totals may not equal sum of components because of independent rounding.

Source: Energy Information Administration, Form ElA-861, "Annual Electric Utility Report" Data are submitted on a calendar year. 
Table 25. Number of Consumers, Sales, and Operating Revenue by Major U.S. Publicly Owned Electric Utility Within State, 1995 (Continued)

\begin{tabular}{|c|c|c|c|c|c|c|}
\hline Item & $\begin{array}{c}\text { South Dakota } \\
\text { Pierre } \\
\text { City of } \\
\text { December } 31\end{array}$ & $\begin{array}{c}\text { South Dakota } \\
\text { Watertown } \\
\text { Municipal } \\
\text { Utilities } \\
\text { December } 31\end{array}$ & $\begin{array}{c}\text { Tennessee } \\
\text { Alcoa } \\
\text { Utitities } \\
\text { June } 30\end{array}$ & $\begin{array}{l}\text { Tennessee } \\
\text { Athens } \\
\text { Utility } \\
\text { Board } \\
\text { June } 30\end{array}$ & $\begin{array}{l}\text { Tennessee } \\
\text { Benton } \\
\text { County } \\
\text { June } 30\end{array}$ & $\begin{array}{l}\text { Tennessee } \\
\text { Bolivar } \\
\text { City of } \\
\text { June } 30\end{array}$ \\
\hline \multicolumn{7}{|l|}{ Number of Consumers } \\
\hline 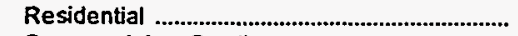 & 6.823 & 8,485 & 18.363 & 9,550 & 7.690 & 8,629 \\
\hline 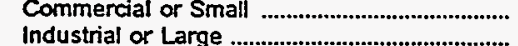 & $\begin{array}{r}692 \\
81\end{array}$ & $\begin{array}{r}1,365 \\
251\end{array}$ & $\begin{array}{r}2,610 \\
213\end{array}$ & $\begin{array}{r}1,787 \\
218\end{array}$ & $\begin{array}{r}1,366 \\
87\end{array}$ & $\begin{array}{r}1,658 \\
94\end{array}$ \\
\hline $\begin{array}{l}\text { Other } \\
\text { Total Ultimate Consumers ........................... } \\
\text { Sales for the Year (megawatthours) }\end{array}$ & $\begin{array}{r}81 \\
80 \\
7,676\end{array}$ & $\begin{array}{r}251 \\
919 \\
11,020\end{array}$ & $\begin{array}{r}213 \\
38 \\
21,224\end{array}$ & $\begin{array}{r}218 \\
113 \\
11,668\end{array}$ & $\begin{array}{r}87 \\
126 \\
9,269\end{array}$ & $\begin{array}{r}94 \\
23 \\
10,404\end{array}$ \\
\hline 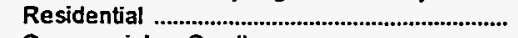 & 77.443 & 90,013 & 259,077 & 129,453 & 96,619 & 118,725 \\
\hline $\begin{array}{l}\text { Commercial or Small } \\
\text { Industrial or Large }\end{array}$ & 20,357 & $\begin{array}{r}28,386 \\
118,309\end{array}$ & $\begin{array}{r}35,349 \\
122,066\end{array}$ & $\begin{array}{r}28,922 \\
374,586\end{array}$ & $\begin{array}{l}16,422 \\
93,688\end{array}$ & $\begin{array}{l}19,300 \\
67,627\end{array}$ \\
\hline 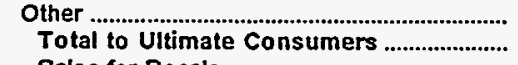 & $\begin{array}{r}13,425 \\
149,862\end{array}$ & $\begin{array}{r}3,095 \\
239,803\end{array}$ & $\begin{array}{r}6,640 \\
423,132\end{array}$ & $\begin{array}{r}5,890 \\
538,851\end{array}$ & $\begin{array}{r}4.297 \\
211,026\end{array}$ & $\begin{array}{r}4,247 \\
209,899\end{array}$ \\
\hline $\begin{array}{l}\text { Sales for Resale } \\
\text { Total Sales } \\
\text { Oper Revenues for the Year (thous) }\end{array}$ & $\begin{array}{r}15,632 \\
165,494\end{array}$ & 239,803 & $\begin{array}{r}0 \\
423,132\end{array}$ & 538,851 & 211,026 & 209,899 \\
\hline 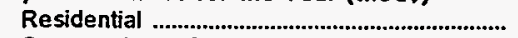 & 3,418 & 3,406 & 14,981 & 7.523 & 5,946 & 7,131 \\
\hline Commercial or Small & 956 & 1,381 & 2,379 & 1.935 & 1.178 & 1,373 \\
\hline 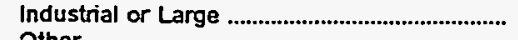 & 1,876 & 4,327 & 6,586 & 15,604 & 4,588 & 3,639 \\
\hline Other & 570 & 251 & 544 & 490 & 378 & 404 \\
\hline $\begin{array}{l}\text { Total to Ultimate Consumers } \\
\text { Sales for Resale }\end{array}$ & $\begin{array}{r}6,820 \\
326\end{array}$ & $\begin{array}{r}9,365 \\
0\end{array}$ & $\begin{array}{r}24,490 \\
0\end{array}$ & 25,552 & 12,090 & 12,547 \\
\hline Total Revenues From Sales of Elec......... & 7,146 & 9,365 & $\begin{array}{r}0 \\
24,490\end{array}$ & 25,552 & $\begin{array}{r}0 \\
12,090\end{array}$ & $\begin{array}{r}0 \\
12,547\end{array}$ \\
\hline
\end{tabular}

\begin{tabular}{|c|c|c|c|c|c|c|}
\hline Item & $\begin{array}{l}\text { Tennessee } \\
\text { Bristol } \\
\text { City of } \\
\text { June } 30\end{array}$ & $\begin{array}{l}\text { Tennessee } \\
\text { Brownsville } \\
\text { City of } \\
\text { June } 30\end{array}$ & $\begin{array}{l}\text { Tennessee } \\
\text { Carroll } \\
\text { County } \\
\text { June } 30\end{array}$ & $\begin{array}{c}\text { Tennessee } \\
\begin{array}{c}\text { Chattanooga } \\
\text { City of }\end{array} \\
\text { June } 30\end{array}$ & $\begin{array}{l}\text { Tennessee } \\
\text { Clarksville } \\
\text { City of } \\
\text { June } 30\end{array}$ & $\begin{array}{l}\text { Tennessee } \\
\text { Cleveland } \\
\text { City of } \\
\text { June } 30\end{array}$ \\
\hline \multirow{2}{*}{\multicolumn{7}{|c|}{ 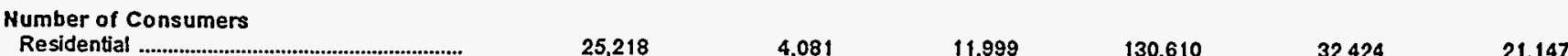 }} \\
\hline & 25,218 & 4.081 & 11,999 & 130.610 & 32,424 & 21,147 \\
\hline 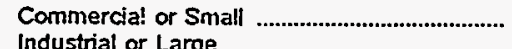 & 3,021 & 812 & 2,368 & 15.587 & 3.793 & 2,842 \\
\hline 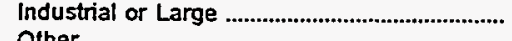 & 490 & 86 & 192 & 2,702 & 493 & 495 \\
\hline Other & 175 & 31 & 118 & 148 & 342 & 107 \\
\hline \multicolumn{7}{|l|}{ Sales for the Year (megawatthours) } \\
\hline 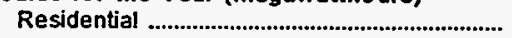 & 381,451 & 53,755 & 168,703 & $1,923,149$ & 444,179 & 314,081 \\
\hline 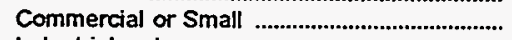 & 47,725 & 11,856 & 26,648 & 316,566 & 79,811 & 55,476 \\
\hline 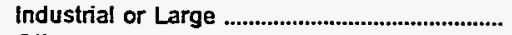 & 337,206 & 125,115 & 170.419 & $3,082,253$ & 331,021 & 509,455 \\
\hline Other ... & $\begin{array}{r}8,383 \\
774,765\end{array}$ & $\begin{array}{r}2,084 \\
192,810\end{array}$ & $\begin{array}{r}7.757 \\
373,527\end{array}$ & $\begin{array}{r}57,690 \\
5,379,658\end{array}$ & $\begin{array}{r}11,564 \\
866,575\end{array}$ & $\begin{array}{r}7,993 \\
887,005\end{array}$ \\
\hline 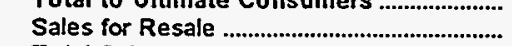 & $\begin{array}{r}114,165 \\
0\end{array}$ & $10<, 0$ & 0 & $\begin{array}{r}0,080,000 \\
0\end{array}$ & $\begin{array}{r}866,3 / 3 \\
0\end{array}$ & $\begin{array}{r}887,005 \\
0\end{array}$ \\
\hline \multicolumn{7}{|l|}{ Oper Revenues for the Year (thou\$) } \\
\hline 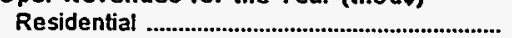 & 20,721 & 2,998 & 10,002 & 113,803 & 25,760 & 18,040 \\
\hline Commercial or Small ……………………………........ & 2,940 & 737 & 1,925 & 20,717 & 5,134 & 3,614 \\
\hline 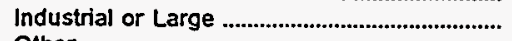 & 15,781 & 5,824 & 8.682 & 143,834 & 17,297 & 24,047 \\
\hline Other & 700 & 156 & 558 & 4,168 & 725 & 587 \\
\hline Total to Ultimate Consumers ............................ & 40,142 & 9,715 & 21,167 & 282,522 & 48,916 & 46,288 \\
\hline Sales for Resale & & & & 0 & & \\
\hline Total Revenues From Sales of Elec......... & 40,142 & 9,715 & 21,167 & 282,522 & 48,916 & 46,288 \\
\hline
\end{tabular}

Note: Totals may not equal sum of components because of independent rounding.

Source: Energy Information Administration, Form ElA-861, "Annual Electric Utility Report" Data are submilted on a calendar year. 
Table 25. Number of Consumers, Sales, and Operating Revenue by Major U.S. Publicly Owned Electric Utility Within State, 1995 (Continued)

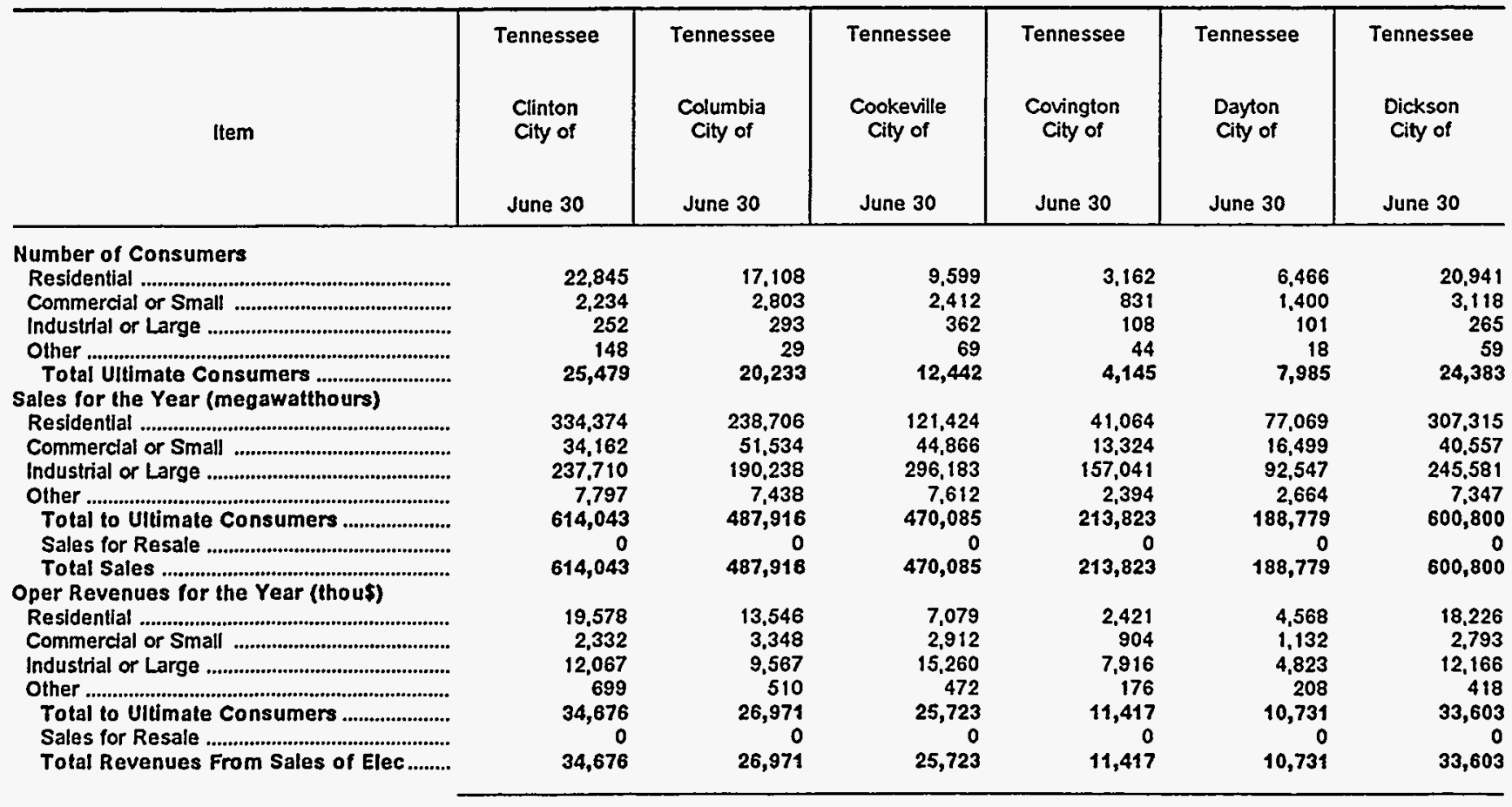

\begin{tabular}{|c|c|c|c|c|c|c|}
\hline Item & $\begin{array}{l}\text { Tennessee } \\
\text { Dyersburg } \\
\text { City of } \\
\text { June } 30\end{array}$ & $\begin{array}{c}\text { Tennessee } \\
\text { Elizabethton } \\
\text { City of } \\
\text { June } 30\end{array}$ & $\begin{array}{l}\text { Tennessee } \\
\text { Envin } \\
\text { Town of } \\
\text { June } 30\end{array}$ & $\begin{array}{l}\text { Etowah } \\
\text { City of } \\
\text { June } 30\end{array}$ & $\begin{array}{l}\text { Tennessee } \\
\text { Fayetteville } \\
\text { City of } \\
\text { June } 30\end{array}$ & $\begin{array}{l}\text { Gallatin } \\
\text { City of } \\
\text { June } 30\end{array}$ \\
\hline \multicolumn{7}{|l|}{ Number of Consumers } \\
\hline 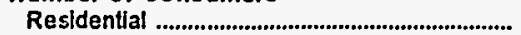 & 9,452 & 20,037 & 6,981 & 4,112 & 12,947 & 8,212 \\
\hline $\begin{array}{l}\text { Commerclal or Small } \\
\text { Industrial or Large }\end{array}$ & $\begin{array}{r}1,688 \\
202\end{array}$ & $\begin{array}{r}2,623 \\
236\end{array}$ & $\begin{array}{r}881 \\
84\end{array}$ & $\begin{array}{r}522 \\
43\end{array}$ & $\begin{array}{r}2.192 \\
146\end{array}$ & $\begin{array}{r}1,255 \\
198\end{array}$ \\
\hline 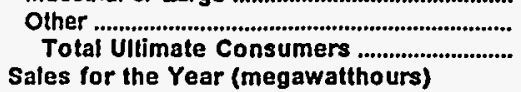 & $\begin{array}{r}60 \\
11,402\end{array}$ & $\begin{array}{r}105 \\
23,001\end{array}$ & $\begin{array}{r}19 \\
7,965\end{array}$ & $\begin{array}{r}23 \\
4,700\end{array}$ & $\begin{array}{r}33 \\
15,318\end{array}$ & $\begin{array}{r}39 \\
9,704\end{array}$ \\
\hline 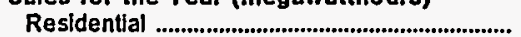 & 120,793 & 272,478 & 84,961 & 53,607 & 175,358 & 121,509 \\
\hline 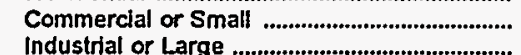 & $\begin{array}{r}32,677 \\
454,037\end{array}$ & $\begin{array}{r}33,247 \\
161,160\end{array}$ & $\begin{array}{r}11,641 \\
103,431\end{array}$ & $\begin{array}{r}7,316 \\
79,866\end{array}$ & $\begin{array}{r}30,498 \\
147,549\end{array}$ & $\begin{array}{r}27,016 \\
327,166\end{array}$ \\
\hline $\begin{array}{l}\text { Other } \\
\text { Total to Ultimate Consumers }\end{array}$ & $\begin{array}{r}5,388 \\
612,895\end{array}$ & $\begin{array}{r}6,938 \\
473,823\end{array}$ & $\begin{array}{r}1,970 \\
202,003\end{array}$ & $\begin{array}{r}1,950 \\
142,739\end{array}$ & $\begin{array}{r}3,474 \\
356,879\end{array}$ & $\begin{array}{r}4,827 \\
480,518\end{array}$ \\
\hline $\begin{array}{l}\text { Sales for Resale } \\
\text { Total Sales } \\
\text { Oper Revenues for the Year (thou\$s) }\end{array}$ & $\begin{array}{r}0 \\
612,895\end{array}$ & $\begin{array}{r}0 \\
473,823\end{array}$ & $\begin{array}{r}0 \\
202,003\end{array}$ & $\begin{array}{r}0 \\
142,739\end{array}$ & $\begin{array}{r}0 \\
356,879\end{array}$ & $\begin{array}{r}0 \\
480,518\end{array}$ \\
\hline 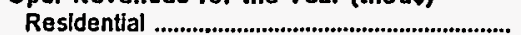 & 7,200 & 16.022 & 4,929 & 3,085 & 11,015 & 6.527 \\
\hline Commercial or Small & 2,188 & 2,303 & 773 & 487 & 2,297 & 1,616 \\
\hline Industrial or Large & 19,185 & 8,737 & 4,615 & 3,223 & 8.223 & 14.060 \\
\hline Other & 477 & 550 & 189 & 186 & 331 & 342 \\
\hline 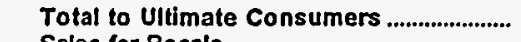 & 29,050 & 27,612 & 10,506 & 6,981 & 21,866 & 22,545 \\
\hline 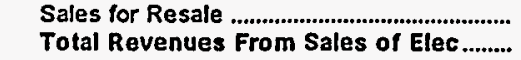 & $\begin{array}{r}0 \\
29,050\end{array}$ & $\begin{array}{r}0 \\
27,612\end{array}$ & $\begin{array}{r}0 \\
10,506\end{array}$ & $\begin{array}{r}0 \\
6,981\end{array}$ & $\begin{array}{r}0 \\
21,866\end{array}$ & $\begin{array}{r}0 \\
22,545\end{array}$ \\
\hline
\end{tabular}

Note: Totals may not equal sum of components because of independent rounding.

Source: Energy Intormation Administration, Form EIA-861. "Annual Electric Utility Report." Data are submitted on a calendar year. 
Table 25. Number of Consumers, Sales, and Operating Revenue by Major U.S. Publicly Owned Electric Utility Within State, 1995 (Continued)

\begin{tabular}{|c|c|c|c|c|c|c|}
\hline Item & $\begin{array}{c}\text { Tennessee } \\
\text { Greeneville } \\
\text { City of } \\
\text { June } 30\end{array}$ & $\begin{array}{l}\text { Tennessee } \\
\text { Harriman } \\
\text { City of } \\
\text { June } 30\end{array}$ & $\begin{array}{l}\text { Tennessee } \\
\text { Humboldt } \\
\text { City of } \\
\text { June } 30\end{array}$ & $\begin{array}{l}\text { Tennessee } \\
\text { Jackson } \\
\text { City of } \\
\text { June } 30\end{array}$ & $\begin{array}{l}\text { Tennessee } \\
\text { Johnson } \\
\text { City City of } \\
\text { June } 30\end{array}$ & $\begin{array}{l}\text { Tennessee } \\
\text { Knoxville } \\
\text { Utilities } \\
\text { Board } \\
\text { June } 30\end{array}$ \\
\hline \multicolumn{7}{|l|}{ Number of Consumers } \\
\hline 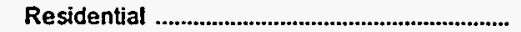 & 25,431 & 9,188 & 3,931 & 22,758 & 49,882 & 141,503 \\
\hline $\begin{array}{l}\text { Commercial or Small } \\
\text { Industrial or Large }\end{array}$ & $\begin{array}{r}4,638 \\
351\end{array}$ & $\begin{array}{r}1,106 \\
111\end{array}$ & $\begin{array}{r}676 \\
95\end{array}$ & $\begin{array}{r}3,656 \\
781\end{array}$ & $\begin{array}{r}6,510 \\
712\end{array}$ & $\begin{array}{r}15,775 \\
2,401\end{array}$ \\
\hline $\begin{array}{l}\text { Other } \\
\text { Total Uitimate Consumers } \\
\text { Sales for the Year (megawatthours) }\end{array}$ & $\begin{array}{r}81 \\
30,501\end{array}$ & $\begin{array}{r}103 \\
10,508\end{array}$ & $\begin{array}{r}11 \\
4,713\end{array}$ & $\begin{array}{r}231 \\
27,426\end{array}$ & $\begin{array}{r}475 \\
57,579\end{array}$ & $\begin{array}{r}1,214 \\
160,893\end{array}$ \\
\hline 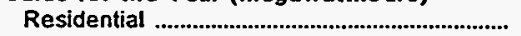 & 368,045 & 120,844 & 50,006 & 293,527 & 724,197 & 2044,548 \\
\hline Commercial or Small & 56,797 & 15,305 & 11,698 & 79,465 & 114,952 & 328,706 \\
\hline Industrial or Large & 468,519 & 134,042 & 169,482 & 891,174 & 690,784 & $2,278,960$ \\
\hline Other Total to Ultimate Consumers & $\begin{array}{r}9,131 \\
902,492\end{array}$ & $\begin{array}{r}3,914 \\
274,105\end{array}$ & $\begin{array}{r}3,090 \\
234,276\end{array}$ & $\begin{array}{r}13,699 \\
1,277,865\end{array}$ & $\begin{array}{r}15,871 \\
1,545,804\end{array}$ & $\begin{array}{r}53,555 \\
4,703,769\end{array}$ \\
\hline 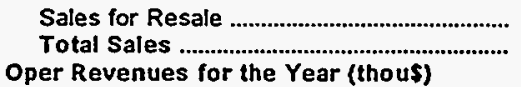 & $\begin{array}{r}0 \\
902,492\end{array}$ & $\begin{array}{r}0 \\
274,105\end{array}$ & $\begin{array}{r}0 \\
234,276\end{array}$ & $\begin{array}{r}0 \\
1,277,865\end{array}$ & $\begin{array}{r}0 \\
1,545,804\end{array}$ & $\begin{array}{r}0 \\
4,703,769\end{array}$ \\
\hline 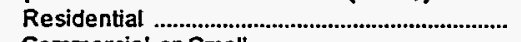 & 20,091 & 7,867 & 2,726 & 17,341 & 40,045 & 120,737 \\
\hline Commercial or Small & 3,645 & 1,171 & 717 & 5,211 & 7,210 & - 21,911 \\
\hline Industrial or Large & 19.973 & 5,538 & 7,976 & 42,104 & 33,938 & 111.220 \\
\hline Other & 887 & 346 & 227 & 1,403 & 1,445 & 4,618 \\
\hline 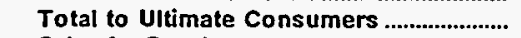 & 44,596 & 14,922 & 11,646 & 66,059 & 82,638 & 258,486 \\
\hline Sales for Resale & & 0 & & 0 & & \\
\hline Total Revenues From Sales of Elec......... & 44,596 & 14,922 & 11,646 & 66,059 & 82,638 & 258,486 \\
\hline
\end{tabular}

\begin{tabular}{|c|c|c|c|c|c|c|}
\hline Item & $\begin{array}{c}\text { Tennessee } \\
\text { Lawrenceburg } \\
\text { City of } \\
\text { June } 30\end{array}$ & $\begin{array}{l}\text { Tennessee } \\
\text { LaFollette } \\
\text { City of } \\
\text { June } 30\end{array}$ & $\begin{array}{l}\text { Tennessee } \\
\text { Lebanon } \\
\text { City of } \\
\text { June } 30\end{array}$ & $\begin{array}{l}\text { Tennessee } \\
\text { Lenoir } \\
\text { City City of } \\
\text { June } 30\end{array}$ & $\begin{array}{l}\text { Tennessee } \\
\text { Lewisburg } \\
\text { City of } \\
\text { June } 30\end{array}$ & $\begin{array}{l}\text { Tennessee } \\
\text { Lexington } \\
\text { Clty of } \\
\text { June } 30\end{array}$ \\
\hline \multicolumn{7}{|l|}{ Number of Consumers } \\
\hline 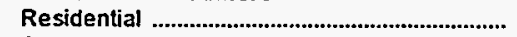 & 15,017 & 15,665 & 6,493 & 33,437 & 4,023 & 15,293 \\
\hline 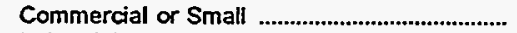 & 2,282 & 2,025 & 1,371 & 5,742 & 958 & 2,822 \\
\hline Industrial or Large & 226 & 239 & 255 & 603 & 134 & 202 \\
\hline Other Total Ultimate Consumers & $\begin{array}{r}75 \\
17,600\end{array}$ & $\begin{array}{r}59 \\
17,988\end{array}$ & $\begin{array}{r}22 \\
8,141\end{array}$ & $\begin{array}{r}71 \\
39,853\end{array}$ & $\begin{array}{r}52 \\
5,167\end{array}$ & $\begin{array}{r}87 \\
18,404\end{array}$ \\
\hline \multicolumn{7}{|l|}{ Sales for the Year (megawatthours) } \\
\hline 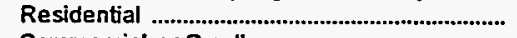 & 204,598 & 197,439 & 91,725 & 549,891 & 54,338 & 183,257 \\
\hline Commercial or Small & 32.288 & 25,193 & 30.858 & 83,893 & 16,208 & 30,202 \\
\hline 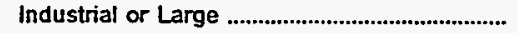 & 209,364 & 106,992 & 221,348 & 379,108 & 209,781 & 164,785 \\
\hline $\begin{array}{l}\text { Other } \\
\text { Total to Ultimate Consumers }\end{array}$ & $\begin{array}{r}5,638 \\
451,888\end{array}$ & $\begin{array}{r}4,447 \\
334,071\end{array}$ & $\begin{array}{r}6,223 \\
350,154\end{array}$ & $\begin{array}{r}9,159 \\
1,022,051\end{array}$ & $\begin{array}{r}3,645 \\
283,972\end{array}$ & $\begin{array}{r}7,794 \\
386,038\end{array}$ \\
\hline $\begin{array}{l}\text { Sales for Resale } \\
\text { Total Sales }\end{array}$ & $\begin{array}{r}401,000 \\
0 \\
451,888\end{array}$ & $\begin{array}{r}0 \\
334,071\end{array}$ & $\begin{array}{r}0 \\
350,154\end{array}$ & $\begin{array}{r}0 \\
0 \\
1,022,051\end{array}$ & $\begin{array}{r}0 \\
083,972\end{array}$ & $\begin{array}{r}0 \\
0\end{array}$ \\
\hline \multicolumn{7}{|l|}{ Oper Revenues for the Year (thou\$) } \\
\hline $\begin{array}{l}\text { Residential } \\
\text { Commercial or Small }\end{array}$ & $\begin{array}{r}11,798 \\
2,165\end{array}$ & $\begin{array}{r}11,881 \\
1,772\end{array}$ & $\begin{array}{l}5,307 \\
1,956\end{array}$ & $\begin{array}{r}32,224 \\
5,761\end{array}$ & $\begin{array}{l}3,170 \\
1,086\end{array}$ & $\begin{array}{r}11,031 \\
2,158\end{array}$ \\
\hline Industrial or Large & 10,021 & 6,163 & $\begin{array}{r}1,956 \\
11,106\end{array}$ & $\begin{array}{r}5,161 \\
20,883\end{array}$ & $\begin{array}{r}1,086 \\
10,086\end{array}$ & $\begin{array}{l}2,158 \\
9,137\end{array}$ \\
\hline Other & 420 & 364 & 430 & 722 & 300 & 653 \\
\hline Total to Ultimate Consumers ........................ & 24,404 & 20,180 & 18,799 & $\mathbf{5 9}, \mathbf{5 9 0}$ & 14,642 & 22,979 \\
\hline Sales for Resale & & & 0 & & & \\
\hline Total Revenues From Sales of Elec......... & 24,404 & 20,180 & 18,799 & 59,590 & 14,642 & 22,979 \\
\hline
\end{tabular}

Note: Totals may not equal sum of components because of independent rounding.

Source: Energy Information Administration, Form ElA-861, "Annual Electric Utility Report." Data are submitted on a calendar year. 
Table 25. Number of Consumers, Sales, and Operating Revenue by Major U.S. Publicly Owned Electric Utility Within State, 1995 (Continued)

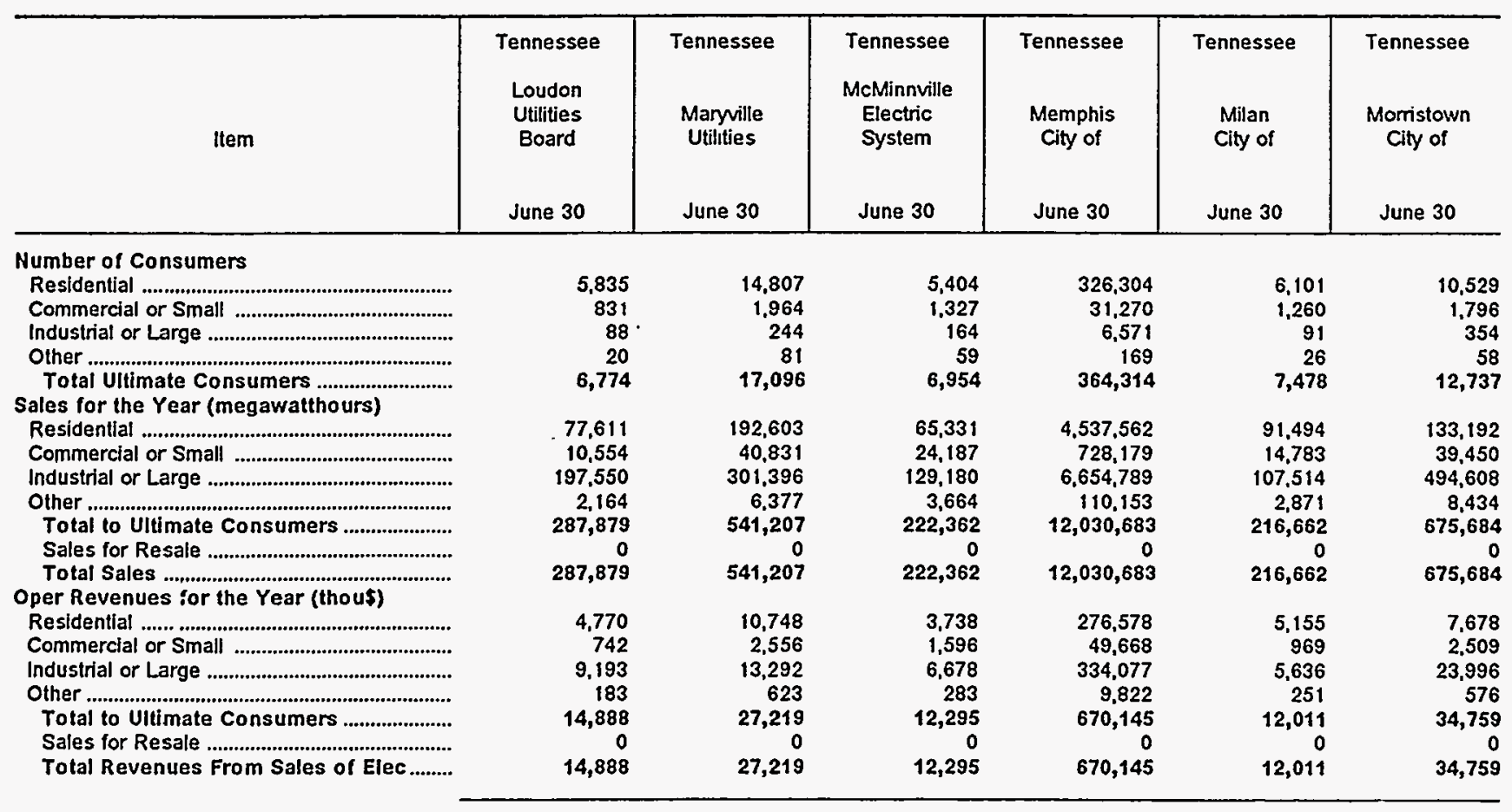

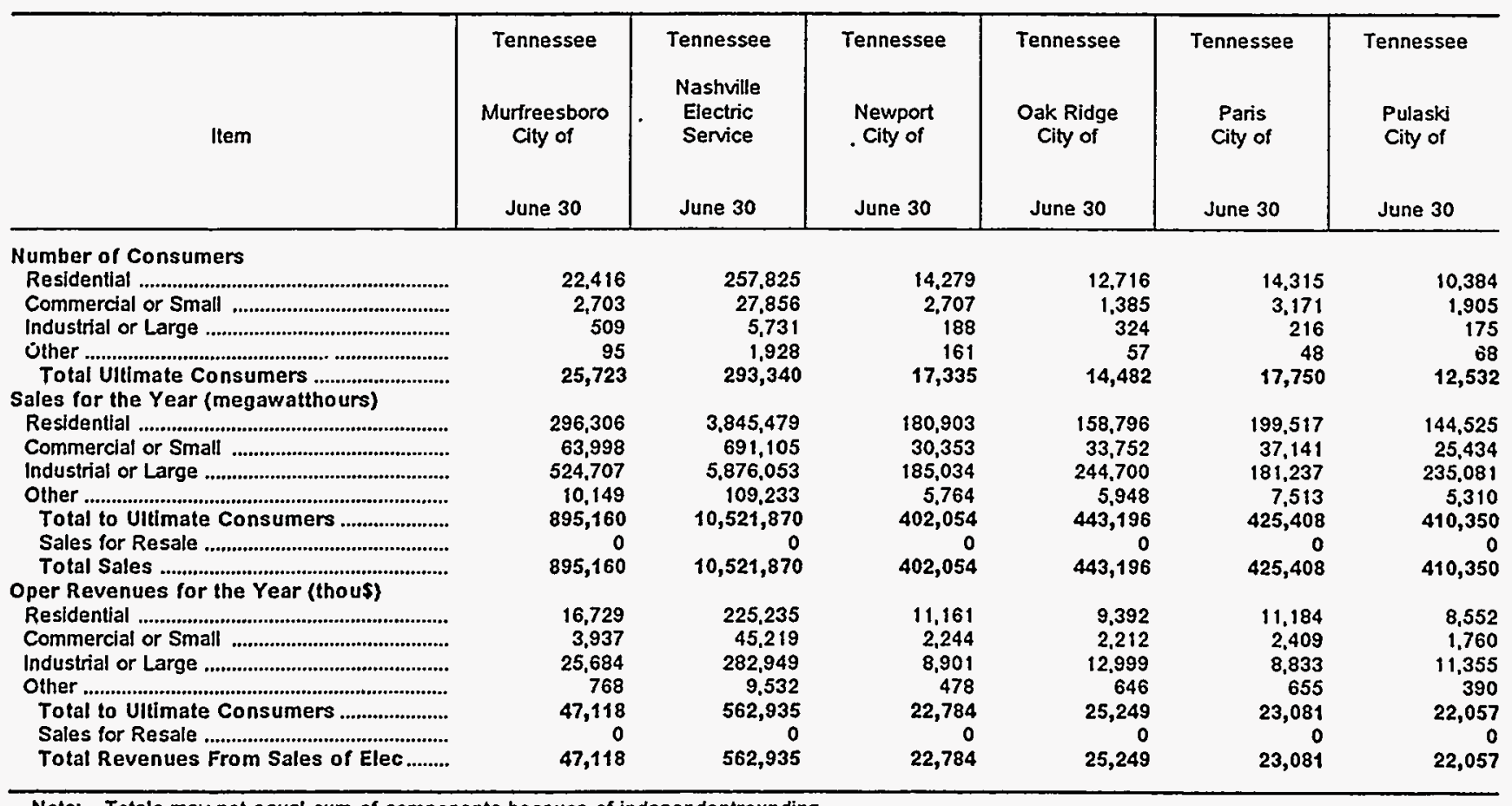

Note: Totals may not equal sum of components because of independentrounding.

Source: Energy Information Administration, Form ElA-861, "Annual Electric Utility Report." Data are submitted on a calendar year. 
Table 25. Number of Consumers, Sales, and Operating Revenue by Major U.S. Publicly Owned Electric Utility Within State, 1995 (Continued)

\begin{tabular}{|c|c|c|c|c|c|c|}
\hline Item & $\begin{array}{l}\text { Tennessee } \\
\text { Ripley } \\
\text { City of } \\
\text { June } 30\end{array}$ & $\begin{array}{l}\text { Tennessee } \\
\text { Rockwood } \\
\text { City of } \\
\text { June } 30\end{array}$ & $\begin{array}{c}\text { Tennessee } \\
\text { Sevier } \\
\text { County } \\
\text { Electric } \\
\text { System } \\
\text { June } 30\end{array}$ & $\begin{array}{l}\text { Shelbyville } \\
\text { City of } \\
\text { June } 30\end{array}$ & $\begin{array}{c}\text { Springfield } \\
\text { City of } \\
\text { June } 30\end{array}$ & $\begin{array}{c}\text { Tennessee } \\
\text { Sweetwater } \\
\text { City of } \\
\text { June } 30\end{array}$ \\
\hline \multicolumn{7}{|l|}{ Number of Consumers } \\
\hline 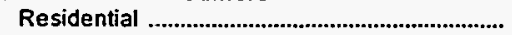 & 5,394 & 10,160 & 26,061 & 6,400 & 5,189 & 5,481 \\
\hline 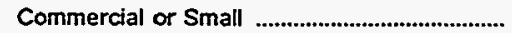 & 1,103 & 1,622 & 5,876 & 931 & 805 & 1.253 \\
\hline Industrial or Large & 109 & 136 & 812 & 179 & 149 & 106 \\
\hline $\begin{array}{l}\text { Other } \\
\text { Total Ultimate Consumers }\end{array}$ & $\begin{array}{r}82 \\
6,688\end{array}$ & $\begin{array}{r}35 \\
11,953\end{array}$ & $\begin{array}{r}308 \\
33,057\end{array}$ & $\begin{array}{r}28 \\
7,538\end{array}$ & $\begin{array}{r}14 \\
6,157\end{array}$ & $\begin{array}{r}22 \\
6,862\end{array}$ \\
\hline \multicolumn{7}{|l|}{ Sales for the Year (megawatthours) } \\
\hline 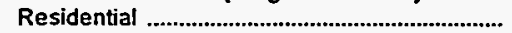 & 66,907 & 146,681 & 361,968 & 77,775 & 66,792 & 76,348 \\
\hline 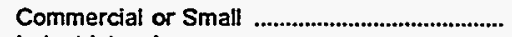 & 17,083 & 20,692 & 108,217 & 21,209 & 17,862 & 15,762 \\
\hline 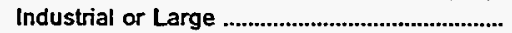 & 149.778 & 98,846 & 420,120 & 224,166 & 120,238 & 93,109 \\
\hline Other & 4,068 & 3,961 & 9,381 & 3,378 & 4,800 & 4,217 \\
\hline 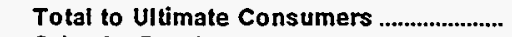 & 237,836 & 270,180 & 899,686 & 326,528 & 209,692 & 189,436 \\
\hline 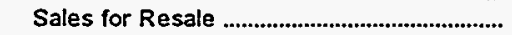 & 0 & 0 & 0 & 0 & 0 & 0 \\
\hline 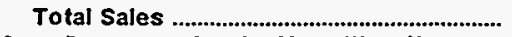 & 237,836 & 270,180 & 899,686 & 326,528 & 209,692 & 189,436 \\
\hline \multicolumn{7}{|l|}{ Oper Revenues for the Year (thou\$) } \\
\hline 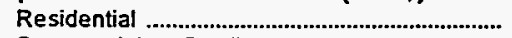 & 3,693 & 8,857 & 21,444 & 4,567 & 4,091 & 4,398 \\
\hline 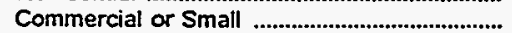 & 1,065 & 1,457 & 7,313 & 1,358 & 1,236 & 1,050 \\
\hline Industrial or Large & 7,647 & 4,945 & 22,503 & 11,146 & 6,213 & 4,656 \\
\hline Other & 311 & 352 & 608 & 278 & 360 & 316 \\
\hline 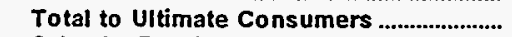 & 12,716 & 15,611 & 51,868 & 17,349 & 11,900 & 10,420 \\
\hline Sales for Resale & $\begin{array}{r}0 \\
12716\end{array}$ & $\begin{array}{r}0 \\
15,611\end{array}$ & $\begin{array}{r}0 \\
51868\end{array}$ & $\begin{array}{r}0 \\
349\end{array}$ & $\begin{array}{r}0 \\
0\end{array}$ & 年 \\
\hline & & 15,611 & 51,868 & 17,349 & 11,900 & 10,420 \\
\hline
\end{tabular}

\begin{tabular}{|c|c|c|c|c|c|c|}
\hline Item & $\begin{array}{c}\text { Tennessee } \\
\text { Tullahoma } \\
\text { Board } \\
\text { of } \\
\text { Pub Utils } \\
\text { June } 30\end{array}$ & $\begin{array}{c}\text { Tennessee } \\
\text { Union } \\
\text { City City of } \\
\text { June } 30\end{array}$ & $\begin{array}{l}\text { Tennessee } \\
\text { Weakley } \\
\text { County } \\
\text { Mun } \\
\text { Elec Sys } \\
\text { June } 30\end{array}$ & $\begin{array}{c}\text { Tennessee } \\
\text { Winchester } \\
\text { City of } \\
\text { June } 30\end{array}$ & $\begin{array}{l}\text { Texas } \\
\text { Austin } \\
\text { City of } \\
\text { September } 30\end{array}$ & $\begin{array}{c}\text { Brenham } \\
\text { Clty of }\end{array}$ \\
\hline \multicolumn{7}{|l|}{ Number of Consumers } \\
\hline 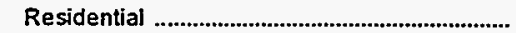 & 7,745 & 4,961 & 15,300 & 3,717 & 266,645 & 4,514 \\
\hline 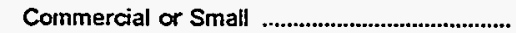 & 1,284 & 826 & 2,855 & 695 & 31,311 & 1,102 \\
\hline 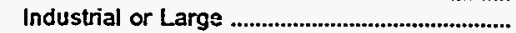 & 181 & 139 & 272 & 86 & 12 & 33 \\
\hline Other & 38 & 12 & 100 & 12 & 690 & 1 \\
\hline $\begin{array}{l}\text { Total UItimate Consumers } \\
\text { Sales for the Year (megavratthours) }\end{array}$ & 9,248 & 5,938 & 18,527 & 4,510 & 298,658 & 5,650 \\
\hline 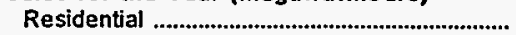 & 106,011 & 59,168 & 235.101 & 52,165 & $2,801,116$ & 62,930 \\
\hline $\begin{array}{l}\text { Commercial or Small } \\
\text { Industrial or Large }\end{array}$ & $\begin{array}{r}26,354 \\
121,458\end{array}$ & $\begin{array}{r}17,419 \\
275,594\end{array}$ & $\begin{array}{r}33,937 \\
170,586\end{array}$ & $\begin{array}{l}12,694 \\
71,345\end{array}$ & $\begin{array}{r}3,696,370 \\
906,682\end{array}$ & $\begin{array}{r}59,190 \\
139,071\end{array}$ \\
\hline 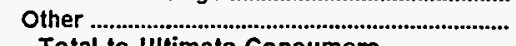 & 4,466 & 2,996 & 7,344 & 2,192 & 274.535 & 1,459 \\
\hline 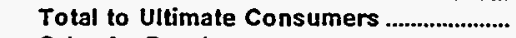 & 258,289 & 355,177 & 446,968 & 138,396 & $7,678,703$ & 262,650 \\
\hline 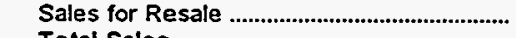 & 0 & 0 & 0 & 0 & 334,423 & \\
\hline \multicolumn{6}{|l|}{ Oper Revenues for the Year (thous) } & 262,650 \\
\hline 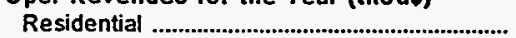 & 6,001 & 3,170 & 13,424 & 3,075 & 208,408 & 3,876 \\
\hline Commercial or Small & 1,658 & 1,015 & 2,261 & 843 & 245,417 & 3,074 \\
\hline 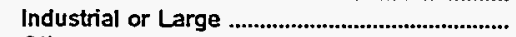 & 6,331 & 10,784 & 9,202 & 3,788 & 40,861 & 5,620 \\
\hline Other & 401 & 248 & 552 & 146 & 19.335 & 92 \\
\hline 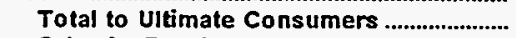 & 14,391 & 15,217 & 25,439 & 7,852 & 514,021 & 12,662 \\
\hline Sales for Resale & & & & & 7,101 & \\
\hline Total Revenues From Sales of Elec......... & 14,391 & 15,217 & 25,439 & 7,852 & 521,122 & 12,662 \\
\hline
\end{tabular}

Note: Totals may not equal sum of components because of independent rounding.

Source: Energy Information Administration. Form ElA-861, "Annual Electric Utility Report" Data are submitted on a calendar year. 
Table 25. Number of Consumers, Sales, and Operating Revenue by Major U.S. Publicly Owned Electric Utility Within State, 1995 (Continued)

\begin{tabular}{|c|c|c|c|c|c|c|}
\hline Item & $\begin{array}{c}\text { Texas } \\
\text { Brownsville } \\
\text { Public } \\
\text { Utils Board } \\
\text { September } 30\end{array}$ & $\begin{array}{c}\text { Texas } \\
\text { Bryan } \\
\text { City of } \\
\text { September } 30\end{array}$ & $\begin{array}{l}\text { Texas } \\
\text { College } \\
\text { Station } \\
\text { City of } \\
\text { September } 30\end{array}$ & $\begin{array}{l}\text { Texas } \\
\text { Denton } \\
\text { City of } \\
\text { September } 30\end{array}$ & $\begin{array}{c}\text { Texas } \\
\text { Floresville } \\
\text { City of } \\
\text { December } 31\end{array}$ & $\begin{array}{l}\text { Texas } \\
\text { Garland } \\
\text { City of } \\
\text { September } 30\end{array}$ \\
\hline \multicolumn{7}{|l|}{ Number of Consumers } \\
\hline 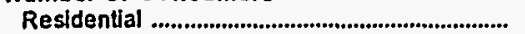 & 27,377 & 21,998 & 18,870 & 26,376 & 7,538 & 56,328 \\
\hline 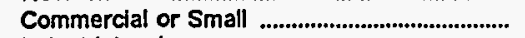 & 2,530 & 2,787 & 1,855 & 3,230 & 1,826 & 4,312 \\
\hline 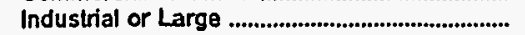 & 1,583 & 50 & 0 & 0 & 1 & 1,087 \\
\hline 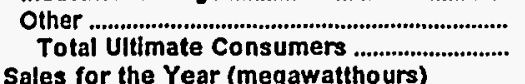 & $\begin{array}{r}0 \\
31,490\end{array}$ & $\begin{array}{r}252 \\
25,087\end{array}$ & $\begin{array}{r}0 \\
20,725\end{array}$ & $\begin{array}{r}1,261 \\
30,867\end{array}$ & $\begin{array}{r}1,708 \\
11,073\end{array}$ & $\begin{array}{r}2,296 \\
64,023\end{array}$ \\
\hline 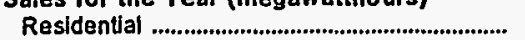 & 306,912 & 390,784 & 235.097 & 296,954 & 103,386 & 870,236 \\
\hline 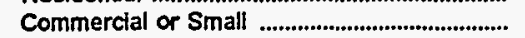 & 28,979 & 202,913 & 228,208 & 530,586 & 50,100 & 168,853 \\
\hline 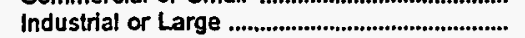 & 390.977 & 161,422 & 0 & 0 & 680 & 774,762 \\
\hline $\begin{array}{l}\text { Other } \\
\text { Total to Ultimate Consumers }\end{array}$ & $\begin{array}{r}0 \\
726,868\end{array}$ & $\begin{array}{r}48,337 \\
803,456\end{array}$ & $\begin{array}{r}0 \\
463,305\end{array}$ & $\begin{array}{r}39,587 \\
867,127\end{array}$ & $\begin{array}{r}1.511 \\
155,677\end{array}$ & $\begin{array}{r}13,796 \\
1,827,647\end{array}$ \\
\hline Sales for Resale & $\begin{array}{r}0 \\
726,868\end{array}$ & $\begin{array}{r}341,051 \\
1,144,507\end{array}$ & $\begin{array}{r}0 \\
463,305\end{array}$ & $\begin{array}{r}172,992 \\
1,040,119\end{array}$ & $\begin{array}{r}0 \\
155,677\end{array}$ & $\begin{array}{r}470,200 \\
2,297,847\end{array}$ \\
\hline \multicolumn{7}{|l|}{ Oper Revenues for the Year (thous) } \\
\hline $\begin{array}{l}\text { Residential } \\
\text { Commerclal or Small }\end{array}$ & $\begin{array}{r}19,791 \\
2,467\end{array}$ & $\begin{array}{l}29,202 \\
15,788\end{array}$ & $\begin{array}{l}17.611 \\
15.133\end{array}$ & $\begin{array}{l}22,442 \\
31,315\end{array}$ & $\begin{array}{l}6.848 \\
3,368\end{array}$ & $\begin{array}{r}63,281 \\
9,309\end{array}$ \\
\hline 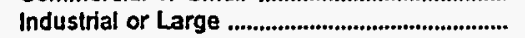 & 22,759 & 9.065 & 0 & 0 & 47 & 39,805 \\
\hline 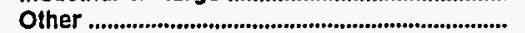 & 0 & 3,479 & 0 & 3,094 & 263 & 382 \\
\hline Total to Ultimate Consumers & 45,017 & 57,534 & 32,744 & 56,851 & 10,526 & 112,777 \\
\hline 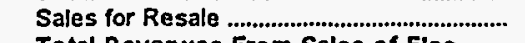 & & 14,107 & & 5,394 & 0 & 11,488 \\
\hline Total Revenues From Sales of Elec......... & 45,017 & 71,641 & 32,744 & 62,245 & 10,526 & 124,265 \\
\hline
\end{tabular}

\begin{tabular}{|c|c|c|c|c|c|c|}
\hline Item & $\begin{array}{c}\text { Texas } \\
\text { Georgetown } \\
\text { City of } \\
\text { September } 30\end{array}$ & $\begin{array}{l}\text { Texas } \\
\text { Greenville } \\
\text { Electric } \\
\text { Util Sys } \\
\text { September } 30\end{array}$ & $\begin{array}{c}\text { Texas } \\
\text { Jasper } \\
\text { City of } \\
\text { September } 30\end{array}$ & $\begin{array}{l}\text { Texas } \\
\text { Kernille } \\
\text { Publlc } \\
\text { Utility } \\
\text { Board } \\
\text { September } 30\end{array}$ & $\begin{array}{l}\text { Texas } \\
\text { Lower } \\
\text { Colorado } \\
\text { River } \\
\text { Authority } \\
\text { June } 30\end{array}$ & $\begin{array}{l}\text { Texas } \\
\text { Lubbock } \\
\text { City of } \\
\text { September } 30\end{array}$ \\
\hline \multicolumn{7}{|l|}{ Number of Consumers } \\
\hline 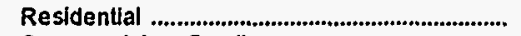 & 7,225 & 9,777 & 3,602 & 14,479 & 4 & 43.837 \\
\hline 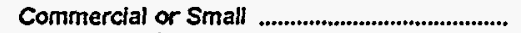 & 1,080 & 991 & 860 & 2,825 & 9 & 5,393 \\
\hline 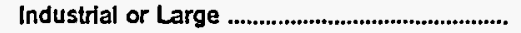 & 45 & 3 & 45 & 0 & 12 & 81 \\
\hline 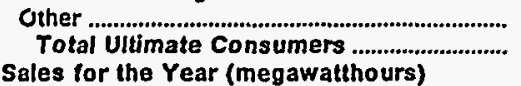 & $\begin{array}{r}134 \\
8,484\end{array}$ & $\begin{array}{r}531 \\
11,302\end{array}$ & $\begin{array}{r}0 \\
4,507\end{array}$ & $\begin{array}{r}142 \\
17,446\end{array}$ & $\begin{array}{r}0 \\
25\end{array}$ & $\begin{array}{r}894 \\
50,205\end{array}$ \\
\hline 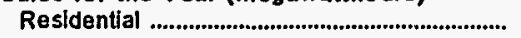 & 97,605 & 106,888 & 44.596 & 190,045 & 44 & 392,829 \\
\hline $\begin{array}{l}\text { Commerclal or Small } \\
\text { Industrial or Large }\end{array}$ & $\begin{array}{l}49,780 \\
33,903\end{array}$ & $\begin{array}{r}262,499 \\
56,602\end{array}$ & $\begin{array}{l}24,700 \\
61,532\end{array}$ & $\begin{array}{r}164,376 \\
0\end{array}$ & $\begin{array}{r}918 \\
175,697\end{array}$ & $\begin{array}{l}222,970 \\
241,630\end{array}$ \\
\hline Other & $\begin{array}{r}1,646 \\
182,934\end{array}$ & $\begin{array}{r}2,021 \\
428,010\end{array}$ & $\begin{array}{r}0 \\
130,828\end{array}$ & $\begin{array}{r}6,269 \\
360,690\end{array}$ & $\begin{array}{r}0 \\
176,659\end{array}$ & $\begin{array}{l}132,652 \\
990,081\end{array}$ \\
\hline $\begin{array}{l}\text { Sales for Resale } \\
\text { Total Sales } \\
\text { Oper Revenues for the Year (thou\$) }\end{array}$ & $\begin{array}{r}0 \\
182,934\end{array}$ & $\begin{array}{r}47,356 \\
475,366\end{array}$ & $\begin{array}{r}0 \\
130,828\end{array}$ & $\begin{array}{r}0 \\
360,690\end{array}$ & $\begin{array}{l}9,739,693 \\
9,916,352\end{array}$ & $\begin{array}{r}0 \\
990,081\end{array}$ \\
\hline 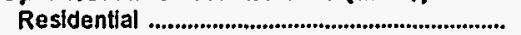 & 6,937 & 8,069 & 4,355 & 12,545 & 3 & 24,106 \\
\hline 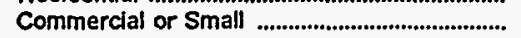 & 3,491 & 15,031 & 2,544 & 9,838 & 54 & 12,341 \\
\hline Industrial or Large & 1,718 & 2,493 & 5,282 & 0 & 6,600 & 10,500 \\
\hline Other & 175 & 252 & 0 & 319 & 0 & 6,478 \\
\hline Total to Ultimate Consumers ....................... & 12,321 & 25,845 & 12,181 & 22,702 & 6,657 & 53,425 \\
\hline 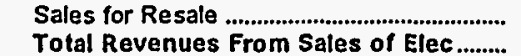 & $\begin{array}{r}0 \\
12,321\end{array}$ & $\begin{array}{r}2,420 \\
28,265\end{array}$ & $\begin{array}{r}0 \\
12,181\end{array}$ & $\begin{array}{r}0 \\
22,702\end{array}$ & $\begin{array}{l}379.160 \\
385,817\end{array}$ & $\begin{array}{r}0 \\
53,425\end{array}$ \\
\hline
\end{tabular}

Note: Tolals may not equal sum of components because of independent rounding.

Source: Energy Information Administration, Form ElA-861, "Annual Electric Utility Report" Data are submitted on a calendar year. 
Table 25. Number of Consumers, Sales, and Operating Revenue by Major U.S. Publicly Owned Electric Utility Within State, 1995 (Continued)

\begin{tabular}{|c|c|c|c|c|c|c|}
\hline Item & $\begin{array}{c}\text { Texas } \\
\begin{array}{c}\text { New Braunfels } \\
\text { City of }\end{array} \\
\text { July } 31\end{array}$ & $\begin{array}{c}\text { Texas } \\
\text { Sam Rayburn } \\
\text { Municipal } \\
\text { Pwr } \\
\text { Agny } \\
\text { September } 30\end{array}$ & $\begin{array}{c}\text { Texas } \\
\text { San Antonio } \\
\text { Public } \\
\text { Service Bd } \\
\text { January } 31\end{array}$ & $\begin{array}{c}\text { Texas } \\
\text { San Marcos } \\
\text { City of } \\
\text { September } 30\end{array}$ & $\begin{array}{c}\text { Seguin } \\
\text { City of } \\
\text { September } 30\end{array}$ & $\begin{array}{c}\text { Texas } \\
\text { Texas } \\
\text { Municipal } \\
\text { Power Agency } \\
\text { September } 30\end{array}$ \\
\hline \multicolumn{7}{|l|}{ Number of Consumers } \\
\hline 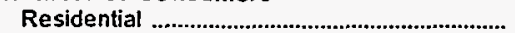 & 16,612 & 0 & 456,461 & 11,426 & 6,405 & 0 \\
\hline 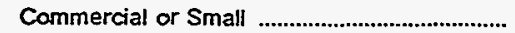 & 2,562 & 0 & 50,988 & 2,260 & 1,087 & 0 \\
\hline Industrial or Large & 12 & 0 & 1,465 & 8 & 7 & 0 \\
\hline Other & 212 & 0 & 5,043 & 110 & 53 & 0 \\
\hline \multicolumn{6}{|l|}{ Sales for the Year (megawatthours) } & 0 \\
\hline 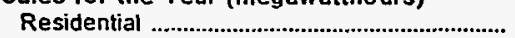 & 223,623 & 0 & $5,612,151$ & 127,629 & 72,815 & 0 \\
\hline Commercial or Small & 160,832 & 0 & $2,237,334$ & 127,791 & 75,258 & 0 \\
\hline Industrial or Large & 380,283 & 0 & $3,863,519$ & 61,256 & 55,953 & 0 \\
\hline Other & 28.811 & 0 & $1,933,832$ & 8,819 & 7,311 & 0 \\
\hline Total to Ultimate Consumers .......................... & 793,549 & $\mathbf{0}$ & $13,646,836$ & 325,495 & 211,337 & 0 \\
\hline Sales for Resale & 0 & 698.574 & 608,454 & 0 & 0 & $2,665,381$ \\
\hline Total Sales & 793,549 & 698,574 & $14,255,290$ & 325,495 & 211,337 & $2,665,381$ \\
\hline \multicolumn{7}{|l|}{ Oper Revenues for the Year (thou\$) } \\
\hline 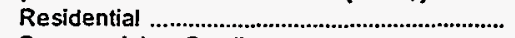 & 12,843 & $\mathbf{0}$ & 361,202 & 8,600 & 4,935 & 0 \\
\hline Commercial or Small & 9,652 & 0 & 134,728 & 7.990 & 4,725 & 0 \\
\hline Industrial or Large & 15,167 & 0 & 170,504 & 3,388 & 2,845 & 0 \\
\hline 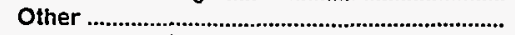 & 1,725 & 0 & 89,713 & 558 & 457 & 0 \\
\hline 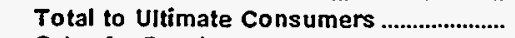 & 39,387 & 0 & 756,147 & 20,536 & 12,962 & 0 \\
\hline Sales for Resale & & 30,394 & 15.547 & 0 & 0 & 144,061 \\
\hline Total Revenues From Sales of Elec......... & 39,387 & 30,394 & 771,694 & 20,536 & 12,962 & 144,061 \\
\hline
\end{tabular}

\begin{tabular}{|c|c|c|c|c|c|c|}
\hline Item & $\begin{array}{l}\text { Texas } \\
\text { Toledo Bend } \\
\text { Project } \\
\text { Joint } \\
\text { Oper } \\
\text { August } 30\end{array}$ & $\begin{array}{c}\text { Texas } \\
\text { Weatherford } \\
\text { Mun } \\
\text { Utility } \\
\text { System } \\
\text { September } 30\end{array}$ & $\begin{array}{c}\text { Utah } \\
\text { Bountiful } \\
\text { City City of } \\
\text { June } 30\end{array}$ & $\begin{array}{c}\text { Utah } \\
\text { Intermountain } \\
\text { Power Agency } \\
\text { June } 30\end{array}$ & $\begin{array}{l}\text { Utah } \\
\text { Logan } \\
\text { City of } \\
\text { June } 30\end{array}$ & $\begin{array}{l}\text { Utah } \\
\text { Murray } \\
\text { City of } \\
\text { June } 30\end{array}$ \\
\hline \multicolumn{7}{|l|}{ Number of Consumers } \\
\hline 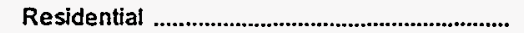 & 0 & 7,204 & 12,146 & 0 & 12,237 & 12,412 \\
\hline 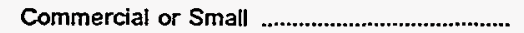 & 0 & 1,045 & 1,021 & 0 & 1.573 & 2,359 \\
\hline Industrial or Large & 0 & 0 & 1 & 0 & 0 & 0 \\
\hline Other & 0 & 201 & 267 & 0 & 2 & 271 \\
\hline Total Ultimate Consumers & 0 & 8,450 & 13,435 & 0 & 13,812 & 15,042 \\
\hline \multicolumn{7}{|l|}{ Sales for the Year (megawatthours) } \\
\hline 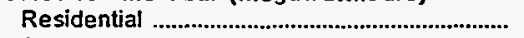 & 0 & 91,098 & 106,712 & 0 & 70.984 & 93,225 \\
\hline 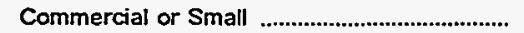 & 0 & 107.382 & 50,602 & 0 & 180,884 & 208,923 \\
\hline Industrial or Large & 0 & 0 & 53,320 & 0 & 0 & 0 \\
\hline Other & 0 & 20.482 & 33,078 & 0 & 54,676 & 8,495 \\
\hline Total to UItimate Consumers ........................ & 0 & 218,962 & 243,712 & $\mathbf{0}$ & 306,544 & 310,643 \\
\hline Sales for Resale & 363,856 & 0 & 0 & $10,648,021$ & 0 & 0 \\
\hline Total Sales & 363,856 & 218,962 & 243,712 & $10,648,021$ & 306,544 & 310,643 \\
\hline \multicolumn{7}{|l|}{ Oper Revenues for the Year (thou\$) } \\
\hline 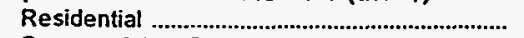 & 0 & 6,305 & 6,065 & 0 & 4,807 & 6,016 \\
\hline Commercial or Small & 0 & 7,008 & 2,670 & 0 & 9,812 & 12,525 \\
\hline 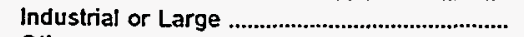 & 0 & 0 & 1,637 & 0 & 0 & 0 \\
\hline Other & 0 & 1,394 & 1,962 & 0 & 2,487 & 386 \\
\hline 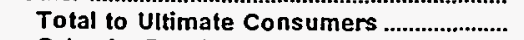 & $\mathbf{0}$ & 14,707 & 12,334 & 0 & 17,106 & 18,927 \\
\hline Sales for Resale & 7,277 & 0 & 0 & 642,662 & 0 & \\
\hline Total Revenues From Sales of Elec........ & 7,277 & 14,707 & 12,334 & 642,662 & 17,106 & 18,927 \\
\hline
\end{tabular}

Note: Totals may not equal sum of components because of independent rounding.

Source: Energy Information Administration, Form EIA-861. "Annual Electric Utility Report" Data are submitted on a calendar year. 
Table 25. Number of Consumers, Sales, and Operating Revenue by Major U.S. Publicly Owned Electric Utility Within State, 1995 (Continued)

\begin{tabular}{|c|c|c|c|c|c|c|}
\hline Item & $\begin{array}{l}\text { Utah } \\
\text { Provo } \\
\text { City Corp } \\
\text { June } 30\end{array}$ & $\begin{array}{c}\text { St George } \\
\text { City of } \\
\text { June } 30\end{array}$ & $\begin{array}{c}\text { Utah } \\
\text { Utah } \\
\text { Associated } \\
\text { Mun } \\
\text { Power Sys } \\
\text { March } 31\end{array}$ & $\begin{array}{c}\text { Utah } \\
\text { Utah } \\
\text { Municipal } \\
\text { Power Agency } \\
\text { June } 30\end{array}$ & $\begin{array}{l}\text { Burlington } \\
\text { City of } \\
\text { June } 30\end{array}$ & $\begin{array}{l}\text { Vermont } \\
\text { Vermont } \\
\text { Public } \\
\text { Pwr } \\
\text { Supply Auth } \\
\text { December } 31\end{array}$ \\
\hline \multicolumn{7}{|l|}{ Number of Consumers } \\
\hline 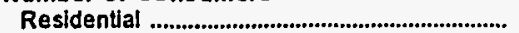 & 23,950 & 12,639 & 0 & 0 & 15,348 & 0 \\
\hline 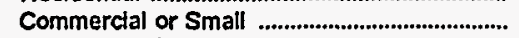 & $\mathbf{3 , 3 2 9}$ & 2,408 & 0 & 0 & 2,849 & 0 \\
\hline 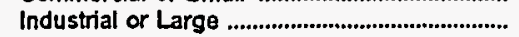 & 1 & 0 & 0 & 0 & 710 & 0 \\
\hline 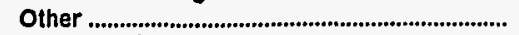 & 0 & 1 & 0 & 0 & 1 & 0 \\
\hline \multicolumn{7}{|l|}{ Sates for the Year (megawatthours) } \\
\hline 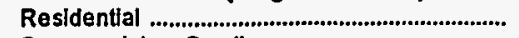 & 170,499 & 155,313 & 0 & 0 & 86.893 & 0 \\
\hline 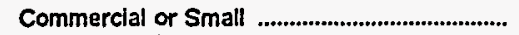 & 290,941 & 170,827 & 0 & 0 & 20,453 & 0 \\
\hline 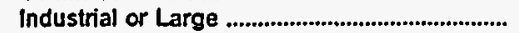 & 112,397 & 0 & 0 & 0 & 213,256 & 0 \\
\hline Other & 0 & 14,002 & 0 & 0 & 3,536 & 0 \\
\hline Total to Ultimate Consumers ...................... & 573,837 & 340,142 & 0 & 0 & 324,138 & $\mathbf{0}$ \\
\hline $\begin{array}{l}\text { Sales for Resale } \\
\text { Total Sales } \\
\text { Oper Revenues for the Year (thous) }\end{array}$ & $\begin{array}{r}0 \\
573,837\end{array}$ & $\begin{array}{r}0 \\
340,142\end{array}$ & $\begin{array}{l}1,901,477 \\
1,901,477\end{array}$ & $\begin{array}{l}836,004 \\
836,004\end{array}$ & $\begin{array}{l}106,743 \\
430,881\end{array}$ & $\begin{array}{r}126,697 \\
126,697\end{array}$ \\
\hline 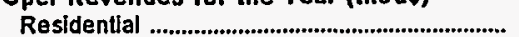 & 12,364 & 8,273 & 0 & 0 & 7.916 & 0 \\
\hline Commercial or Small & 18,167 & 9,531 & 0 & 0 & 2,896 & 0 \\
\hline 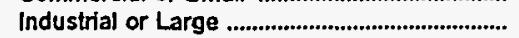 & 5,370 & 0 & 0 & 0 & 24,216 & 0 \\
\hline Other & 0 & 726 & 0 & 0 & 402 & 0 \\
\hline Tatal to UItimate Consumers ...................... & 35,901 & 18,530 & 0 & 0 & 35,430 & o \\
\hline 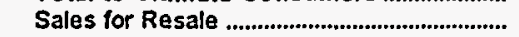 & 0 & 0 & 48,402 & 31,726 & 5,484 & 7,972 \\
\hline Total Revenues From Sales of Elec........ & 35,901 & 18,530 & 48,402 & 31,726 & 40,914 & 7,972 \\
\hline
\end{tabular}

\begin{tabular}{|c|c|c|c|c|c|c|}
\hline Item & $\begin{array}{l}\text { Virginia } \\
\text { Bedford } \\
\text { City of } \\
\text { June } 30\end{array}$ & $\begin{array}{l}\text { Virginia } \\
\text { Bristol } \\
\text { Utilities } \\
\text { Board } \\
\text { June } 30\end{array}$ & $\begin{array}{l}\text { Virginia } \\
\text { Danville } \\
\text { City of } \\
\text { June } 30\end{array}$ & $\begin{array}{l}\text { Virginia } \\
\begin{array}{c}\text { Harrisonburg } \\
\text { City of }\end{array} \\
\text { June } 30\end{array}$ & $\begin{array}{l}\text { Virginia } \\
\begin{array}{c}\text { Manassas } \\
\text { City of }\end{array} \\
\text { June } 30\end{array}$ & $\begin{array}{l}\text { Virginia } \\
\begin{array}{c}\text { Martinsville } \\
\text { City of }\end{array} \\
\text { June } 30\end{array}$ \\
\hline \multicolumn{7}{|l|}{ Number of Consumers } \\
\hline 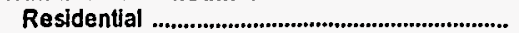 & 5,717 & 12,774 & 29,659 & 11,940 & 11.462 & 7,856 \\
\hline 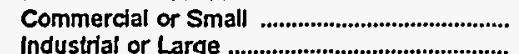 & $\begin{array}{r}800 \\
28\end{array}$ & $\begin{array}{r}1,743 \\
279\end{array}$ & $\begin{array}{r}3,590 \\
74\end{array}$ & 2,125 & $\begin{array}{r}1.767 \\
70\end{array}$ & 214 \\
\hline 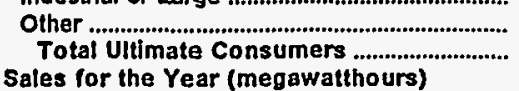 & $\begin{array}{r}0 \\
6,545\end{array}$ & $\begin{array}{r}26 \\
14,822\end{array}$ & $\begin{array}{r}4,532 \\
37,855\end{array}$ & $\begin{array}{r}145 \\
14,221\end{array}$ & $\begin{array}{r}1 \\
13,300\end{array}$ & $\begin{array}{r}143 \\
8,220\end{array}$ \\
\hline 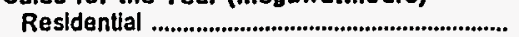 & 65,156 & 177.122 & 431,146 & 126,067 & 117,703 & 91,464 \\
\hline $\begin{array}{l}\text { Commercial or Small } \\
\text { industrial or Large }\end{array}$ & $\begin{array}{r}30,308 \\
107,474\end{array}$ & $\begin{array}{r}30,917 \\
307,390\end{array}$ & $\begin{array}{l}237,166 \\
107,347\end{array}$ & $\begin{array}{l}228,627 \\
132,541\end{array}$ & $\begin{array}{l}98,575 \\
51,606\end{array}$ & $\begin{array}{l}68,567 \\
21,147\end{array}$ \\
\hline Other & $\begin{array}{r}0 \\
202,938\end{array}$ & $\begin{array}{r}6,715 \\
522,144\end{array}$ & $\begin{array}{r}51,430 \\
827,089\end{array}$ & $\begin{array}{r}65,915 \\
553,150\end{array}$ & $\begin{array}{r}1,422 \\
269,306\end{array}$ & $\begin{array}{r}11,869 \\
193,047\end{array}$ \\
\hline 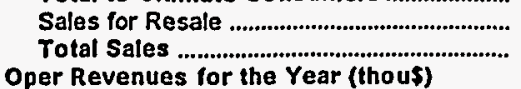 & $\begin{array}{r}0 \\
202,938\end{array}$ & $\begin{array}{r}0 \\
522,144\end{array}$ & $\begin{array}{r}0 \\
827,089\end{array}$ & $\begin{array}{r}0 \\
553,150\end{array}$ & 269,306 & $\begin{array}{r}0 \\
193,047\end{array}$ \\
\hline Residential .................................................... & $\begin{array}{l}4,175 \\
1903\end{array}$ & $\begin{array}{r}10,088 \\
1965\end{array}$ & 24,672 & $\begin{array}{r}8.182 \\
14.009\end{array}$ & 9.412 & 5,566 \\
\hline Industrial or Large & 5,312 & 12,603 & $\begin{array}{r}1,920 \\
4,884\end{array}$ & $\begin{array}{r}19,003 \\
7,033\end{array}$ & 3,789 & $\begin{array}{l}3,289 \\
1,007\end{array}$ \\
\hline 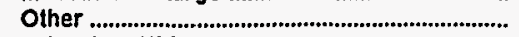 & 0 & 566 & 2,799 & 3,525 & 90 & 653 \\
\hline Total to Uitimate Consumers ....................... & 11,390 & 25,222 & 45,284 & 32,749 & 16,962 & 10,515 \\
\hline 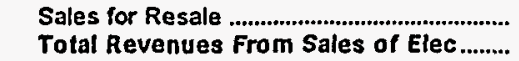 & $\begin{array}{r}0 \\
11,390\end{array}$ & $\begin{array}{r}0 \\
25,222\end{array}$ & $\begin{array}{r}0 \\
45,284\end{array}$ & $\begin{array}{r}0 \\
32,749\end{array}$ & $\begin{array}{r}0 \\
16,962\end{array}$ & $\begin{array}{r}0 \\
10,515\end{array}$ \\
\hline
\end{tabular}

Note: Totals may not equal sum of components because of independent rounding.

Source: Energy Information Administration, Form EIA-861, "Annual Electric Utility Report." Data are submitted on a calendar year. 
Table 25. Number of Consumers, Sales, and Operating Revenue by Major U.S. Publicly Owned Electric Utility Within State, 1995 (Continued)

\begin{tabular}{|c|c|c|c|c|c|c|}
\hline Item & $\begin{array}{l}\text { Virginia } \\
\text { Radford } \\
\text { City of } \\
\text { June } 30\end{array}$ & $\begin{array}{l}\text { Virginia } \\
\text { Salem } \\
\text { City of } \\
\text { June } 30\end{array}$ & $\begin{array}{l}\text { Virginia } \\
\text { Virginia } \\
\text { Tech } \\
\text { Electric } \\
\text { Service } \\
\text { June } 30\end{array}$ & $\begin{array}{l}\text { Washington } \\
\text { Centralia } \\
\text { City of } \\
\text { December } 31\end{array}$ & $\begin{array}{c}\text { Washington } \\
\text { Ellensburg } \\
\text { City of } \\
\text { December } 31\end{array}$ & $\begin{array}{l}\text { Washington } \\
\text { Port Angeles } \\
\text { City of } \\
\text { December } 31\end{array}$ \\
\hline \multicolumn{7}{|l|}{ Number of Consumers } \\
\hline 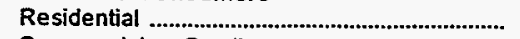 & 6,011 & 9,831 & 4,548 & 7,164 & 5,296 & 8,059 \\
\hline Commercial or Small & 694 & 1.879 & 528 & 1,178 & 975 & 1,374 \\
\hline Industrial or Large & 21 & 98 & 2 & 46 & 1 & 7 \\
\hline Other & 2 & 2 & 321 & 1 & 52 & 200 \\
\hline $\begin{array}{l}\text { Total Ultimate Consumers } \\
\text { Sales for the Year (megawatthours) }\end{array}$ & 6,728 & 11,810 & 5,399 & 8,389 & 6,324 & 9,640 \\
\hline 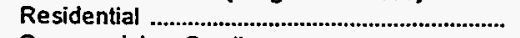 & 63,323 & 116,357 & 47,801 & 107,839 & 53,673 & 127,580 \\
\hline 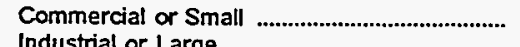 & 24,499 & 64,279 & 32,990 & 78,854 & 53,697 & 88,465 \\
\hline 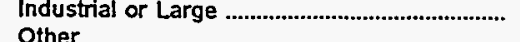 & 258,979 & 139,676 & 10,239 & 29,461 & 16,416 & 419,495 \\
\hline $\begin{array}{l}\text { Other } \\
\text { Total to Ujtimate Consumers }\end{array}$ & $\begin{array}{r}5,900 \\
552,701\end{array}$ & $\begin{array}{r}17,675 \\
337,987\end{array}$ & 138,246 & 1,098 & 45,352 & 3,033 \\
\hline Sales for Resale & 0 & $\begin{array}{r}0.001 \\
0\end{array}$ & $\begin{array}{r}229,216 \\
0\end{array}$ & $\begin{array}{r}217,252 \\
0\end{array}$ & $\begin{array}{r}169,138 \\
0\end{array}$ & $\begin{array}{r}638,573 \\
0\end{array}$ \\
\hline 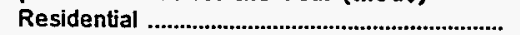 & 3,949 & 6,879 & \multicolumn{4}{|c|}{ Oper Revenues for the Year (thous) } \\
\hline Commercial or Small ................................................ & 1,536 & 3,657 & 2,706 & $\begin{array}{l}4,542 \\
3,348\end{array}$ & $\begin{array}{l}2,712 \\
2,529\end{array}$ & $\begin{array}{l}6,272 \\
3,854\end{array}$ \\
\hline Industrial or Large & 10,129 & 5,654 & 396 & 1,124 & 667 & 12,288 \\
\hline Other & 412 & 1,082 & 6,792 & 29 & 1,781 & 147 \\
\hline Total to Uitimate Consumers ......................... & 16,026 & 17,272 & 12,738 & 9,043 & 7,689 & 22,561 \\
\hline 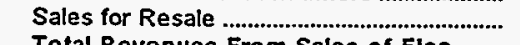 & & & 0 & & & \\
\hline Total Revenues From Sales of Elec........ & 16,026 & 17,272 & 12,738 & 9,043 & 7,689 & 22,561 \\
\hline
\end{tabular}

\begin{tabular}{|c|c|c|c|c|c|c|}
\hline Item & $\begin{array}{c}\text { Washington } \\
\text { PUD No } 1 \\
\text { of } \\
\text { Benton } \\
\text { County } \\
\text { December } 31\end{array}$ & $\begin{array}{c}\text { Washington } \\
\text { PUD No } 1 \\
\text { of } \\
\text { Chelan } \\
\text { County } \\
\text { December } 31\end{array}$ & $\begin{array}{l}\text { Washington } \\
\text { PUD No I of } \\
\text { Clallam } \\
\text { County } \\
\text { December } 31\end{array}$ & $\begin{array}{c}\text { Washington } \\
\text { PUD No } 1 \\
\text { of } \\
\text { Clark } \\
\text { County } \\
\text { December } 31\end{array}$ & $\begin{array}{l}\text { Washington } \\
\text { PUD No } 1 \text { of } \\
\text { Cowlitz } \\
\text { County } \\
\text { December } 31\end{array}$ & $\begin{array}{l}\text { Washington } \\
\text { PUD No } 1 \text { of } \\
\text { Douglas } \\
\text { County } \\
\text { December } 31\end{array}$ \\
\hline \multicolumn{7}{|l|}{ Number of Consumers } \\
\hline 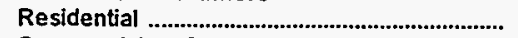 & 31,346 & 28,166 & 22,185 & 114,951 & 36,306 & 11,793 \\
\hline Commercial or Small & 4,604 & 4,356 & 3,019 & 8,871 & 4,738 & 903 \\
\hline Industrial or Large & 1 & 20 & 194 & 16 & 69 & 1 \\
\hline Other & 6 & 3,204 & 771 & 83 & 43 & 765 \\
\hline \multicolumn{6}{|l|}{ Sales for the Year (megawatthours) } & 13,462 \\
\hline 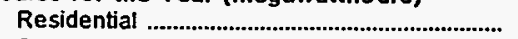 & 582,842 & 576,632 & 330,696 & $1,961,632$ & 676,107 & 281,485 \\
\hline 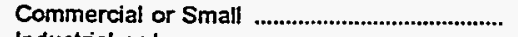 & 699,319 & 388,968 & 54.702 & $1,078,033$ & 333,002 & 108,580 \\
\hline 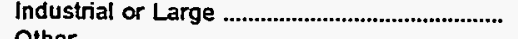 & 87,168 & 251,280 & 77,223 & 582,210 & $3,535,439$ & 238,891 \\
\hline Other & 2,828 & 64,727 & 12,459 & 40,896 & 10,424 & 60,821 \\
\hline 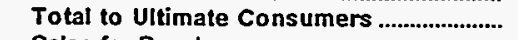 & $1,372,157$ & $1,281,607$ & 475,080 & $3,662,771$ & $4,554,972$ & 689,777 \\
\hline 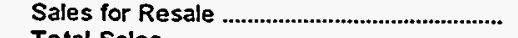 & & $8,319,784$ & 0 & & 2.039 & $3,296,009$ \\
\hline $\begin{array}{l}\text { Total Sales } \\
\text { Oper Revenues for the Year (thous) }\end{array}$ & $1,372,157$ & $9,601,391$ & 475,080 & $3,662,771$ & $4,557,011$ & $3,985,786$ \\
\hline \multicolumn{7}{|l|}{ Oper Revenues for the Year (thou\$) } \\
\hline & 31,146 & 14,855 & 18,548 & 90,420 & 19,593 & 5,687 \\
\hline $\begin{array}{l}\text { Commercial or Small } \\
\text { Industrial or Large }\end{array}$ & 26,574 & 11.039 & 3,033 & 38,385 & 12,933 & 2,172 \\
\hline $\begin{array}{l}\text { Industrial or Large } \\
\text { Other }\end{array}$ & 2,618 & 4,544 & 3,441 & 15.973 & 93,654 & 4,223 \\
\hline Total to UItimate Consumers .................. & $\begin{array}{r}388 \\
60.726\end{array}$ & $\begin{array}{r}2,114 \\
32,552\end{array}$ & $\begin{array}{r}610 \\
659\end{array}$ & 2,417 & 394 & 1,099 \\
\hline Sales for Resale & 0 & $\begin{array}{r}32,552 \\
110,204\end{array}$ & $\begin{array}{r}25,632 \\
0\end{array}$ & $\begin{array}{r}147,195 \\
0\end{array}$ & $\begin{array}{r}126,574 \\
58\end{array}$ & $\begin{array}{l}13,161 \\
23,203\end{array}$ \\
\hline Total Revenues From Sales of Elec......... & 60,726 & 142,756 & 25,632 & 147,195 & 126,632 & 36,364 \\
\hline
\end{tabular}

Note: Totals may not equal sum of components because of independentrounding.

Source: Energy Information Administration, Form ElA-861, "Annual Electric Utility Report." Data are submitted on a calendar year. 
Table 25. Number of Consumers, Sales, and Operating Revenue by Major U.S. Publicly Owned Electric Utility Within State, 1995 (Continued)

\begin{tabular}{|c|c|c|c|c|c|c|}
\hline Item & $\begin{array}{l}\text { Washington } \\
\text { PUD No } 1 \text { of } \\
\text { Franklin } \\
\text { County } \\
\text { December } 31\end{array}$ & $\begin{array}{c}\text { Washington } \\
\text { PUD No } 1 \\
\text { of } \\
\text { Grays } \\
\text { Harbor Cnty } \\
\text { December } 31\end{array}$ & $\begin{array}{l}\text { Washington } \\
\text { PUD No } 1 \text { of } \\
\text { Klickitat } \\
\text { County } \\
\text { December } 31\end{array}$ & $\begin{array}{c}\text { Washington } \\
\text { PUD No } 1 \\
\text { of } \\
\text { Lewis } \\
\text { County } \\
\text { December } 31\end{array}$ & $\begin{array}{l}\text { Washington } \\
\text { PUD No } 1 \text { of } \\
\text { Okanogan } \\
\text { County } \\
\text { December } 31\end{array}$ & $\begin{array}{l}\text { Washington } \\
\text { PUD No } 1 \text { of } \\
\text { Pend Oreille } \\
\text { Cnty } \\
\text { December } 31\end{array}$ \\
\hline \multicolumn{7}{|l|}{ Number of Consumers } \\
\hline 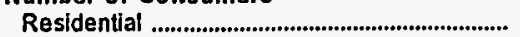 & 12,552 & 32,616 & 7,553 & 21,097 & 14,857 & 6,188 \\
\hline Commercial or Small & 2,519 & 4,525 & 1,258 & 3,222 & 2,180 & 640 \\
\hline Industrial or Large & 0 & 38 & 171 & 84 & 5 & 10 \\
\hline Other & 1,362 & $\begin{array}{r}597 \\
27776\end{array}$ & 228 & $\begin{array}{r}655 \\
25058\end{array}$ & $\begin{array}{r}1,972 \\
10014\end{array}$ & $\begin{array}{r}31 \\
6.869\end{array}$ \\
\hline $\begin{array}{l}\text { Total Uilimate Consumers ............................. } \\
\text { Sales for the Year (megawatthours) }\end{array}$ & 16,433 & 37,776 & 9,210 & 25,058 & & \\
\hline 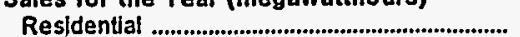 & 214,543 & 524,898 & 107,566 & 342,543 & 273,598 & 105,844 \\
\hline 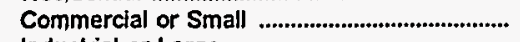 & 312,618 & 227,736 & 25,329 & 122,913 & 187,859 & $\begin{array}{r}38,559 \\
755,900\end{array}$ \\
\hline 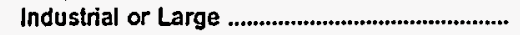 & 0 & 285,887 & 126,788 & 148,482 & 45,903 & 755,900 \\
\hline $\begin{array}{l}\text { Other } \\
\text { Total to Uitimate Consumers }\end{array}$ & $\begin{array}{l}102,370 \\
629,531\end{array}$ & $\begin{array}{r}3,073 \\
1,041,594\end{array}$ & $\begin{array}{r}21,446 \\
281,129\end{array}$ & $\begin{array}{r}60,917 \\
674,855\end{array}$ & $\begin{array}{r}63,175 \\
570,535\end{array}$ & $\begin{array}{r}3,088 \\
903,391\end{array}$ \\
\hline 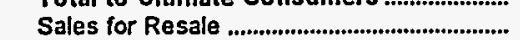 & 0 & 244,755 & 0 & 0 & 0 & 116,464 \\
\hline $\begin{array}{l}\text { Total Sales .................................................. } \\
\text { Oper Revenues for the Year (thous) }\end{array}$ & \multicolumn{2}{|c|}{ Oper Revenues for the Year (thous) } & 281,129 & 674,855 & 570,535 & $1,019,855$ \\
\hline Residential & 11,504 & 23,863 & 6,032 & 14,663 & 7,841 & 3,286 \\
\hline Commercial or Small & 12,937 & 11.429 & 1,435 & 5,494 & 6,077 & 946 \\
\hline 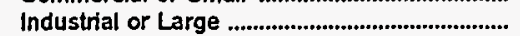 & 0 & 10,283 & 4,389 & 5,876 & 1,232 & 16.059 \\
\hline 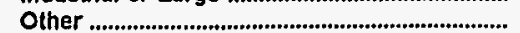 & 3,592 & 477 & 879 & 2,580 & 1,321 & 104 \\
\hline Total to Ultimate Consumers ......................... & 28,033 & 46,052 & 12,735 & 28,613 & 16,471 & 20,395 \\
\hline Sales for Resale & & 4,246 & & 0 & 0 & 1,073 \\
\hline Total Revenues From Sales of Elec......... & 28,033 & 50,298 & 12,735 & 28,613 & 16,471 & 21,468 \\
\hline
\end{tabular}

\begin{tabular}{|c|c|c|c|c|c|c|}
\hline Item & $\begin{array}{c}\text { Washington } \\
\text { PUD No } 1 \text { of } \\
\text { Snohomish } \\
\text { County } \\
\text { - December } 31\end{array}$ & $\begin{array}{l}\text { Washington } \\
\text { PUD No } 1 \text { of } \\
\text { Whatcom } \\
\text { County } \\
\text { December } 31\end{array}$ & $\begin{array}{c}\text { Washington } \\
\text { PUD No } 2 \\
\text { of } \\
\text { Grant } \\
\text { County } \\
\text { December } 31\end{array}$ & $\begin{array}{l}\text { Washington } \\
\text { PUD No } 2 \text { of } \\
\text { Pacific } \\
\text { County } \\
\text { December } 31\end{array}$ & $\begin{array}{c}\text { Washington } \\
\text { PuD No } 3 \\
\text { of } \\
\text { Mason } \\
\text { County } \\
\text { December } 31\end{array}$ & $\begin{array}{l}\text { Washington } \\
\text { Richland } \\
\text { City of } \\
\text { December } 31\end{array}$ \\
\hline \multicolumn{7}{|l|}{ Number of Consumers } \\
\hline 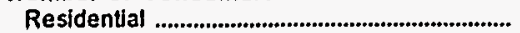 & 209,025 & 0 & 26,487 & 13,003 & 23,420 & 14,847 \\
\hline 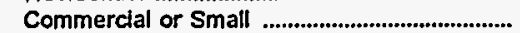 & 22,038 & 0 & 2,811 & 1,501 & 1,637 & 1,058 \\
\hline 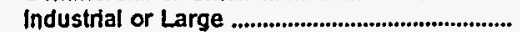 & 88 & 1 & 1,824 & 2 & 1 & 230 \\
\hline Other & 1,027 & 0 & 61 & 541 & 72 & 421 \\
\hline $\begin{array}{l}\text { Total Uitimate Consumers ........................... } \\
\text { Sales for the Year (megawatthours) }\end{array}$ & 232,178 & 1 & 31,183 & 15,047 & 25,130 & 16,556 \\
\hline 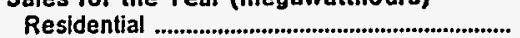 & $3,014,461$ & 0 & 583,768 & 157,447 & 307,730 & 270,147 \\
\hline 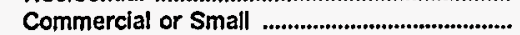 & $1,783,722$ & $\mathbf{0}$ & 488,977 & 57,952 & 137,170 & 54,326 \\
\hline 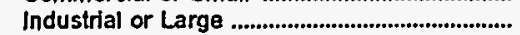 & 864,680 & 157,399 & $1,674,049$ & 25,706 & 64,847 & 305,302 \\
\hline 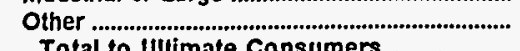 & $\begin{array}{c}19,701 \\
5,682,564\end{array}$ & $\begin{array}{r}0 \\
157.399\end{array}$ & $\begin{array}{r}4,659 \\
2.751 .453\end{array}$ & $\begin{array}{r}23,420 \\
264,525\end{array}$ & $\begin{array}{r}1,845 \\
511,592\end{array}$ & $\begin{array}{r}4.201 \\
633.976\end{array}$ \\
\hline Sales for Resale & $\begin{array}{r}7,002,504 \\
94,024\end{array}$ & 0 & $6,855,085$ & $\begin{array}{r}0.000 \\
0\end{array}$ & 3,472 & \\
\hline Total Sales & $5,776,588$ & 157,399 & $9,606,538$ & 264,525 & 515,064 & 633,976 \\
\hline \multicolumn{7}{|l|}{ Oper Revenues for the Year (thou\$) } \\
\hline Residential & $\begin{array}{r}154,211 \\
78,660\end{array}$ & $\begin{array}{l}\mathbf{0} \\
\mathbf{0}\end{array}$ & $\begin{array}{l}15,434 \\
10,334\end{array}$ & $\begin{array}{l}8.291 \\
3.270\end{array}$ & $\begin{array}{r}16,579 \\
6,848\end{array}$ & $\begin{array}{r}13,496 \\
2,326\end{array}$ \\
\hline Industrial or Large & 29,799 & 4,253 & 24,438 & 924 & $\begin{array}{l}0,040 \\
2,225\end{array}$ & 10,699 \\
\hline Other & 1,418 & 0 & 495 & 1.413 & 106 & 259 \\
\hline Total to Ultimate Consumers ........................ & 264,088 & 4,253 & 50,701 & 13,898 & 25,758 & 26,780 \\
\hline 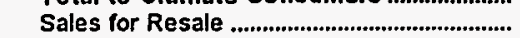 & 2,459 & 0 & 45,375 & & 120 & \\
\hline Total Revenues From Sales of Elec......... & 266,547 & 4,253 & 96,076 & 13,898 & 25,878 & 26,780 \\
\hline
\end{tabular}

Note: Totals may not equal sum of components because of independent rounding.

Source: Energy Information Administration, Form EIA-861, "Annual Electric Utility Report." Data are submitted on a calendar year. 
Table 25. Number of Consumers, Sales, and Operating Revenue by Major U.S. Publicly Owned Electric Utility Within State, 1995 (Continued)

\begin{tabular}{|c|c|c|c|c|c|c|}
\hline Item & $\begin{array}{c}\text { Washington } \\
\text { Seattle } \\
\text { City of } \\
\text { December } 31\end{array}$ & $\begin{array}{l}\text { Washington } \\
\text { Tacoma } \\
\text { City of } \\
\text { December } 31\end{array}$ & $\begin{array}{c}\text { Washington } \\
\text { Vera } \\
\text { Inigation } \\
\text { District \#15 } \\
\text { December } 31\end{array}$ & $\begin{array}{l}\text { Washington } \\
\text { Washington } \\
\text { Pub } \\
\text { Pwr } \\
\text { Supply Sys } \\
\text { June } 30\end{array}$ & $\begin{array}{l}\text { Wisconsin } \\
\text { Badger Power } \\
\text { Marketing } \\
\text { Auth } \\
\text { December } 31\end{array}$ & $\begin{array}{c}\text { Wisconsin } \\
\text { Jefferson } \\
\text { City of } \\
\text { December } 31\end{array}$ \\
\hline \multicolumn{7}{|l|}{ Number of Consumers } \\
\hline 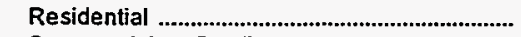 & 303,199 & 126,045 & 6,533 & 0 & 0 & 2,871 \\
\hline 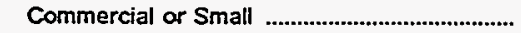 & 29.823 & 10,257 & 588 & 0 & 0 & 422 \\
\hline Industrial or Large & 293 & 1,709 & 0 & 0 & 0 & 34 \\
\hline 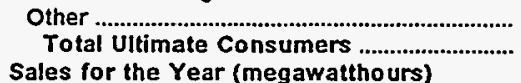 & $\begin{array}{r}2,004 \\
335,319\end{array}$ & $\begin{array}{r}301 \\
138,312\end{array}$ & $\begin{array}{r}38 \\
7,159\end{array}$ & $\begin{array}{l}0 \\
0\end{array}$ & $\begin{array}{l}0 \\
0\end{array}$ & $\begin{array}{r}1 \\
3,328\end{array}$ \\
\hline 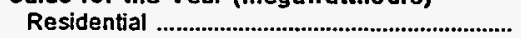 & $3,109,816$ & $1,747,508$ & 117,713 & 0 & 0 & 25,998 \\
\hline $\begin{array}{l}\text { Commercial or Small } \\
\text { Industrial or Large }\end{array}$ & $\begin{array}{l}3,406,116 \\
1,359,805\end{array}$ & $\begin{array}{r}320,638 \\
2,721,785\end{array}$ & $\begin{array}{r}50,939 \\
0\end{array}$ & $\begin{array}{l}0 \\
0\end{array}$ & $\begin{array}{l}0 \\
0\end{array}$ & $\begin{array}{r}12,662 \\
101,080\end{array}$ \\
\hline Other & $\begin{array}{r}913,092 \\
8,788,829\end{array}$ & $\begin{array}{r}541,117 \\
5,331,048\end{array}$ & $\begin{array}{r}5,905 \\
174,557\end{array}$ & $\begin{array}{l}0 \\
0\end{array}$ & $\begin{array}{l}0 \\
0\end{array}$ & $\begin{array}{r}488 \\
140,228\end{array}$ \\
\hline $\begin{array}{l}\text { Sales for Resale } \\
\text { Total Sales } \\
\text { Oper Revenues for the Year (thous) }\end{array}$ & $\begin{array}{r}0 \\
8,788,829\end{array}$ & $\begin{array}{c}595,306 \\
5,926,354\end{array}$ & $\begin{array}{r}0 \\
174,557\end{array}$ & $\begin{array}{l}7,927,861 \\
7,927,861\end{array}$ & $\begin{array}{l}279,409 \\
279,409\end{array}$ & $\begin{array}{r}0 \\
140,228\end{array}$ \\
\hline 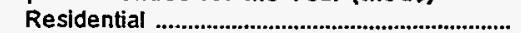 & 122,054 & 75,959 & 4,997 & 0 & 0 & 1578 \\
\hline 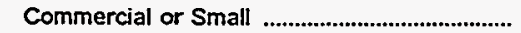 & 127,427 & 14,227 & 2,192 & 0 & 0 & $\begin{array}{r}1.378 \\
860\end{array}$ \\
\hline 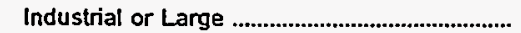 & 46,128 & 78,498 & 0 & 0 & 0 & 4,257 \\
\hline Other & 34,199 & 15,711 & 255 & 0 & 0 & 51 \\
\hline 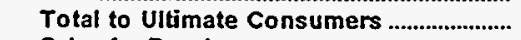 & 329,808 & 184,395 & 7,444 & 0 & o & 6,746 \\
\hline Sales for Resale & & 18,614 & 0 & 463,064 & 10,970 & \\
\hline Total Revenues From Sales of Elec......... & 329,808 & 203,009 & 7,444 & 463,064 & 10,970 & 6,746 \\
\hline
\end{tabular}

\begin{tabular}{|c|c|c|c|c|c|c|}
\hline Item & $\begin{array}{l}\text { Wisconsin } \\
\text { Kaukauna } \\
\text { City of } \\
\text { December } 31\end{array}$ & $\begin{array}{l}\text { Wisconsin } \\
\text { Manitowoc } \\
\text { Public } \\
\text { Utilities } \\
\text { December } 31\end{array}$ & $\begin{array}{l}\text { Wisconsin } \\
\text { Marshfield } \\
\text { City of } \\
\text { December } 31\end{array}$ & $\begin{array}{l}\text { Wisconsin } \\
\text { Menasha } \\
\text { City of } \\
\text { December } 31\end{array}$ & $\begin{array}{l}\text { Wisconsin } \\
\text { New London } \\
\text { Electric\&Water } \\
\text { Util }\end{array}$ & $\begin{array}{c}\text { Wisconsin } \\
\begin{array}{c}\text { Oconomowoc } \\
\text { City of }\end{array} \\
\text { December } 31\end{array}$ \\
\hline \multicolumn{7}{|l|}{ Number of Consumers } \\
\hline 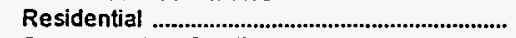 & 9,371 & 14,272 & 10,017 & 6,215 & 2,948 & 5,582 \\
\hline $\begin{array}{l}\text { Commercial or Small } \\
\text { Industrial or Large }\end{array}$ & $\begin{array}{l}872 \\
118\end{array}$ & $\begin{array}{r}1,756 \\
110\end{array}$ & $\begin{array}{r}1,384 \\
35\end{array}$ & $\begin{array}{r}490 \\
65\end{array}$ & $\begin{array}{r}400 \\
23\end{array}$ & $\begin{array}{r}828 \\
83\end{array}$ \\
\hline 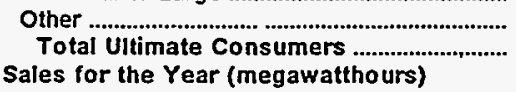 & $\begin{array}{r}33 \\
10,394\end{array}$ & 16,139 & $\begin{array}{r}27 \\
11,463\end{array}$ & $\begin{array}{r}112 \\
6,882\end{array}$ & $\begin{array}{r}13 \\
3,384\end{array}$ & $\begin{array}{r}78 \\
6,571\end{array}$ \\
\hline $\begin{array}{l}\text { Residential } \\
\text { Commercial or Small } \\
\text { Industrial or Large }\end{array}$ & $\begin{array}{r}103,190 \\
24,591 \\
579,068\end{array}$ & $\begin{array}{r}92,902 \\
56,082 \\
340,931\end{array}$ & $\begin{array}{r}90,420 \\
70,261 \\
152,766\end{array}$ & $\begin{array}{r}46,559 \\
10,871 \\
493,147\end{array}$ & $\begin{array}{r}25,165 \\
14,592 \\
122,808\end{array}$ & $\begin{array}{l}50,241 \\
21,839 \\
98,891\end{array}$ \\
\hline $\begin{array}{l}\text { Other } \\
\text { Total to Ultimate Consumers }\end{array}$ & $\begin{array}{r}3,644 \\
710,493\end{array}$ & $\begin{array}{r}4,216 \\
494,131\end{array}$ & $\begin{array}{r}3,745 \\
317,192\end{array}$ & $\begin{array}{r}1,375 \\
551,952\end{array}$ & $\begin{array}{r}1.911 \\
164,476\end{array}$ & $\begin{array}{r}2,372 \\
173,343\end{array}$ \\
\hline 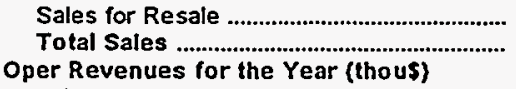 & $\begin{array}{r}0 \\
710,493\end{array}$ & $\begin{array}{r}308 \\
494,439\end{array}$ & $\begin{array}{r}0 \\
317,192\end{array}$ & $\begin{array}{r}0 \\
551,952\end{array}$ & $\begin{array}{r}0 \\
164,476\end{array}$ & $\begin{array}{r}0 \\
173,343\end{array}$ \\
\hline Residential & 4,372 & 5.850 & 4,156 & 3,034 & 1,583 & 2,982 \\
\hline Commercial or Smalt & 1,145 & 3,325 & 3,264 & 712 & 961 & 1,249 \\
\hline Industrial or Large & 19,349 & 14,347 & 5.453 & 17,879 & 5,093 & 4,431 \\
\hline Other & 249 & 395 & 204 & 1,376 & 142 & 222 \\
\hline Total to Ultimate Consumers ......................... & 25,115 & 23,917 & 13,077 & 23,001 & 7,779 & 8,884 \\
\hline $\begin{array}{l}\text { Sales for Resale ....................................... } \\
\text { Total Revenues From Sales of Elec........ }\end{array}$ & $\begin{array}{r}0 \\
25,115\end{array}$ & $\begin{array}{r}10 \\
23,927\end{array}$ & $\begin{array}{r}0 \\
13,077\end{array}$ & $\begin{array}{r}0 \\
23,001\end{array}$ & $\begin{array}{r}0 \\
7,779\end{array}$ & $\begin{array}{r}0 \\
8,884\end{array}$ \\
\hline
\end{tabular}

Note: Totals may not equal sum of components because of independent rounding.

Source: Energy Information Administration, Form EIA-861, "Annual Electric Utility Report." Data are submitted on a calendar year. 
Table 25. Number of Consumers, Sales, and Operating Revenue by Major U.S. Publicly Owned Electric Utility Within State, 1995 (Continued)

\begin{tabular}{|c|c|c|c|c|c|c|}
\hline Item & $\begin{array}{c}\text { Wisconsin } \\
\text { Plymouth } \\
\text { City of } \\
\text { December } 31\end{array}$ & $\begin{array}{l}\text { Wisconsin } \\
\text { Reedsburg } \\
\text { Utility Comm } \\
\text { December } 31\end{array}$ & $\begin{array}{c}\text { Wisconsin } \\
\text { Shawano } \\
\text { Municipal } \\
\text { Utilities } \\
\text { December } 31\end{array}$ & $\begin{array}{c}\text { Wisconsin } \\
\text { Sheboygan } \\
\text { Falls } \\
\text { City of } \\
\text { December } 31\end{array}$ & $\begin{array}{c}\text { Wisconsin } \\
\text { Sturgeon } \\
\text { Bay City of } \\
\text { December } 31\end{array}$ & $\begin{array}{l}\text { Wisconsin } \\
\text { Sun Prairie } \\
\text { Water \& Light } \\
\text { Comm } \\
\text { December } 31\end{array}$ \\
\hline \multicolumn{7}{|l|}{ Number of Consumers } \\
\hline 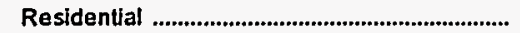 & 5.524 & 2,994 & 3,697 & 2,771 & 6.330 & 6.403 \\
\hline 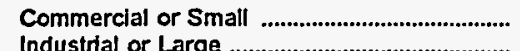 & $\begin{array}{r}639 \\
66\end{array}$ & $\begin{array}{r}508 \\
78\end{array}$ & $\begin{array}{l}896 \\
107\end{array}$ & $\begin{array}{r}340 \\
40\end{array}$ & $\begin{array}{r}787 \\
44\end{array}$ & $\begin{array}{l}808 \\
155\end{array}$ \\
\hline Other & 6 & 54 & 26 & 198 & 308 & 1 \\
\hline $\begin{array}{l}\text { Total Ultimate Consumers ................................... } \\
\text { Sales for the Year (megawatthours) }\end{array}$ & 6,235 & 3,634 & 4,726 & 3,349 & 7,469 & 7,367 \\
\hline 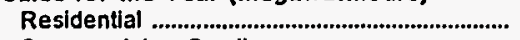 & 55,629 & 27,324 & 30,236 & 21,169 & 51,027 & 58,126 \\
\hline $\begin{array}{l}\text { Commercial or Small } \\
\text { Industrial or Large }\end{array}$ & $\begin{array}{l}18,730 \\
86,037\end{array}$ & $\begin{array}{r}14,367 \\
141,527\end{array}$ & $\begin{array}{r}16,088 \\
150,142\end{array}$ & $\begin{array}{r}9,070 \\
162,779\end{array}$ & $\begin{array}{l}28,048 \\
47,971\end{array}$ & $\begin{array}{l}12,514 \\
88,767\end{array}$ \\
\hline 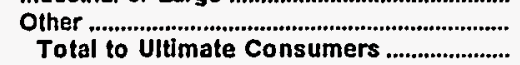 & $\begin{array}{r}712 \\
161,108\end{array}$ & $\begin{array}{r}1,804 \\
185,022\end{array}$ & $\begin{array}{r}1,909 \\
198,375\end{array}$ & $\begin{array}{r}3,240 \\
196,258\end{array}$ & $\begin{array}{r}1,301 \\
128,347\end{array}$ & $\begin{array}{r}827 \\
160,234\end{array}$ \\
\hline 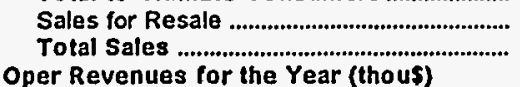 & $\begin{array}{r}0 \\
161,108\end{array}$ & $\begin{array}{r}0 \\
185,022\end{array}$ & 198,375 & $\begin{array}{r}0 \\
196,258\end{array}$ & $\begin{array}{r}0 \\
128,347\end{array}$ & 160,234 \\
\hline 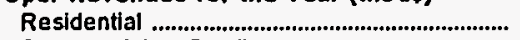 & 3,088 & 1,354 & 1,843 & 954 & 3,189 & 3,224 \\
\hline 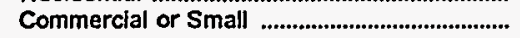 & 1,102 & 802 & 1,088 & 417 & 1,666 & 754 \\
\hline 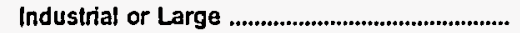 & 3,483 & 5,478 & 6,420 & 6,014 & 2,353 & 3,782 \\
\hline Other & $\begin{array}{r}104 \\
7.777\end{array}$ & $\begin{array}{r}117 \\
7.751\end{array}$ & $\begin{array}{r}160 \\
9,511\end{array}$ & $\begin{array}{r}185 \\
7.570\end{array}$ & $\begin{array}{r}157 \\
7.365\end{array}$ & $\begin{array}{r}83 \\
7,843\end{array}$ \\
\hline 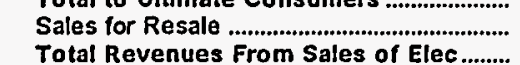 & $\begin{array}{r}0 \\
7,777\end{array}$ & $\begin{array}{r}0 \\
7,751\end{array}$ & 9,511 & $\begin{array}{r}0 \\
7,570\end{array}$ & $\begin{array}{r}0 \\
7,365\end{array}$ & $\begin{array}{r}0 \\
7,843\end{array}$ \\
\hline
\end{tabular}

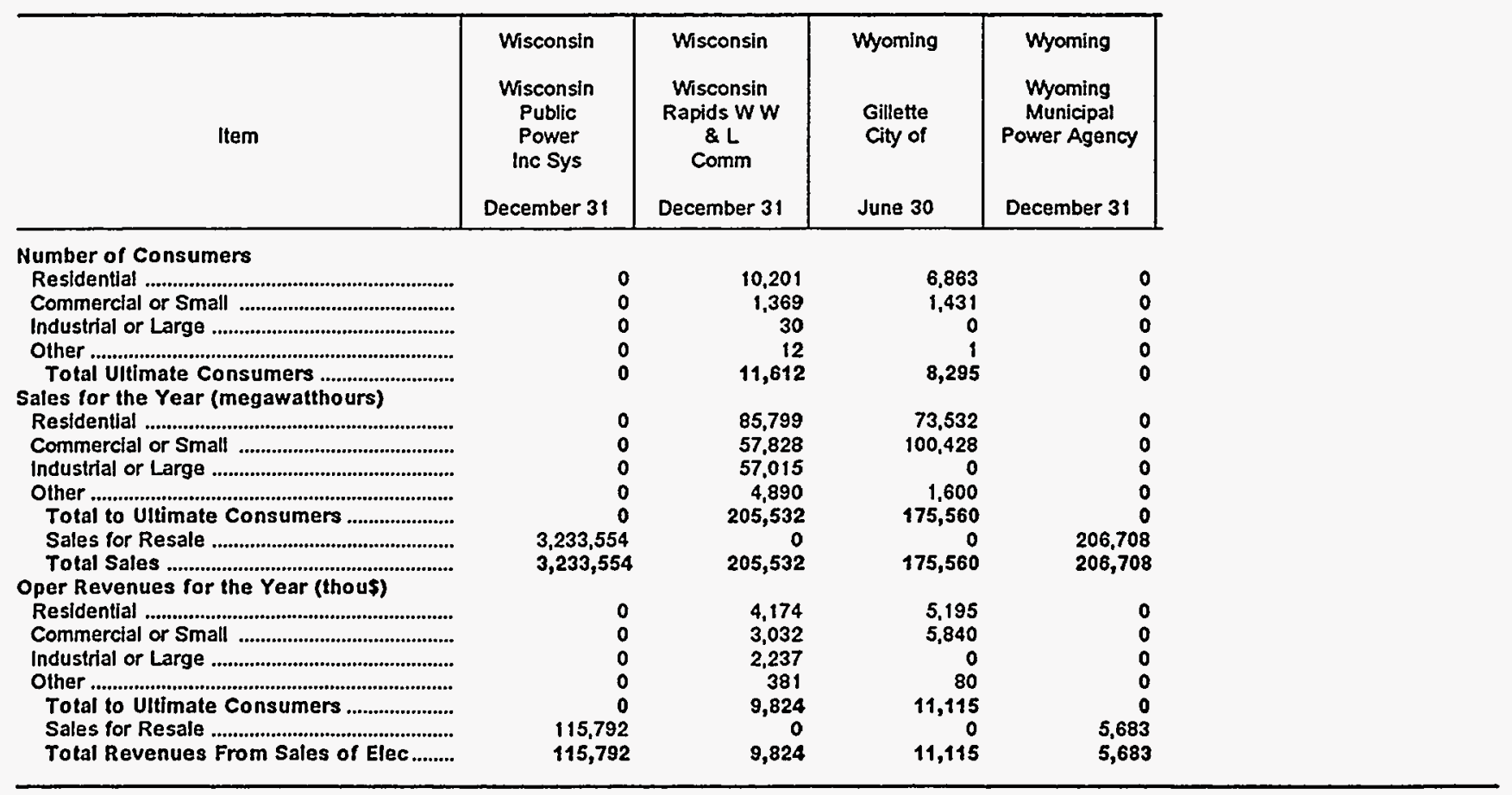

Note: Totals may not equal sum of components because of independentrounding.

Source: Energy Information Administration, Form EIA-861. "Annual Electric Utility Report." Data are submitted on a calendar year. 
Table 26. Electric Energy Account by Major U.S. Publicly Owned Electric Utility Within State, 1995

(Megawatthours)

\begin{tabular}{|c|c|c|c|c|c|c|}
\hline Item & $\begin{array}{l}\text { Alabama } \\
\text { Alabama } \\
\text { Municipal } \\
\text { Elec Auth } \\
\text { September } 30\end{array}$ & $\begin{array}{l}\text { Alabama } \\
\text { Albertville } \\
\text { Municipal } \\
\text { Utils Bd } \\
\text { June } 30\end{array}$ & $\begin{array}{c}\text { Alabama } \\
\text { Andalusia } \\
\text { City of } \\
\text { September } 30\end{array}$ & $\begin{array}{l}\text { Alabama } \\
\text { Alhens } \\
\text { City of } \\
\text { December } 31\end{array}$ & $\begin{array}{l}\text { Alabama } \\
\text { Bessemer } \\
\text { City of } \\
\text { June } 30\end{array}$ & $\begin{array}{c}\text { Alabama } \\
\text { Cullman } \\
\text { Power Board } \\
\text { June } 30\end{array}$ \\
\hline \multicolumn{7}{|l|}{ Sources of Energy } \\
\hline Steam & 0 & 0 & 0 & 0 & 0 & 0 \\
\hline 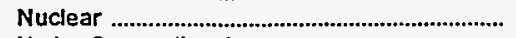 & 0 & 0 & 0 & 0 & 0 & 0 \\
\hline 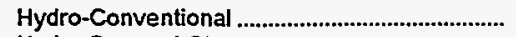 & 0 & 0 & 0 & 0 & 0 & 0 \\
\hline 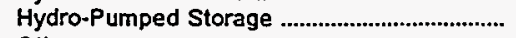 & 0 & 0 & 0 & 0 & 0 & 0 \\
\hline Other & 0 & 0 & 0 & 0 & 0 & 0 \\
\hline 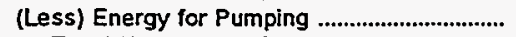 & 0 & $\mathbf{0}$ & 0 & 0 & 0 & 0 \\
\hline Total Net Generation & $\mathbf{0}$ & $\mathbf{0}$ & $\mathbf{0}$ & 0 & $\mathbf{0}$ & $\mathbf{0}$ \\
\hline 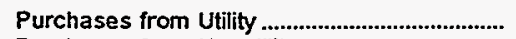 & $2,530,960$ & 473,541 & 331,883 & 710,892 & 328,832 & 322,464 \\
\hline \multicolumn{6}{|l|}{ Power Exchanges } & 0 \\
\hline 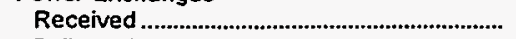 & 0 & 0 & 0 & 0 & 0 & 0 \\
\hline 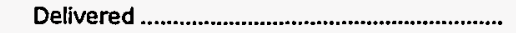 & 0 & 0 & 0 & 0 & 0 & 0 \\
\hline Net Exchanges & 0 & 0 & 0 & 0 & 0 & 0 \\
\hline \multicolumn{7}{|l|}{ Transmission for Others (Wheeling) } \\
\hline 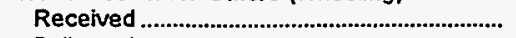 & 0 & 0 & 0 & 0 & 0 & 0 \\
\hline 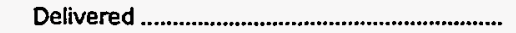 & $\mathbf{0}$ & 0 & 0 & 0 & 0 & 0 \\
\hline 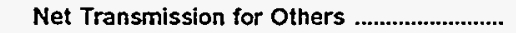 & 0 & 0 & 0 & 0 & 0 & 0 \\
\hline 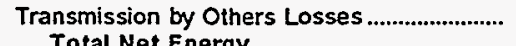 & 0 & 0 & 0 & 0 & 0 & 0 \\
\hline $\begin{array}{l}\text { Total Net Energy } \\
\text { Generated and Received }\end{array}$ & $2,530,960$ & 473,541 & 331,883 & 710,892 & 328,832 & 322,464 \\
\hline \multicolumn{7}{|l|}{ Disposition of Energy } \\
\hline 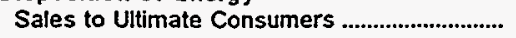 & 0 & 461,204 & 326,564 & 656,218 & 311,750 & 308,957 \\
\hline 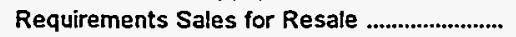 & $2,530,960$ & 0 & 0 & 0 & 0 & 0 \\
\hline Nonrequirements Sales for Resale .................. & 0 & 0 & 0 & 0 & 0 & 0 \\
\hline 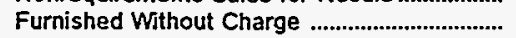 & 0 & 0 & 0 & 0 & 0 & 0 \\
\hline Used by Utility (excluding station use) ............ & $\mathbf{0}$ & 0 & 0 & 0 & 480 & 60 \\
\hline 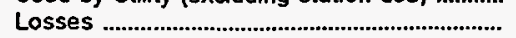 & 0 & 12.338 & 5,319 & 54,674 & 16,602 & 13,447 \\
\hline Total Disposition & $2,530,960$ & 473,541 & 331,883 & 710,892 & 328,832 & 322,464 \\
\hline
\end{tabular}

Note: Totals may not equal sum of components because of independent rounding. Double counting occurs in components of both sources and disposition of energy and thus neither provides a true total. Purchases from utilities, net interchanges, and net wheeling (except for imports) are included in net generation.

Source: Energy Information Administration, Form EIA-412, "Annual Report of Public Electric Utilities." 
Table 26. Electric Energy Account by Major U.S. Publicly Owned Electric Utility Within State, 1995 (Continued)

(Megawatthours)

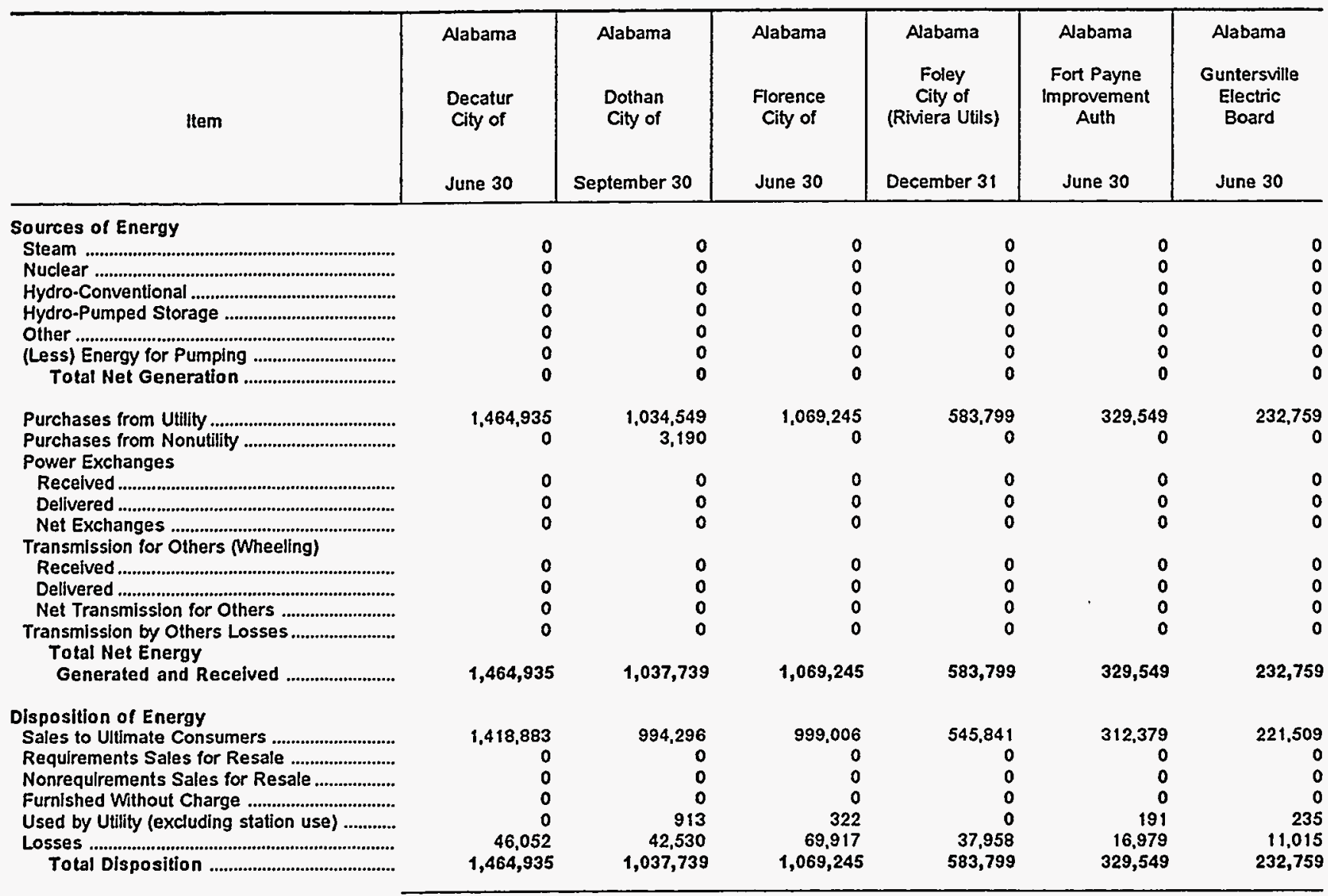

Note: Totals may not equal sum of components because of independent rounding. Dauble counting occurs in components of both sources and disposition of energy and thus neither provides a true total. Purchases from utilities, net interchanges, and net wheeling (except for imports) are included in net generation.

Source: Energy Information Administration, Form EIA-412, "Annual Report of Public Electric Utilities." 
Table 26. Electric Energy Account by Major U.S. Publicly Owned Electric Utility Within State, 1995 (Continued)

(Megawatthours)

\begin{tabular}{|c|c|c|c|c|c|c|}
\hline Hem & $\begin{array}{l}\text { Alabama } \\
\text { Hartselle } \\
\text { City of } \\
\text { June } 30\end{array}$ & $\begin{array}{c}\text { Alabama } \\
\begin{array}{c}\text { Huntsville } \\
\text { City of }\end{array} \\
\text { September } 30\end{array}$ & $\begin{array}{l}\text { Alabama } \\
\text { Muscle } \\
\text { Shoals } \\
\text { City of } \\
\text { June } 30\end{array}$ & $\begin{array}{c}\text { Alabama } \\
\text { Opelika } \\
\text { City of } \\
\text { September } 30\end{array}$ & $\begin{array}{c}\text { Scottsboro } \\
\text { City of } \\
\text { June } 30\end{array}$ & $\begin{array}{l}\text { Alabama } \\
\text { Sheffield } \\
\text { Utilities } \\
\text { June } 30\end{array}$ \\
\hline \multicolumn{7}{|l|}{ Sources of Energy } \\
\hline Steam & 0 & 0 & 0 & 0 & 0 & 0 \\
\hline Nuclear & 0 & 0 & 0 & 0 & 0 & 0 \\
\hline 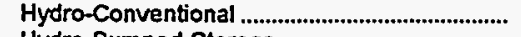 & 0 & 0 & 0 & 0 & 0 & 0 \\
\hline 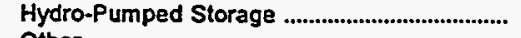 & 0 & 0 & 0 & 0 & 0 & 0 \\
\hline Other & 0 & 0 & 0 & 0 & 0 & 0 \\
\hline 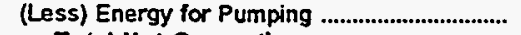 & 0 & 0 & 0 & 0 & 0 & 0 \\
\hline 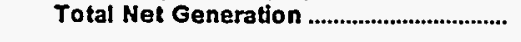 & 0 & 0 & 0 & 0 & $\mathbf{0}$ & 0 \\
\hline Purchases from Utility & 133.786 & $3,869,459$ & 206,397 & 336,969 & 365,724 & 421,141 \\
\hline $\begin{array}{l}\text { Purchases from Nonutility ..................................... } \\
\text { Power Exchanges }\end{array}$ & 0 & 0 & 0 & 0 & 0 & 0 \\
\hline Received & 0 & 0 & 0 & 0 & 0 & 0 \\
\hline 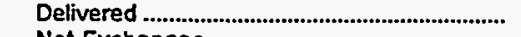 & 0 & 0 & 0 & 0 & 0 & $\mathbf{0}$ \\
\hline Net Exchanges & 0 & 0 & 0 & 0 & 0 & 0 \\
\hline \multicolumn{7}{|l|}{ Transmission for Others (Wheeling) } \\
\hline 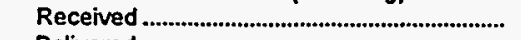 & 0 & 0 & 0 & 0 & 0 & 0 \\
\hline Delivered & 0 & 0 & 0 & 0 & 0 & 0 \\
\hline 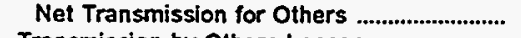 & 0 & 0 & 0 & 0 & 0 & $\mathbf{0}$ \\
\hline $\begin{array}{l}\text { Transmission by Others Losses ....................... } \\
\text { Total Net Energy }\end{array}$ & 0 & 0 & 0 & 0 & 0 & 0 \\
\hline Generated and Received ............................ & 133,786 & $3,869,459$ & 206,397 & 336,969 & 365,724 & 421,141 \\
\hline \multicolumn{7}{|l|}{ Disposition of Energy } \\
\hline Sales to Ultimate Consumers ................................ & 125,807 & $3,690,259$ & 196,927 & 320,884 & 349,765 & 391,803 \\
\hline Requirements Sales for Resale ........................ & $\mathbf{0}$ & 0 & 0 & 0 & 0 & 0 \\
\hline Nonrequirements Sales for Resale .................... & 0 & 0 & 0 & 0 & 0 & 0 \\
\hline Fumished Without Charge ................................ & 0 & 0 & 0 & 0 & 0 & 0 \\
\hline Used by Utility (excluding station use) ............. & 0 & 524 & 262 & $\mathbf{0}$ & 322 & 0 \\
\hline 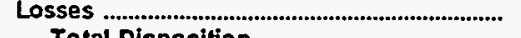 & $\begin{array}{r}7,979 \\
\end{array}$ & 178,677 & 9,207 & 16,085 & 15,636 & 29,339 \\
\hline Total Disposition & 133,786 & $3,869,459$ & 206,397 & 336,969 & 365,724 & 421,141 \\
\hline
\end{tabular}

Note: Totals may not equal sum of components because of independent rounding. Double counting occurs in components of both sources and disposition of energy and thus neither provides a true tolal. Purchases from utilities, net interchanges, and net wheeling (except for imports) are included in net generation.

Source: Energy Information Administration, Form ElA-412, "Annual Report of Public Electric Utilities." 
Table 26. Electric Energy Account by Major U.S. Publicly Owned Electric Utility Within State, 1995 (Continued)

(Megawatthours)

\begin{tabular}{|c|c|c|c|c|c|c|}
\hline Item & $\begin{array}{c}\text { Alabama } \\
\text { Sylacauga } \\
\text { Utilities } \\
\text { Board } \\
\text { September } 30\end{array}$ & $\begin{array}{c}\text { Alabama } \\
\text { Troy } \\
\text { City of } \\
\text { September } 30\end{array}$ & $\begin{array}{l}\text { Alabama } \\
\text { Tuskegee } \\
\text { City of } \\
\text { September } 30\end{array}$ & $\begin{array}{l}\text { Alaska } \\
\text { Alaska } \\
\text { Energy } \\
\text { Authority } \\
\\
\text { June } 30\end{array}$ & $\begin{array}{c}\text { Alaska } \\
\text { Anchorage } \\
\text { City of } \\
\text { December } 31\end{array}$ & $\begin{array}{l}\text { Alaska } \\
\text { Fairbanks } \\
\text { City of } \\
\text { December } 31\end{array}$ \\
\hline \multicolumn{7}{|l|}{ Sources of Energy } \\
\hline Steam & 0 & 0 & 0 & 0 & 138,853 & 121,118 \\
\hline 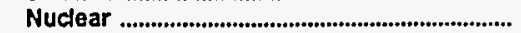 & 0 & 0 & 0 & 0 & 0 & 0 \\
\hline Hydro-Conventional ............................................... & 0 & 0 & 0 & 696,604 & 0 & 0 \\
\hline 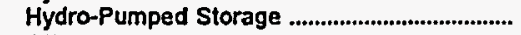 & 0 & 0 & 0 & 0 & 0 & 0 \\
\hline Other & $\mathbf{0}$ & 0 & 0 & 0 & 595,910 & 0 \\
\hline 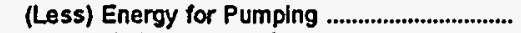 & $\mathbf{0}$ & 0 & 0 & 0 & 0 & 0 \\
\hline 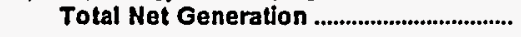 & 0 & 0 & $\mathbf{0}$ & 696,604 & 734,763 & 121,118 \\
\hline 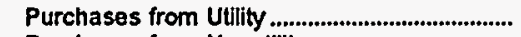 & 186,553 & 252,829 & 166,335 & 0 & 182,047 & 36,376 \\
\hline $\begin{array}{l}\text { Purchases from Nonutility .................................. } \\
\text { Power Exchanges }\end{array}$ & 0 & 0 & 0 & 0 & 0 & 0 \\
\hline 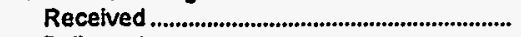 & 0 & 0 & 0 & 0 & $\mathbf{0}$ & 0 \\
\hline 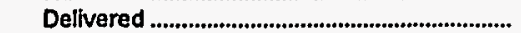 & 0 & 0 & 0 & 0 & 0 & 0 \\
\hline 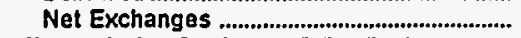 & 0 & 0 & 0 & 0 & 0 & 0 \\
\hline \multicolumn{7}{|l|}{ Transmission for Others (Wheeling) } \\
\hline 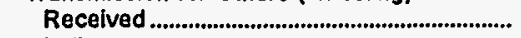 & 0 & 0 & 0 & 328,294 & 0 & 0 \\
\hline Delivered & 0 & 0 & 0 & 328,294 & 0 & 0 \\
\hline Net Transmission for Others ......................... & 0 & 0 & 0 & 0 & 0 & 0 \\
\hline $\begin{array}{l}\text { Transmission by Others Losses ....................... } \\
\text { Total Net Energy }\end{array}$ & 0 & 0 & 0 & 0 & 0 & $\mathbf{0}$ \\
\hline 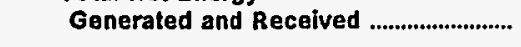 & 186,553 & 252,829 & 166,335 & 696,604 & 916,810 & 157,494 \\
\hline \multicolumn{7}{|l|}{ Dlsposition of Energy } \\
\hline 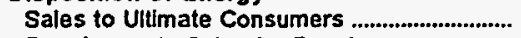 & 178,146 & 231,916 & 140,873 & 0 & 830,768 & 149,600 \\
\hline Requirements Sales for Resale ......................... & 0 & 0 & 0 & 686,694 & 50,079 & 0 \\
\hline Nonrequirements Sales for Resale ................... & 0 & 0 & 0 & 9,910 & 0 & 0 \\
\hline 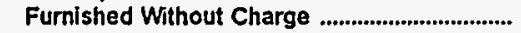 & 0 & 8,773 & 6,350 & 0 & 0 & 0 \\
\hline Used by Utility (excluding station use) ............ & 0 & 6,287 & 0 & $\mathbf{0}$ & 0 & 0 \\
\hline 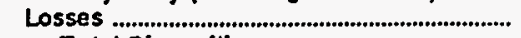 & 8,407 & 5,853 & 19,112 & 0 & 35.963 & 7,894 \\
\hline Total Disposition & 186,553 & 252,829 & 166,335 & 696,604 & $\mathbf{9 1 6 , 8 1 0}$ & 157,494 \\
\hline
\end{tabular}

Note: Totals may not equal sum of components because of independent rounding. Double counting occurs in components of both sources and disposition of energy and thus neither provides a true total. Purchases from utilities, net interchanges, and net wheeling (except for imports) are included in net generation.

Source: Energy Information Administration, Form EIA-412, "Annual Report of Public Electric Utilities." 
Table 26. Electric Energy Account by Major U.S. Publicly Owned Electric Utility Within State, 1995 (Continued) (Megawatthours)

\begin{tabular}{|c|c|c|c|c|c|c|}
\hline Item & $\begin{array}{c}\text { Alaska } \\
\text { Ketchikan } \\
\text { City of } \\
\text { December } 31\end{array}$ & $\begin{array}{l}\text { Arizona } \\
\text { Arizona } \\
\text { Power } \\
\text { Authority } \\
\text { June } 30\end{array}$ & $\begin{array}{c}\text { Arizona } \\
\text { Electrical } \\
\text { Dist } \\
\text { No2 } \\
\text { Pinal Cnty } \\
\text { December } 31\end{array}$ & $\begin{array}{l}\text { Arizona } \\
\text { Mesa } \\
\text { City of } \\
\text { June } 30\end{array}$ & $\begin{array}{l}\text { Arizona } \\
\text { Navajo } \\
\text { Tribat } \\
\text { Utility } \\
\text { Auth } \\
\text { December } 31\end{array}$ & $\begin{array}{l}\text { Arizona } \\
\text { Salt River } \\
\text { Proj Ag } \\
\text { I \& P Dist } \\
\text { April } 30\end{array}$ \\
\hline \multicolumn{7}{|l|}{ Sources of Energy } \\
\hline Steam & $\mathbf{0}$ & 0 & 0 & 0 & 0 & $14,390,065$ \\
\hline 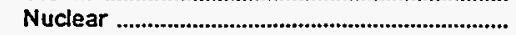 & 0 & 0 & 0 & 0 & 0 & $4,386,219$ \\
\hline Hydro-Conventional ................................................. & 59,908 & 0 & 0 & 0 & 0 & 368,423 \\
\hline 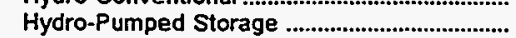 & 0 & 0 & 0 & 0 & 0 & 112,343 \\
\hline 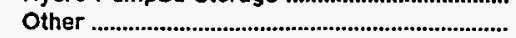 & 35,314 & 0 & 0 & 0 & 0 & 236,851 \\
\hline 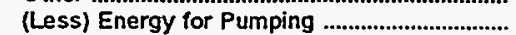 & & 0 & 0 & 0 & 0 & 160,488 \\
\hline 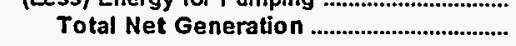 & 95,222 & 0 & o & 0 & o & $19,333,413$ \\
\hline 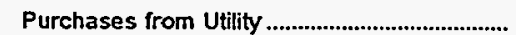 & 59,008 & $1,050,611$ & 178 & 337,553 & 578,434 & $4,813,417$ \\
\hline Purchases from Nonutility ........................................ & 757 & 0 & 0 & 0 & 0 & 184 \\
\hline \multicolumn{7}{|l|}{ Power Exchanges } \\
\hline 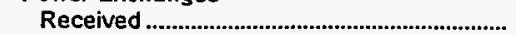 & 0 & 0 & 6 & 0 & 0 & 209.751 \\
\hline 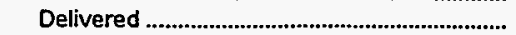 & 0 & 0 & 0 & 0 & 0 & 238,602 \\
\hline 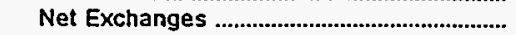 & 0 & 0 & 6 & 0 & 0 & $-28,851$ \\
\hline \multicolumn{7}{|l|}{ Transmission for Others (Wheeling) } \\
\hline 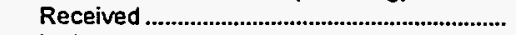 & 0 & 0 & 0 & 0 & 0 & 131,636 \\
\hline 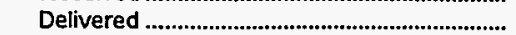 & 0 & 0 & 0 & 0 & 0 & 127,846 \\
\hline 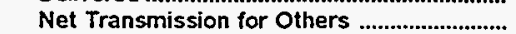 & 0 & 0 & 0 & 0 & 0 & 3,790 \\
\hline 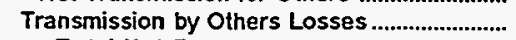 & 0 & 0 & 0 & 0 & 0 & 0 \\
\hline Total Net Energy & & & & & & \\
\hline 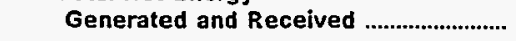 & 154,987 & $1,050,611$ & 184 & 337,553 & 578,434 & $24,121,953$ \\
\hline \multirow{2}{*}{\multicolumn{7}{|c|}{ Disposition of Energy }} \\
\hline & & & 157 & & & 16.667 .262 \\
\hline Requirements Sales for Resale .......................... & & $1,016,063$ & 0 & 140 & 0 & $6,399,775$ \\
\hline Nonrequirements Sales for Resale .................... & 0 & 0 & 0 & 0 & 0 & 0 \\
\hline Furnished Without Charge .................................. & 1,066 & 0 & 0 & 0 & 0 & $1,054,916$ \\
\hline Used by Utility (excluding station use) ................ & 2,978 & 0 & 0 & 0 & 0 & 0 \\
\hline 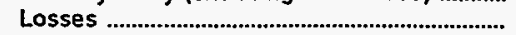 & $-1-0$ & 34,548 & 26 & 12,692 & 51,392 & \\
\hline Total Disposition & 154,987 & $1,050,611$ & 184 & 337,553 & 578,434 & $24,121,953$ \\
\hline
\end{tabular}

Note: Totals may not equal sum of components because of independent rounding. Double counting occurs in components of both sources and disposition of energy and thus neither provides a true total. Purchases from utilities, net interchanges, and net wheeling (except for imports) are inctuded in net generation.

Source: Energy Information Administration, Form EIA-412. "Annual Report of Public Electric Utilities." 
Table 26. Electric Energy Account by Major U.S. Publicly Owned Electric Utility Within State, 1995 (Continued)

(Megawatthours)

\begin{tabular}{|c|c|c|c|c|c|c|}
\hline Item & $\begin{array}{c}\text { Arizona } \\
\text { Tohono } \\
\text { OOdham } \\
\text { Utility Auth } \\
\text { December } 31\end{array}$ & $\begin{array}{l}\text { Arkansas } \\
\text { Benton } \\
\text { City of } \\
\text { December } 31\end{array}$ & $\begin{array}{c}\text { Arkansas } \\
\text { Bentonville } \\
\text { City of }\end{array}$ & $\begin{array}{l}\text { Arkansas } \\
\text { Clarksville } \\
\text { Light } \\
\text { \& } \\
\text { Water Co } \\
\text { September } 30\end{array}$ & $\begin{array}{l}\text { Arkansas } \\
\text { Conway } \\
\text { Corp } \\
\text { December } 31\end{array}$ & $\begin{array}{c}\text { Arkansas } \\
\text { Hope } \\
\text { City of } \\
\text { December } 31\end{array}$ \\
\hline \multicolumn{7}{|l|}{ Sources of Energy } \\
\hline 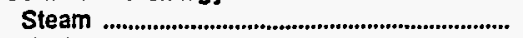 & 0 & 0 & 0 & 0 & 350.785 & 0 \\
\hline 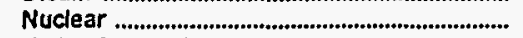 & 0 & 0 & 0 & 0 & 0 & 0 \\
\hline 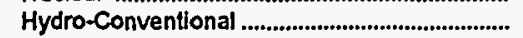 & 0 & 0 & 0 & 0 & 0 & 0 \\
\hline 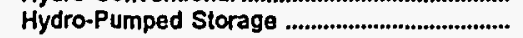 & 0 & 0 & 0 & 0 & 0 & $\mathbf{0}$ \\
\hline Other & 0 & 0 & 0 & 0 & 0 & 0 \\
\hline (Less) Energy for Pumping ............................. & 0 & 0 & 0 & 0 & 0 & 0 \\
\hline 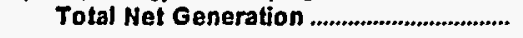 & $\mathbf{0}$ & o & 0 & 0 & 350,785 & 0 \\
\hline 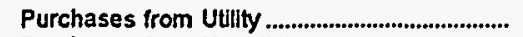 & 98 & 183,540 & 255,696 & 202,498 & 253,104 & 205,921 \\
\hline $\begin{array}{l}\text { Purchases from Nonutility ................................. } \\
\text { Power Exchanges }\end{array}$ & 0 & 0 & 0 & 0 & 0 & 0 \\
\hline 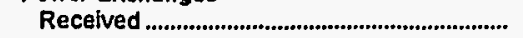 & 0 & 0 & 0 & 0 & 0 & 0 \\
\hline 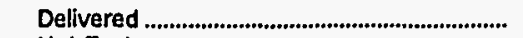 & 0 & 0 & 0 & 0 & 0 & 0 \\
\hline Net Exchanges & 0 & 0 & 0 & 0 & 0 & $\mathbf{0}$ \\
\hline \multicolumn{7}{|l|}{ Transmission for Others (Wheeling) } \\
\hline 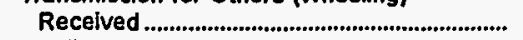 & 0 & 0 & 0 & 0 & 0 & $\mathbf{0}$ \\
\hline 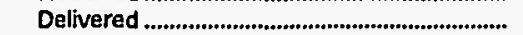 & 0 & 0 & 0 & 0 & 0 & 0 \\
\hline Net Transmission for Others .......................... & 0 & 0 & 0 & 0 & 0 & $\mathbf{0}$ \\
\hline $\begin{array}{l}\text { Transmission by Others Losses........................... } \\
\text { Total Net Energy }\end{array}$ & $\mathbf{0}$ & 0 & 0 & 0 & $-21,428$ & 0 \\
\hline Generated and Received ............................ & 96 & 183,540 & 255,696 & 202,498 & 582,461 & 205,921 \\
\hline \multicolumn{7}{|l|}{ Disposition of Energy } \\
\hline Sales to Ultimate Consumers ........................... & 92 & 171,111 & 242,408 & 180,859 & 565,075 & 197,241 \\
\hline 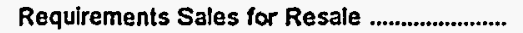 & $\mathbf{0}$ & 0 & 0 & 0 & 0 & 0 \\
\hline Nonrequirements Sales for Resale ................. & $\mathbf{0}$ & $\mathbf{0}$ & $\mathbf{0}$ & 0 & 0 & 0 \\
\hline 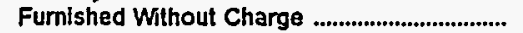 & $\mathbf{0}$ & $\mathbf{0}$ & 0 & 1,495 & 0 & 4,040 \\
\hline Used by Utilty (excluding station use) ........... & $\mathbf{0}$ & 0 & 0 & 3,888 & 0 & 0 \\
\hline Losses & 4 & 12,429 & 13,288 & 16,256 & 17,386 & 4,640 \\
\hline Total Disposition & 96 & 183,540 & 255,698 & 202,498 & 582,461 & 205,921 \\
\hline
\end{tabular}

Note: Totals may not equal sum of components because of independent rounding. Double counting occurs in components of both sources and disposition of energy and thus neither provides a true total. Purchases from utilities, net Interchanges, and net wheeling (except for imports) are Included in net generation.

Source: Energy Information Administration, Form ElA-412, "Annual Report of Public Electric Utilities." 
Table 26. Electric Energy Account by Major U.S. Publicly Owned Electric Utility Within State, 1995 (Continued)

(Megawatthours)

\begin{tabular}{|c|c|c|c|c|c|c|}
\hline Item & $\begin{array}{c}\text { Arkansas } \\
\text { Jonesboro } \\
\text { City of } \\
\text { December } 31\end{array}$ & $\begin{array}{c}\text { Arkansas } \\
\text { North } \\
\text { Little } \\
\text { Rock } \\
\text { City of } \\
\text { December } 31\end{array}$ & $\begin{array}{c}\text { Arkansas } \\
\text { Osceola } \\
\text { City of } \\
\text { December } 31\end{array}$ & $\begin{array}{l}\text { Avkansas } \\
\text { Paragould } \\
\text { Light } \\
\text { \& } \\
\text { Water Comm } \\
\text { December } 31\end{array}$ & $\begin{array}{l}\text { Arkansas } \\
\text { Siloam } \\
\text { Springs } \\
\text { City of } \\
\text { December } 31\end{array}$ & $\begin{array}{l}\text { Arkansas } \\
\text { West } \\
\text { Memphis } \\
\text { Clty of } \\
\text { December } 31\end{array}$ \\
\hline \multicolumn{7}{|l|}{ Sources of Energy } \\
\hline Steam & 235.786 & 0 & 0 & 0 & 0 & 175,393 \\
\hline 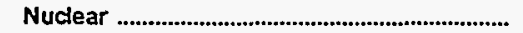 & 0 & $\mathbf{0}$ & 0 & 0 & 0 & \\
\hline 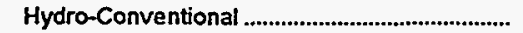 & 0 & 0 & 0 & 0 & 0 & 0 \\
\hline 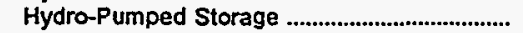 & 0 & 0 & 0 & 0 & 0 & 0 \\
\hline Other & 0 & 0 & 1,018 & 208 & 0 & 0 \\
\hline 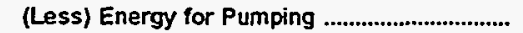 & 0 & 0 & 0 & 0 & 0 & 0 \\
\hline Total Net Generation & 235,786 & 0 & 1,018 & 208 & 0 & 175,393 \\
\hline 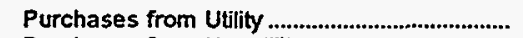 & 772,322 & 893 & 185,856 & 475,366 & 201,177 & 179,981 \\
\hline $\begin{array}{l}\text { Purchases from Nonutility ................................... } \\
\text { Power Exchanges }\end{array}$ & 0 & 0 & 0 & 0 & 0 & \\
\hline 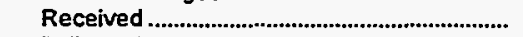 & 0 & 0 & $\mathbf{0}$ & $\mathbf{0}$ & 0 & $\mathbf{0}$ \\
\hline Delivered & 35.987 & $\mathbf{0}$ & 0 & 0 & 0 & 0 \\
\hline 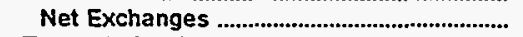 & $-35,987$ & 0 & 0 & 0 & 0 & 0 \\
\hline \multicolumn{7}{|l|}{ Transmission for Others (Wheeling) } \\
\hline 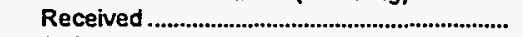 & 0 & 0 & 0 & 0 & 0 & $\mathbf{0}$ \\
\hline 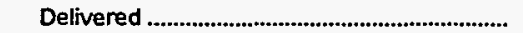 & 0 & 0 & 0 & 0 & 0 & 0 \\
\hline Net Transmission for Others ............................ & 0 & 0 & 0 & 0 & 0 & $\mathbf{0}$ \\
\hline $\begin{array}{l}\text { Transmission by Others Losses ......................... } \\
\text { Total Net Energy }\end{array}$ & 0 & 0 & 0 & 0 & 0 & 0 \\
\hline 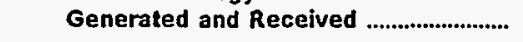 & 972,121 & 893 & 186,874 & 475,574 & 201,177 & 355,374 \\
\hline \multicolumn{7}{|l|}{ Disposition of Energy } \\
\hline 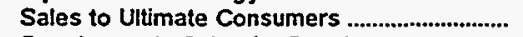 & 854,180 & 851 & 183,996 & 378,394 & 192,585 & 320,470 \\
\hline Requirements Sales for Resale ...................... & 50,567 & 0 & 0 & 67,969 & 0 & 0 \\
\hline Nonrequirements Sales for Resale ................... & 27,225 & 0 & 0 & 0 & 0 & 0 \\
\hline Fumished Without Charge ................................. & 7,935 & 0 & 2,313 & 0 & 0 & 1,913 \\
\hline Used by Utility (excluding station use) ............ & 0 & 0 & 565 & 0 & 0 & 5,283 \\
\hline Losses & 32,214 & 42 & 0 & 29,211 & 8,592 & 27,708 \\
\hline Total Dlsposition & 972,121 & 893 & 186,874 & 475,574 & 201,177 & 355,374 \\
\hline
\end{tabular}


Table 26. Electric Energy Account by Major U.S. Publicly Owned Electric Utility Within State, 1995 (Continued)

(Megawatthours)

\begin{tabular}{|c|c|c|c|c|c|c|}
\hline item & $\begin{array}{l}\text { California } \\
\text { Alameda } \\
\text { City of } \\
\text { June } 30\end{array}$ & $\begin{array}{l}\text { California } \\
\text { Anaheim } \\
\text { City of } \\
\text { June } 30\end{array}$ & $\begin{array}{l}\text { California } \\
\text { Azusa } \\
\text { City of } \\
\text { June } 30\end{array}$ & $\begin{array}{l}\text { California } \\
\text { Burbank } \\
\text { City of } \\
\text { June } 30\end{array}$ & $\begin{array}{l}\text { California } \\
\text { California } \\
\text { Dept } \\
\text { Wtr } \\
\text { Resources } \\
\text { June } 30\end{array}$ & $\begin{array}{l}\text { California } \\
\text { Colton } \\
\text { City of } \\
\text { June } 30\end{array}$ \\
\hline \multicolumn{7}{|l|}{ Sources of Energy } \\
\hline 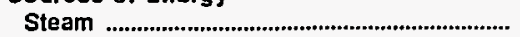 & 0 & 298,914 & 0 & 160,037 & 393,792 & 0 \\
\hline Nuclear & 0 & 491,647 & 0 & 0 & 0 & 15,597 \\
\hline Hydro-Conventional .............................................. & 0 & 0 & 0 & 0 & $2,689,072$ & 3,503 \\
\hline 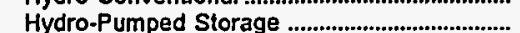 & 0 & 0 & 0 & 0 & $2,071,940$ & 0 \\
\hline Other & 0 & 2,622 & 0 & 0 & 0 & 71,186 \\
\hline 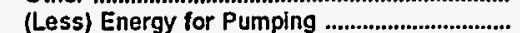 & 0 & 0 & 0 & 0 & 0 & 0 \\
\hline 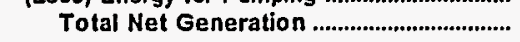 & 0 & 793,183 & 0 & 160,037 & $5,154,804$ & 90,286 \\
\hline 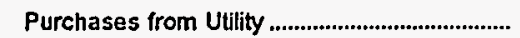 & 507,365 & $2,084,149$ & 363,383 & 880,284 & $1,537,239$ & 129,903 \\
\hline $\begin{array}{l}\text { Purchases from Nonutility ............................................... } \\
\text { Power Exchanges }\end{array}$ & 0 & 0 & 0 & 0 & 561 & 0 \\
\hline 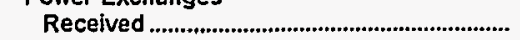 & 0 & $\mathbf{0}$ & 0 & 0 & $4,885,709$ & 0 \\
\hline 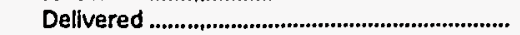 & 0 & 0 & 0 & 0 & $2,575,688$ & 0 \\
\hline Net Exchanges & 0 & 0 & 0 & 0 & $2,310,021$ & 0 \\
\hline \multicolumn{7}{|l|}{ Transmission for Others (Wheeling) } \\
\hline 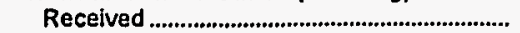 & 0 & $\mathbf{0}$ & 0 & 0 & 0 & 0 \\
\hline 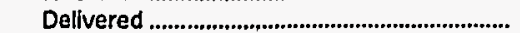 & 0 & 0 & $\mathbf{0}$ & 0 & 0 & 0 \\
\hline 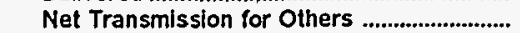 & 0 & 0 & 0 & 0 & 0 & 0 \\
\hline $\begin{array}{l}\text { Transmission by Others Losses ......................... } \\
\text { Total Net Energy }\end{array}$ & 0 & $-115,411$ & 0 & $-41,855$ & 0 & 0 \\
\hline Generated and Received ............................. & 507,365 & $2,761,921$ & 363,383 & 998,466 & $9,002,625$ & 220,189 \\
\hline \multicolumn{7}{|l|}{ Disposition of Energy } \\
\hline 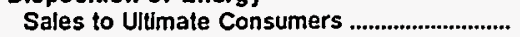 & 491,509 & $2,256,685$ & 201,871 & 946.494 & 0 & 213,042 \\
\hline 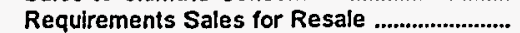 & 0 & 429,246 & 150,751 & 0 & $5,307,033$ & 0 \\
\hline Nonrequirements Sales for Resale .................. & 0 & 0 & 0 & 10,089 & 0 & 0 \\
\hline 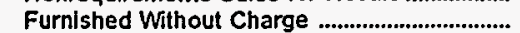 & 0 & 0 & 2,184 & 0 & 0 & 0 \\
\hline Used by Utility (excluding station use) ............ & 0 & 0 & 0 & 0 & $3,479,504$ & 0 \\
\hline Losses & 15,856 & 75,990 & 8,577 & 41,883 & 216,088 & 7,147 \\
\hline Total Disposition & 507,365 & $2,761,921$ & 363,383 & 998,466 & $9,002,625$ & 220,189 \\
\hline
\end{tabular}


Table 26. Electric Energy Account by Major U.S. Publicly Owned Electric Utility Within State, 1995 (Continued)

(Megawatthours)

\begin{tabular}{|c|c|c|c|c|c|c|}
\hline Item & $\begin{array}{c}\text { California } \\
\text { East Bay } \\
\text { Municipal } \\
\text { Util } \\
\text { Dist } \\
\text { December } 31\end{array}$ & $\begin{array}{l}\text { California } \\
\text { Glendale } \\
\text { City of } \\
\text { June } 30\end{array}$ & $\begin{array}{c}\text { California } \\
\text { Imperial } \\
\text { Imigation } \\
\text { District } \\
\text { December } 31\end{array}$ & $\begin{array}{c}\text { California } \\
\text { KIngs River } \\
\text { Conservation } \\
\text { Dist } \\
\text { June } 30\end{array}$ & $\begin{array}{l}\text { California } \\
\text { Lassen } \\
\text { Municipal } \\
\text { Utility Dist } \\
\text { June } 30\end{array}$ & $\begin{array}{l}\text { Californla } \\
\text { Lodi } \\
\text { City of } \\
\text { June } 30\end{array}$ \\
\hline \multicolumn{7}{|l|}{ Sources of Energy } \\
\hline Steam & 0 & 141,110 & 465,339 & $\mathbf{0}$ & 0 & $\mathbf{0}$ \\
\hline 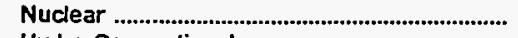 & 0 & 0 & 0 & 0 & 0 & 0 \\
\hline 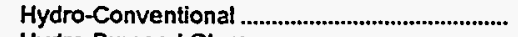 & 0 & 0 & 289,326 & 445,104 & 0 & $\mathbf{0}$ \\
\hline 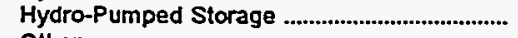 & $\mathbf{0}$ & 0 & 0 & 0 & 0 & 0 \\
\hline Other & 0 & 17,009 & 1,797 & 0 & 0 & 0 \\
\hline 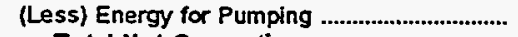 & 0 & 0 & 0 & 0 & 0 & 0 \\
\hline Total Net Generation & $\mathbf{0}$ & 158,119 & 756,462 & 445,104 & 0 & 0 \\
\hline 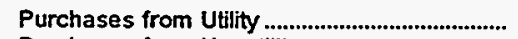 & $\mathbf{0}$ & 969,116 & $2,157,086$ & 0 & 148,063 & 352,103 \\
\hline $\begin{array}{l}\text { Purchases from Nonutility ...................................... } \\
\text { Power Exchanges }\end{array}$ & 0 & 0 & 0 & 0 & 0 & 0 \\
\hline 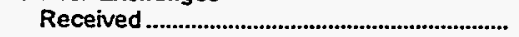 & 0 & 0 & 0 & 0 & 0 & 8,419 \\
\hline 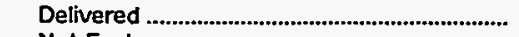 & $\mathbf{0}$ & 0 & 0 & 0 & 0 & 0 \\
\hline Net Exchanges & 0 & 0 & 0 & 0 & 0 & 8,419 \\
\hline \multicolumn{7}{|l|}{ Transmission for Others (Wheeling) } \\
\hline Received & 0 & $\mathbf{0}$ & $3,876,350$ & 0 & 243,121 & 0 \\
\hline 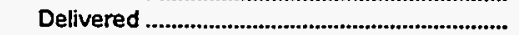 & 0 & 0 & $3,808,421$ & 0 & 243,121 & 0 \\
\hline Net Transmission for Others .............................. & 0 & 0 & 67,929 & 0 & 0 & 0 \\
\hline $\begin{array}{l}\text { Transmission by Others Losses........................... } \\
\text { Total Net Energy }\end{array}$ & 0 & 0 & 0 & 0 & 0 & 0 \\
\hline Generated and Received & $\mathbf{0}$ & $1,127,235$ & $2,981,477$ & 445,104 & 148,063 & 360,522 \\
\hline \multicolumn{7}{|l|}{ Disposition of Energy } \\
\hline 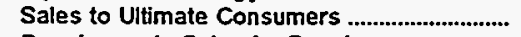 & 0 & $1,011,925$ & $2,301,113$ & 0 & 132,253 & 347,633 \\
\hline 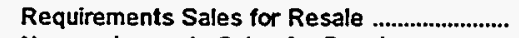 & 0 & 9,663 & 341,712 & 0 & 0 & 0 \\
\hline Nonrequirements Sales for Resale ................... & $\mathbf{0}$ & 0 & 0 & 445,104 & 0 & 0 \\
\hline 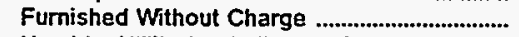 & 0 & 11,229 & 0 & 0 & 0 & 0 \\
\hline Used by Utility (excluding station use) ............ & 0 & 0 & 0 & 0 & 649 & 170 \\
\hline 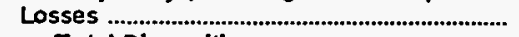 & 0 & 94,418 & 338,652 & $\mathbf{0}$ & 15,161 & 12.719 \\
\hline Total Disposition & $\mathbf{0}$ & $1,127,235$ & $2,981,477$ & 445,104 & 148,063 & 360,522 \\
\hline
\end{tabular}

Note: Totals may not equal sum of components because of independent rounding. Double counting occurs in components of both sources and disposition of energy and thus neither provides a true total. Purchases from utilities, net interchanges, and net wheeling (except for imports) are included in net generation.

Source: Energy Information Administration, Form ElA-412, "Annual Report of Public Electric Utilities." 
Table 26. Electric Energy Account by Major U.S. Publicly Owned Electric Utility Within State, 1995 (Continued)

(Megawatthours)




Table 26. Electric Energy Account by Major U.S. Publicly Owned Electric Utility Wishin State, 1995 (Continued)

(Megawatthours)

\begin{tabular}{|c|c|c|c|c|c|c|}
\hline Item & $\begin{array}{c}\text { California } \\
\text { Oakdale \& } \\
\text { South } \\
\text { San Joaquin } \\
\text { December } 31\end{array}$ & $\begin{array}{c}\text { California } \\
\text { Oroville } \\
\text { Wyandotte } \\
\text { Irrig Dist } \\
\text { December } 31\end{array}$ & $\begin{array}{l}\text { California } \\
\text { Palo Alto } \\
\text { City of } \\
\text { June } 30\end{array}$ & $\begin{array}{l}\text { Pasadena } \\
\text { City of } \\
\text { June } 30\end{array}$ & $\begin{array}{c}\text { California } \\
\text { Placer } \\
\text { County } \\
\text { Water } \\
\text { Agency } \\
\text { December } 31\end{array}$ & $\begin{array}{l}\text { Californla } \\
\text { Redding } \\
\text { City of } \\
\text { June } 30\end{array}$ \\
\hline \multicolumn{7}{|l|}{ Sources of Energy } \\
\hline Steam & 0 & 0 & 0 & 224.418 & 0 & 55,404 \\
\hline Nuclear & 0 & 0 & 0 & 0 & 0 & 0 \\
\hline 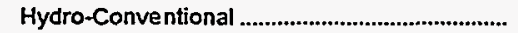 & 553,361 & 738,204 & 0 & 10,684 & $1,609,373$ & 10,973 \\
\hline 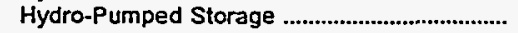 & 0 & 0 & 0 & 0 & 0 & $\mathbf{0}$ \\
\hline Other & 0 & 0 & 0 & 0 & 0 & $\mathbf{0}$ \\
\hline 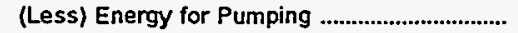 & 0 & 0 & 0 & 0 & 0 & 0 \\
\hline Total Net Generation & 553,361 & 738,204 & 0 & 235,102 & $1,609,373$ & 66,377 \\
\hline 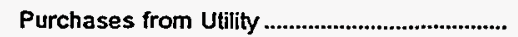 & 0 & $\mathbf{0}$ & $1,080,887$ & 984,139 & 0 & $1,033,437$ \\
\hline $\begin{array}{l}\text { Purchases from Nonutility } \\
\text { Power Exchanges }\end{array}$ & 0 & 0 & 0 & 0 & 0 & 0 \\
\hline 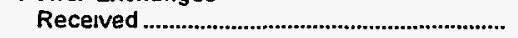 & 0 & 0 & 0 & 0 & 0 & 0 \\
\hline Delivered & 0 & $\mathbf{0}$ & 0 & 0 & 0 & 20,688 \\
\hline Net Exchanges & 0 & 0 & 0 & 0 & 0 & $-20,688$ \\
\hline \multicolumn{7}{|l|}{ Transmission for Others (Wheeling) } \\
\hline Received & 0 & 0 & 0 & 0 & 0 & $\mathbf{0}$ \\
\hline Delivered & 0 & 0 & 0 & 0 & 0 & 0 \\
\hline 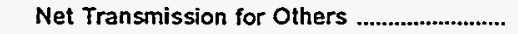 & 0 & 0 & 0 & 0 & 0 & $\mathbf{0}$ \\
\hline $\begin{array}{l}\text { Transmission by Others Losses ........................ } \\
\text { Total Net Energy }\end{array}$ & 0 & 0 & 0 & 0 & 0 & 0 \\
\hline 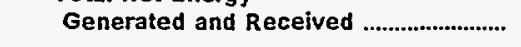 & 553,361 & 738,204 & $1,080,887$ & $1,219,241$ & $1,609,373$ & $1,079,126$ \\
\hline \multicolumn{7}{|l|}{ Disposition of Energy } \\
\hline Sales to Ultimate Consumers & 0 & 0 & $1,051,633$ & $1,087,801$ & 0 & 696,690 \\
\hline 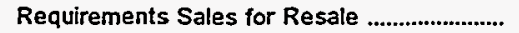 & 553,361 & 0 & 0 & 34,197 & $\mathbf{0}$ & 377,176 \\
\hline Nonrequirements Sales for Resale .................. & 0 & 738,204 & 0 & 0 & $1,601,135$ & $\mathbf{0}$ \\
\hline 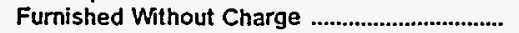 & 0 & 0 & 0 & 0 & 0 & 0 \\
\hline Used by Utility (excluding station use) ............. & 0 & 0 & 0 & 0 & 0 & 0 \\
\hline Losses & 0 & 0 & 29,254 & 97,243 & 8,238 & 5,260 \\
\hline Total Disposition & 553,361 & 738,204 & $1,080,887$ & $1,219,241$ & $1,609,373$ & $1,079,126$ \\
\hline
\end{tabular}

Note: Totals may not equal sum of components because of independent rounding. Double counting occurs in components of both sources and disposition of energy and thus neither provides a true total. Purchases from utilities, net interchanges, and net wheeling (except for imports) are included in net generation.

Source: Energy Information Administration, Form ElA-412, "Annual Report of Public Electric Utilities." 
Table 26. Electric Energy Account by Major U.S. Publicly Owned Electric Utility Within State, 1995 (Continued)

(Megawatthours)

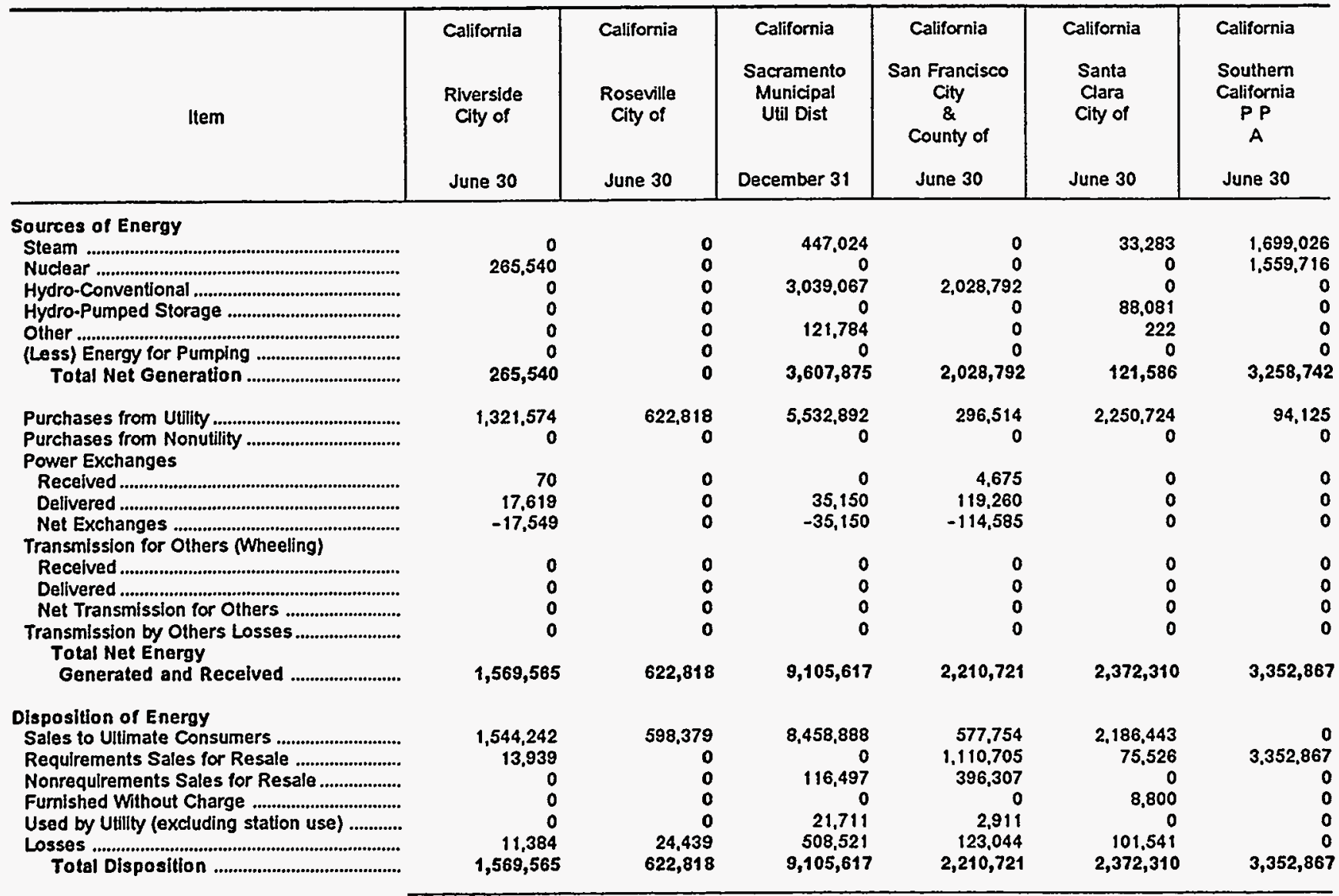

Note: Totals may not equal sum of components because of independent rounding. Double counting occurs in components of both sources and disposition of energy and thus neither provides a true total. Purchases from utilities, net interchanges, and net wheeling (except for imports) are included in net generation.

Source; Energy Information Administration, Form ElA-412, "Annual Report of Public Electric Utilities." 
Table 26. Electric Energy Account by Major U.S. Publicly Owned Electric Utility Within State, 1995 (Continued)

(Megawatthours)

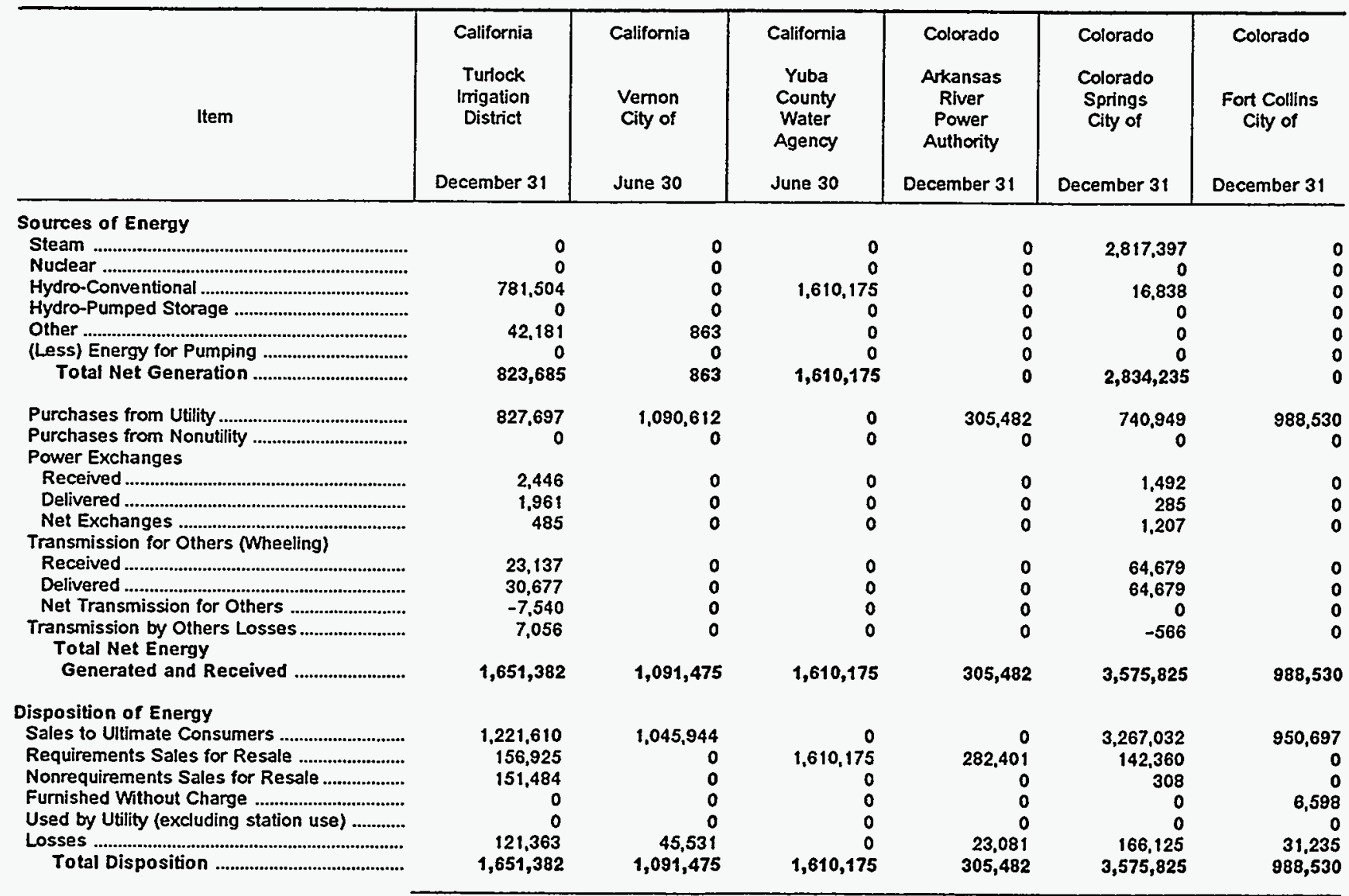

Note: Totals may not equal sum of components because of independent rounding. Double counting occurs in components of both sources and disposition of energy and thus neither provides a true total. Purchases from utilities, net interchanges, and net wheeling (except for imports) are included in net generation.

Source: Energy Information Administration, Form ElA-412, "Annual Report of Public Electric Utilities." 
Table 26. Electric Energy Account by Major U.S. Publicly Owned Electric Utility Within State, 1995 (Continued)

(Megawatthours)

\begin{tabular}{|c|c|c|c|c|c|c|}
\hline Item & $\begin{array}{l}\text { Colorado } \\
\text { Fort Morgan } \\
\text { City of } \\
\text { December } 31\end{array}$ & $\begin{array}{l}\text { Colorado } \\
\text { Longmont } \\
\text { City of }\end{array}$ & $\begin{array}{l}\text { Colorado } \\
\text { Loveland } \\
\text { City of }\end{array}$ & $\begin{array}{l}\text { Colorado } \\
\text { Platte River } \\
\text { Power } \\
\text { Authority } \\
\text { December } 31\end{array}$ & $\begin{array}{l}\text { Connecticut } \\
\text { Connecticut } \\
\text { Mun } \\
\text { Elec } \\
\text { Engy Coop } \\
\text { December } 31\end{array}$ & $\begin{array}{l}\text { Connecticut } \\
\text { Groton } \\
\text { City of } \\
\text { June } 30\end{array}$ \\
\hline \multicolumn{7}{|l|}{ Sources of Energy } \\
\hline 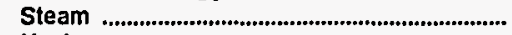 & 0 & $\mathbf{0}$ & 0 & $2,835,973$ & 0 & 0 \\
\hline 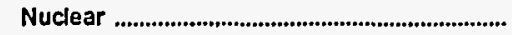 & 0 & 0 & 0 & 0 & 0 & 0 \\
\hline 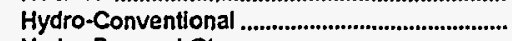 & 0 & 4,242 & 2,360 & 0 & 0 & 0 \\
\hline Hydro-Pumped Storage ................................................ & 0 & 0 & 0 & 0 & 0 & 0 \\
\hline 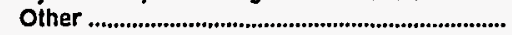 & 0 & 0 & 0 & 0 & 0 & 0 \\
\hline 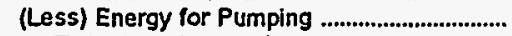 & $\mathbf{0}$ & 0 & 0 & 0 & 0 & 0 \\
\hline 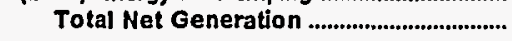 & 0 & 4,242 & 2,360 & $2,835,973$ & $\mathbf{0}$ & 0 \\
\hline 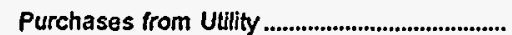 & 0 & 509,435 & 430,267 & 781,061 & $1,630,792$ & 618,634 \\
\hline 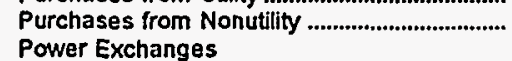 & $\mathbf{1 7 9 , 7 4 8}$ & 0 & 0 & 0 & & 0 \\
\hline 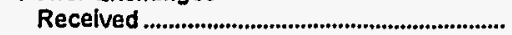 & 0 & 0 & 0 & 19,865 & 49,692 & 0 \\
\hline 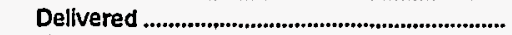 & 0 & 0 & 0 & 32,399 & 24,717 & 0 \\
\hline , Net Exchanges ................................................................ & 0 & 0 & 0 & $-12,534$ & 24,975 & 0 \\
\hline \multicolumn{7}{|l|}{ Transmission for Others (Wheeling) } \\
\hline 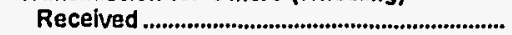 & 0 & 7,956 & 0 & 0 & 0 & 0 \\
\hline 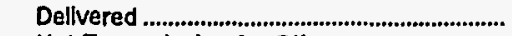 & 0 & 7.762 & 0 & $\mathbf{0}$ & 0 & 0 \\
\hline 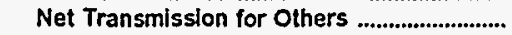 & 0 & 194 & 0 & 0 & 0 & 0 \\
\hline 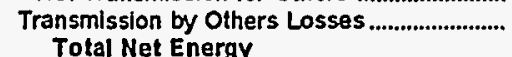 & 0 & 0 & 0 & 0 & 0 & 0 \\
\hline Generated and Received & 179,748 & 513,871 & 432,627 & $3,604,500$ & $1,655,767$ & 618,634 \\
\hline \multicolumn{7}{|l|}{ Dlsposition of Energy } \\
\hline 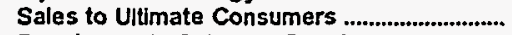 & 168,984 & 491,496 & 415,385 & 0 & 0 & 596.980 \\
\hline 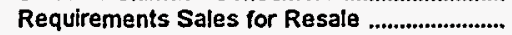 & 0 & & 0 & $2,964,547$ & $1,654,907$ & 5.558 \\
\hline Nonrequirements Sales for Resale ..................... & 0 & & & 579,173 & 0 & 0 \\
\hline Furnished Without Charge .................................. & 0 & 6,178 & 4,589 & 0 & 0 & 420 \\
\hline Used by Utility (excluding station use) ............... & 0 & & & 0 & 0 & 1.015 \\
\hline 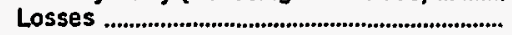 & 10,764 & 16,197 & 12,653 & 60.780 & 860 & 14,661 \\
\hline 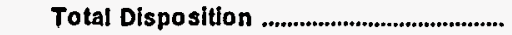 & 179,748 & 513,871 & 432,627 & $3,604,500$ & $1,655,767$ & 618,634 \\
\hline
\end{tabular}

Note: Totals may not equal sum of components because of independent rounding. Double counting occurs in components of both sources and disposition of energy and thus neither provides a true total. Purchases from utilities, net interchanges, and net wheeling (except for imports) are included in net generation.

Source: Energy Information Administration, Form EIA-412, "Annual Report of Public Electric Utilities." 
Table 26. Electric Energy Account by Major U.S. Publicly Owned Electric Utility Within State, 1995 (Continued)

(Megawatthours)

\begin{tabular}{|c|c|c|c|c|c|c|}
\hline Item & $\begin{array}{l}\text { Connecticut } \\
\text { Norwich } \\
\text { City of } \\
\text { June } 30\end{array}$ & $\begin{array}{l}\text { Connecticut } \\
\text { Wallingford } \\
\text { Town of } \\
\text { June } 30\end{array}$ & $\begin{array}{l}\text { Delaware } \\
\text { Dover } \\
\text { City of } \\
\text { June } 30\end{array}$ & $\begin{array}{l}\text { Delaware } \\
\text { Milford } \\
\text { City of } \\
\text { September } 30\end{array}$ & $\begin{array}{l}\text { Delaware } \\
\text { Newark } \\
\text { City of } \\
\text { December } 31\end{array}$ & $\begin{array}{l}\text { Florida } \\
\text { Bartow } \\
\text { City of } \\
\text { September } 30\end{array}$ \\
\hline \multicolumn{7}{|l|}{ Sources of Energy } \\
\hline 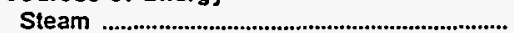 & $\mathbf{0}$ & 582 & 118,793 & 164,137 & 0 & 0 \\
\hline Nuclear & 0 & 0 & 0 & 0 & 0 & 0 \\
\hline 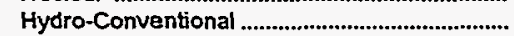 & 3,538 & 0 & 0 & 0 & $\mathbf{0}$ & 0 \\
\hline Hydro-Pumped Storage ...................................... & 0 & 0 & 0 & 0 & 0 & $\mathbf{0}$ \\
\hline Other & 0 & 0 & 7,378 & 0 & $\mathbf{0}$ & 0 \\
\hline 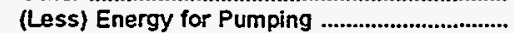 & 0 & 0 & 0 & 0 & 0 & 0 \\
\hline Total Net Generation & 3,538 & 582 & 126,171 & 164,137 & $\mathbf{0}$ & $\mathbf{0}$ \\
\hline 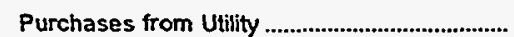 & 305,186 & 570.685 & 411,023 & $\mathbf{0}$ & 322,529 & 275,865 \\
\hline $\begin{array}{l}\text { Purchases from Nonutility ................................... } \\
\text { Power Exchanges }\end{array}$ & 0 & 0 & 37,915 & 0 & 0 & 0 \\
\hline 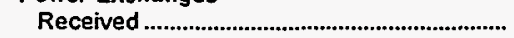 & 0 & 0 & 0 & 0 & 0 & 0 \\
\hline 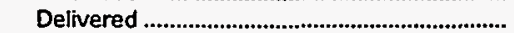 & 0 & 0 & 0 & 0 & 0 & $\mathbf{0}$ \\
\hline 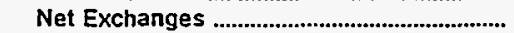 & 0 & 0 & 0 & 0 & 0 & 0 \\
\hline \multicolumn{7}{|l|}{ Transmission for Others (Wheeling) } \\
\hline 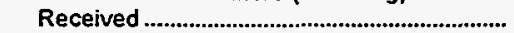 & 0 & 0 & 0 & 0 & 0 & 0 \\
\hline 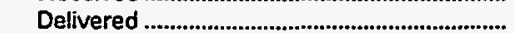 & 0 & 0 & 0 & $\mathbf{0}$ & $\mathbf{0}$ & 0 \\
\hline 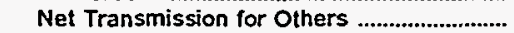 & 0 & 0 & 0 & 0 & 0 & 0 \\
\hline $\begin{array}{l}\text { Transmission by Others Losses........................ } \\
\text { Total Net Energy }\end{array}$ & 0 & 0 & 0 & $\mathbf{0}$ & 0 & $\mathbf{0}$ \\
\hline 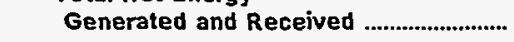 & 308,724 & 571,267 & 575,109 & 164,137 & 322,529 & 275,865 \\
\hline \multicolumn{7}{|l|}{ Disposition of Energy } \\
\hline Sales to Uitimate Consumers ............................ & 289,569 & 556,848 & 544,932 & 155,149 & 291,458 & 260,236 \\
\hline Requirements Sales for Resale ........................... & 0 & 0 & 24,333 & 0 & 0 & 0 \\
\hline 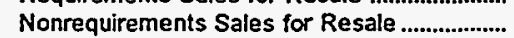 & 0 & 0 & $\begin{array}{r}2,000 \\
0\end{array}$ & 0 & 0 & 0 \\
\hline 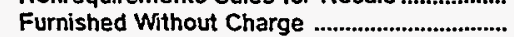 & 0 & 0 & 0 & 0 & 8,354 & 0 \\
\hline Used by Utility (excluding station use) ............ & 0 & 0 & 0 & $\mathbf{0}$ & 2,941 & $\mathbf{0}$ \\
\hline $\begin{array}{l}\text { Losses } \\
\text { Total Disposition }\end{array}$ & $\begin{array}{r}19,155 \\
308,724\end{array}$ & $\begin{array}{r}14,419 \\
571,267\end{array}$ & $\begin{array}{r}5,844 \\
575,109\end{array}$ & $\begin{array}{r}8,988 \\
164,137\end{array}$ & $\begin{array}{r}19,776 \\
322,529\end{array}$ & $\begin{array}{r}15,829 \\
275,885\end{array}$ \\
\hline
\end{tabular}


Table 26. Electric Energy Account by Major U.S. Publicly Owned Electric Utility Within State, 1995 (Continued)

(Megawatthours)

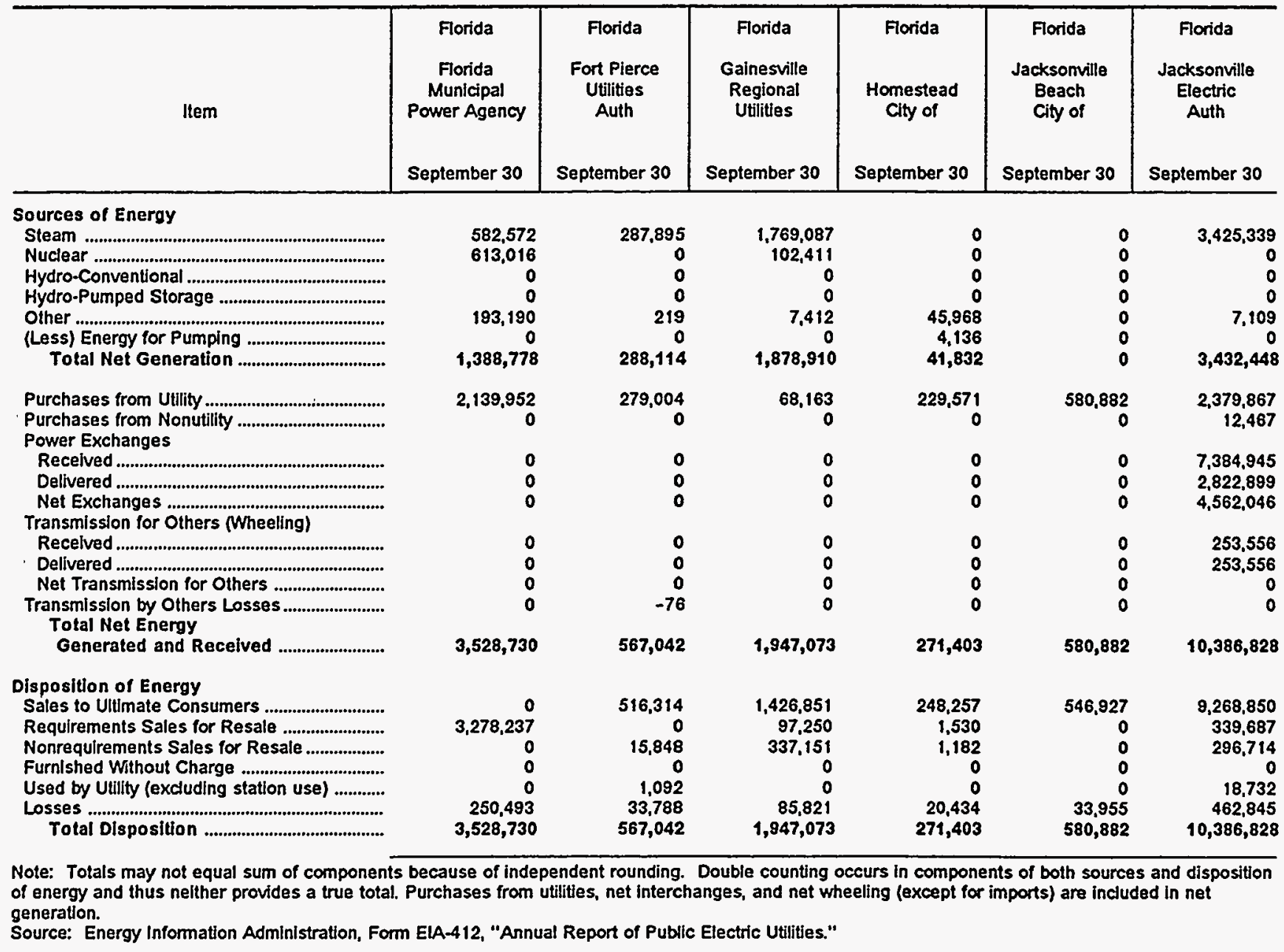


Table 26. Electric Energy Account by Major U.S. Publicly Owned Electric Utility Within State, 1995 (Continued)

(Megawatthours)

\begin{tabular}{|c|c|c|c|c|c|c|}
\hline Item & $\begin{array}{c}\text { Florida } \\
\text { Key West } \\
\text { City of } \\
\text { September } 30\end{array}$ & $\begin{array}{c}\text { Fiorida } \\
\text { Kissimmee } \\
\text { Utility } \\
\text { Authority } \\
\text { September } 30\end{array}$ & $\begin{array}{l}\text { Lake Worth } \\
\text { City of }\end{array}$ & $\begin{array}{l}\text { Lakeland } \\
\text { City of }\end{array}$ & $\begin{array}{l}\text { Florida } \\
\text { Leesburg } \\
\text { City of } \\
\text { September } 30\end{array}$ & $\begin{array}{c}\text { Florida } \\
\text { New Smyrna } \\
\text { Beach } \\
\text { Utils Comm } \\
\text { September } 30\end{array}$ \\
\hline \multicolumn{7}{|l|}{ Sources of Energy } \\
\hline Steam & 8,496 & 362,811 & 172,262 & $1,677,892$ & $\mathbf{0}$ & 0 \\
\hline Nuclear & 0 & 47,696 & 0 & 0 & 60,074 & 39,430 \\
\hline 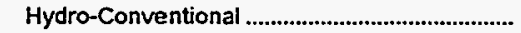 & 0 & $\mathbf{0}$ & 0 & 0 & 0 & 0 \\
\hline Hydro-Pumped Storage & 0 & 0 & 0 & 0 & 0 & 0 \\
\hline Other & 18,226 & 82,417 & 0 & 590,996 & 0 & 181 \\
\hline 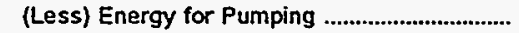 & 5.426 & 0 & 0 & 0 & $\mathbf{0}$ & 0 \\
\hline Total Net Generation & 21,296 & 492,924 & 172,262 & $2,268,888$ & 60,074 & 39,611 \\
\hline 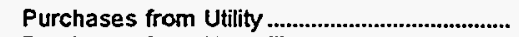 & 601,715 & 404,226 & 0 & 190,725 & 346,115 & 271,784 \\
\hline 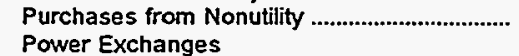 & 0 & 0 & 0 & 0 & 0 & 10,048 \\
\hline 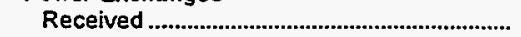 & 0 & 0 & 0 & 0 & 0 & 0 \\
\hline 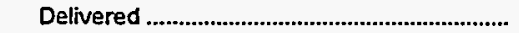 & 0 & 0 & 0 & 0 & 0 & $\mathbf{0}$ \\
\hline 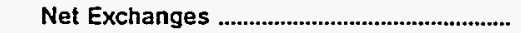 & 0 & 0 & 0 & 0 & 0 & 0 \\
\hline \multicolumn{7}{|l|}{ Transmission for Others (Wheeling) } \\
\hline Received & $\mathbf{0}$ & 0 & 0 & 204,923 & 0 & 0 \\
\hline Delivered & 0 & 0 & 0 & 204,212 & 0 & 0 \\
\hline 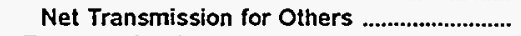 & 0 & 0 & 0 & 711 & 0 & 0 \\
\hline $\begin{array}{l}\text { Transmission by Others Losses ........................ } \\
\text { Total Net Energy }\end{array}$ & 0 & 0 & 1,538 & 0 & 0 & $-2,469$ \\
\hline 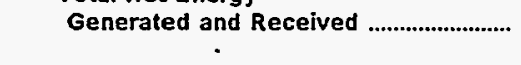 & 623,011 & 897,150 & 377,375 & $2,460,324$ & 406,189 & 318,974 \\
\hline \multicolumn{7}{|l|}{ Disposition of Energy } \\
\hline 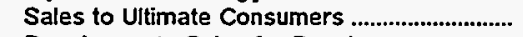 & 577,881 & 842,794 & 353,612 & $2,246,130$ & 384,761 & 299,312 \\
\hline 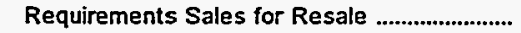 & 5 & 1,248 & 271 & 0 & 0 & 12 \\
\hline Nonrequirements Sales for Resale .................. & 0 & 0 & 0 & 76,737 & 0 & 0 \\
\hline 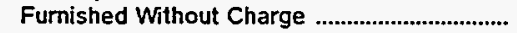 & 0 & 0 & 0 & 0 & 0 & 0 \\
\hline Used by Utility (excluding station use) ............. & 1,011 & 0 & 0 & 0 & 21,428 & 0 \\
\hline Losses & 44,114 & 53,108 & 23,492 & 137,457 & 0 & 19,650 \\
\hline Total Disposition & 623,011 & 897,150 & 377,375 & $2,460,324$ & 406,189 & 318,974 \\
\hline
\end{tabular}


Table 26. Electric Energy Account by Major U.S. Publicly Owned Electric Utility Within State, 1995 (Continued)

(Megawatthours)

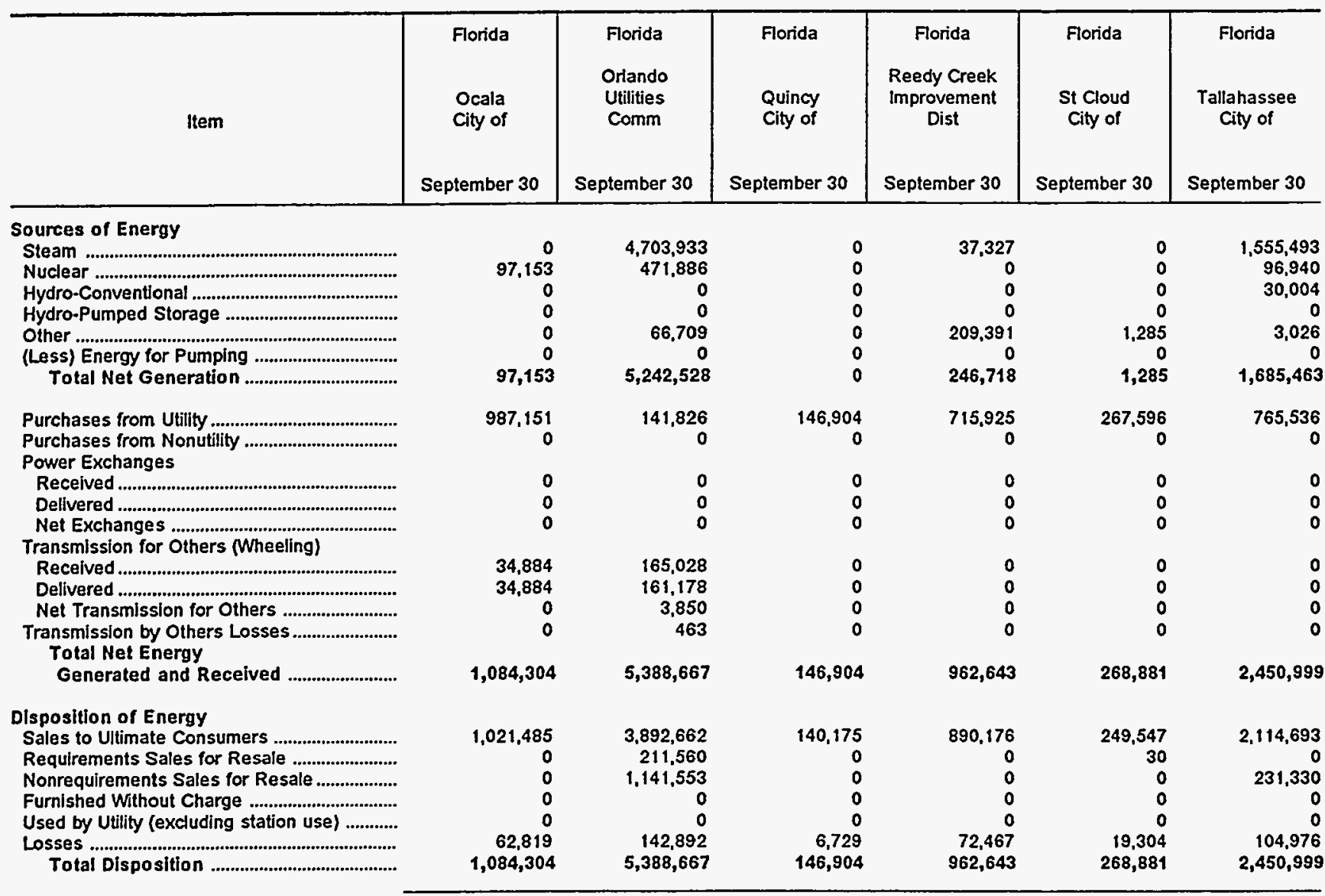

Note: Totals may not equal sum of components because of independent rounding. Double counting occurs in components of both sources and disposition of energy and thus neither provides a true total. Purchases from utilities, net interchanges, and net wheeling (except for imports) are included in net generation.

Source: Energy Information Administration, Form EIA-412, "Annual Report of Public Electric Utilities." 
Table 26. Electric Energy Account by Major U.S. Publicly Owned Electric Utility Within State, 1995 (Continued)

(Megawatthours)

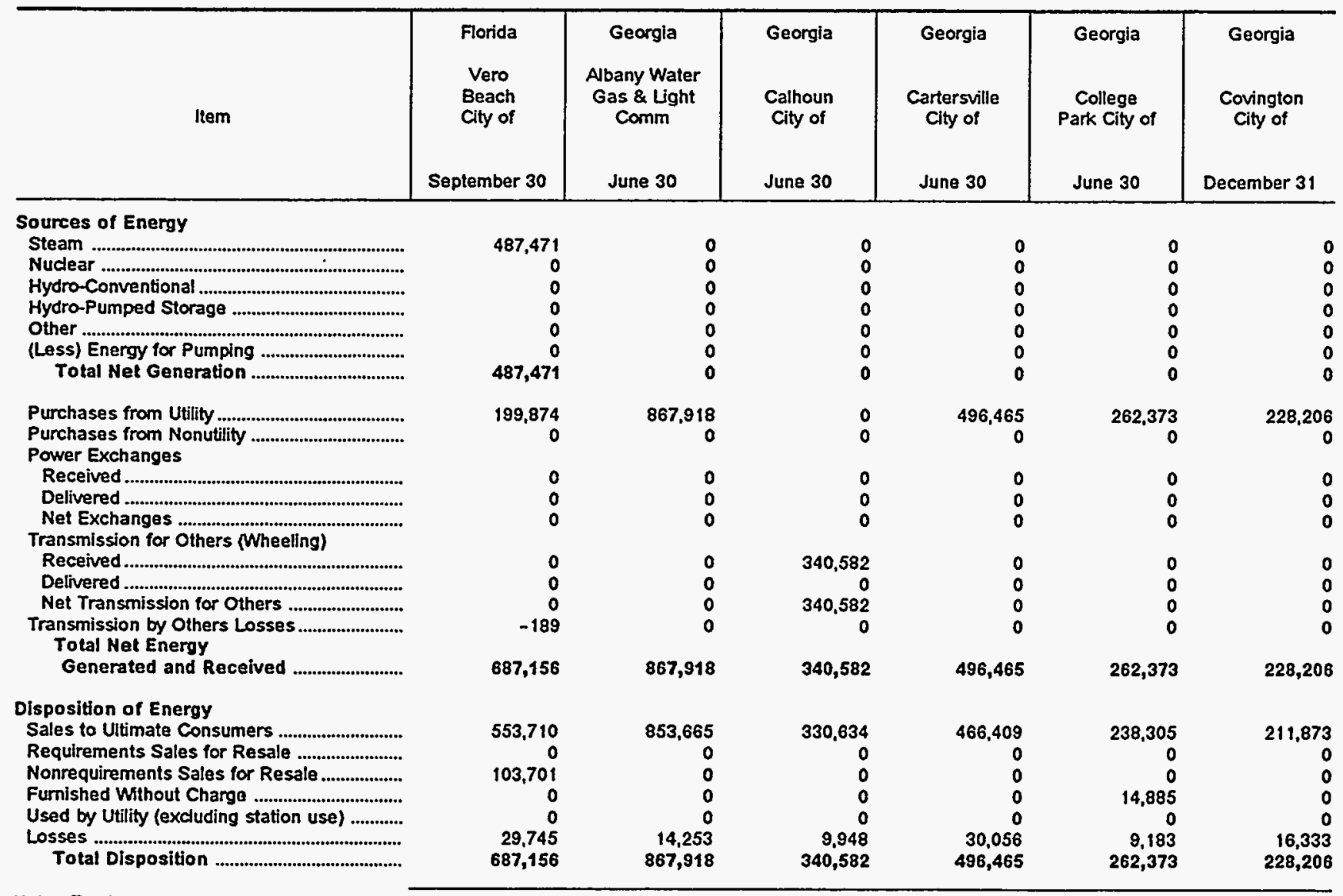

Note: Totals may not equal sum of components because of independent rounding. Double counting occurs in components of both sources and disposition of energy and thus neither provides a true total. Purchases from utilities, net interchanges, and net wheeling (except for imports) are included in net generation.

Source: Energy Information Administration, Form ElA-412, "Annual Report of Public Electric Utilities." 
Table 26. Electric Energy Account by Major U.S. Publicly Owned Electric

Utility Within State, 1995 (Continued)

(Megawatthours)

\begin{tabular}{|c|c|c|c|c|c|c|}
\hline Ifem & $\begin{array}{l}\text { Georgia } \\
\text { Crisp } \\
\text { County } \\
\text { Power } \\
\text { Comm } \\
\text { December } 31\end{array}$ & $\begin{array}{l}\text { Georgia } \\
\text { Dalton } \\
\text { City of } \\
\text { November } 30\end{array}$ & $\begin{array}{l}\text { Georgia } \\
\text { Douglas } \\
\text { City of } \\
\text { June } 30\end{array}$ & $\begin{array}{l}\text { Georgia } \\
\text { East } \\
\text { Point } \\
\text { City of } \\
\text { June } 30\end{array}$ & $\begin{array}{l}\text { Georgia } \\
\text { Fitzgerald } \\
\text { Wtr Lgt } \\
\text { \& Bond Comm } \\
\text { December } 31\end{array}$ & $\begin{array}{l}\text { Georgia } \\
\text { Griffin } \\
\text { City of } \\
\text { June } 30\end{array}$ \\
\hline 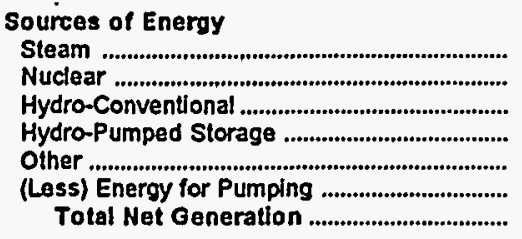 & $\begin{array}{r}-746 \\
0 \\
18,448 \\
0 \\
167 \\
0 \\
17,869\end{array}$ & $\begin{array}{r}230,583 \\
535,504 \\
0 \\
0 \\
0 \\
0 \\
766,087\end{array}$ & $\begin{array}{l}0 \\
0 \\
0 \\
0 \\
0 \\
0 \\
0\end{array}$ & $\begin{array}{l}0 \\
0 \\
0 \\
0 \\
0 \\
0 \\
0\end{array}$ & $\begin{array}{l}0 \\
0 \\
0 \\
0 \\
0 \\
0 \\
0\end{array}$ & $\begin{array}{l}0 \\
0 \\
0 \\
0 \\
0 \\
0 \\
0\end{array}$ \\
\hline 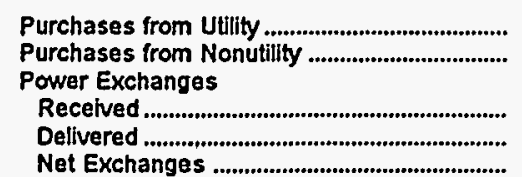 & $\begin{array}{r}339,584 \\
0 \\
0 \\
0 \\
0\end{array}$ & $\begin{array}{r}545,477 \\
0\end{array}$ & $\begin{array}{r}225,346 \\
0\end{array}$ & $\begin{array}{r}314,969 \\
0\end{array}$ & $\begin{array}{r}204,406 \\
0\end{array}$ & $\begin{array}{r}305,395 \\
0\end{array}$ \\
\hline 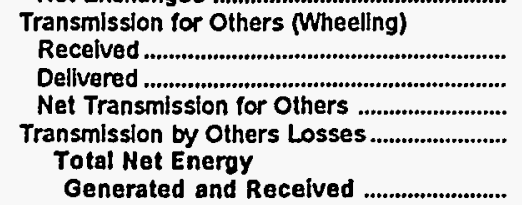 & $\begin{array}{l}0 \\
0 \\
0 \\
0\end{array}$ & $\begin{array}{r}0 \\
0 \\
0 \\
0 \\
1,311,564\end{array}$ & 225,346 & 314,969 & 204,406 & $\begin{array}{r}0 \\
305,395\end{array}$ \\
\hline 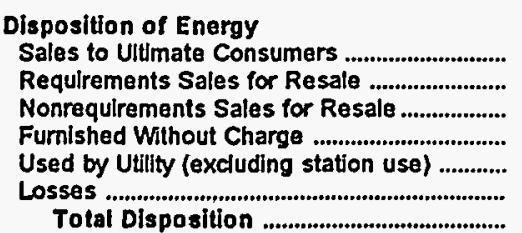 & $\begin{array}{r}349,044 \\
0 \\
0 \\
0 \\
540 \\
7,869 \\
357,453\end{array}$ & $\begin{array}{r}1,199,780 \\
41,162 \\
0 \\
0 \\
0 \\
70,622 \\
1,311,564\end{array}$ & $\begin{array}{r}219,425 \\
0 \\
0 \\
0 \\
0 \\
5,921 \\
225,346\end{array}$ & $\begin{array}{r}302,175 \\
0 \\
0 \\
8.122 \\
4,373 \\
299 \\
314,969\end{array}$ & $\begin{array}{r}187,148 \\
0 \\
0 \\
7,265 \\
0 \\
9,993 \\
204,406\end{array}$ & $\begin{array}{r}300,981 \\
0 \\
0 \\
0 \\
0 \\
4,414 \\
305,395\end{array}$ \\
\hline
\end{tabular}

Note: Totals may not equal sum of components because of independent rounding. Double counting occurs in components of both sources and disposition of energy and thus neither provides a true total. Purchases from utilities, net interchanges, and net wheeling (except for imports) are included in net generation. Sales for resale is included in sales to ultimate consumers.

Source: Energy Information Administration. Form ElA-412, "Annual Report of Public Electric Utilities." 
Table 26. Electric Energy Account by Major U.S. Publicly Owned Electric Utility Within State, 1995 (Continued)

(Megawatthours)

\begin{tabular}{|c|c|c|c|c|c|c|}
\hline Item & $\begin{array}{l}\text { Georgia } \\
\text { La Grange } \\
\text { City of } \\
\text { June } 30\end{array}$ & $\begin{array}{l}\text { Georgia } \\
\text { Lawrenceville } \\
\text { City of } \\
\text { August } 30\end{array}$ & $\begin{array}{l}\text { Georgla } \\
\text { Marietta } \\
\text { City of } \\
\text { June } 30\end{array}$ & $\begin{array}{l}\text { Georgia } \\
\text { Moultrie } \\
\text { City of } \\
\text { September } 30\end{array}$ & $\begin{array}{l}\text { Georgia } \\
\text { Municipal } \\
\text { Electric } \\
\text { Authority } \\
\text { December } 31\end{array}$ & $\begin{array}{c}\text { Georgia } \\
\text { Thomasville } \\
\text { City of }\end{array}$ \\
\hline \multicolumn{7}{|l|}{ Sources of Energy } \\
\hline 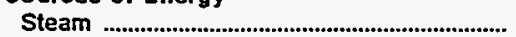 & 0 & $\mathbf{0}$ & $\mathbf{0}$ & 0 & $4,054,739$ & 0 \\
\hline Nuclear & 0 & 0 & 0 & 0 & $6,391,280$ & 0 \\
\hline Hydro-Conventional ............................................. & 0 & 0 & 0 & 0 & 0 & 0 \\
\hline 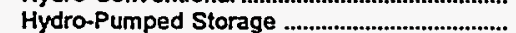 & 0 & 0 & 0 & 0 & 0 & 0 \\
\hline Other & 0 & 0 & 0 & 0 & 0 & 0 \\
\hline 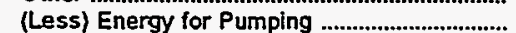 & 0 & $\mathbf{0}$ & 0 & 0 & 32,933 & 0 \\
\hline 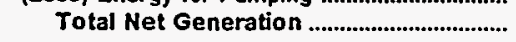 & 0 & 0 & 0 & 0 & $10,413,086$ & $\mathbf{0}$ \\
\hline 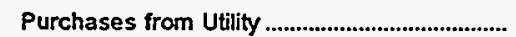 & 463,312 & 221,015 & 867,809 & 176,780 & 360,684 & 430,920 \\
\hline $\begin{array}{l}\text { Purchases from Nonutility } \\
\text { Power Exchanges }\end{array}$ & 0 & 0 & 0 & 0 & 7,285 & \\
\hline 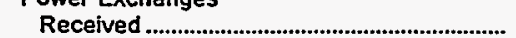 & 0 & 0 & 0 & 0 & 0 & 0 \\
\hline 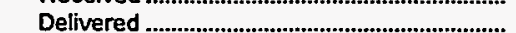 & 0 & 0 & 0 & 0 & 0 & 0 \\
\hline Net Exchanges & 0 & 0 & $\mathbf{0}$ & $\mathbf{0}$ & 0 & 0 \\
\hline \multicolumn{7}{|l|}{ Transmission for Others (Wheeling) } \\
\hline 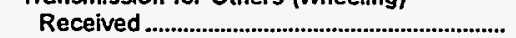 & 0 & 0 & 0 & 0 & 720,929 & $\mathbf{0}$ \\
\hline Delivered & 0 & $\mathbf{0}$ & 0 & 0 & 681,278 & 0 \\
\hline 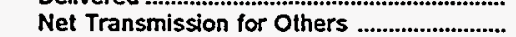 & 0 & 0 & 0 & 0 & 39,651 & $\mathbf{0}$ \\
\hline Transmission by Others Losses ....................... & 0 & 0 & 0 & 0 & 0 & $\mathbf{0}$ \\
\hline 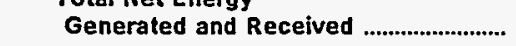 & 463,312 & 221,015 & 867,809 & 176,780 & $10,820,706$ & 430,920 \\
\hline \multicolumn{7}{|l|}{ Disposition of Energy } \\
\hline Sales to Ultimate Consumers ............................. & 447,480 & 206,010 & 814,663 & 153,127 & 0 & 425,455 \\
\hline 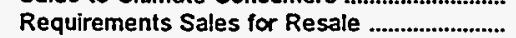 & 0 & 0 & 0 & 0 & $8,720,699$ & 0 \\
\hline Nonrequirements Sales for Resale .................. & 0 & 0 & 0 & 0 & $1,728,605$ & $\mathbf{0}$ \\
\hline Furnished Without Charge .............................. & 0 & 2,299 & 13,641 & 0 & 0 & 2,581 \\
\hline Used by Utility (excluding station use) ............. & 0 & 12,706 & 631 & 0 & 1,456 & 0 \\
\hline 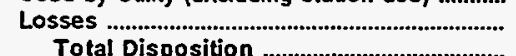 & $\begin{array}{r}15,832 \\
463,312\end{array}$ & 221.015 & $\begin{array}{r}38,874 \\
867,809\end{array}$ & $\begin{array}{r}23,653 \\
976,780\end{array}$ & $\begin{array}{r}369,946 \\
10,820,706\end{array}$ & $\begin{array}{r}2,884 \\
430,920\end{array}$ \\
\hline
\end{tabular}

Note: Totals may not equal sum of components because of independent rounding. Double counting occurs in components of both sources and disposition of energy and thus neither provides a true total. Purchases from utilities, net interchanges, and net wheeling (except for imports) are included In net generation.

Source: Energy Information Administration, Form EIA-412, "Annual Report of Public Electric Utilities." 
Table 26. Electric Energy Account by Major U.S. Publicly Owned Electric Utility Within State, 1995 (Continued)

(Megawatthours)

\begin{tabular}{|c|c|c|c|c|c|c|}
\hline Item & $\begin{array}{c}\text { Idaho } \\
\text { Idaho } \\
\text { Falls } \\
\text { City of } \\
\text { September } 30\end{array}$ & $\begin{array}{l}\text { Illinois } \\
\text { Batavia } \\
\text { City of } \\
\text { December } 31\end{array}$ & $\begin{array}{l}\text { Geneva } \\
\text { City of } \\
\text { April } 30\end{array}$ & $\begin{array}{c}\text { Illinois } \\
\text { Illinois } \\
\text { Municipal } \\
\text { Elec Agency } \\
\text { April } 30\end{array}$ & $\begin{array}{c}\text { Napenille } \\
\text { City of } \\
\text { April } 30\end{array}$ & $\begin{array}{l}\text { Illinois } \\
\text { Rochelle } \\
\text { Municipal } \\
\text { Utilities } \\
\text { April } 30\end{array}$ \\
\hline \multicolumn{7}{|l|}{ Sources of Energy } \\
\hline 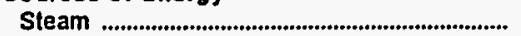 & 0 & 0 & 0 & 404,576 & 0 & 27,587 \\
\hline Nuclear & 0 & 0 & 0 & 0 & 0 & 0 \\
\hline 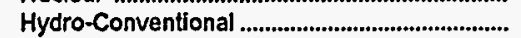 & 238,672 & 0 & 0 & 0 & 0 & 0 \\
\hline 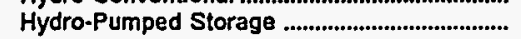 & 0 & 0 & 0 & 0 & 0 & 0 \\
\hline Other & 0 & 0 & 0 & 0 & 0 & 1,492 \\
\hline 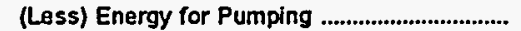 & 0 & 0 & 0 & 0 & 0 & 0 \\
\hline 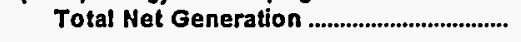 & 238,672 & 0 & 0 & 404,576 & 0 & 29,079 \\
\hline Purchases from Utility.......................................... & 392,566 & 256,887 & 170,465 & $1,120,070$ & 746,166 & 145,292 \\
\hline $\begin{array}{l}\text { Purchases from Nonutility .................................... } \\
\text { Power Exchanges }\end{array}$ & 0 & 0 & 23,087 & 0 & 17,629 & 0 \\
\hline 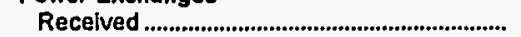 & 0 & 0 & 0 & 0 & 0 & 0 \\
\hline 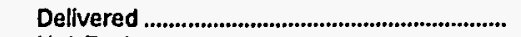 & 0 & 0 & 0 & 0 & 0 & 0 \\
\hline 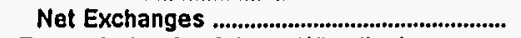 & 0 & 0 & 0 & 0 & o & 0 \\
\hline \multicolumn{7}{|l|}{ Transmission for Others (Wheeling) } \\
\hline 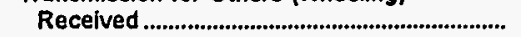 & 0 & 0 & 0 & 0 & 0 & 0 \\
\hline 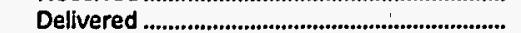 & 0 & 0 & 0 & 0 & 0 & 0 \\
\hline Net Transmission for Others ............................ & $\mathbf{0}$ & 0 & 0 & 0 & 0 & 0 \\
\hline $\begin{array}{l}\text { Transmission by Others Losses....................... } \\
\text { Total Net Energy }\end{array}$ & $\mathbf{0}$ & 0 & 0 & $\mathbf{0}$ & 0 & 0 \\
\hline 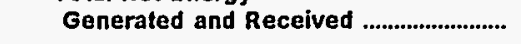 & 631,238 & 256,887 & 193,552 & $1,524,646$ & 763,795 & 174,371 \\
\hline \multicolumn{7}{|l|}{ Disposition of Energy } \\
\hline Sales to Uitimate Consumers ........................... & 607.885 & 243.377 & 188,505 & 0 & 736,998 & 164,435 \\
\hline Requirements Sales for Resale ........................ & 0 & 0 & 0 & $1,468,524$ & 0 & 0 \\
\hline Nonrequirements Sales for Resale ................... & 0 & 0 & 0 & 0 & 0 & 0 \\
\hline Furnished Without Charge ...................................... & 0 & 0 & 3 & 0 & 0 & 0 \\
\hline Used by Utility (excluding station use) ........... & 0 & $\mathbf{0}$ & 115 & 0 & 0 & 0 \\
\hline Losses & 23,353 & 13,510 & 4,929 & 56,122 & 26,797 & 9.936 \\
\hline 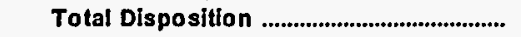 & 631,238 & 256,887 & 193,552 & $1,524,646$ & 763,795 & 174,371 \\
\hline
\end{tabular}

Note: Tolals may not equal sum of components because of independent rounding. Double counting occurs in components of both sources and disposition of energy and thus neither provides a true total. Purchases from utilities, net interchanges, and net wheeling (except for imports) are included in net generation.

Source: Energy Information Administration, Form ElA-412, "Annual Report of Public Electric Utilities." 
Table 26. Electric Energy Account by Major U.S. Publicly Owned Electric Utility Within State, 1995 (Continued)

(Megawatthours)

\begin{tabular}{|c|c|c|c|c|c|c|}
\hline Item & $\begin{array}{l}\text { Ittinois } \\
\begin{array}{c}\text { Springfield } \\
\text { City of }\end{array} \\
\text { February } 28\end{array}$ & $\begin{array}{l}\text { Illinois } \\
\text { St Chartes } \\
\text { City of } \\
\text { April } 30\end{array}$ & $\begin{array}{c}\text { Indiana } \\
\text { Anderson } \\
\text { City of } \\
\text { December } 31\end{array}$ & $\begin{array}{l}\text { Indiana } \\
\text { Auburn } \\
\text { City of } \\
\text { December } 31\end{array}$ & $\begin{array}{l}\text { Indiana } \\
\text { Bluffton } \\
\text { City of } \\
\text { December } 31\end{array}$ & $\begin{array}{c}\text { Indiana } \\
\text { Crawfordsville } \\
\text { Elec } \\
\text { Lgt\&PwT Co } \\
\text { December } 31\end{array}$ \\
\hline \multicolumn{7}{|l|}{ Sources of Energy } \\
\hline Steam & $1,776,061$ & 0 & 0 & 0 & 0 & 11,336 \\
\hline Nudear ................................................................. & 0 & 0 & 0 & 0 & 0 & \\
\hline 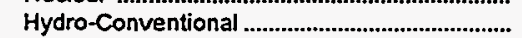 & 0 & $\mathbf{0}$ & 0 & 0 & 0 & 0 \\
\hline Hydro-Pumped Storage .................................................. & 0 & 0 & 0 & 0 & 0 & 0 \\
\hline 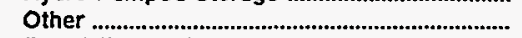 & 423 & 0 & 0 & 0 & 2,308 & 0 \\
\hline 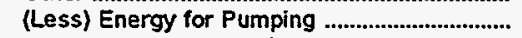 & 0 & 0 & 0 & 0 & 0 & 0 \\
\hline Total Net Generation & $1,776,484$ & 0 & 0 & 0 & 2,308 & 11,336 \\
\hline 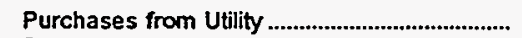 & 36,920 & 387,763 & 697,616 & 409,038 & 178,075 & 389,984 \\
\hline $\begin{array}{l}\text { Purchases from Nonutility .................................... } \\
\text { Power Exchanges }\end{array}$ & 0 & 0 & 0 & 0 & 0 & 0 \\
\hline 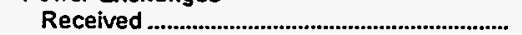 & 0 & 0 & 0 & 0 & 0 & 0 \\
\hline 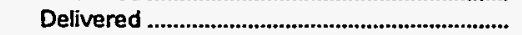 & 0 & 0 & 0 & 0 & 0 & 0 \\
\hline Net Exchanges …………........................................... & 0 & $\mathbf{0}$ & 0 & 0 & 0 & 0 \\
\hline \multicolumn{7}{|l|}{ Transmission for Others (Wheeling) } \\
\hline 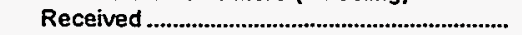 & 0 & 0 & 0 & 0 & 0 & 0 \\
\hline 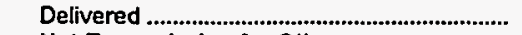 & 0 & 0 & 0 & 0 & 0 & 0 \\
\hline 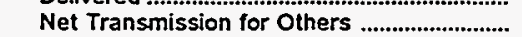 & 0 & 0 & 0 & 0 & 0 & 0 \\
\hline 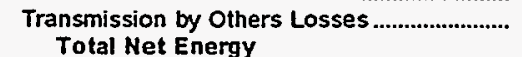 & 0 & 0 & 0 & 0 & 0 & 0 \\
\hline 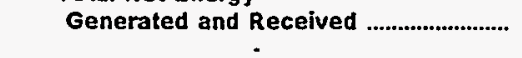 & $1,813,404$ & 387,763 & 697,616 & 409,038 & 180,383 & 401,320 \\
\hline \multicolumn{7}{|l|}{ Disposition of Energy } \\
\hline Sales to Ultimate Consumers ............. & $1,571,787$ & 373,850 & 661,554 & 402,860 & 175,002 & 381,684 \\
\hline Requirements Sales for Resale .............................. & 56,819 & 0 & 0 & 0 & 0 & 0 \\
\hline Nonrequirements Sales for Resale ................... & 94,515 & 0 & 0 & 0 & 0 & 11,336 \\
\hline 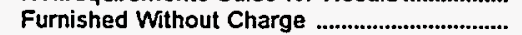 & 26,297 & 0 & 0 & 5,953 & 0 & 0 \\
\hline Used by Utility (excluding station use) ............. & 3,431 & 0 & 0 & 225 & 0 & 1,898 \\
\hline 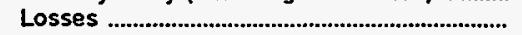 & 60,555 & 13,913 & 36,062 & 0 & 5,381 & 6,402 \\
\hline Total Disposition & $1,813,404$ & 387,763 & 697,616 & 409,038 & 180,383 & 401,320 \\
\hline
\end{tabular}

Note: Totals may not equal sum of components because of independent rounding. Double counting occurs in components of both sources and disposition of energy and thus neither provides a true tolal. Purchases from utilities, net interchanges, and net wheeling (except for imports) are included in net generation.

Source: Energy Information Administration, Form ElA-412, "Annual Report of Public Electric Utilities." 
Table 26. Electric Energy Account by Major U.S. Publicly Owned Electric Utility Within State, 1995 (Continued)

(Megawatthours)

\begin{tabular}{|c|c|c|c|c|c|c|}
\hline Item & $\begin{array}{l}\text { Indiana } \\
\text { Frankfort } \\
\text { City of } \\
\text { December } 31\end{array}$ & $\begin{array}{l}\text { Indiana } \\
\text { Greenfield } \\
\text { City of } \\
\text { December } 31\end{array}$ & $\begin{array}{c}\text { Indiana } \\
\text { Indiana } \\
\text { Municipal } \\
\text { Power Agency } \\
\text { December } 31\end{array}$ & $\begin{array}{l}\text { Indiana } \\
\text { Jasper } \\
\text { City of } \\
\text { December } 31\end{array}$ & $\begin{array}{c}\text { Lebanon } \\
\text { City of }\end{array}$ & $\begin{array}{l}\text { Indiana } \\
\text { Logansport } \\
\text { City of } \\
\text { December } 31\end{array}$ \\
\hline \multicolumn{7}{|l|}{ Sources of Energy } \\
\hline Steam & 0 & 0 & $1,370,984$ & 53,549 & 0 & 146,531 \\
\hline 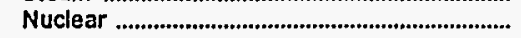 & 0 & 0 & 0 & 0 & 0 & \\
\hline 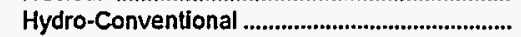 & 0 & 0 & 0 & 0 & 0 & 0 \\
\hline 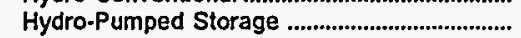 & 0 & 0 & 0 & 0 & 0 & 0 \\
\hline Other & 0 & 0 & 12,337 & 0 & 0 & 700 \\
\hline 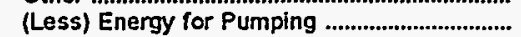 & 0 & 0 & 0 & 0 & $\mathbf{0}$ & 0 \\
\hline Total Net Generation & 0 & 0 & $1,383,321$ & 53,549 & 0 & 147,231 \\
\hline 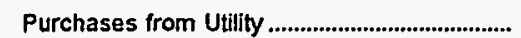 & 327,081 & 187.734 & $2,813,553$ & 234,042 & 144,612 & 182,254 \\
\hline $\begin{array}{l}\text { Purchases from Nonutility .................................. } \\
\text { Power Exchanges }\end{array}$ & 0 & 0 & 0 & 0 & 0 & 0 \\
\hline 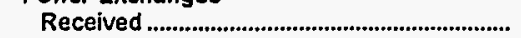 & 0 & 0 & 0 & 0 & 0 & 0 \\
\hline 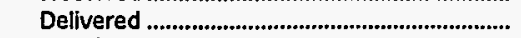 & 0 & 0 & 0 & 0 & 0 & 0 \\
\hline 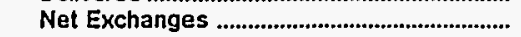 & 0 & 0 & 0 & 0 & 0 & 0 \\
\hline \multicolumn{7}{|l|}{ Transmission for Others (Wheeling) } \\
\hline 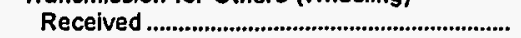 & 0 & 0 & 452,664 & 0 & 0 & 0 \\
\hline 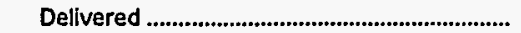 & 0 & 0 & 452,664 & 0 & 0 & 0 \\
\hline 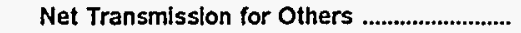 & 0 & 0 & 0 & 0 & 0 & 0 \\
\hline $\begin{array}{l}\text { Transmission by Others Losses ........................ } \\
\text { Total Net Energy }\end{array}$ & 0 & 0 & 0 & 0 & 0 & 0 \\
\hline Generated and Received ........................... & 327,081 & 187,734 & $4,196,874$ & 287,591 & 144,612 & 329,485 \\
\hline \multicolumn{7}{|l|}{ Disposition of Energy } \\
\hline 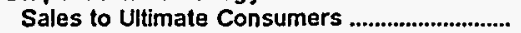 & 319,460 & 180,033 & $\mathbf{0}$ & 275,190 & 139,241 & 309,956 \\
\hline 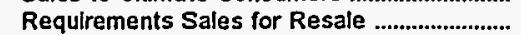 & 0 & 0 & $4,071.803$ & 0 & 0 & \\
\hline Nonrequirements Sales for Resale ................... & 0 & 0 & 893 & 0 & 0 & 0 \\
\hline Furnlshed Without Charge .................................. & 0 & 0 & 0 & 9 & 0 & 0 \\
\hline Used by Utility (excluding station use) ............. & 439 & 0 & 2,449 & 754 & 0 & 0 \\
\hline 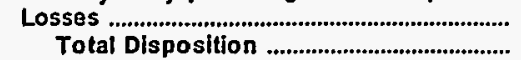 & $\begin{array}{r}7,180 \\
327,081\end{array}$ & $\begin{array}{r}7,701 \\
187,734\end{array}$ & $\begin{array}{r}121,729 \\
4,196,874\end{array}$ & $\begin{array}{r}11,638 \\
287,591\end{array}$ & $\begin{array}{r}5,371 \\
144,612\end{array}$ & $\begin{array}{r}19,529 \\
329,485\end{array}$ \\
\hline
\end{tabular}

Note: Totals may not equal sum of components because of independent rounding. Double counting occurs in components of both sources and disposition of energy and thus neither provides a true total. Purchases from utilities, net interchanges, and net wheeling (except for imports) are included in net generation.

Source: Energy Information Administration, Form ELA-412, "Annual Report of Public Electric Utilities." 
Table 26. Electric Energy Account by Major U.S. Publicly Owned Electric Utility Within State, 1995 (Continued)

(Megawatthours)

\begin{tabular}{c|c|c|c|c|c|c|c|}
\hline & Indiana & Indiana & Indiana & Indiana & Indiana & lowa \\
Item & $\begin{array}{c}\text { Mishawaka } \\
\text { City of }\end{array}$ & $\begin{array}{c}\text { Peru } \\
\text { City of }\end{array}$ & $\begin{array}{c}\text { Richmond } \\
\text { City of }\end{array}$ & $\begin{array}{c}\text { Scottsburg } \\
\text { City of }\end{array}$ & $\begin{array}{c}\text { Washington } \\
\text { City of }\end{array}$ & $\begin{array}{c}\text { Ames } \\
\text { City of }\end{array}$ \\
December 31 & December 31 & December 31 & December 31 & December 31 & June 30 \\
\hline
\end{tabular}

Sources of Energy

Steam

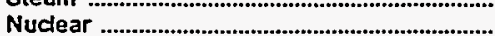

Hydro-Conventional

Hydro-Pumped Storage

Other

Less) Energy for Pumping

Total Net Generation

Purchases from Utility.

Purchases from Nonutility ..................................

Power Exchanges

Received.

Delivered

Net Exchanges ....................................................

Transmission for Others (Wheeling)

Received.

Delivered

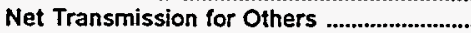

Transmission by Others Losses

Total Net Energy

Disposition of Energy

Sales to Ultimate Consumers

Requirements Sales for Resale

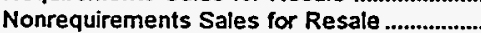

Furnished Without Charge

Used by Utility (excluding station use)

Losses

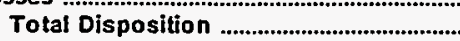

\begin{tabular}{|c|c|c|}
\hline 0 & 5,584 & 574,913 \\
\hline 0 & 0 & 0 \\
\hline 0 & 0 & 0 \\
\hline 0 & 0 & 0 \\
\hline 0 & 0 & 0 \\
\hline 0 & 0 & 0 \\
\hline 0 & 5,584 & 574,913 \\
\hline 512,700 & 206,952 & 293,865 \\
\hline 0 & 0 & 0 \\
\hline 0 & 0 & 0 \\
\hline 0 & 0 & 0 \\
\hline 0 & 0 & 0 \\
\hline 0 & 0 & 0 \\
\hline 0 & 0 & 0 \\
\hline 0 & 0 & 0 \\
\hline 0 & 0 & 0 \\
\hline 512,700 & 212,536 & 868,778 \\
\hline 486,451 & 196,641 & 840,478 \\
\hline 0 & 0 & - - \\
\hline 0 & 0 & 0 \\
\hline 0 & 0 & 5 \\
\hline 0 & 0 & 2,218 \\
\hline 26,249 & 15,895 & 26,077 \\
\hline 512,700 & 212,538 & 868,778 \\
\hline
\end{tabular}

$\begin{array}{rr}574,913 & 0 \\ 0 & 0 \\ 0 & 0 \\ 0 & 0 \\ 0 & 0 \\ 0 & 0 \\ 574,913 & 0\end{array}$

0
0
0
0
0
0
0

274,024

167,942

274.024

0

0

274,024

0

0

134,700

0

0
0
0

229

42

142
87

Note: Totals may not equal sum of components because of independent rounding. Double counting occurs in components of both sources and disposition of energy and thus neither provides a true total. Purchases from utilities, net interchanges, and net wheeling (except for imports) are included In net generation.

Source: Energy Information Administration, Form ElA-412, "Annual Report of Public Electric Utilities." 
Table 26. Electric Energy Account by Major U.S. Publicly Owned Electric Utility Within State, 1995 (Continued)

(Megawatthours)

\begin{tabular}{|c|c|c|c|c|c|c|}
\hline ltem & $\begin{array}{c}\text { lowa } \\
\text { Cedar } \\
\text { Falls } \\
\text { City of } \\
\text { December } 31\end{array}$ & $\begin{array}{c}\text { lowa } \\
\text { Muscatine } \\
\text { City of } \\
\text { December } 31\end{array}$ & $\begin{array}{c}\text { lowa } \\
\text { Pella } \\
\text { City of } \\
\text { December } 31\end{array}$ & $\begin{array}{c}\text { Kansas } \\
\text { Chanute } \\
\text { City of } \\
\text { December } 31\end{array}$ & $\begin{array}{c}\text { Kansas } \\
\text { Coffeyville } \\
\text { City of } \\
\text { December } 31\end{array}$ & $\begin{array}{c}\text { Kansas } \\
\text { Garden } \\
\text { City City of } \\
\text { December } 31\end{array}$ \\
\hline \multicolumn{7}{|l|}{ Sources of Energy } \\
\hline 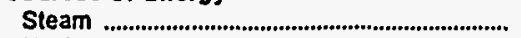 & 267,139 & $1,313,632$ & 82,106 & $\mathbf{0}$ & 76,665 & 0 \\
\hline 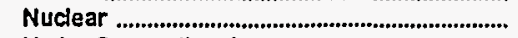 & 0 & 0 & 0 & 0 & 0 & 0 \\
\hline 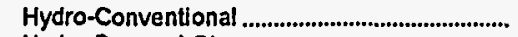 & $\mathbf{0}$ & 0 & 0 & 0 & 0 & 0 \\
\hline 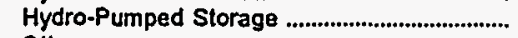 & 0 & 0 & 0 & 0 & 0 & 0 \\
\hline Other & 1,935 & $\mathbf{0}$ & 0 & 9,712 & 0 & 0 \\
\hline 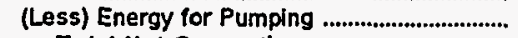 & 0 & 0 & 0 & 0 & 0 & 0 \\
\hline 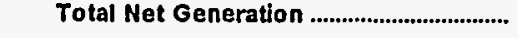 & 269,074 & $1,313,632$ & 82,106 & 9,712 & 76,665 & $\mathbf{0}$ \\
\hline 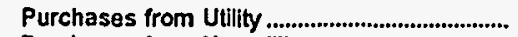 & 95,370 & 27,203 & 70,021 & 156,312 & 114,026 & 178,761 \\
\hline $\begin{array}{l}\text { Purchases from Nonutility ......................................... } \\
\text { Power Exchanges }\end{array}$ & 3 & 0 & 0 & 0 & 0 & 0 \\
\hline 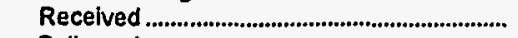 & 0 & 0 & 7,278 & 0 & 113,814 & 0 \\
\hline 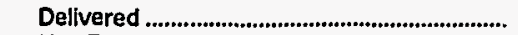 & 0 & 0 & 5,940 & 0 & 114,026 & $\mathbf{0}$ \\
\hline 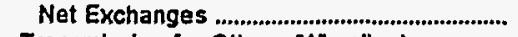 & $\mathbf{0}$ & 0 & 1,338 & 0 & -222 & 0 \\
\hline \multicolumn{7}{|l|}{ Transmission for Others Wheeling) } \\
\hline 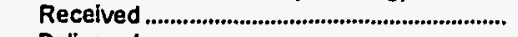 & 0 & 5,098 & 0 & 0 & $\mathbf{0}$ & 0 \\
\hline 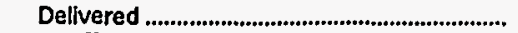 & $\mathbf{0}$ & 1,297 & 0 & 0 & 0 & 0 \\
\hline 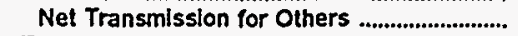 & 0 & 3,801 & 0 & 0 & $\mathbf{0}$ & 0 \\
\hline $\begin{array}{l}\text { Transmission by Others Losses........................... } \\
\text { Total Net Energy }\end{array}$ & 0 & 0 & 0 & 0 & 0 & $-8,704$ \\
\hline Generated and Received ............................ & 364,447 & $1,344,636$ & 153,465 & 166,024 & 190,479 & 170,057 \\
\hline \multicolumn{7}{|l|}{ Disposition of Energy } \\
\hline Sales to Ultimate Consumers ............................ & 330,325 & 819,312 & 145,651 & 161,940 & 176,447 & 156,716 \\
\hline Requlrements Sales for Resale ......................... & 0 & 0 & 0 & 0 & 0 & 0 \\
\hline Nonrequirements Sales for Resale .................. & 7,669 & 491,514 & 0 & 0 & 0 & 0 \\
\hline 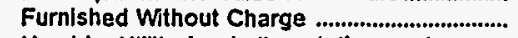 & 0 & 5,089 & 0 & 0 & 4,273 & 1,775 \\
\hline Used by Utility (excluding station use) ............ & 3,085 & 2,596 & 0 & 2,208 & 683 & 4,534 \\
\hline 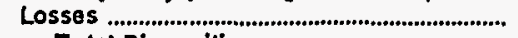 & 23,368 & 26,125 & 7,814 & 1,876 & 9,076 & 7,032 \\
\hline 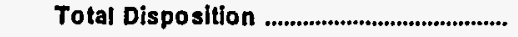 & 364,447 & $1,344,636$ & 153,465 & 166,024 & 190,479 & 170,057 \\
\hline
\end{tabular}


Table 26. Electric Energy Account by Major U.S. Publicly Owned Electric Utility Within State, 1995 (Continued)

(Megawatthours)

\begin{tabular}{|c|c|c|c|c|c|c|}
\hline Item & $\begin{array}{c}\text { Kansas } \\
\text { Kansas } \\
\text { City City of } \\
\text { December } 31\end{array}$ & $\begin{array}{c}\text { Kansas } \\
\text { Kansas } \\
\text { Municipal } \\
\text { Energy } \\
\text { Agency } \\
\text { December } 31\end{array}$ & $\begin{array}{c}\text { Kansas } \\
\text { McPherson } \\
\text { City of } \\
\text { December } 31\end{array}$ & $\begin{array}{l}\text { Kansas } \\
\text { Winfield } \\
\text { City of } \\
\text { December } 31\end{array}$ & $\begin{array}{c}\text { Kentucky } \\
\text { Bardstown } \\
\text { City of } \\
\text { December } 31\end{array}$ & $\begin{array}{l}\text { Kentucky } \\
\text { Bowing } \\
\text { Green } \\
\text { City of } \\
\text { June } 30\end{array}$ \\
\hline \multicolumn{7}{|l|}{ Sources of Energy } \\
\hline Steam & $2,407,045$ & 0 & 5,102 & 40,176 & 0 & 0 \\
\hline 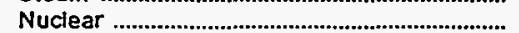 & 0 & 0 & 0 & 0 & $\mathbf{0}$ & 0 \\
\hline 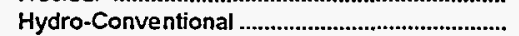 & 0 & 0 & 0 & 0 & 0 & 0 \\
\hline 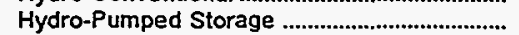 & 0 & 0 & 0 & 0 & 0 & 0 \\
\hline Other & 0 & 0 & 11,284 & 1,362 & 0 & 0 \\
\hline 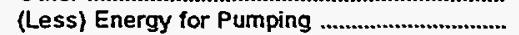 & 0 & 0 & 0 & 0 & 0 & 0 \\
\hline Total Net Generation & $2,407,045$ & 0 & 16,386 & 41,538 & 0 & 0 \\
\hline 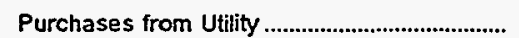 & 264,215 & 304,342 & 557,373 & 213,807 & 154,704 & 707,861 \\
\hline $\begin{array}{l}\text { Purchases from Nonutility ................................... } \\
\text { Power Exchanges }\end{array}$ & 0 & 0 & 0 & 0 & 0 & \\
\hline 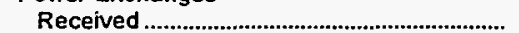 & 0 & 0 & 0 & 0 & 0 & 0 \\
\hline Delivered & 11,626 & 0 & 0 & 0 & 0 & $\mathbf{0}$ \\
\hline 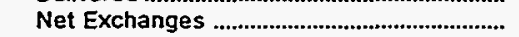 & $-11,626$ & 0 & 0 & 0 & 0 & 0 \\
\hline \multicolumn{7}{|l|}{ Transmission for Others (Wheeling) } \\
\hline 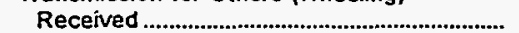 & 0 & 0 & 0 & 0 & 0 & 0 \\
\hline 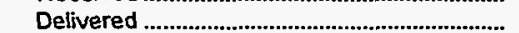 & 0 & 0 & 0 & 0 & 0 & 0 \\
\hline 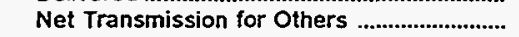 & 0 & 0 & 0 & 0 & 0 & 0 \\
\hline $\begin{array}{l}\text { Transmission by Others Losses......................... } \\
\text {, otal Net Energy }\end{array}$ & 0 & 0 & 0 & 0 & 0 & 0 \\
\hline 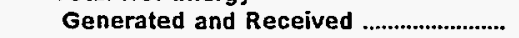 & $2,659,634$ & 304,342 & 573,759 & 255,345 & 154,704 & 707,861 \\
\hline \multicolumn{7}{|l|}{ Disposition of Energy } \\
\hline 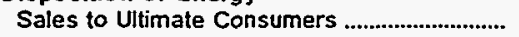 & $2,070,282$ & 0 & 517,987 & 231,258 & 141,202 & 680,424 \\
\hline 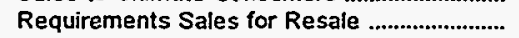 & 404,348 & 304,342 & 39,083 & 4,886 & 0 & 0 \\
\hline Nonrequirements Sales for Resale ................... & 0 & 0 & 0 & 0 & 0 & 0 \\
\hline Furnished Without Charge ............................... & 103,641 & 0 & 160 & 0 & 0 & 0 \\
\hline Used by Utility (excluding station use) ............ & 0 & 0 & 0 & 5,197 & 6,451 & 935 \\
\hline 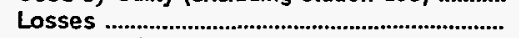 & 81,363 & 0 & 16,529 & 14,004 & 7,051 & 26,502 \\
\hline Total Disposition & $2,659,634$ & 304,342 & 573,759 & 255,345 & 154,704 & 707,861 \\
\hline
\end{tabular}

Note: Totals may not equal sum of components because of independent rounding. Double counting occurs in components of both sources and disposition of energy and thus neither provides a true total. Purchases from utilities, net interchanges, and net wheeling (except for imports) are included in net generation.

Source: Energy Information Administration, Form ElA-412, "Annual Report of Public Electric Utilities." 
Table 26. Electric Energy Account by Major U.S. Publicly Owned Electric Utility Within State, 1995 (Continued)

(Megawatthours)

\begin{tabular}{|c|c|c|c|c|c|c|}
\hline Item & $\begin{array}{l}\text { Kentucky } \\
\text { Frankfort } \\
\text { City of } \\
\text { June } 30\end{array}$ & $\begin{array}{l}\text { Kentucky } \\
\text { Franklin } \\
\text { City of } \\
\text { June } 30\end{array}$ & $\begin{array}{l}\text { Kentucky } \\
\text { Glasgow } \\
\text { City of } \\
\text { June } 30\end{array}$ & $\begin{array}{l}\text { Kentucky } \\
\text { Henderson } \\
\text { City } \\
\text { Utility Comm } \\
\text { May } 31\end{array}$ & $\begin{array}{l}\text { Hopkinsville } \\
\text { City of } \\
\text { June } 30\end{array}$ & $\begin{array}{l}\text { Kentucky } \\
\text { Madisonville } \\
\text { Municipal } \\
\text { Utlls } \\
\text { June } 30\end{array}$ \\
\hline \multicolumn{7}{|l|}{ Sources of Energy } \\
\hline Steam & $\mathbf{0}$ & 0 & 0 & $1,745,822$ & 0 & 0 \\
\hline 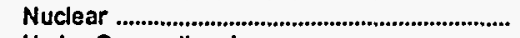 & 0 & 0 & 0 & 0 & 0 & 0 \\
\hline 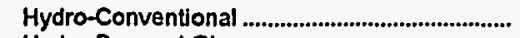 & 0 & 0 & 0 & 0 & 0 & 0 \\
\hline 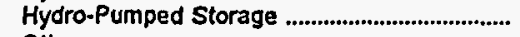 & 0 & 0 & 0 & 0 & 0 & 0 \\
\hline Other & 0 & 0 & 0 & 0 & 0 & 0 \\
\hline 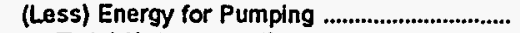 & 0 & 0 & 0 & $\mathbf{0}$ & 0 & 0 \\
\hline Total Net Generation & $\mathbf{0}$ & $\mathbf{0}$ & 0 & $1,745,822$ & 0 & 0 \\
\hline Purchases from Utility & 638,344 & 199,026 & 332,954 & 41,121 & 425,899 & 272.114 \\
\hline $\begin{array}{l}\text { Purchases from Nonutility ................................................ } \\
\text { Power Exchanges }\end{array}$ & $\mathbf{0}$ & 0 & 0 & 0 & 0 & 0 \\
\hline 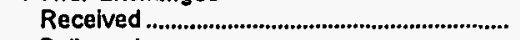 & 0 & 0 & 0 & 0 & 0 & 0 \\
\hline Delivered & 0 & 0 & 0 & 0 & 0 & 0 \\
\hline 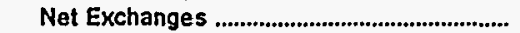 & 0 & 0 & 0 & 0 & 0 & 0 \\
\hline \multicolumn{7}{|l|}{ Transmission for Others (Wheeling) } \\
\hline 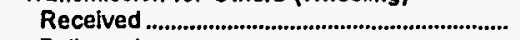 & 0 & 0 & 0 & 0 & 0 & 0 \\
\hline 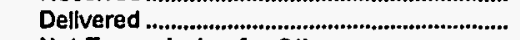 & 0 & 0 & 0 & 0 & 0 & 0 \\
\hline Net Transmission for Others .......................... & 0 & 0 & 0 & 0 & $\mathbf{0}$ & 0 \\
\hline $\begin{array}{l}\text { Transmission by Others Losses ........................ } \\
\text { Total Net Energy }\end{array}$ & 0 & 0 & 0 & 0 & 0 & $\mathbf{0}$ \\
\hline Generated and Received ........................... & 638,344 & 199,026 & 332,954 & $1,786,943$ & 425,899 & 272,114 \\
\hline \multicolumn{7}{|l|}{ Disposition of Energy } \\
\hline Sales to Ultimate Consumers ................................ & 603,320 & 192,119 & 315,491 & 421,843 & 409,506 & 271,508 \\
\hline Requirements Sales for Resale ............................ & $\mathbf{0}$ & 0 & 0 & $1.336,742$ & 0 & 0 \\
\hline Nonrequirements Sales for Resale ................... & 0 & 0 & 0 & 0 & 0 & 0 \\
\hline Furnished Without Charge & $\mathbf{0}$ & 0 & 0 & 5,699 & 0 & 0 \\
\hline Used by Utillty (excluding station use) ............. & 7,760 & 212 & 623 & 362 & 444 & 0 \\
\hline 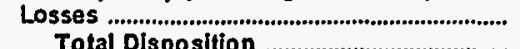 & 27,264 & $\begin{array}{r}6.696 \\
\end{array}$ & 16,840 & 22,297 & 15,949 & 606 \\
\hline 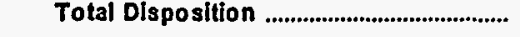 & 638,344 & 199,026 & 332,954 & $1,786,943$ & 425,899 & 272,114 \\
\hline
\end{tabular}

Note: Totals may not equal sum of components because of independent rounding. Double counting occurs in components of both sources and disposition of energy and thus neither provides a true total. Purchases from utilities, net interchanges, and net wheeling (except for imports) are included in net generation.

Source: Energy Information Administration, Form ElA-412, "Annual Report of Public Electric Utilities." 
Table 26. Electric Energy Account by Major U.S. Publicly Owned Electric Utility Within State, 1595 (Continued)

(Megawatthours)

\begin{tabular}{|c|c|c|c|c|c|c|}
\hline Item & $\begin{array}{l}\text { Kentucky } \\
\text { Mayfield } \\
\text { City of } \\
\text { June } 30\end{array}$ & $\begin{array}{l}\text { Kentucky } \\
\text { Murray } \\
\text { City of } \\
\text { June } 30\end{array}$ & $\begin{array}{c}\text { Kentucky } \\
\text { Owensboro } \\
\text { City of } \\
\text { May } 31\end{array}$ & $\begin{array}{l}\text { Kentucky } \\
\text { Paducah } \\
\text { City of } \\
\text { June } 30\end{array}$ & $\begin{array}{l}\text { Louisiana } \\
\text { Alexandria } \\
\text { City of } \\
\text { April } 30\end{array}$ & $\begin{array}{l}\text { Louisiana } \\
\text { Lafayette } \\
\text { City of } \\
\text { October } 31\end{array}$ \\
\hline \multicolumn{7}{|l|}{ Sources of Energy } \\
\hline 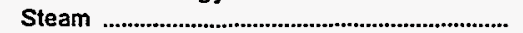 & 0 & 0 & $2,173,686$ & 0 & 4,386 & 534,136 \\
\hline 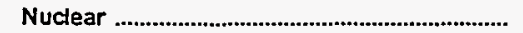 & 0 & 0 & 0 & 0 & 0 & 0 \\
\hline 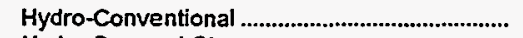 & $\mathbf{0}$ & 0 & 0 & 0 & 0 & 0 \\
\hline 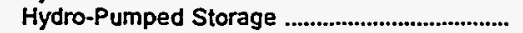 & 0 & 0 & 0 & 0 & 0 & 0 \\
\hline Other & 0 & 0 & 0 & 0 & 0 & $\mathbf{0}$ \\
\hline (Less) Energy for Pumping .................................... & 0 & 0 & 0 & 0 & 0 & 0 \\
\hline Total Net Generation & $\mathbf{0}$ & 0 & $2,173,686$ & 0 & 4,386 & 534,136 \\
\hline 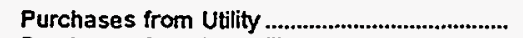 & 146,643 & 242,924 & 22,712 & 544,982 & 634,928 & $1,540,047$ \\
\hline $\begin{array}{l}\text { Purchases from Nonutility ................................... } \\
\text { Power Exchanges }\end{array}$ & 0 & 0 & 0 & 0 & 0 & 0 \\
\hline 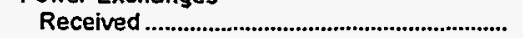 & 0 & $\mathbf{0}$ & 0 & 0 & $\mathbf{0}$ & $\mathbf{0}$ \\
\hline 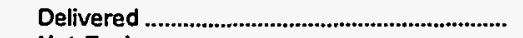 & 0 & 0 & 0 & 0 & 0 & 70 \\
\hline 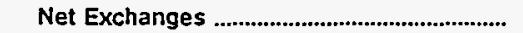 & 0 & $\mathbf{0}$ & 0 & 0 & 0 & -70 \\
\hline \multicolumn{7}{|l|}{ Transmission for Others (Wheeling) } \\
\hline Received & 0 & $\mathbf{0}$ & 0 & $\mathbf{0}$ & 0 & 0 \\
\hline Delivered & 0 & 0 & 0 & 0 & 0 & 0 \\
\hline Net Transmission for Others ............................ & $\mathbf{0}$ & 0 & 0 & 0 & 0 & 0 \\
\hline $\begin{array}{l}\text { Transmission by Others Losses ............................. } \\
\text { Total Net Energy }\end{array}$ & 0 & 0 & 0 & 0 & 0 & 0 \\
\hline Generated and Received ........................... & 146,643 & 242,924 & $2,196,398$ & 544,982 & 639,314 & $2,074,113$ \\
\hline \multicolumn{7}{|l|}{ Disposition of Energy } \\
\hline 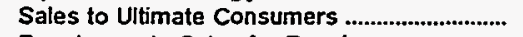 & 143,024 & 225,979 & 765,883 & 519,735 & 585,423 & $1,514,417$ \\
\hline 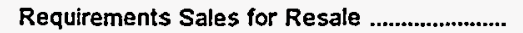 & 0 & 0 & 0 & 0 & 0 & 464,784 \\
\hline Nonrequirements Sales for Resale .................. & 0 & 0 & $1,395,807$ & 0 & $\mathbf{0}$ & 0 \\
\hline 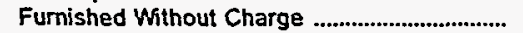 & 0 & 0 & 0 & 0 & 15.006 & 0 \\
\hline Used by Utility (excluding station use) ............ & 184 & 169 & 2,236 & 1,411 & 7,685 & 94,912 \\
\hline Losses & 3,435 & 16,776 & 32.472 & 23,836 & 31,200 & 0 \\
\hline 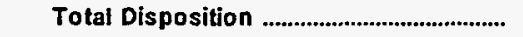 & 146,643 & 242,924 & $2,196,398$ & 544,982 & 639,314 & $2,074,113$ \\
\hline
\end{tabular}


Table 26. Electric Energy Account by Major U.S. Publicly Owned Electric Utility Within State, 1995 (Continued) (Megawatthours)

\begin{tabular}{|c|c|c|c|c|c|c|}
\hline Item & $\begin{array}{l}\text { Louisiana } \\
\text { Lafayette } \\
\text { Public } \\
\text { Power Auth } \\
\text { October } 31\end{array}$ & $\begin{array}{l}\text { Louisiana } \\
\text { Louisiana } \\
\text { Energy } \\
\text { \& } \\
\text { Power Auth } \\
\text { December } 31\end{array}$ & $\begin{array}{l}\text { Louisiana } \\
\text { Morgan } \\
\text { City City of } \\
\text { December } 31\end{array}$ & $\begin{array}{l}\text { Louisiana } \\
\text { Natchitoches } \\
\text { City of } \\
\text { May } 31\end{array}$ & $\begin{array}{l}\text { Louisiana } \\
\text { Ruston } \\
\text { City of } \\
\text { September } 30\end{array}$ & $\begin{array}{c}\text { Louisiana } \\
\text { Terrebonne } \\
\text { Parish } \\
\text { Consol Govt } \\
\\
\text { December } 31\end{array}$ \\
\hline \multicolumn{7}{|l|}{ Sources of Energy } \\
\hline Steam & $1,110,212$ & 624,075 & 0 & 0 & 186,043 & 114,088 \\
\hline 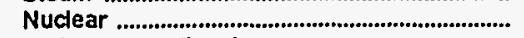 & 0 & $\mathbf{0}$ & 0 & 0 & 0 & \\
\hline 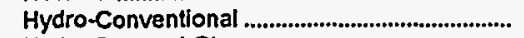 & $\mathbf{0}$ & o & 0 & 0 & 0 & 0 \\
\hline Hydro-Pumped Storage ........................................ & 0 & 0 & 0 & 0 & 0 & 0 \\
\hline 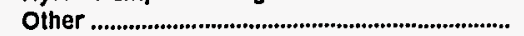 & 0 & $\mathbf{0}$ & 0 & 0 & 0 & 0 \\
\hline (Less) Energy for Pumping ................................ & 0 & $\mathbf{0}$ & 0 & 0 & 0 & 0 \\
\hline 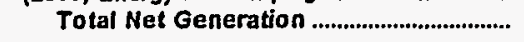 & $1,110,212$ & 624,075 & $\mathbf{0}$ & 0 & 186,043 & 114,088 \\
\hline 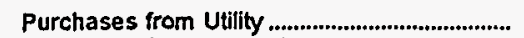 & 0 & 723,440 & 176,534 & 232,367 & 49,539 & 182,550 \\
\hline $\begin{array}{l}\text { Purchases from Nonutility ................................... } \\
\text { Power Exchanges }\end{array}$ & 0 & o & 0 & 0 & 23,268 & \\
\hline 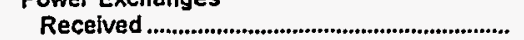 & $\mathbf{0}$ & 0 & 0 & 0 & 0 & $\mathbf{0}$ \\
\hline 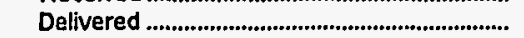 & 0 & 0 & 0 & 0 & 0 & 0 \\
\hline 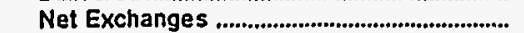 & 0 & 0 & 0 & 0 & 0 & 0 \\
\hline \multicolumn{7}{|l|}{ Transmission for Others (Wheeling) } \\
\hline 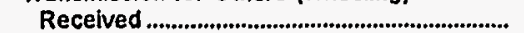 & 0 & $\mathbf{0}$ & 0 & 0 & 0 & 0 \\
\hline 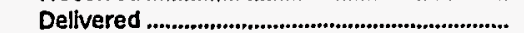 & 0 & 0 & 0 & 0 & 0 & 0 \\
\hline Net Transmission for Others ............................. & $\mathbf{0}$ & 0 & 0 & 0 & 0 & 0 \\
\hline $\begin{array}{l}\text { Transmisslon by Others Losses ........................ } \\
\text { Total Net Energy }\end{array}$ & 0 & 0 & 0 & $-5,809$ & 0 & 0 \\
\hline 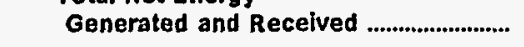 & $1,110,212$ & $1,347,515$ & 176,534 & 226,558 & 258,850 & 296,638 \\
\hline \multicolumn{7}{|l|}{ Disposition of Energy } \\
\hline Sales to Ultimate Consumers .......................... & 0 & 0 & 167,858 & 246,469 & 236.911 & 237,573 \\
\hline 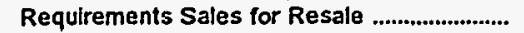 & $1,110,212$ & $1,325,550$ & 0 & 0 & 0 & 37,006 \\
\hline Nonrequlrements Sales for Resale .................. & 0 & 225 & 0 & 0 & 0 & 0 \\
\hline 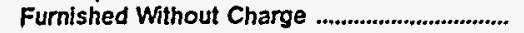 & 0 & $\mathbf{0}$ & 0 & 0 & 0 & $\mathbf{0}$ \\
\hline Used by Utility (excluding station use) ............ & 0 & 0 & 0 & 0 & 0 & 0 \\
\hline 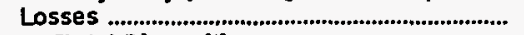 & 0 & 21,740 & 8,676 & $-19,911$ & 21,939 & 22,059 \\
\hline 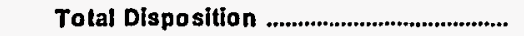 & $1,110,212$ & $1,347,515$ & 176,534 & 226,558 & 258,850 & 296,638 \\
\hline
\end{tabular}

Note: Totals may not equal sum of components because of independent rounding. Double counting occurs in components of both sources and dispo sitton of energy and thus neither provides a true total. Purchases from utilities, net interchanges, and net wheeling (except for imports) are included in net generation. Sales for resale is included in sales to ultimate consumers.

Source: Energy Information Administration, Form EIA-412, "Annual Report of Public Electric Utilities." 
Table 26. Electric Energy Account by Major U.S. Publicly Owned Electric Utility Within State, 1995 (Continued)

(Megawatthours)

\begin{tabular}{|c|c|c|c|c|c|c|}
\hline Item & $\begin{array}{l}\text { Maryiand } \\
\text { Easton } \\
\text { Utilities } \\
\text { Comm } \\
\text { June } 30\end{array}$ & $\begin{array}{l}\text { Maryland } \\
\text { Hagerstown } \\
\text { City of } \\
\text { June } 30\end{array}$ & $\begin{array}{l}\text { Massachusetts } \\
\text { Braintree } \\
\text { Town of } \\
\text { December } 31\end{array}$ & $\begin{array}{l}\text { Massachusetts } \\
\text { Chicopee } \\
\text { City of } \\
\text { December } 31\end{array}$ & $\begin{array}{l}\text { Massachusetts } \\
\text { Concord } \\
\text { Town of } \\
\text { December } 31\end{array}$ & $\begin{array}{l}\text { Massachusetts } \\
\text { Danvers } \\
\text { Town of } \\
\text { December } 31\end{array}$ \\
\hline \multicolumn{7}{|l|}{ Sources of Energy } \\
\hline Steam & 0 & 0 & 111,690 & $\mathbf{0}$ & $\mathbf{0}$ & $\mathbf{0}$ \\
\hline Nuclear & 0 & 0 & 0 & 108.172 & 0 & 0 \\
\hline 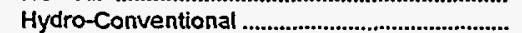 & 0 & 0 & 0 & 0 & 0 & 0 \\
\hline Hydro-Pumped Storage & 0 & 0 & 0 & 0 & 0 & 0 \\
\hline Other & 28,458 & 0 & 295 & 1,142 & 0 & 0 \\
\hline 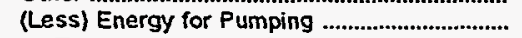 & 1.868 & 0 & 0 & 0 & 0 & 0 \\
\hline 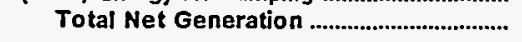 & 26,590 & 0 & 111,985 & 109,314 & $\mathbf{0}$ & 0 \\
\hline 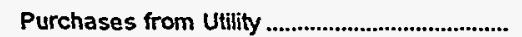 & 0 & 312,317 & 238,768 & 295,644 & 162,044 & 282,160 \\
\hline $\begin{array}{l}\text { Purchases from Nonutility } \\
\text { Power Exchanges }\end{array}$ & 0 & 0 & 0 & 0 & 0 & \\
\hline 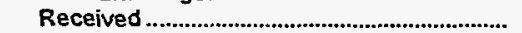 & 202,285 & 0 & 124,090 & 9,251 & $\mathbf{0}$ & 43,571 \\
\hline 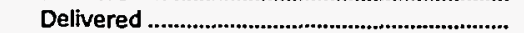 & 1,373 & 0 & 46,299 & 10,139 & 0 & 2,659 \\
\hline 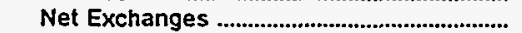 & 200,912 & 0 & $77,79 i$ & -888 & 0 & 40,812 \\
\hline \multicolumn{7}{|l|}{ Transmission for Others (Wheeling) } \\
\hline 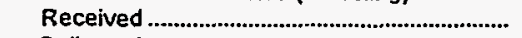 & 0 & $\mathbf{0}$ & $\mathbf{0}$ & 0 & 0 & 0 \\
\hline 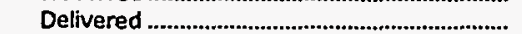 & 0 & 0 & 0 & 0 & 0 & 0 \\
\hline 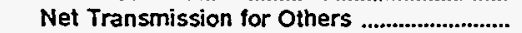 & 0 & 0 & 0 & 0 & 0 & 0 \\
\hline $\begin{array}{l}\text { Transmission by Others Losses ........................ } \\
\text { Total Net Energy }\end{array}$ & 0 & 0 & 0 & 0 & 0 & 0 \\
\hline 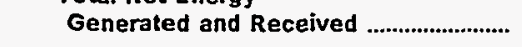 & 227,502 & 312,317 & 428,544 & 404,070 & 162,044 & 323,078 \\
\hline \multicolumn{7}{|l|}{ Disposition of Energy } \\
\hline 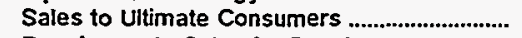 & 217,332 & 305,124 & 352,756 & 376,732 & 156,151 & 312,629 \\
\hline Requirements Sales for Resale ........................... & 0 & 0 & 58,476 & 8,824 & 0 & 7,618 \\
\hline Nonrequirements Sales for Resale .................. & 0 & 0 & 0 & 0 & 0 & 0 \\
\hline 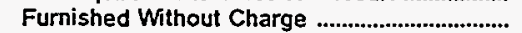 & 15 & 0 & 0 & 0 & 0 & 169 \\
\hline 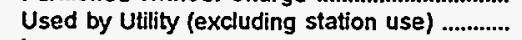 & 219 & 339 & 4,420 & 1,568 & 516 & 626 \\
\hline 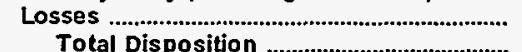 & $\begin{array}{r}9,936 \\
227,502\end{array}$ & $\begin{array}{r}6,854 \\
312,347\end{array}$ & $\begin{array}{r}12,892 \\
428,549\end{array}$ & $\begin{array}{r}16,946 \\
404,070\end{array}$ & $\begin{array}{r}5,377 \\
162,044\end{array}$ & $\begin{array}{r}2,036 \\
323.078\end{array}$ \\
\hline
\end{tabular}


Table 26. Electric Energy Account by Major U.S. Publicly Owned Electric Utility Within State, 1995 (Continued)

(Megawatthours)

\begin{tabular}{|c|c|c|c|c|c|c|}
\hline Item & $\begin{array}{l}\text { Massachusetts } \\
\text { Hingham } \\
\text { City of } \\
\text { December } \mathbf{3 1}\end{array}$ & $\begin{array}{c}\text { Massachusetts } \\
\text { Holyoke } \\
\text { City of } \\
\text { December } 31\end{array}$ & $\begin{array}{l}\text { Massachusetts } \\
\text { Hudson } \\
\text { Town of } \\
\text { December } 31\end{array}$ & $\begin{array}{l}\text { Massachusetts } \\
\text { Littleton } \\
\text { Town of } \\
\text { December } 31\end{array}$ & $\begin{array}{l}\text { Massachusetts } \\
\text { Mansfield } \\
\text { Town of } \\
\text { December } 31\end{array}$ & $\begin{array}{c}\text { Massachusetts } \\
\text { Massachusetts } \\
\text { Mun } \\
\text { Whis } \\
\text { Elec Co } \\
\text { December } 31\end{array}$ \\
\hline \multicolumn{7}{|l|}{ Sources of Energy } \\
\hline Steam & 0 & $-1,279$ & 0 & 3,475 & 0 & 703,049 \\
\hline 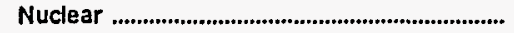 & 0 & $\mathbf{0}$ & 6,484 & 0 & 0 & $1,356,132$ \\
\hline 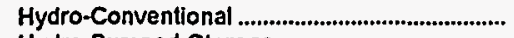 & 0 & 12,888 & 0 & 0 & $\mathbf{0}$ & 0 \\
\hline 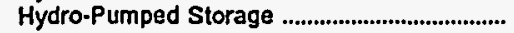 & 0 & $\mathbf{0}$ & 0 & 0 & 0 & 0 \\
\hline Other & 0 & 0 & 4,521 & 0 & 0 & \\
\hline 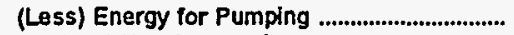 & 0 & $\mathbf{0}$ & 0 & 0 & 0 & 0 \\
\hline 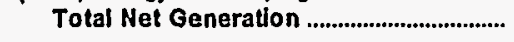 & $\mathbf{0}$ & 11,609 & 11,005 & 3,475 & 0 & $2,059,181$ \\
\hline 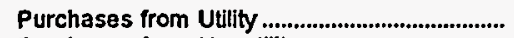 & 116,591 & 268,220 & 253.595 & 166,680 & 184,103 & 377,044 \\
\hline Purchases from Nonutility .................................... & 0 & 0 & 4,865 & 0 & 0 & 104,559 \\
\hline 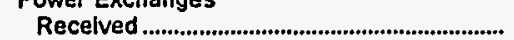 & 71,683 & 0 & 77,759 & 17,627 & 57,317 & 878,348 \\
\hline 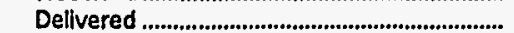 & 34,548 & -1.162 & 9,154 & 17,988 & 42,173 & 505,576 \\
\hline 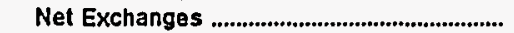 & 37,135 & 1,162 & 68,605 & -361 & 15,144 & 372,772 \\
\hline \multicolumn{7}{|l|}{ Transmission for Others Wheeling) } \\
\hline 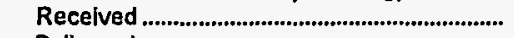 & 0 & 0 & $\mathbf{0}$ & $\mathbf{0}$ & $\mathbf{0}$ & 0 \\
\hline Dellvered & $\mathbf{0}$ & $\mathbf{0}$ & $\mathbf{0}$ & 0 & 0 & 0 \\
\hline 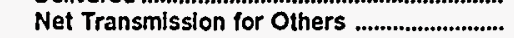 & 0 & 0 & 0 & 0 & 0 & 0 \\
\hline $\begin{array}{l}\text { Transmission by Others Losses........................ } \\
\text { Total Net Energy }\end{array}$ & 0 & $\mathbf{0}$ & $-6,690$ & 0 & 0 & 0 \\
\hline Generated and Recelved ............................ & 153,726 & 280,991 & 331,380 & 169,794 & 199,247 & $2,913,556$ \\
\hline \multicolumn{7}{|l|}{ Disposition of Energy } \\
\hline Sales to Ultimate Consumers ............................ & 143,570 & 265,317 & 319,031 & 162,040 & 177,103 & \\
\hline 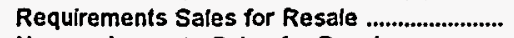 & 395 & 3,352 & 708 & 999 & 3,414 & $2,913,556$ \\
\hline Nonrequirements Sales for Resale ..................... & $\mathbf{0}$ & 0 & 0 & 0 & 0 & 0 \\
\hline 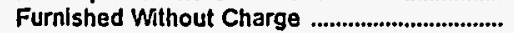 & 0 & 0 & 0 & 0 & 0 & 0 \\
\hline Used by Utility (excluding station use) ............. & 374 & 558 & 260 & 197 & 31 & 0 \\
\hline Losses & 9,387 & 11,764 & 11,381 & 6,558 & 18,699 & \\
\hline Total Disposition & 153,726 & 280,991 & 331,380 & 169,794 & 199,247 & $2,913,556$ \\
\hline
\end{tabular}

Note: Totals may not equal sum of components because of independent rounding. Double counting occurs in components of both sources and disposition of energy and thus nelther provides a true total. Purchases from utilities, net interchanges, and net wheeling (except for imports) are included in net generation.

Source: Energy Information Administration, Fom ElA-412, "Annual Report of Public Electric Utilities." 
Table 26. Electric Energy Account by Major U.S. Publicly Owned Electric Utility Within State, 1995 (Continued) (Megawatthours)

\begin{tabular}{|c|c|c|c|c|c|c|}
\hline Item & $\begin{array}{l}\text { Massachusetts } \\
\text { Middleborough } \\
\text { Town of } \\
\text { December } 31\end{array}$ & $\begin{array}{c}\text { Massachusetts } \\
\text { North } \\
\text { Attleborough } \\
\text { Town of } \\
\text { December } 31\end{array}$ & $\begin{array}{l}\text { Massachusetts } \\
\text { Norwood } \\
\text { City of } \\
\text { June } 30\end{array}$ & $\begin{array}{l}\text { Massachusetts } \\
\text { Peabody } \\
\text { City of } \\
\text { December } 31\end{array}$ & $\begin{array}{l}\text { Massachusetts } \\
\text { Reading } \\
\text { Town of } \\
\text { December } 31\end{array}$ & $\begin{array}{c}\text { Massachusetts } \\
\text { Shrewsbury } \\
\text { Town of } \\
\text { December } 31\end{array}$ \\
\hline \multicolumn{7}{|l|}{ Sources of Energy } \\
\hline Steam & 0 & 7,013 & 0 & 0 & 0 & 0 \\
\hline 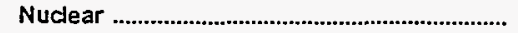 & 0 & 0 & 0 & 0 & $\mathbf{0}$ & 0 \\
\hline 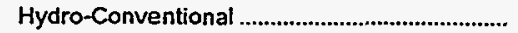 & 0 & 0 & 0 & 0 & 0 & 0 \\
\hline Hydro-Pumped Storage & 0 & 0 & 0 & $\mathbf{0}$ & 0 & 0 \\
\hline Other & 0 & 0 & 0 & 10.741 & 0 & 974 \\
\hline 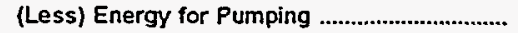 & 0 & 0 & 0 & 0 & 0 & 0 \\
\hline Total Net Generation & o & 7,013 & $\mathbf{0}$ & 10,741 & 0 & 974 \\
\hline 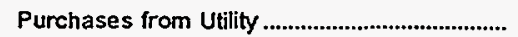 & 166,337 & 124,156 & 321,812 & 282,540 & 525,876 & 256,604 \\
\hline $\begin{array}{l}\text { Purchases from Nonutulity } \\
\text { Power Exchanges }\end{array}$ & 0 & 0 & 0 & 1,374 & 0 & \\
\hline 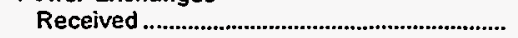 & 34,251 & 108,757 & 0 & 225,509 & 200,928 & 58,024 \\
\hline 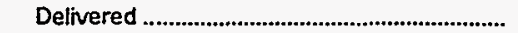 & 19,353 & 29,736 & 0 & 108,571 & 118,305 & 32,769 \\
\hline 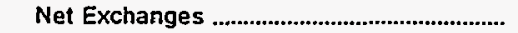 & 14,898 & 79,020 & 0 & 116,938 & 82,623 & 25,255 \\
\hline \multicolumn{7}{|l|}{ Transmission for Others (Wheeling) } \\
\hline 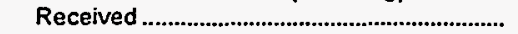 & 0 & 0 & 0 & 0 & 0 & 0 \\
\hline Delivered & 0 & 0 & 0 & 0 & 0 & 0 \\
\hline Net Transmission for Others ............................. & 0 & 0 & 0 & 0 & 0 & 0 \\
\hline $\begin{array}{l}\text { Transmission by Others Losses ............................. } \\
\text { Total Net Energy }\end{array}$ & 0 & 0 & 0 & 0 & 0 & 0 \\
\hline 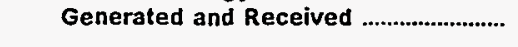 & 181,235 & 210,189 & 321,812 & 411,593 & 608,499 & 282,833 \\
\hline \multicolumn{7}{|l|}{ Disposition of Energy } \\
\hline 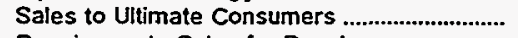 & 174,643 & 197,954 & 308,513 & 399,651 & 573,572 & 261,397 \\
\hline Requirements Sales for Resale ......................... & 231 & 0 & 0 & 0 & 787 & 0 \\
\hline Nonrequirements Sales for Resale ................... & 0 & 279 & 0 & 0 & 0 & 0 \\
\hline Furnished Without Charge ................................ & 0 & 0 & 0 & 22 & 0 & 1,222 \\
\hline Used by Utility (excluding station use) ........... & 0 & 350 & 13,299 & 1,649 & 482 & 0 \\
\hline 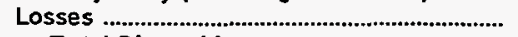 & 6,361 & 11,606 & 0 & 10,271 & 33,658 & 20.214 \\
\hline 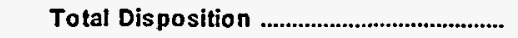 & 181,235 & 210,189 & 321,812 & 411,593 & 608,499 & 282,833 \\
\hline
\end{tabular}

Note: Totals may not equal sum of components because of independent rounding. Double counting occurs in components of both sources and disposition of energy and thus neither provides a true total. Purchases from utilities, net interchanges, and net wheeling (except for imports) are included in net generation.

Source: Energy Information Administration, Form EIA-412, "Annual Report of Public Electric Utilities." 
Table 26. Electric Energy Account by Major U.S. Publicly Owned Electric Utility Within State, 1995 (Continued) (Megawatthours)

\begin{tabular}{|c|c|c|c|c|c|c|}
\hline them & $\begin{array}{l}\text { Massachusetts } \\
\text { Taunton } \\
\text { City of } \\
\text { December } 31\end{array}$ & $\begin{array}{l}\text { Massachusetts } \\
\text { Wakefield } \\
\text { Town of } \\
\text { December } 31\end{array}$ & $\begin{array}{c}\text { Massachusetts } \\
\text { Wellesley } \\
\text { Town of } \\
\text { December } 31\end{array}$ & $\begin{array}{c}\text { Massachusetts } \\
\text { Westfield } \\
\text { City of } \\
\text { December } 31\end{array}$ & $\begin{array}{c}\text { Michigan } \\
\text { Bay } \\
\text { City City of } \\
\text { June } 30\end{array}$ & $\begin{array}{l}\text { Michigan } \\
\text { Coldwater } \\
\text { Board } \\
\text { of } \\
\text { Public Util } \\
\text { June } 30\end{array}$ \\
\hline \multicolumn{7}{|l|}{ Sources of Energy } \\
\hline Steam & 94,783 & 0 & 0 & 0 & 0 & 0 \\
\hline 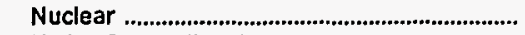 & 0 & 0 & 0 & 0 & 0 & 0 \\
\hline 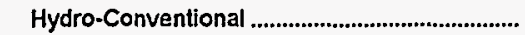 & 0 & 0 & 0 & 0 & 0 & 0 \\
\hline Hydro-Pumped Storage ................................................. & 0 & $\mathbf{0}$ & 0 & 0 & 0 & 0 \\
\hline 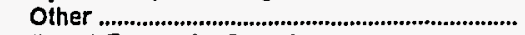 & 20,154 & $\mathbf{0}$ & 0 & 0 & 4,000 & 5.197 \\
\hline 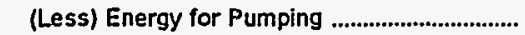 & 0 & o & 0 & 0 & 0 & 0 \\
\hline 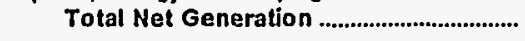 & 114,937 & $\mathbf{0}$ & 0 & 0 & 4,000 & 5,197 \\
\hline 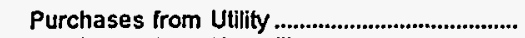 & 133,660 & 165,122 & 196.124 & 272,334 & 298,000 & 166,646 \\
\hline 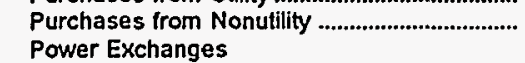 & 0 & 0 & 0 & 0 & 0 & 0 \\
\hline 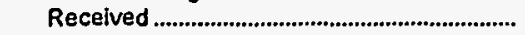 & 340,586 & 0 & 0 & 82,280 & 0 & 0 \\
\hline 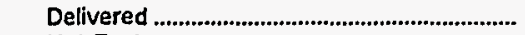 & 13,526 & 0 & 0 & 66,764 & 0 & 0 \\
\hline Net Exchanges .............................................................. & 327,060 & 0 & 0 & 15,516 & 0 & 0 \\
\hline \multicolumn{7}{|l|}{ Transmission for Others (Wheeling) } \\
\hline Recelved ..................................................................... & 0 & 0 & 0 & 0 & 0 & 0 \\
\hline 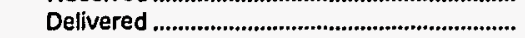 & 0 & 0 & 0 & 0 & 0 & 0 \\
\hline 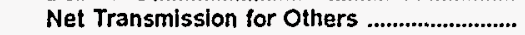 & 0 & 0 & 0 & 0 & 0 & 0 \\
\hline $\begin{array}{l}\text { Transmission by Others Losses............................... } \\
\text { Total Net Energy }\end{array}$ & 0 & 0 & $-1,425$ & 0 & 0 & 0 \\
\hline 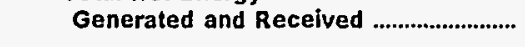 & 575,657 & 165,122 & 194,699 & 287,850 & 302,000 & 171,843 \\
\hline \multicolumn{7}{|l|}{ Disposition of Energy } \\
\hline 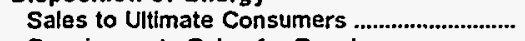 & 507,320 & 156,868 & 184,758 & 266,005 & 282,000 & 160,582 \\
\hline Requirements Sales for Resale .............................. & 41,371 & 0 & 0 & 8,868 & 0 & 0 \\
\hline Nonrequirements Sales for Resale .................... & 0 & 0 & 0 & 0 & 0 & 0 \\
\hline Furnished Without Charge ................................... & 0 & 323 & 146 & 0 & 0 & 0 \\
\hline Used by Utility (excluding station use) ............ & 7,179 & 7.931 & 379 & 111 & 0 & 1,600 \\
\hline Losses & 19,787 & 0 & 9,416 & 12,866 & 20,000 & 9,661 \\
\hline 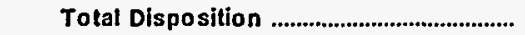 & 575,657 & 165,122 & 194,699 & 287,850 & 302,000 & 171,843 \\
\hline
\end{tabular}

Note: Totals may not equal sum of components because of independent rounding. Double counting occurs in components of both sources and disposition of energy and thus neither provides a true total. Purchases from utilities, net interchanges, and net wheeling (except for imports) are included in net generation.

Source: Energy Information Administration, Form ElA-412, "Annual Report of Public Electric Utilities." 
Table 26. Electric Energy Account by Major U.S. Publicly Owned Electric Utility Within State, 1995 (Continued)

(Megawatthours)

\begin{tabular}{|c|c|c|c|c|c|c|}
\hline Item & $\begin{array}{l}\text { Michigan } \\
\text { Detroit } \\
\text { City of } \\
\text { June } 30\end{array}$ & $\begin{array}{c}\text { Michigan } \\
\begin{array}{c}\text { Grand Haven } \\
\text { City of }\end{array} \\
\text { June } 30\end{array}$ & $\begin{array}{l}\text { Michigan } \\
\text { Hillsdale } \\
\text { Board } \\
\text { of } \\
\text { Public Wks } \\
\text { June } 30\end{array}$ & $\begin{array}{l}\text { Michigan } \\
\text { Holland } \\
\text { City of } \\
\text { June } 30\end{array}$ & $\begin{array}{l}\text { Michigan } \\
\text { Lansing } \\
\text { City of } \\
\text { June } 30\end{array}$ & $\begin{array}{l}\text { Michigan } \\
\text { Marquette } \\
\text { Clty of } \\
\text { June } 30\end{array}$ \\
\hline \multicolumn{7}{|l|}{ Sources of Energy } \\
\hline 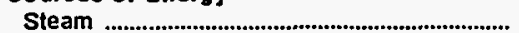 & 314,869 & 321,100 & 0 & 288,264 & $1,657,348$ & 236,971 \\
\hline Nuclear & 0 & 0 & 0 & 0 & 0 & \\
\hline 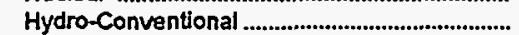 & 0 & 0 & 0 & 0 & 2,864 & 13,404 \\
\hline 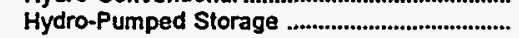 & 0 & 0 & 0 & 0 & 0 & 0 \\
\hline Other & 0 & 0 & 0 & 705 & 0 & 60 \\
\hline 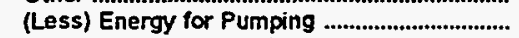 & 0 & 0 & 0 & 0 & 0 & 0 \\
\hline 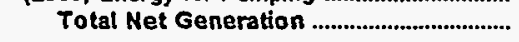 & 314,869 & 321,100 & 0 & 288,969 & $1,660,212$ & 250,435 \\
\hline 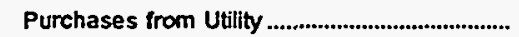 & 359,167 & 41,120 & 147,079 & 500,164 & $1,030,332$ & 18,157 \\
\hline $\begin{array}{l}\text { Purchases from Nonutility .................................. } \\
\text { Power Exchanges }\end{array}$ & 0 & 0 & 0 & 0 & 0 & 0 \\
\hline 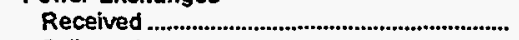 & 0 & 0 & 0 & 670 & 949 & 0 \\
\hline 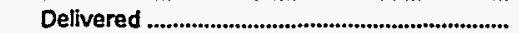 & 0 & $\mathbf{0}$ & 0 & 3.084 & 3,756 & 0 \\
\hline 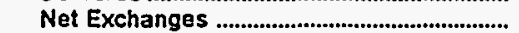 & 0 & $\mathbf{0}$ & 0 & $-2,414$ & $-2,807$ & 0 \\
\hline \multicolumn{7}{|l|}{ Transmission for Others (Wheeling) } \\
\hline 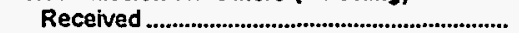 & 0 & $\mathbf{0}$ & 0 & 0 & 0 & 0 \\
\hline 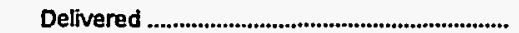 & 0 & 0 & 0 & 0 & 0 & 0 \\
\hline 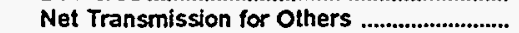 & 0 & 0 & 0 & 0 & 0 & 0 \\
\hline $\begin{array}{l}\text { Transmission by Others Losses........................ } \\
\text { Total Net Energy }\end{array}$ & 0 & 0 & 0 & 0 & 0 & 0 \\
\hline Generated and Received .......................... & 674,036 & 362,220 & 147,079 & 786,719 & $2,687,737$ & 268,592 \\
\hline \multicolumn{7}{|l|}{ Disposition of Energy } \\
\hline 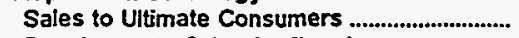 & 503,819 & 275,385 & 135,652 & 744,926 & $2,278,699$ & 240,226 \\
\hline Requirements Sales for Resale ......................... & 0 & 82,586 & 0 & 0 & 321,939 & 11.246 \\
\hline Nonrequirements Sales for Resale ................... & 0 & 0 & $\mathbf{0}$ & 0 & 0 & 2,357 \\
\hline 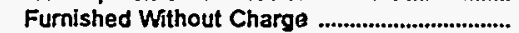 & 131,027 & 416 & 0 & 0 & 0 & 0 \\
\hline Used by Utility (excluding station use) ............. & 2,905 & 0 & 0 & 0 & 0 & 539 \\
\hline 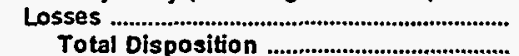 & $\begin{array}{r}36,285 \\
674,036\end{array}$ & $\begin{array}{r}3,833 \\
362,220\end{array}$ & $\begin{array}{r}11,427 \\
147,079\end{array}$ & $\begin{array}{r}41,793 \\
786,719\end{array}$ & $\begin{array}{r}87,099 \\
2,687,737\end{array}$ & $\begin{array}{r}14,224 \\
268,592\end{array}$ \\
\hline
\end{tabular}

Note: Totals may not equal sum of components because of independent rounding. Double counting occurs in components of both sources and disposition of energy and thus neither provides a true total. Purchases from utilities, net interchanges, and net wheeling (except for imports) are included in net generation.

Source: Energy information Administration, Form ElA-412. "Annual Report of Public Electric Utilities." 
Table 26. Electric Energy Account by Major U.S. Publicly Owned Electric Utility Within State, 1995 (Continued)

(Megawatthours)

\begin{tabular}{|c|c|c|c|c|c|c|}
\hline Item & $\begin{array}{c}\text { Michigan } \\
\text { Michigan } \\
\text { Public } \\
\text { Power Agency } \\
\text { December } 31\end{array}$ & $\begin{array}{l}\text { Michigan } \\
\text { Michigan } \\
\text { South } \\
\text { Central } \\
\text { Pwr Agy } \\
\text { June } 30\end{array}$ & $\begin{array}{l}\text { Michigan } \\
\text { Sturgis } \\
\text { City of } \\
\text { September } 30\end{array}$ & $\begin{array}{l}\text { Michigan } \\
\text { Traverse } \\
\text { City City of } \\
\text { June } 30\end{array}$ & $\begin{array}{l}\text { Michigan } \\
\text { Wyandotte } \\
\text { Municipal } \\
\text { Serv Comm } \\
\text { September } 30\end{array}$ & $\begin{array}{l}\text { Michigan } \\
\text { Zeeland } \\
\text { City of } \\
\text { June } 30\end{array}$ \\
\hline \multicolumn{7}{|l|}{ Sources of Energy } \\
\hline Steam & $1,900,853$ & 191,867 & 0 & 336 & 221,367 & $\mathbf{0}$ \\
\hline 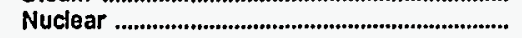 & 0 & 0 & 0 & 0 & 0 & 0 \\
\hline 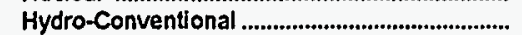 & 0 & $\mathbf{0}$ & 8,062 & 13,910 & 0 & 0 \\
\hline 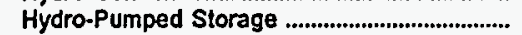 & 0 & 0 & 0 & 0 & $\mathbf{0}$ & 0 \\
\hline 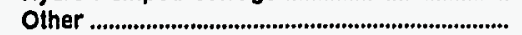 & 0 & 0 & 10,740 & 0 & 0 & 33,322 \\
\hline 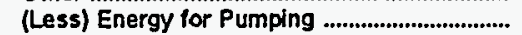 & 0 & 0 & & 0 & 0 & \\
\hline 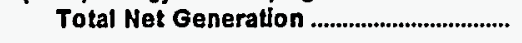 & $1,900,853$ & 191,867 & 18,802 & 14,246 & 221,367 & 33,322 \\
\hline 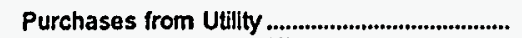 & 926,961 & 277,915 & 203,548 & 226.001 & 79,005 & 150,780 \\
\hline Purchases from Nonutility ........................................... & & 0 & 3.165 & 0 & 0 & \\
\hline \multicolumn{7}{|l|}{ Power Exchanges } \\
\hline 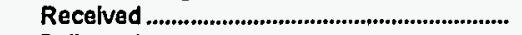 & 0 & $\mathbf{0}$ & 0 & 0 & 0 & 0 \\
\hline 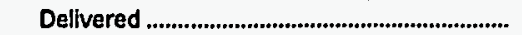 & 4,658 & 0 & 0 & $\mathbf{0}$ & 0 & 0 \\
\hline 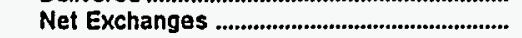 & $-4,658$ & 0 & 0 & 0 & 0 & 0 \\
\hline \multicolumn{7}{|l|}{ Transmission for Others (Wheeling) } \\
\hline 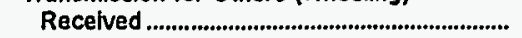 & $\mathbf{0}$ & $\mathbf{0}$ & 0 & 0 & o & $\mathbf{0}$ \\
\hline 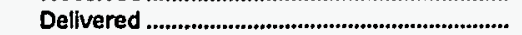 & 0 & 0 & 0 & 0 & 0 & 0 \\
\hline Net Transmission for Others ..................................... & 0 & o & 0 & $\mathbf{0}$ & 0 & 0 \\
\hline 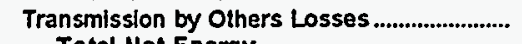 & 0 & 0 & 0 & 0 & 0 & 0 \\
\hline $\begin{array}{l}\text { Total Net Energy } \\
\text { Generated and Received }\end{array}$ & $2,823,156$ & 469,782 & 225,515 & 240,247 & 300,372 & 184,102 \\
\hline \multicolumn{7}{|l|}{ Dispositton of Energy } \\
\hline Sales to Ultumate Consumers ..................................... & & & 217,011 & 221,187 & 240.671 & 176,681 \\
\hline 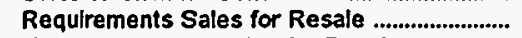 & $1,842,315$ & 461.177 & 0 & 0 & 0 & 0 \\
\hline Nonrequirements Sales for Resale .................... & 968,644 & 0 & 0 & 2,101 & 0 & 0 \\
\hline Furnished Without Charge ..................................... & 0 & 0 & 0 & 0 & 34,861 & 0 \\
\hline Used by Utillty (excluding station use) ............. & & & & 0 & 0 & 1,017 \\
\hline 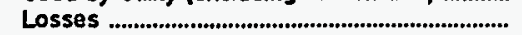 & 12,197 & 8.605 & 8.504 & 16,959 & 24.840 & 6,404 \\
\hline 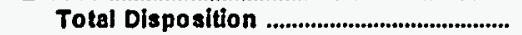 & $2,823,156$ & 469,782 & 225,515 & 240,247 & 300,372 & 184,102 \\
\hline
\end{tabular}


Table 26. Electric Energy Account by Major U.S. Publicly Owned Electric Utility Within State, 1995 (Continued)

(Megawatthours)

\begin{tabular}{|c|c|c|c|c|c|c|}
\hline Item & $\begin{array}{l}\text { Minnesota } \\
\text { Alexandria } \\
\text { City of } \\
\text { December } 31\end{array}$ & $\begin{array}{c}\text { Minnesota } \\
\text { Anoka } \\
\text { City of } \\
\text { December } 31\end{array}$ & $\begin{array}{l}\text { Minnesota } \\
\text { Austin } \\
\text { City of } \\
\text { December } 31\end{array}$ & $\begin{array}{c}\text { Minnesota } \\
\text { Brainerd } \\
\text { Public } \\
\text { Utilities } \\
\text { December } 31\end{array}$ & $\begin{array}{c}\text { Minnesota } \\
\text { Chaska } \\
\text { City of } \\
\text { December } 31\end{array}$ & $\begin{array}{c}\text { Minnesota } \\
\text { Fairmont } \\
\text { Public } \\
\text { Utilities } \\
\text { Comm } \\
\text { December } 31\end{array}$ \\
\hline \multicolumn{7}{|l|}{ Sources of Energy } \\
\hline Steam & 0 & 0 & 81,982 & 0 & 0 & 1,664 \\
\hline 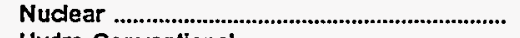 & 0 & 0 & 0 & 0 & 0 & \\
\hline 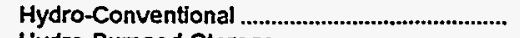 & $\mathbf{0}$ & 0 & 0 & 0 & 0 & 0 \\
\hline 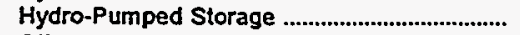 & 0 & 0 & 0 & 0 & 0 & 0 \\
\hline Other & 288 & 0 & 0 & 0 & 0 & 0 \\
\hline 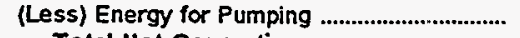 & 362 & $\mathbf{0}$ & 0 & 0 & 0 & 0 \\
\hline 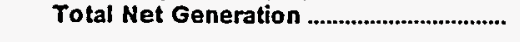 & -74 & $\mathbf{0}$ & 81,982 & 0 & 0 & 1,664 \\
\hline 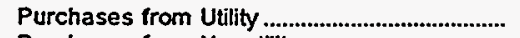 & 204,909 & 236,924 & 273,946 & 155,533 & 185,150 & 148,048 \\
\hline $\begin{array}{l}\text { Purchases from Nonutility .................................... } \\
\text { Power Exchanges }\end{array}$ & 0 & 2 & 0 & 0 & 0 & \\
\hline 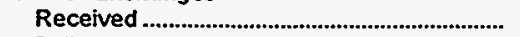 & 0 & $\mathbf{0}$ & 0 & 0 & 0 & 0 \\
\hline Delivered & 0 & 0 & 0 & 0 & 0 & 0 \\
\hline 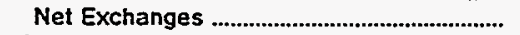 & 0 & 0 & 0 & 0 & 0 & 0 \\
\hline \multicolumn{7}{|l|}{ Transmission for Others (Wheeling) } \\
\hline Received & 0 & $\mathbf{0}$ & 0 & 0 & 0 & 0 \\
\hline Delivered & 0 & 0 & 0 & $\mathbf{0}$ & 0 & 0 \\
\hline 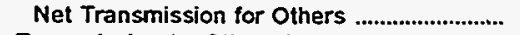 & 0 & 0 & 0 & 0 & 0 & 0 \\
\hline $\begin{array}{l}\text { Transmission by Others Losses ............................ } \\
\text { Total Net Energy }\end{array}$ & 0 & 0 & 0 & 0 & 0 & 0 \\
\hline 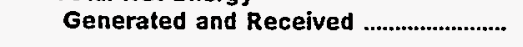 & 204,835 & 236,926 & 355,928 & 155,533 & 185,150 & 149,712 \\
\hline \multicolumn{7}{|l|}{ Disposition of Energy } \\
\hline 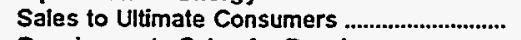 & 188,754 & 226,993 & 258,878 & 142,487 & 178,859 & 144,094 \\
\hline Requirements Sales for Resale ......................... & 0 & 0 & 81,982 & 0 & 0 & 1,664 \\
\hline Nonrequirements Sales for Resale ................... & 0 & 0 & 0 & $\mathbf{0}$ & 0 & 0 \\
\hline Furnished Without Charge & 0 & 0 & 0 & 0 & 0 & $\mathbf{0}$ \\
\hline Used by Utility (excluding station use) ............ & 0 & 0 & 735 & 1,570 & 0 & 0 \\
\hline Losses ...................................................... & 16,081 & 9,933 & 14,333 & 11,476 & 6,291 & 3,954 \\
\hline 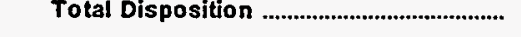 & 204,835 & 236,926 & 355,928 & 155,533 & 185,150 & 149,712 \\
\hline
\end{tabular}

Note: Totals may not equal sum of components because of independent rounding. Double counting occurs in components of both sources and disposition of energy and thus neither provides a true total. Purchases from utilities, net interchanges, and net wheeling (except for imports) are included in net generation.

Source: Energy Information Administration, Form ElA-412, "Annual Report of Public Electric Utilities." 
Table 26. Electric Energy Account by Major U.S. Publicly Owned Electric Utility Within State, 1995 (Continued)

(Megawatthours)

\begin{tabular}{|c|c|c|c|c|c|c|}
\hline Item & $\begin{array}{c}\text { Minnesota } \\
\text { Hutchinson } \\
\text { Utilities } \\
\text { Comm } \\
\text { December } 31\end{array}$ & $\begin{array}{l}\text { Minnesota } \\
\text { Marshall } \\
\text { City of } \\
\text { December } 31\end{array}$ & $\begin{array}{l}\text { Minnesota } \\
\text { Moorhead } \\
\text { City of } \\
\text { December } 31\end{array}$ & $\begin{array}{l}\text { Minnesota } \\
\text { New Ulm } \\
\text { Public } \\
\text { Utilities } \\
\text { Comm } \\
\text { December } 31\end{array}$ & $\begin{array}{c}\text { Minnesota } \\
\text { Northem } \\
\text { Municipal } \\
\text { Power Agny } \\
\text { December } 31\end{array}$ & $\begin{array}{c}\text { Minnesota } \\
\text { Owatonna } \\
\text { City of } \\
\text { December } 31\end{array}$ \\
\hline \multicolumn{7}{|l|}{ Sources of Energy } \\
\hline 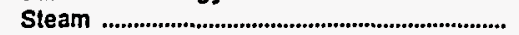 & 0 & $\mathbf{0}$ & 0 & 28,505 & 858,178 & $\mathbf{0}$ \\
\hline 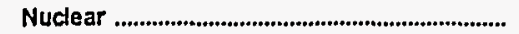 & 0 & $\mathbf{0}$ & 0 & 0 & 0 & 0 \\
\hline 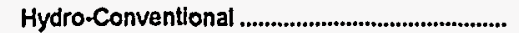 & 0 & 0 & 0 & $\mathbf{0}$ & $\mathbf{0}$ & 0 \\
\hline 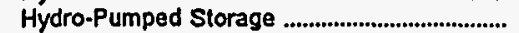 & 0 & $\mathbf{0}$ & $\mathbf{0}$ & 0 & $\mathbf{0}$ & 0 \\
\hline Other & 155,286 & 80 & $\mathbf{0}$ & 1,411 & 0 & 0 \\
\hline (Less) Energy for Pumping ................................. & 0 & 0 & 0 & 0 & 0 & 0 \\
\hline 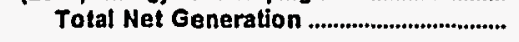 & 455,286 & 80 & 0 & 29,916 & 858,178 & 0 \\
\hline 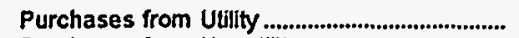 & 136,776 & 380,900 & 367,125 & 156,122 & 0 & 288,966 \\
\hline $\begin{array}{l}\text { Purchases from Nonutility .................................... } \\
\text { Power Exchanges }\end{array}$ & 0 & 536 & 0 & 0 & 0 & \\
\hline 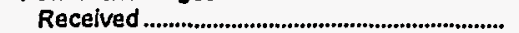 & 0 & 0 & 0 & 0 & 0 & $\mathbf{0}$ \\
\hline 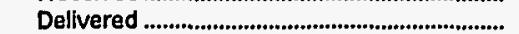 & 0 & 0 & 0 & 0 & 0 & 0 \\
\hline 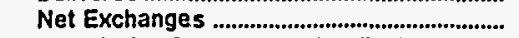 & 0 & 0 & 0 & 0 & 0 & 0 \\
\hline \multicolumn{7}{|l|}{ Transmission for Others (Wheellng) } \\
\hline 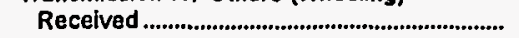 & 0 & $\mathbf{0}$ & 0 & $\mathbf{0}$ & $\mathbf{0}$ & 0 \\
\hline 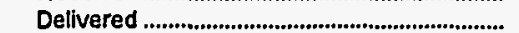 & 0 & $\mathbf{0}$ & 0 & 0 & 0 & 0 \\
\hline 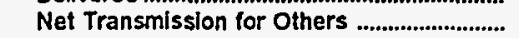 & 0 & 0 & 0 & 0 & 0 & 0 \\
\hline $\begin{array}{l}\text { Transmission by Others Losses ....................... } \\
\text { Total Net Energy }\end{array}$ & $\mathbf{0}$ & 0 & 0 & 0 & 0 & 0 \\
\hline Generated and Recelved ........................... & 292,062 & 381,516 & 367,125 & 186,038 & 858,478 & 288,966 \\
\hline \multicolumn{7}{|l|}{ Disposition of Energy } \\
\hline Sales to Ultimate Consumers .............................. & 277,353 & 360,922 & 349,194 & 175,659 & $\mathbf{0}$ & 273,184 \\
\hline 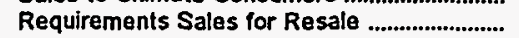 & 0 & 0 & 0 & 0 & 858,178 & 0 \\
\hline Nonrequirements Sales for Resale ................... & 2,174 & 0 & 0 & $\mathbf{0}$ & 0 & 0 \\
\hline Furnished Without Charge ................................ & 0 & 0 & 0 & 0 & 0 & 7.048 \\
\hline 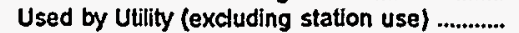 & 8,001 & 80 & 1,541 & 0 & 0 & 0 \\
\hline 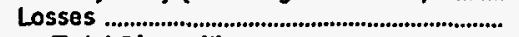 & 4,534 & 20,514 & 16,390 & 10,379 & 0 & 8,734 \\
\hline 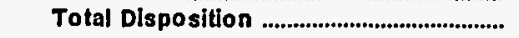 & 292,062 & 381,516 & 367,125 & 186,038 & 858,178 & 288,966 \\
\hline
\end{tabular}

Note: Totals may not equal sum of components because of independent rounding. Double counting occurs in components of both sources and disposition of energy and thus neither provides a true total. Purchases from utilities, net interchanges, and net wheeling (except for imports) are included in net generation.

Source: Energy Information Administration, Form ELA-412, "Annual Report of Public Electric Utilities." 
Table 26. Electric Energy Account by Major U.S. Publicly Owned Electric Utility Within State, 1995 (Continued)

(Megawatthours)

\begin{tabular}{|c|c|c|c|c|c|c|}
\hline Item & $\begin{array}{c}\text { Minnesota } \\
\text { Rochester } \\
\text { Public } \\
\text { Utilities } \\
\text { December } 31\end{array}$ & $\begin{array}{c}\text { Minnesota } \\
\text { Shakopee } \\
\text { Public } \\
\text { Utilities } \\
\text { Comm } \\
\text { December } 31\end{array}$ & $\begin{array}{l}\text { Minnesota } \\
\text { Southern } \\
\text { Minnesota } \\
\text { Mun P } \\
\text { Agny } \\
\text { December } 31\end{array}$ & $\begin{array}{c}\text { Minnesota } \\
\text { Western } \\
\text { Minnesota } \\
\text { Mun } \\
\text { Pwr Agny } \\
\text { December } 31\end{array}$ & $\begin{array}{c}\text { Minnesota } \\
\text { Willmar } \\
\text { Municipal } \\
\text { Utils Comm } \\
\text { December } 31\end{array}$ & $\begin{array}{l}\text { Minnesota } \\
\text { Worthington } \\
\text { City of } \\
\text { December } 31\end{array}$ \\
\hline \multicolumn{7}{|l|}{ Sources of Energy } \\
\hline Steam & 179,419 & 0 & $2,091,528$ & $1,647,783$ & 34,912 & $\mathbf{0}$ \\
\hline 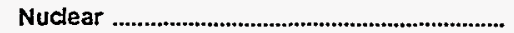 & 0 & 0 & 0 & 0 & 0 & 0 \\
\hline 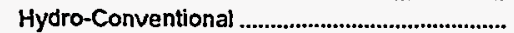 & 12,232 & 0 & 0 & 0 & 0 & 0 \\
\hline 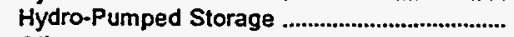 & 0 & 0 & 0 & 0 & 0 & 0 \\
\hline 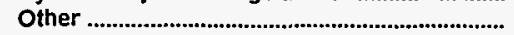 & 1,384 & 0 & 0 & 0 & 0 & 0 \\
\hline 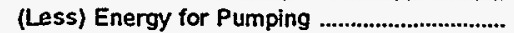 & 0 & 0 & 0 & 0 & 0 & 0 \\
\hline 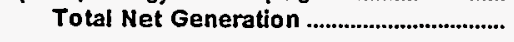 & 193,035 & 0 & $2,091,528$ & $1,647,783$ & 34,812 & 0 \\
\hline 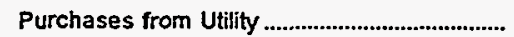 & 946,289 & 161,458 & 451,242 & 0 & 197,643 & 159,419 \\
\hline $\begin{array}{l}\text { Purchases from Nonutility ............................ } \\
\text { Power Exchanges }\end{array}$ & 0 & 0 & 9,454 & 0 & 0 & 0 \\
\hline 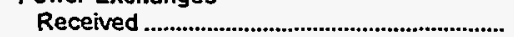 & 0 & 0 & 0 & 0 & 0 & 0 \\
\hline 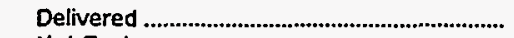 & $-4,345$ & $\mathbf{0}$ & 0 & 0 & 0 & 0 \\
\hline 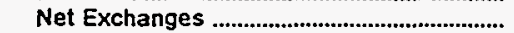 & 4,345 & 0 & 0 & 0 & 0 & 0 \\
\hline \multicolumn{7}{|l|}{ Transmission for Others (Wheeling) } \\
\hline 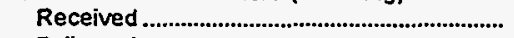 & 0 & 0 & 0 & 0 & $\mathbf{0}$ & 0 \\
\hline 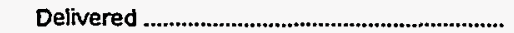 & 0 & 0 & 0 & 0 & 0 & 0 \\
\hline 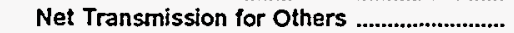 & 0 & 0 & 0 & 0 & 0 & 0 \\
\hline $\begin{array}{l}\text { Transmission by Others Losses......................... } \\
\text { Total Net Energy }\end{array}$ & 0 & 0 & 0 & 0 & 0 & $-6,213$ \\
\hline 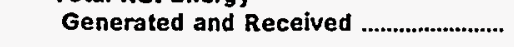 & $1,143,669$ & 161,458 & $2,552,224$ & $1,647,783$ & 232,555 & 153,206 \\
\hline \multicolumn{7}{|l|}{ Disposition of Energy } \\
\hline 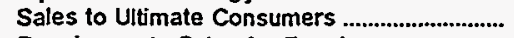 & 920,745 & 150,610 & 0 & 0 & 219,735 & 143,380 \\
\hline 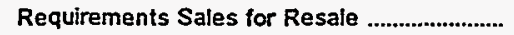 & 133,736 & 0 & $2,476.924$ & $1,647,783$ & 0 & 3,345 \\
\hline Nonrequirements Sales for Resale ................. & 53,697 & 0 & 0 & 0 & 0 & 0 \\
\hline 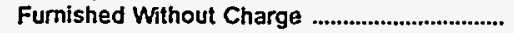 & 0 & 720 & 0 & 0 & 2,543 & 0 \\
\hline Used by Utility (excluding station use) ............ & 3,861 & 1,778 & 0 & 0 & 2,932 & 75 \\
\hline Losses & 31,630 & 8,350 & 75,300 & 0 & 7,345 & 6,406 \\
\hline Total Disposition & $1,143,669$ & 161,458 & $2,552,224$ & $1,647,783$ & 232,555 & 153,206 \\
\hline
\end{tabular}

Note: Totals may not equal sum of components because of independent rounding. Double counting occurs in components of both sources and disposition of energy and thus neither provides a true total. Purchases from utilities, net interchanges, and net wheeling (except for imports) are included in net generation.

Source: Energy Information Administration, Form ElA-412, "Annual Report of Public Electric Utilities." 
Table 26. Electric Energy Account by Major U.S. Publicly Owned Electric Utility Within State, 1995 (Continued)

(Megawatthours)

\begin{tabular}{|c|c|c|c|c|c|c|}
\hline Item & $\begin{array}{l}\text { Mississippi } \\
\text { Aberdeen } \\
\text { City of } \\
\text { June } 30\end{array}$ & $\begin{array}{l}\text { Mississippi } \\
\text { Clarksdale } \\
\text { City of } \\
\text { September } 30\end{array}$ & $\begin{array}{l}\text { Mississippi } \\
\text { Columbus } \\
\text { City of } \\
\text { June } 30\end{array}$ & $\begin{array}{l}\text { Mississippi } \\
\text { Greenwood } \\
\text { Utilities } \\
\text { Comm } \\
\text { September } 30\end{array}$ & $\begin{array}{l}\text { Mississippi } \\
\text { Holly } \\
\text { Springs } \\
\text { City of } \\
\text { June } 30\end{array}$ & $\begin{array}{l}\text { Mississippi } \\
\text { Louisvile } \\
\text { Electric } \\
\text { System } \\
\text { June } 30\end{array}$ \\
\hline \multicolumn{7}{|l|}{ Sources of Energy } \\
\hline Steam & 0 & 53,506 & 0 & 26,773 & 0 & 0 \\
\hline 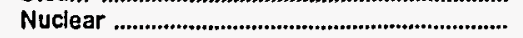 & 0 & 0 & 0 & 0 & $\mathbf{0}$ & 0 \\
\hline 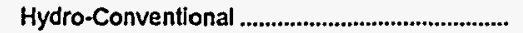 & 0 & 0 & 0 & 0 & 0 & 0 \\
\hline 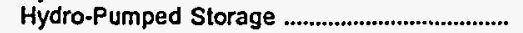 & $\mathbf{0}$ & $\mathbf{0}$ & 0 & 0 & $\mathbf{0}$ & 0 \\
\hline Other & 0 & 0 & 0 & 0 & 0 & 0 \\
\hline 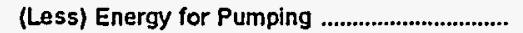 & 0 & 0 & 0 & 0 & 0 & 0 \\
\hline 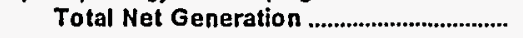 & $\mathbf{0}$ & 53,506 & 0 & 26,773 & 0 & 0 \\
\hline 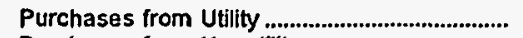 & 179,758 & 193,148 & 471,926 & 280.694 & 217,842 & 167,158 \\
\hline $\begin{array}{l}\text { Purchases from Nonutility ...................................... } \\
\text { Power Exchanges }\end{array}$ & 0 & 0 & 0 & 0 & 0 & 0 \\
\hline 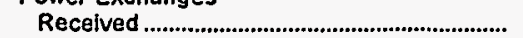 & 0 & $\mathbf{0}$ & 0 & 0 & 0 & 0 \\
\hline 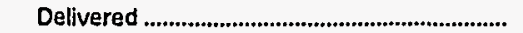 & 0 & 0 & 0 & 0 & 0 & 0 \\
\hline 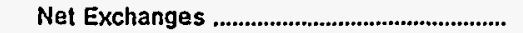 & $\mathbf{0}$ & 0 & 0 & 0 & 0 & 0 \\
\hline \multicolumn{7}{|l|}{ Transmission for Others (Wheeling) } \\
\hline 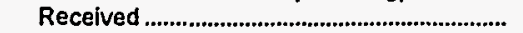 & 0 & $\mathbf{0}$ & 0 & 0 & 0 & 0 \\
\hline 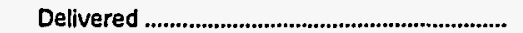 & 0 & 0 & 0 & 0 & 0 & 0 \\
\hline 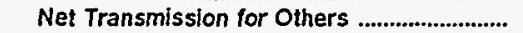 & 0 & 0 & 0 & 0 & 0 & 0 \\
\hline $\begin{array}{l}\text { Transmission by Others Losses........................ } \\
\text { Total Net Energy }\end{array}$ & 0 & 0 & 0 & 0 & 0 & 0 \\
\hline 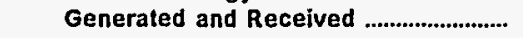 & 179,758 & 246,654 & 471,926 & 307,467 & 217,842 & 167,158 \\
\hline \multicolumn{7}{|l|}{ Disposition of Energy } \\
\hline Sales to Uitimate Consumers ........................... & 172,495 & 179,199 & 453,807 & 286,360 & 201,655 & 158,836 \\
\hline 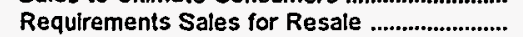 & 0 & 53,506 & 0 & 0 & 0 & 0 \\
\hline Nonrequirements Sales for Resale ................... & 0 & 0 & 0 & 0 & 0 & 0 \\
\hline Furnished Without Charge ..................................... & 0 & 0 & 0 & 0 & 0 & 0 \\
\hline Used by Utility (excluding station use) ............ & 82 & 0 & 191 & 3,480 & 256 & 107 \\
\hline Losses & 7.180 & 13,949 & 17,928 & 17.627 & 15,931 & 8,215 \\
\hline 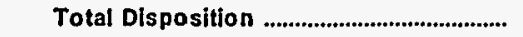 & 179,758 & 246,654 & 471,926 & 307,467 & 217,842 & 167,158 \\
\hline
\end{tabular}

Note: Totals may not equal sum of components because of independent rounding. Double counting occurs in components of both sources and disposition of energy and thus neither provides a true total. Purchases from utilities, net interchanges, and net wheeling (except for imports) are included in net generation. Sales for resale is included in sales to ultimate consumers.

Source: Energy Information Administration, Form ELA-412, "Annual Report of Public Electric Utilities." 
Table 26. Electric Energy Account by Major U.S. Publicly Owned Electric Utility Within State, 1995 (Concinued) (Megawatthours)

\begin{tabular}{|c|c|c|c|c|c|c|}
\hline Item & $\begin{array}{l}\text { Mississippi } \\
\text { Municipal } \\
\text { Energy } \\
\text { Agency } \\
\text { of MS } \\
\text { September } 30\end{array}$ & 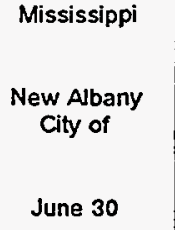 & $\begin{array}{l}\text { Mississippi } \\
\text { Oxford } \\
\text { City of } \\
\text { June } 30\end{array}$ & $\begin{array}{l}\text { Mississippl } \\
\text { Starkville } \\
\text { City of } \\
\text { June } 30\end{array}$ & $\begin{array}{l}\text { Mississippi } \\
\text { Tupelo } \\
\text { City of } \\
\text { June } 30\end{array}$ & $\begin{array}{l}\text { Mississippi } \\
\text { West } \\
\text { Point } \\
\text { City of } \\
\text { June } 30\end{array}$ \\
\hline \multicolumn{7}{|l|}{ Sources of Energy } \\
\hline Steam & 0 & $\mathbf{0}$ & 0 & 0 & 0 & 0 \\
\hline 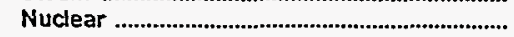 & 0 & 0 & 0 & 0 & 0 & 0 \\
\hline 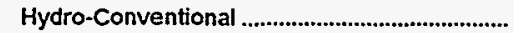 & 0 & 0 & 0 & 0 & $\mathbf{0}$ & 0 \\
\hline 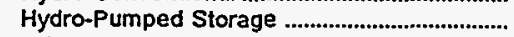 & 0 & 0 & 0 & 0 & 0 & 0 \\
\hline Other & 0 & $\mathbf{0}$ & 0 & 0 & 0 & 0 \\
\hline 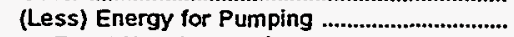 & 0 & 0 & 0 & 0 & 0 & 0 \\
\hline Total Net Generation & 0 & $\mathbf{0}$ & 0 & 0 & 0 & 0 \\
\hline 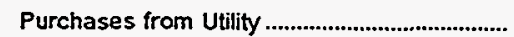 & 863,897 & 244,503 & 158,107 & 343,751 & 650,395 & 190,782 \\
\hline 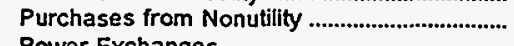 & 0 & 0 & 0 & 0 & 0 & 0 \\
\hline 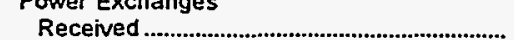 & 0 & 0 & 0 & 0 & 0 & 0 \\
\hline 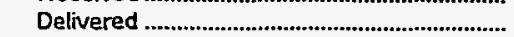 & 0 & 0 & 0 & 0 & 0 & 0 \\
\hline 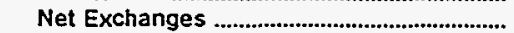 & 0 & 0 & 0 & 0 & 0 & 0 \\
\hline \multicolumn{7}{|l|}{ Transmission for Others (Wheeling) } \\
\hline Received & 0 & 0 & 0 & 0 & 0 & 0 \\
\hline 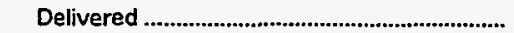 & 0 & 0 & 0 & 0 & 0 & 0 \\
\hline 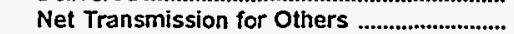 & 0 & 0 & 0 & $\mathbf{0}$ & 0 & 0 \\
\hline $\begin{array}{l}\text { Transmission by Others Losses.......................... } \\
\text { Total Net Energy }\end{array}$ & 0 & 0 & 0 & 0 & 0 & 0 \\
\hline 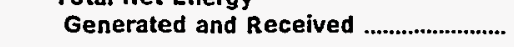 & 863,897 & 244,503 & 158,107 & 343,751 & 650,395 & 190,782 \\
\hline \multicolumn{7}{|l|}{ Disposition of Energy } \\
\hline 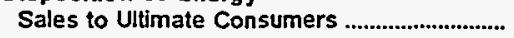 & 0 & 225.372 & 151,920 & 325,661 & 636,748 & 185,399 \\
\hline Requirements Sales for Resale ........................ & 863,897 & 0 & 0 & 0 & 0 & 0 \\
\hline Nonrequirements Sales for Resale ................... & 0 & 0 & 0 & 0 & 0 & 0 \\
\hline Fumished Without Charge & 0 & 0 & 0 & $\mathbf{0}$ & 0 & 0 \\
\hline Used by Utility (excluding station use) ............. & 0 & 177 & 85 & 213 & 390 & 0 \\
\hline Losses & 0 & 18,954 & 6,102 & 17,878 & 13,257 & 5,383 \\
\hline 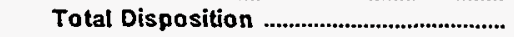 & 863,897 & 244,503 & 158,107 & 343,751 & 650,395 & 190,782 \\
\hline
\end{tabular}

Note: Totals may not equal sum of components because of independent rounding. Double counting occurs in components of both sources and disposition of energy and thus neither provides a true total. Purchases from utilities, net interchanges, and net wheeling (except for imports) are included in net generation.

Source: Energy Information Administration, Form ElA-412, "Annual Report of Public Electric Utilities." 
Table 26. Electric Energy Account by Major U.S. Publicly Owned Electric Utility Within State, 1995 (Continued)

(Megawatthours)

\begin{tabular}{|c|c|c|c|c|c|c|}
\hline Item & $\begin{array}{l}\text { Missouri } \\
\text { Carthage } \\
\text { City of } \\
\text { June } 30\end{array}$ & $\begin{array}{l}\text { Missouri } \\
\text { Columbia } \\
\text { City of } \\
\text { September } 30\end{array}$ & $\begin{array}{l}\text { Missouri } \\
\text { Hannibal } \\
\text { City of } \\
\text { June } 30\end{array}$ & $\begin{array}{c}\text { Missouri } \\
\text { Independence } \\
\text { City of } \\
\text { June } 30\end{array}$ & $\begin{array}{l}\text { Missouri } \\
\text { Kennett } \\
\text { City of } \\
\text { June } 30\end{array}$ & $\begin{array}{l}\text { Missouri } \\
\text { Kirkwood } \\
\text { Clity of } \\
\text { March 3i }\end{array}$ \\
\hline \multicolumn{7}{|l|}{ Sources of Energy } \\
\hline 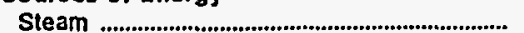 & 0 & 75,372 & 0 & 70,126 & 0 & $\mathbf{0}$ \\
\hline Nuclear & 0 & 0 & 0 & 0 & 0 & 0 \\
\hline Hydro-Conventional .............................................. & 0 & 0 & 0 & 0 & 0 & 0 \\
\hline 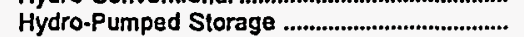 & 0 & $\mathbf{0}$ & 0 & 0 & 0 & 0 \\
\hline Other & 684 & 0 & 0 & 6,501 & 329 & 0 \\
\hline 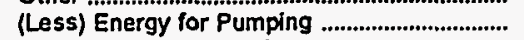 & 915 & 0 & 0 & 0 & 0 & 0 \\
\hline 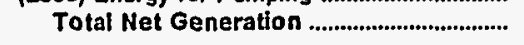 & -231 & 75,372 & 0 & 76,627 & 329 & 0 \\
\hline 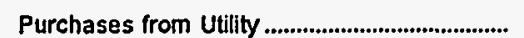 & 212,598 & 762,026 & 200,088 & 805,044 & 164,828 & 183,145 \\
\hline $\begin{array}{l}\text { Purchases from Nonutility ..................................................... } \\
\text { Power Exchanges }\end{array}$ & 0 & 273 & 0 & 0 & 0 & 0 \\
\hline 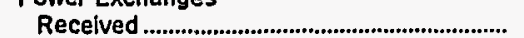 & 0 & 0 & 0 & 800 & 0 & 0 \\
\hline Delivered & 0 & 0 & 0 & 690 & 0 & 0 \\
\hline Net Exchanges & 0 & 0 & 0 & 110 & 0 & 0 \\
\hline \multicolumn{7}{|l|}{ Transmission for Others (Wheeling) } \\
\hline 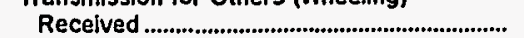 & 0 & 151,644 & 0 & 0 & 0 & 0 \\
\hline Delivered & 0 & 149,225 & 0 & 0 & 0 & 0 \\
\hline 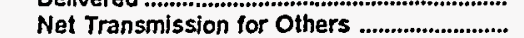 & 0 & 2,419 & 0 & 0 & 0 & 0 \\
\hline $\begin{array}{l}\text { Transmission by Others Losses....................................... } \\
\text { Total Net Energy }\end{array}$ & $-9,040$ & 0 & 0 & 0 & 0 & 0 \\
\hline 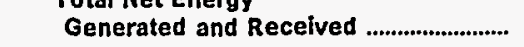 & 203,327 & 840,090 & 200,088 & 881,781 & 165,157 & 183,145 \\
\hline \multicolumn{7}{|l|}{ Disposition of Energy } \\
\hline 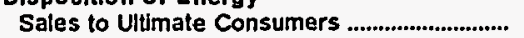 & 195,000 & 801,570 & 192,270 & 812,419 & 144,554 & 171,907 \\
\hline Requirements Sales for Resale ....................... & 0 & 0 & 0 & 2,012 & 0 & 0 \\
\hline Nonrequirements Sales for Resale .................. & 0 & 985 & 0 & 7,802 & 0 & 0 \\
\hline Fumlshed Without Charge .................................. & 0 & 0 & 3,018 & 0 & 0 & 0 \\
\hline Used by Utility (excluding station use) ............. & 0 & 0 & 0 & 1.950 & 323 & $\mathbf{0}$ \\
\hline $\begin{array}{l}\text { Losses } \\
\text { Total Disposition }\end{array}$ & $\begin{array}{r}8,327 \\
203,327\end{array}$ & $\begin{array}{r}37,535 \\
840,090\end{array}$ & $\begin{array}{r}4,800 \\
200,088\end{array}$ & $\begin{array}{r}57,598 \\
881,781\end{array}$ & $\begin{array}{r}20,280 \\
165,157\end{array}$ & $\begin{array}{r}11,238 \\
183,145\end{array}$ \\
\hline
\end{tabular}

Note: Totals may not equal sum of components because of independent rounding. Double counting occurs in components of both sources and disposition of energy and thus nelther provides a true total. Purchases from utilities, net interchanges, and net wheeling (except for imports) are included in net generation.

Source: Energy Information Administration, Form EIA-412, "Annual Report of Public Electric Utilities." 
Table 26. Electric Energy Account by Major U.S. Publicly Owned Electric Utility Within State, 1995 (Continued)

(Megawatthours)

\begin{tabular}{|c|c|c|c|c|c|c|}
\hline Item & $\begin{array}{l}\text { Missouri } \\
\text { Lebanon } \\
\text { City of } \\
\text { October } 31\end{array}$ & $\begin{array}{c}\text { Missouri } \\
\text { Marshall } \\
\text { City of } \\
\text { September } 30\end{array}$ & $\begin{array}{l}\text { Missouri } \\
\text { Monett } \\
\text { City of } \\
\text { March } 31\end{array}$ & $\begin{array}{c}\text { Missouri } \\
\text { Poplar } \\
\text { Bluff } \\
\text { City of } \\
\text { December } 31\end{array}$ & $\begin{array}{c}\text { Missouri } \\
\text { Rolla } \\
\text { City of } \\
\text { September } 30\end{array}$ & $\begin{array}{l}\text { Missouri } \\
\text { Sikeston } \\
\text { City of } \\
\text { May } 31\end{array}$ \\
\hline \multicolumn{7}{|l|}{ Sources of Energy } \\
\hline Steam & 0 & 59,812 & 0 & 0 & 0 & $1,414,101$ \\
\hline 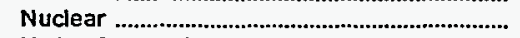 & 0 & 0 & 0 & 0 & 0 & 0 \\
\hline 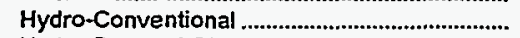 & 0 & 0 & 0 & 0 & $\mathbf{0}$ & 0 \\
\hline 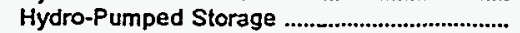 & 0 & 0 & 0 & 0 & 0 & 0 \\
\hline Other & 0 & 0 & 0 & 964 & 0 & 0 \\
\hline 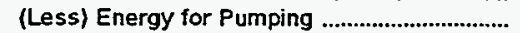 & 0 & 0 & 0 & 0 & 0 & 0 \\
\hline 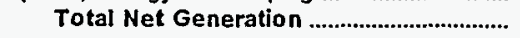 & 0 & 59,812 & 0 & 964 & $\mathbf{0}$ & $1,414,101$ \\
\hline 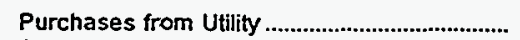 & 200,000 & 103,260 & 163,889 & 289,938 & 235,332 & 146,544 \\
\hline $\begin{array}{l}\text { Purchases from Nonutility ...................................... } \\
\text { Power Exchanges }\end{array}$ & 0 & 0 & 0 & 0 & 0 & 0 \\
\hline 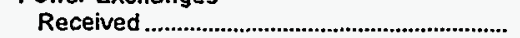 & 0 & 0 & 0 & 0 & 0 & 178,998 \\
\hline 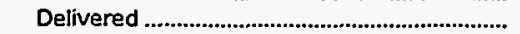 & 0 & 0 & 0 & 0 & 0 & 146,653 \\
\hline Net Exchanges & 0 & 0 & 0 & 0 & 0 & 32,345 \\
\hline \multicolumn{7}{|l|}{ Transmission for Others (Wheeling) } \\
\hline 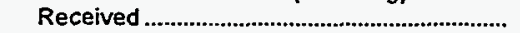 & 0 & 0 & 0 & 0 & 0 & $\mathbf{0}$ \\
\hline 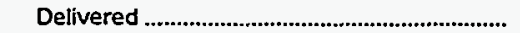 & 0 & 0 & 0 & 0 & 0 & 0 \\
\hline 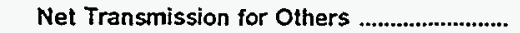 & 0 & 0 & 0 & 0 & 0 & 0 \\
\hline $\begin{array}{l}\text { Transmission by Others Losses ......................... } \\
\text { Total Net Energy }\end{array}$ & 0 & 0 & 0 & 0 & 0 & 0 \\
\hline 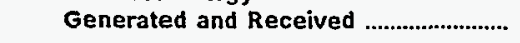 & 200,000 & 163,072 & 163,889 & 290,902 & 235,332 & $1,592,990$ \\
\hline \multicolumn{7}{|l|}{ Disposition of Energy } \\
\hline 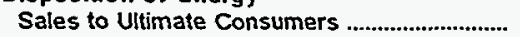 & 147.889 & 156,784 & 153,451 & 267,529 & 218,228 & 247,841 \\
\hline Requirements Sales for Resale .......................... & 0 & 0 & 0 & 0 & 0 & $1,331,619$ \\
\hline Nonrequirements Sales for Resale ................... & 0 & 0 & 0 & 0 & 0 & 0 \\
\hline Furnished Without Charge .................................... & 12,181 & 0 & 0 & 5,213 & 4,390 & 3,218 \\
\hline Used by Utility (excluding station use) ............. & 39,930 & 0 & 4,060 & 56 & 273 & 0 \\
\hline 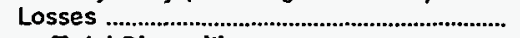 & 0 & 6,288 & 6,378 & 18,104 & 12,441 & 10,312 \\
\hline Total Disposition & 200,000 & 163,072 & 163,889 & 290,902 & 235,332 & $1,592,990$ \\
\hline
\end{tabular}

Note: Totals may not equal sum of components because of independent rounding. Double counting occurs in components of both sources and dispositlon of energy and thus neither provides a true total. Purchases from utilities, net interchanges, and net wheeling (except for imports) are included in net generation.

Source: Energy Information Administration, Form EIA-412, "Annual Report of Public Electric Utilities." 
Table 26. Electric Energy Account by Major U.S. Publicly Owned Electric Utility Within State, 1995 (Continued)

(Megawatthours)

\begin{tabular}{|c|c|c|c|c|c|c|}
\hline Item & $\begin{array}{l}\text { Missouri } \\
\text { Springfield } \\
\text { City of }\end{array}$ & $\begin{array}{l}\text { Missouri } \\
\text { West } \\
\text { Plains } \\
\text { City of } \\
\text { December } 31\end{array}$ & $\begin{array}{l}\text { Nebraska } \\
\text { Beatrice } \\
\text { City of } \\
\text { July } 31\end{array}$ & $\begin{array}{c}\text { Nebraska } \\
\text { Central } \\
\text { Nebraska } \\
\text { Pub } \\
\text { P\&l Dist } \\
\text { December } 31\end{array}$ & $\begin{array}{c}\text { Nebraska } \\
\text { Cornhusker } \\
\text { Public } \\
\text { Power Dist } \\
\text { December } 31\end{array}$ & $\begin{array}{c}\text { Nebraska } \\
\text { Dawson } \\
\text { County } \\
\text { Public } \\
\text { Pwr Dist } \\
\text { December } 31\end{array}$ \\
\hline \multicolumn{7}{|l|}{ Sources of Energy } \\
\hline Steam & $1,842,102$ & 0 & 0 & 0 & 0 & 0 \\
\hline 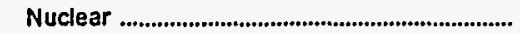 & 0 & 0 & 0 & 0 & 0 & 0 \\
\hline 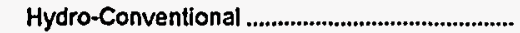 & 0 & $\mathbf{0}$ & 0 & 378,922 & 0 & 0 \\
\hline 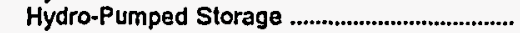 & 0 & 0 & 0 & 0 & 0 & 0 \\
\hline Other & 58,410 & 0 & 0 & 0 & 0 & 0 \\
\hline 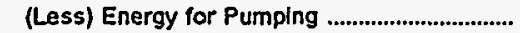 & 0 & 0 & 0 & 0 & 0 & $\mathbf{0}$ \\
\hline Total Net Generation & $1,900,512$ & 0 & 0 & 378,922 & 0 & 0 \\
\hline 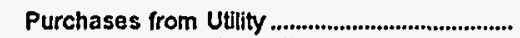 & 681.297 & 164,582 & 143,321 & 0 & 232,361 & 299,467 \\
\hline $\begin{array}{l}\text { Purchases from Nonutility .................................. } \\
\text { Power Exchanges }\end{array}$ & 0 & 0 & 0 & 0 & 0 & 0 \\
\hline 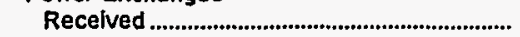 & 0 & $\mathbf{0}$ & 0 & 0 & 0 & 0 \\
\hline 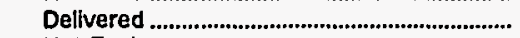 & 111.197 & 0 & 0 & 0 & 0 & 0 \\
\hline 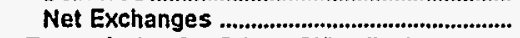 & $-111,197$ & 0 & 0 & 0 & 0 & 0 \\
\hline \multicolumn{7}{|l|}{ Transmission for Others (Wheeling) } \\
\hline 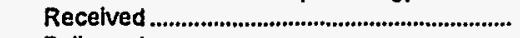 & 0 & $\mathbf{0}$ & 0 & 0 & 2,601 & 0 \\
\hline 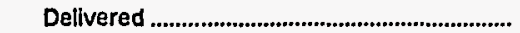 & 0 & 0 & 0 & 0 & 2,601 & 0 \\
\hline 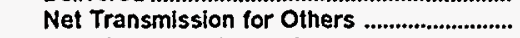 & 0 & $\mathbf{0}$ & 0 & 0 & 0 & 0 \\
\hline $\begin{array}{l}\text { Transmission by Others Losses ........................ } \\
\text { Total Net Energy }\end{array}$ & 144,842 & $\mathbf{0}$ & 0 & 0 & 0 & 0 \\
\hline 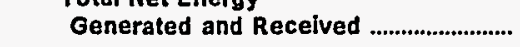 & $2,615,454$ & 164,582 & 143,321 & 378,922 & 232,361 & 299,467 \\
\hline \multicolumn{7}{|l|}{ Disposition of Energy } \\
\hline 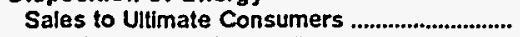 & $2,247,585$ & 140,009 & 131,757 & 0 & 210,149 & 267,765 \\
\hline 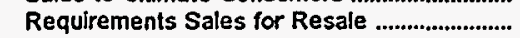 & 101,663 & 0 & 0 & 0 & 2,601 & 5,511 \\
\hline Nonrequirements Sales for Resale .................. & 77,574 & 0 & $\mathbf{0}$ & 378,922 & 0 & 0 \\
\hline 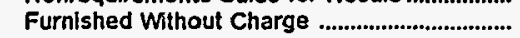 & 63,461 & 4,000 & 1,840 & 0 & 0 & 0 \\
\hline Used by Utility (exciuding station use) ............. & 1.674 & 0 & 846 & 0 & 568 & 208 \\
\hline Losses & 123,497 & 20,573 & 8,878 & $\mathbf{0}$ & 19,043 & 25,983 \\
\hline 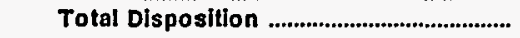 & $2,615,454$ & 164,582 & 143,321 & 378,922 & 232,361 & 299,467 \\
\hline
\end{tabular}

Note: Totals may not equal sum of components because of independent rounding. Double counting occurs in components of both sources and disposition of energy and thus neither provides a true total. Purchases from utilities, net interchanges, and net wheeling (except for imports) are included in net generation.

Source: Energy Information Administration, Form ElA-412, "Annual Report of Public Electric Utilities." 
Table 26. Electric Energy Account by Major U.S. Publicly Owned Electric Utility Within State, 1995 (Continued) (Megawatthours)

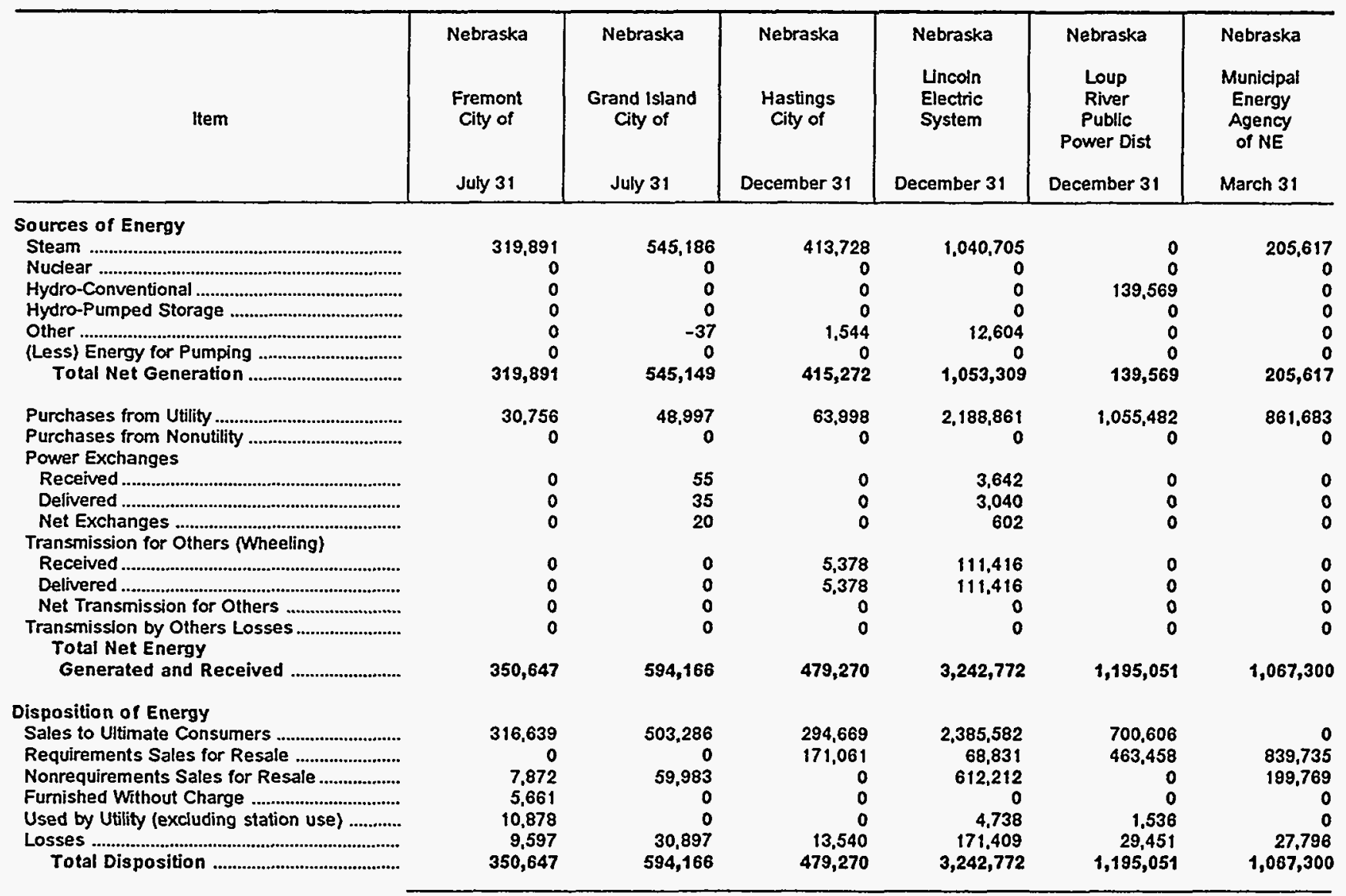

Note: Totals may not equal sum of components because of independent rounding. Double counting occurs in components of both sources and disposition of energy and thus neither provides a true total. Purchases from utilities, net interchanges, and net wheeling (except for imports) are inciuded in net generation.

Source: Energy Information Administration, Form ElA-412, "Annual Report of Public Electric Utilities." 
Table 26. Electric Energy Account by Major U.S. Publicly Owned Electric Utility Within State, 1995 (Continued)

(Megawatthours)

\begin{tabular}{|c|c|c|c|c|c|c|}
\hline Item & $\begin{array}{c}\text { Nebraska } \\
\text { Nebraska } \\
\text { Public } \\
\text { Power } \\
\text { District } \\
\text { December } 31\end{array}$ & $\begin{array}{c}\text { Nebraska } \\
\text { Norris } \\
\text { Public } \\
\text { Power } \\
\text { District } \\
\text { December } 31\end{array}$ & $\begin{array}{l}\text { Nebraska } \\
\text { North } \\
\text { Platte } \\
\text { City of } \\
\text { July } 31\end{array}$ & $\begin{array}{c}\text { Nebraska } \\
\text { Omaha Public } \\
\text { Power } \\
\text { District } \\
\text { December } 31\end{array}$ & $\begin{array}{c}\text { Nebraska } \\
\text { Southem } \\
\text { Nebraska Rural } \\
\text { P P D } \\
\text { December } 31\end{array}$ & $\begin{array}{l}\text { Nevada } \\
\text { Colorado } \\
\text { River } \\
\text { Comm } \\
\text { of Nevada } \\
\text { June } 30\end{array}$ \\
\hline \multicolumn{7}{|l|}{ Sources of Energy } \\
\hline Steam & $2,483,551$ & 0 & 0 & $5,678,118$ & 0 & $\mathbf{0}$ \\
\hline 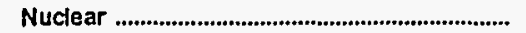 & $4,127,691$ & 0 & 0 & $3,357,760$ & 0 & 0 \\
\hline 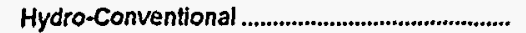 & 139,715 & 0 & 0 & 0 & 0 & 0 \\
\hline Hydro-Pumped Storage & 0 & $\mathbf{0}$ & 0 & 0 & 0 & $\mathbf{0}$ \\
\hline Other & 16,363 & $\mathbf{0}$ & 0 & 38,091 & 0 & 0 \\
\hline (Less) Energy for Pumping ................................. & 0 & $\mathbf{0}$ & 0 & 0 & $\mathbf{0}$ & 0 \\
\hline 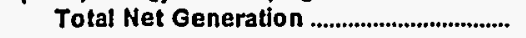 & $6,767,320$ & $\mathbf{0}$ & 0 & $9,073,969$ & 0 & 0 \\
\hline 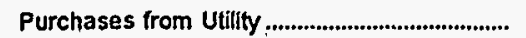 & $1,556,608$ & 446,772 & 234,197 & 419,621 & 483,782 & $1,845,006$ \\
\hline $\begin{array}{l}\text { Purchases from Nonutility ...................................... } \\
\text { Power Exchanges }\end{array}$ & $4,809,579$ & 0 & 0 & 0 & 0 & \\
\hline 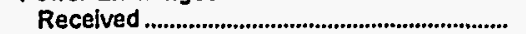 & 107,865 & 0 & 0 & 222,779 & 0 & 0 \\
\hline 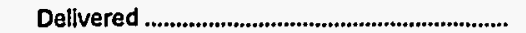 & 43,932 & 0 & 0 & $1,686,685$ & 0 & 0 \\
\hline 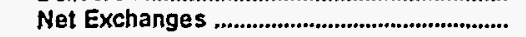 & 63,933 & 0 & 0 & $-1,463,906$ & 0 & 0 \\
\hline \multicolumn{7}{|l|}{ Transmission for Others (Wheeling) } \\
\hline 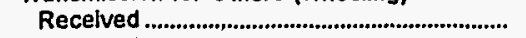 & $\mathbf{0}$ & $\mathbf{0}$ & 0 & 133,290 & 0 & 0 \\
\hline 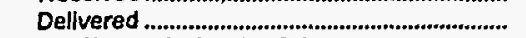 & 0 & 0 & 0 & 127,354 & 0 & 0 \\
\hline Net Transmission for Others .......................... & 0 & 0 & 0 & 5,936 & 0 & 0 \\
\hline $\begin{array}{l}\text { Transmission by Others Losses ....................... } \\
\text { Total Net Energy }\end{array}$ & 0 & 0 & $\mathbf{0}$ & 0 & 0 & 0 \\
\hline 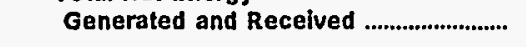 & $13,197,440$ & 446,772 & 234,197 & $8,035,620$ & 483,782 & $1,845,006$ \\
\hline \multicolumn{7}{|l|}{ Disposition of Energy } \\
\hline 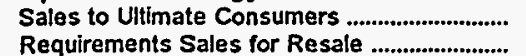 & $\begin{array}{l}2,818,495 \\
5,591,678\end{array}$ & $\begin{array}{r}408,691 \\
15,270\end{array}$ & $\begin{array}{r}217,164 \\
0\end{array}$ & $\begin{array}{r}7.456 .745 \\
168,469\end{array}$ & $\begin{array}{r}436,053 \\
0\end{array}$ & $\begin{array}{l}920,584 \\
924,422\end{array}$ \\
\hline Nonrequlrements Sales for Resale .................. & $4,068,718$ & 0 & 0 & 0 & 0 & 0 \\
\hline Furnished Without Charge ................................. & 0 & 0 & 3,322 & 0 & 0 & 0 \\
\hline Used by Utilly (excluding station use) ............ & 11,607 & 0 & 506 & 0 & 324 & 0 \\
\hline 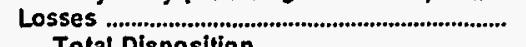 & 706,942 & 22,811 & 13,205 & 410,406 & 47,405 & \\
\hline Total Disposition & $13,197,440$ & 446,772 & 234,197 & $8,035,620$ & 483,782 & $1,845,006$ \\
\hline
\end{tabular}


Table 26. Electric Energy Account by Major U.S. Publicly Owned Electric Utility Within State, 1995 (Continued) (Megawatthours)

\begin{tabular}{|c|c|c|c|c|c|c|}
\hline Item & $\begin{array}{c}\text { Nevada } \\
\text { Overton } \\
\text { Power } \\
\text { District } \\
\text { No } 5 \\
\text { December } 31\end{array}$ & $\begin{array}{l}\text { New Jersey } \\
\text { Madison } \\
\text { Borough } \\
\text { December } \mathbf{3 1}\end{array}$ & $\begin{array}{l}\text { New Jersey } \\
\text { Vineland } \\
\text { City of } \\
\text { June } 30\end{array}$ & $\begin{array}{l}\text { New Mexico } \\
\text { Farmington } \\
\text { City of } \\
\text { June } 30\end{array}$ & $\begin{array}{c}\text { New Mexico } \\
\text { Gallup } \\
\text { City of } \\
\text { June } 30\end{array}$ & $\begin{array}{l}\text { New Mexico } \\
\text { Los Alamos } \\
\text { County } \\
\text { June } 30\end{array}$ \\
\hline \multicolumn{7}{|l|}{ Sources of Energy } \\
\hline Steam & 0 & $\mathbf{0}$ & 63,192 & 401,886 & 0 & 227,331 \\
\hline 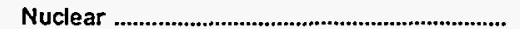 & 0 & 0 & 0 & 0 & 0 & 0 \\
\hline 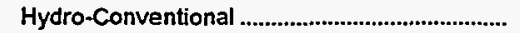 & 0 & $\mathbf{0}$ & 0 & 128,152 & 0 & 74,369 \\
\hline 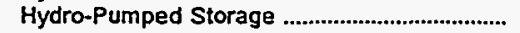 & $\mathbf{0}$ & $\mathbf{0}$ & 0 & 0 & 0 & 0 \\
\hline Other & 0 & 0 & 0 & 0 & 0 & $\mathbf{0}$ \\
\hline 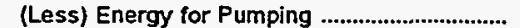 & 0 & $\mathbf{0}$ & 0 & $\mathbf{0}$ & 0 & 0 \\
\hline 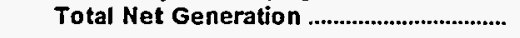 & $\mathbf{0}$ & $\mathbf{0}$ & 63,192 & 530,038 & 0 & 301,700 \\
\hline 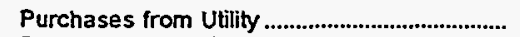 & 212,114 & 133,924 & 20,055 & 120,377 & 187,726 & 220,372 \\
\hline \multicolumn{6}{|l|}{ Power Exchanges } & \\
\hline 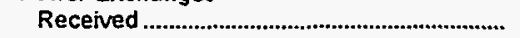 & 0 & 0 & 315,318 & 2,122 & 0 & 45,740 \\
\hline 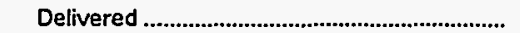 & 0 & 0 & 7,509 & 6,600 & 0 & 57,152 \\
\hline Net Exchanges & $\mathbf{0}$ & $\mathbf{0}$ & 307,809 & $-4,478$ & 0 & $-11,412$ \\
\hline \multicolumn{7}{|l|}{ Transmission for Others (Wheeling) } \\
\hline 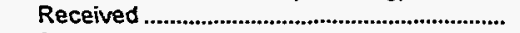 & 0 & 0 & 0 & 9.921 & 0 & 0 \\
\hline Delivered & 0 & 0 & 0 & 9,921 & 0 & $\mathbf{0}$ \\
\hline Net Transmission for Others ............................... & 0 & 0 & 0 & 0 & 0 & $\mathbf{0}$ \\
\hline $\begin{array}{l}\text { Transmission by Others Losses ........................... } \\
\text { Total Net Energy }\end{array}$ & 0 & 0 & 0 & 0 & $\mathbf{0}$ & 0 \\
\hline 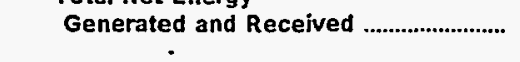 & 212,114 & 133,924 & 440,508 & 645,937 & 187,726 & 510,660 \\
\hline \multicolumn{7}{|l|}{ Disposition of Energy } \\
\hline 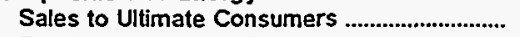 & 196,573 & 131,526 & 418,764 & 598,523 & 176,117 & 455,828 \\
\hline Requirements Sales for Resale ........................... & 11,923 & 0 & 0 & 20,708 & 0 & 26,732 \\
\hline Nonrequirements Sales for Resale .................. & 0 & $\mathbf{0}$ & $\mathbf{0}$ & 15,573 & 0 & 0 \\
\hline 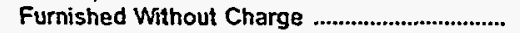 & 0 & 0 & 96 & 0 & 0 & 0 \\
\hline Used by Utility (excluding station use) ............. & 320 & 0 & 1,174 & 0 & 0 & 0 \\
\hline 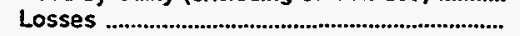 & 3,298 & 2,398 & 20,474 & 11,135 & 11,609 & 28,100 \\
\hline 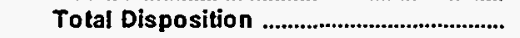 & 212,114 & 133,924 & 440,508 & 645,937 & 187,726 & 510,660 \\
\hline
\end{tabular}

Note: Totals may not equal sum of components because of independent rounding. Double counting occurs in components of both sources and disposition of energy and thus neither provides a true total. Purchases from utilities, net interchanges, and net wheeling (except for imports) are included in net generation.

Source: Energy Information Administration, Form ElA-412, "Annual Report of Public Electric Utilities." 
Table 26. Electric Energy Account by Major U.S. Publicly Owned Electric Utility Within State, 1995 (Continued)

(Megawatthours)

\begin{tabular}{|c|c|c|c|c|c|c|}
\hline Item & $\begin{array}{l}\text { New York } \\
\text { Fairport } \\
\text { Village of } \\
\text { May } 31\end{array}$ & $\begin{array}{l}\text { New York } \\
\text { Freeport } \\
\text { Village of } \\
\text { Inc } \\
\text { February } 28\end{array}$ & $\begin{array}{l}\text { New York } \\
\text { Jamestown } \\
\text { City of } \\
\text { December } 31\end{array}$ & $\begin{array}{l}\text { New York } \\
\text { Lake Placld } \\
\text { Village Inc } \\
\text { July } 31\end{array}$ & $\begin{array}{l}\text { New York } \\
\text { Massena } \\
\text { Town of } \\
\text { December } 31\end{array}$ & $\begin{array}{l}\text { New York } \\
\text { Plattsburgh } \\
\text { City of }\end{array}$ \\
\hline \multicolumn{7}{|l|}{ Sources of Energy } \\
\hline Steam & $\mathbf{0}$ & $\mathbf{0}$ & 156,033 & 0 & 0 & 0 \\
\hline Nuclear ............................................................... & 0 & 0 & 0 & 0 & $\mathbf{0}$ & 0 \\
\hline 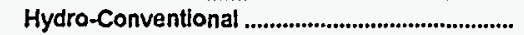 & 0 & 0 & 0 & 0 & 0 & 0 \\
\hline 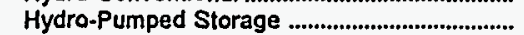 & 0 & 0 & 0 & 0 & 0 & 0 \\
\hline 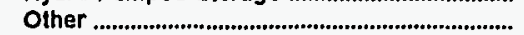 & 0 & 25,775 & 0 & 0 & 0 & 0 \\
\hline 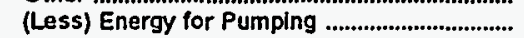 & 0 & & 0 & 0 & 0 & 0 \\
\hline 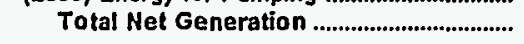 & 0 & 25,775 & 156,033 & 0 & 0 & 0 \\
\hline 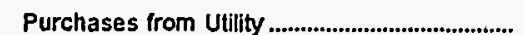 & 359,353 & 231,679 & 460,367 & 129,829 & 158,081 & 545,504 \\
\hline Purchases from Nonutility ........................................ & 0 & 0 & 0 & 0 & 0 & 0 \\
\hline \multicolumn{7}{|l|}{ Power Exchanges } \\
\hline 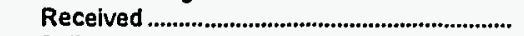 & 0 & 0 & 0 & 0 & 0 & 0 \\
\hline 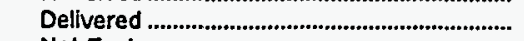 & 0 & 0 & o & 0 & 0 & 0 \\
\hline Net Exchanges ...................................................... & 0 & 0 & 0 & 0 & 0 & 0 \\
\hline \multicolumn{7}{|l|}{ Transmission for Others (Wheeling) } \\
\hline 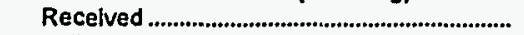 & 0 & 0 & 0 & 0 & 0 & 0 \\
\hline 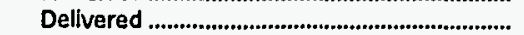 & 0 & 0 & 0 & 0 & 0 & 0 \\
\hline 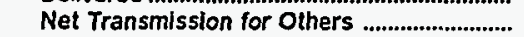 & 0 & 0 & 0 & 0 & 0 & 0 \\
\hline Transmission by Others Losses ........................... & 0 & 0 & $-29,462$ & 0 & 0 & $-15,001$ \\
\hline Generated and Received .......................... & 359,353 & 257,454 & 586,938 & 129,829 & 158,084 & 530,503 \\
\hline \multicolumn{7}{|l|}{ Disposition of Energy } \\
\hline 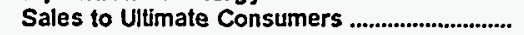 & 341,104 & 248,538 & 480,267 & 122,015 & 156,117 & 509,336 \\
\hline Requirements Sales for Resale .......................... & & 0 & 78,386 & 0 & 0 & \\
\hline Nonrequirements Sales for Resale ....................... & 0 & 0 & 0 & 0 & 0 & 0 \\
\hline 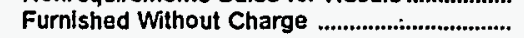 & 0 & 0 & 0 & 1,406 & 0 & 0 \\
\hline Used by Utility (excluding station use) ............. & 400 & 4,328 & 1.056 & 200 & 402 & 1.057 \\
\hline 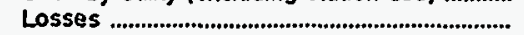 & 17,849 & 4,588 & 27,229 & 6,208 & 1,562 & 20,110 \\
\hline Total Disposition & 359,353 & 257,454 & 586,938 & 129,829 & 158,081 & 530,503 \\
\hline
\end{tabular}

Note: Totals may not equal sum of components because of independent rounding. Double counting occurs in components of both sources and dispositlon of energy and thus neither provides a true total. Purchases from utilities, net interchanges, and net wheeling (except for imports) are included in net generation.

Source: Energy Information Administration, Form ElA-4 12, "Annual Report of Public Electric Utilities." 
Table 26. Electric Energy Account by Major U.S. Publicly Owned Electric Utility Within State, 1995 (Continued)

(Megawatthours)

\begin{tabular}{|c|c|c|c|c|c|c|}
\hline Item & $\begin{array}{c}\text { New York } \\
\text { Power } \\
\text { Authority } \\
\text { of State of NY } \\
\text { December } 31\end{array}$ & $\begin{array}{l}\text { New York } \\
\text { Rockville } \\
\text { Centre } \\
\text { Village of } \\
\text { May } 31\end{array}$ & $\begin{array}{l}\text { New York } \\
\text { Solvay } \\
\text { Village of } \\
\text { May } 31\end{array}$ & $\begin{array}{l}\text { Albemarie } \\
\text { City of } \\
\text { June } 30\end{array}$ & $\begin{array}{l}\text { Concord } \\
\text { City of } \\
\text { June } 30\end{array}$ & $\begin{array}{l}\text { North Carolina } \\
\text { Elizabeth } \\
\text { City City of } \\
\text { June } 30\end{array}$ \\
\hline \multicolumn{7}{|l|}{ Sources of Energy } \\
\hline Steam & $4,182.256$ & 0 & 0 & 0 & 0 & 0 \\
\hline 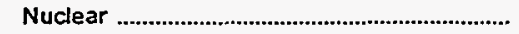 & $6,300,247$ & 0 & 0 & 0 & 0 & $\mathbf{0}$ \\
\hline 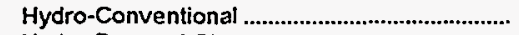 & $21,622,427$ & 0 & 0 & 0 & 0 & 0 \\
\hline 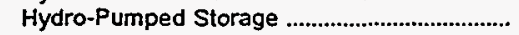 & $2,050,081$ & 0 & 0 & 0 & 0 & 0 \\
\hline Other & 0 & 18,000 & 0 & 0 & 9,809 & 714 \\
\hline 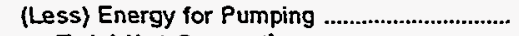 & $3,213,012$ & 0 & 0 & 0 & 0 & 0 \\
\hline 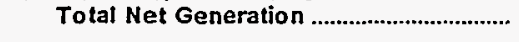 & $30,941,999$ & 18,000 & 0 & 0 & 9,809 & 714 \\
\hline 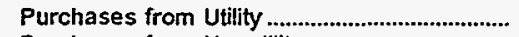 & $10,192,490$ & 167,000 & 0 & 266,764 & 427,889 & 244,310 \\
\hline $\begin{array}{l}\text { Purchases from Nonutility } \\
\text { Power Exchanges }\end{array}$ & 0 & 0 & 227,046 & 0 & 0 & 0 \\
\hline Received & 229,473 & 0 & 0 & 0 & 0 & 0 \\
\hline Delivered & 267,776 & 0 & 0 & 0 & 0 & 0 \\
\hline Net Exchanges & $-38,303$ & 0 & 0 & 0 & 0 & 0 \\
\hline \multicolumn{7}{|l|}{ Transmission for Others (Wheeling) } \\
\hline 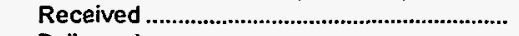 & $1,603,360$ & 0 & 0 & 0 & 0 & 0 \\
\hline Delivered & $1,574,386$ & 0 & 0 & 0 & 0 & 0 \\
\hline Net Transmission for Others ............................ & 28.974 & 0 & 0 & 0 & 0 & 0 \\
\hline $\begin{array}{l}\text { Transmission by Others Losses........................... } \\
\text { Total Net Energy }\end{array}$ & 0 & 0 & 0 & 0 & 0 & 0 \\
\hline 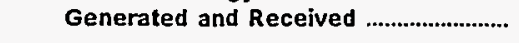 & $41,125,160$ & 185,000 & 227,046 & 266,764 & 437,698 & 245,024 \\
\hline \multicolumn{7}{|l|}{ Disposition of Energy } \\
\hline Sales to Ultimate Consumers ............................... & $13,043,997$ & 171,000 & 207,512 & 248,234 & 411,263 & 232,145 \\
\hline Requirements Sales for Resale ........................... & $4,346,578$ & $\mathbf{0}$ & 0 & 0 & 0 & 0 \\
\hline Nonrequirements Sales for Resale ................. & $23,099,882$ & 0 & 0 & 0 & 0 & 0 \\
\hline 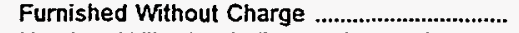 & 8,460 & 0 & 0 & 3,888 & 0 & 0 \\
\hline Used by Utility (excluding station use) ............. & 15,100 & 2,000 & 0 & 125 & 3,868 & 0 \\
\hline Losses & 611,143 & 12,000 & 19,534 & 14.517 & 22,567 & 12,879 \\
\hline Total Disposition & $41,125,160$ & 185,000 & 227,046 & 266,764 & 437,698 & 245,024 \\
\hline
\end{tabular}

Note: Totals may not equal sum of components because of independent rounding. Double counting occurs in components of both sources and disposition of energy and thus neither provides a true total. Purchases from utlities, net interchanges, and net wheeling (except for imports) are included in net generation.

Source: Energy Information Administration, Form E|A-412, "Annual Report of Public Electric Utilities." 
Table 26. Electric Energy Account by Major U.S. Publicly Owned Electric Utility Within State, 1995 (Continued) (Megawatthours)

\begin{tabular}{|c|c|c|c|c|c|c|}
\hline Item & $\begin{array}{l}\text { North Carolina } \\
\text { Fayetteville } \\
\text { Public } \\
\text { Works Comm } \\
\\
\text { June } 30\end{array}$ & $\begin{array}{l}\text { North Carolina } \\
\text { Forest City } \\
\text { Town of } \\
\text { June } 30\end{array}$ & $\begin{array}{l}\text { North Carolina } \\
\text { Gastonia } \\
\text { City of } \\
\text { June } 30\end{array}$ & $\begin{array}{c}\text { North Carolina } \\
\text { Greenville } \\
\text { Utilities } \\
\text { Comm } \\
\text { June } 30\end{array}$ & $\begin{array}{c}\text { North Carolina } \\
\text { High } \\
\text { Point } \\
\text { Town } \\
\text { of } \\
\text { June } 30\end{array}$ & $\begin{array}{l}\text { North Carolina } \\
\text { Kinston } \\
\text { City of } \\
\text { June } 30\end{array}$ \\
\hline \multicolumn{7}{|l|}{ Sources of Energy } \\
\hline 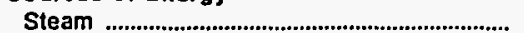 & 0 & 0 & 0 & 0 & 0 & 0 \\
\hline 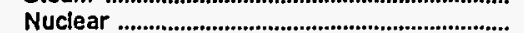 & 0 & 0 & 0 & 0 & 0 & 0 \\
\hline 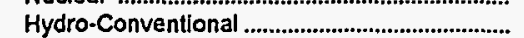 & 0 & 0 & 0 & 0 & 0 & 0 \\
\hline 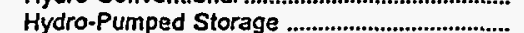 & 0 & 0 & 0 & 0 & 0 & 0 \\
\hline Other & 18,180 & 0 & $\mathbf{0}$ & 0 & 0 & 0 \\
\hline 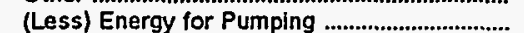 & $\because 0$ & 0 & 0 & 0 & 0 & 0 \\
\hline 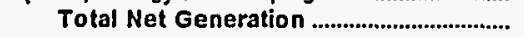 & 18,180 & 0 & 0 & 0 & 0 & 0 \\
\hline 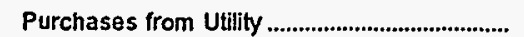 & $1,225,242$ & 148,146 & 617,853 & $1,192,000$ & 844,024 & 452,993 \\
\hline 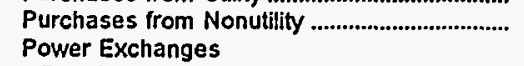 & 0 & 0 & 0 & 0 & 0 & 0 \\
\hline 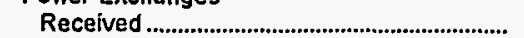 & 589,377 & 0 & 0 & 0 & 0 & 0 \\
\hline 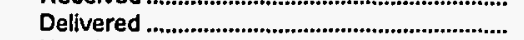 & 3,948 & 0 & 0 & 0 & 0 & 0 \\
\hline Net Exchanges & 585,429 & 0 & 0 & 0 & 0 & 0 \\
\hline \multicolumn{7}{|l|}{ Transmission for Others (Wheeling) } \\
\hline 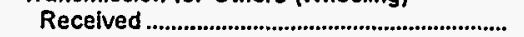 & 0 & 0 & 0 & 0 & 0 & 0 \\
\hline 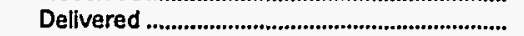 & 0 & 0 & 0 & 0 & 0 & 0 \\
\hline 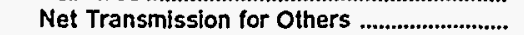 & 0 & 0 & 0 & 0 & 0 & 0 \\
\hline $\begin{array}{l}\text { Transmission by Others Losses........................ } \\
\text { Total Net Energy }\end{array}$ & 0 & 0 & 0 & 0 & 0 & 0 \\
\hline 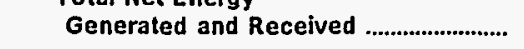 & $1,828,851$ & 148,146 & 617,853 & $1,192,000$ & 844,024 & 452,993 \\
\hline \multicolumn{7}{|l|}{ Dispositton of Energy } \\
\hline Sales to Ultimate Consumers ............................... & $1,750,975$ & 148,133 & 580,697 & $1,104,000$ & 784,063 & 438,692 \\
\hline 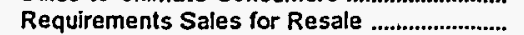 & 0 & 0 & 0 & 29,000 & 0 & 0 \\
\hline Nonrequirements Sales for Resale .................. & 0 & 0 & 0 & 0 & 0 & 0 \\
\hline Furnished Without Charge ................................. & 3,948 & 0 & 0 & $\mathbf{0}$ & 0 & 0 \\
\hline Used by Utility (excluding station use) ............ & 0 & 0 & 0 & 0 & 0 & 0 \\
\hline 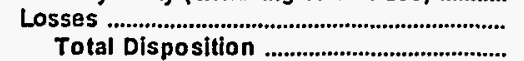 & $\begin{array}{r}73,928 \\
1,828,851\end{array}$ & $\begin{array}{r}13 \\
148,146\end{array}$ & $\begin{array}{r}37,156 \\
617,853\end{array}$ & $\begin{array}{r}59,000 \\
1,192,000\end{array}$ & $\begin{array}{r}59,961 \\
844,024\end{array}$ & $\begin{array}{r}14,301 \\
452,993\end{array}$ \\
\hline
\end{tabular}


Table 26. Electric Energy Account by Major U.S. Publicly Owned Electric Utility Within State, 1995 (Continued)

(Megawatthours)

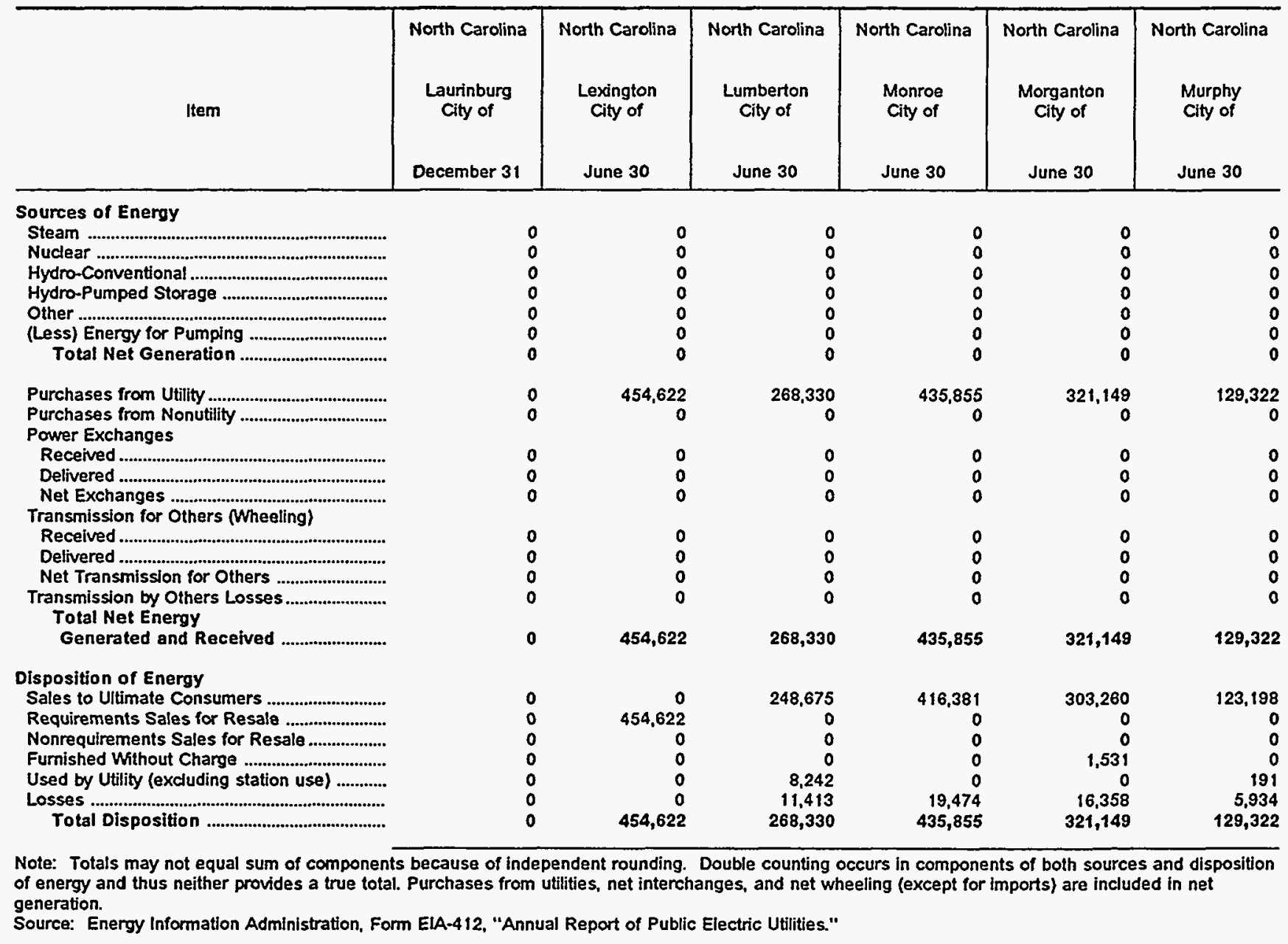


Table 26. Electric Energy Account by Major U.S. Publicly Owned Electric Utility Within State, 1995 (Continued)

(Megawatthours)

\begin{tabular}{|c|c|c|c|c|c|c|}
\hline Item & $\begin{array}{l}\text { North Carolina } \\
\text { New Bern } \\
\text { City of } \\
\text { June } 30\end{array}$ & $\begin{array}{c}\text { North Carolina } \\
\text { New River } \\
\text { Light } \\
\& \\
\text { Power Co } \\
\text { December } 31\end{array}$ & $\begin{array}{c}\text { North Carolina } \\
\text { North } \\
\text { Carolina } \\
\text { Eastern M P A } \\
\text { December } 31\end{array}$ & $\begin{array}{c}\text { North Carolina } \\
\text { North } \\
\text { Carolina } \\
\text { Mun } \\
\text { Power Agny } \\
\text { December } 31\end{array}$ & $\begin{array}{l}\text { North Carolina } \\
\text { Rocky Mount } \\
\text { City of } \\
\text { June } 30\end{array}$ & $\begin{array}{l}\text { North Carolina } \\
\text { Shelby } \\
\text { City of } \\
\text { June } 30\end{array}$ \\
\hline \multicolumn{7}{|l|}{ Sources of Energy } \\
\hline 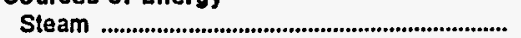 & 0 & 0 & $1,124,130$ & 0 & 0 & 0 \\
\hline 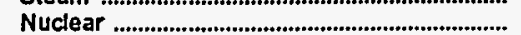 & 0 & 0 & $3,170,593$ & $6,306,136$ & 0 & 0 \\
\hline Hydro-Conventional & 0 & 0 & 0 & 0 & 0 & 0 \\
\hline 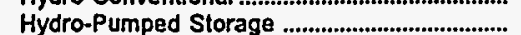 & 0 & 0 & 0 & 0 & 0 & 0 \\
\hline Other & 0 & 0 & 483,060 & 0 & 0 & 0 \\
\hline Less) Energy for Pumping & 0 & 0 & 0 & 0 & 0 & 0 \\
\hline 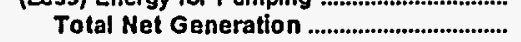 & 0 & 0 & $4,777,783$ & $6,306,136$ & 0 & 0 \\
\hline 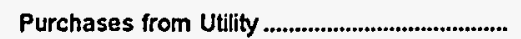 & 0 & 179,930 & $1.867,629$ & 791,905 & 771,932 & 173,940 \\
\hline $\begin{array}{l}\text { Purchases from Nonutility .............................................. } \\
\text { Power Exchanges }\end{array}$ & 371,037 & 0 & 0 & 0 & 0 & 0 \\
\hline 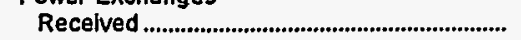 & $\mathbf{0}$ & 0 & $\mathbf{0}$ & 0 & 0 & 0 \\
\hline Dellvered & 0 & 0 & 0 & 0 & 0 & 0 \\
\hline 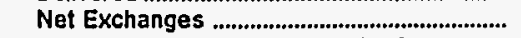 & $\mathbf{0}$ & 0 & 0 & 0 & 0 & 0 \\
\hline \multicolumn{7}{|l|}{ Transmission for Others (Wheeling) } \\
\hline 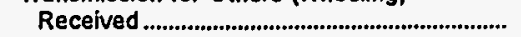 & $\mathbf{0}$ & 0 & 0 & o & 0 & 0 \\
\hline 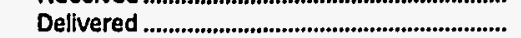 & 0 & 0 & 0 & 0 & 0 & 0 \\
\hline 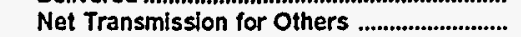 & 0 & 0 & 0 & 0 & 0 & 0 \\
\hline $\begin{array}{l}\text { Transmission by Others Losses } \\
\text { Total Net Energy }\end{array}$ & 0 & 0 & 0 & 0 & 0 & 0 \\
\hline 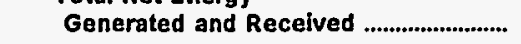 & 371,037 & 179,930 & $6,645,412$ & $7,098,041$ & 771,932 & 173,940 \\
\hline \multicolumn{7}{|l|}{ Disposition of Energy } \\
\hline 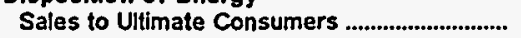 & 356,000 & 172,607 & 0 & 0 & 725,027 & 163,916 \\
\hline 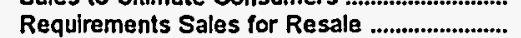 & 0 & 0 & $6,532,836$ & 0 & 17,733 & 0 \\
\hline Nonrequirements Sales for Resale .................. & 0 & 0 & 0 & $7,003,590$ & 0 & 0 \\
\hline Furnished Without Charge .............................. & 0 & 0 & 0 & 0 & 0 & 0 \\
\hline Used by Utility (excluding station use) ............ & 199 & 291 & 0 & 0 & 0 & 0 \\
\hline 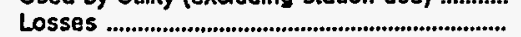 & 14,838 & 7,032 & 112,576 & 94,451 & 29,172 & 10,024 \\
\hline Total Dlsposition & 371,037 & 179,930 & $6,645,412$ & $7,098,041$ & 771,932 & 173,940 \\
\hline
\end{tabular}

Note: Totals may not equal sum of components because of independent rounding. Double counting occurs in components of both sources and disposition of energy and thus neither provides a true total. Purchases from utilities, net interchanges, and net wheelling.(except for imports) are included in net generation.

Source: Energy Information Administration, Form ElA-412, "Annual Report of Public Electric Utilities." 
Table 26. Electric Energy Account by Major U.S. Publicly Owned Electric Utility Within State, 1995 (Continued)

(Megawatthours)

\begin{tabular}{|c|c|c|c|c|c|c|}
\hline Item & $\begin{array}{c}\text { North Carolina } \\
\text { Statesville } \\
\text { City of } \\
\text { June } 30\end{array}$ & $\begin{array}{c}\text { North Carolina } \\
\text { Tarboro } \\
\text { Town of } \\
\text { June } 30\end{array}$ & $\begin{array}{c}\text { North Carolina } \\
\begin{array}{c}\text { Washington } \\
\text { City of }\end{array} \\
\text { June } 30\end{array}$ & $\begin{array}{l}\text { North Carolina } \\
\text { Wilson } \\
\text { City of } \\
\text { June } 30\end{array}$ & $\begin{array}{c}\text { Ohio } \\
\text { American } \\
\text { Mun } \\
\text { Power } \\
\text { Ohio Inc } \\
\text { December } 31\end{array}$ & $\begin{array}{c}\text { Ohio } \\
\text { Bowing } \\
\text { Green } \\
\text { City of } \\
\text { December } 31\end{array}$ \\
\hline \multicolumn{7}{|l|}{ Sources of Energy } \\
\hline Steam & 0 & 0 & 0 & 0 & $1,345,070$ & 0 \\
\hline 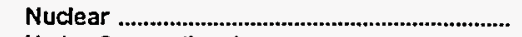 & 0 & 0 & 0 & 0 & 0 & 0 \\
\hline 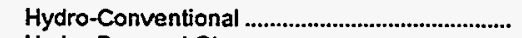 & 0 & 0 & 0 & 0 & 0 & 0 \\
\hline 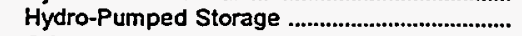 & 0 & 0 & 0 & $\mathbf{0}$ & 0 & 0 \\
\hline Other & 0 & 0 & 0 & 0 & 0 & 0 \\
\hline 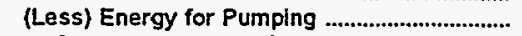 & 0 & 0 & 0 & 0 & 0 & 0 \\
\hline 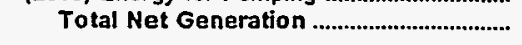 & $\mathbf{0}$ & 0 & $\mathbf{0}$ & 0 & $1,345,070$ & 0 \\
\hline 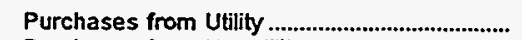 & 398,792 & 243,402 & 244,813 & $1,049,780$ & $4,227,404$ & 325,948 \\
\hline 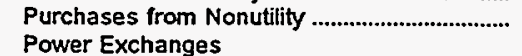 & 0 & 0 & 0 & 0 & 0 & \\
\hline 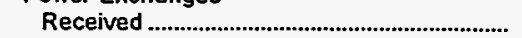 & 0 & $\mathbf{0}$ & 0 & 0 & $\mathbf{0}$ & 0 \\
\hline 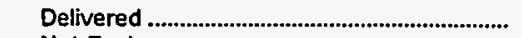 & 0 & 0 & 0 & 0 & 0 & 0 \\
\hline Net Exchanges & 0 & 0 & 0 & 0 & 0 & 0 \\
\hline \multicolumn{7}{|l|}{ Transmission for Others (Wheeling) } \\
\hline 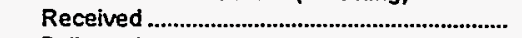 & 0 & 0 & 0 & 0 & 38.740 & 0 \\
\hline Delivered & 0 & 0 & 0 & 0 & 38,740 & 0 \\
\hline 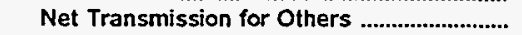 & 0 & 0 & 0 & 0 & 0 & 0 \\
\hline $\begin{array}{l}\text { Transmission by Others Losses ......................... } \\
\text { Total Net Energy }\end{array}$ & 0 & 0 & 0 & 0 & $\mathbf{0}$ & 0 \\
\hline 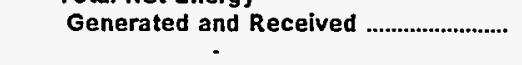 & 398,792 & 243,402 & 244,813 & $1,049,780$ & $5,572,474$ & 325,948 \\
\hline \multicolumn{7}{|l|}{ Disposition of Energy } \\
\hline 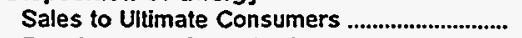 & 379,140 & 233,925 & 230,607 & 940,496 & 788,595 & 307,317 \\
\hline 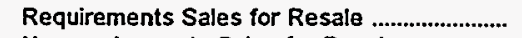 & 0 & 0 & 0 & 62,618 & $4,680,758$ & 2,854 \\
\hline Nonrequirements Sales for Resale ................... & 0 & 0 & 0 & 0 & 0 & 0 \\
\hline 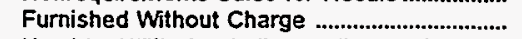 & 0 & 0 & 0 & 0 & 0 & 2,058 \\
\hline Used by Utility (excluding station use) ............. & 0 & 0 & 0 & 10,023 & 0 & 365 \\
\hline 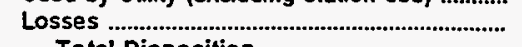 & 19,652 & 9,477 & 14,206 & 36,643 & 103,121 & 13,354 \\
\hline Total Disposition & 398,792 & 243,402 & 244,813 & $1,049,780$ & $5,572,474$ & 325,948 \\
\hline
\end{tabular}


Table 26. Electric Energy Account by Major U.S. Publicly Owned Electric Utility Within State, 1995 (Continued)

(Megawatthours)

\begin{tabular}{|c|c|c|c|c|c|c|}
\hline Hem & $\begin{array}{c}\text { Ohio } \\
\text { Bryan } \\
\text { City of } \\
\text { December } 31\end{array}$ & $\begin{array}{l}\text { Ohio } \\
\text { Celina } \\
\text { City of } \\
\text { December } 31\end{array}$ & $\begin{array}{c}\text { Ohio } \\
\text { Cleveland } \\
\text { City of } \\
\text { December } 31\end{array}$ & $\begin{array}{l}\text { Ohio } \\
\text { Clyde } \\
\text { City of } \\
\text { December } 31\end{array}$ & $\begin{array}{c}\text { Ohio } \\
\text { Columbus } \\
\text { City of } \\
\text { December } 31\end{array}$ & $\begin{array}{c}\text { Ohio } \\
\text { Cuyahoga } \\
\text { Falls } \\
\text { City of } \\
\text { December } 31\end{array}$ \\
\hline \multicolumn{7}{|l|}{ Sources of Energy } \\
\hline Steam & 0 & 0 & 0 & 0 & 0 & 0 \\
\hline 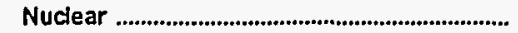 & $\mathbf{0}$ & 0 & 0 & 0 & 0 & 0 \\
\hline Hydro-Conventional ............................................... & 0 & 0 & 0 & 0 & 12,639 & 0 \\
\hline Hydro-Pumped Storage ..................................... & 0 & $\mathbf{0}$ & 0 & 0 & 0 & 0 \\
\hline 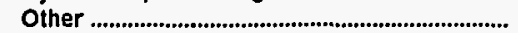 & 31,633 & $\mathbf{0}$ & 11.109 & 0 & 0 & 0 \\
\hline 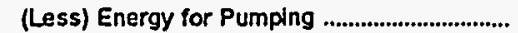 & 0 & $\mathbf{0}$ & 0 & 0 & 0 & 0 \\
\hline 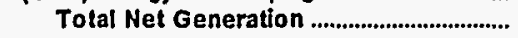 & 31,633 & 0 & 11,109 & 0 & 12,639 & 0 \\
\hline 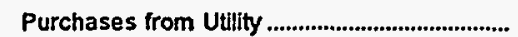 & 198,153 & 159,178 & $1,352,994$ & 140,301 & 695,132 & 346,169 \\
\hline $\begin{array}{l}\text { Purchases from Nonutility .................................. } \\
\text { Power Exchanges }\end{array}$ & 0 & 0 & 0 & 0 & $\begin{array}{r}0.106 \\
0\end{array}$ & 0 \\
\hline 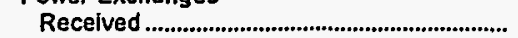 & 0 & $\mathbf{0}$ & 0 & 0 & 0 & 0 \\
\hline 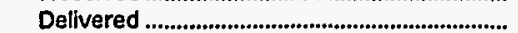 & 0 & 0 & 81,902 & 0 & 0 & 0 \\
\hline 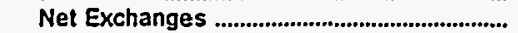 & 0 & 0 & $-81,902$ & 0 & 0 & 0 \\
\hline \multicolumn{7}{|l|}{ Transmission for Others (Wheeling) } \\
\hline 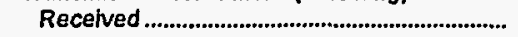 & 0 & $\mathbf{0}$ & 0 & 0 & 707.771 & 0 \\
\hline 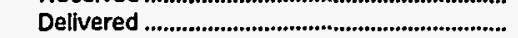 & 0 & $\mathbf{0}$ & 0 & 0 & 707,771 & 0 \\
\hline 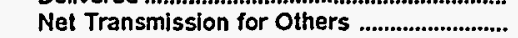 & 0 & 0 & 0 & 0 & 0 & 0 \\
\hline $\begin{array}{l}\text { Transmission by Others Losses........................ } \\
\text { Total Net Energy }\end{array}$ & 0 & 0 & $-16,769$ & 0 & 0 & 0 \\
\hline 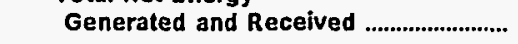 & 229,786 & 159,178 & $1,265,432$ & 140,301 & 707,771 & 346,169 \\
\hline \multicolumn{7}{|l|}{ Disposition of Energy } \\
\hline Sales to Ultimate Consumers ............................. & 220,837 & 145,604 & $1,148,111$ & 140,301 & 632,361 & 312,760 \\
\hline Requirements Sales for Resale ........................ & 40 & 0 & 0 & 0 & 275 & 0 \\
\hline Nonrequirements Sales for Resale .................. & 0 & 0 & o & 0 & 0 & 0 \\
\hline Furnished Without Charge ................................. & 3,268 & 2,319 & 0 & 0 & 28,556 & 10.715 \\
\hline Used by Utility (excluding station use) ............ & 4,091 & 393 & 1.945 & 0 & $\begin{array}{r}1,099 \\
\end{array}$ & 0.70 \\
\hline 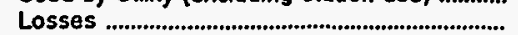 & 1,550 & 10.862 & 115,376 & 0 & 45,480 & 22,694 \\
\hline 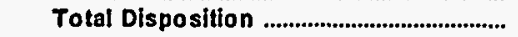 & 229,786 & 159,178 & $1,265,432$ & 140,301 & 707,771 & 346,169 \\
\hline
\end{tabular}

Note: Totals may not equal sum of components because of independent rounding. Double counting occurs in components of both sources and disposition of energy and thus neither provides a true total. Purchases from utilities, net interchanges, and net wheeling (except for imports) are included in net generation.

Source: Energy Information Administration, Form ElA-412, "Annual Report of Public Electric Utilities." 
Table 26. Electric Energy Account by Major U.S. Publicly Owned Electric Utility Within State, 1995 (Continued)

(Megawatthours)

\begin{tabular}{|c|c|c|c|c|c|c|}
\hline Item & $\begin{array}{c}\text { Ohio } \\
\text { Dover } \\
\text { City of } \\
\text { December } 31\end{array}$ & $\begin{array}{c}\text { Ohio } \\
\text { Hamilton } \\
\text { City of }\end{array}$ & $\begin{array}{c}\text { Ohio } \\
\text { Napoleon } \\
\text { City of }\end{array}$ & $\begin{array}{c}\text { Ohio } \\
\text { Niles } \\
\text { City of } \\
\text { December } 31\end{array}$ & $\begin{array}{l}\text { Ohio } \\
\text { Orville } \\
\text { City of } \\
\text { December } 31\end{array}$ & $\begin{array}{c}\text { Onio } \\
\text { Painesville } \\
\text { Clty of } \\
\text { December } 31\end{array}$ \\
\hline \multicolumn{7}{|l|}{ Sources of Energy } \\
\hline Steam & 0 & 226,385 & 0 & 0 & 285,776 & 153,522 \\
\hline Nuclear & 0 & $\begin{array}{r}220,000 \\
0\end{array}$ & 0 & 0 & $\begin{array}{r}0 \\
0\end{array}$ & $\begin{array}{r}100,026 \\
0\end{array}$ \\
\hline 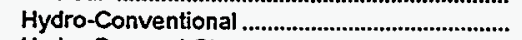 & 0 & 323,459 & 0 & 0 & 0 & 0 \\
\hline 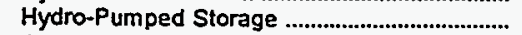 & 0 & 0 & 0 & 0 & $\mathbf{0}$ & 0 \\
\hline Other & 0 & 1,607 & 0 & 0 & 0 & 0 \\
\hline 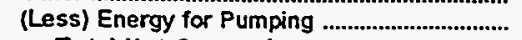 & 0 & 0 & 0 & 0 & 0 & 0 \\
\hline 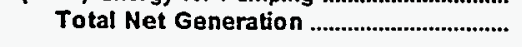 & 0 & 551,451 & 0 & $\mathbf{0}$ & 285,776 & 153,522 \\
\hline 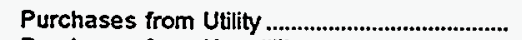 & 65,031 & 224,688 & 160,668 & 271,200 & 41,113 & 55,390 \\
\hline $\begin{array}{l}\text { Purchases from Nonutility ................................... } \\
\text { Power Exchanges }\end{array}$ & 135,308 & 0 & 0 & 0 & 0 & 0 \\
\hline 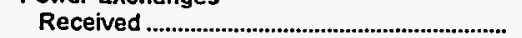 & $\mathbf{0}$ & 12,193 & 0 & 0 & 1,166 & 2,483 \\
\hline 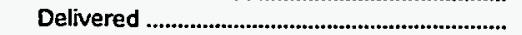 & 0 & 16,081 & 0 & 0 & 1,023 & $\begin{array}{l}2,400 \\
1,684\end{array}$ \\
\hline Net Exchanges & $\mathbf{0}$ & $-3,888$ & 0 & 0 & 143 & 799 \\
\hline \multicolumn{7}{|l|}{ Transmission for Others (Wheeling) } \\
\hline 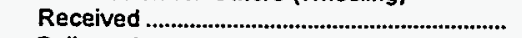 & $\mathbf{0}$ & 0 & 0 & $\mathbf{0}$ & 0 & 0 \\
\hline 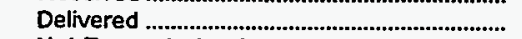 & 0 & 0 & 0 & 0 & 0 & 0 \\
\hline Net Transmission for Others .............................. & 0 & $\mathbf{0}$ & 0 & 0 & 0 & 0 \\
\hline $\begin{array}{l}\text { Transmission by Others Losses ........................... } \\
\text { Total Net Energy }\end{array}$ & 0 & 0 & 0 & 0 & 0 & 0 \\
\hline 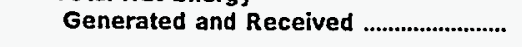 & 200,339 & 772,251 & 160,668 & 271,200 & 327,032 & 208,711 \\
\hline \multicolumn{7}{|l|}{ Disposition of Energy } \\
\hline 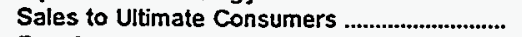 & 180,785 & 577,242 & 151,028 & 244,718 & 262,004 & 195,136 \\
\hline 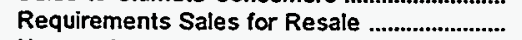 & 0 & 146,692 & 0 & 0 & 41,587 & 0 \\
\hline Nonrequirements Sales for Resale ................... & 0 & 0 & 0 & 0 & 143 & 0 \\
\hline 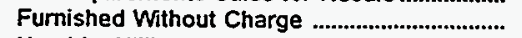 & 0 & 10.992 & 1,606 & 9,603 & 2,073 & 1,993 \\
\hline Used by Utility (exciuding station use) ............. & 0 & 0 & 0 & 42 & 289 & 0 \\
\hline 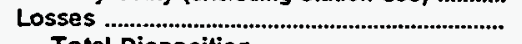 & 19,554 & 37,325 & 8,034 & 16,837 & 20,936 & 12,583 \\
\hline Total Disposition & 200,339 & 772,251 & 160,668 & 271,200 & 327,032 & 209,711 \\
\hline
\end{tabular}

Note: Totals may not equal sum of components because of independent rounding. Double counting occurs in components of both sources and disposition of energy and thus neither provides a true total. Purchases from utilities, net interchanges, and net wheeling (except for imports) are included in net generation.

Source: Energy Information Administration, Form ElA-412, "Annual Report of Public Electric Utilities." 
Table 26. Electric Energy Account by Major U.S. Publicly Owned Electric Utility Within State, 1995 (Continued)

(Megawatthours)

\begin{tabular}{|c|c|c|c|c|c|c|}
\hline Item & $\begin{array}{c}\text { Ohio } \\
\text { Piqua } \\
\text { City of } \\
\text { December } 31\end{array}$ & $\begin{array}{c}\text { Ohio } \\
\text { St Marys } \\
\text { City of } \\
\text { December } 3 t\end{array}$ & $\begin{array}{c}\text { Ohio } \\
\text { Wadsworth } \\
\text { City of } \\
\text { December } 31\end{array}$ & $\begin{array}{c}\text { Ohio } \\
\text { Wapakoneta } \\
\text { City of }\end{array}$ & $\begin{array}{l}\text { Ohio } \\
\text { Westenille } \\
\text { City of } \\
\text { December } 31\end{array}$ & $\begin{array}{l}\text { OkJahoma } \\
\text { Altus } \\
\text { City of } \\
\text { June } 30\end{array}$ \\
\hline \multicolumn{7}{|l|}{ Sources of Energy } \\
\hline Steam & 27,158 & 32,013 & 0 & 0 & 0 & 0 \\
\hline 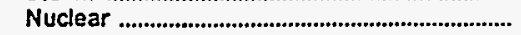 & & 0 & 0 & 0 & 0 & 0 \\
\hline Hydro-Conventional ................................................. & 0 & 0 & 0 & 0 & 0 & 0 \\
\hline Hydro-Pumped Storage ....................................... & 0 & 0 & 0 & 0 & 0 & 0 \\
\hline 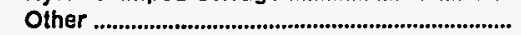 & 1,416 & 0 & 0 & 0 & 0 & 0 \\
\hline (Less) Energy for Pumping ............................. & & 0 & 0 & 0 & 0 & 0 \\
\hline 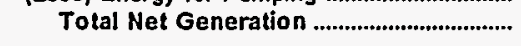 & 28,574 & 32,013 & 0 & 0 & 0 & 0 \\
\hline 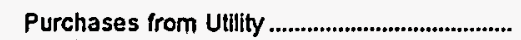 & 254,708 & 142,783 & 230,240 & 155,026 & 376,633 & 157,870 \\
\hline 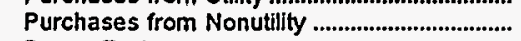 & 0 & 5.434 & 0 & 0 & 0 & 0 \\
\hline \multicolumn{7}{|l|}{ Power Exchanges } \\
\hline 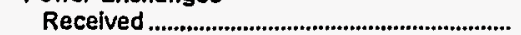 & 0 & 3,193 & 0 & 0 & 0 & 0 \\
\hline Delivered ............................................................... & 19 & 1,761 & 0 & 0 & 0 & 0 \\
\hline Net Exchanges …………………………………..... & -19 & 1,432 & 0 & 0 & 0 & 0 \\
\hline \multicolumn{7}{|l|}{ Transmission for Others (Wheeling) } \\
\hline Received ........................................................... & 0 & 0 & 0 & 0 & 0 & 0 \\
\hline 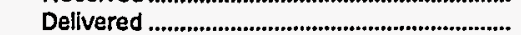 & 0 & 0 & 0 & 0 & 0 & 0 \\
\hline Net Transmission for Others ........................... & 0 & 0 & 0 & 0 & 0 & 0 \\
\hline 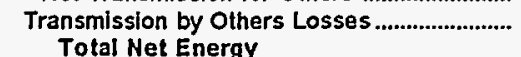 & 0 & 0 & 0 & 0 & 290 & 0 \\
\hline 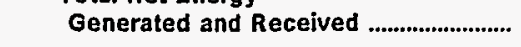 & 283,261 & 181,662 & 230,240 & 155,026 & 376,923 & 157,870 \\
\hline \multicolumn{7}{|l|}{ Disposition of Energy } \\
\hline 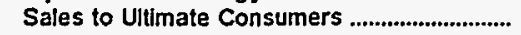 & 265,942 & 161,696 & 212,875 & 148,036 & 352,156 & 153,547 \\
\hline Requirements Sales for Resale .......................... & 129 & 0 & 0 & 0 & 0 & 0 \\
\hline Nonrequirements Sales for Resale .................... & & 8,493 & 0 & $\mathbf{0}$ & 0 & 0 \\
\hline FurnIshed Without Charge .................................... & 3,077 & 2,395 & 6.733 & 6,990 & 1,442 & 0 \\
\hline Used by Utility (excluding station use) ............ & & & 349 & 0 & 0 & 0 \\
\hline Losses ............................................................... & 14,113 & 9,083 & 10,283 & 0 & 23,325 & 4,323 \\
\hline 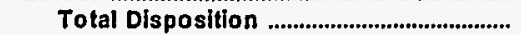 & 283,261 & 181,662 & 230,240 & 155,026 & 376,923 & 157,870 \\
\hline
\end{tabular}

Note: Totals may not equal sum of components because of independent rounding. Double counting occurs in components of both sources and disposition of energy and thus neither provides a true total. Purchases from utilities, net interchanges, and net wheeling (except for imports) are included in net generation.

Source: Energy Information Administration, Form ElA-412, "Annual Report of Public Electric Utilities." 
Table 26. Electric Energy Account by Major U.S. Publicly Owned Electric Utility Within State, 1995 (Continued) (Megawatthours)

\begin{tabular}{|c|c|c|c|c|c|c|}
\hline Item & $\begin{array}{l}\text { Okjahoma } \\
\text { Claremore } \\
\text { City of } \\
\text { June } 30\end{array}$ & $\begin{array}{l}\text { Oklahoma } \\
\text { Duncan } \\
\text { City of } \\
\text { June } 30\end{array}$ & $\begin{array}{l}\text { Oklahoma } \\
\text { Edmond } \\
\text { City of } \\
\text { June } 30\end{array}$ & $\begin{array}{c}\text { Oklahoma } \\
\text { Grand River } \\
\text { Dam } \\
\text { Authority } \\
\text { December } 31\end{array}$ & $\begin{array}{l}\text { Oklahoma } \\
\text { Miami } \\
\text { City of } \\
\text { June } 30\end{array}$ & $\begin{array}{c}\text { OkJahoma } \\
\text { Oklahoma } \\
\text { Municipal } \\
\text { Power Auth } \\
\text { December } 31\end{array}$ \\
\hline \multicolumn{7}{|l|}{ Sources of Energy } \\
\hline Steam & 0 & $\mathbf{0}$ & 0 & $4,551,075$ & 0 & 627,962 \\
\hline 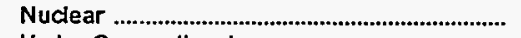 & 0 & 0 & 0 & 0 & 0 & 0 \\
\hline 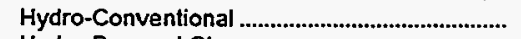 & $\mathbf{0}$ & 0 & 0 & 673,204 & 0 & 126,204 \\
\hline 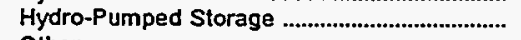 & 0 & 0 & 0 & 91,812 & 0 & 0 \\
\hline Other & 0 & $\mathbf{0}$ & 0 & 0 & 0 & 45,287 \\
\hline 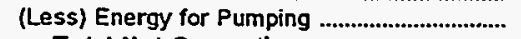 & 0 & 0 & 0 & 157,651 & 0 & 0 \\
\hline 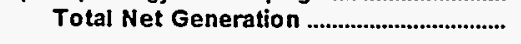 & $\mathbf{0}$ & $\mathbf{0}$ & 0 & $5,158,440$ & $\mathbf{0}$ & 799,453 \\
\hline 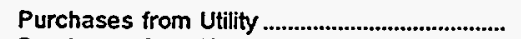 & 219,968 & 155,842 & 493,339 & 358,243 & 147,269 & 815,023 \\
\hline $\begin{array}{l}\text { Purchases from Nonutility } \\
\text { Power Exchanges }\end{array}$ & 0 & 0 & 0 & 0 & 0 & \\
\hline 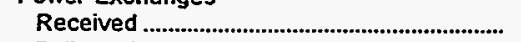 & 0 & 0 & 0 & 0 & 0 & 0 \\
\hline Delivered & 0 & 0 & 0 & 16,853 & 0 & 0 \\
\hline 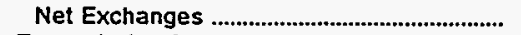 & 0 & 0 & 0 & $-16,853$ & 0 & 0 \\
\hline \multicolumn{7}{|l|}{ Transmission for Others (Wheeling) } \\
\hline Received & 0 & 0 & 0 & 7,813 & 0 & 0 \\
\hline 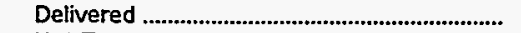 & 0 & 0 & 0 & 7,813 & 0 & 0 \\
\hline 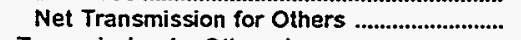 & 0 & 0 & 0 & 0 & 0 & 0 \\
\hline $\begin{array}{l}\text { Transmission by Others Losses ............................ } \\
\text { Total Net Energy }\end{array}$ & 0 & 0 & 0 & $\mathbf{0}$ & 0 & 0 \\
\hline Generated and Received ............................ & 219,968 & 155,842 & 493,339 & $5,499,830$ & 147,269 & $1,614,476$ \\
\hline \multicolumn{7}{|l|}{ Disposition of Energy } \\
\hline 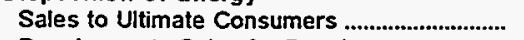 & 208,096 & 143,964 & 453,329 & 656,766 & 140,176 & $\mathbf{0}$ \\
\hline Requirements Sales for Resale ............................ & 0 & 0 & 0 & $4,408,641$ & 10 & $1,581,032$ \\
\hline Nonrequirements Sales for Resale ................... & 0 & 0 & 0 & 217,401 & 0 & 0 \\
\hline 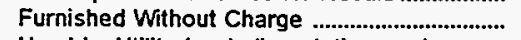 & 3,520 & 0 & 21,350 & 0 & 0 & 0 \\
\hline Used by Utility (excluding station use) ............ & 0 & 0 & 121 & 0 & 4,043 & 0 \\
\hline 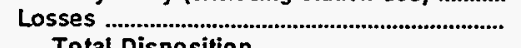 & 8,352 & 11,878 & 18,539 & 217,022 & 3,050 & 33,444 \\
\hline Total Disposition & 219,968 & 155,842 & 493,339 & $5,499,830$ & 147,269 & $1,614,476$ \\
\hline
\end{tabular}


Table 26. Electric Energy Account by Major U.S. Publicly Owned Electric Utility Within State, 1995 (Continued)

(Megawatthours)

\begin{tabular}{|c|c|c|c|c|c|c|}
\hline Item & $\begin{array}{l}\text { Oklahoma } \\
\text { Ponca } \\
\text { City City of } \\
\text { June } 30\end{array}$ & $\begin{array}{l}\text { Oklahoma } \\
\text { Stillwater } \\
\text { Utilities } \\
\text { Authority } \\
\text { June } 30\end{array}$ & $\begin{array}{l}\text { Oregon } \\
\text { Ashland } \\
\text { City of } \\
\text { June } 30\end{array}$ & $\begin{array}{c}\text { Oregon } \\
\text { Central } \\
\text { Lincoln } \\
\text { Peoples } \\
\text { Utt Dt } \\
\text { December } 31\end{array}$ & $\begin{array}{l}\text { Oregon } \\
\text { Clatskanie } \\
\text { Peoples } \\
\text { Util Dist } \\
\text { December } 31\end{array}$ & $\begin{array}{l}\text { Oregon } \\
\text { Columbia } \\
\text { River } \\
\text { Peoples } \\
\text { Ut Dist } \\
\text { December } 31\end{array}$ \\
\hline
\end{tabular}

\section{Sources of Energy}

Steam .

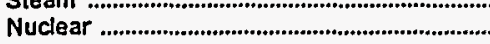

Hydro-Conventional....

Hydro-Pumped Storage

Other ......................................................................

(Less) Energy for Pumping

Total Net Generation ...u.

Purchases from Utility

Purchases from Nonutility ...................................

Power Exchanges

Recelved..

Delivered ....................................................................

Net Exchanges ..................................................

Transmission for Others (Wheeling)

Recelved.

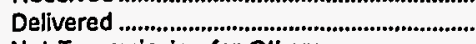

Net Transmission for Others

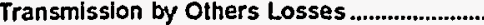

Total Net Energy

Generated and Received .........................

Disposition of Energy

Sales to Ultimate Consumers

Requirements Sales for Resale .........................

Nonrequirements Sales for Resale

Furnished without Charge

Used by Utility (excluding station use)

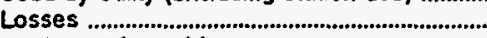

Total Disposition

0
0
0
0
0
0
0

$0 \quad 68,864$

$\begin{array}{ll}0 & 0 \\ 0 & 0 \\ 0 & 0\end{array}$

0 0

$\begin{array}{lr}0 & 2,670 \\ 0 & 66,194\end{array}$

305,258

0

358,460

0

0

0
0
0
0

279,349

0
0
0
0
25,909
305,258

424,654

387,803
0
0
12,181
0
24,670
424,654

0
0
3,012
0
0
0
3,012

164,192

192
0

$1,309,847$

847
0

0
0
0

0
0
0

0

0
0
0
0

167,204

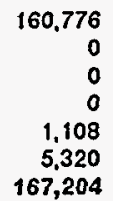

$1,309,847$

890,602

$1,265,287$

0
0
0
308

40,252

$1,309,847$
887,159

270,553

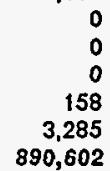

0

386

7.151

278,090

Note: Totals may not equal sum of components because of independent rounding. Double counting occurs in components of both sources and disposition of energy and thus neither provides a true total. Purchases from utilities, net interchanges, and net wheeling (except for imports) are included in net generation.

Source: Energy Information Administration, Form ElA-412, "Annual Report of Public Electric Utilities." 
Table 26. Electric Energy Account by Major U.S. Publicly Owned Electric Utility Within State, 1995 (Continued)

(Megawatthours)

\begin{tabular}{|c|c|c|c|c|c|c|}
\hline Item & $\begin{array}{l}\text { Oregon } \\
\text { Emerald } \\
\text { Peoples } \\
\text { Utility Dist } \\
\text { December } 31\end{array}$ & $\begin{array}{l}\text { Oregon } \\
\text { Eugene } \\
\text { City of } \\
\text { December } 31\end{array}$ & $\begin{array}{c}\text { Forest Grove } \\
\text { City of } \\
\text { June } 30\end{array}$ & $\begin{array}{c}\text { McMinnville } \\
\text { City of } \\
\text { June } 30\end{array}$ & $\begin{array}{c}\text { Oregon } \\
\text { Northern } \\
\text { Wasco } \\
\text { County PUD } \\
\text { December } 31\end{array}$ & $\begin{array}{l}\text { Oregon } \\
\text { Springfield } \\
\text { City of }\end{array}$ \\
\hline \multicolumn{7}{|l|}{ Sources of Energy } \\
\hline Steam & 0 & 103,865 & 0 & 0 & 0 & 0 \\
\hline 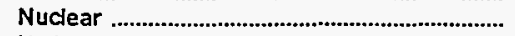 & 0 & 0 & 0 & 0 & 0 & 0 \\
\hline 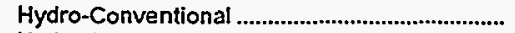 & 0 & 624,117 & 0 & 0 & 39,833 & 0 \\
\hline 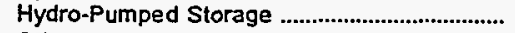 & 0 & 0 & 0 & 0 & 0 & 0 \\
\hline Other & 18,610 & 0 & 0 & 0 & o & 0 \\
\hline 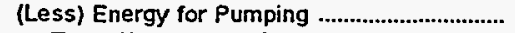 & 0 & 0 & 0 & 0 & 0 & $\mathbf{0}$ \\
\hline 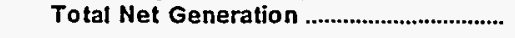 & 18,610 & 727,982 & 0 & 0 & 39,833 & 0 \\
\hline 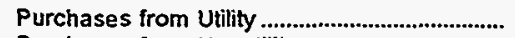 & 387,000 & $1,748,226$ & 225,783 & 677,166 & 257,191 & 862,239 \\
\hline $\begin{array}{l}\text { Purchases from Nonutility .................................. } \\
\text { Power Exchanges }\end{array}$ & 41 & 0 & 0 & 0 & 0 & 0 \\
\hline 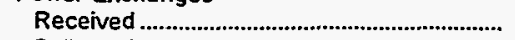 & 0 & 100,443 & 0 & 0 & 0 & 0 \\
\hline Delivered & 0 & 0 & 0 & 0 & 0 & 0 \\
\hline Net Exchanges & 0 & 100,443 & 0 & 0 & 0 & 0 \\
\hline \multicolumn{7}{|l|}{ Transmission for Others (Wheeling) } \\
\hline 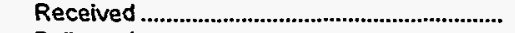 & 0 & 0 & $\mathbf{0}$ & 0 & 0 & 0 \\
\hline 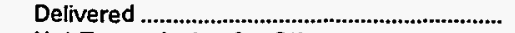 & 0 & 0 & 0 & 0 & 0 & 0 \\
\hline 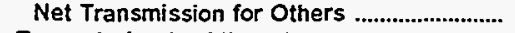 & 0 & 0 & $\mathbf{0}$ & 0 & 0 & 0 \\
\hline $\begin{array}{l}\text { Transmission by Others Losses .......................... } \\
\text { Total Net Energy }\end{array}$ & 0 & 0 & 0 & 0 & 0 & 0 \\
\hline 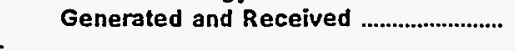 & 405,651 & $2,576,651$ & 225,783 & 677,166 & 297,024 & 862,239 \\
\hline \multicolumn{7}{|l|}{ Disposition of Energy } \\
\hline 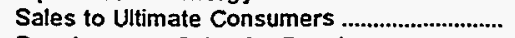 & 379,715 & $2,331,706$ & 213,852 & 663,309 & 253,228 & 845,575 \\
\hline 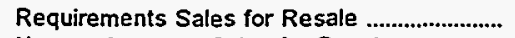 & 0 & 109,386 & 0 & 0 & 0 & 0 \\
\hline Nonrequirements Sales for Resale .................. & 0 & 30,791 & 0 & 0 & 39,208 & 0 \\
\hline 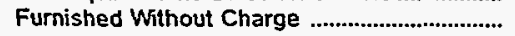 & 0 & 0 & 0 & 0 & 0 & 0 \\
\hline Used by Utility (excluding station use) ............. & 0 & 0 & 0 & 663 & 178 & 3,265 \\
\hline 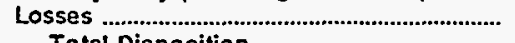 & 25,936 & 104,768 & 11,931 & 13,194 & 4,410 & 13,399 \\
\hline 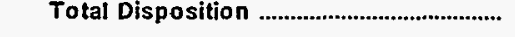 & 405,651 & $2,576,651$ & 225,783 & 677,166 & 297,024 & 862,239 \\
\hline
\end{tabular}

Note: Totals may not equal sum of components because of independent rounding. Double counting occurs in components of both sources and disposition of energy and thus neither provides a true total. Purchases from utilities, net interchanges, and net wheeling (except for imports) are included in net generation.

Source: Energy Information Administration, Form ElA-412, "Annual Report of Public Electric Utilities." 
Table 26. Electric Energy Account by Major U.S. Publicly Owned Electric Utility Within State, 1995 (Continued)

(Megawatthours)

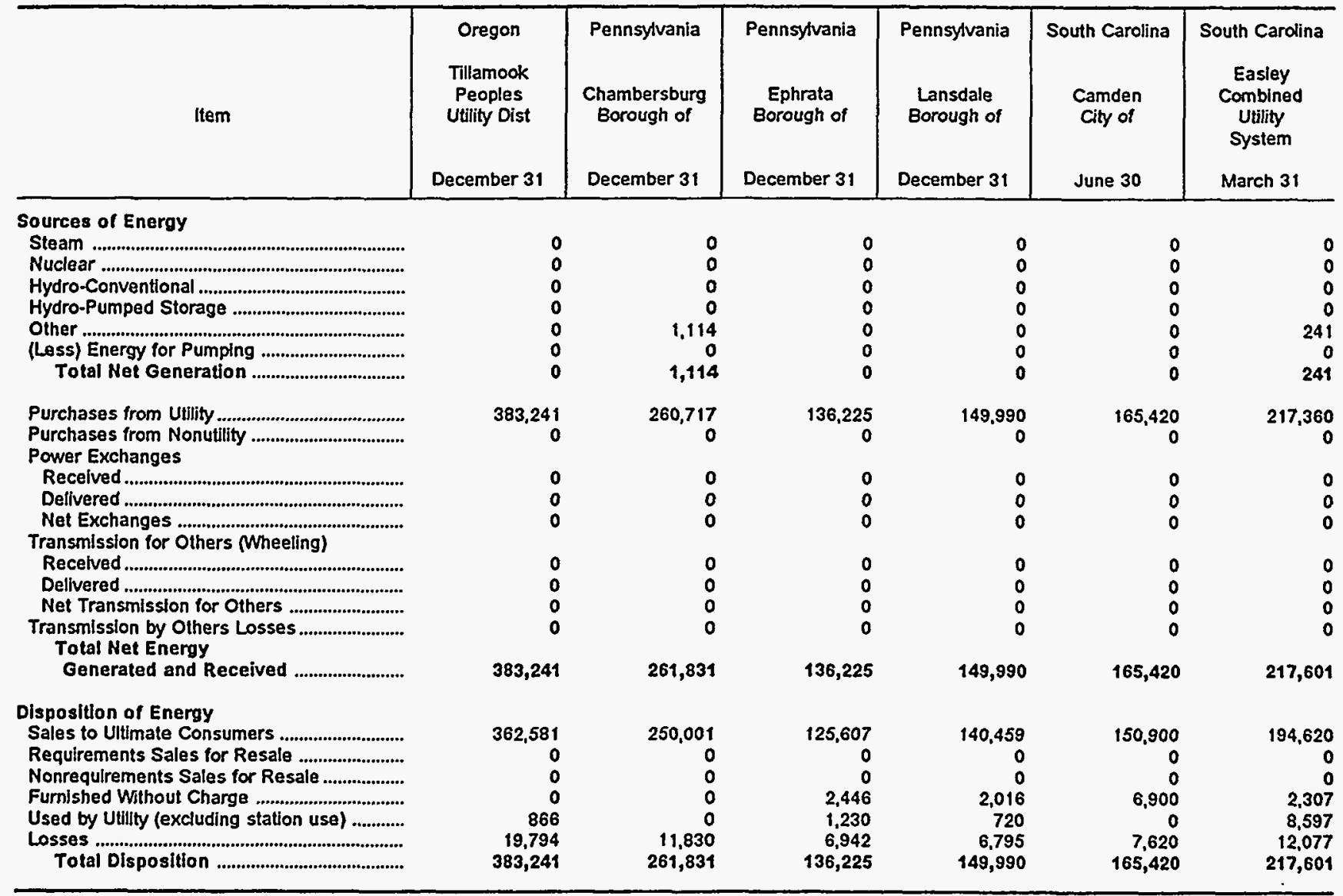

Note: Totals may not equal sum of components because of independent rounding. Double counting occurs in components of both sources and disposition of energy and thus neither provides a true total. Purchases from utilities, net interchanges, and net wheeling (except for imports) are included in net generation. Sales for resale is included in sales to ultimate consumers.

Source: Energy Information Administration, Form ElA-412, "Annual Report of Public Electric Utilities." 
Table 26. Electric Energy Account by Major U.S. Publicly Owned Electric Utility Within State, 1995 (Continued)

(Megawatthours)

\begin{tabular}{|c|c|c|c|c|c|c|}
\hline Item & $\begin{array}{l}\text { South Carolina } \\
\text { Gaffney } \\
\text { City of } \\
\text { March } 31\end{array}$ & $\begin{array}{l}\text { South Carolina } \\
\text { Greenwood } \\
\text { Commissioners } \\
\text { Pub WK } \\
\text { December } 31\end{array}$ & $\begin{array}{c}\text { South Carolina } \\
\text { Greer } \\
\text { Comm } \\
\text { of } \\
\text { Public Works } \\
\text { December } 31\end{array}$ & $\begin{array}{l}\text { South Carolina } \\
\text { Newberry } \\
\text { City of } \\
\text { June } 30\end{array}$ & $\begin{array}{l}\text { South Carolina } \\
\text { Orangeburg } \\
\text { City of }\end{array}$ & $\begin{array}{l}\text { South Carolina } \\
\text { Piedmont } \\
\text { Municipal } \\
\text { Power Agny } \\
\text { December } 31\end{array}$ \\
\hline \multicolumn{7}{|l|}{ Sources of Energy } \\
\hline 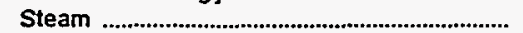 & 0 & 0 & 0 & 0 & 0 & 0 \\
\hline Nuciear & 0 & 0 & 0 & 0 & 0 & $2,089,576$ \\
\hline 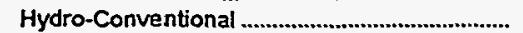 & 0 & 0 & 0 & 0 & 0 & 0 \\
\hline 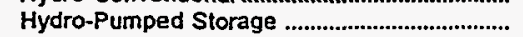 & 0 & 0 & 0 & 0 & 0 & 0 \\
\hline Other & 413 & 0 & 0 & 0 & 13,990 & 0 \\
\hline 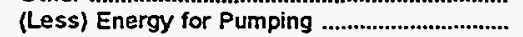 & 0 & 0 & 0 & 0 & 0 & 0 \\
\hline 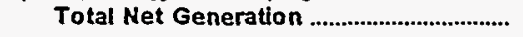 & 413 & 0 & 0 & $\mathbf{0}$ & 13,990 & $2,089,576$ \\
\hline 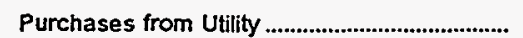 & 186,533 & 253,541 & 182,587 & 145,775 & 764,191 & 505,086 \\
\hline $\begin{array}{l}\text { Purchases from Nonutility ..................................... } \\
\text { Power Exchanges }\end{array}$ & 0 & 0 & 0 & 0 & 0 & 0 \\
\hline 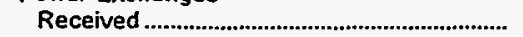 & 0 & 0 & 0 & 0 & 0 & 617,090 \\
\hline 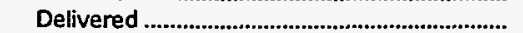 & 0 & 0 & 0 & 0 & 0 & 604,616 \\
\hline Net Exchanges & 0 & 0 & 0 & 0 & 0 & 12,474 \\
\hline \multicolumn{7}{|l|}{ Transmission for Others (Wheeling) } \\
\hline 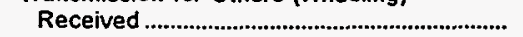 & 0 & 0 & 0 & 0 & 0 & 0 \\
\hline 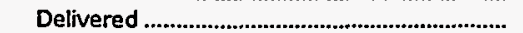 & 0 & 0 & 0 & $\mathbf{0}$ & 0 & 0 \\
\hline 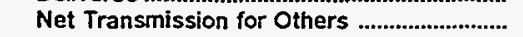 & 0 & 0 & 0 & 0 & 0 & 0 \\
\hline $\begin{array}{l}\text { Transmission by Others Losses ........................ } \\
\text { Total Net Energy }\end{array}$ & 0 & 0 & 0 & 0 & 0 & 0 \\
\hline 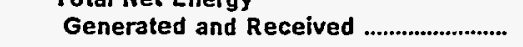 & 186,946 & 253,541 & 182,587 & 145,775 & 778,181 & $2,607,136$ \\
\hline \multicolumn{7}{|l|}{ Disposition of Energy } \\
\hline 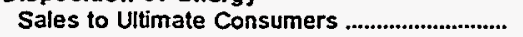 & 160,157 & 240,860 & 164,632 & 139,016 & $74 t, 896$ & $\mathbf{0}$ \\
\hline Requirements Sales for Resale & 0 & 0 & 0 & 0 & 0 & $2,570,736$ \\
\hline Nonrequirements Sales for Resale ................... & 0 & 0 & 0 & 0 & 0 & 0 \\
\hline Furnished Without Charge ................................... & 2,272 & 0 & 5,110 & 1,775 & 0 & 0 \\
\hline Used by Utility (excluding station use) ............. & 10,525 & 0 & 2,516 & 0 & 0 & 0 \\
\hline 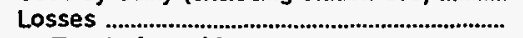 & 13,992 & 12,681 & 10,329 & 4,984 & 36,285 & 36,400 \\
\hline 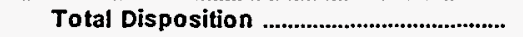 & 186,946 & 253,541 & 182,587 & 145,775 & 778,181 & $2,607,136$ \\
\hline
\end{tabular}


Table 26. Electric Energy Account by Major U.S. Publicly Owned Electric Utility Within State, 1995 (Continued)

(Megawatthours)

\begin{tabular}{|c|c|c|c|c|c|c|}
\hline Item & $\begin{array}{l}\text { South Carolina } \\
\text { Rock Hilf } \\
\text { City of } \\
\text { December } 31\end{array}$ & $\begin{array}{l}\text { South Carolina } \\
\text { Seneca } \\
\text { City of } \\
\text { June } 30\end{array}$ & $\begin{array}{l}\text { South Carolina } \\
\text { South } \\
\text { Carolina } \\
\text { Pub } \\
\text { Sen Auth } \\
\text { December } 31\end{array}$ & $\begin{array}{l}\text { South Dakota } \\
\text { Brookings } \\
\text { City of } \\
\text { December } 31\end{array}$ & $\begin{array}{l}\text { South Dakota } \\
\text { Heartland } \\
\text { Consumers } \\
\text { Power Dist } \\
\text { December } 31\end{array}$ & $\begin{array}{l}\text { South Dakota } \\
\text { Missouri } \\
\text { Basin } \\
\text { Mun } \\
\text { Power Agny } \\
\text { December } 31\end{array}$ \\
\hline \multicolumn{7}{|l|}{ Sources of Energy } \\
\hline 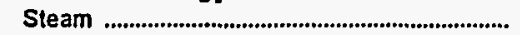 & 0 & 0 & $12,782,434$ & 0 & 291,594 & $\mathbf{0}$ \\
\hline 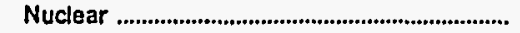 & 0 & 0 & $2,514,826$ & 0 & 0 & 0 \\
\hline 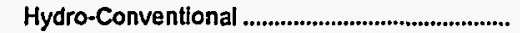 & 0 & 0 & 595.193 & 0 & 0 & $\mathbf{0}$ \\
\hline 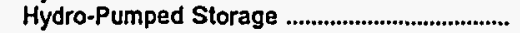 & 0 & 0 & 0 & 0 & 0 & $\mathbf{0}$ \\
\hline Other & 0 & 0 & 5,956 & 0 & 0 & 0 \\
\hline 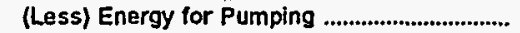 & 0 & $\mathbf{0}$ & 0 & 0 & 0 & 0 \\
\hline 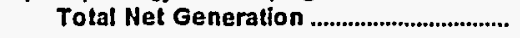 & 0 & 0 & $15,898,409$ & 0 & 291,594 & $\mathbf{0}$ \\
\hline 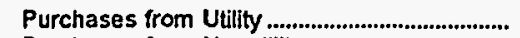 & 548,975 & 135,841 & 605,064 & 210,606 & 134,831 & $1,961,800$ \\
\hline $\begin{array}{l}\text { Purchases from Nonutility ........................................ } \\
\text { Power Exchanges }\end{array}$ & 0 & 3,166 & 2,448 & 0 & 0 & 0 \\
\hline 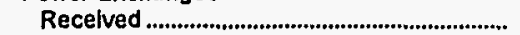 & 0 & 0 & 45,314 & 0 & 8,780 & 92 \\
\hline 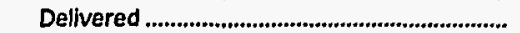 & 0 & 0 & 32,136 & 0 & 53 & 267 \\
\hline 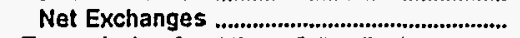 & 0 & 0 & 13.178 & 0 & 8,727 & -175 \\
\hline \multicolumn{7}{|l|}{ Transmission for Others (Wheeling) } \\
\hline 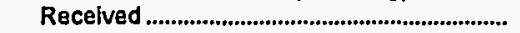 & $\mathbf{0}$ & 0 & 494,657 & 0 & 0 & 0 \\
\hline 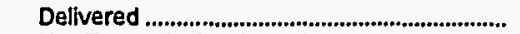 & $\mathbf{0}$ & $\mathbf{0}$ & 487,472 & 0 & 0 & 0 \\
\hline Net Transmission for Others .......................... & 0 & $\mathbf{0}$ & 7,185 & 0 & 0 & 0 \\
\hline 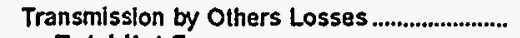 & 0 & $\mathbf{0}$ & 0 & 0 & 0 & 0 \\
\hline Total Net Energy & & & & & & \\
\hline Generated and Received ........................... & 548,975 & 139,007 & $16,526,284$ & 210,606 & 435,152 & $1,961,625$ \\
\hline \multicolumn{7}{|l|}{ Disposition of Energy } \\
\hline 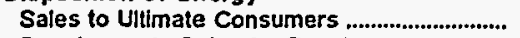 & 527,096 & 129,147 & $7,739,117$ & 192,825 & 0 & 0 \\
\hline Requirements Sales for Resale ........................... & 0 & 0 & $8,283,056$ & 0 & 319,648 & $1,096,582$ \\
\hline Nonrequirements Sales for Resale ................. & 0 & 0 & 0 & 0 & 92,388 & 756,760 \\
\hline Furnished Without Charge ...................................... & $\mathbf{0}$ & 0 & $\mathbf{0}$ & 0 & 0 & 0 \\
\hline Used by Utility (excluding station use) ............ & $\mathbf{0}$ & 4,294 & 19,597 & 0 & 0 & 0 \\
\hline 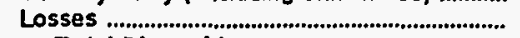 & 21.879 & 5,566 & 484,514 & 17.781 & 23,116 & 108,283 \\
\hline 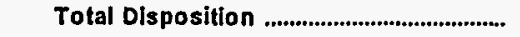 & 548,975 & 139,007 & $16,526,284$ & 210,606 & 435,152 & $1,961,625$ \\
\hline
\end{tabular}

Note: Totals may not equal sum of components because of independent rounding. Double counting occurs in components of both sources and disposition of energy and thus neither provides a true total. Purchases from utilities, net interchanges, and net wheeling (except for imports) are included in net generation.

Source: Energy Information Administration, Form ElA-412, "Annual Report of Public Electric Utilities." 
Table 26. Electric Energy Account by Major U.S. Publicly Owned Electric Utility Within State, 1995 (Continued) (Megawatthours)

\begin{tabular}{|c|c|c|c|c|c|c|}
\hline Item & $\begin{array}{c}\text { South Dakota } \\
\text { Pierre } \\
\text { City of } \\
\text { December } 31\end{array}$ & $\begin{array}{l}\text { South Dakota } \\
\text { Watertown } \\
\text { Municipal } \\
\text { Utilities } \\
\text { December } 31\end{array}$ & $\begin{array}{c}\text { Tennessee } \\
\text { Alcoa } \\
\text { Utilities } \\
\text { June } 30\end{array}$ & $\begin{array}{l}\text { Tennessee } \\
\text { Athens } \\
\text { Utility } \\
\text { Board } \\
\text { June } 30\end{array}$ & $\begin{array}{l}\text { Tennessee } \\
\text { Benton } \\
\text { County } \\
\text { June } 30\end{array}$ & $\begin{array}{l}\text { Tennessee } \\
\text { Bolivar } \\
\text { City of } \\
\text { June } 30\end{array}$ \\
\hline \multicolumn{7}{|l|}{ Sources of Energy } \\
\hline Steam & 0 & $\mathbf{0}$ & 0 & 0 & 0 & $\mathbf{0}$ \\
\hline Nuclear & 0 & 0 & 0 & 0 & 0 & 0 \\
\hline 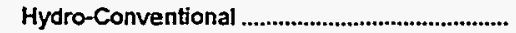 & 0 & 0 & 0 & 0 & 0 & 0 \\
\hline 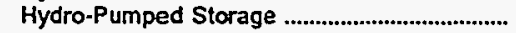 & 0 & 0 & 0 & 0 & 0 & 0 \\
\hline Other & 0 & 0 & 0 & 0 & 0 & $\mathbf{0}$ \\
\hline 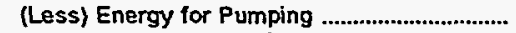 & 0 & 0 & 0 & 0 & 0 & $\mathbf{0}$ \\
\hline 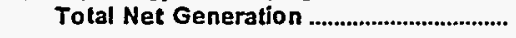 & 0 & $\mathbf{0}$ & $\mathbf{0}$ & $\mathbf{0}$ & 0 & 0 \\
\hline 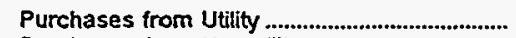 & 179,188 & 263,756 & 447,932 & 559,011 & 226,487 & 221,911 \\
\hline \multicolumn{6}{|l|}{ Power Exchanges } & \\
\hline 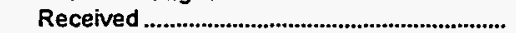 & 0 & 0 & 0 & 0 & 0 & 0 \\
\hline 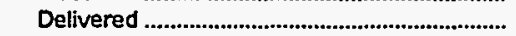 & 0 & 0 & 0 & 0 & 0 & 0 \\
\hline 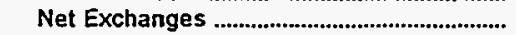 & 0 & 0 & 0 & 0 & 0 & 0 \\
\hline \multicolumn{7}{|l|}{ Transmission for Others (Wheeling) } \\
\hline 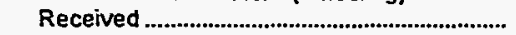 & 0 & 0 & 0 & 0 & 0 & 0 \\
\hline Delivered & 0 & 0 & 0 & 0 & 0 & $\mathbf{0}$ \\
\hline 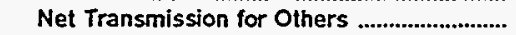 & 0 & 0 & 0 & 0 & 0 & 0 \\
\hline $\begin{array}{l}\text { Transmission by Others Losses........................ } \\
\text { Total Net Energy }\end{array}$ & 0 & 0 & 0 & 0 & $\mathbf{0}$ & 0 \\
\hline 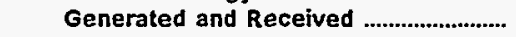 & 179,188 & 263,756 & 447,932 & 559,011 & 226,487 & 221,911 \\
\hline \multicolumn{7}{|l|}{ Disposition of Energy } \\
\hline Sales to Ultimate Consumers ........................... & 149.862 & 239.803 & 423,132 & 538,851 & 211,026 & 209,899 \\
\hline Requirements Sales for Resale ........................ & 15,632 & 0 & 0 & 0 & 0 & 0 \\
\hline Nonrequirements Sales for Resale .................. & 0 & 0 & 0 & 0 & 0 & $\mathbf{0}$ \\
\hline 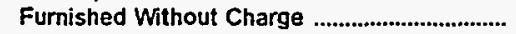 & 0 & 0 & 0 & 0 & 0 & 0 \\
\hline Used by Utility (excluding station use) ............. & 2,000 & 0 & 224 & 607 & 215 & 266 \\
\hline Losses & 11,694 & 23,953 & 24,576 & 18,553 & 15,246 & 11,747 \\
\hline 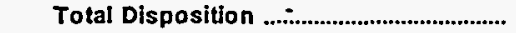 & 179,188 & 263,756 & 447,932 & 559,011 & 226,487 & 221,911 \\
\hline
\end{tabular}

Note: Totals may not equal sum of components because of independent rounding. Double counting occurs in components of both sources and disposition of energy and thus neither provides a true total. Purchases from utilities, net interchanges, and net wheeling (except for imports) are included in net generation.

Source: Energy Information Administration, Form EIA-412, "Annual Report of Public Electric Utilities." 
Table 26. Electric Energy Account by Major U.S. Publicly Owned Electric Utility Within State, 1995 (Continued)

(Megawatthours)

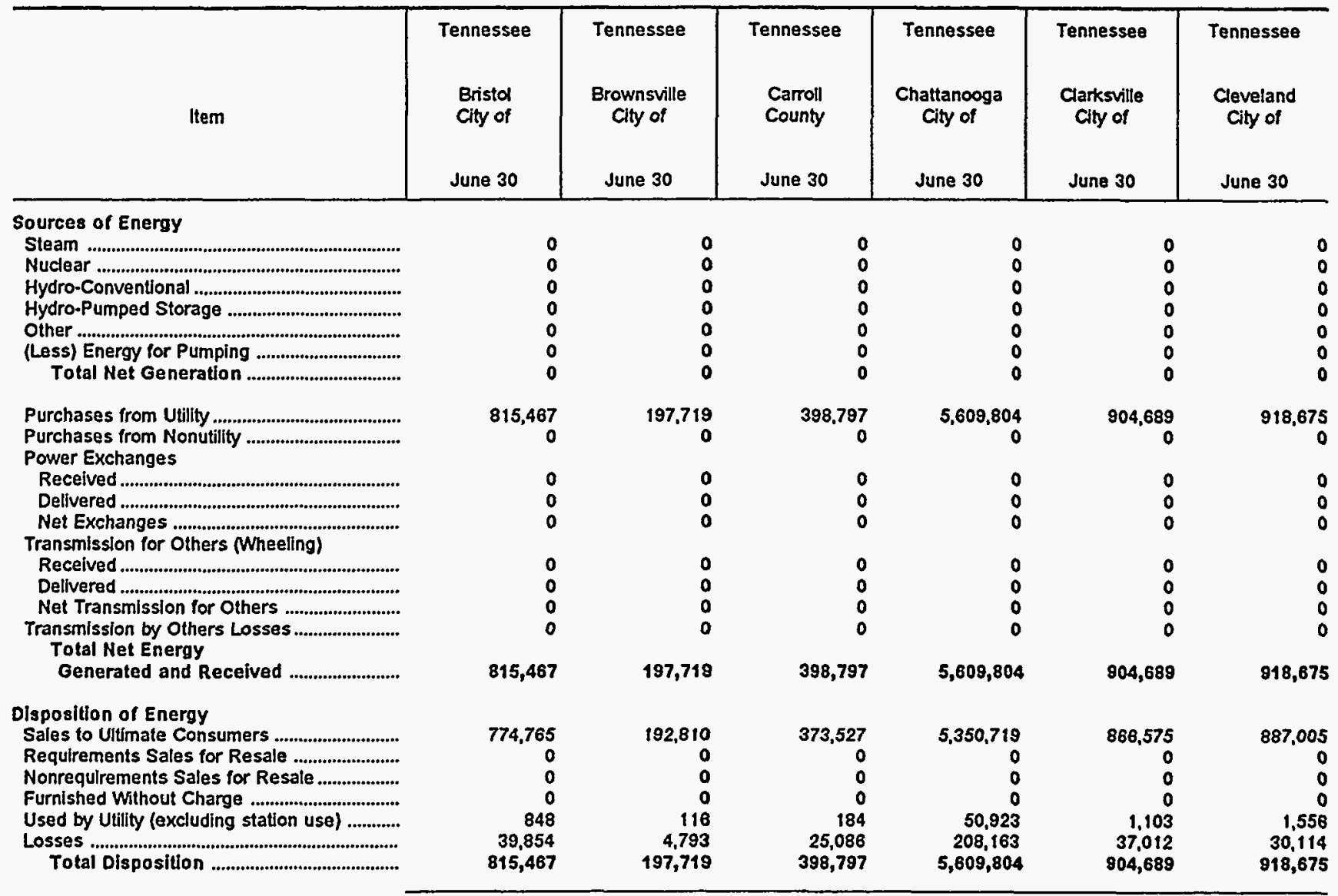

Note: Totals may not equal sum of components because of independent rounding. Double counting occurs in components of both sources and disposition of energy and thus neither provides a true total. Purchases from utilities, net interchanges, and net wheeling (except for imports) are included in net generation.

Source: Energy Intomation Administration, Form EIA-412, "Annual Report of Public Electric Utilities." 
Table 26. Electric Energy Account by Major U.S. Publicly Owned Electric Utility Within State, 1995 (Continued)

(Megawatthours)

\begin{tabular}{|c|c|c|c|c|c|c|}
\hline Item & $\begin{array}{l}\text { Tennessee } \\
\text { Clinton } \\
\text { City of } \\
\text { June } 30\end{array}$ & $\begin{array}{l}\text { Tennessee } \\
\text { Columbia } \\
\text { City of } \\
\text { June } 30\end{array}$ & $\begin{array}{l}\text { Tennessee } \\
\text { Cookeville } \\
\text { City of } \\
\text { June } 30\end{array}$ & $\begin{array}{l}\text { Tennessee } \\
\text { Covington } \\
\text { City of } \\
\text { June } 30\end{array}$ & $\begin{array}{l}\text { Tennessee } \\
\text { Dayton } \\
\text { City of } \\
\text { June } 30\end{array}$ & $\begin{array}{l}\text { Tennessee } \\
\text { Dickson } \\
\text { City of } \\
\text { June } 30\end{array}$ \\
\hline \multicolumn{7}{|l|}{ Sources of Energy } \\
\hline Steam & 0 & 0 & 0 & 0 & 0 & 0 \\
\hline 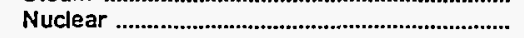 & 0 & 0 & 0 & 0 & 0 & 0 \\
\hline 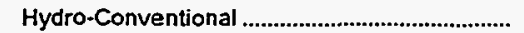 & 0 & 0 & 0 & 0 & 0 & 0 \\
\hline 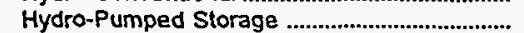 & 0 & 0 & 0 & 0 & 0 & 0 \\
\hline Other & 0 & 0 & 0 & 0 & 0 & 0 \\
\hline 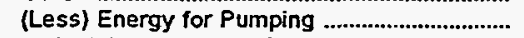 & 0 & 0 & 0 & 0 & 0 & 0 \\
\hline 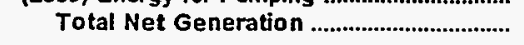 & 0 & 0 & $\mathbf{0}$ & 0 & 0 & 0 \\
\hline 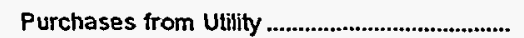 & 641,594 & 515,284 & 488,467 & 220,118 & 201.160 & 636,985 \\
\hline $\begin{array}{l}\text { Purchases from Nonutility .................................... } \\
\text { Power Exchanges }\end{array}$ & 0 & 0 & 0 & 0 & 0 & \\
\hline 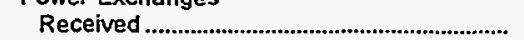 & 0 & 0 & 0 & 0 & 0 & 0 \\
\hline Delivered & 0 & 0 & 0 & 0 & 0 & 0 \\
\hline Net Exchanges & 0 & 0 & 0 & 0 & 0 & 0 \\
\hline \multicolumn{7}{|l|}{ Transmission for Others (Wheeling) } \\
\hline Received & 0 & 0 & 0 & 0 & 0 & 0 \\
\hline 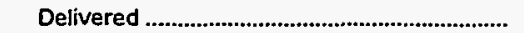 & 0 & 0 & 0 & 0 & 0 & 0 \\
\hline Net Transmission for Others & 0 & 0 & 0 & 0 & 0 & 0 \\
\hline $\begin{array}{l}\text { Transmission by Others Losses ........................... } \\
\text { Total Net Energy }\end{array}$ & 0 & 0 & 0 & 0 & 0 & $\mathbf{0}$ \\
\hline 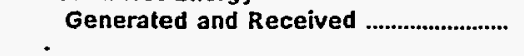 & 641,594 & 515,284 & 488,467 & 220,118 & 201,160 & 636,985 \\
\hline \multicolumn{7}{|l|}{ Disposition of Energy } \\
\hline Sales to Ultimate Consumers & 614,043 & 487,916 & 470,085 & 213,823 & 188,779 & 600,800 \\
\hline Requirements Sales for Resale ........................... & 0 & 0 & 0 & 0 & 0 & 0 \\
\hline Nonrequirements Sales for Resale .................. & 0 & 0 & 0 & 0 & 0 & 0 \\
\hline 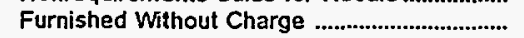 & 0 & 0 & 0 & 0 & $\mathbf{0}$ & 0 \\
\hline Used by Utility (excluding station use) ............ & 0 & 1,007 & 298 & 162 & 0 & 265 \\
\hline Losses & 27,551 & 26,362 & 18,084 & 6,132 & 12,382 & 35,920 \\
\hline Total Disposition & 641,594 & 515,284 & 488,467 & 220,118 & 201,160 & 636,985 \\
\hline
\end{tabular}


Table 26. Electric Energy Account by Major U.S. Publicly Owned Electric Utility Within State, 1995 (Continued)

(Megawatthours)

\begin{tabular}{|c|c|c|c|c|c|c|}
\hline Item & $\begin{array}{l}\text { Tennessee } \\
\text { Dyersburg } \\
\text { City of } \\
\text { June } 30\end{array}$ & $\begin{array}{l}\text { Tennessee } \\
\text { Elizabethton } \\
\text { City of } \\
\text { June } 30\end{array}$ & $\begin{array}{l}\text { Tennessee } \\
\text { Envin } \\
\text { Town of } \\
\text { June } 30\end{array}$ & $\begin{array}{l}\text { Tennessee } \\
\text { Etowah } \\
\text { City of } \\
\text { June } 30\end{array}$ & $\begin{array}{c}\text { Tennessee } \\
\text { Fayetteville } \\
\text { City of } \\
\text { June } 30\end{array}$ & $\begin{array}{l}\text { Tennessee } \\
\text { Gallatin } \\
\text { City of } \\
\text { June } 30\end{array}$ \\
\hline \multicolumn{7}{|l|}{ Sources of Energy } \\
\hline Steam & 0 & $\mathbf{0}$ & 0 & 0 & 0 & 0 \\
\hline 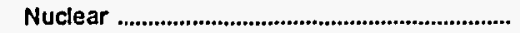 & 0 & 0 & 0 & 0 & 0 & 0 \\
\hline 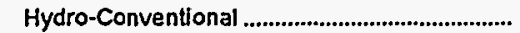 & 0 & 0 & 0 & 0 & 0 & 0 \\
\hline 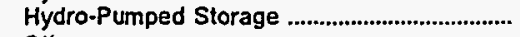 & 0 & 0 & 0 & 0 & 0 & 0 \\
\hline Other & 0 & 0 & 0 & 0 & 0 & 0 \\
\hline 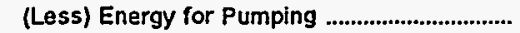 & 0 & 0 & 0 & 0 & 0 & 0 \\
\hline 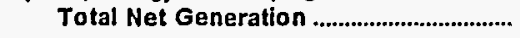 & 0 & $\mathbf{0}$ & 0 & 0 & 0 & 0 \\
\hline 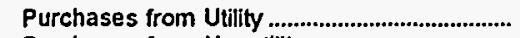 & 630,980 & 503,766 & 211,244 & 147,859 & 380,822 & 496,145 \\
\hline $\begin{array}{l}\text { Purchases from Nonutility ..................................... } \\
\text { Power Exchanges }\end{array}$ & 0 & 0 & $\mathbf{0}$ & 0 & 0 & 0 \\
\hline 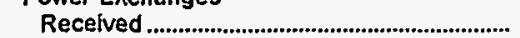 & 0 & 0 & 0 & 0 & 0 & 0 \\
\hline 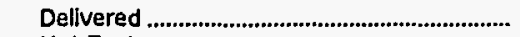 & 0 & 0 & 0 & 0 & 0 & 0 \\
\hline 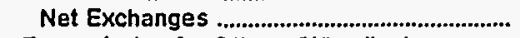 & 0 & 0 & 0 & 0 & 0 & 0 \\
\hline \multicolumn{7}{|l|}{ Transmission for Others (Wheeling) } \\
\hline 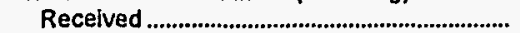 & 0 & 0 & 0 & 0 & 0 & 0 \\
\hline 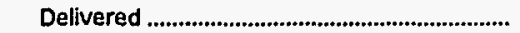 & 0 & 0 & 0 & 0 & 0 & 0 \\
\hline 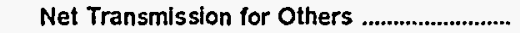 & 0 & 0 & 0 & 0 & 0 & 0 \\
\hline $\begin{array}{l}\text { Transmission by Others Losses........................... } \\
\text { Total Net Energy }\end{array}$ & 0 & 0 & 0 & 0 & 0 & 0 \\
\hline 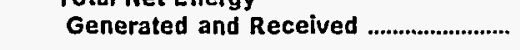 & 630,980 & 503,766 & 211,244 & 147,859 & 380,822 & 496,145 \\
\hline \multicolumn{7}{|l|}{ Disposition of Energy } \\
\hline 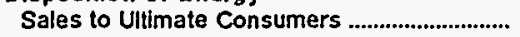 & 612,895 & 473,823 & 202,791 & 142,739 & 356,879 & 480,518 \\
\hline 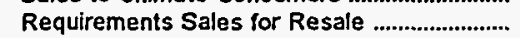 & 0 & 0 & 0 & 0 & 0 & 0 \\
\hline Nonrequirements Sales for Resale .................. & 0 & 0 & 0 & 0 & 0 & 0 \\
\hline 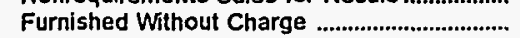 & 0 & 0 & 0 & 0 & 0 & 0 \\
\hline Used by Utility (excluding station use) ............ & 384 & 569 & 152 & 0 & 0 & 269 \\
\hline Losses & 17,702 & 29,374 & 8,301 & 5,119 & 23,942 & 15,359 \\
\hline 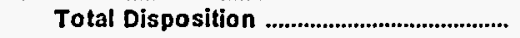 & 630,980 & 503,766 & 211,244 & 147,859 & 380,822 & 496,145 \\
\hline
\end{tabular}

Note: Totals may not equal sum of components because of independent rounding. Double counting occurs in components of both sources and disposition of energy and thus nelther provides a true total. Purchases from utilities, net interchanges, and net wheeling (except for imports) are included in net generation.

Source: Energy Information Administration, Form EIA-412, "Annual Report of Public Electric Utilities." 
Table 26. Electric Energy Account by Major U.S. Publicly Owned Electric Utility Within State, 1995 (Continued) (Megawatthours)

\begin{tabular}{|c|c|c|c|c|c|c|}
\hline llem & $\begin{array}{c}\text { Tennessee } \\
\text { Greeneville } \\
\text { City of } \\
\text { June } 30\end{array}$ & $\begin{array}{l}\text { Tennessee } \\
\begin{array}{c}\text { Harriman } \\
\text { Clty of }\end{array} \\
\text { June } 30\end{array}$ & $\begin{array}{l}\text { Tennessee } \\
\text { Humboldt } \\
\text { City of } \\
\text { June } 30\end{array}$ & $\begin{array}{l}\text { Tennessee } \\
\text { Jackson } \\
\text { City of } \\
\text { June } 30\end{array}$ & $\begin{array}{l}\text { Tennessee } \\
\text { Johnson } \\
\text { City City of } \\
\text { June } 30\end{array}$ & $\begin{array}{c}\text { Tennessee } \\
\text { Knoxville } \\
\text { Utilities } \\
\text { Board } \\
\text { June } 30\end{array}$ \\
\hline \multicolumn{7}{|l|}{ Sources of Energy } \\
\hline 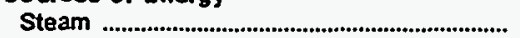 & 0 & $\mathbf{0}$ & 0 & 0 & 0 & $\mathbf{0}$ \\
\hline 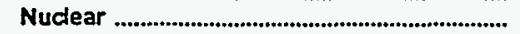 & 0 & $\mathbf{0}$ & 0 & $\mathbf{0}$ & 0 & $\mathbf{0}$ \\
\hline 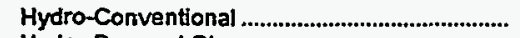 & 0 & 0 & 0 & 0 & 0 & 0 \\
\hline 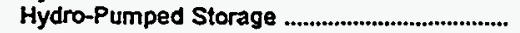 & 0 & 0 & 0 & 0 & 0 & $\mathbf{0}$ \\
\hline Other & 0 & 0 & $\mathbf{0}$ & 0 & 0 & 0 \\
\hline 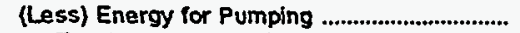 & 0 & 0 & 0 & 0 & 0 & $\mathbf{0}$ \\
\hline 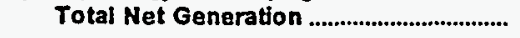 & 0 & 0 & 0 & 0 & 0 & 0 \\
\hline 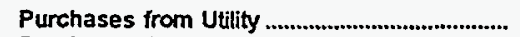 & 941,343 & 288,805 & 242,248 & $1,306,872$ & $1,618,154$ & $4,896,174$ \\
\hline $\begin{array}{l}\text { Purchases from Nonutility ................................... } \\
\text { Power Exchanges }\end{array}$ & 0 & 0 & 0 & 0 & 0 & 17.722 \\
\hline 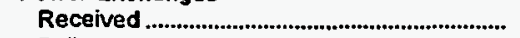 & 0 & 0 & 0 & 0 & 0 & 0 \\
\hline 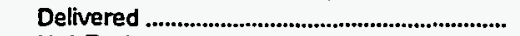 & 0 & 0 & 0 & 0 & $\mathbf{0}$ & 0 \\
\hline 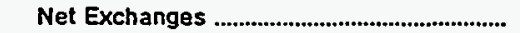 & $\mathbf{0}$ & 0 & 0 & 0 & 0 & 0 \\
\hline \multicolumn{7}{|l|}{ Transmission for Others (Wheeling) } \\
\hline Received & 0 & 0 & 0 & 0 & 0 & $\mathbf{0}$ \\
\hline 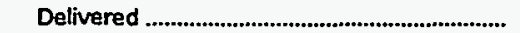 & 0 & 0 & 0 & 0 & 0 & $\mathbf{0}$ \\
\hline 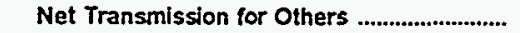 & 0 & 0 & 0 & 0 & $\mathbf{0}$ & 0 \\
\hline $\begin{array}{l}\text { Transmission by Others Losses ........................ } \\
\text { Total Net Energy }\end{array}$ & 0 & 0 & 0 & 0 & 0 & 0 \\
\hline Generated and Received ............................ & 941,343 & 288,805 & 242,248 & $1,306,872$ & $1,618,154$ & $4,913,896$ \\
\hline \multicolumn{7}{|l|}{ Disposition of Energy } \\
\hline 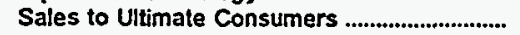 & 902,492 & 274,105 & 234,276 & $1,277,865$ & $1,545,804$ & $4,703,769$ \\
\hline Requirements Sales for Resale ......................... & 0 & 0 & 0 & 0 & 0 & 0 \\
\hline Nonrequirements Sales for Resale ................... & 0 & 0 & 0 & 0 & 0 & 0 \\
\hline Furnished Without Charge .................................. & 0 & 0 & 0 & 0 & 0 & $\mathbf{0}$ \\
\hline Used by Utility (excluding station use) ............ & 761 & 419 & 126 & 0 & 865 & 15,132 \\
\hline $\begin{array}{l}\text { Losses } \\
\text { Total Disposition }\end{array}$ & $\begin{array}{r}38,090 \\
941,343\end{array}$ & $\begin{array}{r}14,281 \\
288,805\end{array}$ & $\begin{array}{r}7,846 \\
242,248\end{array}$ & $\begin{array}{r}29,007 \\
1,306,872\end{array}$ & $\begin{array}{r}71,485 \\
1,618,154\end{array}$ & $\begin{array}{r}194,995 \\
4,913,896\end{array}$ \\
\hline
\end{tabular}

Note: Totals may not equal sum of components because of independent rounding. Double counting occurs in components of both sources and disposition of energy and thus neither provides a true total. Purchases from utilities, net interchanges, and net wheeling (except for imports) are included in net generation.

Source: Energy Information Administration, Form EIA-412, "Annual Report of Public Electric Utilities." 
Table 26. Electric Energy Account by Major U.S. Publicly Owned Electric Utility Within State, 1995 (Continued) (Megawatthours)

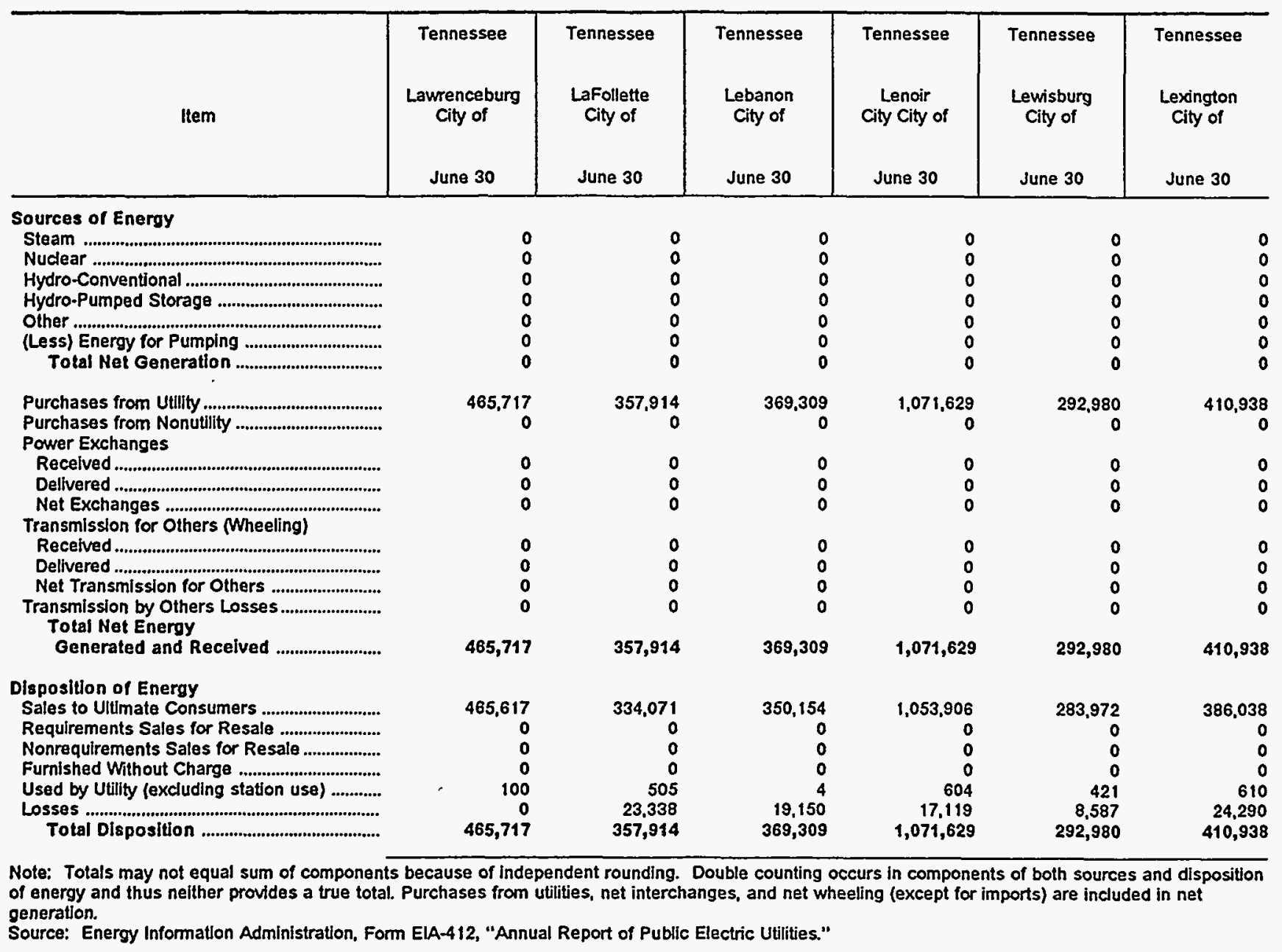


Table 26. Electric Energy Account by Major U.S. Publicly Owned Electric Utility Within State, 1995 (Continued)

(Megawatthours)

\begin{tabular}{|c|c|c|c|c|c|c|}
\hline Item & $\begin{array}{l}\text { Tennessee } \\
\text { Loudon } \\
\text { Utilities } \\
\text { Board } \\
\text { June } 30\end{array}$ & $\begin{array}{l}\text { Tennessee } \\
\text { Maryville } \\
\text { Utilities } \\
\text { June } 30\end{array}$ & $\begin{array}{l}\text { Tennessee } \\
\text { McMinnville } \\
\text { Electric } \\
\text { System } \\
\text { June } 30\end{array}$ & $\begin{array}{l}\text { Tennessee } \\
\text { Memphis } \\
\text { City of } \\
\text { June } 30\end{array}$ & $\begin{array}{l}\text { Tennessee } \\
\text { Milan } \\
\text { City of } \\
\text { June } 30\end{array}$ & $\begin{array}{l}\text { Tennessee } \\
\begin{array}{l}\text { Monristown } \\
\text { City of }\end{array} \\
\text { June } 30\end{array}$ \\
\hline \multicolumn{7}{|l|}{ Sources of Energy } \\
\hline Steam & 0 & $\mathbf{0}$ & 0 & 0 & 0 & 0 \\
\hline 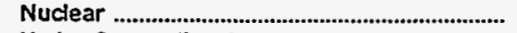 & 0 & 0 & $\mathbf{0}$ & 0 & 0 & 0 \\
\hline 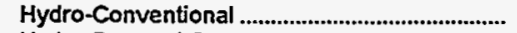 & 0 & 0 & 0 & 0 & $\mathbf{0}$ & 0 \\
\hline 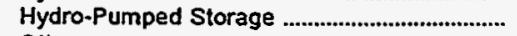 & 0 & 0 & 0 & 0 & 0 & 0 \\
\hline Other & 0 & 0 & 0 & 0 & 0 & 0 \\
\hline 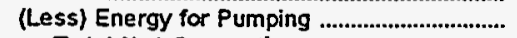 & 0 & 0 & 0 & 0 & 0 & 0 \\
\hline Total Net Generation & $\mathbf{0}$ & 0 & $\mathbf{0}$ & 0 & $\mathbf{0}$ & 0 \\
\hline 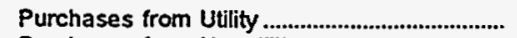 & 304,545 & 561,677 & 233,151 & $12,410,856$ & 228,928 & 698,951 \\
\hline $\begin{array}{l}\text { Purchases from Nonutility } \\
\text { Power Exchanges }\end{array}$ & 0 & 0 & 0 & 0 & 0 & 0 \\
\hline Received & 0 & 0 & 0 & 0 & 0 & 0 \\
\hline Delivered & 0 & 0 & 0 & 0 & 0 & $\mathbf{0}$ \\
\hline Net Exchanges & 0 & $\mathbf{0}$ & 0 & 0 & $\mathbf{0}$ & 0 \\
\hline \multicolumn{7}{|l|}{ Transmission for Others (Wheeling) } \\
\hline 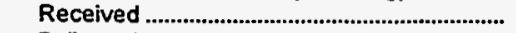 & 0 & 0 & 0 & 0 & 0 & 0 \\
\hline Delivered & 0 & $\mathbf{0}$ & $\mathbf{0}$ & $\mathbf{0}$ & $\mathbf{0}$ & 0 \\
\hline 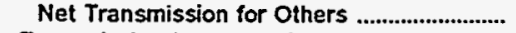 & 0 & 0 & 0 & 0 & 0 & $\mathbf{0}$ \\
\hline $\begin{array}{l}\text { Transmission by Others Losses........................ } \\
\text { Total Net Energy }\end{array}$ & 0 & 0 & 0 & 0 & 0 & 0 \\
\hline 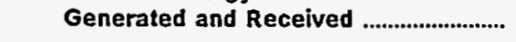 & 304,545 & 561,677 & 233,151 & $12,410,856$ & 228,928 & 698,851 \\
\hline \multicolumn{7}{|l|}{ Disposition of Energy } \\
\hline 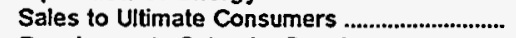 & 287,879 & 541,207 & 222,362 & $12,030,683$ & 216,662 & 676,867 \\
\hline 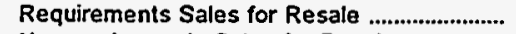 & 0 & 0 & $\mathbf{0}$ & 0 & 0 & 0 \\
\hline Nonrequirements Sales for Resale .................. & 0 & $\mathbf{0}$ & $\mathbf{0}$ & 0 & 0 & 0 \\
\hline 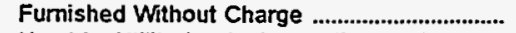 & 0 & 0 & 0 & 0 & $\mathbf{0}$ & 0 \\
\hline Used by Utility (excluding station use) ............ & 0 & 0 & 292 & 5.481 & 0 & 1.096 \\
\hline Losses & 16,666 & 20,470 & 10,498 & 374,692 & 12,266 & 20,989 \\
\hline Total Disposition & 304,545 & 561,677 & 233,151 & $12,410,856$ & 228,928 & 698,951 \\
\hline
\end{tabular}

Note: Totals may not equal sum of components because of independent rounding. Double counting occurs in components of both sources and disposition of energy and thus neither provides a true total. Purchases from utilities, net interchanges, and net wheeling (except for imports) are included in net generation.

Source: Energy Information Administration, Form EIA-412, "Annual Report of Public Electric Utilities." 
Table 26. Electric Energy Account by Major U.S. Publicly Owned Electric Utility Within State, 1995 (Continued)

(Megawatthours)

\begin{tabular}{|c|c|c|c|c|c|c|}
\hline Item & $\begin{array}{l}\text { Tennessee } \\
\begin{array}{c}\text { Murfreesboro } \\
\text { City of }\end{array} \\
\text { June } 30\end{array}$ & $\begin{array}{l}\text { Tennessee } \\
\text { Nashville } \\
\text { Electric } \\
\text { Service } \\
\\
\text { June } 30\end{array}$ & $\begin{array}{l}\text { Tennessee } \\
\text { Newport } \\
\text { City of } \\
\text { June } 30\end{array}$ & $\begin{array}{l}\text { Tennessee } \\
\text { Oak Ridge } \\
\text { City of } \\
\text { June } 30\end{array}$ & $\begin{array}{l}\text { Tennessee } \\
\text { Paris } \\
\text { City of } \\
\text { June } 30\end{array}$ & $\begin{array}{l}\text { Tennessee } \\
\text { Pulaski } \\
\text { City of } \\
\text { June } 30\end{array}$ \\
\hline \multicolumn{7}{|l|}{ Sources of Energy } \\
\hline Steam & $\mathbf{0}$ & 0 & 0 & 0 & 0 & \\
\hline 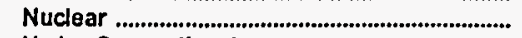 & 0 & 0 & 0 & 0 & 0 & 0 \\
\hline 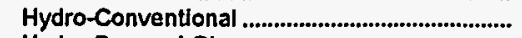 & 0 & 0 & 0 & 0 & 0 & \\
\hline 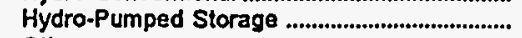 & 0 & 0 & 0 & 0 & 0 & \\
\hline Other & 0 & 0 & 0 & 0 & 0 & \\
\hline (Less) Energy for Pumping ....................................... & 0 & 0 & 0 & 0 & 0 & \\
\hline 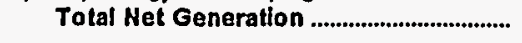 & 0 & 0 & 0 & 0 & 0 & 0 \\
\hline 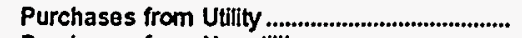 & 930,789 & $10,921,672$ & 90,381 & 466.507 & 449,020 & 437,377 \\
\hline 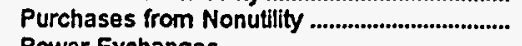 & & & 0 & 0 & 0 & \\
\hline \multicolumn{7}{|l|}{ Power Exchanges } \\
\hline 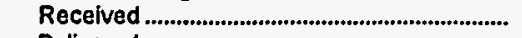 & o & 0 & 0 & 0 & 0 & \\
\hline 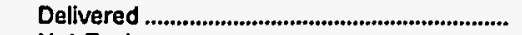 & 0 & 0 & 0 & 0 & 0 & 0 \\
\hline \multirow{2}{*}{\multicolumn{7}{|c|}{ Transmission for Others (Wheeling) }} \\
\hline & & & & & & \\
\hline 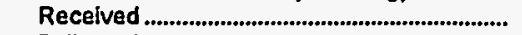 & 0 & 0 & 0 & 0 & 0 & 0 \\
\hline 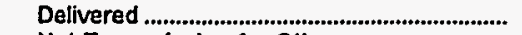 & $\mathbf{0}$ & 0 & 0 & 0 & 0 & 0 \\
\hline 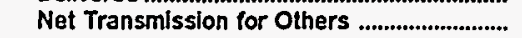 & 0 & 0 & 0 & 0 & 0 & 0 \\
\hline 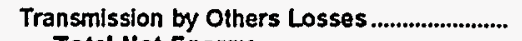 & 0 & 0 & 0 & 0 & 0 & $\mathbf{0}$ \\
\hline $\begin{array}{l}\text { Total Net Energy } \\
\text { Generated and Received ............................ }\end{array}$ & 930,789 & $10,921,672$ & 90,381 & 466,507 & 449,020 & 437,377 \\
\hline \multicolumn{7}{|l|}{ Disposition of Energy } \\
\hline 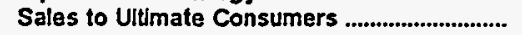 & 895,160 & $10,521,870$ & 87,774 & 443,196 & 425,408 & 414,707 \\
\hline Requirements Sales for Resale .............................. & 0 & 0 & 0 & 0 & 0 & \\
\hline & 0 & 0 & 0 & 0 & 0 & 0 \\
\hline 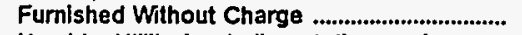 & 0 & 0 & 0 & 0 & 0 & 0 \\
\hline Used by Utility (excluding station use) ............. & 1.044 & 22,592 & 0 & 0 & 237 & 713 \\
\hline Losses & 34,585 & 377,210 & 2,608 & 23,311 & 23,375 & 21,957 \\
\hline 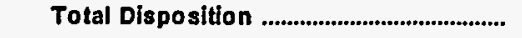 & 930,789 & $10,921,672$ & 90,381 & 466,507 & 449,020 & 437,377 \\
\hline
\end{tabular}

Note: Totals may not equal sum of components because of independent rounding. Double counting occurs in components of both sources and disposition of energy and thus nelther provides a true total. Purchases from utilities, net interchanges, and net wheeling (except for imports) are included in net generation. Sales for resale is included in sales to ultimate consumers.

Source: Energy Infomation Administration. Form ElA-412, "Annual Report of Public Electric Utilities." 
Table 26. Electric Energy Account by Major U.S. Publicly Owned Electric Utility Within State, 1995 (Continued) (Megawatthours)

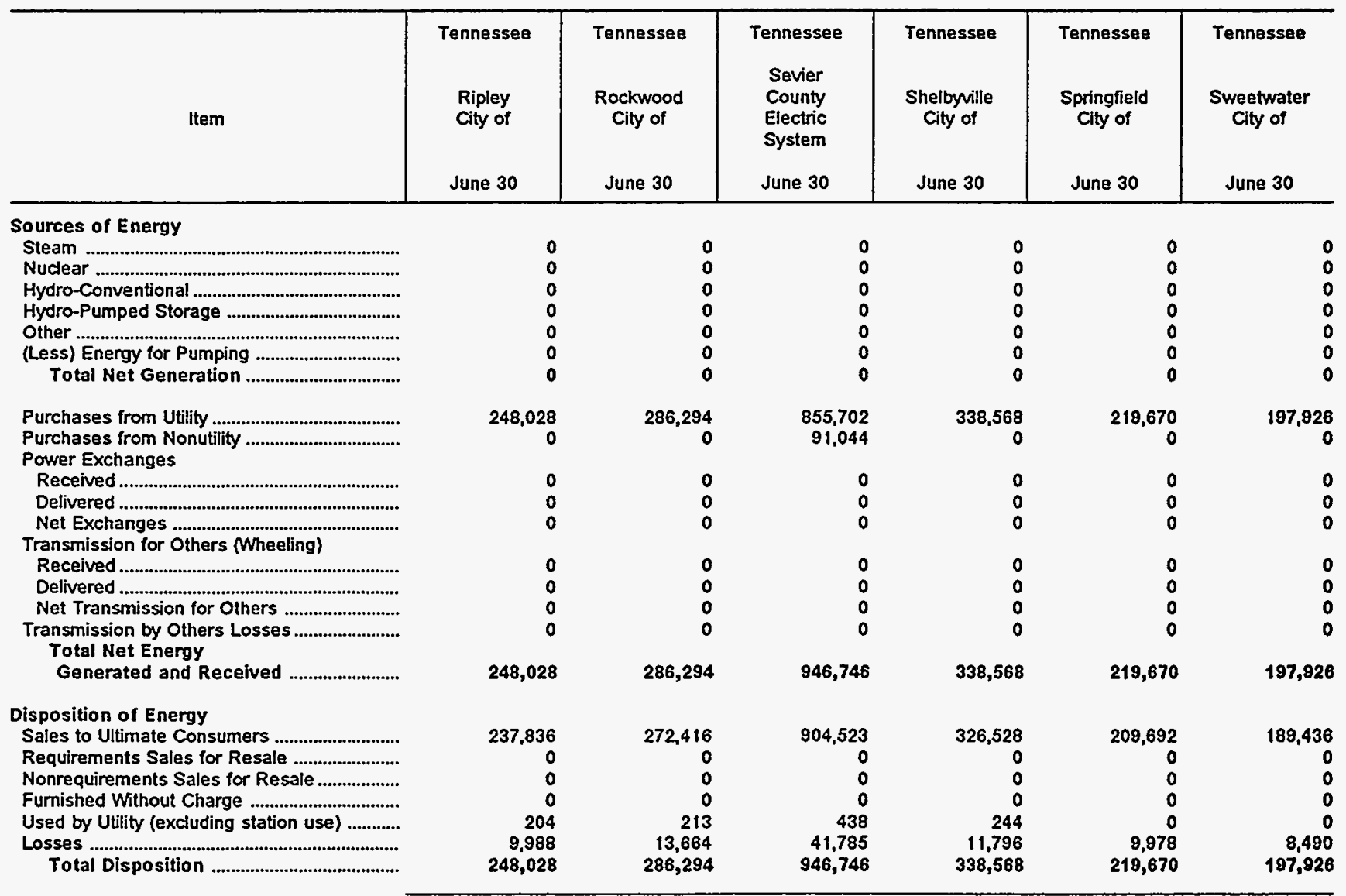

Note: Totals may not equal sum of components because of independent rounding. Double counting occurs in components of both sources and disposition of energy and thus neither provides a true total. Purchases from utilities, net interchanges, and net wheeling (except for imports) are included in net generation.

Source: Energy Information Administration, Form ElA-412, "Annual Report of Public Electric Utilities." 
Table 26. Electric Energy Account by Major U.S. Publicly Owned Electric Utility Within State, 1995 (Continued)

(Megawatthours)

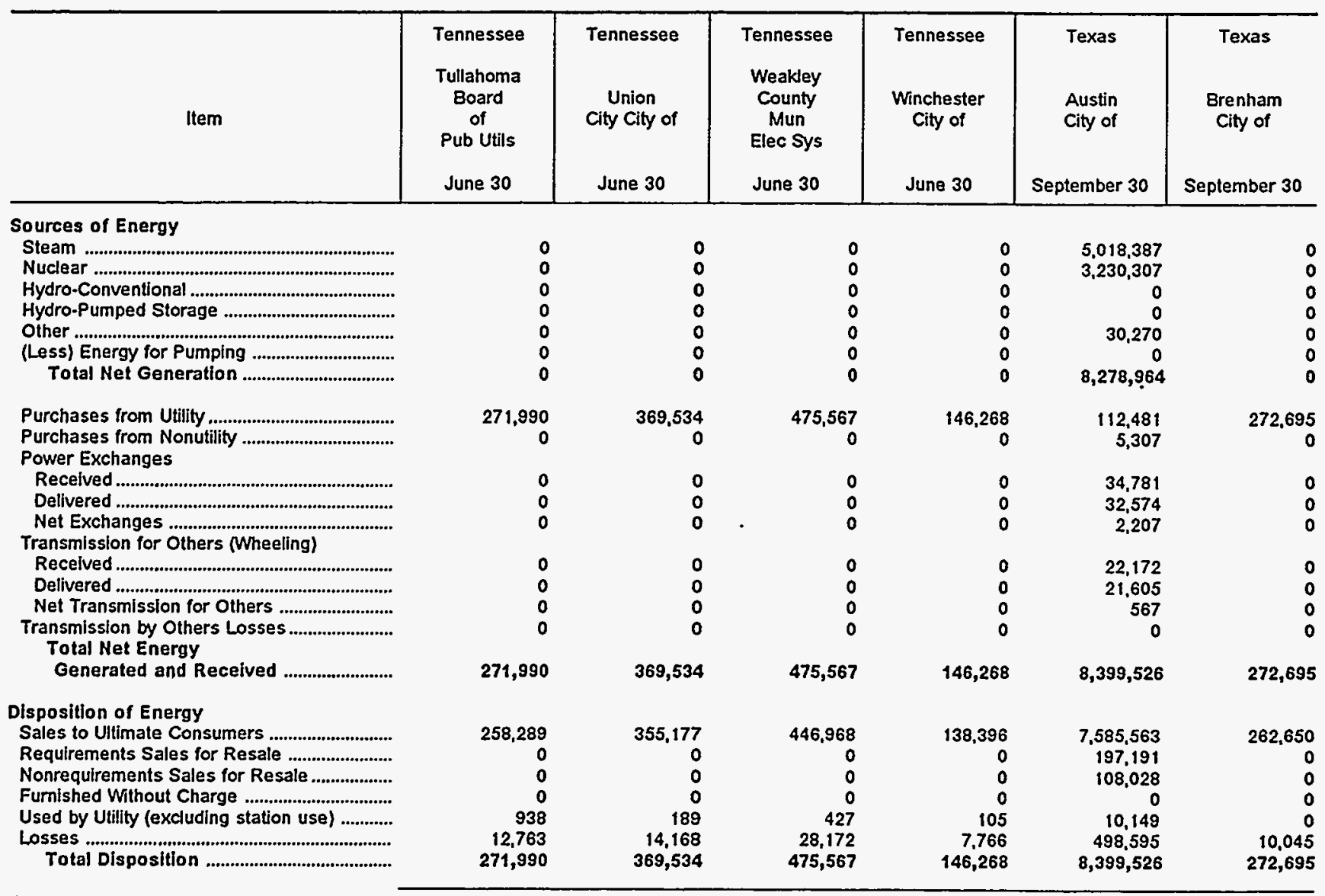

Note: Totals may not equal sum of components because of independent rounding. Double counting occurs in components of both sources and disposition of energy and thus neither provides a true total. Purchases from utilities, net interchanges, and net wheeling (except for imports) are included in net generation.

Source: Energy Information Administration, Form ELA-412, "Annual Report of Public Electric Utilities." 
Table 26. Electric Energy Account by Major U.S. Publicly Owned Electric Utility Within State, 1995 (Continued)

(Megawatthours)

\begin{tabular}{|c|c|c|c|c|c|c|}
\hline Item & $\begin{array}{c}\text { Texas } \\
\text { Brownsville } \\
\text { Public } \\
\text { Utils Board } \\
\text { Seplember } 30\end{array}$ & $\begin{array}{c}\text { Texas } \\
\text { Bryan } \\
\text { City of } \\
\text { September } 30\end{array}$ & $\begin{array}{l}\text { Texas } \\
\text { College } \\
\text { Station } \\
\text { City of } \\
\text { September } 30\end{array}$ & $\begin{array}{l}\text { Texas } \\
\text { Denton } \\
\text { City of } \\
\text { September } 30\end{array}$ & $\begin{array}{l}\text { Texas } \\
\text { Floresville } \\
\text { City of }\end{array}$ & $\begin{array}{l}\text { Texas } \\
\text { Garland } \\
\text { City of } \\
\text { September } 30\end{array}$ \\
\hline \multicolumn{7}{|l|}{ Sources of Energy } \\
\hline Steam & 543,609 & 546,303 & 0 & 338,209 & 0 & $1,415,369$ \\
\hline 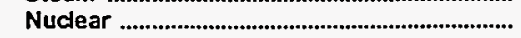 & 0 & 0 & 0 & 0 & 0 & 0 \\
\hline 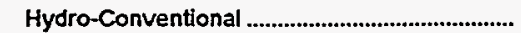 & 0 & $\mathbf{0}$ & 0 & 0 & 0 & $\mathbf{0}$ \\
\hline Hydro-Pumped Storage & 0 & $\mathbf{0}$ & 0 & 0 & 0 & 0 \\
\hline Other & 11,605 & 2,102 & 0 & 0 & 0 & 0 \\
\hline 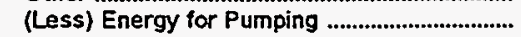 & 0 & 0 & 0 & 0 & 0 & 0 \\
\hline 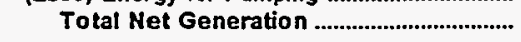 & 555,214 & 548,405 & 0 & 338,209 & $\mathbf{0}$ & $1,415,368$ \\
\hline 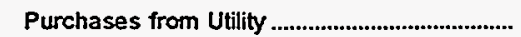 & 301,918 & 645,540 & 499,502 & 740.275 & 171,302 & 992,036 \\
\hline $\begin{array}{l}\text { Purchases from Nonutility ................................... } \\
\text { Power Exchanges }\end{array}$ & 0 & 0 & $\mathbf{0}$ & 0 & 0 & 0 \\
\hline 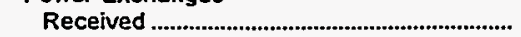 & 3,672 & 76,957 & 0 & 0 & 0 & 0 \\
\hline 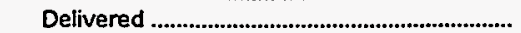 & 7 & 79,651 & 0 & 0 & 0 & 0 \\
\hline Net Exchanges & 3,665 & $-2,694$ & 0 & 0 & 0 & 0 \\
\hline \multicolumn{7}{|l|}{ Transmission for Others (Wheeling) } \\
\hline 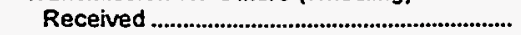 & 0 & $\mathbf{0}$ & 0 & 0 & 0 & 0 \\
\hline 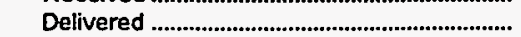 & 0 & 0 & 0 & 0 & 0 & 0 \\
\hline Net Transmission for Others .......................... & 0 & 0 & 0 & 0 & 0 & $\mathbf{0}$ \\
\hline $\begin{array}{l}\text { Transmission by Others Losses ........................ } \\
\text { Total Net Energy }\end{array}$ & $-29,146$ & 0 & 0 & 0 & 0 & $\mathbf{0}$ \\
\hline 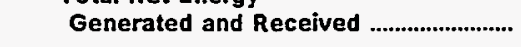 & 831,651 & $1,191,251$ & 499,502 & $1,078,484$ & 171,302 & $2,407,405$ \\
\hline \multicolumn{7}{|l|}{ Disposition of Energy } \\
\hline Sales to Uitimate Consumers ............................ & 756,048 & 803,690 & 478,358 & 862,930 & 155,677 & $1,962,005$ \\
\hline 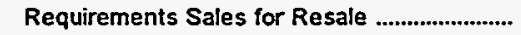 & 0 & 329,069 & 0 & 0 & $\mathbf{0}$ & 370,200 \\
\hline Nonrequirements Sales for Resale ................. & -7 & 0 & 0 & 186,396 & 0 & 0 \\
\hline 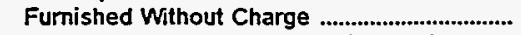 & 23,750 & 0 & 1,426 & 0 & 69 & $\mathbf{0}$ \\
\hline Used by Utility (excluding station use) ............ & 971 & $\mathbf{0}$ & 0 & 0 & 295 & 0 \\
\hline 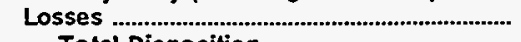 & 50.889 & 58,492 & 19,718 & 29,158 & 15,261 & 75,200 \\
\hline Total Disposition & 831,651 & $1,191,251$ & 499,502 & $1,078,484$ & 171,302 & $2,407,405$ \\
\hline
\end{tabular}

Note: Totals may not equal sum of components because of independent rounding. Double counting occurs in components of both sources and disposition of energy and thus neither provides a true total. Purchases from utilities, net interchanges, and net wheeling (except for imports) are included in net generation.

Source: Energy Information Administration, Form ElA-412, "Annual Report of Public Electric Utilities." 
Table 26. Electric Energy Account by Major U.S. Publicly Owned Electric Utility Within State, 1995 (Continued)

(Megawatthours)

\begin{tabular}{|c|c|c|c|c|c|c|}
\hline Item & $\begin{array}{c}\text { Texas } \\
\text { Georgetown } \\
\text { City of }\end{array}$ & $\begin{array}{c}\text { Texas } \\
\text { Greenville } \\
\text { Electric } \\
\text { Util Sys } \\
\text { September } 30\end{array}$ & $\begin{array}{c}\text { Texas } \\
\text { Jasper } \\
\text { City of } \\
\text { September } 30\end{array}$ & $\begin{array}{l}\text { Texas } \\
\text { Kernille } \\
\text { Public } \\
\text { Utility } \\
\text { Board } \\
\text { September } 30\end{array}$ & $\begin{array}{l}\text { Texas } \\
\text { Lower } \\
\text { Colorado } \\
\text { River } \\
\text { Authority } \\
\text { June } 30\end{array}$ & $\begin{array}{c}\text { Texas } \\
\text { Lubbock } \\
\text { City of } \\
\text { September } 30\end{array}$ \\
\hline \multicolumn{7}{|l|}{ Sources of Energy } \\
\hline Steam & $\mathbf{0}$ & 71,696 & 0 & 0 & $9,514,373$ & 597,703 \\
\hline Nuclear & 0 & 0 & 0 & 0 & 0 & \\
\hline 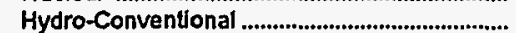 & 0 & 0 & 0 & 0 & 250,381 & 0 \\
\hline Hydro-Pumped Storage ......................................... & 0 & 0 & 0 & 0 & 0 & 0 \\
\hline Other & 0 & -244 & 0 & 0 & 0 & 0 \\
\hline (Less) Energy for Pumping ............................. & 0 & 0 & 0 & 0 & 0 & 0 \\
\hline 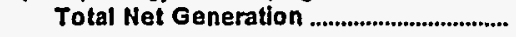 & $\mathbf{0}$ & 71,452 & 0 & $\mathbf{0}$ & $9,764,754$ & 597,703 \\
\hline 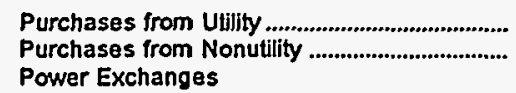 & $\begin{array}{r}192,943 \\
0\end{array}$ & $\begin{array}{r}426,461 \\
0\end{array}$ & $\begin{array}{r}145,935 \\
0\end{array}$ & $\begin{array}{l}0 \\
0\end{array}$ & $\begin{array}{r}140,799 \\
37,994\end{array}$ & $\begin{array}{r}454,625 \\
0\end{array}$ \\
\hline 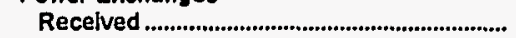 & $\mathbf{0}$ & $\mathbf{0}$ & $\mathbf{0}$ & 376,130 & 0 & 0 \\
\hline Delivered ..................................................................... & 0 & 0 & $\mathbf{0}$ & 0 & 0 & 0 \\
\hline 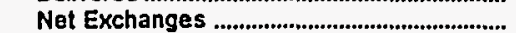 & 0 & 0 & 0 & 376,130 & 0 & 0 \\
\hline \multicolumn{7}{|l|}{ Transmission for Others (Wheeling) } \\
\hline 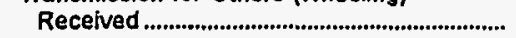 & 0 & 0 & 0 & 0 & 0 & 0 \\
\hline 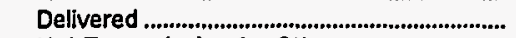 & 0 & 0 & 0 & 0 & 0 & 0 \\
\hline Net Transmission for Others & 0 & 0 & 0 & 0 & 0 & 0 \\
\hline $\begin{array}{l}\text { Transmission by Others Losses......................... } \\
\text { Tolal Net Energy }\end{array}$ & 0 & 0 & 0 & 0 & 0 & 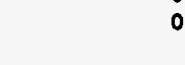 \\
\hline 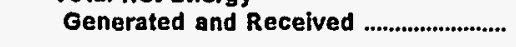 & 192,943 & 497,913 & 145,935 & 376,130 & $9,943,547$ & $1,052,328$ \\
\hline \multicolumn{7}{|l|}{ Disposition of Energy } \\
\hline Sales to Ultimate Consumers ........................... & 182,934 & 428,010 & 131,417 & 357,675 & 176,661 & 990,081 \\
\hline Requirements Sales for Resale ........................ & 0 & 46,618 & 0 & 0 & $9,386,632$ & 0 \\
\hline Nonrequirements Sales for Resale .................. & 0 & 738 & 0 & 0 & 0 & 0 \\
\hline Furnished Without Charge .................................. & 0 & 0 & 1,479 & 0 & 0 & 0 \\
\hline Used by Utility (excluding station use) ............. & 0 & 0 & 0 & 0 & 0 & $\mathbf{0}$ \\
\hline $\begin{array}{l}\text { Losses . } \\
\text { Total Disposition }\end{array}$ & $\begin{array}{r}10,009 \\
192,943\end{array}$ & $\begin{array}{r}22,547 \\
497,913\end{array}$ & $\begin{array}{r}13,039 \\
145,935\end{array}$ & $\begin{array}{r}18,455 \\
376,130\end{array}$ & $\begin{array}{r}380,254 \\
9,943,547\end{array}$ & $\begin{array}{r}62,247 \\
1,052,328\end{array}$ \\
\hline
\end{tabular}


Table 26. Electric Energy Account by Major U.S. Publicly Owned Electric Utility Within State, 1995 (Continued) (Megawatthours)

\begin{tabular}{|c|c|c|c|c|c|c|}
\hline Item & $\begin{array}{c}\text { Texas } \\
\text { New Braunfels } \\
\text { City of } \\
\text { July } 31\end{array}$ & $\begin{array}{c}\text { Texas } \\
\text { Sam Rayburn } \\
\text { Municipal } \\
\text { Pwr } \\
\text { Agny } \\
\text { September } 30\end{array}$ & $\begin{array}{c}\text { Texas } \\
\text { San Antonio } \\
\text { Public } \\
\text { Senvice } 8 d \\
\text { January } 31\end{array}$ & $\begin{array}{c}\text { San Marcos } \\
\text { City of }\end{array}$ & $\begin{array}{c}\text { Texas } \\
\text { Seguin } \\
\text { City of } \\
\text { September } 30\end{array}$ & $\begin{array}{c}\text { Texas } \\
\text { Texas } \\
\text { Municipal } \\
\text { Power Agency } \\
\text { September } 30\end{array}$ \\
\hline \multicolumn{7}{|l|}{ Sources of Energy } \\
\hline Steam & 0 & 609,441 & $9,528,632$ & 0 & 0 & $2,764,190$ \\
\hline Nuclear & 0 & 0 & $5,235,964$ & 0 & 0 & \\
\hline 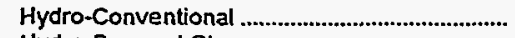 & 0 & 0 & 0 & 0 & 0 & 0 \\
\hline 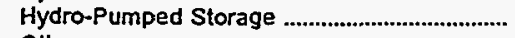 & 0 & 0 & 0 & 0 & 0 & 0 \\
\hline Other & 0 & 0 & 0 & 0 & 0 & $\mathbf{0}$ \\
\hline 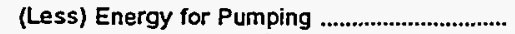 & 0 & 0 & 0 & 0 & 0 & 0 \\
\hline Total Net Generation & 0 & 609,441 & $14,764,596$ & 0 & 0 & $2,764,190$ \\
\hline 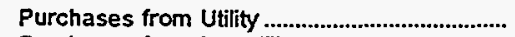 & 793,252 & 95,183 & 125,539 & 350,751 & 217,179 & $\mathbf{0}$ \\
\hline $\begin{array}{l}\text { Purchases from Nonutility } \\
\text { Power Exchanges }\end{array}$ & 0 & 0 & 219,568 & 0 & 0 & 0 \\
\hline 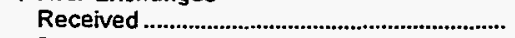 & 0 & 0 & $1,051,447$ & 0 & 0 & 0 \\
\hline 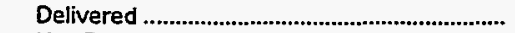 & 0 & 0 & $1,042,134$ & 0 & 0 & 0 \\
\hline Net Exchanges & 0 & 0 & 9,313 & 0 & 0 & 0 \\
\hline \multicolumn{7}{|l|}{ Transmission for Others (Wheeling) } \\
\hline Received & 0 & 0 & 0 & 0 & 0 & $\mathbf{0}$ \\
\hline 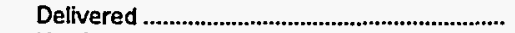 & 0 & 0 & 0 & 0 & 0 & 0 \\
\hline 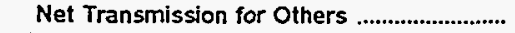 & 0 & 0 & 0 & 0 & 0 & 0 \\
\hline $\begin{array}{l}\text { Transmission by Others Losses .......................... } \\
\text { Total Net Energy }\end{array}$ & 0 & 0 & 0 & 0 & 0 & 0 \\
\hline 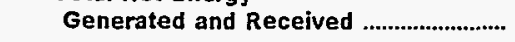 & 793,252 & 704,624 & $15,119,016$ & 350,751 & 217,179 & $2,764,190$ \\
\hline \multicolumn{7}{|l|}{ Disposition of Energy } \\
\hline 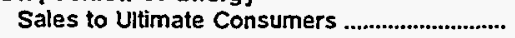 & 770,961 & 0 & $13,646,836$ & 332,366 & 203,073 & 0 \\
\hline 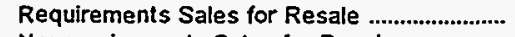 & 0 & 348,989 & 608,454 & 0 & 0 & $2,665,381$ \\
\hline Nonrequirements Sales for Resale ................. & 0 & 349.585 & 0 & 0 & 0 & 0 \\
\hline 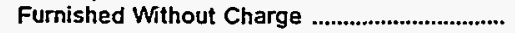 & 2,026 & 0 & 0 & 0 & 14,106 & 48,618 \\
\hline Used by Utility (excluding station use) ............. & 0 & 0 & 49,796 & 0 & 0 & 50.191 \\
\hline 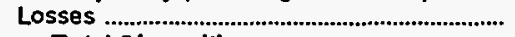 & 20,265 & 6,050 & 813,930 & 18,385 & 0 & 0 \\
\hline Total Disposition & 793,252 & 704,624 & $15,119,016$ & 350,751 & 217,179 & $2,764,190$ \\
\hline
\end{tabular}

Note: Totals may not equal sum of components because of independent rounding. Double counting occurs in components of both sources and dispositlon of energy and thus neither provides a true total. Purchases from utilities, net interchanges, and net wheeling (except for imports) are included in net generation.

Source: Energy Information Administration, Form EIA-412, "Annual Report of Public Electric Utilities." 
Table 26. Electric Energy Account by Major U.S. Publicly Owned Electric Utility Within State, 1995 (Continued)

(Megawatthours)

\begin{tabular}{|c|c|c|c|c|c|c|}
\hline Item & $\begin{array}{c}\text { Texas } \\
\text { Toledo Bend } \\
\text { Project } \\
\text { Joint } \\
\text { Oper } \\
\text { August } 30\end{array}$ & $\begin{array}{c}\text { Texas } \\
\text { Weatherford } \\
\text { Mun } \\
\text { Utility } \\
\text { System } \\
\text { September } 30\end{array}$ & $\begin{array}{c}\text { Utah } \\
\text { Bountiful } \\
\text { City City of } \\
\text { June } 30\end{array}$ & $\begin{array}{l}\text { Intermountain } \\
\text { Power Agency } \\
\text { June } 30\end{array}$ & $\begin{array}{l}\text { Utah } \\
\text { Logan } \\
\text { City of } \\
\text { June } 30\end{array}$ & $\begin{array}{l}\text { Utah } \\
\text { Murray } \\
\text { City of } \\
\text { June } 30\end{array}$ \\
\hline \multicolumn{7}{|l|}{ Sources of Energy } \\
\hline 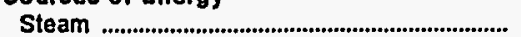 & 0 & 0 & 0 & $10,647,834$ & 0 & $\mathbf{0}$ \\
\hline 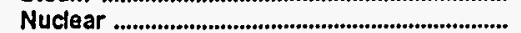 & 0 & 0 & 0 & 0 & 0 & $\mathbf{0}$ \\
\hline 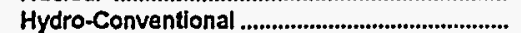 & 476,525 & 0 & 15,824 & 0 & 22,190 & 11,333 \\
\hline Hydro-Pumped Storage ...................................... & 0 & 0 & 0 & 0 & 0 & 0 \\
\hline 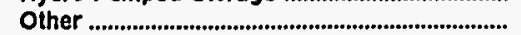 & 0 & 486 & 5,129 & 0 & -326 & 269 \\
\hline 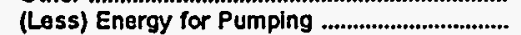 & 0 & 0 & 0 & 0 & 0 & \\
\hline 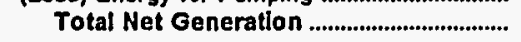 & 476,525 & 486 & 20,953 & $10,647,834$ & 21,864 & 11,602 \\
\hline 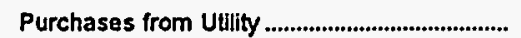 & 0 & 234,191 & 237,806 & 187 & 288,858 & 314,967 \\
\hline Purchases from Nonutility ................................. & 0 & 0 & 0 & 0 & 0 & 0 \\
\hline Received. & 0 & 0 & 0 & 0 & 0 & 0 \\
\hline Delivered .............................................................. & 0 & 0 & 0 & 0 & 0 & 0 \\
\hline Net Exchanges & 0 & 0 & 0 & 0 & 0 & 0 \\
\hline \multicolumn{7}{|l|}{ Transmission for Others (Wheeling) } \\
\hline 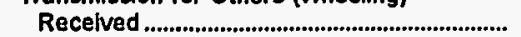 & 0 & 0 & 0 & 0 & 0 & 0 \\
\hline Dellvered & 0 & 0 & 0 & 0 & 0 & 0 \\
\hline Net Transmission for Others & $\mathbf{0}$ & 0 & 0 & 0 & 0 & $\mathbf{0}$ \\
\hline Transmission by Others Losses....................... & 0 & 0 & 0 & 0 & 0 & 0 \\
\hline $\begin{array}{l}\text { Total Net Energy } \\
\text { Generated and Received }\end{array}$ & 476,525 & 234,677 & 258,759 & $10,648,021$ & 310,722 & 326,569 \\
\hline \multicolumn{7}{|l|}{ Disposittion of Energy } \\
\hline Sales to Ultimate Consumers ............................... & 0 & 218,962 & 246,633 & 0 & 300,488 & 310,643 \\
\hline Requirements Sales for Resale ........................ & 0 & 0 & 0 & $10,648,021$ & 0 & 0 \\
\hline Nonrequirements Sales for Resale ................... & 476,065 & 0 & 0 & 0 & 0 & 0 \\
\hline Furnished Without Charge ................................... & 0 & 0 & 0 & 0 & 0 & 1,483 \\
\hline Used by Utility (excluding station use) ............ & 228 & 0 & 3,909 & $\mathbf{0}$ & 418 & 0 \\
\hline 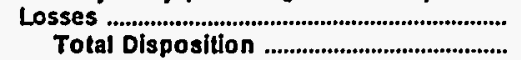 & $\begin{array}{r}232 \\
476,525\end{array}$ & $\begin{array}{r}15,715 \\
234,677\end{array}$ & $\begin{array}{r}8,217 \\
258,759\end{array}$ & $\begin{array}{r}0 \\
10,648,021\end{array}$ & $\begin{array}{r}9,816 \\
310,722\end{array}$ & $\begin{array}{r}14,443 \\
326,569\end{array}$ \\
\hline
\end{tabular}

Note: Totals may not equal sum of components because of independent rounding. Double counting occurs in components of both sources and disposition of energy and thus nelther provides a true total. Purchases from utilities, net interchanges, and net wheeling (except for imports) are included in net generation.

Source: Energy Information Administration. Form ElA-412, "Annual Report of Public Electric Utilities." 
Table 26. Electric Energy Account by Major U.S. Publicly Owned Electric Utility Within State, 1995 (Continued)

(Megawatthours)

\begin{tabular}{|c|c|c|c|c|c|c|}
\hline Item & $\begin{array}{c}\text { Utah } \\
\text { Provo } \\
\text { City Corp } \\
\text { June } 30\end{array}$ & $\begin{array}{l}\text { Utah } \\
\text { St George } \\
\text { City of } \\
\text { June } 30\end{array}$ & $\begin{array}{c}\text { Utah } \\
\text { Utah } \\
\text { Associated } \\
\text { Mun } \\
\text { Power Sys } \\
\text { March } 31\end{array}$ & $\begin{array}{c}\text { Utah } \\
\text { Utah } \\
\text { Municipal } \\
\text { Power Agency } \\
\text { June } 30\end{array}$ & $\begin{array}{c}\text { Vermont } \\
\text { Burtington } \\
\text { City of } \\
\text { June } 30\end{array}$ & $\begin{array}{l}\text { Vermont } \\
\text { Vermont } \\
\text { Public } \\
\text { Pwr } \\
\text { Supply Auth } \\
\text { December } 31\end{array}$ \\
\hline \multicolumn{7}{|l|}{ Sources of Energy } \\
\hline Steam & 0 & $\mathbf{0}$ & 634,634 & 370,507 & 55,418 & 25,862 \\
\hline 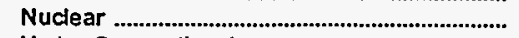 & 0 & 0 & 0 & 0 & 0 & 0 \\
\hline 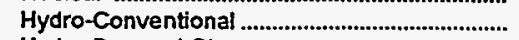 & 0 & 0 & 0 & 7,567 & 0 & 0 \\
\hline 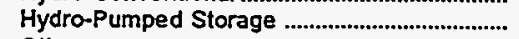 & 0 & 0 & 0 & 0 & 0 & 0 \\
\hline Other & 0 & 1,355 & 0 & 34,881 & 1,112 & 0 \\
\hline 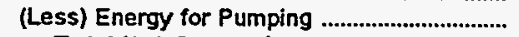 & 0 & 0 & $\mathbf{0}$ & 0 & 0 & 0 \\
\hline 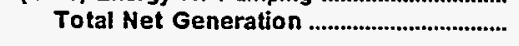 & 0 & 1,355 & 634,634 & 412,955 & 56,530 & 25,862 \\
\hline 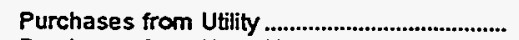 & 594,388 & 367,735 & 554,197 & 444,580 & 355,766 & 100,865 \\
\hline 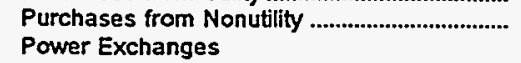 & 0 & 0 & 0 & 0 & 23,286 & \\
\hline 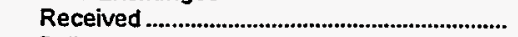 & 0 & $\mathbf{0}$ & 18,979 & 0 & 0 & $\mathbf{0}$ \\
\hline 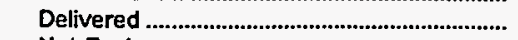 & 0 & 0 & 25,212 & 0 & 0 & 0 \\
\hline 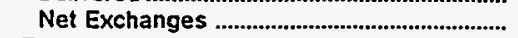 & 0 & 0 & $-6,234$ & 0 & 0 & 0 \\
\hline \multicolumn{7}{|l|}{ Transmission for Others (Wheeling) } \\
\hline 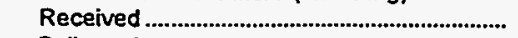 & 0 & 0 & $\mathbf{0}$ & 0 & 354 & $\mathbf{0}$ \\
\hline 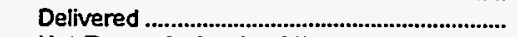 & 0 & 0 & 0 & 0 & 354 & $\mathbf{0}$ \\
\hline Net Transmission for Others .......................... & 0 & 0 & 0 & 0 & 0 & $\mathbf{0}$ \\
\hline $\begin{array}{l}\text { Transmission by Others Losses............................ } \\
\text { Total Net Energy }\end{array}$ & 0 & 0 & 0 & 0 & 0 & 0 \\
\hline 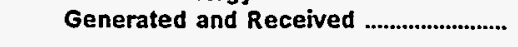 & 594,388 & 369,090 & $1,182,597$ & 857,535 & 435,582 & 126,727 \\
\hline \multicolumn{7}{|l|}{ Disposition of Energy } \\
\hline 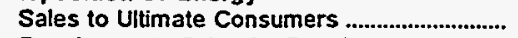 & 573,838 & 340,142 & 0 & 0 & 322,524 & $\mathbf{0}$ \\
\hline 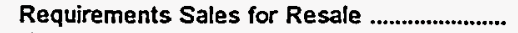 & 0 & 0 & 0 & 757,889 & 0 & $\mathbf{0}$ \\
\hline Nonrequirements Sales for Resale .................... & 0 & $\mathbf{0}$ & $1,182,597$ & 78,114 & 87,800 & 126,727 \\
\hline 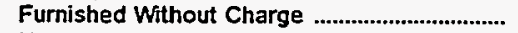 & 5,630 & 25,000 & 0 & 0 & 0 & 0 \\
\hline Used by Utility (excluding station use) ............ & 314 & 0 & 0 & 0 & 1,357 & 0 \\
\hline $\begin{array}{l}\text { Losses } \\
\text { Total Disposition }\end{array}$ & $\begin{array}{r}14,606 \\
594,388\end{array}$ & $\begin{array}{r}3,948 \\
369,090\end{array}$ & $\begin{array}{r}0 \\
1,182,597\end{array}$ & $\begin{array}{r}21,532 \\
857,535\end{array}$ & $\begin{array}{r}23,901 \\
435,582\end{array}$ & $\begin{array}{r}0 \\
126.727\end{array}$ \\
\hline
\end{tabular}

Note: Totals may not equal sum of components because of independent rounding. Double counting occurs in components of both sources and disposition of energy and thus neither provides a true total. Purchases from utilities, net interchanges, and net wheeling (except for imports) are included in net generation.

Source: Energy Information Administration, Form ElA-412, "Annual Report of Public Electric Utilities." 
Table 26. Electric Energy Account by Major U.S. Publicly Owned Electric Utility Within State, 1995 (Continued)

(Megawatthours)

\begin{tabular}{|c|c|c|c|c|c|c|}
\hline Item & $\begin{array}{l}\text { Virginia } \\
\text { Bedford } \\
\text { City of } \\
\text { June } 30\end{array}$ & $\begin{array}{l}\text { Virginia } \\
\text { Bristol } \\
\text { Utilities } \\
\text { Board } \\
\\
\text { June } 30\end{array}$ & $\begin{array}{l}\text { Virginia } \\
\text { Danville } \\
\text { City of } \\
\text { June } 30\end{array}$ & $\begin{array}{l}\text { Virginia } \\
\begin{array}{l}\text { Harrisonburg } \\
\text { City of }\end{array} \\
\text { June } 30\end{array}$ & $\begin{array}{l}\text { Virginia } \\
\text { Manassas } \\
\text { City of } \\
\text { June } 30\end{array}$ & $\begin{array}{l}\text { Virginia } \\
\begin{array}{l}\text { Martinsville } \\
\text { City of }\end{array} \\
\text { June } 30\end{array}$ \\
\hline \multicolumn{7}{|l|}{ Sources of Energy } \\
\hline 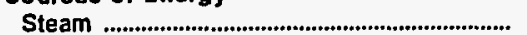 & 0 & 0 & 0 & 0 & 0 & 0 \\
\hline 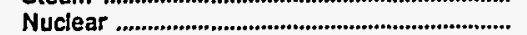 & 0 & 0 & 0 & 0 & 0 & o \\
\hline 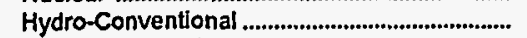 & 12,393 & 0 & 17,040 & 0 & $\uparrow, 380$ & 6,613 \\
\hline 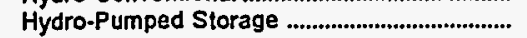 & 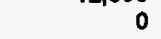 & 0 & 0 & 0 & 0 & 0 \\
\hline 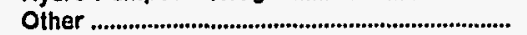 & 0 & 0 & 0 & 0 & 2,103 & 0 \\
\hline 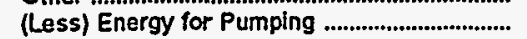 & 0 & 0 & 0 & 0 & & 0 \\
\hline 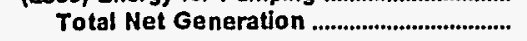 & 12,393 & o & 17,040 & 0 & 3,483 & 6,613 \\
\hline 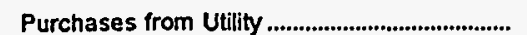 & 202,379 & 545,466 & 826,010 & 545,129 & 278,039 & 302,728 \\
\hline Purchases from Nonutility .................................... & 0 & 0 & 0 & 0 & 0 & \\
\hline Power Exchanges & & & & & & \\
\hline 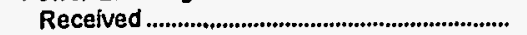 & 0 & 0 & 0 & 0 & 0 & 0 \\
\hline Delivered ................................................................... & 0 & 0 & 0 & 0 & 0 & 0 \\
\hline 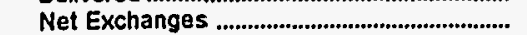 & 0 & 0 & 0 & 0 & 0 & 0 \\
\hline \multicolumn{7}{|l|}{ Transmission for Others (Wheeling) } \\
\hline 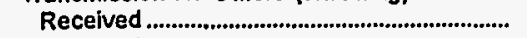 & 0 & 0 & 0 & 0 & 0 & 0 \\
\hline 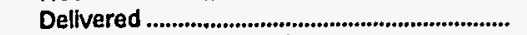 & 0 & 0 & 0 & 0 & 0 & 0 \\
\hline 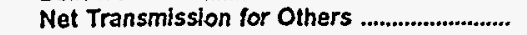 & 0 & 0 & 0 & 0 & 0 & 0 \\
\hline Transmission by Others Losses.......................... & -217 & 0 & 0 & 0 & 0 & 0 \\
\hline $\begin{array}{l}\text { Total Net Energy } \\
\text { Generated and Received ........................... }\end{array}$ & 214,555 & 545,466 & 843,050 & 545,129 & 281,522 & 309,341 \\
\hline \multicolumn{7}{|l|}{ Disposition of Energy } \\
\hline 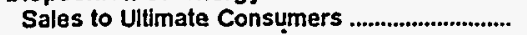 & 202,938 & 522,144 & 798,491 & 528,478 & 269,306 & 193,388 \\
\hline Requirements Sales for Resale .............................. & 0 & 0 & 0 & 0 & 0 & 0 \\
\hline Nonrequirements Sales for Resale .................... & 0 & o & 0 & $\mathbf{0}$ & 0 & 0 \\
\hline Furnlshed Without Charge ..................................... & 0 & a & 0 & 0 & 0 & 1,245 \\
\hline Used by Utillty (excluding station use) ............. & 0 & $\mathbf{0}$ & 0 & 0 & 0 & 180 \\
\hline 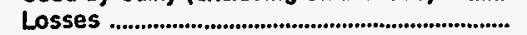 & 11,617 & 23,323 & 44.559 & 16,651 & 12,216 & 114,528 \\
\hline Total Disposition .................................................. & 214,555 & 545,466 & 843,050 & 545,129 & 281,522 & 309,341 \\
\hline
\end{tabular}

Nole: Totals may not equal sum of components because of independent rounding. Double counting occurs in components of both sources and disposition of energy and thus neither provides a true total. Purchases from utilities, net interchanges, and net wheeling (except for imports) are included in net generation.

Source: Energy Information Administration, Form EIA-412, "Annual Report of Public Electric Utilities." 
Table 26. Electric Energy Account by Major U.S. Publicly Owned Electric Utility Within State, 1995 (Continued)

(Megawatthours)

\begin{tabular}{|c|c|c|c|c|c|c|}
\hline Item & $\begin{array}{l}\text { Virginia } \\
\text { Radford } \\
\text { City of } \\
\text { June } 30\end{array}$ & $\begin{array}{l}\text { Virginia } \\
\text { Salem } \\
\text { City of } \\
\text { June } 30\end{array}$ & $\begin{array}{l}\text { Virginia } \\
\text { Virginia } \\
\text { Tech } \\
\text { Electric } \\
\text { Senvice } \\
\text { June } 30\end{array}$ & $\begin{array}{c}\text { Washington } \\
\text { Centralia } \\
\text { City of } \\
\text { December } 31\end{array}$ & $\begin{array}{l}\text { Washington } \\
\text { Ellensburg } \\
\text { City of } \\
\text { December } 31\end{array}$ & $\begin{array}{l}\text { Washington } \\
\text { Port Angeles } \\
\text { City of } \\
\text { December } 31\end{array}$ \\
\hline \multicolumn{7}{|l|}{ Sources of Energy } \\
\hline 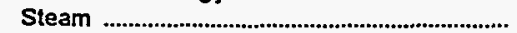 & 0 & $\mathbf{0}$ & 14,610 & 0 & 0 & 0 \\
\hline 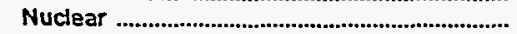 & 0 & 0 & 0 & 0 & 0 & 0 \\
\hline 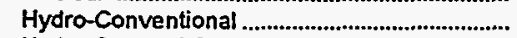 & 4,854 & 0 & 0 & 79,586 & 0 & 2,568 \\
\hline Hydro-Pumped Storage & 0 & 0 & 0 & 0 & 0 & 0 \\
\hline Other & 0 & 0 & 0 & 0 & 0 & 0 \\
\hline (Less) Energy for Pumping ................................ & 0 & 0 & 0 & 0 & 0 & 0 \\
\hline 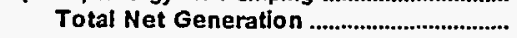 & 4,854 & 0 & 14,610 & 79,586 & 0 & 2,588 \\
\hline 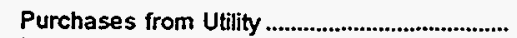 & 356,863 & 345,870 & 217,138 & 150,946 & 173,902 & 641,111 \\
\hline $\begin{array}{l}\text { Purchases from Nonutility ..................................... } \\
\text { Power Exchanges }\end{array}$ & 0 & 0 & 0 & 0 & 0 & \\
\hline 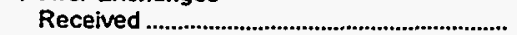 & 0 & 0 & 0 & 0 & 0 & 0 \\
\hline 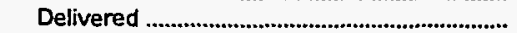 & 0 & 0 & 0 & 0 & 0 & 0 \\
\hline 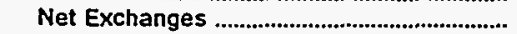 & 0 & 0 & 0 & 0 & 0 & 0 \\
\hline \multicolumn{7}{|l|}{ Transmission for Others (Wheeling) } \\
\hline Received & 0 & 0 & 0 & 0 & 0 & 0 \\
\hline 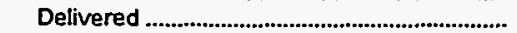 & 0 & 0 & 0 & 0 & 0 & 0 \\
\hline 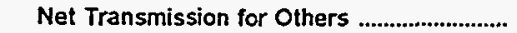 & 0 & 0 & 0 & 0 & 0 & 0 \\
\hline $\begin{array}{l}\text { Transmission by Others Losses ........................ } \\
\text { Total Net Energy }\end{array}$ & 0 & 0 & 0 & 0 & 0 & 0 \\
\hline Generated and Received & 361,717 & 345,870 & 231,748 & 230,532 & 173,902 & 643,679 \\
\hline \multicolumn{7}{|l|}{ Disposition of Energy } \\
\hline 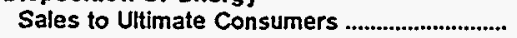 & 352,701 & 328.870 & 222,667 & 211,976 & 169,138 & 638,573 \\
\hline 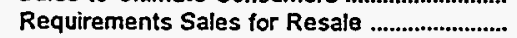 & 0 & 0 & 0 & 0 & 0 & 0 \\
\hline Nonrequirements Sales for Resale ................. & 0 & 0 & 0 & 0 & $\mathbf{0}$ & 0 \\
\hline 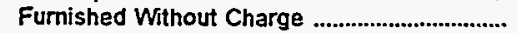 & 10 & 0 & 0 & 0 & 0 & 1,418 \\
\hline Used by Utility (excluding station use) ............. & 15 & 0 & 0 & 293 & $\mathbf{0}$ & 534 \\
\hline $\begin{array}{l}\text { Losses } \\
\text { Total Disposition }\end{array}$ & $\begin{array}{r}8,991 \\
361,717\end{array}$ & $\begin{array}{r}17,000 \\
345,870\end{array}$ & $\begin{array}{r}9,081 \\
231,748\end{array}$ & $\begin{array}{r}18,263 \\
230,532\end{array}$ & $\begin{array}{r}4,764 \\
173,902\end{array}$ & $\begin{array}{r}3,154 \\
643,679\end{array}$ \\
\hline
\end{tabular}

Note: Totals may not equal sum of components because of independent rounding. Double counting occurs in components of both sources and disposition of energy and thus neither provides a true total. Purchases from utilities, net interchanges, and net wheeling (except for imports) are included in net generation.

Source: Energy Information Administration, Form ElA-412, "Annual Report of Public Electric Utilities." 
Table 26. Electric Energy Account by Major U.S. Publicly Owned Electric Utility Within State, 1995 (Continued)

(Megawatthours)

\begin{tabular}{|c|c|c|c|c|c|c|}
\hline Item & $\begin{array}{c}\text { Washington } \\
\text { PUD No } 1 \\
\text { of } \\
\text { Benton } \\
\text { County } \\
\text { December } 31\end{array}$ & $\begin{array}{c}\text { Washington } \\
\text { PUD No } 1 \\
\text { of } \\
\text { Chelan } \\
\text { County } \\
\text { December } 31\end{array}$ & $\begin{array}{l}\text { Washington } \\
\text { PUD No } 1 \text { of } \\
\text { Clallam } \\
\text { County } \\
\text { December } 31\end{array}$ & $\begin{array}{c}\text { Washington } \\
\text { PUD No } 1 \\
\text { of } \\
\text { Clark } \\
\text { County } \\
\text { December } 31\end{array}$ & $\begin{array}{l}\text { Washington } \\
\text { PUD No } 1 \text { of } \\
\text { Cowitz } \\
\text { County } \\
\text { December } 31\end{array}$ & $\begin{array}{l}\text { Washington } \\
\text { PUD No I of } \\
\text { Douglas } \\
\text { County } \\
\text { December } 31\end{array}$ \\
\hline \multicolumn{7}{|l|}{ Sources of Energy } \\
\hline 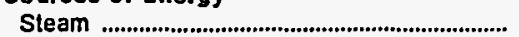 & 0 & 0 & 0 & 0 & 0 & 0 \\
\hline 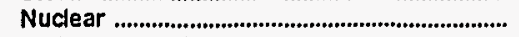 & 0 & 0 & 0 & 0 & 0 & 0 \\
\hline 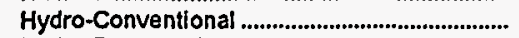 & 0 & $8,820,728$ & $\mathbf{0}$ & 0 & 274,644 & $4,277,868$ \\
\hline Hydro-Pumped Storage ........................................ & 0 & 0 & 0 & 0 & 0 & 0 \\
\hline Other & 0 & 0 & 0 & 0 & 0 & 0 \\
\hline 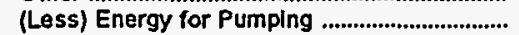 & 0 & 0 & 0 & 0 & 0 & 0 \\
\hline 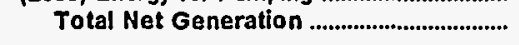 & 0 & $8,820,728$ & 0 & 0 & 274,644 & $4,277,868$ \\
\hline 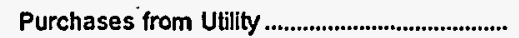 & $1,427,955$ & 194,730 & 508,174 & $3,620,997$ & $4,325,982$ & 170,246 \\
\hline $\begin{array}{l}\text { Purchases from Nonutility ................................. } \\
\text { Power Exchanges }\end{array}$ & 0 & 0 & 249 & 68,682 & 0 & \\
\hline 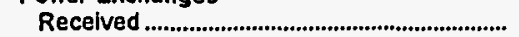 & 0 & $1,032,147$ & 0 & 0 & 0 & 369,368 \\
\hline 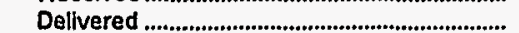 & 0 & 453,285 & 0 & 0 & 0 & 376,002 \\
\hline 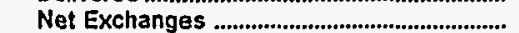 & 0 & 578,862 & 0 & 0 & 0 & $-6,634$ \\
\hline \multicolumn{7}{|l|}{ Transmission for Others (Wheeling) } \\
\hline 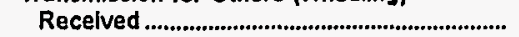 & 0 & 63,748 & 0 & 0 & 367,085 & 0 \\
\hline 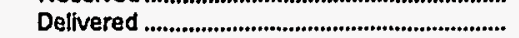 & 0 & 46,618 & 0 & 0 & 367,085 & 0 \\
\hline Net Transmission for Others ............................. & 0 & 17,130 & 0 & 0 & 0 & 0 \\
\hline $\begin{array}{l}\text { Transmission by Others Losses .......................... } \\
\text { Total Net Eneray }\end{array}$ & $\mathbf{0}$ & $-1,505$ & 0 & $\mathbf{0}$ & 0 & 0 \\
\hline 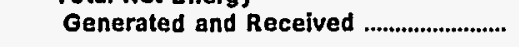 & $1,427,955$ & $9,609,945$ & 508,423 & $3,689,679$ & $4,600,626$ & $4,441,480$ \\
\hline \multicolumn{7}{|l|}{ Disposition of Energy } \\
\hline 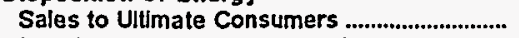 & $1,372,157$ & $1,281,607$ & 475,080 & $3,662,771$ & $4,554,973$ & 689.777 \\
\hline Requirements Sales for Resale ........................ & 0 & $6,368,190$ & 0 & 0 & 2,039 & $2,951,695$ \\
\hline Nonrequirements Sales for Resale ................... & 0 & $1,951,594$ & 0 & $\mathbf{0}$ & 0 & 344,314 \\
\hline 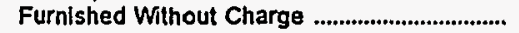 & 0 & 21 & 0 & $\mathbf{0}$ & 0 & 366,518 \\
\hline Used by Utility (excluding station use) ............ & 1,415 & 382 & 1,193 & 9,591 & 2,807 & 2,394 \\
\hline $\begin{array}{l}\text { Losses } \\
\text { Total Disposition }\end{array}$ & $\begin{array}{r}54,383 \\
1,427,955\end{array}$ & $\begin{array}{r}8,151 \\
9,609,945\end{array}$ & $\begin{array}{r}32,150 \\
508,423\end{array}$ & $\begin{array}{r}17,317 \\
3,689,679\end{array}$ & $\begin{array}{r}40,807 \\
4,600,626\end{array}$ & $\begin{array}{r}86,782 \\
4,441,480\end{array}$ \\
\hline
\end{tabular}

Note: Totals may not equal sum of components because of independent rounding. Double counting occurs in components of both sources and disposition of energy and thus nelther provides a true total. Purchases from utiities, net interchanges, and net wheeling (except for imports) are included in net generation. Sales for resale is included in sales to ultimate consumers.

Source: Energy Information Administration, Form ElA-412, "Annual Report of Public Electric Utilities." 
Table 26. Electric Energy Account by Major U.S. Publicly Owned Electric Utility Within State, 1995 (Continued)

(Megawatthours)

\begin{tabular}{|c|c|c|c|c|c|c|}
\hline Item & $\begin{array}{l}\text { Washington } \\
\text { PUD No } 1 \text { of } \\
\text { Franklin } \\
\text { County } \\
\text { December } 31\end{array}$ & $\begin{array}{c}\text { Washington } \\
\text { PUD No } 1 \\
\text { of } \\
\text { Grays } \\
\text { Harbor Cnty } \\
\text { December } 31\end{array}$ & $\begin{array}{l}\text { Washington } \\
\text { PUD No } 1 \text { of } \\
\text { Klickitat } \\
\text { County } \\
\text { December } 31\end{array}$ & $\begin{array}{c}\text { Washington } \\
\text { PUD No } 1 \\
\text { of } \\
\text { Lewis } \\
\text { County } \\
\text { December } 31\end{array}$ & $\begin{array}{c}\text { Washington } \\
\text { PUD No } 1 \text { of } \\
\text { Okanogan } \\
\text { County } \\
\text { December } 31\end{array}$ & $\begin{array}{l}\text { Washington } \\
\text { PUD No } 1 \text { of } \\
\text { Pend Oreille } \\
\text { Cnty } \\
\text { December } 31\end{array}$ \\
\hline \multicolumn{7}{|l|}{ Sources of Energy } \\
\hline Steam & 0 & 244,183 & 0 & 0 & 0 & 0 \\
\hline 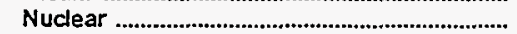 & 0 & 0 & 0 & 0 & 0 & 0 \\
\hline 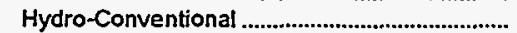 & 0 & 0 & 0 & 1,039 & 0 & 497,650 \\
\hline 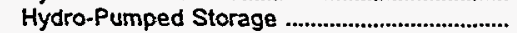 & 0 & 0 & 0 & 0 & 0 & 0 \\
\hline Other & 0 & 0 & 0 & 0 & 0 & 0 \\
\hline 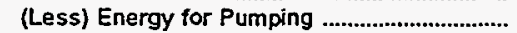 & 0 & $\mathbf{0}$ & 0 & 0 & 0 & 0 \\
\hline 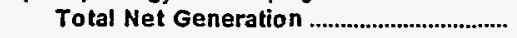 & o & 244,183 & 0 & 1,039 & $\mathbf{0}$ & 497,650 \\
\hline 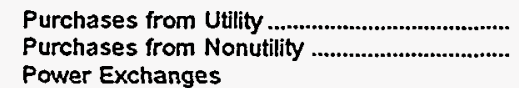 & $\begin{array}{r}657,228 \\
18,245\end{array}$ & $\begin{array}{r}923,971 \\
0\end{array}$ & $\begin{array}{r}302,717 \\
0\end{array}$ & $\begin{array}{r}710,589 \\
0\end{array}$ & $\begin{array}{r}594,457 \\
11,037\end{array}$ & $\begin{array}{r}530,471 \\
0\end{array}$ \\
\hline 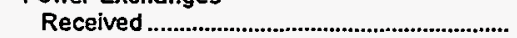 & 0 & 35,377 & 0 & 0 & 0 & 35,182 \\
\hline 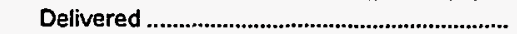 & 0 & 35,377 & 0 & 0 & 0 & 29,397 \\
\hline Net Exchanges & 0 & 0 & 0 & 0 & 0 & 5,785 \\
\hline \multicolumn{7}{|l|}{ Transmission for Others (Wheeling) } \\
\hline 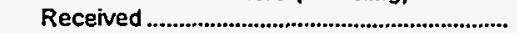 & 0 & 0 & 0 & 0 & 0 & 0 \\
\hline 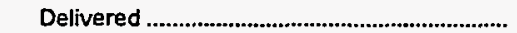 & 0 & 0 & 0 & 0 & 0 & 0 \\
\hline 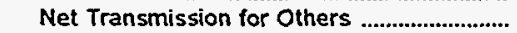 & 0 & 0 & 0 & 0 & 0 & 0 \\
\hline $\begin{array}{l}\text { Transmission by Others Losses ......................... } \\
\text { Total Net Energy }\end{array}$ & 0 & 0 & 0 & 0 & 0 & $-1,732$ \\
\hline 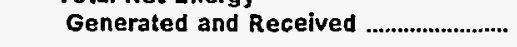 & 675,473 & $1,168,154$ & 302,717 & 711,628 & 605,494 & $1,032,174$ \\
\hline \multicolumn{7}{|l|}{ Disposition of Energy } \\
\hline 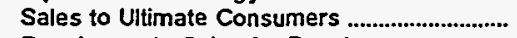 & 629,531 & $1,007,426$ & 281,129 & 674,855 & 570,535 & 903,391 \\
\hline 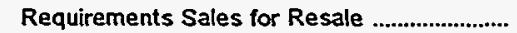 & 0 & 0 & 0 & 0 & 0 & 116,464 \\
\hline Nonrequirements Sales for Resale ................... & 0 & 103,042 & 0 & 0 & 0 & 0 \\
\hline 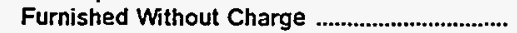 & 0 & 0 & 0 & 0 & 0 & 0 \\
\hline Used by Utility (excluding station use) ............ & 890 & 3,237 & 799 & $83 i$ & 1,383 & 699 \\
\hline $\begin{array}{l}\text { Losses . } \\
\text { Total Disposition }\end{array}$ & $\begin{array}{r}45,052 \\
675,473\end{array}$ & $\begin{array}{r}54,449 \\
1,168,154\end{array}$ & $\begin{array}{r}20,789 \\
302,717\end{array}$ & $\begin{array}{r}35,942 \\
711,628\end{array}$ & $\begin{array}{r}33,576 \\
605,494\end{array}$ & $\begin{array}{r}11,620 \\
1,032,174\end{array}$ \\
\hline
\end{tabular}

Note: Totals may not equal sum of components because of independent rounding. Double counting occurs in components of both sources and disposition of energy and thus neither provides a true total. Purchases from utilities, net interchanges, and net wheeling (except for imports) are inciuded in net generation.

Source: Energy Information Administration, Form ElA-412, "Annual Report of Public Electric Utlities." 
Table 26. Electric Energy Account by Major U.S. Publicly Owned Electric Utility Within State, 1995 (Continued)

(Megawatthours)

\begin{tabular}{|c|c|c|c|c|c|c|}
\hline Item & $\begin{array}{l}\text { Washington } \\
\text { PUD No } 1 \text { of } \\
\text { Snohomish } \\
\text { County } \\
\text { - } \\
\text { December } 31\end{array}$ & $\begin{array}{l}\text { Washington } \\
\text { PUD No } 1 \text { of } \\
\text { Whatcom } \\
\text { County } \\
\text { December } 31\end{array}$ & $\begin{array}{c}\text { Washington } \\
\text { PUD No } 2 \\
\text { of } \\
\text { Grant } \\
\text { County } \\
\text { December } 31\end{array}$ & $\begin{array}{l}\text { Washington } \\
\text { PUD No } 2 \text { of } \\
\text { Pacific } \\
\text { County } \\
\text { December } 31\end{array}$ & $\begin{array}{c}\text { Washington } \\
\text { PUD No } 3 \\
\text { of } \\
\text { Mason } \\
\text { County } \\
\text { December } 31\end{array}$ & $\begin{array}{l}\text { Washington } \\
\text { Richland } \\
\text { City of } \\
\text { December } 31\end{array}$ \\
\hline \multicolumn{7}{|l|}{ Sources of Energy } \\
\hline 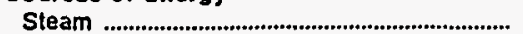 & 391,742 & 0 & 0 & 0 & 0 & 0 \\
\hline 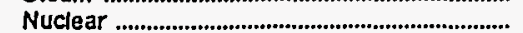 & 0 & 0 & 0 & 0 & 0 & 0 \\
\hline Hydro-Conventlonal ............................................. & 451,335 & 0 & $10,018,537$ & 0 & 0 & 0 \\
\hline 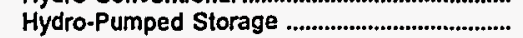 & 0 & 0 & 0 & 0 & 0 & 0 \\
\hline 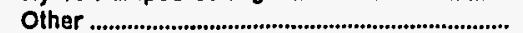 & 0 & 0 & 0 & 0 & 0 & 0 \\
\hline (Less) Energy for Pumping & 0 & 0 & 0 & 0 & 0 & 0 \\
\hline 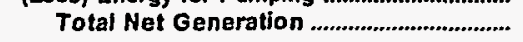 & 843,077 & 0 & $10,018,537$ & $\mathbf{0}$ & 0 & 0 \\
\hline 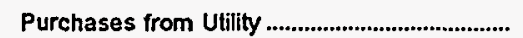 & $5,182,728$ & 157,339 & 545,498 & 276,647 & 531,834 & 644,409 \\
\hline $\begin{array}{l}\text { Purchases from Nonutility .......................................... } \\
\text { Power Exchanges }\end{array}$ & 0 & 0 & 0 & 0 & 0 & 0 \\
\hline 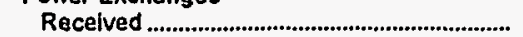 & 43,676 & 0 & 258,765 & 0 & 0 & 0 \\
\hline Dellvered & 38,209 & 0 & 343,195 & 0 & 0 & 0 \\
\hline Net Exchanges & 5,467 & 0 & $-84,430$ & 0 & 0 & 0 \\
\hline \multicolumn{7}{|l|}{ Transmission for Others (Wheeling) } \\
\hline 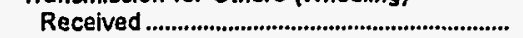 & 0 & 0 & 0 & 0 & 0 & 0 \\
\hline 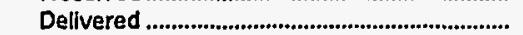 & 0 & 0 & 0 & 0 & 0 & 0 \\
\hline Net Transmission for Others ............................ & 0 & 0 & 0 & 0 & 0 & 0 \\
\hline $\begin{array}{l}\text { Transmission by Others Losses ............................. } \\
\text { Total Nel Energy }\end{array}$ & 0 & 0 & 0 & 0 & $\mathbf{0}$ & 0 \\
\hline 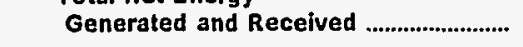 & $6,031,272$ & 157,339 & $10,479,605$ & 276,647 & 531,834 & 644,409 \\
\hline \multicolumn{7}{|l|}{ Dlsposition of Energy } \\
\hline 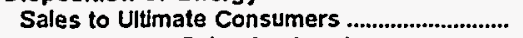 & $5,682,565$ & 157,339 & $2,751,453$ & 264,525 & 511.592 & 633,976 \\
\hline Requirements Sales for Resale ........................ & 94,024 & 0 & $5,993,289$ & 0 & 3,472 & 0 \\
\hline Nonrequirements Sales for Resale .................. & 0 & 0 & 861,796 & 0 & 0 & 0 \\
\hline Furnished Without Charge .................................. & 0 & 0 & 740,436 & 0 & 0 & 0 \\
\hline Used by Utility (excluding station use) ............ & 13,340 & 0 & 7,840 & 480 & 782 & 0 \\
\hline $\begin{array}{l}\text { Losses } \\
\text { Total Disposition }\end{array}$ & $\begin{array}{r}241,343 \\
6,031,272\end{array}$ & $\begin{array}{r}0 \\
157,339\end{array}$ & $\begin{array}{r}124,791 \\
10,479,605\end{array}$ & $\begin{array}{r}11,642 \\
276,647\end{array}$ & $\begin{array}{r}15,988 \\
531,834\end{array}$ & $\begin{array}{r}10,433 \\
644,409\end{array}$ \\
\hline
\end{tabular}

Note: Totals may not equal sum of components because of independent rounding. Double counting occurs in components of both sources and disposition of energy and thus neither provides a true tota!. Purchases from utilities, net interchanges, and net wheeling (except for imports) are inciuded in net generation.

Source: Energy Information Administration, Form EIA-412, "Annual Report of Public Electric Utilities." 
Table 26. Electric Energy Account by Major U.S. Publicly Owned Electric Utility Within State, 1995 (Continued)

(Megawatthours)

\begin{tabular}{|c|c|c|c|c|c|c|}
\hline Item & $\begin{array}{c}\text { Washington } \\
\text { Seattle } \\
\text { City of } \\
\text { December } 31\end{array}$ & $\begin{array}{c}\text { Washington } \\
\text { Tacoma } \\
\text { City of } \\
\text { December } 31\end{array}$ & $\begin{array}{c}\text { Washington } \\
\text { Vera } \\
\text { Irrigation } \\
\text { District \#15 } \\
\text { December } 31\end{array}$ & $\begin{array}{l}\text { Washington } \\
\text { Washington } \\
\text { Pub } \\
\text { Pur } \\
\text { Supply Sys } \\
\text { June } 30\end{array}$ & $\begin{array}{l}\text { Wisconsin } \\
\text { Badger Power } \\
\text { Marketing } \\
\text { Auth }\end{array}$ & $\begin{array}{c}\text { Wisconsin } \\
\text { Jefferson } \\
\text { City of } \\
\text { December } 31\end{array}$ \\
\hline \multicolumn{7}{|l|}{ Sources of Energy } \\
\hline Steam & 441,939 & 590,673 & 0 & 0 & 0 & 0 \\
\hline Nuclear & 0 & 0 & 0 & $6,942,686$ & 0 & 0 \\
\hline 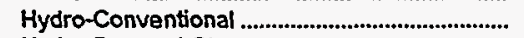 & $7,009,856$ & $3,170,720$ & 0 & 60,678 & 0 & 0 \\
\hline Hydro-Pumped Storage & 0 & 0 & 0 & 0 & 0 & 0 \\
\hline Other & $-10,767$ & $\mathbf{0}$ & 0 & 0 & 0 & 0 \\
\hline 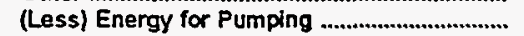 & 0 & 0 & 0 & 0 & 0 & 0 \\
\hline 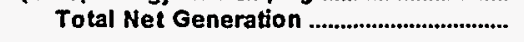 & $7,441,028$ & $3,761,393$ & 0 & $7,003,364$ & 0 & 0 \\
\hline 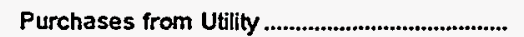 & $2,213,281$ & $1,762,412$ & 179,230 & 0 & 281 & 144,241 \\
\hline $\begin{array}{l}\text { Purchases from Nonutility ...................................... } \\
\text { Power Exchanges }\end{array}$ & 12,748 & 514.200 & 0 & 0 & 0 & \\
\hline 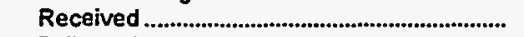 & $7,407,289$ & 66,503 & 0 & 0 & 0 & 0 \\
\hline 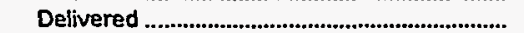 & $7,671,645$ & 31,442 & 0 & 0 & 0 & $\mathbf{0}$ \\
\hline Net Exchanges & $-264,356$ & 35,061 & 0 & 0 & 0 & 0 \\
\hline \multicolumn{7}{|l|}{ Transmission for Others (Wheeling) } \\
\hline Received & 42,314 & $1,297,286$ & 0 & 0 & 0 & $\mathbf{0}$ \\
\hline 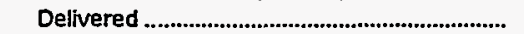 & 42,314 & $1,297,286$ & 0 & 0 & 0 & 0 \\
\hline 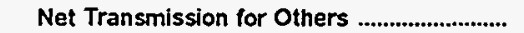 & 0 & 0 & 0 & 0 & 0 & 0 \\
\hline $\begin{array}{l}\text { Transmission by Others Losses ........................ } \\
\text { Total Net Energy }\end{array}$ & 0 & 0 & 0 & 0 & 0 & 0 \\
\hline Generated and Received & $9,402,701$ & $6,073,066$ & 179,230 & $7,003,364$ & 281 & 144,241 \\
\hline \multicolumn{7}{|l|}{ Disposition of Energy } \\
\hline 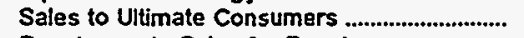 & $8,788,829$ & $5,331,048$ & 174,557 & 0 & 0 & 140.228 \\
\hline 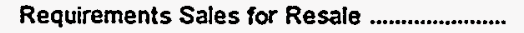 & 0 & 359,328 & 0 & $6,998,827$ & 279 & 0 \\
\hline Nonrequirements Sales for Resala ................... & 0 & 235,978 & 0 & 0 & 0 & $\mathbf{0}$ \\
\hline Fumished Without Charge .................................. & 0 & 0 & 0 & 0 & 0 & 0 \\
\hline Used by Utility (excluding station use) ............ & 28,891 & 5,463 & 0 & 0 & 0 & 0 \\
\hline Losses & 584,981 & 141,249 & 4,673 & 4,537 & 2 & 4,013 \\
\hline Total Disposition & $9,402,701$ & $6,073,066$ & 179,230 & $7,003,364$ & 281 & 144,241 \\
\hline
\end{tabular}


Table 26. Electric Energy Account by Major U.S. Publicly Owned Electric Utility Within State, 1995 (Continued)

(Megawatthours)

\begin{tabular}{|c|c|c|c|c|c|c|}
\hline Item & $\begin{array}{l}\text { Wisconsin } \\
\text { Kaukauna } \\
\text { City of } \\
\text { December } 31\end{array}$ & $\begin{array}{l}\text { Wisconsin } \\
\text { Manitowoc } \\
\text { Public } \\
\text { Utilities } \\
\text { December } 31\end{array}$ & $\begin{array}{l}\text { Wisconsin } \\
\begin{array}{l}\text { Marshfield } \\
\text { City of }\end{array} \\
\text { December } 31\end{array}$ & $\begin{array}{l}\text { Wisconsin } \\
\text { Menasha } \\
\text { City of } \\
\text { December } 31\end{array}$ & $\begin{array}{l}\text { Wisconsin } \\
\text { New London } \\
\text { Electric\&Water } \\
\text { Util } \\
\text { December } 31\end{array}$ & $\begin{array}{l}\text { Wisconsin } \\
\text { Oconornowac } \\
\text { City of } \\
\text { December } 31\end{array}$ \\
\hline 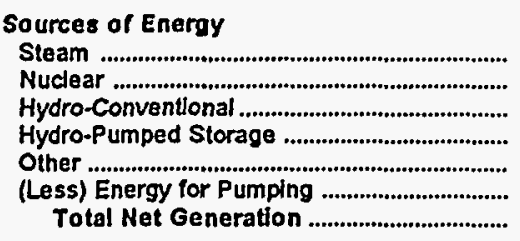 & $\begin{array}{r}0 \\
0 \\
152,442 \\
0 \\
0 \\
0 \\
152,442\end{array}$ & $\begin{array}{r}235,405 \\
0 \\
0 \\
0 \\
3,951 \\
0 \\
239,356\end{array}$ & $\begin{array}{l}0 \\
0 \\
0 \\
0 \\
0 \\
0 \\
0\end{array}$ & $\begin{array}{l}0 \\
0 \\
0 \\
0 \\
0 \\
0 \\
0\end{array}$ & $\begin{array}{l}0 \\
0 \\
0 \\
0 \\
0 \\
0 \\
0\end{array}$ & $\begin{array}{l}0 \\
0 \\
0 \\
0 \\
0 \\
0 \\
0\end{array}$ \\
\hline 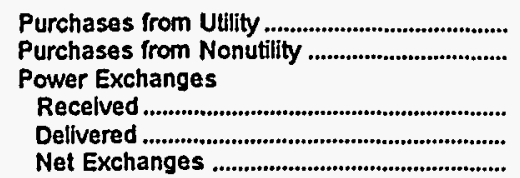 & $\begin{array}{r}578,424 \\
0\end{array}$ & $\begin{array}{r}276.508 \\
0\end{array}$ & $\begin{array}{r}329.531 \\
0\end{array}$ & $\begin{array}{r}561,586 \\
0\end{array}$ & $\begin{array}{r}168,122 \\
0\end{array}$ & $\begin{array}{r}179,127 \\
0\end{array}$ \\
\hline 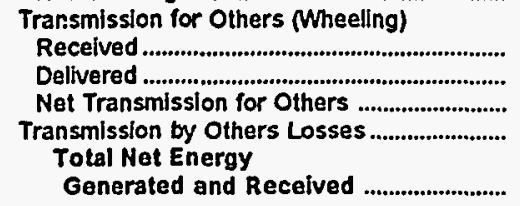 & 730,866 & 515,864 & $\begin{array}{l}0 \\
0 \\
0 \\
0\end{array}$ & 561,586 & 168,122 & 179,127 \\
\hline 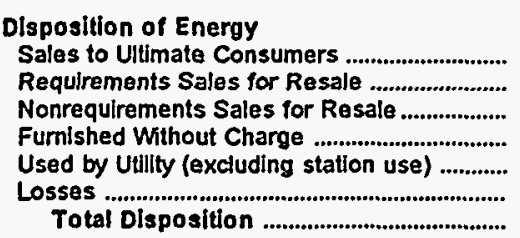 & $\begin{array}{r}710,493 \\
0 \\
0 \\
0 \\
688 \\
19,685 \\
730,866\end{array}$ & $\begin{array}{r}494,131 \\
308 \\
0 \\
0 \\
399 \\
21,026 \\
515,864\end{array}$ & $\begin{array}{r}317,192 \\
0 \\
0 \\
0 \\
1,727 \\
10,612 \\
329,531\end{array}$ & $\begin{array}{r}551,952 \\
0 \\
0 \\
0 \\
281 \\
9,353 \\
561,586\end{array}$ & $\begin{array}{r}164,476 \\
0 \\
0 \\
0 \\
1,322 \\
2,324 \\
168,122\end{array}$ & $\begin{array}{r}173,343 \\
0 \\
0 \\
0 \\
0 \\
0 \\
5,784 \\
179,127\end{array}$ \\
\hline
\end{tabular}

Note: Totals may not equal sum of components because of independent rounding. Double counting occurs in components of both sources and disposition of energy and thus neither provides a true total. Purchases from utilities, net interchanges, and net wheeling (except for imports) are included in net generation.

Source: Energy Information Administration, Form ElA-412, "Annual Report of Public Electric Utilities." 
Table 26. Electric Energy Account by Major U.S. Publicly Owned Electric Utility Within State, 1995 (Continued)

(Megawatthours)

\begin{tabular}{|c|c|c|c|c|c|c|}
\hline Item & $\begin{array}{l}\text { Wisconsin } \\
\text { Plymouth } \\
\text { City of } \\
\text { December } 31\end{array}$ & $\begin{array}{l}\text { Wisconsin } \\
\text { Reedsburg } \\
\text { Utility Comm } \\
\text { December } 31\end{array}$ & $\begin{array}{c}\text { Wisconsin } \\
\text { Shawano } \\
\text { Municipal } \\
\text { Utilities } \\
\text { December } 31\end{array}$ & $\begin{array}{c}\text { Wisconsin } \\
\text { Sheboygan } \\
\text { Falls } \\
\text { City of } \\
\text { December } 31\end{array}$ & $\begin{array}{c}\text { Wisconsin } \\
\text { Sturgeon } \\
\text { Bay City of } \\
\text { December } 31\end{array}$ & $\begin{array}{l}\text { Wisconsin } \\
\text { Sun Prairie } \\
\text { Water \& Light } \\
\text { Comm } \\
\text { December } 31\end{array}$ \\
\hline \multicolumn{7}{|l|}{ Sources of Energy } \\
\hline 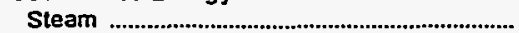 & 0 & 0 & 0 & 0 & 0 & $\mathbf{0}$ \\
\hline Nuclear & 0 & 0 & $\mathbf{0}$ & 0 & 0 & 0 \\
\hline 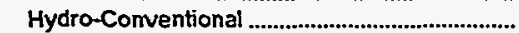 & 0 & $\mathbf{0}$ & 0 & 0 & 0 & 0 \\
\hline 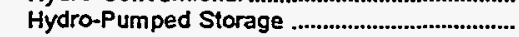 & 0 & 0 & 0 & 0 & 0 & 0 \\
\hline Other & 0 & 0 & 0 & 0 & 0 & $\mathbf{0}$ \\
\hline 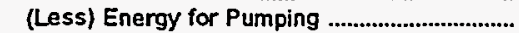 & 0 & 0 & 0 & 0 & 0 & 0 \\
\hline 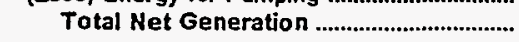 & 0 & 0 & 0 & 0 & 0 & 0 \\
\hline 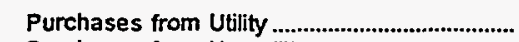 & 171,744 & 189,504 & 202,797 & 203,182 & 135,458 & 167,042 \\
\hline $\begin{array}{l}\text { Purchases from Nonutility ..................................... } \\
\text { Power Exchanges }\end{array}$ & 0 & 0 & 0 & 0 & 0 & 0 \\
\hline 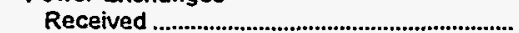 & 0 & 0 & 0 & 0 & 0 & 0 \\
\hline 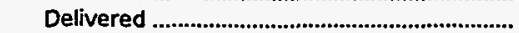 & 0 & 0 & 0 & 0 & 0 & 0 \\
\hline Net Exchanges & 0 & 0 & 0 & 0 & 0 & 0 \\
\hline \multicolumn{7}{|l|}{ Transmission for Others (Wheeling) } \\
\hline 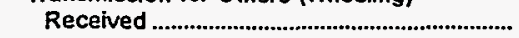 & 0 & 0 & 0 & $\mathbf{0}$ & 0 & $\mathbf{0}$ \\
\hline 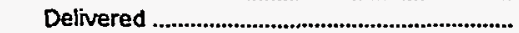 & 0 & 0 & 0 & 0 & 0 & 0 \\
\hline 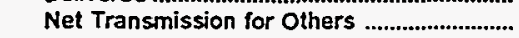 & 0 & 0 & 0 & 0 & 0 & 0 \\
\hline $\begin{array}{l}\text { Transmission by Others Losses...................... } \\
\text { Total Net Energy }\end{array}$ & 0 & 0 & 0 & 0 & 0 & $\mathbf{0}$ \\
\hline 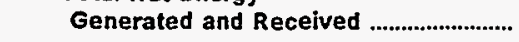 & 171,744 & 189,504 & 202,797 & 203,182 & 135,458 & 167,042 \\
\hline \multicolumn{7}{|l|}{ Disposition of Energy } \\
\hline 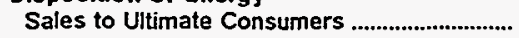 & 161,108 & 185,022 & 198,375 & 196,258 & 128,347 & 160,234 \\
\hline 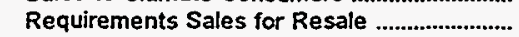 & 0 & 0 & 0 & 0 & 0 & 0 \\
\hline Nonrequirements Sales for Resale ..................... & 0 & 0 & 0 & 0 & 0 & 0 \\
\hline Furnished Without Charge & 0 & 0 & 0 & 0 & 0 & 0 \\
\hline Used by Utility (exciuding station use) ............. & 118 & 0 & 0 & 0 & 0 & 232 \\
\hline 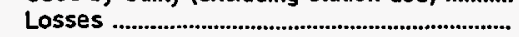 & 10,518 & 4,482 & 4,422 & 6,924 & 7,111 & 6,576 \\
\hline Total Disposition & 171,744 & 189,504 & 202,797 & 203,182 & 135,458 & 167,042 \\
\hline
\end{tabular}


Table 26. Electric Energy Account by Major U.S. Publicly Owned Electric Utility Within State, 1995 (Continued)

(Megawatthours)

\begin{tabular}{|c|c|c|c|c|}
\hline Item & $\begin{array}{l}\text { Wisconsin } \\
\text { Wisconsin } \\
\text { Public } \\
\text { Power } \\
\text { Inc Sys } \\
\text { December } 31\end{array}$ & $\begin{array}{l}\text { Wisconsin } \\
\text { Wisconsin } \\
\text { Rapids W W } \\
\& L \\
\text { Comm } \\
\text { December } 31\end{array}$ & $\begin{array}{l}\text { Wyoming } \\
\text { Gillette } \\
\text { City of } \\
\text { June } 30\end{array}$ & $\begin{array}{l}\text { Wyoming } \\
\text { Myoming } \\
\text { Municipal } \\
\text { Power Agency } \\
\text { December } 31\end{array}$ \\
\hline \multicolumn{5}{|l|}{ Sources of Energy } \\
\hline Steam & 764,364 & 0 & 0 & 157,307 \\
\hline Nuclear & 0 & 0 & 0 & 0 \\
\hline 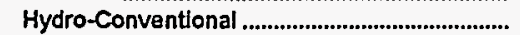 & 0 & 0 & 0 & 0 \\
\hline 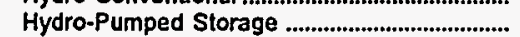 & 0 & 0 & 0 & 0 \\
\hline Other & 4,134 & 0 & 0 & 0 \\
\hline 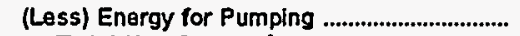 & 0 & 0 & 0 & 0 \\
\hline 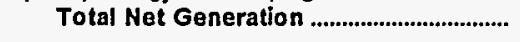 & 768,498 & 0 & 0 & 157,307 \\
\hline 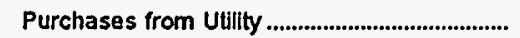 & $2,510,087$ & 216,744 & 186,829 & 56,572 \\
\hline $\begin{array}{l}\text { Purchases from Nonutility .................................. } \\
\text { Power Exchanges }\end{array}$ & 0 & $\mathbf{0}$ & 0 & 0 \\
\hline 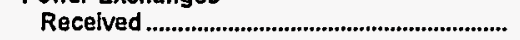 & 0 & 0 & 0 & 2,618 \\
\hline 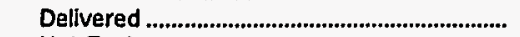 & 0 & $\mathbf{0}$ & 0 & 2,475 \\
\hline 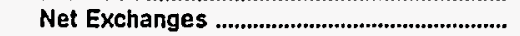 & 0 & 0 & 0 & 143 \\
\hline \multicolumn{5}{|l|}{ Transmission for Others (Wheeling) } \\
\hline 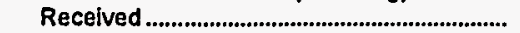 & $\mathbf{0}$ & 0 & 0 & 0 \\
\hline 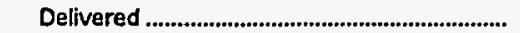 & 0 & 0 & 0 & 0 \\
\hline Net Transmission for Others ......................... & 0 & 0 & 0 & 0 \\
\hline $\begin{array}{l}\text { Transmission by Others Losses ......................... } \\
\text { Total Net Energy }\end{array}$ & 0 & 0 & 0 & 0 \\
\hline Generated and Received ............................. & $3,278,585$ & 216,744 & 186,829 & 214,022 \\
\hline \multicolumn{5}{|l|}{ Disposition of Energy } \\
\hline 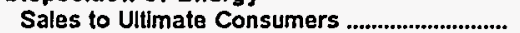 & 0 & 205,532 & 175,560 & 0 \\
\hline Requirements Sales for Resale ........................ & $3,233,554$ & 0 & 0 & 206,708 \\
\hline Nonrequirements Sales for Resale .................. & 0 & 0 & 0 & 0 \\
\hline 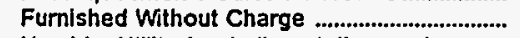 & 0 & 0 & 0 & 0 \\
\hline Used by Utility (excluding station use) ............ & 0 & 188 & 0 & 0 \\
\hline 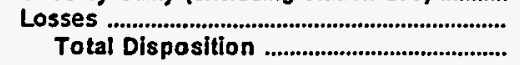 & $\begin{array}{r}45,031 \\
3,278,585\end{array}$ & $\begin{array}{r}11,024 \\
216,744\end{array}$ & $\begin{array}{r}11,269 \\
186,829\end{array}$ & $\begin{array}{r}7,314 \\
214,022\end{array}$ \\
\hline
\end{tabular}

Note: Totals may not equal sum of components because of independent rounding. Double counting occurs in components of both sources and disposition of energy and thus neither provides a true total. Purchases from utilities, net interchanges, and net wheeling (except for imports) are inciuded in net generation. Sales for resale is included in sales to ultimate consumers.

Gource: Energy Information Administration, Form EIA-412, "Annual Report of Public Electric Utilities." 
Summary Statistics of U.S. Federal Electric Utilities 


\section{Financial Performance}

\section{Background}

There are 10 Federal electric utilities in the United States. They are the Department of Defense's U.S. Army Corps of Engineers; the Department of Energy's five power marketing administrations, Alaska, Bonneville, Southeastern, Southwestern, and Western Area Power Administrations; the Department of Interior's U.S. Bureau of Indian Affairs and the U.S. Bureau of Reclamation; the Department of State's International Water and Boundary Commission; and, the Tennessee Valley Authority.

The Federal electric utilities are primarily generators and wholesalers of electricity rather than distributors to ultimate consumers. Federal electric utilities operate over 150 power plants and produce approximately 8 percent of the electricity generated in the United States. Most of the power plants are Federal hydroelectric projects initially designed for flood control and irrigation purposes. Federal power is sold at cost. This cost includes production expenses and the repayment of the federally provided financing. Most Federal generation is sold for resale to municipals, cooperative electric utilities, and other nonprofit preference customers, as required by law.

There are three major producers of electricity: the Tennessee Valley Authority (TVA), the largest Federal producer; the U.S. Army Corps of Engineers (USCE); and the U.S. Bureau of Reclamation (USBR). The TVA markets its own power while generation by the USCE, except for the North Central Division (Saint Mary's Falls at Sault St. Marie, Michigan), and the USBR is marketed by four of the Federal power marketing administrations - Bonneville, Southeastern, Southwestern, and Western Area. These four power marketing administrations also purchase energy for resale from other electric utilities in the United States and Canada. Alaska, the fifth power marketing administration, operates its own power plants and distributes power to ultimate consumers.

\section{Income Statement}

As of the end of the fiscal year (September 31, 1995), operating revenues for the federal electric utilities totaled $\$ 8,742.8$ million. Total electric utility operating expenses were $\$ 6,161.6$ million in 1995 . A major portion of these total electric utility operating expenses include production expenses that totaled $\$ 4,218.8$ million. Production expenses for the Federal electric utilities were 68.5 percent of total electric utility operating expenses. Total electric operation and maintenance expenses were $\$ 5,013.3$ million, 81.4 percent of total electric utility operating expenses for the Federal electric utilities.

Total electric utility income for the Federal electric utilities was $\$ 2,307.1$ million. Income deductions totaled $\$ 2,265.0$ million. Of the income deductions, $\$ 1,982.0$ million came from interest on long-term debt, which represented 87.5 percent of total income deductions. Net income for the Federal electric utilities as of the end of September 1995 was $\$ 309.3$ million virtually unchanged from the $\mathbf{3 0 9 . 6}$ million in 1994.

\section{Balance Sheet}

As of September 30, 1995, net investment in electric utility plant for the Federal electric utilities was $\$ 36,485.3$ million, including construction work in progress, which decreased to $\$ 16,461.2$ million, compared with \$16,626.4 million in 1994.

Total proprietary capital was $\$ 10,038.0$ million in 1995 , a slight decrease from $\$ 10,089.3$ million in 1994 , 20.1 percent of total liabilities and other credits. The amount of long-term debt and current and accrued liabilities was $\$ 31,225.0$ million, 62.5 percent of total liabilities and other credits of the Federal electric utilities.

\section{Sales of Electric Power}

In 1995, the Federal electric utilities had sales of electric energy to ultimate consumers of 49.9 million megawatthours and electricity sold for resale of $\mathbf{2 0 9 . 2}$ million mcgawatthours. Total disposition of energy was 279.2 million megawatthours of which the Federal electric utilities had a net generation of 261.1 million megawatthours (Table 32). 


\section{Historical Synopsis of Tennessee Valley Authority}

The Tennessee Valley Authority (TVA) was the first of the wholesale marketing organizations to be formed. It was authorized under the Tennessee Valley Authority Act in 1933 "for the purposes of maintaining and operating the properties now owned by the United States in the vicinity of Muscle Shoals, Alabama, in the interest of national defense and for agricultural and industrial development, and to improve navigation in the Tennessee River and to control the destructive flood waters in the Tennessee River and Mississippi River Basins." It was given the authority to both own and operate dams, transmission lines, and power plants along the Tennessee River and its tributaries. By the beginning of World War II, the TVA had developed most of its water resources, but growing war demands and domestic needs required new capacity. In 1949, Congress approved construction of a steam plant, opening the way for construction of other nonhydroelectric facilities. The TVA's fossil-fueled capacity and nuclear capacity now each exceed its hydroclectric capacity (run of river and pumped storage).

\section{Tennessee Valley Authority 1995 Summary}

In 1995, Tennessee Valley Authority (TVA) remained one of America's largest producers of electric power. Through 160 municipal and cooperative power distributors, TVA serves more than 7 million people in an 80,000 square-mile region. The four largest munici- palities are the Tennessee cities of Memphis, Nashville, Chattanooga, and Knoxville. Of the 131.6 million megawatthours of electricity generated in 1995 by TVA, the four largest municipals distributed 33.9 million megawatthours or 23.9 percent of TVA's total generation to their customers. For this reporting period, the power system consisted of three nuclear generating units, 11 coal-fired plants, and 29 hydroelectric dams, and as of September 30, 1995, TVA had 16,559 employees.

In 1995 , TVA experienced a $\$ 57.0$ million increase in construction work in progress, a $\$ 56.9$ million decrease in nuclear fuel assets, and a $\$ 377.6$ million increase in long-term debt (Figure 2). Reclassification of a portion of the capitalized interest component of nuclear plant to other assets resulted in a reduction in nuclear fuel. Long-term debt was increased to finance the completion of one nuclear fuel unit under construction, improvements at existing facilities, transmission lines, and environmental compliance. Future earnings, which will cover these debts, are dependent upon energy sales that are subject to factors such as weather, economic conditions, growth, competition, and open transmission access and TVA's ability to manage within existing rates or to raise rates to cover these cost.

Figure 2. Long-Term Debt, Construction Work In Process, and Nuclear Fuel for TVA, 1991-1995

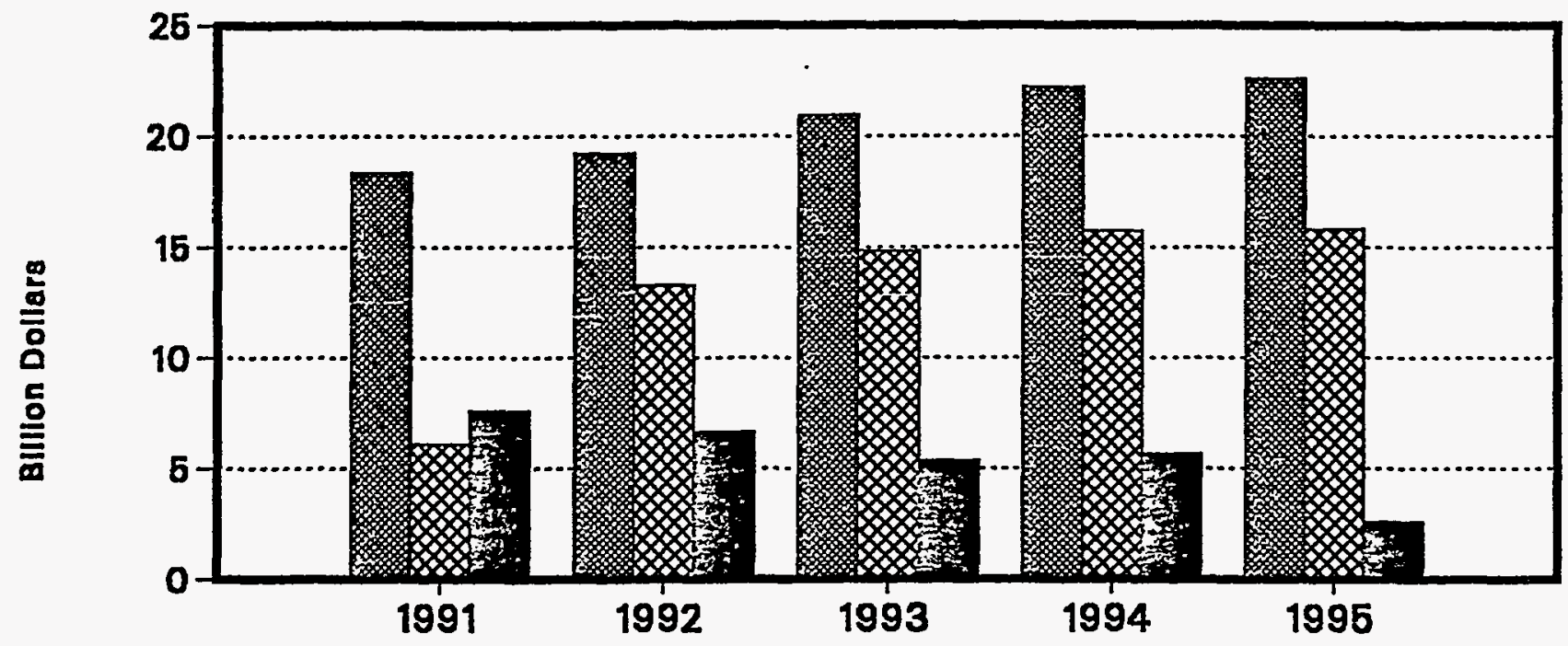

Source: Tennesege Valley Authority. ‘1895 Annual Report." (Knoxville, TN, 1896). 
Operating revenues were $\$ 5.4$ billion for $1995, \$ 5.4$ billion in 1993, and $\$ 5.3$ billion in 1993. These increases occurred in spite of steady power rates since 1987. Total kilowatthour sales were 137 billion in 1995,123 billion in 1994, and $119 \mathrm{kWh}$ billion in 1993 . The impact on sales of mild summer temperatures in 1995 was offset by overall sales growth of 11.9 percent in 1995 and 5.0 percent in 1994. Operating expenses remained decreased from $\$ 2.3$ in 1994 to $\$ 2.2$ billion for 1995.

\section{TVA's Energy Future}

Besides taking cost cutting measures today, TVA has begun a two-year Integrated Resource Planning Process. During these two years, TVA will evaluate ways to produce and conserve power, enhance efficiency, and develop a 25-year plan -- called Energy Vision 2020 -- to meet future needs. Energy Vision 2020 focuses on demand-side management techniques, evaluating existing facilities for future demand needs, and exploring innovative technologies that may hold the key to future energy supply. Although TVA has used energy planning in the past, Energy Vision 2020 reprcsents the first time the agency has asked the public to participate on a large scale through conducting public meetings and interviews.

TVA's primary competitors in the utility industry are the natural gas industry and other electric utilities hoping to expand their consumer base in the Tennessee Valley. In 1995, with the support of their distributors, TVA began new marketing initiatives. These new initiatives promote the agency, the power distributors, and electricity, as well as emphasize the wise use of energy. ${ }^{1}$ 
Figure 3. The Department of Energy's Five Power Marketing Administrations Service Areas, 1995

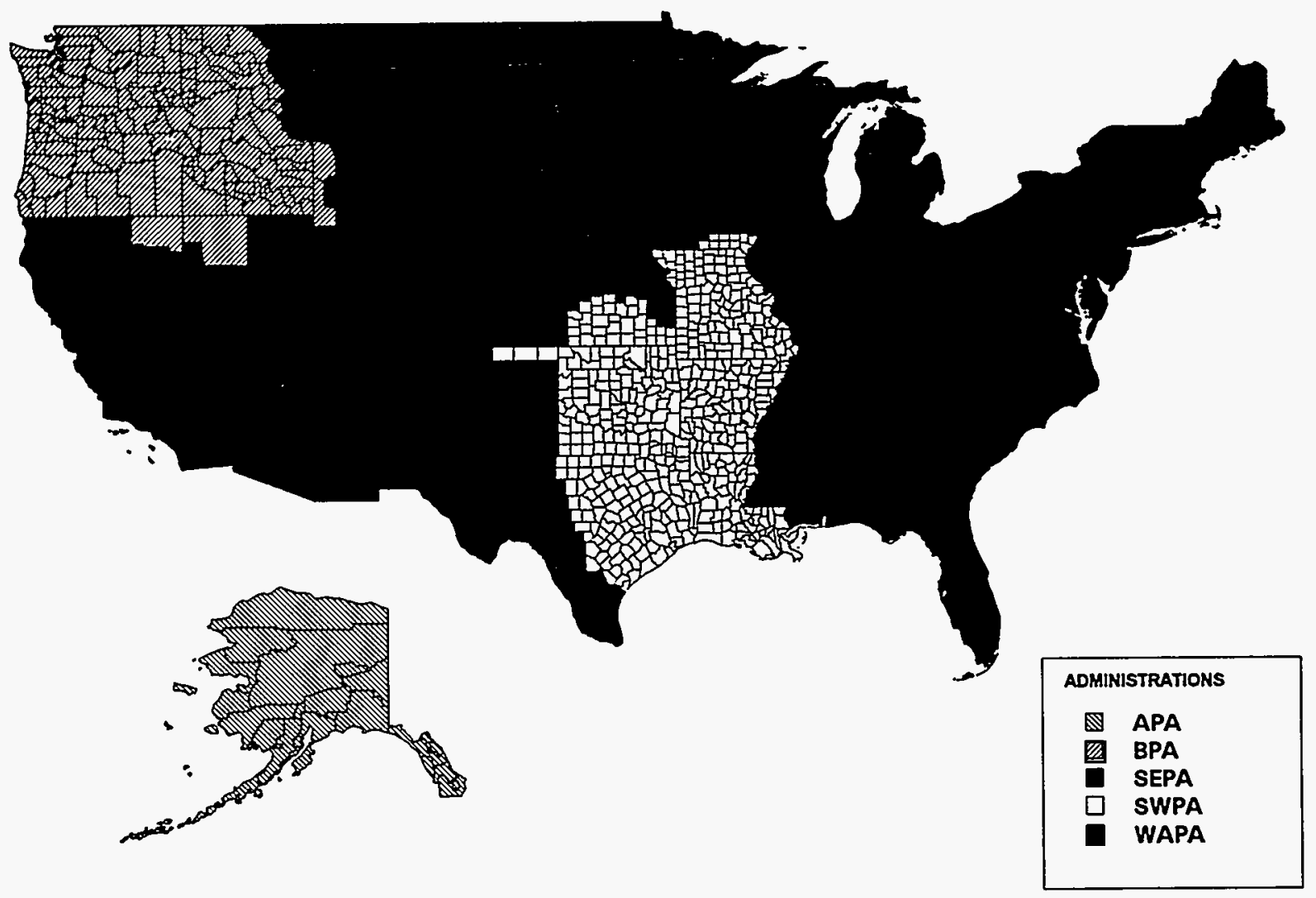

Source: Energy Information Adminlatration. Form ElA-412, “Annual Report of Public Elactric Utilitios." 


\section{Historical Synopsis of Alaska Power Administration}

The Alaska Power Marketing Administration (APA) was formed in 1967 under the Flood Control Act of 1944 to both operate and market power from two hydroelectric plants in Alaska: the Eklutna Project (30 megawatts) and the Snettisham Project $(78$ megawatts). The TVA and the APA are the only two Federal marketing organizations to operate their own plants.

\section{Alaska Power Administration 1995 Summary}

In 1995, the Alaska Power Administration (APA) had sales and revenues totaling 416.3 million kilowatthours and $\$ 10.7$ million, respectively. This was APA's highest revenue year on record. Receipts exceeded cash outlays before repayment to the U.S. Treasury by $\$ 5.4$ million. In fiscal year 1995 , the Snettisham Project generated 249 million kilowatthours, which produced revenues of $\$ 7.9$ million, and the Eklutna
Project sales of 167 million kilowatthours that yielded $\$ 2.8$ million in revenues.

\section{APA's Energy Future}

Implementation of the Alaska Power Administration Asset Sale and Termination Act will be the primary mission of the Alaska Power Administration until final termination. A detailed Transition Plan for the Eklutna Project was signed on May 28, 1996, and Public Law 104-188, signed August 20, 1996, includes Section 1804 that provides tax exempt bonds for the sale of the Snettisham Project. This legislation completes the divestiture of the Alaska Power Administration. At the present time, Alaska Power Administration estimates final transfer of both projects for November 28, 1997.

Unlike the other power marketing administrations, APA owns hydoelectric projects; operates the projects for the sole purpose of producing power; operates entirely in one state; and was never intended to remain under government control indefinitely. After taking these points into consideration for more than six years, the Congress has divested APA. ${ }^{2}$

Figure 4. Revenue Applied Chart for APA, 1991-1995

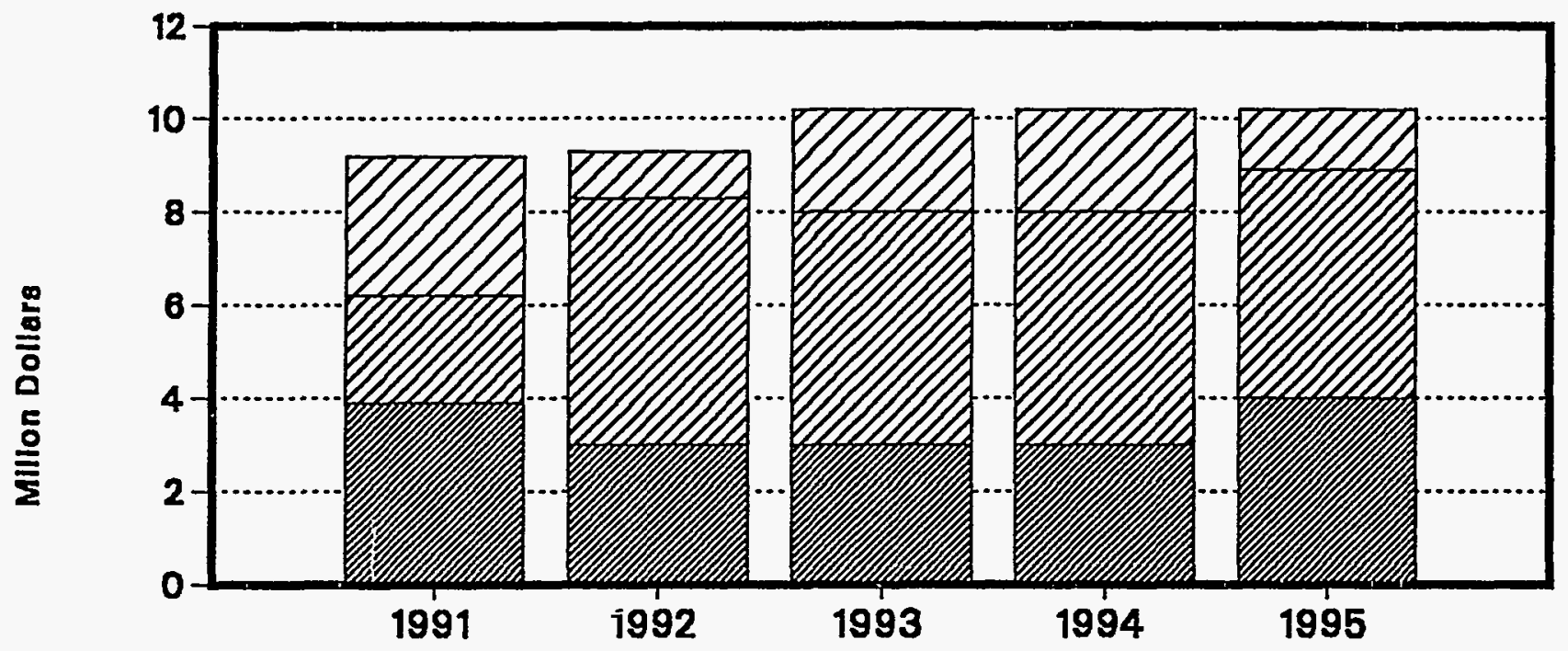

ZD Principal Payment
ZU Interest Expense
$\mathbb{Z}$ O\&M

Sourca: Aleska Powor Administration, '1885 Annual Roport, DOE/APA` (Junoeu, AK, 1886).

2 Alaska Power Administration, 1995 Annual Report, DOE/APA (Juncau, AK, 1996). 


\section{Historical Synopsis of Bonneville Power Administration}

During the depression in the early 1930's, New Deal legislation was passed that authorized construction of a number of Federal dams, including Grand Coulee and Bonneville dams in the Pacific Northwest. In 1937, the Government decided that the U.S. Bureau of Reclamation would be responsible for building and operating the dams in the Northwest, and a new marketing administration, the Bonneville Power Administration (BPA), was created by the Bonneville Project Act of 1937 to build and operate transmission facilities and to market the power. The BPA grew, but in the late 1960's, like the TVA, the BPA faced a potential shortage of hydroelectric capacity to meet their load. In 1980, the Pacific Northwest Electric Power Planning and Conservation Act gave the BPA the authority to plan for and acquire additional power to meet its growing load requirements. The BPA's responsibilities were also extended from only marketing Federal power to supplying the power. Its authority to supply power, however, was restricted to obtaining it from plants built by others; BPA cannot build its own power plants. Only the BPA and TVA are responsible for meeting their consumers loads. Under the $1980 \mathrm{Act}$, the BPA also must protect and enhance the fish and wildlife of the Columbia River and its tributaries.

\section{Bonneville Power Administration 1995 Summary}

Total Bonneville Power Adminisrtation oerating revenues rose from last year by $\$ 190$ million to $\$ 2,377.6$ million, an increase of 9 percent (Figure 5). This primarily reflects improved water conditions, meaning a long-awaited return to almost average runoff in the Columbia River Basin, plus increased revenues from aluminum companies due to higher aluminum prices and therefore higher payments to Bonneville Power Administration under the variable rate. Bonneville's variable rate is tied to the world price of aluminum and rose from its floor of 22.1 mills per kilowatt-hour in November 1994 to its cap of 31.7 mills per $\mathrm{kWh}$ before settling back to the plateau rate of 25.9 mills per kWh by September 1995. Over its lifetime, the variable rate has earned more than $\$ 50$ million more than Bonneville would have made under the industrial power rate. Therefore, the variable rate has contributed to the economic well-being of the region.

Bonneville also received a credit of $\$ 56$ million toward its U.S. Treasury payment to help pay for fish and wildlife impacts of non-power uses of the Northwest's federal dams.

Figure 5. Total Revenue and Expenses for BPA, 1991-1995
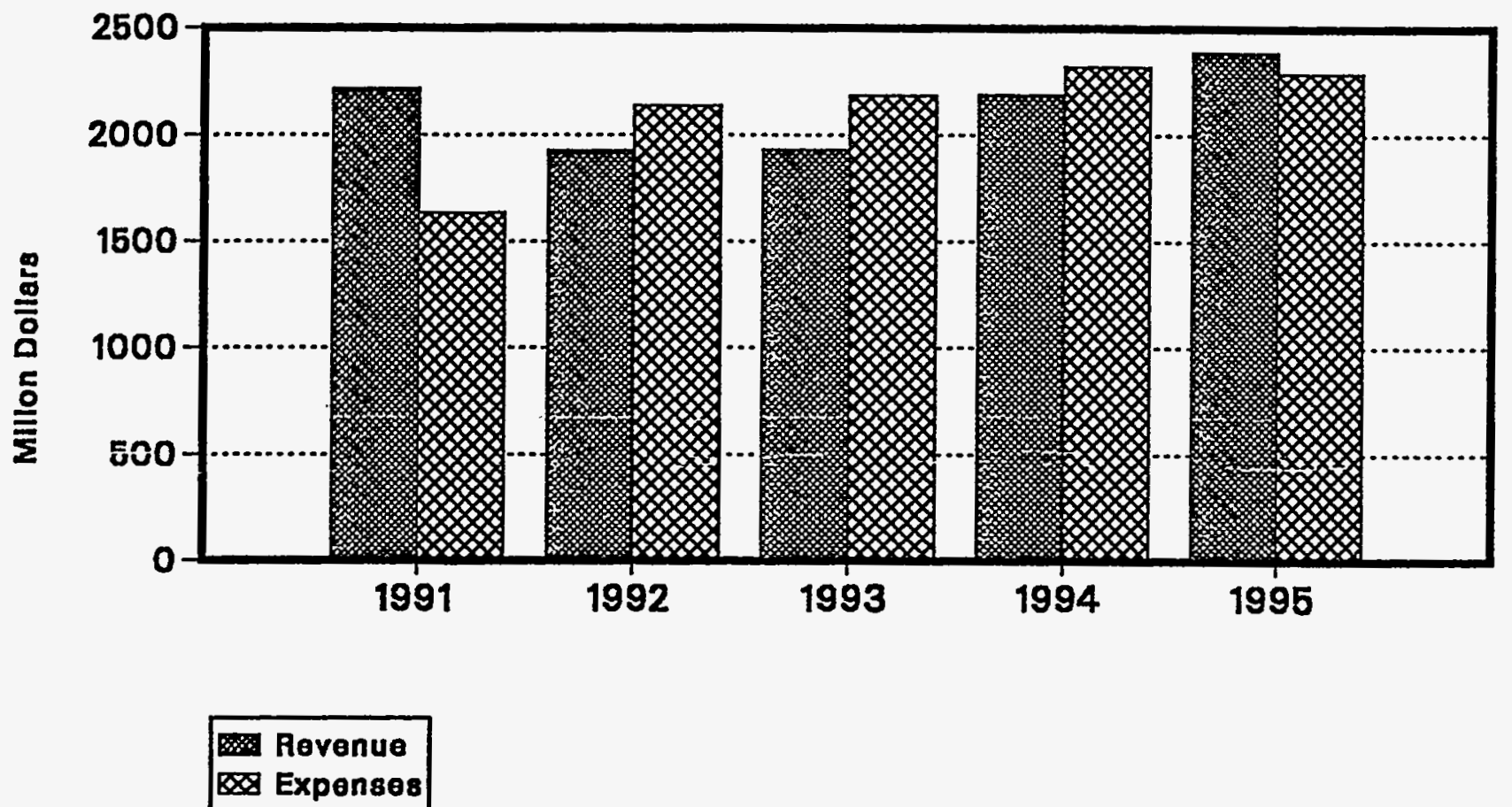

Source: Bonneville Power Adminlstration, 1896 Annual Report, DOE/BP-2621 (Portlend, OR, Jan. 1898) 
Revenues from power sales to publicly owned and cooperative electric utilities account for about half of total Bonneville revenues. These revenues decreased by $\$ 35$ million, or 3 percent to $\$ 1,169$ million, reflecting a mild winter. These utilities are BPA's largest and fastest growing consumer base in revenues and number of sales. Included in this category are 28 public utility districts, 41 municipals, and 56 cooperatives.

Revenues from the eight aluminum companies that buy power from BPA were $\$ 491$ million in 1995 an increase of $\$ 99$ million, or 25 percent, continuing a recovery in revenue from this customer class which began last year. Wetter weather and higher worldmarket aluminum prices caused the improvement. BPA restored service to the top quartile of its industrial load in January 1995, after extended curtailment due to poor weather conditions.

Revenues from seven investor-owned electric utilities rose $\$ 22$ million, or 7.0 percent, to $\$ 325$ million, pri- marily reflecting higher nonfirm energy sales on the spot market as water conditions improved.

Revenues from seven Federal agencies and eight nonaluminum industries rose $\$ 11$ million, or 20 percent, in 1995 to $\$ 65$ million. Sales to this group had dropped the two previous years, bottoming out at $\$ 54$ million in 1994.

\section{BPA's Energy Future}

BPA's customers continue to be courted by alternate suppliers. BPA has responded by lowering its proposed power rates to meet the market, simplifying its contract requirements and procedures, and reorganizing itself around customer needs. As a result, BPA is holding its customer base. Future revenues from direct-service industries have been stabilized under five-year block sale agreements signed this year, contigent on the outcome of the rate case. ${ }^{3}$

3 Bonneville Power Administration, 1995 Annual Report, DOE/BP-2521 (Portland, OR, January 1996). 
Historical Synopsis of Southwestern Power Administration

In 1943, the Southwestern Power Administration (SWPA) was created using the Executive Branch's emergency war powers authority to meet the growing power demands from weapons devclopment and domestic needs. Later, the SWPA's authority to continue to operate after World War II came from the Flood Control Act of 1944. Initially, the SWPA was assigned to market power from dams in Arkansas, Oklahoma, and Texas that were operated by the U.S. Department of Army to serve munitions plants. In 1945, the SWPA was designated as the agent for marketing power generated by the U.S. Army Corps of Engineers in the States of Arkansas, Kansas, Louisiana, Missouri, Oklahoma, and Texas. Today, SWPA sells power from 24 hydroelectric facilitics in these States that total 2,158 megawatts of installed capacity.

\section{Southwestern Power Administration 1995 Summary}

At the end of 1995, Southwestern Power Administration (SWPA) marketed power to 11 cooperatives, 3 military installations, 41 municipal utilities, and three municipal utility joint action agencies. SWPA experienced another above average year in hydropower generation with 7.2 gigawatthours of energy produced. SWPA collected revenues totaling $\$ 114.3$ million, which allowed $\$ 36.5$ million to be repaid on Federal investment, raising the total cumulative payment to $\$ 366.4$ million. million. During 1995 , two SWPA customers received rate increases.

In order to maintain a positive debt ratio and cash flow, SWPA has developed four financial performance measures as management tools to help monitor specific area of interest. These tools include SWPA debt coverage ratio, cumulative principal payments as a percent of total Federal investment, percent variance of actual from planned and annual payments, and net cash flow to the U.S. Treasury (Figure 6).

\begin{tabular}{|c|c|c|c|c|c|c|}
\hline e 6. Financlal Pertorman & tor SW & A, 1991 & 1993 & 1994 & 1995 & Analysis \\
\hline \multicolumn{7}{|l|}{ Debt senvice coverage ratio } \\
\hline & 0.834 & 1.053 & 1.332 & 1.194 & 1.185 & $\begin{array}{l}\text { Annual revenues were sufficient to } \\
\text { service the agencys planned pay- } \\
\text { ments. }\end{array}$ \\
\hline \multicolumn{7}{|l|}{$\begin{array}{l}\text { Cumulative principal payments as a } \\
\text { percent of total Federal investment }\end{array}$} \\
\hline & 22.84 & 25.36 & 29.86 & 32.74 & 36.38 & $\begin{array}{l}\text { Southwestern has made continuous } \\
\text { progress towards the repayment of } \\
\text { its total investment. }\end{array}$ \\
\hline $\begin{array}{l}\text { Percent variance of actual from } \\
\text { planned annualprincipal payments ..... }\end{array}$ & -8.90 & 13.08 & 66.16 & 35.98 & 42.45 & $\begin{array}{l}\text { Southwesterns ability to match its } \\
\text { planned principal payments is di- } \\
\text { rectly impacted by water conditions. }\end{array}$ \\
\hline Net cash flow to Treasury(000s) ......... & 17,504 & 32,324 & 38,162 & 25,579 & 10,745 & Provided positive cash flow. \\
\hline
\end{tabular}

Source: Southwestern Power Administration, 1995 Annual Report, DOE/SWPA-950I (Tulsa, OK, 1995).

\section{SWPA's Energy Future}

During FY 1995, the initial power investment in Southwestern's first power projects, Norfolk and Denison, were fully repaid. Initial power investment in the most recent of Southwestern's projects, Clarence Cannon, will be fully repaid by FY 2036. Initial capital costs of the Robert D. Willis project, which came on-line in FY 1990, were paid in advance by the non-Federal sponsor, the Sam Rayburn Municipal Power Agency. ${ }^{4}$ 


\section{Historical Synopsis of Southeastern Power Administration}

Southeastern Power Administration (SEPA), was established in 1950 under the authority of the Flood Control Act of 1944 to sell power produced by the U.S. Army Corps of Engineers in the Southeast. The SEPA currently markets power in West Virginia, Virginia, North Carolina, South Carolina, Georgia, Florida, Alabama, Mississippi, Tennessee, and Kentucky. The SEPA is unique from the other marketing authorities in that it owns no transmission lines. It must rely on private firms to transmit the power it sells. In its role to market energy generated by the Southeastirn Federal reservoir projects, it participated in the establishment of the Southeastern Federal Power Alliance, which consists of SEPA, the South Atlantic Division of the U.S. Army Corps of Engineers, and SEPA's preference customers. The purpose of this organization is to improve communication and establish a strategy by which the three groups can better implement the Federal Power Program in the southeast.

\section{Southeastern Power Administration 1995 Summary}

In 1995, the Southeastern Power Administration (SEPA) marketed wholesale power to 293 wholesale customers in 11 southern states. The sale of 7.1 billion kilowatthours of energy and approximately 3.0 million kilowatts of capacity generated revenues of $\$ 155$ million.
In 1994, SEPA opened a temporary Operations Center which enabled scheduling hourly generation of hydroelectric projects in the marketing area. The facility also serves as an emergency center in the advent of a disaster.

The Stonewall Jackson Project, located in West Virginia, was operated and energized in 1995 and became SEPA's 23rd project. The 300 kilowatt generator was added to the existing dam and commercial operation began in September. Energy generated in excess of project use is marketed to the Monongahela Power Company. During fiscal year 1995, 1,359,254 kilowatthours were generated. FY 1995 was its first full year of operation. The average annual generation for this project is expected to be $1,420,000$ kilowatthours.

SEPA's rates and repayments are sound and sufficient to cover all costs associated with power production and transmission costs. SEPA has maintained an average debt service ratio of 1.1 for 5 years, and a ratio of 1.0 indicates enough cash flow to make principal and interest payments on outstanding debts, as well as meeting all other cash expenses (Figure 7).

Cumulative principal payment as a percent of total investment indicates profitability. SEPA's repayment of investment funds advanced have increased over the past 5 years from 24 percent to 33 percent of the total Federal investment.

Figure 7. Debt Service Coverage Ratio for SEPA, 1991-1995

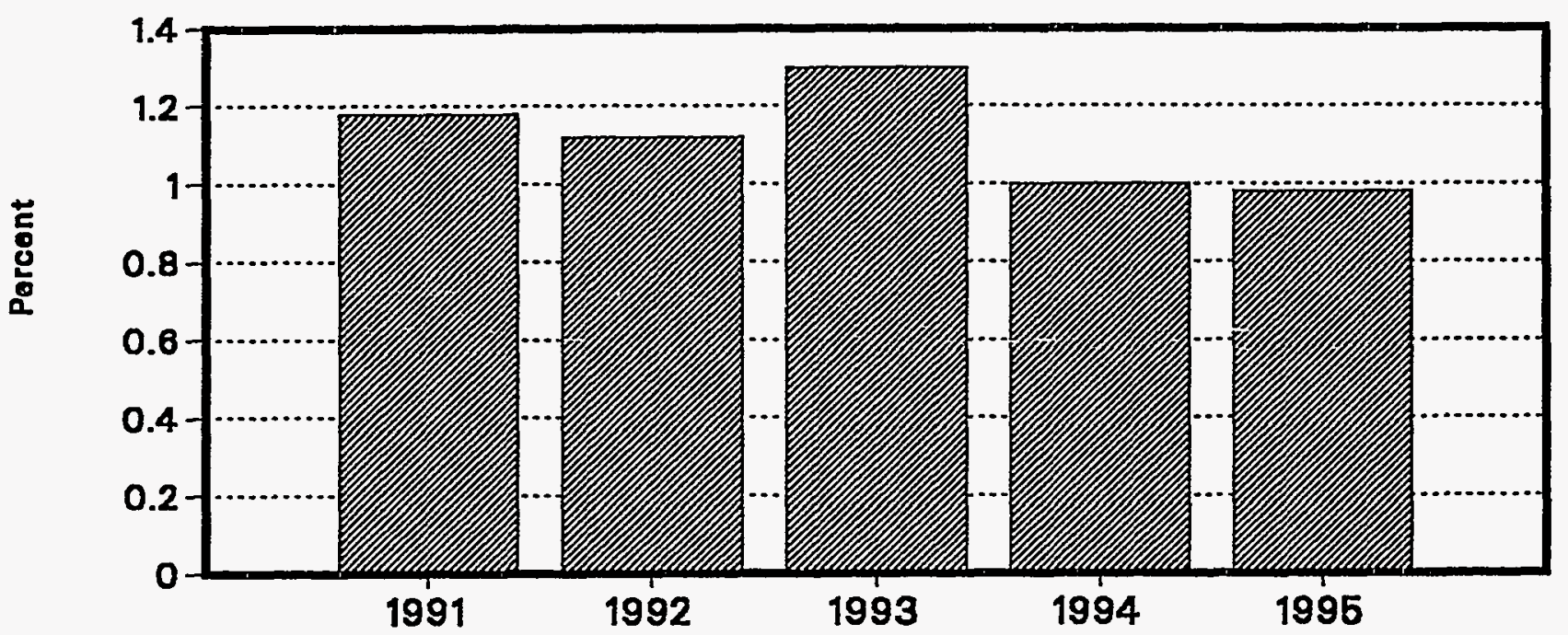

Source: Southeastern Powor Administration. "1995 Annual Report. DOE/SEPA' (Elberton, GA, 1996). 


\section{SEPA's Energy Future}

Manufactured housing accounts for a significant portion of SEPA's residential consumer load. Therefore, SEPA, in conjunction with some other entities, has funded a research project that will result in a significant improvement in the energy efficicncy of manufactured housing. In 1995, the Resource Planning Guide was available to SEPA's customers who found it a good tool for developing Competitive Resource Strategies. ${ }^{5}$ 


\section{Historical Synopsis of Western Area Power Administration}

The last Federal marketing administration to be created was the Western Area P'ower Administration (WAPA), which was formed in 1977 when the Congress created the U.S. Department of Energy and assigned the other Federal marketing administrations to be a part of the new energy department. The territory served by WAPA covers the 15 Central and Western States of Arizona, California, Colorado, Iowa, Kansas, Minnesota, Montana, Nebraska, Nevada, New Mexico, North Dakota, South Dakota, Texas, Utah, and Wyoming. Its mission is to market Federally-owned hydroelectric resources "...in such a manner as to encourage the most widespread use thereof at the lowest possible rates to consumers consistent with sound business principles ..." The WAPA's authority was extended through the Hoover Power Plant Act of 1984 to require customer utilities to undertake certain conservation activities and to withhold a part of customers' power allocations if they did not comply. The WAPA markets hydroelectric power from 51 plants operated by the U.S. Bureau of Reclamation, the U.S. Army Corps of Engineers, and the International Boundary and Water Commission. In addition, the WAPA markets the Federal Government's 547 megawatt entitlement from the coal-fired Navajo Generating Station in Arizona.

\section{Western Area Power Administration 1995 Summary}

In 1995, Western Area Power Administration (WAPA) marketed hydroelectric power to 638 customers, operated and maintained 16,760 miles of transmission lines (including 257 substations), sold more than 38 billion kilowatthours of energy which resulted in $\$ 714$ million net operating revenues (Figure 8). These revenues were earned though the lingering effects of drought years limited hydroelectric generation to about 90 percent of a average year and operational constraints increased expenses.

Total operating expenses during FY 95 continued to increase for WAPA because of environmental and recreational concerns. WAPA's cost to replace power resulting from new operating requirements was approximately $\$ 21$ million from August 1991 to September 1995. In 1994, the U.S. Corps of Engineers published a draft environmental impact statement that would result in lost revenue for the hydropower system of an estimated $\$ 3$ million annually.

As of September 1995, the investment to be repaid by WAPA's power systems totaled about $\$ 5.9$ billion, of which $\$ 2.3$ billion (38.0) percent has been repaid.

Figure 8. Electric Sales and Revenue for Western Area Power Administration, 1995

\begin{tabular}{|c|c|c|c|}
\hline Customer group & Number & Sales kWh(000) & Revenue $\mathbf{s ( 0 0 0 )}$ \\
\hline 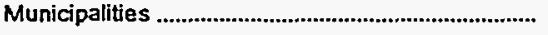 & 296 & $9,007.954$ & 173,266 \\
\hline 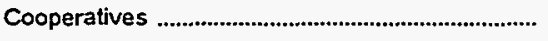 & 52 & $7,850,605$ & 139.031 \\
\hline 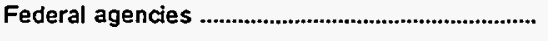 & 59 & $1,989,905$ & 51,440 \\
\hline State agencies & 62 & $9,625,294$ & 163.519 \\
\hline Public utility districts & 19 & $3,831,813$ & 100,820 \\
\hline 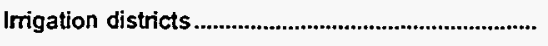 & 57 & 696,184 & 12,684 \\
\hline Investor-owned utilities & 44 & $3,863,667$ & 63,018 \\
\hline Interdepartmental & 4 & 8,196 & 0 \\
\hline Bureau of Reclamation & 74 & $1,245,859$ & 9.718 \\
\hline 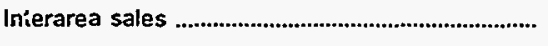 & 5 & 40,511 & 395 \\
\hline Total & 638 & $38,159,988$ & 713,895 \\
\hline
\end{tabular}

Source: Western Area Power Administration, "1995 Annual Report, DOE/APA (Golden, CO, 1996)." 


\section{WAPA's Energy Future}

WAPA continues developing the Energy Planning and Management Program to ensure long-term planning and efficient energy use by customers. In addition, WAPA continues to provide technical assistance to meet customer needs through the Energy Services program.

The Mead-Phoenix and Mead-Adelanto Projects are prime examples of WAPA's joint participation with others in the industry to provide the necded transmission capacity and to offer the most efficient utilization of existing energy resources. These projects link the Phoenix, Arizona area with Southern California and create regional marketing opportunitics for electricity and efficient application of WAPA's power resources through interregional power transfers and seasonal diversity exchanges. WAPA is participating with other electric utilities in a project that will provide a positive rate impact to WAPA's customers. ${ }^{6}$ 
Table 27. Statement of Income by U.S. Federal Electric Utility, 1995 (Thousand Dollars)

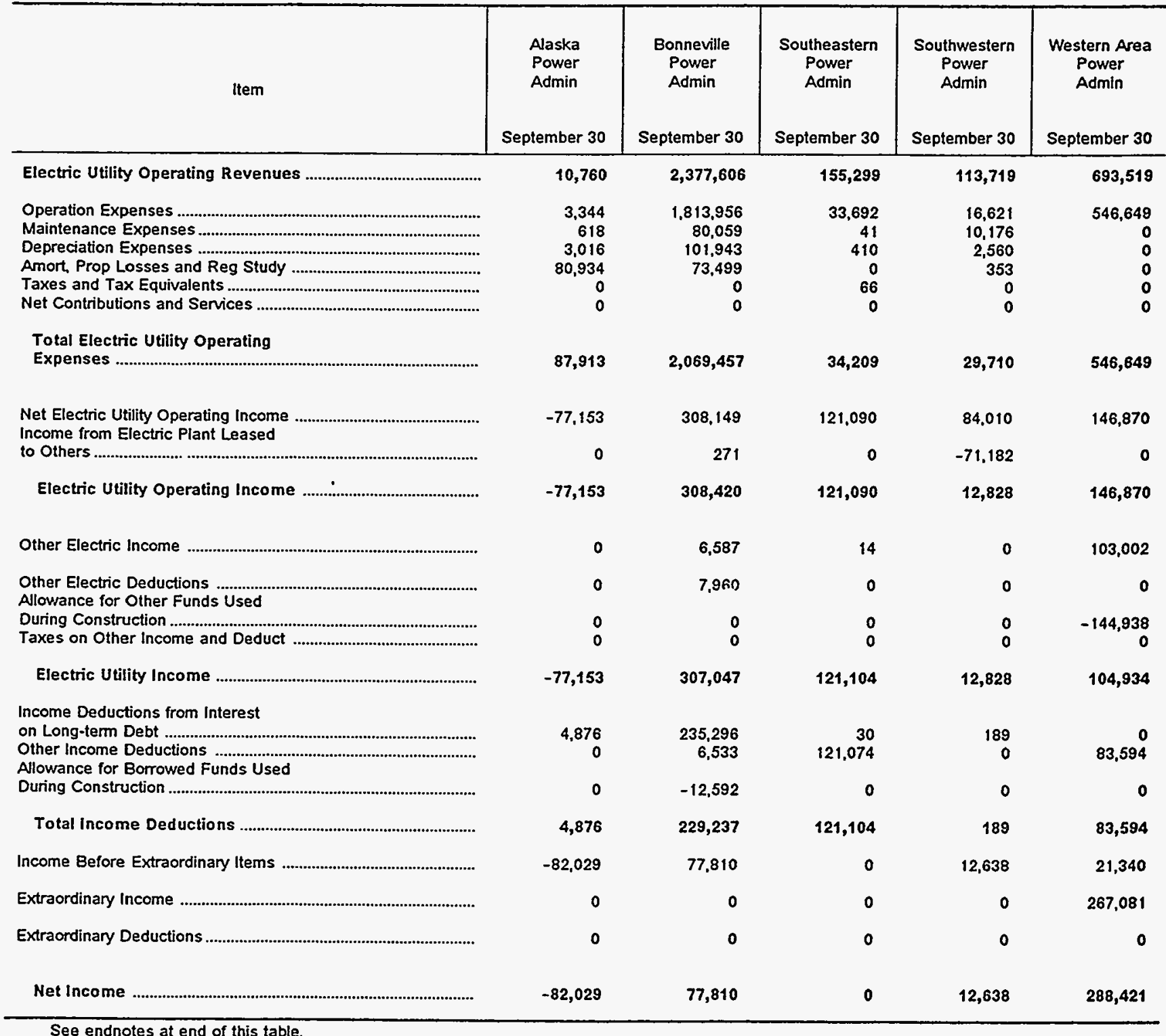


Table 27. Statement of Income by U.S. Federal Electric Utility, 1995 (Continued) (Thousand Dollars)

\begin{tabular}{|c|c|c|c|c|c|}
\hline \multirow[b]{2}{*}{ Item } & \multirow[b]{2}{*}{$\begin{array}{c}\text { Tennessee } \\
\text { Valley } \\
\text { Authority } \\
\text { September } 30\end{array}$} & \multicolumn{2}{|c|}{ U.S. Bureau of Indian Affairs } & \multirow[b]{2}{*}{$\begin{array}{l}\text { USCE- } \\
\text { North Central } \\
\text { Division }^{4} \\
\text { September } 30\end{array}$} & \multirow[b]{2}{*}{$\begin{array}{c}\text { Total } \\
\text { September } 30\end{array}$} \\
\hline & & $\begin{array}{c}\text { Mission } \\
\text { Valley Power } \\
\text { September } 30\end{array}$ & $\begin{array}{l}\text { San Cartos } \\
\text { September } 30\end{array}$ & & \\
\hline 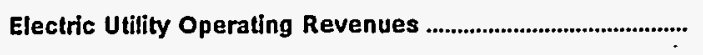 & $5,375,231$ & 15,111 & - & 1,537 & $8,742,781$ \\
\hline 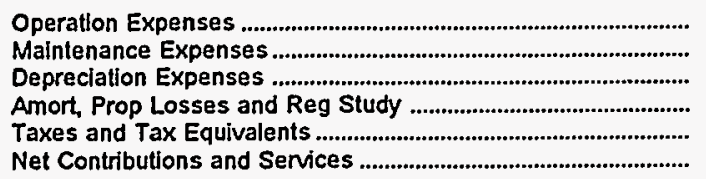 & $\begin{array}{r}2,189,138 \\
304,936 \\
633,531 \\
0 \\
251,723 \\
0\end{array}$ & $\begin{array}{r}10,892 \\
867 \\
0 \\
0 \\
0 \\
0\end{array}$ & $\begin{array}{l}- \\
- \\
-\end{array}$ & $\begin{array}{r}838 \\
1.488 \\
243 \\
0 \\
0 \\
0\end{array}$ & $\begin{array}{r}4,615,130 \\
398,185 \\
741,703 \\
154,786 \\
251,789 \\
0\end{array}$ \\
\hline 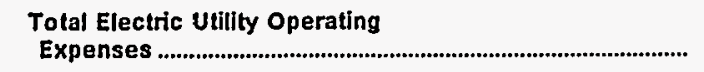 & $3,379,328$ & 11,759 & - & 2,568 & $6,161,593$ \\
\hline $\begin{array}{l}\text { Net Electric Utility Operating Income } \\
\text { Income from Electric Plant Leased }\end{array}$ & $1,995,903$ & 3,352 & - & $-1,032$ & $2,581,189$ \\
\hline 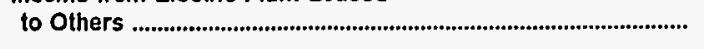 & $-69,015$ & 0 & - & 0 & $-139,926$ \\
\hline 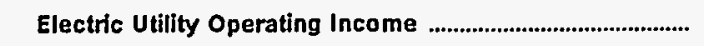 & $1,926,888$ & 3,352 & - & $-1,032$ & $2,441,263$ \\
\hline Other Electric Income & 10,864 & 102 & - & 0 & 120,570 \\
\hline $\begin{array}{l}\text { Other Electric Deductions } \\
\text { Allowance for Other Funds Used }\end{array}$ & 101,695 & 0 & - & 185 & 109,840 \\
\hline 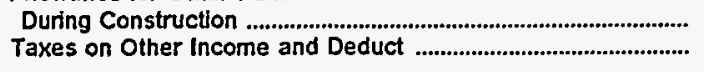 & $\begin{array}{l}0 \\
0\end{array}$ & $\begin{array}{l}0 \\
0\end{array}$ & - & $\begin{array}{l}0 \\
0\end{array}$ & $\begin{array}{r}-144,938 \\
0\end{array}$ \\
\hline 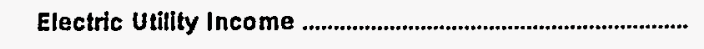 & $1,836,058$ & 3,454 & $=$ & $-1,217$ & $2,307,055$ \\
\hline 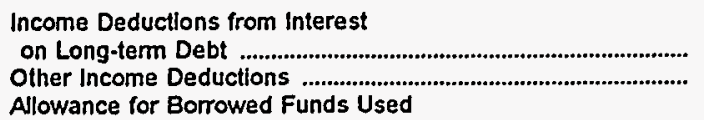 & $\begin{array}{r}1,741,532 \\
282,593\end{array}$ & $\begin{array}{l}0 \\
0\end{array}$ & - & $\begin{array}{l}0 \\
0\end{array}$ & $\begin{array}{r}1.981,924 \\
493,793\end{array}$ \\
\hline 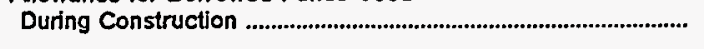 & $-198,275$ & 0 & - & 0 & $-210,867$ \\
\hline 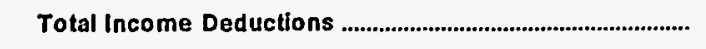 & $1,825,850$ & 0 & - & 0 & $2,264,851$ \\
\hline 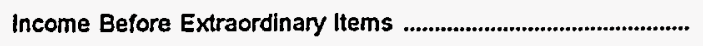 & 10,207 & 3.454 & - & $-1,217$ & 42,204 \\
\hline 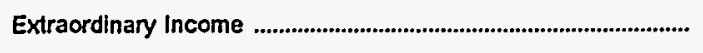 & 0 & 0 & $=$ & 0 & 267,081 \\
\hline 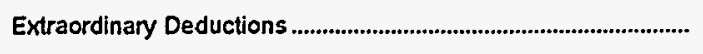 & 0 & 0 & - & 0 & 0 \\
\hline Net Income & 10,207 & 3,454 & - & $-1,217$ & 309,285 \\
\hline
\end{tabular}


Table 28. Balance Sheet by U.S. Federal Electric Utility on September 30, 1995

(Thousand Dollars)

\begin{tabular}{|c|c|c|c|c|c|}
\hline Item & $\begin{array}{c}\text { Alaska } \\
\text { Power } \\
\text { Admin } \\
\text { September } 30\end{array}$ & $\begin{array}{c}\text { Bonneville } \\
\text { Power } \\
\text { Admin }\end{array}$ & $\begin{array}{l}\text { Southeastern } \\
\text { Power } \\
\text { Admin } \\
\text { September } 30\end{array}$ & $\begin{array}{l}\text { Southwestern } \\
\text { Power } \\
\text { Admin }\end{array}$ & $\begin{array}{l}\text { Western Area } \\
\text { Power } \\
\text { Admin } \\
\text { September } 30\end{array}$ \\
\hline \multicolumn{6}{|l|}{ Electric Utility Plant } \\
\hline 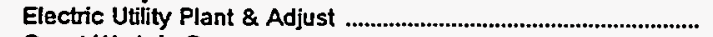 & 187,057 & $4,367,727$ & 965 & 126.153 & $4,888,829$ \\
\hline Const Work in Progress & & 274,141 & $\mathbf{0}$ & 37,248 & 362,501 \\
\hline 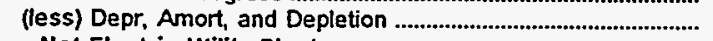 & 100,057 & $1,376,965$ & 522 & 31,913 & $1,585,133$ \\
\hline 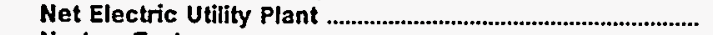 & 87,000 & $3,264,903$ & 443 & 131,487 & $3,666,297$ \\
\hline 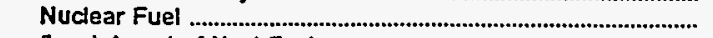 & 0 & 0 & 0 & 0 & 0 \\
\hline (less) Amort of Nucd Fuel & 0 & 0 & 0 & 0 & 0 \\
\hline 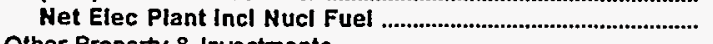 & 87,000 & $3,264,903$ & 443 & 131,487 & $3,666,297$ \\
\hline \multicolumn{6}{|l|}{ Other Property \& Investments } \\
\hline Nonutility Property ........................................ & 0 & o & 0 & 0 & $\mathbf{0}$ \\
\hline 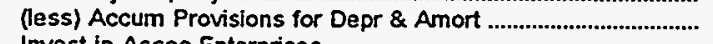 & 0 & 0 & 0 & 0 & 0 \\
\hline 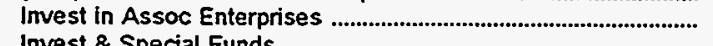 & 0 & 0 & 0 & 0 & 0 \\
\hline Invest \& Special Funds & 0 & 0 & 0 & 0 & 0 \\
\hline $\begin{array}{l}\text { Total Other Property \& Investments } \\
\text { Current and Accrued Assets }\end{array}$ & 0 & 0 & 0 & 0 & 0 \\
\hline Cash, Working Funds \& Investments & 4,301 & 165,732 & 19.588 & 19,902 & 341,655 \\
\hline 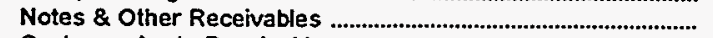 & 7 & 0 & 2 & 0 & 0 \\
\hline 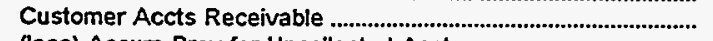 & 1,058 & 55.007 & 2,308 & 15,447 & 143,236 \\
\hline 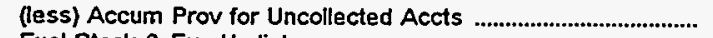 & 0 & 0 & 0 & 0 & 0 \\
\hline 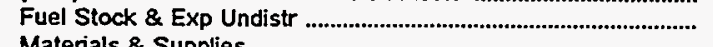 & $\mathbf{0}$ & 0 & 0 & 0 & $\mathbf{0}$ \\
\hline 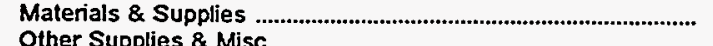 & 0 & 70,490 & $\mathbf{0}$ & 6,363 & $\mathbf{0}$ \\
\hline & 0 & & 0 & 0 & 0 \\
\hline Prepayments & 0 & 184,742 & 0 & $\mathbf{0}$ & 0 \\
\hline Accrued Utility Revenues & 0 & 102,986 & 8,563 & 15,111 & 0 \\
\hline 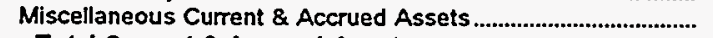 & 0 & 0 & 0 & 23 & 98,678 \\
\hline $\begin{array}{l}\text { Total Current \& Accrued Assets ............................................................. } \\
\text { Deferred Debits }\end{array}$ & 5,366 & 578,957 & 30,460 & 56,846 & 581,569 \\
\hline Unamortized Debt Expenses & 0 & 0 & 0 & 0 & 0 \\
\hline 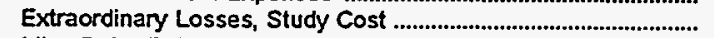 & 0 & 0 & 0 & 0 & 0 \\
\hline 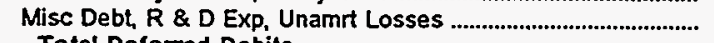 & 0 & $8,257,314$ & 0 & 0 & 0 \\
\hline 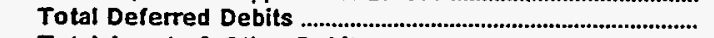 & 0 & $8,257,314$ & 0 & 0 & 0 \\
\hline \multicolumn{6}{|l|}{ Proprietary Capital } \\
\hline 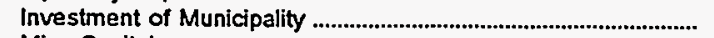 & 170,759 & $1,464,049$ & 28,504 & 64,381 & $11,474,453$ \\
\hline Mise Capital & & 0 & 0 & 0 & $-7,816,918$ \\
\hline $\begin{array}{l}\text { Retained Earnings } \\
\text { Totat Proprietary Capital }\end{array}$ & $-78,798$ & 296,445 & 0 & 83,660 & 288,421 \\
\hline \multicolumn{6}{|l|}{ 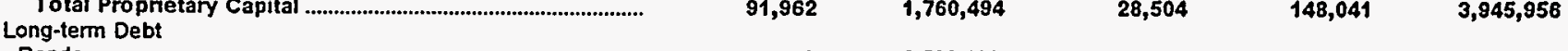 } \\
\hline 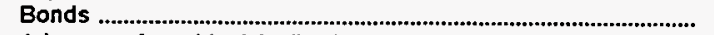 & 0 & $2,563,400$ & 0 & 0 & 0 \\
\hline 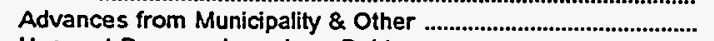 & $\mathbf{0}$ & 0 & 0 & 0 & 0 \\
\hline 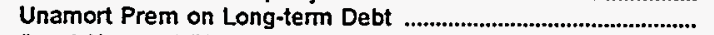 & 0 & 0 & 0 & 0 & 0 \\
\hline 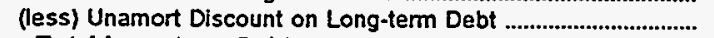 & 0 & 0 & 0 & 0 & 0 \\
\hline 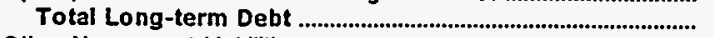 & 0 & $2,563,400$ & 0 & 0 & 0 \\
\hline \multicolumn{6}{|l|}{ Other Noncurrent Liabilities } \\
\hline 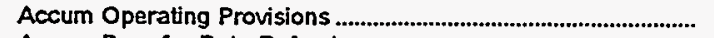 & 0 & 0 & 0 & 0 & $\mathbf{0}$ \\
\hline 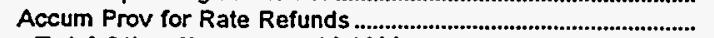 & 0 & 0 & 0 & 0 & 0 \\
\hline 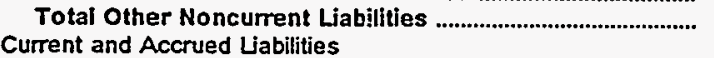 & 0 & \multicolumn{3}{|c|}{ Current and Accrued Labilities } & 0 \\
\hline 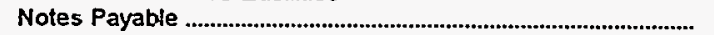 & 0 & 0 & 0 & 6,981 & 0 \\
\hline 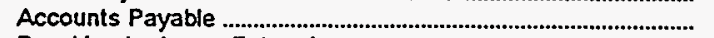 & 0 & 200,341 & 2,218 & 0 & 46,940 \\
\hline 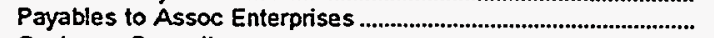 & 0 & 0 & 71 & 0 & 0 \\
\hline 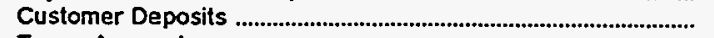 & 0 & 0 & 0 & 0 & 0 \\
\hline Taxes Accrued & 0 & 0 & o & 0 & 0 \\
\hline 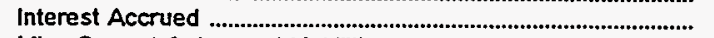 & 0 & 0 & o & 0 & 0 \\
\hline $\begin{array}{l}\text { Misc Current \& Accrued Liabilities } \\
\text { Total Current \& Accrued Liabilities }\end{array}$ & $\begin{array}{l}0 \\
0\end{array}$ & $\begin{array}{l}173,551 \\
373,892\end{array}$ & $\begin{array}{r}110 \\
2,399\end{array}$ & $\begin{array}{r}0 \\
6,981\end{array}$ & $\begin{array}{l}254,970 \\
301,910\end{array}$ \\
\hline \multicolumn{6}{|l|}{ Deferred Credits } \\
\hline 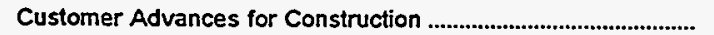 & $\mathbf{0}$ & 0 & 0 & 0 & $\mathbf{0}$ \\
\hline 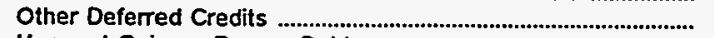 & 0 & 0 & $\mathbf{0}$ & 33,311 & 0 \\
\hline 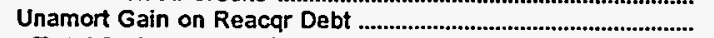 & 404 & $7,403,388$ & 0 & 0 & 0 \\
\hline Total Deferred Credits & 404 & $7,403,388$ & 0 & 33,311 & 0 \\
\hline 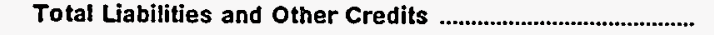 & 92,366 & $12,101,174$ & 30,903 & 188,333 & $4,247,866$ \\
\hline
\end{tabular}

See endnotes at end of this table. 
Table 28. Balance Sheet by U.S. Federal Electric Utility on September 30, 1995 (Continued) (Thousand Dollars)

\begin{tabular}{|c|c|c|c|c|c|}
\hline \multirow[b]{2}{*}{ Item } & \multirow[b]{2}{*}{$\begin{array}{c}\text { Tennessee } \\
\text { Valley } \\
\text { Authority } \\
\text { September } 30\end{array}$} & \multicolumn{2}{|c|}{ U.S. Bureau of Indian Affairs } & \multirow[b]{2}{*}{$\begin{array}{l}\text { USCE- } \\
\text { North Central } \\
\text { Division' } \\
\text { September } 30\end{array}$} & \multirow[b]{2}{*}{$\begin{array}{c}\text { Total } \\
\text { September } 30\end{array}$} \\
\hline & & $\begin{array}{c}\text { Mission } \\
\text { Valley Power } \\
\text { September } 30\end{array}$ & September 30 & & \\
\hline \multicolumn{6}{|l|}{ Electric Utility Plant } \\
\hline 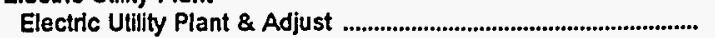 & $18,618,601$ & 30,892 & - & 12,343 & $28,232,668$ \\
\hline 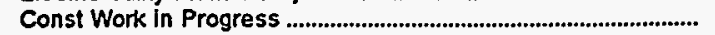 & $15,782,693$ & 4,589 & - & & $16.461,172$ \\
\hline 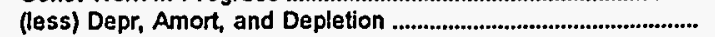 & $6,058,360$ & 9,317 & - & 3,524 & $9,165,792$ \\
\hline 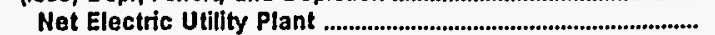 & $28,342,934$ & 26,164 & - & 8,819 & $35,528,048$ \\
\hline 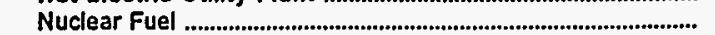 & $2,572,916$ & 0 & - & 0 & $2,572,916$ \\
\hline 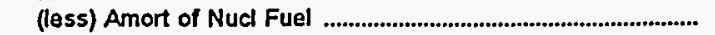 & $1,615,712$ & 0 & - & & $1,615,712$ \\
\hline 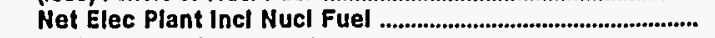 & $29,300,138$ & 26,164 & - & 8,819 & $36,485,252$ \\
\hline \multicolumn{6}{|l|}{ Other Property \& Investments } \\
\hline 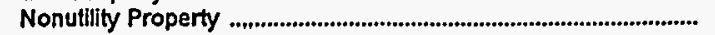 & 4,054 & 0 & - & 0 & 4,054 \\
\hline 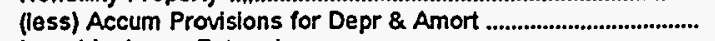 & 2,978 & 0 & - & 0 & 2,978 \\
\hline 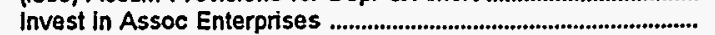 & & 0 & - & 0 & \\
\hline 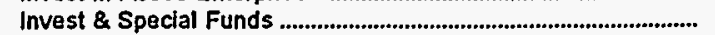 & 260,333 & 0 & - & 0 & 260,333 \\
\hline 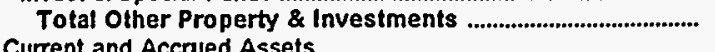 & 261,409 & o & - & $\mathbf{0}$ & 261,409 \\
\hline \multicolumn{6}{|l|}{ Current and Accrued Assets } \\
\hline Notes \& Other Recelvables & 36,225 & $\begin{aligned} 0.700 \\
-1\end{aligned}$ & - & 0 & 36,233 \\
\hline 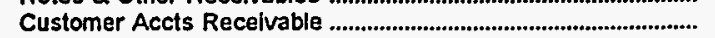 & 649.104 & 527 & - & 0 & 866,686 \\
\hline (less) Accum Prov for Uncollected Accts ......................................... & 4,359 & -106 & - & 0 & 4,253 \\
\hline 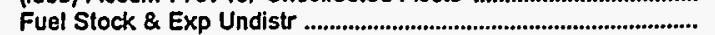 & 104.017 & 0 & - & 0 & 104,017 \\
\hline 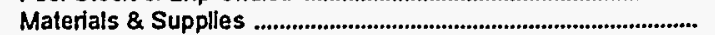 & & 777 & - & 0 & 77,630 \\
\hline 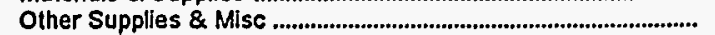 & 251,085 & 314 & - & 0 & 251,399 \\
\hline 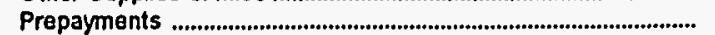 & 0 & 52 & - & 0 & 184,794 \\
\hline 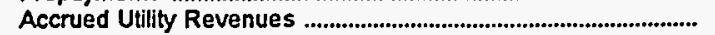 & 0 & 0 & - & 0 & 126,660 \\
\hline 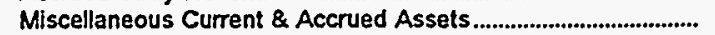 & & 0 & - & 0 & 96,701 \\
\hline 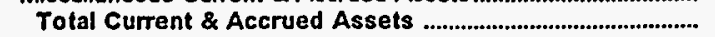 & $1,087,596$ & 5,208 & - & 1 & $2, \mathbf{3 4 6 , 0 0 3}$ \\
\hline \multicolumn{6}{|l|}{ Deferred Debits } \\
\hline 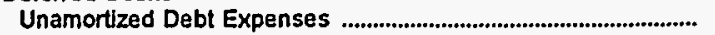 & $1,232,746$ & 0 & - & 0 & $1,232,746$ \\
\hline 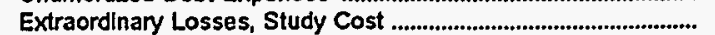 & $1,022,092$ & 0 & - & 0 & $1,022,092$ \\
\hline 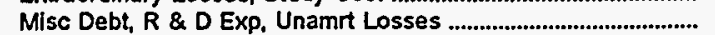 & 389,515 & 0 & - & 0 & $8,646,829$ \\
\hline 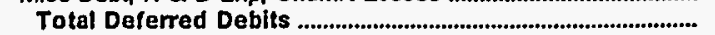 & $2,644,354$ & o & - & 0 & $10,901,668$ \\
\hline 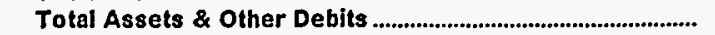 & $33,293,496$ & 31,372 & - & 8,820 & $49,994,331$ \\
\hline \multicolumn{6}{|l|}{ Proprietary Capital } \\
\hline 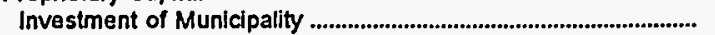 & 628,315 & 0 & - & 8,820 & $13,839,281$ \\
\hline 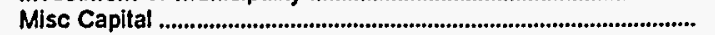 & & 0 & - & 0 & $-7,816,918$ \\
\hline 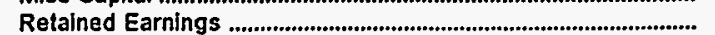 & $3,402,176$ & 23,723 & - & 0 & $4,015,627$ \\
\hline 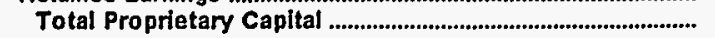 & $4,030,491$ & 23,723 & - & 8,820 & $10,037,990$ \\
\hline \multicolumn{6}{|l|}{ Long-term Debt } \\
\hline 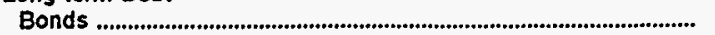 & $22,953,000$ & 0 & - & 0 & $25,516,400$ \\
\hline 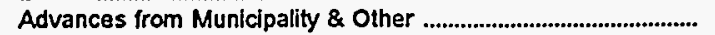 & & 5,387 & - & 0 & 5,387 \\
\hline 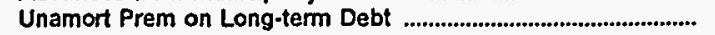 & 35.965 & 0 & - & 0 & 35.965 \\
\hline 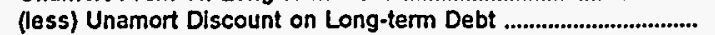 & 405,737 & o & - & 0 & 405,737 \\
\hline 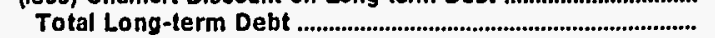 & $22,583,228$ & 5,387 & - & 0 & $25,152,014$ \\
\hline \multicolumn{6}{|l|}{ Other Noncurrent Uabilities } \\
\hline 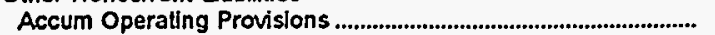 & 206,025 & 0 & - & 0 & 206,025 \\
\hline 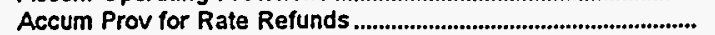 & 274,802 & 0 & - & 0 & 274,802 \\
\hline Total Other Noncurrent Liabilities ......................................... & 480,827 & 0 & - & 0 & 480,827 \\
\hline \multicolumn{6}{|l|}{ Current and Accrued Labilities } \\
\hline 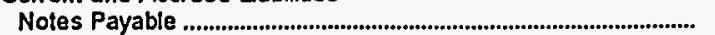 & $2,831,212$ & 0 & - & 0 & $2,838,193$ \\
\hline 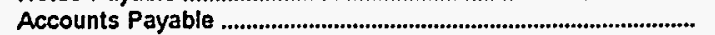 & 820,261 & 2,142 & - & 0 & $1,071,902$ \\
\hline 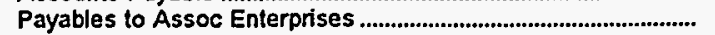 & 0 & 0 & - & 0 & 71 \\
\hline 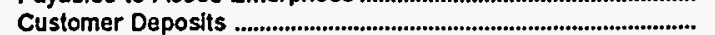 & 0 & 187 & - & 0 & 187 \\
\hline 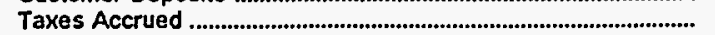 & 0 & 0 & - & 0 & \\
\hline 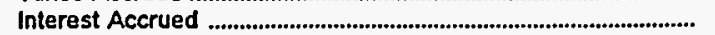 & 454.597 & 0 & - & 0 & 454,597 \\
\hline 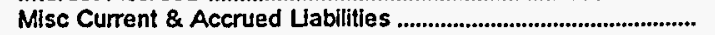 & $1,309,900$ & -487 & - & $\mathbf{0}$ & $1,738,044$ \\
\hline 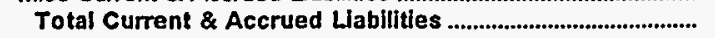 & $5,415,970$ & 1,843 & - & 0 & $6,102,995$ \\
\hline \multicolumn{6}{|l|}{ Deferred Credits } \\
\hline Customer Advances for Construction & 0 & 489 & - & 0 & 489 \\
\hline 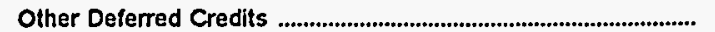 & 782,981 & -69 & - & 0 & 816,223 \\
\hline 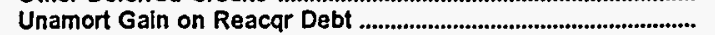 & 0 & 0 & - & 0 & $7,403,792$ \\
\hline 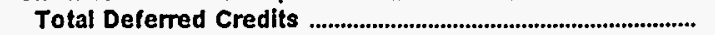 & 782,981 & 420 & - & 0 & $8,220,504$ \\
\hline 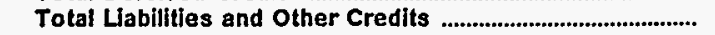 & $33,293,496$ & 31,372 & - & 8,820 & $49,994,331$ \\
\hline
\end{tabular}

* Fiscal year 1995 financial data not available.

- Includes data only for Saint Mary's Falls at Sault St. Marie, Michigan. The rest of the generation produced by the U.S. Army Corps of Engineers (USCE) Is sold by the Department of Energy-Bonneville, Southeastern, Southwestern, and Western Area Power Administrations.

Note: Totals may not equal sum of components because of independent rounding.

Source: Energy Information Administration, Form EIA-412, "Annual Report of Public Electric Utilities." 
Table 29. Electric Operation and Maintenance Expenses

by U.S. Federal Electric Utility, 1995

(Thousand Dollars)

\begin{tabular}{|c|c|c|c|c|c|}
\hline Item & $\begin{array}{c}\text { Alaska } \\
\text { Power } \\
\text { Admin }\end{array}$ & $\begin{array}{l}\text { Bonneville } \\
\text { Power } \\
\text { Admin }\end{array}$ & $\begin{array}{l}\text { Southeastern } \\
\text { Power } \\
\text { Admin }\end{array}$ & $\begin{array}{c}\text { Southwestern } \\
\text { Power } \\
\text { Admin }\end{array}$ & $\begin{array}{c}\text { Western Area } \\
\text { Power } \\
\text { Admin }\end{array}$ \\
\hline \multicolumn{6}{|l|}{ Production Expenses } \\
\hline 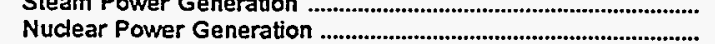 & $\mathbf{0}$ & $\begin{array}{l}0 \\
0\end{array}$ & $\stackrel{0}{0}$ & $: 0$ & $\begin{array}{l}0 \\
0\end{array}$ \\
\hline 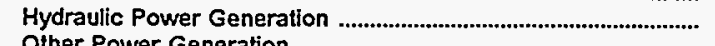 & 853 & 1,274 & $\stackrel{0}{0}$ & 0 & 208,679 \\
\hline Other Power Generation & $\begin{array}{l}0 \\
0\end{array}$ & $\begin{array}{r}0 \\
1,089,025\end{array}$ & $\begin{array}{r}0 \\
4,541\end{array}$ & $\begin{array}{r}0 \\
6,570\end{array}$ & $\begin{array}{r}0 \\
178,426\end{array}$ \\
\hline 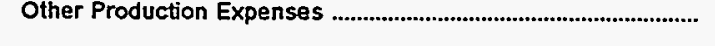 & 0 & 568,169 & 0 & 3,606 & 84,762 \\
\hline 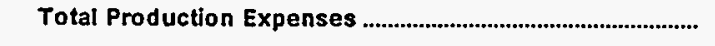 & 853 & $1,658,468$ & 4,541 & 10,176 & 471,867 \\
\hline 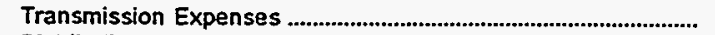 & 1,002 & 166,759 & 26,373 & 10,176 & 26,518 \\
\hline 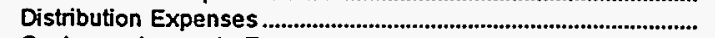 & 0 & 0 & 41 & o & 0 \\
\hline $\begin{array}{l}\text { Customer Accounts Expenses.............................................................. } \\
\text { Customer Service and Information }\end{array}$ & 0 & 942 & 37 & 0 & o \\
\hline 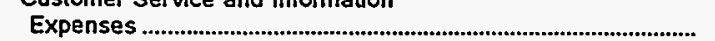 & 0 & 0 & $\mathbf{0}$ & 0 & 0 \\
\hline $\begin{array}{l}\text { Sales Expenses ... General } \\
\text { Administrative and }\end{array}$ & 0 & 0 & 0 & 6.446 & 0 \\
\hline Expenses & 2,107 & 67,846 & 2,741 & o & 48,264 \\
\hline \multicolumn{6}{|l|}{$\begin{array}{l}\text { Total Electric Operation and } \\
\text { Maintenance Expenses }\end{array}$} \\
\hline Maintenance Expenses .......................................................................... & 3,962 & $1,894,015$ & $\mathbf{3 3 , 7 3 3}$ & 26,797 & 546,649 \\
\hline \multicolumn{6}{|l|}{ Number of Elec Dept Employees } \\
\hline Regular Full-time & 29 & $3,830,000$ & 36 & 191 & 1,335 \\
\hline Part-time \& Temporary & 4 & 124.000 & 3 & 0 & 64 \\
\hline Total Elec Dept Employees & 33 & $3,954,000$ & 39 & 191 & 1,399 \\
\hline
\end{tabular}


Table 29. Electric Operation and Maintenance Expenses by U.S. Federal Electric Utility, 1995 (Continued) (Thousand Dollars)

\begin{tabular}{|c|c|c|c|c|c|}
\hline \multirow[b]{2}{*}{ Item } & \multirow[b]{2}{*}{$\begin{array}{c}\text { Tennessee } \\
\text { Valley } \\
\text { Authority } \\
\text { September } 30\end{array}$} & \multicolumn{2}{|c|}{ U.S. Bureau of Indlan Affairs } & \multirow[b]{2}{*}{$\begin{array}{l}\text { USCE- } \\
\text { North Central } \\
\text { Division' } \\
\text { September } 30\end{array}$} & \multirow[b]{2}{*}{$\begin{array}{c}\text { Total } \\
\text { September } 30\end{array}$} \\
\hline & & $\begin{array}{c}\text { Mission } \\
\text { Valley Power } \\
\text { September } 30\end{array}$ & $\begin{array}{l}\text { San Carlos } \\
\text { September } 30\end{array}$ & & \\
\hline \multicolumn{6}{|l|}{ Production Expenses } \\
\hline 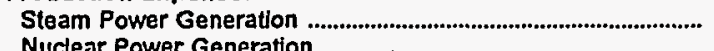 & $\begin{array}{r}1,513,201 \\
382739\end{array}$ & $\begin{array}{l}0 \\
0\end{array}$ & - & 0 & $\begin{array}{r}1,513,201 \\
382739\end{array}$ \\
\hline Hydraulic Power Generation & 41,044 & 3 & - & 2,133 & 253,986 \\
\hline 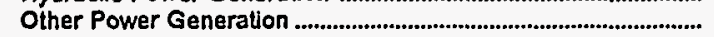 & 18,822 & 0 & - & 0 & 18,822 \\
\hline Purchased Power & 95.186 & 7,504 & - & 0 & $1,381,252$ \\
\hline 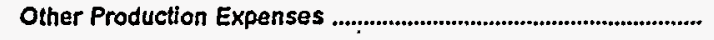 & 12,305 & 0 & - & 0 & 668,842 \\
\hline Total Production Expenses & $2,063,298$ & 7,507 & - & 2,133 & $4,218,842$ \\
\hline Transmission Expenses & 59,097 & 139 & - & 0 & 290,064 \\
\hline 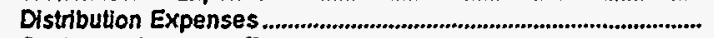 & & 1,488 & - & 0 & 1.529 \\
\hline 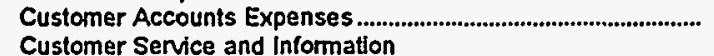 & 1,077 & 412 & - & 0 & 2,468 \\
\hline 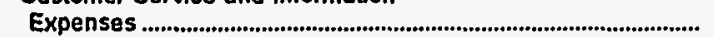 & 29,115 & 222 & - & 0 & 29,337 \\
\hline 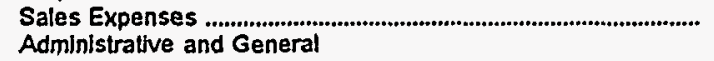 & 34,066 & 0 & - & 0 & 40,512 \\
\hline 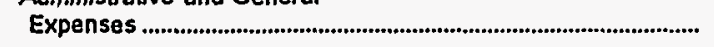 & 307,422 & 1,992 & - & 192 & 430,563 \\
\hline $\begin{array}{l}\text { Total Electric Operation and } \\
\text { Maintenance Expenses }\end{array}$ & $2,494,074$ & 11,759 & - & 2,326 & $5,013,315$ \\
\hline \multicolumn{6}{|l|}{ Number of Elec Dept Employees } \\
\hline Regular Full-time & 16,559 & 78 & - & 8 & $3,848,236$ \\
\hline 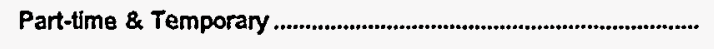 & 0 & 1 & - & 1 & 124,073 \\
\hline Total Elec Dept Employees & 16,559 & 79 & - & 9 & $3,972,309$ \\
\hline
\end{tabular}

* Fiscal year 1995 financial data not available.

1 Includes data only for Saint Mary's Falls at Sault St. Marie, Michigan. The rest of the generation produced by the U.S. Army Corps of Engineers (USCE) is sold by the Department of Energy-Bonneville, Southeastern, Southwestern, and Western Area Power Administrations.

Note: Totals may not equal sum of components because of independent rounding.

Source: Energy Information Administration. Form ElA-412, "Annual Report of Public Electric Utilities." 
Table 30. Electric Utility Plant by U.S. Federal Electric Utility on September 30, 1995

(Thousand Dollars)

\begin{tabular}{|c|c|c|c|c|c|}
\hline Hem & $\begin{array}{c}\text { Alaska } \\
\text { Power } \\
\text { Admin }\end{array}$ & $\begin{array}{l}\text { Bonneville } \\
\text { Power } \\
\text { Admin }\end{array}$ & $\begin{array}{l}\text { Southeastern } \\
\text { Power } \\
\text { Admin } \\
\text { September } 30\end{array}$ & $\begin{array}{l}\text { Southwestem } \\
\text { Power } \\
\text { Admin } \\
\text { September } 30\end{array}$ & $\begin{array}{l}\text { Western Area } \\
\text { Power } \\
\text { Admin }\end{array}$ \\
\hline 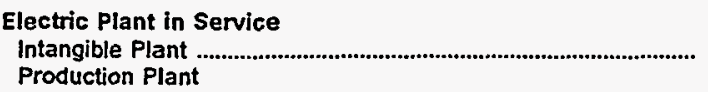 & 331 & 0 & 0 & 0 & 0 \\
\hline Steam & 0 & 0 & 0 & 0 & 0 \\
\hline Nuclear & 0 & 0 & 0 & 0 & 0 \\
\hline 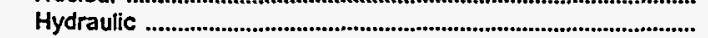 & 148,617 & 0 & o & 0 & $2,805,795$ \\
\hline Other & 0 & 0 & 0 & 0 & 0 \\
\hline $\begin{array}{l}\text { Total Production Plant } \\
\text { Transmission Plant }\end{array}$ & $\begin{array}{r}148,617 \\
32,431\end{array}$ & $\begin{array}{r}0 \\
3,825,265\end{array}$ & $\begin{array}{l}0 \\
0\end{array}$ & 98,350 & $\begin{array}{l}2,805,795 \\
2,083,134\end{array}$ \\
\hline 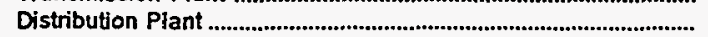 & 0 & 0 & 0 & 0 & $4,000.70$ \\
\hline $\begin{array}{l}\text { General Plant } \\
\text { Total Electric Plant in Service }\end{array}$ & $\begin{array}{r}5,678 \\
187,057\end{array}$ & $\begin{array}{r}540,569 \\
4,365,834\end{array}$ & $\begin{array}{l}965 \\
965\end{array}$ & $\begin{array}{r}27,803 \\
126,153\end{array}$ & $\begin{array}{r}0 \\
4,888,929\end{array}$ \\
\hline $\begin{array}{l}\text { Electric Plant Leased to Others } \\
\text { Construction Work in Progress - Electric }\end{array}$ & $\begin{array}{l}0 \\
0\end{array}$ & $\begin{array}{r}188 \\
274,141\end{array}$ & $\begin{array}{l}0 \\
0\end{array}$ & $\begin{array}{r}0 \\
37.248\end{array}$ & $\begin{array}{r}0 \\
362,501\end{array}$ \\
\hline 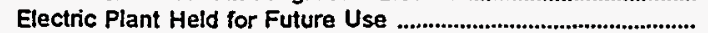 & 0 & 1,705 & 0 & 0 & 0 \\
\hline 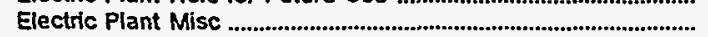 & 0 & 0 & 0 & $\mathbf{0}$ & 0 \\
\hline 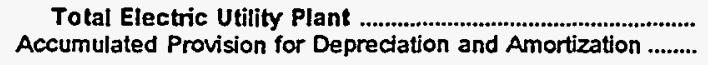 & $\begin{array}{l}187,057 \\
100,057\end{array}$ & $\begin{array}{l}4,641,868 \\
1,376,965\end{array}$ & $\begin{array}{l}965 \\
522\end{array}$ & $\begin{array}{r}163,401 \\
31,913\end{array}$ & $\begin{array}{l}5,251,430 \\
1,585,133\end{array}$ \\
\hline 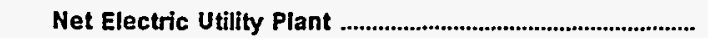 & 87,000 & $3,264,903$ & 443 & 131,487 & $3,666,297$ \\
\hline
\end{tabular}

\begin{tabular}{|c|c|c|c|c|c|}
\hline \multirow[b]{2}{*}{ Hem } & \multirow[b]{2}{*}{$\begin{array}{c}\text { Tennessee } \\
\text { Valley } \\
\text { Authority } \\
\text { September } 30\end{array}$} & \multicolumn{2}{|c|}{ U.S. Bureau of Indian Affairs } & \multirow[b]{2}{*}{$\begin{array}{l}\text { USCE- } \\
\text { North Central } \\
\text { Division' } \\
\text { September } 30\end{array}$} & \multirow[b]{2}{*}{$\begin{array}{c}\text { Total } \\
\text { September } 30\end{array}$} \\
\hline & & $\begin{array}{c}\text { Mission } \\
\text { Valley Power } \\
\text { September } 30\end{array}$ & September 30 & & \\
\hline \multicolumn{6}{|l|}{ Electric Plant in Service } \\
\hline $\begin{array}{l}\text { Intangible Plant } \\
\text { Production Plant }\end{array}$ & 0 & \multicolumn{2}{|l|}{28} & 0 & 359 \\
\hline Steam & $6,825,649$ & \multirow{2}{*}{\multicolumn{2}{|c|}{$\begin{array}{r}0 \\
69\end{array}$}} & 0 & $6,825,649$ \\
\hline 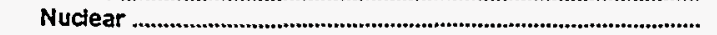 & $5,813,356$ & & & 0 & $5,813,424$ \\
\hline 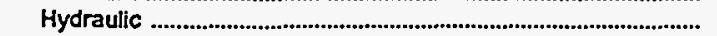 & $1,184,366$ & \multicolumn{2}{|l|}{0} & 12,343 & $4,151,121$ \\
\hline Other & 406.203 & \multicolumn{2}{|l|}{0} & 0 & 406,203 \\
\hline Total Production Plant & $14,229,573$ & \multirow{2}{*}{\multicolumn{2}{|c|}{$\begin{array}{r}69 \\
3,377\end{array}$}} & 12,343 & $17,198,397$ \\
\hline 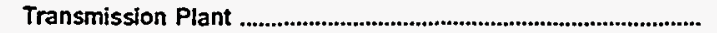 & $2,659,117$ & & & 0 & $8,701,674$ \\
\hline Distribution Plant & 0 & \multicolumn{2}{|l|}{19,710} & 0 & 19,710 \\
\hline General Plant & $1,217.521$ & \multirow{2}{*}{\multicolumn{2}{|c|}{$\begin{array}{r}7,709 \\
30,892\end{array}$}} & 0 & $1,800,245$ \\
\hline Total Electric Plant in Service & $18,106,211$ & & & 12,343 & $27,718,385$ \\
\hline Electric Plant Leased to Others & 81,023 & \multicolumn{2}{|l|}{0} & 0 & 81,211 \\
\hline 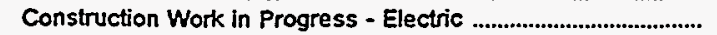 & $15,782,693$ & \multicolumn{2}{|l|}{4,589} & 0 & $16,461,172$ \\
\hline Electric Plant Held for Future Use & 431,366 & \multicolumn{2}{|l|}{0} & 0 & 433,071 \\
\hline Electric Plant Misc & 0 & \multicolumn{2}{|l|}{0} & 0 & \\
\hline Total Electric Utility Plant & $34,401,294$ & \multirow{2}{*}{\multicolumn{2}{|c|}{$\begin{array}{r}35,481 \\
9,317\end{array}$}} & 12,343 & $44,693,839$ \\
\hline Accumulated Provision for Depreciation and Amortization ......... & $6,058,360$ & & & 3.524 & $8,165,792$ \\
\hline 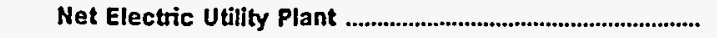 & $28,342,934$ & \multicolumn{2}{|l|}{26,164} & 8,819 & $35,528,048$ \\
\hline
\end{tabular}

- Fiscal year 1995 financial data not available.

' Includes data only for Saint Mary's Falls at Sault St. Marie, Michigan. The rest of the generation produced by the U.S. Arny Corps of Engineers (USCE) is sold by the Department of Energy-Bonneville, Southeastern, Southwestern, and Western Area Power Administrations.

Note: Totals may not equal sum of components because of independent rounding

Source: Energy Information Administration, Form ElA-412, "Annual Report of Public Electric Utilities." 
Table 31. Number of Consumers, Sales, and Operating Revenue by U.S. Federal Electric Utility, 1995

\begin{tabular}{|c|c|c|c|c|c|}
\hline Item & $\begin{array}{c}\text { Alaska } \\
\text { Power } \\
\text { Admin }\end{array}$ & $\begin{array}{l}\text { Bonneville } \\
\text { Power } \\
\text { Admin }\end{array}$ & $\begin{array}{c}\text { Southeastem } \\
\text { Power } \\
\text { Admin }\end{array}$ & $\begin{array}{l}\text { Southwestern } \\
\text { Power } \\
\text { Admin } \\
\text { December } 31\end{array}$ & $\begin{array}{c}\text { Western Area } \\
\text { Power } \\
\text { Admin } \\
\text { December } 31\end{array}$ \\
\hline \multicolumn{6}{|l|}{ Number of Consumers } \\
\hline 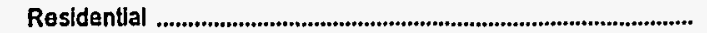 & 0 & 0 & 0 & 0 & 0 \\
\hline 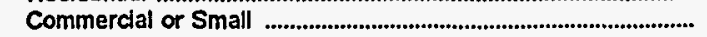 & 0 & $\mathbf{0}$ & 0 & 0 & $\mathbf{0}$ \\
\hline Industrial or Large & 0 & 16 & 0 & 0 & 0 \\
\hline Other & 2 & 7 & 0 & 0 & 164 \\
\hline $\begin{array}{l}\text { Total Ultimate Consumers } \\
\text { Sales for the Year (megawatthours) }\end{array}$ & 2 & 23 & $\mathbf{0}$ & 0 & 164 \\
\hline 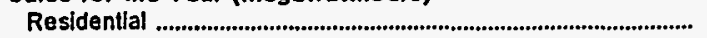 & 0 & 0 & 0 & 0 & 0 \\
\hline 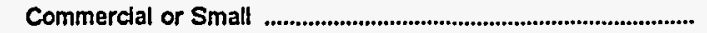 & 0 & 0 & $\mathbf{0}$ & 0 & 0 \\
\hline Industrial or Large & 0 & $20,718,293$ & $\mathbf{0}$ & 0 & 0 \\
\hline Other & 3,593 & 803,541 & 0 & $\mathbf{0}$ & $3,196,214$ \\
\hline 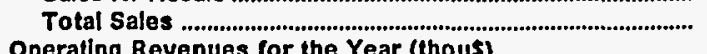 & 439,456 & $81,965,182$ & $7,120,979$ & $6,961,886$ & $37,025,214$ \\
\hline 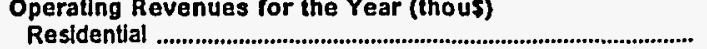 & 0 & 0 & 0 & 0 & 0 \\
\hline Commercial or Small & 0 & 0 & 0 & 0 & 0 \\
\hline 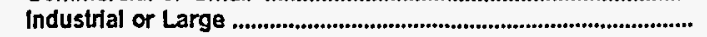 & 0 & 549,534 & 0 & 0 & 0 \\
\hline Other & $\begin{array}{l}82 \\
82\end{array}$ & $\begin{array}{r}22,674 \\
572,208\end{array}$ & $\begin{array}{l}0 \\
0\end{array}$ & $\begin{array}{l}0 \\
0\end{array}$ & $\begin{array}{l}73,740 \\
\mathbf{7 3 , 7 4 0}\end{array}$ \\
\hline 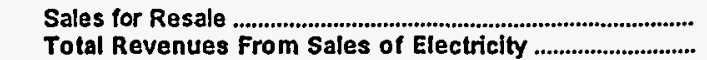 & $\begin{array}{l}10,620 \\
10,702\end{array}$ & $\begin{array}{l}1,642,528 \\
2,214,736\end{array}$ & $\begin{array}{l}155,298 \\
155,298\end{array}$ & $\begin{array}{l}98,491 \\
98,491\end{array}$ & $\begin{array}{l}619,780 \\
693,520\end{array}$ \\
\hline
\end{tabular}

\begin{tabular}{|c|c|c|c|c|c|}
\hline \multirow[b]{2}{*}{ Item } & \multirow[b]{2}{*}{$\begin{array}{c}\text { Tennessee } \\
\text { Valiey } \\
\text { Authority } \\
\text { December } 31\end{array}$} & \multicolumn{2}{|c|}{ U.S. Bureau of Indian Affalrs } & \multirow[b]{2}{*}{$\begin{array}{l}\text { USCE- } \\
\text { North Central } \\
\text { Division' } \\
\text { December } 31\end{array}$} & \multirow[b]{2}{*}{$\begin{array}{c}\text { Total } \\
\text { December } 31\end{array}$} \\
\hline & & $\begin{array}{c}\text { Mission } \\
\text { Valley Power } \\
\text { December } 31\end{array}$ & December 31 & & \\
\hline \multicolumn{6}{|l|}{ Number of Consumers } \\
\hline 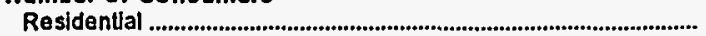 & 0 & 11,050 & 10,338 & 0 & 21,388 \\
\hline Commercial or Small & 0 & 2,224 & 1,166 & 0 & 3,390 \\
\hline Industrial or Large & 70 & 1 & 69 & $\mathbf{0}$ & 156 \\
\hline Other & 37 & 1.053 & 611 & 0 & 1,874 \\
\hline \multicolumn{6}{|l|}{ Sates for the Year (megawatthours) } \\
\hline 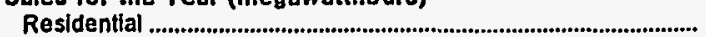 & 0 & 154,814 & 87,879 & 0 & 242,693 \\
\hline Commercial or Small & 0 & 76,698 & 63.284 & 0 & 139.982 \\
\hline Industrtal or Large & $23,900,518$ & 18,713 & 98,144 & 0 & $44,735,688$ \\
\hline Other & 268,145 & 20,770 & 29,981 & 0 & $4,322,244$ \\
\hline 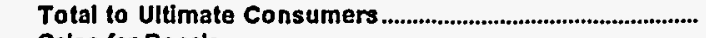 & $24,168,663$ & 270,995 & 279,288 & 0 & $49,440,587$ \\
\hline Sales for Resale & $112,914,758$ & 0 & 0 & 125.990 & 221.831 .824 \\
\hline \multicolumn{6}{|l|}{ Operating Revenues for the Year \{thous\} } \\
\hline 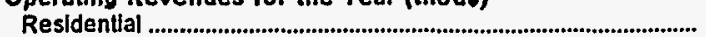 & o & 8,032 & 7,598 & 0 & 15,630 \\
\hline Commercial or Small & 0 & 4,614 & 4,867 & 0 & $\mathbf{9 , 4 8 1}$ \\
\hline Industrial or Large & 633,644 & 819 & 6,408 & 0 & $1,190,405$ \\
\hline Other & 11,392 & 893 & 2.680 & 0 & 111,461 \\
\hline 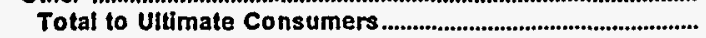 & 645,036 & 14,358 & 21,553 & 0 & $1,326,977$ \\
\hline Sales for Resale & $4,778,993$ & & 0 & 1,537 & $7,307,247$ \\
\hline Total Revenues From Sales of Electricity............................. & $5,424,029$ & 14,358 & 21,553 & 1,537 & $8,634,224$ \\
\hline
\end{tabular}

'Includes data only for Saint Mary's Falls at Sault St. Marie, Michigan. The rest of the generation produced by the U.S. Army Corps of Engineers (USCE) Is sold by the Department of Energy-Bonneville, Southeastern, Southwestern, and Western Area Power Administrations.

Note: Totals may not equal sum of components because of independent rounding. Data are submitted on a calendar year.

Source: Energy Information Administration, Form ElA-861, "Annual Electric Utitity Report." Data are submitted on a calendar year. 
Table 32. Electric Energy Account by U.S. Federal Electric Utility, 1995 (Megawatthours)

\begin{tabular}{|c|c|c|c|c|c|}
\hline Item & $\begin{array}{c}\text { Alaska } \\
\text { Power } \\
\text { Admin }\end{array}$ & $\begin{array}{l}\text { Bonneville } \\
\text { Power } \\
\text { Admin }\end{array}$ & $\begin{array}{l}\text { Southeastern } \\
\text { Power } \\
\text { Admin } \\
\text { September } 30\end{array}$ & $\begin{array}{c}\text { Southwestern } \\
\text { Power } \\
\text { Admin }\end{array}$ & $\begin{array}{c}\text { Western Area } \\
\text { Power } \\
\text { Admin }\end{array}$ \\
\hline \multicolumn{6}{|l|}{ Sources of Energy } \\
\hline 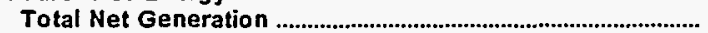 & 416,325 & $81,152,406$ & $7,209,670$ & $7,754,593$ & $32,778,000$ \\
\hline 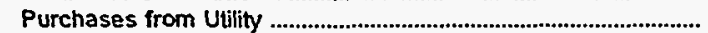 & 0 & $7,111,422$ & 287,348 & 22,304 & $7,721,000$ \\
\hline 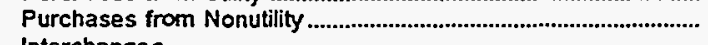 & 0 & & 15,975 & 0 & 13,000 \\
\hline Interchanges & & $\cdot$ & & & \\
\hline In grross\} & 0 & $12,633,595$ & 1,301 & 658,117 & $1,118,000$ \\
\hline Out (gross) & 0 & $18,057,590$ & 0 & 409,495 & $1,244,000$ \\
\hline Net Interchanges & 0 & $-5,423,995$ & 1,301 & 248,622 & $-126,000$ \\
\hline \multicolumn{6}{|l|}{ Transmission for/ by Others (Wheeling) } \\
\hline 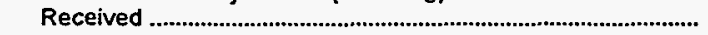 & 338,422 & $40,865,563$ & $4,456,671$ & 0 & $5,706,138$ \\
\hline Delivered & 338,422 & $40,246,399$ & $4,456,671$ & 0 & $5,708,138$ \\
\hline 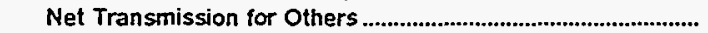 & 0 & 619,164 & 0 & 0 & 0 \\
\hline 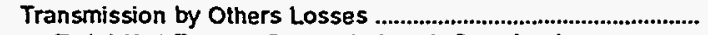 & 0 & 0 & 0 & $\mathbf{0}$ & $\mathbf{0}$ \\
\hline Total Net Energy Generated and Received .......................... & 416,325 & $83,458,997$ & $7,514,294$ & $8,025,519$ & $40,386,000$ \\
\hline \multicolumn{6}{|l|}{ Disposition of Energy } \\
\hline Sales to Ultimate Consumers & 3,739 & $21,383,087$ & 0 & 0 & $3,196,000$ \\
\hline Requirements Sales for Resale & 407.779 & $59,021,478$ & $7,120,979$ & $7,716,236$ & $24,586,000$ \\
\hline Nonrequirements Sales for Resale & 0 & 0 & 0 & 0 & $9,243,000$ \\
\hline Furnished Without Charge & 0 & 0 & 180,000 & 236,560 & 8,000 \\
\hline 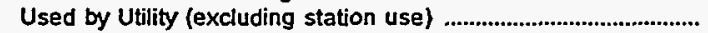 & 0 & 65,405 & 4,008 & 0 & $1,235,000$ \\
\hline 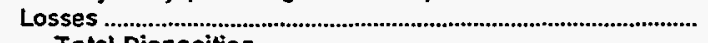 & 4,807 & $2,989,027$ & 209,307 & 72,723 & $2.118,000$ \\
\hline Total Disposition & 416,325 & $83,458,997$ & $7,514,294$ & $8,025,519$ & $40,386,000$ \\
\hline
\end{tabular}

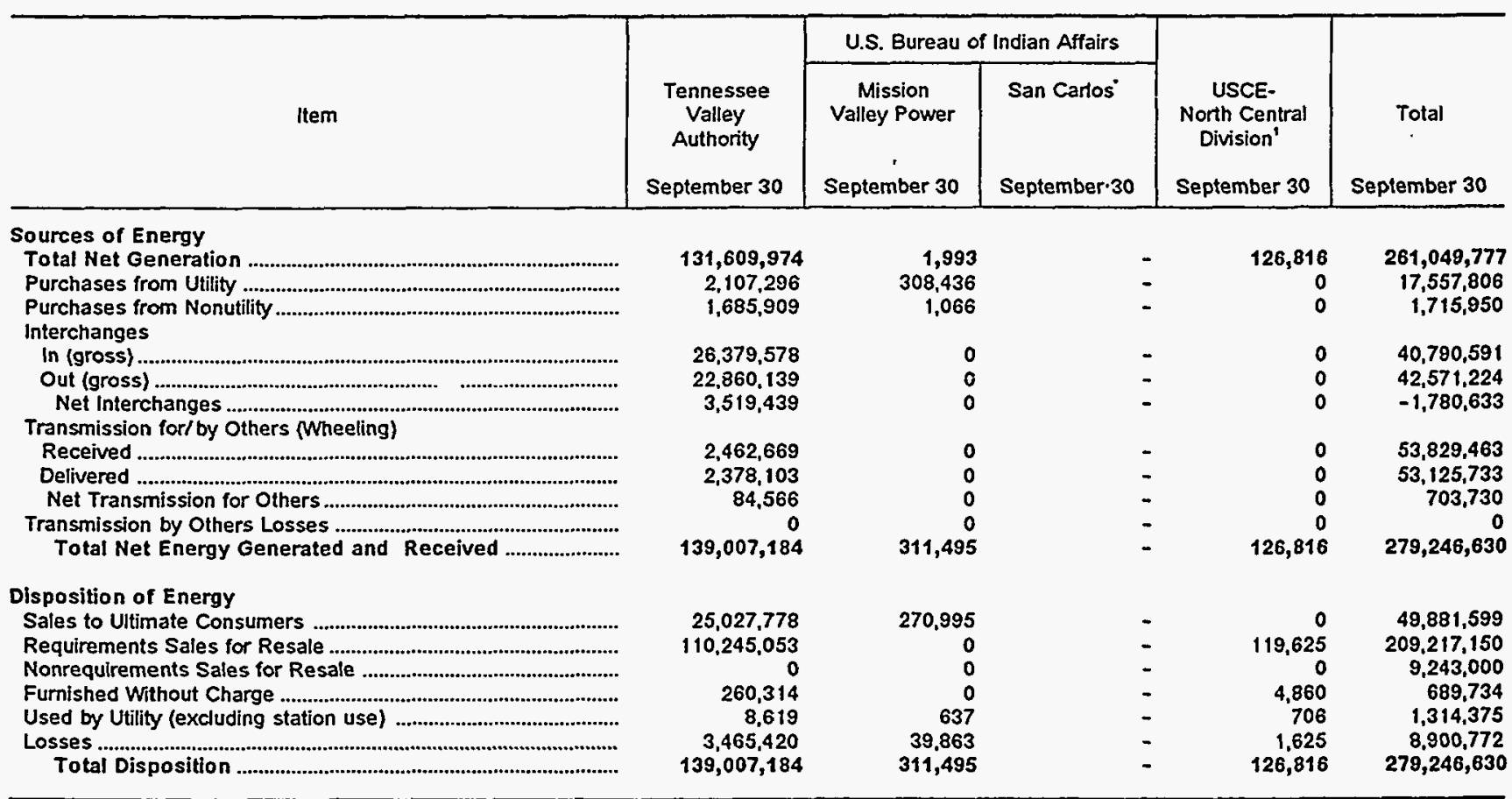

* Fiscal year 1995 financial data not available.

1 Includes data only for Saint Mary's Falls at Sault St. Marie, Michigan. The rest of the generation produced by the U.S. Army Corps of Engineers (USCE) is sold by the Department of Energy-Bonneville, Southeastern, Southwestern, and Western Area Power Administrations.

Note: Totals may not equal sum of components because of independent rounding.

Source: Energy information Administration, Form EIA-412, "Annual Report of Public Electric Utilities." 
Appendix A

Summary

Statistics of

U.S. Rural

Electric

Cooperative

Borrowers 


\section{Summary Statistics of U.S. Rural Electric Cooperative Borrowers}

\section{Background}

The Rural Utilities Service (RUS), U.S. Department of Agriculture, previously The Rural Electrification Administration (REA), was established under the Rural Electrification Act of 1936. The purpose was to extend electric service to small rural communities (usually under 1,500 customers) and farms where it was more expensive to provide service. Through the REA, electric cooperatives (customer-owned, nonprofit entities) were formed and provided with low interest rate, government-guaranteed loans to allow them to build power lines to transmit and distribute wholesale electricity purchased from other electric utilities. By the early 1960's, the REA began to make large loans to cooperatives for the construction of generating plants and transmission facilities to "protect the security and effectiveness of REA-financed systems."

The latest statistics taken from the 1995 Statistical Report, Rural Electric Borrowers ${ }^{7}$ publication show that 808 of 855 cooperative borrowers were distribution borrowers. The remaining 47 were power supply borrowers. By the end of 1995 , the RUS-financed electric utilities were serving more than 11 million consumers in 46 States. When the REA was formed, less than 10 percent of rural areas in the United States had electric service. Today, about 99 percent of U.S. farmers have electric power.

\section{Composite Income Account}

Operating revenues for cooperative borrowers were $\$ 25.0$ billion in 1995 , compared with $\$ 23.8$ billion in 1994 , and $\$ 24.9$ billion in 1993 .

Total electric utility operating expenses for the cooperative borrowers were $\$ 22.1$ billion in 1995 . Operation and maintenance expenses represented $\$ 19.6$ billion or 89.0 percent of the total operating expenses.
Purchased power, a major portion of operation and maintenance expenses, was $\$ 13.1$ billion. Taxes were $\$ 0.6$ billion or 2.8 percent of total electric operating expenses.

Utility operating income for cooperative borrowers was $\$ 2.9$ billion in 1995 . Utility operating income, as a proportion of net utility plant, was 6.5 percent. Net income was $\$ 1.2$ billion.

Interest expense on long-term debt was $\$ 2.2$ billion in 1995 , a decrease from $\$ 2.4$ billion in 1994. Interest expenses as a percentage of long-term debt was 5.5 percent in 1995, compared with 6.0 percent in 1994.

\section{Balance Sheet}

The net investment in electric utility plant for cooperative borrowers was $\$ 44.6$ billion at the end of 1995 , which includes $\$ 1.4$ billion for construction work in progress (CWIP). The CWIP was \$1.8 billion in 1994. As a percentage of net investment in electric utility plant, CWIP was about 8.9 percent higher in 1995 , compared with 1991. The investment and funds accounts were $\$ 5.9$ billion and long-term debt was $\$ 40.2$ billion at the end of 1995 .

\section{Electric Utility Operating Revenues}

The number of residential consumers served by cooperative borrowers was 10.4 million in 1995 , up slightly from 10.2 million in 1994. Revenues from residential consumers were $\$ 9.9$ billion or 66.5 percent of total revenues from all ultimate consumers. In 1995, consumption of electricity by each residential customer averaged 12.4 megawatthours at an average annual cost of $\$ 955.89$, an increase from 1994 when each residential customer averaged 12.1 megawatthours at an average annual cost of $\$ 933.61$.

7 U.S. Department of Agriculture, Rural Electrification Administration, Bulletin No. 1-1. 
Table A1. Composite Statement of Income for the U.S.

Cooperative Borrowers, 1991-1995

(Thousand Dollars)

\begin{tabular}{|c|c|c|c|c|c|}
\hline Item & 1995 & 1994 & 1993 & 1992 & 1991 \\
\hline $\begin{array}{l}\text { Electric Utility Operating Revenues ................... } \\
\text { Utility Operating Expenses }\end{array}$ & $24,951,053$ & $23,776,646$ & $24,872,684$ & $23,325,191$ & $22,784,208$ \\
\hline Operation and Maintenance Expenses ............... & $19,585,547$ & $18,649,528$ & $19,291,776$ & $18,038,115$ & $17.654,756$ \\
\hline Depreciation and Amortization .................................... & $1,853,943$ & $1,741,836$ & $1,767,525$ & $1,709,293$ & $1,639,148$ \\
\hline $\begin{array}{l}\text { Taxes } \\
\text { Total Electric Utility Operating }\end{array}$ & 635,740 & 601,259 & 615,890 & 605,275 & 592,850 \\
\hline 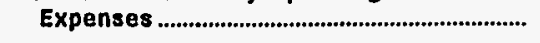 & $22,075,231$ & $20,992,623$ & $21,675,191$ & $20,352,683$ & $19,886,754$ \\
\hline 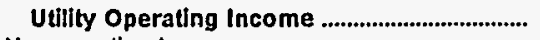 & $2,875,823$ & $2,784,023$ & $3,197,493$ & $2,972,507$ & $2,897,454$ \\
\hline 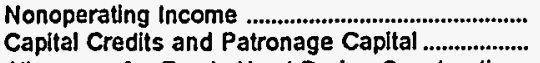 & $\begin{array}{l}392,062 \\
287,494\end{array}$ & $\begin{array}{l}293,164 \\
279,622\end{array}$ & 399,378 & $\begin{array}{l}433,518 \\
248,996\end{array}$ & $\begin{array}{l}506,859 \\
234,137\end{array}$ \\
\hline Allowance for Funds Used During Construction. & 34,881 & 48,008 & 50,906 & 55,440 & 52,481 \\
\hline Gross Income & $3,590,260$ & $3,404,817$ & $3,971,122$ & $3,710,461$ & $3,690,931$ \\
\hline \multicolumn{6}{|l|}{ Income Deductions from } \\
\hline 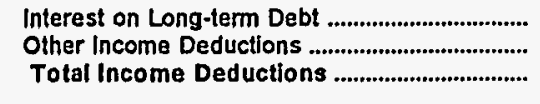 & $\begin{array}{r}2,205,011 \\
130,330 \\
2,875,822\end{array}$ & $\begin{array}{r}2.418,973 \\
164,995 \\
2,583,968\end{array}$ & $\begin{array}{r}2,718,249 \\
218,024 \\
2,936,273\end{array}$ & $\begin{array}{c}2,833,653 \\
165,921 \\
2,999,574\end{array}$ & $\begin{array}{r}2,883,852 \\
67,847 \\
2,951,699\end{array}$ \\
\hline Net Income and Patronage Capital ............. & $1,254,919$ & 820,849 & $1,034,849$ & 710,887 & 739,232 \\
\hline
\end{tabular}

Notes: Totals may not equal sum of components because of independent rounding. Data for 1995 represent 808 Distribution Borrowers and 47 Power Supply Borrowers; Data for 1994 represent 808 Distribution Borrowers and 47 Power Supply Borrowers; data for 1993 represent 855 Distribution Bonrowers and 54 Power Supply Borrowers; data for 1992 represent 862 Distribution Borrowers and 54 Power Supply Borrowers; data for 1991 represent 832 Distribution Borrowers and 55 Power Supply Borrowers.

Source: U.S. Department of Agriculture, Rural Utilities Senvice (prior Rural Electrification Administration), Statistical Report, Rural Electric Borrowers publications for the years 1991, 1992, 1993, 1994, and 1995.

Table A2. Composite Balance Sheet for the U.S. Cooperative Borrowers on December 31, 1991-1995

(Thousand Dollars)

\begin{tabular}{|c|c|c|c|c|c|}
\hline Item & 1995 & 1994 & 1993 & 1992 & 1991 \\
\hline \multicolumn{6}{|l|}{ Assets and Other Debits } \\
\hline Utility Plant & $63,208,763$ & $59,512,615$ & $60,946,122$ & $59,043,411$ & $56,752,533$ \\
\hline $\begin{array}{l}\text { Construction Work in Progress ........................ } \\
\text { (Less) Accumulated Provisions for }\end{array}$ & $1,445,995$ & $1,760,475$ & $1,708,168$ & $1,626,552$ & $1,511,459$ \\
\hline 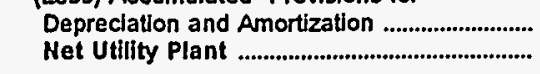 & $\begin{array}{l}20,026,896 \\
44,627,862\end{array}$ & $\begin{array}{l}18,266,323 \\
43,006,767\end{array}$ & $\begin{array}{l}17,907.939 \\
44,746,351\end{array}$ & $\begin{array}{l}16,594,358 \\
44,075,606\end{array}$ & $\begin{array}{l}15,093,304 \\
43,170,688\end{array}$ \\
\hline Investment and Fund Accounts ............................ & $5,920,849$ & $5,607,909$ & $5,379,236$ & $5,379,400$ & $5,017,772$ \\
\hline Current and Accrued Assets............................ & $7,810,224$ & $7,108,589$ & $7,986,359$ & $7.810,050$ & $8,002,973$ \\
\hline 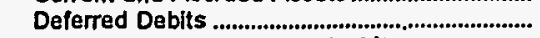 & $4,049,068$ & $3,911,037$ & $3,970,658$ & $2,287,018$ & $1,811,064$ \\
\hline 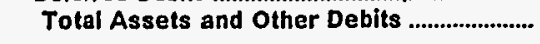 & $62,408,003$ & $59,634,347$ & $62,430,395$ & $59,552,073$ & $58,002,497$ \\
\hline \multicolumn{6}{|l|}{ Liabilities and Other Credits } \\
\hline 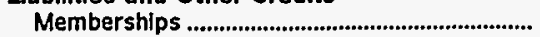 & 116,501 & 104,652 & 97,081 & 96.146 & 91.664 \\
\hline 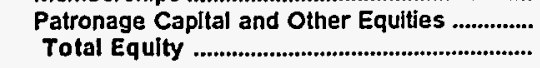 & $\begin{array}{l}13,176,332 \\
13,292,833\end{array}$ & $\begin{array}{l}12,277,054 \\
12,381,706\end{array}$ & $\begin{array}{l}12,230,419 \\
12,327,500\end{array}$ & $\begin{array}{l}11,372,465 \\
11,468,611\end{array}$ & $\begin{array}{l}10,470,168 \\
10,561,832\end{array}$ \\
\hline 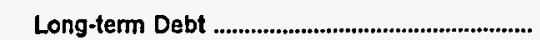 & $40,205,742$ & $40,129,573$ & $42,719,188$ & $42,691,944$ & $42,273,766$ \\
\hline Current and Accrued Labilities ............................ & $3,888,552$ & $3,660,865$ & $3,852,903$ & $3,381,957$ & $3,194,377$ \\
\hline 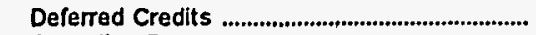 & $1,707,630$ & $1,581,853$ & $1,555,059$ & $1,469,722$ & $1,442,849$ \\
\hline 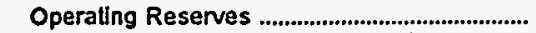 & $3,313,245$ & $1,881,552$ & $1,975,745$ & 539.839 & 529,673 \\
\hline Total Llabilities and Other Credits .............. & $62,408,003$ & $59,634,347$ & $62,430,395$ & $59,552,073$ & $58,002,497$ \\
\hline
\end{tabular}

Notes: Totals may not equal sum of components because of independent rounding. Data for 1995 represent 808 Distribution Borrowers and 47 Power Supply Borrowers; Data for 1994 represent 808 Distribution Borrowers and 47 Power Supply Borrowers; data for 1993 represent 855 Distribution Borrowers and 54 Power Supply Borrowers; data for 1992 represent 862 Distribution Borrowers and 54 Power Supply Borrowers; data for 1991 represent 832 Distribution Borrowers and 55 Power Supply Borrowers.

Source; U.S. Department of Agriculture, Rural Utilities Service (prior Rural Electrification Administration), Statistical Report, Rural Electric Borrowers publications for the years 1991, 1992, 1993, 1994 and 1995. 
Table A3. Electric Operation and Maintenance Expenses for the U.S. Cooperative Borrowers, 1991-1995

(Thousand Dollars)

\begin{tabular}{|c|c|c|c|c|c|}
\hline Item & 1995 & 1994 & 1993 & 1992 & 1991 \\
\hline 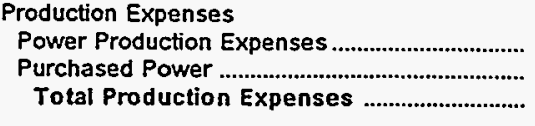 & $\begin{array}{r}3,093,246 \\
13,065,741 \\
16,158,987\end{array}$ & $\begin{array}{r}2,972,356 \\
12,498,458 \\
15,470,814\end{array}$ & $\begin{array}{r}3,083,578 \\
13,017,485 \\
16,101,063\end{array}$ & $\begin{array}{r}2,998,260 \\
12,061,066 \\
15,059,326\end{array}$ & $\begin{array}{r}2,978,362 \\
11,857,765 \\
14,836,127\end{array}$ \\
\hline 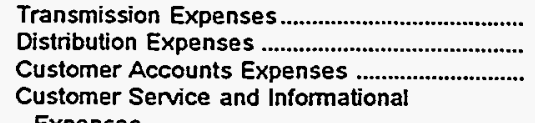 & $\begin{array}{r}365,972 \\
1,126,924 \\
383,154\end{array}$ & $\begin{array}{r}321,636 \\
1,052,738 \\
374,126\end{array}$ & $\begin{array}{r}336,401 \\
1,044,359 \\
386,310\end{array}$ & $\begin{array}{l}323,527 \\
980,017 \\
368,563\end{array}$ & $\begin{array}{l}312,982 \\
916,569 \\
348,605\end{array}$ \\
\hline 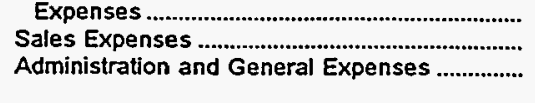 & $\begin{array}{r}111,930 \\
71,620 \\
1,366,960\end{array}$ & $\begin{array}{r}104,508 \\
60,584 \\
1,265,122\end{array}$ & $\begin{array}{r}100,991 \\
57,438 \\
1,265,214\end{array}$ & $\begin{array}{r}94,907 \\
52,235 \\
1,159,540\end{array}$ & $\begin{array}{r}89,029 \\
47,153 \\
1,104,291\end{array}$ \\
\hline $\begin{array}{l}\text { Total Electric Operation and } \\
\text { Maintenance Expenses }\end{array}$ & $19,585,547$ & $18,649,528$ & $19,291,776$ & $18,038,115$ & $17,654,756$ \\
\hline
\end{tabular}

Notes: Totals may not equal sum of components because of independent rounding. Data for 1995 represent 808 Distribution Borrowers and 47 Power Supply Borrowers; Data for 1994 represent 808 Distribution Borrowers and 47 Power Supply Borrowers; data for 1993 represent 855 Distribution Borrowers and 54 Power Supply Borrowers; data for 1992 represent 862 Distribution Borrowers and 54 Power Supply Borrowers; data for 1991 represent 832 Distribu. tion Borrowers and 55 Power Supply Borrowers.

Source: U.S. Department of Agriculture, Rural Utilities Senvice (priog Rural Electrification Administration), Statistical Report, Rural Electric Borrowers publications for the years $1991,1992,1993,1994$ and 1995.

Table A4. Number of Consumers, Sales, and Operating Revenue for the U.S. Cooperative Distributor Borrowers, 1991-1995

\begin{tabular}{|c|c|c|c|c|c|}
\hline Item & 1995 & 1994 & 1993 & 1992 & 1991 \\
\hline \multicolumn{6}{|l|}{ Number of Consumers on December 34} \\
\hline $\begin{array}{l}\text { Residential (fam and nonfarm) ............................... } \\
\text { Commercial and Industrial }\end{array}$ & $10,391,876$ & $10,184,867$ & $10,533,502$ & $10,320,348$ & $9,865,739$ \\
\hline Small (or commercial) & $1,005,674$ & 970,786 & $1,007,028$ & 987,261 & 928,085 \\
\hline 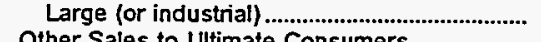 & 7,044 & $\begin{array}{r}7,944 \\
\end{array}$ & 6,922 & 6,499 & 6,238 \\
\hline Other Sales to Ultimate Consumers .................... & 175,831 & 182,387 & 176,307 & 172,995 & 157,506 \\
\hline $\begin{array}{l}\text { Total Ultimate Consumers } \\
\text { Sales for Resale }\end{array}$ & $\begin{array}{r}11,580,346 \\
251\end{array}$ & $\begin{array}{r}11,345,984 \\
516\end{array}$ & $\begin{array}{r}11,723,759 \\
274\end{array}$ & $\begin{array}{r}11,487,103 \\
251\end{array}$ & $\begin{array}{r}10,957,568 \\
197\end{array}$ \\
\hline Total Number of Consumers .......................... & $11,580,597$ & $11,346,500$ & $11,723,973$ & $41,487,354$ & $10,957,765$ \\
\hline \multicolumn{6}{|l|}{ Sales for the Year (Megawatthours) } \\
\hline $\begin{array}{l}\text { Residential (farm and nonfarm) } \\
\text { Commercial and Industrial }\end{array}$ & $129,131,768$ & $122,877,875$ & $129,030,270$ & $118,692,082$ & $195,975,516$ \\
\hline 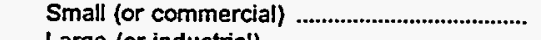 & $39,501,036$ & $37,833,413$ & $38,747,491$ & $37,109,870$ & $34,862,307$ \\
\hline 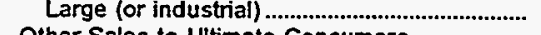 & $41,608,998$ & $39,237,790$ & $39,237,790$ & $36,852,497$ & $33,619,491$ \\
\hline Other Sales to Ultimate Consumers ..................... & $5,895,590$ & $6,717,253$ & $5,581,171$ & $5,633,095$ & $5,603,651$ \\
\hline 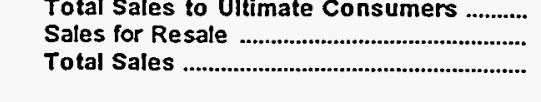 & $\begin{array}{r}216,137,436 \\
2,109,908 \\
218,247,344\end{array}$ & $\begin{array}{r}207,226,809 \\
2,375,599 \\
209,602,408\end{array}$ & $\begin{array}{r}212,596,722 \\
2,645,738 \\
215,242,460\end{array}$ & $\begin{array}{r}198,287,544 \\
2,741,863 \\
201,029,407\end{array}$ & $\begin{array}{r}190,060,965 \\
1,934,117 \\
191,995,082\end{array}$ \\
\hline \multicolumn{6}{|l|}{$\begin{array}{l}\text { Operating Revenues for the Year (thousand } \\
\text { dollars) }\end{array}$} \\
\hline $\begin{array}{l}\text { Residential (farm and nonfarm) .............................. } \\
\text { Commercial and Industrial }\end{array}$ & $9,933,468$ & $9,508,739$ & $9,969,111$ & $9,172,348$ & $8,806,081$ \\
\hline 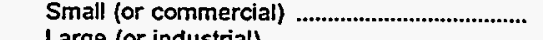 & $2,848,262$ & $2,735,018$ & $2,823,106$ & $2,719,063$ & $2,543,472$ \\
\hline 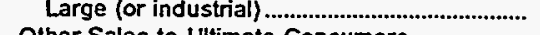 & $1,744,039$ & $1,740,572$ & $1,717,394$ & $1,617,928$ & $1,502,148$ \\
\hline \multirow{3}{*}{ 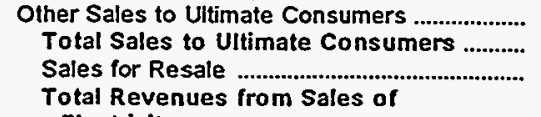 } & 414,203 & 445,806 & 384,628 & 371,405 & 365,037 \\
\hline & $14,939,972$ & $14,430,135$ & $14,894,239$ & $13,880,744$ & $13,216,738$ \\
\hline & 97,459 & 85,781 & 95,737 & 94,602 & 84,548 \\
\hline 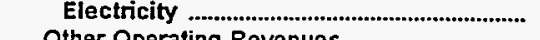 & $15,037,431$ & $14,515,916$ & $14,989,976$ & $13,975,346$ & $13,301,286$ \\
\hline 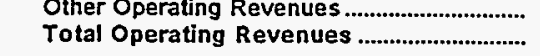 & $\begin{array}{r}216,357 \\
15,253,789\end{array}$ & $\begin{array}{r}210,772 \\
14,726,688\end{array}$ & $\begin{array}{r}210,831 \\
15,200,807\end{array}$ & $\begin{array}{r}214,504 \\
14,189,850\end{array}$ & $\begin{array}{r}198,943 \\
13,500,229\end{array}$ \\
\hline
\end{tabular}

Notes: Totals may not equal sum of components because of independent rounding. This table does not include in 1995 the 47 Power Supply Borrowers, in 1994 the 47 Power Supply Borrowers, in 1993 the 54 Power Supply Borrowers, in 1992 the 54 Power Supply Borrowers, and in 1991 the 55 Power Supply Borrowers included in Tables A1, A2, and A3. Data for 1995 represent 808 Distribution Borrowers; data for 1994 renresent 808 Distribution Borrowers: data for 1993 represent 855 Distribution Borrowers; data for 1992 represent 862 Distribution Borrowers; and data for 1991 represent 832 Distribution Borrowers.

Source: U.S. Department of Agriculture, Rural Utilities Service (prior Rural Electrification Administration), Statistical Report, Rural Electric Borrowers publications for the years 1991, 1992, 1993, 1994, and 1995. 
Appendix B

\author{
Major U.S. \\ Publicly \\ Owned \\ Electric Utility \\ Respondents
}




\section{Major U.S. Publicly Owned Electric Utility Respondents}

Table B1. Publicly Owned Electric Utilities Added to and Deleted from the Form EIA-412, 1991-1995

\begin{tabular}{|c|c|c|c|c|c|}
\hline \multirow{2}{*}{ Year } & \multicolumn{2}{|r|}{ Added } & \multicolumn{2}{|r|}{ Deleted } & \multirow{2}{*}{$\begin{array}{l}\text { Total Number } \\
\text { Availabla' }\end{array}$} \\
\hline & No. & Name & No. & Name & \\
\hline $1991 \ldots . . . .$. & 08 & $\begin{array}{l}\text { Benton City of (Arkansas) } \\
\text { Hillsdale Board of Pub Works (Michigan) } \\
\text { Kennett City of (Missouri) } \\
\text { Lebanon City of (Missouri) } \\
\text { Monett City of (Missouri) } \\
\text { Reedsburg Util Commission (Wisconsin) } \\
\text { St Marys City of (Ohio) } \\
\text { Sturgeon Bay Combined Utils(Wisconsin) }\end{array}$ & 05 & $\begin{array}{l}\text { Kings River Consen Dist (California) } \\
\text { McCook Public Power Dist (Nebraska) } \\
\text { Merced Irrigation District (California) } \\
\text { Sebring Utilties Commission (Florida) } \\
\text { Solvay Village of (New York) }\end{array}$ & 470 \\
\hline $1992 \ldots . . . .$. & 14 & $\begin{array}{l}\text { Badger Power Marketing Auth (Wisconsin) } \\
\text { Brainerd City of (Minnesota) } \\
\text { Chanute City of (Kansas) } \\
\text { Duncan City of (Oklahoma) } \\
\text { Electrical Dist No2 Pinal Cnty (Avizona) } \\
\text { Floresville City of (Texas) } \\
\text { Greenfield City of (Indiana) } \\
\text { Lafayette Public Power Auth (Louisiana) } \\
\text { Massena Town of (New York) } \\
\text { Milford City of (Delaware) } \\
\text { Pella City of (lowa) } \\
\text { Reedy Creek Improvement Dist (Florida) } \\
\text { Sebring Utilities Commission (Florida) } \\
\text { Tohono O dham Utllity Auth (Arizona) }\end{array}$ & 01 & Milan City of (Tennessee) & 483 \\
\hline $1993 \ldots . . . . .$. & 13 & $\begin{array}{l}\text { Chaska City of (Minnesota) } \\
\text { Clarksville Light \& Water Co (Arkansas) } \\
\text { Forest City Town of (North Carolina) } \\
\text { Fort Morgan City of (Colorado) } \\
\text { Lansdale Borough of (Pennyslvannia) } \\
\text { Lassen Municipal Utility Dist (California) } \\
\text { Merced Irrigation Dist (California) } \\
\text { Miami City of (OKlahoma) } \\
\text { Napoleon City of (Unio) } \\
\text { Seneca City of (South Carolina) } \\
\text { Shakopee Public Utilities Comm (Minnesota) } \\
\text { Sun Praine Water \& Light Comm (Wisconsin) } \\
\text { Zeeland City of (Michigan) }\end{array}$ & 01 & Sebring Utilities Commission (Florida) & 495 \\
\hline $1994 \ldots \ldots$ & 08 & $\begin{array}{l}\text { Beatrice City of (Nebraska) } \\
\text { Clyde Light \& Power (Ohio) } \\
\text { Hartselle City of (Alabama) } \\
\text { Kings River Conversation (California) } \\
\text { Lake Placid Village Ine (New York) } \\
\text { Milan City of (Tennessee) } \\
\text { Solvay Village of (New York) } \\
\text { Worthington Public Utility (Minnesota) }\end{array}$ & $\cdot$ & & 503 \\
\hline $1995 \ldots \ldots$. & 09 & $\begin{array}{l}\text { Bardstown City of (Kentucky) } \\
\text { Ephrata Borough of (Pennsylvania) } \\
\text { Lebanon City of (Indiana) } \\
\text { Jasper City of (Texas) } \\
\text { Madison City of (New Jersey) } \\
\text { Overton City of (Nevada) } \\
\text { Scottsburg City of (Indiana) } \\
\text { West Plains City of (Montana) } \\
\text { Winchester City of (Tennessee) }\end{array}$ & - & & 512 \\
\hline
\end{tabular}

1 Excluded are the Federal electric utilities.

Source: Energy Information Administration, Fomn EIA-4 12, "Annual Report of Public Electric Utilities." 
Table B2. Major U.S. Publicly Owned Electric Utilities by Fiscal Year and Generator/Nongenerator Status from the Form ElA-412, 1995

\begin{tabular}{|c|c|c|c|}
\hline Fiscal Year & All Respondents & Generator Respondents & Nongenerator Respondents \\
\hline 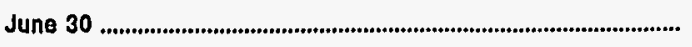 & 203 & 59 & 144 \\
\hline December 31 & 214 & 108 & 106 \\
\hline Other & 95 & 59 & 36 \\
\hline Total & 512 & 226 & 286 \\
\hline
\end{tabular}

Source: Energy Information Administration, Form ElA-412, "Annual Report of Public Electric Utilities." 
Table B3. Major U.S. Publicly Owned Electric Utiltiies by State and Generator/Nongenerator Status, 1995

\begin{tabular}{|c|c|c|c|}
\hline State & $\begin{array}{c}\text { All } \\
\text { Respondents }\end{array}$ & $\begin{array}{c}\text { Generator } \\
\text { Respondents }\end{array}$ & $\begin{array}{l}\text { Nongenerator } \\
\text { Respondents }\end{array}$ \\
\hline Alabama & 21 & 0 & 21 \\
\hline Alaska & 4 & 4 & 0 \\
\hline Avizona & 6 & 1 & 5 \\
\hline Arkansas & 11 & 5 & 6 \\
\hline California & 32 & 26 & 6 \\
\hline Colorado & 7 & 4 & 3 \\
\hline Connecticut & 4 & 2 & 2 \\
\hline Delaware & 3 & 2 & 1 \\
\hline Florida & 20 & 17 & 3 \\
\hline Georgia & 17 & 3 & 14 \\
\hline Hawaii & 0 & 0 & 0 \\
\hline Idaho & 1 & 1 & 0 \\
\hline ullinois & 7 & 3 & 4 \\
\hline Indiana & 15 & 7 & 8 \\
\hline lowa & 4 & 4 & 0 \\
\hline Kansas & 7 & 5 & 2 \\
\hline Kentucky & 12 & 2 & 10 \\
\hline Louisiana & 8 & 6 & 2 \\
\hline 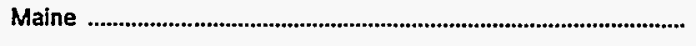 & 0 & 0 & 0 \\
\hline Maryland & 2 & 1 & 1 \\
\hline 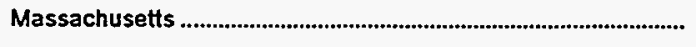 & 20 & 10 & 10 \\
\hline Michigan & 14 & 13 & 1 \\
\hline 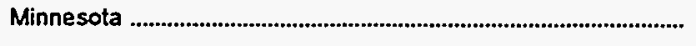 & 18 & 11 & 7 \\
\hline Mississippi & 12 & 2 & 10 \\
\hline Missourt & 14 & 8 & 6 \\
\hline Montana & 0 & 0 & $\mathbf{0}$ \\
\hline Nebraska & 15 & 8 & 6 \\
\hline 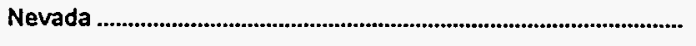 & 2 & 0 & 2 \\
\hline 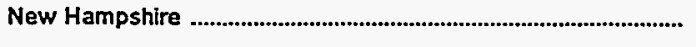 & 0 & 0 & 0 \\
\hline New Jersey & 2 & 1 & 1 \\
\hline New Mexico & 3 & 2 & 1 \\
\hline New York & 9 & 4 & 5 \\
\hline North Cardina & 24 & 5 & 19 \\
\hline North Dakota & 0 & 0 & 0 \\
\hline Ohio & 19 & $\theta$ & 10 \\
\hline Oklahoma & 9 & 3 & 6 \\
\hline Oregon & 11 & 4 & 7 \\
\hline
\end{tabular}


Table B3. Major U.S. Publicly Owned Electric Utiltiies by State and Generator/Nongenerator Status, 1995 Continued

\begin{tabular}{|c|c|c|c|}
\hline State & $\begin{array}{c}\text { All } \\
\text { Respondents }\end{array}$ & $\begin{array}{c}\text { Generator } \\
\text { Respondents }\end{array}$ & $\begin{array}{l}\text { Nongenerator } \\
\text { Respondents }\end{array}$ \\
\hline 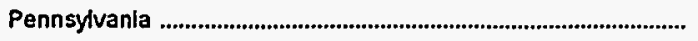 & 3 & 1 & 2 \\
\hline 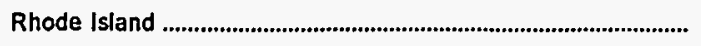 & 0 & 0 & 0 \\
\hline South Carolina & 11 & 5 & 6 \\
\hline South Dakota & 5 & 1 & 4 \\
\hline 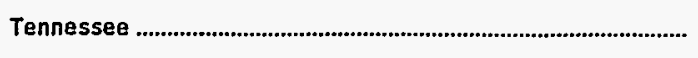 & 56 & 0 & 56 \\
\hline Texas & 22 & 13 & 9 \\
\hline Utah & 8 & 7 & 1 \\
\hline Vermont & 2 & 2 & 0 \\
\hline 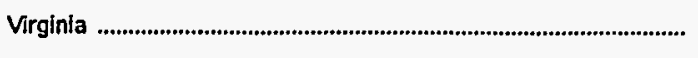 & 9 & 6 & 3 \\
\hline Washington & 25 & 13 & 12 \\
\hline 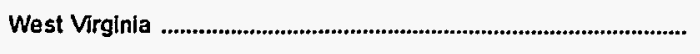 & 0 & 0 & 0 \\
\hline Wisconsin & 16 & 3 & 13 \\
\hline 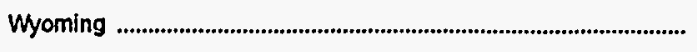 & 2 & 1 & 1 \\
\hline Total & 512 & 226 & 286 \\
\hline
\end{tabular}


Table B4. Publicly Owned Electric Utilities That Submitted the Form EIA-412, 1995

\begin{tabular}{|c|c|c|c|}
\hline Publicly Owned Electric Utilities & State & Reporting Date & Generating Status \\
\hline  & 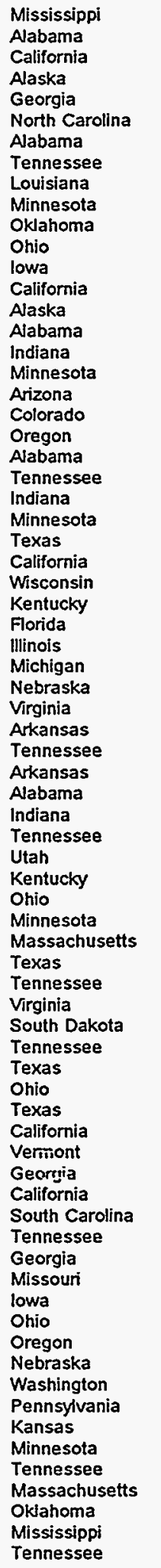 & 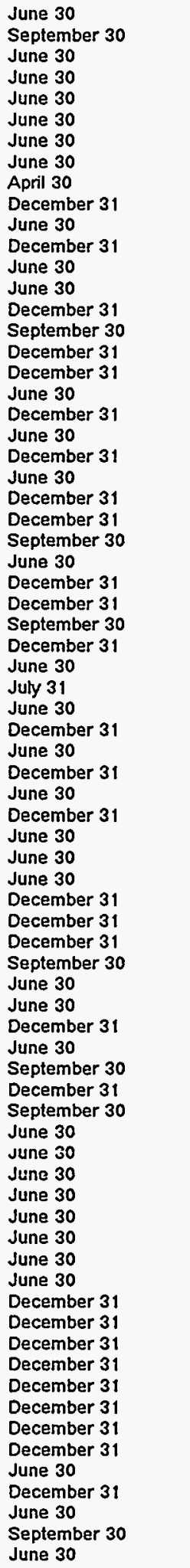 & 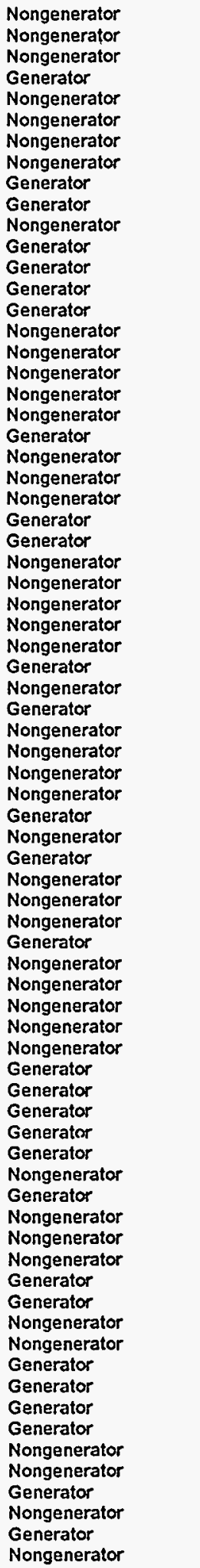 \\
\hline
\end{tabular}

See endnotes at end of this table. 
Table B4. Publicly Owned Electric Utilities That Submitted the Form EIA-412, 1995 (Continued)

\begin{tabular}{|c|c|c|c|}
\hline Publicly Owned Electric Utilities & State & Reporting Date & Generating Status \\
\hline 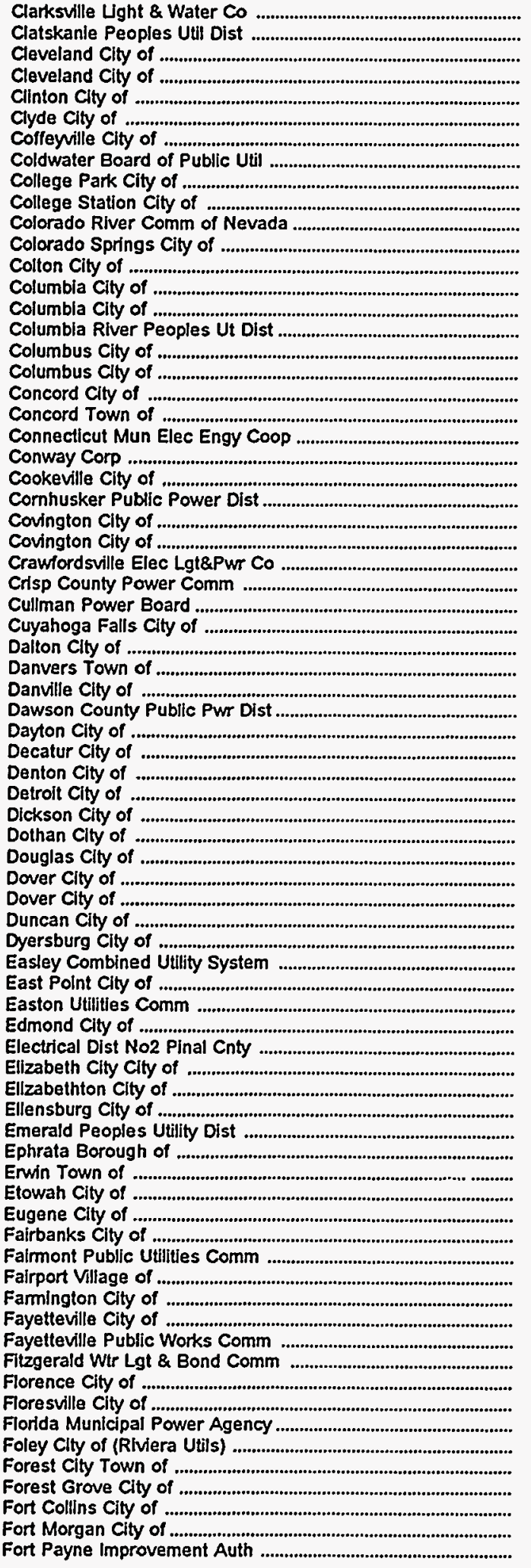 & 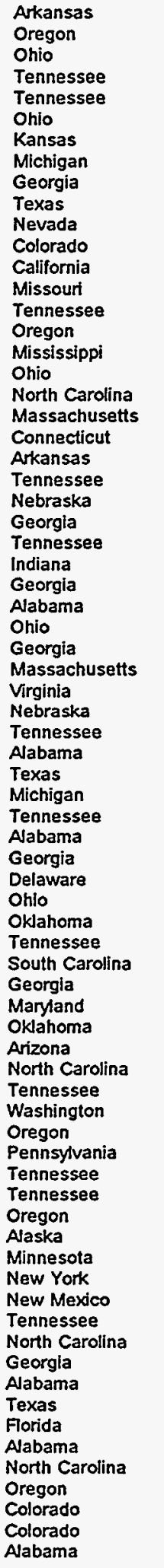 & 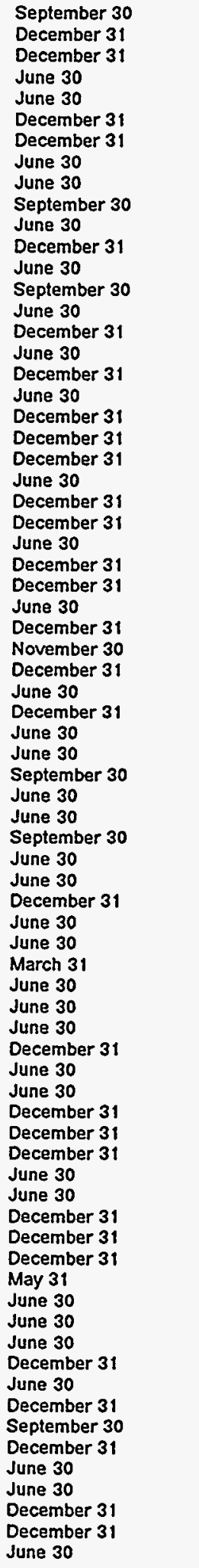 & 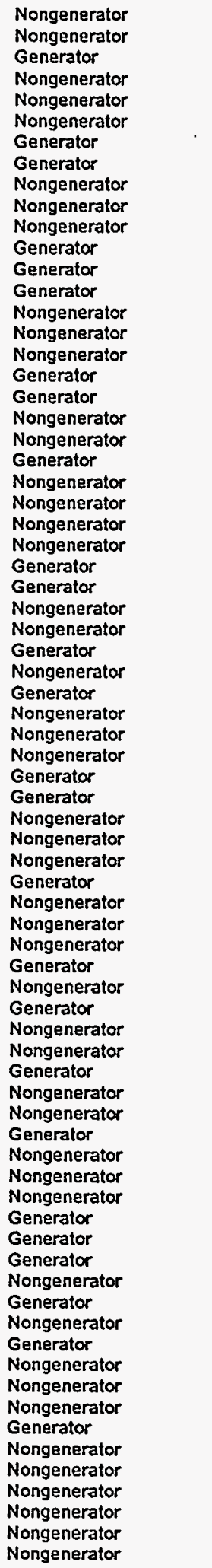 \\
\hline
\end{tabular}

See endnotes at end of this table. 
Table B4. Publicly Owned Electric Utilities That Submitted the Form EIA-412, 1995 (Continued)

\begin{tabular}{|c|c|c|c|}
\hline Publicly Owned Electric Utilities & State & Reporting Date & Generating Status \\
\hline 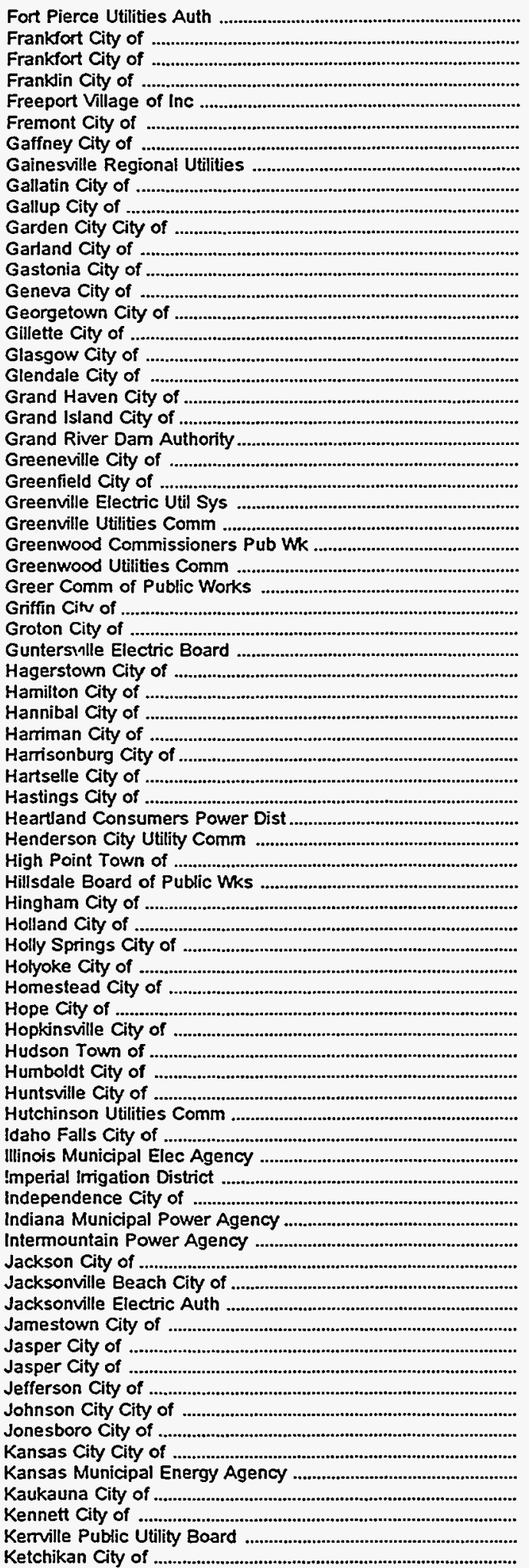 & 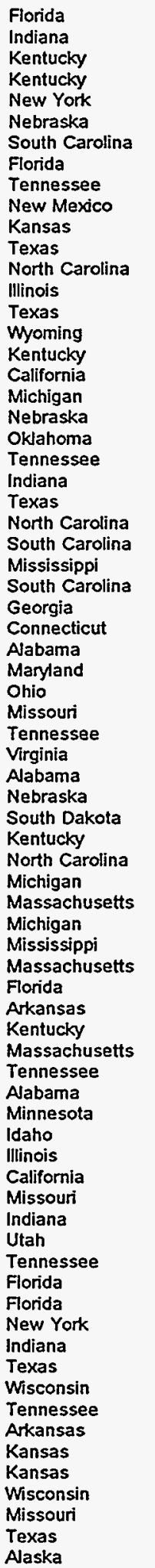 & 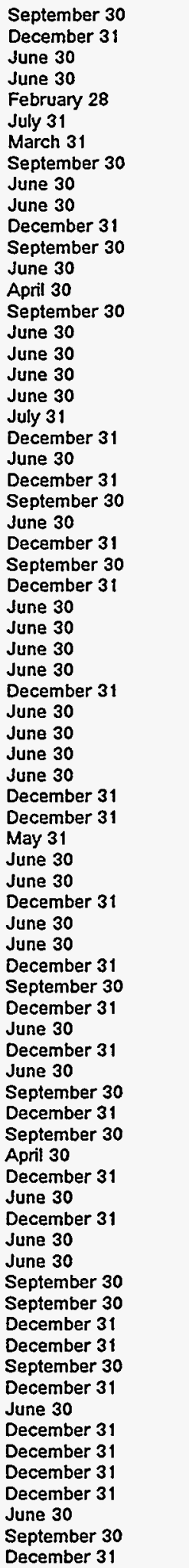 & 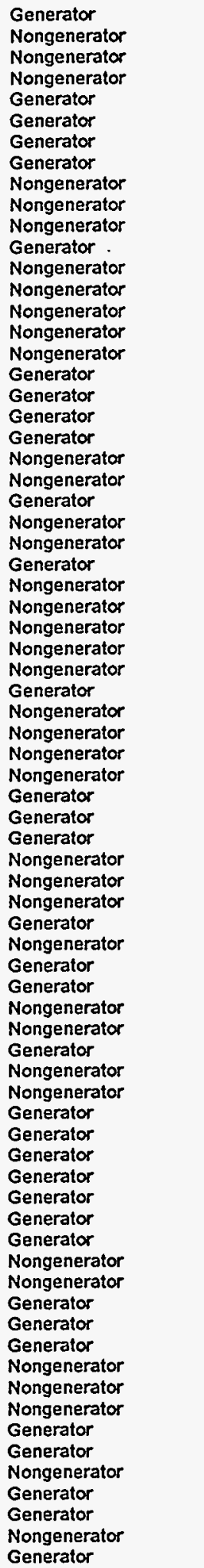 \\
\hline
\end{tabular}

See endnotes at end of this table. 
Table B4. Publicly Owned Electric Utilities That Submitted the Form EIA-412, 1995 (Continued)

\begin{tabular}{|c|c|c|c|}
\hline Publicly Owned Electric Utilities & State & Reporting Date & Generating Status \\
\hline 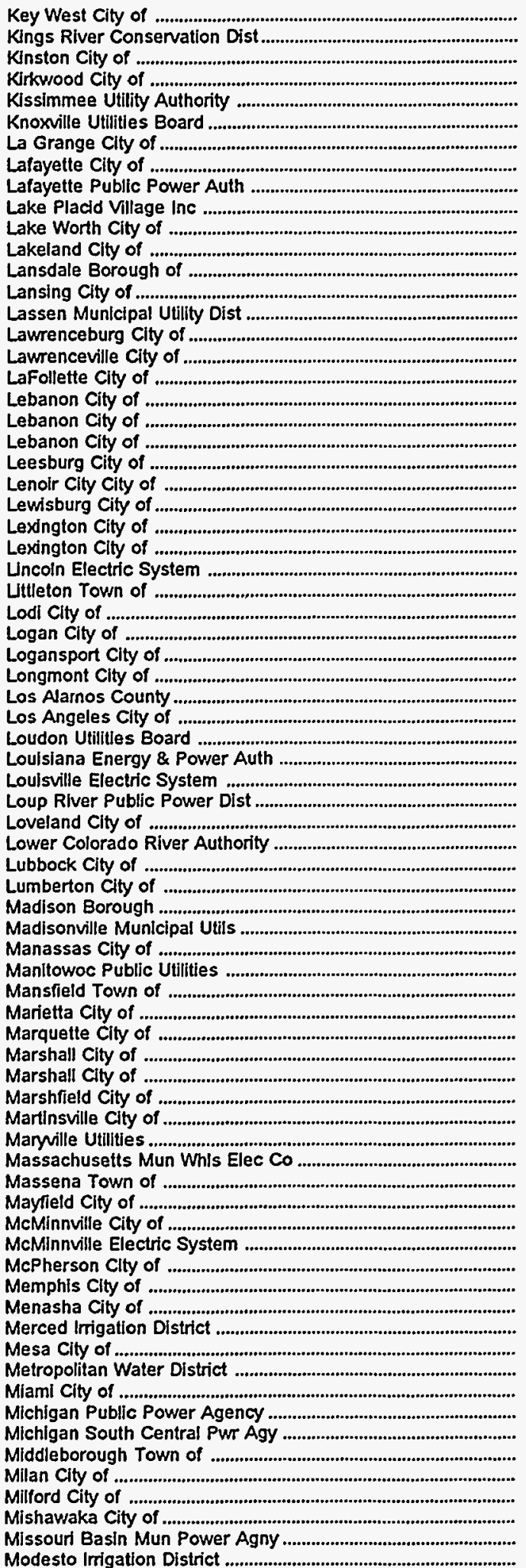 & 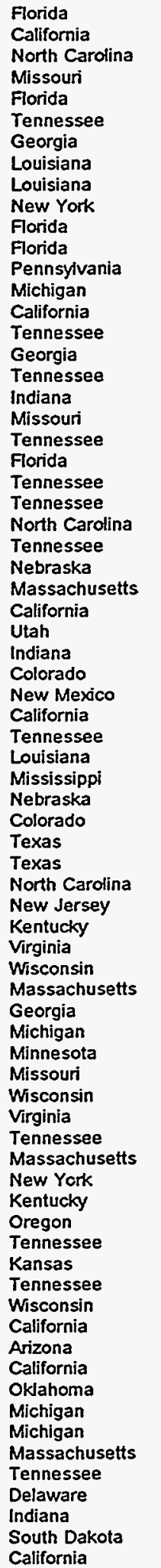 & 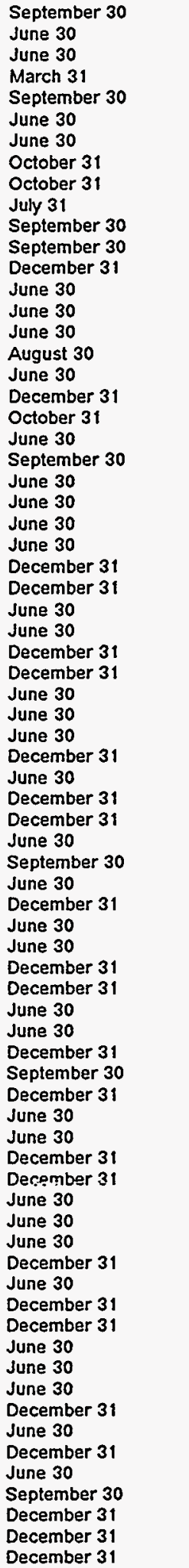 & 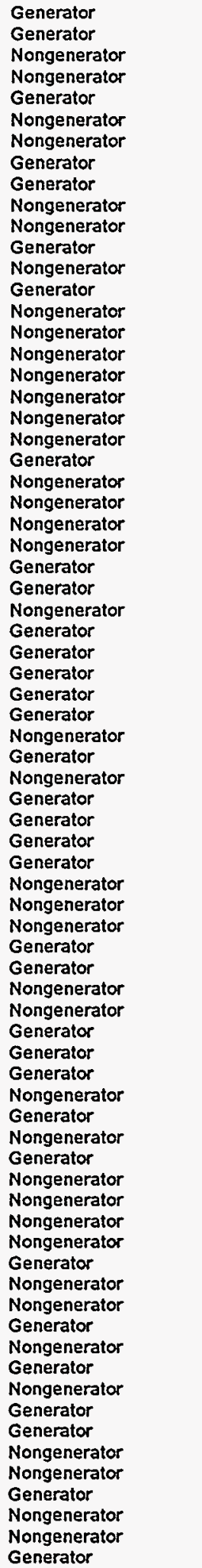 \\
\hline
\end{tabular}

See endnotes at end of this table. 
Table B4. Publicly Owned Electric Utilities That Submitted the Form EIA-412, 1995 (Continued)

\begin{tabular}{|c|c|c|c|}
\hline Publicly Owned Electric Utitities & State & Reporting Date & Generating Status \\
\hline 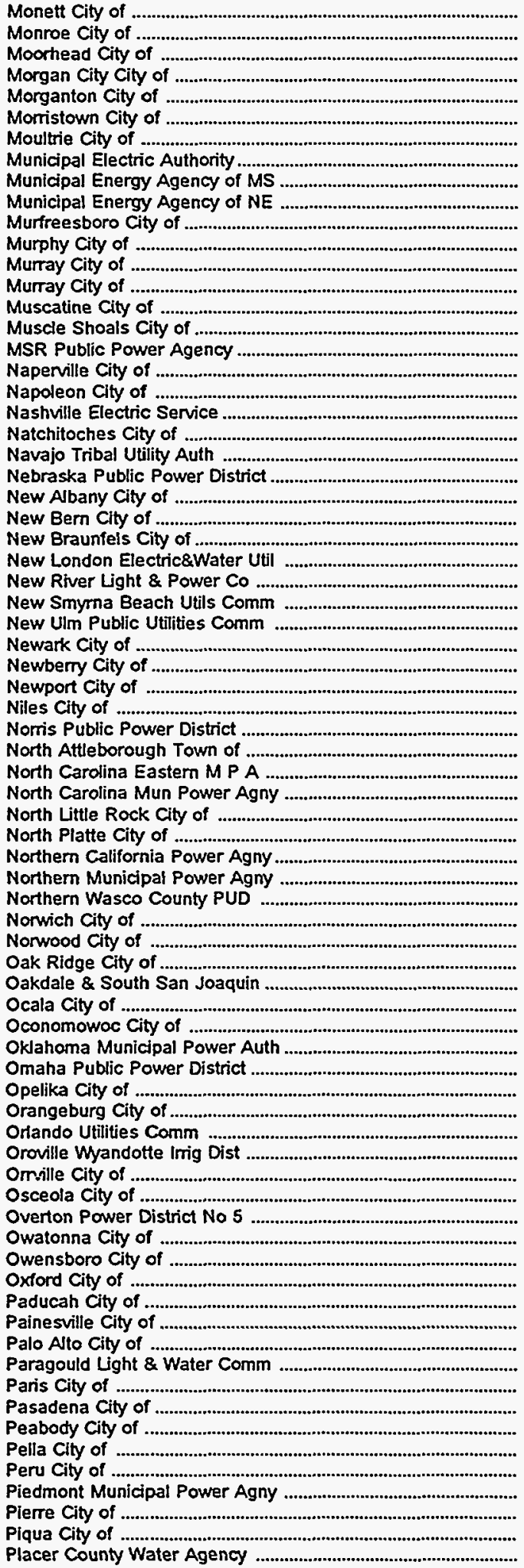 & 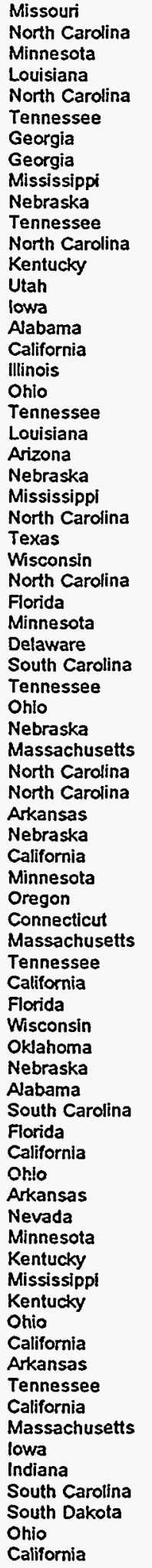 & 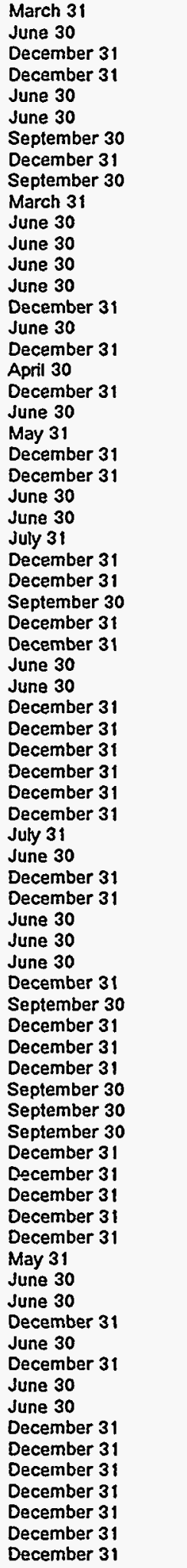 & 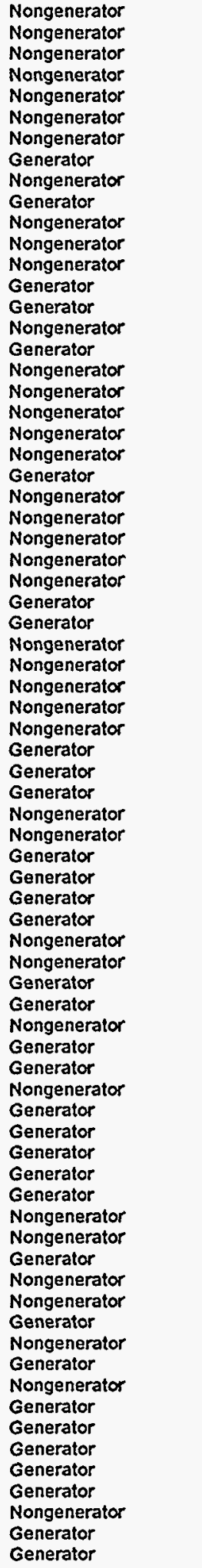 \\
\hline
\end{tabular}

See endnotes at end of this table. 
Table B4. Publicly Owned Electric Utilities That Submitted the Form ElA-412, 1995 (Continued)

\begin{tabular}{|c|c|c|c|}
\hline Publicly Owned Electric Utilities & State & Reporting Date & Generating Status \\
\hline 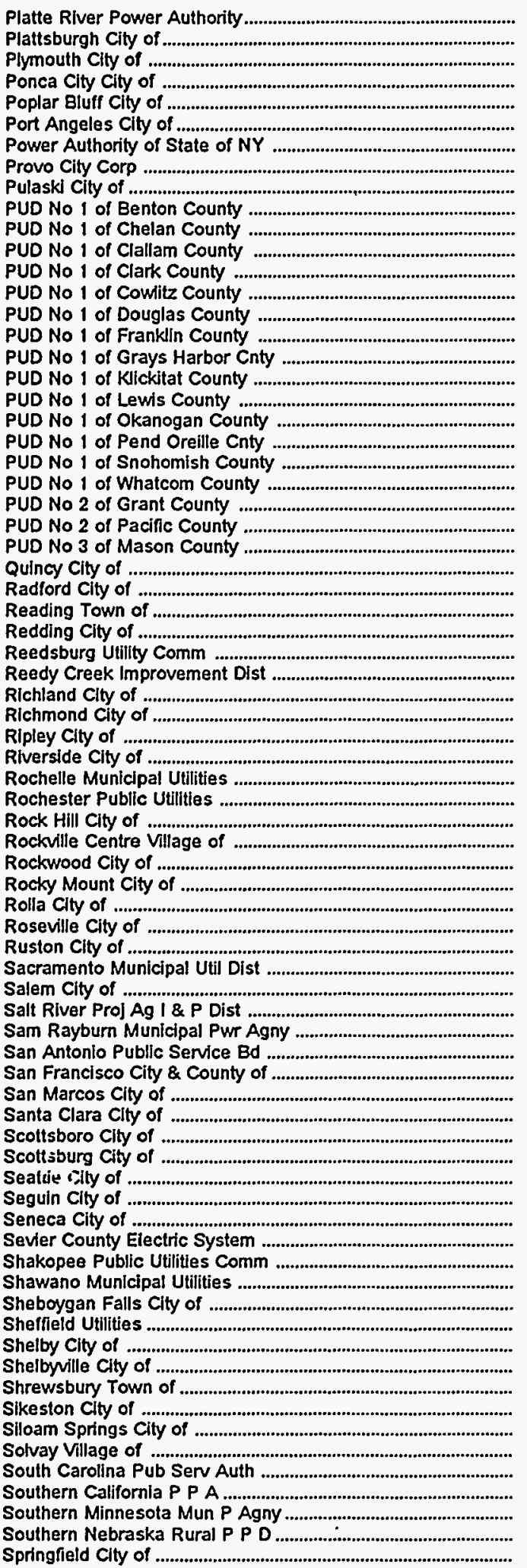 & 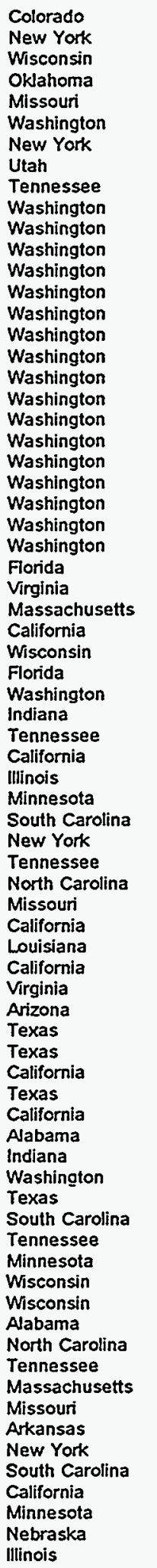 & 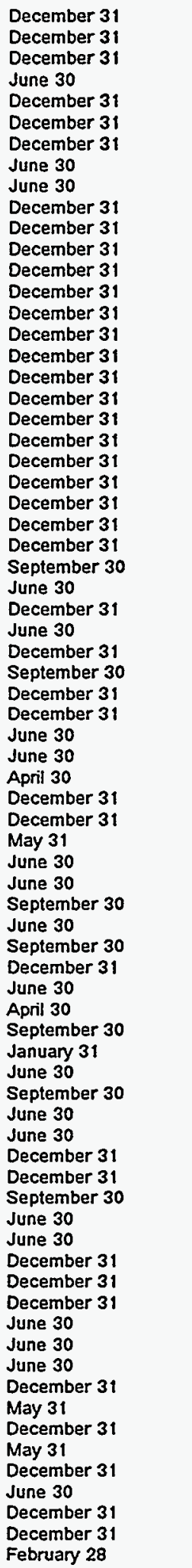 & 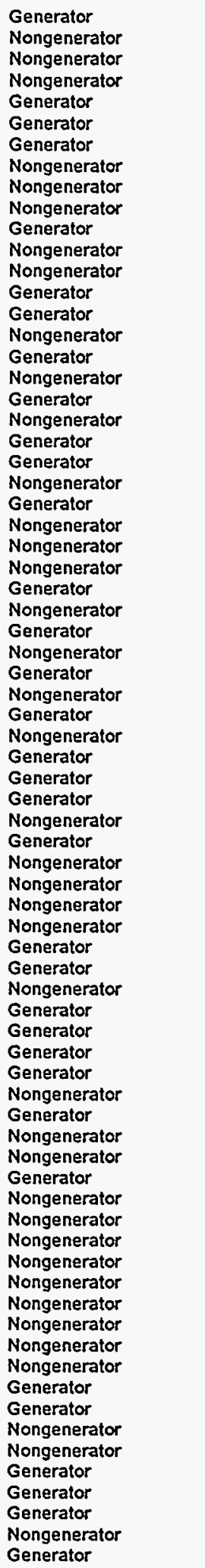 \\
\hline
\end{tabular}

See endnotes at end of this table. 
Table B4. Publicly Owned Electric Utilities That Submitted the Form EIA-412, 1995 (Continued)

\begin{tabular}{|c|c|c|c|}
\hline Publicly Owned Electric Utilities & State & Reporting Date & Generating Status \\
\hline 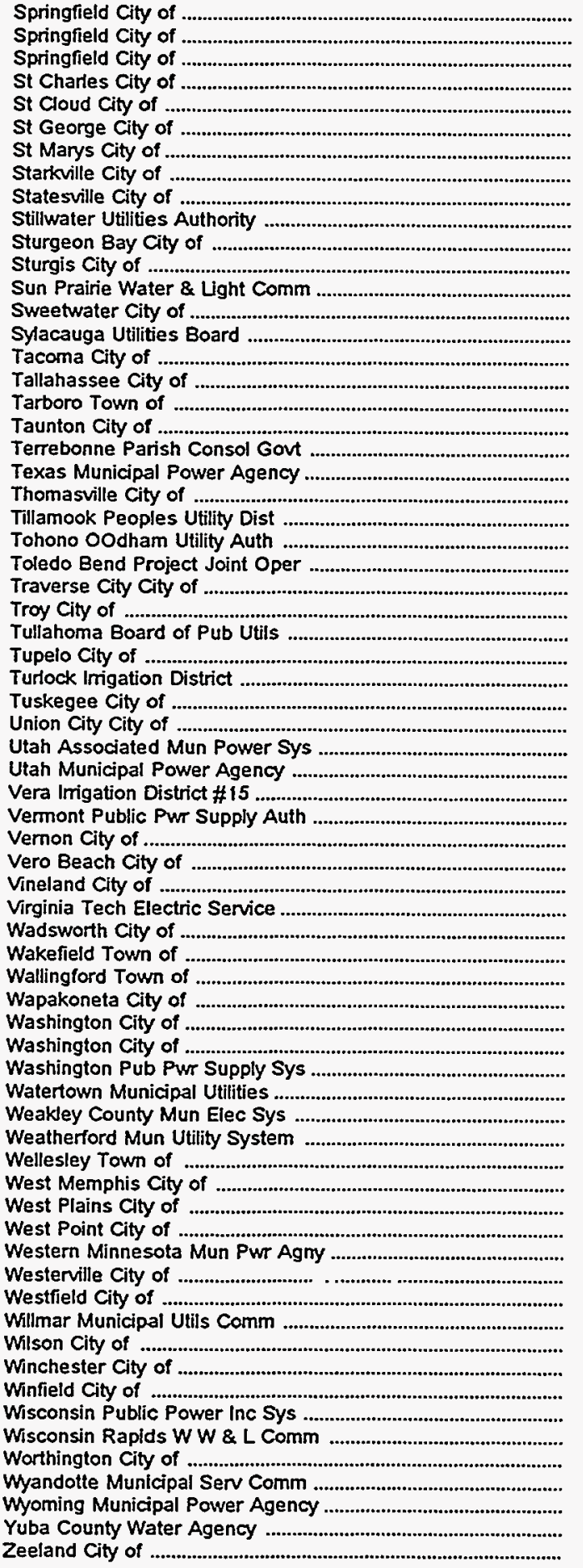 & $\begin{array}{l}\text { Missouri } \\
\text { Oregon } \\
\text { Tennessee } \\
\text { Illinois } \\
\text { Florida } \\
\text { Utah } \\
\text { Ohio } \\
\text { Mississippi } \\
\text { North Carolina } \\
\text { Oklahoma } \\
\text { Wisconsin } \\
\text { Michigan } \\
\text { Wisconsin } \\
\text { Tennessee } \\
\text { Alabama } \\
\text { Washington } \\
\text { Florida } \\
\text { North Carolina } \\
\text { Massachusetts } \\
\text { Louisiana } \\
\text { Texas } \\
\text { Georgia } \\
\text { Oregon } \\
\text { Arizona } \\
\text { Texas } \\
\text { Michigan } \\
\text { Alabama } \\
\text { Tennessee } \\
\text { Mississippi } \\
\text { California } \\
\text { Alabama } \\
\text { Tennessee } \\
\text { Utah } \\
\text { Utah } \\
\text { Washington } \\
\text { Vermont } \\
\text { California } \\
\text { Florida } \\
\text { New Jersey } \\
\text { Virginia } \\
\text { Ohio } \\
\text { Massachusetts } \\
\text { Connecticut } \\
\text { Ohio } \\
\text { Indiana } \\
\text { North Carolina } \\
\text { Washington } \\
\text { South Dakota } \\
\text { Tennessee } \\
\text { Texas } \\
\text { Massachusetts } \\
\text { Askansas } \\
\text { Missouri } \\
\text { Mississippi } \\
\text { Minnesota } \\
\text { Ohio } \\
\text { Massachusetts } \\
\text { Minnesota } \\
\text { North Carolina } \\
\text { Tennessee } \\
\text { Kansas } \\
\text { Wisconsin } \\
\text { Wisconsin } \\
\text { Minnesota } \\
\text { Michigan } \\
\text { Wyoming } \\
\text { California } \\
\text { Michigan }\end{array}$ & 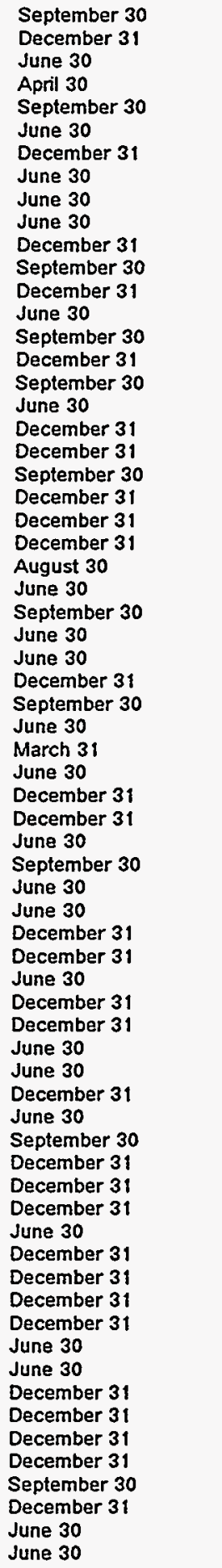 & $\begin{array}{l}\text { Generator } \\
\text { Nongenerator } \\
\text { Nongenerator } \\
\text { Nongenerator } \\
\text { Generator } \\
\text { Generator } \\
\text { Generator } \\
\text { Nongenerator } \\
\text { Nongenerator } \\
\text { Generator } \\
\text { Nongenerator } \\
\text { Generator } \\
\text { Nongenerator } \\
\text { Nongenerator } \\
\text { Nongenerator } \\
\text { Generator } \\
\text { Generator } \\
\text { Nongenerator } \\
\text { Generator } \\
\text { Generator } \\
\text { Generator } \\
\text { Nongenerator } \\
\text { Nongenerator } \\
\text { Nongenerator } \\
\text { Generator } \\
\text { Generator } \\
\text { Nongenerator } \\
\text { Nongenerator } \\
\text { Nongenerator } \\
\text { Generator } \\
\text { Nongenerator } \\
\text { Nongenerator } \\
\text { Generator } \\
\text { Generator } \\
\text { Nongenerator } \\
\text { Generator } \\
\text { Generator } \\
\text { Generator } \\
\text { Generator } \\
\text { Generator } \\
\text { Nongenerator } \\
\text { Nongenerator } \\
\text { Generator } \\
\text { Nongenerator } \\
\text { Nongenerator } \\
\text { Nongenerator } \\
\text { Nongenerator } \\
\text { Generator } \\
\text { Nongenerator } \\
\text { Nongenerator } \\
\text { Nongenerator } \\
\text { Nongengtor } \\
\text { Nongenerator } \\
\text { Gengenerator } \\
\text { Generator } \\
\text { Generator } \\
\text { Generator } \\
\text { Generator } \\
\text { Nongerator } \\
\text { Noner } \\
\text { Nonger } \\
\text { Nonger }\end{array}$ \\
\hline
\end{tabular}

Source: Energy Information Administration, Form ElA-412, "Annual Report of Public Electric Utilities." 
Figure B1. Principal Business Office of the Major U.S. Publicly Owned Electric Utilities, 1995

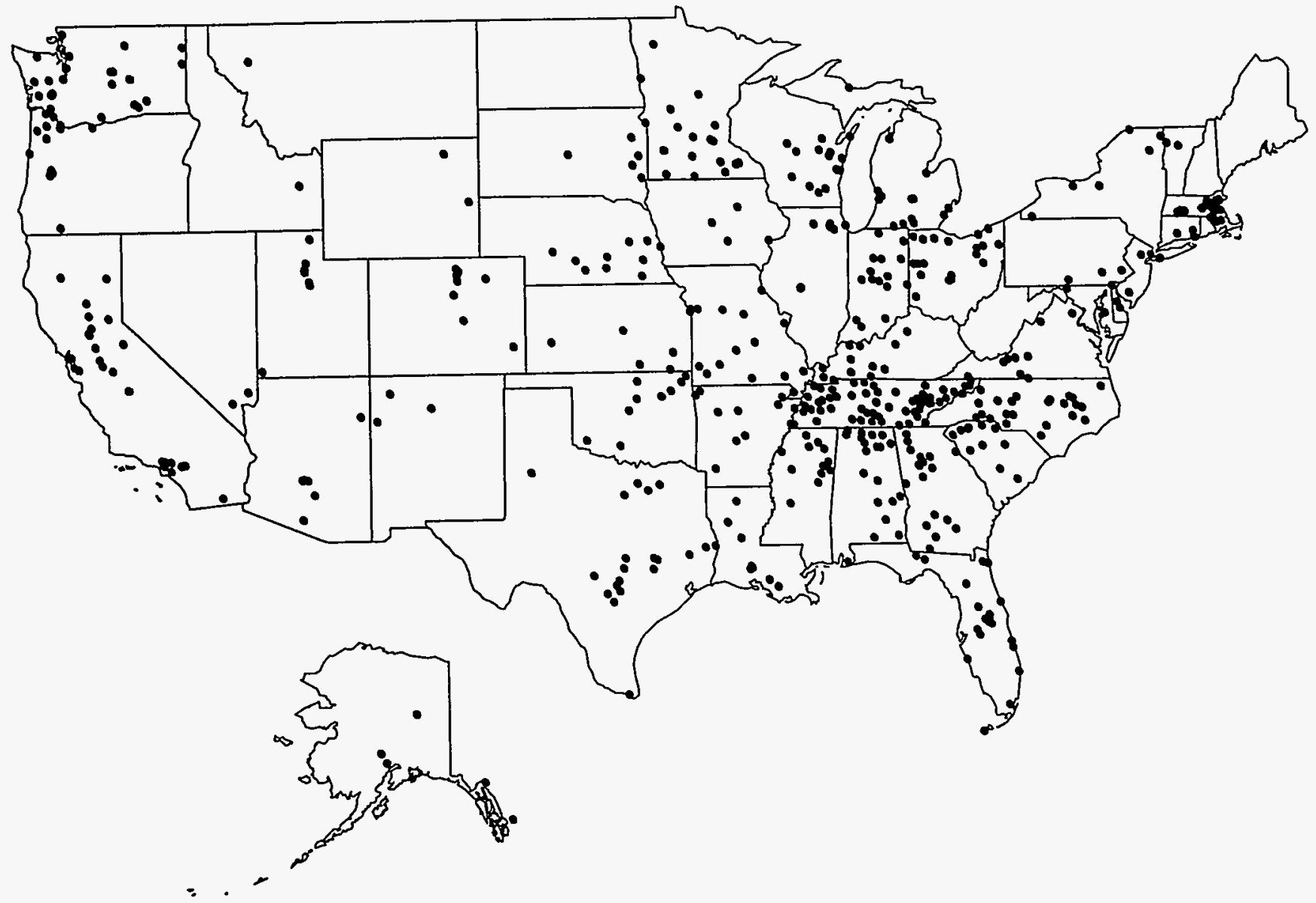

Source: Energy Information Adminlatration. Form ElA-412. 'Annual Report of Public Electric Utilitios." 


\section{Appendix C}

Major U.S.

Generatorl

Nongenerator

Respondents

by June 30

and December

31 Fiscal

Years and by

All

Respondents,

1991-1995 
Appendix C

Major U.S. Generator/Nongenerator Respondents by June 30 and December 31 Fiscal Years and by All Respondents, 1991-1995 
Table C1. Ten Largest U.S. Publicly Owned Generator Electric Utilities Ranked by Megawatthour Sales to Ultimate Consumers with Financial Year Ending on June 30, 1995

\begin{tabular}{|c|c|c|c|}
\hline Publicly Owned Electric Utilities & State & Amount & Percent \\
\hline Los Angeles City of & California & $20,513,243$ & 44.52 \\
\hline Anaheim City of & California & $2,256,685$ & 4.90 \\
\hline Santa Clara Clty of & California & $2,186,443$ & 4.75 \\
\hline 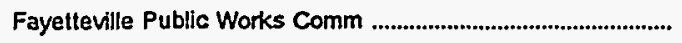 & North Carolina & $1,750,975$ & 3.80 \\
\hline Rlverside Clity of & California & $1,544,242$ & 3.35 \\
\hline Pasadena City of & California & $1,087,801$ & 2.36 \\
\hline 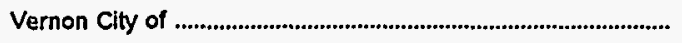 & California & $1,045,944$ & 2.27 \\
\hline 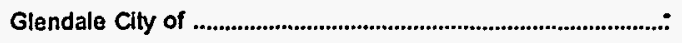 & California & $1,011,925$ & 2.20 \\
\hline Subtotal & & $34,622,451$ & 75.14 \\
\hline
\end{tabular}

Source: Energy Information Administration, Form ELA-412, "Annual Report of Public Electric Utilities."

Table C2. Ten Largest U.S. Publicly Owned Generator Electric Utilities Ranked by Megawatthour Sales for Resale with Financial Year Ending on June 30, 1995

\begin{tabular}{|c|c|c|c|}
\hline Publicly Owned Electric Utilities & State & Amount & Percent \\
\hline 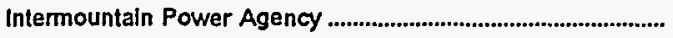 & Utah & $10,648,021$ & 22.24 \\
\hline 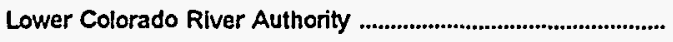 & Texas & $9,386,632$ & 19.60 \\
\hline 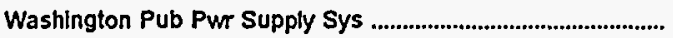 & Washington & $6,998.827$ & 14.62 \\
\hline 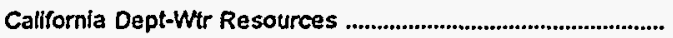 & California & $5,307,033$ & 11.08 \\
\hline Southern California P P A & California & $3,352,867$ & 7.00 \\
\hline 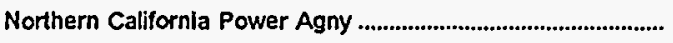 & California & $3,244,638$ & 6.78 \\
\hline 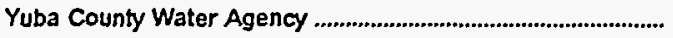 & California & $1,610.175$ & 3.36 \\
\hline 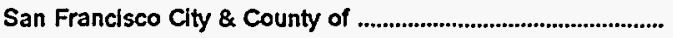 & California & $1,507.012$ & 3.15 \\
\hline 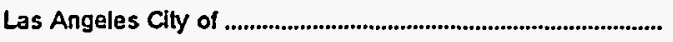 & California & $1,235,077$ & 2.58 \\
\hline Subtotal & & $44,472,879$ & 92.87 \\
\hline
\end{tabular}

Source: Energy Information Administration, Form ElA-412, "Annual Report of Public Electric Utilities." 
Table C3. Composite Statement of Income for Major U.S. Publicly Owned Generator Electric Utilities with Financial Year Ending on June 30, 1991-1995

(Thousand Dollars)

\begin{tabular}{|c|c|c|c|c|c|}
\hline Item & 1995 & 1994 & 1993 & 1992 & 1991 \\
\hline Electric Utility Operating Revenues .................... & $6,189,104$ & $6,322,194$ & $6,056,616$ & $5,873,621$ & $5,583,983$ \\
\hline 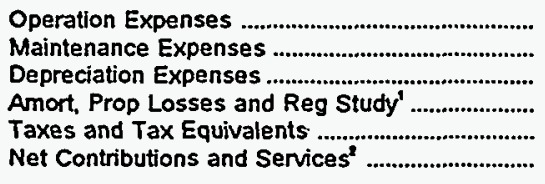 & $\begin{array}{r}3,604,623 \\
378,487 \\
771,714 \\
4,015 \\
127,377 \\
-\end{array}$ & $\begin{array}{r}3,750,469 \\
400,442 \\
733,717 \\
4,988 \\
125,721 \\
-\end{array}$ & $\begin{array}{r}3,607,659 \\
376,031 \\
665,941 \\
46,572 \\
126,376 \\
-\end{array}$ & $\begin{array}{r}3,525,928 \\
368,959 \\
627,770 \\
36,028 \\
109,783 \\
-\end{array}$ & $\begin{array}{r}3,389,558 \\
350,956 \\
623,168 \\
107,916 \\
66,809\end{array}$ \\
\hline $\begin{array}{l}\text { Total Electric Utility Operating } \\
\text { Expenses ....................................... }\end{array}$ & $4,886,217$ & $5,015,337$ & $4,822,580$ & $4,668,469$ & $4,538,407$ \\
\hline 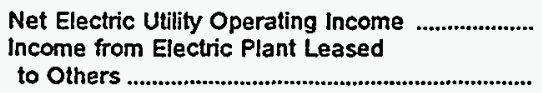 & $\begin{array}{r}1,302,887 \\
964\end{array}$ & $\begin{array}{r}1,306,856 \\
725\end{array}$ & $\begin{array}{r}1,234,036 \\
791\end{array}$ & $1,205,152$ & $1,045,576$ \\
\hline Electric Utility Operating Income .................... & $1,303,851$ & $1,307,582$ & $1,234,827$ & $1,207,627$ & $1,046,295$ \\
\hline Other Electric Income & 312,350 & 326,137 & 336,677 & 391.113 & 355.740 \\
\hline $\begin{array}{l}\text { Other Electric Deductions } \\
\text { Allowance for Other Funds Used }\end{array}$ & 82,340 & 91,770 & 109,123 & 122,334 & 1.824 \\
\hline 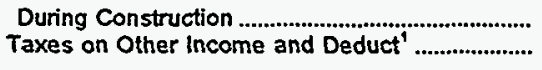 & - & $12,67 \overline{6}^{-}$ & 64 & 885 & 6.143 \\
\hline Electric Utility income & $1,533,860$ & $1,529,273$ & $1,462,317$ & $1,475,521$ & $1,406,354$ \\
\hline 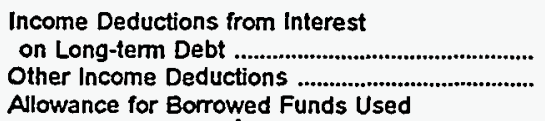 & $\begin{array}{r}1,260,071 \\
49,288\end{array}$ & $\begin{array}{r}1,266.410 \\
151\end{array}$ & $\begin{array}{r}1,219.759 \\
-73,744\end{array}$ & $\begin{array}{r}1,298,247 \\
-12,878\end{array}$ & $\begin{array}{r}1,182,775 \\
-87,632\end{array}$ \\
\hline During Construction' & $-3,712$ & $-7,380$ & $-15,152$ & $-10,592$ & - \\
\hline 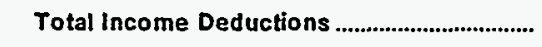 & $1,305,647$ & $1,259,181$ & $1,130,863$ & $1,274,778$ & $1,095,143$ \\
\hline 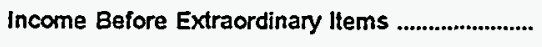 & 228,214 & 270,091 & 331,453 & 200,744 & 311,212 \\
\hline Extraordinary Income & 16,146 & 5,975 & 7,174 & 6,593 & 5,763 \\
\hline 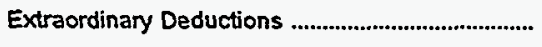 & 39,960 & 171,428 & 112,481 & 73,027 & 132,571 \\
\hline Net Income & 204,399 & 104,638 & 226,146 & 134,310 & 184,403 \\
\hline
\end{tabular}

Data reporting Sititiated in 1992.

- Data reporting discontinued in 1992.

- Data not available.

Note: Totals may not equal sum of components because of independent rounding. The number of generating publicly owned electric utilities for end of period is 59 for June 30, 1995; 57 for June 30, 1994; 56 for June 30, 1993; 56 for June 30, 1992; and 53 for June 30, 1991. The City of Vineland (NJ) changed fiscal year from June 30 to December 31 in 1991: the California Department of Water Resources (CA) changed fiscal year from December 31 to June 30 in 1992; the Wisconsin Power inc Sys (WI) changed fiscal year from June 30 to December 31 in 1993; and the City of Pella (IA) changed fiscal year from June 30 to December 31 in 1994, and the City of Burlingotn NT) changed fiscal year from December 31 to June 30 in 1994. The City of Gaffney (SC), City of Osceola (AR), and City of Redding (CA) were nongenerators for 1991 through 1993, but became generators in 1994. The City of Kennett (MO) and City of Morgan City (LA) were generators for 1991 through 1993, but became nongenerators in 1994. Emerald Peoples Utility District (OR). City of Bryan (OH), and Northern Wasco County PUD (OR) were nongenerators for 1991, but became generators in 1992.

Source: Energy Information Administration, Form ElA-412, "Annual Report of Public Electric Utilities." 
Table C4. Composite Balance Sheet for Major U.S. Publicly Owned Generator Electric Utilities with Financial Year Ending on June 30 at End of Period, 1991-1995 (Thousand Dollars)

\begin{tabular}{|c|c|c|c|c|c|}
\hline Item & 1995 & 1994 & 1993 & 1992 & 1991 \\
\hline \multicolumn{6}{|l|}{ Electric Utility Plant } \\
\hline 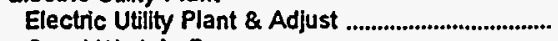 & $23,813,519$ & $23,649,149$ & $22,458,024$ & $21,821,753$ & $21,287,167$ \\
\hline Const Work in Progress & 948,126 & 843,150 & 879,753 & $1,007,230$ & \\
\hline 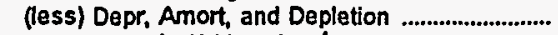 & $7,802.514$ & $7,247,501$ & $6,525,704$ & $6,047,224$ & $5,313,940$ \\
\hline Net Electric Utility Plant $t^{1}, \ldots . . . . . . . . . . . . . . . . . . . . . . . . . . . . . .$. & $16,959,131$ & $17,244,798$ & $16,812,072$ & $16,781,759$ & - \\
\hline 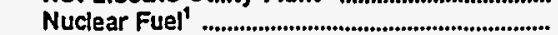 & 396,089 & 354,050 & 363,138 & 307,982 & - \\
\hline 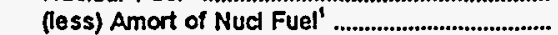 & 209.501 & 201,855 & 197,885 & 138,151 & \\
\hline 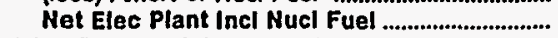 & $17,145,720$ & $17,396,994$ & $16,977,326$ & $16,951,590$ & $15,973,226$ \\
\hline \multicolumn{6}{|l|}{ Other Property \& Investments } \\
\hline 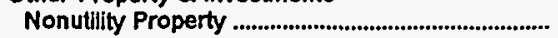 & $5,810,617$ & $5,282,581$ & $4,783,966$ & $4,390,194$ & $4,083,541$ \\
\hline (less) Accum Provisions for Depr \& Amort ............ & $1,765,771$ & $1,643,704$ & $1,532,462$ & $1,426,040$ & $1,323,745$ \\
\hline 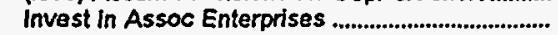 & 12,265 & 34,364 & 30,539 & 38,999 & 2,351 \\
\hline 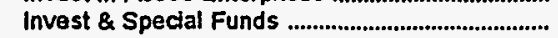 & $5,848,427$ & $5,976,191$ & $5.470,789$ & $3,958,741$ & $4,048,793$ \\
\hline Total Other Property \& Investments ............. & $9,905,538$ & $\mathbf{9 , 6 4 9 , 4 3 3}$ & $8,752,832$ & $6,961,895$ & $6,810,940$ \\
\hline \multicolumn{6}{|l|}{ Current and Accrued Assets } \\
\hline Cash, Working Funds \& Investments ....................... & $3,370,548$ & $3,637,073$ & $3,842,190$ & $3,167,797$ & $2,879,170$ \\
\hline 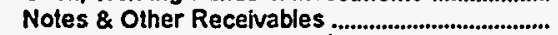 & 260,772 & 263,092 & 251,043 & 274,818 & 666,963 \\
\hline 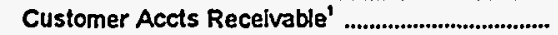 & 508,885 & 600,752 & 553,561 & 521,135 & \\
\hline (less) Accum Prov for Uncollected Accts ............. & 22,517 & 19.483 & 18,891 & 14,961 & 11,322 \\
\hline 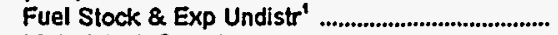 & 170,403 & 211.474 & 219,279 & 230,592 & \\
\hline 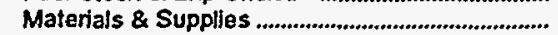 & 293,025 & 318,585 & 308,887 & 306,329 & 425,083 \\
\hline 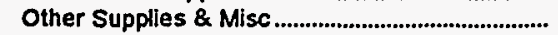 & 19.133 & & & - & - \\
\hline Prepayments ...................................................... & 105,653 & 84,928 & 73,367 & 74,489 & 79,627 \\
\hline Accrued Utility Revenues' ................................. & 137,929 & 134,879 & 130,552 & 118,743 & - \\
\hline Miscellaneous Current \& Accrued Assets ............ & 480,926 & 476,221 & 317,320 & 267,360 & 269,715 \\
\hline Total Current \& Accrued Assets ........................ & $5,324,757$ & $5,707,521$ & $5,677,308$ & $4,946,301$ & $4,309,236$ \\
\hline \multicolumn{6}{|l|}{ Deferred Debits } \\
\hline Unamortized Debt Expenses ................ & $1,441,454$ & $1,515,843$ & $1,115,871$ & 920,381 & 951,622 \\
\hline Extraordinary Losses, Study Cost.............. & 29.921 & 22,426 & 395,404 & 12,920 & \\
\hline Misc Debt, $R \&$ D Exp, Unamnt Losses ................. & $2,293,374$ & $2,469,450$ & $2,379,389$ & $2,598,210$ & $2,399,812$ \\
\hline Total Deferred Debits .................................................. & $3,764,750$ & $4,007,720$ & $3,890,664$ & $3,531,511$ & $3,351,435$ \\
\hline 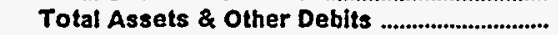 & $36,140,764$ & $36,761,667$ & $35,298,129$ & $32,391,297$ & $30,444,837$ \\
\hline \multicolumn{6}{|l|}{ Proprietary Capital } \\
\hline Investment of Municipality ... & $1,253,767$ & $1,010,703$ & 980,695 & $1,020,857$ & $1,171,715$ \\
\hline 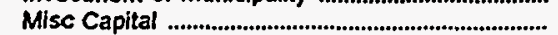 & 86,913 & 118,973 & 97,246 & $-14,376$ & $-251,794$ \\
\hline 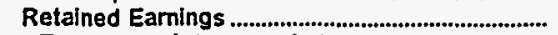 & $7,481,164$ & $7,489,894$ & $7,165,700$ & $6,911,454$ & $6,796,166$ \\
\hline Total Proprietary Capital ......................................... & $8,821,844$ & $8,619,570$ & $8,243,641$ & $7,917,934$ & $7,716,086$ \\
\hline \multicolumn{6}{|l|}{ Long-term Debt } \\
\hline 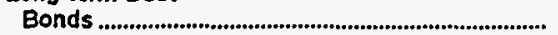 & $22,390,678$ & $22,970,895$ & $22,602,706$ & $20,377,974$ & $18,835,964$ \\
\hline Advances from Municipality \& Other .......................... & $1,551,506$ & $1,577,910$ & 987,761 & 553,413 & 594,617 \\
\hline Unamort Prem on Long-term Debt ........................... & 8,991 & 9.674 & 8,000 & 3.743 & 688 \\
\hline (less) Unamort Discount on Long-term Debt ....... & 883,366 & 943,800 & $1,049,664$ & $1,072,415$ & 986,782 \\
\hline \multirow{2}{*}{\multicolumn{6}{|c|}{ Other Noncurrent Uablilites }} \\
\hline & & & & & \\
\hline Accum Operating Provisions...... & 55.232 & 119,569 & 69,777 & 69.277 & 32,515 \\
\hline Accum Prov for Rate Refunds' ................................. & 55,786 & & & & \\
\hline Total Other Nancurrent Liabilities .................... & 111,018 & 119,569 & 69,777 & 69,277 & 32,515 \\
\hline \multicolumn{6}{|l|}{ Current and Accrued Labilities } \\
\hline 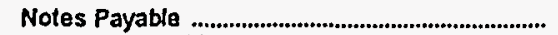 & 108,184 & 112,848 & 115,216 & 124,960 & 100.631 \\
\hline 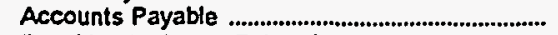 & 858,722 & 914,732 & 838,032 & 836.494 & 746,541 \\
\hline 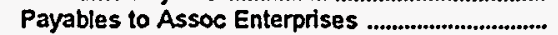 & 136.545 & 135,708 & 150,227 & 145,023 & 149,637 \\
\hline 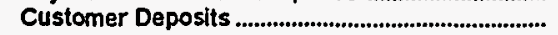 & 118,380 & 100,781 & 79,307 & 93,187 & 75,121 \\
\hline 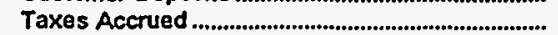 & 13.622 & 14,141 & 16,668 & 21,663 & 21,522 \\
\hline 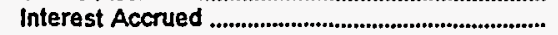 & 494,970 & 443,461 & 432,509 & 382.500 & 410,709 \\
\hline Misc Current \& Accrued Liabilities............................. & $1,909,881$ & $1,968,441$ & $1,912,747$ & $1,940,659$ & $1,627,133$ \\
\hline Total Current \& Accrued Liabilities ................. & $3,640,302$ & $3,690,113$ & $3,544,706$ & $3,544,487$ & $3,331,293$ \\
\hline \multicolumn{6}{|l|}{ Deferred Credits } \\
\hline Customer Advances for Construction ....................... & 50,791 & 45,136 & 43,288 & 42,340 & 51,082 \\
\hline 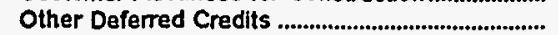 & 626.741 & 651,166 & 742,733 & 811.973 & 695,188 \\
\hline 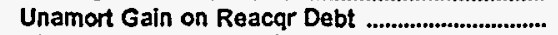 & $-177,740$ & 21,434 & 105,182 & 142,572 & 174,185 \\
\hline Total Deferred Credits ......................................... & 499,791 & 717,736 & 891,203 & 998,885 & 920,455 \\
\hline Total Labilities and Other Credits .................. & $36,140,764$ & $36,761,667$ & $35,298,129$ & $32,391,297$ & $30,444,837$ \\
\hline
\end{tabular}

Data reporting initiated in 1992.

Note: Totals may not equal sum of components because of independent rounding. The number of generating publicly owned electric utilities for end of period is 59 for June 30, 1995; 57 for June 30. 1994; 56 for June 30, 1993; 56 for June 30, 1992; and 53 for June 30 . 1991. The City of Vineland (NJ) changed fiscal year from June 30 to December 31 in 1991; the California Department of Water Resources (CA) changed fiscal year from December 31 to June 30 in 1992; the Wisconsin Public Power Inc Sys MI) changed fiscal year from December 31 to June 30 in 1993; and the Clty of Pella (LA) changed fiscal year from June 30 to December 31 in 1994, and the City of Burtington (VT) changed fiscal year from December 31 to June 30 in 1994. The City of Gaffney (SC), City of Osceola (AR), and City of Redding (CA) were nongenerators for 1991 through 1993; but became generators in 1994. The City of Kennett (MO) and City of Morgan City (LA) were generators for 1991 through 1993; but became nongenerators in 1994. Emerald Peoples Utility District (OR), City of Bryan (OH), and Northern Wasco County PUD (OR) were nongenerators for 1991, but became generators in 1992. The Utah Associated Municipal Power System (UT) Changed fiscal year from June 30 to March 31 in 1991.

Source: Energy Information Administration. Form EIA-4 12, "Annual Report of Public Electric Utilities." 
Table C5. Composite Financial Indicators for Major U.S. Publicly Owned Generator Electric Utilities with Financial Year Ending on June 30, 1991-1995

\begin{tabular}{|c|c|c|c|c|c|}
\hline Item & 1995 & 1994 & 1993 & 1992 & 1991 \\
\hline Total Electric Utility Plant per Dollar of Revenue & 4.1 & 3.9 & 3.9 & 3.9 & 3.8 \\
\hline Current Assets to Current Liabilities ......................... & 1.5 & 1.5 & 1.6 & 1.4 & 1.3 \\
\hline $\begin{array}{l}\text { Tolal Electric Utility Plant as a Percent of Total } \\
\text { Assets }\end{array}$ & 69.6 & 67.6 & 67.1 & 71.4 & 69.9 \\
\hline 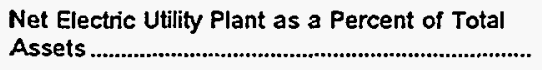 & 47.4 & 47.3 & 48.1 & 52.3 & 52.5 \\
\hline Debt as a Percent of Total Liabilities ...................... & 73.9 & 74.3 & 73.9 & 72.3 & 71.5 \\
\hline $\begin{array}{l}\text { Depreciation, Amortization and Depletion } \\
\text { as a Percent of Total Electric Utility Plant ........... }\end{array}$ & 31.8 & 30.0 & 28.4 & 26.7 & 25.0 \\
\hline $\begin{array}{l}\text { Electric Operation and Maintenance Expenses } \\
\text { as a Percent of } \\
\text { Electric Utility Operating Revenues ......................... }\end{array}$ & 64.4 & 65.7 & 65.8 & 66.3 & 67.0 \\
\hline $\begin{array}{l}\text { Electric Depreciation and Amortization } \\
\text { as a Percent of } \\
\text { Electric Utility Operating Revenues .......................... }\end{array}$ & 12.5 & $\mathfrak{1 1 . 6}$ & 11.0 & 10.7 & 11.2 \\
\hline $\begin{array}{l}\text { Taxes and Tax Equivalents } \\
\text { as a Percent of } \\
\text { Electric Utility Operating Revenues ....................... }\end{array}$ & 2.1 & 2.0 & 2.1 & 1.9 & 1.9 \\
\hline $\begin{array}{l}\text { Interest on Long-term Debt } \\
\text { as a Percent of } \\
\text { Electric Utility Operating Revenues ....................... }\end{array}$ & 20.4 & 20.0 & 20.1 & 22.1 & 21.2 \\
\hline 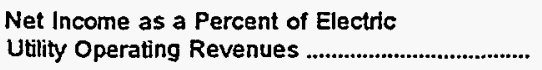 & 3.3 & 1.7 & 3.7 & 2.3 & 3.3 \\
\hline Purchased Power Cents Per Kilowatthour............ & 4.3 & 4.5 & 4.3 & 4.3 & 4.5 \\
\hline Generated Cents Per Kilowatthour ........................ & 2.1 & 2.3 & 2.3 & 2.3 & 2.3 \\
\hline $\begin{array}{l}\text { Total Power Supply Per } \\
\text { Kilowatthour Sold }\end{array}$ & 3.2 & 3.4 & 3.4 & 3.5 & 3.5 \\
\hline
\end{tabular}

Note: Totals may not equal sum of components because of independent rounding. The number of generating publicly owned electric utilities tor end of period is 59 for June 30, 1995; 57 for June 30, 1994; 56 for June 30, 1993; 56 for June 30 . 1992; and 53 for June 30 1991. The City of Vineland (NJ) changed fiscal year from June 30 to December 31 in 1991; the California Department of Water Resources (CA) changed fiscal year from December 31 to June 30 in 1992; the Wisconsin Public Power Inc Sys (W) changed fiscal year from December 31 to June 30 in 1993; and the City of Pella (LA) changed fiscal year from June 30 to December 31 in 1994, and the City of Burlington (NT) changed fiscal year from December 31 to June 30 in 1994. The City of Gaffney (SC). City of Osceola (AR). and City of Redding (CA) were nongenerators for 1991 through 1993; but became generators in 1994. The City of Kennett (MO) and City of Morgan City (La) were generators for 1991 through 1993; but became nongenerators in 1994. Emerald Peoples Utility District (OR), City of Bryan (OH), and Northern Wasco County PUD (OR) were nongenerators for 1991, but became generators in 1992. The Utah Associated Municipal Power System (UT) changed fiscal year from June 30 to March 31 in 1991 .

Source: Energy Information Administration, Form ElA-4 12, "Annual Report of Public Electric Utilities." 
Table C6. Electric Operation and Maintenance Expenses for Major U.S.

Publicly Owned Generator Electric Utilities with Financial

Year Ending on June 30, 1991-1995

(Thousand Dollars)

\begin{tabular}{|c|c|c|c|c|c|}
\hline Item & 1995 & 1994 & 1993 & 1992 & 1991 \\
\hline \multicolumn{6}{|l|}{ Production Expenses } \\
\hline 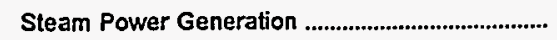 & 970,882 & $1,080,342$ & $1,078,045$ & 952,188 & 920.777 \\
\hline 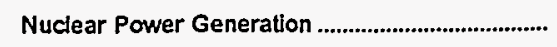 & 218,444 & 234,047 & 211,994 & 195,820 & 208,094 \\
\hline 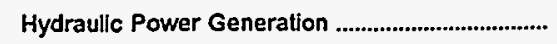 & 54,523 & 48,678 & 51,177 & 51,216 & 49,211 \\
\hline 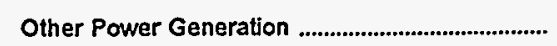 & 62,988 & 46,086 & 41,629 & 38,213 & 24,478 \\
\hline Purchased Power & $1,619,076$ & $1,723,456$ & $1,618,260$ & $1,696,102$ & $1,634,208$ \\
\hline 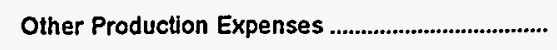 & 35,910 & 20,082 & 15,753 & 25,393 & 26,376 \\
\hline 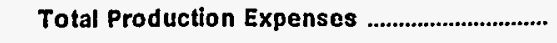 & $2,961,823$ & $3,152,691$ & $3,016,859$ & $2,958,932$ & $2,863,145$ \\
\hline 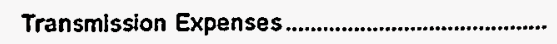 & 149,263 & 141,292 & 128,866 & 122,955 & 114,691 \\
\hline 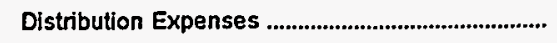 & 239,748 & 250.442 & 267,820 & 249,276 & 232,287 \\
\hline 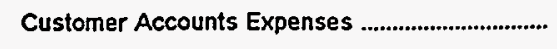 & 91,609 & 84.175 & 92,470 & 85,956 & 77.482 \\
\hline Customer Service and Information Expenses ..... & 29,759 & 31,735 & 29,378 & 23,888 & 19,756 \\
\hline Sales Expenses & 906 & 812 & 813 & 1,507 & 3,126 \\
\hline Administrative and General Expenses .................... & 510,000 & 489,764 & 447,484 & 452,373 & 430,027 \\
\hline $\begin{array}{l}\text { Total Electric Operation } \\
\text { and Maintenance Expenses ............................. }\end{array}$ & $3,983,110$ & $4,150,911$ & $3,983,691$ & $3,894,887$ & $3,740,513$ \\
\hline \multicolumn{6}{|l|}{ Fuel Expenses in Operation } \\
\hline 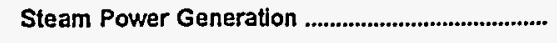 & 627,974 & 812,127 & 799,613 & 702,909 & 651,050 \\
\hline 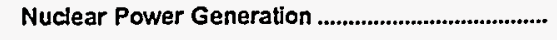 & 39,804 & 59,630 & 54,438 & 38.524 & 56,309 \\
\hline 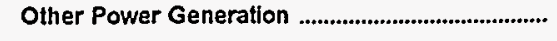 & 10,478 & 21,917 & 19,689 & 17,832 & 16,092 \\
\hline \multicolumn{6}{|l|}{ Number of Elec Dept Employees } \\
\hline Regular Full-time' & 14,949 & 15,653 & 15.442 & 16,894 & - \\
\hline Part-time \& Temporary' & 597 & 815 & 967 & 1,217 & - \\
\hline 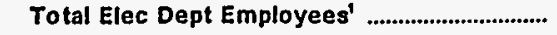 & 15,546 & 16,468 & 16,409 & 18,111 & - \\
\hline
\end{tabular}

- Data reporting initiated in 1992.

Note: Totals may not equal sum of components because of independent rounding. The number of generating publicly owned electric utilities for end of period is 59 for June 30. 1995; 57 for June 30, 1994; 56 for June 30, 1993; 56 for June 30, 1992; and 53 for June 30. 1991. The City of Vineland (NJ) changed fiscal year from June 30 to December 31 in 1991; the California Department of Water Resources (CA) changed fiscal year from December 31 to June 30 in 1992; the Wisconsin Public Power Inc Sys (WI) changed fiscal year from December 31 to June 30 in 1993; and the City of Pella (IA) changed fiscal year from June 30 to December 31 in 1994, and the City of Burlington (VT) changed fiscal year from December 31 to June 30 in 1994. The City of Gafiney (SC), City of Osceola (AR), and City of Redding (CA) were nongenerators for 1991 through 1993; but became generators in 1994. The City of Kennett (MO) and City of Morgan City (LA) were generators for 1991 through 1993; but became nongenerators in 1994. Emerald Peoples Utility District (OR). City of Bryan (OH), and Northern Wasco County PUD (OR) were nongenerators for 1991, but became generators in 1992. The Utah Associated Municipal Power System (UT) changed fiscal year from June 30 to March 31 in 1991.

Source: Energy Information Administration. Form EIA-412, "Annual Report of Public Electric Utilities." 
Table C7. Electric Utility Plant for Major U.S. Publicly Owned Generator

Electric Utilities with Financial Year Ending

on June 30 at End of Period, 1991-1995

(Thousand Dollars)

\begin{tabular}{|c|c|c|c|c|c|}
\hline Item & 1995 & 1994 & 1993 & 1992 & 1991 \\
\hline \multicolumn{6}{|l|}{ Electric Plant in Service } \\
\hline Intangible Plant & 89,558 & 88,908 & 88,231 & 103,370 & 141,436 \\
\hline \multicolumn{6}{|l|}{ Production Plant } \\
\hline Steam & $6,470,103$ & $6,264,976$ & $6,381,047$ & $6,074,387$ & $5,849,534$ \\
\hline Nuclear & $4,646,849$ & $4,586,603$ & $4,580,460$ & $4,584,312$ & $4,859,875$ \\
\hline 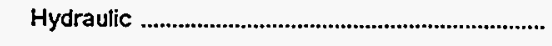 & $2,692,206$ & $2,785,014$ & $2,627,882$ & $2,618,895$ & $1,794,146$ \\
\hline Other & 907,358 & 981,621 & 435.135 & 590,691 & 248,642 \\
\hline Total Production Plant ............................................. & $14,716,515$ & $14,618,215$ & $14,024,524$ & $13,868,285$ & $12,752,197$ \\
\hline 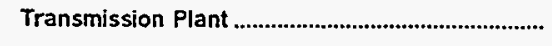 & $2,523,452$ & $2,488,678$ & $2,443,364$ & $2,372,536$ & $2,257,636$ \\
\hline 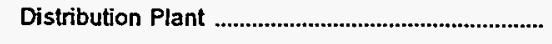 & $4,583,704$ & $4,433,062$ & $4,237,454$ & $4,056,844$ & $3,757,918$ \\
\hline 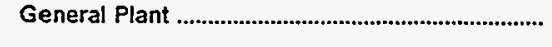 & $1,592,593$ & $1,701,054$ & $1,373,699$ & $1,189,667$ & $1,123,472$ \\
\hline Total Electric Plant in Service .............................. & $23,505,822$ & $23,329,917$ & $22,167,272$ & $21,590,702$ & $20,032,658$ \\
\hline 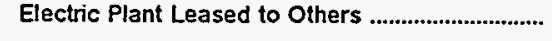 & 1 & 1 & 1 & 1 & 655 \\
\hline Construction Work in Progress - Electric ................ & 948,126 & 843,150 & 879,753 & $1,007,230$ & $1,002,642$ \\
\hline 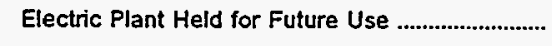 & 2,227 & 12,216 & 9,487 & 17 & 264,295 \\
\hline 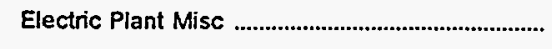 & 305,470 & 307,016 & 281,264 & 231,033 & $-13,083$ \\
\hline 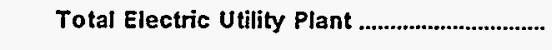 & $24,761,645$ & $24,492,299$ & $23,337,776$ & $22,828,983$ & $21,287,167$ \\
\hline 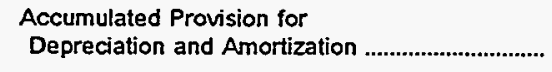 & $7,802,514$ & $7,247,501$ & $6,525,704$ & $6,047,224$ & $5,313,940$ \\
\hline 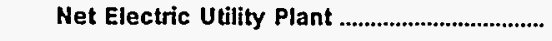 & $16,959,131$ & $17,244,798$ & $16,812,072$ & $16,781,759$ & $15,973,226$ \\
\hline
\end{tabular}

Note: Totals may not equal sum of components because of independent rounding. The number of generating publicly ow/ned electric utilities for end of period is 59 for June 30, 1995; 57 for June 30, 1994; 56 for June 30, 1993; 56 for June 30, 1992; and 53 for June 30, 1991. The City of Vineland (NJ) changed fiscal year from June 30 to December 31 in 1991; the California Department of Water Resources (CA) changed fiscal year from December 31 to June 30 in 1992; the Wisconsin Public Power Inc Sys (WI) changed fiscal year from December 31 to June 30 in 1993; and the City of Pella (IA) changed fiscal year from June 30 to December 31 in 1994, and the City of Burlington NT) changed fiscal year from December 31 to June 30 in 1994. The City of Gaffney (SC). City of Osceola (AR), and City of Redding (CA) were nongenerators for 1991 through 1993; but became generators in 1994. The City of Kennett (MO) and City of Morgan City (La) were generators for 1991 through 1993; but became nongenerators in 1994. Emerald Peoples Utility District (OR), City of Bryan (OH), and Northern Wasco County PUD (OR) were nongenerators for 1991, but became genzrators in 1992. The Utah Associated Municipal Power System (UT) changed fiscal year from June 30 to March 31 in 1991.

Source: Energy Information Administration, Form EIA-412, "Annual Report of Public Electric Utilities." 
Table C8. Number of Consumers, Sales, and Operating Revenue for Major U.S. Publicly Owned Generator Electric Utilities with Financial Year Ending on June 30, 1991-1995

\begin{tabular}{|c|c|c|c|c|c|}
\hline Item & 1995 & 1994 & 1993 & 1992 & 1991 \\
\hline \multicolumn{6}{|l|}{ Number of Consumers } \\
\hline 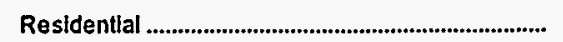 & $2,092,371$ & $2,093,440$ & $2,068,364$ & $2,051,709$ & $2,099,789$ \\
\hline Commercial or Small & 306,755 & 306,525 & 299,862 & 298,130 & 234,033 \\
\hline Industrial or Large & 22,468 & 24,124 & 23,482 & 23,782 & 20,265 \\
\hline Other & 18,141 & 18,286 & 16.039 & 19,858 & 20,055 \\
\hline 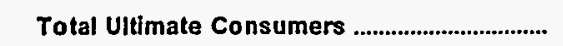 & $2,439,735$ & $2,442,375$ & $2,407,747$ & $2,393,479$ & $2,374,142$ \\
\hline \multicolumn{6}{|l|}{ Sales for the Year (megawatthours) } \\
\hline 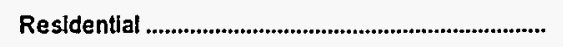 & $13,360,217$ & $13,186,592$ & $12,646,336$ & $12,802,964$ & $12,232,289$ \\
\hline Commercial or Small & $19,736,464$ & $15,495,316$ & $19,091,042$ & $18,772,290$ & $18,643,257$ \\
\hline Industrial or Large & $11,242,614$ & $16,261,239$ & $12,437,301$ & $12,741,755$ & $12,451,053$ \\
\hline Other & $2,578,959$ & $2,334,719$ & $2,180,702$ & $2,628,594$ & $2,299,173$ \\
\hline Total Sales to Uitimate Consumers ................. & $46,918,254$ & $47,277,866$ & $46,355,381$ & $46,945,603$ & $45,625,772$ \\
\hline Sales for Resale & $48,994,945$ & $44,154,103$ & $44,312,299$ & $39,068,959$ & $33,831,354$ \\
\hline Total Sales & $95,913,199$ & $91,431,969$ & $90,667,680$ & $86,014,562$ & $79,457,126$ \\
\hline \multicolumn{6}{|l|}{$\begin{array}{l}\text { Operating Revenues for the Year } \\
\text { (thousand dollars) }\end{array}$} \\
\hline 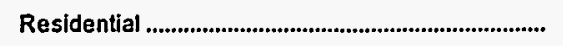 & $1,171,645$ & $1,160,463$ & $1,109,153$ & $1,073,325$ & $1,002,074$ \\
\hline Commercial or Small & $1,670,058$ & $1,342,630$ & $1,618,563$ & $1,535,038$ & $1,469,595$ \\
\hline Industrial or Large & 784,173 & $1,193,294$ & 905,778 & 881,541 & 838,360 \\
\hline Other & 158,976 & 159,079 & 143,731 & 177,005 & 145,979 \\
\hline $\begin{array}{l}\text { Tatal Revenues from Sales to } \\
\text { Uitimate Consumers }\end{array}$ & $3,784,852$ & $3,855,466$ & $3,777,225$ & $3,666,909$ & $3,456,008$ \\
\hline Sales for Resale & $2,216,554$ & $2,272,651$ & $2,131,533$ & $2,065,351$ & 1.858 .972 \\
\hline $\begin{array}{l}\text { Total Revenues From Sales of } \\
\text { Electricity }\end{array}$ & $6,001,406$ & $6,128,117$ & $5,908,758$ & $5,732,260$ & $5,314,980$ \\
\hline
\end{tabular}

Note: Totals may not equal sum of components because of independent rounding. The number of generating publicty owned electric utilities for end of period is 59 for June 30, 1995; 57 for June 30, 1994; 56 for June 30, 1993; 56 for June 30, 1992; and 53 for June 30, 1991. The City of Vineland (NJ) changed fiscal year from Jure 20 to December 31 in 1991; tiut California Department of Water Resources (CA) changed fiscal year from December 31 to June 30 in 1992; the Wisconsin Public Power Inc Sys (WI) changed fiscal year (rom December 31 to June 30 in 1993; and the City of Pella (IA) changed fiscal year from June 30 to December 31 in 1994, and the City of Burlington (VT) changed fiscal year from December 31 to June 30 in 1994. The City of Gaffney (SC), City of Osceola (AR), and City of Redding (CA) were nongenerators for 1991 through 1993; but became generators in 1994. The City of Kennett (MO) and City of Morgan City (LA) were generators for 1991 through 1993; but became nongenerators in 1994. Emerald Peoples Utility District (OR). City of Bryan (OH), and Northern Wasco County PUD (OR) were nongenerators for 1991, but became generators in 1992. The Utah Associated Municipal Power System (UT) changed fiscal year from June 30 to March 31 in 1991. Source: Energy Information Administration, Form ElA-861, "Annual Electric Utility Report." Data are based on calendar year submis-
slons. 
Table C9. Electric Energy Account for Major U.S. Publicly Owned

Generator Electric Utilities with Financial Year Ending

on June 30, 1991-1995

(Megawatthours)

\begin{tabular}{|c|c|c|c|c|c|}
\hline Item & 1995 & 1994 & 1993 & 1992 & 1991 \\
\hline \multicolumn{6}{|l|}{ Sources of Energy } \\
\hline Steam & $40,044,844$ & $42,721,159$ & $39,909,551$ & $38,133,584$ & $35,805,972$ \\
\hline 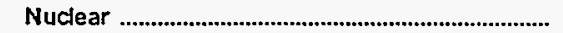 & $10,779,961$ & $10,528,784$ & $10,074,201$ & $7,253,503$ & $9,571,421$ \\
\hline 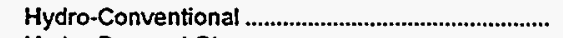 & $9,681,575$ & $7,392,578$ & $8,244,651$ & $7,347,109$ & $5,277,435$ \\
\hline Hydro-Pumped Storage & $3,234,118$ & $1,819,704$ & $2,247,668$ & $2,414,851$ & $1,247,928$ \\
\hline Other & 251,296 & 603.785 & 496.659 & 580,196 & 777,690 \\
\hline $\begin{array}{l}\text { (Less) Energy for Pumping } \\
\text { Total Net Generation }\end{array}$ & $\begin{array}{r}451,498 \\
63,540,296\end{array}$ & $\begin{array}{r}951,103 \\
62,114,906\end{array}$ & $\begin{array}{r}937,070 \\
60,035,659\end{array}$ & $\begin{array}{r}1,161,213 \\
54,568,030\end{array}$ & $\begin{array}{r}720,925 \\
51,959,522\end{array}$ \\
\hline 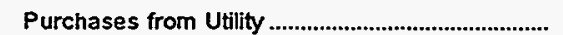 & $34,860,785$ & $36,657,410$ & $35,417,196$ & $37,654,330$ & $36,465,229$ \\
\hline $\begin{array}{l}\text { Purchases from Nonutility } \\
\text { Power Exchanges }\end{array}$ & 907,444 & 569,610 & 630,280 & 153,015 & 60,371 \\
\hline 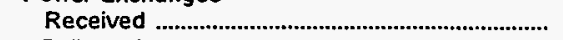 & $6,051,872$ & $4,954,839$ & $5,475,410$ & $5,699,468$ & $1,748,125$ \\
\hline 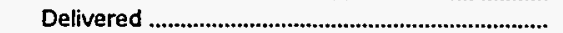 & $4,400.176$ & $3,791,556$ & $3,780,680$ & $3,637,592$ & $1,807,581$ \\
\hline Net Exchanges & $1,651,696$ & $1,163,283$ & $1,694,730$ & $2,061,876$ & $-59,456$ \\
\hline Transmission for Others (Wheeling) & & & & & \\
\hline 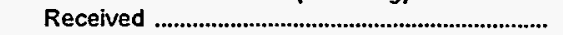 & $14,428,382$ & $14,581,581$ & $16,078,009$ & $14,009,909$ & $17,569,869$ \\
\hline 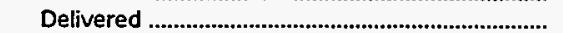 & $14,396,551$ & $14,528,824$ & $16,021,994$ & $13,959,201$ & $17,509,416$ \\
\hline 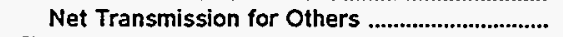 & 31,831 & 52,758 & 56,015 & 50,708 & 60,453 \\
\hline 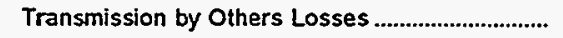 & $-166,523$ & $-214,516$ & $-174,994$ & $-141,770$ & $-130,869$ \\
\hline \multicolumn{6}{|l|}{ Total Net Energy Generated and } \\
\hline 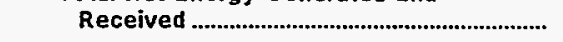 & $100,825,529$ & $100,343,451$ & $97,658,887$ & $94,346,189$ & $88,355,250$ \\
\hline \multicolumn{6}{|l|}{ Disposition of Energy } \\
\hline 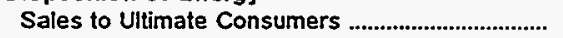 & $46,076,430$ & $47,153,236$ & $47,089,512$ & $46,312,232$ & $45,847,782$ \\
\hline 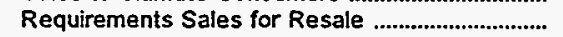 & $45,580,165$ & $42,479,566$ & $40,980,045$ & $36,745,586$ & $34,776,080$ \\
\hline 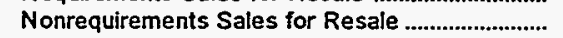 & $2,304,988$ & $1,886,792$ & 947,898 & 453,567 & 759,838 \\
\hline 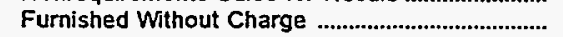 & 186,650 & 194,995 & 235,866 & 200,424 & 180,152 \\
\hline 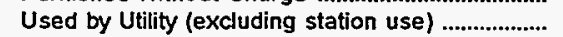 & $3,593,552$ & $4,727,042$ & $4,631,889$ & $6,179,980$ & $2,590,094$ \\
\hline Losses & $3,083,744$ & $3,901,820$ & $3,773,677$ & $4,454,398$ & $4,201,299$ \\
\hline Total Disposition & $100,825,529$ & $100,343,451$ & $97,658,887$ & $94,346,189$ & $88,355,250$ \\
\hline
\end{tabular}

Note: Totals may not equal sum of components because of independent rounding. The number of generating publicly owned electric utilities for end of period is 59 for June 30,$1995 ; 57$ for June 30, 1994: 56 for June 30, 1993; 56 for June 30, 1992; and 53 for June 30, 1991. The City of Vineland (NJ) changed fiscal year from June 30 to December 31 in 1991; the California Department of Water Resources (CA) changed fiscal year from December 31 to June 30 in 1992; the Wisconsin Public Power Inc Sys (WI) changed fiscal year from December 31 to June 30 in 1993; and the City of Pella (IA) changed fiscal year from June 30 to December 31 in 1994, and the City of Burlington (VT) changed fiscal year from December 31 to June 30 in 1994. The City of Gaffiney (SC), City of Osceola (AR), and City of Redding (CA) were nongenerators for 1991 through 1993; but became generators in 1994. The City of Kennett (MO) and City of Morgan City (LA) were generators for 1991 through 1993; but became nongenerators in 1994. Emerald Peoples Utility District (OR), City of Bryan (OH), and Northern Wasco County PUD (OR) were nongenerators for 1991, but became generators in 1992 . The Utah Associated Municipal Power System (UT) changed fiscal year from June 30 to March 31 in 1991 .

Source: Energy Information Administration, Form ElA-412, "Annual Report of Public Electnc Utilities." 
Table C10. Ten Largest U.S. Publicly Owned Generator Electric Utilities Ranked by Megawatthour Sales to Ultimate Consumers with Financial Year Ending on December 31, 1995

\begin{tabular}{|c|c|c|c|}
\hline Publicly Owned Electric Utilities & State & Amount & Percent \\
\hline 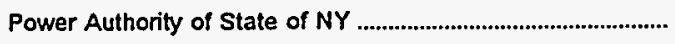 & New York & $13,043,997$ & 11.74 \\
\hline Seattle City of & Washington & $8,788,829$ & 7.91 \\
\hline Sacramento Municipal Util Dist & California & $8,458,888$ & 7.62 \\
\hline South Carolina Pub Serv Auth & South Carolina & $7,739.117$ & 6.97 \\
\hline Omaha Public Power District & Nebraska & $7,456.745$ & 6.71 \\
\hline PUD No 1 of Snohomish County & Washington & $5,682,565$ & 5.12 \\
\hline Tacoma City of & Washington & $5,331,048$ & 4.80 \\
\hline 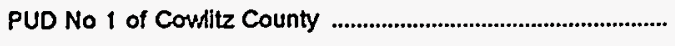 & Washington & $4,554,973$ & 4.10 \\
\hline Colorado Springs City of & Colorado & $3,267,032$ & 2.94 \\
\hline 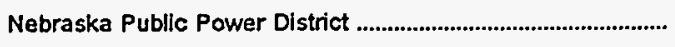 & Nebraska & $2,818,495$ & 2.54 \\
\hline Subtotal & & $67,141,689$ & 60.45 \\
\hline
\end{tabular}

Source: Energy Information Administration, Form EIA-412, "Annual Report of Public Electric Utilities."

Table C11. Ten Largest U.S. Publicly Owned Generator Electric Utilities Ranked by Megawatthour Sales for Resale with Financial Year Ending on December 31, 1995

\begin{tabular}{|c|c|c|c|}
\hline Publicly Owned Electric Utilities & State & Amount & Percent \\
\hline 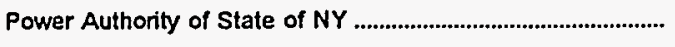 & New York & $27,446,460$ & 20.19 \\
\hline 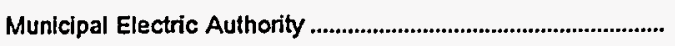 & Georgia & $10,449,304$ & 7.69 \\
\hline Nebraska Public Power District & Nebraska & $9,660,396$ & 7.11 \\
\hline 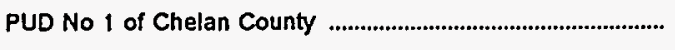 & Washington & $8,319,784$ & 6.12 \\
\hline 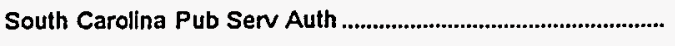 & South Carolina & $8,283,056$ & 6.09 \\
\hline 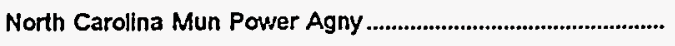 & North Carolina & $7,003,590$ & 5.15 \\
\hline 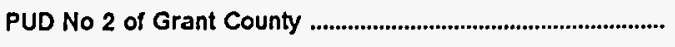 & Washington & $6,855,085$ & 5.04 \\
\hline North Carolina Eastern M P A & North Carolina & $6,532,836$ & 4.81 \\
\hline 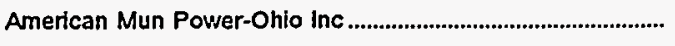 & Ohio & $4,680,758$ & 3.44 \\
\hline 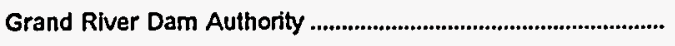 & OKlahoma & $4,626,042$ & 3.40 \\
\hline Subtotal ..., & & $93,857,311$ & 69.06 \\
\hline
\end{tabular}

Source: Energy Information Administration, Form ElA-412, "Annual Report of Public Electric Utilities." 
Table C12. Composite Statement of Income for Major U.S. Publicly Owned Generator Electric Utilities with Financial Year Ending on

December 31, 1991-1995

(Thousand Dollars)

\begin{tabular}{|c|c|c|c|c|c|}
\hline Item & 1995 & 1994 & 1993 & 1992 & 1991 \\
\hline Electric Utility Operating Revenues ...................... & $10,681,781$ & $10,636,841$ & $10,265,144$ & $9,978,727$ & $9,945,735$ \\
\hline $\begin{array}{l}\text { Operation Expenses } \\
\text { Maintenance Expenses }\end{array}$ & $\begin{array}{r}6,581,774 \\
749,959\end{array}$ & $\begin{array}{r}6.449,328 \\
735,879\end{array}$ & $\begin{array}{r}6,271,036 \\
726,808\end{array}$ & $\begin{array}{r}5,929,885 \\
785,806\end{array}$ & $\begin{array}{r}5,834,899 \\
681,105\end{array}$ \\
\hline Depreciation Expenses & $1,236,692$ & $1,159,118$ & $1,082,958$ & $1,042,213$ & $1,096,953$ \\
\hline 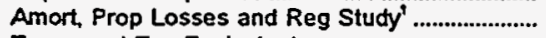 & 116,100 & 112.749 & 99,467 & 93,501 & \\
\hline 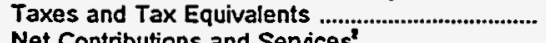 & 269.795 & 260,857 & 261,135 & 236,234 & 237,008 \\
\hline 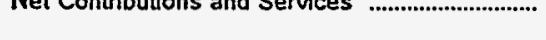 & - & - & - & - & 32,237 \\
\hline $\begin{array}{l}\text { Total Electric Utility Operating } \\
\text { Expenses }\end{array}$ & $8,954,320$ & $8,717,931$ & $8,441,404$ & $8,087,639$ & $7,892,200$ \\
\hline 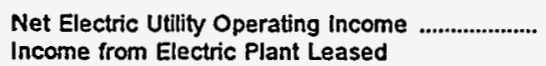 & $1,727,461$ & $1,918,910$ & $1,823,740$ & $1,891,088$ & $2,053,535$ \\
\hline to Others & 6,556 & 19,756 & 10,131 & 1,865 & 2,272 \\
\hline Electric Utility Operating Income ...................... & $1,734,017$ & $1,938,665$ & $1,833,871$ & $1,892,953$ & $2,055,807$ \\
\hline 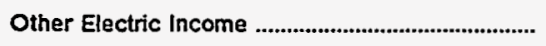 & 704,513 & 521,486 & 720.647 & $1.021,872$ & 947,124 \\
\hline $\begin{array}{l}\text { Other Electric Deductions } \\
\text { Allowance for Other Funds Used }\end{array}$ & 76,439 & $-1,286$ & 34,484 & 31,702 & 24,235 \\
\hline 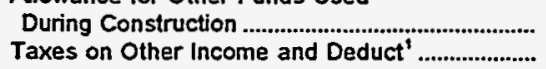 & $\begin{array}{l}8,197 \\
5,132\end{array}$ & $\begin{array}{l}5,888 \\
3,059\end{array}$ & $\begin{array}{l}5,721 \\
2,952\end{array}$ & $\begin{array}{l}6,151 \\
2,755\end{array}$ & 15,842 \\
\hline 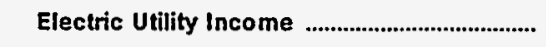 & $2,365,155$ & $2,464,266$ & $2,522,803$ & $2,886,519$ & $2,994,538$ \\
\hline $\begin{array}{l}\text { Income Deductions from Interest } \\
\text { on Long-term Debt }\end{array}$ & & 2020119 & & & \\
\hline $\begin{array}{l}\text { Other Income Deductions } \\
\text { Allowance for Borrowed Funds Used }\end{array}$ & $\begin{array}{r}1,963,170 \\
218,562\end{array}$ & $\begin{array}{l}2,020,118 \\
178,527\end{array}$ & $\begin{array}{r}2,088,036 \\
173,302\end{array}$ & $\begin{array}{r}2,258,140 \\
136,087\end{array}$ & $\begin{array}{r}2,400,347 \\
119,052\end{array}$ \\
\hline During Construction' & $-20,977$ & $-12,812$ & $-10,057$ & $-10,843$ & - \\
\hline 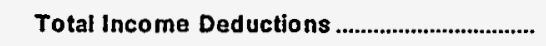 & $2,161,355$ & $2,185,833$ & $2,251,282$ & $2,383,383$ & $2,524,389$ \\
\hline Income Before Extraordinary Items .......................... & 203,800 & 278,433 & 271,521 & 503,136 & 470,139 \\
\hline Extraordinary Income & 53,778 & 67,950 & 54,810 & 72,686 & 84,099 \\
\hline 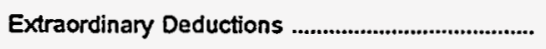 & 15,603 & 18,296 & 137,312 & 126,373 & 26,113 \\
\hline Net Income & 241,975 & 328,086 & 189,020 & 449,449 & 528,125 \\
\hline
\end{tabular}

Data reporting initiated in 1992.

- Data reporting oiscontinued in 1992.

- Data not available.

Note: Totals may not equal sum of components because of independent rounding. The number of generating publicly owned electric utilities for end of period is 108 for December 31, 1995; 112 for December 31, 1994; 113 for December 31, 1993; 111 for December 31. 1992; and 110 for December 31, 1991. The City of Vineland (NJ) changed fiscal year from June 30 to December 31 in 1991; the California Department of Water Resources (CA) changed fiscal year from December 31 to June 30 in 1992; the Wisconsin Public Power Inc Sys (WI) changed fiscal year from December 31 to June 30 in 1993; and the City of Pelia changed fiscal year from June 30 to Decemebr 31 , and the City of Burlington (NT) changed fiscal year from December 31 to June 30 in 1994. The City of Gaffney (SC). City of Osceola (AR), and City of Redding (CA) were nongenerators for 1991 through 1993, but became generators in 1994. The City of Kennett (MO) and City of Morgan City (LA) were generators for 1991 through 1993, but became nongenerators in 1994. Emerald Peoples Utility District (OR). City of Bryan (OH), and Northern Wasco County PUD (OR) were nongenerators for 1991, but became generators in 1992. The Utah Associated Municipa! Power System (UT) changed fiscal year from June 30 to March 31 in 1991.

Source: Energy Information Administration, Form ElA-412, "Annual Report of Public Electric Utilities." 
Table C13. Composite Balance Sheet for Major U.S. Publicly Owned Generator Electric Utilities with Financial Year Ending on December 31 at End of Period, 1991-1995 (Thousand Dollars)

\begin{tabular}{|c|c|c|c|c|c|}
\hline Item & 1995 & 1994 & 1993 & 1992 & 1991 \\
\hline \multicolumn{6}{|l|}{ Electric Utility Plant } \\
\hline Electric Utility Plant \& Adjust ................................... & $38,223,333$ & $37,327,308$ & $36,270,042$ & $35,222,457$ & $37,479,683$ \\
\hline Const Work in Progress & $1.906,103$ & $2,065,590$ & $1,950,440$ & $1,523,008$ & - \\
\hline (less) Depr, Amort, and Depletion ........................ & $13,122,194$ & $12,251,762$ & $11,345,511$ & $10,493,142$ & $10,075,535$ \\
\hline Net Electric Utility Plant' & $27,007,243$ & $27,141,136$ & $26,874,970$ & $26,252,323$ & - \\
\hline Nuclear Fuel' & $1,642,191$ & $1,665,312$ & $1,705,807$ & $1,653,317$ & - \\
\hline (less) Amort of Nucl Fuel' & $1,148,674$ & $1,131,769$ & $1,150,437$ & $1,042,691$ & - \\
\hline 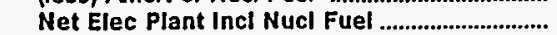 & $27,500,760$ & $27,674,679$ & $27,430,340$ & $26,862,950$ & $27,404,148$ \\
\hline \multicolumn{6}{|l|}{ Other Property \& Investments } \\
\hline 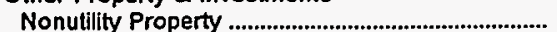 & 304,358 & 431,540 & 430,836 & 370,608 & 403,811 \\
\hline (less) Accum Provisions for Depr \& Amort .......... & 64,712 & 195,510 & 182,708 & 172,216 & 163,570 \\
\hline 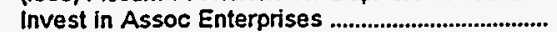 & $-3,662$ & 195,315 & 295,967 & 188,979 & 60,343 \\
\hline 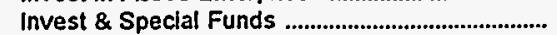 & $6,915,284$ & $6,930,525$ & $7,101,773$ & $6,994,760$ & $6,462,983$ \\
\hline Total Other Property \& Investments ................ & $7,151,268$ & $7,361,870$ & $7,645,868$ & $7,399,131$ & $6,763,567$ \\
\hline \multicolumn{6}{|l|}{ Current and Accrued Assets } \\
\hline Cash, Working Funds $\&$ Investments ..................... & $3,968,919$ & $4,469,068$ & $4,303,347$ & $4,546,678$ & $5,266,571$ \\
\hline 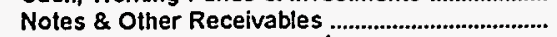 & 432,039 & 339,165 & 375,331 & 281,987 & 963,205 \\
\hline Customer Accts Receivable' & 897,922 & 902,986 & 872,478 & 770,319 & - \\
\hline (less) Accum Prov for Uncollected Accts ............ & 25.139 & 21,816 & 20,667 & 20,575 & 19,880 \\
\hline Fuel Stock \& Exp Undistr' & 171,240 & 163,651 & 122,831 & 183,952 & - \\
\hline 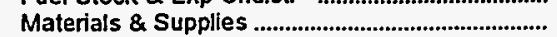 & 447,204 & 470,433 & 457,540 & 436,404 & 700,104 \\
\hline 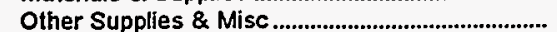 & 15,798 & - & - & - & - \\
\hline 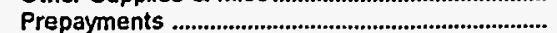 & 100,454 & 154,265 & 151,661 & 148,608 & 148,138 \\
\hline Accrued Utility Revenues' & 176,662 & 99,997 & 97.627 & 88,636 & - \\
\hline Miscellaneous Current \& Accrued Assets ........... & 708,129 & 760.070 & 614,489 & 640,721 & 250,407 \\
\hline Total Current \& Accrued Assets ........................ & $6,893,228$ & $7,337,819$ & $6,974,638$ & $7,076,731$ & $7,308,543$ \\
\hline \multicolumn{6}{|l|}{ Deferred Debits } \\
\hline 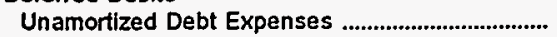 & 997,680 & $1,038,464$ & $1,083,853$ & 942,727 & 736,895 \\
\hline 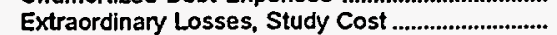 & $1,204,623$ & 425.374 & 443.321 & 384.193 & 34,360 \\
\hline Misc Debt, R \& D Exp. Unamrt Losses ................ & $5,701,868$ & $5,982,141$ & $6,112,902$ & $5,228,559$ & $5,075,383$ \\
\hline Total Deferred Debits ......................................... & $7,904,171$ & $7,445,979$ & $7,640,077$ & $6,555,478$ & $5,846,637$ \\
\hline Total Assets \& Other Debits & $49,449,426$ & $49,820,347$ & $49,690,923$ & $47,894,290$ & $47,322,895$ \\
\hline \multicolumn{6}{|l|}{ Proprietary Capital } \\
\hline 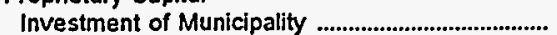 & 398,679 & 385,076 & 382,728 & 394,516 & 308,846 \\
\hline 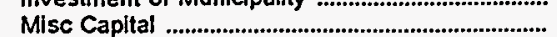 & 58,378 & 40.945 & 54,912 & 50,262 & 66,098 \\
\hline 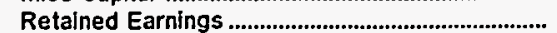 & $8,109,618$ & $7,866,971$ & $7,607,441$ & $7,443,810$ & $7,426,859$ \\
\hline 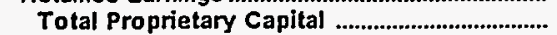 & $8,566,675$ & $8,292,993$ & $8,045,082$ & $7,888,588$ & $7,801,802$ \\
\hline \multicolumn{6}{|l|}{ Long-term Debt } \\
\hline 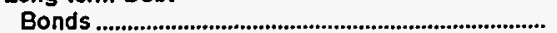 & $33,450,397$ & $34,488,676$ & $34,703,101$ & $34,287,344$ & $33,165,999$ \\
\hline Advances trom Municipality \& Other .................. & $1,973,168$ & $2,268,730$ & $1,762,850$ & $1,223,179$ & $1,883,188$ \\
\hline Unamort Prem on Long-term Debt .......................... & 25,427 & 27,659 & 68,644 & 35,176 & 8,141 \\
\hline (less) Unamort Discount on Long-term Debt ...... & $1,265,868$ & $1,460,972$ & 916,321 & $1,012,260$ & 984,342 \\
\hline 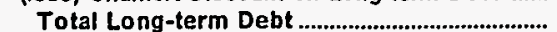 & $34,183,124$ & $35,324,094$ & $35,618,275$ & $34,533,438$ & $34,072,986$ \\
\hline \multicolumn{6}{|l|}{ Other Noncurrent Liabilities } \\
\hline Accum Operating Provisions ................................... & 158,108 & 133,156 & 109,206 & 409,800 & 414,731 \\
\hline Accum Prov for Rate Refunds' & 101,520 & 103,878 & 109,290 & 4,277 & - \\
\hline Total Other Noncurrent Liabilities .................. & 259,628 & 237,035 & 218,495 & 414,077 & 414,731 \\
\hline \multicolumn{6}{|l|}{ Current and Accrued Liabilities } \\
\hline 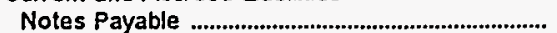 & $1,127,030$ & $1,053,159$ & $1,089,125$ & 861.989 & 761,201 \\
\hline 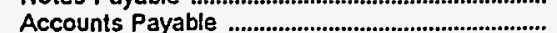 & 786,417 & 768,765 & 733,766 & 690,877 & 646,324 \\
\hline Payables to Assoc Enterprises .............................. & 81,547 & 62,883 & 55,730 & 38,023 & 46,715 \\
\hline 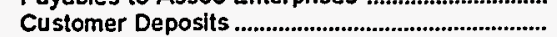 & 46,511 & 45,455 & 44,848 & 44,205 & 46.508 \\
\hline 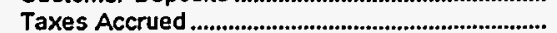 & 111,101 & 111,791 & 108,973 & 89,751 & 90,009 \\
\hline 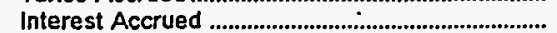 & 678.512 & 709,566 & 700,474 & 716,138 & 755,391 \\
\hline Misc Current \& Accrued Labilities .......................... & 929,816 & 907,434 & 826.121 & 550,077 & 506,597 \\
\hline 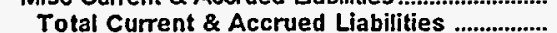 & $3,760,934$ & $3,659,055$ & $3,559,037$ & $2,991,060$ & $2,852,744$ \\
\hline \multicolumn{6}{|l|}{ Deferred Credits } \\
\hline Customer Advances for Construction ...................... & 42,227 & 40,752 & 37,909 & 37,120 & 27,116 \\
\hline Other Deferred Credits ............................................... & $2,433,084$ & $2,067,330$ & $2,021,905$ & $1,813,190$ & $1,914,443$ \\
\hline Unamort Gain on Reacqr Debt & 203,753 & 199,089 & 190,221 & 216,817 & 239,073 \\
\hline 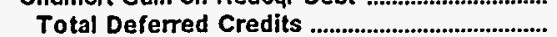 & $2,679,065$ & $2,307,171$ & $2,250,035$ & $2,067,127$ & $2,180,632$ \\
\hline 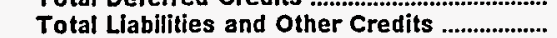 & $49,449,426$ & $49,820,347$ & $49,690,923$ & $47,894,290$ & $47,322,895$ \\
\hline
\end{tabular}

Data reporting initiated in 1992.

Note: Totals may not equal sum of components because of independent rounding. The number of generating publicly owned electric utllitles for end of period is 108 for December 31, 1995; 112 for December 31, 1994; 113 for December 31, $1993 ; 111$ for December 31. 1992; and 110 for December 31, 1991. The City of Vineland (NJ) changed fiscal year from June 30 to December 31 in 1991 ; the California Department of Water Resources (CA) changed fiscal year from December 31 to June 30 in 1992; the Wisconsin Public Power Inc Sys (WI) changed fiscal year from December 31 to June 30 in 1993; and the City of Pella changed fiscal year from June 30 to Decemebr 31 , and the City of Burlington (VT) changed fiscal year from December 31 to June 30 in 1994. The City of Gaffney (SC). City of Osceola (AR), and City of Redding (CA) were nongenerators for 1991 through 1993, but became generators in 1994. The City of Kennett (MO) and City of Morgan City (LA) were generators for 1991 through 1993, but became nongenerators in 1994. Emerald Peoples Utility District (OR), City of Bryan (OH), and Northern Wasco County PUD (OR) were nongenerators for 1991, but became generators in 1992. The Utah Associated Municipal Power System (UT) changed fiscal year from June 30 to March 31 in 1991.

Source: Energy Information Administration, Form EIA-412, "Annual Report of Public Electric Utilities." 
Table C14. Composite Financial Indicators for Major U.S. Publicly Owned Generator Electric Utilities with Financial Year Ending on

December 31, 1991-1995

\begin{tabular}{|c|c|c|c|c|c|}
\hline Item & 1995 & 1994 & 1993 & 1992 & 1991 \\
\hline Total Electric Utility Plant per Dollar of Revenue & 3.9 & 3.9 & 3.9 & 3.8 & 3.8 \\
\hline Current Assets to Current Labilities ........................... & 1.8 & 2.0 & 2.0 & 2.4 & 2.6 \\
\hline $\begin{array}{l}\text { Total Electric Utility Plant as a Percent of Total } \\
\text { Assets }\end{array}$ & 84.5 & 82.4 & 80.3 & 80.2 & 79.2 \\
\hline $\begin{array}{l}\text { Net Electric Utility Plant as a Percent of Total } \\
\text { Assets }\end{array}$ & 55.6 & 55.5 & 55.2 & 56.1 & 57.9 \\
\hline Debt as a Percent of Total Liabilities .......................... & 76.7 & 78.2 & 78.8 & 78.3 & 78.0 \\
\hline $\begin{array}{l}\text { Depreciation, Amortization and Depletion } \\
\text { as a Percent of Total Electric Utlity Plant ........... }\end{array}$ & 34.2 & 32.6 & 31.3 & 30.0 & 26.9 \\
\hline $\begin{array}{l}\text { Electric Operation and Maintenance Expenses } \\
\text { as a Percent of } \\
\text { Electric Utility Operating Revenues ........................ }\end{array}$ & 68.6 & 67.6 & 68.2 & 67.3 & 65.6 \\
\hline $\begin{array}{l}\text { Electric Depreciation and Amortization } \\
\text { as a Percent of } \\
\text { Electric Utility Operating Revenues ........................ }\end{array}$ & 11.6 & 10.9 & 10.5 & 10.4 & 11.0 \\
\hline $\begin{array}{l}\text { Taxes and Tax Equivalents } \\
\text { as a Percent of } \\
\text { Electric Utility Operating Revenues ........................ }\end{array}$ & 2.5 & 2.5 & 2.5 & 2.4 & 2.4 \\
\hline $\begin{array}{l}\text { Interest on Long-term Debt } \\
\text { as a Percent of } \\
\text { Electric Utifity Operating Revenues ........................ }\end{array}$ & 18.4 & 19.0 & 20.3 & 22.6 & 24.2 \\
\hline $\begin{array}{l}\text { Net Income as a Percent of Electric } \\
\text { Electric Operating Revenues }\end{array}$ & 2.3 & 3.1 & 1.8 & 4.5 & 5.3 \\
\hline Purchased Power Cents Per Kilowatthour............ & 3.5 & 3.2 & 3.2 & 3.4 & 3.4 \\
\hline Generated Cents Per Kilowatthour ............................ & 1.4 & 1.5 & 1.5 & 1.6 & 1.4 \\
\hline 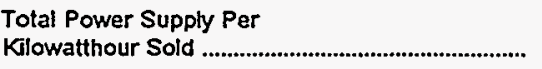 & 2.2 & 2.2 & 2.2 & 2.3 & 2.1 \\
\hline
\end{tabular}

Note: Totals may not equal sum of components because of independent rounding. The number of generating publicly owned electric utilities for end of period is 108 for December 31, 1995; 112 for December 31, 1994; 113 for December 31, 1993: 111 for December 31. 1992; and 110 for December 31, 1991. The City of Vineland (NJ) changed fiscal year from June 30 to December 31 in 1991; the California Department of Water Resources (CA) changed fiscal year from December 31 to June 30 in 1992; the Wisconsin Public Power (nc Sys (WI) changed fiscal year from December 31 to June 30 in 1993; and the City of Pella changed fiscal year from June 30 to Decemebr 31, and the City of Burtington (VT) changed fiscal year from December 31 to June 30 in 1994. The City of Gaffney (SC). City of Osceola (AR), and City of Redding (CA) were nongenerators for 1991 through 1993, but became generators in 1994. The City of Kennett (MO) and City of Morgan City (LA) were generators for 1991 through 1993, but became nongenerators in 1994. Emerald Peoples Utility District (OR). City of Bryan $(\mathrm{OH})$, and Northern Wasco County PUD (OR) were nongenerators for 1991, but became generators in 1992. The Utah Associated Municipal Power System (UT) changed fiscal year from June 30 to March 31 in 1991.

Source: Energy Information Administration. Form EIA-4 12, "Annual Report of Public Electric Utilities." 
Table C15. Electric Operation and Maintenance Expenses for Major U.S.

Publicly Owned Generator Electric Utilities with Financial

Year Ending on December 31, 1991-1995

(Thousand Dollars)

\begin{tabular}{|c|c|c|c|c|c|}
\hline Item & 1995 & 1994 & 1993 & 1992 & 1991 \\
\hline \multicolumn{6}{|l|}{ Production Expenses } \\
\hline 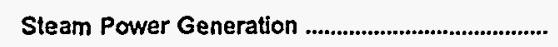 & $1,337,834$ & $1,350,805$ & $1,338,540$ & $1,282,834$ & $1,300,701$ \\
\hline Nuclear Power Generation ........................................... & 798,873 & 803,743 & 833,951 & 874,038 & 775,240 \\
\hline 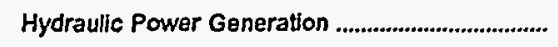 & 185.529 & 183,959 & 176,149 & 179,079 & 169,004 \\
\hline 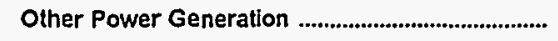 & 76,132 & 59,723 & 56,429 & 73,927 & 83,339 \\
\hline Purchased Power & $2,985,912$ & $2,935,592$ & $2,794,807$ & $2,659,016$ & $2,569,367$ \\
\hline 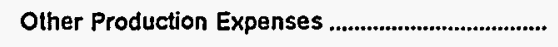 & 110,486 & 91,726 & 94,807 & 31,459 & 46.277 \\
\hline 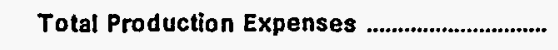 & $5,494,766$ & $5,425,548$ & $5,294,683$ & $5,100,351$ & $4,943,929$ \\
\hline 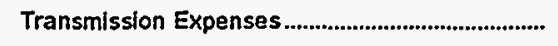 & 512,799 & 493.491 & 482,984 & 439,935 & 429,942 \\
\hline Distribution Expenses & 338,581 & 344,322 & 330,158 & 308,399 & 286,590 \\
\hline 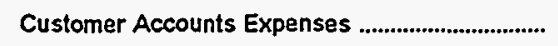 & 123,586 & 127,227 & 124,537 & $\$ 16,469$ & 115,765 \\
\hline Customer Service and Information Expenses..... & 40,304 & 42,526 & 38,145 & 40,755 & 36,664 \\
\hline 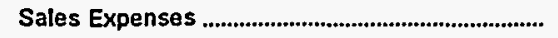 & 13,012 & 10,597 & 7,990 & 8,274 & 7.617 \\
\hline Administrative and General Expenses ...................... & 808,684 & 742,985 & 719,348 & 701,509 & 705.496 \\
\hline $\begin{array}{l}\text { Total Electric Operation } \\
\text { and Maintenance Expenses }\end{array}$ & $7,331,733$ & $7,186,697$ & $6,997,844$ & $6,715,691$ & $6,526,004$ \\
\hline \multicolumn{6}{|l|}{ Fuel Expenses in Operation } \\
\hline Steam Power Generation ................................................. & 575,620 & 949,985 & 951.608 & 899,205 & 893,191 \\
\hline 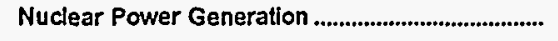 & 133,784 & 192,535 & 205,222 & 183,294 & 215,353 \\
\hline 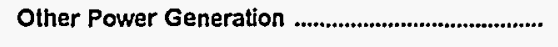 & 48,007 & 37,290 & 32,663 & 32,799 & 42,796 \\
\hline \multicolumn{6}{|l|}{ Number of Elec Dept Employees } \\
\hline 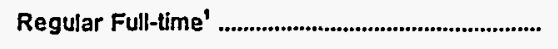 & 24,798 & 25,928 & 26,313 & 26,379 & - \\
\hline 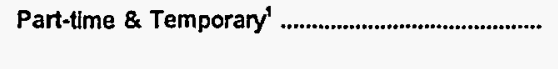 & $\begin{array}{r}962 \\
25,760\end{array}$ & $\begin{array}{r}1,191 \\
27,119\end{array}$ & $\begin{array}{r}973 \\
27,286\end{array}$ & $\begin{array}{r}1,127 \\
27,506\end{array}$ & - \\
\hline
\end{tabular}

- Data reporting Initiated in 1992.

Note: Totals may not equal sum of components because of independent rounding. The number of generating publicly owned electric utilities for end of period is 108 for December 31, 1995; 112 for December 31,$1994 ; 113$ for December 31, $1993 ; 111$ for December 31 , 1992; and 110 for December 31, 1991. The City of Vineland (NJ) changed fiscal year from June 30 to December 31 in 1991; the California Department of Water Resources (CA) changed fiscal year from December 31 to June 30 in 1992; the Wisconsin Public Power Inc Sys (WI) changed fiscal year from December 31 to June 30 in 1993; and the City of Pella changed fiscal year from June 30 to Decemebr 31 , and the City of Burtington (VT) changed fiscal year from December 31 to June 30 in 1994. The City of Gaffney (SC). City of Osceola (AR), and City of Redding (CA) were nongenerators for 1991 through 1993, but became generators in 1994. The City of Kennett (MO) and City of Morgan City (LA) were generators for 1991 through 1993, but became nongenerators in 1994. Emerald Peoples Utility District (OR), City of Bryan $(O H)$, and Northern Wasco County PUD (OR) were nongenerators for 1991, but became generators in 1992. The Utah Associated Municipal Power System (UT) changed fiscal year from June 30 to March 31 in 1991.

Source: Energy Information Administration, Form EIA-412, "Annual Report of Public Electric Utilities." 
Table C16. Electric Utility Plant for Major U.S. Publicly Owned Generator Electric Utilities with Financial Year Ending on

December 31 at End of Period, 1991-1995

(Thousand Dollars)

\begin{tabular}{|c|c|c|c|c|c|}
\hline Item & 1995 & 1994 & 1993 & 1992 & 1991 \\
\hline \multicolumn{6}{|l|}{ Electric Plant in Service } \\
\hline 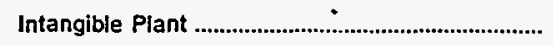 & 322,727 & 281,796 & 187,454 & 147,119 & 166,530 \\
\hline \multicolumn{6}{|l|}{ Production Plant } \\
\hline Steam & $8,888.446$ & $9,037,839$ & $8,922,654$ & $8,631,927$ & $8,826,802$ \\
\hline Nuclear & $9,079,196$ & $9,106,436$ & $9,156,237$ & $9,134,357$ & $9,494,275$ \\
\hline 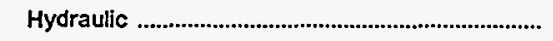 & $4,891,907$ & $4,774,883$ & $4,742,634$ & $4,615,920$ & $4,940,668$ \\
\hline Other & 933,799 & 878,763 & 744,582 & 653,883 & 898,234 \\
\hline Total Production Plant .......................................... & $23,793,348$ & $23,797,922$ & $23,566,107$ & $23,036,088$ & $24,157,980$ \\
\hline 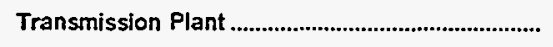 & $4,617,421$ & $4,545,568$ & $4,415,887$ & $4,391,256$ & $4,332,303$ \\
\hline 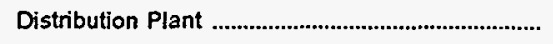 & $6,175,369$ & $5,873,794$ & $5,391,646$ & $5,099,992$ & $4,908,645$ \\
\hline 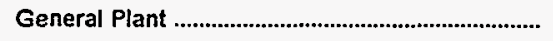 & $2,271,154$ & $2,098,518$ & $1,885,786$ & $1,761,568$ & $1,928,771$ \\
\hline Total Electric Plant in Service ............................. & $37,180,018$ & $36,597,599$ & $35,446,880$ & $34,436,024$ & $35,494,228$ \\
\hline Electric Plant Leased to Others .................................... & 35,606 & 15,141 & 16,297 & 17,376 & 18,558 \\
\hline Construction Work in Progress - Electric ................ & $1,906,103$ & $2,065,590$ & $1,950,440$ & $1,523,008$ & $1,524.793$ \\
\hline Electric Plant Held for Future Use ............................. & 20,658 & 21,559 & 34,897 & 35,048 & 96,163 \\
\hline Electric Plant Misc & 987,051 & 693.008 & 771,967 & 734,009 & 345,941 \\
\hline Total Electric Utility Plant ...................................... & $40,129,437$ & $39,392,898$ & $38,220,481$ & $36,745,465$ & $37,479,683$ \\
\hline \multicolumn{6}{|l|}{ Accumulated Provision for } \\
\hline 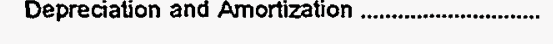 & $13,122,194$ & $12,251,762$ & $11,345,511$ & $10,493,142$ & $10,075,535$ \\
\hline 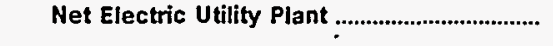 & $27,007,243$ & $27,141,136$ & $26,874,970$ & $26,252,323$ & $27,404,148$ \\
\hline
\end{tabular}

Note: Totals may not equal sum of components because of independent rounding. The number of generating publicly owned electric utilities for end of period is 108 for December 31, 1995; 112 for December 31, 1994; 113 for December 31, $1993 ; 111$ for December 31, 1992; and 110 for December 31, 1991 . The City of Vineland (NJ) changed fiscal year from June 30 to December 31 in 1991 ; the California Department of Water Resources (CA) changed fiscal year from December 31 to June 30 in 1992; the Wisconsin Public Power Inc Sys (WI) changed fiscal year from December 31 to June 30 in 1993; and the City of Pella changed fiscal year from June 30 to Decemebr 31 , and the City of Burlington (VT) changed fiscal year trom December 31 to June 30 in 1994. The City of Gaffney (SC). City of Osceola (AR), and City of Redding (CA) were nongenerators for 1991 through 1993, but became generators in 1994. The City of Kennett (MO) and City of Morgan City (LA) were generators for 1991 through 1993, but became nongenerators in 1994. Emerald Peoples Utility District (OR). City of Bryan $(\mathrm{OH})$, and Northern Wasco County PUD (OR) were nongenerators for 1991, but became generators in 1992. The !ltah Associated Municipal Power System (UT) changed fiscal year from June 30 to March 31 in 1991.

Source: Energy Information Administration, Form EIA-412, "Annual Report of Public Electric Utilities." 
Table C17. Number of Consumers, Sales, and Operating Revenue for Major

U.S. Publicly Owned Generator Electric Utilities with

Financial Year Ending on December 31, 1991-1995

\begin{tabular}{|c|c|c|c|c|c|}
\hline Item & 1995 & 1994 & 1993 & 1992 & 1991 \\
\hline \multicolumn{6}{|l|}{ Number of Consumers } \\
\hline 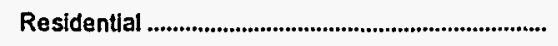 & $2,876,943$ & $2,877.171$ & $2,849,810$ & $2,814,249$ & $2,764,821$ \\
\hline Commercial or Small & 369,673 & 367,325 & 375,533 & 374,138 & 364,247 \\
\hline Industral or Large & 19,566 & 20.128 & 19.037 & 17.308 & 17.030 \\
\hline Other & 34,749 & 34.191 & 32,448 & 31.715 & 38,909 \\
\hline 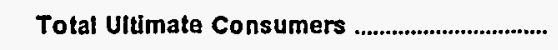 & $3,300,931$ & $3,298,815$ & $3,276,828$ & $3,237,410$ & $3,185,007$ \\
\hline \multicolumn{6}{|l|}{ Sales for the Year (megawatthours) } \\
\hline 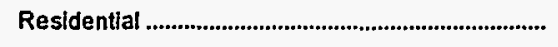 & $30,706,097$ & $30,425,166$ & $30,738,423$ & $28,973,686$ & $30,255,280$ \\
\hline Commercial or Small & $24,179,421$ & $23,875,138$ & $23,277,718$ & $22,588,007$ & $22,393,283$ \\
\hline Industrial or Large & $44,132,758$ & $44,343,337$ & $43,249,135$ & $43,005,294$ & $41,800,834$ \\
\hline Other & $12,086,822$ & $12,289,490$ & $11,832,364$ & $11,573,845$ & $11,674,348$ \\
\hline Total Sales to Ultimate Consumers..................... & $111,105,098$ & $110,933,131$ & $109,097,640$ & $106,140,832$ & $106,123,745$ \\
\hline Sales for Resale & $138,116,998$ & $130,489,161$ & 128.758 .878 & $119,936,732$ & $127,090,088$ \\
\hline 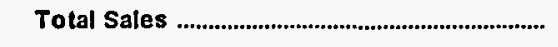 & $249,222,096$ & $241,422,292$ & $237,856,518$ & $226,077,564$ & $233,213,833$ \\
\hline \multicolumn{6}{|l|}{$\begin{array}{l}\text { Operating Revenues for the Year } \\
\text { (thousand dollars) }\end{array}$} \\
\hline 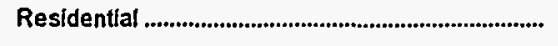 & $1,813,724$ & $1,810,153$ & $1,731,902$ & $1,643,062$ & $1,662,361$ \\
\hline Commercial or Small & $1,335,020$ & $1,327,964$ & $1,266,181$ & $1,207.356$ & $1,182,160$ \\
\hline Industrial or Large & $1,653,302$ & $1,684,922$ & $1,635,752$ & $1,606,898$ & $1,571,144$ \\
\hline Other & 878,301 & 944,538 & 829,771 & 829,977 & 739,838 \\
\hline 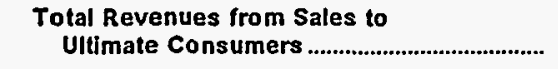 & $5,680,347$ & $5,767,577$ & $5,525,606$ & $5,287,293$ & $5,155,503$ \\
\hline Sales for Resale & $4,583,138$ & $4,670,772$ & $4,554,309$ & $4,266,138$ & $4,317.957$ \\
\hline $\begin{array}{l}\text { Total Revenues From Sales of } \\
\text { Electricity }\end{array}$ & $10,263,485$ & $10,438,349$ & $10,079,915$ & $9,553,431$ & $9,473,460$ \\
\hline
\end{tabular}

1 Net income reflects $\$ 584$ million of extraordinary deduction associated with the abandonment of the Rancho Seco Nuclear Plant reported by the Sacramento Municipal Utility District.

Note: Totals may not equal sum of components because of independent rounding. The number of generating publicly owned electric utilities for end of period is 108 for December 31, 1995; 112 for December 31, 1994; 113 for December 31. 1993; 111 for December 31, 1992; and 110 for December 31, 1991. The City of Vineland (NJ) changed fiscal year from June 30 to December 31 in 1991 ; the California Department of Water Resources (CA) changed fiscal year from December 31 to June 30 in 1992; the Wisconsin Public Power Inc Sys (WI) changed fiscal year from December 31 to June 30 in 1993; and the City of Pella changed fiscal year from June 30 to Decemebr 31 . and the City of Burlington (NT) changed fiscal year from December 31 to June 30 in 1994. The City of Gaffney (SC). City of Osceola (AR), and City of Redding (CA) were nongenerators for 1991 through 1993, but became generators in 1994. The City of Kennett (MO) and City of Morgan City (LA) were generators for 1991 through 1993, but became nongenerators in 1994. Emerald Peoples Utility District (OR). City of Bryan (OH), and Northern Wasco County PUD (OR) were nongenerators for 1991, but became generators in 1992. The Utah Associated Municipal Power System (UT) changed fiscal year from June 30 to March 31 in 1991 . sions.

Source: Energy Information Administration, Form ElA-861. "Annual Electric Utility Report." Data are based on calendar year submis- 
Table C18. Electric Energy Account for Major U.S. Publicly Owned

Generator Electric Utilities with Financial Year

Ending on December 31, 1991-1995

(Megawatthours)

\begin{tabular}{|c|c|c|c|c|c|}
\hline Item & 1995 & 1994 & 1993 & 1992 & 1991 \\
\hline \multicolumn{6}{|l|}{ Sources of Energy } \\
\hline Steam & $65,710,430$ & $70,059,538$ & $68,884,126$ & $65,609,210$ & $66,891,679$ \\
\hline 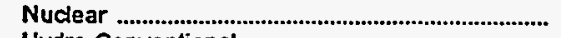 & $35,728,897$ & $31,690,091$ & $31,537,345$ & $31,849,000$ & $36,462,063$ \\
\hline 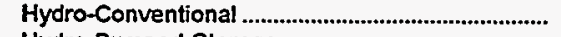 & $67,443,317$ & $56,393,285$ & $61,442,436$ & $57,178,818$ & $67,268,340$ \\
\hline 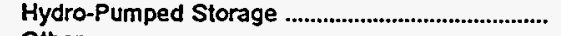 & $2,141,893$ & $2,185,137$ & $2,100,289$ & $2,170,285$ & $2,364,088$ \\
\hline 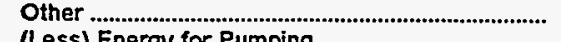 & $1,853,400$ & $1,373,792$ & 933,116 & $1,203,274$ & $1,302,950$ \\
\hline 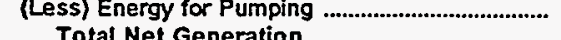 & $\begin{array}{r}3,403,958 \\
\end{array}$ & $\begin{array}{r}3,433,444 \\
4,968\end{array}$ & $3,309,882$ & $2,897,644$ & $2,942,457$ \\
\hline 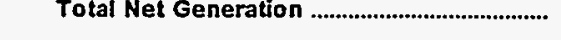 & $169,473,979$ & $158,268,402$ & $161,587,430$ & $155,112,932$ & $171,346,662$ \\
\hline Purchases from Utility & $81,206,442$ & $91,292,304$ & $87,548,082$ & $79,898,277$ & $76,660,807$ \\
\hline $\begin{array}{l}\text { Purchases from Nonutility ........................................ } \\
\text { Power Exchanges }\end{array}$ & $5,473,283$ & 674,308 & 704,617 & 711,796 & 925,307 \\
\hline 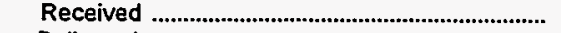 & $12,596,439$ & $11,407,000$ & $12,472,066$ & $11,060,566$ & $15,364,045$ \\
\hline Delivered & $12,765,492$ & $11,143,025$ & $14,404,251$ & $12,420,396$ & $18,418,514$ \\
\hline Net Exchanges & $-169,064$ & 263,975 & $-1,932,178$ & $-1,359,823$ & $-3,054,468$ \\
\hline \multicolumn{6}{|l|}{ Transmission for Others (Wheeling) } \\
\hline 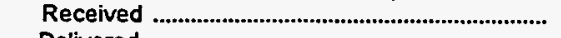 & $10,023,671$ & $14,263,247$ & $10,300,909$ & $7,563,741$ & $6,457,352$ \\
\hline 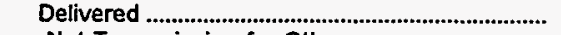 & $9,860,411$ & $14,031,759$ & $10,105,033$ & $7,426,968$ & $6,321,064$ \\
\hline 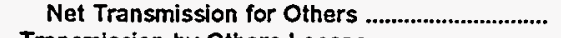 & 163,260 & 231,488 & 195,876 & 136,773 & 136.287 \\
\hline 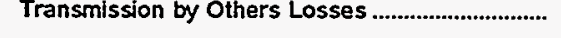 & $-71,096$ & $-102,774$ & $-50,570$ & $-42,446$ & $-12,108$ \\
\hline \multicolumn{6}{|l|}{ Total Net Energy Generated and } \\
\hline 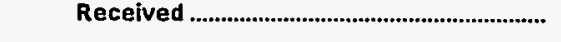 & $256,076,818$ & $250,627,705$ & $248,053,261$ & $234,457,495$ & $246,002,489$ \\
\hline \multicolumn{6}{|l|}{ Disposition of Energy } \\
\hline $\begin{array}{l}\text { Sales to Ultimate Consumers } \\
\text { Requirements Sales for Resale }\end{array}$ & $\begin{array}{r}111,075,139 \\
90,140,469\end{array}$ & $\begin{array}{r}110,979,294 \\
97,099,485\end{array}$ & $\begin{array}{r}109,361,116 \\
96,509,633\end{array}$ & $\begin{array}{r}106,146,840 \\
92,606,439\end{array}$ & $\begin{array}{l}106,253,382 \\
102,726,112\end{array}$ \\
\hline Nonrequirements Sales for Resale ......................... & $45,768,673$ & $33,340,798$ & $32,199,271$ & $27,422,443$ & $24,241,019$ \\
\hline 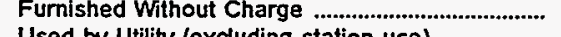 & $1,315,378$ & $1,306,975$ & $1,306,097$ & $1,250,309$ & $1,299,635$ \\
\hline Used by Utility (excluding station use) ................... & 218,840 & 227,473 & 254,107 & 258,375 & $4,793,554$ \\
\hline 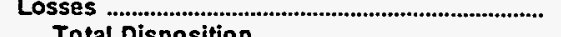 & $7,558,320$ & $7,673,666$ & $8,423,045$ & $6,773,090$ & $6,688,779$ \\
\hline 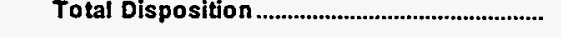 & $256,076,818$ & $250,627,705$ & $248,053,261$ & $234,457,495$ & $246,002,489$ \\
\hline
\end{tabular}

Note: Totals may not equal sum of components because of independent rounding. The number of generating publicly owned electric utilities for end of period is 108 for December 31, 1995; 112 for December 31, 1994; 113 for December 31, 1993; 111 for December 31, 1992; and 110 for December 31, 1991. The City of Vineland (NJ) changed fiscal year from June 30 to December 31 in 1991 ; the California Department of Water Resources (CA) changed fiscal year from December 31 to June 30 in 1992; the Wisconsin Public Power Inc Sys (Wi) changed fiscal year from December 31 to June 30 in 1993; and the City of Pella changed fiscal year from June 30 to Decemebr 31 , and the City of Burlington (VT) changed fiscal year from December 31 to June 30 in 1994. The City of Gaffney (SC). City of Osceola (AR), and City of Redding (CA) were nongenerators for 1991 through 1993, but became generators in 1994. The City of Kennett (MO) and City of Morgan City (LA) were generators for 199 i through 1993, but became nongenerators in 1994. Emerald Peoples Utility District (OR), City of Bryan $(O H)$, and Northern Wasco County PUD (OR) were nongenerators for 1991, but became generators in 1992. The Utah Associated Municipal Power System (UT) changed fiscal year from June 30 to March 31 in 1991 .

Source: Energy Information Administration, Form EIA-412, "Annual Report of Public Electric Utilities." 
Table C19. Ten Largest U.S. Publicly Owned Nongenerator Electric Utilities Ranked by Megawatthour Sales to Ultimate Consumers with Financial Year Ending on June 30, 1995

\begin{tabular}{|c|c|c|c|}
\hline Publicly Owned Electric Utilities & State & Amount & Percent \\
\hline Memphis Clty of & Tennessee & $12,030,683$ & 13.60 \\
\hline 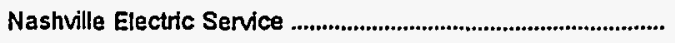 & Tennessee & $10,521,870$ & 11.89 \\
\hline Chattanooga City of & Tennessee & $5,350,719$ & 6.05 \\
\hline 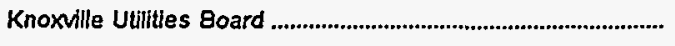 & Tennessee & $4,703,769$ & 5.32 \\
\hline Johnson Clty City of & Tennessee & $1,545,804$ & 1.75 \\
\hline Decatur City of & Alabama & $1,418,883$ & 1.60 \\
\hline Jackson City of & Tennessee & $1,277,865$ & 1.44 \\
\hline 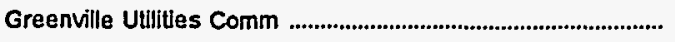 & North Carolina & $1,104,000$ & 1.25 \\
\hline 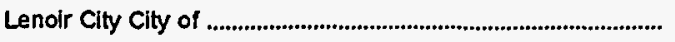 & Tennessee & $1,053,906$ & 1.19 \\
\hline Subtotal & & $40,059,132$ & 45.27 \\
\hline
\end{tabular}

Source: Energy Information Administration, Form EIA-412, "Annual Report of Public Electric Utilities."

Table C20. U.S. Publicly Owned Nongenerator Electric Utilities Ranked by Megawatthour Sales for Resale with Financial Year Ending on June 30, 1995

\begin{tabular}{|c|c|c|c|}
\hline Publicly Owned Electric Utilities & State & Amount & Percent \\
\hline 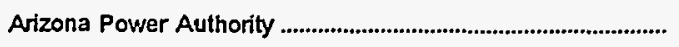 & Arizona & $1,016,063$ & 38.18 \\
\hline 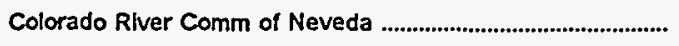 & Nevada & 924,422 & 34.74 \\
\hline 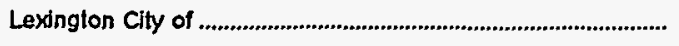 & North Carolina & 454,622 & 17.09 \\
\hline Azusa City of & California & 150,751 & 5.67 \\
\hline Wilson City of & North Carolina & 62,618 & 2.35 \\
\hline Greenville Utilities Comm & North Carolina & 29,000 & 1.09 \\
\hline 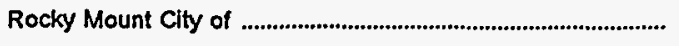 & North Carolina & 17,733 & .67 \\
\hline Groton Cly of & Connecticut & 5,558 & .21 \\
\hline 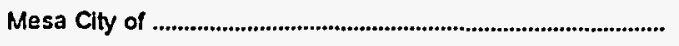 & Arizona & 140 & .01 \\
\hline 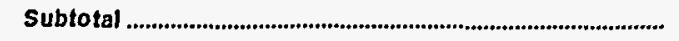 & & $2,660,907$ & 100.00 \\
\hline
\end{tabular}

Source: Energy Information Administration, Form ElA-412, "Annual Report of Public Electric Utilities." 
Table C21. Composite Statement of Income for Major U.S. Publicly Owned Nongenerator Electric Utilities with Financial Year Ending on June 30, 1991-1995

(Thousand Dollars)

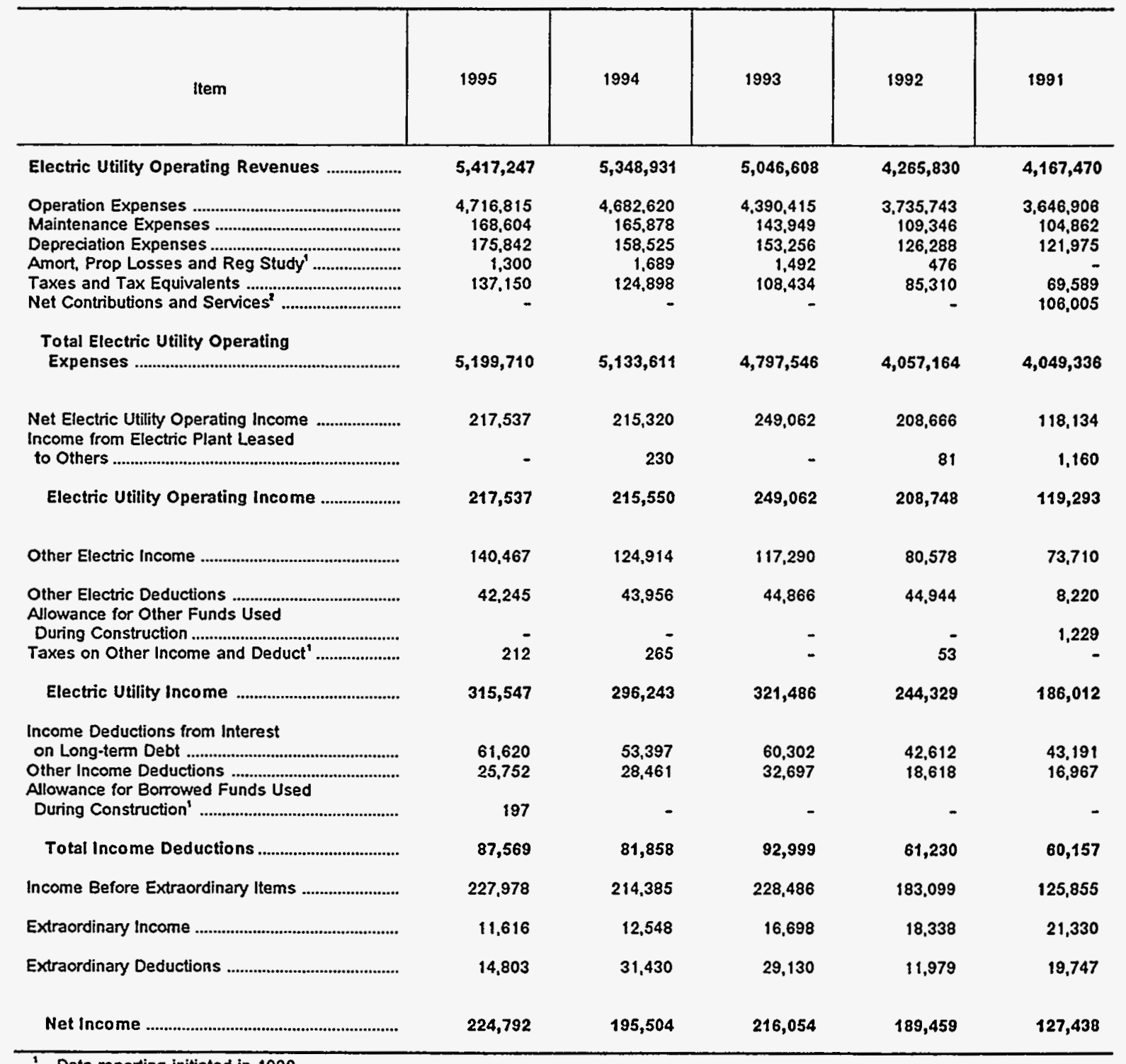

Data reporting initiated in 1992.

- Data reporting discontinued in 1992.

- Data not available.

Note: Totals may not equal sum of components because of independent rounding. The number of nongenerating publicly owned electric utilities for end of period is 144 for June 30, 1995; 144 for June 30, 1994; 142 for June 30, 1993; 137 for June 30, $1992 ;$ and 135 for June 30 1991. The City of Pella (IA) changed fiscal year from June 30 to December 31 in 1994; and the City of Buflington (NT) changed fis. cal year from June 30 to December 31 in 1994; the City of Hagerstown (MD) changed fiscal year from December 31 to June 30 in 1993; and the City of Memphis (TN) and the City of LaFollette (TN) changed fiscal years from December 31 to June 30 in 1992 . The City of Gaffney (SC). City of Osceola (AR), and City of Redding (CA) generators for 1991 through 1993, but became generators in 1994. The City of Kennett (MO) and City of Morgan City (LA) were generators for 1991 through 1993, but became nongenerators in 1994. Emerald Peoples Utility District (OR), City of Bryan (OH), and Northern Wasco County PUD (OR) were nongenerators for , but became generators in 1992. Source: Energy Information Administration, Form ElA-412, "Annual Report of Public Electric Utidities." 
Table C22. Composite Balance Sheet for Major U.S. Publicly Owned Nongenerator Electric Utilities with Financial Year Ending on June 30 at End of Period, 1991-1995

(Thousand Dollars)

\begin{tabular}{|c|c|c|c|c|c|}
\hline Item & 1995 & 1994 & 1993 & 1992 & 1991 \\
\hline \multicolumn{6}{|l|}{ Electric Utility Plant } \\
\hline Electric Utility Plant \& Adjust ...................................... & $5,577,820$ & $5,097,032$ & $4,931,174$ & $3,876,053$ & $3,793,405$ \\
\hline Const Work in Progress & 182,996 & 137,145 & 151,064 & 131,760 & \\
\hline 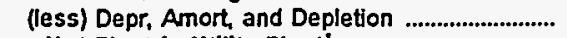 & $2,130,817$ & $1,968,516$ & $1,866,469$ & $1,457,939$ & $1,356,953$ \\
\hline 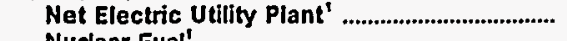 & $3,629,999$ & $3,265,662$ & $3,215,769$ & $2,549,875$ & \\
\hline & - & - & - & - & - \\
\hline $\begin{array}{l}\text { (less) Amort of Nuct Fuel' } \\
\text { Net Elec Plant Incl Nucl Fuel }\end{array}$ & & & & ז70 & \\
\hline \multirow{2}{*}{ Other Property \& Investments } & $3,629,999$ & $3,265,662$ & $3,215,769$ & $2,549,875$ & $2,436,453$ \\
\hline & $1,205,657$ & $1,155,762$ & $1,119,736$ & $1,081,940$ & $1,025,569$ \\
\hline (less) Accum Provisions for Depr \& Amort........... & 316,772 & 286,802 & 277,219 & 246,838 & 224.761 \\
\hline 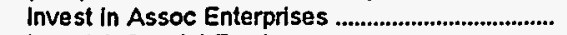 & 44,355 & 9,960 & 11,010 & 8,808 & 9,821 \\
\hline 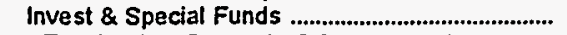 & 518.091 & 402,807 & 467.481 & 373,447 & 342.179 \\
\hline Total Other Property \& Investments .............. & $1,451,331$ & $1,281,726$ & $1,321,008$ & $1,217,357$ & $1,152,807$ \\
\hline $\begin{array}{l}\text { Current and Accrued Assets } \\
\text { Cash, Working Funds \& Investments ..................... }\end{array}$ & Current and Accrued Assets & 713,076 & 759,413 & 645,610 & 606,203 \\
\hline 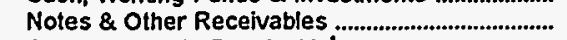 & 354,234 & 344.874 & 330,984 & 220,262 & 431,451 \\
\hline Customer Accts Receivable & 165,164 & 152,084 & 145,997 & 173,544 & \\
\hline (less) Accum Prov for Uncollected Accts ............. & 8,294 & 8,536 & 8,418 & 10,382 & 10,519 \\
\hline 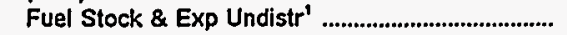 & & 108 & & 680 & \\
\hline 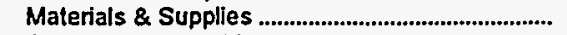 & 97.135 & 95,061 & 95,307 & 81,063 & 82,498 \\
\hline 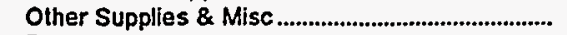 & 2,043 & & & & \\
\hline 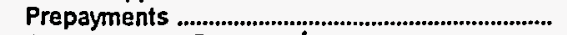 & 23,800 & 23,969 & 23,649 & 21,100 & 20,390 \\
\hline 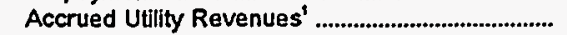 & 12,904 & 16,966 & 14,928 & 14,061 & \\
\hline Miscellaneous Current \& Accrued Assets ............ & 73,516 & 70,772 & 63.745 & 42,405 & 33,666 \\
\hline 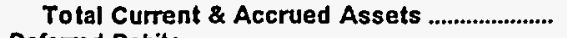 & $1,600,883$ & $1,408,372$ & $1,425,605$ & $1,188,343$ & $1,163,690$ \\
\hline \multicolumn{6}{|l|}{ Deferred Debits } \\
\hline 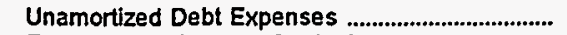 & 70,652 & 64.746 & 67,342 & 54,266 & 40,495 \\
\hline 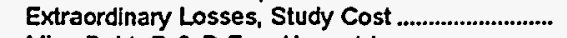 & 1,232 & 73 & 283 & 380 & \\
\hline 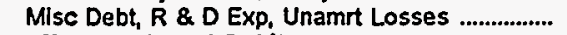 & 218,807 & 221,074 & 231,823 & 207,957 & 171,031 \\
\hline Total Deferred Debits ...................................................... & 290,690 & 285,893 & 299,449 & 262,602 & 211,527 \\
\hline 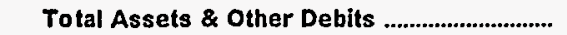 & $6,972,904$ & $6,241,654$ & $6,261,830$ & $5,218,177$ & $4,964,477$ \\
\hline \multirow{2}{*}{\multicolumn{6}{|c|}{$\begin{array}{l}\text { Proprietary Capital } \\
\text { Investment of Municipality }\end{array}$}} \\
\hline & 148,223 & 146,341 & 140.533 & 130,155 & 181,752 \\
\hline 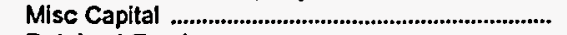 & 327,056 & 332,346 & 322,812 & 321,883 & 309,795 \\
\hline Retained Earnings & $3,669,131$ & $3,288,856$ & 3.182 .217 & $2,655,556$ & $2,464,326$ \\
\hline 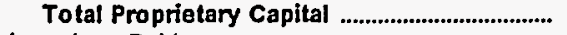 & $4,144,410$ & $3,767,643$ & $3,645,562$ & $3,107,593$ & $2,955,873$ \\
\hline \multicolumn{6}{|l|}{ Long-term Debt } \\
\hline 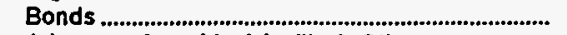 & $1.636,727$ & $1,320,555$ & $1,499,796$ & $1,121,996$ & $1,021,581$ \\
\hline Advances from Municipality \& Other ....................... & 359,698 & 355,209 & 367,687 & 350,771 & 306,400 \\
\hline 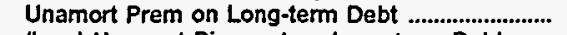 & $-2,397$ & 1,780 & $-1,857$ & 6.144 & 1,317 \\
\hline (less) Unamort Discount on Long-term Debt ....... & 7,842 & 2,327 & 7.964 & 8,254 & 14,948 \\
\hline 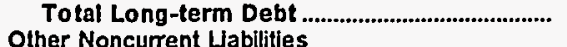 & $1,986,186$ & $1,675,218$ & $1,857,682$ & $1,470,657$ & $1,314,349$ \\
\hline \multicolumn{5}{|l|}{ Other Noncurrent Labilities } & \\
\hline 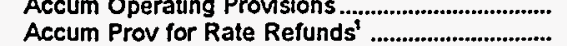 & $2,0<4$ & & & 206 & $\begin{array}{r}18,478 \\
-\end{array}$ \\
\hline Total Other Noncurrent Liabilities ........................ & 2,024 & 1,976 & 1,694 & 3,643 & 18,478 \\
\hline \multicolumn{6}{|l|}{ Current and Accrued Liabilities } \\
\hline 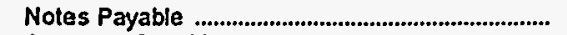 & 76,747 & 30.728 & 22,173 & 24,735 & 23,134 \\
\hline 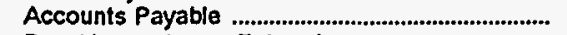 & 471.756 & 465,214 & 450.921 & 353,395 & 358,975 \\
\hline 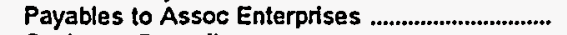 & 5.127 & 4,833 & 5,786 & 10,252 & 24,142 \\
\hline 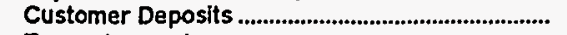 & 99,396 & 100,135 & 95,581 & 87,252 & 79,605 \\
\hline 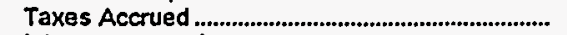 & 11.188 & 12,199 & 10,564 & 9,891 & 25.935 \\
\hline 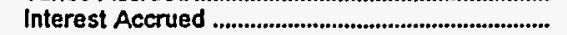 & 24,176 & 24,530 & 24,215 & 46,566 & 27,387 \\
\hline 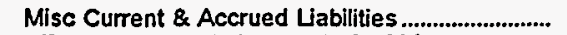 & 72.872 & 67,888 & 62,787 & 50,848 & 40.828 \\
\hline Total Current \& Accrued Liabilities ................. & 761,262 & 705,526 & 672,008 & 582,938 & 580,007 \\
\hline \multicolumn{6}{|l|}{ Deferred Credits } \\
\hline Customer Advances for Construction ...................... & 6.497 & 5.746 & 5.712 & 3,614 & 3,597 \\
\hline 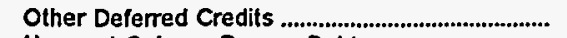 & 72,525 & 85,544 & 79,194 & 49.733 & 91,505 \\
\hline 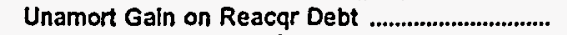 & & & & & 666 \\
\hline Total Deferred Credits ............................................... & 79,022 & 91,290 & 84,906 & 53,346 & 95,769 \\
\hline Total Liabilities and Other Credits ................... & $6,972,904$ & $6,241,654$ & $6,261,830$ & $5,218,177$ & $4,964,477$ \\
\hline
\end{tabular}

Data reporting initiated in 1992.

Note: Totals may not equal sum of components because of independent rounding. The number of nongenerating publicly owned electric utilities for end of period is 144 for June 30, 1995; 144 for June 30, 1994; 142 for June 30, 1993; 137 for June 30, 1992; and 135 for June 30 1991. The City of Pella (IA) changed fiscal year from June 30 to December 31 in 1994; and the City of Burlington (VT) changed fiscal year from June 30 to December 31 in 1994; the City of Hagerstown (MD) changed fiscal year from December 31 to June 30 in 1993; and the Clty of Memphls (TN) and the City of LaFollette (TN) changed fiscal years from December 31 to June 30 in 1992 . The City of Gatfney (SC). City of Osceola (AR), and City of Redding (CA) generators for 1991 through 1993, but became generators in 1994. The City of Kennett (MO) and City of Morgan City (LA) were generators for 1991 through 1993, but became nongenerators in 1994. Emerald Peoples Utility District (OR). City of Bryan (OH), and Northern Wasco County PUD (OR) were nongenerators for, but became generators in 1992.

Source: Energy Information Administration, Form E1A-412, "Annual Report of Public Electric Utilities." 
Table C23. Composite Financial Indicators for Major U.S. Publicly Owned Nongenerator Electric Utilities with Financial Year Ending on June 30, 1991-1995

\begin{tabular}{|c|c|c|c|c|c|}
\hline Item & 1995 & 1994 & 1993 & 1992 & 1991 \\
\hline Total Electric Utility Plant per Dollar of Revenue & 1.1 & 1.0 & 1.0 & 0.9 & 0.9 \\
\hline Current Assets to Current Liabilities ........................ & 2.1 & 2.0 & 2.1 & 2.0 & 2.0 \\
\hline 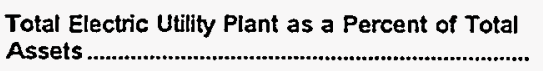 & 82.6 & 83.9 & 81.2 & 76.8 & 76.4 \\
\hline $\begin{array}{l}\text { Net Electric Utility Plant as a Percent of Total } \\
\text { Assets }\end{array}$ & 52.1 & 52.3 & 51.4 & 48.9 & 49.1 \\
\hline Debt as a Percent of Total Liabilities ........................ & 39.4 & 38.1 & 40.4 & 39.4 & 38.2 \\
\hline $\begin{array}{l}\text { Depreciation, Amortization and Depletion } \\
\text { as a Percent of Total Electric Utility Plant ........... }\end{array}$ & 37.0 & 37.6 & 36.7 & 36.4 & 35.8 \\
\hline $\begin{array}{l}\text { Electric Operation and Maintenance Expenses } \\
\text { as a Percent of } \\
\text { Electric Utility Operating Revenues ....................... }\end{array}$ & 90.2 & 90.6 & 89.8 & 90.1 & 90.0 \\
\hline 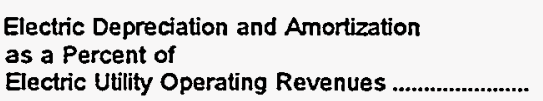 & 3.2 & 3.0 & 3.0 & 3.0 & 2.9 \\
\hline $\begin{array}{l}\text { Taxes and Tax Equivalents } \\
\text { as a Percent of } \\
\text { Electric Utility Operating Revenues .......................... }\end{array}$ & 2.5 & 2.3 & 2.1 & 2.0 & 1.7 \\
\hline $\begin{array}{l}\text { Interest on Long-term Debt } \\
\text { as a Percent of } \\
\text { Electric Utility Operating Revenues .......................... }\end{array}$ & 1.1 & 1.0 & 1.2 & 1.0 & 1.0 \\
\hline 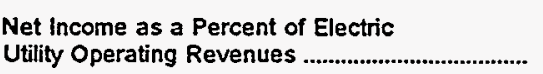 & 4.1 & 3.7 & 4.3 & 4.4 & 3.1 \\
\hline Purchased Power Cents Per Kilowatthour........... & 4.5 & 4.4 & 4.3 & 4.4 & 4.4 \\
\hline
\end{tabular}

Note: Totals may not equal sum of components because of independent rounding. The number of nongenerating publicly owned electric utilities for end of period is 144 for June 30, 1995; 144 for June 30, 1994; 142 for June 30, 1993; 137 for June 30, 1992 ; and 135 for June 30 1991. The City of Fella (IA) changed fiscal year from June 30 to December 31 in 1994; and the City of Burlington (VT) changed fiscal year from June 30 to December 31 in 1994; the City of Hagerstown (MD) changed fiscal year from December 31 to June 30 in 1993; and the City of Memphis (TN) and the City if LaFollette (TN) changed fiscal years from December 31 to June 30 in 1992. The City of Gaftney (SC). City of Osceola (AR), and City of Redding (CA) generators for 1991 through 1993, but became generators in 1994. The City of Kennett (MO) and City of Morgan City (LA) were generators for 1991 through 1993, but became nongenerators in 1994. Emerald Peoples Utility District (OR), City of Bryan $(\mathrm{OH})$, and Northern Wasco County PUD (OR) were nongenerators for ,but became generators in 1992.

Source: Energy information Administration, Form ElA-412, "Annual Report of Public Electric Utilities." 
Table C24. Electric Operation and Maintenance Expenses for Major U.S.

Publicly Owned Nongenerator Electric Utilities with Financial

Year Ending on June 30, 1991-1995

(Thousand Dollars)

\begin{tabular}{|c|c|c|c|c|c|}
\hline Item & 1995 & 1994 & 1993 & 1992 & 1991 \\
\hline \multicolumn{6}{|l|}{ Production Expenses } \\
\hline 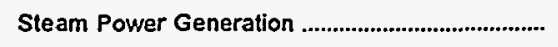 & 810 & - & - & - & - \\
\hline 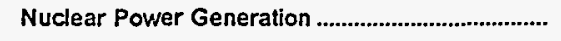 & - & - & - & - & - \\
\hline 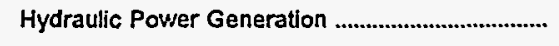 & 55 & - & - & - & - \\
\hline 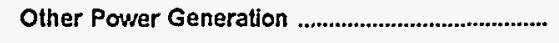 & 8,579 & 437 & - & - & - \\
\hline 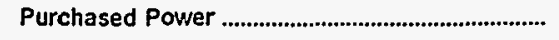 & $4,259,417$ & $4,271,419$ & $3,981,725$ & $3,410,265$ & $3,339,710$ \\
\hline 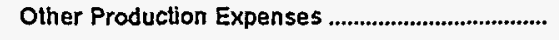 & 6,471 & 5,853 & 2,789 & 2,565 & 6,949 \\
\hline 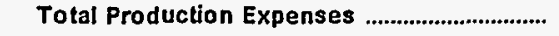 & $4,275,332$ & $4,277,709$ & $3,984,514$ & $3,412,829$ & $3,346,659$ \\
\hline Transmission Expenses & 20,368 & 18,929 & 18,336 & 17,158 & 13,330 \\
\hline 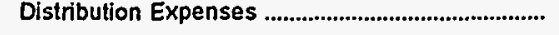 & 277,980 & 276.734 & 253,320 & 194,782 & 167,664 \\
\hline 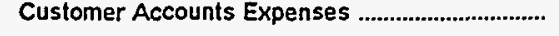 & 80,592 & 76,473 & 77,485 & 64,164 & 60.355 \\
\hline Customer Senvice and Information Expenses ..... & 9,191 & 9,417 & $\mathbf{9 , 5 5 9}$ & 7.703 & 9,006 \\
\hline Sales Expenses & 6,613 & 7,121 & 6,386 & 8,597 & 9,731 \\
\hline Administrative and General Expenses ...................... & 215,343 & 182,115 & 184,764 & 139,857 & 145,023 \\
\hline $\begin{array}{l}\text { Total Electric Operation } \\
\text { and Maintenance Expenses ............................... }\end{array}$ & $4,885,419$ & $4,848,498$ & $4,534,363$ & $3,845,089$ & $3,751,767$ \\
\hline \multicolumn{6}{|l|}{ Fuel Expenses in Operation } \\
\hline Steam Power Generation ............................................... & - & - & - & - & - \\
\hline Nuclear Power Generation ............................................... & - & - & - & - & - \\
\hline Other Power Generation ................................................ & 124 & 13 & - & - & - \\
\hline \multicolumn{6}{|l|}{ Number of Elec Dept Employees } \\
\hline 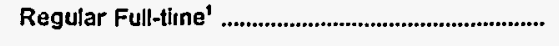 & 9,233 & 9,716 & 9.749 & 7.772 & - \\
\hline 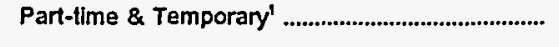 & 70 & 67 & 101 & 165 & - \\
\hline Total Elec Dept Employees' ................................... & 9,303 & 9,783 & $\mathbf{9 , 8 5 0}$ & 7,937 & - \\
\hline
\end{tabular}

- Data reporting initiated in 1992.

Note: Totals may not equal sum of components because of independent rounding. The number of nongenerating publicly owned electric utilities for end of period is 144 for June 30, 1995; 144 for June 30. 1994: 142 for June 30, 1993; 137 for June 30. 1992; and 135 for June 30 1991. The City of Pella (IA) changed fiscal year from June 30 to December 31 in 1994; and the City of Burlington (VT) changed fiscal year from June 30 to December 31 in 1994; the City of Hagerstown (MD) changed fiscal year from December 31 to June 30 in 1993; and the City of Memphis (TN) and the City of LaFollette (TN) changed fiscal years from December 31 to June 30 in 1992 . The City of Gafiney (SC), City of Osceola (AR), and City of Redding (CA) generators for 1991 through 1993, but became generators in 1994. The City of Kennett (MO) and City of Morgan City (LA) were generators for 1991 through 1993, but became nongenerators in 1994. Emerald Peoples Utility District (OR), City of Bryan (OH), and Northern Wasco County PUD (OR) were nongenerators for but became generators in t992.

Source: Energy Information Administration, Form ElA-412, "Annual Report of Public Electric Utilities." 
Table C25. Electric Utility Plant for Major U.S. Publicly Owned Nongenerator Electric Utilities with Financial Year Ending on June 30 at End of Period, 1991-1995

(Thousand Dollars)

\begin{tabular}{|c|c|c|c|c|c|}
\hline Item & 1995 & 1994 & 1993 & 1992 & 1991 \\
\hline \multicolumn{6}{|l|}{ Electric Plant in Service } \\
\hline Intangible Plant & - & 102 & 102 & 102 & 1 \\
\hline \multicolumn{6}{|l|}{ Production Plant } \\
\hline Steam & 61,798 & 44,786 & 53,463 & 41,649 & 40,412 \\
\hline Nuclear & - & - & - & - & - \\
\hline 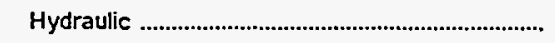 & 136,573 & - & - & - & - \\
\hline Other & 42,807 & 19,549 & 13,151 & 12,615 & 12,622 \\
\hline 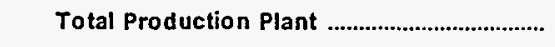 & 241,179 & 64,336 & 66,613 & 54,264 & 53,034 \\
\hline 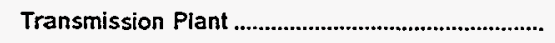 & 476,193 & 445,363 & 409,023 & 264,009 & 303,770 \\
\hline 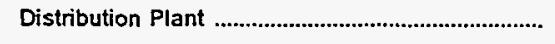 & $4,079,094$ & $3,828,961$ & $3,595,158$ & $2,793,942$ & $2,665,391$ \\
\hline General Plant & 750,455 & 726,406 & 813,520 & 719,782 & 657,870 \\
\hline 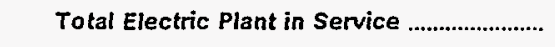 & $5,546,921$ & $5,065,167$ & $4,884,416$ & $3,832,099$ & $3,680,067$ \\
\hline Electric Plant Leased to Others .............................. & 18,871 & - & 0 & - & - \\
\hline Construction Work in Progress - Electric .............. & 182,996 & 137,145 & 151,064 & 131,760 & 91,741 \\
\hline 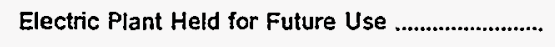 & 2,017 & 1,198 & 14,976 & 14,765 & 3,207 \\
\hline 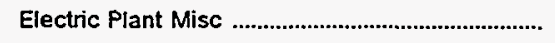 & 10,012 & 30,667 & 31,782 & 29,189 & 18,391 \\
\hline 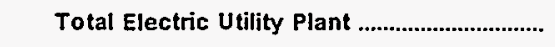 & $5,760,816$ & $5,234,178$ & $5,082,237$ & $4,007,814$ & $3,793,405$ \\
\hline \multicolumn{6}{|l|}{ Accumulated Provision for } \\
\hline Depreciation and Amortization .................................... & $2,130,817$ & $1,968,516$ & $1,866,469$ & 1.457 .939 & $1,356,953$ \\
\hline 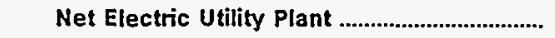 & $3,629,999$ & $3,265,662$ & $3,215,769$ & $2,549,875$ & $2,436,453$ \\
\hline
\end{tabular}

Note: Totals may not equal sum of components because of independent rounding. The number of nongenerating publicly owned electric utilities for end of period is 144 for June 30, 1995; 144 for June 30, 1994; 142 for June 30, 1993; 137 for June 30, 1992; and 135 for June 30 1991. The City of Pella (IA) changed fiscal year from June 30 to December 31 in 1994; and the City of Burtington (VT) changed fiscal year from June 30 to December 31 in 1994; the City of Hagerstown (MD) changed fiscal year from December 31 to June 30 in 1993; and the City of Memphis (TN) and the City of LaFollette (TN) changed fiscal years from December 31 to June 30 in 1992 . The City of Gaffney (SC). City of Osceola (AR), and City of Redding (CA) generators for 1991 through 1993, but became generators in 1994. The City of Kennett (MO) and City of Morgan City (LA) were generators for 1991 through 1993, but became nongenerators in 1994. Emerald Peoples Utility District (OR). City of Bryan (OH), and Northern Wasco County PUD (OR) were nongenerators for ,but became generators in 1992.

Source: Energy Information Administration, Form EIA-412, "Annual Riport of Public Electric Utilities." 
Table C26. Number of Consumers, Sales, and Operating Revenue for Major

U.S. Publicly Owned Nongenerator Electric Utilities with

Financial Year Ending on June 30, 1991-1995

\begin{tabular}{|c|c|c|c|c|c|}
\hline Item & 1995 & 1994 & 1993 & 1992 & 1991 \\
\hline \multicolumn{6}{|l|}{ Number of Consumers } \\
\hline 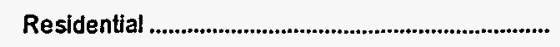 & $2,557,864$ & $2,516,576$ & $2,483,259$ & $2,076,553$ & $2,043,331$ \\
\hline Commercial or Small & 359,897 & 357,545 & 344,439 & 302.966 & 304,983 \\
\hline Industrial or Large & 41,387 & 39,825 & 36.716 & 28,125 & 21,272 \\
\hline Other & 26,607 & 28,486 . & 28.713 & 29,744 & 37,337 \\
\hline 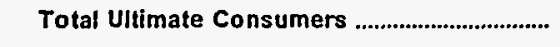 & $2,985,755$ & $2,942,432$ & $2,893,127$ & $2,437,388$ & $2,406,923$ \\
\hline \multicolumn{6}{|l|}{ Sales for the Year (megawatthours) } \\
\hline Residential & $32,536,450$ & $34,215.665$ & $32,114,016$ & $26,477,707$ & $26,467,624$ \\
\hline Commercial or Small & $12,661,614$ & $12,773,866$ & $12,317,727$ & $11,831,242$ & $12,926,802$ \\
\hline Industrial or Large & $46,176,156$ & $42,836,730$ & $40.115,218$ & $31,979,721$ & $30,010,647$ \\
\hline Other & $1,440,092$ & $1,386,109$ & $1.501,485$ & $1,304,399$ & $1,335,152$ \\
\hline Total Sales to Ultimate Consumers .................... & $92,814,312$ & $91,212,370$ & $86,048,446$ & $71,593,069$ & $70,740,225$ \\
\hline Sales for Resale & $2,274,495$ & $1.929,669$ & $1,611,743$ & $1,601,017$ & $1,729.566$ \\
\hline 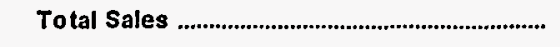 & $95,088,807$ & $93,142,039$ & $87,660,189$ & $73,194,086$ & $72,469,791$ \\
\hline \multicolumn{6}{|l|}{$\begin{array}{l}\text { Operating Revenues for the Year } \\
\text { (thousand dollars) }\end{array}$} \\
\hline 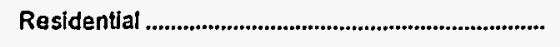 & $2,066,393$ & $2,153,567$ & $1,995,684$ & $1,638,723$ & $1,607,450$ \\
\hline Commercial or Small & 891,817 & 903,477 & 878,922 & 830,365 & 874,603 \\
\hline Industrial or Large & $2,313,456$ & $2,110,190$ & $2,027,104$ & $1,634,958$ & $1,539,511$ \\
\hline Other & 117,260 & 106.227 & 113,894 & 98,564 & 100,996 \\
\hline $\begin{array}{l}\text { Total Revenues from Sales to } \\
\text { Uitimate Consumers }\end{array}$ & $5,388,926$ & $5,273,461$ & $5,015,604$ & $4,202,610$ & $4,122,560$ \\
\hline Sales for Resale & 50,953 & 44,215 & 43,755 & 37,832 & 34.291 \\
\hline $\begin{array}{l}\text { Total Revenues From Sales of } \\
\text { Electricity }\end{array}$ & $5,439,879$ & $5,317,676$ & $5,059,359$ & $4,240,442$ & $4,456,851$ \\
\hline
\end{tabular}

Note: Totals may not equal sum of components because of independent rounding. The number of nongenerating publicty owned electric utilities for end of period is 144 for June 30,1995; 144 for June 30, 1994; 142 for June 30, 1993; 137 for June 30, 1992; and 135 for June 30 1991. The City of Pella (IA) changed tiscal year from June 30 to December 31 in 1994, and the City of Burtington (NT) changed fiscal year from June 30 to December 31 in 1994; the City of Hagerstown (MD) changed fiscal year from December 31 to June 30 in 1993; and the City of Memphis (TN) and the City of LaFollette (TN) changed fiscal years from December 31 to June 30 in 1992 . The City of Gaffney (SC). City of Osceola (AR), and City of Redding (CA) generators for 1991 through 1993, but became generators in 1994. The Clty of Kennett (MO) and City of Morgan City (LA) were generators for 1991 through 1993, but became nongenerators in 1994. Emerald Peoples Utility District (OR), City of Bryan (OH), and Northern Wasco County PUD (OR) were nongenerators for ,but became generators in 1992. sions.

Source: Energy Information Administration, Form EIA-861, "Annual Electric Utility Report." Data are based on calendar year submis- 
Table C27. Electric Energy Account for Major U.S. Publicly Owned Nongenerator Electric Utilities with Financial Year Ending on

June 30, 1991-1995

(Megawatthours)

\begin{tabular}{|c|c|c|c|c|c|}
\hline Item & 1995 & 1994 & 1993 & 1992 & 1991 \\
\hline \multicolumn{6}{|l|}{ So urces of Energy } \\
\hline Steam & - & - & - & - & - \\
\hline Nuclear & - & - & - & - & - \\
\hline 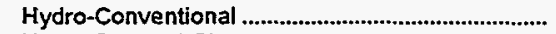 & - & - & - & - & - \\
\hline Hydro-Pumped Storage ............................................... & - & - & - & - & - \\
\hline Other & - & - & - & - & - \\
\hline 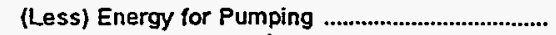 & - & - & - & - & - \\
\hline Total Net Generation & - & - & - & - & - \\
\hline 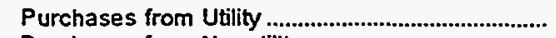 & $95,077,436$ & $97,458,889$ & $91,646,505$ & $76,788,784$ & $75,437,318$ \\
\hline $\begin{array}{l}\text { Purchases from Nonutility ......................................... } \\
\text { Power Exchanges }\end{array}$ & 482,969 & 16,213 & 2 & 2 & 2,040 \\
\hline 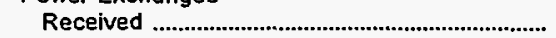 & 8,433 & - & 3,314 & - & - \\
\hline Delivered & - & - & 11,649 & - & - \\
\hline 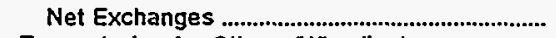 & 8.433 & - & $-8,335$ & - & - \\
\hline \multicolumn{6}{|l|}{ Transmission for Others (Wheeling) } \\
\hline 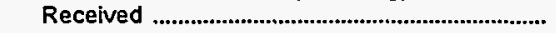 & 583,703 & 351,967 & 304,378 & - & - \\
\hline Delivered & 243,121 & 351,967 & 300,448 & - & - \\
\hline 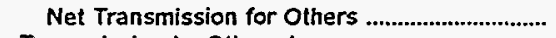 & 340,582 & - & 3,930 & - & - \\
\hline 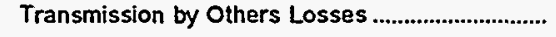 & - & - & $-3,930$ & - & - \\
\hline \multicolumn{6}{|l|}{ Total Net Energy Generated and } \\
\hline Received & $95,909,414$ & $97,475,102$ & $91,638,172$ & $76,788,786$ & $75,439,358$ \\
\hline \multicolumn{6}{|l|}{ Disposition of Energy } \\
\hline $\begin{array}{l}\text { Sales to Uitimate Consumers } \\
\text { Requirements Sales for Resale }\end{array}$ & $\begin{array}{r}89,406,093 \\
2,660,907\end{array}$ & $\begin{array}{r}91,130,426 \\
1,955,584\end{array}$ & $\begin{array}{r}85,534,702 \\
1,517,540\end{array}$ & $\begin{array}{r}71,571,297 \\
1,668,178\end{array}$ & $\begin{array}{r}70,032,792 \\
1,860,185\end{array}$ \\
\hline 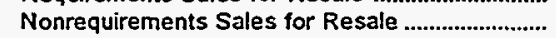 & - & - & - & 6,542 & 0 \\
\hline Furnished Without Charge & 86,864 & 110,975 & 78,854 & 51,491 & 67,296 \\
\hline 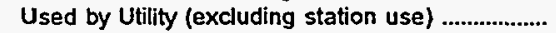 & 176,605 & 100,833 & 126,866 & 112,766 & 128,449 \\
\hline $\begin{array}{l}\text { Losses } \\
\text { Total Disposition }\end{array}$ & $\begin{array}{r}3,578,945 \\
95,909,414\end{array}$ & $\begin{array}{r}4,177,289 \\
97,475,102\end{array}$ & $\begin{array}{r}4,380,140 \\
91,638,172\end{array}$ & $\begin{array}{r}3,378,453 \\
76,788,786\end{array}$ & $\begin{array}{r}3,350,648 \\
75,439,358\end{array}$ \\
\hline
\end{tabular}

Note: Totals may not equal sum of components because of independent rounding. The number of nongenerating publicly owned electric utilities for end of period is 144 for June 30, 1995; 144 for June 30, 1994; 142 for June 30, 1993; 137 for June 30, 1992; and 135 for June 30 1991. The City of Pella (IA) changed fiscal year from June 30 to December 31 in 1994; and the City of Burtington $N T$ ) changed fiscal year from June 30 to December 31 in 4994; the City of Hagerstown (MD) changed fiscal year from December 31 to June 30 in 1993; and the City of Memphis (TN) and the City of LaFollette (TN) changed fiscal years from December 31 to June 30 in 1992 . The City of Gaffney (SC). City of Osceola (AR), and City of Redding (CA) generators for 1991 through 1993, but became generators in 1994. The City of Kennett (MO) and City of Morgan City (LA) were generators for 1991 through 1993, but became nongenerators in 1994. Emerald Peoples Utility District (OR). City of Bryan (OH), and Northern Wasco County PUD (OR) were nongenerators for ,but became generators in 1992.

Source: Energy Information Administration. Form ElA-412, "Annual Report of Public Electric Utilities." 
Table C28. Ten Largest U.S. Publicly Owned Nongenerator Electric Utilities Ranked by Megawatthour Sales to Ultimate Consumers with Financial Year Ending on December 31, 1995

\begin{tabular}{|c|c|c|c|}
\hline Publicly Owned Electric Utilities & State & Amount & Percent \\
\hline 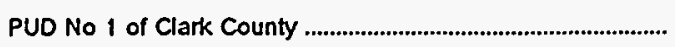 & Washington & $3,662,771$ & 11.44 \\
\hline 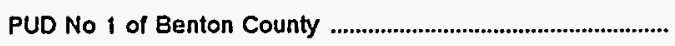 & Washington & $1,372,157$ & 4.29 \\
\hline 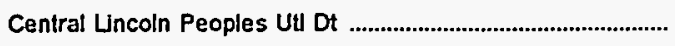 & Oregon & $1,265,287$ & 3.95 \\
\hline Fort Collins Clty of & Colorado & 950,697 & 2.97 \\
\hline 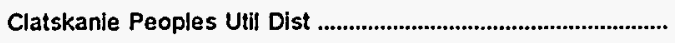 & Oregon & 887,159 & 2.77 \\
\hline Springfield City of & Oregon & 845,575 & 2.64 \\
\hline Anderson City of & Indiana & 661,554 & 2.07 \\
\hline Athens City of & Alabama & 656,218 & 2.05 \\
\hline Richland City of & Washington & 633,976 & 1.98 \\
\hline 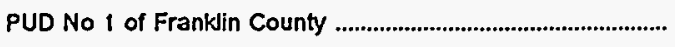 & Washington & 629.531 & 1.97 \\
\hline Subtotal & & $11,564,925$ & 36.14 \\
\hline
\end{tabular}

Source: Energy Information Administration, Form ElA-412, "Annual Report of Public Electric Utilities."

Table C29. Ten Largest U.S. Publicly Owned Nongenerator Electric Utilities Ranked by Megawatthour Sales for Resale with Financial Year Ending on December 31, 1995

\begin{tabular}{|c|c|c|c|}
\hline Publicly Owned Electric Utilities & State & Amount & Percent \\
\hline 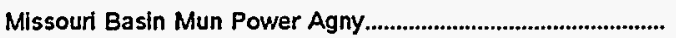 & South Dakota & $1,853,342$ & 44.50 \\
\hline Connecticut Mun Elec Engy Coop & Connecticut & $1,654,907$ & 39.73 \\
\hline 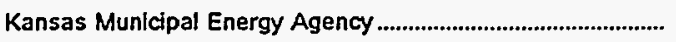 & Kansas & 304,342 & 7.31 \\
\hline 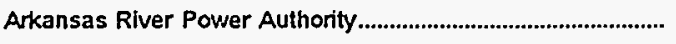 & Colorado & 282,401 & 6.78 \\
\hline 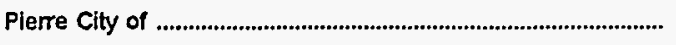 & South Dakota & 15,632 & .38 \\
\hline Norris Publlc Power District & Nebraska & 15,270 & .37 \\
\hline Westfield City of & Massachusetts & 8,868 & .21 \\
\hline Danvers Town of & Massachusetts & 7.618 & .18 \\
\hline 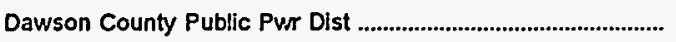 & Nebraska & 5.511 & .13 \\
\hline PUD No 3 of Mason County & Washington & 3,472 & .08 \\
\hline 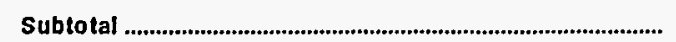 & & $4,151,363$ & 99.66 \\
\hline
\end{tabular}

Source: Energy Information Administration, Form ElA-412, "Annual Report of Public Electric Utilities." 
Table C30. Composite Statement of Income for Major U.S. Publicly Owned Nongenerator Electric Utilities with Financial Year Ending on December 31, 1991-1995 (Thousand Dollars)

\begin{tabular}{|c|c|c|c|c|c|}
\hline Item & 1995 & 1994 & 1993 & 1992 & 1991 \\
\hline Electric Utility Operating Revenues .................. & $1,977,474$ & $1,735,983$ & $1,629,821$ & $2,158,597$ & $2,251,181$ \\
\hline $\begin{array}{l}\text { Operation Expenses } \\
\text { Maintenance Expenses } \\
\text { Depreciation Expenses } \\
\text { Amort, Prop Losses and Reg Study' } \\
\text { Taxes and Tax Equivalents } \\
\text { Net Contributions and Services }\end{array}$ & $\begin{array}{r}1,610,840 \\
55,945 \\
97,869 \\
1,367 \\
79,001 \\
-\end{array}$ & $\begin{array}{r}1,428,431 \\
48,814 \\
82,297 \\
3,097 \\
52,911 \\
\end{array}$ & $\begin{array}{r}1,343,821 \\
46,241 \\
74,479 \\
2,168 \\
48,592 \\
-\end{array}$ & $\begin{array}{r}1,833,153 \\
68,719 \\
87,335 \\
2,340 \\
56,344 \\
\end{array}$ & $\begin{array}{r}1,894,483 \\
63,243 \\
93,189 \\
- \\
54,151 \\
35,714\end{array}$ \\
\hline $\begin{array}{c}\text { Total Electric Utility Operating } \\
\text { Expenses }\end{array}$ & $1,845,022$ & $1,615,551$ & $1,515,301$ & $2,047,891$ & $2,140,780$ \\
\hline $\begin{array}{l}\text { Net Electric Utility Operating Income } \\
\text { Income from Electric Plant Leased } \\
\text { to Others }\end{array}$ & $\begin{array}{r}132,452 \\
3,299\end{array}$ & 120,432 & 114,520 & 110,707 & $\begin{array}{r}110.401 \\
360\end{array}$ \\
\hline Electric Utility Operating Income ...................... & 135,751 & 121,373 & 115,960 & 111,456 & 110,761 \\
\hline Other Electric Income & 46,695 & 32,199 & 34,556 & 65,687 & 51,653 \\
\hline $\begin{array}{l}\text { Other Electric Deductions } \\
\text { Allowance for Other Funds Used }\end{array}$ & 10,205 & 14,718 & 8,155 & 23,319 & 4,873 \\
\hline 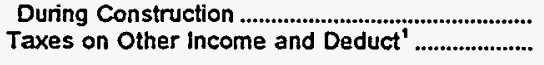 & $\begin{array}{r}9 \\
3,033\end{array}$ & $\begin{array}{r}32 \\
2,616\end{array}$ & $\begin{array}{r}87 \\
1,838\end{array}$ & $\begin{array}{r}21 \\
1,374\end{array}$ & 361 \\
\hline Electric Utility Income & 169,217 & 136,269 & 140,610 & 152,471 & 157,902 \\
\hline 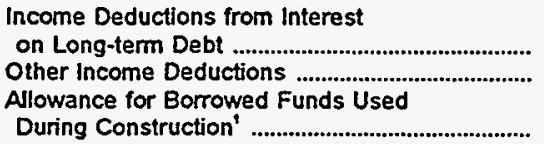 & $\begin{array}{r}40,547 \\
8,121\end{array}$ & $\begin{array}{r}30,434 \\
6,394\end{array}$ & $\begin{array}{l}30,060 \\
14,211\end{array}$ & $\begin{array}{r}46,371 \\
4,172\end{array}$ & $\begin{array}{r}61,140 \\
4,724\end{array}$ \\
\hline 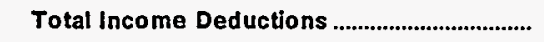 & 48,518 & 36,653 & 44,002 & 50,465 & 65,864 \\
\hline 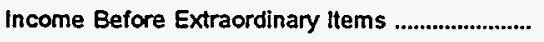 & 120,698 & 99,616 & 96,609 & 102,006 & 92,038 \\
\hline Extraordinary Income & 4,042 & 18,254 & 1,284 & 13,557 & 1,973 \\
\hline 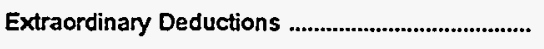 & 1,254 & 436 & 1,900 & 14,209 & 5.428 \\
\hline Net Income & 123,487 & 117,435 & 95,993 & 101,354 & 88,585 \\
\hline
\end{tabular}

Data reporting jnitiated in 1992.

- Data reporting discontinued in 1992.

- Data not available.

Note: Totals may not equal sum of components because of independent rounding. The number of nongenerating publicly owned electric utilities for end of period is 106 for December 31, 1995; 95 for December 31, 1994; 93 for December 31, $1993 ; 88$ for December 31, 1992; and 86 for December 31, 1991. The City of Pella (IA) changed fiscal year from June 30 to December 31 in 1994, and the City of Burlington $(V T)$ changed fiscal year from December 31 to June 30 in 1994; the City of Hagerstown (MD) changed fiscal year from December 31 to June 30 in 1993; and the City of Memphis (TN) and the City of LaFollette (TN) changed fiscal years from December 31 to June 30 in 1992. The City of Gaffney (SC). City of Osceola (AR), and City of Redding (CA) were nongenerators for 1991 through 1993, but became generators in 1994. The City of Kennett (MO) and City of Morgan City (LA) were generators for 1991 through 1993. but became nongenerators in 1994. Emerald Peoples Utility District (OR). City of Bryan (OH), and Northern Wasco County PUD (OR) were nongenerators for 1991, but became generators in 1992.

Source: Energy Information Administration, Form EIA-412, "Annual Report of Public Electric Utilities." 
Table C31. Composite Balance Sheet for Major U.S. Publicly Owned Nongenerator Electric Utilities with Financial Year Ending un December 31 at End of Period, 1991-1995 (Thousand Dollars)

\begin{tabular}{|c|c|c|c|c|c|}
\hline Item & 1995 & 1994 & 1993 & 1992 & 1991 \\
\hline \multicolumn{6}{|l|}{ Electric Utility Plant } \\
\hline Electric Utility Plant \& Adjust .................................... & $2,984,283$ & $2,551,527$ & $\begin{array}{r}2,354,689 \\
85,520\end{array}$ & $\begin{array}{r}2,882,052 \\
115,017\end{array}$ & $2,852,226$ \\
\hline $\begin{array}{l}\text { Const Work in Progress } \\
\text { (less) Depr.................. Amort and Depletion }\end{array}$ & $\begin{array}{r}91,787 \\
1,49,397\end{array}$ & $\begin{array}{r}86.019 \\
986.935\end{array}$ & $\begin{array}{r}85,520 \\
907,475\end{array}$ & & \\
\hline $\begin{array}{l}\text { (less) Depr, Amort, and Depletion } \\
\text { Net Electric Utility Plant' }\end{array}$ & $\begin{array}{l}1,149,397 \\
1,926,673\end{array}$ & $\begin{array}{r}986,935 \\
1,650,611\end{array}$ & $\begin{array}{r}907,475 \\
1,532,734\end{array}$ & $\begin{array}{l}1,096,972 \\
1,900,097\end{array}$ & $1,035,192$ \\
\hline Nuclear Fuel' & 787 & - & - & - & - \\
\hline (less) Amort of Nucl Fuel' & & $5 \cos -$ & - & & \\
\hline 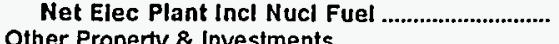 & $1,927,460$ & $1,650,611$ & $1,532,734$ & $1,900,097$ & $1,816,434$ \\
\hline \multicolumn{6}{|l|}{ Other Property \& Investments } \\
\hline 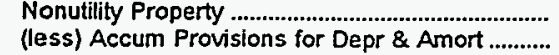 & $\begin{array}{r}240.731 \\
57.327\end{array}$ & 225,807 & 227,813 & 203,618 & 198,098 \\
\hline $\begin{array}{l}\text { (less) Accum Provisions for Depr \& Amort } \\
\text { Invest in Assoc Enterprises }\end{array}$ & 22,104 & $\begin{array}{l}49,099 \\
10,140\end{array}$ & $\begin{array}{r}54,766 \\
9,550\end{array}$ & $\begin{array}{r}48.346 \\
7762\end{array}$ & $\begin{array}{r}45,858 \\
99\end{array}$ \\
\hline 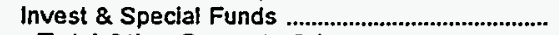 & 278,806 & 201,944 & 207,033 & $\begin{array}{r}7.762 \\
304.054\end{array}$ & 370,683 \\
\hline $\begin{array}{l}\text { Total Other Property \& Investments .............. } \\
\text { Current and Accrued Assets }\end{array}$ & 484,314 & 388,793 & 389,631 & 467,088 & 523,021 \\
\hline 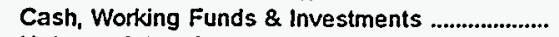 & 447,635 & 379,980 & 357,472 & 339,322 & 362,180 \\
\hline 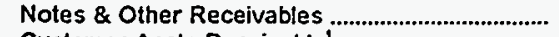 & 63,238 & 42,893 & 26,934 & 71,293 & 235,845 \\
\hline Customer Accts Receivable' & 196,112 & 161.292 & 162,190 & 147,247 & \\
\hline (less) Accum Prov for Uncollected Accts ............. & 8,058 & 7,068 & 7,801 & 8,016 & 7,590 \\
\hline 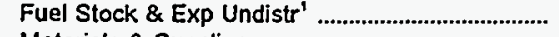 & 168 & 1.518 & 264 & 500 & - \\
\hline 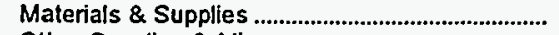 & 62,358 & 61.447 & 61,358 & 69,972 & 67,872 \\
\hline 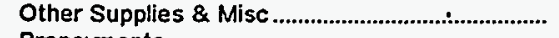 & 5,179 & - & & - & - \\
\hline 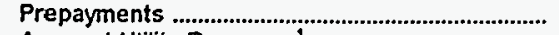 & 24,290 & 21,326 & 23.490 & 21,237 & 83,368 \\
\hline Accrued Utility Revenues' & 26,332 & 12,861 & 12,311 & 11,517 & - \\
\hline Miscellaneous Current \& Accrued Assets ............ & 19,297 & 8,803 & 9.526 & 15,415 & 27,160 \\
\hline Total Current \& Accrued Assets ...................... & 836,551 & 683,052 & 645,745 & 668,487 & 768,834 \\
\hline \multicolumn{3}{|l|}{ Deferred Debits } & 22,259 & 18,917 & 25,875 \\
\hline 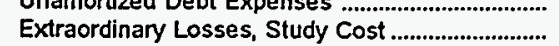 & $\begin{array}{r}57,615 \\
7,448\end{array}$ & 5,086 & 6,434 & 3,980 & 20,060 \\
\hline Misc Debt, R \& D Exp. Unamrt Losses ................ & 74,828 & 24,352 & 24,497 & 39.228 & 80,645 \\
\hline Total Deferred Debits ............................................ & 139,831 & 51,645 & 53,190 & 62,125 & 106,520 \\
\hline 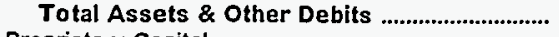 & $3,388,217$ & $2,774,101$ & $2,621,300$ & $3,097,797$ & $3,214,809$ \\
\hline \multicolumn{6}{|l|}{ Proprietary Capital } \\
\hline 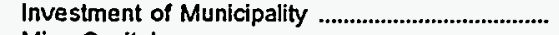 & 173.256 & 145,798 & 135,447 & 91.968 & 95,426 \\
\hline 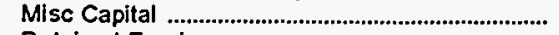 & 184,379 & 116,911 & 81,107 & 88,736 & 136,711 \\
\hline Retained Earnings & $1,610,246$ & $1,542,416$ & $1,471,780$ & $1.702,946$ & $1.512,670$ \\
\hline \multicolumn{2}{|l|}{ Long-term Debt } & $1,805,126$ & $1,688,335$ & $1,883,650$ & $1,744,806$ \\
\hline Bonds & 834,302 & 544,692 & 547,884 & 759,756 & $1,011,891$ \\
\hline 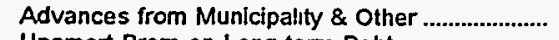 & 141,678 & 71,133 & 55,206 & 70.241 & 58,600 \\
\hline Unamort Prem on Long-term Debt ............................ & 2,295 & 2,681 & 2,398 & 2,791 & 7 \\
\hline (less) Unamort Discount on Long-term Debt ...... & 2,563 & 2,783 & 2,151 & 1.481 & 1,283 \\
\hline & 975,713 & 615,724 & 603,337 & 831,307 & $1,069,215$ \\
\hline \multicolumn{6}{|l|}{ Other Noncurrent Labilities } \\
\hline 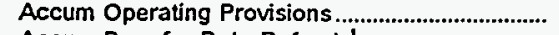 & 7.651 & 9,268 & 8.712 & 6,035 & 36,590 \\
\hline Accum Prov for Rate Refunds' ................................. & 376 & 34 & 224 & & \\
\hline $\begin{array}{l}\text { Total Other Noncurrent Liabilities ...................... } \\
\text { Current and Accrued Labilities }\end{array}$ & 8,027 & 9,302 & 8,936 & 6,035 & 36,590 \\
\hline 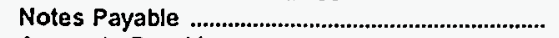 & 40,986 & 30.220 & 29,567 & 22,041 & 24,474 \\
\hline Accounts Payable & 166,823 & 153.115 & 149.460 & 190,881 & 192,092 \\
\hline 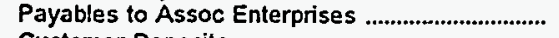 & 11,359 & 2,696 & 2,700 & 2,998 & 1,898 \\
\hline 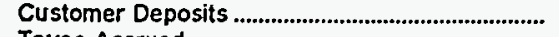 & 20,119 & 19,155 & 17,498 & 16,811 & 15,768 \\
\hline 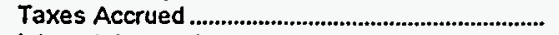 & 14,953 & 14,293 & 12,960 & 11,124 & 10,501 \\
\hline 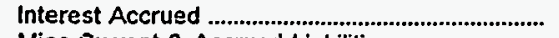 & 13,472 & 8,872 & 7.859 & 8,666 & 10,514 \\
\hline 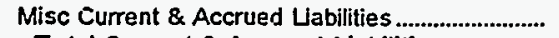 & 46,823 & 38,341 & 35,012 & 40,286 & 34,968 \\
\hline $\begin{array}{l}\text { Total Current \& Accrued Liabilities ...................... } \\
\text { Deferred Credits }\end{array}$ & 314,535 & 266,693 & 255,055 & 291,528 & 290,214 \\
\hline Customer Advances for Construction ...................... & 43,191 & 44,785 & 43,169 & 35,813 & 35,394 \\
\hline 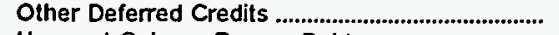 & 60,244 & 27,572 & 20.959 & 43,212 & 37,365 \\
\hline Unamort Gain on Reacgr Debt ...................................... & 18,626 & 4,900 & 1,508 & 4,973 & 1,224 \\
\hline 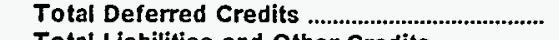 & 122,060 & 77,257 & 65,637 & 83,998 & 73,982 \\
\hline Total Liabilities and Other Credits .................. & $3,388,217$ & $2,774,101$ & $2,621,300$ & $3,097,797$ & $3,214,809$ \\
\hline
\end{tabular}

Note: Totals may not equal sum of components because of independent rounding. The number of nongenerating publicly owned electric utilities for end of period is 106 for December 31, 1995; 95 for December 31, 1994; 93 for December 31, 1993 ; 88 for December 31, 1992; and 86 for December 31,1991 . The City of Pella (IA) changed fiscal year from June 30 to December 31 in 1994 , and the City of Burlington (VT) changed fiscal year from December 31 to June 30 in 1994; the City of Hagerstown (MD) changed fiscal year from December 31 to June 30 in 1993; and the City of Memphis (TN) and the City of LaFollette (TN) changed fiscal years from December 31 to June 30 in 1992. The City of Gaffney (SC). City of Osceola (AR), and City of Redding (CA) were nongenerators for 1991 through 1993, but became generators in 1994. The City of Kennett (MO) and City of Morgan City (LA) were generators for 1991 through 1993, but became nongenerators in 1994. Emerald Peoples Utility District (OR), City of Bryan (OH), and Northern Wasco County PuD (OR) were nongenerators for 1991, but became generators in 1992.

Source: Energy Information Administration, Form ElA-412, "Annual Report of Public Electric Utilities." 
Table C32. Composite Financial Indicators for Major U.S. Publicly Owned Nongenerator Electric Utilities with Financial Year Ending on December 31, 1991-1995

\begin{tabular}{|c|c|c|c|c|c|}
\hline Item & 1995 & 1994 & 1993 & 1992 & 1991 \\
\hline Total Electric Utility Plant per Dollar of Revenue & 1.6 & 1.5 & 1.5 & 1.4 & 1.3 \\
\hline Current Assets to Current Liabilities ........................... & 2.7 & 2.6 & 2.5 & 2.3 & 2.6 \\
\hline $\begin{array}{l}\text { Total Electric Utility Plant as a Percent of Total } \\
\text { Assets }\end{array}$ & 90.8 & 95.1 & 93.1 & 96.7 & $\mathbf{8 8 . 7}$ \\
\hline $\begin{array}{l}\text { Net Electric Utility Plant as a Percent of Total } \\
\text { Assets }\end{array}$ & 56.9 & 59.5 & 58.5 & 61.3 & 56.5 \\
\hline Debt as a Percent of Total Labilities ....................... & 38.1 & 31.8 & 32.7 & 36.2 & 42.3 \\
\hline $\begin{array}{l}\text { Depreciation, Amortization and Depletion } \\
\text { as a Percent of Total Electric Utility Plant ........... }\end{array}$ & 37.4 & 37.4 & 37.2 & 36.6 & 36.3 \\
\hline $\begin{array}{l}\text { Electric Operation and Maintenance Expenses } \\
\text { as a Percent of } \\
\text { Electric Utility Operating Revenues ......................... }\end{array}$ & 84.3 & 85.1 & 85.3 & 88.1 & 87.0 \\
\hline $\begin{array}{l}\text { Electric Depreciation and Amortization } \\
\text { as a Percent of } \\
\text { Electric Utility Operating Revenues ........................ }\end{array}$ & 4.9 & 4.7 & 4.6 & 4.0 & 4.1 \\
\hline $\begin{array}{l}\text { Taxes and Tax Equivalents } \\
\text { as a Percent of } \\
\text { Electric Utility Operating Revenues ..................... }\end{array}$ & 4.0 & 3.0 & 3.0 & 2.6 & 2.4 \\
\hline $\begin{array}{l}\text { Interest on Long-term Debt } \\
\text { as a Percent of } \\
\text { Electric Utility Operating Revenues ........................ }\end{array}$ & 2.1 & 1.8 & 1.8 & 2.1 & 2.7 \\
\hline $\begin{array}{l}\text { Net Income as a Percent of Electric } \\
\text { Utility Operating Revenues ...................................... }\end{array}$ & 6.2 & 6.8 & 5.9 & 4.7 & 3.9 \\
\hline Purchased Power Cents Per Kilowatthour ............. & 3.6 & 3.5 & 3.3 & 3.6 & 3.6 \\
\hline
\end{tabular}

Note: Totals may not equal sum of components because of independent rounding. The number of nongenerating publicly owned electric utilities for end of period is 106 for December 31, 1995; 95 for December 31, 1994; 93 for December 31, $1993 ; 88$ for December 31 , 1992; and 86 for December 31, 1991. The City of Pella (IA) changed fiscal year from Jure 30 to December 31 in 1994 , and the City of Burlington (VT) changed fiscal year from December 31 to June 30 in 1994; the City of Hagerstown (MD) changed fiscal year from December 31 to June 30 in 1993; and the City of Memphis (TN) and the City of LaFollette (TN) changed fiscal years from December 31 to June 30 in 1992. The City of Gaffney (SC) City of Osceola (AR) and City of Redding (CA) were nongenerators for 1991 through 1993, but became generators in 1994. The City of Kennett (MO) and City of Morgan City (LA) were generators for 1991 through 1993, but became nongenerators in 1994. Emerald Peoples Utility District (OR), City of Bryan (OH), and Northern Wasco County PUD (OR) were nongenerators for 1991, but became generators in 1992

Source: Energy Information Administration, Form ElA-412, "Annual Report of Public Electric Utilities." 
Table C33. Electric Operation and Maintenance Expenses for Major U.S.

Publicly Owned Nongenerator Electric Utilities with

Financial Year Ending on December 31, 1991-1995

(Thousand Dollars)

\begin{tabular}{|c|c|c|c|c|c|}
\hline Item & 1995 & 1994 & 1993 & 1992 & 1991 \\
\hline Production Expenses & & & & & \\
\hline 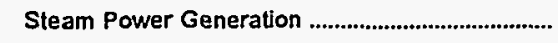 & 967 & 284 & 362 & 416 & 544 \\
\hline 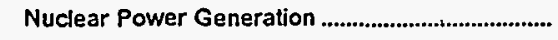 & - & - & - & - & - \\
\hline 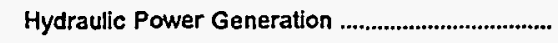 & 19 & 11 & $\mathbf{9}$ & 1 & - \\
\hline 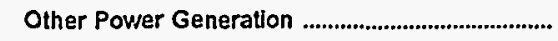 & 8,996 & 1,063 & 1,249 & 622 & 97 \\
\hline 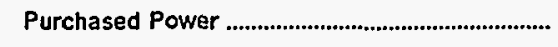 & $1,359,541$ & $1,222,573$ & $1,140,781$ & $1,579,889$ & $1,648,190$ \\
\hline 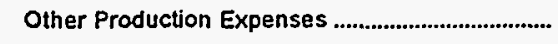 & 17.112 & 6,605 & 8,113 & 4,576 & 7.328 \\
\hline 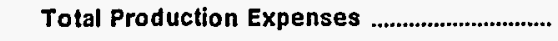 & $1,386,635$ & $1,230,536$ & $1,150,514$ & $1,585,505$ & $1,656,156$ \\
\hline 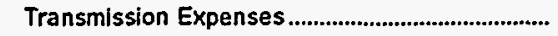 & 19.761 & 21,067 & 19.145 & 22,387 & 20,321 \\
\hline 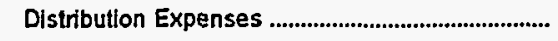 & 114,258 & 95,362 & 97,151 & 134,814 & 125,756 \\
\hline 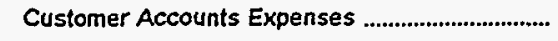 & 35,612 & 33,948 & 33,441 & 38.622 & 37,058 \\
\hline Customer Service and Information Expenses ..... & 6,726 & 5,699 & 5,753 & 6.113 & 5.280 \\
\hline Sales Expenses & 2,765 & 2,649 & 2,167 & 2,495 & 1,582 \\
\hline 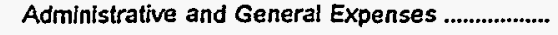 & 101,029 & 87,985 & 81,871 & 111,937 & 111,572 \\
\hline $\begin{array}{l}\text { Total Electric Operation } \\
\text { and Maintenance Expenses ................................ }\end{array}$ & $1,666,785$ & $1,477,246$ & $1,390,042$ & $1,901,872$ & $1,957,726$ \\
\hline
\end{tabular}

Fuel Expenses in Operation

Steam Power Generation

Nuclear Power Generation

Other Power Generation

2

13

2

$-$

$-2$

Number of Elec Dept Employees

Regular full-time'

3.787

3.764

Part-time \& Temporary

1 Data reporting initiated in 1992

Note: Totals may not equal sum of components because of independent rounding. The number of nongenerating publicly owned electric utilities for end of period is 106 for December 31, 1995; 95 for December 31, 1994; 93 for December 31, $1993 ; 88$ for December 31, 1992; and 86 for December 31, 1991. The City of Pella (IA) changed fiscal year from June 30 to December 31 in 1994, and the City of Burlington $(\mathrm{VT})$ changed fiscal year from December 31 to June 30 in 1994; the City of Hagerstown (MD) changed fiscal year from December 31 to June 30 in 1993; and the City of Memphis (TN) and the City of LaFollette (TN) changed fiscal years from December 31 to June 30 in 1992. The City of Gaffney (SC). City of Osceola (AR), and City of Redding (CA) were nongenerators for 1991 through 1993, but became generators in 1994. The City of Kennett (MO) and City of Morgan City (LA) were generators for 1991 through 1993. but became nongenerators in 1994. Emerald Peoples Utility District (OR), City of Bryan (OH), and Northern Wasco County PUD (OR) were nongenerators for 1991 , but became generators in 1992.

Source: Energy Information Administration, Form ElA-412, "Annual Report of Public Electric Utilities." 
Table C34. Electric Utility Plant for Major U.S. Publicly Owned Nongenerator Electric Utilities with Financial Year Ending on

December 31 at End of Period, 1991-1995

(Thousand Dollars)

\begin{tabular}{|c|c|c|c|c|c|}
\hline Item & 1995 & 1994 & 1993 & 1992 & 1991 \\
\hline \multicolumn{6}{|l|}{ Electric Plant in Service } \\
\hline Intangible Plant & 6,871 & 5,929 & 10,181 & 10,091 & 7,860 \\
\hline \multicolumn{6}{|l|}{ Production Plant } \\
\hline Steam & 43,051 & 34,995 & 16,298 & 28,078 & 27,651 \\
\hline Nuclear & - & - & - & - & - \\
\hline 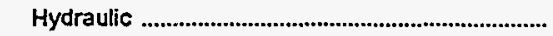 & 112,386 & 588 & 582 & 582 & 582 \\
\hline Other & 19,353 & 15,701 & 13.931 & 6,369 & 6.541 \\
\hline Total Production Plant ........................................ & 174,790 & 51,283 & 30,811 & 35,029 & 34,774 \\
\hline Transmission Plant & 273,202 & 184,372 & 157,091 & 287,707 & 251,496 \\
\hline 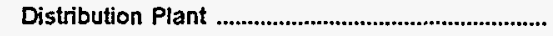 & $1,967,739$ & $1,848,637$ & $1,752,874$ & $2,129,995$ & $2,060,843$ \\
\hline 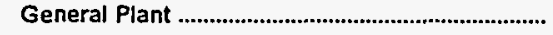 & 513,423 & 416,677 & 359,138 & 376,397 & 346,682 \\
\hline Total Electric Plant in Service ......................... & $2,936,023$ & $2,506,898$ & $2,310,095$ & $2,839,219$ & $2,701,656$ \\
\hline 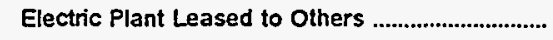 & 755 & 745 & 704 & 615 & 662 \\
\hline Construction Work in Progress - Electric .............. & 91,787 & 86,019 & 85,520 & 115,017 & 103,296 \\
\hline 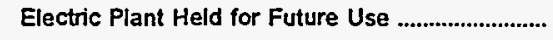 & 10,426 & 9,871 & 1,292 & 1,309 & 10,653 \\
\hline 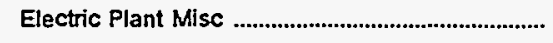 & 37,079 & 34,013 & 42,599 & 40,909 & 35,960 \\
\hline 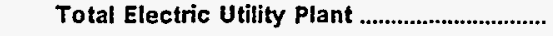 & $3,076,070$ & $2,637,546$ & $2,440,209$ & $2,997,069$ & $2,852,226$ \\
\hline 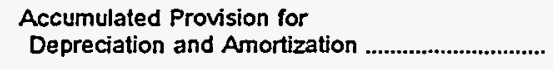 & $1,149.397$ & 986,935 & 907,475 & $1,096,972$ & $1,035,792$ \\
\hline 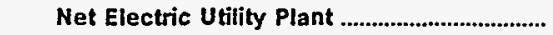 & $1,926,673$ & $1,650,611$ & $1,532,734$ & $1,900,097$ & $1,816,434$ \\
\hline
\end{tabular}

Note: Totals may not equal sum of components because of independent rounding. The number of nongenerating publicly owned electric utilities for end of period is 106 for December 31, 1995; 95 for December 31, 1994; 93 for December 31, $1993 ; 88$ for December 31, 1992; and 88 for December 31, 1991. The City of Pella (IA) changed fiscal year from June 30 to December 31 in 1994, and the City of Burlington (VT) changed fiscal year from December 31 to June 30 in 1994; the City of Hagerstown (MD) changed fiscal year from December 31 to June 30 in 1993; and the City of Memphis (TN) and the City of LaFollette (TN) changed fiscal years from December 31 to June 30 in 1992. The City of Gaffney (SC). City of Osceola (AR), and City of Redding (CA) were nongenerators for 1991 through 1993, but became generators in 1994. The City of Kennett (MO) and City of Morgan City (LA) were generators for 1991 through 1993, but became nongenerators in 1994. Emerald Peoples Utility District (OR). City of Bryan (OH), and Northern Wasco County PUD (OR) were nongenerators for 1991, but became generators in 1992.

Source: Energy Information Administration, Form EIA-412, "Annual Report of Public Electric Utilities." 
Table C35. Number of Consumers, Sales, and Operating Revenue for Major

U.S. Publicly Owned Nongenerator Electric Utilities with

Financial Year Ending on December 31, 1991-1995

\begin{tabular}{|c|c|c|c|c|c|}
\hline Item & 1995 & 1994 & 1993 & 1992 & 1991 \\
\hline \multicolumn{6}{|l|}{ Number of Consumers } \\
\hline Residential & $1,068,368$ & 991,878 & 959,670 & $1,252,787$ & $1,215,874$ \\
\hline 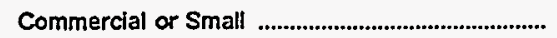 & 132,839 & 127,666 & ${ }^{*} 118,845$ & 143,672 & 146,187 \\
\hline Industrial or Large & 8,639 & 8,525 & ${ }^{\text {A }} 8,683$ & 14,306 & 6.913 \\
\hline Other & 43,298 & 33,200 & " 35,169 & 49,680 & 58,258 \\
\hline 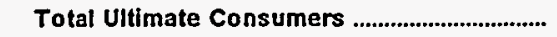 & $1,253,144$ & $1,161,269$ & ${ }^{*} 1,122,367$ & $1,460,445$ & $1,427,232$ \\
\hline \multicolumn{6}{|l|}{ Sales for the Year (megawatthours) } \\
\hline 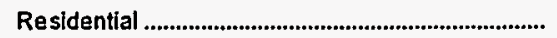 & $12,620,247$ & $11,779,639$ & R $11,728,301$ & $15,090,546$ & $15,659,505$ \\
\hline Commercial or Small & $8,114,055$ & $7,443,714$ & ${ }^{R} 6,937,032$ & $7,259,565$ & $11,332,825$ \\
\hline Industrial or Large & $11,779,846$ & $10,610,208$ & ${ }^{R} 10,315,963$ & $15,685,347$ & $11,090,867$ \\
\hline Other & $1,028,996$ & 938,474 & 783,628 & $1,250,985$ & $1,432,510$ \\
\hline Total Sales to Ultimate Consumers ................ & $33,543,144$ & $30,772,035$ & $29,764,924$ & $39,286,443$ & $39,515,707$ \\
\hline Sales for Resale & $4,168,582$ & $2,785,813$ & $2,725,475$ & $2,881,020$ & $4,786,485$ \\
\hline Total Sales & $37,711,726$ & $33,557,848$ & ${ }^{R} 32,490,399$ & $42,167,463$ & $44,302,192$ \\
\hline \multicolumn{6}{|l|}{$\begin{array}{l}\text { Operating Revenues for the Year } \\
\text { (thousand dollars) }\end{array}$} \\
\hline Residential & 746,501 & 686,077 & 651,990 & 851,333 & 859,173 \\
\hline Commercial or Small & 451,333 & 416,137 & 376,440 & 399.907 & 625.575 \\
\hline 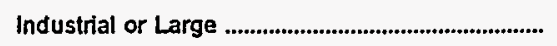 & 523,081 & 469,267 & 450,122 & 726.419 & 464,741 \\
\hline Other & 64,824 & 56,992 & ${ }^{n} 49,644$ & 71,459 & 79,256 \\
\hline 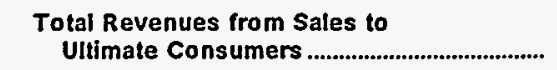 & $1,785,739$ & $1,628,473$ & $1,528,198$ & $2,049,118$ & $2,028,745$ \\
\hline Sales for Resale & 175,171 & 90,366 & 84,259 & 79,291 & 164,736 \\
\hline $\begin{array}{l}\text { Total Revenues From Sales of } \\
\text { Electricity }\end{array}$ & $1,960,910$ & $1,718,839$ & $1,612,455$ & $2,128,409$ & $2,193,481$ \\
\hline
\end{tabular}

$R=$ Revised Data.

Note: Totals may not equal sum of components because of independent rounding. The number of nongenerating publicty owned electric utilities for end of period is 106 for December 31, 1995; 95 for December 31, 1994; 93 for December 31, $1993 ; 88$ for December 31 . 1992; and 86 for December 31, 1991. The City of Pella (IA) changed fiscal year from June 30 to December 31 in 1994, and the City of Burlington (NT) changed fiscal year from December 31 to June 30 in 1994; the City of Hagerstown (MD) changed fiscal year from December 31 to June 30 in 1993; and the City of Memphis (TN) and the City of LaFollette (TN) changed fiscal years from December 31 to June 30 in 1992. The City of Gaffney (SC). City of Osceola (AR), and City of Redding (CA) were nongenerators for 1991 through t993, but became generators in 1994. The City of Kennett (MO) and City of Morgan City (LA) were generators for 1991 through 1993, but became nongenerators in 1994. Emerald Peoples Utility District (OR), City of Bryan (OH), and Northern Wasco County PUD (OR) were nongenerators for 1991. but became generators in 1992. sions.

Source: Energy Information Administration, Form ElA-861. "Annual Electric Utility Report." Data are based on calendar year submis- 
Table C36. Electric Energy Account for Major U.S. Publicly Owned Nongenerator Electric Utilities with Financial Year

Ending on December 31, 1991-1995

(Megawatthours)

\begin{tabular}{|c|c|c|c|c|c|}
\hline Item & 1995 & 1994 & 1993 & 1992 & 1991 \\
\hline \multicolumn{6}{|l|}{ Sources of Energy } \\
\hline Steam & - & - & - & - & - \\
\hline 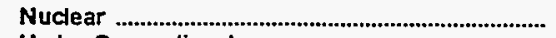 & - & - & - & - & - \\
\hline 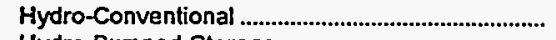 & - & - & - & - & - \\
\hline 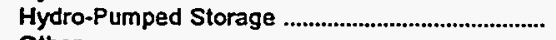 & - & - & - & - & - \\
\hline Other & - & - & - & - & - \\
\hline 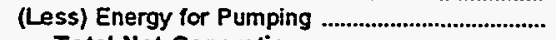 & - & - & - & - & - \\
\hline Total Net Generation & - & - & - & - & - \\
\hline $\begin{array}{l}\text { Purchases from Utility } \\
\text { Purchases from Nonutility } \\
\text { Power Exchanges }\end{array}$ & $\begin{array}{r}36,909,610 \\
413,271\end{array}$ & $\begin{array}{r}34,770,562 \\
176,000\end{array}$ & $\begin{array}{r}33,801,100 \\
156,083\end{array}$ & $\begin{array}{r}43,971,877 \\
160,421\end{array}$ & $\begin{array}{r}45,754,785 \\
318,282\end{array}$ \\
\hline Received & 639,820 & 505,977 & 325,173 & 363,092 & 289,014 \\
\hline $\begin{array}{l}\text { Delivered } \\
\text { Net Exchanges }\end{array}$ & $\begin{array}{l}126,371 \\
513,449\end{array}$ & $\begin{array}{l}163,845 \\
342,132\end{array}$ & $\begin{array}{l}116,248 \\
208,926\end{array}$ & $\begin{array}{l}158,997 \\
204,095\end{array}$ & $\begin{array}{r}202,905 \\
86,109\end{array}$ \\
\hline \multicolumn{6}{|l|}{ Transmission for Others (Wheeling) } \\
\hline 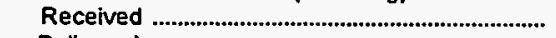 & 2,601 & - & 7,476 & 1,986 & 7,164 \\
\hline Delivered & 2,601 & - & 7.476 & 1,986 & 7,164 \\
\hline 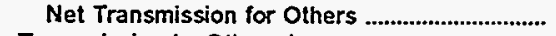 & - & - & - & - & - \\
\hline 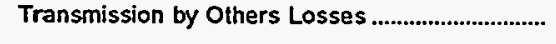 & $-31,053$ & $-2,416$ & - & -220 & - \\
\hline \multicolumn{6}{|l|}{ Total Net Energy Generated and } \\
\hline 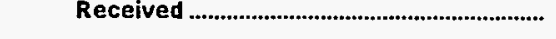 & $37,805,260$ & $35,286,279$ & $34,166,108$ & $44,336,172$ & $46,159,176$ \\
\hline \multicolumn{6}{|l|}{ Disposition of Energy } \\
\hline 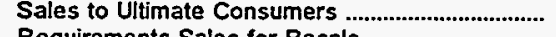 & $32,004,172$ & $30,772,100$ & $29,773,216$ & $39,282,927$ & $39,512,479$ \\
\hline 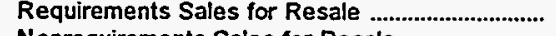 & $3,408,509$ & $1,645,780$ & $1,806,499$ & $1,459,980$ & $3,775,557$ \\
\hline Nonrequirements Sales for Resale .......................... & 756,760 & 857,994 & 918,823 & $1,420,967$ & $1.010,926$ \\
\hline Furnished Without Charge ..................................... & 91,052 & 87,554 & 106,278 & 77,698 & 78,966 \\
\hline 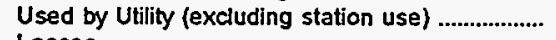 & 62,467 & 52,972 & 58,697 & 57,199 & 54.114 \\
\hline Losses & $1,482,300$ & $1,587,845$ & $1,502,590$ & $2,037,395$ & $1,727,132$ \\
\hline Total Disposition & $37,805,260$ & $35,286,279$ & $34,166,108$ & $44,336,172$ & $46,159,176$ \\
\hline
\end{tabular}

- Data not available.

Note: Totals may not equal sum of components because of independent rounding. The number of nongenerating publicly owned electric utilities for end of period is 106 for December 31, 1995; 95 for December 31, 1994; 93 for December 31, 1993; 88 for December 31, 1992; and 86 for December 31, 1991 . The City of Pella (IA) changed fiscal year from June 30 to December 31 in 1994 , and the City of Burlington (NT) changed fiscal year from December 31 to June 30 in 1994; the City of Hagerstown (MD) changed fiscal year from December 31 to June 30 in 1993; and the City of Memphis (TN) and the City of LaFollette (TN) changed fiscal years from December 31 to June 30 in 1992. The City of Gaffney (SC). City of Osceola (AR), and City of Redding (CA) were nongenerators for 1991 through 1993, but became generators in 1994. The City of Kennett (MO) and City of Morgan City (LA) were generators for 1991 through 1993, but became nongenerators in 1994. Emerald Peoples Utility District (OR), City of Bryan (OH), and Northern Wasco County PUD (OR) were nongenerators for 1991, but became generators in 1992.

Source: Energy Information Administration, Form EIA-412, "Annual Report of Public Electric Utilities." 
Table C37. Twenty Largest U.S. Publicly Owned Electric Utilities Ranked by Megawatthour Sales to Uitimate Consumers for All Respondents, 1995

\begin{tabular}{|c|c|c|c|}
\hline Publicly Owned Electric Utilities & State & Amount & Reporting Date \\
\hline 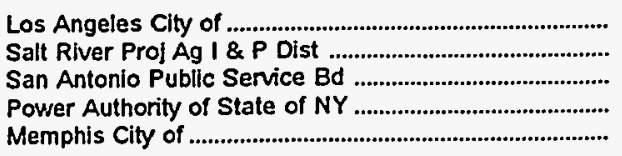 & $\begin{array}{l}\text { California } \\
\text { Avizona } \\
\text { Texas } \\
\text { New York } \\
\text { Tennessee }\end{array}$ & $\begin{array}{l}20,513,243 \\
16,667,262 \\
13,646,836 \\
13,043,997 \\
12,030,683\end{array}$ & $\begin{array}{l}\text { June } 30 \\
\text { April } 30 \\
\text { January } 31 \\
\text { December } 31 \\
\text { June } 30\end{array}$ \\
\hline 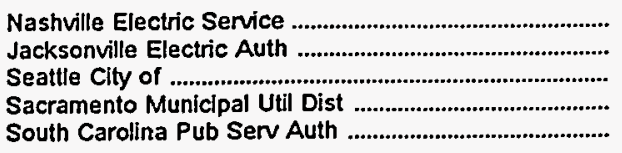 & $\begin{array}{l}\text { Tennessee } \\
\text { Florida } \\
\text { Washington } \\
\text { California } \\
\text { South Carolina }\end{array}$ & $\begin{array}{r}10,521,870 \\
9,268,850 \\
8,788,829 \\
8,458,888 \\
7,739,117\end{array}$ & $\begin{array}{l}\text { June } 30 \\
\text { September } 30 \\
\text { December } 31 \\
\text { December } 31 \\
\text { December } 31\end{array}$ \\
\hline 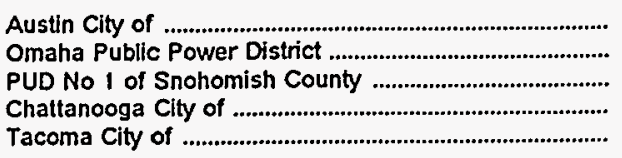 & $\begin{array}{l}\text { Texas } \\
\text { Nebraska } \\
\text { Washington } \\
\text { Tennessee } \\
\text { Washington }\end{array}$ & $\begin{array}{l}7,585,563 \\
7,456,745 \\
5,682,565 \\
5,350,719 \\
5,331,048\end{array}$ & $\begin{array}{l}\text { September } 30 \\
\text { December } 31 \\
\text { December } 31 \\
\text { June } 30 \\
\text { December } 31\end{array}$ \\
\hline 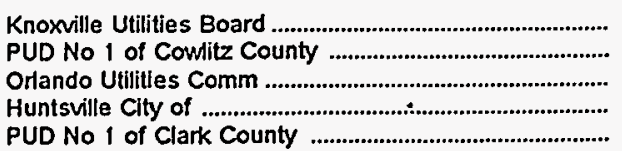 & $\begin{array}{l}\text { Tennessee } \\
\text { Washington } \\
\text { Florida } \\
\text { Alabama } \\
\text { Washington }\end{array}$ & $\begin{array}{l}4,703,769 \\
4,554,973 \\
3,892,662 \\
3,690,259 \\
3,662,771\end{array}$ & $\begin{array}{l}\text { June } 30 \\
\text { December } 31 \\
\text { September } 30 \\
\text { September } 30 \\
\text { December } 31\end{array}$ \\
\hline
\end{tabular}

Source: Energy Information Administration, Form ElA-412, "Annual Report of Public Electric Utilities." Individual electric utilities report fiscal year data. Appendix 8 shows the fiscal year for each electric utility.

Table C38. Twenty Largest U.S. Publicly Owned Electric Utilities Ranked by Megawatthour Sales for Resale for All Respondents, 1995

\begin{tabular}{|c|c|c|c|}
\hline Publicly Owned Electric Utilities & State & Amount & Reporting Date \\
\hline 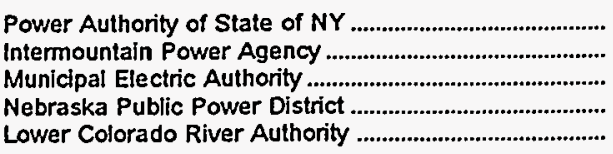 & $\begin{array}{l}\text { New York } \\
\text { Utah } \\
\text { Georgia } \\
\text { Nebraska } \\
\text { Texas }\end{array}$ & $\begin{array}{r}27,446,460 \\
10,648,021 \\
10,449,304 \\
9,660,396 \\
9,386,632\end{array}$ & $\begin{array}{l}\text { December } 31 \\
\text { June } 30 \\
\text { December } 31 \\
\text { December } 31 \\
\text { June } 30\end{array}$ \\
\hline 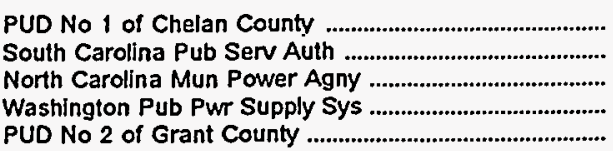 & $\begin{array}{l}\text { Washington } \\
\text { South Carolina } \\
\text { North Carolina } \\
\text { Washington } \\
\text { Washington }\end{array}$ & $\begin{array}{l}8,319,784 \\
8,283,056 \\
7,003,590 \\
6,998,827 \\
6,855,085\end{array}$ & $\begin{array}{l}\text { December } 31 \\
\text { December } 31 \\
\text { December } 31 \\
\text { June } 30 \\
\text { December } 31\end{array}$ \\
\hline 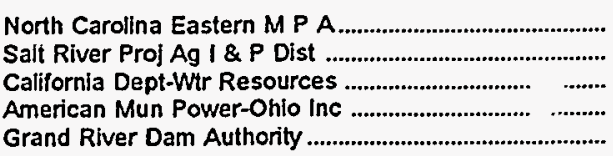 & $\begin{array}{l}\text { North Carolina } \\
\text { Arizona } \\
\text { California } \\
\text { Ohio } \\
\text { Oklahoma }\end{array}$ & $\begin{array}{l}6,532,836 \\
6,399,775 \\
5,307,033 \\
4,680,758 \\
4,626,042\end{array}$ & $\begin{array}{l}\text { December } 31 \\
\text { April } 30 \\
\text { June } 30 \\
\text { December } 31 \\
\text { December } 31\end{array}$ \\
\hline 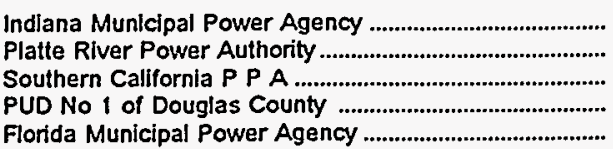 & $\begin{array}{l}\text { Indiana } \\
\text { Colorado } \\
\text { California } \\
\text { Washington } \\
\text { Florida }\end{array}$ & $\begin{array}{l}4,072,696 \\
3,543,720 \\
3,352,867 \\
3,296,009 \\
3,278,237\end{array}$ & $\begin{array}{l}\text { December } 31 \\
\text { December } 31 \\
\text { June } 30 \\
\text { December } 31 \\
\text { September } 30\end{array}$ \\
\hline
\end{tabular}

Source: Energy Information Administration, Form EIA-412, "Annual Report of Public Electric Utilities." Individual electric utilities report fiscal year data. Appendix $B$ shows the fiscal year for each electric utility. 
Table C39. Twenty Largest U.S. Publicly Owned Electric Utilities Ranked by Electric Utility Revenues for All Respondents, 1995 (Thousand Dollars)

\begin{tabular}{|c|c|c|c|}
\hline Publicly Owned Electric Utitities & State & Amount & Reporting Date \\
\hline 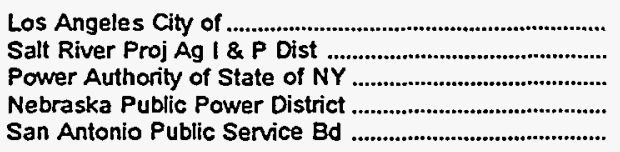 & $\begin{array}{l}\text { California } \\
\text { Avizona } \\
\text { New York } \\
\text { Nebraska } \\
\text { Texas }\end{array}$ & $\begin{array}{r}1,972,786 \\
1,443,555 \\
1,412,691 \\
814,362 \\
775,987\end{array}$ & $\begin{array}{l}\text { June } 30 \\
\text { April } 30 \\
\text { December } 31 \\
\text { December } 31 \\
\text { January } 31\end{array}$ \\
\hline $\begin{array}{l}\text { Jacksonville Electric Auth } \\
\text { Memphis City of } \\
\text { Intermountain Power Agency } \\
\text { South Carolina Pub Serv Auth } \\
\text { Sacramento Municipal Util Dist }\end{array}$ & $\begin{array}{l}\text { Florida } \\
\text { Tennessee } \\
\text { Utah } \\
\text { South Carolina } \\
\text { California }\end{array}$ & $\begin{array}{l}739,386 \\
675,956 \\
642,846 \\
640,361 \\
613,896\end{array}$ & $\begin{array}{l}\text { September } 30 \\
\text { June } 30 \\
\text { June } 30 \\
\text { December } 31 \\
\text { December } 31\end{array}$ \\
\hline 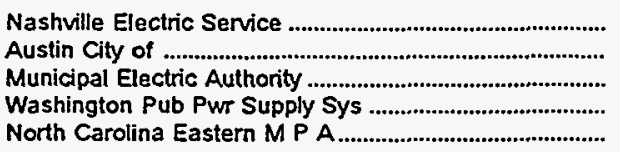 & $\begin{array}{l}\text { Tennessee } \\
\text { Texas } \\
\text { Georgia } \\
\text { Washington } \\
\text { North Carolina }\end{array}$ & $\begin{array}{l}566,281 \\
522,751 \\
500,592 \\
464,591 \\
462,664\end{array}$ & $\begin{array}{l}\text { June } 30 \\
\text { September } 30 \\
\text { December } 31 \\
\text { June } 30 \\
\text { December } 31\end{array}$ \\
\hline 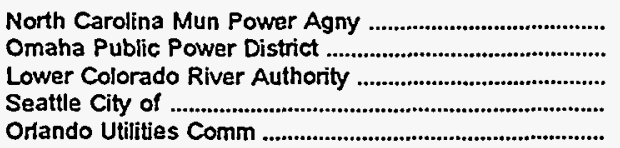 & $\begin{array}{l}\text { North Carolina } \\
\text { Nebraska } \\
\text { Texas } \\
\text { Washington } \\
\text { Florida }\end{array}$ & $\begin{array}{l}413,852 \\
412,354 \\
374,513 \\
329,808 \\
317,225\end{array}$ & $\begin{array}{l}\text { December } 31 \\
\text { December } 31 \\
\text { June } 30 \\
\text { December } 31 \\
\text { September } 30\end{array}$ \\
\hline
\end{tabular}

Source: Energy Information Administration, Form EIA-412, "Annual Report of Public Electric Utilities." Individual electric utilities report fiscal year data. Appendix $B$ shows the fiscal year for each electric utility.

Table C40. Twenty Largest U.S. Publicly Owned Electric Utilities Ranked by Purchase Power Expenses for All Respondents, 1995 (Thousand Dollars)

\begin{tabular}{|c|c|c|c|}
\hline Publicly Owned Electric Utilities & State & Amount & Reporting Date \\
\hline 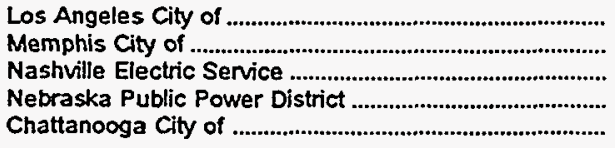 & $\begin{array}{l}\text { California } \\
\text { Tennessee } \\
\text { Tennessee } \\
\text { Nebraska } \\
\text { Tennessee }\end{array}$ & $\begin{array}{l}659,612 \\
515,555 \\
466,754 \\
301,460 \\
231,098\end{array}$ & $\begin{array}{l}\text { June } 30 \\
\text { June } 30 \\
\text { June } 30 \\
\text { December } 31 \\
\text { June } 30\end{array}$ \\
\hline 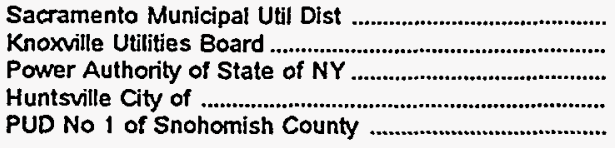 & $\begin{array}{l}\text { California } \\
\text { Tennessee } \\
\text { New York } \\
\text { Alabama } \\
\text { Washington }\end{array}$ & $\begin{array}{l}230,517 \\
209,313 \\
190,905 \\
168,959 \\
168,049\end{array}$ & $\begin{array}{l}\text { December } 31 \\
\text { June } 30 \\
\text { December } 31 \\
\text { September } 30 \\
\text { December } 31\end{array}$ \\
\hline 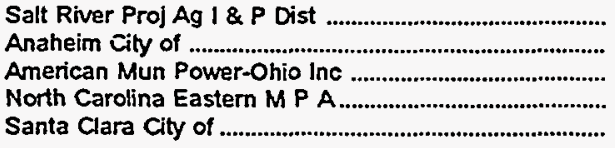 & $\begin{array}{l}\text { Arizona } \\
\text { California } \\
\text { Ohio } \\
\text { North Carolina } \\
\text { California }\end{array}$ & $\begin{array}{l}151,701 \\
128,925 \\
116,591 \\
115,694 \\
113,183\end{array}$ & $\begin{array}{l}\text { April } 30 \\
\text { June } 30 \\
\text { December } 31 \\
\text { December } 31 \\
\text { June } 30\end{array}$ \\
\hline 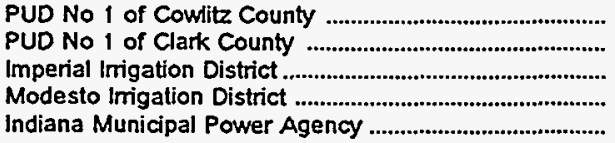 & $\begin{array}{l}\text { Washington } \\
\text { Washington } \\
\text { California } \\
\text { California } \\
\text { Indiana }\end{array}$ & $\begin{array}{r}103,832 \\
103,613 \\
87,584 \\
87,315 \\
85,255\end{array}$ & $\begin{array}{l}\text { December } 31 \\
\text { December } 31 \\
\text { December } 31 \\
\text { December } 31 \\
\text { December } 31\end{array}$ \\
\hline
\end{tabular}

Source: Energy Information Administration, Form EIA-412, "Annual Report of Public Electric Utilities." Individual electric utilities report fiscal year data. Appendix B shows the fiscal year for each electric utility. 
Table C41. Twenty Largest U.S. Publicly Owned Electric Utilities Ranked by Electric Utility Plant for All Respondents, 1995

(Thousand Dollars)

\begin{tabular}{|c|c|c|c|}
\hline Publicly Owned Electric Utilities & State & Amount & Reporting Date \\
\hline 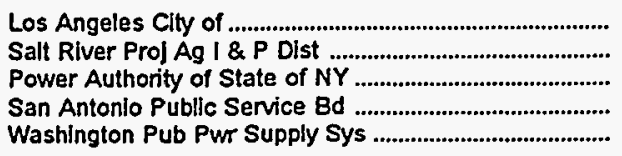 & $\begin{array}{l}\text { California } \\
\text { Arizona } \\
\text { New York } \\
\text { Texas } \\
\text { Washington }\end{array}$ & $\begin{array}{l}6,640,603,631 \\
5,768,002,329 \\
5,088,363,000 \\
4,577,102,507 \\
3,396,453,272\end{array}$ & $\begin{array}{l}\text { June } 30 \\
\text { April } 30 \\
\text { December } 31 \\
\text { January } 31 \\
\text { June } 30\end{array}$ \\
\hline 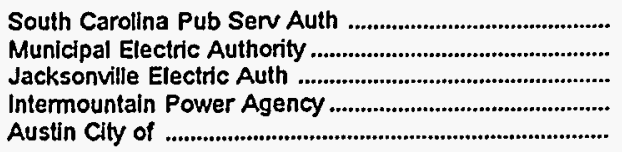 & $\begin{array}{l}\text { South Carolina } \\
\text { Georgia } \\
\text { Florida } \\
\text { Utah } \\
\text { Texas }\end{array}$ & $\begin{array}{l}3,181,541,000 \\
3,059,779,000 \\
3,018,402,462 \\
2,768,307,000 \\
2,305,447,938\end{array}$ & $\begin{array}{l}\text { December } 31 \\
\text { December } 31 \\
\text { September } 30 \\
\text { June } 30 \\
\text { September } 30\end{array}$ \\
\hline 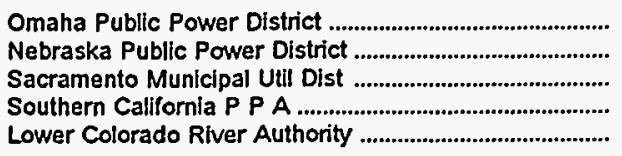 & $\begin{array}{l}\text { Nebraska } \\
\text { Nebraska } \\
\text { California } \\
\text { California } \\
\text { Texas }\end{array}$ & $\begin{array}{l}2,059,371,490 \\
1,849,445,649 \\
1,660,596,082 \\
1,513,681,486 \\
1,486,601,722\end{array}$ & $\begin{array}{l}\text { December } 31 \\
\text { December } 31 \\
\text { December } 31 \\
\text { June } 30 \\
\text { June } 30\end{array}$ \\
\hline 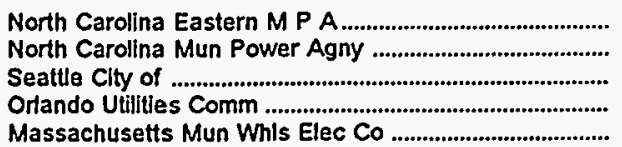 & $\begin{array}{l}\text { North Carolina } \\
\text { North Carolina } \\
\text { Washington } \\
\text { Florida } \\
\text { Massachusetts }\end{array}$ & $\begin{array}{l}1,435,731,000 \\
1,405,440,000 \\
1,382,194,085 \\
1,320,031,346 \\
1,233,476,846\end{array}$ & $\begin{array}{l}\text { December } 31 \\
\text { December } 31 \\
\text { December } 31 \\
\text { September } 30 \\
\text { December } 31\end{array}$ \\
\hline
\end{tabular}

Source: Energy Information Administration, Form EIA-412, "Annual Report of Public Electric Utilities." Individual electric utilities report fiscal year data. Appendix $B$ shows the fiscal year for each electric utility.

Table C42. Twenty Largest U.S. Publicly Owned Electric Utilities Ranked by Construction Work in Progress for All Respondents, 1995 (Thousand Dollars)

\begin{tabular}{|c|c|c|c|}
\hline Publicly Owned Electric Utilities & State & Amount & Reporting Date \\
\hline 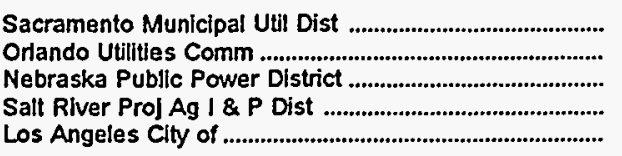 & $\begin{array}{l}\text { California } \\
\text { Florida } \\
\text { Nebraska } \\
\text { Arizona } \\
\text { California }\end{array}$ & $\begin{array}{l}328,525,975 \\
286,166,755 \\
255,741,210 \\
253,640,325 \\
219,780,065\end{array}$ & $\begin{array}{l}\text { December } 31 \\
\text { September } 30 \\
\text { December } 31 \\
\text { April } 30 \\
\text { June } 30\end{array}$ \\
\hline 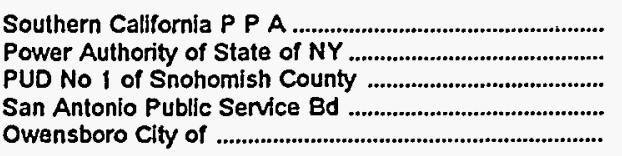 & $\begin{array}{l}\text { California } \\
\text { New York } \\
\text { Washington } \\
\text { Texas } \\
\text { Kentucky }\end{array}$ & $\begin{array}{l}206,572,739 \\
203,691,000 \\
176,180,515 \\
162,313,314 \\
145,608,840\end{array}$ & $\begin{array}{l}\text { June } 30 \\
\text { December } 31 \\
\text { December } 31 \\
\text { January } 31 \\
\text { May } 31\end{array}$ \\
\hline 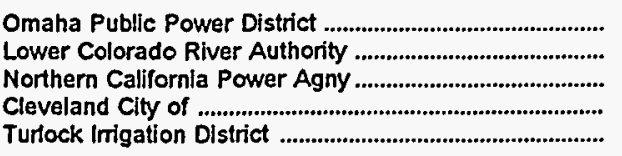 & $\begin{array}{l}\text { Nebraska } \\
\text { Texas } \\
\text { California } \\
\text { Ohio } \\
\text { California }\end{array}$ & $\begin{array}{r}109.036,309 \\
83,426,992 \\
81,011,000 \\
76,304,018 \\
75,716,000\end{array}$ & $\begin{array}{l}\text { December } 31 \\
\text { June } 30 \\
\text { June } 30 \\
\text { December } 31 \\
\text { December } 31\end{array}$ \\
\hline 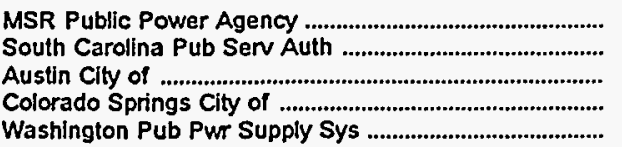 & $\begin{array}{l}\text { California } \\
\text { South Carolina } \\
\text { Texas } \\
\text { Colorado } \\
\text { Washington }\end{array}$ & $\begin{array}{l}72,087,561 \\
71,661,000 \\
70,005,106 \\
65,888,641 \\
63,656,445\end{array}$ & $\begin{array}{l}\text { December } 31 \\
\text { December } 31 \\
\text { September } 30 \\
\text { December } 31 \\
\text { June } 30\end{array}$ \\
\hline
\end{tabular}

Source: Energy Information Administration, Form ElA-412, "Annual Report of Public Electric Utilities." Indhidual electric utilities report fiscal year data. Appendix B shows the fiscal year for each electric utility. 
Table C43. Composite Statement of Income for Major U.S. Publicly Owned Electric Utilities for All Respondents, 1991-1995 (Thousand Dollars)

\begin{tabular}{|c|c|c|c|c|c|}
\hline Item & 1995 & 1994 & 1993 & 1992 & 1991 \\
\hline Electric Utility Operating Revenues ................... & $31,908,333$ & $31,262,318$ & $30,045,300$ & $28,933,756$ & $28,202,745$ \\
\hline $\begin{array}{l}\text { Operation Expenses } \\
\text { Maintenance Expenses } \\
\text { Depreciation Expenses } \\
\text { Amort, Prop Losses and Reg Study' } \\
\text { Taxes and Tax Equivalents } \\
\text { Net Contributions and Services' }\end{array}$ & $\begin{array}{r}20,825,743 \\
1,824,788 \\
3,112,365 \\
133,953 \\
1,040,837 \\
-\end{array}$ & $\begin{array}{r}20,435,585 \\
1,818,411 \\
2,860,213 \\
134,117 \\
967,106 \\
-\end{array}$ & $\begin{array}{r}19,666,365 \\
1,772,339 \\
2,694,777 \\
158,059 \\
933,886 \\
-\end{array}$ & $\begin{array}{r}18,772,266 \\
1,757,427 \\
2,533,847 \\
134,511 \\
836,134 \\
-\end{array}$ & $\begin{array}{r}18,274,460 \\
1,632,563 \\
2,547,126 \\
734,209 \\
558,182\end{array}$ \\
\hline $\begin{array}{l}\text { Total Electric Utility Operating } \\
\text { Expenses }\end{array}$ & $26,937,686$ & $26,215,432$ & $25,225,425$ & $24,034,185$ & $23,746,541$ \\
\hline 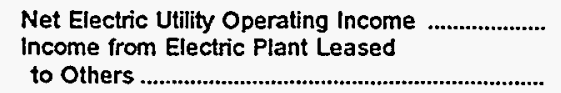 & $\begin{array}{r}4,970,646 \\
20,710\end{array}$ & 32,426 & $\begin{array}{r}4,819,876 \\
25,981\end{array}$ & $\begin{array}{r}4,899,571 \\
16,902\end{array}$ & $\begin{array}{r}4,456,204 \\
9,207\end{array}$ \\
\hline Electric Utility Operating Income ..................... & $4,991,356$ & $5,079,312$ & $4,845,856$ & $4,916,473$ & $4,465,411$ \\
\hline 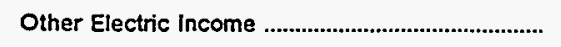 & $1,587.180$ & $1,415,582$ & $1,628,552$ & $2,012,422$ & $2,037,255$ \\
\hline $\begin{array}{l}\text { Other Electric Deductions } \\
\text { Allowance for Other Funds Used }\end{array}$ & 272,663 & 216,181 & 336,659 & 324,310 & 137,294 \\
\hline 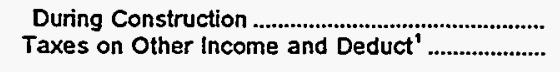 & $\begin{array}{r}9,186 \\
27,883\end{array}$ & $\begin{array}{r}7.923 \\
43,164\end{array}$ & $\begin{array}{l}28,582 \\
27,925\end{array}$ & $\begin{array}{l}24,222 \\
25,807\end{array}$ & $\begin{array}{r}72,632 \\
-\end{array}$ \\
\hline 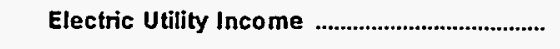 & $6,287,175$ & $6,243,471$ & $6,138,407$ & $6,603,001$ & $6,438,004$ \\
\hline 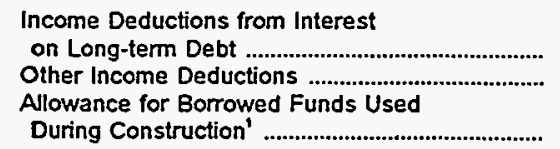 & $\begin{array}{r}4,333,306 \\
611,883 \\
\\
-48,495\end{array}$ & $\begin{array}{r}4,440,943 \\
435,458\end{array}$ & $\begin{array}{r}4,547,594 \\
350,500 \\
\\
-43,279\end{array}$ & $\begin{array}{r}4,866,961 \\
345,454 \\
-45,797\end{array}$ & $\begin{array}{r}4,887,034 \\
458,570\end{array}$ \\
\hline 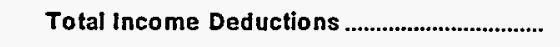 & $4,896,694$ & $4,837,574$ & $4,854,815$ & $5,166,618$ & $5,345,605$ \\
\hline Income Before Extraordinary Items ......................... & $1,390,481$ & $1,405,898$ & $1,283,592$ & $1,436,382$ & $1,092,399$ \\
\hline 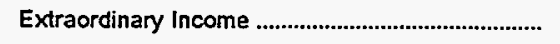 & 323,098 & 113,547 & 87,738 & 146,747 & 123,504 \\
\hline 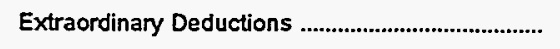 & 78,840 & 241,579 & 327,565 & 264,178 & 198,300 \\
\hline 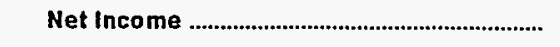 & $1,634,740$ & $1,277,865$ & $1,043,766$ & $1,318,951$ & $1,017,603$ \\
\hline $\begin{array}{l}\text { Data reporting initiated in } 1992 \text {. } \\
\text { Data reporting discontinued in } 1992 \text {. } \\
\text { Data not available. } \\
\text { Note: Totals may not equal sum of compone } \\
\text { nd of period is } 512 \text { for } 1995,503 \text { for } 1994,495 \text { fo } \\
\text { Source: Energy Information Administration, Fo } \\
\text { scal year data. Appendix } B \text { shows the fiscal year }\end{array}$ & $\begin{array}{l}\text { ecause of in } \\
3,483 \text { for } 18 \\
\text { A-412, "Ann } \\
\text { ach electric }\end{array}$ & $\begin{array}{l}\text { dent roundir } \\
\text { nd } 470 \text { for } 1 \\
\text { eport of Pub }\end{array}$ & $\begin{array}{l}\text { he number o } \\
\text { ctric Utilities. }\end{array}$ & -5 & $\begin{array}{l}\text { utillies for } \\
\text { des report }\end{array}$ \\
\hline
\end{tabular}


Table C44. Composite Balance Sheet for Major U.S. Publicly Owned Electric Utilities for All Respondents at End of Period, 1991-1995

(Thousand Dollars)

\begin{tabular}{|c|c|c|c|c|c|}
\hline Item & 1995 & 1994 & 1993 & 1992 & 1991 \\
\hline \multicolumn{6}{|l|}{ Electric Utility Plant } \\
\hline 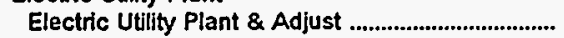 & $96,514,499$ & $93,757,308$ & $90,051,059$ & $87,030,170$ & $88,854,231$ \\
\hline 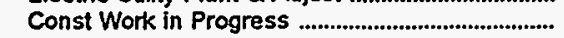 & $4,592,439$ & $4,482,626$ & $4,038,613$ & $3,790,826$ & \\
\hline 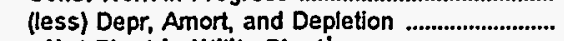 & $32,264,546$ & $30,043,282$ & $27,273,454$ & $25,153,126$ & $23,454,394$ \\
\hline 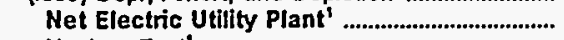 & $68,842,392$ & $68,196,652$ & $66,816,218$ & $65,667,870$ & - \\
\hline Nuclear Fuel' ........................................... & $2,601,232$ & $2,564,002$ & $2,580,570$ & $2,271,919$ & - \\
\hline 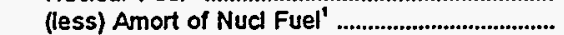 & $1,763,678$ & $1,688,491$ & $1,650,975$ & $1,348,032$ & - \\
\hline Net Elec Plant Incl Nuct Fuel .................................... & $69,679,946$ & $69,072,163$ & $67,745,814$ & $66,591,756$ & $65,399,837$ \\
\hline \multicolumn{6}{|l|}{ Other Property \& Investments } \\
\hline Nonutility Property ..................................................... & $8,069,208$ & $7,541,303$ & $6,957,760$ & $6,407,886$ & $6,069,837$ \\
\hline (less) Accum Provislons for Depr \& Amort ............ & $2,330,245$ & $2,281,902$ & $2,138,049$ & $1,977,104$ & $1,840,621$ \\
\hline & 108,000 & 282,296 & 371,792 & 255,261 & 87,717 \\
\hline Invest \& Special Funds ................................. & $17,346,848$ & $17,336,494$ & $17,207,623$ & $15,416,345$ & $14,865,256$ \\
\hline & $23,193,812$ & $22,878,191$ & $22,399,126$ & $20,119,388$ & $19,182,188$ \\
\hline \multicolumn{6}{|l|}{ Current and Accrued Assets } \\
\hline 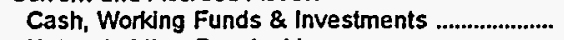 & $10,362,961$ & $10,864,021$ & $10,890,858$ & $10,521,181$ & $10,428.543$ \\
\hline 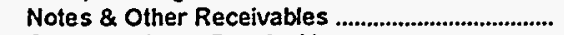 & $1,248,745$ & $1,099,320$ & $1,102,841$ & $1,047,920$ & $3,065,407$ \\
\hline Customer Accts Receivable ............................................ & $2,396,525$ & $2,384,190$ & $2,374,004$ & $2,14 i, 086$ & 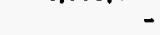 \\
\hline $\begin{array}{l}\text { (less) Accum Prov for Uncollected Accts } \\
\text { Fuel Stock \& Exp Undistr' }\end{array}$ & $\begin{array}{r}93,127 \\
540,206\end{array}$ & $\begin{array}{r}86,436 \\
545,130\end{array}$ & $\begin{array}{l}125,658 \\
496,413\end{array}$ & $\begin{array}{l}121,384 \\
545,311\end{array}$ & 114,245 \\
\hline 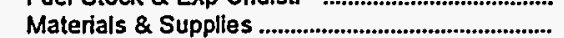 & $1,263,123$ & $1,306,958$ & $1,283,844$ & $1,331,630$ & $1,796,964$ \\
\hline 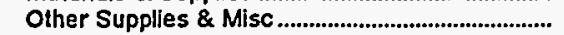 & 56,839 & & - & - & \\
\hline 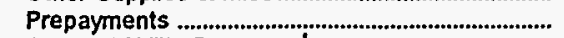 & 360,396 & 395,189 & 393,267 & 405,601 & 377,684 \\
\hline 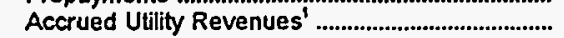 & 440,845 & 347,559 & 334,841 & 287,479 & - \\
\hline Miscellaneous Current \& Accrued Assets ............. & $1,394,017$ & $1,424,177$ & $1,102,461$ & $1.058,968$ & 692,469 \\
\hline $\begin{array}{l}\text { Total Current \& Accrued Assets ....................... } \\
\text { Deferred Debits }\end{array}$ & & $17,217,791$ & $16,246,822$ \\
\hline 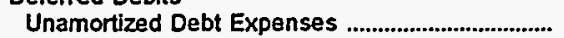 & $2,726,265$ & $2,889,438$ & $2,536,132$ & $2,291,314$ & $1,909,159$ \\
\hline 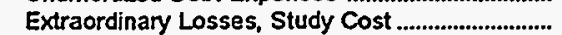 & $1,642,157$ & 522,396 & 918,432 & 469,651 & 34,360 \\
\hline Misc Debt, R \& D Exp, Unamrt Losses ................. & $10,366,946$ & $10,902,367$ & $10,956,667$ & $9,642,339$ & $9,271,082$ \\
\hline 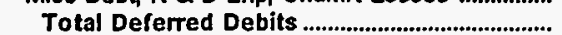 & $14,735,368$ & $14,314,201$ & $14,411,230$ & $12,403,304$ & $11,214,601$ \\
\hline 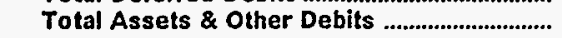 & $125,579,656$ & $124,544,663$ & $122,409,042$ & $116,332,239$ & $112,043,449$ \\
\hline \multicolumn{6}{|l|}{ Proprietary Capital } \\
\hline 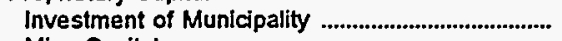 & $2,246,446$ & $1,897,267$ & $1,891,224$ & $1,865,553$ & $2,089.179$ \\
\hline 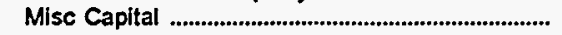 & 836,320 & 772,032 & 656,589 & 522,116 & 452,305 \\
\hline 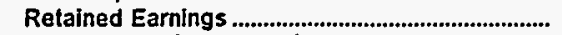 & $29,303,365$ & $28,131,199$ & $26,963,161$ & $25,957,799$ & $24,925,509$ \\
\hline 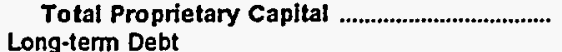 & \\
\hline 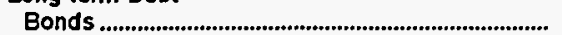 & $76,256,520$ & $77,480,231$ & $77,624,677$ & $74,650,183$ & $70,415,936$ \\
\hline Advances from Municipality \& Other ....................... & $4,945,640$ & $5,378,929$ & $4,189,527$ & $2,972,620$ & $3,581,623$ \\
\hline Unamort Prem on Long-term Debt ........................... & 347,940 & 60,952 & 97,445 & 70,350 & 15,850 \\
\hline (less) Unamort Discount on Long-term Debt ....... & $3,126,187$ & $3,381,297$ & $2,844,050$ & $2,975,041$ & $2,599,459$ \\
\hline 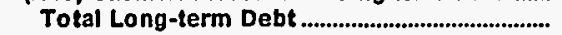 & $78,423,914$ & $79,538,816$ & $79,067,600$ & $74,718,112$ & $71,413,951$ \\
\hline \multicolumn{6}{|l|}{ Other Noncurrent Uabilities } \\
\hline Accum Operating Provisions...... & 569,350 & 608,278 & 486,149 & 704,151 & 677.995 \\
\hline Accum Prov for Rate Refunds' ................................. & 161,183 & 104,542 & 115,389 & 4,483 & \\
\hline Total Other Noncurrent Liabilities .................... & 730,533 & 712,820 & 601,538 & 708,635 & 677,995 \\
\hline \multicolumn{6}{|l|}{ Current and Accrued Labillties } \\
\hline 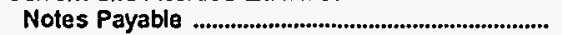 & $1,471,926$ & $1,314,967$ & $1,364,779$ & $1,167,670$ & $1,234,282$ \\
\hline 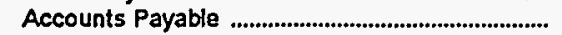 & $2,862,965$ & $2,839,333$ & $2,723,943$ & $2,627,626$ & $2,437,591$ \\
\hline 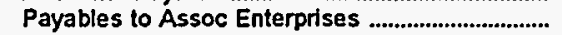 & 374,750 & 325,697 & 314,445 & 300,678 & 269,323 \\
\hline 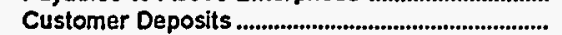 & 467.452 & 455,925 & 422,191 & 423,866 & 384,587 \\
\hline 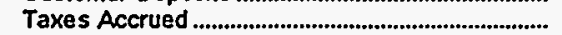 & 242,160 & 246,280 & 226,289 & 213,220 & 295,651 \\
\hline 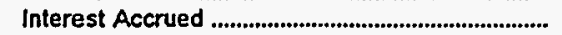 & $1,580,370$ & $1,545,141$ & $1,508,730$ & $1,524,242$ & $1,549,877$ \\
\hline Misc Current \& Accrued Labilities .......................... & $3,317,862$ & $3,284,753$ & $3,073,542$ & $2,807,340$ & $2,642,284$ \\
\hline Total Current \& Accrued Liabilities .................. & $10,317,486$ & $10,012,095$ & $9,633,919$ & $9,063,364$ & $8,813,594$ \\
\hline \multicolumn{6}{|l|}{ Deferred Credits } \\
\hline Customer Advances for Construction ..................... & 260,047 & 231,478 & $\begin{array}{r}228,397 \\
2055,2,4\end{array}$ & 216,947 & 189,349 \\
\hline $\begin{array}{l}\text { Other Deferred Credits } \\
\text { Unamort Galn on Reacgr Debt }\end{array}$ & $3,406,465$ & $3,010,570$ & $\begin{array}{r}3,055,314 \\
311,30 ?\end{array}$ & $\begin{array}{r}2,888,796 \\
389,640\end{array}$ & $2,912,524$ \\
\hline $\begin{array}{l}\text { Unamort Galn on Reacqr Debt } \\
\text { Total Deferred Credits }\end{array}$ & $\begin{array}{r}55,081 \\
3.721 .593\end{array}$ & $\begin{array}{r}238,386 \\
3,480,434\end{array}$ & $\begin{array}{r}311,302 \\
3,595,012\end{array}$ & $\begin{array}{r}389,640 \\
3,495,383\end{array}$ & $\begin{array}{r}569,043 \\
3,670,916\end{array}$ \\
\hline 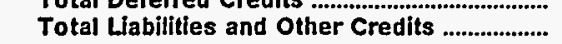 & $125,579,656$ & $124,544,663$ & $122,409,042$ & $116,332,239$ & $112,043,449$ \\
\hline
\end{tabular}

Data reporting Initiated in 1992.

Note: Totals may not equal sum of components because of independent rounding. The number of publicly owned electric utilities for end of period is 512 for 1995, 503 for 1994, 495 for 1993, 483 for 1992, and 470 for 1991.

Source: Energy Information Administration. Form ElA-412, "Annual Report of Public Electric Utilities." Individual electric utilities report fiscal year data. Appendix $B$ shows the fiscal year for each electric utility. 
Table C45. Composite Financial Indicators for Major U.S. Publicly Owned Electric Utilities for All Respondents, 1991-1995

\begin{tabular}{|c|c|c|c|c|c|}
\hline Item & 1995 & 1994 & 1993 & 1992 & 1991 \\
\hline Total Electric Utility Plant per Dollar of Revenue & 3.3 & 3.2 & 3.2 & 3.2 & 3.2 \\
\hline Current Assets to Current Ljabilities .......................... & 1.7 & 1.8 & 1.9 & 1.8 & 1.8 \\
\hline $\begin{array}{l}\text { Total Electric Utility Plant as a Percent of Total } \\
\text { Assets }\end{array}$ & 82.6 & 80.9 & 79.0 & 80.0 & 79.3 \\
\hline 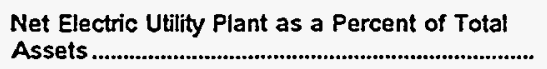 & 55.5 & 55.5 & 55.3 & 57.2 & 58.4 \\
\hline Debt as a Percent of Total Liabilities ........................ & 70.7 & 71.9 & 72.5 & 72.0 & 71.6 \\
\hline $\begin{array}{l}\text { Depreciation, Amortization and Depletion } \\
\text { as a Percent of Total Electric Utility Plant ........... }\end{array}$ & 32.8 & 31.5 & 29.9 & 28.5 & 26.4 \\
\hline $\begin{array}{l}\text { Electric Operation and Maintenance Expenses } \\
\text { as a Percent of } \\
\text { Electric Utility Operating Revenues ......................... }\end{array}$ & 71.0 & 71.2 & 71.4 & 71.0 & 70.6 \\
\hline $\begin{array}{l}\text { Electric Depreciation and Amortization } \\
\text { as a Percent of } \\
\text { Electric Utility Operating Revenues ......................... }\end{array}$ & 9.8 & 9.1 & 9.0 & 8.8 & 9.0 \\
\hline $\begin{array}{l}\text { Taxes and Tax Equivalents } \\
\text { as a Percent of } \\
\text { Electric Utility Operating Revenues ........................ }\end{array}$ & 3.3 & 3.1 & 3.1 & 2.9 & 2.6 \\
\hline $\begin{array}{l}\text { Interest on Long-term Debt } \\
\text { as a Percent of } \\
\text { Electric Utility Operating Revenues .......................... }\end{array}$ & 13.6 & 14.2 & 15.1 & 16.8 & 17.3 \\
\hline 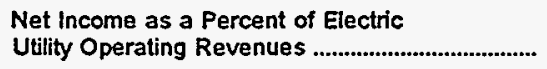 & 5.1 & 4.1 & 3.5 & 4.6 & 3.6 \\
\hline Purchased Power Cents Per Kllowatthour............. & 3.9 & 3.8 & 3.8 & 3.9 & 3.9 \\
\hline Generated Cents Per Kilowatthour .......................... & 1.8 & 1.9 & 1.9 & 1.9 & 1.8 \\
\hline $\begin{array}{l}\text { Total Power Supply Per } \\
\text { Kilowatthour Sold }\end{array}$ & 3.0 & 3.0 & 3.0 & 3.1 & 3.0 \\
\hline
\end{tabular}


Table C46. Electric Operation and Maintenance Expenses for Major U.S.

Publicly Owned Electric Utilities for All Respondents, 1991-1995

(Thousand Dollars)

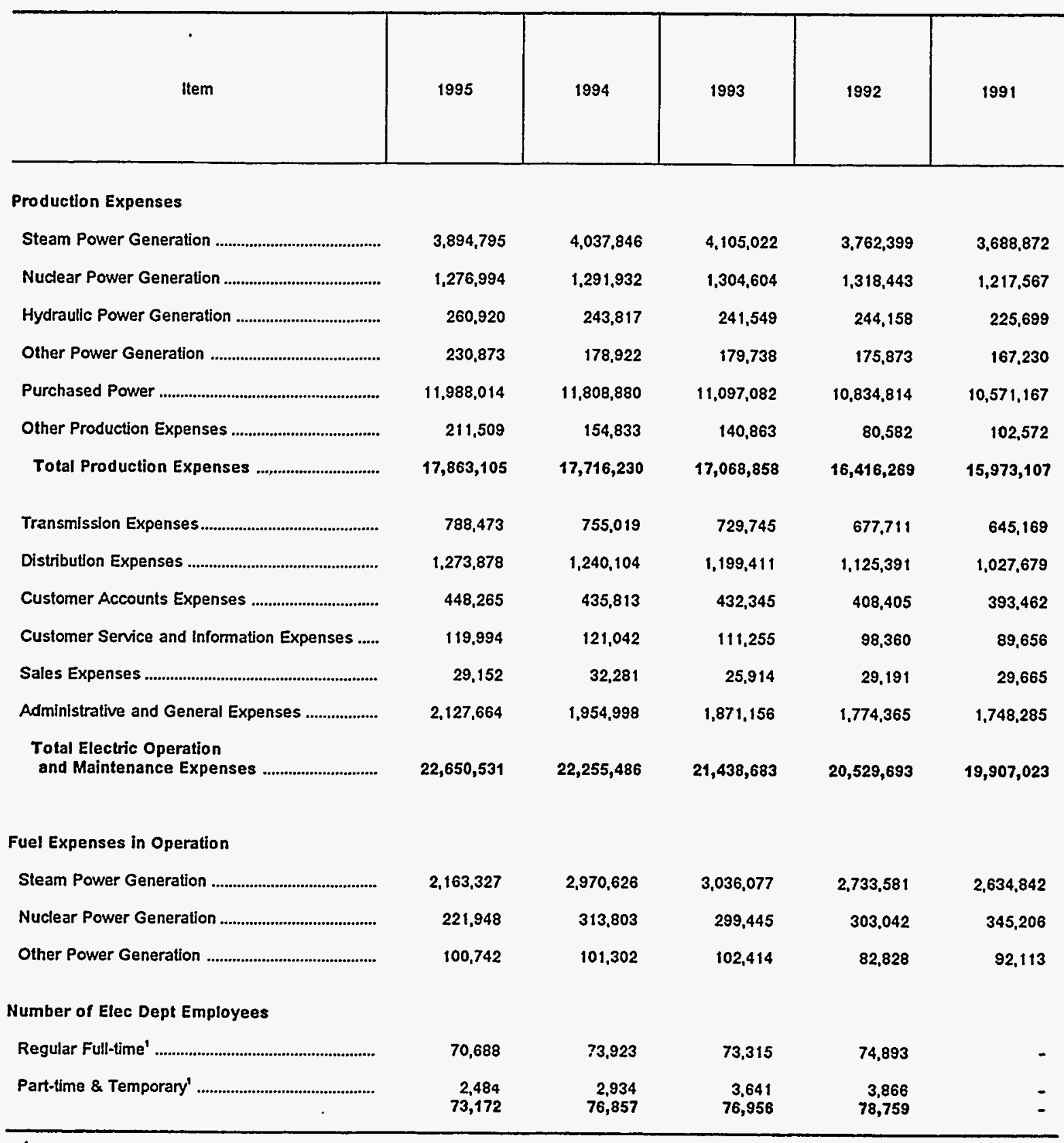

Data reporting initiated in 1992.

Note: Totals may not equal sum of components because of independent rounding. The number of publichy owned electric utilities for end of period is 512 for 1995,503 for 1994, 495 for 1993, 483 for 1992, and 470 for 1991 .

Source: Energy Information Administration, Form EIA-412, "Annual Report of Public Electric Utilities." Individual electric utilities report fiscal year data. Appendix B shows the fiscal year for each electric utility. 
Table C47. Electric Utility Plant for Major U.S. Publicly Owned Electric Utilities for All Respondents at End of Period, 1991-1995 (Thousand Dollars)

\begin{tabular}{|c|c|c|c|c|c|}
\hline Item & 1995 & 1994 & 1993 & 1992 & 1991 \\
\hline \multicolumn{6}{|l|}{ Electric Plant in Service } \\
\hline Intangible Plant & 642,085 & 527,021 & 351,952 & 294,715 & 373,212 \\
\hline \multicolumn{6}{|l|}{ Production Plant } \\
\hline Steam & $24,669,840$ & $24,334,206$ & $24,239,169$ & $23,415,826$ & $22,556,413$ \\
\hline 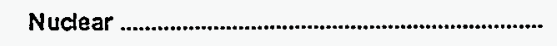 & $18,663,445$ & $18,786,140$ & $18,814,910$ & $18.743,463$ & $19,440,482$ \\
\hline 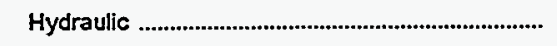 & $8,124,665$ & $7,839,107$ & $7,648,279$ & $7,506,785$ & $6,991,010$ \\
\hline Other & $2,540,910$ & $2,471,596$ & $1,843,331$ & $1,887,069$ & $1,576,299$ \\
\hline 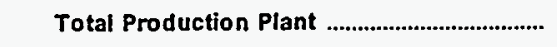 & $53,998,860$ & $53,431,049$ & $52,545,689$ & $51,553,142$ & $50,564,203$ \\
\hline 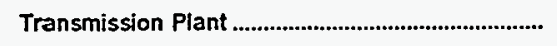 & $10,320,798$ & $9.920,599$ & $9,548,867$ & $9,345,935$ & $9,079,912$ \\
\hline Distribution Plant & $22,859,351$ & $21,598,897$ & $20,145,751$ & $18,846,975$ & $17,779,290$ \\
\hline 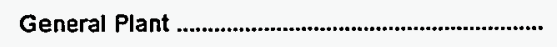 & $6,841,840$ & 6.768 .554 & $5,860,450$ & $5,455,979$ & $5,221,061$ \\
\hline Total Electric Plant in Service ........................... & $94,662,935$ & $92,246,120$ & $88,452,709$ & $85,496,746$ & $83,017,677$ \\
\hline 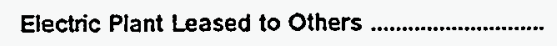 & 55,635 & 16,290 & 17,404 & 68,195 & 566,610 \\
\hline Construction Work in Progress - Electric .............. & $4,592,439$ & $4,482,626$ & $4,038,613$ & $3,790,826$ & $4,119,184$ \\
\hline Electric Plant Held for Future Use & 306,095 & 313,636 & 337,975 & 321,639 & 640,637 \\
\hline 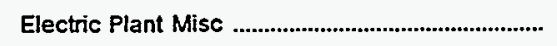 & 1.489 .834 & $1,181,262$ & $1,242,970$ & $1,143,590$ & 510,123 \\
\hline Total Electric Utility Plant ....................................... & $101,106,938$ & $98,239,934$ & $94,089,672$ & $90,820,996$ & $88,854,231$ \\
\hline 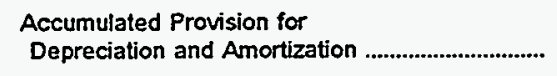 & $32,264,546$ & $30,043,282$ & $27,273,454$ & $25,153,126$ & $23,454,394$ \\
\hline 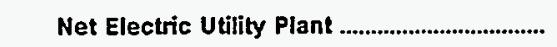 & $68,842,392$ & $68,196,652$ & $66,816,218$ & $65,667,870$ & $65,399,837$ \\
\hline
\end{tabular}

Note: Totals may not equal sum of components because of independent rounding. The number of publicly owned electric utilities for end of period is 512 for 1995,503 for 1994,495 for 1993,483 for 1992, and 470 for 1991 .

Source: Energy Information Administration, Form EIA-412, "Annual Report of Public Electric Utilities." Individual electric utilities report fiscal year data. Appendix $B$ shows the fiscal year for each electric utility. 
Table C48. Number of Consumers, Sales, and Operating Revenue

for Major U.S. Publicly Owned Electric Utilities

for All Respondents, 1991-1995

\begin{tabular}{|c|c|c|c|c|c|}
\hline Item & 1995 & 1994 & 1993 & 1992 & 1991 \\
\hline \multicolumn{6}{|l|}{ Number of Consumers } \\
\hline 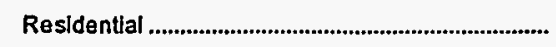 & $11,754,462$ & $11,528,503$ & $11,319,426$ & $11,105,178$ & $10,944,056$ \\
\hline Commercial or Small & $1,561,164$ & $1,534,098$ & $1,502,701$ & $1,477,033$ & $1,398,521$ \\
\hline 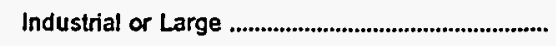 & 106,568 & 106,152 & 100.641 & 96,002 & 75,831 \\
\hline Other & 178,420 & 164,096 & 160.934 & 245,135 & 266,248 \\
\hline 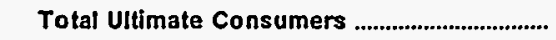 & $13,600,614$ & $13,332,849$ & $13,083,702$ & $12,923,348$ & $12,684,656$ \\
\hline
\end{tabular}

Sales for the Year (megawatthours)

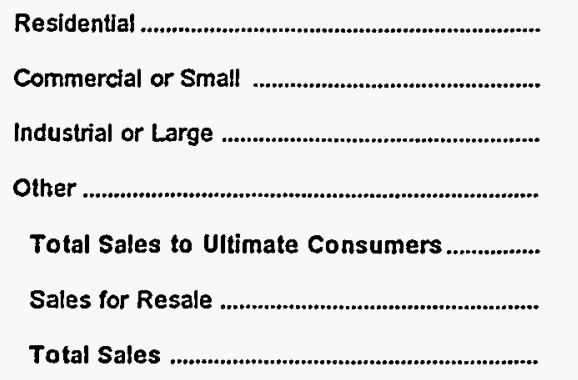

$\begin{array}{rrrrr}128,616,996 & 127,257,239 & 123,061,766 & 117,620,115 & 118,476,942 \\ 97,485,730 & 89,727,454 & 90,531,672 & 88,617,000 & 92,271,342 \\ 135,447,952 & 135,277,889 & 125,970,019 & 122,151,852 & 113,244,276 \\ 21,482,141 & 21,481,742 & 20,474,342 & 20,914,175 & 20,790,016 \\ 383,032,819 & 373,744,324 & 360,037,799 & 349,303,142 & 344,782,576 \\ 224,069,615 & 211,395,551 & 206,078,207 & 191,766,731 & 190,797,303 \\ 607,102,434 & 585,139,875 & 566,116,006 & 541,069,873 & 535,579,879\end{array}$

Operating Revenues for the Year (thousand dollars)

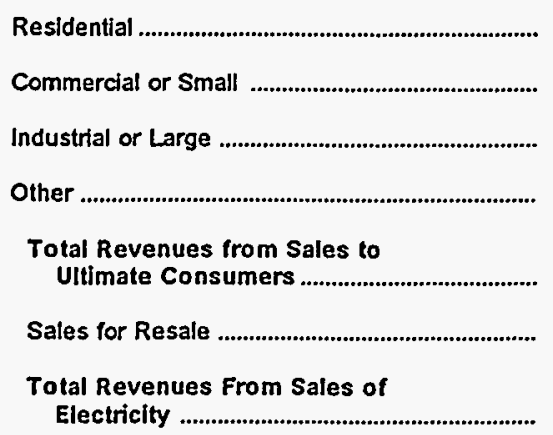

\begin{tabular}{rrrrr}
$8,594,016$ & $8,538,126$ & $8,125,239$ & $7,671,053$ & $7,512,382$ \\
$6,441,772$ & $5,983,051$ & $6,107,246$ & $5,846,417$ & $5,924,545$ \\
$6,322,700$ & $6,510,719$ & $6,040,622$ & $5,797,866$ & $5,305,256$ \\
$1,477,990$ & $1,538,894$ & $1,462,014$ & $1,431,809$ & $1,303,801$ \\
$22,836,478$ & $22,570,790$ & $21,735,121$ & $20,747,145$ & $20,045,984$ \\
$8,087,488$ & $8,165,966$ & $7,838,949$ & $7,479,049$ & $7,221,545$ \\
& & & & \\
$30,923,966$ & $30,736,756$ & $29,574,070$ & $28,226,194$ & $27,267,529$ \\
\hline
\end{tabular}

Note: Totals may not equal sum of components because of independent rounding. The number of publicty owned electric utilities for

end of period is 512 for 1995,503 for 1994, 495 for 1993,483 for 1992, and 470 for 1991.
Source: Energy Information Administration, Form ElA-861, "Annual Electric Utility Report." Data are based on calender year submissions. 
Table C49. Electric Energy Account for Major U.S. Publicly Owned Electric Utilities for All Respondents, 1991-1955 (Megawatthours)

\begin{tabular}{|c|c|c|c|c|c|}
\hline ttem & 1995 & 1994 & 1993 & 1992 & 1991 \\
\hline \multicolumn{6}{|l|}{ Sources of Energy } \\
\hline Steam & $170,232,784$ & $181,935,951$ & $179,616,592$ & $169,087,041$ & $164,401,739$ \\
\hline Nuclear & $61,425,458$ & $53,082,028$ & $48,580,405$ & $52,565,245$ & $57,756.871$ \\
\hline 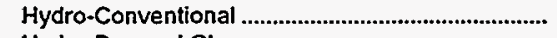 & $78,246,578$ & $64,584,646$ & $71,114,954$ & $65,807,396$ & $73,348,633$ \\
\hline 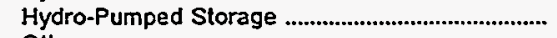 & $5,488,354$ & $4,161,991$ & $4,423,179$ & $4,722,771$ & $3,789,638$ \\
\hline Other & $3,741,342$ & $3,288,915$ & $3,053,440$ & $2,940,656$ & $3,137,344$ \\
\hline $\begin{array}{l}\text { (Less) Energy for Pumping } \\
\text { Total Net Generation }\end{array}$ & $\begin{array}{r}4,025,506 \\
315,109,010\end{array}$ & $\begin{array}{r}4,609,045 \\
302,444,488\end{array}$ & $\begin{array}{r}4,354,233 \\
302,434,335\end{array}$ & $\begin{array}{r}4,255,476 \\
290,867,622\end{array}$ & $\begin{array}{r}3,904.547 \\
298,529,666\end{array}$ \\
\hline $\begin{array}{l}\text { Purchases from Utility } \\
\text { Purchases from Nonutility } \\
\text { Power Exchanges }\end{array}$ & $\begin{array}{r}292,413,856 \\
8,075,028\end{array}$ & $\begin{array}{r}305,007,688 \\
1,640,476\end{array}$ & $\begin{array}{r}289,691,688 \\
1,543,815\end{array}$ & $\begin{array}{r}276,321,959 \\
1,085,377\end{array}$ & $\begin{array}{r}269,663,812 \\
1,380.739\end{array}$ \\
\hline Received & $28,532,264$ & $19,042,914$ & $21,477,360$ & $18,993,247$ & 19.788 .332 \\
\hline Delivered & $21,973,488$ & $16,912,965$ & $21,164,186$ & $18,641,568$ & $22,835,269$ \\
\hline Net Exchanges & $6,558,765$ & $2,129,952$ & 313,183 & 351,686 & $-3,046,936$ \\
\hline \multicolumn{6}{|l|}{ Transmission for Others (Wheeling) } \\
\hline Received & $26,002,200$ & $30,085,871$ & $27,233,740$ & $22,142,579$ & $27,661,154$ \\
\hline Delivered & $25,455,190$ & $29,787,957$ & $26,962,627$ & $21,938,318$ & $27,454,743$ \\
\hline 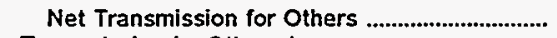 & 547.010 & 297,915 & 271,113 & 204,261 & 206.410 \\
\hline 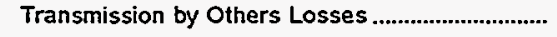 & $-161,056$ & $-357,929$ & $-286,279$ & $-243,202$ & $-169,733$ \\
\hline \multicolumn{6}{|l|}{ Total Net Energy Generated and } \\
\hline 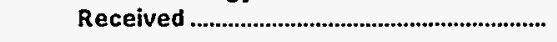 & $622,542,622$ & $611,162,593$ & $593,967,859$ & $568,587,689$ & $566,563,961$ \\
\hline \multicolumn{6}{|l|}{ Disposition of Energy } \\
\hline 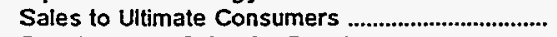 & $374,821,005$ & $372,306,680$ & $359,971,921$ & $347,801,781$ & $343,531,980$ \\
\hline 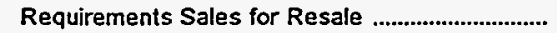 & $164,826,112$ & $165,817,872$ & $161,161,514$ & $152,099,605$ & $161,294,421$ \\
\hline 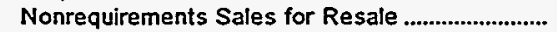 & $55,174,544$ & $43,051,318$ & $41,942,525$ & $37,818,022$ & $31,087,612$ \\
\hline 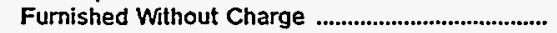 & $3,027,202$ & $1,996,571$ & $2,008,578$ & $1,851,080$ & $1,881,389$ \\
\hline 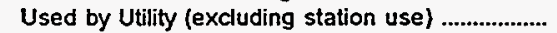 & $4,434,146$ & $5,442,205$ & $5,333,241$ & $6,877,310$ & $7,865,267$ \\
\hline Losses & $20,259,625$ & $22,547,945$ & $23,550,023$ & $22,139,822$ & $20,903,280$ \\
\hline Total Disposition & $622,542,622$ & $611,162,593$ & $593,967,859$ & $568,587,689$ & $566,563,961$ \\
\hline
\end{tabular}

Note: Totals may not equal sum of components because of independent rounding. The number of publicly owned electric utilities for end of period is 512 for 1995,503 for 1994,495 for 1993,483 for 1992, and 470 for 1991. Double counting occurs in components of both sources and disposition of energy and thus neither provides a true total. Purchases from utilities, net exchanges, and net wheeling (except for imports) are included in net generation. Sales for resale is included in sales to ultimate consumers.

Source: Energy Information Administration, Form EIA-4 12, "Annual Report of Public Electric Utilities." Individual electric utilities report fiscal year data. Appendix $B$ shows the fiscal year for each electric utility. 
Table C50. Comparison of the Energy Account for Major U.S. Publicly Owned Electric Utilities for All Respondents, 1991-1995

\begin{tabular}{|c|c|c|c|c|c|}
\hline Item & $\begin{array}{c}1995 \\
\text { (mitlion } \\
\text { megawatthours) }\end{array}$ & $\begin{array}{c}1994 \\
\text { (million } \\
\text { megawatthours) }\end{array}$ & $\begin{array}{c}1993 \\
\text { (million } \\
\text { megawatthours) }\end{array}$ & $\begin{array}{c}1992 \\
\text { (million } \\
\text { megawatthours) }\end{array}$ & $\begin{array}{c}1991 \\
\text { (million } \\
\text { megawatthours) }\end{array}$ \\
\hline \multicolumn{6}{|l|}{ Sources of Energy } \\
\hline 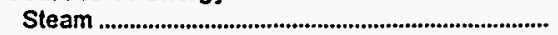 & 170.2 & 181.9 & 179.6 & 169.1 & 164.4 \\
\hline Nuclear & 61.4 & 53.1 & 48.6 & 52.6 & 57.8 \\
\hline 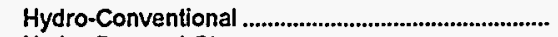 & 78.2 & 64.6 & 71.1 & 65.8 & 73.3 \\
\hline 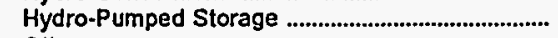 & 5.5 & 4.2 & 4.4 & 4.7 & 3.8 \\
\hline Other & 3.7 & 3.3 & 3.1 & 2.9 & 3.1 \\
\hline 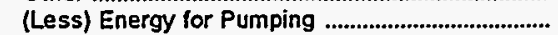 & 4.0 & 4.6 & 4.4 & 4.3 & 3.9 \\
\hline 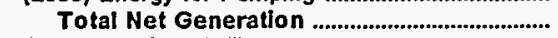 & 315.1 & 302.4 & 302.4 & 290.9 & 298.5 \\
\hline 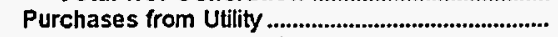 & 292.4 & 305.0 & 289.7 & 276.3 & 269.7 \\
\hline 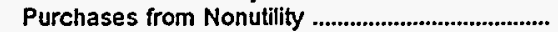 & 8.1 & 1.6 & 1.5 & 1.1 & 1.4 \\
\hline 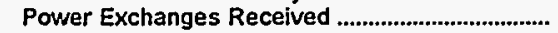 & 28.5 & 19.0 & 21.5 & 19.0 & 19.8 \\
\hline 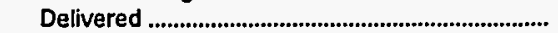 & 22.0 & 16.9 & 21.2 & 18.6 & 22.8 \\
\hline 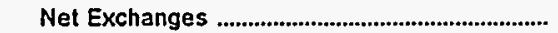 & 6.6 & 2.1 & .3 & .4 & -3.0 \\
\hline Transmission for Others (Wheeling) Received ... & 26.0 & 30.1 & 27.2 & 22.1 & 27.7 \\
\hline 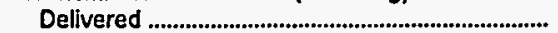 & 25.5 & 29.8 & 27.0 & 21.9 & 27.5 \\
\hline 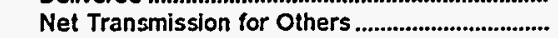 & .5 & .3 & 3 & .2 & .2 \\
\hline $\begin{array}{l}\text { Transmission by Others Losses ................................. } \\
\text { Total Net Energy Generated and }\end{array}$ & -.2 & -.4 & -.3 & -.2 & -.2 \\
\hline 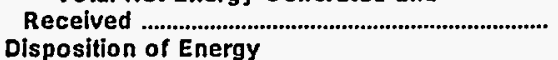 & 622.5 & 611.2 & 594.0 & 568.6 & 566.6 \\
\hline Sales to Ultimate Consumers .................................. & 374.8 & 372.3 & 360.0 & 347.8 & 343.5 \\
\hline 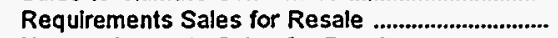 & 164.8 & 165.8 & 161.2 & 152.1 & 161.3 \\
\hline Nonrequirements Sales for Resale ........................ & 55.2 & 43.1 & 41.9 & 37.8 & 31.1 \\
\hline 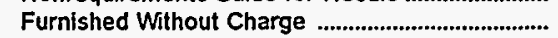 & 3.0 & 2.0 & 2.0 & 1.9 & 1.9 \\
\hline Used by Utility(excluding station use) .................. & 4.4 & 5.4 & 5.3 & 6.9 & 7.9 \\
\hline Losses & 20.3 & 22.5 & 23.6 & 22.1 & 20.9 \\
\hline Total Disposition & 622.5 & 611.2 & 594.0 & 568.6 & 566.6 \\
\hline
\end{tabular}

TABLE C50.

\begin{tabular}{|c|c|c|c|c|}
\hline Item & $\begin{array}{l}\text { Percent } \\
\text { Change } \\
\text { 1994-95 }\end{array}$ & $\begin{array}{l}\text { Percent } \\
\text { Change } \\
1993-94\end{array}$ & $\begin{array}{l}\text { Percent } \\
\text { Change } \\
1992-93\end{array}$ & $\begin{array}{c}\text { Percent } \\
\text { Change } \\
1991-92\end{array}$ \\
\hline \multicolumn{5}{|l|}{ Sources of Energy } \\
\hline Steam & -6.4 & 1.3 & 6.2 & 2.9 \\
\hline 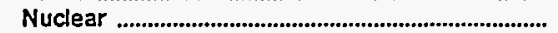 & 15.6 & 9.3 & -7.6 & -9.0 \\
\hline 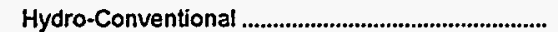 & 20.9 & -9.1 & 8.1 & -10.2 \\
\hline 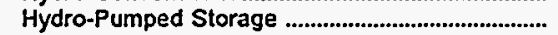 & 31.1 & -4.5 & -6.4 & 23.7 \\
\hline Other & 12.1 & 6.5 & 6.9 & -6.5 \\
\hline (Less) Energy for Pumping .................................... & -13.0 & 4.5 & 2.3 & 10.3 \\
\hline 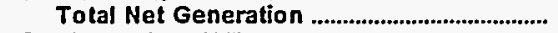 & 4.2 & .0 & 4.0 & 2.5 \\
\hline 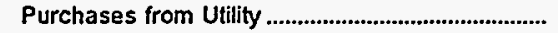 & -4.1 & 5.3 & 4.8 & 2.4 \\
\hline 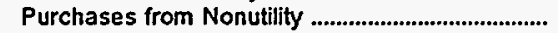 & 406.3 & 6.7 & 36.4 & -21.4 \\
\hline 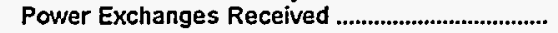 & 50.0 & -11.6 & 13.2 & -4.0 \\
\hline Delivered & 30.2 & -20.3 & 14.0 & -18.4 \\
\hline Net Exchanges & 214.3 & 600.0 & -25.0 & -113.3 \\
\hline Transmission for Others (Wheeling) Received ... & -13.6 & 10.7 & 23.1 & -20.2 \\
\hline Delivered & -14.4 & 10.4 & 23.3 & -20.4 \\
\hline 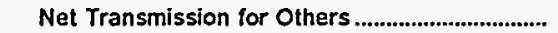 & 66.7 & .0 & 50.0 & .0 \\
\hline $\begin{array}{l}\text { Transmission by Others Losses } \\
\text { Total Net Energy Generated and }\end{array}$ & -100.0 & -33.3 & -50.0 & .0 \\
\hline Received & 1.8 & 2.9 & 4.5 & .4 \\
\hline \multicolumn{5}{|l|}{ Disposition of Energy } \\
\hline Sales to Ultimate Consumers & .7 & 3.4 & 3.5 & 1.3 \\
\hline 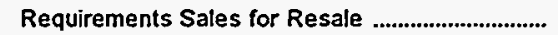 & -.6 & 2.9 & 6.0 & -5.7 \\
\hline 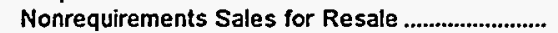 & 28.1 & 2.9 & 10.8 & 21.5 \\
\hline 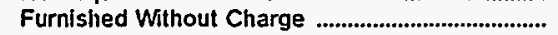 & 50.0 & .0 & 5.3 & .0 \\
\hline 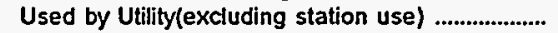 & -18.5 & 1.9 & -23.2 & -12.7 \\
\hline Losses & -9.8 & -4.7 & 6.8 & 5.7 \\
\hline Total Disposition & 1.8 & 2.9 & 4.5 & .4 \\
\hline
\end{tabular}

Note: Totals may not equal sum of components because of independent rounding. The number of publicly owned electric utillthes for end of period is 512 for 1995, 503 for 1994, 495 for 1993, 483 for 1992, and 470 for 199t. Double counting occurs in components of both sources and disposition of energy and thus neither provides a true total. Purchases from utilities, net exchanges, and net wheeling (except for imports) are included in net generation. Sales for resale is included in sales to ultimate consumers. Source: Energy Information Administration, Form ElA-4 12, "Annual Report of Public Electric Utilities." Individual electric utilities report fiscal year data. Appendix B shows the fiscal year for each electric utility. 


\title{
Appendix D
}

\author{
Regulation of \\ U.S. Publicly \\ Owned \\ Electric \\ Utilities
}




\section{Regulation of U.S. Publicly Owned Electric Utilities}

Table D1. State Agency Authority to Regulate Rates of Public Owned Electric Utilities, 1995

\begin{tabular}{|c|c|c|c|c|c|c|}
\hline \multirow[b]{2}{*}{ State } & \multirow[b]{2}{*}{ State Agency Authority } & \multirow{2}{*}{$\begin{array}{l}\text { Authority } \\
\text { To Regulate } \\
\text { Rates }\end{array}$} & \multirow[b]{2}{*}{ Boundaries } & \multicolumn{3}{|c|}{ Sales Regulated } \\
\hline & & & & $\begin{array}{c}\text { Ultimate } \\
\text { Consumer }\end{array}$ & $\begin{array}{l}\text { Public } \\
\text { Authority }\end{array}$ & $\begin{array}{c}\text { Sales for } \\
\text { Resale }\end{array}$ \\
\hline$A L$ & Alabama Public Senvice Commission & No & & & & \\
\hline AK & Alaska Public Utilities Commission & YES & Inside \& outside & $x$ & $x$ & $x$ \\
\hline$A Z$ & Arizona Corporation Commission & NO & & & & \\
\hline AR & Arkansas Public Service Commission & No & & & & \\
\hline CA & California Public Utilities Commission & NO & & & & \\
\hline co & Colorado Public Utilities Commission & LTD & outside & & & \\
\hline CT & Connecticut Department of Public Utility Control & LTD & & & & $x$ \\
\hline DE & Delaware Public Senvice Commission & No & & & & \\
\hline FL & Florida Public Senvice Commision & LTD & inside \& outside' & $x$ & $\mathrm{x}$ & \\
\hline GA & Georgia Public Service Commission & No & outside home cty & & & \\
\hline HI & Hawaii Public Utilities Commission & NO & & & & \\
\hline ID & Idaho Public Utilities Commission & No & & & & \\
\hline IL ... & illinois Commerce Commission & NO & inside \& outside & & & \\
\hline IN & Indiana Utility Regulatory Commision & LTD & inside \& outside? & $x$ & $x$ & $x$ \\
\hline IA & lowa Utilities Board & No & inside \& outside & $x$ & $x$ & \\
\hline ks & Kansas State Corporation Commission & YES & outside & $x$ & $x$ & $\mathrm{x}$ \\
\hline KY & Kentucky Puitic Service Commission & No & & & & \\
\hline LA & Lousiana Public Service Commission & No & & & & \\
\hline ME & Maine Public Utilities Commission & YES & outside & $\mathrm{x}$ & $x$ & \\
\hline MD & Maryland Public Senvice Commission & YES & inside $\&$ outside & $x$ & $x$ & \\
\hline MA & Massachusetts Department of Public Utilities & YES & inside \& outside & $x$ & $x$ & $x$ \\
\hline MI & Michigan Public Service Commission & No & & & & \\
\hline MN & Minnesota Public Service Commission & No & & & & \\
\hline MS & Mississippi Public Senvice Commission & LTD & safety inside, full outside & $x$ & $x$ & \\
\hline MO & Missouri Public Service Commission & No & & & & \\
\hline MT & Montana Public Service Commission & NO & Inside \& outside ${ }^{3}$ & & & \\
\hline
\end{tabular}

Rate Schedule

2 Rates Only.

- Annual revenue increase greater than 12 percent. See endnotes at end of this table. 
Table D1. State Agency Authority to Regulate Rates of Public Owned Electric Utilities, 1995-(Continued)

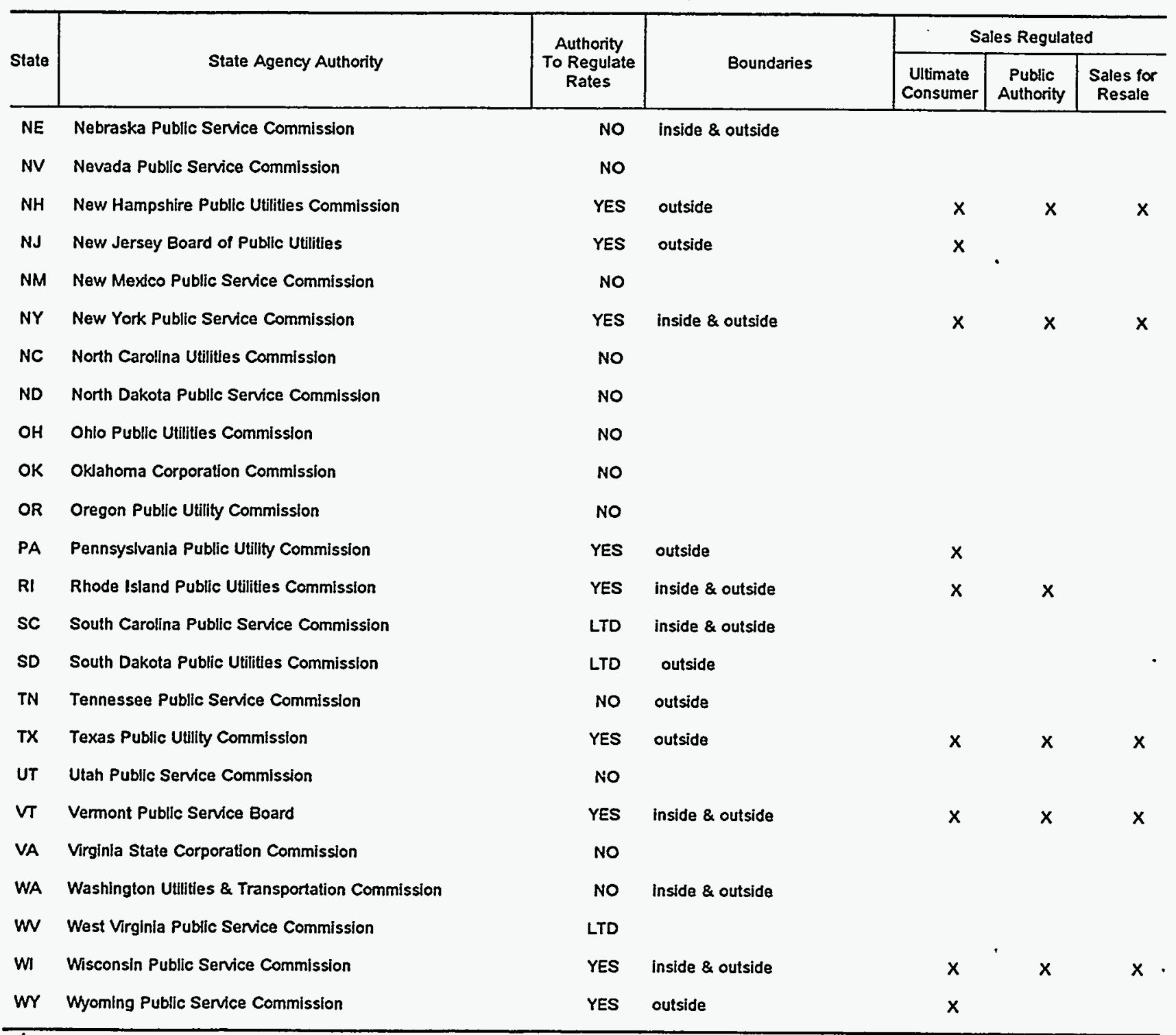

Rate Schedule.

- Rates Only.

- Annual revenue increase greater than 12 percent. Note: There are no publicly owned electric utilities in the District of Columbia. The District of Columbia Public Senvice Commission does regulate invester-owned electric utilities.

Source: National Association of Regulatory Utility Commissioners. Utility Regulatory Policy in the United States and Canada Compilation 1994-1995, publication. 
Appendix E

\section{Technical \\ Notes}


Appendix E

\section{Technical Notes}




\section{Sources of Data}

The Financial Statistics of Major US. Publicly Owned Electric Utilities (FSMPO) publication is prepared by the Coal and Electric Data and Renewables Division; Office of Coal, Nuclear, Electric and Alternate Fuels; Energy Information Administration (EI $\Lambda$ ); U.S. Department of Energy (DOE). Detailed financial data published in this publication are from the Form EIA-412, "Annual Report of Public Electric Utilities. "Other summary data are provided from the Form EIA-861, "Annual Electric Utility Report," and the Rural Utilities Scrvice statistics taken from the Statistical Report, Rural Electric Borrowers publication for the years 1990 through 1995. A brief summary of surveys used in this publication is presented below.

\section{Form EIA-412}

The Form EIA-412 is used annually to collect accounting, financial, and operating data from major publicly owned elcctric utilities in the United States. For the fiscal or calendar year that ended December 31,1995 , the criteria used to select the respondents for this survey resulted in submissions by 512 publicly owned and 8 Federal electric utilities. Those publicly owned electric utilities engaged in the generation, transmission, or distribution of electricity which had 120,000 megawatthours of sales to ultimate consumers and/or 120,000 megawatthours of sales for resale for the 2 previous years, as reported on the Form EIA-861, "Annual Electric Utility Report," must submit the Form EIA-412. Summary data are also published in the Electric Power Annual, Volume II .

Federally owned electric utilities are required to file the Form EIA-412. The financial data for the U.S. Army Corps of Engineers (except for Saint Mary's Falls at Sault St. Marie, Michigan), the U.S. International Boundary and Water Commission, and the U.S. Department of Interior Bureau of Reclamation were collected on the Form EIA-412 from the Federal power marketing administrations.

Instrument and Design History. The FPC created the Form IM in 1961 as a mandatory survey. It became the responsibility of the EIA in October 1977 when the FPC was merged with DOE. Since 1979, the FPC Form IM has been superseded by the Economic Regulatory Administration (ERA) Form ERA-412, and in January 1980 by the Form EIA-412.

Data Processing. The processing of data reported on this survey is the responsibility of the Coal and Electric Data and Renweables Division; Office of Coal, Nuclear, Electric and Alternate Fuels. The completed surveys are due on April 30 or before the last day of the third month following the close of the fiscal year. Nonresponse follow-up procedures are used to attain 100 percent response. Automated systems are used to edit data from the surveys using deterministic and statistical checks. When all data have passed the edit process, the data are aggrcgated into a master file used as input to the publication.

\section{Form EIA-861}

The Form EIA-861 is a mandatory census of electric utilities in the United States, its territorics, and Pucrto Rico. The survey is used to collect information on power production and sales data from approximately 3,200 electric utilities in the United States and its territories. These data collected are used to maintain and update the electric utility frame data base for the EIA. This data base supports queries from the Executive Branch, Congress, other public agencies, and the general public. Summary data from the Form EIA-861 are also contained in Electric Power Monthly, Electric Power Annual, Electric Sales and Revenue, Annual Outlook for US. Electric Power, Financial Statistics of Major US. Investor-Owned Electric Utilities and Financial Statistics of Major US. Publicly Owned Electric Utilities. These reports present aggregate totals for electric utilities on the national and State level by and by ownership type.

Instrument and Design History. The Form EIA-861 was implemented in January 1985 to collect data as of year-end 1984. The Federal Administration Act of 1974 (Public Law 93-275) defines the legislative authority to collect these data.

Data Processing. The Form EIA-861 is mailed to the respondents at year end to collect data for the calendar year. The completed surveys are due to the EIA by April 30. These data are manually edited before being entered into an interactive on-line system. Internal edit checks are performed to verify that current data total across and between schedules and are comparable to data reported the previous year. Edit checks are also performed to compare data reported on the Form EIA-861 with similar data reported on the Form EIA-826, "Monthly Electric Utility Sales and Revenue Report with State Distributions," the FERC Form 1, "Annual Report of Major Electric Utilities, Licensees and Others," and the Form EIA-412, "Annual Report of Public Electric Utilities." These are utility-level checks. Respondents are called to clarify reported data and to obtain missing data.

\section{Rural Utiltities Service}

The Rural Utilities Service (RUS), prior the The Rural Electrification Administration (REA), in the U.S. Department of Agriculture is authorized to provide long-term financing and guarantee long-term loans for utilities supplying power to rural America. Borrowing electric utilities file the RUS Form 7, "Financial and Statistical Report" and the RUS Form 12 a through 12i, "Electric Power Supply Borrowers" or the RUS Form 12c through $12 \mathrm{~g}$, "Electric Distribution Borrowers with Generating Facilities." Data are provided on a yearly basis. Other revenue and expense statistics show the year's financial operations. For 1995, borrowers' operations data are based on the 
financial and operating statements of 855 active borrowers, of which 808 were distribution borrowers and 47 werc power supply borrowers. Operations of cooperative borrowers systems are based on reports submitted by borrowers. The reports are subject to possible revisions from audits and adjustments. No attempt has been made to consolidate (in the technical accounting sense) the borrowers' accounts in the summary statement appearing in this publication. The combined totals represent the sum of all accounts as reported by the individual borrowers. 


\section{Quality of Data}

The Office of Coal, Nuclear, Electric and Alternate Fucls (CNEAF) is responsible for routine data improvement and quality assurance. All operations at CNEAF are done in accordance with formal standards established by EIA. Data improvement efforts include verification of data-keyed input by computerized methods, editing by subject matter specialists, and follow-up on nonrespondents. CNEAF reviews the structure of information requirements and proposed designs for new and revised data collection surveys and systems. Once started, the performance of working data collection systems is also validated. Computerized respondent data files are checked to identify those respondents which fail to respond to the survey. EIA tries to obtain required information by encouraging the cooperation of nonrespondents. By law, nonrespondents may be fincd or penalized for not filing a mandatory EIA data survey.

CNEAF screens submitted surveys for completeness and keys the data onto computer tapes for storage. These data are transferred to random access databases for computer processing. The information coded on the computer tapes is manually spot-checked against the surveys to certify accuracy of the tapes. To ensure EIA quality standards, formulas using the past history of data values in the data base have been designed and implemented to automatically check data input for errors. Data values falling outside the ranges prescribed in the formulas are verified by telephoning respondents to resolve any discrepancies.

Conceptual problcms affecting the quality of data are discussed in the report, An Assessment of the Quality of Selected EIA Data Series : Electric Power Data. This report is published by the Office of Statistical Standards in EIA.

\section{Data Entry System}

Manual editing of the reported data is completed prior to data entry. Additional edit checks of the data are performed through computer programs. The program edits include both deterministic checks, in which records are checked for the presence of data in required fields, and statistical checks, in which data are checked against a range of values based on historical data values and for logical or mathematical consistency with data elements reported in the survey. Discrepancies found in the data, as a result of these checks, are resolved either by the processing office or by further information obtained from a telephone call to the respondent.

\section{Confidentiality of the Data}

Data collected on the surveys for this publication are not confidential.

\section{Rounding Rules for Data}

Given a number with $r$ digits to the left of the decimal and $d+t$ digits in the fraction part, with $d$ being the place to which the number is to be rounded and $t$ being the remaining digits which will be truncated. This number is then rounded to $\mathrm{r}+\mathrm{d}$ digits by adding five to the $(r+d+1)$ th digit when the number is positive or by subtracting five when the number is negative. The $t$ digits are then truncated at the $(r+d+1)$ th digit. The symbol for a rounded number truncated to zero is $\left(^{*}\right)$.

\section{Data Correction and Revision Procedures}

The CNEAF has adopted the following policy with respect to the revision and correction of recurrent data in energy publications :

- Annual survey data collected by this office are published either as preliminary or final when first appearing in a data report. Data initially released as preliminary will be so noted in the report. These data will be revised, if necessary, and declared final in the next publication of the data.

- All monthly and quarterly survey data collected by this office are published as preliminary. These data are revised only after the completion of the 12 -month cycle of the data. No revisions arc made to the published data before this.

- The magnitudes of changes due to revisions experienced in the past will be included in the data reports, so that the reader can assess the accuracy of the data.

- After data are published as final, corrections will be made only in the event of a greater than one percent difference at the national level. Corrections for differences that are less than the before-mentioned threshold are left to the discretion of the Office Director.

\section{Formulas and Calculations}


Composite Financial Indicators for
Selected Publicly Owned Electric Utilities

Total Electric Utility Plant per Dollar of Revenue =

$\frac{\sum_{i}\left(T E U P_{i}\right)}{\sum_{i}\left(E U O R_{i}\right)}$

where TEUP is the Total Electric Utility Plant for the $i^{t_{i}}$ public utility; and, EUOR is the Electric Utility Operating Revenue for the $i^{\nu_{i}}$ public utility.

Current Assets to Current Liabilities =

$\frac{\sum_{i}\left(C A_{i}\right)}{\sum_{i}\left(C L_{i}\right)}$,

where $C A_{t}$ are the Current and Accrued Assets for the $i^{\text {th }}$ public utility; and, $C L_{i}$ are the Current and Accrued Liabilities for the $i^{t_{i}}$ public utility.

Total Electric Utility Plant as a Percent of Total Assets $=$

$\frac{\sum_{i}\left(T E U P_{i}\right)}{\sum_{i}\left(T A_{i}\right)} \times 100$,

where $T E U P_{i}$ is the Total Electric Utility Plant for the $i^{t_{i}}$ public utility; and, $T A_{i}$ are the Total Assets for the $i^{t_{t}}$ public utility.

Net Electric Utility Plant as a Percent of

Total Assets =

$\frac{\sum_{i}\left(N E U P_{i}\right)}{\sum_{i}\left(T A_{i}\right)} \times 100$

where $N E U P_{i}$ is the Net Electric Utility Plant for the $i^{t_{t}}$ public utility; and, $T A_{i}$ is the Total Assets for the $i^{\theta_{t}}$ public utility.

Debt as a percent of Total Liabilities $=$

$\frac{\sum_{i}\left(D_{i}\right)}{\sum_{i}\left(T L_{i}\right)} \times 100$

where $D_{i}$ is the Debt for the $i^{\text {th }}$ public utility; and, $T L_{i}$ is the Total Liabilitics for the $i^{t_{1}}$ public utility.

Depreciation, Amortization and Depletion as a Percent of Total Electric Utility Plant $=$
$\frac{\sum_{i}\left(D A D_{i}\right)}{\sum_{i}\left(T E U P_{i}\right)} \times 100$,

where $D A D_{i}$ is the Depreciation, Amortization and Depletion for the $i^{\text {th }}$ public utility; and, TEUP is the Total Electric Plant for the $i^{t_{t}}$ public utility.

Electric Operation and Maintenance Expenses as a Percent of Electric Utility Operating Revenues =

$\frac{\sum_{i}\left(E O M E_{i}\right)}{\sum_{i}\left(E U O R_{i}\right)} \times 100$

where $E O M E_{i}$ is the Electric Operation and Maintenance Expenses for the $i^{t_{l}}$ public utility; and, EUOR is the Electric Utility Operating Revenues for the $i^{\text {th }}$ public utility.

Clectric Depreciation and Amortization as a Percent of Electric Utility Operating Revenues =

$\frac{\sum_{i}\left(E D A_{i}\right)}{\sum_{i}\left(E U O R_{i}\right)} \times 100$

where $E D A_{i}$ is Electric Depreciation and Amortization for the $i^{\text {th }}$ public utility; and, EUOR ${ }_{i}$ is the Electric Utility Operating Revenues for the $i^{\nu_{i}}$ public utility.

Taxes and Tax Equivalents as a Percent of Electric Utility Operating Revenues =

$\frac{\sum_{i}\left(T T E_{i}\right)}{\sum_{i}\left(E U O R_{i}\right)} \times 100$

where $T T E_{i}$ are the Taxes and Tax Equivalerits for the $i^{\text {th }}$ public utility; and, EUOR is the Electric Utility Operating Revenues for the $i^{\text {th }}$ public utility.

Interest on Long-term Debt as a Percent of Electric Utility Operating Revenues =

$\frac{\sum_{i}\left(I L T D_{i}\right)}{\sum_{i}\left(E U O R_{i}\right)} \times 100$

where $I L T D_{i}$ is the Intcrest on Long-term Debt for the $i^{\text {th }}$ public utility; and, EUOR $i$ is the Electric Utility Operating Revenues for the $i^{t_{2}}$ public utility.

Net Income as a Percent of Electric Utility Operating Revenues $=$ 


$$
\frac{\sum_{l}\left(N I_{l}\right)}{\sum_{l}\left(E U O R_{l}\right)} \times 100
$$

where $N I_{i}$ is the Net Income for the $i^{t_{1}}$ public utility; and, EUOR, is the Electric Utility Operating Revenucs for the $i^{\text {th }}$ public utility.

Purchase Power Cents Per Kilowatthour =

$$
\frac{\sum_{l}\left(P P C_{l}\right)}{\sum_{l}\left(P P K_{l}\right)} \times 10
$$

where $P P C_{l}$ is the Purchase Power Costs (in cents) for the $i^{\nu_{1}}$ public utility; and, $P P K_{i}$ is the Purchased Power Kilowatthours for the $i^{t_{i}}$ public utility.

Generated Cents Per Kilowatthour =

$$
\frac{\sum_{l}\left(T G C_{l}\right)}{\sum_{l}\left(T G K_{l}\right)} \times 10,
$$

where $T G C_{i}$ is the Total Generation Costs (in cents) for the $i^{t_{i}}$ public utility; and, $T G K_{i}$ is the Total Generated Kilowatthours for the $i^{\text {th }}$ public utility.

Total Power Supply Per Kilowatthour Sold =

$$
\frac{\sum_{l}\left(T P C_{l}\right)}{\sum_{l}\left(T P K_{l}\right)} \times 10,
$$

where $T P C_{l}$ is the Total Generation and Purchase Power Cost for the $i^{\text {th }}$ public utility; and, $T P K_{i}$ is the Total Generated and Purchased Power Kilowatthours Sold for the $i^{\nu_{t}}$ public utility.

\section{General Information}

\section{Use of the Glossary}

The terms in the glossary have been defined for gencral use. Restrictions on the definitions, as used in these data collection systems, are included in each definition when necessary to define the terms as they are used in this report.

\section{Obtaining Copies of Data}

Upon EIA approval of the Financial Statistics of Major U.S. Publicly Owned Electric Utilities, these data are availablc for public use.

Computer listings are obtained by submitting a written request to :

Energy Information Administration

Coal and Electric Data and Renewables, EI-523

U.S. Department of Energy

1000 Independence Avenue, S.W.

Washington, DC 20585

(202) $426-1160$

FAX (202) 426-1308

Magnetic tapes may be purchased by using Visa, Master Card, or American Express cards, as well as money orders or checks payable to the National Technical Information Service (NTIS). Purchasers may also use NTIS and Government Printing Office deposit accounts. To place an order, contact :

National Technical Information Service (NTIS)

Office of Data Base Services

U.S. Department of Commerce

5285 Port Royal Road

Springfield, Virginia 22161

(703) $487-4650$

FAX (703) $321-8547$

Personal computer diskettes ( $31 / 2^{\prime \prime}$ or $51 / 4^{\prime \prime}$ ) may be purchased by using Visa or Master Card, as well as money orders or checks payable to the Superintendent of Documents. Purchasers may also use Government Printing Office deposit accounts. To place an order, contact :

Superintendent of Documents

U.S. Government Printing Office

Attn : Electronic Products Sales Coordinator

P.O. Box 37080

Washington, DC 20013-7082

(202) $512-1530$

FAX (202) 512-1262 


\section{Glossary}

Accounting System: A method of recording accounting data for a utility or company or a method of supplying accounting information for controlling, evaluating, planning and decisionmaking.

Administrative and General Expenses: Expenses of an electric utility relating to the overall directions of its corporate offices and administrative affairs, as contrasted with expenses incurred for specialized functions. Examples include office salaries, office supplies, advertising, and other gencral expenses.

Allowance for Funds Used During Construction (AFUDC): A noncash item representing the estimated composite interest costs of dcbt and a rcturn on equity funds used to finance construction. The allowance is capitalized in the property accounts and included in income.

Amortization: The gradual write-off of an amount in an account by distributing such amount over a fixed period, over the life of the asset or liability to which it applies, or over the period during which it is anticipated the benefit will be realized.

Asset: An economic resource, tangible or intangible, which is expected to provide benefits to a business.

Average Stream Flow: The rate, usually expressed in cubic feet per second, at which water passes a given point in a stream over a set period of time.

Capacity: The amount of electric power delivered or required for which a gencrator, turbine, transformer, transmission circuit, station, or system is rated by the manufacturer.

Capacity (Purchased): The amount of energy and capacity available for purchase from outside the system.

Capital: The equity interest of the owners consisting of common stock, preferred stock, and retained earnings in the entity, that is the difference between assets and liabilities.

Capital (Financial): The line items on the right side of a balance sheet, that include debt, preferred stock, and common equity. A net increase in assets must be financed by an increase in one or more forms of capital.

Capital Intensive: A condition in which investment in plant and equipment is rclatively large compared to labor and to operation and maintenance expenses.

Capitalization: The long-tcrm sources of funds comprising an entity's total capitalization; that is, the long- term debt, preferred stock, and common equity. The short-term sources of capital are not included.

Capitalization Ratio: The percentage of dcbt, or preferred stock, or common stock, or other equity to the total capital structure of an entity.

Circuit: A conductor or a system of conductors through which electric current flows.

Circuit-Mile: The total length in miles of separate circuits regardless of the number of conductors used per circuit.

Classes of Service: Consumers grouped by similar characteristics in order to be identified for the purpose of setting a common rate for electric service. Usually classified into groups identified as residential, commercial, industrial and other.

Commercial: The commercial sector is generally defined as nonmanufacturing business establishments, including hotels, motels, restaurants, wholesalc businesses, retail stores, and health, social, and educational institutions. The utility may classify commercial service as all consumers whose demand or annual use exceeds some specified limit. The limit may be set by the utility based on the rate schedule of the utility.

Commercial and Industrial: Classes of service supplied to a similar grouping of consumers. These customer groupings are usually subdivided into smaller segments by classifying such consumers as commercial or industrial using the Federal Government's Office Of Management and Budget's Standard Industrial Classification Guide and/or a scalc of energy usage as yardsticks; other consumers are reclassified as commercial or industrial when their demands or annual use exceeds some specificd limit. These limits are generally based on a utility's rate schedules, except for those consumers who are supplicd under special contracts or agreements calling for particular services.

Common Equity (Book Valuc): The retaincd carnings and common stock earnings plus the balances in common equity reserves and all other common stock accounts. This also includes the capital surplus, the paid-in surplus, the premium on common stocks, except those balances specifically related to preferred or preference stocks; less any common stocks held in the treasury.

Condenser Cooling Water: A source of water external to a boiler's feed system is passed through the steam lcaving the turbine in order to cool and condense the steam. This reduces the steam's exit pressure and recaptures its heat, which is then used to prehcat fluid entering the boiler, thereby increasing the plant's thermody namic efficiency. 
Conditionally Effective Rates: $\Lambda$ n electric rate schedule that has been put into effect by the FERC subject to refund pending final disposition or refiling.

Construction Costs (of the electric power industry): All direct and indirect costs incurred in acquiring and constructing clectric utility plant and equipment and proportionate shares of common utility plant. Included are the cost of land and improvements, nuclear fuel and spare parts, allowance for funds used during construction, general overheads capitalized, less the cost of acquiring plant and equipment previously operated in utility service.

Construction Expenditures (of the clectric power industry): The gross expenditures for construction costs, including the cost of replacing worn-out plants, and electric construction costs and land held for future use.

Construction Work In Progress (CWIP): The balance shown on a utility's balance shcet for construction work not yet completed but in process. This balance line item may or may not be included in the rate base.

Conventional Hydroclectric Plant: A plant in which all of the power is produced from natural streamflow as regulated by available storage.

Cooperative Electric Utility: An electric utility legally established to be owned by and operated for the benefit of those using its service. The utility company will generate, transmit, and/or distribute supplies of electric energy to a specified area not being serviced by another utility. Such ventures are gencrally exempt from Federal income tax laws. Most electric cooperatives have been initially financed by the Rural Electrification Administration, U.S. Department of Agriculture.

Cost: The amount paid to acquire resources, such as plant and equipment, fucl, or labor services.

Cost of Capital: The rate of return a utility must offer to obtain additional funds. The cost of capital varies with the leverage ratio, the effective income tax rate, conditions in the bond and stock markets, growth rate of the utility, its dividend strategy, stability of net income, the amount of new capital required, and other factors dealing with business and financial risks. It is a composite of the cost for debt interest, preferred stock dividends, and common stockholders' earnings that provide the facilities used in supplying utility service.

Cost of Debt: The interest rate paid on new increments of debt capital multiplied by 1 minus the tax rate.

Cost of Preferred Stock: The preferred dividend divided by the net price of preferred stock.

Cost of Retained Earnings: The residual of a utility's earnings over expenditures, including taxes and dividends, that are reinvested in its busincss. The cost of these funds is always lower than the cost of new equity capital, due to taxes and transactions costs. Therefore, the cost of retaincd earnings is the yield that retained earnings accrue upon reinvestment.

Cost of Service: A ratemaking concept used for the design and development of rate schedules to ensure that the filed rate schedules recover only the cost of providing the electric service at issuc. These costs include operating and maintenance expenses, depreciation and amortization expenses, and income and other taxes found just and reasonable by the regulatory agency for ratemaking purposes plus, in the case of privately owned electric utilities, an allowance for a return on capital (usually computed by applying a rate of return to the rate base). This concept attempts to equate the cost incurred by the utility to the revenue received for the service provided to each of the consumer classes.

Current Assets: Cash and other assets that are expected to be turned into cash, sold, or exchanged within the normal operating cycle of the utility, usually one year. Current assets include cash, marketable securities, receivables, inventory and current prepayments.

Current Liabilities: A debt or other obligation that must be discharged within one year or the normal operating cycle of the utility by expending a current asset or the incurrence of another short-term obligation. Current liabilities included account payable, short-term notes payable, and accrued expenses payable such as taxes and salaries payable.

Current Ratio: The ratio of current assets divided by current liabilities that shows the ability of a utility to pay its current obligations from its current assets. A measure of liquidity, the higher the current ratio, the more assurance that current liabilities can be paid.

Debt: Money or services owed through a legal obligation to an outside party. Debt may be classified short-term which is one year or less or long-term which is more than one year.

Deferred Cost: An expenditure not recognized as a cost of operation of the period in which incuried, but carried forward to be written off in future periods.

Deferred Fuel Costs: An expenditure for fuel that is not recognized for bookkeeping practices as a cost in the operating period incurred, but carried forward to be written off in future periods.

Deferred Income Tax (Liability): A liability in the balance sheet representing the additional Federal income taxes that would have been due if a utility had not been allowed to compute tax expenses differently for income tax reporting purposes than for ratemaking purposes.

Deprcciation: Charges made against income for distributing the cost of a tangible asset, so as to allocate it systematically across the period in which the asset is used. 
Design Head: The achieved river, pondage, or reservoir surface height (forebay elevation) that provides the water level to produce the full flow at the gate of the turbine in order to attain the manufacturer's installed nameplate rating for generation capacity.

Dicsel-Electric Plant: A generating station that uses diesel engines to drive its electric gencrators.

Distribution System: The portion of an electric system that is dedicated to delivering electric energy to an end user.

Docket: A formal record of a Federal Energy Regulatory Commission proceeding. These records are available for inspection and copying by the public. Each individual case proceeding is identified by an assigned number.

Economy of Scale: The principle that larger production facilitics have lower unit costs than smaller facilities.

Electric Expenses: The cost of labor, material, and expenses incurred in opcrating a facility's prime movers, generators, auxiliary apparatus, switching gear, and other electric equipment for each of the points where electricity enters the transmission or distribution grid.

Electric Operating Expenses: Summation of electric operation-related expenses, such as operation expenses, maintenance expenses, depreciation expenses, amortization, taxes other than income taxes, Federal income taxes, other income taxes, provision for deferred income taxes, provision for deferred income-credit, and investment tax credit adjustment.

Electric Plant (Financial): Assets comprising land, building, and equipment permanently employed.

Electric Power Industry: The privately, publicly, federally and cooperatively owned electric utilities of the United States taken as a whole. This includes all electric systems serving the public: regulated investorowned electric utility companies; Federal power projects; State, municipal, and other governmentowned systems, including electric public utility districts; electric cooperatives, including generation and transmission entities. Excluded from this definition are the special purpose electric facilities or systems that do not offer service to the public.

Electric Power System: An individual electric power entity -- a company, an electric cooperative, a public electric supply corporation as the Tennessee Valley Authority, a similar Federal department or agency as the Bonneville Power Administration, the Burcau of Reclamation or the Corps of Engineers, a municipally owned, electric department offering service to the public, or an electric public utility district (a "PUD "); also a jointly owned clectric supply project such as the Keystone.

Electric Rate Schclule: A statement of the electric rate and the terms and conditions governing its appli- cation, including attendant contract terms and conditions that have been accepted by a regulatory body with appropriate oversite authority.

Electric Utility: A corporation, person, agency, authority, or other legal entity or instrumentality that owns and/or operates facilities within the United States, its territories, or Puerto Rico for the generation, transmission, distribution, or sale of electric energy primarily for use by the public and files forms listed in the Code of Federal Regulations, Title 18, Part 141. Facilities that qualify as cogenerators or small power producers under the Public Utility Regulatory Policies Act (PURP'A) are not considercd electric utilities.

Electrical System Energy Losses: The amount of energy lost during generation, transmission, and distribution of electricity, including plant and unaccounted for use.

End Uscr: The final consumer of electricity.

Energy: The capacity for doing work as measured by the capability of doing work (potential energy) or the conversion of this capability to motion (kinetic energy). Energy has several forms, some of which are easily convertible and can be changed to another form useful for work. Most of the world's convertible energy comes from fossil fuels that are burned to produce heat that is then used as a transfer medium to mechanical or other means in order to accomplish tasks. Electrical energy is usually measured in kilowatthours, while heat energy is usually measured in British thermal units.

Energy Deliverics: Energy generated by one electric utility system and delivered to another system through one or more transmission lines.

Energy Information Administration (EIA): An independent agency within the U.S. Department of Energy that develops surveys, collects energy data, and does analytical and modeling analyses of energy issues. The Agency must satisfy the requests of Congress, other elements within the Department of Energy, Federal Energy Regulatory Commission, the Executive Branch, its own independent needs, and assist the gencral public, or other interest groups, without taking a policy position.

Energy Loss: The difference between energy input and output as a result of transfer of energy between two points.

Energy Receipts: Energy gencrated by one electric utility system and received by another system through one or more transmission lines.

Equity (Financial): Ownership of shareholders in a corporation represented by stock.

Equity Capital: The sum of capital from retained earnings and the issuance of stocks. 
Exchauge Energy: Exchange energy refers to specific electricity transactions between electric utilities where electricity received is returned in kind at a later time or accumulated as encrgy balances until the end of the stated period, after which settlement may be by monetary payment.

Expenditure: The incurrence of a liability to obtain an asset or service.

Federal Electric Utility: A utility that is either owned or financed by the Fedcral Government.

Federal Energy Regulatory Commission (FERC): A quasi-independent regulatory agency within the Department of Energy having jurisdiction over interstate electricity sales, wholesale electric rates, hydroelectric licensing, natural gas pricing, oil pipeline rates, and gas pipcline certification.

Federal Power Act: Enacted in 1920, and amended in 1935, the Act consists of three parts. The first part incorporated the Federal Water Power Act administered by the former Federal Power Commission, whose activities were confined almost entirely to licensing non-Federal hydroelectric projects. Parts II and III were added with the passage of the Public Utility Act. These parts extended the Act's jurisdiction to include regulating the interstate transmission of electrical energy and rates for its sale as wholesale in interstate commerce. The Federal Energy Regulatory Commission is now charged with the administration of this law.

Federal Power Commission: The predecessor agency of the Federal Energy Regulatory Commission. The Federal Power Commission (FPC) was created by an Act of Congress under the Federal Water Power Act on June 10, 1920. It was charged originally with regulating the electric power and natural gas industries. The FPC was abolished on September 20, 1977, when the Department of Energy was created. The functions of the FPC were divided between the Department of Energy and the Federal Energy Regulatory Commission.

FERC: The Federal Energy Regulatory Commission.

FERC Guidelines: A compilation of the Federal Energy Regulatory Commission's enabling statutes, procedural and program regulations, and orders, opinions and decisions.

Financial Accounting Standards Board (FASB): An independent board responsible, since 1973, for establishing generally accepted accounting principles. Its official pronouncement are called "Statements of Financial Accounting Standards" and "Interpretations of Financial Accounting Standards."

Iiscal Ycar: A financial year based on a predetermined starting date. The Federal Government's financial year runs from October 1 through September 30.
Fixed Asset Turnover: A ratio of revenue to fixed assets which is a measure of the productivity and efficiency of property, plant, and equipment in generating revenue. A higher turnover reflects positively on the entity's ability to utilize properly its fixed assets in business operations.

Fixed Assets: Tangible property used in the operations of an entity, but not expected to be consumed or converted into cash in the ordinary course of events. With a life in excess of one year, not intended for resale to customers, and subject to depreciation (with the exception of land), they are usually referred to as property, plant, and equipment.

Fixed Charge Coverage: The ratio of earnings available to pay so-called fixed charges to such fixed charges. Fixed charges include interest on funded debt, including leases, plus the related amortization of debt discount, premium and expense. Earnings available for fixed charges may be computed before or after deducting income taxes. Occasionally credits for the "allowance for fund used during construction" are excluded from the earnings figures. The precise procedures followed in calculating fixed charge or interest coverages vary widely.

Fixed Cost (expense): An expenditure or expense that does not vary with volume level of activity.

Fixed Operating Costs: Costs other than those associated with capital investment that do not vary with the operation, such as maintenance and payroll.

Fossil Fucl: Any naturally occurring organic fuel, such as petroleum, coal, and natural gas.

Fossil-Fuel Plant: A plant using coal, petroleum, or gas as its source of energy.

Fucl Expenses: These costs include the fuel used in the production of steam or driving another prime mover for the generation of electricity. Other associated expenses include unloading the shipped fucl and all handling of the fuel up to the point where it enters the first bunker, hopper, bucket, tank, or holder in the boiler-house structure.

Gas Turbine Plant: A plant in which the prime mover is a gas turbine. A gas turbine consists typically of an axial-flow air compressor, one or more combustion chambers, where liquid or gaseous fucl is burned and the hot gases are passed to the turbine and where the hot gases expand to drive the gencrator and are then used to run the compressor.

Generally Accepted Accounting Principles (GAAP): Defined by the FASB as the conventions, rules, and procedures necessary to define accepted accounting practice at a particular time; includes both broad guidelines and relatively detailed practices and procedures.

Generating Unit: Any combination of physically connected generator(s), reactor(s), boiler(s), combustion 
turbine(s), or other prime mover(s) opcrated together to produce electric power.

Generator Nameplate Capacity: The full-load continuous rating of a generator, prime mover, or other electric power production equipment under specific conditions as designated by the manufacturer. Installed generator nameplate rating is usually indicated on a namcplate physically attached to the generator.

Geothermal Plant: A plant in which the prime mover is a stcam turbine. The turbine is driven either by steam produced from hot water or by natural steam that derives its energy from heat found in rocks or fluids at various depths beneath the surface of the earth. The energy is extracted by drilling and/or pumping.

Grid: The layout of an electrical distribution system.

Gross Generation: The total amount of electric energy produced by a generating facility, as measured at the generator terminals.

Head: The product of the water's weight and a usable difference in elevation gives a measurement of the potential energy possessed by water.

Historical Plant Cost of Equipment: The charges for equipment assigned to power production include: the net purchased price thereof; sales taxes; investigation and inspection expenses necessary for such purchases, any expenses of transportation when borne by the utility; labor employed charges; materials and supplies consumed; and expenses incurred by the utility in unloading and placing the equipment in readiness to operate.

Historical Plant Cost of Land and Land Rights: The cost of land purchased or the fees paid by the utility for rights, interests, and privileges to be held by the utility in land owned by others. The types of rights acquired include lcaseholds, easements, water and water power rights, rights-of-way, and other like interests.

Historical Plant Cost of Structures and Improvements (Expenses): The cost of all buildings and facilities to house, support, or safeguard property or persons, including all fixtures permanently attached to and made a part of building. Also includes the cost incurred in connection with the first clearing and grading of land and rights-of-ways.

Holding Company: A company that confines its activities to owning stock in, and supervising management of, other companies. The Securities and Exchange Commission, as administrator of the Public Utility Iolding Company Act of 1935, defines a holding company as "a company which directly or indirectly owns, controls or holds 10 percent or more of the outstanding voting securities of a holding company" (15 USC 79b, par. a (7)).
Hydroclectric Encrgy: The production of electricity from kinetic energy in flowing water.

Hydroelectric Plant: A plant in which the turbine generators are driven by falling water.

Hydroclectric Plant Capacity: This capacity figure is a function of fluid flow losses, hydraulic turbines, head, and water flow. The minimum net head limits the firm capacity of the plant.

Hydroclectric Power: The harnessing of flowing water to produce mechanical or clectrical energy.

Independent Power Producer: A corporation, person, agency, authority, or other legal entity or instrumentality that owns electric generating capacity and is a wholesale electric producer without a designated franchised service area. The entity is not a qualifying facility as defined in the Public Utility Regulatory Policies Act of 1978.

Industrial: The industrial sector is generally defined as manufacturing, construction, mining, agriculture, fishing and forestry establishments Standard Industrial Classification (SIC) codes 01-39. The utility may classify industrial service using the SIC codes, or based on demand or annual usage exceeding some specified limit. The limit may be set by the utility based on the rate schedule of the utility.

Instantaneous Peak Demand: The maximum demand at the instant of greatest load.

Interchange Energy: Kilowatthours delivered to or received by one electric utility or pooling system from another. Settlement may be by payment, returned in kind at a later time or accumulated as energy balances until the end of the stated period.

Interconnection: Two or more electric systems having a common transmission line that permits a flow of energy between them. The physical connection of the electric power transmission facilities allows for the sale or exchange of energy.

Interdepartmental Service (Electric): Interdepartmental service includes amounts charged by the electric department at tariff or other specified rates for electricity supplied by it to other utility departments.

Interest Coverage Ratio: The number of times that fixed interest charges were earned. It indicates the margin of safety of interest on fixed debt. The timesinterest-earned ratio is calculated using net income before and after income taxes; and the credits of interest charged to construction being treated as other income. The interest charges include interest on longterm debt, interest on debt of associated companies, and other interest expcnse.

Intcrlocking Directorates: The holding of a significant position in management or a position on the corporate board of a utility, while simultancously holding a comparable position with another utility, or with a firm doing business with the utility. 
Internal Combustion Plant: A plant in which the prime mover is an internal combustion engine. An internal combustion engine has one or more cylinders in which the process of combustion takes place, converting energy released from the rapid burning of a fucl-air mixture into mechanical energy. Diesel or gasfured engines are the principal types used in electric plants. The plant is usually operated during periods of high demand for electricity.

Investor-Owned Electric Utility: A class of utility that is investor owned and organized as a tax paying business, usually financed by the sales of securities in the capital market.

Kilowatt $(\mathrm{kW})$ : One thousand watts.

Kilowatthour ( $(\mathrm{WWh})$ : One thousand watthours.

Leverage Ratio: A measure that indicates the financial ability to meet debt service requirements and increase the value of the investment to the stockholders. (i.e. the ratio of total debt to total assets).

Liability: An amount payable in dollars or by future services to be rendered.

Licensees: Entity that has been granted permission to engage in an activity otherwise unlawful (i.e. hydropower project).

Line Loss: Energy kilowatthours lost in transmission and distribution lines.

Load (Electric): The amount of electric power delivered or required at any specific point or points on a system. The requirement originates at the energyconsuming equipment of the consumers.

Long-term Debt: Debt sccurities or borrowings having a maturity of more than one year.

Maintenance Expenses: That portion of operating expenses consisting of labor, materials, and other direct and indirect expenses incurred for preserving the operating efficiency and/or physical condition of utility plants used for power production, transmission. and distribution of energy.

Maximum Demand: The greatest of all demands of the load that has occurred within a specified period of time.

Mcf: One thousand cubic fect.

Megawatt (MW): One million watts.

Megawatthour (MWh): One million watthours.

Mill: A monetary cost and billing unit used by utilities; it is equal to $1 / 1000$ of the U.S. dollar (equivalent to $1 / 10$ of 1 cent).

Multiple Purpose Reservoir: Stored water and its usage governed by advanced water resource conservation practices to achieve more than one water control objective. Some of the objectives include flood control, hydro- electric power development, irrigation, recreation usage, and wilderness protection.

Municipality: (As defined in section 3, paragraph (7) of the Federal Power Act, P.L. 66-280 as amcnded) A city, county, irrigation district, drainage district, or other political subdivision or agency of a State competent under the laws thereof to carry on the business of developing, transmitting, utilizing, or distributing power (41 Stat. 1064; 49 Stat. 838; 16 U.S.C. 796(7)).

Net Generation: Gross generation minus plant use from all electric utility owned plants. The energy required for pumping at a pumped-storage plant is regarded as plant use and must be deducted from the gross generation.

Net Income: The excess of all revenues and gains for a period over all expenses and losses of the period.

Nonutility Power Producer: A corporation, person, agency, authority, or other legal entity or instrumentality that owns electric generating capacity and is not an electric utility. Nonutility power producers include qualifying cogenerators, qualifying small power producers, and other nonutility generators (including independent power producers) without a designated franchised service area, and which do not file forms listed in the Code of Federal Regulations, Title 18, Part 141.

Nuclear Fuel: Fissionable materials that have been enriched to such a composition that, when placed in a nuclear reactor, will support a self-sustaining fission chain reaction, producing heat in a controlled manner for process use.

Nuclear Power Plant: A facility in which heat produced in a reactor by the fissioning of nuclear fuel is used to drive a steam turbine.

Nuclear Reactor: An apparatus in which the nuclear fission chain can be initiated, maintained, and controlled so that energy is released at a specific rate. The reactor includes fissionable material (fue!), such as uranium or plutonium; fertile material; moderating material (unless it is a fast reactor); a heavy-walled pressure vessel; shielding to protect personnel; provision for heat removal; and control elements and instrumentation.

Ohm: The unit of measurement of electrical resistance. The resistance of a circuit in which a potential difference of 1 volt produces a current of 1 ampere.

Operating Expenses: Expenses related to utility operations, which include operation and maintenance expenses, provisions for depreciation and amortization, taxes other than income taxes, income taxes, provision for deferred income taxes, income taxes deferred in prior years-- credit and investment tax credit adjustments--net.

Operating Income: Operating revenues less operating expenses. 
Operation Expenses: The components of power production expenses that incur cost for operations that are directly related to producing elcctricity. The major itcm is almost always fuel that has to be burned to generate the electricity.

Operation Supervision and Engineering (Expenses): These expenses include the cost of labor and expenses incurred in the general supervision and direction of the operation of power generation stations. The supervision and engineering costs consist of the pay and expenses of staff and consultants engaged in supervising and directing the operation of each utility function. Direct supervision and engineering of activities, such as fuel handling, boiler room operations, and generator operations, are charged to the appropriate accounts.

Original Cost: The initial amount of money spent to acquire an asset. It is equal to the price paid, or present value of the liability incurred, or fair value of stock issued, plus normal incidental costs necessary to put the asset into its initial use.

Other Generation: Electricity originating from these sources: biomass, fuel cells, geothermal heat, solar power, waste, wind, and wood.

Owner's Equity: Interest of the owners in the assets of the business represented by capital contributions and retained earnings.

Parent Company: Company owning more than 50 percent of the voting shares of another company, called the subsidiary.

Plant: A facility at which are located prime movers, electric generators, and auxiliary equipment for converting mechanical, chemical, and/or nuclear energy into electric energy. A plant may contain more than one type of prime mover. Electric utility plants exclude facilities that satisfy the definition of a qualifying facility under the Public Utility Regulatory Policies Act of 1978.

Plant-Use Elcctricity: The electric energy used in the operation of a plant. This energy total is subtracted from the gross energy production of the plant; for reporting purposes the plant energy production is then reported as a net figure. The energy required for pumping at pumped-storage plants is, by definition, subtracted, and the energy production for these plants is then reported as a net figure.

Polc-Mile: A unit of measuring the simple length of a transmission line carrying electric conductors, without regard to the number of conductors carried.

Power: The rate at which energy is transferred. Electrical cnergy is usually measured in watts. Also used for a mcasurcment of capacity.

Power (Electrical): An electric measurement unit of power called a voltampere is equal to the product of 1 volt and 1 ampere. This is equivalent to 1 Watt for a direct current system and a unit of apparent power is separated into real and rcactive power. Real power is the work- producing part of apparent power that measures the rate of supply of energy and is denoted as Kilowatts $(\mathrm{KW})$. Reactive power is the portion of apparent power that does no work and is referred to as kilovars; this type of power must be supplied to most types of magnetic equipment, such as motors, and is supplied by generator or by electrostatic equipment. Voltamperes are usually divided by 1,000 and called kilovoltamperes (kVA). Energy is denoted by the product of real power and the length of time utilized; this product is expressed as kilowatthours.

Power Production Plant: All the land and land rights, structures and improvements, boiler or reactor vessel equipment, engines and engine-driven generator, turbogenerator units, accessory electric equipment, and miscellaneous power plant equipment are grouped together for each individual facility.

Preferred Stock: Ownership interests in a corporation which have been granted a preference, usually in the distribution of dividends before payment of dividends to common stockholders and assets in dissolution. It is usually nonvoting.

Price: The amount of money or consideration-in-kind for which a service is bought, sold, or offered for sale.

Prime Mover: The motive force that drives an electric generator (e.g., steam engine, turbine, or water wheel).

Production (Electric): Act or process of producing electric energy from other forms of energy; also, the amount of electric energy expressed in watthours (Wh).

Production Expenses: Costs incurred in the production of electric power that conform to the accounting requirements of the Operation and Maintenance Expense Accounts of the FERC Uniform System of Accounts.

Profit: The income remaining after all business expenses are paid.

Public Authority Service to Public Authoritics: Public authority service includes electricity supplied and scrvices rendered to municipalities or divisions or agencies of State or Federal governments, under special contracts or agreements or service classifications applicable only to public authorities.

Public Strect and Highway Lighting: Public street and highway lighting includes electricity supplied and services rendered for the purposes of lighting streets, highways, parks, and other public places; or for traffic or other signal system service, for municipalities, or other divisions or agencies of State or Federal governments.

Public Utility: Enterprise providing essential public services as elcctric, gas, tclephone, water, and sewer, under legally established monopoly conditions. 
Public Utility District: Municipal corporations organized to provide electric service to both incorporated citics and towns and unincorporated rural areas. Public utility districts, sometimes called "People's Utility Districts" or "Public Power Districts," operate in six States.

Publicly Owned Electric Utility: A class of ownership found in the electric power industry. This group includes those utilities operated by municipalities, and State and Federal power agencies.

Pumped-Storage Hydroelectric Plant: A plant that usually generates electric energy during peak-load periods by using water previously pumped into an elevated storage reservoir during off-peak periods when excess generating capacity is available to do so. When additional generating capacity is needed, the water can be released from the reservoir through a conduit to turbine generators located in a power plant at a lower level.

Purchased Power: Power purchased or available for purchase from a source outside the system.

Railroad and Railway Services: Railroad and railway services include electricity supplied and services rendered to railroads and interurban and street railways, for general railroad use, including the propulsion of cars or locomotives, where such electricity is supplied under separate and distinct rate schedules.

Rate Base: The value of property upon which a utility is permitted to earn a specified rate of return as established by a regulatory authority. The rate base generally represents the value of property used by the utility in providing service and may be calculated by any one or a combination of the following accounting methods: fair valuc, prudent investment, reproduction cost, or original cost. Depending on which method is used, the rate base includes cash, working capital, materials and supplies, and deductions for accumulated provisions for depreciation, contributions in aid of construction, customer advances for construction, accumulated deferred income taxes, and accumulated deferred investment tax credits.

Ratemaking Authority: A utility commission's legal authority to fix, modify, approve, or disapprove rates, as determined by the powers given the commission by a State or Federal legislature.

Rate of Return: The ratio of net operating income earned by a utility is calculated as a percentage of its rate base.

Rate of Return on Rate Base: The ratio of net operating income earned by a utility calculated as a percentage of its rate base.

Refunding: Retirement of one security issue with proceeds received from selling another. Refunding provides for retiring maturing debt by taking advantage of favorable money market conditions.
Regulation: The governmental function of controlling or directing economic entities through the process of rulemaking and adjudication.

Resale (Wholesale) Sales: Resale or wholesale sales are electrciity sold (except under exchange agreements) to other electric utilities or to the public authorities for resale distribution.

Residential: The residential sector is defined as private household establishments which consume energy primarily for space heating, water heating, air conditioning, lighting, refrigeration, cooking and clothes drying. The classification of an individual consumer's account, where the use is both residential and commercial, is based on principal use. For the residential class, do not duplicate consumer accounts due to multiple metering for special services (water, heating, etc.). Apartment houses are also included.

Retail: Sales covering electrical energy supplicd for residential, commercial, and industrial end-use purposes. Other small classes, such as agriculture and street lighting, also are included in this category.

Retail Whecling: An arrangement in which a utility transmits electricity from outside its service territory to a retail customer within its customer service territory.

Retained Earnings: The balance, either debit or credit, of appropriated or unappropriated earnings of an entity that are retained in the business.

Return on Common Equity: The net income less preferred stock dividends divided by the average common stock equity.

Return on Common Stock Equity: An entity's earnings available for common stockholders calculated as a percentage of its common equity capital.

Revenue: The total amount of money received by a firm from sales of its products and/or scrvices, gains from the sales or exchange of assets, interest and diviciends earned on investments, and other increases in the owner's equity except those arising from capital adjustments.

Revenue Requircment: The total revenue that the utility is authorized an opportunity to rccover, which includes operating expenses and a reasonable return on rate base.

Rural Electrification Administration (REA): $A$ lending agency of the U.S. Department of Agriculture, the REA makes self-liquidation loans to qualified borrowers to finance electric and telephone service to rural areas. The REA also finances the construction and operation of generating plants, electric transmission and distribution lines, or systems for the furnishing of initial and continued adequate electric services to persons in rural areas not receiving central station service. 
Salcs: The amount of kilowatthours sold in a given period of time; usually grouped by classes of service, such as residential, commercial, industrial, and other. Other sales include public street and highway lighting, other sales to public authorities and railways, and interdepartmental sales.

Sales for Resale: Energy supplied to other electric utilities, cooperatives, municipalities, and Federal and State electric agencies for resale to ultimate consumers.

Short-term Debt or Borrowings: Debt securities or borrowings having a maturity of less than one year.

Solar Energy: Energy produced from the sun's radiation.

Steam-Electric Plant (Conventional): A plant in which the prime mover is a steam turbine. The steam used to drive the turbine is produced in a boiler where fossil fuels are burned.

Steam Expenses: The cost of labor, matcrials, fuel, and other expenses incurred in production of steam for elcctric generation.

Steam from other Sources: Steam purchased, transferred from another department of the utility, or acquired from others under a joint-facility operating agreement.

Steam Transferred-Credit: The expenses of producing steam charged to others or to other utility departments under a joint operating arrangement.

Substation: Facility equipment that switches, changes, or regulates electric voltage.

Switching Station: Facility equipment used to tie together two or more electric circuits through switches. The switches are selectively arranged to permit a circuit to be disconnected, or to change the electric connection between the circuits.

System (Electric): Physically connected generation, transmission, and distribution facilities opcrated as an integrated unit under one central m:magement, or operating supervision.
Transformer: An clectrical device for changing the voltage of alternating current.

Transmission: The movement or transfer of electric energy over an interconnected group of lines and associated equipment between points of supply and points at which it is transformed for delivery to consumers, or is delivered to other electric systems. Transmission is considered to end when the energy is transformed for distribution to the consumer.

Transmission System (Electric): An interconnected group of electric transmission lines and associated equipment for moving or transfcrring electric energy in bulk between points of supply and points at which it is transformed for delivery over the distribution system lines to consumers, or is delivered to other elcctric systems.

Turbine: A machine for generating rotary mechanical power from the energy of a stream of fluid (such as water, steam, or hot gas). Turbines convert the kinctic energy of fluids to mechanical energy through the principles of impulse and reaction, or a mixture of the two.

Ultimate Consumer: A consumer that purchases electricity for its own use and not for resale.

Uniform System of Accounts: Prescribed financial rules and regulations established by the Federal Energy Regulatory Commission for utilities subject to its jurisdiction under the authority granted by the Federal Power Act.

Utility Generation: Generation by electric systems engaged in selling electric energy to the public.

Watt: The electrical unit of power. The rate of energy transfer equivalent to 1 ampere flowing under a pressure of 1 volt at unity power factor.

Watthour (Wh): An elcctrical energy unit of measure equal to 1 watt of power supplied to, or taken from, an electric circuit stcadily for 1 hour.

Whecling Service: The movement of electricity from one system to another over transmission facilities of intervening systems. Whecling service contracts can be established betwcen two or more systems. 